DOE/EIA-0437(96)/2

\title{
Financial Statistics of Major U.S. Publicly Owned Electric Utilities 1996
}

March 1998

\author{
PECEIVED \\ APR 161908 \\ OSTI
}
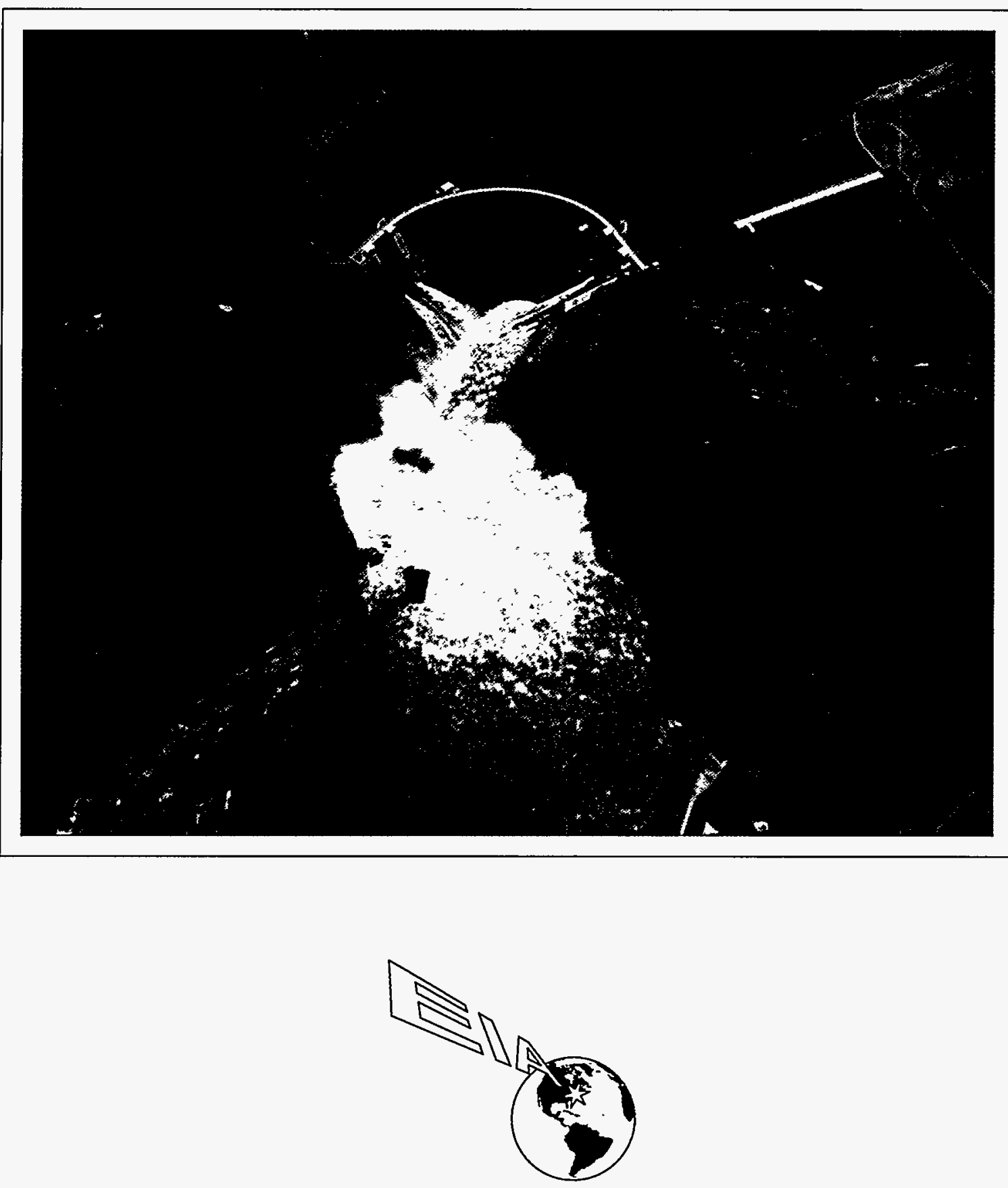


\section{HOW TO OBTAIN EIA PRODUCTS AND SERVICES}

For further information on any of the following services, or for answers to energy information questions, please contact EIA's National Energy Information Center:

\author{
National Energy Information Center (NEIC) \\ Energy Information Administration \\ Forrestal Building, Room 1F-048 \\ Washington, DC 20585
}

(202) 586-8800

(202) 586-0727 (fax)

TTY: (202) 586-1181

E-mail: infoctr@eia.doe.gov

\section{Electronic Products and Services}

EIA's Internet Site Services offer nearly all EIA publications. Users can view and download selected pages or entire reports, search for information, download EIA data and analysis applications, and find out about new EIA information products and services.

\section{World Wide Web: http://www.eia.doe.gov \\ Gopher: gopher://gopher.eia.doe.gov \\ FTP: ftp://ftp.eia.doe.gov}

EIA also offers a listserve service for EIA press releases and other short documents. Sign up on the EIA World Wide Web site.

EIA's CD-ROM, Energy InfoDisc, contains most EIA publications, several databases, and an energy forecasting model. The Energy InfoDisc, produced quarterly, is available for a fee from STAT-USA, Department of Commerce, 1-800-STAT-USA.

The Comprehensive Oil and Gas Information Source (COGIS), a bulletin board service, contains data files from most of EIA's oil- and gas-related reports. It is available for a fee from STAT-USA, on 1-800-STAT-USA.

EIA's Electronic Publishing System (EPUB) bulletin board contains data files, directories, and forecasts from most EIA reports. It can be accessed free of charge by dialing (202) 586-2557.

Many of EIA's data files and modeling programs are available for sale on diskette, tape, or cartridge, through either the National Technical Information Service or the Office of Scientific and Technical Information, Department of Energy. Contact NEIC for information on specific products, sources, and media, and ordering instructions.

\section{Printed Publications}

EIA directories are available free of charge from NEIC. Recent EIA periodicals and other publications are available from the Government Printing Office. Older reports are available from the National Technical Information Service:

\section{Superintendent of Documents \\ U.S. Government Printing Office \\ P.O. Box 371954 \\ Pittsburgh, PA 15250-7954}

(202) 512-1800; (202)-512-2250 (fax)

\author{
National Technical Information Service \\ U.S. Department of Commerce \\ 5285 Port Royal Road \\ Springfield, VA 22161 \\ (703) 487-4650; (703) 321-8547 (fax)
}

Questions concerning the contents of this report should be directed to Roger L. Sacquety, (202) 426-1311.

\section{Cover Photo:}

The Boundary Dam, a hydroelectric plant, is located in Pend Oreille County, State of Washington, and owned by the City of Seattle. 
DOE/EIA-0437(96)/2

Distribution Category

UC-98

\title{
Financial Statistics Major U.S. Publicly Owned Electric Utilities 1996
}

\author{
March 1998
}

Energy Information Administration

Office of Coal, Nuclear, Electric and Alternate Fuels

U.S. Department of Energy

Washington, DC 20585

DISTRIBUTION OF THIS DOCUMENT IS UNLIMITED 


\section{Contacts}

The Financial Statistics of Major U.S. Publicly Owned Electric Utilities is prepared annually by the Electric Power Division; Office of Coal, Nuclear, Electric and Alternate Fuels (CNEAF); Energy Information Administration (EIA); U.S. Department of Energy (DOE).

General information regarding the contents of this publication may be directed to:

National Energy Information Center (202/586-8800)

Internet E-Mail: INFOCTR@EIA.DOE.GOV

General information about the data appearing in this publication may be directed to:

Robert Schnapp

Director, Electric Power Division (202/426-1211) or Fax (202/426-1311)

Internet E-Mail: RSCHNAPP@EIA.DOE.GOV
Questions and comments may be directed to:

Roger L. Sacquety

Project Manager

(202/426-1160) or Fax (202/426-1311)

Internet E-Mail: RSACQUET@EIA.DOE.GOV

Specific information about the data contained in the FORM EIA-412 may be directed to:

Charlene Harris-Russell

Survey Statistician

(202/426-1163) or Fax (202/426-1311)

Internet E-Mail: CHARRISR @EIA.DOE.GOV

Historial data may be obtained from:

Charlene Harris-Russell

Survey Statistician

(202/426-1163) or Fax (202/426-1311)

Internet E-Mail: CHARRISR @EIA.DOE.GOV

\section{Quality}

You are entitled to quality products and quality service. We ask your help in ensuring that this report meets the highest standards for quality. If you have any comments or suggestions about this publication, please contact Roger L. Sacquety on (202) 426-1160 or FAX (202) 426-1311.

For general inquiries about energy data, please contact the National Energy Information Center on (202) 586-8800. Internet users may contact them at this address: INFOCTR@EIA.DOE.GOV 


\section{DISCLAIMER}

This report was prepared as an account of work sponsored by an agency of the United States Government. Neither the United States Government nor any agency thereof, nor any of their employees, makes any warranty, express or implied, or assumes any legal liability or responsibility for the accuracy, completeness, or usefulness of any information, apparatus, product, or process disclosed, or represents that its use would not infringe privately owned rights. Reference herein to any specific commercial product, process, or service by trade name, trademark, manufacturer, or otherwise does not necessarily constitute or imply its endorsement, recommendation, or favoring by the United States Government or any agency thereof. The views and opinions of authors expressed herein do not necessarily state or reflect those of the United States Government or any agency thereof. 


\section{DISCLAIMER}

Portions of this document may be illegible electronic image products. Images are produced from the best available original document. 


\section{Tables}

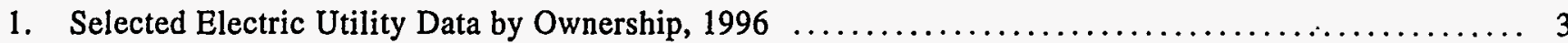

2. Selected Data for Major U.S. Publicly Owned and Federal Electric Utilities Compared to All U.S. Publicly Owned and Federal Electric Utilities, $1996 \ldots \ldots \ldots \ldots \ldots \ldots \ldots \ldots \ldots \ldots \ldots \ldots \ldots . \ldots \ldots$

3. Ten Largest U.S. Publicly Owned Generator Electric Utilities Ranked by Megawatthour Sales to Ultimate Consumers, 1996

(1)

4. Ten Largest U.S. Publicly Owned Generator Electric Utilities Ranked by Megawatthour Sales for

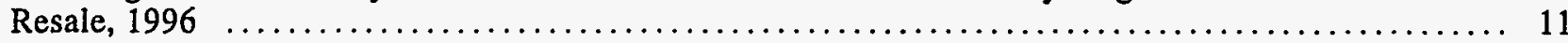

5. Composite Statement of Income for Major U.S. Publicly Owned Generator Electric Utilities, 1992-1996 12

6. Composite Balance Sheet for Major U.S. Publicly Owned Generator Electric Utilities at End of Period, $1992-1996$

7. Composite Financial Indicators for Major U.S. Publicly Owned Generator Electric Utilities, 1992-1996

8. Electric Operation and Maintenance Expenses for Major U.S. Publicly Owned Generator Electric Utilities, 1992-1996

9. Electric Utility Plant for Major U.S. Publicly Owned Generator Electric Utilities at End of Period, 1992-1996

10. Number of Consumers, Sales, and Operating Revenue for Major U.S. Publicly Owned Generator

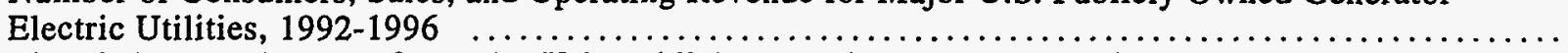

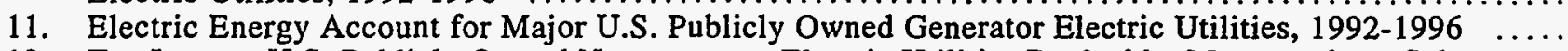

12. Ten Largest U.S. Publicly Owned Nongenerator Electric Utilities Ranked by Megawatthour Sales to Ultimate Consumers, 1996

13. Ten Largest U.S. Publicly Owned Nongenerator Electric Utilities Ranked by Megawatthour Sales for Resale, 1996

14. Composite Statement of Income for Major U.S. Publicly Owned Nongenerator Electric Utilities,

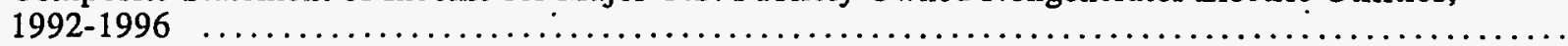

15. Composite Balance Sheet for Major U.S. Publicly Owned Nongenerator Electric Utilities at End of Period, 1992-1996

Composite Financial Indicators for Major U.S. Publicly Owned Nongenerator Electric Utilities, 1992-1996

Electric Operation and Maintenance Expenses for Major U.S. Publicly Owned Nongenerator Electric Utilities, 1992-1996

Electric Utility Plant for Major U.S. Publicly Owned Nongenerator Electric Utilities at End of Period, 1992-1996

19. Number of Consumers, Sales, and Operating Revenue for Major U.S. Publicly Owned Nongenerator Electric Utilities, 1992-1996 ............................................ 27

20. Electric Energy Account for Major U.S. Publicly Owned Nongenerator Electric Utilities, $1992-1996 \ldots 28$

21. Statement of Income by Major U.S. Publicly Owned Electric Utility Within State, $1996 \ldots \ldots . \ldots . .30$

22. Balance Sheet by Major U.S. Publicly Owned Electric Utility Within State at End of Period, $1996 \ldots \ldots$

23. Electric Operation and Maintenance Expenses by Major U.S. Publicly Owned Electric Utility Within

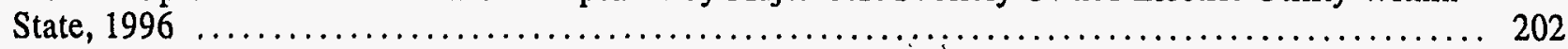

24. Electric Utility Plant by Major U.S. Publicly Owned Electric Utility Within State at End of Period,

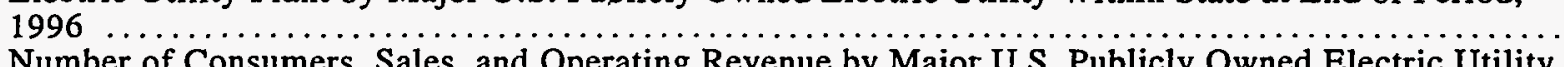

25. Number of Consumers, Sales, and Operating Revenue by Major U.S. Publicly Owned Electric Utility

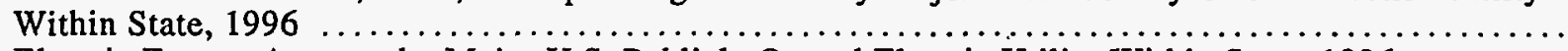

26. Electric Energy Account by Major U.S. Publicly Owned Electric Utility Within State, $1996 \ldots \ldots \ldots$

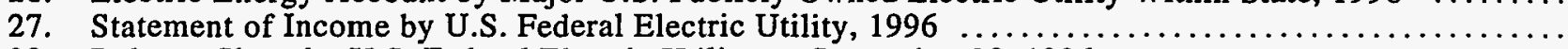

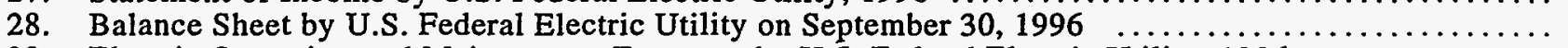

29. Electric Operation and Maintenance Expenses by U.S. Federal Electric Utility, $1996 \ldots \ldots \ldots \ldots \ldots \ldots$

30. Electric Utility Plant by U.S. Federal Electric Utility on September $30,1996 \ldots \ldots \ldots \ldots \ldots \ldots \ldots \ldots$

31. Number of Consumers, Sales, and Operating Revenue by U.S. Federal Electric Utility, $1996 \ldots \ldots \ldots$

32. Electric Energy Account by U.S. Federal Electric Utility, $1996 \ldots \ldots \ldots \ldots \ldots \ldots \ldots \ldots \ldots \ldots \ldots$

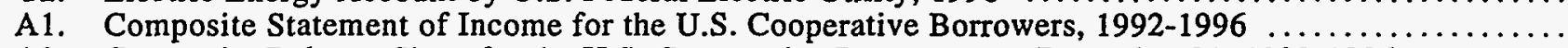

A2. Composite Balance Sheet for the U.S. Cooperative Borrowers on December 31, $1992-1996 \ldots \ldots \ldots \ldots$

A3. Electric Operation and Maintenance Expenses for the U.S. Cooperative Borrowers, 1992-1996 ..........

A4. Number of Consumers, Sales, and Operating Revenue for the U.S. Cooperative Distributor Borrowers, 1992-1996 
B1. Major U.S. Publicly Owned Electric Utilities Added to and Deleted from the Form EIA-412, 1992-1996

B2. Major U.S. Publicly Owned Electric Utilities by Fiscal Year and Generator/Nongenerator Status from the Form EIA-412, 1996

B3. Major U.S. Publicly Owned Electric Utilities by State and Generator/Nongenerator Status, $1996 \ldots \ldots$

B4. Major U.S. Publicly Owned Electric Utilities That Submitted the Form EIA-412, $1996 \ldots \ldots \ldots \ldots$. . . .

C1. Ten Largest U.S. Publicly Owned Generator Electric Utilities Ranked by Megawatthour Sales to Ultimate Consumers with Financial Year Ending on June 30, $1996 \ldots \ldots \ldots \ldots \ldots \ldots \ldots \ldots \ldots \ldots$

C2. Ten Largest U.S. Publicly Owned Generator Electric Utilities Ranked by Megawatthour Sales for Resale with Financial Year Ending on June 30, 1996

C3. Composite Statement of Income for Major U.S. Publicly Owned Generator Electric Utilities with Financial Year Ending on June 30, 1992-1996

C4. Composite Balance Sheet for Major U.S. Publicly Owned Generator Electric Utilities with Financial Year Ending on June 30 at End of Period, 1992-1996

C5. Composite Financial Indicators for Major U.S. Publicly Owned Generator Electric Utilities with Financial Year Ending on June 30, 1992-1996

C6. Electric Operation and Maintenance Expenses for Major U.S. Publicly Owned Generator Electric Utilities with Financial Year Ending on June 30, 1992-1996

C7. Electric Utility Plant for Major U.S. Publicly Owned Generator Electric Utilities with Financial Year Ending on June 30 at End of Period, 1992-1996

C8. Number of Consumers, Sales, and Operating Revenue for Major U.S. Publicly Owned Generator Electric Utilities with Financial Year Ending on June 30, 1992-1996

C9. Electric Energy Account for Major U.S. Publicly Owned Generator Electric Utilities with Financial Year Ending on June 30, 1992-1996

C10. Ten Largest U.S. Publicly Owned Generator Electric Utilities Ranked by Megawatthour Sales to Ultimate Consumers with Financial Year Ending on December 31, 1996

Ten Largest U.S. Publicly Owned Generator Electric Utilities Ranked by Megawatthour Sales for Resale with Financial Year Ending on December 31, 1996

C12. Composite Statement of Income for Major U.S. Publicly Owned Generator Electric Utilities with Financial Year Ending on December 31, 1992-1996

C13. Composite Balance Sheet for Major U.S. Publicly Owned Generator Electric Utilities with Financial Year Ending on December 31 at End of Period, 1992-1996

C14. Composite Financial Indicators for Major U.S. Publicly Owned Generator Electric Utilities with Financial Year Ending on December 31, 1992-1996

C15. Electric Operation and Maintenance Expenses for Major U.S. Publicly Owned Generator Electric Utilities with Financial Year Ending on December 31, 1992-1996

Electric Utility Plant for Major U.S. Publicly Owned Generator Electric Utilities with Financial Year

Ending on December 31 at End of Period, 1992-1996

C17. Number of Consumers, Sales, and Operating Revenue for Major U.S. Publicly Owned Generator Electric Utilities with Financial Year Ending on December 31, 1992-1996

C18. Electric Energy Account for Major U.S. Publicly Owned Generator Electric Utilities with Financial Year Ending on December 31, 1992-1996

C19. Ten Largest U.S. Publicly Owned Nongenerator Electric Utilities Ranked by Megawatthour Sales to Ultimate Consumers with Financial Year Ending on June 30, 1996

C20. U.S. Publicly Owned Nongenerator Electric Utilities Ranked by Megawatthour Sales for Resale with Financial Year Ending on June 30, 1996

C.21. Composite Statement of Income for Major U.S. Publicly Owned Nongenerator Electric Utilities with Financial Year Ending on June 30, 1992-1996

C.22. Composite Balance Sheet for Major U.S. Publicly Owned Nongenerator Electric Utilities with Financial Year Ending on June 30 at End of Period, 1992-1996

C23. Composite Financial Indicators for Major U.S. Publicly Owned Nongenerator Electric Utilities with Financial Year Ending on June 30, 1992-1996

C24. Electric Operation and Maintenance Expenses for Major U.S. Publicly Owned Nongenerator Electric Utilities with Financial Year Ending on June 30, 1992-1996

C25. Electric Utility Plant for Major U.S. Publicly Owned Nongenerator Electric Utilities with Financial Year Ending on June 30 at End of Period, 1992-1996

C26. Number of Consumers, Sales, and Operating Revenue for Major U.S. Publicly Owned Nongenerator Electric Utilities with Financial Year Ending on June 30, 1992-1996

C27. Electric Energy Account for Major U.S. Publicly Owned Nongenerator Electric Utilities with

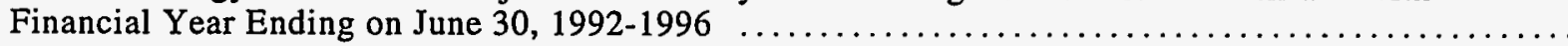

C28. Ten Largest U.S. Publicly Owned Nongenerator Electric Utilities Ranked by Megawatthour Sales to Ultimate Consumers with Financial Year Ending on December 31, 1996

C29. Ten Largest U.S. Publicly Owned Nongenerator Electric Utilities Ranked by Megawatthour Sales for

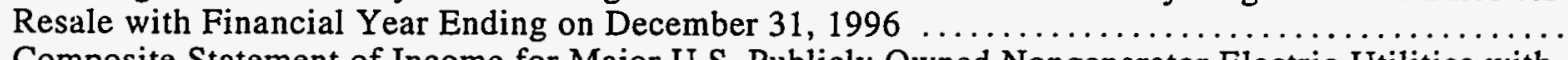

C30. Composite Statement of Income for Major U.S. Publicly Owned Nongenerator Electric Utilities with Financial Year Ending on December 31, 1992-1996 
C31. Composite Balance Sheet for Major U.S. Publicly Owned Nongenerator Electric Utilities with Financial Year Ending on December 31 at End of Period, 1992-1996

C32. Composite Financial Indicators for Major U.S. Publicly Owned Nongenerator Electric Utilities with

Financial Year Ending on December 31, 1992-1996

C33. Electric Operation and Maintenance Expenses for Major U.S. Publicly Owned Nongenerator Electric Utilities with Financial Year Ending on December 31, 1992-1996

C34. Electric Utility Plant for Major U.S. Publicly Owned Nongenerator Electric Utilities with Financial Year Ending on December 31 at End of Period, 1992-1996

C35. Number of Consumers, Sales, and Operating Revenue for Major U.S. Publicly Owned Nongenerator Electric Utilities with Financial Year Ending on December 31, 1992-1996

C36. Electric Energy Account for Major U.S. Publicly Owned Nongenerator Electric Utilities with Financial Year Ending on December 31, 1992-1996

C37. Twenty Largest U.S. Publicly Owned Electric Utilities Ranked by Megawatthour Sales to Ultimate Consumers for All Respondents, 1996

C38. Twenty Largest U.S. Publicly Owned Electric Utilities Ranked by Megawatthour Sales for Resale for All Respondents, 1996

C39. Twenty Largest U.S. Publicly Owned Electric Utilities Ranked by Electric Utility Revenues for All Respondents, 1996

C40. Twenty Largest U.S. Publicly Owned Electric Utilities Ranked by Purchase Power Expenses for All Respondents, 1996

C41. Twenty Largest U.S. Publicly Owned Electric Utilities Ranked by Electric Utility Plant for All Respondents, 1996

C42. Twenty Largest U.S. Publicly Owned Electric Utilities Ranked by Construction Work in Progress for All Respondents, 1996

C43. Composite Statement of Income for Major U.S. Publicly Owned Electric Utilities for All Respondents, 1992-1996

C44. Composite Balance Sheet for Major U.S. Publicly Owned Electric Utilities for All Respondents at End of Period, 1992-1996

C45. Composite Financial Indicators for Major U.S. Publicly Owned Electric Utilities for All Respondents, $1992-1996$

C46. Electric Operation and Maintenance Expenses for Major U.S. Publicly Owned Electric Utilities for All Respondents, 1992-1996

C47. Electric Utility Plant for Major U.S. Publicly Owned Electric Utilities for All Respondents at End of Period, 1992-1996

C48. Number of Consumers, Sales, and Operating Revenue for Major U.S. Publicly Owned Electric Utilities for All Respondents, 1992-1996 ................................................

C49. Electric Energy Account for Major U.S. Publicly Owned Electric Utilities for All $\mathrm{P}$ inndents, 1992-1996

C50. Comparison of the Electric Energy Account for Major U.S. Publicly Owned Elect, Respondents, 1992-1996

lities for All

D1. State Agency Authority to Regulate Rate of U.S. Publicly Owned Electric Utilities. ............. 522 523 524 525 526 527 527 528 528 529 529 530 533 535 536 537 540

\section{Illustrations}

1. Total Electric Utility Plant per Dollar of Revenue, $1992-1996 \ldots \ldots \ldots \ldots \ldots \ldots \ldots \ldots \ldots \ldots \ldots \ldots . \ldots 7$

B1. Principal Business Office of the Major U.S. Publicly Owned Electric Utilities, $1996 \ldots \ldots \ldots \ldots \ldots \ldots$ 


\section{Introduction}

\section{About This Publication}

The 1996 edition of The Financial Statistics of Major U.S. Publicly Owned Electric Utilities publication presents 5 years (1992 through 1996) of summary financial data and current year detailed financial data on the major publicly owned electric utilities. The objective of the publication is to provide Federal and State governments, industry, and the general public with current and historical data that can be used for policymaking and decisionmaking purposes related to publicly owned electric utility issues.

Generator (Tables 3 through 11) and nongenerator (Tables 12 through 20) summaries are presented in this publication. Five years of summary financial data are provided (Tables 5 through 11 and 14 through 20). Summaries of generators for fiscal years ending June 30 and December 31 , nongenerators for fiscal years ending June 30 and December 31 , and summaries of all respondents are provided in Appendix C.

The composite tables present aggregates of income statement and balance sheet data, as well as financial indicators. Composite tables also display electric operation and maintenance expenses, electric utility plant, number of consumers, sales of electricity, and operating revenue, and electric energy account data.

The primary source of publicly owned financial data is the Form EIA-412, "Annual Report of Public Electric Utilities." Public electric utilities file this survey on a fiscal year, rather than a calendar year basis, in conformance with their recordkeeping practices. The EIA undertook a review of the Form EIA-412 submissions to determine if alternative classifications of publicly owned electric utilities would permit the inclusion of all respondents. The review indicated that financial indicators differ most according to whether or not a publicly owned electric utility generates electricity. Therefore, the main body of the report provides summary information in generator/nongenerator classifications.

\section{History}

As the result of the Federal Power Act of 1935, the Federal Power Commission (FPC), which was the predecessor to the Federal Energy Regulatory Commission (FERC), began collecting financial statistics for investor-owned electric utilities in 1938. In 1946, the FPC started collecting financial statistics on publicly owned electric utilities. The Energy Information Administration (EIA) upon its establishment in October 1977 took over the responsibility of gathering and publishing the financial statistics from the FERC.
In 1982, the EIA combined the contents of two publications containing financial statistics of investorowned (private) and publicly owned electric utilities into a single volume, the Financial Statistics of Selected Electric Utilities . In 1991, the publication titles were changed to the Financial Statistics of Major Investor-Owned Electric Utilities and the Financial Statistics of Major Publicly Owned Electric Utilities. In 1992, the publication titles were further changed to the Financial Statistics of Major U.S. Investor-Owned Electric Utilities and the Financial Statistics of Major U.S. Publicly Owned Electric Utilities.

Currently, the Financial Statistics of Major U.S. Publicly Owned Electric Utilities publication is prepared by the Electric Operating and Financial Data Branch; Electric Power Division; Office of Coal, Nuclear, Electric and Alternate Fuels; EIA; U.S. Department of Energy. The format was designed to be used by a variety of private, electric power industry, and government users. The publication contents and format have evolved over the years to better serve the needs and requirements of the targeted audience.

\section{About The Industry}

The U.S. electric power industry is a combination of electric utilities (investor-owned, publicly owned, cooperatives, and Federal) and nonutility power producers. Investor-owned electric utilities account for over three-fourths of the sales of electricity and revenue in the industry. Historically, the investorowned electric utilities served the large consolidated markets and operated in all States except Nebraska. Hawaii is the only State in which all electricity is supplied by investor-owned electric utilities.

Publicly owned electric utilities are nonprofit operations that have been established to serve their communities and nearby consumers at cost. The publicly owned electric utilities in this publication include municipals, public power districts, State authorities, irrigation districts, and other State organizations. Publicly owned electric utilities are exempt from taxes and can obtain new financing at lower rates than investor-owned electric utilities.

The publicly owned electric utilities are divided into generators and nongenerators (In contrast, virtually all investor-owned electric utilities own and operate generating capacity). Generators are those electric utilities that own/operate generating capacity to supply some or all of their consumer needs. However, some generators supplement their demand by purchasing power. The nongenerators do not produce electric 
power for end use and rely exclusively on purchasing power. Their primary function is to transmit and distribute electricity to their consumers. The nongenerators comprise over half of the total number of major publicly owned electric utilities.

Cooperative electric utilities are owned by their members and are established to provide electricity to those members. The Rural Electrification Administration (prior to the Rural Utilities Service), U.S. Department of Agriculture, was established under the Rural Electrification Act of 1936 with the purpose to extend electric service to small rural communities (usually under 1,500 consumers) and farms where it was more expensive to provide service. The National Rural Utilities Cooperative Finance Corporation, the Federal Financing Bank, and the Bank for Cooperatives are the most important sources of debt financing for Cooperatives. Cooperative borrowers (832 of 932 in 1996 total cooperatives) currently operate in 46 States. Financial data for the cooperative borrowers are found in the Statistical Report, Rural Electric Borrowers published by the Rural Utilities Service of the U.S. Department of Agriculture. Summary tables for the cooperative borrowers are provided in Appendix A.

Federal electric utilities are also presented in this publication and include the five Federal power marketing administrations, the Tennessee Valley Authority, the U.S. Army Corps of Engineers, and the U.S. Bureau of Indian Affairs. The five Federal power marketing administrations are the Alaska Power Administration, the Bonneville Power Administration, the Southeastern Power Administration, the Southwestern Power Administration, and the Western Area Power Administration. Electric power produced by Federal electric utilities is generated primarily by water resources. This power, which is not produced for profit, is primarily wholesaled to other electric utilities rather than being distributed to ultimate consumers. As required by law, publicly owned and cooperative electric utilities are given preference in the purchase of this less expensive power produced by the Federal electric utilities.

\section{Data Users}

The Financial Statistics of Major U.S. Publicly Owned Electric Utilities publication provides information about the financial results from operations of publicly owned electric utilities for use by government, industry, electric utilities, financial organizations and educational institutions in energy planning. In the private sector, the readers of this publication are researchers and analysts associated with the financial markets, the policymaking and decisionmaking members of electric utility companies, and economic development organizations. Other organizations that may be interested in the data presented in this publication include manufacturers of electric power equipment and marketing organizations. In the public sector, the readers of this publication include analysts, researchers, statisticians, and other professionals engaged in regulatory, policy, and program activities. These individuals are generally associated with the Congress, other legislative bodies, State public service commissions, universities, and national strategic planning organizations.

\section{Sources and Coverage}

Publicly owned electric utilities are required to submit the Form EIA-412 when the generation, transmission, or distribution of electricity, for the two previous years, results in one of the following :

- 120,000 megawatthours of sales to ultimate consumers.

- 120,000 megawatthours of sales for resale.

These criteria are based on data reported on the Form EIA-861, "Annual Electric Utility Report." This survey is submitted by all electric utilities in the United States, its territories, and Puerto Rico. Appendix B contains a list of the major publicly owned electric utilities that submitted form EIA-412 data for 1996.

Many of the publicly owned electric utilities are selfregulated while some fall under the jurisdiction of State public service commissions as shown in Appendix D. Because of the absence of required reporting to a specific regulatory body, the accounting practices and policies of publicly owned electric utilities vary considerably. Many use the FERC Uniform System of Accounts or variation's of this and other accounting systems. The composite statistics provided in this publication must be viewed with an appropriate degree of caution.

The Form EIA-412 is used to collect detailed annual accounting, financial, and other operating characteristics of publicly owned electric utilities for publication in EIA reports. In 1996, 515 major publicly owned electric utilities submitted data to the EIA. Although calendar year reporting of data is preferred, electric utilities are given the option of reporting data on a fiscal year basis. This option is permitted in order to minimize respondent burden in preparing the data. When reporting by fiscal year, electric utilities must report operational data for a 12-month period and show consistency in fiscal periods and accounting practices. 


\section{Industry Profile}

Selected electric utility data for 1996 are compiled from the Form EIA-861 for the total universe of electric utilities. In 1996, there were 3,195 investorowned, publicly owned, Federal, and cooperative electric utilities (Table 1).

Key facts concerning sales and revenues in 1996 are as follows :

- The 243 investor-owned electric utilities $(7.6$ percent of all electric utilities) accounted for 78.5 percent of all revenues from sales of electricity to ultimate consumers and 43.1 percent of all revenues from sales for resale.

- The 2,010 publicly owned electric utilities $(62.9$ percent of all electric utilities) accounted for 12.8 percent of all revenues from sales to ultimate con- sumers and 18.2 percent of all revenues from sales for resale.

- The 932 cooperative electric utilities $(29.2$ percent of all electric utilities) accounted for 8.2 percent of all revenues from sales to ultimate consumers and 22.8 percent of all revenues from sales for resale.

- The 10 Federal electric utilities accounted for 0.6 percent of all revenues from sales to ultimate consumers and 15.9 percent of all revenues from sales for resale.

- The average ultimate consumers revenue per kilowatthour ranged from 2.5 to 7.1 cents depending on the type of electric utility. The overall average was 6.9 cents.

- The average sales for resale revenue per kilowatthour ranged from 3.0 to 3.6 cents, depending on the type of electric utility. The overall average was 3.3 cents.

Table 1. Selected Electric Utility Data by Ownership, 1996

\begin{tabular}{|c|c|c|c|c|c|}
\hline \multirow[b]{2}{*}{ Item } & \multicolumn{5}{|c|}{ Type of Electric Utility } \\
\hline & Investor-Owned & Publicly Owned & Cooperative & Federal & Total 1 \\
\hline 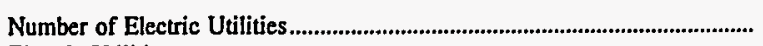 & 243 & 2,010 & 932 & .10 & 3,195 \\
\hline 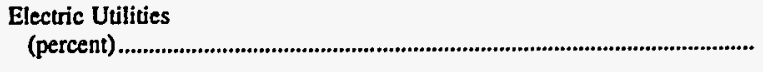 & 7.6 & 62.9 & 29.2 & 0.3 & 100.0 \\
\hline $\begin{array}{l}\text { Revenues from Sales to Ultimate Consumers } \\
\text { (thousand dollars)................................................... }\end{array}$ & $166,795,617$ & $27,098,025$ & $17,408,907$ & $1,152,025$ & $212,454,574$ \\
\hline 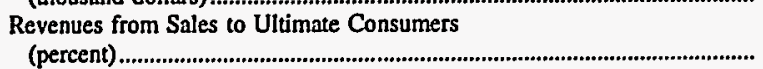 & 78.5 & 12.8 & 8.2 & 0.6 & 100.0 \\
\hline $\begin{array}{l}\text { Sales of Electricity to Ultimate Consumers } \\
\text { (thousand megawatthours).............................. }\end{array}$ & $2,342,808$ & 450,928 & 258,447 & 45,626 & $3,097,810$ \\
\hline Sales of Electricity to Ultimate Consumers & 75.6 & 14.6 & 8.3 & 1.5 & 100.0 \\
\hline 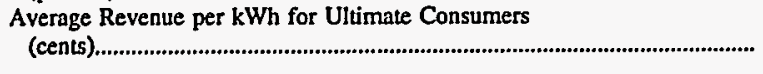 & 7.1 & 6.0 & 6.7 & 2.5 & 6.9 \\
\hline 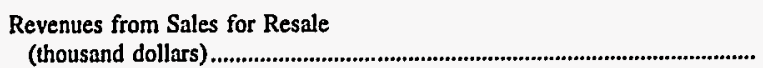 & $20,162,331$ & $8,531,310$ & $10,663,010$ & $7,413,511$ & $46,770,162$ \\
\hline 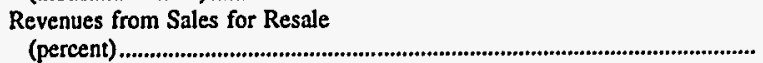 & 43.1 & 18.2 & 22.8 & 15.9 & 100.0 \\
\hline 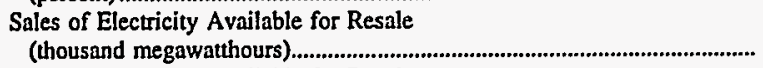 & 644,245 & 244,435 & 293,239 & 249,258 & $1,431,178$ \\
\hline $\begin{array}{l}\text { Sales of Electricity Available for Resale } \\
\text { (percent) }\end{array}$ & 45.0 & 17.1 & 20.5 & 17.4 & 100.0 \\
\hline 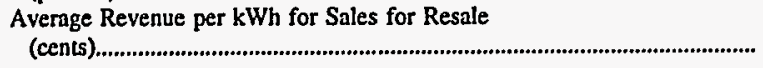 & 3.1 & 3.5 & 3.6 & 3.0 & 3.3 \\
\hline
\end{tabular}

1 Includes only those electric utilities in the United States and the District of Columbia. Note: Totals may not equal sum of components because of independent rounding.

Source: Energy Information Administration, Form EIA-861, "Annual Electric Utility Report." Data are based on calendar year submissions. 
This publication will concentrate on selected operational data for 515 of the 2,010 publicly owned electric utilities and for 8 of the 10 Federal electric utilities in the United States. Table 2 compares these utilities with the total values reported by all publicly owned and Federal electric utilities on the Form EIA-861.

In 1996, the 515 major publicly owned electric utilities in this publication accounted for 88.0 percent of the revenues from sales to ultimate consumers and 99.2 percent of the revenues from sales for resale of all publicly owned electric utilities (Table 2). The 8 Federal electric utilities in this publication essentially cover the entire Federal segment.

This publication contains summary and detailed data for 515 major publicly owed electric utilities (tables 3 through 26). Also, included are summary and detailed data for the 8 Federal electric utilities (tables 27 through 32).

Appendix A tables contain 5 years of summary statistics on U.S. rural electric cooperative borrowers (Tables A1 through A4).

Appendix B contains a list of the major U.S publicly owned electric utility respondents. The major U.S. publicly owned electric utilities added and deleted for 1992 through 1996 are listed (Table B1). The number of generator/nongenerator respondents for June 30, for December 31, and for the "other" fiscal years are provided (Table B2). The total number of respondents by State and generating status of the respondents are also provided (Table B3). The name, State, financial reporting date, and generating status of the respondents are also provided (Table B4).

Appendix C contains summary statistics for generating and nongenerating major U.S. publicly owned electric utilities for the fiscal year periods ending June 30 and December 31 , as well as for all respondents (Tables C1 through C50).

Appendix D contains a list of the State agencies which have regulatory oversight of publicly owned electric utilities.

Appendix E contains all Technical Notes for the publication. The key sections are Sources of Data, Quality of Data, Formulas and Calculations, and General Information.

The Glossary defines common terms used in the publication.

Table 2. Selected Data for Major U.S. Publicly Owned and Federal Electric Utilities Compared to All U.S. Publicly Owned and Federal Electric Utilities, 1996

\begin{tabular}{|c|c|c|}
\hline Item & Publicly Owned & Federall \\
\hline $\begin{array}{l}\text { Number of Electric Utilities in This Report } \\
\text { Share of Electric Utilities Within Ownership Class }\end{array}$ & 515 & 8 \\
\hline 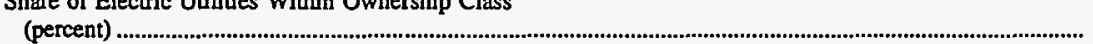 & 25.6 & 80.0 \\
\hline $\begin{array}{l}\text { Revenues from Sales to Ultimate Consumers } \\
\text { (thousand dollars) }\end{array}$ & $23,850,966$ & $1,126,258$ \\
\hline $\begin{array}{l}\text { Share of Revenues from Sales to Ultimate Consumers } \\
\text { (percent) }\end{array}$ & 88.0 & 97.8 \\
\hline $\begin{array}{l}\text { Sales of Electricity to Ulimate Consumers } \\
\text { (thousand megawatthours) }\end{array}$ & 400,416 & 45,268 \\
\hline $\begin{array}{l}\text { Share of Sales of Electricity to Ultimate Consumers } \\
\text { (percent) }\end{array}$ & 88.8 & 99.2 \\
\hline $\begin{array}{l}\text { Revenues from Sales for Resale } \\
\text { (thousand dollars) }\end{array}$ & $8,463,467$ & $7,412,951$ \\
\hline $\begin{array}{l}\text { Share of Revenues from Sales for Resale } \\
\text { (percent) }\end{array}$ & 99.2 & 100.0 \\
\hline Sales of Electricity Available for Resale & 242,563 & 249,208 \\
\hline $\begin{array}{l}\text { Share of Sales of Electricity Available for Resale } \\
\text { (percent) }\end{array}$ & 99.2 & 100.0 \\
\hline
\end{tabular}

1 The Department of Interior-U.S. Bureau of Reclamation and the Department of State-International Water and Boundary Commission do not file the Form EIA-412; however, their energy is marketed and reported by the Bonneville Power Administration, the Southeastern Power Administration, the Southwestern Power Administration, and the Westem Area Power Administration.

Source: Energy Information Administration, Form EIA-861, "Annual Electric Utility Report." Data are based on calendar year submissions. 
Summary Statistics of Major U.S. Publicly Owned Electric Utilities 


\section{Factors Affecting Major U.S. Publicly Owned Electric Utilities During 1996}

\section{Overview}

Summary financial statistics are provided for major U.S. publicly owned electric utilities. These statistics include data for 515 electric utilities for 1996; 512 electric utilities for $1995 ; 503$ electric utilities for 1994; 495 electric utilities for 1993; and 483 electric utilities for 1992 . Over the five years summarized in this report, a net of 32 publicly owned electric utilities have been added as Form EIA-412 respondents. Currently, these additional respondents represent 6.2 percent of the 1996 total respondents base, but have a small impact on overall reported publicly owned electric utility investments.

Economic Context. Strong economic growth characterized 1996 with real gross domestic product (GDP) exceeding the rate of expansion that occurred in 1995. After severe weather during January and an automobile manufacturer's strike in March, the economy recovered and remained strong throughout the year. Another sign of the sturdy economy was that the civilian unemployment rate declined to 5.3 percent by December. The consumer price index (CPI) rose during the year largely due to increases in energy and food prices. However, the other core component increases were at a smaller rate compared with 1995. The total industrial production index increased 3.2 percent, closely approximating the 1995 increase. The budget deficit fell again for the fourth consecutive year and amounted to approximately 1.4 percent of real GDP. This was primarily due to the combination of government spending reductions and the increased revenues as a result of the healthy economy.

The Federal funds rate was cut in January to about 5.25 percent and remained steady. Long-term interest rates mirrored economic activity by rising earlier in the year, declining in the autumn, and then rising in the last quarter. Keeping interest rates fairly steady was the unusual combination of declining unemployment and the relatively low rate of increase in the consumer price index. ${ }^{1}$

Weather. Heating and cooling degree-days actually averaged close to normal levels. Degree-days are relative measurements of outdoor air temperature with cooling- degree days being the number of degrees that the daily average temperature rises above 65 degrees and conversely, heating degree-days the number of degrees the average daily temperature falls below 65 degrees Fahrenheit. Heating degree-days were only 4.1 percent above normal in 1996 and cooling degreedays 3.7 percent below normal. Variations in weather can significantly contribute to departures from normal by month and by geographical region and the subsequent effect on electricity demand, primarily in the residential sector. ${ }^{2}$

\section{Generator Electric Utilities versus Nongenerator Electric Utilities}

The next section of the publication discusses generator and nongenerator electric utilities separately. The two groups are distinct because of operational differences resulting in significantly different financial profiles. For example, significant plant production expenses would not exist for nongenerator electric utilities because existing production plant expenses are mainly maintenance costs for standby plants. It should be noted that both generator and nongenerator electric utilities report according to varying fiscal years that are determined by their political localities.

Because nongenerator electric utilities purchase all their power needs, they have less plant investment than generator electric utilities do per dollar of revenue generated. In 1996, generator electric utilities showed $\$ 3.91$ of electric utility plant (without nuclear fuel) per dollar of electric utility operating revenue, compared with $\$ 1.16$ for nongenerator electric utilities.

Operation and maintenance (O\&M) expenses represent very different costs between the two groups of electric utilities. Purchase power expenses, which comprise the majority of nongenerators' $O \& M$ expenses, contain all the associated costs for the generating plants from which the power was purchased, including depreciation. This causes nongenerators' O\&M expenses to appear higher than generators' O\&M expenses on a mills per kilowatthour basis. In 1996, nongenerators' $O \& M$ expenses were 88.6 percent of revenues and depreciation was only 3.6 percent. For generators, depreciation of plant is shown directly, since all or some of their generating needs are met by their own plants. Generators' O\&M expenses represented only 63.6 percent of revenues, but depreciation was 11.9 percent of revenues.

Financing is also different for the two groups. Generator electric utilities, with their larger plant investments per dollar of revenue, have more debt per dollar of revenue than nongenerator electric utilities. The large amount of debt creates greater interest expense. Interest expense represented 17.2 percent of revenues in 1996 for the generators versus just 1.2 percent of revenues for the nongenerators (Tables 7 and 16). 
Figure 1. Total Electric Utility Plant per Dollar of Revenue, 1992-1996

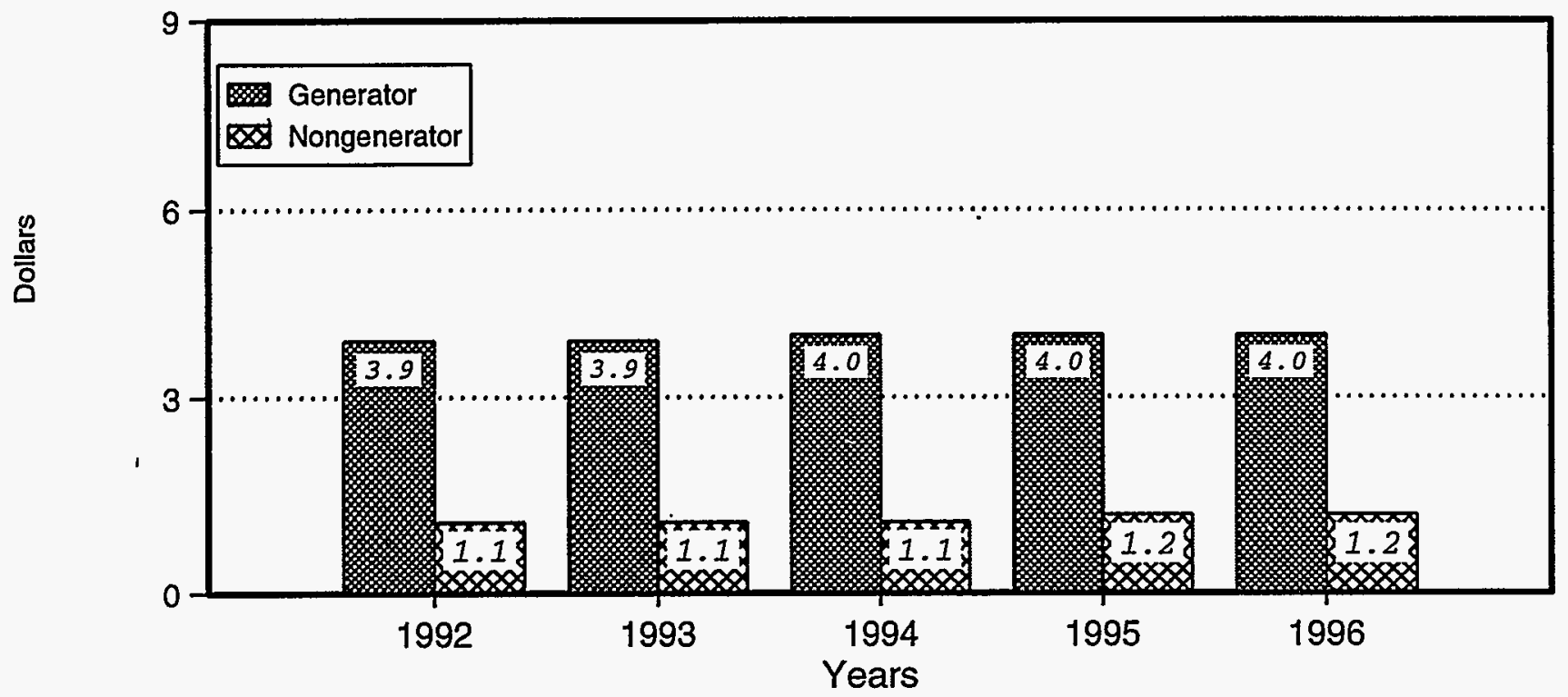

Note: Summary date are provided in Tables 7 and 16.

Source: Energy Information Administrotion, Form ElA-412. "Annual Report of Public Electric Utilities." 


\section{Financial Performance for Generator Electric Utilities}

Financial statistical summaries are provided for major publicly owned generator electric utilities which include 231 electric utilities for 1996; 226 electric utilities for 1995; 227 electric utilities for 1994; 226 electric utilities for 1993; and 226 electric utilities for 1992. New respondents and electric utilities no longer reporting from the previous years are listed in Appendix Table B1.

\section{Highlights of Generator Financial Performance}

Increased sales and revenues combined with lower operating expenses to yield a healthy 13.7-percent increase in electric operating income. After accounting for changes in other income and deductions, net income grew 42.3 percent over the prior year (note that 1993 was an off-year for this segment with net income down 30.5 percent below 1992 levels). Key indicators of the generator electric utilities financial performance were:

- Electric revenues were up 3.1 percent on the basis of a 6.0 percent increase in retail sales and a 14.6-percent increase in sales for resale.

- Electric operation and maintenance expenses were up 1.2 percent, and on a per kilowatthour sold basis decreased to 30.6 mills.

- Interest expense continued its downward trend in 1996, dropping for the fifth year.

- Assets increased $\$ 1.4$ billion after a modest $\$ 0.5$ billion decrease in 1995.

- Investments in distribution plant continued to increase the most in electric plant, up $\$ 973.0$ million.

\section{Income Statement}

The Composite Statement of Income for major publicly owned generator electric utilities for the years 1992 to 1996 is presented in Table 5. Net income of $\$ 1.7$ billion for generator electric utilities was up a substantial 42.3 percent from the previous year.

Revenues. Generator electric utilities revenues were $\$ 24.2$ billion a 3.1-percent increase from the previous year. In 1996, there was greater retail than wholesale growth as revenues increased from both wholesale and retail consumers.

Electric Utility Operating Expenses. Total electric utility operating expenses of $\$ 19.1$ billion were up 0.7 percent over the previous year, and the largest increase in expenses was in operation expenses, up $\$ 0.1$ billion to $\$ 13.8$ billion in 1996 . Operation expenses accounted for 72.1 percent of the total electric operating expenses. The second largest contrib- utor to increased expenses was depreciation expenses, which account for 15.0 percent of total electric utility operating expenses (up 2.5 percent over the previous year). Expenses associated with tax amortization in 1996 contributed to the increase in total electric utility operating expenses. Operation and tax and tax equivalent expenses decreased from the previous year.

Production Expenses. Production expenses were $\$ 12.0$ billion in 1996 , up 5.2 percent over the prior year (Table 8). Production expenses represented 78.1 percent of total operations and maintenance expenses and declined on a mills per kilowatthour basis 0.6 percent (26.1 mills per kilowatthours sold in 1996).

At $\$ 6.8$ billion in 1996, purchased power represents the largest production expense. Historically, despite self generation, generating publicly owned electric utilities have spent less than 50 percent of total production expenses on purchased power. Purchased power expenses were up 19.9 percent over the previous year.

In 1996, steam generating expenses were the second largest production expense, $\$ 3.8$ billion, representing 31.3 percent of total production expenses. Steam production expenses were down 2.9 percent from the prior year. Nuclear power production expenses of $\$ 0.9$ billion were also down, 28.3 percent from the prior year's value, and represented 7.6 percent of total production expenses in 1996.

Hydraulic, other power generation, and other production expenses accounted for the remaining $\$ 0.6$ billion of total power production expenses. Combined these production expenses accounted for only 5.0 percent of the total production expenses.

Fuel expenses in 1996 were $\$ 2.5$ billion, up 0.5 percent from the previous year, and represented 20.7 percent of total production expenses. This was down from 21.7 percent of total production expenses in 1995 and yielded to increased purchased power production expenses.

Transmission and Distribution Expenses. After increasing 2.2 percent in 1995, transmission and distribution expenses were down 3.2 percent in 1996. Transmission expenses of $\$ 0.6$ billion were down 19.8 percent over the prior year, while distribution expenses of $\$ 0.9$ billion were up 11.7 percent. On a mills per kilowatthour sold basis, both transmission and distribution expenses remained unchanged at 1.6 and 1.9 , respectively.

Electric Utility Income. Operating revenues increased $\$ 0.7$ billion, while expenses increased $\$ 0.1$ billion and provided an increase of $\$ 0.6$ billion in electric utility operating income. An increase in other electric income of $\$ 0.1$ billion accompanied by a slight increase in other electric deductions, led to the increase in electric utility income (11.8 percent from the prior year).

Interest Expense. Interest expense was $\$ 4.2$ billion in 1996, just 0.1 percent less than the 1995 amount. Debt outstanding as reported on the balance sheet decreased 
$\$ 1.0$ billion compared with the $\$ 1.7$ billion decrease between 1994 and 1995.

Net Income. The positive effect of the reduction in interest expense mentioned above was aided by an decrease in other income deductions which yielded a modest $\$ 0.8$ billion increase to $\$ 1.7$ billion for income before extraordinary items.

\section{Balance Sheet}

The Composite Balance Sheet for publicly owned generator electric utilities revealed a 0.1 -percent increase in assets for the year (Table 6).

Assets and Other Debits. Increases in total assets were slightly up from prior years values by $\$ 0.1$ billion. This 1996 increase in assets follows with the $\$ 0.5$ billion increase in 1995 . Net electric utility plant (including net nuclear fuel) represents 56.3 percent of the assets. Total other property and investments accounted for 17.3 percent of the total assets or $\$ 19.7$ billion. Other changes in assets include:

- Construction work in progress (CWIP) decreased in 1996 , down 25.8 percent over the $\$ 4.2$ billion figure for 1995.

- Changes in miscellaneous current and accrued assets directly offset the increase in total current and accrued assets. Miscellaneous accounts represented $\$ 1.3$ billion and increase of 2.2 percent from the previous year.

Electric Utility Plant. Electric utility plant in service increased 5.2 percent to $\$ 89.6$ billion in 1996 (Table 9). Net utility plant increased to $\$ 63.3$ billion (Table 6). Notable changes in electric utility plant account included:

- Increases in total production plant up $\$ 2.1$ billion represented 49.1 of the change in total electric plant in service. Steam production plant remains the largest component of production plant at $\$ 25.6$ billion, and provided the greatest increase in 1996, up $\$ 1.1$ billion over the prior year. Other production plant only accounted for $\$ 2.9$ billion out of the total production plant of $\$ 55.7$ billion at the end of 1996. While essentially unchanged from the prior year, nuclear plant investments of $\$ 18.9$ billion accounted for 21.1 percent of the total electric plant in service. (Publicly owned generator electric utilities have significant nuclear plant investment exposure.) Production plant accounts for 62.1 percent of the total electric plant in service.

- The increase in distribution plant was significant, amounting to $\$ 1.0$ billion. By the end of 1996 , distribution plant accounted for 19.1 percent of total electric plant in service.

- Transmission plant changed during 1996, increasing $\$ 0.8$ billion and represented 11.5 percent of total electric plant in service.
- General plant showed an increase from the previous year to $\$ 5.9$ billion in 1996. However, general plant remained at 6.6 percent of total electric plant in service.

Liabilities and Other Credits. Proprietary capital increased $\$ 2.0$ billion or 8.0 percent. Increases in retained earnings added $\$ 2.2$ billion to the net $\$ 2.0$ billion of additional proprietary capital at year's end. Proprietary capital increased from 25.4 percent in 1995 to 27.1 percent in 1996 of total capitalization (proprietary capital plus long-term debt). Other significant changes in liability and other credit accounts included:

- Long-term debt decreased $\$ 1.0$ billion, or 1.4 percent to $\$ 74.0$ billion in 1996. Advances from municipalities and other increased slightly and was aided by a $\$ 0.8$ billion increase in the deduction from the unamortized discount on longterm debt.

- Accounts payable accounted for the greatest portion ( $\$ 2.4$ billion) of the nearly $\$ 8.2$ billion in total current and accrued liabilities.

- Total deferred credits changed little during 1996, representing a 0.3 percent increase.

\section{Consumers, Sales, and Revenue}

The information in this section is based on the data reported on the Form EIA-861.

Sales Growth. Sales to ultimate consumers of the major publicly owned generator electric utilities grew 5.6 percent in 1996, a modest improvement over the 1.2-percent increase in sales between 1994 and 1995 (Table 10). Industrial sales represented 30.4 percent of total sales to ultimate consumers in 1996, up from 29.9 percent in 1995. Commercial sales increased 3.5 percent in 1996 compared with 9.8 percent in 1995 .

Residential sales were up a 6.6 percent in 1996 versus the 1.8-percent increase in sales experienced in 1995. Residential sales represented 32.4 percent of total sales to ultimate consumers for 1996.

Average Revenue (Revenues Divided by Sales). Average revenues from sales to ultimate consumers remained essentially unchanged between 1995 and 1996 , decreasing modestly 2.1 percent to 61.3 mills per kilowatthour. Residential and commercial consumers both provided decreases in average revenues of 1.1 percent, while industrial consumers provided an increase of 0.7 percent. The average revenue provided by residential consumers in 1996 was 69.9 mills per kilowatthour versus 69.8 mills per kilowatthour in 1995. The average revenue provided by industrial consumers in 1996 was 45.1 mills per kilowatthour versus 44.8 mills per kilowatthour in 1995 . The average revenue provided by commercial consumers in 1996 was 66.6 mills per kilowatthour verses 66.4 mills per kilowatthour in 1995 .

Average revenue per consumer per month from the commercial and residential consumers, in 1996, 
increased 1.4 and 3.3 percent, respectively. The average revenue monthly provided by commercial consumers was $\$ 406.15$ per month up from 1995 when the average was $\$ 404.65$ per month. The average revenue monthly provided by residential consumers was $\$ 60.76$ in 1996 compared with \$58.82 in 1995 .

In 1996, average revenue provided by industrial consumers decreased $\$ 127.42$ to $\$ 5,309.47$. Average industrial revenue increased 2.5 percent from the 1995 average of $\$ 5,182.05$.

Sales for Resale. Sales for resale were up $\mathbf{8 . 6}$ percent in 1996 , reaching 47.7 percent of total electricity sales. The share of total electricity sales provided by sales for resale increased marginally in 1996 (up 0.7 percent from the 47.0-percent level in 1995). The share of revenues represented by sales for resale was 34.3 percent in 1996 compared to 34.4 percent in 1995 (a modest increase of 5.5 percent to $\$ 8.2$ billion). Average revenues from sales for resale decreased 2.7 percent to 35.1 mills per kilowatthour, down from 36.1 mills per kilowatthour in 1995.

\section{Generation and Purchased Power.}

In 1996, total net energy generated and received increased 10.0 percent, which corresponded closely with the increase in sales volume (Table 11). Net generation as a percent of the total net energy required increased moderately in 1996 , to 64.5 percent. The corresponding figures for 1995 and 1994 were 66.6 percent and 65.7 percent, respectively.
Net hydroelectric generation (conventional hydroelectric generation and net hydro-pumped storage) increased 7.1 percent from the prior year, increasing its proportion of total purchased power and net generation (i.e., total supply) to 26.7 percent. Steam generation increased 4.4 percent in 1996 , accounting for 53.0 percent of the total supply. Nuclear generation increased 12.0 percent. Nuclear generation accounted for 20.5 percent of total supply in 1996, up from 19.5 percent in 1995.

Purchased power continues to play an ever increasing role in the supply mix of publicly owned generator electric utilities. In 1996, purchased power represented 34.1 percent of the supply mix and purchases from electric utilities dominated the power purchases, accounting for 98.7 percent of power purchases. However, purchases from nonutilities are decreasing at 66.3 percent in 1995.

In 1996, steam power production expenses were 21.2 mills per kilowatthour generated, down 7.0 percent from 22.8 mills per kilowatthour in 1995. Nuclear power production expenses were 13.3 mills per kilowatthour generated compared with 20.8 mills per kilowatthour generated in 1995. 
Table 3. Ten Largest U.S. Publicly Owned Generator Electric Utilities Ranked by Megawatthour Sales to Ultimate Consumers, 1996

\begin{tabular}{|c|c|c|c|}
\hline Publicly Owned Electric Utilities & State & Amount & Percent \\
\hline Los Angeles City of & Califomia & $21,233,474$ & 8.37 \\
\hline Salt River Proj Ag I \& P Dist & Arizona & $17,634,028$ & 6.95 \\
\hline 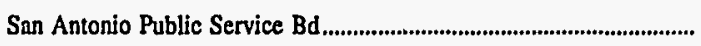 & Texas & $14,595,910$ & 5.75 \\
\hline Power Authority of State of NY & New York & $13,017,530$ & 5.13 \\
\hline 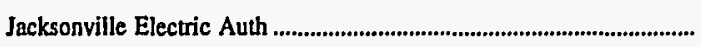 & Florida & $9,753,452$ & 3.84 \\
\hline Seattle City of & Washington & $9,188,000$ & 3.62 \\
\hline 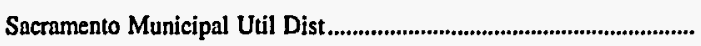 & California & $8,889,261$ & 3.50 \\
\hline South Carolina Pub Serv Auth.... & South Carolina & $8,209,218$ & 3.23 \\
\hline 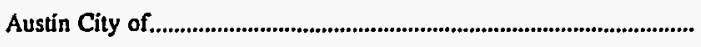 & Texas & $8,138,417$ & 3.21 \\
\hline 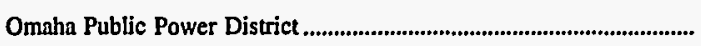 & Nebraska & $7,756,491$ & 3.06 \\
\hline 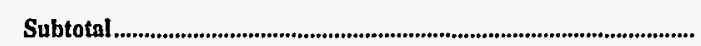 & & $118,415,781$ & 46.66 \\
\hline
\end{tabular}

Note: Percentage calculations are based on total generator electric utilities.

Source: Energy Information Administration, Form ElA-412, "Annual Report of Public Electric Utilities." Individual electric utilities report fiscal year data. Appendix B shows the fiscal year for each electric utility.

Table 4. Ten Largest U.S. Publicly Owned Generator Electric Utilities Ranked by Megawatthour Sales for Resale, 1996

\begin{tabular}{|c|c|c|c|}
\hline Publicly Owned Electric Utilities & State & Amount & Percent \\
\hline Power Authority of State of NY ............... & New York & $27,555,179$ & 11.35 \\
\hline Nebraska Public Power District....... & Nebraska & $24,235,179$ & 9.99 \\
\hline PUD No 1 of Chelan County & Washington & $10,845,639$ & 4.47 \\
\hline 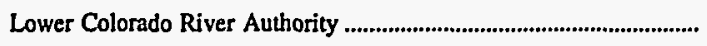 & Texas & $10,645,538$ & 4.39 \\
\hline 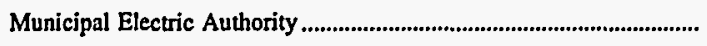 & Georgia & $10,264,912$ & 4.23 \\
\hline Intermountain Power Agency & Utah & $9,760,982$ & 4.02 \\
\hline 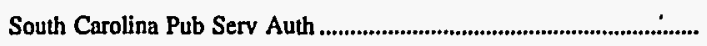 & South Carolina & $9,339,589$ & 3.85 \\
\hline 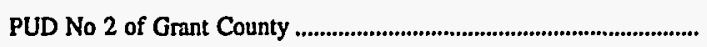 & Washington & $8,482,068$ & 3.49 \\
\hline 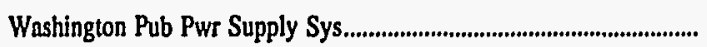 & Washington & $7,780,202$ & 3.21 \\
\hline 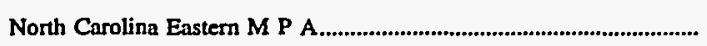 & North Carolina & $6,709,020$ & 2.76 \\
\hline 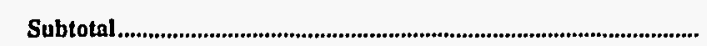 & & $125,618,308$ & 51.76 \\
\hline
\end{tabular}

Note: Percentage calculations are based on total generator electric utilities.

Source: Energy Information Administration, Form EIA-412, "Annual Report of Public Electric Utilities." Individual electric utilities report fiscal year data. Appendix B shows the fiscal year for each electric utility. 
Table 5. Composite Statement of Income for Major U.S. Publicly Owned Generator Electric Utilities, 1992-1996 (Thousand Dollars)

\begin{tabular}{|c|c|c|c|c|c|}
\hline Item & 1996 & 1995 & 1994 & 1993 & 1992 \\
\hline Electric Utility Operating Revenues................................ & $24,207,226$ & $23,472,888$ & $2,266,686$ & $22,521,847$ & $21,686,349$ \\
\hline 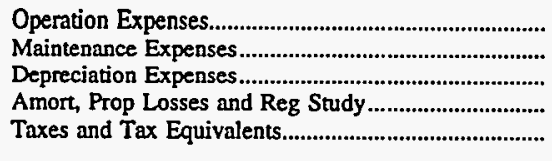 & $\begin{array}{r}13,768,044 \\
1,637,828 \\
2,871,448 \\
144,216 \\
662,443\end{array}$ & $\begin{array}{r}13,652,884 \\
1,575,208 \\
2,802,473 \\
131,121 \\
797,189\end{array}$ & $\begin{array}{r}13,577,615 \\
1,584,444 \\
2,591,423 \\
129,137 \\
766,068\end{array}$ & $\begin{array}{r}13,241,567 \\
1,565,293 \\
2,441,927 \\
154,172 \\
759,205\end{array}$ & $\begin{array}{r}12,527,435 \\
1,564,792 \\
2,285,807 \\
131,472 \\
681,140\end{array}$ \\
\hline 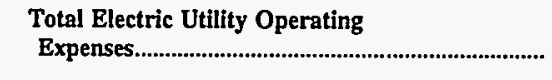 & $19,083,980$ & $18,958,876$ & $18,648,687$ & $18,162,164$ & $17,190,647$ \\
\hline 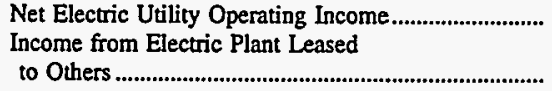 & $\begin{array}{r}5,123,246 \\
25,914\end{array}$ & $4,514,013$ & $4,617,999$ & $4,359,683$ & $\begin{array}{r}4,495,703 \\
15,129\end{array}$ \\
\hline Electric Utility Operating Income ............................... & $5,149,160$ & $4,530,377$ & $4,648,240$ & $4,383,258$ & $4,510,832$ \\
\hline Other Electric Income & $1,440,435$ & $1,371,621$ & $1,237,067$ & $1,455,984$ & $1,839,484$ \\
\hline $\begin{array}{l}\text { Other Electric Deductions................................................ } \\
\text { Allowance for Other Funds Used }\end{array}$ & 231,405 & 198,944 & 136,369 & 262,574 & 225,472 \\
\hline 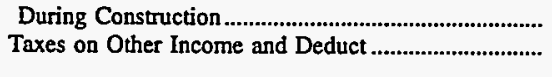 & $\begin{array}{l}6,660 \\
4,431\end{array}$ & $\begin{array}{r}9,145 \\
23,870\end{array}$ & $\begin{array}{r}7,872 \\
39,890\end{array}$ & $\begin{array}{l}28,476 \\
25,751\end{array}$ & $\begin{array}{l}24,183 \\
24,380\end{array}$ \\
\hline 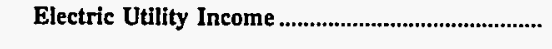 & $6,360,419$ & $5,688,329$ & $5,716,920$ & $5,579,392$ & $6,124,646$ \\
\hline $\begin{array}{l}\text { Income Deductions from Interest } \\
\text { on Long-term Debt................................................... } \\
\text { Other Income Deductions......................................... } \\
\text { Allowance for Borrowed Funds Used }\end{array}$ & $\begin{array}{r}\cdot \\
4,155,829 \\
515,462\end{array}$ & $\begin{array}{r}4,206,294 \\
570,311\end{array}$ & $\begin{array}{r}4,332,296 \\
387,497\end{array}$ & $\begin{array}{r}4,433,067 \\
291,966\end{array}$ & $\begin{array}{r}4,757,583 \\
313,894\end{array}$ \\
\hline 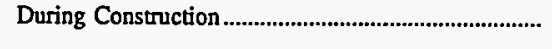 & $-36,743$ & $-48,543$ & $-38,652$ & $-43,010$ & $-45,719$ \\
\hline 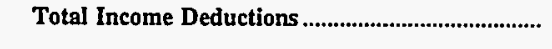 & $4,634,548$ & $4,728,063$ & $4,681,141$ & $4,682,023$ & $5,025,758$ \\
\hline 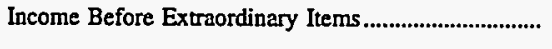 & $1,725,871$ & 960,266 & $1,035,779$ & 897,369 & $1,098,889$ \\
\hline 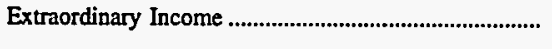 & 234,884 & 307,740 & 77,340 & 69,757 & 111,239 \\
\hline 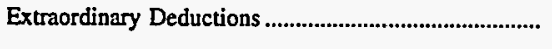 & 237,188 & 56,822 & 201,551 & 283,984 & 226,514 \\
\hline 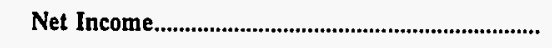 & $1,723,567$ & $1,211,184$ & 911,568 & 683,142 & 983,613 \\
\hline
\end{tabular}

Note: Totals may not equal sum of components because of independent rounding. Detailed data are provided in Table 21. The number of publicly owned generating electric utilities for end of period is 231 for 1996, 226 for 1995, 227 for 1994, 226 for 1993, 225 for 1992 The City of Gaffney (SC), City of Osceola (AR), and City of Redding (CA) were nongenerators for 1992 through 1993, but became generators in 1994. The City of Kennett (MO) and the City of Morgan City (LA) were generators 1992 through 1993, but became nongenerators in 1994

Source: Energy Information Administration, Form EIA-412, "Annual Report of Public Electric Utilities." Individual electric utilities report fiscal year data. Appendix B shows the fiscal year for each electric utility. 
Table 6. Composite Balance Sheet for Major U.S. Publicly Owned Generator

Electric Utilities at End of Period, 1992-1996

(Thousand Dollars)

\begin{tabular}{|c|c|c|c|c|c|}
\hline Item & 1996 & 1995 & 1994 & 1993 & 1992 \\
\hline \multicolumn{6}{|l|}{ Electric Utility Plant } \\
\hline 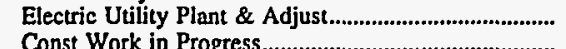 & $91,574,571$ & $86,958,613$ & $85,250,576$ & $81,995,168$ & $\begin{array}{r}79,555,377 \\
2532,58 ?\end{array}$ \\
\hline 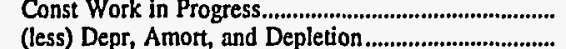 & $\begin{array}{r}3,123,475 \\
31,339,433\end{array}$ & $\begin{array}{r}4,212,261 \\
28,600,640\end{array}$ & $\begin{array}{r}4,229,508 \\
26,779,491\end{array}$ & $\begin{array}{r}3,777,408 \\
24,224,587\end{array}$ & $\begin{array}{r}3,532,582 \\
22,301,093\end{array}$ \\
\hline 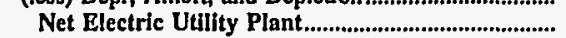 & $63,358,614$ & $62,570,234$ & $62,700,593$ & $61,547,988$ & $60,786,867$ \\
\hline 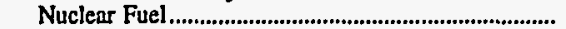 & $2,734,959$ & $2,600,445$ & $2,564,002$ & $2,580,570$ & $2,271,919$ \\
\hline (less) Amort of Nucl Fuel ............................................... & $1,934,162$ & $1,758,071$ & $1,688,491$ & $1,650,975$ & $1,348,032$ \\
\hline Net Elec Plant Inel Nucl Fuel........................................ & $64,159,411$ & $63,412,608$ & $63,576,104$ & $62,477,584$ & $61,710,753$ \\
\hline \multicolumn{6}{|l|}{ Other Property \& Investments } \\
\hline Nonutility Property ............................... & $7,063,879$ & $6,478,362$ & $6,011,888$ & $5,453,823$ & $5,000,781$ \\
\hline (less) Accum Provisions for Depr \& Amort.................. & $2,036,245$ & $1,910,192$ & $1,903,408$ & $1,763,781$ & $1,646,040$ \\
\hline 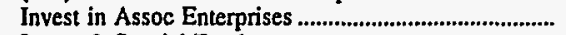 & 67,353 & 36,316 & 259,765 & 351,033 & 255,493 \\
\hline Invest \& Special Funds....................................................... & $14,579,925$ & $16,392,429$ & $16,605,752$ & $16,446,328$ & $14,618,703$ \\
\hline Total Other Property \& Investments............................ & $19,674,912$ & $20,996,914$ & $20,973,996$ & $20,487,402$ & $18,228,937$ \\
\hline \multicolumn{6}{|l|}{ Current and Accrued Assets } \\
\hline 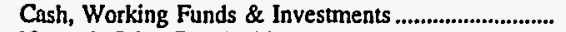 & $9,801,652$ & $8,811,457$ & $9,571,515$ & $9,563,657$ & $9,378,734$ \\
\hline 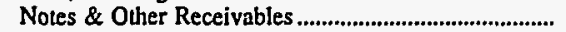 & 894,491 & 809,388 & 693,020 & 725,707 & 736,137 \\
\hline 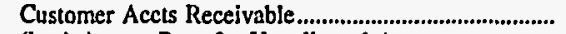 & $2,168,581$ & $1,952,922$ & $2,001,427$ & $1,999,590$ & $1,763,091$ \\
\hline (less) Accum Prov for Uncollected Accts .................... & 77,810 & 72,376 & 66,493 & 106,485 & 99,830 \\
\hline Fuel Stock \& Exp Undistr............................................... & 612,406 & 539,131 & 542,697 & 496,149 & 544,131 \\
\hline 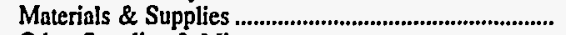 & $1,070,141$ & $1,081,332$ & $1,130,673$ & $1,107,019$ & $1,163,156$ \\
\hline 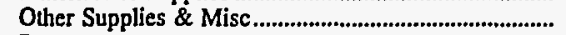 & 34,193 & 45,965 & & 241,763 & 249,621 \\
\hline 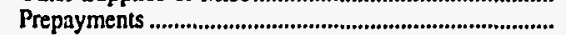 & 334,169 & 223,028 & 253,603 & - & 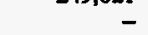 \\
\hline 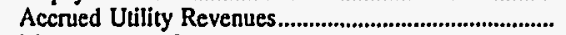 & 358,767 & 398,826 & 313,896 & 303,140 & 258,068 \\
\hline Miscellaneous Current \& Accrued Assets ........................ & $1,325,154$ & $1,296,771$ & $1,341,955$ & $1,026,573$ & 997,599 \\
\hline \multirow{2}{*}{\multicolumn{6}{|c|}{ Deferred Debits }} \\
\hline & & & & & \\
\hline Unamortized Debt Expenses..... & $1,706,650$ & $2,582,636$ & $2,784,363$ & $2,427,106$ & $2,200,298$ \\
\hline Extraordinary Losses, Study Cost........................................ & $1,163,881$ & $1,633,362$ & 517,236 & 911,714 & 465,291 \\
\hline Misc Debt, $R$ \& D Exp, Unamrt Losses............................... & $10,650,194$ & $10,026,679$ & $10,612,155$ & $10,648,504$ & $9,351,452$ \\
\hline Total Deferred Debits .......................................................... & $13,520,724$ & $14,242,677$ & $13,913,754$ & $13,987,324$ & $12,017,041$ \\
\hline 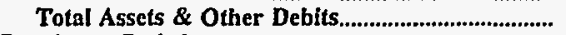 & $113,876,791$ & $113,738,640$ & $114,246,146$ & $112,309,422$ & $106,947,439$ \\
\hline \multicolumn{6}{|l|}{ Proprietary Capital . } \\
\hline 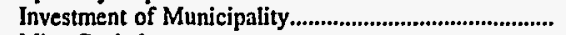 & $1,627,763$ & $1,878,305$ & $1,553,731$ & $1,565,518$ & $1,601,685$ \\
\hline 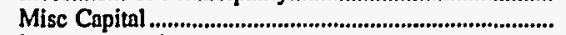 & 378,204 & 261,665 & 270,335 & 205,855 & 92,311 \\
\hline Retnined Earnings .................................................................. & $25,466,380$ & $23,307,191$ & $22,694,785$ & $21,756,224$ & $21,129,231$ \\
\hline Total Proprietary Capital ................................................ & $27,472,346$ & $25,447,162$ & $24,518,851$ & $23,527,598$ & $22,823,226$ \\
\hline \multicolumn{6}{|l|}{ Long-term Debt } \\
\hline Bonds....................... & $73,053,082$ & $73,320,395$ & $75,197,478$ & $75,154,364$ & $72,372,625$ \\
\hline 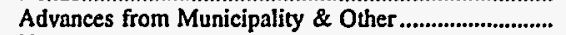 & $4,447,814$ & $4,426,379$ & $4,934,423$ & $3,225,141$ & $2,531,683$ \\
\hline Unamort Prem on Long-term Debt................................... & 411,778 & 348,015 & 56,467 & 619,279 & 60,388 \\
\hline (less) Unamort Discount on Long-term Debt................. & $3,962,260$ & $3,112,633$ & $3,373,060$ & $2,830,002$ & $2,960,305$ \\
\hline 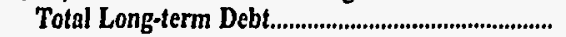 & $73,950,415$ & $74,982,156$ & $76,815,309$ & $76,168,783$ & $72,004,391$ \\
\hline \multicolumn{6}{|l|}{ Other Noncurrent Liabilities } \\
\hline 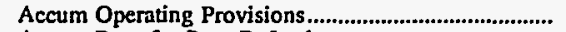 & 630,974 & 556,419 & 596,899 & 475,624 & 694,074 \\
\hline 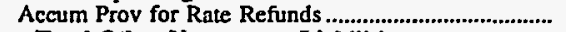 & 135,119 & 157,935 & 104,507 & 115,164 & 4,277 \\
\hline \multirow{2}{*}{\multicolumn{6}{|c|}{ Current and Accrued Liabilities }} \\
\hline & & & & & \\
\hline Notes Payable............................... & $1,748,503$ & $1,348,606$ & $1,249,705$ & $1,310,284$ & $1,117,110$ \\
\hline 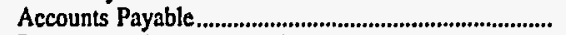 & $2,356,476$ & $2,142,509$ & $2,151,413$ & $2,056,839$ & $2,019,801$ \\
\hline Payables to Assoc Enterprises............................................ & 342,057 & 351,767 & 312,779 & 304,054 & 284,324 \\
\hline 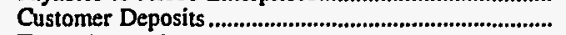 & 377,789 & 320,250 & 311,864 & 284,735 & 297,901 \\
\hline 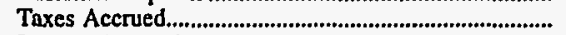 & 220,991 & 215,340 & 219,358 & 202,354 & 191,865 \\
\hline Interest Accrued .......................................................... & $1,608,534$ & $1,536,951$ & $1,506,666$ & $1,472,136$ & $1,464,605$ \\
\hline Misc Current \& Accrued Liabilities....................................... & $1,513,319$ & $3,169,439$ & $3,161,371$ & $2,963,651$ & $2,705,171$ \\
\hline Total Current \& Accrued Liabilities......................... & $8,167,668$ & $9,084,862$ & $8,913,155$ & $8,5,94,053$ & $8,080,777$ \\
\hline \multicolumn{6}{|l|}{ Deferred Credits } \\
\hline 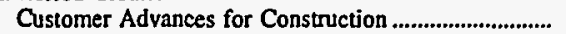 & 168,814 & 199,920 & 171,987 & & 168,889 \\
\hline 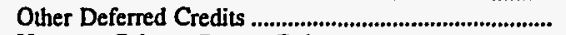 & $3,336,836$ & $3,272,692$ & $2,891,952$ & $2,947,484$ & $2,787,138$ \\
\hline Unamort Gain on Reacqr Debl............................................. & 14,619 & 37,494 & 233,486 & 309,794 & 384,667 \\
\hline 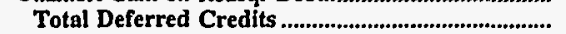 & $3,520,270$ & $3,510,106$ & $\mathbf{3 , 2 9 7 , 4 2 5}$ & $3,428,200$ & $3,340,694$ \\
\hline Total Llabiltites and Other Credits ........................... & $113,876,791$ & $113,738,640$ & $114,246,146$ & $112,309,422$ & $106,947,439$ \\
\hline
\end{tabular}

Note: Totals may not equal sum of components because of independent rounding. Detailed data are provided in Table 22 . The number of publicly owned generating electric utilities for end of period is 231 for 1996, 226 for 1995, 227 for 1994, 226 for 1993, 225 for 1992. The City of Gaffney (SC), City of Osceola (AR), and City of Redding (CA) were nongenerators for 1992 through 1993, but became generators in 1994. The City of Kennett (MO) and the City of Morgan City (LA) were generators 1992 through 1993, but became nongenerators in 1994.

Source: Energy Information Administration, Form EIA-412, "Annual Report of Public Electric Utilities." Individual electric utilities report fiscal year data. Appendix B shows the fiscal year for each electric utility. 
Table 7. Composite Financial Indicators for Major U.S. Publicly Owned Generator Electric Utilities, 1992-1996

\begin{tabular}{|c|c|c|c|c|c|}
\hline Item & 1996 & 1995 & 1994 & 1993 & 1992 \\
\hline Total Electric Utility Plant per Dollar of Revenue & 4.0 & 4.0 & 4.0 & 3.9 & 3.9 \\
\hline Current Assets to Current Liabilities .............................. & 2.0 & 1.7 & 1.8 & 1.8 & 1.9 \\
\hline 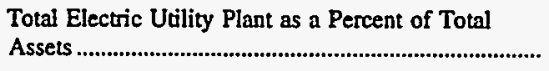 & 85.6 & 82.4 & 80.6 & 78.7 & 79.8 \\
\hline $\begin{array}{l}\text { Net Electric Utility Plant as a Percent of Totai } \\
\text { Assets }\end{array}$ & 56.3 & 55.8 & 55.6 & 55.6 & 57.7 \\
\hline Debt as a Percent of Total Liabilities ............................. & 72.1 & 73.9 & 75.0 & 75.5 & 74.9 \\
\hline $\begin{array}{l}\text { Depreciation, Amortization and Depletion } \\
\text { as a Percent of Total Electric Utility Plant ................. }\end{array}$ & 34.2 & 32.4 & 30.9 & 29.3 & 27.7 \\
\hline $\begin{array}{l}\text { Electric Operation and Maintenance Expenses } \\
\text { as a Percent of } \\
\text { Electric Utility Operating Revenues ............................ }\end{array}$ & 63.6 & 64.9 & 65.2 & 65.7 & 65.0 \\
\hline 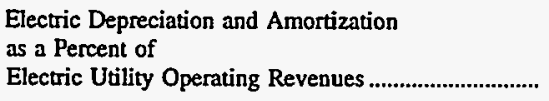 & 11.9 & 11.9 & 11.1 & 10.8 & 10.5 \\
\hline 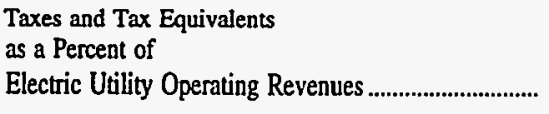 & 2.7 & 3.4 & 3.3 & 3.4 & 3.1 \\
\hline $\begin{array}{l}\text { Interest on Long-term Debt } \\
\text { as a Percent of } \\
\text { Electric Utility Operating Revenues }\end{array}$ & 17.2 & 17.9 & 18.6 & 19.7 & 21.9 \\
\hline 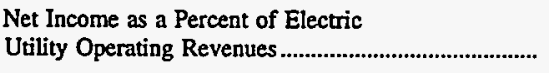 & 7.1 & 5.2 & 3.9 & 3.0 & 4.5 \\
\hline Purchased Power Cents Per Kilowatthour ...................... & 3.8 & 3.6 & 3.6 & 3.6 & 3.7 \\
\hline Generated Cents Per Kilowatthour.................................... & 1.5 & 1.8 & 1.9 & 1.9 & 1.9 \\
\hline $\begin{array}{l}\text { Total Power Supply Per } \\
\text { Kilowatthour Sold............. }\end{array}$ & 2.4 & 2.5 & 2.6 & 2.6 & 2.6 \\
\hline
\end{tabular}

Note: Totals may not equal sum of components because of independent rounding. The number of publicly owned generating electric utilities for end of period is 231 for 1996, 226 for 1995, 227 for 1994, 226 for 1993, 225 for 1992. The City of Gaffney (SC), City of Osceola (AR), and City of Redding (CA) were nongenerators for 1992 through 1993, but became generators in 1994. The City of Kennett (MO) and the City of Morgan City (LA) were generators 1992 through 1993, but became nongenerators in 1994.

Source: Energy Information Administration, Form EIA-412, "Annual Report of Public Electric Utilities." Individual electric utilities report fiscal year data. Appendix B shows the fiscal year for each electric utility. 
Table 8. Electric Operation and Maintenance Expenses for Major U.S.

Publicly Owned Generator Electric Utilities, 1992-1996

(Thousand Dollars)

\begin{tabular}{|c|c|c|c|c|c|}
\hline Item & 1996 & 1995 & 1994 & 1993 & 1992 \\
\hline \multicolumn{6}{|l|}{ Production Expenses } \\
\hline 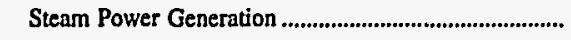 & $3,772,416$ & $3,883,864$ & $4,037,562$ & $4,104,660$ & $3,761,983$ \\
\hline 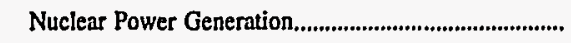 & 915,094 & $1,276,994$ & $1,291,932$ & $1,304,604$ & $1,318,443$ \\
\hline 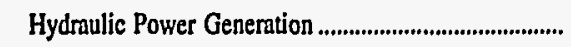 & 220,076 & 260,833 & 243,794 & 241,456 & 244,143 \\
\hline 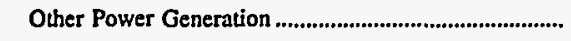 & 251,248 & 213,297 & 177,422 & 178,489 & 175,250 \\
\hline 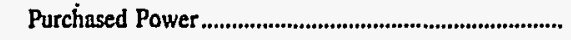 & $6,751,217$ & $5,630,686$ & $5,639,389$ & $5,350,345$ & $5,225,943$ \\
\hline 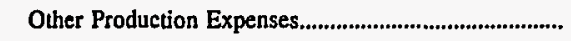 & 127,545 & 175,466 & 140,427 & 127,581 & 72,589 \\
\hline Total Production Expenses .............................................. & $12,037,596$ & $11,441,140$ & $11,530,527$ & $11,307,136$ & $10,798,351$ \\
\hline Transmission Expenses ............................................................ & 594,553 & 741,704 & 710,745 & 687,949 & 634,583 \\
\hline 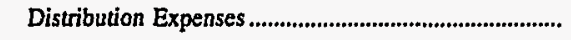 & 928,194 & 831,151 & 826,853 & 812,479 & 767,396 \\
\hline 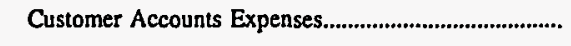 & 365,277 & 323,122 & 316,794 & 314,992 & 299,209 \\
\hline Customer Service and Information Expenses................. & 103,390 & 102,061 & 104,101 & 94,089 & 82,731 \\
\hline 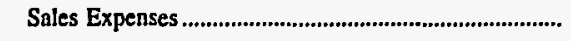 & 17,528 & 19,617 & 22,436 & 17,210 & 17,545 \\
\hline 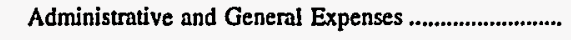 & $1,360,111$ & $1,769,298$ & $1,652,093$ & $1,573,005$ & $1,492,411$ \\
\hline $\begin{array}{l}\text { Total Electric Operation } \\
\text { and Maintenance Expenses ...................................... }\end{array}$ & $15,406,649$ & $15,228,092$ & $15,163,549$ & $14,806,860$ & $14,092,227$ \\
\hline \multicolumn{6}{|l|}{ Fuel Expenses in Operation } \\
\hline 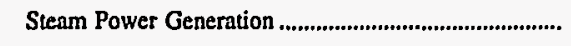 & $2,177,924$ & $2,163,202$ & $2,970,626$ & $3,036,075$ & $2,562,513$ \\
\hline 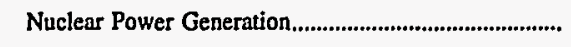 & 229,664 & 221,948 & 313,803 & 299,445 & 290,674 \\
\hline 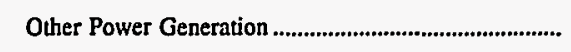 & 89,627 & 100,619 & 101,290 & 102,401 & 82,753 \\
\hline \multicolumn{6}{|l|}{ Number of Elec Dept Employees } \\
\hline 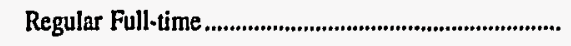 & 55,071 & 56,051 & 59,073 & 58,603 & 60,435 \\
\hline 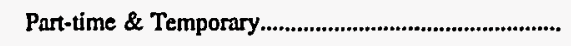 & 1,878 & 2,150 & 2,567 & 2,610 & 2,812 \\
\hline 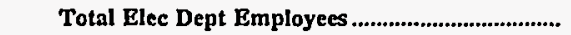 & 56,949 & 58,201 & 61,640 & 61,213 & 63,247 \\
\hline
\end{tabular}

Note: Totals may not equal sum of components because of independent rounding. Detailed data are provided in Table 23. The number of publicly owned generating electric utilities for end of period is 231 for 1996, 226 for 1995, 227 for 1994, 226 for 1993, 225 for 1992. The City of Gaffney (SC). City of Osceola (AR), and City of Redding (CA) were nongenerators for 1992 through 1993, but became generntors in 1994. The City of Kennett (MO) and the City of Morgan City (LA) were generators 1992 through 1993, but became nongenerators in 1994.

Source: Energy Information Administration, Form EIA-412, "Annual Report of Public Electric Utilities." Individual electric utilities report fiscal year datn. Appendix B shows the fiscal year for each electric utility. 
Table 9. Electric Utility Plant for Major U.S. Publicly Owned Generator Electric Utilities at End of Period, 1992-1996

(Thousand Dollars)

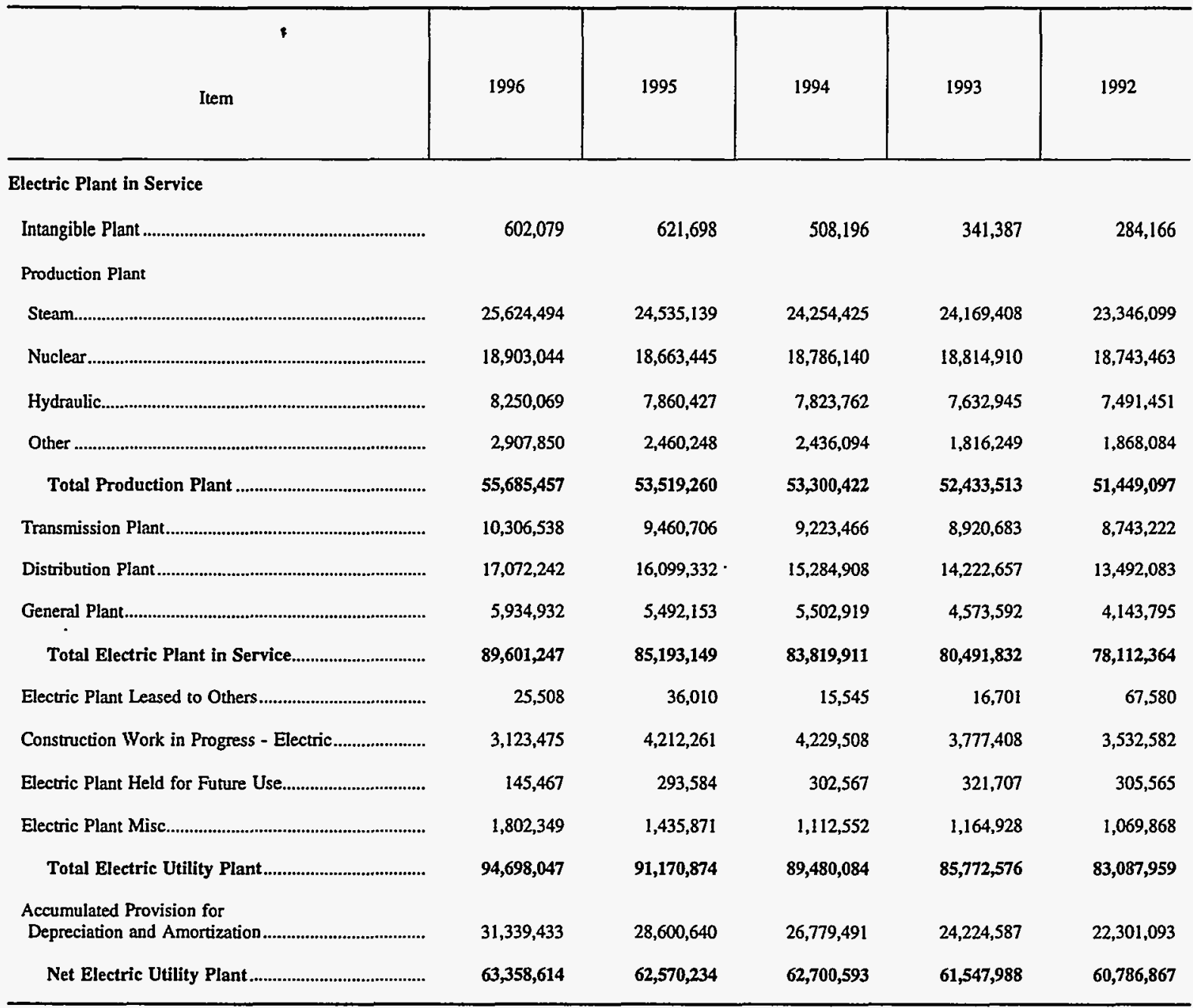

Note: Totals may not equal sum of components because of independent rounding. Detailed data are provided in Table 24. The number of publicly owned generating electric utilities for end of period is 231 for 1996, 226 for 1995, 227 for 1994, 226 for 1993,225 for 1992. The City of Gaffney (SC), City of Osceola (AR), and City of Redding (CA) were nongenerators for 1992 through 1993, but became generators in 1994. The City of Kennett (MO) and the City of Morgan City (LA) were generators 1992 through 1993, but became nongenerators in 1994.

Source: Energy Information Administration, Form EIA-412, "Annual Report of Public Electric Utilities." Individual electric utilities report fiscal year data. Appendix B shows the fiscal year for each electric utility. 
Table 10. Number of Consumers, Sales, and Operating Revenue for Major U.S. Publicly Owned Generator Electric Utilities, 1992-1996

\begin{tabular}{|c|c|c|c|c|c|c|}
\hline Item & 1996 & & 1995 & 1994 & 1993 & 1992 \\
\hline \multicolumn{7}{|l|}{ Number of Consumers } \\
\hline 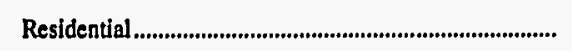 & $7,918,094$ & R & $7,658,917$ & $7,614,061$ & $7,489,340$ & $7,399,653$ \\
\hline 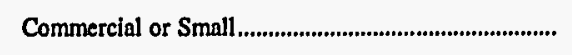 & $1,033,946$ & $\mathbf{R}$ & $1,000,856$ & 992,375 & 985,258 & 977,783 \\
\hline 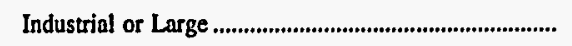 & 55,351 & & 51,768 & 54,196 & 51,989 & 50,465 \\
\hline 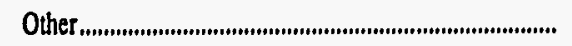 & 113,602 & & 104,078 & 99,554 & 92,891 & 158,098 \\
\hline 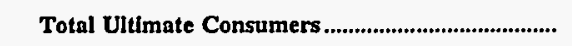 & $9,120,993$ & $\mathbf{R}$ & $8,815,619$ & $8,760,186$ & $8,619,478$ & $8,585,999$ \\
\hline \multicolumn{7}{|l|}{ Sales for the Year (megawatthours) } \\
\hline 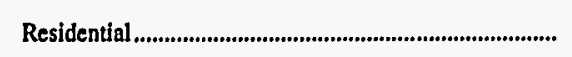 & $82,549,502$ & $\mathbf{R}$ & $77,447,645$ & $75,909,946$ & $74,252,932$ & $71,313,263$ \\
\hline 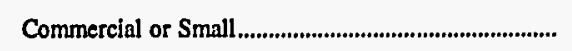 & $75,643,208$ & $\mathbf{R}$ & $73,101,668$ & $66,553,738$ & $68,401,493$ & $66,801,045$ \\
\hline 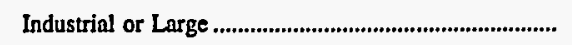 & $77,630,449$ & & $72,156,095$ & $77,301,989$ & $71,517,638$ & $70,698,216$ \\
\hline 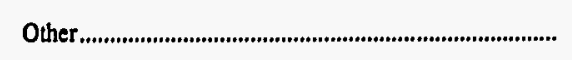 & $19,119,841$ & $\mathbf{R}$ & $18,702,989$ & $18,727,718$ & $17,804,844$ & $17,977,295$ \\
\hline 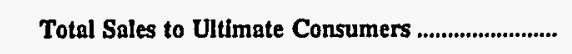 & $254,943,000$ & $R_{2}$ & $241,408,397$ & $238,493,391$ & $231,976,907$ & $226,789,819$ \\
\hline 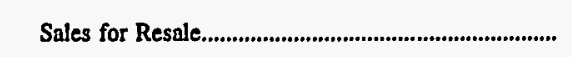 & $232,712,521$ & $\mathrm{R}_{2}$ & $214,227,775$ & $203,426,731$ & $198,650,136$ & $184,259,846$ \\
\hline 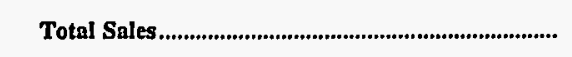 & $487,655,521$ & R 4 & $455,636,172$ & $441,920,122$ & $430,627,043$ & $411,049,665$ \\
\hline \multicolumn{7}{|l|}{$\begin{array}{l}\text { Operating Revenues for the Year } \\
\text { (thousand dollars) }\end{array}$} \\
\hline 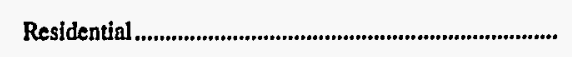 & $5,772,829$ & $\mathbf{R}$ & $5,405,315$ & $5,363,914$ & $5,168,480$ & $4,885,087$ \\
\hline Commercial or Small & $5,034,661$ & $\mathbf{R}$ & $4,855,839$ & $4,468,693$ & $4,658,839$ & $4,434,108$ \\
\hline 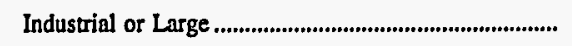 & $3,504,248$ & & $3,233,599$ & $3,709,714$ & $3,365,369$ & $3,243,937$ \\
\hline Other & $1,319,999$ & $\mathbf{R}$ & $1,274,059$ & $1,352,861$ & $1,279,902$ & $1,242,026$ \\
\hline 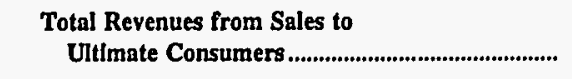 & $15,631,737$ & $\mathbf{R}$ & $14,768,812$ & $14,895,182$ & $14,472,590$ & $13,805,158$ \\
\hline 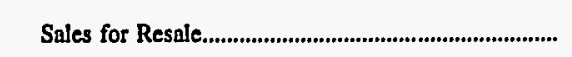 & $8,163,401$ & $\mathbf{R}$ & $7,734,977$ & $7,902,934$ & $7,592,335$ & $7,246,170$ \\
\hline 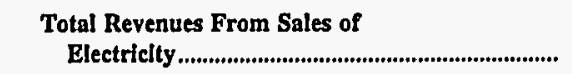 & $23,795,138$ & R & $22,503,789$ & $22,798,116$ & $22,064,925$ & $21,051,328$ \\
\hline
\end{tabular}

$R=$ Revised data.

Note: Totals may not equal sum of components because of independent rounding. Detailed data are provided in Table 25 . The number of publicly owned generating electric utilities for end of period is 231 for 1996, 226 for 1995, 227 for 1994, 226 for 1993, 225 for 1992. The City of Gaffney (SC), City of Osceola (AR), and City of Redding (CA) were nongenerators for 1992 through 1993, but became generators in 1994. The City of Kennett (MO) and the City of Morgan City (LA) were generators 1992 through 1993, but became nongenerators in 1994. sions.

Source: Energy Information Administration, Form EIA-861, "Annual Electric Utility Report." Data are based on calendar year submis- 
Table 11. Electric Energy Account for Major U.S. Publicly Owned

Generator Electric Utilities, 1992-1996

(Megawatthours)

\begin{tabular}{|c|c|c|c|c|c|}
\hline Item & 1996 & 1995 & 1994 & 1993 & 1992 \\
\hline \multicolumn{6}{|l|}{ Sources of Energy } \\
\hline Steam & $177,758,982$ & $170,232,784$ & $181,935,951$ & $179,616,592$ & $169,087,041$ \\
\hline 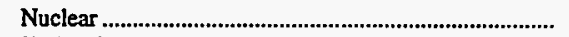 & $68,817,700$ & $61,425,458$ & $53,082,028$ & $48,580,405$ & $52,565,245$ \\
\hline 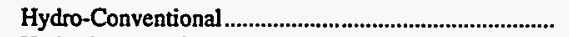 & $84,439,609$ & $78,246,578$ & $64,584,646$ & $71,114,954$ & $65,807,396$ \\
\hline 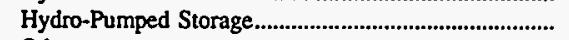 & $5,232,725$ & $5,488,354$ & $4,161,991$ & $4,423,179$ & $4,722,771$ \\
\hline Other & $3,668,948$ & $3,741,342$ & $3,288,915$ & $3,053,440$ & $2,940,656$ \\
\hline 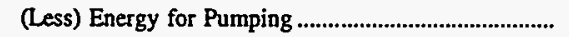 & $4,399,426$ & $4,025,506$ & $4,609,045$ & $4,354,233$ & $4,255,476$ \\
\hline 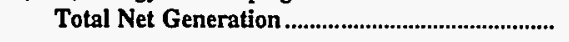 & $335,518,538$ & $315,109,010$ & $302,444,488$ & $302,434,335$ & $290,867,622$ \\
\hline 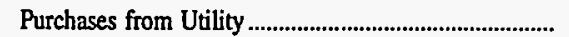 & $175,029,801$ & $145,038,513$ & $155,682,364$ & $148,390,636$ & $140,184,294$ \\
\hline 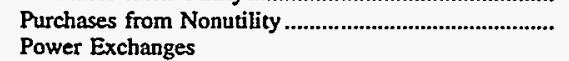 & $2,239,479$ & $6,655,007$ & $1,330,033$ & $1,353,022$ & 887,430 \\
\hline 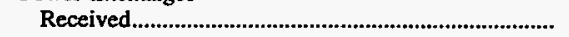 & $21,427,769$ & $27,607,895$ & $18,536,937$ & $21,148,873$ & $18,630,155$ \\
\hline 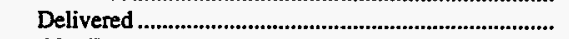 & $21,104,555$ & $21,664,702$ & $16,749,120$ & $21,036,289$ & $18,482,57 !$ \\
\hline 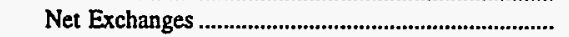 & 323,208 & $5,943,182$ & $1,787,820$ & 112,592 & 147,591 \\
\hline \multicolumn{6}{|l|}{ Transmission for Others (Wheeling) } \\
\hline 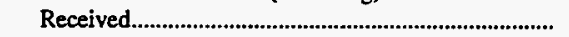 & $33,926,675$ & $25,415,896$ & $29,584,752$ & $26,921,886$ & $22,140,593$ \\
\hline 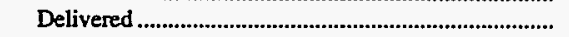 & $26,572,037$ & $25,209,468$ & $29,288,330$ & $26,654,703$ & $21,936,332$ \\
\hline 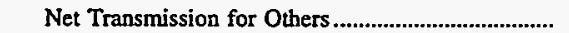 & $7,354,637$ & 206,428 & 296,423 & 267,183 & 204,261 \\
\hline 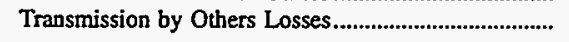 & $-369,587$ & $-124,194$ & $-355,513$ & $-282,349$ & $-242,982$ \\
\hline \multicolumn{6}{|l|}{ Total Net Energy Generated and } \\
\hline 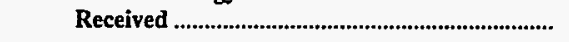 & $520,096,076$ & $472,827,955$ & $461,185,617$ & $452,275,424$ & $432,048,203$ \\
\hline \multicolumn{6}{|l|}{ Disposition of Energy } \\
\hline 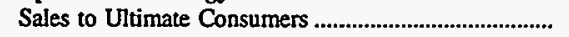 & $253,813,296$ & $239,543,049$ & $237,232,643$ & $232,596,331$ & $225,275,670$ \\
\hline 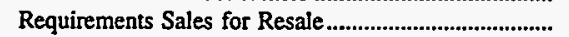 & $177,143,570$ & $157,420,636$ & $158,681,120$ & $154,746,622$ & $145,946,599$ \\
\hline 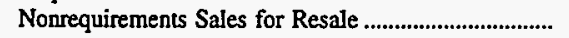 & $65,553,103$ & $54,417,784$ & $42,193,324$ & $41,023,702$ & $36,390,513$ \\
\hline 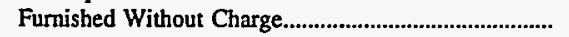 & $1,643,407$ & $2,788,094$ & $1,697,254$ & $1,727,438$ & $1,632,802$ \\
\hline 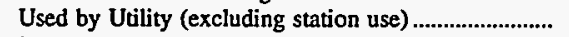 & $5,826,302$ & $4,116,098$ & $5,222,487$ & $5,071,240$ & $6,633,786$ \\
\hline 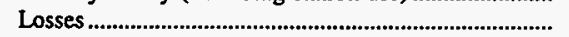 & $16,116,398$ & $14,542,300$ & $16,158,776$ & $17,110,110$ & $16,168,831$ \\
\hline 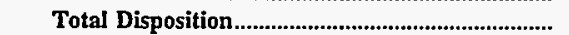 & $520,096,076$ & $472,827,955$ & $461,185,617$ & $452,275,424$ & $432,048,203$ \\
\hline
\end{tabular}

Note: Totals may not equal sum of components because of independent rounding. Detailed data are provided in Table 26. The number of publicly owned generating electric utilities for end of period is 231 for 1996, 226 for 1995, 227 for 1994, 226 for 1993, 225 for 1992. The City of Gaffney (SC), City of Osceola (AR), and City of Redding (CA) were nongenerators for 1992 through 1993, but became generators in 1994. The City of Kennett (MO) and the City of Morgan City (LA) were generators 1992 through 1993, but became nongenerators in 1994. Double counting occurs in components of both sources and disposition of energy and thus neither provides a true total. Purchases from utilities, net exchanges, and net wheeling (except for imports) are included in net generation. Sales for resale is included in sales to ultimate consumers.

Source: Energy Information Administration, Form EIA-412, “Annual Report of Public Electric Utilities." Individual electric utilities report fiscal year data. Appendix B shows the fiscal year for each electric utility. 


\section{Financial Performance for Nongenerator Electric Utilities}

Financial statistical summaries are provided for major publicly owned nongenerator electric utilities which include 284 electric utilities for 1996; 286 electric utilities for 1995; 276 electric utilities for 1994; 269 electric utilities for 1993; and 258 electric utilities for 1992. New respondents and electric utilities no longer reporting from the previous years are listed in Appendix Table B1.

\section{Highlights of Nongenerator Financial Performance}

Despite total electric utility operating costs increasing faster than revenue, the publicly owned nongenerator electric utilities net income was up 8.7 percent. Key factors in the financial performance of the nongenerator electric utilities were:

: Revenues were up 1.7 percent with total electric operating expenses up 1.8 percent.

- Purchased power costs per kilowatthour sold increased 2.3 percent to $\$ 6.5$ billion.

- Debt outstanding decreased $\$ 0.8$ billion or 24.6 percent, whereas interest expenses declined 21.4 percent.

\section{Income Statement}

The Composite Statement of Income for major publicly owned nongenerator electric utilities for the years 1992 to 1996 is presented (Table 14). Net income of $\$ 0.5$ billion for nongenerator electric utilities was up 8.7 percent over the prior year. Income before extraordinary items increased 8.0 percent in 1996.

Revenues. Nongenerator electric utilities revenues showed an increase of 1.7 percent to $\$ 8.6$ billion in 1996. Increased sales to residential consumers were a major contributing factor to increased revenues. Revenues from sales to ultimate consumers increased by $\$ 0.1$ billion in 1996 .

Electric Utility Operating Expenses. Total electric utility operating expenses of $\$ 8.1$ billion were up 1.8 percent over the previous year. The largest dollar increase was in operation expenses (up 2.6 percent or $\$ 0.2$ billion in 1996). Operation expenses accounted for 90.6 percent of total electric utility expenses. Depreciation expense, was down 1.4 percent over the prior year. Maintenance expenses were down 2.2 percent over the previous year. Tax and tax equivalents dropped 15.3 percent in 1996.

Production Expenses. Production expenses were up 2.4 percent over the prior year, accounting for $\$ 6.6$ billion of expenses (Table 17). Purchased power expenses represented virtually all of production expenses, averaged 40.3 mills per kilowatthour sold, compared with 42.7 mills per kilowatthour in 1995.

Transmission and Distribution Expenses. Transmission expenses were up 31.8 percent. Distribution expenses were up 5.5 percent in 1996.

Electric Utility Income. With increasing revenues matching increased total electric operating expenses, net electric utility operating income was up 2.3 percent to $\$ 0.5$ billion in 1996 . Electric utility income increased 2.3 percent to $\$ 0.6$ billion in 1996 .

Interest Expense. Nongenerator electric utilities decreased their long-term debt by $\$ 0.8$ billion for the year ending 1996, while interest expenses dropped 21.5 percent, which amounted to \$0.1 billion in 1996 .

Net Income. Net income increased 8.76 percent in 1996. The net income of $\$ 0.5$ billion in 1996 was up for the sixth year in a row.

\section{Balance Sheet}

The Composite Balance Sheet for publicly owned nongenerator electric utilities is presented in Table 15.

Assets and Other Debits. Total assets and other debits amounted to $\$ 11.3$ billion in 1996, down from $\$ 11.8$ billion in 1995 .

Electric Utility Plant. Electric utility plant in service decreased 0.5-percent to $\$ 9.4$ billion in 1996 (Table 18). Distribution plant increased 6.3 percent from $\$ 6.8$ billion in 1995 to $\$ 7.2$ billion in 1996. Distribution plant represented 76.2 percent of total utility electric plant in service for the nongenerator electric utilities. Other changes in asset and debt accounts include:

- Net electric plant including nuclear fuel represented $\$ 6.3$ billion, about the same as reported in 1995.

- Total other property and investments decreased 14.2 percent, ending the year at $\$ 1.9$ billion.

- Total current and accrued assets of $\$ 2.7$ billion decreased from the $\$ 2.9$ billion in 1995 .

Liabilities and Other Credits. The most significant increase in liabilities and other credits was a 3.0 -percent increase in total proprietary capital. The total proprietary capital account represents the equity that the nongenerator electric utilities have in electric operations. Other changes in liabilities and other credits included:

- Long-term debt at year-end decreased from $\$ 3.4$ billion in 1995 to $\$ 2.6$ billion in 1996 .

- Total proprietary capital increased $\$ 0.2$ billion to $\$ 7.2$ billion in 1996 .

- Total capitalization represented 86.6 percent of total liabilities and other credits in 1996, down from 87.7 percent in 1995 . 
- Current and accrued liabilities increased 2.5 percent to $\$ 1.3$ biilion.

\section{Consumers, Sales, and Revenue}

The information in this section is based upon the Form EIA-861.

Sales Growth. Megawatthour sales to ultimate consumers of the publicly owned nongenerator electric utilities grew 2.6 percent in 1996, a decrease from the 4.8 percent sales growth between 1994 and 1995 (Table 19). Residential sales increased at a Average Revenue (Revenues Divided by Sales). Residential consumers paid on average 61.7 mills per kilowatthour for electricity in 1996, while commercial consumers paid 63.6 mills per kilowatthour and industrial consumers paid 48.2 mills per kilowatthour. This compares with 62.3, 64.8, and 48.9 mills per killowatthour in 1995.

Consumption per consumer in the residential and commercial sector was up 9.4 percent and 3.0 percent respectively. Industrial consumption per consumer was down 0.2 percent in 1996 . The average monthly bill paid by residential, commercial and industrial consumers amounted to \$70.33, \$237.22, and $\$ 4,607.60$, respectively. The industrial monthly bill decreased 1.7 percent, while the commercial and residential monthly bills increased 1.0 percent and 8.4 percent, respectively.

Resale sales decreased 7.8 percent in 1996 after jumping 23.6 percent from 1994 to 1995 . Sales for resale accounted, for 5.9 percent of the total nongenerator electric utility sales of electricity in 1996. 7.7-percent rate. Commercial sales increased at a 2.8-percent, while industrial sales decreased at a 1.5 -percent rate.

The variance in growth rates across the sectors slightly shifted the relative sector mix of sales to ultimate consumers and proved to be another area where nongenerator electric utilities varied significantly from generator electric utilities. The commercial share of total sales to ultimate consumers of nongenerator electric utilities accounted for only 17.2 percent. In the case of generator electric utilities, commercial sales accounted for 29.7 percent of total sales (a figure parallel with that of the investor-owned segment of the electric power industry).

Without any generating resources of their own, sales for resale in the nongenerator segment are not very significant to the overall sales and revenues of these entities. In 1996, sales for resale revenues accounted for $\$ 0.3$ billion dollars or 3.2 percent of total revenues from the sale of electricity.

Total revenues were up 0.7 percent for the year. Increased sales volume resulted in increased revenues in 1996. Average revenues were 54.9 mills per kilowatthour sold in 1996 versus 55.6 mills per kilowatthour sold in 1995.

\section{Purchased Power}

In 1996, purchased power from electric utilities and nonutilities jumped to 161.2 million megawatthhours compared to 148.8 million megawatthours in 1995 . Purchased power averaged 40.3 mills per per kilowatthour in 1996 and 42.7 mills per killowatthour in 1995. 
Table 12. Ten Largest U.S. Publicly Owned Nongenerator Electric Utilities Ranked by Megawatthour Sales to Ultimate Consumers, 1996

\begin{tabular}{|c|c|c|c|}
\hline Publicly Owned Electric Utilities & State & Amount & Percent \\
\hline Memphis City of & Tennessee & $12,577,300$ & 8.65 \\
\hline 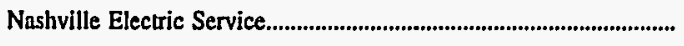 & Tennessee & $11,262,557$ & 7.74 \\
\hline Chattanooga City of & Tennessee & $5,764,479$ & 3.96 \\
\hline 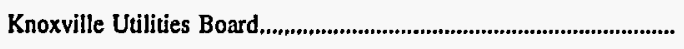 & Tennessee & $5,184,292$ & 3.56 \\
\hline 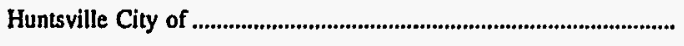 & Alabama & $4,107,294$ & 2.82 \\
\hline 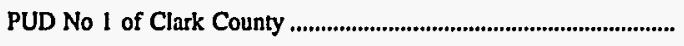 & Washington & $3,687,150$ & 2.54 \\
\hline Johnson City City of & Tennessee & $1,713,206$ & 1.18 \\
\hline 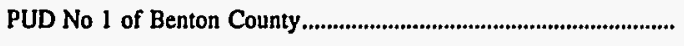 & Washington & $1,613,799$ & 1.11 \\
\hline Decatur City of & Alabama & $1,519,863$ & 1.05 \\
\hline Jackson City of ...., & Tennessee & $1,329,434$ & .91 \\
\hline (n) & & $48,759,374$ & 33.53 \\
\hline
\end{tabular}

Note: Percentage calculations are based on total nongenerator electric utilities.

Source: Energy Information Administration, Form EIA-412, "Annual Report of Public Electric Utilities." Individual electric utilities report fiscal year data. Appendix B shows the fiscal year for each electric utility.

Table 13. Ten Largest U.S. Publicly Owned Nongenerator Electric Utilities Ranked by Megawatthour Sales for Resale, 1996

\begin{tabular}{|c|c|c|c|}
\hline Publicly Owned Electric Utilities & State & Amount & Percent \\
\hline Alabama Municipal Elec Auth & Alabama & $2,634,724$ & 32.02 \\
\hline 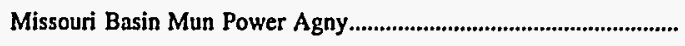 & South Dakota & $1,978,368$ & 24.04 \\
\hline Arizona Power Authority & Arizona & $1,181,512$ & 14.36 \\
\hline Colorado River Comm of Nevada & Nevada & $1,142,235$ & 13.88 \\
\hline Kansas Municipal Energy Agency & Kansas & 293,506 & 3.57 \\
\hline 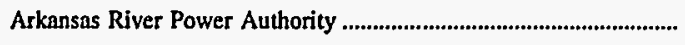 & Colorado & 286,209 & 3.48 \\
\hline 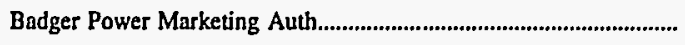 & Wisconsin & 282,054 & 3.43 \\
\hline 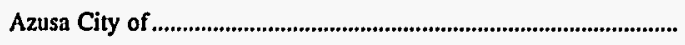 & California & 178,151 & 2.16 \\
\hline 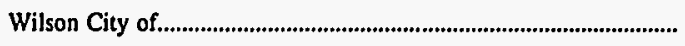 & North Carolina & 64,858 & .79 \\
\hline Quincy City of & Florida & 44,809 & .54 \\
\hline 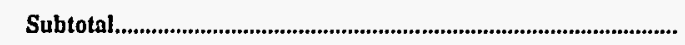 & & $8,086,426$ & 98.27 \\
\hline
\end{tabular}

Note: Percentage calculations are based on total nongenerator electric utilities.

Source: Energy Information Administration, Form EIA-412, "Annual Report of Public Electric Utilities." Individual electric utilities report fiscal year data. Appendix B shows the fiscal year for each electric utility. 
Table 14. Composite Statement of Income for Major U.S. Publicly Owned Nongenerator Electric Utilities, 1992-1996

(Thousand Dollars)

\begin{tabular}{|c|c|c|c|c|c|}
\hline Item & 1996 & 1995 & 1994 & 1993 & 1992 \\
\hline Electric Utility Operating Revenues............................... & $8,581,642$ & $8,435,445$ & $7,995,632$ & $7,523,453$ & $7,247,407$ \\
\hline 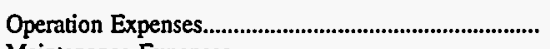 & $7,358,592$ & $7,172,858$ & $6,857,970$ & $6,424,798$ & $6,244,831$ \\
\hline 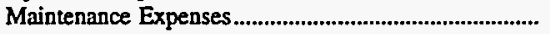 & 244,115 & 249,580 & 233,967 & 207,046 & 192,635 \\
\hline 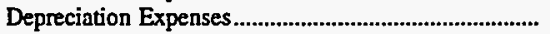 & 305,612 & 309,892 & 268,790 & 252,850 & 248,040 \\
\hline 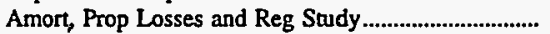 & 8,108 & 2,832 & 4,980 & 3,887 & 3,039 \\
\hline 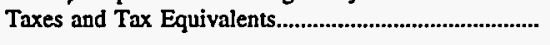 & 206,389 & 243,648 & 210,038 & 174,681 & 154,994 \\
\hline Total Electric Utility Operating & & & & & \\
\hline 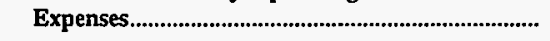 & $8,122,815$ & $7,978,811$ & $7,566,745$ & $7,063,260$ & $6,843,539$ \\
\hline $\begin{array}{l}\text { Net Electric Utility Operating Income.............................. } \\
\text { Income from Electric Plant Leased }\end{array}$ & 458,827 & 456,634 & 428,887 & 460,193 & 403,868 \\
\hline to Others & 12,569 & 4,345 & 2,185 & 2,405 & 1,773 \\
\hline Electric Utility Operating Income & 471,396 & 460,979 & 431,071 & 462,598 & 405,642 \\
\hline Other Electric Income & 207,859 & 215,559 & 178,515 & 172,569 & 172,938 \\
\hline 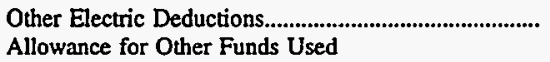 & 62,562 & 73,718 & 79,813 & 74,084 & 98,838 \\
\hline 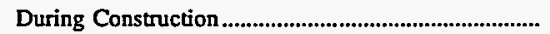 & 70 & 41 & 51 & 106 & 39 \\
\hline Taxes on Other Income and Deduct ................................... & 4,072 & 4,013 & 3,274 & 2,174 & 1,427 \\
\hline Electric Utility Income ............. & 612,691 & 598,847 & 526,551 & 559,015 & 478,354 \\
\hline Income Deductions from Interest & & & & & \\
\hline 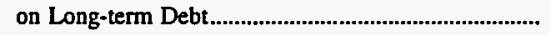 & 99,768 & 127,013 & 108,647 & 114,527 & 109,378 \\
\hline 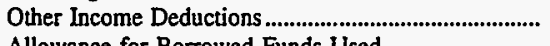 & 47,605 & 41,571 & 47,961 & 58,534 & 31,560 \\
\hline $\begin{array}{l}\text { Allowance for Borrowed Funds Used } \\
\text { During Construction }\end{array}$ & 773 & 48 & -175 & -270 & -78 \\
\hline Total Income Deductions & 148,146 & 168,632 & 156,433 & 172,792 & 140,861 \\
\hline 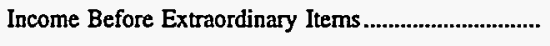 & 464,545 & 430,215 & 370,118 & 386,223 & 337,493 \\
\hline Extraordinary Income & 13,897 & 15,359 & 36,207 & 17,981 & 35,508 \\
\hline Extraordinary Deductions & 17,962 & 22,018 & 40,028 & 43,581 & 37,664 \\
\hline 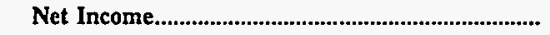 & 460,479 & 423,556 & 366,297 & 360,624 & 335,338 \\
\hline
\end{tabular}

Note: Totals may not equal sum of components because of independent rounding. Detailed data are provided in Table 21. The number of publicly owned nongenerating electric utilities for end of period is 284 for 1996, 286 for 1995, 276 for 1994, 269 for 1993, and 258 for 1992. The City of Gaffney (SC), City of Osceola (AR), and City of Redding (CA) were nongenerators for 1992 through 1993, but became generators in 1994. The City of Kennett (MO) and City of Morgan City (LA) were generators for 1992 through 1993, but became nongenerators in 1994.

Source: Energy Information Administration, Form EIA-412, “Annual Report of Public Electric Utilities." Individual electric utilities report fiscal year data. Appendix B shows the fiscal year for each electric utility. 
Table 15. Composite Balance Sheet for Major U.S. Publicly Owned Nongenerator Electric Utilities at End of Period, 1992-1996

'(Thousand Dollars)

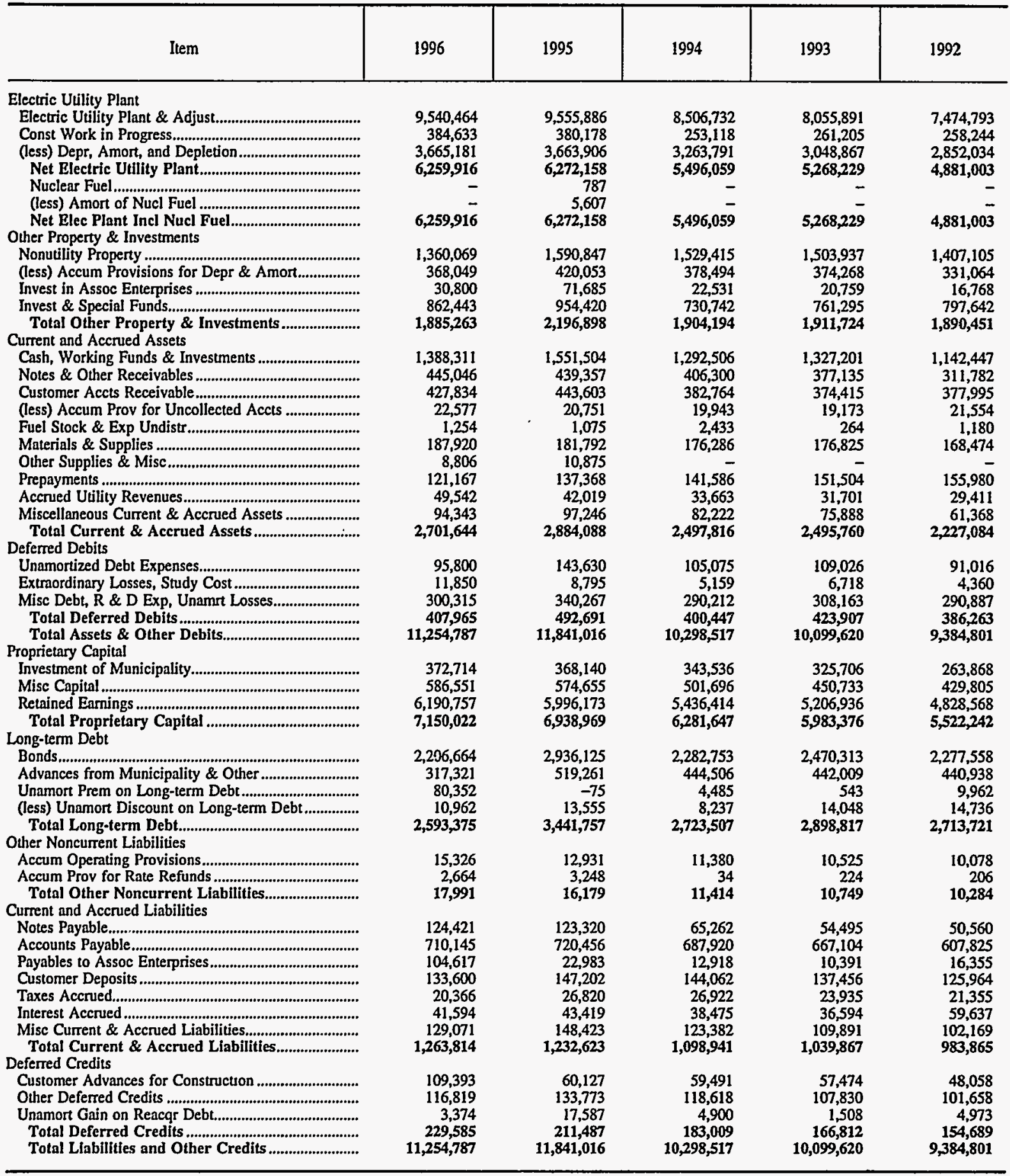

- Data not available.

Note: Totals may not equal sum of components because of independent rounding. Detailed data are provided in Table 22 . The number of publicly owned nongenerating electric utilities for end of period is 284 for 1996, 286 for 1995,276 for 1994,269 for 1993 , and 258 for 1992. The City of Gaffney (SC), City of Osceola (AR), and City of Redding (CA) were nongenerators for 1992 through 1993, but became generators in 1994. The City of Kennett (MO) and City of Morgan City (LA) were generators for I992 through 1993, but became nongenerators in 1994.

Source: Energy Information Administration, Form EIA-412, “Annual Report of Public Electric Public Eleçtric Utilities." Individual clectric utilities report fiscal year data. Appendix B shows the fiscal year for each electric utility. 
Table 16. Composite Financial Indicators for Major U.S. Publicly Owned Nongenerator Electric Utilities, 1992-1996

\begin{tabular}{|c|c|c|c|c|c|}
\hline Item & 1996 & 1995 & 1994 & 1993 & 1992 \\
\hline Total Electric Utility Plant per Dollar of Revenue & 1.2 & 1.2 & 1.1 & 1.1 & 1.1 \\
\hline 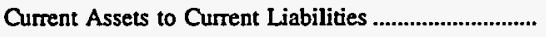 & 2.1 & 2.3 & 2.3 & 2.4 & 2.3 \\
\hline $\begin{array}{l}\text { Total Electric Utility Plant as a Percent of Total } \\
\text { Assets }\end{array}$ & 88.2 & 83.9 & 85.1 & 82.4 & 82.4 \\
\hline $\begin{array}{l}\text { Net Electric Utility Plant as a Percent of Total } \\
\text { Assets }\end{array}$ & 55.6 & 52.9 & 53.4 & 52.2 & 52.0 \\
\hline 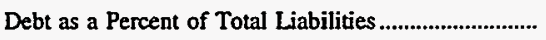 & 34.3 & 39.5 & 37.1 & 39.0 & 39.4 \\
\hline $\begin{array}{l}\text { Depreciation, Amortization and Depletion } \\
\text { as a Percent of Total Electric Utility Plant .................. }\end{array}$ & 36.9 & 36.9 & 37.3 & 36.7 & 36.9 \\
\hline 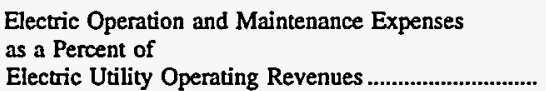 & 88.6 & 88.0 & 88.7 & 88.1 & 88.8 \\
\hline $\begin{array}{l}\text { Electric Depreciation and Amortization } \\
\text { as a Percent of } \\
\text { Electric Utility Operating Revenues }\end{array}$ & 3.6 & 3.7 & 3.4 & 3.4 & 3.4 \\
\hline $\begin{array}{l}\text { Taxes and Tax Equivalents } \\
\text { as a Percent of } \\
\text { Electric Utility Operating Revenues }\end{array}$ & 2.4 & 2.9 & 2.5 & 2.3 & 2.1 \\
\hline $\begin{array}{l}\text { Interest on Long-term Debt } \\
\text { as a Percent of } \\
\text { Electric Utility Operating Revenues }\end{array}$ & 1.2 & 1.5 & 1.4 & 1.5 & 1.5 \\
\hline 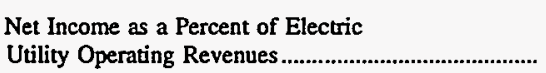 & 5.4 & 5.0 & 4.6 & 4.8 & 4.6 \\
\hline Purchased Power Cents Per Kilowatthour ...................... & 4.0 & 4.3 & 4.1 & 4.1 & 4.1 \\
\hline
\end{tabular}

Note: Totals may not equal sum of components because of independent rounding. The number of publicly owned nongenerating electric utilities for end of period is 284 for 1996, 286 for 1995, 276 for 1994, 269 for 1993, and 258 for 1992. The City of Gaffney (SC), City of Osceola (AR), and City of Redding (CA) were nongenerators for 1992 through 1993, but became generators in 1994. The City of Kennett

(MO) and City of Morgan City (LA) were generators for 1992 through 1993, but became nongenerators in 1994.

Source: Energy Information Administration, Form EIA-412, "Annual Report of Public Electric Utilities." Individual electric utilities report fiscal year data. Appendix B shows the fiscal year for each electric utility. 
Table 17. Electric Operation and Maintenance Expenses for Major U.S.

Publicly Owned Nongenerator Electric Utilities, 1992-1996

(Thousand Dollars)

\begin{tabular}{|c|c|c|c|c|c|}
\hline Item & 1996 & 1995 & 1994 & 1993 & 1992 \\
\hline \multicolumn{6}{|l|}{ Production Expenses } \\
\hline 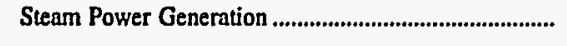 & 1,242 & 10,931 & 284 & 362 & 416 \\
\hline 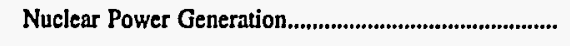 & - & - & - & - & - \\
\hline Hydraulic Power Generation ................................................ & 29 & 87 & 23 & 92 & 15 \\
\hline 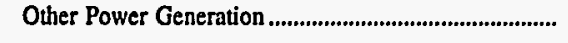 & 15,062 & 17,575 & 1,500 & 1,249 & 622 \\
\hline Purchased Power........, & $6,501,072$ & $6,357,328$ & $6,169,491$ & $5,746,737$ & $5,608,871$ \\
\hline 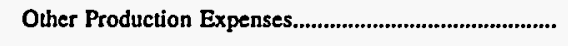 & 60,939 & 36,043 & 14,405 & 13,283 & 7,993 \\
\hline 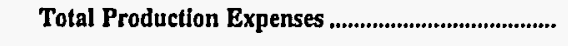 & $6,578,344$ & $6,421,965$ & $6,185,703$ & $5,761,722$ & $5,617,918$ \\
\hline Transmission Expenses & 61,645 & 46,769 & 44,274 & 41,796 & 43,128 \\
\hline 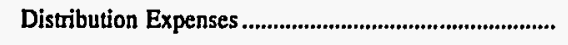 & 466,911 & 442,727 & 413,250 & 386,932 & 357,995 \\
\hline 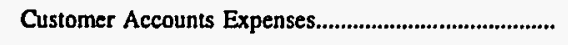 & 141,458 & 125,143 & 119,019 & 117,353 & 109,196 \\
\hline Customer Service and Information Expenses................ & 18,229 & 17,934 & 16,941 & 17,166 & 15,629 \\
\hline 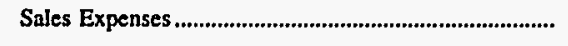 & 11,616 & 9,535 & 9,845 & 8,704 & 11,646 \\
\hline 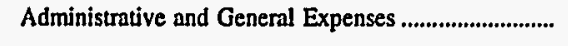 & 324,503 & 358,367 & 302,904 & 298,151 & 281,954 \\
\hline $\begin{array}{l}\text { Total Electric Operation } \\
\text { and Maintenance Expenses ...................................... }\end{array}$ & $7,602,706$ & $7,422,439$ & $\mathbf{7 , 0 9 1 , 9 3 7}$ & $6,631,823$ & $6,437,466$ \\
\hline \multicolumn{6}{|l|}{ Fuel Expenses in Operation } \\
\hline 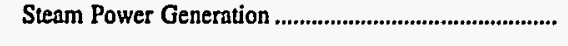 & - & 124 & - & 2 & 13 \\
\hline 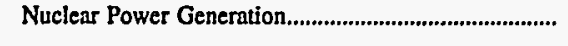 & - & - & - & - & - \\
\hline Other Power Generation ............................................................ & - & 122 & 13 & 13 & 5 \\
\hline \multicolumn{6}{|l|}{ Number of Elec Dept Employees } \\
\hline 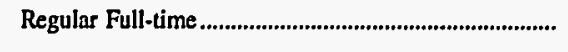 & 14,627 & 14,637 & 14,850 & 14,712 & 14,458 \\
\hline Partime \& Temporary................................................................ & 344 & 334 & 367 & 1,031 & 1,054 \\
\hline Total Elec Dept Employees & 14,971 & 14,971 & 15,217 & 15,743 & 15,512 \\
\hline
\end{tabular}

Note: Totals may not equal sum of components because of independent rounding. Detailed data are provided in Table 23 . The number of publicly owned nongenerating electric utilities for end of period is 284 for 1996, 286 for 1995, 276 for 1994, 269 for 1993, and 258 for 1992. The City of Gaffney (SC), City of Osceola (AR), and City of Redding (CA) were nongenerators for 1992 through 1993, but became generators in 1994. The City of Kennett (MO) and City of Morgan City (LA) were generators for 1992 through 1993, but became nongenerators in 1994.

Source: Energy Information Administration, Form EIA-412, “Annual Report of Public Electric Utilities." Individual electric utilities report fiscal year.data. Appendix B shows the fiscal year for each electric utility. 
Table 18. Electric Utility Plant for Major U.S. Publicly Owned Nongenerator

Electric Utilities at End of Period, 1992-1996

(Thousand Dollars)

\begin{tabular}{|c|c|c|c|c|c|}
\hline Item & 1996 & 1995 & 1994 & 1993 & 1992 \\
\hline \multicolumn{6}{|l|}{ Electric Plant in Service } \\
\hline Intangible Plant & 20,895 & 20,387 & 18,825 & 10,565 & 10,549 \\
\hline \multicolumn{6}{|l|}{ Production Plant } \\
\hline Steam & 80,637 & 134,701 & 79,781 & 69,761 & 69,727 \\
\hline 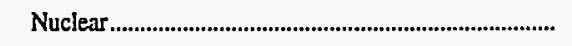 & - & - & - & - & - \\
\hline Hydraulic. & 15,867 & 264,238 & 15,345 & 15,334 & 15,334 \\
\hline Other & 31,316 & 80,662 & 35,502 & 27,082 & 18,984 \\
\hline Total Production Plant & 127,820 & 479,601 & 130,628 & 112,177 & 104,045 \\
\hline Transimission Plant & 792,416 & 860,091 & 697,132 & 628,184 & 602,713 \\
\hline 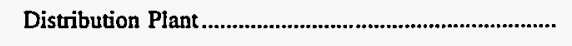 & $7,183,804$ & $6,760,020$ & $6,313,989$ & $5,923,094$ & $5,354,892$ \\
\hline General Plant & $1,299,599$ & $1,349,688$ & $1,265,635$ & $1,286,857$ & $1,312,183$ \\
\hline 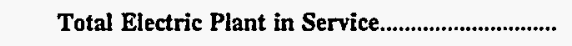 & $9,424,534$ & $9,469,786$ & $8,426,208$ & $7,960,877$ & $7,384,383$ \\
\hline 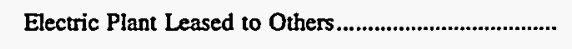 & 14,177 & 19,625 & 745 & 704 & 615 \\
\hline Construction Work in Progress - Electric ........................... & 384,633 & 380,178 & 253,118 & 261,205 & 258,244 \\
\hline 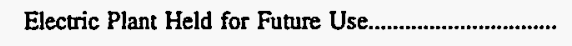 & 12,102 & 12,511 & 11,069 & 16,268 & 16,074 \\
\hline 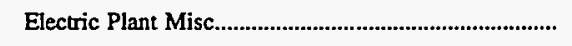 & 89,650 & 53,963 & 68,710 & 78,042 & 73,722 \\
\hline Total Electric Utility Plant & $9,925,097$ & $9,936,064$ & $8,759,850$ & $8,317,096$ & $7,733,037$ \\
\hline 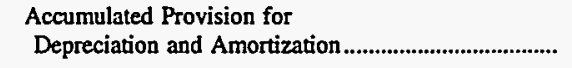 & $3,665,181$ & $3,663,906$ & $3,263,791$ & $3,048,867$ & $2,852,034$ \\
\hline 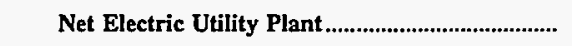 & $6,259,916$ & $6,272,158$ & $5,496,059$ & $5,268,229$ & $4,881,003$ \\
\hline
\end{tabular}

Note: Totals may not equal sum of components because of independent rounding. Detailed data are provided in Table 24 . The number of publicly owned nongenerating electric utilities for end of period is 284 for 1996, 286 for 1995, 276 for 1994,269 for 1993 , and 258 for 1992. The City of Gaffney (SC), City of Osceola (AR), and City of Redding (CA) were nongenerators for 1992 through 1993, but became generators in 1994. The City of Kennett (MO) and City of Morgan City (LA) were generators for 1992 through 1993, but became nongenerators in 1994.

Source: Energy Information Administration, Form EIA-412, “Annual Report of Public Electric Utilities." Individual electric utilities report fiscal year data. Appendix B shows the fiscal year for each electric utility. 
Table 19. Number of Consumers, Sales, and Operating Revenue for Major U.S. Publicly Owned Nongenerator Electric Utilities, 1992-1996

\begin{tabular}{|c|c|c|c|c|c|}
\hline Item & 1996 & 1995 & 1994 & 1993 & 1992 \\
\hline \multicolumn{6}{|l|}{ Number of Consumers } \\
\hline Residential ........................................................................................ & $4,033,654$ & R $4,096,448$ & $3,914,442$ & $3,830,086$ & $3,705,525$ \\
\hline 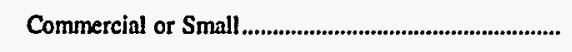 & 559,601 & R 560,652 & 541,723 & 517,443 & 499,250 \\
\hline Industrial or Large & 54,354 & $\mathrm{R}_{55,074}$ & 51,956 & 48,652 & 45,537 \\
\hline 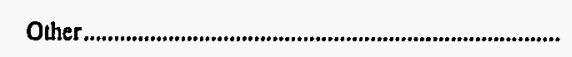 & 71,370 & R 74,373 & 64,542 & 68,043 & 87,037 \\
\hline 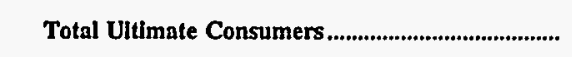 & 4,718,979 & R $4,786,547$ & $4,572,663$ & $4,464,224$ & $4,337,349$ \\
\hline \multicolumn{6}{|l|}{ Sales for the Year (megawatthours) } \\
\hline 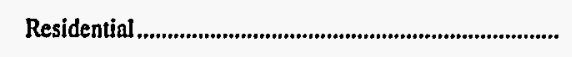 & $55,134,265$ & R $51,185,580$ & $51,347,293$ & $48,808,834$ & $46,306,852$ \\
\hline 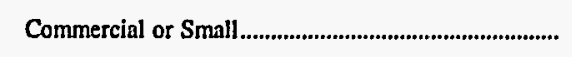 & $25,048,037$ & R $24,365,020$ & $23,173,716$ & $22,130,179$ & $21,815,955$ \\
\hline 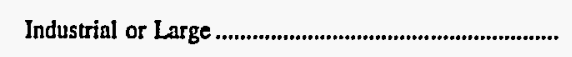 & $62,401,787$ & R $63,359,409$ & $57,975,900$ & $54,452,381$ & $51,453,636$ \\
\hline 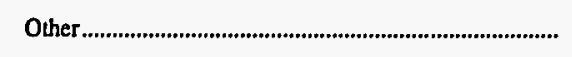 & $2,742,886$ & R $2,785,454$ & $2,754,024$ & $2,669,498$ & $2,936,880$ \\
\hline Total Sales to Ultimate Consumers .............................. & $145,326,975$ & R $141,695,463$ & $135,250,933$ & $128,060,892$ & $122,513,323$ \\
\hline Sales for Resale & $9,079,982$ & $\begin{array}{l}\text { R } 9,850,129 \\
0\end{array}$ & $7,968,820$ & $7,428,071$ & $7,506,885$ \\
\hline Total Sales.................................................................... & $154,406,957$ & R $\quad 151,545,592$ & $143,219,753$ & $135,488,963$ & $130,020,208$ \\
\hline \multicolumn{6}{|l|}{$\begin{array}{l}\text { Operating Revenues for the Year } \\
\text { (thousand doflars) }\end{array}$} \\
\hline 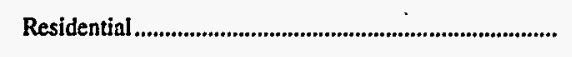 & $3,404,361$ & R $3,190,950$ & $3,174,212$ & $2,956,759$ & $2,785,966$ \\
\hline 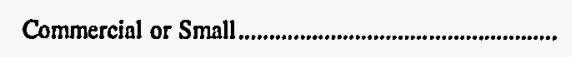 & $1,592,960$ & R $1,579,992$ & $1,514,358$ & $1,448,407$ & $1,412,309$ \\
\hline 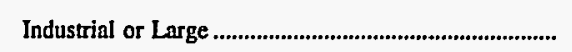 & $3,005,299$ & R $3,096,907$ & $2,801,005$ & $2,675,253$ & $2,553,929$ \\
\hline 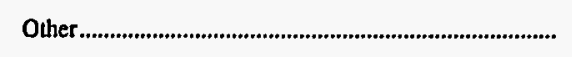 & 203,477 & R 203,489 & 186,033 & 182,112 & 189,783 \\
\hline 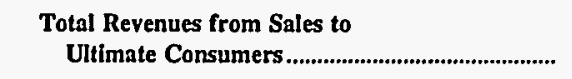 & $8,206,097$ & ${ }_{8} 8,071,338$ & $7,675,608$ & $7,262,531$ & $6,941,987$ \\
\hline Sales for Resale & 272,677 & R 349,877 & 263,032 & 246,614 & 232,879 \\
\hline 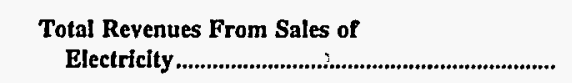 & $8,478,774$ & $\begin{array}{l}\text { R } 8,421,215 \\
0\end{array}$ & $7,938,640$ & $7,509,145$ & $7,174,866$ \\
\hline
\end{tabular}

$\mathrm{R}=$ Revised data.

Note: Totals may not equal sum of components because of independent rounding. Detailed data are provided in Table 25 . The number of publicly owned nongenerating electric utilities for end of period is 284 for 1996, 286 for 1995, 276 for 1994, 269 for 1993, and 258 for 1992. The City of Gaffney (SC), City of Osceola (AR), and City of Redding (CA) were nongenerators for 1992 through 1993, but became generators in 1994. The City of Kennett (MO) and City of Morgan City (LA) were generators for 1992 through 1993, but became nongenerators in 1994. sions.

Source: Energy Information Administration, Form EIA-861, “Annual Electric Utility Report." Data are based on calendar year submis- 
Table 20. Electric Energy Account for Major U.S. Publicly Owned Nongenerator Electric Utilities, 1992-1996

(Megawatthours)

\begin{tabular}{|c|c|c|c|c|c|}
\hline Item & 1996 & 1995 & 1994 & 1993 & 1992 \\
\hline \multicolumn{6}{|l|}{ Sources of Energy } \\
\hline Steam & - & - & - & - & - \\
\hline Nuclear & - & - & - & - & - \\
\hline 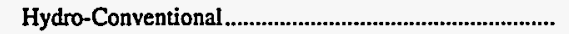 & - & - & - & - & - \\
\hline Hydro-Pumped Storage & - & - & - & - & - \\
\hline Other & - & - & - & - & - \\
\hline 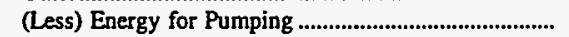 & - & - & - & - & - \\
\hline Total Net Generation & - & - & - & - & - \\
\hline 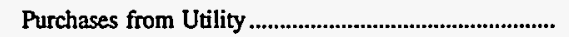 & $159,331,176$ & $147,375,343$ & $149,325,324$ & $141,301,052$ & $136,137,665$ \\
\hline $\begin{array}{l}\text { Purchases from Nonutility } \\
\text { Power Exchanges }\end{array}$ & $1,914,551$ & $1,420,021$ & 310,443 & 190,793 & 197,947 \\
\hline 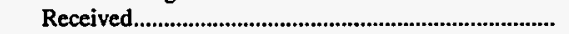 & 500,568 & 924,369 & 505,977 & 328,487 & 363,092 \\
\hline 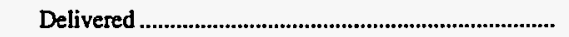 & 196,249 & 308,786 & 163,845 & 127,897 & 158,997 \\
\hline 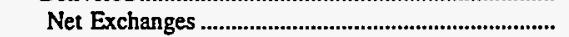 & 304,319 & 615,583 & 342,132 & 200,591 & 204,095 \\
\hline \multicolumn{6}{|l|}{ Transmission for Others (Wheeling) } \\
\hline 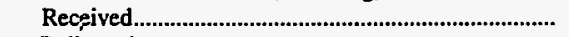 & 176,412 & 586,304 & 501,119 & 311,854 & 1,986 \\
\hline 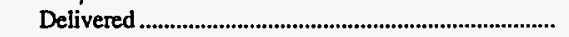 & 176,412 & 245,722 & 499,627 & 307,924 & 1,986 \\
\hline 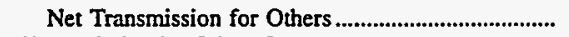 & - & 340,582 & 1,492 & 3,930 & - \\
\hline Transmission by Others Losses........................................... & $-23,487$ & $-36,862$ & $-2,416$ & $-3,930$ & -220 \\
\hline \multicolumn{6}{|l|}{ Total Net Energy Generated and } \\
\hline 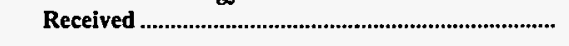 & $161,526,559$ & $149,714,667$ & $149,976,976$ & $141,692,435$ & $136,539,486$ \\
\hline \multicolumn{6}{|l|}{ Disposition of Energy } \\
\hline 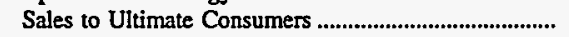 & $145,963,606$ & $135,277,956$ & $135,074,037$ & $127,375,590$ & $122,526,111$ \\
\hline 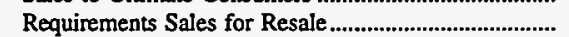 & $7,363,387$ & $7,405,476$ & $7,136,752$ & $6,414,892$ & $6,153,006$ \\
\hline 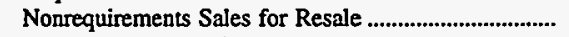 & 865,708 & 756,760 & 857,994 & 918,823 & $1,427,509$ \\
\hline 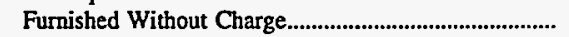 & 239,869 & 239,108 & 299,317 & 281,140 & 218,278 \\
\hline 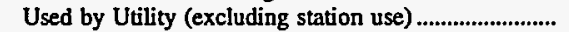 & 255,840 & 318,048 & 219,718 & 262,001 & 243,524 \\
\hline Losses & $6,838,149$ & $5,717,325$ & $6,389,169$ & $6,439,913$ & $5,970,991$ \\
\hline Total Disposition & $161,526,559$ & $149,714,667$ & $149,976,976$ & $141,692,435$ & $136,539,486$ \\
\hline
\end{tabular}

- Data not available.

Note: Totals may not equal sum of components because of independent rounding. Detailed data are provided in Table 26. The number of publicly owned nongenerating electric utilities for end of period is 284 for 1996, 286 for 1995,276 for 1994,269 for 1993 , and 258 for 1992. The City of Gaffney (SC), City of Osceola (AR), and City of Redding (CA) were nongenerators for 1992 through 1993, but became generators in 1994. The City of Kennett (MO) and City of Morgan City (LA) were generators for 1992 through 1993, but became nongenerators in 1994. Double counting occurs in components of both sources and disposition of energy and thus neither provides a true total. Purchases from utilities, net exchanges, and net wheeling (except for imports) are included in net generation. Sales for resale is included in sales to ultimate consumers.

Source: Energy Information Administration, Form ELA-412, "Annual Report of Public Electric Utilities." Individual electric utilities report fiscal year data. Appendix B shows the fiscal year for each electric utility. 


\section{Detailed Statistics of Major U.S. Publicly Owned Electric Utilities}


Table 21. Statement of Income by Major U.S. Publicly Owned Electric Utility

Within State, 1996

(Thousand Dollars)

\begin{tabular}{|c|c|c|c|c|c|c|}
\hline Item & $\begin{array}{l}\text { Alabama } \\
\text { Alabama } \\
\text { Municipal } \\
\text { Elec Auth } \\
\text { September } 30\end{array}$ & $\begin{array}{c}\text { Alabama } \\
\text { Albertville } \\
\text { Municipal } \\
\text { Utils Bd }\end{array}$ & $\begin{array}{l}\text { Alabama } \\
\text { Andalusia } \\
\text { City of } \\
\text { September } 30\end{array}$ & $\begin{array}{l}\text { Alabama } \\
\text { Athens } \\
\text { City of } \\
\text { December } 31\end{array}$ & $\begin{array}{l}\text { Alabama } \\
\text { Bessemer } \\
\text { City of } \\
\text { June } 30\end{array}$ & $\begin{array}{l}\text { Alabama } \\
\text { Cullman } \\
\text { Power Board } \\
\text { June } 30\end{array}$ \\
\hline Electric Utility Operating Revenues........................ & 102,756 & 21,555 & 14,313 & 43,485 & 18,655 & 18,077 \\
\hline 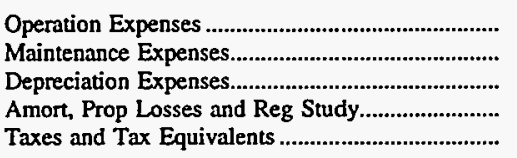 & $\begin{array}{r}79,213 \\
0 \\
283 \\
0 \\
978\end{array}$ & $\begin{array}{r}19,825 \\
635 \\
559 \\
0 \\
429\end{array}$ & $\begin{array}{r}13,123 \\
190 \\
340 \\
0 \\
0\end{array}$ & $\begin{array}{r}37,593 \\
1,259 \\
1,174 \\
7 \\
973\end{array}$ & $\begin{array}{r}16,177 \\
920 \\
792 \\
0 \\
815\end{array}$ & $\begin{array}{r}16,573 \\
242 \\
475 \\
0 \\
335\end{array}$ \\
\hline $\begin{array}{l}\text { Total Electric Utility Operating } \\
\text { Expenses }\end{array}$ & 80,474 & 21,449 & 13,653 & 41,006 & 18,705 & 17,626 \\
\hline 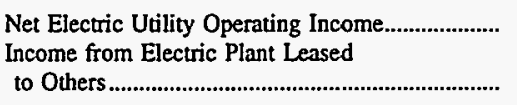 & $\begin{array}{r}22,281 \\
0\end{array}$ & 107 & 660 & 2,478 & $\begin{array}{r}-50 \\
0\end{array}$ & $\begin{array}{r}451 \\
0\end{array}$ \\
\hline Electric Utility Operating Income.................... & 22,281 & 107 & 660 & 2,478 & -50 & 451 \\
\hline Other Electric Income & 468 & 351 & 80 & 725 & 283 & 276 \\
\hline $\begin{array}{l}\text { Other Electric Deductions } \\
\text { Allowance for Other Funds Used }\end{array}$ & 12,785 & 0 & 2,352 & 0 & 0 & 5 \\
\hline 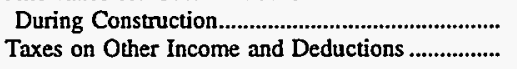 & $\begin{array}{l}0 \\
0\end{array}$ & $\begin{array}{l}0 \\
0\end{array}$ & $\begin{array}{l}0 \\
0\end{array}$ & $\begin{array}{l}0 \\
0\end{array}$ & $\begin{array}{l}0 \\
0\end{array}$ & $\begin{array}{l}0 \\
0\end{array}$ \\
\hline Electric Utility Income & 9,965 & 457 & $-1,612$ & 3,203 & 233 & 723 \\
\hline $\begin{array}{l}\text { Income Deductions from Interest } \\
\text { on Long-term Debt ...................................................... }\end{array}$ & $\begin{array}{r}9,740 \\
0\end{array}$ & $\begin{array}{l}\mathbf{0} \\
0\end{array}$ & $\begin{array}{l}0 \\
0\end{array}$ & $\begin{array}{r}1,603 \\
30\end{array}$ & $\begin{array}{r}149 \\
2\end{array}$ & $\begin{array}{r}169 \\
11\end{array}$ \\
\hline 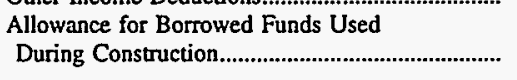 & 0 & 0 & 0 & 0 & 0 & 0 \\
\hline 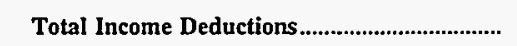 & 9,740 & 0 & $\mathbf{0}$ & 1,633 & 151 & 180 \\
\hline Income Before Extraordinary Items........................... & 225 & 457 & $-1,612$ & 1,570 & 82 & 543 \\
\hline Extraordinary Income & $\mathbf{0}$ & 0 & 0 & 0 & 0 & 0 \\
\hline 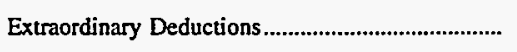 & 0 & 0 & 0 & $\mathbf{0}$ & 0 & 0 \\
\hline Net Income & 225 & 457 & $-1,612$ & 1,570 & 82 & 543 \\
\hline
\end{tabular}

Note: Totals may not equal sum of components because of independent rounding.

Source: Energy Information Administration, Form EIA-412, "Annual Report of Public Electric Utilities." 
Table 21. Statement of Income by Major U.S. Publicly Owned Electric Utility Within State, 1996 (Continued)

(Thousand Dollars)

\begin{tabular}{|c|c|c|c|c|c|c|}
\hline Item & $\begin{array}{l}\text { Alabama } \\
\text { Decatur } \\
\text { City of } \\
\text { June } 30\end{array}$ & $\begin{array}{l}\text { Alabama } \\
\text { Dothan } \\
\text { City of } \\
\text { September } 30\end{array}$ & $\begin{array}{l}\text { Alabama } \\
\text { Florence } \\
\text { City of } \\
\text { June } 30\end{array}$ & $\begin{array}{c}\text { Alabama } \\
\text { Foley } \\
\text { City of } \\
\text { (Riviera Utils) } \\
\text { December } 31\end{array}$ & $\begin{array}{l}\text { Alabama } \\
\text { Fort Payne } \\
\text { Improvement } \\
\text { Auth } \\
\text { June } 30\end{array}$ & $\begin{array}{l}\text { Alabama } \\
\text { Guntersville } \\
\text { Electric } \\
\text { Board } \\
\text { June } 30\end{array}$ \\
\hline Electric Utility Operating Revenues....................... & 63,927 & 55,548 & 66,956 & 39,533 & 19,035 & 12,968 \\
\hline 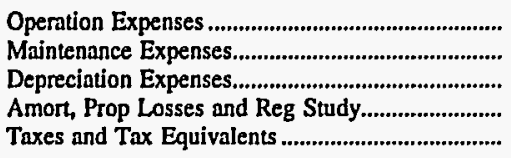 & $\begin{array}{r}60,581 \\
801 \\
1,372 \\
33 \\
1,096\end{array}$ & $\begin{array}{r}46,834 \\
858 \\
2,459 \\
0 \\
0\end{array}$ & $\begin{array}{r}58,467 \\
2,016 \\
2,549 \\
12 \\
2,204\end{array}$ & $\begin{array}{r}30,208 \\
650 \\
2,403 \\
0 \\
3,386\end{array}$ & $\begin{array}{r}17,064 \\
477 \\
412 \\
6 \\
330\end{array}$ & $\begin{array}{r}11,670 \\
272 \\
319 \\
0 \\
264\end{array}$ \\
\hline $\begin{array}{l}\text { Total Electric Utility Operating } \\
\text { Expenses }\end{array}$ & 63,882 & 50,151 & 65,249 & 36,646 & 18,290 & 12,525 \\
\hline $\begin{array}{l}\text { Net Electric Utility Operating Income } \\
\text { Income from Electric Plant Leased }\end{array}$ & $\begin{array}{r}45 \\
0\end{array}$ & $\begin{array}{r}5,397 \\
0\end{array}$ & $\begin{array}{r}1,707 \\
0\end{array}$ & $\begin{array}{r}2,887 \\
0\end{array}$ & $\begin{array}{r}745 \\
0\end{array}$ & $\begin{array}{r}443 \\
0\end{array}$ \\
\hline Electric Utillity Operating Income..................... & 45 & 5,397 & 1,707 & 2,887 & 745 & 443 \\
\hline Other Electric Income & 702 & 270 & 988 & 661 & 366 & 216 \\
\hline Other Electric Deductions ......................................... & 0 & 0 & 0 & 0 & 0 & 3 \\
\hline 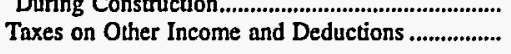 & $\begin{array}{l}0 \\
0\end{array}$ & $\begin{array}{l}0 \\
0\end{array}$ & $\begin{array}{l}\mathbf{0} \\
\mathbf{0}\end{array}$ & $\begin{array}{l}0 \\
0\end{array}$ & $\begin{array}{l}\mathbf{0} \\
\mathbf{0}\end{array}$ & $\begin{array}{l}0 \\
0\end{array}$ \\
\hline 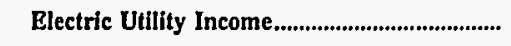 & 747 & 5,668 & 2,695 & 3,548 & 1,111 & 656 \\
\hline $\begin{array}{l}\text { Income Deductions from Interest } \\
\text { on Long-term Debt ...................................................... } \\
\text { Other Income Deductions................................... } \\
\text { Allowance for Borrowed Funds Used }\end{array}$ & $\begin{array}{l}0 \\
0\end{array}$ & $\begin{array}{l}0 \\
0\end{array}$ & $\begin{array}{l}0 \\
0\end{array}$ & $\begin{array}{r}596 \\
21\end{array}$ & $\begin{array}{r}260 \\
45\end{array}$ & $\begin{array}{r}22 \\
1\end{array}$ \\
\hline 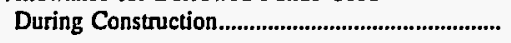 & $\mathbf{0}$ & 0 & 0 & 0 & 0 & 0 \\
\hline 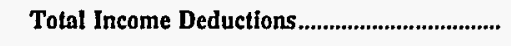 & $\mathbf{0}$ & $\mathbf{0}$ & o & 617 & 305 & 23 \\
\hline 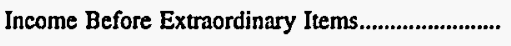 & 747 & 5,668 & 2,694 & 2,931 & 806 & 633 \\
\hline Extraordinary Income & 0 & 0 & 0 & 0 & 0 & 0 \\
\hline 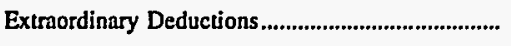 & $\mathbf{0}$ & $\mathbf{0}$ & 0 & 462 & 0 & 0 \\
\hline 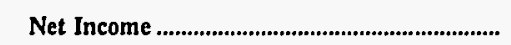 & 747 & 5,668 & 2,694 & 2,469 & 806 & 633 \\
\hline
\end{tabular}

Note: Totals may not equal sum of components because of independent rounding.

Source: Energy Information Administration, Form EIA-412, "Annual Report of Public Electric Utilities." 
Table 21. Statement of Income by Major U.S. Publicly Owned Electric Utility Within State, 1996 (Continued)

(Thousand Dollars)

\begin{tabular}{|c|c|c|c|c|c|c|}
\hline Item & $\begin{array}{l}\text { Alabama } \\
\text { Hartselle } \\
\text { City of } \\
\text { June } 30\end{array}$ & $\begin{array}{l}\text { Alabama } \\
\text { Huntsville } \\
\text { City of } \\
\text { September } 30\end{array}$ & $\begin{array}{l}\text { Alabama } \\
\text { Muscle } \\
\text { Shoals } \\
\text { City of } \\
\text { June } 30\end{array}$ & $\begin{array}{l}\text { Alabama } \\
\text { Opelika } \\
\text { City of } \\
\text { September } 30\end{array}$ & $\begin{array}{l}\text { Alabama } \\
\text { Scottsboro } \\
\text { City of } \\
\text { June } 30\end{array}$ & $\begin{array}{l}\text { Alabama } \\
\text { Sheffield } \\
\text { Utilities } \\
\text { June } 30\end{array}$ \\
\hline 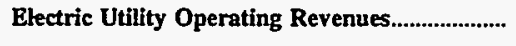 & 7,940 & 211,290 & 12,636 & 18,362 & 18,884 & 26,215 \\
\hline 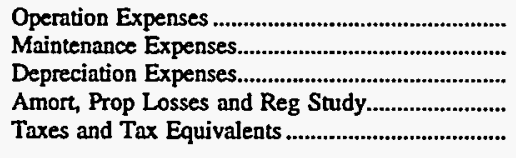 & $\begin{array}{r}7,356 \\
287 \\
195 \\
3 \\
104\end{array}$ & $\begin{array}{r}194,149 \\
4,973 \\
5,471 \\
0 \\
5,639\end{array}$ & $\begin{array}{r}10,944 \\
422 \\
488 \\
0 \\
435\end{array}$ & $\begin{array}{r}14,621 \\
625 \\
786 \\
0 \\
0\end{array}$ & $\begin{array}{r}16,952 \\
833 \\
519 \\
0 \\
352\end{array}$ & $\begin{array}{r}23,292 \\
1,002 \\
1,129 \\
21 \\
758\end{array}$ \\
\hline 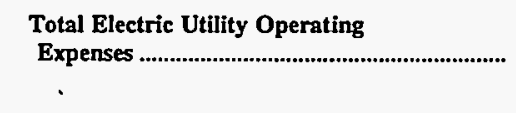 & 7,945 & 210,230 & 12,289 & 16,033 & 18,656 & 26,202 \\
\hline 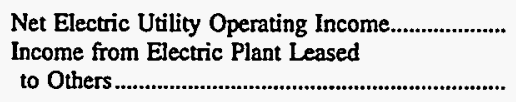 & $\begin{array}{r}-5 \\
0\end{array}$ & 1,060 & 347 & 2,329 & 228 & 14 \\
\hline Electric Utility Operating Income ..................... & -5 & 1,060 & 347 & 2,329 & 228 & 14 \\
\hline Other Electric Income & 144 & 7,363 & 205 & 639 & 297 & 672 \\
\hline $\begin{array}{l}\text { Other Electric Deductions } \\
\text { Allowance for Other Funds Used }\end{array}$ & 0 & 0 & $\mathbf{0}$ & 120 & 4 & 18 \\
\hline 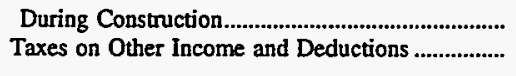 & $\begin{array}{l}0 \\
0\end{array}$ & $\begin{array}{l}0 \\
0\end{array}$ & $\begin{array}{l}0 \\
0\end{array}$ & $\begin{array}{l}0 \\
0\end{array}$ & $\begin{array}{l}\mathbf{0} \\
\mathbf{0}\end{array}$ & $\begin{array}{l}0 \\
0\end{array}$ \\
\hline 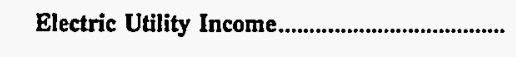 & 139 & 8,423 & 552 & 2,848 & 520 & 668 \\
\hline 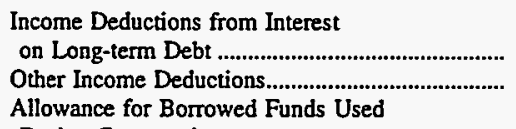 & $\begin{array}{r}31 \\
1\end{array}$ & $\begin{array}{l}367 \\
601\end{array}$ & $\begin{array}{r}53 \\
3\end{array}$ & $\begin{array}{r}190 \\
1,237\end{array}$ & $\begin{array}{r}108 \\
30\end{array}$ & $\begin{array}{r}87 \\
1\end{array}$ \\
\hline 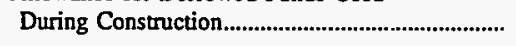 & 0 & 0 & 0 & 0 & 103 & 0 \\
\hline 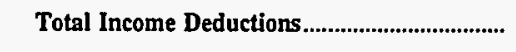 & 32 & 968 & 56 & 1,428 & 241 & 88 \\
\hline Income Before Extraordinary Items............................. & 108 & 7,455 & 497 & 1,420 & 279 & 579 \\
\hline Extraordinary Income & 0 & 0 & 0 & 0 & 0 & 0 \\
\hline 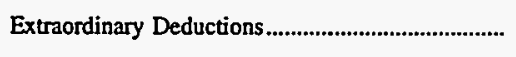 & 0 & 0 & 0 & 441 & 0 & 0 \\
\hline Net Income & 108 & $\mathbf{7 , 4 5 5}$ & 497 & 979 & 279 & 579 \\
\hline
\end{tabular}

Note: Totals may not equal sum of components because of independent rounding.

Source: Energy Information Administration, Form EIA-412, "Annual Report of Public Electric Utilities." 
Table 21. Statement of Income by Major U.S. Publicly Owned Electric Utility Within State, 1996 (Continued)

(Thousand Dollars)

\begin{tabular}{|c|c|c|c|c|c|c|}
\hline Item & $\begin{array}{l}\text { Alabama } \\
\text { Sylacauga } \\
\text { Utilities } \\
\text { Board } \\
\text { September } 30\end{array}$ & $\begin{array}{c}\text { Alabama } \\
\text { Troy } \\
\text { City of } \\
\text { September } 30\end{array}$ & $\begin{array}{l}\text { Alabama } \\
\text { Tuskegee } \\
\text { City of } \\
\text { September } 30\end{array}$ & $\begin{array}{l}\text { Alaska } \\
\text { Alaska } \\
\text { Energy } \\
\text { Authority } \\
\text { June } 30\end{array}$ & $\begin{array}{l}\text { Alaska } \\
\text { Anchorage } \\
\text { City of } \\
\text { December } 31\end{array}$ & $\begin{array}{l}\text { Alaska } \\
\text { Fairbanks } \\
\text { City of } \\
\text { December } 31\end{array}$ \\
\hline Electric Utility Operating Revenues...................... & 12,106 & 14,737 & 9,750 . & 16,610 & 69,649 & 16,356 \\
\hline 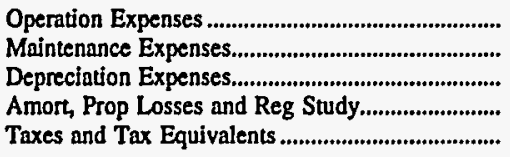 & $\begin{array}{r}7,688 \\
366 \\
503 \\
0 \\
1,325\end{array}$ & $\begin{array}{r}11,173 \\
393 \\
847 \\
0 \\
2,464\end{array}$ & $\begin{array}{r}9,117 \\
0 \\
292 \\
0 \\
226\end{array}$ & $\begin{array}{r}4,801 \\
1,240 \\
23,046 \\
0 \\
0\end{array}$ & $\begin{array}{r}35,727 \\
3,994 \\
10,910 \\
515 \\
2,137\end{array}$ & $\begin{array}{r}12,470 \\
357 \\
1,820 \\
0 \\
938\end{array}$ \\
\hline $\begin{array}{l}\text { Total Electric Utility Operating } \\
\text { Expenses ............................................................... }\end{array}$ & 9,882 & 14,877 & 9,635 & 29,087 & 53,283 & 15,585 \\
\hline 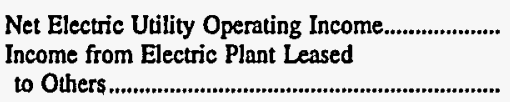 & $\begin{array}{r}2,224 \\
0\end{array}$ & $\begin{array}{r}-140 \\
0\end{array}$ & 115 & $\begin{array}{r}-12,478 \\
0\end{array}$ & $\begin{array}{r}16,367 \\
0\end{array}$ & 771 \\
\hline Electric Utillty Operating Income.................... & 2,224 & -140 & 115 & $-12,478$ & 16,367 & 771 \\
\hline Other Electric Income & 0 & 459 & 239 & 2,890 & 4,052 & $\mathbf{0}$ \\
\hline $\begin{array}{l}\text { Other Electric Deductions } \\
\text { Allowance for Other Funds Used }\end{array}$ & $\mathbf{0}$ & $\mathbf{0}$ & 680 & 0 & 0 & 0 \\
\hline 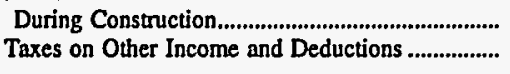 & $\begin{array}{l}0 \\
0\end{array}$ & $\begin{array}{l}0 \\
0\end{array}$ & $\begin{array}{l}\mathbf{0} \\
\mathbf{0}\end{array}$ & $\begin{array}{l}0 \\
0\end{array}$ & $\begin{array}{l}\mathbf{0} \\
\mathbf{0}\end{array}$ & $\begin{array}{r}62 \\
0\end{array}$ \\
\hline Electric Utility Income............................................ & 2,224 & 319 & -326 & $-9,587$ & 20,419 & 833 \\
\hline $\begin{array}{l}\text { Income Deductions from Interest } \\
\text { on Long-term Debt ................................................... } \\
\text { Other Income Deductions.......................................... } \\
\text { Allowance for Borrowed Funds Used }\end{array}$ & $\begin{array}{r}121 \\
0\end{array}$ & $\begin{array}{l}528 \\
272\end{array}$ & $\begin{array}{l}\mathbf{0} \\
\mathbf{0}\end{array}$ & $\begin{array}{r}11,279 \\
0\end{array}$ & $\begin{array}{r}12,557 \\
2,986\end{array}$ & $\begin{array}{r}1,044 \\
0\end{array}$ \\
\hline 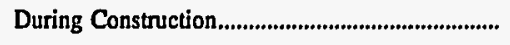 & 0 & 0 & $\mathbf{0}$ & 0 & -952 & $\mathbf{0}$ \\
\hline 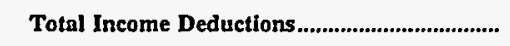 & 121 & 799 & $\mathbf{0}$ & 11,279 & 14,590 & 1,044 \\
\hline Income Before Extraordinary Items............................ & 2,103 & -480 & -326 & $-20,866$ & 5,828 & -211 \\
\hline 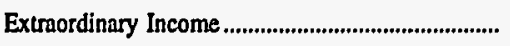 & $\mathbf{0}$ & 0 & 0 & $\mathbf{0}$ & 0 & 0 \\
\hline 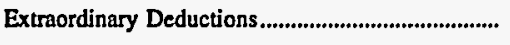 & 0 & 0 & 0 & 0 & 0 & 748 \\
\hline 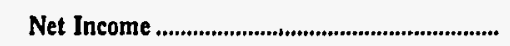 & 2,103 & -480 & -326 & $-20,866$ & 5,828 & -959 \\
\hline
\end{tabular}

Note: Totals may not equal sum of components because of independent rounding.

Source: Energy Information Administration, Form EIA-412, "Annual Report of Public Electric Utilities." 
Table 21. Statement of Income by Major U.S. Publicly Owned Electric Utility Within State, 1996 (Continued) (Thousand Dollars)

\begin{tabular}{|c|c|c|c|c|c|c|}
\hline Item & $\begin{array}{c}\text { Alaska } \\
\begin{array}{c}\text { Ketchikan } \\
\text { City of }\end{array} \\
\text { December } 31\end{array}$ & $\begin{array}{l}\text { Arizona } \\
\text { Arizona } \\
\text { Power } \\
\text { Authority } \\
\text { June } 30\end{array}$ & $\begin{array}{c}\text { Arizona } \\
\text { Electrical } \\
\text { Dist } \\
\text { No2 } \\
\text { Pinal Cnty } \\
\text { December } 31\end{array}$ & $\begin{array}{l}\text { Arizona } \\
\begin{array}{c}\text { Mesa } \\
\text { City of }\end{array} \\
\text { June } 30\end{array}$ & $\begin{array}{c}\text { Arizona } \\
\text { Navajo } \\
\text { Tribal } \\
\text { Utility } \\
\text { Auth } \\
\text { December } 31\end{array}$ & $\begin{array}{l}\text { Arizona } \\
\text { Salt River } \\
\text { Proj Ag } \\
\text { I \& P Dist } \\
\text { April } 30\end{array}$ \\
\hline 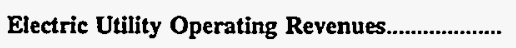 & 13,398 & 21,392 & 8,925 & 23,911 & 37,865 & $1,347,496$ \\
\hline 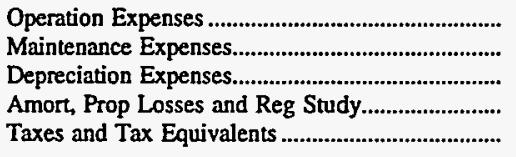 & $\begin{array}{r}9,265 \\
1,131 \\
1,729 \\
0 \\
295\end{array}$ & $\begin{array}{r}20,347 \\
0 \\
68 \\
0 \\
0\end{array}$ & $\begin{array}{r}7,137 \\
242 \\
778 \\
0 \\
0\end{array}$ & $\begin{array}{r}16,465 \\
2,244 \\
1,480 \\
3,030 \\
0\end{array}$ & $\begin{array}{r}28.376 \\
1,027 \\
4,584 \\
0 \\
0\end{array}$ & $\begin{array}{r}599,769 \\
86,003 \\
192,620 \\
12,252 \\
101,243\end{array}$ \\
\hline $\begin{array}{l}\text { Total Electric Utility Operating } \\
\text { Expenses }\end{array}$ & 12,421 & 20,415 & 8,157 & 23,219 & 33,987 & 991,887 \\
\hline 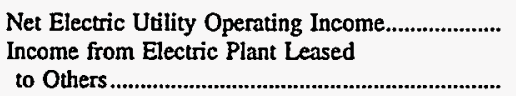 & 977 & 977 & 767 & 692 & 3,878 & $\begin{array}{r}355,609 \\
182\end{array}$ \\
\hline Electric Utility Operating Income ..................... & 977 & 977 & 767 & 692 & 3,878 & 355,791 \\
\hline Other Electric Income & 555 & 4,374 & 175 & 0 & 829 & 44,890 \\
\hline $\begin{array}{l}\text { Other Electric Deductions ........................................ } \\
\text { Allowance for Other Funds Used }\end{array}$ & 0 & 0 & 0 & 0 & 245 & 61,680 \\
\hline 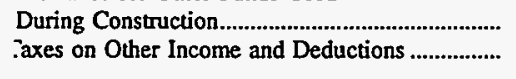 & $\begin{array}{l}0 \\
0\end{array}$ & $\begin{array}{l}0 \\
0\end{array}$ & $\begin{array}{l}0 \\
0\end{array}$ & $\begin{array}{l}0 \\
0\end{array}$ & $\begin{array}{l}\mathbf{0} \\
\mathbf{0}\end{array}$ & $\begin{array}{l}0 \\
0\end{array}$ \\
\hline Electric Utility Income........................................... & 1,533 & 5,351 & 942 & 692 & 4,462 & 339,001 \\
\hline 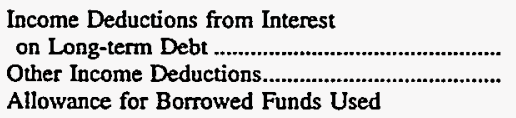 & $\begin{array}{r}483 \\
18\end{array}$ & $\begin{array}{r}4,104 \\
120\end{array}$ & $\begin{array}{l}0 \\
0\end{array}$ & $\begin{array}{l}0 \\
0\end{array}$ & $\begin{array}{r}1,507 \\
31\end{array}$ & $\begin{array}{r}203,013 \\
17,239\end{array}$ \\
\hline 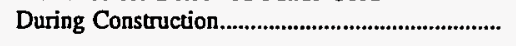 & 0 & 0 & 0 & 0 & -141 & $-9,584$ \\
\hline Total Income Deductions........................................ & 501 & 4,223 & 0 & $\mathbf{0}$ & 1,397 & 210,668 \\
\hline 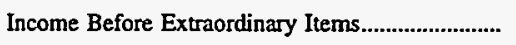 & 1,032 & 1,128 & 942 & 692 & 3,065 & 128,334 \\
\hline Extraordinary Income & 106 & 0 & 61 & 0 & 0 & $\mathbf{0}$ \\
\hline 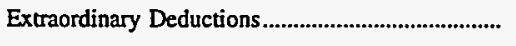 & $\mathbf{0}$ & 0 & 1,003 & 0 & 0 & $\mathbf{0}$ \\
\hline Net Income & 1,138 & 1,128 & 0 & 692 & 3,065 & 128,334 \\
\hline
\end{tabular}

Note: Totals may not equal sum of components because of independent rounding.

Source: Energy Information Administration, Form EIA-412, "Annual Report of Public Electric Utilities." 
Table 21. Statement of Income by Major U.S. Publicly Owned Electric Utility Within State, 1996 (Continued)

(Thousand Dollars)

\begin{tabular}{|c|c|c|c|c|c|c|}
\hline Item & $\begin{array}{l}\text { Arizona } \\
\text { Tohono } \\
\text { OOdham } \\
\text { Utility Auth } \\
\text { December } 31\end{array}$ & $\begin{array}{l}\text { Arkansas } \\
\text { Benton } \\
\text { City of } \\
\text { December } 31\end{array}$ & $\begin{array}{c}\text { Arkansas } \\
\text { Bentonville } \\
\text { City of } \\
\text { December } 31\end{array}$ & $\begin{array}{c}\text { Arkansas } \\
\text { Clarksville } \\
\text { Light } \\
\& \\
\text { Water Co } \\
\text { September } 30\end{array}$ & $\begin{array}{l}\text { Arkansas } \\
\text { Conway } \\
\text { Corp } \\
\text { December } 31\end{array}$ & $\begin{array}{c}\text { Arkansas } \\
\text { Hope } \\
\text { City of } \\
\text { December } 31\end{array}$ \\
\hline Electric Utility Operating Revenues...................... & 6,225 & 15,724 & 11,418 & 9,938 & 31,404 & 13,801 \\
\hline 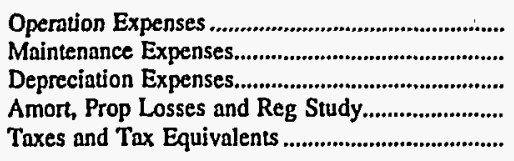 & $\begin{array}{r}5,431 \\
122 \\
338 \\
0 \\
0\end{array}$ & $\begin{array}{r}10,629 \\
370 \\
392 \\
0 \\
661\end{array}$ & $\begin{array}{r}9,081 \\
453 \\
275 \\
0 \\
675\end{array}$ & $\begin{array}{r}7,360 \\
218 \\
528 \\
0 \\
0\end{array}$ & $\begin{array}{r}21,226 \\
1,444 \\
2,698 \\
0 \\
669\end{array}$ & $\begin{array}{r}10,047 \\
664 \\
668 \\
0 \\
527\end{array}$ \\
\hline 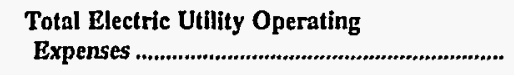 & 5,891 & 12,052 & 10,484 & 8,106 & 26,037 & 11,906 \\
\hline 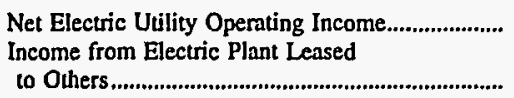 & $\begin{array}{r}334 \\
0\end{array}$ & $\begin{array}{r}3,672 \\
0\end{array}$ & 934 & 1,832 & 5,367 & 1,895 \\
\hline Electric Utility Operating Income..................... & 334 & 3,672 & 934 & 1,832 & 5,367 & 1,895 \\
\hline 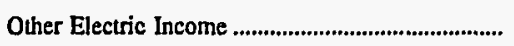 & 48 & 510 & 18 & 206 & 1,683 & 0 \\
\hline $\begin{array}{l}\text { Other Electric Deductions......................................... } \\
\text { Allowance for Other Funds Used }\end{array}$ & 0 & 0 & 0 & 0 & 2,350 & 88 \\
\hline 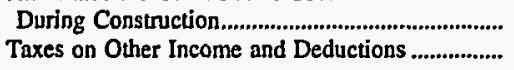 & $\begin{array}{l}\mathbf{0} \\
0\end{array}$ & $\begin{array}{l}\mathbf{0} \\
\mathbf{0}\end{array}$ & $\begin{array}{l}\mathbf{0} \\
\mathbf{0}\end{array}$ & $\begin{array}{l}\mathbf{0} \\
\mathbf{0}\end{array}$ & $\begin{array}{l}0 \\
0\end{array}$ & $\begin{array}{l}\mathbf{0} \\
\mathbf{0}\end{array}$ \\
\hline Electric Utility Income, & 382 & 4,182 & 952 & 2,038 & 4,700 & 1,807 \\
\hline $\begin{array}{l}\text { Income Deductions from Interest } \\
\text { on Long-term Debt ................................................. } \\
\text { Other Income Deductions............................. } \\
\text { Allowance for Borrowed Funds Used }\end{array}$ & $\begin{array}{r}240 \\
52\end{array}$ & $\begin{array}{l}0 \\
0\end{array}$ & $\begin{array}{r}165 \\
0\end{array}$ & $\begin{array}{r}3 \\
901\end{array}$ & $\begin{array}{r}1,373 \\
41\end{array}$ & $\begin{array}{l}0 \\
0\end{array}$ \\
\hline 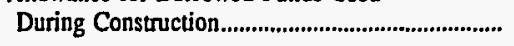 & 0 & 0 & 0 & 0 & 0 & 0 \\
\hline 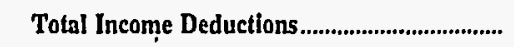 & 292 & $\mathbf{0}$ & 165 & 903 & 1,413 & 0 \\
\hline Income Before Extraordinary Items............................... & 90 & 4,182 & .786 & 1.135 & 3,287 & 1.807 \\
\hline 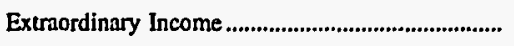 & $\mathbf{0}$ & $\mathbf{0}$ & $\mathbf{0}$ & $\mathbf{0}$ & 0 & 0 \\
\hline 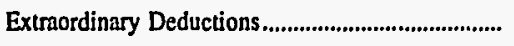 & 0 & 0 & 0 & 0 & 0 & $\mathbf{0}$ \\
\hline Net Income & 90 & 4,182 & 786 & 1,135 & 3,287 & 1,807 \\
\hline
\end{tabular}

Note: Totals may not equal sum of components because of independent rounding.

Source: Energy Information Administration, Form EIA-412, "Annual Report of Public Electric Utilities." 
Table 21. Statement of Income by Major U.S. Publicly Owned Electric Utility Within State, 1996 (Continued)

(Thousand Dollars)

\begin{tabular}{|c|c|c|c|c|c|c|}
\hline Item & $\begin{array}{c}\text { Arkansas } \\
\text { Jonesboro } \\
\text { City of } \\
\text { December } 31\end{array}$ & $\begin{array}{c}\text { Arkansas } \\
\text { North } \\
\text { Little } \\
\text { Rock } \\
\text { City of } \\
\text { December 31 }\end{array}$ & $\begin{array}{l}\text { Arkansas } \\
\text { Osceola } \\
\text { City of } \\
\text { December } 31\end{array}$ & $\begin{array}{c}\text { Arkansas } \\
\text { Paragould } \\
\text { Light } \\
\& \\
\text { Water Comm } \\
\text { December } 31\end{array}$ & $\begin{array}{c}\text { Arkansas } \\
\text { Siloam } \\
\text { Springs } \\
\text { City of } \\
\text { December } 31\end{array}$ & $\begin{array}{c}\text { Arkansas } \\
\text { West } \\
\text { Memphis } \\
\text { City of } \\
\text { December } 31\end{array}$ \\
\hline 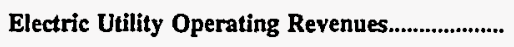 & 53,146 & 64,818 & 10,933 & 16,005 & 11,791 & 22,819 \\
\hline 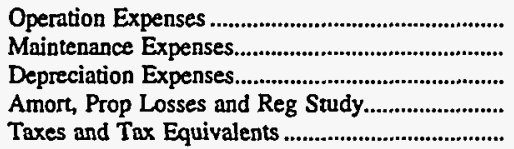 & $\begin{array}{r}34,953 \\
1,850 \\
6,329 \\
0 \\
1,022\end{array}$ & $\begin{array}{r}37,759 \\
2,438 \\
4,071 \\
0 \\
13,466\end{array}$ & $\begin{array}{r}10,453 \\
181 \\
0 \\
0 \\
0\end{array}$ & $\begin{array}{r}12,618 \\
0 \\
1,069 \\
81 \\
0\end{array}$ & $\begin{array}{r}8.179 \\
304 \\
0 \\
0 \\
0\end{array}$ & $\begin{array}{r}17,499 \\
328 \\
2,072 \\
0 \\
829\end{array}$ \\
\hline $\begin{array}{l}\text { Total Electric Utility Operating } \\
\text { Expenses }\end{array}$ & 44,155 & 57,734 & 10,634 & 13,768 & $\mathbf{8 , 4 8 4}$ & 20,728 \\
\hline 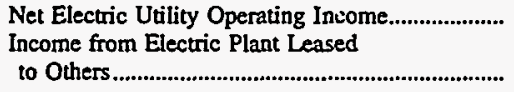 & 8,991 & $\begin{array}{r}7,083 \\
0\end{array}$ & 298 & 2,237 & $\begin{array}{r}3,307 \\
0\end{array}$ & 2,091 \\
\hline Electric Utility Operating Income........................ & 8,991 & 7,083 & 298 & 2,237 & 3,307 & 2,091 \\
\hline Other Electric Income & 4,450 & 2,696 & 0 & 320 & 190 & 1,395 \\
\hline $\begin{array}{l}\text { Other Electric Deductions } \\
\text { Allowance for Other Funds Used }\end{array}$ & 0 & 142 & 0 & 0 & 0 & 0 \\
\hline 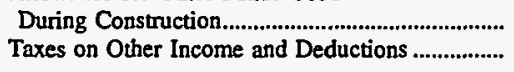 & $\begin{array}{l}0 \\
0\end{array}$ & $\begin{array}{l}0 \\
0\end{array}$ & $\begin{array}{l}0 \\
0\end{array}$ & $\begin{array}{l}0 \\
0\end{array}$ & $\begin{array}{l}0 \\
0\end{array}$ & $\begin{array}{l}0 \\
0\end{array}$ \\
\hline 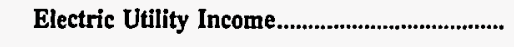 & 13,440 & 9,637 & 298 & 2,557 & 3,497 & 3,486 \\
\hline 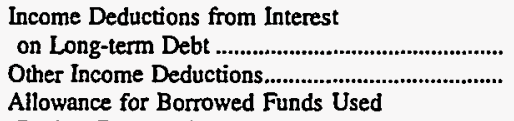 & $\begin{array}{r}3,035 \\
254\end{array}$ & $\begin{array}{r}9,585 \\
0\end{array}$ & $\begin{array}{r}225 \\
0\end{array}$ & $\begin{array}{r}428 \\
0\end{array}$ & $\begin{array}{l}0 \\
0\end{array}$ & $\begin{array}{r}1,475 \\
159\end{array}$ \\
\hline During Construction & o & 0 & 0 & 0 & 0 & 0 \\
\hline 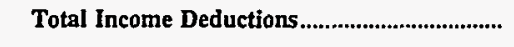 & 3,289 & 9,585 & 225 & 428 & 0 & 1,634 \\
\hline 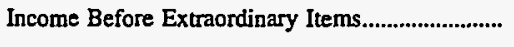 & 10,152 & 52 & 73 & 2,129 & 3,497 & 1,851 \\
\hline Extraordinary Income & 0 & 0 & 0 & 0 & 0 & 0 \\
\hline 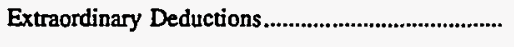 & 0 & 0 & 0 & 0 & 0 & 0 \\
\hline Net Income & 10,152 & 52 & 73 & 2,129 & 3,497 & 1,851 \\
\hline
\end{tabular}

Note: Totals may not equal sum of components because of independent rounding.

Source: Energy Information Administration, Form EIA-412, "Annual Report of Public Electric Utilities." 
Table 21. Statement of Income by Major U.S. Publicly Owned Electric Utility

Within State, 1996 (Continued)

(Thousand Dollars)

\begin{tabular}{|c|c|c|c|c|c|c|}
\hline Item & $\begin{array}{l}\text { Califomia } \\
\text { Alameda } \\
\text { City of } \\
\text { June } 30\end{array}$ & $\begin{array}{l}\text { California } \\
\text { Anaheim } \\
\text { City of } \\
\text { June } 30\end{array}$ & $\begin{array}{l}\text { California } \\
\text { Azusa } \\
\text { City of } \\
\text { June } 30\end{array}$ & $\begin{array}{l}\text { California } \\
\text { Burbank } \\
\text { City of } \\
\text { June } 30\end{array}$ & $\begin{array}{l}\text { California } \\
\text { California } \\
\text { Dept } \\
\text { Wrt } \\
\text { Resources } \\
\text { June } 30\end{array}$ & $\begin{array}{l}\text { Califomia } \\
\text { Colton } \\
\text { City of } \\
\text { June } 30\end{array}$ \\
\hline Electric Utillty Operating Revenues...................... & 43,835 & 246,479 & 22,693 & 90,731 & 117,958 & 24,669 \\
\hline 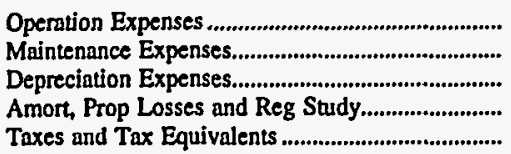 & $\begin{array}{r}34,944 \\
449 \\
2,144 \\
0 \\
348\end{array}$ & $\begin{array}{r}169,203 \\
11,391 \\
16,558 \\
743 \\
0\end{array}$ & $\begin{array}{r}16,964 \\
1,648 \\
360 \\
0 \\
1,919\end{array}$ & $\begin{array}{r}76,856 \\
3,126 \\
5,129 \\
0 \\
5,873\end{array}$ & $\begin{array}{r}38,276 \\
0 \\
14,634 \\
0 \\
1,527\end{array}$ & $\begin{array}{r}23,241 \\
197 \\
447 \\
0 \\
0\end{array}$ \\
\hline $\begin{array}{l}\text { Total Electric Utility Operating } \\
\text { Expenses }\end{array}$ & 37,886 & 197,895 & 20,891 & 90,984 & 54,437 & 23,885 \\
\hline 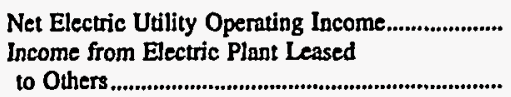 & $\begin{array}{r}5,950 \\
0\end{array}$ & $\begin{array}{r}48,584 \\
0\end{array}$ & $\begin{array}{r}1,802 \\
0\end{array}$ & $\begin{array}{r}-253 \\
0\end{array}$ & $\begin{array}{r}63,521 \\
0\end{array}$ & $\begin{array}{r}784 \\
0\end{array}$ \\
\hline Electric Utility Operating Income.................... & 5,950 & 48,584 & 1,802 & -253 & 63,521 & 784 \\
\hline 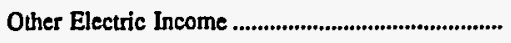 & 1,216 & 7,069 & 1,372 & 2,816 & 8,371 & 2,014 \\
\hline 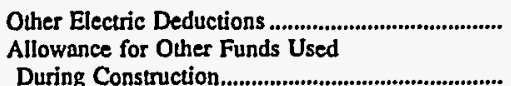 & 0 & 0 & 1,461 & 0 & 0 & 66 \\
\hline Taxes on Other Income and Deductions & 0 & $\begin{array}{l}0 \\
0\end{array}$ & $\begin{array}{l}0 \\
0\end{array}$ & $\begin{array}{l}0 \\
0\end{array}$ & 0 & 0 \\
\hline 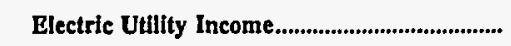 & 7,165 & 55,653 & 1,713 & 2,563 & 71,892 & 2,732 \\
\hline $\begin{array}{l}\text { Income Deductions from Interest } \\
\text { on Long-term Debt ................................................ } \\
\text { Other Income Deductions............................... } \\
\text { Allowance for Borrowed Funds Used }\end{array}$ & $\begin{array}{r}521 \\
36\end{array}$ & $\begin{array}{r}21,292 \\
0\end{array}$ & $\begin{array}{l}0 \\
0\end{array}$ & $\begin{array}{r}1,863 \\
0\end{array}$ & $\begin{array}{r}50,054 \\
0\end{array}$ & $\begin{array}{r}178 \\
0\end{array}$ \\
\hline 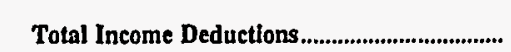 & 557 & 21,292 & $\mathbf{0}$ & 1,863 & 50,054 & 178 \\
\hline Income Before Extraordinary Items........................... & 6,608 & 34,361 & 1,713 & 700 & 21,838 & 2,554 \\
\hline 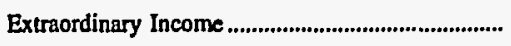 & 0 & 0 & 0 & 0 & 9,301 & $\mathbf{0}$ \\
\hline 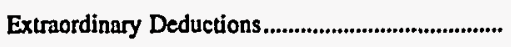 & $\mathbf{0}$ & 0 & $\mathbf{0}$ & 0 & 211 & 0 \\
\hline 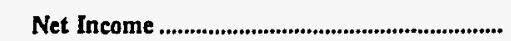 & 6,608 & 34,361 & 1,713 & 700 & 30,928 & 2,554 \\
\hline
\end{tabular}

Nole: Totals may not equal sum of components because of independent rounding.

Source: Energy Information Administration, Form EIA-412, "Annual Report of Public Electric Utilities." 
Table 21. Statement of Income by Major U.S. Publicly Owned Electric Utility Within State, 1996 (Continued)

(Thousand Dollars)

\begin{tabular}{|c|c|c|c|c|c|c|}
\hline Item & $\begin{array}{l}\text { California } \\
\text { Glendale } \\
\text { City of } \\
\text { June } 30\end{array}$ & $\begin{array}{l}\text { California } \\
\text { Imperial } \\
\text { Irrigation } \\
\text { District } \\
\\
\text { December } 31\end{array}$ & $\begin{array}{c}\text { Califomia } \\
\text { Kings River } \\
\text { Conservation } \\
\text { Dist } \\
\text { June } 30\end{array}$ & $\begin{array}{l}\text { Califomia } \\
\text { Lassen } \\
\text { Municipal } \\
\text { Utility Dist } \\
\text { June } 30\end{array}$ & $\begin{array}{l}\text { California } \\
\text { Lodi } \\
\text { City of } \\
\text { June } 30\end{array}$ & $\begin{array}{l}\text { Califomia } \\
\begin{array}{l}\text { Los Angeles } \\
\text { City of }\end{array} \\
\text { June } 30\end{array}$ \\
\hline Electric Utility Operating Revenues......................... & 98,020 & 202,300 & 15,021 & 14,050 & 34,926 & $1,946,851$ \\
\hline 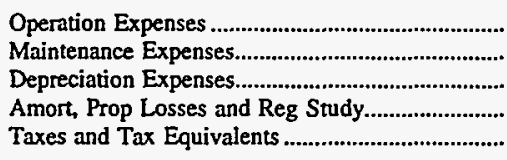 & $\begin{array}{r}69,366 \\
6,246 \\
9,413 \\
0 \\
0\end{array}$ & $\begin{array}{r}128,416 \\
13,388 \\
20,572 \\
0 \\
1,332\end{array}$ & $\begin{array}{r}6,206 \\
563 \\
1,522 \\
132 \\
0\end{array}$ & $\begin{array}{r}7,423 \\
526 \\
804 \\
0 \\
0\end{array}$ & $\begin{array}{r}32,724 \\
2,189 \\
491 \\
0 \\
23\end{array}$ & $\begin{array}{r}1,212,797 \\
188,955 \\
218,698 \\
0 \\
13,149\end{array}$ \\
\hline $\begin{array}{l}\text { Total Electric Utility Operating } \\
\text { Expenses }\end{array}$ & 85,025 & 163,708 & 8,423 & 8,753 & 35,428 & $1,633,599$ \\
\hline $\begin{array}{l}\text { Net Electric Utility Operating Income................. } \\
\text { Income from Electric Plant Leased } \\
\text { to Others... }\end{array}$ & $\begin{array}{r}12,995 \\
0\end{array}$ & $\begin{array}{r}38,592 \\
0\end{array}$ & $\begin{array}{r}6,598 \\
0\end{array}$ & $\begin{array}{r}5,297 \\
0\end{array}$ & $\begin{array}{r}-502 \\
0\end{array}$ & $\begin{array}{r}313,252 \\
0\end{array}$ \\
\hline Electric Utility Operating Income.................... & 12,995 & 38,592 & 6,598 & 5,297 & -502 & 313,252 \\
\hline Other Electric Income & 5,025 & $4,81 t$ & 390 & 630 & 1,495 & 24,161 \\
\hline $\begin{array}{l}\text { Other Electric Deductions ....................................... } \\
\text { Allowance for Other Funds Used }\end{array}$ & 10,845 & 538 & 0 & 0 & 0 & 28,694 \\
\hline 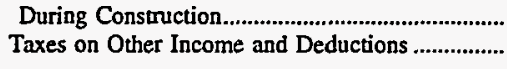 & $\begin{array}{l}0 \\
0\end{array}$ & $\begin{array}{l}0 \\
0\end{array}$ & $\begin{array}{l}\mathbf{0} \\
\mathbf{0}\end{array}$ & $\begin{array}{l}0 \\
0\end{array}$ & $\begin{array}{l}\mathbf{0} \\
0\end{array}$ & $\begin{array}{l}0 \\
0\end{array}$ \\
\hline Electric Utility Income & 7,175 & 42,865 & 6,987 & 5,927 & 994 & 308,719 \\
\hline 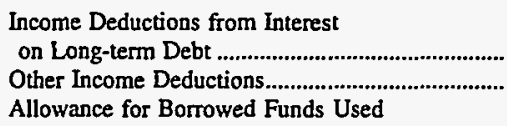 & $\begin{array}{r}743 \\
0\end{array}$ & $\begin{array}{r}9,696 \\
0\end{array}$ & $\begin{array}{l}4,062 \\
2,983\end{array}$ & $\begin{array}{r}1,790 \\
0\end{array}$ & $\begin{array}{r}0 \\
700\end{array}$ & $\begin{array}{r}181,200 \\
0\end{array}$ \\
\hline 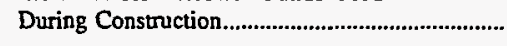 & 0 & 0 & 0 & 0 & 0 & $-5,191$ \\
\hline 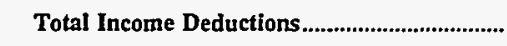 & 743 & 9,696 & 7,045 & 1,790 & 700 & 176,009 \\
\hline 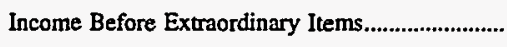 & 6,432 & 33,169 & -57 & 4,136 & 293 & 132,710 \\
\hline Extraordinary Income & 0 & 0 & 0 & 0 & 0 & 0 \\
\hline 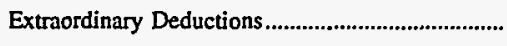 & 0 & 0 & 0 & 0 & 0 & 0 \\
\hline Net Income & 6,432 & 33,169 & $-\mathbf{5 7}$ & 4,136 & 293 & 132,710 \\
\hline
\end{tabular}

Note: Totals may not equal sum of components because of independent rounding.

Source: Energy Information Administration, Form ElA-412, "Annual Report of Public Electric Utilities." 
Table 21. Statement of Income by Major U.S. Publicly Owned Electric Utility Within State, 1996 (Continued)

(Thousand Dollars)

\begin{tabular}{|c|c|c|c|c|c|c|}
\hline Item & $\begin{array}{l}\text { California } \\
\text { Merced } \\
\text { Irrigation } \\
\text { District } \\
\text { December } 31\end{array}$ & $\begin{array}{c}\text { Califomia } \\
\text { Metropolitan } \\
\text { Water } \\
\text { District } \\
\text { June } 30\end{array}$ & $\begin{array}{l}\text { California } \\
\text { Modesto } \\
\text { Irigation } \\
\text { District } \\
\text { December } 31\end{array}$ & $\begin{array}{c}\text { Califormia } \\
\text { MSR } \\
\text { Public } \\
\text { Power } \\
\text { Agency } \\
\text { December } 31\end{array}$ & $\begin{array}{l}\text { California } \\
\text { Northern } \\
\text { California } \\
\text { Power Agny } \\
\text { June } 30\end{array}$ & $\begin{array}{l}\text { California } \\
\text { Oakdale \& } \\
\text { South } \\
\text { San Joaquin } \\
\text { December } 31\end{array}$ \\
\hline Electric Utillty Operating Revenues...................... & 5,191 & 11,079 & 137,349 & 105,496 & 184,055 & 6,940 \\
\hline 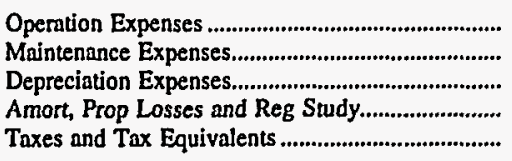 & $\begin{array}{r}1,987 \\
1,288 \\
632 \\
7 \\
671\end{array}$ & $\begin{array}{r}1,653 \\
0 \\
2,516 \\
0 \\
0\end{array}$ & $\begin{array}{r}110,663 \\
6,911 \\
9,955 \\
0 \\
0\end{array}$ & $\begin{array}{r}58,216 \\
2,100 \\
9,901 \\
12 \\
1,061\end{array}$ & $\begin{array}{r}91,590 \\
4,683 \\
31,035 \\
0 \\
0\end{array}$ & $\begin{array}{r}2,114 \\
467 \\
850 \\
0 \\
0\end{array}$ \\
\hline $\begin{array}{l}\text { Total Electric Utillty Operating } \\
\text { Expenses .................................................................... }\end{array}$ & 4,585 & 4,169 & 127,529 & 71,289 & 127,308 & 3,432 \\
\hline 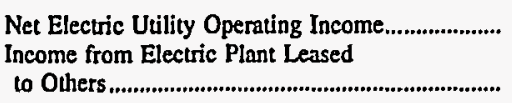 & $\begin{array}{r}606 \\
0\end{array}$ & $\begin{array}{r}6,910 \\
0\end{array}$ & $\begin{array}{r}9,819 \\
0\end{array}$ & $\begin{array}{r}34,207 \\
0\end{array}$ & $\begin{array}{r}56,747 \\
0\end{array}$ & $\begin{array}{r}3,508 \\
0\end{array}$ \\
\hline Electric Utility Operating Income..................... & 606 & 6,910 & 9,819 & 34,207 & 56,747 & 3,508 \\
\hline Other Electric Income & 23 & 0 & 14,662 . & 8,716 & 39,013 & 918 \\
\hline 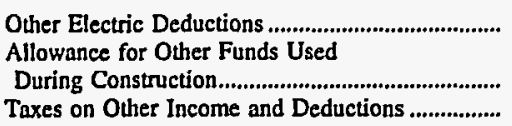 & $\begin{array}{l}52 \\
0 \\
0\end{array}$ & $\begin{array}{l}0 \\
0 \\
0\end{array}$ & $\begin{array}{r}930 \\
0 \\
0\end{array}$ & $\begin{array}{r}2,206 \\
0 \\
0\end{array}$ & $\begin{array}{l}0 \\
0 \\
0\end{array}$ & $\begin{array}{l}0 \\
0 \\
0\end{array}$ \\
\hline 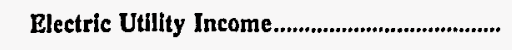 & 577 & 6,910 & 23,551 & 40,717 & 95,760 & 4,426 \\
\hline 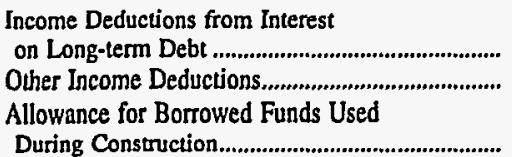 & $\begin{array}{r}796 \\
0\end{array}$ & $\begin{array}{l}0 \\
0\end{array}$ & $\begin{array}{r}17,934 \\
541\end{array}$ & $\begin{array}{r}38,536 \\
1,299\end{array}$ & $\begin{array}{r}104,905 \\
8,270\end{array}$ & $\begin{array}{l}0 \\
0\end{array}$ \\
\hline 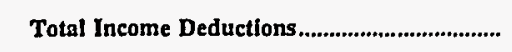 & 796 & 0 & 18,476 & 39,835 & 113,175 & 0 \\
\hline Income Before Extraordinary Items............................ & -218 & 6,910 & 5,075 & 883 & $-17,414$ & 4,426 \\
\hline 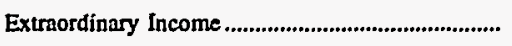 & 0 & 0 & 0 & 0 & 0 & 0 \\
\hline Extraordinary Deductions & 0 & 0 & 0 & 0 & 0 & 0 \\
\hline Net Income & -218 & 6,910 & 5,075 & 883 & $-17,414$ & 4,426 \\
\hline
\end{tabular}

Note: Totals may not equal sum of components because of independent rounding.

Source: Energy Information Administration, Form EIA-412, "Annual Report of Public Electric Utilities." 
Table 21. Statement of Income by Major U.S. Publicly Owned Electric Utility

Within State, 1996 (Continued)

(Thousand Dollars)

\begin{tabular}{|c|c|c|c|c|c|c|}
\hline Item & $\begin{array}{l}\text { Califomia } \\
\text { Oroville } \\
\text { Wyandotte } \\
\text { Irrig Dist } \\
\text { December } 31\end{array}$ & $\begin{array}{l}\text { California } \\
\text { Palo Alto } \\
\text { City of } \\
\text { June } 30\end{array}$ & $\begin{array}{l}\text { California } \\
\text { Pasadena } \\
\text { City of } \\
\text { June } 30\end{array}$ & $\begin{array}{c}\text { California } \\
\text { Placer } \\
\text { County } \\
\text { Water } \\
\text { Agency } \\
\text { December 31 }\end{array}$ & $\begin{array}{l}\text { California } \\
\text { Redding } \\
\text { City of } \\
\text { June } 30\end{array}$ & $\begin{array}{l}\text { Califomia } \\
\text { Riverside } \\
\text { Ciry of } \\
\text { June } 30\end{array}$ \\
\hline Electric Utility Operating Revenues........................... & 9,383 & 62,988 & 106,712 & 8,195 & 72,620 & 164,821 \\
\hline 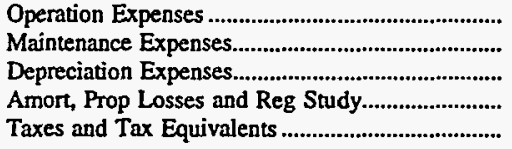 & $\begin{array}{r}2,083 \\
1,590 \\
-1,874 \\
0 \\
0\end{array}$ & $\begin{array}{r}33,530 \\
1,815 \\
3,910 \\
0 \\
0\end{array}$ & $\begin{array}{r}79,934 \\
4,477 \\
7,524 \\
0 \\
4\end{array}$ & $\begin{array}{r}1,831 \\
999 \\
1,667 \\
0 \\
0\end{array}$ & $\begin{array}{r}55,643 \\
2,886 \\
8,031 \\
0 \\
0\end{array}$ & $\begin{array}{r}127,557 \\
5,864 \\
10,626 \\
0 \\
0\end{array}$ \\
\hline $\begin{array}{l}\text { Total Electric Utility Operating } \\
\text { Expenses }\end{array}$ & 1,799 & 39,255 & 91,939 & 4,498 & 66,560 & 144,047 \\
\hline 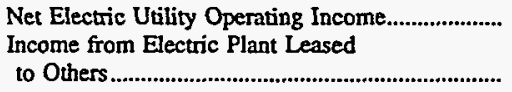 & $\begin{array}{r}7,584 \\
0\end{array}$ & $\begin{array}{r}23,733 \\
0\end{array}$ & $\begin{array}{r}14,773 \\
0\end{array}$ & 3,697 & 6,061 & $\begin{array}{r}20,775 \\
0\end{array}$ \\
\hline 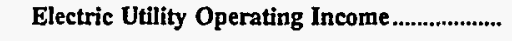 & 7,584 & 23,733 & 14,773 & 3,697 & 6,061 & 20,775 \\
\hline 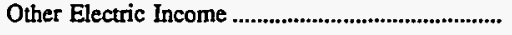 & 583 & 3,428 & 4,263 & 57 & 2,672 & 7,591 \\
\hline $\begin{array}{l}\text { Other Electric Deductions } \\
\text { Allowance for Other Funds Used }\end{array}$ & 1,285 & 8,653 & $\mathbf{0}$ & 59 & 0 & 16,335 \\
\hline 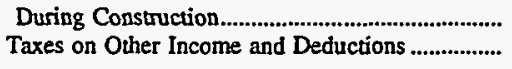 & $\begin{array}{l}0 \\
0\end{array}$ & $\begin{array}{l}0 \\
0\end{array}$ & $\begin{array}{l}0 \\
0\end{array}$ & $\begin{array}{l}0 \\
0\end{array}$ & $\begin{array}{l}\mathbf{0} \\
\mathbf{0}\end{array}$ & $\begin{array}{l}0 \\
0\end{array}$ \\
\hline 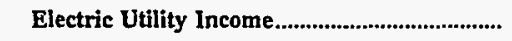 & 6,883 & 18,508 & 19,036 & 3,695 & 8,733 & 12,031 \\
\hline 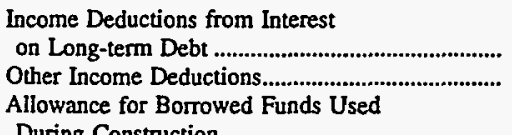 & $\begin{array}{r}1,990 \\
18\end{array}$ & $\begin{array}{r}0 \\
7,235\end{array}$ & $\begin{array}{r}4,065 \\
0\end{array}$ & $\begin{array}{r}2,222 \\
0\end{array}$ & $\begin{array}{r}6,911 \\
0 \\
0\end{array}$ & $\begin{array}{r}10,765 \\
0\end{array}$ \\
\hline 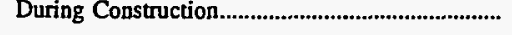 & 0 & 0 & 0 & 0 & 0 & 0 \\
\hline 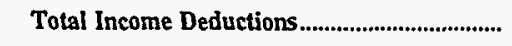 & 2,008 & 7,235 & 4,065 & 2,222 & 6,911 & 10,765 \\
\hline 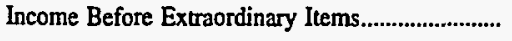 & 4,875 & 11,273 & 14,971 & 1,474 & 1,822 & 1,266 \\
\hline Extraordinary Income & 111 & 0 & 994 & 0 & $\mathbf{0}$ & 0 \\
\hline 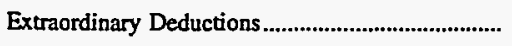 & 0 & 0 & 0 & 0 & 0 & 0 \\
\hline Net Income & 4,986 & 11,273 & 15,965 & 1,474 & 1,822 & 1,266 \\
\hline
\end{tabular}

Note: Totals may not equal sum of components because of independent rounding.

Source: Energy Information Administration, Form EIA-412, "Annual Report of Public Electric Utilities." 
Table 21. Statement of Income by Major U.S. Publicly Owned Electric Utility Within State, 1996 (Continued)

(Thousand Dollars)

\begin{tabular}{|c|c|c|c|c|c|c|}
\hline Item & $\begin{array}{l}\text { California } \\
\text { Roseville } \\
\text { City of } \\
\text { June } 30\end{array}$ & $\begin{array}{l}\text { California } \\
\text { Sacramento } \\
\text { Municipal } \\
\text { Util Dist } \\
\text { December } 31\end{array}$ & $\begin{array}{c}\text { California } \\
\text { San Francisco } \\
\text { City } \\
\& \\
\text { County of } \\
\text { June } 30\end{array}$ & $\begin{array}{l}\text { California } \\
\text { Santa } \\
\text { Clara } \\
\text { City of } \\
\text { June } 30\end{array}$ & $\begin{array}{l}\text { California } \\
\text { Southem } \\
\text { California } \\
\text { P P } \\
\text { A } \\
\text { June } 30\end{array}$ & $\begin{array}{l}\text { California } \\
\text { Turlock } \\
\text { Irrigation } \\
\text { District } \\
\text { December } 31\end{array}$ \\
\hline Electric Utillity Operating Revenues..................... & 51,582 & 670,284 & 74,408 & 183,901 & 274,625 & 105,115 \\
\hline 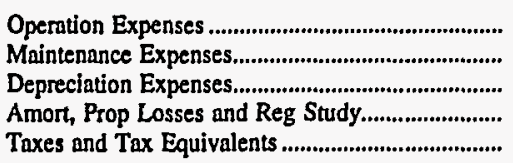 & $\begin{array}{r}32,934 \\
6,619 \\
2,629 \\
0 \\
1,875\end{array}$ & $\begin{array}{r}366,683 \\
29,883 \\
67,471 \\
78,737 \\
142\end{array}$ & $\begin{array}{r}32,210 \\
4,541 \\
7,446 \\
0 \\
986\end{array}$ & $\begin{array}{r}149,769 \\
7,767 \\
8,368 \\
0 \\
9,621\end{array}$ & $\begin{array}{r}39,006 \\
43,761 \\
64,933 \\
0 \\
11,414\end{array}$ & $\begin{array}{r}74,758 \\
8,092 \\
7,557 \\
0 \\
0\end{array}$ \\
\hline $\begin{array}{l}\text { Total Electric Utility Operating } \\
\text { Expenses }\end{array}$ & 44,057 & 542,915 & 45,184 & 175,524 & 159,114 & 90,407 \\
\hline 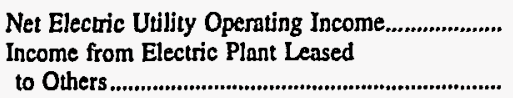 & $\begin{array}{r}7,525 \\
0\end{array}$ & $\begin{array}{r}127,369 \\
0\end{array}$ & $\begin{array}{r}29,225 \\
0\end{array}$ & 8,377 & $\begin{array}{r}115,511 \\
0\end{array}$ & $\begin{array}{r}14,707 \\
0\end{array}$ \\
\hline Electric Utility Operating Income...................... & 7,525 & 127,369 & 29,225 & 8,377 & 115,511 & 14,707 \\
\hline Other Electric Income & 1,505 & 61,019 & 17,973 & 15,875 & 44,399 & 4,481 \\
\hline 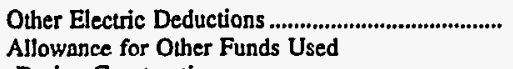 & 0 & 29,982 & 537 & 1,368 & 0 & 0 \\
\hline 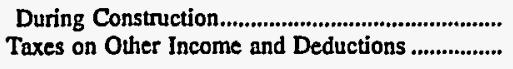 & $\begin{array}{l}0 \\
0\end{array}$ & $\begin{array}{r}413 \\
\quad \\
0\end{array}$ & $\begin{array}{l}0 \\
0\end{array}$ & $\begin{array}{l}0 \\
0\end{array}$ & $\begin{array}{l}0 \\
0\end{array}$ & $\begin{array}{l}0 \\
0\end{array}$ \\
\hline 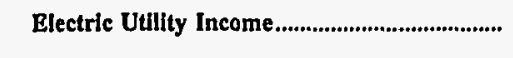 & 9,030 & 158,818 & 46,660 & 22,884 & 159,910 & 19,189 \\
\hline $\begin{array}{l}\text { Income Deductions from Interest } \\
\text { on Long-term Debt ............................................... } \\
\text { Oher Income Deductions...................................... } \\
\text { Allowance for Borrowed Funds Used }\end{array}$ & $\begin{array}{r}408 \\
0\end{array}$ & $\begin{array}{r}132,926 \\
19,367\end{array}$ & $\begin{array}{l}0 \\
0\end{array}$ & $\begin{array}{r}12,368 \\
30\end{array}$ & $\begin{array}{r}202,706 \\
0\end{array}$ & $\begin{array}{l}8,952 \\
3,294\end{array}$ \\
\hline 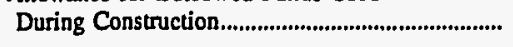 & 0 & $-3,542$ & $\mathbf{0}$ & 0 & 0 & 0 \\
\hline 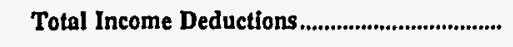 & 408 & 148,751 & $\mathbf{0}$ & 12,398 & 202,706 & 12,246 \\
\hline 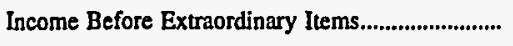 & 8,622 & 10,067 & 46,660 & 10,487 & $-42,796$ & 6,943 \\
\hline Extraordinary Income & 0 & 0 & 2,836 & 0 & 0 & 0 \\
\hline 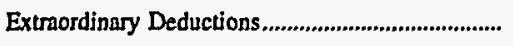 & 0 & 0 & 37,703 & 27,686 & 0 & 0 \\
\hline Net Income & 8,622 & 10,067 & 11,793 & $-17,200$ & $-42,796$ & 6,943 \\
\hline
\end{tabular}

Note: Totals may not equal sum of components because of independent rounding.

Source: Energy Information Administration, Form EIA-412, "Annual Report of Public Electric Utilities." 
Table 21. Statement of Income by Major U.S. Publicly Owned Electric Utility Within State, 1996 (Continued)

(Thousand Dollars)

\begin{tabular}{|c|c|c|c|c|c|c|}
\hline Item & $\begin{array}{l}\text { Califomia } \\
\text { Vernon } \\
\text { City of } \\
\text { June } 30\end{array}$ & $\begin{array}{c}\text { California } \\
\text { Yuba } \\
\text { County } \\
\text { Water } \\
\text { Agency } \\
\text { June } 30\end{array}$ & $\begin{array}{c}\text { Colorado } \\
\text { Arkansas } \\
\text { River } \\
\text { Power } \\
\text { Authority } \\
\text { December } 31\end{array}$ & $\begin{array}{l}\text { Colorado } \\
\text { Colorado } \\
\text { Springs } \\
\text { City of } \\
\text { December } 31\end{array}$ & $\begin{array}{l}\text { Colorado } \\
\text { Fort Collins } \\
\text { City of } \\
\text { December } 31\end{array}$ & $\begin{array}{l}\text { Colorado } \\
\text { Fort Morgan } \\
\text { City of } \\
\text { December } 31\end{array}$ \\
\hline Electric Utility Operating Revenues..................... & 50,026 & 12,761 & 10,115 & 189,509 & 51,594 & 7,703 \\
\hline Operation Expenses & 30,198 & 2,829 & 9,948 & 103,491 & 45,745 & 5,310 \\
\hline 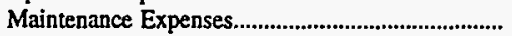 & 2,683 & 1,109 & 0 & 18,585 & 605 & 434 \\
\hline 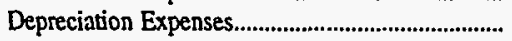 & 3,223 & 2,583 & 0 & 29,519 & 4,172 & 388 \\
\hline Amort, Prop Losses and Reg Study........................... & 0 & 116 & 0 & 0 & 0 & 0 \\
\hline 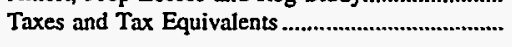 & 1,450 & 0 & 0 & 12,439 & 2,920 & 770 \\
\hline $\begin{array}{l}\text { Total Electric Utility Operating } \\
\text { Expenses }\end{array}$ & 37,555 & 6,637 & 9,948 & 164,034 & 53,442 & 6,903 \\
\hline $\begin{array}{l}\text { Net Electric Utility Operating Income.................... } \\
\text { Income from Electric Plant Leased }\end{array}$ & 12,471 & 6,123 & 167 & 25,475 & $-1,848$ & 800 \\
\hline 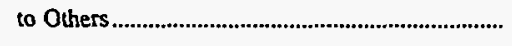 & 0 & 0 & 0 & 0 & 0 & 0 \\
\hline Electric Utility Operating Income .................... & 12,471 & 6,123 & 167 & 25,475 & $-1,848$ & 800 \\
\hline Other Electric Income & 10,941 & 896 & 679 & 4,189 & 3,038 & 654 \\
\hline $\begin{array}{l}\text { Other Electric Deductions } \\
\text { Allowance for Other Funds Used }\end{array}$ & 240 & 0 & 0 & 0 & 0 & 0 \\
\hline 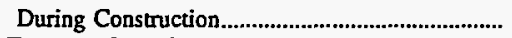 & 0 & $\mathbf{0}$ & 0 & 220 & $\mathbf{0}$ & 0 \\
\hline 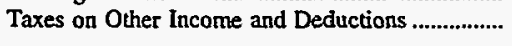 & 0 & 0 & 0 & 0 & 0 & 0 \\
\hline Electric Utility Income & 23,173 & 7,019 & 846 & 29,884 & 1,190 & 1,454 \\
\hline $\begin{array}{l}\text { Income Deductions from Interest } \\
\text { on Long-term Debt ........................... }\end{array}$ & 0 & 4,021 & 0 & 20,109 & 0 & 0 \\
\hline $\begin{array}{l}\text { Other Income Deductions...................................... } \\
\text { Allowance for Borrowed Funds Us }\end{array}$ & 8,210 & 16 & 0 & 429 & 0 & 0 \\
\hline 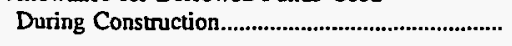 & 0 & 0 & 0 & -555 & 0 & 0 \\
\hline 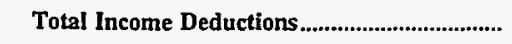 & 8,210 & 4,036 & $\mathbf{0}$ & 19,983 & $\mathbf{0}$ & $\mathbf{0}$ \\
\hline 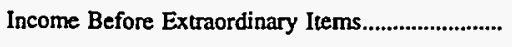 & 14,963 & 2,983 & 846 & 9,901 & 1,190 & 1,454 \\
\hline Extraordinary Income & 0 & 0 & 0 & 0 & 0 & 0 \\
\hline 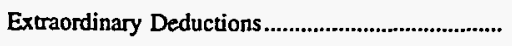 & $\mathbf{0}$ & 0 & 0 & 0 & 0 & 0 \\
\hline Net Income & 14,963 & 2,983 & 846 & 9,901 & 1,190 & 1,454 \\
\hline
\end{tabular}

Note: Totals may not equal sum of components because of independent rounding.

Source: Energy Information Administration, Form EIA-412, "Annual Report of Public Electric Utilities." 
Table 21. Statement of Income by Major U.S. Publicly Owned Electric Utility Within State, 1996 (Continued)

(Thousand Dollars)

\begin{tabular}{|c|c|c|c|c|c|c|}
\hline Item & $\begin{array}{l}\text { Colorado } \\
\text { Longmont } \\
\text { City of } \\
\text { December } 31\end{array}$ & $\begin{array}{l}\text { Colorado } \\
\text { Loveland } \\
\text { City of } \\
\text { December } 31\end{array}$ & $\begin{array}{l}\text { Colorado } \\
\text { Platte River } \\
\text { Power } \\
\text { Authority } \\
\text { December 31 }\end{array}$ & $\begin{array}{l}\text { Connecticut } \\
\text { Connecticut } \\
\text { Mun } \\
\text { Elec } \\
\text { Engy Coop } \\
\text { December } 31\end{array}$ & $\begin{array}{l}\text { Connecticut } \\
\text { Groton } \\
\text { City of } \\
\text { June } 30\end{array}$ & $\begin{array}{l}\text { Connecticut } \\
\text { Norwich } \\
\text { City of } \\
\text { June } 30\end{array}$ \\
\hline Electric Utility Operating Revenues....................... & 25,549 & 21,745 & 135,957 . & 107,127 & 44,235 & 28,354 \\
\hline 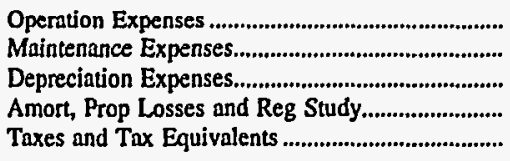 & $\begin{array}{r}23,132 \\
894 \\
1,142 \\
0 \\
1,583\end{array}$ & $\begin{array}{r}17,008 \\
957 \\
1,484 \\
0 \\
1,300\end{array}$ & $\begin{array}{r}65,145 \\
7,447 \\
21,936 \\
5,694 \\
0\end{array}$ & $\begin{array}{r}99,827 \\
1,194 \\
1,763 \\
67 \\
75\end{array}$ & $\begin{array}{r}39,480 \\
488 \\
1,130 \\
0 \\
1,764\end{array}$ & $\begin{array}{r}24,872 \\
1,046 \\
1,138 \\
0 \\
1,447\end{array}$ \\
\hline 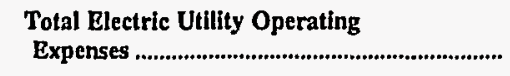 & 26,751 & 20,749 & 100,222 & 102,926 & 42,862 & 28,502 \\
\hline 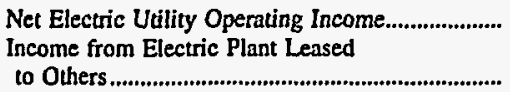 & $\begin{array}{r}-1,202 \\
0\end{array}$ & 996 & $\begin{array}{r}35,735 \\
0\end{array}$ & 4,202 & 1,373 & $\begin{array}{r}-148 \\
641\end{array}$ \\
\hline Electric Utility Operating Income...................... & $-1,202$ & 996 & 35,735 & 4,202 & 1,373 & 493 \\
\hline 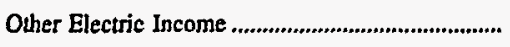 & 565 & 1,266 & 13,988 & 6,807 & 825 & 137 \\
\hline $\begin{array}{l}\text { Other Electric Deductions............................................. } \\
\text { Allowance for Other Funds Used }\end{array}$ & 27 & 894 & 0 & 0 & 151 & 0 \\
\hline 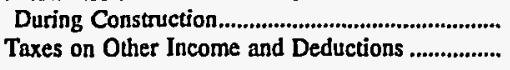 & $\begin{array}{l}\mathbf{0} \\
\mathbf{0}\end{array}$ & $\begin{array}{l}0 \\
0\end{array}$ & $\begin{array}{l}0 \\
0\end{array}$ & $\begin{array}{l}\mathbf{0} \\
\mathbf{0}\end{array}$ & $\begin{array}{l}\mathbf{0} \\
\mathbf{0}\end{array}$ & $\begin{array}{l}0 \\
0\end{array}$ \\
\hline Electric Utility Income & -664 & 1,368 & 49,724 & 11,009 & 2,046 & 630 \\
\hline 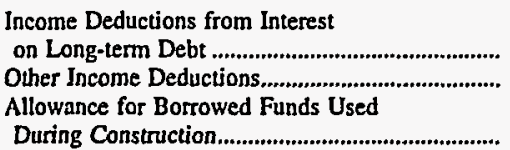 & $\begin{array}{l}0 \\
0\end{array}$ & $\begin{array}{r}17 \\
0\end{array}$ & $\begin{array}{r}29,093 \\
4,757\end{array}$ & $\begin{array}{r}10,087 \\
0\end{array}$ & $\begin{array}{r}416 \\
1,337\end{array}$ & $\begin{array}{r}443 \\
0\end{array}$ \\
\hline 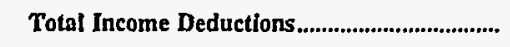 & 0 & 17 & 33,849 & 10,087 & 1,753 & 443 \\
\hline Income Before Extraordinary Items............................... & -664 & 1,351 & 15,874 & 922 & 293 & 187 \\
\hline Extraordinary Income & 0 & 0 & 0 & 0 & 0 & 0 \\
\hline 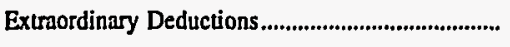 & $\mathbf{0}$ & 0 & 3,371 & $\mathbf{0}$ & 0 & 0 \\
\hline 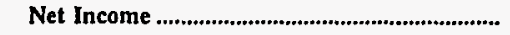 & -664 & 1,351 & 12,504 & 922 & 293 & 187 \\
\hline
\end{tabular}

Note: Totals may not equal sum of components because of independent rounding

Source: Energy Information Administration, Form EIA-412, "Annual Report of Public Electric Utilities." 
Table 21. Statement of Income by Major U.S. Publicly Owned Electric Utility Within State, 1996 (Continued)

(Thousand Dollars)

\begin{tabular}{|c|c|c|c|c|c|c|}
\hline Item & $\begin{array}{l}\text { Connecticut } \\
\text { Wallingford } \\
\text { Town of } \\
\text { June } 30\end{array}$ & $\begin{array}{l}\text { Delaware } \\
\text { Dover } \\
\text { City of } \\
\text { June } 30 \\
\end{array}$ & $\begin{array}{c}\text { Delaware } \\
\text { Milford } \\
\text { City of } \\
\text { September } 30 \\
\end{array}$ & $\begin{array}{l}\text { Delaware } \\
\text { Newark } \\
\text { City of } \\
\text { December } 31\end{array}$ & $\begin{array}{l}\text { Florida } \\
\text { Bartow } \\
\text { City of } \\
\text { September } 30\end{array}$ & $\begin{array}{c}\text { Forida } \\
\text { Florida } \\
\text { Municipal } \\
\text { Power Agency } \\
\text { September } 30\end{array}$ \\
\hline Electric Utility Operating Revenues..................... & 40,218 & 45,299 & 11,424 & 20,886 & 23,325 & 184,673 \\
\hline 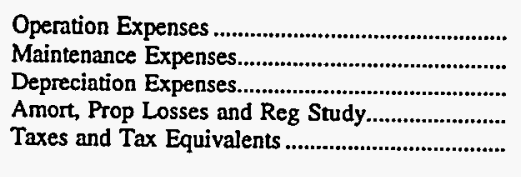 & $\begin{array}{r}30,131 \\
1,201 \\
1,507 \\
0 \\
3,259\end{array}$ & $\begin{array}{r}31,576 \\
0 \\
2,768 \\
0 \\
998\end{array}$ & $\begin{array}{r}7,574 \\
378 \\
0 \\
0 \\
0\end{array}$ & $\begin{array}{r}15,168 \\
414 \\
488 \\
0 \\
0\end{array}$ & $\begin{array}{r}16,583 \\
0 \\
432 \\
0 \\
0\end{array}$ & $\begin{array}{r}124,532 \\
6,508 \\
10,496 \\
0 \\
0\end{array}$ \\
\hline 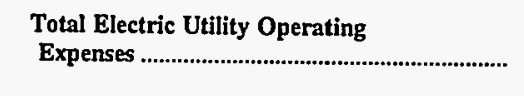 & 36,098 & 35,343 & 7,952 & 16,070 & 17,016 & 141,536 \\
\hline 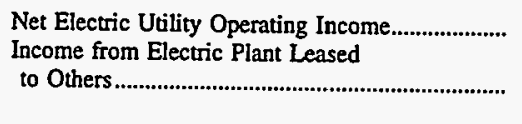 & $\begin{array}{r}4,121 \\
0\end{array}$ & $\begin{array}{r}9,957 \\
0\end{array}$ & $\begin{array}{r}3,473 \\
0\end{array}$ & $\begin{array}{r}4,816 \\
0\end{array}$ & $\begin{array}{r}6,310 \\
0\end{array}$ & $\begin{array}{r}43,136 \\
0\end{array}$ \\
\hline 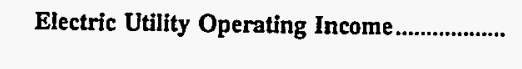 & 4,121 & 9,957 & 3,473 & 4,816 & 6,310 & 43,136 \\
\hline Other Electric Income & 692 & 2,003 & 363 & 326 & 334 & 13,986 \\
\hline $\begin{array}{l}\text { Other Electric Deductions ............................................ } \\
\text { Allowance for Other Funds Used }\end{array}$ & 151 & 0 & 2,438 & 0 & 0 & 0 \\
\hline 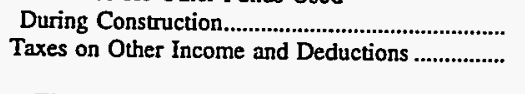 & $\begin{array}{l}0 \\
\mathbf{0}\end{array}$ & $\begin{array}{l}0 \\
0\end{array}$ & $\begin{array}{l}0 \\
0\end{array}$ & $\begin{array}{l}0 \\
0\end{array}$ & $\begin{array}{l}0 \\
0\end{array}$ & $\begin{array}{l}\mathbf{0} \\
\mathbf{0}\end{array}$ \\
\hline 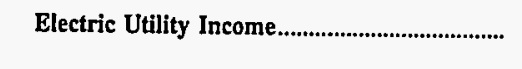 & 4,661 & 11,959 & 1,397 & 5,142 & 6,644 & 57,122 \\
\hline 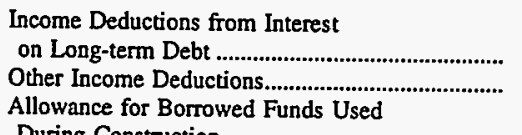 & $\begin{array}{r}21 \\
0\end{array}$ & $\begin{array}{r}1,903 \\
0\end{array}$ & $\begin{array}{l}\mathbf{0} \\
\mathbf{0}\end{array}$ & $\begin{array}{r}19 \\
0\end{array}$ & $\begin{array}{r}0 \\
6,206\end{array}$ & $\begin{array}{l}37,260 \\
19,862\end{array}$ \\
\hline 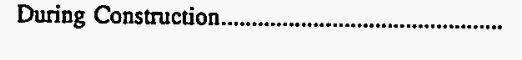 & 0 & 71 & 0 & 0 & 0 & 0 \\
\hline Total Income Deductions........................................ & 21 & 1,974 & $\mathbf{0}$ & 19 & 6,206 & 57,122 \\
\hline 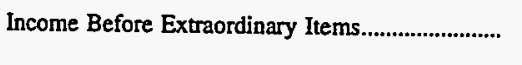 & 4,641 & 9,985 & 1,397 & 5,123 & 438 & 0 \\
\hline 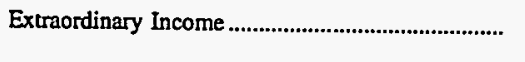 & 1,473 & 0 & 0 & 0 & 0 & 0 \\
\hline 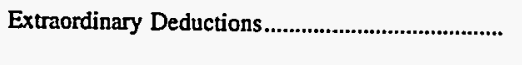 & 0 & 3,720 & 0 & 0 & 0 & 0 \\
\hline Net Income & 6,114 & 6,265 & 1,397 & 5,123 & 438 & $\mathbf{0}$ \\
\hline
\end{tabular}

Note: Totals may not equal sum of components because of independent rounding.

Source: Energy Information Administration, Form EIA-412, "Annual Report of Public Electric Utilities." 
Table 21. Statement of Income by Major U.S. Publicly Owned Electric Utility Within State, 1996 (Continued)

(Thousand Dollars)

\begin{tabular}{|c|c|c|c|c|c|c|}
\hline Item & $\begin{array}{l}\text { Florida } \\
\text { Fort Pierce } \\
\text { Utilities } \\
\text { Auth } \\
\text { September } 30\end{array}$ & $\begin{array}{l}\text { Florida } \\
\text { Gainesville } \\
\text { Regional } \\
\text { Utilities } \\
\text { September } 30\end{array}$ & $\begin{array}{c}\text { Forida } \\
\text { Homestead } \\
\text { City of } \\
\text { September } 30\end{array}$ & $\begin{array}{c}\text { Florida } \\
\text { Jacksonville } \\
\text { Beach } \\
\text { City of } \\
\text { September } 30\end{array}$ & $\begin{array}{c}\text { Florida } \\
\text { Jacksonville } \\
\text { Electric } \\
\text { Auth } \\
\text { September } 30\end{array}$ & $\begin{array}{c}\text { Florida } \\
\begin{array}{c}\text { Key West } \\
\text { City of }\end{array} \\
\text { September } 30\end{array}$ \\
\hline Electric Utillty Operating Revenues........................... & 43,553 & 130,518 & 23,906 & 48,135 & 785,111 & 54,944 \\
\hline 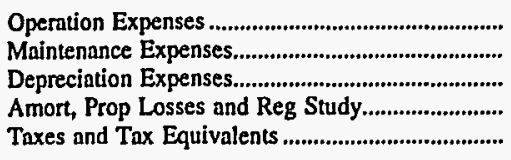 & $\begin{array}{r}30,140 \\
2,066 \\
4,245 \\
0 \\
987\end{array}$ & $\begin{array}{r}66,410 \\
9,955 \\
16,372 \\
0 \\
13,763\end{array}$ & $\begin{array}{r}19,117 \\
3,086 \\
2,312 \\
0 \\
1,340\end{array}$ & $\begin{array}{r}36,469 \\
793 \\
2,605 \\
0 \\
393\end{array}$ & $\begin{array}{r}382,413 \\
48,193 \\
97,595 \\
0 \\
16,770\end{array}$ & $\begin{array}{r}35,354 \\
3,407 \\
5,287 \\
0 \\
1,400\end{array}$ \\
\hline 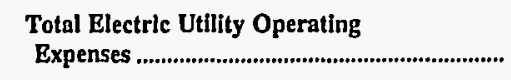 & 37,439 & 106,500 & 25,856 & 40,260 & 544,972 & 45,448 \\
\hline 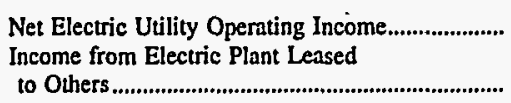 & $\begin{array}{r}6,114 \\
0\end{array}$ & $\begin{array}{r}24,019 \\
7,454\end{array}$ & $\begin{array}{r}-1,950 \\
0\end{array}$ & 7,875 & $\begin{array}{r}240,140 \\
0\end{array}$ & $\begin{array}{r}9,496 \\
0\end{array}$ \\
\hline 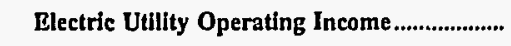 & 6,114 & 31,472 & $-1,950$ & 7,875 & 240,140 & 9,496 \\
\hline 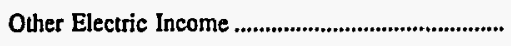 & 1,313 & $-17,406$ & 1,953 & 1,315 & 44,084 & 1,638 \\
\hline $\begin{array}{l}\text { Other Electric Deductions } \\
\text { Allowance for Other Funds Used }\end{array}$ & 0 & 0 & 0 & 2,816 & 0 & 0 \\
\hline 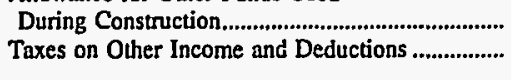 & $\begin{array}{l}0 \\
0\end{array}$ & $\begin{array}{l}0 \\
0\end{array}$ & $\begin{array}{l}0 \\
0\end{array}$ & $\begin{array}{l}0 \\
0\end{array}$ & $\begin{array}{l}0 \\
0\end{array}$ & $\begin{array}{l}0 \\
0\end{array}$ \\
\hline Electric Utility Income & 7,427 & 14,067 & 3 & 6,374 & 284,224 & 11,135 \\
\hline $\begin{array}{l}\text { Income Deductions from Interest } \\
\text { on Long-term Debt ................................................. } \\
\text { Other Income Deductions.................................. } \\
\text { Allowance for Borrowed Funds Used }\end{array}$ & $\begin{array}{l}3,257 \\
2,694\end{array}$ & $\begin{array}{l}0 \\
0\end{array}$ & $\begin{array}{r}433 \\
0\end{array}$ & $\begin{array}{r}4,213 \\
0\end{array}$ & $\begin{array}{r}146,797 \\
18,017\end{array}$ & $\begin{array}{r}8,548 \\
211\end{array}$ \\
\hline 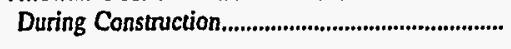 & 0 & 0 & 0 & 0 & $-1,836$ & 0 \\
\hline 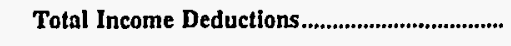 & 5,950 & $\mathbf{0}$ & 433 & 4,213 & 162,979 & 8,759 \\
\hline Income Before Extraordinary Items........................... & 1,477 & 14,057 & -430 & 2,161 & 121,245 & 2,376 \\
\hline Extraordinary Income & 0 & 0 & 0 & 0 & 0 & 0 \\
\hline 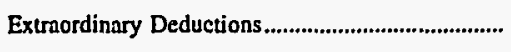 & 0 & 0 & $\mathbf{0}$ & 0 & 0 & 0 \\
\hline Net Income & 1,477 & 14,067 & -430 & 2,161 & 121,245 & 2,376 \\
\hline
\end{tabular}

Note: Totals may not equal sum of components because of independent rounding.

Source: Energy Information Administration, Form EIA-412, "Annual Report of Public Electric Utilities." 
Table 21. Statement of Income by Major U.S. Publicly Owned Electric Utility Within State, 1996 (Continued)

(Thousand Dollars)

\begin{tabular}{|c|c|c|c|c|c|c|}
\hline Item & $\begin{array}{l}\text { Florida } \\
\text { Kissimmee } \\
\text { Utility } \\
\text { Authority } \\
\text { September } 30\end{array}$ & $\begin{array}{l}\text { Florida } \\
\text { Lake Worth } \\
\text { City of } \\
\text { September } 30\end{array}$ & $\begin{array}{l}\text { Florida } \\
\text { Lakeland } \\
\text { City of } \\
\text { September } 30\end{array}$ & $\begin{array}{l}\text { Florida } \\
\text { Leesburg } \\
\text { City of } \\
\text { September } 30\end{array}$ & $\begin{array}{c}\text { Florida } \\
\text { New Smyma } \\
\text { Beach } \\
\text { Utils Comm } \\
\text { September } 30\end{array}$ & $\begin{array}{l}\text { Forida } \\
\text { Ocala } \\
\text { City of } \\
\text { September } 30\end{array}$ \\
\hline Electric Utility Operating Revenues....................... & 72,193 & 33,687 & 166,473 & 31,667 & 25,873 & 78,246 \\
\hline 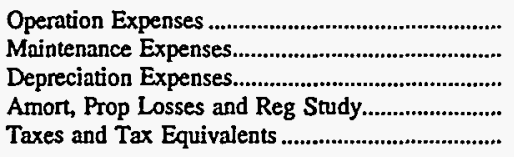 & $\begin{array}{r}42,933 \\
4,469 \\
10,703 \\
-2,789 \\
12\end{array}$ & $\begin{array}{r}23,711 \\
1,425 \\
2,765 \\
0 \\
4,507\end{array}$ & $\begin{array}{r}91,903 \\
15,433 \\
19,669 \\
0 \\
0\end{array}$ & $\begin{array}{r}20,548 \\
1,172 \\
1,935 \\
165 \\
771\end{array}$ & $\begin{array}{r}18,354 \\
744 \\
1,839 \\
197 \\
1,609\end{array}$ & $\begin{array}{r}55,547 \\
2,481 \\
3,212 \\
349 \\
1,949\end{array}$ \\
\hline $\begin{array}{l}\text { Total Electric Utility Operating } \\
\text { Expenses }\end{array}$ & 55,327 & 32,408 & 127,005 & 24,592 & 22,744 & 63,538 \\
\hline 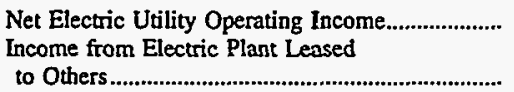 & 16,866 & $\begin{array}{r}1,279 \\
0\end{array}$ & $\begin{array}{r}39,468 \\
0\end{array}$ & 7,075 & 3,129 & 14,708 \\
\hline Electric Utility Operating Income .................... & 16,866 & 1,279 & 39,468 & 7,075 & 3,129 & 14,708 \\
\hline Other Electric Income & 5,080 & 1,652 & 27,269 & 1,357 & 625 & 1,457 \\
\hline $\begin{array}{l}\text { Other Electric Deductions } \\
\text { Allowance for Other Funds Used }\end{array}$ & 6,498 & 0 & 11,521 & 3,558 & 44 & 822 \\
\hline 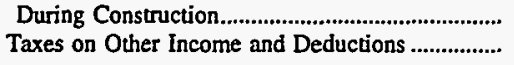 & $\begin{array}{l}0 \\
0\end{array}$ & $\begin{array}{l}0 \\
0\end{array}$ & $\begin{array}{l}0 \\
0\end{array}$ & $\begin{array}{l}0 \\
0\end{array}$ & $\begin{array}{l}0 \\
0\end{array}$ & $\begin{array}{l}0 \\
0\end{array}$ \\
\hline Electric Utility Income & 15,448 & 2,931 & 55,216 & 4,874 & 3,709 & 15,342 \\
\hline 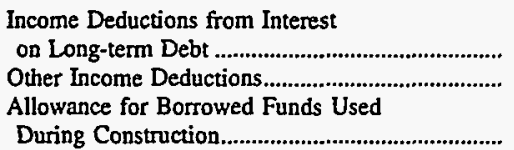 & $\begin{array}{l}5,923 \\
1,421\end{array}$ & $\begin{array}{r}1,910 \\
0\end{array}$ & $\begin{array}{r}22,809 \\
455\end{array}$ & $\begin{array}{r}1,124 \\
0\end{array}$ & $\begin{array}{r}1,761 \\
134\end{array}$ & $\begin{array}{r}840 \\
0\end{array}$ \\
\hline 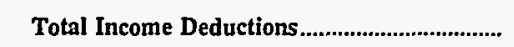 & 7,344 & 1,910 & 23,264 & 1,124 & 1,895 & 840 \\
\hline Income Before Extraordinary Items........................... & 8,104 & 1,021 & 31,952 & 3,750 & 1,813 & 14,503 \\
\hline 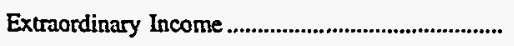 & 0 & 0 & 0 & 0 & $\mathbf{0}$ & 0 \\
\hline 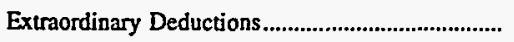 & 0 & 0 & 0 & 0 & 0 & 0 \\
\hline 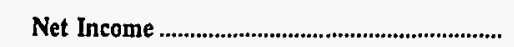 & 8,104 & 1,021 & 31,952 & 3,750 & 1,813 & 14,503 \\
\hline
\end{tabular}

Note: Totals may not equal sum of components because of independent rounding.

Source: Energy Information Administration, Form EIA-412, "Annual Report of Public Electric Utilities." 
Table 21. Statement of Income by Major U.S. Publicly Owned Electric Utility

Within State, 1996 (Continued)

(Thousand Dollars)

\begin{tabular}{|c|c|c|c|c|c|c|}
\hline Item & $\begin{array}{l}\text { Florida } \\
\text { Orlando } \\
\text { Utilities } \\
\text { Comm } \\
\text { September } 30\end{array}$ & $\begin{array}{c}\text { Florida } \\
\text { Quincy } \\
\text { City of } \\
\text { September } 30\end{array}$ & $\begin{array}{c}\text { Florida } \\
\text { Reedy Creek } \\
\text { Improvement } \\
\text { Dist } \\
\text { September } 30\end{array}$ & $\begin{array}{l}\text { Florida } \\
\text { St Cloud } \\
\text { City of } \\
\text { September } 30\end{array}$ & $\begin{array}{l}\text { Florida } \\
\text { Tallahassee } \\
\text { City of } \\
\text { September } 30\end{array}$ & $\begin{array}{c}\text { Florida } \\
\text { Vero } \\
\text { Beach } \\
\text { City of } \\
\text { September } 30\end{array}$ \\
\hline Electric Utility Operating Revenues....................... & 354,419 & 10,678 & 65,444 & 27,434 & 191,321 & 48,645 \\
\hline 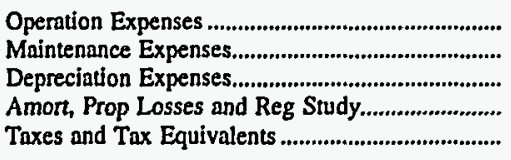 & $\begin{array}{r}178,255 \\
27,329 \\
40,383 \\
136 \\
18,554\end{array}$ & $\begin{array}{r}6,606 \\
400 \\
249 \\
0 \\
171\end{array}$ & $\begin{array}{r}45,537 \\
4,338 \\
4,045 \\
0 \\
2,093\end{array}$ & $\begin{array}{r}18,354 \\
453 \\
3,203 \\
0 \\
613\end{array}$ & $\begin{array}{r}139,143 \\
4,468 \\
13,367 \\
160 \\
0\end{array}$ & $\begin{array}{r}31,877 \\
3,288 \\
4,553 \\
0 \\
163\end{array}$ \\
\hline 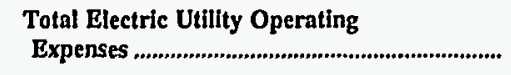 & 264,657 & 7,426 & 56,013 & 22,624 & 157,138 & 39,881 \\
\hline 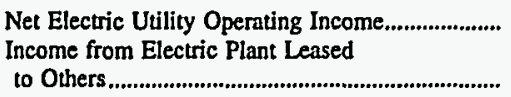 & $\begin{array}{r}89,762 \\
0\end{array}$ & $\begin{array}{r}3,252 \\
0\end{array}$ & $\begin{array}{r}9,431 \\
0\end{array}$ & $\begin{array}{r}4,811 \\
0\end{array}$ & $\begin{array}{r}34,183 \\
0\end{array}$ & $\begin{array}{r}8,764 \\
0\end{array}$ \\
\hline Electric Utility Operating Income..................... & 89,762 & 3,252 & 9,431 & 4,811 & 34,183 & 8,764 \\
\hline Other Electric Income & 30,098 & 506 & 0 & 474 & 8,185 & 1,643 \\
\hline 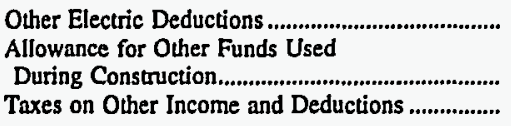 & $\begin{array}{l}0 \\
0\end{array}$ & $\begin{array}{l}0 \\
0 \\
0\end{array}$ & $\begin{array}{l}0 \\
0 \\
0\end{array}$ & $\begin{array}{l}0 \\
0 \\
0\end{array}$ & $\begin{array}{r}208 \\
0 \\
0\end{array}$ & $\begin{array}{l}0 \\
0 \\
0\end{array}$ \\
\hline Electric Utilty Income............................................. & 119,860 & 3,758 & 9,431 & 5,284 & 42,160 & 10,407 \\
\hline 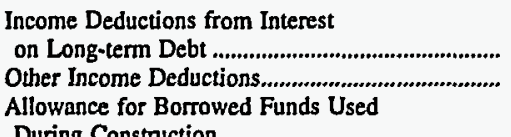 & $\begin{array}{l}71,880 \\
10,800\end{array}$ & $\begin{array}{l}0 \\
0\end{array}$ & $\begin{array}{r}5,116 \\
145\end{array}$ & $\begin{array}{r}1,619 \\
0\end{array}$ & $\begin{array}{r}6,367 \\
36,713 \\
\end{array}$ & $\begin{array}{r}4,934 \\
3,193 \\
\end{array}$ \\
\hline 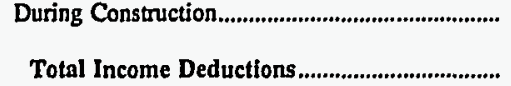 & $\begin{array}{r}0 \\
82,680\end{array}$ & $\begin{array}{l}0 \\
\text { o }\end{array}$ & $\begin{array}{r}0 \\
5,261\end{array}$ & $\begin{array}{r}0 \\
1,619\end{array}$ & $\begin{array}{l}-3,627 \\
39,453\end{array}$ & $\begin{array}{r}0 \\
8,127\end{array}$ \\
\hline Income Before Extraordinary Items............................ & 37,179 & 3,758 & 4,170 & 3,665 & 2,707 & 2,280 \\
\hline 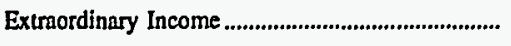 & 0 & 0 & 0 & 0 & 0 & 0 \\
\hline Extmordinary Deductions.................................................. & 0 & 0 & 0 & 0 & 0 & 0 \\
\hline Net Income & 37,179 & 3,758 & 4,170 & 3,665 & 2,707 & 2,280 \\
\hline
\end{tabular}

Note: Totals may not equal sum of components because of independent rounding.

Source: Energy Information Administration, Form EIA-412, "Annual Report of Public Electric Utilities." 
Table 21. Statement of Income by Major U.S. Publicly Owned Electric Utility Within State, 1996 (Continued)

(Thousand Dollars)

\begin{tabular}{|c|c|c|c|c|c|c|}
\hline Item & $\begin{array}{l}\text { Georgia } \\
\text { Albany Water } \\
\text { Gas \& Light } \\
\text { Comm } \\
\text { June } 30\end{array}$ & $\begin{array}{l}\text { Georgia } \\
\text { Calhoun } \\
\text { City of } \\
\text { June } 30\end{array}$ & $\begin{array}{l}\text { Georgia } \\
\text { Cartersville } \\
\text { City of } \\
\text { June } 30\end{array}$ & $\begin{array}{l}\text { Georgia } \\
\text { College } \\
\text { Park City of } \\
\text { June } 30\end{array}$ & $\begin{array}{l}\text { Georgia } \\
\text { Covington } \\
\text { City of } \\
\text { December } 31\end{array}$ & $\begin{array}{l}\text { Georgia } \\
\text { Crisp } \\
\text { County } \\
\text { Power } \\
\text { Comm } \\
\text { December } 31\end{array}$ \\
\hline Electric Utility Operating Revenues..................... & 58,330 & 20,944 & 27,739 & 18,067 & 16,802 & 18,489 \\
\hline 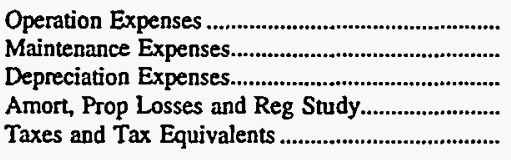 & $\begin{array}{r}51,845 \\
1,569 \\
1,242 \\
0 \\
0\end{array}$ & $\begin{array}{r}17,553 \\
177 \\
339 \\
0 \\
0\end{array}$ & $\begin{array}{r}23,985 \\
76 \\
376 \\
0 \\
0\end{array}$ & $\begin{array}{r}16,880 \\
198 \\
0 \\
0 \\
0\end{array}$ & $\begin{array}{r}13,900 \\
192 \\
222 \\
0 \\
760\end{array}$ & $\begin{array}{r}14,660 \\
838 \\
1,655 \\
0 \\
821\end{array}$ \\
\hline $\begin{array}{l}\text { Total Electric Utility Operating } \\
\text { Expenses }\end{array}$ & 54,656 & 18,069 & 24,437 & 17,078 & 15,074 & 17,975 \\
\hline 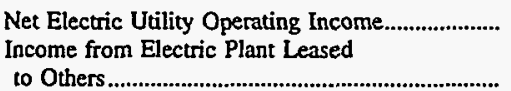 & 3,674 & $\begin{array}{r}2,875 \\
0\end{array}$ & $\begin{array}{r}3,302 \\
0\end{array}$ & $\begin{array}{r}990 \\
0\end{array}$ & $\begin{array}{r}1,728 \\
0\end{array}$ & $\begin{array}{r}514 \\
0\end{array}$ \\
\hline 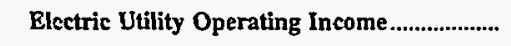 & 3,674 & 2,875 & 3,302 & 990 & 1,728 & 514 \\
\hline Other Electric Income & 1,209 & 0 & 198 & 0 & 419 & 353 \\
\hline $\begin{array}{l}\text { Other Electric Deductions............................. } \\
\text { Allowance for Other Funds Used }\end{array}$ & 0 & 0 & 3,093 & 0 & 0 & 54 \\
\hline 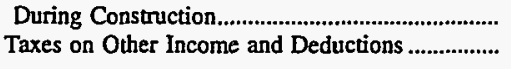 & $\begin{array}{l}0 \\
0\end{array}$ & $\begin{array}{l}0 \\
0\end{array}$ & $\begin{array}{l}0 \\
0\end{array}$ & $\begin{array}{l}0 \\
0\end{array}$ & $\begin{array}{l}0 \\
0\end{array}$ & $\begin{array}{l}0 \\
0\end{array}$ \\
\hline 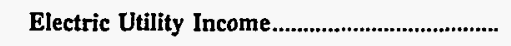 & 4,883 & 2,875 & 407 & 990 & 2,147 & 814 \\
\hline 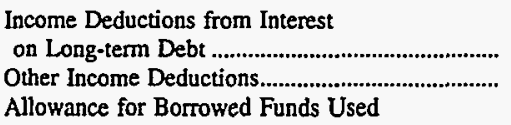 & $\begin{array}{l}0 \\
0\end{array}$ & $\begin{array}{l}0 \\
0\end{array}$ & $\begin{array}{l}4 \\
0\end{array}$ & $\begin{array}{l}0 \\
0\end{array}$ & $\begin{array}{r}11 \\
0\end{array}$ & $\begin{array}{r}0 \\
313\end{array}$ \\
\hline 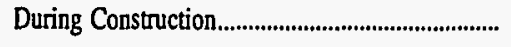 & 0 & 0 & 0 & 0 & 0 & 0 \\
\hline 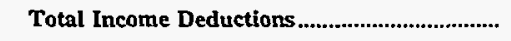 & $\mathbf{0}$ & 0 & 4 & $\mathbf{0}$ & 11 & 313 \\
\hline Income Before Extraordinary Items.......................... & 4,883 & 2,875 & 403 & 990 & 2,135 & 501 \\
\hline Extraordinary Income & 0 & 9,139 & 0 & 0 & 0 & 0 \\
\hline 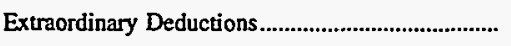 & 0 & 5,738 & $\mathbf{0}$ & 0 & 0 & 0 \\
\hline Net Income & 4,883 & 6,276 & 403 & 990 & 2,135 & 501 \\
\hline
\end{tabular}

Note: Totals may not equal sum of components because of independent rounding.

Source: Energy Information Administration, Form EIA-412, "Annual Report of Public Electric Utilities." 
Table 21. Statement of Income by Major U.S. Publicly Owned Electric Utility Within State, 1996 (Continued)

(Thousand Dollars)

\begin{tabular}{|c|c|c|c|c|c|c|}
\hline Item & $\begin{array}{c}\text { Georgia } \\
\text { Dalton } \\
\text { City of } \\
\text { November } 30\end{array}$ & $\begin{array}{l}\text { Georgia } \\
\text { Douglas } \\
\text { City of } \\
\text { June } 30\end{array}$ & $\begin{array}{c}\text { Georgia } \\
\text { Enst } \\
\text { Point } \\
\text { City of } \\
\text { June } 30\end{array}$ & $\begin{array}{l}\text { Georgia } \\
\text { Fitzgerald } \\
\text { Wtr Lgt } \\
\text { \& Bond Comm } \\
\text { December } 31\end{array}$ & $\begin{array}{l}\text { Georgia } \\
\text { Griffin } \\
\text { City of } \\
\text { June } 30\end{array}$ & $\begin{array}{l}\text { Georgia } \\
\text { La Grange } \\
\text { City of } \\
\text { June } 30\end{array}$ \\
\hline Electric Utility Operating Revenues....................... & 42,295 & 16,061 & 23,119 & 13,377 & 26,150 & 29,013 \\
\hline 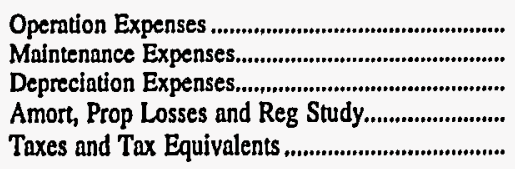 & $\begin{array}{r}34,367 \\
5,213 \\
6,403 \\
0 \\
1,224\end{array}$ & $\begin{array}{r}13,196 \\
31 \\
197 \\
0 \\
2,292\end{array}$ & $\begin{array}{r}18,946 \\
742 \\
175 \\
0 \\
0\end{array}$ & $\begin{array}{r}11,584 \\
554 \\
268 \\
0 \\
0\end{array}$ & $\begin{array}{r}17,412 \\
126 \\
3,822 \\
0 \\
0\end{array}$ & $\begin{array}{r}24,912 \\
0 \\
280 \\
0 \\
0\end{array}$ \\
\hline 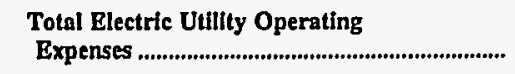 & 47,207 & 15,716 & 19,863 & 12,405 & 21,360 & 25,192 \\
\hline 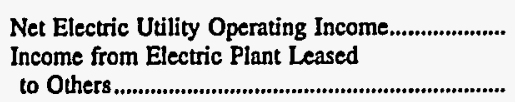 & $\begin{array}{r}-4,912 \\
1,474\end{array}$ & $\begin{array}{r}345 \\
0\end{array}$ & $\begin{array}{r}3,256 \\
0\end{array}$ & 971 & 4,790 & 3,821 \\
\hline Electric Utility Operating Income ..................... & $-3,438$ & 345 & 3,256 & 971 & 4,790 & $\mathbf{3 , 8 2 1}$ \\
\hline 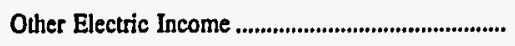 & 21,274 & 359 & 0 & 1,379 & 657 & 0 \\
\hline $\begin{array}{l}\text { Other Electric Deductions .................................... } \\
\text { Allowance for Other Funds Used } \\
\text { During Construction............................................... } \\
\text { Taxes on Other Income and Deductions ................ }\end{array}$ & $\begin{array}{l}0 \\
0 \\
0\end{array}$ & $\begin{array}{l}0 \\
0 \\
0\end{array}$ & $\begin{array}{l}0 \\
0 \\
0\end{array}$ & $\begin{array}{l}0 \\
0 \\
0\end{array}$ & $\begin{array}{l}0 \\
0\end{array}$ & $\begin{array}{l}0 \\
0 \\
0\end{array}$ \\
\hline Electric Utility Income & 17,836 & 704 & 3,256 & 2,350 & 5,448 & 3,821 \\
\hline 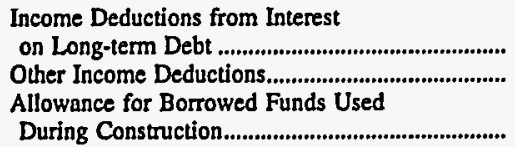 & $\begin{array}{r}5,545 \\
0\end{array}$ & $\begin{array}{l}0 \\
0\end{array}$ & $\begin{array}{r}0 \\
2,447\end{array}$ & $\begin{array}{r}297 \\
0 \\
0\end{array}$ & $\begin{array}{l}0 \\
0\end{array}$ & $\begin{array}{l}0 \\
0\end{array}$ \\
\hline 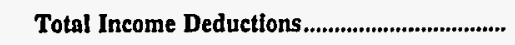 & 5,545 & 0 & 2,447 & 297 & o & $\mathbf{0}$ \\
\hline Income Before Extraordinary Items............................ & 12,291 & 704 & 809 & 2,052 & 5,448 & 3,821 \\
\hline Extraordinary Income & 0 & 0 & 0 & 0 & 0 & 0 \\
\hline 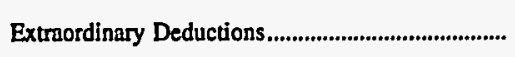 & 0 & 0 & 0 & $\mathbf{0}$ & 0 & 0 \\
\hline 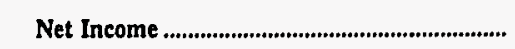 & 12,291 & 704 & 809 & 2,052 & 5,448 & 3,821 \\
\hline
\end{tabular}

Note: Totals may not equal sum of components because of independent rounding.

Source: Energy Information Administration, Form EIA-412, "Annual Report of Public Electric Utilities." 
Table 21. Statement of Income by Major U.S. Publicly Owned Electric Utility Within State, 1996 (Continued) (Thousand Dollars)

\begin{tabular}{|c|c|c|c|c|c|c|}
\hline Item & $\begin{array}{c}\text { Georgia } \\
\begin{array}{l}\text { Lawrenceville } \\
\text { City of }\end{array} \\
\text { August } 30\end{array}$ & $\begin{array}{l}\text { Georgia } \\
\text { Marietta } \\
\text { City of } \\
\text { June } 30\end{array}$ & $\begin{array}{c}\text { Georgia } \\
\text { Moultrie } \\
\text { City of } \\
\text { September } 30\end{array}$ & $\begin{array}{c}\text { Georgia } \\
\text { Municipal } \\
\text { Electric } \\
\text { Authority } \\
\text { December } 31\end{array}$ & $\begin{array}{l}\text { Georgia } \\
\text { Thomasville } \\
\text { City of } \\
\text { December } 31\end{array}$ & $\begin{array}{l}\text { Idaho } \\
\text { Idaho } \\
\text { Falls } \\
\text { City of } \\
\text { September } 30\end{array}$ \\
\hline 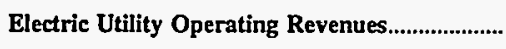 & 16,746 & 76,333 & 13,608 & 500,805 & 29,683 & 35,730 \\
\hline 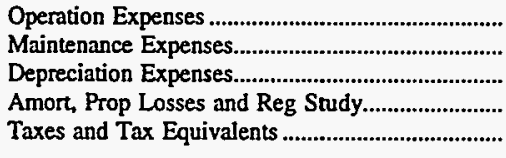 & $\begin{array}{r}14,824 \\
13 \\
393 \\
0 \\
0\end{array}$ & $\begin{array}{r}60,148 \\
0 \\
1,688 \\
0 \\
0\end{array}$ & $\begin{array}{r}11,255 \\
0 \\
258 \\
0 \\
0\end{array}$ & $\begin{array}{r}172,321 \\
41,741 \\
96,923 \\
26,920 \\
3,275\end{array}$ & $\begin{array}{r}25,349 \\
813 \\
879 \\
0 \\
120\end{array}$ & $\begin{array}{r}19,752 \\
2,688 \\
3,622 \\
0 \\
2,267\end{array}$ \\
\hline $\begin{array}{l}\text { Total Electric Utility Operating } \\
\text { Expenses }\end{array}$ & 15,230 & 61,835 & 11,513 & 341,180 & 27,162 & 28,330 \\
\hline 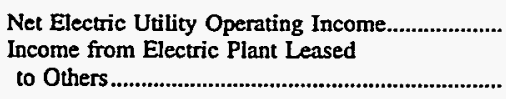 & $\begin{array}{r}1,516 \\
0\end{array}$ & $\begin{array}{r}14,498 \\
0\end{array}$ & $\begin{array}{r}2,095 \\
0\end{array}$ & $\begin{array}{r}159,625 \\
0\end{array}$ & $\begin{array}{r}2,521 \\
0\end{array}$ & $\begin{array}{r}7,400 \\
0\end{array}$ \\
\hline Electric Utility Operating Income...................... & 1,516 & 14,498 & 2,095 & 159,625 & 2,521 & 7,400 \\
\hline 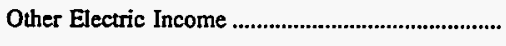 & 12 & 0 & 29 & 39,095 & 214 & 1,133 \\
\hline $\begin{array}{l}\text { Other Electric Deductions ..................................... } \\
\text { Allowance for Other Funds Used }\end{array}$ & 0 & 0 & 0 & 0 & 0 & 565 \\
\hline 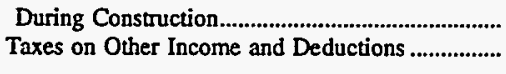 & $\begin{array}{r}0 \\
1,528\end{array}$ & $\begin{array}{l}0 \\
0\end{array}$ & $\begin{array}{l}\mathbf{0} \\
\mathbf{0}\end{array}$ & $\begin{array}{l}\mathbf{0} \\
\mathbf{0}\end{array}$ & $\begin{array}{l}0 \\
0\end{array}$ & $\begin{array}{l}0 \\
0\end{array}$ \\
\hline 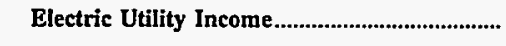 & o & 14,498 & 2,124 & 198,720 & 2,736 & 7,969 \\
\hline 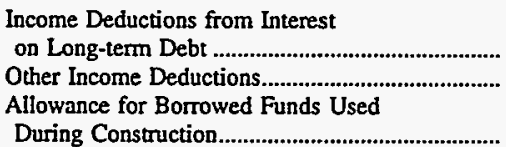 & $\begin{array}{l}0 \\
0\end{array}$ & $\begin{array}{l}0 \\
0\end{array}$ & $\begin{array}{r}0 \\
1,492\end{array}$ & $\begin{array}{r}228,345 \\
-31,597 \\
406\end{array}$ & $\begin{array}{r}89 \\
0\end{array}$ & $\begin{array}{r}6,258 \\
715\end{array}$ \\
\hline 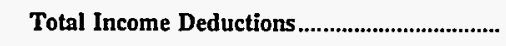 & $\mathbf{0}$ & 0 & 1,492 & 197,154 & 89 & 6,973 \\
\hline 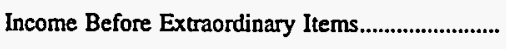 & 0 & 14,498 & 632 & 1,566 & 2,647 & 995 \\
\hline Extraordinary Income & 0 & 0 & 0 & 0 & 0 & 0 \\
\hline Extraordinary Deductions & $\mathbf{0}$ & 0 & 0 & 0 & 0 & 0 \\
\hline Net Income & 0 & 14,498 & 632 & 1,566 & 2,647 & 995 \\
\hline
\end{tabular}

Note: Totals may not equal sum of components because of independent rounding

Source: Energy Information Administration, Form EIA-412, “Annual Report of Public Electric Utilities." 
Table 21. Statement of Income by Major U.S. Publicly Owned Electric Utility Within State, 1996 (Continued)

(Thousand Dollars)

\begin{tabular}{|c|c|c|c|c|c|c|}
\hline Item & $\begin{array}{l}\text { Illinois } \\
\text { Batavia } \\
\text { City of } \\
\text { December } 31\end{array}$ & $\begin{array}{l}\text { Illinois } \\
\text { Geneva } \\
\text { City of } \\
\text { April } 30\end{array}$ & $\begin{array}{c}\text { Illinois } \\
\text { Illinois } \\
\text { Municipal } \\
\text { Elec Agency } \\
\text { April } 30\end{array}$ & $\begin{array}{l}\text { Illinois } \\
\text { Naperville } \\
\text { City of } \\
\text { April } 30\end{array}$ & $\begin{array}{l}\text { Illinois } \\
\text { Rochelle } \\
\text { Municipal } \\
\text { Utilities } \\
\text { April } 30\end{array}$ & $\begin{array}{l}\text { Illinois } \\
\begin{array}{l}\text { Springfield } \\
\text { City of }\end{array} \\
\text { February } 28\end{array}$ \\
\hline Electric Utility Operating Revenues....................... & 15,844 & 11,245 & 71,590 & 57,337 & 13,808 & 99,920 \\
\hline 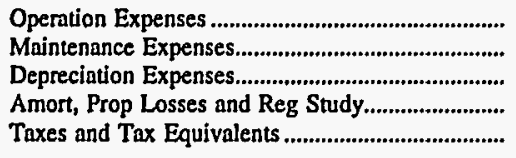 & $\begin{array}{r}13,043 \\
122 \\
696 \\
0 \\
635\end{array}$ & $\begin{array}{r}7,964 \\
667 \\
1,027 \\
0 \\
408\end{array}$ & $\begin{array}{r}60,246 \\
549 \\
3,150 \\
0 \\
0\end{array}$ & $\begin{array}{r}46,118 \\
732 \\
3,445 \\
0 \\
0\end{array}$ & $\begin{array}{r}9,492 \\
716 \\
1,214 \\
0 \\
0\end{array}$ & $\begin{array}{r}53,439 \\
15,314 \\
13,076 \\
87 \\
4,138\end{array}$ \\
\hline 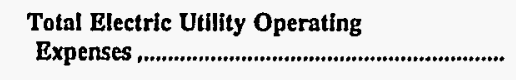 & 14,496 & 10,066 & 63,946 & 50,295 & 11,423 & 86,054 \\
\hline 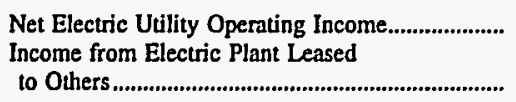 & $\begin{array}{r}1,348 \\
0\end{array}$ & $\begin{array}{r}1,180 \\
0\end{array}$ & $\begin{array}{r}7,644 \\
0\end{array}$ & $\begin{array}{r}7,041 \\
0\end{array}$ & $\begin{array}{r}2,385 \\
0\end{array}$ & 13,865 \\
\hline Electric Utility Operating Income........................ & 1,348 & 1,180 & 7,644 & 7,041 & 2,385 & 13,865 \\
\hline Other Electric Income & 541 & 906 & 1,977 & 3,065 & 371 & 2,963 \\
\hline Other Electric Deductions ............................................ & 0 & 58 & $\mathbf{0}$ & 0 & $\mathbf{0}$ & 0 \\
\hline 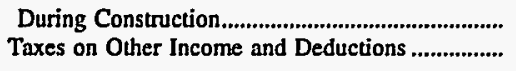 & $\begin{array}{l}0 \\
0\end{array}$ & $\begin{array}{l}0 \\
0\end{array}$ & $\begin{array}{l}0 \\
0\end{array}$ & $\begin{array}{l}0 \\
0\end{array}$ & $\begin{array}{l}\mathbf{0} \\
\mathbf{0}\end{array}$ & o \\
\hline 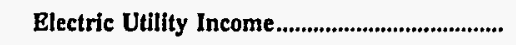 & 1,889 & 2,028 & 9,622 & 10,106 & 2,756 & 16,829 \\
\hline $\begin{array}{l}\text { Income Deductions from Interest } \\
\text { on Long-term Debt .................................................... } \\
\text { Other Income Deductions................................... } \\
\text { Allowance for Borrowed Funds Used }\end{array}$ & $\begin{array}{l}\mathbf{0} \\
\mathbf{0}\end{array}$ & $\begin{array}{r}134 \\
12\end{array}$ & $\begin{array}{r}7,030 \\
620\end{array}$ & $\begin{array}{r}1,071 \\
0\end{array}$ & $\begin{array}{r}614 \\
57\end{array}$ & $\begin{array}{r}6,517 \\
266\end{array}$ \\
\hline 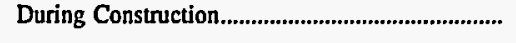 & 0 & 0 & 0 & $\mathbf{0}$ & -8 & 0 \\
\hline 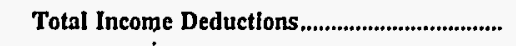 & $\mathbf{0}$ & 146 & 7,650 & 1,071 & 663 & 6,783 \\
\hline 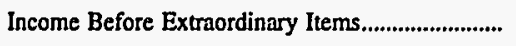 & 1,889 & 1,882 & 1,972 & 9,035 & 2,094 & 10,046 \\
\hline 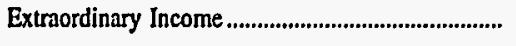 & 0 & 0 & 125 & $\mathbf{0}$ & 0 & 1,003 \\
\hline 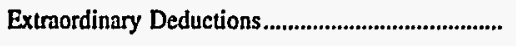 & 215 & 0 & 0 & 0 & 0 & 0 \\
\hline 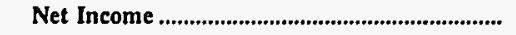 & 1,674 & 1,882 & 2,097 & 9,035 & 2,094 & 11,048 \\
\hline
\end{tabular}

Note: Totals may not equal sum of components because of independent rounding.

Source: Energy Information Administration, Form EIA-412, "Annual Report of Public Electric Utilities." 
Table 21. Statement of Income by Major U.S. Publicly Owned Electric Utility Within State, 1996 (Continued)

(Thousand Dollars)

\begin{tabular}{|c|c|c|c|c|c|c|}
\hline Item & $\begin{array}{l}\text { Illinois } \\
\text { St Charles } \\
\text { City of } \\
\text { April } 30\end{array}$ & $\begin{array}{l}\text { Indiana } \\
\begin{array}{c}\text { Anderson } \\
\text { City of }\end{array} \\
\text { December } 31\end{array}$ & $\begin{array}{l}\text { Indiana } \\
\text { Auburn } \\
\text { City of } \\
\text { December } 31\end{array}$ & $\begin{array}{l}\text { Indiana } \\
\begin{array}{c}\text { Bluffton } \\
\text { City of }\end{array} \\
\text { December } 31\end{array}$ & $\begin{array}{c}\text { Indiana } \\
\text { Crawfordsville } \\
\text { Elec } \\
\text { Lgt\&Pwr Co } \\
\text { December } 31\end{array}$ & $\begin{array}{l}\text { Indiana } \\
\text { Frankfort } \\
\text { City of } \\
\text { December } 31\end{array}$ \\
\hline 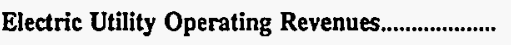 & 25,990 & 37,264 & 20,677 & 8,709 & 20,802 & 15,712 \\
\hline 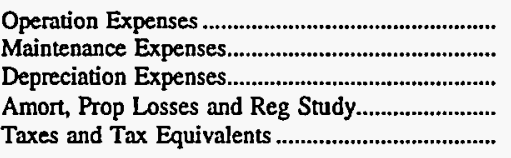 & $\begin{array}{r}17,849 \\
5,234 \\
1,073 \\
0 \\
0\end{array}$ & $\begin{array}{r}31,795 \\
1,164 \\
1,819 \\
0 \\
1,056\end{array}$ & $\begin{array}{r}18,226 \\
665 \\
671 \\
0 \\
244\end{array}$ & $\begin{array}{r}8,052 \\
200 \\
285 \\
0 \\
157\end{array}$ & $\begin{array}{r}16,331 \\
1,122 \\
1,136 \\
84 \\
498\end{array}$ & $\begin{array}{r}13.537 \\
265 \\
712 \\
0 \\
262\end{array}$ \\
\hline $\begin{array}{l}\text { Total Electric Utility Operating } \\
\text { Expenses }\end{array}$ & 24,155 & 35,834 & 19,805 & 8,694 & 19,171 & 14,776 \\
\hline 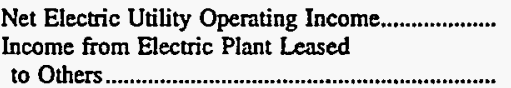 & 1,835 & 1,430 & 871 & 15 & $\begin{array}{r}1,631 \\
0\end{array}$ & 936 \\
\hline Electric Utility Operating Income...................... & 1,835 & 1,430 & 871 & 15 & 1,631 & 936 \\
\hline Other Electric Income & 0 & 271 & 353 & 191 & 365 & 276 \\
\hline $\begin{array}{l}\text { Other Electric Deductions } \\
\text { Allowance for Other Funds Used }\end{array}$ & 0 & 0 & 3 & 0 & 106 & 0 \\
\hline 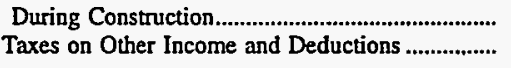 & $\begin{array}{l}0 \\
0\end{array}$ & $\begin{array}{l}0 \\
0\end{array}$ & $\begin{array}{l}0 \\
0\end{array}$ & $\begin{array}{l}0 \\
0\end{array}$ & $\begin{array}{l}0 \\
0\end{array}$ & $\begin{array}{l}0 \\
0\end{array}$ \\
\hline Electric Utility Income............................................. & 1,835 & 1,700 & 1,221 & 206 & 1,890 & 1,212 \\
\hline 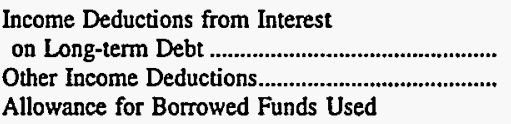 & $\begin{array}{l}0 \\
0\end{array}$ & $\begin{array}{r}214 \\
30\end{array}$ & $\begin{array}{r}18 \\
0\end{array}$ & $\begin{array}{l}0 \\
2\end{array}$ & $\begin{array}{l}383 \\
153\end{array}$ & $\begin{array}{l}0 \\
0\end{array}$ \\
\hline 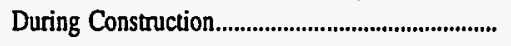 & 0 & 0 & 0 & 0 & 0 & 0 \\
\hline 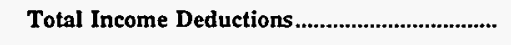 & $\mathbf{0}$ & 244 & 18 & 2 & 537 & $\mathbf{0}$ \\
\hline 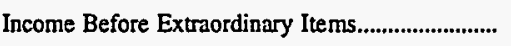 & 1,835 & 1,456 & 1,203 & 204 & 1,354 & 1,212 \\
\hline Extraordinary Income & 0 & 0 & 0 & 0 & 0 & 0 \\
\hline Extraordinary Deductions & 0 & 0 & 0 & 0 & 0 & 0 \\
\hline Net Income & 1,835 & 1,456 & 1,203 & 204 & 1,354 & 1,212 \\
\hline
\end{tabular}

Note: Totals may not equal sum of components because of independent rounding.

Source: Energy Information Administration, Form EIA-412, "Annual Report of Public Electric Utilities." 
Table 21. Statement of Income by Major U.S. Publicly Owned Electric Utility

Within State, 1996 (Continued)

(Thousand Dollars)

\begin{tabular}{|c|c|c|c|c|c|c|}
\hline Item & $\begin{array}{l}\text { Indiana } \\
\text { Greenfield } \\
\text { City of } \\
\text { December } 31\end{array}$ & $\begin{array}{c}\text { Indiana } \\
\text { Indiana } \\
\text { Municipal } \\
\text { Power Agency } \\
\text { December } 31\end{array}$ & $\begin{array}{c}\text { Indiana } \\
\text { Jasper } \\
\text { City of } \\
\text { December } 31\end{array}$ & $\begin{array}{l}\text { Indiana } \\
\text { Lebanon } \\
\text { City of } \\
\text { December } 31\end{array}$ & $\begin{array}{l}\text { Indiana } \\
\text { Logansport } \\
\text { City of } \\
\text { December } 31\end{array}$ & $\begin{array}{l}\text { Indiana } \\
\text { Mishawaka } \\
\text { City of } \\
\text { December } 31\end{array}$ \\
\hline Electric Utility Operating Revenues...................... & 9,213 & 157,176 & 15,205 & 8,102 & 19,053 & 29,787 \\
\hline 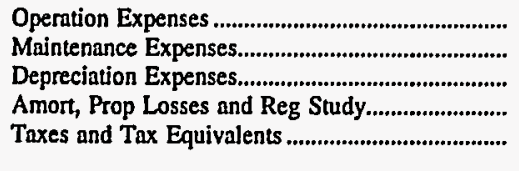 & $\begin{array}{r}7,643 \\
751 \\
291 \\
0 \\
0\end{array}$ & $\begin{array}{r}118,687 \\
3,342 \\
8,816 \\
56 \\
971\end{array}$ & $\begin{array}{r}12,506 \\
323 \\
1,360 \\
0 \\
281\end{array}$ & $\begin{array}{r}6,682 \\
302 \\
354 \\
0 \\
97\end{array}$ & $\begin{array}{r}13,829 \\
1,771 \\
1,530 \\
0 \\
403\end{array}$ & $\begin{array}{r}24,452 \\
697 \\
1,252 \\
0 \\
495\end{array}$ \\
\hline $\begin{array}{l}\text { Total Electric Utility Operating } \\
\text { Expenses ................................................................ }\end{array}$ & 8,684 & 131,872 & 14,470 & 7,434 & 17,534 & 26,896 \\
\hline 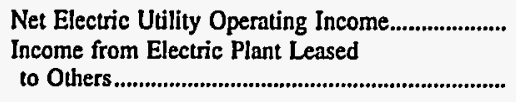 & $\begin{array}{r}528 \\
0\end{array}$ & $\begin{array}{r}25,304 \\
0\end{array}$ & $\begin{array}{r}735 \\
0\end{array}$ & 668 & $\begin{array}{r}1,519 \\
0\end{array}$ & 2,892 \\
\hline Electric Utillty Operating Income...................... & 528 & 25,304 & 735 & 668 & 1,519 & 2,892 \\
\hline Other Electric Income & 121 & 6,106 & 242 & 0 & 701 & 335 \\
\hline 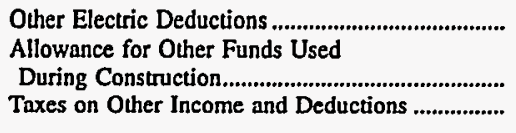 & $\begin{array}{l}0 \\
0 \\
0\end{array}$ & $\begin{array}{l}0 \\
0\end{array}$ & $\begin{array}{l}\mathbf{0} \\
\mathbf{0}\end{array}$ & $\begin{array}{l}0 \\
0\end{array}$ & $\begin{array}{l}0 \\
0\end{array}$ & $\begin{array}{l}0 \\
0\end{array}$ \\
\hline 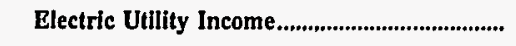 & 650 & 31,403 & 977 & 668 & 2,220 & 3,227 \\
\hline 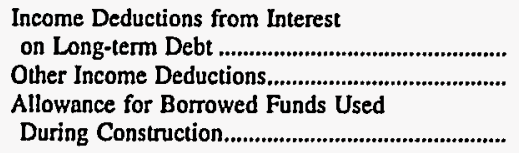 & $\begin{array}{r}98 \\
0\end{array}$ & $\begin{array}{r}22,683 \\
4,278 \\
-78\end{array}$ & $\begin{array}{r}469 \\
31\end{array}$ & $\begin{array}{l}0 \\
0\end{array}$ & $\begin{array}{r}0 \\
720\end{array}$ & $\begin{array}{r}0 \\
41 \\
0\end{array}$ \\
\hline 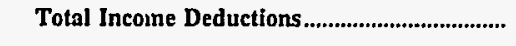 & 98 & 26,883 & 499 & $\mathbf{0}$ & 720 & 41 \\
\hline Income Before Extraordinary Items............................... & 552 & 4,520 & 478 & 668 & 1,500 & 3,186 \\
\hline 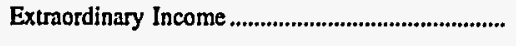 & 0 & 3,430 & 0 & 0 & 0 & 0 \\
\hline 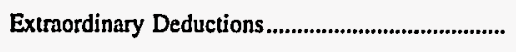 & 3 & 0 & 1,186 & 0 & 0 & 0 \\
\hline 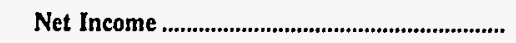 & 549 & 7,950 & -708 & 668 & 1,500 & 3,186 \\
\hline
\end{tabular}

Note: Totals may not equal sum of components because of independent rounding.

Source: Energy Information Administration, Form ElA-412, "Annual Report of Public Electric Utilities." 
Table 21. Statement of Income by Major U.S. Publicly Owned Electric Utility Within State, 1996 (Continued)

(Thousand Dollars)

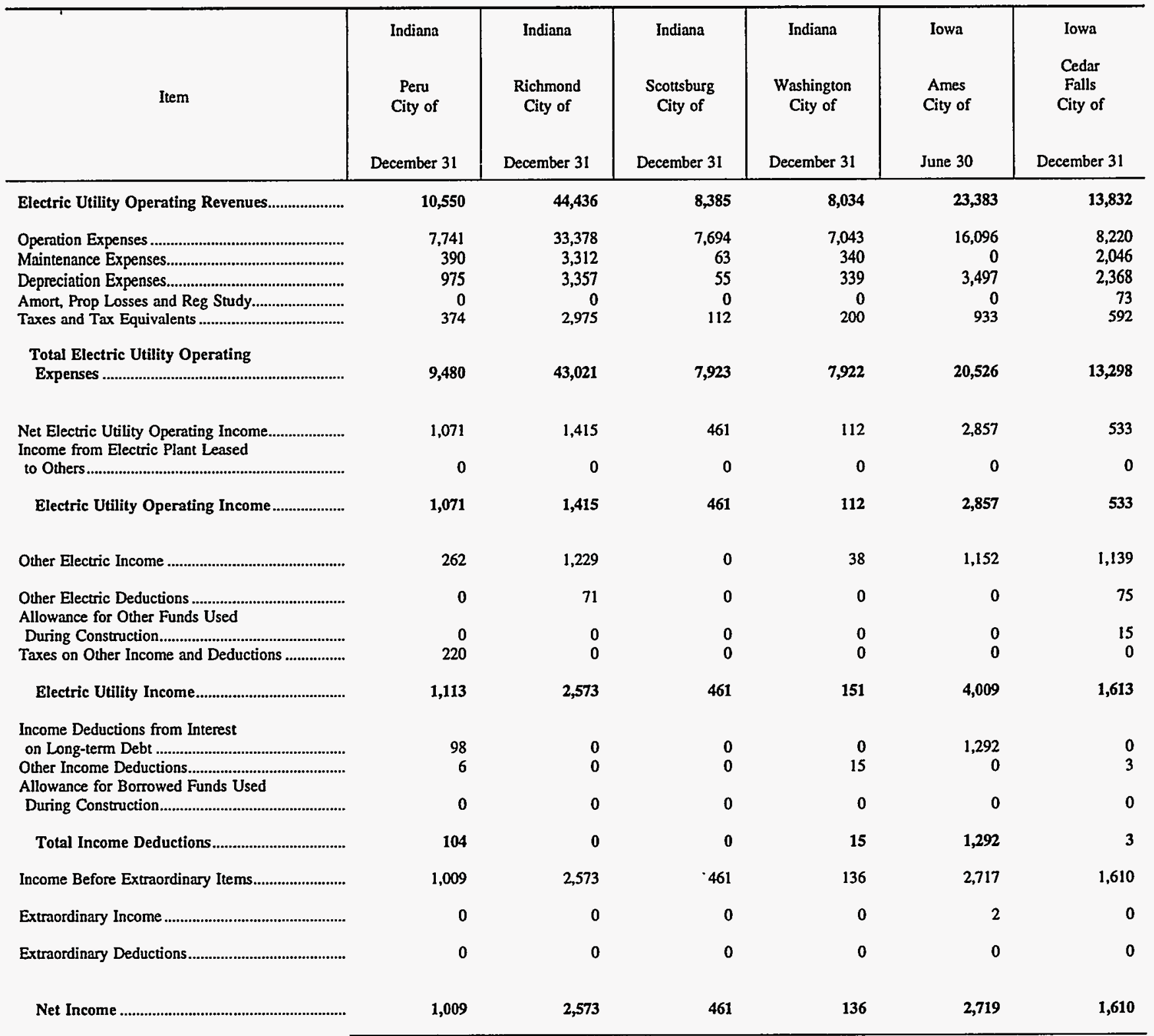

Note: Totals may not equal sum of components because of independent rounding.

Source: Energy Information Administration, Form EIA-412, "Annual Report of Public Electric Utilities." 
Table 21. Statement of Income by Major U.S. Publicly Owned Electric Utility Within State, 1996 (Continued)

(Thousand Dollars)

\begin{tabular}{|c|c|c|c|c|c|c|}
\hline Item & $\begin{array}{c}\text { Iowa } \\
\text { Muscatine } \\
\text { City of } \\
\text { December } 31\end{array}$ & $\begin{array}{c}\text { Iowa } \\
\text { Pella } \\
\text { City of } \\
\text { December } 31\end{array}$ & $\begin{array}{l}\text { Kansas } \\
\text { Chanute } \\
\text { City of } \\
\text { December } 31\end{array}$ & $\begin{array}{l}\text { Kansas } \\
\text { Coffeyville } \\
\text { City of } \\
\text { December } 31\end{array}$ & $\begin{array}{c}\text { Kansas } \\
\text { Garden } \\
\text { City City of } \\
\text { December } 31\end{array}$ & $\begin{array}{c}\text { Kansas } \\
\text { Kansas } \\
\text { City City of } \\
\text { December } 31\end{array}$ \\
\hline Electric Utility Operating Revenues...................... & 48,443 & 11,843 & 9,338 & 11,851 & 12,926 & 128,881 \\
\hline 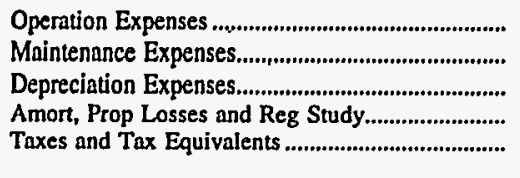 & $\begin{array}{r}29,637 \\
5,176 \\
8,571 \\
0 \\
89\end{array}$ & $\begin{array}{r}7,983 \\
780 \\
0 \\
0 \\
0\end{array}$ & $\begin{array}{r}5,168 \\
810 \\
577 \\
0 \\
700\end{array}$ & $\begin{array}{r}7,903 \\
-372 \\
1,687 \\
0 \\
550\end{array}$ & $\begin{array}{r}11,715 \\
0 \\
375 \\
0 \\
0\end{array}$ & $\begin{array}{r}84,916 \\
14,268 \\
17,319 \\
807 \\
2,387\end{array}$ \\
\hline $\begin{array}{l}\text { Total Electric Utility Operating } \\
\text { Expenses ............................................................... }\end{array}$ & 43,472 & 8,763 & 7,255 & 9,768 & 12,090 & 119,696 \\
\hline 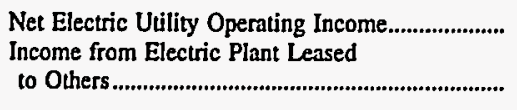 & $\begin{array}{r}4,970 \\
0\end{array}$ & $\begin{array}{r}3,080 \\
0\end{array}$ & $\begin{array}{r}2,083 \\
0\end{array}$ & $\begin{array}{r}2,083 \\
0\end{array}$ & $\begin{array}{r}836 \\
0\end{array}$ & $\begin{array}{r}9,185 \\
0\end{array}$ \\
\hline Electric Utility Operating Income...................... & 4,970 & 3,080 & 2,083 & 2,083 & 836 & 9,185 \\
\hline 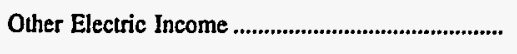 & 5,046 & 147 & 112 & 176 & 35 & 1,782 \\
\hline 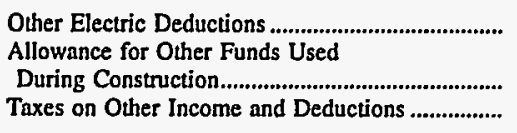 & $\begin{array}{l}0 \\
0 \\
0\end{array}$ & $\begin{array}{r}5,128 \\
0 \\
0\end{array}$ & $\begin{array}{l}0 \\
0 \\
0\end{array}$ & $\begin{array}{r}463 \\
0 \\
0\end{array}$ & $\begin{array}{l}0 \\
0 \\
0\end{array}$ & $\begin{array}{l}0 \\
0\end{array}$ \\
\hline Electric Utility Income........................................... & 10,016 & $-1,900$ & 2,195 & 1,797 & 871 & 10,967 \\
\hline 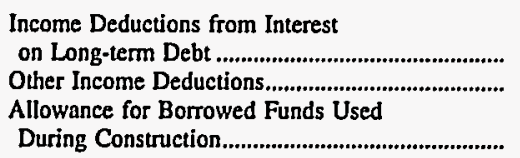 & $\begin{array}{r}8,177 \\
0 \\
0\end{array}$ & $\begin{array}{r}504 \\
0\end{array}$ & $\begin{array}{r}1,424 \\
0 \\
0\end{array}$ & $\begin{array}{l}0 \\
0\end{array}$ & $\begin{array}{r}0 \\
230\end{array}$ & $\begin{array}{r}12,199 \\
0\end{array}$ \\
\hline Total Income Deductions..................................... & 8,177 & 504 & 1,424 & $\mathbf{0}$ & 230 & 12,199 \\
\hline Income Before Extraordinary Items.......................... & 1,838 & $-2,404$ & 771 & 1,797 & 641 & $-1,232$ \\
\hline 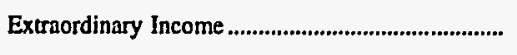 & 0 & 0 & 0 & 647 & 0 & 0 \\
\hline 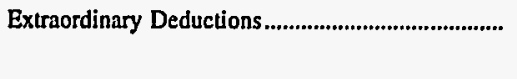 & 4,635 & 0 & 0 & $\mathbf{0}$ & 0 & 0 \\
\hline Net Income & $-2,796$ & $-2,404$ & 771 & 2,444 & 641 & $-1,232$ \\
\hline
\end{tabular}

Note: Totals may not equal sum of components because of independent rounding.

Source: Energy Information Administration, Form EIA-412, "Annual Report of Public Electric Utilities." 
Table 21. Statement of Income by Major U.S. Publicly Owned Electric Utility Within State, 1996 (Continued)

(Thousand Dollars)

\begin{tabular}{|c|c|c|c|c|c|c|}
\hline Item & $\begin{array}{c}\text { Kansas } \\
\text { Kansas } \\
\text { Municipal } \\
\text { Energy } \\
\text { Agency } \\
\text { December } 31\end{array}$ & $\begin{array}{c}\text { Kansas } \\
\text { McPherson } \\
\text { City of } \\
\text { December } 31\end{array}$ & $\begin{array}{c}\text { Kansas } \\
\text { Winfield } \\
\text { City of } \\
\text { December } 31\end{array}$ & $\begin{array}{c}\text { Kentucky } \\
\text { Bardstown } \\
\text { City of } \\
\text { December } 31\end{array}$ & $\begin{array}{l}\text { Kentucky } \\
\text { Bowling } \\
\text { Green } \\
\text { City of } \\
\text { June } 30\end{array}$ & $\begin{array}{l}\text { Kentucky } \\
\text { Frankfor } \\
\text { City of } \\
\text { June } 30\end{array}$ \\
\hline 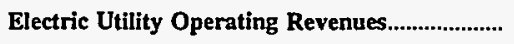 & 8,797 & 21,066 & 13,671 & 7,689 & 42,374 & 26,343 \\
\hline 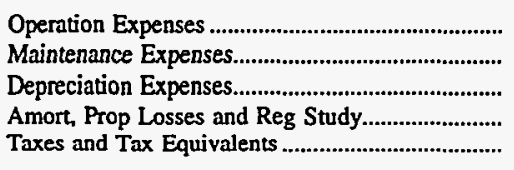 & $\begin{array}{r}9,890 \\
1 \\
79 \\
192 \\
34\end{array}$ & $\begin{array}{r}16,796 \\
1,920 \\
1,869 \\
0 \\
845\end{array}$ & $\begin{array}{r}11,184 \\
0 \\
906 \\
0 \\
0\end{array}$ & $\begin{array}{r}5,533 \\
129 \\
368 \\
0 \\
0\end{array}$ & $\begin{array}{r}36,379 \\
1,266 \\
1,561 \\
0 \\
1,724\end{array}$ & $\begin{array}{r}23,450 \\
1,034 \\
988 \\
0 \\
80\end{array}$ \\
\hline 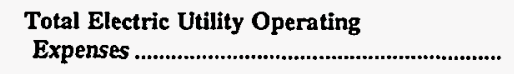 & 10,196 & 21,430 & 12,090 & 6,030 & 40,930 & 25,552 \\
\hline 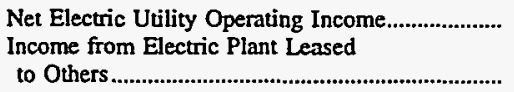 & $\begin{array}{r}-1,399 \\
1,728\end{array}$ & $\begin{array}{r}-363 \\
0\end{array}$ & 1,581 & 1,658 & 1,444 & $\begin{array}{r}791 \\
0\end{array}$ \\
\hline Electric Utility Operating Income...................... & 329 & -363 & 1,581 & 1,658 & 1,444 & 791 \\
\hline Other Electric Income & 401 & 3,156 & 609 & 244 & 957 & 8,604 \\
\hline $\begin{array}{l}\text { Other Electric Deductions } \\
\text { Allowance for Other Funds Used }\end{array}$ & 104 & 0 & 1,112 & 1,000 & 0 & 7,678 \\
\hline 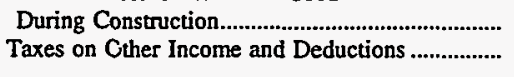 & $\begin{array}{l}0 \\
0\end{array}$ & $\begin{array}{l}0 \\
0\end{array}$ & $\begin{array}{l}\mathbf{0} \\
\mathbf{0}\end{array}$ & $\begin{array}{l}0 \\
0\end{array}$ & $\begin{array}{l}\mathbf{0} \\
\mathbf{0}\end{array}$ & $\begin{array}{r}0 \\
76\end{array}$ \\
\hline 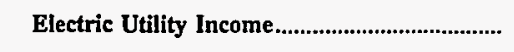 & 626 & 2,793 & 1,078 & 903 & 2,401 & 1,642 \\
\hline 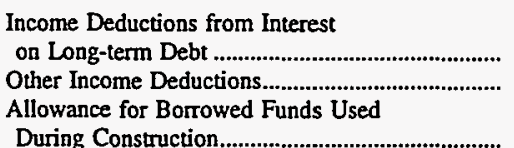 & $\begin{array}{r}629 \\
0\end{array}$ & $\begin{array}{r}2,011 \\
0 \\
-983\end{array}$ & $\begin{array}{r}257 \\
32\end{array}$ & $\begin{array}{l}0 \\
0\end{array}$ & $\begin{array}{l}449 \\
112\end{array}$ & $\begin{array}{r}216 \\
0 \\
0\end{array}$ \\
\hline Total Income Deductions & 629 & 1,028 & 290 & $\mathbf{0}$ & 561 & 216 \\
\hline 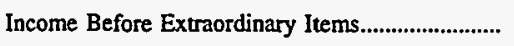 & -3 & 1,765 & 789 & 903 & 1,840 & 1,426 \\
\hline Extraordinary Income & 0 & 0 & $\mathbf{0}$ & 0 & $\mathbf{0}$ & 0 \\
\hline 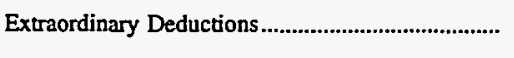 & 0 & 0 & 0 & 0 & 0 & 0 \\
\hline 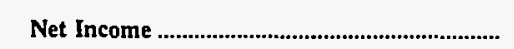 & -3 & 1,765 & 789 & 903 & 1,840 & 1,426 \\
\hline
\end{tabular}

Note: Totals may not equal sum of components because of independent rounding.

Source: Energy Information Administration, Form EIA-412, "Annual Report of Public Electric Utilities." 
Table 21. Statement of Income by Major U.S. Publicly Owned Electric Utility

Within State, 1996 (Continued)

(Thousand Dollars)

\begin{tabular}{|c|c|c|c|c|c|c|}
\hline Item & $\begin{array}{l}\text { Kentucky } \\
\text { Franklin } \\
\text { City of } \\
\text { June } 30\end{array}$ & $\begin{array}{l}\text { Kentucky } \\
\text { Glasgow } \\
\text { City of } \\
\text { June } 30\end{array}$ & $\begin{array}{c}\text { Kentucky } \\
\text { Henderson } \\
\text { City } \\
\text { Utility Comm } \\
\text { May } 31\end{array}$ & $\begin{array}{l}\text { Kentucky } \\
\text { Hopkinsville } \\
\text { City of } \\
\text { June } 30\end{array}$ & $\begin{array}{l}\text { Kentucky } \\
\text { Madisonville } \\
\text { Municipal } \\
\text { Utils } \\
\text { June } 30\end{array}$ & $\begin{array}{l}\text { Kentucky } \\
\text { Mayfield } \\
\text { City of } \\
\text { June } 30\end{array}$ \\
\hline Electric Utility Operating Revenues...................... & 9,682 & 16,989 & 32,316 & 21,877 & 12,943 & 9,361 \\
\hline 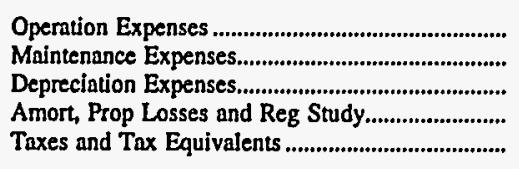 & $\begin{array}{r}8,698 \\
165 \\
182 \\
0 \\
366\end{array}$ & $\begin{array}{r}15,163 \\
309 \\
646 \\
9 \\
438\end{array}$ & $\begin{array}{r}17,633 \\
6,615 \\
6,157 \\
0 \\
0\end{array}$ & $\begin{array}{r}20,258 \\
655 \\
505 \\
0 \\
766\end{array}$ & $\begin{array}{r}9,688 \\
1,107 \\
308 \\
0 \\
0\end{array}$ & $\begin{array}{r}8,325 \\
484 \\
163 \\
0 \\
393\end{array}$ \\
\hline $\begin{array}{l}\text { Total Electric Utility Operating } \\
\text { Expenses }\end{array}$ & 9,412 & 16,565 & 30,405 & 22,184 & 11,103 & 9,365 \\
\hline 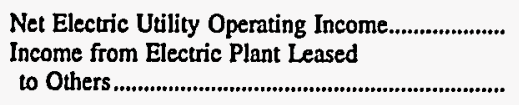 & $\begin{array}{r}270 \\
0\end{array}$ & $\begin{array}{r}424 \\
0\end{array}$ & $\begin{array}{r}1,911 \\
0\end{array}$ & $\begin{array}{r}-307 \\
\cdot \quad 0\end{array}$ & $\begin{array}{r}1,840 \\
0\end{array}$ & -5 \\
\hline Electric Utility Operating Income..................... & 270 & 424 & 1,911 & -307 & 1,840 & -5 \\
\hline 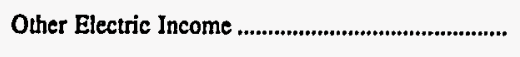 & 155 & 28 & 1,887 & 660 & 22 & 78 \\
\hline $\begin{array}{l}\text { Other Electric Deductions ............................................. } \\
\text { Allowance for Other Funds Used }\end{array}$ & 0 & 1 & 0 & 0 & 0 & 0 \\
\hline 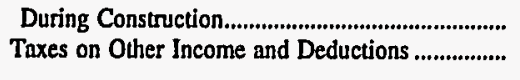 & $\begin{array}{l}0 \\
0\end{array}$ & $\begin{array}{l}0 \\
0\end{array}$ & $\begin{array}{l}0 \\
0\end{array}$ & $\begin{array}{l}0 \\
0\end{array}$ & $\begin{array}{l}0 \\
0\end{array}$ & $\begin{array}{l}0 \\
0\end{array}$ \\
\hline 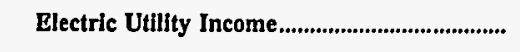 & 425 & 451 & 3,798 & 352 & 1,862 & 73 \\
\hline 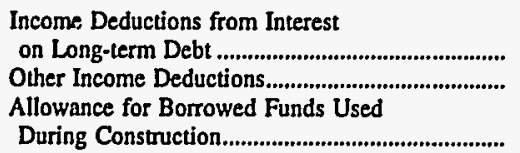 & $\begin{array}{r}0 \\
10\end{array}$ & $\begin{array}{r}424 \\
0\end{array}$ & $\begin{array}{r}2,023 \\
0\end{array}$ & $\begin{array}{r}115 \\
26\end{array}$ & $\begin{array}{r}0 \\
2,438\end{array}$ & $\begin{array}{l}0 \\
8\end{array}$ \\
\hline 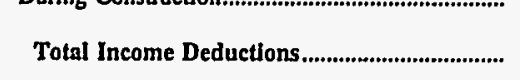 & 10 & 424 & 2,023 & 141 & 2,438 & $\begin{array}{l}0 \\
8\end{array}$ \\
\hline Income Before Extraordinary Items............................ & 416 & 27 & 1,775 & 211 & -575 & 65 \\
\hline Extraordinary Income ..................................................... & 0 & 0 & 0 & 0 & 0 & 0 \\
\hline 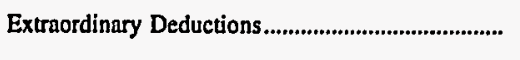 & $0^{-}$ & 0 & 0 & 0 & 0 & $\mathbf{0}$ \\
\hline 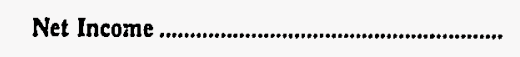 & 416 & 27 & 1,775 & 211 & -575 & 65 \\
\hline
\end{tabular}

Note: Totals may not equal sum of components because of independent rounding.

Source: Energy Information Administration, Form EIA-412, "Annual Report of Public Electric Utilities." 
Table 21. Statement of Income by Major U.S. Publicly Owned Electric Utility Within State, 1996 (Continued)

(Thousand Dollars)

\begin{tabular}{|c|c|c|c|c|c|c|}
\hline Item & $\begin{array}{l}\text { Kentucky } \\
\text { Murray } \\
\text { City of } \\
\text { June } 30\end{array}$ & $\begin{array}{c}\text { Kentucky } \\
\text { Owensboro } \\
\text { Cíty of } \\
\text { May } 31\end{array}$ & $\begin{array}{l}\text { Kentucky } \\
\text { Paducah } \\
\text { City of } \\
\text { June } 30\end{array}$ & $\begin{array}{l}\text { Kentucky } \\
\begin{array}{c}\text { Russellville } \\
\text { City of }\end{array} \\
\text { June } 30\end{array}$ & $\begin{array}{l}\text { Louisiana } \\
\begin{array}{c}\text { Alexandria } \\
\text { City of }\end{array} \\
\text { April } 30\end{array}$ & $\begin{array}{l}\text { Louisiana } \\
\text { Lafayette } \\
\text { City of } \\
\text { October } 31\end{array}$ \\
\hline Electric Utility Operating Revenues...................... & 13,487 & 64,065 & 34,109 & 7,202 & 42,693 & 103,494 \\
\hline 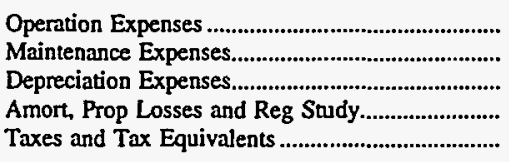 & $\begin{array}{r}12,183 \\
340 \\
315 \\
0 \\
515\end{array}$ & $\begin{array}{r}35,510 \\
8,672 \\
6,865 \\
0 \\
0\end{array}$ & $\begin{array}{r}29,698 \\
866 \\
1,618 \\
0 \\
1,630\end{array}$ & $\begin{array}{r}6,397 \\
138 \\
134 \\
0 \\
271\end{array}$ & $\begin{array}{r}26,915 \\
905 \\
1,813 \\
0 \\
2,213\end{array}$ & $\begin{array}{r}73,424 \\
2,771 \\
5,013 \\
1,878 \\
8,877\end{array}$ \\
\hline $\begin{array}{l}\text { Total Electric Utility Operating } \\
\text { Expenses }\end{array}$ & 13,353 & 51,046 & 33,813 & 6,940 & 31,846 & 91,962 \\
\hline 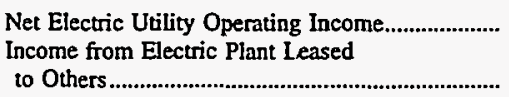 & $\begin{array}{r}135 \\
0\end{array}$ & $\begin{array}{r}13,018 \\
0\end{array}$ & $\begin{array}{r}297 \\
0\end{array}$ & $\begin{array}{r}262 \\
0\end{array}$ & $\begin{array}{r}10,847 \\
0\end{array}$ & $\begin{array}{r}11,532 \\
0\end{array}$ \\
\hline Electric Utility Operating Income ....................... & 135 & 13,018 & 297 & 262 & 10,847 & 11,532 \\
\hline Other Electric Income & 145 & 6,604 & 631 & 129 & 3,188 & 3,982 \\
\hline $\begin{array}{l}\text { Other Electric Deductions } \\
\text { Allowance for Other Funds Used }\end{array}$ & 0 & 0 & 75 & 4 & 3,628 & 0 \\
\hline 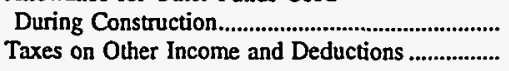 & $\begin{array}{l}0 \\
0\end{array}$ & $\begin{array}{l}0 \\
0\end{array}$ & $\begin{array}{l}0 \\
0\end{array}$ & $\begin{array}{l}0 \\
0\end{array}$ & $\begin{array}{r}0 \\
860\end{array}$ & $\begin{array}{l}0 \\
0\end{array}$ \\
\hline Electric Utility Income.................. & 279 & 19,622 & 853 & 388 & 9,547 & 15,514 \\
\hline $\begin{array}{l}\text { Income Deductions from Interest } \\
\text { on Long-term Debt ................................................ } \\
\text { Other Income Deductions................................... } \\
\text { Allowance for Borrowed Funds Used }\end{array}$ & $\begin{array}{r}0 \\
10\end{array}$ & $\begin{array}{r}17,562 \\
0\end{array}$ & $\begin{array}{r}258 \\
40\end{array}$ & $\begin{array}{r}0 \\
14\end{array}$ & $\begin{array}{l}3,492 \\
5,609\end{array}$ & $\begin{array}{r}1,569 \\
538\end{array}$ \\
\hline 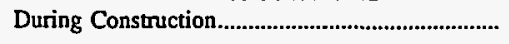 & 0 & $\mathbf{0}$ & 0 & 0 & 0 & 0 \\
\hline 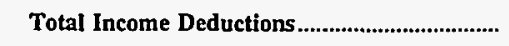 & 10 & 17,562 & 298 & 14 & 9,101 & 2,107 \\
\hline Income Before Extraordinary Items........................... & 269 & 2,061 & 555 & 374 & 446 & 13,407 \\
\hline 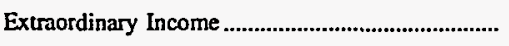 & 0 & 0 & 0 & $\mathbf{0}$ & 0 & 0 \\
\hline 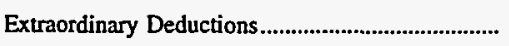 & 0 & 0 & 0 & 0 & 0 & 0 \\
\hline Net Income & 269 & 2,061 & 555 & 374 & 446 & 13,407 \\
\hline
\end{tabular}

Note: Totals may not equal sum of components because of independent rounding.

Source: Energy Information Administration, Form EIA-412, "Annual Report of Public Electric Utilities." 
Table 21. Statement of Income by Major U.S. Publicly Owned Electric Utility Within State, 1996 (Continued)

(Thousand Dollars)

\begin{tabular}{|c|c|c|c|c|c|c|}
\hline Item & $\begin{array}{l}\text { Louisiana } \\
\text { Lafayette } \\
\text { Public } \\
\text { Power Auth } \\
\text { October } 31\end{array}$ & $\begin{array}{c}\text { Louisiana } \\
\text { Louisiana } \\
\text { Energy } \\
\& \\
\text { Power Auth } \\
\text { December } 31\end{array}$ & $\begin{array}{l}\text { Louisiana } \\
\text { Morgan } \\
\text { City City of } \\
\text { December } 31\end{array}$ & $\begin{array}{l}\text { Louisiana } \\
\text { Natchitoches } \\
\text { City of } \\
\text { May } 31\end{array}$ & $\begin{array}{l}\text { Louisiana } \\
\text { Ruston } \\
\text { City of } \\
\text { September } 30\end{array}$ & $\begin{array}{c}\text { Louisiana } \\
\text { Terrebonne } \\
\text { Parish } \\
\text { Consol Govt } \\
\text { December } 31\end{array}$ \\
\hline Electric Utility Operating Revenues...................... & 42,578 & 54,126 & 11,340 & 21,420 & 13,118 & 18,964 \\
\hline 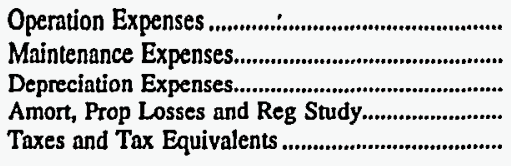 & $\begin{array}{r}28,199 \\
1,830 \\
4,435 \\
0 \\
0\end{array}$ & $\begin{array}{r}43,700 \\
911 \\
2,307 \\
1,860 \\
0\end{array}$ & $\begin{array}{r}8,486 \\
336 \\
845 \\
0 \\
0\end{array}$ & $\begin{array}{r}13,315 \\
0 \\
4,998 \\
0 \\
0\end{array}$ & $\begin{array}{r}11,002 \\
973 \\
0 \\
0 \\
0\end{array}$ & $\begin{array}{r}12,779 \\
1,763 \\
1,565 \\
0 \\
367\end{array}$ \\
\hline 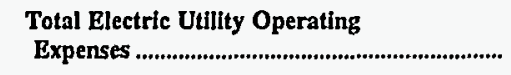 & 34,464 & 48,778 & 9,667 & 18,313 & 11,975 & 16,474 \\
\hline 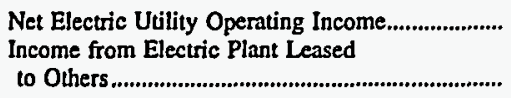 & $\begin{array}{r}8,115 \\
0\end{array}$ & $\begin{array}{r}5,349 \\
0\end{array}$ & $\begin{array}{r}1,673 \\
0\end{array}$ & $\begin{array}{r}3,107 \\
0\end{array}$ & $\begin{array}{r}1,143 \\
0\end{array}$ & $\begin{array}{r}2,491 \\
0\end{array}$ \\
\hline Electric Utility Operating Income...................... & 8,115 & 5,349 & 1,673 & 3,107 & 1,143 & 2,491 \\
\hline Other Electric Income & 1,178 & 2,150 & 41 & 0 & 645 & 724 \\
\hline $\begin{array}{l}\text { Other Electric Deductions } \\
\text { Allowance for Other Funds Used }\end{array}$ & 0 & 0 & 0 & 0 & 0 & 682 \\
\hline 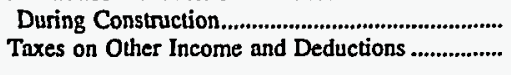 & $\begin{array}{l}0 \\
0\end{array}$ & $\begin{array}{l}0 \\
0\end{array}$ & $\begin{array}{l}0 \\
0\end{array}$ & $\begin{array}{l}0 \\
0\end{array}$ & $\begin{array}{l}\mathbf{0} \\
\mathbf{0}\end{array}$ & $\begin{array}{l}\mathbf{0} \\
\mathbf{0}\end{array}$ \\
\hline 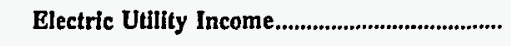 & 9,292 & 7,498 & 1,715 & 3,107 & 1,788 & 2,532 \\
\hline 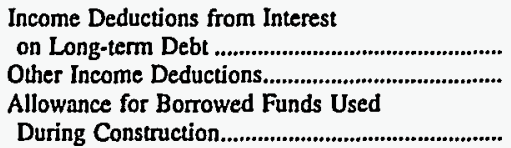 & $\begin{array}{l}7,399 \\
1,634\end{array}$ & $\begin{array}{r}7,606 \\
0\end{array}$ & $\begin{array}{r}282 \\
0\end{array}$ & $\begin{array}{l}\mathbf{0} \\
\mathbf{0}\end{array}$ & $\begin{array}{r}95 \\
1,056\end{array}$ & $\begin{array}{l}0 \\
0 \\
0\end{array}$ \\
\hline 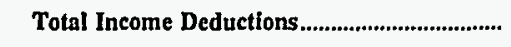 & 9,033 & 7,606 & 282 & $\mathbf{0}$ & 1,151 & $\mathbf{0}$ \\
\hline Income Before Extraordinary Items................................. & 259 & -108 & 1,433 & 3,107 & 637 & 2,532 \\
\hline Extraordinary Income & 0 & 0 & 0 & 0 & 0 & 0 \\
\hline 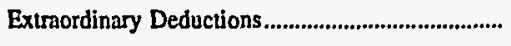 & 0 & 0 & $\mathbf{0}$ & 0 & $\mathbf{0}$ & o \\
\hline 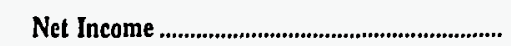 & 259 & -108 & 1,433 & 3,107 & 637 & 2,532 \\
\hline
\end{tabular}

Note: Totals may not equal sum of components because of independent rounding.

Source: Energy Information Administration, Form EIA-412, "Annual Report of Public Electric Utilities." 
Table 21. Statement of Income by Major U.S. Publicly Owned Electric Utility Within State, 1996 (Continued)

(Thousand Dollars)

\begin{tabular}{|c|c|c|c|c|c|c|}
\hline Item & $\begin{array}{l}\text { Maryland } \\
\text { Easton } \\
\text { Utilities } \\
\text { Comm } \\
\text { June } 30\end{array}$ & $\begin{array}{l}\text { Maryland } \\
\text { Hagerstown } \\
\text { City of } \\
\text { June } 30\end{array}$ & $\begin{array}{l}\text { Massachusetts } \\
\text { Braintree } \\
\text { Town of } \\
\text { December } 3 !\end{array}$ & $\begin{array}{c}\text { Massachusetts } \\
\text { Chicopee } \\
\text { City of } \\
\text { December } 31\end{array}$ & $\begin{array}{l}\text { Massachusetts } \\
\text { Concord } \\
\text { Town of } \\
\text { December } 31\end{array}$ & $\begin{array}{l}\text { Massachusetts } \\
\text { Danvers } \\
\text { Town of } \\
\text { December } 31\end{array}$ \\
\hline Electric Utility Operating Revenues........................ & 15,694 & 20,331 & 31,847 & 31,236 & 13,738 & 28,612 \\
\hline 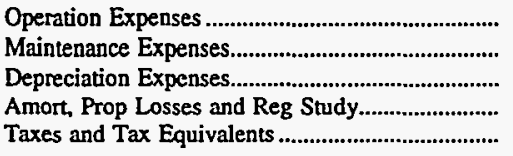 & $\begin{array}{r}10,646 \\
631 \\
1,581 \\
0 \\
532\end{array}$ & $\begin{array}{r}17,878 \\
254 \\
755 \\
0 \\
318\end{array}$ & $\begin{array}{r}25,938 \\
2,281 \\
1,991 \\
0 \\
0\end{array}$ & $\begin{array}{r}24,423 \\
2,016 \\
3,296 \\
0 \\
901\end{array}$ & $\begin{array}{r}10,655 \\
380 \\
900 \\
0 \\
0\end{array}$ & $\begin{array}{r}28,594 \\
324 \\
739 \\
0 \\
0\end{array}$ \\
\hline $\begin{array}{l}\text { Total Electric Utility Operating } \\
\text { Expenses }\end{array}$ & 13,391 & 19,205 & 30,210 & 30,636 & 11,935 & 29,657 \\
\hline 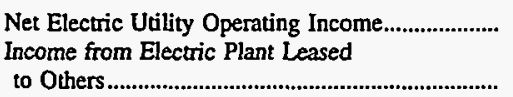 & 2,302 & $\begin{array}{r}1,126 \\
0\end{array}$ & 1,637 & 599 & $\begin{array}{r}1,803 \\
0\end{array}$ & $\begin{array}{r}-1,045 \\
0\end{array}$ \\
\hline 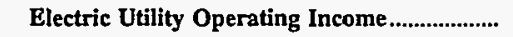 & 2,302 & 1,126 & 1,637 & 599 & 1,803 & $-1,045$ \\
\hline Other Electric Income & 119 & 262 & 394 & 650 & 598 & 780 \\
\hline $\begin{array}{l}\text { Other Electric Deductions } \\
\text { Allowance for Other Funds Used }\end{array}$ & 0 & 0 & 0 & 53 & 0 & 0 \\
\hline 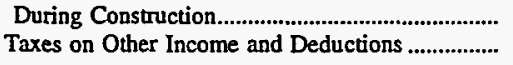 & $\begin{array}{l}0 \\
0\end{array}$ & $\begin{array}{l}0 \\
0\end{array}$ & $\begin{array}{l}0 \\
0\end{array}$ & $\begin{array}{l}\mathbf{0} \\
\mathbf{0}\end{array}$ & $\begin{array}{l}0 \\
0\end{array}$ & $\begin{array}{l}0 \\
0\end{array}$ \\
\hline Electric Utility Income ......................................... & 2,421 & 1,388 & 2,031 & 1,197 & 2,401 & -265 \\
\hline 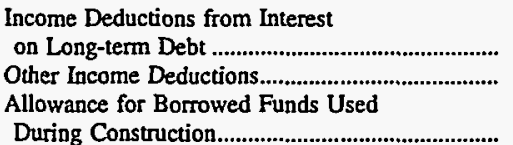 & $\begin{array}{r}517 \\
53\end{array}$ & $\begin{array}{r}54 \\
0\end{array}$ & $\begin{array}{l}0 \\
0\end{array}$ & $\begin{array}{r}0 \\
55\end{array}$ & $\begin{array}{r}392 \\
11\end{array}$ & $\begin{array}{r}17 \\
7\end{array}$ \\
\hline 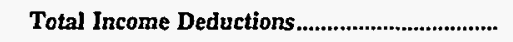 & 569 & 54 & $\mathbf{0}$ & 55 & 403 & 24 \\
\hline Income Before Extraordinary Items.......................... & 1,852 & 1,334 & 2,031 & 1,141 & 1,998 & -289 \\
\hline Extraordinary Income & 0 & 0 & 0 & $\mathbf{0}$ & 0 & 0 \\
\hline 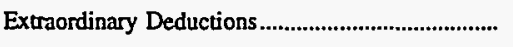 & 0 & 0 & 0 & 0 & 0 & 0 \\
\hline 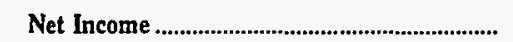 & 1,852 & 1,334 & 2,031 & 1,141 & 1,998 & -289 \\
\hline
\end{tabular}

Note: Totals may not equal sum of components because of independent rounding.

Source: Energy Information Administration, Form ElA-412, "Annual Report of Public Electric Utilities." 
Table 21. Statement of Income by Major U.S. Publicly Owned Electric Utility Within State, 1996 (Continued)

(Thousand Dollars)

\begin{tabular}{|c|c|c|c|c|c|c|}
\hline Item & $\begin{array}{l}\text { Massachusetts } \\
\text { Hingham } \\
\text { City of } \\
\text { December } 31\end{array}$ & $\begin{array}{l}\text { Massachusetts } \\
\begin{array}{c}\text { Holyoke } \\
\text { City of }\end{array} \\
\text { December } 31\end{array}$ & $\begin{array}{l}\text { Massachusetts } \\
\text { Hudson } \\
\text { Town of } \\
\text { December } 31\end{array}$ & $\begin{array}{l}\text { Massachusetts } \\
\text { Littleton } \\
\text { Town of } \\
\text { December } 31\end{array}$ & $\begin{array}{l}\text { Massachusetts } \\
\text { Mansfield } \\
\text { Town of } \\
\text { December } 31\end{array}$ & $\begin{array}{c}\text { Massachusetts } \\
\text { Massachusetts } \\
\text { Mun } \\
\text { Whls } \\
\text { Elec Co } \\
\text { December } 31\end{array}$ \\
\hline Electric Utility Operating Revenues...................... & 14,127 & 27,571 & 26,431 & 15,808 & 16,591 & 211,216 \\
\hline 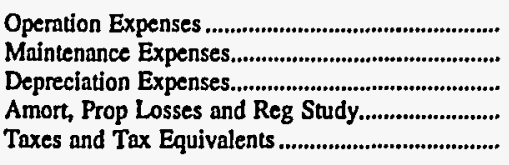 & $\begin{array}{r}12,017 \\
517 \\
673 \\
0 \\
0\end{array}$ & $\begin{array}{r}22,825 \\
1,357 \\
1,469 \\
0 \\
0\end{array}$ & $\begin{array}{r}24,628 \\
563 \\
580 \\
0 \\
252\end{array}$ & $\begin{array}{r}13,818 \\
402 \\
441 \\
0 \\
9\end{array}$ & $\begin{array}{r}16,271 \\
411 \\
163 \\
0 \\
285\end{array}$ & $\begin{array}{r}88,456 \\
11,553 \\
48,242 \\
0 \\
7,466\end{array}$ \\
\hline 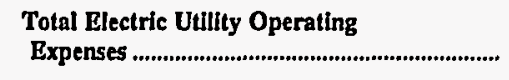 & 13,208 & 25,651 & 26,023 & 14,670 & 17,130 & 155,717 \\
\hline 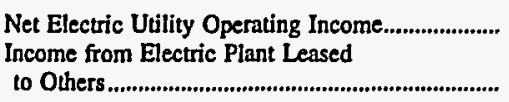 & $\begin{array}{r}919 \\
0\end{array}$ & $\begin{array}{r}1,920 \\
216\end{array}$ & $\begin{array}{l}408 \\
.0\end{array}$ & $\begin{array}{r}1,138 \\
0\end{array}$ & $\begin{array}{r}-539 \\
0\end{array}$ & $\begin{array}{r}55,499 \\
0\end{array}$ \\
\hline 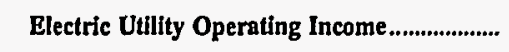 & 919 & 2,135 & 408 & 1,138 & -539 & 55,499 \\
\hline 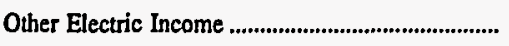 & 63 & 0 & 832 & 673 & 345 & 14.494 \\
\hline 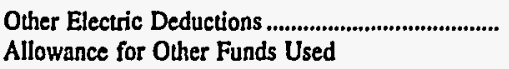 & 0 & 0 & 0 & $\mathbf{0}$ & 0 & 0 \\
\hline 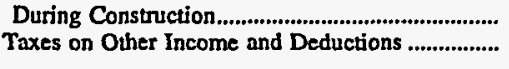 & $\begin{array}{l}0 \\
0\end{array}$ & $\begin{array}{l}0 \\
0\end{array}$ & $\begin{array}{l}\mathbf{0} \\
0\end{array}$ & $\begin{array}{l}\mathbf{0} \\
\mathbf{0}\end{array}$ & $\begin{array}{l}\mathbf{0} \\
\mathbf{0}\end{array}$ & $\begin{array}{r}62 \\
0\end{array}$ \\
\hline 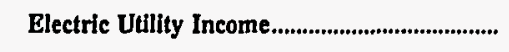 & 982 & 2,135 & 1,240 & 1,811 & -194 & 70,055 \\
\hline $\begin{array}{l}\text { Income Deductions from Interest } \\
\text { on Long-term Debt ................................................ } \\
\text { Other Income Deductions................................... } \\
\text { Allowance for Borrowed Funds Used }\end{array}$ & $\begin{array}{r}219 \\
23\end{array}$ & $\begin{array}{r}222 \\
36\end{array}$ & $\begin{array}{r}0 \\
244 \\
0\end{array}$ & $\begin{array}{l}0 \\
2\end{array}$ & $\begin{array}{r}0 \\
16\end{array}$ & $\begin{array}{r}71,584 \\
2,909\end{array}$ \\
\hline 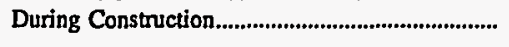 & $\mathbf{0}$ & $\mathbf{0}$ & $\mathbf{0}$ & $\mathbf{0}$ & 0 & $\mathbf{0}$ \\
\hline 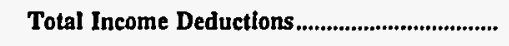 & 242 & 258 & 244 & 2 & 16 & 74,493 \\
\hline Income Before Extraordinary Items........................... & 741 & 1,877 & 996 & 1,809 & -211 & $-4,438$ \\
\hline 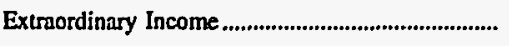 & $\mathbf{0}$ & 0 & $\mathbf{0}$ & 0 & 0 & 4,438 \\
\hline 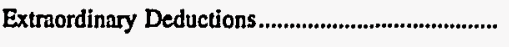 & 0 & 0 & 0 & 0 & 0 & 0 \\
\hline Net Income & 741 & 1,877 & 996 & 1,809 & -211 & o \\
\hline
\end{tabular}

Note: Totals may not equal sum of components because of independent rounding.

Source: Energy Information Administration, Form ElA-412, "Annual Report of Public Electric Utilities." 
Table 21. Statement of Income by Major U.S. Publicly Owned Electric Utility Within State, 1996 (Continued)

(Thousand Dollars)

\begin{tabular}{|c|c|c|c|c|c|c|}
\hline Item & $\begin{array}{l}\text { Massachusetts } \\
\text { Middleborough } \\
\text { Town of } \\
\text { December } 31\end{array}$ & $\begin{array}{l}\text { Massachusetts } \\
\text { North } \\
\text { Attleborough } \\
\text { Town of } \\
\text { December } 31\end{array}$ & $\begin{array}{l}\text { Massachusetts } \\
\text { Norwood } \\
\text { City of } \\
\text { June } 30\end{array}$ & $\begin{array}{l}\text { Massachusetts } \\
\text { Peabody } \\
\text { City of } \\
\text { December } 31\end{array}$ & $\begin{array}{l}\text { Massachusetts } \\
\text { Reading } \\
\text { Town of } \\
\text { December } 31\end{array}$ & $\begin{array}{l}\text { Massachusetts } \\
\text { Shrewsbury } \\
\text { Town of } \\
\text { December } 31\end{array}$ \\
\hline Electric Utility Operating Revenues.......................... & 17,029 & 20,046 & 26,960 & 38,161 & 54,153 & 21,983 \\
\hline 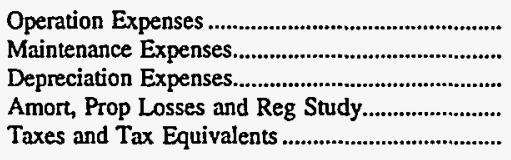 & $\begin{array}{r}15,164 \\
966 \\
193 \\
0 \\
270\end{array}$ & $\begin{array}{r}16,740 \\
813 \\
1,033 \\
0 \\
32\end{array}$ & $\begin{array}{r}23,058 \\
845 \\
1,148 \\
0 \\
0\end{array}$ & $\begin{array}{r}32,859 \\
635 \\
1,726 \\
77 \\
0\end{array}$ & $\begin{array}{r}47,558 \\
1,220 \\
2,108 \\
0 \\
577\end{array}$ & $\begin{array}{r}18,763 \\
636 \\
773 \\
0 \\
0\end{array}$ \\
\hline $\begin{array}{l}\text { Total Electric Utility Operating } \\
\text { Expenses }\end{array}$ & 16,594 & 18,619 & 25,051 & 35,296 & 51,464 & 20,172 \\
\hline 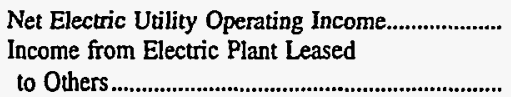 & 435 & 1,427 & 1,909 & 2,865 & 2,689 & 1,811 \\
\hline Electric Utility Operating Income ................... & 435 & $1, \mathbf{4 2 7}$ & 1,909 & 2,865 & 2,689 & 1,811 \\
\hline Other Electric Income & 185 & 970 & 4 & 485 & 1,008 & 59 \\
\hline $\begin{array}{l}\text { Other Electric Deductions } \\
\text { Allowance for Other Funds Used }\end{array}$ & 0 & 0 & 0 & 0 & 0 & 0 \\
\hline 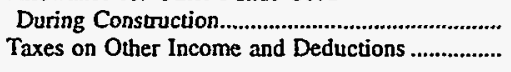 & $\begin{array}{l}0 \\
0\end{array}$ & $\begin{array}{l}0 \\
0\end{array}$ & $\begin{array}{l}0 \\
0\end{array}$ & $\begin{array}{l}0 \\
\mathbf{0}\end{array}$ & $\begin{array}{l}0 \\
0\end{array}$ & 0 \\
\hline Electric Utility Income & 620 & 2,397 & 1,914 & 3,350 & 3,697 & 1,869 \\
\hline 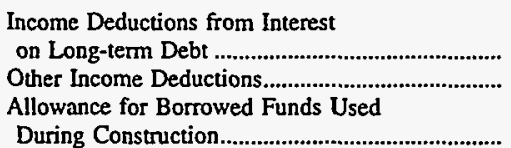 & $\begin{array}{r}0 \\
57\end{array}$ & $\begin{array}{r}177 \\
18\end{array}$ & $\begin{array}{r}0 \\
116\end{array}$ & $\begin{array}{r}1,218 \\
19\end{array}$ & $\begin{array}{r}295 \\
49\end{array}$ & $\begin{array}{l}15 \\
22\end{array}$ \\
\hline 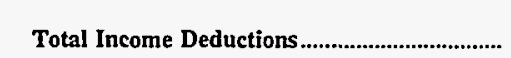 & 57 & 194 & 116 & 1,237 & 345 & 36 \\
\hline 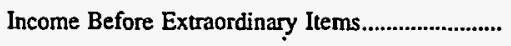 & 563 & 2,202 & 1,797 & 2,112 & 3,352 & 1,833 \\
\hline Extraordinary Income & 0 & 0 & 0 & 0 & 0 & 0 \\
\hline 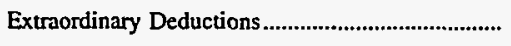 & 0 & 0 & 0 & 0 & 0 & 0 \\
\hline 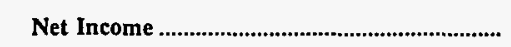 & 563 & 2,202 & 1,797 & 2,112 & 3,352 & 1,833 \\
\hline
\end{tabular}

Note: Totals may not equal sum of components because of independent rounding.

Source: Energy Information Administration, Form EIA-412, "Annual Report of Public Electric Utilities." 
Table 21. Statement of Income by Major U.S. Publicly Owned Electric Utility Within State, 1996 (Continued)

(Thousand Dollars)

\begin{tabular}{|c|c|c|c|c|c|c|}
\hline Item & $\begin{array}{l}\text { Massachusetts } \\
\text { Taunton } \\
\text { City of } \\
\text { December } 31\end{array}$ & $\begin{array}{l}\text { Mussachusetts } \\
\text { Wakefield } \\
\text { Town of } \\
\text { December } 31\end{array}$ & $\begin{array}{l}\text { Massachusetts } \\
\text { Wellesley } \\
\text { Town of } \\
\text { December } 31\end{array}$ & $\begin{array}{l}\text { Massachusetts } \\
\text { Westfield } \\
\text { City of } \\
\text { December } 31\end{array}$ & $\begin{array}{l}\text { Michigan } \\
\text { Bay } \\
\text { City City of } \\
\text { June } 30\end{array}$ & $\begin{array}{l}\text { Michigan } \\
\text { Coldwater } \\
\text { Board } \\
\text { of } \\
\text { Public Util } \\
\text { June } 30\end{array}$ \\
\hline 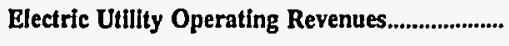 & 46,489 & 16,375 & 17,352 & 32,531 & 20,811 & 12,669 \\
\hline 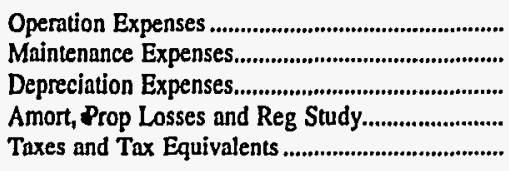 & $\begin{array}{r}31,574 \\
3,932 \\
4,383 \\
0 \\
0\end{array}$ & $\begin{array}{r}14,995 \\
429 \\
726 \\
0 \\
569\end{array}$ & $\begin{array}{r}13,149 \\
794 \\
819 \\
0 \\
0\end{array}$ & $\begin{array}{r}29,716 \\
930 \\
759 \\
0 \\
0\end{array}$ & $\begin{array}{r}14,297 \\
750 \\
1,660 \\
0 \\
369\end{array}$ & $\begin{array}{r}11,372 \\
200 \\
460 \\
0 \\
703\end{array}$ \\
\hline $\begin{array}{l}\text { Total Electric Utillty Operating } \\
\text { Expenses ................................................................ }\end{array}$ & 39,889 & 16,720 & 14,762 & 31,405 & 17,077 & 12,734 \\
\hline 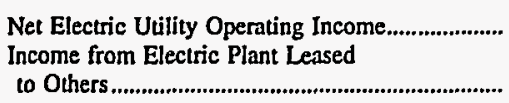 & $\begin{array}{r}6,600 \\
0\end{array}$ & $\begin{array}{r}-344 \\
0\end{array}$ & $\begin{array}{r}2,591 \\
0\end{array}$ & $\begin{array}{r}1,126 \\
0\end{array}$ & $\begin{array}{r}3,734 \\
0\end{array}$ & -65 \\
\hline 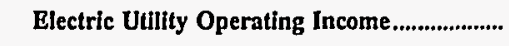 & 6,600 & -344 & 2,591 & 1,126 & 3,734 & -65 \\
\hline 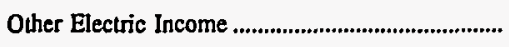 & 176 & 166 & 75 & 556 & 1.736 & 386 \\
\hline $\begin{array}{l}\text { Other Electric Deductions } \\
\text { Allowance for Other Funds Used }\end{array}$ & 1,158 & 0 & 0 & 0 & 572 & 0 \\
\hline 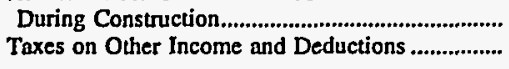 & $\begin{array}{r}0 \\
2,360\end{array}$ & $\begin{array}{l}\mathbf{0} \\
\mathbf{0}\end{array}$ & $\begin{array}{l}0 \\
0\end{array}$ & $\begin{array}{l}\mathbf{0} \\
\mathbf{0}\end{array}$ & $\begin{array}{l}\mathbf{0} \\
0\end{array}$ & $\begin{array}{l}0 \\
0\end{array}$ \\
\hline 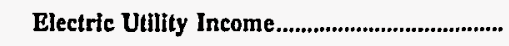 & 3,258 & -178 & 2,666 & 1,681 & 4,898 & 321 \\
\hline $\begin{array}{l}\text { Income Deductions from Interest } \\
\text { on Long-term Debt ................................................... } \\
\text { Other Income Deductions...................................... } \\
\text { Allowance for Borrowed Funds Used }\end{array}$ & $\begin{array}{r}1,168 \\
20\end{array}$ & $\begin{array}{r}0 \\
30\end{array}$ & $\begin{array}{l}20 \\
25\end{array}$ & $\begin{array}{r}290 \\
5\end{array}$ & $\begin{array}{r}1,426 \\
0\end{array}$ & $\begin{array}{r}44 \\
0\end{array}$ \\
\hline 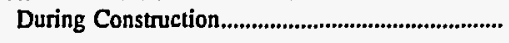 & $\mathbf{0}$ & 0 & 0 & 0 & 0 & o \\
\hline 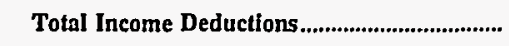 & 1,188 & 30 & 45 & 296 & 1,426 & 44 \\
\hline Income Before Extraordinary Items........................... & 2,069 & -208 & 2,621 & 1,386 & 3,471 & 277 \\
\hline Extraordinary Income & $\mathbf{0}$ & 0 & 0 & $\mathbf{0}$ & 0 & 0 \\
\hline 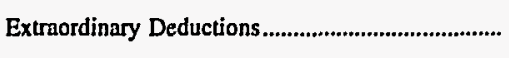 & $\mathbf{0}$ & 0 & 0 & 0 & 0 & 0 \\
\hline Net Income & 2,069 & -208 & 2,621 & 1,386 & 3,471 & 277 \\
\hline
\end{tabular}

Note: Totals may not equal sum of components because of independent rounding.

Source: Energy Information Administration, Form EIA-412, "Annual Report of Public Electric Utilities." 
Table 21. Statement of Income by Major U.S. Publicly Owned Electric Utility Within State, 1996 (Continued)

(Thousand Dollars)

\begin{tabular}{|c|c|c|c|c|c|c|}
\hline Item & $\begin{array}{l}\text { Michigan } \\
\text { Detroit } \\
\text { City of } \\
\text { June } 30\end{array}$ & $\begin{array}{l}\text { Michigan } \\
\text { Grand Haven } \\
\text { City of } \\
\text { June } 30\end{array}$ & $\begin{array}{l}\text { Michigan } \\
\text { Hillsdale } \\
\text { Board } \\
\text { of } \\
\text { Public Wks } \\
\text { June } 30\end{array}$ & $\begin{array}{l}\text { Michigan } \\
\text { Holland } \\
\text { City of } \\
\text { June } 30\end{array}$ & $\begin{array}{l}\text { Michigan } \\
\text { Lansing } \\
\text { City of } \\
\text { June } 30\end{array}$ & $\begin{array}{l}\text { Michigan } \\
\text { Marquette } \\
\text { City of } \\
\text { June } 30\end{array}$ \\
\hline Electric Utility Operating Revenues..................... & 79,222 & 20,981 & 9,730 & 46,365 & 143,848 & 17,175 \\
\hline 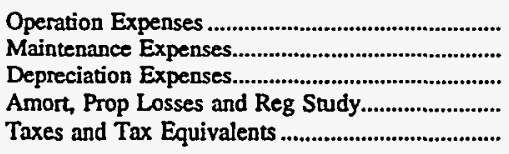 & $\begin{array}{r}45,481 \\
13,245 \\
5,068 \\
0 \\
969\end{array}$ & $\begin{array}{r}10,473 \\
1,467 \\
3,038 \\
0 \\
944\end{array}$ & $\begin{array}{r}8,046 \\
775 \\
436 \\
0 \\
356\end{array}$ & $\begin{array}{r}31,423 \\
2,613 \\
4,891 \\
0 \\
1,500\end{array}$ & $\begin{array}{r}104,779 \\
7,987 \\
12,700 \\
0 \\
0\end{array}$ & $\begin{array}{r}10,017 \\
1,946 \\
3,140 \\
0 \\
1,318\end{array}$ \\
\hline $\begin{array}{l}\text { Total Electric Utility Operating } \\
\text { Expenses }\end{array}$ & 64,763 & 15,922 & 9,613 & 40,428 & 125,466 & 16,422 \\
\hline 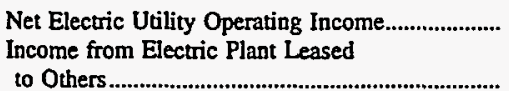 & 14,459 & 5,059 & 117 & 5,937 & 18,382 & $\begin{array}{r}754 \\
0\end{array}$ \\
\hline Electric Utility Operating Income..................... & 14,459 & 5,059 & 117 & 5,937 & 18,382 & 754 \\
\hline 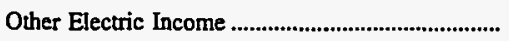 & 0 & 1,083 & 296 & 2,525 & 3,492 & 1,056 \\
\hline $\begin{array}{l}\text { Other Electric Deductions } \\
\text { Allowance for Other Funds Used }\end{array}$ & 0 & 1 & 0 & 0 & 0 & 0 \\
\hline 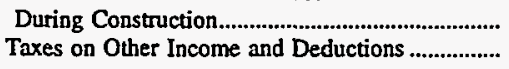 & $\begin{array}{l}\mathbf{0} \\
0\end{array}$ & $\begin{array}{l}\mathbf{0} \\
\mathbf{0}\end{array}$ & $\begin{array}{l}0 \\
0\end{array}$ & $\begin{array}{l}\mathbf{0} \\
\mathbf{0}\end{array}$ & $\begin{array}{l}0 \\
0\end{array}$ & $\begin{array}{l}0 \\
0\end{array}$ \\
\hline 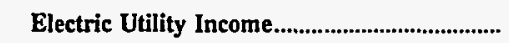 & 14,459 & 6,140 & 414 & 8,462 & 21,874 & 1,809 \\
\hline 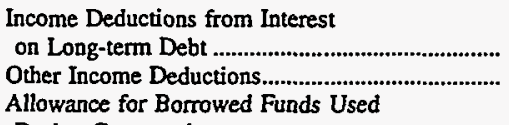 & $\begin{array}{r}5,600 \\
0\end{array}$ & $\begin{array}{r}6,155 \\
2\end{array}$ & $\begin{array}{l}0 \\
0\end{array}$ & $\begin{array}{r}1,857 \\
0\end{array}$ & $\begin{array}{r}1,289 \\
43\end{array}$ & $\begin{array}{r}1,885 \\
68\end{array}$ \\
\hline During Construction ........................................................ & 0 & 0 & 0 & 0 & 0 & 0 \\
\hline 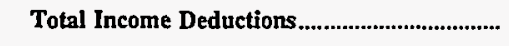 & 5,600 & 6,157 & o & 1,857 & 1,333 & 1,953 \\
\hline Income Before Extraordinary Items........................... & 8,859 & -18 & 414 & 6,605 & 20,542 & -143 \\
\hline 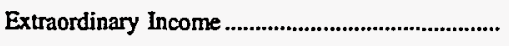 & 0 & 0 & 0 & $\mathbf{0}$ & 0 & 0 \\
\hline 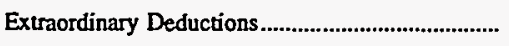 & 0 & 0 & 0 & 0 & 0 & 0 \\
\hline Net Income & 8,859 & -18 & 414 & 6,605 & 20,542 & -143 \\
\hline
\end{tabular}

Note: Totals may not equal sum of components because of independent rounding.

Source: Energy Information Administration, Form EIA-412, "Annual Report of Public Electric Utilities." 
Table 21. Statement of Income by Major U.S. Publicly Owned Electric Utility Within State, 1996 (Continued)

(Thousand Dollars)

\begin{tabular}{|c|c|c|c|c|c|c|}
\hline Item & $\begin{array}{c}\text { Michigan } \\
\text { Michigan } \\
\text { Public } \\
\text { Power Agency } \\
\text { December } 31\end{array}$ & $\begin{array}{l}\text { Michigan } \\
\text { Michigan } \\
\text { South } \\
\text { Central } \\
\text { Pwr Agy } \\
\text { June } 30\end{array}$ & $\begin{array}{l}\text { Michigan } \\
\text { Sturgis } \\
\text { City of } \\
\text { September } 30\end{array}$ & $\begin{array}{l}\text { Michigan } \\
\text { Traverse } \\
\text { City City of } \\
\text { June } 30\end{array}$ & $\begin{array}{l}\text { Michigan } \\
\text { Wyandotte } \\
\text { Municipal } \\
\text { Serv Comm } \\
\text { September } 30\end{array}$ & $\begin{array}{l}\text { Michigan } \\
\text { Zeeland } \\
\text { City of } \\
\text { June } 30\end{array}$ \\
\hline Electric Utility Operating Revenues...................... & 106,623 & 26,037 & 14,160 & 14,735 & 20,420 & 11,687 \\
\hline 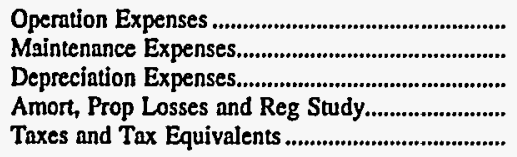 & $\begin{array}{r}72,795 \\
3,485 \\
13,668 \\
1,335 \\
566\end{array}$ & $\begin{array}{r}15,886 \\
961 \\
3,117 \\
0 \\
40\end{array}$ & $\begin{array}{r}10,392 \\
435 \\
1,285 \\
0 \\
948\end{array}$ & $\begin{array}{r}10,239 \\
1,393 \\
966 \\
34 \\
758\end{array}$ & $\begin{array}{r}13,849 \\
403 \\
3,667 \\
0 \\
431\end{array}$ & $\begin{array}{r}8,709 \\
387 \\
862 \\
0 \\
0\end{array}$ \\
\hline $\begin{array}{l}\text { Total Electric Utility Operating } \\
\text { Expenses .............................................................. }\end{array}$ & 91,849 & 20,004 & 13,060 & 13,390 & 18,349 & 9,959 \\
\hline 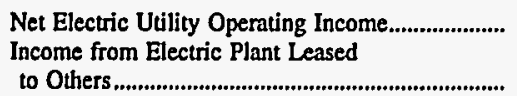 & $\begin{array}{r}14,774 \\
0\end{array}$ & $\begin{array}{r}6,033 \\
0\end{array}$ & $\begin{array}{r}1,101 \\
0\end{array}$ & $\begin{array}{r}1,345 \\
0\end{array}$ & $\begin{array}{r}2,070 \\
0\end{array}$ & $\begin{array}{r}1,729 \\
0\end{array}$ \\
\hline Electric Utility Operating Income..................... & 14,774 & 6,033 & 1,101 & 1,345 & 2,070 & 1,729 \\
\hline Ouher Electric Income & 6,937 & 1,998 & 560 & 442 & 649 & 333 \\
\hline $\begin{array}{l}\text { Other Electric Deductions } \\
\text { Allowance for Other Funds Used }\end{array}$ & $-1,505$ & 0 & 0 & 0 & 0 & 0 \\
\hline 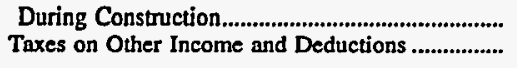 & $\begin{array}{l}0 \\
0\end{array}$ & $\begin{array}{l}0 \\
0\end{array}$ & $\begin{array}{l}\mathbf{0} \\
\mathbf{0}\end{array}$ & $\begin{array}{l}0 \\
0\end{array}$ & $\begin{array}{l}\mathbf{0} \\
\mathbf{0}\end{array}$ & $\begin{array}{l}0 \\
0\end{array}$ \\
\hline 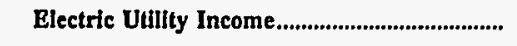 & 23,216 & 8,031 & 1,661 & 1,787 & 2,719 & 2,061 \\
\hline 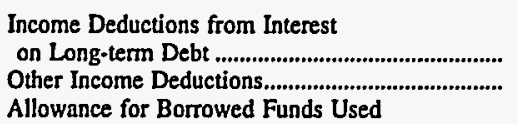 & $\begin{array}{r}23,265 \\
0\end{array}$ & $\begin{array}{l}5,633 \\
1,595\end{array}$ & $\begin{array}{r}175 \\
0\end{array}$ & $\begin{array}{r}116 \\
4\end{array}$ & $\begin{array}{r}3,592 \\
93\end{array}$ & $\begin{array}{l}159 \\
187\end{array}$ \\
\hline 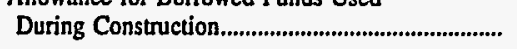 & 0 & 0 & 0 & 0 & 0 & 0 \\
\hline Total Income Deductions ........................................ & 23,265 & 7,229 & 175 & 120 & 3,684 & 346 \\
\hline Income Before Extraordinary Items................................ & -50 & 803 & 1,486 & 1,667 & -965 & 1,716 \\
\hline 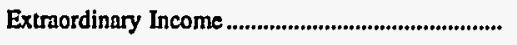 & 0 & 0 & 59 & 0 & 0 & 0 \\
\hline 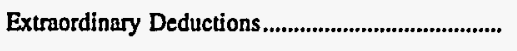 & 0 & 0 & $\mathbf{0}$ & 0 & 0 & 0 \\
\hline Net Income & -50 & 803 & 1,545 & 1,667 & -965 & 1,716 \\
\hline
\end{tabular}

Note: Totals may not equal sum of components because of independent rounding.

Source: Energy Information Administration, Form EIA-412, "Annual Report of Public Electric Utilities." 
Table 21. Statement of Income by Major U.S. Publicly Owned Electric Utility Within State, 1996 (Continued)

(Thousand Dollars)

\begin{tabular}{|c|c|c|c|c|c|c|}
\hline Item & $\begin{array}{l}\text { Minnesota } \\
\text { Alexandria } \\
\text { City of } \\
\text { December } 31\end{array}$ & $\begin{array}{l}\text { Minnesota } \\
\text { Anoka } \\
\text { City of } \\
\text { December } 31\end{array}$ & $\begin{array}{l}\text { Minnesota } \\
\text { Austin } \\
\text { City of } \\
\text { December } 31\end{array}$ & $\begin{array}{l}\text { Minnesota } \\
\text { Brainerd } \\
\text { Public } \\
\text { Utilities } \\
\text { December } 31\end{array}$ & $\begin{array}{l}\text { Minnesota } \\
\text { Chaska } \\
\text { City of } \\
\text { December } 31\end{array}$ & $\begin{array}{l}\text { Minnesota } \\
\text { Fairmont } \\
\text { Public } \\
\text { Utilities } \\
\text { Comm } \\
\text { December } 31\end{array}$ \\
\hline Electric Utility Operating Revenues.......................... & 9,534 & 12,982 & 17,369 & 7,747 & 10,705 & 8,833 \\
\hline 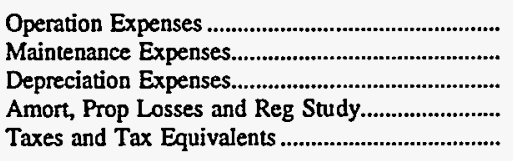 & $\begin{array}{r}7,872 \\
397 \\
493 \\
0 \\
477\end{array}$ & $\begin{array}{r}10,470 \\
179 \\
562 \\
0 \\
180\end{array}$ & $\begin{array}{r}20,321 \\
1,097 \\
799 \\
0 \\
4\end{array}$ & $\begin{array}{r}6,909 \\
76 \\
509 \\
0 \\
0\end{array}$ & $\begin{array}{r}7,999 \\
0 \\
381 \\
0 \\
0\end{array}$ & $\begin{array}{r}9,677 \\
991 \\
531 \\
0 \\
0\end{array}$ \\
\hline $\begin{array}{l}\text { Total Electric Utility Operating } \\
\text { Expenses }\end{array}$ & 9,239 & 11,391 & 22,220 & 7,493 & 8,380 & 11,199 \\
\hline $\begin{array}{l}\text { Net Electric Utility Operating Income.................... } \\
\text { Income from Electric Plant Leased }\end{array}$ & 295 & 1,591 & $-4,852$ & 254 & 2,325 & $-2,367$ \\
\hline 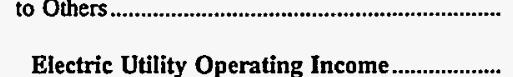 & $\begin{array}{r}0 \\
295\end{array}$ & $\begin{array}{r}0 \\
1,591\end{array}$ & $\begin{array}{r}5,842 \\
990\end{array}$ & $\begin{array}{r}0 \\
254\end{array}$ & $\begin{array}{r}0 \\
2,325\end{array}$ & $\begin{array}{r}0 \\
-2.367\end{array}$ \\
\hline Other Electric Income & 335 & 106 & 415 & 303 & 363 & 2,333 \\
\hline $\begin{array}{l}\text { Other Electric Deductions } \\
\text { Allowance for Other Funds Used }\end{array}$ & 0 & 0 & 4 & 0 & 0 & 0 \\
\hline 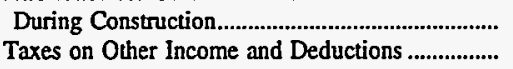 & $\begin{array}{l}0 \\
0\end{array}$ & $\begin{array}{l}0 \\
0\end{array}$ & $\begin{array}{r}0 \\
990\end{array}$ & $\begin{array}{l}0 \\
0\end{array}$ & $\begin{array}{r}0 \\
1,121\end{array}$ & $\begin{array}{l}0 \\
0\end{array}$ \\
\hline 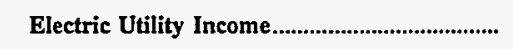 & 630 & 1,697 & 411 & 557 & 1,567 & -34 \\
\hline 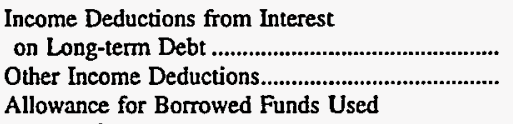 & $\begin{array}{l}4 \\
0\end{array}$ & $\begin{array}{l}0 \\
0\end{array}$ & $\begin{array}{l}\mathbf{0} \\
\mathbf{0}\end{array}$ & $\begin{array}{l}\mathbf{0} \\
\mathbf{0}\end{array}$ & $\begin{array}{r}52 \\
0\end{array}$ & $\begin{array}{l}0 \\
0\end{array}$ \\
\hline 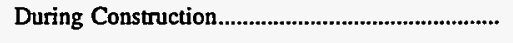 & 0 & 0 & 0 & 0 & 0 & 0 \\
\hline 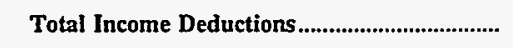 & 4 & $\mathbf{0}$ & $\mathbf{0}$ & $\mathbf{0}$ & 52 & o \\
\hline 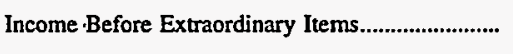 & 625 & 1,697 & 411 & 557 & 1,515 & -34 \\
\hline Extraordinary Income & $\mathbf{0}$ & 0 & 0 & 0 & 0 & 0 \\
\hline 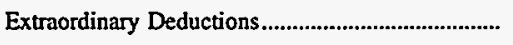 & 0 & 0 & $\mathbf{0}$ & 0 & 0 & 0 \\
\hline Net Income & 625 & 1,697 & 411 & 557 & 1,515 & -34 \\
\hline
\end{tabular}

Note: Totals may not equal sum of components because of independent rounding.

Source: Energy Information Administration, Form EIA-412, "Annual Report of Public Electric Utilities." 
Table 21. Statement of Income by Major U.S. Publicly Owned Electric Utility Within State, 1996 (Continued)

(Thousand Dollars)

\begin{tabular}{|c|c|c|c|c|c|c|}
\hline Item & $\begin{array}{l}\text { Minnesota } \\
\text { Hutchinson } \\
\text { Utilities } \\
\text { Comm } \\
\text { December } 31\end{array}$ & $\begin{array}{l}\text { Minnesota } \\
\text { Marshall } \\
\text { City of } \\
\text { December } 31\end{array}$ & $\begin{array}{c}\text { Minnesota } \\
\text { Moorhead } \\
\text { City of } \\
\text { December } 31\end{array}$ & $\begin{array}{l}\text { Minnesota } \\
\text { New Ulm } \\
\text { Public } \\
\text { Utilities } \\
\text { Comm } \\
\text { December } 31\end{array}$ & $\begin{array}{l}\text { Minnesota } \\
\text { Northern } \\
\text { Municipal } \\
\text { Power Agny } \\
\text { December } 31\end{array}$ & $\begin{array}{l}\text { Minnesota } \\
\text { Owatonna } \\
\text { City of } \\
\text { December 31 }\end{array}$ \\
\hline Electric Utility Operating Revenues.......................... & 11,538 & 14,476 & 15,156 & 10,170 & 38,785 & 19,530 \\
\hline 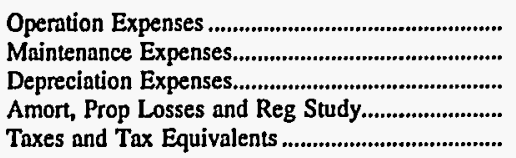 & $\begin{array}{r}8,156 \\
856 \\
1,345 \\
0 \\
0\end{array}$ & $\begin{array}{r}12,531 \\
598 \\
852 \\
0 \\
543\end{array}$ & $\begin{array}{r}10,678 \\
543 \\
813 \\
30 \\
3,061\end{array}$ & $\begin{array}{r}7,753 \\
544 \\
777 \\
0 \\
509\end{array}$ & $\begin{array}{r}10,450 \\
2,872 \\
8,530 \\
0 \\
0\end{array}$ & $\begin{array}{r}16,654 \\
1,280 \\
972 \\
0 \\
0\end{array}$ \\
\hline $\begin{array}{l}\text { Total Electric Utility Operating } \\
\text { Expenses }\end{array}$ & 10,357 & 14,523 & 15,126 & 9,583 & 21,852 & 18,906 \\
\hline 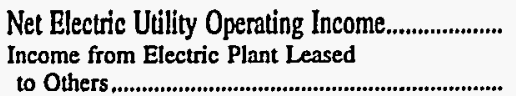 & 1,181 & -48 & 31 & 587 & 16,934 & 624 \\
\hline Electric Utility Operating Income..................... & 1,181 & 163 & 129 & 587 & 16,934 & 624 \\
\hline Other Electric Income & 199 & 862 & 384 & 446 & 3,229 & 436 \\
\hline 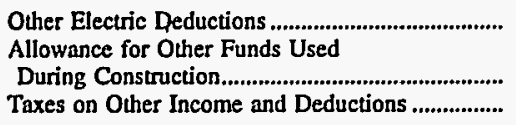 & $\begin{array}{l}0 \\
0\end{array}$ & $\begin{array}{r}20 \\
0\end{array}$ & $\begin{array}{l}\mathbf{0} \\
\mathbf{0}\end{array}$ & $\begin{array}{l}5 \\
0 \\
0\end{array}$ & $\begin{array}{l}0 \\
0 \\
0\end{array}$ & 582 \\
\hline 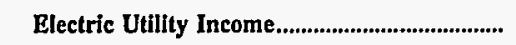 & 1,380 & 1,045 & 512 & 1,028 & 20,163 & 478 \\
\hline 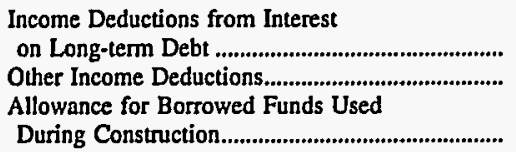 & $\begin{array}{r}636 \\
17\end{array}$ & $\begin{array}{l}0 \\
0\end{array}$ & $\begin{array}{l}202 \\
122\end{array}$ & $\begin{array}{l}178 \\
690\end{array}$ & $\begin{array}{l}0 \\
0\end{array}$ & $\begin{array}{r}363 \\
0\end{array}$ \\
\hline Total Income Deductions ........................................ & 653 & $\mathbf{0}$ & 324 & 868 & 0 & 363 \\
\hline 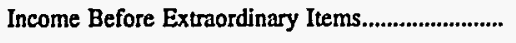 & 727 & 1,045 & 188 & 161 & 20,163 & 114 \\
\hline Extraordinary Income & $\mathbf{0}$ & $\mathbf{0}$ & $\mathbf{0}$ & 0 & $\mathbf{0}$ & $\mathbf{0}$ \\
\hline 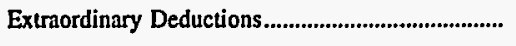 & 0 & 0 & $\mathbf{0}$ & 0 & $\mathbf{0}$ & $\mathbf{0}$ \\
\hline 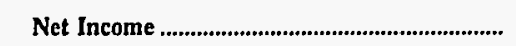 & 727 & 1,045 & 188 & 161 & 20,163 & 114 \\
\hline
\end{tabular}

Note: Totals may not equal sum of components because of independent rounding.

Source: Energy Information Administration, Form EIA-412, "Annual Report of Public Electric Utilities." 
Table 21. Statement of Income by Major U.S. Publicly Owned Electric Utility Within State, 1996 (Continued)

(Thousand Dollars)

\begin{tabular}{|c|c|c|c|c|c|c|}
\hline Item & $\begin{array}{c}\text { Minnesota } \\
\text { Rochester } \\
\text { Public } \\
\text { Utilities } \\
\text { December } 31\end{array}$ & $\begin{array}{l}\text { Minnesota } \\
\text { Shakopee } \\
\text { Public } \\
\text { Utilities } \\
\text { Comm } \\
\text { December } 31\end{array}$ & $\begin{array}{c}\text { Minnesota } \\
\text { Southern } \\
\text { Minnesota } \\
\text { Mun P } \\
\text { Agny } \\
\text { December } 31\end{array}$ & $\begin{array}{c}\text { Minnesota } \\
\text { Western } \\
\text { Minnesota } \\
\text { Mun } \\
\text { Pwr Agny } \\
\text { December } 31\end{array}$ & $\begin{array}{l}\text { Minnesota } \\
\text { Willmar } \\
\text { Municipal } \\
\text { Utils Comm } \\
\text { December } 31\end{array}$ & $\begin{array}{c}\text { Minnesota } \\
\begin{array}{c}\text { Worthington } \\
\text { City of }\end{array} \\
\text { December } 31\end{array}$ \\
\hline Electric Utility Operating Revenues...................... & 73,596 & 8,888 & 115,209 & 44,273 & 12,564 & 8,989 \\
\hline 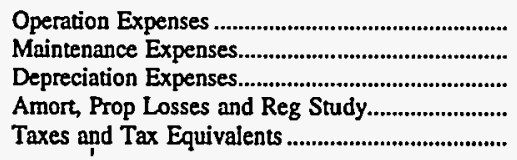 & $\begin{array}{r}57,158 \\
2,345 \\
2,222 \\
57 \\
5,514\end{array}$ & $\begin{array}{r}7,134 \\
562 \\
238 \\
66 \\
546\end{array}$ & $\begin{array}{r}53,044 \\
4,519 \\
7,209 \\
0 \\
8,729\end{array}$ & $\begin{array}{r}19,153 \\
3,867 \\
7,950 \\
0 \\
1,326\end{array}$ & $\begin{array}{r}8,562 \\
432 \\
952 \\
0 \\
1,108\end{array}$ & $\begin{array}{r}7,442 \\
208 \\
405 \\
0 \\
0\end{array}$ \\
\hline $\begin{array}{l}\text { Total Electric Utility Operating } \\
\text { Expenses }\end{array}$ & 67,295 & 8,547 & 73,502 & 32,297 & 11,054 & 8,055 \\
\hline 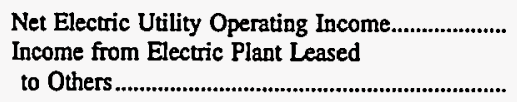 & 6,301 & 342 & 41,708 & 11,976 & 1,510 & 934 \\
\hline 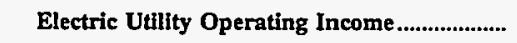 & 6,301 & 342 & 41,708 & 11,976 & 1,510 & 934 \\
\hline Other Electric Income & 1,033 & 259 & 8,741 & 4,564 & 1,015 & 327 \\
\hline $\begin{array}{l}\text { Other Electric Deductions ......................................... } \\
\text { Allowance for Other Funds Used }\end{array}$ & 113 & 0 & 0 & 0 & 0 & 17 \\
\hline 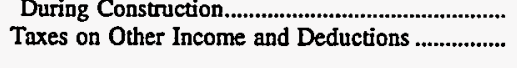 & $\begin{array}{l}0 \\
0\end{array}$ & $\begin{array}{l}0 \\
0\end{array}$ & $\begin{array}{l}0 \\
0\end{array}$ & $\begin{array}{l}0 \\
0\end{array}$ & $\begin{array}{l}0 \\
0\end{array}$ & $\begin{array}{l}0 \\
0\end{array}$ \\
\hline 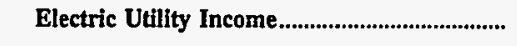 & 7,220 & 601 & 50,448 & 16,539 & 2,525 & 1,245 \\
\hline $\begin{array}{l}\text { Income Deductions from Interest } \\
\text { on Long-term Debt .............................................. } \\
\text { Other Income Deductions................................... } \\
\text { Allowance for Borrowed Funds Used }\end{array}$ & $\begin{array}{r}0 \\
114\end{array}$ & $\begin{array}{r}186 \\
0\end{array}$ & $\begin{array}{r}37,320 \\
7,979\end{array}$ & $\begin{array}{r}16,539 \\
0\end{array}$ & $\begin{array}{r}564 \\
56\end{array}$ & $\begin{array}{l}0 \\
0\end{array}$ \\
\hline 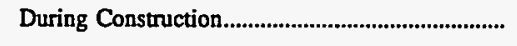 & $\mathbf{0}$ & $\mathbf{0}$ & -34 & 0 & 0 & $\cdot$ \\
\hline 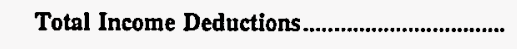 & 114 & 186 & 45,265 & 16,539 & 620 & $\mathbf{0}$ \\
\hline 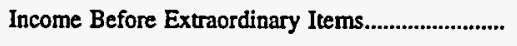 & 7,105 & 414 & 5,183 & 0 & 1,904 & 1,245 \\
\hline Extraordinary Income & 0 & 0 & 0 & 0 & 0 & 0 \\
\hline 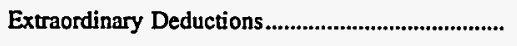 & 0 & 0 & 0 & 0 & 0 & 0 \\
\hline Net Income & 7,105 & 414 & 5,183 & $\mathbf{0}$ & 1,904 & 1,245 \\
\hline
\end{tabular}

Note: Totals may not equal sum of components because of independent rounding.

Source: Energy Information Administration, Form EIA-412, "Annual Report of Public Electric Utilities." 
Table 21. Statement of Income by Major U.S. Publicly Owned Electric Utility Within State, 1996 (Continued)

(Thousand Dollars)

\begin{tabular}{|c|c|c|c|c|c|c|}
\hline Item & $\begin{array}{l}\text { Mississippi } \\
\text { Aberdeen } \\
\text { City of } \\
\text { June } 30\end{array}$ & $\begin{array}{l}\text { Mississippi } \\
\text { Amory } \\
\text { City of } \\
\text { June } 30\end{array}$ & $\begin{array}{l}\text { Mississippi } \\
\text { Clarksdale } \\
\text { City of } \\
\text { September } 30\end{array}$ & $\begin{array}{l}\text { Mississippi } \\
\text { Columbus } \\
\text { City of } \\
\text { June } 30\end{array}$ & $\begin{array}{l}\text { Mississippi } \\
\text { Greenwood } \\
\text { Utilities } \\
\text { Comm } \\
\text { September } 30\end{array}$ & $\begin{array}{c}\text { Mississippi } \\
\text { Holly } \\
\text { Springs } \\
\text { City of } \\
\\
\text { June } 30\end{array}$ \\
\hline 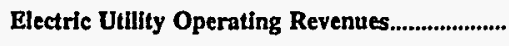 & 8,726 & 7,396 & 12,725 & 25,350 & 16,099 & 12,949 \\
\hline 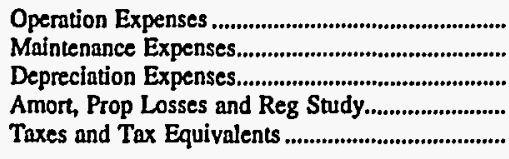 & $\begin{array}{r}7,995 \\
172 \\
146 \\
0 \\
280\end{array}$ & $\begin{array}{r}6,409 \\
145 \\
242 \\
-7 \\
296\end{array}$ & $\begin{array}{r}9,469 \\
563 \\
938 \\
0 \\
0\end{array}$ & $\begin{array}{r}23,237 \\
631 \\
576 \\
0 \\
1,168\end{array}$ & $\begin{array}{r}12,182 \\
690 \\
739 \\
0 \\
0\end{array}$ & $\begin{array}{r}10,920 \\
600 \\
391 \\
0 \\
667\end{array}$ \\
\hline 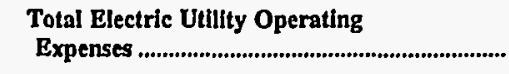 & 8,594 & 7,084 & 10,970 & 25,612 & 13,611 & 12,578 \\
\hline 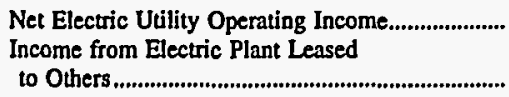 & 132 & 312 & 1,755 & -262 & 2,488 & 370 \\
\hline Electric Utility Operating Income...................... & 132 & 312 & 1,755 & -262 & 2,488 & 370 \\
\hline 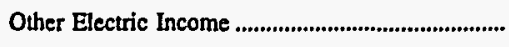 & 104 & 147 & 386 & 402 & 841 & 373 \\
\hline 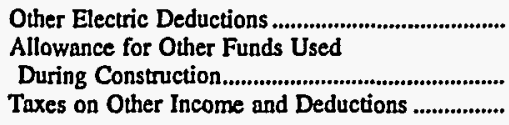 & $\begin{array}{l}0 \\
0\end{array}$ & $\begin{array}{l}0 \\
0\end{array}$ & $\begin{array}{r}188 \\
0 \\
0\end{array}$ & $\begin{array}{l}0 \\
0\end{array}$ & $\begin{array}{r}1,834 \\
0 \\
0\end{array}$ & 10 \\
\hline 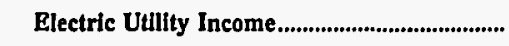 & 223 & 417 & 1,953 & 137 & 1,495 & 734 \\
\hline 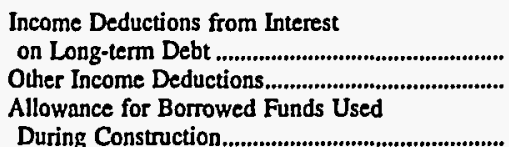 & $\begin{array}{r}46 \\
6\end{array}$ & $\begin{array}{l}0 \\
0\end{array}$ & $\begin{array}{l}0 \\
0\end{array}$ & $\begin{array}{r}0 \\
16\end{array}$ & $\begin{array}{l}4 \\
0\end{array}$ & $\begin{array}{l}0 \\
4\end{array}$ \\
\hline 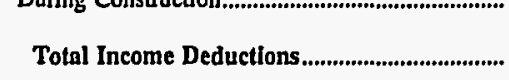 & 52 & 0 & $\mathbf{0}$ & 16 & 4 & 4 \\
\hline Income Before Extraordinary Items........................... & 171 & 417 & 1,953 & 122 & 1,491 & 730 \\
\hline 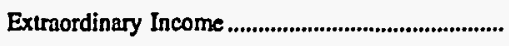 & $\mathbf{0}$ & 0 & 40 & $\mathbf{0}$ & $\mathbf{0}$ & 0 \\
\hline Extraordinary Deductions................................................... & $\mathbf{0}$ & 0 & 0 & 0 & $\mathbf{0}$ & $\mathbf{0}$ \\
\hline Net Income & 171 & 417 & 1,993 & 122 & 1,491 & 730 \\
\hline
\end{tabular}

Note: Totals may not equal sum of components because of independent rounding.

Source: Energy Information Administration, Form EIA-412, "Annual Report of Public Electric Utilities." 
Table 21. Statement of Income by Major U.S. Publicly Owned Electric Utility Within State, 1996 (Continued)

(Thousand Dollars)

\begin{tabular}{|c|c|c|c|c|c|c|}
\hline Item & $\begin{array}{c}\text { Mississippi } \\
\text { Louisville } \\
\text { Electric } \\
\text { System } \\
\\
\text { June } 30\end{array}$ & $\begin{array}{c}\text { Mississippi } \\
\text { Municipal } \\
\text { Energy } \\
\text { Agency } \\
\text { of MS } \\
\text { September } 30\end{array}$ & 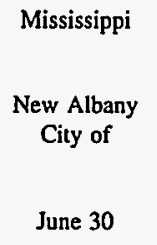 & $\begin{array}{l}\text { Mississippi } \\
\text { Oxford } \\
\text { City of } \\
\text { June } 30\end{array}$ & $\begin{array}{l}\text { Mississippi } \\
\text { Philadelphia } \\
\text { City of } \\
\text { June } 30\end{array}$ & $\begin{array}{l}\text { Mississippi } \\
\text { Starkville } \\
\text { City of } \\
\text { June } 30\end{array}$ \\
\hline 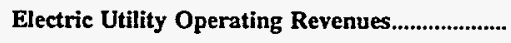 & 9,146 & 28,238 & 14,313 & 9,262 & 7,124 & 19,040 \\
\hline 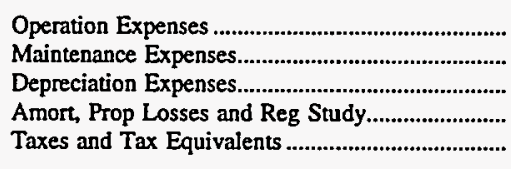 & $\begin{array}{r}8,231 \\
193 \\
325 \\
0 \\
219\end{array}$ & $\begin{array}{r}28,367 \\
31 \\
54 \\
0 \\
0\end{array}$ & $\begin{array}{r}12,874 \\
690 \\
374 \\
0 \\
493\end{array}$ & $\begin{array}{r}8,280 \\
167 \\
184 \\
0 \\
524\end{array}$ & $\begin{array}{r}6,297 \\
141 \\
225 \\
0 \\
223\end{array}$ & $\begin{array}{r}16,896 \\
436 \\
383 \\
11 \\
817\end{array}$ \\
\hline $\begin{array}{l}\text { Total Electric Utility Operating } \\
\text { Expenses }\end{array}$ & 8,969 & 28,452 & 14,431 & 9,154 & 6,886 & 18,542 \\
\hline 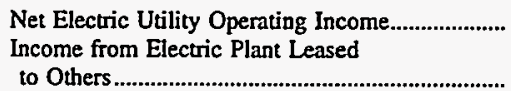 & 177 & -214 & $\begin{array}{r}-119 \\
0\end{array}$ & 107 & 238 & $\begin{array}{r}498 \\
0\end{array}$ \\
\hline Electric Utility Operating Income ..................... & 177 & -214 & -119 & 107 & 238 & 498 \\
\hline Other Electric Income & 118 & 318 & 329 & 164 & 99 & 239 \\
\hline 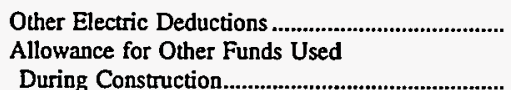 & 6 & 0 & 3 & 20 & 2 & 11 \\
\hline 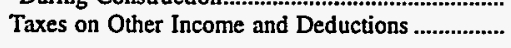 & 0 & 0 & 0 & $\begin{array}{l}0 \\
0\end{array}$ & $\begin{array}{l}0 \\
0\end{array}$ & $\begin{array}{l}0 \\
0\end{array}$ \\
\hline 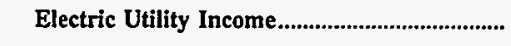 & 290 & 104 & 208 & 251 & 335 & 726 \\
\hline 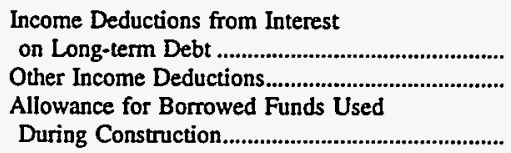 & $\begin{array}{l}0 \\
0\end{array}$ & $\begin{array}{l}0 \\
0\end{array}$ & $\begin{array}{l}0 \\
4\end{array}$ & $\begin{array}{r}0 \\
17\end{array}$ & $\begin{array}{r}77 \\
1\end{array}$ & $\begin{array}{r}304 \\
34\end{array}$ \\
\hline 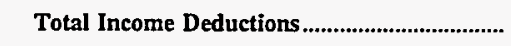 & $\mathbf{0}$ & $\mathbf{0}$ & 4 & 17 & 78 & 347 \\
\hline 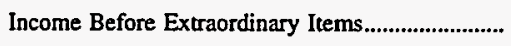 & 289 & 104 & 204 & 234 & 256 & 379 \\
\hline Extraordinary Income & 0 & 0 & 0 & 0 & 0 & 0 \\
\hline 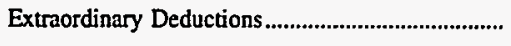 & 0 & 0 & 0 & 0 & 0 & 0 \\
\hline Net Income & 289 & 104 & 204 & 234 & 256 & 379 \\
\hline
\end{tabular}

Note: Totals may not equal sum of components because of independent rounding.

Source: Energy Information Administration, Form EIA-412, "Annual Report of Public Electric Utilities." 
Table 21. Statement of Income by Major U.S. Publicly Owned Electric Utility Within State, 1996 (Continued)

(Thousand Dollars)

\begin{tabular}{|c|c|c|c|c|c|c|}
\hline Item & $\begin{array}{l}\text { Mississippi } \\
\text { Tupelo } \\
\text { City of } \\
\text { June } 30\end{array}$ & $\begin{array}{c}\text { Mississippi } \\
\text { West } \\
\text { Point } \\
\text { City of } \\
\text { June } 30\end{array}$ & $\begin{array}{l}\text { Missouri } \\
\begin{array}{l}\text { Carthage } \\
\text { City of }\end{array} \\
\text { June } 30\end{array}$ & $\begin{array}{c}\text { Missouri } \\
\begin{array}{c}\text { Columbia } \\
\text { City of }\end{array} \\
\text { September } 30\end{array}$ & $\begin{array}{l}\text { Missouri } \\
\text { Hannibal } \\
\text { City of } \\
\text { June } 30\end{array}$ & $\begin{array}{c}\text { Missouri } \\
\begin{array}{c}\text { Independence } \\
\text { City of }\end{array} \\
\text { June } 30\end{array}$ \\
\hline Electric Utility Operating Revenues..................... & 35,021 & 10,649 & 10,552 & 53,644 & 11,394 & 60,470 \\
\hline 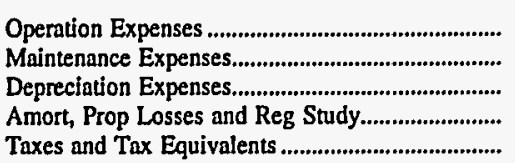 & $\begin{array}{r}32,173 \\
499 \\
793 \\
0 \\
2,113\end{array}$ & $\begin{array}{r}9,435 \\
347 \\
238 \\
0 \\
573\end{array}$ & $\begin{array}{r}9,270 \\
315 \\
570 \\
0 \\
0\end{array}$ & $\begin{array}{r}38,703 \\
3,236 \\
4,071 \\
0 \\
4,611\end{array}$ & $\begin{array}{r}9,734 \\
634 \\
361 \\
0 \\
466\end{array}$ & $\begin{array}{r}36,361 \\
6,178 \\
6,717 \\
0 \\
6,356\end{array}$ \\
\hline 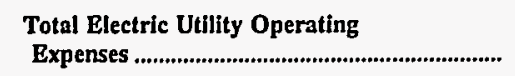 & 35,578 & 10,593 & 10,154 & 50,620 & 11,195 & 55,612 \\
\hline $\begin{array}{l}\text { Net Electric Utility Operating Income...................... } \\
\text { Income from Electric Plant Leased }\end{array}$ & $\begin{array}{r}-556 \\
0\end{array}$ & 55 & 398 & 3,024 & 199 & 4,858 \\
\hline Electric Utility Operating Income..................... & -556 & 55 & 398 & 3,024 & 199 & 4,858 \\
\hline 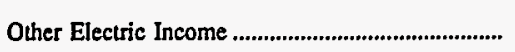 & 665 & 49 & 299 & 2,997 & 560 & 2,511 \\
\hline $\begin{array}{l}\text { Other Electric Deductions ........................................ } \\
\text { Allowance for Other Funds Used }\end{array}$ & 0 & 0 & 141 & 234 & 0 & 0 \\
\hline 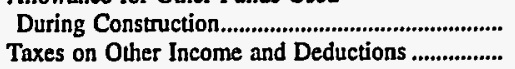 & $\begin{array}{l}\mathbf{0} \\
\mathbf{0}\end{array}$ & $\begin{array}{l}\mathbf{0} \\
\mathbf{0}\end{array}$ & $\begin{array}{l}0 \\
0\end{array}$ & $\begin{array}{l}\mathbf{0} \\
\mathbf{0}\end{array}$ & $\begin{array}{l}0 \\
0\end{array}$ & $\begin{array}{l}\mathbf{0} \\
\mathbf{0}\end{array}$ \\
\hline 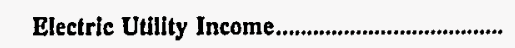 & 109 & 105 & 556 & 5,787 & 759 & 7,369 \\
\hline 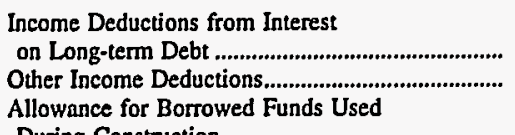 & $\begin{array}{l}0 \\
0\end{array}$ & $\begin{array}{l}3 \\
3\end{array}$ & $\begin{array}{l}0 \\
0\end{array}$ & $\begin{array}{r}2,296 \\
16\end{array}$ & $\begin{array}{l}0 \\
0\end{array}$ & $\begin{array}{r}2,272 \\
74\end{array}$ \\
\hline 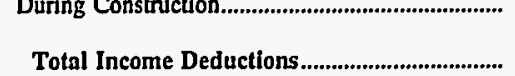 & 0 & 6 & 0 & $\begin{array}{r}0 \\
2,312\end{array}$ & $\begin{array}{l}0 \\
0\end{array}$ & 2,346 \\
\hline Income Before Extraordinary Items........................... & 109 & 98 & 556 & 3,475 & 759 & 5,023 \\
\hline 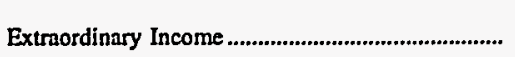 & $\mathbf{0}$ & 0 & 0 & 0 & 0 & 0 \\
\hline 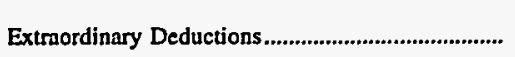 & 0 & $\mathbf{0}$ & 0 & $\mathbf{0}$ & 0 & $\mathbf{0}$ \\
\hline 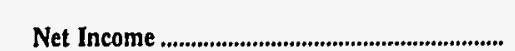 & 109 & 98 & 556 & 3,475 & 759 & 5,023 \\
\hline
\end{tabular}

Note: Totals may not equal sum of components because of independent rounding.

Source: Energy Information Administration, Form EIA-412, "Annual Report of Public Electric Utilities." 
Table 21. Statement of Income by Major U.S. Publicly Owned Electric Utility Within State, 1996 (Continued)

(Thousand Dollars)

\begin{tabular}{|c|c|c|c|c|c|c|}
\hline Item & $\begin{array}{l}\text { Missouri } \\
\text { Kennett } \\
\text { City of } \\
\text { June } 30\end{array}$ & $\begin{array}{l}\text { Missouri } \\
\text { Kirkwood } \\
\text { City of } \\
\text { March } 31\end{array}$ & $\begin{array}{l}\text { Missouri } \\
\text { Lebanon } \\
\text { City of } \\
\text { October } 31\end{array}$ & $\begin{array}{l}\text { Missouri } \\
\text { Marshall } \\
\text { City of } \\
\text { September } 30\end{array}$ & $\begin{array}{l}\text { Missouri } \\
\text { Monett } \\
\text { City of } \\
\text { March } 31\end{array}$ & $\begin{array}{c}\text { Missouri } \\
\text { Poplar } \\
\text { Bluff } \\
\text { City of } \\
\text { December 31 }\end{array}$ \\
\hline Electric Utility Operating Revenues............................ & 5,792 & 12,348 & 12,849 & 9,987 & 9,110 & 11,811 \\
\hline 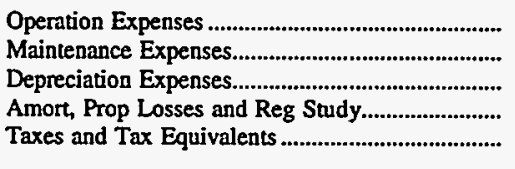 & $\begin{array}{r}5,027 \\
261 \\
510 \\
0 \\
0\end{array}$ & $\begin{array}{r}8,077 \\
958 \\
173 \\
0 \\
0\end{array}$ & $\begin{array}{r}9,680 \\
0 \\
0 \\
0 \\
0\end{array}$ & $\begin{array}{r}5,024 \\
1,293 \\
1,501 \\
0 \\
0\end{array}$ & $\begin{array}{r}6,609 \\
81 \\
221 \\
0 \\
0\end{array}$ & $\begin{array}{r}9,349 \\
739 \\
750 \\
0 \\
0\end{array}$ \\
\hline $\begin{array}{l}\text { Total Electric Utility Operating } \\
\text { Expenses ................................................................ }\end{array}$ & 5,797 & 9,207 & 9,680 & 7,818 & 6,911 & 10,838 \\
\hline 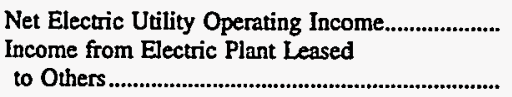 & $\begin{array}{r}-5 \\
298\end{array}$ & $\begin{array}{r}3,140 \\
0\end{array}$ & $\begin{array}{r}3,169 \\
0\end{array}$ & $\begin{array}{r}2,168 \\
0\end{array}$ & 2,199 & 974 \\
\hline Electric Utility Operating Income....................... & 292 & 3,140 & 3,169 & 2,168 & 2,199 & .974 \\
\hline Other Electric Income & 0 & 442 & 280 & 465 & 0 & 802 \\
\hline $\begin{array}{l}\text { Other Electric Deductions } \\
\text { Allowance for Other Funds Used }\end{array}$ & 118 & $\mathbf{0}$ & 1,214 & 1,084 & 0 & 0 \\
\hline 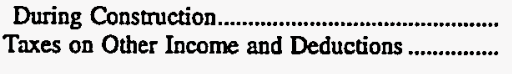 & $\begin{array}{l}0 \\
0\end{array}$ & $\begin{array}{l}0 \\
0\end{array}$ & $\begin{array}{l}\mathbf{0} \\
\mathbf{0}\end{array}$ & $\begin{array}{l}\mathbf{0} \\
\mathbf{0}\end{array}$ & $\begin{array}{l}0 \\
0\end{array}$ & $\begin{array}{l}0 \\
0\end{array}$ \\
\hline 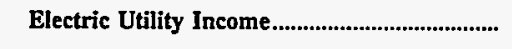 & 174 & 3,582 & 2,235 & 1,549 & 2,199 & 1,775 \\
\hline 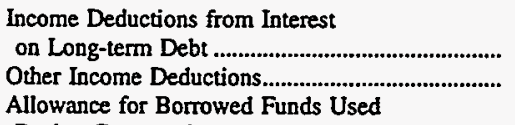 & $\begin{array}{l}\mathbf{0} \\
\mathbf{0}\end{array}$ & $\begin{array}{r}77 \\
0\end{array}$ & $\begin{array}{l}240 \\
220\end{array}$ & $\begin{array}{l}75 \\
30\end{array}$ & $\begin{array}{r}0 \\
155\end{array}$ & $\begin{array}{l}0 \\
0\end{array}$ \\
\hline 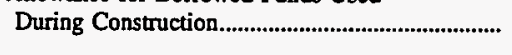 & 0 & 0 & 0 & 0 & 0 & 0 \\
\hline 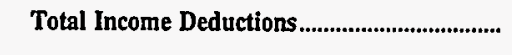 & 0 & 77 & 460 & 105 & 155 & 0 \\
\hline 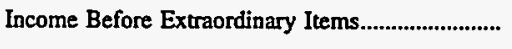 & 174 & 3,505 & 1,775 & 1,444 & 2,044 & 1,775 \\
\hline 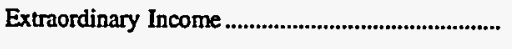 & 0 & 0 & -300 & 0 & 0 & 0 \\
\hline 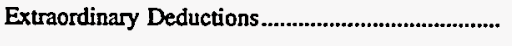 & 0 & 0 & 0 & 0 & 0 & 0 \\
\hline Net Income & 174 & 3,505 & 1,475 & 1,444 & 2,044 & 1,775 \\
\hline
\end{tabular}

Note: Totals may not equal sum of components because of independent rounding.

Source: Energy Information Administration, Form EIA-412, "Annual Report of Public Electric Utilities." 
Table 21. Statement of Income by Major U.S. Publicly Owned Electric Utility Within State, 1996 (Continued)

(Thousand Dollars)

\begin{tabular}{|c|c|c|c|c|c|c|}
\hline Item & $\begin{array}{l}\text { Missouri } \\
\text { Rolla } \\
\text { City of } \\
\text { September } 30\end{array}$ & $\begin{array}{l}\text { Missouri } \\
\text { Sikeston } \\
\text { City of } \\
\text { May } 31\end{array}$ & $\begin{array}{l}\text { Missouri } \\
\text { Springfield } \\
\text { City of } \\
\text { September } 30\end{array}$ & $\begin{array}{c}\text { Missouri } \\
\text { West } \\
\text { Plains } \\
\text { City of } \\
\text { December 31 }\end{array}$ & $\begin{array}{l}\text { Nebraska } \\
\text { Beatrice } \\
\text { City of } \\
\text { July } 31\end{array}$ & $\begin{array}{c}\text { Nebraska } \\
\text { Central } \\
\text { Nebraska } \\
\text { Pub } \\
\text { P\&I Dist } \\
\text { December } 31\end{array}$ \\
\hline 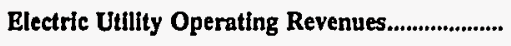 & 13,002 & 55,193 & 112,161 & 11,675 & 9,602 & 11,379 \\
\hline 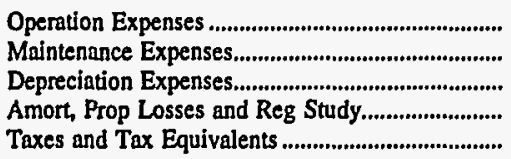 & $\begin{array}{r}10,534 \\
503 \\
472 \\
0 \\
619\end{array}$ & $\begin{array}{r}33,065 \\
5,795 \\
3,772 \\
0 \\
0\end{array}$ & $\begin{array}{r}64,691 \\
14,396 \\
15,203 \\
0 \\
3,441\end{array}$ & $\begin{array}{r}10,350 \\
0 \\
0 \\
0 \\
\cdot \quad 0\end{array}$ & $\begin{array}{r}8,021 \\
248 \\
617 \\
0 \\
0\end{array}$ & $\begin{array}{r}2,222 \\
1,875 \\
2,247 \\
0 \\
8\end{array}$ \\
\hline $\begin{array}{l}\text { Total Electric Utillty Operating } \\
\text { Expenses ................................................................ }\end{array}$ & 12,127 & 42,631 & 97,731 & 10,350 & $\mathbf{8 , 8 8 6}$ & 6,352 \\
\hline 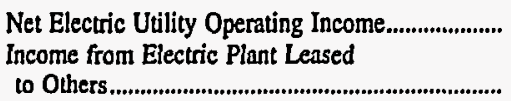 & 875 & 12,561 & 14,430 & 1,325 & 716 & 5,028 \\
\hline Electric Utilty Operating Income........................ & 875 & 12,561 & 20,712 & 1,325 & 716 & 5,079 \\
\hline Other Electric Income & 383 & 2,559 & 15,590 & 0 & 42 & 1,451 \\
\hline 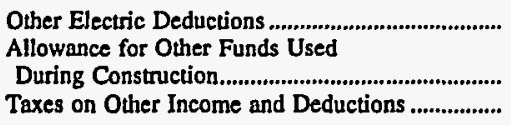 & $\begin{array}{r}-24 \\
0 \\
0\end{array}$ & $\begin{array}{l}0 \\
0\end{array}$ & $\begin{array}{r}0 \\
521 \\
0\end{array}$ & $\begin{array}{l}0 \\
0 \\
0\end{array}$ & $\begin{array}{r}344 \\
0 \\
0\end{array}$ & $\begin{array}{l}0 \\
0\end{array}$ \\
\hline Electric Utility Income & 1,283 & 15,120 & 36,823 & 1,325 & 415 & 6,530 \\
\hline 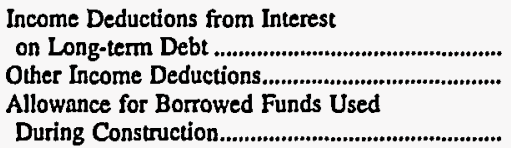 & $\begin{array}{r}0 \\
-139\end{array}$ & $\begin{array}{r}11,565 \\
297\end{array}$ & $\begin{array}{r}8,797 \\
825 \\
-1,044\end{array}$ & $\begin{array}{l}0 \\
0 \\
0\end{array}$ & $\begin{array}{l}0 \\
0 \\
0\end{array}$ & $\begin{array}{r}0 \\
110 \\
0\end{array}$ \\
\hline 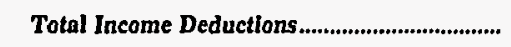 & -139 & 11,862 & 8,578 & 0 & $\mathbf{0}$ & 110 \\
\hline Income Before Extraordinary Items........................... & 1,421 & 3,258 & 28,245 & 1,325 & 415 & 6,420 \\
\hline 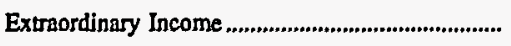 & 0 & 0 & $\mathbf{0}$ & 0 & 0 & 1,396 \\
\hline 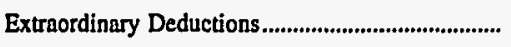 & 0 & $\mathbf{0}$ & 0 & 0 & 0 & 0 \\
\hline Net Income & 1,421 & 3,258 & 28,245 & 1,325 & 415 & 7,816 \\
\hline
\end{tabular}

Note: Totals may not equal sum of components because of independent rounding.

Source: Energy Information Administration, Form EIA-412, "Annual Report of Public Electric Utilities." 
Table 21. Statement of Income by Major U.S. Publicly Owned Electric Utility Within State, 1996 (Continued)

(Thousand Dollars)

\begin{tabular}{|c|c|c|c|c|c|c|}
\hline Item & $\begin{array}{c}\text { Nebraska } \\
\text { Cornhusker } \\
\text { Public } \\
\text { Power Dist } \\
\text { December } 31\end{array}$ & $\begin{array}{c}\text { Nebraska } \\
\text { Dawson } \\
\text { County } \\
\text { Public } \\
\text { Pwr Dist } \\
\text { December } 31\end{array}$ & $\begin{array}{c}\text { Nebraska } \\
\text { Fremont } \\
\text { City of } \\
\text { July } 31\end{array}$ & $\begin{array}{l}\text { Nebraska } \\
\begin{array}{l}\text { Grand Island } \\
\text { City of }\end{array} \\
\text { July } 31\end{array}$ & $\begin{array}{l}\text { Nebraska } \\
\text { Hastings } \\
\text { City of } \\
\text { December } 31\end{array}$ & $\begin{array}{l}\text { Nebraska } \\
\text { Lincoln } \\
\text { Electric } \\
\text { System } \\
\text { December } 31\end{array}$ \\
\hline Electric Utility Operating Revenues...................... & 11,444 & 16,921 & 17,978 & 31,366 & 16,816 & 133,760 \\
\hline Operation Expenses & 9,302 & 13,328 & 11,553 & 14,583 & 8,541 & 76,247 \\
\hline 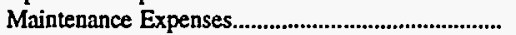 & 645 & 587 & 1,560 & 2,574 & 1,829 & 6,055 \\
\hline 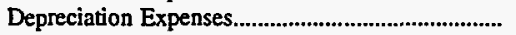 & 1,064 & 1,278 & 2,752 & 6,089 & 2,761 & 14,230 \\
\hline Amort, Prop Losses and Reg Study............................. & 0 & 0 & 0 & 132 & 0 & 671 \\
\hline 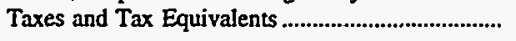 & 1 & 211 & 1,599 & 710 & 612 & 5,819 \\
\hline $\begin{array}{l}\text { Total Electric Utility Operating } \\
\text { Expenses }\end{array}$ & 11,012 & $15,40 S$ & 17,464 & 24,088 & 13,742 & 103,022 \\
\hline $\begin{array}{l}\text { Net Electric Utility Operating Income.................... } \\
\text { Income from Electric Plant Leased }\end{array}$ & 431 & 1,516 & 514 & 7,278 & 3,073 & 30,738 \\
\hline to Others & 0 & 0 & 0 & 0 & $\mathbf{0}$ & 0 \\
\hline 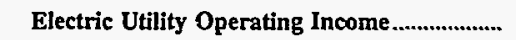 & 431 & 1,516 & 514 & 7,278 & 3,073 & 30,738 \\
\hline Other Electric Income & 278 & 1,073 & 1,418 & 1,618 & 3,224 & 2,762 \\
\hline $\begin{array}{l}\text { Other Electric Deductions } \\
\text { Allowance for Other Funds Used }\end{array}$ & 0 & 0 & 208 & 41 & $\mathbf{0}$ & 0 \\
\hline 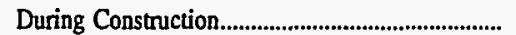 & 0 & 0 & 0 & 0 & 0 & 0 \\
\hline Taxes on Other Income and Deductions .................. & 0 & 0 & 0 & 0 & 0 & 0 \\
\hline 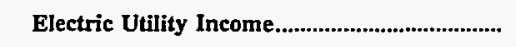 & 709 & 2,589 & 1,724 & 8,856 & 6,297 & 33,500 \\
\hline 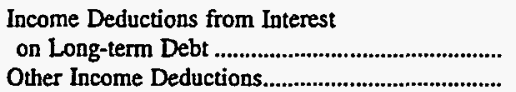 & $\begin{array}{r}617 \\
-156\end{array}$ & $\begin{array}{r}385 \\
34\end{array}$ & $\begin{array}{r}320 \\
0\end{array}$ & $\begin{array}{r}2,417 \\
0\end{array}$ & $\begin{array}{r}3,490 \\
0\end{array}$ & $\begin{array}{r}15,108 \\
2,186\end{array}$ \\
\hline 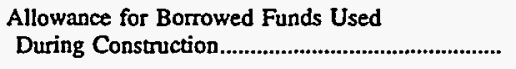 & 0 & 0 & 0 & $\mathbf{0}$ & 0 & -725 \\
\hline 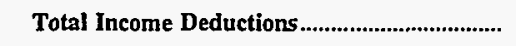 & 462 & 419 & 320 & 2,417 & 3,490 & 16,569 \\
\hline 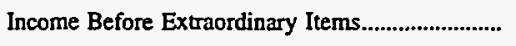 & 248 & 2,170 & 1,404 & 6,439 & 2,807 & 16,931 \\
\hline Extraordinary Income & 0 & 0 & $\mathbf{0}$ & 0 & 0 & 0 \\
\hline 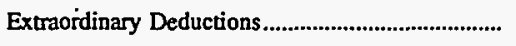 & 0 & 0 & 0 & 0 & 0 & 0 \\
\hline Net Income & 248 & 2,170 & 1,404 & 6,439 & 2,807 & 16,931 \\
\hline
\end{tabular}

Note: Totals may not equal sum of components because of independent rounding.

Source: Energy Information Administration, Form ElA-412, "Annual Report of Public Electric Utilities." 
Table 21. Statement of Income by Major U.S. Publicly Owned Electric Utility Within State, 1996 (Continued)

(Thousand Dollars)

\begin{tabular}{|c|c|c|c|c|c|c|}
\hline Item & $\begin{array}{c}\text { Nebraska } \\
\text { Loup } \\
\text { River } \\
\text { Public } \\
\text { Power Dist } \\
\text { December } 31\end{array}$ & $\begin{array}{c}\text { Nebraska } \\
\text { Municipal } \\
\text { Energy } \\
\text { Agency } \\
\text { of NE } \\
\text { March } 31\end{array}$ & $\begin{array}{c}\text { Nebraska } \\
\text { Nebraska } \\
\text { Public } \\
\text { Power } \\
\text { District } \\
\text { December } 31\end{array}$ & $\begin{array}{c}\text { Nebraska } \\
\text { Norris } \\
\text { Public } \\
\text { Power } \\
\text { District } \\
\text { December } 31\end{array}$ & $\begin{array}{l}\text { Nebraska } \\
\text { North } \\
\text { Platte } \\
\text { City of } \\
\text { July } 31\end{array}$ & $\begin{array}{c}\text { Nebraska } \\
\text { Omaha Public } \\
\text { Power } \\
\text { District } \\
\text { December } 31\end{array}$ \\
\hline Electric Utility Operating Revenues....................... & 46,606 & 34,498 & 535,740 & 24,063 & 14,842 & 420,090 \\
\hline 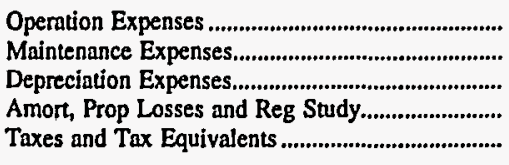 & $\begin{array}{r}39,102 \\
1,936 \\
1,870 \\
0 \\
2,587\end{array}$ & $\begin{array}{r}31,520 \\
0 \\
1,198 \\
0 \\
0\end{array}$ & $\begin{array}{r}408,327 \\
20,326 \\
53,700 \\
9,271 \\
5,971\end{array}$ & $\begin{array}{r}17,505 \\
1,352 \\
2,011 \\
0 \\
110\end{array}$ & $\begin{array}{r}12,064 \\
479 \\
582 \\
0 \\
1,075\end{array}$ & $\begin{array}{r}202,558 \\
47,757 \\
79,632 \\
0 \\
15,499\end{array}$ \\
\hline $\begin{array}{l}\text { Total Electric Utility Operating } \\
\text { Expenses ............................................................. }\end{array}$ & 45,495 & 32,718 & 497,595 & 20,977 & 14,201 & 345,446 \\
\hline 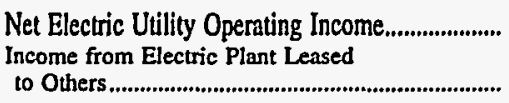 & $\begin{array}{r}1,111 \\
0\end{array}$ & $\begin{array}{r}1,781 \\
0\end{array}$ & $\begin{array}{r}38,146 \\
0\end{array}$ & $\begin{array}{r}3,086 \\
0\end{array}$ & $\begin{array}{r}641 \\
0\end{array}$ & 74,643 \\
\hline Electric Utility Operating Income........................ & 1,111 & 1,781 & 38,146 & 3,086 & 641 & 74,643 \\
\hline 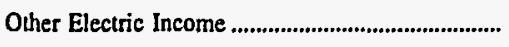 & 1,068 & 538 & 10,316 & 551 & 271 & 24,279 \\
\hline 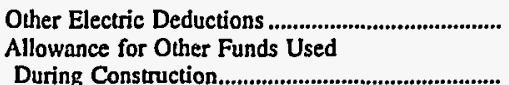 & 88 & $\mathbf{0}$ & 121 & $\mathbf{0}$ & 0 & 0 \\
\hline 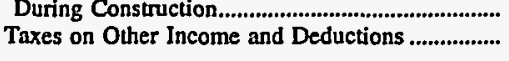 & $\begin{array}{l}0 \\
0\end{array}$ & $\begin{array}{l}0 \\
0\end{array}$ & $\begin{array}{r}782 \\
0\end{array}$ & $\begin{array}{l}0 \\
0\end{array}$ & $\begin{array}{l}0 \\
0\end{array}$ & $\begin{array}{r}949 \\
0\end{array}$ \\
\hline 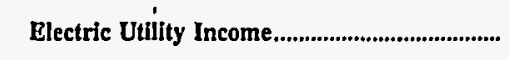 & 2,090 & 2,319 & 49,123 & 3,637 & 912 & 99,871 \\
\hline $\begin{array}{l}\text { Income Deductions from Interest } \\
\text { on Long-term Debt ................................................. } \\
\text { Other Income Deductions.................................... } \\
\text { Allowance for Bortowed Funds Used }\end{array}$ & $\begin{array}{l}0 \\
0\end{array}$ & $\begin{array}{r}2,723 \\
0\end{array}$ & $\begin{array}{l}23,938 \\
10,356\end{array}$ & $\begin{array}{r}1,005 \\
79\end{array}$ & $\begin{array}{l}0 \\
0\end{array}$ & $\begin{array}{l}51,797 \\
10,301\end{array}$ \\
\hline 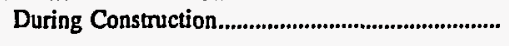 & 0 & 0 & 0 & 0 & $\mathbf{0}$ & $-2,432$ \\
\hline 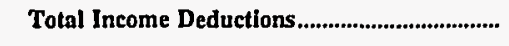 & $\mathbf{0}$ & 2,723 & 34,294 & 1,083 & $\mathbf{0}$ & 59,666 \\
\hline Income Before Extraordinary Items............................. & 2,090 & -405 & 14,829 & 2,554 & 912 & 40,205 \\
\hline Extraordinary Income & 0 & 0 & 0 & 0 & 0 & $\mathbf{0}$ \\
\hline 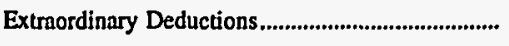 & $\mathbf{0}$ & 0 & 0 & 0 & 0 & 0 \\
\hline 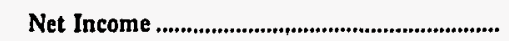 & 2,090 & -405 & 14,829 & 2,554 & 912 & 40,205 \\
\hline
\end{tabular}

Note: Totals may not equal sum of components because of independent rounding.

Source: Energy Information Administration, Form EIA-412, “Annual Report of Public Electric Utilities." 
Table 21. Statement of Income by Major U.S. Publicly Owned Electric Utility Within State, 1996 (Continued)

(Thousand Dollars)

\begin{tabular}{|c|c|c|c|c|c|c|}
\hline Item & $\begin{array}{c}\text { Nebraska } \\
\text { Southern } \\
\text { Nebraska Rural } \\
\text { P P D } \\
\text { December } 31\end{array}$ & $\begin{array}{c}\text { Nevada } \\
\text { Colorado } \\
\text { River } \\
\text { Comm } \\
\text { of Nevada } \\
\text { June } 30\end{array}$ & $\begin{array}{c}\text { Nevada } \\
\text { Overon } \\
\text { Power } \\
\text { District } \\
\text { No } 5 \\
\text { December } 31\end{array}$ & $\begin{array}{l}\text { New Jersey } \\
\text { Madison } \\
\text { Borough } \\
\text { December } 31\end{array}$ & $\begin{array}{l}\text { New Jersey } \\
\text { Vineland } \\
\text { City of } \\
\text { June } 30\end{array}$ & $\begin{array}{l}\text { New Mexico } \\
\text { Farmington } \\
\text { City of } \\
\text { June } 30\end{array}$ \\
\hline Electric Utility Operating Revenues.......................... & 23,520 & 24,676 & 12,711 & 13,289 & 40,487 & 47,382 \\
\hline 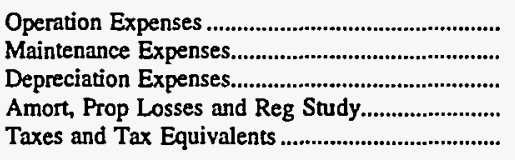 & $\begin{array}{r}19,251 \\
1,188 \\
2,586 \\
0 \\
131\end{array}$ & $\begin{array}{r}24,566 \\
0 \\
0 \\
0 \\
0\end{array}$ & $\begin{array}{r}7,494 \\
188 \\
838 \\
0 \\
15\end{array}$ & $\begin{array}{r}8,741 \\
0 \\
0 \\
0 \\
0\end{array}$ & $\begin{array}{r}33,287 \\
2,264 \\
2,118 \\
0 \\
608\end{array}$ & $\begin{array}{r}17,149 \\
3,059 \\
5,236 \\
0 \\
3,187\end{array}$ \\
\hline $\begin{array}{l}\text { Total Electric Utility Operating } \\
\text { Expenses }\end{array}$ & 23,156 & 24,566 & 8,535 & 8,741 & 38,277 & 28,630 \\
\hline 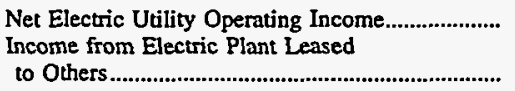 & $\begin{array}{r}364 \\
0\end{array}$ & $\begin{array}{r}110 \\
0\end{array}$ & $\begin{array}{r}4,177 \\
0\end{array}$ & $\begin{array}{l}4,548 \\
9,113\end{array}$ & $\begin{array}{r}2,210 \\
0\end{array}$ & $\begin{array}{r}18,752 \\
0\end{array}$ \\
\hline Electric Utility Operating Income..................... & 364 & 110 & 4,177 & 13,661 & 2,210 & 18,752 \\
\hline Other Electric Income & 796 & 94 & 309 & 0 & 1,519 & 2,200 \\
\hline 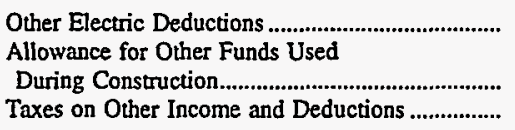 & $\begin{array}{l}0 \\
0 \\
0\end{array}$ & $\begin{array}{r}120 \\
0 \\
0\end{array}$ & $\begin{array}{r}943 \\
0 \\
0\end{array}$ & $\begin{array}{l}0 \\
0 \\
0\end{array}$ & $\begin{array}{l}0 \\
0 \\
0\end{array}$ & $\begin{array}{l}0 \\
0\end{array}$ \\
\hline Electric Utility Income & 1,161 & 84 & 3,543 & 13,661 & 3,729 & 20,952 \\
\hline 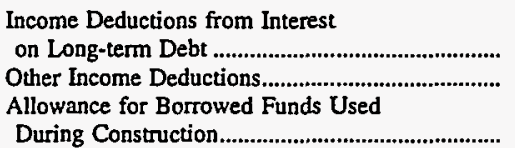 & $\begin{array}{l}0 \\
0\end{array}$ & $\begin{array}{l}0 \\
0\end{array}$ & $\begin{array}{l}0 \\
0\end{array}$ & $\begin{array}{r}4,200 \\
0\end{array}$ & $\begin{array}{l}196 \\
126\end{array}$ & $\begin{array}{r}9,612 \\
541\end{array}$ \\
\hline 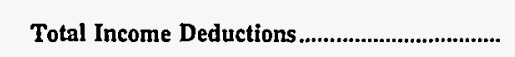 & $\mathbf{0}$ & 0 & $\mathbf{0}$ & 4,200 & 322 & 10,152 \\
\hline 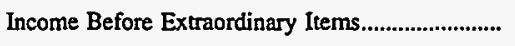 & 1,161 & 84 & 3,543 & 9,461 & 3,407 & 10,800 \\
\hline 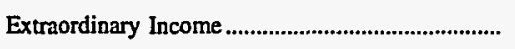 & 0 & 0 & 0 & 0 & 0 & 0 \\
\hline 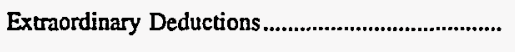 & 0 & 0 & 0 & 0 & 0 & 0 \\
\hline Net Income & 1,161 & 84 & 3,543 & 9,461 & 3,407 & 10,800 \\
\hline
\end{tabular}

Note: Totals may not equal sum of components because of independent rounding.

Source: Energy Information Administration, Form EIA-412, "Annual Report of Public Electric Utilities." 
Table 21. Statement of Income by Major U.S. Publicly Owned Electric Utility Within State, 1996 (Continued)

(Thousand Dollars)

\begin{tabular}{|c|c|c|c|c|c|c|}
\hline Item & $\begin{array}{l}\text { New Mexico } \\
\text { Gallup } \\
\text { City of } \\
\text { June } 30\end{array}$ & $\begin{array}{l}\text { New Mexico } \\
\begin{array}{l}\text { Los Alamos } \\
\text { County }\end{array} \\
\text { June } 30\end{array}$ & $\begin{array}{c}\text { New York } \\
\text { Fairport } \\
\text { Village of } \\
\text { May } 31\end{array}$ & $\begin{array}{c}\text { New York } \\
\text { Freeport } \\
\text { Village of } \\
\text { Ine } \\
\text { February } 28\end{array}$ & $\begin{array}{l}\text { New York } \\
\text { Jamestown } \\
\text { City of } \\
\text { December } 31\end{array}$ & $\begin{array}{l}\text { New York } \\
\text { Lake Placid } \\
\text { Village Inc } \\
\text { July } 31\end{array}$ \\
\hline Electric Utility Operating Revenues...................... & 13,884 & 28,065 & 12,781 & 16,009 & 24,617 & 4,282 \\
\hline 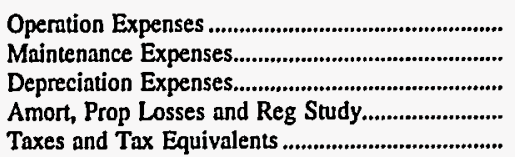 & $\begin{array}{r}11,377 \\
247 \\
498 \\
0 \\
711\end{array}$ & $\begin{array}{r}16,179 \\
1,875 \\
2,886 \\
3 \\
602\end{array}$ & $\begin{array}{r}9,700 \\
286 \\
687 \\
0 \\
559\end{array}$ & $\begin{array}{r}11,316 \\
956 \\
998 \\
0 \\
1,598\end{array}$ & $\begin{array}{r}14,194 \\
1,759 \\
2,420 \\
0 \\
2,229\end{array}$ & $\begin{array}{r}3,537 \\
29 \\
275 \\
0 \\
56\end{array}$ \\
\hline $\begin{array}{l}\text { Total Electric Utillty Operating } \\
\text { Expenses .................................................................. }\end{array}$ & 12,833 & 21,545 & 11,231 & 14,869 & 20,602 & 3,897 \\
\hline 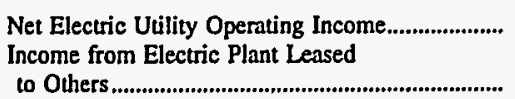 & $\begin{array}{r}1,051 \\
0\end{array}$ & 6,520 & 1,550 & 1,141 & 4,015 & 386 \\
\hline Electric Utility Operating Income..................... & 1,051 & 6,520 & 1,566 & 1,146 & 4,015 & 386 \\
\hline 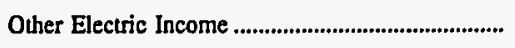 & 45 & 1,532 & 184 & 254 & 164 & 16 \\
\hline $\begin{array}{l}\text { Other Electric Deductions } \\
\text { Allowance for Other Funds Used }\end{array}$ & 1,019 & 3 & 9 & $\mathbf{0}$ & 5 & 0 \\
\hline $\begin{array}{l}\text { During Construction } \\
\text { Taxes on Other Income and Deductions }\end{array}$ & $\begin{array}{l}0 \\
0\end{array}$ & $\begin{array}{l}0 \\
0\end{array}$ & $\begin{array}{l}0 \\
0\end{array}$ & $\begin{array}{l}0 \\
0\end{array}$ & $\begin{array}{l}0 \\
0\end{array}$ & $\begin{array}{l}0 \\
0\end{array}$ \\
\hline Electric Utility Income & 78 & 8,049 & 1,740 & 1,401 & 4,174 & 402 \\
\hline 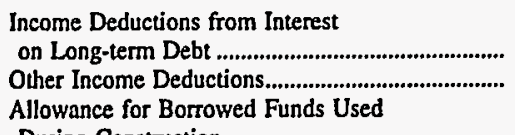 & $\begin{array}{l}0 \\
0\end{array}$ & $\begin{array}{l}6,260 \\
1,461\end{array}$ & $\begin{array}{r}61 \\
3\end{array}$ & $\begin{array}{r}307 \\
38\end{array}$ & $\begin{array}{r}971 \\
0\end{array}$ & $\begin{array}{r}277 \\
0\end{array}$ \\
\hline 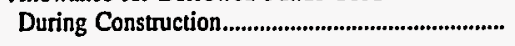 & 0 & 0 & 0 & 0 & 0 & 0 \\
\hline 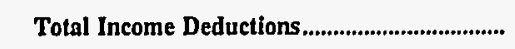 & $\mathbf{0}$ & $\mathbf{7 , 7 2 2}$ & 64 & 345 & 971 & 277 \\
\hline 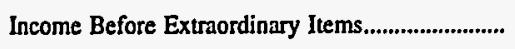 & 78 & 327 & 1,676 & 1,056 & 3,203 & 125 \\
\hline Extraordinary Income & 0 & 0 & 0 & 0 & 0 & 0 \\
\hline Extraordinary Deductions............................................... & 0 & 0 & 0 & $\mathbf{0}$ & 0 & 0 \\
\hline 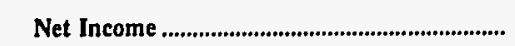 & 78 & 327 & 1,676 & 1,056 & 3,203 & 125 \\
\hline
\end{tabular}

Note: Totals may not equal sum of components because of independent rounding.

Source: Energy Information Administration, Form ElA-412, "Annual Report of Public Electric Utilities." 
Table 21. Statement of Income by Major U.S. Publicly Owned Electric Utility Within State, 1996 (Continued)

(Thousand Dollars)

\begin{tabular}{|c|c|c|c|c|c|c|}
\hline Item & $\begin{array}{l}\text { New York } \\
\text { Massena } \\
\text { Town of } \\
\text { December } 31\end{array}$ & $\begin{array}{l}\text { New York } \\
\text { Plattsburgh } \\
\text { City of } \\
\text { December } 31\end{array}$ & $\begin{array}{c}\text { New York } \\
\text { Power } \\
\text { Authority } \\
\text { of State of NY } \\
\text { December } 31\end{array}$ & $\begin{array}{l}\text { New York } \\
\text { Rockville } \\
\text { Centre } \\
\text { Village of } \\
\text { May } 31\end{array}$ & $\begin{array}{l}\text { New York } \\
\text { Solvay } \\
\text { Village of } \\
\text { May } 31\end{array}$ & $\begin{array}{l}\text { North Carolina } \\
\text { Albemarie } \\
\text { City of } \\
\text { June } 30\end{array}$ \\
\hline Electric Utility Operating Revenues..................... & 6,507 & 11,352 & $1,430,150$ & 12,712 & 5,253 & 20,710 \\
\hline 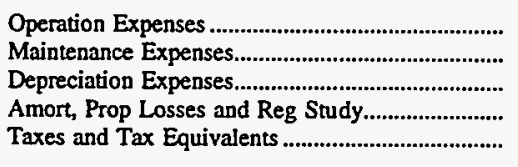 & $\begin{array}{r}3,616 \\
205 \\
448 \\
287 \\
0\end{array}$ & $\begin{array}{r}8,205 \\
416 \\
916 \\
0 \\
31\end{array}$ & $\begin{array}{r}884,440 \\
144,628 \\
199,929 \\
0 \\
0\end{array}$ & $\begin{array}{r}8,983 \\
0 \\
1,084 \\
0 \\
1,403\end{array}$ & $\begin{array}{r}4,773 \\
108 \\
0 \\
0 \\
0\end{array}$ & $\begin{array}{r}19,044 \\
0 \\
593 \\
0 \\
0\end{array}$ \\
\hline $\begin{array}{l}\text { Total Electric Utility Operating } \\
\text { Expenses .................................................... }\end{array}$ & 4,557 & 9,567 & $1,228,997$ & 11,470 & 4,881 & 19,637 \\
\hline 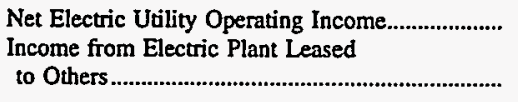 & $\begin{array}{r}1,950 \\
0\end{array}$ & $\begin{array}{r}1,784 \\
0\end{array}$ & $\begin{array}{r}201,153 \\
1,639\end{array}$ & 1,242 & 372 & $\begin{array}{r}1,073 \\
0\end{array}$ \\
\hline Electric Utility Operating Income..................... & 1,950 & 1,784 & 202,792 & 1,242 & 372 & 1,073 \\
\hline 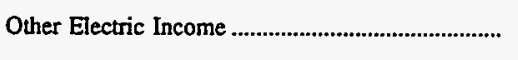 & 160 & 64 & 84,130 & 134 & 28 & 163 \\
\hline $\begin{array}{l}\text { Other Electric Deductions } \\
\text { Allowance for Other Funds Used }\end{array}$ & 0 & 0 & 0 & 0 & 0 & 1,023 \\
\hline 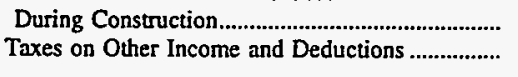 & $\begin{array}{r}0 \\
280\end{array}$ & $\begin{array}{l}0 \\
0\end{array}$ & $\begin{array}{l}0 \\
0\end{array}$ & $\begin{array}{l}0 \\
0\end{array}$ & $\begin{array}{l}0 \\
0\end{array}$ & $\begin{array}{l}0 \\
0\end{array}$ \\
\hline Electric Utility Income........................................... & 1,831 & 1,848 & 286,922 & 1,376 & 401 & 213 \\
\hline 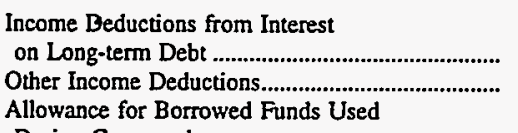 & $\begin{array}{r}463 \\
4\end{array}$ & $\begin{array}{r}164 \\
25\end{array}$ & $\begin{array}{r}174,186 \\
7,254\end{array}$ & $\begin{array}{r}785 \\
46\end{array}$ & $\begin{array}{r}164 \\
0\end{array}$ & $\begin{array}{l}0 \\
0\end{array}$ \\
\hline 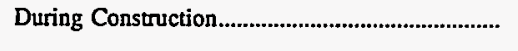 & 0 & 0 & 0 & 0 & 0 & 0 \\
\hline Total Income Deductions....................................... & 466 & 190 & 181,440 & 831 & 164 & o \\
\hline 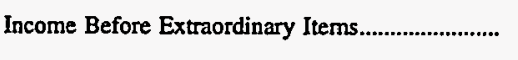 & 1,364 & 1,658 & 105,482 & 545 & 237 & 213 \\
\hline 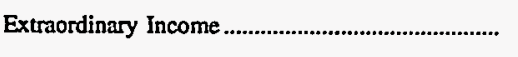 & 0 & 0 & 0 & 0 & 0 & 0 \\
\hline 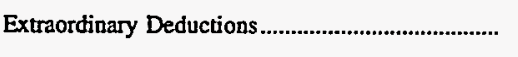 & 0 & 0 & 0 & 0 & 0 & 0 \\
\hline Net Income & 1,364 & 1,658 & 105,482 & 545 & 237 & 213 \\
\hline
\end{tabular}

Note: Totals may not equal sum of components because of independent rounding.

Source: Energy Information Administration, Form EIA-412, "Annual Report of Public Electric Utilities." 
Table 21. Statement of Income by Major U.S. Publicly Owned Electric Utility Within State, 1996 (Continued)

(Thousand Dollars)

\begin{tabular}{|c|c|c|c|c|c|c|}
\hline Item & $\begin{array}{l}\text { North Carolina } \\
\text { Concord } \\
\text { City of } \\
\text { June } 30\end{array}$ & $\begin{array}{l}\text { North Carolina } \\
\text { Elizabeth } \\
\text { City City of } \\
\text { June } 30\end{array}$ & $\begin{array}{l}\text { North Carolina } \\
\text { Fayetteville } \\
\text { Public } \\
\text { Works Comm } \\
\text { June } 30\end{array}$ & $\begin{array}{l}\text { North Carolina } \\
\text { Forest City } \\
\text { Town of } \\
\text { June } 30\end{array}$ & $\begin{array}{l}\text { North Carolina } \\
\text { Gastonia } \\
\text { City of } \\
\text { June } 30\end{array}$ & $\begin{array}{l}\text { North Carolina } \\
\text { Greenville } \\
\text { Utilities } \\
\text { Comm } \\
\text { June } 30\end{array}$ \\
\hline Electric Utility Operating Revenues..................... & 31,417 & 23,662 & 126,688 & 8,558 & 47,122 & 108,478 \\
\hline 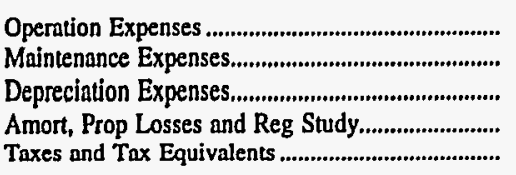 & $\begin{array}{r}20,687 \\
3,658 \\
1,179 \\
0 \\
0\end{array}$ & $\begin{array}{r}21,641 \\
486 \\
952 \\
0 \\
481\end{array}$ & $\begin{array}{r}86,336 \\
2,915 \\
8,893 \\
0 \\
14,796\end{array}$ & $\begin{array}{r}6,894 \\
21 \\
120 \\
0 \\
0\end{array}$ & $\begin{array}{r}37,493 \\
1,378 \\
1,482 \\
0 \\
0\end{array}$ & $\begin{array}{r}101,051 \\
0 \\
3,847 \\
0 \\
2,732\end{array}$ \\
\hline 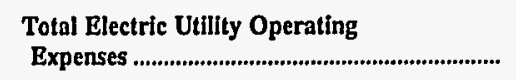 & 25,524 & 23,560 & 112,940 & 7,035 & 40,352 & 107,629 \\
\hline 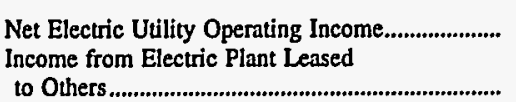 & $\begin{array}{r}5,892 \\
0\end{array}$ & $\begin{array}{r}103 \\
0\end{array}$ & $\begin{array}{r}13,748 \\
0\end{array}$ & $\begin{array}{r}1,523 \\
0\end{array}$ & $\begin{array}{r}6,770 \\
0\end{array}$ & $\begin{array}{r}849 \\
0\end{array}$ \\
\hline Electric Utility Operating Income..................... & 5,892 & 103 & 13,748 & 1,523 & 6,770 & 849 \\
\hline 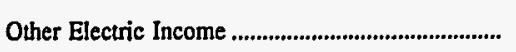 & 589 & 96 & 2,444 & 294 & 1,187 & 993 \\
\hline $\begin{array}{l}\text { Other Electric Deductions } \\
\text { Allowance for Other Funds Used }\end{array}$ & 0 & 454 & 0 & 0 & 0 & 0 \\
\hline $\begin{array}{l}\text { During Construction } \\
\text { Taxes on Other Income and Deductions }\end{array}$ & $\begin{array}{l}0 \\
0\end{array}$ & $\begin{array}{l}\mathbf{0} \\
\mathbf{0}\end{array}$ & $\begin{array}{l}\mathbf{0} \\
\mathbf{0}\end{array}$ & $\begin{array}{l}0 \\
0\end{array}$ & $\begin{array}{l}\mathbf{0} \\
\mathbf{0}\end{array}$ & $\begin{array}{l}0 \\
0\end{array}$ \\
\hline 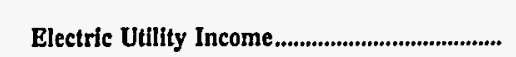 & 6,481 & -255 & 16,192 & 1,817 & 7,957 & 1,842 \\
\hline 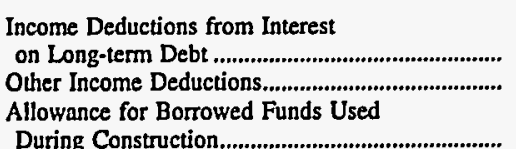 & $\begin{array}{r}656 \\
3,323 \\
0\end{array}$ & $\begin{array}{l}0 \\
0\end{array}$ & $\begin{array}{r}3,214 \\
424\end{array}$ & $\begin{array}{l}\mathbf{0} \\
\mathbf{0}\end{array}$ & $\begin{array}{r}0 \\
896\end{array}$ & $\begin{array}{r}291 \\
0 \\
0\end{array}$ \\
\hline Total Income Deductions...................................... & 3,979 & $\mathbf{0}$ & 3,638 & $\mathbf{0}$ & 896 & 291 \\
\hline Income Before Extraordinary Items.......................... & 2,502 & -255 & 12,554 & 1,817 & 7,061 & 1,551 \\
\hline 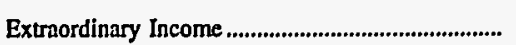 & 0 & 0 & 0 & 0 & 0 & 0 \\
\hline 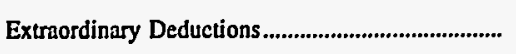 & 0 & 0 & 0 & 0 & 0 & 0 \\
\hline 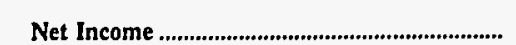 & 2,502 & -255 & 12,554 & 1,817 & 7,061 & 1,551 \\
\hline
\end{tabular}

Note: Totals may not equal sum of components because of independent rounding.

Source: Energy Information Administration, Form EIA-412, "Annual Report of Public Electric Utilities." 
Table 21. Statement of Income by Major U.S. Publicly Owned Electric Utility Within State, 1996 (Continued)

(Thousand Dollars)

\begin{tabular}{|c|c|c|c|c|c|c|}
\hline Item & $\begin{array}{l}\text { North Carolina } \\
\text { High } \\
\text { Point } \\
\text { Town } \\
\text { of } \\
\text { June } 30\end{array}$ & $\begin{array}{l}\text { North Carolina } \\
\text { Kinston } \\
\text { City of } \\
\text { June } 30\end{array}$ & $\begin{array}{l}\text { North Carolina } \\
\text { Lexington } \\
\text { City of } \\
\text { June } 30\end{array}$ & $\begin{array}{l}\text { North Carolina } \\
\text { Lumberton } \\
\text { City of } \\
\text { June } 30\end{array}$ & $\begin{array}{l}\text { North Carolina } \\
\text { Monroe } \\
\text { City of } \\
\text { June } 30\end{array}$ & $\begin{array}{l}\text { North Carolina } \\
\text { Morganton } \\
\text { City of } \\
\text { June } 30\end{array}$ \\
\hline Electric Utility Operating Revenues..................... & 69,833 & 38,620 & 38,413 & 22,248 & 31,470 & 20,941 \\
\hline 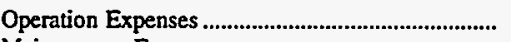 & 55,833 & 33,549 & 32,809 & 21,963 & 25,278 & 17,953 \\
\hline 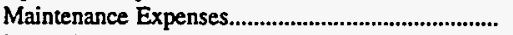 & 5,922 & 0 & 158 & 243 & 0 & 0 \\
\hline 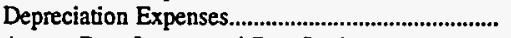 & 1,810 & 733 & 804 & 697 & 1,020 & 474 \\
\hline 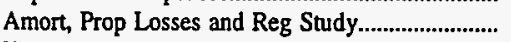 & 0 & 15 & 0 & 0 & 0 & 0 \\
\hline 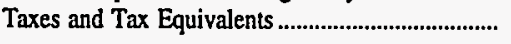 & 0 & 0 & 907 & 0 & 810 & 0 \\
\hline $\begin{array}{c}\text { Total Electric Utility Operating } \\
\text { Expenses }\end{array}$ & 63,565 & 34,297 & 34,677 & 22,904 & 27,108 & 18,427 \\
\hline $\begin{array}{l}\text { Net Electric Utility Operating Income.................... } \\
\text { Income from Electric Plant Leased }\end{array}$ & 6,268 & 4,323 & 3,736 & -656 & 4,362 & 2,514 \\
\hline 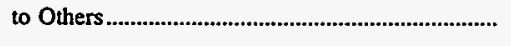 & 0 & 0 & 0 & 0 & $\mathbf{0}$ & 0 \\
\hline Electric Utility Operating Income.................... & 6,268 & 4,323 & 3,736 & -656 & 4,362 & 2,514 \\
\hline 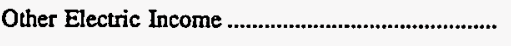 & 0 & 463 & 169 & 738 & 1,245 & 621 \\
\hline $\begin{array}{l}\text { Other Electric Deductions .............................................. } \\
\text { Allowance for Other Funds Used }\end{array}$ & 0 & 0 & 0 & 1,154 & 0 & 0 \\
\hline During Construction & 0 & 0 & 0 & 0 & 0 & 0 \\
\hline Taxes on Other Income and Deductions ................. & 0 & 0 & 0 & 0 & 0 & 0 \\
\hline 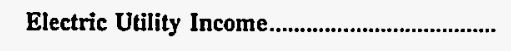 & 6,268 & 4,787 & 3,906 & $-1,072$ & 5,607 & 3,135 \\
\hline $\begin{array}{l}\text { Income Deductions from Interest } \\
\text { on Long-term Debt }\end{array}$ & 0 & 401 & 89 & 0 & 2 & 0 \\
\hline $\begin{array}{l}\text { Other Income Deductions.................................. } \\
\text { Allowance for Borrowed Funds Used }\end{array}$ & 0 & 0 & 151 & 115 & 1,211 & 1,082 \\
\hline 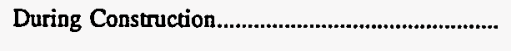 & 0 & 0 & 0 & 0 & 0 & 0 \\
\hline 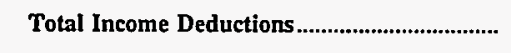 & $\mathbf{0}$ & 401 & 240 & 115 & 1,213 & 1,082 \\
\hline Income Before Extraordinary Items........................... & 6,268 & 4,386 & 3,666 & $-1,187$ & 4,394 & 2,053 \\
\hline 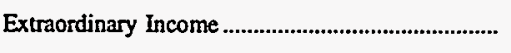 & 0 & 0 & 0 & 0 & 0 & 0 \\
\hline Extraordinary Deductions.......................................... & 0 & 0 & 0 & 0 & 0 & 0 \\
\hline 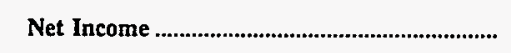 & 6,268 & 4,386 & 3,666 & $-1,187$ & 4,394 & 2,053 \\
\hline
\end{tabular}

Note: Totals may not equal sum of components because of independent rounding.

Source: Energy Information Administration, Form EIA-412, “Annual Report of Public Electric Uulities." 
Table 21. Statement of Income by Major U.S. Publicly Owned Electric Utility Within State, 1996 (Continued)

(Thousand Dollars)

\begin{tabular}{|c|c|c|c|c|c|c|}
\hline Item & $\begin{array}{l}\text { North Carolina } \\
\text { Murphy } \\
\text { City of } \\
\text { June } 30\end{array}$ & $\begin{array}{l}\text { North Carolina } \\
\text { New Bern } \\
\text { City of } \\
\text { June } 30\end{array}$ & $\begin{array}{l}\text { North Carolina } \\
\text { New River } \\
\text { Light } \\
\& \\
\text { Power Co } \\
\text { December } 31\end{array}$ & $\begin{array}{c}\text { North Carolina } \\
\text { North } \\
\text { Carolina } \\
\text { Eastern M P A } \\
\text { December } 31\end{array}$ & $\begin{array}{l}\text { North Carolina } \\
\text { North } \\
\text { Carolina } \\
\text { Mun } \\
\text { Power Agny } \\
\text { December } 31\end{array}$ & $\begin{array}{l}\text { Norh Carolina } \\
\begin{array}{c}\text { Rocky Mount } \\
\text { City of }\end{array} \\
\text { June } 30\end{array}$ \\
\hline Electric Uttlity Operating Revenues....................... & 7,125 & $\mathbf{3 7 , 7 2 4}$ & 12,352 & 460,674 & 375,577 & 66,294 \\
\hline 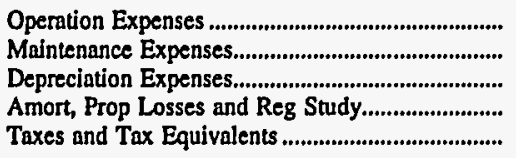 & $\begin{array}{r}6,499 \\
135 \\
242 \\
0 \\
100\end{array}$ & $\begin{array}{r}34,865 \\
0 \\
999 \\
0 \\
0\end{array}$ & $\begin{array}{r}10,280 \\
0 \\
370 \\
0 \\
397\end{array}$ & $\begin{array}{r}220,945 \\
17,633 \\
52,015 \\
0 \\
20,709\end{array}$ & $\begin{array}{r}168,230 \\
35,996 \\
47,145 \\
0 \\
22,226\end{array}$ & $\begin{array}{r}60,011 \\
0 \\
2,024 \\
0 \\
0\end{array}$ \\
\hline 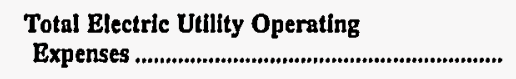 & 6,976 & 35,864 & 11,047 & 311,302 & 273,597 & 62,034 \\
\hline 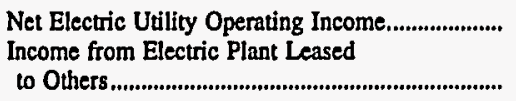 & $\begin{array}{r}149 \\
0\end{array}$ & $\begin{array}{r}1,860 \\
0\end{array}$ & $\begin{array}{r}1,305 \\
0\end{array}$ & 149,372 & 101,980 & 4,259 \\
\hline Electric Utility Operating Income ........................ & 149 & 1,860 & 1,305 & 149,372 & 101,980 & 4,259 \\
\hline Other Electric Income & 217 & 258 & 141 & 99,863 & 61,081 & 274 \\
\hline 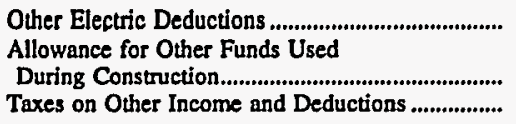 & $\begin{array}{l}10 \\
0 \\
0\end{array}$ & $\begin{array}{l}0 \\
0\end{array}$ & $\begin{array}{l}0 \\
0\end{array}$ & $\begin{array}{l}0 \\
0 \\
0\end{array}$ & $\begin{array}{l}0 \\
0\end{array}$ & $\begin{array}{l}0 \\
0\end{array}$ \\
\hline 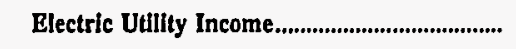 & 356 & 2,118 & 1,446 & 249,235 & 163,061 & 4,534 \\
\hline 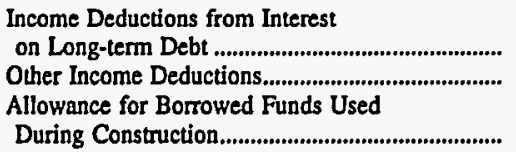 & $\begin{array}{l}\mathbf{0} \\
\mathbf{0}\end{array}$ & $\begin{array}{r}65 \\
0\end{array}$ & $\begin{array}{l}0 \\
0\end{array}$ & $\begin{array}{r}214,799 \\
35,256 \\
-820\end{array}$ & $\begin{array}{r}134,087 \\
28,974\end{array}$ & $\begin{array}{r}175 \\
3,895\end{array}$ \\
\hline Total Income Deductions........................................ & $\mathbf{0}$ & 65 & $\mathbf{0}$ & 249,235 & 163,061 & 4,070 \\
\hline 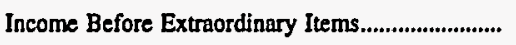 & 356 & 2,053 & 1,446 & $\mathbf{0}$ & 0 & 464 \\
\hline 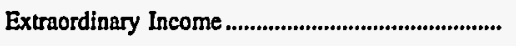 & $\mathbf{0}$ & 0 & 0 & $\mathbf{0}$ & 0 & $\mathbf{0}$ \\
\hline 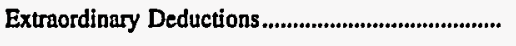 & 0 & 0 & 0 & 0 & 0 & 0 \\
\hline 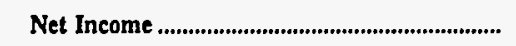 & 356 & 2,053 & 1,446 & o & $\mathbf{0}$ & 464 \\
\hline
\end{tabular}

Note: Totals may not equal sum of components because of independent rounding.

Source: Energy Information Administration, Form EIA-412, "Annual Report of Public Electric Utilities." 
Table 21. Statement of Income by Major U.S. Publicly Owned Electric Utility Within State, 1996 (Continued)

(Thousand Dollars)

\begin{tabular}{|c|c|c|c|c|c|c|}
\hline Item & $\begin{array}{l}\text { North Carolina } \\
\text { Shelby } \\
\text { City of } \\
\text { June } 30\end{array}$ & $\begin{array}{l}\text { North Carolina } \\
\text { Statesville } \\
\text { City of } \\
\text { June } 30\end{array}$ & $\begin{array}{l}\text { North Carolina } \\
\text { Tarboro } \\
\text { Town of } \\
\text { June } 30\end{array}$ & $\begin{array}{l}\text { North Carolina } \\
\text { Washington } \\
\text { City of } \\
\text { June } 30\end{array}$ & $\begin{array}{l}\text { North Carolina } \\
\text { Wilson } \\
\text { City of } \\
\text { June } 30\end{array}$ & $\begin{array}{c}\text { Ohio } \\
\text { American } \\
\text { Mun } \\
\text { Power } \\
\text { Ohio Inc } \\
\text { December } 31\end{array}$ \\
\hline 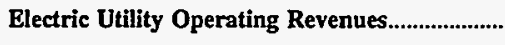 & 13,644 & 27,469 & 22,051 & 23,212 & 88,144 & 165,121 \\
\hline 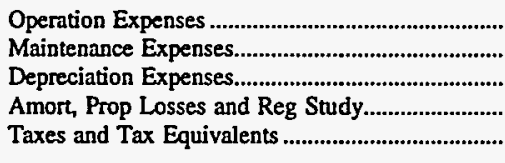 & $\begin{array}{r}11,087 \\
333 \\
292 \\
0 \\
0\end{array}$ & $\begin{array}{r}25,823 \\
0 \\
587 \\
0 \\
0\end{array}$ & $\begin{array}{r}19,794 \\
0 \\
645 \\
0 \\
0\end{array}$ & $\begin{array}{r}21,170 \\
1,118 \\
1,202 \\
0 \\
0\end{array}$ & $\begin{array}{r}79,990 \\
628 \\
1,767 \\
0 \\
0\end{array}$ & $\begin{array}{r}139,545 \\
7,456 \\
3,629 \\
548 \\
9,152\end{array}$ \\
\hline $\begin{array}{l}\text { Total Electric Utility Operating } \\
\text { Expenses }\end{array}$ & 11,712 & 26,410 & 20,439 & 23,490 & 82,385 & 160,329 \\
\hline 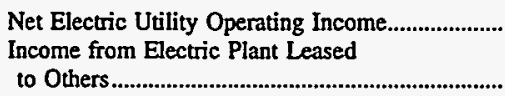 & 1,933 & 1,060 & $\begin{array}{r}1,612 \\
0\end{array}$ & $\begin{array}{r}-278 \\
0\end{array}$ & 5,759 & 4,792 \\
\hline 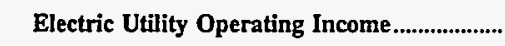 & 1,933 & 1,060 & 1,612 & -278 & 5,759 & 4,792 \\
\hline Other Electric Income & 212 & 438 & 441 & 848 & 1,447 & 1,635 \\
\hline $\begin{array}{l}\text { Other Electric Deductions } \\
\text { Allowance for Other Funds Used }\end{array}$ & 1,006 & 61 & 463 & 0 & 165 & 0 \\
\hline 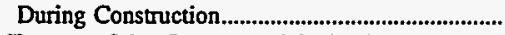 & 0 & 0 & 0 & 0 & 0 & 0 \\
\hline Taxes on Other Income and Deductions .................... & 0 & 0 & 0 & 0 & 0 & 0 \\
\hline Electric Utility Income & 1,139 & 1,436 & 1,590 & 570 & 7,041 & 6,427 \\
\hline 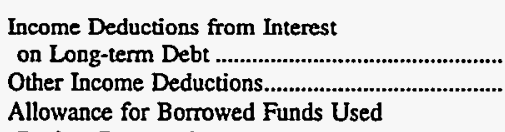 & $\begin{array}{r}226 \\
0\end{array}$ & $\begin{array}{l}0 \\
0\end{array}$ & $\begin{array}{l}0 \\
0\end{array}$ & $\begin{array}{l}\mathbf{0} \\
0\end{array}$ & $\begin{array}{r}135 \\
0\end{array}$ & $\begin{array}{r}6,763 \\
0\end{array}$ \\
\hline 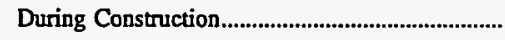 & 0 & 0 & 0 & 0 & $\mathbf{0}$ & o \\
\hline 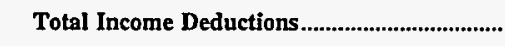 & 226 & 0 & $\mathbf{0}$ & $\mathbf{0}$ & 135 & 6,763 \\
\hline 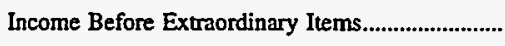 & 914 & 1,436 & 1,590 & 570 & 6,906 & -336 \\
\hline Extraordinary Income & 0 & $\mathbf{0}$ & 0 & 0 & 0 & $\mathbf{0}$ \\
\hline 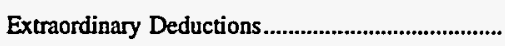 & 0 & $\mathbf{0}$ & 0 & 0 & 0 & 0 \\
\hline 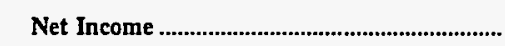 & 914 & 1,436 & 1,590 & 570 & 6,906 & -336 \\
\hline
\end{tabular}

Note: Totals may not equal sum of components because of independent rounding.

Source: Energy Information Administration, Form EIA-412, "Annual Report of Public Electric Utilities." 
Table 21. Statement of Income by Major U.S. Publicly Owned Electric Utility Within State, 1996 (Continued)

(Thousand Dollars)

\begin{tabular}{|c|c|c|c|c|c|c|}
\hline Item & $\begin{array}{c}\text { Ohio } \\
\text { Bowling } \\
\text { Green } \\
\text { City of } \\
\text { December } 31\end{array}$ & $\begin{array}{c}\text { Ohio } \\
\text { Bryan } \\
\text { City of } \\
\text { December } 31\end{array}$ & $\begin{array}{l}\text { Ohio } \\
\text { Celina } \\
\text { City of } \\
\text { December } 31\end{array}$ & $\begin{array}{l}\text { Ohio } \\
\text { Cleveland } \\
\text { City of } \\
\text { December } 31\end{array}$ & $\begin{array}{l}\text { Ohio } \\
\text { Clyde } \\
\text { City of } \\
\text { December } 31\end{array}$ & $\begin{array}{l}\text { Ohio } \\
\text { Columbus } \\
\text { City of } \\
\text { December } 31\end{array}$ \\
\hline Electric Utility Operating Revenues..................... & 19,338 & 12,434 & 7,785 & 98,932 & 6,654 & 41,242 \\
\hline 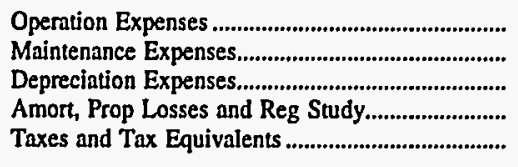 & $\begin{array}{r}16,984 \\
831 \\
726 \\
0 \\
1\end{array}$ & $\begin{array}{r}10,219 \\
1,228 \\
376 \\
0 \\
0\end{array}$ & $\begin{array}{r}6,065 \\
609 \\
0 \\
0 \\
0\end{array}$ & $\begin{array}{r}56,014 \\
12,552 \\
6,246 \\
0 \\
0\end{array}$ & $\begin{array}{r}5,016 \\
0 \\
0 \\
0 \\
0\end{array}$ & $\begin{array}{r}25,282 \\
7,741 \\
2,752 \\
0 \\
0\end{array}$ \\
\hline 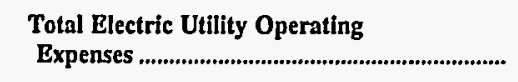 & 18,542 & 11,824 & 6,674 & 74,812 & 5,016 & 35,775 \\
\hline 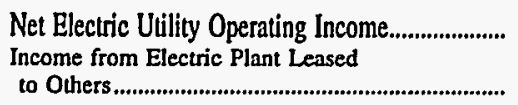 & $\begin{array}{r}796 \\
0\end{array}$ & 610 & $\begin{array}{r}1,111 \\
0\end{array}$ & $\begin{array}{r}24,120 \\
0\end{array}$ & $\begin{array}{r}1,638 \\
0\end{array}$ & $\begin{array}{r}5,468 \\
0\end{array}$ \\
\hline Electric Utility Operating Income...................... & 796 & 610 & 1,111 & 24,120 & 1,638 & 5,468 \\
\hline Other Electric Income & 827 & 317 & 48 & 949 & 7 & 1,058 \\
\hline $\begin{array}{l}\text { Other Electric Deductions.............................................. } \\
\text { Allowance for Other Funds Used }\end{array}$ & 0 & 4 & 0 & 140 & 74 & $\mathbf{0}$ \\
\hline 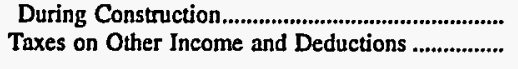 & $\begin{array}{l}0 \\
0\end{array}$ & $\begin{array}{l}0 \\
0\end{array}$ & $\begin{array}{l}\mathbf{0} \\
\mathbf{0}\end{array}$ & $\begin{array}{l}0 \\
0\end{array}$ & $\begin{array}{l}\mathbf{0} \\
\mathbf{0}\end{array}$ & $\begin{array}{l}\mathbf{0} \\
\mathbf{0}\end{array}$ \\
\hline 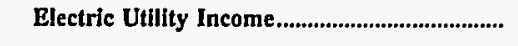 & 1,623 & 923 & 1,159 & 24,929 & 1,572 & 6,526 \\
\hline 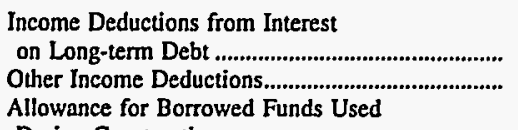 & $\begin{array}{r}198 \\
0\end{array}$ & $\begin{array}{r}0 \\
20\end{array}$ & $\begin{array}{l}\mathbf{0} \\
\mathbf{0}\end{array}$ & $\begin{array}{r}10,268 \\
0\end{array}$ & $\begin{array}{r}775 \\
0\end{array}$ & $\begin{array}{r}3,354 \\
0\end{array}$ \\
\hline 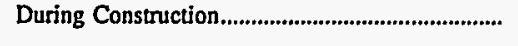 & 0 & 0 & 0 & 0 & $\mathbf{0}$ & $\mathbf{0}$ \\
\hline 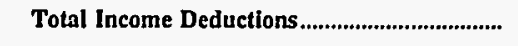 & 198 & 20 & 0 & 10,268 & 775 & $\mathbf{3 , 3 5 4}$ \\
\hline 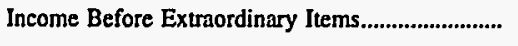 & 1,425 & 903 & 1,159 & 14,661 & 797 & 3,172 \\
\hline Extraordinary Income & $\mathbf{0}$ & 0 & $\mathbf{0}$ & $\mathbf{0}$ & 0 & 0 \\
\hline 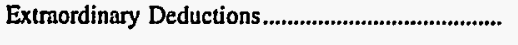 & 0 & 0 & 0 & 0 & 0 & $\mathbf{0}$ \\
\hline Net Income & 1,425 & 903 & 1,159 & 14,661 & 797 & 3,172 \\
\hline
\end{tabular}

Note: Totals may not equal sum of components because of independent rounding.

Source: Energy Information Administration, Form EIA-412, "Annual Report of Public Electric Utilities." 
Table 21. Statement of Income by Major U.S. Publicly Owned Electric Utility Within State, 1996 (Continued)

(Thousand Dollars)

\begin{tabular}{|c|c|c|c|c|c|c|}
\hline Item & $\begin{array}{c}\text { Ohio } \\
\text { Cuyahoga } \\
\text { Falls } \\
\text { City of } \\
\text { December } 31\end{array}$ & $\begin{array}{c}\text { Ohio } \\
\text { Dover } \\
\text { City of } \\
\text { December } 31\end{array}$ & $\begin{array}{l}\text { Ohio } \\
\text { Hamilton } \\
\text { City of } \\
\text { December } 31\end{array}$ & $\begin{array}{l}\text { Ohio } \\
\text { Napoleon } \\
\text { City of } \\
\text { December } 31\end{array}$ & $\begin{array}{l}\text { Ohio } \\
\text { Niles } \\
\text { City of } \\
\text { December } 31\end{array}$ & $\begin{array}{l}\text { Ohio } \\
\text { Orrville } \\
\text { City of } \\
\text { December } 31\end{array}$ \\
\hline Electric Utility Operating Revenues......................... & 22,270 & 10,783 & 45,508 & 9,549 & 17,798 & 16,188 \\
\hline 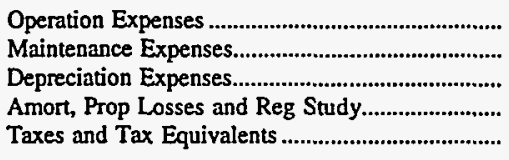 & $\begin{array}{r}18,368 \\
0 \\
777 \\
0 \\
0\end{array}$ & $\begin{array}{r}11,414 \\
0 \\
0 \\
0 \\
0\end{array}$ & $\begin{array}{r}25,010 \\
3,666 \\
7,333 \\
0 \\
0\end{array}$ & $\begin{array}{r}9,247 \\
0 \\
0 \\
0 \\
0\end{array}$ & $\begin{array}{r}15,879 \\
0 \\
0 \\
0 \\
0\end{array}$ & $\begin{array}{r}10,345 \\
2,082 \\
2,020 \\
0 \\
0\end{array}$ \\
\hline $\begin{array}{l}\text { Total Electric Utility Operating } \\
\text { Expenses }\end{array}$ & 19,144 & 11,414 & 36,010 & 9,247 & 15,879 & 14,447 \\
\hline 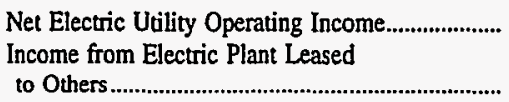 & 3,125 & -631 & 9,498 & 302 & 1,919 & 1,741 \\
\hline Electric Utility Operating Income......................... & 3,125 & -631 & 9,498 & 634 & 1,919 & 1,741 \\
\hline Other Electric Income & 0 & 74 & 2,365 & 0 & 71 & 0 \\
\hline $\begin{array}{l}\text { Other Electric Deductions } \\
\text { Allowance for Other Funds Used }\end{array}$ & 0 & 0 & 0 & 0 & 0 & 0 \\
\hline 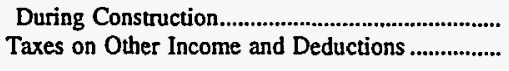 & $\begin{array}{l}0 \\
0\end{array}$ & $\begin{array}{l}0 \\
0\end{array}$ & $\begin{array}{l}0 \\
0\end{array}$ & $\begin{array}{l}0 \\
0\end{array}$ & $\begin{array}{l}0 \\
0\end{array}$ & $\begin{array}{l}0 \\
0\end{array}$ \\
\hline 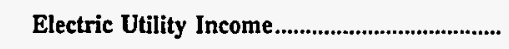 & 3,125 & -557 & 11,863 & 634 & 1,990 & 1,741 \\
\hline 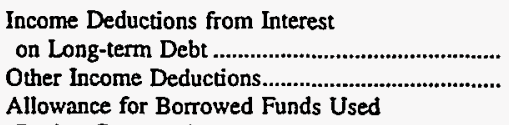 & $\begin{array}{r}270 \\
4\end{array}$ & $\begin{array}{r}-375 \\
0\end{array}$ & $\begin{array}{r}12,944 \\
0\end{array}$ & $\begin{array}{l}0 \\
0\end{array}$ & $\begin{array}{l}0 \\
0\end{array}$ & $\begin{array}{l}0 \\
0\end{array}$ \\
\hline 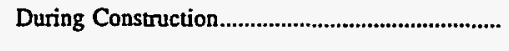 & 0 & 0 & 0 & 0 & 0 & 0 \\
\hline 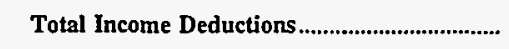 & 273 & -375 & 12,944 & $\mathbf{0}$ & $\mathbf{0}$ & $\mathbf{0}$ \\
\hline 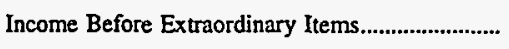 & 2,852 & -182 & $-1,080$ & 634 & 1,990 & 1,741 \\
\hline Extraordinary Income & 0 & 0 & 0 & 0 & 0 & 0 \\
\hline 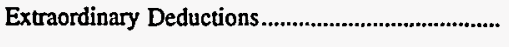 & 0 & 0 & 0 & 0 & 0 & 0 \\
\hline Net Income & 2,852 & -182 & $-1,080$ & 634 & 1,990 & 1,741 \\
\hline
\end{tabular}

Note: Totals may not equal sum of components because of independent rounding.

Source: Energy Information Administration, Form EIA-412, "Annual Report of Public Electric Utilities." 
Table 21. Statement of Income by Major U.S. Publicly Owned Electric Utility Within State, 1996 (Continued)

(Thousand Dollars)

\begin{tabular}{|c|c|c|c|c|c|c|}
\hline Item & $\begin{array}{c}\text { Ohio } \\
\text { Painesville } \\
\text { City of } \\
\text { December } 31\end{array}$ & $\begin{array}{c}\text { Ohio } \\
\text { Piqua } \\
\text { City of } \\
\text { December } 31\end{array}$ & $\begin{array}{c}\text { Ohio } \\
\text { St Marys } \\
\text { City of } \\
\text { December } 31\end{array}$ & $\begin{array}{c}\text { Ohio } \\
\text { Wadsworth } \\
\text { City of } \\
\text { December } 31\end{array}$ & $\begin{array}{c}\text { Ohio } \\
\text { Wapakoneta } \\
\text { City of } \\
\text { December } 31\end{array}$ & $\begin{array}{c}\text { Ohio } \\
\text { Westerville } \\
\text { City of } \\
\text { December } 31\end{array}$ \\
\hline Electric Utility Operating Revenues....................... & 14,050 & 15,532 & 7,737 & 13,282 & 7,292 & 19,412 \\
\hline 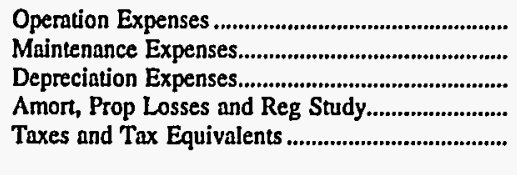 & $\begin{array}{r}11,688 \\
0 \\
1,155 \\
0 \\
0\end{array}$ & $\begin{array}{r}10,747 \\
959 \\
1,086 \\
0 \\
0\end{array}$ & $\begin{array}{r}5,725 \\
846 \\
157 \\
0 \\
0\end{array}$ & $\begin{array}{r}13,239 \\
0 \\
118 \\
0 \\
0\end{array}$ & $\begin{array}{r}7,090 \\
0 \\
513 \\
0 \\
0\end{array}$ & $\begin{array}{r}12,393 \\
1,139 \\
1,114 \\
0 \\
0\end{array}$ \\
\hline $\begin{array}{l}\text { Total Electric Utility Operating } \\
\text { Expenses ................................................................ }\end{array}$ & 12,843 & 12,792 & 6,728 & 13,357 & 7,602 & 14,647 \\
\hline 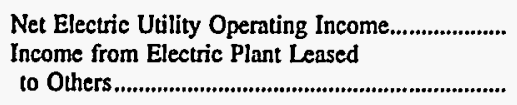 & 1,206 & 2,740 & 1,009 & -76 & $\begin{array}{r}-311 \\
0\end{array}$ & 4,766 \\
\hline Electric Utility Operating Income..................... & 1,206 & 2,740 & 1,009 & -76 & -311 & 4,766 \\
\hline 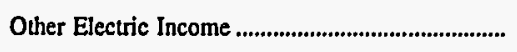 & 177 & 388 & 247 & 1,017 & $\mathbf{0}$ & 0 \\
\hline 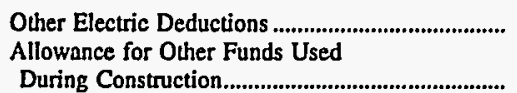 & 17 & 225 & 0 & 867 & 0 & 0 \\
\hline 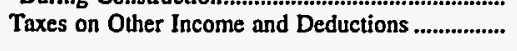 & 0 & 0 & 0 & 0 & $\begin{array}{l}0 \\
0\end{array}$ & 0 \\
\hline 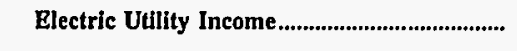 & 1,366 & 2,903 & 1,256 & 75 & -311 & 4,766 \\
\hline 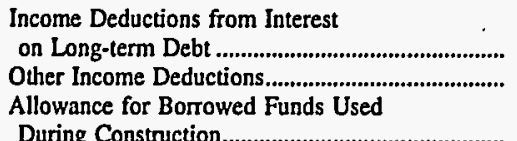 & $\begin{array}{r}346 \\
1\end{array}$ & $\begin{array}{r}470 \\
0\end{array}$ & $\begin{array}{r}-287 \\
-1 \\
0\end{array}$ & $\begin{array}{l}0 \\
0\end{array}$ & $\begin{array}{l}0 \\
0\end{array}$ & $\begin{array}{l}0 \\
0\end{array}$ \\
\hline 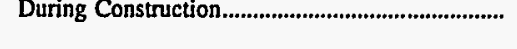 & 0 & 0 & 0 & 0 & 0 & 0 \\
\hline 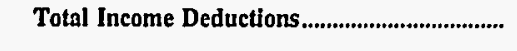 & 347 & 470 & -288 & $\mathbf{0}$ & 0 & o \\
\hline Income Before Extraordinary ltems.............................. & 1,019 & 2,434 & 1,544 & 75 & -311 & 4,766 \\
\hline Extraordinary Income & 5 & 0 & 0 & 0 & $\mathbf{0}$ & $\mathbf{0}$ \\
\hline 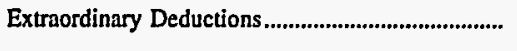 & 27 & 0 & 0 & 0 & $\mathbf{0}$ & 0 \\
\hline 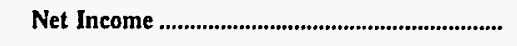 & 997 & 2,434 & 1,544 & 75 & -311 & 4,766 \\
\hline
\end{tabular}

Note: Totals may not equal sum of components because of independent rounding.

Source: Energy Information Administration, Form ElA-412, “Annual Report of Public Electric Utilities." 
Table 21. Statement of Income by Major U.S. Publicly Owned Electric Utility Within State, 1996 (Continued)

(Thousand Dollars)

\begin{tabular}{|c|c|c|c|c|c|c|}
\hline Item & $\begin{array}{l}\text { Oklahoma } \\
\text { Altus } \\
\text { City of } \\
\text { June } 30\end{array}$ & $\begin{array}{l}\text { Oklahoma } \\
\text { Claremore } \\
\text { City of } \\
\text { June } 30\end{array}$ & $\begin{array}{l}\text { Oklahoma } \\
\text { Duncan } \\
\text { City of } \\
\text { June } 30\end{array}$ & $\begin{array}{l}\text { Oklahoma } \\
\text { Edmond } \\
\text { City of } \\
\text { June } 30\end{array}$ & $\begin{array}{l}\text { Oklahoma } \\
\text { Grand River } \\
\text { Dam } \\
\text { Authority } \\
\text { December } 31\end{array}$ & $\begin{array}{l}\text { Oklahoma } \\
\text { Miami } \\
\text { City of } \\
\text { June } 30\end{array}$ \\
\hline 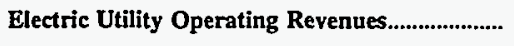 & 10,605 & 13,648 & 8,582 & 32,077 & 173,231 & 7,688 \\
\hline 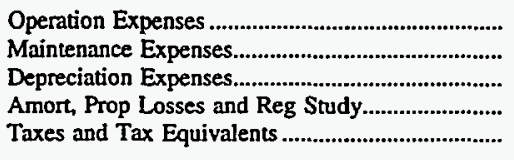 & $\begin{array}{r}8,852 \\
39 \\
492 \\
0 \\
0\end{array}$ & $\begin{array}{r}8,562 \\
1,184 \\
0 \\
0 \\
0\end{array}$ & $\begin{array}{r}6,131 \\
0 \\
703 \\
0 \\
0\end{array}$ & $\begin{array}{r}26,950 \\
118 \\
1,289 \\
0 \\
2,932\end{array}$ & $\begin{array}{r}80,820 \\
12,397 \\
25,480 \\
0 \\
0\end{array}$ & $\begin{array}{r}5,667 \\
549 \\
129 \\
0 \\
1,038\end{array}$ \\
\hline $\begin{array}{l}\text { Total Electric Utility Operating } \\
\text { Expenses }\end{array}$ & 9,383 & 9,746 & 6,834 & 31,289 & 118,697 & 7,383 \\
\hline 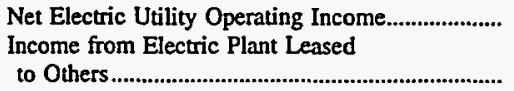 & 1,222 & 3,902 & 1,748 & 788 & $\begin{array}{r}54,534 \\
0\end{array}$ & $\begin{array}{r}305 \\
0\end{array}$ \\
\hline 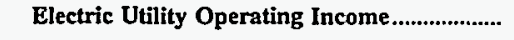 & 1,222 & 3,902 & 1,748 & 788 & 54,534 & 305 \\
\hline Other Electric Income & 577 & 0 & 275 & 486 & 15,850 & 340 \\
\hline $\begin{array}{l}\text { Other Electric Deductions....................... } \\
\text { Allowance for Other Funds Used }\end{array}$ & $\mathbf{0}$ & 0 & 0 & 36 & 77 & 0 \\
\hline 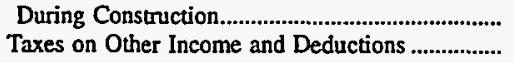 & $\begin{array}{l}\mathbf{0} \\
0\end{array}$ & $\begin{array}{l}0 \\
0\end{array}$ & $\begin{array}{l}0 \\
0\end{array}$ & $\begin{array}{l}0 \\
0\end{array}$ & $\begin{array}{l}0 \\
0\end{array}$ & $\begin{array}{l}\mathbf{0} \\
\mathbf{0}\end{array}$ \\
\hline 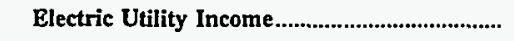 & 1,799 & 3,902 & 2,023 & 1,237 & 70,307 & 645 \\
\hline 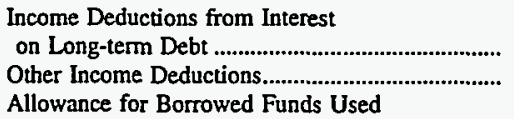 & $\begin{array}{l}0 \\
0\end{array}$ & $\begin{array}{l}0 \\
0\end{array}$ & $\begin{array}{r}0 \\
2,722\end{array}$ & $\begin{array}{r}142 \\
0\end{array}$ & $\begin{array}{l}57,908 \\
14,216\end{array}$ & $\begin{array}{l}0 \\
0\end{array}$ \\
\hline During Construction & $\mathbf{0}$ & 0 & 0 & 0 & 0 & 0 \\
\hline 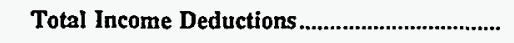 & $\mathbf{0}$ & 0 & 2,722 & 142 & 72,124 & $\mathbf{0}$ \\
\hline 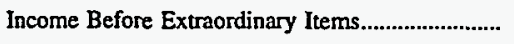 & 1,799 & 3,902 & -700 & 1,095 & $-1,817$ & 645 \\
\hline Extraordinary Income & $\mathbf{0}$ & 0 & 0 & 0 & 0 & 0 \\
\hline 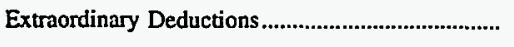 & 1,619 & 0 & 0 & 0 & 215 & 0 \\
\hline Net Income & 180 & 3,902 & -700 & 1,095 & $-2,032$ & 645 \\
\hline
\end{tabular}

Note: Totals may not equal sum of components because of independent rounding.

Source: Energy Information Administration, Form EIA-412, "Annual Report of Public Electric Utilities." 
Table 21. Statement of Income by Major U.S. Publicly Owned Electric Utility Within State, 1996 (Continued)

(Thousand Dollars)

\begin{tabular}{|c|c|c|c|c|c|c|}
\hline Item & $\begin{array}{c}\text { Oklahoma } \\
\text { Oklahoma } \\
\text { Municipal } \\
\text { Power Auth } \\
\text { December } 31\end{array}$ & $\begin{array}{l}\text { Oklahoma } \\
\text { Ponca } \\
\text { City City of } \\
\text { June } 30\end{array}$ & $\begin{array}{l}\text { Oklahoma } \\
\text { Stillwater } \\
\text { Utilities } \\
\text { Authority } \\
\text { June } 30\end{array}$ & $\begin{array}{l}\text { Oregon } \\
\text { Ashland } \\
\text { City of } \\
\text { June } 30\end{array}$ & $\begin{array}{c}\text { Oregon } \\
\text { Central } \\
\text { Lincoln } \\
\text { Peoples } \\
\text { Ud Dt } \\
\text { December } 31\end{array}$ & $\begin{array}{l}\text { Oregon } \\
\text { Clatskanie } \\
\text { Peoples } \\
\text { Util Dist } \\
\text { December } 31\end{array}$ \\
\hline Electric Utility Operating Revenues....................... & 76,990 & 22,224 & 24,298 & 7,353 & 54,280 & 26,562 \\
\hline 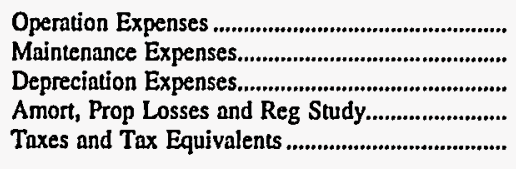 & $\begin{array}{r}56,634 \\
1,464 \\
6,273 \\
0 \\
1,268\end{array}$ & $\begin{array}{r}16,538 \\
1,369 \\
806 \\
0 \\
3,402\end{array}$ & $\begin{array}{r}15,976 \\
1,556 \\
1,794 \\
0 \\
3,473\end{array}$ & $\begin{array}{r}5,962 \\
496 \\
0 \\
0 \\
814\end{array}$ & $\begin{array}{r}42,471 \\
1,232 \\
3,850 \\
0 \\
1,949\end{array}$ & $\begin{array}{r}24,747 \\
614 \\
403 \\
0 \\
132\end{array}$ \\
\hline 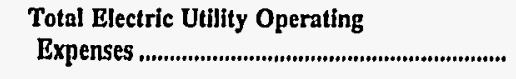 & 65,639 & 22,114 & 22,799 & 7,272 & 49,502 & 25,895 \\
\hline 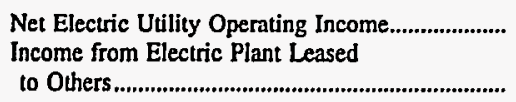 & $\begin{array}{r}11,351 \\
18\end{array}$ & 109 & $\begin{array}{r}1,500 \\
0\end{array}$ & $\begin{array}{r}81 \\
0\end{array}$ & $\begin{array}{r}4,778 \\
0\end{array}$ & 666 \\
\hline Electric Utility Operating Income..................... & 11,370 & 109 & 1,500 & 81 & 4,778 & 666 \\
\hline Other Electric Income & 5,748 & 295 & 961 & 823 & 677 & 538 \\
\hline $\begin{array}{l}\text { Other Electric Deductions } \\
\text { Allowance for Other Funds Used }\end{array}$ & $\mathbf{0}$ & 0 & 0 & 0 & 0 & 0 \\
\hline 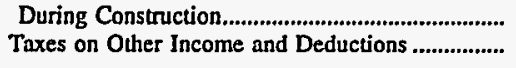 & $\begin{array}{l}0 \\
0\end{array}$ & $\begin{array}{l}0 \\
0\end{array}$ & $\begin{array}{l}\mathbf{0} \\
\mathbf{0}\end{array}$ & $\begin{array}{l}0 \\
0\end{array}$ & $\begin{array}{l}0 \\
0\end{array}$ & $\begin{array}{l}0 \\
0\end{array}$ \\
\hline 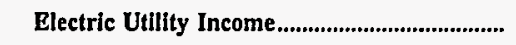 & 17,117 & 405 & 2,460 & 904 & 5,455 & 1,204 \\
\hline 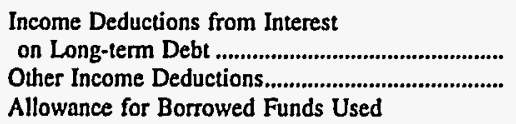 & $\begin{array}{r}21,348 \\
548\end{array}$ & $\begin{array}{l}0 \\
0\end{array}$ & $\begin{array}{l}0 \\
0\end{array}$ & $\begin{array}{l}0 \\
0\end{array}$ & $\begin{array}{l}993 \\
154\end{array}$ & $\begin{array}{l}0 \\
0\end{array}$ \\
\hline 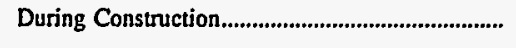 & 0 & 0 & 0 & 0 & $\mathbf{0}$ & 0 \\
\hline 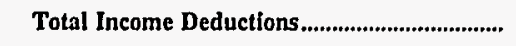 & 21,895 & $\mathbf{0}$ & o & $\mathbf{0}$ & 1,148 & 0 \\
\hline 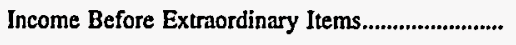 & $-4,778$ & 405 & 2,460 & 904 & 4,307 & 1,204 \\
\hline 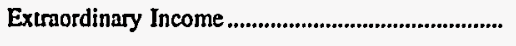 & 6,845 & 0 & 0 & $\mathbf{0}$ & 0 & 0 \\
\hline 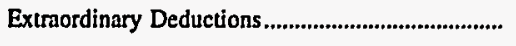 & 0 & 0 & 0 & $\mathbf{0}$ & 0 & 0 \\
\hline 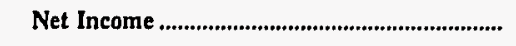 & 2,067 & 405 & 2,460 & 904 & 4,307 & 1,204 \\
\hline
\end{tabular}

Note: Totals may not equal sum of components because of independent rounding.

Source: Energy Information Administration, Form EIA-412, "Annual Report of Public Electric Utilities." 
Table 21. Statement of Income by Major U.S. Publicly Owned Electric Utility Within State, 1996 (Continued)

(Thousand Dollars)

\begin{tabular}{|c|c|c|c|c|c|c|}
\hline Item & $\begin{array}{l}\text { Oregon } \\
\text { Columbia } \\
\text { River } \\
\text { Peoples } \\
\text { Ut Dist } \\
\text { December } 31\end{array}$ & $\begin{array}{l}\text { Oregon } \\
\text { Emerald } \\
\text { Peoples } \\
\text { Utility Dist } \\
\text { December } 31\end{array}$ & $\begin{array}{l}\text { Oregon } \\
\text { Eugene } \\
\text { City of } \\
\text { December } 31\end{array}$ & $\begin{array}{l}\text { Oregon } \\
\text { Forest Grove } \\
\text { City of } \\
\text { June } 30\end{array}$ & $\begin{array}{l}\text { Oregon } \\
\begin{array}{l}\text { McMinnville } \\
\text { City of }\end{array} \\
\text { June } 30\end{array}$ & $\begin{array}{c}\text { Oregon } \\
\text { Northem } \\
\text { Wasco } \\
\text { County PUD } \\
\text { December } 31\end{array}$ \\
\hline Electric Utility Operating Revenues.......................... & 13,261 & 22,879 & 103,735 & 8,508 & 23,336 & 13,423 \\
\hline Operation Expenses & 9,837 & 12,665 & 72,204 & 6,920 & 21,475 & 9,405 \\
\hline 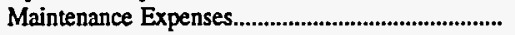 & 513 & 1,417 & 4,392 & 417 & 0 & 620 \\
\hline 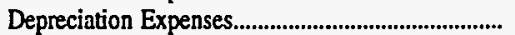 & 535 & 2,381 & 11,097 & 428 & 822 & 1,124 \\
\hline 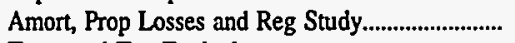 & 228 & 727 & 0 & 0 & 0 & 0 \\
\hline 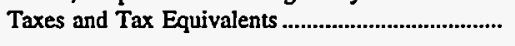 & 241 & 370 & 6,929 & 470 & 1,192 & 483 \\
\hline 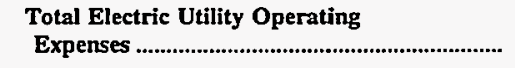 & 11,355 & 17,560 & 94,622 & 8,235 & 23,489 & 11,633 \\
\hline $\begin{array}{l}\text { Net Electric Utility Operating Income....................... } \\
\text { Income from Electric Plant Leased }\end{array}$ & 1,906 & 5,319 & 9,114 & 273 & -153 & 1,791 \\
\hline 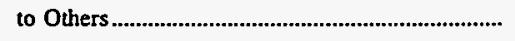 & 0 & 10 & 0 & 0 & 0 & 0 \\
\hline 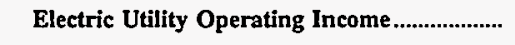 & 1,906 & 5,329 & 9,114 & 273 & -153 & 1,791 \\
\hline Other Electric Income & 870 & 1,163 & 3,138 & 74 & 722 & 1,226 \\
\hline $\begin{array}{l}\text { Other Electric Deductions } \\
\text { Allowance for Other Funds Used }\end{array}$ & 0 & 0 & 1,700 & 0 & 0 & 0 \\
\hline During Construction.......................... & 0 & 0 & 248 & 0 & 0 & 0 \\
\hline 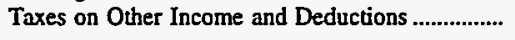 & 0 & 0 & 0 & 0 & 0 & 0 \\
\hline 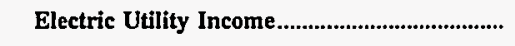 & 2,776 & 6,493 & 10,799 & 347 & 570 & $\mathbf{3 , 0 1 7}$ \\
\hline $\begin{array}{l}\text { Income Deductions from Interest } \\
\text { on Long-term Debt }\end{array}$ & 915 & 4,041 & 5,680 & 0 & 0 & 2,278 \\
\hline 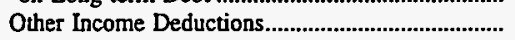 & 179 & 788 & 0 & 61 & 250 & 113 \\
\hline 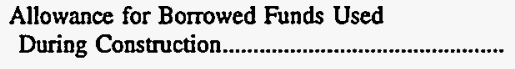 & 0 & 0 & -193 & 0 & 0 & 0 \\
\hline 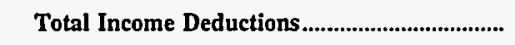 & 1,094 & 4,829 & 5,486 & 61 & 250 & 2,391 \\
\hline 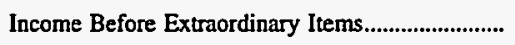 & 1,682 & 1,664 & 5,313 & 286 & 319 & 625 \\
\hline Extraordinary Income & 0 & 0 & 0 & 0 & 0 & 0 \\
\hline 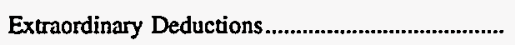 & 0 & 0 & 0 & $\mathbf{0}$ & 0 & 0 \\
\hline 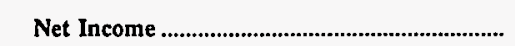 & 1,682 & 1,664 & 5,313 & 286 & 319 & 625 \\
\hline
\end{tabular}

Note: Totals may not equal sum of components because of independent rounding.

Source: Energy Information Administration, Form EIA-412, "Annual Report of Public Electric Utilities." 
Table 21. Statement of Income by Major U.S. Publicly Owned Electric Utility Within State, 1996 (Continued)

(Thousand Dollars)

\begin{tabular}{|c|c|c|c|c|c|c|}
\hline Item & $\begin{array}{c}\text { Oregon } \\
\text { Springfield } \\
\text { City of } \\
\text { December } 31\end{array}$ & $\begin{array}{l}\text { Oregon } \\
\text { Tillamook } \\
\text { Peoples } \\
\text { Utility Dist } \\
\text { December } 31\end{array}$ & $\begin{array}{l}\text { Pennsylvania } \\
\text { Chambersburg } \\
\text { Borough of } \\
\text { December } 31\end{array}$ & $\begin{array}{c}\text { Pennsylvania } \\
\text { Ephrata } \\
\text { Borough of } \\
\text { December } 31\end{array}$ & $\begin{array}{l}\text { Pennsylvania } \\
\text { Lansdale } \\
\text { Borough of } \\
\text { December } 31\end{array}$ & $\begin{array}{l}\text { South Carolina } \\
\text { Camden } \\
\text { City of } \\
\text { June } 30\end{array}$ \\
\hline Electric Utility Operating Revenues....................... & 32,791 & 19,031 & 14,879 & 8,932 & 10,438 & 11,095 \\
\hline 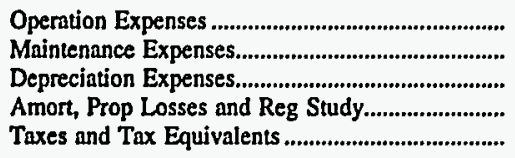 & $\begin{array}{r}24,620 \\
1,266 \\
1,207 \\
169 \\
1,481\end{array}$ & $\begin{array}{r}15,185 \\
1,004 \\
1,273 \\
41 \\
571\end{array}$ & $\begin{array}{r}11,724 \\
377 \\
627 \\
0 \\
0\end{array}$ & $\begin{array}{r}8,820 \\
0 \\
0 \\
0 \\
0\end{array}$ & $\begin{array}{r}6,035 \\
731 \\
396 \\
0 \\
0\end{array}$ & $\begin{array}{r}9,675 \\
0 \\
0 \\
0 \\
0\end{array}$ \\
\hline $\begin{array}{c}\text { Total Electric Utility Operating } \\
\text { Expenses ................................................................... }\end{array}$ & 28,744 & 18,074 & 12,727 & 8,820 & 7,163 & 9,675 \\
\hline 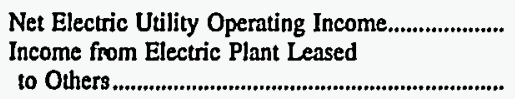 & 4,047 & 957 & 2,152 & .112 & 3,276 & $\begin{array}{r}1,420 \\
0\end{array}$ \\
\hline Electric Utility Operating Income.................... & 4,047 & 957 & 2,152 & 112 & 3,276 & $1, \mathbf{4 2 0}$ \\
\hline Other Electric Income & 649 & 732 & 554 & 0 & 888 & 1,149 \\
\hline $\begin{array}{l}\text { Other Electric Deductions ......................................... } \\
\text { Allowance for Other Funds Used }\end{array}$ & 0 & 0 & 551 & 0 & 452 & 0 \\
\hline 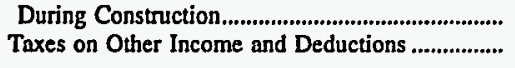 & $\begin{array}{r}21 \\
0\end{array}$ & $\begin{array}{l}0 \\
0\end{array}$ & $\begin{array}{l}0 \\
0\end{array}$ & $\begin{array}{l}0 \\
0\end{array}$ & $\begin{array}{l}0 \\
0\end{array}$ & $\begin{array}{l}0 \\
0\end{array}$ \\
\hline 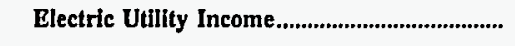 & 4,717 & 1,689 & 2,156 & 112 & 3,712 & 2,569 \\
\hline 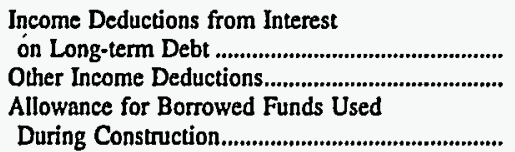 & $\begin{array}{r}170 \\
34\end{array}$ & $\begin{array}{r}714 \\
42\end{array}$ & $\begin{array}{l}0 \\
0\end{array}$ & $\begin{array}{l}0 \\
0\end{array}$ & $\begin{array}{l}0 \\
0\end{array}$ & $\begin{array}{r}222 \\
0 \\
0\end{array}$ \\
\hline Total Income Deductions.......................................... & 204 & 720 & $\mathbf{0}$ & $\mathbf{0}$ & 0 & 222 \\
\hline Income Before Extraordinary Items............................. & 4,513 & 969 & 2,156 & 112 & 3,712 & 2,347 \\
\hline Extraordinary Income & 0 & 0 & $\mathbf{0}$ & 0 & $\cdot 0$ & 95 \\
\hline 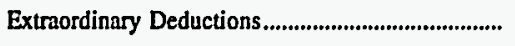 & 0 & 0 & 0 & 0 & 0 & 2,147 \\
\hline Net Income & 4,513 & 969 & 2,156 & 112 & 3,712 & 294 \\
\hline
\end{tabular}

Note: Totals may not equal sum of components because of independent rounding.

Source: Energy Information Administration, Form EIA-412, "Annual Report of Public Electric Utilities." 
Table 21. Statement of Income by Major U.S. Publicly Owned Electric Utility Within State, 1996 (Continued)

(Thousand Dollars)

\begin{tabular}{|c|c|c|c|c|c|c|}
\hline Item & $\begin{array}{l}\text { South Carolina } \\
\text { Easley } \\
\text { Combined } \\
\text { Utility } \\
\text { System } \\
\text { March } 31\end{array}$ & $\begin{array}{l}\text { South Carolina } \\
\text { Gaffney } \\
\text { City of } \\
\text { March 31 }\end{array}$ & $\begin{array}{l}\text { South Carolina } \\
\text { Greenwood } \\
\text { Commissioners } \\
\text { Pub Wk } \\
\text { December } 31\end{array}$ & $\begin{array}{c}\text { South Carolina } \\
\text { Greer } \\
\text { Comm } \\
\text { of } \\
\text { Public Works } \\
\text { December } 31\end{array}$ & $\begin{array}{l}\text { South Carolina } \\
\text { Newberry } \\
\text { City of } \\
\text { June } 30\end{array}$ & $\begin{array}{l}\text { South Carolina } \\
\text { Orangeburg } \\
\text { City of } \\
\text { September } 30\end{array}$ \\
\hline Electric Utility Operating Revenues..................... & 15,656 & 13,449 & 15,371 & 12,427 & 10,680 & 42,054 \\
\hline Operation Expenses & 12,209 & 10,854 & 13,249 & 10,696 & 9,318 & 35,029 \\
\hline Maintenance Expenses.............................................. & 499 & 86 & 0 & 0 & 0 & 0 \\
\hline 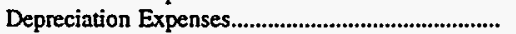 & 594 & 948 & 449 & 609 & 237 & 1,579 \\
\hline 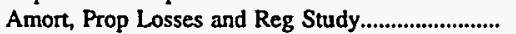 & 0 & 0 & $\mathbf{0}$ & 0 & 0 & 0 \\
\hline 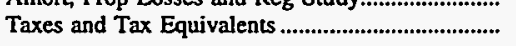 & 0 & 0 & 0 & 0 & 0 & 0 \\
\hline 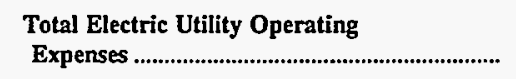 & 13,302 & 11,888 & 13,699 & 11,305 & 9,555 & 36,608 \\
\hline $\begin{array}{l}\text { Net Electric Utility Operating Income....................... } \\
\text { Income from Electric Plant Leased }\end{array}$ & 2,353 & 1,560 & 1,673 & 1,122 & 1,125 & 5,446 \\
\hline to Others & 0 & 0 & 0 & 0 & 0 & 0 \\
\hline Electric Utility Operating Income.................... & 2,353 & 1,560 & 1,673 & 1,122 & 1,125 & 5,446 \\
\hline Other Electric Income & 0 & 405 & 270 & 2,265 & 331 & 468 \\
\hline $\begin{array}{l}\text { Other Electric Deductions } \\
\text { Allowance for Other Funds Used }\end{array}$ & 181 & 131 & 0 & 0 & 103 & 0 \\
\hline $\begin{array}{l}\text { During Construction } \\
\text { Taxes on Other Income and Deductions }\end{array}$ & $\begin{array}{l}0 \\
0\end{array}$ & $\begin{array}{l}0 \\
0\end{array}$ & $\begin{array}{l}0 \\
0\end{array}$ & $\begin{array}{l}\mathbf{0} \\
\mathbf{0}\end{array}$ & $\begin{array}{l}0 \\
0\end{array}$ & $\begin{array}{l}0 \\
0\end{array}$ \\
\hline 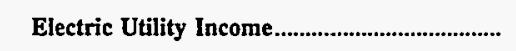 & 2,172 & 1,835 & 1,943 & 3,387 & 1,353 & 5,914 \\
\hline 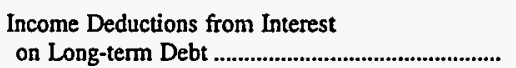 & 199 & 0 & $\mathbf{0}$ & 576 & 76 & 0 \\
\hline 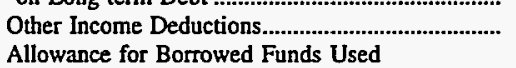 & 1,005 & 0 & 0 & 1,273 & 0 & 0 \\
\hline During Construction & 0 & $\mathbf{0}$ & 0 & 0 & $\mathbf{0}$ & 0 \\
\hline 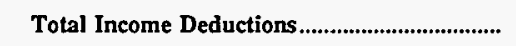 & 1,205 & $\mathbf{0}$ & $\mathbf{0}$ & 1,849 & 76 & 0 \\
\hline 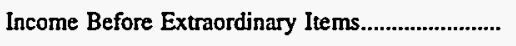 & 968 & 1,835 & 1,943 & 1,538 & 1,278 & 5,914 \\
\hline Extraordinary Income & 0 & $\mathbf{0}$ & 0 & 0 & 0 & 0 \\
\hline 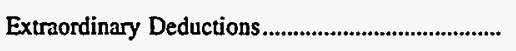 & 0 & 0 & 0 & 0 & 0 & 0 \\
\hline 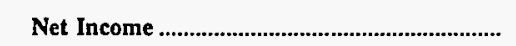 & 968 & 1,835 & 1,943 & 1,538 & 1,278 & 5,914 \\
\hline
\end{tabular}

Note: Totals may not equal sum of components because of independent rounding.

Source: Energy Information Administration, Form EIA-412, "Annual Report of Public Electric Utilities." 
Table 21. Statement of Income by Major U.S. Publicly Owned Electric Utility Within State, 1996 (Continued)

(Thousand Dollars)

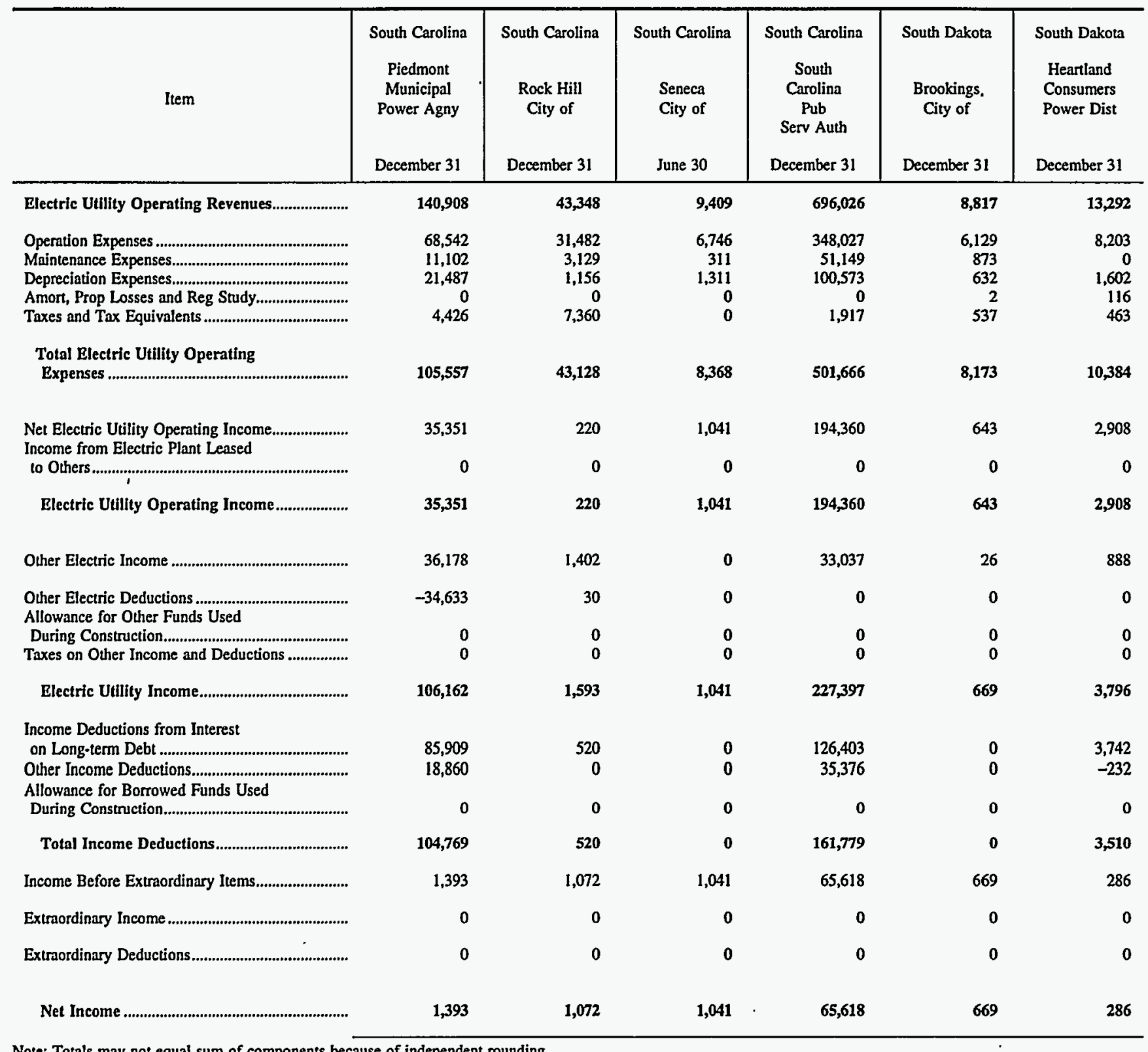

Note: Totals may not equal sum of components because of independent rounding.

Source: Energy Information Administration, Form EIA-412, "Annual Report of Public Electric Utilities." 
Table 21. Statement of Income by Major U.S. Publicly Owned Electric Utility Within State, 1996 (Continued)

(Thousand Dollars)

\begin{tabular}{|c|c|c|c|c|c|c|}
\hline Item & $\begin{array}{l}\text { South Dakota } \\
\text { Missouri } \\
\text { Basin } \\
\text { Mun } \\
\text { Power Agny } \\
\text { December } 31\end{array}$ & $\begin{array}{c}\text { South Dakota } \\
\text { Pierre } \\
\text { City of } \\
\text { December } 31\end{array}$ & $\begin{array}{l}\text { South Dakota } \\
\text { Watertown } \\
\text { Municipal } \\
\text { Utilities } \\
\text { December } 31\end{array}$ & $\begin{array}{l}\text { Tennessee } \\
\text { Alcoa } \\
\text { Utilities } \\
\text { June } 30\end{array}$ & $\begin{array}{l}\text { Tennessee } \\
\text { Athens } \\
\text { Utility } \\
\text { Board } \\
\text { June } 30\end{array}$ & $\begin{array}{l}\text { Tennessee } \\
\text { Benton } \\
\text { County } \\
\text { June } 30\end{array}$ \\
\hline Electric Utility Operating Revenues...................... & 61,786 & 7,471 & 9,997 & 27,469 & 27,206 & 12,855 \\
\hline Operation Expenses & 59,030 & 5,156 & 7,871 & 24,677 & 24,814 & 11,280 \\
\hline 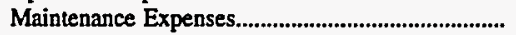 & 0 & 209 & 737 & 1,010 & 913 & 747 \\
\hline 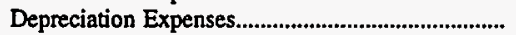 & 79 & 0 & 831 & 716 & 651 & 506 \\
\hline Amort, Prop Losses and Reg Study............................... & 0 & 0 & 0 & 0 & 2 & 0 \\
\hline 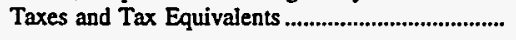 & 19 & 0 & 494 & 528 & 530 & 361 \\
\hline Total Electric Utility Operating & & & & & & \\
\hline Expenses & 59,128 & 5,365 & 9,933 & 26,930 & 26,911 & 12,895 \\
\hline $\begin{array}{l}\text { Net Electric Utility Operating Income......................... } \\
\text { Income from Electric Plant Leased }\end{array}$ & 2,658 & 2,106 & 63 & 539 & 295 & -40 \\
\hline 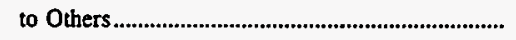 & 0 & 0 & 0 & 0 & $\mathbf{0}$ & 0 \\
\hline Electric Utility Operating Income..................... & 2,658 & 2,106 & 63 & 539 & 295 & -40 \\
\hline Other Electric Income & 1,241 & -66 & 339 & 627 & 301 & 337 \\
\hline $\begin{array}{l}\text { Other Electric Deductions } \\
\text { Allowance for Other Funds Used }\end{array}$ & $\mathbf{0}$ & 2,060 & 67 & 0 & 38 & 0 \\
\hline 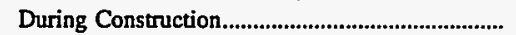 & $\mathbf{0}$ & 0 & 0 & 0 & 0 & 0 \\
\hline Taxes on Other Income and Deductions .................. & 0 & 0 & 0 & 0 & 0 & 0 \\
\hline Electric Utility Income............................................ & 3,899 & -20 & 335 & 1,166 & 557 & 296 \\
\hline $\begin{array}{l}\text { Income Deductions from Interest } \\
\text { on Long-term Debt }\end{array}$ & 0 & 0 & 0 & 05 & 0 & \\
\hline 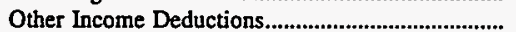 & 0 & 0 & 0 & 95 & 0 & 24 \\
\hline Allowance for Borrowed Funds Used & & & & 10 & 0 & 1 \\
\hline 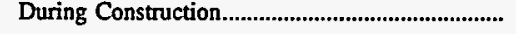 & 0 & 0 & 0 & 0 & 0 & 0 \\
\hline Total Income Deductions............................................ & 0 & $\mathbf{0}$ & 295 & 110 & $\mathbf{0}$ & 26 \\
\hline Income Before Extraordinary Items............................... & 3,899 & -20 & 40 & 1,056 & 557 & 271 \\
\hline Extraordinary Income & $\mathbf{0}$ & 0 & 0 & 0 & 0 & 0 \\
\hline 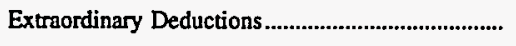 & 0 & 0 & 0 & 0 & 0 & 0 \\
\hline 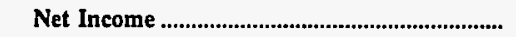 & 3,899 & -20 & 40 & 1,056 & $\mathbf{5 5 7}$ & 271 \\
\hline
\end{tabular}

Note: Totals may not equal sum of components because of independent rounding.

Source: Energy Information Administration, Form EIA-412, "Annual Report of Public Electric Utilities." 
Table 21. Statement of Income by Major U.S. Publicly Owned Electric Utility

Within State, 1996 (Continued)

(Thousand Dollars)

\begin{tabular}{|c|c|c|c|c|c|c|}
\hline Item & $\begin{array}{l}\text { Tennessee } \\
\text { Bolivar } \\
\text { City of } \\
\text { June } 30\end{array}$ & $\begin{array}{l}\text { Tennessee } \\
\text { Bristol } \\
\text { City of } \\
\text { June } 30\end{array}$ & $\begin{array}{c}\text { Tennessee } \\
\text { Brownsville } \\
\text { City of } \\
\text { June } 30\end{array}$ & $\begin{array}{l}\text { Tennessee } \\
\text { Carroll } \\
\text { County } \\
\text { June } 30\end{array}$ & $\begin{array}{c}\text { Tennessee } \\
\text { Chattanooga } \\
\text { City of } \\
\text { June } 30\end{array}$ & $\begin{array}{c}\text { Tennessee } \\
\text { Clarksville } \\
\text { City of } \\
\text { June } 30\end{array}$ \\
\hline Electric Utiltity Operating Revenues........................ & 13,896 & 44,641 & 9,984 & 22,797 & 307,823 & 55,125 \\
\hline 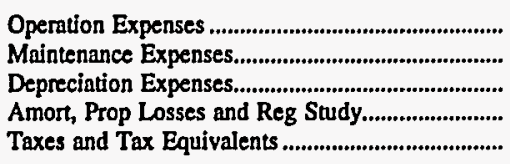 & $\begin{array}{r}12,426 \\
456 \\
1,555 \\
0 \\
361\end{array}$ & $\begin{array}{r}40,393 \\
2,030 \\
1,308 \\
0 \\
1,004\end{array}$ & $\begin{array}{r}9,238 \\
152 \\
220 \\
37 \\
193\end{array}$ & $\begin{array}{r}20,204 \\
716 \\
656 \\
-24 \\
436\end{array}$ & $\begin{array}{r}277,085 \\
11,701 \\
9,063 \\
0 \\
7,513\end{array}$ & $\begin{array}{r}48,832 \\
1,717 \\
1,292 \\
1,862 \\
1,094\end{array}$ \\
\hline 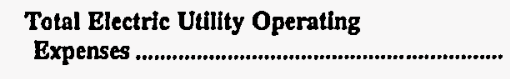 & 14,797 & 44,735 & 9,839 & 21,988 & 305,361 & 54,796 \\
\hline 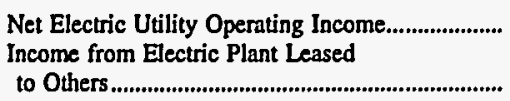 & $\begin{array}{r}-901 \\
0\end{array}$ & -94 & 146 & $\begin{array}{r}809 \\
0\end{array}$ & $\begin{array}{r}2,462 \\
0\end{array}$ & 328 \\
\hline Electric Utility Operating Income..................... & -901 & -94 & 146 & 809 & 2,462 & 328 \\
\hline Other Electric Income & 1,170 & 2,261 & 164 & 375 & 4,175 & 1,597 \\
\hline 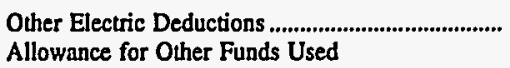 & 0 & 0 & $\mathbf{0}$ & 4 & 0 & 3 \\
\hline 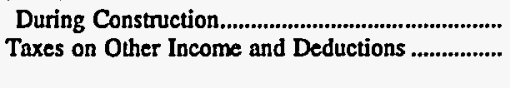 & $\begin{array}{l}0 \\
0\end{array}$ & $\begin{array}{l}0 \\
0\end{array}$ & $\begin{array}{l}0 \\
0\end{array}$ & $\begin{array}{l}0 \\
0\end{array}$ & $\begin{array}{l}\mathbf{0} \\
\mathbf{0}\end{array}$ & $\begin{array}{l}0 \\
0\end{array}$ \\
\hline 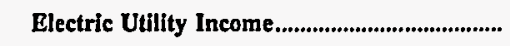 & 269 & 2,168 & 310 & 1,181 & 6,636 & 1,923 \\
\hline 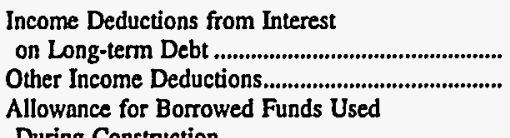 & $\begin{array}{r}145 \\
2\end{array}$ & $\begin{array}{r}0 \\
16\end{array}$ & $\begin{array}{r}27 \\
1\end{array}$ & $\begin{array}{r}37 \\
4\end{array}$ & $\begin{array}{r}0 \\
281\end{array}$ & $\begin{array}{r}436 \\
53\end{array}$ \\
\hline 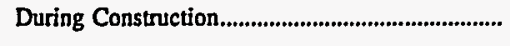 & 0 & $\mathbf{0}$ & 0 & 0 & 0 & 0 \\
\hline 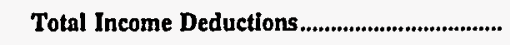 & 147 & 16 & 27 & 40 & 281 & 488 \\
\hline 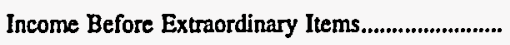 & 122 & 2,151 & 282 & 1,140 & 6,355 & 1,435 \\
\hline 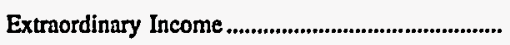 & 0 & 0 & 0 & 0 & 0 & 0 \\
\hline 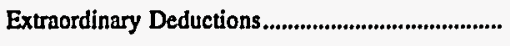 & 0 & 0 & $\mathbf{0}$ & 0 & 0 & 0 \\
\hline Net Income & 122 & 2,151 & 282 & 1,140 & 6,355 & 1,435 \\
\hline
\end{tabular}

Note: Totals may not equal sum of components because of independent rounding.

Source: Energy Information Administration, Form EIA-412, "Annual Report of Public Electric Utilities." 
Table 21. Statement of Income by Major U.S. Publicly Owned Electric Utility Within State, 1996 (Continued)

(Thousand Dollars)

\begin{tabular}{|c|c|c|c|c|c|c|}
\hline Item & $\begin{array}{l}\text { Tennessee } \\
\text { Cleveland } \\
\text { City of } \\
\text { June } 30\end{array}$ & $\begin{array}{l}\text { Tennessee } \\
\text { Clinton } \\
\text { City of } \\
\text { June } 30\end{array}$ & $\begin{array}{l}\text { Tennessee } \\
\text { Columbia } \\
\text { City of } \\
\text { June } 30\end{array}$ & $\begin{array}{c}\text { Tennessee } \\
\text { Cookeville } \\
\text { City of } \\
\text { June } 30\end{array}$ & $\begin{array}{c}\text { Tennessee } \\
\text { Covington } \\
\text { City of } \\
\text { June } 30\end{array}$ & $\begin{array}{l}\text { Tennessee } \\
\text { Dayton } \\
\text { City of } \\
\text { June } 30\end{array}$ \\
\hline Electric Utility Operating Revenues.................... & 50,024 & 38,955 & 29,994 & 28,404 & 12,235 & 11,615 \\
\hline 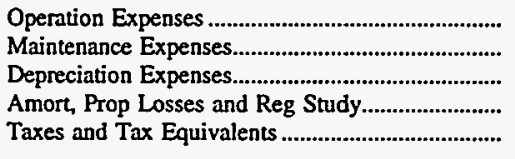 & $\begin{array}{r}44,861 \\
1,668 \\
1,528 \\
181 \\
1,106\end{array}$ & $\begin{array}{r}34,273 \\
1,304 \\
1,332 \\
0 \\
998\end{array}$ & $\begin{array}{r}26,465 \\
1,051 \\
1,073 \\
0 \\
655\end{array}$ & $\begin{array}{r}25,107 \\
594 \\
664 \\
87 \\
500\end{array}$ & $\begin{array}{r}10,964 \\
211 \\
235 \\
175 \\
232\end{array}$ & $\begin{array}{r}10,508 \\
325 \\
270 \\
0 \\
246\end{array}$ \\
\hline $\begin{array}{c}\text { Total Electric Utility Operating } \\
\text { Expenses }\end{array}$ & 49,343 & 37,906 & 29,244 & 26,953 & 11,818 & 11,350 \\
\hline 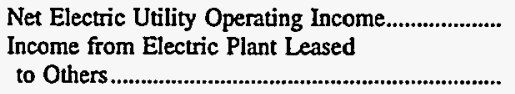 & 681 & 1,049 & 750 & 1,451 & 417 & 266 \\
\hline Electric Utility Operating Income ..................... & 681 & 1,049 & 750 & 1,451 & 417 & 266 \\
\hline 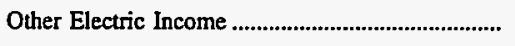 & 694 & 553 & 430 & 436 & 497 & 151 \\
\hline Other Electric Deductions .................................. & 0 & 0 & 0 & 0 & 4 & 0 \\
\hline 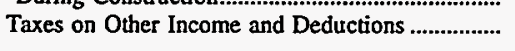 & 0 & 0 & 0 & 0 & 0 & 0 \\
\hline 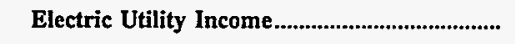 & 1,375 & 1,602 & 1,180 & 1,887 & 910 & 417 \\
\hline 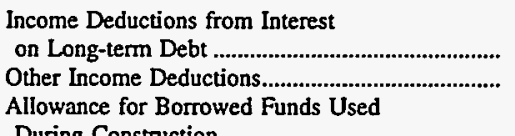 & $\begin{array}{r}0 \\
51\end{array}$ & $\begin{array}{r}73 \\
0\end{array}$ & $\begin{array}{r}135 \\
28\end{array}$ & $\begin{array}{l}61 \\
15\end{array}$ & $\begin{array}{r}35 \\
2\end{array}$ & $\begin{array}{l}0 \\
0\end{array}$ \\
\hline 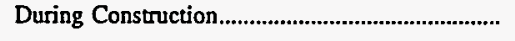 & 0 & 0 & 0 & 0 & 0 & 0 \\
\hline Total Income Deductions...................................... & 51 & 73 & 164 & 76 & 37 & 0 \\
\hline Income Before Extraordinary Items.......................... & 1,324 & 1,529 & 1,016 & 1,811 & 872 & 417 \\
\hline 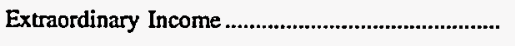 & 0 & 0 & 0 & 0 & 0 & 0 \\
\hline Extraordinary Deductions............................................ & 0 & 0 & 0 & 0 & 0 & 0 \\
\hline 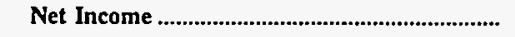 & 1,324 & 1,529 & 1,016 & 1,811 & 872 & 417 \\
\hline
\end{tabular}

Note: Totals may not equal sum of components because of independent rounding.

Source: Energy Information Administration, Form EIA-412, "Annual Report of Public Electric Utilities." 
Table 21. Statement of Income by Major U.S. Publicly Owned Electric Utility

Within State, 1996 (Continued)

(Thousand Dollars)

\begin{tabular}{|c|c|c|c|c|c|c|}
\hline Item & $\begin{array}{l}\text { Tennessee } \\
\text { Dickson } \\
\text { City of } \\
\text { June } 30\end{array}$ & $\begin{array}{l}\text { Tennessee } \\
\text { Dyersburg } \\
\text { City of } \\
\text { June } 30\end{array}$ & $\begin{array}{c}\text { Tennessee } \\
\text { Elizabethton } \\
\text { City of } \\
\text { June } 30\end{array}$ & $\begin{array}{l}\text { Tennessee } \\
\text { Erwin } \\
\text { Town of } \\
\text { June } 30\end{array}$ & $\begin{array}{l}\text { Tennessee } \\
\text { Etowah } \\
\text { City of } \\
\text { June } 30\end{array}$ & $\begin{array}{l}\text { Tennessee } \\
\text { Fayetteville } \\
\text { City of } \\
\text { June } 30\end{array}$ \\
\hline Electric Utllity Operating Revenues...................... & 38,185 & 30,660 & 30,970 & 11,517 & 7,490 & 23,837 \\
\hline 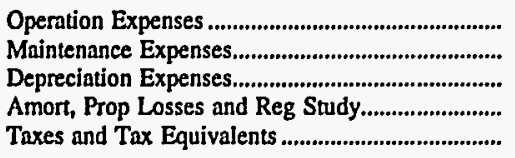 & $\begin{array}{r}32,905 \\
1,329 \\
1,272 \\
0 \\
591\end{array}$ & $\begin{array}{r}26,912 \\
785 \\
1,025 \\
0 \\
772\end{array}$ & $\begin{array}{r}26,915 \\
1,396 \\
911 \\
0 \\
803\end{array}$ & $\begin{array}{r}10,602 \\
317 \\
278 \\
0 \\
237\end{array}$ & $\begin{array}{r}6,698 \\
242 \\
214 \\
0 \\
150\end{array}$ & $\begin{array}{r}20,026 \\
521 \\
1,012 \\
0 \\
701\end{array}$ \\
\hline $\begin{array}{c}\text { Total Electric Utility Operating } \\
\text { Expenses }\end{array}$ & 36,097 & 29,493 & 30,024 & 11,434 & 7,303 & 22,261 \\
\hline 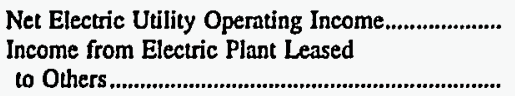 & 2,088 & 1,167 & 946 & 83 & 187 & $\begin{array}{r}1,576 \\
0\end{array}$ \\
\hline Electric Utility Operating Income..................... & 2,088 & 1,167 & 946 & 83 & 187 & 1,576 \\
\hline 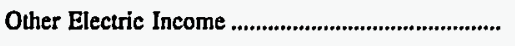 & 630 & 761 & 441 & 333 & 109 & 611 \\
\hline $\begin{array}{l}\text { Other Electric Deductions .......................................... } \\
\text { Allowance for Other Funds Used }\end{array}$ & 0 & 6 & 0 & 0 & 1 & 4 \\
\hline 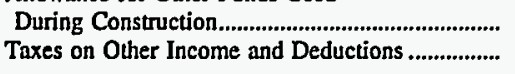 & $\begin{array}{l}\mathbf{0} \\
\mathbf{0}\end{array}$ & $\begin{array}{l}0 \\
0\end{array}$ & $\begin{array}{l}0 \\
0\end{array}$ & $\begin{array}{l}0 \\
0\end{array}$ & $\begin{array}{l}0 \\
0\end{array}$ & $\begin{array}{l}0 \\
0\end{array}$ \\
\hline Electric Utility Income.......................................... & 2,719 & 1,922 & 1,387 & 417 & 294 & 2,183 \\
\hline $\begin{array}{l}\text { Income Deductions from Interest } \\
\text { on Long-term Debt ................................................. } \\
\text { Other Income Deductions....................................... } \\
\text { Allowance for Borrowed Funds Used }\end{array}$ & $\begin{array}{l}273 \\
830\end{array}$ & $\begin{array}{r}429 \\
39\end{array}$ & $\begin{array}{l}44 \\
24\end{array}$ & $\begin{array}{l}6 \\
5\end{array}$ & $\begin{array}{r}0 \\
29\end{array}$ & $\begin{array}{r}518 \\
21\end{array}$ \\
\hline 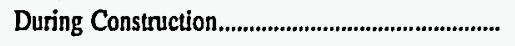 & 7 & 0 & 8 & 0 & 0 & 0 \\
\hline Total Income Deductions..................................... & 1,110 & 468 & 76 & 11 & 29 & 539 \\
\hline 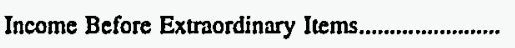 & 1,609 & 1,454 & 1,311 & 406 & 266 & 1,644 \\
\hline 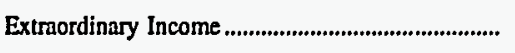 & 0 & 0 & 0 & $\mathbf{0}$ & 0 & 0 \\
\hline Extraordinary Deductions............................................ & $\mathbf{0}$ & 0 & 0 & $\mathbf{0}$ & 0 & 0 \\
\hline 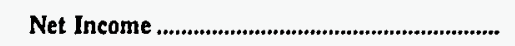 & 1,609 & 1,454 & 1,311 & 406 & 266 & 1,644 \\
\hline
\end{tabular}

Note: Totals may not equal sum of components because of independent rounding.

Source: Energy Information Administration, Form EIA-412, "Annual Report of Public Electric Utilities." 
Table 21. Statement of Income by Major U.S. Publicly Owned Electric Utility Within State, 1996 (Continued)

(Thousand Dollars)

\begin{tabular}{|c|c|c|c|c|c|c|}
\hline Item & $\begin{array}{l}\text { Tennessee } \\
\text { Gallatin } \\
\text { City of } \\
\text { June } 30\end{array}$ & $\begin{array}{c}\text { Tennessee } \\
\text { Greeneville } \\
\text { City of } \\
\text { June } 30\end{array}$ & $\begin{array}{c}\text { Tennessee } \\
\text { Harriman } \\
\text { City of } \\
\text { June } 30\end{array}$ & $\begin{array}{l}\text { Tennessee } \\
\begin{array}{c}\text { Humboldt } \\
\text { City of }\end{array} \\
\text { June } 30\end{array}$ & $\begin{array}{l}\text { Tennessee } \\
\text { Jackson } \\
\text { City of } \\
\text { June } 30\end{array}$ & $\begin{array}{c}\text { Tennessee } \\
\text { Johnson } \\
\text { City City of } \\
\text { June } 30\end{array}$ \\
\hline 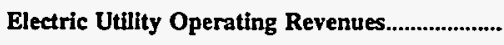 & 23,987 & 50,381 & 15,293 & 11,999 & 69,380 & 92,164 \\
\hline 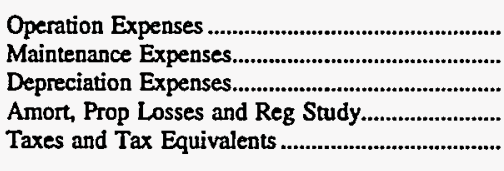 & $\begin{array}{r}22,512 \\
336 \\
459 \\
59 \\
315\end{array}$ & $\begin{array}{r}46,162 \\
1,622 \\
1,629 \\
0 \\
898\end{array}$ & $\begin{array}{r}12,832 \\
901 \\
796 \\
0 \\
262\end{array}$ & $\begin{array}{r}11,428 \\
218 \\
239 \\
59 \\
201\end{array}$ & $\begin{array}{r}61,178 \\
1,308 \\
2,322 \\
26 \\
1,615\end{array}$ & $\begin{array}{r}84,436 \\
2,964 \\
2,201 \\
0 \\
1,721\end{array}$ \\
\hline $\begin{array}{l}\text { Total Electric Utility Operating } \\
\text { Expenses }\end{array}$ & 23,681 & 50,310 & 14,792 & 12,144 & 66,449 & 91,322 \\
\hline 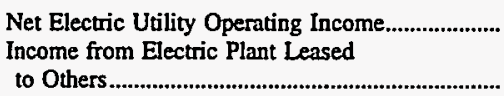 & 306 & 71 & 502 & $\begin{array}{r}-146 \\
0\end{array}$ & $\begin{array}{r}2,931 \\
0\end{array}$ & 841 \\
\hline Electric Utility Operating Income....................... & 306 & 71 & 502 & -146 & 2,931 & 841 \\
\hline Other Electric Income & 556 & 2,023 & 437 & 240 & 1,231 & 1,643 \\
\hline $\begin{array}{l}\text { Other Electric Deductions } \\
\text { Allowance for Other Funds Used }\end{array}$ & 5 & 21 & $\mathbf{0}$ & 2 & 1 & 0 \\
\hline 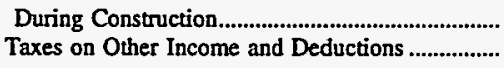 & $\begin{array}{l}0 \\
0\end{array}$ & $\begin{array}{l}0 \\
0\end{array}$ & $\begin{array}{l}\mathbf{0} \\
\mathbf{0}\end{array}$ & $\begin{array}{l}0 \\
0\end{array}$ & $\begin{array}{l}\mathbf{0} \\
\mathbf{0}\end{array}$ & $\begin{array}{l}0 \\
0\end{array}$ \\
\hline 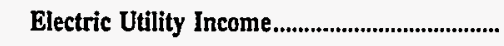 & 857 & 2,073 & 939 & 92 & 4,161 & 2,484 \\
\hline 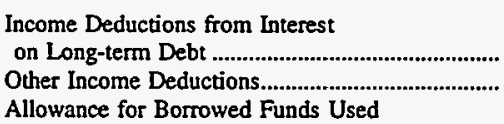 & $\begin{array}{l}0 \\
6\end{array}$ & $\begin{array}{l}\mathbf{0} \\
\mathbf{0}\end{array}$ & $\begin{array}{r}22 \\
1\end{array}$ & $\begin{array}{l}8 \\
0\end{array}$ & $\begin{array}{r}939 \\
38\end{array}$ & $\begin{array}{l}43 \\
22\end{array}$ \\
\hline 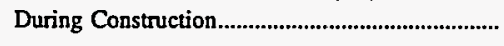 & 0 & 0 & 17 & 0 & 0 & 0 \\
\hline 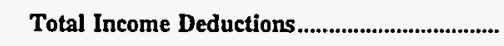 & 6 & $\mathbf{0}$ & 39 & 8 & 976 & 65 \\
\hline Income Before Extraordinary Items......................... & 851 & 2,073 & 899 & 84 & 3,184 & 2,419 \\
\hline Extraordinary Income & 0 & 0 & 0 & 0 & 0 & 0 \\
\hline 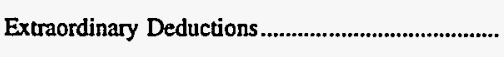 & 0 & 0 & 0 & 0 & 0 & 0 \\
\hline Net Income & 851 & 2,073 & 899 & 84 & 3,184 & 2,419 \\
\hline
\end{tabular}

Note: Totals may not equal sum of components because of independent rounding.

Source: Energy Information Administration, Form EIA-412, "Annual Report of Public Electric Utilities." 
Table 21. Statement of Income by Major U.S. Publicly Owned Electric Utility Within State, 1996 (Continued)

(Thousand Dollars)

\begin{tabular}{|c|c|c|c|c|c|c|}
\hline Ilem & $\begin{array}{l}\text { Tennessee } \\
\text { Knoxville } \\
\text { Utilities } \\
\text { Board } \\
\text { June } 30\end{array}$ & $\begin{array}{c}\text { Tennessee } \\
\text { Lawrenceburg } \\
\text { City of } \\
\text { June } 30\end{array}$ & $\begin{array}{l}\text { Tennessee } \\
\text { LaFollette } \\
\text { City of } \\
\text { June } 30\end{array}$ & $\begin{array}{l}\text { Tennessee } \\
\text { Lebanon } \\
\text { City of } \\
\text { June } 30\end{array}$ & $\begin{array}{l}\text { Tennessee } \\
\text { Lenoir } \\
\text { City City of } \\
\text { June } 30\end{array}$ & $\begin{array}{l}\text { Tennessee } \\
\begin{array}{c}\text { Lewisburg } \\
\text { City of }\end{array} \\
\text { June } 30\end{array}$ \\
\hline Electric Utility Operating Revenues...................... & 285,245 & 26,260 & 23,425 & 20,380 & 67,710 & 15,321 \\
\hline 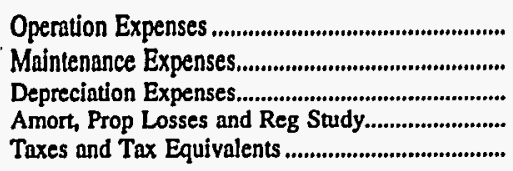 & $\begin{array}{r}252,917 \\
10,195 \\
9,331 \\
0 \\
7,248\end{array}$ & $\begin{array}{r}23,884 \\
871 \\
788 \\
0 \\
592\end{array}$ & $\begin{array}{r}20,316 \\
838 \\
955 \\
0 \\
536\end{array}$ & $\begin{array}{r}18,789 \\
328 \\
410 \\
17 \\
355\end{array}$ & $\begin{array}{r}59,318 \\
1,949 \\
2,052 \\
0 \\
1,545\end{array}$ & $\begin{array}{r}14,025 \\
217 \\
358 \\
44 \\
335\end{array}$ \\
\hline $\begin{array}{l}\text { Total Electric Utility Operating } \\
\text { Expenses ..................................................................... }\end{array}$ & 279,691 & 26,135 & 22,645 & 19,898 & 64,863 & 14,979 \\
\hline 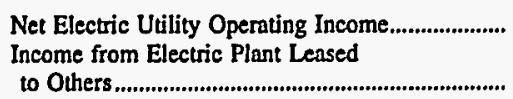 & $\begin{array}{r}5,554 \\
0\end{array}$ & $\begin{array}{r}124 \\
0\end{array}$ & $\begin{array}{r}779 \\
0\end{array}$ & $\begin{array}{r}482 \\
0\end{array}$ & $\begin{array}{r}2,846 \\
0\end{array}$ & 342 \\
\hline Electric Utilty Operating Income...................... & 5,554 & 124 & 779 & 482 & 2,846 & 342 \\
\hline 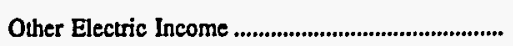 & 5,734 & 401 & 561 & 258 & 1,267 & 215 \\
\hline $\begin{array}{l}\text { Other Electric Deductions .................................... } \\
\text { Allowance for Other Funds Used }\end{array}$ & 0 & 24 & 0 & 60 & 2 & 3 \\
\hline 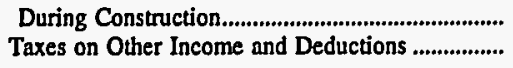 & $\begin{array}{l}\mathbf{0} \\
\mathbf{0}\end{array}$ & $\begin{array}{l}0 \\
0\end{array}$ & $\begin{array}{l}0 \\
0\end{array}$ & $\begin{array}{l}0 \\
0\end{array}$ & $\begin{array}{l}0 \\
0\end{array}$ & $\begin{array}{l}0 \\
0\end{array}$ \\
\hline Electric Utility Income............................................ & 11,288 & 501 & 1,340 & 680 & 4,111 & 554 \\
\hline 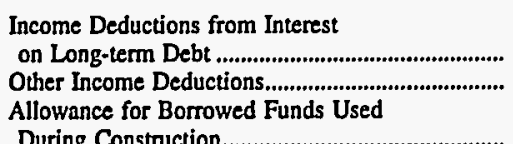 & $\begin{array}{r}2,345 \\
367 \\
\end{array}$ & $\begin{array}{l}0 \\
0\end{array}$ & $\begin{array}{r}574 \\
31\end{array}$ & $\begin{array}{r}67 \\
3\end{array}$ & $\begin{array}{r}1,435 \\
69\end{array}$ & $\begin{array}{r}28 \\
3\end{array}$ \\
\hline 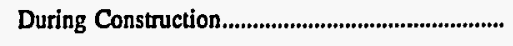 & $\mathbf{0}$ & 0 & $\mathbf{0}$ & 0 & 33 & 0 \\
\hline 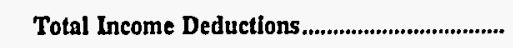 & 2,712 & $\mathbf{0}$ & 605 & 70 & $\mathbf{1 , 5 3 7}$ & 32 \\
\hline 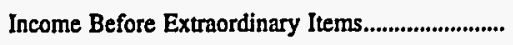 & 8,576 & 501 & 735 & 610 & 2,574 & 522 \\
\hline Extraordinary Income & 0 & 0 & 0 & $\mathbf{0}$ & 0 & 0 \\
\hline Extraordinary Deductions.......................................... & $\mathbf{0}$ & 0 & 0 & $\mathbf{0}$ & 0 & 0 \\
\hline Net Income & 8,576 & 501 & 735 & 610 & 2,574 & 522 \\
\hline
\end{tabular}

Note; Totals may not equal sum of components because of independent rounding.

Source: Energy Information Administration, Form EIA-412, "Annual Report of Public Electric Utilities." 
Table 21. Statement of Income by Major U.S. Publicly Owned Electric Utility Within State, 1996 (Continued)

(Thousand Dollars)

\begin{tabular}{|c|c|c|c|c|c|c|}
\hline Item & $\begin{array}{l}\text { Tennessee } \\
\begin{array}{c}\text { Lexington } \\
\text { City of }\end{array} \\
\text { June } 30\end{array}$ & $\begin{array}{l}\text { Tennessee } \\
\text { Loudon } \\
\text { Utilities } \\
\text { Board } \\
\text { June } 30\end{array}$ & $\begin{array}{l}\text { Tennessee } \\
\text { Maryville } \\
\text { Utilities } \\
\text { June } 30\end{array}$ & $\begin{array}{l}\text { Tennessee } \\
\text { McMinnville } \\
\text { Electric } \\
\text { System } \\
\text { June } 30\end{array}$ & $\begin{array}{l}\text { Tennessee } \\
\text { Memphis } \\
\text { City of } \\
\text { June } 30\end{array}$ & $\begin{array}{l}\text { Tennessee } \\
\text { Milan } \\
\text { City of } \\
\text { June } 30\end{array}$ \\
\hline Electric Utility Operating Revenues...................... & 24,480 & 16,893 & 30,018 & 13,449 & 711,356 & 13,234 \\
\hline 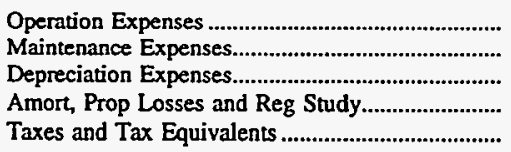 & $\begin{array}{r}21,971 \\
888 \\
824 \\
0 \\
519\end{array}$ & $\begin{array}{r}14,812 \\
337 \\
516 \\
0 \\
367\end{array}$ & $\begin{array}{r}27,493 \\
864 \\
1.018 \\
4 \\
653\end{array}$ & $\begin{array}{r}12,058 \\
357 \\
467 \\
125 \\
304\end{array}$ & $\begin{array}{r}637,224 \\
26,949 \\
21,284 \\
0 \\
21,455\end{array}$ & $\begin{array}{r}12,415 \\
603 \\
335 \\
0 \\
225\end{array}$ \\
\hline $\begin{array}{l}\text { Total Electric Utility Operating } \\
\text { Expenses }\end{array}$ & 24,201 & 16,031 & 30,031 & 13,311 & 706,911 & 13,578 \\
\hline 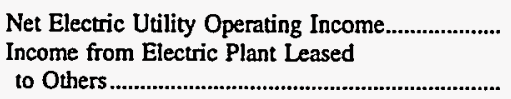 & $\begin{array}{r}279 \\
0\end{array}$ & $\begin{array}{r}861 \\
0\end{array}$ & $\begin{array}{r}-13 \\
0\end{array}$ & $\begin{array}{r}138 \\
0\end{array}$ & $\begin{array}{r}4,444 \\
0\end{array}$ & $\begin{array}{r}-344 \\
0\end{array}$ \\
\hline 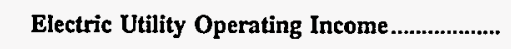 & 279 & 861 & -13 & 138 & 4,444 & -344 \\
\hline Other Electric Income & 453 & 611 & 501 & 309 & 33,520 & 241 \\
\hline $\begin{array}{l}\text { Other Electric Deductions } \\
\text { Allowance for Other Funds Used }\end{array}$ & 0 & 61 & 1 & 7 & 0 & 0 \\
\hline 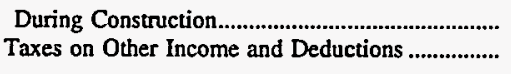 & $\begin{array}{l}0 \\
0\end{array}$ & $\begin{array}{l}0 \\
0\end{array}$ & $\begin{array}{l}0 \\
0\end{array}$ & $\begin{array}{l}0 \\
0\end{array}$ & $\begin{array}{l}\mathbf{0} \\
\mathbf{0}\end{array}$ & $\begin{array}{l}0 \\
0\end{array}$ \\
\hline 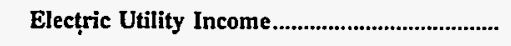 & 732 & 1,411 & 487 & 440 & 37,965 & -103 \\
\hline 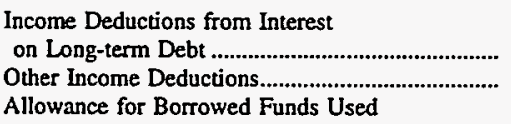 & $\begin{array}{l}\mathbf{0} \\
\mathbf{0}\end{array}$ & $\begin{array}{r}433 \\
71\end{array}$ & $\begin{array}{r}168 \\
10\end{array}$ & $\begin{array}{r}0 \\
18\end{array}$ & $\begin{array}{r}11,946 \\
883\end{array}$ & $\begin{array}{l}0 \\
0\end{array}$ \\
\hline 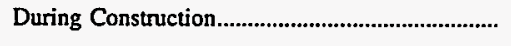 & 0 & 24 & 0 & 0 & 0 & 0 \\
\hline 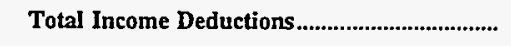 & o & $\mathbf{5 2 8}$ & 178 & 18 & 12,830 & 0 \\
\hline 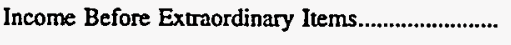 & 732 & 884 & 309 & 422 & 25,135 & -103 \\
\hline Extraordinary Income & 0 & 0 & 0 & 0 & 0 & 2 \\
\hline 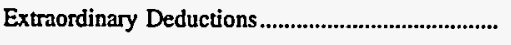 & 0 & 0 & 0 & $\mathbf{0}$ & 0 & 0 \\
\hline 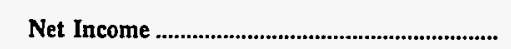 & 732 & 884 & 309 & 422 & 25,135 & -101 \\
\hline
\end{tabular}

Note: Totals may not equal sum of components because of independent rounding.

Source: Energy Information Administration, Form EIA-412, "Annual Report of Public Electric Utilities." 
Table 21. Statement of Income by Major U.S. Publicly Owned Electric Utility Within State, 1996 (Continued)

(Thousand Dollars)

\begin{tabular}{|c|c|c|c|c|c|c|}
\hline Item & $\begin{array}{l}\text { Tennessee } \\
\text { Morristown } \\
\text { City of } \\
\text { June } 30\end{array}$ & $\begin{array}{l}\text { Tennessee } \\
\begin{array}{l}\text { Murfreesboro } \\
\text { City of }\end{array} \\
\text { June } 30\end{array}$ & $\begin{array}{l}\text { Tennessee } \\
\text { Nashville } \\
\text { Electric } \\
\text { Service } \\
\text { June } 30\end{array}$ & $\begin{array}{l}\text { Tennessee } \\
\text { Newpor } \\
\text { City of } \\
\text { June } 30\end{array}$ & $\begin{array}{l}\text { Tennessee } \\
\text { Oak Ridge } \\
\text { City of } \\
\text { June } 30\end{array}$ & $\begin{array}{l}\text { Tennessee } \\
\text { Paris } \\
\text { City of } \\
\text { June } 30\end{array}$ \\
\hline Electric Utility Operating Revenues....................... & 37,414 & 51,797 & 604,910 & 25,209 & 28,363 & 25,024 \\
\hline 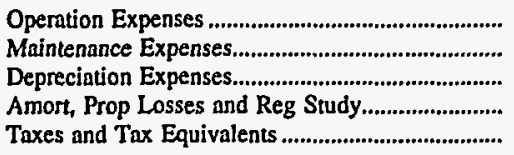 & $\begin{array}{r}33,807 \\
927 \\
896 \\
290 \\
690\end{array}$ & $\begin{array}{r}47,017 \\
747 \\
1,354 \\
154 \\
1,313\end{array}$ & $\begin{array}{r}544,514 \\
19,649 \\
20,061 \\
0 \\
12,444\end{array}$ & $\begin{array}{r}21,983 \\
706 \\
1,110 \\
0 \\
657\end{array}$ & $\begin{array}{r}24,161 \\
917 \\
846 \\
11 \\
711\end{array}$ & $\begin{array}{r}22,330 \\
911 \\
929 \\
0 \\
527\end{array}$ \\
\hline 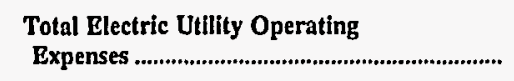 & 36,609 & 50,585 & 596,668 & 24,457 & 26,646 & 24,697 \\
\hline 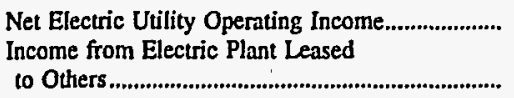 & $\begin{array}{r}805 \\
0\end{array}$ & $\begin{array}{r}1,212 \\
0\end{array}$ & $\begin{array}{r}8,242 \\
0\end{array}$ & $\begin{array}{r}752 \\
0\end{array}$ & $\begin{array}{r}1,716 \\
0\end{array}$ & $\begin{array}{r}327 \\
0\end{array}$ \\
\hline Electric Utillty Operating Income..................... & 805 & 1,212 & 8,242 & 752 & 1,716 & 327 \\
\hline Other Electric Income & 603 & 1,210 & 11,763 & 627 & 761 & 481 \\
\hline $\begin{array}{l}\text { Other Electric Deductions .................................... } \\
\text { Allowance for Other Funds Used }\end{array}$ & 3 & 11 & 0 & 8 & 0 & 2 \\
\hline 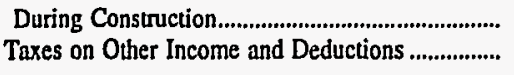 & $\begin{array}{l}0 \\
0\end{array}$ & $\begin{array}{l}0 \\
0\end{array}$ & $\begin{array}{l}0 \\
0\end{array}$ & $\begin{array}{l}0 \\
0\end{array}$ & $\begin{array}{l}0 \\
0\end{array}$ & $\begin{array}{l}0 \\
0\end{array}$ \\
\hline Electric Utility Income & 1,405 & 2,410 & 20,005 & 1,371 & 2,478 & 807 \\
\hline 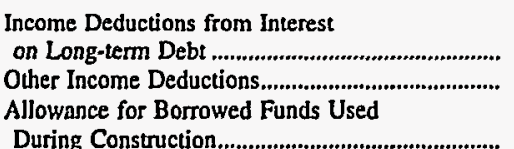 & $\begin{array}{r}1 \\
34\end{array}$ & $\begin{array}{r}383 \\
49\end{array}$ & $\begin{array}{r}10,384 \\
1,081\end{array}$ & $\begin{array}{r}351 \\
25 \\
16\end{array}$ & $\begin{array}{r}299 \\
6 \\
672\end{array}$ & $\begin{array}{r}155 \\
4 \\
0\end{array}$ \\
\hline 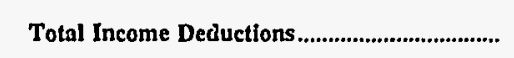 & 35 & 432 & 11,465 & 392 & 977 & 159 \\
\hline 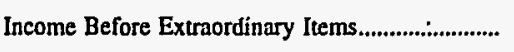 & 1,370 & 1,978 & 8,540 & 980 & 1,500 & 648 \\
\hline 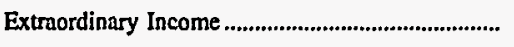 & 0 & 0 & 0 & 0 & 1,664 & $\mathbf{0}$ \\
\hline 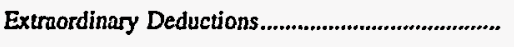 & $\mathbf{0}$ & 0 & 0 & 0 & 832 & $\mathbf{0}$ \\
\hline Net Income & 1,370 & 1,978 & 8,540 & 980 & 2,332 & 648 \\
\hline
\end{tabular}

Note: Totals may not equal sum of components because of independent rounding.

Source: Energy Information Administration, Form EIA-412, "Annual Report of Public Electric Utilities." 
Table 21. Statement of Income by Major U.S. Publicly Owned Electric Utility Within State, 1996 (Continued)

(Thousand Dollars)

\begin{tabular}{|c|c|c|c|c|c|c|}
\hline Item & $\begin{array}{l}\text { Tennessee } \\
\text { Pulaski } \\
\text { City of } \\
\text { June } 30\end{array}$ & $\begin{array}{l}\text { Tennessee } \\
\text { Ripley } \\
\text { City of } \\
\text { June } 30\end{array}$ & $\begin{array}{c}\text { Tennessee } \\
\text { Sevier } \\
\text { County } \\
\text { Electric } \\
\text { System } \\
\text { June } 30\end{array}$ & $\begin{array}{l}\text { Tennessee } \\
\text { Rockwood } \\
\text { City of } \\
\text { June } 30\end{array}$ & $\begin{array}{c}\text { Tennessee } \\
\begin{array}{c}\text { Shelbyville } \\
\text { City of }\end{array} \\
\text { June } 30\end{array}$ & $\begin{array}{l}\text { Tennessee } \\
\begin{array}{c}\text { Springfield } \\
\text { City of }\end{array} \\
\text { June } 30\end{array}$ \\
\hline 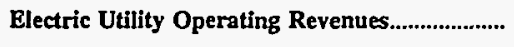 & 23,648 & 13,512 & 60,183 & 18,427 & 18,372 & 13,368 \\
\hline 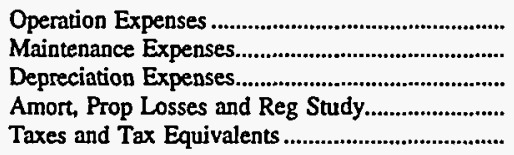 & $\begin{array}{r}20,812 \\
865 \\
817 \\
0 \\
646\end{array}$ & $\begin{array}{r}12,969 \\
143 \\
247 \\
77 \\
227\end{array}$ & $\begin{array}{r}52,599 \\
1,496 \\
2,222 \\
41 \\
1,035\end{array}$ & $\begin{array}{r}15,545 \\
721 \\
491 \\
20 \\
491\end{array}$ & $\begin{array}{r}17,169 \\
342 \\
337 \\
39 \\
376\end{array}$ & $\begin{array}{r}11,240 \\
190 \\
445 \\
116 \\
268\end{array}$ \\
\hline 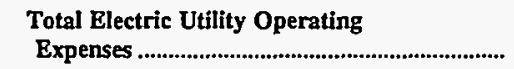 & 23,140 & 13,662 & 57,392 & 17,268 & 18,263 & 12,259 \\
\hline 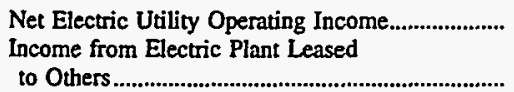 & $\begin{array}{r}508 \\
0\end{array}$ & $\begin{array}{r}-149 \\
0\end{array}$ & $\begin{array}{r}2,791 \\
0\end{array}$ & $\begin{array}{r}1,159 \\
0\end{array}$ & $\begin{array}{r}109 \\
0\end{array}$ & $\begin{array}{r}1,109 \\
0\end{array}$ \\
\hline Electric Utility Operating Income....................... & 508 & -149 & 2,791 & 1,159 & 109 & 1,109 \\
\hline 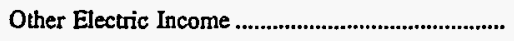 & 304 & 419 & 1,087 & 277 & 279 & 279 \\
\hline $\begin{array}{l}\text { Other Electric Deductions } \\
\text { Allowance for Other Funds Used }\end{array}$ & 8 & 5 & 0 & 29 & 4 & 0 \\
\hline 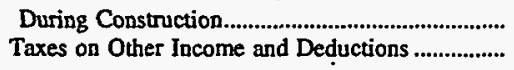 & $\begin{array}{l}0 \\
0\end{array}$ & $\begin{array}{l}0 \\
0\end{array}$ & $\begin{array}{l}0 \\
0\end{array}$ & $\begin{array}{l}0 \\
0\end{array}$ & $\begin{array}{l}0 \\
0\end{array}$ & $\begin{array}{l}0 \\
0\end{array}$ \\
\hline Electric Utility Income & 804 & 264 & 3,878 & 1,408 & 384 & 1,388 \\
\hline 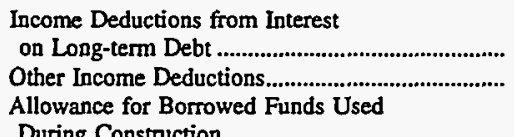 & $\begin{array}{r}211 \\
15\end{array}$ & $\begin{array}{l}0 \\
0\end{array}$ & $\begin{array}{r}85 \\
119\end{array}$ & $\begin{array}{l}0 \\
0\end{array}$ & $\begin{array}{r}2 \\
19\end{array}$ & $\begin{array}{r}45 \\
5\end{array}$ \\
\hline Total Income Deductions......................................... & 225 & $\mathbf{0}$ & 204 & 61 & 21 & 49 \\
\hline 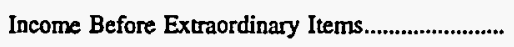 & 579 & 264 & 3,674 & 1,347 & 362 & 1,339 \\
\hline Extraordinary Income & 0 & 0 & 0 & 0 & 0 & 0 \\
\hline 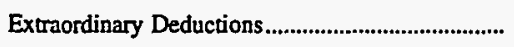 & 0 & 0 & 0 & 0 & 0 & 0 \\
\hline 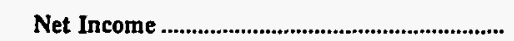 & 579 & 264 & 3,674 & 1,347 & 362 & 1,339 \\
\hline
\end{tabular}

Note: Totals may not equal sum of components because of independent rounding.

Source: Energy Information Administration, Form EIA-412, "Annual Report of Public Electric Utilities." 
Table 21. Statement of Income by Major U.S. Publicly Owned Electric Utility Within State, 1996 (Continued)

(Thousand Dollars)

\begin{tabular}{|c|c|c|c|c|c|c|}
\hline Item & $\begin{array}{l}\text { Tennessee } \\
\text { Sweetwater } \\
\text { City of } \\
\text { June } 30\end{array}$ & $\begin{array}{l}\text { Tennessee } \\
\text { Tullahoma } \\
\text { Board } \\
\text { of } \\
\text { Pub Utils } \\
\text { June } 30\end{array}$ & $\begin{array}{c}\text { Tenmessee } \\
\text { Union } \\
\text { City City of } \\
\text { June } 30\end{array}$ & $\begin{array}{l}\text { Tennessee } \\
\text { Weakley } \\
\text { County } \\
\text { Mun } \\
\text { Elec Sys } \\
\text { June } 30\end{array}$ & $\begin{array}{c}\text { Tendessee } \\
\text { Winchester } \\
\text { City of } \\
\text { December } 31\end{array}$ & $\begin{array}{c}\text { Texas } \\
\text { Austin } \\
\text { City of } \\
\text { September } 30\end{array}$ \\
\hline Electric Utility Operating Revenues...................... & 11,497 & 15,737 & 16,052 & 27,592 & 8,544 & 613,648 \\
\hline 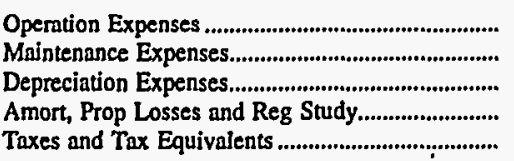 & $\begin{array}{r}9,938 \\
410 \\
444 \\
0 \\
236\end{array}$ & $\begin{array}{r}14,162 \\
540 \\
519 \\
12 \\
353\end{array}$ & $\begin{array}{r}15,369 \\
322 \\
379 \\
0 \\
262\end{array}$ & $\begin{array}{r}24,976 \\
646 \\
908 \\
0 \\
566\end{array}$ & $\begin{array}{r}7,507 \\
223 \\
270 \\
2 \\
176\end{array}$ & $\begin{array}{r}269,044 \\
44,453 \\
72,884 \\
0 \\
0\end{array}$ \\
\hline 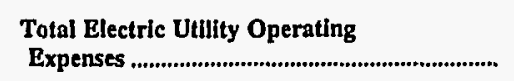 & 11,027 & 15,586 & 16,332 & 27,096 & 8,179 & 386,381 \\
\hline 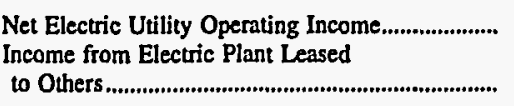 & $\begin{array}{r}470 \\
0\end{array}$ & 151 & $\begin{array}{r}-279 \\
0\end{array}$ & $\begin{array}{r}496 \\
0\end{array}$ & $\begin{array}{r}365 \\
0\end{array}$ & $\begin{array}{r}227,267 \\
0\end{array}$ \\
\hline Electric Utility Operating Income ..................... & 470 & 151 & -279 . & 496 & 365 & 227,267 \\
\hline 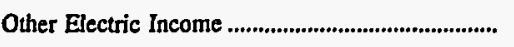 & 300 & 311 & 342 & 486 & 105 & 21,841 \\
\hline $\begin{array}{l}\text { Other Electric Deductions ..................................... } \\
\text { Allowance for Other Funds Used }\end{array}$ & o & 3 & 1 & 0 & 5 & 10 \\
\hline 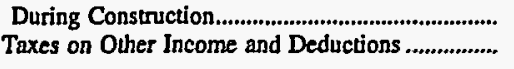 & $\begin{array}{l}\mathbf{0} \\
\mathbf{0}\end{array}$ & $\begin{array}{l}\mathbf{0} \\
\mathbf{0}\end{array}$ & $\begin{array}{l}\mathbf{0} \\
\mathbf{0}\end{array}$ & $\begin{array}{l}\mathbf{0} \\
0\end{array}$ & $\begin{array}{l}0 \\
0\end{array}$ & $\begin{array}{l}0 \\
0\end{array}$ \\
\hline 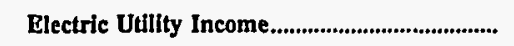 & 770 & 458 & 61 & 982 & 465 & 249,098 \\
\hline 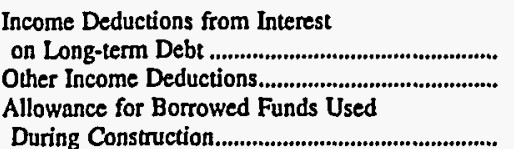 & $\begin{array}{l}0 \\
5\end{array}$ & $\begin{array}{r}88 \\
2\end{array}$ & $\begin{array}{l}\mathbf{0} \\
\mathbf{0}\end{array}$ & $\begin{array}{r}0 \\
15\end{array}$ & $\begin{array}{l}0 \\
4\end{array}$ & $\begin{array}{r}135,880 \\
51,211\end{array}$ \\
\hline 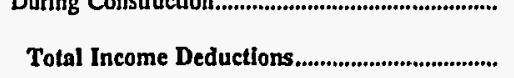 & 5 & 91 & 0 & 15 & $\begin{array}{l}0 \\
4\end{array}$ & $\begin{array}{r}0 \\
187,091\end{array}$ \\
\hline 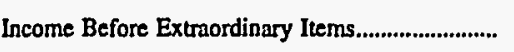 & 766 & 367 & 61 & 967 & 461 & 62,007 \\
\hline 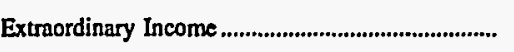 & 0 & $\mathbf{0}$ & 0 & 0 & 0 & 0 \\
\hline Extraordinary Deductions.............................................. & 0 & 0 & 0 & 0 & 0 & 0 \\
\hline 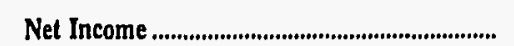 & 766 & 367 & 61 & 967 & 461 & 62,007 \\
\hline
\end{tabular}

Source: Energy Information Administration, Form EIA-412, "Annual Report of Public Electric Utilities." 
Table 21. Statement of Income by Major U.S. Publicly Owned Electric Utility Within State, 1996 (Continued)

(Thousand Dollars)

\begin{tabular}{|c|c|c|c|c|c|c|}
\hline Item & $\begin{array}{c}\text { Texas } \\
\text { Brenham } \\
\text { City of } \\
\text { September } 30\end{array}$ & $\begin{array}{c}\text { Texas } \\
\text { Brownsville } \\
\text { Public } \\
\text { Utils Board } \\
\text { September } 30\end{array}$ & $\begin{array}{c}\text { Texas } \\
\text { Bryan } \\
\text { City of } \\
\text { September } 30\end{array}$ & $\begin{array}{c}\text { Texas } \\
\text { College } \\
\text { Station } \\
\text { City of } \\
\text { September } 30\end{array}$ & $\begin{array}{l}\text { Texas } \\
\text { Denton } \\
\text { City of } \\
\text { September } 30\end{array}$ & $\begin{array}{c}\text { Texas } \\
\text { Floresville } \\
\text { City of } \\
\text { December } 31\end{array}$ \\
\hline 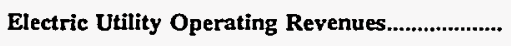 & 13,991 & 52,256 & 86,114 & 32,198 & 63,796 & 12,449 \\
\hline 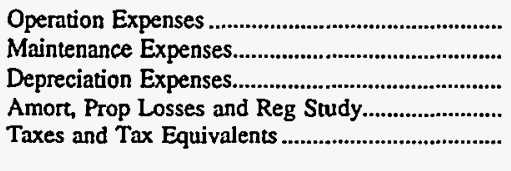 & $\begin{array}{r}11,648 \\
847 \\
233 \\
0 \\
691\end{array}$ & $\begin{array}{r}32,565 \\
2,112 \\
3,828 \\
0 \\
437\end{array}$ & $\begin{array}{r}64,805 \\
3,364 \\
4,539 \\
0 \\
4,246\end{array}$ & $\begin{array}{r}26,387 \\
413 \\
989 \\
0 \\
3,945\end{array}$ & $\begin{array}{r}50,194 \\
2,739 \\
3,088 \\
0 \\
2,964\end{array}$ & $\begin{array}{r}9,799 \\
295 \\
741 \\
0 \\
0\end{array}$ \\
\hline $\begin{array}{l}\text { Total Electric Utility Operating } \\
\text { Expenses }\end{array}$ & 13,418 & 38,943 & 76,953 & 31,735 & 58,985 & 10,835 \\
\hline 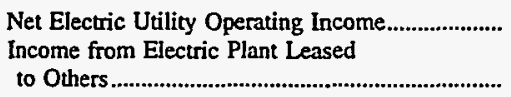 & 574 & $\begin{array}{r}13,313 \\
0\end{array}$ & $\begin{array}{r}9,160 \\
0\end{array}$ & 464 & 4,811 & $\begin{array}{r}1,614 \\
0\end{array}$ \\
\hline Electric Utility Operating Income..................... & 574 & 13,313 & 9,160 & 464 & 4,811 & 1,614 \\
\hline Other Electric Income & 21 & 23,227 & 1,442 & 1,118 & 3,591 & 431 \\
\hline $\begin{array}{l}\text { Other Electric Deductions } \\
\text { Allowance for Other Funds Used }\end{array}$ & 0 & 2,263 & 155 & 0 & 879 & 0 \\
\hline 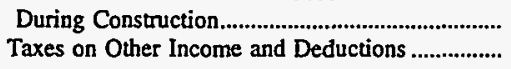 & $\begin{array}{l}0 \\
0\end{array}$ & $\begin{array}{l}0 \\
0\end{array}$ & $\begin{array}{l}0 \\
0\end{array}$ & $\begin{array}{l}0 \\
0\end{array}$ & $\begin{array}{l}0 \\
0\end{array}$ & $\begin{array}{l}0 \\
0\end{array}$ \\
\hline Electric Utility Income & 595 & 34,277 & 10,447 & 1,581 & 7,523 & 2,045 \\
\hline 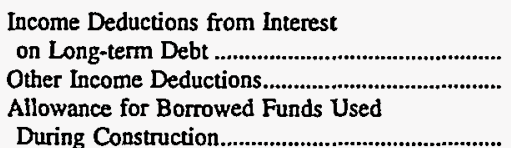 & $\begin{array}{r}27 \\
0\end{array}$ & $\begin{array}{r}8,127 \\
18,677\end{array}$ & $\begin{array}{l}917 \\
303\end{array}$ & $\begin{array}{r}794 \\
30\end{array}$ & $\begin{array}{r}1,176 \\
84\end{array}$ & $\begin{array}{r}329 \\
0\end{array}$ \\
\hline 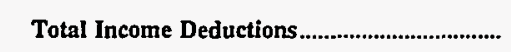 & 27 & 26,804 & 1,220 & 824 & 1,260 & 329 \\
\hline 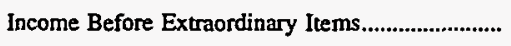 & 567 & 7,473 & 9,227 & 757 & 6,264 & 1,716 \\
\hline Extraordinary Income & 0 & 0 & 0 & 0 & 0 & 0 \\
\hline 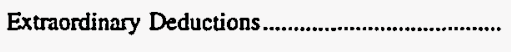 & 0 & 0 & 0 & 0 & 0 & 0 \\
\hline Net Income & 567 & $\mathbf{7 , 4 7 3}$ & 9,227 & 757 & 6,264 & 1,716 \\
\hline
\end{tabular}

Note: Totals may not equal sum of components because of independent rounding.

Source: Energy Information Administration, Form EIA-412, "Annual Report of Public Electric Utilities." 
Table 21. Statement of Income by Major U.S. Publicly Owned Electric Utility Within State, 1996 (Continued)

(Thousand Dollars)

\begin{tabular}{|c|c|c|c|c|c|c|}
\hline Item & $\begin{array}{c}\text { Texas } \\
\text { Garland } \\
\text { City of } \\
\text { September } 30\end{array}$ & $\begin{array}{c}\text { Texas } \\
\text { Georgetown } \\
\text { City of } \\
\text { September } 30\end{array}$ & $\begin{array}{c}\text { Texis } \\
\text { Greenville } \\
\text { Electric } \\
\text { Util Sys } \\
\text { September } 30\end{array}$ & $\begin{array}{c}\text { Texas } \\
\text { Jasper } \\
\text { City of } \\
\text { September } 30\end{array}$ & $\begin{array}{c}\text { Texas } \\
\text { Kerrville } \\
\text { Public } \\
\text { Utility } \\
\text { Board } \\
\text { September } 30\end{array}$ & $\begin{array}{l}\text { Texas } \\
\text { Lower } \\
\text { Colorado } \\
\text { River } \\
\text { Authority } \\
\text { June } 30\end{array}$ \\
\hline Blectric Uillty Operating Revenues.................... & 152,518 & 14,794 & 30,300 & 12,599 & 25,167 & 414,657 \\
\hline 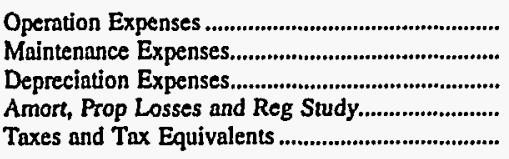 & $\begin{array}{r}112,951 \\
9,091 \\
7,262 \\
0 \\
7,929\end{array}$ & $\begin{array}{r}10,335 \\
730 \\
313 \\
0 \\
295\end{array}$ & $\begin{array}{r}23,730 \\
2,199 \\
1,800 \\
0 \\
0\end{array}$ & $\begin{array}{r}11,682 \\
199 \\
194 \\
0 \\
0\end{array}$ & $\begin{array}{r}19,995 \\
746 \\
1,090 \\
178 \\
17\end{array}$ & $\begin{array}{r}226,245 \\
24,327 \\
60,192 \\
0 \\
0\end{array}$ \\
\hline 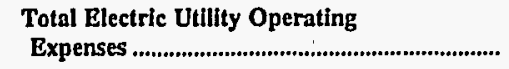 & 137,232 & 11,673 & 27,729 & 12,075 & 22,026 & 310,764 \\
\hline 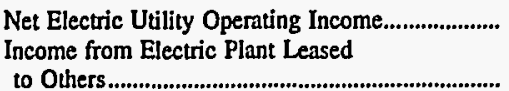 & 15,285 & 3,121 & 2,571 & $\begin{array}{r}523 \\
0\end{array}$ & $\begin{array}{r}3,142 \\
0\end{array}$ & 103,892 \\
\hline Electric Utility Operating Income...................... & 15,285 & 3,121 & 2,571 & 523 & 3,142 & 103,892 \\
\hline 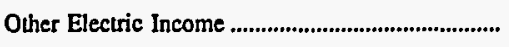 & 1,840 & 187 & 535 & 87 & 601 & 31,574 \\
\hline $\begin{array}{l}\text { Other Electric Deductions } \\
\text { Allowance for Other Funds Used }\end{array}$ & 0 & 0 & 0 & 3 & 0 & 32,359 \\
\hline 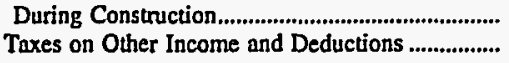 & $\begin{array}{l}\mathbf{0} \\
\mathbf{0}\end{array}$ & $\begin{array}{l}\mathbf{0} \\
\mathbf{0}\end{array}$ & $\begin{array}{l}\mathbf{0} \\
\mathbf{0}\end{array}$ & $\begin{array}{l}\mathbf{0} \\
\mathbf{0}\end{array}$ & $\begin{array}{r}49 \\
0\end{array}$ & $\begin{array}{l}\mathbf{0} \\
0\end{array}$ \\
\hline Electric Utility Income............................................ & 17,126 & 3,307 & 3,106 & 608 & 3,792 & 103,108 \\
\hline 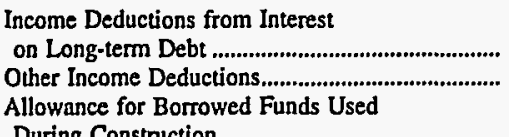 & $\begin{array}{r}715 \\
3,721\end{array}$ & $\begin{array}{r}71 \\
2,521\end{array}$ & $\begin{array}{r}733 \\
75\end{array}$ & $\begin{array}{r}0 \\
479\end{array}$ & $\begin{array}{r}1,918 \\
0\end{array}$ & $\begin{array}{r}74,534 \\
0\end{array}$ \\
\hline Total Ineome Deductions............................................ & 4,436 & 2,592 & 808 & 479 & 1,918 & 74,534 \\
\hline Income Before Extraordinary Items............................ & 12,690 & 716 & 2,298 & 128 & 1,874 & 28,574 \\
\hline 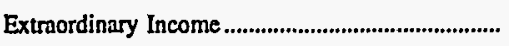 & 0 & 0 & 0 & 0 & 0 & 0 \\
\hline 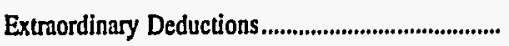 & 0 & 0 & 0 & 0 & 0 & 0 \\
\hline Net Income & 12,690 & 716 & 2,298 & 128 & 1,874 & 28,574 \\
\hline
\end{tabular}

Note: Totals may not equal sum of components because of independent rounding.

Source: Energy Information Administration, Form EIA-412, "Annual Report of Public Electric Utilities." 
Table 21. Statement of Income by Major U.S. Publicly Owned Electric Utility Within State, 1996 (Continued)

(Thousand Dollars)

\begin{tabular}{|c|c|c|c|c|c|c|}
\hline Item & $\begin{array}{l}\text { Texas } \\
\text { Lubbock } \\
\text { City of } \\
\text { September } 30\end{array}$ & $\begin{array}{c}\text { Texas } \\
\text { New Braunfels } \\
\text { City of } \\
\text { July } 31\end{array}$ & $\begin{array}{c}\text { Texas } \\
\text { Sam Rayburn } \\
\text { Municipal } \\
\text { Pwr } \\
\text { Agny } \\
\text { September } 30\end{array}$ & $\begin{array}{c}\text { Texas } \\
\text { San Antonio } \\
\text { Public } \\
\text { Service Bd } \\
\text { January } 31\end{array}$ & $\begin{array}{c}\text { Texas } \\
\text { San Marcos } \\
\text { City of } \\
\text { September } 30\end{array}$ & $\begin{array}{l}\text { Texas } \\
\text { Seguin } \\
\text { City of } \\
\text { September } 30\end{array}$ \\
\hline Electric Utility Operating Revenues...................... & 57,126 & 43,104 & 33,393 & 840,177 & 21,788 & 13,765 \\
\hline 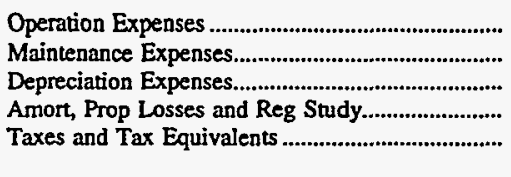 & $\begin{array}{r}43,697 \\
1,059 \\
4,299 \\
0 \\
6,388\end{array}$ & $\begin{array}{r}34,986 \\
796 \\
1,830 \\
0 \\
1,255\end{array}$ & $\begin{array}{r}15,648 \\
3,239 \\
4,730 \\
0 \\
0\end{array}$ & $\begin{array}{r}300,986 \\
62,180 \\
145,175 \\
0 \\
19,013\end{array}$ & $\begin{array}{r}19,451 \\
890 \\
609 \\
0 \\
0\end{array}$ & $\begin{array}{r}9,853 \\
164 \\
198 \\
0 \\
0\end{array}$ \\
\hline $\begin{array}{l}\text { Total Electric Utility Operating } \\
\text { Expenses }\end{array}$ & 55,444 & 38,867 & 23,617 & 527,354 & 20,950 & 10,215 \\
\hline 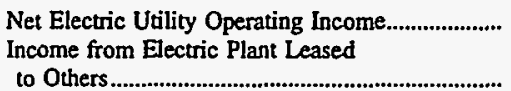 & $\begin{array}{r}1,682 \\
0\end{array}$ & $\begin{array}{r}4,237 \\
978\end{array}$ & 9,776 & $\begin{array}{r}312,823 \\
1,522\end{array}$ & 838 & $\begin{array}{r}3,550 \\
0\end{array}$ \\
\hline Electric Utility Operating Income ...................... & 1,682 & 5,215 & 9,776 & 314,345 & 838 & 3,550 \\
\hline 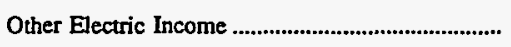 & 3,588 & $893^{\circ}$ & 11,164 & 35,914 & 931 & 204 \\
\hline $\begin{array}{l}\text { Other Electric Deductions.... } \\
\text { Allowance for Other Funds Used }\end{array}$ & 0 & 0 & 0 & 1,278 & 0 & 0 \\
\hline 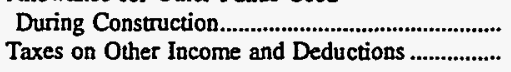 & $\begin{array}{l}0 \\
0\end{array}$ & $\begin{array}{l}0 \\
0\end{array}$ & $\begin{array}{l}0 \\
0\end{array}$ & $\begin{array}{l}0 \\
0\end{array}$ & $\begin{array}{l}0 \\
0\end{array}$ & $\begin{array}{l}0 \\
0\end{array}$ \\
\hline 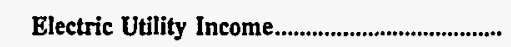 & 5,270 & 6,108 & 20,940 & 348,981 & 1,769 & 3,754 \\
\hline 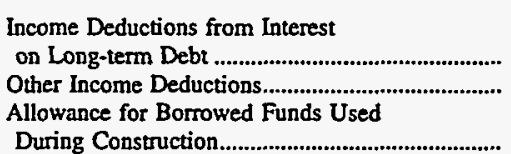 & $\begin{array}{r}1,891 \\
0\end{array}$ & $\begin{array}{r}349 \\
0\end{array}$ & $\begin{array}{r}15,034 \\
4,990\end{array}$ & $\begin{array}{r}147,440 \\
35,377 \\
-3,654\end{array}$ & $\begin{array}{r}884 \\
20\end{array}$ & $\begin{array}{l}0 \\
0\end{array}$ \\
\hline 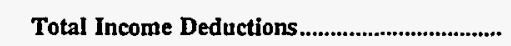 & 1,891 & 349 & 20,024 & 179,164 & 904 & 0 \\
\hline Income Before Extraordinary Items........................ & 3,379 & 5,759 & 916 & 169,818 & 864 & 3,754 \\
\hline Extraordinary Income & $\mathbf{0}$ & 0 & $\mathbf{0}$ & 147,980 & 0 & 0 \\
\hline Extraordinary Deductions............................................ & 0 & 0 & 0 & 122,710 & 0 & $\mathbf{0}$ \\
\hline Net Income & 3,379 & 5,759 & 916 & 195,087 & 864 & $\mathbf{3 , 7 5 4}$ \\
\hline
\end{tabular}

Note: Totals may not equal sum of components because of independent rounding.

Source: Energy Information Administration, Form EIA-412, "Annual Report of Public Electric Utilities." 
Table 21. Statement of Income by Major U.S. Publicly Owned Electric Utility Within State, 1996 (Continued)

(Thousand Dollars)

\begin{tabular}{|c|c|c|c|c|c|c|}
\hline Item & $\begin{array}{c}\text { Texas } \\
\text { Texas } \\
\text { Municipal } \\
\text { Power Agency } \\
\text { September } 30\end{array}$ & $\begin{array}{l}\text { Texas } \\
\text { Toledo Bend } \\
\text { Project } \\
\text { Joint } \\
\text { Oper } \\
\text { August } 30\end{array}$ & $\begin{array}{c}\text { Texas } \\
\text { Weatherford } \\
\text { Mun } \\
\text { Utility } \\
\text { System } \\
\text { September } 30\end{array}$ & $\begin{array}{c}\text { Utah } \\
\text { Bountiful } \\
\text { City City of } \\
\text { June 30' }\end{array}$ & $\begin{array}{c}\text { Utah } \\
\text { Intermountain } \\
\text { Power Agency } \\
\text { June } 30\end{array}$ & $\begin{array}{l}\text { Utah } \\
\text { Logan } \\
\text { City of } \\
\text { June } 30\end{array}$ \\
\hline Electric Utility Operating Revenues....................... & 163,661 & 641 & 16,091 & 13,329 & 611,861 & 17,413 \\
\hline 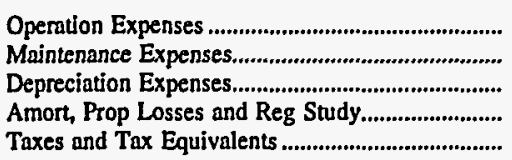 & $\begin{array}{r}61,746 \\
8,820 \\
18,124 \\
0 \\
0\end{array}$ & $\begin{array}{r}100 \\
10,187 \\
736 \\
0 \\
0\end{array}$ & $\begin{array}{r}9,444 \\
1,047 \\
522 \\
0 \\
790\end{array}$ & $\begin{array}{r}6,908 \\
1,459 \\
1,254 \\
0 \\
2,307\end{array}$ & $\begin{array}{r}189,467 \\
27,162 \\
95,672 \\
0 \\
24,845\end{array}$ & $\begin{array}{r}11,181 \\
229 \\
1,151 \\
0 \\
0\end{array}$ \\
\hline 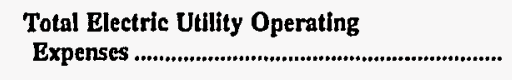 & 88,690 & 11,022 & 11,803 & 11,929 & 337,146 & 12,561 \\
\hline 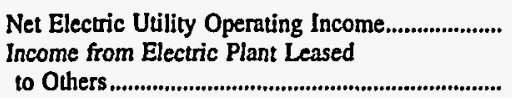 & $\begin{array}{r}74,971 \\
-16\end{array}$ & $\begin{array}{r}-10,381 \\
0\end{array}$ & $\begin{array}{r}4,288 \\
0\end{array}$ & $\begin{array}{r}1,400 \\
0\end{array}$ & $\begin{array}{r}274,715 \\
0\end{array}$ & 4,853 \\
\hline Electric Utility Operating Income..................... & 74,955 & $-10,381$ & 4,288 & 1,400 & 274,715 & 4,853 \\
\hline 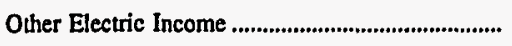 & 18,929 & 3,090 & 448 & 98 & 63,033 & 218 \\
\hline 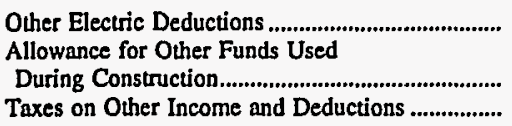 & $\begin{array}{r}17,733 \\
0 \\
0\end{array}$ & $\begin{array}{l}0 \\
0\end{array}$ & $\begin{array}{l}0 \\
0\end{array}$ & $\begin{array}{l}0 \\
0\end{array}$ & $\begin{array}{l}0 \\
0 \\
0\end{array}$ & $\begin{array}{l}0 \\
0 \\
0\end{array}$ \\
\hline Electric Utility Income............... & 76,151 & $-7,291$ & 4,736 & 1,498 & 337,748 & 5,070 \\
\hline 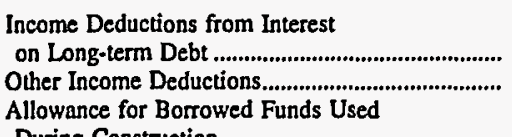 & $\begin{array}{l}76,357 \\
18,986\end{array}$ & $\begin{array}{r}1,794 \\
0\end{array}$ & $\begin{array}{r}133 \\
0\end{array}$ & $\begin{array}{l}0 \\
0\end{array}$ & $\begin{array}{r}326,487 \\
11,261\end{array}$ & $\begin{array}{r}484 \\
0\end{array}$ \\
\hline 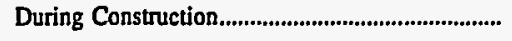 & 0 & 0 & 0 & $\mathbf{0}$ & 0 & 0 \\
\hline 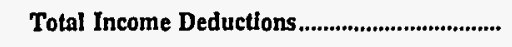 & 95,343 & 1,794 & 133 & $\mathbf{0}$ & 337,748 & 484 \\
\hline Income Before Extraordinary Items.......................... & $-19,192$ & $-9,085$ & 4,602 & 1,498 & 0 & 4,586 \\
\hline 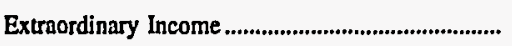 & 52,233 & 0 & 0 & $\mathbf{0}$ & 0 & 0 \\
\hline 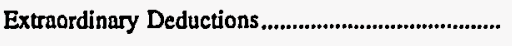 & 34,838 & 0 & 0 & 0 & 0 & 0 \\
\hline Net Income & $-1,797$ & $-9,085$ & 4,602 & 1,498 & $\mathbf{0}$ & 4,586 \\
\hline
\end{tabular}

Note: Totals may not equal sum of components because of independent rounding.

Source: Enorgy Information Administration, Form EIA-412, "Annual Report of Public Electric Utilities." 
Table 21. Statement of Income by Major U.S. Publicly Owned Electric Utility Within State, 1996 (Continued)

(Thousand Dollars)

\begin{tabular}{|c|c|c|c|c|c|c|}
\hline Item & $\begin{array}{l}\text { Utah } \\
\text { Murray } \\
\text { City of } \\
\text { June } 30\end{array}$ & $\begin{array}{l}\text { Utah } \\
\text { Provo } \\
\text { City Corp } \\
\text { June } 30\end{array}$ & $\begin{array}{c}\text { Utah } \\
\text { St George } \\
\text { City of } \\
\text { June } 30\end{array}$ & $\begin{array}{c}\text { Utah } \\
\text { Utah } \\
\text { Associated } \\
\text { Mun } \\
\text { Power Sys } \\
\text { March 31 }\end{array}$ & $\begin{array}{c}\text { Utah } \\
\text { Utah } \\
\text { Municipal } \\
\text { Power Agency } \\
\text { June } 30\end{array}$ & $\begin{array}{l}\text { Vermont } \\
\text { Burlington } \\
\text { City of } \\
\text { June } 30\end{array}$ \\
\hline Electric Utility Operating Revenues........................... & 19,518 & 38,899 & 22,470 & 54,263 & 32,655 & 40,863 \\
\hline 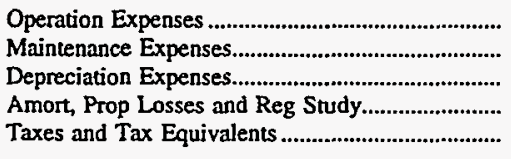 & $\begin{array}{r}12,561 \\
821 \\
1,714 \\
0 \\
1,715\end{array}$ & $\begin{array}{r}27,847 \\
0 \\
3,762 \\
0 \\
0\end{array}$ & $\begin{array}{r}17,392 \\
0 \\
1,439 \\
0 \\
1,933\end{array}$ & $\begin{array}{r}39,034 \\
1,619 \\
4,587 \\
0 \\
807\end{array}$ & $\begin{array}{r}26,957 \\
1,567 \\
963 \\
0 \\
125\end{array}$ & $\begin{array}{r}25,382 \\
1,580 \\
1,721 \\
983 \\
1,363\end{array}$ \\
\hline $\begin{array}{l}\text { Total Electric Utility Operating } \\
\text { Expenses }\end{array}$ & 16,811 & 31,609 & 20,764 & 46,047 & 29,612 & 31,028 \\
\hline 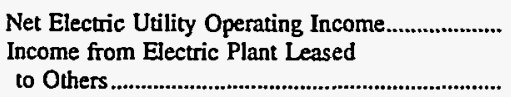 & $\begin{array}{r}2,707 \\
0\end{array}$ & $\begin{array}{r}7,290 \\
0\end{array}$ & $\begin{array}{r}1,706 \\
0\end{array}$ & $\begin{array}{r}8,216 \\
0\end{array}$ & $\begin{array}{r}3,044 \\
0\end{array}$ & $\begin{array}{r}9,835 \\
0\end{array}$ \\
\hline 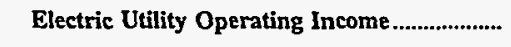 & 2,707 & 7,290 & 1,706 & 8,216 & 3,044 & 9,835 \\
\hline 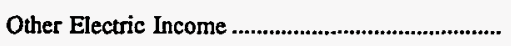 & 0 & 406 & 785 & 590 & 1,076 & 2,089 \\
\hline $\begin{array}{l}\text { Other Electric Deductions................................................. } \\
\text { Allowance for Other Funds Used }\end{array}$ & 0 & 0 & 0 & 0 & 0 & 241 \\
\hline 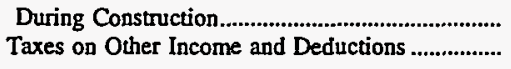 & $\begin{array}{l}0 \\
0\end{array}$ & $\begin{array}{l}0 \\
0\end{array}$ & $\begin{array}{l}0 \\
0\end{array}$ & $\begin{array}{l}0 \\
0\end{array}$ & $\begin{array}{l}0 \\
0\end{array}$ & $\begin{array}{l}0 \\
0\end{array}$ \\
\hline Electric Utility Income........... & 2,707 & 7,696 & 2,491 & 8,806 & 4,120 & 11,683 \\
\hline 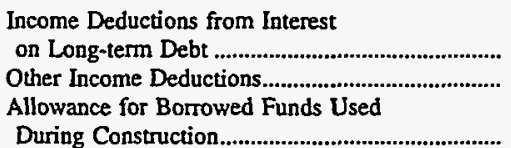 & $\begin{array}{l}0 \\
0\end{array}$ & $\begin{array}{r}3,079 \\
105\end{array}$ & $\begin{array}{l}\mathbf{0} \\
\mathbf{0}\end{array}$ & $\begin{array}{r}8,806 \\
0\end{array}$ & $\begin{array}{r}3,059 \\
143\end{array}$ & $\begin{array}{r}6,404 \\
350\end{array}$ \\
\hline 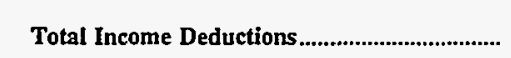 & 0 & 3,184 & 0 & 8,806 & 3,202 & 6,754 \\
\hline 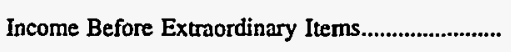 & 2,707 & 4,512 & 2,491 & 0 & 917 & 4,929 \\
\hline Extraordinary Income & 0 & 0 & 0 & 0 & 0 & 0 \\
\hline 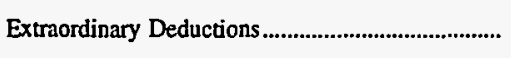 & 0 & 3,763 & 0 & 0 & 0 & 0 \\
\hline 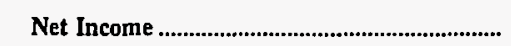 & 2,707 & 749 & 2,491 & 0 & 917 & 4,929 \\
\hline
\end{tabular}

Note: Totals may not equal sum of components because of independent rounding.

Source: Energy Information Administration, Form EIA-412, "Annual Report of Public Electric Utilities." 
Table 21. Statement of Income by Major U.S. Publicly Owned Electric Utility

Within State, 1996 (Continued)

(Thousand Dollars)

\begin{tabular}{|c|c|c|c|c|c|c|}
\hline Item & $\begin{array}{c}\text { Vermont } \\
\text { Vermont } \\
\text { Public } \\
\text { Pwr } \\
\text { Supply Auth } \\
\text { December } 31\end{array}$ & $\begin{array}{l}\text { Virginia } \\
\text { Bedford } \\
\text { City of } \\
\text { June } 30\end{array}$ & $\begin{array}{l}\text { Virginia } \\
\text { Bristol } \\
\text { Utilities } \\
\text { Board } \\
\text { June } 30\end{array}$ & $\begin{array}{l}\text { Virginia } \\
\text { Danville } \\
\text { City of } \\
\text { June } 30\end{array}$ & $\begin{array}{c}\text { Virginia } \\
\begin{array}{c}\text { Harrisonburg } \\
\text { City of }\end{array} \\
\text { June } 30\end{array}$ & $\begin{array}{c}\text { Virginia } \\
\text { Manassas } \\
\text { City of } \\
\text { June } 30\end{array}$ \\
\hline Electric Utility Operating Revenues..................... & 10,077 & 12,307 & 27,687 & 47,258 & 34,761 & 19,028 \\
\hline 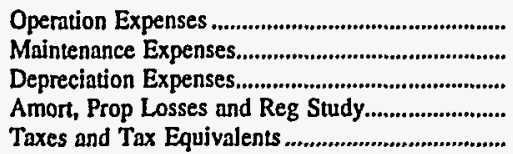 & $\begin{array}{r}6,491 \\
409 \\
618 \\
0 \\
210\end{array}$ & $\begin{array}{r}8,825 \\
422 \\
576 \\
0 \\
0\end{array}$ & $\begin{array}{r}25,195 \\
1,010 \\
764 \\
0 \\
533\end{array}$ & $\begin{array}{r}33,847 \\
1,538 \\
1,680 \\
0 \\
0\end{array}$ & $\begin{array}{r}27,623 \\
533 \\
1,553 \\
184 \\
183\end{array}$ & $\begin{array}{r}16,416 \\
749 \\
1,435 \\
0 \\
482\end{array}$ \\
\hline $\begin{array}{l}\text { Total Electric Utility Operating } \\
\text { Expenses }\end{array}$ & 7,729 & 9,822 & 27,501 & 37,065 & 30,076 & 19,082 \\
\hline 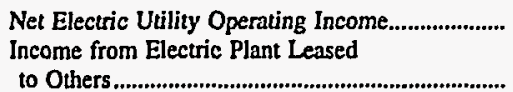 & 2,348 & 2,485 & 186 & $\begin{array}{r}10,193 \\
85\end{array}$ & 4,684 & $\begin{array}{r}-54 \\
0\end{array}$ \\
\hline Electric Utility Operating Income.................... & 2,348 & 2,485 & 186 & 10,277 & 4,684 & -54 \\
\hline 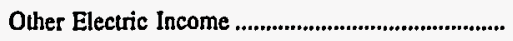 & 282 & 223 & 784 & 590 & 285 & 1,932 \\
\hline $\begin{array}{l}\text { Other Electric Deductions ........................................... } \\
\text { Allowance for Other Funds Used }\end{array}$ & 0 & 0 & 0 & 0 & 0 & 31 \\
\hline 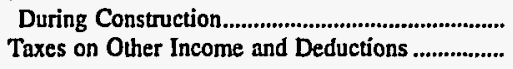 & $\begin{array}{l}0 \\
0\end{array}$ & $\begin{array}{l}0 \\
0\end{array}$ & $\begin{array}{l}0 \\
0\end{array}$ & $\begin{array}{l}\mathbf{0} \\
\mathbf{0}\end{array}$ & $\begin{array}{l}0 \\
0\end{array}$ & $\begin{array}{l}\mathbf{0} \\
\mathbf{0}\end{array}$ \\
\hline 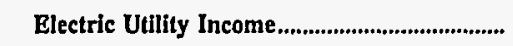 & 2,631 & 2,708 & 970 & 10,868 & 4,969 & 1,847 \\
\hline $\begin{array}{l}\text { Income Deductions from Interest } \\
\text { on Long-term Debt ................................................... } \\
\text { Other Income Deductions..................................... } \\
\text { Allowance for Bortowed Funds Used }\end{array}$ & $\begin{array}{r}1,911 \\
681\end{array}$ & $\begin{array}{r}922 \\
1,209\end{array}$ & $\begin{array}{r}0 \\
18\end{array}$ & $\begin{array}{r}406 \\
0\end{array}$ & $\begin{array}{r}173 \\
0\end{array}$ & $\begin{array}{r}735 \\
0\end{array}$ \\
\hline 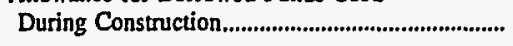 & $\mathbf{0}$ & 0 & 0 & 0 & 0 & 0 \\
\hline 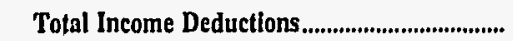 & 2,592 & 2,131 & 18 & 406 & 173 & 735 \\
\hline 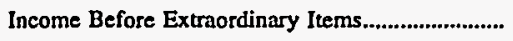 & 39 & 577 & 952 & 10,461 & 4,796 & 1,112 \\
\hline Extraordinary Income & 0 & $\mathbf{0}$ & $\mathbf{0}$ & $\mathbf{0}$ & 0 & $\mathbf{0}$ \\
\hline 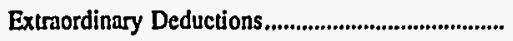 & 0 & $\mathbf{0}$ & 0 & 0 & 0 & 0 \\
\hline Net Income & 39 & $\mathbf{5 7 7}$ & 952 & 10,461 & 4,796 & 1,112 \\
\hline
\end{tabular}

Note: Totals may not equal sum of components because of independent rounding.

Source: Energy Information Administration, Form EIA-412, "Annual Report of Public Electric Utilities." 
Table 21. Statement of Income by Major U.S. Publicly Owned Electric Utility Within State, 1996 (Continued)

(Thousand Dollars)

\begin{tabular}{|c|c|c|c|c|c|c|}
\hline Item & $\begin{array}{c}\text { Virginia } \\
\begin{array}{c}\text { Martinsville } \\
\text { City of }\end{array} \\
\text { June } 30\end{array}$ & $\begin{array}{l}\text { Virginia } \\
\text { Radford } \\
\text { City of } \\
\text { June } 30\end{array}$ & $\begin{array}{l}\text { Virginia } \\
\text { Salem } \\
\text { City of } \\
\text { June } 30\end{array}$ & $\begin{array}{l}\text { Virginia } \\
\text { Virginia } \\
\text { Tech } \\
\text { Electric } \\
\text { Service } \\
\text { June } 30\end{array}$ & $\begin{array}{l}\text { Washington } \\
\text { Centralia } \\
\text { City of } \\
\text { December } 31\end{array}$ & $\begin{array}{l}\text { Washington } \\
\text { Ellensburg } \\
\text { City of } \\
\text { December } 31\end{array}$ \\
\hline Electric Utility Operating Revenues...................... & 11,033 & 16,723 & 17,954 & 12,322 & 9,930 & 8,359 \\
\hline 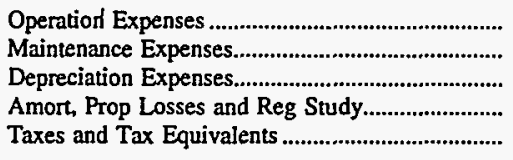 & $\begin{array}{r}7,279 \\
751 \\
878 \\
0 \\
87\end{array}$ & $\begin{array}{r}13,518 \\
370 \\
741 \\
0 \\
150\end{array}$ & $\begin{array}{r}14,994 \\
198 \\
738 \\
0 \\
1,000\end{array}$ & $\begin{array}{r}10,877 \\
618 \\
0 \\
0 \\
250\end{array}$ & $\begin{array}{r}7,272 \\
478 \\
437 \\
3 \\
896\end{array}$ & $\begin{array}{r}6,106 \\
282 \\
444 \\
0 \\
855\end{array}$ \\
\hline 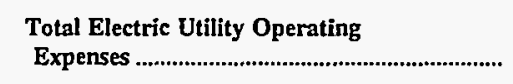 & 8,996 & 14,780 & 16,930 & 11,746 & 9,085 & 7,688 \\
\hline 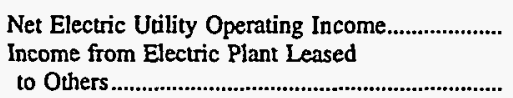 & $\begin{array}{r}2,037 \\
0\end{array}$ & $\begin{array}{r}1,943 \\
0\end{array}$ & $\begin{array}{r}1.024 \\
0\end{array}$ & $\begin{array}{r}576 \\
0\end{array}$ & $\begin{array}{r}844^{\circ} \\
0\end{array}$ & 671 \\
\hline Electric Utility Operating Income....................... & 2,037 & 1,943 & 1,024 & 576 & 844 & 671 \\
\hline Other Electric Income & 4 & 442 & 227 & 171 & 1,384 & 219 \\
\hline $\begin{array}{l}\text { Other Electric Deductions } \\
\text { Allowance for Other Funds Used }\end{array}$ & 2,165 & 1,571 & 0 & 94 & 0 & 44 \\
\hline 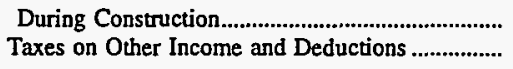 & $\begin{array}{l}0 \\
0\end{array}$ & $\begin{array}{l}0 \\
0\end{array}$ & $\begin{array}{l}0 \\
0\end{array}$ & $\begin{array}{l}0 \\
0\end{array}$ & $\begin{array}{l}0 \\
0\end{array}$ & $\begin{array}{l}0 \\
0\end{array}$ \\
\hline 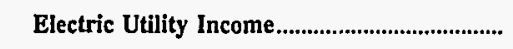 & -124 & 814 & 1,251 & 653 & 2,228 & 847 \\
\hline 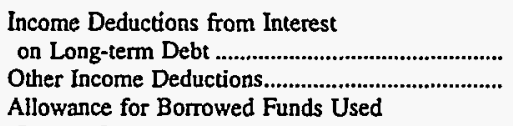 & $\begin{array}{l}0 \\
0\end{array}$ & $\begin{array}{r}199 \\
0\end{array}$ & $\begin{array}{r}509 \\
0\end{array}$ & $\begin{array}{l}169 \\
110\end{array}$ & $\begin{array}{r}190 \\
6\end{array}$ & $\begin{array}{l}4 \\
0\end{array}$ \\
\hline 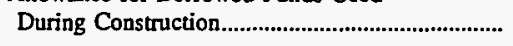 & 0 & 0 & 0 & $\mathbf{0}$ & 0 & 0 \\
\hline 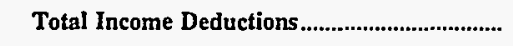 & $\mathbf{0}$ & 199 & 509 & 279 & 195 & 4 \\
\hline 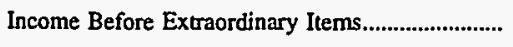 & -124 & 615 & 742 & 374 & 2,033 & 843 \\
\hline Extraordinary Income & 0 & 0 & 0 & 0 & 0 & 0 \\
\hline Extraordinary Deductions & 0 & 0 & 0 & $\mathbf{0}$ & 0 & 0 \\
\hline 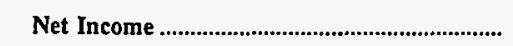 & -124 & 615 & 742 & 374 & 2,033 & 843 \\
\hline
\end{tabular}

Note: Totals may not equal sum of components because of independent rounding.

Source: Energy Information Administration, Form EIA-412, "Annual Report of Public Electric Utilities." 
Table 21. Statement of Income by Major U.S. Publicly Owned Electric Utility Within State, 1996 (Continued)

(Thousand Dollars)

\begin{tabular}{|c|c|c|c|c|c|c|}
\hline Item & $\begin{array}{l}\text { Washington } \\
\text { Port Angeles } \\
\text { City of } \\
\text { December } 31\end{array}$ & $\begin{array}{l}\text { Washington } \\
\text { PUD No } 1 \\
\text { of } \\
\text { Benton } \\
\text { County } \\
\text { December } 31\end{array}$ & $\begin{array}{c}\text { Washington } \\
\text { PUD No } 1 \\
\text { of } \\
\text { Chelan } \\
\text { County } \\
\text { December } 31\end{array}$ & $\begin{array}{l}\text { Washington } \\
\text { PUD No } 1 \text { of } \\
\text { Clallam } \\
\text { County } \\
\text { December } 31\end{array}$ & $\begin{array}{l}\text { Washington } \\
\text { PUD No } 1 \\
\text { of } \\
\text { Clark } \\
\text { County } \\
\text { December } 31\end{array}$ & $\begin{array}{l}\text { Washington } \\
\text { PUD No } 1 \text { of } \\
\text { Cowlitz } \\
\text { County } \\
\text { December } 31\end{array}$ \\
\hline Electric Utility Operating Revenues...................... & 22,584 & 68,586 & 164,629 & 28,276 & 153,376 & 110,827 \\
\hline 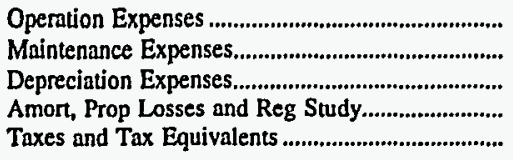 & $\begin{array}{r}17,684 \\
2,243 \\
416 \\
0 \\
2,188\end{array}$ & $\begin{array}{r}52,021 \\
3,794 \\
3,858 \\
0 \\
7,340\end{array}$ & $\begin{array}{r}79,750 \\
12,416 \\
18,017 \\
32 \\
6,943\end{array}$ & $\begin{array}{r}19,940 \\
1,285 \\
2,075 \\
0 \\
997\end{array}$ & $\begin{array}{r}128,471 \\
3,880 \\
9,941 \\
0 \\
8,848\end{array}$ & $\begin{array}{r}91,172 \\
1,859 \\
4,066 \\
72 \\
5,555\end{array}$ \\
\hline $\begin{array}{l}\text { Total Electric Utility Operating } \\
\text { Expenses }\end{array}$ & 22,531 & 67,013 & 117,158 & 24,298 & 151,139 & 102,724 \\
\hline 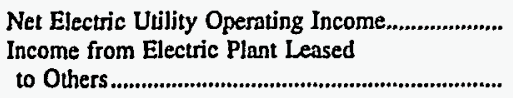 & 53 & 1,573 & $\begin{array}{r}47,471 \\
0\end{array}$ & $\begin{array}{r}3,978 \\
0\end{array}$ & $\begin{array}{r}2,237 \\
0\end{array}$ & $\begin{array}{r}8,103 \\
0\end{array}$ \\
\hline Electric Utility Operating Income ................... & 53 & 1,573 & 47,471, & 3,978 & 2,237 & 8,103 \\
\hline 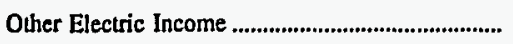 & 371 & 1,710 & 9,762 & 1,232 & 823 & 1.725 \\
\hline $\begin{array}{l}\text { Other Electric Deductions .................................... } \\
\text { Allowance for Other Funds Used }\end{array}$ & 247 & 0 & 4,174 & 0 & 6,178 & 27 \\
\hline 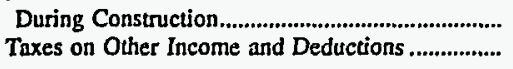 & $\begin{array}{l}0 \\
0\end{array}$ & $\begin{array}{l}0 \\
0\end{array}$ & $\begin{array}{l}\mathbf{0} \\
\mathbf{0}\end{array}$ & $\begin{array}{r}0 \\
594\end{array}$ & $\begin{array}{l}\mathbf{0} \\
0\end{array}$ & $\begin{array}{l}0 \\
0\end{array}$ \\
\hline 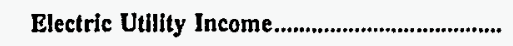 & 178 & 3,283 & 53,059 & 4,616 & $-3,118$ & 9,801 \\
\hline 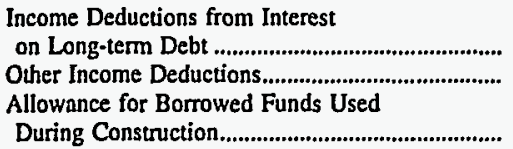 & $\begin{array}{r}106 \\
0\end{array}$ & $\begin{array}{r}2,411 \\
60\end{array}$ & $\begin{array}{r}43,653 \\
1,149\end{array}$ & $\begin{array}{r}390 \\
19\end{array}$ & $\begin{array}{l}0 \\
0 \\
0\end{array}$ & $\begin{array}{r}51 \\
1 \\
0\end{array}$ \\
\hline 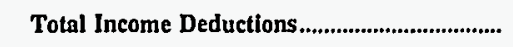 & 106 & 2,471 & 44,802 & 408 & $\mathbf{0}$ & 53 \\
\hline Income Before Extraordinary Items........................... & 72 & 812 & 8,257 & 4,208 & $-3,118$ & 9,748 \\
\hline 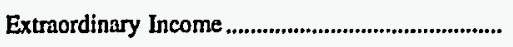 & 0 & 1,161 & 0 & 0 & 0 & 4 \\
\hline 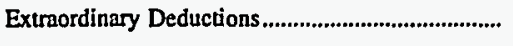 & 0 & 972 & $\mathbf{0}$ & 0 & 0 & 0 \\
\hline 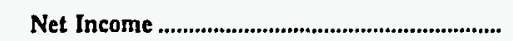 & 72 & 1,001 & 8,257 & 4,208 & $-3,118$ & 9,752 \\
\hline
\end{tabular}

Note: Totals may not equal sum of components because of independent rounding.

Source: Energy Information Administration, Form EIA-412, "Annual Report of Public Electric Utilities." 
Table 21. Statement of Income by Major U.S. Publicly Owned Electric Utility Within State, 1996 (Continued)

(Thousand Dollars)

\begin{tabular}{|c|c|c|c|c|c|c|}
\hline Item & $\begin{array}{l}\text { Washington } \\
\text { PUD No } 1 \text { of } \\
\text { Douglas } \\
\text { County } \\
\text { December } 31\end{array}$ & $\begin{array}{l}\text { Washington } \\
\text { PUD No } 1 \text { of } \\
\text { Franklin } \\
\text { County } \\
\text { December } 31\end{array}$ & $\begin{array}{l}\text { Washington } \\
\text { PUD No } 1 \\
\text { of } \\
\text { Grays } \\
\text { Harbor Cnty } \\
\text { December } 31\end{array}$ & $\begin{array}{c}\text { Washington } \\
\text { PUD No } 1 \\
\text { of } \\
\text { Klickitat } \\
\text { County } \\
\text { December } 31\end{array}$ & $\begin{array}{l}\text { Washington } \\
\text { PUD No } 1 \\
\text { of } \\
\text { Lewis } \\
\text { County } \\
\text { December } 31\end{array}$ & $\begin{array}{l}\text { Washington } \\
\text { PUD No } 1 \text { of } \\
\text { Okanogan } \\
\text { County } \\
\text { December } 31\end{array}$ \\
\hline Electric Utility Operating Revenues...................... & 41,031 & 29,099 & 46,507 & 13,246 & 32,869 & 18,013 \\
\hline Operation Expenses & 13,009 & 22,336 & 30,457 & 9,746 & 23,387 & 14,940 \\
\hline Maintenance Expenses........................................................... & 4,178 & 708 & 4,781 & 656 & 1,226 & 660 \\
\hline 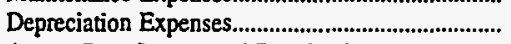 & 5,015 & 1,631 & 3,426 & 1,141 & 1,724 & 1,798 \\
\hline Amort, Prop Losses and Reg Study............................... & 0 & 65 & 0 & 0 & 0 & 28 \\
\hline 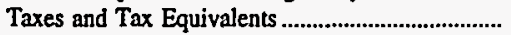 & 2,440 & 2,025 & 2,635 & 798 & 1,953 & 1,828 \\
\hline $\begin{array}{l}\text { Total Electric Utility Operating } \\
\text { Expenses }\end{array}$ & 24,641 & 26,765 & 41,299 & 12,341 & 28,290 & 19,254 \\
\hline $\begin{array}{l}\text { Net Electric Utility Operating Income..................... } \\
\text { Income from Electric Plant Leased }\end{array}$ & 16,389 & 2,334 & 5,207 & 905 & 4,579 & $-1,241$ \\
\hline to Others & 0 & 0 & 0 & 0 & 0 & 0 \\
\hline Electric Utility Operating Income....................... & 16,389 & 2,334 & 5,207 & 905 & 4,579 & $-1,241$ \\
\hline Other Electric Income & 3,731 & 935 & 3,926 & 785 & 934 & 791 \\
\hline $\begin{array}{l}\text { Other Electric Deductions } \\
\text { Allowance for Other Funds Used }\end{array}$ & 234 & 36 & 0 & $\mathbf{0}$ & 0 & 38 \\
\hline 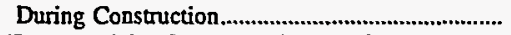 & 0 & 0 & 19 & 0 & 0 & 0 \\
\hline Taxes on Other Income and Deductions ................. & 0 & 0 & 0 & 0 & 0 & 0 \\
\hline Electric Utility Income & 19,886 & 3,233 & 9,152 & 1,690 & 5,513 & -488 \\
\hline 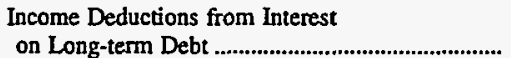 & 9,874 & 1,636 & 777 & 1,278 & 0 & 2 \\
\hline $\begin{array}{l}\text { Other Income Deductions....................................... } \\
\text { Allowance for Borrowed Funds Used }\end{array}$ & 833 & 0 & 2,677 & 58 & 0 & 0 \\
\hline 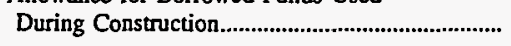 & 0 & 0 & 0 & 0 & 0 & 0 \\
\hline 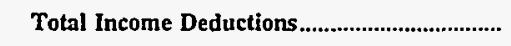 & 10,707 & 1,636 & 3,454 & 1,335 & $\mathbf{0}$ & 2 \\
\hline Income Before Extraordinary Items................................ & 9,179 & 1,597 & 5,699 & 355 & 5,513 & -490 \\
\hline Extraordinary Income & 0 & 513 & 0 & 725 & 269 & 287 \\
\hline 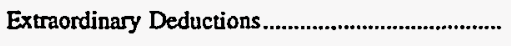 & 0 & 0 & 0 & 0 & 0 & 0 \\
\hline Net Income & 9,179 & 2,110 & 5,699 & 1,080 & 5,782 & -203 \\
\hline
\end{tabular}

Note: Totals may not equal sum of components because of independent rounding.

Source: Energy Information Administration, Form ElA-412, "Annual Report of Public Electric Utilities." 
Table 21. Statement of Income by Major U.S. Publicly Owned Electric Utility Within State, 1996 (Continued)

(Thousand Dollars)

\begin{tabular}{|c|c|c|c|c|c|c|}
\hline Item & $\begin{array}{l}\text { Washington } \\
\text { PUD No } 1 \text { of } \\
\text { Pend Oreille } \\
\text { Cnty } \\
\text { December } 31\end{array}$ & $\begin{array}{l}\text { Washington } \\
\text { PUD No I of } \\
\text { Snohomish } \\
\text { County } \\
\text { December } 31\end{array}$ & $\begin{array}{l}\text { Washington } \\
\text { PUD No I of } \\
\text { Whatcom } \\
\text { County } \\
\text { December } 31\end{array}$ & $\begin{array}{c}\text { Washington } \\
\text { PUD No } 2 \\
\text { of } \\
\text { Grant } \\
\text { County } \\
\text { December } 31\end{array}$ & $\begin{array}{l}\text { Washington } \\
\text { PUD No } 2 \text { of } \\
\text { Pacific } \\
\text { County } \\
\text { December } 31\end{array}$ & $\begin{array}{c}\text { Washington } \\
\text { PUD No } 3 \\
\text { of } \\
\text { Mason } \\
\text { County } \\
\text { December } 31\end{array}$ \\
\hline Electric Utility Operating Revenues...................... & 20,088 & 354,551 & 4,919 & 104,998 & 14,690 & 28,584 \\
\hline 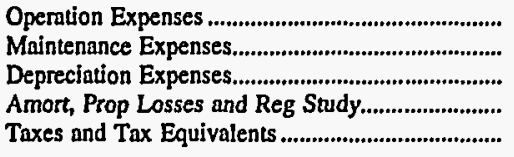 & $\begin{array}{r}13,884 \\
1,322 \\
1,166 \\
0 \\
1,275\end{array}$ & $\begin{array}{r}251,428 \\
16,064 \\
27,293 \\
0 \\
14,569\end{array}$ & $\begin{array}{r}4,820 \\
9 \\
84 \\
0 \\
297\end{array}$ & $\begin{array}{r}40,484 \\
15,880 \\
15,952 \\
0 \\
7,028\end{array}$ & $\begin{array}{r}10,467 \\
741 \\
1,073 \\
0 \\
632\end{array}$ & $\begin{array}{r}20,731 \\
2,128 \\
2,605 \\
0 \\
1,088\end{array}$ \\
\hline 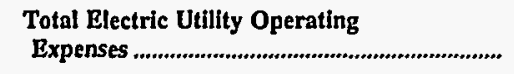 & 17,647 & 309,354 & 5,209 & 79,343 & 12,913 & 26,552 \\
\hline 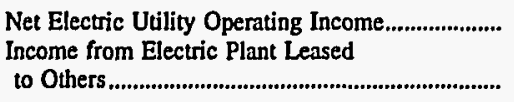 & 2,442 & 45,197 & -290 & 25,655 & 1,777 & 2,032 \\
\hline Electric Utility Operating Income...................... & 2,442 & 45,197 & -290 & 25,655 & 1,777 & 2,032 \\
\hline 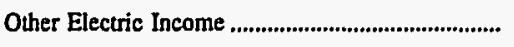 & 514 & 15,205 & 98 & 9,718 & 1,077 & 1,041 \\
\hline $\begin{array}{l}\text { Other Electric Deductions } \\
\text { Allowance for Other Funds Used }\end{array}$ & 0 & 3.349 & $\mathbf{0}$ & 0 & 705 & 11 \\
\hline Taxes on Other Income and Deductions ............... & 0 & 0 & 0 & 0 & 316 & 19 \\
\hline Electric Utility Income........................................... & 2,956 & 63,751 & -193 & 35,373 & 1,834 & 3,042 \\
\hline 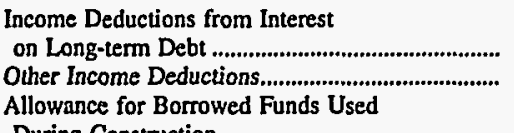 & $\begin{array}{r}150 \\
92\end{array}$ & $\begin{array}{r}41,222 \\
6,388\end{array}$ & $\begin{array}{l}0 \\
0\end{array}$ & $\begin{array}{r}23,004 \\
926\end{array}$ & $\begin{array}{r}302 \\
0\end{array}$ & $\begin{array}{r}935 \\
33\end{array}$ \\
\hline 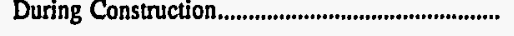 & 0 & 0 & $\mathbf{0}$ & 0 & 0 & 0 \\
\hline Total Income Deductions.................................... & 242 & 47,609 & 0 & 23,930 & 302 & 968 \\
\hline Income Before Extraordinary Items.......................... & 2,714 & 16,142 & -193 & 11,443 & 1,531 & 2,074 \\
\hline Extraordinary Income & $\mathbf{0}$ & 0 & 0 & 1,587 & 414 & 1 \\
\hline 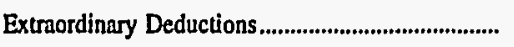 & 0 & 0 & 0 & 0 & 765 & 0 \\
\hline 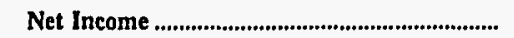 & 2,714 & 16,142 & -193 & 13,030 & 1,181 & 2,075 \\
\hline
\end{tabular}

Note: Totals may not equal sum of components because of independent rounding.

Source: Energy Information Administration, Form ELA-412, "Annual Report of Public Electric Utilities." 
Table 21. Statement of Income by Major U.S. Publicly Owned Electric Utility Within State, 1996 (Continued)

(Thousand Dollars)

\begin{tabular}{|c|c|c|c|c|c|c|}
\hline Item & $\begin{array}{l}\text { Washington } \\
\text { Richland } \\
\text { City of } \\
\text { December } 31\end{array}$ & $\begin{array}{c}\text { Washington } \\
\text { Seattle } \\
\text { City of } \\
\text { December } 31\end{array}$ & $\begin{array}{l}\text { Washington } \\
\text { Tacoma } \\
\text { City of } \\
\text { December } 31\end{array}$ & $\begin{array}{c}\text { Washington } \\
\text { Vera } \\
\text { Irrigation } \\
\text { District \#15 } \\
\text { December } 31\end{array}$ & $\begin{array}{c}\text { Washington } \\
\text { Washington } \\
\text { Pub } \\
\text { Pwr } \\
\text { Supply Sys } \\
\text { June } 30\end{array}$ & $\begin{array}{l}\text { Wisconsin } \\
\text { Badger Power } \\
\text { Marketing } \\
\text { Auth }\end{array}$ \\
\hline Electric Utility Operating Revenues....................... & 26,347 & 356,671 & 217,685 & 8,121 & 447,049 & 10,465 \\
\hline 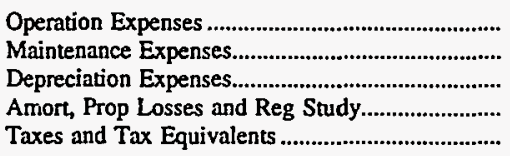 & $\begin{array}{r}22,563 \\
579 \\
1,232 \\
0 \\
3,104\end{array}$ & $\begin{array}{r}190,818 \\
22,352 \\
45,917 \\
0 \\
36,090\end{array}$ & $\begin{array}{r}104,463 \\
16,897 \\
19,741 \\
225 \\
23,611\end{array}$ & $\begin{array}{r}6,730 \\
321 \\
479 \\
0 \\
311\end{array}$ & $\begin{array}{r}152,873 \\
35,712 \\
112,180 \\
588 \\
2,649\end{array}$ & $\begin{array}{r}9,689 \\
22 \\
158 \\
36 \\
112\end{array}$ \\
\hline $\begin{array}{c}\text { Total Electric Utility Operating } \\
\text { Expenses }\end{array}$ & 27,477 & 295,176 & 164,938 & 7,840 & 304,002 & 10,017 \\
\hline 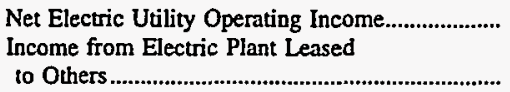 & $\begin{array}{r}-1,130 \\
0\end{array}$ & 61,495 & 52,747 & 280 & 143,046 & 448 \\
\hline Electric Utility Operating Income..................... & $-1,130$ & 61,495 & 52,747 & 283 & 143,046 & 453 \\
\hline Other Electric Income & 577 & 10,911 & 8,564 & 231 & 22,609 & 161 \\
\hline $\begin{array}{l}\text { Other Electric Deductions } \\
\text { Allowance for Other Funds Used }\end{array}$ & 0 & 229 & 281 & 0 & 189 & 0 \\
\hline 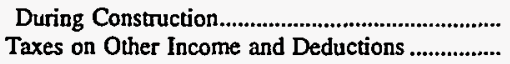 & $\begin{array}{l}0 \\
0\end{array}$ & $\begin{array}{l}0 \\
0\end{array}$ & $\begin{array}{l}\mathbf{0} \\
\mathbf{0}\end{array}$ & $\begin{array}{l}0 \\
0\end{array}$ & $\begin{array}{l}0 \\
0\end{array}$ & $\begin{array}{l}0 \\
0\end{array}$ \\
\hline Electric Utility Income........................................... & -553 & 72,176 & 61,030 & 514 & 165,466 & 614 \\
\hline 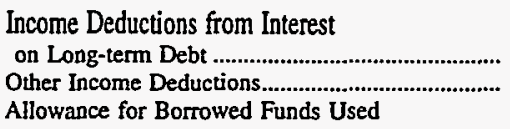 & $\begin{array}{l}897 \\
553\end{array}$ & $\begin{array}{r}42,343 \\
7,452\end{array}$ & $\begin{array}{r}25,538 \\
5,119\end{array}$ & $\begin{array}{r}188 \\
0\end{array}$ & $\begin{array}{r}160,202 \\
5,264\end{array}$ & $\begin{array}{l}313 \\
114\end{array}$ \\
\hline During Construction & 0 & $-1,961$ & 0 & 0 & 0 & 0 \\
\hline 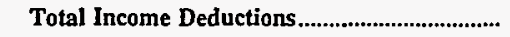 & 1,450 & 47,833 & 30,657 & 188 & 165,466 & 427 \\
\hline 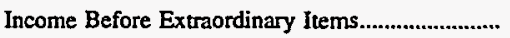 & $-2,003$ & 24,343 & 30,373 & 327 & 0 & 187 \\
\hline Extraordinary Income & 0 & 0 & 0 & 0 & 0 & 0 \\
\hline 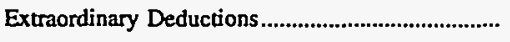 & 0 & 0 & 0 & 0 & 0 & 0 \\
\hline 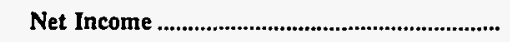 & $-2,003$ & 24,343 & 30,373 & 327 & 0 & 187 \\
\hline
\end{tabular}

Source: Energy Information Administration, Form EIA-412, "Annual Report of Public Electric Utilities." 
Table 21. Statement of Income by Major U.S. Publicly Owned Electric Utility Within State, 1996 (Continued)

(Thousand Dollars)

\begin{tabular}{|c|c|c|c|c|c|c|}
\hline Item & $\begin{array}{l}\text { Wisconsin } \\
\text { Jefferson } \\
\text { City of } \\
\text { December } 31\end{array}$ & $\begin{array}{l}\text { Wisconsin } \\
\text { Kaukauna } \\
\text { City of } \\
\text { December } 31\end{array}$ & $\begin{array}{l}\text { Wisconsin } \\
\text { Manitowoc } \\
\text { Public } \\
\text { Utilities } \\
\text { December } 31\end{array}$ & $\begin{array}{l}\text { Wisconsin } \\
\text { Marshfield } \\
\text { City of } \\
\text { December } 31\end{array}$ & $\begin{array}{l}\text { Wisconsin } \\
\text { Menasha } \\
\text { City of } \\
\text { December } 31\end{array}$ & $\begin{array}{c}\text { Wisconsin } \\
\text { New London } \\
\begin{array}{c}\text { Electric\&Water } \\
\text { Util }\end{array} \\
\text { December } 31\end{array}$ \\
\hline Electric Utillty Operating Revenues...................... & 6,668 & 24,746 & 25,094 & 13,963 & 22,211 & $\mathbf{7 , 5 7 8}$ \\
\hline 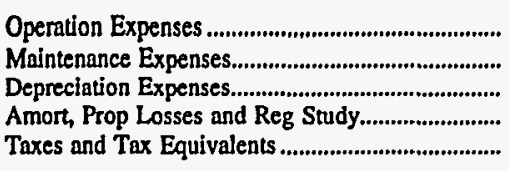 & $\begin{array}{r}5,520 \\
113 \\
303 \\
0 \\
209\end{array}$ & $\begin{array}{r}19,736 \\
524 \\
1,228 \\
0 \\
1,034\end{array}$ & $\begin{array}{r}15,788 \\
1,556 \\
2,459 \\
0 \\
1,575\end{array}$ & $\begin{array}{r}10,322 \\
462 \\
879 \\
5 \\
569\end{array}$ & $\begin{array}{r}19,108 \\
379 \\
880 \\
5 \\
765\end{array}$ & $\begin{array}{r}6,379 \\
117 \\
282 \\
0 \\
290\end{array}$ \\
\hline $\begin{array}{l}\text { Total Electric Utility Operating } \\
\text { Expenses .................................................................... }\end{array}$ & 6,144 & 22,522 & 21,378 & 12,238 & 21,137 & 7,067 \\
\hline 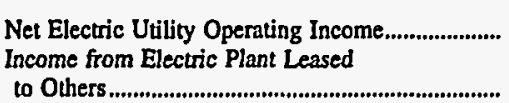 & $\begin{array}{r}524 \\
0\end{array}$ & 2,224 & 3,717 & 1,726 & 1,074 & $\begin{array}{r}510 \\
0\end{array}$ \\
\hline Electric Utility Operating Income.................... & 524 & 2,224 & 3,717 & 1,726 & 1,074 & 510 \\
\hline 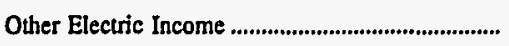 & 171 & 398 & 679 & 244 & 226 & 536 \\
\hline $\begin{array}{l}\text { Other Electric Deductions } \\
\text { Allowance for Other Funds Used }\end{array}$ & 0 & 0 & $\mathbf{0}$ & 218 & 3 & 1 \\
\hline 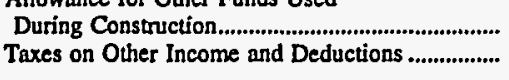 & $\begin{array}{l}0 \\
0\end{array}$ & $\begin{array}{l}\mathbf{0} \\
\mathbf{0}\end{array}$ & $\begin{array}{l}\mathbf{0} \\
0\end{array}$ & $\begin{array}{l}0 \\
0\end{array}$ & $\begin{array}{l}0 \\
0\end{array}$ & $\begin{array}{l}0 \\
0\end{array}$ \\
\hline 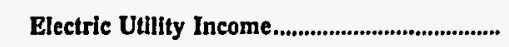 & 695 & 2,622 & 4,395 & 1,752 & 1,297 & 1,045 \\
\hline 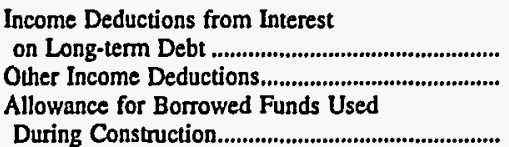 & $\begin{array}{r}347 \\
0\end{array}$ & $\begin{array}{l}0 \\
0\end{array}$ & $\begin{array}{r}1,350 \\
131\end{array}$ & $\begin{array}{r}436 \\
20 \\
0\end{array}$ & $\begin{array}{c}603 \\
28 \\
i \\
0\end{array}$ & $\begin{array}{r}536 \\
62 \\
0\end{array}$ \\
\hline 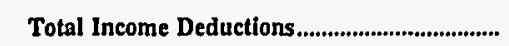 & 347 & 0 & 1,481 & 456 & 630 & 598 \\
\hline Income Before Extraordinary Items........................... & 348 & 2,622 & 2,915 & 1,297 & 667 & 447 \\
\hline Extrnordinary Income & 0 & 0 & 0 & 0 & 0 & $\mathbf{0}$ \\
\hline 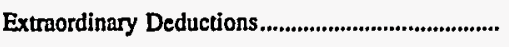 & $\mathbf{0}$ & 0 & $\mathbf{0}$ & 0 & 138 & 0 \\
\hline 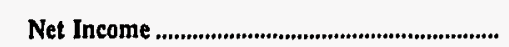 & 348 & 2,622 & 2,915 & 1,297 & 529 & 447 \\
\hline
\end{tabular}

Note: Totals may not equal sum of components because of independent rounding.

Source: Energy Information Administration, Form EIA-412, "Annual Report of Public Electric Utilities." 
Table 21. Statement of Income by Major U.S. Publicly Owned Electric Utility Within State, 1996 (Continued)

(Thousand Dollars)

\begin{tabular}{|c|c|c|c|c|c|c|}
\hline Item & $\begin{array}{l}\text { Wisconsin } \\
\begin{array}{c}\text { Oconomowoc } \\
\text { City of }\end{array} \\
\text { December } 31\end{array}$ & $\begin{array}{l}\text { Wisconsin } \\
\text { Plymouth } \\
\text { City of } \\
\text { December } 31\end{array}$ & $\begin{array}{l}\text { Wisconsin } \\
\text { Reedsburg } \\
\text { Utility Comm } \\
\text { December } 31\end{array}$ & $\begin{array}{c}\text { Wisconsin } \\
\text { Shawano } \\
\text { Municipal } \\
\text { Utilities } \\
\text { December 31 }\end{array}$ & $\begin{array}{c}\text { Wisconsin } \\
\text { Sheboygan } \\
\text { Falls } \\
\text { City of } \\
\text { December 31 }\end{array}$ & $\begin{array}{c}\text { Wisconsin } \\
\text { Sturgeon } \\
\text { Bay City of } \\
\text { December } 31\end{array}$ \\
\hline Electric Utility Operating Revenues..................... & 8,456 & 7,797 & 7,811 & 9,180 & 7,682 & 7,242 \\
\hline 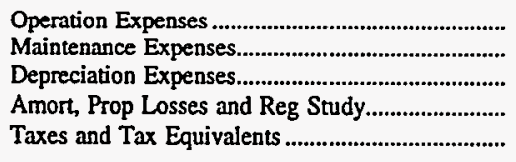 & $\begin{array}{r}6,574 \\
328 \\
519 \\
32 \\
411\end{array}$ & $\begin{array}{r}6,259 \\
151 \\
458 \\
0 \\
285\end{array}$ & $\begin{array}{r}6,863 \\
126 \\
340 \\
8 \\
249\end{array}$ & $\begin{array}{r}7,773 \\
122 \\
359 \\
0 \\
147\end{array}$ & $\begin{array}{r}6,884 \\
0 \\
289 \\
0 \\
173\end{array}$ & $\begin{array}{r}5,094 \\
215 \\
585 \\
0 \\
341\end{array}$ \\
\hline 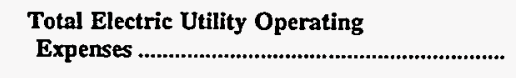 & 7,864 & 7,154 & 7,585 & 8,400 & 7,345 & 6,235 \\
\hline 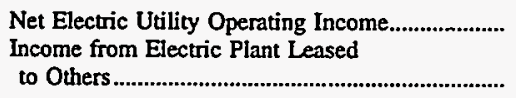 & 592 & 643 & 226 & $\begin{array}{l}780 \\
296\end{array}$ & 337 & 1,007 \\
\hline Electric Utility Operating Income .................... & 592 & 643 & 226 & 1,076 & 337 & 1,007 \\
\hline Other Electric Income & 224 & 53 & 355 & 231 & 0 & 194 \\
\hline $\begin{array}{l}\text { Other Electric Deductions ...................................... } \\
\text { Allowance for Other Funds Used }\end{array}$ & 0 & 14 & 6 & 41 & 0 & 47 \\
\hline 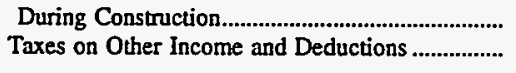 & $\begin{array}{l}0 \\
0\end{array}$ & $\begin{array}{l}0 \\
0\end{array}$ & $\begin{array}{l}0 \\
0\end{array}$ & $\begin{array}{r}0 \\
139\end{array}$ & $\begin{array}{l}0 \\
0\end{array}$ & $\begin{array}{l}0 \\
0\end{array}$ \\
\hline 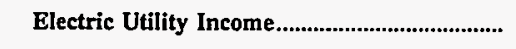 & 816 & 683 & 574 & 1,128 & 337 & 1,154 \\
\hline 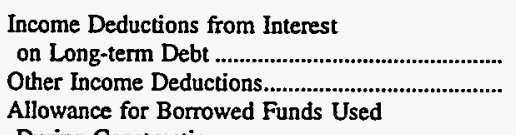 & $\begin{array}{r}107 \\
0\end{array}$ & $\begin{array}{l}17 \\
27\end{array}$ & $\begin{array}{r}287 \\
53\end{array}$ & $\begin{array}{l}88 \\
57\end{array}$ & $\begin{array}{l}0 \\
0\end{array}$ & $\begin{array}{r}382 \\
92\end{array}$ \\
\hline 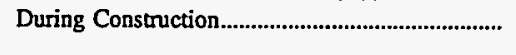 & 0 & 0 & 0 & 0 & 0 & 0 \\
\hline 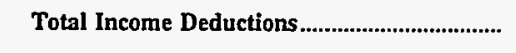 & 107 & 44 & 341 & 144 & $\mathbf{0}$ & 473 \\
\hline 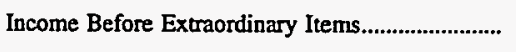 & 709 & 639 & 234 & 983 & 337 & 681 \\
\hline Extraordinary Income & 0 & 0 & 0 & 136 & 0 & 0 \\
\hline 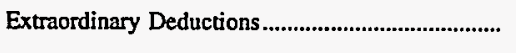 & 0 & 0 & 0 & 2 & 0 & 0 \\
\hline 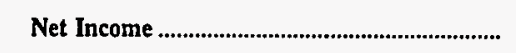 & 709 & 639 & 234 & 1,117 & 337 & 681 \\
\hline
\end{tabular}

Source: Energy Information Administration, Form EIA-412, "Annual Report of Public Electric Utilities." 
Table 21. Statement of Income by Major U.S. Publicly Owned Electric Utility

Within State, 1996 (Continued)

(Thousand Dollars)

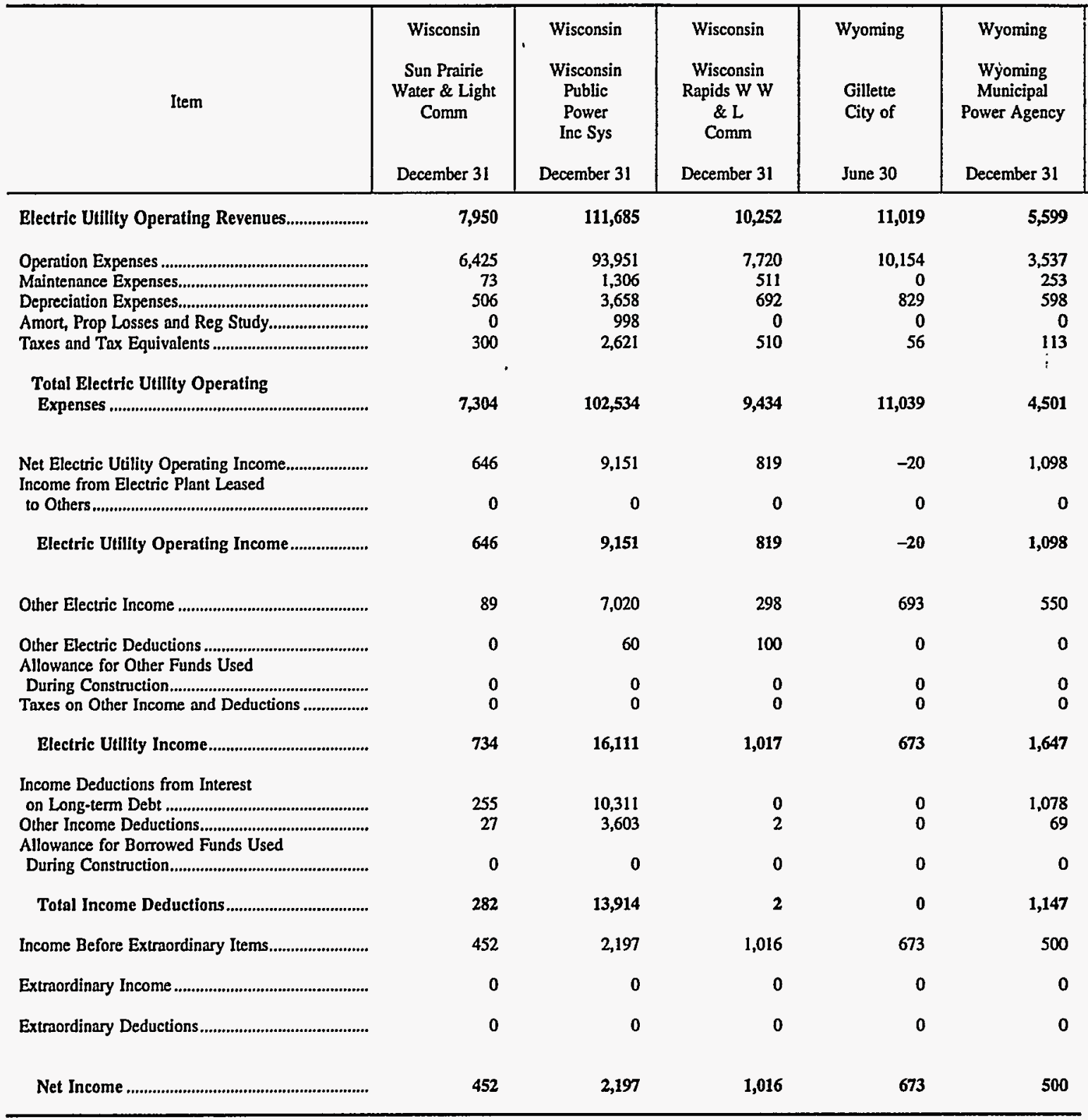

Note: Totals may not equal sum of components because of independent rounding.

Source: Energy Information Administration, Form EIA-412, "Annual Report of Public Electric Utilities." 
Table 22. Balance Sheet by Major U.S. Publicly Owned Electric Utility Within State at End of Period, 1996

(Thousand Dollars)

\begin{tabular}{|c|c|c|c|c|c|c|}
\hline Item & $\begin{array}{l}\text { Alabama } \\
\text { Alabama } \\
\text { Municipal } \\
\text { Elec Auth } \\
\text { September } 30\end{array}$ & $\begin{array}{l}\text { Alabama } \\
\text { Albertville } \\
\text { Municipal } \\
\text { Utils Bd } \\
\text { June } 30\end{array}$ & $\begin{array}{l}\text { Alabama } \\
\text { Andalusia } \\
\text { City of } \\
\text { September } 30\end{array}$ & $\begin{array}{l}\text { Alabama } \\
\text { Athens } \\
\text { City of } \\
\text { December } 31\end{array}$ & $\begin{array}{l}\text { Alabama } \\
\text { Bessemer } \\
\text { City of } \\
\text { June } 30\end{array}$ & $\begin{array}{l}\text { Alabama } \\
\text { Cullman } \\
\text { Power Board } \\
\text { June } 30\end{array}$ \\
\hline \multicolumn{7}{|l|}{ Electric Utility Plant } \\
\hline Electric Utility Plant \& Adjust ....................................... & 0 & 14,289 & 3,920 & 45,913 & 21,328 & 14,041 \\
\hline 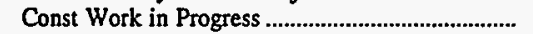 & 0 & 14 & & 1,178 & 1,620 & 230 \\
\hline 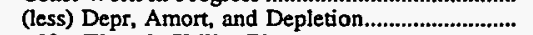 & 0 & 5,576 & 1,428 & 17,152 & 11,202 & 5,972 \\
\hline 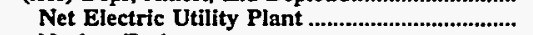 & 0 & 8,727 & 2,493 & 29,938 & 11,746 & 8,299 \\
\hline 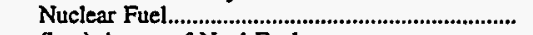 & o & 0 & 0 & & & 0 \\
\hline 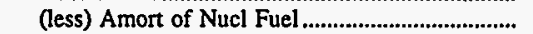 & 0 & 0 & 0 & 0 & 0 & 0 \\
\hline 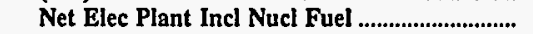 & 0 & 8,727 & 2,493 & 29,938 & 11,746 & 8,299 \\
\hline \multicolumn{7}{|l|}{ Other Property \& Investments } \\
\hline 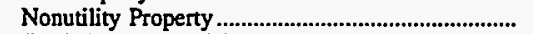 & 3,391 & 0 & 12,216 & 0 & 0 & $\mathbf{0}$ \\
\hline (less) Accum Provisions for Depr \& Amort .......... & 827 & 0 & 2,548 & 0 & 0 & 0 \\
\hline 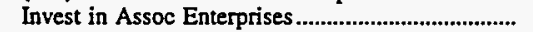 & 0 & 0 & 3,451 & 0 & 0 & 0 \\
\hline 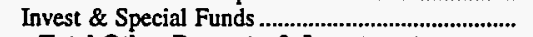 & 25,608 & 19 & 565 & 16,001 & 36 & 414 \\
\hline Total Other Property \& Investments................. & 28,172 & 19 & 13,684 & 16,001 & 36 & 414 \\
\hline \multicolumn{7}{|l|}{ Current and Accrued Assets } \\
\hline Cash, Working Funds \& Investments........................ & 5,720 & 3,326 & 457 & 3,102 & 984 & 873 \\
\hline Notes \& Other Receivables..................................... & & 1,787 & 11 & 3,758 & 4,927 & 2,635 \\
\hline Customer Accts Receivable & 9,332 & 0 & 1,225 & 0 & 0 & 0 \\
\hline (less) Accum Prov for Uncollected Accts............... & 0 & 0 & 0 & 0 & 0 & 0 \\
\hline Fuel Stock \& Exp Undistr......................................... & 0 & 0 & 0 & 0 & 0 & 0 \\
\hline Materials \& Supplies ................................................. & 439 & 152 & 195 & 423 & 285 & 416 \\
\hline 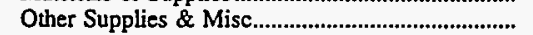 & 0 & 0 & 0 & 0 & 0 & 0 \\
\hline 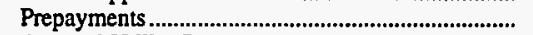 & 74,367 & 0 & 46 & 0 & 0 & 0 \\
\hline Accrued Utility Revenues .......................................... & 0 & 24 & 0 & 233 & 145 & 10 \\
\hline Miscellaneous Current \& Accrued Assets................ & 0 & 47 & 0 & 72 & 347 & 47 \\
\hline Total Current \& Accrued Assets............................ & 89,856 & 5,336 & 1,934 & 7,588 & 6,689 & 3,980 \\
\hline \multicolumn{7}{|l|}{ Deferred Debits } \\
\hline 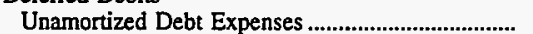 & 9,247 & 1,051 & 49 & 1,283 & 10 & 104 \\
\hline Extraordinary Losses, Study Cost................................. & & 0 & 0 & 0 & 0 & 0 \\
\hline Misc Debt, R \& D Exp, Unamrt Losses ..................... & 42,030 & 0 & 0 & 270 & 2,247 & 811 \\
\hline 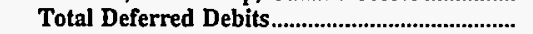 & 51,277 & 1,051 & 49 & 1,553 & 2,257 & 915 \\
\hline Total Assets \& Other Debits .................................... & 169,306 & 15,133 & 18,159 & 55,079 & 20,728 & 13,608 \\
\hline \multicolumn{7}{|l|}{ Proprietary Capital } \\
\hline 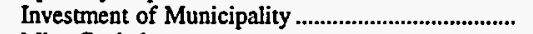 & 0 & 0 & 5,430 & 0 & 0 & $\mathbf{0}$ \\
\hline 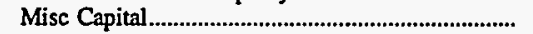 & 0 & 0 & 232 & 0 & 0 & 0 \\
\hline 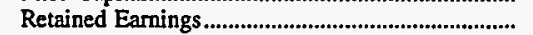 & 1,009 & 11,125 & 7,206 & 22,196 & 9,930 & 7,247 \\
\hline \multirow{2}{*}{\multicolumn{7}{|c|}{ Long-term Debt }} \\
\hline & & & & & & \\
\hline Bonds & 160,930 & 0 & 3,823 & 0 & 0 & 0 \\
\hline Advances from Municipality \& Other...................... & 0 & 1,011 & 0 & 27,015 & 2,010 & 2,900 \\
\hline Unamort Prem on Long-term Debt................................. & 0 & 0 & 0 & 275 & 2,085 & 780 \\
\hline (less) Unamort Discount on Long-term Debt & 1,041 & 0 & 0 & 0 & 17 & 0 \\
\hline Total Long-term Debt & 159,889 & 1,011 & 3,823 & 27,290 & 4,078 & 3,680 \\
\hline \multicolumn{7}{|l|}{ Other Noncurrent Liabilities } \\
\hline 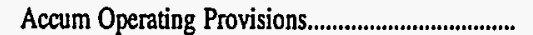 & 0 & 0 & 0 & 0 & 0 & 0 \\
\hline 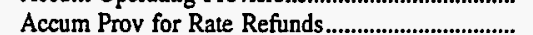 & 0 & 0 & 0 & 0 & 0 & 0 \\
\hline 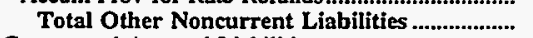 & 0 & 0 & 0 & o & 0 & o \\
\hline \multicolumn{7}{|l|}{ Current and Accrued Liabilities } \\
\hline Notes Payable ............................................................. & 0 & 2,010 & 0 & 0 & 12 & 0 \\
\hline 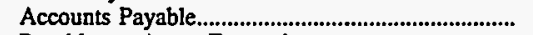 & 7,620 & & 986 & 3,460 & 5,660 & 1,870 \\
\hline 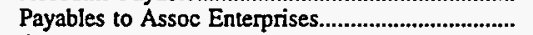 & 0 & 605 & 0 & 0 & 0 & 0 \\
\hline 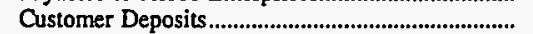 & 0 & 0 & 352 & 1,246 & 373 & 486 \\
\hline 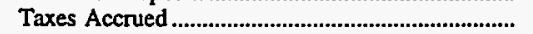 & 0 & 0 & 71 & 0 & 8 & 24 \\
\hline 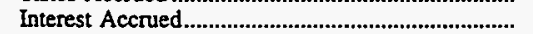 & 731 & 381 & 59 & 524 & 0 & 56 \\
\hline Misc Current \& Accrued Liabilities ............................... & 57 & 0 & & 360 & 668 & 174 \\
\hline Total Current \& Accrued Liabilities ..................... & 8,408 & 2,997 & 1,468 & 5,591 & 6,720 & 2,611 \\
\hline \multicolumn{7}{|l|}{ Deferred Credits } \\
\hline Customer Advances for Construction ............................. & 0 & 0 & 0 & 3 & 0 & 70 \\
\hline 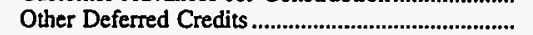 & 0 & 0 & 0 & 0 & 0 & 0 \\
\hline 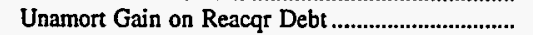 & 0 & 0 & 0 & 0 & 0 & 0 \\
\hline 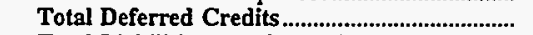 & o & & & 3 & 0 & 70 \\
\hline Total Liabilities and Other Credits..................... & 169,306 & 15,133 & 18,159 & 55,079 & 20,728 & 13,608 \\
\hline
\end{tabular}

Note: Totals may not equal sum of components because of independent rounding.

Source: Energy Information Administration, Form EIA-412, "Annual Report of Public Electric Utilities." 
Table 22. Balance Sheet by Major U.S. Publicly Owned Electric Utility Within State at End of Period, 1996 (Continued)

(Thousand Dollars)

\begin{tabular}{|c|c|c|c|c|c|c|}
\hline Item & $\begin{array}{l}\text { Alabama } \\
\text { Decatur } \\
\text { City of } \\
\text { June } 30\end{array}$ & $\begin{array}{l}\text { Alabama } \\
\text { Dothan } \\
\text { City of } \\
\text { September } 30\end{array}$ & $\begin{array}{l}\text { Alabama } \\
\text { Florence } \\
\text { City of } \\
\text { June } 30\end{array}$ & $\begin{array}{c}\text { Alabama } \\
\text { Foley } \\
\text { City of } \\
\text { (Riviera Utils) } \\
\text { December } 31\end{array}$ & $\begin{array}{c}\text { Alabama } \\
\text { Fort Payne } \\
\text { Improvement } \\
\text { Auth } \\
\text { June } 30\end{array}$ & $\begin{array}{l}\text { Alabama } \\
\text { Guntersville } \\
\text { Electric } \\
\text { Board } \\
\text { June } 30\end{array}$ \\
\hline \multicolumn{7}{|l|}{ Electric Utility Plant } \\
\hline 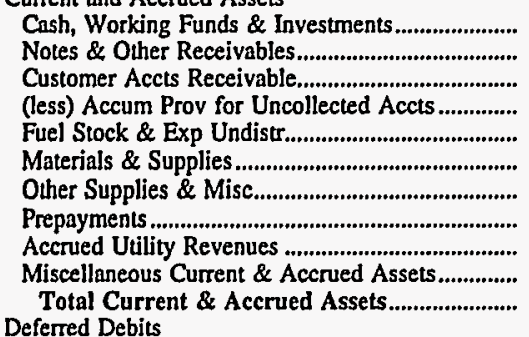 & $\begin{array}{r}4,185 \\
6,586 \\
0 \\
0 \\
0 \\
542 \\
0 \\
0 \\
23 \\
1 \\
11,337\end{array}$ & $\begin{array}{r}9,814 \\
117 \\
3,711 \\
0 \\
0 \\
238 \\
0 \\
0 \\
13 \\
0 \\
13,893\end{array}$ & $\begin{array}{r}2,208 \\
8,469 \\
0 \\
0 \\
0 \\
1,495 \\
0 \\
0 \\
3,920 \\
151 \\
16,243\end{array}$ & $\begin{array}{r}7,218 \\
1,736 \\
4,010 \\
47 \\
0 \\
911 \\
0 \\
1,336 \\
0 \\
32 \\
15,196\end{array}$ & $\begin{array}{r}2,234 \\
1,923 \\
0 \\
0 \\
0 \\
228 \\
0 \\
0 \\
47 \\
54 \\
4,485\end{array}$ & $\begin{array}{r}1,511 \\
1,124 \\
0 \\
0 \\
0 \\
104 \\
0 \\
51 \\
0 \\
38 \\
2,828\end{array}$ \\
\hline 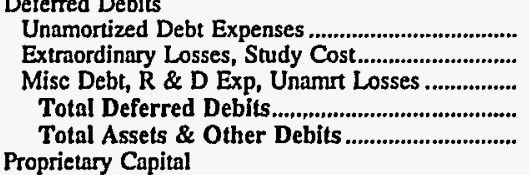 & $\begin{array}{r}0 \\
0 \\
1,689 \\
1,689 \\
38,133\end{array}$ & $\begin{array}{r}0 \\
0 \\
0 \\
\mathbf{0} \\
\mathbf{5 1 , 5 7 2}\end{array}$ & $\begin{array}{r}0 \\
0 \\
2,700 \\
2,700 \\
67,670\end{array}$ & $\begin{array}{r}135 \\
0 \\
0 \\
135 \\
64,728\end{array}$ & $\begin{array}{r}122 \\
0 \\
1,736 \\
1,857 \\
16,063\end{array}$ & $\begin{array}{r}14 \\
0 \\
606 \\
620 \\
9,952\end{array}$ \\
\hline 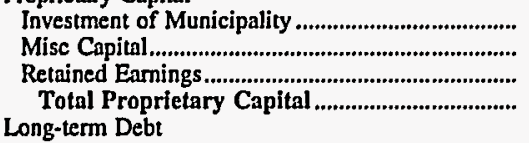 & $\begin{array}{r}0 \\
0 \\
32,849 \\
32,849\end{array}$ & $\begin{array}{r}0 \\
0 \\
39,495 \\
39,495\end{array}$ & $\begin{array}{r}0 \\
0 \\
49,538 \\
49,538\end{array}$ & $\begin{array}{r}0 \\
-941 \\
52,718 \\
51,777\end{array}$ & $\begin{array}{r}0 \\
0 \\
8,418 \\
8,418\end{array}$ & $\begin{array}{r}0 \\
0 \\
7,512 \\
7,512\end{array}$ \\
\hline 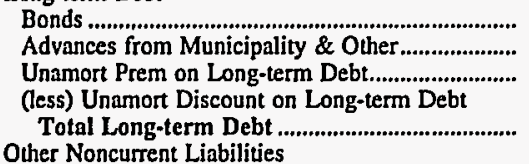 & $\begin{array}{r}0 \\
0 \\
121 \\
0 \\
121\end{array}$ & $\begin{array}{r}4,647 \\
0 \\
0 \\
0 \\
4,647\end{array}$ & $\begin{array}{r}0 \\
157 \\
2,747 \\
0 \\
2,904\end{array}$ & $\begin{array}{r}7,235 \\
0 \\
0 \\
0 \\
7,235\end{array}$ & $\begin{array}{r}0 \\
4,415 \\
565 \\
0 \\
4,980\end{array}$ & $\begin{array}{r}335 \\
628 \\
0 \\
0 \\
963\end{array}$ \\
\hline 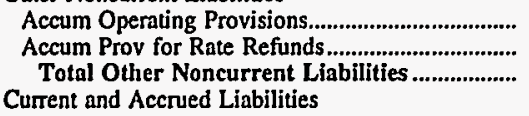 & $\begin{array}{l}0 \\
0 \\
0\end{array}$ & $\begin{array}{r}0 \\
0 \\
0\end{array}$ & $\begin{array}{l}0 \\
0 \\
0\end{array}$ & $\begin{array}{r}223 \\
0 \\
223\end{array}$ & $\begin{array}{l}0 \\
0 \\
0\end{array}$ & $\begin{array}{l}0 \\
0 \\
0\end{array}$ \\
\hline 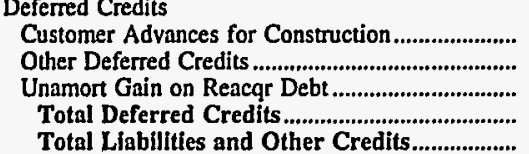 & $\begin{array}{r}0 \\
0 \\
0 \\
0 \\
\mathbf{3 8}, 133\end{array}$ & $\begin{array}{r}0 \\
0 \\
0 \\
0 \\
\mathbf{5 1 , 5 7 2}\end{array}$ & $\begin{array}{r}0 \\
0 \\
0 \\
0 \\
67,670\end{array}$ & $\begin{array}{r}0 \\
30 \\
0 \\
30 \\
64,728\end{array}$ & $\begin{array}{r}2 \\
0 \\
0 \\
2 \\
16,063\end{array}$ & $\begin{array}{r}0 \\
0 \\
0 \\
0 \\
9,952\end{array}$ \\
\hline
\end{tabular}

Note: Totals may not equal sum of components because of independent rounding.

Source: Energy Information Administration, Form EIA-412, "Annual Report of Public Electric Utilities." 
Table 22. Balance Sheet by Major U.S. Publicly Owned Electric Utility Within State at End of Period, 1996 (Continued)

(Thousand Dollars)

\begin{tabular}{|c|c|c|c|c|c|c|}
\hline Item & $\begin{array}{l}\text { Alabama } \\
\text { Hartselle } \\
\text { City of } \\
\text { June } 30\end{array}$ & $\begin{array}{l}\text { Alabama } \\
\text { Huntsville } \\
\text { City of } \\
\text { September } 30\end{array}$ & $\begin{array}{l}\text { Alabama } \\
\text { Muscle } \\
\text { Shoals } \\
\text { City of } \\
\text { June } 30\end{array}$ & $\begin{array}{l}\text { Alabama } \\
\text { Opelika } \\
\text { City of } \\
\text { September } 30\end{array}$ & $\begin{array}{l}\text { Alabama } \\
\begin{array}{c}\text { Scottsboro } \\
\text { City of }\end{array} \\
\text { June } 30\end{array}$ & $\begin{array}{l}\text { Alabama } \\
\text { Sheffield } \\
\text { Utilities } \\
\text { June } 30\end{array}$ \\
\hline \multicolumn{7}{|l|}{ Elecric Utility Plant } \\
\hline 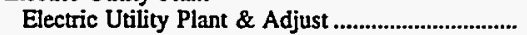 & 6,636 & 176,023 & 16,048 & 20,468 & 16,090 & 36,606 \\
\hline 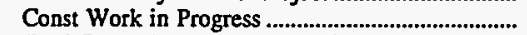 & 107 & 10,939 & 117 & 717 & 293 & 1,828 \\
\hline 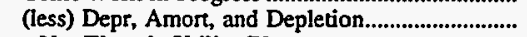 & 3,274 & 72,742 & 5,415 & 11,712 & 6,458 & 16,397 \\
\hline Net Electric Utility Plant ........................................ & $\mathbf{3 , 4 7 0}$ & 114,220 & 10,750 & 9,473 & 9,925 & 22,037 \\
\hline Nuclear Fuel............................................................ & 0 & 0 & 0 & 0 & 0 & 0 \\
\hline 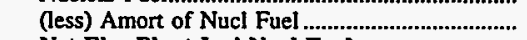 & & & 0 & 0 & 0 & 0 \\
\hline Net Elec Plant Incl Nucl Fuel ............................ & $\mathbf{3 , 4 7 0}$ & 114,220 & 10,750 & 9,473 & 9,925 & 22,037 \\
\hline \multicolumn{7}{|l|}{ Other Property \& Investments } \\
\hline 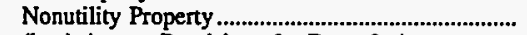 & 0 & 0 & 0 & 0 & 0 & 148 \\
\hline (less) Accum Provisions for Depr \& Amort .......... & 0 & 0 & 0 & 0 & 0 & 0 \\
\hline 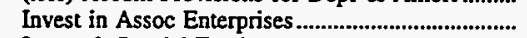 & 0 & 0 & 0 & 68 & 0 & 0 \\
\hline 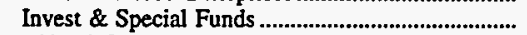 & 6 & 34,769 & 150 & 903 & 543 & 1,312 \\
\hline Total Other Property \& Investments.................. & 6 & 34,769 & 150 & 971 & 543 & 1,460 \\
\hline \multicolumn{7}{|l|}{ Current and Accrued Assets } \\
\hline Cash, Working Funds \& Investments....................... & 669 & 21,068 & 757 & 5,561 & 316 & 507 \\
\hline 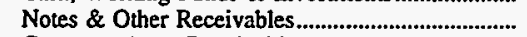 & 694 & 12,798 & 1,397 & 154 & 1,811 & 2,928 \\
\hline 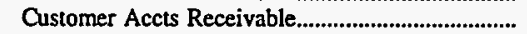 & 0 & 0 & 0 & 2,864 & 0 & 0 \\
\hline (less) Accum Prov for Uncollected Accts ................... & 0 & 0 & 0 & 0 & 0 & 0 \\
\hline 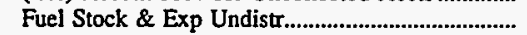 & 0 & 0 & 0 & 0 & 0 & 0 \\
\hline 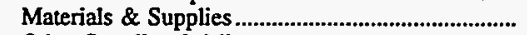 & 180 & 3,332 & 181 & 306 & 172 & 986 \\
\hline 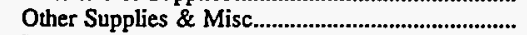 & 0 & 0 & 0 & 0 & 0 & 0 \\
\hline 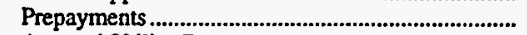 & 8 & 45 & 106 & 1 & 30 & 199 \\
\hline 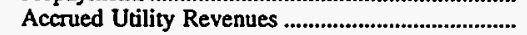 & 0 & 0 & 0 & 0 & 0 & 0 \\
\hline Miscellaneous Current \& Accrued Assets............... & 17 & 691 & 30 & 28 & 58 & 94 \\
\hline Total Current \& Accrued Assets......................... & 1,568 & $\mathbf{3 7 , 9 3 3}$ & 2,472 & 8,914 & 2,387 & $\mathbf{4 , 7 1 3}$ \\
\hline \multicolumn{7}{|l|}{ Deferred Debits } \\
\hline 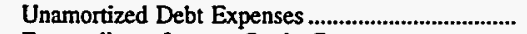 & 9 & 329 & 25 & 70 & 24 & 11 \\
\hline Extraordinary Losses, Study Cost................................ & 0 & 0 & 0 & 0 & 0 & 0 \\
\hline Misc Debt, R \& D Exp, Unamrt Losses .................... & 463 & 1,777 & 960 & 0 & 1,580 & 2,507 \\
\hline Total Deferred Debits................................................. & 472 & 2,106 & 984 & 70 & 1,604 & 2,518 \\
\hline Total Assets \& Other Dejits ..................................... & 5,516 & 189,029 & 14,356 & 19,429 & 14,458 & 30,728 \\
\hline \multicolumn{7}{|l|}{ Proprietary Capital } \\
\hline 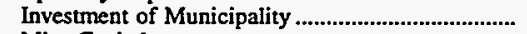 & 0 & 0 & 0 & 0 & 0 & 0 \\
\hline 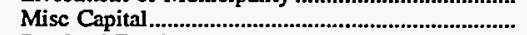 & 0 & 0 & 0 & 0 & 0 & 0 \\
\hline Retained Earnings................................................. & 3,971 & 140,321 & 10,679 & 13,297 & 7,231 & 23,136 \\
\hline Total Proprietary Capital & 3,971 & 140,321 & 10,679 & 13,297 & 7,231 & 23,136 \\
\hline \multicolumn{7}{|l|}{ Long-term Debt } \\
\hline 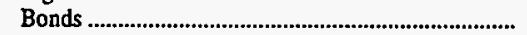 & 457 & 14,295 & 765 & 2,343 & 1,904 & 1,065 \\
\hline 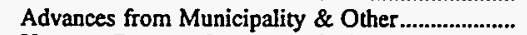 & 345 & 124 & 984 & 949 & 1,480 & 2,429 \\
\hline Unamort Prem on Long-term Debt.......................... & 0 & 0 & 0 & 0 & 1,242 & 0 \\
\hline (less) Unamort Discount on Long-term Debt & 0 & 0 & 0 & 0 & 31 & 0 \\
\hline Total Long-term Debt .................................... & 802 & 14,419 & 1,749 & 3,292 & 4,595 & 3,494 \\
\hline \multicolumn{7}{|l|}{ Other Noncurrent Liabilities } \\
\hline 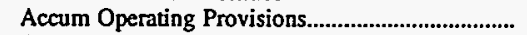 & 0 & $\mathbf{0}$ & 0 & 0 & 0 & 0 \\
\hline 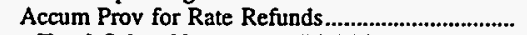 & 0 & 0 & 0 & 0 & 0 & 0 \\
\hline 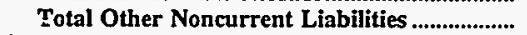 & 0 & 0 & 0 & 0 & $\mathbf{0}$ & 0 \\
\hline \multicolumn{7}{|l|}{ Current and Accrued Liabilities } \\
\hline 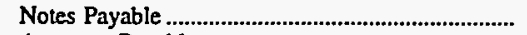 & 0 & 65 & 0 & 500 & 42 & 14 \\
\hline Accounts Payable & 667 & 19,427 & 1,290 & 1,544 & 1,951 & 2,772 \\
\hline Payables to Assoc Enterprises.................................... & 0 & & 0 & 0 & 0 & 0 \\
\hline 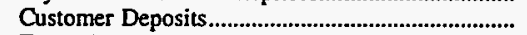 & 0 & 11,864 & 469 & 645 & 453 & 686 \\
\hline 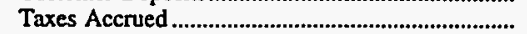 & 0 & 0 & 0 & 0 & 24 & 32 \\
\hline 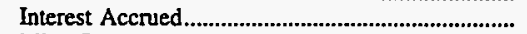 & 0 & 0 & 13 & 13 & 24 & 0 \\
\hline Misc Current \& Accrued Liabilities .......................... & 76 & 1,754 & 157 & 138 & 138 & 527 \\
\hline Total Current \& Accrued Liabilities ................... & 743 & 33,110 & 1,928 & 2,840 & 2,631 & $\mathbf{4 , 0 3 2}$ \\
\hline \multicolumn{7}{|l|}{ Deferred Credits } \\
\hline 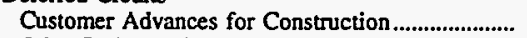 & $\mathbf{0}$ & 0 & 0 & 0 & 0 & 0 \\
\hline 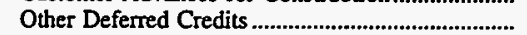 & 0 & 1,179 & 0 & 0 & 0 & 65 \\
\hline Unamort Gain on Reacgr Debt...................................... & 0 & 0 & 0 & 0 & 0 & 0 \\
\hline Total Deferred Credits & 0 & 1,179 & & 0 & 0 & 65 \\
\hline Total Liabilities and Other Credits.................. & 5,516 & 189,029 & 14,356 & 19,429 & 14,458 & 30,728 \\
\hline
\end{tabular}

Note: Totals may not equal sum of components because of independent rounding.

Source: Energy Information Administration, Form EIA-412, "Annual Report of Public Electric Utilities." 
Table 22. Balance Sheet by Major U.S. Publicly Owned Electric Utility Within State at End of Period, 1996 (Continued)

(Thousand Dollars)

\begin{tabular}{|c|c|c|c|c|c|c|}
\hline Item & $\begin{array}{c}\text { Alabama } \\
\text { Sylacauga } \\
\text { Utilities } \\
\text { Board } \\
\text { September } 30\end{array}$ & $\begin{array}{c}\text { Alabama } \\
\text { Troy } \\
\text { City of } \\
\text { September } 30\end{array}$ & $\begin{array}{c}\text { Alabama } \\
\text { Tuskegee } \\
\text { City of } \\
\text { September } 30\end{array}$ & $\begin{array}{l}\text { Alaska } \\
\text { Alaska } \\
\text { Energy } \\
\text { Authority } \\
\text { June } 30\end{array}$ & $\begin{array}{c}\text { Alaska } \\
\text { Anchorage } \\
\text { City of } \\
\text { December } 31\end{array}$ & $\begin{array}{l}\text { Alaska } \\
\text { Fairbanks } \\
\text { City of } \\
\text { December } 31\end{array}$ \\
\hline \multicolumn{7}{|l|}{ Electric Utility Plant } \\
\hline Electric Utility Plant \& Adjust .................................. & 11,420 & 11,613 & 7,233 & 930,452 & 408,220 & 49,661 \\
\hline 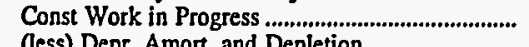 & & & 33 & & 8,154 & 694 \\
\hline 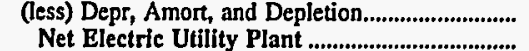 & $\begin{array}{l}5,941 \\
5,479\end{array}$ & 6,201 & 3,973 & 218,067 & 133,392 & 31,680 \\
\hline 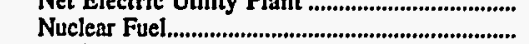 & $\begin{array}{r}5,479 \\
0\end{array}$ & $\begin{array}{r}5,412 \\
0\end{array}$ & $\begin{array}{r}3,293 \\
0\end{array}$ & $\begin{array}{r}712,385 \\
0\end{array}$ & $\begin{array}{r}282,982 \\
0\end{array}$ & 18,675 \\
\hline 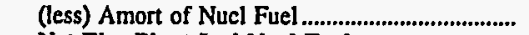 & 0 & 0 & $\mathbf{0}$ & 0 & $\mathbf{0}$ & $\begin{array}{l}0 \\
0\end{array}$ \\
\hline $\begin{array}{l}\text { Net Elec Plant Incl Nucl Fuel ................................... } \\
\text { Other Property \& Investments }\end{array}$ & 5,479 & 5,412 & 3,293 & 712,385 & 282,982 & 18,675 \\
\hline 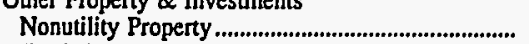 & 0 & 0 & 0 & 0 & 0 & \\
\hline (less) Accum Provisions for Depr \& Amort ......... & 0 & 0 & 0 & 0 & 0 & $\begin{array}{r}142,532 \\
0\end{array}$ \\
\hline 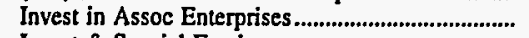 & 0 & 0 & 0 & 0 & 0 & 0 \\
\hline 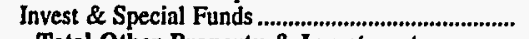 & 4,808 & 4,316 & 0 & 0 & 60,168 & 0 \\
\hline $\begin{array}{l}\text { Total Other Property \& Investments................... } \\
\text { Current and Accrued Assets }\end{array}$ & 4,808 & 4,316 & 0 & 0 & 60,168 & 142,532 \\
\hline 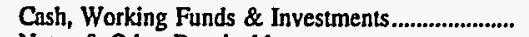 & 266 & 285 & 1,033 & 52,129 & 2,861 & 11,620 \\
\hline Notes \& Other Receivables........................................ & 0 & 0 & 77 & 0 & 0 & 129 \\
\hline 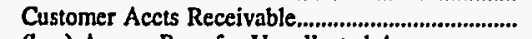 & 1,083 & 2,351 & 4,952 & 0 & 6,333 & 4,534 \\
\hline (less) Accum Prov for Uncollected Accts ............... & 0 & 0 & 1,225 & 0 & 245 & 317 \\
\hline Fuel Stock \& Exp Undistr........................................ & 0 & 0 & 0 & 0 & 688 & 0 \\
\hline Materials \& Supplies ...................................................... & 514 & 329 & 32 & 0 & 2,904 & 3,637 \\
\hline 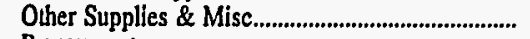 & 0 & 0 & 0 & 0 & 0 & 0 \\
\hline 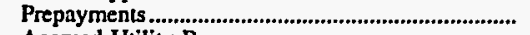 & 0 & 10 & $\mathbf{0}$ & 0 & 1,039 & 212 \\
\hline 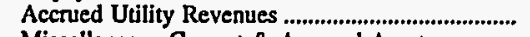 & 0 & 0 & 0 & 825 & 0 & 2,956 \\
\hline Miscellaneous Current \& Accrued Assets............... & 34 & 0 & 0 & 1,190 & 690 & 0 \\
\hline $\begin{array}{l}\text { Total Current \& Accrued Assets........................ } \\
\text { Deferred Debits }\end{array}$ & 1,897 & 2,975 & 4,869 & 54,144 & 14,270 & 22,770 \\
\hline 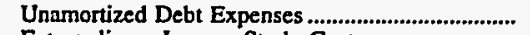 & 130 & 0 & 156 & 0 & 3,484 & $\mathbf{0}$ \\
\hline Extraordinary Losses, Study Cost............................... & 0 & $\mathbf{0}$ & $\mathbf{0}$ & 0 & 0 & $\mathbf{0}$ \\
\hline Misc Debt, R \& D Exp, Unamrt Losses ................. & $\mathbf{0}$ & 0 & 0 & 0 & 34,521 & 0 \\
\hline 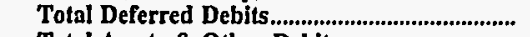 & 130 & 0 & 156 & $\mathbf{0}$ & 38,005 & $\mathbf{0}$ \\
\hline $\begin{array}{l}\text { Total Assets \& Other Debits } \\
\text { Proprietary Capital......................... }\end{array}$ & 12,313 & 12,703 & 8,318 & 766,529 & 395,425 & 183,977 \\
\hline \multicolumn{7}{|l|}{ Proprictary Capital } \\
\hline 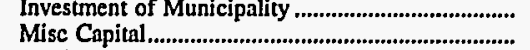 & $\begin{array}{r}625 \\
0\end{array}$ & $\begin{array}{l}\mathbf{0} \\
\mathbf{0}\end{array}$ & $\begin{array}{r}4,515 \\
0\end{array}$ & 619,801 & $\mathbf{0}$ & 8,785 \\
\hline 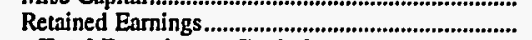 & 8,809 & 896 & $\begin{array}{r}0 \\
1,906\end{array}$ & $\begin{array}{r}0 \\
-203681\end{array}$ & $\begin{array}{r}0 \\
070\end{array}$ & 60,393 \\
\hline Total Proprietary Capital ........................................ & 9,435 & 896 & $\begin{array}{l}1,906 \\
6,421\end{array}$ & $\begin{array}{r}-203,681 \\
416,120\end{array}$ & $\begin{array}{l}60,578 \\
60,578\end{array}$ & $\begin{array}{r}38,238 \\
107,417\end{array}$ \\
\hline \multicolumn{7}{|l|}{ Long-term Debt } \\
\hline 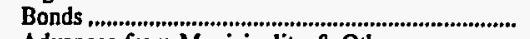 & 2,006 & 11,285 & 540 & 168,110 & 316,995 & 48,784 \\
\hline 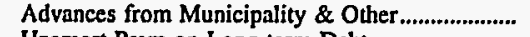 & 0 & 0 & $\mathbf{0}$ & 184,847 & 0 & 0 \\
\hline 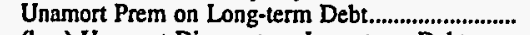 & 0 & 0 & 0 & 0 & 9,661 & 0 \\
\hline (less) Unamort Discount on Long-term Debt & 0 & -224 & 0 & 15,461 & 3,467 & 0 \\
\hline 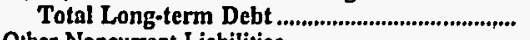 & 2,006 & 11,509 & 540 & 337,496 & 323,189 & 48,784 \\
\hline \multicolumn{7}{|l|}{ Other Noncurrent Liabilities } \\
\hline 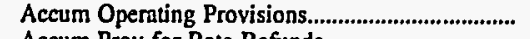 & 0 & 0 & 0 & 0 & 150 & 12,939 \\
\hline 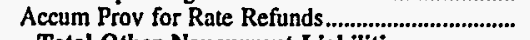 & 0 & 0 & 0 & 0 & 0 & 0 \\
\hline Total Other Noncurrent Liabilities .................... & $\mathbf{0}$ & $\mathbf{0}$ & $\mathbf{0}$ & $\mathbf{0}$ & 150 & 12,939 \\
\hline \multicolumn{7}{|l|}{ Current and Accrued Liabilities } \\
\hline 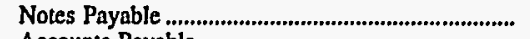 & 317 & 0 & 116 & 3,000 & 0 & 1,920 \\
\hline Accounts Payable & 333 & 1,020 & 871 & 953 & 5,900 & 2,617 \\
\hline 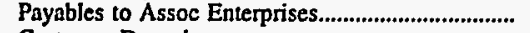 & $\mathbf{0}$ & 0 & 0 & 0 & 0 & 0 \\
\hline 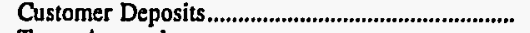 & 179 & 267 & 370 & $\mathbf{0}$ & 1,061 & 811 \\
\hline 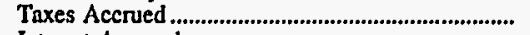 & 0 & 0 & 0 & $\mathbf{0}$ & 0 & 53 \\
\hline 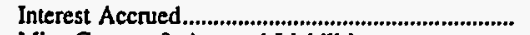 & 44 & 161 & 0 & 5,222 & 2,255 & 1,573 \\
\hline 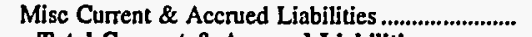 & 0 & 149 & 0 & 3,738 & 1,457 & 7,863 \\
\hline $\begin{array}{l}\text { Total Current \& Accrued Liabilities ................. } \\
\text { Deferred Credits }\end{array}$ & 872 & 1,597 & 1,357 & 12,912 & 10,672 & 14,838 \\
\hline $\begin{array}{l}\text { Deferred Credits } \\
\text { Customer Advances for Construction.......................... }\end{array}$ & 0 & 0 & 0 & $\mathbf{0}$ & 244 & Deferred Credits \\
\hline Other Deferred Credits ................................................ & 0 & 0 & 0 & 0 & 593 & 0 \\
\hline Unamort Gain on Reacqr Debt ................................... & 0 & $-1,299$ & 0 & 0 & 0 & 0 \\
\hline 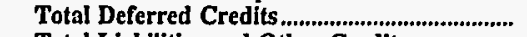 & 0 & $-1,299$ & $\mathbf{0}$ & $\mathbf{0}$ & 836 & 0 \\
\hline Total Liabilities and Other Credits.................. & 12,313 & 12,703 & 8,318 & 766,529 & 395,425 & 183,977 \\
\hline
\end{tabular}

Note: Totals may not equal sum of components because of independent rounding.

Source: Energy Information Administration, Form EIA-412, "Annual Report of Public Electric Utilities." 
Table 22. Balance Sheet by Major U.S. Publicly Owned Electric Utility Within State at End of Period, 1996 (Continued)

(Thousand Dollars)

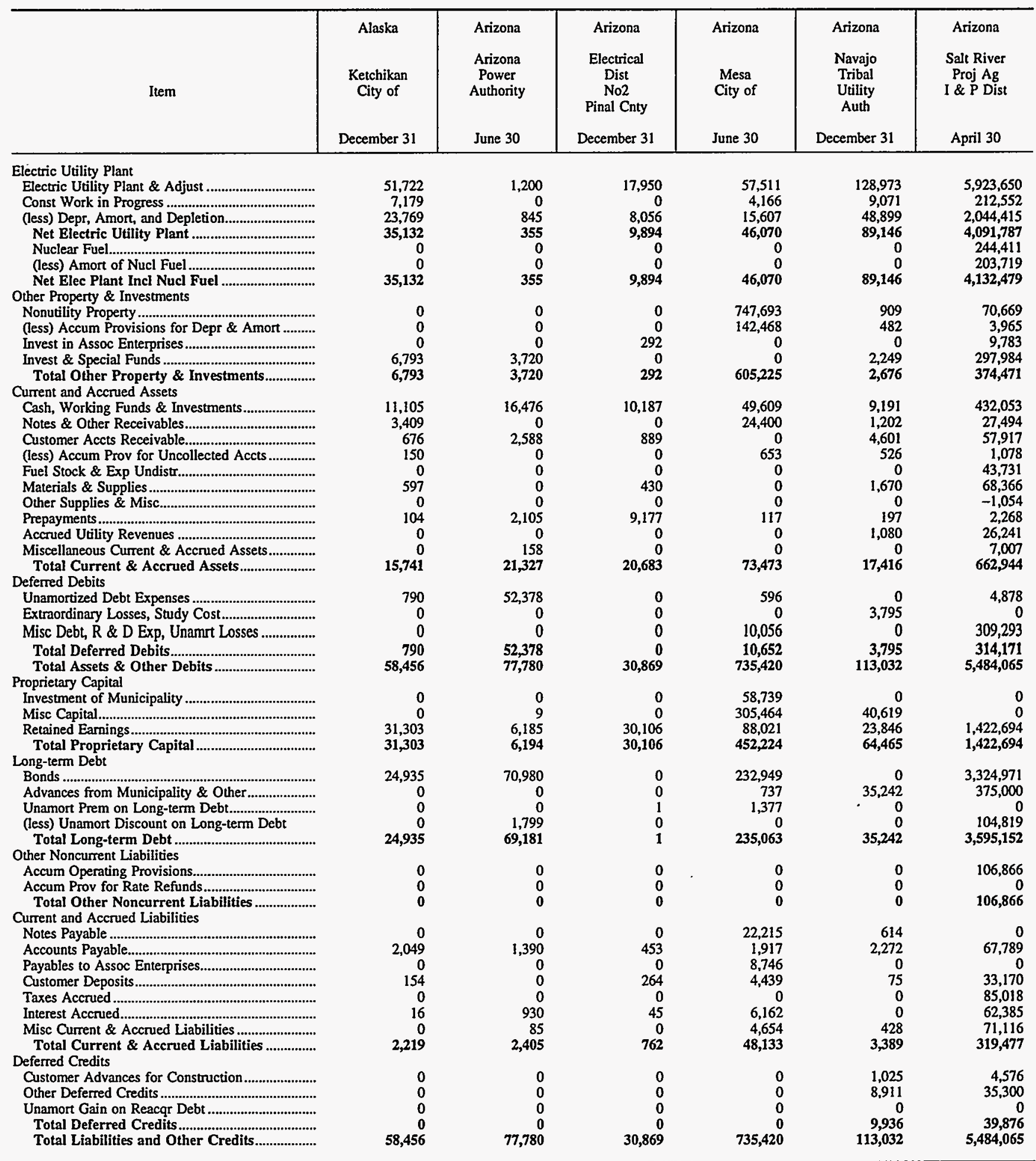

Note: Totals may not equal sum of components because of independent rounding.

Source: Energy Information Administration, Form EIA-412, "Annual Report of Public Electric Utilities." 
Table 22. Balance Sheet by Major U.S. Publicly Owned Electric Utility Within State at End of Period, 1996 (Continued)

(Thousand Dollars)

\begin{tabular}{|c|c|c|c|c|c|c|}
\hline Item & $\begin{array}{l}\text { Arizona } \\
\text { Tohono } \\
\text { OOdham } \\
\text { Utility Auth } \\
\text { December } 31\end{array}$ & $\begin{array}{l}\text { Arkansas } \\
\text { Benton } \\
\text { City of } \\
\text { December } 31\end{array}$ & $\begin{array}{l}\text { Arkansas } \\
\text { Bentonville } \\
\text { City of }\end{array}$ & $\begin{array}{l}\text { Arkansas } \\
\text { Clarksville } \\
\text { Light } \\
\& \\
\text { Water Co } \\
\text { September } 30\end{array}$ & $\begin{array}{l}\text { Arkansas } \\
\text { Conway } \\
\text { Corp } \\
\text { December } 31\end{array}$ & $\begin{array}{c}\text { Arkansas } \\
\text { Hope } \\
\text { City of } \\
\text { December } 31\end{array}$ \\
\hline \multicolumn{7}{|l|}{ Electric Utility Plant } \\
\hline Electric Utility Plant \& Adjust ................................ & 11,300 & 9,337 & 55,081 & 13,618 & 74,147 & 16,534 \\
\hline 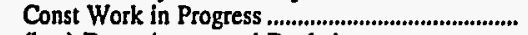 & & & & 229 & 25 & 103 \\
\hline 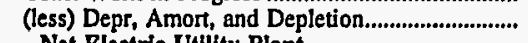 & 3,331 & 6,113 & 12,412 & 4,549 & 30,308 & 4,720 \\
\hline Net Electric Utility Plant ........................................... & 8,024 & 3,224 & 42,726 & 9,299 & 43,864 & 11,918 \\
\hline Nuclear Fuel........................................................................ & 0 & $\mathbf{0}$ & $\mathbf{0}$ & 0 & 0 & 0 \\
\hline 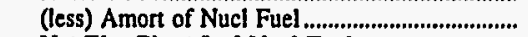 & & & 0 & 0 & 0 & 0 \\
\hline Net Elec Plant Incl Nucl Fuel .................................. & 8,024 & 3,224 & 42,726 & 9,299 & 43,864 & 11,918 \\
\hline \multicolumn{7}{|l|}{ Other Property \& Investments } \\
\hline Nonutility Property........................ & 0 & 0 & 0 & 29,629 & 468 & 630 \\
\hline (less) Accum Provisions for Depr \& Amort .......... & 0 & 0 & $\mathbf{0}$ & 6,459 & 0 & 0 \\
\hline 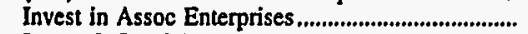 & 176 & 0 & 0 & 19 & 7,255 & 0 \\
\hline 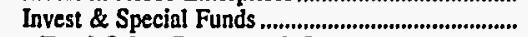 & 0 & 2,701 & 6,047 & 3,041 & 13,941 & 1,246 \\
\hline Total Other Property \& Investments................. & 176 & $\mathbf{2 , 7 0 1}$ & 6,047 & 26,230 & 21,664 & 1,876 \\
\hline \multicolumn{7}{|l|}{ Current and Accrued Assets } \\
\hline Cash, Working Funds \& Investments...................... & 552 & 656 & 3,135 & 3,704 & 1,166 & 4,971 \\
\hline 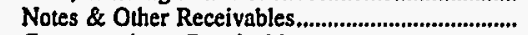 & 87 & 1,419 & 572 & 76 & 1,319 & 95 \\
\hline 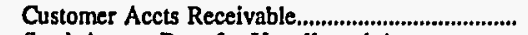 & 1,102 & 0 & 689 & 1,546 & 2,300 & 937 \\
\hline (less) Accum Prov for Uncollected Accts ............... & 0 & 0 & 0 & 51 & 108 & 0 \\
\hline 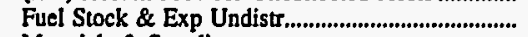 & 0 & 0 & 0 & $\mathbf{0}$ & 1,093 & 4 \\
\hline Materials \& Supplies ....................................................... & 221 & 218 & 818 & 748 & 402 & 224 \\
\hline 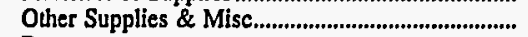 & 0 & 0 & $\mathbf{0}$ & 0 & 1,131 & 0 \\
\hline 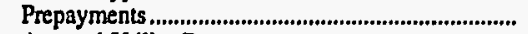 & 3 & 0 & 7 & 76 & 29 & 39 \\
\hline Accrued Utility Revenues ............................................. & 0 & 0 & 1,033 & 526 & 0 & 589 \\
\hline Miscellaneous Current \& Accrued Assets.............. & 2 & 3 & 0 & 0 & $531^{\circ}$ & 11 \\
\hline Total Current \& Accrued Assets............................. & 1,967 & 2,296 & 6,255 & 6,625 & 7,863 & 6,868 \\
\hline 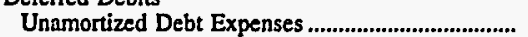 & 0 & 0 & 602 & \multicolumn{3}{|c|}{ Deferred Debils } \\
\hline Extraordinary Losses, Study Cost............................. & 0 & 0 & 0 & 0 & 0 & $\begin{array}{r}91 \\
0\end{array}$ \\
\hline Misc Debt, R \& D Exp, Unamrt Losses ................... & 28 & 0 & 0 & 0 & 0 & 0 \\
\hline Total Deferred Debits............................................ & 28 & 0 & 602 & 53 & 325 & 91 \\
\hline 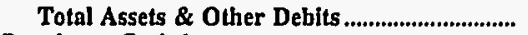 & 10,195 & 8,220 & 55,630 & 42,207 & 73,716 & 20,753 \\
\hline \multicolumn{7}{|l|}{ Proprietary Capital } \\
\hline 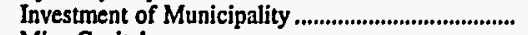 & 0 & 0 & 9,004 & 0 & 179 & 0 \\
\hline 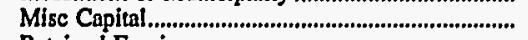 & 0 & 0 & & 12,094 & 0 & 0 \\
\hline 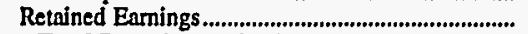 & 4,429 & 6,993 & 23,887 & 21,154 & 44,293 & 14,000 \\
\hline Total Proprietary Capital ............................. & 4,429 & 6,993 & 32,891 & 33,247 & 44,472 & 14,000 \\
\hline \multicolumn{7}{|l|}{ Long-term Debt } \\
\hline 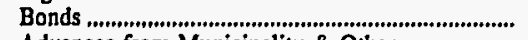 & 0 & 0 & 9,015 & 7,875 & 23,335 & 4,870 \\
\hline Advances from Municipality \& Other..................... & 4,971 & 0 & 11,599 & 0 & 0 & 0 \\
\hline Unamort Prem on Long-term Debt............................ & 0 & 0 & 0 & 0 & 0 & 0 \\
\hline (less) Unamort Discount on Long-term Debt & & 0 & 0 & 135 & 292 & 0 \\
\hline Other Noncurrent Liabilities & 4,971 & o & 20,614 & $\mathbf{7 , 7 4 0}$ & 23,043 & 4,870 \\
\hline 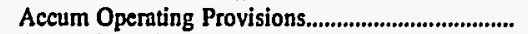 & 0 & 0 & $\mathbf{0}$ & 0 & $\mathbf{0}$ & 0 \\
\hline 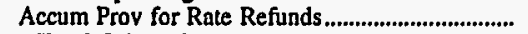 & 0 & 0 & 0 & 0 & 0 & 0 \\
\hline Total Other Noncurrent Liabilities ......................... & 0 & 0 & 0 & 0 & 0 & 0 \\
\hline \multicolumn{7}{|l|}{ Current and Acerued Liabilities } \\
\hline 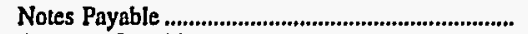 & 0 & 0 & $\mathbf{0}$ & 0 & 0 & 120 \\
\hline 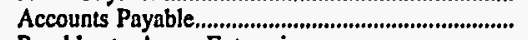 & 638 & 730 & 909 & 757 & 2,925 & 1,040 \\
\hline Payables to Assoc Enterprises.................................... & 0 & 0 & 76 & 0 & 0 & 0 \\
\hline 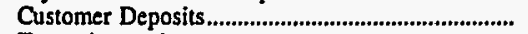 & 6 & 475 & 505 & 224 & 568 & 445 \\
\hline 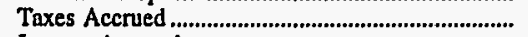 & 0 & 18 & 69 & 0 & 0 & 0 \\
\hline 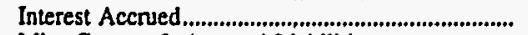 & 0 & 0 & 378 & 70 & 516 & 203 \\
\hline Misc Curtent \& Accrued Liabilities ........................... & 151 & 4 & 189 & 168 & 0 & 72 \\
\hline Total Current \& Accrued Llabilities ................. & 795 & 1,228 & 2,125 & 1,219 & 4,008 & 1,879 \\
\hline \multicolumn{7}{|l|}{ Deferred Credits } \\
\hline 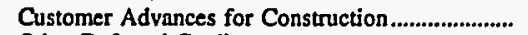 & 0 & 0 & $\mathbf{0}$ & 0 & 2,242 & 3 \\
\hline 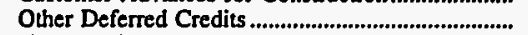 & 0 & 0 & 0 & 0 & -50 & 0 \\
\hline Unamort Gain on Reacqr Debt ....................................... & 0 & 0 & 0 & 0 & 0 & 0 \\
\hline 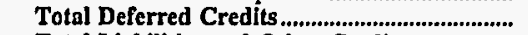 & 0 & o & 0 & 0 & 2,192 & 3 \\
\hline Total Llabillties and Other Credits.................... & 10,195 & 8,220 & 55,630 & 42,207 & 73,716 & 20,753 \\
\hline
\end{tabular}

Note: Totals may not equal sum of components because of independent rounding.

Source: Energy Information Administration, Form EIA-412, "Annual Report of Public Electric Utilities." 
Table 22. Balance Sheet by Major U.S. Publicly Owned Electric Utility Within State at End of Period, 1996 (Continued)

(Thousand Dollars)

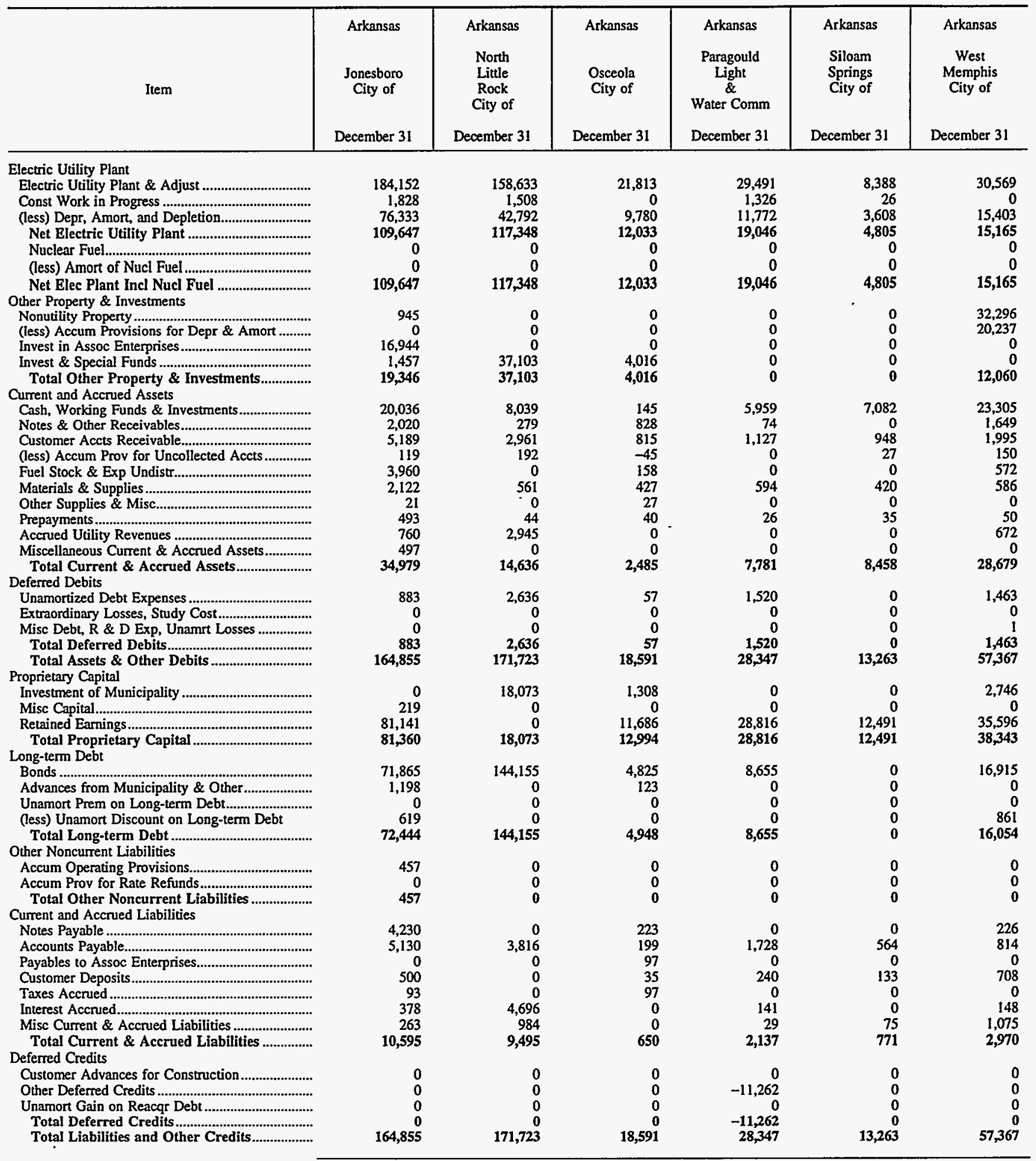

Note: Totals may not equal sum of components because of independent rounding.

Source: Energy Information Administration, Form EIA-412, "Annual Report of Public Electric Utilities." 
Table 22. Balance Sheet by Major U.S. Publicly Owned Electric Utility Within State at End of Period, 1996 (Continued)

(Thousand Dollars)

\begin{tabular}{|c|c|c|c|c|c|c|}
\hline Item & $\begin{array}{l}\text { Califomia } \\
\text { Alameda } \\
\text { City of } \\
\text { June } 30\end{array}$ & $\begin{array}{l}\text { California } \\
\text { Anaheim } \\
\text { City of } \\
\text { June } 30\end{array}$ & $\begin{array}{l}\text { California } \\
\text { Azusa } \\
\text { City of } \\
\text { June } 30\end{array}$ & $\begin{array}{l}\text { California } \\
\text { Burbank } \\
\text { City of } \\
\text { June } 30\end{array}$ & $\begin{array}{c}\text { California } \\
\text { California } \\
\text { Dept } \\
\text { Wu } \\
\text { Resources } \\
\text { June } 30\end{array}$ & $\begin{array}{l}\text { Califomia } \\
\text { Colton } \\
\text { City of } \\
\text { June } 30\end{array}$ \\
\hline \multicolumn{7}{|l|}{ Electric Utility Plant } \\
\hline 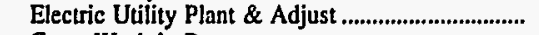 & 52,263 & 540,942 & 18,038 & 184,366 & 866,426 & 14,562 \\
\hline 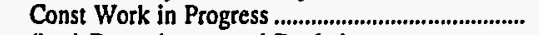 & & 32,905 & 0 & 8,477 & 0 & 11,961 \\
\hline (less) Depr, Amor, and Depletion.............................. & 17,161 & 151,311 & 2,940 & 106,068 & 323,247 & 6,530 \\
\hline Net Electric Utility Plant .......................................... & 35,102 & 422,536 & 15,098 & 86,775 & 543,179 & 19,993 \\
\hline Nuclear Fuel........................................................................ & 0 & 46,545 & $\mathbf{0}$ & 0 & 0 & 0 \\
\hline (less) Amort of Nucl Fuel ...................................... & & 41,564 & 0 & 0 & 0 & \\
\hline Net Elec Plant Incl Nucl Fuel .................................. & 35,102 & 427,517 & 15,098 & 86,775 & 543,179 & 19,993 \\
\hline \multicolumn{7}{|l|}{ Other Property \& Investments } \\
\hline 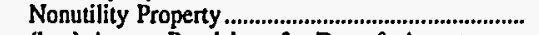 & 0 & 0 & 0 & 0 & 0 & 0 \\
\hline (less) Accum Provisions for Depr \& Amort ........... & 0 & 0 & $\mathbf{0}$ & $\mathbf{0}$ & 0 & 0 \\
\hline 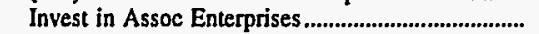 & 0 & 0 & 8,773 & 0 & 0 & 0 \\
\hline 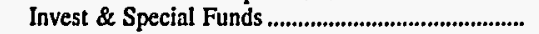 & 22,770 & 0 & 0 & 0 & 55,085 & 2,372 \\
\hline Total Other Property \& Investments................ & 22,770 & $\mathbf{0}$ & 8,773 & $\mathbf{0}$ & 55,085 & 2,372 \\
\hline \multicolumn{7}{|l|}{ Current and Accrued Assets } \\
\hline 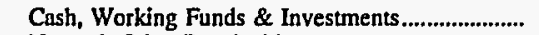 & 14,296 & 182,088 & 13,231 & 17,371 & 110,462 & 9,177 \\
\hline Notes \& Other Receivables........................................ & & 4,103 & 4,491 & 1,540 & 26,078 & 59 \\
\hline 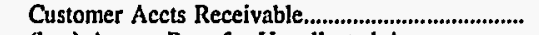 & 3,407 & 27,870 & 2,641 & 17,218 & 0 & 2,836 \\
\hline (less) Accum Prov for Uncollected Accts................ & & & 0 & $\mathbf{0}$ & $\mathbf{0}$ & 0 \\
\hline 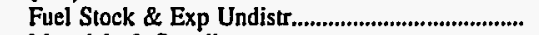 & 0 & 0 & 0 & 0 & 14,062 & 0 \\
\hline 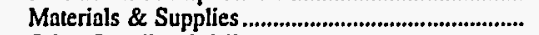 & 1,160 & 5,080 & 376 & 2,644 & 0 & 1,734 \\
\hline 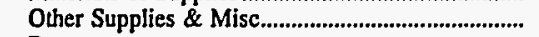 & $\mathbf{0}$ & 0 & 0 & 0 & $\mathbf{0}$ & 0 \\
\hline 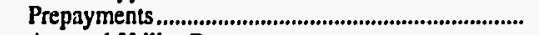 & 59 & 2,372 & 575 & 2,024 & 0 & 0 \\
\hline 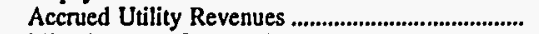 & 0 & & 0 & 0 & o & 0 \\
\hline Miscellaneous Current \& Accrued Assets.............. & 355 & 3,599 & 0 & 0 & 0 & 8,765 \\
\hline Total Current \& Accrued Assets............................. & 19,275 & 225,112 & 21,313 & 40,797 & 150,602 & 22,571 \\
\hline \multicolumn{7}{|l|}{ Deferred Debits } \\
\hline 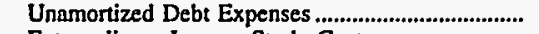 & 80 & 21,227 & $\mathbf{0}$ & 452 & 0 & 0 \\
\hline 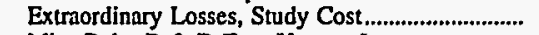 & & 0 & 0 & 0 & 0 & 0 \\
\hline 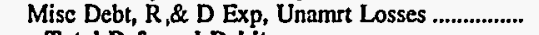 & $-3,589$ & 30 & 0 & 0 & 231,167 & 516 \\
\hline 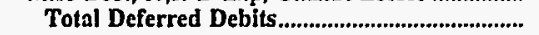 & $-3,509$ & 21,257 & o & 452 & 231,167 & 516 \\
\hline Total Assets \& Other Debits & 73,637 & 673,886 & 45,184 & 128,024 & 980,033 & 45,452 \\
\hline \multicolumn{7}{|l|}{ Proprietary Capital } \\
\hline 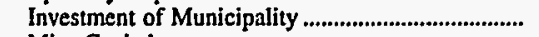 & 14,654 & 14,629 & 687 & $\mathbf{0}$ & 36,569 & 0 \\
\hline 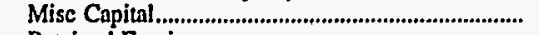 & & 40,818 & & 6,304 & 0 & 0 \\
\hline 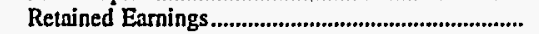 & 47,199 & 180,594 & 41,892 & 75,561 & 15,216 & 24,048 \\
\hline 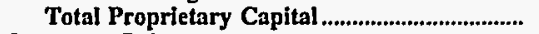 & 61,853 & 236,041 & 42,580 & 81,865 & 51,785 & 24,048 \\
\hline \multicolumn{7}{|l|}{ Long-term Debt } \\
\hline Bonds .................. & 0 & 309,543 & 0 & 31,498 & 749,959 & 18,070 \\
\hline 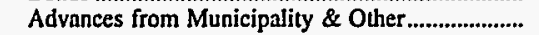 & 7,325 & 11,690 & 242 & 2,186 & 0 & 216 \\
\hline Unamort Prem on Long-term Debt ................................... & 0 & & 0 & 0 & 0 & 0 \\
\hline (less) Unamort Discount on Long-term Debt & 0 & 7,136 & 0 & 0 & 16,912 & 0 \\
\hline 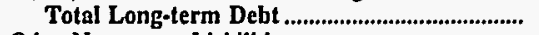 & 7,325 & 314,097 & 242 & 33,684 & 733,047 & 18,286 \\
\hline \multicolumn{7}{|l|}{ Other Noncursent Liabilities } \\
\hline 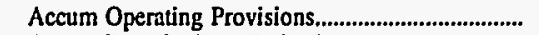 & 0 & 0 & 0 & $\mathbf{0}$ & 540 & 0 \\
\hline 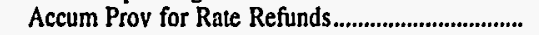 & 0 & 37,177 & 0 & $\mathbf{0}$ & 0 & 0 \\
\hline Total Other Noncurrent Liabilities.................... & 0 & 37,177 & $\mathbf{0}$ & 0 & 540 & $\mathbf{0}$ \\
\hline \multicolumn{7}{|l|}{ Current and Accrued Liabilities } \\
\hline 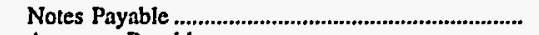 & 0 & 23,900 & 0 & 0 & $\mathbf{7 , 4 7 7}$ & \\
\hline 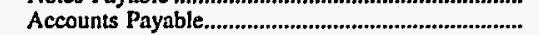 & 523 & 13,123 & 1,015 & 7,844 & 10,944 & 1,162 \\
\hline 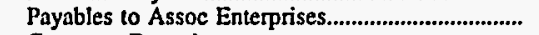 & 71 & & 0 & 1,925 & 0 & 0 \\
\hline 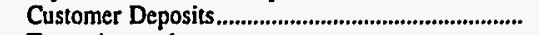 & 161 & 5,689 & 1,348 & 699 & 0 & 638 \\
\hline 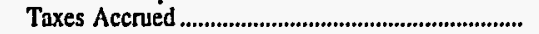 & 0 & 0 & 0 & 0 & 0 & 0 \\
\hline 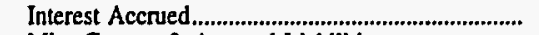 & 41 & 4,872 & 0 & 146 & 6,644 & 0 \\
\hline 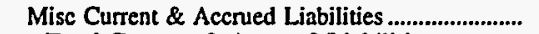 & 2,069 & 13,543 & 0 & 960 & 19,975 & 1,319 \\
\hline Total Current \& Accrued Liabilities.................... & $\mathbf{2 , 8 6 4}$ & 61,127 & 2,363 & 11,574 & 45,040 & $\mathbf{3 , 1 1 8}$ \\
\hline \multicolumn{7}{|l|}{ Deferred Credits } \\
\hline 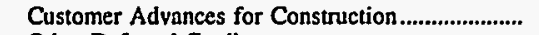 & $\mathbf{0}$ & 0 & $\mathbf{0}$ & $\mathbf{0}$ & 0 & $\mathbf{0}$ \\
\hline 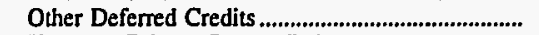 & 1,595 & 25,444 & 0 & 901 & 149,621 & 0 \\
\hline 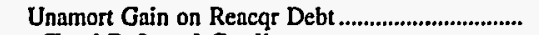 & & & 0 & 0 & 0 & 0 \\
\hline Total Deferred Credits................................................. & 1,595 & 25,444 & & 901 & 149,621 & \\
\hline Total Liabilities and Other Credits.......................... & 73,637 & 673,886 & 45,184 & 128,024 & 980,033 & 45,452 \\
\hline
\end{tabular}

Note: Totals may not equal sum of components because of independent rounding.

Source: Energy Information Administration, Form EIA-412, "Annual Report of Public Electric Utilities." 
Table 22. Balance Sheet by Major U.S. Publicly Owned Electric Utility Within State at End of Period, 1996 (Continued)

(Thousand Dollars)

\begin{tabular}{|c|c|c|c|c|c|c|}
\hline ltem & $\begin{array}{l}\text { California } \\
\text { Glendale } \\
\text { City of } \\
\text { June } 30\end{array}$ & $\begin{array}{c}\text { California } \\
\text { Imperial } \\
\text { Irrigation } \\
\text { District } \\
\text { December } 31\end{array}$ & $\begin{array}{c}\text { California } \\
\text { Kings River } \\
\text { Conservation } \\
\text { Dist } \\
\text { June } 30\end{array}$ & $\begin{array}{l}\text { Califomia } \\
\text { Lassen } \\
\text { Municipal } \\
\text { Utility Dist } \\
\text { June } 30\end{array}$ & $\begin{array}{l}\text { California } \\
\text { Lodi } \\
\text { City of } \\
\text { June } 30\end{array}$ & $\begin{array}{l}\text { California } \\
\begin{array}{c}\text { Los Angeles } \\
\text { City of }\end{array} \\
\text { June } 30\end{array}$ \\
\hline \multicolumn{7}{|l|}{ Electric Utility Plant } \\
\hline 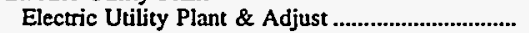 & 247,573 & 740,144 & 65,520 & 24,954 & 15,648 & $6,815,947$ \\
\hline 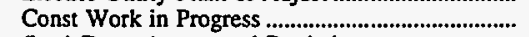 & 9,224 & 11,790 & 0 & 0 & 0 & 203,705 \\
\hline (less) Depr, Amor, and Depletion............................... & 121,192 & 233,109 & 18,330 & 5,677 & 4,106 & $2,418,936$ \\
\hline 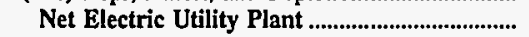 & 135,605 & 518,825 & 47,190 & 19,278 & 11,542 & $4,600,716$ \\
\hline 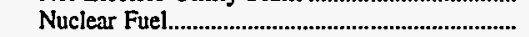 & 0 & 0 & 0 & 0 & 0 & 87,623 \\
\hline 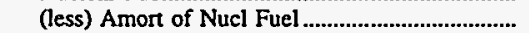 & 0 & 0 & 0 & 0 & 0 & 75,876 \\
\hline Net Elec Plant Incl Nucl Fuel .......................... & 135,605 & 518,825 & 47,190 & 19,278 & 11,542 & $4,612,463$ \\
\hline \multicolumn{7}{|l|}{ Other Property \& Investments } \\
\hline Nonutility Property & 0 & 0 & 0 & 0 & 0 & 0 \\
\hline (less) Accum Provisions for Depr \& Amort .......... & 0 & 0 & 0 & 0 & 0 & 0 \\
\hline 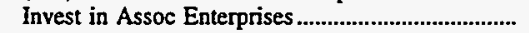 & 0 & 0 & $\mathbf{0}$ & 0 & 0 & 0 \\
\hline Invest \& Special Funds & 0 & 105,971 & 6,664 & 0 & 0 & $1,151,649$ \\
\hline 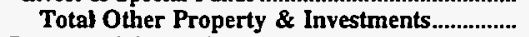 & 0 & 105,971 & 6,664 & 0 & 0 & $1,151,649$ \\
\hline \multicolumn{7}{|l|}{ Current and Accrued Assets } \\
\hline 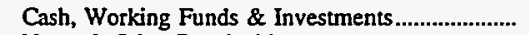 & 47,849 & 2,131 & 2,304 & 9,946 & 7,326 & 343,003 \\
\hline Notes \& Other Receivables..................................... & 13,043 & 0 & 0 & 49 & 1,075 & 28,266 \\
\hline 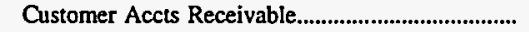 & 0 & 19,409 & 0 & 2,223 & 2,532 & 180,737 \\
\hline (less) Accum Prov for Uncollected Accts .............. & 216 & 3,414 & 0 & 380 & 136 & 13,202 \\
\hline 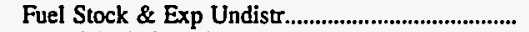 & 0 & 2,875 & 0 & 0 & 0 & 29,825 \\
\hline 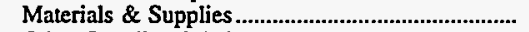 & 3,467 & 8,187 & 53 & 967 & 893 & 89,016 \\
\hline 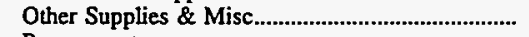 & 0 & 0 & 0 & 0 & 0 & 0 \\
\hline 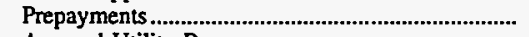 & 1,409 & 2,770 & 28 & 17 & 0 & 65,290 \\
\hline 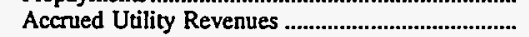 & 0 & 0 & 0 & 0 & 0 & 106,477 \\
\hline Miscellaneous Current \& Accrued Assets.............. & 0 & 0 & 0 & 0 & 0 & 0 \\
\hline 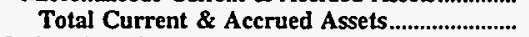 & 65,552 & 31,957 & 2,385 & 12,822 & 11,690 & 829,412 \\
\hline \multicolumn{7}{|l|}{ Deferred Debits } \\
\hline 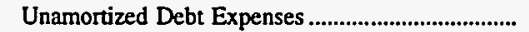 & 0 & 0 & 602 & 636 & 0 & 1,316 \\
\hline 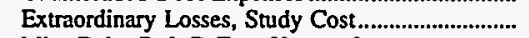 & 0 & 0 & 0 & 0 & 0 & 0 \\
\hline Misc Debt, R \& D Exp, Unamrt Losses ................ & 0 & 0 & 13,253 & 505 & 0 & 0 \\
\hline 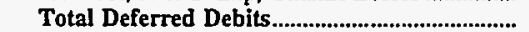 & $\mathbf{0}$ & 0 & 13,855 & 1,141 & 0 & 1,316 \\
\hline 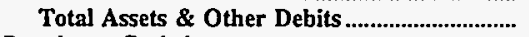 & 201,157 & 656,754 & 70,094 & 33,241 & 23,232 & $6,594,840$ \\
\hline \multicolumn{7}{|l|}{ Proprietary Capital } \\
\hline 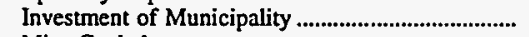 & 0 & 0 & 0 & 0 & 0 & 0 \\
\hline 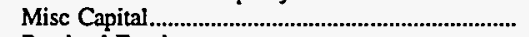 & 24,006 & 0 & 280 & 1,602 & 0 & 225,261 \\
\hline 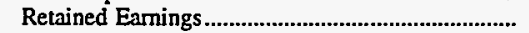 & 155,563 & 451,694 & 0 & 8,956 & 21,985 & $2,017,075$ \\
\hline 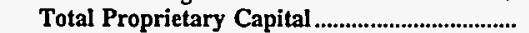 & 179,569 & 451,694 & 280 & 10,558 & 21,985 & $2,242,336$ \\
\hline \multicolumn{7}{|l|}{ Long-term Debt } \\
\hline 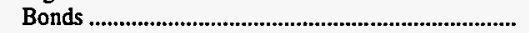 & 5,568 & 0 & 64,836 & 21,510 & 0 & $2,622,327$ \\
\hline 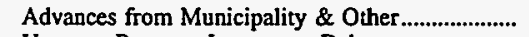 & 0 & 145,334 & 0 & 0 & 0 & $1,112,469$ \\
\hline Unamort Prem on Long-term Debt.......................... & 0 & 1,354 & 0 & 0 & 0 & 0 \\
\hline (less) Unamort Discount on Long-term Debt & 0 & 283 & 0 & 0 & 0 & 0 \\
\hline Total Long-term Debt & 5,568 & 146,405 & 64,836 & 21,510 & $\mathbf{0}$ & $3,734,796$ \\
\hline \multicolumn{7}{|l|}{ Other Noncurrent Liabilities } \\
\hline 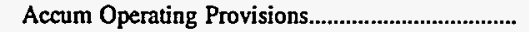 & 0 & 0 & 0 & 0 & 0 & 0 \\
\hline 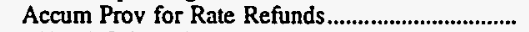 & 0 & 0 & 0 & 0 & 0 & 0 \\
\hline 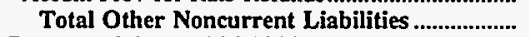 & $\mathbf{0}$ & 0 & 0 & 0 & $\mathbf{0}$ & $\mathbf{0}$ \\
\hline \multicolumn{7}{|l|}{ Current and Accrued Liabilities } \\
\hline Notes Payable & 3,430 & 0 & 0 & 0 & 0 & 64,910 \\
\hline Accounts Payable & 5,432 & 12,217 & 858 & 476 & 1,103 & 197,822 \\
\hline 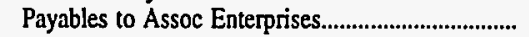 & 0 & 0 & 0 & 0 & 0 & 90,000 \\
\hline 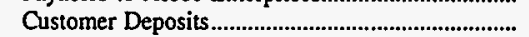 & 1,239 & 1,662 & 0 & 111 & 145 & 99,851 \\
\hline Taxes Accrued & 4 & 0 & 0 & 0 & 0 & 10,292 \\
\hline 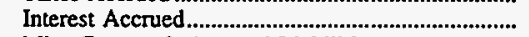 & 47 & 1,771 & 2,014 & 61 & 0 & 66,525 \\
\hline Misc Current \& Accrued Liabilities ......................... & 5,233 & 38,946 & 1,405 & 454 & 0 & 25,144 \\
\hline Total Current \& Accrued Liabilities ................... & 15,385 & 54,597 & 4,277 & 1,102 & 1,247 & 554,544 \\
\hline \multicolumn{7}{|l|}{ Deferred Credits } \\
\hline 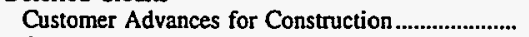 & 635 & 10 & 0 & 71 & 0 & 5,899 \\
\hline 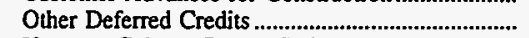 & 0 & 4,048 & 701 & 0 & 0 & 57,265 \\
\hline 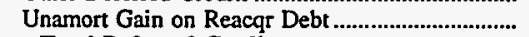 & 0 & 0 & 0 & 0 & 0 & 0 \\
\hline 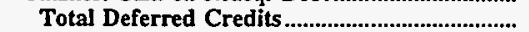 & 635 & 4,058 & 701 & 71 & $\mathbf{0}$ & 63,164 \\
\hline 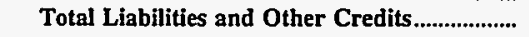 & 201,157 & 656,754 & 70,094 & 33,241 & 23,232 & $6,594,840$ \\
\hline
\end{tabular}

Note: Totals may not equal sum of components because of independent rounding.

Source: Energy Information Administration, Form EIA-412, "Annual Report of Public Electric Utilities." 
Table 22. Balance Sheet by Major U.S. Publicly Owned Electric Utility Within State at End of Period, 1996 (Continued)

(Thousand Dollars)

\begin{tabular}{|c|c|c|c|c|c|c|}
\hline Item & $\begin{array}{l}\text { California } \\
\text { Merced } \\
\text { Irrigation } \\
\text { District } \\
\text { December } 31\end{array}$ & $\begin{array}{c}\text { California } \\
\text { Metropolitan } \\
\text { Water } \\
\text { District } \\
\text { June } 30\end{array}$ & $\begin{array}{l}\text { California } \\
\text { Modesto } \\
\text { Irrigation } \\
\text { District } \\
\text { December } 31\end{array}$ & $\begin{array}{c}\text { California } \\
\text { MSR } \\
\text { Public } \\
\text { Power } \\
\text { Agency } \\
\text { December } 31\end{array}$ & $\begin{array}{l}\text { California } \\
\text { Northern } \\
\text { California } \\
\text { Power Agny } \\
\text { June } 30\end{array}$ & $\begin{array}{c}\text { California } \\
\text { Oakdale \& } \\
\text { South } \\
\text { San Joaquin } \\
\text { December } 31\end{array}$ \\
\hline \multicolumn{7}{|l|}{ Electric Utility Plant } \\
\hline Electric Utility Plant \& Adjust .. & 55,125 & 126,750 & 293,439 & 360,791 & $1,002,235$ & 61,180 \\
\hline 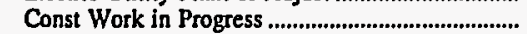 & 1,010 & 23,627 & 3,362 & 738 & 825 & 247 \\
\hline (less) Depr, Amort, and Depletion................................. & 24,003 & 27,132 & 111,579 & 109,536 & 294,601 & 25,236 \\
\hline Net Electric Utility Plant .......................................... & 32,132 & 123,245 & 185,222 & 251,993 & 708,459 & 36,191 \\
\hline 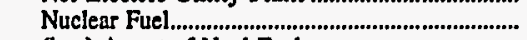 & & & 0 & & & \\
\hline 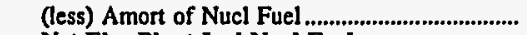 & & & $\mathbf{0}$ & 0 & 0 & \\
\hline Net Elec Plant Incl Nucl Fuel .................................... & 32,132 & 123,245 & 185,222 & 251,993 & 708,459 & 36,191 \\
\hline \multicolumn{7}{|l|}{ Other Property \& Investments } \\
\hline & 718 & $6,309,626$ & 0 & 15,383 & $\mathbf{0}$ & \\
\hline (less) Accum Provisions for Depr \& Amort ........... & 680 & $1,878,990$ & 0 & 927 & 0 & \\
\hline 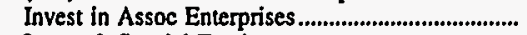 & 430 & 0 & $-112,747$ & 0 & $\mathbf{0}$ & 0 \\
\hline 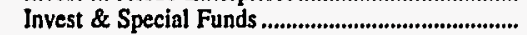 & 0 & 494,642 & 80,234 & 53,805 & 850,294 & 0 \\
\hline Total Other Property \& Investments................. & 468 & $4,925,278$ & $-32,513$ & 68,261 & 850,294 & 0 \\
\hline 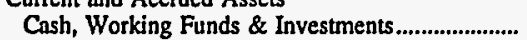 & 105 & 654,336 & 139,720 & 73,095 & 42,460 & 23.552 \\
\hline Notes \& Other Receivables....................................... & 20,765 & 33,100 & 3,969 & 0 & 687 & 1,035 \\
\hline 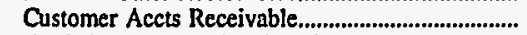 & 137 & 123,901 & 9,371 & 9,979 & 3,039 & \\
\hline (less) Accum Prov for Uncollected Accts................... & $\mathbf{0}$ & 0 & 0 & 0 & 0 & 0 \\
\hline Fuel Stock \& Exp Undistr......................................... & 1 & 59 & 296 & 1,506 & 0 & 0 \\
\hline 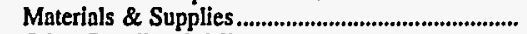 & 0 & 10,417 & 3,003 & 971 & 3,894 & 0 \\
\hline 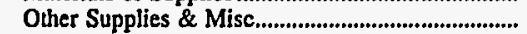 & $\mathbf{0}$ & 1,855 & 0 & 0 & 0 & \\
\hline Prepayments .................................................................. & 120 & 0 & 232 & 54 & 572 & 328 \\
\hline Accnied Utility Revenues .......................................... & 0 & 0 & 0 & 0 & 0 & 0 \\
\hline Miscellaneous Current \& Accrued Assets:............... & & 0 & 4,352 & 1,296 & 8,749 & 170 \\
\hline Total Current \& Accrued Assets............................ & 21,128 & 823,668 & 160,942 & 86,902 & 59,402 & 25,086 \\
\hline \multicolumn{7}{|l|}{ Deferred Debits } \\
\hline Unamortized Debt Expenses .......................................... & 0 & 4,730 & 8,941 & 13,980 & 22,263 & 0 \\
\hline Extraordinary Losses, Study Cost................................... & 0 & & 0 & 18 & 200 & \\
\hline Misc Debt, R \& D Exp, Unamrt Losses ...................... & 0 & 238,569 & 0 & 0 & 416,375 & 0 \\
\hline 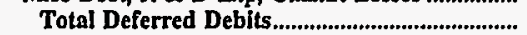 & $\mathbf{0}$ & 243,299 & 8,941 & 13,997 & $\mathbf{4 3 8 , 8 3 7}$ & \\
\hline Total Assets \& Other Debits ...................................... & 53,728 & $6,115,490$ & 322,592 & 421,154 & $2,056,992$ & 61,277 \\
\hline \multicolumn{7}{|l|}{ Proprietary Capital } \\
\hline Investment of Municipality ........ & 10,819 & 0 & 0 & 0 & 0 & 0 \\
\hline 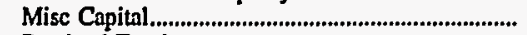 & & 0 & 0 & 0 & 0 & 0 \\
\hline 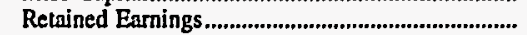 & -132 & $3,363,426$ & 15,155 & $-225,675$ & 23,189 & 59,532 \\
\hline 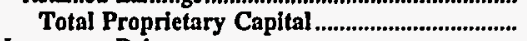 & 10,686 & $3,363,426$ & 15,155 & $-225,675$ & 23,189 & 59,532 \\
\hline \multicolumn{7}{|l|}{ Long-term Debt } \\
\hline Bonds ,......................... & 19,515 & $2,081,909$ & 190,950 & 637,620 & $1,888,850$ & \\
\hline 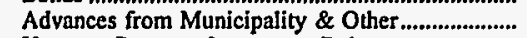 & & 180,654 & 98,465 & & & \\
\hline Unamort Prem on Long-term Debt........................... & 0 & 4,182 & 0 & $\mathbf{0}$ & 7,780 & 842 \\
\hline (less) Unamort Discount on Long-term Debt & & 30,780 & 8,132 & 28,572 & 34,780 & \\
\hline Total Long-term Debt .................................................. & 19,515 & $2,235,965$ & 281,282 & 609,048 & $1,861,851$ & 842 \\
\hline \multicolumn{7}{|l|}{ Other Noncurrent Liabilities } \\
\hline 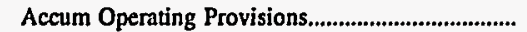 & 371 & $\mathbf{0}$ & 10,454 & 12,800 & 0 & 0 \\
\hline 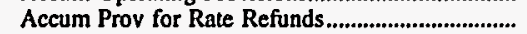 & 0 & 0 & & & 0 & 0 \\
\hline Total Other Noncurrent Liabillties ..................... & 371 & 0 & 10,454 & 12,800 & 0 & o \\
\hline \multicolumn{7}{|l|}{ Current and Accrued Liabilities } \\
\hline 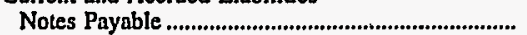 & 0 & $\mathbf{0}$ & & & 0 & \\
\hline 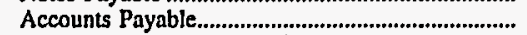 & 386 & 422,834 & 9,548 & 5,278 & 10,204 & 292 \\
\hline 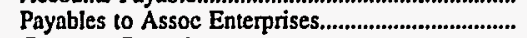 & 304 & 0 & 27 & 0 & 19 & 0 \\
\hline Customer Deposits....... & 0 & 45,763 & 485 & $\mathbf{0}$ & 0 & 0 \\
\hline 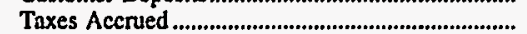 & 3 & 0 & 1 & 0 & 24 & 0 \\
\hline 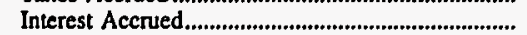 & 36 & 47,502 & 3,967 & 19,703 & 49,417 & 0 \\
\hline Misc Current \& Accrued Liabilities .......................... & 62 & 0 & 1,201 & 0 & & 611 \\
\hline Total Current \& Accrued Liabilities ....................... & 791 & 516,099 & 15,229 & 24,981 & 59,673 & 903 \\
\hline \multicolumn{7}{|l|}{ Deferred Credits } \\
\hline Customer Advances for Construction.......................... & 0 & 0 & 449 & 0 & 10,446 & 0 \\
\hline 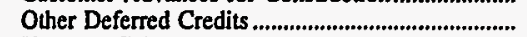 & 22,363 & 0 & 22 & 0 & 101,834 & 0 \\
\hline 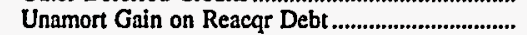 & 0 & 0 & 0 & 0 & 0 & 0 \\
\hline Total Deferred Credits............................................ & 22,363 & & 472 & & 112,280 & \\
\hline Total Liabilities and Other Credits........................ & 53,728 & $6,115,490$ & 322,592 & 421,154 & $2,056,992$ & 61,277 \\
\hline
\end{tabular}

Note: Totals may not equal sum of components because of independent rounding

Source: Energy Information Administration, Form EIA-412, "Annual Report of Public Electric Utilities." 
Table 22. Balance Sheet by Major U.S. Publicly Owned Electric Utility Within State at End of Period, 1996

(Thousand Dollars)

\begin{tabular}{|c|c|c|c|c|c|c|}
\hline Item & $\begin{array}{l}\text { California } \\
\text { Oroville } \\
\text { Wyandotte } \\
\text { Irrig Dist } \\
\text { December } 31\end{array}$ & $\begin{array}{l}\text { California } \\
\text { Palo Alto } \\
\text { City of } \\
\text { June } 30\end{array}$ & $\begin{array}{l}\text { Califomia } \\
\text { Pasadena } \\
\text { City of } \\
\text { June } 30\end{array}$ & $\begin{array}{c}\text { California } \\
\text { Placer } \\
\text { County } \\
\text { Water } \\
\text { Agency } \\
\text { December } 31\end{array}$ & $\begin{array}{l}\text { California } \\
\text { Redding } \\
\text { City of } \\
\text { June } 30\end{array}$ & $\begin{array}{l}\text { California } \\
\text { Riverside } \\
\text { City of } \\
\text { June } 30\end{array}$ \\
\hline \multicolumn{7}{|l|}{ Electric Uülity Plant } \\
\hline 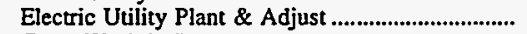 & 85,463 & 130,576 & 264,469 & 117,330 & 204,930 & 312,009 \\
\hline 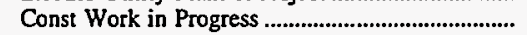 & 882 & 6,363 & 13,465 & 694 & 2,233 & 29,516 \\
\hline 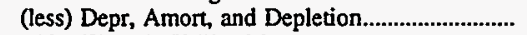 & 42,276 & 50,873 & 126,937 & 45,823 & 54,925 & 122,403 \\
\hline 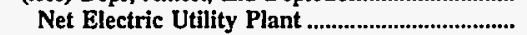 & 44,069 & 86,066 & 150,997 & 72,201 & 152,238 & 219,122 \\
\hline Nuclear Fuel................................................. & 0 & 0 & 0 & 0 & 0 & 4,797 \\
\hline (less) Amort of Nucl Fuel ............................................. & & 0 & $\mathbf{0}$ & 0 & 0 & 1,249 \\
\hline Net Elec Plant Incl Nucl Fuel ................................... & 44,069 & 86,066 & 150,997 & 72,201 & 152,238 & 222,670 \\
\hline \multicolumn{7}{|l|}{ Other Property \& Investments } \\
\hline Nonutility Property.................... & 0 & $\mathbf{0}$ & $\mathbf{0}$ & 0 & 4,839 & \\
\hline (less) Accum Provisions for Depr \& Amort .......... & 0 & 0 & 0 & 0 & 0 & $\mathbf{0}$ \\
\hline 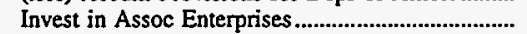 & 0 & 0 & 0 & 0 & 33 & 0 \\
\hline 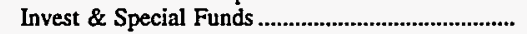 & 0 & $\mathbf{0}$ & 0 & 1,102 & 0 & 42,219 \\
\hline Total Other Property \& Investments................ & 0 & 0 & 0 & 1,102 & 4,872 & 42,219 \\
\hline \multicolumn{7}{|l|}{ Current and Accrued Assets } \\
\hline 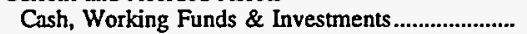 & 5,601 & 60,424 & 55,647 & 404 & 49,950 & 53,179 \\
\hline 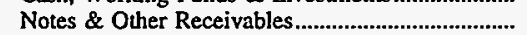 & 1,356 & 5,521 & 367 & 76 & 2,923 & 17,049 \\
\hline Customer Accts Receivable & 0 & 2,314 & 12,773 & 0 & 4,789 & 20,225 \\
\hline (less) Accum Prov for Uncollected Accts .................. & 0 & 68 & 381 & 0 & 100 & 959 \\
\hline Fuel Stock \& Exp Undistr.......................................... & 0 & $\mathbf{0}$ & 828 & 0 & 0 & 0 \\
\hline 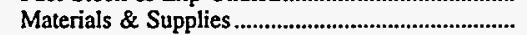 & 0 & 0 & 4,201 & 0 & 4,149 & 998 \\
\hline 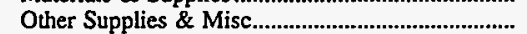 & 0 & 0 & 0 & 0 & 0 & 0 \\
\hline 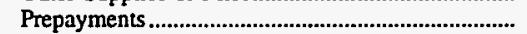 & 74 & 0 & 5,107 & 351 & 41,460 & 1,387 \\
\hline Accrued Utility Revenues .................................. & 0 & 0 & 0 & 0 & 2,820 & 0 \\
\hline Miscellaneous Current \& Accrued Assets.............. & 0 & 0 & 0 & 16 & 0 & 983 \\
\hline Total Current \& Accrued Assets............................. & 7,031 & 68,191 & 78,542 & 847 & 105,990 & 92,863 \\
\hline \multicolumn{7}{|l|}{ Deferred Debits } \\
\hline Unamortized Debt Expenses ........................................ & 0 & 0 & 0 & 0 & 2,951 & 1,872 \\
\hline Extraordinary Losses, Study Cost................................. & 0 & 0 & 0 & 0 & 0 & 0 \\
\hline Misc Debt, R \& D Exp, Unamrt Losses ..................... & 0 & 0 & 0 & 0 & 0 & 686 \\
\hline 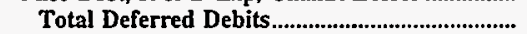 & 0 & 0 & o & 0 & 2,951 & 2,558 \\
\hline 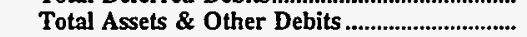 & 51,100 & 154,257 & 229,538 & 74,150 & 266,051 & 360,311 \\
\hline \multicolumn{7}{|l|}{ Proprietary Capital } \\
\hline Investment of Municipality ............ & 0 & 0 & 0 & 0 & 0 & 0 \\
\hline 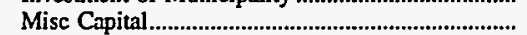 & 0 & 17,138 & 0 & 0 & 25,545 & 40,416 \\
\hline 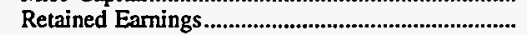 & 6,027 & 135,640 & 144,859 & 13,752 & 34,086 & 59,006 \\
\hline Total Proprietary Capital & 6,027 & 152,778 & 144,859 & $\mathbf{1 3 , 7 5 2}$ & 59,632 & 99,422 \\
\hline \multicolumn{7}{|l|}{ Long-term Debt } \\
\hline Bonds ................... & 40,039 & 0 & 70,970 & 56,775 & 190,925 & 180,615 \\
\hline Advances from Municipality \& Other......................... & 3,162 & 0 & 0 & 412 & 1,208 & $\mathbf{0}$ \\
\hline Unamort Prem on Long-term Debt.............................. & & 0 & 0 & 186 & 0 & \\
\hline (less) Unamort Discount on Long-term Debt & 1,401 & 0 & 0 & 0 & 456 & 3,403 \\
\hline 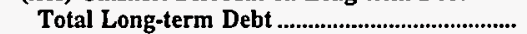 & 41,800 & 0 & 70,970 & $\mathbf{5 7 , 3 7 3}$ & 191,676 & 177,212 \\
\hline \multicolumn{7}{|l|}{ Other Noncurrent Liabilities } \\
\hline 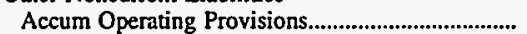 & 0 & 0 & 0 & 149 & 0 & 0 \\
\hline 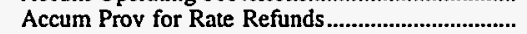 & 0 & 0 & 0 & 0 & 0 & 0 \\
\hline Total Other Noncurrent Liabilities ................... & 0 & 0 & 0 & 149 & 0 & 0 \\
\hline \multicolumn{7}{|l|}{ Current and Accrued Liabilities } \\
\hline Notes Payable ............................... & 0 & 0 & 0 & 1,445 & 0 & 0 \\
\hline 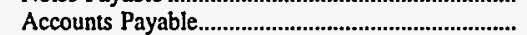 & 513 & 1,213 & 2,192 & 64 & 5,950 & 7,105 \\
\hline 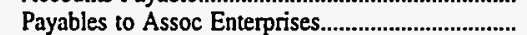 & 0 & 0 & 0 & 0 & 0 & 0 \\
\hline 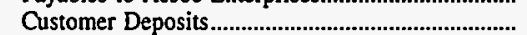 & 0 & 170 & 1,914 & 0 & 0 & 2,122 \\
\hline 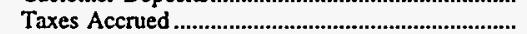 & 0 & 0 & 0 & 0 & 0 & 0 \\
\hline 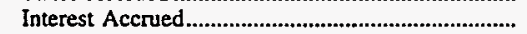 & 970 & 0 & 1,703 & 1,077 & 1,723 & 2,495 \\
\hline Misc Current \& Accrued Liabilities ....................... & 1,790 & 96 & 7,901 & 291 & 7,070 & 21,486 \\
\hline Total Current \& Accrued Liabilities ..................... & 3,273 & 1,479 & 13,710 & 2,877 & 14,743 & 33,209 \\
\hline \multicolumn{7}{|l|}{ Deferned Credits } \\
\hline 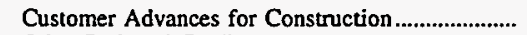 & 0 & $\mathbf{0}$ & 0 & 0 & 0 & \\
\hline Other Deferred Credits ................................................ & 0 & 0 & 0 & 0 & 0 & 50,468 \\
\hline 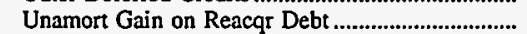 & 0 & 0 & 0 & 0 & 0 & \\
\hline 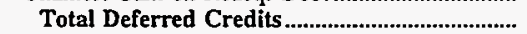 & 0 & 0 & o & & o & 50,468 \\
\hline Total Liabilities and Other Credits................... & 51,100 & 154,257 & 229,538 & 74,150 & 266,051 & 360,311 \\
\hline
\end{tabular}

Note: Totals may not equal sum of components because of independent rounding.

Source: Energy Information Administration, Form EIA-412, "Annual Report of Public Electric Utilities." 
Table 22. Balance Sheet by Major U.S. Publicly Owned Electric Utility Within State at End of Period, 1996

(Thousand Dollars)

\begin{tabular}{|c|c|c|c|c|c|c|}
\hline Item & $\begin{array}{l}\text { California } \\
\text { Roseville } \\
\text { City of } \\
\text { June } 30\end{array}$ & $\begin{array}{l}\text { California } \\
\text { Sacramento } \\
\text { Municipal } \\
\text { Util Dist } \\
\text { December } 31\end{array}$ & $\begin{array}{c}\text { Califomia } \\
\text { San Francisco } \\
\text { City } \\
\& \\
\text { County of } \\
\text { June } 30\end{array}$ & $\begin{array}{l}\text { Califomia } \\
\text { Santa } \\
\text { Clara } \\
\text { City of } \\
\text { June } 30\end{array}$ & $\begin{array}{l}\text { California } \\
\text { Southern } \\
\text { California } \\
\text { P P } \\
\text { A } \\
\text { June } 30\end{array}$ & $\begin{array}{l}\text { California } \\
\text { Turlock } \\
\text { Irrigation } \\
\text { District } \\
\text { December } 31\end{array}$ \\
\hline \multicolumn{7}{|l|}{ Electric Utility Plant } \\
\hline 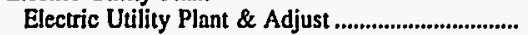 & 98,638 & $1,806,812$ & 382,359 & 267,434 & $1,737,254$ & 364,281 \\
\hline 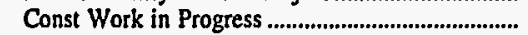 & 1,638 & 387,345 & 10,581 & 6,589 & 16,120 & 6,696 \\
\hline 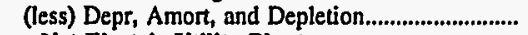 & 20,344 & 542,475 & 188,826 & 76,583 & 482,871 & 98,210 \\
\hline Net Electric Utility Plant ........................................ & 79,931 & $1,651,682$ & 204,114 & 197,441 & $1,270,503$ & 272,768 \\
\hline 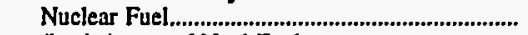 & & 0 & 0 & & 97,258 & 0 \\
\hline (less) Amort of Nucl Fuel ............................................ & 0 & 0 & 0 & 0 & 84,033 & 0 \\
\hline Net Elec Plant Incl Nucl Fuel .................................. & 79,931 & $1,651,682$ & 204,114 & 197,441 & $1,283,728$ & 272,768 \\
\hline \multicolumn{7}{|l|}{ Other Property \& Investments } \\
\hline Nonutility Property...................... & 0 & 0 & 410 & 0 & 0 & 34,695 \\
\hline (less) Accum Provisions for Depr \& Amort .......... & 0 & $\mathbf{0}$ & 0 & 0 & 0 & 9,158 \\
\hline 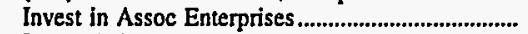 & 0 & 2,293 & 0 & 6,898 & 0 & 0 \\
\hline Invest \& Special Funds ....................................................... & 1,453 & 704,718 & 0 & 5,000 & 0 & 89,582 \\
\hline Total Other Property \& Investments................. & 1,453 & 707,011 & 410 & 11,898 & o & 115,119 \\
\hline \multicolumn{7}{|l|}{ Current and Accrued Assets } \\
\hline Cash, Working Funds \& Investments......................... & 13,131 & 107,253 & 46,385 & 187,651 & $1,151,962$ & 20,198 \\
\hline 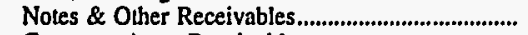 & 743 & 99,853 & 761 & 5,982 & 0 & 1.411 \\
\hline 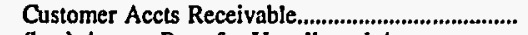 & 34 & 90,212 & 5,697 & 21,320 & 4,478 & 10,212 \\
\hline (less) Accum Prov for Uncollected Accts ................ & 0 & 8,007 & 0 & 27 & 0 & 431 \\
\hline 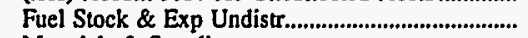 & 0 & 39 & 0 & & 0 & 0 \\
\hline 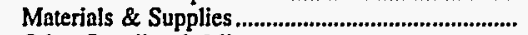 & 3,592 & 16,566 & 240 & 2,933 & 12,809 & 1,898 \\
\hline Other Supplies \& Misc......................................................... & 0 & 2,693 & 0 & 0 & 0 & 0 \\
\hline 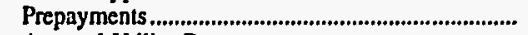 & 3,925 & 16,512 & 0 & $\mathbf{0}$ & 29,761 & 289 \\
\hline 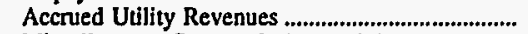 & 7,120 & 0 & 0 & 0 & 0 & 0 \\
\hline Miscellaneous Current \& Accrued Assets................ & & 7,020 & 7 & 3,328 & 469,927 & 279 \\
\hline Total Current \& Accrued Assets............................ & 28,545 & 332,139 & 53,090 & 221,187 & $1,668,937$ & 33,854 \\
\hline \multicolumn{7}{|l|}{ Deferred Debits } \\
\hline 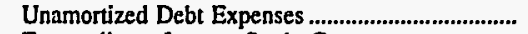 & 145 & 35,383 & 0 & $\mathbf{0}$ & 413,348 & 6,824 \\
\hline 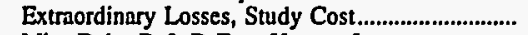 & 0 & 717,175 & 0 & 0 & 0 & 0 \\
\hline 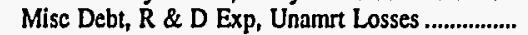 & 9 & 360,251 & 0 & 0 & 0 & 0 \\
\hline 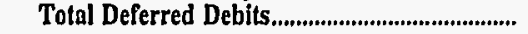 & 154 & $1,112,809$ & 0 & 0 & 413,348 & 6,824 \\
\hline Total Assets \& Other Debits ................................... & 110,083 & $3,803,641$ & 257,614 & 430,526 & $3,366,013$ & 428,565 \\
\hline \multicolumn{7}{|l|}{ Proprietary Capital } \\
\hline 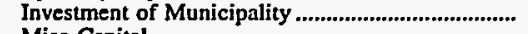 & $\mathbf{0}$ & 0 & $\mathbf{0}$ & 644 & $\mathbf{0}$ & 0 \\
\hline 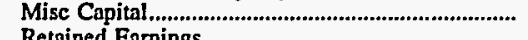 & 0 & 3,875 & $\mathbf{0}$ & $\mathbf{0}$ & $\mathbf{0}$ & 39,832 \\
\hline 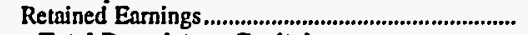 & 98,415 & 213,360 & 252,544 & 182,004 & 0 & 132,258 \\
\hline 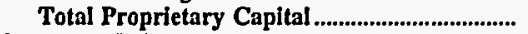 & 98,415 & 217,234 & 252,544 & 182,648 & 0 & 172,090 \\
\hline \multicolumn{7}{|l|}{ Long-term Debt } \\
\hline 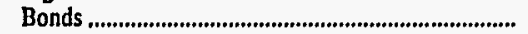 & 6,630 & $2,585,166$ & 0 & 229,940 & $3,521,360$ & 137,125 \\
\hline Advances from Municipality \& Other....................... & & 6,596 & 1,236 & 0 & 0 & 80,244 \\
\hline 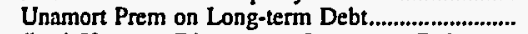 & $\mathbf{0}$ & 0 & 0 & 0 & 0 & 0 \\
\hline (less) Unamort Discount on Long-term Debt & $\mathbf{0}$ & 31,148 & 0 & 5,458 & 307,427 & 4,273 \\
\hline Total Long-term Debt ................................................. & 6,630 & $2,560,614$ & 1,236 & 224,482 & $3,213,933$ & 213,096 \\
\hline \multicolumn{7}{|l|}{ Other Noncurrent Liabilities } \\
\hline 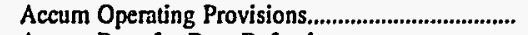 & 789 & 47,885 & 0 & 0 & 0 & 0 \\
\hline 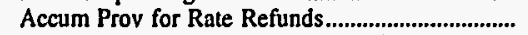 & 0 & 0 & 0 & 0 & 0 & 0 \\
\hline Total Other Noncurrent Liabilities ................... & 789 & 47,885 & 0 & 0 & 0 & 0 \\
\hline \multicolumn{7}{|l|}{ Current and Accrued Liabilities } \\
\hline 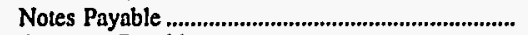 & 0 & 195,121 & 0 & 5,865 & 0 & 0 \\
\hline 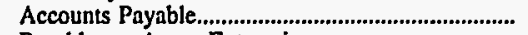 & 727 & 78,276 & 2,114 & 12,159 & 17,479 & 19,111 \\
\hline 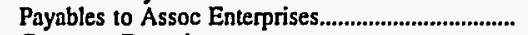 & 0 & 0 & 0 & 0 & 0 & 0 \\
\hline 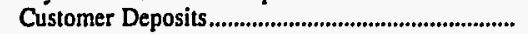 & 281 & 8,736 & 74 & 0 & 0 & 708 \\
\hline 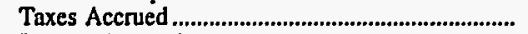 & 0 & 2,926 & 0 & 0 & 0 & 0 \\
\hline 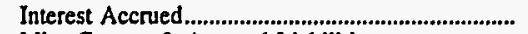 & 171 & 47,825 & 0 & 5,372 & 88,182 & 4,367 \\
\hline 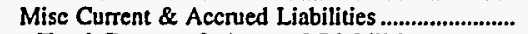 & 166 & 19,877 & 1,246 & & 46,319 & 6,511 \\
\hline Total Current \& Accrued Liabilities ................. & 1,345 & 352,761 & $\mathbf{3 , 4 3 5}$ & 23,396 & 151,980 & 30,697 \\
\hline \multicolumn{7}{|l|}{ Deferred Credits } \\
\hline Customer Advances for Construction....................... & & 7,615 & 343 & 0 & 0 & 364 \\
\hline 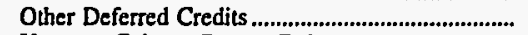 & 2,904 & 598,453 & 55 & 0 & 100 & 12,319 \\
\hline Unamort Gain on Reacgr Debt..................................... & 0 & 19,079 & 0 & 0 & 0 & \\
\hline Total Deferred Credits................................................ & 2,904 & 625,147 & 399 & 0 & 100 & 12,682 \\
\hline Total Liabilities and Other Credits.................... & 110,083 & $3,803,641$ & 257,614 & 430,526 & $3,366,013$ & 428,565 \\
\hline
\end{tabular}

Note: Totals may not equal sum of components because of independent rounding.

Source: Energy Information Administration, Form EIA-412, "Annual Report of Public Electric Utilities." 
Table 22. Balance Sheet by Major U.S. Publicly Owned Electric Utility Within State at End of Period, 1996

(Thousand Dollars)

\begin{tabular}{|c|c|c|c|c|c|c|}
\hline Item & $\begin{array}{l}\text { California } \\
\text { Vernon } \\
\text { City of } \\
\text { June } 30\end{array}$ & $\begin{array}{c}\text { Califormia } \\
\text { Yuba } \\
\text { County } \\
\text { Water } \\
\text { Agency } \\
\text { June } 30\end{array}$ & $\begin{array}{c}\text { Colorado } \\
\text { Arkansas } \\
\text { River } \\
\text { Power } \\
\text { Authority } \\
\text { December } 31\end{array}$ & $\begin{array}{l}\text { Colorado } \\
\text { Colorado } \\
\text { Springs } \\
\text { City of } \\
\text { December } 31\end{array}$ & $\begin{array}{l}\text { Colorado } \\
\text { Fort Collins } \\
\text { City of } \\
\text { December } 31\end{array}$ & $\begin{array}{l}\text { Colorado } \\
\text { Fort Morgan } \\
\text { City of } \\
\text { December } 31\end{array}$ \\
\hline \multicolumn{7}{|l|}{ Electric Uaility Plant } \\
\hline 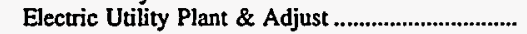 & 93,829 & 199,644 & 2,710 & 771,402 & 101,486 & 13,097 \\
\hline Const Work in Progress ..................................... & 1,190 & & & 31,842 & 1,954 & 35 \\
\hline (less) Depr, Amor, and Depletion................................... & 32,770 & 60,067 & 486 & 284,834 & 45,289 & 4,316 \\
\hline Net Electric Utility Plant ............................................. & 62,248 & 139,577 & 2,224 & 518,410 & 58,151 & 8,816 \\
\hline 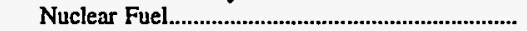 & 0 & 0 & 0 & & 0 & 0 \\
\hline (less) Amort of Nucl Fuel ....................................... & $\mathbf{0}$ & o & $\mathbf{0}$ & 0 & $\mathbf{0}$ & $\mathbf{0}$ \\
\hline \multirow{2}{*}{\multicolumn{7}{|c|}{ Other Property \& Investments }} \\
\hline & & & & & & \\
\hline Nonutility Property ............................................................ & 482 & 527 & 401 & 0 & 270 & 0 \\
\hline (less) Accum Provisions for Depr \& Amort .......... & 0 & 116 & 161 & 0 & 0 & 0 \\
\hline 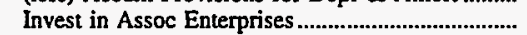 & 0 & 0 & 0 & 631 & 0 & 0 \\
\hline 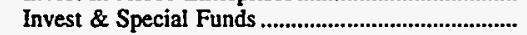 & 79,291 & 42,727 & 2,179 & 72,447 & 0 & 0 \\
\hline Total Other Property \& Investments................ & 79,773 & 43,138 & $\mathbf{2 , 4 2 0}$ & 73,078 & 270 & 0 \\
\hline \multicolumn{7}{|l|}{ Current and Accrued Assets } \\
\hline 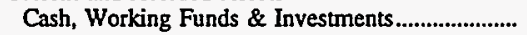 & 39,005 & 140 & 4,252 & 107,365 & 20,351 & 912 \\
\hline 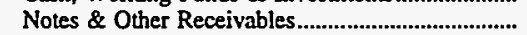 & 6,906 & 781 & 0 & 4,931 & 277 & 0 \\
\hline Customer Accts Receivable & 1,955 & 0 & 955 & 46,461 & 7,426 & 720 \\
\hline (less) Accum Prov for Uncollected Accts............... & 0 & 0 & 0 & 2,746 & 150 & 16 \\
\hline 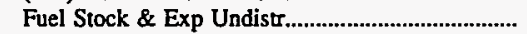 & 316 & 0 & 0 & 0 & 0 & 0 \\
\hline Materials \& Supplies & 80 & $\mathbf{0}$ & 33 & 20,358 & 2,446 & 433 \\
\hline Other Supplies \& Misc.................................................... & $\mathbf{0}$ & 0 & 0 & 0 & 0 & 0 \\
\hline 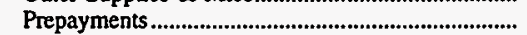 & 6,256 & 456 & 74 & 2,086 & 0 & 0 \\
\hline 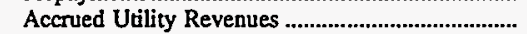 & 3,487 & 0 & 0 & 0 & 0 & 0 \\
\hline Miscellaneous Current \& Accrued Assets................... & 598 & 0 & 0 & 1,753 & 0 & 13 \\
\hline 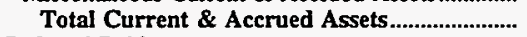 & 58,604 & 1,377 & 5,313 & 180,207 & 30,351 & 2,062 \\
\hline \multicolumn{7}{|l|}{ Deferred Debits } \\
\hline Unamortized Debt Expenses ............................................. & 0 & 1,378 & 86 & 14,006 & $\mathbf{0}$ & 0 \\
\hline 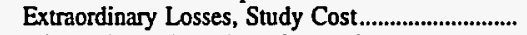 & 0 & 0 & 0 & 0 & 0 & 0 \\
\hline Misc Debt, R \& D Exp, Unamrt Losses ................. & 0 & 0 & 0 & 4,203 & 0 & 0 \\
\hline Total Deferred Debits................................................. & 0 & 1,378 & 86 & 18,208 & 0 & 0 \\
\hline 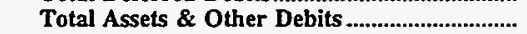 & 200,625 & 185,469 & 10,043 & 789,903 & 88,772 & 10,878 \\
\hline \multicolumn{7}{|l|}{ Proprietary Capital } \\
\hline Investment of Municipality ......................................... & $\mathbf{0}$ & 0 & 0 & 0 & 25,985 & $\mathbf{0}$ \\
\hline 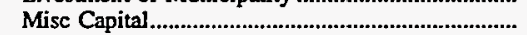 & 0 & 0 & & 974 & 0 & 0 \\
\hline Retained Earnings.................................................................... & 193,131 & 66,122 & 6,564 & 244,726 & 58,088 & 8,814 \\
\hline 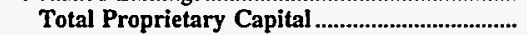 & 193,131 & 66,122 & 6,564 & 245,700 & 84,073 & 8,814 \\
\hline \multicolumn{7}{|l|}{ Long-term Debt } \\
\hline 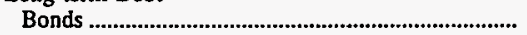 & $\mathbf{0}$ & 94,696 & 2,412 & 289,940 & 0 & 0 \\
\hline 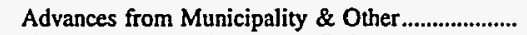 & 3,229 & 1,700 & 0 & 0 & 0 & 0 \\
\hline 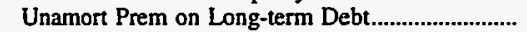 & 0 & 0 & 0 & 0 & 0 & 0 \\
\hline (less) Unamort Discount on Long-term Debt & 0 & 0 & 20 & & 0 & 0 \\
\hline 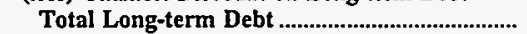 & 3,229 & 96,396 & 2,392 & 289,940 & $\mathbf{0}$ & 0 \\
\hline \multicolumn{7}{|l|}{ Other Noncurrent Liabilities } \\
\hline Accum Operating Provisions..... & 0 & 0 & 0 & 3,918 & 0 & 0 \\
\hline Accum Prov for Rate Refunds................................... & 0 & 0 & 0 & 2,083 & 0 & 0 \\
\hline Total Other Noncurrent Liabilities .......................... & $\mathbf{0}$ & $\mathbf{0}$ & $\mathbf{0}$ & 6,001 & $\mathbf{0}$ & 0 \\
\hline \multicolumn{7}{|l|}{ Current and Accrued Liabilities } \\
\hline 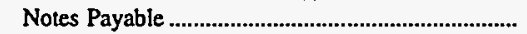 & 0 & 0 & 0 & 0 & 0 & $\mathbf{0}$ \\
\hline Accounts Payable & 2,984 & 2,307 & 1,045 & 46,665 & 3,722 & 0 \\
\hline 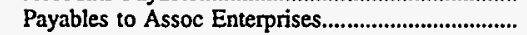 & 377 & 0 & 0 & 0 & 0 & 0 \\
\hline 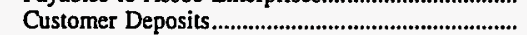 & 277 & 0 & 0 & 965 & 0 & 93 \\
\hline 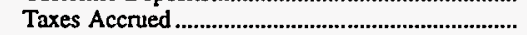 & 522 & 0 & 0 & 0 & 0 & 0 \\
\hline 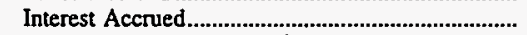 & 0 & 2,984 & 11 & 4,492 & 0 & 0 \\
\hline Misc Current \& Accrued Liabilities ............................. & 104 & $\mathbf{0}$ & 32 & 23,633 & 977 & 7 \\
\hline Total Current \& Accrued Liabilities ..................... & 4,265 & 5,291 & 1,088 & $\mathbf{7 5 , 7 5 5}$ & 4,699 & 101 \\
\hline \multicolumn{7}{|l|}{ Deferred Credits } \\
\hline Customer Advances for Construction ........................ & 0 & & 0 & 5,951 & 0 & 1,964 \\
\hline 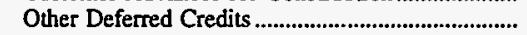 & 0 & 17,660 & 0 & 1,194 & 0 & 0 \\
\hline 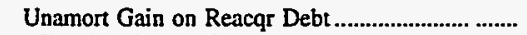 & $\mathbf{0}$ & $\mathbf{0}$ & 0 & 165,362 & 0 & 0 \\
\hline Total Deferred Credits................................................. & 0 & 17,660 & $\mathbf{0}$ & 172,507 & $\mathbf{0}$ & 1,964 \\
\hline 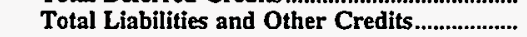 & 200,625 & 185,469 & 10,043 & 789,903 & 88,772 & 10,878 \\
\hline
\end{tabular}

Note: Totals may not equal sum of components because of independent rounding.

Source: Energy Information Administration, Form EIA-412, "Annual Report of Public Electric Uuilities." 
Table 22. Balance Sheet by Major U.S. Publicly Owned Electric Utility Within State at End of Period, 1996

(Thousand Dollars)

\begin{tabular}{|c|c|c|c|c|c|c|}
\hline Item & $\begin{array}{l}\text { Colorado } \\
\text { Longmont } \\
\text { City of } \\
\text { December } 31\end{array}$ & $\begin{array}{l}\text { Colorado } \\
\text { Loveland } \\
\text { City of } \\
\text { December } 31\end{array}$ & $\begin{array}{c}\text { Colorado } \\
\text { Platte River } \\
\text { Power } \\
\text { Authority } \\
\text { December } 31\end{array}$ & $\begin{array}{l}\text { Connecticut } \\
\text { Connecticut } \\
\text { Mun } \\
\text { Elec } \\
\text { Engy Coop } \\
\text { December } 31\end{array}$ & $\begin{array}{l}\text { Connecticut } \\
\text { Groton } \\
\text { City of } \\
\text { June } 30\end{array}$ & $\begin{array}{l}\text { Connecticut } \\
\text { Norwich } \\
\text { City of } \\
\text { June } 30\end{array}$ \\
\hline \multicolumn{7}{|l|}{ Electric Utility Plant } \\
\hline 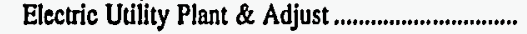 & 43,595 & 49,738 & 771,461 & 54,734 & 32,288 & 31,754 \\
\hline Const Work in Progress & & 366 & 3,374 & 2 & 758 & 6,198 \\
\hline 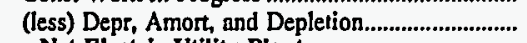 & 18,048 & 13,748 & 290,278 & 17,851 & 17,703 & 18.917 \\
\hline Net Electric Utility Plant ....................................... & 25,547 & 36,356 & 484,557 & $\mathbf{3 6 , 8 8 5}$ & 15,343 & $\mathbf{1 9 , 0 3 5}$ \\
\hline Nuclear Fuel.................................................................. & & 0 & 0 & 4,423 & 0 & 0 \\
\hline 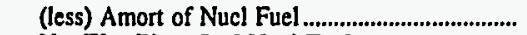 & 0 & $\mathbf{0}$ & 0 & 3,769 & $\mathbf{0}$ & 0 \\
\hline 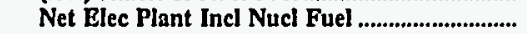 & 25,547 & 36,356 & 484,557 & 37,540 & 15,343 & 19,035 \\
\hline \multicolumn{7}{|l|}{ Other Property \& Investments } \\
\hline Nonutility Property..................... & 0 & 0 & 0 & 0 & $\mathbf{0}$ & 0 \\
\hline (less) Accum Provisions for Depr \& Amort .......... & 0 & 0 & 0 & 0 & 0 & 0 \\
\hline 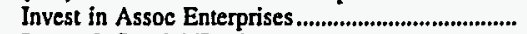 & 0 & 478 & 0 & $\mathbf{0}$ & 0 & 0 \\
\hline 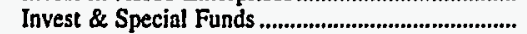 & 0 & 4,276 & 203,161 & 26,781 & 0 & 363 \\
\hline \multicolumn{7}{|l|}{ Current and Accrued Assets } \\
\hline 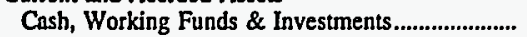 & 7,118 & 7,648 & 24,133 & 25,380 & 6,613 & 3,991 \\
\hline 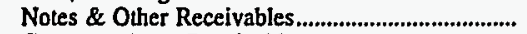 & 15 & 0 & 205 & 28,485 & 0 & 2,029 \\
\hline 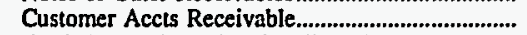 & 3,238 & 1,197 & 12,264 & 15,817 & 4,514 & 3,131 \\
\hline (less) Accum Prov for Uncollected Accts ............... & 91 & 19 & 0 & 0 & 237 & 1,014 \\
\hline Fuel Stock \& Exp Undistr......................................... & 0 & 0 & 2,932 & 86 & 0 & $\mathbf{0}$ \\
\hline 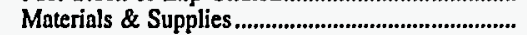 & 0 & 1,101 & 7,674 & 0 & 630 & 263 \\
\hline Other Supplies \& Misc.............................................. & 0 & 0 & 18 & 0 & 0 & 0 \\
\hline 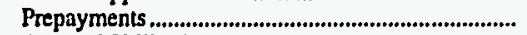 & 0 & 14 & 376 & 297 & 74 & 88 \\
\hline 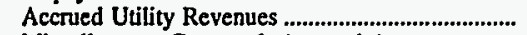 & 0 & 0 & 0 & 0 & 1,688 & 0 \\
\hline Miscellaneous Current \& Accrued Assets............... & 63 & 255 & 3,168 & 82 & 20 & 0 \\
\hline Total Current \& Accrued Assets........................... & 10,344 & 10,196 & 50,770 & $\mathbf{7 0 , 1 4 8}$ & 13,302 & 8,489 \\
\hline \multicolumn{7}{|l|}{ Deferred Debits } \\
\hline Unamortized Debt Expenses ......................................... & 0 & 0 & 4,494 & 1,963 & 0 & 0 \\
\hline 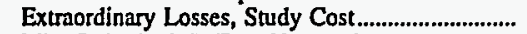 & $\mathbf{0}$ & 0 & 751 & 0 & 0 & $\mathbf{0}$ \\
\hline Misc Debt, R \& D Exp, Unamut Losses ..................... & 0 & $\mathbf{0}$ & 1,485 & 66,720 & 187 & 0 \\
\hline 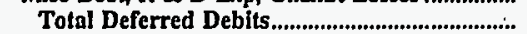 & & 0 & 6,730 & 68,683 & 187 & 0 \\
\hline 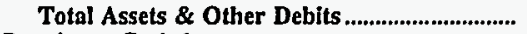 & 35,891 & 51,307 & 745,217 & 203,151 & 28,831 & 27,887 \\
\hline \multicolumn{7}{|l|}{ Proprietary Capital } \\
\hline 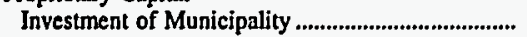 & 12,949 & 0 & 0 & 806 & 0 & $\mathbf{0}$ \\
\hline 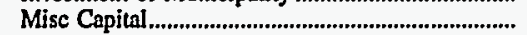 & & 0 & 356 & 0 & 0 & $\mathbf{0}$ \\
\hline 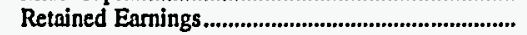 & 20,135 & 45,153 & 235,621 & 5,805 & 11,810 & 14,989 \\
\hline Total Proprietary Capital.......................................... & 33,084 & 45,153 & 235,977 & 6,611 & 11,810 & 14,989 \\
\hline \multicolumn{7}{|l|}{ Long-term Debt } \\
\hline 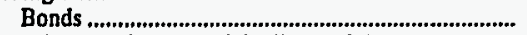 & 0 & 0 & 501,475 & 142,000 & 6,079 & 243 \\
\hline 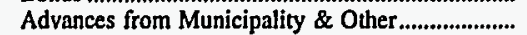 & 14 & 428 & 40,367 & 0 & 0 & 6,879 \\
\hline 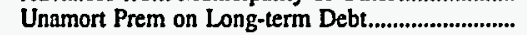 & 0 & 0 & & 754 & 0 & 0 \\
\hline (less) Unamort Discount on Long-term Debt & 0 & 0 & 52,226 & 1,034 & 0 & 0 \\
\hline 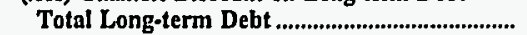 & 14 & 428 & 489,616 & 141,720 & 6,079 & 7,121 \\
\hline \multicolumn{7}{|l|}{ Other Noncurrent Liabilities } \\
\hline Accum Operating Provisions...... & 0 & 0 & 7,422 & 0 & 0 & 0 \\
\hline 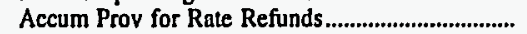 & 0 & $\mathbf{0}$ & 0 & 0 & 0 & 0 \\
\hline Total Other Noncurrent Liabilities ................... & 0 & 0 & 7,422 & 0 & 0 & 0 \\
\hline \multicolumn{7}{|l|}{ Current and Accrued Liabilities } \\
\hline Notes Payable ................................. & 0 & 122 & 0 & 2,060 & 0 & 0 \\
\hline 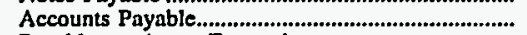 & 1,712 & 1,786 & 7,509 & 19,651 & 6,208 & 3,729 \\
\hline 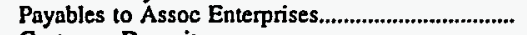 & 0 & 0 & $\mathbf{0}$ & $\mathbf{0}$ & 0 & 0 \\
\hline 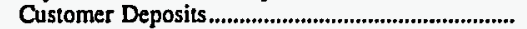 & 535 & 284 & $\mathbf{0}$ & 0 & 2,102 & 241 \\
\hline 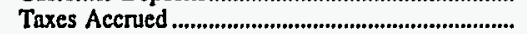 & 68 & 0 & 0 & 136 & 340 & 281 \\
\hline 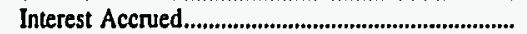 & 0 & 0 & 2,597 & 2,865 & 44 & 0 \\
\hline Misc Current \& Accrued Liabilities ............................... & 479 & 236 & 1,858 & 2,541 & 2,249 & 111 \\
\hline Total Current \& Accrued Liabilities ................ & 2,794 & 2,428 & 11,965 & 27,253 & 10,942 & 4,362 \\
\hline \multicolumn{7}{|l|}{ Deferred Credits } \\
\hline 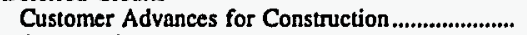 & 0 & 210 & $\mathbf{0}$ & 0 & $\mathbf{0}$ & $\mathbf{0}$ \\
\hline Other Deferred Credits & 0 & 3,087 & 238 & 27,567 & 0 & 1,414 \\
\hline 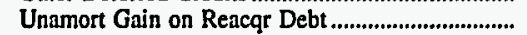 & 0 & 0 & 0 & 0 & 0 & 0 \\
\hline Total Deferred Credits.............................................. & & 3,297 & 238 & 27,567 & & $1, \mathbf{4 1 4}$ \\
\hline Total Llabillties and Other Credits....................... & 35,891 & 51,307 & 745,217 & 203,151 & 28,831 & 27,887 \\
\hline
\end{tabular}

Note: Totals may not equal sum of components because of independent rounding.

Source: Energy Information Administration, Form EIA-412, "Annual Report of Public Electric Utilities." 
Table 22. Balance Sheet by Major U.S. Publicly Owned Electric Utility Within State at End of Period, 1996

(Thousand Dollars)

\begin{tabular}{|c|c|c|c|c|c|c|}
\hline Item & $\begin{array}{l}\text { Connecticut } \\
\text { Wallingford } \\
\text { Town of } \\
\text { June } 30\end{array}$ & $\begin{array}{l}\text { Delaware } \\
\text { Dover } \\
\text { City of } \\
\text { June } 30\end{array}$ & $\begin{array}{l}\text { Delaware } \\
\text { Milford } \\
\text { City of } \\
\text { September } 30\end{array}$ & $\begin{array}{l}\text { Delaware } \\
\text { Newark } \\
\text { City of } \\
\text { December } 31\end{array}$ & $\begin{array}{l}\text { Florida } \\
\text { Bartow } \\
\text { City of. } \\
\text { September } 30\end{array}$ & $\begin{array}{c}\text { Florida } \\
\text { Florida } \\
\text { Municipal } \\
\text { Power Agency } \\
\text { September } 30\end{array}$ \\
\hline \multicolumn{7}{|l|}{ Electric Utility Plant } \\
\hline $\begin{array}{l}\text { Electric Utility Plant \& Adjust } \\
\text { Const Work in Progress }\end{array}$ & $\begin{array}{r}52,785 \\
0\end{array}$ & $\begin{array}{r}104,889 \\
32\end{array}$ & $\begin{array}{r}7,529 \\
0\end{array}$ & $\begin{array}{r}13,542 \\
0\end{array}$ & $\begin{array}{r}14,615 \\
40\end{array}$ & $\begin{array}{l}242,852 \\
176,178\end{array}$ \\
\hline 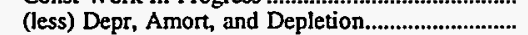 & 28,306 & 37,848 & 4,747 & 6,717 & 6,039 & 98,124 \\
\hline Net Electric Utility Plant .................................... & 24,479 & 67,073 & 2,782 & 6,825 & 8,616 & 320,906 \\
\hline Nuclear Fuel...……………………………………..... & 0 & 0 & 0 & 0 & 0 & 7,723 \\
\hline 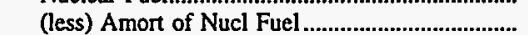 & 0 & 0 & 0 & 0 & 0 & 0 \\
\hline Net Elec Plant Incl Nucl Fuel .......................... & 24,479 & 67,073 & $\mathbf{2 , 7 8 2}$ & 6,825 & 8,616 & 328,629 \\
\hline \multicolumn{7}{|l|}{ Other Property \& Investments } \\
\hline Nonutility Property .................... & 0 & 0 & 0 & 0 & 0 & 0 \\
\hline (less) Accum Provisions for Depr \& Amort .......... & 0 & 0 & $\mathbf{0}$ & 0 & 0 & 0 \\
\hline Invest in Assoc Enterprises ....................................... & 0 & 0 & 0 & 0 & 0 & 0 \\
\hline 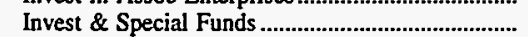 & 0 & 22,387 & 0 & 0 & 4,718 & 93,396 \\
\hline Total Other Property \& Investments.................... & 0 & 22,387 & 0 & o & 4,718 & $\mathbf{9 3 , 3 9 6}$ \\
\hline \multicolumn{7}{|l|}{ Current and Accrued Assets } \\
\hline 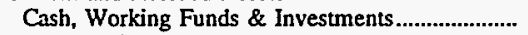 & 8,878 & 171 & 6,793 & 8,940 & 28 & 46,068 \\
\hline 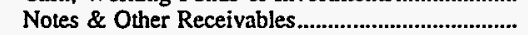 & 0 & 1,214 & 21 & 892 & 2,079 & 12,089 \\
\hline Customer Accts Receivable & 4,670 & 4,323 & 1,373 & 1,697 & 2,677 & 5,783 \\
\hline (less) Accum Prov for Uncollected Accts.......................... & 114 & 54 & 0 & 0 & 200 & 0 \\
\hline 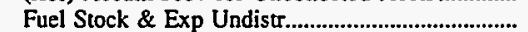 & 33 & 0 & 0 & 0 & 1,090 & 670 \\
\hline 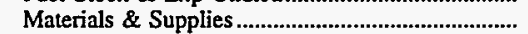 & 937 & 2,004 & 770 & 647 & 0 & 0 \\
\hline 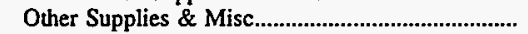 & 5 & 0 & 0 & 0 & 0 & $\mathbf{0}$ \\
\hline 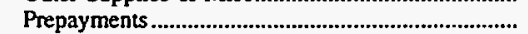 & 0 & 0 & 0 & 0 & 0 & 0 \\
\hline 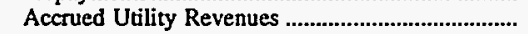 & 0 & 0 & 0 & 0 & 0 & 2,401 \\
\hline Miscellaneous Current \& Accrued Assets................... & 461 & 0 & $\mathbf{0}$ & 0 & 0 & 0 \\
\hline 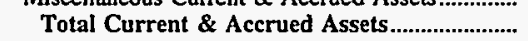 & 14,869 & 7,658 & 8,957 & 12,176 & 5,674 & 67,011 \\
\hline \multicolumn{7}{|l|}{ Deferred Debits } \\
\hline Unamortized Debt Expenses.. & 0 & 0 & 0 & 0 & 0 & 8,671 \\
\hline 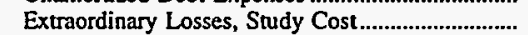 & 0 & 0 & 0 & 0 & 0 & 0 \\
\hline Misc Debt, R \& D Exp, Unamrt Losses ......................... & 4,228 & 0 & 0 & 0 & 0 & 228,487 \\
\hline Total Deferred Debits............................................ & 4,228 & 0 & 0 & $\mathbf{0}$ & $\mathbf{0}$ & $\mathbf{2 3 7 , 1 5 8}$ \\
\hline \multirow{2}{*}{\multicolumn{7}{|c|}{$\begin{array}{l}\text { Total Assets \& Other Debits ................................ } \\
\text { Proprietary Capital }\end{array}$}} \\
\hline & & & & & & \\
\hline 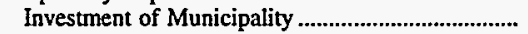 & 0 & 0 & 0 & 0 & 27 & 0 \\
\hline Misc Capital....... & 0 & 0 & 0 & 0 & 0 & 0 \\
\hline 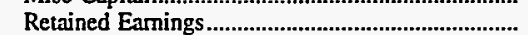 & 37,221 & 51,675 & 10,885 & 16,947 & 13,542 & 0 \\
\hline Total Proprietary Capital ....................................... & 37,221 & 51,675 & 10,885 & 16,947 & 13,570 & 0 \\
\hline \multicolumn{7}{|l|}{ Long-term Debt } \\
\hline 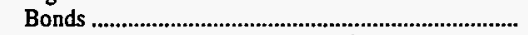 & 300 & 30,010 & 0 & 0 & 0 & 630,774 \\
\hline 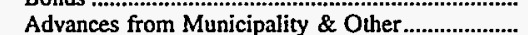 & 0 & 0 & 0 & 0 & 0 & 17,134 \\
\hline Unamort Prem on Long-term Debt.............................. & 0 & 0 & 0 & 0 & 0 & \\
\hline (less) Unamort Discount on Long-term Debt & 0 & 0 & 0 & 0 & 0 & 5,237 \\
\hline Total Long-term Debt .............................................. & 300 & 30,010 & 0 & 0 & 0 & 642,671 \\
\hline \multicolumn{7}{|l|}{ Other Noncurrent Liabilities } \\
\hline Accum Operating Provisions........................................ & $\mathbf{0}$ & 10,726 & 0 & 0 & 0 & 0 \\
\hline Accum Prov for Rate Refunds.................................... & 0 & 0 & 0 & 0 & 0 & 0 \\
\hline 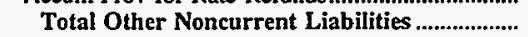 & 0 & 10,726 & 0 & $\mathbf{0}$ & 0 & 0 \\
\hline \multicolumn{7}{|l|}{ Current and Accrued Liabilities } \\
\hline 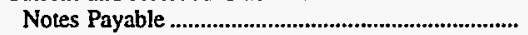 & 0 & 0 & 0 & 0 & 0 & 20,720 \\
\hline Accounts Payable........................................ & 2,630 & 2,719 & 533 & 1,242 & 4,095 & 40,017 \\
\hline Payables to Assoc Enterprises........................................ & 0 & 0 & 0 & 338 & 385 & 0 \\
\hline 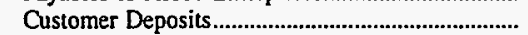 & 1,306 & 626 & 162 & 458 & 688 & 0 \\
\hline 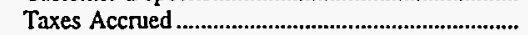 & 398 & 0 & 0 & 0 & 104 & 0 \\
\hline 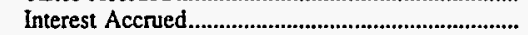 & 251 & 960 & 0 & $\mathbf{0}$ & 0 & 17,507 \\
\hline Misc Current \& Accrued Liabilities ............................. & 1,195 & 403 & 117 & 0 & 165 & 3,066 \\
\hline Total Current \& Accrued Liabilities ................. & 5,780 & 4,708 & 812 & 2,038 & 5,438 & 81,309 \\
\hline \multicolumn{7}{|l|}{ Deferred Credits } \\
\hline Customer Advances for Construction.......................... & 126 & 0 & 0 & 16 & 0 & \\
\hline Other Deferred Credits .................................................... & 150 & 0 & 42 & 0 & 0 & 2,214 \\
\hline 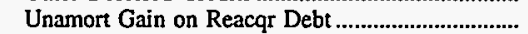 & 0 & 0 & 0 & 0 & 0 & \\
\hline Total Deferred Credits & 276 & 0 & 42 & 16 & & 2,214 \\
\hline Total Liabilities and Other Credits................... & 43,577 & 97,118 & 11,739 & 19,001 & 19,008 & 726,194 \\
\hline
\end{tabular}

Note: Totals may not equal sum of components because of independent rounding.

Source: Energy Information Administration, Form ElA-412, "Annual Report of Public Electric Utilities." 
Table 22. Balance Sheet by Major U.S. Publicly Owned Electric Utility Within State at End of Period, 1996

(Thousand Dollars)

\begin{tabular}{|c|c|c|c|c|c|c|}
\hline Item & $\begin{array}{c}\text { Florida } \\
\text { Fort Pierce } \\
\text { Utilities } \\
\text { Auth } \\
\text { September } 30\end{array}$ & $\begin{array}{c}\text { Florida } \\
\text { Gainesville } \\
\text { Regional } \\
\text { Utilities } \\
\text { September } 30\end{array}$ & $\begin{array}{l}\text { Florida } \\
\begin{array}{c}\text { Homestead } \\
\text { City of }\end{array} \\
\text { September } 30\end{array}$ & $\begin{array}{c}\text { Florida } \\
\text { Jacksonville } \\
\text { Beach } \\
\text { City of } \\
\text { September } 30\end{array}$ & $\begin{array}{c}\text { Florida } \\
\text { Jacksonville } \\
\text { Electric } \\
\text { Auth } \\
\text { September } 30\end{array}$ & $\begin{array}{c}\text { Florida } \\
\text { Key West } \\
\text { City of } \\
\text { September } 30\end{array}$ \\
\hline \multicolumn{7}{|l|}{ Electric Utility Plant } \\
\hline 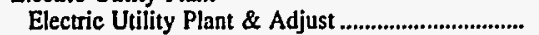 & 117,384 & 477,013 & 47,801 & 82,019 & $3,085,809$ & 173,275 \\
\hline 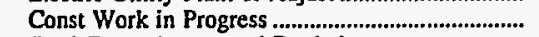 & 1,481 & 14,072 & & 4,301 & 25,335 & 3,264 \\
\hline (less) Depr, Amort, and Depletion........................... & 53,112 & 162,595 & 23,364 & 26,729 & 854,991 & 68,474 \\
\hline Net Electric Utility Plant ........................................... & 65,753 & 328,490 & 24,479 & 59,591 & $2,256,153$ & 108,065 \\
\hline Nuclear Fuel........................................................ & 0 & 6,029 & 0 & 0 & 0 & 0 \\
\hline (less) Amort of Nucl Fuel ......................................... & & 5,012 & 0 & 0 & 0 & 0 \\
\hline Net Elec Plant Incl Nucl Fuel .............................. & 65,753 & 329,507 & 24,479 & 59,591 & $2,256,153$ & 108,065 \\
\hline \multicolumn{7}{|l|}{ Other Property \& Investments } \\
\hline 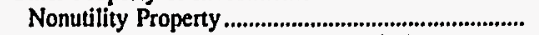 & $\mathbf{0}$ & 0 & 0 & 0 & 0 & 0 \\
\hline (less) Accum Provisions for Depr \& Amort ......... & 0 & 0 & 0 & 0 & 0 & 0 \\
\hline Invest in Assoc Enterprises ....................................... & & 0 & 0 & 0 & 0 & 0 \\
\hline Invest \& Special Funds ........................................... & 12,184 & 0 & 0 & 17,698 & 649,585 & 21,638 \\
\hline Total Other Property \& Investments............... & 12,184 & $\mathbf{0}$ & 0 & 17,698 & 649,585 & 21,638 \\
\hline \multicolumn{7}{|l|}{ Current and Accrued Assets } \\
\hline 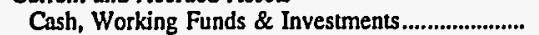 & 13,069 & 125,410 & 5,183 & 7,764 & 125,549 & 4,506 \\
\hline 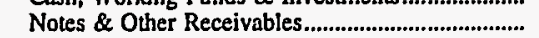 & 67 & 5,961 & 13,343 & 0 & 5,583 & 492 \\
\hline Customer Accts Receivable........................................... & 3,888 & 9,815 & 3,076 & 5,975 & 88,681 & 4,183 \\
\hline (less) Accum Prov for Uncollected Accts .................. & 36 & 835 & 809 & 124 & 1,597 & 123 \\
\hline 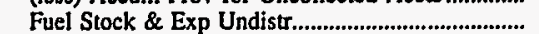 & $\mathbf{0}$ & 5,109 & 168 & 0 & 30,049 & 630 \\
\hline Materials \& Supplies .................................................... & 2,173 & 4,044 & 2,693 & $\mathbf{0}$ & 44,629 & 2,352 \\
\hline 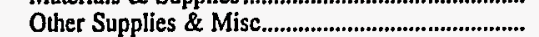 & 1,163 & 93 & 0 & 1,957 & 0 & 0 \\
\hline Prepayments,................................................................... & 96 & 0 & 14 & 0 & 35 & 580 \\
\hline Accrued Utility Revenues .............................................. & 2,060 & 8,677 & 1,504 & 0 & 0 & 0 \\
\hline Miscellaneous Current \& Accrued Assets................ & 429 & 335 & 0 & 0 & 10,689 & \\
\hline \multirow{2}{*}{\multicolumn{7}{|c|}{ Deferred Debits }} \\
\hline & & & & & & \\
\hline Unamortized Debt Expenses ......................................... & 983 & 2,627 & 0 & 801 & 22,300 & 2,772 \\
\hline Extraordinary Losses, Study Cost..................................... & $\begin{array}{l}168 \\
922\end{array}$ & $\begin{array}{r}0 \\
38,037\end{array}$ & $\begin{array}{l}0 \\
0\end{array}$ & $\begin{array}{l}0 \\
0\end{array}$ & $\begin{array}{r}0 \\
394,457\end{array}$ & $\begin{array}{r}0 \\
319\end{array}$ \\
\hline 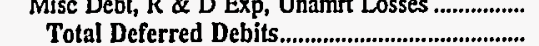 & 2,073 & 40,664 & 0 & 801 & 416,757 & 3,091 \\
\hline 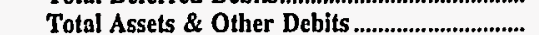 & 102,918 & 528,781 & 49,651 & 93,662 & $3,626,112$ & 145,412 \\
\hline \multicolumn{7}{|l|}{ Proprietary Capital } \\
\hline 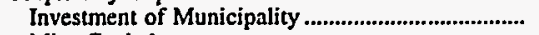 & $\mathbf{0}$ & $\mathbf{0}$ & 3,951 & 0 & 0 & $\mathbf{0}$ \\
\hline 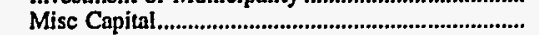 & 0 & 0 & & 8,374 & 0 & $\mathbf{0}$ \\
\hline Retained Earnings................................................ & 40,652 & 191,475 & 31,596 & 12,009 & 612,957 & 20,789 \\
\hline Total Proprietary Capital ................................. & 40,652 & 191,475 & 35,547 & 20,383 & 612,957 & 20,789 \\
\hline \multicolumn{7}{|l|}{ Long-term Debt } \\
\hline Bonds .................. & 52,311 & 251,263 & 0 & 60,243 & $2,712,609$ & 113,116 \\
\hline rom Municipality \& Other..................... & $\mathbf{0}$ & 45,917 & 6,402 & $\mathbf{0}$ & 6,424 & \\
\hline Long-term Debt................................ & 0 & 0 & 0 & 0 & 0 & $\mathbf{0}$ \\
\hline (less) Unamort Discount on Long-term Debt & & 3,385 & & & 51,452 & \\
\hline 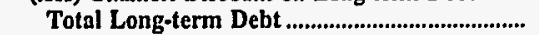 & 52,311 & 293,795 & 6,402 & 60,243 & $2,667,580$ & 113,116 \\
\hline \multicolumn{7}{|l|}{ Other Noncurrent Liabilities } \\
\hline Accum Operating Provisions.. & 2,068 & $\mathbf{0}$ & 0 & 576 & 180,520 & 0 \\
\hline 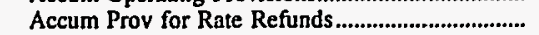 & & 0 & 0 & 0 & 0 & $\mathbf{0}$ \\
\hline \multirow{2}{*}{\multicolumn{7}{|c|}{ Current and Accrued Liabilities }} \\
\hline & & & & & & \\
\hline 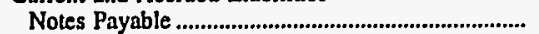 & 1,526 & $\mathbf{0}$ & 0 & 1,285 & 0 & \\
\hline Accounts Payabl & 1,840 & 7,115 & 2,405 & 3,344 & 39,238 & 4,613 \\
\hline Payables to Assoc Enterprises............................. & 0 & 0 & 1,992 & 0 & 4,067 & 634 \\
\hline Customer Deposits..... & 2,531 & 5,588 & 1,619 & 2,217 & 15,611 & 4,041 \\
\hline Taxes Accrued ............................................................ & 527 & 280 & 0 & $\mathbf{0}$ & 1,750 & 220 \\
\hline 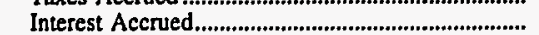 & 1,463 & 8,153 & 1,686 & 1,884 & 71,962 & 1,123 \\
\hline Misc Current \& Accrued Liabilities ....................... & & 17,574 & & $\mathbf{3 , 7 3 0}$ & 18,673 & 768 \\
\hline Total Current \& Accrued Liabilities .................... & 7,887 & 38,711 & $\mathbf{7 , 7 0 2}$ & 12,460 & 151,300 & 11,398 \\
\hline \multicolumn{7}{|l|}{ Deferred Credits } \\
\hline Customer Advances for Construction ......................... & 0 & & 0 & $\mathbf{0}$ & 0 & $\mathbf{0}$ \\
\hline 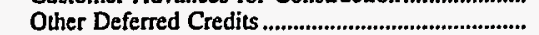 & 0 & 4,801 & 0 & 0 & 13,754 & 109 \\
\hline 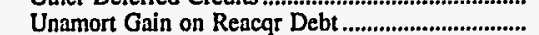 & 0 & 0 & 0 & 0 & 0 & 0 \\
\hline Total Deferred Credits.............................................. & $\mathbf{0}$ & 4,801 & $\mathbf{0}$ & $\mathbf{0}$ & 13,754 & 109 \\
\hline Total Llabillities and Other Credits.................. & 102,918 & 528,781 & 49,651 & 93,662 & $3,626,112$ & 145,412 \\
\hline
\end{tabular}

Note: Totals may not equal sum of components because of independent rounding.

Source: Energy Information Administration, Form EIA-412, "Annual Report of Public Electric Utilities." 
Table 22. Balance Sheet by Major U.S. Publicly Owned Electric Utility Within State at End of Period, 1996

(Thousand Dollars)

\begin{tabular}{|c|c|c|c|c|c|c|}
\hline Item & $\begin{array}{c}\text { Florida } \\
\text { Kissimmee } \\
\text { Utility } \\
\text { Authority } \\
\text { September } 30 \\
\end{array}$ & $\begin{array}{l}\text { Florida } \\
\text { Lake Worth } \\
\text { City of } \\
\text { September } 30 \\
\end{array}$ & $\begin{array}{c}\text { Florida } \\
\text { Lakeland } \\
\text { City of } \\
\text { September } 30 \\
\end{array}$ & $\begin{array}{l}\text { Florida } \\
\text { Leesburg } \\
\text { City of } \\
\text { September } 30\end{array}$ & $\begin{array}{c}\text { Florida } \\
\text { New Smyrna } \\
\text { Beach } \\
\text { Utils Comm } \\
\text { September } 30\end{array}$ & $\begin{array}{c}\text { Florida } \\
\text { Ocala } \\
\text { City of } \\
\text { September } 30\end{array}$ \\
\hline \multicolumn{7}{|l|}{ Electric Utility Plant } \\
\hline 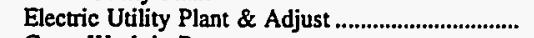 & 234,849 & 84,917 & 587,015 & 48,855 & 59,106 & 96,494 \\
\hline 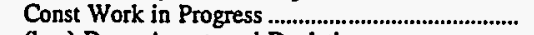 & 13,484 & & 33,011 & 2,500 & 1,242 & 12,551 \\
\hline 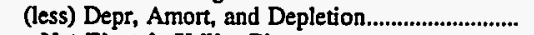 & 75,062 & 44,390 & 206,581 & 18,361 & 24,196 & 35,702 \\
\hline 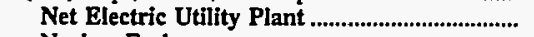 & 173,271 & 40,547 & $\mathbf{4 1 3 , 4 4 5}$ & 32,995 & 36,152 & 73,343 \\
\hline 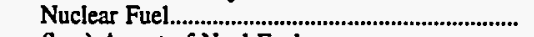 & 2,872 & 0 & 0 & 1,069 & 2,201 & 2,524 \\
\hline (less) Amort of Nucl Fuel ............................................. & 2,389 & 0 & 0 & 542 & 2,042 & 1,672 \\
\hline & 173,755 & 40,547 & 413,445 & 33,522 & 36,311 & 74,195 \\
\hline \multicolumn{7}{|l|}{ Other Property \& Investments } \\
\hline (less) Accum Provisions for Depr \& Amort .......... & 0 & 0 & $\begin{array}{l}74,249 \\
19,318\end{array}$ & $\begin{array}{l}0 \\
0\end{array}$ & $\begin{array}{l}66,649 \\
19,879\end{array}$ & $\begin{array}{l}0 \\
0\end{array}$ \\
\hline 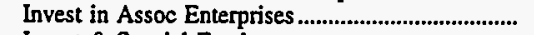 & $\mathbf{0}$ & 0 & 0 & 0 & 0 & 1,261 \\
\hline 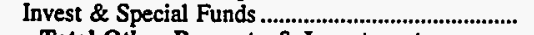 & 115,487 & 15,479 & 215,259 & 15,902 & 16,920 & 30,095 \\
\hline & 115,487 & 15,479 & 270,190 & 15,902 & 63,689 & 31,356 \\
\hline Cash, Working Funds \& Investments...................... & 13,584 & 2,683 & 16,406 & 8,089 & 1,668 & Current and Accrued Assets \\
\hline Notes \& Other Receivables......................................... & 1,912 & 120 & 2,108 & 2,151 & $\begin{array}{r}1,000 \\
290\end{array}$ & $\begin{array}{r}2 \\
1,478\end{array}$ \\
\hline 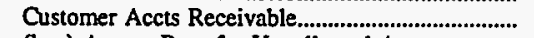 & 9,011 & 2,587 & 14,072 & 2,362 & 1,644 & 6,962 \\
\hline (less) Accum Prov for Uncollected Accts............... & 198 & 0 & 523 & 515 & 57 & 557 \\
\hline 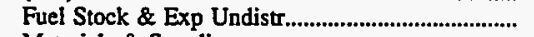 & 370 & 0 & 5,552 & 0 & 0 & 0 \\
\hline 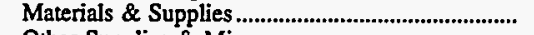 & 5,864 & 0 & 19,000 & 1,204 & 1,608 & 2,296 \\
\hline 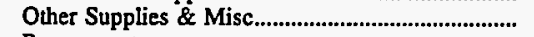 & 0 & 0 & 0 & 0 & 15 & 0 \\
\hline 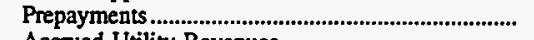 & 130 & 1,834 & 290 & 0 & 150 & 345 \\
\hline Accrued Utility Revenues & 0 & 70 & 8,026 & 0 & 1,873 & 5,145 \\
\hline Miscellaneous Current \& Accrued Assets................ & 65 & 0 & 512 & 0 & 0 & 236 \\
\hline $\begin{array}{l}\text { Total Current \& Accrued Assets.................................... } \\
\text { Deferted Debits }\end{array}$ & \multicolumn{6}{|c|}{ Deferred Debits } \\
\hline Unamortized Debt Expenses .......................................... & 2,523 & 512 & 1,846 & 107 & 704 & 170 \\
\hline 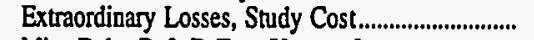 & 0 & 0 & 0 & 0 & 0 & 0 \\
\hline Misc Debt, R \& D Exp, Unamrt Losses .................... & 57,199 & 0 & 0 & 0 & 1,492 & 0 \\
\hline Total Deferred Debits....................................................... & 59,722 & 512 & 1,846 & 107 & 2,196 & 170 \\
\hline 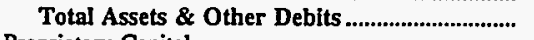 & 379,703 & 63,831 & 750,924 & 62,821 & 109,386 & 121,629 \\
\hline \multicolumn{7}{|l|}{ Proprietary Capital } \\
\hline & 0 & 0 & 0 & 0 & 32,804 & 0 \\
\hline 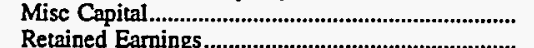 & 0 & 0 & 0 & 0 & & 0 \\
\hline & 119,786 & 25,202 & 245,944 & 39,972 & 7,192 & 81,685 \\
\hline \multirow{2}{*}{\multicolumn{7}{|c|}{ Long-term Debt }} \\
\hline & & & & & & \\
\hline & 234,905 & 33,430 & 477,196 & 13,295 & 63,310 & 20,938 \\
\hline 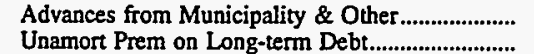 & & $\begin{array}{l}0 \\
0\end{array}$ & $\begin{array}{r}20,784 \\
6279\end{array}$ & $\begin{array}{r}2,036 \\
0\end{array}$ & $\begin{array}{l}0 \\
0\end{array}$ & $\begin{array}{l}0 \\
0\end{array}$ \\
\hline $\begin{array}{l}\text { Unamort Prem on Long-term Debt............................ } \\
\text { (less) Unamort Discount on Long-term Det }\end{array}$ & 4,701 & & 27,035 & 88 & 1,190 & $\begin{array}{l}0 \\
0\end{array}$ \\
\hline 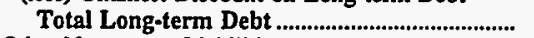 & 230,204 & 33,430 & 477,225 & 15,242 & 62,120 & 20,938 \\
\hline \multicolumn{7}{|l|}{ Other Noncurrent Liabilities } \\
\hline 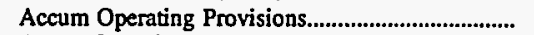 & 0 & 0 & 0 & 0 & 1,647 & 1,771 \\
\hline 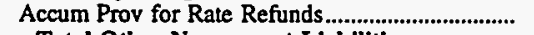 & 120 & 0 & 0 & 0 & & \\
\hline Total Other Noncurrent Liabilities ....................... & 120 & 0 & 0 & 0 & 1,647 & 1,771 \\
\hline \multicolumn{7}{|l|}{ Current and Accrued Liabilities } \\
\hline 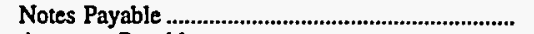 & 0 & 0 & 0 & 0 & 0 & 0 \\
\hline 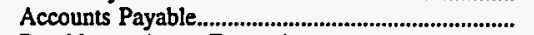 & 3,917 & 1,865 & 10,813 & 1,668 & 1,752 & 5,014 \\
\hline 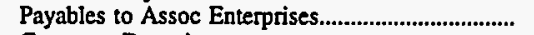 & 1,191 & 559 & 0 & 0 & 0 & 1,237 \\
\hline 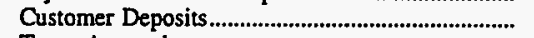 & 2,857 & 0 & 5,428 & 1,389 & 1,024 & 3,441 \\
\hline Taxes Accrued ........................................................... & 459 & 175 & 431 & 0 & 0 & 372 \\
\hline 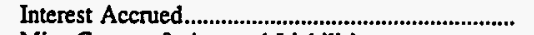 & 6,738 & 0 & 7,982 & 439 & 1,391 & 647 \\
\hline Misc Current \& Accrued Liabilities........................... & 13,241 & 2,601 & 2,052 & 909 & 1,420 & 413 \\
\hline $\begin{array}{l}\text { Total Current \& Accrued Liabilities ................ } \\
\text { Defered Credits }\end{array}$ & 28,403 & 5,200 & 26,705 & 4,406 & 5,587 & 11,123 \\
\hline \multicolumn{6}{|l|}{ Deferred Credits } & \\
\hline 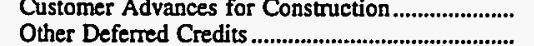 & $\begin{array}{l}1,109 \\
0\end{array}$ & $\begin{array}{l}0 \\
0\end{array}$ & $\begin{array}{r}0 \\
1050\end{array}$ & $\begin{array}{r}155 \\
3046\end{array}$ & $\begin{array}{r}0 \\
36\end{array}$ & $\begin{array}{l}4,813 \\
1299\end{array}$ \\
\hline 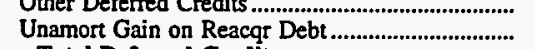 & 0 & 0 & 0 & $\begin{array}{l}1 \\
0\end{array}$ & $\begin{array}{r}50 \\
0\end{array}$ & $\begin{array}{r}1,299 \\
0\end{array}$ \\
\hline Total Deferred Credits........................................... & 1,189 & & 1,050 & 3,201 & 36 & 6,112 \\
\hline Total Liabilities and Other Credits........................ & 379,703 & 3,831 & 50,924 & 62,821 & 109,386 & 121,629 \\
\hline
\end{tabular}

Note: Totals may not equal sum of components because of independent rounding.

Source: Energy Information Administration, Form EIA-412, "Annual Report of Public Electric Utilities." 
Table 22. Balance Sheet by Major U.S. Publicly Owned Electric Utility Within State at End of Period, 1996

(Thousand Dollars)

\begin{tabular}{|c|c|c|c|c|c|c|}
\hline Item & $\begin{array}{l}\text { Florida } \\
\text { Orlando } \\
\text { Utilities } \\
\text { Comm } \\
\text { September } 30\end{array}$ & $\begin{array}{c}\text { Florida } \\
\text { Quincy } \\
\text { City of } \\
\text { September } 30\end{array}$ & $\begin{array}{c}\text { Florida } \\
\text { Reedy Creek } \\
\text { Improvement } \\
\text { Dist } \\
\text { September } 30\end{array}$ & $\begin{array}{l}\text { Florida } \\
\text { St Cloud } \\
\text { City of } \\
\text { September } 30\end{array}$ & $\begin{array}{c}\text { Florida } \\
\text { Tallahassee } \\
\text { City of } \\
\text { September } 30\end{array}$ & $\begin{array}{c}\text { Florida } \\
\text { Vero } \\
\text { Beach } \\
\text { City of } \\
\text { September } 30\end{array}$ \\
\hline \multicolumn{7}{|l|}{ Electric Utility Plant } \\
\hline Electric Utility Plant \& Adjust ................................. & $1,646,908$ & 6,811 & 139,946 & 75,786 & 416,666 & 160,758 \\
\hline 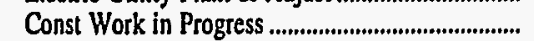 & 45,098 & 0 & 15,217 & 509 & 52,924 & 3 \\
\hline (less) Depr, Amort, and Depletion............................. & 426,779 & 3,231 & 27,673 & 26,997 & 184,913 & 52,482 \\
\hline Net Electric Utility Plant & $1,265,227$ & 3,580 & 127,490 & 49,299 & 284,677 & 108,279 \\
\hline Nuclear Fuel.................................................................... & 20,378 & 0 & 0 & 0 & 8,527 & 0 \\
\hline 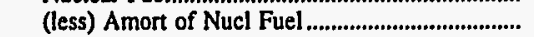 & 19,077 & 0 & 0 & 0 & 4,727 & 0 \\
\hline $\begin{array}{l}\text { Net Elec Plant Incl Nucl Fuel ............................... } \\
\text { Other Property \& Investments }\end{array}$ & $1,266,528$ & 3,580 & 127,490 & 49,299 & 288,477 & 108,279 \\
\hline Nonutility Property & 400 & 0 & $\mathbf{0}$ & 0 & 0 & 0 \\
\hline (less) Accum Provisions for Depr \& Amort .......... & 8 & 0 & 0 & 0 & $\mathbf{0}$ & 0 \\
\hline Invest in Assoc Enterprises................................. & 0 & 0 & 0 & 0 & 0 & 0 \\
\hline 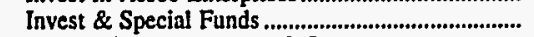 & 256,797 & 1,031 & $\mathbf{0}$ & 0 & 89,563 & 13,046 \\
\hline Total Other Property \& Investments.............. & 257,189 & 1,031 & $\mathbf{0}$ & o & 89,563 & 13,046 \\
\hline \multicolumn{7}{|l|}{ Current and Accrued Assets } \\
\hline 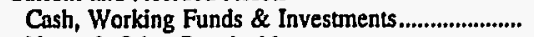 & 111,251 & 260 & 15,627 & 4,729 & 10,205 & 11,601 \\
\hline Notes \& Other Receivables.................................. & 7,238 & 550 & 621 & 14 & 656 & 126 \\
\hline Customer Accts Receivable...................................... & 37,098 & 1,108 & 1,641 & 1,689 & 15,169 & 6,905 \\
\hline (less) Accum Prov for Uncollected Accts.............. & 585 & 298 & 0 & 191 & 1,287 & 958 \\
\hline 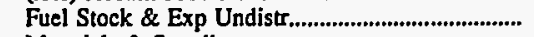 & 13,665 & 0 & 111 & 0 & 3,726 & 2,262 \\
\hline 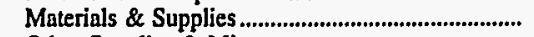 & 25,457 & 105 & 1,044 & 1,574 & 0 & 2,212 \\
\hline Other Supplies \& Misc................................................ & 457 & 3 & 0 & 0 & 0 & 0 \\
\hline 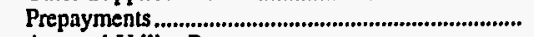 & 780 & 0 & 110 & 7 & 0 & 3 \\
\hline 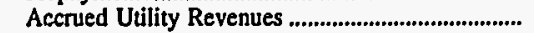 & 14,284 & 0 & 3,413 & 2,183 & 0 & 0 \\
\hline Miscellaneous Current \& Accrued Assets.............. & 2,503 & 0 & 0 & 0 & 0 & 154 \\
\hline $\begin{array}{l}\text { Total Current \& Accrued Assets........................ } \\
\text { Deferred Debits }\end{array}$ & 212,148 & 1,728 & 22,567 & 10,005 & 28,469 & 22,305 \\
\hline 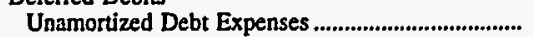 & 2,186 & $\mathbf{0}$ & 2,195 & 424 & 318 & 1,020 \\
\hline Extraordinary Losses, Study Cost............................. & & 0 & 0 & 0 & 0 & 0 \\
\hline Misc Debt, R \& D Exp, Unamrt Losses ................ & 37,110 & 0 & 0 & 3,930 & 0 & 0 \\
\hline 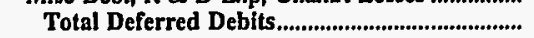 & 39,296 & 0 & 2,195 & 4,354 & 318 & 1,020 \\
\hline 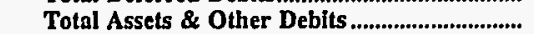 & $1,775,161$ & 6,339 & 152,252 & 63,659 & 406,827 & 144,650 \\
\hline \multicolumn{7}{|l|}{ Proprietary Capital } \\
\hline 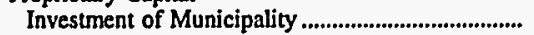 & $\mathbf{0}$ & $\mathbf{0}$ & 0 & 0 & $\mathbf{0}$ & 18,243 \\
\hline 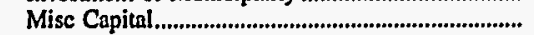 & 0 & 209 & 0 & 4,562 & 0 & 0 \\
\hline 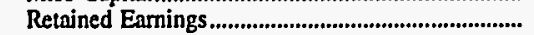 & 360,264 & 5,070 & 6,428 & 32,393 & 271,411 & 33,193 \\
\hline Total Proprietary Capital ..................................... & 360,264 & 5,279 & 6,428 & 36,955 & 271,411 & 51,437 \\
\hline \multicolumn{7}{|l|}{ Long-term Debt } \\
\hline Bonds & $1,296,263$ & 0 & 139,383 & 23,665 & 106,542 & 86,359 \\
\hline 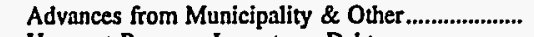 & $\mathbf{0}$ & 0 & 0 & 0 & 0 & 385 \\
\hline 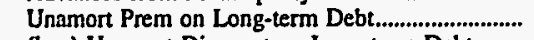 & 0 & 0 & 0 & 0 & $\mathbf{0}$ & 0 \\
\hline (less) Unamort Discount on Long-term Debt & 137,719 & 0 & 8,658 & 274 & 1,002 & 1,711 \\
\hline 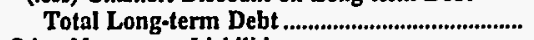 & $1,158,544$ & 0 & 130,725 & 23,391 & 105,540 & 85,034 \\
\hline \multicolumn{7}{|l|}{ Other Noncurrent Liabilities } \\
\hline Accum Operating Provisions................................... & 0 & 0 & 0 & 0 & $\mathbf{0}$ & 0 \\
\hline 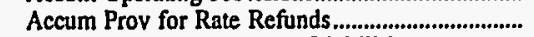 & 0 & 0 & 0 & 0 & $\mathbf{0}$ & 0 \\
\hline Total Other Noncurrent Liabilities.................. & $\mathbf{0}$ & 0 & $\mathbf{0}$ & 0 & 0 & 0 \\
\hline \multicolumn{7}{|l|}{ Current and Accrued Liabilities } \\
\hline 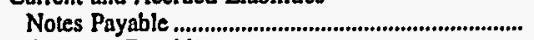 & 110,668 & 645 & 0 & 735 & 0 & 1,381 \\
\hline 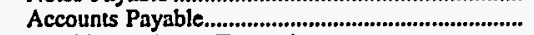 & 42,054 & 0 & 10,708 & 1,538 & 21,738 & 2,866 \\
\hline 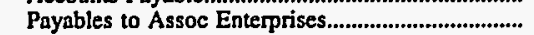 & 3,903 & 367 & 0 & 0 & 0 & 0 \\
\hline 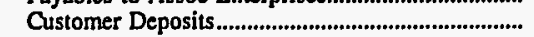 & 14,070 & 0 & 0 & 485 & 7,779 & 1,855 \\
\hline 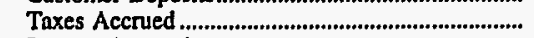 & & 0 & 453 & 0 & 0 & 0 \\
\hline 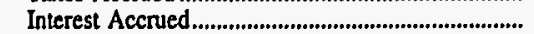 & 34,562 & 0 & 0 & 251 & 0 & 1,547 \\
\hline Misc Current \& Accrued Liabilities .......................... & 6,495 & 48 & 0 & 303 & 0 & 531 \\
\hline $\begin{array}{l}\text { Total Current \& Accrued Liabilities ................ } \\
\text { Deferred Credits }\end{array}$ & 211,753 & 1,060 & 11,161 & 3,313 & 29,517 & 8,180 \\
\hline $\begin{array}{l}\text { Deferted Credus } \\
\text { Customer Advances for Construction....................... }\end{array}$ & 6,777 & 0 & 0 & 0 & 0 & 0 \\
\hline 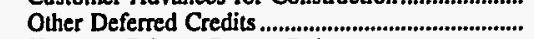 & 37,822 & 0 & 3,938 & 0 & 359 & 0 \\
\hline Unamort Gain on Reacqr Debt & 0 & 0 & 0 & $\mathbf{0}$ & 0 & 0 \\
\hline 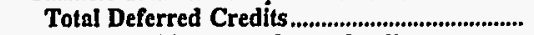 & 44,600 & & 3,938 & & 359 & \\
\hline Total Liabilities and Other Credits....................... & $1,775,161$ & 6,339 & 152,252 & 63,659 & 406,827 & 144,650 \\
\hline
\end{tabular}

Note: Totals may not equal sum of components because of independent rounding.

Source: Energy Information Administration, Form EIA-412, "Annual Report of Public Electric Utilities." 
Table 22. Balance Sheet by Major U.S. Publicly Owned Electric Utility Within State at End of Period, 1996

(Thousand Dollars)

\begin{tabular}{|c|c|c|c|c|c|c|}
\hline Item & $\begin{array}{l}\text { Georgia } \\
\text { Albany Water } \\
\text { Gas \& Light } \\
\text { Comm } \\
\text { June } 30\end{array}$ & $\begin{array}{l}\text { Georgia } \\
\text { Calhoun } \\
\text { City of } \\
\text { June } 30\end{array}$ & $\begin{array}{l}\text { Georgia } \\
\begin{array}{c}\text { Cartersville } \\
\text { City of }\end{array} \\
\text { June } 30\end{array}$ & $\begin{array}{c}\text { Georgia } \\
\text { College } \\
\text { Park City of } \\
\text { June } 30\end{array}$ & $\begin{array}{l}\text { Georgia } \\
\text { Covington } \\
\text { City of } \\
\text { December } 31\end{array}$ & $\begin{array}{c}\text { Georgia } \\
\text { Crisp } \\
\text { County } \\
\text { Power } \\
\text { Comm } \\
\text { December } 31\end{array}$ \\
\hline \multicolumn{7}{|l|}{ Electric Utility Plant } \\
\hline 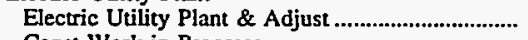 & 32,154 & 70,219 & 12,990 & 9,462 & 7,050 & 43,891 \\
\hline 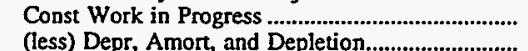 & $\begin{array}{l}21,191 \\
10.963\end{array}$ & $\begin{array}{r}1,810 \\
17,949\end{array}$ & $\begin{array}{r}0 \\
4,085\end{array}$ & $\begin{array}{r}0 \\
4,222\end{array}$ & & $\begin{array}{r}22 \\
25,237\end{array}$ \\
\hline 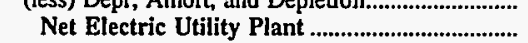 & 42,382 & 54,080 & $\begin{array}{l}4,005 \\
8,905\end{array}$ & $\begin{array}{l}4,222 \\
5,240\end{array}$ & $\begin{array}{l}3,778 \\
\mathbf{3 , 2 7 1}\end{array}$ & 18,676 \\
\hline Nuclear Fuel............................................... & 0 & 0 & 0 & 0 & 0 & 0 \\
\hline (less) Amort of Nucl Fuel ................................. & 0 & 0 & 0 & 0 & 0 & 0 \\
\hline $\begin{array}{l}\text { Net Elec Plant Incl Nucl Fuel ...................................... } \\
\text { Other Property \& Investments }\end{array}$ & 42,382 & 54,080 & 8,905 & 5,240 & 3,271 & 18,676 \\
\hline 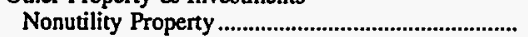 & 14,837 & 0 & 0 & 0 & 0 & \\
\hline (less) Accum Provisions for Depr \& Amort .......... & 28,197 & 0 & 0 & 0 & 0 & 0 \\
\hline 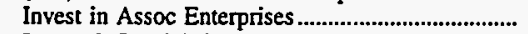 & & 0 & 0 & 0 & 0 & 0 \\
\hline 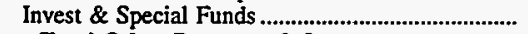 & 13,666 & 0 & 0 & 0 & 0 & 1,559 \\
\hline Total Other Property \& Investments................. & 306 & 0 & 0 & 0 & 0 & 1,559 \\
\hline \multicolumn{7}{|l|}{ Current and Accrued Assets } \\
\hline 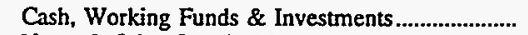 & 2,639 & 7,717 & 2,649 & 8,123 & 1 & 1,849 \\
\hline 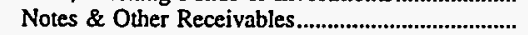 & 834 & 92 & 0 & 106 & 0 & 12 \\
\hline 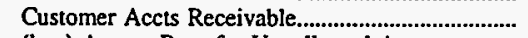 & 11,792 & 3,362 & 3,865 & 1,935 & 1,567 & 1,265 \\
\hline (less) Accum Prov for Uncollected Accts............... & 280 & 0 & 328 & 114 & 9 & 48 \\
\hline 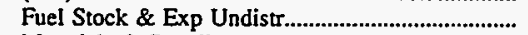 & 0 & 0 & 0 & 0 & 1 & 143 \\
\hline 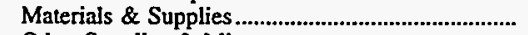 & 2,857 & 0 & 902 & 0 & 328 & 426 \\
\hline 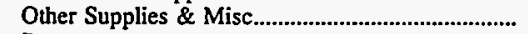 & 0 & 1,504 & 0 & 0 & 0 & 137 \\
\hline 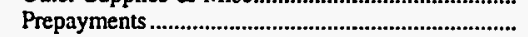 & 493 & 95 & 0 & 46 & 15 & 80 \\
\hline 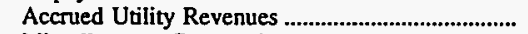 & 0 & 0 & 0 & 0 & 0 & 10 \\
\hline 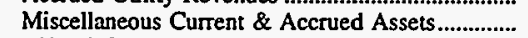 & 0 & 55 & 0 & 0 & 136 & 0 \\
\hline Total Current \& Accrued Assets.......................... & 18,336 & 12,825 & 7,087 & 10,095 & 2,040 & 3,873 \\
\hline \multicolumn{7}{|l|}{ Deferred Debits } \\
\hline 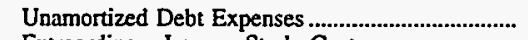 & 0 & 1,011 & 0 & 0 & 0 & 0 \\
\hline 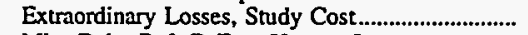 & 0 & 0 & 0 & 0 & 0 & 0 \\
\hline Misc Debt, R \& D Exp, Unamrt Losses ................. & 1,391 & 0 & 0 & 0 & 0 & 0 \\
\hline 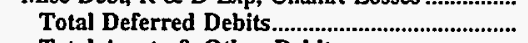 & 1,391 & 1,011 & 0 & 0 & 0 & 0 \\
\hline \multirow{2}{*}{\multicolumn{7}{|c|}{ Proprietary Capital }} \\
\hline & & & & & & \\
\hline 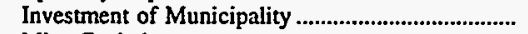 & 0 & 5,811 & 0 & 1,285 & 15 & 0 \\
\hline 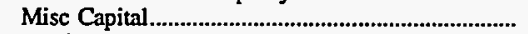 & 736 & & 0 & 0 & 0 & 501 \\
\hline 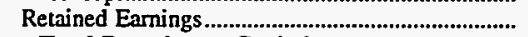 & 50,494 & 36,901 & 12,751 & 12,230 & 3,727 & 21,770 \\
\hline Total Proprietary Capital ......................................... & 51,229 & 42,712 & 12,751 & 13,515 & 3,743 & $\mathbf{2 2 , 2 7 0}$ \\
\hline \multicolumn{7}{|l|}{ Long-term Debt } \\
\hline 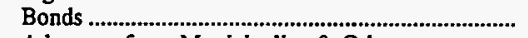 & 402 & 5,820 & 0 & 0 & 165 & 0 \\
\hline Advances from Municipality \& Other....................... & 0 & 14,515 & 0 & 0 & 0 & 0 \\
\hline Unamort Prem on Long-term Debt.............................. & 0 & 0 & 0 & 0 & 0 & 0 \\
\hline (less) Unamort Discount on Long-term Debt & 0 & & 0 & 0 & 0 & 0 \\
\hline Total Long-term Debt ..... & 402 & 20,335 & o & $\mathbf{0}$ & 165 & 0 \\
\hline \multicolumn{7}{|l|}{ Other Noncurrent Liabilities } \\
\hline Accum Operating Provisions... & 0 & 0 & 0 & 0 & 0 & 0 \\
\hline 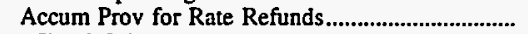 & 0 & 0 & 0 & 0 & 0 & 0 \\
\hline Total Other Noncurrent Liabilities .................... & $\mathbf{0}$ & $\mathbf{0}$ & $\mathbf{0}$ & 0 & 0 & 0 \\
\hline \multicolumn{7}{|l|}{ Current and Accrued Liabilities } \\
\hline 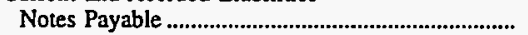 & 184 & 1,135 & 0 & 0 & 0 & \\
\hline 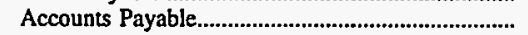 & 5,381 & 2,319 & 2,222 & 1,513 & 944 & 1,093 \\
\hline 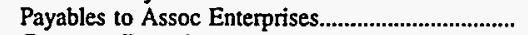 & 1,953 & 86 & 0 & 0 & 0 & 0 \\
\hline 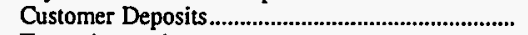 & 249 & 1,061 & 485 & 0 & 396 & 384 \\
\hline 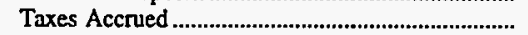 & 0 & 8 & 0 & 0 & 0 & 114 \\
\hline 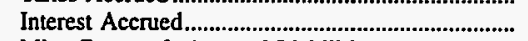 & 0 & 106 & 0 & 0 & I & 0 \\
\hline Misc Current \& Accrued Liabilities ............................... & 1,627 & 154 & 434 & 307 & 44 & 247 \\
\hline Total Current \& Accrued Liabilities ....................... & 9,393 & 4,869 & 3,141 & 1,820 & 1,385 & 1,839 \\
\hline \multicolumn{7}{|l|}{ Deferred Credits } \\
\hline 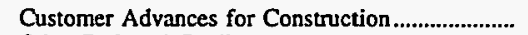 & 0 & 0 & 100 & 0 & 18 & 0 \\
\hline 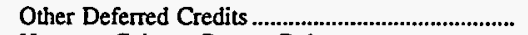 & 1,391 & 0 & 0 & 0 & 0 & 0 \\
\hline 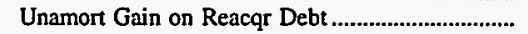 & 0 & 0 & 0 & 0 & 0 & 0 \\
\hline Total Deferred Credits........................................ & 1,391 & & 100 & 0 & 18 & \\
\hline Total Liabilities and Other Credits.................... & 62,416 & 67,916 & 15,992 & 15,335 & 5,311 & 24,109 \\
\hline
\end{tabular}

Note: Totals may not equal sum of components because of independent rounding.

Source: Energy Information Administration, Form EIA-412, "Annual Report of Public Electric Utilities." 
Table 22. Balance Sheet by Major U.S. Publicly Owned Electric Utility Within State at End of Period, 1996

(Thousand Dollars)

\begin{tabular}{|c|c|c|c|c|c|c|}
\hline Item & $\begin{array}{l}\text { Georgia } \\
\text { Dalton } \\
\text { City of } \\
\text { November } 30\end{array}$ & $\begin{array}{l}\text { Georgia } \\
\text { Douglas } \\
\text { City of } \\
\text { June } 30\end{array}$ & $\begin{array}{c}\text { Georgia } \\
\text { East } \\
\text { Point } \\
\text { City of } \\
\text { June } 30\end{array}$ & $\begin{array}{c}\text { Georgia } \\
\text { Fitzgerald } \\
\text { Wtr Lgt } \\
\text { \& Bond Comm } \\
\text { December 31 }\end{array}$ & $\begin{array}{l}\text { Georgia } \\
\text { Griffin } \\
\text { City of } \\
\text { June } 30\end{array}$ & $\begin{array}{l}\text { Georgia } \\
\text { La Grange } \\
\text { City of } \\
\text { June } 30\end{array}$ \\
\hline \multicolumn{7}{|l|}{ Electric Utility Plant } \\
\hline 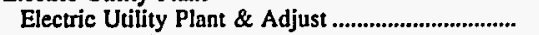 & 209,336 & 4,617 & 7,850 & 7,311 & 12,557 & 9.551 \\
\hline 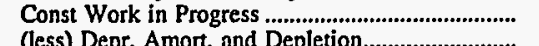 & $\begin{array}{r}38 \\
75.478\end{array}$ & $\begin{array}{r}0 \\
2527\end{array}$ & $\begin{array}{r}0 \\
4.208\end{array}$ & $\begin{array}{r}0 \\
3.456\end{array}$ & $\begin{array}{r}0 \\
340\end{array}$ & $\begin{array}{r}0 \\
2284\end{array}$ \\
\hline 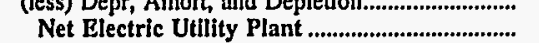 & $\begin{array}{r}75,478 \\
133,896\end{array}$ & 2,089 & 3,642 & 3,855 & 12,217 & 7,267 \\
\hline Nuclear Fuel. & 10,950 & 0 & 0 & 0 & 0 & 0 \\
\hline 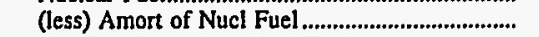 & 6,215 & 0 & 0 & 0 & $\mathbf{0}$ & 0 \\
\hline 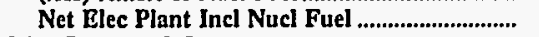 & 138,631 & 2,089 & 3,642 & 3,855 & 12,217 & 7,267 \\
\hline \multicolumn{7}{|l|}{ Other Property \& Investments } \\
\hline 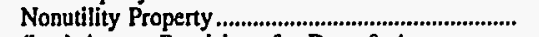 & 1,379 & 780 & 0 & 18,949 & 36,571 & 0 \\
\hline (less) Accum Provisions for Depr \& Amort ........... & 552 & 475 & 0 & 5,565 & 12,023 & 0 \\
\hline 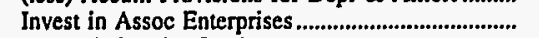 & 11,215 & 0 & 0 & 0 & 0 & 0 \\
\hline 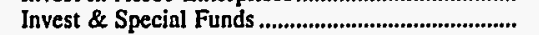 & 222,653 & 0 & 1,116 & 2,415 & 0 & 0 \\
\hline Total Other Property \& Investments................ & 234,695 & 305 & 1,116 & 15,799 & 24,549 & 0 \\
\hline \multicolumn{7}{|l|}{ Current and Accrued Assets } \\
\hline 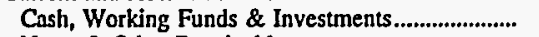 & 1,954 & 1,214 & 0 & 1,589 & 1,718 & 0 \\
\hline 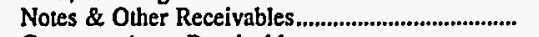 & 345 & 316 & 2,726 & 9 & 3,922 & 0 \\
\hline 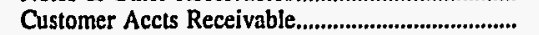 & 2,014 & 2,187 & 3,389 & 545 & 0 & 0 \\
\hline (less) Accum Prov for Uncollected Accts................. & 96 & 70 & 164 & 136 & 0 & 0 \\
\hline 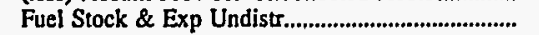 & 2,015 & 0 & 0 & 1 & 0 & 0 \\
\hline 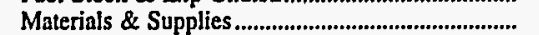 & 4,435 & 585 & 913 & 696 & 857 & 0 \\
\hline 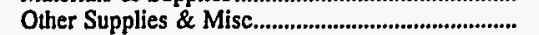 & 0 & 0 & 0 & 0 & 0 & 0 \\
\hline 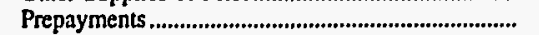 & 87 & 0 & 51 & 0 & 100 & 0 \\
\hline Accrued Utility Revenues .......................................... & 1,439 & 0 & 993 & 0 & 0 & 0 \\
\hline Miscellaneous Current \& Accrued Assets................ & & 0 & 0 & 0 & 0 & $\mathbf{0}$ \\
\hline 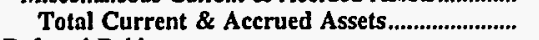 & 12,193 & 4,232 & 7,908 & 2,704 & 6,596 & 0 \\
\hline \multicolumn{7}{|l|}{ Deferred Debits } \\
\hline 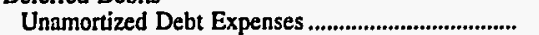 & 676 & 0 & $\mathbf{0}$ & 785 & 0 & 0 \\
\hline 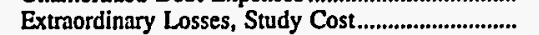 & 0 & 0 & 0 & 0 & 0 & 0 \\
\hline 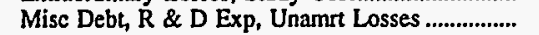 & 984 & 0 & 0 & 0 & 0 & 0 \\
\hline 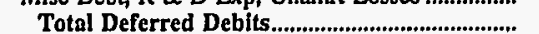 & 1,660 & 0 & 0 & 785 & 0 & 0 \\
\hline Total Assets \& Other Debits ................................ & 387,179 & 6,626 & 12,665 & 23,142 & 43,362 & 7,267 \\
\hline \multicolumn{7}{|l|}{ Proprietary Capital } \\
\hline 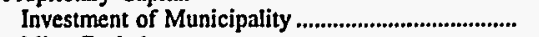 & 0 & 280 & 0 & 0 & 0 & 0 \\
\hline 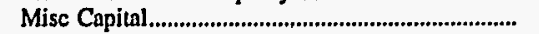 & 0 & 1,292 & 0 & 0 & 0 & 0 \\
\hline 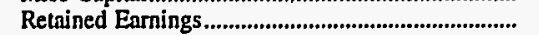 & 285,671 & 4,663 & 8,797 & 15,975 & 29,465 & 7,267 \\
\hline 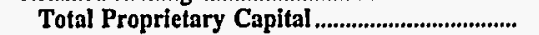 & 285,671 & 6,235 & 8,797 & 15,975 & 29,465 & 7,267 \\
\hline \multicolumn{7}{|l|}{ Long-term Debt } \\
\hline Bonds ........................ & 80,570 & 0 & 0 & 3,680 & 12,366 & 0 \\
\hline Advances from Municipality \& Other............................. & $\mathbf{0}$ & $\mathbf{0}$ & 0 & 0 & 0 & $\mathbf{0}$ \\
\hline 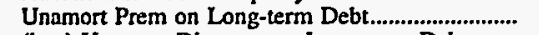 & $\mathbf{0}$ & $\mathbf{0}$ & 0 & 2,399 & 0 & $\mathbf{0}$ \\
\hline (less) Unamor Discount on Long-term Debt & 116 & 0 & 0 & 609 & 0 & $\mathbf{0}$ \\
\hline 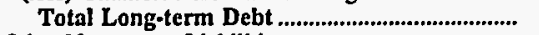 & 80,454 & $\mathbf{0}$ & $\mathbf{0}$ & 5,469 & 12,366 & $\mathbf{0}$ \\
\hline \multicolumn{7}{|l|}{ Other Noncurrent Liabilities } \\
\hline 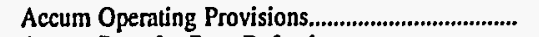 & 987 & 0 & 0 & 0 & 0 & 0 \\
\hline Accum Prov for Rate Refunds.................................. & 0 & 0 & 0 & 0 & 0 & 0 \\
\hline 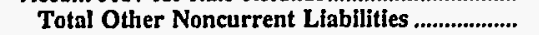 & 987 & $\mathbf{0}$ & 0 & 0 & 0 & 0 \\
\hline \multicolumn{7}{|l|}{ Current and Accrued Liabilities } \\
\hline 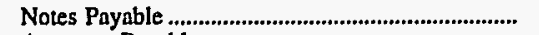 & 0 & 0 & 0 & 0 & 0 & $\mathbf{0}$ \\
\hline 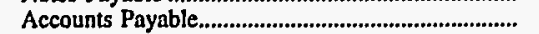 & 3,184 & 0 & 2,799 & 1,295 & 32 & $\mathbf{0}$ \\
\hline Payables to Assoc Enterprises................................... & 150 & 0 & 0 & 0 & 0 & 0 \\
\hline 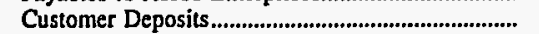 & 751 & 302 & 460 & 243 & 981 & 0 \\
\hline 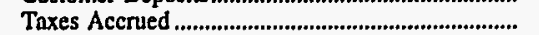 & 0 & 0 & 0 & 0 & 0 & 0 \\
\hline 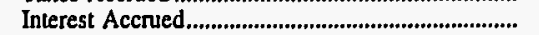 & 2,266 & 0 & 0 & 51 & 0 & 0 \\
\hline Misc Current \& Accrued Liabilities .......................... & 4,750 & 88 & 609 & 106 & 518 & $\mathbf{0}$ \\
\hline Total Current \& Accrued Liabilities ................. & 11,101 & 390 & 3,868 & 1,695 & 1,531 & $\mathbf{0}$ \\
\hline \multicolumn{7}{|l|}{ Deferred Credits } \\
\hline Customer Advances for Construction......................... & 2,289 & $\mathbf{0}$ & 0 & $\mathbf{0}$ & 0 & 0 \\
\hline 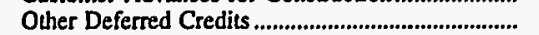 & 6,677 & $\mathbf{0}$ & 0 & 3 & 0 & 0 \\
\hline Unamort Gain on Reacgr Debt.................................. & 0 & 0 & 0 & 0 & 0 & 0 \\
\hline 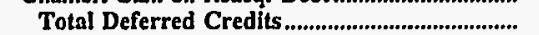 & 8,966 & o & o & 3 & o & 0 \\
\hline Total Llabilities and Other Credits.......................... & 387,179 & 6,626 & 12,665 & 23,142 & 43,362 & 7,267 \\
\hline
\end{tabular}

Note: Totals may not equal sum of components because of independent rounding.

Source: Energy Information Administration, Form EIA-412, "Annual Report of Public Electric Utilities." 
Table 22. Balance Sheet by Major U.S. Publicly Owned Electric Utility Within State at End of Period, 1996

(Thousand Dollars)

\begin{tabular}{|c|c|c|c|c|c|c|}
\hline Item & $\begin{array}{c}\text { Georgia } \\
\begin{array}{c}\text { Lawrenceville } \\
\text { City of }\end{array} \\
\text { August } 30\end{array}$ & $\begin{array}{c}\text { Georgia } \\
\text { Marietta } \\
\text { City of } \\
\text { June } 30\end{array}$ & $\begin{array}{c}\text { Georgia } \\
\text { Moultrie } \\
\text { City of } \\
\text { September } 30\end{array}$ & $\begin{array}{l}\text { Georgia } \\
\text { Municipal } \\
\text { Electric } \\
\text { Authority } \\
\text { December } 31\end{array}$ & $\begin{array}{c}\text { Thomasville } \\
\text { City of }\end{array}$ & $\begin{array}{l}\text { Idaho } \\
\text { Idaho } \\
\text { Falls } \\
\text { City of } \\
\text { September } 30\end{array}$ \\
\hline \multicolumn{7}{|l|}{ Electric Utility Plant } \\
\hline 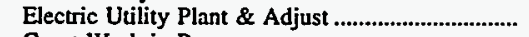 & 13,245 & 45,129 & 6,864 & $3,073,703$ & 18,779 & 132,674 \\
\hline Const Work in Progress & & 0 & 0 & 27,710 & 4 & 1,516 \\
\hline 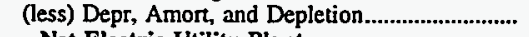 & 4,103 & 19,942 & 4,146 & $1,031,797$ & 5,960 & 41,504 \\
\hline 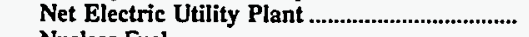 & 9,142 & 25,187 & 2,718 & $2,069,616$ & 12,823 & 92,686 \\
\hline 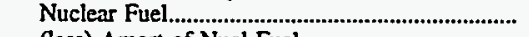 & 0 & 0 & 0 & 415,640 & 0 & 0 \\
\hline 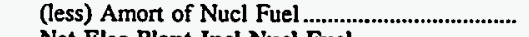 & 0 & 0 & 0 & 366,277 & 0 & 0 \\
\hline & 9,142 & 25,187 & 2,718 & $2,118,979$ & 12,823 & 92,686 \\
\hline 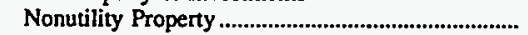 & 0 & 51,181 & 773 & 0 & 0 & 0 \\
\hline (less) Accum Provisions for Depr \& Amort ......... & 0 & 22,624 & 582 & 0 & 0 & 0 \\
\hline 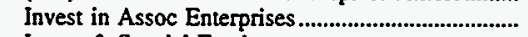 & 0 & 0 & 0 & 0 & 0 & $\mathbf{0}$ \\
\hline Invest \& Special Funds & 0 & 0 & 0 & $1,331,855$ & 0 & 10,886 \\
\hline Total Other Property \& Investments................. & $\mathbf{0}$ & 28,557 & 191 & $1,331,855$ & 0 & 10,886 \\
\hline \multicolumn{7}{|l|}{ Current and Accrued Assets } \\
\hline 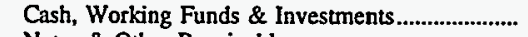 & 1,052 & 32,413 & 677 & 142,170 & 54 & 4,322 \\
\hline 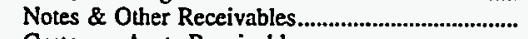 & 0 & 140 & 30 & 33,129 & 2,546 & 816 \\
\hline 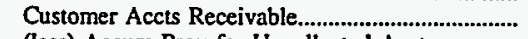 & 2,022 & 12,972 & 1,538 & 32,137 & 2,279 & 2,810 \\
\hline (less) Accum Prov for Uncollected Accts ............... & 198 & 937 & 450 & 0 & 454 & 484 \\
\hline 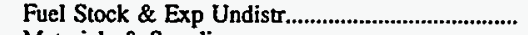 & 0 & 0 & 0 & 12,734 & 0 & 0 \\
\hline 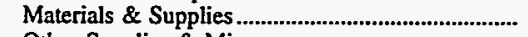 & 0 & 2,254 & 741 & 37,914 & 710 & 1,928 \\
\hline 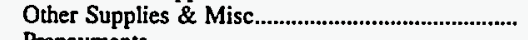 & 0 & 267 & 0 & 490 & 0 & 0 \\
\hline 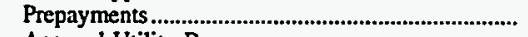 & 0 & 22 & 18 & 1,866 & 45 & 0 \\
\hline 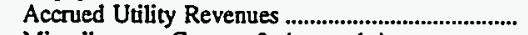 & 0 & 0 & 0 & 0 & 1,656 & 0 \\
\hline Miscellaneous Current \& Accrued Assets............... & 0 & $\mathbf{0}$ & 0 & 0 & 32 & 362 \\
\hline $\begin{array}{l}\text { Total Current \& Accrued Assets........................... } \\
\text { Deferred Debits }\end{array}$ & 2,875 & 47,132 & 2,556 & 260,440 & 6,868 & 9,755 \\
\hline 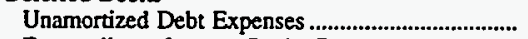 & 0 & 0 & 0 & 310,113 & 0 & 1,368 \\
\hline 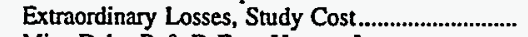 & 0 & 0 & 0 & 0 & 0 & 1,807 \\
\hline 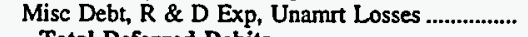 & 0 & 2,446 & 0 & 739,825 & 0 & 1,306 \\
\hline 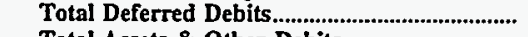 & 0 & 2,446 & $\mathbf{0}$ & $1,049,938$ & 0 & 4,481 \\
\hline 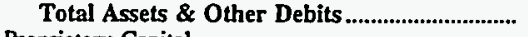 & 12,017 & 103,323 & 5,465 & $4,761,212$ & 19,691 & 117,808 \\
\hline \multicolumn{7}{|l|}{ Proprietary Capital } \\
\hline 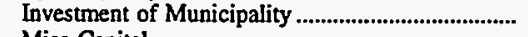 & 0 & 1,206 & 12 & 0 & 0 & 0 \\
\hline 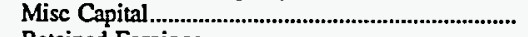 & 0 & 49 & 0 & 0 & 310 & 0 \\
\hline 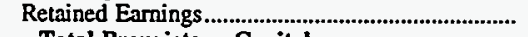 & 10,802 & 90,471 & 5,105 & 0 & 14,514 & 33,234 \\
\hline 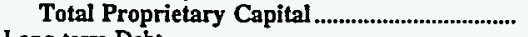 & 10,802 & 91,726 & 5,117 & $\mathbf{0}$ & 14,823 & 33,234 \\
\hline \multicolumn{7}{|l|}{ Long-term Debt } \\
\hline Bonds & 0 & 0 & 0 & $3,550,063$ & 0 & 48,628 \\
\hline 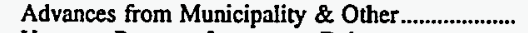 & 0 & 88 & 0 & 732,670 & 0 & 0 \\
\hline 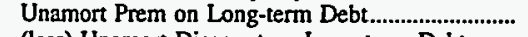 & 0 & 0 & 0 & 29,403 & 0 & 2,559 \\
\hline (less) Unamort Discount on Long-term Debt & 0 & 0 & 0 & 62,591 & 0 & 0 \\
\hline Total Long-term Debt & $\mathbf{0}$ & 88 & 0 & $4,249,545$ & $\mathbf{0}$ & 51,187 \\
\hline \multicolumn{7}{|l|}{ Other Noncurrent Liabilities } \\
\hline 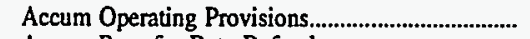 & 0 & 0 & 0 & 6,948 & 0 & 0 \\
\hline 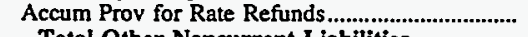 & 0 & 0 & 0 & 0 & 0 & 0 \\
\hline Total Other Noncurrent Liabilities ........................ & 0 & $\mathbf{0}$ & 0 & 6,948 & $\mathbf{0}$ & $\mathbf{0}$ \\
\hline \multicolumn{7}{|l|}{ Current and Accrued Liabilities } \\
\hline 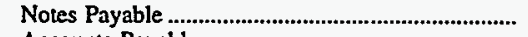 & 0 & 0 & 19 & 16,307 & 1,910 & 0 \\
\hline 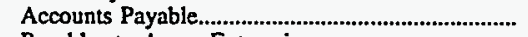 & 0 & 5,729 & 322 & 56,364 & 1,977 & 1,694 \\
\hline 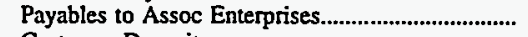 & 1,216 & 0 & 0 & 0 & 110 & 128 \\
\hline 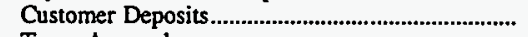 & 0 & 2,446 & 0 & 0 & 654 & 1 \\
\hline 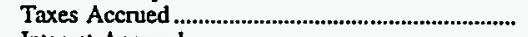 & 0 & 423 & 0 & 2 & 40 & $\mathbf{0}$ \\
\hline 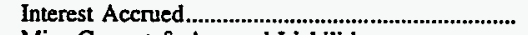 & 0 & 0 & 0 & 96,460 & 0 & 23,487 \\
\hline Misc Current \& Accrued Liabilities .......................... & 0 & 2,911 & 0 & 866 & 176 & 8,077 \\
\hline $\begin{array}{l}\text { Total Current \& Accrued Liabilities ................ } \\
\text { Deferred Credits }\end{array}$ & 1,216 & 11,509 & 341 & 169,999 & 4,868 & 33,387 \\
\hline Customer Advances for Construction ...................... & 0 & 0 & 0 & 0 & 0 & 0 \\
\hline 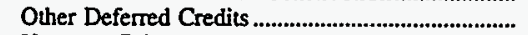 & 0 & 0 & 7 & 334,720 & 0 & $\mathbf{0}$ \\
\hline 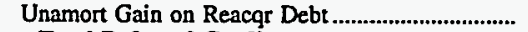 & 0 & 0 & 0 & 0 & 0 & 0 \\
\hline 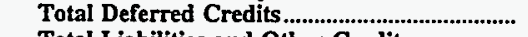 & 0 & $\mathbf{0}$ & & $\mathbf{3 3 4 , 7 2 0}$ & 0 & 0 \\
\hline Total Liabilities and Other Credits.................. & 12,017 & 103,323 & 5,465 & $4,761,212$ & 19,691 & 117,808 \\
\hline
\end{tabular}

Note: Totals may not equal sum of components because of independent rounding.

Source: Energy Information Administration, Form EIA-412, “Annual Report of Public Electric Utilities." 
Table 22. Balance Sheet by Major U.S. Publicly Owned Electric Utility Within State at End of Period, 1996

(Thousand Dollars)

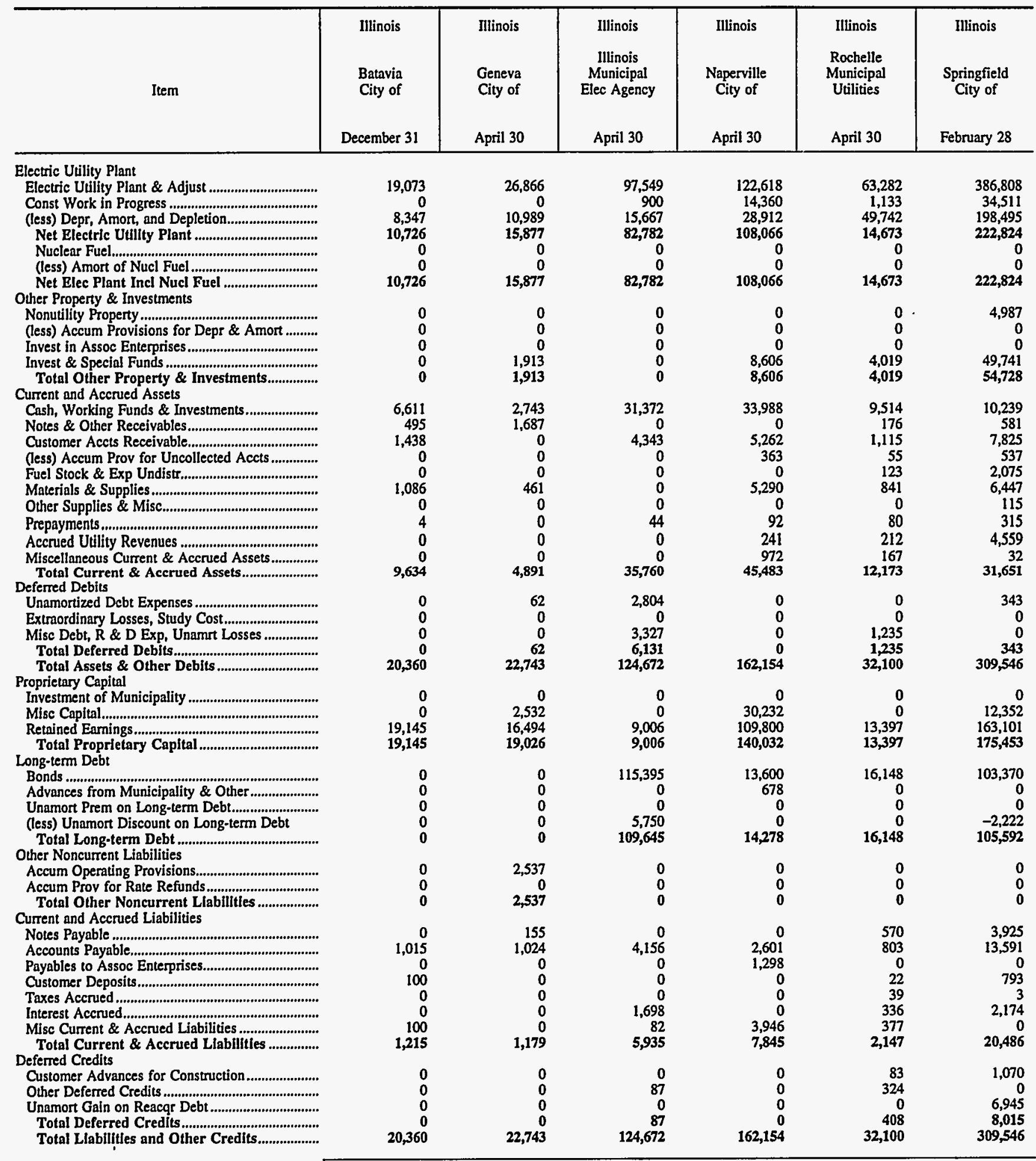

Note: Totals may not equal sum of components because of independent rounding.

Source: Energy Information Administration, Form EIA-412, "Annual Report of Public Electric Utilities." 
Table 22. Balance Sheet by Major U.S. Publicly Owned Electric Utility Within State at End of Period, 1996 (Thousand Dollars)

\begin{tabular}{|c|c|c|c|c|c|c|}
\hline Item & $\begin{array}{l}\text { Illinois } \\
\text { St Charles } \\
\text { City of } \\
\text { April } 30\end{array}$ & $\begin{array}{c}\text { Indiana } \\
\text { Anderson } \\
\text { City of } \\
\text { December } 31\end{array}$ & $\begin{array}{l}\text { Indiana } \\
\text { Auburn } \\
\text { City of } \\
\text { December } 31\end{array}$ & $\begin{array}{l}\text { Indiana } \\
\text { Bluffton } \\
\text { City of } \\
\text { December } 31\end{array}$ & $\begin{array}{c}\text { Indiana } \\
\text { Crawfordsville } \\
\text { Elec } \\
\text { Lgt\&Pwr Co } \\
\text { December } 31\end{array}$ & $\begin{array}{c}\text { Indiana } \\
\text { Frankfort } \\
\text { City of } \\
\text { December } 31\end{array}$ \\
\hline \multicolumn{7}{|l|}{ Electric Utility Plant } \\
\hline Electric Utility Plant \& Adjust & 30,674 & 59,656 & 16,949 & 9,286 & 33,333 & 19,405 \\
\hline Const Work in Progress & & 1,020 & 3,243 & 0 & 126 & 801 \\
\hline 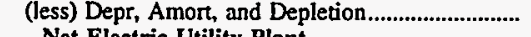 & 6,847 & 25,472 & 5,894 & 4,927 & 18,601 & 7,946 \\
\hline Net Electric Utility Plant ....................................... & 23,826 & 35,204 & 14,297 & 4,359 & 14,857 & 12,260 \\
\hline 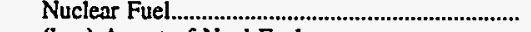 & 0 & 0 & 0 & 0 & 0 & 0 \\
\hline 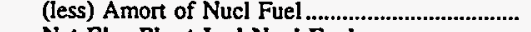 & 0 & 0 & 0 & 0 & 0 & 0 \\
\hline $\begin{array}{l}\text { Net Elec Plant Ind Nucl Fuel ........................................ } \\
\text { Other Property \& Investments }\end{array}$ & 23,826 & 35,204 & 14,297 & 4,359 & 14,857 & 12,260 \\
\hline Nonutility Property & 0 & 0 & 0 & \\
\hline (less) Accum Provisions for Depr \& Amort .......... & 0 & 0 & 0 & 0 & 0 & 0 \\
\hline 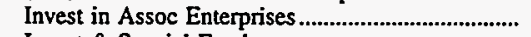 & 0 & 0 & 0 & 0 & 0 & 0 \\
\hline Invest \& Special Funds & 0 & 0 & 0 & 0 & 0 & 0 \\
\hline Total Other Property \& Investments................. & 0 & $\mathbf{0}$ & $\mathbf{0}$ & $\mathbf{0}$ & $\mathbf{0}$ & $\mathbf{0}$ \\
\hline \multicolumn{7}{|l|}{ Current and Accrued Assets } \\
\hline 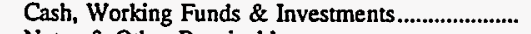 & 15,010 & 4,280 & 9,242 & 2,104 & 7,682 & 9,854 \\
\hline 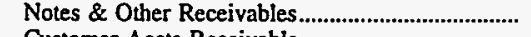 & 599 & 276 & $\mathbf{0}$ & 13 & 0 & 259 \\
\hline 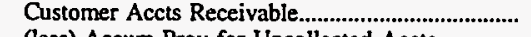 & 1,537 & 1,887 & 179 & 478 & 709 & 984 \\
\hline (less) Accum Prov for Uncollected Accts ............... & 4 & 450 & 0 & 37 & 0 & 0 \\
\hline 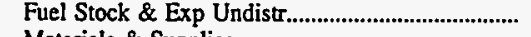 & 0 & 0 & 0 & 0 & 81 & 0 \\
\hline 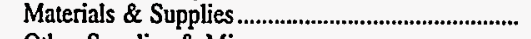 & 44 & 959 & 606 & 666 & 689 & 500 \\
\hline 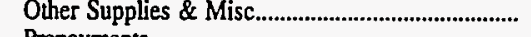 & 14 & 8 & 0 & 14 & 1 & 0 \\
\hline 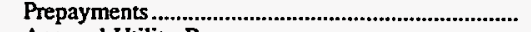 & 129 & 0 & 33 & 0 & 123 & 36 \\
\hline Accrued Utility Revenues & 78 & 0 & 0 & 0 & 0 & 0 \\
\hline Miscellaneous Current \& Accrued Assets.............. & 0 & 0 & 0 & 0 & 68 & 16 \\
\hline $\begin{array}{l}\text { Total Current \& Accrued Assets......................... } \\
\text { Deferred Debits }\end{array}$ & 17,407 & 6,961 & 10,060 & 3,239 & 9,353 & 11,650 \\
\hline 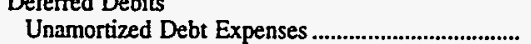 & \multicolumn{6}{|c|}{ Deferred Debits } \\
\hline 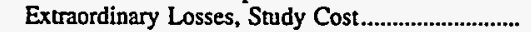 & 0 & $\begin{array}{r}189 \\
0\end{array}$ & $\begin{array}{l}0 \\
0\end{array}$ & 0 & 135 & 0 \\
\hline Misc Debt, R \& D Exp, Unamrt Losses ..................... & 0 & 450 & 274 & $\begin{array}{r}0 \\
36\end{array}$ & $\begin{array}{r}0 \\
482\end{array}$ & $\begin{array}{l}0 \\
0\end{array}$ \\
\hline 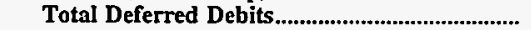 & $\mathbf{0}$ & 638 & 274 & 36 & $\begin{array}{l}482 \\
617\end{array}$ & $\mathbf{0}$ \\
\hline 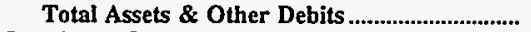 & 41,233 & 42,804 & 24,631 & $\mathbf{7 , 6 3 4}$ & 24,828 & 23,910 \\
\hline \multicolumn{7}{|l|}{ Proprietary Capital } \\
\hline 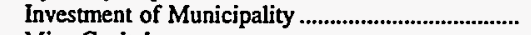 & 0 & 0 & 0 & 0 & 0 & 0 \\
\hline 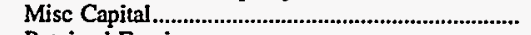 & 0 & 0 & 0 & $\mathbf{0}$ & 0 & 0 \\
\hline 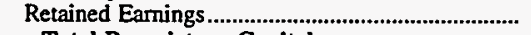 & 39,142 & 30,212 & 22,797 & 6,679 & 16,672 & 19,535 \\
\hline Total Proprietary Capital & 39,142 & 30,212 & 22,797 & 6,679 & 16,672 & 19,535 \\
\hline \multicolumn{7}{|l|}{ Long-term Debt } \\
\hline 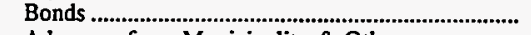 & 0 & 3,830 & 345 & 0 & 6,005 & 0 \\
\hline 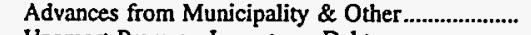 & 0 & 0 & 0 & 0 & $\mathbf{0}$ & 0 \\
\hline Unamort Prem on Long-term Debt............................ & 0 & 0 & 0 & 0 & 0 & 0 \\
\hline (less) Unamort Discount on Long-term Debt & 0 & 0 & 0 & 0 & 0 & 0 \\
\hline 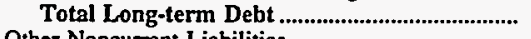 & $\mathbf{0}$ & 3,830 & 345 & $\mathbf{0}$ & 6,005 & $\mathbf{0}$ \\
\hline \multicolumn{7}{|l|}{ Other Noncurrent Liabilities } \\
\hline 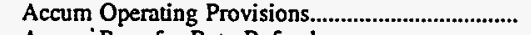 & $\mathbf{0}$ & 53 & 0 & 0 & 0 & 0 \\
\hline 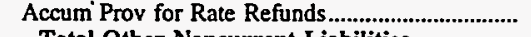 & 0 & 0 & 0 & 0 & 0 & 0 \\
\hline Total Other Noncurrent Liabilities ....................... & $\mathbf{0}$ & 53 & $\mathbf{0}$ & 0 & $\mathbf{0}$ & 0 \\
\hline \multicolumn{7}{|l|}{ Current and Accrued Liabilities } \\
\hline 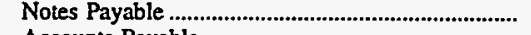 & 0 & 0 & 0 & 0 & 0 & $\mathbf{0}$ \\
\hline Accounts Payable & 1,471 & 4,587 & 1,436 & 641 & 1,874 & 1,015 \\
\hline 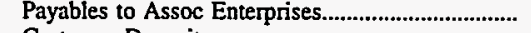 & 406 & 0 & 0 & 0 & 0 & 0 \\
\hline 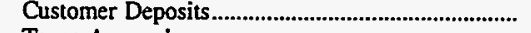 & 188 & 319 & 27 & 111 & 90 & 215 \\
\hline 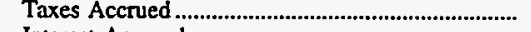 & 1 & 113 & 21 & 2 & 5 & -2 \\
\hline Interest Accrued & 0 & 0 & 0 & 0 & 0 & 0 \\
\hline 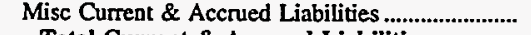 & 0 & 0 & 5 & 0 & 182 & 274 \\
\hline Total Current \& Accrued Liabilities ................ & 2,066 & 5,018 & 1,489 & 753 & 2,151 & 1,502 \\
\hline \\
\hline 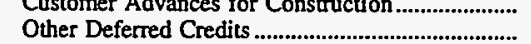 & 25 & $\begin{array}{r}3,690 \\
0\end{array}$ & $\begin{array}{l}0 \\
0\end{array}$ & $\begin{array}{r}196 \\
5\end{array}$ & $\begin{array}{l}\mathbf{0} \\
0\end{array}$ & \\
\hline Unamort Gain on Reacgr Debt & 0 & 0 & 0 & $\begin{array}{l}3 \\
0\end{array}$ & $\begin{array}{l}0 \\
0\end{array}$ & $\begin{array}{r}2,873 \\
0\end{array}$ \\
\hline 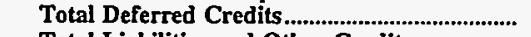 & 25 & 3,690 & 0 & 201 & 0 & 2,873 \\
\hline Total Liabjlities and Other Credits.................... & 41,233 & 42,804 & 24,631 & 7,634 & 24,828 & 23,910 \\
\hline
\end{tabular}

Note: Totais may not equal sum of components because of independent rounding. Source: Energy Information Administration, Form ElA-412, "Annual Report of Public Electric Utilities." 
Table 22. Balance Sheet by Major U.S. Publicly Owned Electric Utility Within State at End of Period, 1996 (Thousand Dollars)

\begin{tabular}{|c|c|c|c|c|c|c|}
\hline Item & $\begin{array}{l}\text { Indiana } \\
\text { Greenfield } \\
\text { City of } \\
\text { December } 31\end{array}$ & $\begin{array}{c}\text { Indiana } \\
\text { Indiana } \\
\text { Municipal } \\
\text { Power Agency } \\
\text { December } 31\end{array}$ & $\begin{array}{l}\text { Indiana } \\
\text { Jasper } \\
\text { City of } \\
\text { December } 31\end{array}$ & $\begin{array}{l}\text { Indiana } \\
\text { Lebanon } \\
\text { City of } \\
\text { December } 31\end{array}$ & $\begin{array}{l}\text { Indiana } \\
\text { Loganspor } \\
\text { City of } \\
\text { December } 31\end{array}$ & $\begin{array}{l}\text { Indiana } \\
\text { Mishawaka } \\
\text { City of } \\
\text { December } 31\end{array}$ \\
\hline \multicolumn{7}{|l|}{ Electric Utility Plant } \\
\hline Electric Utility Plant \& Adjust .................................... & 10,097 & 314,819 & 21,727 & 9,685 & 61,807 & 35,727 \\
\hline 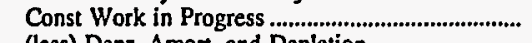 & & 3,082 & 301 & & 151 & 279 \\
\hline 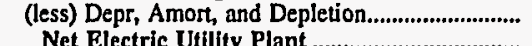 & 2,733 & 82,790 & 7,535 & 5,189 & 30,190 & 17,852 \\
\hline & 7,364 & 235,111 & 14,494 & 4,496 & 31,768 & 18,154 \\
\hline $\begin{array}{l}\text { Nuclear Fuel... } \\
\text { (less) Amort of Nucl Fuel }\end{array}$ & & & $\mathbf{0}$ & $\mathbf{0}$ & $\mathbf{0}$ & 0 \\
\hline $\begin{array}{l}\text { (less) Amort of Nucl Fuel ........................................ } \\
\text { Net Elec Plant Incl Nucl Fuel ............................ }\end{array}$ & $\begin{array}{r}0 \\
7,364\end{array}$ & $\begin{array}{r}0 \\
235,111\end{array}$ & $\begin{array}{r}0 \\
14,494\end{array}$ & $\begin{array}{r}0 \\
4,496\end{array}$ & $\begin{array}{r}0 \\
31,768\end{array}$ & $\begin{array}{r}0 \\
18,154\end{array}$ \\
\hline \multicolumn{7}{|l|}{ Other Property \& Investments } \\
\hline 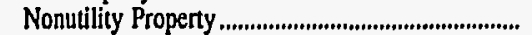 & 0 & 0 & $\mathbf{0}$ & 0 & 0 & 18 \\
\hline (less) Accum Provisions for Depr \& Amort .......... & 0 & 0 & 0 & 0 & 0 & 0 \\
\hline 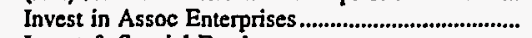 & 0 & 0 & 0 & 0 & 0 & 0 \\
\hline 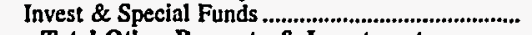 & 731 & $\mathbf{0}$ & 2,009 & $\mathbf{0}$ & 8.477 & 1,276 \\
\hline $\begin{array}{l}\text { Total Other Property \& Investments................. } \\
\text { Current and Accrued Assets }\end{array}$ & \multicolumn{5}{|c|}{ Current and Accrued Assets } & 1,293 \\
\hline 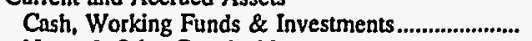 & 1,498 & 118,723 & 1,356 & 4,312 & 533 & 5,636 \\
\hline 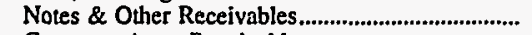 & 399 & 2,122 & 0 & 0 & 76 & 22 \\
\hline 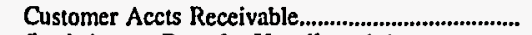 & 398 & 18,821 & 1,258 & 628 & 1,464 & 2,832 \\
\hline (less) Accum Prov for Uncollected Accts .............. & $\mathbf{0}$ & & 35 & 0 & 0 & 497 \\
\hline 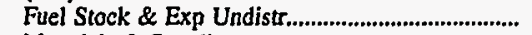 & 0 & 2,405 & 31 & 0 & D & 0 \\
\hline 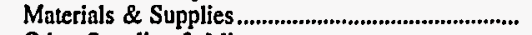 & 493 & 1,242 & 1,677 & 286 & 164 & 1,523 \\
\hline 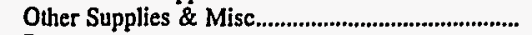 & 0 & 94 & 0 & 0 & 1,753 & 0 \\
\hline 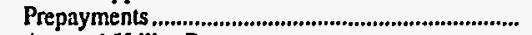 & $\mathbf{0}$ & 2,768 & 78 & 0 & 317 & 60 \\
\hline 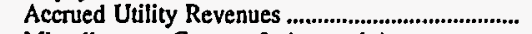 & 0 & 0 & 0 & $\mathbf{0}$ & 44 & $\mathbf{0}$ \\
\hline Miscellaneous Current \& Accrued Assets............... & 0 & 1,722 & 0 & 25 & 0 & 0 \\
\hline $\begin{array}{l}\text { Total Current \& Accrued Assets.......................... } \\
\text { Deferred Debjts }\end{array}$ & 2,789 & 147,896 & 4,366 & 5,251 & 4,351 & 9,576 \\
\hline & 36 & 5,002 & 100 & 0 & 0 & $\mathbf{0}$ \\
\hline Extraordinary Losses, Study Cost................................ & 0 & & -2 & 0 & 0 & 0 \\
\hline Misc Debt, R \& D Exp, Unamrt Losses ................. & 0 & 65,149 & 5 & 0 & 0 & 0 \\
\hline Total Deferred Debits........................................................... & 36 & 70,151 & 103 & $\mathbf{0}$ & $\mathbf{0}$ & \\
\hline 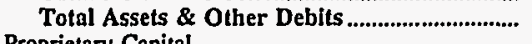 & 10,920 & 453,159 & 20,972 & 9,746 & 44,597 & 29,024 \\
\hline \multicolumn{7}{|l|}{ Proprietary Capital } \\
\hline Investment of Municipality ....... & $\mathbf{0}$ & 0 & 0 & 0 & 0 & 0 \\
\hline 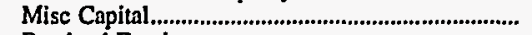 & 0 & & 149 & 0 & 0 & 0 \\
\hline 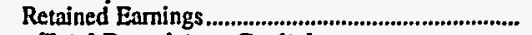 & 8,140 & 58,239 & 11,250 & 8,521 & 28,574 & 25,730 \\
\hline Total Proprietary Capital .............................................. & 8,140 & 58,239 & 11,399 & 8,521 & 28,574 & 25,730 \\
\hline \multicolumn{7}{|l|}{ Long-term Debt } \\
\hline Bonds ... & 690 & 401,535 & 7,620 & 0 & 11,990 & 0 \\
\hline Advances from Municipality \& Other....................... & 0 & $-36,044$ & 0 & 0 & 0 & 101 \\
\hline 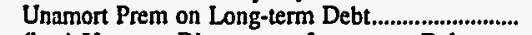 & 0 & & 0 & $\mathbf{0}$ & 0 & 0 \\
\hline (less) Unamort Discount on Long-term Debt & 0 & 12,469 & 0 & 0 & 0 & 0 \\
\hline 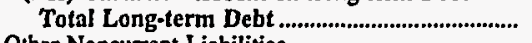 & 690 & 353,021 & 7,620 & $\mathbf{0}$ & 11,990 & 101 \\
\hline \multicolumn{7}{|l|}{ Other Noncurrent Liabilities } \\
\hline Accum Operating Provisions..................................... & 0 & 5,236 & 0 & 190 & 284 & 0 \\
\hline 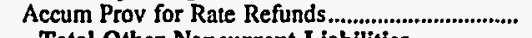 & $\mathbf{0}$ & & $\mathbf{0}$ & $\mathbf{0}$ & 0 & \\
\hline Total Other Noncurrent Liabilities................... & $\mathbf{0}$ & 5,236 & $\mathbf{0}$ & 190 & 284 & 0 \\
\hline \multicolumn{7}{|l|}{ Current and Accrued Liabilities } \\
\hline$\ldots$ & & & 0 & $\mathbf{0}$ & 0 & $\mathbf{0}$ \\
\hline 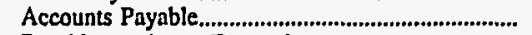 & 1,109 & 11,338 & 970 & 315 & 998 & 1,992 \\
\hline 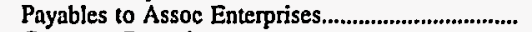 & 0 & & 0 & 0 & 0 & 0 \\
\hline Customer Deposits.............. & 104 & $\mathbf{0}$ & 190 & 88 & 81 & 716 \\
\hline 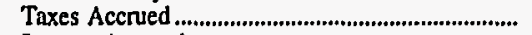 & 20 & 1,000 & 0 & 49 & 0 & 172 \\
\hline 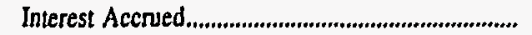 & 0 & 11,341 & $\mathbf{0}$ & 0 & 360 & 29 \\
\hline Misc Current \& Accrued Liabilities ............................. & 17 & 12,984 & -2 & 446 & 2,309 & 0 \\
\hline Total Current \& Accrued Liabilities .................. & 1,250 & 36,663 & 1,158 & 898 & 3,748 & 2,909 \\
\hline \multicolumn{7}{|l|}{ Deferred Cred } \\
\hline $\begin{array}{l}\text { Customer Advances for Construction ........................ } \\
\text { Other Deferred Credits }\end{array}$ & 0 & 0 & 794 & $\begin{array}{r}137 \\
0\end{array}$ & ${ }_{0}^{0}$ & 284 \\
\hline $\begin{array}{l}\text { Other Deferred Credits } \\
\text { Unamort Gain on Reacar Debt }\end{array}$ & & 0 & $\begin{array}{r}194 \\
0\end{array}$ & $\begin{array}{l}0 \\
0\end{array}$ & $\begin{array}{l}0 \\
0\end{array}$ & \\
\hline & 840 & 0 & 794 & 137 & $\begin{array}{l}0 \\
0\end{array}$ & $\begin{array}{r}0 \\
284\end{array}$ \\
\hline 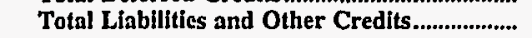 & 10,920 & 453,159 & 20,972 & 9,746 & 44,597 & 29,024 \\
\hline
\end{tabular}

Note: Totals may not equal sum of components because of independent rounding.

Source: Energy Information Administration, Form EIA-412, "Annual Report of Public Electric Utilities." 
Table 22. Balance Sheet by Major U.S. Publicly Owned Electric Utility Within State at End of Period, 1996

(Thousand Dollars)

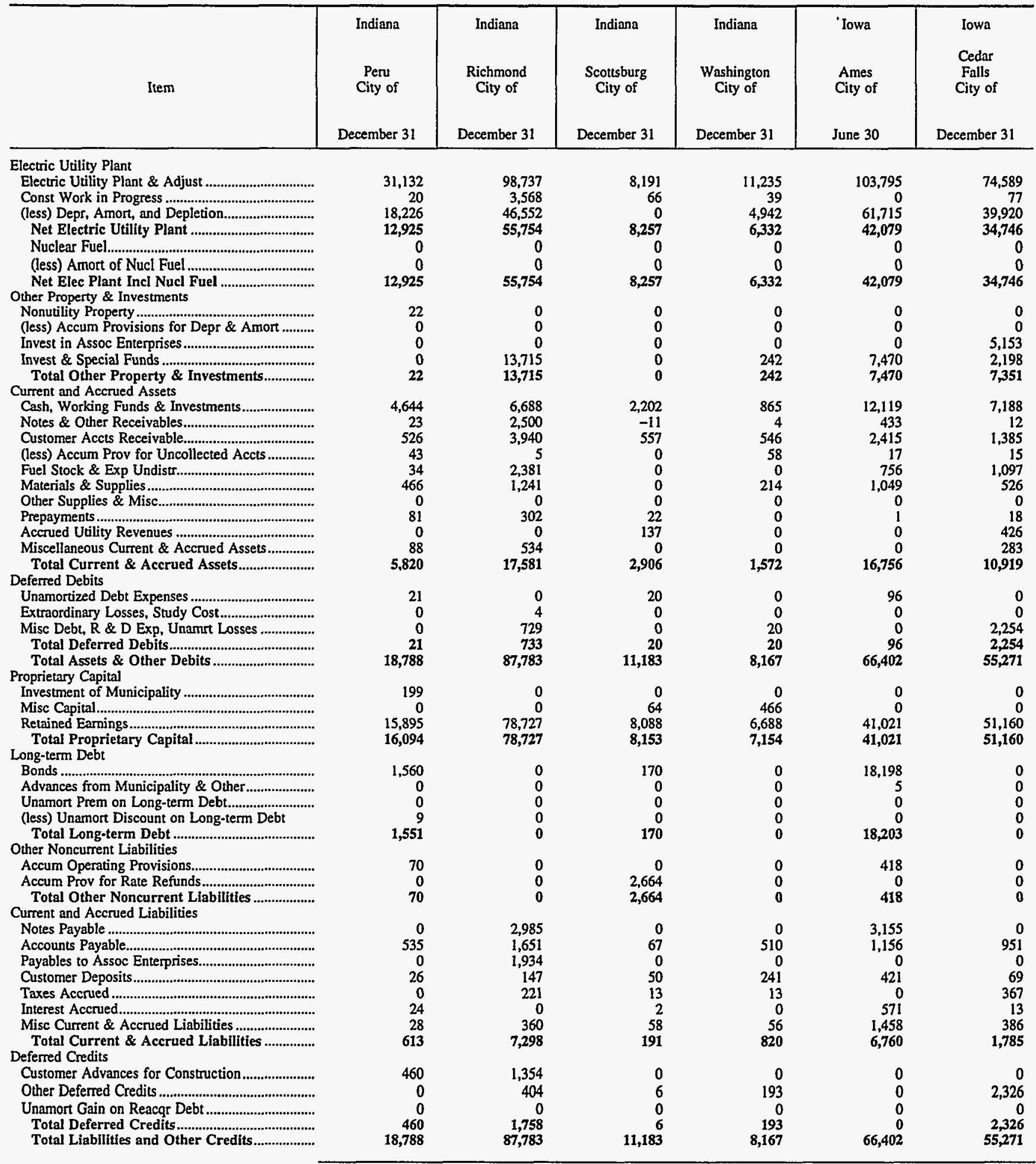

Note: Totals may not equal sum of components because of independent rounding.

Source: Energy Information Administration, Form EIA-412, "Annual Report of Public Electric Utilities." 
Table 22. Balance Sheet by Major U.S. Publicly Owned Electric Utility Within State at End of Period, 1996

(Thousand Dollars)

\begin{tabular}{|c|c|c|c|c|c|c|}
\hline Item & $\begin{array}{c}\text { Iowa } \\
\begin{array}{c}\text { Muscatine } \\
\text { City of }\end{array} \\
\text { December } 31\end{array}$ & $\begin{array}{c}\text { Iowa } \\
\text { Pella } \\
\text { City of } \\
\text { December } 31\end{array}$ & $\begin{array}{l}\text { Kansas } \\
\text { Chanute } \\
\text { City of } \\
\text { December } 31\end{array}$ & $\begin{array}{c}\text { Kansas } \\
\begin{array}{c}\text { Coffeyville } \\
\text { City of }\end{array} \\
\text { December } 31\end{array}$ & $\begin{array}{c}\text { Kansas } \\
\text { Garden } \\
\text { City City of } \\
\text { December } 31\end{array}$ & $\begin{array}{c}\text { Kansas } \\
\text { Kansas } \\
\text { City City of } \\
\text { December } 31 \\
\end{array}$ \\
\hline \multicolumn{7}{|l|}{ Electric Utility Piant } \\
\hline 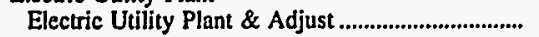 & 297,093 & 0 & 29,146 & 42,164 & 16,736 & 619,609 \\
\hline Const Work in Progress ........................................... & 640 & 0 & $\begin{array}{r}0 \\
115\end{array}$ & $\begin{array}{r}0 \\
26.632\end{array}$ & $\begin{array}{r}0 \\
9.332\end{array}$ & $\begin{array}{r}37,484 \\
269,425\end{array}$ \\
\hline (less) Depr, Amort, and Depletion................................. & 137,460 & $\begin{array}{l}0 \\
0\end{array}$ & $\begin{array}{l}11,615 \\
17,531\end{array}$ & 26,632 & 9,332 & $\begin{array}{l}269,425 \\
387,668\end{array}$ \\
\hline 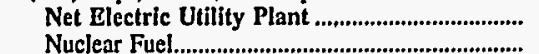 & $\begin{array}{r}160,272 \\
0\end{array}$ & $\begin{array}{l}0 \\
0\end{array}$ & $\begin{array}{r}17,531 \\
0\end{array}$ & $\begin{array}{r}15,532 \\
0\end{array}$ & $\begin{array}{r}7,404 \\
0\end{array}$ & $\begin{array}{r}387,668 \\
0\end{array}$ \\
\hline 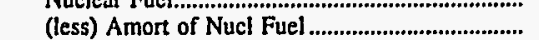 & 0 & 0 & 0 & 0 & 0 & \\
\hline 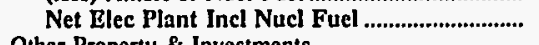 & 160,272 & 0 & 17,531 & 15,532 & 7,404 & 387,668 \\
\hline \multicolumn{7}{|l|}{ Other Property \& Investments } \\
\hline 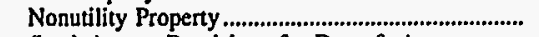 & $\mathbf{0}$ & 0 & 0 & 0 & 560 & 0 \\
\hline (less) Accum Provisions for Depr \& Amor ........... & $\mathbf{0}$ & 0 & $\mathbf{0}$ & $\mathbf{0}$ & 382 & $\mathbf{0}$ \\
\hline 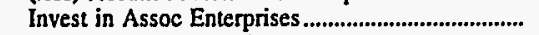 & 0 & 0 & 0 & $\mathbf{0}$ & 66 & 0 \\
\hline 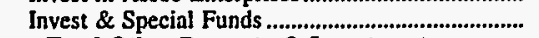 & 75,523 & 0 & 0 & 253 & 0 & 17,344 \\
\hline Total Other Property \& Investments................. & 75,523 & 0 & o & 253 & 244 & 17,344 \\
\hline \multicolumn{7}{|l|}{ Current and Accrued Assets } \\
\hline Cash, Working Funds \& Investments...................... & 7,939 & 13,909 & 2,233 & 9,717 & 1,451 & 26,209 \\
\hline Notes \& Other Receivables.............................................. & 13 & 0 & 0 & 0 & 25 & 3,679 \\
\hline 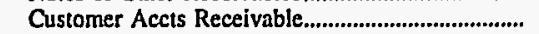 & 4,499 & 823 & 293 & 748 & 614 & 15,885 \\
\hline (less) Accum Prov for Uncollected Accts ............... & -20 & 0 & 0 & 0 & 0 & 1,855 \\
\hline 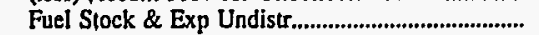 & 3,734 & 0 & 18 & $\mathbf{0}$ & $\mathbf{0}$ & 11,067 \\
\hline 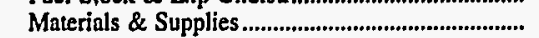 & 4,075 & 305 & 356 & 720 & 0 & 14,838 \\
\hline 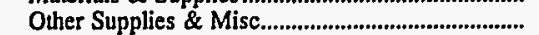 & 0 & 0 & 0 & $\mathbf{0}$ & 0 & 0 \\
\hline 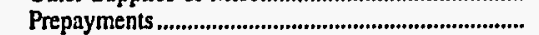 & 419 & 0 & 0 & 0 & 0 & 1,268 \\
\hline 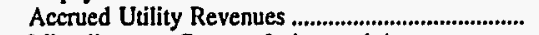 & 0 & 0 & $\mathbf{0}$ & $\mathbf{0}$ & 0 & 5,280 \\
\hline Miscellaneous Current \& Accrued Assets................ & 317 & 397 & 0 & 0 & 0 & \\
\hline 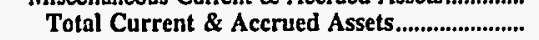 & 21,016 & 15,434 & 2,900 & 11,185 & 2,090 & 76,370 \\
\hline \multicolumn{7}{|l|}{ Deferred Debits } \\
\hline 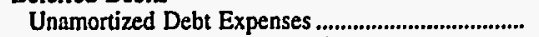 & 1,617 & 42 & 0 & 0 & 0 & 4,823 \\
\hline 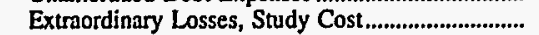 & 7,082 & 0 & 0 & 0 & 0 & 0 \\
\hline 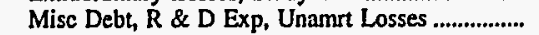 & 3,991 & 0 & 0 & $\mathbf{0}$ & 0 & 2,334 \\
\hline Total Deferred Debits............................................... & 12,690 & 42 & $\mathbf{0}$ & 0 & 0 & 7,158 \\
\hline 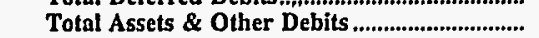 & 269,501 & 15,476 & 20,431 & 26,970 & $\mathbf{9 , 7 3 8}$ & 488,540 \\
\hline \multicolumn{7}{|l|}{ Proprietary Capital } \\
\hline 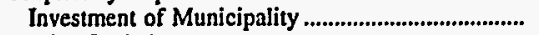 & $\mathbf{0}$ & 0 & $\mathbf{0}$ & 9,159 & 0 & 0 \\
\hline 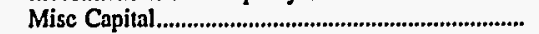 & & & 0 & & 0 & 1,422 \\
\hline Retained Earnings.................................................... & 130,576 & 4,026 & 5,756 & 12,096 & 8,820 & 275,375 \\
\hline \multirow{2}{*}{\multicolumn{7}{|c|}{ Long-term Debt }} \\
\hline & & & & & & \\
\hline 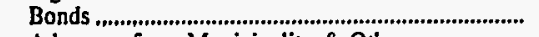 & 128,010 & 10,535 & 14,675 & 0 & 0 & 183,730 \\
\hline 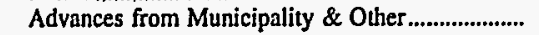 & 0 & 0 & 0 & $\mathbf{0}$ & 29 & \\
\hline Unamort Prem on Long-term Debt............................ & 0 & 0 & 0 & 0 & 0 & 0 \\
\hline (less) Unamort Discount on Long-term Debt & 6,071 & 146 & 0 & $\mathbf{0}$ & 0 & \\
\hline Total Long-term Debt ................................................ & 121,939 & 10,389 & 14,675 & $\mathbf{0}$ & 29 & 183,730 \\
\hline \multicolumn{7}{|l|}{ Other Noncurrent Liabilities } \\
\hline 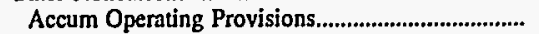 & 0 & 0 & 0 & 720 & 0 & 1,078 \\
\hline Accum Prov for Rate Refunds........................................... & 0 & 0 & 0 & 0 & 0 & \\
\hline Total Other Noncurrent Liabilities ....................... & o & $\mathbf{0}$ & 0 & 720 & $\mathbf{0}$ & 1,078 \\
\hline \multicolumn{7}{|l|}{ Current and Accrued Liabilities } \\
\hline Notes Payable ...................................... & 0 & 0 & $\mathbf{0}$ & & 27 & \\
\hline 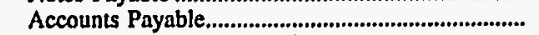 & 522 & 910 & $\mathbf{0}$ & 3,994 & 770 & 21,296 \\
\hline Payables to Assoc Enterprises....................................... & 0 & 0 & 0 & 0 & 0 & \\
\hline Customer Deposits....... & 150 & 1 & 0 & 253 & 91 & 1,968 \\
\hline 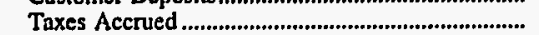 & 153 & 0 & $\mathbf{0}$ & $\mathbf{0}$ & 0 & 131 \\
\hline 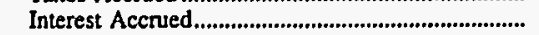 & 3,675 & 44 & $\mathbf{0}$ & $\mathbf{0}$ & 0 & 3,540 \\
\hline Misc Current \& Accrued Liabilities ........................... & 1,413 & 106 & 0 & & $\mathbf{0}$ & \\
\hline Total Current \& Accrued Liabilities .................... & 5,913 & 1,061 & 0 & 4,247 & 888 & 26,935 \\
\hline \multicolumn{7}{|l|}{ Deferred Credits } \\
\hline Customer Advances for Construction ........................ & & 0 & $\mathbf{0}$ & 0 & 0 & \\
\hline 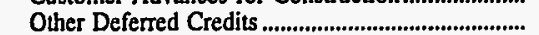 & 11,073 & 0 & 0 & 748 & 0 & \\
\hline 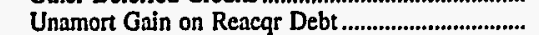 & & 0 & $\mathbf{0}$ & 0 & 0 & 0 \\
\hline 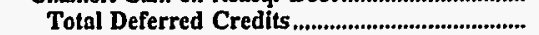 & 11,073 & & $\mathbf{0}$ & 748 & & \\
\hline Total Liabilities and Other Credits.................... & 269,501 & 15,476 & 20,431 & 26,970 & $\mathbf{9 , 7 3 8}$ & 488,540 \\
\hline
\end{tabular}

Note: Totals may not equal sum of components because of independent rounding.

Source: Energy Information Administration, Form EIA-412, "Annual Report of Public Electric Utilities." 
Table 22. Balance Sheet by Major U.S. Publicly Owned Electric Utility Within State at End of Period, 1996

(Thousand Dollars)

\begin{tabular}{|c|c|c|c|c|c|c|}
\hline Item & $\begin{array}{c}\text { Kansas } \\
\text { Kansas } \\
\text { Municipal } \\
\text { Energy } \\
\text { Agency } \\
\text { December } 31\end{array}$ & $\begin{array}{l}\text { Kansas } \\
\text { McPherson } \\
\text { City of } \\
\text { December } 31\end{array}$ & $\begin{array}{c}\text { Kansas } \\
\text { Winfield } \\
\text { City of } \\
\text { December } 31\end{array}$ & $\begin{array}{c}\text { Kentucky } \\
\text { Bardstown } \\
\text { City of } \\
\text { December } 31\end{array}$ & $\begin{array}{l}\text { Kentucky } \\
\text { Bowling } \\
\text { Green } \\
\text { City of } \\
\text { June } 30\end{array}$ & $\begin{array}{l}\text { Kentucky } \\
\text { Frankfort } \\
\text { City of } \\
\text { June } 30\end{array}$ \\
\hline \multicolumn{7}{|l|}{ Electric Utility Plant } \\
\hline 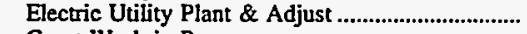 & 1,523 & 51,819 & 33,479 & 4,468 & 43,323 & 24,673 \\
\hline 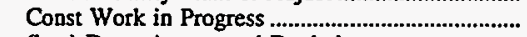 & 0 & 5,563 & 204 & 0 & 3,920 & \\
\hline (less) Depr, Amort, and Depletion............................ & 680 & 30,379 & 16,960 & 992 & 14,775 & 13,580 \\
\hline Net Electric Utility Plant & 843 & 27,003 & 16,723 & 3,476 & 32,469 & 11,093 \\
\hline 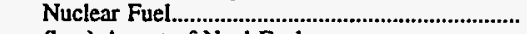 & 0 & 0 & 0 & 0 & 0 & 0 \\
\hline 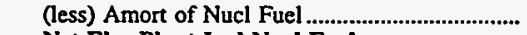 & 0 & 0 & 0 & 0 & 0 & 0 \\
\hline Net Elec Plant Incl Nucl Fuel .................................... & 843 & 27,003 & 16,723 & 3,476 & 32,469 & 11,093 \\
\hline \multicolumn{7}{|l|}{ Other Property \& Investments } \\
\hline Nonutility Property ........................ & 0 & 441 & 0 & 443 & 0 & 31,834 \\
\hline (less) Accum Provisions for Depr \& Amort ........... & 0 & 0 & 0 & 257 & 0 & 11,274 \\
\hline 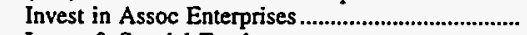 & 0 & $\mathbf{0}$ & 0 & 0 & 0 & 0 \\
\hline Invest \& Special Funds ......................................................... & 6,254 & 42,288 & 789 & 0 & 1,933 & 4,580 \\
\hline Total Other Property \& Investments.................. & 6,254 & 42,729 & 789 & 185 & 1,933 & 25,141 \\
\hline \multicolumn{7}{|l|}{ Current and Accrued Assets } \\
\hline Cash, Working Funds \& Investments.......................... & 1,008 & 5,918 & 3,123 & 3,079 & 2,808 & 1,295 \\
\hline 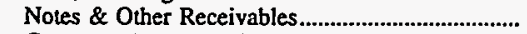 & 1,174 & 0 & 13 & 0 & 2,985 & 4,213 \\
\hline 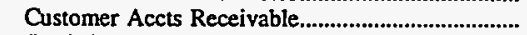 & 0 & 1,859 & 1,138 & 754 & 0 & 0 \\
\hline (less) Accum Prov for Uncollected Accts.................... & 0 & 0 & 0 & 0 & 0 & 3 \\
\hline 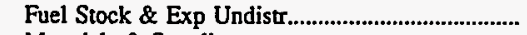 & 0 & 33 & 71 & 0 & 0 & 0 \\
\hline 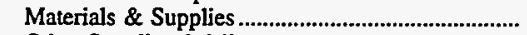 & 0 & 990 & 458 & 696 & 714 & 2,659 \\
\hline 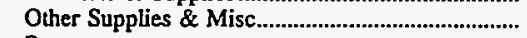 & 0 & 0 & 0 & 0 & 0 & 0 \\
\hline 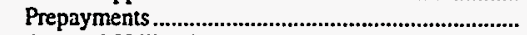 & 183 & 0 & 0 & 0 & 0 & 127 \\
\hline 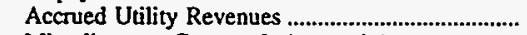 & 0 & 0 & 0 & 0 & 144 & 0 \\
\hline Miscellaneous Current \& Accrued Assets............... & 0 & 606 & 115 & 361 & 39 & 2 \\
\hline Total Current \& Accrued Assets........................ & 2,365 & $\mathbf{9 , 4 0 6}$ & 4,919 & 4,890 & 6,691 & 8,294 \\
\hline \multicolumn{7}{|l|}{ Deferred Debits } \\
\hline Unamortized Debt Expenses ............................................ & 430 & 194 & 0 & 0 & 42 & 0 \\
\hline 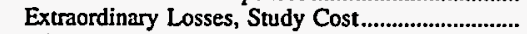 & 0 & 0 & 0 & 0 & 0 & 0 \\
\hline Misc Debt, R \& D Exp, Unamrt Losses ..................... & 4,486 & 0 & 0 & $\mathbf{0}$ & 1,234 & 0 \\
\hline 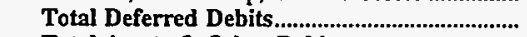 & 4,916 & 194 & 0 & 0 & 1,276 & 0 \\
\hline Total Assets \& Other Debits & 14,378 & 79,333 & 22,431 & $\mathbf{8 , 5 5 1}$ & 42,369 & 44,528 \\
\hline \multicolumn{7}{|l|}{ Proprietary Capital } \\
\hline Investment of Municipality ............................................. & $\mathbf{0}$ & 0 & 0 & 0 & 0 & 0 \\
\hline 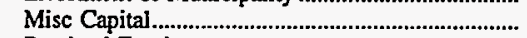 & 0 & 0 & 160 & 13 & 0 & 0 \\
\hline 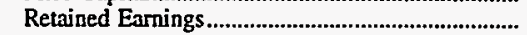 & 2,259 & 33,099 & 16,501 & 7,935 & 25,812 & 35,689 \\
\hline Total Proprietary Capital ............................................. & 2,259 & 33,099 & 16,661 & $\mathbf{7 , 9 4 8}$ & 25,812 & 35,689 \\
\hline \multicolumn{7}{|l|}{ Long-term Debt } \\
\hline 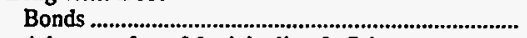 & 10,350 & 44,097 & 4,909 & 0 & 0 & 3,459 \\
\hline Advances from Municipality \& Other..................... & 0 & 0 & 0 & 0 & 8,970 & 0 \\
\hline 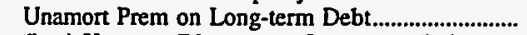 & 0 & 0 & 0 & 0 & 1,181 & 0 \\
\hline (less) Unamort Discount on Long-term Debt & 127 & 0 & 0 & 0 & 0 & 0 \\
\hline 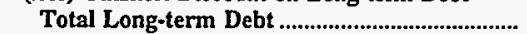 & 10,223 & 44,097 & 4,909 & 0 & 10,151 & 3,459 \\
\hline \multicolumn{7}{|l|}{ Other Noncurrent Liabilities } \\
\hline 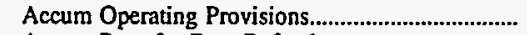 & 0 & 0 & 0 & 0 & 0 & 0 \\
\hline 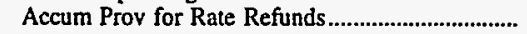 & 0 & 0 & 0 & 0 & 0 & 0 \\
\hline Total Other Noncurrent Liabilities ...................... & 0 & 0 & 0 & 0 & $\mathbf{0}$ & 0 \\
\hline \multicolumn{7}{|l|}{ Current and Accrued Liabilities } \\
\hline 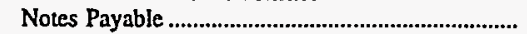 & 0 & 0 & 0 & 0 & 674 & 0 \\
\hline Accounts Payable & 1,114 & 1,534 & 794 & 459 & 2,584 & 3,469 \\
\hline 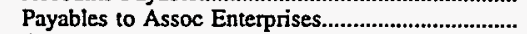 & 0 & 0 & 0 & 0 & 0 & 0 \\
\hline 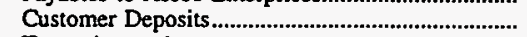 & o & 171 & 0 & 123 & 2,486 & 645 \\
\hline 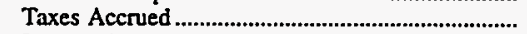 & 0 & 0 & 0 & 0 & 175 & 230 \\
\hline 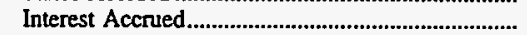 & 54 & 208 & 66 & 0 & 438 & 225 \\
\hline Misc Current \& Accrued Liabilities ............................. & 111 & 224 & 0 & 20 & 0 & 468 \\
\hline Total Current \& Accrued Liabilities ..................... & 1,279 & 2,137 & 860 & 602 & 6,357 & 5,038 \\
\hline \multicolumn{7}{|l|}{ Deferred Credits } \\
\hline Customer Advances for Construction ....................... & 0 & 0 & 0 & 0 & 0 & 0 \\
\hline Other Deferred Credits & 617 & 0 & 0 & 0 & 49 & 342 \\
\hline 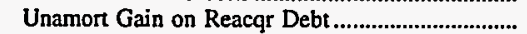 & 0 & 0 & 0 & 0 & 0 & 0 \\
\hline 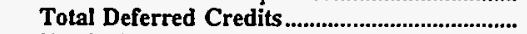 & 617 & $\mathbf{0}$ & 0 & 0 & 49 & 342 \\
\hline 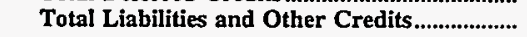 & 14,378 & 79,333 & 22,431 & 8,551 & 42,369 & 44,528 \\
\hline
\end{tabular}

Note: Totals may not equal sum of components because of independent rounding.

Source: Energy Information Administration, Form EIA-412, "Annual Report of Public Electric Utilities." 
Table 22. Balance Sheet by Major U.S. Publicly Owned Electric Utility Within State at End of Period, 1996

(Thousand Dollars)

\begin{tabular}{|c|c|c|c|c|c|c|}
\hline Item & $\begin{array}{l}\text { Kentucky } \\
\text { Franklin } \\
\text { City of } \\
\text { June } 30\end{array}$ & $\begin{array}{l}\text { Kentucky } \\
\text { Glasgow } \\
\text { City of } \\
\text { June } 30\end{array}$ & $\begin{array}{c}\text { Kentucky } \\
\text { Henderson } \\
\text { City } \\
\text { Utility Comm } \\
\text { May } 31\end{array}$ & $\begin{array}{c}\text { Kentucky } \\
\begin{array}{l}\text { Hopkinsville } \\
\text { City of }\end{array} \\
\text { June } 30\end{array}$ & $\begin{array}{l}\text { Kentucky } \\
\text { Madisonville } \\
\begin{array}{c}\text { Municipal } \\
\text { Utils }\end{array} \\
\text { June } 30\end{array}$ & $\begin{array}{l}\text { Kentucky } \\
\text { Mayfield } \\
\text { City of } \\
\text { June } 30\end{array}$ \\
\hline \multicolumn{7}{|l|}{ Electric Utility Plant } \\
\hline Electric Utility Plant \& Adjust ............................ & 6,384 & 17,412 & 147,666 & 16,197 & 4,928 & 6,247 \\
\hline 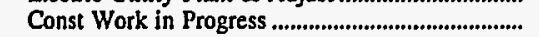 & 112 & 194 & & 105 & 0 & 131 \\
\hline (less) Depr, Amort, and Depletion................................ & 2,050 & 6,392 & 72,829 & 7,456 & 0 & 2,748 \\
\hline Net Electric Utility Plant ....................................... & 4,446 & 11,213 & $\mathbf{7 4 , 8 3 8}$ & 8,846 & 4,928 & 3,631 \\
\hline Nuclear Fuel................................................................. & & & $\mathbf{0}$ & $\mathbf{0}$ & 0 & 0 \\
\hline 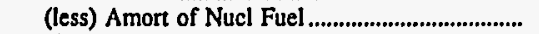 & & & 0 & 0 & 0 & 0 \\
\hline Net Elec Plant Incl Nucl Fuel ....................................... & 4,446 & 11,213 & 74,838 & 8,846 & 4,928 & 3,631 \\
\hline \multicolumn{7}{|l|}{ Other Property \& Investments } \\
\hline Nonutility Property..................... & 0 & 0 & 0 & 97 & 0 & 0 \\
\hline (less) Accum Provisions for Deps \& Amort ........... & 0 & 0 & 0 & 0 & 0 & 0 \\
\hline 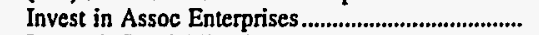 & 0 & 381 & 0 & 0 & 0 & 0 \\
\hline 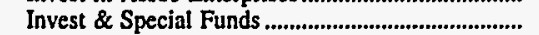 & 469 & 656 & 25,529 & 2,685 & 0 & 10 \\
\hline Total Other Property \& Investments................ & 469 & 1,037 & 25,529 & $\mathbf{2 , 7 8 2}$ & 0 & 10 \\
\hline \multicolumn{7}{|l|}{ Current and Accrued Assets } \\
\hline 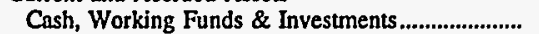 & 1,173 & 166 & 3,246 & 2,074 & 247 & 233 \\
\hline 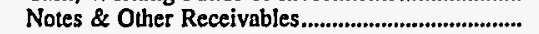 & 835 & 59 & 82 & 1,800 & 7 & 1,172 \\
\hline Customer Accts Receivable...................................... & 0 & 1,476 & 269 & 0 & 1,397 & 0 \\
\hline (less) Accum Prov for Uncollected Accts.................. & 0 & -2 & 3 & 0 & 0 & 0 \\
\hline 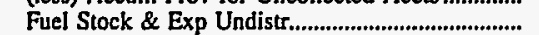 & 0 & 0 & 1,038 & 0 & 0 & 0 \\
\hline 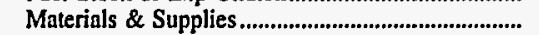 & 124 & 361 & 749 & 242 & 429 & 137 \\
\hline 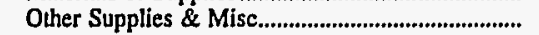 & 0 & 0 & 1,602 & 0 & 0 & 0 \\
\hline 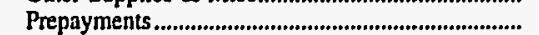 & 38 & 104 & 50 & 150 & 28 & 12 \\
\hline 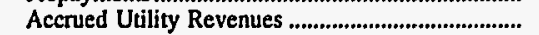 & 0 & 0 & 984 & 0 & 0 & 0 \\
\hline Miscellaneous Current \& Accrued Assets............... & 11 & 9 & 0 & 103 & 5 & 6 \\
\hline Total Current \& Accrued Assets........................... & 2,181 & 2,175 & 8,018 & 4,368 & 2,113 & 1,559 \\
\hline \multicolumn{7}{|l|}{ Deferred Debits } \\
\hline Unamortized Debt Expenses..... & 0 & 68 & 402 & 12 & 0 & 0 \\
\hline 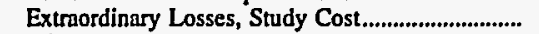 & 0 & 0 & 0 & 0 & 0 & 0 \\
\hline Misc Debt, R \& D Exp, Unamrt Losses ................. & 105 & 67 & 0 & 202 & 0 & 2 \\
\hline Total Deferred Debits................................................ & 105 & 136 & 402 & 214 & o & 2 \\
\hline Total Assets \& Other Debits .................................... & 7,200 & 14,562 & 108,787 & 16,210 & 7,041 & 5,201 \\
\hline \multicolumn{7}{|l|}{ Proprietary Capital } \\
\hline 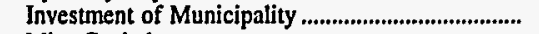 & $\mathbf{0}$ & $\mathbf{0}$ & $\mathbf{0}$ & 0 & $\mathbf{0}$ & $\mathbf{0}$ \\
\hline 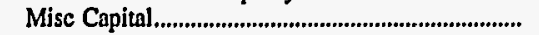 & $\mathbf{0}$ & 0 & 0 & 0 & 130 & 0 \\
\hline 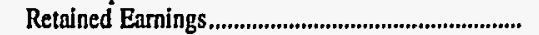 & 6,046 & 7,369 & 30,162 & 11,996 & 3,965 & 3,986 \\
\hline Total Proprietary Capital ......................................... & 6,046 & 7,369 & 30,162 & 11,996 & 4,095 & 3,986 \\
\hline \multicolumn{7}{|l|}{ Long-term Debt } \\
\hline Bonds .................... & 0 & 4,615 & 29,245 & 1,625 & 0 & 0 \\
\hline Advances from Municipality \& Other........................... & 100 & 0 & 0 & 205 & 32 & 2 \\
\hline 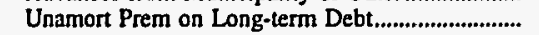 & 0 & 0 & 0 & -14 & 0 & 0 \\
\hline (less) Unamort Discount on Long-term Debt & 0 & 80 & $\mathbf{0}$ & 0 & 0 & 0 \\
\hline 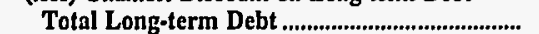 & 100 & 4,535 & 29,245 & 1,817 & 32 & 2 \\
\hline \multicolumn{7}{|l|}{ Other Noncurrent Liabilities } \\
\hline 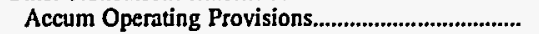 & $\mathbf{0}$ & 18 & $\mathbf{0}$ & $\mathbf{0}$ & 0 & $\mathbf{0}$ \\
\hline Accum Prov for Rate Refunds........................................ & $\mathbf{0}$ & $\mathbf{0}$ & $\mathbf{0}$ & $\mathbf{0}$ & 0 & $\mathbf{0}$ \\
\hline Total Other Noncurrent Liabilities ..................... & $\mathbf{0}$ & 18 & o & 0 & 0 & 0 \\
\hline \multicolumn{7}{|l|}{ Current and Accrued Liabilities } \\
\hline Notes Payable .................................. & $\mathbf{0}$ & 188 & 3,985 & 39 & 0 & 0 \\
\hline 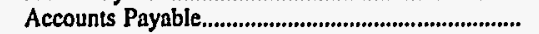 & 735 & 1,403 & 2,834 & 1,681 & 2,607 & 862 \\
\hline 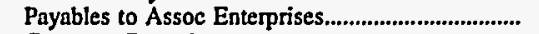 & 0 & & 0 & 0 & 0 & 0 \\
\hline Customer Deposits........................................................ & 235 & 505 & 345 & 459 & 229 & 203 \\
\hline 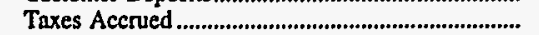 & 22 & 83 & 0 & 113 & 0 & 65 \\
\hline 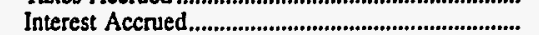 & 0 & 23 & 474 & 0 & 77 & 0 \\
\hline Misc Current \& Accrued Liabilities ................. & 41 & 7 & 37,168 & 56 & 0 & 83 \\
\hline Total Current \& Accrued Liabilities ..................... & 1,032 & 2,209 & 44,806 & 2,347 & 2,914 & 1,213 \\
\hline \multicolumn{7}{|l|}{ Deferred Credits } \\
\hline 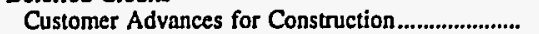 & 0 & 0 & 4,575 & 0 & 0 & 0 \\
\hline Other Deferred Credits ................................................... & 21 & 430 & 0 & 50 & 0 & 0 \\
\hline Unamort Gain on Reacgr Debt ..................................... & 0 & 0 & & 0 & 0 & 0 \\
\hline 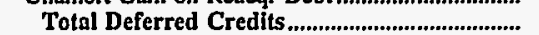 & 21 & 430 & 4,575 & 50 & 0 & 0 \\
\hline Total Liabilities and Other Credits........................ & 7,200 & 14,562 & 108,787 & 16,210 & 7,041 & 5,201 \\
\hline
\end{tabular}

Note: Totals may not equal sum of components because of independent rounding.

Source: Energy Information Administration, Form EIA-412, "Annual Report of Public Electric Utilities." 
Table 22. Balance Sheet by Major U.S. Publicly Owned Electric Utility Within State at End of Period, 1996

(Thousand Dollars)

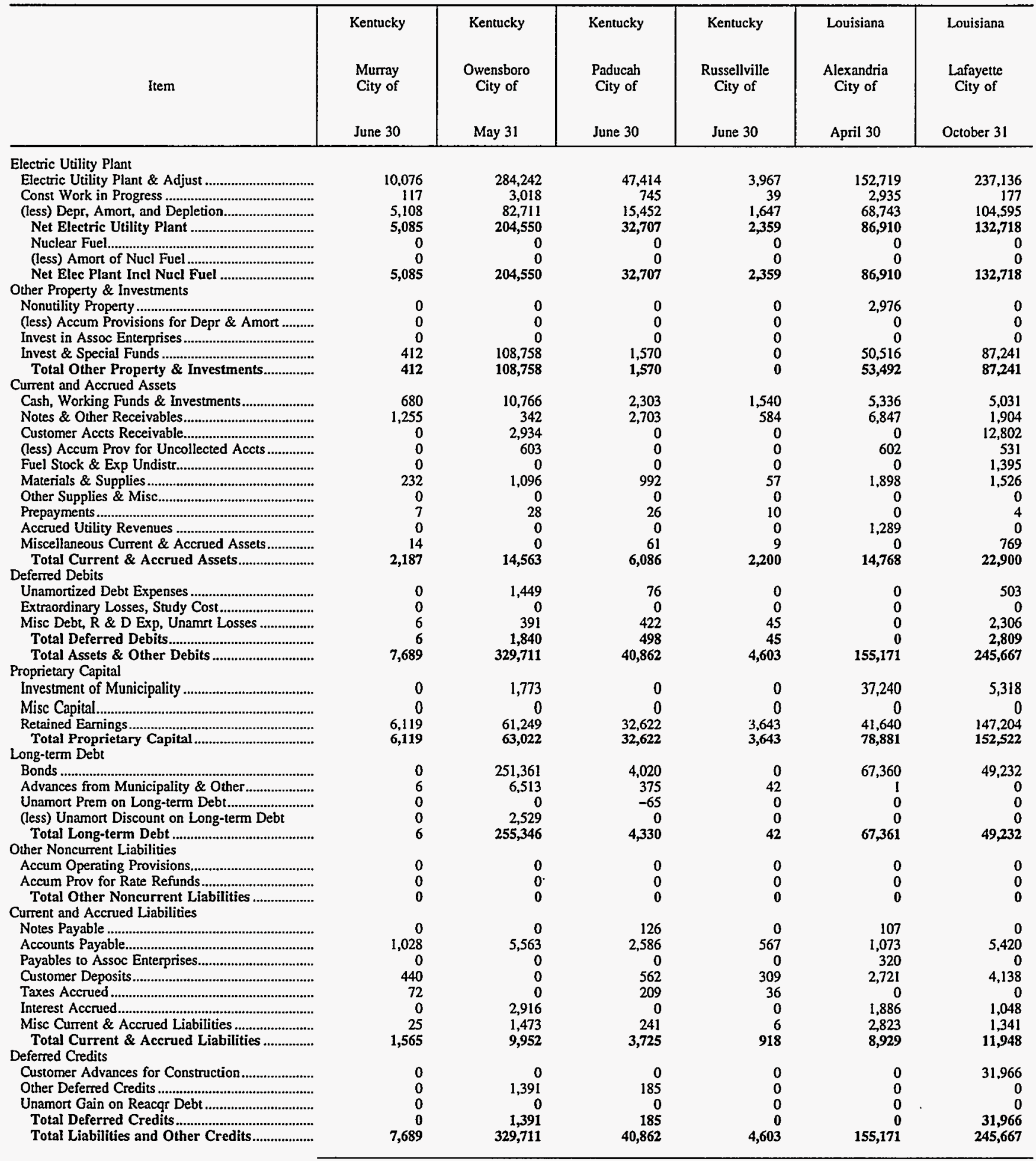

Note: Totals may not equal sum of components because of independent rounding.

Source: Energy Information Administration, Form EIA-412, "Annual Report of Public Electric Utilities." 
Table 22. Balance Sheet by Major U.S. Publicly Owned Electric Utility Within State at End of Period, 1996

(Thousand Dollars)

\begin{tabular}{|c|c|c|c|c|c|c|}
\hline Item & $\begin{array}{l}\text { Louisiana } \\
\text { Lafayette } \\
\text { Public } \\
\text { Power Auth } \\
\text { October } 31\end{array}$ & $\begin{array}{c}\text { Louisiana } \\
\text { Louisiana } \\
\text { Energy } \\
\& \\
\text { Power Auth } \\
\text { December } 31\end{array}$ & $\begin{array}{l}\text { Louisiana } \\
\text { Morgan } \\
\text { City City of } \\
\text { December } 31\end{array}$ & $\begin{array}{l}\text { Louisiana } \\
\text { Natchitoches } \\
\text { City of } \\
\text { May } 31\end{array}$ & $\begin{array}{l}\text { Louisiana } \\
\text { Ruston } \\
\text { City of } \\
\text { September } 30\end{array}$ & $\begin{array}{c}\text { Louisiana } \\
\text { Terrebonne } \\
\text { Parish } \\
\text { Consol Govt } \\
\\
\text { December } 31\end{array}$ \\
\hline \multicolumn{7}{|l|}{ Electric Utility Plant } \\
\hline Electric Utility Plant \& Adjust .................................... & 152,341 & 87,859 & 28,991 & 59,823 & 31,687 & 54,619 \\
\hline Const Work in Progress .............................................. & 583 & 273 & & & 172 & 4,570 \\
\hline (less) Depr, Amort, and Depletion............................ & 67,445 & 25,237 & 20,559 & 19,099 & 20,646 & 37,891 \\
\hline Net Electric Utllity Plant .......................................... & 85,479 & 62,895 & 8,432 & 40,724 & 11,213 & 21,299 \\
\hline Nuclear Fuel.................................................................... & 0 & 0 & 0 & 0 & 0 & 0 \\
\hline 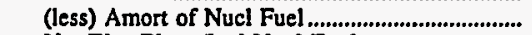 & & & 0 & & 0 & 0 \\
\hline Net Elec Plant Incl Nucl Fuel ................................ & 85,479 & 62,895 & 8,432 & 40,724 & 11,213 & 21,299 \\
\hline \multicolumn{7}{|l|}{ Other Property \& Investments } \\
\hline Nonutility Property..................... & 0 & 1,393 & 0 & 0 & 0 & 15,263 \\
\hline (less) Accum Provisions for Depr \& Amort ........... & 0 & 180 & 0 & 0 & 0 & 6,517 \\
\hline 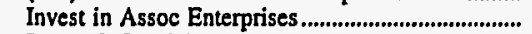 & 0 & 0 & 0 & 0 & 150 & 0 \\
\hline 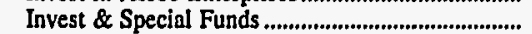 & 18,107 & 15,627 & 0 & 0 & 3,916 & 10,573 \\
\hline Total Other Property \& Investments............... & 18,107 & 16,839 & 0 & o & 4,066 & 19,319 \\
\hline \multicolumn{7}{|l|}{ Current and Accrued Assets } \\
\hline Cash, Working Funds \& Investments........................ & 19,877 & 13,306 & 6,444 & 843 & 1,011 & 10,431 \\
\hline 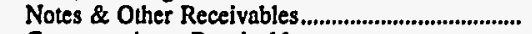 & 22 & 103 & 75 & 192 & 63 & 235 \\
\hline 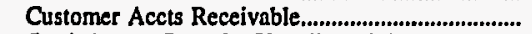 & 280 & 2,831 & 1,001 & 3,857 & 824 & 1,130 \\
\hline (less) Accum Prov for Uncollected Accts............... & 0 & 0 & 0 & -14 & 0 & 0 \\
\hline 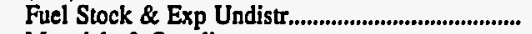 & 7,857 & 2,517 & 0 & 0 & 0 & 0 \\
\hline 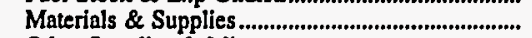 & 1,648 & 0 & 187 & 607 & 0 & 21 \\
\hline 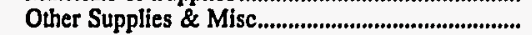 & 0 & 0 & 0 & 0 & 459 & 0 \\
\hline 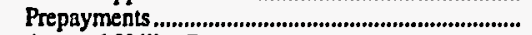 & 6 & 102 & 294 & 0 & 28 & 0 \\
\hline 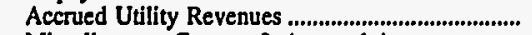 & 0 & 0 & 747 & 0 & 874 & 2,477 \\
\hline Miscellaneous Current \& Accrued Assets................ & 0 & 0 & 400 & 0 & 0 & 5,485 \\
\hline Total Current \& Accrued Assets............................ & 29,689 & 18,860 & 9,148 & 5,513 & 3,259 & 19,779 \\
\hline \multicolumn{7}{|l|}{ Deferred Debits } \\
\hline Unamortized Debt Expenses ......................................... & 1,043 & 31,099 & 115 & 0 & 0 & 0 \\
\hline Extraordinary Losses, Study Cost................................. & 22,944 & 751 & 0 & $\mathbf{0}$ & 0 & 0 \\
\hline Misc Debt, R \& D Exp, Unamrt Losses ...................... & 19,661 & 0 & 0 & 0 & 0 & 0 \\
\hline Total Deferred Debits.............................................. & 43,648 & 31,851 & 115 & 0 & 0 & 0 \\
\hline 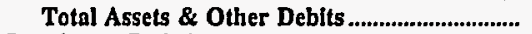 & 176,923 & 130,445 & 17,695 & 46,237 & 18,538 & 60,397 \\
\hline \multicolumn{7}{|l|}{ Proprietary Capital } \\
\hline Investment of Municipality ............................................... & 0 & $\mathbf{0}$ & 2,048 & 551 & 0 & 7,260 \\
\hline 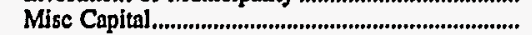 & 0 & 0 & 2,375 & 27,612 & 325 & 0 \\
\hline 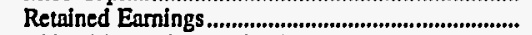 & 7,758 & 9,322 & 3,558 & 1,701 & 13,643 & 32,238 \\
\hline \multicolumn{7}{|l|}{ Long-term Debt } \\
\hline 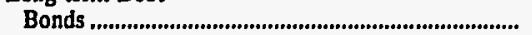 & 165,475 & 116,700 & 5,268 & 14,099 & 1,835 & 15,745 \\
\hline 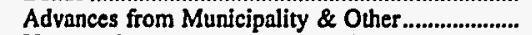 & 0 & 0 & 935 & 0 & 110 & 0 \\
\hline Unamort Prem on Long-term Debt........................... & 0 & 0 & 0 & 0 & 0 & 0 \\
\hline (less) Unamort Discount on Long-term Debt & 2,106 & 5,165 & 0 & & & \\
\hline 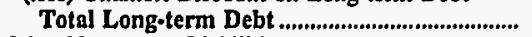 & 163,369 & 111,535 & 6,203 & 14,099 & 1,945 & 15,745 \\
\hline \multicolumn{7}{|l|}{ Other Noncurrent Liabilities } \\
\hline 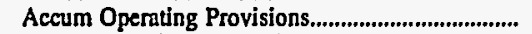 & 0 & $\mathbf{0}$ & 94 & $\mathbf{0}$ & 0 & $\mathbf{0}$ \\
\hline Accum Prov for Rate Refunds.................................. & 0 & 0 & 0 & 0 & 0 & 0 \\
\hline Total Other Noncurrent Llabillties ................... & o & 0 & 94 & o & 0 & 0 \\
\hline \multicolumn{7}{|l|}{ Current and Accrued Liabilities } \\
\hline 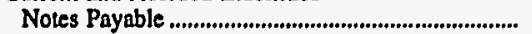 & 0 & 0 & 943 & 0 & 0 & 720 \\
\hline 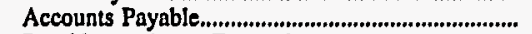 & 2,037 & 3,260 & 53 & 1,454 & 1,022 & 2,195 \\
\hline Payables to Assoc Enterprises..................................... & 214 & 0 & 0 & 0 & 608 & 0 \\
\hline 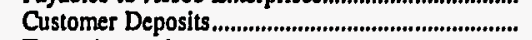 & 0 & 0 & 750 & 696 & 564 & 872 \\
\hline 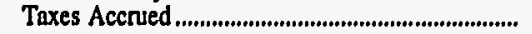 & 0 & 0 & 0 & 124 & 0 & 0 \\
\hline 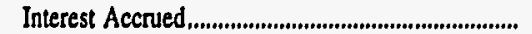 & 3,545 & 3,790 & 169 & 0 & 197 & 0 \\
\hline Misc Current \& Accrued Liabilities .......................... & 0 & 2,537 & 1,504 & 0 & 234 & 1,367 \\
\hline $\begin{array}{l}\text { Total Current \& Accrued Llabillties ................. } \\
\text { Deferred Credits }\end{array}$ & 5,796 & 9,587 & $\mathbf{3 , 4 1 7}$ & 2,274 & 2,625 & 5,154 \\
\hline \multicolumn{7}{|l|}{ Deferred Credits } \\
\hline 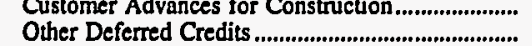 & 0 & 0 & $\begin{array}{l}0 \\
0\end{array}$ & $\begin{array}{l}0 \\
0\end{array}$ & $\begin{array}{l}0 \\
0\end{array}$ & $\begin{array}{l}0 \\
0\end{array}$ \\
\hline Unamort Gain on Reacgr Debt.................................... & 0 & 0 & 0 & 0 & 0 & 0 \\
\hline Total Deferred Credits........................................... & & & & 0 & & \\
\hline Total Llabillties and Other Credits........................ & 176,923 & 130,445 & 17,695 & 46,237 & 18,538 & 60,397 \\
\hline
\end{tabular}

Note: Totals may not equal sum of components because of independent rounding.

Source: Energy Information Administration, Form EIA-412, "Annual Report of Public Electric Utilities." 
Table 22. Balance Sheet by Major U.S. Publicly Owned Electric Utility Within State at End of Period, 1996

(Thousand Dollars)

\begin{tabular}{|c|c|c|c|c|c|c|}
\hline Item & $\begin{array}{l}\text { Maryland } \\
\text { Easton } \\
\text { Utilities } \\
\text { Comm } \\
\text { June } 30\end{array}$ & $\begin{array}{l}\text { Maryland } \\
\begin{array}{l}\text { Hagerstown } \\
\text { City of }\end{array} \\
\text { June } 30\end{array}$ & $\begin{array}{l}\text { Massachusetts } \\
\text { Braintree } \\
\text { Town of } \\
\text { December } 31\end{array}$ & $\begin{array}{l}\text { Massarhusetts } \\
\text { Chicopee } \\
\text { City of } \\
\text { December } 31\end{array}$ & $\begin{array}{l}\text { Massachusetts } \\
\text { Concord } \\
\text { Town of } \\
\text { December } 31\end{array}$ & $\begin{array}{c}\text { Massachusetts } \\
\text { Danvers } \\
\text { Town of } \\
\text { December } 31\end{array}$ \\
\hline \multicolumn{7}{|l|}{ Electric Utility Plant } \\
\hline 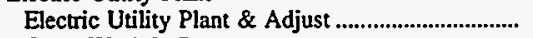 & 43,502 & 26,031 & 72,811 & 71,608 & 32,245 & 13,888 \\
\hline 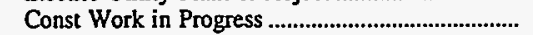 & 2,142 & 1,825 & & 245 & 273 & $\mathbf{0}$ \\
\hline (less) Depr, Amort, and Depletion................................. & 18,930 & 11,645 & 34,430 & 29,966 & 9,477 & 0 \\
\hline Net Electric Utility Plant ........................................ & 26,714 & 16,211 & 38,381 & 41,886 & 23,042 & 13,888 \\
\hline Nuclear Fuel.......................................................... & 0 & 0 & 0 & 4,497 & 0 & 0 \\
\hline (less) Amort of Nucl Fuel ........................................... & 0 & 0 & 0 & 3,918 & 0 & 0 \\
\hline Net Elec Plant Incl Nucl Fuel .......................... & 26,714 & 16,211 & $\mathbf{3 8 , 3 8 1}$ & 42,466 & 23,042 & 13,888 \\
\hline \multicolumn{7}{|l|}{ Other Property \& Investments } \\
\hline Nonutility Property ............................................... & 688 & 0 & 0 & 0 & $\mathbf{0}$ & 0 \\
\hline (less) Accum Provisions for Depr \& Amort .......... & 99 & 0 & 0 & 0 & 0 & 0 \\
\hline 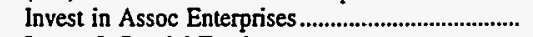 & 0 & 0 & 0 & 0 & 0 & 0 \\
\hline 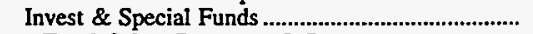 & 0 & 0 & 3,100 & 9,588 & 5,112 & 5.326 \\
\hline Total Other Property \& Investments.................. & 589 & o & 3,100 & 9,588 & 5,112 & 5,326 \\
\hline \multicolumn{7}{|l|}{ Current and Accrued Assets } \\
\hline Cash, Working Funds \& Investments....................... & 1,781 & 6,210 & 3,858 & 1,649 & 4,476 & 4,015 \\
\hline 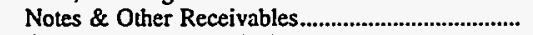 & 69 & 240 & 100 & 937 & 259 & 69 \\
\hline 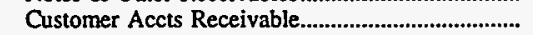 & 1,401 & 3,079 & 2,756 & 3,139 & 1,637 & 3.912 \\
\hline (less) Accum Prov for Uncollected Accts............... & 0 & 842 & 248 & 183 & 30 & 153 \\
\hline 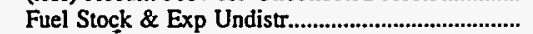 & 370 & 0 & 0 & 40 & 0 & 0 \\
\hline 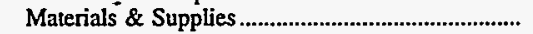 & 1,297 & 0 & 283 & 1,383 & 738 & 1,008 \\
\hline 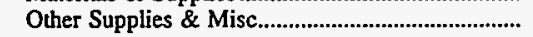 & 0 & 297 & 0 & 0 & 0 & 0 \\
\hline 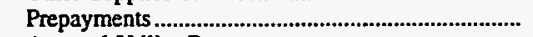 & 50 & 3 & 134 & 1,084 & 58 & 110 \\
\hline 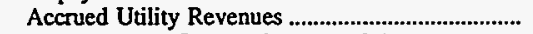 & 1,184 & 0 & 781 & 0 & 0 & 0 \\
\hline Miscellaneous Current \& Accrued Assets............... & 0 & 0 & 11 & 24 & 544 & 412 \\
\hline 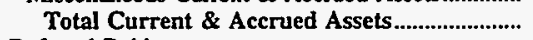 & 6,152 & 8,988 & 7,675 & 8,074 & $\mathbf{7 , 6 8 1}$ & 9,373 \\
\hline \multicolumn{7}{|l|}{ Deferred Debits } \\
\hline Unamortized Debt Expenses..... & 107 & 0 & 0 & 0 & 51 & $\mathbf{0}$ \\
\hline 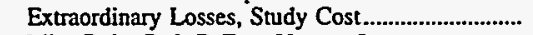 & 0 & 0 & 0 & 2 & 0 & $\mathbf{0}$ \\
\hline 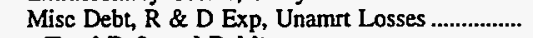 & 26 & 0 & 426 & 2,027 & 0 & 18 \\
\hline 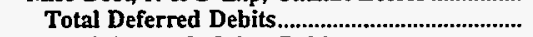 & 134 & 0 & 426 & 2,028 & si & 18 \\
\hline Total Assets \& Other Debits ................................... & 33,589 & 25,199 & 49,583 & 62,155 & 35,885 & 28,605 \\
\hline \multicolumn{7}{|l|}{ Proprietary Capital } \\
\hline 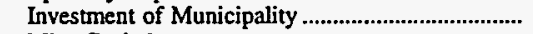 & 14,436 & 0 & 45,525 & 0 & 4,549 & 26,599 \\
\hline 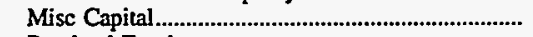 & & 560 & 0 & 0 & 0 & 0 \\
\hline 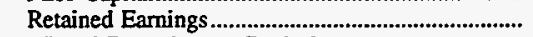 & 7,530 & 19,616 & 0 & 52,342 & 20,947 & 0 \\
\hline 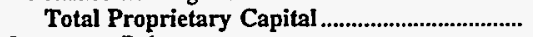 & 21,966 & 20,176 & 45,525 & 52,342 & 25,496 & 26,599 \\
\hline \multicolumn{7}{|l|}{ Long-term Debt } \\
\hline 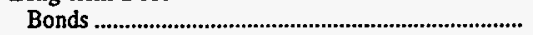 & 8,380 & 655 & 0 & 0 & 7,705 & 200 \\
\hline 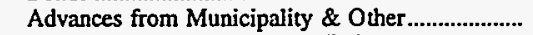 & 307 & 0 & 0 & 0 & 0 & $\mathbf{0}$ \\
\hline Unamort Prem on Long-term Debt.............................. & 0 & 0 & 0 & 0 & 0 & 0 \\
\hline (less) Unamort Discount on Long-term Debt & 0 & 0 & 0 & 0 & 0 & 0 \\
\hline 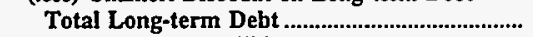 & 8,688 & 655 & 0 & 0 & 7,705 & 200 \\
\hline \multicolumn{7}{|l|}{ Other Noncurrent Liabilities } \\
\hline 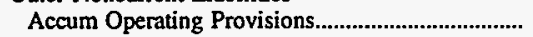 & 0 & 0 & 0 & 0 & 55 & 0 \\
\hline 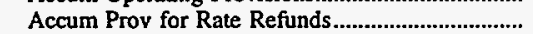 & 0 & 0 & 0 & 0 & 0 & 0 \\
\hline Total Other Noncurrent Liabilities ........................ & $\mathbf{0}$ & $\mathbf{0}$ & 0 & o & 55 & o \\
\hline \multicolumn{7}{|l|}{ Current and Accrued Liabilities } \\
\hline 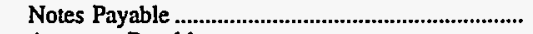 & 655 & 90 & 0 & 0 & 86 & 0 \\
\hline 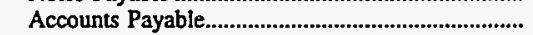 & 877 & 2,839 & 3,677 & 2,680 & 1,882 & 1,271 \\
\hline Payables to Assoc Enterprises................................. & 0 & 0 & 0 & 0 & 0 & 0 \\
\hline 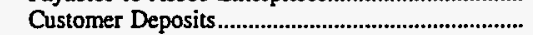 & 83 & 554 & 189 & 883 & 131 & 0 \\
\hline 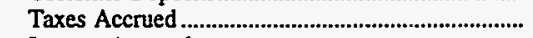 & 0 & 45 & 0 & 250 & 13 & 0 \\
\hline 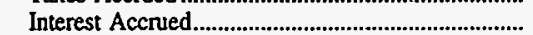 & 124 & 55 & 0 & 170 & 152 & 2 \\
\hline Misc Current \& Accrued Liabilfties .............................. & 920 & 786 & 0 & 878 & -90 & 215 \\
\hline Total Current \& Accrued Liabilities .................. & 2,659 & 4,369 & 3,866 & 4,862 & 2,174 & 1,488 \\
\hline \multicolumn{7}{|l|}{ Deferred Credits } \\
\hline Customer Advances for Construction ........................... & 277 & 0 & 192 & 2,039 & 96 & 17 \\
\hline 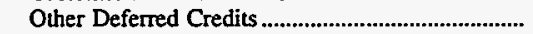 & 0 & 0 & 0 & 2,911 & 359 & 301 \\
\hline 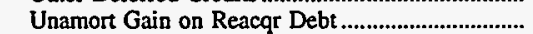 & 0 & 0 & 0 & 0 & 0 & 0 \\
\hline 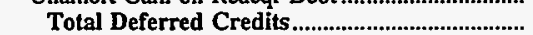 & 277 & 0 & 192 & 4,951 & 455 & 318 \\
\hline Total Liabilities and Other Credits....................... & 33,589 & 25,199 & 49,583 & 62,155 & 35,885 & 28,605 \\
\hline
\end{tabular}

Note: Totals may not equal sum of components because of independent rounding.

Source: Energy Information Administration, Form EIA-412, "Annual Report of Public Electric Utilities." 
Table 22. Balance Sheet by Major U.S. Publicly Owned Electric Utility Within State at End of Period, 1996

(Thousand Dollars)

\begin{tabular}{|c|c|c|c|c|c|c|}
\hline Item & $\begin{array}{l}\text { Massachusetts } \\
\text { Hingham } \\
\text { City of } \\
\text { December } 31\end{array}$ & $\begin{array}{l}\text { Massachusetts } \\
\text { Holyoke } \\
\text { City of } \\
\text { December } 31\end{array}$ & $\begin{array}{l}\text { Massachusetts } \\
\text { Hudson } \\
\text { Town of } \\
\text { December } 31\end{array}$ & $\begin{array}{l}\text { Massachusetts } \\
\text { Littleton } \\
\text { Town of } \\
\text { December } 31\end{array}$ & $\begin{array}{l}\text { Massachusetts } \\
\text { Mansfield } \\
\text { Town of } \\
\text { December } 31\end{array}$ & $\begin{array}{l}\text { Massachusetts } \\
\text { Massachusetts } \\
\text { Mun } \\
\text { Whls } \\
\text { Elec Co } \\
\text { December } 31\end{array}$ \\
\hline \multicolumn{7}{|l|}{ Electric Utility Plant } \\
\hline 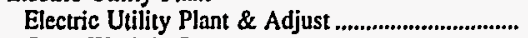 & 23,175 & 57,149 & 19,964 & 17,050 & 11,519 & $1,234,201$ \\
\hline 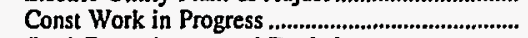 & & 2,325 & & 206 & & 3,104 \\
\hline 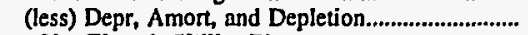 & 7,440 & 33,731 & 14,108 & 6,885 & 6,690 & 371,762 \\
\hline 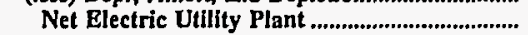 & 15,734 & 25,744 & 5,856 & 10,372 & 4,829 & 865,544 \\
\hline Nuclear Fuel........................................................... & & & 268 & D & 0 & 83,324 \\
\hline (less) Amort of Nucl Fuel...................................... & & & 204 & 0 & 0 & 69,824 \\
\hline Net Elec Plant Incl Nucl Fuel .............................. & 15,734 & 25,744 & 5,921 & 10,372 & 4,829 & 879,044 \\
\hline \multicolumn{7}{|l|}{ Other Property \& Investments } \\
\hline Nonutility Propenty ........................... & 0 & 22,445 & 0 & 0 & 0 & 0 \\
\hline (less) Accum Provisions for Depr \& Amort ........ & 0 & 12,025 & 0 & 0 & 0 & 0 \\
\hline 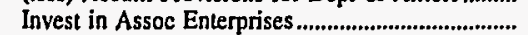 & 0 & 1,587 & 142 & 0 & 0 & 0 \\
\hline 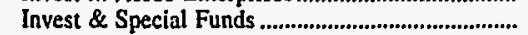 & 1,779 & 0 & 12,641 & 8,743 & 2,126 & 0 \\
\hline Total Other Property \& Investments................... & 1,779 & 12,006 & 12,782 & 8,743 & 2,126 & 0 \\
\hline \multicolumn{7}{|l|}{ Current and Accrued Assets } \\
\hline 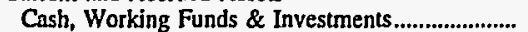 & 1,010 & 6,028 & 2,556 & 36 & 1,158 & 225,092 \\
\hline Notes \& Other Receivables................................... & 4 & 519 & 31 & 192 & 61 & 6,042 \\
\hline 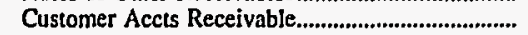 & 1,516 & 5,844 & 2,735 & 1,388 & 1,306 & 172 \\
\hline (less) Accum Prov for Uncollected Accts................ & 0 & 500 & 0 & 20 & 0 & 0 \\
\hline 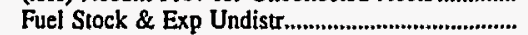 & 0 & 1,137 & 192 & 0 & 0 & 4,398 \\
\hline 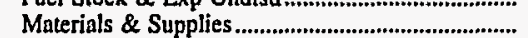 & 204 & 1,340 & 788 & 542 & 400 & 9,440 \\
\hline 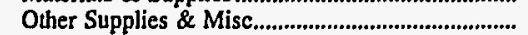 & 0 & 0 & 0 & 0 & 0 & 35 \\
\hline 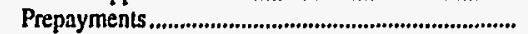 & 584 & 1,159 & 1,910 & 2,247 & 5,012 & 12,393 \\
\hline Accrued Utility Revenues & 0 & 0 & 0 & 0 & 0 & 6,620 \\
\hline 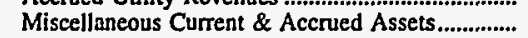 & .0 & 1,147 & 42 & 0 & 0 & \\
\hline Total Current \& Accrued Assets.......................... & 3,319 & 16,675 & 8,255 & 4,384 & 7,937 & 264,191 \\
\hline \multicolumn{7}{|l|}{ Deferred Debits } \\
\hline 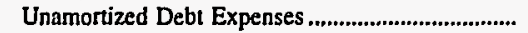 & 59 & 140 & $\mathbf{0}$ & 0 & 0 & 29,865 \\
\hline Extraordinary Losses, Study Cost ............................ & 0 & 0 & 0 & 0 & 0 & 1,213 \\
\hline 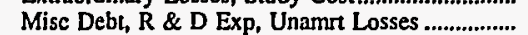 & 0 & 1,132 & 0 & 0 & 3 & 225,789 \\
\hline Total Deferred Debits............................................. & 59 & 1,272 & & o & 3 & 256,867 \\
\hline \multirow{2}{*}{\multicolumn{7}{|c|}{ Proprietary Capital }} \\
\hline & & & & & & \\
\hline 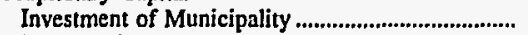 & 0 & 0 & 20 & 22,034 & 0 & $\mathbf{0}$ \\
\hline 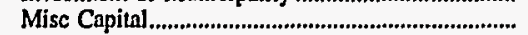 & 0 & 0 & 0 & 0 & 13 & 0 \\
\hline 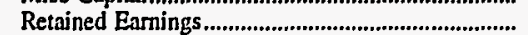 & 14,735 & 43,519 & 25,050 & 0 & 13,496 & 0 \\
\hline Total Proprietary Capital..................................... & 14,735 & 43,519 & 25,070 & 22,034 & $\mathbf{1 3 , 5 0 8}$ & 0 \\
\hline \multicolumn{7}{|l|}{ Long-term Debt } \\
\hline 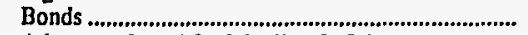 & 3,035 & 3,240 & 0 & 0 & 0 & $1,264,050$ \\
\hline Advances from Municipality \& Other...................... & 0 & $\mathbf{0}$ & 0 & 84 & 0 & 0 \\
\hline Unamort Prem on Long-term Debt............................. & 0 & 0 & 0 & 0 & 0 & 0 \\
\hline (less) Unamort Discount on Long-term Debt & 0 & 0 & 0 & 0 & 0 & 0 \\
\hline 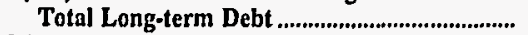 & 3,035 & 3,240 & 0 & 84 & 0 & $1,264,050$ \\
\hline \multicolumn{7}{|l|}{ Other Noncurrent Liabilities } \\
\hline Accum Opernting Provisions....................................... & 0 & 0 & 605 & 0 & 46 & 2,111 \\
\hline Accum Prov for Rate Refunds.................................. & 0 & 0 & 0 & 0 & 0 & \\
\hline \multirow{2}{*}{\multicolumn{7}{|c|}{ Cument and Accrued Liabilities }} \\
\hline & & & & & & \\
\hline 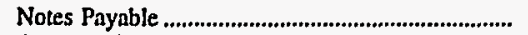 & 0 & 0 & $\mathbf{0}$ & 0 & 0 & 0 \\
\hline 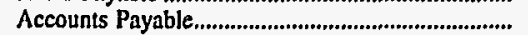 & 1,238 & 7,560 & 833 & 1,348 & 858 & 40,263 \\
\hline Payables to Assoc Enterprises................................ & 338 & 0 & 0 & 0 & 293 & 0 \\
\hline 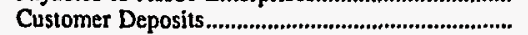 & 397 & 924 & 350 & 32 & 198 & 0 \\
\hline 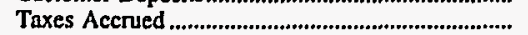 & 4 & 0 & 15 & 0 & -9 & 44 \\
\hline 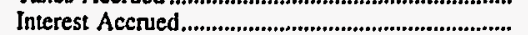 & 63 & 34 & 0 & 0 & 0 & 283 \\
\hline Misc Current \& Accrued Liabilities ............................. & 116 & 0 & 59 & 0 & 0 & 51,705 \\
\hline Total Current \& Accrued Liabilities ..................... & 2,156 & 8,518 & 1,256 & 1,380 & 1,341 & 92,294 \\
\hline \multicolumn{7}{|l|}{ Deferred Credits } \\
\hline 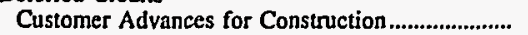 & 537 & 0 & 2 & 0 & 0 & -2 \\
\hline 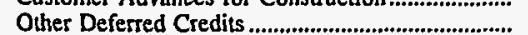 & 428 & 421 & 24 & 0 & 0 & 41,649 \\
\hline Unamort Gain on Reacgr Debt............................ & 0 & 0 & 0 & 0 & 0 & \\
\hline Total Deferred Credits .............................................. & 965 & 421 & 26 & & & 41,647 \\
\hline Total Liabilities and Other Credits................... & 20,891 & 55,698 & 26,958 & 23,499 & 14,895 & $1,400,102$ \\
\hline
\end{tabular}

Note: Totals may not equal sum of components because of independent rounding.

Source: Energy Information Administration, Form EIA-412, "Annual Report of Public Electric Utilities." 
Table 22. Balance Sheet by Major U.S. Publicly Owned Electric Utility Within State at End of Period, 1996

(Thousand Dollars)

\begin{tabular}{|c|c|c|c|c|c|c|}
\hline Item & $\begin{array}{l}\text { Massachusetts } \\
\text { Middleborough } \\
\text { Town of } \\
\text { December } 31\end{array}$ & $\begin{array}{l}\text { Massachusetts } \\
\text { North } \\
\text { Attleborough } \\
\text { Town of } \\
\text { December } 31\end{array}$ & $\begin{array}{l}\text { Massachusetts } \\
\text { Norwood } \\
\text { City of } \\
\text { June } 30\end{array}$ & $\begin{array}{l}\text { Massachusetts } \\
\text { Peabody } \\
\text { City of } \\
\text { December } 31\end{array}$ & $\begin{array}{l}\text { Massachusetts } \\
\text { Reading } \\
\text { Town of } \\
\text { December } 31\end{array}$ & $\begin{array}{l}\text { Massachusetts } \\
\text { Shrewsbury } \\
\text { Town of } \\
\text { December } 31\end{array}$ \\
\hline \multicolumn{7}{|l|}{ Electric Utility Plant } \\
\hline 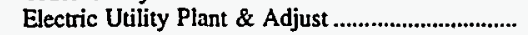 & 16,481 & 21,469 & 23,577 & 65,472 & 54,135 & 26,934 \\
\hline 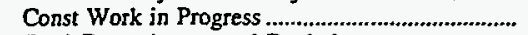 & & 3,039 & & & & 1,500 \\
\hline 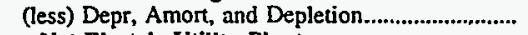 & 7,591 & 7,981 & 17,024 & 26,901 & 24,082 & 12,919 \\
\hline 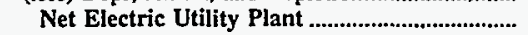 & 8,890 & 16,528 & 6,553 & 38,570 & 30,053 & 15,514 \\
\hline 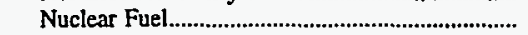 & 0 & 0 & 0 & 0 & 0 & 0 \\
\hline 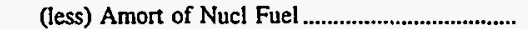 & 0 & 0 & 0 & 0 & 0 & 0 \\
\hline Net Blec Plant Incl Nucl Fuel .................................. & $\mathbf{8 , 8 9 0}$ & 16,528 & 6,553 & $\mathbf{3 8 , 5 7 0}$ & 30,053 & 15,514 \\
\hline \multicolumn{7}{|l|}{ Other Property \& Investments } \\
\hline Nonutility Property .......................................................... & 0 & 0 & 0 & 0 & $\mathbf{0}$ & 0 \\
\hline (less) Accum Provisions for Depr \& Amort ........... & 0 & 0 & 0 & 0 & 0 & 0 \\
\hline 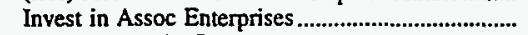 & 102 & 86 & $\mathbf{0}$ & 0 & 433 & 150 \\
\hline 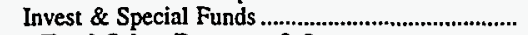 & 1,576 & 3,169 & 3,548 & 10,060 & 4,158 & 4,242 \\
\hline Total Other Property \& Investments................... & 1,678 & 3,255 & $\mathbf{3 , 5 4 8}$ & 10,060 & 4,592 & 4,392 \\
\hline \multicolumn{7}{|l|}{ Current and Accrued Assets } \\
\hline 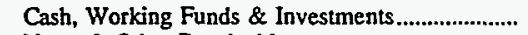 & 3,136 & 6,529 & 1,307 & 4,739 & 15,410 & 5,632 \\
\hline 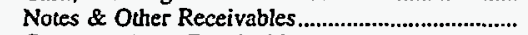 & 90 & 32 & & 129 & 322 & 24 \\
\hline Customer Accts Receivable & 3,362 & 1,606 & 1,520 & 3,855 & 2,682 & 1,527 \\
\hline (less) Accum Prov for Uncollected Accts................... & 650 & 599 & 630 & 100 & 300 & 0 \\
\hline 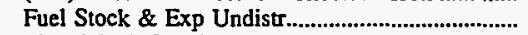 & 0 & 12 & 0 & 117 & 0 & 0 \\
\hline 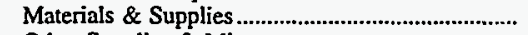 & 763 & 776 & 0 & 831 & 734 & 180 \\
\hline 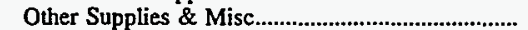 & 0 & 0 & 0 & 0 & 63 & 0 \\
\hline 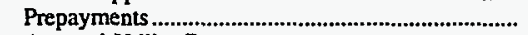 & 1,745 & 171 & 0 & 748 & 656 & 1,748 \\
\hline 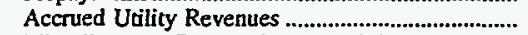 & 0 & 0 & 0 & 0 & 0 & 0 \\
\hline Miscellaneous Current \& Accrued Assets............... & 0 & 0 & 0 & $\mathbf{0}$ & 0 & 0 \\
\hline Total Current \& Accrued Assets.............................. & 8,446 & 8,527 & 2,197 & 10,320 & 19,567 & 9,111 \\
\hline \multicolumn{7}{|l|}{ Deferred Debits } \\
\hline Unamortized Debt Expenses .......................................... & 0 & 252 & 0 & 156 & 36 & $\mathbf{0}$ \\
\hline 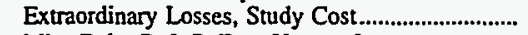 & 0 & 95 & 0 & 0 & 0 & 0 \\
\hline Misc Debt, R \& D Exp, Unamrt Losses ................. & 6 & 0 & 0 & 0 & 466 & 6 \\
\hline 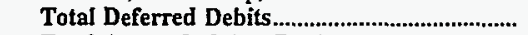 & 6 & 346 & 0 & 156 & 502 & 6 \\
\hline 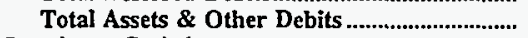 & 19,020 & 28,656 & 12,297 & 59,106 & 54,714 & 29,024 \\
\hline \multicolumn{7}{|l|}{ Proprietary Capital } \\
\hline 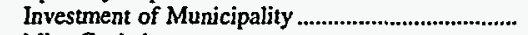 & 11,779 & 684 & 8,367 & 6,485 & 38,950 & 0 \\
\hline 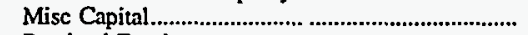 & 3,341 & 22,443 & & & 0 & 0 \\
\hline 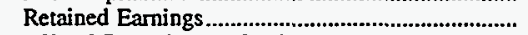 & 0 & & 1,428 & 22,702 & 0 & 25,158 \\
\hline Total Proprietary Capital ............................................ & 15,120 & 23,127 & 9,795 & 29,187 & 38,950 & 25,158 \\
\hline \multicolumn{7}{|l|}{ Long-term Debt } \\
\hline Bonds ................... & 680 & 2,673 & 0 & 17,650 & 5,751 & 955 \\
\hline Advances from Municipality \& Other........................ & 0 & 0 & 0 & 0 & 0 & 95 \\
\hline 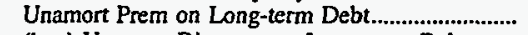 & 0 & 0 & 0 & 0 & 0 & 0 \\
\hline (less) Unamort Discount on Long-term Debt & $\mathbf{0}$ & 0 & 0 & 0 & 0 & 0 \\
\hline 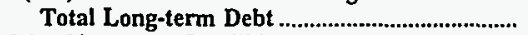 & 680 & 2,673 & 0 & 17,650 & 5,751 & 1,050 \\
\hline \multicolumn{7}{|l|}{ Other Noncurrent Liabilities } \\
\hline Accum Operating Provisions.............................................. & 0 & 0 & 0 & 8.059 & 0 & 0 \\
\hline 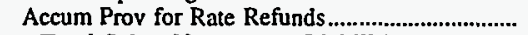 & 0 & 0 & 0 & 0 & 0 & 295 \\
\hline Total Other Noncurrent Liabilities ........................ & 0 & 0 & $\mathbf{0}$ & 8,059 & $\mathbf{0}$ & 295 \\
\hline \multicolumn{7}{|l|}{ Current and Accrued Liabilities } \\
\hline 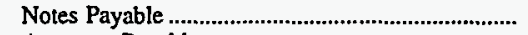 & 0 & 0 & 0 & 0 & 0 & $\mathbf{0}$ \\
\hline 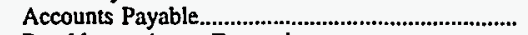 & 1,068 & 2,179 & 1,855 & 1,970 & 4,081 & 1,948 \\
\hline 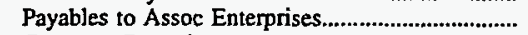 & 0 & 0 & 0 & 154 & 0 & 0 \\
\hline 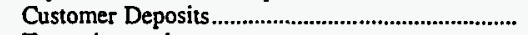 & 9 & 294 & 365 & 1,716 & 676 & 462 \\
\hline 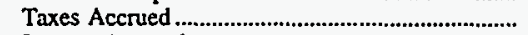 & 8 & 6 & 130 & 0 & 0 & 31 \\
\hline 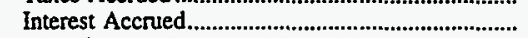 & 27 & 14 & 0 & 372 & 103 & 19 \\
\hline Misc Current \& Accrued Liabilities ............................ & 290 & 365 & 17 & 0 & 1,258 & 0 \\
\hline Total Current \& Accrued Liabilities .................... & 1,401 & 2,856 & 2,367 & 4,211 & 6,118 & 2,459 \\
\hline \multicolumn{7}{|l|}{ Deferred Credits } \\
\hline 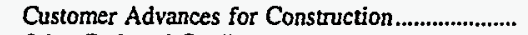 & 0 & 0 & 135 & 0 & 3,782 & 0 \\
\hline 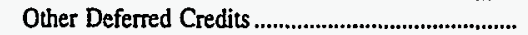 & 1,819 & 0 & 0 & 0 & 114 & 61 \\
\hline 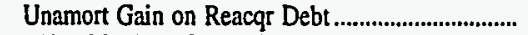 & 0 & 0 & 0 & 0 & 0 & 0 \\
\hline Total Deferred Credits................................................. & 1,819 & 0 & 135 & 0 & 3,895 & 61 \\
\hline Total Liabilities and Other Credits..................... & 19,020 & 28,656 & 12,297 & 59,106 & 54,714 & 29,024 \\
\hline
\end{tabular}

Note: Totals may not equal sum of components because of independent rounding.

Source: Energy Information Administration, Form EIA-412, "Annual Report of Public Electric Utilities." 
Table 22. Balance Sheet by Major U.S. Publicly Owned Electric Utility Within State at End of Period, 1996

(Thousand Dollars)

\begin{tabular}{|c|c|c|c|c|c|c|}
\hline Item & $\begin{array}{c}\text { Massachusetts } \\
\text { Taunton } \\
\text { City of } \\
\text { December } 31\end{array}$ & $\begin{array}{l}\text { Massachusetts } \\
\text { Wakefield } \\
\text { Town of } \\
\text { December } 31\end{array}$ & $\begin{array}{l}\text { Massachusetts } \\
\text { Wellesley } \\
\text { Town of } \\
\text { December } 31\end{array}$ & $\begin{array}{l}\text { Massachusetts } \\
\text { Westfield } \\
\text { City of } \\
\text { December } 31\end{array}$ & $\begin{array}{l}\text { Michigan } \\
\text { Bay } \\
\text { City City of } \\
\text { June } 30\end{array}$ & $\begin{array}{l}\text { Michigan } \\
\text { Coldwater } \\
\text { Board } \\
\text { of } \\
\text { Public Util } \\
\text { June } 30\end{array}$ \\
\hline \multicolumn{7}{|l|}{ Electric Utility Plant } \\
\hline 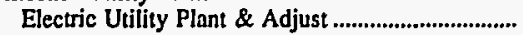 & 111,396 & 14,883 & 29,722 & 29,374 & 47,216 & 24,109 \\
\hline 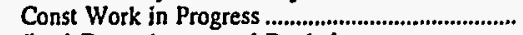 & 1,197 & & 1,370 & 33 & & \\
\hline 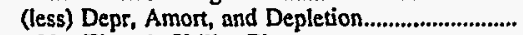 & 64,944 & 12,620 & 13,368 & 1,783 & 16,995 & 8,967 \\
\hline Net Electric Utility Plant ........................................ & 47,649 & 2,263 & 17,724 & 27,625 & 30,221 & 15,142 \\
\hline 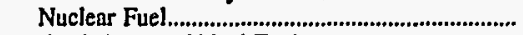 & 346 & & 0 & 0 & & 0 \\
\hline 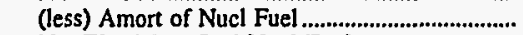 & 257 & 0 & 0 & 0 & 0 & 0 \\
\hline 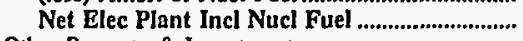 & 47,739 & 2,263 & 17,724 & 27,625 & 30,221 & 15,142 \\
\hline \multicolumn{7}{|l|}{ Other Property \& Investments } \\
\hline Nonutility Property....................... & $\mathbf{0}$ & 0 & 0 & 0 & 0 & 0 \\
\hline (less) Accum Provisions for Depr \& Amort .......... & 0 & 0 & 0 & $\mathbf{0}$ & $\mathbf{0}$ & 0 \\
\hline 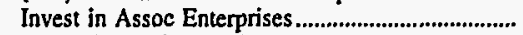 & 0 & 0 & 0 & 0 & 0 & 0 \\
\hline 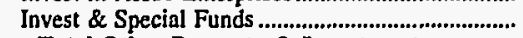 & 11,337 & 755 & 2,012 & 1,404 & 7,140 & 3,734 \\
\hline Total OGher Property \& Investments................ & 11,337 & 755 & 2,012 & 1,404 & 7,140 & $\mathbf{3 , 7 3 4}$ \\
\hline \multicolumn{7}{|l|}{ Current and Accrued Assets } \\
\hline Cash, Working Funds \& Investments...................... & 1,401 & 2,233 & 4,464 & 7,861 & 14,631 & 108 \\
\hline Notes \& Other Receivables.......................................... & 289 & 341 & 0 & 267 & 74 & 1,620 \\
\hline 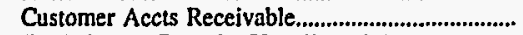 & 5,157 & 2,231 & 1,585 & 5,304 & 1,774 & 1,307 \\
\hline (less) Accum Prov for Uncollected Accts.............. & 0 & 145 & 45 & 1,316 & 46 & 0 \\
\hline Fuel Stock \& Exp Undistr................................................. & 353 & 0 & 0 & 0 & 0 & 0 \\
\hline 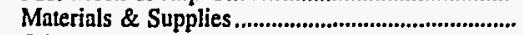 & 947 & 447 & 807 & 1,200 & 1,887 & 479 \\
\hline Other Supplies \& Misc........................................................... & -111 & 0 & 0 & 0 & 0 & 0 \\
\hline 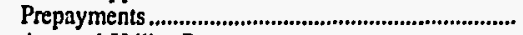 & 766 & 775 & 6 & 1,217 & 0 & 16 \\
\hline Accrued Utility Revenues ................................................ & 0 & 0 & 0 & 0 & 0 & 0 \\
\hline 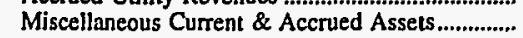 & 97 & 0 & 40 & 0 & 0 & 0 \\
\hline Total Current \& Accrued Assets......................... & 8,898 & 5,881 & 6,858 & 14,533 & 18,320 & 3,531 \\
\hline \multicolumn{7}{|l|}{ Deferred Debits } \\
\hline Unamortized Debt Expenses ............................................ & $\mathbf{0}$ & 0 & $\mathbf{0}$ & 35 & 821 & 0 \\
\hline 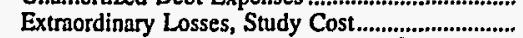 & 0 & 0 & 0 & 0 & 0 & 0 \\
\hline Misc Debt, R \& D Exp, Unamrt Losses ................. & 113 & 4 & 0 & 14 & 1,997 & 0 \\
\hline Total Deferred Debits.................................. & 113 & 4 & 0 & 49 & $\mathbf{2 , 8 1 9}$ & 0 \\
\hline 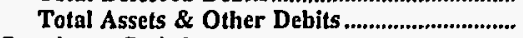 & 68,086 & 8,903 & 26,594 & 43,611 & 58,499 & 22,406 \\
\hline \multicolumn{7}{|l|}{ Proprietary Capital } \\
\hline 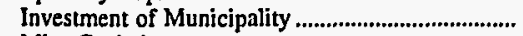 & 47,902 & 0 & 2,128 & 25,592 & 0 & 9,927 \\
\hline 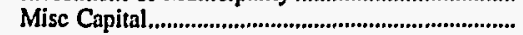 & & 0 & 0 & 0 & 0 & 0 \\
\hline 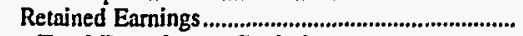 & $\mathbf{0}$ & 5,762 & 20,872 & 0 & 33,550 & 0 \\
\hline Total Proprietary Capital ........................................ & 47,902 & 5,762 & 23,000 & 25,592 & 33,550 & 9,927 \\
\hline \multicolumn{7}{|l|}{ Long-term Debt } \\
\hline Bonds ......................... & 14,530 & 0 & 200 & 8,290 & 22,625 & 8,500 \\
\hline Advances from Municipality \& Other........................ & 0 & 0 & 0 & 0 & 96 & 1,142 \\
\hline Unamort Prem on Long-term Debt............................. & 0 & 0 & 0 & 0 & 0 & 0 \\
\hline (less) Unamort Discount on Long-term Debt & 0 & 0 & $\mathbf{0}$ & 0 & $\mathbf{0}$ & 0 \\
\hline Total Long-term Debt ................................................. & 14,530 & $\mathbf{0}$ & 200 & 8,290 & 22,721 & 9,642 \\
\hline \multicolumn{7}{|l|}{ Other Noncurrent Liabilities } \\
\hline 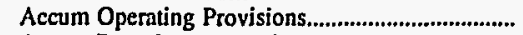 & 0 & $\mathbf{0}$ & 0 & 0 & $\mathbf{0}$ & 0 \\
\hline 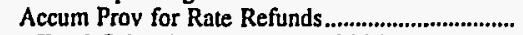 & 0 & 0 & 0 & 0 & 0 & 0 \\
\hline . Total Other Noncurrent Liabilities ................... & 0 & $\mathbf{0}$ & $\mathbf{0}$ & o & $\mathbf{0}$ & $\mathbf{0}$ \\
\hline \multicolumn{7}{|l|}{ Current and Accrued Liabilities } \\
\hline 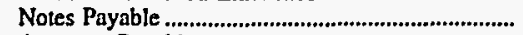 & 0 & 0 & 0 & 0 & 1,320 & 0 \\
\hline Accounts Payable...................................................... & 3,742 & 543 & 2,845 & 4,239 & 86 & 1,143 \\
\hline 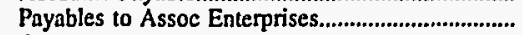 & 0 & 0 & 0 & 42 & 487 & 178 \\
\hline 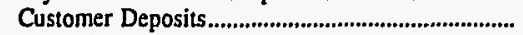 & 433 & 659 & 465 & 176 & 72 & 75 \\
\hline 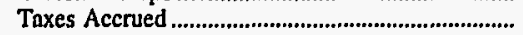 & 0 & 0 & 0 & 14 & 0 & 0 \\
\hline 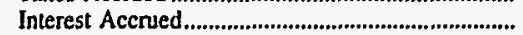 & 498 & 0 & $\mathbf{0}$ & & 0 & 34 \\
\hline Misc Current \& Accrued Liabilities .......................... & 407 & 1,939 & 1 & 3,801 & 219 & 1,407 \\
\hline Total Current \& Accrued Liabilities .................... & 5,080 & 3,142 & 3,311 & 8,272 & 2,185 & $\mathbf{2 , 8 3 8}$ \\
\hline \multicolumn{7}{|l|}{ Deferred Credits } \\
\hline Customer Advances for Construction........................ & 30 & 0 & 83 & & 44 & $\mathbf{0}$ \\
\hline Other Deferred Credits .............................................. & -338 & 0 & 0 & 1,458 & 0 & 0 \\
\hline Unamort Gain on Reacqr Debt ........................................ & 883 & 0 & 0 & o & 0 & 0 \\
\hline Total Deferred Credits.................................................... & 575 & $\mathbf{0}$ & 83 & 1,458 & 44 & 0 \\
\hline Total Liabilities and Other Credits................... & 68,086 & 8,903 & 26,594 & 43,611 & 58,499 & 22,406 \\
\hline
\end{tabular}

Note: Totals may not equal sum of components because of independent rounding.

Source: Energy Information Administration, Form EIA-412, "Annual Report of Public Electric Utilities." 
Table 22. Balance Sheet by Major U.S. Publicly Owned Electric Utility Within State at End of Period, 1996

(Thousand Dollars)

\begin{tabular}{|c|c|c|c|c|c|c|}
\hline Item & $\begin{array}{l}\text { Michigan } \\
\text { Detroit } \\
\text { City of } \\
\text { June } 30\end{array}$ & 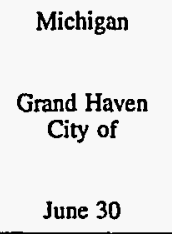 & $\begin{array}{c}\text { Michigan } \\
\text { Hillsdale } \\
\text { Board } \\
\text { of } \\
\text { Public Wks } \\
\text { June } 30\end{array}$ & $\begin{array}{l}\text { Michigan } \\
\text { Holland } \\
\text { City of } \\
\text { June } 30\end{array}$ & $\begin{array}{l}\text { Michigan } \\
\text { Lansing } \\
\text { City of } \\
\text { June } 30\end{array}$ & $\begin{array}{c}\text { Michigan } \\
\begin{array}{c}\text { Marquelte } \\
\text { City of }\end{array} \\
\text { June } 30\end{array}$ \\
\hline \multicolumn{7}{|l|}{ Electric Utility Plant } \\
\hline Electric Utility Plant \& Adjust ........................................ & 290,653 & 106,391 & 11,538 & 107,235 & 412,415 & 99,751 \\
\hline 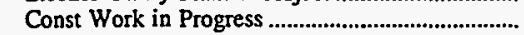 & 15,787 & 293 & 685 & 4,112 & 21,725 & 17 \\
\hline 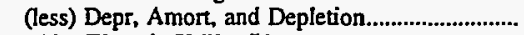 & 130,673 & 49,408 & 8,036 & 50,990 & 240,643 & 48,241 \\
\hline Net Electric Utility Plant ....................................... & 175,766 & 57,276 & 4,187 & 60,357 & 193,497 & 51,527 \\
\hline Nuclear Fuel.......................................................... & 0 & 0 & 0 & 0 & 0 & 0 \\
\hline (less) Amort of Nucl Fuel ............................... & 0 & & 0 & 0 & $\mathbf{0}$ & $\mathbf{0}$ \\
\hline Net Elec Plant Incl Nucl Fuel .................................. & 175,766 & 57,276 & 4,187 & 60,357 & 193,497 & 51,527 \\
\hline \multicolumn{7}{|l|}{ Other Property \& Investments } \\
\hline Nonutility Property & 0 & 0 & $\mathbf{0}$ & 0 & $\mathbf{0}$ & $\mathbf{0}$ \\
\hline (less) Accum Provisions for Depr \& Amort .......... & 0 & 0 & 0 & 0 & 0 & 0 \\
\hline 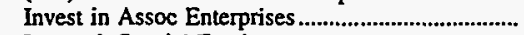 & 0 & 0 & 1,397 & 0 & 0 & 0 \\
\hline 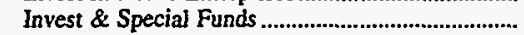 & 0 & 0 & 0 & 0 & 24,180 & 14,578 \\
\hline Total Other Property \& Investments................ & $\mathbf{0}$ & $\mathbf{0}$ & 1,397 & 0 & 24,180 & 14,578 \\
\hline \multicolumn{7}{|l|}{ Current and Accrued Assets } \\
\hline 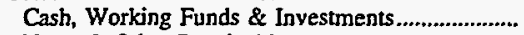 & 61,669 & 22,491 & 4,920 & 44,697 & 55,029 & 4,735 \\
\hline Notes \& Other Receivables ............................................ & 12,656 & 299 & 255 & 890 & 0 & 0 \\
\hline Customer Accts Receivable................................................ & 22,768 & 1,812 & 1,156 & 2,165 & 11,579 & 1,126 \\
\hline (less) Accum Prov for Uncollected Accts............... & 2,685 & 0 & 120 & 10 & 637 & 148 \\
\hline Fuel Stock \& Exp Undistr.............................................. & 2,620 & 2,167 & 0 & 3,207 & 6,367 & 1,033 \\
\hline Materials \& Supplies .................................................... & 8,048 & 0 & 802 & 2,428 & 4,395 & 330 \\
\hline 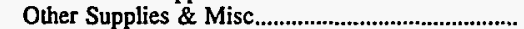 & 0 & 0 & 0 & 0 & 0 & 0 \\
\hline 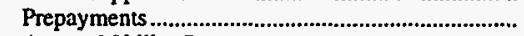 & 0 & 47 & 10 & 0 & 236 & 36 \\
\hline 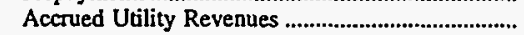 & 0 & 0 & 31 & 2,032 & 0 & 0 \\
\hline Miscellaneous Current \& Accrued Assets............... & 0 & 34 & 0 & 0 & 2,265 & 5 \\
\hline Total Current \& Accrued Assets.......................... & 105,076 & 26,850 & 7,054 & 55,410 & 79,233 & 7,117 \\
\hline \multicolumn{7}{|l|}{ Deferred Debits } \\
\hline Unamortized Debt Expenses........................................ & 0 & 828 & 0 & 0 & $\mathbf{0}$ & 383 \\
\hline Extraordinary Losses, Study Cost.............................. & 0 & 0 & 0 & 0 & $\mathbf{0}$ & 0 \\
\hline 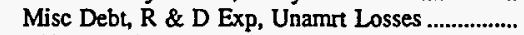 & 1,484 & 0 & 0 & 0 & 3,832 & 0 \\
\hline Total Deferred Debits...................................... & 1,484 & 828 & 0 & 0 & $\mathbf{3 , 8 3 2}$ & 383 \\
\hline 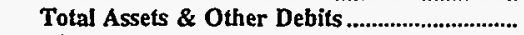 & 282,327 & 84,954 & 12,638 & 115,767 & 300,742 & 73,604 \\
\hline \multicolumn{7}{|l|}{ Proprietary Capital } \\
\hline 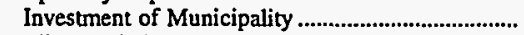 & 251,244 & 0 & 0 & 0 & 0 & 0 \\
\hline 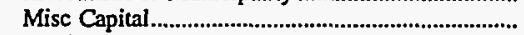 & $-227,272$ & 0 & 0 & 0 & $-38,085$ & 0 \\
\hline 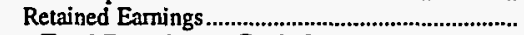 & 177,453 & 892 & 11,210 & 77,455 & 276,795 & 30,693 \\
\hline 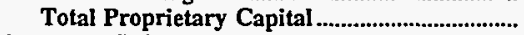 & 201,426 & 892 & 11,210 & $\mathbf{7 7 , 4 5 5}$ & $\mathbf{2 3 8 , 7 1 0}$ & 30,693 \\
\hline \multicolumn{7}{|l|}{ Long-term Debt } \\
\hline Bonds .................. & 66,983 & 92,180 & 0 & 31,305 & 21,167 & 37,860 \\
\hline 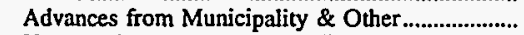 & 0 & 0 & 0 & 0 & 2,276 & 0 \\
\hline Unamort Prem on Long-term Debt............................. & 0 & 0 & 0 & 0 & 0 & 0 \\
\hline (less) Unamort Discount on Long-term Debt & 0 & 14,636 & 0 & 1,435 & 0 & 433 \\
\hline Total Long-term Debt ............................................. & 66,983 & $\mathbf{7 7 , 5 4 4}$ & $\mathbf{0}$ & 29,870 & 23,443 & $\mathbf{3 7 , 4 2 7}$ \\
\hline \multicolumn{7}{|l|}{ Other Noncurrent Ljabilities } \\
\hline Accum Operating Provisions...... & 0 & 0 & 0 & 0 & 25,841 & 776 \\
\hline Accum Prov for Rate Refunds...................................... & 0 & 0 & 0 & 0 & 0 & 0 \\
\hline Total Other Noncurrent Liabilities ...................... & $\mathbf{0}$ & $\mathbf{0}$ & 0 & 0 & 25,841 & 776 \\
\hline \multicolumn{7}{|l|}{ Current and Acerued Liabilities } \\
\hline 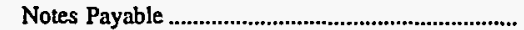 & 0 & 0 & 0 & 0 & 0 & 0 \\
\hline Accounts Payable................................................................. & 0 & 1,767 & 769 & 7,044 & 8,639 & 1,981 \\
\hline Payables to Assoc Enterprises............................................ & 8,359 & 0 & 0 & 0 & 0 & 0 \\
\hline Customer Deposits............................................................... & 0 & 185 & 17 & 234 & 724 & 1,000 \\
\hline 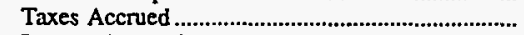 & 569 & 80 & 18 & -9 & 0 & 107 \\
\hline 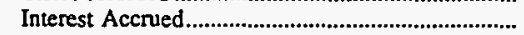 & 0 & 2,476 & 0 & 850 & 582 & 942 \\
\hline Misc Current \& Accrued Liabilities ............................. & 4,990 & 2,010 & 540 & 323 & 2,744 & 0 \\
\hline Total Current \& Accrued Liabilities .................. & 13,918 & 6,517 & 1,344 & $8, \mathbf{4 4 2}$ & 12,690 & 4,031 \\
\hline \multicolumn{7}{|l|}{ Deferred Credits } \\
\hline Customer Advances for Construction....................... & 0 & 0 & 0 & 0 & 58 & 677 \\
\hline 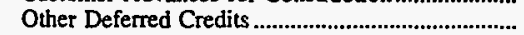 & 0 & 0 & 84 & 0 & 0 & 0 \\
\hline Unamort Gain on Reacqr Debt ....................................... & 0 & 0 & 0 & 0 & 0 & 0 \\
\hline Total Deferred Credits............................................. & 0 & & 84 & 0 & 58 & 677 \\
\hline Total Liabilities and Other Credits....................... & 282,327 & 84,954 & 12,638 & 115,767 & 300,742 & 73,604 \\
\hline
\end{tabular}

Note: Totals may not equal sum of components because of independent rounding.

Source: Energy Information Administration, Form EIA-412, "Annual Report of Public Electric Utilities." 
Table 22. Balance Sheet by Major U.S. Publicly Owned Electric Utility

Within State at End of Period, 1996

(Thousand Dollars)

\begin{tabular}{|c|c|c|c|c|c|c|}
\hline Item & $\begin{array}{c}\text { Michigan } \\
\begin{array}{c}\text { Michigan } \\
\text { Public } \\
\text { Power Agency }\end{array} \\
\text { December } 31\end{array}$ & $\begin{array}{l}\text { Michigan } \\
\text { Michigan } \\
\text { South } \\
\text { Central } \\
\text { Pwr Agy } \\
\text { June } 30 \\
\end{array}$ & $\begin{array}{l}\text { Michigan } \\
\text { Sturgis } \\
\text { City of } \\
\text { September } 30\end{array}$ & $\begin{array}{l}\text { Michigan } \\
\text { Traverse } \\
\text { City City of } \\
\text { June } 30 \\
\end{array}$ & $\begin{array}{c}\text { Michigan } \\
\text { Wyandotte } \\
\text { Municipal } \\
\text { Serv Comm } \\
\text { September } 30\end{array}$ & $\begin{array}{l}\text { Zeeland } \\
\text { City of } \\
\text { June } 30\end{array}$ \\
\hline \multicolumn{7}{|l|}{ Electric Uuility Plant } \\
\hline 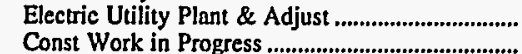 & $\begin{array}{r}470,788 \\
0\end{array}$ & 77,033 & 34,992 & 34,263 & 108,480 & 28,648 \\
\hline 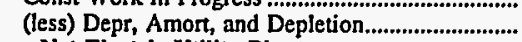 & 164,643 & 31,303 & 17,141 & 14,311 & $\begin{array}{r}1,018 \\
41,856\end{array}$ & 9,195 \\
\hline Net Electric Utility Plant ...................................... & 306,145 & 46,063 & 17,851 & 20,219 & 67,642 & 19,494 \\
\hline 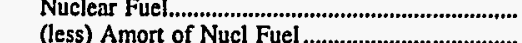 & & & & & & \\
\hline 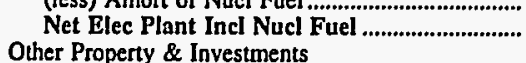 & 306,145 & 46,063 & 17,851 & 20,219 & $\begin{array}{r}0 \\
67,642\end{array}$ & 19,494 \\
\hline Nonutility Property & 653 & 0 & 0 & $\mathbf{0}$ & 0 & \\
\hline $\begin{array}{l}\text { (less) Accum Provisions for Depr \& Amor ........ } \\
\text { Invest in Assoc Enterprises }\end{array}$ & $\begin{array}{r}88 \\
0\end{array}$ & $\begin{array}{l}0 \\
0\end{array}$ & $\begin{array}{l}0 \\
0\end{array}$ & $\begin{array}{l}0 \\
0\end{array}$ & 0 & 0 \\
\hline Invest \& Special Funds .................................................. & 64,384 & 25,105 & 5,817 & 655 & 10,149 & 4,526 \\
\hline $\begin{array}{l}\text { Total Other Property \& Investments................ } \\
\text { Current and Accrued Assets }\end{array}$ & 64,948 & 25,105 & 5,817 & 655 & 10,149 & 4,526 \\
\hline \multicolumn{3}{|l|}{ Current and Acerued Assets } & o & 7,790 & 3.574 & 1314 \\
\hline 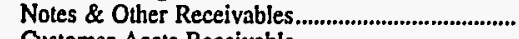 & 0 & 365 & 167 & 332 & 283 & $\begin{array}{l}1,314 \\
0\end{array}$ \\
\hline Customer Accts Receivable & 9,270 & 3,608 & 1,821 & 1,431 & 1,659 & 1,109 \\
\hline $\begin{array}{l}\text { (less) Accum Prov for Uncollected Accts............... } \\
\text { Fuel Stock \& Exp Undistr... }\end{array}$ & 9.948 & 0 & 0 & 51 & 55 & 0 \\
\hline 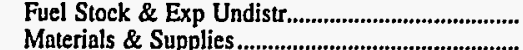 & $\begin{array}{l}9,948 \\
2,897\end{array}$ & 870 & 0 & 0 & 606 & 0 \\
\hline 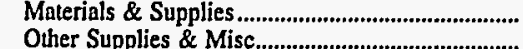 & $\begin{array}{r}2,897 \\
0\end{array}$ & 17 & 460 & 593 & 840 & 310 \\
\hline 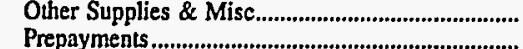 & 0 & 0 & 0 & 671 & 0 & 0 \\
\hline $\begin{array}{l}\text { Prepayments. } \\
\text { Accrued Utility Revenues }\end{array}$ & 0 & 52 & 3 & 114 & 163 & 7 \\
\hline Miscellaneous Current \& Accrued Assets............... & 957 & $\begin{array}{r}0 \\
497\end{array}$ & $\begin{array}{r}0 \\
1308\end{array}$ & 0 & 2,135 & 0 \\
\hline $\begin{array}{l}\text { Total Current \& Accrued Assets.......................... } \\
\text { Deferred Debits }\end{array}$ & 96,721 & 5,462 & $\begin{array}{l}1,398 \\
3,849\end{array}$ & 10,886 & $\begin{array}{r}0 \\
9,205\end{array}$ & $\begin{array}{r}0 \\
2,740\end{array}$ \\
\hline \multicolumn{7}{|l|}{$\begin{array}{l}\text { Deferred Debits } \\
\text { Unamortized Debt Expenses ............ }\end{array}$} \\
\hline 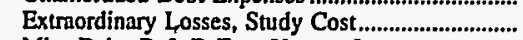 & 0 & $\begin{array}{l}2,100 \\
134\end{array}$ & 0 & 0 & o & 要 \\
\hline Misc Debt, $\mathrm{R} \&$ D Exp, Unamrt Losses ................. & 0 & 26,345 & 0 & 0 & 0 & 0 \\
\hline 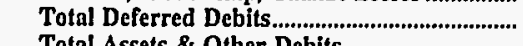 & 3,524 & 28,665 & 0 & 340 & & \\
\hline 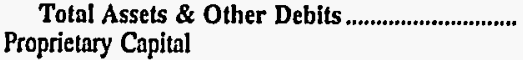 & 471,339 & 105,296 & $\mathbf{2 7 , 5 1 7}$ & 32,100 & 86,997 & 26,760 \\
\hline Investment of Municipality .......................................... & 423 & 0 & 0 & 382 & 0 & 0 \\
\hline 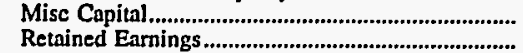 & $\begin{array}{r}0 \\
209\end{array}$ & $\begin{array}{r}0 \\
5,480\end{array}$ & $\begin{array}{r}0 \\
21,417\end{array}$ & $\begin{array}{r}0 \\
27,419\end{array}$ & $\begin{array}{r}2,269 \\
19,228\end{array}$ & $\begin{array}{r}597 \\
16.631\end{array}$ \\
\hline \multirow{2}{*}{\multicolumn{4}{|c|}{ 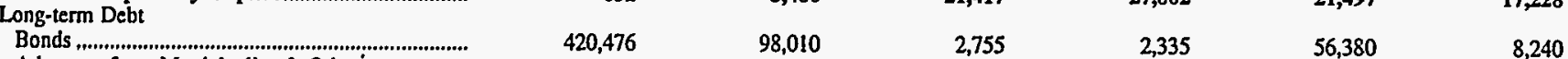 }} & 27,802 & 21,497 & 17,228 \\
\hline & & 98,010 & 2,755 & 2,335 & 56,380 & 8.240 \\
\hline Advances from Municipality \& Other...................... & & & 359 & 0 & 0 & 0 \\
\hline Unamort Prem on Long-term Debt.... & & $\begin{array}{r}0 \\
2605\end{array}$ & 0 & 0 & 0 & 0 \\
\hline 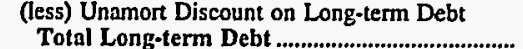 & $\begin{array}{r}0 \\
420.476\end{array}$ & $\begin{array}{r}2,645 \\
95,365\end{array}$ & 3.114 & 2.335 & $\begin{array}{r}0 \\
56380\end{array}$ & 0 \\
\hline \multicolumn{7}{|l|}{$\begin{array}{l}\text { Ohter Noncurrent L Liabilities } \\
\text { Accum Operati........ }\end{array}$} \\
\hline (............................... & 0 & $\mathbf{0}$ & 1,259 & 340 & 4,970 & 0 \\
\hline Liabilities & $\begin{array}{l}0 \\
0\end{array}$ & 0 & $\begin{array}{r}0 \\
0\end{array}$ & 0 & 0 & 0 \\
\hline \multirow{2}{*}{\multicolumn{7}{|c|}{ 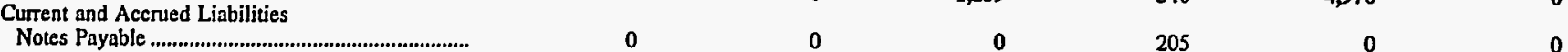 }} \\
\hline & 0 & 0 & 0 & 205 & 0 & 0 \\
\hline Payable........................................................ & 5,287 & 3,082 & 1,424 & 980 & 0 & 1,152 \\
\hline 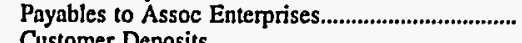 & 0 & 0 & 0 & 0 & 0 & 0 \\
\hline 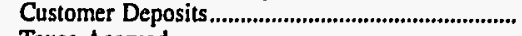 & 0 & 0 & 3 & 84 & 181 & 0 \\
\hline 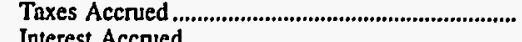 & & 59 & 0 & 0 & 0 & 0 \\
\hline Accrued Liabilities & $\begin{array}{l}11,593 \\
812\end{array}$ & $\begin{array}{l}933 \\
377\end{array}$ & 0 & 58 & 41 & 109 \\
\hline $\begin{array}{l}\text { Misc Current \& Accrued Liabilitites ............................ } \\
\text { Total Current \& Accrued Liabilities }\end{array}$ & 17.692 & 571 & & 296 & 3,928 & 32 \\
\hline & 1,624 & 4,151 & 1,293 \\
\hline Customer Advances for Construction ......... & 0 & 0 & 300 & 0 & 0 & 0 \\
\hline 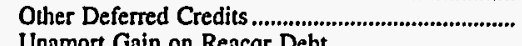 & 32,539 & 0 & 0 & 0 & $\mathbf{0}$ & \\
\hline 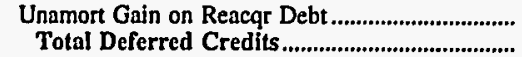 & $\begin{array}{r}0 \\
32,539\end{array}$ & & 300 & $\begin{array}{l}0 \\
0\end{array}$ & $\begin{array}{l}0 \\
0\end{array}$ & $\begin{array}{l}0 \\
0\end{array}$ \\
\hline 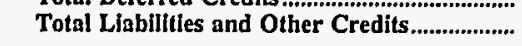 & 471,339 & 105,296 & 27,517 & 32,100 & 86,997 & 26,760 \\
\hline
\end{tabular}

Note: Totals may not equal sum of components because of independent rounding.

Source: Energy Information Administration, Form EIA-412, "Annual Report of Public Electric Utilities." 
Table 22. Balance Sheet by Major U.S. Publicly Owned Electric Utility Within State at End of Period, 1996

(Thousand Dollars)

\begin{tabular}{|c|c|c|c|c|c|c|}
\hline Item & $\begin{array}{l}\text { Minnesota } \\
\text { Alexandria } \\
\text { City of } \\
\text { December } 31\end{array}$ & $\begin{array}{l}\text { Minnesota } \\
\text { Anoka } \\
\text { City of } \\
\text { December } 31\end{array}$ & $\begin{array}{l}\text { Minnesota } \\
\text { Austin } \\
\text { City of } \\
\text { December } 31\end{array}$ & $\begin{array}{c}\text { Minnesota } \\
\text { Brainerd } \\
\text { Public } \\
\text { Utilities } \\
\text { December } 31\end{array}$ & $\begin{array}{l}\text { Minnesota } \\
\text { Chaska } \\
\text { City of } \\
\text { December } 31\end{array}$ & $\begin{array}{l}\text { Minnesota } \\
\text { Fairmont } \\
\text { Public } \\
\text { Utilities } \\
\text { Comm } \\
\text { December 31 }\end{array}$ \\
\hline \multicolumn{7}{|l|}{ Electric Utility Plant } \\
\hline 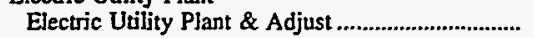 & 16,616 & 16,931 & 35,319 & 7,803 & 9,898 & 19,519 \\
\hline Const Work in Progress & 2,074 & & 211 & 3,017 & 0 & \\
\hline 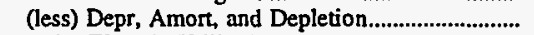 & 9,621 & 7,407 & 21,887 & 3,846 & 4,311 & 12,300 \\
\hline 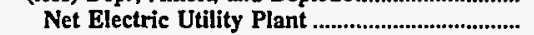 & 9,069 & 9,524 & 13,643 & 6,974 & 5,587 & 7,219 \\
\hline 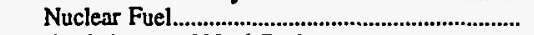 & 0 & 0 & 0 & 0 & 0 & 0 \\
\hline (less) Amort of Nucl Fuel........................................ & 0 & 0 & 0 & 0 & 0 & 0 \\
\hline Net Elec Plant Incl Nucl Fuel ........................... & 9,069 & 9,524 & 13,643 & 6,974 & 5,587 & 7,219 \\
\hline \multicolumn{7}{|l|}{ Other Property \& Investments } \\
\hline Nonutility Property.................. & 5,604 & 0 & 16,130 & 1,426 & 0 & 0 \\
\hline (less) Accum Provisions for Depr \& Amort ........... & 2,213 & 0 & 7,151 & 840 & 0 & 0 \\
\hline 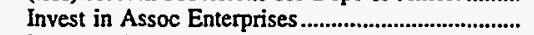 & 0 & 0 & 0 & 0 & 0 & 0 \\
\hline 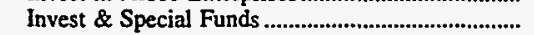 & 4,862 & 0 & 13,712 & 2,562 & 0 & 0 \\
\hline Total Other Property \& Investments............... & 8,253 & 0 & 22,692 & 3,147 & o & 0 \\
\hline \multicolumn{7}{|l|}{ Current and Accrued Assets } \\
\hline Cash, Working Funds \& Investments .......................... & 56 & 5,689 & 4,140 & 686 & 5,540 & 701 \\
\hline 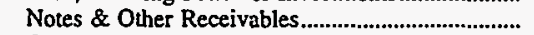 & 84 & 0 & 115 & 39 & 883 & 5,398 \\
\hline 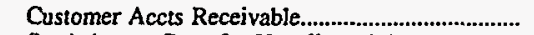 & 365 & 1,670 & 2,941 & 701 & 1,041 & 1,904 \\
\hline (less) Accum Prov for Uncollected Accts ................... & 11 & & 60 & 0 & 9 & 32 \\
\hline 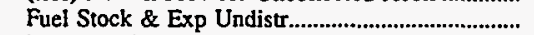 & 4 & 0 & 5 & 0 & 0 & 23 \\
\hline 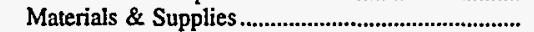 & 20 & 338 & 1,194 & 636 & 658 & 268 \\
\hline 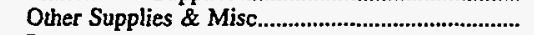 & 477 & 0 & & 0 & 0 & 0 \\
\hline 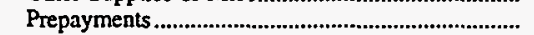 & 99 & 0 & 736 & 51 & 0 & 0 \\
\hline 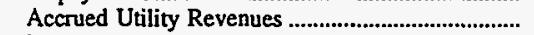 & 0 & 0 & 0 & 0 & 466 & 0 \\
\hline Miscellaneous Current \& Accrued Assets............... & 0 & 79 & 264 & 0 & 0 & 0 \\
\hline \multirow{2}{*}{\multicolumn{7}{|c|}{ Deferred Debits }} \\
\hline & & & & & & \\
\hline 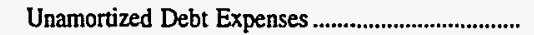 & 0 & 0 & 493 & 0 & 1,972 & 0 \\
\hline 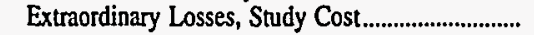 & 0 & 0 & 0 & 0 & 0 & 0 \\
\hline Misc Debt, R \& D Exp, Unamrt Losses ................ & 747 & 0 & 0 & 0 & 0 & 0 \\
\hline 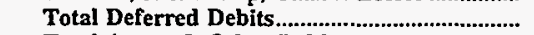 & 747 & $\mathbf{0}$ & 493 & $\mathbf{0}$ & 1,972 & 0 \\
\hline Total Assets \& Other Debits .................................... & 19,163 & 17,300 & 46,164 & 12,235 & 16,137 & 15,481 \\
\hline \multicolumn{7}{|l|}{ Proptietary Capital } \\
\hline 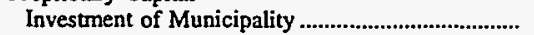 & 0 & 0 & 0 & 833 & 0 & 320 \\
\hline 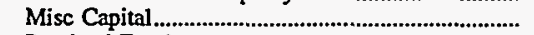 & 2,332 & 0 & 0 & 18 & 1,544 & 0 \\
\hline 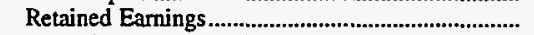 & 14,370 & 15,185 & 33,949 & 9,442 & 11,133 & 14,384 \\
\hline Total Proprietary Capital ...................................... & 16,702 & 15,185 & 33,949 & 10,294 & 12,677 & 14,703 \\
\hline \multicolumn{7}{|l|}{ Long-term Debt } \\
\hline Bonds .............. & 0 & 0 & 0 & 0 & 615 & 0 \\
\hline Advances from Municipality \& Other .......................... & 0 & 0 & 0 & 0 & 1,815 & 0 \\
\hline Unamort Prem on Long-term Debt................................ & 0 & 0 & 0 & 0 & 0 & 0 \\
\hline (less) Unamort Discount on Long-term Debt & 0 & 0 & 0 & 0 & 0 & 0 \\
\hline Total Long-term Debt .............................................. & $\mathbf{0}$ & $\mathbf{0}$ & $\mathbf{0}$ & $\mathbf{0}$ & 2,430 & 0 \\
\hline \multicolumn{7}{|l|}{ Other Noncurrent Liabilities } \\
\hline 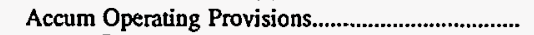 & 0 & 0 & 5,128 & 205 & $\mathbf{0}$ & 0 \\
\hline Accum Prov for Rate Refunds...................................... & 0 & 0 & 0 & 0 & 0 & 0 \\
\hline Total Other Noncurrent Liabilities ..................... & 0 & 0 & 5,128 & 205 & 0 & $\mathbf{0}$ \\
\hline \multicolumn{7}{|l|}{ Current and Accrued Liabilities } \\
\hline 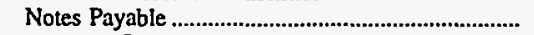 & 0 & 0 & 0 & 0 & 0 & 0 \\
\hline 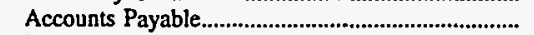 & 697 & 694 & 2,898 & 475 & 963 & 730 \\
\hline 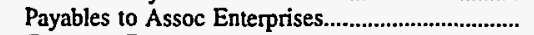 & 442 & 0 & 0 & 1,116 & 0 & 18 \\
\hline 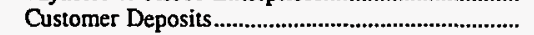 & 91 & 1,179 & 126 & 93 & 65 & 30 \\
\hline 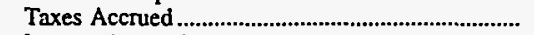 & 0 & 0 & 148 & 30 & 0 & 0 \\
\hline 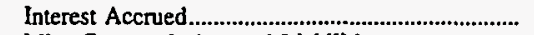 & 0 & 60 & 4 & 0 & 2 & $\mathbf{0}$ \\
\hline Misc Current \& Accrued Liabilities ............................... & 485 & 181 & 652 & 21 & 0 & 0 \\
\hline Total Current \& Accrued Liabilities ................ & 1,715 & 2,115 & $\mathbf{3 , 8 2 8}$ & 1,736 & 1,030 & 778 \\
\hline \multicolumn{7}{|l|}{ Deferred Credits } \\
\hline Customer Advances for Construction ........................ & 0 & 0 & 0 & 0 & 0 & 0 \\
\hline 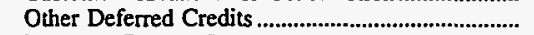 & 747 & 0 & 3,259 & 0 & 0 & 0 \\
\hline Unamort Gain on Reacqr Debt .......................................... & 0 & 0 & 0 & 0 & 0 & $\mathbf{0}$ \\
\hline 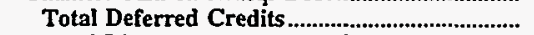 & 747 & 0 & 3,259 & 0 & 0 & 0 \\
\hline Total Liabilities and Other Credits................... & 19,163 & 17,300 & 46,164 & 12,235 & 16,137 & 15,481 \\
\hline
\end{tabular}

Note: Totals may not equal sum of components because of independent rounding.

Source: Energy Information Administration, Form EIA-412, "Annual Report of Public Electric Utilities." 
Table 22. Balance Sheet by Major U.S. Publicly Owned Electric Utility Within State at End of Period, 1996

(Thousand Dollars)

\begin{tabular}{|c|c|c|c|c|c|c|}
\hline Item & $\begin{array}{l}\text { Minnesota } \\
\text { Hutchinson } \\
\text { Utilities } \\
\text { Comm } \\
\text { December } 31\end{array}$ & $\begin{array}{l}\text { Minnesota } \\
\text { Marshall } \\
\text { City of } \\
\text { December 31 }\end{array}$ & $\begin{array}{c}\text { Minnesota } \\
\text { Moorhead } \\
\text { City of } \\
\text { December } 31\end{array}$ & $\begin{array}{l}\text { Minnesota } \\
\text { New Ulm } \\
\text { Public } \\
\text { Utilities } \\
\text { Comm } \\
\text { December } 31\end{array}$ & $\begin{array}{c}\text { Minnesota } \\
\text { Northern } \\
\text { Municipal } \\
\text { Power Agny } \\
\text { December } 31\end{array}$ & $\begin{array}{c}\text { Minnesota } \\
\text { Owatonna } \\
\text { City of } \\
\text { December } 31\end{array}$ \\
\hline \multicolumn{7}{|l|}{ Electric Utility Plant } \\
\hline Electric Utility Plant \& Adjust ...................................... & 50,000 & 23,111 & 31,644 & 28,505 & 322,689 & 28,953 \\
\hline 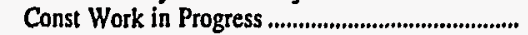 & & 136 & 639 & 0 & 0 & 123 \\
\hline (less) Depr, Amort, and Depletion................................ & 17,288 & 8,239 & 16,551 & 15,386 & 34,180 & 14,923 \\
\hline Net Electric Utility Plant ........................................ & 32,712 & 15,008 & 15,732 & 13,118 & 288,509 & 14,153 \\
\hline Nuclear Fuel.......................................................... & 0 & 0 & 0 & & 0 & $\mathbf{0}$ \\
\hline 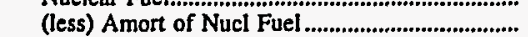 & & & & 0 & 0 & 0 \\
\hline 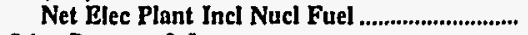 & 32,712 & 15,008 & 15,732 & 13,118 & 288,509 & 14,153 \\
\hline \multicolumn{7}{|l|}{ Other Property \& Investments } \\
\hline 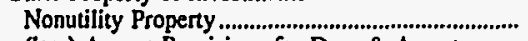 & 0 & 0 & 0 & 0 & 0 & 0 \\
\hline (less) Accum Provisions for Depr \& Amort .......... & 0 & 0 & 0 & 0 & 0 & 0 \\
\hline 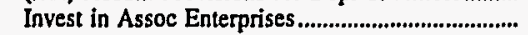 & 0 & 1,960 & 0 & 0 & 0 & 0 \\
\hline Invest \& Special Funds ........................................................ & 1,430 & 1,516 & 4,585 & 368 & 57,837 & 912 \\
\hline Total Other Property \& Investments................ & 1,430 & 3,476 & 4,585 & 368 & 57,837 & 912 \\
\hline \multicolumn{7}{|l|}{ Current and Accrued Assets } \\
\hline Cash, Working Funds \& Investments........................ & 1.493 & 9,366 & 146 & 3,457 & 149 & 6,683 \\
\hline Notes \& Other Receivables................................ & & & 87 & 938 & 1,485 & 102 \\
\hline 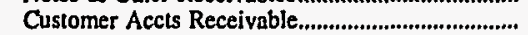 & 1,332 & 1,556 & 1,083 & 107 & 0 & 1,325 \\
\hline (less) Accum Prov for Uncollected Accts............... & 27 & 0 & 0 & 0 & 0 & 60 \\
\hline 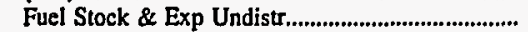 & 0 & 0 & 0 & 199 & 0 & 0 \\
\hline Materials \& Supplies ..................................................... & 547 & 0 & 311 & 1,069 & 0 & 452 \\
\hline 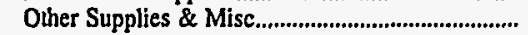 & 0 & 545 & 0 & 0 & 0 & 0 \\
\hline 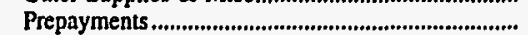 & 0 & 38 & 1 & 9 & 0 & 53 \\
\hline Accrued Utility Revenues .......................................... & 0 & 0 & 0 & 755 & 0 & 434 \\
\hline Miscellaneous Current \& Accrued Assets............. & 22 & 0 & 0 & 0 & 0 & 1,423 \\
\hline Total Current \& Accrued Assets.............................. & 3,368 & 11,504 & 1,629 & 6,533 & 1,634 & 10,412 \\
\hline \multicolumn{7}{|l|}{ Deferred Debits } \\
\hline 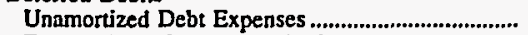 & 150 & 214 & 0 & 0 & $\mathbf{0}$ & 546 \\
\hline Extruordinary Losses, Study Cost............................ & 0 & 123 & 0 & 0 & 0 & 0 \\
\hline Misc Debt, R \& D Exp, Unamrt Losses .................. & 0 & -85 & 0 & 0 & 0 & 23 \\
\hline Total Deferred Debits..................................... & 150 & 252 & & 0 & 0 & 569 \\
\hline 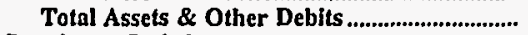 & 37,660 & 30,241 & 21,946 & 20,020 & 347,979 & 26,045 \\
\hline \multicolumn{7}{|l|}{ Proprietary Capital } \\
\hline Investment of Munjejpality ......................................... & 18,025 & 0 & 0 & 0 & $\mathbf{0}$ & 0 \\
\hline 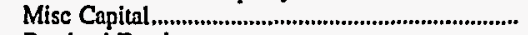 & & 0 & 0 & 0 & 0 & 0 \\
\hline 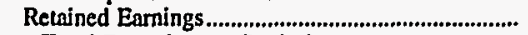 & 5,151 & 19,802 & 17,178 & 17,635 & 0 & 16,609 \\
\hline 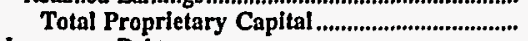 & 23,175 & 19,802 & 17,178 & 17,635 & $\mathbf{0}$ & 16,609 \\
\hline \multicolumn{7}{|l|}{ Long-term Debt } \\
\hline Bonds .,..................... & 12,250 & 8,733 & 2,878 & 1,340 & 337,540 & 6,628 \\
\hline 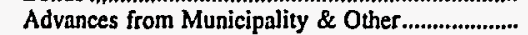 & & 0 & 0 & 0 & 0 & 0 \\
\hline Unamort Prem on Long-term Debt.......................... & 0 & 0 & 0 & 0 & $\mathbf{0}$ & 0 \\
\hline (less) Unamort Discount on Long-term Debt & 0 & $\mathbf{0}$ & 0 & 27 & 0 & 127 \\
\hline Total Long-term Debt ........................................... & 12,250 & 8,733 & 2,878 & 1,313 & $\mathbf{3 3 7 , 5 4 0}$ & 6,501 \\
\hline \multicolumn{7}{|l|}{ Other Noncurrent Liabilities } \\
\hline 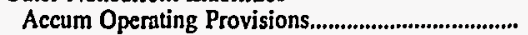 & 0 & 0 & 0 & 0 & 0 & 549 \\
\hline Accum Prov for Rate Refunds................................. & 0 & $\mathbf{0}$ & 0 & 0 & 0 & 0 \\
\hline Total Other Noncurrent Liabilities ................... & $\mathbf{0}$ & 0 & 0 & 0 & 0 & 549 \\
\hline \multicolumn{7}{|l|}{ Current and Accrued Liabilities } \\
\hline Notes Payable ................................ & 1,125 & 296 & 146 & 220 & $\mathbf{0}$ & $\mathbf{0}$ \\
\hline 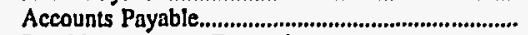 & 754 & 1,087 & 1,129 & 649 & 358 & 1,495 \\
\hline Payables to Assoc Enterprises................................... & 24 & 0 & 297 & 0 & 0 & 112 \\
\hline 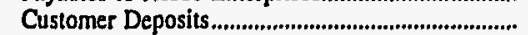 & 50 & 43 & 104 & 0 & 0 & 19 \\
\hline Taxes Accred & 0 & 0 & 49 & 0 & 0 & 0 \\
\hline 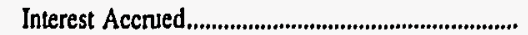 & 31 & 209 & 28 & 6 & 10,081 & 182 \\
\hline Misc Current \& Accrued Liabilities................................ & 250 & 71 & 137 & 198 & & 517 \\
\hline \multirow{2}{*}{\multicolumn{7}{|c|}{ Deferred Credits }} \\
\hline & & & & & & \\
\hline Customer Advances for Construction ........................ & 0 & 0 & 0 & 0 & 0 & 0 \\
\hline Oulser Deferred Credits................... & 0 & 0 & 0 & 0 & 0 & 61 \\
\hline Unamort Gain on Reacgr Debt................................... & 0 & 0 & 0 & 0 & 0 & 0 \\
\hline Total Deferred Credits................................................... & & & & & 0 & 61 \\
\hline Total Liabillties and Other Credits.................... & 37,660 & 30,241 & 21,946 & 20,020 & 347,979 & 26,045 \\
\hline
\end{tabular}

Note: Totals may not equal sum of components because of independent rounding.

Source: Energy Information Administration, Form EIA-412, "Annual Report of Public Electric Utilities." 
Table 22. Balance Sheet by Major U.S. Publicly Owned Electric Utility Within State at End of Period, 1996

(Thousand Dollars)

\begin{tabular}{|c|c|c|c|c|c|c|}
\hline Item & $\begin{array}{c}\text { Minnesota } \\
\text { Rochester } \\
\text { Public } \\
\text { Utilities } \\
\text { December } 31\end{array}$ & $\begin{array}{c}\text { Minnesota } \\
\text { Shakopee } \\
\text { Public } \\
\text { Utilities } \\
\text { Comm } \\
\text { December } 31 \\
\end{array}$ & $\begin{array}{c}\text { Minnesota } \\
\text { Southern } \\
\text { Minnesota } \\
\text { Mun P } \\
\text { Agny } \\
\text { December 31 }\end{array}$ & $\begin{array}{c}\text { Minnesota } \\
\text { Western } \\
\text { Minnesota } \\
\text { Mun } \\
\text { Pwr Agny } \\
\text { December 31 }\end{array}$ & $\begin{array}{c}\text { Minnesota } \\
\text { Willmar } \\
\text { Municipal } \\
\text { Utils Comm } \\
\text { December } \mathbf{3 1}\end{array}$ & $\begin{array}{l}\text { Minnesota } \\
\text { Worthington } \\
\text { City of } \\
\text { December } 31\end{array}$ \\
\hline \multicolumn{7}{|l|}{ Electric Utility Plant } \\
\hline 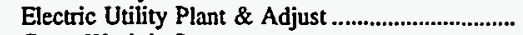 & 113,599 & 7,919 & 541,463 & 244,357 & 30,780 & 13,700 \\
\hline 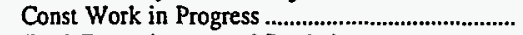 & 3,422 & 1,482 & 7,877 & 343 & 1,979 & \\
\hline (less) Depr, Amort, and Depletion................................. & 57,260 & 2,667 & 144,106 & 57,946 & 17,538 & 5,668 \\
\hline Net Electric Utility Plant ....................................... & 59,761 & 6,734 & 405,234 & 186,754 & 15,221 & 8,033 \\
\hline 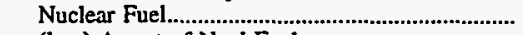 & 0 & 0 & 0 & 0 & 0 & 0 \\
\hline (less) Amort of Nucl Fuel ........................................... & & 0 & 0 & 0 & 0 & 0 \\
\hline $\begin{array}{l}\text { Net Elec Plant Incl Nucl Fuel ..................................... } \\
\text { Other Property \& Investments }\end{array}$ & 59,761 & 6,734 & 405,234 & 186,754 & 15,221 & 8,033 \\
\hline \multicolumn{7}{|l|}{ Other Property \& Investments } \\
\hline (less) Accum Provisions for Depr \& Amort .......... & 171 & 0 & 0 & 0 & 4,239 & 0 \\
\hline Invest in Assoc Enterprises............................................. & 0 & 0 & 0 & 6,882 & 0 & 0 \\
\hline Invest \& Special Funds ............................................... & 542 & 3,627 & 72,910 & 48,380 & 5,824 & 0 \\
\hline Total Other Property \& Investments............... & 706 & $\mathbf{3 , 6 2 7}$ & 72,954 & 55,261 & 13,917 & o \\
\hline \multicolumn{7}{|l|}{ Current and Accrued Assets } \\
\hline Cash, Working Funds \& Investments....................... & 18,222 & 734 & 96,778 & 18,123 & 5,968 & 4,554 \\
\hline Notes \& Other Receivables & 926 & 105 & 0 & 0 & 0 & 1,028 \\
\hline 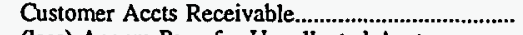 & 3,813 & 982 & 10,320 & 4,963 & 1,406 & 11 \\
\hline (less) Accum Prov for Uncollected Accts.............. & 60 & 0 & 0 & 0 & 0 & 0 \\
\hline 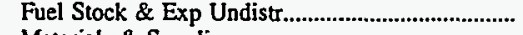 & 535 & 0 & 1,762 & 1,394 & 111 & 0 \\
\hline Materials \& Supplies ......................................................... & 2,150 & 0 & 3,237 & 2,225 & 377 & 53 \\
\hline 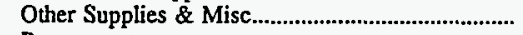 & 0 & 421 & 0 & 0 & 0 & 0 \\
\hline Prepayments & 222 & 18 & 3,973 & 64 & 126 & 14 \\
\hline 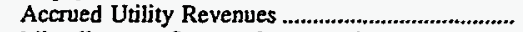 & 3,082 & 0 & 0 & 0 & 0 & 0 \\
\hline Miscellaneous Current \& Accrued Assets.............. & 354 & 43 & 8,837 & 917 & 0 & 0 \\
\hline Total Current \& Accrued Assets...................... & 29,244 & 2,302 & 124,907 & 27,685 & 7,988 & 5,661 \\
\hline \multicolumn{7}{|l|}{ Deferred Debits } \\
\hline 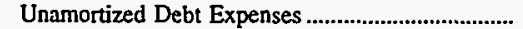 & 0 & 78 & 158,981 & 10,421 & 270 & 0 \\
\hline Extraordinary Losses, Study Cost............................. & 0 & 0 & 221 & 0 & 0 & 0 \\
\hline Misc Debt, R \& D Exp, Unamrt Losses ................. & 1.400 & 0 & 126,586 & 2,445 & 0 & 0 \\
\hline Total Deferred Debits............................................... & 1,400 & 78 & $\mathbf{2 8 5 , 7 8 8}$ & 12,865 & 270 & 0 \\
\hline 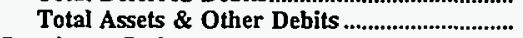 & 91,111 & 12,741 & 888,883 & 282,566 & 37,396 & 13,694 \\
\hline \multicolumn{7}{|l|}{ Proprietary Capital } \\
\hline 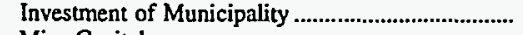 & 0 & 0 & 0 & 0 & 0 & 0 \\
\hline 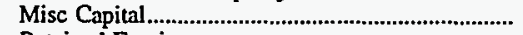 & 0 & 0 & 0 & 0 & 0 & 0 \\
\hline 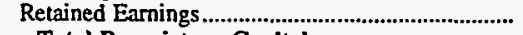 & 76,176 & 8,462 & 23,704 & 0 & 25,623 & 13,027 \\
\hline Total Proprietary Capital .......................................... & 76,176 & 8,462 & 23,704 & $\mathbf{0}$ & 25,623 & 13,027 \\
\hline \multicolumn{7}{|l|}{ Long-term Debt } \\
\hline$\ldots \ldots \ldots \ldots \ldots+\ldots \ldots$ & 0 & 2,630 & $1,196,190$ & 269,955 & 8,245 & 0 \\
\hline Advances from Municipality \& Other.................... & 1,200 & 277 & 0 & 0 & 0 & 0 \\
\hline Unamort Prem on Long-term Debt............................. & 0 & 0 & 0 & 2,533 & 0 & 0 \\
\hline (less) Unamort Discount on Long-term Debt & 0 & 0 & 458,740 & 10,076 & 0 & 0 \\
\hline Total Long-term Debt .......................................... & 1,200 & 2,907 & $\mathbf{7 3 7}, \mathbf{4 5 0}$ & 262,412 & 8,245 & 0 \\
\hline \multicolumn{7}{|l|}{ Other Noncurrent Liabilities } \\
\hline Accum Operating Provisions.... & 4,090 & 0 & 0 & 11,204 & 0 & 0 \\
\hline 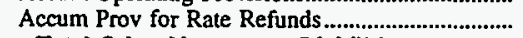 & & 0 & 0 & 0 & 0 & 0 \\
\hline Total Other Noncurrent Liabilities .................... & 4,090 & 0 & 0 & 11,204 & o & $\mathbf{0}$ \\
\hline \multicolumn{7}{|l|}{ Current and Accrued Liabilities } \\
\hline 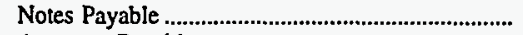 & 0 & 0 & 24,000 & 0 & 1,409 & 0 \\
\hline Accounts Payable & 5,621 & 981 & 9,865 & 1,993 & 658 & 562 \\
\hline 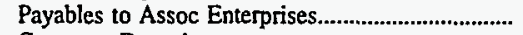 & 592 & 213 & 998 & 0 & 145 & 24 \\
\hline 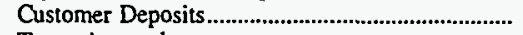 & 587 & 124 & 0 & 0 & 118 & 74 \\
\hline 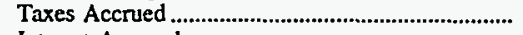 & 427 & 0 & 8,135 & 858 & 83 & 0 \\
\hline 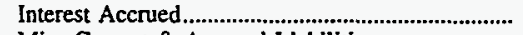 & 0 & 55 & 18,281 & 6,099 & 267 & 0 \\
\hline Misc Current \& Accrued Liabilities .............................. & 1,193 & 0 & 29,032 & 0 & 848 & 6 \\
\hline Total Current \& Accrued Liabilities ............... & 8,419 & 1,373 & 90,311 & 8,950 & $\mathbf{3 , 5 2 8}$ & 667 \\
\hline \multicolumn{7}{|l|}{ Deferred Credits } \\
\hline 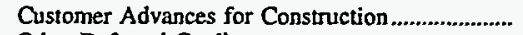 & $\mathbf{0}$ & 0 & 0 & 0 & 0 & 0 \\
\hline 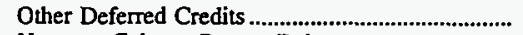 & 1,227 & 0 & 37,417 & 0 & 0 & 0 \\
\hline Unamort Gain on Reacqr Debt .................................... & $\mathbf{0}$ & 0 & 0 & 0 & 0 & 0 \\
\hline 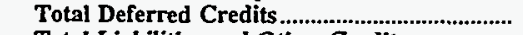 & 1,227 & $\mathbf{0}$ & 37,417 & $\mathbf{0}$ & 0 & 0 \\
\hline Total Liabilities and Other Credits................... & 91,111 & 12,741 & 888,883 & 282,566 & 37,396 & 13,694 \\
\hline
\end{tabular}

Note: Totals may not equal sum of components because of independent rounding

Source: Energy Information Administration, Form EIA-412, "Annual Report of Public Electric Utilities." 
Table 22. Balance Sheet by Major U.S. Publicly Owned Electric Utility Within State at End of Period, 1996

(Thousand Dollars)

\begin{tabular}{|c|c|c|c|c|c|c|}
\hline Item & $\begin{array}{l}\text { Mississippi } \\
\text { Aberdeen } \\
\text { City of } \\
\text { June } 30\end{array}$ & $\begin{array}{l}\text { Mississippi } \\
\text { Amory } \\
\text { City of } \\
\text { June } 30\end{array}$ & $\begin{array}{l}\text { Mississippi } \\
\begin{array}{c}\text { Clarksdale } \\
\text { City of }\end{array} \\
\text { September } 30\end{array}$ & $\begin{array}{l}\text { Mississippi } \\
\text { Columbus } \\
\text { City of } \\
\text { June } 30\end{array}$ & $\begin{array}{l}\text { Mississippi } \\
\text { Greenwood } \\
\text { Utilities } \\
\text { Comm } \\
\text { September } 30\end{array}$ & $\begin{array}{l}\text { Mississippi } \\
\text { Holly } \\
\text { Springs } \\
\text { City of } \\
\text { June } 30\end{array}$ \\
\hline \multicolumn{7}{|l|}{ Electric Utility Plant } \\
\hline 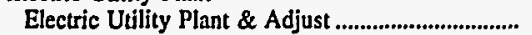 & 4,916 & 7,628 & 27,823 & 27,810 & 27,407 & 14,767 \\
\hline 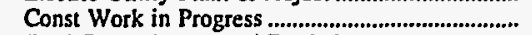 & 225 & 109 & 1,424 & & 5,764 & 1,347 \\
\hline 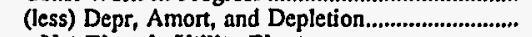 & 2,388 & 3,442 & 20,261 & 9,596 & 16,412 & 5,948 \\
\hline 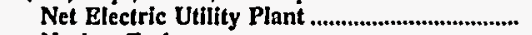 & 2,754 & 4,295 & 8,986 & 18,245 & 16,759 & 10,166 \\
\hline Nuclear Fuel............................................................. & 0 & 0 & 0 & 0 & 0 & 0 \\
\hline 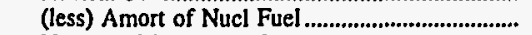 & 0 & 0 & & 0 & 0 & 0 \\
\hline Net Elec Plant Incl Nucl Fuel ................................. & 2,754 & 4,295 & 8,986 & 18,245 & 16,759 & 10,166 \\
\hline \multicolumn{7}{|l|}{ Other Property \& Investments } \\
\hline 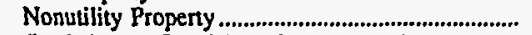 & 0 & 0 & 0 & 0 & 0 & 0 \\
\hline (less) Accum Provisions for Depr \& Amort .......... & 0 & 0 & 0 & 0 & 0 & 0 \\
\hline 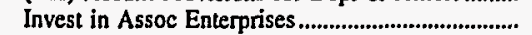 & 0 & 0 & 3,019 & 0 & 0 & 0 \\
\hline 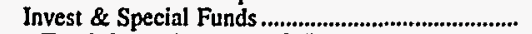 & 1,949 & 1,257 & 3,813 & $\mathbf{0}$ & 9,516 & 659 \\
\hline Total Olher Property \& Investments............... & 1,949 & 1,257 & 6,832 & 0 & 9,516 & 659 \\
\hline \multicolumn{7}{|l|}{ Current and Accrued Assets } \\
\hline 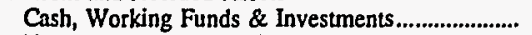 & 34 & 591 & 1,750 & 399 & 4,600 & 2,301 \\
\hline Notes \& Other Receivables............................................. & 1,333 & 972 & 1,434 & 2,239 & 174 & 1,234 \\
\hline 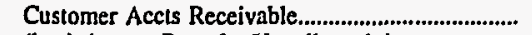 & 0 & 0 & 1,040 & 0 & 1,753 & 0 \\
\hline (less) Accum Prov for Uncollected Accts ............... & 0 & 0 & 0 & 0 & 78 & 0 \\
\hline Fuel Stock \& Exp Undistr........................................ & 0 & 0 & 305 & 0 & 637 & 0 \\
\hline 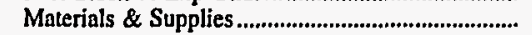 & 115 & 151 & 158 & 520 & 360 & 248 \\
\hline 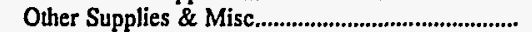 & 0 & 0 & 0 & 0 & 0 & 0 \\
\hline 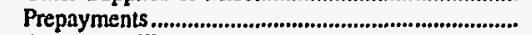 & 12 & 11 & 201 & 0 & 110 & 16 \\
\hline 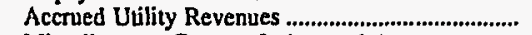 & $\mathbf{0}$ & 0 & 456 & 32 & 566 & 0 \\
\hline Miscellaneous Current \& Accrued Assets............... & 37 & 28 & 1,395 & 33 & 0 & 56 \\
\hline Total Current \& Accrued Assets.............................. & 1,532 & 1,753 & 6,739 & 3,224 & 8,122 & $\mathbf{3 , 8 5 6}$ \\
\hline \multicolumn{7}{|l|}{ Deferred Debits } \\
\hline Unamortized Debt Expenses..... & 0 & $\mathbf{0}$ & 0 & $\mathbf{0}$ & 0 & 0 \\
\hline 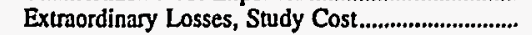 & 22 & 0 & 0 & 0 & 0 & 0 \\
\hline Misc Debt, R \& D Exp, Unamrt Losses .................. & 506 & 239 & 0 & 215 & 0 & 12 \\
\hline 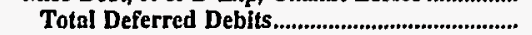 & 527 & 239 & o & 215 & 0 & 12 \\
\hline Total Assets \& Other Debits ....................................... & 6,762 & 7,544 & 22,557 & 21,684 & 34,397 & 14,693 \\
\hline \multicolumn{7}{|l|}{ Proprietary Capital } \\
\hline Investment of Municipality ...... & $\mathbf{0}$ & $\mathbf{0}$ & 2,059 & 0 & 0 & 0 \\
\hline Misc Capital .................................. & & 0 & 167 & 0 & 0 & 0 \\
\hline 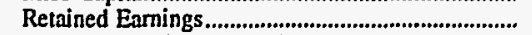 & 2,899 & 6,205 & 16,656 & 10,444 & 32,375 & 11,886 \\
\hline 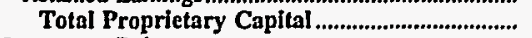 & $\mathbf{2 , 8 9 9}$ & 6,205 & 18,882 & 10,444 & 32,375 & 11,886 \\
\hline \multicolumn{7}{|l|}{ Long-term Debt } \\
\hline Bonds ........................... & 2,200 & 0 & 1,830 & 500 & 0 & 0 \\
\hline Advances from Municipality \& Other.......................... & 513 & 255 & 37 & $\mathbf{0}$ & 8 & 9 \\
\hline 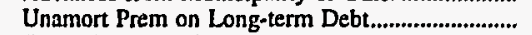 & 0 & 0 & 0 & 221 & 0 & 0 \\
\hline (less) Unamort Discount on Long-term Debt & & $\mathbf{0}$ & 0 & 0 & 0 & 0 \\
\hline Total Long-term Debt ................................................ & 2,713 & 255 & 1,867 & 721 & 8 & 9 \\
\hline \multicolumn{7}{|l|}{ Other Noncurrent Liabilities } \\
\hline 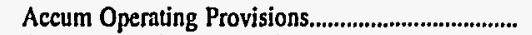 & 0 & 0 & 0 & 0 & 0 & 0 \\
\hline Accum Prov for Rate Refunds....................................... & 0 & 0 & 0 & 0 & 0 & 0 \\
\hline Total Other Noncurrent Liabilities..................... & 0 & 0 & 0 & 0 & o & o \\
\hline \multicolumn{7}{|l|}{ Current and Accrued Liabilities } \\
\hline Notes Payable ................................................................ & & & 0 & 2,821 & 0 & \\
\hline Accounts Payable....................................................... & 876 & 809 & 995 & 0 & 1,219 & 2,198 \\
\hline Payables to Assoc Enterprises.................................. & 0 & 0 & 0 & 1,119 & 69 & 0 \\
\hline 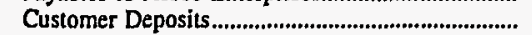 & 196 & 242 & 560 & 0 & 532 & 529 \\
\hline 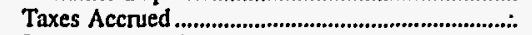 & 1 & 0 & 45 & 0 & 88 & 46 \\
\hline 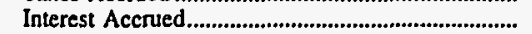 & 51 & 0 & 1 & 96 & 0 & 0 \\
\hline Misc Current \& Accrued Liabilities .............................. & 26 & 29 & 207 & & 83 & 23 \\
\hline 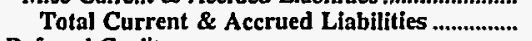 & 1,150 & 1,080 & 1,808 & 4,035 & 1,990 & 2,797 \\
\hline \multicolumn{7}{|l|}{ Deferred Credits } \\
\hline 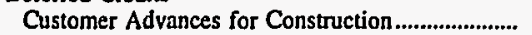 & 0 & 0 & $\mathbf{0}$ & 6,483 & 0 & 0 \\
\hline 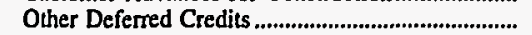 & 0 & 3 & 0 & 0 & 23 & 2 \\
\hline 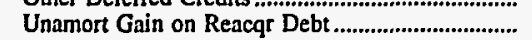 & 0 & 0 & 0 & 0 & 0 & 0 \\
\hline Total Deferred Credits......................................... & 0 & 3 & 0 & 6,483 & 23 & 2 \\
\hline Total Liabilities and Other Credits................... & 6,762 & 7,544 & 22,557 & 21,684 & 34,397 & 14,693 \\
\hline
\end{tabular}

Note: Totnls may not equal sum of components because of independent rounding.

Source: Energy Information Administration, Form EIA-412, "Annual Report of Public Electric Utilities." 
Table 22. Balance Sheet by Major U.S. Publicly Owned Electric Utility Within State at End of Period, 1996

(Thousand Dollars)

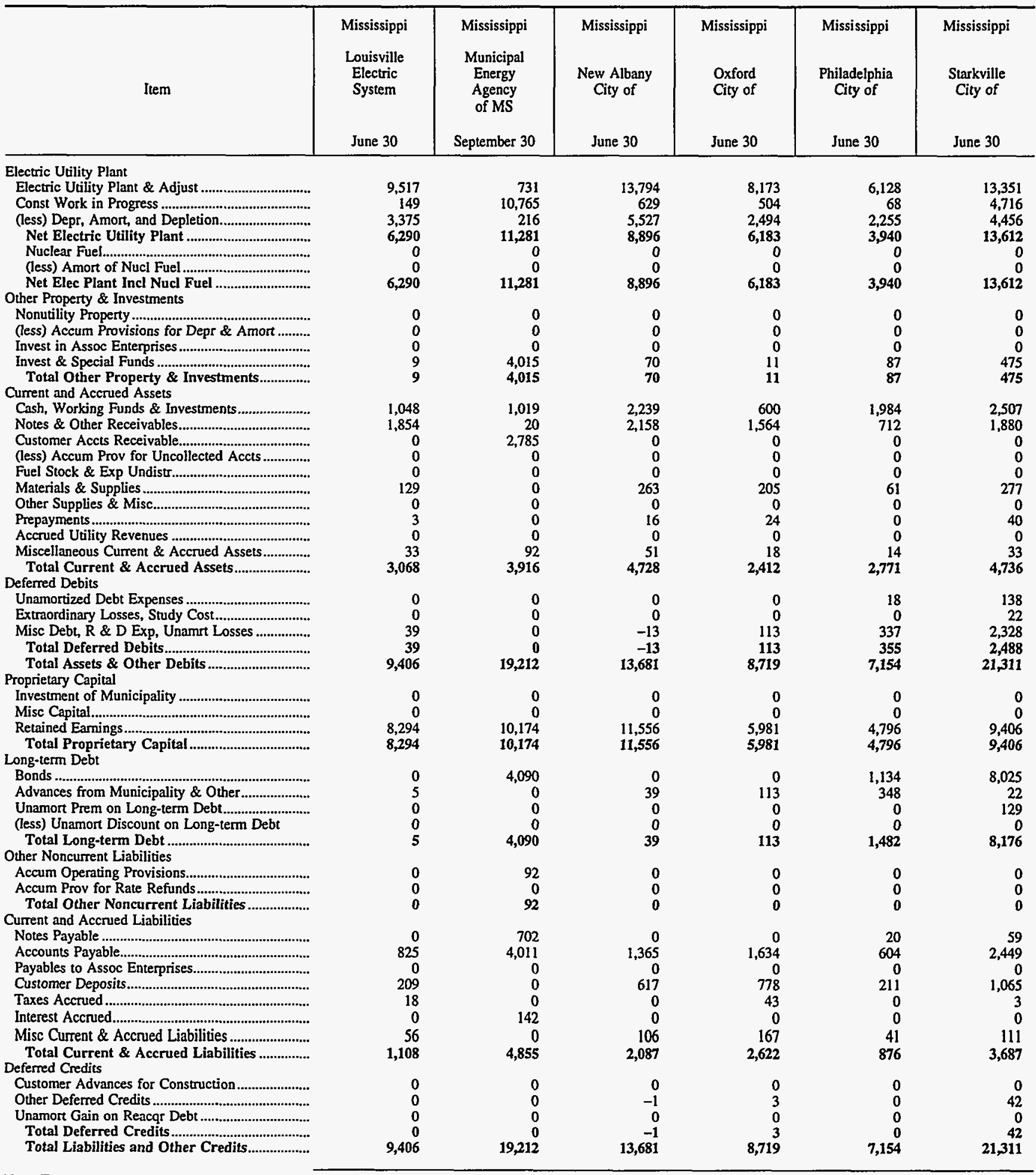

Note: Totals may not equal sum of components because of independent rounding.

Source: Energy Information Administration, Form EIA-412, "Annual Report of Public Electric Utilities." 
Table 22. Balance Sheet by Major U.S. Publicly Owned Electric Utility Within State at End of Period, 1996

(Thousand Dollars)

\begin{tabular}{|c|c|c|c|c|c|c|}
\hline Item & $\begin{array}{l}\text { Mississippi } \\
\text { Tupelo } \\
\text { City of } \\
\text { June } 30\end{array}$ & $\begin{array}{c}\text { Mississippi } \\
\text { West } \\
\text { Point } \\
\text { City of } \\
\text { June } 30\end{array}$ & $\begin{array}{l}\text { Missouri } \\
\text { Carthage } \\
\text { City of } \\
\text { June } 30\end{array}$ & $\begin{array}{l}\text { Missouri } \\
\text { Columbia } \\
\text { City of } \\
\text { September } 30\end{array}$ & $\begin{array}{l}\text { Missouri } \\
\text { Hannibal } \\
\text { City of } \\
\text { June } 30\end{array}$ & $\begin{array}{c}\text { Missouri } \\
\text { Independence } \\
\text { City of } \\
\text { June } 30\end{array}$ \\
\hline \multicolumn{7}{|l|}{ Electric Utility Plant } \\
\hline 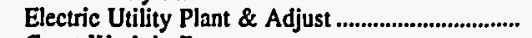 & 26,453 & 7,487 & 21,805 & 88,907 & 11,359 & 189,933 \\
\hline 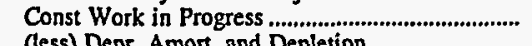 & $\begin{array}{r}20 \\
8767\end{array}$ & 261 & 221 & $\begin{array}{r}4,544 \\
38,614\end{array}$ & 125 & $\begin{array}{r}5,148 \\
09503\end{array}$ \\
\hline 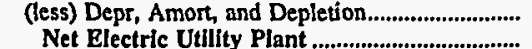 & $\begin{array}{r}8,767 \\
17,707\end{array}$ & $\begin{array}{l}2,901 \\
4,847\end{array}$ & $\begin{array}{r}14,683 \\
7343\end{array}$ & $\begin{array}{l}38,614 \\
54837\end{array}$ & $\begin{array}{l}7,732 \\
7,75 ?\end{array}$ & $\begin{array}{r}99,503 \\
05570\end{array}$ \\
\hline 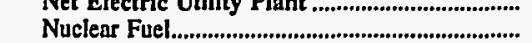 & $\begin{aligned} 11,701 \\
0\end{aligned}$ & $\begin{array}{r}4,847 \\
0\end{array}$ & $\begin{array}{r}7,343 \\
0\end{array}$ & $\begin{array}{r}54,057 \\
0\end{array}$ & $\begin{array}{r}3,752 \\
0\end{array}$ & $\begin{aligned} 90,379 \\
0\end{aligned}$ \\
\hline (less) Amort of Nucl Fuel ,......................................... & & & $\mathbf{0}$ & 0 & 0 & 0 \\
\hline Net Elec Plant Incl Nucl Fuel .............................. & 17,707 & 4,847 & 7,343 & 54,837 & $\mathbf{3 , 7 5 2}$ & 95,579 \\
\hline \multicolumn{7}{|l|}{ Other Property \& Investments } \\
\hline 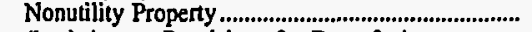 & $\mathbf{0}$ & 0 & 0 & 52,441 & $\mathbf{0}$ & 0 \\
\hline (less) Accum Provisions for Depr \& Amort ........... & $\mathbf{0}$ & 0 & $\mathbf{0}$ & 11,805 & 0 & 0 \\
\hline 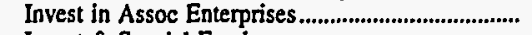 & 0 & 0 & 0 & & 882 & 0 \\
\hline 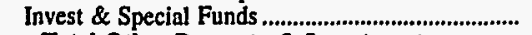 & 28 & 102 & 104 & 17,378 & 9,673 & 27,542 \\
\hline Total Other Property \& Investments................. & 28 & 102 & 104 & 58,013 & 10,555 & 27,542 \\
\hline \multicolumn{7}{|l|}{ Current and Accrued Assets } \\
\hline Cash, Working Funds \& Investments...................... & 3,658 & 156 & 2,341 & 6,738 & 765 & 8,814 \\
\hline 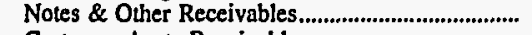 & 3,781 & 1,259 & 294 & 376 & 122 & \\
\hline 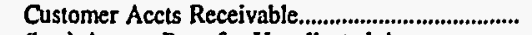 & 0 & 0 & 755 & 6,340 & 861 & 4,346 \\
\hline (less) Accum Prov for Uncollected Accts................ & $\mathbf{0}$ & 0 & 20 & 75 & 20 & 318 \\
\hline 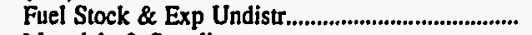 & $\mathbf{0}$ & 0 & 0 & 387 & 0 & 3,148 \\
\hline 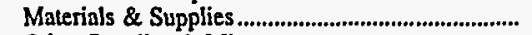 & 335 & 186 & 320 & 3,306 & 283 & 4,085 \\
\hline 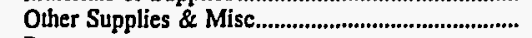 & 0 & 0 & 0 & 519 & 0 & 0 \\
\hline 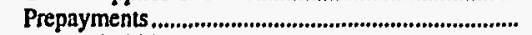 & 33 & 1 & 31 & 47 & 51 & 25 \\
\hline Accrued Utility Revenues ................................................. & 0 & 0 & 0 & 2,493 & 0 & 4,304 \\
\hline Miscellaneous Current \& Accrued Assets.............. & $3 I$ & 2 & 16 & 934 & 0 & 422 \\
\hline Total Current \& Accrued Assets........................ & $\mathbf{7 , 8 3 7}$ & 1,604 & 3,736 & 21,065 & 2,062 & 24,829 \\
\hline \multicolumn{7}{|l|}{ Deferred Debits } \\
\hline 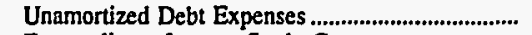 & 0 & -3 & 108 & 358 & 0 & 2,799 \\
\hline 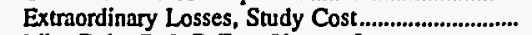 & 0 & 0 & 0 & 0 & 0 & 0 \\
\hline Misc Debt, R \& D Exp, Unamrt Losses .................. & 297 & 16 & 0 & $\mathbf{0}$ & o & 1,930 \\
\hline Total Deferred Debits...................................................... & 297 & 13 & 108 & 358 & 0 & 4,728 \\
\hline 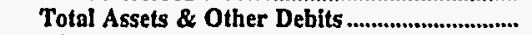 & 25,869 & 6,566 & 11,291 & 134,273 & 16,369 & 152,678 \\
\hline \multicolumn{7}{|l|}{ Proprietary Capital } \\
\hline 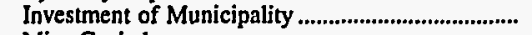 & 0 & $\mathbf{0}$ & 0 & 4,064 & 0 & 0 \\
\hline 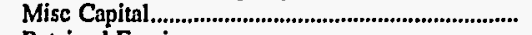 & 0 & 0 & 236 & & $\mathbf{0}$ & 0 \\
\hline 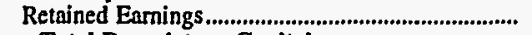 & 20,634 & 4,982 & 7,262 & 71,120 & 14,879 & 110,897 \\
\hline Total Proprietary Capital............................................ & 20,634 & 4,982 & 7,499 & 75,184 & 14,879 & 110,897 \\
\hline \multicolumn{7}{|l|}{ Long'term Debt } \\
\hline Bonds ................... & 0 & 95 & 0 & 47,845 & 0 & 33,205 \\
\hline 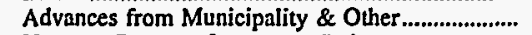 & 310 & 17 & 2,668 & 0 & 0 & 0 \\
\hline 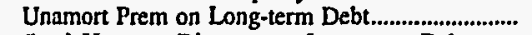 & 0 & 0 & $\mathbf{0}$ & $\mathbf{0}$ & 0 & 0 \\
\hline (less) Unamort Discount on Long-term Debt & 0 & 0 & 0 & 368 & 0 & 0 \\
\hline 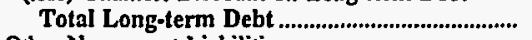 & 310 & 112 & 2,668 & $\mathbf{4 7 , 4 7 7}$ & $\mathbf{0}$ & 33,205 \\
\hline \multicolumn{7}{|l|}{ Other Noncurrent Liabilities } \\
\hline Accum Operating Provisions.......................................... & 0 & 0 & 0 & $\mathbf{0}$ & 295 & 1,761 \\
\hline 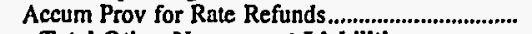 & 0 & $\mathbf{0}$ & $\mathbf{0}$ & 0 & 0 & 0 \\
\hline Total Other Noncurrent Liabilities .................... & $\mathbf{0}$ & $\mathbf{0}$ & $\mathbf{0}$ & $\mathbf{0}$ & 295 & 1,761 \\
\hline \multicolumn{7}{|l|}{ Current and Accrued Liabilities } \\
\hline Notes Payable ................................. & 0 & $\mathbf{0}$ & $\mathbf{0}$ & 0 & 0 & 0 \\
\hline 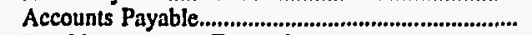 & 3,668 & 1,123 & 1,039 & 3,301 & 1,061 & 3,531 \\
\hline 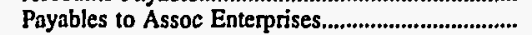 & 0 & 0 & 0 & 0 & 0 & 498 \\
\hline 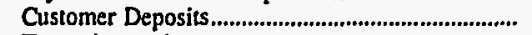 & 930 & 301 & 86 & 1,824 & 132 & 629 \\
\hline 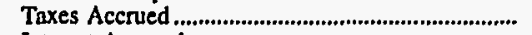 & 0 & $\mathbf{0}$ & $\mathbf{0}$ & 741 & 0 & 0 \\
\hline 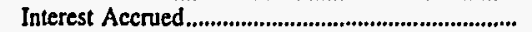 & 0 & 3 & 0 & 1,033 & 0 & 184 \\
\hline 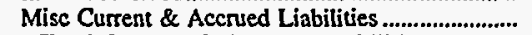 & 328 & 45 & 0 & 4,714 & 2 & 907 \\
\hline Total Current \& Accrued Liabilities .................... & 4,926 & 1,472 & 1,125 & 11,612 & 1,196 & 5,750 \\
\hline \multicolumn{7}{|l|}{ Deferred Credits } \\
\hline 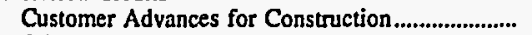 & 0 & 0 & $\mathbf{0}$ & 0 & 0 & 1,065 \\
\hline 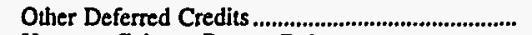 & 0 & $\mathbf{0}$ & $\mathbf{0}$ & $\mathbf{0}$ & 0 & 0 \\
\hline 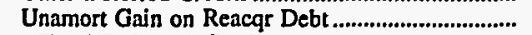 & 0 & 0 & 0 & 0 & 0 & 0 \\
\hline Total Deferred Credits................................................ & & 0 & 0 & 0 & o & 1,065 \\
\hline Total Llabilities and Other Credits.................... & 25,869 & 6,566 & 11,291 & 134,273 & 16,369 & 152,678 \\
\hline
\end{tabular}

Note: Totals may not equal sum of components because of independent rounding

Source: Encrgy Information Administration, Form EIA-412, "Annual Report of Public Electric Utilities." 
Table 22. Balance Sheet by Major U.S. Publicly Owned Electric Utility Within State at End of Period, 1996

(Thousand Dollars)

\begin{tabular}{|c|c|c|c|c|c|c|}
\hline Item & $\begin{array}{l}\text { Missouri } \\
\text { Kennett } \\
\text { City of } \\
\text { June } 30\end{array}$ & $\begin{array}{l}\text { Missouri } \\
\text { Kirkwood } \\
\text { City of } \\
\text { March } 31\end{array}$ & $\begin{array}{l}\text { Missouri } \\
\text { Lebanon } \\
\text { City of } \\
\text { October } 31\end{array}$ & $\begin{array}{l}\text { Missouri } \\
\text { Marshall } \\
\text { City of } \\
\text { September } 30\end{array}$ & $\begin{array}{l}\text { Missouri } \\
\text { Monett } \\
\text { City of } \\
\text { March 31 }\end{array}$ & $\begin{array}{c}\text { Missouri } \\
\text { Poplar } \\
\text { Bluff } \\
\text { City of } \\
\text { December } 31\end{array}$ \\
\hline \multicolumn{7}{|l|}{ Electric Utility Plant } \\
\hline 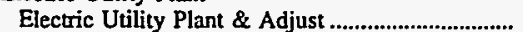 & 14,592 & 5,651 & 0 & 41.525 & 5,158 & 25,353 \\
\hline 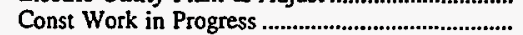 & & 0 & 0 & 44 & 0 & \\
\hline 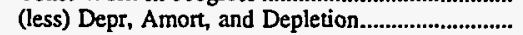 & 11,843 & 2,905 & 0 & 20,215 & 3,547 & 10,400 \\
\hline Net Electric Utility Plant ..................................... & 2,749 & 2,747 & 0 & 21,354 & 1,611 & 14,953 \\
\hline 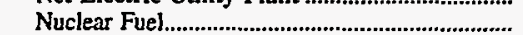 & 0 & 0 & 0 & 0 & 0 & \\
\hline (less) Amort of Nucl Fuel................................. & 0 & 0 & 0 & 0 & 0 & 0 \\
\hline Net Elec Plant Incl Nucl Fuel .......................... & 2,749 & $\mathbf{2 , 7 4 7}$ & 0 & 21,354 & 1,611 & 14,953 \\
\hline \multicolumn{7}{|l|}{ Other Property \& Investments } \\
\hline 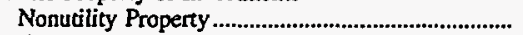 & 0 & 0 & 0 & 0 & 0 & 0 \\
\hline (less) Accum Provisions for Depr \& Amort & 0 & 0 & 0 & 0 & 0 & 0 \\
\hline 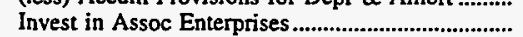 & 0 & 0 & 0 & 0 & 0 & o \\
\hline Invest \& Special Funds .................................................... & 0 & 0 & 0 & 0 & 0 & 12,730 \\
\hline Total Other Property \& Investments............. & 0 & 0 & 0 & 0 & 0 & 12,730 \\
\hline \multicolumn{7}{|l|}{ Current and Accrued Assets } \\
\hline 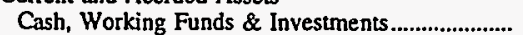 & 2,901 & 7,505 & 0 & 9,262 & 19,436 & 1,184 \\
\hline 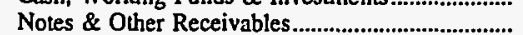 & 0 & 26 & 0 & 133 & 763 & 8 \\
\hline 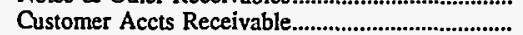 & 208 & 1,134 & 0 & 859 & 0 & 628 \\
\hline (less) Accum Prov for Uncollected Accts .................. & 0 & 0 & 0 & 0 & 0 & 131 \\
\hline 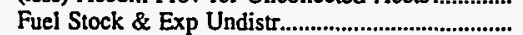 & 84 & 0 & 0 & 57 & 0 & 46 \\
\hline Materials \& Supplies & 0 & 167 & 0 & 734 & 0 & 0 \\
\hline 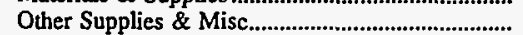 & 0 & 0 & 0 & 0 & 0 & 626 \\
\hline Prepayments & 378 & 0 & 0 & 62 & 0 & 47 \\
\hline 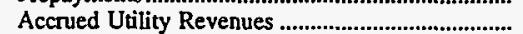 & 0 & 0 & 0 & 208 & 0 & 722 \\
\hline Miscellaneous Current \& Accrued Assets.................. & 0 & 0 & 0 & 47 & 0 & 294 \\
\hline 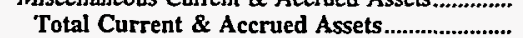 & 3,571 & 8,832 & 0 & 11,361 & 20,199 & $\mathbf{3 , 4 2 4}$ \\
\hline \multicolumn{7}{|l|}{ Deferred Debits } \\
\hline 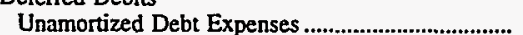 & 0 & 0 & 0 & 0 & 0 & 0 \\
\hline Extraordinary Losses, Study Cost................................ & 0 & 0 & 0 & 0 & 0 & 0 \\
\hline 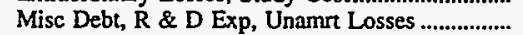 & 0 & 0 & 0 & 0 & 0 & 0 \\
\hline 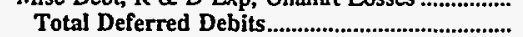 & 0 & 0 & 0 & 0 & 0 & 0 \\
\hline Total Assets \& Other Debits & 6,320 & 11,579 & $\mathbf{0}$ & 32,715 & 21,810 & 31,107 \\
\hline \multicolumn{7}{|l|}{ Proprietary Capital } \\
\hline 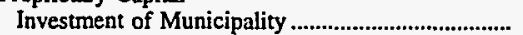 & 191 & 0 & 0 & 180 & 0 & 0 \\
\hline 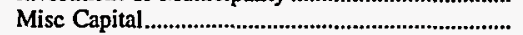 & 12 & 268 & 0 & 0 & 0 & 0 \\
\hline 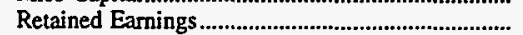 & 5,305 & 9,747 & 0 & 29,702 & 21,104 & 29,938 \\
\hline 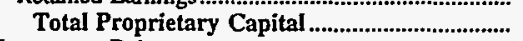 & 5,508 & 10,015 & 0 & 29,882 . & 21,104 & 29,938 \\
\hline \multicolumn{7}{|l|}{ Long-term Debt } \\
\hline 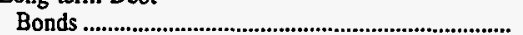 & 0 & 1,047 & 0 & 1,160 & 0 & 0 \\
\hline 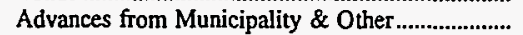 & 0 & 0 & 0 & 0 & 0 & 0 \\
\hline Unamort Prem on Long-term Debt................................. & 0 & 0 & 0 & 0 & 0 & 0 \\
\hline (less) Unamort Discount on Long-term Debt & 0 & 0 & 0 & 0 & 0 & 0 \\
\hline \multirow{2}{*}{\multicolumn{7}{|c|}{ Other Noncurrent Liabilities }} \\
\hline & & & & & & \\
\hline 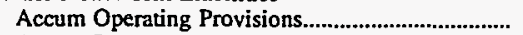 & 0 & 52 & 0 & 0 & 0 & 0 \\
\hline Accum Prov for Rate Refunds....................................... & 0 & 0 & 0 & 0 & 0 & 0 \\
\hline Total Other Noncurrent Liabilities .......................... & 0 & 52 & 0 & 0 & 0 & 0 \\
\hline \multicolumn{7}{|l|}{ Current and Accrued Liabilities } \\
\hline 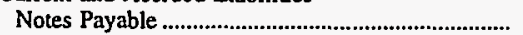 & 0 & 0 & 0 & 0 & 0 & 0 \\
\hline Accounts Payable & 397 & 90 & 0 & 843 & 549 & 641 \\
\hline Payables to Assoc Enterprises................................... & 0 & 10 & 0 & 0 & 0 & 0 \\
\hline 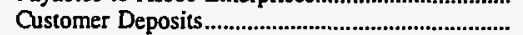 & 294 & 140 & 0 & 182 & 157 & 177 \\
\hline 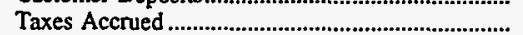 & 0 & 0 & 0 & 293 & 0 & 31 \\
\hline 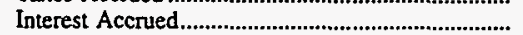 & 0 & 18 & 0 & 18 & 0 & 0 \\
\hline Misc Current \& Accrued Liabilities ........................ & 121 & 187 & 0 & 338 & 0 & 192 \\
\hline 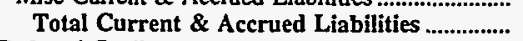 & 812 & 445 & 0 & 1,673 & 706 & 1,041 \\
\hline \multicolumn{7}{|l|}{ Deferred Credits } \\
\hline 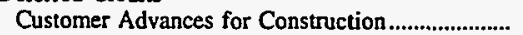 & 0 & 0 & 0 & 0 & 0 & 128 \\
\hline 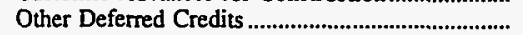 & 0 & 20 & 0 & 0 & 0 & 0 \\
\hline Unamort Gain on Reacqr Debt & 0 & 0 & 0 & 0 & 0 & 0 \\
\hline 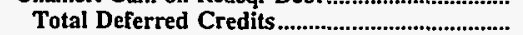 & 0 & 20 & 0 & 0 & 0 & 128 \\
\hline Total Liabilities and Other Credits.................... & 6,320 & 11,579 & 0 & 32,715 & 21,810 & 31,107 \\
\hline
\end{tabular}

Note: Totals may not equal sum of components because of independent rounding.

Source: Energy Information Administration, Form EIA-412, "Annual Report of Public Electric Utilities." 
Table 22. Balance Sheet by Major U.S. Publicly Owned Electric Utility Within State at End of Period, 1996

(Thousand Dollars)

\begin{tabular}{|c|c|c|c|c|c|c|}
\hline Item & $\begin{array}{c}\text { Missouri } \\
\text { Rolla } \\
\text { City of } \\
\text { September } 30\end{array}$ & $\begin{array}{l}\text { Missouri } \\
\text { Sikeston } \\
\text { City of } \\
\text { May } 31\end{array}$ & $\begin{array}{l}\text { Missouri } \\
\text { Springfield } \\
\text { City of } \\
\text { September } 30\end{array}$ & $\begin{array}{c}\text { Missouri } \\
\text { West } \\
\text { Plains } \\
\text { City of } \\
\text { December } 31\end{array}$ & $\begin{array}{l}\text { Nebraska } \\
\text { Beatrice } \\
\text { City of } \\
\text { July } 31\end{array}$ & $\begin{array}{c}\text { Nebraska } \\
\text { Central } \\
\text { Nebraska } \\
\text { Pub } \\
\text { P\&I Dist } \\
\text { December } 31\end{array}$ \\
\hline \multicolumn{7}{|l|}{ Electric Utility Plant } \\
\hline 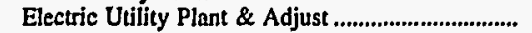 & 10,656 & 226,032 & 452,879 & 5,812 & 14,349 & 119,812 \\
\hline 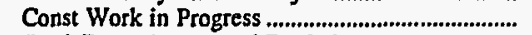 & & 952 & 6,036 & & 743 & 155 \\
\hline 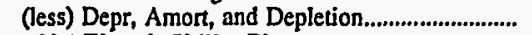 & 7,123 & 73,036 & 125,786 & $\mathbf{0}$ & 8,206 & 41,913 \\
\hline Net Electric Utillty Plant ........................................ & $\mathbf{3 , 5 3 3}$ & 153,948 & 333,129 & 5,812 & 6,886 & $\mathbf{7 8 , 0 5 3}$ \\
\hline 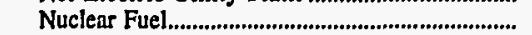 & & & & 0 & 0 & 0 \\
\hline (less) Amort of Nucl Fuel ............................................ & & 0 & 0 & 0 & $\mathbf{0}$ & 0 \\
\hline 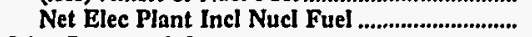 & $\mathbf{3 , 5 3 3}$ & 153,948 & 333,129 & 5,812 & 6,886 & 78,053 \\
\hline \multicolumn{7}{|l|}{ Other Property \& Investments } \\
\hline 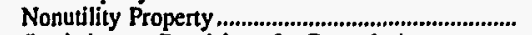 & 6,244 & 0 & 0 & 17,140 & 0 & 68 \\
\hline (less) Accum Provisions for Depr \& Amort ........... & 3,355 & 0 & 0 & 7,007 & 0 & 0 \\
\hline 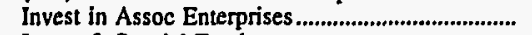 & 0 & 0 & 0 & 8 & 0 & 0 \\
\hline 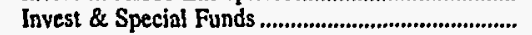 & 5,663 & 33,051 & 148,000 & 640 & 0 & 21,687 \\
\hline 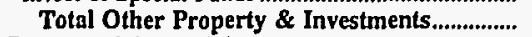 & 8,552 & 33,051 & 148,000 & 10,781 & 0 & 21,755 \\
\hline \multicolumn{7}{|l|}{ Current and Accrued Assets } \\
\hline 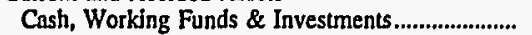 & 1,270 & 12,784 & 16,130 & 481 & 1,038 & 1,376 \\
\hline 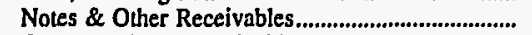 & & 170 & 1,309 & 24 & 178 & 3,490 \\
\hline 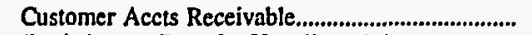 & 1,090 & 5,413 & 17,657 & 1,010 & 504 & 0 \\
\hline (less) Accum Prov for Uncollected Accts............... & 15 & 119 & 146 & 0 & 0 & 4 \\
\hline 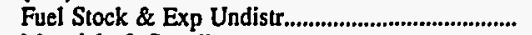 & 0 & 9,290 & 11,776 & $\mathbf{0}$ & 0 & 0 \\
\hline 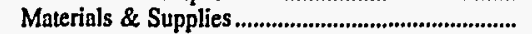 & 447 & 2,182 & 13,767 & 733 & 274 & 601 \\
\hline Other Supplies \& Misc................................................... & 0 & 0 & 0 & 0 & 5 & 0 \\
\hline 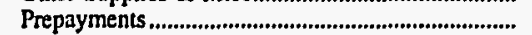 & 20 & 240 & 433 & 18 & 3 & 0 \\
\hline 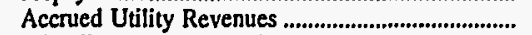 & 0 & 0 & 0 & 0 & 299 & 0 \\
\hline Miscellaneous Current \& Accrued Assets............... & 108 & 807 & 0 & 0 & 0 & 2,993 \\
\hline 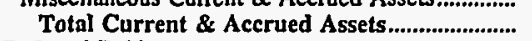 & 2,921 & 30,767 & 60,926 & 2,265 & 2,301 & 8,456 \\
\hline \multicolumn{7}{|l|}{ Deferred Debits } \\
\hline 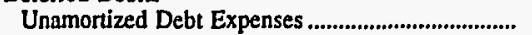 & 0 & 14,486 & 496 & 0 & 0 & 0 \\
\hline Extraordinary Losses, Study Cost..................................... & 0 & & 0 & 0 & 0 & 58 \\
\hline 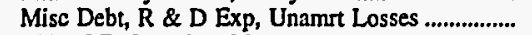 & 0 & 14,148 & 10,964 & 0 & 0 & -39 \\
\hline 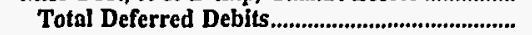 & 0 & 28,634 & 11,460 & 0 & 0 & 19 \\
\hline 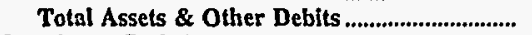 & 15,005 & 246,400 & 553,515 & 18,858 & 9,187 & 108,283 \\
\hline \multicolumn{7}{|l|}{ Proprietary Capital } \\
\hline 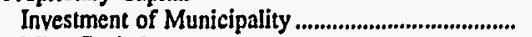 & 90 & $\mathbf{0}$ & $\mathbf{0}$ & 5,515 & 379 & 0 \\
\hline 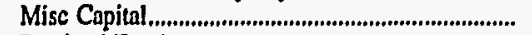 & 0 & 0 & 0 & 1,502 & 199 & 0 \\
\hline 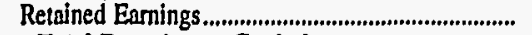 & 13,287 & 2,992 & 374,938 & 9,581 & 7,556 & 50,582 \\
\hline 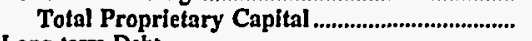 & 13,377 & 2,992 & 374,938 & 16,599 & 8,135 & $\mathbf{5 0 , 5 8 2}$ \\
\hline \multicolumn{7}{|l|}{$\begin{array}{l}\text { Long-term Debt } \\
\text { Bonds }\end{array}$} \\
\hline 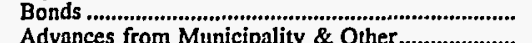 & 0 & 232,205 & 107,610 & 575 & $\mathbf{0}$ & 0 \\
\hline & 0 & 0 & 13,805 & 300 & 0 & 0 \\
\hline 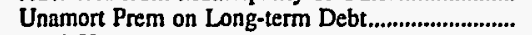 & 0 & 0 & 0 & 0 & 0 & 0 \\
\hline (less) Unamort Discount on Long-term Debt & 0 & 4,528 & 1,469 & 0 & 0 & $\mathbf{0}$ \\
\hline 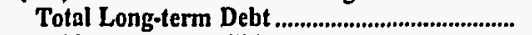 & $\mathbf{0}$ & 227,677 & 119,946 & 875 & 0 & 0 \\
\hline \multicolumn{7}{|l|}{ Other Noncurtent Liab } \\
\hline 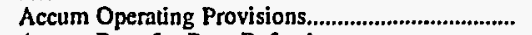 & 0 & 0 & 12,670 & 0 & $\mathbf{0}$ & 1,122 \\
\hline 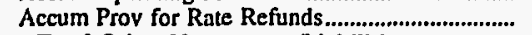 & 0 & 0 & & 0 & 0 & 0 \\
\hline Total Other Noncurrent Llabilities ........................ & 0 & 0 & 12,670 & o & 0 & 1,122 \\
\hline \multicolumn{7}{|l|}{ Current and Accrued Liabilities } \\
\hline 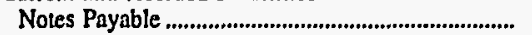 & 0 & 0 & $\mathbf{0}$ & 207 & 0 & 0 \\
\hline 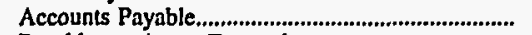 & 978 & 2,605 & 11,610 & 833 & 727 & 782 \\
\hline Payables to Assoc Enterprises........ & 229 & 0 & 1,694 & 0 & 61 & 0 \\
\hline 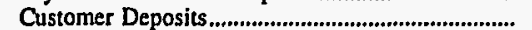 & 336 & 331 & 1,457 & 319 & 76 & l \\
\hline 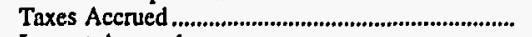 & 0 & 18 & 0 & 0 & $\mathbf{0}$ & 8 \\
\hline Interest Accrued................................................................. & 0 & 4,876 & 2,183 & 0 & 0 & 0 \\
\hline Misc Current \& Accrued Liabilities ................................ & 85 & 786 & 11,526 & 26 & 189 & 460 \\
\hline Total Current \& Accrued Liabilities ................ & 1,628 & 8,616 & 28,470 & 1,384 & 1,053 & 1,250 \\
\hline \multicolumn{7}{|l|}{ Deferred Credits } \\
\hline Customer Advances for Construction......................... & 0 & 0 & & 0 & 0 & \\
\hline 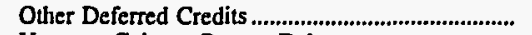 & 0 & 7,116 & 17,489 & 0 & $\mathbf{0}$ & 55,329 \\
\hline 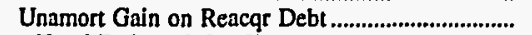 & 0 & 0 & 0 & 0 & 0 & 0 \\
\hline Total Deferred Credits........................................... & & 7,116 & 17,491 & & & 55,329 \\
\hline Total Llabilltites and Other Credits......................... & 15,005 & 246,400 & 553,515 & 18,858 & 9,187 & 108,283 \\
\hline
\end{tabular}

Note: Totals may not equal sum of components because of independent rounding.

Source: Energy Information Administration, Form EIA-412, "Annual Report of Public Electric Utilities." 
Table 22. Balance Sheet by Major U.S. Publicly Owned Electric Utility Within State at End of Period, 1996

(Thousand Dollars)

\begin{tabular}{|c|c|c|c|c|c|c|}
\hline Item & $\begin{array}{l}\text { Nebraska } \\
\text { Cornhusker } \\
\text { Public } \\
\text { Power Dist } \\
\text { December } 31\end{array}$ & $\begin{array}{c}\text { Nebraska } \\
\text { Dawson } \\
\text { County } \\
\text { Public } \\
\text { Pwr Dist } \\
\text { December } 31\end{array}$ & $\begin{array}{l}\text { Nebraska } \\
\text { Fremont } \\
\text { City of } \\
\text { July } 31\end{array}$ & $\begin{array}{c}\text { Nebraska } \\
\begin{array}{l}\text { Grand Island } \\
\text { City of }\end{array} \\
\text { July } 31\end{array}$ & $\begin{array}{c}\text { Nebraska } \\
\text { Hastings } \\
\text { City of } \\
\text { December } 31\end{array}$ & $\begin{array}{l}\text { Nebraska } \\
\text { Lincoln } \\
\text { Electric } \\
\text { System } \\
\text { December } 31\end{array}$ \\
\hline \multicolumn{7}{|l|}{ Electric Utility Plant } \\
\hline 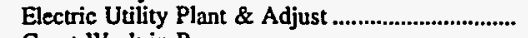 & 35,575 & 50,692 & 67,947 & 170,875 & 108,681 & 474,729 \\
\hline 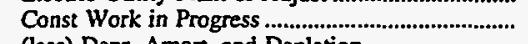 & 306 & 171 & 2,643 & 2,472 & 302 & 54,005 \\
\hline 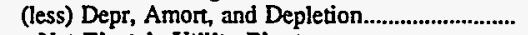 & 11,588 & 20,415 & 52,301 & 77,882 & 42,296 & 161,891 \\
\hline Net Electric Utility Plant ........................................... & 24,293 & 30,449 & 18,289 & 95,466 & 66,688 & 366,843 \\
\hline 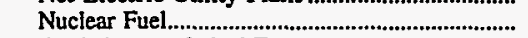 & 0 & 0 & 0 & & & 0 \\
\hline 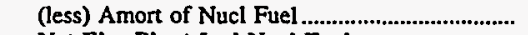 & 0 & $\mathbf{0}$ & 0 & 0 & 0 & 0 \\
\hline Net Elec Plant Incl Nucl Fuel ............................ & 24,293 & $\mathbf{3 0 , 4 4 9}$ & 18,289 & 95,466 & 66,688 & 366,843 \\
\hline \multicolumn{7}{|l|}{ Other Property \& Investments } \\
\hline 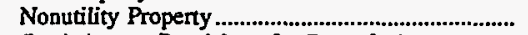 & 0 & 23 & $\mathbf{0}$ & 371 & 0 & 0 \\
\hline (less) Accum Provisions for Depr \& Amort ........... & $\mathbf{0}$ & 7 & 0 & 0 & 0 & 0 \\
\hline 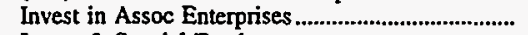 & 775 & 48 & 0 & 0 & 0 & 0 \\
\hline 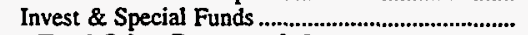 & 1,842 & 1,171 & 0 & 17,110 & 12,069 & 14,784 \\
\hline Total Other Property \& Investments................... & 2,617 & 1,236 & 0 & 17,481 & 12,069 & 14,784 \\
\hline \multicolumn{7}{|l|}{ Current and Accrued Assets } \\
\hline Cash, Working Funds \& Investments....................... & 2,316 & 14,722 & 742 & 3,786 & 7,885 & 35,185 \\
\hline 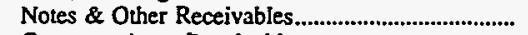 & 22 & 223 & 318 & 63 & 0 & 3,847 \\
\hline 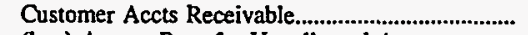 & 1,917 & 2,000 & 10 & 2,239 & 2,439 & 4,415 \\
\hline (less) Accum Prov for Uncollected Accts............... & 16 & 89 & 30 & 118 & 0 & 225 \\
\hline 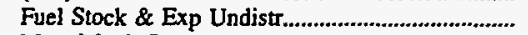 & 5 & 0 & 1,075 & 1,771 & 1,039 & 1,320 \\
\hline 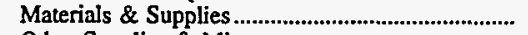 & 579 & 1,069 & 882 & 0 & 0 & 5,192 \\
\hline 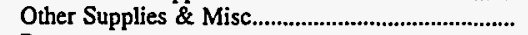 & 0 & 8 & 929 & 3,127 & 735 & 15 \\
\hline Prepayments & 48 & 109 & 101 & 255 & 131 & 523 \\
\hline 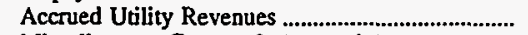 & 0 & 0 & 1,954 & 1,274 & 0 & 6,414 \\
\hline Miscellaneous Current \& Accrued Assets............... & 21 & 234 & 718 & 253 & 199 & 2,811 \\
\hline Total Current \& Accrued Assets...................... & 4,893 & 18,275 & 6,699 & 12,650 & 12,427 & 59,496 \\
\hline \multicolumn{7}{|l|}{ Deferred Debits } \\
\hline 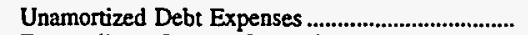 & 364 & 50 & 0 & 273 & $\mathbf{0}$ & 35,178 \\
\hline 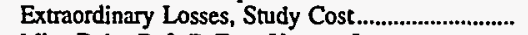 & 0 & 0 & 16,847 & 0 & 0 & 1,657 \\
\hline 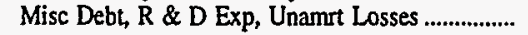 & 477 & 186 & 8 & 2,609 & 5 & 11,383 \\
\hline Total Deferred Debits........................................... & 841 & 236 & 16,855 & 2,882 & 5 & 48,218 \\
\hline Total Assets \& Other Debits & 32,644 & 50,196 & $\mathbf{4 1 , 8 4 3}$ & 128,479 & 91,189 & 489,341 \\
\hline \multicolumn{7}{|l|}{ Proprietary Capital } \\
\hline 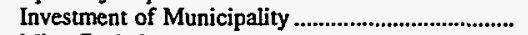 & $\mathbf{0}$ & 0 & $\mathbf{0}$ & 0 & 0 & 0 \\
\hline Misc Capital & 0 & 0 & 0 & 0 & 0 & 0 \\
\hline 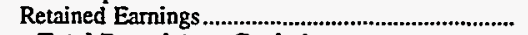 & 16,241 & 38,123 & 40,530 & 96,575 & 28,792 & 146,126 \\
\hline 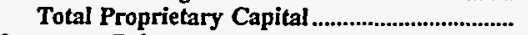 & 16,241 & 38,123 & 40,530 & $\mathbf{9 6 , 5 7 5}$ & 28,792 & 146,126 \\
\hline \multicolumn{7}{|l|}{ Long-term Debt } \\
\hline Bonds .................. & 12,225 & 0 & 0 & 29,075 & 61,295 & 0 \\
\hline Advances from Municipality \& Other.......................... & 0 & 8,000 & 0 & 671 & 0 & 262,960 \\
\hline 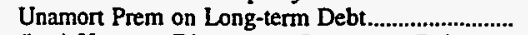 & 0 & 0 & 0 & 0 & 0 & 43,575 \\
\hline (less) Unamort Discount on Long-term Debt & 0 & 0 & 0 & & 1,421 & \\
\hline 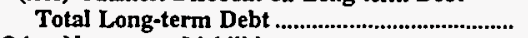 & 12,225 & 8,000 & $\mathbf{0}$ & 29,746 & 59,874 & 306,535 \\
\hline \multicolumn{7}{|l|}{ Other Noncurrent Liabilities } \\
\hline Accum Operating Provisions.......... & 0 & 1,018 & 0 & 0 & 0 & $\mathbf{0}$ \\
\hline 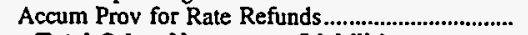 & 0 & & $\mathbf{0}$ & 0 & 0 & 0 \\
\hline \multirow{2}{*}{\multicolumn{7}{|c|}{ Current and Accrued Liabilities }} \\
\hline & & & & & & \\
\hline 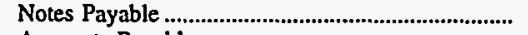 & 0 & 0 & 0 & 0 & 0 & 8,420 \\
\hline 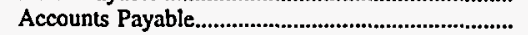 & 787 & 1,089 & 597 & 439 & 204 & 7,656 \\
\hline 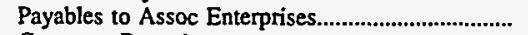 & 0 & 0 & 0 & 0 & 40 & 0 \\
\hline 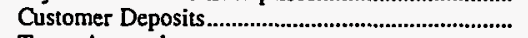 & 80 & 150 & 75 & 104 & 50 & 15 \\
\hline 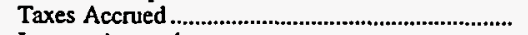 & 38 & 107 & 71 & 916 & 0 & 6,119 \\
\hline 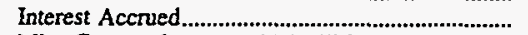 & 242 & 15 & 0 & 158 & 1,716 & 4,720 \\
\hline 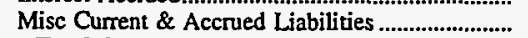 & 181 & 752 & 415 & 541 & 0 & 5,400 \\
\hline Total Current \& Accrued Liabilities ................ & 1,328 & 2,113 & 1,158 & 2,158 & 2,010 & 32,330 \\
\hline \multicolumn{7}{|l|}{ Deferred Credits } \\
\hline 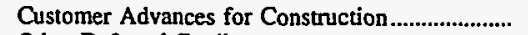 & 0 & 0 & 0 & 0 & 0 & 0 \\
\hline 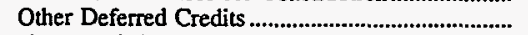 & 133 & 941 & 155 & 0 & 512 & 4,350 \\
\hline Unamort Gain on Reacqr Debt..................................... & 2,717 & 0 & 0 & 0 & 0 & 0 \\
\hline 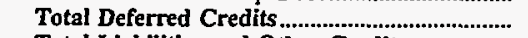 & 2,850 & 941 & 155 & 0 & 512 & 4,350 \\
\hline Total Liabilities and Other Credits.................... & 32,644 & 50,196 & 41,843 & 128,479 & 91,189 & 489,341 \\
\hline
\end{tabular}

Note: Totals may not equal sum of components because of independent rounding.

Source: Energy Information Administration, Form EIA-412, "Annual Report of Public Electric Utilities." 
Table 22. Balance Sheet by Major U.S. Publicly Owned Electric Utility Within State at End of Period, 1996

(Thousand Dollars)

\begin{tabular}{|c|c|c|c|c|c|c|}
\hline Item & $\begin{array}{c}\text { Nebraskn } \\
\text { Loup } \\
\text { River } \\
\text { Public } \\
\text { Power Dist } \\
\text { December } 31\end{array}$ & $\begin{array}{c}\text { Nebraska } \\
\text { Municipal } \\
\text { Energy } \\
\text { Agency } \\
\text { of NE } \\
\text { March } 31\end{array}$ & $\begin{array}{c}\text { Nebraska } \\
\text { Nebraska } \\
\text { Public } \\
\text { Power } \\
\text { District } \\
\text { December } 31\end{array}$ & $\begin{array}{c}\text { Nebraska } \\
\text { Norris } \\
\text { Public } \\
\text { Power } \\
\text { District } \\
\text { December } 31\end{array}$ & $\begin{array}{l}\text { Nebraska } \\
\text { North } \\
\text { Platte } \\
\text { City of } \\
\text { July } 31\end{array}$ & $\begin{array}{c}\text { Nebraska } \\
\text { Omaha Public } \\
\text { Power } \\
\text { District } \\
\text { December } 31\end{array}$ \\
\hline \multicolumn{7}{|l|}{ Electric Utility Plant } \\
\hline 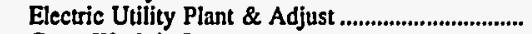 & 62,127 & 33,963 & $1,906,738$ & 66,023 & 14,901 & $2,162,510$ \\
\hline 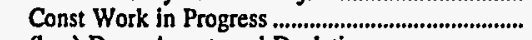 & 2,119 & & 261,269 & 777 & 564 & 84,645 \\
\hline (less) Depr, Amort, and Depletion................................. & 27,054 & 4,082 & 916,404 & 21,527 & 9,059 & 834,916 \\
\hline 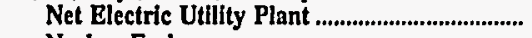 & 37,191 & 29,881 & $1,251,604$ & 45,273 & 6,406 & $1,412,239$ \\
\hline Nuclear Fuel................................................................... & 0 & 0 & 471,141 & 0 & 0 & 115,535 \\
\hline (less) Amort of Nucl Fuel........................................... & 0 & & 375,588 & 0 & 0 & 55,257 \\
\hline 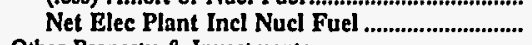 & 37,191 & 29,881 & $1,347,157$ & 45,273 & 6,406 & $1,472,517$ \\
\hline \multicolumn{7}{|l|}{ Other Property \& Investments } \\
\hline 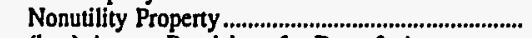 & 482 & 4,684 & $\mathbf{0}$ & 0 & 0 & 0 \\
\hline (less) Accum Provisions for Depr \& Amort .......... & $\mathbf{0}$ & 601 & 0 & 0 & 0 & 0 \\
\hline 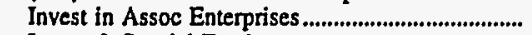 & 0 & 0 & 0 & 0 & 0 & 0 \\
\hline 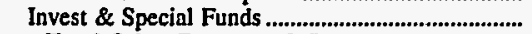 & 10,348 & 8,041 & 209,056 & 3,674 & 0 & 297,145 \\
\hline \multicolumn{5}{|l|}{ Current and Accrued Assets } & 0 & 297,145 \\
\hline 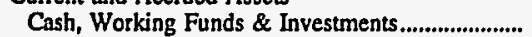 & 7,295 & 226 & 275,346 & 6,267 & 3,518 & 17,289 \\
\hline Notes \& Other Receivables......................................... & 66 & 0 & 28,811 & 19 & 0 & 47,999 \\
\hline 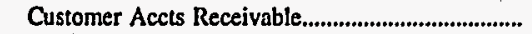 & 3,584 & 4,322 & 46,917 & 2,207 & 934 & 29,461 \\
\hline (less) Accum Prov for Uncollected Accts................ & 1 & 0 & 37 & 46 & 38 & 922 \\
\hline Fuel Stock \& Exp Undistr............................................... & 0 & 0 & 92,161 & 0 & 0 & 9,609 \\
\hline 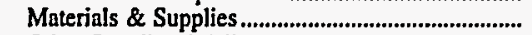 & 930 & 0 & 8,565 & 1,423 & 537 & 36,010 \\
\hline 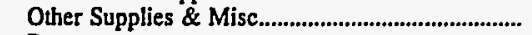 & 25 & 0 & 0 & 0 & 0 & 383 \\
\hline 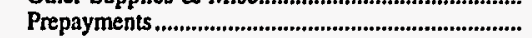 & 179 & 36 & 70,604 & 111 & 9 & 2,540 \\
\hline 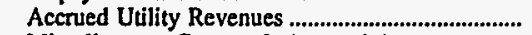 & 0 & 0 & 0 & 961 & 0 & 16,351 \\
\hline Miscellaneous Current \& Accrued Assets............... & 303 & 864 & 0 & 0 & 73 & 3,200 \\
\hline $\begin{array}{l}\text { Total Current \& Accrued Assets.................................... } \\
\text { Deferred Debits }\end{array}$ & 12,381 & 5,448 & 522,365 & 10,944 & 5,034 & 161,920 \\
\hline \multicolumn{7}{|l|}{ Deferred Debits } \\
\hline 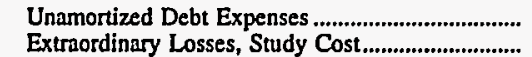 & 0 & $\begin{array}{r}3,579 \\
0\end{array}$ & $\begin{array}{r}1,886 \\
286\end{array}$ & 706 & 0 & $\begin{array}{r}1.421 \\
0\end{array}$ \\
\hline & $\begin{array}{r}47 \\
530\end{array}$ & 10,406 & $\begin{array}{r}286 \\
0\end{array}$ & $\begin{array}{r}0 \\
25\end{array}$ & $\begin{array}{l}0 \\
0\end{array}$ & $\begin{array}{r}0 \\
86,873\end{array}$ \\
\hline 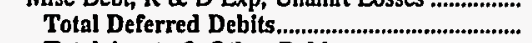 & 577 & 13,985 & 2,171 & 730 & $\mathbf{0}$ & 88,294 \\
\hline Total Assets \& Other Debits...................................... & 60,979 & 61,437 & $2,080,749$ & 60,621 & 11,440 & $2,019,877$ \\
\hline \multicolumn{7}{|l|}{ Proprietary Capital } \\
\hline 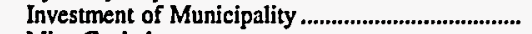 & $\mathbf{0}$ & $\mathbf{0}$ & 0 & 0 & 0 & $\mathbf{0}$ \\
\hline 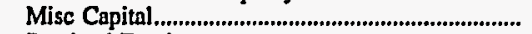 & $\mathbf{0}$ & 0 & 0 & 0 & 0 & $\mathbf{0}$ \\
\hline Retained Earnings...................... & 54,898 & 2,671 & 255,577 & 36,864 & 10,119 & 851,504 \\
\hline Total Proprietary Capital ............................................... & 54,898 & $\mathbf{2 , 6 7 1}$ & 255,577 & 36,864 & 10,119 & 851,504 \\
\hline \multicolumn{7}{|l|}{ Long-term Debt } \\
\hline 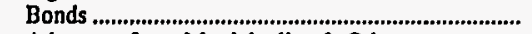 & $\mathbf{0}$ & 47,920 & $1,300,890$ & 18,427 & 0 & 733,860 \\
\hline Advances from Municipality \& Other......................... & 0 & $\mathbf{0}$ & 1,529 & 120 & 0 & 83,648 \\
\hline Unamort Prem on Long-term Debt........................... & 0 & 0 & & 0 & 0 & 0 \\
\hline (less) Unamort Discount on Long-term Debt & 0 & & 3,581 & 0 & 0 & 8,391 \\
\hline 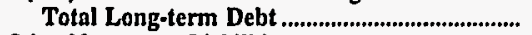 & $\mathbf{0}$ & 47,920 & $1,298,838$ & 18,547 & $\mathbf{0}$ & 809,117 \\
\hline \multicolumn{7}{|l|}{ Other Noncurrent Liabilities } \\
\hline Accum Operating Provisions..... & $\mathbf{0}$ & 4,051 & $\mathbf{0}$ & 0 & 0 & 5,291 \\
\hline 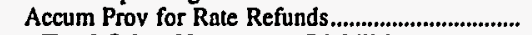 & 0 & & 0 & 0 & $\mathbf{0}$ & \\
\hline \multirow{2}{*}{\multicolumn{7}{|c|}{ Current and Accrued Linbilities }} \\
\hline & & & & & & \\
\hline 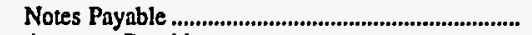 & 0 & 2,000 & 127,011 & 4,265 & 0 & 27,262 \\
\hline 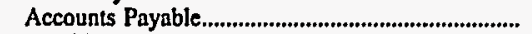 & 3,283 & 3,345 & 66,099 & 0 & 1,202 & 37,478 \\
\hline Payables to Assoc Enterprises....................................... & 0 & 0 & 3,015 & 0 & 0 & 0 \\
\hline Customer Deposits........................................................ & 181 & 0 & 1,392 & 53 & 118 & 6,112 \\
\hline 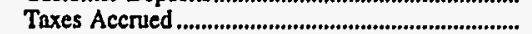 & 1,863 & 0 & 6,421 & 162 & 0 & 14,561 \\
\hline 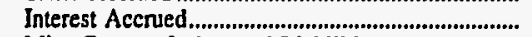 & 0 & 1,367 & 201 & 190 & 0 & 19,712 \\
\hline Misc Current \& Accrued Liabilities ........................... & 229 & 83 & 299,530 & 541 & 0 & 22,023 \\
\hline Total Current \& Accrued Liabilities ................... & 5,557 & 6,795 & 503,669 & 5,210 & 1,320 & 127,148 \\
\hline \multicolumn{7}{|l|}{ Deferred Credits } \\
\hline Customer Advances for Construction ........................... & $\mathbf{0}$ & 0 & 0 & 0 & 0 & \\
\hline 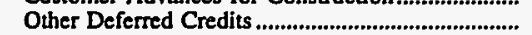 & 523 & 0 & 22,144 & 0 & 0 & 226,336 \\
\hline 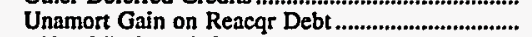 & 0 & 0 & 522 & 0 & 0 & \\
\hline $\begin{array}{l}\text { Total Deferred Credits............................................. } \\
\text { Total Liabilities and Other Credits. }\end{array}$ & $\begin{array}{r}523 \\
60.979\end{array}$ & $\begin{array}{r}0 \\
61.437\end{array}$ & $\begin{array}{r}22,666 \\
2,080,749\end{array}$ & $\begin{array}{r}0 \\
60.621\end{array}$ & $\begin{array}{r}0 \\
11.440\end{array}$ & $\begin{array}{r}226,816 \\
2,019,877\end{array}$ \\
\hline 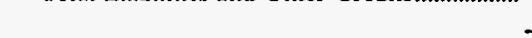 & & & & > & & \\
\hline
\end{tabular}

Note: Totals may not equal sum of components because of independent rounding

Source: Energy Information Administration, Form EIA-412, "Annual Report of Public Electric Utilities." 
Table 22. Balance Sheet by Major U.S. Publicly Owned Electric Utility Within State at End of Period, 1996

(Thousand Dollars)

\begin{tabular}{|c|c|c|c|c|c|c|}
\hline Item & $\begin{array}{c}\text { Nebraska } \\
\text { Southern } \\
\text { Nebraska Rural } \\
\text { P P D } \\
\text { December } 31\end{array}$ & $\begin{array}{c}\text { Nevada } \\
\text { Colorado } \\
\text { River } \\
\text { Comm } \\
\text { of Nevada } \\
\text { June } 30\end{array}$ & $\begin{array}{c}\text { Nevada } \\
\text { Overton } \\
\text { Power } \\
\text { District } \\
\text { No } 5 \\
\text { December } 31\end{array}$ & $\begin{array}{l}\text { New Jersey } \\
\text { Madison } \\
\text { Borough } \\
\text { December } 31\end{array}$ & $\begin{array}{l}\text { New Jersey } \\
\text { Vineland } \\
\text { City of } \\
\text { June } 30\end{array}$ & $\begin{array}{l}\text { New Mexico } \\
\text { Farmington } \\
\text { City of } \\
\text { June } 30\end{array}$ \\
\hline \multicolumn{7}{|l|}{ Electric Utility Plant } \\
\hline Electric Utility Plant \& Adjust ............................... & 80,135 & 0 & 34,461 & 9,146 & 74,484 & 199,773 \\
\hline 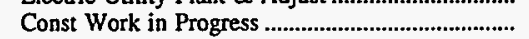 & 513 & 0 & 764 & 2,447 & 7,474 & 4,762 \\
\hline 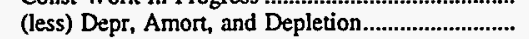 & 36,376 & 0 & 6,899 & 0 & 38,811 & 64,795 \\
\hline 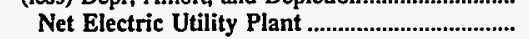 & 44,272 & 0 & 28,325 & 11,593 & 43,147 & 139,740 \\
\hline 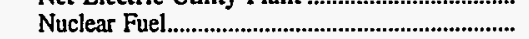 & 0 & 0 & 0 & 0 & 0 & 0 \\
\hline 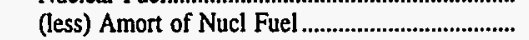 & 0 & 0 & 0 & 0 & 0 & 0 \\
\hline Net Elec Plant Incl Nucl Fuel ............................. & 44,272 & 0 & 28,325 & 11,593 & 43,147 & 139,740 \\
\hline \multicolumn{7}{|l|}{ Other Property \& Investments } \\
\hline Nonutility Property & 0 & 230 & 0 & 0 & $\mathbf{0}$ & $\mathbf{0}$ \\
\hline (less) Accum Provisions for Depr \& Amort ......... & 0 & 0 & 0 & 0 & 0 & 0 \\
\hline 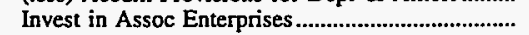 & 1,577 & 0 & 0 & 0 & 0 & 0 \\
\hline 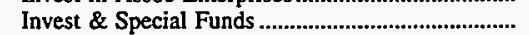 & 0 & 82,629 & 0 & 0 & 5,581 & 0 \\
\hline 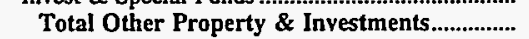 & 1,577 & 82,859 & $\mathbf{0}$ & 0 & 5,581 & 0 \\
\hline \multicolumn{7}{|l|}{ Current and Accrued Assets } \\
\hline 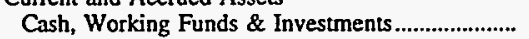 & 11,075 & 5,785 & 5,733 & 11,059 & 23,778 & 16,226 \\
\hline 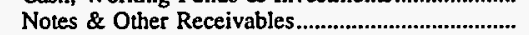 & & 846 & 132 & 0 & 2 & 0 \\
\hline 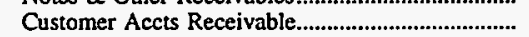 & 2,025 & 2,098 & 801 & 909 & 3,613 & 3,677 \\
\hline (less) Accum Prov for Uncollected Accts ................. & 46 & 0 & 14 & 0 & 0 & 312 \\
\hline 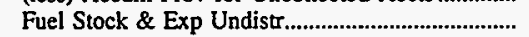 & $\mathbf{0}$ & 0 & 0 & 0 & 1,039 & 442 \\
\hline Materials \& Supplies & 1,796 & 0 & 1,242 & $\mathbf{0}$ & 604 & 2,185 \\
\hline 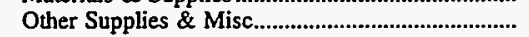 & 0 & 0 & 0 & 0 & 0 & 0 \\
\hline 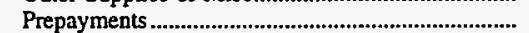 & 55 & 6,962 & 35 & 0 & 0 & 0 \\
\hline 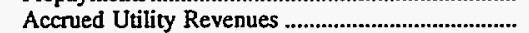 & 0 & 0 & 0 & $\mathbf{0}$ & 0 & 2,296 \\
\hline Miscellaneous Current \& Accrued Assets.............. & 177 & 0 & 19 & 0 & 0 & 19,638 \\
\hline \multirow{2}{*}{\multicolumn{7}{|c|}{ Deferred Debits }} \\
\hline & & & & & & \\
\hline 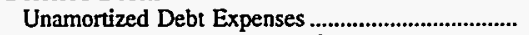 & 0 & 55 & 60 & 0 & 0 & 2,807 \\
\hline 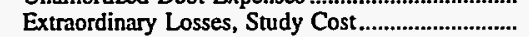 & 0 & 0 & 0 & 0 & 0 & 0 \\
\hline Misc Debt, R \& D Exp, Unamrt Losses .................. & 1,230 & 45,564 & 0 & 0 & 0 & 0 \\
\hline 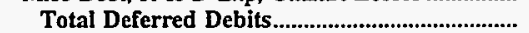 & 1,230 & 45,619 & 60 & 0 & 0 & 2,807 \\
\hline 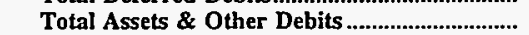 & 62,161 & 144,169 & 36,333 & 23,560 & 77,764 & 186,700 \\
\hline \multicolumn{7}{|l|}{ Proprietary Capital } \\
\hline 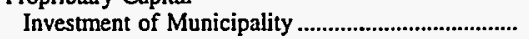 & 0 & 0 & 0 & 0 & 0 & 0 \\
\hline 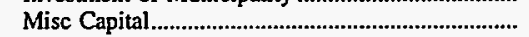 & 0 & 0 & 0 & 0 & 0 & 15,332 \\
\hline 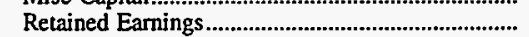 & 57,476 & 5,299 & 25,515 & 11,593 & 63,372 & 26,021 \\
\hline 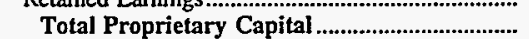 & 57,476 & 5,299 & 25,515 & 11,593 & 63,372 & 41,353 \\
\hline \multicolumn{7}{|l|}{ Long-term Debt } \\
\hline 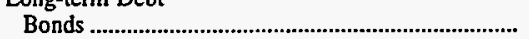 & 0 & 78,995 & 8,890 & 0 & 2,230 & 137,703 \\
\hline 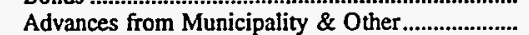 & 0 & 923 & 157 & 0 & 0 & 0 \\
\hline 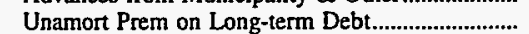 & 0 & 0 & 0 & 0 & 0 & 0 \\
\hline (less) Unamort Discount on Long-term Debt & 0 & 0 & 0 & 0 & 0 & 2,379 \\
\hline Total Long-term Debt & 0 & 79,918 & 9,047 & 0 & 2,230 & 135,324 \\
\hline \multicolumn{7}{|l|}{ Other Noncurrent Liabilities } \\
\hline 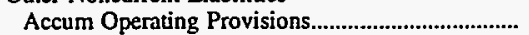 & 0 & 0 & 0 & 0 & 5,581 & 0 \\
\hline 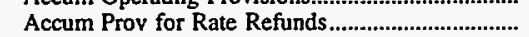 & 0 & 0 & 0 & 0 & 0 & 0 \\
\hline 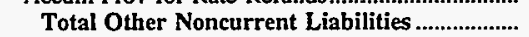 & 0 & 0 & 0 & $\mathbf{0}$ & 5,581 & 0 \\
\hline \multicolumn{7}{|l|}{ Current and Accrued Liabilities } \\
\hline 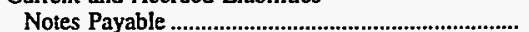 & 0 & 0 & 0 & 1,598 & 0 & 0 \\
\hline 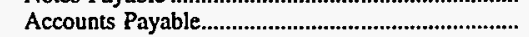 & 3,197 & 2,707 & 1,007 & 0 & 5,765 & 1,489 \\
\hline 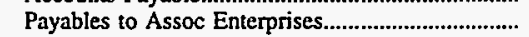 & 0 & 52,948 & 0 & 0 & 0 & 0 \\
\hline 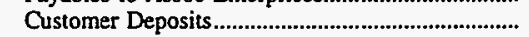 & 53 & 0 & 122 & 909 & 469 & 213 \\
\hline Taxes Accrued & 0 & 0 & 0 & 0 & 0 & 510 \\
\hline 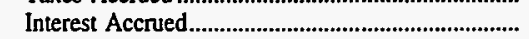 & 0 & 1,299 & 0 & 0 & 142 & 1,039 \\
\hline 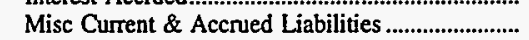 & 1,435 & 1,902 & 368 & 9,461 & 156 & 628 \\
\hline 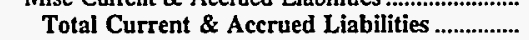 & 4,685 & 58,856 & 1,497 & 11,968 & 6,532 & 3,878 \\
\hline \multicolumn{7}{|l|}{ Deferred Credits } \\
\hline Customer Advances for Construction ...................... & 0 & 0 & 274 & 0 & 50 & 5,164 \\
\hline 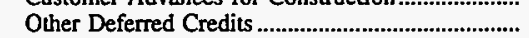 & 0 & 95 & 0 & 0 & 0 & 980 \\
\hline Unamort Gain on Reacqr Debt ................................ & 0 & 0 & 0 & 0 & 0 & 0 \\
\hline 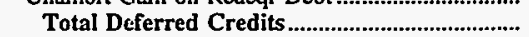 & $\mathbf{0}$ & 95 & 274 & o & 50 & 6,144 \\
\hline 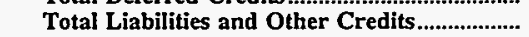 & 62,161 & 144,169 & 36,333 & 23,560 & 77,764 & 186,700 \\
\hline
\end{tabular}

Note: Totals may not equal sum of components because of independent rounding.

Source: Energy Information Administration, Form EIA-412, "Annual Report of Public Electric Utilities." 
Table 22. Balance Sheet by Major U.S. Publicly Owned Electric Utility Within State at End of Period, 1996

(Thousand Dollars)

\begin{tabular}{|c|c|c|c|c|c|c|}
\hline Item & $\begin{array}{l}\text { New Mexico } \\
\text { Gallup } \\
\text { City of } \\
\text { June } 30\end{array}$ & $\begin{array}{l}\text { New Mexico } \\
\begin{array}{c}\text { Los Alamos } \\
\text { County }\end{array} \\
\text { June } 30\end{array}$ & $\begin{array}{c}\text { New York } \\
\text { Fairport } \\
\text { Village of } \\
\text { May } 31\end{array}$ & $\begin{array}{c}\text { New York } \\
\text { Freeport } \\
\text { Village of } \\
\text { Inc } \\
\text { February } 28\end{array}$ & $\begin{array}{l}\text { New York } \\
\text { Jamestown } \\
\text { City of } \\
\text { December } 31\end{array}$ & $\begin{array}{l}\text { New York } \\
\text { Lake Placid } \\
\text { Village Inc } \\
\text { July } 31\end{array}$ \\
\hline \multicolumn{7}{|l|}{ Electric Utility Plant } \\
\hline 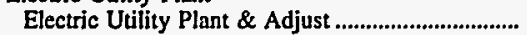 & 12,422 & 112,720 & 17,675 & 31,909 & 85,559 & 12,640 \\
\hline 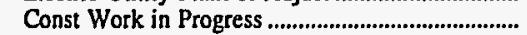 & & 636 & & 15,277 & 1,715 & 28 \\
\hline (less) Depr, Amort, and Depletion.............................. & 6,961 & 29,534 & 8,819 & 20,920 & 30,895 & 3,430 \\
\hline Net Electric Utility Plant .......................................... & 5,461 & 83,822 & 8,873 & 26,266 & 56,379 & 9,237 \\
\hline 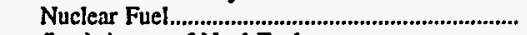 & 0 & & 0 & & $\mathbf{0}$ & 0 \\
\hline (less) Amort of Nucl Fuel ............................................. & 0 & 0 & 0 & 0 & 0 & 0 \\
\hline Net Elec Plant Incl Nucl Fuel .................................. & 5,461 & 83,822 & 8,873 & 26,266 & 56,379 & 9,237 \\
\hline \multicolumn{7}{|l|}{ Other Property \& Investments } \\
\hline 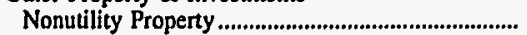 & 27,782 & $\mathbf{0}$ & 0 & 0 & 10 & 82 \\
\hline (less) Accum Provisions for Depr \& Amort ......... & 12,810 & 0 & 0 & 0 & 0 & 0 \\
\hline 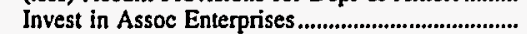 & 0 & 0 & 0 & 0 & 0 & 0 \\
\hline 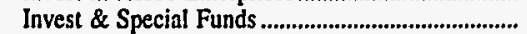 & 0 & 16,076 & 3,995 & 0 & 2,796 & 0 \\
\hline Total Other Property \& Investments................... & 14,972 & 16,076 & 3,995 & o & 2,806 & 82 \\
\hline \multicolumn{7}{|l|}{ Current and Accrued Assets } \\
\hline 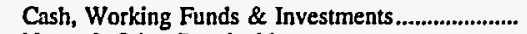 & 2,916 & 10,088 & 737 & 5,113 & 379 & 967 \\
\hline 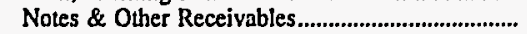 & 0 & 0 & 0 & 18 & 1,065 & 55 \\
\hline 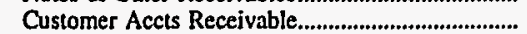 & 2,299 & 2,088 & 461 & 2,037 & 2,171 & 557 \\
\hline (less) Accum Prov for Uncollected Accts................... & 306 & 92 & 8 & 84 & 125 & 169 \\
\hline 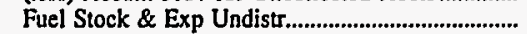 & 0 & 376 & 0 & 0 & 0 & 0 \\
\hline 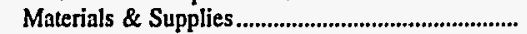 & 0 & 374 & 662 & 1,689 & 823 & 335 \\
\hline 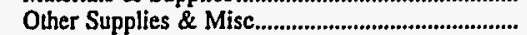 & 1,356 & 0 & 0 & 0 & 0 & 0 \\
\hline 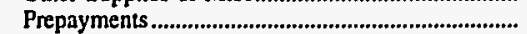 & 0 & 35 & 423 & 4 & 53 & 222 \\
\hline Accried Utility Revenues ........................................... & 0 & 334 & 0 & 0 & 0 & 0 \\
\hline Miscellaneous Current \& Accrued Assets................ & 2,346 & 667 & 8 & 0 & 0 & 0 \\
\hline 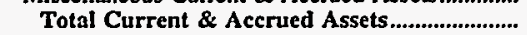 & 8,611 & 13,871 & 2,283 & 8,776 & 4,365 & 1,968 \\
\hline \multicolumn{7}{|l|}{ Deferred Debits } \\
\hline Unamortized Debt Expenses.............................................. & 108 & 3,577 & $\mathbf{0}$ & 0 & 0 & 0 \\
\hline 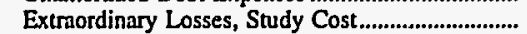 & 0 & 4 & 0 & 0 & 0 & 0 \\
\hline Misc Debt, R \& D Exp, Unamrt Losses .................. & 0 & 9,064 & 0 & 0 & 139 & 0 \\
\hline Total Deferred Debits............................................. & 108 & 12,646 & 0 & o & 139 & 0 \\
\hline Total Assets \& Other Debits ................................... & 29,152 & 126,414 & 15,151 & 35,043 & 63,689 & 11,287 \\
\hline \multicolumn{7}{|l|}{ Proprietary Capital } \\
\hline 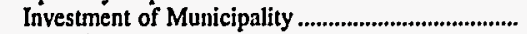 & 13,888 & 2,322 & $-5,539$ & 0 & 75,012 & 0 \\
\hline 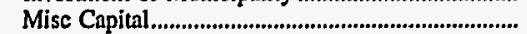 & 7,703 & & 557 & 0 & $-28,524$ & 5,481 \\
\hline Retained Earnings................................................... & 0 & 10,266 & 18,520 & 17,475 & 0 & 0 \\
\hline 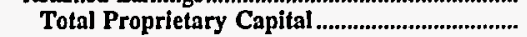 & 21,591 & 12,588 & $\mathbf{1 3 , 5 3 7}$ & $\mathbf{1 7 , 4 7 5}$ & 46,488 & 5,481 \\
\hline \multicolumn{7}{|l|}{ Long-term Debt } \\
\hline 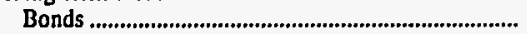 & 5,480 & 109,780 & 911 & 168 & 13,265 & 1,440 \\
\hline Advances from Municipality \& Other....................... & 58 & 65 & 0 & 0 & $\mathbf{0}$ & 161 \\
\hline Unamort Prem on Long-term Debt................................. & 0 & 0 & 0 & 0 & 0 & 0 \\
\hline (less) Unamort Discount on Long-term Debt & 0 & 1,839 & 0 & 0 & 0 & 0 \\
\hline Total Long-term Debt .................................................. & $\mathbf{5 , 5 3 8}$ & 108,006 & 911 & 168 & 13,265 & 1,601 \\
\hline \multicolumn{7}{|l|}{ Other Noncurrent Liabilities } \\
\hline Accum Operating Provisions..................................... & 0 & 0 & 0 & 1,637 & 0 & 400 \\
\hline Accum Prov for Rate Refunds............................... & 0 & 0 & 0 & 0 & 0 & 0 \\
\hline Total Other Noncurrent Liabilities .................. & $\mathbf{0}$ & $\mathbf{0}$ & 0 & 1,637 & $\mathbf{0}$ & 400 \\
\hline \multicolumn{7}{|l|}{ Current and Accrued Liabilities } \\
\hline 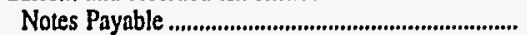 & 0 & 0 & 0 & 13,000 & 0 & 817 \\
\hline 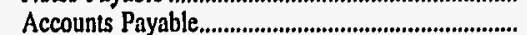 & 974 & 955 & 511 & 348 & 1,297 & 152 \\
\hline Payables to Assoc Enterprises............................ & 0 & 955 & 0 & 602 & 11 & 200 \\
\hline 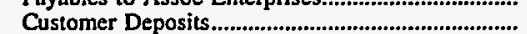 & 781 & 43 & 177 & 1,208 & 81 & 58 \\
\hline 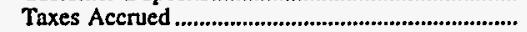 & 74 & 30 & 0 & 27 & 0 & 0 \\
\hline 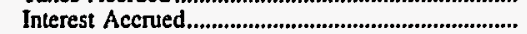 & 0 & 3,130 & 13 & 397 & 268 & 40 \\
\hline Misc Current \& Accrued Liabilities ....................... & 194 & 352 & 1 & 0 & 1 & 2,538 \\
\hline Total Current \& Accrued Liabilities ................... & 2,023 & 5,465 & 703 & 15,582 & 1,658 & $\mathbf{3 , 8 0 5}$ \\
\hline \multicolumn{7}{|l|}{ Deferred Credits } \\
\hline Customer Advances for Construction........................ & 0 & 0 & 0 & 181 & 200 & 0 \\
\hline 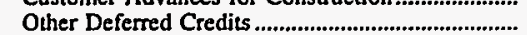 & 0 & 355 & 0 & 0 & 2,078 & 0 \\
\hline 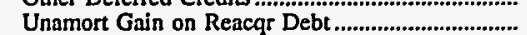 & 0 & 0 & 0 & 0 & 0 & 0 \\
\hline 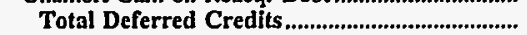 & & 355 & & 181 & 2,278 & \\
\hline Total Liabilities and Other Credits.................... & 29,152 & 126,414 & 15,151 & 35,043 & 63,689 & 11,287 \\
\hline
\end{tabular}

Note: Totals may not equal sum of components because of independent rounding.

Source: Energy Information Administration, Form EIA-412, "Annual Report of Public Electric Utilities." 
Table 22. Balance Sheet by Major U.S. Publicly Owned Electric Utility Within State at End of Period, 1996

(Thousand Dollars)

\begin{tabular}{|c|c|c|c|c|c|c|}
\hline Item & $\begin{array}{l}\text { New York } \\
\text { Massena } \\
\text { Town of } \\
\text { December } 31\end{array}$ & $\begin{array}{l}\text { New York } \\
\text { Plattsburgh } \\
\text { City of } \\
\text { December } 31\end{array}$ & $\begin{array}{c}\text { New York } \\
\text { Power } \\
\text { Authority } \\
\text { of State of NY } \\
\text { December } 31\end{array}$ & $\begin{array}{c}\text { New York } \\
\text { Rockville } \\
\text { Centre } \\
\text { Village of } \\
\text { May } 31\end{array}$ & $\begin{array}{l}\text { New York } \\
\text { Solvay } \\
\text { Village of } \\
\text { May } 31\end{array}$ & $\begin{array}{c}\text { North Carolina } \\
\text { Albemarle } \\
\text { City of } \\
\text { June } 30\end{array}$ \\
\hline \multicolumn{7}{|l|}{ Electric Utility Plant } \\
\hline Electric Utility Plant \& Adjust ................................... & 23,502 & 29,894 & $5,222,394$ & 37,165 & 10,888 & 18,877 \\
\hline Const Work in Progress & & 2,222 & 101,499 & 349 & 188 & \\
\hline & 9,046 & 13,054 & $1,997,121$ & 15,340 & 4,578 & 11,564 \\
\hline Net Electric Utility Plant ............................................ & 14,530 & 19,061 & $3,326,772$ & 22,173 & 6,498 & 7,313 \\
\hline $\begin{array}{l}\text { Nuclear Fuel................... } \\
\text { (less) Amort of Nucl Fuel }\end{array}$ & 0 & 0 & 317,077 & 0 & 0 & 0 \\
\hline & 0 & 0 & 157,879 & 0 & 0 & 0 \\
\hline 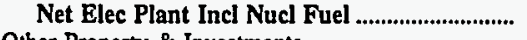 & 14,530 & 19,061 & $3,485,970$ & 22,173 & 6,498 & 7,313 \\
\hline \multicolumn{7}{|l|}{ Other Property \& Investments } \\
\hline 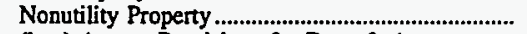 & 0 & 0 & 0 & 0 & 0 & 0 \\
\hline (less) Accum Provisions for Depr \& Amort .......... & 0 & 0 & 0 & 0 & 0 & 0 \\
\hline 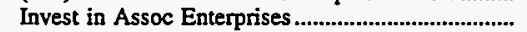 & 0 & 0 & 0 & 0 & 0 & 0 \\
\hline 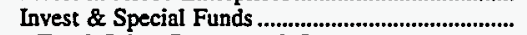 & 3,330 & 1,449 & 499,655 & 862 & 0 & 0 \\
\hline Total Other Property \& Investments................. & 3,330 & 1,449 & 499,655 & 862 & 0 & 0 \\
\hline \multicolumn{7}{|l|}{ Current and Accrued Assets } \\
\hline Cash, Working Funds \& Investments....................... & 1,278 & 296 & 955,774 & 625 & 1,254 & 3,167 \\
\hline 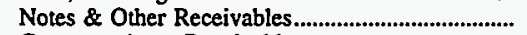 & & 1,616 & 25,124 & 1,626 & 42 & 0 \\
\hline 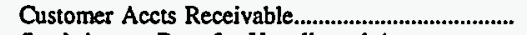 & 619 & 0 & 139,675 & 1,147 & 1,616 & 2,337 \\
\hline (less) Accum Prov for Uncollected Accts................ & 0 & 171 & 0 & 218 & 707 & 0 \\
\hline 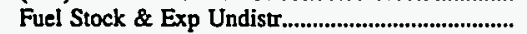 & 0 & 0 & 15,502 & 0 & 0 & 0 \\
\hline 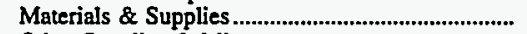 & 657 & 974 & 73,422 & 498 & 347 & 1,216 \\
\hline 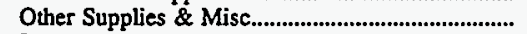 & 65 & 0 & 0 & 949 & 0 & 0 \\
\hline 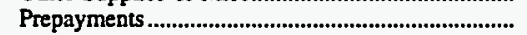 & 83 & 16 & 6,378 & 145 & 7 & 17 \\
\hline 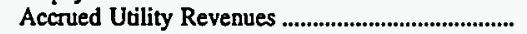 & 0 & 0 & 0 & 775 & 0 & 0 \\
\hline Miscellaneous Current \& Accrued Assets............... & 0 & 0 & 20,605 & 0 & 3,022 & 0 \\
\hline Total Current \& Accrued Assets......................... & 2,702 & $\mathbf{2 , 7 3 1}$ & $1,236,480$ & 5,547 & 5,581 & 6,737 \\
\hline \multicolumn{7}{|l|}{ Deferred Debits } \\
\hline 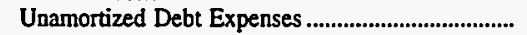 & 0 & 16 & 20,618 & 124 & 0 & 0 \\
\hline 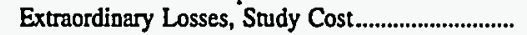 & 0 & 0 & 0 & 0 & 0 & 0 \\
\hline 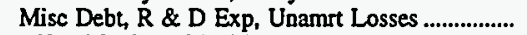 & 0 & 0 & 271,893 & 0 & 0 & 0 \\
\hline Total Deferred Debits........................................................ & o & 16 & 292,511 & 125 & & $\mathbf{0}$ \\
\hline Total Assets \& Other Debits .................................... & 20,562 & 23,258 & $5,514,616$ & 28,707 & 12,079 & 14,050 \\
\hline \multicolumn{7}{|l|}{ Proprietary Capital } \\
\hline 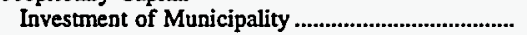 & 0 & $-12,737$ & 0 & $-6,801$ & 0 & 5,345 \\
\hline 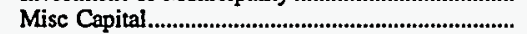 & 0 & & 0 & & 0 & 0 \\
\hline 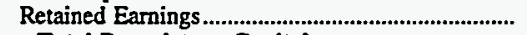 & 14,396 & 30,429 & $1,500,942$ & 19,385 & 4,600 & 6,758 \\
\hline Total Proprietary Capital & 14,396 & 17,693 & $1,500,942$ & 12,584 & 4,600 & 12,103 \\
\hline \multicolumn{7}{|l|}{ Long-term Debt } \\
\hline 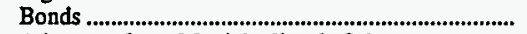 & 5,305 & 3,100 & $2,702,605$ & 12,948 & 4,129 & 0 \\
\hline Advances from Municipality \& Other........................ & 0 & 380 & 197,365 & 0 & 0 & 0 \\
\hline 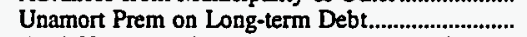 & 0 & 7 & & 0 & 29 & 0 \\
\hline (less) Unamort Discount on Long-term Debt & & & 52,896 & & 0 & 0 \\
\hline Total Long-term Debt .................................................. & 5,305 & 3,488 & $2,847,074$ & 12,948 & 4,158 & 0 \\
\hline \multicolumn{7}{|l|}{ Other Noncurrent Liabilities } \\
\hline 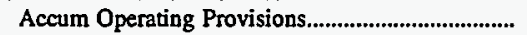 & 0 & 0 & 5,602 & 1,438 & $\mathbf{0}$ & 0 \\
\hline 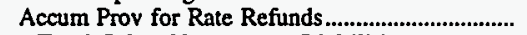 & 0 & 0 & & & 0 & 0 \\
\hline Total Other Noncurrent Liabilities....................... & $\mathbf{0}$ & 0 & 5,602 & 1,438 & 0 & 0 \\
\hline \multicolumn{7}{|l|}{ Current and Accrued Liabilities } \\
\hline 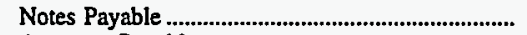 & 0 & 0 & 219,850 & 0 & 401 & 0 \\
\hline 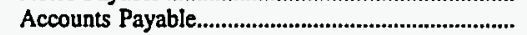 & 330 & 1,316 & 17,237 & 710 & 603 & 1,749 \\
\hline Payables to Assoc Enterprises...................................... & 0 & 0 & 0 & 0 & 198 & 0 \\
\hline 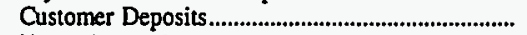 & 119 & 71 & 0 & 516 & 32 & 156 \\
\hline 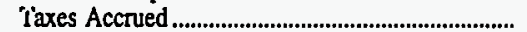 & 0 & 27 & 0 & 0 & 0 & 0 \\
\hline 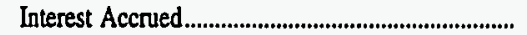 & 110 & -18 & 3,290 & 226 & 74 & 0 \\
\hline Misc Current \& Accrued Liabilities ............................... & 0 & 682 & 174,448 & 273 & 564 & 42 \\
\hline Total Current \& Accrued Liabilities ................ & 560 & 2,077 & 414,825 & 1,725 & 1,872 & 1,947 \\
\hline \multicolumn{7}{|l|}{ Deferred Credits } \\
\hline 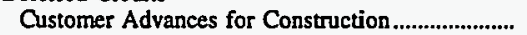 & 301 & & & 0 & 1,450 & 0 \\
\hline Other Deferred Credits & 0 & 0 & 746,173 & 13 & 0 & 0 \\
\hline 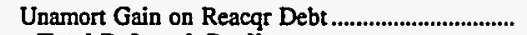 & 0 & 0 & $\mathbf{0}$ & 0 & 0 & $\mathbf{0}$ \\
\hline Total Deferred Credits...................................................... & 301 & 0 & 746,173 & 13 & 1,450 & $\mathbf{0}$ \\
\hline Total Liabilities and Other Credits..................... & 20,562 & 23,258 & $5,514,616$ & 28,707 & 12,079 & 14,050 \\
\hline
\end{tabular}

Note: Totals may not equal sum of components because of independent rounding.

Source: Energy Information Administration, Form EIA-412, “Annual Report of Public Electric Utilities." 
Table 22. Balance Sheet by Major U.S. Publicly Owned Electric Utility Within State at End of Period, 1996

(Thousand Dollars)

\begin{tabular}{|c|c|c|c|c|c|c|}
\hline Item & $\begin{array}{l}\text { North Carolina } \\
\text { Concord } \\
\text { City of } \\
\text { June } 30\end{array}$ & $\begin{array}{l}\text { North Carolina } \\
\text { Elizabeth } \\
\text { City City of } \\
\text { June } 30\end{array}$ & $\begin{array}{l}\text { North Carolina } \\
\text { Fayetteville } \\
\text { Public } \\
\text { Works Comm } \\
\\
\text { June } 30\end{array}$ & $\begin{array}{l}\text { North Carolina } \\
\text { Forest City } \\
\text { Town of } \\
\text { June } 30\end{array}$ & $\begin{array}{l}\text { North Carolina } \\
\text { Gastonia } \\
\text { City of } \\
\text { June } 30\end{array}$ & $\begin{array}{c}\text { North Carolina } \\
\text { Greenville } \\
\text { Utilities } \\
\text { Comm } \\
\text { June } 30\end{array}$ \\
\hline \multicolumn{7}{|l|}{ Electric Utility Piant } \\
\hline Electric Utility Plant \& Adjust ..................................... & 41,966 & 25,307 & 235,489 & 5,337 & 45,326 & 96,423 \\
\hline 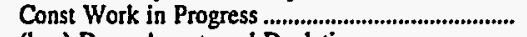 & & & 18,376 & & & $\begin{array}{r}8,504 \\
50,032\end{array}$ \\
\hline (less) Depr, Amort, and Depletion.................................... & 22,313 & $\begin{array}{r}9,862 \\
15445\end{array}$ & $\begin{array}{r}81,449 \\
1172,416\end{array}$ & 2,726 & 23,655 & 50,932 \\
\hline 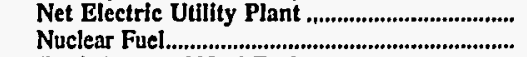 & $\begin{array}{r}19,652 \\
0\end{array}$ & $\begin{array}{r}15,445 \\
0\end{array}$ & $\begin{array}{r}172,416 \\
0\end{array}$ & $\begin{array}{r}2,611 \\
0\end{array}$ & $\begin{array}{r}21,671 \\
0\end{array}$ & $\begin{array}{r}53,995 \\
0\end{array}$ \\
\hline 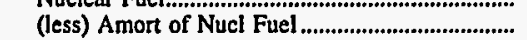 & 0 & 0 & 0 & 0 & 0 & 0 \\
\hline 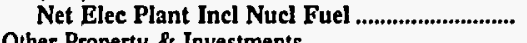 & 19,652 & 15,445 & 172,416 & 2,611 & 21,671 & 53,995 \\
\hline \multicolumn{7}{|l|}{ Other Property \& Investments } \\
\hline 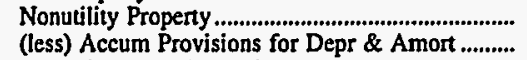 & $\begin{array}{l}0 \\
0\end{array}$ & $\begin{array}{l}\mathbf{0} \\
\mathbf{0}\end{array}$ & $\begin{array}{l}\mathbf{0} \\
\mathbf{0}\end{array}$ & $\begin{array}{l}\mathbf{0} \\
\mathbf{0}\end{array}$ & $\begin{array}{l}0 \\
0\end{array}$ & $\begin{array}{l}0 \\
0\end{array}$ \\
\hline 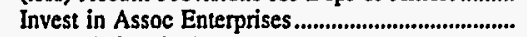 & 0 & 202 & 0 & 0 & 0 & 0 \\
\hline 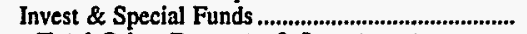 & 0 & 0 & 3,289 & 2,067 & $\mathbf{0}$ & 0 \\
\hline Total Other Property \& Investments................ & 0 & 202 & 3,289 & $\mathbf{2 , 0 6 7}$ & 0 & 证 \\
\hline \multicolumn{7}{|l|}{ Current and Accrued Assets } \\
\hline Cash, Working Funds \& Investments....................... & 9,857 & 4,129 & 42,403 & 2,508 & 5,516 & 15,479 \\
\hline Notes \& Other Receivables.............................................. & 226 & 1,000 & 2,773 & 0 & 0 & 555 \\
\hline 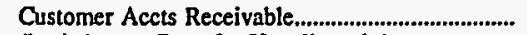 & 3,296 & 2,542 & 9,267 & 1,234 & 4,305 & 13,373 \\
\hline (less) Accum Prov for Uncollected Accts............... & 0 & 142 & 178 & 0 & 1,263 & 0 \\
\hline 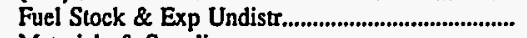 & 0 & 0 & 1,112 & $\mathbf{0}$ & 0 & 0 \\
\hline 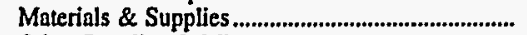 & 2,160 & 1,412 & 5,613 & $\mathbf{0}$ & 418 & 3,157 \\
\hline 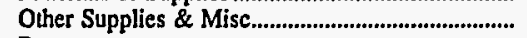 & 0 & 0 & 1,699 & 0 & 0 & 0 \\
\hline 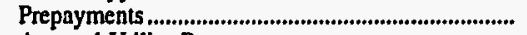 & 0 & 0 & 37 & $\mathbf{0}$ & $\mathbf{0}$ & 88 \\
\hline Accrued Utility Revenues.. & 0 & 0 & 6,501 & $\mathbf{0}$ & 0 & 0 \\
\hline Miscellaneous Current \& Accrued Assets............... & 0 & 4 & 292 & 0 & 2,406 & 0 \\
\hline Total Current \& Accrued Assets........................... & 15,539 & 8,945 & 69,518 & 3,742 & 11,381 & 32,652 \\
\hline \multicolumn{7}{|l|}{ Deferred Debits } \\
\hline 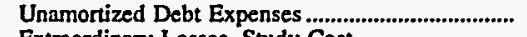 & 333 & 0 & 2,548 & 0 & $\mathbf{0}$ & 0 \\
\hline 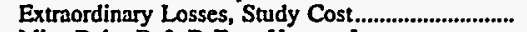 & & 0 & & $\mathbf{0}$ & $\mathbf{0}$ & 0 \\
\hline Misc Debt, R \& D Exp, Unamrt Losses ................. & $\mathbf{0}$ & 0 & 0 & 0 & $\mathbf{0}$ & 0 \\
\hline 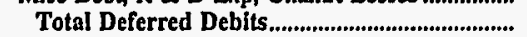 & 333 & 0 & 2,548 & & 0 & 0 \\
\hline 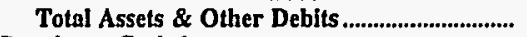 & 35,524 & 24,592 & 247,771 & 8,419 & 33,052 & 86,648 \\
\hline \multicolumn{7}{|l|}{ Proprietary Capital } \\
\hline 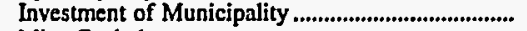 & $\mathbf{0}$ & 161 & 0 & 2,308 & 4,116 & 0 \\
\hline ………………............. & $\mathbf{0}$ & 0 & 0 & 0 & 0 & 0 \\
\hline 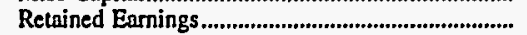 & 21,192 & 22,324 & 161,184 & 5,341 & 24,812 & 61,902 \\
\hline Total Proprietary Capital...... & 21,192 & 22,486 & 161,184 & 7,649 & 28,927 & 61,902 \\
\hline \multicolumn{7}{|l|}{ Long-term Debt } \\
\hline 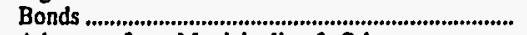 & 10,970 & 0 & 69,293 & 0 & 0 & 10,333 \\
\hline Municipality \& Other........................ & & 0 & 0 & $\mathbf{0}$ & 0 & \\
\hline 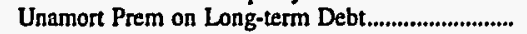 & $\mathbf{0}$ & 0 & 0 & 0 & 0 & 0 \\
\hline (less) Unamort Discount on Long-term Debt & & 0 & & $\mathbf{0}$ & 0 & \\
\hline Total Long-term Debt.. & 10,970 & 0 & 69,293 & $\mathbf{0}$ & 0 & 10,333 \\
\hline \multicolumn{7}{|l|}{ Other Noncurrent Liabilities } \\
\hline Accum Operating Provisions..... & 0 & 0 & 0 & 0 & 0 & 0 \\
\hline Accum Prov for Rate Refunds & 0 & 0 & 0 & 0 & 0 & 0 \\
\hline Total Other Noncurrent Llabilities .................... & 0 & 0 & o & 0 & 0 & 0 \\
\hline \multicolumn{7}{|l|}{ Current and Accrued Liabilities } \\
\hline Notes Payable.... & $\mathbf{0}$ & $\mathbf{0}$ & & 0 & 0 & \\
\hline (............................................. & 2,657 & 1,757 & 10,532 & 550 & 3,852 & 11,246 \\
\hline 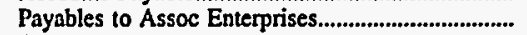 & 0 & 0 & 0 & $\mathbf{0}$ & 0 & \\
\hline 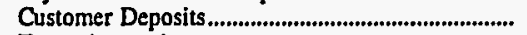 & 530 & 271 & 1,293 & 211 & 164 & 806 \\
\hline ................. & 0 & 0 & 25 & $\mathbf{0}$ & 0 & 0 \\
\hline 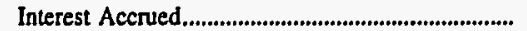 & 52 & 0 & 1,228 & 0 & 0 & 150 \\
\hline Misc Current \& Accrued Liabilities............................ & 124 & 78 & 4,216 & 10 & 109 & 2,033 \\
\hline Total Current \& Accrued Liabilities ................. & 3,362 & 2,106 & 17,294 & 770 & 4,125 & 14,235 \\
\hline \multicolumn{7}{|l|}{ Deferred Credits } \\
\hline Customer Advances for Construction........................ & 0 & 0 & 0 & 0 & 0 & 177 \\
\hline ............................ & 0 & 0 & 0 & 0 & 0 & \\
\hline Unamort Gain on Reacqr Debt......................................... & 0 & 0 & 0 & 0 & 0 & 0 \\
\hline Total Deferred Credits ...................................................... & & & 0 & 0 & & 177 \\
\hline Total Liabilities and Other Credits.................... & 35,524 & 24,592 & 247,771 & 8,419 & 33,052 & 86,648 \\
\hline
\end{tabular}

Note: Totals may not equal sum of components because of independent rounding.

Source: Energy Information Administration, Form EIA-412, "Annual Report of Public Electric Utilities." 
Table 22. Balance Sheet by Major U.S. Publicly Owned Electric Utility Within State at End of Period, 1996

(Thousand Dollars)

\begin{tabular}{|c|c|c|c|c|c|c|}
\hline Item & $\begin{array}{l}\text { North Carolina } \\
\text { High } \\
\text { Point } \\
\text { Town } \\
\text { of } \\
\text { June } 30\end{array}$ & $\begin{array}{l}\text { North Carolina } \\
\text { Kinston } \\
\text { City of } \\
\text { June } 30\end{array}$ & $\begin{array}{l}\text { North Carolina } \\
\text { Lexington } \\
\text { City of } \\
\text { June } 30\end{array}$ & $\begin{array}{l}\text { North Carolina } \\
\text { Lumberton } \\
\text { City of } \\
\text { June } 30\end{array}$ & $\begin{array}{l}\text { North Carolina } \\
\text { Monroe } \\
\text { City of } \\
\text { June } 30\end{array}$ & $\begin{array}{l}\text { North Carolina } \\
\text { Morganton } \\
\text { City of } \\
\text { June } 30\end{array}$ \\
\hline \multicolumn{7}{|l|}{ Electric Utility Plant } \\
\hline 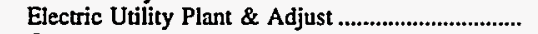 & 66,387 & 20,764 & 31,372 & 12,721 & 26,752 & 13,623 \\
\hline 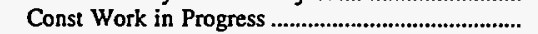 & & 3,940 & 3,024 & 130 & 8,496 & \\
\hline 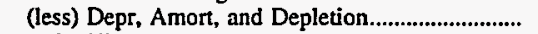 & 27,154 & 9,120 & 10,665 & 7,177 & 9,161 & 5,750 \\
\hline 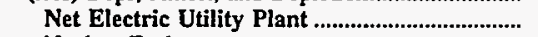 & 39,233 & 15,584 & 23,731 & 5,674 & 26,087 & $\mathbf{7 , 9 3 4}$ \\
\hline 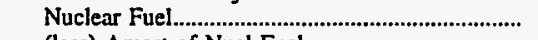 & & & & 0 & 0 & \\
\hline 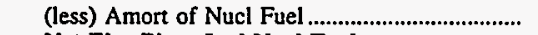 & $\mathbf{0}$ & 0 & 0 & 0 & 0 & $\mathbf{0}$ \\
\hline Net Elec Plant Incl Nucl Fuel ..................................... & 39,233 & 15,584 & 23,731 & 5,674 & 26,087 & 7,934 \\
\hline 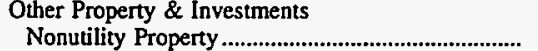 & \multicolumn{6}{|c|}{ Other Property \& Investments } \\
\hline (less) Accum Provisions for Depr \& Amort .......... & 0 & 0 & 0 & 0 & 0 & 0 \\
\hline 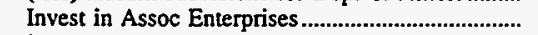 & 0 & 0 & 0 & 0 & 0 & 0 \\
\hline 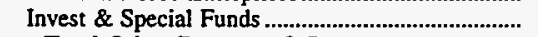 & 0 & 0 & 0 & 0 & 2,158 & 0 \\
\hline \multirow{2}{*}{\multicolumn{7}{|c|}{ Current and Accrued Assets }} \\
\hline & & & & & & \\
\hline 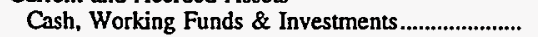 & 18,615 & 8,445 & 1,472 & 746 & 20,517 & 10,559 \\
\hline Notes \& Other Receivables................................................ & & 1,269 & 3,122 & 40 & 0 & 618 \\
\hline 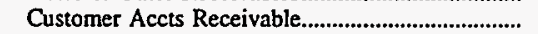 & 4,522 & 4,464 & 0 & 1,569 & 2,351 & 2,123 \\
\hline (less) Accum Prov for Uncollected Accts ................... & 0 & 289 & 0 & 0 & 0 & 0 \\
\hline 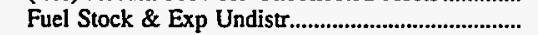 & 0 & 0 & 0 & 0 & 0 & 0 \\
\hline 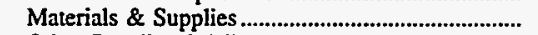 & 0 & 1,346 & 348 & 402 & 1,698 & 0 \\
\hline 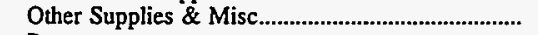 & 0 & 0 & 0 & 0 & 0 & 0 \\
\hline 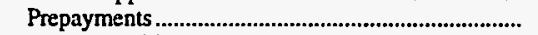 & $\mathbf{0}$ & 0 & 729 & 0 & 0 & 0 \\
\hline 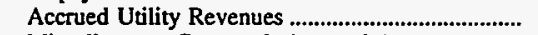 & 0 & 0 & 565 & 0 & 0 & 0 \\
\hline Miscellaneous Current \& Accrued Assets................... & 110 & 0 & 0 & 0 & $\mathbf{0}$ & 135 \\
\hline Total Current \& Accrued Assets............................. & 23,247 & 15,233 & 6,235 & $\mathbf{2 , 7 5 7}$ & 24,566 & 13,435 \\
\hline \multicolumn{7}{|l|}{ Deferred Debits } \\
\hline 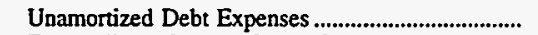 & 0 & 332 & 0 & 0 & 0 & $\mathbf{0}$ \\
\hline 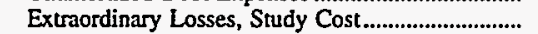 & 0 & 0 & 0 & 0 & 0 & 0 \\
\hline Misc Debt, R \& D Exp, Unamrt Losses ................. & 0 & 0 & 0 & 0 & 177 & 0 \\
\hline Total Deferred Debits................................................... & 0 & 332 & 0 & $\mathbf{0}$ & 177 & 0 \\
\hline 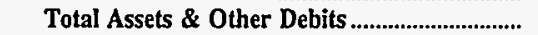 & 63,227 & 31,149 & 29,966 & 8,431 & 52,987 & 21,369 \\
\hline \multicolumn{7}{|l|}{ Proprietary Capital } \\
\hline 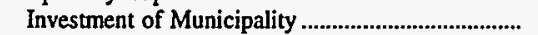 & 0 & 0 & 3,926 & 957 & 0 & 3,172 \\
\hline 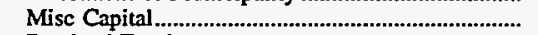 & 158 & 0 & & & 997 & \\
\hline 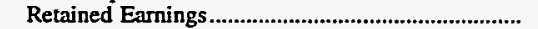 & 57,038 & 15,773 & 11,351 & 4,749 & 43,900 & 16,160 \\
\hline Total Proprietary Capital .......................................... & 57,197 & 15,773 & 15,277 & 5,706 & 44,897 & 19,331 \\
\hline \multicolumn{7}{|l|}{ Long-term Debt } \\
\hline Bonds ................. & 0 & 10,315 & 2,400 & 0 & 0 & 0 \\
\hline Advances from Municipality \& Other........................... & 0 & 1,206 & 8,157 & 0 & 0 & 0 \\
\hline 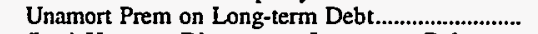 & 0 & 0 & 0 & 0 & 0 & 0 \\
\hline (less) Unamort Discount on Long-term Debt & 0 & 0 & 0 & 0 & 0 & 0 \\
\hline 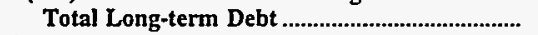 & $\mathbf{0}$ & 11,521 & 10,557 & o & $\mathbf{0}$ & 0 \\
\hline \multicolumn{7}{|l|}{ Other Noncurrent Liabilities } \\
\hline Accum Operating Provisions...... & 0 & 0 & 0 & 60 & 0 & 0 \\
\hline Accum Prov for Rate Refunds...................................... & 0 & 0 & 0 & 0 & $\mathbf{0}$ & o \\
\hline Total Other Noncurrent Liabilities....... & $\mathbf{0}$ & 0 & $\mathbf{0}$ & 60 & $\mathbf{0}$ & 0 \\
\hline \multicolumn{7}{|l|}{ Current and Accrued Liabilities } \\
\hline 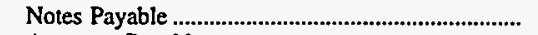 & $\mathbf{0}$ & 0 & 734 & 0 & 4,813 & 0 \\
\hline Accounts Payable.... & 5,213 & 3,201 & 2,781 & 2.139 & 2,792 & 1,779 \\
\hline 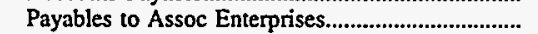 & 0 & 0 & 0 & 0 & 0 & 0 \\
\hline 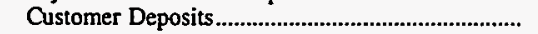 & 434 & 550 & 565 & 526 & 457 & 211 \\
\hline 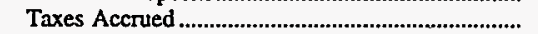 & 0 & 0 & 0 & 0 & 0 & 0 \\
\hline 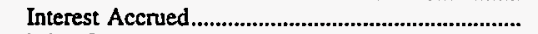 & 0 & 0 & 0 & 0 & 0 & 0 \\
\hline Misc Current \& Accrued Liabilities .............................. & 382 & 103 & 52 & 0 & 29 & 46 \\
\hline Total Current \& Accrued Liabilities ..................... & 6,030 & $\mathbf{3 , 8 5 5}$ & 4,132 & 2,665 & 8,090 & 2,037 \\
\hline \multicolumn{7}{|l|}{ Deferred Credits } \\
\hline 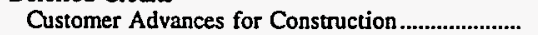 & & 0 & 0 & 0 & ó & 0 \\
\hline 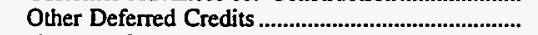 & 0 & 0 & 0 & 0 & 0 & 0 \\
\hline Unamort Gain on Reacqr Debt ...................................... & 0 & 0 & 0 & 0 & 0 & $\mathbf{0}$ \\
\hline 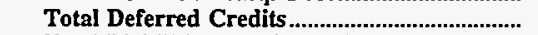 & 0 & & & 0 & 0 & \\
\hline Total Liabilities and Other Credits.................. & 63,227 & 31,149 & 29,966 & 8,431 & 52,987 & 21,369 \\
\hline
\end{tabular}

Note: Totals may not equal sum of components because of independent rounding.

Source: Energy Information Administration, Form EIA-412, "Annual Report of Public Electric Utilities." 
Table 22. Balance Sheet by Major U.S. Publicly Owned Electric Utility Within State at End of Period, 1996

(Thousand Dollars)

\begin{tabular}{|c|c|c|c|c|c|c|}
\hline Item & $\begin{array}{l}\text { North Carolina } \\
\text { Murphy } \\
\text { City of } \\
\text { June } 30\end{array}$ & $\begin{array}{l}\text { North Carolina } \\
\text { New Bern } \\
\text { City of } \\
\text { June } 30\end{array}$ & $\begin{array}{c}\text { North Carolina } \\
\text { New River } \\
\text { Light } \\
\& \\
\text { Power Co } \\
\text { December } 31\end{array}$ & $\begin{array}{c}\text { North Carolina } \\
\text { North } \\
\text { Carolina } \\
\text { Eastem M P A } \\
\text { December } 31\end{array}$ & $\begin{array}{l}\text { North Carolina } \\
\text { North } \\
\text { Carolina } \\
\text { Mun } \\
\text { Power Agny } \\
\text { December } 31\end{array}$ & $\begin{array}{l}\text { North Carolina } \\
\text { Rocky Mount } \\
\text { City of } \\
\text { June } 30\end{array}$ \\
\hline \multicolumn{7}{|l|}{ Electric Utility Plant } \\
\hline Electric Utility Plant \& Adjust ..................................... & 8,243 & 27,167 & 12,899 & $1,448,307$ & $1,427,479$ & 42,836 \\
\hline 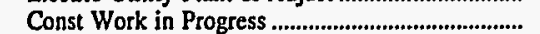 & 309 & 134 & 86 & 4,342 & 12,875 & 0 \\
\hline (less) Depr, Amort, and Depletion................................ & 2,691 & 11,398 & 3,551 & 489,293 & 387,581 & 17,253 \\
\hline Net Electric Utility Plant ...................................... & 5,861 & 15,903 & 9,434 & 963,356 & $1,052,773$ & 25,582 \\
\hline 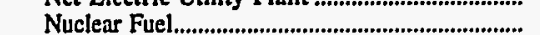 & & & & 66,071 & 96,782 & \\
\hline 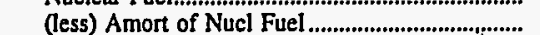 & & 0 & & 35,170 & 57,994 & 0 \\
\hline Net Elec Plant Incl Nucl Fuel ............................... & 5,861 & 15,903 & 9,434 & 994,257 & $1,091,561$ & 25,582 \\
\hline \multicolumn{7}{|l|}{ Other Property \& Investments } \\
\hline 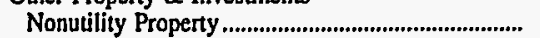 & 0 & 0 & 0 & 2,375 & 3,426 & 0 \\
\hline (less) Accum Provisions for Depr \& Amort ........... & 0 & 0 & 0 & 515 & 1,297 & 0 \\
\hline 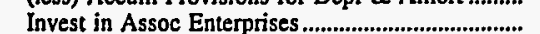 & 0 & 0 & 5,906 & 0 & 0 & 0 \\
\hline 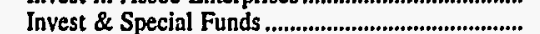 & 2,269 & 0 & 2,500 & 524,697 & 367,527 & 0 \\
\hline Total Other Property \& Investments............... & $\mathbf{2 , 2 6 9}$ & $\mathbf{0}$ & 8,406 & 526,557 & 369,656 & 0 \\
\hline \multicolumn{7}{|l|}{ Current and Accrued Assets } \\
\hline Cash, Working Funds \& Investments............................. & 563 & 6,148 & 34 & 207,369 & 25,102 & 1,899 \\
\hline Notes \& Other Receivables................................... & 534 & & 1,156 & 0 & 3,356 & 37 \\
\hline 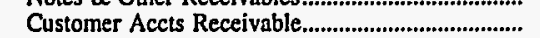 & 0 & 4,461 & 43 & 33,940 & 19,417 & 7,441 \\
\hline (less) Accum Prov for Uncollected Accts............... & 0 & 85 & 34 & & 0 & 0 \\
\hline 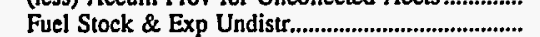 & 0 & & 0 & 2,639 & 0 & 0 \\
\hline 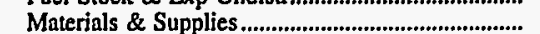 & 175 & 1,330 & 283 & 8,453 & 15,102 & 646 \\
\hline 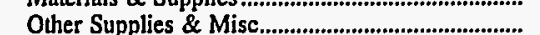 & 0 & 0 & 0 & 0 & 0 & 0 \\
\hline 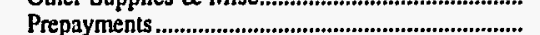 & 139 & 0 & 12 & 900 & 156 & 0 \\
\hline Accrued Utility Revenues ................................... & 0 & 0 & 0 & 0 & 0 & 0 \\
\hline Miscellaneous Current \& Accrued Assets.............. & 0 & 0 & 2 & 0 & 576,593 & 0 \\
\hline 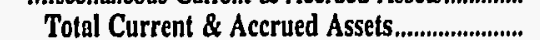 & 1,411 & 11,855 & 1,495 & 253,301 & 639,726 & 10,023 \\
\hline \multicolumn{7}{|l|}{ Deferred Debits } \\
\hline 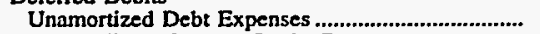 & 0 & 0 & $\mathbf{0}$ & 45,950 & 31,644 & 0 \\
\hline 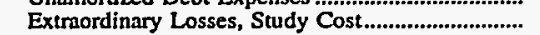 & 0 & 0 & 0 & & 326,798 & 0 \\
\hline 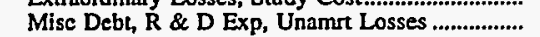 & 80 & 0 & 0 & $1,807,218$ & 4,901 & 0 \\
\hline Total Deferred Debits............................................. & 80 & & & $1,853,168$ & 363,343 & \\
\hline Total Assets \& Other Debits .................................... & 9,621 & 27,758 & 19,336 & $\mathbf{3 , 6 2 7 , 2 8 3}$ & $2,464,286$ & 35,605 \\
\hline \multicolumn{7}{|l|}{ Proprietary Capital } \\
\hline Investment of Municipality .... & 0 & 4,323 & 0 & 0 & 0 & 0 \\
\hline Misc Capital & 0 & & 0 & 0 & 0 & 1,139 \\
\hline 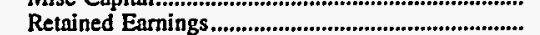 & 8,824 & 15,248 & 16,929 & 26,000 & 7,400 & 23,883 \\
\hline Total Proprietary Capital ...................................... & 8,824 & 19,571 & 16,929 & 26,000 & $\mathbf{7 , 4 0 0}$ & 25,023 \\
\hline \multicolumn{7}{|l|}{ Long-term Debt } \\
\hline Bonds .................. & 0 & 0 & 0 & $3,417,035$ & $2,273,082$ & 377 \\
\hline Advances from Municipality \& Other................... & 68 & 3,361 & 0 & 41,282 & 261,368 & 3,074 \\
\hline Unamort Prem on Long-term Debt.......................... & 0 & 0 & 1,040 & 16,787 & 10,372 & 0 \\
\hline (less) Unamort Discount on Long-term Debt & 0 & 0 & & 124,626 & 165,788 & 0 \\
\hline Total Long-term Debt ............................................ & 68 & 3,361 & 1,040 & $3,350,478$ & $2,379,034$ & 3,451 \\
\hline \multicolumn{7}{|l|}{ Other Noncurrent Liabilities } \\
\hline Accum Operating Provisions.................................. & 0 & $\mathbf{0}$ & 0 & 0 & $\mathbf{0}$ & o \\
\hline Accum Prov for Rate Refunds............................. & 0 & 0 & 0 & 0 & 0 & 0 \\
\hline Total Other Noncurrent Liabilities .................. & $\mathbf{0}$ & 0 & o & o & 0 & o \\
\hline \multicolumn{7}{|l|}{ Current and Accrued Liabilities } \\
\hline Notes Payable ..................................................... & 0 & 1,176 & 230 & 137,000 & 0 & 0 \\
\hline Accounts Payable & 458 & 2,839 & 888 & 12,671 & 677 & 5,496 \\
\hline 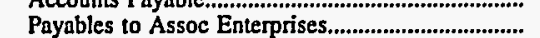 & 0 & 0 & 0 & 0 & 0 & 0 \\
\hline 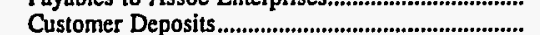 & 257 & 735 & 226 & 0 & 0 & 810 \\
\hline 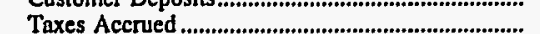 & 0 & 0 & 0 & 5,619 & 13,270 & 0 \\
\hline 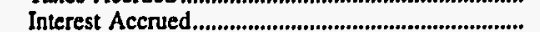 & $\mathbf{0}$ & 77 & 19 & 95,515 & 63,905 & 175 \\
\hline Misc Current \& Accrued Liabilities..................... & 14 & 0 & & 0 & 0 & 649 \\
\hline Total Current \& Accrued Liabilities ..................... & 729 & 4,827 & 1,366 & 250,805 & $\mathbf{7 7 , 8 5 2}$ & $\mathbf{7 , 1 3 1}$ \\
\hline \multicolumn{7}{|l|}{ Deferred Credits } \\
\hline Customer Advances for Construction ......................... & 0 & 0 & 0 & 0 & $\mathbf{0}$ & $\mathbf{0}$ \\
\hline 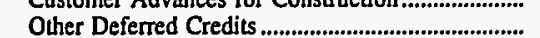 & 0 & 0 & 0 & 0 & 0 & 0 \\
\hline 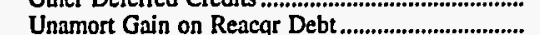 & 0 & 0 & 0 & 0 & 0 & 0 \\
\hline 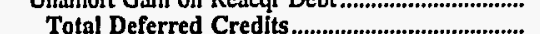 & 0 & & & $\mathbf{0}$ & 0 & \\
\hline Total Llabilities and Other Credits................ & 9,621 & 27,758 & 19,336 & $3,627,283$ & $2,464,286$ & 35,605 \\
\hline
\end{tabular}

Note: Totals may not equal sum of components because of independent rounding.

Source: Energy Information Administration, Form EIA-412, "Annual Report of Public Electric Utilities." 
Table 22. Balance Sheet by Major U.S. Publicly Owned Electric Utility Within State at End of Period, 1996

(Thousand Dollars)

\begin{tabular}{|c|c|c|c|c|c|c|}
\hline Item & $\begin{array}{l}\text { North Carolina } \\
\text { Shelby } \\
\text { City of } \\
\text { June } 30\end{array}$ & $\begin{array}{l}\text { North Carolina } \\
\text { Statesville } \\
\text { City of } \\
\text { June } 30\end{array}$ & $\begin{array}{l}\text { North Carolina } \\
\text { Tarboro } \\
\text { Town of } \\
\text { June } 30\end{array}$ & $\begin{array}{l}\text { North Carolina } \\
\begin{array}{c}\text { Washington } \\
\text { City of }\end{array} \\
\text { June } 30\end{array}$ & $\begin{array}{l}\text { North Carolina } \\
\text { Wilson } \\
\text { City of } \\
\text { June } 30\end{array}$ & $\begin{array}{c}\text { Ohio } \\
\text { American } \\
\text { Mun } \\
\text { Power } \\
\text { Ohio Inc } \\
\text { December } 31\end{array}$ \\
\hline \multicolumn{7}{|l|}{ Electric Utility Plant } \\
\hline 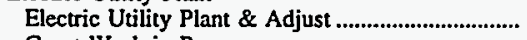 & 9,338 & 17,567 & 22,591 & 30,636 & 56,337 & 72,632 \\
\hline Const Work in Progress & & 577 & 0 & 158 & 3,389 & \\
\hline 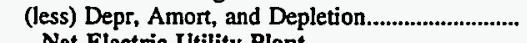 & 5,164 & $\begin{array}{r}7,423 \\
1971\end{array}$ & 7,161 & 13,780 & $\begin{array}{l}29,570 \\
30157\end{array}$ & 26,744 \\
\hline Net Electric Utility Plant ...................................... & 4,174 & 10,721 & 15,431 & 17,014 & 30,157 & 45,888 \\
\hline 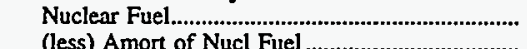 & 0 & 0 & 0 & 0 & 0 & \\
\hline & 0 & $\mathbf{0}$ & 0 & 0 & 0 & \\
\hline $\begin{array}{l}\text { Net Elec Plant Incl Nucl Fuel ..................................... } \\
\text { Other Property \& Investments }\end{array}$ & 4,174 & 10,721 & 15,431 & 17,014 & 30,157 & 45,888 \\
\hline 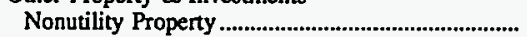 & 0 & 1,184 & 0 & 0 & 0 & 4,554 \\
\hline (less) Accum Provisions for Depr \& Amort .......... & $\mathbf{0}$ & 633 & 0 & 0 & 0 & 647 \\
\hline 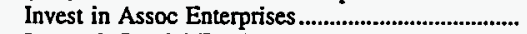 & 0 & 0 & 0 & 0 & 0 & \\
\hline 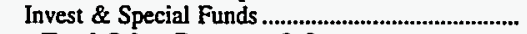 & 1,526 & 0 & 0 & 0 & 0 & 18,487 \\
\hline Total Other Property \& Investments................ & 1,526 & 551 & 0 & 0 & 0 & 22,394 \\
\hline \multicolumn{7}{|l|}{ Current and Accrued Assets } \\
\hline Cash, Working Funds \& Investments...................... & 3,768 & 7,923 & 7,930 & 6,933 & 24,131 & 14,531 \\
\hline 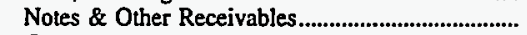 & 922 & 204 & 2,194 & 0 & 1,404 & 80 \\
\hline 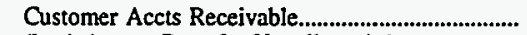 & 0 & 3,628 & 0 & 2,418 & 2,863 & 14,463 \\
\hline (less) Accum Prov for Uncollected Accts.................... & 0 & 130 & 31 & 0 & 184 & \\
\hline 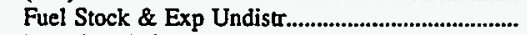 & 0 & 0 & 0 & 0 & 0 & 0 \\
\hline Materials \& Supplies............................................................. & 801 & 1,103 & 651 & 0 & 1,253 & 5,573 \\
\hline 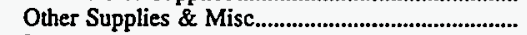 & 0 & 0 & 0 & 639 & 0 & 0 \\
\hline 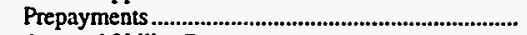 & 0 & 0 & 0 & 0 & 29 & 263 \\
\hline 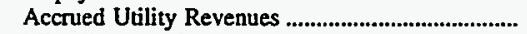 & 0 & 0 & 0 & 0 & 6,296 & \\
\hline Miscellaneous Current \& Accrued Assets.............. & 0 & 0 & 0 & 0 & & 1,228 \\
\hline Total Current \& Accrued Assets................................... & $\mathbf{5 , 4 9 0}$ & 12,728 & 10,745 & 9,991 & 35,793 & 36,137 \\
\hline \multicolumn{7}{|l|}{ Deferred Debits } \\
\hline Unamortized Debt Expenses. & 2 & 0 & 0 & 0 & 0 & 0 \\
\hline 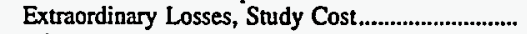 & 0 & 0 & 0 & 0 & 0 & \\
\hline Misc Debt, R \& D Exp, Unamrt Losses .................. & 0 & 0 & 0 & 0 & 0 & 0 \\
\hline Total Deferred Debits................................................ & 2 & 0 & 0 & 0 & 0 & \\
\hline 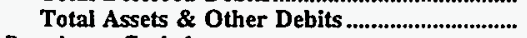 & 11,193 & 24,000 & 26,176 & 27,005 & 65,949 & 104,419 \\
\hline \multicolumn{7}{|l|}{ Proprietary Capital } \\
\hline 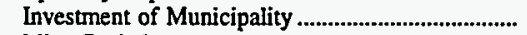 & 0 & 33 & 2,203 & 267 & 83 & 566 \\
\hline 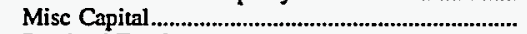 & 88 & 154 & 0 & 167 & 10 & \\
\hline 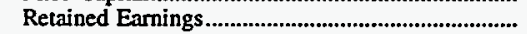 & 5,598 & 21,115 & 21,316 & 19,253 & 54,865 & 3,871 \\
\hline 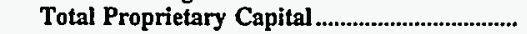 & 5,686 & 21,301 & 23,519 & 19,687 & 54,959 & 4,437 \\
\hline \multicolumn{7}{|l|}{ Long-term Debt } \\
\hline 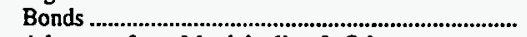 & 3,873 & 0 & 0 & 2,291 & 0 & 69,132 \\
\hline Advances from Municipality \& Other....................... & 0 & 0 & 0 & 1,939 & 0 & \\
\hline Unamort Prem on Long-term Debt....................... & 0 & 0 & 0 & 0 & 0 & \\
\hline (less) Unamort Discount on Long-term Debt & 0 & 0 & 0 & 0 & 0 & \\
\hline Total Long-term Debt.... & 3,873 & 0 & 0 & 4,230 & 0 & 69,132 \\
\hline \multicolumn{7}{|l|}{ Other Noncurrent Liabilities } \\
\hline Accum Operating Provision & 0 & 76 & 0 & 0 & 0 & 0 \\
\hline 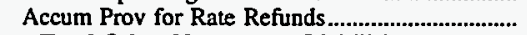 & 0 & 0 & 0 & 0 & 0 & 0 \\
\hline Total Other Noncurrent Liabilities ................... & o & 76 & 0 & 0 & 0 & 0 \\
\hline \multicolumn{7}{|l|}{ Current and Accrued Liabilities } \\
\hline Notes Payable ........................ & 87 & 0 & 0 & 711 & 2,317 & \\
\hline 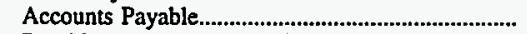 & 1,195 & 2,541 & 2,438 & 1,799 & 7,522 & 13,697 \\
\hline Payables to Assoc Enterprises......................................... & 0 & 0 & 0 & 0 & 0 & 324 \\
\hline 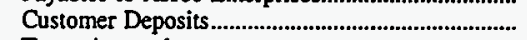 & 266 & 82 & 166 & 166 & 691 & \\
\hline Taxes Accrued .......................... & 0 & 0 & 0 & 0 & 0 & 6,158 \\
\hline 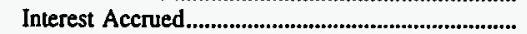 & 0 & 0 & 0 & 412 & 0 & 1,789 \\
\hline 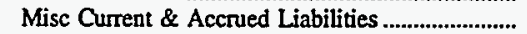 & 87 & 0 & 52 & & 461 & 4,437 \\
\hline Total Current \& Accrued Liabilities ...................... & 1,634 & 2,623 & 2,657 & 3,088 & 10,991 & 26,404 \\
\hline \multicolumn{7}{|l|}{ Deferred Credits } \\
\hline 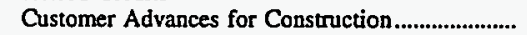 & 0 & 0 & 0 & 0 & 0 & \\
\hline 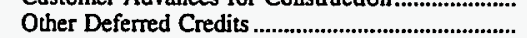 & 0 & 0 & 0 & 0 & 0 & 4,446 \\
\hline 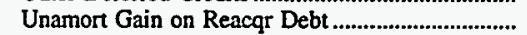 & 0 & 0 & 0 & 0 & 0 & \\
\hline Total Deferred Credits............................................... & & & & & & 4,446 \\
\hline Total Liabilities and Other Credits..................... & 11,193 & 24,000 & 26,176 & 27,005 & 65,949 & 104,419 \\
\hline
\end{tabular}

Note: Totals may not equal sum of components because of independent rounding.

Source: Energy Information Administration, Form EIA-412, "Annual Report of Public Electric Utilities." 
Table 22. Balance Sheet by Major U.S. Publicly Owned Electric Utility

Within State at End of Period, 1996

(Thousand Dollars)

\begin{tabular}{|c|c|c|c|c|c|c|}
\hline Item & $\begin{array}{c}\text { Ohio } \\
\text { Bowling } \\
\text { Green } \\
\text { City of } \\
\text { December } 31\end{array}$ & $\begin{array}{c}\text { Ohio } \\
\text { Bryan } \\
\text { City of } \\
\text { December } 31\end{array}$ & $\begin{array}{c}\text { Ohio } \\
\text { Celina } \\
\text { City of } \\
\text { December } 31\end{array}$ & $\begin{array}{c}\text { Ohio } \\
\text { Cleveland } \\
\text { City of } \\
\text { December } 31\end{array}$ & $\begin{array}{l}\text { Ohio } \\
\text { Clyde } \\
\text { City of } \\
\text { December } 31\end{array}$ & $\begin{array}{l}\text { Ohio } \\
\text { Columbus } \\
\text { City of } \\
\text { December } 31\end{array}$ \\
\hline \multicolumn{7}{|l|}{ Electric Utility Plant } \\
\hline Electric Utility Plant \& Adjust .................................... & 18,933 & 16,335 & 21,118 & 280,919 & 10,765 & 94,751 \\
\hline 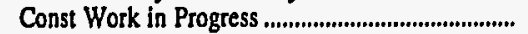 & 1,770 & & 0 & 76,304 & 0 & 0 \\
\hline (less) Depr, Amort, and Depletion................................. & 9,815 & 11,858 & 0 & 109,010 & 0 & 37,315 \\
\hline Net Electric Utility Plant ........................................... & 10,888 & 4,477 & 21,118 & 248,213 & 10,765 & 57,436 \\
\hline 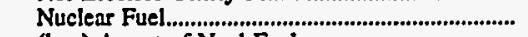 & & 0 & & & & 0 \\
\hline (less) Amort of Nucl Fuel ......................................... & 0 & 0 & 0 & 0 & 0 & 0 \\
\hline Net Elec Plant Inel Nucl Fuel .................................. & 10,888 & 4,477 & 21,118 & 248,213 & 10,765 & 57,436 \\
\hline \multicolumn{7}{|l|}{ Other Property \& Investments } \\
\hline Nonutility Property ........................ & 0 & 0 & 0 & 0 & 0 & 0 \\
\hline (less) Accum Provisions for Depr \& Amort .......... & 0 & 0 & 0 & 0 & 0 & \\
\hline 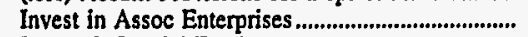 & 0 & 896 & 0 & 0 . & 0 & 14,635 \\
\hline Invest \& Special Funds .................................................. & 7,166 & 0 & 0 & 66,833 & 1,254 & 5,600 \\
\hline Total Other Property \& Investments................ & 7,166 & 896 & $\mathbf{0}$ & 66,833 & 1,254 & 20,235 \\
\hline \multicolumn{7}{|l|}{ Current and Accrued Assets } \\
\hline Cash, Working Funds \& Investments........................ & 1 & 2,790 & 791 & 10,690 & 1,841 & 2,300 \\
\hline 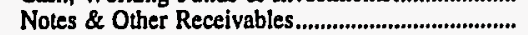 & 11 & 2 & 0 & 0 & 0 & 528 \\
\hline 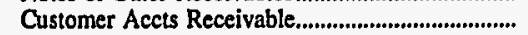 & 691 & 1,374 & 448 & 11,843 & 685 & 5,287 \\
\hline (less) Accum Prov for Uncollected Accts............... & 0 & 0 & 370 & 229 & 0 & 0 \\
\hline Fuel Stock \& Exp Undistr....................................... & 0 & 0 & 0 & 0 & 0 & 0 \\
\hline Materials \& Supplies ...................................................... & 1,214 & 650 & 957 & 9,607 & 192 & 893 \\
\hline 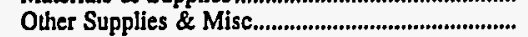 & 0 & $\mathbf{0}$ & 4 & 0 & 1 & $\mathbf{0}$ \\
\hline 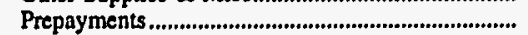 & 13 & 9 & 11 & 51 & 0 & 0 \\
\hline 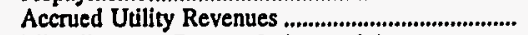 & 1,148 & $\mathbf{0}$ & 589 & 3,500 & 11 & 0 \\
\hline Miscellaneous Current \& Accrued Assets............... & 0 & 0 & 0 & 39 & 0 & 174 \\
\hline Total Current \& Accrued Assets.......................... & 3,077 & 4,826 & 2,430 & 35,501 & $\mathbf{2 , 7 3 0}$ & 9,182 \\
\hline \multicolumn{7}{|l|}{ Deferted Debits } \\
\hline Unamortized Debt Expenses..... & 0 & 0 & $\mathbf{0}$ & 3,964 & 1,299 & 0 \\
\hline 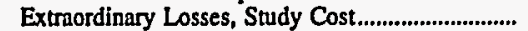 & 0 & 0 & $\mathbf{0}$ & 0 & 0 & 0 \\
\hline Misc Debt, R \& D Exp, Unamrt Losses .................. & 0 & 0 & $\mathbf{0}$ & 0 & 0 & 0 \\
\hline 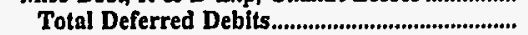 & o & $\mathbf{0}$ & 0 & 3,964 & 1,299 & \\
\hline 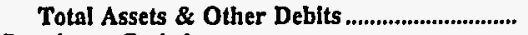 & 21,131 & 10,199 & 23,548 & 354,510 & 16,048 & 86,853 \\
\hline \multicolumn{7}{|l|}{ Proprietary Capital } \\
\hline 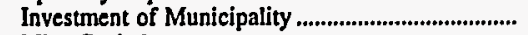 & 11,540 & 0 & 22,075 & 12,183 & 0 & 17,350 \\
\hline 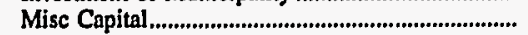 & & $\mathbf{0}$ & 0 & & 68 & \\
\hline 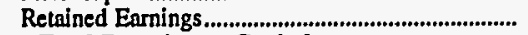 & 1,425 & 7,632 & 1,211 & 79,052 & 4,188 & $-24,621$ \\
\hline Total Proprietary Capital ................................. & 12,965 & 7,632 & 23,286 & 91,235 & 4,256 & $-\mathbf{7 , 2 7 2}$ \\
\hline \multicolumn{7}{|l|}{ Long-term Debt } \\
\hline Bonds .................... & 0 & 0 & 0 & 241,935 & 10,965 & 87,849 \\
\hline Advances from Municipality \& Other..................... & 0 & 0 & 0 & 0 & 0 & \\
\hline 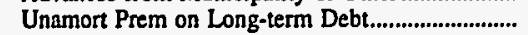 & 0 & 0 & 0 & 0 & o & 0 \\
\hline (less) Unamort Discount on Long-term Debt & 0 & 0 & 0 & 0 & & \\
\hline 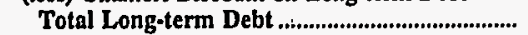 & $\mathbf{0}$ & 0 & 0 & 241,935 & 10,965 & 87,849 \\
\hline \multicolumn{7}{|l|}{ Other Noncurrent Liabilities } \\
\hline Accum Operating Provisions............... & 0 & 0 & 56 & 0 & $\mathbf{0}$ & 0 \\
\hline 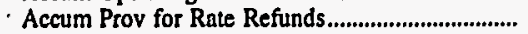 & 0 & 0 & 0 & 0 & 0 & 0 \\
\hline Total Other Noncurrent Llabilities ................... & 0 & 0 & 56 & 0 & 0 & $\mathbf{0}$ \\
\hline \multicolumn{7}{|l|}{ Current and Accrued Liabilities } \\
\hline 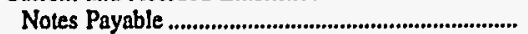 & 5,825 & 1,500 & 0 & 0 & 392 & 313 \\
\hline Accounts Payable................................................................... & 1,615 & 757 & 92 & 12,020 & $\mathbf{0}$ & 2,558 \\
\hline 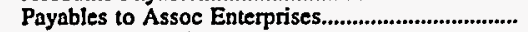 & 0 & 0 & 0 & 0 & $\mathbf{0}$ & 196 \\
\hline 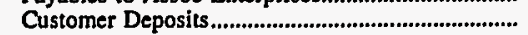 & 0 & 0 & 115 & 682 & $\mathbf{0}$ & 506 \\
\hline 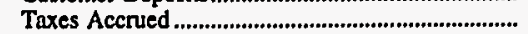 & 0 & 0 & $\mathbf{0}$ & 0 & $\mathbf{0}$ & 0 \\
\hline Interest Accrued............................................................... & 42 & 8 & 0 & 1,552 & 101 & 486 \\
\hline Misc Current \& Accrued Liabilities .......................... & 376 & 302 & $\mathbf{0}$ & 7,086 & 334 & 1,400 \\
\hline Total Current \& Accrued Llabilities ................ & $\mathbf{7 , 8 5 8}$ & 2,567 & 206 & 21,340 & 827 & 5,458 \\
\hline \multicolumn{7}{|l|}{ Deferted Credits } \\
\hline 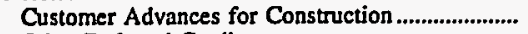 & 308 & 0 & 0 & 0 & $\mathbf{0}$ & \\
\hline Other Deferred Credits & $\mathbf{0}$ & $\mathbf{0}$ & $\mathbf{0}$ & 0 & 0 & 818 \\
\hline Unamort Gain on Reacqr Debt............................. & 0 & $\mathbf{0}$ & $\mathbf{0}$ & $\mathbf{0}$ & 0 & \\
\hline 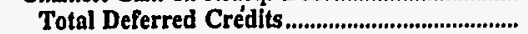 & 308 & & & $\mathbf{0}$ & $\mathbf{0}$ & 818 \\
\hline Total Llabillties and Other Credits.................... & 21,131 & 10,199 & 23,548 & 354,510 & 16,048 & 86,853 \\
\hline
\end{tabular}

Note: Totals may not equal sum of components because of independent rounding.

Source: Energy Information Administration, Form EIA-412, "Annual Report of Public Electric Utilities." 
Table 22. Balance Sheet by Major U.S. Publicly Owned Electric Utility Within State at End of Period, 1996

(Thousand Dollars)

\begin{tabular}{|c|c|c|c|c|c|c|}
\hline Item & $\begin{array}{c}\text { Ohio } \\
\text { Cuyahoga } \\
\text { Falls } \\
\text { City of } \\
\text { December } 31\end{array}$ & $\begin{array}{c}\text { Ohio } \\
\text { Dover } \\
\text { City of } \\
\text { December } 31\end{array}$ & $\begin{array}{c}\text { Ohio } \\
\begin{array}{c}\text { Hamilton } \\
\text { City of }\end{array} \\
\text { December } 31\end{array}$ & $\begin{array}{c}\text { Ohio } \\
\text { Napoleon } \\
\text { City of } \\
\text { December } 31\end{array}$ & $\begin{array}{c}\text { Ohio } \\
\text { Niles } \\
\text { City of } \\
\text { December } 31\end{array}$ & $\begin{array}{c}\text { Ohio } \\
\text { Orrville } \\
\text { City of } \\
\text { December } 31\end{array}$ \\
\hline \multicolumn{7}{|l|}{ Electric Utility Plant } \\
\hline 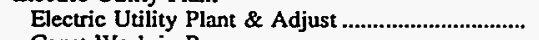 & 22,805 & 10.678 & 244,300 & 2,461 & 12,013 & 56,145 \\
\hline 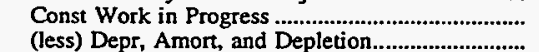 & $\begin{array}{r}0 \\
12,079\end{array}$ & $\begin{array}{l}0 \\
0\end{array}$ & $\begin{array}{r}7,332 \\
83,301\end{array}$ & $\begin{array}{l}0 \\
0\end{array}$ & $\begin{array}{r}0 \\
7,315\end{array}$ & $\begin{array}{r}17 \\
30.599\end{array}$ \\
\hline 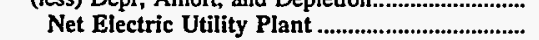 & 10,727 & 10,678 & 168,331 & 2,461 & 4,698 & $\mathbf{2 5 , 5 6 3}$ \\
\hline 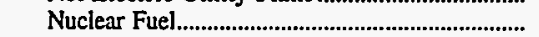 & 0 & 0 & 0 & 0 & 0 & 0 \\
\hline (less) Amort of Nucl Fuel ....................................... & 0 & 0 & 0 & 0 & 0 & 0 \\
\hline \multicolumn{7}{|l|}{ Other Property \& Investments } \\
\hline Nonutility Property .............................................. & 0 & 0 & 0 & 0 & 0 & 0 \\
\hline (less) Accum Provisions for Depr \& Amort .......... & 0 & 0 & 0 & $\mathbf{0}$ & 0 & 0 \\
\hline 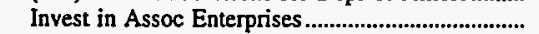 & 0 & 0 & 0 & 0 & 0 & 0 \\
\hline Invest \& Special Funds ............................................... & 0 & 0 & 24,431 & 0 & 0 & 0 \\
\hline Total Other Property \& Investments................ & 0 & o & 24,431 & 0 & 0 & 0 \\
\hline Cash, Working Funds \& Investments......................... & 9,443 & 70 & 9,991 & 0 & 7,874 & 9.577 \\
\hline Notes \& Other Receivables......................................... & 908 & 56 & 6,852 & 0 & 0 & 33 \\
\hline Customer Accts Receivable & 3,572 & 1,685 & 0 & 0 & 1,610 & 2,182 \\
\hline (less) Accum Prov for Uncollected Accts ................ & 0 & 0 & 0 & 0 & 0 & 218 \\
\hline 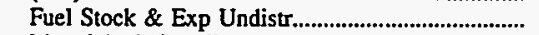 & 0 & 0 & 0 & 0 & 0 & 0 \\
\hline 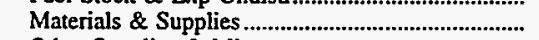 & 2,233 & 735 & 1,556 & 0 & 0 & 2,280 \\
\hline 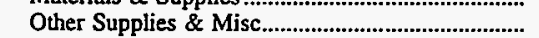 & 0 & 253 & 0 & 0 & 0 & 2,200 \\
\hline 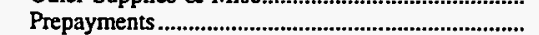 & 25 & 100 & 275 & 0 & 0 & 33 \\
\hline 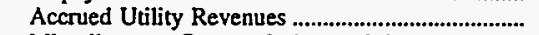 & 0 & 1,058 & 0 & 0 & 0 & 432 \\
\hline Miscellaneous Current \& Accrued Assets.................... & 0 & 8,968 & 5,925 & 0 & 0 & 63 \\
\hline 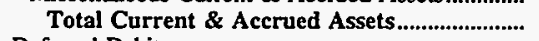 & 16,181 & 12,926 & 24,601 & 0 & 9,484 & 14,382 \\
\hline \multicolumn{7}{|l|}{ Deferred Debits } \\
\hline Unamortized Debt Expenses.... & 0 & 0 & 2,452 & 0 & 0 & 0 \\
\hline 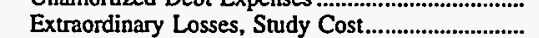 & 0 & 0 & 0 & 0 & 0 & 0 \\
\hline Misc Debt, R \& D Exp, Unamrt Losses ..................... & 0 & 0 & 0 & 0 & 0 & 0 \\
\hline Total Deferred Debits............................................. & 0 & 0 & 2,452 & 0 & 0 & 0 \\
\hline 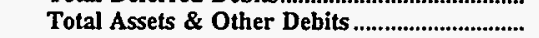 & 26,907 & 23,604 & 219,815 & 2,461 & 14,182 & 39,945 \\
\hline \multicolumn{7}{|l|}{ Proprietary Capital } \\
\hline Investment of Municipality & 0 & 135 & 3,074 & 0 & 0 & 0 \\
\hline 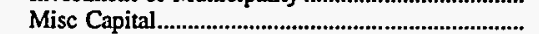 & 6 & & $-6,087$ & 0 & 0 & 576 \\
\hline 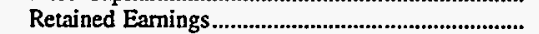 & 21,109 & 10,485 & 0 & 2,461 & 12,895 & 20,423 \\
\hline \multirow{2}{*}{\multicolumn{7}{|c|}{ Long-term Debt }} \\
\hline & & & & & & \\
\hline (1) & 3,419 & 10,510 & 203,269 & 0 & 0 & 16,695 \\
\hline 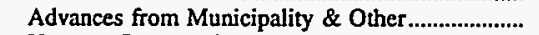 & & 382 & 0 & 0 & 0 & \\
\hline 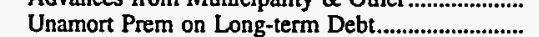 & 0 & 0 & 0 & 0 & 0 & 0 \\
\hline (less) Unamort Discount on Long-term Debt & & & & 0 & 0 & 0 \\
\hline \multirow{2}{*}{\multicolumn{7}{|c|}{ Other Noncurrent Liabilities }} \\
\hline & & & & & & \\
\hline 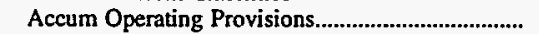 & 0 & 0 & 1,638 & 0 & 0 & 0 \\
\hline Accum Prov for Rate Refunds........ & 0 & 0 & 0 & 0 & $\mathbf{0}$ & 0 \\
\hline Total Other Noncurrent Liabilities .......................... & 0 & $\mathbf{0}$ & 1,638 & 0 & 0 & 0 \\
\hline \multicolumn{7}{|l|}{ Current and Accrued Liabilities } \\
\hline 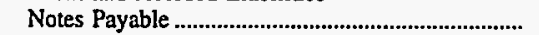 & 0 & 0 & 3,105 & 0 & 0 & 480 \\
\hline 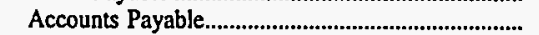 & 1,317 & 499 & 4,488 & 0 & 0 & 979 \\
\hline 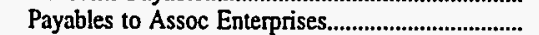 & 65 & 102 & 6,400 & 0 & 1,287 & 205 \\
\hline 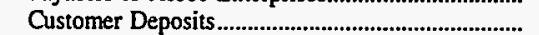 & 184 & 64 & 397 & 0 & 0 & 0 \\
\hline 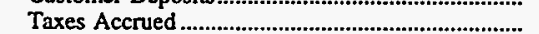 & 0 & 0 & 0 & 0 & 0 & 0 \\
\hline Interest Accrued. & 17 & 55 & 2,820 & 0 & 0 & 119 \\
\hline Misc Current \& Accrued Liabilities ............................. & 790 & 1,372 & 710 & 0 & 0 & 469 \\
\hline Total Current \& Accrued Liabilities ...................... & 2,373 & 2,091 & 17,920 & 0 & 1,287 & 2,251 \\
\hline \multicolumn{7}{|l|}{ Deferred Credits } \\
\hline 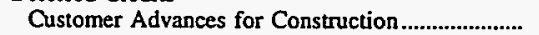 & 0 & 0 & 0 & 0 & $\mathbf{0}$ & 0 \\
\hline Other Deferred Credits ........................................... & 0 & 0 & 0 & 0 & 0 & 0 \\
\hline 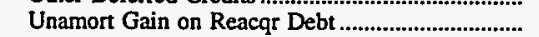 & 0 & 0 & 0 & 0 & 0 & \\
\hline Total Deferred Credits ....................................... & 0 & 0 & 0 & 0 & 0 & 0 \\
\hline Total Liabilities and Other Credits........................... & 26,907 & 23,604 & 219,815 & 2,461 & 14,182 & 39,945 \\
\hline
\end{tabular}

Note: Totals may not equal sum of components because of independent rounding.

Source: Energy Information Administration, Form EIA-412, "Annual Report of Public Electric Utilities." 
Table 22. Balance Sheet by Major U.S. Publicly Owned Electric Utility Within State at End of Period, 1996

(Thousand Dollars)

\begin{tabular}{|c|c|c|c|c|c|c|}
\hline Item & $\begin{array}{c}\text { Ohio } \\
\begin{array}{c}\text { Painesville } \\
\text { City of }\end{array} \\
\text { December } 31\end{array}$ & $\begin{array}{l}\text { Ohio } \\
\text { Piqua } \\
\text { City of } \\
\text { December } 31\end{array}$ & $\begin{array}{l}\text { Ohio } \\
\text { St Marys } \\
\text { City of } \\
\text { December } 31\end{array}$ & $\begin{array}{c}\text { Ohio } \\
\text { Wadsworth } \\
\text { City of } \\
\text { December } 31\end{array}$ & $\begin{array}{c}\text { Ohio } \\
\text { Wapakoneta } \\
\text { City of } \\
\text { December } 31\end{array}$ & $\begin{array}{c}\text { Ohio } \\
\text { Westerville } \\
\text { City of } \\
\text { December } 31\end{array}$ \\
\hline \multicolumn{7}{|l|}{ Electric Utility Plant } \\
\hline Electric Utility Plant \& Adjust ................................ & 35,778 & 47,059 & 15,234 & 14,702 & 0 & 27,229 \\
\hline 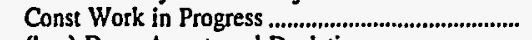 & & 694 & & & 0 & \\
\hline 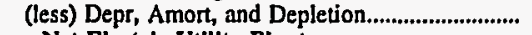 & 21,016 & 22,094 & 9,722 & 5,115 & 0 & 11,142 \\
\hline 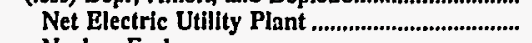 & 14,762 & 25,659 & 5,526 & 9,588 & 0 & 16,087 \\
\hline Nuclear Fuel................................................................. & 0 & 0 & 0 & 0 & 0 & 0 \\
\hline 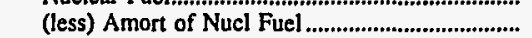 & 0 & 0 & 0 & 0 & 0 & 0 \\
\hline $\begin{array}{l}\text { Net Elec Plant Incl Nucl Fuel } \\
\text { Other Property \& Investments }\end{array}$ & 14,762 & 25,659 & 5,526 & 9,588 & o & 16,087 \\
\hline 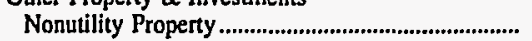 & 0 & 0 & 0 & 0 & 0 & 0 \\
\hline (less) Accum Provisions for Depr \& Amort ........... & 0 & 0 & 0 & 0 & 0 & 0 \\
\hline 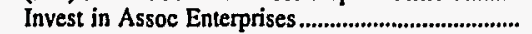 & 0 & 0 & 0 & 0 & 0 & 0 \\
\hline 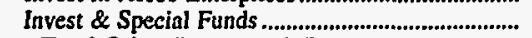 & 7,286 & 1,123 & 3,543 & o & 0 & 0 \\
\hline Total Other Property \& Investments................ & 7,286 & 1,123 & 3,543 & 0 & 0 & 0 \\
\hline \multicolumn{7}{|l|}{ Current and Accrued Assets } \\
\hline 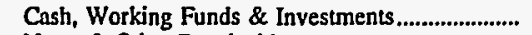 & 3,089 & 3,501 & 1,958 & 1,542 & 2,383 & 35,708 \\
\hline 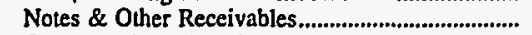 & 0 & 173 & 13 & 2,837 & 0 & \\
\hline Customer Accts Receivable,............................................. & 1,791 & 1,068 & 619 & 1,857 & 0 & 2,778 \\
\hline (less) Accum Prov for Uncollected Accts............... & 0 & 107 & 0 & 0 & 0 & 71 \\
\hline Fuel Stock \& Exp Undistr................................................. & 0 & 122 & 0 & 0 & 0 & 0 \\
\hline Materials \& Supplies ................................................ & 649 & 462 & 278 & 737 & 0 & 800 \\
\hline 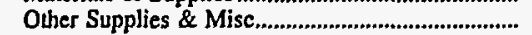 & 0 & 0 & 0 & 0 & 0 & 0 \\
\hline 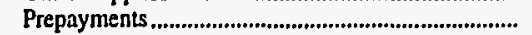 & 4 & 184 & 1 & 15 & 0 & 0 \\
\hline 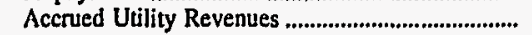 & 0 & 730 & 22 & 0 & 0 & 0 \\
\hline Miscellaneous Current \& Accrued Assets............... & 8 & 79 & 6 & 0 & 0 & 19 \\
\hline Total Current \& Accrued Assets........................ & 5,540 & 6,211 & 2,898 & 6,988 & 2,383 & 39,233 \\
\hline \multicolumn{7}{|l|}{ Deferred Debits } \\
\hline Unamortized Debt Expense & $\mathbf{0}$ & 0 & 192 & 0 & 0 & 0 \\
\hline 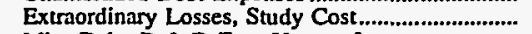 & 0 & 0 & 0 & 0 & 0 & 0 \\
\hline Misc Debt, R \& D Exp, Unamrt Losses ..................... & 0 & 0 & 0 & 0 & 0 & 0 \\
\hline Total Deferred Debits............................................. & & 0 & 192 & 0 & 0 & 0 \\
\hline Total Assets \& Other Debits.................................... & 27,588 & 32,993 & 12,159 & 16,575 & 2,383 & 55,320 \\
\hline \multicolumn{7}{|l|}{ Proprietary Capital } \\
\hline Investment of Municipality & 37 & 0 & 0 & 0 & 289 & 0 \\
\hline 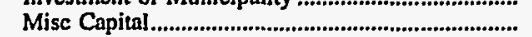 & & & 0 & 52 & 0 & 325 \\
\hline 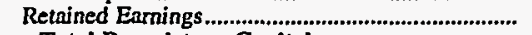 & 20,036 & 23,546 & $\mathbf{0}$ & 11,581 & 2,094 & 52,444 \\
\hline \multirow{2}{*}{\multicolumn{7}{|c|}{ Long-term Debt }} \\
\hline & & & & & & \\
\hline 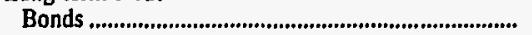 & 5,650 & 7,378 & 4,742 & 0 & 0 & 0 \\
\hline 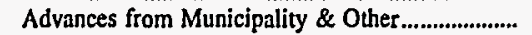 & 0 & 0 & 137 & 2,564 & 0 & 0 \\
\hline 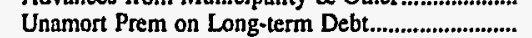 & 0 & 0 & 0 & 0 & 0 & 0 \\
\hline (less) Unamort Discount on Long-term Debt & $\mathbf{0}$ & & & & 0 & 0 \\
\hline Total Long-term Debt.... & 5,650 & 7,378 & 4,878 & 2,564 & 0 & o \\
\hline \multicolumn{7}{|l|}{ Other Noncurrent Liabilities } \\
\hline Accum Operating Provision: & 258 & 388 & 0 & 0 & 0 & 356 \\
\hline 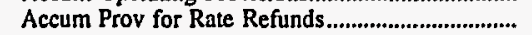 & 0 & 0 & 0 & 0 & 0 & 0 \\
\hline Total Other Noncurrent Liabilities ......................... & 258 & 388 & $\mathbf{0}$ & 0 & 0 & 356 \\
\hline \multicolumn{7}{|l|}{ Current and Accrued Liabilities } \\
\hline 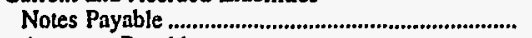 & $\mathbf{0}$ & 0 & 0 & 0 & 0 & \\
\hline 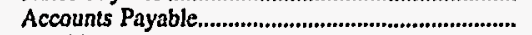 & 1,344 & 1,170 & 360 & 1,689 & 0 & 2,005 \\
\hline 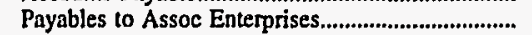 & 0 & 0 & 0 & 0 & 0 & 0 \\
\hline 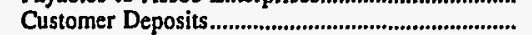 & 263 & 0 & 227 & 0 & 0 & 41 \\
\hline 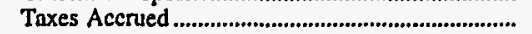 & 0 & 0 & 0 & 0 & 0 & 0 \\
\hline Interest Accrued .................................................................. & 0 & 0 & 23 & 43 & 0 & 0 \\
\hline Misc Current \& Accrued Liabilities............................ & 0 & 511 & 103 & 647 & 0 & 149 \\
\hline Total Current \& Accrued Liabilities .................... & 1,607 & 1,681 & 713 & 2,379 & o & 2,195 \\
\hline \multicolumn{7}{|l|}{ Deferred Credits } \\
\hline Customer Advances for Construction............................. & 0 & 0 & 6,568 & 0 & 0 & 0 \\
\hline 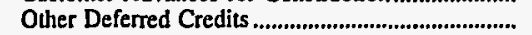 & 0 & 0 & 0 & 0 & 0 & 0 \\
\hline 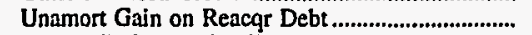 & 0 & 0 & 0 & 0 & 0 & 0 \\
\hline 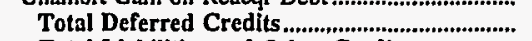 & 0 & 0 & 6,568 & & & \\
\hline Total Liabilities and Other Credits.................... & 27,588 & 32,993 & 12,159 & 16,575 & 2,383 & 55,320 \\
\hline
\end{tabular}

Note: Totals may not equal sum of components because of independent rounding.

Source: Energy Information Administration, Form EIA-412, "Annual Report of Public Electric Utilities." 
Table 22. Balance Sheet by Major U.S. Publicly Owned Electric Utility Within State at End of Period, 1996

(Thousand Dollars)

\begin{tabular}{|c|c|c|c|c|c|c|}
\hline Item & $\begin{array}{c}\text { Oklahoma } \\
\text { Altus } \\
\text { City of } \\
\text { June } 30\end{array}$ & $\begin{array}{c}\text { Oklahoma } \\
\text { Claremore } \\
\text { City of } \\
\text { June } 30\end{array}$ & $\begin{array}{l}\text { Oklahoma } \\
\begin{array}{l}\text { Duncan } \\
\text { City of }\end{array} \\
\text { June } 30\end{array}$ & $\begin{array}{l}\text { Oklahoma } \\
\text { Edmond } \\
\text { City of } \\
\text { June } 30\end{array}$ & $\begin{array}{l}\text { Oklahoma } \\
\text { Grand River } \\
\text { Dam } \\
\text { Authority } \\
\text { December } 31\end{array}$ & $\begin{array}{l}\text { Oklahoma } \\
\text { Miami } \\
\text { City of } \\
\text { June } 30\end{array}$ \\
\hline \multicolumn{7}{|l|}{ Electric Utility Plant } \\
\hline 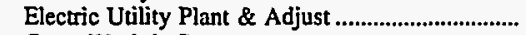 & 9,203 & 1,032 & 20,284 & 41,679 & 881,890 & 3,006 \\
\hline 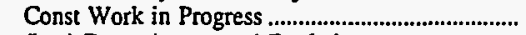 & & & & & 11,421 & 0 \\
\hline 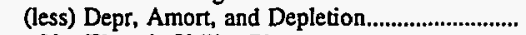 & 6,138 & 0 & 11,044 & 19,180 & 348,934 & 2,337 \\
\hline 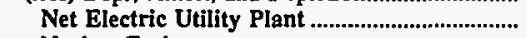 & 3,064 & 1,032 & 9,241 & 22,544 & 544,377 & 669 \\
\hline 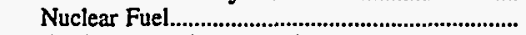 & 0 & 0 & 0 & 0 & 0 & 0 \\
\hline (less) Amort of Nucl Fuel ....... & 0 & 0 & 0 & 0 & 0 & 0 \\
\hline Net Elec Plant Incl Nucl Fuel ................................. & 3,064 & 1,032 & 9,241 & 22,544 & 544,377 & 669 \\
\hline \multicolumn{7}{|l|}{ Other Property \& Investments } \\
\hline Nonutility Property ........................ & 0 & 0 & 0 & 0 & 33 & 12,619 \\
\hline (less) Accum Provisions for Depr \& Amort .......... & 0 & 0 & 0 & 0 & 0 & 5,287 \\
\hline 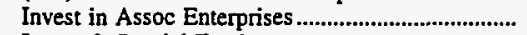 & 0 & 0 & 0 & 0 & 0 & 0 \\
\hline 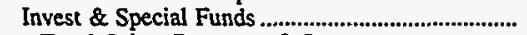 & 0 & 0 & 0 & 3,455 & 104,374 & 0 \\
\hline Total Other Property \& Investments.................... & 0 & 0 & 0 & 3,455 & 104,407 & $\mathbf{7 , 3 3 2}$ \\
\hline \multicolumn{7}{|l|}{ Current and Accrued Assets } \\
\hline Cash, Working Funds \& Investments........................... & 5,956 & 767 & 3,087 & 3,220 & 119,636 & 8,809 \\
\hline 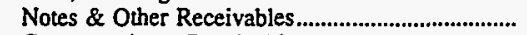 & 0 & 0 & 0 & 1 & 28,160 & 110 \\
\hline Customer Accts Receivable........................................... & 1,575 & 1,584 & 1,597 & 4,677 & 14,547 & 922 \\
\hline (less) Accum Prov for Uncollected Accts ................ & -310 & 335 & 0 & 59 & 50 & 219 \\
\hline 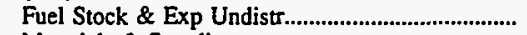 & 0 & 0 & 0 & 0 & 9,287 & 0 \\
\hline 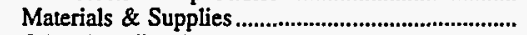 & 631 & 0 & 0 & 0 & 19,946 & 780 \\
\hline 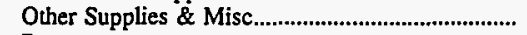 & 0 & 0 & 0 & 0 & 3 & 0 \\
\hline 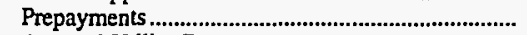 & 0 & 0 & 0 & 0 & 608 & 0 \\
\hline 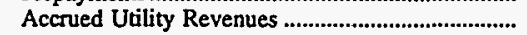 & 0 & 0 & 0 & 0 & 0 & 0 \\
\hline Miscellaneous Current \& Accrued Assets............... & 128 & 0 & 17 & 107 & 1,358 & 0 \\
\hline Total Current \& Accrued Assets............................. & 8,600 & 2,017 & 4,701 & 7,946 & 193,494 & 10,402 \\
\hline \multicolumn{7}{|l|}{ Deferred Debits } \\
\hline 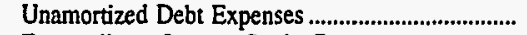 & -611 & 0 & 0 & 14 & 8,617 & 0 \\
\hline 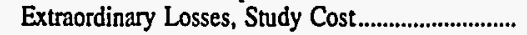 & 0 & 0 & 0 & 0 & 2 & 0 \\
\hline 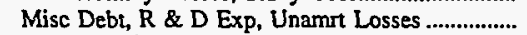 & 0 & 0 & 0 & 0 & 239,135 & 0 \\
\hline 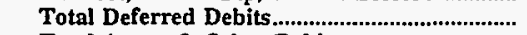 & -611 & & & 14 & 247,754 & 0 \\
\hline Total Assets \& Other Debits..................................... & 11,054 & 3,048 & 13,942 & 33,959 & $1,090,032$ & 18,403 \\
\hline \multicolumn{7}{|l|}{ Proprietary Capital } \\
\hline 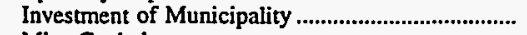 & 3,184 & 0 & 12,892 & 0 & 0 & 0 \\
\hline 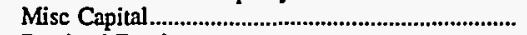 & & 0 & 2 & 0 & 0 & 0 \\
\hline 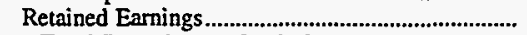 & 6,869 & 1,298 & 0 & 24,627 & 27,962 & 17,157 \\
\hline 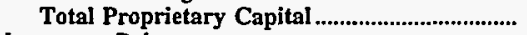 & 10,053 & 1,298 & 12,894 & 24,628 & 27,962 & 17,157 \\
\hline \multicolumn{7}{|l|}{ Long-term Debt } \\
\hline ......................................... & 0 & 0 & 0 & 2,508 & $1,036,375$ & 0 \\
\hline 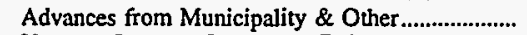 & 0 & 0 & 0 & 0 & 1,436 & 0 \\
\hline 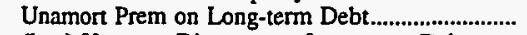 & 0 & 0 & 0 & 0 & 5,175 & 0 \\
\hline (less) Unamort Discount on Long-term Debt & 0 & 0 & 0 & 0 & 22,081 & 0 \\
\hline Total Long-term Debt ..... & $\mathbf{0}$ & $\mathbf{0}$ & o & 2,508 & $1,020,905$ & 0 \\
\hline \multicolumn{7}{|l|}{ Other Noncurrent Liabilities } \\
\hline 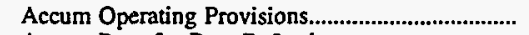 & 0 & 0 & 0 & 128 & 0 & 0 \\
\hline 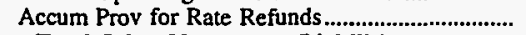 & $\mathbf{0}$ & $\mathbf{0}$ & 0 & $\mathbf{0}$ & 0 & $\mathbf{0}$ \\
\hline Total Other Noncurrent Liabilities ........................ & 0 & 0 & 0 & 128 & 0 & 0 \\
\hline \multicolumn{7}{|l|}{ Current and Accrued Liabilities } \\
\hline 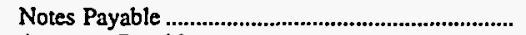 & 0 & 768 & 0 & 0 & 0 & 0 \\
\hline 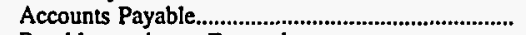 & 1,001 & 959 & 2 & 3,923 & 9,289 & 931 \\
\hline 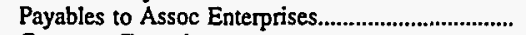 & 0 & 0 & 708 & 0 & 0 & 0 \\
\hline Customer Deposits & 0 & 0 & 337 & 2,618 & 0 & 315 \\
\hline 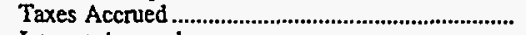 & 0 & 0 & 0 & 0 & 0 & 0 \\
\hline 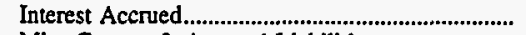 & 0 & 0 & 0 & 92 & 4,750 & 0 \\
\hline 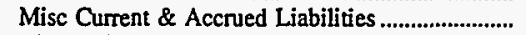 & 0 & 23 & 0 & 0 & 6,761 & 0 \\
\hline \multirow{2}{*}{\multicolumn{7}{|c|}{ Deferred Credits }} \\
\hline & & & & & & \\
\hline 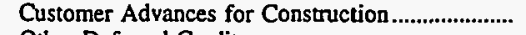 & 0 & 0 & 0 & 0 & 0 & 0 \\
\hline 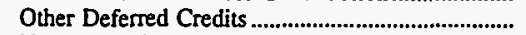 & 0 & 0 & 0 & 63 & 20,365 & 0 \\
\hline 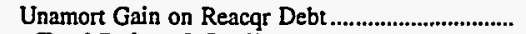 & 0 & 0 & 0 & 0 & 0 & 0 \\
\hline Total Deferred Credits............................................ & & & $\mathbf{0}$ & 63 & 20,365 & 0 \\
\hline Total Liabilities and Other Credits.................... & 11,054 & 3,048 & 13,942 & 33,959 & $1,090,032$ & 18,403 \\
\hline
\end{tabular}

Note: Totals may not equal sum of components because of independent rounding.

Source: Energy Information Administration, Form EIA-412, "Annual Report of Public Electric Utilities." 
Table 22. Balance Sheet by Major U.S. Publicly Owned Electric Utility Within State at End of Period, 1996

(Thousand Dollars)

\begin{tabular}{|c|c|c|c|c|c|c|}
\hline Item & $\begin{array}{l}\text { Oklahoma } \\
\text { OkJahoma } \\
\text { Municipal } \\
\text { Power Auth } \\
\text { December } 31\end{array}$ & $\begin{array}{l}\text { Oklahoma } \\
\text { Ponca } \\
\text { City City of } \\
\cdot \\
\text { June } 30\end{array}$ & $\begin{array}{l}\text { Oklahoma } \\
\text { Stillwater } \\
\text { Utilities } \\
\text { Authority } \\
\text { June } 30\end{array}$ & $\begin{array}{l}\text { Oregon } \\
\text { Ashland } \\
\text { City of } \\
\text { June } 30\end{array}$ & $\begin{array}{l}\text { Oregon } \\
\text { Central } \\
\text { Lincoin } \\
\text { Peoples } \\
\text { Utl Dt } \\
\text { December } 31\end{array}$ & $\begin{array}{l}\text { Oregon } \\
\text { Clatskanie } \\
\text { Peoples } \\
\text { Util Dist } \\
\text { December 31 }\end{array}$ \\
\hline \multicolumn{7}{|l|}{ Electric Utulity Plant } \\
\hline 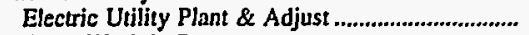 & 201,551 & 36,556 & 41,759 & 13,396 & 88,026 & $\mathbf{7 , 7 7 6}$ \\
\hline 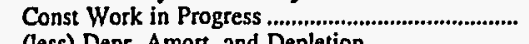 & 74 & & 715 & & 19,995 & 246 \\
\hline (less) Depr, Amort, and Depletion............................... & 44,100 & 17,903 & 16,902 & 0 & 42,744 & 4,056 \\
\hline Net Electric Utility Plant ...................................... & 157,526 & 18,653 & 25,573 & 13,396 & 65,277 & 3,967 \\
\hline 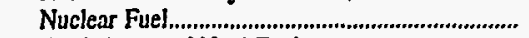 & 0 & 0 & 0 & 0 & 0 & 0 \\
\hline 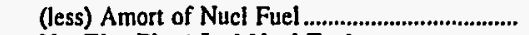 & 0 & 0 & 0 & 0 & 0 & 0 \\
\hline 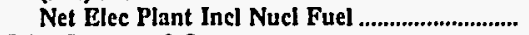 & 157,526 & 18,653 & 25,573 & 13,396 & 65,277 & 3,967 \\
\hline \multicolumn{7}{|l|}{ Other Property \& Investments } \\
\hline Nonutility Propenty & 0 & 0 & 0 & 0 & 0 & 0 \\
\hline (less) Accum Provisions for Depr \& Amort .......... & 0 & 0 & $\mathbf{0}$ & $\mathbf{0}$ & 0 & 0 \\
\hline 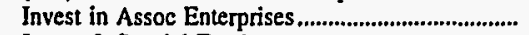 & 0 & 0 & 0 & 0 & 0 & 0 \\
\hline Invest \& Special Funds .................................................. & 63,288 & 2,831 & $\mathbf{0}$ & 0 & 6,321 & 241 \\
\hline Total Other Property \& Investments................ & 63,288 & $\mathbf{2 , 8 3 1}$ & 0 & $\mathbf{0}$ & 6,321 & 241 \\
\hline \multicolumn{7}{|l|}{ Current and Accrued Assets } \\
\hline Cash, Working Funds \& Investments........................ & 34,553 & 1 & 16,617 & 1,098 & 3,111 & 5.547 \\
\hline 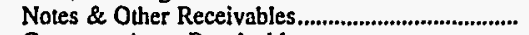 & 7,349 & -49 & 23 & 58 & 0 & 0 \\
\hline 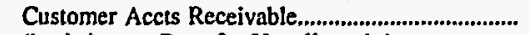 & 0 & 2,262 & 4,197 & 426 & 4,403 & 2,555 \\
\hline (less) Accum Prov for Uncollected Accts.............. & 0 & 0 & 11 & 0 & 256 & 7 \\
\hline 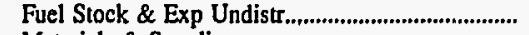 & 0 & 0 & 0 & $\mathbf{0}$ & 0 & 0 \\
\hline Materials \& Supplies ..................................................... & 0 & 0 & 606 & 510 & 2,270 & 206 \\
\hline 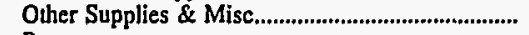 & 0 & 0 & 0 & 0 & 819 & 0 \\
\hline 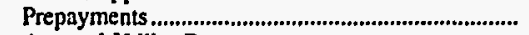 & $\mathbf{0}$ & 0 & 0 & $\mathbf{0}$ & 1,351 & 70 \\
\hline 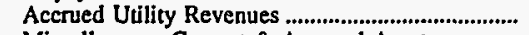 & 0 & $\mathbf{0}$ & 0 & 0 & 91 & 0 \\
\hline Miscellaneous Current \& Accrued Assets............... & 1,907 & 0 & 0 & 40 & 0 & 46 \\
\hline Total Current \& Accrued Assets......................... & 43,809 & 2,213 & 21,431 & 2,133 & 11,789 & 8,417 \\
\hline \multicolumn{7}{|l|}{ Deferred Debits } \\
\hline 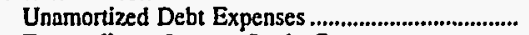 & 103,131 & 0 & 0 & 450 & 312 & 0 \\
\hline 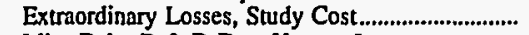 & & 0 & $\mathbf{0}$ & $\mathbf{0}$ & 0 & 0 \\
\hline Misc Debt, R \& D Exp, Unamrt Losses ................. & 48,785 & $\mathbf{0}$ & $\mathbf{0}$ & 0 & 7,485 & 0 \\
\hline Total Deferred Debits.................................................. & 151,916 & $\mathbf{0}$ & 0 & 450 & $\mathbf{7 , 7 9 8}$ & 0 \\
\hline 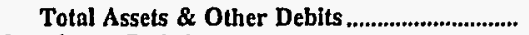 & 416,538 & 23,698 & 47,003 & 15,978 & 91,185 & 12,625 \\
\hline \multicolumn{7}{|l|}{ Proprietary Capital } \\
\hline Investment of Municipality ............................................ & 0 & 0 & 11,947 & 2,267 & 0 & 0 \\
\hline 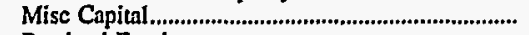 & 0 & 0 & & 10,941 & $\mathbf{0}$ & 0 \\
\hline 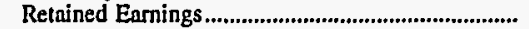 & 14,021 & 21,342 & 32,923 & 1,611 & 61,298 & 9,904 \\
\hline Total Proprietary Capital ............................................ & 14,021 & 21,342 & 44,870 & 14,819 & 61,298 & 9,904 \\
\hline \multicolumn{7}{|l|}{ Long-term Debt } \\
\hline Bonds ................... & 385,965 & 1,296 & 0 & 450 & 18,290 & 0 \\
\hline Advances from Municipality \& Other..................... & & 0 & 0 & 0 & 0 & 0 \\
\hline 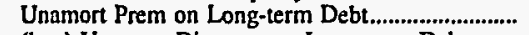 & & 0 & $\mathbf{0}$ & $\mathbf{0}$ & 0 & 0 \\
\hline (less) Unamort Discount on Long-term Debt & 14,534 & & 0 & 0 & 0 & 0 \\
\hline 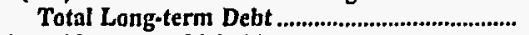 & 371,431 & 1,296 & 0 & 450 & 18,290 & 0 \\
\hline \multicolumn{7}{|l|}{ Other Noncurrent Liabilities } \\
\hline Accum Operating Provisions........ & 0 & 0 & 0 & 0 & 2,411 & 43 \\
\hline Accum Prov for Rate Refunds..................................... & 0 & 0 & 0 & 0 & & 0 \\
\hline Total Other Noncurrent Liabilities .................... & $\mathbf{0}$ & 0 & o & $\mathbf{0}$ & 2,411 & 43 \\
\hline \multicolumn{7}{|l|}{ Current and Accrued Liabilities } \\
\hline 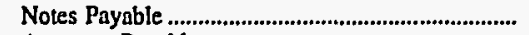 & 0 & 0 & 0 & 0 & 0 & 0 \\
\hline 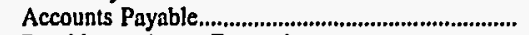 & $\mathbf{0}$ & 89 & 1,930 & 579 & 4,849 & 2,115 \\
\hline Payables to Ássoc Enterprises....................................... & 5,490 & 0 & 5 & $\mathbf{0}$ & 0 & 0 \\
\hline 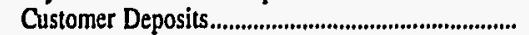 & 0 & 844 & 0 & 103 & 213 & 24 \\
\hline 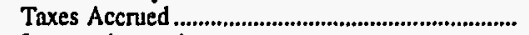 & & 0 & 0 & 0 & 0 & 2 \\
\hline 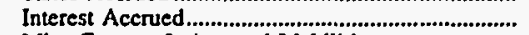 & 10,674 & 53 & 0 & 0 & 17 & 1 \\
\hline Mise Current \& Accrued Liabilities.......................... & 4,465 & 74 & 199 & 0 & 0 & 0 \\
\hline Total Current \& Accrued Liabilities .................. & 20,628 & 1,061 & 2,133 & 682 & 5,080 & 2,142 \\
\hline \multicolumn{7}{|l|}{ Deferred Credits } \\
\hline Customer Advances for Construction ........................ & 10,000 & 0 & 0 & 0 & 1 & 489 \\
\hline 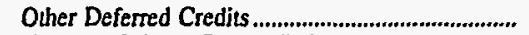 & 458 & 0 & $\mathbf{0}$ & 28 & 4,105 & 46 \\
\hline Unamort Gain on Reacgr Debt................................. & & 0 & 0 & 0 & & 0 \\
\hline Total Deferred Credits................................................... & 10,458 & & o & 28 & 4,105 & 536 \\
\hline Total Liabilties and Other Credits................... & 416,538 & 23,698 & 47,003 & 15,978 & 91,185 & 12,625 \\
\hline
\end{tabular}

Note: Totals may not equal sum of components because of independent rounding.

Source: Energy Information Administration, Form ElA-412, "Annual Report of Public Electric Utilities." 
Table 22. Balance Sheet by Major U.S. Publicly Owned Electric Utility Within State at End of Period, 1996

(Thousand Dollars)

\begin{tabular}{|c|c|c|c|c|c|c|}
\hline Item & $\begin{array}{c}\text { Oregon } \\
\text { Columbia } \\
\text { River } \\
\text { Peoples } \\
\text { Ut Dist } \\
\text { December } 31\end{array}$ & $\begin{array}{l}\text { Oregon } \\
\text { Emerald } \\
\text { Peoples } \\
\text { Utility Dist } \\
\text { December } 31\end{array}$ & $\begin{array}{l}\text { Oregon } \\
\text { Eugene } \\
\text { City of } \\
\text { December } 31\end{array}$ & $\begin{array}{l}\text { Oregon } \\
\begin{array}{c}\text { Forest Grove } \\
\text { City of }\end{array} \\
\text { June } 30\end{array}$ & $\begin{array}{c}\text { Oregon } \\
\begin{array}{c}\text { McMinnville } \\
\text { City of }\end{array} \\
\text { June } 30\end{array}$ & $\begin{array}{c}\text { Oregon } \\
\text { Northern } \\
\text { Wasco } \\
\text { County PUD } \\
\text { December } 31\end{array}$ \\
\hline \multicolumn{7}{|l|}{ Electric Utility Plant } \\
\hline 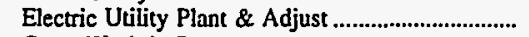 & 25,826 & 77,623 & 322,265 & 12,317 & 23,720 & 35,686 \\
\hline 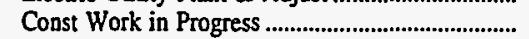 & 139 & 280 & 12,627 & 391 & 277 & 5,888 \\
\hline (less) Depr, Amort, and Depletion........................... & 5,438 & 31,186 & 145,660 & 4,381 & 6,870 & 11,427 \\
\hline 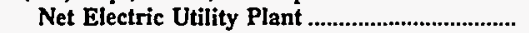 & 20,527 & 46,717 & 189,233 & 8,326 & 17,127 & 30,147 \\
\hline 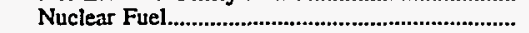 & 0 & 0 & 0 & 0 & 0 & 0 \\
\hline 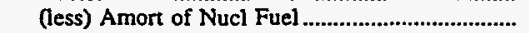 & 0 & 0 & 0 & 0 & 0 & 0 \\
\hline $\begin{array}{l}\text { Net Elec Plant Incl Nucl Fuel ............................ } \\
\text { Other Property \& Investments }\end{array}$ & 20,527 & 46,717 & 189,233 & 8,326 & 17,127 & 30,147 \\
\hline 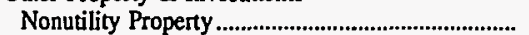 & 1 & 0 & 0 & 0 & 0 & 0 \\
\hline (less) Accum Provisions for Depr \& Amort .......... & 0 & 0 & 0 & 0 & 0 & 0 \\
\hline 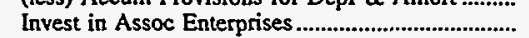 & 0 & 0 & 0 & 0 & 0 & 0 \\
\hline 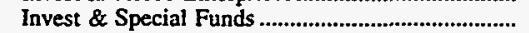 & 1,583 & 919 & 701 & 0 & 0 & 26,107 \\
\hline Total Other Property \& Investments.................. & 1,583 & 919 & 701 & 0 & $\mathbf{0}$ & 26,107 \\
\hline \multicolumn{7}{|l|}{ Current and Accrued Assets } \\
\hline 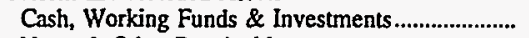 & 1,818 & 11,794 & 20,390 & 1,952 & 4,838 & 5,654 \\
\hline Notes \& Other Receivables...................................... & 0 & 3,780 & 0 & 2 & 358 & 461 \\
\hline 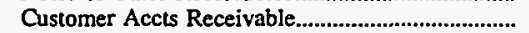 & 1,465 & 1,956 & 14,039 & $45 \overline{5}$ & 1,446 & 738 \\
\hline (less) Accum Prov for Uncollected Accts .............. & 21 & -40 & 216 & 81 & 14 & 79 \\
\hline 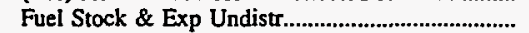 & 0 & 0 & 0 & 0 & 0 & 0 \\
\hline 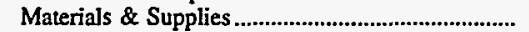 & 273 & 444 & 2,234 & 0 & 240 & 421 \\
\hline 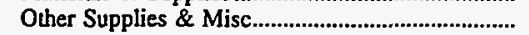 & 0 & 191 & 0 & 166 & 0 & 0 \\
\hline 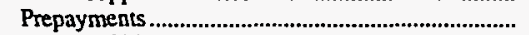 & 51 & 1,033 & 783 & 0 & 0 & 123 \\
\hline 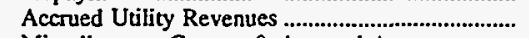 & 0 & 0 & 7,537 & 0 & 0 & 0 \\
\hline Miscellaneous Current \& Accrued Assets............... & 0 & 0 & 11,453 & 128 & 0 & 0 \\
\hline 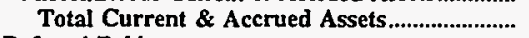 & 3,586 & 19,239 & 56,222 & 2,623 & 6,868 & 7,318 \\
\hline \multicolumn{7}{|l|}{ Deferred Debits } \\
\hline 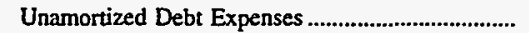 & 2,502 & 1.258 & 599 & 0 & 0 & 633 \\
\hline 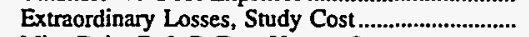 & 0 & 0 & 4,042 & 0 & 0 & 60 \\
\hline Misc Debt, R \& D Exp, Unamrt Losses ................ & 0 & 8,548 & 40,129 & 0 & 730 & 14,939 \\
\hline 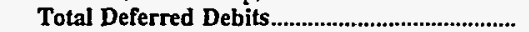 & 2,502 & 9,807 & 44,770 & $\mathbf{0}$ & 730 & 15,632 \\
\hline 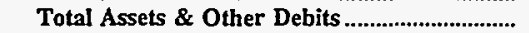 & 28,199 & 76,681 & 290,926 & 10,949 & 24,725 & 79,205 \\
\hline \multicolumn{7}{|l|}{ Proprietary Capital } \\
\hline 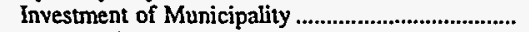 & 0 & 0 & 0 & 9,673 & 440 & 76 \\
\hline Misc Capital & 11,718 & 0 & 0 & 0 & 4,142 & 55 \\
\hline 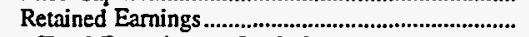 & 0 & 3,641 & 140,673 & 286 & 17,751 & 13,158 \\
\hline 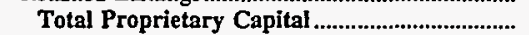 & 11,718 & 3,641 & 140,673 & 9,959 & 22,333 & 13,288 \\
\hline \multicolumn{7}{|l|}{ Long-term Debt } \\
\hline 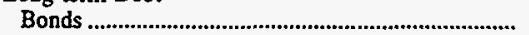 & 13,920 & 62,320 & 110,735 & 0 & 0 & 62,364 \\
\hline Advances from Municipality \& Other...................... & 0 & 3,193 & 0 & 0 & 742 & 0 \\
\hline Unamort Prem on Long-term Debt.......................... & 196 & 0 & 0 & 0 & 0 & 0 \\
\hline (less) Unamort Discount on Long-term Debt & 0 & -562 & 2,725 & 0 & 0 & 0 \\
\hline 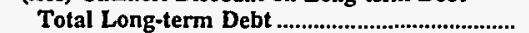 & 14,116 & 66,075 & 108,011 & $\mathbf{0}$ & 742 & 62,364 \\
\hline \multicolumn{7}{|l|}{ Other Noncurrent Liabilities } \\
\hline 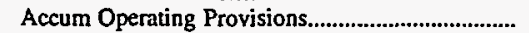 & 0 & 0 & 0 & 0 & 0 & 0 \\
\hline Accum Prov for Rate Refunds................................ & 0 & 0 & 0 & 0 & 0 & 0 \\
\hline Total Other Noncurrent Liabilities ...................... & $\mathbf{0}$ & 0 & 0 & 0 & 0 & $\mathbf{0}$ \\
\hline \multicolumn{7}{|l|}{ Current and Accrued Liabilities } \\
\hline 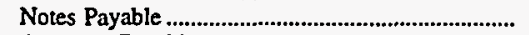 & 0 & 0 & 0 & 121 & 0 & 0 \\
\hline Accounts Payable. & 814 & 2,368 & 26,017 & 404 & 1,473 & 1,526 \\
\hline Payables to Assoc Enterprises................................... & 0 & 0 & 0 & 0 & 0 & 0 \\
\hline 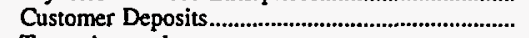 & 61 & 17 & 229 & 0 & 17 & 79 \\
\hline 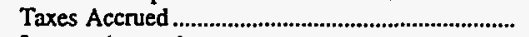 & 86 & 13 & 652 & 0 & 0 & 0 \\
\hline 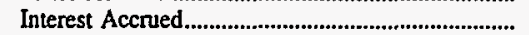 & 54 & 673 & 3,304 & 0 & 0 & 677 \\
\hline Misc Current \& Accrued Liabilities .............................. & 276 & 3,319 & 1,624 & 0 & 160 & 272 \\
\hline Total Current \& Accrued Liabilities ................. & 1,290 & 6,390 & 31,826 & 525 & 1,649 & 2,555 \\
\hline \multicolumn{7}{|l|}{ Deferred Credits } \\
\hline Customer Advances for Construction .......................... & 0 & 0 & 8,253 & 423 & 0 & 15 \\
\hline 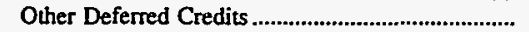 & 1,074 & 575 & 940 & 43 & 0 & 982 \\
\hline 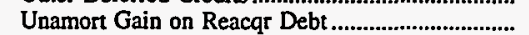 & 0 & 0 & 1,222 & 0 & 0 & 0 \\
\hline Total Deferred Credits & 1,074 & 575 & 10,416 & 466 & 0 & 997 \\
\hline Total Liabilities and Other Credits................... & 28,199 & 76,681 & 290,926 & 10,949 & 24,725 & 79,205 \\
\hline
\end{tabular}

Note: Totals may not equal sum of components because of independent rounding.

Source: Energy Information Administration, Form EIA-412, "Annual Report of Public Electric Utilities." 
Table 22. Balance Sheet by Major U.S. Publicly Owned Electric Utility Within State at End of Period, 1996

(Thousand Dollars)

\begin{tabular}{|c|c|c|c|c|c|c|}
\hline Item & $\begin{array}{c}\text { Oregon } \\
\text { Springfield } \\
\text { City of } \\
\text { December } 31\end{array}$ & $\begin{array}{c}\text { Oregon } \\
\text { Tillamook } \\
\text { Peoples } \\
\text { Utility Dist } \\
\text { December } 31\end{array}$ & $\begin{array}{c}\text { Pennsylvania } \\
\text { Chambersburg } \\
\text { Borough of } \\
\text { December } 31\end{array}$ & $\begin{array}{c}\text { Pennsylvania } \\
\text { Ephrata } \\
\text { Borough of } \\
\text { December } 31\end{array}$ & $\begin{array}{l}\text { Pennsylvania } \\
\text { Lansdale } \\
\text { Borough of } \\
\text { December } 31\end{array}$ & $\begin{array}{l}\text { South Carolina } \\
\text { Camden } \\
\text { City of } \\
\text { June } 30\end{array}$ \\
\hline \multicolumn{7}{|l|}{ Electric Utility Plant } \\
\hline 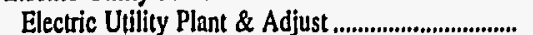 & 48,069 & 41,112 & 28,484 & 0 & 10,445 & 11,868 \\
\hline 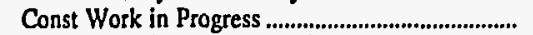 & 1,747 & 800 & 529 & 0 & 0 & 1,027 \\
\hline (less) Depr, Amort, and Depletion.................................... & 15,411 & 11,014 & 15,503 & $\mathbf{0}$ & 4,865 & 5,944 \\
\hline 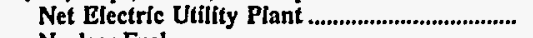 & 34,405 & 30,899 & 13,509 & 0 & 5,580 & 6,951 \\
\hline Nuclear Fuel.................................................................. & & & 0 & 0 & 0 & \\
\hline (less) Amort of Nucl Fuel ........................................... & & 0 & $\mathbf{0}$ & 0 & 0 & 0 \\
\hline Net Elec Plant Incl Nucl Fuel ................................ & 34,405 & 30,899 & 13,509 & 0 & 5,580 & 6,951 \\
\hline \multicolumn{7}{|l|}{ Other Property \& Investments } \\
\hline 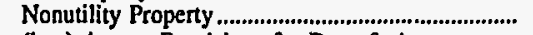 & 0 & 0 & 0 & $\mathbf{0}$ & 0 & 13,194 \\
\hline (less) Accum Provisions for Depr \& Amort ........... & 0 & 0 & $\mathbf{0}$ & 0 & 0 & 5,959 \\
\hline 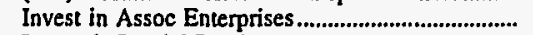 & 0 & 13 & 0 & 0 & 0 & 0 \\
\hline 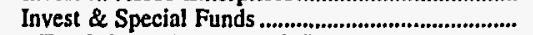 & 3,443 & 0 & 2,848 & $\mathbf{0}$ & 7,523 & 713 \\
\hline Total Other Property \& Investments................. & $\mathbf{3 , 4 4 3}$ & 13 & 2,848 & o & 7,523 & 7,948 \\
\hline \multicolumn{7}{|l|}{ Current and Accrued Assets } \\
\hline 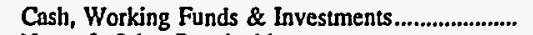 & 7,448 & 7,075 & 3,139 & 4,105 & 9,254 & 1,095 \\
\hline 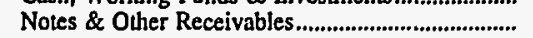 & 548 & 990 & 0 & 0 & 112 & 0 \\
\hline 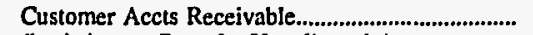 & 3,473 & 1,525 & 829 & 0 & 987 & 969 \\
\hline (less) Accum Prov for Uncollected Accts.................... & 160 & 99 & 3 & 0 & 58 & 0 \\
\hline 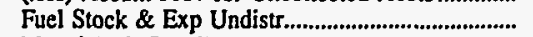 & 0 & 0 & 27 & 0 & 0 & 0 \\
\hline 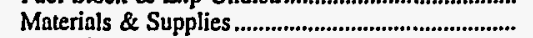 & 1,280 & 533 & 0 & 0 & 340 & 476 \\
\hline 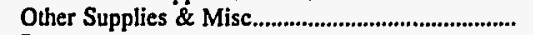 & 0 & 24 & 0 & 0 & 0 & 0 \\
\hline 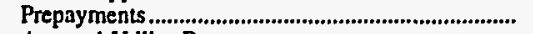 & 49 & 160 & 7 & 0 & 0 & 41 \\
\hline 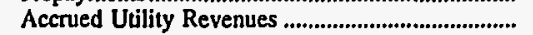 & 0 & 0 & 851 & 0 & 0 & 0 \\
\hline Miscellaneous Current \& Accrued Assets................ & 28 & 51 & 174 & 0 & 178 & 61 \\
\hline \multirow{2}{*}{\multicolumn{7}{|c|}{ Deferred Debits }} \\
\hline & & & & & & \\
\hline 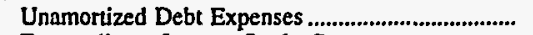 & 45 & 179 & 0 & $\mathbf{0}$ & 117 & $\mathbf{0}$ \\
\hline 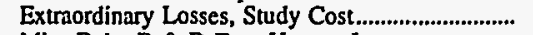 & 0 & 42 & 0 & $\mathbf{0}$ & 0 & 0 \\
\hline Misc Debt, R \& D Exp, Unamrt Losses .................. & 4,130 & 1,435 & 0 & 0 & 0 & 0 \\
\hline Total Deferred Debits.................................................. & 4,175 & 1,656 & o & 0 & 117 & 0 \\
\hline 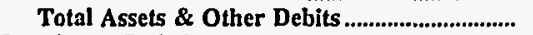 & 54,689 & 42,828 & 21,381 & 4,105 & 24,033 & 17,542 \\
\hline \multicolumn{7}{|l|}{ Proprietary Capital } \\
\hline Investment of Municipality ...... & 0 & 0 & 764 & 0 & 1,580 & 0 \\
\hline Misc Capital................................ & 3,923 & 0 & 0 & 0 & 0 & 0 \\
\hline 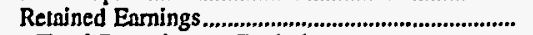 & 40,547 & 23,967 & 19,171 & 3,964 & 14,804 & 13,795 \\
\hline \multicolumn{6}{|l|}{ Long-term Debt } & 13,795 \\
\hline 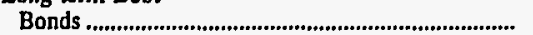 & 3,095 & 14,319 & 0 & 0 & 6,810 & 2,050 \\
\hline Advances from Municipality \& Other............................ & & & 0 & 0 & 0 & 0 \\
\hline Unamort Prem on Long-term Debt............................... & 0 & 0 & 0 & 0 & 0 & 0 \\
\hline (less) Unamort Discount on Long-term Debt & 0 & & 0 & 0 & 0 & o \\
\hline \multirow{2}{*}{\multicolumn{7}{|c|}{ Other Noncurrent Ljabilities }} \\
\hline & & & & & & \\
\hline 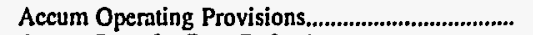 & 0 & $\mathbf{0}$ & 0 & 0 & 0 & 38 \\
\hline Rate Refunds......................................... & 0 & 0 & 0 & 0 & 0 & 0 \\
\hline Total Other Noneurrent Liabilities ........................ & 0 & $\mathbf{0}$ & 0 & 0 & o & 38 \\
\hline \multicolumn{7}{|l|}{ Current and Accrued Ljabilities } \\
\hline Notes Payable ................................ & 4,494 & 0 & 0 & 0 & 0 & 0 \\
\hline 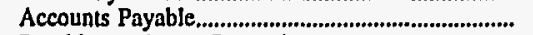 & 0 & 2,542 & 928 & 0 & 424 & 1,059 \\
\hline 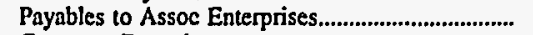 & 0 & $\mathbf{0}$ & 0 & 0 & 0 & 0 \\
\hline 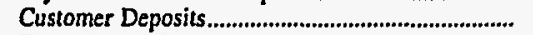 & 584 & 71 & 0 & 136 & 316 & 308 \\
\hline 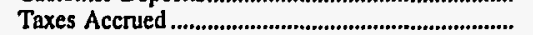 & 23 & 0 & 0 & 6 & 0 & 0 \\
\hline 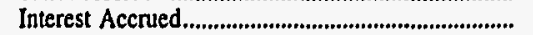 & 85 & 356 & 0 & 0 & 0 & 44 \\
\hline Misc Current \& Accrued Liabilities .............................. & 714 & 561 & 140 & 0 & 99 & 247 \\
\hline Total Current \& Accrued Liabilities ................ & 5,899 & 3,531 & 1,068 & 142 & 839 & 1,658 \\
\hline \multicolumn{7}{|l|}{ Deferred Credit } \\
\hline Customer Advances for Construction.......................... & 11 & $\mathbf{0}$ & 377 & 0 & 0 & $\mathbf{0}$ \\
\hline 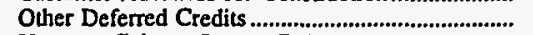 & 1,215 & 1,011 & 0 & 0 & 0 & 0 \\
\hline Unamort Gain on Reacqr Debt ..................................... & 0 & 0 & 0 & 0 & 0 & 0 \\
\hline 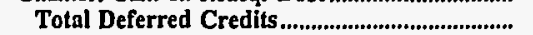 & 1,226 & 1,011 & 377 & 0 & 0 & 0 \\
\hline Total Llabilitles and Other Credits.................... & 54,689 & 42,828 & 21,381 & 4,105 & 24,033 & 17,542 \\
\hline
\end{tabular}

Note: Totals may not equal sum of components because of independent rounding.

Source: Energy Information Administration, Form EIA-412, "Annual Report of Public Electric Utilities." 
Table 22. Balance Sheet by Major U.S. Publicly Owned Electric Utility Within State at End of Period, 1996

(Thousand Dollars)

\begin{tabular}{|c|c|c|c|c|c|c|}
\hline Item & $\begin{array}{l}\text { South Carolina } \\
\text { Easley } \\
\text { Combined } \\
\text { Utility } \\
\text { System } \\
\text { March 31 }\end{array}$ & $\begin{array}{l}\text { South Carolina } \\
\text { Gaffney } \\
\text { City of } \\
\text { March } 31\end{array}$ & $\begin{array}{l}\text { South Carolina } \\
\text { Greenwood } \\
\text { Commissioners } \\
\text { Pub Wk } \\
\text { December } 31\end{array}$ & $\begin{array}{c}\text { South Carolina } \\
\text { Greer } \\
\text { Comm } \\
\text { of } \\
\text { Public Works } \\
\text { December } 31\end{array}$ & $\begin{array}{l}\text { South Carolina } \\
\text { Newberry } \\
\text { City of } \\
\text { June } 30\end{array}$ & $\begin{array}{l}\text { South Carolina } \\
\text { Orangeburg } \\
\text { City of } \\
\text { September } 30\end{array}$ \\
\hline \multicolumn{7}{|l|}{ Electric Utility Plant } \\
\hline Electric Utility Plant \& Adjust ....... & 20,045 & 2,238 & 10,502 & 97,768 & 8,387 & 58,435 \\
\hline 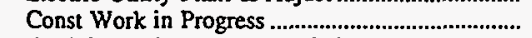 & & 0 & & 3,918 & 0 & 667 \\
\hline (less) Depr, Amort, and Depletion.................................. & 6,895 & 1,007 & 4,519 & 15,678 & 4,827 & 15,453 \\
\hline Net Electric Utility Plant ................................ & 13,150 & 1,232 & 5,984 & 86,008 & 3,561 & 43,649 \\
\hline Nuclear Fuel............................................................ & 0 & 0 & 0 & 0 & 0 & 0 \\
\hline 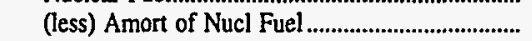 & 0 & 0 & 0 & 0 & 0 & 0 \\
\hline Net Elec Plant Ind Nucl Fuel .................................... & 13,150 & 1,232 & 5,984 & 86,008 & 3,561 & 43,649 \\
\hline \multicolumn{7}{|l|}{ Other Property \& Investments } \\
\hline Nonutility Property ..................... & 34,568 & 16,800 & 68,125 & 0 & 25,162 & 5,591 \\
\hline (less) Accum Provisions for Depr \& Amort ........... & 13,110 & 6,641 & 17,981 & 0 & 10,900 & 2,292 \\
\hline 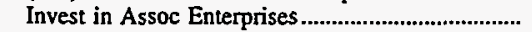 & & 0 & 0 & 0 & 0 & 0 \\
\hline 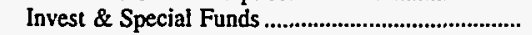 & 3,776 & 0 & 7,158 & 1,665 & 6,296 & 14,876 \\
\hline Total Other Property \& Investments................. & 25,234 & 10,159 & 57,303 & 1,665 & 20,558 & 18,175 \\
\hline \multicolumn{7}{|l|}{ Current and Accrued Assets } \\
\hline 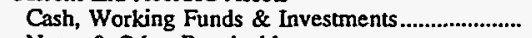 & 1,190 & 6,284 & 10,509 & 2,556 & 2,705 & 2,019 \\
\hline 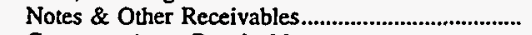 & 243 & 0 & & 590 & 13 & 0 \\
\hline Customer Accts Receivable........................................... & 2,004 & 940 & 5,605 & 4,434 & 2,346 & 2,162 \\
\hline (less) Accum Prov for Uncollected Accts................... & 0 & 37 & 0 & 0 & 188 & 46 \\
\hline 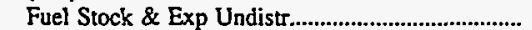 & 0 & 0 & 0 & 12 & 0 & 70 \\
\hline 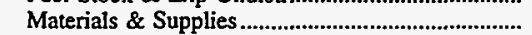 & 674 & 424 & 1,388 & 646 & 610 & 2,552 \\
\hline Other Supplies \& Misc................................................... & 0 & 13 & 0 & 0 & 0 & 0 \\
\hline 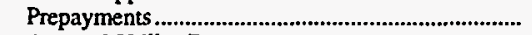 & 0 & 0 & 23 & 0 & 0 & 0 \\
\hline Accrued Utility Revenues & 0 & 1,047 & 0 & 0 & 0 & 3,647 \\
\hline Miscellaneous Current \& Accrued Assets................... & 0 & 0 & 3 & 0 & 329 & 59,874 \\
\hline Total Current \& Accrued Assets......................... & 4,110 & 8,672 & 17,527 & 8,239 & 5,815 & $\mathbf{7 0 , 2 7 7}$ \\
\hline \multicolumn{7}{|l|}{ Deferred Debits } \\
\hline 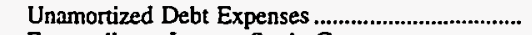 & 17 & 0 & 466 & 35 & 0 & 0 \\
\hline Extraordinary Losses, Study Cost.................................. & 0 & 0 & 0 & 0 & 0 & 0 \\
\hline Misc Debt, R \& D Exp, Unamrt Losses ...................... & 0 & 0 & 1,219 & 0 & 0 & 0 \\
\hline Total Deferred Debits................................... & 17 & 0 & 1,685 & 35 & 0 & 0 \\
\hline Total Assets \& Other Debits .................................. & 42,511 & 20,063 & 82,498 & 95,947 & 29,934 & 132,101 \\
\hline \multicolumn{7}{|l|}{ Proprietary Capital } \\
\hline Investment of Municipality & 229 & $\mathbf{0}$ & 0 & 0 & 0 & $\mathbf{0}$ \\
\hline 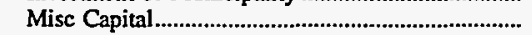 & 13,840 & 0 & 6,358 & 19,001 & 507 & 0 \\
\hline 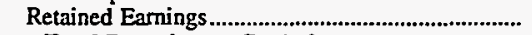 & 19,464 & 16,889 & 48,361 & 52,428 & 18,809 & 122,153 \\
\hline 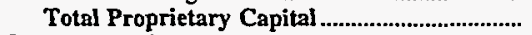 & 33,532 & 16,889 & 54,719 & 71,429 & 19,316 & 122,153 \\
\hline \multicolumn{7}{|l|}{ Long-term Debt } \\
\hline Bonds .......................... & 3,815 & 2,105 & 19,785 & 17,800 & 9,005 & 3,250 \\
\hline 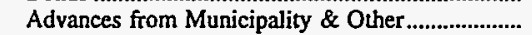 & 0 & 0 & 0 & 0 & 376 & 0 \\
\hline Unamort Prem on Long-term Debt................................ & 0 & 0 & 0 & 0 & 0 & 0 \\
\hline (less) Unamort Discount on Long-term Debt & 0 & 0 & 0 & 0 & 0 & 0 \\
\hline 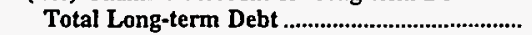 & 3,815 & 2,105 & 19,785 & 17,800 & 9,381 & 3,250 \\
\hline \multicolumn{7}{|l|}{ Other Noncurrent Liabilities } \\
\hline Accum Operating Provisions...... & 0 & 0 & 2,102 & 0 & 0 & 200 \\
\hline Accum Prov for Rate Refunds....................................... & 0 & 0 & & 0 & 0 & 0 \\
\hline Total Other Noncurrent Liabilities................... & 0 & 0 & 2,102 & 0 & $\mathbf{0}$ & 200 \\
\hline \multicolumn{7}{|l|}{ Current and Accrued Liabilities } \\
\hline Notes Payable .................................. & 685 & 0 & 1,235 & 0 & 0 & 0 \\
\hline 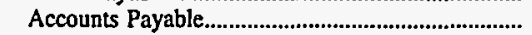 & 258 & 128 & 4,435 & 3,458 & 1,052 & 4,710 \\
\hline 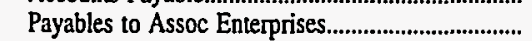 & 0 & 0 & 0 & 0 & 0 & 0 \\
\hline 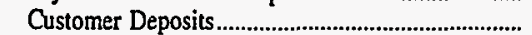 & 463 & 321 & 100 & 377 & 0 & 714 \\
\hline 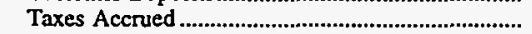 & 0 & 76 & 0 & 0 & 0 & 0 \\
\hline 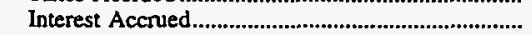 & 63 & 0 & 91 & 0 & 91 & 0 \\
\hline Misc Current \& Accrued Liabilities ..................... & 1,415 & 545 & 31 & 2,883 & 93 & 1,075 \\
\hline Total Current \& Accrued Liabilities ................ & 2,884 & 1,070 & 5,893 & 6,718 & 1,236 & 6,499 \\
\hline \multicolumn{7}{|l|}{ Deferred Credits } \\
\hline 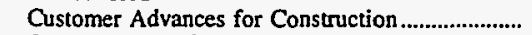 & 235 & 0 & 0 & 0 & $\mathbf{0}$ & 0 \\
\hline 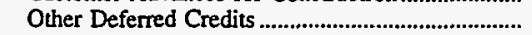 & 2,045 & 0 & 0 & 0 & 0 & 0 \\
\hline Unamort Gain on Reacqr Debt ........................................ & 0 & 0 & 0 & 0 & 0 & $\mathbf{0}$ \\
\hline Total Deferred Credits................................................. & 2,279 & & & 0 & $\mathbf{0}$ & 0 \\
\hline Total Liabilities and Other Credits.................... & 42,511 & 20,063 & 82,498 & 95,947 & 29,934 & 132,101 \\
\hline
\end{tabular}

Note: Totals may not equal sum of components because of independent rounding.

Source: Energy Information Administration, Form EIA-412, "Annual Report of Public Electric Utilities." 
Table 22. Balance Sheet by Major U.S. Publicly Owned Electric Utility Within State at End of Period, 1996

(Thousand Dollars)

\begin{tabular}{|c|c|c|c|c|c|c|}
\hline Item & $\begin{array}{c}\text { South Carolina } \\
\text { Piedmont } \\
\text { Municipal } \\
\text { Power Agny } \\
\text { December } 31\end{array}$ & $\begin{array}{l}\text { South Carolina } \\
\text { Rock Hill } \\
\text { City of } \\
\text { December } 31\end{array}$ & $\begin{array}{l}\text { South Carolina } \\
\text { Seneca } \\
\text { City of } \\
\text { Jurie } 30\end{array}$ & $\begin{array}{l}\text { South Carolina } \\
\text { South } \\
\text { Carolina } \\
\text { Pub } \\
\text { Serv Auth } \\
\text { December } 31\end{array}$ & $\begin{array}{l}\text { South Dakota } \\
\text { Brookings } \\
\text { City of } \\
\text { December } 31\end{array}$ & $\begin{array}{l}\text { South Dakota } \\
\text { Heartland } \\
\text { Consumers } \\
\text { Power Dist } \\
\text { December } 31\end{array}$ \\
\hline \multicolumn{7}{|l|}{ Electric Utility Plant } \\
\hline Electric Utility Plant \& Adjust ..................................... & 544,256 & 35,383 & 29,331 & $3,231,816$ & 20,404 & 58,125 \\
\hline 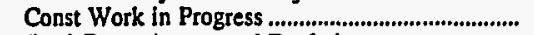 & 17,945 & 4,930 & 50 & 68,031 & 232 & 63 \\
\hline 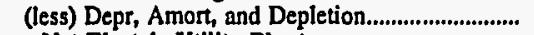 & 185,904 & 13,901 & 12,511 & $1,044,121$ & 6,608 & 10,807 \\
\hline Net Electric Utility Plant ...................................... & 376,297 & 26,411 & 16,870 & $2,255,726$ & 14,027 & 47,380 \\
\hline 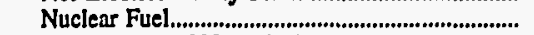 & 39,917 & & 0 & 45,240 & 0 & 0 \\
\hline (less) Amort of Nucl Fuel ......................................... & 27,754 & & & 25,634 & 0 & \\
\hline Net Elec Plant Incl Nucl Fuel ............................... & 388,460 & 26,411 & 16,870 & $2,275,332$ & 14,027 & 47,380 \\
\hline \multicolumn{7}{|l|}{ Other Property \& Investments } \\
\hline Nonutility Propenty................... & 0 & 113,642 & 0 & 2,021 & 0 & 0 \\
\hline (less) Accum Provisions for Depr \& Amort ......... & 0 & 28,597 & 0 & 258 & 0 & 0 \\
\hline Invest in Assoc Enterprises & & & 0 & 0 & 0 & 0 \\
\hline Invest \& Special Funds ............................................ & 174,597 & 12,355 & 0 & 215,338 & 0 & 9,817 \\
\hline Total Other Property \& Investments................ & 174,597 & 97,401 & o & 217,101 & 0 & 9,817 \\
\hline \multicolumn{7}{|l|}{ Current and Accrued Assets } \\
\hline Cash, Working Funds \& Investments..................... & 306,552 & 6,029 & 5,848 & 262,335 & 1,912 & 5,562 \\
\hline Notes \& Other Receivables............................................. & 1,031 & 4,592 & 0 & & 63 & 14 \\
\hline 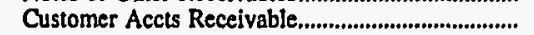 & 8,628 & 7,225 & 1,266 & 69,188 & 781 & 961 \\
\hline (less) Accum Prov for Uncollected Accts .................... & & 0 & 0 & 859 & 8 & 0 \\
\hline Fuel Stock \& Exp Undistr............................................ & 0 & 0 & 0 & 42,387 & 0 & 0 \\
\hline 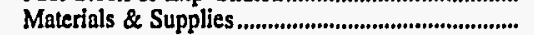 & 4,984 & 1,317 & 334 & 31,537 & 248 & 2,009 \\
\hline Other Supplies \& Misc................................................. & 0 & 0 & 0 & 0 & 0 & 0 \\
\hline 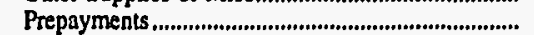 & 0 & 0 & 66 & 83 & 24 & 14 \\
\hline Accrued Utility Revenues ............................................ & 0 & 0 & 0 & 0 & 431 & 18 \\
\hline Miscellaneous Current \& Accrued Assets............... & 0 & 0 & 20 & 2,638 & 40 & 108 \\
\hline 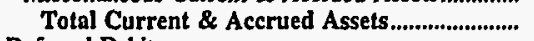 & 321,195 & 19,163 & 7,535 & 407,309 & 3,491 & 8,686 \\
\hline \multicolumn{7}{|l|}{ Deferred Debils } \\
\hline 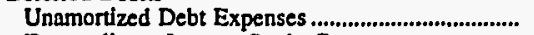 & 21,368 & 0 & 0 & 24,370 & 0 & 3,700 \\
\hline Extraordinary Losses, Study Cost............................... & & 0 & 0 & & 0 & 0 \\
\hline Misc Debt, R \& D Exp, Unamrt Losses .................. & 469,658 & 0 & 0 & 785,595 & 352 & 1,153 \\
\hline Total Deferred Debits.............................................. & 491,026 & & & 809,965 & 352 & 4,853 \\
\hline Total Assets \& Other Debits & $1,375,278$ & 142,975 & 24,405 & $\mathbf{3 , 7 0 9 , 7 0 7}$ & 17,870 & 70,736 \\
\hline \multicolumn{7}{|l|}{ Proprietary Capital } \\
\hline 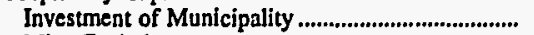 & 0 & 0 & 4,199 & 34,438 & 0 & 0 \\
\hline Misc Capital....................................................................... & 0 & 45,801 & 0 & 0 & 0 & 0 \\
\hline 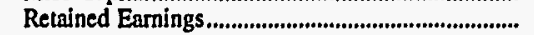 & 11,968 & 26,465 & 19,371 & 755,918 & 17,148 & 2,321 \\
\hline 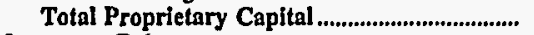 & 11,968 & 72,265 & 23,569 & 790,356 & 17,148 & 2,321 \\
\hline \multicolumn{7}{|l|}{ Long-term Debt } \\
\hline Bonds .................. & $1,354,584$ & 65,590 & 0 & $2,383,710$ & 0 & 61,120 \\
\hline 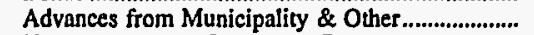 & & 0 & 0 & 42,713 & 0 & 0 \\
\hline 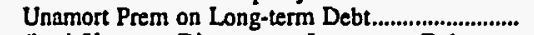 & 1,389 & 0 & 0 & & 0 & \\
\hline (less) Unamort Discount on Long-term Debt & 61,644 & 4,665 & 0 & 57,263 & o & 0 \\
\hline 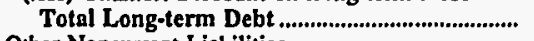 & $1,294,329$ & 60,925 & o & $2,369,160$ & 0 & 61,120 \\
\hline \multicolumn{7}{|l|}{ Other Noncurrent Liabilities } \\
\hline Accum Operating Provisions... & 19,388 & 0 & 0 & 0 & 0 & 0 \\
\hline Accum Prov for Rate Refunds....................................... & & 0 & D & 0 & 0 & 0 \\
\hline \multirow{2}{*}{\multicolumn{7}{|c|}{ Current and Accrued Liabilities }} \\
\hline & & & & & & \\
\hline 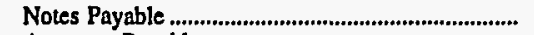 & 0 & 0 & 0 & 359,085 & 0 & 0 \\
\hline 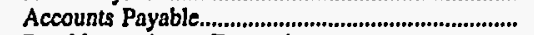 & 673 & & 81 & 30,448 & 602 & 1,123 \\
\hline Payables to Assoc Enterprises................................. & 0 & 4,453 & 0 & 0 & 2 & 0 \\
\hline 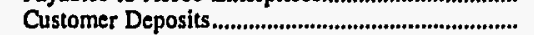 & 0 & 1,502 & 444 & 5,985 & 0 & 0 \\
\hline 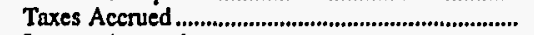 & 4,368 & 0 & 0 & 2,579 & 34 & 169 \\
\hline 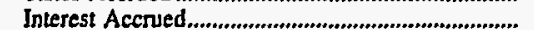 & 44,552 & 1,663 & 0 & 65,182 & 0 & 1,871 \\
\hline 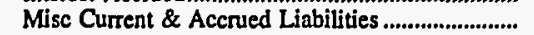 & & 1,390 & 311 & 85,235 & 84 & 1,700 \\
\hline $\begin{array}{l}\text { Total Current \& Accrued Liabilities.................. } \\
\text { Deferred Credits }\end{array}$ & 49,593 & 9,008 & 836 & 548,514 & 722 & 4,863 \\
\hline 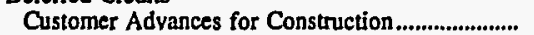 & 0 & 0 & 0 & & 0 & 0 \\
\hline 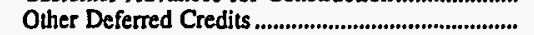 & 0 & 777 & 0 & 1,594 & 0 & 404 \\
\hline 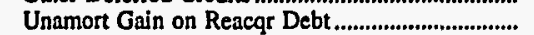 & 0 & 0 & 0 & 83 & 0 & 2,028 \\
\hline Total Deferred Credits .................................................... & & 777 & & 1,677 & & $\mathbf{2 , 4 3 2}$ \\
\hline Total Labillties and Other Credits....................... & $1,375,278$ & 142,975 & 24,405 & $3,709,707$ & 17,870 & 70,736 \\
\hline
\end{tabular}

Note: Totals may not equal sum of components because of independent rounding

Source: Energy Information Administration, Form EIA-412, "Annual Report of Public Electric Utilities." 
Table 22. Balance Sheet by Major U.S. Publicly Owned Electric Utility Within State at End of Period, 1996

(Thousand Dollars)

\begin{tabular}{|c|c|c|c|c|c|c|}
\hline Item & $\begin{array}{l}\text { South Dakota } \\
\text { Missouri } \\
\text { Basin } \\
\text { Mun } \\
\text { Power Agny } \\
\text { December 31 }\end{array}$ & $\begin{array}{c}\text { South Dakota } \\
\text { Pierre } \\
\text { City of } \\
\text { December } 31\end{array}$ & $\begin{array}{c}\text { South Dakota } \\
\text { Watertown } \\
\text { Municipal } \\
\text { Utilities } \\
\text { December 31 }\end{array}$ & $\begin{array}{c}\text { Tennessee } \\
\text { Alcoa } \\
\text { Utilities } \\
\text { June } 30\end{array}$ & $\begin{array}{l}\text { Tennessee } \\
\text { Athens } \\
\text { Utility } \\
\text { Board } \\
\text { June } 30\end{array}$ & $\begin{array}{l}\text { Tennessee } \\
\text { Benton } \\
\text { County } \\
\text { June } 30\end{array}$ \\
\hline \multicolumn{7}{|l|}{ Electric Utility Plant } \\
\hline 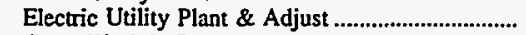 & 2,848 & 8,646 & 18,367 & 22,329 & 20,396 & 16,044 \\
\hline 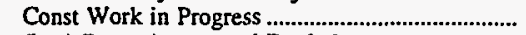 & & & 324 & 1,237 & 804 & 201 \\
\hline 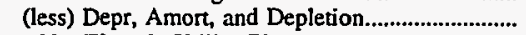 & 875 & 3,327 & 12,298 & 7,724 & 7,217 & 6,246 \\
\hline 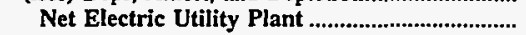 & 1,972 & 5,318 & 6,393 & 15,842 & 13,984 & 10,000 \\
\hline Nuclear Fuel.............................................................. & 0 & 0 & 0 & 0 & 0 & 0 \\
\hline 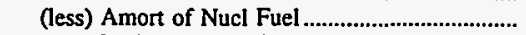 & 0 & 0 & 0 & 0 & 0 & 0 \\
\hline Net Elec Plant Incl Nucl Fuel ............................. & 1,972 & 5,318 & 6,393 & 15,842 & 13,984 & 10,000 \\
\hline \multicolumn{7}{|l|}{ Other Property \& Investments } \\
\hline Nonutility Property .................. & 0 & 0 & 0 & 0 & 0 & 0 \\
\hline (less) Accum Provisions for Depr \& Amort ........... & 0 & 0 & 0 & 0 & 0 & 0 \\
\hline 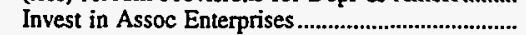 & 0 & 0 & 0 & 0 & 0 & 0 \\
\hline 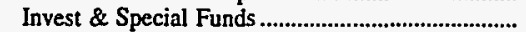 & 13,516 & 453 & 0 & 1,649 & 0 & 2,289 \\
\hline Total Other Property \& Investments................... & 13,516 & 453 & 0 & 1,649 & 0 & 2,289 \\
\hline \multicolumn{7}{|l|}{ Current and Accrued Assets } \\
\hline 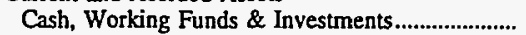 & 8,826 & 2,769 & 1,996 & 4,666 & 206 & 35 \\
\hline 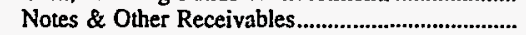 & 0 & 0 & 485 & 1,774 & 1,740 & 891 \\
\hline Customer Accts Receivable & 6,466 & 544 & 898 & 0 & 0 & 0 \\
\hline (less) Accum Prov for Uncollected Accts................... & 0 & 80 & 9 & 0 & 0 & 0 \\
\hline 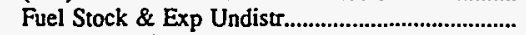 & 51 & 0 & 0 & 0 & 0 & $\mathbf{0}$ \\
\hline 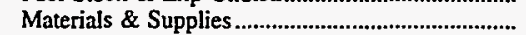 & 0 & 536 & 314 & 396 & 220 & 144 \\
\hline 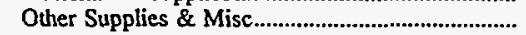 & 0 & 0 & 0 & 0 & 0 & 0 \\
\hline 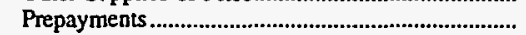 & 10 & 0 & 28 & 0 & 0 & 0 \\
\hline Accrued Utility Revenues .......................... & 0 & 0 & 42 & 3 & 6 & 88 \\
\hline Miscellaneous Current \& Accrued Assets................ & 338 & 0 & 0 & 157 & 176 & 14 \\
\hline Total Current \& Accrued Assets.................................. & 15,691 & 3,769 & 3,755 & 6,996 & 2,349 & 1,172 \\
\hline \multicolumn{7}{|l|}{ Deferred Debits } \\
\hline Unamortized Debt Expenses ........................................ & 0 & 0 & 0 & 0 & 0 & 20 \\
\hline 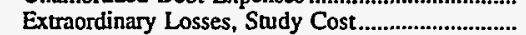 & 0 & 0 & 0 & 36 & 0 & 0 \\
\hline 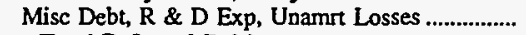 & 1,590 & 0 & 0 & 1,223 & 777 & 299 \\
\hline 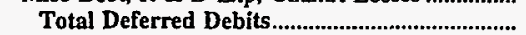 & 1,590 & 0 & 0 & 1,259 & 777 & 319 \\
\hline Total Assets \& Other Debits .................................... & 32,769 & 9,540 & 10,148 & 25,745 & 17,109 & 13,780 \\
\hline \multicolumn{7}{|l|}{ Proprietary Capital } \\
\hline Investment of Municipality.... & 0 & 62 & 0 & 0 & 0 & 0 \\
\hline 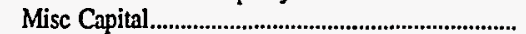 & 0 & 0 & 0 & 0 & 0 & 0 \\
\hline 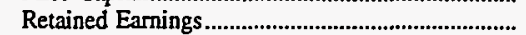 & 26,306 & 8,601 & 8,482 & 14,386 & 14,789 & 9,405 \\
\hline 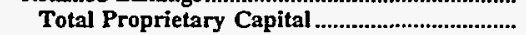 & 26,306 & 8,663 & 8,482 & 14,386 & 14,789 & 9,405 \\
\hline \multicolumn{7}{|l|}{ Long-term Debt } \\
\hline Bonds ...................... & 0 & 0 & 0 & 0 & 0 & 0 \\
\hline Advances from Municipality \& Other....................... & 0 & 0 & 0 & 3,455 & 0 & 1,920 \\
\hline Unamort Prem on Long-term Debt.............................. & 0 & 0 & 0 & 988 & 786 & 304 \\
\hline (less) Unamort Discount on Long-term Debt & 0 & 0 & 0 & 22 & 0 & 23 \\
\hline Total Long-term Debt ........................................... & 0 & $\mathbf{0}$ & 0 & 4,421 & 786 & 2,201 \\
\hline \multicolumn{7}{|l|}{ Other Noncurrent Liabilities } \\
\hline 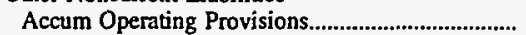 & 0 & 85 & 0 & 0 & 0 & 0 \\
\hline Accum Prov for Rate Refunds...................................... & 0 & 0 & 0 & 0 & 0 & 0 \\
\hline Total Other Noncurrent Liabilities ...................... & 0 & 85 & o & 0 & 0 & 0 \\
\hline \multicolumn{7}{|l|}{ Current and Accrued Liabilities } \\
\hline Notes Payable .............................. & 0 & 0 & 13 & 44 & 1,373 & 13 \\
\hline 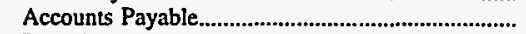 & 6,441 & 505 & 874 & 3,857 & 0 & 913 \\
\hline Payables to Assoc Enterprises...................................... & 0 & 0 & 0 & 1,737 & 0 & 425 \\
\hline 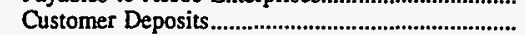 & 0 & 245 & 169 & 0 & 0 & 0 \\
\hline 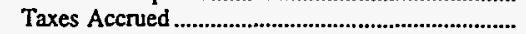 & 22 & 31 & 27 & 0 & 0 & 0 \\
\hline 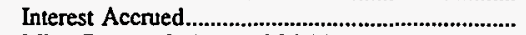 & 0 & 0 & 0 & 795 & 157 & 822 \\
\hline Misc Current \& Accrued Liabilities ............................. & 0 & 11 & 582 & 0 & 0 & 0 \\
\hline Total Current \& Accrued Liabilities ..................... & 6,463 & 792 & 1,666 & 6,432 & 1,531 & 2,173 \\
\hline \multicolumn{7}{|l|}{ Deferred Credits } \\
\hline Customer Advances for Construction ......................... & 0 & 0 & 0 & 0 & 4 & 1 \\
\hline 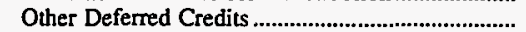 & 0 & 0 & 0 & 505 & 0 & 0 \\
\hline Unamort Gain on Reacgr Debt .................................... & 0 & 0 & 0 & 0 & 0 & 0 \\
\hline 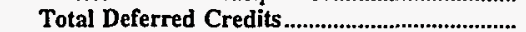 & 0 & 0 & & 505 & & \\
\hline 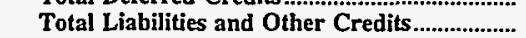 & 32,769 & 9,540 & 10,148 & 25,745 & 17,109 & 13,780 \\
\hline
\end{tabular}

Note: Totals may not equal sum of components because of independent rounding.

Source: Energy Information Administration, Form EIA-412, "Annual Report of Public Electric Utilities." 
Table 22. Balance Sheet by Major U.S. Publicly Owned Electric Utility Within State at End of Period, 1996

(Thousand Dollars)

\begin{tabular}{|c|c|c|c|c|c|c|}
\hline Item & $\begin{array}{l}\text { Tennessee } \\
\text { Bolivar } \\
\text { City of } \\
\text { June } 30\end{array}$ & $\begin{array}{l}\text { Tennessee } \\
\text { Bristol } \\
\text { City of } \\
\text { June } 30\end{array}$ & $\begin{array}{c}\text { Tennessee } \\
\begin{array}{c}\text { Brownsville } \\
\text { City of }\end{array} \\
\text { June } 30\end{array}$ & $\begin{array}{l}\text { Tennessee } \\
\text { Carroll } \\
\text { County } \\
\text { June } 30\end{array}$ & $\begin{array}{l}\text { Tennessee } \\
\text { Chattanooga } \\
\text { City of } \\
\text { June } 30\end{array}$ & $\begin{array}{c}\text { Tennessee } \\
\text { Clarksville } \\
\text { City of } \\
\text { June } 30\end{array}$ \\
\hline \multicolumn{7}{|l|}{ Electric Utility Plant } \\
\hline 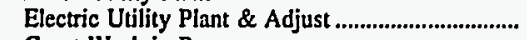 & 16,703 & 45,348 & 7,429 & 21,562 & 277,041 & 50,138 \\
\hline 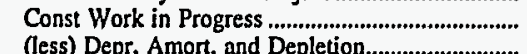 & 747 & 4,663 & 1,037 & 423 & 7,814 & 385 \\
\hline 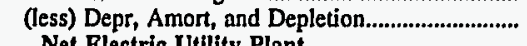 & 6,019 & 24,498 & 2,954 & 8,713 & 111,892 & 13,358 \\
\hline & 11,431 & 25,514 & $\mathbf{5 , 5 1 1}$ & 13,271 & 172,964 & 37,165 \\
\hline $\begin{array}{l}\text { Nuclear Fuel.,. } \\
\text { (less) Amort of Nucl Fuel }\end{array}$ & $\begin{array}{l}0 \\
0\end{array}$ & $\begin{array}{l}0 \\
0\end{array}$ & 0 & 0 & 0 & 0 \\
\hline Net Elec Plant Incl Nucl Fuel ....................... & 11,431 & 25.514 & 5,511 & 13271 & $\begin{array}{r}0 \\
172.964\end{array}$ & $\begin{array}{r}0 \\
37.165\end{array}$ \\
\hline \multicolumn{7}{|l|}{$\begin{array}{l}\text { Other Property \& Investments } \\
\text { Nonutility Property.................. }\end{array}$} \\
\hline 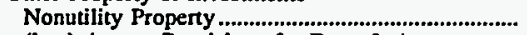 & 0 & 224 & 0 & 0 & $\mathbf{0}$ & 207 \\
\hline 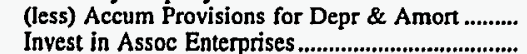 & $\begin{array}{l}0 \\
0\end{array}$ & 0 & 0 & 0 & 0 & \\
\hline 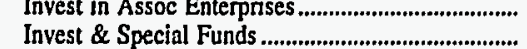 & $\begin{array}{r}0 \\
144\end{array}$ & 8,200 & $\begin{array}{r}0 \\
682\end{array}$ & $\begin{array}{r}0 \\
1720\end{array}$ & $\begin{array}{r}0 \\
8.310\end{array}$ & 7244 \\
\hline Total Other Property \& Investments.................. & 144 & 8,424 & 682 & 1,720 & $\begin{array}{l}0,310 \\
8,310\end{array}$ & $\begin{array}{l}7,244 \\
7,451\end{array}$ \\
\hline \multicolumn{7}{|l|}{ Current and Accrued Assets } \\
\hline 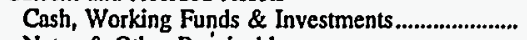 & 1,070 & 1,402 & 333 & 720 & 16,600 & 1,273 \\
\hline 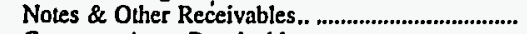 & 1,659 & 3,021 & 888 & 2,088 & 17,162 & 3,655 \\
\hline 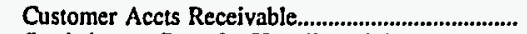 & 0 & 0 & $\mathbf{0}$ & 0 & 0 & 0 \\
\hline (less) Accum Prov for Uncollected Accts............... & 0 & 0 & 0 & 0 & $\mathbf{0}$ & 0 \\
\hline 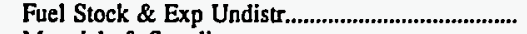 & 0 & $\mathbf{0}$ & $\mathbf{0}$ & 0 & 0 & 0 \\
\hline 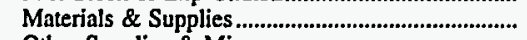 & 290 & 536 & 190 & 443 & 3,712 & 520 \\
\hline 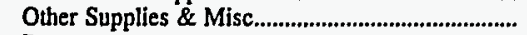 & 0 & 0 & 0 & 0 & 0 & 0 \\
\hline 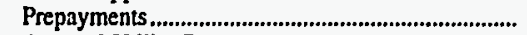 & 0 & 0 & 54 & 0 & 0 & 0 \\
\hline 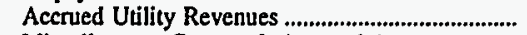 & 5 & 135 & 0 & 97 & 785 & 0 \\
\hline Miscellaneous Current \& Accrued Assets............... & 23 & 58 & 23 & 60 & 17,950 & 79 \\
\hline $\begin{array}{l}\text { Total Current \& Accrued Assets......................... } \\
\text { Deferred Debits }\end{array}$ & 3,047 & 5,151 & 1,488 & $\mathbf{3 , 4 0 8}$ & 56,209 & 5,527 \\
\hline $\begin{array}{l}\text { Deferred Debits } \\
\text { Unamortized Debt Expenses ........................................ }\end{array}$ & 51 & 0 & \\
\hline 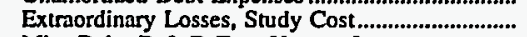 & 0 & 0 & 0 & 0 & 0 & 0 \\
\hline 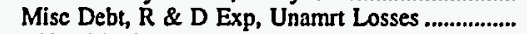 & 1,200 & 9,605 & 12 & 53 & 11,315 & 5,337 \\
\hline Total Deferred Debits................................................ & 1,251 & 9,605 & 14 & 65 & 11,315 & 5,452 \\
\hline 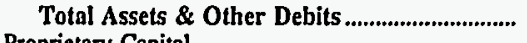 & 15,872 & 48,695 & 7,695 & 18,465 & 248,798 & 55,594 \\
\hline \multicolumn{7}{|l|}{ Proprietary Capital } \\
\hline 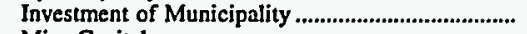 & 0 & $\mathbf{0}$ & $\mathbf{0}$ & $\mathbf{0}$ & $\mathbf{0}$ & 0 \\
\hline 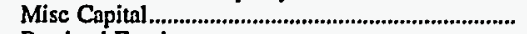 & 0 & 0 & 0 & 0 & 0 & 0 \\
\hline 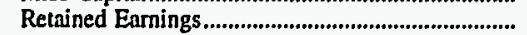 & 8,334 & 43,866 & 5,926 & 14,542 & 183,689 & 30,011 \\
\hline 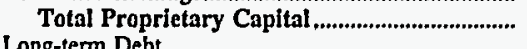 & 8,334 & 43,866 & 5,926 & 14,542 & 183,689 & 30,011 \\
\hline \multicolumn{7}{|l|}{ Long-term Debt } \\
\hline Bonds & 0 & 0 & 360 & 0 & 11,163 & 0 \\
\hline Advances from Municipality \& Other..................... & 1,135 & 0 & 0 & 730 & 0 & 9,010 \\
\hline Unamort Prem on Long-term Debt............................... & 3,301 & 0 & 0 & 45 & 13,539 & 4,199 \\
\hline (less) Unamort Discount on Long-term Debt & & 0 & 0 & 8 & & 100 \\
\hline Total Long-term Debt ..... & 4,436 & $\mathbf{0}$ & 360 & $\mathbf{7 6 7}$ & 24,703 & 13,109 \\
\hline \multicolumn{7}{|l|}{ Other Noncurrent Liabilities } \\
\hline 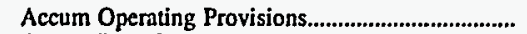 & $\mathbf{0}$ & 0 & 0 & $\mathbf{0}$ & 0 & 0 \\
\hline Accum Psov for Rate Refunds........................................ & 0 & 0 & 0 & 0 & 0 & 0 \\
\hline Total Other Noncurrent Liabilities ...................... & $\mathbf{0}$ & 0 & 0 & 0 & $\mathbf{0}$ & 0 \\
\hline \multicolumn{7}{|l|}{ Current and Accrued Liabilities } \\
\hline 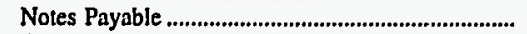 & 8 & 3,467 & 0 & 1,815 & 1,405 & 144 \\
\hline 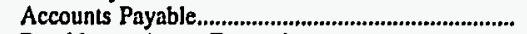 & 2,273 & 0 & 1,093 & 0 & 22,953 & 3,995 \\
\hline 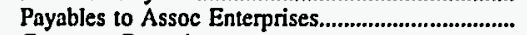 & 495 & 647 & 0 & 478 & 5,904 & 1,598 \\
\hline 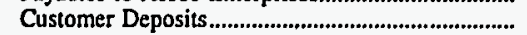 & 0 & 222 & 195 & 344 & 6,179 & 0 \\
\hline 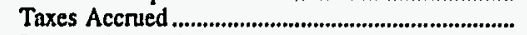 & 1 & 0 & 0 & 0 & 0 & 0 \\
\hline 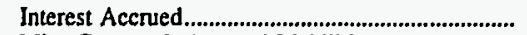 & 326 & 465 & 24 & 514 & 1,819 & 1,273 \\
\hline Misc Current \& Accrued Liabilities ......................... & & & & 0 & & 0 \\
\hline \multirow{2}{*}{\multicolumn{7}{|c|}{ Deferred Credits }} \\
\hline & & & & & & \\
\hline $\begin{array}{l}\text { Customer Advances for Construction } \\
\text { Other Deferred Credits }\end{array}$ & $\begin{array}{l}0 \\
0\end{array}$ & $\begin{array}{r}29 \\
0\end{array}$ & $\begin{array}{r}0 \\
96\end{array}$ & 0 & 2,146 & 5,465 \\
\hline 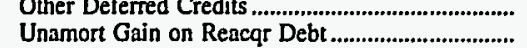 & 0 & 0 & $\begin{array}{r}96 \\
0\end{array}$ & $\begin{array}{l}5 \\
0\end{array}$ & $\begin{array}{l}0 \\
0\end{array}$ & $\begin{array}{l}0 \\
0\end{array}$ \\
\hline 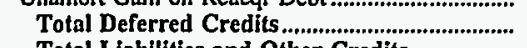 & & 29 & 96 & & 2,146 & 5,465 \\
\hline Total Liabilities and Other Credits...................... & 15,872 & 48,695 & 7,695 & 18,465 & 248,798 & 55,594 \\
\hline
\end{tabular}

Note: Totals may not equal sum of components because of independent rounding.

Source: Energy Information Administration, Form EIA-412, "Annual Report of Public Electric Utilities." 
Table 22. Balance Sheet by Major U.S. Publicly Owned Electric Utility Within State at End of Period, 1996

(Thousand Dollars)

\begin{tabular}{|c|c|c|c|c|c|c|}
\hline Item & $\begin{array}{c}\text { Tennessee } \\
\text { Cleveland } \\
\text { City of } \\
\text { June } 30\end{array}$ & $\begin{array}{l}\text { Tennessee } \\
\text { Clinton } \\
\text { City of } \\
\text { June } 30\end{array}$ & $\begin{array}{c}\text { Tennessee } \\
\text { Columbia } \\
\text { City of } \\
\text { June } 30\end{array}$ & $\begin{array}{c}\text { Tennessee } \\
\begin{array}{c}\text { Cookeville } \\
\text { City of }\end{array} \\
\text { June } 30\end{array}$ & $\begin{array}{c}\text { Tennessee } \\
\begin{array}{c}\text { Covington } \\
\text { City of }\end{array} \\
\text { June } 30\end{array}$ & $\begin{array}{l}\text { Tennessee } \\
\begin{array}{l}\text { Dayton } \\
\text { City of }\end{array} \\
\text { June } 30\end{array}$ \\
\hline \multicolumn{7}{|l|}{ Electric Utility Plant } \\
\hline Electric Utility Plant \& Adjust .......... & 55,244 & 41,258 & 30,994 & 20,983 & 8,626 & 12,361 \\
\hline 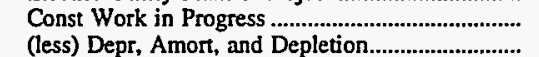 & $\begin{array}{r}836 \\
18,850\end{array}$ & $\begin{array}{r}1,462 \\
14,619\end{array}$ & $\begin{array}{r}365 \\
11,215\end{array}$ & $\begin{array}{r}324 \\
5,560\end{array}$ & $\begin{array}{r}47 \\
2,905\end{array}$ & $\begin{array}{r}100 \\
4,034\end{array}$ \\
\hline 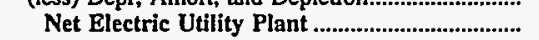 & $\mathbf{3 7 , 2 3 0}$ & 28,102 & 20,144 & 15,748 & 5,768 & 8,428 \\
\hline Nuclear Fuel........................................................ & & 0 & 0 & & 0 & 0 \\
\hline 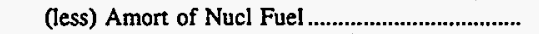 & 0 & 0 & 0 & 0 & 0 & 0 \\
\hline Net Elec Plant Incl Nucl Fuel .................................. & $\mathbf{3 7 , 2 3 0}$ & 28,102 & 20,144 & 15,748 & 5,768 & 8,428 \\
\hline \multicolumn{7}{|l|}{ Other Property \& Investments } \\
\hline 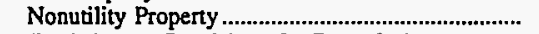 & $\mathbf{0}$ & 0 & 0 & 0 & 0 & $\mathbf{0}$ \\
\hline (less) Accum Provisions for Depr \& Amort ........... & 0 & 0 & 0 & 0 & 0 & 0 \\
\hline 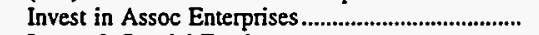 & 0 & 0 & $\mathbf{0}$ & 0 & $\mathbf{0}$ & $\mathbf{0}$ \\
\hline 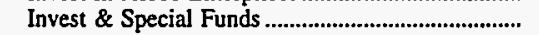 & 46 & 924 & 1,993 & 130 & 866 & 0 \\
\hline Total Other Property \& Investments.................... & 46 & 924 & 1,993 & 130 & 866 & $\mathbf{0}$ \\
\hline \multicolumn{7}{|l|}{ Current and Accrued Assets } \\
\hline Cash, Working Funds \& Investments............................ & 1,957 & 1,328 & 483 & 1,078 & 5,780 & 1,252 \\
\hline 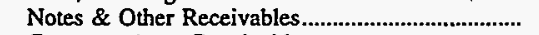 & 4,696 & 3,685 & 1,919 & 2,475 & 1,087 & 1,035 \\
\hline 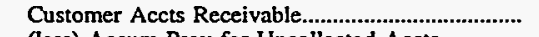 & $\mathbf{0}$ & 0 & o & 0 & $\mathbf{0}$ & 0 \\
\hline (less) Accum Prov for Uncollected Accts .................. & 0 & 0 & $\mathbf{0}$ & $\mathbf{0}$ & $\mathbf{0}$ & $\mathbf{0}$ \\
\hline 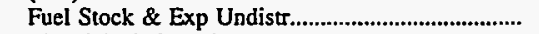 & 0 & $\mathbf{0}$ & 0 & 0 & $\mathbf{0}$ & $\mathbf{0}$ \\
\hline 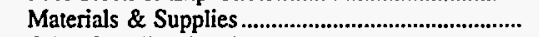 & 835 & 723 & 597 & 642 & 131 & 67 \\
\hline 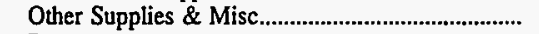 & 0 & 0 & 0 & 0 & 0 & 0 \\
\hline 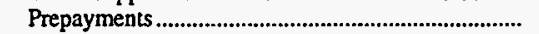 & 0 & 0 & 0 & 0 & 0 & 7 \\
\hline Accrued Utility Revenues ................................................ & 7 & 226 & 51 & 4 & 293 & 0 \\
\hline Miscellaneous Current \& Accrued Assets............... & 243 & 123 & 62 & 36 & 30 & 52 \\
\hline 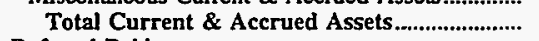 & $\mathbf{7 , 7 3 8}$ & 6,084 & 3,112 & 4,236 & 7,321 & $\mathbf{2 , 4 1 4}$ \\
\hline \multicolumn{7}{|l|}{ Deferred Debits } \\
\hline Unamortized Debt Expenses.... & 0 & 0 & 48 & 6 & 9 & 0 \\
\hline 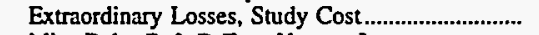 & 0 & 0 & 0 & 0 & 0 & 0 \\
\hline 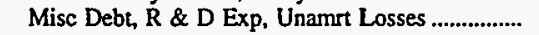 & 2,359 & 3,042 & 1,053 & 268 & 260 & 218 \\
\hline Total Deferred Debits.................................................. & 2,359 & 3,042 & 1,101 & 274 & 269 & 218 \\
\hline 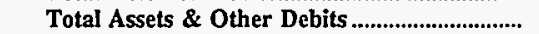 & 47,372 & 38,152 & 26,351 & 20,388 & 14,224 & 11,060 \\
\hline \multicolumn{7}{|l|}{ Proprietary Capital } \\
\hline 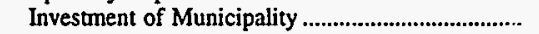 & 0 & 0 & 0 & 0 & 0 & 0 \\
\hline 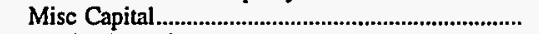 & $\mathbf{0}$ & 0 & 0 & $\mathbf{0}$ & $\mathbf{0}$ & 0 \\
\hline 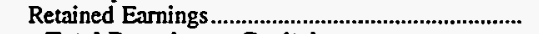 & 37,239 & 28,265 & 19,463 & 16,345 & 11,488 & 9,478 \\
\hline 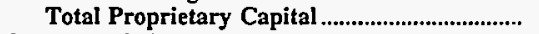 & 37,239 & 28,265 & 19,463 & 16,345 & 11,488 & 9,478 \\
\hline \multicolumn{7}{|l|}{ Long-term Debt } \\
\hline Bonds ............... & 0 & 0 & 0 & 0 & 0 & $\mathbf{0}$ \\
\hline Advances from Municipality \& Other.......................... & 280 & 1,620 & 2,870 & 885 & 505 & 219 \\
\hline Unamort Prem on Long-term Debt.............................. & 2,079 & 3,072 & 981 & 280 & 113 & 0 \\
\hline (less) Unamort Discount on Long-term Debt & & & 37 & 0 & 6 & 0 \\
\hline Total Long-term Debt & 2,359 & 4,692 & 3,814 & 1,165 & 612 & 219 \\
\hline \multicolumn{7}{|l|}{ Other Noncurrent Liabilities } \\
\hline 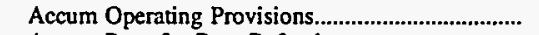 & 0 & 0 & 0 & 0 & 0 & 0 \\
\hline 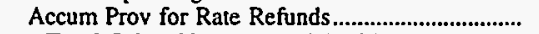 & 0 & 0 & 0 & 0 & 0 & 0 \\
\hline Total Other Noncurrent Liabilities ....................... & 0 & 0 & $\mathbf{0}$ & 0 & o & 0 \\
\hline \multicolumn{7}{|l|}{ Current and Accrued Liabilities } \\
\hline Notes Payable ................................. & 35 & 27 & 45 & 15 & 9 & 0 \\
\hline Accounts Payable & 4,620 & 3,055 & 1,416 & 2,343 & 998 & 1,146 \\
\hline 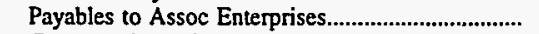 & 1,035 & 1,039 & 1,009 & 290 & 282 & 0 \\
\hline 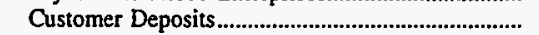 & 0 & 0 & 0 & 0 & 0 & 158 \\
\hline 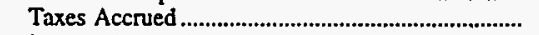 & 0 & 0 & 0 & 0 & 0 & $\mathbf{0}$ \\
\hline 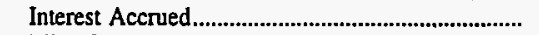 & 498 & 1,053 & 603 & 69 & 54 & 0 \\
\hline Misc Current \& Accrued Liabilities .............................. & 0 & 0 & 0 & 0 & 0 & 59 \\
\hline Total Current \& Accrued Liabilities ................... & 6,188 & 5,174 & 3,073 & 2,717 & 1,343 & 1,363 \\
\hline \multicolumn{7}{|l|}{ Deferred Credits } \\
\hline 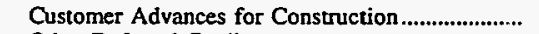 & 1,587 & 20 & 0 & 161 & 781 & $\mathbf{0}$ \\
\hline 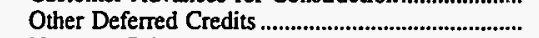 & 0 & 0 & 0 & 0 & 0 & 0 \\
\hline Unamort Gain on Reacqr Debt ........................................ & 0 & 0 & 0 & $\mathbf{0}$ & 0 & 0 \\
\hline Total Deferred Credits & 1,587 & 20 & 0 & 161 & 781 & \\
\hline Total Liabilities and Other Credits........................ & 47,372 & 38,152 & 26,351 & 20,388 & 14,224 & 11,060 \\
\hline
\end{tabular}

Note: Totals may not equal sum of components because of independent rounding

Source: Energy Information Administration, Form EIA-412, "Annual Report of Public Electric Utilities." 
Table 22. Balance Sheet by Major U.S. Publicly Owned Electric Utility Within State at End of Period, 1996

(Thousand Dollars)

\begin{tabular}{|c|c|c|c|c|c|c|}
\hline Item & $\begin{array}{l}\text { Tennessee } \\
\text { Dickson } \\
\text { City of } \\
\text { June } 30\end{array}$ & $\begin{array}{l}\text { Tennessee } \\
\text { Dyersburg } \\
\text { City of } \\
\text { June } 30\end{array}$ & $\begin{array}{l}\text { Tennessee } \\
\text { Elizabethton } \\
\text { City of } \\
\text { June } 30\end{array}$ & $\begin{array}{l}\text { Tennessee } \\
\text { Erwin } \\
\text { Town of } \\
\text { June } 30\end{array}$ & $\begin{array}{l}\text { Tennessee } \\
\text { Etowah } \\
\text { City of } \\
\text { June } 30\end{array}$ & $\begin{array}{l}\text { Tennessee } \\
\text { Fayetteville } \\
\text { City of } \\
\text { June } 30\end{array}$ \\
\hline \multicolumn{7}{|l|}{ Electric Utility Plant } \\
\hline 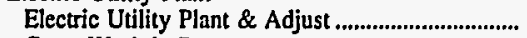 & 45,940 & 29,520 & 32,806 & 9,825 & 6,301 & 33,030 \\
\hline 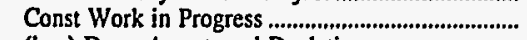 & 2,790 & 1,910 & 829 & 791 & 134 & 1,516 \\
\hline (less) Depr, Amort, and Depletion............................. & 14,527 & 9,571 & 12,348 & 3,821 & 2,705 & 10,922 \\
\hline Net Electric Utility Plant ........................................ & $\mathbf{3 4 , 2 0 3}$ & 21,859 & 21,288 & 6,796 & $\mathbf{3 , 7 3 0}$ & 23,624 \\
\hline 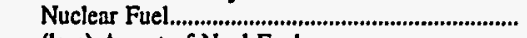 & $\mathbf{0}$ & 0 & 0 & 0 & 0 & 0 \\
\hline 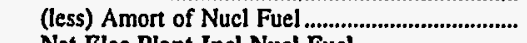 & 0 & 0 & 0 & 0 & 0 & \\
\hline 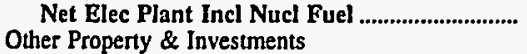 & 34,203 & 21,859 & 21,288 & 6,796 & $\mathbf{3 , 7 3 0}$ & 23,624 \\
\hline 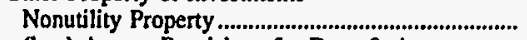 & $\mathbf{0}$ & 0 & 0 & 0 & 0 & \\
\hline (less) Accum Provisions for Depr \& Amort .......... & 0 & 0 & 0 & 0 & 0 & 0 \\
\hline 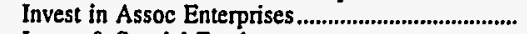 & 0 & $\mathbf{0}$ & 0 & 0 & 0 & 0 \\
\hline Invest \& Special Funds .......................................................... & 3,387 & 5,052 & 703 & 17 & 626 & 5,878 \\
\hline Total Other Property \& Investments..................... & 3,387 & 5,052 & 703 & 17 & 626 & 5,878 \\
\hline \multicolumn{7}{|l|}{ Current and Accrued Assets } \\
\hline & 3,198 & 1,529 & 1,054 & 1,290 & 99 & 476 \\
\hline 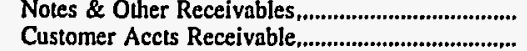 & 3,121 & $\begin{array}{r}2,302 \\
0\end{array}$ & $\begin{array}{r}2,232 \\
0\end{array}$ & $\begin{array}{r}1,051 \\
0\end{array}$ & 740 & $\begin{array}{r}1,691 \\
0\end{array}$ \\
\hline 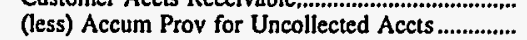 & 0 & 0 & 0 & 0 & 0 & $\begin{array}{l}0 \\
0\end{array}$ \\
\hline Fuel Stock \& Exp Undistr................................................. & 0 & 0 & 0 & 0 & 0 & 0 \\
\hline 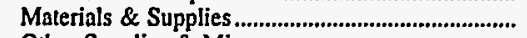 & 607 & 512 & 499 & 207 & 143 & 565 \\
\hline 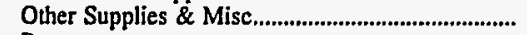 & 0 & 0 & 0 & 0 & 0 & 0 \\
\hline 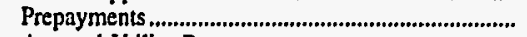 & 0 & 0 & $\mathbf{0}$ & 0 & 12 & 0 \\
\hline 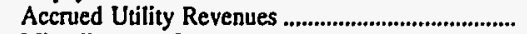 & 0 & 54 & 0 & 0 & 0 & 41 \\
\hline Miscellaneous Current \& Accrued Assets................ & 134 & 70 & 56 & 319 & 18 & 73 \\
\hline Total Current \& Accrued Assets........................... & 7,059 & 4,466 & 3,841 & 2,867 & 1,013 & 2,845 \\
\hline \multicolumn{7}{|l|}{ Deferred Debits } \\
\hline 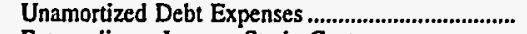 & 75 & 100 & 0 & 0 & 0 & 152 \\
\hline 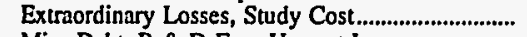 & 12 & 0 & 0 & 0 & 0 & 0 \\
\hline Misc Debt, $\bar{R}$ \& D Exp, Unamrt Losses ................. & 627 & 1,045 & 3,205 & 747 & 609 & 605 \\
\hline 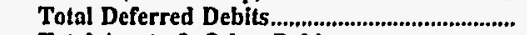 & 714 & 1,146 & 3,205 & 747 & 609 & 756 \\
\hline Total Assets \& Other Debits ...................................... & 45,364 & 32,522 & 29,037 & 10,427 & 5,978 & 33,103 \\
\hline \multicolumn{7}{|l|}{ Proprietary Capital } \\
\hline 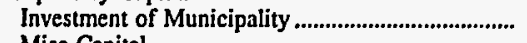 & 0 & $0^{\circ}$ & 0 & 0 & 0 & 0 \\
\hline 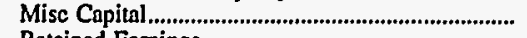 & 0 & 0 & $\mathbf{0}$ & $\mathbf{0}$ & 0 & 0 \\
\hline 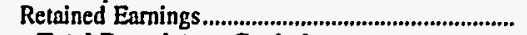 & 18,793 & 18,364 & 20,248 & 7,152 & 3,574 & 16,468 \\
\hline 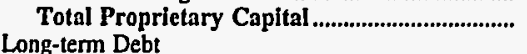 & 18,793 & 18,364 & 20,248 & 7,152 & 3,574 & 16,468 \\
\hline \multicolumn{7}{|l|}{ Long-term Debt } \\
\hline 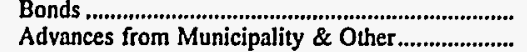 & $\begin{array}{l}5,270 \\
5,135\end{array}$ & $\begin{array}{r}0 \\
9,765\end{array}$ & $\begin{array}{r}0 \\
1,760\end{array}$ & $\begin{array}{r}0 \\
347\end{array}$ & $\begin{array}{r}75 \\
386\end{array}$ & $\begin{array}{r}0 \\
11,110\end{array}$ \\
\hline Unamort Prem on Long-term Debt................................ & 11,443 & 797 & 3,398 & 684 & 500 & 2,096 \\
\hline (less) Unamort Discount on Long-term Debt & 13 & 102 & & 0 & 0 & 53 \\
\hline 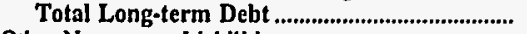 & 21,835 & 10,460 & 5,158 & 1,031 & 961 & 13,153 \\
\hline \multicolumn{7}{|l|}{ Other Noncurrent Liabilities } \\
\hline 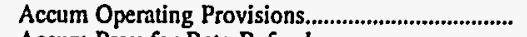 & 0 & 0 & 0 & 0 & 0 & $\mathbf{0}$ \\
\hline Accum Prov for Rate Refunds.... & 0 & 0 & 0 & 0 & 0 & 0 \\
\hline Total Other Noncurrent Liabilities ........................ & $\mathbf{0}$ & 0 & 0 & $\mathbf{0}$ & $\mathbf{0}$ & 0 \\
\hline \multicolumn{7}{|l|}{ Current and Accrued Liabilities } \\
\hline 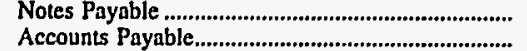 & $\begin{array}{r}100 \\
2,845\end{array}$ & $\begin{array}{r}208 \\
2,588\end{array}$ & $\begin{array}{r}2 \\
1,875\end{array}$ & $\begin{array}{r}1,886 \\
0\end{array}$ & $\begin{aligned} 0 \\
1,011\end{aligned}$ & $\begin{array}{r}132 \\
1,745\end{array}$ \\
\hline 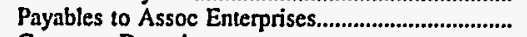 & 1,395 & 461 & 925 & 185 & 0 & 639 \\
\hline 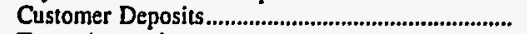 & 0 & 0 & 0 & 0 & 70 & 0 \\
\hline 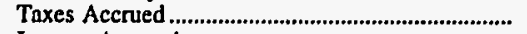 & 254 & 0 & 0 & 0 & 0 & 27 \\
\hline 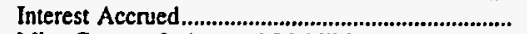 & 143 & 188 & 831 & 113 & 5 & 930 \\
\hline Misc Current \& Accrued Liabilities ............................... & 0 & 0 & 0 & & 126 & 0 \\
\hline $\begin{array}{l}\text { Total Current \& Accrued Liabilities .................. } \\
\text { Deferred Credits }\end{array}$ & 4,737 & 3,446 & 3,632 & 2,183 & 1,212 & $\mathbf{3 , 4 7 3}$ \\
\hline 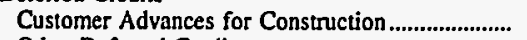 & 0 & 252 & 0 & 1 & 0 & 9 \\
\hline 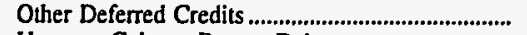 & 0 & 0 & 0 & 60 & 231 & 0 \\
\hline Unamort Gain on Reacqr Debt ........................................ & 0 & 0 & 0 & 0 & 0 & 0 \\
\hline Total Deferred Credits........................................ & & 252 & 0 & 61 & 231 & 9 \\
\hline Liabilities: & 45,364 & 32,522 & 29,037 & 10,427 & 5,978 & $\mathbf{3 3 , 1 0 3}$ \\
\hline
\end{tabular}

Note: Totals may not equal sum of components because of independent rounding.

Source: Energy Information Administration, Form EIA-412, "Annual Report of Public Electric Utilities." 
Table 22. Balance Sheet by Major U.S. Publicly Owned Electric Utility Within State at End of Period, 1996

(Thousand Dollars)

\begin{tabular}{|c|c|c|c|c|c|c|}
\hline Item & $\begin{array}{l}\text { Tennessee } \\
\text { Gallatin } \\
\text { City of } \\
\text { June } 30\end{array}$ & $\begin{array}{c}\text { Tennessee } \\
\text { Greeneville } \\
\text { City of } \\
\text { June } 30\end{array}$ & $\begin{array}{c}\text { Tennessee } \\
\text { Harriman } \\
\text { City of } \\
\text { June } 30\end{array}$ & $\begin{array}{c}\text { Tennessee } \\
\begin{array}{c}\text { Humboldt } \\
\text { City of }\end{array} \\
\text { June } 30\end{array}$ & $\begin{array}{l}\text { Tennessee } \\
\text { Jackson } \\
\text { City of } \\
\text { June } 30\end{array}$ & $\begin{array}{l}\text { Tennessee } \\
\text { Johnson } \\
\text { City City of } \\
\text { June } 30\end{array}$ \\
\hline \multicolumn{7}{|l|}{ Electric Utility Plant } \\
\hline Electric Utility Plant \& Adjust ............................... & 12,644 & 48,376 & 21,647 & 8,234 & 63,595 & 74,650 \\
\hline 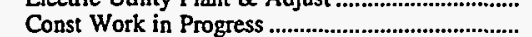 & 75 & $\begin{array}{r}40,300 \\
330\end{array}$ & 127 & 39 & 3,524 & 3,960 \\
\hline 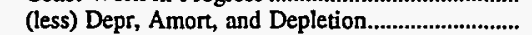 & 6,088 & 18,405 & 9,283 & 2,963 & 25,292 & 28,493 \\
\hline 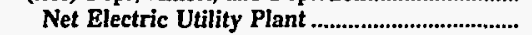 & 6,631 & 30,301 & $\mathbf{1 2 , 4 9 1}$ & 5,311 & 41,827 & 50,118 \\
\hline 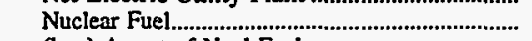 & & 0 & 0 & 0 & 0 & \\
\hline (less) Amort of Nucl Fuel ........................................ & 0 & 0 & 0 & 0 & 0 & 0 \\
\hline Net Elec Plant Incl Nucl Fuel ................................ & 6,631 & 30,301 & 12,491 & 5,311 & 41,827 & 50,118 \\
\hline \multicolumn{7}{|l|}{ Other Property \& Investments } \\
\hline Nonutility Property.................. & 0 & 0 & 0 & 0 & 0 & 0 \\
\hline (less) Accum Provisions for Depr \& Amort .......... & 0 & 0 & 0 & 0 & 0 & 0 \\
\hline 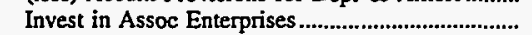 & 0 & 0 & 0 & 0 & 0 & 0 \\
\hline 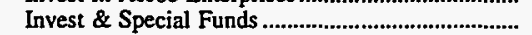 & 2,588 & 7,335 & 195 & 402 & 6,808 & 4,611 \\
\hline 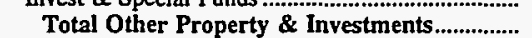 & 2,588 & 7,335 & 195 & 402 & 6,808 & 4,611 \\
\hline \multicolumn{7}{|l|}{ Current and Accrued Assets } \\
\hline Cash, Working Funds \& Investments.................... & 3,895 & 4,285 & 2,867 & 1,276 & 3,654 & 1,164 \\
\hline 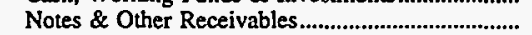 & 1,797 & 3,263 & 1,260 & 1,458 & 6,183 & 4,935 \\
\hline Customer Accts Receivable................................... & 0 & 0 & 0 & 0 & 0 & 0 \\
\hline (less) Accum Prov for Uncollected Accts ................... & 0 & 0 & 0 & 0 & $\mathbf{0}$ & 0 \\
\hline 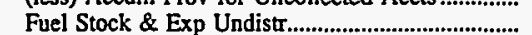 & 0 & 0 & 0 & 0 & 0 & 0 \\
\hline Materials \& Supplies ........................................... & 280 & 1,096 & 193 & 230 & 671 & 946 \\
\hline 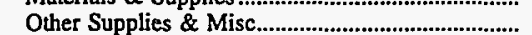 & 0 & 0 & 0 & 0 & 0 & 0 \\
\hline Prepayments & 0 & 0 & 4 & 25 & 0 & 0 \\
\hline 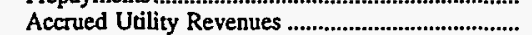 & 110 & 88 & 0 & 0 & 0 & 0 \\
\hline Miscellaneous Current \& Accrued Assets................... & 24 & 274 & 959 & 23 & 78 & 429 \\
\hline 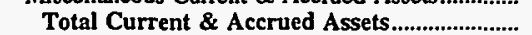 & 6,105 & 9,006 & 5,284 & 3,012 & 10,586 & $\mathbf{7 , 4 7 5}$ \\
\hline \multicolumn{7}{|l|}{ Deferred Debits } \\
\hline Unamorized Debt Expenses...... & 0 & 0 & 2 & 0 & 43 & 0 \\
\hline 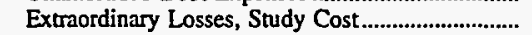 & 0 & 0 & 0 & 0 & 0 & 0 \\
\hline Misc Debt, R \& D Exp, Unamrt Losses ................... & 295 & 6,332 & 1,059 & 509 & 4,658 & 7,804 \\
\hline 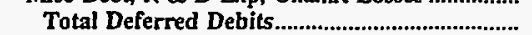 & 295 & 6,332 & 1,060 & 509 & 4,702 & 7,804 \\
\hline Total Assets \& Other Debits .................................. & 15,620 & 52,975 & 19,030 & 9,234 & 63,923 & 70,008 \\
\hline \multicolumn{7}{|l|}{ Proprietary Capital } \\
\hline Investment of Municipality .................................... & 0 & 0 & 0 & 0 & 0 & 0 \\
\hline 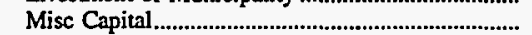 & 0 & 0 & 0 & 0 & 0 & 0 \\
\hline 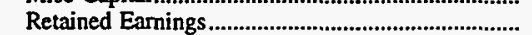 & 12,788 & 45,630 & 14,686 & 7,167 & 37,021 & 51,516 \\
\hline 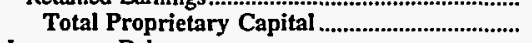 & 12,788 & 45,630 & 14,686 & 7,167 & 37,021 & 51,516 \\
\hline \multicolumn{7}{|l|}{ Long-term Debt } \\
\hline Bonds ..................... & 0 & 0 & 266 & 160 & 15,894 & 1,250 \\
\hline 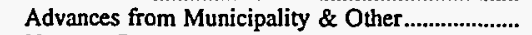 & 0 & 0 & 145 & 390 & 686 & 7,794 \\
\hline Unamort Prem on Long-term Debt.............................. & 308 & 6,071 & 303 & 0 & -72 & 0 \\
\hline (less) Unamort Discount on Long-term Debt & 0 & 0 & 0 & 0 & 0 & 0 \\
\hline \multicolumn{6}{|l|}{ Other Noncurrent Liabilities } & 9,044 \\
\hline 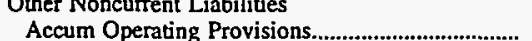 & 0 & 0 & 0 & 0 & 0 & 0 \\
\hline 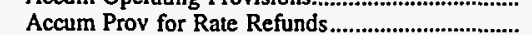 & 0 & 0 & 0 & 0 & 0 & 0 \\
\hline Total Other Noncurrent Liabilities................. & 0 & 0 & 0 & $\mathbf{0}$ & 0 & $\mathbf{0}$ \\
\hline \multicolumn{7}{|l|}{ Current and Accrued Liabilities } \\
\hline Notes Payable ............................ & 1,843 & 304 & 4 & 0 & 387 & 0 \\
\hline Accounts Payable................. & 0 & 0 & 2,095 & 1,077 & 6,548 & 6,311 \\
\hline Payables to Assoc Enterprises..................................... & 464 & 182 & 0 & 0 & 0 & 0 \\
\hline 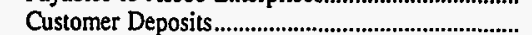 & 0 & 0 & 418 & 96 & 0 & 791 \\
\hline Taxes Accrued & 0 & 0 & 0 & -1 & 0 & 0 \\
\hline 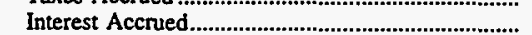 & 178 & 819 & 0 & 0 & 0 & 15 \\
\hline 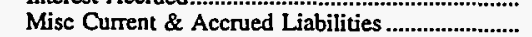 & 0 & & 177 & 148 & 699 & 2,325 \\
\hline 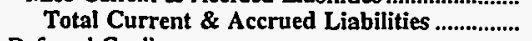 & 2,485 & 1,304 & 2,694 & 1,322 & $\mathbf{7 , 6 3 4}$ & $\mathbf{9 , 4 4 2}$ \\
\hline \multicolumn{7}{|l|}{ Deferred Credits } \\
\hline 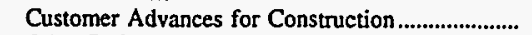 & 39 & -30 & 0 & 0 & 0 & 6 \\
\hline 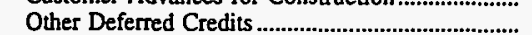 & 0 & 0 & 937 & 196 & 2759 & 0 \\
\hline Unamort Gain on Reacqr Debt ...................................... & 0 & 0 & 0 & 0 & 0 & 0 \\
\hline Total Deferred Credits............................................... & 39 & -30 & 937 & 196 & 2,759 & \\
\hline Total Liabilities and Other Credits......................... & 15,620 & 52,975 & 19,030 & 9,234 & 63,923 & 70,008 \\
\hline
\end{tabular}

Note: Totals may not equal sum of components because of independent rounding.

Source: Energy Information Administration, Form EIA-412, "Annual Report of Public Electric Utilities." 
Table 22. Balance Sheet by Major U.S. Publicly Owned Electric Utility Within State at End of Period, 1996

(Thousand Dollars)

\begin{tabular}{|c|c|c|c|c|c|c|}
\hline Item & $\begin{array}{c}\text { Tennessee } \\
\text { Knoxville } \\
\text { Utilities } \\
\text { Board } \\
\text { June } 30\end{array}$ & $\begin{array}{c}\text { Tennessee } \\
\begin{array}{c}\text { Lawrenceburg } \\
\text { City of }\end{array} \\
\text { June } 30 \\
\end{array}$ & $\begin{array}{l}\text { Tennessee } \\
\text { LaFollette } \\
\text { City of } \\
\text { June } 30\end{array}$ & $\begin{array}{l}\text { Tennessee } \\
\text { Lebanon } \\
\text { City of } \\
\text { June } 30\end{array}$ & $\begin{array}{c}\text { Tennessee } \\
\text { Lenoir } \\
\text { City City of } \\
\text { June } 30\end{array}$ & $\begin{array}{l}\text { Tennessee } \\
\text { Lewisburg } \\
\text { City of } \\
\text { June } 30\end{array}$ \\
\hline \multicolumn{7}{|l|}{ Electric Utility Plant } \\
\hline Electric Utility Plant \& Adjust ..................................... & 316,032 & 26,649 & 31,998 & 14,492 & 72,556 & 11,450 \\
\hline Const Work in Progress & 8,157 & 953 & 3,281 & 428 & 776 & 122 \\
\hline (less) Depr, Amort, and Depletion............................ & 147,308 & 10,518 & 10,736 & 4,993 & 16,710 & 3,869 \\
\hline Net Electric Utility Plant & 176,881 & 17,085 & 24,544 & 9,927 & 56,621 & $\mathbf{7 , 7 0 3}$ \\
\hline 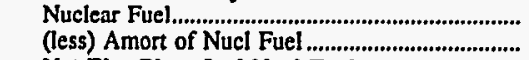 & & & & $\begin{array}{l}0 \\
0\end{array}$ & $\begin{array}{l}0 \\
0\end{array}$ & \\
\hline 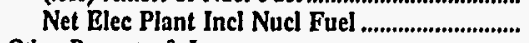 & 176,881 & 17,085 & 24,544 & 9,927 & 56,621 & 7,703 \\
\hline \multicolumn{7}{|l|}{ Other Property \& Investments } \\
\hline Nonutility Property & $\mathbf{0}$ & 441 & 0 & 0 & $\mathbf{0}$ & $\mathbf{0}$ \\
\hline (less) Accum Provisions for Depr \& Amort .......... & 0 & 0 & 0 & 0 & 0 & 0 \\
\hline 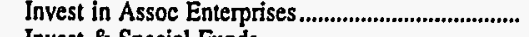 & 0 & 0 & 0 & 0 & 0 & 0 \\
\hline 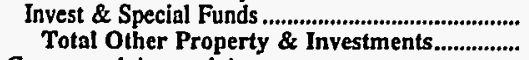 & $\begin{array}{l}14,146 \\
14,146\end{array}$ & $\begin{array}{l}15,465 \\
15,906\end{array}$ & $\begin{array}{l}1,337 \\
1,337\end{array}$ & $\begin{array}{l}2,466 \\
2,466\end{array}$ & $\begin{array}{l}8,586 \\
8,586\end{array}$ & $\begin{array}{l}158 \\
158\end{array}$ \\
\hline \multicolumn{7}{|l|}{ Current and Accrued Assets } \\
\hline Cash, Working Funds \& Investments........................ & 12,416 & 1,780 & 2,832 & 1,254 & $\begin{array}{r}90 \\
5078\end{array}$ & 2,957 \\
\hline 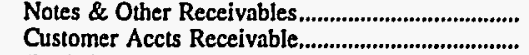 & $\begin{array}{r}22,848 \\
0\end{array}$ & $\begin{array}{r}1,496 \\
0\end{array}$ & $\begin{array}{r}1,923 \\
0\end{array}$ & $\begin{array}{r}1,497 \\
0\end{array}$ & $\begin{array}{r}5,078 \\
0\end{array}$ & $\begin{array}{r}711 \\
0\end{array}$ \\
\hline (less) Accum Prov for Uncollected Accts .............. & 0 & 0 & 0 & 0 & 0 & 0 \\
\hline Fuel Stock \& Exp Undistr................................................. & 0 & 0 & 0 & 0 & 0 & 0 \\
\hline Materials \& Supplies................................................. & 3,729 & 347 & 541 & 289 & 933 & 337 \\
\hline 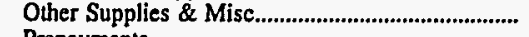 & 0 & 0 & $\mathbf{0}$ & 0 & 0 & 0 \\
\hline 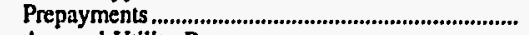 & 444 & 28 & $\mathbf{0}$ & 5 & 92 & -2 \\
\hline 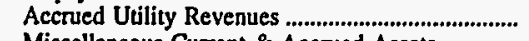 & 0 & 0 & 0 & 0 & 0 & 0 \\
\hline Miscellaneous Current \& Accrued Assets.............. & 136 & 970 & 1,234 & 14 & 1,897 & 11 \\
\hline Total Current \& Accrued Assets.......................... & 39,573 & 4,622 & 6,529 & 3,059 & 8,091 & 4,015 \\
\hline \multicolumn{7}{|l|}{ Deferred Debits } \\
\hline Extraordinary Losses, Study Cost.................................. & & 83 & 0 & 0 & 0 & 0 \\
\hline Misc Debt, R \& D Exp, Unamrt Losses ................. & 11,945 & 2,055 & 1,175 & 333 & $2,33 i$ & 324 \\
\hline Total Deferred Debits................................................... & 12,111 & 2,504 & 1,377 & 368 & $\mathbf{2 , 7 3 8}$ & 324 \\
\hline 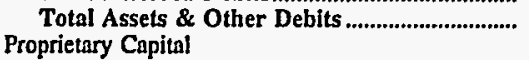 & 242,712 & 40,116 & 33,788 & 15,819 & 76,036 & 12,201 \\
\hline 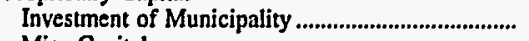 & 0 & 0 & 0 & 0 & 0 & \\
\hline 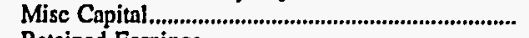 & 0 & 0 & 0 & 0 & 0 & 0 \\
\hline 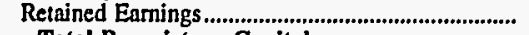 & 132,612 & 17,218 & 16,889 & 10,044 & 35,497 & 9,616 \\
\hline Total Proprietary Capital .......................................... & 132,612 & 17,218 & 16,889 & 10,044 & 35,497 & 9,616 \\
\hline \multicolumn{7}{|l|}{ 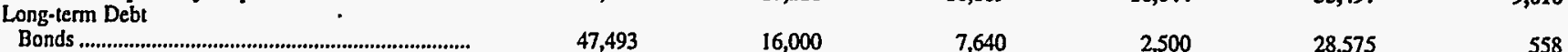 } \\
\hline Advances from Municipality \& Other .......... & 10,123 & 2,231 & 4,049 & 137 & $\begin{array}{r}28,313 \\
2,231\end{array}$ & 172 \\
\hline 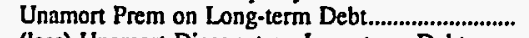 & -504 & -16 & -23 & -36 & -103 & 0 \\
\hline (less) Unamort Discount on Long-term Debt & & 0 & 0 & 0 & 0 & \\
\hline \multicolumn{5}{|l|}{ Other Noncurrent Ljabilities } & 30,704 & 730 \\
\hline 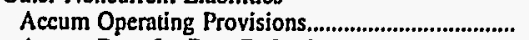 & 0 & 0 & 0 & 0 & $\mathbf{0}$ & 0 \\
\hline 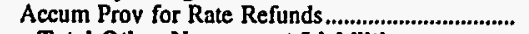 & 0 & 0 & 0 & 0 & 0 & 0 \\
\hline Total Other Noncurrent Liabilities ..................... & 0 & 0 & $\mathbf{0}$ & 0 & 0 & 0 \\
\hline \multicolumn{7}{|l|}{ Current and Accrued Liabilities } \\
\hline Notes Payable ................................................................... & 1,144 & 77 & 68 & 21 & 86 & 0 \\
\hline 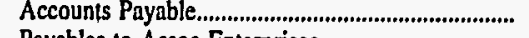 & 19,625 & 3,988 & 3,850 & 2,516 & 5,654 & 1,190 \\
\hline Payables to Ássoc Enterprises...................................... & 0 & 0 & 0 & 0 & 132 & 0 \\
\hline 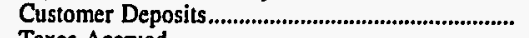 & 7,341 & 307 & 691 & 557 & 2,127 & 235 \\
\hline 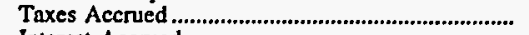 & 0 & 0 & 119 & 49 & 0 & $\mathbf{0}$ \\
\hline 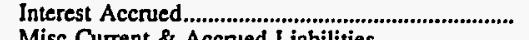 & 0 & 0 & 24 & 0 & 0 & 0 \\
\hline Misc Current \& Accrued Liabilities ..................... & 8,978 & 261 & 481 & 31 & 1,140 & 146 \\
\hline $\begin{array}{l}\text { Total Current \& Accrued Liabilities ................ } \\
\text { Deferred Credits }\end{array}$ & 37,087 & 4,633 & 5,233 & $\mathbf{3 , 1 7 4}$ & 9,139 & 1,571 \\
\hline 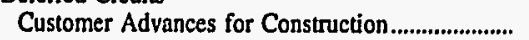 & 2,184 & 41 & 0 & 0 & 682 & \\
\hline 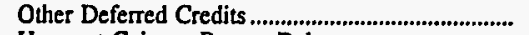 & 13,717 & 9 & 0 & 1 & 14 & 284 \\
\hline 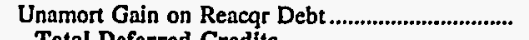 & & 0 & 0 & 0 & 0 & 0 \\
\hline 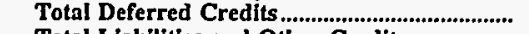 & 15,901 & 50 & & & 696 & 284 \\
\hline Total Liabilities and Other Credits................... & 242,712 & 40,116 & 33,788 & 15,819 & 76,036 & 12,201 \\
\hline
\end{tabular}

Note: Totals may not equal sum of components because of independent rounding.

Source: Energy Information Administration, Form EIA-412, "Annual Report of Public Electric Utilities." 
Table 22. Balance Sheet by Major U.S. Publicly Owned Electric Utility Within State at End of Period, 1996

(Thousand Dollars)

\begin{tabular}{|c|c|c|c|c|c|c|}
\hline Item & $\begin{array}{l}\text { Tennessee } \\
\text { Lexington } \\
\text { City of } \\
\text { June } 30\end{array}$ & $\begin{array}{l}\text { Tennessee } \\
\text { Loudon } \\
\text { Utilities } \\
\text { Board } \\
\text { June } 30\end{array}$ & $\begin{array}{c}\text { Tennessee } \\
\begin{array}{c}\text { Maryville } \\
\text { Utilities }\end{array} \\
\text { June } 30\end{array}$ & $\begin{array}{c}\text { Tennessee } \\
\text { McMinnville } \\
\text { Electric } \\
\text { System } \\
\text { June } 30\end{array}$ & $\begin{array}{l}\text { Tennessee } \\
\text { Memphis } \\
\text { City of } \\
\text { June } 30\end{array}$ & $\begin{array}{l}\text { Tennessee } \\
\text { Milan } \\
\text { City of } \\
\text { June } 30\end{array}$ \\
\hline \multicolumn{7}{|l|}{ Electric Utility Plant } \\
\hline Electric Utility Plant \& Adjust ..................................... & 24,904 & 20,787 & 28,373 & 13,690 & 798,369 & 11,894 \\
\hline Const Work in Progress & 1,988 & 2,839 & 380 & & 18,950 & 561 \\
\hline 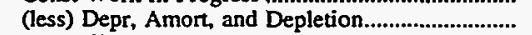 & 9,157 & 4,796 & 9,357 & 5,813 & 274,114 & 5,548 \\
\hline Net Electric Utility Plant ................................... & 17,735 & 18,829 & 19,396 & 7,931 & 543,205 & 6,907 \\
\hline 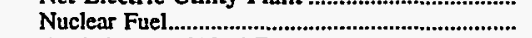 & & & & 0 & & \\
\hline (less) Amort of Nucl Fuel .......................................... & & 0 & 0 & 0 & 0 & 0 \\
\hline Net Elec Plant Incl Nucl Fuel ................................ & 17,735 & 18,829 & 19,396 & 7,931 & 543,205 & 6,907 \\
\hline \multicolumn{7}{|l|}{ Other Property \& Investments } \\
\hline Nonutility Property ........................... & 0 & 0 & 85 & 0 & 0 & 0 \\
\hline (less) Accum Provisions for Depr \& Amort ........... & 0 & 0 & 0 & 0 & 0 & 0 \\
\hline 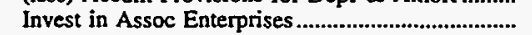 & & 0 & 0 & 0 & 0 & 0 \\
\hline 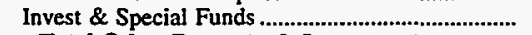 & 1,529 & 1,287 & 952 & 400 & 62,493 & 0 \\
\hline Total Other Property \& Investments.................. & 1,529 & 1,287 & 1,037 & 400 & 62,493 & 0 \\
\hline \multicolumn{7}{|l|}{ Current and Accrued Assets } \\
\hline 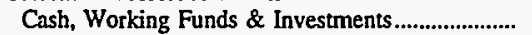 & 678 & 257 & 2,603 & 731 & 34,461 & 62 \\
\hline 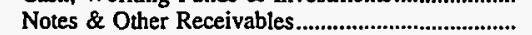 & 1,676 & 2,116 & 1,808 & 926 & 66,307 & 907 \\
\hline Customer Accts Receivable.............................................. & 0 & 0 & 0 & 0 & 0 & 0 \\
\hline (less) Accum Prov for Uncollected Accts.................. & 0 & 0 & 0 & 0 & 0 & 0 \\
\hline 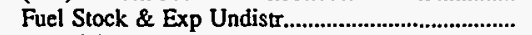 & 0 & 0 & 0 & 0 & 0 & 0 \\
\hline 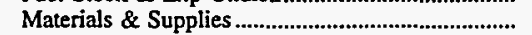 & 490 & 324 & 611 & 157 & 10,709 & 190 \\
\hline Other Supplies \& Misc...................................................... & 0 & 0 & 0 & 0 & 0 & 0 \\
\hline 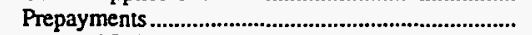 & 50 & -8 & 19 & 27 & $\mathbf{0}$ & 15 \\
\hline Accrued Utility Revenues .................................................... & $\mathbf{0}$ & 0 & 0 & 0 & 0 & 0 \\
\hline Miscellaneous Current \& Accrued Assets............... & 87 & 17 & 98 & 28 & 1,158 & 26 \\
\hline 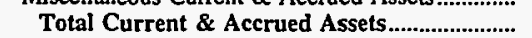 & 2,981 & 2,705 & 5,139 & 1,868 & 112,635 & 1,200 \\
\hline \multicolumn{7}{|l|}{ Deferred Debits } \\
\hline Unamortized Debt Expenses..... & 0 & 68 & 36 & 0 & 2,467 & 0 \\
\hline 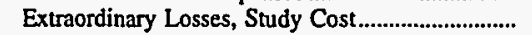 & 0 & 0 & 0 & 0 & 0 & 0 \\
\hline Misc Debt, R \& D Exp, Unamrt Losses ...................... & 765 & 1,101 & 721 & 635 & 18,769 & 733 \\
\hline 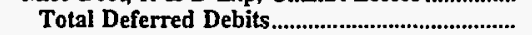 & 765 & 1,169 & 757 & 635 & 21,236 & 733 \\
\hline Total Assets \& Other Debits .................................. & 23,010 & 23,990 & 26,329 & 10,834 & 739,569 & 8,840 \\
\hline \multicolumn{7}{|l|}{ Proprietary Capital } \\
\hline Investment of Municipality .............................................. & 0 & $\mathbf{0}$ & 0 & 0 & 0 & o \\
\hline 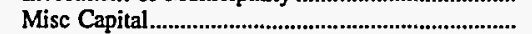 & 0 & 0 & 0 & 0 & 0 & 0 \\
\hline 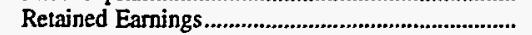 & 18,985 & 10,163 & 16,605 & 8,919 & 419,379 & 6,719 \\
\hline Total Proprietary Capital............................................... & 18,985 & 10,163 & 16,605 & 8,919 & 419,379 & 6,719 \\
\hline \multicolumn{7}{|l|}{ Long-term Debt } \\
\hline Bonds & 0 & 10,360 & 5,305 & 0 & 215,965 & 0 \\
\hline Advances from Municipality \& Other........................... & 803 & & 576 & 659 & 2,383 & 721 \\
\hline 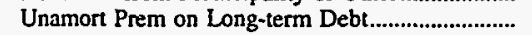 & 0 & -81 & -49 & 0 & 0 & 0 \\
\hline (less) Unamort Discount on Long-term Debt & 0 & & 0 & 0 & 0 & 0 \\
\hline 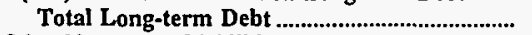 & 803 & 10,279 & 5,833 & 659 & 218,348 & 721 \\
\hline \multicolumn{7}{|l|}{ Other Noncurrent Liabilities } \\
\hline Accum Operating Provisions............................................ & 0 & 0 & 0 & 0 & 0 & 0 \\
\hline Accum Prov for Rate Refunds..................................... & 0 & 0 & 0 & 0 & 0 & 0 \\
\hline Total Other Noncurrent Liabilities ....................... & 0 & 0 & 0 & $\mathbf{0}$ & 0 & 0 \\
\hline \multicolumn{7}{|l|}{ Current and Accrued Liabilities } \\
\hline 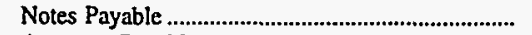 & 0 & 16 & 60 & 0 & 0 & 0 \\
\hline Accounts Payable & 1,903 & 3,229 & 3,135 & 104 & 70,672 & 1,113 \\
\hline 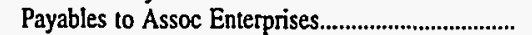 & 0 & 0 & 0 & 0 & 0 & 0 \\
\hline 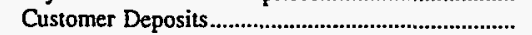 & 145 & 0 & 315 & 474 & 0 & 179 \\
\hline 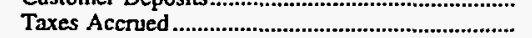 & 0 & 0 & 0 & 0 & 2,374 & 0 \\
\hline Interest Accrued & 0 & 0 & 0 & 0 & 0 & 0 \\
\hline Misc Current \& Accrued Liabilities .............................. & 1,173 & 276 & 381 & 217 & 5,190 & 100 \\
\hline Total Current \& Accrued Liabilities ........................ & 3,221 & 3,521 & 3,891 & 795 & 78,236 & 1,393 \\
\hline \multicolumn{7}{|l|}{ Deferred Credits } \\
\hline Customer Advances for Construction.......................... & 0 & 27 & 0 & 0 & 1,763 & 8 \\
\hline 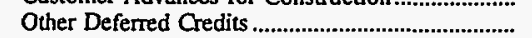 & 0 & 0 & 0 & 461 & 21,844 & 0 \\
\hline 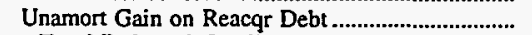 & 0 & 0 & 0 & 0 & 0 & 0 \\
\hline Total Deferred Credits ............................................ & 0 & 27 & 0 & 461 & 23,607 & \\
\hline Total Liabilities and Other Credits....................... & 23,010 & 23,990 & 26,329 & 10,834 & 739,569 & $\mathbf{8 , 8 4 0}$ \\
\hline
\end{tabular}

Note: Totals may not equal sum of components because of independent rounding.

Source: Energy Information Administration, Form EIA-412, "Annual Report of Public Electric Utilities." 
Table 22. Balance Sheet by Major U.S. Publicly Owned Electric Utility Within State at End of Period, 1996

(Thousand Dollars)

\begin{tabular}{|c|c|c|c|c|c|c|}
\hline Item & $\begin{array}{l}\text { Tennessee } \\
\begin{array}{c}\text { Morristown } \\
\text { City of }\end{array} \\
\text { June } 30\end{array}$ & $\begin{array}{c}\text { Tennessee } \\
\begin{array}{c}\text { Murfreesboro } \\
\text { City of }\end{array} \\
\text { June } 30\end{array}$ & $\begin{array}{c}\text { Tennessee } \\
\text { Nashville } \\
\text { Electric } \\
\text { Service } \\
\text { June } 30\end{array}$ & $\begin{array}{l}\text { Tennessee } \\
\begin{array}{l}\text { Newport } \\
\text { City of }\end{array} \\
\text { June } 30\end{array}$ & $\begin{array}{l}\text { Tennessee } \\
\text { Oak Ridge } \\
\text { City of } \\
\text { June } 30\end{array}$ & $\begin{array}{c}\text { Tennessee } \\
\text { Paris } \\
\text { City of } \\
\text { June } 30\end{array}$ \\
\hline \multicolumn{7}{|l|}{ Electric Utility Plant } \\
\hline 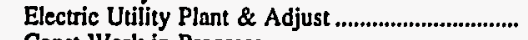 & 32,172 & 44,388 & 600,415 & 35,284 & 28,608 & 29,547 \\
\hline 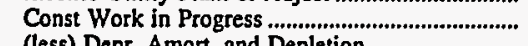 & 1,521 & 883 & 24,972 & & 19,432 & 350 \\
\hline (less) Depr, Amort, and Depletion............................ & 11,413 & 12,730 & 227,272 & 13,128 & 11,266 & 13,206 \\
\hline Net Electric Utility Plant ........................................... & $\mathbf{2 2 , 2 8 1}$ & 32,541 & 398,114 & 22,184 & 36,775 & 16,691 \\
\hline & $\begin{array}{l}0 \\
0\end{array}$ & $\begin{array}{l}0 \\
0\end{array}$ & $\begin{array}{l}0 \\
0\end{array}$ & $\begin{array}{l}0 \\
0\end{array}$ & $\begin{array}{l}\mathbf{0} \\
\mathbf{0}\end{array}$ & $\begin{array}{l}0 \\
0\end{array}$ \\
\hline Net Elec Plant Incl Nucl Fuel ................................. & 22,281 & 32,541 & 398,114 & 22,184 & 36,775 & 16,691 \\
\hline \multicolumn{7}{|l|}{ Other Property \& Investments } \\
\hline 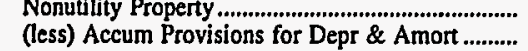 & $\begin{array}{l}\mathbf{0} \\
\mathbf{0}\end{array}$ & $\begin{array}{l}0 \\
0\end{array}$ & $\begin{array}{l}0 \\
0\end{array}$ & 0 & 0 & 0 \\
\hline 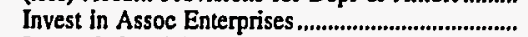 & $\begin{array}{l}0 \\
0\end{array}$ & 0 & 0 & $\begin{array}{l}0 \\
0\end{array}$ & $\begin{array}{l}0 \\
0\end{array}$ & $\begin{array}{l}0 \\
0\end{array}$ \\
\hline Invest \& Special Funds .......................................................... & 14 & 4,716 & 89,187 & 2,842 & 523 & $\begin{array}{r}0 \\
5,648\end{array}$ \\
\hline $\begin{array}{l}\text { Total Other Property \& Investments................ } \\
\text { Current and Accrued Assets }\end{array}$ & 14 & 4,716 & 89,187 & 2,842 & 523 & 5,648 \\
\hline Cash, Working Funds \& Investments............................. & 4,906 & 3,251 & 33,587 & 2,089 & 838 & 839 \\
\hline Notes \& Other Receivables....................................... & 3,067 & 2,451 & 38,902 & 1,094 & 3,003 & 1,088 \\
\hline Customer Accts Receivable...................................... & 0 & 0 & $\mathbf{0}$ & 0 & 0 & 0 \\
\hline (less) Accum Prov for Uncollected Accts................ & 0 & 0 & $\mathbf{0}$ & 0 & 0 & 0 \\
\hline 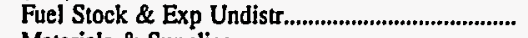 & 0 & 0 & 0 & 0 & 0 & 0 \\
\hline 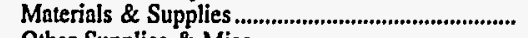 & 588 & 629 & 8,455 & 397 & 410 & 316 \\
\hline 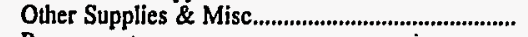 & 0 & 0 & 0 & 0 & 0 & 0 \\
\hline Prepayments ................................................................ & 236 & 18 & 333 & 14 & 0 & 4 \\
\hline 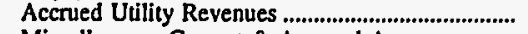 & 0 & 0 & 0 & $\mathbf{0}$ & $\cdot 0$ & 0 \\
\hline Miscellaneous Current \& Accrued Assets................ & 1,188 & 46 & 27,947 & 1,348 & 855 & 81 \\
\hline $\begin{array}{l}\text { Total Current \& Acerued Assets........................... } \\
\text { Deferred Debits }\end{array}$ & & 109,226 & 4,942 & 5,106 & 2,327 \\
\hline 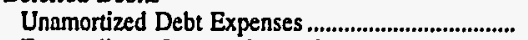 & 0 & 47 & $1,987^{\circ}$ & 144 & 40 & 102 \\
\hline 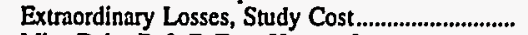 & 0 & & 0 & 0 & 0 & 0 \\
\hline Misc Debt, $\mathrm{R}$ \& D Exp, Unamrt Losses ................. & 1,826 & 1,798 & 22,999 & 1,642 & 3,734 & 2,021 \\
\hline 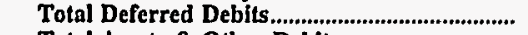 & 1,826 & 1,845 & 24,987 & 1,786 & 3,775 & 2,123 \\
\hline \multirow{2}{*}{\multicolumn{7}{|c|}{ Proprietary Capital }} \\
\hline & & & & & & 0 \\
\hline 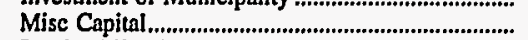 & 0 & 0 & $\begin{array}{l}0 \\
0\end{array}$ & $\begin{array}{l}0 \\
0\end{array}$ & $\begin{array}{l}0 \\
0\end{array}$ & $\begin{array}{l}0 \\
0\end{array}$ \\
\hline 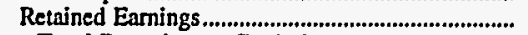 & 24,981 & 34,155 & 271,318 & 20,027 & 15,149 & 16,056 \\
\hline \multirow{2}{*}{\multicolumn{5}{|c|}{ Long-term Debt }} & & 16,056 \\
\hline & & & & 6,705 & 5,730 & 6,170 \\
\hline Advances from Municipality \& Other........................ & 1,865 & 1,363 & 13,559 & 1,421 & 3,832 & 1,958 \\
\hline Unamort Prem on Long-term Debt............................ & 0 & -32 & $-2,871$ & -70 & 16,000 & 0 \\
\hline (less) Unamort Discount on Long-term Debt & & 0 & 0 & 0 & 66 & 0 \\
\hline \multicolumn{6}{|l|}{ Other Noncurrent Liabilities } & 8,128 \\
\hline 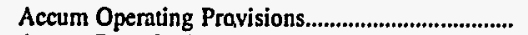 & 0 & 0 & 0 & 0 & 0 & $\mathbf{0}$ \\
\hline 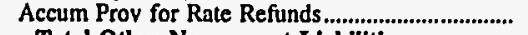 & $\mathbf{0}$ & 0 & 0 & 0 & 0 & 0 \\
\hline Total Other Noncurrent Llabilities..................... & $\mathbf{0}$ & 0 & o & 0 & 0 & 0 \\
\hline \multicolumn{7}{|l|}{ Current and Accrued Liabilities } \\
\hline 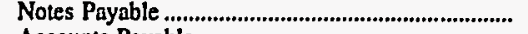 & 0 & 30 & 1,616 & 132 & 98 & 50 \\
\hline 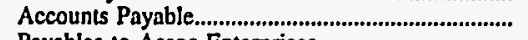 & 3,391 & 581 & 77,892 & 2,210 & 4,677 & 1,732 \\
\hline 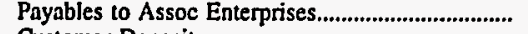 & & & 0 & 0 & 0 & 0 \\
\hline 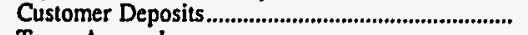 & 1,324 & 1,403 & 6,500 & 866 & 445 & 490 \\
\hline 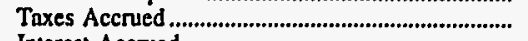 & 0 & 0 & 0 & 0 & 0 & 0 \\
\hline 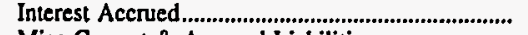 & 0 & 0 & $\mathbf{0}$ & 0 & 200 & 0 \\
\hline Misc Current \& Accrued Liabilities ............................ & 1,006 & 667 & 2,310 & 437 & 83 & 203 \\
\hline \multicolumn{5}{|l|}{ Deferred Credits } & 5,502 & 2,475 \\
\hline 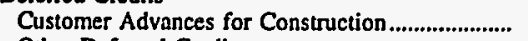 & 0 & $\mathbf{0}$ & 515 & 27 & 0 & 0 \\
\hline 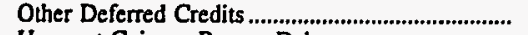 & 1,535 & 770 & 11,309 & 0 & 30 & 131 \\
\hline Unamort Gain on Reacgr Debt ...................................... & 0 & 0 & & $\mathbf{0}$ & 0 & 0 \\
\hline Total Deferred Credits........................................ & 1,535 & 770 & 11,824 & 27 & & 131 \\
\hline 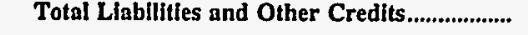 & 34,105 & 45,497 & 621,513 & 31,754 & 46,178 & 26,790 \\
\hline
\end{tabular}

Note: Totals may not equal sum of components because of independent rounding

Source: Energy Information Administration, Form EIA-412, "Annual Report of Public Electric Utilities." 
Table 22. Balance Sheet by Major U.S. Publicly Owned Electric Utility Within State at End of Period, 1996

(Thousand Dollars)

\begin{tabular}{|c|c|c|c|c|c|c|}
\hline Item & $\begin{array}{l}\text { Tennessee } \\
\text { Pulaski } \\
\text { City of } \\
\text { June } 30\end{array}$ & $\begin{array}{l}\text { Tennessee } \\
\text { Ripley } \\
\text { City of } \\
\text { June } 30\end{array}$ & $\begin{array}{c}\text { Tennessee } \\
\text { Sevier } \\
\text { County } \\
\text { Electric } \\
\text { System } \\
\text { June } 30\end{array}$ & $\begin{array}{l}\text { Tennessee } \\
\text { Rockwood } \\
\text { City of } \\
\text { June } 30\end{array}$ & $\begin{array}{c}\text { Tennessee } \\
\text { Shelbyville } \\
\text { City of } \\
\text { June } 30\end{array}$ & $\begin{array}{l}\text { Tennessee } \\
\begin{array}{c}\text { Springfield } \\
\text { City of }\end{array} \\
\text { June } 30\end{array}$ \\
\hline \multicolumn{7}{|l|}{ Electric Utility Plant } \\
\hline 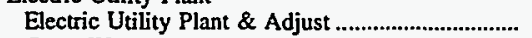 & 27,169 & 9,207 & 73,173 & 20,212 & 12,822 & 12,229 \\
\hline 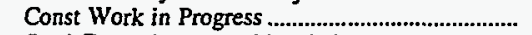 & 1,666 & 149 & 1,284 & 438 & 1,893 & 188 \\
\hline (less) Depr, Amort, and Depletion.................................. & 10,330 & 2,833 & 20,842 & 6,298 & 5,349 & 4,496 \\
\hline Net Electric Utility Plant ....................................... & 18,505 & 6,523 & 53,615 & 14,352 & 9,366 & 7,921 \\
\hline Nuclear Fuel......................................... & 0 & 0 & 0 & 0 & 0 & 0 \\
\hline (less) Amort of Nucl Fuel ........................................... & 0 & 0 & 0 & 0 & 0 & 0 \\
\hline Net Elec Plant Incl Nucl Fuel ............................. & 18,505 . & 6,523 & 53,615 & 14,352 & 9,366 & 7,921 \\
\hline \multicolumn{7}{|l|}{ Other Property \& Investments } \\
\hline Nonutility Property ................... & 0 & 0 & $\mathbf{0}$ & 0 & 0 & 0 \\
\hline (less) Accum Provisions for Depr \& Amort ........... & 0 & 0 & 0 & 0 & 0 & 0 \\
\hline 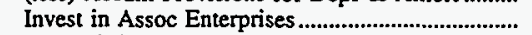 & 0 & 0 & 0 & 0 & 0 & 0 \\
\hline 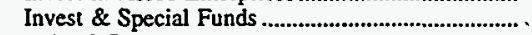 & 678 & 3,670 & 2,072 & 12 & 15 & 1,881 \\
\hline Total Other Property \& Investments................... & 678 & $\mathbf{3 , 6 7 0}$ & 2,072 & 12 & 15 & 1,881 \\
\hline \multicolumn{7}{|l|}{ Current and Accrued Assets } \\
\hline 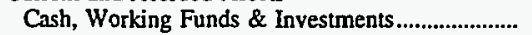 & 180 & 286 & 3,747 & 1,416 & 3,095 & 1,314 \\
\hline Notes \& Other Receivables............................................. & 1,560 & 1,242 & 3,236 & 735 & 2,059 & 893 \\
\hline Customer Accts Receivable............................................ & 0 & 0 & 0 & 0 & 0 & 0 \\
\hline (less) Accum Prov for Uncollected Accts .................. & 0 & 0 & 0 & 0 & 0 & 0 \\
\hline 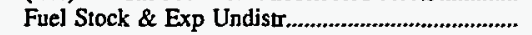 & 0 & 0 & 0 & 0 & 0 & 0 \\
\hline 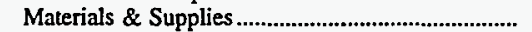 & 261 & 264 & 894 & 231 & 208 & 191 \\
\hline 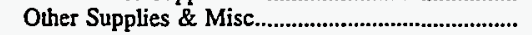 & 0 & 0 & 0 & 0 & 0 & 0 \\
\hline 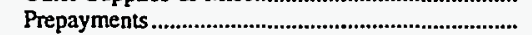 & 88 & 87 & 0 & 0 & 51 & 170 \\
\hline 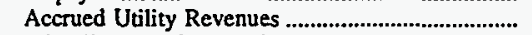 & 0 & 0 & 0 & 0 & 0 & 0 \\
\hline Miscellaneous Current \& Accrued Assets............... & 1,236 & 20 & 2,358 & 906 & 83 & 10 \\
\hline Total Current \& Accrued Assets......................... & 3,326 & 1,899 & 10,236 & $\mathbf{3 , 2 8 8}$ & 5,496 & 2,579 \\
\hline \multicolumn{7}{|l|}{ Deferred Debits } \\
\hline 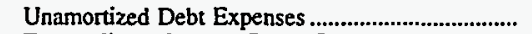 & 171 & 0 & 0 & 0 & 0 & 9 \\
\hline 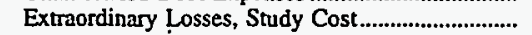 & 0 & 0 & 0 & 0 & 0 & 0 \\
\hline 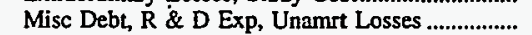 & 1,161 & 1,065 & 1,716 & 0 & 610 & 369 \\
\hline 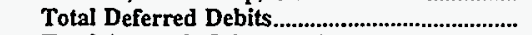 & 1,332 & 1,065 & 1,716 & $\mathbf{0}$ & 610 & 378 \\
\hline Total Assets \& Other Debits .................................. & 23,840 & 13,156 & 67,639 & 17,652 & 15,488 & 12,759 \\
\hline \multicolumn{7}{|l|}{ Proprietary Capital } \\
\hline Investment of Municipality & 0 & 0 & 0 & 0 & 0 & 0 \\
\hline 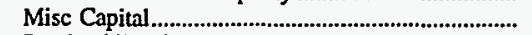 & 0 & 0 & 0 & 0 & 0 & 0 \\
\hline 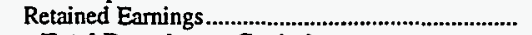 & 16,153 & 10,868 & 53,451 & 13,952 & 10,974 & 8,950 \\
\hline Total Proprietary Capital ........................................... & 16,153 & 10,868 & $\mathbf{5 3 , 4 5 1}$ & 13,952 & 10,974 & 8,950 \\
\hline \multicolumn{7}{|l|}{ Long-term Debt } \\
\hline Bonds ................... & 3,948 & 0 & 2,280 & 0 & 1,273 & 620 \\
\hline 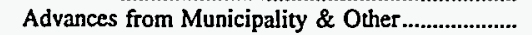 & 1,171 & 0 & 1,624 & 885 & 616 & 367 \\
\hline Unamort Prem on Long-term Debt................................. & 0 & 0 & 0 & 0 & 0 & 0 \\
\hline (less) Unamort Discount on Long-term Debt & 0 & 0 & 0 & 0 & 0 & 0 \\
\hline Total Long-term Debt .......................................... & 5,119 & o & 3,904 & 885 & 1,889 & 987 \\
\hline \multicolumn{7}{|l|}{ Other Noncurrent Liabilities } \\
\hline 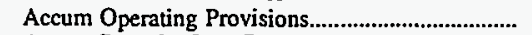 & 0 & 0 & 0 & 0 & 0 & 0 \\
\hline 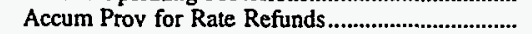 & 0 & 0 & 0 & 0 & 0 & 0 \\
\hline Total Other Noncurrent Liabilities ....................... & $\mathbf{0}$ & 0 & 0 & 0 & 0 & 0 \\
\hline \multicolumn{7}{|l|}{ Current and Accrued Liabilities } \\
\hline 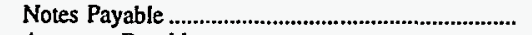 & 9 & 0 & 42 & 0 & 0 & 3 \\
\hline 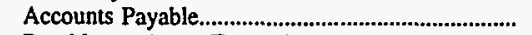 & 2,096 & 1,233 & 4,431 & 2,181 & 1,867 & 2,090 \\
\hline 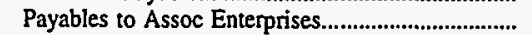 & 0 & 0 & 0 & 0 & 0 & 0 \\
\hline 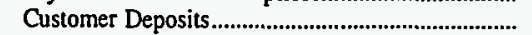 & 226 & 470 & 4,390 & 431 & 509 & 76 \\
\hline 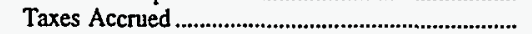 & 47 & 0 & 0 & 0 & 0 & 0 \\
\hline 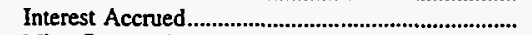 & 0 & 0 & 0 & 12 & 0 & 0 \\
\hline Misc Current \& Accrued Liabilities ............................... & 185 & 167 & 1,375 & 182 & 75 & 56 \\
\hline Total Current \& Accrued Liabilities ................. & 2,563 & 1,869 & 10,238 & 2,806 & 2,451 & 2,225 \\
\hline \multicolumn{7}{|l|}{ Deferred Credits } \\
\hline Customer Advances for Construction........................... & 0 & 0 & 0 & 0 & 0 & 0 \\
\hline Other Deferred Credits & 5 & 419 & 46 & 8 & 174 & 598 \\
\hline 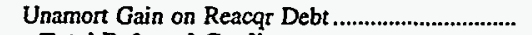 & 0 & 0 & 0 & 0 & 0 & 0 \\
\hline 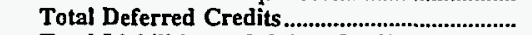 & $\mathbf{5}$ & 419 & 46 & & 174 & 598 \\
\hline Total Liabilities and Other Credits....................... & 23,840 & 13,156 & 67,639 & 17,652 & 15,488 & 12,759 \\
\hline
\end{tabular}

Note: Totals may not equal sum of components because of independent rounding.

Source: Energy Information Administration, Form EIA-412, "Annual Report of Public Electric Utilities." 
Table 22. Balance Sheet by Major U.S. Publicly Owned Electric Utility Within State at End of Period, 1996

(Thousand Dollars)

\begin{tabular}{|c|c|c|c|c|c|c|}
\hline Item & $\begin{array}{l}\text { Tennessee } \\
\text { Sweetwater } \\
\text { City of } \\
\text { June } 30\end{array}$ & $\begin{array}{c}\text { Tennessee } \\
\text { Tullahoma } \\
\text { Board } \\
\text { of } \\
\text { Pub Utils } \\
\text { June } 30\end{array}$ & $\begin{array}{l}\text { Tennessee } \\
\text { Union } \\
\text { City City of } \\
\text { June } 30\end{array}$ & $\begin{array}{c}\text { Tennessee } \\
\text { Weakley } \\
\text { County } \\
\text { Mun } \\
\text { Elec Sys } \\
\text { June } 30\end{array}$ & $\begin{array}{l}\text { Tennessee } \\
\text { Winchester } \\
\text { City of } \\
\text { December } 31\end{array}$ & $\begin{array}{c}\text { Texas } \\
\text { Austin } \\
\text { City of } \\
\text { September } 30\end{array}$ \\
\hline \multicolumn{7}{|l|}{ Electric Utility Plant } \\
\hline Electric Utility Plant \& Adjust ..................................... & 13,229 & 14,213 & 10,728 & 30,982 & 8,349 & $2,368,509$ \\
\hline & & 267 & 89 & 1,752 & 634 & 88,107 \\
\hline $\begin{array}{l}\text { (less) Depr, Amort, and Depletion...................................... } \\
\text { Net Electric Utility Plant }\end{array}$ & $\begin{array}{l}4,310 \\
8,991\end{array}$ & $\begin{array}{l}6,456 \\
8,024\end{array}$ & 4,086 & 14,617 & 3,580 & 745,059 \\
\hline & $\begin{array}{r}8,991 \\
0\end{array}$ & $\begin{array}{r}8,024 \\
0\end{array}$ & $\begin{array}{r}6,731 \\
0\end{array}$ & $\begin{array}{r}18,118 \\
0\end{array}$ & $\begin{array}{r}5,404 \\
0\end{array}$ & $\begin{array}{l}1,711,558 \\
102,838\end{array}$ \\
\hline (less) Amort of Nucl Fuel ............................................. & 0 & 0 & 0 & 0 & 0 & 73,360 \\
\hline & 8,991 & 8,024 & 6,731 & 18,118 & 5,404 & $1,741,037$ \\
\hline \multicolumn{4}{|l|}{ Other Property \& Investments } & 0 & $\mathbf{0}$ & \\
\hline (less) Accum Provisions for Depr \& Amort ......... & 0 & 0 & 0 & 0 & 0 & \\
\hline 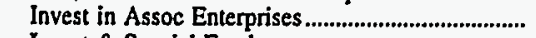 & 0 & 0 & $\mathbf{0}$ & 0 & 0 & \\
\hline 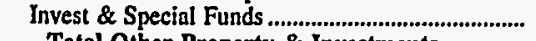 & 571 & 266 & 254 & 1,879 & 15 & 274,131 \\
\hline $\begin{array}{l}\text { Total Other Property \& Investments................. } \\
\text { Current and Accrued Assets }\end{array}$ & 571 & \multicolumn{4}{|c|}{ Curent and Accrued Assets } & \\
\hline Cash, Working Funds \& Investments....................... & 373 & 2,464 & 2,758 & 465 & 1,246 & 129,271 \\
\hline Notes \& Other Receivables............................................ & 349 & 1,097 & 1,340 & 1,818 & 806 & 84 \\
\hline Customer Accts Receivable........................................ & 0 & 0 & 0 & 0 & 0 & 69,109 \\
\hline (less) Accum Prov for Uncollected Accts .............. & 0 & 0 & $\mathbf{0}$ & 0 & $\mathbf{0}$ & 3,547 \\
\hline Fuel Stock \& Exp Undistr.................................................... & 0 & 0 & 0 & 0 & $\mathbf{0}$ & 18,202 \\
\hline 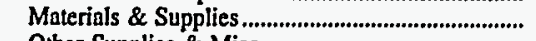 & 297 & 426 & 256 & 509 & 112 & 30,608 \\
\hline 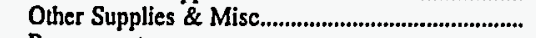 & 0 & 0 & 0 & 0 & 0 & 0 \\
\hline 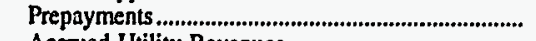 & 864 & 46 & 4 & 56 & 33 & 734 \\
\hline 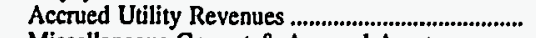 & 0 & 0 & 0 & $\mathbf{0}$ & 0 & \\
\hline Miscellaneous Current \& Accrued Assets............... & 31 & 38 & 85 & 93 & 14 & \\
\hline $\begin{array}{l}\text { Total Current \& Accrued Assets............................. } \\
\text { Deferred Debits }\end{array}$ & 1,913 & 4,071 & 4,443 & 2,941 & 2,211 & 244,461 \\
\hline Unamortized Debt Expenses ..................................... & 0 & 10 & 0 & $\mathbf{0}$ & 0 & 9,161 \\
\hline Extmordinary Losses, Study Cost.................................... & 0 & 0 & 4 & 0 & 0 & 0 \\
\hline Misc Debt, $R$ \& D Exp, Unamrt Losses .................... & 863 & 546 & 120 & 1,896 & 142 & 348,075 \\
\hline Total Deferred Debits............................................ & 863 & 555 & 124 & 1,896 & 142 & 357,236 \\
\hline & & \\
\hline 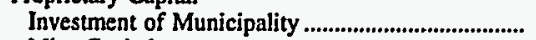 & $\mathbf{0}$ & 0 & 0 & & 0 & 564 \\
\hline 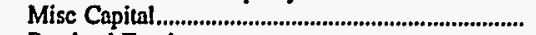 & 0 & 0 & 0 & 0 & 0 & 64,611 \\
\hline 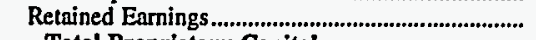 & 11,232 & 8,544 & 9,807 & 19,812 & 6,423 & 534,303 \\
\hline & \\
\hline 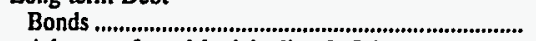 & 0 & 1,380 & 0 & 0 & 0 & $1,723,297$ \\
\hline Advances from Municipality \& Other..................... & 0 & 542 & 127 & 1,936 & 138 & 105,990 \\
\hline Unamort Prem on Long-term Debt............................ & 0 & -6 & 0 & 0 & 0 & 14,063 \\
\hline (less) Unamort Discount on Long-term Debt & 0 & 0 & 0 & 0 & 0 & 47,346 \\
\hline 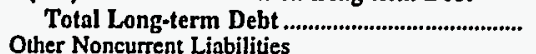 & 0 & 1,916 & 127 & 1,936 & \multicolumn{2}{|c|}{ Other Noncurtent Liabilities } \\
\hline 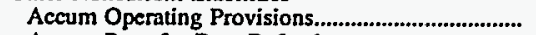 & 0 & 0 & $\mathbf{0}$ & 0 & 0 & 31.789 \\
\hline 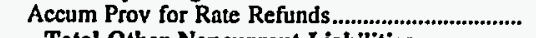 & 0 & $\mathbf{0}$ & $\mathbf{0}$ & 0 & 0 & \\
\hline Total Other Noncurrent Liabilities..................... & 0 & 0 & 0 & 0 & $\mathbf{0}$ & 31,789 \\
\hline \multicolumn{7}{|l|}{ Current and Accrued Liabilities } \\
\hline 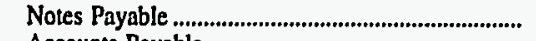 & 0 & 21 & $\mathbf{0}$ & $\mathbf{0}$ & 0 & 0 \\
\hline 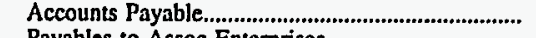 & 763 & 1,569 & 1,364 & 2,022 & 819 & 38,582 \\
\hline 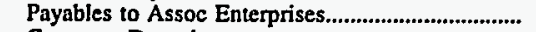 & 0 & 0 & 0 & 0 & 0 & 0 \\
\hline 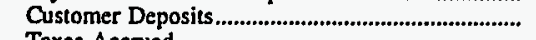 & 171 & 609 & 134 & 522 & 262 & 3,290 \\
\hline Taxes Accrued & $\mathbf{0}$ & 0 & 0 & 0 & 0 & 1,278 \\
\hline Interest Accrued & 0 & 0 & $\mathbf{0}$ & $\mathbf{0}$ & 0 & 109,530 \\
\hline Misc Current \& Accrued Liabilities............................ & 171 & 153 & 138 & 538 & 73 & 11,293 \\
\hline $\begin{array}{l}\text { Total Current \& Accrued Liabilities ...................... } \\
\text { Deferred Credits }\end{array}$ & 1,106 & 2,351 & 1,636 & $\mathbf{3 , 0 8 2}$ & 1,155 & 163,973 \\
\hline Customer Advances for Construction ....................... & 0 & 0 & 0 & 0 & 0 & $\mathbf{0}$ \\
\hline 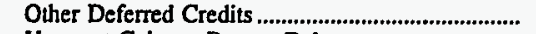 & $\mathbf{0}$ & 105 & 21 & 4 & 0 & 25,622 \\
\hline Unamort Gain on Reacgr Debt.................................... & 0 & 0 & 0 & 0 & 55 & \\
\hline 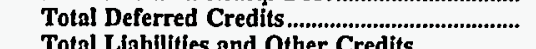 & & 105 & 21 & & 55 & 25,622 \\
\hline Total Llabilities and Other Cre & 12,338 & 12,916 & 11,590 & 24,833 & $\mathbf{7 , 7 7 1}$ & $2,616,865$ \\
\hline
\end{tabular}

Note: Totals may not equal sum of components because of independent rounding.

Source: Energy Information Administration, Form EIA-412, "Annual Report of Public Electric Utilities." 
Table 22. Balance Sheet by Major U.S. Publicly Owned Electric Utility Within State at End of Period, 1996

(Thousand Dollars)

\begin{tabular}{|c|c|c|c|c|c|c|}
\hline Item & $\begin{array}{c}\text { Texas } \\
\begin{array}{c}\text { Brenham } \\
\text { City of }\end{array} \\
\text { September } 30\end{array}$ & $\begin{array}{c}\text { Texas } \\
\text { Brownsville } \\
\text { Public } \\
\text { Utils Board } \\
\text { September } 30\end{array}$ & $\begin{array}{c}\text { Texas } \\
\text { Bryan } \\
\text { City of } \\
\text { September } 30\end{array}$ & $\begin{array}{c}\text { Texas } \\
\text { College } \\
\text { Station } \\
\text { City of } \\
\text { September } 30\end{array}$ & $\begin{array}{l}\text { Texas } \\
\text { Denton } \\
\text { City of } \\
\text { September } 30\end{array}$ & $\begin{array}{c}\text { Texas } \\
\begin{array}{c}\text { Floresville } \\
\text { City of }\end{array} \\
\text { December } 31\end{array}$ \\
\hline \multicolumn{7}{|l|}{ Electric Utility Plant } \\
\hline 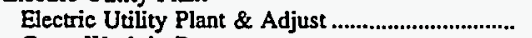 & 9,441 & 275,930 & 141,672 & 31,121 & 103,961 & 29,282 \\
\hline 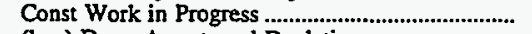 & & 73,415 & & 8,154 & 1,140 & \\
\hline 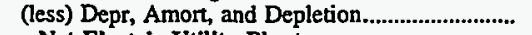 & 3,657 & 93,487 & 63,192 & 10,882 & 62,650 & 11,213 \\
\hline 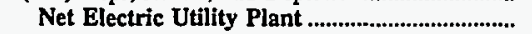 & $\mathbf{5 , 7 8 4}$ & 255,858 & $\mathbf{7 8 , 5 9 1}$ & 28,393 & 42,451 & $\mathbf{1 8 , 0 6 9}$ \\
\hline Nuclear Fuel........................................................... & & & 0 & & & 0 \\
\hline 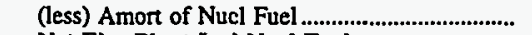 & 0 & 0 & 0 & 0 & 0 & 0 \\
\hline Net Elec Plant Incl Nucl Fuel .................................. & 5,784 & 255,858 & 78,591 & 28,393 & 42,451 & 18,069 \\
\hline \multicolumn{7}{|l|}{ Other Property \& Investments } \\
\hline Nonutility Property................... & 0 & 0 & 0 & 0 & 0 & 0 \\
\hline (less) Accum Provisions for Depr \& Amort ......... & 0 & 0 & 0 & 0 & 0 & 0 \\
\hline 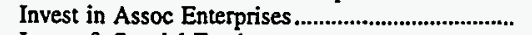 & 0 & 0 & 181 & 0 & 4,832 & 0 \\
\hline 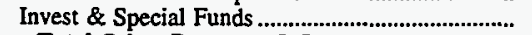 & 3,144 & 27,140 & 9,495 & 0 & 0 & 3,253 \\
\hline Total Other Property \& Investments.................... & 3,144 & 27,140 & 9,676 & 0 & 4,832 & 3,253 \\
\hline \multicolumn{7}{|l|}{ Current and Accrued Assets } \\
\hline 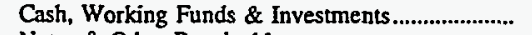 & 1,431 & 16,006 & 18,085 & 17,481 & 56,874 & 2,484 \\
\hline 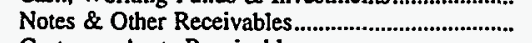 & 0 & 649 & 7,771 & 1,359 & 462 & 40 \\
\hline 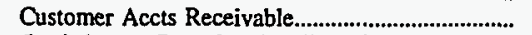 & 1,092 & 6,187 & 6,677 & 2,733 & 12,843 & 731 \\
\hline (less) Accum Prov for Uncollected Accts .................... & 33 & 142 & 217 & 914 & 6,766 & 17 \\
\hline 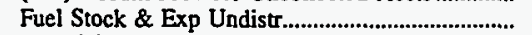 & 0 & 1,737 & 0 & 0 & 917 & 0 \\
\hline 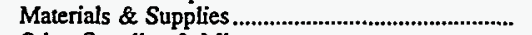 & 74 & 1,700 & 2,727 & 779 & 0 & 325 \\
\hline 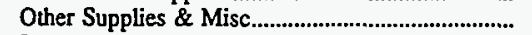 & 0 & 0 & -2 & 1 & 0 & 0 \\
\hline 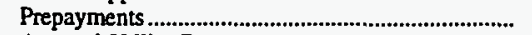 & 8 & 14 & 0 & 0 & 10 & 96 \\
\hline 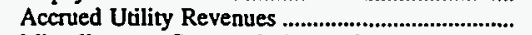 & 0 & 3,734 & 500 & 1,162 & 3,710 & 0 \\
\hline Miscellaneous Current \& Accrued Assets............... & 0 & 415 & 52 & 809 & 1,163 & 5 \\
\hline Total Current \& Accrued Assets............................. & 2,572 & 30,300 & 35,593 & 23,411 & 69,213 & 3,665 \\
\hline \multicolumn{7}{|l|}{ Deferred Debits } \\
\hline 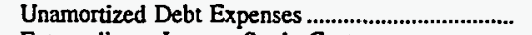 & 4 & 4,361 & $\mathbf{0}$ & 122 & 0 & 0 \\
\hline 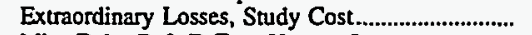 & 0 & & 0 & 0 & 259 & 0 \\
\hline Misc Debt, R \& D Exp, Unamrt Losses ................. & 0 & 3,079 & 28 & 0 & 0 & 0 \\
\hline 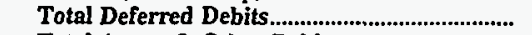 & 4 & 7,441 & 28 & 122 & 259 & 0 \\
\hline 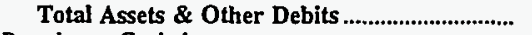 & 11,504 & 320,738 & 123,888 & 51,926 & 116,754 & 24,987 \\
\hline \multicolumn{7}{|l|}{ Proprietary Capital } \\
\hline Investment of Municipality ...... & $\mathbf{0}$ & 44,283 & 0 & 3,196 & 0 & 0 \\
\hline 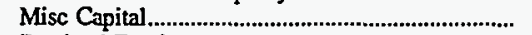 & 16 & & 0 & 0 & 465 & 0 \\
\hline 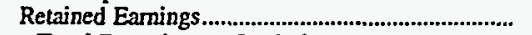 & 8,951 & 69,743 & 97,328 & 26,905 & 83,278 & 16,882 \\
\hline Total Proprietary Capital ......................................... & 8,967 & 114,025 & 97,328 & 30,102 & 83,743 & 16,882 \\
\hline \multicolumn{7}{|l|}{ Long-term Debt } \\
\hline 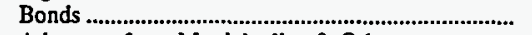 & 330 & 166,845 & 17,634 & 12,950 & 20,157 & 6,820 \\
\hline Advances from Municipality \& Other....................... & 0 & 34,621 & 0 & 39 & 0 & 0 \\
\hline 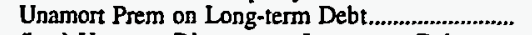 & 0 & & $\mathbf{0}$ & 1 & o & 0 \\
\hline (less) Unamort Discount on Long-term Debt & 0 & 11,134 & 0 & 0 & 124 & 119 \\
\hline 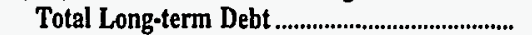 & 330 & 190,332 & 17,634 & 12,991 & 20,033 & 6,701 \\
\hline \multicolumn{7}{|l|}{ Other Noncurrent Liabilities } \\
\hline Accum Operating Provisions.... & 0 & 0 & 0 & 62 & o & 0 \\
\hline 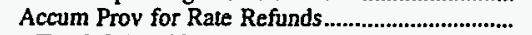 & 0 & 0 & 0 & 0 & 0 & 0 \\
\hline 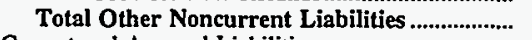 & $\mathbf{0}$ & 0 & 0 & 62 & 0 & 0 \\
\hline \multicolumn{7}{|l|}{ Current and Accrued Liabilities } \\
\hline Notes Payable ................................................................. & 0 & 0 & 0 & 0 & 0 & 263 \\
\hline 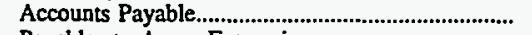 & 1,177 & 8,558 & 5,750 & 6,518 & 2,611 & 719 \\
\hline 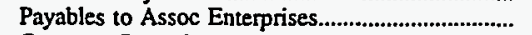 & 48 & 0 & 0 & 0 & 0 & 0 \\
\hline 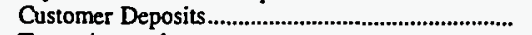 & 888 & 1,532 & 1,522 & 1,768 & 1,158 & 258 \\
\hline 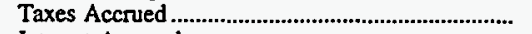 & 0 & 36 & 0 & 0 & 0 & 13 \\
\hline Interest Accrued........................ & 5 & 968 & 189 & 131 & 375 & 31 \\
\hline Misc Current \& Accrued Liabilities ............................... & 90 & 5,124 & 726 & 327 & 8,835 & 106 \\
\hline \multirow{2}{*}{\multicolumn{7}{|c|}{ Deferred Credits }} \\
\hline & & & & & & \\
\hline 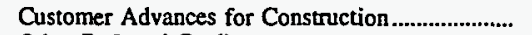 & 0 & 11 & 469 & 24 & 0 & 15 \\
\hline 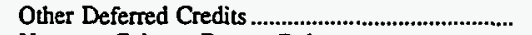 & 0 & 151 & 270 & 3 & 0 & 0 \\
\hline Unamort Gain on Reacqr Debt .......................................... & 0 & 0 & 0 & 0 & 0 & 0 \\
\hline Total Deferred Credits.................................................... & & 162 & 739 & & 0 & 15 \\
\hline Total Liabilities and Other Credits.................... & 11,504 & 320,738 & 123,888 & 51,926 & 116,754 & 24,987 \\
\hline
\end{tabular}

Note: Totals may not equal sum of components because of independent rounding.

Source: Energy Information Administration, Form ELA-412, "Annual Report of Public Electric Utilities." 
Table 22. Balance Sheet by Major U.S. Publicly Owned Electric Utility Within State at End of Period, 1996

(Thousand Dollars)

\begin{tabular}{|c|c|c|c|c|c|c|}
\hline Item & $\begin{array}{l}\text { Texas } \\
\text { Garland } \\
\text { City of } \\
\text { September } 30\end{array}$ & $\begin{array}{c}\text { Texas } \\
\begin{array}{c}\text { Georgetown } \\
\text { City of }\end{array} \\
\text { September } 30\end{array}$ & $\begin{array}{l}\text { Texas } \\
\text { Greenville } \\
\text { Electric } \\
\text { Util Sys } \\
\text { September } 30\end{array}$ & $\begin{array}{l}\text { Texas } \\
\text { Jasper } \\
\text { City of } \\
\text { September } 30\end{array}$ & $\begin{array}{c}\text { Texas } \\
\text { Kerrville } \\
\text { Public } \\
\text { Utility } \\
\text { Board } \\
\text { September } 30\end{array}$ & $\begin{array}{l}\text { Texas } \\
\text { Lower } \\
\text { Colorado } \\
\text { River } \\
\text { Authority } \\
\text { June } 30\end{array}$ \\
\hline \multicolumn{7}{|l|}{ Electric Utility Plant } \\
\hline Electric Utility Plant \& Adjust ................................... & 217,738 & 9,056 & 54,502 & 0 & 31,685 & $1,563,791$ \\
\hline 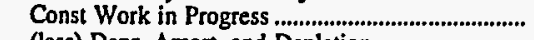 & 4,939 & 612 & & 0 & 427 & 60,262 \\
\hline (less) Depr, Amor, and Depletion................................. & 104,892 & 2,840 & 32,903 & 0 & 10,208 & 505,958 \\
\hline Net Electric Utility Plant ............................................. & 117,786 & 6,829 & 21,599 & $\mathbf{0}$ & 21,904 & $1,118,095$ \\
\hline & 0 & $\mathbf{0}$ & 0 & 0 & 0 & \\
\hline 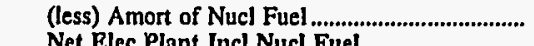 & 0 & 0 & & 0 & & \\
\hline & 117,786 & 6,829 & 21,599 & o & 21,904 & $1,118,095$ \\
\hline 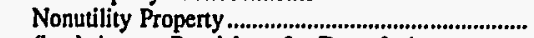 & 0 & 786 & 0 & 8,807 & $\mathbf{0}$ & 7,350 \\
\hline (less) Accum Provisions for Depr \& Amort .......... & 0 & 139 & 0 & 4,359 & 0 & 1,902 \\
\hline 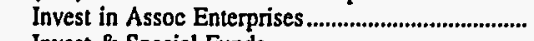 & 0 & 0 & 0 & 0 & 0 & 0 \\
\hline 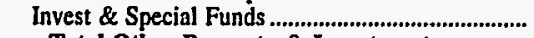 & 5,454 & 0 & 9,186 & 130 & 6,820 & 200,861 \\
\hline Total Other Property \& Investments................. & 5,454 & 647 & 9,186 & 4,578 & 6,820 & 206,310 \\
\hline \multicolumn{7}{|l|}{ Current and Accrued Assets } \\
\hline 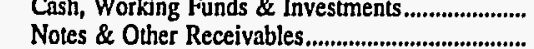 & $\begin{array}{r}39,209 \\
6,829\end{array}$ & $\begin{array}{l}2,087 \\
1,511\end{array}$ & $\begin{array}{r}3,064 \\
0\end{array}$ & $\begin{array}{r}1,814 \\
0\end{array}$ & $\begin{array}{r}3,939 \\
60\end{array}$ & 43,076 \\
\hline 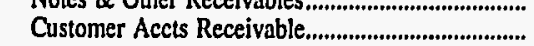 & $\begin{array}{r}0,029 \\
19,417\end{array}$ & $\begin{array}{l}1,011 \\
2,054\end{array}$ & $\begin{array}{r}0 \\
4,498\end{array}$ & $\begin{array}{r}0 \\
1,977\end{array}$ & $\begin{array}{r}60 \\
1.284\end{array}$ & $\begin{array}{r}7,534 \\
47035\end{array}$ \\
\hline (less) Accum Prov for Uncollected Accts.................. & & $\begin{array}{l}2,034 \\
58\end{array}$ & $\begin{array}{r}4,490 \\
75\end{array}$ & 0 & $\begin{array}{r}1,284 \\
105\end{array}$ & \\
\hline 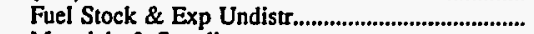 & 2,753 & 0 & 0 & 0 & 0 & 36,768 \\
\hline Materials \& Supplies ................................................ & 842 & 0 & 1,183 & $\mathbf{0}$ & 603 & 23,295 \\
\hline 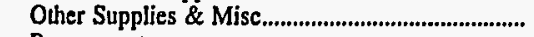 & 0 & 0 & 0 & 260 & 0 & 2 \\
\hline 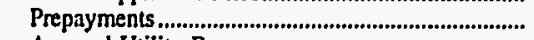 & $\mathbf{0}$ & 0 & $\mathbf{0}$ & $\mathbf{0}$ & 0 & 3,958 \\
\hline 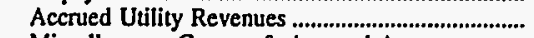 & $\mathbf{0}$ & 0 & 0 & 89 & 1,624 & 7,458 \\
\hline Miscellaneous Current \& Accrued Assets................ & 177 & 0 & & 0 & -183 & 2,558 \\
\hline $\begin{array}{l}\text { Total Current \& Accrued Assets.......................... } \\
\text { Deferred Debits }\end{array}$ & 69,227 & 5,594 & 8,670 & 4,139 & 7,222 & 171,106 \\
\hline \multicolumn{7}{|l|}{ Deferred Debits } \\
\hline 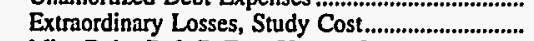 & 0 & 0 & $\begin{aligned} 309 \\
0\end{aligned}$ & 0 & $\begin{array}{r}369 \\
0\end{array}$ & $\begin{array}{r}16,413 \\
0\end{array}$ \\
\hline Misc Debt, R \& D Exp, Unamrt Losses .................. & 35 & 0 & 0 & $\mathbf{0}$ & 109 & 207,133 \\
\hline Total Deferred Debits.......................................... & 35 & 59 & 389 & & 679 & 223,547 \\
\hline 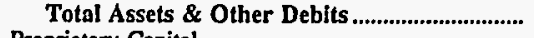 & 192,502 & 13,128 & 39,844 & 8,717 & 36,625 & $1,719,057$ \\
\hline \multicolumn{7}{|l|}{ Proprietary Capital } \\
\hline 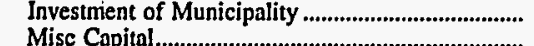 & $\mathbf{0}$ & 4,345 & 200 & 0 & $\mathbf{0}$ & 0 \\
\hline & $\begin{array}{r}0 \\
0\end{array}$ & & 0 & 0 & 0 & 12,063 \\
\hline 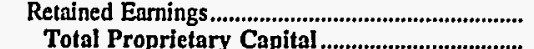 & $\begin{array}{l}174,332 \\
179332\end{array}$ & 4,331 & 21,434 & 7,259 & 4,969 & 454,775 \\
\hline \multicolumn{6}{|l|}{ Long-term Debt } & 466,839 \\
\hline 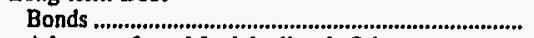 & 10,496 & 2,473 & 13,838 & $\mathbf{0}$ & 29,530 & $1,282,383$ \\
\hline Advances from Municipality \& Other & 0 & 9 & $\mathbf{0}$ & 6 & 0 & \\
\hline Unamort Prem on Long-term Debt........................... & 0 & 0 & 0 & 0 & $-1,076$ & \\
\hline (less) Unamort Discount on Long-term Debt & & $\mathbf{0}$ & & 0 & & 107,935 \\
\hline 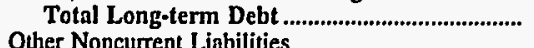 & 10,496 & 2,482 & 13,838 & 6 & \\
\hline 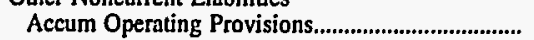 & 0 & 0 & 0 & 0 & 0 & 0 \\
\hline Accum Prov for Rate Refunds..... & 0 & 0 & $\mathbf{0}$ & 0 & 0 & 0 \\
\hline \multirow{2}{*}{\multicolumn{7}{|c|}{ Current and Accrued Linbilities }} \\
\hline & & & & & & \\
\hline $\begin{array}{l}\text { Notes Payable } \\
\text { Accounts Payable }\end{array}$ & $\begin{array}{r}20 \\
6,633\end{array}$ & $\begin{array}{r}0 \\
1,469\end{array}$ & $\begin{array}{l}1,705 \\
1,072\end{array}$ & $\begin{array}{r}35 \\
939\end{array}$ & $\begin{array}{r}0 \\
2,124\end{array}$ & $\begin{array}{r}132,000 \\
25,422\end{array}$ \\
\hline 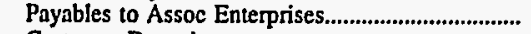 & 55 & 0 & 0 & 132 & 0 & 0 \\
\hline 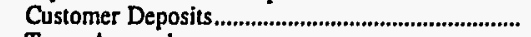 & $\mathbf{0}$ & 387 & 540 & 211 & 281 & 96 \\
\hline 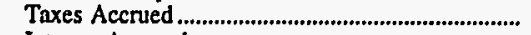 & 0 & 0 & 0 & 0 & 0 & 869 \\
\hline 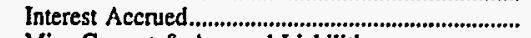 & 1 & 33 & 86 & 0 & 798 & 30,897 \\
\hline Misc Current \& Accrued Liabilities ....................... & 921 & 81 & 356 & 135 & 0 & 29,270 \\
\hline Total Current \& Accrued Liabilities .................. & 7,629 & 1,970 & 3,759 & 1,452 & 3,202 & 218,554 \\
\hline \multicolumn{7}{|l|}{ Deferred Credits } \\
\hline $\begin{array}{l}\text { Customer Advances for Construction ........................... } \\
\text { Other Deferred Credits }\end{array}$ & $\begin{array}{r}0 \\
44\end{array}$ & 0 & 613 & 0 & 0 & 187 \\
\hline & $\begin{array}{r}44 \\
0\end{array}$ & 0 & $\mathbf{0}$ & $\mathbf{0}$ & 0 & 42,247 \\
\hline 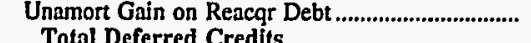 & 0 & $\mathbf{0}$ & 0 & 0 & 0 & $-183,218$ \\
\hline 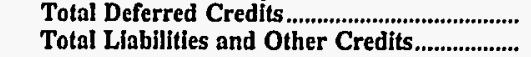 & $\begin{array}{r}44 \\
192,502\end{array}$ & $\begin{array}{r}0 \\
13,128\end{array}$ & $\begin{array}{r}613 \\
39,844\end{array}$ & $\begin{array}{r}0 \\
8,717\end{array}$ & $\begin{array}{r}0 \\
36,625\end{array}$ & $\begin{array}{r}-140,783 \\
1,719,057\end{array}$ \\
\hline & & & & & & \\
\hline
\end{tabular}

Note: Totals may not equal sum of components because of independent rounding.

Source: Energy Information Administration, Form EIA-412, "Annual Report of Public Electric Utilities." 
Table 22. Balance Sheet by Major U.S. Publicly Owned Electric Utility Within State at End of Period, 1996

(Thousand Dollars)

\begin{tabular}{|c|c|c|c|c|c|c|}
\hline Item & $\begin{array}{c}\text { Texas } \\
\text { Lubbock } \\
\text { City of } \\
\text { September } 30\end{array}$ & $\begin{array}{c}\text { New Braunfels } \\
\text { City of } \\
\text { July } 31\end{array}$ & $\begin{array}{c}\text { Texas } \\
\text { Sam Rayburn } \\
\text { Municipal } \\
\text { Pwr } \\
\text { Agny } \\
\text { September } 30\end{array}$ & $\begin{array}{c}\text { Texas } \\
\text { San Antonio } \\
\text { Public } \\
\text { Service Bd } \\
\text { January } 31\end{array}$ & $\begin{array}{c}\text { Texas } \\
\text { San Marcos } \\
\text { City of } \\
\text { September } 30\end{array}$ & $\begin{array}{l}\text { Texas } \\
\text { Seguin } \\
\text { City of } \\
\text { September } 30\end{array}$ \\
\hline \multicolumn{7}{|l|}{ Electric Utility Plant } \\
\hline 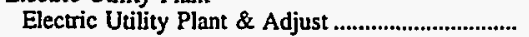 & 144,274 & 58,606 & 151,413 & $4,700,348$ & 13,441 & 6,793 \\
\hline 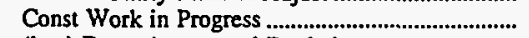 & 12,300 & 152 & 150 & 159,664 & 2,366 & \\
\hline (less) Depr, Amort, and Depletion........................... & 62,007 & 23,912 & 53,737 & $1,048,205$ & 2,817 & 4,378 \\
\hline 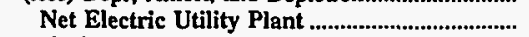 & 94,568 & 34,846 & 97,826 & $3,811,807$ & 12,990 & 2,415 \\
\hline 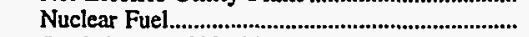 & 0 & 0 & 0 & 198,016 & 0 & 0 \\
\hline 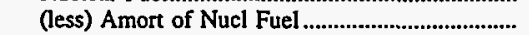 & 0 & 0 & 0 & 143,760 & 0 & 0 \\
\hline $\begin{array}{l}\text { Net Elec Plant Incl Nucl Fuel ................................. } \\
\text { Other Property \& Investments }\end{array}$ & 94,568 & 34,846 & 97,826 & $3,866,063$ & 12,990 & 2,415 \\
\hline 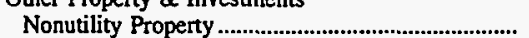 & 0 & 68,822 & 0 & 0 & 0 & 0 \\
\hline (less) Accum Provisions for Depr \& Amort .......... & 0 & 24,541 & 0 & 0 & 0 & 0 \\
\hline 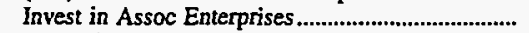 & 0 & 0 & 0 & 0 & 0 & 0 \\
\hline 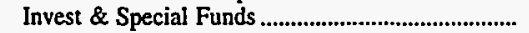 & $\mathbf{0}$ & 11,138 & 48,785 & 346,028 & 0 & 1,781 \\
\hline Total Other Property \& Investments................ & 0 & 55,419 & 48,785 & 346,028 & $\mathbf{0}$ & 1,781 \\
\hline \multicolumn{7}{|l|}{ Current and Accrued Assets } \\
\hline 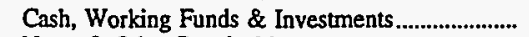 & 8,433 & 11,967 & 14,587 & 211,262 & 14,239 & 2,063 \\
\hline 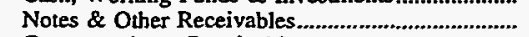 & 4,479 & 2,208 & 1,512 & 10,221 & 358 & 75 \\
\hline 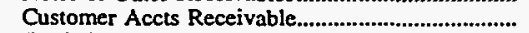 & 0 & 4,350 & 2,185 & 72,199 & 4,297 & 1,190 \\
\hline (less) Accum Prov for Uncollected Accts.............. & 0 & 0 & 0 & 2,525 & 1,207 & 0 \\
\hline 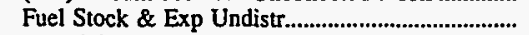 & 0 & 0 & 1,433 & 22,718 & 0 & 0 \\
\hline 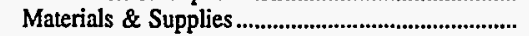 & 0 & 862 & 806 & 55,114 & 185 & 748 \\
\hline 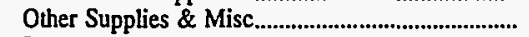 & 0 & 0 & 0 & 1,629 & 0 & 0 \\
\hline 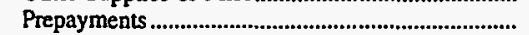 & 0 & 119 & 132 & 4,353 & 29 & 0 \\
\hline Accrued Utility Revenues ......................................... & 0 & 0 & 0 & 0 & 0 & 546 \\
\hline Miscellaneous Current \& Accrued Assets.............. & 185 & 0 & 67 & 7,205 & 0 & 0 \\
\hline Total Current \& Accrued Assets......................... & 13,097 & 19,505 & $\mathbf{2 0 , 7 2 3}$ & 382,177 & 17,901 & 4,621 \\
\hline \multicolumn{7}{|l|}{ Deferred Debits } \\
\hline 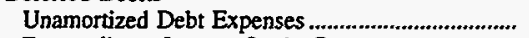 & 0 & 0 & 3,310 & 5,382 & 271 & 17 \\
\hline Extraordinary Losses, Study Cost............................... & 0 & 0 & 0 & 0 & 0 & 0 \\
\hline Misc Debt, R \& D Exp, Unamrt Losses ................. & 26,600 & 0 & 114,841 & 15,134 & 0 & 0 \\
\hline 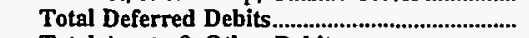 & 26,600 & 0 & 118,151 & 20,516 & 271 & 17 \\
\hline 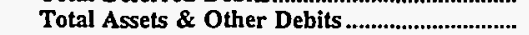 & 134,264 & 109,770 & 285,485 & $4,614,784$ & 31,162 & 8,835 \\
\hline \multicolumn{7}{|l|}{ Proprietary Capital } \\
\hline 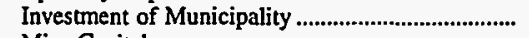 & 8,132 & 2,426 & 0 & 0 & 0 & 0 \\
\hline 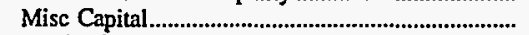 & 0 & 0 & 0 & 0 & 788 & 3,157 \\
\hline 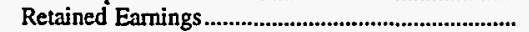 & 95,503 & 47,565 & 43,199 & $1,833,984$ & 10,883 & 4,290 \\
\hline Total Proprietary Capital & 103,635 & 49,991 & 43,199 & $1,833,984$ & 11,671 & 7,447 \\
\hline \multicolumn{7}{|l|}{ Long-term Debt } \\
\hline 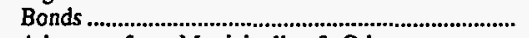 & 23,017 & 26,767 & 233,870 & $2,694,770$ & 15,695 & 0 \\
\hline Advances from Municipality \& Other ................ & 1,412 & 13,921 & 0 & 0 & 0 & 0 \\
\hline Unamort Prem on Long-term Debt.......................... & 0 & 0 & 0 & 250,800 & 0 & 0 \\
\hline (less) Unamort Discount on Long-term Debt & 0 & 186 & 0 & 470,418 & 282 & 0 \\
\hline 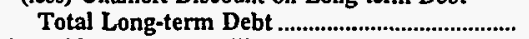 & 24,430 & 40,501 & 233,870 & $2,475,152$ & 15,413 & $\mathbf{0}$ \\
\hline \multicolumn{7}{|l|}{ Other Noncurrent Liabilities } \\
\hline 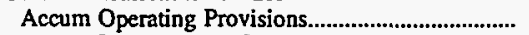 & 0 & 0 & 0 & 40,075 & 79 & 0 \\
\hline 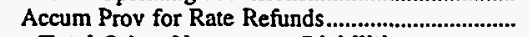 & 0 & 0 & 0 & 0 & 0 & 0 \\
\hline Total Other Noncurrent Liabilities ........................ & $\mathbf{0}$ & $\mathbf{0}$ & $\mathbf{0}$ & 40,075 & 79 & 0 \\
\hline \multicolumn{7}{|l|}{ Current and Accrued Liabilities } \\
\hline Notes Payable & 0 & 2,064 & 0 & 0 & 430 & 0 \\
\hline 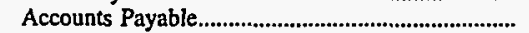 & 5,318 & 3,999 & 899 & 78,357 & 1,594 & 1,054 \\
\hline 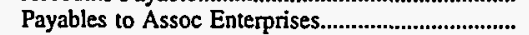 & 0 & 0 & 0 & 120,145 & 135 & 0 \\
\hline 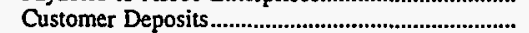 & 31 & 653 & 0 & 26,122 & 1,016 & 232 \\
\hline 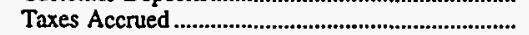 & 59 & 0 & 0 & 726 & 65 & 0 \\
\hline 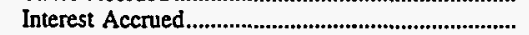 & 615 & 143 & 7,517 & 2,563 & 357 & 0 \\
\hline 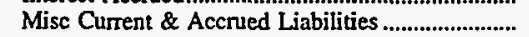 & 177 & 1,314 & 0 & 726 & 402 & 101 \\
\hline \multirow{2}{*}{\multicolumn{7}{|c|}{ Deferred Credits }} \\
\hline & & & & & & \\
\hline 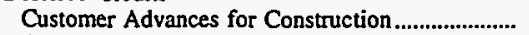 & 0 & 11,106 & 0 & 12,149 & 0 & 0 \\
\hline Other Deferred Credits & 0 & 0 & 0 & 24,785 & 0 & $\mathbf{0}$ \\
\hline 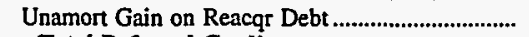 & 0 & 0 & 0 & 0 & 0 & 0 \\
\hline 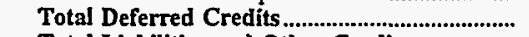 & 0 & 11,106 & 0 & 36,934 & 0 & \\
\hline Total Liabilities and Other Credits................... & 134,264 & 109,770 & 285,485 & $4,614,784$ & 31,162 & 8,835 \\
\hline
\end{tabular}

Note: Totals may not equal sum of components because of independent rounding

Source: Energy Information Administration, Form EIA-412, "Annual Report of Public Electric Utilities." 
Table 22. Balance Sheet by Major U.S. Publicly Owned Electric Utility Within State at End of Period, 1996

(Thousand Dollars)

\begin{tabular}{|c|c|c|c|c|c|c|}
\hline Item & $\begin{array}{c}\text { Texas } \\
\text { Texas } \\
\text { Municipal } \\
\text { Power Agency } \\
\text { September } 30\end{array}$ & $\begin{array}{l}\text { Texas } \\
\text { Toledo Bend } \\
\text { Project } \\
\text { Joint } \\
\text { Oper } \\
\text { August } 30\end{array}$ & $\begin{array}{c}\text { Texas } \\
\text { Weatherford } \\
\text { Mun } \\
\text { Utility } \\
\text { System } \\
\text { September } 30\end{array}$ & $\begin{array}{c}\text { Utah } \\
\begin{array}{c}\text { Bountiful } \\
\text { City City of }\end{array} \\
\text { June } 30\end{array}$ & $\begin{array}{c}\text { Utah } \\
\text { Intermountain } \\
\text { Power Agency } \\
\text { June } 30\end{array}$ & $\begin{array}{l}\text { Utah } \\
\text { Logan } \\
\text { City of } \\
\text { June } 30\end{array}$ \\
\hline \multicolumn{7}{|l|}{ Electric Utility Plant } \\
\hline 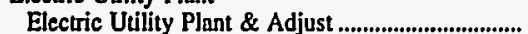 & 830,528 & 72,893 & 14,521 & 36,364 & $2,771,435$ & 28,920 \\
\hline 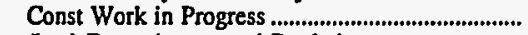 & 10,586 & & 2,529 & 672 & 0 & 0 \\
\hline (less) Depr, Amort, and Depletion............................... & 357,237 & 0 & 7,920 & 14,272 & 716,847 & 11,380 \\
\hline 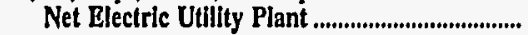 & 483,877 & $\mathbf{7 2 , 8 9 3}$ & 9,130 & 22,764 & $2,054,588$ & 17,540 \\
\hline 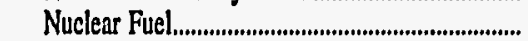 & 0 & 0 & 0 & 0 & 0 & 0 \\
\hline 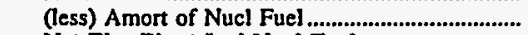 & & & & & & \\
\hline Net Elec Plant Ind Nucl Fuel ............................... & 483,877 & $\mathbf{7 2 , 8 9 3}$ & 9,130 & 22,764 & $2,054,588$ & 17,540 \\
\hline \multicolumn{7}{|l|}{ Other Property \& Investments } \\
\hline 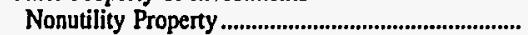 & 0 & 0 & 54,746 & 0 & 24,123 & 334 \\
\hline (less) Accum Provisions for Depr \& Amort .......... & 0 & $\mathbf{0}$ & 7,444 & 0 & 0 & 156 \\
\hline Invest in Assoc Enterprises..................................... & 0 & $\mathbf{0}$ & & 9,752 & 0 & 0 \\
\hline Invest \& Special Funds ................................................. & 126,238 & 0 & 2,453 & 0 & 998,653 & 0 \\
\hline Total Other Property \& Investments................ & 126,238 & 0 & 49,755 & $\mathbf{9 , 7 5 2}$ & $1,022,776$ & 178 \\
\hline \multicolumn{7}{|l|}{ Current and Accrued Assets } \\
\hline Cash, Working Funds \& Investments........................ & 58,288 & 189 & 6,839 & 6,976 & 77,272 & 8,408 \\
\hline 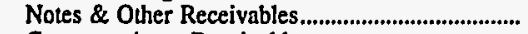 & 446 & 0 & 147 & 56 & 18,609 & 164 \\
\hline 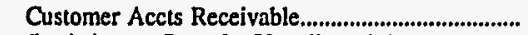 & 8,512 & 0 & 1,664 & 1,798 & 0 & 2,187 \\
\hline (less) Accum Prov for Uncollected Accts ............... & 0 & 0 & 114 & 16 & $\mathbf{0}$ & 53 \\
\hline 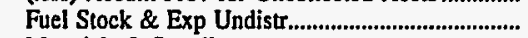 & 2,748 & 0 & 0 & 0 & 53,551 & 0 \\
\hline 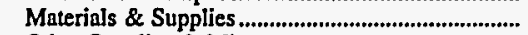 & 3,840 & 0 & 1,390 & 1,301 & 13,120 & 920 \\
\hline 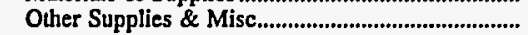 & 0 & 0 & 0 & 2 & 0 & 0 \\
\hline 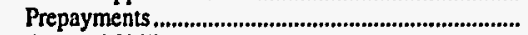 & 253 & 0 & $\mathbf{0}$ & 0 & 0 & 0 \\
\hline Accrued Utility Revenues ............................................... & 0 & 0 & 773 & 0 & 0 & o \\
\hline Miscellaneous Current \& Accrued Assets............... & 2,000 & 4 & 216 & 0 & 350 & 0 \\
\hline Total Current \& Accrued Assets............................. & 76,087 & 193 & 10,916 & 10,116 & 162,902 & 11,626 \\
\hline \multicolumn{7}{|l|}{ Deferred Debits } \\
\hline 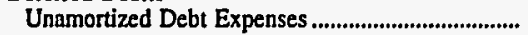 & 17,506 & 0 & 446 & 0 & 44,633 & 77 \\
\hline Extruordinary Losses, Study Cost................................. & 970 & 0 & 0 & 0 & 0 & 0 \\
\hline Misc Debt, $\dot{R} \&$ D Exp, Unamrt Losses .................. & 818,053 & 0 & $\mathbf{0}$ & 0 & $1,086,658$ & 0 \\
\hline Total Deferred Debits............................................... & 836,529 & 0 & 446 & 0 & $1,131,291$ & 77 \\
\hline 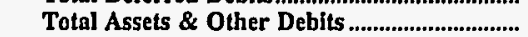 & $1,522,731$ & 73,086 & 70,246 & 42,632 & $4,371,557$ & 29,421 \\
\hline \multicolumn{7}{|l|}{ Proprietary Capital } \\
\hline 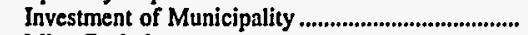 & 0 & 72,893 & 8,142 & $\mathbf{0}$ & 0 & 0 \\
\hline 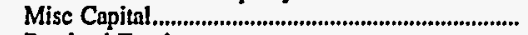 & 0 & & 0 & 0 & 0 & 874 \\
\hline 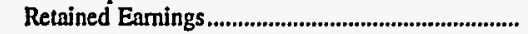 & 36,835 & 175 & 38,197 & 35,192 & 0 & 19,625 \\
\hline 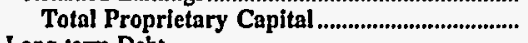 & 36,835 & 73,069 & 46,339 & 35,192 & $\mathbf{0}$ & 20,499 \\
\hline \multicolumn{7}{|l|}{ Long-term Debt } \\
\hline 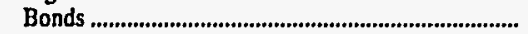 & $1,087,447$ & 0 & 21,430 & $\mathbf{0}$ & $5,323,275$ & 6,255 \\
\hline Advances from Municipality \& Other........................ & 67,822 & 0 & 0 & 4,629 & 19,550 & 76 \\
\hline 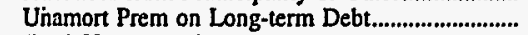 & & 0 & 0 & 0 & 0 & 0 \\
\hline (less) Unamort Discount on Long-term Debt & 21,521 & 0 & 1,444 & 0 & $1,140,108$ & \\
\hline 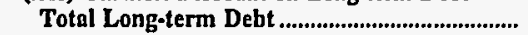 & $1,133,748$ & $\mathbf{0}$ & 19,986 & 4,629 & $4,202,717$ & 6,331 \\
\hline \multicolumn{7}{|l|}{ Other Noncurrent Liabilities } \\
\hline 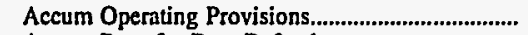 & 0 & 0 & 0 & $\mathbf{0}$ & 0 & 0 \\
\hline Accum Prov for Rate Refunds... & 0 & 0 & 0 . & 0 & 0 & 0 \\
\hline Total Other Noncurrent Liabilities ........................ & $\mathbf{0}$ & 0 & 0 & 0 & 0 & 0 \\
\hline \multicolumn{7}{|l|}{ Curnent and Accrued Liabilities } \\
\hline 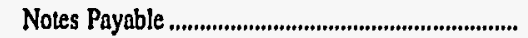 & 176,289 & 0 & 0 & 0 & 0 & 12 \\
\hline 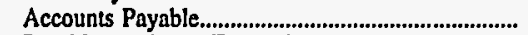 & 39,130 & 18 & 2,428 & 1,406 & 49,660 & 1,432 \\
\hline 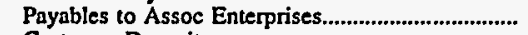 & 356 & $\mathbf{0}$ & 0 & 433 & 0 & 0 \\
\hline 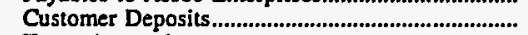 & 0 & 0 & 57 & 442 & 0 & 748 \\
\hline 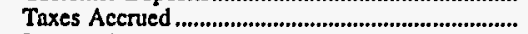 & 12 & 0 & 143 & 0 & 0 & 0 \\
\hline 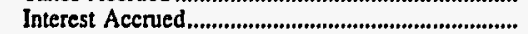 & 94,120 & 0 & 93 & 0 & 119,180 & 203 \\
\hline Misc Current \& Accrued.Liabilities .......................... & 42,241 & 0 & 871 & 0 & 0 & 195 \\
\hline Total Current \& Accrued Liabilities ................. & 352,148 & 18 & 3,592 & 2,281 & 168,840 & 2,591 \\
\hline \multicolumn{7}{|l|}{ Deferred Credits } \\
\hline Customer Advances for Construction.......................... & $\mathbf{0}$ & 0 & 0 & 531 & 0 & $\mathbf{0}$ \\
\hline Other Deferred Credits & $\mathbf{0}$ & $\mathbf{0}$ & 329 & 0 & 0 & 0 \\
\hline 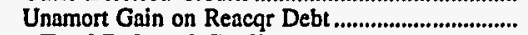 & $\mathbf{0}$ & 0 & 0 & 0 & 0 & 0 \\
\hline 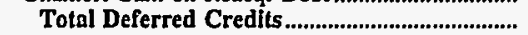 & 0 & 0 & 329 & 531 & 0 & 0 \\
\hline Total Llabilities and Other Credits................... & $1,522,731$ & 73,086 & 70,246 & 42,632 & $4,371,557$ & 29,421 \\
\hline
\end{tabular}

Note: Totals may not equal sum of components because of independent rounding.

Source: Energy Information Administration, Form EIA-412, "Annual Report of Public Electric Utilities." 
Table 22. Balance Sheet by Major U.S. Publicly Owned Electric Utility Within State at End of Period, 1996

(Thousand Dollars)

\begin{tabular}{|c|c|c|c|c|c|c|}
\hline Item & $\begin{array}{l}\text { Utah } \\
\text { Murray } \\
\text { City of } \\
\text { June } 30\end{array}$ & $\begin{array}{l}\text { Utah } \\
\text { Provo } \\
\text { City Corp } \\
\text { June } 30\end{array}$ & $\begin{array}{c}\text { Utah } \\
\text { St George } \\
\text { City of } \\
\text { June } 30\end{array}$ & $\begin{array}{c}\text { Utah } \\
\text { Utah } \\
\text { Associated } \\
\text { Mun } \\
\text { Power Sys } \\
\text { March } 31\end{array}$ & $\begin{array}{c}\text { Utah } \\
\text { Utah } \\
\text { Municipal } \\
\text { Power Agency } \\
\text { June } 30\end{array}$ & $\begin{array}{l}\text { Vermont } \\
\text { Burlington } \\
\text { City of } \\
\text { June } 30\end{array}$ \\
\hline \multicolumn{7}{|l|}{ Electric Utility Plant } \\
\hline 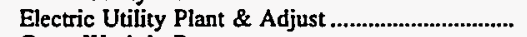 & 43,851 & 94,334 & 35,496 & 130,723 & 38,515 & 77,774 \\
\hline 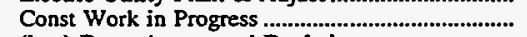 & 2,309 & & & & & 245 \\
\hline 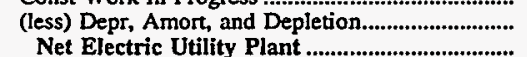 & $\begin{array}{l}24,194 \\
21,965\end{array}$ & $\begin{array}{l}45,617 \\
48,717\end{array}$ & $\begin{array}{l}11,970 \\
23,527\end{array}$ & $\begin{array}{r}28,523 \\
102,200\end{array}$ & $\begin{array}{r}9,161 \\
29,353\end{array}$ & $\begin{array}{l}31,273 \\
46,745\end{array}$ \\
\hline 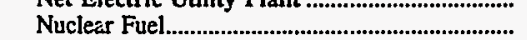 & 0 & 0 & 0 & 0 & 0 & 0 \\
\hline (less) Amort of Nucl Fuel .............................................. & 0 & 0 & 0 & 0 & 0 & 0 \\
\hline 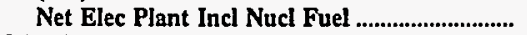 & 21,965 & 48,717 & 23,527 & 102,200 & 29,353 & 46,745 \\
\hline \multicolumn{7}{|l|}{ Other Property \& Investments } \\
\hline Nonutility Property ........................... & 0 & 1,800 & 0 & 0 & 0 & 776 \\
\hline (less) Accum Provisions for Depr \& Amort ........... & $\mathbf{0}$ & & 0 & 0 & 0 & \\
\hline Invest in Assoc Enterprises & 15 & 0 & 0 & 0 & $\mathbf{0}$ & 2,198 \\
\hline 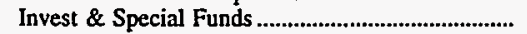 & 45 & 0 & 0 & 0 & 7,095 & 12,711 \\
\hline Total Other Property \& Investments................... & 60 & 1,800 & 0 & 0 & 7,095 & 15,685 \\
\hline \multicolumn{7}{|l|}{ Current and Accrued Assets } \\
\hline 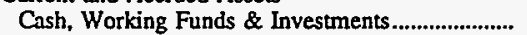 & 19,651 & 6,661 & 12,347 & 21,191 & 9,078 & 8,848 \\
\hline 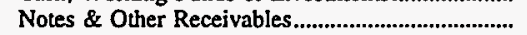 & & 101 & 1,589 & 0 & 5,543 & 990 \\
\hline 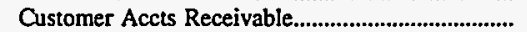 & 2,444 & 5,427 & 3,045 & 14,971 & 174 & 3,826 \\
\hline (less) Accum Prov for Uncollected Accts.............. & 104 & 0 & 381 & & 0 & 433 \\
\hline 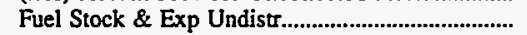 & 0 & 0 & 0 & 0 & 1,457 & 309 \\
\hline Materials \& Supplies & 851 & 1,207 & 2,067 & 0 & 273 & 1,526 \\
\hline Other Supplies \& Misc....................................... & 0 & 0 & 0 & 0 & 0 & 235 \\
\hline 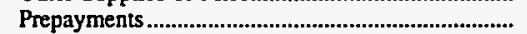 & 3,316 & 0 & 0 & 1,110 & 245 & 1,813 \\
\hline 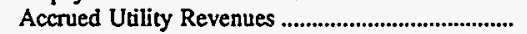 & 0 & 0 & 0 & 0 & 0 & 261 \\
\hline Miscellaneous Current \& Accrued Assets.............. & 197 & 0 & 66 & 154 & 110 & \\
\hline 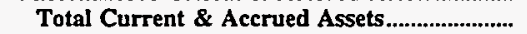 & 26,355 & 13,396 & 18,733 & 37,426 & 16,881 & 17,374 \\
\hline \multicolumn{7}{|l|}{ Deferred Debits } \\
\hline 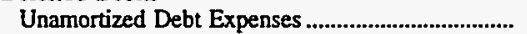 & 114 & 0 & 0 & 5,798 & 929 & 1,763 \\
\hline Extraordinary Losses, Study Cost............................. & 0 & 0 & 0 & 40,000 & 0 & 21 \\
\hline 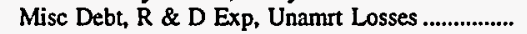 & 0 & 0 & 0 & 0 & 4,691 & 52,614 \\
\hline 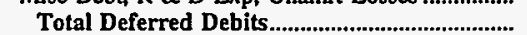 & 114 & 0 & 0 & 45,798 & 5,621 & 54,398 \\
\hline Total Assets \& Other Debits ................................. & 48,493 & 63,913 & 42,259 & 185,424 & 58,950 & 134,202 \\
\hline \multicolumn{7}{|l|}{ Proprietary Capital } \\
\hline 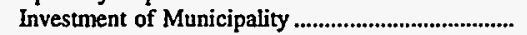 & 77 & 0 & 0 & 127 & 3 & \\
\hline 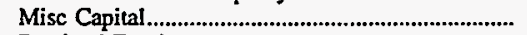 & 88 & 0 & 1,523 & 0 & $\mathbf{0}$ & 32,228 \\
\hline 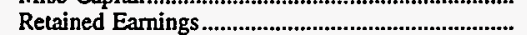 & 40,499 & 5,186 & 37,508 & 0 & 0 & 0 \\
\hline 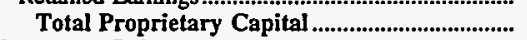 & 40,664 & 5,186 & 39,031 & 127 & 3 & 32,228 \\
\hline \multicolumn{7}{|l|}{ Long-term Debt } \\
\hline Bonds .................... & 5,675 & 54,582 & 0 & 150,596 & 56,600 & 95,842 \\
\hline Advances from Municipality \& Other....................... & 0 & 0 & 0 & 481 & 0 & 12 \\
\hline Unamort Prem on Long-term Debt.......................... & 0 & $-1,033$ & 0 & 0 & 0 & 1,555 \\
\hline (less) Unamort Discount on Long-term Debt & 0 & & 0 & 0 & 1,747 & 469 \\
\hline 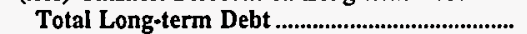 & 5,675 & $\mathbf{5 3 , 5 4 9}$ & 0 & 151,077 & $\mathbf{5 4 , 8 5 3}$ & 96,940 \\
\hline \multicolumn{7}{|l|}{ Other Noncurrent Liabilities } \\
\hline 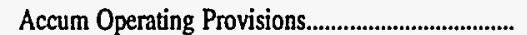 & 0 & 0 & 0 & 0 & 0 & 476 \\
\hline Accum Prov for Rate Refunds........ & 0 & 0 & 0 & 0 & 0 & \\
\hline 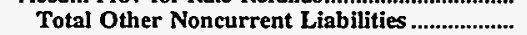 & $\mathbf{0}$ & $\mathbf{0}$ & $\mathbf{0}$ & $\mathbf{0}$ & 0 & 476 \\
\hline \multicolumn{7}{|l|}{ Current and Accrued Liabilities } \\
\hline Notes Payable ................................ & 0 & 0 & 0 & 0 & 0 & 4 \\
\hline 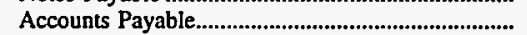 & 1,173 & 2,736 & 2,637 & 2,771 & 951 & 1,692 \\
\hline 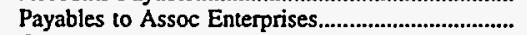 & 70 & 36 & 0 & 0 & 531 & 82 \\
\hline 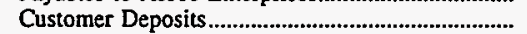 & 519 & 1,166 & 591 & 0 & 0 & 5 \\
\hline 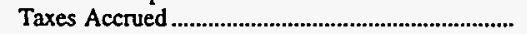 & 0 & 0 & 0 & 724 & 0 & 131 \\
\hline 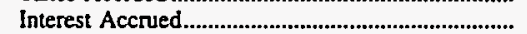 & 32 & 422 & 0 & 1,943 & 1,529 & 1,876 \\
\hline 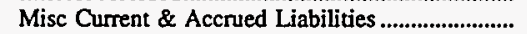 & 360 & 818 & 0 & 10,368 & 1,083 & 641 \\
\hline Total Current \& Accrued Liabilities ................ & 2,154 & 5,178 & 3,228 & 15,805 & 4,094 & 4,432 \\
\hline \multicolumn{7}{|l|}{ Deferred Credits } \\
\hline 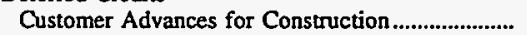 & 0 & 0 & 0 & 0 & 0 & \\
\hline 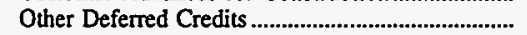 & $\mathbf{0}$ & 0 & 0 & 18,414 & 0 & 119 \\
\hline Unamort Gain on Reacgr Debt ....................................... & 0 & 0 & 0 & 0 & 0 & 0 \\
\hline 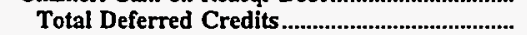 & & 0 & & 18,414 & & \\
\hline Total Liabilities and Other Credits.................... & 48,493 & 63,913 & 42,259 & 185,424 & 58,950 & 134,202 \\
\hline
\end{tabular}

Note: Totals may not equal sum of components because of independent rounding.

Source: Energy Information Administration, Form EIA-412, "Annual Report of Public Electric Utilities." 
Table 22. Balance Sheet by Major U.S. Publicly Owned Electric Utility Within State at End of Period, 1996

(Thousand Dollars)

\begin{tabular}{|c|c|c|c|c|c|c|}
\hline Item & $\begin{array}{c}\text { Vermont } \\
\text { Vermont } \\
\text { Public } \\
\text { Pwr } \\
\text { Supply Auth } \\
\text { December } 31\end{array}$ & $\begin{array}{l}\text { Virginia } \\
\text { Bedford } \\
\text { City of } \\
\text { June } 30\end{array}$ & $\begin{array}{l}\text { Virginia } \\
\text { Bristol } \\
\text { Utilities } \\
\text { Board } \\
\\
\text { June } 30\end{array}$ & $\begin{array}{l}\text { Virginia } \\
\text { Danville } \\
\text { City of } \\
\text { June } 30\end{array}$ & $\begin{array}{c}\text { Virginia } \\
\begin{array}{c}\text { Harrisonburg } \\
\text { City of }\end{array} \\
\text { June } 30\end{array}$ & $\begin{array}{l}\text { Virginia } \\
\text { Manassas } \\
\text { City of } \\
\text { June } 30\end{array}$ \\
\hline \multicolumn{7}{|l|}{ Electric Utility Plant } \\
\hline Electric Utility Plant \& Adjust ................................... & 20,973 & 20,758 & 24,960 & 66,446 & 49,007 & 42,287 \\
\hline 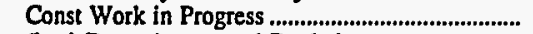 & & & 501 & 3,469 & 2,559 & 348 \\
\hline 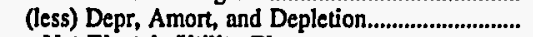 & 9,987 & 6,579 & 11,376 & 26,952 & 17,696 & 15,245 \\
\hline Net Electric Utillty Plant & 10,986 & 14,179 & 14,086 & 42,963 & $\mathbf{3 3 , 8 7 1}$ & 27,391 \\
\hline Nuclear Fuel...................................................................... & 0 & 0 & 0 & 0 & 0 & 0 \\
\hline (less) Amort of Nucl Fuel ........................................ & & $\mathbf{0}$ & 0 & 0 & 0 & 0 \\
\hline 'Net Elec Plant Incl Nucl Fuel ..................................... & 10,986 & 14,179 & 14,086 & 42,963 & 33,871 & 27,391 \\
\hline Nonutility Property....................................................... & $\mathbf{0}$ & $\mathbf{0}$ & 56 & 0 & 0 & 0 \\
\hline (less) Accum Provisions for Depr \& Amort ......... & 0 & 0 & 0 & $\begin{array}{l}0 \\
0\end{array}$ & $\begin{array}{l}0 \\
0\end{array}$ & 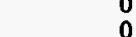 \\
\hline Invest in Assoc Enterprises ........................................... & 0 & 0 & 0 & 0 & 0 & 0 \\
\hline 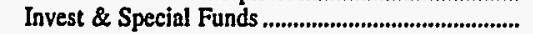 & 5,511 & 0 & 595 & 0 & 1 & 0 \\
\hline Total Other Property \& Investments................. & 5,511 & 0 & 651 & 0 & 1 & 0 \\
\hline \multicolumn{7}{|l|}{ Current and Accrued Assets } \\
\hline Cash, Working Funds \& Investments........................ & 160 & 5,300 & 5,744 & 11,197 & 3,670 & 917 \\
\hline 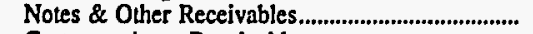 & 0 & & 1,074 & & 400 & 0 \\
\hline 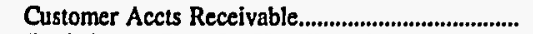 & 1,614 & 1,510 & 0 & 5,645 & 2,534 & 2,280 \\
\hline (less) Accum Prov for Uncollected Acets ................ & 0 & 0 & 0 & 0 & 0 & 11 \\
\hline Fuel Stock \& Exp Undistr.................................................. & 292 & $\mathbf{0}$ & 0 & 0 & 0 & 0 \\
\hline 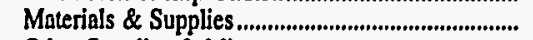 & 0 & 0 & 429 & 922 & 1,486 & 0 \\
\hline 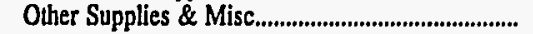 & 0 & 0 & 0 & 0 & 0 & 0 \\
\hline 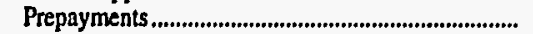 & 0 & 0 & $\mathbf{0}$ & 0 & 14 & $\mathbf{0}$ \\
\hline 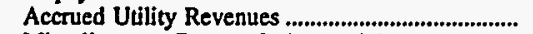 & & 0 & 0 & 0 & 361 & 0 \\
\hline Miscellaneous Current \& Accrued Assets................ & 10,033 & 109 & 1,336 & 0 & 13 & 0 \\
\hline Total Current \& Accrued Assets............................. & 12,100 & 6,919 & $\mathbf{8 , 5 8 3}$ & 17,764 & 8,477 & 3,186 \\
\hline \multicolumn{7}{|l|}{ Deferred Debits } \\
\hline 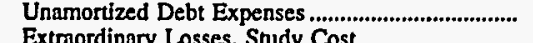 & 1,153 & 2,313 & $\mathbf{0}$ & 0 & 10 & $\mathbf{0}$ \\
\hline & 0 & & $\mathbf{0}$ & 0 & 0 & $\mathbf{0}$ \\
\hline Misc Debt, R \& D Exp, Unamrt Losses.................. & 0 & 0 & 1,625 & 0 & 0 & 0 \\
\hline 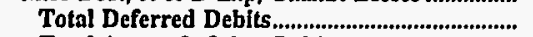 & 1,153 & 2,313 & 1,625 & 0 & 10 & 0 \\
\hline 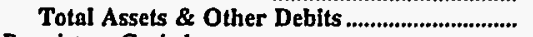 & 29,750 & 23,411 . & 24,944 & 60,727 & 42,358 & 30,577 \\
\hline \multicolumn{7}{|l|}{ Proprietary Capital } \\
\hline 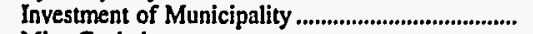 & 0 & 4,265 & 0 & 42,145 & 1,199 & 0 \\
\hline 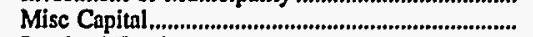 & & 0 & $\mathbf{0}$ & & 0 & 662 \\
\hline 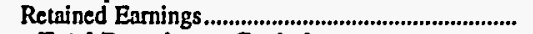 & $-3,374$ & -715 & 20,575 & 3,810 & 35,587 & 11,659 \\
\hline 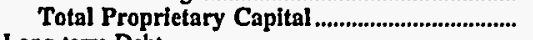 & $-3,374$ & 3,551 & 20,575 & 45,955 & 36,786 & 12,322 \\
\hline \multicolumn{7}{|l|}{ Long-term Debt } \\
\hline Bonds & 31,850 & 18,585 & 0 & 9,475 & 0 & 15,182 \\
\hline 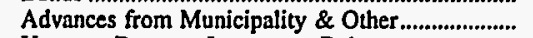 & 917 & 0 & 0 & 121 & 1,860 & 825 \\
\hline 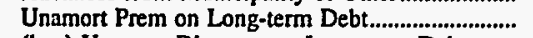 & 0 & 0 & 0 & 0 & 0 & 0 \\
\hline (less) Unamort Discount on Long-term Debt & 3,129 & & 0 & 0 & 0 & 0 \\
\hline 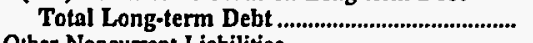 & 29,638 & 18,585 & o & 9,596 & 1,860 & 16,007 \\
\hline \multicolumn{7}{|l|}{ Other Noncurrent Liabilities } \\
\hline 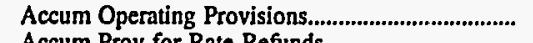 & 0 & 0 & 0 & 0 & 348 & 0 \\
\hline Accum Prov for Rate Refunds.................................. & $\mathbf{0}$ & 0 & 0 & $\mathbf{0}$ & 0 & 0 \\
\hline Total Other Noncurrent Liabilities ............................... & $\mathbf{0}$ & 0 & 0 & $\mathbf{0}$ & 348 & o \\
\hline \multicolumn{7}{|l|}{ Current and Accrued Liabilities } \\
\hline 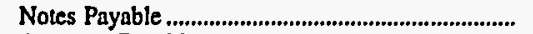 & $\mathbf{0}$ & 0 & 3,646 & $\mathbf{0}$ & 315 & $\mathbf{0}$ \\
\hline 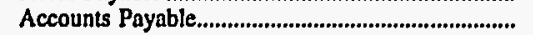 & 989 & 691 & 0 & 3,039 & 2,518 & 1,285 \\
\hline Payables to Assoc Enterprises.................................. & 0 & 0 & 442 & 0 & 0 & 1,20J \\
\hline 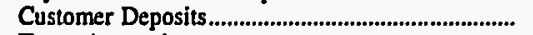 & 0 & 109 & 20 & 1,273 & 299 & 464 \\
\hline 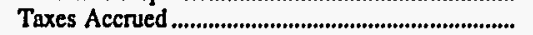 & 0 & 0 & 0 & 0 & 0 & 0 \\
\hline 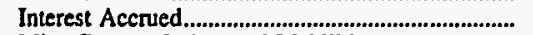 & 948 & 85 & 261 & 161 & 24 & 231 \\
\hline Misc Cument \& Accrued Liabilities .............................. & 1,548 & 390 & 0 & 702 & 207 & 268 \\
\hline Total Current \& Accrued Llabilities .................... & $\mathbf{3 , 4 8 6}$ & 1,275 & 4,370 & 5,175 & 3,364 & 2,248 \\
\hline \multicolumn{7}{|l|}{ Deferred Credits } \\
\hline 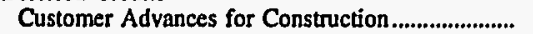 & 0 & 0 & 0 & 0 & 0 & 0 \\
\hline 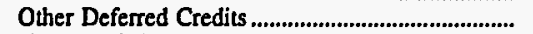 & 0 & 0 & 0 & 0 & 0 & 0 \\
\hline Unamort Gain on Reacgr Debt............................... & 0 & 0 & 0 & 0 & 0 & 0 \\
\hline Total Deferred Credits....................................................... & & & & & & \\
\hline Total Llabilities and Other Credits.................. & 29,750 & 23,411 & 24,944 & 60,727 & 42,358 & 30,577 \\
\hline
\end{tabular}

Note: Totals may not equal sum of components because of independent rounding.

Source: Energy Information Administration, Form EIA-412, "Annual Report of Public Electric Utilities." 
Table 22. Balance Sheet by Major U.S. Publicly Owned Electric Utility Within State at End of Period, 1996

(Thousand Dollars)

\begin{tabular}{|c|c|c|c|c|c|c|}
\hline Item & $\begin{array}{l}\text { Virginia } \\
\begin{array}{c}\text { Martinsville } \\
\text { City of }\end{array} \\
\text { June } 30\end{array}$ & $\begin{array}{l}\text { Virginia } \\
\text { Radford } \\
\text { City of } \\
\text { June } 30 \\
\end{array}$ & $\begin{array}{l}\text { Virginia } \\
\text { Salem } \\
\text { City of } \\
\text { June } 30 \\
\end{array}$ & $\begin{array}{c}\text { Virginia } \\
\text { Virginia } \\
\text { Tech } \\
\text { Electric } \\
\text { Service } \\
\text { June } 30 \\
\end{array}$ & $\begin{array}{l}\text { Washington } \\
\text { Centralia } \\
\text { City of } \\
\text { December } 31 \\
\end{array}$ & $\begin{array}{l}\text { Washington } \\
\text { Ellensburg } \\
\text { City of } \\
\text { December } 31\end{array}$ \\
\hline \multicolumn{7}{|l|}{ Electric Utility Plant } \\
\hline 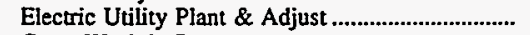 & 18,373 & 15,298 & 21,463 & 0 & 21,972 & 14,591 \\
\hline 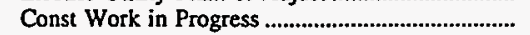 & & 0 & 0 & 0 & 0 & \\
\hline (less) Depr, Amort, and Depletion.................................. & 8,508 & 9,406 & 11,566 & 0 & 8,592 & 6,693 \\
\hline Net Electric Utility Plant & 9,865 & 5,892 & 9,897 & 0 & 13,381 & 7,899 \\
\hline Nuclear Fuel......................................................... & 0 & 0 & 0 & 0 & 0 & 0 \\
\hline 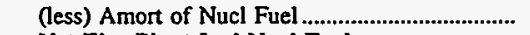 & 0 & 0 & 0 & 0 & $\mathbf{0}$ & 0 \\
\hline Net Elec Plant Incl Nucl Fuel ............................. & 9,865 & 5,892 & 9,897 & 0 & 13,381 & $\mathbf{7 , 8 9 9}$ \\
\hline \multicolumn{7}{|l|}{ Other Property \& Investments } \\
\hline Nonutility Property ................... & 0 & 0 & 0 & 0 & 69 & 332 \\
\hline (less) Accum Provisions for Depr \& Amort .......... & 0 & 0 & 0 & 0 & 0 & 119 \\
\hline 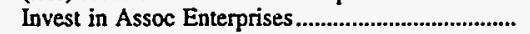 & 0 & 0 & 0 & 0 & 0 & 0 \\
\hline 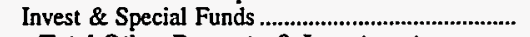 & 0 & 0 & 1,168 & 0 & 1,062 & 0 \\
\hline Total Other Property \& Investments................ & 0 & 0 & 1,168 & $\mathbf{0}$ & 1,131 & 212 \\
\hline \multicolumn{7}{|l|}{ Current and Accrued Assets } \\
\hline Cash, Working Funds \& Investments............................ & 2,129 & 4,806 & 1,761 & 3,574 & -216 & 1,308 \\
\hline 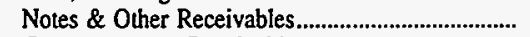 & 0 & 3,938 & 63 & 20 & 21 & 0 \\
\hline 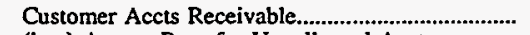 & 1.510 & 1,386 & 889 & 449 & 994 & 1,204 \\
\hline (less) Accum Prov for Uncollected Accts.............. & 21 & 101 & 47 & 0 & 10 & 9 \\
\hline 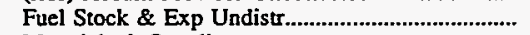 & 0 & 0 & 0 & 0 & 0 & \\
\hline 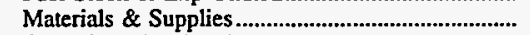 & 0 & 217 & 554 & 320 & 225 & 374 \\
\hline 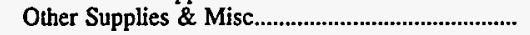 & 0 & 0 & 0 & 0 & 0 & 0 \\
\hline 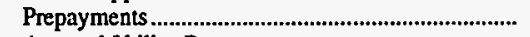 & 172 & 0 & 0 & 3 & 0 & 0 \\
\hline 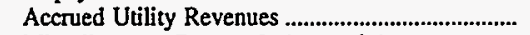 & 0 & 0 & 1,341 & 0 & 0 & 0 \\
\hline Miscellaneous Current \& Accrued Assets................. & 0 & 0 & 0 & 0 & 7 & \\
\hline Total Current \& Accrued Assets............................ & 3,790 & 10,245 & 4,561 & 4,365 & 1,020 & 2,880 \\
\hline \multicolumn{7}{|l|}{ Deferred Debits } \\
\hline Unamortized Debt Expenses............... & 0 & $\mathbf{0}$ & $\mathbf{0}$ & 2,360 & $\mathbf{0}$ & $\mathbf{0}$ \\
\hline 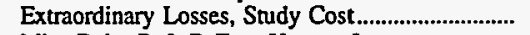 & 0 & 0 & 0 & 0 & 0 & 0 \\
\hline 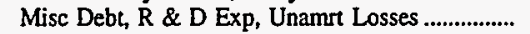 & 0 & 0 & $\mathbf{0}$ & 0 & 0 & 0 \\
\hline 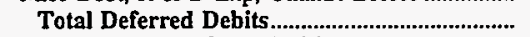 & 0 & 0 & 0 & 2,360 & $\mathbf{0}$ & \\
\hline Total Assets \& Other Debits ................................... & 13,655 & 16,138 & 15,626 & 6,725 & 15,532 & 10,991 \\
\hline \multicolumn{7}{|l|}{ Proprietary Capital } \\
\hline 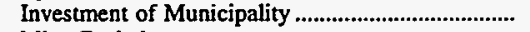 & 0 & 0 & 0 & 0 & 532 & 0 \\
\hline 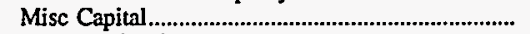 & 0 & 0 & 0 & 0 & 0 & \\
\hline 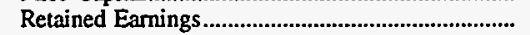 & 13,412 & 11,849 & 6,211 & 3,283 & 11,135 & 9,808 \\
\hline Total Proprietary Capital ........................................... & 13,412 & 11,849 & 6,211 & 3,283 & 11,667 & 9,808 \\
\hline \multicolumn{7}{|l|}{ Long-term Debt } \\
\hline 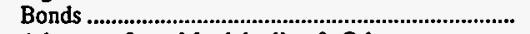 & 0 & 3,000 & 7,725 & 2,360 & 2,475 & 0 \\
\hline Advances from Municipality \& Other......................... & $\mathbf{0}$ & 0 & 35 & 0 & $\mathbf{0}$ & $\mathbf{0}$ \\
\hline Unamort Prem on Long-term Debt.................................. & 0 & 0 & 0 & 0 & 0 & 0 \\
\hline (less) Unamor Discount on Long-term Debt & 0 & 0 & 49 & 0 & 11 & 0 \\
\hline Total Long-term Debt........ & 0 & 3,000 & $\mathbf{7 , 7 1 1}$ & 2,360 & 2,464 & $\mathbf{0}$ \\
\hline \multicolumn{7}{|l|}{ Other Noncurrent Liabilities } \\
\hline Accum Operating Provisions.......................................... & 0 & $\mathbf{0}$ & 0 & $\mathbf{0}$ & 339 & 0 \\
\hline 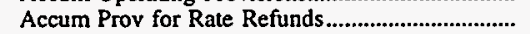 & 0 & 0 & 0 & $\mathbf{0}$ & 0 & 0 \\
\hline Total Other Noncurrent Liabilities........................ & 0 & 0 & $\mathbf{0}$ & 0 & 339 & 0 \\
\hline \multicolumn{7}{|l|}{ Current and Accrued Liabilities } \\
\hline 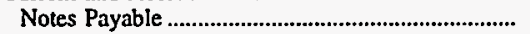 & 0 & 0 & 0 & 0 & 0 & 0 \\
\hline Accounts Payable & 30 & 1,060 & 1,269 & 798 & 707 & 1,062 \\
\hline 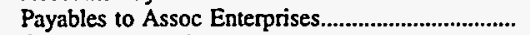 & 0 & 0 & 0 & 0 & 0 & 0 \\
\hline 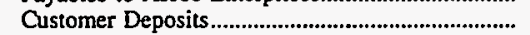 & 172 & 123 & 252 & 0 & 316 & 0 \\
\hline 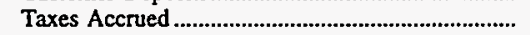 & 0 & 0 & 0 & 0 & 0 & 0 \\
\hline 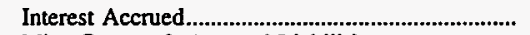 & $\mathbf{0}$ & 0 & 42 & 14 & 12 & 0 \\
\hline Misc Current \& Accrued Liabilities ............................... & 40 & 106 & 140 & 270 & & 121 \\
\hline Total Current \& Accrued Liabilities ................ & 242 & 1,289 & 1,704 & 1,082 & 1,035 & 1,183 \\
\hline \multicolumn{7}{|l|}{ Deferred Credits } \\
\hline Customer Advances for Construction ....................... & 0 & 0 & 0 & 0 & 16 & 0 \\
\hline Other Deferred Credits ................................................. & 0 & 0 & 0 & 0 & 11 & 0 \\
\hline 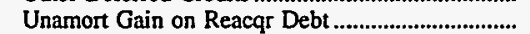 & 0 & 0 & 0 & 0 & 0 & 0 \\
\hline 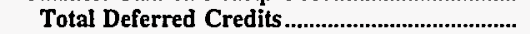 & 0 & o & 0 & $\mathbf{0}$ & 27 & \\
\hline Total Liabilities and Other Credits.................... & 13,655 & 16,138 & 15,626 & 6,725 & 15,532 & 10,991 \\
\hline
\end{tabular}

Note: Totals may not equal sum of components because of independent rounding.

Source: Energy Information Administration, Form EIA-412, "Annual Report of Public Electric Utilities." 
Table 22. Balance Sheet by Major U.S. Publicly Owned Electric Utility Within State at End of Period, 1996

(Thousand Dollars)

\begin{tabular}{|c|c|c|c|c|c|c|}
\hline Item & $\begin{array}{l}\text { Washington } \\
\begin{array}{l}\text { Port Angeles } \\
\text { City of }\end{array} \\
\text { December } 31\end{array}$ & $\begin{array}{l}\text { Washington } \\
\text { PUD No } 1 \\
\text { of } \\
\text { Benton } \\
\text { County } \\
\text { December 31 }\end{array}$ & $\begin{array}{l}\text { Washington } \\
\text { PUD No } 1 \\
\text { of } \\
\text { Chelan } \\
\text { County } \\
\text { December } 31\end{array}$ & $\begin{array}{l}\text { Washington } \\
\text { PUD No } 1 \text { of } \\
\text { Clallam } \\
\text { County }\end{array}$ & $\begin{array}{l}\text { Washington } \\
\text { PUD No } 1 \\
\text { of } \\
\text { Clark } \\
\text { County } \\
\text { December } 31\end{array}$ & $\begin{array}{l}\text { Washington } \\
\text { PUD No } 1 \text { of } \\
\text { Cowlitz } \\
\text { County } \\
\text { December } 31\end{array}$ \\
\hline \multicolumn{7}{|l|}{ Electric Utility Plant } \\
\hline 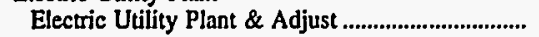 & 21,542 & 103,505 & 955,911 & 67,117 & 273,306 & 129,387 \\
\hline 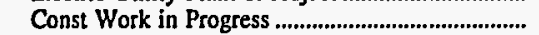 & 1,608 & 1,791 & 15,592 & 3,387 & 5,027 & 704 \\
\hline (less) Depr, Amort, and Depletion............................... & 8,443 & 41,896 & 190,709 & 37,279 & 107,215 & 57,617 \\
\hline Net Electric Utility Plant ................................ & $\mathbf{1 4 , 7 0 7}$ & 63,400 & $\mathbf{7 8 0 , 7 9 4}$ & 33,225 & 171,118 & $\mathbf{7 2 , 4 7 3}$ \\
\hline 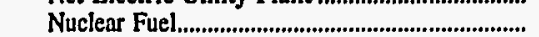 & & & & 0 & 0 & \\
\hline (less) Amort of Nucl Fuel ......................................... & 0 & 0 & 0 & 0 & 0 & 0 \\
\hline Net Elec Plant Incl Nucl Fuel ............................... & 14,707 & 63,400 & 780,794 & 33,225 & 171,118 & 72,473 \\
\hline \multicolumn{7}{|l|}{ Other Property \& Investments } \\
\hline Nonutility Property................................................ & 0 & 0 & 0 & 0 & 3,914 & \\
\hline (less) Accum Provisions for Depr \& Amort ........... & 0 & 0 & 0 & 0 & 121 & 0 \\
\hline 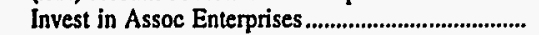 & $\mathbf{0}$ & 0 & 6,762 & 0 & $\mathbf{0}$ & 1,135 \\
\hline Invest \& Special Funds ........................................ & 0 & 16,656 & 93,018 & 4,339 & 9,141 & 2,053 \\
\hline Total Other Property \& Investments............... & $\mathbf{0}$ & 16,656 & 99,780 & 4,339 & 12,934 & $\mathbf{3 , 1 8 8}$ \\
\hline \multicolumn{7}{|l|}{ Current and Accrued Assets } \\
\hline 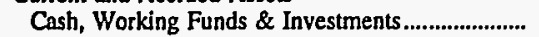 & 6,522 & 12,591 & 32,307 & 4,910 & 7,809 & 24,789 \\
\hline 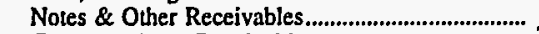 & 509 & 483 & $\mathbf{7 , 3 4 5}$ & 419 & 1,759 & 1,861 \\
\hline 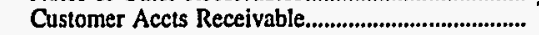 & 2,503 & 5,998 & 9,297 & 1,914 & 25,241 & 9,181 \\
\hline (less) Accum Prov for Uncollected Accts.............. & 0 & 21 & 30 & 38 & 1,541 & 43 \\
\hline 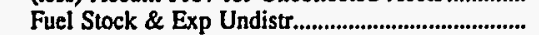 & o & 0 & 0 & 0 & 0 & 0 \\
\hline 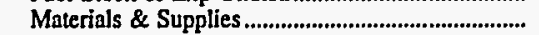 & 976 & 1,813 & 5,796 & 1,132 & 2,382 & 1,747 \\
\hline 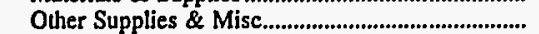 & 0 & 231 & -73 & 235 & 145 & 14 \\
\hline Prepayments ................................... & $\mathbf{0}$ & 59 & 606 & 286 & 671 & 513 \\
\hline Accrued Utility Revenues .......................................... & 0 & 31 & 0 & 0 & 8,983 & 0 \\
\hline Miscellaneous Current \& Accrued Assets............... & 0 & 796 & 1,115 & 54 & & 99 \\
\hline Total Current \& Accrued Assets......................... & 10,511 & 21,981 & 56,363 & 8,912 & 45,448 & 38,160 \\
\hline \multicolumn{7}{|l|}{ Deferred Debits } \\
\hline Unamortized Debt Expenses & 52 & 794 & 15,229 & 152 & 2,284 & 1 \\
\hline Extraordinary Losses, Study Cost. & 0 & 0 & 38 & 0 & 0 & 0 \\
\hline 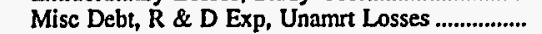 & $\mathbf{0}$ & 118 & 33,452 & 0 & 2,342 & 46 \\
\hline 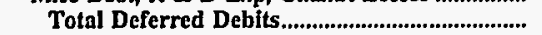 & 52 & 911 & 48,719 & 152 & 4,626 & 47 \\
\hline 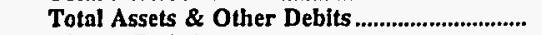 & 25,270 & 102,949 & 985,656 & 46,628 & 234,126 & 113,869 \\
\hline \multicolumn{7}{|l|}{ Proprietary Capital } \\
\hline 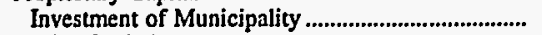 & 987 & $\mathbf{0}$ & 24,196 & 0 & $\mathbf{0}$ & 0 \\
\hline 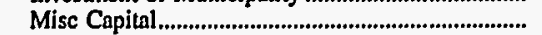 & 0 & 0 & & 0 & 0 & 0 \\
\hline 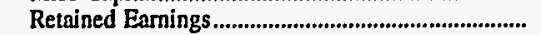 & 12,449 & 36,093 & 238,223 & 33,241 & 72,038 & 81,075 \\
\hline 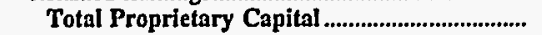 & 13,436 & 36,093 & 262,419 & 33,241 & $\mathbf{7 2 , 0 3 8}$ & 81,075 \\
\hline \multicolumn{7}{|l|}{ Long-term Debt } \\
\hline Bonds .................. & 5,390 & 44,920 & 450,867 & 6,006 & 92,200 & 1,080 \\
\hline 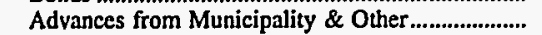 & 0 & 2,132 & 205,305 & 30 & 2,520 & 0 \\
\hline 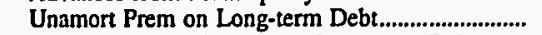 & 0 & 721 & & 0 & 0 & 0 \\
\hline (less) Unamort Discount on Long-term Debt & 0 & 327 & 4,617 & 0 & 1 & 1 \\
\hline Total Long-term Debt .............................................. & 5,390 & 47,446 & 651,555 & 6,036 & 94,719 & 1,079 \\
\hline \multicolumn{7}{|l|}{ Other Noncurrent Liabilities } \\
\hline 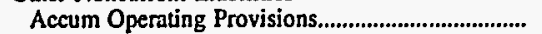 & 231 & $\mathbf{0}$ & $\mathbf{0}$ & 0 & $\mathbf{0}$ & 1,895 \\
\hline 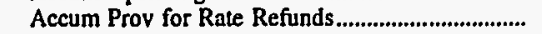 & 0 & 0 & 0 & 0 & $\mathbf{0}$ & 979 \\
\hline Total Other Noncurrent Liabilities....................... & 231 & $\mathbf{0}$ & $\mathbf{0}$ & $\mathbf{0}$ & 0 & $\mathbf{2 , 8 7 4}$ \\
\hline \multicolumn{7}{|l|}{ Current and Accrued Liabilities } \\
\hline Notes Payable ............................. & 0 & 3,658 & 0 & 0 & 4,268 & 0 \\
\hline 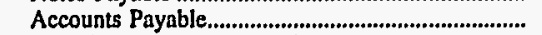 & 3,027 & 4,232 & 24,949 & 3,753 & 22,312 & 10,855 \\
\hline Payables to Assoc Enterprises...................................... & 41 & 0 & 13,021 & 0 & 0 & 65 \\
\hline Customer Deposits................................................. & 196 & 612 & 228 & 278 & 2 & 315 \\
\hline 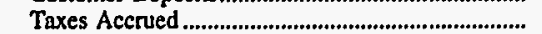 & 112 & 1,959 & 3,347 & 772 & 3,673 & 2,080 \\
\hline Interest Accrued................................................ & 196 & 771 & 2,452 & 157 & 2,631 & 14 \\
\hline Misc Current \& Accrued Liabilities ........................ & 291 & 1,266 & 16,165 & 398 & 6,816 & 460 \\
\hline Total Current \& Accrued Liabilities .................... & 3,863 & 12,499 & 60,162 & 5,358 & 39,703 & 13,789 \\
\hline \multicolumn{7}{|l|}{ Deferred Credits } \\
\hline Customer Advances for Construction......................... & 2,350 & 6,858 & & 61 & 25,669 & 14,970 \\
\hline 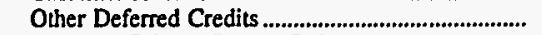 & 0 & 53 & 11,520 & 1,932 & 1,999 & 82 \\
\hline 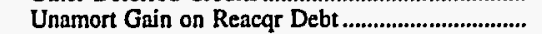 & 0 & 0 & & 0 & 0 & \\
\hline 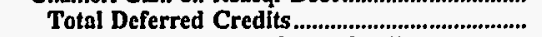 & 2,350 & 6,912 & 11,520 & 1,993 & 27,668 & 15,052 \\
\hline Total Liabilities and Other Credits....................... & 25,270 & 102,949 & 985,656 & 46,628 & 234,126 & 113,869 \\
\hline
\end{tabular}

Note: Totals may not equal sum of components because of independent rounding.

Source: Energy Information Administration, Form EIA-412, "Annual Report of Public Electric Utilities." 
Table 22. Balance Sheet by Major U.S. Publicly Owned Electric Utility Within State at End of Period, 1996

(Thousand Dollars)

\begin{tabular}{|c|c|c|c|c|c|c|}
\hline Item & $\begin{array}{l}\text { Washington } \\
\text { PUD No } 1 \text { of } \\
\text { Douglas } \\
\text { County } \\
\text { December } 31\end{array}$ & $\begin{array}{l}\text { Washington } \\
\text { PUD No } 1 \text { of } \\
\text { Franklin } \\
\text { County } \\
\text { December } 31\end{array}$ & $\begin{array}{c}\text { Washington } \\
\text { PUD No } 1 \\
\text { of } \\
\text { Grays } \\
\text { Harbor Cnty } \\
\text { December } 31\end{array}$ & $\begin{array}{l}\text { Washington } \\
\text { PUD No } 1 \\
\text { of } \\
\text { Klickitat } \\
\text { County } \\
\text { December } 31\end{array}$ & $\begin{array}{l}\text { Washington } \\
\text { PUD No } 1 \\
\text { of } \\
\text { Lewis } \\
\text { County } \\
\text { December } 31\end{array}$ & $\begin{array}{l}\text { Washington } \\
\text { PUD No } 1 \text { of } \\
\text { Okanogan } \\
\text { County } \\
\text { December } 31\end{array}$ \\
\hline \multicolumn{7}{|l|}{ Electric Utility Plant } \\
\hline 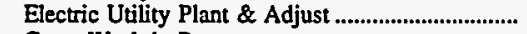 & 294,999 & 51,591 & 110,609 & 41,769 & 70,150 & 55,743 \\
\hline 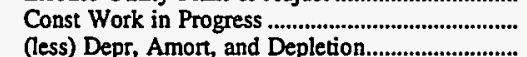 & $\begin{array}{r}1,142 \\
60,562\end{array}$ & $\begin{array}{r}1,410 \\
19,304\end{array}$ & $\begin{array}{r}8,497 \\
40,280\end{array}$ & $\begin{array}{r}4,892 \\
15,503\end{array}$ & $\begin{array}{r}9,461 \\
17,638\end{array}$ & $\begin{array}{r}2,214 \\
29,207\end{array}$ \\
\hline Net Electric Utility Plant .................................... & 235,579 & 33,697 & $\mathbf{7 8 , 8 2 6}$ & 31,158 & 61,973 & $\begin{array}{ll}28,201 \\
28,751\end{array}$ \\
\hline 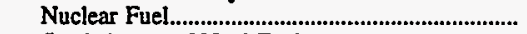 & & & 0 & 0 & 0 & \\
\hline 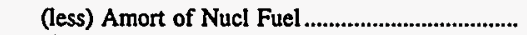 & 0 & 0 & 0 & 0 & 0 & \\
\hline $\begin{array}{l}\text { Net Elec Plant Incl Nucl Fuel ............................... } \\
\text { Other Property \& Investments }\end{array}$ & 235,579 & 33,697 & 78,826 & 31,158 & 61,973 & 28,751 \\
\hline 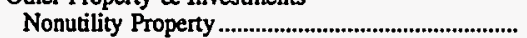 & 0 & 0 & 121 & 0 & 0 & 0 \\
\hline (less) Accum Provisions for Depr \& Amort .......... & $\mathbf{0}$ & $\mathbf{0}$ & 0 & 0 & 0 & 0 \\
\hline 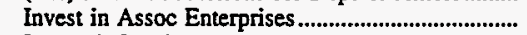 & 0 & 0 & 0 & 0 & 0 & \\
\hline 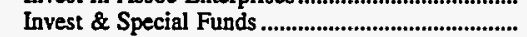 & 29,533 & 7,130 & 5,137 & 3,257 & 11,766 & 4,513 \\
\hline Total Other Property \& Investments................ & 29,533 & $\mathbf{7 , 1 3 0}$ & 5,258 & 3,257 & 11,766 & 4,513 \\
\hline Cash, Working Funds \& Investments........................ & 21,870 & 9,412 & 19,277 & 11,997 & 6,793 & 12,006 \\
\hline 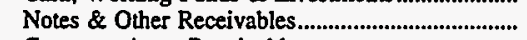 & 1,938 & 215 & 0 & 0 & 0 & 106 \\
\hline Customer Accts Receivable........................................ & 854 & 3,456 & 5,409 & 1,608 & 3,661 & 1,062 \\
\hline (less) Accum Prov for Uncollected Accts............... & 11 & 6 & 101 & 28 & 165 & 14 \\
\hline 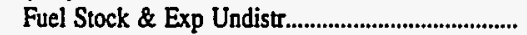 & 0 & 0 & 0 & 0 & 0 & 0 \\
\hline Materials \& Supplies & 1,649 & 1,852 & 3,205 & 723 & 2,121 & 1,581 \\
\hline 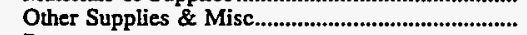 & 25 & 0 & 0 & 0 & 280 & -31 \\
\hline 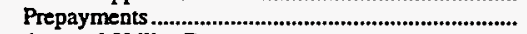 & 614 & 49 & 62 & 11 & 22 & 23 \\
\hline 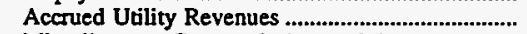 & & 0 & 0 & 330 & 1,797 & \\
\hline Miscellaneous Current \& Accrued Assets............... & 1,806 & 727 & 0 & 0 & & 0 \\
\hline Total Current \& Accrued Assets......................... & 28,745 & 15,704 & 27,852 & 14,640 & 14,510 & 14,733 \\
\hline \multicolumn{7}{|l|}{ Deferred Debits } \\
\hline 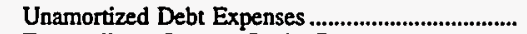 & 2,357 & 517 & 311 & 648 & $\mathbf{0}$ & 0 \\
\hline 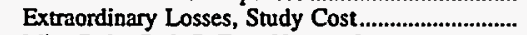 & 272 & 0 & 99 & 6,159 & 0 & 67 \\
\hline 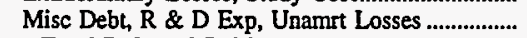 & 30,068 & 10 & 40 & -470 & 91 & 314 \\
\hline 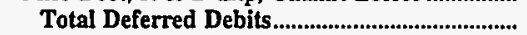 & 32,697 & 527 & 449 & 6,337 & 91 & 381 \\
\hline Total Assets \& Other Debits ................................... & 326,555 & 57,059 & 112,383 & 55,393 & 88,339 & 48,378 \\
\hline \multicolumn{7}{|l|}{ Proprietary Capital } \\
\hline 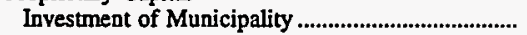 & 0 & 1,958 & $\mathbf{0}$ & 6,249 & 0 & \\
\hline 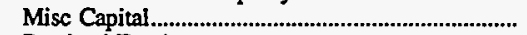 & 0 & & 0 & 0 & 1,310 & 0 \\
\hline 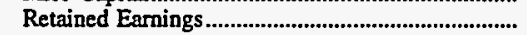 & 114,282 & 17,415 & 82,034 & 16,294 & 79,360 & 43,524 \\
\hline 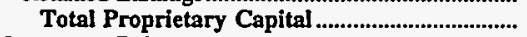 & 114,282 & 19,373 & 82,034 & 22,543 & 80,670 & 43,524 \\
\hline \multicolumn{7}{|l|}{ Long-term Debt } \\
\hline Bonds ................. & 195,355 & 29,480 & 9,995 & 17,320 & 0 & 0 \\
\hline 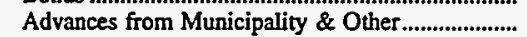 & 0 & 0 & 770 & 10,662 & 766 & 14 \\
\hline Unamort Prem on Long-term Debt........................ & 0 & 0 & 0 & 0 & 0 & 0 \\
\hline (less) Unamort Discount on Long-term Debt & 0 & 569 & 0 & 0 & 0 & 0 \\
\hline 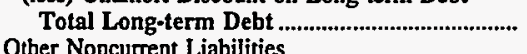 & 195,355 & 28,911 & 10,765 & 27,982 & 766 & 14 \\
\hline \multicolumn{7}{|l|}{ Other Noncurrent Liabilities } \\
\hline 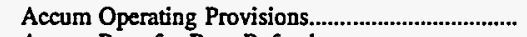 & 0 & 1,099 & 0 & 0 & 0 & 983 \\
\hline Accum Prov for Rate Refunds................................ & 0 & & 0 & 0 & 0 & \\
\hline 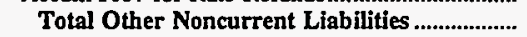 & o & 1,099 & 0 & 0 & 0 & 983 \\
\hline \multicolumn{7}{|l|}{ Current and Accrued Liabilities } \\
\hline 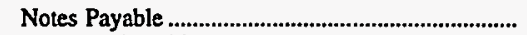 & 1,583 & 2,175 & 1,337 & 0 & 0 & 946 \\
\hline 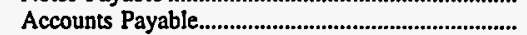 & 1,546 & 60 & 9,551 & 2,784 & 162 & 1,664 \\
\hline 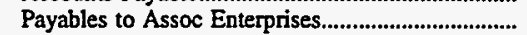 & 0 & 0 & 0 & 0 & 2,034 & 0 \\
\hline 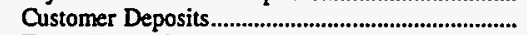 & 150 & 307 & 721 & 173 & 406 & 204 \\
\hline 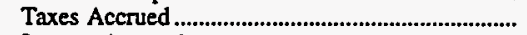 & 1,387 & 900 & 1,306 & 384 & 865 & 507 \\
\hline 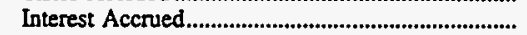 & 3,354 & 603 & 499 & 321 & 0 & 0 \\
\hline Misc Current \& Accrued Liabilities ................................... & 2,699 & 3,575 & 1,950 & 953 & 2,775 & 538 \\
\hline Total Current \& Accrued Liabilities ................. & 10,719 & 7,619 & 15,365 & 4,615 & 6,243 & $\mathbf{3 , 8 5 8}$ \\
\hline \multicolumn{7}{|l|}{ Deferred Credits } \\
\hline Customer Advances for Construction ........................ & 37 & 0 & 31 & 14 & 0 & \\
\hline 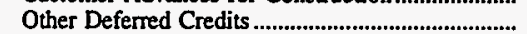 & 5,533 & 57 & 4,188 & 240 & 660 & 0 \\
\hline Unamort Gain on Reacqr Debt ..................................... & 628 & 0 & 0 & 0 & 0 & 0 \\
\hline Total Deferred Credits............................................. & 6,199 & 57 & 4,220 & 254 & 660 & \\
\hline Total Liabilities and Other Credits..................... & 326,555 & 57,059 & 112,383 & 55,393 & 88,339 & 48,378 \\
\hline
\end{tabular}

Note: Totals may not equal sum of components because of independent rounding.

Source: Energy Information Administration, Form EIA-412, "Annual Report of Public Electric Utilities." 
Table 22. Balance Sheet by Major U.S. Publicly Owned Electric Utility Within State at End of Period, 1996

(Thousand Dollars)

\begin{tabular}{|c|c|c|c|c|c|c|}
\hline Item & $\begin{array}{l}\text { Washington } \\
\text { PUD No } 1 \text { of } \\
\text { Pend Oreille } \\
\text { Cnty } \\
\text { December } 31\end{array}$ & $\begin{array}{l}\text { Washington } \\
\text { PUD No } 1 \text { of } \\
\text { Snohomish } \\
\text { County } \\
\text { December } 31\end{array}$ & $\begin{array}{l}\text { Washington } \\
\text { PUD No } 1 \text { of } \\
\text { Whatcom } \\
\text { County } \\
\text { December } 31\end{array}$ & $\begin{array}{l}\text { Washington } \\
\text { PUD No } 2 \\
\text { of } \\
\text { Grant } \\
\text { County } \\
\text { December } 31\end{array}$ & $\begin{array}{l}\text { Washington } \\
\text { PUD No } 2 \text { of } \\
\text { Pacific } \\
\text { County } \\
\text { December } 31\end{array}$ & $\begin{array}{l}\text { Washington } \\
\text { PUD No } 3 \\
\text { of } \\
\text { Mason } \\
\text { County } \\
\text { December } 31\end{array}$ \\
\hline \multicolumn{7}{|l|}{ Electric Utility Plant } \\
\hline 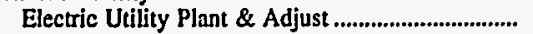 & 49,615 & $1,003,372$ & 2,648 & 711,004 & 30,480 & 78,087 \\
\hline Const Work in Progress ... & 22,071 & 30,303 & 35 & 35,925 & 9,075 & 5,107 \\
\hline (less) Depr, Amort, and Depletion.................................. & 17,983 & 237,940 & 732 & 249,908 & 17,254 & 21,685 \\
\hline Net Electric Utility Plant ............................... & $\mathbf{5 3 , 7 0 3}$ & 795,734 & 1,950 & 497,021 & 22,301 & 61,509 \\
\hline 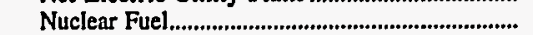 & & & 0 & 0 & 0 & 0 \\
\hline (less) Amort of Nucl Fuel ............................................ & & & & & $\mathbf{0}$ & \\
\hline Net Elec Plant Incl Nucl Fuel .................................. & 53,703 & 795,734 & 1,950 & 497,021 & 22,301 & 61,509 \\
\hline \multicolumn{7}{|l|}{ Other Property \& Investments } \\
\hline Nonutility Property .................................. & 36 & 0 & 0 & $\mathbf{0}$ & $\mathbf{0}$ & 0 \\
\hline (less) Accum Provisions for Depr \& Amort ......... & 0 & 0 & 0 & 0 & 0 & 0 \\
\hline 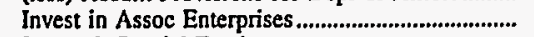 & 0 & 61,347 & $\mathbf{0}$ & 0 & 0 & 0 \\
\hline 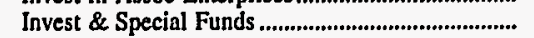 & 5,170 & 171,880 & 1,333 & 91,631 & 5,657 & 4,400 \\
\hline Total Other Property \& Investments................. & 5,207 & 233,227 & 1,333 & 91,631 & 5,657 & 4,400 \\
\hline \multicolumn{7}{|l|}{ Current and Accrued Assets } \\
\hline Cash, Working Funds \& Investments........................ & 12,468 & 51,215 & 0 & 194,123 & 36 & 10,144 \\
\hline 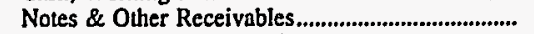 & 4,195 & 10,819 & 308 & 33,240 & 181 & 447 \\
\hline Customer Accts Receivable.............................................. & 405 & 47,699 & 792 & 3,210 & 1,117 & 1,781 \\
\hline (less) Accum Prov for Uncollected Accts............. & 7 & 1,594 & 0 & 355 & 38 & 75 \\
\hline Fuel Stock \& Exp Undistr............................................... & $\mathbf{0}$ & 2,282 & 0 & 0 & 0 & \\
\hline 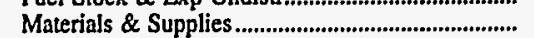 & 727 & 6,615 & 0 & 4,141 & 2,294 & 1,654 \\
\hline 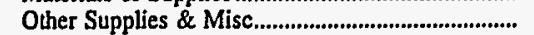 & 0 & 19 & $\mathbf{0}$ & 796 & 37 & 54 \\
\hline 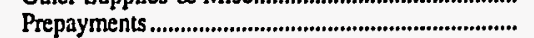 & 230 & 250 & 15 & 742 & 0 & 17 \\
\hline Accrued Utility Revenues ........................................ & 0 & 0 & 0 & 0 & 1 & 0 \\
\hline Miscellaneous Current \& Accrued Assets............... & 98 & 1,529 & 341 & 2,469 & 0 & \\
\hline Total Current \& Accrued Assets....................... & 18,115 & 118,834 & 1,456 & 238,366 & $\mathbf{3 , 6 2 8}$ & 14,030 \\
\hline \multicolumn{7}{|l|}{ Deferred Debits } \\
\hline Unamortized Debt Expense & 402 . & 7,498 & 0 & 5,349 & 1,057 & 250 \\
\hline 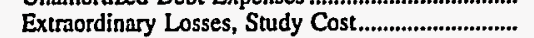 & 0 & 29 & o & 1,904 & 0 & 266 \\
\hline Misc Debt, R \& D Exp, Unamrt Losses .................... & 6,603 & 219,947 & 0 & 4,218 & 157 & \\
\hline Total Deferred Debits............................................. & 7,005 & 227,473 & 0 & 11,471 & 1,214 & 516 \\
\hline 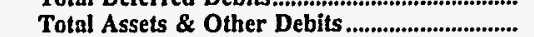 & 84,030 & $1,375,269$ & 4,739 & 838,488 & 32,801 & 80,455 \\
\hline \multicolumn{7}{|l|}{ Proprietary Capital } \\
\hline 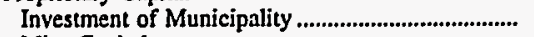 & 0 & 0 & 0 & $\mathbf{0}$ & & \\
\hline 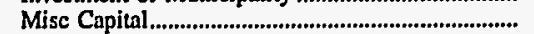 & 0 & 0 & 1,547 & $\mathbf{0}$ & 4,205 & \\
\hline Retained Eamings......................................................... & 42,813 & 238,445 & 2,283 & 286,360 & 19,586 & 44,534 \\
\hline 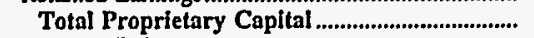 & 42,813 & 238,445 & $\mathbf{3}, 830$ & 286,360 & 23,792 & 44,534 \\
\hline \multicolumn{7}{|l|}{ Long-term Debt } \\
\hline ...................................... & 27,000 & 713,969 & 0 & 460,900 & 4,775 & 14,890 \\
\hline n Municipality \& Other...................... & 4,300 & 17,782 & $\mathbf{0}$ & 3,200 & 582 & \\
\hline Unamort Prem on Long-term Debt.............................. & 0 & 364 & $\mathbf{0}$ & 140 & 0 & 0 \\
\hline (less) Unamort Discount on Long-term Debt & 462 & 13,149 & 0 & 12,696 & 0 & \\
\hline 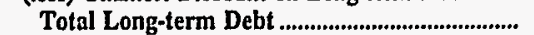 & 30,837 & 718,966 & 0 & 451,544 & 5,357 & 14,890 \\
\hline \multicolumn{7}{|l|}{ Other Noncurrent Liabilities } \\
\hline Accum Operating Provision & 0 & 1,263 & 0 & 0 & 0 & 0 \\
\hline Accum Prov for Rate Refunds... & 0 & & 0 & 0 & 0 & \\
\hline Total Other Noncurrent Liabilities ................... & 0 & 1,263 & $\mathbf{0}$ & $\mathbf{0}$ & $\mathbf{0}$ & o \\
\hline \multicolumn{7}{|l|}{ Current and Accrued Liabilities } \\
\hline Notes Payable ................................. & 307 & 23,873 & $\mathbf{0}$ & 922 & 56 & 2,512 \\
\hline 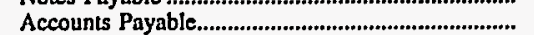 & 3,481 & 38,230 & 753 & 8,393 & 2,010 & 2,275 \\
\hline Payables to Assoc Enterprises.................................. & 2,449 & 264 & 0 & 28,462 & 0 & \\
\hline Customer Deposits...... & 87 & 622 & $\mathbf{0}$ & 699 & 351 & 252 \\
\hline 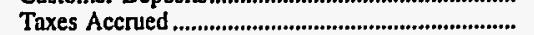 & 588 & 7,961 & 156 & 3,883 & 46 & 771 \\
\hline 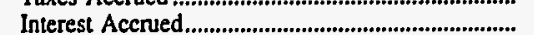 & 839 & 23,888 & 0 & 11,574 & 232 & 456 \\
\hline Misc Current \& Accrued Liabilities ......................... & 873 & 10,533 & 0 & 46,159 & & 1,079 \\
\hline Total Current \& Accrued Liabilities ................ & 8,624 & 105,370 & 909 & 100,093 & 2,695 & 7,347 \\
\hline \multicolumn{7}{|l|}{ Deferred Credits } \\
\hline 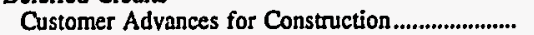 & 520 & & $\mathbf{0}$ & 330 & 567 & 949 \\
\hline Other Deferred Credits ............................................. & 1,235 & 310,203 & 0 & 161 & 1 & 12,735 \\
\hline Unamort Gain on Reacgr Debt .................................... & & 1,023 & 0 & 0 & 389 & \\
\hline Total Deferred Credits........................................... & 1,755 & 311,226 & & 491 & 957 & 13,684 \\
\hline 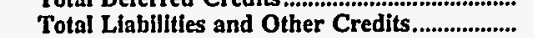 & 84,030 & $1,375,269$ & 4,739 & 838,488 & 32,801 & 80,455 \\
\hline
\end{tabular}

Note: Totals may not equal sum of components because of independent rounding.

Source: Energy Information Administration, Form EIA-412, "Annual Report of Public Electric Utilities." 
Table 22. Balance Sheet by Major U.S. Publicly Owned Electric Utility Within State at End of Period, 1996

(Thousand Dollars)

\begin{tabular}{|c|c|c|c|c|c|c|}
\hline Item & $\begin{array}{l}\text { Washington } \\
\text { Richland } \\
\text { City of } \\
\text { December } 31\end{array}$ & $\begin{array}{c}\text { Washington } \\
\text { Seattle } \\
\text { City of } \\
\text { December } 31\end{array}$ & $\begin{array}{l}\text { Washington } \\
\text { Tacoma } \\
\text { City of } \\
\text { December } 31\end{array}$ & $\begin{array}{c}\text { Washington } \\
\text { Vera } \\
\text { Irrigation } \\
\text { District \# 15 } \\
\text { December } 31\end{array}$ & $\begin{array}{l}\text { Washington } \\
\text { Washington } \\
\text { Pub } \\
\text { Pwr } \\
\text { Supply Sys } \\
\text { June } 30\end{array}$ & $\begin{array}{l}\text { Wisconsin } \\
\text { Badger Power } \\
\text { Marketing } \\
\text { Auth } \\
\text { December } 31\end{array}$ \\
\hline \multicolumn{7}{|l|}{ Electric Utility Plant } \\
\hline 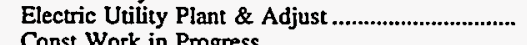 & 50,920 & $1,425,029$ & 732,833 & 15,564 & $3,458,611$ & 5,984 \\
\hline 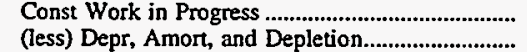 & $\begin{array}{r}5,201 \\
19,164\end{array}$ & $\begin{array}{r}60,530 \\
598,453\end{array}$ & $\begin{array}{r}39,707 \\
280,204\end{array}$ & $\begin{array}{r}373 \\
5.314\end{array}$ & $\begin{array}{r}15,434 \\
1225,848\end{array}$ & $\begin{array}{r}0 \\
1634\end{array}$ \\
\hline 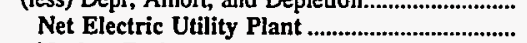 & 36,956 & 887,106 & $\begin{array}{l}280,204 \\
492,336\end{array}$ & $\begin{array}{r}5,314 \\
10,624\end{array}$ & $\begin{array}{l}1,225,848 \\
2,248,197\end{array}$ & $\begin{array}{l}1,634 \\
4,350\end{array}$ \\
\hline Nuclear Fuel. & 0 & 0 & 0 & 0 & 230,936 & 0 \\
\hline (less) Amort of Nucl Fuel ................................. & $\begin{array}{r}0 \\
36956\end{array}$ & 0 & 0 & 0 & 89,401 & 0 \\
\hline $\begin{array}{l}\text { Net Elec Plant Incl Nucl Fuel .............................. } \\
\text { Other Property \& Investments }\end{array}$ & 36,956 & 887,106 & 492,336 & 10,624 & $2,389,732$ & 4,350 \\
\hline 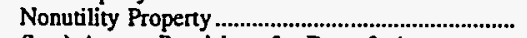 & 0 & 7,704 & 175 & 0 & 0 & \\
\hline (less) Accum Provisions for Depr \& Amort .......... & 0 & 2,833 & 8 & 0 & 0 & \\
\hline 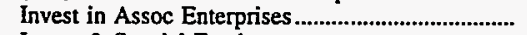 & 0 & 399 & 0 & 0 & 0 & 0 \\
\hline 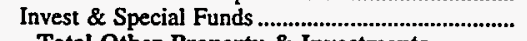 & 1,648 & 145,385 & 59,406 & 440 & 220,009 & 2,159 \\
\hline $\begin{array}{l}\text { Total Other Property \& Investments............... } \\
\text { Current and Accrued Assets }\end{array}$ & 1,648 & 150,655 & 59,573 & 440 & 220,009 & $\mathbf{2 , 1 5 9}$ \\
\hline 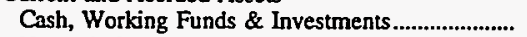 & 585 & 41,281 & 97,066 & 1,762 & 45,239 & \\
\hline Notes \& Other Receivables.............................................. & 1,648 & 13,777 & 14,509 & 560 & 74,403 & 839 \\
\hline 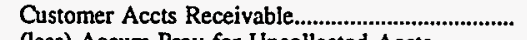 & 1,496 & 37,591 & 16,389 & 761 & 2 & 0 \\
\hline (less) Accum Prov for Uncollected Accts.............. & 134 & 2,705 & 397 & 0 & 155 & 0 \\
\hline Fuel Stock \& Exp Undistr............................................... & 0 & 2,886 & 2,900 & 0 & 0 & $\mathbf{0}$ \\
\hline 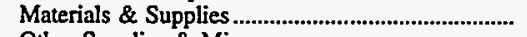 & 970 & 20,453 & 4,543 & 288 & 50,587 & 0 \\
\hline 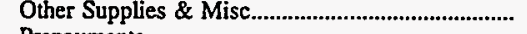 & 0 & 212 & 0 & 0 & 9,105 & 0 \\
\hline Prepayments & 0 & 854 & 623 & 58 & 770 & 16 \\
\hline Accrued Utility Revenues ................................................... & 0 & 32,464 & 14,029 & 0 & 0 & \\
\hline Miscellaneous Current \& Accrued Assets............... & 8 & 5,272 & 1,387 & 0 & 0 & 25 \\
\hline Total Current \& Accrued Assets.......................... & 4,572 & 152,086 & 151,051 & 3,429 & 179,951 & 886 \\
\hline \multicolumn{7}{|l|}{ Deferred Debits } \\
\hline Unamortized Debt Expenses................................... & 0 & 1,795 & 4,351 & 101 & 15,913 & 186 \\
\hline & 0 & & 0 & 0 & 17,430 & 617 \\
\hline Misc Debt, R \& D Exp, Unamrt Losses ................. & 403 & 108,744 & 11,609 & 0 & 3,589 & 0 \\
\hline Total Deferred Debits.................................................... & 403 & 110,539 & 15,960 & 101 & 36,932 & 803 \\
\hline 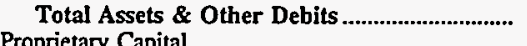 & 43,580 & $1,300,386$ & 718,920 & 14,594 & $2,826,624$ & 8,198 \\
\hline \multicolumn{7}{|l|}{ Proprietary Capital } \\
\hline Investment of Municipality ...... & 0 & 0 & 0 & 0 & 0 & 0 \\
\hline 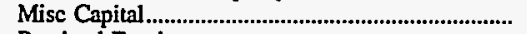 & 0 & 0 & 0 & 221 & 0 & \\
\hline 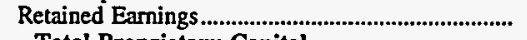 & 9,406 & 287,672 & 280,589 & 8,842 & 0 & 1,037 \\
\hline Total Proprietary Capital ...................................... & 9,406 & 287,672 & 280,589 & 9,063 & 0 & 1,037 \\
\hline \multicolumn{7}{|l|}{ Long-term Debt } \\
\hline 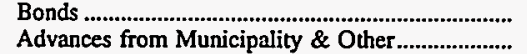 & $\begin{array}{r}15,430 \\
0\end{array}$ & $\begin{array}{r}853,595 \\
0\end{array}$ & $\begin{aligned} 394,154 \\
0\end{aligned}$ & $\begin{array}{r}2,471 \\
0\end{array}$ & $\begin{array}{r}2,644,731 \\
0\end{array}$ & $\begin{array}{r}6,055 \\
0\end{array}$ \\
\hline 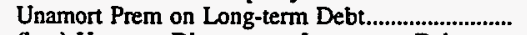 & 0 & 0 & 162 & 0 & 1,863 & 0 \\
\hline (less) Unamort Discount on Long-term Debt & 572 & 9,738 & 4,851 & & 97,808 & \\
\hline Total Long-term Debt.... & 14,858 & 843,857 & 389,465 & 2,471 & $2,548,786$ & 6,055 \\
\hline \multicolumn{7}{|l|}{ Other Noncurrent Liabilities } \\
\hline Accum Operating Provisions...... & 0 & 2,237 & 0 & 0 & 5,559 & 0 \\
\hline Accum Prov for Rate Refunds... & 0 & 94,465 & 0 & 0 & 0 & 0 \\
\hline Total Other Noncurrent Liabilities ........................ & $\mathbf{0}$ & 96,702 & 0 & 0 & 5,559 & 0 \\
\hline \multicolumn{7}{|l|}{ Current and Accrued Liabilities } \\
\hline Notes Payable ...................................................................... & 1,456 & 0 & 0 & 1,062 & 0 & \\
\hline 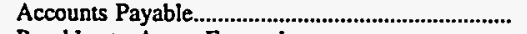 & 2,636 & 36,126 & 19,248 & 1,323 & 73,952 & 795 \\
\hline Payables to Assoc Enterprises.... & 0 & 4,904 & 636 & 404 & 27,926 & 0 \\
\hline 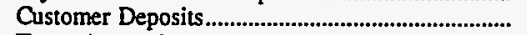 & 0 & 2,034 & 1,569 & 0 & 0 & 0 \\
\hline Taxes Accrued & 0 & 4,784 & 3,683 & 0 & 675 & 0 \\
\hline Interest Accrued....................... & 0 & 12,711 & 10,029 & 94 & 2,091 & 74 \\
\hline Misc Current \& Accrued Liabilities ............................ & 147 & 10,121 & 11,601 & 176 & 46,011 & 0 \\
\hline Total Current \& Accrued Liabilities ................ & 4,238 & 70,679 & 46,765 & 3,060 & 150,655 & 869 \\
\hline \multicolumn{7}{|l|}{ Deferred Credits } \\
\hline Customer Advances for Construction........................ & 15,078 & 0 & 1,105 & 0 & 0 & 23 \\
\hline 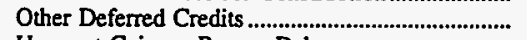 & 0 & 1,475 & 995 & 0 & 121,564 & 214 \\
\hline Unamort Gain on Reacqr Debt ...................................... & 0 & 0 & 0 & 0 & 60 & 0 \\
\hline Total Deferred Credits .................................................... & 15,078 & 1,475 & 2,101 & & 121,624 & 237 \\
\hline Total Liabilities and Other Credits.................... & 43,580 & $1,300,386$ & 718,920 & 14,594 & $2,826,624$ & 8,198 \\
\hline
\end{tabular}

Note: Totals may not equal sum of components because of independent rounding.

Source: Energy Information Administration, Form EIA-412, "Annual Report of Public Electric Utilities." 
Table 22. Balance Sheet by Major U.S. Publicly Owned Electric Utility Within State at End of Period, 1996

(Thousand Dollars)

\begin{tabular}{|c|c|c|c|c|c|c|}
\hline Item & $\begin{array}{l}\text { Wisconsin } \\
\text { Jefferson } \\
\text { City of } \\
\text { December } 31\end{array}$ & $\begin{array}{l}\text { Wisconsin } \\
\text { Kaukauna } \\
\text { City of } \\
\text { December } 31\end{array}$ & $\begin{array}{l}\text { Wisconsin } \\
\text { Manitowoc } \\
\text { Public } \\
\text { Utilities } \\
\text { December } 31\end{array}$ & $\begin{array}{l}\text { Wisconsin } \\
\begin{array}{c}\text { Marshfield } \\
\text { City of }\end{array} \\
\text { December } 31\end{array}$ & $\begin{array}{c}\text { Wisconsin } \\
\text { Menasha } \\
\text { City of } \\
\text { December } 31\end{array}$ & $\begin{array}{c}\text { Wisconsin } \\
\text { New London } \\
\text { Electric\&Water } \\
\text { Util } \\
\text { December } 31\end{array}$ \\
\hline \multicolumn{7}{|l|}{ Electric Utility Plant } \\
\hline Electric Utility Plant \& Adjust ................................ & 8,576 & 43,222 & 67,675 & 31,450 & 23,309 & 8,793 \\
\hline Const Work in Progress .................................................. & 117 & 590 & 842 & 466 & 338 & 0 \\
\hline (less) Depr, Amort, and Depletion............................ & 2,679 & 17,910 & 24,156 & 7,950 & 11,861 & 2,771 \\
\hline Net Electric Utility Plant ........................................... & 6,013 & 25,902 & 44,361 & 23,967 & 11,785 & 6,022 \\
\hline Nuclear Fuel................................................................ & 0 & 0 & 0 & 0 & 0 & 0 \\
\hline (less) Amort of Nucl Fuel ................................. & 0 & 0 & 0 & 0 & 0 & 0 \\
\hline Net Elec Plant Incl Nucl Fuel .......................... & 6,013 & 25,902 & 44,361 & 23,967 & 11,785 & 6,022 \\
\hline \multicolumn{7}{|l|}{ Other Property \& Investments } \\
\hline 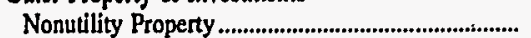 & 0 & 657 & 524 & 7,067 & 259 & 7,141 \\
\hline (less) Accum Provisions for Depr \& Amort .......... & 0 & 218 & 5 & 6,340 & 0 & 1,273 \\
\hline 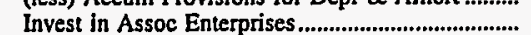 & 0 & 0 & 0 & 0 & 0 & 0 \\
\hline Invest \& Special Funds ............................................. & 0 & 4,918 & 4,505 & 1,564 & 4,188 & 2,742 \\
\hline Total Other Property \& Investments.............. & 0 & 5,357 & 5,024 & 2,292 & 4,447 & 8,609 \\
\hline \multicolumn{7}{|l|}{ Current and Accrued Assets } \\
\hline 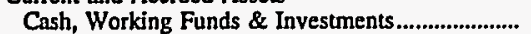 & 3,187 & 599 & 9,901 & 3,919 & 91 & 313 \\
\hline Notes \& Other Receivables...................................... & 17 & 1,399 & 276 & 49 & 24 & 64 \\
\hline 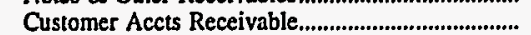 & 558 & 1,924 & 1,609 & 1,043 & 1,800 & 939 \\
\hline (less) Accum Prov for Uncollected Accts............... & 0 & 50 & 0 & 0 & 3 & 0 \\
\hline 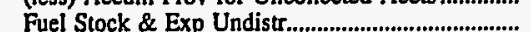 & 0 & 0 & 0 & 90 & 0 & 0 \\
\hline 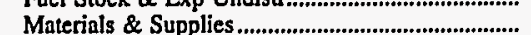 & 181 & 628 & 662 & 355 & 241 & 205 \\
\hline Ouher Supplies \& Misc............................................. & 0 & 27 & 0 & 0 & 0 & 0 \\
\hline 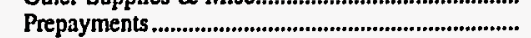 & 3 & 567 & 59 & 14 & 42 & 39 \\
\hline Accrued Utility Revenues ................................ & 0 & 0 & 0 & 0 & 0 & 215 \\
\hline Miscellaneous Current \& Accrued Assets............... & 15 & 17 & 0 & 31 & 40 & 55 \\
\hline Total Current \& Accrued Assets................................... & 3,962 & 5,111 & 12,506 & 5,500 & 2,235 & 1,830 \\
\hline \multicolumn{7}{|l|}{ Deferred Debits } \\
\hline 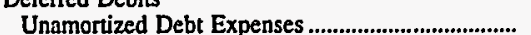 & 700 & 265 & 1,011 & 163 & 399 & 159 \\
\hline 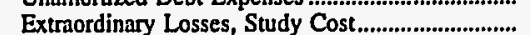 & 0 & 46 & 129 & 0 & 0 & 127 \\
\hline Misc Debt, R \& D Exp, Unamrt Losses ................... & 0 & 839 & 150 & -45 & 669 & 585 \\
\hline Total Deferred Debits & 700 & 1,150 & 1.290 & 118 & 1,068 & 870 \\
\hline Total Assets \& Other Debits & 10,675 & 37,521 & 63,182 & 31,876 & 19,535 & 17,332 \\
\hline \multicolumn{7}{|l|}{ Proprietary Capital } \\
\hline 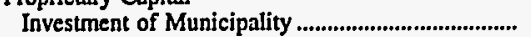 & 160 & 0 & 0 & $\mathbf{0}$ & 435 & 348 \\
\hline Misc Capital......................................................... & 262 & 0 & 0 & $\mathbf{0}$ & 7,794 & 1,991 \\
\hline 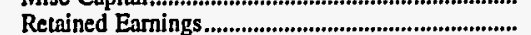 & 4,056 & 16,899 & 34,218 & 19,996 & 657 & 5,645 \\
\hline Total Proprietary Capital. ............................ & 4,478 & 16,899 & 34,218 & 19,996 & $\mathbf{8 , 8 8 6}$ & 7,985 \\
\hline \multicolumn{7}{|l|}{ Long-term Debt } \\
\hline 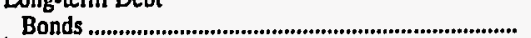 & 5,315 & 15,200 & 22,064 & 8,050 & 6,460 & 7,220 \\
\hline Advances from Municipality \& Other.................... & & & 16 & 0 & 625 & 86 \\
\hline Unamort Prem on Long-term Debt........................... & 0 & 0 & & 0 & 0 & $\mathbf{0}$ \\
\hline (less) Unamort Discount on Long-term Debt & 0 & & 0 & 0 & & 0 \\
\hline Total Long-term Debt .......................................... & 5,315 & 15,200 & 22,079 & 8,050 & 7,085 & 7,306 \\
\hline \multicolumn{7}{|l|}{ Other Noneurrent Liabilities } \\
\hline Accum Operating Provisions...................................... & 0 & 0 & 1,011 & 0 & 0 & 205 \\
\hline 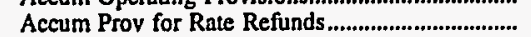 & 0 & 0 & 0 & 0 & 0 & 0 \\
\hline 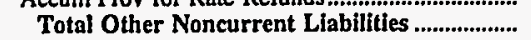 & 0 & 0 & 1,011 & 0 & 0 & 205 \\
\hline \multicolumn{7}{|l|}{ Current and Accrued Liabilities } \\
\hline Notes Payable ......................................................... & 0 & 0 & 799 & 0 & 0 & 0 \\
\hline 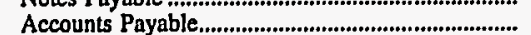 & 534 & 1,729 & 1,426 & 1,053 & 1,560 & 593 \\
\hline Payables to Assoc Enterprises................................ & 0 & 0 & 0 & 0 & 0 & 78 \\
\hline 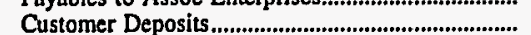 & 0 & 3 & 39 & 62 & 0 & 26 \\
\hline 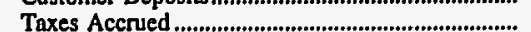 & 164 & 625 & 1,350 & 420 & 605 & 690 \\
\hline Interest Accrued & 142 & 43 & 530 & 49 & 106 & 54 \\
\hline Misc Current \& Accrued Liabilities .................... & 35 & 83 & 102 & 195 & 0 & 28 \\
\hline Total Current \& Accrued Liabilities ................. & 875 & 2,482 & 4,246 & 1,779 & 2,271 & 1,469 \\
\hline \multicolumn{7}{|l|}{ Deferred Credits } \\
\hline Customer Advances for Construction ......................... & 7 & 2,839 & 1,605 & 2,051 & 395 & 5 \\
\hline Other Deferred Credits .......................................... & 0 & 100 & 22 & 0 & 898 & 362 \\
\hline 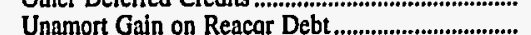 & 0 & 0 & 0 & 0 & 0 & 0 \\
\hline Total Deferred Credits & 7 & 2,939 & 1,627 & 2,051 & 1,292 & 367 \\
\hline Total Liabilities and Other Credits.................. & 10,675 & 37,521 & 63,182 & 31,876 & 19,535 & 17,332 \\
\hline
\end{tabular}

Note: Totals may not equal sum of components because of independent rounding.

Source: Energy Information Administration, Form EIA-412, "Annual Report of Public Electric Utilities." 
Table 22. Balance Sheet by Major U.S. Publicly Owned Electric Utility Within State at End of Period, 1996

(Thousand Dollars)

\begin{tabular}{|c|c|c|c|c|c|c|}
\hline ltem & $\begin{array}{l}\text { Wisconsin } \\
\text { Oconomowoc } \\
\text { City of } \\
\text { December } 31\end{array}$ & $\begin{array}{l}\text { Wisconsin } \\
\text { Plymouth } \\
\text { City of } \\
\text { December } 31\end{array}$ & $\begin{array}{l}\text { Wisconsin } \\
\text { Reedsburg } \\
\text { Utility Comm } \\
\text { December } 31\end{array}$ & $\begin{array}{c}\text { Wisconsin } \\
\text { Shawano } \\
\text { Municipal } \\
\text { Utilities } \\
\text { December } 31\end{array}$ & $\begin{array}{c}\text { Wisconsin } \\
\text { Sheboygan } \\
\text { Falls } \\
\text { City of } \\
\text { December } 31\end{array}$ & $\begin{array}{l}\text { Wisconsin } \\
\text { Sturgeon } \\
\text { Bay City of } \\
\text { December } 31\end{array}$ \\
\hline \multicolumn{7}{|l|}{ Electric Utility Plant } \\
\hline 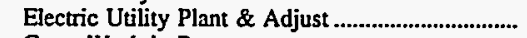 & 17,315 & 15,008 & 10,040 & 9,817 & 9,134 & 16,718 \\
\hline Const Work in Progress & 81 & 225 & 42 & 243 & 535 & 110 \\
\hline (less) Depr, Amort, and Depletion............................. & 6,417 & 6,295 & 3,107 & 3,388 & 3,732 & 5,904 \\
\hline 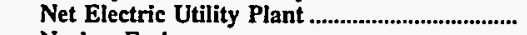 & 10,979 & 8,937 & 6,975 & 6,672 & 5,936 & 10,924 \\
\hline 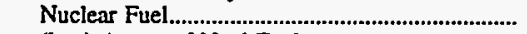 & 0 & 0 & 0 & 0 & 0 & \\
\hline 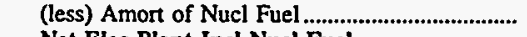 & & 0 & 0 & 0 & 0 & 0 \\
\hline 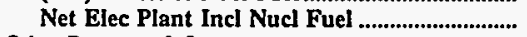 & 10,979 & 8,937 & 6,975 & 6,672 & 5,936 & 10,924 \\
\hline \multicolumn{7}{|l|}{ Other Property \& Investments } \\
\hline Nonutility Property & 0 & 0 & 4,626 & 0 & 6,241 & 0 \\
\hline (less) Accum Provisions for Depr \& Amort ........... & 0 & 0 & 871 & 0 & 1,074 & 0 \\
\hline 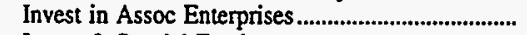 & 0 & 0 & 0 & 7,786 & 44 & 0 \\
\hline 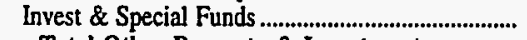 & 1,329 & 1,041 & 1,298 & 1,394 & 0 & 1,690 \\
\hline Total Other Property \& Investments................ & 1,329 & 1,041 & 5,053 & 9,180 & 5,210 & 1,690 \\
\hline \multicolumn{7}{|l|}{ Current and Accrued Assets } \\
\hline & $\begin{array}{r}2,657 \\
604\end{array}$ & $\begin{array}{r}0 \\
86\end{array}$ & $\begin{array}{r}1,247 \\
373\end{array}$ & 2,191 & 862 & 1,482 \\
\hline 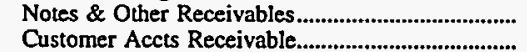 & 604 & $\begin{array}{r}86 \\
618\end{array}$ & 373 & 125 & 370 & 41 \\
\hline & 791 & 618 & 723 & 933 & 997 & 642 \\
\hline (less) Accum Prov for Uncollected Accts ............... & 0 & 0 & $\mathbf{0}$ & 0 & 0 & 22 \\
\hline Fuel Stock \& Exp Undist.................................................... & 0 & 0 & 0 & 0 & 0 & 0 \\
\hline 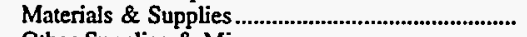 & 312 & 272 & 316 & 274 & 257 & 398 \\
\hline 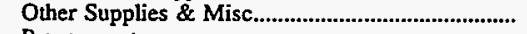 & 0 & 0 & 0 & 0 & 0 & 0 \\
\hline 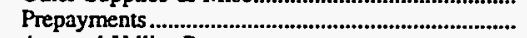 & 11 & 17 & 0 & 127 & 0 & 47 \\
\hline Accrued Utility Revenues & 0 & 0 & 0 & 0 & 0 & 0 \\
\hline Miscellaneous Current \& Accrued Assets............... & 6 & 0 & 0 & 38 & 0 & 12 \\
\hline Total Current \& Accrued Assets....................... & 4,380 & 994 & 2,660 & 3,688 & 2,486 & 2,601 \\
\hline \multicolumn{7}{|l|}{ Deferred Debits } \\
\hline & 30 & 10 & 83 & 18 & 28 & 609 \\
\hline Extraordinary Losses, Study Cost.................................... & 0 & 0 & 156 & 231 & 179 & 33 \\
\hline Misc Debt, R \& D Exp, Unamrt Losses ................... & 149 & 0 & 0 & 0 & 0 & 23 \\
\hline Total Deferred Debits................................................... & 179 & 10 & 239 & 249 & 207 & 666 \\
\hline Total Assets \& Other Debits .................................. & 16,867 & 10,981 & 14,926 & 19,790 & 13,839 & 15,880 \\
\hline \multicolumn{7}{|l|}{ Proprietary Capital } \\
\hline 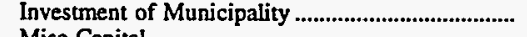 & 297 & 1,439 & 1,188 & 2,184 & 1,459 & 26 \\
\hline Misc Capital & 2,546 & & 2,691 & 0 & 2,710 & $\mathbf{0}$ \\
\hline 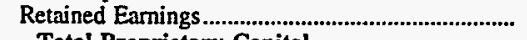 & 11,440 & 8,174 & 4,839 & 10,626 & 7,430 & 6,411 \\
\hline 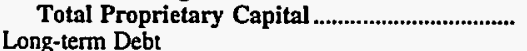 & 14,283 & 9,613 & 8,717 & 12,810 & 11,599 & 6,437 \\
\hline 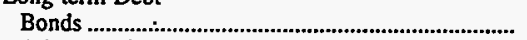 & 1,595 & 291 & 4,645 & 1,625 & 0 & 6,613 \\
\hline Advances from Municipality \& Other..................... & 0 & 276 & 0 & 912 & 1,400 & 0 \\
\hline Unamort Prem on Long-term Debt.............................. & 0 & 0 & 0 & 0 & 0 & 0 \\
\hline (less) Unamor Discount on Long-term Debt & & 0 & 0 & 0 & 0 & 0 \\
\hline Total Long-term Debt ..... & 1,595 & 568 & 4,645 & 2,537 & 1,400 & 6,613 \\
\hline \multicolumn{7}{|l|}{ Other Noncurrent Liabilities } \\
\hline 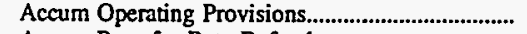 & $\mathbf{0}$ & $\mathbf{0}$ & 0 & 0 & 0 & 0 \\
\hline 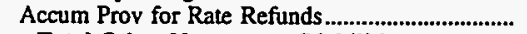 & 0 & 0 & 0 & 0 & 0 & 0 \\
\hline Current and Accrued Liabilities & 0 & 0 & 0 & 0 & $\mathbf{0}$ & 0 \\
\hline 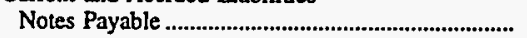 & 0 & 0 & 0 & 0 & 0 & 0 \\
\hline 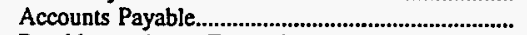 & 590 & 502 & 630 & 833 & 321 & 442 \\
\hline 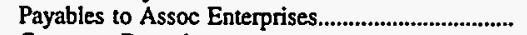 & $\mathbf{0}$ & 0 & 146 & 0 & 68 & 0 \\
\hline Customer Deposits.............................................................. & 37 & 7 & 7 & 52 & 4 & 26 \\
\hline 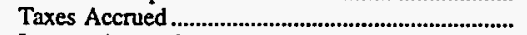 & 326 & 144 & 305 & 257 & 226 & 255 \\
\hline Interest Accrued & 36 & 7 & 31 & 30 & 40 & 193 \\
\hline 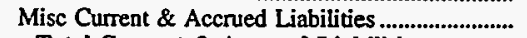 & 0 & 0 & 9 & 29 & 121 & 64 \\
\hline $\begin{array}{l}\text { Total Current \& Accrued Liabilities ................... } \\
\text { Deferred Credits }\end{array}$ & 989 & 660 & 1,127 & 1,201 & 780 & 980 \\
\hline Customer Advances for Construction ......................... & 0 & 0 & 0 & 2,791 & 39 & 39 \\
\hline 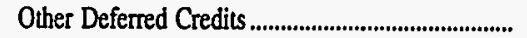 & 0 & 141 & 437 & 450 & 21 & 299 \\
\hline 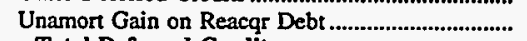 & 0 & 0 & 0 & 0 & 0 & 1,512 \\
\hline Total Deferred Credits................................................... & o & 141 & 437 & 3,242 & 60 & 1,850 \\
\hline Total Liabilities and Other Credits..................... & 16,867 & 10,981 & 14,926 & 19,790 & 13,839 & 15,880 \\
\hline
\end{tabular}

Note: Totals may not equal sum of components because of independent rounding.

Source: Energy Information Administration, Form EIA-412, "Annual Report of Public Electric Utilities." 
Table 22. Balance Sheet by Major U.S. Publicly Owned Electric Utility Within State at End of Period, 1996

(Thousand Dollars)

\begin{tabular}{|c|c|c|c|c|c|}
\hline Item & $\begin{array}{l}\text { Wisconsin } \\
\text { Sun Prairie } \\
\text { Water \& Light } \\
\text { Comm }\end{array}$ & $\begin{array}{l}\text { Wisconsin } \\
\text { Wisconsin } \\
\text { Public } \\
\text { Powes } \\
\text { Inc Sys } \\
\text { December } 31\end{array}$ & $\begin{array}{l}\text { Wisconsin } \\
\text { Wisconsin } \\
\text { Rapids W W } \\
\& \mathrm{~L} \\
\text { Comm } \\
\text { December } 31\end{array}$ & $\begin{array}{l}\text { Wyoming } \\
\text { Gillette } \\
\text { City of } \\
\text { June } 30\end{array}$ & $\begin{array}{c}\text { Wyoming } \\
\text { Wyoming } \\
\text { Municipal } \\
\text { Power Agency } \\
\text { December } 31\end{array}$ \\
\hline \multicolumn{6}{|l|}{ Electric Utility Plant } \\
\hline 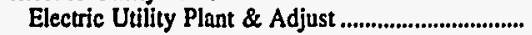 & 15,185 & 179,173 & 37,065 & 20,239 & 22,743 \\
\hline 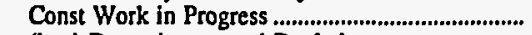 & 120 & & 357 & 0 & \\
\hline (less) Depr, Amort, and Depletion................................ & 4,277 & 41,389 & 11,880 & 10,543 & 8,656 \\
\hline Net Electric Utility Plant ......................................... & 11,028 & 137,803 & 25,542 & 9,696 & 14,088 \\
\hline 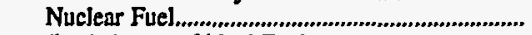 & & & & 0 & 0 \\
\hline 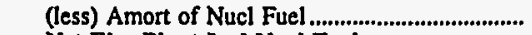 & & & 0 & 0 & 0 \\
\hline Net Elec Plant Incl Nucl Fuel ................................ & 11,028 & 137,803 & 25,542 & 9,696 & 14,088 \\
\hline \multicolumn{6}{|l|}{ Other Property \& Investments } \\
\hline 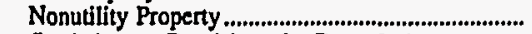 & 10,549 & 0 & 0 & $\mathbf{0}$ & 0 \\
\hline (less) Accum Provisions for Depr \& Amort ........... & 1,515 & 0 & 0 & 0 & 0 \\
\hline 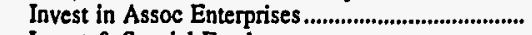 & & 0 & 0 & $\mathbf{0}$ & 0 \\
\hline Invest \& Special Funds ................................................... & 1,362 & 37,489 & 3,880 & 723 & 6,196 \\
\hline Total Other Property \& Investments.............. & 10,396 & 37,489 & $\mathbf{3 , 8 8 0}$ & 723 & 6,196 \\
\hline \multicolumn{6}{|l|}{ Current and Accrued Assets } \\
\hline Cash, Working Funds \& Investments......................... & 293 & 13,040 & 2,203 & 973 & 4,101 \\
\hline 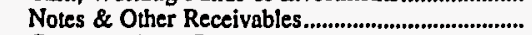 & 48 & 272 & 612 & 18 & 66 \\
\hline Customer Accts Receivable........................................ & 821 & 9,475 & 1,048 & 874 & 488 \\
\hline (less) Accum Prov for Uncollected Accts............... & 0 & 0 & 0 & 81 & D \\
\hline 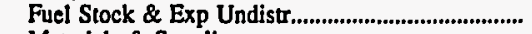 & $\mathbf{0}$ & 1,193 & 0 & $\mathbf{0}$ & 108 \\
\hline Materials \& Supplies ...................................................... & 177 & 1,357 & 722 & 0 & 697 \\
\hline 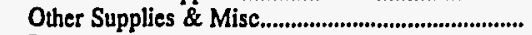 & 0 & 0 & 0 & 0 & 0 \\
\hline Prepayments & 4 & 120 & 92 & 0 & 16 \\
\hline Accrued Utility Revenues ............................................. & 0 & 0 & 0 & 0 & 574 \\
\hline Miscellaneous Current \& Accrued Assets............... & 33 & 486 & 25 & 0 & 85 \\
\hline \multirow{2}{*}{\multicolumn{6}{|c|}{ Deferred Debits }} \\
\hline & & & & & \\
\hline 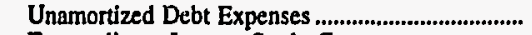 & 60 & 3,419 & 2 & $\mathbf{0}$ & 1,108 \\
\hline 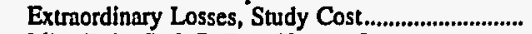 & $\mathbf{0}$ & & 0 & 0 & 197 \\
\hline Misc Debt, R \& D Exp, Unamrt Losses ................. & 6 & 31,325 & 54 & 0 & 353 \\
\hline Total Deferred Debits......................................... & 66 & 34,745 & 57 & 0 & 1,659 \\
\hline 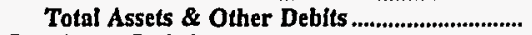 & 22,866 & 235,980 & 34,180 & 12,204 & 28,077 \\
\hline \multicolumn{6}{|l|}{ Proprietary Capital } \\
\hline Investment of Municipality ....... & 810 & 0 & 1,363 & 0 & 0 \\
\hline 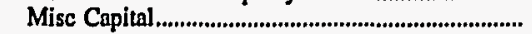 & 0 & 0 & 0 & 0 & 0 \\
\hline 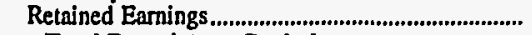 & 9,791 & 13,458 & 23,201 & 11,018 & 8,318 \\
\hline 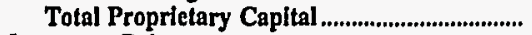 & 10,601 & 13,458 & 24,564 & 11,018 & 8,318 \\
\hline \multicolumn{6}{|l|}{ Long-term Debt } \\
\hline Bonds ..................... & 4,725 & 198,990 & 0 & 0 & 17,710 \\
\hline Advances from Municipality \& Other...................... & 391 & 0 & 634 & 0 & 0 \\
\hline 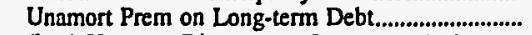 & 0 & & 0 & 0 & 0 \\
\hline (less) Unamort Discount on Long-term Debt & 0 & 4,471 & 0 & 0 & 0 \\
\hline 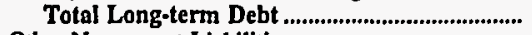 & 5,116 & 194,519 & 634 & $\mathbf{0}$ & 17,710 \\
\hline \multicolumn{6}{|l|}{ Other Noncurrent Liabilities } \\
\hline 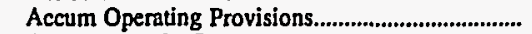 & 0 & 4,269 & $\mathbf{0}$ & 0 & 0 \\
\hline 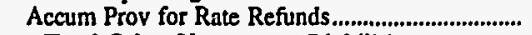 & 0 & & 0 & $\mathbf{0}$ & 0 \\
\hline Total Other Noncurrent Liabilities................... & 0 & 4,269 & 0 & 0 & 0 \\
\hline \multicolumn{6}{|l|}{ Current and Accrued Liabilities } \\
\hline Notes Payable ................................. & 0 & & $\mathbf{0}$ & $\mathbf{0}$ & 0 \\
\hline 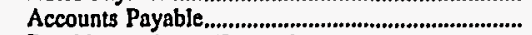 & 661 & 9,260 & 836 & 801 & 407 \\
\hline 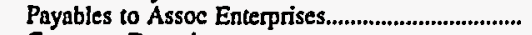 & 3 & 0 & 217 & 0 & 0 \\
\hline 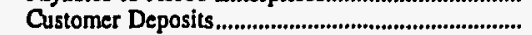 & 23 & 0 & 31 & 221 & 0 \\
\hline Taxes Accrued ................................................................... & 465 & 1,650 & 688 & 0 & 0 \\
\hline 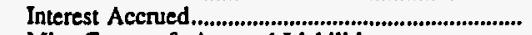 & 78 & 5,028 & 10 & $\mathbf{0}$ & 539 \\
\hline Misc Current \& Accrued Liabilities ........................ & 74 & 4,281 & 610 & 164 & 1,104 \\
\hline Total Current \& Accrued Liabilities ................ & 1,304 & 20,219 & 2,392 & 1,186 & 2,049 \\
\hline \multicolumn{6}{|l|}{ Deferred Credits } \\
\hline Customer Advances for Construction......................... & 5,846 & 0 & 20 & 0 & 0 \\
\hline 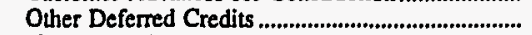 & 0 & 3,515 & 6,571 & 0 & 0 \\
\hline Unamort Gain on Reacgr Debt.................................... & 0 & 0 & 0 & 0 & 0 \\
\hline Total Deferred Credits.................................................. & $\mathbf{5 , 8 4 6}$ & 3,515 & 6,591 & 0 & 0 \\
\hline Total Llabillites and Other Credits.................. & 22,866 & 235,980 & 34,180 & 12,204 & 28,077 \\
\hline
\end{tabular}

Note: Totals may not equal sum of components because of independent rounding.

Source: Energy Information Administration, Form EIA-412, "Annual Report of Public Electric Utilities." 
Table 23. Electric Operation and Maintenance Expenses by Major U.S. Publicly Owned Electric Utility Within State, 1996 (Thousand Dollars)

\begin{tabular}{|c|c|c|c|c|c|c|}
\hline Item & $\begin{array}{l}\text { Alabama } \\
\text { Alabama } \\
\text { Municipal } \\
\text { Elec Auth }\end{array}$ & $\begin{array}{l}\text { Alabama } \\
\text { Albertville } \\
\text { Municipal } \\
\text { Utils Bd }\end{array}$ & $\begin{array}{l}\text { Alabama } \\
\text { Andalusia } \\
\text { City of }\end{array}$ & $\begin{array}{l}\text { Alabama } \\
\text { Athens } \\
\text { City of }\end{array}$ & $\begin{array}{l}\text { Alabama } \\
\text { Bessemer } \\
\text { City of }\end{array}$ & $\begin{array}{c}\text { Cullman } \\
\text { Power Board }\end{array}$ \\
\hline & September 30 & June 30 & September 30 & December 31 & June 30 & June 30 \\
\hline
\end{tabular}

Production Expenses

Steam Power Generation...

fear Power Generation .

Hydraulic Power Generation

Other Power Generation

Purchased Power

Other Production Expenses

Total Production Expenses

Transmission Expenses.

Distribution Expenses.

Customer Accounts Expenses

Customer Service and Information

Expense

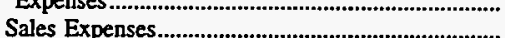

Administrative and General

Expenses

Total Electric Operation and

Maintenance Expenses

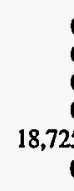

0
0
0
0
8,725
0

75,462

2,524

0
0

18,725

0

935

296

39

26

1,227

79,213

440

20,460

0
0
0
0
11,493
0

11,493

0

190
661

0
0

969

13,313

0
0
0
0
35,371
0

35,371

229

1,858

654

22

28

691

38,852

$\begin{array}{rr}0 & 0 \\ 0 & 0 \\ 0 & 0 \\ 0 & 0 \\ 14,641 & 15,345 \\ 0 & 0\end{array}$

14,641

15,345

0
1,252

320

0

396

38

21

525

16,815

17,097

Fuel Expenses in Operation

Steam Power Generation ...........................................

Nuclear Power Generation

Other Power Generation

Number of Elec Dept Employees

Regular Full-time

Part-time \& Temporary

Total Elec Dept Employees $\mathbf{0}$

0

0 $\mathbf{0}$

0

0

30

0

30
0

0

0

0

Note: Totals may not equal sum of components because of independent rounding.

Source: Energy Information Administration, Form EIA-412, "Annual Report of Public Electric Utilities." 
Table 23. Electric Operation and Maintenance Expenses by Major U.S. Publicly Owned Electric Utility Within State, 1996 (Continued)

(Thousand Dollars)

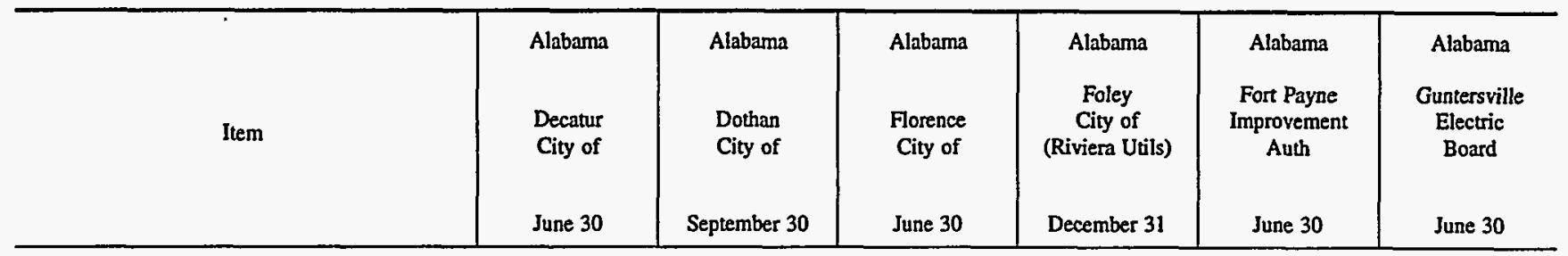

Production Expenses

Steam Power Generation.

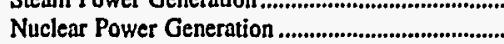

Hydraulic Power Generation

Other Power Generation.

Purchased Power.

Other Production Expenses .....................................

Total Production Expenses.................................

Transmission Expenses.

Distribution Expenses

Customer Accounts Expenses ..................................

Customer Service and Information

Expenses...

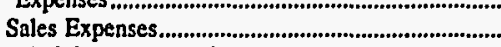

Administmive and General

Expenses,

Total Electric Operation and

Maintenance Expenses.

Fuel Expenses in Operation

Steam Power Generation .........................................

Nuclear Power Generation

Other Power Generation.

Number of Elec Dept Employees

Regular Full-time.

Part-time \& Temporary

62

70

161

0

62

2

72

161

Total Elec Dept Employees

0
0
0
0
26,939
0

26,939

260

1,315

520

23

69

1,731

30,857

$\begin{array}{rr}0 & 0 \\ 0 & 0 \\ 0 & 0 \\ 0 & 0 \\ 16,095 & 10,853 \\ 0 & 0\end{array}$

16,095

10,853

0

223

0

231

26

18

18

320

287

17,542

11,942

Note: Totals may not equal sum of components because of independent rounding.

Source: Energy Information Administration, Form EIA-412, "Annual Report of Public Electric Utilities." 
Table 23. Electric Operation and Maintenance Expenses by Major U.S. Publicly Owned Electric Utility Within State, 1996 (Continued)

(Thousand Dollars)

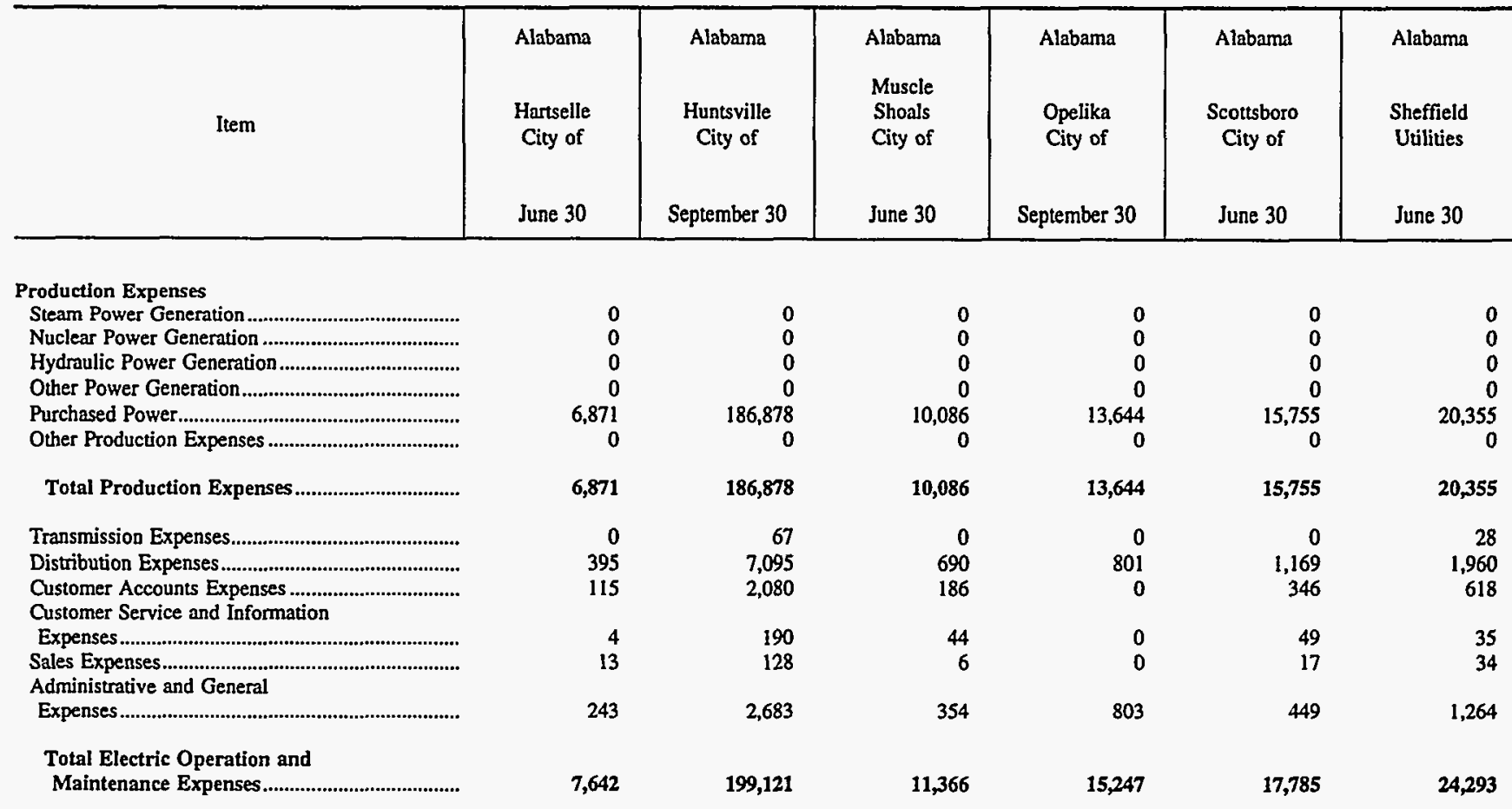

Fuel Expenses in Operation

Steam Power Generation

Nuclear Power Generation .

0

0

0

0

0

0

0

0

Other Power Generation

Number of Elec Dept Employees

Regular Full-time

13

247

22

32

31

63

Part-time \& Temporary

0

0

0

0

0

0

Total Elec Dept Employees

13

247

22

32

31

63

Note: Totals may not equal sum of components because of independent rounding

Source: Energy Information,Administration, Form EIA-412, "Annual Report of Public Electric Utilities." 
Table 23. Electric Operation and Maintenance Expenses by Major U.S. Publicly Owned Electric Utility Within State, 1996 (Continued)

(Thousand Dollars)

\begin{tabular}{|c|c|c|c|c|c|c|}
\hline Item & $\begin{array}{l}\text { Alabama } \\
\text { Sylacauga } \\
\text { Utilities } \\
\text { Board } \\
\text { September } 30\end{array}$ & $\begin{array}{c}\text { Alabama } \\
\text { Troy } \\
\text { City of } \\
\text { September } 30\end{array}$ & $\begin{array}{l}\text { Alabama } \\
\text { Tuskegee } \\
\text { City of } \\
\text { September } 30\end{array}$ & $\begin{array}{l}\text { Alaska } \\
\text { Alaska } \\
\text { Energy } \\
\text { Authority } \\
\text { June } 30\end{array}$ & $\begin{array}{c}\text { Alaska } \\
\text { Anchorage } \\
\text { City of } \\
\text { December } 31\end{array}$ & $\begin{array}{l}\text { Alaska } \\
\text { Fairbanks } \\
\text { City of } \\
\text { December } 31\end{array}$ \\
\hline Production Expenses & & & & & & \\
\hline 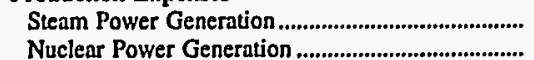 & $\begin{array}{l}0 \\
0\end{array}$ & $\begin{array}{l}0 \\
0\end{array}$ & $\begin{array}{l}0 \\
0\end{array}$ & $\begin{array}{l}0 \\
0\end{array}$ & $\begin{array}{r}1,893 \\
0\end{array}$ & $\begin{array}{r}8,814 \\
0\end{array}$ \\
\hline 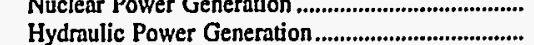 & 0 & 0 & 0 & 1,301 & 0 & 0 \\
\hline 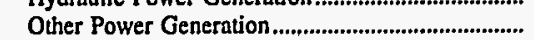 & 0 & 0 & 0 & 0 & 19,346 & 0 \\
\hline Purchnsed Power.................................................. & 6,692 & 9,469 & 6,587 & 0 & 4,799 & 1,960 \\
\hline 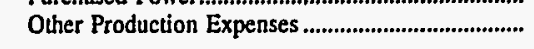 & 0 & 0 & 0 & 433 & 965 & 0 \\
\hline 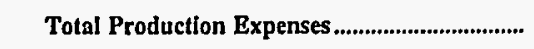 & 6,692 & 9,469 & 6,587 & 1,734 & 27,004 & 10,774 \\
\hline Transmission Expense & 0 & 0 & $\mathbf{0}$ & 1,343 & 574 & 0 \\
\hline Distribution Expenses.................................................... & 928 & 575 & $\mathbf{0}$ & $\mathbf{0}$ & 5,652 & 833 \\
\hline $\begin{array}{l}\text { Customer Accounts Expenses ................................................ } \\
\text { Customer Service and Information }\end{array}$ & 118 & 0 & 0 & 0 & 2,869 & 0 \\
\hline 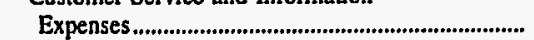 & 45 & 568 & 0 & $\mathbf{0}$ & 164 & $\mathbf{0}$ \\
\hline 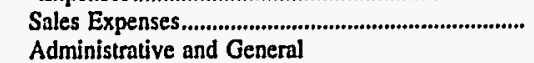 & 0 & 0 & 0 & 0 & 0 & 0 \\
\hline 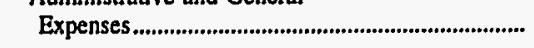 & 272 & 954 & 2,530 & 2,964 & 3,457 & 1,220 \\
\hline $\begin{array}{l}\text { Total Electric Operation and } \\
\text { Maintenance Expenses............. }\end{array}$ & 8,054 & 11,566 & 9,117 & 6,041 & 39,721 & 12,827 \\
\hline
\end{tabular}

Fuel Expenses in Operation

Steam Power Generation ..............................................

Nuclear Power Generation.

Other Power Generation.

Number of Elec Dept Employees

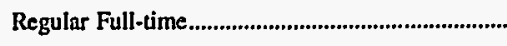

Part-time \& Temporary

Total Blec Dept Employees....................................

Note: Totals may not equal sum of components because of independent rounding.

Source: Energy Information Administration, Form EIA-412, "Annual Report of Public Electric Utilities."

0
0

0
0
0

0

$\begin{array}{rr}0 & 0 \\ 0 & 0 \\ 15,971 & 0\end{array}$

\begin{tabular}{rrrrrr}
19 & 15 & 66 & 4 & 203 & 40 \\
0 & 0 & 0 & 1 & 21 & 10 \\
19 & 15 & 66 & 5 & 224 & 50 \\
\hline
\end{tabular}

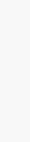


Table 23. Electric Operation and Maintenance Expenses by Major U.S. Publicly

Owned Electric Utility Within State, 1996 (Continued)

(Thousand Dollars)

\begin{tabular}{|c|c|c|c|c|c|c|}
\hline Item & $\begin{array}{c}\text { Alaska } \\
\begin{array}{c}\text { Ketchikan } \\
\text { City of }\end{array} \\
\text { December 31 }\end{array}$ & $\begin{array}{l}\text { Arizona } \\
\text { Arizona } \\
\text { Power } \\
\text { Authority } \\
\text { June } 30\end{array}$ & $\begin{array}{c}\text { Arizona } \\
\text { Electrical } \\
\text { Dist } \\
\text { No2 } \\
\text { Pinal Cnty } \\
\text { December 31 }\end{array}$ & $\begin{array}{l}\text { Arizona } \\
\text { Mesa } \\
\text { City of } \\
\text { June } 30\end{array}$ & $\begin{array}{c}\text { Arizona } \\
\text { Navajo } \\
\text { Tribal } \\
\text { Utility } \\
\text { Auth } \\
\text { December } 31\end{array}$ & $\begin{array}{l}\text { Arizona } \\
\text { Salt River } \\
\text { Proj Ag } \\
\text { I \& P Dist } \\
\text { April } 30\end{array}$ \\
\hline \multicolumn{7}{|l|}{ Production Expenses } \\
\hline Steam Power Generation & 0 & 0 & 0 & 0 & 0 & 253,965 \\
\hline 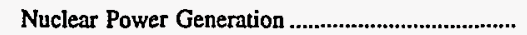 & 0 & 0 & 0 & 0 & 0 & 84,314 \\
\hline Hydraulic Power Generation.......................................... & 760 & 0 & 0 & 0 & $\mathbf{0}$ & 12,065 \\
\hline Other Power Generation & 2,490 & 0 & 0 & 0 & 0 & 9,957 \\
\hline 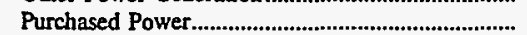 & 4,306 & 15,610 & 5,934 & 14,166 & 20,257 & 159,082 \\
\hline 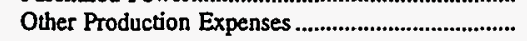 & 0 & 0 & 0 & 0 & 0 & 3,682 \\
\hline 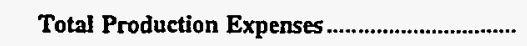 & 7,556 & 15,610 & 5,934 & 14,166 & 20,257 & 523,065 \\
\hline 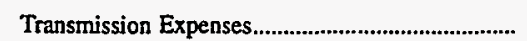 & 2 & 3,748 & 0 & 0 & 413 & 13,688 \\
\hline 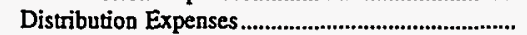 & 1,383 & $\mathbf{0}$ & 942 & 2,866 & 2,516 & 41,041 \\
\hline 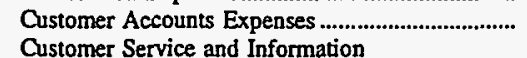 & 0 & 0 & 225 & 0 & 1,631 & 24,780 \\
\hline 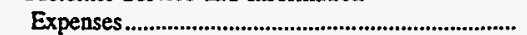 & 179 & 0 & 0 & 483 & 5 & 9,621 \\
\hline Sales Expenses............................................. & 0 & 0 & 0 & 79 & 38 & 2,354 \\
\hline 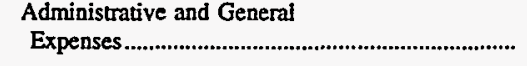 & 1,276 & 989 & 278 & 1,114 & 4,543 & 71,224 \\
\hline 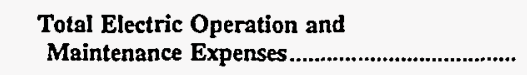 & 10,397 & 20,347 & 7,379 & 18,709 & 29,403 & 685,772 \\
\hline \multicolumn{7}{|l|}{ Fuel Expenses in Operation } \\
\hline 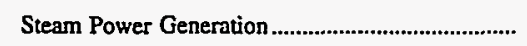 & 0 & 0 & 0 & 0 & 0 & 192,746 \\
\hline Nuclear Power Generation ....................................... & 0 & 0 & 0 & 0 & 0 & 24,091 \\
\hline Other Power Generation & 1,510 & $\mathbf{0}$ & $\mathbf{0}$ & 0 & 0 & 5,846 \\
\hline \multicolumn{7}{|l|}{ Number of Elec Dept Employees } \\
\hline 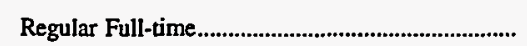 & 45 & 10 & 18 & 53 & 99 & 3,809 \\
\hline 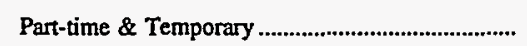 & 1 & $\mathbf{0}$ & 1 & 0 & 0 & 167 \\
\hline 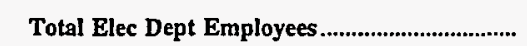 & 46 & 10 & 19 & 53 & 99 & 3,976 \\
\hline
\end{tabular}

Note: Totals may not equal sum of components because of independent rounding.

Source: Energy Information Administration, Form EIA-412, "Annual Report of Public Electric Utilities." 
Table 23. Electric Operation and Maintenance Expenses by Major U.S. Publicly Owned Electric Utility Within State, 1996 (Continued)

(Thousand Dollars)

\begin{tabular}{|c|c|c|c|c|c|c|}
\hline Item & $\begin{array}{l}\text { Arizona } \\
\text { Tohono } \\
\text { OOdham } \\
\text { Utility Auth } \\
\text { December } 31\end{array}$ & $\begin{array}{l}\text { Arkansas } \\
\text { Benton } \\
\text { City of } \\
\text { December } 31\end{array}$ & $\begin{array}{l}\text { Arkansas } \\
\text { Bentonville } \\
\text { City of } \\
\text { December } 31\end{array}$ & $\begin{array}{c}\text { Arkansas } \\
\text { Clarksville } \\
\text { Light } \\
\& \\
\text { Water Co } \\
\text { September } 30\end{array}$ & $\begin{array}{l}\text { Arkansas } \\
\text { Conway } \\
\text { Corp } \\
\text { December 31 }\end{array}$ & $\begin{array}{l}\text { Arkansas } \\
\text { Hope } \\
\text { City of } \\
\text {. } \\
\text { December } 31\end{array}$ \\
\hline \multicolumn{7}{|l|}{ Production Expen } \\
\hline 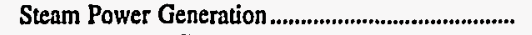 & 0 & 0 & 0 & 0 & 6,883 & $\mathbf{0}$ \\
\hline 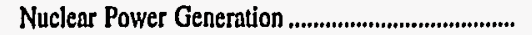 & 0 & 0 & 0 & 0 & $\mathbf{0}$ & $\mathbf{0}$ \\
\hline 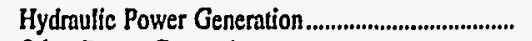 & 0 & 0 & 0 & 0 & 0 & 0 \\
\hline 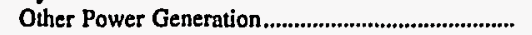 & 0 & 8 & 0 & 0 & 0 & 0 \\
\hline 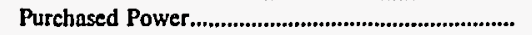 & 4,539 & 8,631 & 8,262 & 6,534 & 11,226 & 9,143 \\
\hline 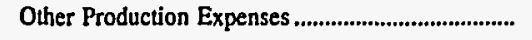 & 0 & 0 & 0 & 0 & $\mathbf{0}$ & 2 \\
\hline Total Production Expenses................ & 4,539 & 8,639 & 8,262 & 6,534 & 18,108 & 9,146 \\
\hline Transmission Expenses.. & 7 & $\mathbf{0}$ & o & $\mathbf{0}$ & 1,614 & 123 \\
\hline Distribution Expenses..... & 363 & 1,624 & 1,171 & 749 & 2,061 & 664 \\
\hline Customer Accounts Expenses ...................................... & 190 & 0 & 0 & 0 & 354 & 0 \\
\hline 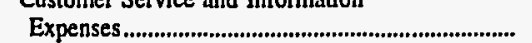 & 0 & 0 & $\mathbf{0}$ & 0 & 0 & 0 \\
\hline 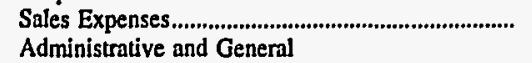 & 2 & 138 & 0 & $\mathbf{0}$ & 0 & 0 \\
\hline 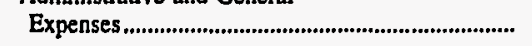 & 452 & 598 & 101 & 296 & 533 & 778 \\
\hline $\begin{array}{l}\text { Total Electric Operation and } \\
\text { Malntenance Expenses.......................................... }\end{array}$ & 5,553 & 10,999 & 9,534 & 7,578 & 22,670 & 10,711 \\
\hline
\end{tabular}

Fuel Expenses in Operation

Steam Power Generation ........................................

Other Power Generation.

Number of Elec Dept Employees

Regular Full-time.

Part-time \& Temporary.

Total Elec Dept Employees

0
0
0

$\mathbf{0}$

$\mathbf{0}$

0
0

$\mathbf{0}$

0
0

$\mathbf{0}$

0

Note: Totals may not equal sum of components because of independent rounding.

Source: Energy Information Administration, Form EIA-412, "Annual Report of Public Electric Utilities." 
Table 23. Electric Operation and Maintenance Expenses by Major U.S. Publicly Owned Electric Utility Within State, 1996 (Continued)

(Thousand Dollars)

\begin{tabular}{|c|c|c|c|c|c|c|}
\hline Item & $\begin{array}{l}\text { Arkansas } \\
\text { Jonesboro } \\
\text { City of } \\
\text { December } 31\end{array}$ & $\begin{array}{c}\text { Arkansas } \\
\text { North } \\
\text { Little } \\
\text { Rock } \\
\text { City of } \\
\text { December } 31\end{array}$ & $\begin{array}{c}\text { Arkansas } \\
\text { - Osceola } \\
\text { City of } \\
\text { December } 31\end{array}$ & $\begin{array}{c}\text { Arkansas } \\
\text { Paragould } \\
\text { Light } \\
\& \\
\text { Water Comm } \\
\text { December } 31\end{array}$ & $\begin{array}{l}\text { Arkansas } \\
\text { Siloam } \\
\text { Springs } \\
\text { City of } \\
\text { December } 31\end{array}$ & $\begin{array}{c}\text { Arkansas } \\
\text { West } \\
\text { Memphis } \\
\text { City of } \\
\text { December } 31\end{array}$ \\
\hline \multicolumn{7}{|l|}{ Production Experses } \\
\hline 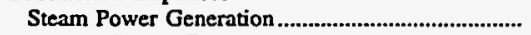 & 21,284 & 0 & 0 & 0 & 0 & 316 \\
\hline 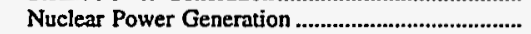 & 0 & 0 & 0 & 0 & 0 & 0 \\
\hline Hydraulic Power Generation........................................... & 0 & 0 & 0 & 0 & 0 & 0 \\
\hline Other Power Generation & 0 & 589 & 0 & 0 & 0 & 0 \\
\hline 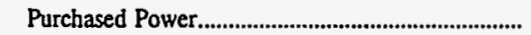 & 10,842 & 31,313 & 5,438 & 10,159 & 6,961 & 12.534 \\
\hline 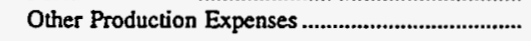 & 114 & 0 & 89 & 0 & 0 & 0 \\
\hline 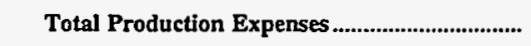 & 32,240 & 31,902 & 5,528 & 10,159 & 6,961 & 12,850 \\
\hline 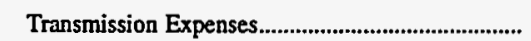 & 0 & 0 & 0 & 0 & 63 & 991 \\
\hline 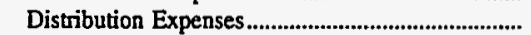 & 2,231 & 3,167 & 1,245 & 1,664 & 1,382 & 0 \\
\hline 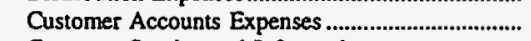 & 1,152 & 1,546 & 0 & 303 & 0 & 0 \\
\hline \multicolumn{7}{|l|}{ Customer Service and Information } \\
\hline 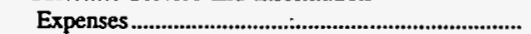 & 0 & 0 & 0 & 0 & 0 & 0 \\
\hline 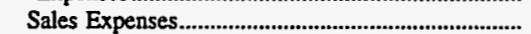 & 9 & 0 & 0 & 0 & 0 & 0 \\
\hline \multicolumn{7}{|l|}{ Administrative and General } \\
\hline 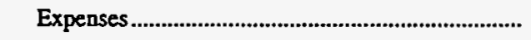 & 1,171 & 3,581 & 3,862 & 492 & 79 & 3,986 \\
\hline $\begin{array}{l}\text { Total Electric Operation and } \\
\text { Maintenance Expenses........................................... }\end{array}$ & 36,803 & 40,197 & 10,634 & 12,618 & 8,484 & 17,827 \\
\hline
\end{tabular}

Fuel Expenses in Operation

Steam Power Generation .........................................

Nuclear Power Generation

Other Power Generation

Number of Elec Dept Employees

Regular Full-time...

Part-time \& Temporary

Total Elec Dept Employees.

.....
105

5

110

16,494

0

0

98

0

98
0

$0 \quad 0$

0

0
0

0

0

88

2

90

$\begin{array}{ll}0 & 0 \\ 0 & 0 \\ 0 & 0\end{array}$

Note: Totals may not equal sum of components because of independent rounding.

Source: Energy Information Administration, Form EIA-412, "Annual Report of Public Electric Utilities." 
Table 23. Electric Operation and Maintenance Expenses by Major U.S. Publicly Owned Electric Utility Within State, 1996 (Continued)

(Thousand Dollars)

\begin{tabular}{|c|c|c|c|c|c|c|}
\hline Item & $\begin{array}{l}\text { California } \\
\text { Alameda } \\
\text { City of } \\
\text { June } 30\end{array}$ & $\begin{array}{l}\text { Califomia } \\
\text { Anaheim } \\
\text { City of } \\
\text { June } 30\end{array}$ & $\begin{array}{l}\text { Califomia } \\
\text { Azusa } \\
\text { City of } \\
\text { June } 30\end{array}$ & $\begin{array}{l}\text { California } \\
\text { Burbank } \\
\text { City of } \\
\text { June } 30\end{array}$ & $\begin{array}{l}\text { California } \\
\text { California } \\
\text { Dept } \\
\text { Wtr } \\
\text { Resources } \\
\text { June } 30\end{array}$ & $\begin{array}{l}\text { California } \\
\text { Colton } \\
\text { City of } \\
\text { June } 30\end{array}$ \\
\hline \multicolumn{7}{|l|}{ Production Expenses } \\
\hline 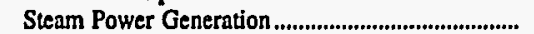 & 0 & 8,213 & $\mathbf{0}$ & 13,386 & 797 & 0 \\
\hline Nuclear Power Generation ............................................ & 0 & 18,628 & $\mathbf{0}$ & 0 & $\mathbf{0}$ & 0 \\
\hline 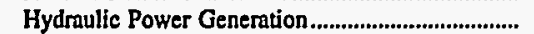 & 0 & 0 & 0 & 0 & 8,944 & 0 \\
\hline Other Power Generation................................................. & 0 & 0 & 0 & $\mathbf{0}$ & 28,535 & 0 \\
\hline 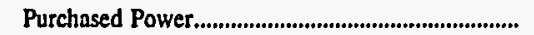 & 28,828 & 127,839 & 15,450 & 44,971 & 0 & 16,484 \\
\hline 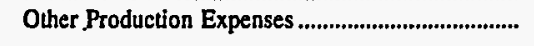 & 375 & 0 & 0 & 0 & 0 & 0 \\
\hline Total Production Expenses..................................... & 29,203 & 154,680 & 15,450 & 58,357 & 38,276 & 16,484 \\
\hline 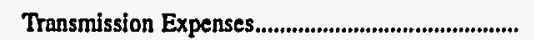 & 34 & 6,082 & 0 & 7,895 & 0 & 0 \\
\hline Distribution Expenses ................................................ & 1,451 & 12,143 & 1,648 & $\mathbf{5 , 7 9 0}$ & 0 & 1,913 \\
\hline 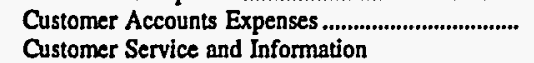 & 1,267 & 2,886 & 722 & 2,500 & 0 & 192 \\
\hline 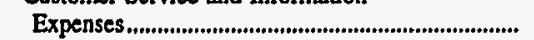 & 297 & 0 & 0 & 0 & 0 & 0 \\
\hline 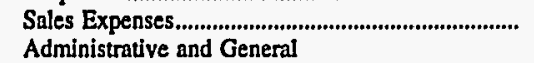 & 24 & 0 & 0 & 0 & 0 & 0 \\
\hline 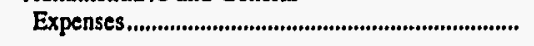 & 3,118 & 4,803 & 792 & 5,440 & 0 & 4,849 \\
\hline $\begin{array}{l}\text { Total Electric Operatfon and } \\
\text { Maintenance Expenses........................................... }\end{array}$ & 35,393 & 180,594 & 18,612 & 79,982 & 38,276 & 23,438 \\
\hline \multicolumn{7}{|l|}{ Fuel Expenses in Operation } \\
\hline 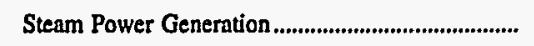 & 0 & 6,250 & 0 & 4,333 & 0 & 0 \\
\hline 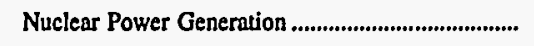 & 0 & 3,370 & 0 & 0 & 0 & 0 \\
\hline 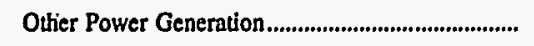 & 0 & 0 & 0 & 0 & 0 & 0 \\
\hline \multicolumn{7}{|l|}{ Number of Elec Dept Employees } \\
\hline 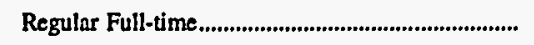 & 87 & 246 & 27 & 263 & 96 & 41 \\
\hline 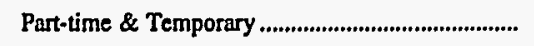 & 4 & 22 & 2 & 3 & 0 & 0 \\
\hline 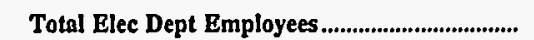 & 91 & 268 & 29 & 266 & 96 & 41 \\
\hline
\end{tabular}

Note: Totals may not equal sum of components because of independent rounding.

Source: Energy Information Administration, Form ELA-412, "Annual Report of Public Electric Utilities." 
Table 23. Electric Operation and Maintenance Expenses by Major U.S. Publicly Owned Electric Utility Within State, 1996 (Continued)

(Thousand Dollars)

\begin{tabular}{|c|c|c|c|c|c|c|}
\hline Item & $\begin{array}{l}\text { California } \\
\text { Glendale } \\
\text { City of } \\
\text { June } 30\end{array}$ & $\begin{array}{c}\text { California } \\
\text { Imperial } \\
\text { Inigation } \\
\text { District } \\
\text { December } 31\end{array}$ & $\begin{array}{c}\text { California } \\
\text { Kings River } \\
\text { Conservation } \\
\text { Dist } \\
\text { June } 30\end{array}$ & $\begin{array}{c}\text { California } \\
\text { Lassen } \\
\text { Municipal } \\
\text { Utility Dist } \\
\text { June } 30\end{array}$ & $\begin{array}{l}\text { California } \\
\text { Lodi } \\
\text { City of } \\
\text { June } 30\end{array}$ & $\begin{array}{l}\text { Califomia } \\
\text { Los Angeles } \\
\text { City of } \\
\text { June } 30\end{array}$ \\
\hline \multicolumn{7}{|l|}{ Production Expenses } \\
\hline Steam Power Generation & 10,198 & 18,115 & 0 & 0 & 0 & 241,587 \\
\hline 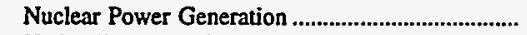 & 0 & 0 & $\mathbf{0}$ & 0 & $\mathbf{0}$ & 23,986 \\
\hline Hydraulic Power Generation............................................... & 0 & 5,636 & 6.769 & 0 & 0 & 21,683 \\
\hline 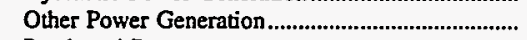 & 1,577 & 1,164 & 0 & 0 & 0 & 279 \\
\hline 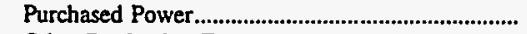 & 38,500 & 88,709 & 0 & 5,314 & 25,816 & 707,938 \\
\hline 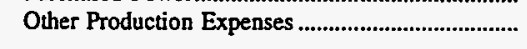 & 5,773 & 726 & 0 & 0 & 0 & 0 \\
\hline 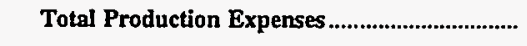 & 56,048 & 114,349 & 6,769 & 5,314 & 25,816 & 995,474 \\
\hline 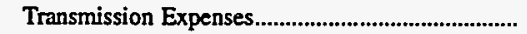 & 1,138 & 1,767 & 0 & 18 & 0 & 47,612 \\
\hline 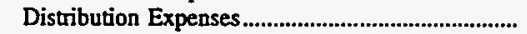 & 5,353 & 10,440 & 0 & 850 & 2,189 & 212,738 \\
\hline 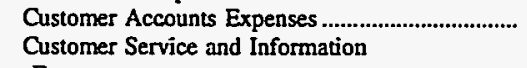 & 2,922 & 3,181 & 0 & 267 & 1,048 & 84,181 \\
\hline 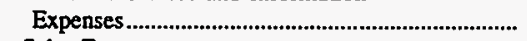 & 0 & 0 & $\mathbf{0}$ & 143 & 0 & 23,271 \\
\hline 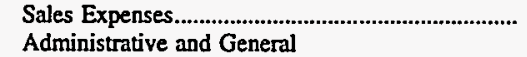 & 0 & 0 & 0 & 0 & $\mathbf{0}$ & 0 \\
\hline 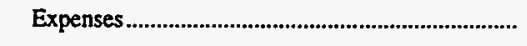 & 10,151 & 12,068 & 0 & 1,357 & 5,859 & 38,476 \\
\hline $\begin{array}{l}\text { Total Electric Operation and } \\
\text { Maintenance Expenses......................................... }\end{array}$ & 75,612 & 141,804 & 6,769 & 7,949 & 34,913 & $1,401,752$ \\
\hline \multicolumn{7}{|l|}{ Fuel Expenses in Operation } \\
\hline Steam Power Generation & 6,202 & 11,652 & 0 & 0 & $\mathbf{0}$ & 142,386 \\
\hline Nuclear Power Generation & 0 & 0 & 0 & 0 & 0 & 8.653 \\
\hline Other Power Generation & 927 & 508 & 0 & 0 & 0 & 0 \\
\hline \multicolumn{7}{|l|}{ Number of Elec Dept Employees } \\
\hline Regular Full-time & 257 & 514 & 17 & 16 & 39 & 6,813 \\
\hline 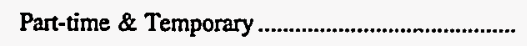 & 0 & 13 & 0 & $\mathbf{0}$ & 5 & 249 \\
\hline 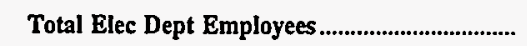 & 257 & 527 & 17 & 16 & 44 & 7,062 \\
\hline
\end{tabular}

Source: Energy Information Administration, Form EIA-412, "Annual Report of Public Electric Utilities." 
Table 23. Electric Operation and Maintenance Expenses by Major U.S. Publicly Owned Electric Utility Within State, 1996 (Continued)

(Thousand Dollars)

\begin{tabular}{|c|c|c|c|c|c|c|}
\hline Item & $\begin{array}{l}\text { Califomia } \\
\text { Merced } \\
\text { Irrigation } \\
\text { District } \\
\text { December } 31\end{array}$ & $\begin{array}{c}\text { California } \\
\text { Metropolitan } \\
\text { Water } \\
\text { District } \\
\text { June } 30\end{array}$ & $\begin{array}{l}\text { California } \\
\text { Modesto } \\
\text { Irngation } \\
\text { District } \\
\text { December } 31\end{array}$ & $\begin{array}{c}\text { Califomia } \\
\text { MSR } \\
\text { Public } \\
\text { Power } \\
\text { Agency } \\
\text { December } 31\end{array}$ & $\begin{array}{l}\text { California } \\
\text { Northern } \\
\text { California } \\
\text { Power Agny } \\
\text { June } 30\end{array}$ & $\begin{array}{c}\text { California } \\
\text { Oakdale \& } \\
\text { South } \\
\text { San Joaquin } \\
\text { December 31 }\end{array}$ \\
\hline \multicolumn{7}{|l|}{ Production Expenses } \\
\hline 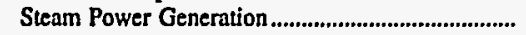 & 0 & $\mathbf{0}$ & $\mathbf{0}$ & 21,901 & 51,850 & 0 \\
\hline Nuclear Power Generation .......................................... & 0 & 0 & $\mathbf{0}$ & 0 & 0 & 0 \\
\hline Hydraulic Power Generation............................................ & 1,933 & 1,653 & 565 & 0 & 2,504 & 1,250 \\
\hline 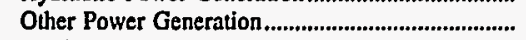 & 0 & 0 & 3,414 & 0 & 2,424 & 0 \\
\hline 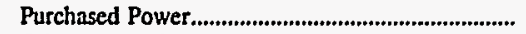 & 785 & 0 & 92,826 & 33,890 & 17,614 & 0 \\
\hline Other Production Expenses ........................................... & 0 & 0 & 1,802 & 70 & 5,932 & 0 \\
\hline 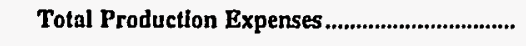 & 2,717 & 1,653 & 98,608 & 55,860 & 80,324 & 1,250 \\
\hline 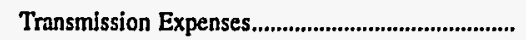 & 48 & 0 & 531 & 2,624 & 11,711 & 0 \\
\hline 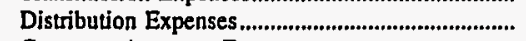 & 68 & 0 & 5,530 & 0 & 0 & 0 \\
\hline 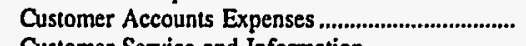 & 0 & 0 & 3,835 & 0 & 0 & 0 \\
\hline Customer Service and Information & & & & & & \\
\hline Expenses & 0 & 0 & 537 & 0 & 3 & 0 \\
\hline 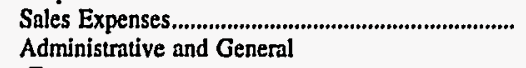 & 52 & 0 & 0 & 0 & 0 & 0 \\
\hline 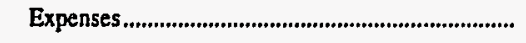 & 390 & 0 & 8,532 & 1,831 & 4,235 & 1,332 \\
\hline $\begin{array}{l}\text { Total Electric Operation and } \\
\text { Maintenance Expenses........................................... }\end{array}$ & 3,275 & 1,653 & 117,574 & 60,316 & 96,273 & 2,582 \\
\hline \multicolumn{7}{|l|}{ Fuel Expenses in Operation } \\
\hline 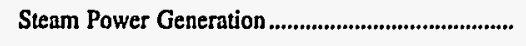 & 0 & 0 & 0 & 18,321 & 44,010 & 0 \\
\hline 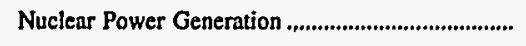 & 0 & 0 & 0 & $\mathbf{0}$ & $\mathbf{0}$ & 0 \\
\hline 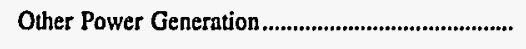 & $\mathbf{0}$ & 0 & 1,479 & 0 & 592 & 0 \\
\hline \multicolumn{7}{|l|}{ Number of Elec Dept Employees } \\
\hline 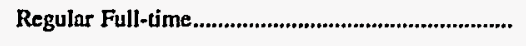 & 11 & 57 & 257 & 8 & 172 & 20 \\
\hline 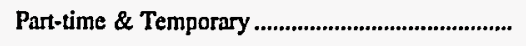 & 0 & 0 & 15 & 0 & 2 & 1 \\
\hline Total Elec Dept Employees ......................................... & 11 & 57 & 272 & 8 & 174 & 21 \\
\hline
\end{tabular}

Note: Totals may not equal sum of components because of independent rounding.

Source: Energy Information Administration, Form EIA-412, "Annual Report of Public Electric Utilities." 
Table 23. Electric Operation and Maintenance Expenses by Major U.S. Publicly Owned Electric Utility Within State, 1996 (Continued)

(Thousand Dollars)

\begin{tabular}{|c|c|c|c|c|c|c|}
\hline Item & $\begin{array}{l}\text { California } \\
\text { Oroville } \\
\text { Wyandotte } \\
\text { Irrig Dist } \\
\text { December } 31\end{array}$ & $\begin{array}{l}\text { California } \\
\text { Palo Alto } \\
\text { City of } \\
\text { June } 30\end{array}$ & $\begin{array}{l}\text { Califomia } \\
\text { Pasadena } \\
\text { City of } \\
\text { June } 30\end{array}$ & $\begin{array}{c}\text { California } \\
\text { Placer } \\
\text { County } \\
\text { Water } \\
\text { Agency } \\
\text { December } 31\end{array}$ & $\begin{array}{l}\text { California } \\
\text { Redding } \\
\text { City of } \\
\text { June } 30\end{array}$ & $\begin{array}{l}\text { California } \\
\text { Riverside } \\
\text { City of } \\
\text { June } 30\end{array}$ \\
\hline \multicolumn{7}{|l|}{ Production Expenses } \\
\hline Steam Power Generation ................................................... & 0 & $\mathbf{0}$ & 11,865 & 0 & 3,295 & 0 \\
\hline 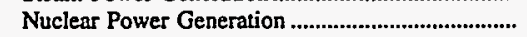 & 0 & 0 & 0 & 0 & 0 & 9,854 \\
\hline 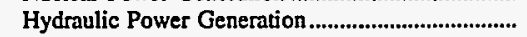 & 3,673 & 0 & 84 & 1,657 & 25 & 0 \\
\hline Other Power Generation............................................ & 0 & 0 & 80 & 0 & 34 & $\mathbf{0}$ \\
\hline Purchased Power................................................................ & 0 & 24,492 & 56,555 & 0 & 38,899 & 84,464 \\
\hline 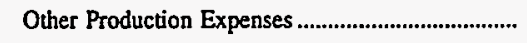 & 0 & 0 & 692 & 2 & 0 & 697 \\
\hline Total Production Expenses ...................................... & 3,673 & 24,492 & 69,276 & 1,659 & 42,253 & 95,016 \\
\hline 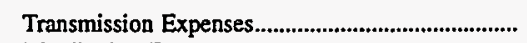 & 0 & 0 & 1,057 & 157 & 0 & 16,179 \\
\hline 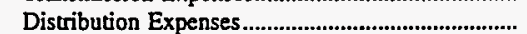 & 0 & 7,183 & 4,451 & 0 & 5,489 & 6,211 \\
\hline 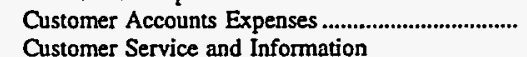 & 0 & 0 & 1,147 & 0 & 1,280 & 5,384 \\
\hline 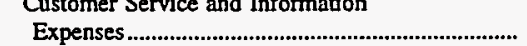 & 0 & 0 & 0 & 0 & 0 & 969 \\
\hline 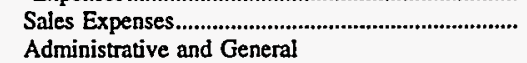 & 0 & 0 & 166 & $\mathbf{0}$ & 0 & $\mathbf{0}$ \\
\hline 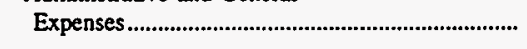 & 0 & 3,670 & 8,313 & 1,015 & 9,507 & 9,661 \\
\hline 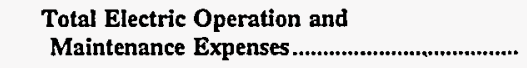 & 3,673 & 35,345 & 84,411 & 2,831 & 58,529 & 133,420 \\
\hline ' & & & & & & \\
\hline \multicolumn{7}{|l|}{ Fuel Expenses in Operation } \\
\hline 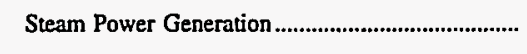 & 0 & $\mathbf{0}$ & 7,577 & 0 & 965 & 0 \\
\hline 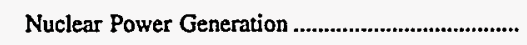 & 0 & 0 & 0 & 0 & 0 & 1,249 \\
\hline 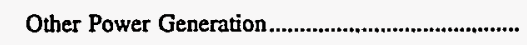 & 0 & 0 & 0 & 0 & 3 & 0 \\
\hline \multicolumn{7}{|l|}{ Number of Elec Dept Employees } \\
\hline Regular Full-time & 0 & 92 & 262 & 16 & 106 & 245 \\
\hline Part-time \& Temporary & 0 & 0 & 0 & 3 & 4 & 15 \\
\hline 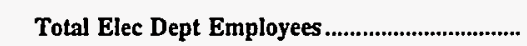 & 0 & 92 & 262 & 19 & 110 & 260 \\
\hline
\end{tabular}

Note: Totals may not equal sum of components because of independent rounding.

Source: Energy Information Administration, Form ElA-412, "Annual Report of Public Electric Utilities." 
Table 23. Electric Operation and Maintenance Expenses by Major U.S. Publicly

Owned Electric Utility Within State, 1996 (Continued)

(Thousand Dollars)

\begin{tabular}{|c|c|c|c|c|c|c|}
\hline Item & $\begin{array}{l}\text { California } \\
\text { Roseville } \\
\text { City of } \\
\text { June } 30\end{array}$ & $\begin{array}{l}\text { California } \\
\text { Sacramento } \\
\text { Municipal } \\
\text { Util Dist } \\
\text { December } 31\end{array}$ & $\begin{array}{c}\text { California } \\
\text { San Francisco } \\
\text { City } \\
\& \\
\text { County of } \\
\text { June } 30\end{array}$ & $\begin{array}{c}\text { California } \\
\text { Santa } \\
\text { Clara } \\
\text { City of } \\
\text { June } 30\end{array}$ & $\begin{array}{l}\text { California } \\
\text { Southern } \\
\text { California } \\
\text { P P } \\
\text { A } \\
\text { June } 30\end{array}$ & $\begin{array}{c}\text { California } \\
\text { Turlock } \\
\text { Irrigation } \\
\text { District } \\
\text { December } 31\end{array}$ \\
\hline
\end{tabular}

Production Expenses

Steam Power Generation

Nuclear Power Generation

Hydraulic Power Generation...................................

Other Power Generation.

Other Production Expenses ........................................

Total Production Expenses .................................

Transmission Expenses.

Distribution Expenses.

Customer Accounts Expenses ...................................

Customer Service and Information

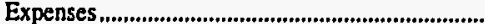

Sales Expenses............................................................

Administrative and General

Expenses.

\begin{tabular}{rr}
0 & 19,545 \\
0 & 0 \\
0 & 9,184 \\
0 & 11,341 \\
28,922 & 220,056 \\
3,239 & 5,504 \\
& \\
\hline 32,161 & 265,630
\end{tabular}

0
0
4,623

$32,161 \quad 265,630$

$0 \quad 21,714$

$6,619 \quad 29,872$

$\begin{array}{ll}0 & 27,289\end{array}$

$0 \quad 9,283$

$0 \quad 1,027$

$773 \quad 41,751$

0

16,779
0

21,402

2,010

$\mathbf{0}$
$\mathbf{0}$

0

$\mathbf{0}$
$\mathbf{0}$

13,340

Total Electric Operation and

Maintenance Expenses.

39,553

396,565 .

36,751

$\begin{array}{rr}0 & 32,15 \\ 0 & 23,01 \\ 59 & \\ 7,555 & \\ 127,270 & 1,95 \\ 614 & 268\end{array}$

23,016

0

3,439

$951 \quad 57,197$

$35,498-57,386$
1396,039

53

3,374

15,953

65,039

500

7,063

(a)

0

$\mathbf{0}$
$\mathbf{0}$

8,557

10,247

9,428

82,850

Fuel Expenses in Operation

Steam Power Generation.

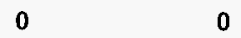

0

0

Nuclear Power Generation ........................................

0

$0 \quad 6,376$

o

0

0

1,410

0

$\mathbf{0}$

, 573

Number of Elec Dept Employees

Regular Full-time.

2,191

33

102

393

$15 \quad 98$

0

7

Total Elec Dept Employees.

$79 \quad 2,289$

33

109

436

Note: Totals may not equal sum of components because of independent rounding.

Source: Energy Information Administration, Form EIA-412, "Annual Report of Public Electric Utilities." 
Table 23. Electric Operation and Maintenance Expenses by Major U.S. Publicly Owned Electric Utility Within State, 1996 (Continued) (Thousand Dollars)

\begin{tabular}{|c|c|c|c|c|c|c|}
\hline Item & $\begin{array}{l}\text { Califomia } \\
\text { Vernon } \\
\text { City of } \\
\text { June } 30\end{array}$ & $\begin{array}{c}\text { California } \\
\text { Yuba } \\
\text { County } \\
\text { Water } \\
\text { Agency } \\
\text { June } 30\end{array}$ & $\begin{array}{c}\text { Colorado } \\
\text { Arkansas } \\
\text { River } \\
\text { Power } \\
\text { Authority } \\
\text { December 31 }\end{array}$ & $\begin{array}{l}\text { Colorado } \\
\text { Colorado } \\
\text { Springs } \\
\text { City of } \\
\text { December 31 }\end{array}$ & $\begin{array}{l}\text { Colorado } \\
\text { Fort Collins } \\
\text { City of } \\
\text { December } 31\end{array}$ & $\begin{array}{l}\text { Colorado } \\
\text { Fort Morgan } \\
\text { City of } \\
\text { December } 31\end{array}$ \\
\hline \multicolumn{7}{|l|}{ Production Expenses } \\
\hline Steam Power Generation ................................................. & 0 & 0 & 0 & 63,790 & 0 & 0 \\
\hline Nuclear Power Generation ............................................. & 0 & 0 & 0 & 0 & 0 & 0 \\
\hline 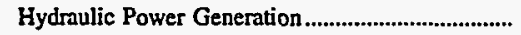 & 0 & 2,494 & 0 & 266 & 0 & 0 \\
\hline 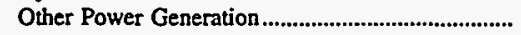 & 923 & 0 & 0 & $\mathbf{0}$ & 0 & 0 \\
\hline 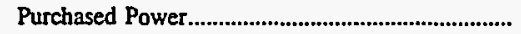 & 23,717 & 0 & 8,338 & 19,723 & 0 & 4,649 \\
\hline 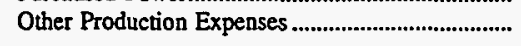 & 0 & 0 & 0 & 0 & 36,632 & 0 \\
\hline 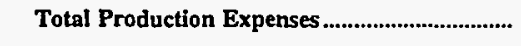 & 24,640 & 2,494 & 8,338 & 83,779 & 36,632 & 4,649 \\
\hline 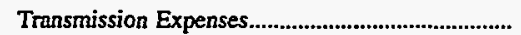 & 2,105 & 0 & 879 & 2,149 & 0 & 0 \\
\hline 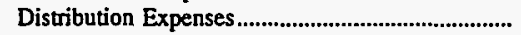 & 3,635 & 0 & 0 & 15,040 & 3,921 & 532 \\
\hline Customer Accounts Expenses ........................................... & 0 & 0 & 59 & 5,655 & 1,620 & 64 \\
\hline Customer Service and Information & & & & & & \\
\hline 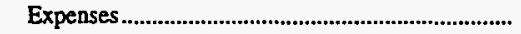 & 373 & 0 & 0 & 470 & 547 & 0 \\
\hline 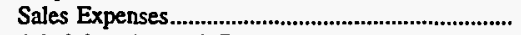 & 0 & 0 & 0 & 0 & 3,630 & 0 \\
\hline Administrative and General & & & & & & \\
\hline 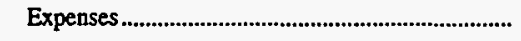 & 2,129 & 1,444 & 673 & 14,984 & 0 & 499 \\
\hline $\begin{array}{l}\text { Total Electric Operation and } \\
\text { Maintenance Expenses............. }\end{array}$ & 32,881 & $\mathbf{3 , 9 3 8}$ & 9,948 & 122,076 & 46,350 & 5,744 \\
\hline \multicolumn{7}{|l|}{ Fuel Expenses in Operation } \\
\hline Steam Power Generation & 0 & 0 & 0 & 0 & 0 & 0 \\
\hline 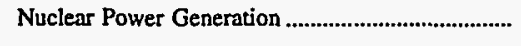 & 0 & 0 & 0 & 0 & 0 & 0 \\
\hline 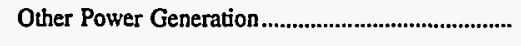 & 0 & 0 & 0 & 0 & 0 & 0 \\
\hline \multicolumn{7}{|l|}{ Number of Elec Dept Employees } \\
\hline Regular Full-time & 40 & 17 & 5 & 528 & 108 & 9 \\
\hline 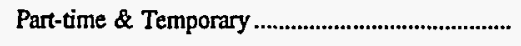 & 0 & 1 & 0 & 22 & 24 & 0 \\
\hline 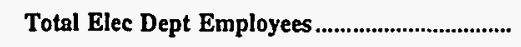 & 40 & 18 & 5 & 550 & 132 & 9 \\
\hline
\end{tabular}

Note: Totals may not equal sum of components because of independent rounding.

Source: Energy Information Administration, Form EIA-412, "Annual Report of Public Electric Utilities." 
Table 23. Electric Operation and Maintenance Expenses by Major U.S. Publicly Owned Electric Utility Within State, 1996 (Continued)

(Thousand Dollars)

\begin{tabular}{|c|c|c|c|c|c|c|}
\hline Item & $\begin{array}{c}\text { Colorado } \\
\text { Longmont } \\
\text { City of } \\
\text { December } 31\end{array}$ & $\begin{array}{l}\text { Colorado } \\
\text { Loveland } \\
\text { City of } \\
\text { December } 31\end{array}$ & $\begin{array}{c}\text { Colorado } \\
\text { Platte River } \\
\text { Power } \\
\text { Authority } \\
\text { December } 31\end{array}$ & $\begin{array}{l}\text { Connecticut } \\
\text { Connecticut } \\
\text { Mun } \\
\text { Elec } \\
\text { Engy Coop } \\
\text { December } 31\end{array}$ & $\begin{array}{l}\text { Connecticut } \\
\text { Groton } \\
\text { City of } \\
\text { June } 30\end{array}$ & $\begin{array}{l}\text { Connecticut } \\
\text { Norwich } \\
\text { City of } \\
\text { June } 30\end{array}$ \\
\hline \multicolumn{7}{|l|}{ Production Expenses } \\
\hline Steam Power Generation ................................................... & 0 & 0 & 46,102 & 0 & $\mathbf{0}$ & $\mathbf{0}$ \\
\hline Nuclear Power Generation ............................................... & 0 & 0 & $\mathbf{0}$ & 1,941 & $\mathbf{0}$ & 0 \\
\hline Hydraulic Power Generation.......................................... & 0 & 58 & 0 & 0 & 0 & 333 \\
\hline Other Power Generation............................................ & 0 & 0 & 0 & 0 & 0 & 111 \\
\hline Purchased Power............................................................ & 18,789 & 15,231 & 16,135 & 92,449 & 35,764 & 18,225 \\
\hline Other Production Expenses ............................................ & 0 & 0 & 1,021 & 0 & 0 & 0 \\
\hline 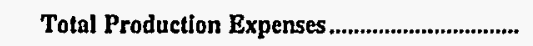 & 18,789 & 15,289 & 63,259 & 94,390 & 35,764 & 18,670 \\
\hline 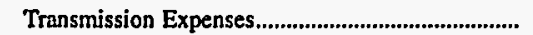 & 0 & 0 & 2,707 & 3,682 & 61 & 224 \\
\hline 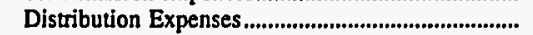 & 2,398 & 1,569 & 0 & 0 & 1,082 & 987 \\
\hline $\begin{array}{l}\text { Customer Accounts Expenses .................................... } \\
\text { Customer Service and Information }\end{array}$ & 0 & 743 & 0 & 0 & 358 & 891 \\
\hline 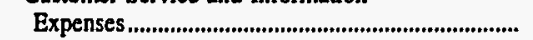 & 1,364 & 134 & 0 & 0 & 14 & 0 \\
\hline $\begin{array}{l}\text { Sales Expenses.................................................... } \\
\text { Administrative and General }\end{array}$ & 0 & 0 & 0 & 0 & 3 & 0 \\
\hline 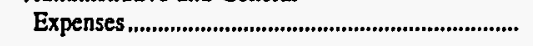 & 1,475 & 229 & 6,627 & 2,948 & 2,685 & 5,145 \\
\hline $\begin{array}{l}\text { Total Electric Operation and } \\
\text { Maintenance Expenses......................................... }\end{array}$ & 24,025 & 17,965 & 72,593 & 101,020 & 39,968 & 25,918 \\
\hline \multicolumn{7}{|l|}{ Fuel Expenses in Operation } \\
\hline 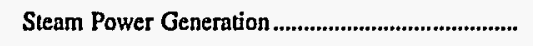 & 0 & 0 & 27,267 & $\mathbf{0}$ & $\mathbf{0}$ & 0 \\
\hline 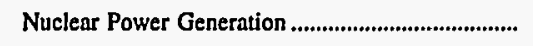 & 0 & 0 & 0 & 0 & 0 & 0 \\
\hline 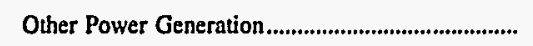 & 0 & 0 & 0 & 0 & 0 & 0 \\
\hline \multicolumn{7}{|l|}{ Number of Elec Dept Employees } \\
\hline 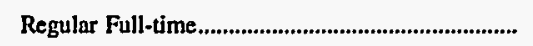 & 55 & 56 & 181 & 18 & 41 & 53 \\
\hline Part-time \& Temporary & 2 & 4 & 4 & 0 & 3 & $\mathbf{0}$ \\
\hline Total Elec Dept Employees........................................ & 57 & 60 & 185 & 18 & 44 & 53 \\
\hline
\end{tabular}

Note: Totals may not equal sum of components because of independent rounding.

Source: Energy Information Administration, Form EIA-412, "Annual Report of Public Electric Utilities." 
Table 23. Electric Operation and Maintenance Expenses by Major U.S. Publicly Owned Electric Utility Within State, 1996 (Continued)

(Thousand Dollars)

\begin{tabular}{|c|c|c|c|c|c|c|}
\hline Item & $\begin{array}{l}\text { Connecticut } \\
\text { Wallingford } \\
\text { Town of } \\
\text { June } 30\end{array}$ & $\begin{array}{l}\text { Delaware } \\
\text { Dover } \\
\text { City of } \\
\text { June } 30\end{array}$ & $\begin{array}{l}\text { Delaware } \\
\text { Milford } \\
\text { City of } \\
\text { September } 30\end{array}$ & $\begin{array}{c}\text { Delaware } \\
\text { Newark } \\
\text { City of } \\
\text { December } 31\end{array}$ & $\begin{array}{c}\text { Florida } \\
\text { Bartow } \\
\text { City of } \\
\text { September } 30\end{array}$ & $\begin{array}{c}\text { Florida } \\
\text { Florida } \\
\text { Municipal } \\
\text { Power Agency } \\
\text { September } 30\end{array}$ \\
\hline \multicolumn{7}{|l|}{ Production Expenses } \\
\hline 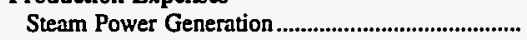 & 479 & 12,753 & 0 & 0 & 0 & 20,146 \\
\hline 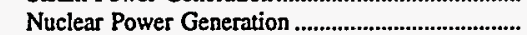 & 0 & 0 & 0 & 0 & 0 & 11,694 \\
\hline 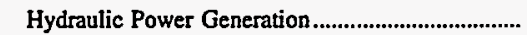 & 0 & 0 & 0 & 0 & 0 & 0 \\
\hline 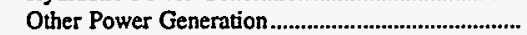 & 0 & 0 & 0 & 0 & 0 & 10,665 \\
\hline Purchased Power........................................................... & 25,002 & 11,619 & 6,266 & 13,686 & 14,694 & 69,179 \\
\hline 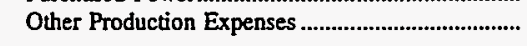 & 0 & 0 & 0 & 0 & 0 & 543 \\
\hline 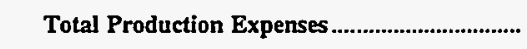 & 25,482 & 24,371 & 6,266 & 13,686 & 14,694 & 112,228 \\
\hline 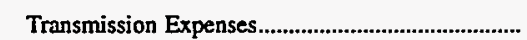 & 14 & 3,085 & 0 & 0 & 0 & 11,957 \\
\hline Distribution Expenses & 1,616 & 0 & 1,686 & 1,896 & 1,889 & 0 \\
\hline $\begin{array}{l}\text { Customer Accounts Expenses ................................. } \\
\text { Customer Service and Information }\end{array}$ & 868 & 0 & 0 & 0 & 0 & 0 \\
\hline 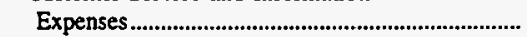 & 77 & $\mathbf{0}$ & 0 & 0 & 0 & 0 \\
\hline 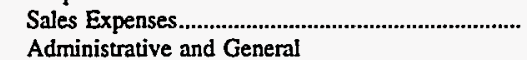 & 0 & 0 & 0 & 0 & 0 & 0 \\
\hline Expenses & 3,274 & 4,120 & 0 & $\mathbf{0}$ & 0 & 6,855 \\
\hline 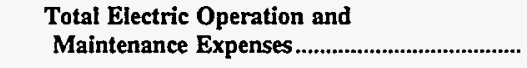 & 31,332 & 31,576 & 7,952 & 15,582 & 16,583 & 131,040 \\
\hline \multicolumn{7}{|l|}{ Fuel Expenses in Operation } \\
\hline 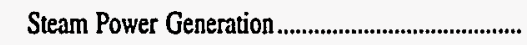 & 0 & 9,666 & 0 & 0 & 0 & 0 \\
\hline Nuclear Power Generation & 0 & 0 & 0 & 0 & 0 & 0 \\
\hline Other Power Generation & 0 & 0 & 0 & 0 & 0 & 0 \\
\hline \multicolumn{7}{|l|}{ Number of Elec Dept Employees } \\
\hline Regular Full-time & 76 & 65 & 11 & 20 & 35 & 30 \\
\hline Part-time \& Temporary & 1 & 1 & 0 & 0 & 0 & 0 \\
\hline 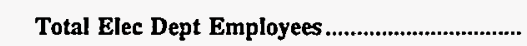 & 77 & 66 & 11 & 20 & 35 & 30 \\
\hline
\end{tabular}

Note: Totals may not equal sum of components because of independent rounding.

Source: Energy Information Administration, Form EIA-412, "Annual Report of Public Electric Utilities." 
Table 23. Electric Operation and Maintenance Expenses by Major U.S. Publicly Owned Electric Utility Within State, 1996 (Continued)

(Thousand Dollars)

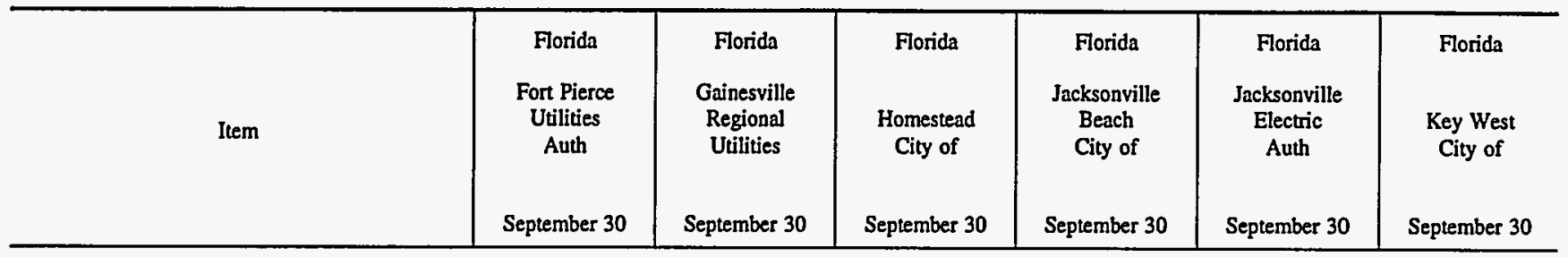

Production Expenses

Steam Power Generation.

Nuclear Power Generation.

Hydraulic Power Generation.......................................

Other Power Generation.

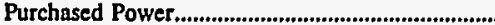

Other Production Expenses ...........................................

Total Production Expenses..................................

Transmission Expenses................................................

. Distribution Expenses......................................................

Customer Accounts Expenses ......................................

Customer Service and Information

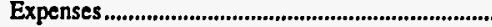

Sales Expenses................................................................

Administrative and General

Expenses.

Total Electric Operation and

Maintenance Expenses.

$\begin{array}{rr}10,583 & 49,378 \\ 0 & 2,04 \\ 0 & \\ 14 & \\ 15,725 & 164 \\ 0 & 5,138 \\ & 427 \\ 26,322 & \\ & 57,14\end{array}$

\section{8}

, 042

\section{4}

5,138

427

433
1,745
365

1,745
365

$0 \quad 58$

$0 \quad 406$

$3,341 \quad 10,643$

$32,206 \quad 76,365$

0
0
0
3,908
10,906
445

0
0
0
0
30,589
0

271,557

$\begin{array}{rr}271,557 & 1,387 \\ 0 & 0 \\ 0 & 0 \\ 945 & 2,043 \\ 77,661 & 25,996 \\ 0 & 168\end{array}$

15,259

30,589

350,164

29,593

9,251

21,820

10,743

264

2,105

1,653

3,791$$
1,865
$$

807

0

$\begin{array}{ll}0 & 0 \\ 0 & 0\end{array}$

3,690

570

37,821

5,866

22,204

37,262

430,606

38,761

\section{Fuel Expenses in Operation}

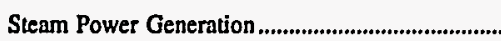

Nuclear Power Generation .

Other Power Generation.

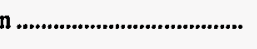

7,873

38,187

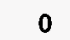

203,698

0

300

0

3

68

1,842

0

0

o

435

0

Number of Elec Dept Employees

Regular Full-time....................................................

Part-time \& Temporary

$\begin{array}{rr}88 & 422 \\ 0 & 3\end{array}$

90

74

1,700

164

\begin{tabular}{ll}
88 & 425 \\
\hline
\end{tabular}

0

90

108

1

Total Elec Dept Employees.

Note: Totals may not equal sum of components because of independent rounding.

Source: Energy Information Administration, Form EIA-412, "Annual Report of Public Electric Utilities." 
Table 23. Electric Operation and Maintenance Expenses by Major U.S. Publicly Owned Electric Utility Within State, 1996 (Continued)

(Thousand Dollars)

\begin{tabular}{|c|c|c|c|c|c|c|}
\hline Item & $\begin{array}{c}\text { Florida } \\
\text { Kissimmee } \\
\text { Utility } \\
\text { Authority } \\
\text { September } 30\end{array}$ & $\begin{array}{l}\text { Florida } \\
\text { Lake Worth } \\
\text { City of } \\
\text { September } 30\end{array}$ & $\begin{array}{l}\text { Florida } \\
\text { Lakeland } \\
\text { City of } \\
\text { September } 30\end{array}$ & $\begin{array}{c}\text { Florida } \\
\text { Leesburg } \\
\text { City of } \\
\text { September } 30\end{array}$ & $\begin{array}{c}\text { Florida ' } \\
\text { New Smyrna } \\
\text { Beach } \\
\text { Utils Comm } \\
\text { September } 30\end{array}$ & $\begin{array}{l}\text { Florida } \\
\text { Ocala } \\
\text { City of } \\
\text { September } 30\end{array}$ \\
\hline \multicolumn{7}{|l|}{ Production Expenses } \\
\hline Steam Power Generation & 12,297 & 8,949 & 45,370 & 0 & 0 & 0 \\
\hline 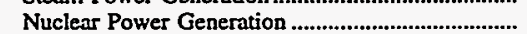 & 1,185 & 0 & 0 & 1,009 & 863 & 2,226 \\
\hline Hydraulic Power Generation........................................ & 0 & 0 & $\mathbf{0}$ & $\mathbf{0}$ & 0 & 0 \\
\hline Other Power Generation................................................. & 4,281 & $\mathbf{0}$ & 20,840 & 0 & 319 & 0 \\
\hline 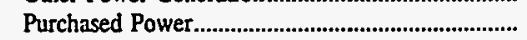 & 20,407 & 13,008 & 11,335 & 17,624 & 13,523 & 47,209 \\
\hline 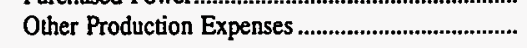 & 0 & 405 & 0 & 0 & 359 & 0 \\
\hline 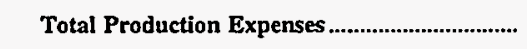 & 38,170 & 22,363 & 77,545 & 18,633 & 15,064 & 49,435 \\
\hline 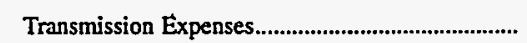 & 405 & 612 & 1,394 & 0 & 234 & 0 \\
\hline 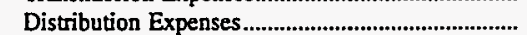 & 2,957 & 918 & 7,803 & 1,822 & 1,131 & 5,253 \\
\hline 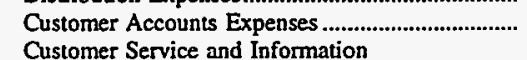 & 2,020 & 0 & 2,224 & 894 & 509 & 783 \\
\hline 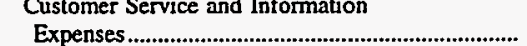 & 759 & 0 & 924 & 0 & 0 & 250 \\
\hline 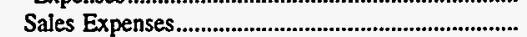 & 0 & 0 & 0 & 0 & 0 & 233 \\
\hline Administrative and General & & & & & & \\
\hline 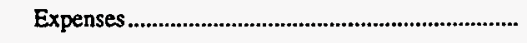 & 3,090 & 1,243 & 17,447 & 372 & 2,161 & 2,075 \\
\hline $\begin{array}{l}\text { Total Electric Operation and } \\
\text { Maintenance Expenses........................................ }\end{array}$ & 47,402 & 25,136 & 107,336 & 21,721 & 19,098 & 58,028 \\
\hline \multicolumn{7}{|l|}{ Fuel Expenses in Operation } \\
\hline 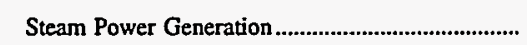 & 0 & 0 & 36,079 & 0 & 0 & 0 \\
\hline 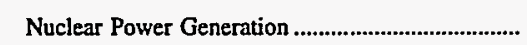 & 0 & 0 & $\mathbf{0}$ & 0 & 0 & 0 \\
\hline Other Power Generation & 0 & 0 & 9,881 & 0 & 0 & 0 \\
\hline \multicolumn{7}{|l|}{ Number of Elec Dept Employees } \\
\hline 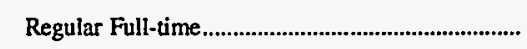 & 253 & 138 & 749 & 49 & 87 & 147 \\
\hline 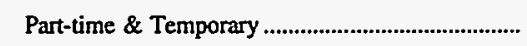 & 0 & 3 & 41 & $\mathbf{0}$ & 0 & 0 \\
\hline 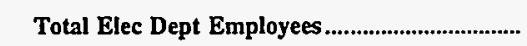 & 253 & 141 & 790 & 49 & 87 & 147 \\
\hline
\end{tabular}

Note: Totals may not equal sum of components because of independent rounding.

Source: Energy Information Administration, Form EIA-412, "Annual Report of Public Electric Utilities." 
Table 23. Electric Operation and Maintenance Expenses by Major U.S. Publicly Owned Electric Utility Within State, 1996 (Continued)

(Thousand Dollars)

\begin{tabular}{|c|c|c|c|c|c|c|}
\hline Item & $\begin{array}{l}\text { Florida } \\
\text { Orlando } \\
\text { Utilities } \\
\text { Comm } \\
\text { September } 30\end{array}$ & $\begin{array}{l}\text { Florida } \\
\text { Quincy } \\
\text { City of } \\
\text { September } 30\end{array}$ & $\begin{array}{c}\text { Florida } \\
\text { Reedy Creek } \\
\text { Improvement } \\
\text { Dist } \\
\text { September } 30\end{array}$ & $\begin{array}{l}\text { Florida } \\
\text { St Cloud } \\
\text { City of } \\
\text { September } 30\end{array}$ & $\begin{array}{l}\text { Florida } \\
\text { Tallahassee } \\
\text { City of } \\
\text { September } 30\end{array}$ & $\begin{array}{c}\text { Florida } \\
\text { Vero } \\
\text { Beach } \\
\text { City of } \\
\text { September } 30\end{array}$ \\
\hline \multicolumn{7}{|l|}{ Production Expenses } \\
\hline 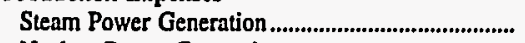 & 136,495 & 0 & 797 & 0 & 63,862 & 14,977 \\
\hline Nuclear Power Generation ............................................. & 11,161 & 0 & 0 & 0 & 1,619 & 0 \\
\hline Hydrnulic Power Generation.............................................. & & 0 & 0 & $\mathbf{0}$ & 398 & 0 \\
\hline 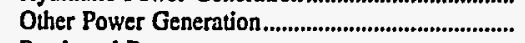 & 3,633 & $\mathbf{0}$ & 5,176 & 2,082 & 277 & 0 \\
\hline 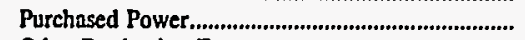 & 14,331 & 6,197 & 32,942 & 13,271 & 39,749 & 15,010 \\
\hline Other Production Expenses ............................................. & 9 & 0 & 339 & 0 & 350 & 0 \\
\hline 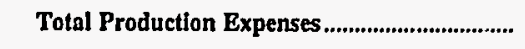 & 165,629 & 6,197 & 39,254 & 15,354 & 106,255 & 29,987 \\
\hline 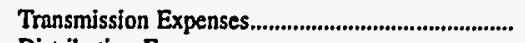 & 5,860 & 0 & 0 & 85 & 5,763 & 1,007 \\
\hline 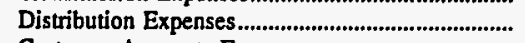 & 7,719 & 400 & 9,662 & 2,426 & 4,443 & 1,007 \\
\hline $\begin{array}{l}\text { Customer Accounts Expenses ................................... } \\
\text { Customer Service and Information }\end{array}$ & 6,111 & 233 & 0 & 0 & 16,810 & 429 \\
\hline 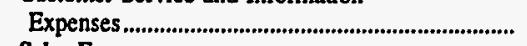 & 1,564 & $\mathbf{0}$ & $\mathbf{0}$ & 1,171 & 0 & 429 \\
\hline 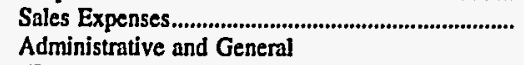 & 75 & $\mathbf{0}$ & $\mathbf{0}$ & 0 & 0 & 0 \\
\hline 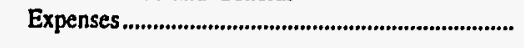 & 18,627 & 176 & 958 & -228 & 10,340 & 2,307 \\
\hline $\begin{array}{l}\text { Total Electric Operation and } \\
\text { Maintenance Expenses .......................................... }\end{array}$ & 205,584 & 7,005 & 49,874 & 18,807 & 143,611 & 35,166 \\
\hline \multicolumn{7}{|l|}{ Fuel Expenses in Operation } \\
\hline Steam Power Generation ................................................ & 112,247 & 0 & 516 & 0 & 56,480 & 12,038 \\
\hline 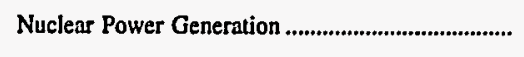 & 2,118 & 0 & 0 & 0 & 0 & $\mathbf{0}$ \\
\hline 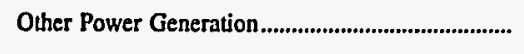 & 2,533 & 0 & 3,013 & $\mathbf{0}$ & 192 & 0 \\
\hline \multicolumn{7}{|l|}{ Number of Elec Dept Employees } \\
\hline 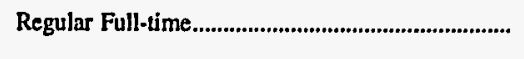 & 514 & 10 & 76 & 83 & 357 & 141 \\
\hline 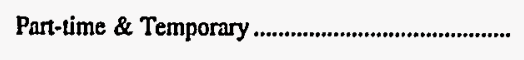 & 0 & 0 & 0 & 4 & 6 & $\mathbf{0}$ \\
\hline Total Elec Dept Employees........................................... & 514 & 10 & 76 & 87 & 363 & 141 \\
\hline
\end{tabular}

Note: Totals may not equal sum of components because of independent rounding.

Source: Energy Information Administration, Form EIA-412, "Annual Report of Public Electric Utilities." 
Table 23. Electric Operation and Maintenance Expenses by Major U.S. Publicly Owned Electric Utility Within State, 1996 (Continued)

(Thousand Dollars)

\begin{tabular}{|c|c|c|c|c|c|c|}
\hline Item & $\begin{array}{l}\text { Georgia } \\
\text { Albany Water } \\
\text { Gas \& Light } \\
\text { Comm } \\
\text { June } 30\end{array}$ & $\begin{array}{l}\text { Georgia } \\
\text { Calhoun } \\
\text { City of } \\
\text { June } 30\end{array}$ & $\begin{array}{c}\text { Georgia } \\
\text { Cartersville } \\
\text { City of } \\
\text { June } 30\end{array}$ & $\begin{array}{c}\text { Georgia } \\
\text { College } \\
\text { Park City of } \\
\text { June } 30\end{array}$ & $\begin{array}{c}\text { Georgia } \\
\text { Covington } \\
\text { City of } \\
\text { December } 31\end{array}$ & $\begin{array}{c}\text { Georgia } \\
\text { Crisp } \\
\text { County } \\
\text { Power } \\
\text { Comm } \\
\text { December } 31\end{array}$ \\
\hline \multicolumn{7}{|l|}{ Production Expenses } \\
\hline 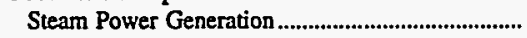 & 0 & 0 & 0 & 0 & 0 & 675 \\
\hline Nuclear Power Generation ............................................... & 0 & 0 & 0 & 0 & 0 & 0 \\
\hline 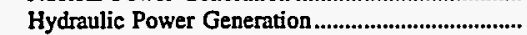 & 0 & 0 & 0 & $\mathbf{0}$ & 0 & 372 \\
\hline 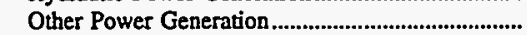 & 0 & 0 & 0 & 0 & 0 & 91 \\
\hline Purchased Power................................................................ & 45,962 & 16,407 & 21,553 & 15,469 & 12,479 & 11,863 \\
\hline 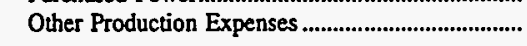 & 0 & 0 & 0 & 0 & 0 & 0 \\
\hline 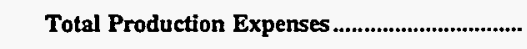 & 45,962 & 16,407 & 21,553 & 15,469 & 12,479 & 13,000 \\
\hline 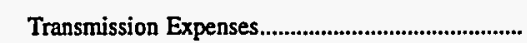 & 3,431 & 0 & 0 & 0 & 0 & 99 \\
\hline 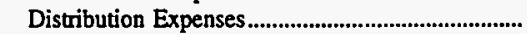 & 0 & 1,323 & 2,508 & 1,160 & 1,312 & 652 \\
\hline 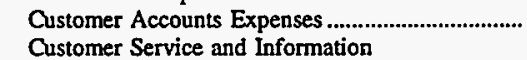 & 0 & 0 & $\mathbf{0}$ & 321 & 157 & 363 \\
\hline 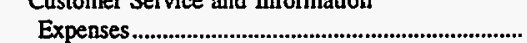 & 0 & 0 & 0 & 0 & 0 & 0 \\
\hline 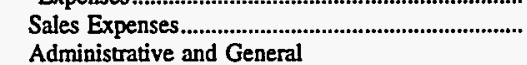 & 0 & 0 & 0 & 0 & 0 & 23 \\
\hline 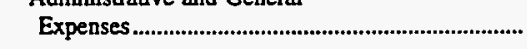 & 4,021 & 0 & 0 & 127 & 144 & 1,363 \\
\hline 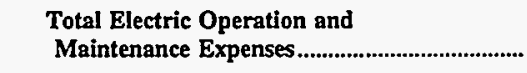 & 53,414 & 17,731 & 24,061 & 17,078 & 14,093 & 15,499 \\
\hline \multicolumn{7}{|l|}{ Fuel Expenses in Operation } \\
\hline Steam Power Generation & 0 & 0 & 0 & 0 & 0 & 0 \\
\hline 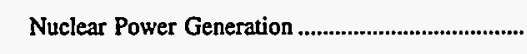 & $\mathbf{0}$ & 0 & 0 & 0 & 0 & 0 \\
\hline 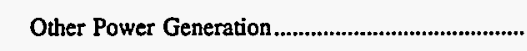 & 0 & 0 & $\mathbf{0}$ & 0 & 0 . & 0 \\
\hline \multicolumn{7}{|l|}{ Number of Elec Dept Employees } \\
\hline Regular Full-time & 252 & 23 & 21 & 24 & 22 & 66 \\
\hline 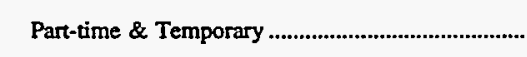 & 5 & 0 & 0 & 0 & 0 & 5 \\
\hline Total Elec Dept Employees....................................... & 257 & 23 & 21 & 24 & 22 & 71 \\
\hline
\end{tabular}

Note: Totals may not equal sum of components because of independent rounding.

Source: Energy Information Administration, Form EIA-412, "Annual Report of Public Electric Utilities." 
Table 23. Electric Operation and Maintenance Expenses by Major U.S. Publicly Owned Electric Utility Within State, 1996 (Continued)

(Thousand Dollars)

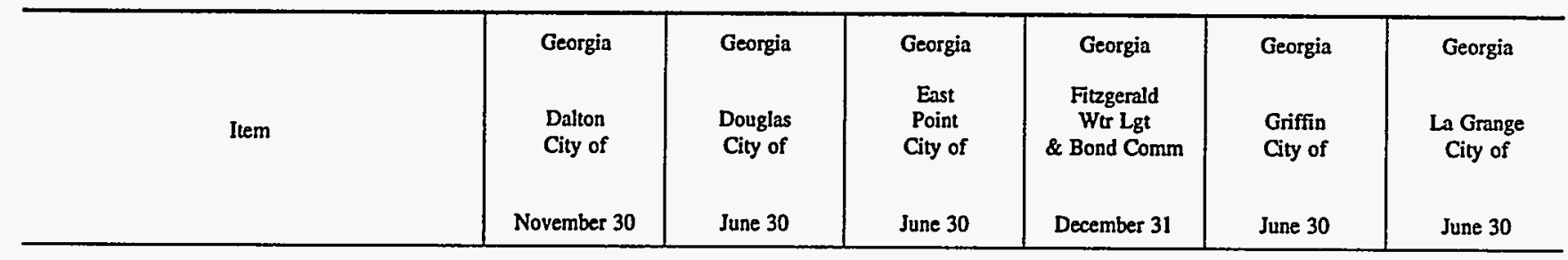

Production Expenses

Steam Power Generation....

Nuclear Power Generation ........

Hydnalic Power Generation......................................

Other Power Generation..

Purchased Power.

Other Production Expenses ..........................................

Total Production Expenses...............................

Transmission Expenses.

Distribution Expenses

Customer Accounts Expenses ....................................

Customer Service and Information

Expenses.

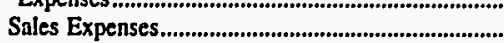

Administrative and General

Expenses.

Total Electric Operation and

Maintenance Expenses

Fuel Expenses in Operation

Steam Power Generation ...........................................

Nuclear Power Generation .....................................

Other Power Generation.

Number of Elec Dept Employees

Regular Full-time.

Part-time \& Temporary

Total Elec Dept Employees.

4,914
12,021
0
0
18,594
0

0
0
0
0
12,377
0

\section{5,529}

1,173

2,159

0

0

719

$$
12,377
$$

0

31
0

$\mathbf{0}$
$\mathbf{0}$

818

39,580

13,227

0
0
0
0
16,527
0

16,527

0
2,540

0

194
0

427

19,688

0
0
0
0
10,686
7

10,693

0
1,094

, 094
0

o

350

12,137

24,912

Note: Totals may not equal sum of components because of independent rounding.

Source: Energy Information Administration, Form EIA-412, "Annual Report of Public Electric Utilities."

$\begin{array}{rrrrrr}3,994 & 0 & 0 & 0 & 0 & 0 \\ 3,041 & 0 & 0 & 0 & 0 & 0 \\ 0 & 0 & 0 & 0 & 0 & 0\end{array}$

\begin{tabular}{rrrrrr}
18 & 16 & 34 & 17 & 27 & 12 \\
0 & 0 & 0 & 0 & 0 & 0 \\
18 & 16 & 34 & 17 & 27 & 12 \\
\hline
\end{tabular}


Table 23. Electric Operation and Maintenance Expenses by Major U.S. Publicly Owned Electric Utility Within State, 1996 (Continued)

(Thousand Dollars)

\begin{tabular}{|c|c|c|c|c|c|c|}
\hline Item & $\begin{array}{c}\text { Georgia } \\
\text { Lawrenceville } \\
\text { City of } \\
\text { August } 30\end{array}$ & $\begin{array}{l}\text { Georgia } \\
\text { Marietta } \\
\text { City of } \\
\text { June } 30\end{array}$ & $\begin{array}{l}\text { Georgia } \\
\text { Moultrie } \\
\text { City of } \\
\text { September } 30\end{array}$ & $\begin{array}{l}\text { Georgia } \\
\text { Municipal } \\
\text { Electric } \\
\text { Authority } \\
\text { December } 31\end{array}$ & $\begin{array}{c}\text { Georgia } \\
\text { Thomasville } \\
\text { City of } \\
\text { December } 31\end{array}$ & $\begin{array}{l}\text { Idaho } \\
\text { Idaho } \\
\text { Falls } \\
\text { City of } \\
\text { September } 30\end{array}$ \\
\hline \multicolumn{7}{|l|}{ Production Expenses } \\
\hline 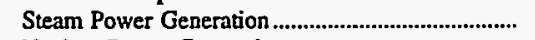 & 0 & 0 & 1,162 & 79,389 & $\mathbf{0}$ & 0 \\
\hline 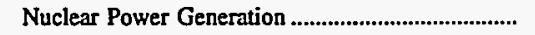 & 0 & 0 & 0 & 85,052 & 0. & 0 \\
\hline 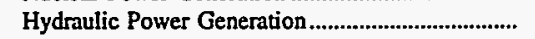 & 0 & 0 & 0 & 0 & 0 & 1,267 \\
\hline 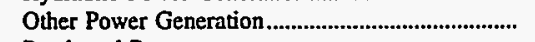 & 0 & 0 & 0 & 91 & 0 & 0 \\
\hline 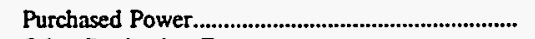 & 12,790 & 52,522 & 1 & 19,126 & 22,971 & 15,998 \\
\hline 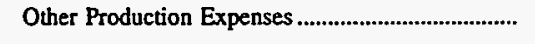 & 0 & 37 & 0 & 4,291 & 0 & 0 \\
\hline Total Production Expenses................................... & 12,790 & 52,559 & 1,162 & 187,949 & 22,971 & 17,265 \\
\hline 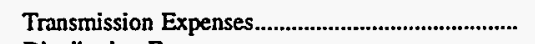 & 0 & 0 & 0 & 3,738 & 0 & 95 \\
\hline 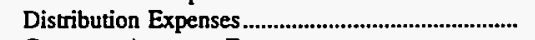 & 13 & 7,588 & 0 & 3,856 & 1,209 & 2,182 \\
\hline $\begin{array}{l}\text { Customer Accounts Expenses .................................... } \\
\text { Customer Service and Information }\end{array}$ & 0 & 0 & 10,092 & 0 & 459 & 1,000 \\
\hline 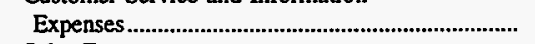 & 0 & 0 & 0 & 0 & 259 & 13 \\
\hline 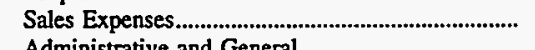 & 0 & 0 & 0 & 483 & 3 & 0 \\
\hline 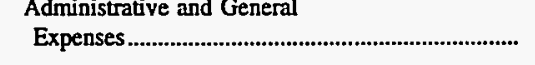 & 2,034 & 0 & 0 & 18,036 & 1,262 & 1,886 \\
\hline 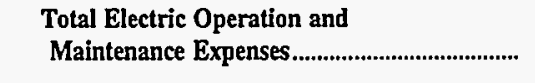 & 14,837 & 60,148 & 11,255 & 214,062 & 26,162 & 22,441 \\
\hline \multicolumn{7}{|l|}{ Fuel Expenses in Operation } \\
\hline 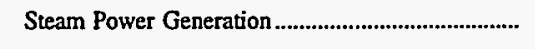 & 0 & 0 & 0 & 63,997 & 0 & $\mathbf{0}$ \\
\hline 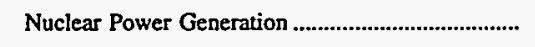 & 0 & 0 & 0 & 33,548 & 0 & $\mathbf{0}$ \\
\hline 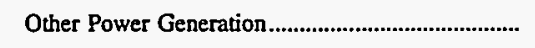 & 0 & 0 & 0 & 95 & 0 & 0 \\
\hline \multicolumn{7}{|l|}{ Number of Elec Dept Employees } \\
\hline 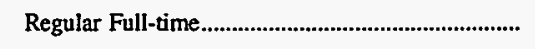 & 11 & 116 & 14 & 142 & 3 & 56 \\
\hline Part-time \& Temporary .............................................. & 0 & 0 & 0 & 0 & 0 & 1 \\
\hline 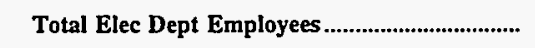 & 11 & 116 & 14 & 142 & 3 & 57 \\
\hline
\end{tabular}

Note: Totals may not equal sum of components because of independent rounding.

Source: Energy Information Administration, Form EIA-412, “Annual Report of Public Electric Utilities." 
Table 23. Electric Operation and Maintenance Expenses by Major U.S. Publicly Owned Electric Utility Within State, 1996 (Continued)

(Thousand Dollars)

\begin{tabular}{|c|c|c|c|c|c|c|}
\hline Item & $\begin{array}{l}\text { Illinois } \\
\text { Batavia } \\
\text { City of } \\
\text { December } 31\end{array}$ & $\begin{array}{l}\text { Illinois } \\
\text { Geneva } \\
\text { City of } \\
\text { April } 30\end{array}$ & $\begin{array}{c}\text { Illinois } \\
\text { Illinois } \\
\text { Municipal } \\
\text { Elec Agency } \\
\text { April } 30\end{array}$ & $\begin{array}{l}\text { Illinois } \\
\begin{array}{c}\text { Naperville } \\
\text { City of }\end{array} \\
\text { April } 30\end{array}$ & $\begin{array}{l}\text { Illinois } \\
\text { Rochelle } \\
\text { Municipal } \\
\text { Utilities } \\
\text { April } 30\end{array}$ & $\begin{array}{l}\text { Illinois } \\
\text { Springfield } \\
\text { City of } \\
\text { February } 28\end{array}$ \\
\hline \multicolumn{7}{|l|}{ Production Expenses } \\
\hline 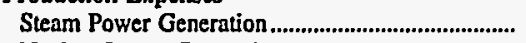 & 0 & $\mathbf{0}$ & 6,619 & $\mathbf{0}$ & 2,177 & 45,157 \\
\hline Nuclear Power Generation ............................................... & 0 & 0 & 0 & 0 & 0 & 0 \\
\hline Hydraulic Power Generation........................................... & 0 & 0 & 0 & 0 & $\mathbf{0}$ & 0 \\
\hline 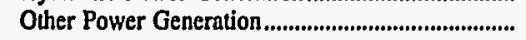 & 0 & 0 & 0 & 0 & 616 & 182 \\
\hline Purchased Power............................................................... & 11,577 & 7,432 & 38,412 & 35,940 & 5,631 & 755 \\
\hline 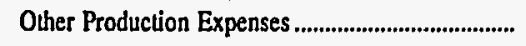 & 0 & 0 & 8,035 & 0 & 0 & 0 \\
\hline Total Production Expenses..................................... & 11,577 & 7,432 & 53,066 & 35,940 & 8,424 & 46,093 \\
\hline 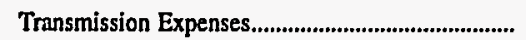 & 0 & 0 & 5,697 & 0 & 2 & 1,240 \\
\hline 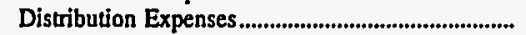 & 912 & 667 & 0 & 6,444 & 483 & 6,222 \\
\hline 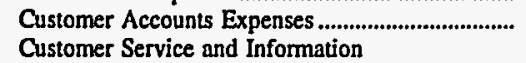 & 504 & 532 & 0 & 559 & 96 & 3,878 \\
\hline 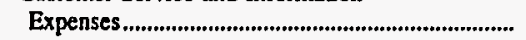 & $\mathbf{0}$ & $\mathbf{0}$ & $\mathbf{0}$ & 677 & 0 & 620 \\
\hline 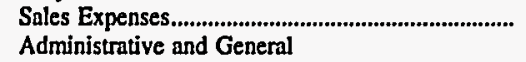 & $\mathbf{0}$ & 0 & $\mathbf{0}$ & $\mathbf{0}$ & 0 & 0 \\
\hline 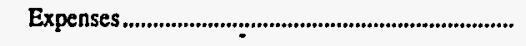 & 171 & 0 & 2,032 & 3,231 & 1,203 & 10,699 \\
\hline $\begin{array}{l}\text { Total Electric Operation and } \\
\text { Maintenance Expenses.......................................... }\end{array}$ & 13,165 & 8,631 & 60,795 & 46,851 & 10,208 & 68,753 \\
\hline \multicolumn{7}{|l|}{ Fuel Expenses in Operation } \\
\hline 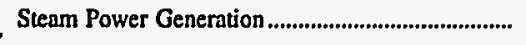 & 0 & $\mathbf{0}$ & 4,021 & 0 & 1,316 & 24,809 \\
\hline 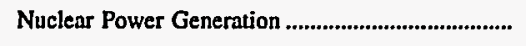 & 0 & 0 & $\mathbf{0}$ & $\mathbf{0}$ & $\mathbf{0}$ & $\mathbf{0}$ \\
\hline 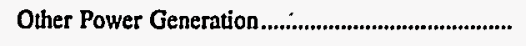 & 0 & 0 & $\mathbf{0}$ & 0 & 240 & 84 \\
\hline \multicolumn{7}{|l|}{ Number of Blec Dept Employees } \\
\hline 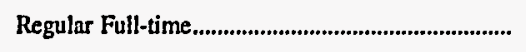 & 20 & 20 & 14 & 106 & 42 & 584 \\
\hline 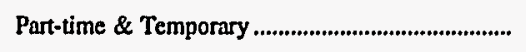 & 1 & 0 & $\mathbf{0}$ & 1 & 1 & 35 \\
\hline Total Elec Dept Employees .......................................... & 21 & 20 & 14 & 107 & 43 & 619 \\
\hline
\end{tabular}

Note: Totals may not equal sum of components because of independent rounding.

Source: Energy Information Administration, Form EIA-412, "Annual Report of Public Electric Utilities." 
Table 23. Electric Operation and Maintenance Expenses by Major U.S. Publicly Owned Electric Utility Within State, 1996 (Continued)

(Thousand Dollars)

\begin{tabular}{c|c|c|c|c|c|c}
\hline & Illinois & Indiana & Indiana & Indiana & Indiana \\
Item & $\begin{array}{c}\text { St Charles } \\
\text { City of }\end{array}$ & $\begin{array}{c}\text { Anderson } \\
\text { City of }\end{array}$ & $\begin{array}{c}\text { Auburn } \\
\text { City of }\end{array}$ & $\begin{array}{c}\text { Bluffton } \\
\text { City of }\end{array}$ & $\begin{array}{c}\text { Indiana } \\
\text { Elec } \& \text { Por }\end{array}$ & $\begin{array}{c}\text { Frankfort } \\
\text { City of }\end{array}$ \\
April 30 & December 31 & December 31 & December 31 & December 31 & December 31 \\
\hline
\end{tabular}

Production Expenses

Steam Power Generation

Nuclear Power Generation .......................................

Hydraulic Power Generation

Other Power Generation.

Purchased Power........................................................

Other Production Expenses ......................................

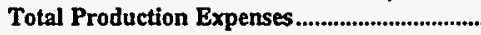

Transmission Expenses..

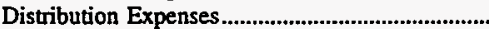

Customer Accounts Expenses .................................

Customer Service and Information

Expenses...

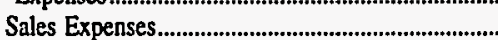

Administrative and General

Expenses

Total Electric Operation and

Maintenance Expenses.

Fuel Expenses in Operation

Steam Power Generation ...........................................

Nuclear Power Generation.

Other Power Generation.

Number of Elec Dept Employees

Regular Full-time

Part-time \& Temporary

Total Elec Dept Employees

0
0
0
0
27,379
0

17,849

$$
27,379
$$

0
5,234

0

0

0

0

23,083

$$
\begin{array}{r}
9 \\
2,453
\end{array}
$$

2,453$$
0
$$

$$
0
$$$$
2,684
$$

32,959
17,581

0
883

883

0

0

400

18,891

0
0
0
314
6,896
0

7,210

1,506
0
0
0
13,653
0

15,159

$$
\begin{array}{r}
4 \\
865
\end{array}
$$

$$
\begin{array}{r}
465 \\
\hline
\end{array}
$$$$
243
$$$$
\begin{aligned}
& 0 \\
& 0
\end{aligned}
$$

1,183

17,454

8,252

Note: Totals may not equal sum $o^{f}$ components because of independent rounding.

Source: Energy Information Administration, Form EIA-412, "Annual Report of Public Electric Utilities."

\begin{tabular}{rrrr}
0 & 0 & 377 & 0 \\
0 & 0 & 0 & 0 \\
0 & 0 & 0 & 0 \\
14 & 37 & 53 & 27 \\
0 & 1 & 2 & 2 \\
14 & 38 & 55 & 29 \\
\hline
\end{tabular}

\begin{tabular}{rrrrrr}
24 & 81 & 14 & 37 & 53 & 27 \\
6 & 1 & 0 & 1 & 2 & 2 \\
30 & 82 & 14 & 38 & 55 & 29 \\
\hline
\end{tabular}


Table 23. Electric Operation and Maintenance Expenses by Major U.S. Publicly Owned Electric Utility Within State, 1996 (Continued)

(Thousand Dollars)

\begin{tabular}{c|c|c|c|c|c|c}
\hline & Indiana & Indiana & Indiana & Indiana & Indiana & Indiana \\
Item & $\begin{array}{c}\text { Greenfield } \\
\text { City of }\end{array}$ & $\begin{array}{c}\text { Municipal } \\
\text { Power Agency }\end{array}$ & $\begin{array}{c}\text { Jasper } \\
\text { City of }\end{array}$ & $\begin{array}{c}\text { Lebanon } \\
\text { City of }\end{array}$ & $\begin{array}{c}\text { Logansport } \\
\text { City of }\end{array}$ & $\begin{array}{c}\text { Mishawaka } \\
\text { City of }\end{array}$ \\
& December 31 & December 31 & December 31 & December 31 & December 31 & December 31 \\
\hline
\end{tabular}

Production Expenses

Steam Power Generation.

Nuclear Power Generation .......................................

Hydraulic Power Generation

Other Power Generation.

Purchased Power.........................................................

Other Production Expenses ........................................

Total Production Expenses...............................

Transmission Expenses

Distribution Expenses..............................................

Customer Accounts Expenses ...................................

Customer Service and Information

Expenses.................................................................

Sales Expenses...........................................................

Administrative and General

Expenses.

Total Electric Operation and

Maintenance Expenses

Fuel Expenses in Operation

Steam Power Generation.............................................

Nuclear Power Generation

Other Power Generation

7

7,167

7,167

0
751

751
108

$\mathbf{0}$

368

8,393
25,829

0

970

85,501

446

112,747

5,664

1,051

0

165

2,402

122,029

17,611

0

0 582

0
2,125

0

, 010

0

11,135

0

769

48

0
0

878

12,829

0

1,344

0

0

46

0

46
22

$\begin{array}{rr}16 & 22 \\ 4 & 1 \\ 20 & 23\end{array}$

23
0
0
0
0
5,794
0

5,794

3

370
150

2

0

664

6,983

6,644

6,644
0
0
25
5,991

5,991
0

12,660

0
1,571

190

25
0

1,154

15,600

25,149

Number of Elec Dept Employees

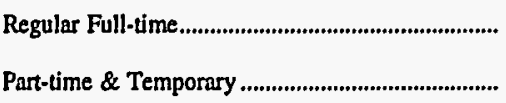

Total Elec Dept Employees.

0
0
0

0

0

0

Note: Totals may not equal sum of components because of independent rounding.

Source: Energy Information Administration, Form EIA-412, "Annual Report of Public Electric Utilities." 
Table 23. Electric Operation and Maintenance Expenses by Major U.S. Publicly Owned Electric Utility Within State, 1996 (Continued)

(Thousand Dollars)

\begin{tabular}{|c|c|c|c|c|c|c|}
\hline Item & $\begin{array}{c}\text { Indiana } \\
\text { Peru } \\
\text { City of } \\
\text { December } 31\end{array}$ & $\begin{array}{l}\text { Indiana } \\
\text { Richmond } \\
\text { City of } \\
\text { December } 31\end{array}$ & $\begin{array}{l}\text { Indiana } \\
\text { Scottsburg } \\
\text { City of } \\
\text { December } 31\end{array}$ & $\begin{array}{c}\text { Indiana } \\
\text { Washington } \\
\text { City of } \\
\text { December } 31\end{array}$ & $\begin{array}{l}\text { Jowa } \\
\text { Ames } \\
\text { City of } \\
\text { June } 30\end{array}$ & $\begin{array}{c}\text { Iowa } \\
\text { Cedar } \\
\text { Falls } \\
\text { City of } \\
\text { December } 31\end{array}$ \\
\hline \multicolumn{7}{|l|}{ Production Expenses } \\
\hline 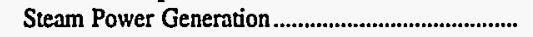 & 570 & 13,962 & 0 & 0 & 9,819 & 4,396 \\
\hline Nuclear Power Generation .......................................... & 0 & 0 & 0 & 0 & 0 & 0 \\
\hline Hydraulic Power Generation........................................ & 0 & 0 & 0 & 0 & 0 & 0 \\
\hline 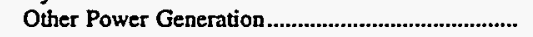 & 0 & 0 & 0 & 0 & 0 & 373 \\
\hline 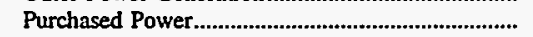 & 5,708 & 14,718 & 6,580 & 6,263 & 1,823 & 1,228 \\
\hline 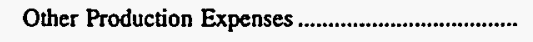 & 0 & 0 & 0 & 0 & 565 & 109 \\
\hline 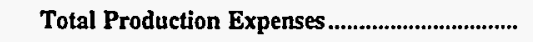 & 6,277 & 28,680 & 6,580 & 6,263 & 12,208 & 6,106 \\
\hline 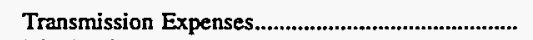 & 36 & 83 & 320 & 0 & 0 & 525 \\
\hline 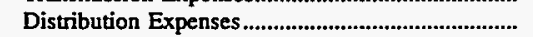 & 595 & 2,292 & 244 & 651 & 2,534 & 1,601 \\
\hline $\begin{array}{l}\text { Customer Accounts Expenses................................ } \\
\text { Customer Service and Information }\end{array}$ & 130 & 615 & 83 & 190 & 0 & 420 \\
\hline 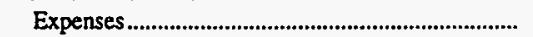 & 0 & 151 & 104 & 0 & 822 & 179 \\
\hline $\begin{array}{l}\text { Sales Expenses.................................................... } \\
\text { Administrative and General }\end{array}$ & 9 & 43 & 0 & 0 & 0 & 0 \\
\hline 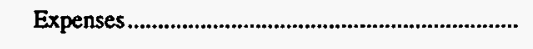 & 1,084 & 4,827 & 425 & 279 & 532 & 1,435 \\
\hline 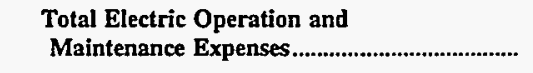 & 8,131 & 36,689 & 7,757 & 7,383 & 16,096 & 10,266 \\
\hline \multicolumn{7}{|l|}{ Fuel Expenses in Operation } \\
\hline Steam Power Generation............................................ & 118 & 0 & 0 & 0 & 6,218 & 2,376 \\
\hline Nuclear Power Generation ....................................... & 0 & 0 & 0 & 0 & 0 & 0 \\
\hline Other Power Generation & 0 & 0 & 0 & 0 & 0 & 57 \\
\hline \multicolumn{7}{|l|}{ Number of Elec Dept Employees } \\
\hline 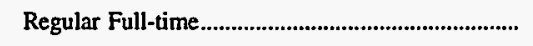 & 39 & 164 & 7 & 27 & 83 & 82 \\
\hline 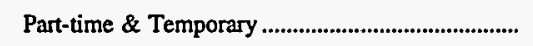 & 9 & 0 & 0 & 0 & 1 & 8 \\
\hline 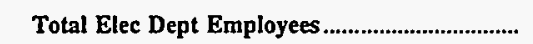 & 48 & 164 & 7 & 27 & 84 & 90 \\
\hline
\end{tabular}

Note: Totals may not equal sum of components because of independent rounding.

Source: Energy Information Administration, Form EIA-412, "Annual Report of Public Electric Utilities." 
Table 23. Electric Operation and Maintenance Expenses by Major U.S. Publicly

Owned Electric Utility Within State, 1996 (Continued)

(Thousand Dollars)

\begin{tabular}{|c|c|c|c|c|c|c|}
\hline Item & $\begin{array}{c}\text { Iowa } \\
\text { Muscatine } \\
\text { City of } \\
\text { December } 31\end{array}$ & $\begin{array}{c}\text { Iowa } \\
\text { Pella } \\
\text { City of } \\
\text { December } 31\end{array}$ & $\begin{array}{l}\text { Kansas } \\
\text { Chanute } \\
\text { City of } \\
\text { December } 31\end{array}$ & $\begin{array}{c}\text { Kansas } \\
\text { Coffeyville } \\
\text { City of } \\
\text { December } 31\end{array}$ & $\begin{array}{l}\text { Kansas } \\
\text { Garden } \\
\text { City City of } \\
\text { December } 31\end{array}$ & $\begin{array}{c}\text { Kansas } \\
\text { Kansas } \\
\text { City City of } \\
\text { December } 31\end{array}$ \\
\hline \multicolumn{7}{|l|}{ Production Expenses } \\
\hline 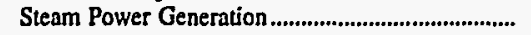 & 25,005 & 3,744 & 0 & 2,767 & 0 & 62,104 \\
\hline Nuclear Power Generation .............................................. & 0 & 0 & 0 & 0 & 0 & 0 \\
\hline Hydraulic Power Generation.......................................... & 0 & 0 & 0 & 0 & 0 & 0 \\
\hline 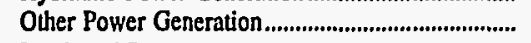 & 0 & 0 & 949 & 0 & 0 & 0 \\
\hline 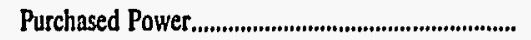 & 705 & 2,399 & 3,606 & 2,959 & 9,589 & 8,760 \\
\hline 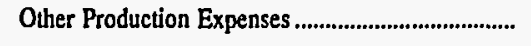 & 1,065 & 0 & 158 & 0 & 17 & 641 \\
\hline Total Production Expenses......................................... & 26,774 & 6,143 & 4,713 & 5,726 & 9,606 & 71,505 \\
\hline 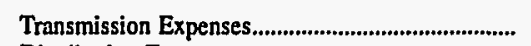 & 300 & 0 & 32 & $\mathbf{0}$ & 0 & 542 \\
\hline 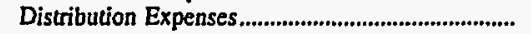 & 1,651 & 836 & 602 & 1,053 & 821 & 8,265 \\
\hline 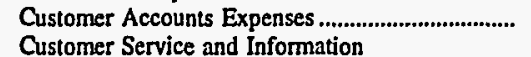 & 294 & 0 & 171 & 0 & 0 & 3,413 \\
\hline Expenses & 100 & $\mathbf{0}$ & 152 & 183 & 6 & 0 \\
\hline 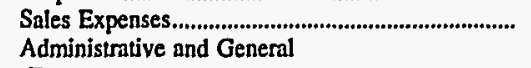 & 0 & 0 & o & 0 & 586 & 0 \\
\hline 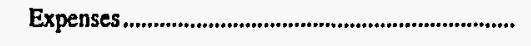 & 5,694 & 1,783 & 307 & 569 & 695 & 15,458 \\
\hline $\begin{array}{l}\text { Total Electric Operation and } \\
\text { Maintenance Expenses......................................... }\end{array}$ & 34,813 & 8,763 & 5,978 & 7,531 & 11,715 & 99,184 \\
\hline \multicolumn{7}{|l|}{ Fuel Expenses in Operation } \\
\hline 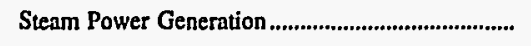 & 16,814 & 0 & 0 & 1,801 & 0 & 43,274 \\
\hline 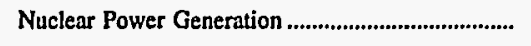 & 0 & $\mathbf{0}$ & 0 & 0 & 0 & $\mathbf{0}$ \\
\hline 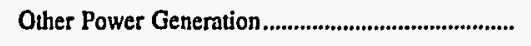 & 0 & $\mathbf{0}$ & 175 & 0 & 0 & $\mathbf{0}$ \\
\hline \multicolumn{7}{|l|}{ Number of Elec Dept Employees } \\
\hline 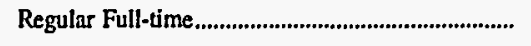 & 241 & 33 & 25 & 42 & 16 & 608 \\
\hline 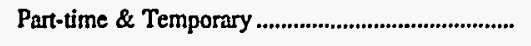 & 3 & $\mathbf{0}$ & 0 & 6 & 0 & 0 \\
\hline 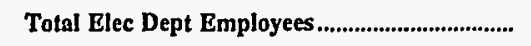 & 244 & 33 & 25 & 48 & 16 & 608 \\
\hline
\end{tabular}

Note: Totals may not equal sum of components because of independent rounding.

Source: Energy Information Administration, Form EIA-412, "Annual Report of Public Electric Utilities." 
Table 23. Electric Operation and Maintenance Expenses by Major U.S. Publicly

Owned Electric Utility Within State, 1996 (Continued)

(Thousand Dollars)

\begin{tabular}{|c|c|c|c|c|c|c|}
\hline Item & $\begin{array}{c}\text { Kansas } \\
\text { Kansas } \\
\text { Municipal } \\
\text { Energy } \\
\text { Agency } \\
\text { December } 31\end{array}$ & $\begin{array}{c}\text { Kansas } \\
\text { McPherson } \\
\text { City of } \\
\text { December } 31\end{array}$ & $\begin{array}{c}\text { Kansas } \\
\text { Winfield } \\
\text { City of } \\
\text { December } 31\end{array}$ & $\begin{array}{c}\text { Kentucky } \\
\text { Bardstown } \\
\text { City of } \\
\text { December } 31\end{array}$ & $\begin{array}{c}\text { Kentucky } \\
\text { Bowling } \\
\text { Green } \\
\text { City of } \\
\text { June } 30\end{array}$ & $\begin{array}{c}\text { Kentucky } \\
\text { Frankfort } \\
\text { City of } \\
\text { June } 30\end{array}$ \\
\hline
\end{tabular}

Production Expenses

Steam Power Generation.

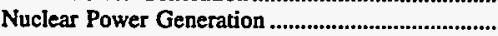

Hydraulic Power Generation..................................

Other Power Generation.

Purchased Power.

Production Expenses

Total Production Expenses.................................

Transmission Expenses

Distribution Expenses...............................................

Customer Accounts Expenses ..................................

Customer Service and Information

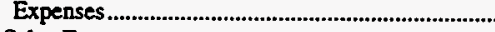

Sales Expenses...

Administrative and General

Expenses.

Total Electric Operation and

Maintenance Expenses.

Fuel Expenses in Operation

Steam Power Generation..

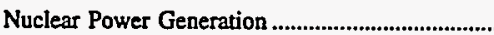

Other Power Generation.

Number of Elec Dept Employees

Regular Full-time.

Part-time \& Temporary

Total Elec Dept Employees.
0

8,814

8,814

152

1

0

0
0

924

9,891

0
0
0
0
4
0
4

1
0
0
0

950
0
0
1,258
13,331
494

16,034

61

1,756

128

2

728

18,716

192

0

377

0

0

0

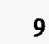

1

10

0
0
0
0
7,601
1,427

9,028

0

994
195

195

0
0

966

11,184 $\begin{array}{rr}0 & 0 \\ 0 & 0 \\ 0 & 0 \\ 0 & 0 \\ 32,952 & 21,221 \\ 0 & 0\end{array}$

32,952

21,221

70

964

379

0

$1,148 \quad 1,849$

37,644

24,484

Note: Totals may not equal sum of components because of independent rounding.

Source: Energy Information Administration, Form EIA-412, "Annual Report of Public Electric Utilities." 
Table 23. Electric Operation and Maintenance Expenses by Major U.S. Publicly

Owned Electric Utility Within State, 1996 (Continued)

(Thousand Dollars)

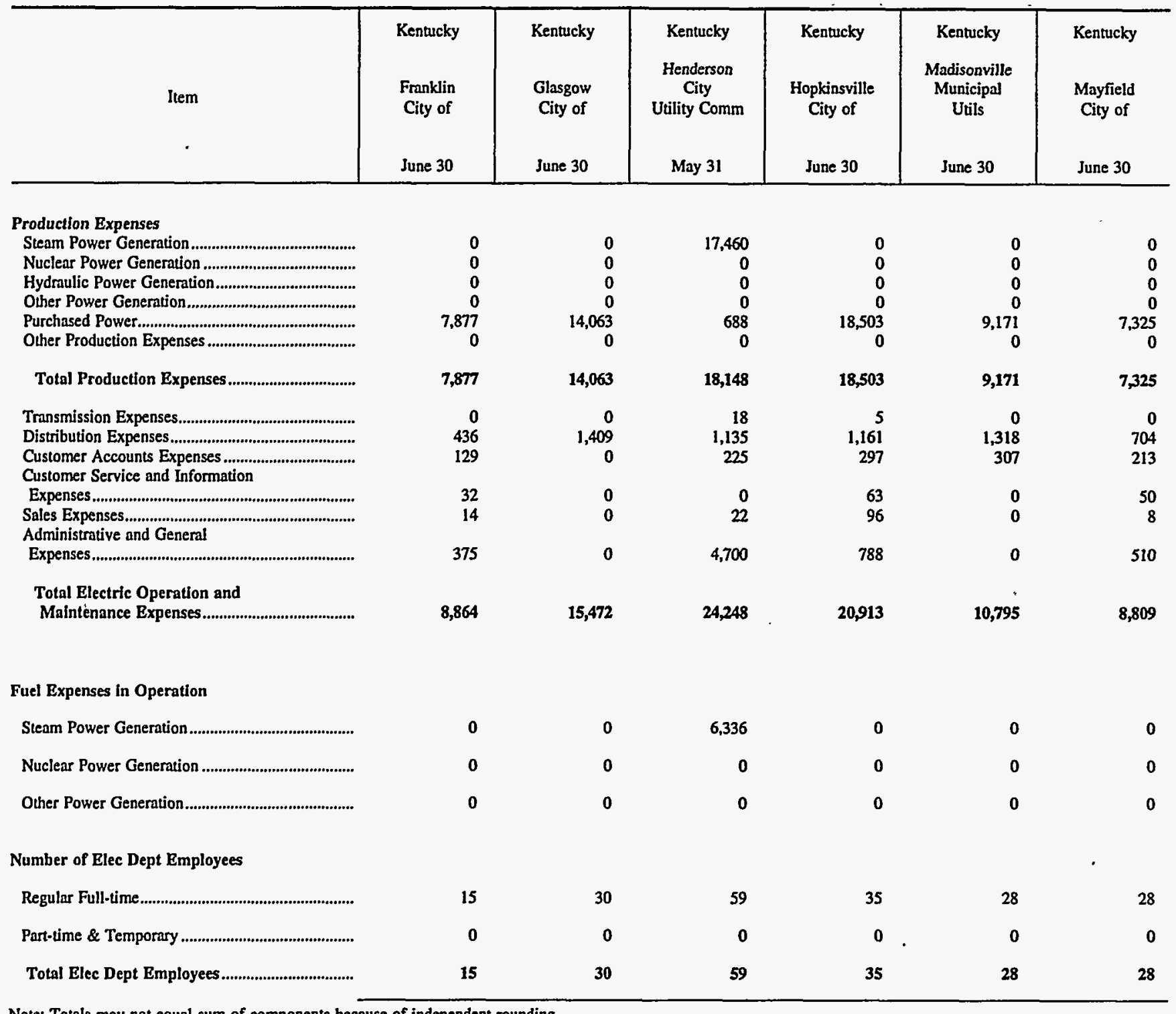

Note: Totals may not equal sum of components because of independent rounding.

Source: Energy Information Administration, Form EIA-412, “Annual Report of Public Electric Utilities." 
Table 23. Electric Operation and Maintenance Expenses by Major U.S. Publicly

Owned Electric Utility Within State, 1996 (Continued)

(Thousand Dollars)

\begin{tabular}{|c|c|c|c|c|c|c|}
\hline Item & $\begin{array}{l}\text { Kentucky } \\
\text { Murray } \\
\text { City of } \\
\text { June } 30\end{array}$ & $\begin{array}{l}\text { Kentucky } \\
\text { Owensboro } \\
\text { City of } \\
\text { May } 31\end{array}$ & $\begin{array}{l}\text { Kentucky } \\
\text { Paducah } \\
\text { City of } \\
\text { June } 30\end{array}$ & $\begin{array}{c}\text { Kentucky } \\
\text { Russellville } \\
\text { City of } \\
\text { June } 30\end{array}$ & $\begin{array}{l}\text { Louisiana } \\
\text { Alexandria } \\
\text { City of } \\
\text { April } 30\end{array}$ & $\begin{array}{l}\text { Louisiana } \\
\text { Lafayette } \\
\text { City of } \\
\text { October } 31\end{array}$ \\
\hline \multicolumn{7}{|l|}{ Production Expenses } \\
\hline 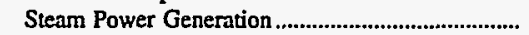 & 0 & 36,124 & 0 & 0 & 1,200 & 13,272 \\
\hline 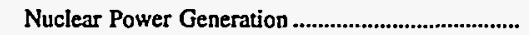 & 0 & 0 & 0 & 0 & 0 & 0 \\
\hline 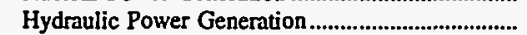 & 0 & 0 & 0 & 0 & 0 & 0 \\
\hline Other Power Generation.............................................. & 0 & 0 & 0 & 0 & 0 & 35 \\
\hline 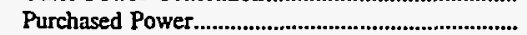 & 11,337 & 501 & 26,140 & 5,697 & 14,978 & 48,815 \\
\hline 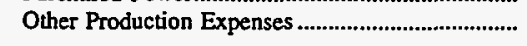 & 0 & 0 & 0 & 0 & 7,468 & 0 \\
\hline Total Production Expenses .......................................... & 11,337 & 36,624 & 26,140 & 5,697 & 23,646 & 62,122 \\
\hline 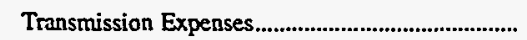 & 0 & 150 & 43 & 0 & 0 & 3,705 \\
\hline 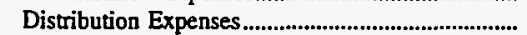 & 594 & 2,939 & 1,786 & 428 & 2,712 & 3,093 \\
\hline 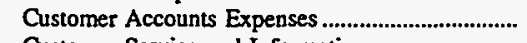 & 170 & 751 & 774 & 127 & 0 & 2,085 \\
\hline Customer Service and Information & & & & & & \\
\hline Expenses & 14 & 0 & 85 & 9 & 0 & 0 \\
\hline $\begin{array}{l}\text { Sales Expenses............................................. } \\
\text { Administrative and Genel }\end{array}$ & 16 & 0 & 256 & 13 & 0 & 18 \\
\hline 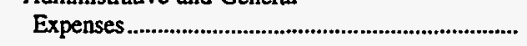 & 393 & 3,717 & 1,480 & 261 & 1,463 & 5,173 \\
\hline $\begin{array}{l}\text { Total Electric Operation and } \\
\text { Maintenance Expenses...................................... }\end{array}$ & 12,523 & 44,182 & 30,564 & 6,535 & 27,820 & 76,195 \\
\hline \multicolumn{7}{|l|}{ Fuel Expenses in Operation } \\
\hline 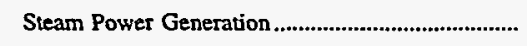 & 0 & 26,547 & 0 & 0 & 0 & 0 \\
\hline 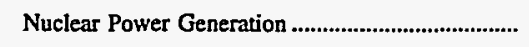 & 0 & $\mathbf{0}$ & 0 & 0 & $\mathbf{0}$ & 0 \\
\hline Other Power Generation & 0 & 0 & 0 & 0 & 0 & 0 \\
\hline \multicolumn{7}{|l|}{ Number of Elec Dept Employees } \\
\hline Regular Full-time. & 19 & 187 & 70 & 13 & 23 & 172 \\
\hline 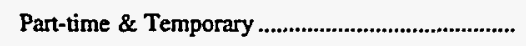 & $\mathbf{0}$ & 5 & 0 & $\mathbf{0}$ & 0 & 5 \\
\hline 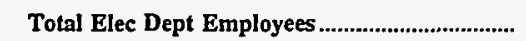 & 19 & 192 & 70 & 13 & 23 & 177 \\
\hline
\end{tabular}

Note: Totals may not equal sum of components because of independent rounding.

Source: Energy Information Administration, Form EIA-412, "Annual Report of Public Electric Utilities." 
Table 23. Electric Operation and Maintenance Expenses by Major U.S. Publicly Owned Electric Utility Within State, 1996 (Continued)

(Thousand Dollars)

\begin{tabular}{|c|c|c|c|c|c|c|}
\hline Item & $\begin{array}{c}\text { Louisiana } \\
\text { Lafayette } \\
\text { Public } \\
\text { Power Auth } \\
\text { October } 31\end{array}$ & $\begin{array}{c}\text { Louisiana } \\
\text { Louisiana } \\
\text { Energy } \\
\& \\
\text { Power Auth } \\
\text { December } 31\end{array}$ & $\begin{array}{l}\text { Louisiana } \\
\text { Morgan } \\
\text { City City of } \\
\text { December } 31\end{array}$ & $\begin{array}{l}\text { Louisiana } \\
\text { Natchitoches } \\
\text { City of } \\
\text { May } 31\end{array}$ & $\begin{array}{l}\text { Louisiana } \\
\text { Ruston } \\
\text { City of } \\
\text { September } 30 \\
\end{array}$ & $\begin{array}{c}\text { Louisiana } \\
\text { Terrebonne } \\
\text { Parish } \\
\text { Consol Govt } \\
\\
\text { December } 31 \\
\end{array}$ \\
\hline \multicolumn{7}{|l|}{ Production Expenses } \\
\hline Steam Power Generation ................................................ & 27,798 & 21,997 & 72 & 0 & 6,147 & 8,742 \\
\hline Nuclear Power Generation ............................................. & & 0 & 0 & 0 & 0 & 0 \\
\hline Hydraulic Power Generation.......................................... & 0 & 0 & $\mathbf{0}$ & 0 & $\mathbf{0}$ & 0 \\
\hline 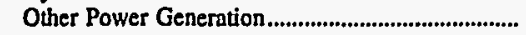 & 0 & $\mathbf{0}$ & $\mathbf{0}$ & 0 & 3 & 0 \\
\hline 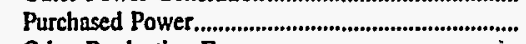 & 0 & 15,727 & 7,557 & 7,864 & 3,108 & 3,543 \\
\hline 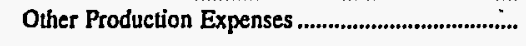 & 163 & 0 & 0 & 2,949 & 0 & 0 \\
\hline 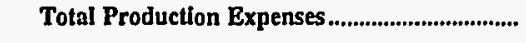 & 27,961 & $\mathbf{3 7 , 7 2 3}$ & 7,629 & 10,813 & 9,258 & 12,285 \\
\hline - Transmission Expenses................................................... & 1 & 4,462 & 881 & 0 & 0 & \\
\hline Distribution Expenses...................................................... & 0 & 0 & 0 & 1,691 & 1,420 & 988 \\
\hline Customer Accounts Expenses ................................... & 0 & 0 & 0 & 540 & 547 & 0 \\
\hline 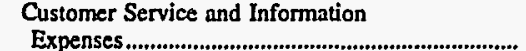 & 0 & 0 & 0 & 0 & 0 & \\
\hline 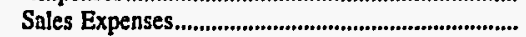 & 0 & 0 & 0 & 0 & $\begin{array}{l}0 \\
0\end{array}$ & $\begin{aligned} 395 \\
0\end{aligned}$ \\
\hline Administrative and General & & & & & & \\
\hline 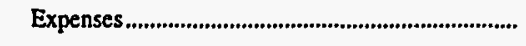 & 2,067 & 2,426 & 312 & 271 & 750 & 873 \\
\hline $\begin{array}{l}\text { Total Electric Operation and } \\
\text { Malntenance Expenses........................................... }\end{array}$ & 30,029 & 44,610 & 8,822 & 13,315 & 11,975 & 14,541 \\
\hline \multicolumn{7}{|l|}{ Fuel Expenses in Operation } \\
\hline 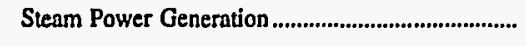 & 0 & 16,618 & 0 & 0 & 4,100 & 3,387 \\
\hline Nuclear Power Generation & $\mathbf{0}$ & 0 & 0 & $\mathbf{0}$ & 0 & 0 \\
\hline Other Power Generation & 0 & 0 & 0 & 0 & 0 & 0 \\
\hline \multicolumn{7}{|l|}{ Number of Elec Dept Employees } \\
\hline 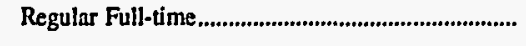 & 190 & 40 & 10 & 39 & 59 & 42 \\
\hline 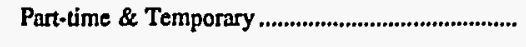 & 0 & 0 & $\mathbf{0}$ & 6 & $\mathbf{0}$ & 0 \\
\hline Total Elec Dept Employees ............................................. & 190 & 40 & 10 & 45 & 59 & 42 \\
\hline
\end{tabular}

Note: Totals may not equal sum of components because of independent rounding.

Source: Energy Information Administration, Form EIA-412, "Annual Report of Public Electric Utilities." 
Table 23. Electric Operation and Maintenance Expenses by Major U.S. Publicly Owned Electric Utility Within State, 1996 (Continued)

(Thousand Dollars)

\begin{tabular}{|c|c|c|c|c|c|c|}
\hline Item & $\begin{array}{l}\text { Maryland } \\
\text { Easton } \\
\text { Utilities } \\
\text { Comm } \\
\text { June } 30\end{array}$ & $\begin{array}{l}\text { Maryland } \\
\text { Hagerstown } \\
\text { City of } \\
\text { June } 30\end{array}$ & $\begin{array}{l}\text { Massachusetts } \\
\text { Braintree } \\
\text { Town of } \\
\text { December } 31\end{array}$ & $\begin{array}{l}\text { Massachusetts } \\
\text { Chicopee } \\
\text { City of } \\
\text { December } 31\end{array}$ & $\begin{array}{l}\text { Massachusetts } \\
\text { Concord } \\
\text { Town of } \\
\text { December } 31\end{array}$ & $\begin{array}{c}\text { Massachusetts } \\
\text { Danvers } \\
\text { Town of } \\
\text { December } 31\end{array}$ \\
\hline \multicolumn{7}{|l|}{ Production Expenses } \\
\hline Steam Power Generation & 0 & 3 & 5,181 & 0 & 0 & o \\
\hline 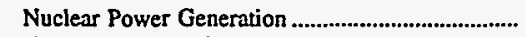 & 0 & 0 & 0 & 2,628 & 0 & 0 \\
\hline 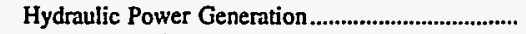 & $\mathbf{0}$ & 0 & 0 & 0 & 0 & 0 \\
\hline 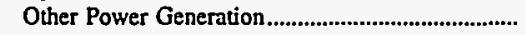 & 2,361 & $\mathbf{0}$ & 24 & 50 & $\mathbf{0}$ & $\mathbf{0}$ \\
\hline 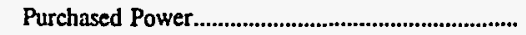 & 6,459 & 14,922 & 17,400 & 16,971 & 8,901 & 22,987 \\
\hline 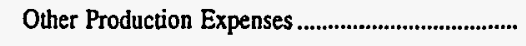 & 214 & 0 & 225 & 302 & 94 & 350 \\
\hline Total Production Expenses .................................... & 9,035 & 14,926 & 22,830 & 19,951 & 8,995 & 23,337 \\
\hline 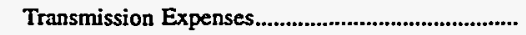 & 36 & $\mathbf{0}$ & 63 & 68 & 81 & 1.704 \\
\hline 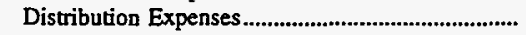 & 747 & 900 & 2,083 & 2,025 & 456 & 1,306 \\
\hline 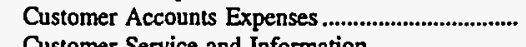 & 272 & 521 & 818 & 794 & 166 & 597 \\
\hline Customer Service and Information & & & & & & \\
\hline 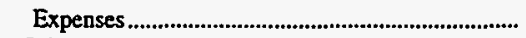 & 2 & 19 & 0 & 261 & 26 & 0 \\
\hline 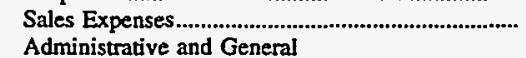 & 0 & 0 & 111 & 0 & 22 & 0 \\
\hline 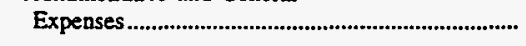 & 1,186 & 1,766 & 2,314 & 3,341 & 1,289 & 1,974 \\
\hline 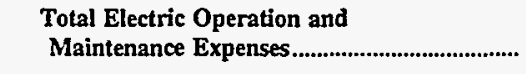 & 11,278 & 18,132 & 28,219 & 26,439 & 11,034 & 28,918 \\
\hline \multicolumn{7}{|l|}{ Fuel Expenses in Operation } \\
\hline 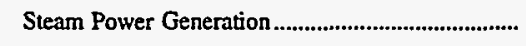 & 0 & 0 & 3,051 & 0 & 0 & 0 \\
\hline Nuclear Power Generation & 0 & $\mathbf{0}$ & 0 & 27 & 0 & 0 \\
\hline 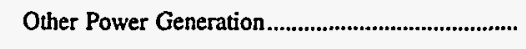 & 0 & 0 & 3 & 14 & 0 & 0 \\
\hline \multicolumn{7}{|l|}{ Number of Elec Dept Employees } \\
\hline Regular Full-time & 63 & 36 & 80 & 72 & 29 & 38 \\
\hline 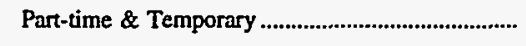 & 0 & 1 & 1 & 1 & 4 & 2 \\
\hline Total Elec Dept Employees........................................... & 63 & 37 & 81 & 73 & 33 & 40 \\
\hline
\end{tabular}

Note: Totals may not equal sum of components because of independent rounding.

Source: Energy Information Administration, Form EIA-412, "Annual Report of Public Electric Utilities." 
Table 23. Electric Operation and Maintenance Expenses by Major U.S. Publicly Owned Electric Utility Within State, 1996 (Continued) (Thousand Dollars)

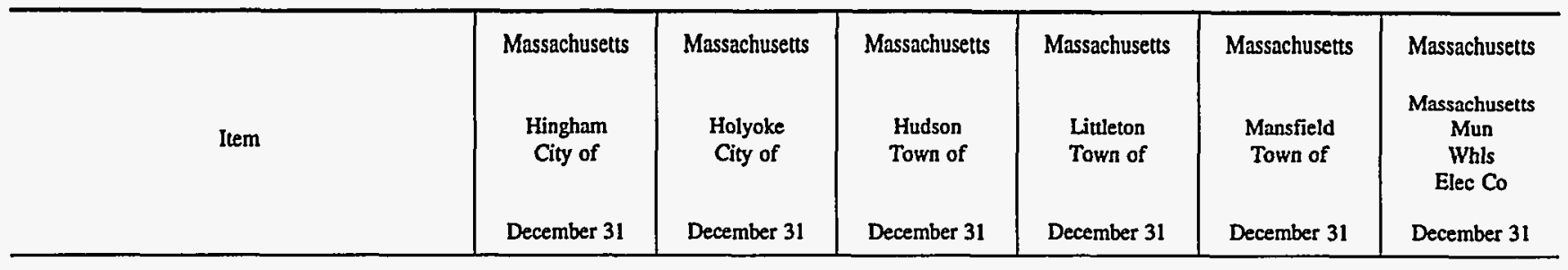

Production Expenses

Steam Power Generation..

Nuclear Power Generation .........................................

Hydraulic Power Generation

Other Power Generation..

Other Production Expenses

Total Production Expenses

Transmission Expenses..

Distribution Expenses.

Customer Accounts Expenses ..................................

Customer Service and Information

Expenses.....................................................................

Sales Expenses..............................................................

Administrative and General

Expenses...

Total Electric Operation and

Maintenance Expenses.

Fuel Expenses in Operation

Steam Power Generation...

Nuclear Power Generation

Other Power Generation

Number of Elec Dept Employees

Regular Full-time.

Part-time \& Temporary

1

Total Elec Dept Employees
0
0
0
0
10,008
89

10,096

454

810

300

$\mathbf{0}$
$\mathbf{0}$

873

12,534

937

937
0
137

0

17,536

80

18,691

682

1,811

816

0

29

2,154

24,183

0

104
0

500

21,366

49

22,020

1,273

454

306

0

10

1,127

25,191

$\begin{array}{rr}0 & 679 \\ 0 & 23,741 \\ 0 & 0 \\ 0 & 15,066 \\ 0 & 43,236 \\ 13,677 & 8\end{array}$

10,997

13,677

82,730

2,844

1,199

783

232

0

0

4,435

790

100,008

16,682

Note: Totals may not equal sum of components because of independent rounding.

Source: Energy Information Administration, Form EIA-412, "Annual Report of Public Electric Utilities." 
Table 23. Electric Operation and Maintenance Expenses by Major U.S. Publicly Owned Electric Utility Within State, 1996 (Continued)

(Thousand Dollars)

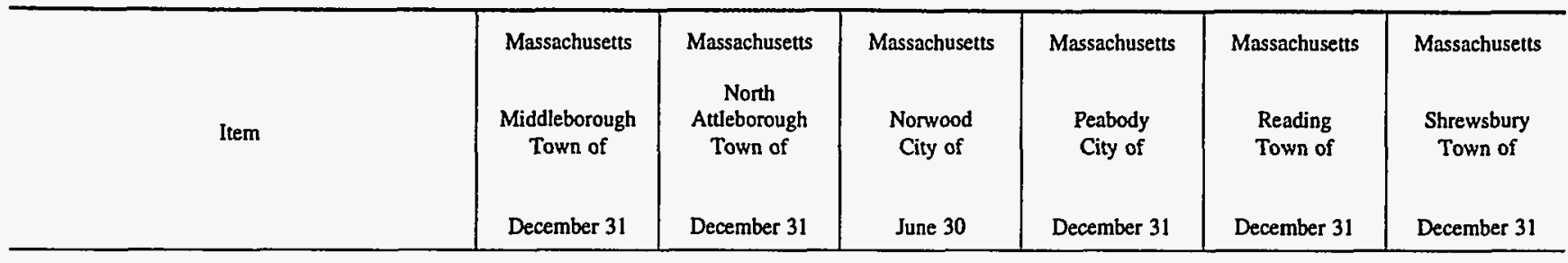

\section{Production Expenses}

Steam Power Generation.

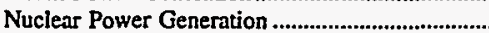

Hydraulic Power Generation

Other Power Generation.

Total Production Expenses

Transmission Expenses.

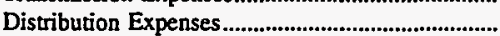

Customer Accounts Expenses.

Customer Service and Information

Expenses...

Expes Expenses

Administrative and General

Expenses

Total Electric Operation and

Maintenance Expenses

Fuel Expenses in Operation

Steam Power Generation ...........................................

Nuclear Power Generation...

Other Power Generation

Number of Elec Dept Employees

Regular Full-time.

Part-time \& Temporary

Total Elec Dept Employees

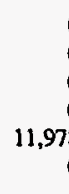

0
0
0
0
978
0

11,978

769

1,416

745

0
30

1,193

16,131
318
0
0
0
12,919
182

13,420

1,119

974

422

93

1,526

17,554

0
0
0
0
20,441
0

0
0
0
296
27,543
0

20,441

27,838

0
1,341

472

0
127

1,522

23,903

162
1,412

533

0

3,547

33,494

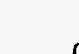

$\begin{array}{rr}0 & 0 \\ 0 & 0 \\ 0 & 0 \\ 13,681 & 81 \\ 24,336 & 15,742 \\ 0 & 170\end{array}$

38,017

15,994

2,365

3,057

1,819

855

368

0

57

369

1,171

3,142

48,779

19,399

Note: Totals may not equal sum of components because of independent rounding.

Source: Energy Information Administration, Form EIA-412, "Annual Report of Public Electric Utilities." 
Table 23. Electric Operation and Maintenance Expenses by Major U.S. Publicly Owned Electric Utility Within State, 1996 (Continued)

(Thousand Dollars)

\begin{tabular}{|c|c|c|c|c|c|c|}
\hline \multirow{3}{*}{ Item } & Massachusetts & Massachusetts & Massachusetts & Massachusetts & Michigan & Michigan \\
\hline & $\begin{array}{l}\text { Taunton } \\
\text { City of }\end{array}$ & $\begin{array}{l}\text { Wakefield } \\
\text { Town of }\end{array}$ & $\begin{array}{l}\text { Wellesley } \\
\text { Town of }\end{array}$ & $\begin{array}{l}\text { Westfield } \\
\text { City of }\end{array}$ & $\begin{array}{c}\text { Bay } \\
\text { City City of }\end{array}$ & $\begin{array}{c}\text { Coldwater } \\
\text { Board } \\
\text { of } \\
\text { Public Util }\end{array}$ \\
\hline & December 31 & December 31 & December 31 & December 31 & June 30 & June 30 \\
\hline
\end{tabular}

Production Expenses

Steam Power Generation

Nuclear Power Generation ...........................................

Hydraulic Power Generation

Other Power Generation

Purchased Power............................................................

Other Production Expenses..

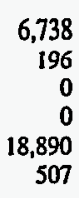

6,738
196
0
0
8,890
507

Total Production Expenses.

Transmission Expenses.

Distribution Expenses.....................................................

Customer Accounts Expenses ...................................

Customer Service and Information

Expenses......................................................................

Sales Expenses.................................................................

Administrative and General

Expenses.

Total Electric Operation and

Maintenance Expenses.

Fuel Expenses in Operation

Steam Power Generation ......................................

Nuclear Power Generation .

Other Power Generation.

Number of Elec Dept Employees

Regular Full-time.

Part-time \& Temporary.

26,331

451

2,681

1,437

0

21

4,585

35,506

0
0
0
0
12,664
0

11,451

12,664

322

0
1237

1,237

418

0

22

1,084

15,425

0

11,451

1,384

1,384
276

0

0
44

466

13,943

$\begin{array}{rr}2,238 & 0 \\ 35 & 0 \\ 0 & 0\end{array}$

0

0

0
0
0
0
23,284
188

$\begin{array}{rr}0 & 91 \\ 0 & 0 \\ 0 & 0 \\ 0 & 211 \\ 10,600 & 9,594 \\ 0 & 600\end{array}$

23,472

10,600

10,496

1,408

2,218

1,161

0

380

0

2,421
0

0
440
93

0

0

2,026

15,047

11,571

30,646

Total Elec Dept Employees.

$\begin{array}{rr}168 & 34 \\ 0 & 1 \\ 168 & 35\end{array}$

\begin{abstract}
40
0

40
\end{abstract}

0

42

17

0

60

17

Note: Totals may not equal sum of components because of independent rounding.

Source: Energy Information Administration, Form EIA-412, "Annual Report of Public Electric Utilities." 
Table 23. Electric Operation and Maintenance Expenses by Major U.S. Publicly Owned Electric Utility Within State, 1996 (Continued)

(Thousand Dollars)

\begin{tabular}{|c|c|c|c|c|c|c|}
\hline Item & $\begin{array}{l}\text { Michigan } \\
\text { Detroit } \\
\text { City of } \\
\text { June } 30\end{array}$ & $\begin{array}{l}\text { Michigan } \\
\text { Grand Haven } \\
\text { City of } \\
\text { June } 30\end{array}$ & $\begin{array}{c}\text { Michigan } \\
\text { Hillsdale } \\
\text { Board } \\
\text { of } \\
\text { Public Wks } \\
\text { June } 30\end{array}$ & $\begin{array}{l}\text { Michigan } \\
\text { Holland } \\
\text { City of } \\
\text { June } 30\end{array}$ & $\begin{array}{l}\text { Michigan } \\
\text { Lansing } \\
\text { City of } \\
\text { June } 30\end{array}$ & $\begin{array}{l}\text { Michigan } \\
\text { Marquette } \\
\text { City of } \\
\text { June } 30\end{array}$ \\
\hline \multicolumn{7}{|l|}{ Production Expenses } \\
\hline Steam Power Generation ............................................. & 18,960 & 8,349 & 0 & 10,170 & 39,802 & 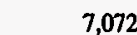 \\
\hline Nuclear Power Generation .............................................. & 0 & 0 & 0 & 0 & 0 & 0 \\
\hline 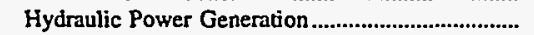 & 0 & 0 & 0 & 0 & 32 & 157 \\
\hline 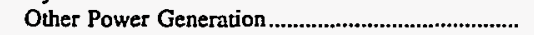 & 0 & 121 & 587 & 319 & 0 & 55 \\
\hline 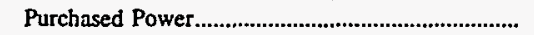 & 12,072 & 1,247 & 7,204 & 19,140 & 44,638 & 644 \\
\hline Other Production Expenses .............................................. & 0 & 103 & -25 & 0 & 0 & 0 \\
\hline Total Production Expenses........................................ & 31,032 & 9,820 & 7,765 & 29,630 & 84,472 & 7,928 \\
\hline 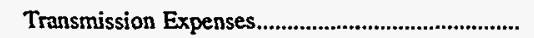 & 988 & 0 & 0 & 0 & 1,083 & 1 \\
\hline 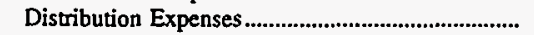 & 13,461 & 697 & 618 & 2,032 & 4,759 & 780 \\
\hline 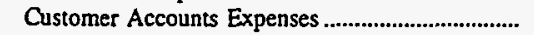 & 0 & 310 & 22 & 226 & 2,725 & 362 \\
\hline Customer Service and Information & & & & & & \\
\hline 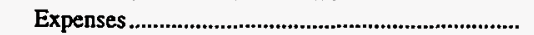 & 0 & 0 & 2 & 148 & 0 & 25 \\
\hline 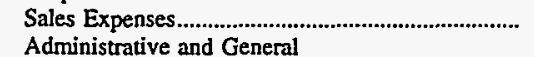 & 0 & 8 & 0 & 55 & 277 & 24 \\
\hline 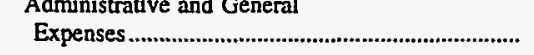 & 13.245 & 1,105 & 413 & 1,945 & 19,450 & 2,844 \\
\hline 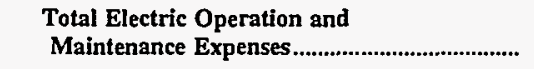 & 58,726 & 11,939 & 8,821 & 34,036 & 112,766 & 11,963 \\
\hline \multicolumn{7}{|l|}{ Fuel Expenses in Operation } \\
\hline 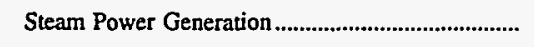 & 0 & 0 & 0 & 6,838 & 28,986 & 4,567 \\
\hline 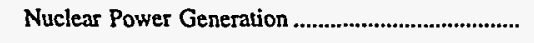 & 0 & 0 & 0 & 0 & 0 & 0 \\
\hline 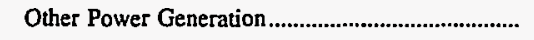 & 0 & 0 & 88 & 254 & 0 & 28 \\
\hline \multicolumn{7}{|l|}{ Number of Elec Dept Employees } \\
\hline 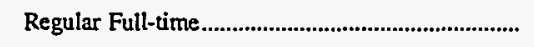 & 100 & 59 & 29 & 74 & 614 & 81 \\
\hline 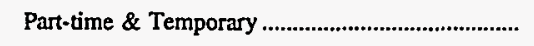 & 0 & 0 & 0 & 1 & 1 & 1 \\
\hline 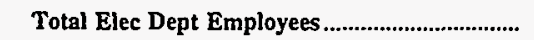 & 100 & 59 & 29 & 75 & 615 & 82 \\
\hline
\end{tabular}

Note: Totals may not equal sum of components because of independent rounding.

Source: Energy Information Administration, Form EIA-412, "Annual Report of Public Electric Utilities." 
Table 23. Electric Operation and Maintenance Expenses by Major U.S. Publicly

Owned Electric Utility Within State, 1996 (Continued)

(Thousand Dollars)

\begin{tabular}{|c|c|c|c|c|c|c|}
\hline Item & $\begin{array}{c}\text { Michigan } \\
\text { Michigan } \\
\text { Public } \\
\text { Power Agency } \\
\text { December } 31\end{array}$ & $\begin{array}{l}\text { Michigan } \\
\text { Michigan } \\
\text { South } \\
\text { Central } \\
\text { Pwr Agy } \\
\text { June } 30\end{array}$ & $\begin{array}{c}\text { Michigan } \\
\text { Sturgis } \\
\text { City of } \\
\text { September } 30\end{array}$ & $\begin{array}{l}\text { Michigan } \\
\text { Traverse } \\
\text { City City of } \\
\text { June } 30\end{array}$ & $\begin{array}{l}\text { Michigan } \\
\text { Wyandotte } \\
\text { Municipal } \\
\text { Serv Comm } \\
\text { September } 30\end{array}$ & $\begin{array}{l}\text { Michigan } \\
\text { Zeeland } \\
\text { City of } \\
\text { June } 30\end{array}$ \\
\hline \multicolumn{7}{|l|}{ Production Expenses } \\
\hline Steam Power Generation ................................................ & 32,854 & 6,573 & $\mathbf{0}$ & 1,819 & 8,839 & 0 \\
\hline Nuclear Power Generation & 0 & 0 & 0 & $\mathbf{0}$ & 0 & o \\
\hline Hydraulic Power Generation ........................................... & 0 & 0 & 73 & 77 & 0 & 0 \\
\hline 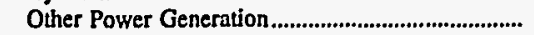 & 0 & 43 & 766 & 0 & 0 & 1,079 \\
\hline 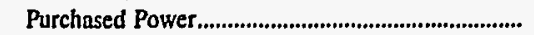 & 35,139 & 8,513 & 7,891 & 7,381 & 1,648 & 6,540 \\
\hline 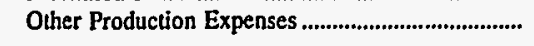 & 0 & 0 & 0 & 0 & 0 & 148 \\
\hline Total Production Expenses.................................... & 67,993 & 15,129 & 8,731 & 9,278 & 10,487 & 7,767 \\
\hline 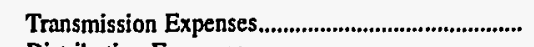 & 2,980 & 191 & 99 & 0 & 830 & 527 \\
\hline 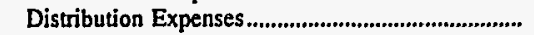 & 0 & 0 & 947 & 1,057 & 133 & 425 \\
\hline 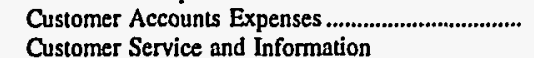 & 0 & 0 & 0 & -63 & 130 & 105 \\
\hline Expenses & 0 & 0 & 0 & 307 & 343 & 0 \\
\hline 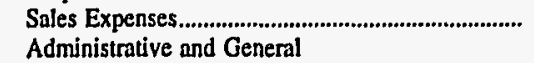 & 0 & 0 & 0 & 36 & 112 & 0 \\
\hline 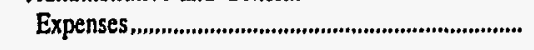 & 5,307 & 1,528 & 1,049 & 1,016 & 2.218 & 273 \\
\hline $\begin{array}{l}\text { Total Electric Operation and } \\
\text { Maintenance Expenses........................................ }\end{array}$ & 76,280 & 16,848 & 10,826 & 11,632 & 14,252 & 9,096 \\
\hline \multicolumn{7}{|l|}{ Fuel Expenses in Operation } \\
\hline 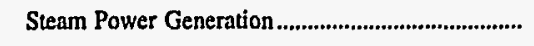 & 0 & 3,301 & $\mathbf{0}$ & 142 & 4,859 & 0 \\
\hline 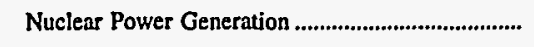 & $\mathbf{0}$ & 0 & 0 & 0 & $\mathbf{0}$ & 0 \\
\hline Other Power Generation ................................................. & 0 & 0 & 337 & 0 & 0 & 517 \\
\hline \multicolumn{7}{|l|}{ Number of Elec Dept Employees } \\
\hline 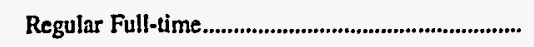 & 9 & 51 & 29 & 43 & 75 & 19 \\
\hline 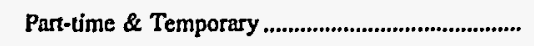 & 0 & 1 & $\mathbf{0}$ & 0 & 0 & 3 \\
\hline 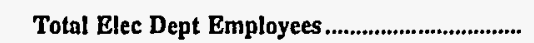 & 9 & 52 & 29 & 43 & 75 & 22 \\
\hline
\end{tabular}

Note: Totals may not equal sum of components because of independent rounding.

Source: Energy Information Administration, Form EIA-412, "Annual Report of Public Electric Utilities." 
Table 23. Electric Operation and Maintenance Expenses by Major U.S. Publicly Owned Electric Utility Within State, 1996 (Continued) (Thousand Dollars)

\begin{tabular}{|c|c|c|c|c|c|c|}
\hline Item & $\begin{array}{l}\text { Minnesota } \\
\text { Alexandria } \\
\text { City of } \\
\text { December } 31\end{array}$ & $\begin{array}{l}\text { Minnesota } \\
\text { Anoka } \\
\text { City of } \\
\text { December } 31\end{array}$ & $\begin{array}{c}\text { Minnesota } \\
\text { Austin } \\
\text { City of } \\
\text { December } 31\end{array}$ & $\begin{array}{l}\text { Minnesota } \\
\text { Brainerd } \\
\text { Public } \\
\text { Utilities } \\
\text { December } 31\end{array}$ & $\begin{array}{l}\text { Minnesota } \\
\text { Chaska } \\
\text { City of } \\
\text { December } 31\end{array}$ & $\begin{array}{l}\text { Minnesota } \\
\text { Fairmont } \\
\text { Public } \\
\text { Utilities } \\
\text { Comm } \\
\text { December 31 }\end{array}$ \\
\hline \multicolumn{7}{|l|}{ Production Expenses } \\
\hline 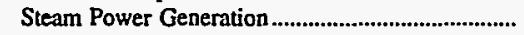 & 0 & $\mathbf{0}$ & 5,471 & 0 & 0 & 1,320 \\
\hline 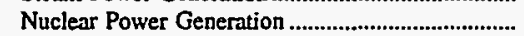 & 0 & 0 & 0 & 0 & 0 & 0 \\
\hline 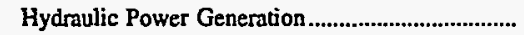 & 0 & $\mathbf{0}$ & 0 & 0 & $\mathbf{0}$ & 0 \\
\hline 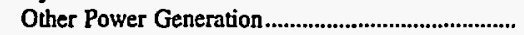 & 91 & 0 & 9 & 0 & 0 & 0 \\
\hline Purchased Power........................................................... & 5,615 & 8,540 & 13,574 & 5,512 & 7,033 & 7,609 \\
\hline 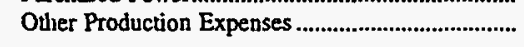 & 6 & 0 & 53 & 145 & 0 & 0 \\
\hline 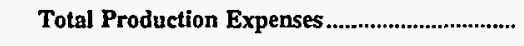 & 5,712 & 8,540 & 19,108 & 5,657 & 7,033 & 8,930 \\
\hline 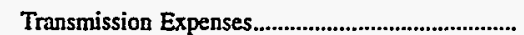 & 1,155 & 0 & 0 & 0 & 0 & 13 \\
\hline Distribution Expenses.......................................................... & 560 & 589 & 934 & 698 & 615 & 534 \\
\hline Customer Accounts Expenses ..................................... & 264 & 327 & 245 & 0 & $\mathbf{0}$ & 0 \\
\hline 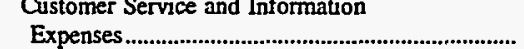 & 8 & 0 & 73 & 0 & $\mathbf{0}$ & 0 \\
\hline 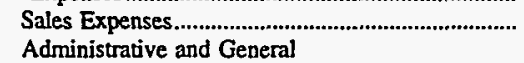 & 0 & 0 & 0 & 0 & 0 & 0 \\
\hline Expenses & 571 & 1,194 & 1,058 & 629 & 351 & 1,192 \\
\hline 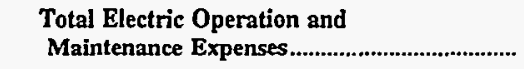 & 8,269 & 10,649 & 21,418 & 6,984 & 7,999 & 10,668 \\
\hline \multicolumn{7}{|l|}{ Fuel Expenses in Operation } \\
\hline 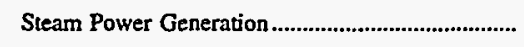 & 0 & 0 & 2,873 & 0 & 0 & 36 \\
\hline 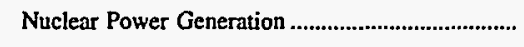 & 0 & 0 & 0 & 0 & 0 & 0 \\
\hline Other Power Generation & 0 & 0 & 0 & 0 & 0 & 0 \\
\hline \multicolumn{7}{|l|}{ Number of Elec Dept Employees } \\
\hline Regular Full-time & 27 & 21 & 54 & 10 & 8 & 25 \\
\hline 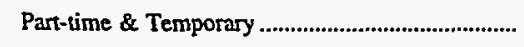 & 0 & 6 & 8 & 4 & 3 & 0 \\
\hline 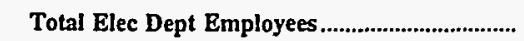 & 27 & 27 & 62 & 14 & 11 & 25 \\
\hline
\end{tabular}

Note: Totals may not equal sum of components because of independent rounding.

Source: Energy Information Administration, Form EIA-412, "Annual Report of Public Electric Utilities." 
Table 23. Electric Operation and Maintenance Expenses by Major U.S. Publicly Owned Electric Utility Within State, 1996 (Continued)

(Thousand Dollars)

\begin{tabular}{|c|c|c|c|c|c|c|}
\hline Item & $\begin{array}{c}\text { Minnesota } \\
\text { Hutchinson } \\
\text { Utilities } \\
\text { Comm } \\
\text { December } 31\end{array}$ & $\begin{array}{l}\text { Minnesota } \\
\text { Marshall } \\
\text { City of } \\
\text { December } 31\end{array}$ & $\begin{array}{l}\text { Minnesota } \\
\text { Moorhead } \\
\text { City of } \\
\text { December } 31\end{array}$ & $\begin{array}{c}\text { Minnesota } \\
\text { New Ulm } \\
\text { Public } \\
\text { Utilities } \\
\text { Comm } \\
\text { December } 31\end{array}$ & $\begin{array}{l}\text { Minnesota } \\
\text { Northem } \\
\text { Municipal } \\
\text { Power Agny } \\
\text { December } 31\end{array}$ & $\begin{array}{c}\text { Minnesota } \\
\text { Owatonna } \\
\text { City of } \\
\text { December } 31\end{array}$ \\
\hline \multicolumn{7}{|l|}{ Production Expenses } \\
\hline 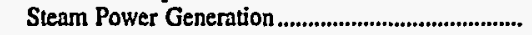 & $\mathbf{0}$ & 0 & $\mathbf{0}$ & 2,893 & 11,722 & o \\
\hline Nuclear Power Generation ............................................ & 0 & 0 & 0 & 0 & 0 & $\mathbf{0}$ \\
\hline Hydmulic Power Genemation.......................................... & 0 & 0 & 0 & 0 & 0 & 0 \\
\hline 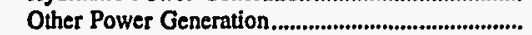 & 4,554 & 598 & 192 & 0 & 0 & 1,000 \\
\hline 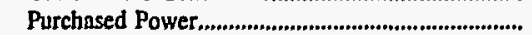 & 2,881 & 9,959 & 8,724 & 3,521 & 0 & 14,595 \\
\hline 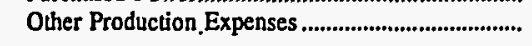 & 0 & 0 & 0 & 777 & 0 & 0 \\
\hline Total Production Expenses................................... & 7,435 & 10,557 & 8,915 & 7,190 & 11,722 & 15,595 \\
\hline 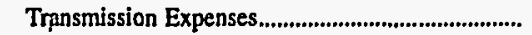 & 22 & 897 & 0 & 32 & 1,362 & 0 \\
\hline 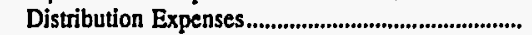 & 392 & 901 & 898 & 515 & 0 & 993 \\
\hline 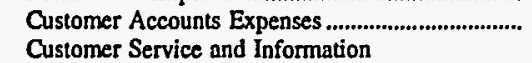 & 108 & 0 & 317 & 91 & 0 & 388 \\
\hline Expenses...., & 19 & 27 & 312 & 0 & 0 & 57 \\
\hline 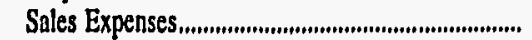 & 0 & 0 & 0 & 0 & 0 & 0 \\
\hline Administrative and General & & & & & & \\
\hline Expenses & 1,035 & 747 & 778 & 1,246 & 237 & 900 \\
\hline $\begin{array}{l}\text { Total Electric Operation and } \\
\text { Maintenance Expenses }\end{array}$ & 9,011 & 13,129 & 11,222 & 9,074 & 13,322 & 17,934 \\
\hline \multicolumn{7}{|l|}{ Fuel Expenses in Operation } \\
\hline 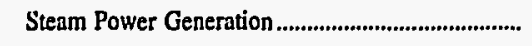 & 0 & 0 & 0 & 1,954 & 7,815 & 0 \\
\hline 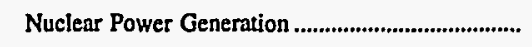 & $\mathbf{0}$ & 0 & 0 & 0 & 0 & 0 \\
\hline 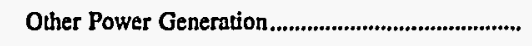 & 2,837 & 0 & 0 & 0 & 0 & 0 \\
\hline \multicolumn{7}{|l|}{ Number of Elec Dept Employees } \\
\hline 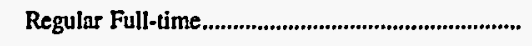 & 48 & 10 & 20 & 22 & $\mathbf{0}$ & 40 \\
\hline 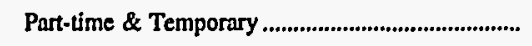 & 0 & 0 & 6 & $\mathbf{0}$ & 0 & o \\
\hline Total Elec Dept Employees .................................... & 48 & 10 & 26 & 22 & o & 40 \\
\hline
\end{tabular}

Note: Totals may not equal sum of components because of independent rounding.

Source: Energy Information Administration, Form EIA-412, "Annual Report of Public Electric Utilities." 
Table 23. Electric Operation and Maintenance Expenses by Major U.S. Publicly Owned Electric Utility Within State, 1996 (Continued)

(Thousand Dollars)

\begin{tabular}{|c|c|c|c|c|c|c|}
\hline Item & $\begin{array}{c}\text { Minnesota } \\
\text { Rochester } \\
\text { Public } \\
\text { Utilities } \\
\text { December } 31\end{array}$ & $\begin{array}{c}\text { Minnesota } \\
\text { Shakopee } \\
\text { Public } \\
\text { Utilities } \\
\text { Comm } \\
\text { December } 31\end{array}$ & $\begin{array}{l}\text { Minnesota } \\
\text { Southern } \\
\text { Minnesota } \\
\text { Mun P } \\
\text { Agny } \\
\text { December } 31\end{array}$ & $\begin{array}{c}\text { Minnesota } \\
\text { Western } \\
\text { Minnesota } \\
\text { Mun } \\
\text { Pwr Agny } \\
\text { December } 31\end{array}$ & $\begin{array}{l}\text { Minnesota } \\
\text { Willmar } \\
\text { Municipal } \\
\text { Utils Comm } \\
\text { December } 31\end{array}$ & $\begin{array}{l}\text { Minnesota } \\
\text { Worthington } \\
\text { City of } \\
\text { December 31 }\end{array}$ \\
\hline \multicolumn{7}{|l|}{ Production Expenses } \\
\hline 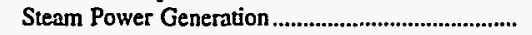 & 7,003 & 0 & 33,373 & 19,920 & 1,978 & 0 \\
\hline 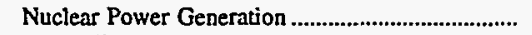 & $\mathbf{0}$ & $\mathbf{0}$ & 0 & 0 & 0 & $\mathbf{0}$ \\
\hline 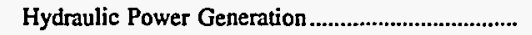 & 99 & 0 & 0 & 0 & $\mathbf{0}$ & $\mathbf{0}$ \\
\hline 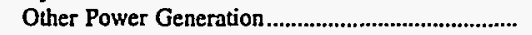 & 128 & 0 & 0 & 0 & 0 & 0 \\
\hline 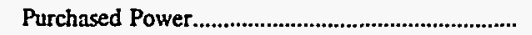 & 45,081 & 6,577 & 17,925 & 0 & 5,045 & 5,631 \\
\hline 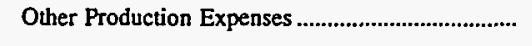 & 433 & 0 & 1,086 & 0 & 0 & 0 \\
\hline 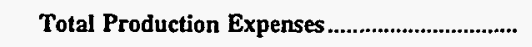 & 52,745 & 6,577 & 52,384 & 19,920 & $\mathbf{7 , 0 2 2}$ & 5,631 \\
\hline 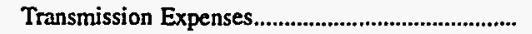 & 215 & $\mathbf{0}$ & 766 & 585 & 22 & 1,098 \\
\hline 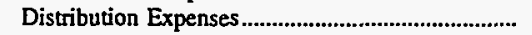 & 2,103 & 697 & $\mathbf{0}$ & 0 & 632 & 391 \\
\hline $\begin{array}{l}\text { Customer Accounts Expenses ....................................... } \\
\text { Customer Service and Information }\end{array}$ & 1,076 & 146 & 0 & 0 & 187 & 133 \\
\hline 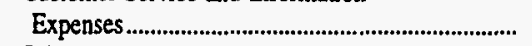 & 117 & 0 & 0 & 0 & 0 & 61 \\
\hline 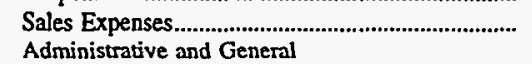 & 53 & 0 & 0 & 0 & 0 & 0 \\
\hline 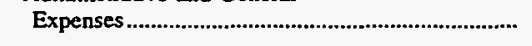 & 3,194 & 275 & 4,414 & 2,515 & 1,131 & 336 \\
\hline 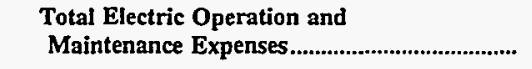 & 59,502 & 7,696 & 57,564 & 23,021 & 8,994 & 7,650 \\
\hline
\end{tabular}

Fuel Expenses in Operation

Steam Power Generation

Nuclear Power Generation .

Other Power Generation

$0 \quad 0$

21,825

0

0

1,228

0

0

0

90

0

0

0

Number of Elec Dept Employees

Regular Full-time

156

16

33

24

45

10

Part-time \& Temporary .

0

0

0

0

0

Total Elec Dept Employees

156

21

33

24

45

10

Note: Totals may not equal sum of components because of independent rounding.

Source: Energy Information Administration, Form EIA-412, "Annual Report of Public Electric Utilities." 
Table 23. Electric Operation and Maintenance Expenses by Major U.S. Publicly Owned Electric Utility Within State, 1996 (Continued)

(Thousand Dollars)

\begin{tabular}{|c|c|c|c|c|c|c|}
\hline Item & $\begin{array}{l}\text { Mississippi } \\
\text { Aberdeen } \\
\text { City of } \\
\text { June } 30\end{array}$ & $\begin{array}{l}\text { Mississippi } \\
\text { Amory } \\
\text { City of } \\
\text { June } 30\end{array}$ & $\begin{array}{l}\text { Mississippi } \\
\text { Clarksdale } \\
\text { City of } \\
\text { Seprember 3C }\end{array}$ & $\begin{array}{l}\text { Mississippi } \\
\text { Columbus } \\
\text { Cíty of } \\
\text { June } 30\end{array}$ & $\begin{array}{l}\text { Mississippi } \\
\text { Greenwood } \\
\text { Utilities } \\
\text { Comm } \\
\text { September } 30\end{array}$ & $\begin{array}{l}\text { Mississippi } \\
\text { Holly } \\
\text { Springs } \\
\text { City of } \\
\text { June } 30\end{array}$ \\
\hline 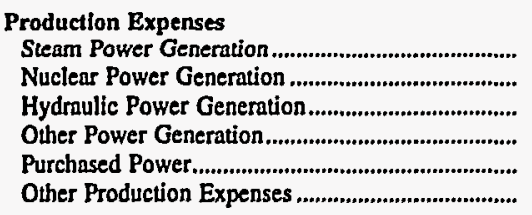 & $\begin{array}{r}0 \\
0 \\
0 \\
0 \\
7,389 \\
0\end{array}$ & $\begin{array}{r}0 \\
0 \\
0 \\
0 \\
5,942 \\
0\end{array}$ & $\begin{array}{r}2,355 \\
0 \\
0 \\
0 \\
6,047 \\
12\end{array}$ & $\begin{array}{r}0 \\
0 \\
0 \\
0 \\
21,960 \\
0\end{array}$ & $\begin{array}{r}2,322 \\
0 \\
0 \\
0 \\
8,399 \\
0\end{array}$ & $\begin{array}{r}0 \\
0 \\
0 \\
0 \\
10,015 \\
0\end{array}$ \\
\hline Total Productlon Expenses.......................................... & 7,389 & 5,942 & 8,414 & 21,960 & 10,722 & 10,015 \\
\hline 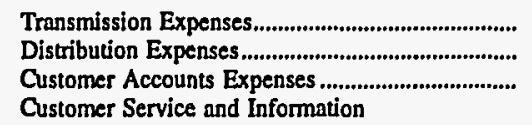 & $\begin{array}{r}0 \\
307 \\
129\end{array}$ & $\begin{array}{r}0 \\
357 \\
75\end{array}$ & $\begin{array}{r}10 \\
414 \\
215\end{array}$ & $\begin{array}{r}0 \\
903 \\
237\end{array}$ & $\begin{array}{r}0 \\
649 \\
208\end{array}$ & $\begin{array}{r}0 \\
784 \\
335\end{array}$ \\
\hline 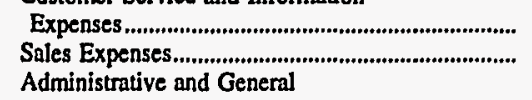 & $\begin{array}{l}39 \\
21\end{array}$ & $\begin{array}{l}17 \\
10\end{array}$ & $\begin{array}{l}0 \\
0\end{array}$ & $\begin{array}{r}16 \\
122\end{array}$ & $\begin{array}{l}0 \\
2\end{array}$ & $\begin{array}{r}4 \\
10\end{array}$ \\
\hline 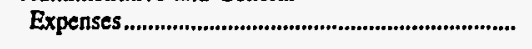 & 283 & 152 & 979 & 630 & 1,292 & 372 \\
\hline $\begin{array}{l}\text { Total Electric Operation and } \\
\text { Maintenance Expenses.......................................... }\end{array}$ & 8,168 & 6,553 & 10,032 & 23,868 & 12,872 & 11,520 \\
\hline \multicolumn{7}{|l|}{ Fuel Expenses in Operation } \\
\hline 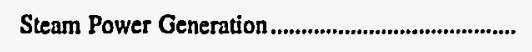 & 0 & 0 & 1,620 & 0 & 1,201 & 0 \\
\hline 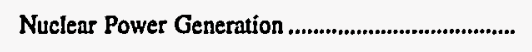 & 0 & 0 & 0 & 0 & 0 & 0 \\
\hline 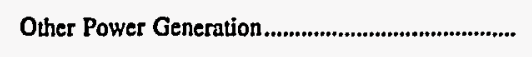 & $\mathbf{0}$ & $\mathbf{0}$ & 0 & 0 & 0 & 0 \\
\hline \multicolumn{7}{|l|}{ Number of Elec Dept Employees } \\
\hline 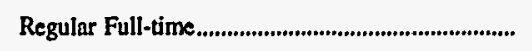 & 15 & 18 & 39 & 32 & 76 & 43 \\
\hline 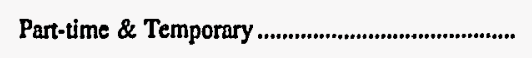 & 0 & 0 & 2 & o & 1 & 0 \\
\hline 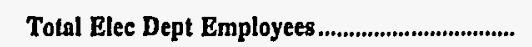 & 15 & 18 & 41 & 32 & 77 & 43 \\
\hline
\end{tabular}

Note: Totals may not equal sum of components because of independent rounding.

Source: Energy Information Administration, Form EIA-412, "Annual Report of Public Electric Utilities." 
Table 23. Electric Operation and Maintenance Expenses by Major U.S. Publicly Owned Electric Utility Within State, 1996 (Continued)

(Thousand Dollars)

\begin{tabular}{|c|c|c|c|c|c|c|}
\hline Item & $\begin{array}{l}\text { Mississippi } \\
\text { Louisville } \\
\text { Electric } \\
\text { System } \\
\text { June } 30\end{array}$ & $\begin{array}{c}\text { Mississippi } \\
\text { Municipal } \\
\text { Energy } \\
\text { Agency } \\
\text { of MS } \\
\text { September } 30\end{array}$ & $\begin{array}{l}\text { Mississippi } \\
\text { New Albany } \\
\text { City of } \\
\text { June } 30\end{array}$ & $\begin{array}{l}\text { Mississippi } \\
\text { Oxford } \\
\text { City of } \\
\text { June } 30\end{array}$ & $\begin{array}{l}\text { Mississippi } \\
\text { Philadelphia } \\
\text { City of } \\
\text { June } 30\end{array}$ & $\begin{array}{l}\text { Mississippi } \\
\text { Starkville } \\
\text { City of } \\
\text { June } 30\end{array}$ \\
\hline \multicolumn{7}{|l|}{ Production Expenses } \\
\hline Steam Power Generation & 0 & 0 & 0 & 0 & 0 & $\mathbf{0}$ \\
\hline 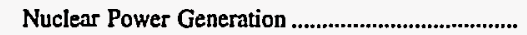 & 0 & 0 & 0 & 0 & 0 & 0 \\
\hline 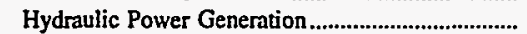 & 0 & 0 & 0 & 0 & 0 & 0 \\
\hline 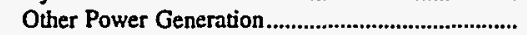 & 0 & 0 & 0 & 0 & 0 & 0 \\
\hline 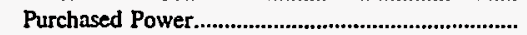 & 7,635 & 26,146 & 11,836 & 7,671 & 5,865 & 15,795 \\
\hline 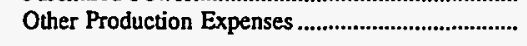 & 0 & 0 & 0 & 0 & 0 & 0 \\
\hline 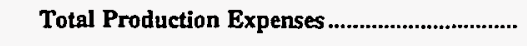 & 7,635 & 26,146 & 11,836 & 7,671 & 5,865 & 15,795 \\
\hline Transmission Expenses....... & 0 & 1,421 & 0 & 0 & $\mathbf{0}$ & 3 \\
\hline 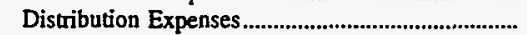 & 379 & 206 & 1,143 & 330 & 280 & 730 \\
\hline 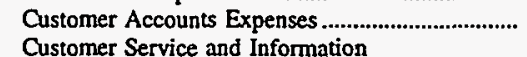 & 109 & 0 & 261 & 148 & 73 & 189 \\
\hline 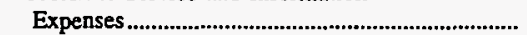 & 3 & 0 & 10 & 20 & 5 & 20 \\
\hline 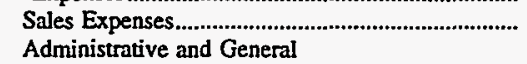 & 25 & 0 & 13 & 31 & 16 & 17 \\
\hline 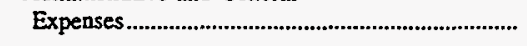 & 274 & 625 & 302 & 247 & 199 & 579 \\
\hline 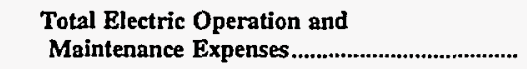 & 8,125 & 28,398 & 13,564 & 8,446 & 6,438 & 17,332 \\
\hline
\end{tabular}

Fuel Expenses in Operation

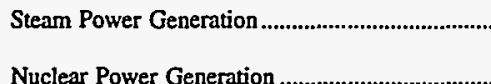

Other Power Generation

Number of Elec Dept Employees

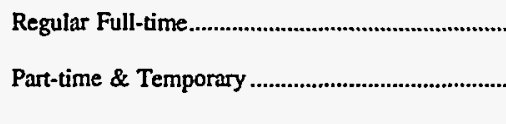

Total Elec Dept Employees
0

0

0

14

$14-5$

0

14
0

0

0
5

39

25

15

35

0

0

0

39

25

35

Note: Totals may not equal sum of components because of independent rounding

Source: Energy Information Administration, Form EIA-412, "Annual Report of Public Electric Utilities." 
Table 23. Electric Operation and Maintenance Expenses by Major U.S. Publicly

Owned Electric Utility Within State, 1996 (Continued)

(Thousand Dollars)

\begin{tabular}{c|c|c|c|c|c|c}
\hline & Mississippi & Mississippi & Missouri & Missouri & Missouri & Missouri \\
Item & $\begin{array}{c}\text { Tupelo } \\
\text { City of }\end{array}$ & $\begin{array}{c}\text { Point } \\
\text { City of }\end{array}$ & $\begin{array}{c}\text { Carthage } \\
\text { City of }\end{array}$ & $\begin{array}{c}\text { Columbia } \\
\text { City of }\end{array}$ & $\begin{array}{c}\text { Hannibal } \\
\text { City of }\end{array}$ & $\begin{array}{c}\text { Independence } \\
\text { City of }\end{array}$ \\
June 30 & June 30 & June 30 & September 30 & June $30 \quad$ June 30 \\
\hline
\end{tabular}

Production Expenses

Steam Power Generation .......................................

Nuclear Power Generation .......................................

Hydraulic Power Generation

Other Power Generation.

Purchased Power.

Other Production Expenses.........................................

Total Production Expenses

Transmission Expenses..

Distribution Expenses..........................................

Customer Accounts Expenses .................................

Customer Service and Information

Expenses.,

Sales Expenses.

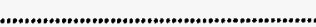

Administrative and Genera

Expenses.

Total Electric Operation and

Maintenance Expenses

Fuel Expenses in Operation

Steam Power Generation......................................

Nuclear Power Generation

Other Power Generation

Number of Elec Dept Employees

Regular Full-time....................................................

Part-time \& Temporary

30,72

0
0
0
0
0,725
0

30,725

0
986

413

54

58

435

32,671
0

0

0

64

0

64

0
0
0
417
7,381
75

5,276
0
0
0
29,102
30

0
0
0
0
8,625
0

6,427

0

682

21,247

616

34,408

8,625

28,971

$0 \quad 2,070$

$634 \quad 5,559$

$149 \quad 1,812$

3,895
1,482

29

207

150

79

3,919

197

1,244

2,153

852

9,783

9,585

41,938

10,368

42,539

0

0

0

12

0

12

36

168
2,102

0

497

208

0

208

Note; Totals may not equal sum of components because of independent rounding.

Source: Energy Information Administration, Form EIA-412, "Annual Report of Public Electric Utilities." 
Table 23. Electric Operation and Maintenance Expenses by Major U.S. Publicly Owned Electric Utility Within Sțate, 1996 (Continued)

(Thousand Dollars)

\begin{tabular}{|c|c|c|c|c|c|c|}
\hline Item & $\begin{array}{l}\text { Missouri } \\
\text { Kennett } \\
\text { City of }\end{array}$ & $\begin{array}{l}\text { Missouri } \\
\text { Kirkwood } \\
\text { City of }\end{array}$ & $\begin{array}{l}\text { Missouri } \\
\text { Lebanon } \\
\text { City of }\end{array}$ & $\begin{array}{c}\text { Missouri } \\
\text { Marshall } \\
\text { City of }\end{array}$ & $\begin{array}{l}\text { Missouri } \\
\text { Monet } \\
\text { City of }\end{array}$ & $\begin{array}{l}\text { Missouri } \\
\text { Poplar } \\
\text { Bluff } \\
\text { City of }\end{array}$ \\
\hline & June 30 & March 31 & October 31 & September 30 & March 31 & December 31 \\
\hline
\end{tabular}

Production Expenses

Steam Power Generation...

Nuclear Power Generation ........................................

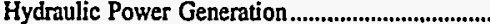

Other Power Generation....

Purchased Power

Total Production Expenses.

Transmission Expenses

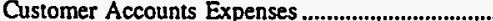

Customer Service and Information

Expenses............

Sales Expenses

Administrative and General

Expenses

Total Electric Operation and

Maintenance Expenses.

Fuel Expenses in Operation

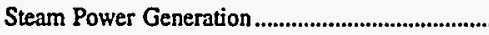

Nuclear Power Generation.

Other Power Generation.

Number of Elec Dept Employees

Regular Full-time.

Part-time \& Temporary

Total Elec Dept Employees

0
0
0
452
3,665
0

4,117

0
713

0

0

458

5,288

0
0
0
0
7,310
0

7,310

0
1,128

180

0

0

416

9,034
0
0
0
0
7,868
0

7,868

0
1,531

0

0
0

281

9,680

3,079
0
0
0
1,914
0

4,992

35
434

400

0

456

0
0
0
0
5,879
0

5,879

0

81

0

$$
\begin{aligned}
& 0 \\
& 0
\end{aligned}
$$

730

6,690

Note: Totals may not equal sum of components because of independent rounding.

Source: Energy Information Administration, Form ElA-412, "Annual Report of Public Electric Utilities." 
Table 23. Electric Operation and Maintenance Expenses-by Major U.S. Publicly Owned Electric Utility Within State, 1996 (Continued) :

(Thousand Dollars)

\begin{tabular}{|c|c|c|c|c|c|c|}
\hline Item & $\begin{array}{c}\text { Missouri } \\
\text { Rolla } \\
\text { City of } \\
\text { September } 30\end{array}$ & $\begin{array}{l}\text { Missouri } \\
\text { Sikeston } \\
\text { City of } \\
\text { May } 31\end{array}$ & $\begin{array}{l}\text { Missouri } \\
\text { Springfield } \\
\text { City of } \\
\text { September } 30\end{array}$ & $\begin{array}{c}\text { Missouri } \\
\text { West } \\
\text { Plains } \\
\text { City of } \\
\text { December } 31\end{array}$ & $\begin{array}{l}\text { Nebraska } \\
\text { Beatrice } \\
\text { City of } \\
\text { July } 31\end{array}$ & $\begin{array}{c}\text { Nebraska } \\
\text { Central } \\
\text { Nebraska } \\
\text { Pub } \\
\text { P\&I Dist } \\
\text { December } 31\end{array}$ \\
\hline \multicolumn{7}{|l|}{ Production Expenses } \\
\hline 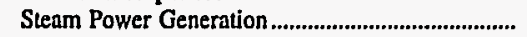 & $\mathbf{0}$ & 34,252 & 44,910 & 0 & 0 & 0 \\
\hline Nuclear Power Generation .............................................. & 0 & 0 & 0 & 0 & 0 & 0 \\
\hline Hydraulic Power Generation......................................... & 0 & 0 & 0 & 0 & 0 & 2,925 \\
\hline 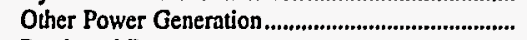 & 0 & 0 & 1,530 & 0 & 0 & 0 \\
\hline 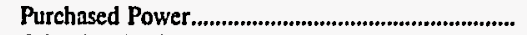 & 9,954 & -375 & 12,424 & 6,256 & 6,855 & 0 \\
\hline 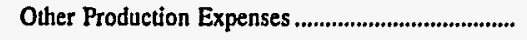 & 0 & 0 & $\mathbf{0}$ & 0 & 0 & 0 \\
\hline Total Production Expenses ....................................... & 9,954 & 33,877 & 58,864 & 6,256 & 6,855 & 2,925 \\
\hline 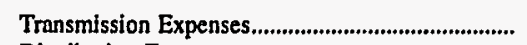 & 0 & 0 & 301 & 537 & 0 & $\mathbf{0}$ \\
\hline Distribution Expenses...................................................... & 503 & 1,304 & 7,955 & 3,168 & 739 & $\mathbf{0}$ \\
\hline $\begin{array}{l}\text { Customer Accounts Expenses ..................................... } \\
\text { Customer Service and Information }\end{array}$ & 162 & 338 & 1,787 & 0 & 58 & $\mathbf{0}$ \\
\hline 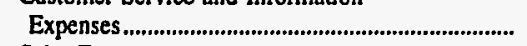 & 0 & $\mathbf{0}$ & 11 & 0 & 92 & 0 \\
\hline 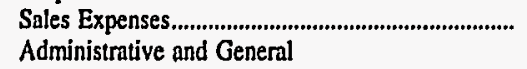 & 0 & $\mathbf{0}$ & 0 & 0 & 0 & 0 \\
\hline 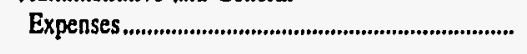 & 419 & 3,340 & 10,169 & 389 & 524 & 1,172 \\
\hline $\begin{array}{l}\text { Total Electric Operation and } \\
\text { Malntenance Expenses........................................ }\end{array}$ & 11,037 & 38,860 & 79,087 & 10,350 & 8,269 & 4,096 \\
\hline
\end{tabular}

Fuel Expenses in Operation

Steam Power Generation........................................

Nuclear Power Generation

$\begin{array}{rrr}0 & 26,978 & 30,968 \\ 0 & 0 & 0 \\ 0 & 0 & 1,375\end{array}$

$\begin{array}{lll}0 & 0 & 0\end{array}$

$\begin{array}{lll}0 & 0 & 0\end{array}$

Other Power Generntion............................................

0

0

Number of Elec Dept Employees

Regular Full-time...................................................

Part-time \& Temporary ...........................................

Total Elec Dept Employees.
27

0

27
$172 \quad 516$

0

172
26

542
18

0

18
31

67

71

Note: Totals may not equal sum of components because of independent rounding.

Source: Energy Information Administration, Form EIA-412, "Annual Report of Public Electric Utilities." 
Table 23. Electric Operation and Maintenance Expenses by Major U.S. Publicly Owned Electric Utility Within State, 1996 (Continued)

(Thousand Dollars)

\begin{tabular}{c|c|c|c|c|c|c}
\hline & Nebraska & Nebraska & Nebraska & Nebraska & Nebraska & Nebraska \\
& $\begin{array}{c}\text { Combusker } \\
\text { Item }\end{array}$ & $\begin{array}{c}\text { Dawson } \\
\text { Public } \\
\text { Power Dist }\end{array}$ & $\begin{array}{c}\text { County } \\
\text { Public } \\
\text { Pwr Dist }\end{array}$ & $\begin{array}{c}\text { Fremont } \\
\text { City of }\end{array}$ & $\begin{array}{c}\text { Grand Island } \\
\text { City of }\end{array}$ & $\begin{array}{c}\text { Hastings } \\
\text { City of } \\
\text { Electric } \\
\text { System }\end{array}$ \\
& December 31 & December 31 & July 31 & July 31 & December 31 & December 31 \\
\hline
\end{tabular}

Production Expenses

Steam Power Generation

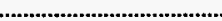

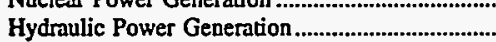

Other Power Generation.............................................

Purchased Power..........................................................

Other Production Expenses ........................................

Total Production Expenses ..............................

Transmission Expenses.

Distribution Expenses

Customer Accounts Expenses ....................................

Customer Service and Information

Expenses........

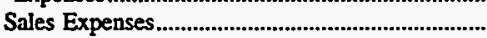

Administrative and General

Expenses.

0
0
0
0
7.717
0

0
0
0
0
10,541
0

7,740
0
0
0
1,614
1

$$
7,71
$$

9,356
49

$176 \quad 49$

10,541

1,046

1,587

234

1,302

262

$106 \quad 58$

15

653

1,248

0
0

2,143

9,947

13,916

13,113

9,654
0
0
0
2,114
0

6,676
0
0
1155
1,243
0

13,185

0

Total Electric Operation and

Maintenance Expenses.

Fuel Expenses in Operation

Steam Power' Generation

0

0

0

5,634

3,734

63,690

152

8,074

0

3,117

6,044

Nuclear Power Generation.

Other Power Generation

0

0

0

0

0

0

0

0

73

0

0

Number of Elec Dept Employees

Regular Full-time.

47

68

142

118

95

393

Part-time \& Temporary .........................................

Total Elec Dept Employees
0

68
4

146
0

118
0

409

Note: Totals may not equal sum of components because of independent rounding.

Source: Energy Information Administration, Form EIA-412, “Annual Report of Public Electric Utilities." 
Table 23. Electric Operation and Maintenance Expenses by Major U.S. Publicly Owned Electric Utility Within State, 1996 (Continued)

(Thousand Dollars)

\begin{tabular}{|c|c|c|c|c|c|c|}
\hline Item & $\begin{array}{c}\text { Nebraskn } \\
\text { Loup } \\
\text { River } \\
\text { Public } \\
\text { Power Dist } \\
\text { December 31 }\end{array}$ & $\begin{array}{c}\text { Nebraska } \\
\text { Municipal } \\
\text { Energy } \\
\text { Agency } \\
\text { of NE } \\
\text { March } 31\end{array}$ & $\begin{array}{c}\text { Nebraska } \\
\text { Nebraska } \\
\text { Public } \\
\text { Power } \\
\text { District } \\
\text { December } 31\end{array}$ & $\begin{array}{c}\text { Nebraska } \\
\text { Norris } \\
\text { Public } \\
\text { Power } \\
\text { District } \\
\text { December } 31\end{array}$ & $\begin{array}{l}\text { Nebraska } \\
\text { North } \\
\text { Platte } \\
\text { City of } \\
\text { July } 31\end{array}$ & $\begin{array}{c}\text { Nebraska } \\
\text { Omaha Public } \\
\text { Power } \\
\text { District } \\
\text { December } 31\end{array}$ \\
\hline \multicolumn{7}{|l|}{ Production Expenses } \\
\hline 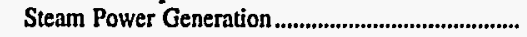 & 0 & 2,203 & 36,678 & 0 & 0 & 80,565 \\
\hline Nuclear Power Generation ............................................ & 0 & 0 & 21,177 & 0 & 0 & 105,666 \\
\hline Hydraulic Power Genemation .......................................... & 1,598 & 0 & 3,127 & 0 & $\mathbf{0}$ & 0 \\
\hline Other Power Generation................................................ & 4 & 0 & 3,672 & 0 & $\mathbf{0}$ & 1,896 \\
\hline 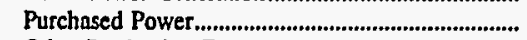 & 34,940 & 19,986 & 302,587 & 14,978 & 10,564 & $-10,384$ \\
\hline Other Production Expenses .......................................... & 0 & 2,382 & 3,287 & 0 & 0 & 2,154 \\
\hline Total Production Expenses....................................... & 36,541 & 24,571 & 370,527 & 14,978 & 10,564 & 179,897 \\
\hline 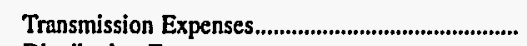 & 349 & 4,272 & 16,792 & 42 & 37 & 4,803 \\
\hline 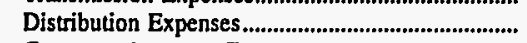 & 1,173 & 0 & 12,374 & 2,152 & 863 & 30,936 \\
\hline & 538 & 0 & 6,070 & 413 & 429 & 11,018 \\
\hline 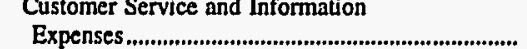 & 98 & $\mathbf{0}$ & 3.030 & 243 & 130 & 4.183 \\
\hline $\begin{array}{l}\text { Sales Expenses...................................................... } \\
\text { Administrative and General }\end{array}$ & 27 & 0 & 5,278 & 0 & 0 & $\begin{array}{r}4,100 \\
210\end{array}$ \\
\hline 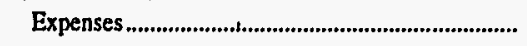 & 2,310 & 2,677 & 14,581 & 1,028 & 521 & 19,269 \\
\hline $\begin{array}{l}\text { Total Electric Operation and } \\
\text { Maintenance Expenses........................................... }\end{array}$ & 41,038 & 31,520 & 428,653 & 18,857 & 12,544 & 250,315 \\
\hline \multicolumn{7}{|l|}{ Fuel Expenses in Operation } \\
\hline 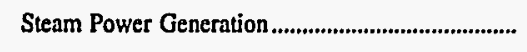 & 0 & 1,334 & 0 & $\mathbf{0}$ & 0 & 48,750 \\
\hline 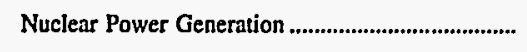 & $\mathbf{0}$ & 0 & $\mathbf{0}$ & 0 & 0 & 28,815 \\
\hline 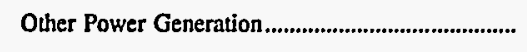 & 0 & 0 & 0 & 0 & 0 & 1,380 \\
\hline \multicolumn{7}{|l|}{ Number of Elec Dept Employees } \\
\hline 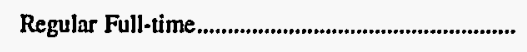 & 107 & 38 & 2,370 & 71 & 35 & 2,231 \\
\hline 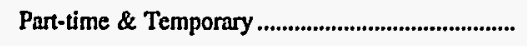 & 19 & 2 & $\mathbf{0}$ & 4 & 0 & 80 \\
\hline Total Elec Dept Employees................................. & 126 & 40 & 2,370 & 75 & 35 & 2,311 \\
\hline
\end{tabular}

Note: Totals may not equal sum of components because of independent rounding.

Source: Energy Information Administration, Form EIA-412, "Annual Report of Public Electric Utilities." 
Table 23. Electric Operation and Maintenance Expenses by Major U.S. Publicly Owned Electric Utility Within State, 1996 (Continued)

(Thousand Dollars)

\begin{tabular}{|c|c|c|c|c|c|c|}
\hline Item & $\begin{array}{l}\text { Nebraska } \\
\text { Southern } \\
\text { Nebraska Rural } \\
\text { P P D } \\
\text { December } 31\end{array}$ & $\begin{array}{c}\text { Nevada } \\
\text { Colorado } \\
\text { River } \\
\text { Comm } \\
\text { of Nevada } \\
\text { June } 30\end{array}$ & $\begin{array}{c}\text { Nevada } \\
\text { Overton } \\
\text { Power } \\
\text { District } \\
\text { No } 5 \\
\text { December 31 }\end{array}$ & $\begin{array}{l}\text { New Jersey } \\
\text { Madison } \\
\text { Borough } \\
\text { December } 31\end{array}$ & $\begin{array}{l}\text { New Jersey } \\
\text { Vineland } \\
\text { City of } \\
\text { June } 30\end{array}$ & $\begin{array}{l}\text { New Mexico } \\
\text { Farmington } \\
\text { City of } \\
\text { June } 30\end{array}$ \\
\hline \multicolumn{7}{|l|}{ Production Expenses } \\
\hline Steam Power Generation & 0 & 0 & 0 & 0 & 7,599 & 7,921 \\
\hline Nuclear Power Generation .............................................. & 0 & 0 & 0 & 0 & 0 & 0 \\
\hline 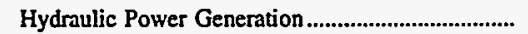 & 0 & 0 & 0 & 0 & 0 & 546 \\
\hline 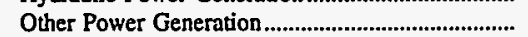 & 0 & 0 & 0 & 0 & 617 & 2,962 \\
\hline Purchased Power .................................................... & 16,840 & 24,566 & 5,346 & 6,893 & 20,308 & 3,153 \\
\hline 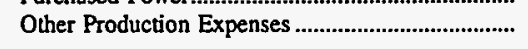 & 0 & 0 & 0 & 0 & 103 & 242 \\
\hline 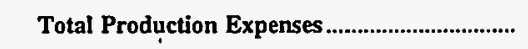 & 16,840 & 24,566 & 5,346 & 6,893 & 28,628 & 14,823 \\
\hline 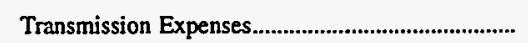 & 110 & 0 & 89 & 0 & 10 & 478 \\
\hline 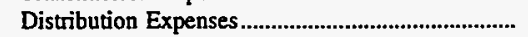 & 1,399 & 0 & 785 & 1,848 & 2,655 & 1,858 \\
\hline Customer Accounts Expenses ....................................... & 415 & 0 & 216 & 0 & 1,227 & 1,087 \\
\hline Customer Service and Information & & & & & & \\
\hline 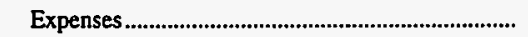 & 112 & 0 & 12 & 0 & $\mathbf{0}$ & 28 \\
\hline 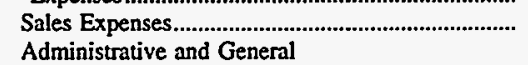 & 17 & 0 & 0 & 0 & 9 & 2 \\
\hline 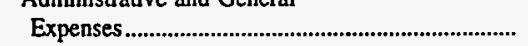 & 1,547 & 0 & 1,234 & $\mathbf{0}$ & 3,021 & 1,931 \\
\hline $\begin{array}{l}\text { Total Electric Operation and } \\
\text {. Maintenance Expenses....................................... }\end{array}$ & 20,439 & 24,566 & 7,682 & 8,741 & 35,551 & 20,207 \\
\hline \multicolumn{7}{|l|}{ Fuel Expenses in Operation } \\
\hline 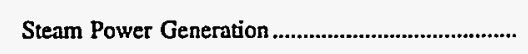 & 0 & 0 & 0 & 0 & 2,410 & 5,009 \\
\hline 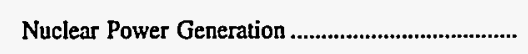 & 0 & 0 & 0 & 0 & 0 & 0 \\
\hline Other Power Generation & 0 & 0 & 0 & 0 & 501 & 2,849 \\
\hline \multicolumn{7}{|l|}{ Number of Elec Dept Employees } \\
\hline Regular Full-time & 77 & 8 & 38 & 0 & 164 & 94 \\
\hline 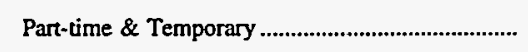 & 0 & 11 & 0 & 0 & 7 & 1 \\
\hline 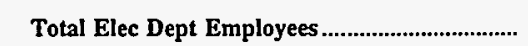 & 77 & 19 & 38 & 0 & 171 & 95 \\
\hline
\end{tabular}

Note: Totals may not equal sum of components because of independent rounding.

Source: Energy Information Administration, Form EIA-412, "Annual Report of Public Electric Utilities." 
Table 23. Electric Operation and Maintenance Expenses by Major U.S. Publicly Owned Electric Utility Within State, 1996 (Continued)

(Thousand Dollars)

\begin{tabular}{|c|c|c|c|c|c|c|}
\hline Item & $\begin{array}{l}\text { New Mexico } \\
\text { Gallup } \\
\text { City of } \\
\text { June } 30\end{array}$ & $\begin{array}{l}\text { New Mexico } \\
\text { Los Alamos } \\
\text { County } \\
\text { June } 30\end{array}$ & $\begin{array}{l}\text { New York } \\
\text { Fairport } \\
\text { Village of } \\
\text { May } 31\end{array}$ & $\begin{array}{c}\text { New York } \\
\text { Freeport } \\
\text { Village of } \\
\text { Inc } \\
\text { February } 28\end{array}$ & $\begin{array}{c}\text { New York } \\
\text { Jumestown } \\
\text { City of } \\
\text { December } 31\end{array}$ & $\begin{array}{c}\text { New York } \\
\text { Lake Placid } \\
\text { Village Inc } \\
\text { July } 31\end{array}$ \\
\hline \multicolumn{7}{|l|}{ Production Expenses } \\
\hline Steam Power Generation ............................................... & 0 & 5,401 & 0 & 0 & 5,872 & \\
\hline 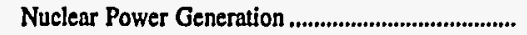 & 0 & 0 & $\mathbf{0}$ & $\mathbf{0}$ & 0 & 0 \\
\hline Hydraulic Power Generation.......................................... & 0 & 661 & 0 & 0 & 0 & 0 \\
\hline 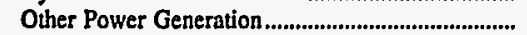 & 0 & 0 & 0 & 2,628 & 0 & 0 \\
\hline Purchased Power.................................................... & 8,656 & $\mathbf{7 , 4 1 1}$ & 7,341 & 5,725 & 6,137 & 2,357 \\
\hline 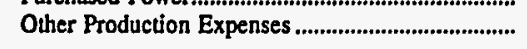 & 0 & 568 & 0 & 0 & 0 & 0 \\
\hline Total Production Expenses.................................... & 8,656 & 14,041 & $\mathbf{7 , 3 4 1}$ & 8,353 & 12,009 & 2,357 \\
\hline 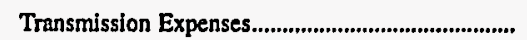 & 0 & 1,672 & 34 & 21 & 131 & 9 \\
\hline 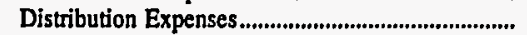 & 247 & 1,206 & 1,305 & 556 & 1,156 & 544 \\
\hline 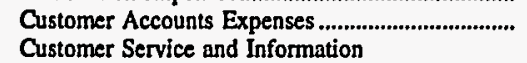 & 230 & 462 & 361 & 571 & 613 & 202 \\
\hline 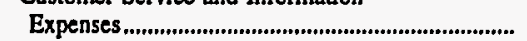 & 0 & 0 & 0 & 0 & 0 & 0 \\
\hline 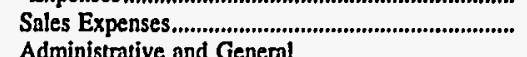 & 0 & 0 & 0 & 5 & -41 & 6 \\
\hline 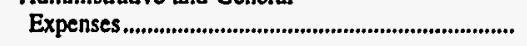 & 2,492 & 674 & 945 & 2,766 & 2,084 & 448 \\
\hline 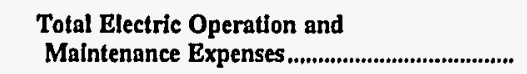 & 11,624 & 18,054 & 9,986 & 12,272 & 15,953 & 3,566 \\
\hline
\end{tabular}

Fuel Expenses In Operation

Steam Power Generation...

Nuclear Power Generation ............................................

Other Power Generation ................................................

$\begin{array}{rr}0 & 4,034 \\ 0 & 0 \\ 0 & 0\end{array}$

0

0

0

0

$0 \quad 890$

$\begin{array}{ll}0 & 0 \\ 0 & 0 \\ 0 & 0\end{array}$

Number of Elec Dept Employees

Regular Full-time..........................................................

Total Elec Dept Employees

\begin{tabular}{rrrrrr}
21 & 24 & 35 & 54 & 96 & 18 \\
0 & 0 & 4 & 1 & 0 & 0 \\
21 & 24 & 39 & 55 & 96 & 18 \\
\hline
\end{tabular}

Note: Totals may not equal sum of components because of independent rounding.

Source: Energy Information Administration, Form EIA-412, "Annual Report of Public Electric Utilities." 
Table 23. Electric Operation and Maintenance Expenses by Major U.S. Publicly Owned Electric Utility Within State, 1996 (Continued)

(Thousand Dollars)

\begin{tabular}{|c|c|c|c|c|c|c|}
\hline Item & $\begin{array}{c}\text { New York } \\
\text { Massena } \\
\text { Town of } \\
\text { December } 31\end{array}$ & $\begin{array}{c}\text { New York } \\
\text { Plattsburgh } \\
\text { City of } \\
\text { December } 31\end{array}$ & $\begin{array}{c}\text { New York } \\
\text { Power } \\
\text { Authority } \\
\text { of State of NY } \\
\text { December } 31\end{array}$ & $\begin{array}{c}\text { New York } \\
\text { Rockville } \\
\text { Centre } \\
\text { Village of } \\
\text { May } 31\end{array}$ & $\begin{array}{c}\text { New York } \\
\text { Solvay } \\
\text { Village of } \\
\text { May } 31\end{array}$ & $\begin{array}{l}\text { North Carolina } \\
\begin{array}{c}\text { Albemarle } \\
\text { City of }\end{array} \\
\text { June } 30\end{array}$ \\
\hline \multicolumn{7}{|l|}{ Production Expenses } \\
\hline Steam Power Generation & 0 & 0 & 0 & 0 & 0 & 0 \\
\hline Nuclear Power Generation .............................................. & 0 & 0 & 0 & 0 & 0 & 0 \\
\hline 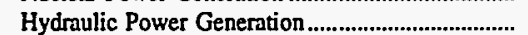 & 0 & 0 & 0 & 0 & 0 & 0 \\
\hline 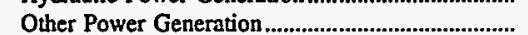 & 0 & 0 & 0 & 1,888 & 0 & 0 \\
\hline Purchased Power & 2,306 & 5,691 & 884,440 & 4,084 & 3,247 & 17,129 \\
\hline 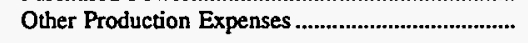 & 0 & 0 & 0 & 0 & 0 & 0 \\
\hline 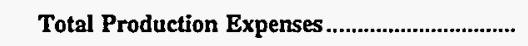 & 2,306 & 5,692 & 884,440 & 5,972 & 3,247 & 17,129 \\
\hline 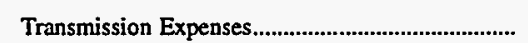 & 18 & 474 & 144,628 & 100 & 0 & 0 \\
\hline 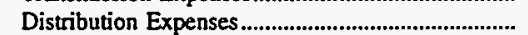 & 437 & 1,186 & 0 & 846 & 699 & 1,430 \\
\hline 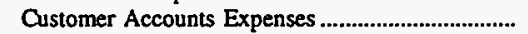 & 209 & 218 & 0 & 342 & 117 & 0 \\
\hline Customer Service and Information & & & & & & \\
\hline 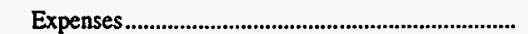 & 0 & 217 & 0 & 0 & 0 & $\mathbf{0}$ \\
\hline 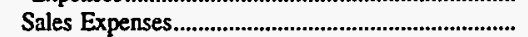 & 0 & -20 & 0 & 0 & 1 & 0 \\
\hline Administrative and General & & & & & & \\
\hline 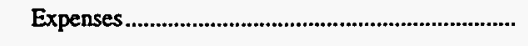 & 852 & 855 & 0 & 1,723 & 817 & 485 \\
\hline 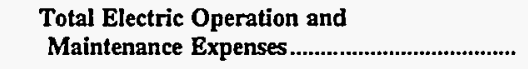 & 3,821 & 8,621 & $1,029,068$ & 8,983 & 4,881 & 19,044 \\
\hline \multicolumn{7}{|l|}{ Fuel Expenses in Operation } \\
\hline 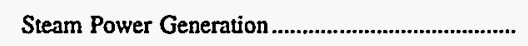 & 0 & 0 & 0 & 0 & 0 & 0 \\
\hline 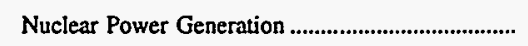 & 0 & 0 & 0 & 0 & 0 & 0 \\
\hline Other Power Generation & 0 & 0 & 0 & $\mathbf{0}$ & 0 & 0 \\
\hline \multicolumn{7}{|l|}{ Number of Elec Dept Employees } \\
\hline 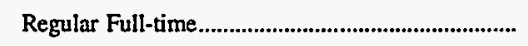 & 22 & 33 & 1,300 & 44 & 23 & 33 \\
\hline 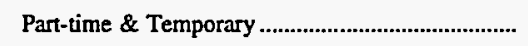 & 0 & 0 & 0 & 4 & 0 & 1 \\
\hline Total Elec Dept Employees & 22 & 33 & 1,300 & 48 & 23 & 34 \\
\hline
\end{tabular}

Note: Totals may not equal sum of components because of independent rounding

Source: Energy Information Administration, Form EIA-412, "Annual Report of Public Electric Utilities." 
Table 23. Electric Operation and Maintenance Expenses by Major U.S. Publicly Owned Electric Utility Within State, 1996 (Continued)

(Thousand Dollars)

\begin{tabular}{c|c|c|c|c|c|c}
\hline & North Carolina & North Carolina & North Carolina & North Carolina & North Carolina & North Carolina \\
Item & $\begin{array}{c}\text { Concord } \\
\text { City of }\end{array}$ & $\begin{array}{c}\text { Elizabeth } \\
\text { City City of }\end{array}$ & $\begin{array}{c}\text { Fayetteville } \\
\text { Public } \\
\text { Works Comm }\end{array}$ & $\begin{array}{c}\text { Forest City } \\
\text { Town of }\end{array}$ & $\begin{array}{c}\text { Gastonia } \\
\text { City of } \\
\text { Utilities } \\
\text { Comm }\end{array}$ \\
June 30 & June 30 & June 30 & June 30 & June 30 & June 30 \\
\hline
\end{tabular}

\section{Production Expenses}

Steam Power Generation..

Nuclear Power Generation ......................................

Hydraulic Power Generation.

Oiher Power Generation

Purchased Power..................................................................

Other Production Expenses.

Total Production Expenses.

Transmission Expenses.

Distribution Expenses..............................................

Customer Accounts Expenses .....................................

Customer Service and Information

Expenses........................................................................

Sales Expenses...........................................................

Administrative and General

Expenses.

Total Electric Operation and

Maintenance Expenses.

$\begin{array}{rr}0 & \\ 0 & \\ 0 & \\ 0 & 19,7 \\ 19,104 & \\ 0 & \end{array}$

$19,104 \quad 19,715$

0
3,658
0

$\mathbf{0}$
$\mathbf{0}$

1,583

24,345

22,127
155
0
0
372
75,783
0

76,310

283

4,688

1,422

826
0

5,721

89,251

0
0
0
0
6,145
0

$\begin{array}{rr}0 & 0 \\ 0 & 0 \\ 0 & 0 \\ 0 & 0 \\ 35,501 & 91,565 \\ 0 & 0\end{array}$

6,145

35,501

91,565

0

629
0

0
1,661

0
4,697

4,697
1,307

0

40

$\mathbf{0}$

$$
\begin{aligned}
& \mathbf{0} \\
& \mathbf{0}
\end{aligned}
$$

3,482

6,915

38,871

101,051

Fuel Expenses in Operation

Stcam Power Generation...........................................

Nuclear Power Generation

Other Power Generation.

Number of Elec Dept Employees

Regular Full-time.

Part-time \& Temporary

54

0

54

0

0

0

15

0

15

Total Elec Dept Employees.

$\begin{array}{rr}0 & 0 \\ 0 . & 0 \\ 204 & 0\end{array}$

0

0

0

0

Note: Totals may not equal sum of components because of independent rounding.

Source: Energy Information Administration, Form EIA-412, “Annual Report of Public Electric Utilities." 
Table 23. Electric Operation and Maintenance Expenses by Major U.S. Publicly Owned Electric Utility Within State, 1996 (Continued) (Thousand Dollars)

\begin{tabular}{|c|c|c|c|c|c|c|}
\hline Item & $\begin{array}{c}\text { North Carolina } \\
\text { High } \\
\text { Point } \\
\text { Town } \\
\text { of } \\
\text { June } 30\end{array}$ & $\begin{array}{l}\text { North Carolina } \\
\text { Kinston } \\
\text { City of } \\
\text { June } 30\end{array}$ & $\begin{array}{l}\text { North Carolina } \\
\text { Lexington } \\
\text { City of } \\
\text { June } 30\end{array}$ & $\begin{array}{l}\text { North Carolina } \\
\text { Lumberton } \\
\text { City of } \\
\text { June } 30\end{array}$ & $\begin{array}{l}\text { North Carolina } \\
\text { Monroe } \\
\text { City of } \\
\text { June } 30\end{array}$ & $\begin{array}{l}\text { North Carolina } \\
\text { Morganton } \\
\text { City of } \\
\text { June } 30\end{array}$ \\
\hline
\end{tabular}

Production Expenses

Steam Power Generation.

Nuclear Power Generation.

Hydraulic Power Generation

Other Power Generation

Purchased Power

Other Production Expenses

Total Production Expenses..

Transmission Expenses.

Distribution Expenses.

Customer Accounts Expenses .................................

Customer Service and Information

Expenses.

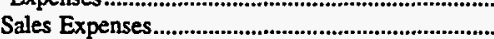

Administrative and General

Expenses.

Total Electric Operation and

Maintenance Expenses.

Fuel Expenses in Operation

Steam Power Generation .........................................

Nuclear Power Generation .

Other Power Generation

Number of Elec Dept Employees

Regular Full-time

Part-time \& Temporary

Total Elec Dept Employees

0
0
0
0
53,062

53,062
739

53,801

4,499

1,495

783

704
0

472

61,756
0
0
0
0
28,665
0

28,665

2,424

1,414

0

0

1,046

33,549
0
0
0
0

29,123

9,123
0

29,123

3,843

0

0

0

0

32,966

22,207

779

867

194

0

625

$\begin{array}{rr}0 & 0 \\ 0 & 0 \\ 0 & 0 \\ 0 & 0 \\ 23,239 & 16,256 \\ 0 & 0\end{array}$

23,239

16,256

0
1,556

349

0

128

25,278

Note: Totals may not equal sum of components because of independent rounding.

Source: Energy Information Administration, Form EIA-412, "Annual Report of Public Electric Utilities." 
Table 23. Electric Operation and Maintenance Expenses by Major U.S. Publicly Owned Electric Utility Within State, 1996 (Continued)

(Thousand Dollars)

\begin{tabular}{|c|c|c|c|c|c|c|}
\hline Item & $\begin{array}{l}\text { North Carolina } \\
\text { Murphy } \\
\text { City of } \\
\text { June } 30\end{array}$ & $\begin{array}{l}\text { North Carolina } \\
\text { New Bern } \\
\text { City of } \\
\text { June } 30\end{array}$ & $\begin{array}{c}\text { North Carolina } \\
\text { New River } \\
\text { Light } \\
\& \\
\text { Power Co } \\
\text { December } 31\end{array}$ & $\begin{array}{c}\text { North Carolina } \\
\text { North } \\
\text { Carolina } \\
\text { Eastern M P A } \\
\text { December } 31\end{array}$ & $\begin{array}{c}\text { North Carolina } \\
\text { North } \\
\text { Carolina } \\
\text { Mun } \\
\text { Power Agny } \\
\text { December } 31\end{array}$ & $\begin{array}{l}\text { North Carolina } \\
\text { Rocky Mount } \\
\text { City of } \\
\text { June } 30\end{array}$ \\
\hline Production Expenses & & & & & & \\
\hline Steam Power Generation .................................................. & $\mathbf{0}$ & $\mathbf{0}$ & 0 & 23,392 & $\mathbf{0}$ & $\mathbf{0}$ \\
\hline Nuclear Power Generation ............................................... & $\mathbf{0}$ & 0 & 0 & 51,026 & 87,378 & o \\
\hline 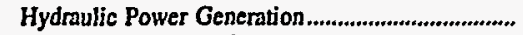 & 0 & $\mathbf{0}$ & 0 & $\mathbf{0}$ & 0 & $\mathbf{0}$ \\
\hline 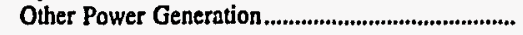 & $\mathbf{0}$ & $\mathbf{0}$ & 0 & $\mathbf{0}$ & $\mathbf{0}$ & 0 \\
\hline 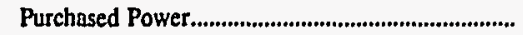 & 5,686 & 29,717 & 9,012 & 115,028 & 59,745 & 54,787 \\
\hline 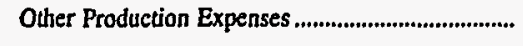 & 0 & 356 & 0 & 4,244 & 16,079 & 0 \\
\hline 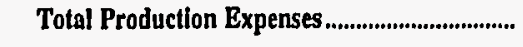 & 5,686 & 30,072 & 9,012 & 193,690 & 163,202 & 54,787 \\
\hline 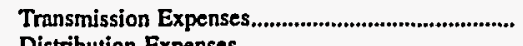 & 0 & 0 & 0 & 13,812 & 10,349 & 0 \\
\hline 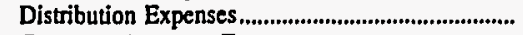 & 348 & 839 & 560 & 2,475 & 2,046 & 4,584 \\
\hline $\begin{array}{l}\text { Customer Accounts Expenses .................................... } \\
\text { Customer Service and Information }\end{array}$ & 123 & 104 & 344 & 0 & 0 & 0 \\
\hline 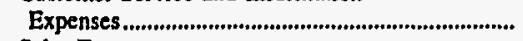 & 10 & $\mathbf{0}$ & 23 & 0 & 0 & 0 \\
\hline 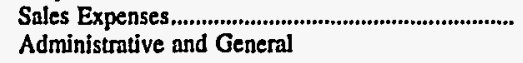 & 9 & $\mathbf{0}$ & $\mathbf{0}$ & $\mathbf{0}$ & $\mathbf{0}$ & 0 \\
\hline 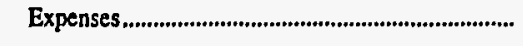 & 459 & 3,850 & 340 & 28,601 & 28,629 & 641 \\
\hline $\begin{array}{l}\text { Total Electric Operation and } \\
\text { Maintenance Expenses.......................................... }\end{array}$ & 6,634 & 34,865 & 10,280 & 238,578 & 204,226 & 60,011 \\
\hline \multicolumn{7}{|l|}{ Fuel Expenses in Operation } \\
\hline 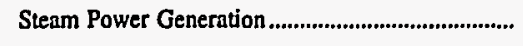 & $\mathbf{0}$ & $\mathbf{0}$ & $\mathbf{0}$ & 19,790 & $\mathbf{0}$ & 0 \\
\hline Nuclear Power Generation ............................................. & $\mathbf{0}$ & $\mathbf{0}$ & o & 14,698 & 29,763 & 0 \\
\hline 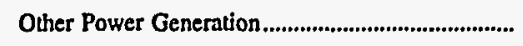 & o & $\mathbf{0}$ & $\mathbf{0}$ & 0 & $\mathbf{0}$ & 0 \\
\hline \multicolumn{7}{|l|}{ Number of Elec Dept Employees } \\
\hline 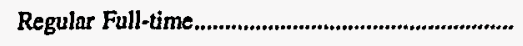 & 3 & 58 & 27 & 90 & 0 & 49 \\
\hline Part-time \& Temporary & 0 & $\mathbf{0}$ & 1 & 0 & $\mathbf{0}$ & $\mathbf{0}$ \\
\hline 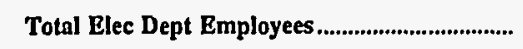 & 3 & 58 & 28 & 90 & $\mathbf{0}$ & 49 \\
\hline
\end{tabular}

Note: Totals may not equal sum of components because of independent rounding.

Source: Energy Information Administration, Form EIA-412, "Annual Report of Public Electric Utilities." 
Table 23. Electric Operation and Maintenance Expenses by Major U.S. Publicly Owned Electric Utility Within State, 1996 (Continued)

(Thousand Dollars)

\begin{tabular}{|c|c|c|c|c|c|c|}
\hline Item & $\begin{array}{l}\text { North Carolina } \\
\text { Shelby } \\
\text { City of } \\
\text { June } 30\end{array}$ & $\begin{array}{l}\text { North Carolina } \\
\text { Statesville } \\
\text { City of } \\
\text { June } 30\end{array}$ & $\begin{array}{l}\text { North Carolina } \\
\text { Tarboro } \\
\text { Town of } \\
\text { June } 30\end{array}$ & $\begin{array}{l}\text { North Carolina } \\
\begin{array}{c}\text { Washington } \\
\text { City of }\end{array} \\
\text { June } 30\end{array}$ & $\begin{array}{l}\text { North Carolina } \\
\text { Wilson } \\
\text { City of } \\
\text { June } 30\end{array}$ & $\begin{array}{c}\text { Ohio } \\
\text { American } \\
\text { Mun } \\
\text { Power } \\
\text { Ohio Ine } \\
\text { December } 31\end{array}$ \\
\hline \multicolumn{7}{|l|}{ Production Expenses } \\
\hline 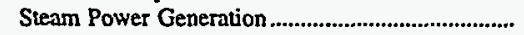 & 0 & 0 & 0 & 0 & 0 & 18,041 \\
\hline 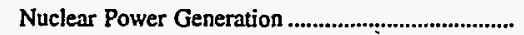 & 0 & 0 & 0 & 0 & 0 & 0 \\
\hline 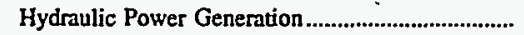 & 0 & 0 & 0 & 0 & 0 & 0 \\
\hline 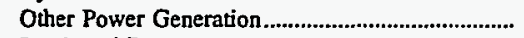 & 0 & 0 & 0 & 0 & 0 & 0 \\
\hline Purchased Power......................................................... & 10,406 & 22,739 & 18,257 & 17,521 & 74,036 & 122,270 \\
\hline Other Production Expenses ........................................... & 0 & 0 & 0 & 0 & 0 & 0 \\
\hline Total Production Expenses....................................... & 10,406 & 22,739 & 18,257 & 17,521 & 74,036 & 140,311 \\
\hline 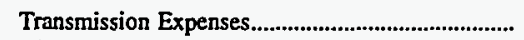 & $\mathbf{0}$ & 0 & 0 & 0 & 0 & 0 \\
\hline 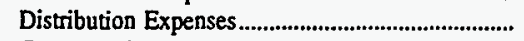 & 589 & 0 & 0 & 1,428 & 2,423 & 181 \\
\hline Customer Accounts Expenses ...................................... & 0 & 0 & 0 & 400 & 2,627 & 0 \\
\hline Customer Service and Information & & & & & & \\
\hline Expenses...................................................................... & 0 & 0 & 0 & 162 & 0 & 0 \\
\hline 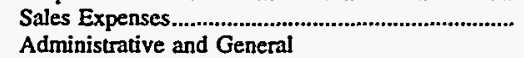 & 0 & 0 & 0 & 0 & 4 & 0 \\
\hline 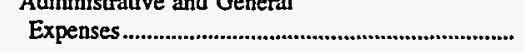 & 425 & 3,084 & 1,537 & 2,776 & 1,527 & 6,509 \\
\hline $\begin{array}{l}\text { Total Electric Operation and } \\
\text { Maintenance Expenses............ }\end{array}$ & 11,420 & 25,823 & 19,794 & 22,288 & 80,618 & 147,001 \\
\hline \multicolumn{7}{|l|}{ Fuel Expenses in Operation } \\
\hline 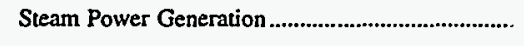 & 0 & $\mathbf{0}$ & 0 & 0 & 0 & 6,774 \\
\hline 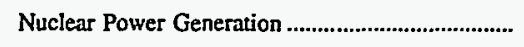 & 0 & 0 & 0 & 0 & 0 & 0 \\
\hline Other Power Generation & 0 & $\mathbf{0}$ & 0 & 0 & 0 & $\mathbf{0}$ \\
\hline \multicolumn{7}{|l|}{ Number of Elec Dept Employees } \\
\hline Regular Full-time & 13 & 24 & 21 & 43 & 70 & 108 \\
\hline 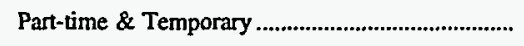 & 0 & 0 & 0 & 2 & 0 & $\mathbf{0}$ \\
\hline 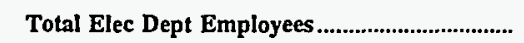 & 13 & 24 & 21 & 45 & 70 & 108 \\
\hline
\end{tabular}

Note: Totals may not equal sum of components because of independent rounding.

Source: Energy Information Administration, Form EIA-412, "Annual Report of Public Electric Utilities." 
Table 23. Electric Operation and Maintenance Expenses by Major U.S. Publicly Owned Electric Utility Within State, 1996 (Continued)

(Thousand Dollars)

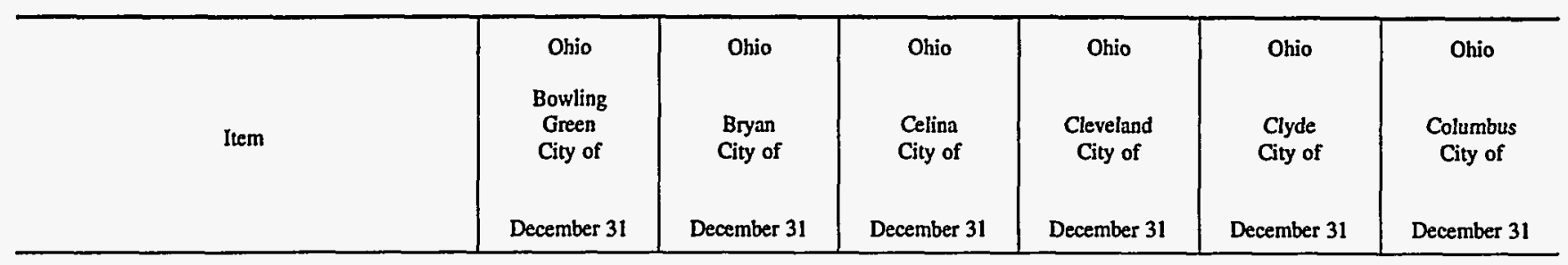

Production Expenses

Steam Power Generation.............................................

Nuclear Power Generation

Hydraulic Power Generation......................................

Other Power Generation..

Purchased Power

Other Production Expenses ...........................................

Total Production Expenses.

Transmission Expenses...

Cxpenses.........................................................

Customer Accounts Expenses

Customer Service and Information

Expenses.

Sales Expenses

Administrative and General

Expenses...

Total Electric Operation and

Maintenance Expenses.

Fuel Expenses in Operation

Steam Power Generation ..................................................

Nuclear Power Generation

Other Power Generation

Number of Elec Dept Employees

ReguJar FulJ-time,

Part-ime \& Temporary .

Total Elec Dept Employees

0
0
0
0
15,131
0

0

0
0

743

7,992

0

15,131

8,735

140
1,359

417

2
1,066

1,192

0

0

32

735

17,815

6,674

0
0
0
674
45,207
1,216

47,097

716

14,093

717

167

0
77

870

1,273

4,517

68,566

Note: Totals may not equal sum of components because of independent rounding.

Source: Energy Information Administration, Form EIA-412, "Annual Report of Public Electric Utilities." 
Table 23. Electric Operation and Maintenance Expenses by Major U.S. Publicly Owned Electric Utility Within State, 1996 (Continued)

(Thousand Dollars)

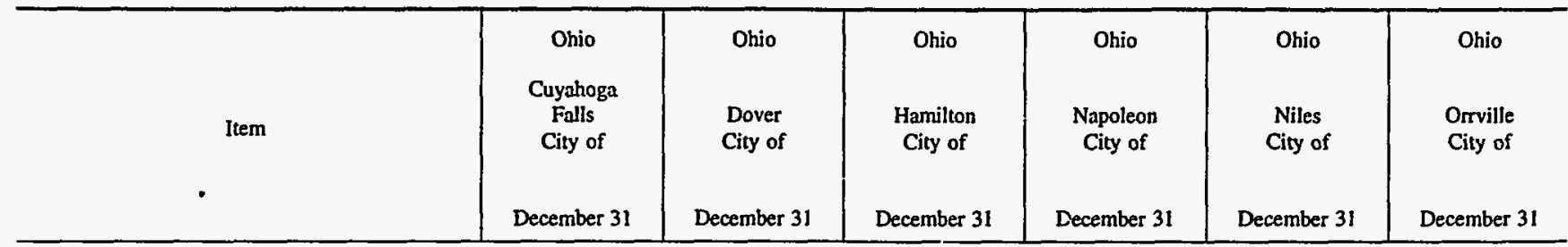

Production Expenses

Steam Power Generation

Nuclear Power Generation ...............................

Hydraulic Power Generation........................................

Other Power Generation.

Purchased Power.

Other Production Expenses.

Total Production Expenses.

0
0
0
0
14,652
0

0
0
0
0
11,414
0

9,929
0

1,070

287

7,847

14,652

11,414

19,776

Transmission Expenses.

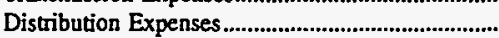

Customer Accounts Expenses

Customer Service and Information

Expenses..

Sales Expenses.

Administrative and General

Expenses.

698

$0 \quad 286$

286
1,506

314

0

2,908

408

246

6,139

Total Electric Operation and

Maintenance Expenses

18,368

28,676

0
0
0
0
7,243
0

0
0

0

0

7,243

15,879

8,037

11,414

28,676

to

0

0

0

1,279

279
0

9,315

Fuel Expenses in Operation

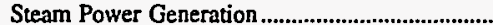

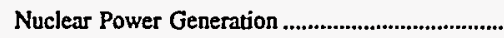

Other Power Generation

$\begin{array}{ll}0 & 0 \\ 0 & 0 \\ 0 & 0\end{array}$

7,134
0
0

0

- 0

0

4,090

0

0

0

0

0
861

861
181

149

63

1,858

Number of Elec Dept Employees

Regular Full-time.

46

38

109

18

43

82

Part-time \& Temporary .

0

0

2

46

38

111

18

3

2

Total Elec Dept Employees..

Note: Totals may not equal sum of components because of independent rounding.

Source: Energy Information Administration, Form EIA-412, "Annual Report of Public Electric Utilities." 
Table 23. Electric Operation and Maintenance Expenses by Major U.S. Publicly Owned Electric Utility Within State, 1996 (Continued)

(Thousand Dollars)

\begin{tabular}{c|c|c|c|c|c|c}
\hline & Ohio & Ohio & Ohio & Ohio & Ohio & Ohio \\
Item & $\begin{array}{c}\text { Painesville } \\
\text { City of }\end{array}$ & $\begin{array}{c}\text { Piqua } \\
\text { City of } \\
\text { December 31 }\end{array}$ & $\begin{array}{c}\text { St Marys } \\
\text { City of } \\
\text { December 31 }\end{array}$ & $\begin{array}{c}\text { Wadsworth } \\
\text { City of }\end{array}$ & $\begin{array}{c}\text { Wapakoneta } \\
\text { City of }\end{array}$ & $\begin{array}{c}\text { Westerville } \\
\text { City of }\end{array}$ \\
December 31 & December 31 & December 31 & December 31 \\
\hline
\end{tabular}

\section{Production Expenses}

Steam Power Generation...

Nuclear Power Generatic

Hydraulic Power Generation.

Other Power Generntion ............................................

Purchased Power............................................................

Other Production Expenses

Total Production Expenses

Transmission Expenses..

Distribution Expenses.

Customer Accounts Expenses ...................................

Customer Service and Information

Expenses...........

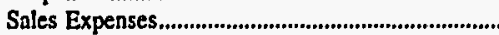

Administrative and General

Expenses.

Total Electric Operation and

Maintenance Expenses.

Fuel Expenses in Operation

Steam Power Generation

Nuclear Power Generation ....................................

Other Power Generation.

Number of Elec Dept Employees

Regular Full-time.......................................................

Part-time \& Temporary.

Total Elec Dept Employees

Note: Totals may not equal sum of components because of independent rounding.

Source: Energy Information Administration, Form EIA-412, "Annual Report of Public Electric Utilities."

0

1,211

0

0

\begin{tabular}{|c|c|c|c|c|c|}
\hline 4,716 & 2,491 & 1,892 & 0 & 0 & 0 \\
\hline 0 & 0 & 0 & 0 & 0 & 0 \\
\hline 0 & 0 & 0 & 0 & 0 & 0 \\
\hline 0 & 0 & 0 & 0 & 0 & 0 \\
\hline 1,954 & 6,438 & 3,699 & 9,653 & 5,095 & 11,767 \\
\hline 5,018 & 0 & 0 & 0 & 0 & 0 \\
\hline 11,688 & 8,929 & 5,591 & 9,653 & 5,095 & 11,767 \\
\hline 0 & 67 & 0 & 0 & 0 & 0 \\
\hline 0 & 646 & 776 & 2,350 & 1,828 & 1,139 \\
\hline 0 & 296 & 184 & 227 & 81 & 0 \\
\hline 0 & 0 & 0 & 375 & 0 & 0 \\
\hline 0 & 387 & 0 & 0 & 0 & 0 \\
\hline 0 & 1,381 & 19 & 634 & 85 & 626 \\
\hline 11,688 & 11,706 & 6,571 & 13,239 & 7,090 & 13,532 \\
\hline
\end{tabular}

879

0

$\mathbf{0}$

0

0

0

0

o

\begin{tabular}{rrrrrr}
63 & 57 & 23 & 41 & 11 & 34 \\
0 & 0 & 0 & 1 & 3 & 0 \\
63 & 57 & 23 & 42 & 14 & 34 \\
\hline
\end{tabular}


Table 23. Electric Operation and Maintenance Expenses by Major U.S. Publicly Owned Electric Utility Within State, 1996 (Continued)

(Thousand Dollars)

\begin{tabular}{|c|c|c|c|c|c|c|}
\hline Item & $\begin{array}{l}\text { Oklahoma } \\
\text { Altus } \\
\text { City of } \\
\text { June } 30\end{array}$ & $\begin{array}{l}\text { Oklahoma } \\
\text { Claremore } \\
\text { City of } \\
\text { June } 30\end{array}$ & $\begin{array}{l}\text { Oklahoma } \\
\text { Duncan } \\
\text { City of } \\
\text { June } 30\end{array}$ & $\begin{array}{l}\text { Oklahoma } \\
\text { Edmond } \\
\text { City of } \\
\text { June } 30\end{array}$ & $\begin{array}{l}\text { Oklahoma } \\
\text { Grand River } \\
\text { Dam } \\
\text { Authority } \\
\text { December } 31\end{array}$ & $\begin{array}{l}\text { Oklahoma } \\
\text { Miami } \\
\text { City of } \\
\text { June } 30\end{array}$ \\
\hline \multicolumn{7}{|l|}{ Production Expenses } \\
\hline Steam Power Generation & 0 & $\mathbf{0}$ & 0 & $\mathbf{0}$ & 57,166 & 0 \\
\hline Nuclear Power Generation ......................................... & 0 & 0 & 0 & 0 & 0 & 0 \\
\hline 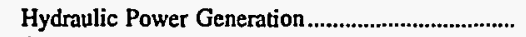 & 0 & 0 & 0 & 0 & 4,995 & 0 \\
\hline 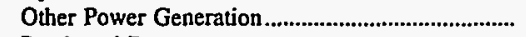 & 0 & 0 & 0 & 0 & 0 & 0 \\
\hline 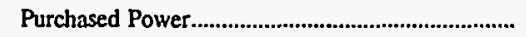 & 7,490 & 8,195 & 5,002 & 23,853 & 13,884 & 5,338 \\
\hline 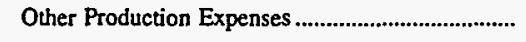 & 0 & 0 & 0 & 0 & 0 & 0 \\
\hline 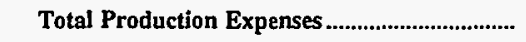 & 7,490 & 8,195 & 5,002 & 23,853 & 76,044 & 5,338 \\
\hline 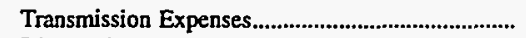 & $\mathbf{0}$ & 0 & 0 & $\mathbf{0}$ & 6,290 & 0 \\
\hline 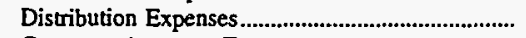 & 813 & 1,184 & 1,129 & 1,971 & 0 & 549 \\
\hline $\begin{array}{l}\text { Customer Accounts Expenses ......................................... } \\
\text { Customer Service and Information }\end{array}$ & 197 & 367 & 0 & 300 & 156 & 56 \\
\hline 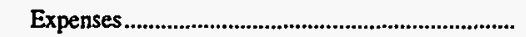 & 172 & 0 & 0 & 405 & 98 & 43 \\
\hline 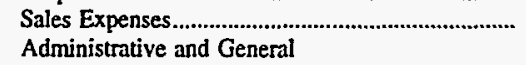 & 0 & 0 & 0 & 0 & 0 & 0 \\
\hline 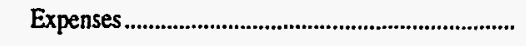 & 218 & 0 & 0 & 539 & 10,629 & 229 \\
\hline 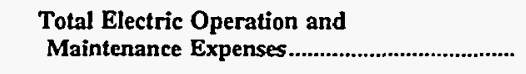 & 8,891 & 9,746 & 6,131 & 27,068 & 93,217 & 6,216 \\
\hline \multicolumn{7}{|l|}{ Fuel Expenses in Operation } \\
\hline 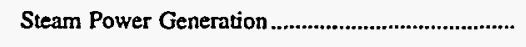 & 0 & 0 & 0 & 0 & 46,109 & 0 \\
\hline 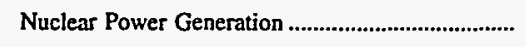 & 0 & 0 & 0 & 0 & 0 & 0 \\
\hline 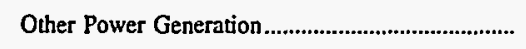 & 0 & 0 & 0 & 0 & 0 & 0 \\
\hline \multicolumn{7}{|l|}{ Number of Elec Dept Employees } \\
\hline Regular Full-time & 18 & 32 & 17 & 38 & 450 & 15 \\
\hline 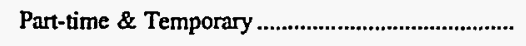 & 0 & 1 & 0 & 0 & 7 & $\mathbf{0}$ \\
\hline 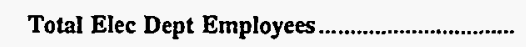 & 18 & 33 & 17 & 38 & 457 & 15 \\
\hline
\end{tabular}

Note: Totals may not equal sum of components because of independent rounding.

Source: Energy Information Administration, Form EIA-412, "Annual Report of Public Electric Utilities." 
Table 23. Electric Operation and Maintenance Expenses by Major U.S. Publicly Owned Electric Utility Within State, 1996 (Continued)

(Thousand Dollars)

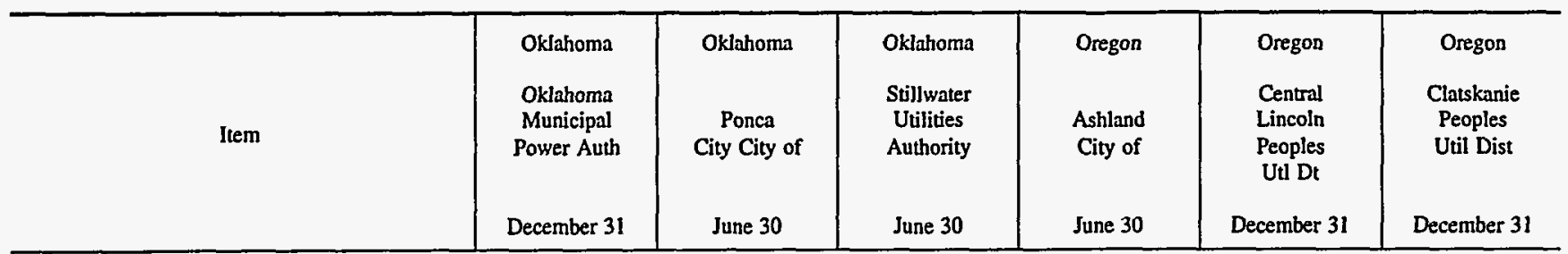

Production Expenses

Steam Power Generation..

Hydraulic Power Generation....................................

Other Power Generation.

- Purchased Power...........................................................

Other Production Expenses

Total Production Expenses..

Transmission Expenses.

Distribution Expenses

Customer Accounts Expenses ..................................

Customer Service and Information

Expenses

Sales Expenses,.........................................................

Administrative and General

Expenses

Total Electric Operation and

Maintenance Expenses.

Fuel Expenses in Operation

Steam Power Generation ..........................................

Nuclear Power Generation..

Other Power Generation.

Number of Elec Dept Employees

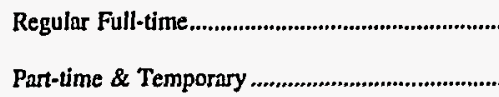

Total Elec Dept Employees.

$\begin{array}{rr}14,164 & 6 \\ 0 & \\ 308 & \\ 1,879 & 5 \\ 31,039 & 13,909 \\ 0 & \end{array}$

47,390

8,478

0
0

0

2,229

$\mathbf{5 8 , 0 9 8}$

17,907

17,532

0
0
0
0
4,524
0

0
0

0

36,439

0

4,524

36,439

0
1,934

0
2.751

1,208

301

3,004

43,703

25,361

$\begin{array}{rrrrrr}11,722 & 0 & 1,076 & 0 & 0 & 0 \\ 0 & 0 & 0 & 0 & 0 & 0 \\ 1,102 & 0 & 0 & 0 & 0 & 0\end{array}$

29

29

66

15

143

21

0

0

8

0

13

o

29

29

74

15

156

Note: Totals may not equal sum of components because of independent rounding.

Source: Energy Information Administration, Form EIA-412, "Annual Report of Public Electric Utilities." 
Table 23. Electric Operation and Maintenance Expenses by Major U.S. Publicly Owned Electric Utility Within State, 1996 (Continued)

(Thousand Dollars)

\begin{tabular}{|c|c|c|c|c|c|c|}
\hline Item & $\begin{array}{c}\text { Oregon } \\
\text { Columbia } \\
\text { River } \\
\text { Peoples } \\
\text { Ut Dist } \\
\text { December } 31\end{array}$ & $\begin{array}{l}\text { Oregon } \\
\text { Emerald } \\
\text { Peoples } \\
\text { Utility Dist } \\
\text { December } 31\end{array}$ & $\begin{array}{l}\text { Oregon } \\
\text { Eugene } \\
\text { City of } \\
\text { December } 31\end{array}$ & $\begin{array}{l}\text { Oregon } \\
\text { Forest Grove } \\
\text { City of } \\
\text { June } 30\end{array}$ & $\begin{array}{l}\text { Oregon } \\
\begin{array}{l}\text { McMinnville } \\
\text { City of }\end{array} \\
\text { June } 30\end{array}$ & $\begin{array}{c}\text { Oregon } \\
\text { Northern } \\
\text { Wasco } \\
\text { County PUD } \\
\text { December } 31\end{array}$ \\
\hline \multicolumn{7}{|l|}{ Production Expenses } \\
\hline 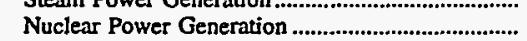 & 0 & 0 & $\begin{array}{r}1,4 / 0 \\
0\end{array}$ & 0 & 0 & 0 \\
\hline 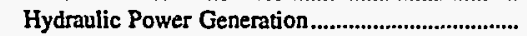 & 0 & 0 & 3,092 & 0 & 0 & 190 \\
\hline 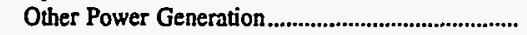 & 0 & 200 & 1,724 & 0 & 0 & 0 \\
\hline Purchased Power............................................................... & 7,442 & 9,908 & 40,627 & 5,715 & 19,237 & 7.739 \\
\hline 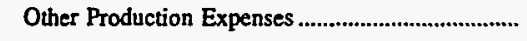 & 0 & 0 & 2,473 & 0 & 0 & 0 \\
\hline 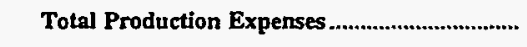 & $\mathbf{7 , 4 4 2}$ & 10,108 & 49,392 & 5,715 & 19,237 & 7,929 \\
\hline 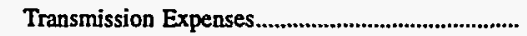 & 0 & 1 & 2,936 & 0 & 0 & 165 \\
\hline Distribution Expenses........................................................ & 999 & 2,011 & 7,553 & 489 & 1,144 & 658 \\
\hline $\begin{array}{l}\text { Customer Accounts Expenses ...................................... } \\
\text { Customer Service and Information }\end{array}$ & 346 & 675 & 3,673 & 44 & 187 & 216 \\
\hline 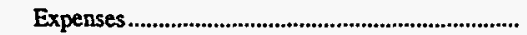 & 0 & 73 & 1,134 & 0 & 0 & 279 \\
\hline 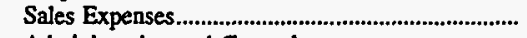 & 376 & 0 & 0 & 0 & 0 & 0 \\
\hline Administrative and General & & & & & & \\
\hline 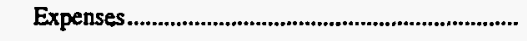 & 1,188 & 1,213 & 11,908 & 1,090 & 907 & 778 \\
\hline $\begin{array}{l}\text { Total Electric Operation and } \\
\text { Maintenance Expenses......................................... }\end{array}$ & 10,350 & 14,082 & 76,596 & 7,337 & 21,475 & 10,026 \\
\hline \multicolumn{7}{|l|}{ Fuel Expenses in Operation } \\
\hline Steam Power Generation .............................................. & 0 & 0 & 0 & 0 & 0 & 0 \\
\hline 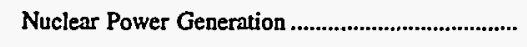 & 0 & 0 & $\mathbf{0}$ & $\mathbf{0}$ & 0 & 0 \\
\hline Other Power Generation & 0 & 13 & 0 & 0 & 0 & 0 \\
\hline \multicolumn{7}{|l|}{ Number of Elec Dept Employees } \\
\hline Regular Full-time & 34 & 65 & 372 & 23 & 29 & 32 \\
\hline Part-time \& Temporary & 0 & 11 & 6 & 0 & 0 & 10 \\
\hline 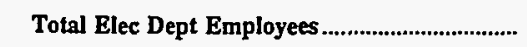 & 34 & 76 & 378 & 23 & 29 & 42 \\
\hline
\end{tabular}

Note: Totals may not equal sum of components because of independent rounding.

Source: Energy Information Administration, Form EIA-412, "Annual Report of Public Electric Utilities." 
Table 23. Electric Operation and Maintenance Expenses by Major U.S. Publicly Owned Electric Utility Within State, 1996 (Continued)

(Thousand Dollars)

\begin{tabular}{|c|c|c|c|c|c|c|}
\hline Item & $\begin{array}{c}\text { Oregon } \\
\text { Springfield } \\
\text { City of }\end{array}$ & $\begin{array}{c}\text { Oregon } \\
\text { Tillamook } \\
\text { Peoples } \\
\text { Utility Dist }\end{array}$ & $\begin{array}{c}\text { Pennsylvania } \\
\text { Chambersburg } \\
\text { Borough of }\end{array}$ & $\begin{array}{c}\text { Pennsylvania } \\
\text { Ephrata } \\
\text { Borough of }\end{array}$ & $\begin{array}{c}\text { Pennsylvania } \\
\text { Lansdale } \\
\text { Borough of }\end{array}$ & South Carolina \\
\hline & December 31 & December 31 & December 31 & December 31 & December 31 & June 30 \\
\hline
\end{tabular}

Production Expenses

Steam Power Generation...

Nuclear Power Generation

Hydraulic Power Generation

Other Power Generation

Purchnsed Power.

Other Production Expenses .......................................

Total Production Expenses...................................

Transmission Expenses...........................................

Distribution Expenses ...............................................

Customer Accounts Expenses ...................................

Customer Service and Information

Expenses..

Sales Expenses..............................................................

Administrative and General

Expenses

Total Electric Operation and

Maintenance Expenses

Fuel Expenses in Operation

Steam Power Generation ........................................

Nuclear Power Generation .

Other Power Generation

Number of Elec Dept Employees

Regular Full-time.

90

Part-time \& Temporary

90

Total Elec Dept Employees

$\begin{array}{rr}0 & \\ 0 & \\ 0 & \\ 0 & \\ 20,257 & \\ 0 & 10,8\end{array}$

20,257

10,926

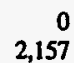

1,222

1,642

607

25,886

16,189

11
0
0
174
10,547
47

10,779

31

529

222

o

539

12,100

0
0
0
0
4,986
0

$\begin{array}{rr}0 & 0 \\ 0 & 0 \\ 0 & 0 \\ 0 & 0 \\ 4,702 & 8,513 \\ 0 & 0\end{array}$

4,986

4,702

8,513

0
1,476

26

705

249

0

1,085

6,766

8,820

9,675

0

0

0

0

0

0

69

12

81
0

$\mathbf{0}$

o
0

$\mathbf{0}$

0
0

0

0

19

0

19 o

0

0

Note: Totals may not equal sum of components because of independent rounding.

Source: Energy Information Administration, Form EIA-412, "Annual Report of Public Electric Utilities."
28

2

30

8

8

12

4

16 
Table 23. Electric Operation and Maintenance Expenses by Major U.S. Publicly Owned Electric Utility Within State, 1996 (Continued)

(Thousand Dollars)

\begin{tabular}{|c|c|c|c|c|c|c|}
\hline Item & $\begin{array}{l}\text { South Carolina } \\
\text { Easley } \\
\text { Combined } \\
\text { Utility } \\
\text { System } \\
\text { March } 31\end{array}$ & $\begin{array}{l}\text { South Carolina } \\
\text { Gaffney } \\
\text { City of } \\
\text { March } 31\end{array}$ & $\begin{array}{l}\text { South Carolina } \\
\text { Greenwood } \\
\text { Commissioners } \\
\text { Pub Wk } \\
\text { December } 31\end{array}$ & $\begin{array}{c}\text { South Carolina } \\
\text { Greer } \\
\text { Comm } \\
\text { of } \\
\text { Public Works } \\
\text { December } 31\end{array}$ & $\begin{array}{l}\text { South Carolina } \\
\text { Newberry } \\
\text { City of } \\
\text { June } 30\end{array}$ & $\begin{array}{l}\text { South Carolina } \\
\text { Orangeburg } \\
\text { City of } \\
\text { September } 30\end{array}$ \\
\hline \multicolumn{7}{|l|}{ Production Expenses } \\
\hline 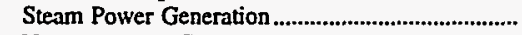 & 0 & 0 & 0 & 0 & 0 & 0 \\
\hline 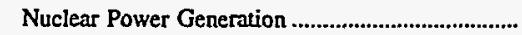 & 0 & 0 & 0 & 0 & 0 & 0 \\
\hline 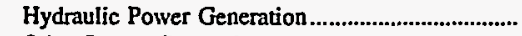 & $\mathbf{0}$ & $\mathbf{0}$ & 0 & $\mathbf{0}$ & 0 & 0 \\
\hline 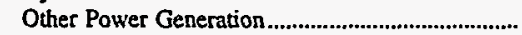 & 0 & 38 & 0 & 0 & 0 & 1,316 \\
\hline Purchased Power.............................................................. & 11,670 & 8,642 & $\$ 1,124$ & 9,994 & 8,404 & 30,581 \\
\hline 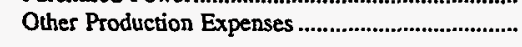 & 0 & 0 & 0 & 0 & 0 & 0 \\
\hline Total Production Expenses & 11,670 & 8,679 & 11,124 & 9,994 & 8,404 & 31,897 \\
\hline 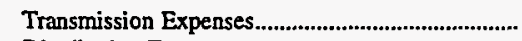 & 0 & 0 & 0 & 274 & 0 & 0 \\
\hline Distribution Expenses........................................................ & 996 & 1,004 & 1,273 & 0 & 434 & 886 \\
\hline $\begin{array}{l}\text { Customer Accounts Expenses................................ } \\
\text { Customer Service and Information }\end{array}$ & 34 & $\mathbf{0}$ & 40 & 231 & 85 & 113 \\
\hline 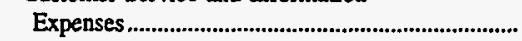 & 0 & 0 & 0 & 0 & 0 & 0 \\
\hline $\begin{array}{l}\text { Sales Expenses.................................................... } \\
\text { Administrative and General }\end{array}$ & 0 & 0 & 0 & 0 & 196 & 0 \\
\hline Expenses & 8 & 1,256 & 812 & 197 & 199 & 2,133 \\
\hline 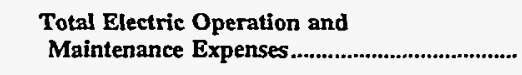 & 12,708 & 10,940 & 13,249 & 10,696 & 9,318 & 35,029 \\
\hline \multicolumn{7}{|l|}{ Fuel Expenses in Operation } \\
\hline 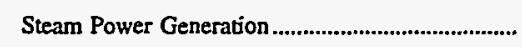 & 0 & 0 & 0 & 0 & 0 & 0 \\
\hline Nuclear Power Generation & 0 & 0 & 0 & 0 & 0 & 0 \\
\hline Other Power Generation & 0 & 0 & 0 & 0 & 0 & 658 \\
\hline \multicolumn{7}{|l|}{ Number of Elec Dept Employees } \\
\hline 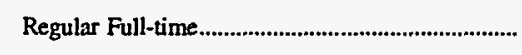 & 21 & 19 & 27 & 24 & 12 & 40 \\
\hline 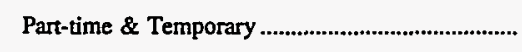 & 0 & 1 & 0 & 0 & 0 & 0 \\
\hline 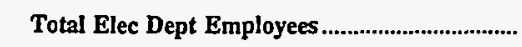 & 21 & 20 & 27 & 24 & 12 & 40 \\
\hline
\end{tabular}

Note: Totals may not equal sum of components because of independent rounding.

Source: Energy Information Administration, Form ElA-412, "Annual Report of Public Electric Utilities." 
Table 23. Electric Operation and Maintenance Expenses by Major U.S. Publicly Owned Electric Utility Within State, 1996 (Continued)

(Thousand Dollars)

\begin{tabular}{|c|c|c|c|c|c|c|}
\hline Item & $\begin{array}{l}\text { South Carolina } \\
\text { Piedmont } \\
\text { Municipal } \\
\text { Power Agny } \\
\text { December } 31\end{array}$ & $\begin{array}{l}\text { South Carolina } \\
\text { Rock Hill } \\
\text { City of }\end{array}$ & $\begin{array}{l}\text { South Carolina } \\
\text { Seneca } \\
\text { City of } \\
\text { June } 30\end{array}$ & $\begin{array}{c}\text { South Carolina } \\
\text { South } \\
\text { Carolina } \\
\text { Pub } \\
\text { Serv Auth } \\
\text { December } 31\end{array}$ & $\begin{array}{l}\text { South Dakota } \\
\text { Brookings } \\
\text { City of } \\
\text { December } 31\end{array}$ & $\begin{array}{l}\text { South Dakota } \\
\text { Heartland } \\
\text { Consumers } \\
\text { Power Dist } \\
\text { December 31 }\end{array}$ \\
\hline \multicolumn{7}{|l|}{ Production Expenses } \\
\hline 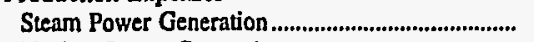 & 0 & 0 & 0 & 257,606 & 0 & 3,714 \\
\hline 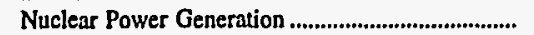 & 30,161 & 0 & 0 & 35,146 & 0 & 0 \\
\hline 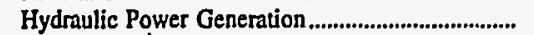 & 0 & 0 & 0 & 4,331 & 0 & 0 \\
\hline Other Power Generation ........................................................ & 0 & $\mathbf{0}$ & 0 & 1,751 & 0 & 0 \\
\hline Purchased Power.............................................................. & 31,650 & 30,431 & 6,746 & 13,327 & 5,415 & 2,100 \\
\hline 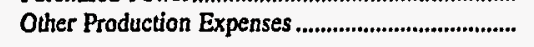 & 0 & 0 & 0 & 955 & 45 & 36 \\
\hline 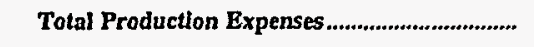 & 61,811 & 30,431 & 6,746 & 313,117 & 5,459 & 5,850 \\
\hline 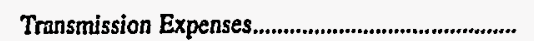 & 3,856 & 0 & $\mathbf{0}$ & 10,131 & 88 & 1,359 \\
\hline 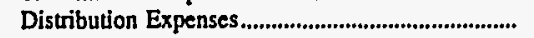 & 1,684 & 3,129 & 311 & 6,271 & 833 & 0 \\
\hline $\begin{array}{l}\text { Customer Accounts Expenses ......................................... } \\
\text { Customer Service and Information }\end{array}$ & 9 & 0 & 0 & 2,924 & 142 & 0 \\
\hline 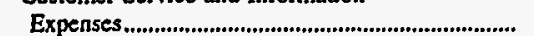 & 0 & 0 & 0 & 882 & 0 & $\mathbf{0}$ \\
\hline 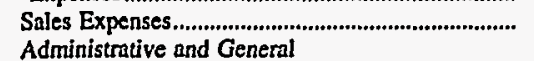 & 0 & 0 & $\mathbf{0}$ & 1,560 & 0 & 0 \\
\hline 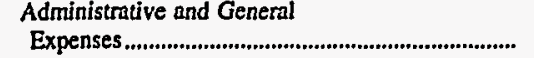 & 12,284 & 1,051 & $\mathbf{0}$ & 64,292 & 480 & 995 \\
\hline 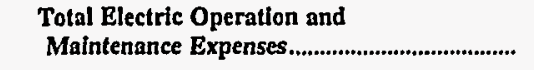 & 79,644 & 34,612 & 7,057 & 399,176 & 7,003 & 8,203 \\
\hline \multicolumn{7}{|l|}{ Fuel Expenses in Operation } \\
\hline 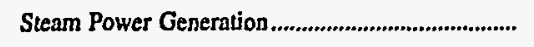 & 0 & $\mathbf{0}$ & 0 & 214,256 & 0 & 2,456 \\
\hline Nuclear Power Generation ............................................. & 7,362 & $\mathbf{0}$ & 0 & $\mathbf{1 1 , 7 3 5}$ & 0 & 0 \\
\hline 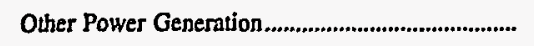 & 0 & 0 & 0 & 366 & 0 & $\mathbf{0}$ \\
\hline \multicolumn{7}{|l|}{ Number of Elec Dept Employees } \\
\hline 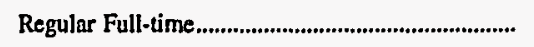 & 13 & 29 & 7 & 1,742 & 25 & 7 \\
\hline 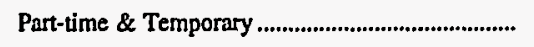 & 0 & 0 & 0 & 17 & 4 & 1 \\
\hline 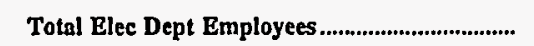 & 13 & 29 & 7 & 1,759 & 29 & 8 \\
\hline
\end{tabular}

Note: Totals may not equal sum of components because of independent rounding.

Source: Energy Information Administration, Form EIA-412, "Annual Report of Public Electric Utilities." 
Table 23. Electric Operation and Maintenance Expenses by Major U.S. Publicly Owned Electric Utility Within State, 1996 (Continued) (Thousand Dollars)

\begin{tabular}{|c|c|c|c|c|c|c|}
\hline Item & $\begin{array}{l}\text { South Dakota } \\
\text { Missouri } \\
\text { Basin } \\
\text { Mun } \\
\text { Power Agny } \\
\text { December } 31\end{array}$ & $\begin{array}{c}\text { South Dakota } \\
\text { Pierre } \\
\text { City of } \\
\text { December } 31\end{array}$ & $\begin{array}{l}\text { South Dakota } \\
\text { Watertown } \\
\text { Municipal } \\
\text { Utilities } \\
\text { December } 31\end{array}$ & $\begin{array}{c}\text { Tennessee } \\
\text { Alcoa } \\
\text { Utilities } \\
\text { June } 30\end{array}$ & $\begin{array}{l}\text { Tennessee } \\
\text { Athens } \\
\text { Utility } \\
\text { Board } \\
\\
\text { June } 30\end{array}$ & $\begin{array}{l}\text { Tennessee } \\
\text { Benton } \\
\text { County } \\
\text { June } 30\end{array}$ \\
\hline \multicolumn{7}{|l|}{ Production Expenses } \\
\hline 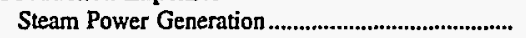 & 0 & 0 & 0 & 0 & 0 & 0 \\
\hline Nuclear Power Generation .......................................... & 0 & 0 & 0 & 0 & 0 & 0 \\
\hline 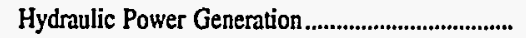 & 0 & 0 & 0 & 0 & 0 & 0 \\
\hline 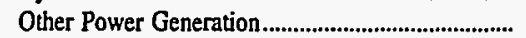 & 0 & 0 & 0 & 0 & 0 & 0 \\
\hline 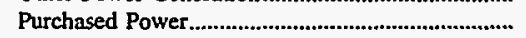 & 45,265 & 4,306 & 7,035 & 22,454 & 22,862 & 10,091 \\
\hline Other Production Expenses ........................................... & 81 & 0 & 20 & 0 & 0 & 0 \\
\hline 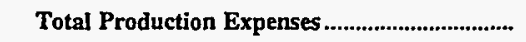 & 45,346 & 4,306 & 7,055 & 22,454 & 22,862 & 10,091 \\
\hline Transmission Expenses................................................. & 11,273 & 0 & 0 & 155 & 59 & 0 \\
\hline 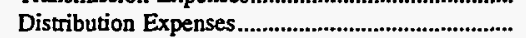 & 0 & 1,059 & 867 & 1,466 & 1,731 & 1,042 \\
\hline $\begin{array}{l}\text { Customer Accounts Expenses } \\
\text { Customer Service and Information }\end{array}$ & 3 & 0 & 325 & 593 & 350 & 368 \\
\hline 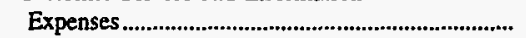 & 0 & 0 & 0 & 1 & 0 & 7 \\
\hline 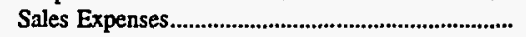 & 0 & 0 & 49 & 35 & 39 & 21 \\
\hline \multicolumn{7}{|l|}{ Administrative and General } \\
\hline 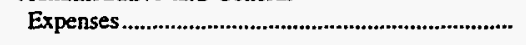 & 2,408 & 0 & 312 & 983 & 687 & 498 \\
\hline 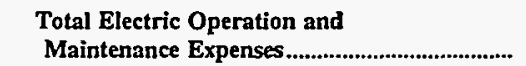 & 59,030 & 5,365 & 8,608 & 25,687 & 25,727 & 12,028 \\
\hline
\end{tabular}

Fuel Expenses in Operation

Steam Power Generation

Nuclear Power Generation...

0

0

0

Other Power Generation

Number of Elec Dept Employees

Regular Full-time

Part-time \& Temporary

Total Elec Dept Employees
26
0

0

0

0

0

0

0

Note: Totals may not equal sum of components because of independent rounding.

Source: Energy Information Administration, Form EIA-412, "Annual Report of Public Electric Utilities." 
Table 23. Electric Operation and Maintenance Expenses by Major U.S. Publicly Owned Electric Utility Within State, 1996 (Continued)

(Thousand Dollars)

\begin{tabular}{c|c|c|c|c|c|c}
\hline & Tennessee & Tennessee & Tennessee & Tennessee & Tennessee & Tennessee \\
Item & $\begin{array}{l}\text { Bolivar } \\
\text { City of }\end{array}$ & $\begin{array}{c}\text { Bristol } \\
\text { City of }\end{array}$ & $\begin{array}{c}\text { Brownsville } \\
\text { City of }\end{array}$ & $\begin{array}{c}\text { Carroll } \\
\text { County }\end{array}$ & $\begin{array}{c}\text { Chattanooga } \\
\text { City of }\end{array}$ & $\begin{array}{c}\text { Clarksville } \\
\text { City of }\end{array}$ \\
June 30 & June 30 & June 30 & June 30 & June 30 & June 30 \\
\hline
\end{tabular}

\section{Production Expenses}

Steam Power Generation.

Nuclear Power Generation

Hydraulic Power Generation

Purchused Power.............................................................

Other Production Expenses ......................................

Total Production Expenses ..................................

Transmission Expenses..

Distribution Expenses.

Customer Accounts Expenses .................................

Customer Service and Information

Expenses,.

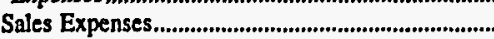

Administrative and General

Expenses.

Total Electric Operation and

Maintenance Expenses.

Fuel Expenses in Operation

Steam Power Generation ..........................................

Nuclear Power Generation

Other Power Generation

Number of Elec Dept Employees

Regular Full-time.

Part-time \& Temporary

0
0
0
0
11,035
0

11,035

0
0
0
0
38,475
0

38,475

0
771

771
295

295

25
13

742

12,881

$$
\begin{array}{r}
161 \\
2416
\end{array}
$$

2,416

495

91

87

697

42,422

9,390

0
0
0
0
8,576
0

0
0
0
0
18,513
0

0
0
0
0
251,684
0

0

, 576

18,513

251,684

0
406

136

1
1,299

561

1,054

18,356

6,186

956

918

9,632

514

20,920

288,786
38

$\begin{array}{ll}0 & 0 \\ 0 & 0 \\ 0 & 0\end{array}$

0

0

60

0

60

38
0

0

0

\begin{abstract}
15
\end{abstract}
0

15

\section{0}

0

o

50

0

50
463

86

0

86

Note: Totals may not equal sum of components because of independent rounding.

Source: Energy Information Administration, Form EIA-412, "Annual Report of Public Electric Utilities." 
Table 23. Electric Operation and Maintenance Expenses by Major U.S. Publicly Owned Electric Utility Within State, 1996 (Continued)

(Thousand Dollars)

\begin{tabular}{c|c|c|c|c|c|c}
\hline & Tennessee & Tennessee & Tennessee & Tennessee & Tennessee & Tennessec \\
Item & $\begin{array}{c}\text { Cleveland } \\
\text { City of }\end{array}$ & $\begin{array}{c}\text { Clinton } \\
\text { City of }\end{array}$ & $\begin{array}{c}\text { Columbia } \\
\text { City of }\end{array}$ & $\begin{array}{c}\text { Cookeville } \\
\text { City of }\end{array}$ & $\begin{array}{c}\text { Covington } \\
\text { City of }\end{array}$ & $\begin{array}{c}\text { Dayton } \\
\text { City of }\end{array}$ \\
June 30 & June 30 & June 30 & June 30 & June 30 & June 30 \\
\hline
\end{tabular}

\section{Production Expenses}

Steam Power Generation.

Nuclear Power Generation ........................................

Other Power Generation.

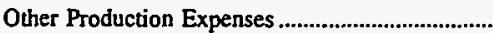

Total Production Expenses

Transmission Expenses.

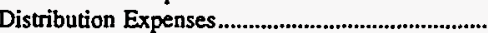

Customer Accounts Expenses .................................

Customer Service and Information

Expenses..............................................................

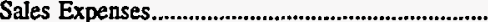

Administrative and General

Expenses.

Total Electric Operation and

Maintenance Expenses

Fuel Expenses in Operation

Steam Power Generation .............................................

Nuclear Power Generation ........................................

Other Power Generation

Number of Elec Dept Employees

Regular Full-time.

Part-time \& Temporary

Total Elec Dept Employees.

0
0
0
0
41,911

0
0
0
0
31,391
0

0
0
0
0
24,553
0

41,911

31,391

38
2,473
635

186
2,041

858

97

107

1,269

12
50

1,038

46,529

35,577

24,553

0
1,834

389

46

14

680

27,516
0
0
0
0
23,485

23,485

0
1,456

314

16

11

418

0
0
0
0
10,316
0

10,316

1
397

397
133

5

10

312

11,175

Note: Totals may not equal sum of components because of independent rounding.

Source: Energy Information Administration, Form EIA-412, "Annual Report of Public Electric Utilities." 
Table 23. Electric Operation and Maintenance Expenses by Major U.S. Publicly Owned Electric Utility Within State, 1996 (Continued)

(Thousand Dollars)

\begin{tabular}{c|c|c|c|c|c|c}
\hline & Tennessee & Tennessee & Tennessee & Tennessee & Tennessee & Tennessee \\
Item & $\begin{array}{c}\text { Dickson } \\
\text { City of }\end{array}$ & $\begin{array}{c}\text { Dyersburg } \\
\text { City of }\end{array}$ & $\begin{array}{c}\text { Elizabethton } \\
\text { City of }\end{array}$ & $\begin{array}{c}\text { Enwin } \\
\text { Town of }\end{array}$ & $\begin{array}{c}\text { Etowah } \\
\text { City of }\end{array}$ & $\begin{array}{c}\text { Fayetteville } \\
\text { City of }\end{array}$ \\
June 30 & June 30 & June 30 & June 30 & June 30 & June 30 \\
\hline
\end{tabular}

Production Expenses

Steam Power Generation...

Nuclear Power Generation

Hydraulic Power Generation

Other Power Generation.

Purchased Power.

Other Production Expenses.

Total Production Expenses...

Transmission Expenses.

Distribution Expenses.

Customer Accounts Expenses ....................................

Customer Service and Information

Expenses.....

Sales Expenses................................................................

Administrative and General

Expenses

Total Electric Operation and

Maintenance Expenses

Fuel Expenses in Operation

Steam Power Generation .........................................

Nuclear Power Generation ......................................

Other Power Generation

Number of Elec Dept Employees

Regular Full-time.....................................................

Part-time \& Temporary

50

$\mathbf{0}$

65

Total Elec Dept Employees

0

0

0

0

0

0

$\begin{array}{rr}0 & 0 \\ 0 & 0 \\ 0 & 0 \\ 0 & 0 \\ 30,487 & 25,076 \\ 0 & 0 \\ 30,487 & 25,076\end{array}$

o

0
0
0

24,152

0
0

24,152

$\begin{array}{rr}0 & 4 \\ 2,040 & 1,337\end{array}$

934

415

66
2324

0

134

1,030

791

27,697

28,311

$\begin{array}{rr}0 & 0 \\ 0 & 0 \\ 0 & 0 \\ 0 & 0 \\ 6,187 & 17,824 \\ 0 & 0\end{array}$

6,187

17,824

357

137

0
1,193

622

189

429

78

22

318

1,001

244

20,547

0

0

0

10,919

6,940

Note: Totals may not equal sum of components because of independent rounding

Source: Energy Information Administration, Form EIA-412, "Annual Report of Public Electric Utilities."
0

$\$ 5$
0

0

0

25

0

25

17

0

$17 \quad 66$
0

0

6


Table 23. Electric Operation and Maintenance Expenses by Major U.S. Publicly Owned Electric Utility Within State, 1996 (Continued)

(Thousand Dollars)

\begin{tabular}{|c|c|c|c|c|c|c|}
\hline Item & $\begin{array}{l}\text { Tennessee } \\
\text { Gallatin } \\
\text { City of } \\
\text { June } 30\end{array}$ & $\begin{array}{c}\text { Tennessee } \\
\text { Greeneville } \\
\text { City of } \\
\text { June } 30\end{array}$ & $\begin{array}{l}\text { Tennessee } \\
\text { Harriman } \\
\text { City of } \\
\text { June } 30\end{array}$ & $\begin{array}{l}\text { Tennessee } \\
\text { Humboldt } \\
\text { City of } \\
\text { June } 30\end{array}$ & $\begin{array}{l}\text { T'ennessee } \\
\text { Jackson } \\
\text { City of } \\
\text { June } 30\end{array}$ & $\begin{array}{l}\text { Tennessee } \\
\text { Johnson } \\
\text { City City of } \\
\text { June } 30\end{array}$ \\
\hline \multicolumn{7}{|l|}{ Production Expenses } \\
\hline 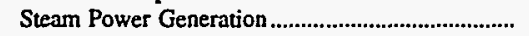 & 0 & 0 & 0 & 0 & D & 0 \\
\hline Nuclear Power Generation .......................................... & 0 & 0 & 0 & 0 & 0 & 0 \\
\hline Hydraulic Power Generation & 0 & 0 & 0 & 0 & $\mathbf{0}$ & 0 \\
\hline 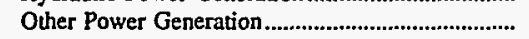 & 0 & 0 & $\mathbf{0}$ & 0 & 0 & 0 \\
\hline Purchased Power.......................................................... & 21,402 & 42,292 & 11,573 & 10,772 & 57,133 & 78,695 \\
\hline 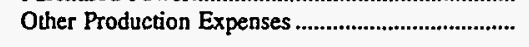 & 0 & 0 & 0 & 0 & 0 & 0 \\
\hline 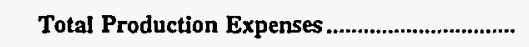 & 21,402 & 42,292 & 11,573 & 10,772 & 57,133 & 78,695 \\
\hline 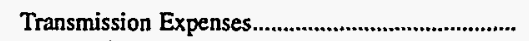 & 1 & 61 & 10 & 8 & 133 & 241 \\
\hline Distribution Expenses....................................................... & 702 & 3,265 & 1,112 & 454 & 2,494 & 4,905 \\
\hline $\begin{array}{l}\text { Customer Accounts Expenses................................. } \\
\text { Customer Service and Information }\end{array}$ & 306 & 849 & 388 & 91 & 864 & 1,873 \\
\hline $\begin{array}{l}\text { Customer Service and Information } \\
\text { Expenses }\end{array}$ & 7 & 60 & 2 & 11 & 142 & 83 \\
\hline 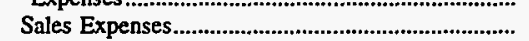 & 15 & 98 & 0 & il & 29 & 156 \\
\hline Administrative and General & & & & & & \\
\hline 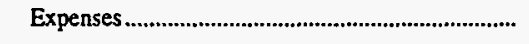 & 415 & 1,158 & 630 & 299 & 1,691 & 1,447 \\
\hline $\begin{array}{l}\text { Total Electric Operation and } \\
\text { Maintenance Expenses............... }\end{array}$ & 22,848 & 47,783 & 13,734 & 11,645 & 62,487 & 87,400 \\
\hline \multicolumn{7}{|l|}{ Fuel Expenses in Operation } \\
\hline 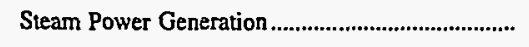 & 0 & 0 & 0 & 0 & 0 & 0 \\
\hline 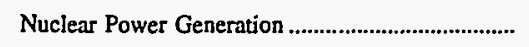 & 0 & 0 & 0 & 0 & 0 & 0 \\
\hline 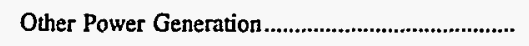 & 0 & 0 & 0 & 0 & 0 & 0 \\
\hline \multicolumn{7}{|l|}{ Number of Elec Dept Employees } \\
\hline Regular Full-time ........................................................ & 29 & 68 & 40 & 17 & 103 & 122 \\
\hline Part-time \& Temporary & 0 & 0 & 0 & 0 & 0 & 0 \\
\hline 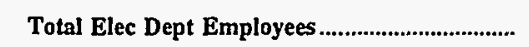 & 29 & 68 & 40 & 17 & 103 & 122 \\
\hline
\end{tabular}

Note: Totals may not equal sum of components because of independent rounding.

Source: Energy Information Administration, Form EIA-412, "Annual Report of Public Electric Utilities." 
Table 23. Electric Operation and Maintenance Expenses by Major U.S. Publicly Owned Electric Utility Within State, 1996 (Continued) (Thousand Dollars)

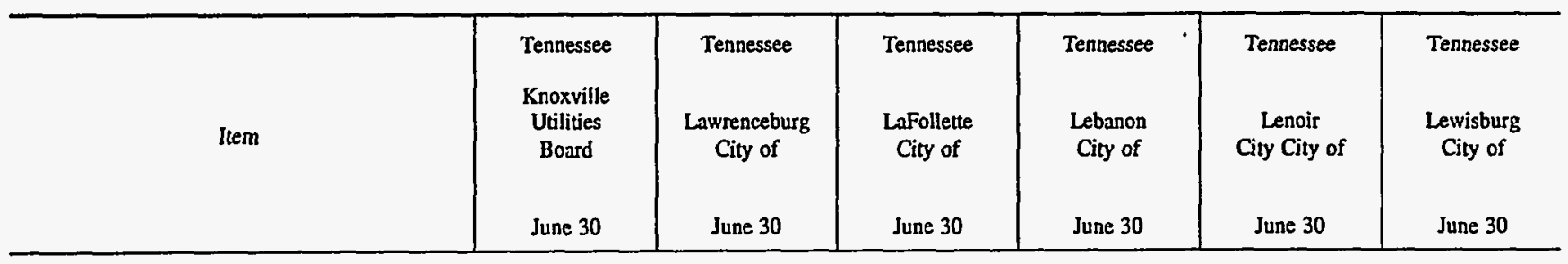

Production Expenses

Steam Power Generation.

Nuclear Power Generation .............................

Hydmulic Power Generation.

Other Power Generation.............................................

Purchased Power..........................................................

Other Production Expenses.

Total Production Expenses

Transmission Expenses.

Distribution Expenses.....................................................

Customer Accounts Expenses ....................................

Customer Service and Information

Expenses ....................................................................

Sales Expenses..................................................................

Administrative and General

Expenses..

Total Electric Operation and

Mainterance Expenses.

Fuel Rxpenses in Operation

Steam Power Generation

Nuclear Power Generation.

Other Power Generation

Number of Elec Dept Employees

Regular Full-time

Part-lime \& Temporary

Total Elec Dept Employees.

0
0
0
0
230,769

0

230,769

0
15,930

5,923

821
0

9,670

263,113
0
0
0
0
21,714
0

21,714

69

1,283

542

75

14

1,059

24,755

0
0
0
0
$17,58.3$
0

0
0
0
0
54,246
0

0
0
0
0
13,034
0

54,246

13,034

0
3,530

1,557

0

568

150

$\begin{array}{rr}0 & 19 \\ 25 & 9\end{array}$

$1,908 \quad 462$

591

19,117

61,267

14,242

Note: Totols may not equal sum of components because of independent rounding.

Source: Energy Information Administration, Form EIA-412, "Annual Report of Public Electric Utilities." 
Table 23. Electric Operation and Maintenance Expenses by Major U.S. Publicly Owned Electric Utility Within State, 1996 (Continued)

(Thousand Dollars)

\begin{tabular}{|c|c|c|c|c|c|c|}
\hline Item & $\begin{array}{l}\text { Tennessee } \\
\text { Lexington } \\
\text { City of } \\
\text { June } 30\end{array}$ & $\begin{array}{l}\text { Tennessee } \\
\text { Loudon } \\
\text { Utilities } \\
\text { Board } \\
\text { June } 30\end{array}$ & $\begin{array}{l}\text { Tennessee } \\
\text { Maryville } \\
\text { Utilities } \\
\text { June } 30\end{array}$ & $\begin{array}{c}\text { Tennessee } \\
\text { MeMinnville } \\
\text { Electric } \\
\text { System } \\
\text { June } 30\end{array}$ & $\begin{array}{l}\text { Tennessee } \\
\text { Memphis } \\
\text { City of } \\
\text { June } 30\end{array}$ & $\begin{array}{l}\text { Tennessee } \\
\text { Milan } \\
\text { City of } \\
\text { June } 30\end{array}$ \\
\hline \multicolumn{7}{|l|}{ Production Expenses } \\
\hline Steam Power Generation & 0 & 0 & 0 & 0 & 0 & 0 \\
\hline Nuclear Power Generation .............................................. & 0 & 0 & 0 & 0 & 0 & 0 \\
\hline 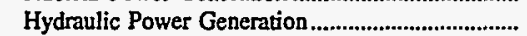 & 0 & 0 & 0 & 0 & 0 & 0 \\
\hline 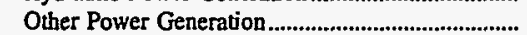 & 0 & 0 & 0 & 0 & 0 & 0 \\
\hline 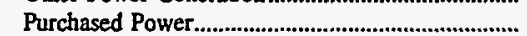 & 19,354 & 13,848 & 25,654 & 10,875 & 574,568 & 11.510 \\
\hline 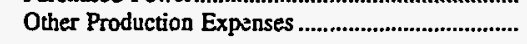 & 0 & 0 & 0 & 0 & 0 & 0 \\
\hline 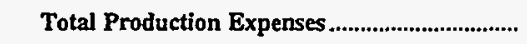 & 19,354 & 13,848 & 25,654 & 10,875 & 574,568 & 11,510 \\
\hline 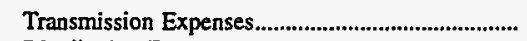 & 0 & 0 & 8 & 0 & 3,850 & 14 \\
\hline 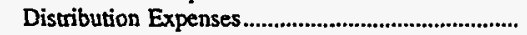 & 1,733 & 695 & 1,386 & 614 & 43,904 & 775 \\
\hline $\begin{array}{l}\text { Customer Accounts Expenses ................................. } \\
\text { Customer Service and Information }\end{array}$ & 475 & 135 & 443 & 219 & 8,767 & 202 \\
\hline 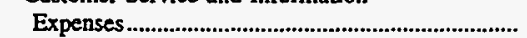 & 28 & 0 & 1 & 61 & 676 & 14 \\
\hline 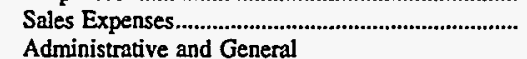 & 34 & -31 & 44 & 39 & 653 & 44 \\
\hline 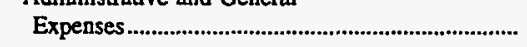 & 1,234 & 501 & 821 & 607 & 31,755 & 460 \\
\hline $\begin{array}{l}\text { Total Electric Operation and } \\
\text { Maintenance Expenses............. }\end{array}$ & 22,858 & 15,149 & 28,357 & 12,415 & 664,173 & 13,019 \\
\hline \multicolumn{7}{|l|}{ Fuel Expenses in Operation } \\
\hline 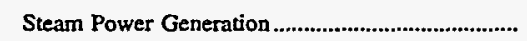 & 0 & 0 & 0 & 0 & 0 & 0 \\
\hline 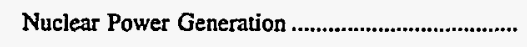 & 0 & 0 & 0 & 0 & 0 & 0 \\
\hline 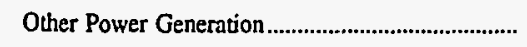 & 0 & 0 & 0 & 0 & 0 & 0 \\
\hline \multicolumn{7}{|l|}{ Number of Elec Dept Employees } \\
\hline Regular Full-time & 71 & 19 & 39 & 31 & 1,508 & 27 \\
\hline Part-ime \& Temporary & $\mathbf{0}$ & 0 & 0 & 0 & 0 & 0 \\
\hline 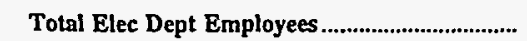 & 71 & 19 & 39 & 31 & 1,508 & 27 \\
\hline
\end{tabular}

Note: Totals may not equal sum of components because of independent rounding.

Source: Energy Information Administration, Form EIA-412, "Annual Report of Public Electric Utilities." 
Table 23. Electric Operation and Maintenance Expenses by Major U.S. Publicly

Owned Electric Utility Within State, 1996 (Continued)

(Thousand Dollars)

\begin{tabular}{|c|c|c|c|c|c|c|}
\hline Irem & $\begin{array}{c}\text { Tennessee } \\
\text { Morristown } \\
\text { City of } \\
\text { June } 30\end{array}$ & $\begin{array}{l}\text { Tennessee } \\
\text { Murfreesboro } \\
\text { City of } \\
\text { June } 30\end{array}$ & $\begin{array}{c}\text { Tennessee } \\
\text { Nashville } \\
\text { Electric } \\
\text { Service } \\
\text { June } 30\end{array}$ & $\begin{array}{l}\text { Tennessee } \\
\text { Newport } \\
\text { City of } \\
\text { June } 30\end{array}$ & $\begin{array}{l}\text { Tennessee } \\
\text { Oak Ridge } \\
\text { City of } \\
\text { June } 30\end{array}$ & $\begin{array}{c}\text { Tennessee } \\
\text { Paris } \\
\text { City of } \\
\text { June } 30\end{array}$ \\
\hline 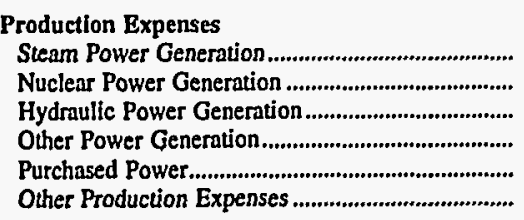 & $\begin{array}{r}0 \\
0 \\
0 \\
0 \\
31,795 \\
0\end{array}$ & $\begin{array}{r}0 \\
0 \\
0 \\
0 \\
44,391 \\
0\end{array}$ & $\begin{array}{r}0 \\
0 \\
0 \\
0 \\
499,317 \\
0\end{array}$ & $\begin{array}{r}0 \\
0 \\
0 \\
0 \\
19,741 \\
0\end{array}$ & $\begin{array}{r}0 \\
0 \\
0 \\
0 \\
22,874 \\
0\end{array}$ & $\begin{array}{r}0 \\
0 \\
0 \\
0 \\
20,907 \\
0\end{array}$ \\
\hline Total Production Expenses ...................................... & 31,795 & 44,391 & 499,317 & 19,741 & 22,874 & 20,907 \\
\hline 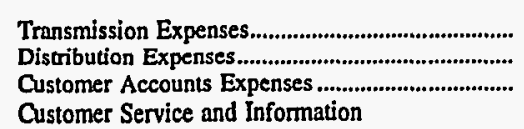 & $\begin{array}{r}16 \\
1,649 \\
315\end{array}$ & $\begin{array}{r}0 \\
1,395 \\
839\end{array}$ & $\begin{array}{r}0 \\
27,678 \\
13,729\end{array}$ & $\begin{array}{r}0 \\
1,455 \\
650\end{array}$ & $\begin{array}{r}88 \\
1,121 \\
384\end{array}$ & $\begin{array}{r}18 \\
1,229 \\
438\end{array}$ \\
\hline 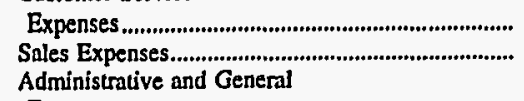 & $\begin{array}{r}0 \\
80\end{array}$ & $\begin{array}{l}21 \\
83\end{array}$ & $\begin{array}{r}1,022 \\
70\end{array}$ & $\begin{array}{l}21 \\
28\end{array}$ & $\begin{array}{r}5 \\
73\end{array}$ & $\begin{array}{l}39 \\
16\end{array}$ \\
\hline 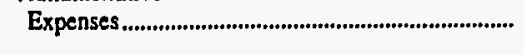 & 879 & 1,036 & 22,347 & 795 & 532 & 595 \\
\hline 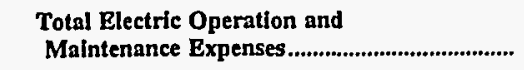 & $\mathbf{3 4 , 7 3 4}$ & 47,764 & 564,163 & 22,690 & 25,078 & 23,241 \\
\hline \multicolumn{7}{|l|}{ Fuel Expenses in Operation } \\
\hline 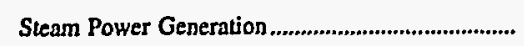 & 0 & 0 & $\mathbf{0}$ & $\mathbf{0}$ & 0 & 0 \\
\hline Nuclear Power Generation ........................................... & 0 & 0 & $\mathbf{0}$ & 0 & $\mathbf{0}$ & 0 \\
\hline 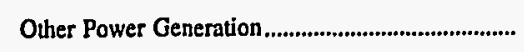 & 0 & 0 & 0 & $\mathbf{0}$ & $\mathbf{0}$ & 0 \\
\hline \multicolumn{7}{|l|}{ Number of Elec Dept Employees } \\
\hline 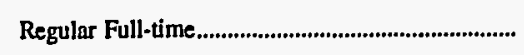 & 87 & 60 & 981 & 54 & 67 & 50 \\
\hline 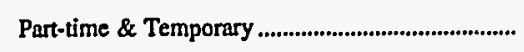 & 0 & 0 & 0 & 0 & 0 & 0 \\
\hline Total Elec Dept Employees....................................... & 87 & 60 & 981 & 54 & 67 & 50 \\
\hline
\end{tabular}

Note: Totals may not equal sum of components because of independent rounding.

Source: Energy Information Administration, Form EIA-412, "Annual Report of Public Electric Utilities." 
Table 23. Electric Operation and Maintenance Expenses by Major U.S. Publicly Owned Electric Utility Within State, 1996 (Continued)

(Thousand Dollars)

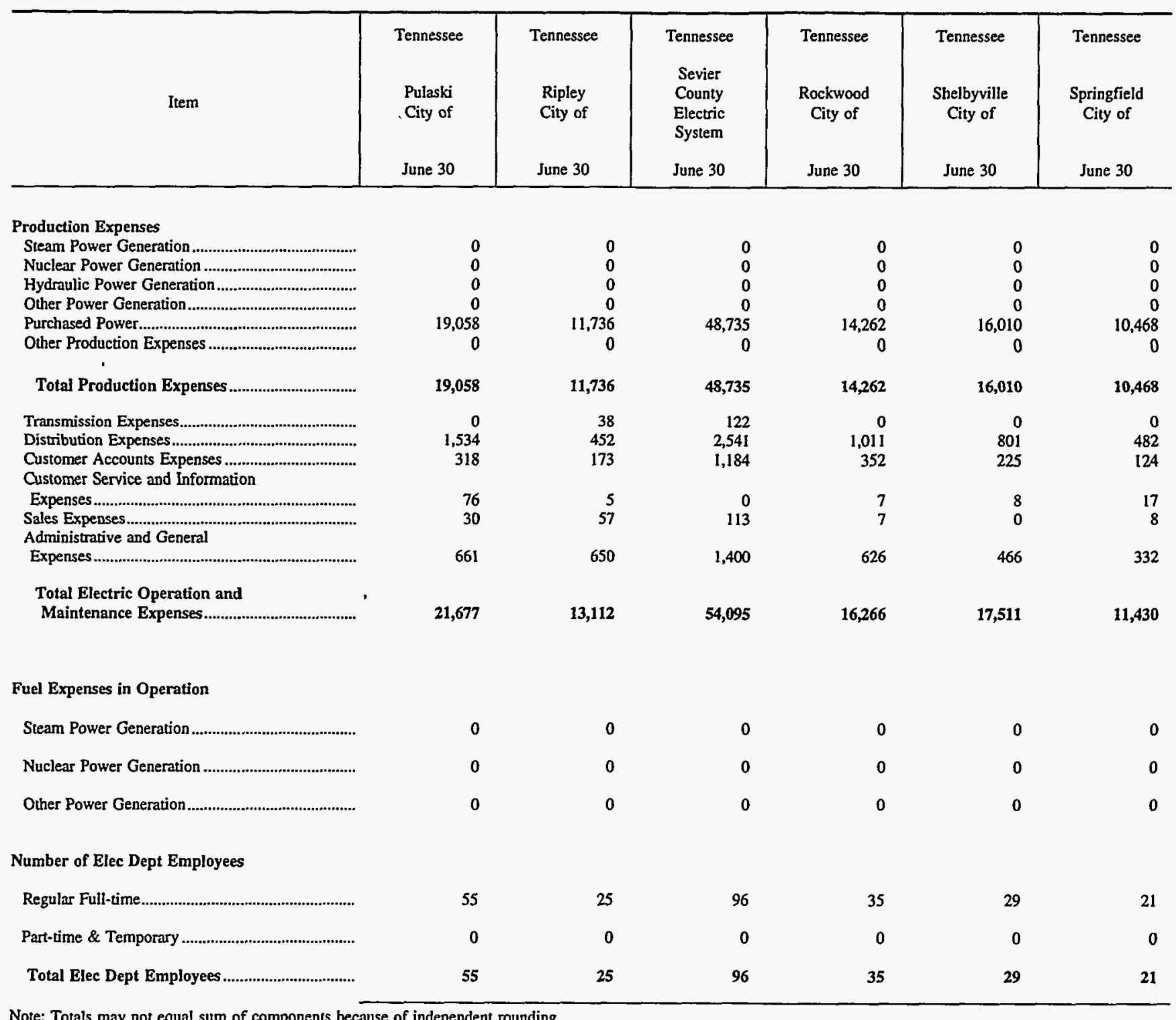

Note: Totals may not equal sum of components because of independent rounding.

Source: Energy Information Administration, Form EIA-412, "Annual Report of Public Electric Utilities." 
Table 23. Electric Operation and Maintenance Expenses by Major U.S. Publicly Owned Electric Utility Within State, 1996 (Continued)

(Thousand Dollars)

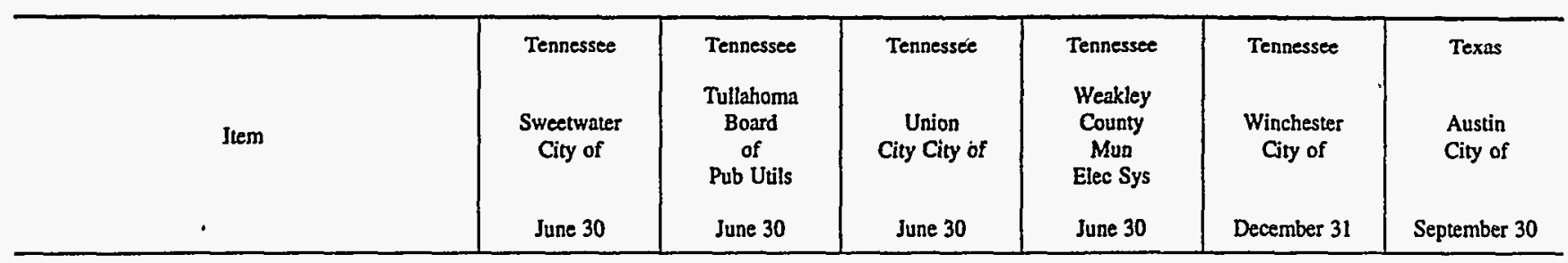

Production Expenses

Steam Power Generation....

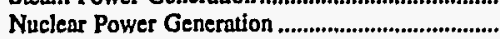

Hydraulic Power Generation

Other Power Generation

Purchased Power........................................................

Other Production Expenses .........................................

Total Production Expenses.

Transmission Expenses.

Distribution Expenses

Customer Accounts Expenses ....................................

Customer Service and Information

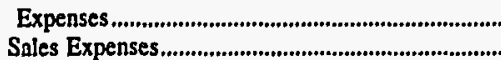

Sales Expenses........................................................

Expenses.................................

Total Electric Operation and

Maintenance Expenses.
9,2

0
0
0
0
9,258
0

9,258

0
535
152

152

9
9

384

10,348

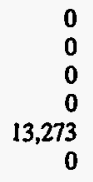

13,273

0
797

797

174

\section{2}

38

398

14,702

15,691

0
0
0
0
23,084
0

0
0
0
0
7,093

145,224

52,946

0

14,554

3,663

216,386

2,918

25,780

14,075

11,125

0

43,214

669

171

313,497

\section{Fuel Expenses in Operation}

Steam Power Generation,

0

0

Nuclear Power Generation

Other Power Generation.

Number of Elec Dept Employees

Regular Full-time .........................................................

Part-time \& Temporary

Total Elec Dept Employees
27

0

27 $\mathbf{0}$

0

0

28

0

28

25,622

$\mathbf{7 , 7 3 1}$

Note: Totals may not equal sum of components because of independent rounding.

Source: Energy Information Administration, Form EIA-412, "Annual Report of Public Electric Utilities." 
Table 23. Electric Operation and Maintenance Expenses by Major U.S. Publicly Owned Electric Utility Within State, 1996 (Continued)

. (Thousand Dollars)

\begin{tabular}{|c|c|c|c|c|c|c|}
\hline Item & $\begin{array}{c}\text { Texas } \\
\text { Brenham } \\
\text { City of } \\
\text { September } 30\end{array}$ & $\begin{array}{c}\text { Texas } \\
\text { Brownsville } \\
\text { Public } \\
\text { Utils Board } \\
\text { September } 30\end{array}$ & $\begin{array}{c}\text { Texas } \\
\text { Bryan } \\
\text { City of } \\
\text { September } 30\end{array}$ & $\begin{array}{c}\text { Texas } \\
\text { College } \\
\text { Station } \\
\text { City of } \\
\text { September } 30\end{array}$ & $\begin{array}{l}\text { Texas } \\
\text { Denton } \\
\text { City of } \\
\text { September } 30\end{array}$ & $\begin{array}{c}\text { Texas } \\
\text { Floresville } \\
\text { City of } \\
\text { December } 31\end{array}$ \\
\hline \multicolumn{7}{|l|}{ Production Expenses } \\
\hline 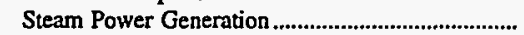 & $\mathbf{0}$ & 6,274 & 15,582 & 0 & 9,924 & 0 \\
\hline 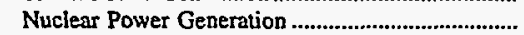 & 0 & 0 & 0 & 0 & 0 & 0 \\
\hline 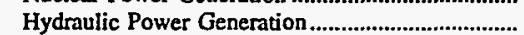 & 0 & 0 & 0 & 0 & 164 & 0 \\
\hline Other Power Generation........................................ & 0 & 12,341 & 106 & 0 & 0 & 0 \\
\hline Purchased Power.......................................................... & 11,142 & 7,756 & 43,648 & 17,450 & 34,384 & 7,671 \\
\hline 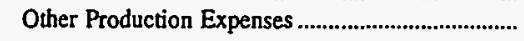 & 0 & 868 & 0 & 0 & 0 & 0 \\
\hline 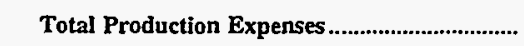 & 11,142 & 27,239 & 59,337 & 17,450 & $\mathbf{4 4 , 4 7 1}$ & 7,671 \\
\hline 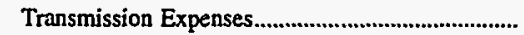 & 0 & 1,151 & 396 & 4,243 & 89 & 0 \\
\hline Distribution Expenses.................................................. & 847 & 929 & 3,953 & 1,580 & 4,211 & 955 \\
\hline 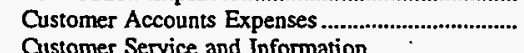 & 0 & 688 & 1,454 & 1,080 & 1,239 & 692 \\
\hline $\begin{array}{l}\text { Customer Service and Information } \\
\text { Expenses }\end{array}$ & 0 & 0 & 0 & 0 & 257 & 0 \\
\hline $\begin{array}{l}\text { Sales Expenses........................................... } \\
\text { Administrative and Genel }\end{array}$ & 0 & 0 & 0 & 0 & 0 & 0 \\
\hline 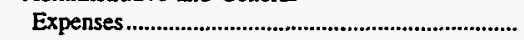 & 506 & 4,670 & 3,029 & 2,448 & 2,665 & 776 \\
\hline 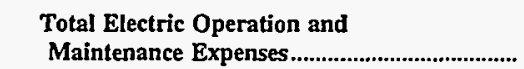 & 12,494 & 34,678 & 68,168 & 26,801 & 52,933 & 10,093 \\
\hline \multicolumn{7}{|l|}{ Fuel Expenses in Operation } \\
\hline 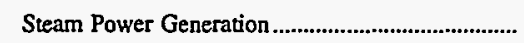 & 0 & 5,207 & 12,038 & 0 & 6,949 & 0 \\
\hline 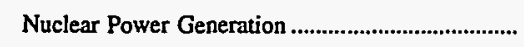 & 0 & 0 & 0 & 0 & 0 & 0 \\
\hline Other Power Generation & 0 & 8,221 & 95 & 0 & 0 & 0 \\
\hline \multicolumn{7}{|l|}{ Number of Elec Dept Employees } \\
\hline Regular Full-time & 9 & 118 & 199 & 51 & 34 & 62 \\
\hline Part-time \& Temporary & 0 & 70 & 1 & 2 & 2 & 7 \\
\hline 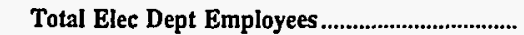 & 9 & 188 & 200 & 53 & 36 & 69 \\
\hline
\end{tabular}

Note: Totals may not equal sum of components because of independent rounding.

Source: Energy Information Administration, Form EIA-412, "Annual Report of Public Electric Utilities." 
Table 23. Electric Operation and Maintenance Expenses by Major U.S. Publicly

Owned Electric Utility Within State, 1996 (Continued)

(Thousand Dollars)

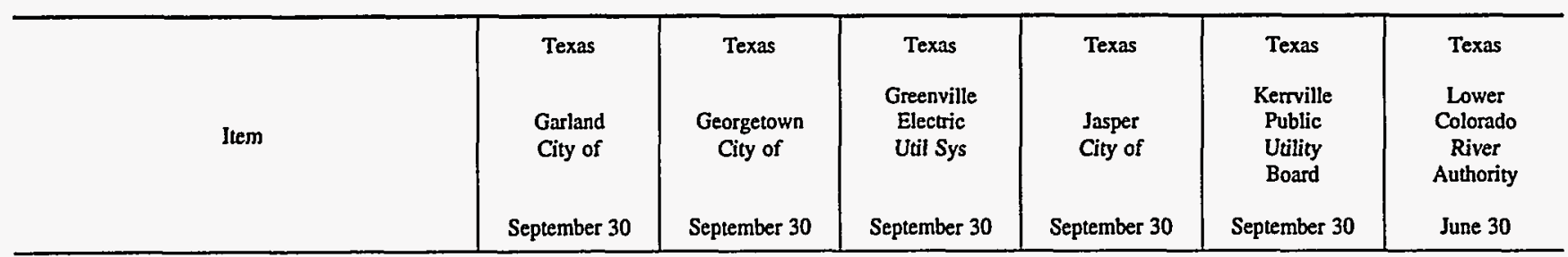

Production Expenses

Steam Power Generation

Nuclear Power Generation.

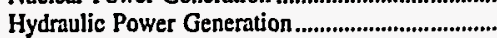

Other Power Generation.

Purchased Power....................

Other Production Expenses ........................................

Total Production Expenses ...............................

Transmission Expenses

Distribution Expenses

Customer Accounts Expenses ..................................

Customer Service and Information

Expenses.

Sales Expenses..............................................................

Administrative and General

Expenses..

Total Electric Operation and

Maintenance Expenses

Fuel Expenses in Operation

Steam Power Generation ........................................

Nuclear Power Generation.

Other Power Generation

Number of Elec Dept Employees

Regular Full-time .................................................

Part-time \& Temporary.

Total Elec Dept Employees

Note: Totals may not equal sum of components because of independent rounding.

Source: Energy Information Administration, Form ElA-412, "Annual Report of Public Electric Utilities."
30,292

0

0

$\begin{array}{rr}223 & 14 \\ 6 & 0\end{array}$

$\begin{array}{rrrr}4,191 & 0 & 0 & 180,613 \\ 0 & 0 & 0 & 0 \\ 0 & 0 & 0 & 3,395 \\ 187 & 0 & 0 & 0 \\ 16,380 & 10,494 & 17,575 & 14,286 \\ 0 & 0 & 0 & 4,161 \\ 20,758 & 10,494 & 17,575 & 202,456 \\ 0 & 0 & 0 & 24,495 \\ 1,983 & 638 & 1,265 & 0 \\ 850 & 0 & 448 & 433 \\ 0 & 0 & 103 & 1,237 \\ 0 & 0 & 0 & 425 \\ 2,338 & 750 & 1,349 & 21,527 \\ & & & \\ 25,929 & 11,881 & 20,740 & 250,572\end{array}$

73

1

74
0

0

o

143,564

0

0

25

69

1,633

0

0

69

1,633 
Table 23. Electric Operation and Maintenance Expenses by Major U.S. Publicly Owned Electric Utility Within State, 1996 (Continued)

(Thousand Dollars)

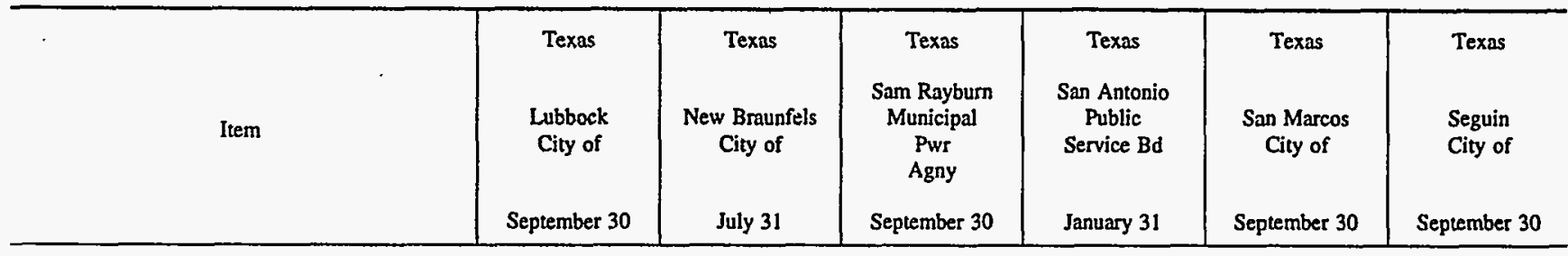

Production Expenses

Steam Power Generation

Nuclear Power Generation

Hydraulic Power Generatio

Other Power Generation

Purchased Power..........

Other Production Expenses ......................................

Total Production Expenses

Transmission Expenses.

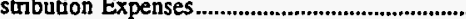

Customer Accounts Expenses...

Customer Service and Information

Expenses....

Administrative and General

Expenses

Total Electric Operation and

Maintenance Expenses.

Fuel Expenses in Operation

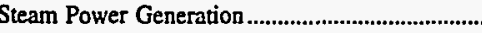

Nuclear Power Generation.

Other Power Generation

Number of Elec Dept Employees

Regular Full-time..

Part-time \& Temporary

20,300

0
0
0

15,013

35,313

35,313

0
3,737

3,677

1.025

1,625

404

44,757

0
0
15
0
32,989
0

12,788
0
0
0
5,188
0

33,004

17,976

161,414
80,935
0
0
1,523
8,321

252,193

2,413

30,858

8,009

2,026

0

67,667

363,166

18,887

35,782

203

16,299

0

0

$\begin{array}{rr}203 & 68 \\ 1 & 0 \\ 204 & 68\end{array}$

68
9,361

0

0

0
0
0
0
15,071
0

0
0
0
0
9,210
0

15,071

9,210

0
1,182

970

0
807

807
0

0

0

3,050

20,341

10,017

Total Elec Dept Employees.

8

2
1
3

2,912

45

19

39

0

2,951

19

Note: Totals may not equal sum of components because of independent rounding.

Source: Energy Information Administration, Form EIA-412, "Annual Report of Public Electric Utilities." 
Table 23. Electric Operation and Maintenance Expenses by Major U.S. Publicly Owned Electric Utility Within State, 1996 (Continued)

(Thousand Dollars)

\begin{tabular}{|c|c|c|c|c|c|c|}
\hline Item & $\begin{array}{c}\text { Texas } \\
\text { Texas } \\
\text { Municipal } \\
\text { Power Agency } \\
\text { September } 30\end{array}$ & $\begin{array}{l}\text { Texas } \\
\text { Toledo Bend } \\
\text { Project } \\
\text { Joint } \\
\text { Oper } \\
\text { August } 30\end{array}$ & $\begin{array}{c}\text { Texas } \\
\text { Weatherford } \\
\text { Mun } \\
\text { Utility } \\
\text { System } \\
\text { September } 30\end{array}$ & $\begin{array}{c}\text { Utah } \\
\text { Bountiful } \\
\text { City City of } \\
\text { June } 30\end{array}$ & $\begin{array}{c}\text { Utah } \\
\text { Intermountain } \\
\text { Power Agency } \\
\text { June } 30\end{array}$ & $\begin{array}{l}\text { Utah } \\
\text { Logan } \\
\text { City of } \\
\text { June } 30\end{array}$ \\
\hline
\end{tabular}

Production Expenses

Steam Power Generation...

Nuclear Power Generation

Hydraulic Power Generation......................................

Other Power Generation...

Purchased Power

Other Production Expenses .......................................

Total Production Expenses

Transmission Expenses.

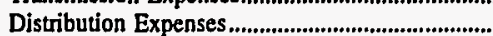

Customer Accounts Expenses

Customer Service and Information

Expenses...

Expes Expenses

Administrative and General

Expenses.

Total Electric Operation and

Maintenance Expenses.

Fuel Expenses in Operation

Steam Power Generation........................................

Nuclear Power Generation.

Other Power Generation.

Number of Elec Dept Employees

Regular Full-time...

Part-time \& Temporary .

150

0

150

Total Elec Dept Employees.. .....
54,617

5
0
0
957
1,085

56,659

3,482

41,297

0

0

0
0
10,287
0
0
0

10,287

0
0
0

0
0
0

0

0

10,287

10,491

1,047

0

1,129

0
0
219
282
5,208
291

191,791

0
0
0
0
0

0
0
162
361
8,872
0

6,000

191,791

9,395

10,585

0

I52

0
1,059

75

0

1,233

8,367

216,629

11,410

Note: Totals may not equal sum of components because of independent rounding

Source: Energy Information Administration, Form EIA-412, “Annual Report of Public Electric Utilities." 
Table 23. Electric Operation and Maintenance Expenses by Major U.S. Publicly Owned Electric Utility Within State, 1996 (Continued)

(Thousand Dollars)

\begin{tabular}{|c|c|c|c|c|c|c|}
\hline Item & $\begin{array}{l}\text { Utah } \\
\text { Murray } \\
\text { City of } \\
\text { June } 30\end{array}$ & $\begin{array}{c}\text { Utah } \\
\text { Provo } \\
\text { City Corp } \\
\text { June } 30\end{array}$ & $\begin{array}{l}\text { Utah } \\
\text { St George } \\
\text { City of } \\
\text { June } 30\end{array}$ & $\begin{array}{c}\text { Utah } \\
\text { Utah } \\
\text { Associated } \\
\text { Mun } \\
\text { Power Sys } \\
\text { March } 31\end{array}$ & $\begin{array}{c}\text { Utah } \\
\text { Utah } \\
\text { Municipal } \\
\text { Power Agency } \\
\text { June } 30\end{array}$ & $\begin{array}{l}\text { Vermont } \\
\text { Burlington } \\
\text { City of } \\
\text { June } 30\end{array}$ \\
\hline \multicolumn{7}{|l|}{ Production Expenses } \\
\hline 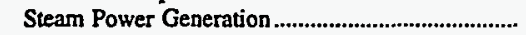 & 0 & $\mathbf{0}$ & 0 & 11,836 & 9,039 & 3,539 \\
\hline 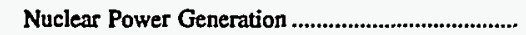 & $\mathbf{0}$ & 0 & . 0 & 0 & 0 & 0 \\
\hline Hydraulic Power Generation....................................... & 114 & 0 & $\mathbf{0}$ & 0 & 0 & 0 \\
\hline 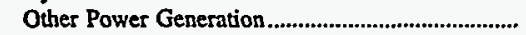 & 98 & 0 & 179 & 0 & 7,760 & 208 \\
\hline 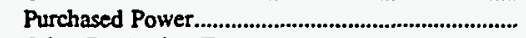 & 9,340 & 24,627 & 14,403 & 19,991 & $\mathbf{9 , 7 5 5}$ & 14,684 \\
\hline 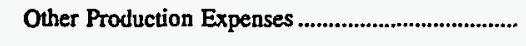 & 0 & $-2,653$ & $\mathbf{0}$ & 15 & 670 & 751 \\
\hline 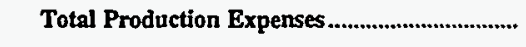 & 9,552 & 21,974 & 14,581 & 31,842 & 27,225 & 19,181 \\
\hline Transmission Expenses......................................................... & 77 & 214 & 0 & 4,457 & 778 & 468 \\
\hline 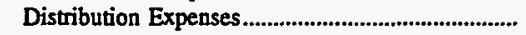 & 1,548 & 2,943 & 0 & 0 & 0 & 1,797 \\
\hline $\begin{array}{l}\text { Customer Accounts Expenses ............................... } \\
\text { Customer Service and Information }\end{array}$ & 391 & 1,394 & 0 & 0 & 0 & 1,644 \\
\hline 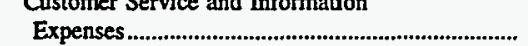 & 217 & 130 & 0 & 0 & 0 & 402 \\
\hline 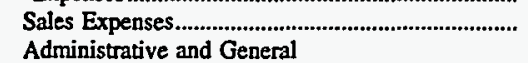 & 0 & 0 & 0 & 0 & $\mathbf{0}$ & 74 \\
\hline 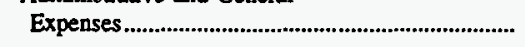 & 1,597 & 1,192 & 2,810 & 4,354 & 521 & 3,394 \\
\hline 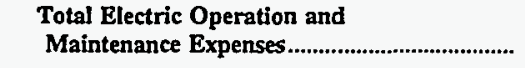 & 13,382 & 27,847 & 17,392 & 40,653 & 28,524 & 26,962 \\
\hline \multicolumn{7}{|l|}{ Fuel Expenses in Operation } \\
\hline 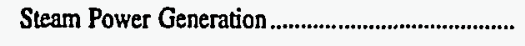 & 0 & 0 & 0 & 0 & 7,113 & 2,338 \\
\hline 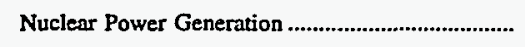 & 0 & 0 & 0 & 0 & 0 & 0 \\
\hline Other Power Generation & 8 & 0 & 0 & 0 & 0 & 0 \\
\hline \multicolumn{7}{|l|}{ Number of Elec Dept Employees } \\
\hline Regular Full-time & 53 & 95 & 38 & 27 & 27 & 158 \\
\hline 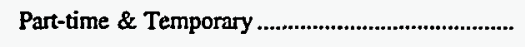 & 0 & 2 & 12 & 0 & 0 & 4 \\
\hline Total Elec Dept Employees....................................... & 53 & 97 & 50 & 27 & 27 & 162 \\
\hline
\end{tabular}

Note: Totals may not equal sum of components because of independent rounding.

Source: Energy Information Administration, Form EIA-412, "Annual Report of Public Electric Utilities." 
Table 23. Electric Operation and Maintenance Expenses by Major U.S. Publicly Owned Electric Utility Within State, 1996 (Continued)

(Thousand Dollars)

\begin{tabular}{|c|c|c|c|c|c|c|}
\hline Item & $\begin{array}{c}\text { Vermont } \\
\text { Vermont } \\
\text { Public } \\
\text { Pwr } \\
\text { Supply Auth } \\
\text { December } 31\end{array}$ & $\begin{array}{l}\text { Virginia } \\
\text { Bedford } \\
\text { City of } \\
\text { June } 30\end{array}$ & $\begin{array}{l}\text { Virginia } \\
\text { Bristol } \\
\text { Utilities } \\
\text { Board } \\
\text { June } 30\end{array}$ & $\begin{array}{l}\text { Virginia } \\
\text { Danville } \\
\text { City of } \\
\text { June } 30\end{array}$ & $\begin{array}{c}\text { Virginia } \\
\begin{array}{c}\text { Harrisonburg } \\
\text { City of }\end{array} \\
\text { June } 30\end{array}$ & $\begin{array}{l}\text { Virginia } \\
\text { Manassas } \\
\text { City of } \\
\text { June } 30\end{array}$ \\
\hline \multicolumn{7}{|l|}{ Production Expenses } \\
\hline Steam Power Generation ................................................. & 1,665 & 0 & 0 & 0 & 0 & 0 \\
\hline Nuclear Power Generation .............................................. & 0 & 0 & $\mathbf{0}$ & 0 & 0 & 0 \\
\hline Hydraulic Power Generation......................................... & 0 & 278 & 0 & 455 & 0 & 31 \\
\hline Other Power Generation............................................. & 0 & 0 & $\mathbf{0}$ & 0 & 0 & 768 \\
\hline Purchased Power............................................................... & 4,019 & 6,980 & 23,130 & 30,700 & 25,474 & 12,565 \\
\hline Other Production Expenses ........................................ & 0 & 485 & 0 & 141 & 0 & 0 \\
\hline Total Production Expenses .................................... & 5,684 & 7,743 & 23,130 & 31,296 & 25,474 & 13,365 \\
\hline 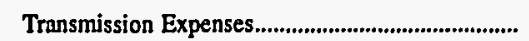 & 249 & 185 & 0 & 325 & 61 & 0 \\
\hline 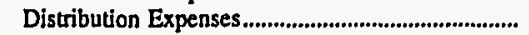 & 0 & 658 & 1,784 & 1,936 & 1,025 & 1,146 \\
\hline $\begin{array}{l}\text { Customer Accounts Expenses................................................ } \\
\text { Customer Service and Information }\end{array}$ & 0 & 142 & 353 & 1,087 & 483 & 499 \\
\hline 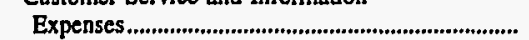 & 0 & 0 & 22 & 0 & 0 & 199 \\
\hline $\begin{array}{l}\text { Sales Expenses,........................................................ } \\
\text { Administrative and General }\end{array}$ & 0 & 0 & 72 & $\mathbf{0}$ & 20 & 0 \\
\hline 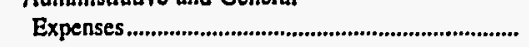 & 968 & 518 & 844 & 741 & 1,094 & 1,956 \\
\hline $\begin{array}{l}\text { Total Electric Operation and } \\
\text { Maintenance Expenses........................................... }\end{array}$ & 6,901 & 9,246 & 26,204 & 35,385 & 28,157 & 17,166 \\
\hline \multicolumn{7}{|l|}{ Fuel Expenses in Operation } \\
\hline 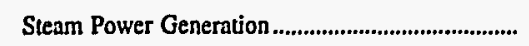 & 0 & 0 & 0 & 0 & 0 & 0 \\
\hline 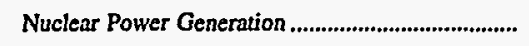 & 0 & 0 & $\mathbf{0}$ & 0 & 0 & 0 \\
\hline 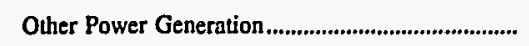 & 0 & 0 & 0 & 0 & 0 & 202 \\
\hline \multicolumn{7}{|l|}{ Number of Elec Dept Employees } \\
\hline 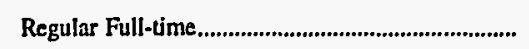 & 10 & 18 & 40 & 72 & 48 & 50 \\
\hline Part-time \& Temporary & 0 & 0 & 0 & 1 & 1 & 0 \\
\hline Total Elec Dept Employees ........................................ & 10 & 18 & 40 & 73 & 49 & 50 \\
\hline
\end{tabular}

Note: Totals may not equal sum of components because of independent rounding.

Source: Energy Information Administration, Form EIA-412, "Annual Report of Public Electric Utilities." 
Table 23. Electric Operation and Maintenance Expenses by Major U.S. Publicly Owned Electric Utility Within State, 1996 (Continued)

(Thousand Dollars)

\begin{tabular}{|c|c|c|c|c|c|c|}
\hline Item & $\begin{array}{c}\text { Virginia } \\
\begin{array}{c}\text { Martinsville } \\
\text { City of }\end{array} \\
\text { June } 30\end{array}$ & $\begin{array}{l}\text { Virginia } \\
\text { Radford } \\
\text { City of } \\
\text { June } 30\end{array}$ & $\begin{array}{l}\text { Virginia } \\
\text { Salem } \\
\text { City of } \\
\text { June } 30\end{array}$ & $\begin{array}{c}\text { Virginia } \\
\text { Virginia } \\
\text { Tech } \\
\text { Electric } \\
\text { Service } \\
\text { June } 30\end{array}$ & $\begin{array}{c}\text { Washington } \\
\text { Centralia } \\
\text { City of } \\
\text { December } 31\end{array}$ & $\begin{array}{l}\text { Washington } \\
\begin{array}{c}\text { Ellensburg } \\
\text { City of }\end{array} \\
\text { December } 31\end{array}$ \\
\hline \multicolumn{7}{|l|}{ Production Expenses } \\
\hline 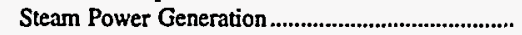 & 0 & 0 & 0 & 279 & 0 & $\mathbf{0}$ \\
\hline 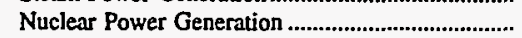 & 0 & 0 & 0 & 0 & 0 & 0 \\
\hline Hydraulic Power Generation........................................... & 211 & 16 & 0 & 0 & 554 & 0 \\
\hline Other Power Generation & 0 & 0 & 0 & 0 & 0 & 0 \\
\hline 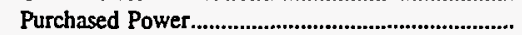 & 6,814 & 12,789 & 13,042 & 7,774 & 5,375 & 5,252 \\
\hline 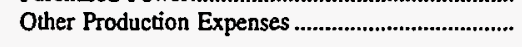 & 0 & 12 & 0 & 0 & 0 & 0 \\
\hline 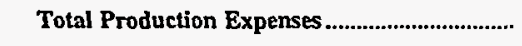 & 7,025 & 12,818 & 13,042 & 8,054 & 5,929 & 5,252 \\
\hline Transmission Expenses................................................... & 0 & 1 & 0 & 0 & 112 & 0 \\
\hline Distribution Expenses.................................................... & 786 & 378 & 1,373 & 2,340 & 893 & 331 \\
\hline 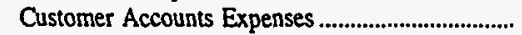 & 138 & 0 & 0 & 359 & 90 & 242 \\
\hline \multicolumn{7}{|l|}{ Customer Service and Information } \\
\hline 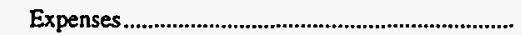 & 0 & 163 & 221 & $\mathbf{0}$ & 0 & 0 \\
\hline $\begin{array}{l}\text { Sales Expenses.............................................. } \\
\text { Administrative and Genal }\end{array}$ & 0 & 0 & 0 & 0 & 0 & 2 \\
\hline 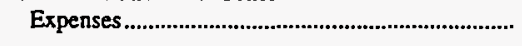 & 82 & 529 & 556 & 742 & 726 & 561 \\
\hline 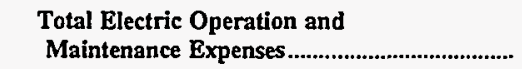 & 8,030 & 13,889 & 15,192 & 11,496 & 7,750 & 6,388 \\
\hline \multicolumn{7}{|l|}{ Fuel Expenses in Operation } \\
\hline 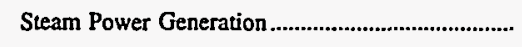 & 0 & 0 & 0 & 178 & 0 & 0 \\
\hline 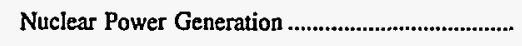 & 0 & 0 & 0 & 0 & 0 & 0 \\
\hline Other Power Generation ................................................. & 0 & 0 & 0 & 0 & 0 & 0 \\
\hline \multicolumn{7}{|l|}{ Number of Elec Dept Employees } \\
\hline Regular Full-time & 19 & 22 & 26 & 28 & 25 & 12 \\
\hline Part-time \& Temporary & 3 & 0 & 2 & 11 & 13 & 0 \\
\hline Total Elec Dept Employees ........................................ & 22 & 22 & 28 & 39 & 38 & 12 \\
\hline
\end{tabular}

Note: Totals may not equal sum of components because of independent rounding.

Source: Energy Information Administration, Form EIA-412, "Annual Report of Public Electric Utilities." 
Table 23. Electric Operation and Maintenance Expenses by Major U.S. Publicly Owned Electric Utility Within State, 1996 (Continued)

(Thousand Dollars)

\begin{tabular}{|c|c|c|c|c|c|c|}
\hline \multirow{3}{*}{ Item } & Washington & Washington & Washington & Washington & Washington & Washington \\
\hline & $\begin{array}{l}\text { Port Angeles } \\
\text { City of }\end{array}$ & $\begin{array}{c}\text { PUD No } 1 \\
\text { of } \\
\text { Benton } \\
\text { County }\end{array}$ & $\begin{array}{c}\text { PUD No } 1 \\
\text { of } \\
\text { Chelan } \\
\text { County }\end{array}$ & $\begin{array}{l}\text { PUD No I of } \\
\text { Clallam } \\
\text { County }\end{array}$ & $\begin{array}{c}\text { PUD No } 1 \\
\text { of } \\
\text { Clark } \\
\text { County }\end{array}$ & $\begin{array}{l}\text { PUD No } 1 \text { of } \\
\text { Cowlitz } \\
\text { County }\end{array}$ \\
\hline & December 31 & December 31 & December 31 & December 31 & December 31 & December 31 \\
\hline
\end{tabular}

Production Expenses

Steam Power Generation..........................................

Nuclear Power Generation.

Hydraulic Power Generation

Other Power Generation..

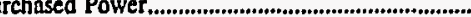

Other Production Expenses..

Total Production Expenses.

Transmission Expenses.

Distribution Expenses.................................................

Customer Accounts Expenses.

Customer Service and Information

Expenses...

Bales Expenses.

Administrative and General

Expenses.

Total Electric Operation and

Maintenance Expenses.

0
0
66
0
16,855
0

(n)

46

46,318

61

16,921

0
2,176

0

0

8

829

19,927

$$
46,380
$$

22
3,773

1,456

261

261
2

3,921

55,815
0
0
30,038
0
36,002
218

66,258

2,671

5,226

763

648

0

16,600

92,166

21,225
0
0
297
0
84,083
64

84,443

512

2,880

1,731

489
0

2,975

8,267

132,350

93,031

Fuel Expenses in Operation

Steam Power Generation.........................................

Nuclear Power Generation .......................................

Other Power Generation

Number of Elec Dept Employees

Regular Full-time

Part-time \& Temporary

30

Total Elec Dept Employees. $\mathbf{0}$

30

0

0

0

0

0

0

133

2

135

0
0
0

0

0

0

0

Note: Totals may not equal sum of components because of independent rounding.

Source: Energy Information Administration, Form ElA-412, "Annual Report of Public Electric Utilities." 
Table 23. Electric Operation and Maintenance Expenses by Major U.S. Publicly Owned Electric Utility Within State, 1996 (Continued)

(Thousand Dollars)

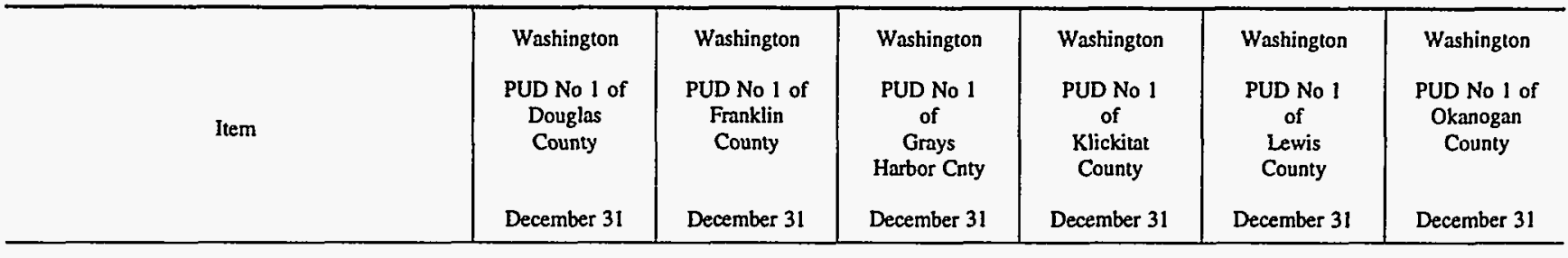

\section{Production Expenses}

Steam Power Generation

Nuclear Power Generation

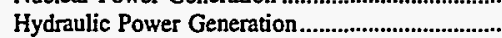

Other Power Generation.

Purchased Power......................................................

Other Production Expenses .......................................

Total Production Expenses

Transmission Expenses.

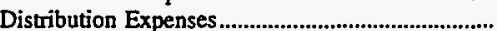

Customer Accounts Expenses ..................................

Customer Service and Information

Expenses......

Administrative and General

Expenses..

Total Electric Operation and

Maintenance Expenses.

Fuel Expenses in Operation

Steam Power Generation .......................................

Nuclear Power Generation .......................................

Other Power Generation.

Number of Elec Dept Employees

Regular Full-time

Part-time \& Temporary

0
0
7,445
0
808
235

8,489

964

1,979

410

\section{0}

0
0

0

939

0

18,939

1
1,289

641

6,350

0

16,851

851
0

23,202

608

5,916

1,671

142

46
0

5,298

-43
0

2,217

17,187

23,044

0
0
0
0
8,097
0

0

0

13
0

19,885

885
0

8,097

19,898

322

2,009

818

406

85

0

1,562

807

10,402

24,613
0

0

0

0

$\mathbf{0}$

0

5,637

0

0
129

60

4

64

164

12

133

176
58

7

7

Total Elec Dept Employees.

65

Note: Totals may not equal sum of components because of independent rounding.

Source: Energy Information Administration, Form EIA-412, “Annual Report of Public Electric Utilities." 
Table 23. Electric Operation and Maintenance Expenses by Major U.S. Publicly Owned Electric Utility Within State, 1996 (Continued)

(Thousand Dollars)

\begin{tabular}{|c|c|c|c|c|c|c|}
\hline Item & $\begin{array}{l}\text { Washington } \\
\text { PUD No } 1 \text { of } \\
\text { Pend Oreille } \\
\text { Cnty } \\
\text { December } 31\end{array}$ & $\begin{array}{l}\text { Washington } \\
\text { PUD No } 1 \text { of } \\
\text { Snohomish } \\
\text { County } \\
\text { December } 31\end{array}$ & $\begin{array}{l}\text { Washington } \\
\text { PUD No } 1 \text { of } \\
\text { Whatcom } \\
\text { County } \\
\text { December } 31\end{array}$ & $\begin{array}{c}\text { Washington } \\
\text { PUD No } 2 \\
\text { of } \\
\text { Grant } \\
\text { County } \\
\text { December } 31\end{array}$ & $\begin{array}{l}\text { Washington } \\
\text { PUD No } 2 \text { of } \\
\text { Pacific } \\
\text { County } \\
\text { December } 31\end{array}$ & $\begin{array}{l}\text { Washington } \\
\text { PUD No } 3 \\
\text { of } \\
\text { Mason } \\
\text { County } \\
\text { December } 31\end{array}$ \\
\hline \multicolumn{7}{|l|}{ Production Expenses } \\
\hline 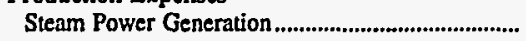 & 0 & 13,931 & 0 & 0 & 0 & o \\
\hline 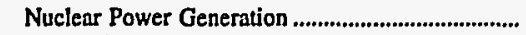 & 0 & 0 & 0 & 0 & 0 & 0 \\
\hline 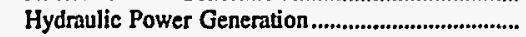 & 1,457 & 1,186 & 0 & 20,225 & 0 & 0 \\
\hline 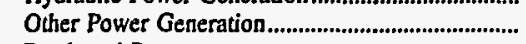 & 0 & 0 & 0 & 0 & 0 & 0 \\
\hline Purchased Power................................................................. & 8,582 & 183,095 & 4,624 & 14,154 & 8,580 & 16,339 \\
\hline 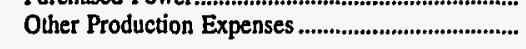 & 84 & 499 & 0 & 2 & 0 & 0 \\
\hline 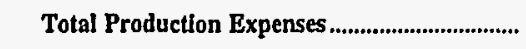 & 10,123 & 198,710 & 4,624 & 34,382 & 8,580 & 16,339 \\
\hline Transmission Expenses...................................................... & 1,379 & 10,749 & 26 & 1,811 & 0 & 0 \\
\hline 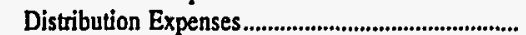 & 1,340 & 26,298 & 0 & 7,037 & 1,076 & 3,426 \\
\hline $\begin{array}{l}\text { Customer Accounts Expenses .................................. } \\
\text { Customer Service and Information }\end{array}$ & 395 & 9,647 & 0 & 2,011 & 589 & 1,076 \\
\hline 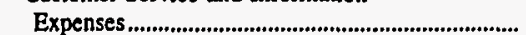 & 0 & 2,359 & $\mathbf{0}$ & 441 & 90 & 294 \\
\hline 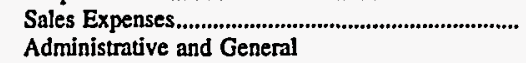 & 9 & 0 & 0 & $\mathbf{0}$ & 2 & 0 \\
\hline 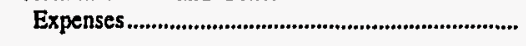 & 1,960 & 19,728 & 178 & 10,681 & 872 & 1,724 \\
\hline $\begin{array}{l}\text { Total Electric Operation and } \\
\text { Maintenance Expenses......................................... }\end{array}$ & 15,206 & 267,492 & 4,829 & 56,364 & 11,208 & 22,859 \\
\hline \multicolumn{7}{|l|}{ Fuel Expenses in Operation } \\
\hline 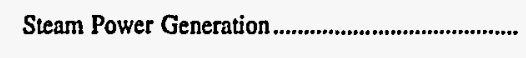 & 0 & 12,439 & 0 & 0 & 0 & 0 \\
\hline 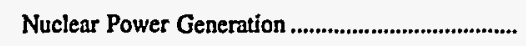 & 0 & 0 & 0 & 0 & 0 & 0 \\
\hline Other Power Generation & 0 & 0 & 0 & 0 & 0 & 0 \\
\hline \multicolumn{7}{|l|}{ Number of Elec Dept Employees } \\
\hline 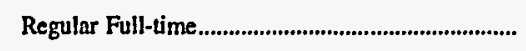 & 62 & 959 & $\mathbf{0}$ & 436 & 48 & 105 \\
\hline 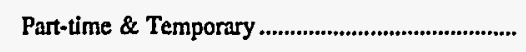 & 1 & 0 & 1 & 47 & $\mathbf{0}$ & 43 \\
\hline 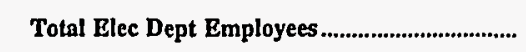 & 63 & 959 & 1 & 483 & 48 & 148 \\
\hline
\end{tabular}

Note: Totals may not equal sum of components because of independent rounding

Source: Energy Information Administration, Form EIA-412, "Annual Report of Public Electric Utilities." 
Table 23. Electric Operation and Maintenance Expenses by Major U.S. Publicly Owned Electric Utility Within State, 1996 (Continued)

(Thousand Dollars)

\begin{tabular}{|c|c|c|c|c|c|c|}
\hline Item & $\begin{array}{l}\text { Washington } \\
\text { Richland } \\
\text { City of } \\
\text { December } 31\end{array}$ & $\begin{array}{l}\text { Washington } \\
\text { Seattle } \\
\text { City of } \\
\text { December } 31\end{array}$ & $\begin{array}{l}\text { Washington } \\
\text { Tacoma } \\
\text { City of } \\
\text { December } 31\end{array}$ & $\begin{array}{c}\text { Washington } \\
\text { Vera } \\
\text { Irrigation } \\
\text { District \# } 15 \\
\text { December } 31\end{array}$ & $\begin{array}{c}\text { Washington } \\
\text { Washington } \\
\text { Pub } \\
\text { Pwr } \\
\text { Supply Sys } \\
\text { June } 30\end{array}$ & $\begin{array}{l}\text { Wisconsin } \\
\text { Badger Power } \\
\text { Marketing } \\
\text { Auth } \\
\text { December } 31\end{array}$ \\
\hline \multicolumn{7}{|l|}{ Production Expenses } \\
\hline & 0 & 11,819 & 17,333 & 0 & 0 & 0 \\
\hline $\begin{array}{l}\text { Nuclear Power Generation } \\
\text { Hydraulic Power Generation. }\end{array}$ & 0 & 0 & 0 & 0 & 133,380 & 0 \\
\hline & 0 & 17,593 & 8,632 & 0 & 107 & 0 \\
\hline 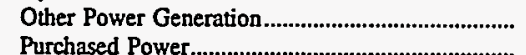 & 0 & 0 & 0 & 0 & 0 & $\mathbf{0}$ \\
\hline & 19,055 & 60,485 & 49,811 & 5,776 & 0 & 9,453 \\
\hline 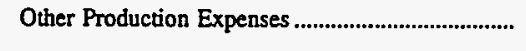 & 0 & 3,142 & 860 & 0 & 0 & 0 \\
\hline 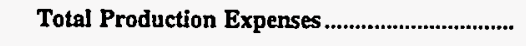 & 19,055 & 93,038 & 76,636 & 5,776 & 133,486 & 9,453 \\
\hline Transmission Expenses................................................ & 0 & 18,984 & 3,671 & 0 & 563 & 45 \\
\hline 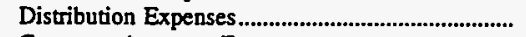 & 2,320 & 34,075 & 14,286 & 555 & 0 & 0 \\
\hline $\begin{array}{l}\text { Customer Accounts Expenses............................................. } \\
\text { Customer Service and Information }\end{array}$ & 462 & 17,333 & 3,833 & 296 & 0 & 0 \\
\hline 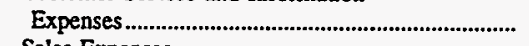 & 286 & 7,352 & 1,852 & 85 & 0 & 0 \\
\hline 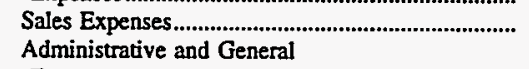 & 0 & 0 & 35 & 5 & 0 & 0 \\
\hline 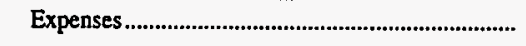 & 1,020 & 42,388 & 21,048 & 334 & 54,536 & 213 \\
\hline $\begin{array}{l}\text { Total Electric Operation and } \\
\text { Maintenance Expenses................. }\end{array}$ & 23142 & 213170 & & $=0=1$ & $100-08$ & ת \\
\hline \multicolumn{7}{|l|}{ Fuel Expenses in Operation } \\
\hline 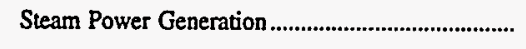 & 0 & 0 & 11,869 & 0 & 0 & 0 \\
\hline 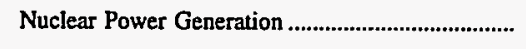 & 0 & 0 & 0 & 0 & 37,393 & 0 \\
\hline Other Power Generation & 0 & 0 & 0 & 0 & 0 & 0 \\
\hline \multicolumn{7}{|l|}{ Number of Elec Dept Employees } \\
\hline Regular Full-time & 56 & 1,668 & 710 & 29 & 1,044 & 0 \\
\hline 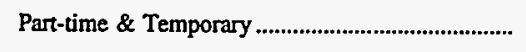 & 1 & 182 & 41 & 0 & 1 & 0 \\
\hline 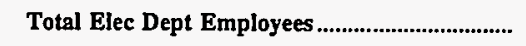 & 57 & 1,850 & 751 & 29 & 1,045 & $\mathbf{0}$ \\
\hline
\end{tabular}

Note: Totals may not equal sum of components because of independent rounding.

Source: Energy Information Administration, Form ElA-412, "Annual Report of Public Electric Utilities." 
Table 23. Electric Operation and Maintenance Expenses by Major U.S. Publicly Owned Electric Utility Within State, 1996 (Continued)

(Thousand Dollars)

\begin{tabular}{|c|c|c|c|c|c|c|}
\hline Item & $\begin{array}{l}\text { Wisconsin } \\
\text { Jefferson } \\
\text { City of } \\
\text { December } 31\end{array}$ & $\begin{array}{l}\text { Wisconsin } \\
\text { Kaukauna } \\
\text { City of } \\
\text { December } 31\end{array}$ & $\begin{array}{l}\text { Wisconsin } \\
\text { Manitowoc } \\
\text { Public } \\
\text { Utilities } \\
\text { December } 31\end{array}$ & $\begin{array}{l}\text { Wisconsin } \\
\text { Marshrield } \\
\text { City of } \\
\text { December } 31\end{array}$ & $\begin{array}{l}\text { Wisconsin } \\
\text { Menasha } \\
\text { City of } \\
\text { December } 31\end{array}$ & $\begin{array}{c}\text { Wisconsin } \\
\text { New London } \\
\text { Electric\&Water } \\
\text { Util } \\
\text { December } 31\end{array}$ \\
\hline \multicolumn{7}{|l|}{ Production Expenses } \\
\hline 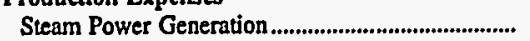 & $\mathbf{0}$ & 0 & 7,822 & 6 & 673 & 0 \\
\hline Nuclear Power Generation ............................................ & 0 & 0 & 0 & $\mathbf{0}$ & 0 & 0 \\
\hline Hydraulic Power Generation............................................. & 0 & 639 & 0 & 0 & 0 & 0 \\
\hline Other Power Generation................................................ & 0 & 47 & 150 & 181 & 0 & $\mathbf{0}$ \\
\hline 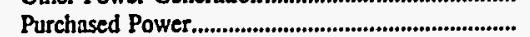 & 5,027 & 17,508 & 6,975 & 8,943 & 17,236 & 5,887 \\
\hline 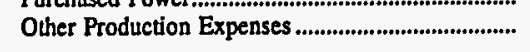 & 0 & 216 & 24 & 0 & 0 & 0 \\
\hline 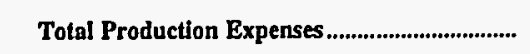 & 5,027 & 18,410 & 14,971 & 9,129 & 17,909 & 5,887 \\
\hline 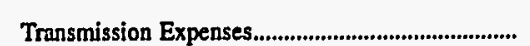 & 0 & 39 & 135 & 9 & 10 & 0 \\
\hline 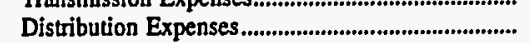 & 318 & 555 & 689 & 742 & 456 & 261 \\
\hline 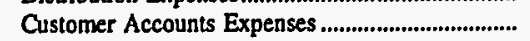 & 53 & 223 & 267 & 168 & 146 & 62 \\
\hline $\begin{array}{l}\text { Customer Service and Information } \\
\text { Expenses }\end{array}$ & 0 & $\mathbf{0}$ & 0 & 0 & 0 & 0 \\
\hline 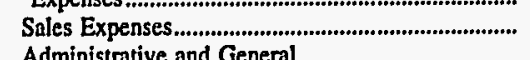 & 26 & 5 & 103 & 201 & 200 & 70 \\
\hline $\begin{array}{l}\text { Administrative and General } \\
\text { Expenses }\end{array}$ & 210 & 1,026 & 1,179 & 535 & 766 & 216 \\
\hline $\begin{array}{l}\text { Total Electric Operation and } \\
\text { Maintenance Expenses......................................... }\end{array}$ & 5,633 & 20,260 & 17,344 & 10,785 & 19,487 & 6,495 \\
\hline \multicolumn{7}{|l|}{ Fuel Expenses in Operation } \\
\hline 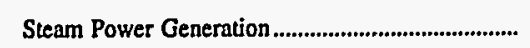 & 0 & $r \quad 0$ & 5,084 & $\mathbf{0}$ & 5 & 0 \\
\hline 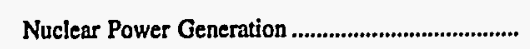 & $\mathbf{0}$ & 0 & $\mathbf{0}$ & 0 & 0 & 0 \\
\hline 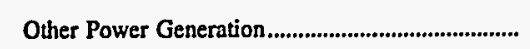 & $\mathbf{0}$ & 4 & 56 & 0 & $\mathbf{0}$ & $\mathbf{0}$ \\
\hline \multicolumn{7}{|l|}{ Number of Elec Dept Employees } \\
\hline 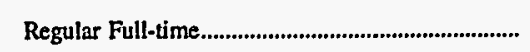 & 7 & 43 & 63 & 24 & 36 & 12 \\
\hline 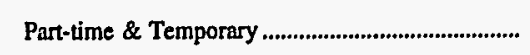 & 0 & 3 & 1 & 2 & 0 & 0 \\
\hline Total Elec Dept Employees...................................... & 7 & 46 & 64 & 26 & 36 & 12 \\
\hline
\end{tabular}

Note: Totals may not equal sum of components because of independent rounding.

Source: Energy Information Administration, Form EIA-412, "Annual Report of Public Electric Utilities." 
Table 23. Electric Operation and Maintenance Expenses by Major U.S. Publicly Owned Electric Utility Within State, 1996 (Continued)

(Thousand Dollars)

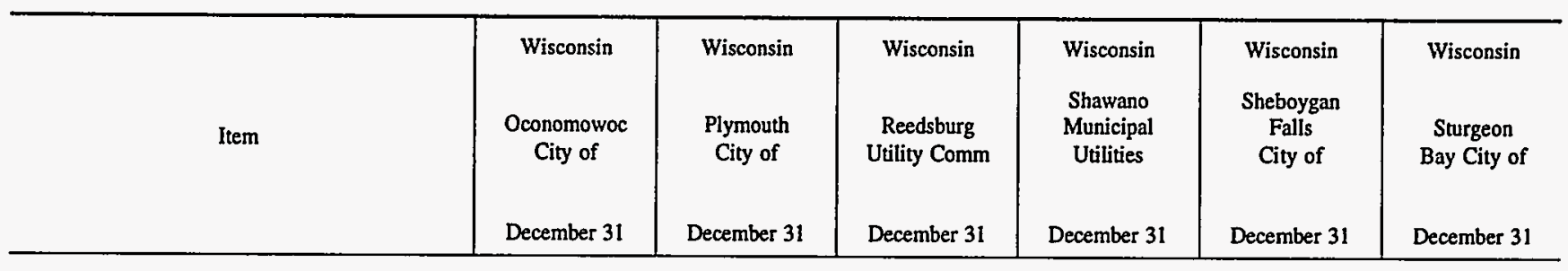

\section{Production Expenses}

Steam Power Generation.

Nuclear Power Generation.

Hydraulic Power Generation

Other Power Generation

Purchased Power.

Other Production Expenses

Total Production Expenses

Transmission Expenses.

Distribution Expenses.................................................

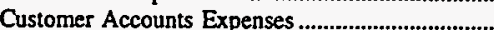

Customer Service and Information

Expenses.....................................................................

Sales Expenses.............................................................

Administrative and General

Expenses.

Total Electric Operation and

Maintenance Expenses.
5,9

0
0
0
0
5,928
0

5,928

0

328
126

0

105

415

6,902

0
0
0
0
5,620
0

5,620

0

412

90

0

9

280

6,410

6,989
0
0
0
0
7,337
0

7,337

3
211

71

0

273

7,895

$\begin{array}{rr}0 & 0 \\ 0 & 0 \\ 0 & 0 \\ 0 & 0 \\ 6,370 & 4,511 \\ 0 & 0\end{array}$

6,370

4,511

0
285

285
59

7

330

145

6

256

170

6,884

5,310

Fuel Expenses in Operation

Steam Power Generation....

Nuclear Power Generation

0

0

0

Other Power Generation

Number of Elec Dept Employees

Regular Full-time.

Part-time \& Temporar

Total Elec Dept Employees
18

36
0

0

0

18

o

18
0

0

0
0

0

0

12

0

12
0

0

0

Note: Totals may not equal sum of components because of independent rounding.

Source: Energy Information Administration, Form ElA-412, "Annual Report of Public Electric Utilities." 
Table 23. Electric Operation and Maintenance Expenses by Major U.S. Publicly Owned Electric Utility Within State, 1996 (Continued)

(Thousand Dollars)

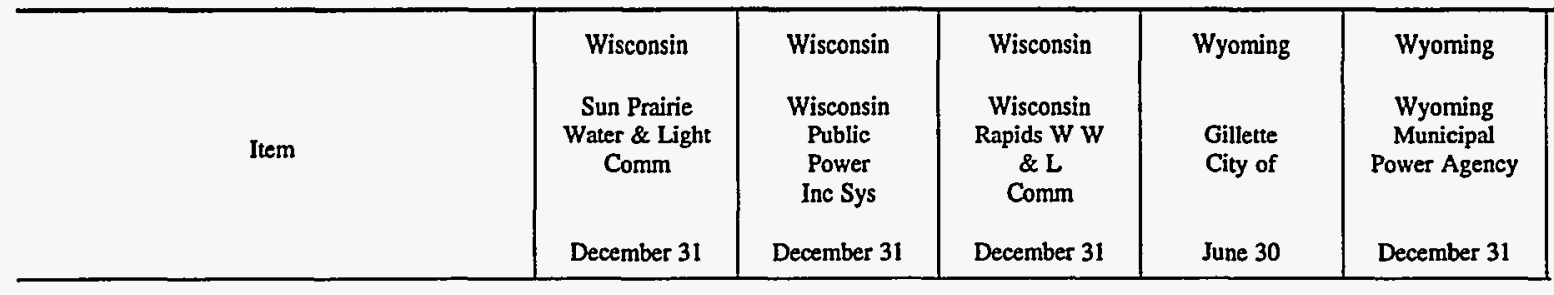

Production Expenses

Steam Power Generation.

Nuclear Power Generation

Hydraulic Power Generation.......................................

Other Power Generation.

Purchased Power.

Other Production Expenses ....................................

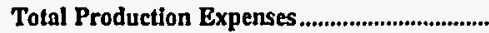

Transmission Expenses.

Distribution Expenses

Customer Accounts Expenses ..................................

Customer Service and Information

Expenses........................................................................

Sales Expenses ...........................................................

Administrative and General

Expenses

Total Electric Operation and

Maintenance Expenses

Fuel Expenses in Operation

Steam Power Generation

Nuclear Power Generation .....................................

Other Power Generation.

Number of Elec Dept Employees

Regular Full-time.

Part-time \& Temporary.

23

2

Total Elec Dept Employees

0
0
0
0
5,849
0

5,849

1
273

98

0

0
82

196

6,498

11,610

0
0
921
73,313

0

0

0

6,709

0

85,844

5,471

5,471
0
0

0

258

0

557

3,943

95,257

8,231

10,154

$\begin{array}{rr}0 & 1,543 \\ 0 & 0 \\ 0 & 0 \\ 0 & 0 \\ 8,886 & 1,638 \\ 0 & 0\end{array}$

8,886

3,181

79

701

32

154

0

304

3,790

Note: Totals may not equal sum of components because of independent rounding.

Source: Energy Information Administration, Form EIA-412, "Annual Report of Public Electric Utilities." 
Table 24. Electric Utility Plant by Major U.S. Publicly Owned Electric Utility Within State at End of Period, 1996

(Thousand Dollars)

\begin{tabular}{|c|c|c|c|c|c|c|}
\hline Item & $\begin{array}{l}\text { Alabama } \\
\text { Alabama } \\
\text { Municipal } \\
\text { Elec Auth } \\
\text { September } 30\end{array}$ & $\begin{array}{l}\text { Alabama } \\
\text { Albertville } \\
\text { Municipal } \\
\text { Utils Bd } \\
\text { June } 30\end{array}$ & $\begin{array}{l}\text { Alabama } \\
\text { Andalusia } \\
\text { City of } \\
\text { September } 30\end{array}$ & $\begin{array}{l}\text { Alabama } \\
\text { Athens } \\
\text { City of } \\
\text { December } 31\end{array}$ & $\begin{array}{l}\text { Alabama } \\
\text { Bessemer } \\
\text { City of } \\
\text { June } 30\end{array}$ & $\begin{array}{l}\text { Alabama } \\
\text { Cullman }^{\prime} \\
\text { Power Board } \\
\text { June } 30\end{array}$ \\
\hline \multicolumn{7}{|l|}{ Electric Plant in Service } \\
\hline 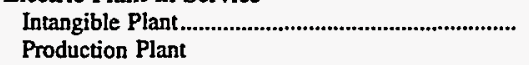 & 0 & 0 & 0 & 0 & 0 & 0 \\
\hline Steam & 0 & 0 & 0 & 0 & 0 & 0 \\
\hline 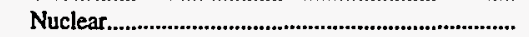 & 0 & 0 & 0 & 0 & 0 & 0 \\
\hline 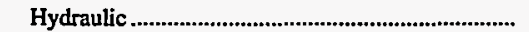 & 0 & 0 & 0 & 0 & 0 & 0 \\
\hline Other & $\mathbf{0}$ & 0 & 0 & 0 & 0 & 0 \\
\hline 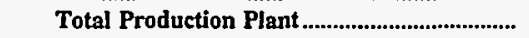 & 0 & 0 & 0 & 0 & $\mathbf{0}$ & 0 \\
\hline 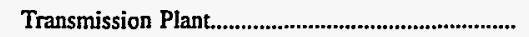 & 0 & 0 & 0 & 5,634 & 0 & 0 \\
\hline 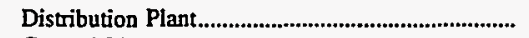 & $\mathbf{0}$ & 12,465 & 3,920 & 37,617 & 18,801 & 11,573 \\
\hline 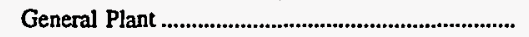 & 0 & 1,823 & 0 & 2,661 & 2,475 & 2,468 \\
\hline Total Electric Plant in Service ........................... & 0 & 14,289 & 3,920 & 45,913 & 21,275 & 14,041 \\
\hline 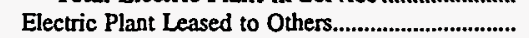 & 0 & 0 & 0 & 0 & 0 & 0 \\
\hline Electric Plant Held for Future Use .............................. & 0 & 0 & 0 & 0 & 53 & 0 \\
\hline 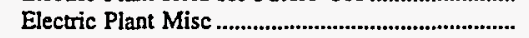 & 0 & 0 & 0 & 0 & 0 & 0 \\
\hline Total Electric Utility Plant................................. & 0 & 14,289 & 3,920 & 45,913 & 21,328 & 14,041 \\
\hline $\begin{array}{l}\text { Construction Work in Progress - Electric................. } \\
\text { Accumulated Provision for Depreciation }\end{array}$ & 0 & 14 & 0 & 1,178 & 1,620 & 230 \\
\hline 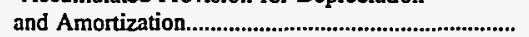 & 0 & 5,576 & 1,428 & 17,152 & 11,202 & 5,972 \\
\hline 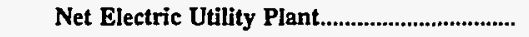 & $\mathbf{0}$ & 8,727 & 2,493 & 29,938 & 11,746 & 8,299 \\
\hline
\end{tabular}

\begin{tabular}{|c|c|c|c|c|c|c|}
\hline Item & $\begin{array}{l}\text { Alabama } \\
\text { Decatur } \\
\text { City of } \\
\text { June } 30\end{array}$ & $\begin{array}{l}\text { Alabama } \\
\text { Dothan } \\
\text { City of } \\
\text { September } 30\end{array}$ & $\begin{array}{l}\text { Alabama } \\
\text { Florence } \\
\text { City of } \\
\text { June } 30\end{array}$ & $\begin{array}{c}\text { Alabama } \\
\text { Foley } \\
\text { City of } \\
\text { (Riviera Utils) } \\
\text { December } 31\end{array}$ & $\begin{array}{l}\text { Alabama } \\
\text { Fort Payne } \\
\text { Improvement } \\
\text { Auth } \\
\text { June } 30\end{array}$ & $\begin{array}{l}\text { Alabama } \\
\text { Guntersville } \\
\text { Electric } \\
\text { Board } \\
\text { June } 30\end{array}$ \\
\hline 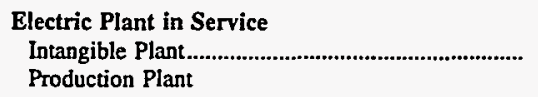 & 0 & 0 & 0 & 0 & 0 & 0 \\
\hline Steam & 0 & 0 & 0 & 0 & 0 & 0 \\
\hline 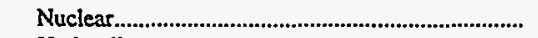 & 0 & 0 & 0 & 0 & 0 & 0 \\
\hline 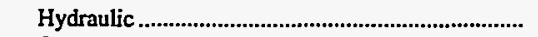 & 0 & 0 & 0 & 0 & 0 & 0 \\
\hline Other & 0 & 0 & 0 & 4 & 0 & 0 \\
\hline Total Production Plant & $\mathbf{0}$ & 0 & $\mathbf{0}$ & 4 & 0 & $\mathbf{0}$ \\
\hline 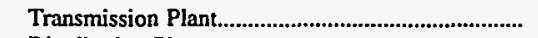 & 0 & 0 & 14,908 & 12,923 & 0 & 0 \\
\hline 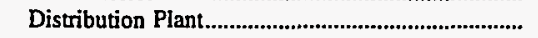 & 40,490 & 0 & 58,379 & 41,798 & 12,348 & 9,722 \\
\hline General Plant & 3,119 & 62,953 & 7,614 & 9,535 & 1,661 & 920 \\
\hline Total Electric Plant in Service ............................ & 43,610 & 62,953 & 80,900 & 64,260 & 14,009 & 10,642 \\
\hline 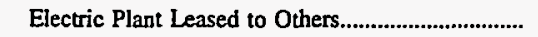 & 0 & 0 & 0 & 0 & 0 & 0 \\
\hline Electric Plant Held for Future Use .............................. & 309 & 0 & 0 & 0 & 0 & 0 \\
\hline Electric Plant Misc & 0 & 0 & 94 & 0 & 43 & 0 \\
\hline 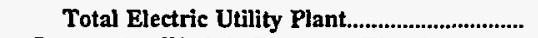 & 43,918 & 62,953 & 80,994 & 64,260 & 14,052 & 10,642 \\
\hline $\begin{array}{l}\text { Construction Work in Progress - Electric............... } \\
\text { Accumulated Provision for Depreciation }\end{array}$ & 472 & 0 & 1,782 & 764 & 798 & 152 \\
\hline and Amortization. & 19,286 & 25,273 & 35,838 & 22,628 & 5,464 & 4,314 \\
\hline Net Electric Utility Plant....................................... & 25,104 & 37,680 & 46,938 & 42,396 & 9,385 & 6,481 \\
\hline
\end{tabular}

Note: Totals may not equal sum of components because of independent rounding.

Source: Energy Information Administration, Form EIA-412, "Annual Report of Public Electric Utilities." 
Table 24. Electric Utility Plant by Major U.S. Publicly Owned Electric Utility Within State at End of Period, 1996 (Continued)

(Thousand Dollars)

\begin{tabular}{|c|c|c|c|c|c|c|}
\hline Item & $\begin{array}{c}\text { Alabama } \\
\text { Hartselle } \\
\text { City of } \\
\text { June } 30\end{array}$ & $\begin{array}{l}\text { Alabama } \\
\text { Huntsville } \\
\text { City of } \\
\text { September } 30\end{array}$ & $\begin{array}{l}\text { Alabama } \\
\text { Muscle } \\
\text { Shoals } \\
\text { City of } \\
\text { June } 30\end{array}$ & $\begin{array}{l}\text { Alabama } \\
\text { Opelika } \\
\text { City of } \\
\text { September } 30\end{array}$ & $\begin{array}{l}\text { Alabama } \\
\text { Scottsboro } \\
\text { City of } \\
\text { June } 30\end{array}$ & $\begin{array}{l}\text { Alabama } \\
\text { Sheffield } \\
\text { Utilities } \\
\text { June } 30\end{array}$ \\
\hline \multicolumn{7}{|l|}{ Electric Plant in Service } \\
\hline $\begin{array}{l}\text { Intangible Plant } \\
\text { Production Plant }\end{array}$ & 0 & 0 & 0 & 0 & 0 & 0 \\
\hline 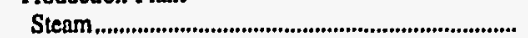 & 0 & 0 & 0 & D & 0 & 0 \\
\hline 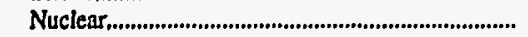 & 0 & 0 & 0 & 0 & 0 & 0 \\
\hline 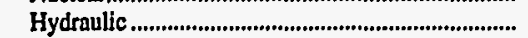 & 0 & 0 & 0 & 0 & 0 & 0 \\
\hline Other & 0 & 0 & 0 & 0 & 0 & 0 \\
\hline Tofal Production Plant......................................... & 0 & 0 & 0 & 0 & 0 & 0 \\
\hline 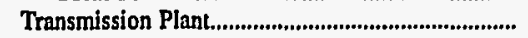 & 0 & 16,731 & 0 & 20,468 & 0 & 1,299 \\
\hline 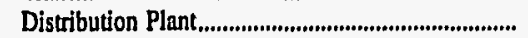 & 6,231 & 147,179 & 13,543 & 0 & 14,383 & 30,653 \\
\hline 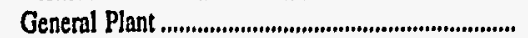 & 393 & 12,113 & 2,505 & 0 & 1,707 & 4,556 \\
\hline Total Electric Plant in Service ............................ & 6,624 & 176,023 & 16,048 & 20,468 & 16,090 & 36,508 \\
\hline Electric Plant Leased to Others................................ & 0 & 0 & 0 & 0 & 0 & 0 \\
\hline Electric Plant Held for Future Use .............................. & 13 & 0 & 0 & 0 & 0 & 0 \\
\hline 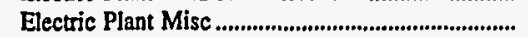 & 0 & 0 & 0 & 0 & 0 & 97 \\
\hline Total Electric Utillity Plant.............................. & 6,636 & 176,023 & 16,048 & 20,468 & 16,090 & 36,606 \\
\hline $\begin{array}{l}\text { Construction Work in Progress - Electric............... } \\
\text { Accumulated Provision for Depreciation }\end{array}$ & 107 & 10,939 & 117 & 717 & 293 & 1,828 \\
\hline 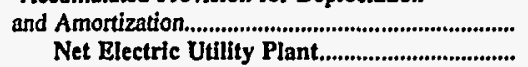 & $\begin{array}{l}3,274 \\
\mathbf{3 , 4 7 0}\end{array}$ & $\begin{array}{r}72,742 \\
114,2,20\end{array}$ & $\begin{array}{r}5,415 \\
10,750\end{array}$ & $\begin{array}{r}11,712 \\
9,473\end{array}$ & $\begin{array}{l}6,458 \\
9,925\end{array}$ & $\begin{array}{l}16,397 \\
22,037\end{array}$ \\
\hline
\end{tabular}

\begin{tabular}{|c|c|c|c|c|c|c|}
\hline Item & $\begin{array}{l}\text { Alabama } \\
\text { Sylacauga } \\
\text { Utilities } \\
\text { Board } \\
\text { September } 30\end{array}$ & $\begin{array}{c}\text { Alabama } \\
\text { Troy } \\
\text { City of } \\
\text { September } 30\end{array}$ & $\begin{array}{l}\text { Alabama } \\
\text { Tuskegee } \\
\text { City of } \\
\text { September } 30\end{array}$ & $\begin{array}{l}\text { Alaska } \\
\text { Alaska } \\
\text { Energy } \\
\text { Authority } \\
\text { June } 30\end{array}$ & $\begin{array}{c}\text { Alaska } \\
\text { Anchorage } \\
\text { City of } \\
\text { December } 31\end{array}$ & $\begin{array}{l}\text { Alaska } \\
\text { Fairbanks } \\
\text { City of } \\
\text { December } 31\end{array}$ \\
\hline \multicolumn{7}{|l|}{ Electric Plant in Service } \\
\hline 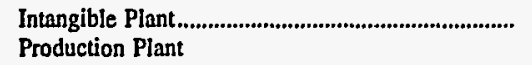 & 0 & 0 & 0 & 2,989 & 14,113 & 169 \\
\hline Steam & 0 & 0 & $\mathbf{0}$ & 0 & 20,173 & 31,691 \\
\hline 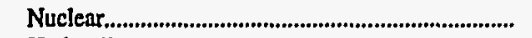 & 0 & 0 & 0 & 0 & 0 & 0 \\
\hline Hydraulic & 0 & 0 & 0 & 580,838 & 0 & 0 \\
\hline 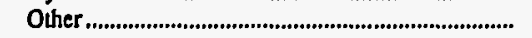 & 0 & 0 & 0 & 0 & 218,924 & 4,330 \\
\hline 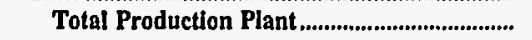 & $\mathbf{0}$ & 0 & 0 & 580,838 & 239,097 & 36,021 \\
\hline 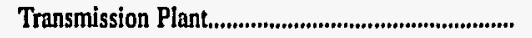 & 0 & 0 & 0 & 339,022 & 16,754 & 3,698 \\
\hline Distribution Plant....................................................... & 10,248 & 10,183 & 7,233 & 0 & 99,093 & 8,531 \\
\hline General Plant & 1,172 & 1,430 & 0 & 7,603 & 34,162 & 1,242 \\
\hline Total Electric Plant in Service & 11,420 & 11,613 & 7,233 & 930,452 & 403,220 & 49,661 \\
\hline Electric Plant Leased to Others................................. & 0 & 0 & 0 & 0 & 0 & 0 \\
\hline 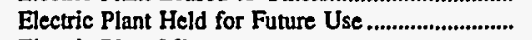 & 0 & 0 & 0 & $\mathbf{0}$ & 0 & 0 \\
\hline 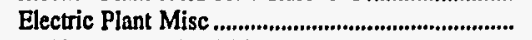 & 0 & 0 & $\mathbf{0}$ & 0 & 5,000 & 0 \\
\hline Total Electric Utility Plant................................. & 11,420 & 11,613 & $\mathbf{7 , 2 3 3}$ & 930,452 & 408,220 & 49,661 \\
\hline $\begin{array}{l}\text { Construction Work in Progress - Electric.............. } \\
\text { Accumulated Provision for Depreciation }\end{array}$ & 0 & 0 & 33 & 0 & 8,154 & 694 \\
\hline 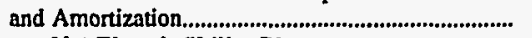 & 5,941 & 6,201 & 3,973 & 218,067 & 133,392 & 31,680 \\
\hline Net Electric Utllity Plant..................................... & 5,479 & 5,412 & 3,293 & 712,385 & 282,982 & 18,675 \\
\hline
\end{tabular}

Note: Totals may not equal sum of components because of independent rounding.

Source: Energy Information Administration, Form EIA-412, "Annual Report of Public Electric Utilities." 
Table 24. Electric Utility Plant by Major U.S. Publicly Owned Electric Utility Within State at End of Period, 1996 (Continued)

(Thousand Dollars)

\begin{tabular}{|c|c|c|c|c|c|c|}
\hline Item & $\begin{array}{c}\text { Alaska } \\
\text { Ketchikan } \\
\text { City of } \\
\text { December } 31\end{array}$ & $\begin{array}{l}\text { Arizona } \\
\text { Arizona } \\
\text { Power } \\
\text { Authority } \\
\text { June } 30\end{array}$ & $\begin{array}{l}\text { Arizona } \\
\text { Electrical } \\
\text { Dist } \\
\text { No2 } \\
\text { Pinal Cnty } \\
\text { December } 31\end{array}$ & $\begin{array}{l}\text { Arizona } \\
\text { Mesa } \\
\text { City of } \\
\text { June } 30\end{array}$ & $\begin{array}{l}\text { Arizona } \\
\text { Navajo } \\
\text { Tribal } \\
\text { Utility } \\
\text { Auth } \\
\text { December } 31\end{array}$ & $\begin{array}{l}\text { Arizona } \\
\text { Salt River } \\
\text { Proj Ag } \\
\text { I \& P Dist } \\
\text { April } 30\end{array}$ \\
\hline $\begin{array}{l}\text { Electric Plant in Service } \\
\text { Intangible Plant } \\
\text { Production Plant }\end{array}$ & 133 & 0 & 0 & 0 & $\mathbf{0}$ & 87,621 \\
\hline Steam & 0 & 0 & 0 & 0 & 0 & $1,551,704$ \\
\hline 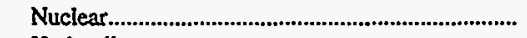 & 0 & 0 & 0 & 0 & 0 & $1,596,572$ \\
\hline 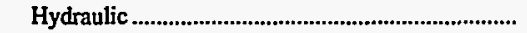 & 17,936 & 0 & 0 & 0 & 0 & 90,042 \\
\hline Other & 4,677 & $\mathbf{0}$ & 0 & 0 & 0 & 113,400 \\
\hline 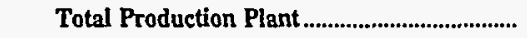 & 22,614 & 0 & $\mathbf{0}$ & 0 & $\mathbf{0}$ & $3,351,718$ \\
\hline 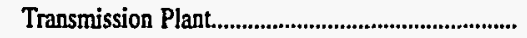 & 1,184 & 289 & 0 & 0 & 7,551 & 640,360 \\
\hline Distribution Plant. & 24,047 & 217 & 15,223 & 0 & 101,187 & $1,227,117$ \\
\hline 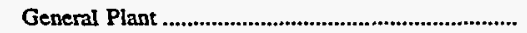 & 3,670 & 694 & 2,728 & 57,511 & 13,365 & 543,255 \\
\hline Total Electric Plant in Service ........................... & 51,646 & 1,200 & 17,950 & 57,511 & 122,103 & $5,850,071$ \\
\hline 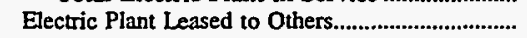 & 0 & 0 & 0 & 0 & 0 & 0 \\
\hline Electric Plant Held for Future Use .............................. & 76 & 0 & 0 & 0 & $\mathbf{0}$ & 31,712 \\
\hline 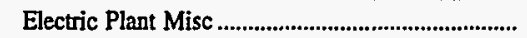 & 0 & 0 & 0 & 0 & 6,871 & 41,867 \\
\hline 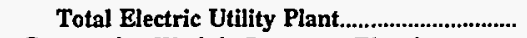 & 51,722 & 1,200 & 17,950 & 57,511 & 128,973 & $5,923,650$ \\
\hline $\begin{array}{l}\text { Construction Work in Progress - Electric................ } \\
\text { Accumulated Provision for Depreciation }\end{array}$ & 7,179 & 0 & 0 & 4,166 & 9,071 & 212,552 \\
\hline 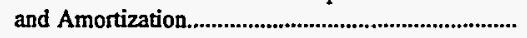 & 23,769 & 845 & 8,056 & 15,607 & 48,899 & $2,044,415$ \\
\hline 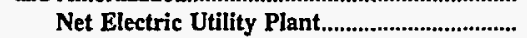 & 35,132 & 355 & 9,894 & 46,070 & 89,146 & $4,091,787$ \\
\hline
\end{tabular}

\begin{tabular}{|c|c|c|c|c|c|c|}
\hline Item & $\begin{array}{c}\text { Arizona } \\
\text { Tohono } \\
\text { OOdham } \\
\text { Utility Auth } \\
\text { December } 31\end{array}$ & $\begin{array}{l}\text { Arkansas } \\
\text { Benton } \\
\text { City of } \\
\text { December } 31\end{array}$ & $\begin{array}{c}\text { Arkansas } \\
\text { Bentonville } \\
\text { City of }\end{array}$ & $\begin{array}{l}\text { Arkansas } \\
\text { Clarksville } \\
\text { Light } \\
\& \\
\text { Water Co } \\
\text { September } 30\end{array}$ & $\begin{array}{l}\text { Arkansas } \\
\text { Conway } \\
\text { Corp } \\
\text { December } 31\end{array}$ & $\begin{array}{c}\text { Arkansas } \\
\text { Hope } \\
\text { City of } \\
\text { December } 31\end{array}$ \\
\hline \multicolumn{7}{|l|}{ Electric Plant in Service } \\
\hline 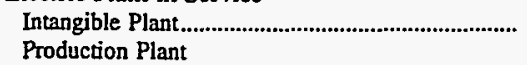 & 0 & 0 & 164 & 0 & $\mathbf{0}$ & 0 \\
\hline Steam & 0 & 0 & 0 & 0 & 39,491 & 0 \\
\hline 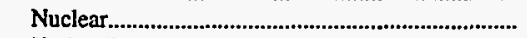 & 0 & 0 & 0 & 0 & 0 & 0 \\
\hline 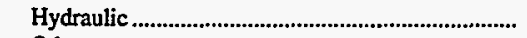 & 0 & $\mathbf{0}$ & 0 & 0 & 0 & 0 \\
\hline Other & 0 & 1,689 & 0 & 0 & 0 & 7,669 \\
\hline Total Production Plant ..................................... & 0 & 1,689 & $\mathbf{0}$ & 0 & 39,491 & 7,669 \\
\hline 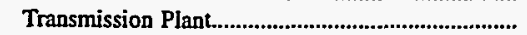 & 1,885 & 0 & 0 & 3,388 & 0 & 0 \\
\hline 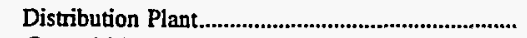 & 8,285 & 7,649 & 0 & 9,259 & 29,079 & 8,241 \\
\hline 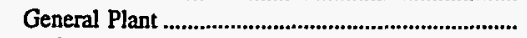 & 1,130 & 0 & 54,917 & 972 & 5,578 & 624 \\
\hline Total Electric Plant in Service .......................... & 11,300 & 9,337 & 55,081 & 13,618 & 74,147 & 16,534 \\
\hline Electric Plant Leased to Others................................. & 0 & 0 & 0 & 0 & 0 & 0 \\
\hline Electric Plant Held for Future Use ........................... & 0 & 0 & 0 & 0 & 0 & 0 \\
\hline 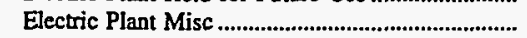 & 0 & 0 & 0 & 0 & 0 & $\mathbf{0}$ \\
\hline Total Electric Utility Plant & 11,300 & 9,337 & 55,081 & 13,618 & 74,147 & 16,534 \\
\hline $\begin{array}{l}\text { Construction Work in Progress - Electric.................... } \\
\text { Accumulated Provision for Depreciation }\end{array}$ & 56 & 0 & 57 & 229 & 25 & 103 \\
\hline 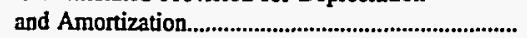 & 3,331 & 6,113 & 12,412 & 4,549 & 30,308 & 4,720 \\
\hline 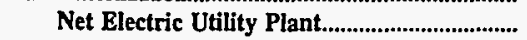 & 8,024 & 3,224 & 42,726 & 9,299 & 43,864 & 11,918 \\
\hline
\end{tabular}

Note: Totals may not equal sum of components because of independent rounding.

Source: Energy Information Administration, Form EIA-412, "Annual Report of Public Electric Utilities." 
Table 24. Electric Utility Plant by Major U.S. Publicly Owned Electric Utility Within State at End of Period, 1996 (Continued)

(Thousand Dollars)

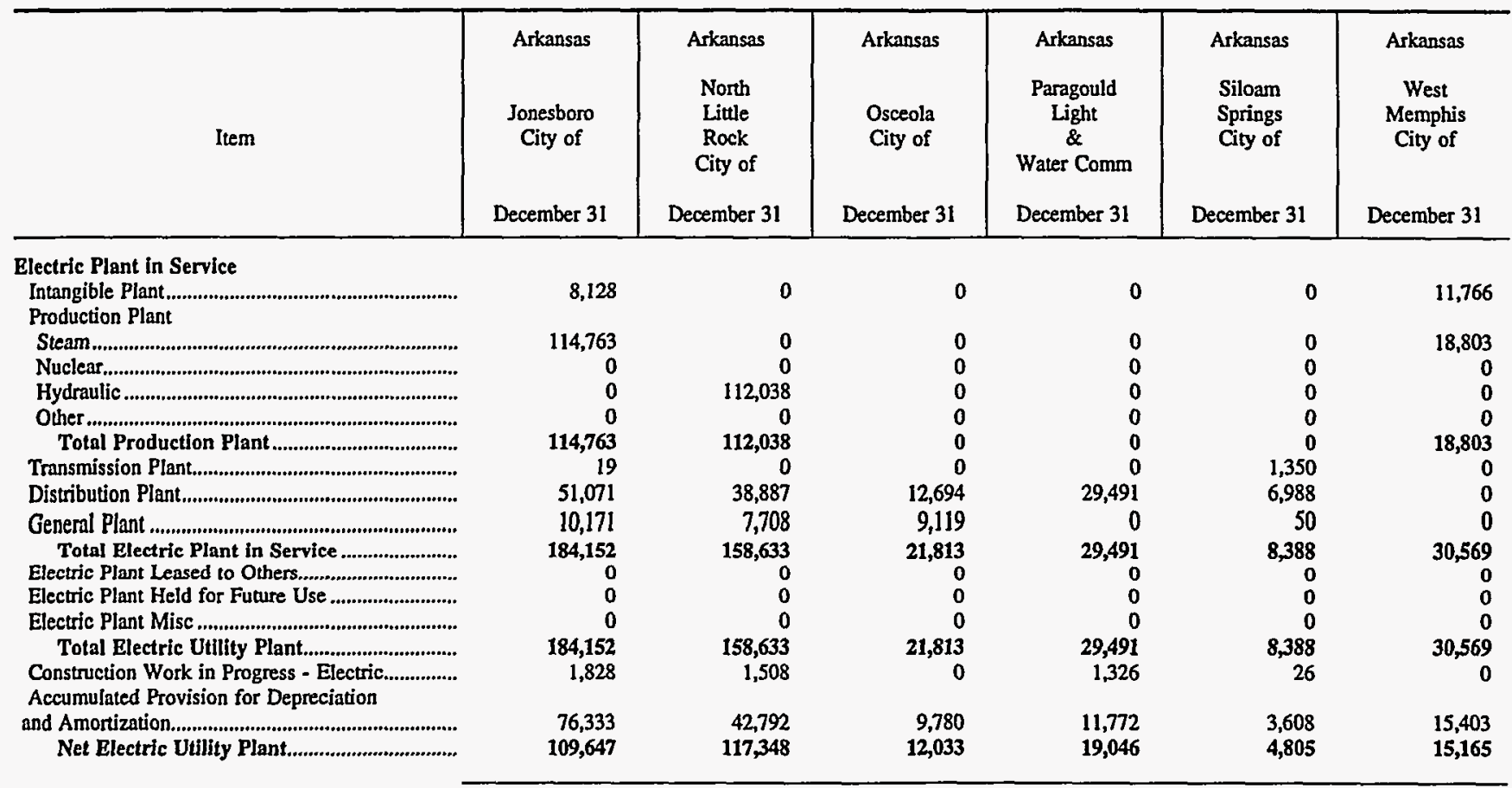

\begin{tabular}{|c|c|c|c|c|c|c|}
\hline Item & $\begin{array}{l}\text { California } \\
\text { Alameda } \\
\text { City of } \\
\text { June } 30\end{array}$ & $\begin{array}{l}\text { California } \\
\text { Anaheim } \\
\text { City of } \\
\text { June } 30\end{array}$ & $\begin{array}{l}\text { California } \\
\text { Azusa } \\
\text { City of } \\
\text { June } 30\end{array}$ & $\begin{array}{l}\text { California } \\
\text { Burbank } \\
\text { City of } \\
\text { June } 30\end{array}$ & $\begin{array}{l}\text { California } \\
\text { California } \\
\text { Dept } \\
\text { Wur } \\
\text { Resources } \\
\text { June } 30\end{array}$ & $\begin{array}{l}\text { California } \\
\text { Colton } \\
\text { City of } \\
\text { June } 30\end{array}$ \\
\hline \multicolumn{7}{|l|}{ Electric Plant in Service } \\
\hline 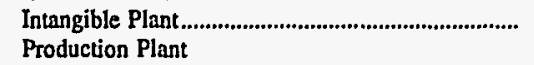 & 0 & 0 & 0 & 16,930 & 0 & 0 \\
\hline Steam & 0 & 55,708 & 0 & 51,219 & 0 & 0 \\
\hline 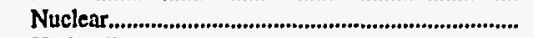 & 0 & 194,652 & $\mathbf{0}$ & $\mathbf{0}$ & 0 & 0 \\
\hline 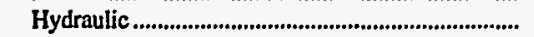 & 0 & 0 & 0 & 0 & 550,457 & 0 \\
\hline 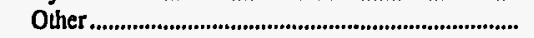 & 0 & 35,282 & 0 & 0 & 315,969 & 0 \\
\hline Total Production Plant ................................... & 0 & 285,642 & 0 & 51,219 & 866,426 & 0 \\
\hline Transmission Plant.................................................... & 3,594 & 18,271 & 0 & 18,504 & 0 & 0 \\
\hline 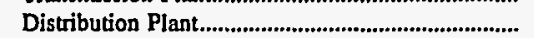 & 39,819 & 188,818 & 18,038 & 86,656 & 0 & 0 \\
\hline 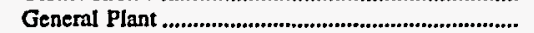 & 8,849 & 48,211 & 0 & 11,057 & $\mathbf{0}$ & 14,562 \\
\hline 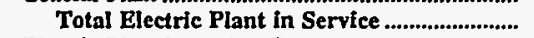 & 52,263 & 540,942 & 18,038 & 184,366 & 866,426 & 14,562 \\
\hline Electric Plant Leased to Others.................................... & 0 & 0 & 0 & 0 & 0 & 0 \\
\hline Electric Plant Held for Future Use ............................. & 0 & 0 & $\mathbf{0}$ & 0 & $\mathbf{0}$ & 0 \\
\hline 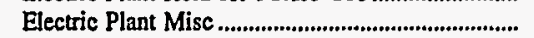 & 0 & 0 & 0 & 0 & $\mathbf{0}$ & 0 \\
\hline 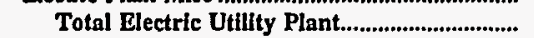 & 52,263 & 540,942 & 18,038 & 184,366 & 866,426 & 14,562 \\
\hline $\begin{array}{l}\text { Construction Work in Progress - Electric............... } \\
\text { Accumulated Provision for Depreciation }\end{array}$ & 0 & 32,905 & 0 & 8,477 & $\mathbf{0}$ & 11,961 \\
\hline 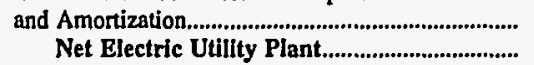 & $\begin{array}{l}17,161 \\
35,102\end{array}$ & $\begin{array}{l}151,311 \\
422,536\end{array}$ & $\begin{array}{r}2,940 \\
15,098\end{array}$ & $\begin{array}{r}106,068 \\
86,775\end{array}$ & $\begin{array}{l}323,247 \\
543,179\end{array}$ & $\begin{array}{r}6,530 \\
19,993\end{array}$ \\
\hline
\end{tabular}

Note: Totals may not equal sum of components because of independent rounding.

Source: Energy Information Administration, Form EIA-412, "Annual Report of Public Electric Utilities." 
Table 24. Electric Utility Plant by Major U.S. Publicly Owned Electric Utility Within State at End of Period, 1996 (Continued)

(Thousand Dollars)

\begin{tabular}{|c|c|c|c|c|c|c|}
\hline Item & $\begin{array}{c}\text { Califomia } \\
\text { Glendale } \\
\text { City of } \\
\text { June } 30\end{array}$ & $\begin{array}{l}\text { Califomia } \\
\text { Imperial } \\
\text { Irrigation } \\
\text { District } \\
\text { December } 31\end{array}$ & $\begin{array}{c}\text { California } \\
\text { Kings River } \\
\begin{array}{c}\text { Conservation } \\
\text { Dist }\end{array} \\
\text { June } 30\end{array}$ & $\begin{array}{l}\text { California } \\
\text { Lassen } \\
\text { Municipal } \\
\text { Utility Dist } \\
\text { June } 30\end{array}$ & $\begin{array}{l}\text { California } \\
\text { Lodi } \\
\text { City of } \\
\text { June } 30\end{array}$ & $\begin{array}{l}\text { Califomia } \\
\text { Los Angeles } \\
\text { City of } \\
\text { June } 30\end{array}$ \\
\hline $\begin{array}{l}\text { Electric Plant in Service } \\
\text { Intangible Plant............................................................. } \\
\text { Production Plant }\end{array}$ & 0 & 769 & 0 & 0 & 0 & 0 \\
\hline 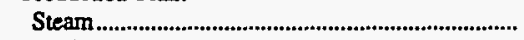 & 44,666 & 116,684 & 0 & 0 & 0 & $1,024,670$ \\
\hline 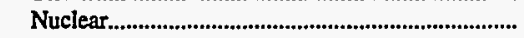 & 0 & 0 & 0 & 0 & 0 & 510,325 \\
\hline 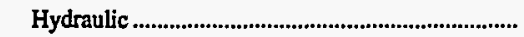 & 0 & 52,586 & 65,520 & 0 & 0 & 485,584 \\
\hline Other & 0 & 24,555 & 0 & 0 & 0 & 297,311 \\
\hline 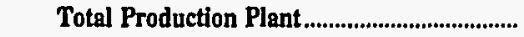 & 44,666 & 193,825 & 65,520 & 0 & 0 & $2,317,891$ \\
\hline Transmission Plant........................................................... & 49,511 & 220,513 & 0 & 5,493 & 0 & 758,085 \\
\hline 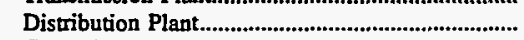 & 116,105 & 265,791 & 0 & 17,107 & 15,648 & $3,020,680$ \\
\hline 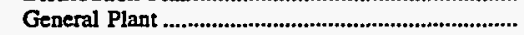 & 37,291 & 58,569 & 0 & 2,354 & 0 & 761,913 \\
\hline Total Electric Plant in Service & 247,573 & 739,467 & 65,520 & 24,954 & 15,648 & $6,858,569$ \\
\hline 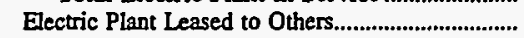 & 0 & 0 & 0 & 0 & 0 & 0 \\
\hline 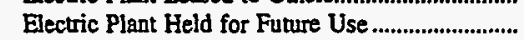 & 0 & 677 & 0 & 0 & 0 & 0 \\
\hline 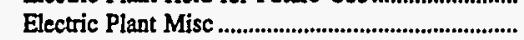 & 0 & 0 & 0 & 0 & 0 & -42.622 \\
\hline 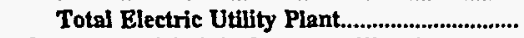 & 247,573 & 740,144 & 65,520 & 24,954 & 15,648 & $6,815,947$ \\
\hline $\begin{array}{l}\text { Construction Work in Progress - Electric............... } \\
\text { Accumulated Provision for Depreciation }\end{array}$ & 9,224 & 11,790 & 0 & 0 & 0 & 203,705 \\
\hline and Amortization. & 121,192 & 233,109 & 18,330 & 5,677 & 4,106 & $2,418,936$ \\
\hline 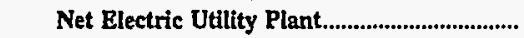 & 135,605 & 518,825 & 47,190 & 19,278 & 11,542 & $4,600,716$ \\
\hline
\end{tabular}

\begin{tabular}{|c|c|c|c|c|c|c|}
\hline Item & $\begin{array}{l}\text { Califomia } \\
\text { Merced } \\
\text { Irigation } \\
\text { District } \\
\text { December 31 }\end{array}$ & $\begin{array}{c}\text { Califormia } \\
\text { Metropolitan } \\
\text { Water } \\
\text { District } \\
\text { June } 30\end{array}$ & $\begin{array}{l}\text { California } \\
\text { Modesto } \\
\text { Irrigation } \\
\text { District } \\
\text { December } 31\end{array}$ & $\begin{array}{c}\text { California } \\
\text { MSR } \\
\text { Public } \\
\text { Power } \\
\text { Agency } \\
\text { December } 31\end{array}$ & $\begin{array}{l}\text { California } \\
\text { Northern } \\
\text { California } \\
\text { Power Agny } \\
\text { June } 30\end{array}$ & $\begin{array}{c}\text { Califomia } \\
\text { Oakdale \& } \\
\text { South } \\
\text { San Joaquin } \\
\text { December } 31\end{array}$ \\
\hline \multicolumn{7}{|l|}{ Electric Plant in Service } \\
\hline $\begin{array}{l}\text { Intangible Plant.............................................................. } \\
\text { Production Plant }\end{array}$ & 19,055 & 0 & 122 & 108 & 0 & $\mathbf{0}$ \\
\hline Steam & 0 & 0 & 0 & 281,858 & 499,463 & 0 \\
\hline 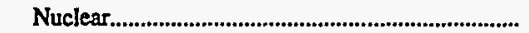 & 0 & 0 & 0 & 0 & 0 & 0 \\
\hline 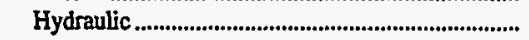 & 34,926 & 126,750 & 27,138 & 0 & 383,679 & 58,967 \\
\hline Other & 0 & 0 & 76,980 & 0 & 110,172 & 0 \\
\hline Total Production Plant...................................... & 34,926 & 126,750 & 104,118 & 281,858 & 993,313 & 58,967 \\
\hline 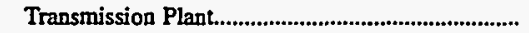 & 599 & 0 & 20,244 & 77,713 & 3,791 & 0 \\
\hline 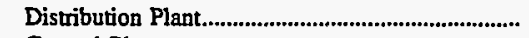 & 0 & 0 & 126,143 & 88 & 0 & 0 \\
\hline 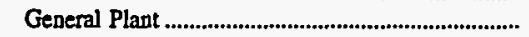 & 544 & 0 & 42,811 & 1,023 & 5,131 & 2,212 \\
\hline Total Electric Plant in Service ............................ & 55,125 & 126,750 & 293,439 & 360,791 & $1,002,235$ & 61,180 \\
\hline 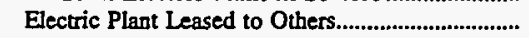 & 0 & 0 & 0 & 0 & 0 & 0 \\
\hline 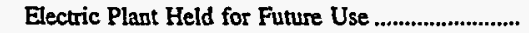 & 0 & 0 & 0 & 0 & 0 & 0 \\
\hline Electric Plant Misc & 0 & $\mathbf{0}$ & 0 & 0 & 0 & 0 \\
\hline Total Electric Utility Plant............................... & 55,125 & 126,750 & 293,439 & 360,791 & $1,002,235$ & 61,180 \\
\hline $\begin{array}{l}\text { Construction Work in Progress - Electric.............. } \\
\text { Accumulated Provision for Depreciation }\end{array}$ & 1,010 & 23,627 & 3,362 & 738 & .825 & 247 \\
\hline 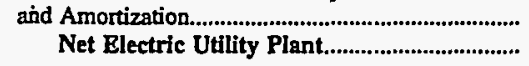 & $\begin{array}{l}24,003 \\
32,132\end{array}$ & $\begin{array}{r}27,132 \\
123,245\end{array}$ & $\begin{array}{l}111,579 \\
185,222\end{array}$ & $\begin{array}{l}109,536 \\
251,993\end{array}$ & $\begin{array}{l}294,601 \\
708,459\end{array}$ & $\begin{array}{l}25,236 \\
36,191\end{array}$ \\
\hline
\end{tabular}

Note: Totals may not equal sum of components because of independent rounding.

Source: Energy Information Administration, Form ELA-412, "Annual Report of Public Electric Utilities." 
Table 24. Electric Utility Plant by Major U.S. Publicly Owned Electric Utility Within State at End of Period, 1996

(Thousand Dollars)

\begin{tabular}{|c|c|c|c|c|c|c|}
\hline Item & $\begin{array}{l}\text { California } \\
\text { Oroville } \\
\text { Wyandotte } \\
\text { Irrig Dist } \\
\text { December } 31\end{array}$ & $\begin{array}{l}\text { Califomia } \\
\text { Palo Alto } \\
\text { City of } \\
\text { June } 30\end{array}$ & $\begin{array}{l}\text { California } \\
\text { Pasadena } \\
\text { City of } \\
\text { June } 30\end{array}$ & $\begin{array}{c}\text { California } \\
\text { Placer } \\
\text { County } \\
\text { Water } \\
\text { Agency } \\
\text { December } 31\end{array}$ & $\begin{array}{l}\text { California } \\
\text { Redding } \\
\text { City of } \\
\text { June } 30\end{array}$ & $\begin{array}{l}\text { California } \\
\text { Riverside } \\
\text { City of } \\
\text { June } 30\end{array}$ \\
\hline \multicolumn{7}{|l|}{ Electric Plant in Service } \\
\hline $\begin{array}{l}\text { Intangible Plant................................................................ } \\
\text { Production Plant }\end{array}$ & 0 & $\mathbf{0}$ & 0 & 143 & $\mathbf{0}$ & 0 \\
\hline 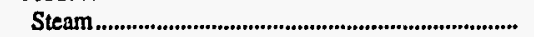 & 0 & 0 & 53,363 & 0 & 14,152 & 0 \\
\hline 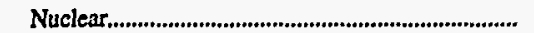 & $\mathbf{0}$ & $\mathbf{0}$ & 0 & $\mathbf{0}$ & 0 & 124,079 \\
\hline 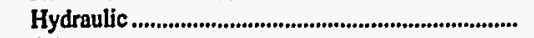 & 0 & $\mathbf{0}$ & 5,694 & 110,774 & 4,025 & 0 \\
\hline 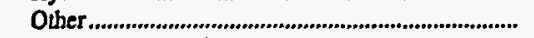 & 0 & 0 & 6,973 & 8 & 57,343 & 0 \\
\hline 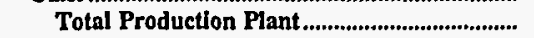 & 0 & $\mathbf{0}$ & 66,030 & 110,783 & 75,520 & 124,079 \\
\hline 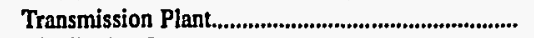 & 1,136 & 0 & 43,026 & 439 & 0 & 14,692 \\
\hline 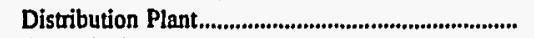 & 79,938 & 130,576 & 146,435 & 0 & 0 & 151,303 \\
\hline 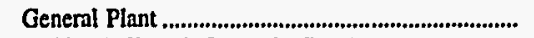 & 4,389 & 0 & 8,978 & 5,965 & 129,410 & 21,936 \\
\hline Total Electric Plant in Service ........................ & 85,463 & 130,576 & 264,469 & 117,330 & 204,930 & 312,009 \\
\hline Electric Plant Leased to Others................................. & 0 & 0 & 0 & 0 & 0 & 0 \\
\hline 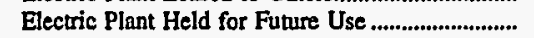 & 0 & 0 & 0 & 0 & 0 & 0 \\
\hline 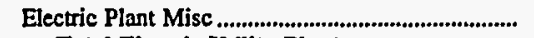 & $\mathbf{0}$ & 0 & 0 & 0 & 0 & 0 \\
\hline Total Electric Utillty Plant................................. & 85,463 & 130,576 & 264,469 & 117,330 & 204,930 & 312,009 \\
\hline $\begin{array}{l}\text { Construction Work in Progress - Electric............... } \\
\text { Accumulated Provision for Depreciation }\end{array}$ & 882 & 6,363 & 13,465 & 694 & 2,233 & 29,516 \\
\hline 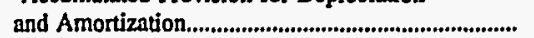 & 42,276 & 50,873 & 126,937 & 45,823 & 54,925 & 122,403 \\
\hline 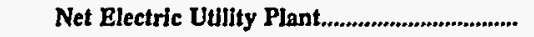 & 44,069 & 86,066 & 150,997 & 72,201 & 152,238 & 219,122 \\
\hline
\end{tabular}

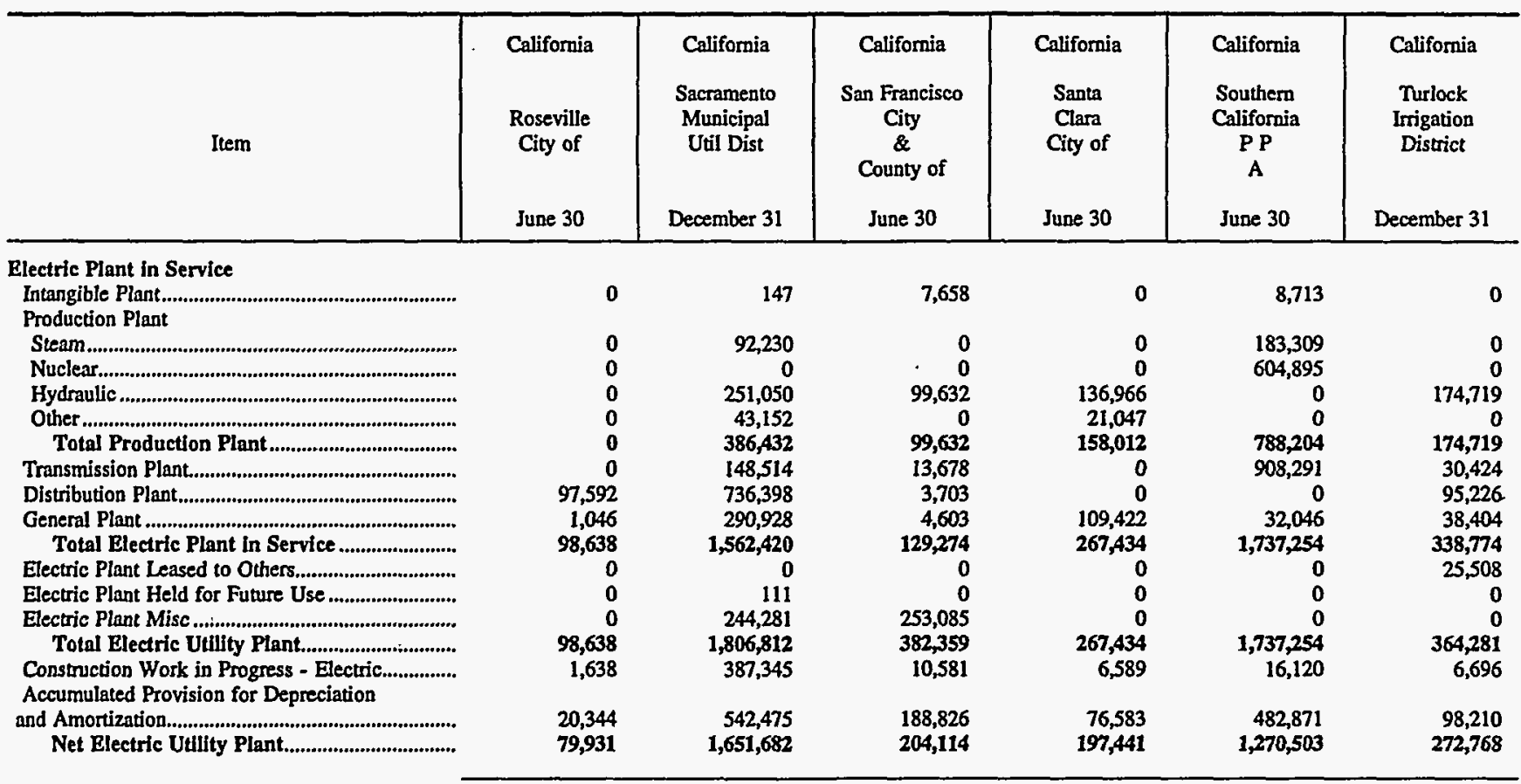

Note: Totals may not equal sum of components because of independent rounding.

Source: Energy Information Administration, Form EIA-412, "Annual Report of Public Electric Utilities." 
Table 24. Electric Utility Plant by Major U.S. Publicly Owned Electric Utility Within State at End of Period, 1996 (Continued)

(Thousand Dollars)

\begin{tabular}{|c|c|c|c|c|c|c|}
\hline Item & $\begin{array}{l}\text { California } \\
\text { Vemon } \\
\text { City of } \\
\text { June } 30\end{array}$ & $\begin{array}{l}\text { California } \\
\text { Yuba } \\
\text { County } \\
\text { Water } \\
\text { Agency } \\
\text { June } 30\end{array}$ & $\begin{array}{l}\text { Colorado } \\
\text { Arkansas } \\
\text { River } \\
\text { Power } \\
\text { Authority } \\
\text { December } 31\end{array}$ & $\begin{array}{l}\text { Colorado } \\
\text { Colorado } \\
\text { Springs } \\
\text { City of } \\
\text { December } 31\end{array}$ & $\begin{array}{l}\text { Colorado } \\
\text { Fort Collins } \\
\text { City of } \\
\text { December } 31\end{array}$ & $\begin{array}{l}\text { Colorado } \\
\text { Fort Morgan } \\
\text { City of } \\
\text { December } 31\end{array}$ \\
\hline 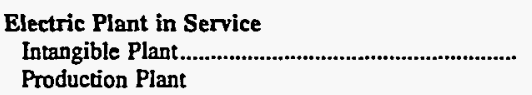 & 0 & 505 & 0 & 0 & 17 & $\mathbf{0}$ \\
\hline Steam & 0 & 0 & 0 & 259,993 & 0 & 0 \\
\hline 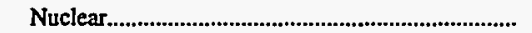 & 0 & 0 & $\mathbf{0}$ & 0 & 0 & 0 \\
\hline 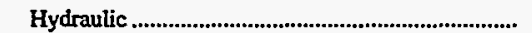 & 0 & 189,999 & 0 & 2,597 & 0 & 0 \\
\hline Other & 9,834 & 0 & 0 & 0 & 0 & 0 \\
\hline 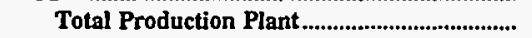 & 9,834 & 189,999 & $\mathbf{0}$ & 262,590 & 0 & 0 \\
\hline 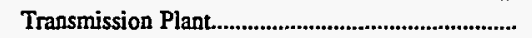 & 58,086 & 1,508 & 2,710 & 61,295 & 1,471 & 0 \\
\hline 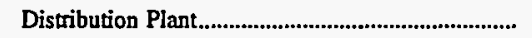 & 23,815 & 0 & 0 & 400,953 & 82,470 & 12,182 \\
\hline 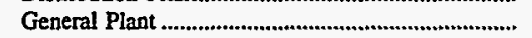 & 2,094 & 3,147 & 0 & 46,564 & 17,528 & 915 \\
\hline Total Electric Plant in Service .......................... & 93,829 & 195,159 & 2,710 & 771,402 & 101,486 & 13,097 \\
\hline Electric Plant Leased to Others.................................. & 0 & 0 & 0 & 0 & 0 & 0 \\
\hline Electric Plant Held for Future Use .............................. & 0 & 0 & 0 & 0 & 0 & 0 \\
\hline Electric Plant Misc & 0 & 4,485 & 0 & 0 & 0 & 0 \\
\hline 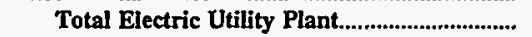 & 93,829 & 199,644 & 2,710 & 771,402 & 101,486 & 13,097 \\
\hline $\begin{array}{l}\text { Construction Work in Progress - Electric............... } \\
\text { Accumulated Provision for Depreciation }\end{array}$ & 1,190 & 0 & 0 & 31,842 & 1,954 & 35 \\
\hline 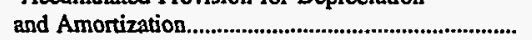 & 32,770 & 60,067 & 486 & 284,834 & 45,289 & 4,316 \\
\hline 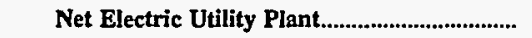 & 62,248 & 139,577 & 2,224 & 518,410 & 58,151 & $\mathbf{8 , 8 1 6}$ \\
\hline
\end{tabular}

\begin{tabular}{|c|c|c|c|c|c|c|}
\hline Item & $\begin{array}{l}\text { Colorado } \\
\text { Longmont } \\
\text { City of } \\
\text { December } 31\end{array}$ & $\begin{array}{l}\text { Colorado } \\
\text { Loveland } \\
\text { City of } \\
\text { December } 31\end{array}$ & $\begin{array}{l}\text { Colorado } \\
\text { Platte River } \\
\text { Power } \\
\text { Authority } \\
\text { December } 31\end{array}$ & $\begin{array}{l}\text { Connecticut } \\
\text { Connecticut } \\
\text { Mun } \\
\text { Elec } \\
\text { Engy Coop } \\
\text { December } 31\end{array}$ & $\begin{array}{l}\text { Connecticut } \\
\text { Groton } \\
\text { City of } \\
\text { June } 30\end{array}$ & $\begin{array}{l}\text { Connecticut } \\
\text { Norwich } \\
\text { City of } \\
\text { June } 30\end{array}$ \\
\hline \multicolumn{7}{|l|}{ Electric Plant in Service } \\
\hline 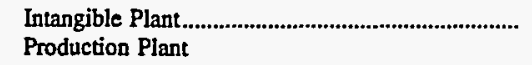 & 0 & 0 & 0 & 942 & 0 & 0 \\
\hline 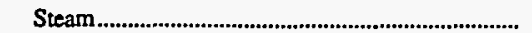 & 0 & 0 & 638,206 & 0 & 0 & 0 \\
\hline 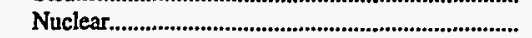 & 0 . & 0 & 0 & 50,691 & 0 & 0 \\
\hline 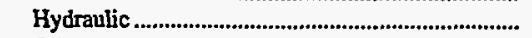 & 380 & 1,545 & 0 & 0 & 0 & 2,921 \\
\hline Other & 3,358 & 0 & 0 & 0 & 0 & 2,377 \\
\hline 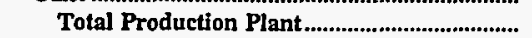 & 3,738 & 1,545 & 638,206 & 50,691 & 0 & 5,298 \\
\hline 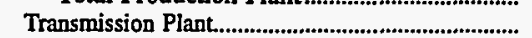 & 0 & 3,933 & 107,519 & 1,138 & 7,188 & 3,911 \\
\hline 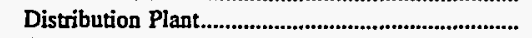 & 39,357 & 38,682 & 0 & 0 & 16,566 & 18,488 \\
\hline 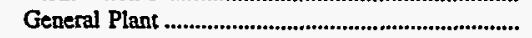 & 499 & 5,578 & 13,362 & 1,964 & 3,143 & 4,057 \\
\hline 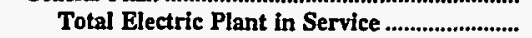 & 43,595 & 49,738 & 759,086 & 54,734 & 26,897 & 31,754 \\
\hline 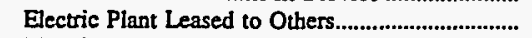 & 0 & 0 & 0 & 0 & 0 & 0 \\
\hline Electric Plant Held for Funure Use ............................. & 0 & 0 & 0 & 0 & 0 & 0 \\
\hline Electric Plant Misc & 0 & 0 & 12,375 & $\mathbf{0}$ & 5,391 & 0 \\
\hline 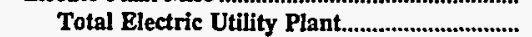 & 43,595 & 49,738 & 771,461 & 54,734 & 32,288 & 31,754 \\
\hline $\begin{array}{l}\text { Construction Work in Progress - Electric............... } \\
\text { Accumulated Provision for Depreciation }\end{array}$ & 0 & 366 & 3,374 & 2 & 758 & 6,198 \\
\hline 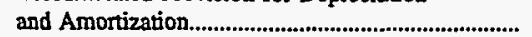 & 18,048 & 13,748 & 290,278 & 17,851 & 17,703 & 18,917 \\
\hline 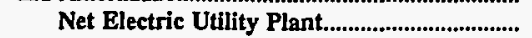 & 25,547 & 36,356 & $\mathbf{4 8 4 , 5 5 7}$ & 36,885 & 15,343 & 19,035 \\
\hline
\end{tabular}

Note: Totals may not equal sum of components because of independent rounding.

Source: Energy Information Administration, Form ElA-412, "Annual Report of Public Electric Utilities." 
Table 24. Electric Utility Plant by Major U.S. Publicly Owned Electric Utility Within State at End of Period, 1996 (Continued)

(Thousand Dollars)

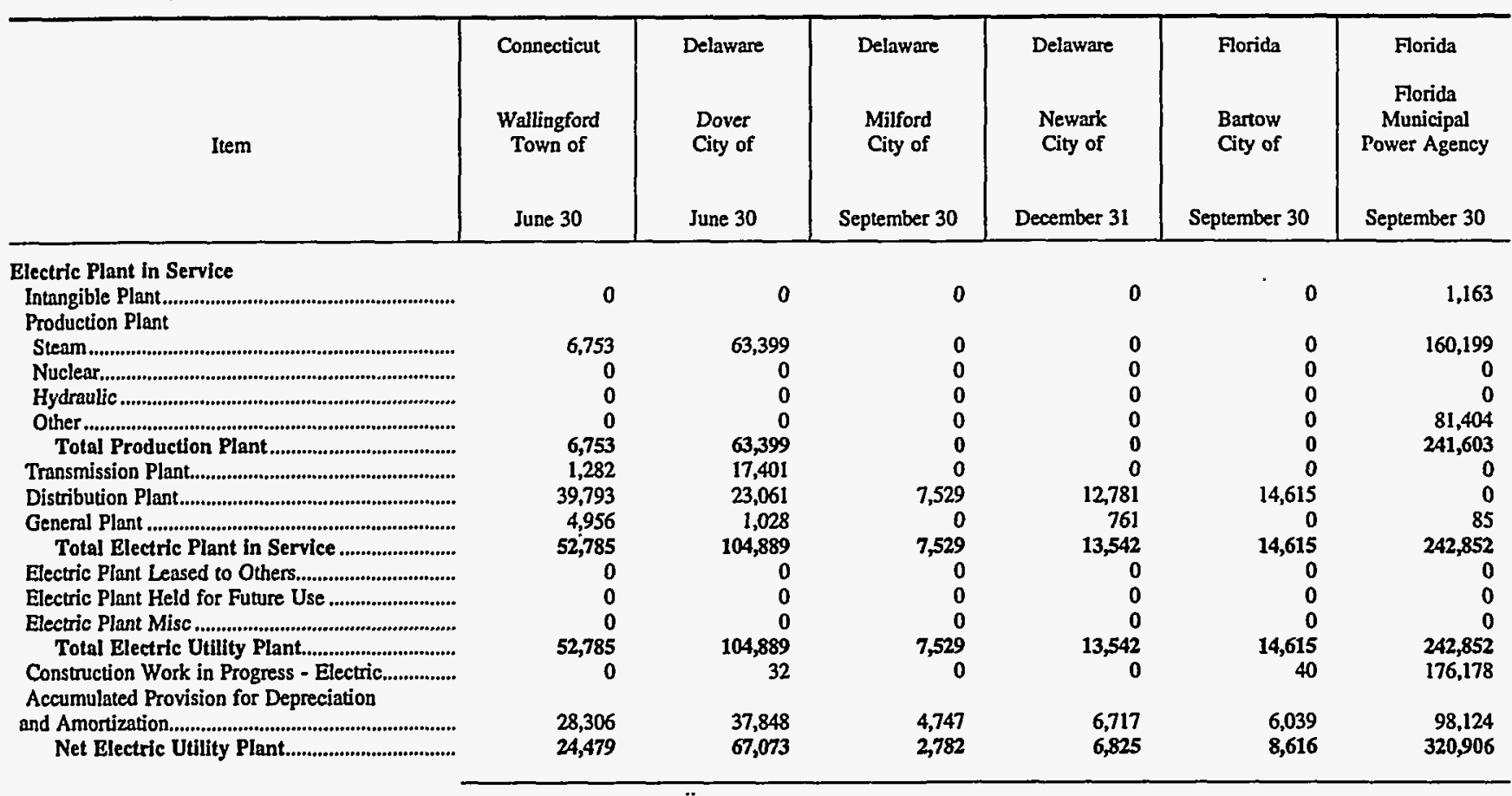

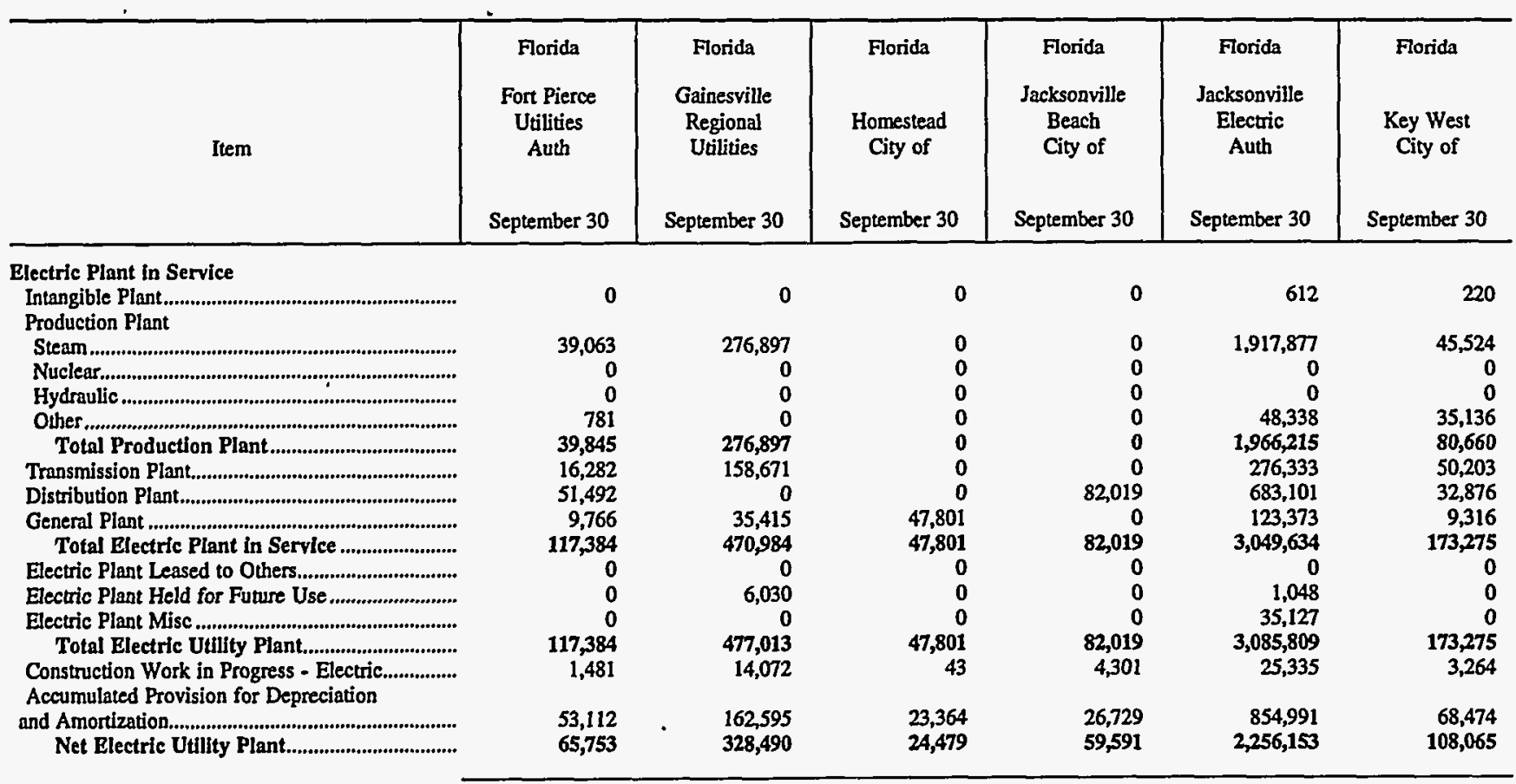

Note: Totals may not equal sum of components because of independent rounding.

Source: Energy Information Administration, Form EIA-412, "Annual Report of Public Electric Utilities." 
Table 24. Electric Utility Piant by Major U.S. Publicly Owned Electric Utility Within State at End of Period, 1996 (Continued)

(Thousand Dollars)

\begin{tabular}{|c|c|c|c|c|c|c|}
\hline Item & $\begin{array}{c}\text { Florida } \\
\text { Kissimmee } \\
\text { Utility } \\
\text { Authority } \\
\text { September } 30\end{array}$ & $\begin{array}{l}\text { Florida } \\
\text { Lake Worth } \\
\text { City of } \\
\text { September } 30\end{array}$ & $\begin{array}{l}\text { Florida } \\
\text { Lakeland } \\
\text { City of } \\
\text { September } 30\end{array}$ & $\begin{array}{l}\text { Florida } \\
\text { Leesburg } \\
\text { City of } \\
\text { September } 30\end{array}$ & $\begin{array}{c}\text { Florida } \\
\text { New Smyrna } \\
\text { Beach } \\
\text { Utils Comm } \\
\text { September } 30\end{array}$ & $\begin{array}{l}\text { Florida } \\
\text { Ocala } \\
\text { City of } \\
\text { September } 30\end{array}$ \\
\hline \multicolumn{7}{|l|}{ Electric Plant in Service } \\
\hline 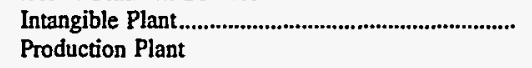 & 1,060 & 59 & 0 & 127 & 408 & 0 \\
\hline Steam & 68,494 & 32,281 & 270,506 & 0 & 0 & 0 \\
\hline 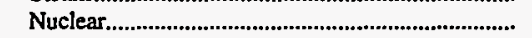 & 5,117 & 0 & 0 & 7,350 & 4,292 & 11,249 \\
\hline 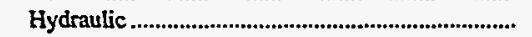 & 0 & 0 & 0 & 0 & 0 & 0 \\
\hline Other & 67,143 & 18,205 & 51,321 & 0 & 6,586 & 0 \\
\hline Total Production Plant & 140,753 & 50,485 & 321,827 & 7,350 & 10,878 & 11,249 \\
\hline 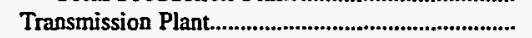 & 31,401 & 30,619 & 81,497 & 9 & 11,761 & 6,647 \\
\hline 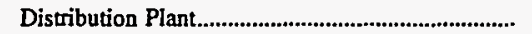 & 44,036 & $\mathbf{0}$ & 133,814 & 35,445 & 31,622 & 77,616 \\
\hline 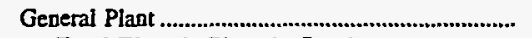 & 16,573 & 0 & 49,876 & 5,924 & 4,438 & 982 \\
\hline 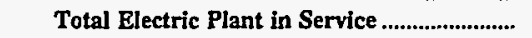 & 233,822 & 81,164 & 587,015 & 48,855 & 59,106 & 96,494 \\
\hline 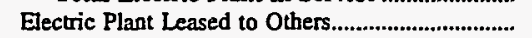 & 0 & 0 & 0 & 0 & 0 & 0 \\
\hline 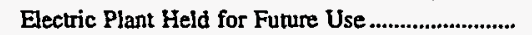 & 1,027 & 68 & 0 & 0 & $\mathbf{0}$ & 0 \\
\hline Electric Plant Misc & 0 & 3,685 & 0 & 0 & 0 & 0 \\
\hline 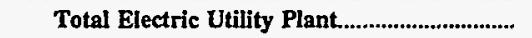 & 234,849 & 84,917 & 587,015 & 48,855 & 59,106 & 96,494 \\
\hline $\begin{array}{l}\text { Construction Work in Progress - Electric............... } \\
\text { Accumulated Provision for Depreciation }\end{array}$ & 13,484 & 21 & 33,011 & 2,500 & 1,242 & 12,551 \\
\hline 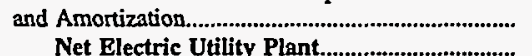 & $\begin{array}{r}75,062 \\
173,271\end{array}$ & $\begin{array}{l}44,390 \\
40,547\end{array}$ & $\begin{array}{l}206,581 \\
413,445\end{array}$ & $\begin{array}{l}18,361 \\
32,995\end{array}$ & $\begin{array}{l}24,196 \\
36,152\end{array}$ & $\begin{array}{l}35,702 \\
73,343\end{array}$ \\
\hline
\end{tabular}

\begin{tabular}{|c|c|c|c|c|c|c|}
\hline Item & $\begin{array}{l}\text { Florida } \\
\text { Oriando } \\
\text { Utilities } \\
\text { Comm } \\
\text { September } 30\end{array}$ & $\begin{array}{l}\text { Florida } \\
\text { Quincy } \\
\text { City of } \\
\text { September } 30\end{array}$ & $\begin{array}{c}\text { Florida } \\
\text { Reedy Creek } \\
\text { Improvement } \\
\text { Dist } \\
\text { September } 30\end{array}$ & $\begin{array}{l}\text { Florida } \\
\text { St Cloud } \\
\text { City of } \\
\text { September } 30\end{array}$ & $\begin{array}{c}\text { Florida } \\
\text { Tallahassee } \\
\text { City of } \\
\text { September } 30\end{array}$ & $\begin{array}{c}\text { Florida } \\
\text { Vero } \\
\text { Beach } \\
\text { City of } \\
\text { September } 30\end{array}$ \\
\hline \multicolumn{7}{|l|}{ Electric Plant in Service } \\
\hline $\begin{array}{l}\text { Intangible Plant } \\
\text { Production Plant }\end{array}$ & 4,459 & 0 & 0 & 0 & 0 & 2,519 \\
\hline Steam & 919,070 & 0 & 2,732 & 0 & 138,309 & 76,025 \\
\hline 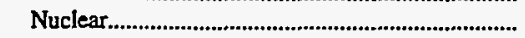 & 105,010 & 0 & 0 & 0 & 10,229 & 0 \\
\hline 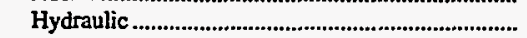 & 0 & 0 & 0 & $\mathbf{0}$ & 16,993 & $\mathbf{0}$ \\
\hline 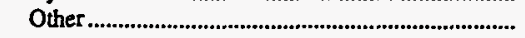 & 60,476 & $\mathbf{0}$ & 26,498 & 26,496 & 7,972 & 314 \\
\hline Total Production Plant & $1,084,556$ & 0 & 29,230 & 26,496 & 173,503 & 76,339 \\
\hline 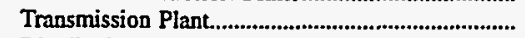 & 179,939 & 0 & 0 & 12,512 & 43,550 & 32,882 \\
\hline Distribution Plant & 298,720 & 6,094 & 110,147 & 36,779 & 195,946 & 44,614 \\
\hline 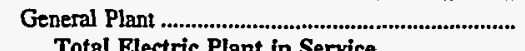 & 79,234 & 717 & 569 & $\begin{aligned} 0 \\
0\end{aligned}$ & $\begin{array}{r}3,667 \\
\end{array}$ & 4,405 \\
\hline Total Electric Plant in Service & $\begin{array}{r}1,646,908 \\
0\end{array}$ & $\begin{array}{r}6,811 \\
0\end{array}$ & $\begin{array}{r}139,946 \\
0\end{array}$ & $\begin{array}{r}75,786 \\
0\end{array}$ & $\begin{array}{r}416,666 \\
0\end{array}$ & $\begin{array}{r}160,758 \\
0\end{array}$ \\
\hline 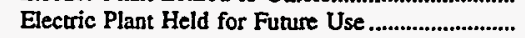 & 0 & 0 & 0 & 0 & 0 & 0 \\
\hline 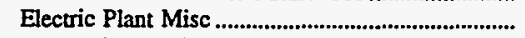 & 0 & 0 & 0 & 0 & 0 & 0 \\
\hline 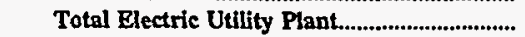 & $1,646,908$ & 6,811 & 139,946 & 75,786 & 416,666 & 160,758 \\
\hline $\begin{array}{l}\text { Construction Work in Progress - Electric............... } \\
\text { Accumulated Provision for Depreciation }\end{array}$ & 45,098 & 0 & 15,217 & 509 & 52,924 & 3 \\
\hline 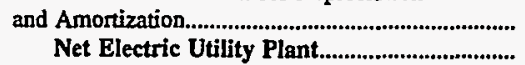 & $\begin{array}{r}426,779 \\
1,265,227\end{array}$ & $\begin{array}{l}3,231 \\
3,580\end{array}$ & $\begin{array}{r}27,673 \\
127,490\end{array}$ & $\begin{array}{l}26,997 \\
49,299\end{array}$ & $\begin{array}{l}184,913 \\
284,677\end{array}$ & $\begin{array}{r}52,482 \\
108,279\end{array}$ \\
\hline
\end{tabular}

Note: Totals may not equal sum of components because of independent rounding.

Source: Energy Information Administration, Form ElA-412, "Annual Report of Public Electric Utilities." 
Table 24. Electric Utility Plant by Major U.S. Publicly Owned Electric Utility Within State at End of Period, 1996 (Continued)

(Thousand Dollars)

\begin{tabular}{|c|c|c|c|c|c|c|}
\hline Item & $\begin{array}{c}\text { Georgia } \\
\text { Albany Water } \\
\text { Gas \& Light } \\
\text { Comm } \\
\text { June } 30\end{array}$ & $\begin{array}{l}\text { Georgia } \\
\text { Calhoun } \\
\text { City of } \\
\text { June } 30\end{array}$ & $\begin{array}{l}\text { Georgia } \\
\text { Cartersville } \\
\text { City of } \\
\text { June } 30\end{array}$ & $\begin{array}{c}\text { Georgia } \\
\text { College } \\
\text { Park City of } \\
\text { June } 30\end{array}$ & $\begin{array}{l}\text { Georgia } \\
\text { Covington } \\
\text { City of } \\
\text { December } 31\end{array}$ & $\begin{array}{l}\text { Georgia } \\
\text { Crisp } \\
\text { County } \\
\text { Power } \\
\text { Comm } \\
\text { December } 31\end{array}$ \\
\hline \multicolumn{7}{|l|}{ Electric Plant in Service } \\
\hline $\begin{array}{l}\text { Intangible Plant } \\
\text { Production Plant }\end{array}$ & 0 & 0 & 0 & $\mathbf{0}$ & 0 & 106 \\
\hline 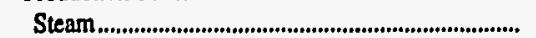 & 0 & 0 & 0 & 0 & 0 & 5,456 \\
\hline 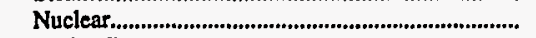 & 0 & 0 & 0 & 0 & 0 & 0 \\
\hline 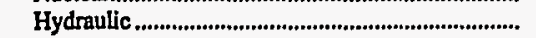 & $\mathbf{0}$ & 0 & $\mathbf{0}$ & $\mathbf{0}$ & 0 & 5,970 \\
\hline 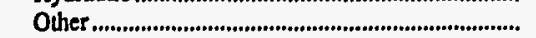 & 0 & $\mathbf{0}$ & 0 & 0 & 0 & 0 \\
\hline 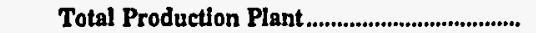 & $\mathbf{0}$ & 0 & 0 & $\mathbf{0}$ & 0 & 11,426 \\
\hline 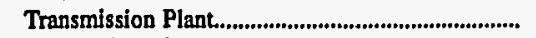 & 32,154 & 0 & 0 & $\mathbf{0}$ & 0 & 2,121 \\
\hline 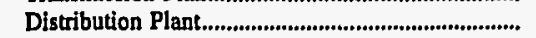 & 0 & 70,219 & 12,990 & 9,462 & 7,050 & 25,935 \\
\hline 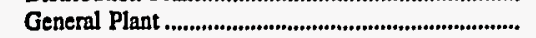 & 0 & 0 & 0 & 0 & 0 & 4,304 \\
\hline Total Electric Plant in Service ......................... & 32,154 & 70,219 & 12,990 & 9,462 & 7,050 & 43,891 \\
\hline 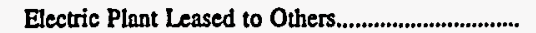 & 0 & 0 & 0 & 0 & 0 & 0 \\
\hline Electric Plant Held for Future Use ........................... & $\mathbf{0}$ & 0 & 0 & 0 & 0 & $\mathbf{0}$ \\
\hline 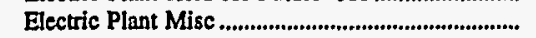 & 0 & 0 & 0 & 0 & 0 & 0 \\
\hline 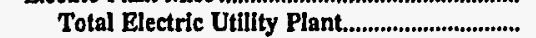 & 32,154 & 70,219 & 12,990 & 9,462 & 7,050 & 43,891 \\
\hline $\begin{array}{l}\text { Construction Work in Progress - Electric................. } \\
\text { Accumulated Provision for Depreciation }\end{array}$ & 21,191 & 1,810 & 0 & 0 & 0 & 22 \\
\hline 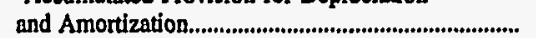 & 10,963 & 17,949 & 4,085 & 4,222 & 3,778 & 25,237 \\
\hline Net Electric Utility Plant................................... & 42,382 & 54,080 & 8,905 & 5,240 & 3,271 & 18,676 \\
\hline
\end{tabular}

\begin{tabular}{|c|c|c|c|c|c|c|}
\hline Item & $\begin{array}{l}\text { Georgia } \\
\text { Dalton } \\
\text { City of } \\
\text { November } 30\end{array}$ & $\begin{array}{l}\text { Georgia } \\
\text { Douglas } \\
\text { City of } \\
\text { June } 30\end{array}$ & $\begin{array}{l}\text { Georgia } \\
\text { East } \\
\text { Point } \\
\text { City of } \\
\\
\text { June } 30\end{array}$ & $\begin{array}{c}\text { Georgia } \\
\text { Fitzgerald } \\
\text { Wr Lgt } \\
\text { \& Bond Comm } \\
\text { December } 31\end{array}$ & $\begin{array}{l}\text { Georgia } \\
\text { Griffin } \\
\text { City of } \\
\text { June } 30\end{array}$ & $\begin{array}{l}\text { Georgia } \\
\text { La Grange } \\
\text { City of } \\
\text { June } 30\end{array}$ \\
\hline \multicolumn{7}{|l|}{ Electric Plant in Service } \\
\hline $\begin{array}{l}\text { Intangible Plant............................................................. } \\
\text { Production Plant }\end{array}$ & 0 & 0 & 0 & 0 & 0 & 0 \\
\hline Steam & 22,539 & 0 & 0 & 0 & 0 & 0 \\
\hline 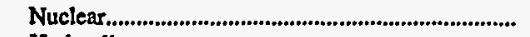 & 132,633 & 0 & $\mathbf{0}$ & 0 & 0 & 0 \\
\hline 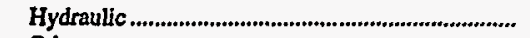 & 0 & 0 & $\mathbf{0}$ & 0 & 0 & 0 \\
\hline Other & 0 & 0 & $\mathbf{0}$ & 0 & $\mathbf{0}$ & 0 \\
\hline 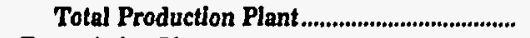 & 155,172 & $\mathbf{0}$ & $\mathbf{0}$ & $\mathbf{0}$ & $\mathbf{0}$ & $\mathbf{0}$ \\
\hline 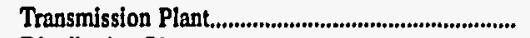 & 33,219 & 0 & 0 & 2,373 & 0 & 0 \\
\hline 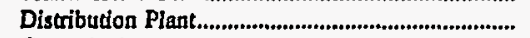 & 19,566 & 4,617 & 1,608 & 3,114 & 0 & 9,551 \\
\hline General Plant & 1,379 & 0 & 6,242 & 1,824 & 12,557 & 0 \\
\hline Total Electric Plant in Service & 209,336 & 4,617 & 7,850 & $\mathbf{7 , 3 1 1}$ & 12,557 & 9,551 \\
\hline Electric Plant Leased to Others..................................... & 0 & 0 & $\mathbf{0}$ & 0 & 0 & $\mathbf{0}$ \\
\hline 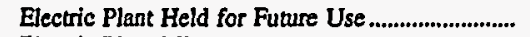 & 0 & 0 & 0 & 0 & $\mathbf{0}$ & 0 \\
\hline 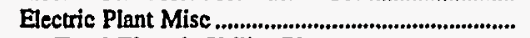 & 0 & 0 & $\mathbf{0}$ & 0 & 0 & $\mathbf{0}$ \\
\hline 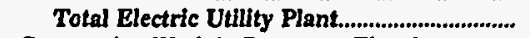 & 209,336 & 4,617 & 7,850 & 7,311 & 12,557 & 9,551 \\
\hline $\begin{array}{l}\text { Construction Work in Progress - Electric................ } \\
\text { Accumulated Provision for Depreciation }\end{array}$ & 38 & 0 & 0 & 0 & 0 & 0 \\
\hline 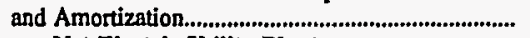 & 75,478 & 2,527 & 4,208 & 3,456 & 340 & 2,284 \\
\hline 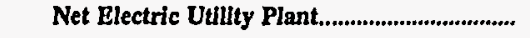 & 133,896 & 2,089 & 3,642 & 3,855 & 12,217 & 7,267 \\
\hline
\end{tabular}

Note: Totals may not equal sum of components because of independent rounding.

Source: Energy Information Administration, Form EIA-412, "Annual Report of Public Electric Utilities." 
Table 24. Electric Utility Plant by Major U.S. Publicly Owned Electric Utility Within State at End of Period, 1996

(Thousand Dollars)

\begin{tabular}{|c|c|c|c|c|c|c|}
\hline Item & $\begin{array}{c}\text { Georgia } \\
\text { Lawrenceville } \\
\text { City of } \\
\text { August } 30\end{array}$ & $\begin{array}{l}\text { Georgia } \\
\text { Marietta } \\
\text { City of } \\
\text { June } 30\end{array}$ & $\begin{array}{l}\text { Georgia } \\
\text { Moultrie } \\
\text { City of } \\
\text { September } 30\end{array}$ & $\begin{array}{l}\text { Georgia } \\
\text { Municipal } \\
\text { Electric } \\
\text { Authority } \\
\text { December } 31\end{array}$ & $\begin{array}{c}\text { Georgia } \\
\text { Thomasville } \\
\text { City of }\end{array}$ & $\begin{array}{l}\text { Idaho } \\
\text { Idaho } \\
\text { Falls } \\
\text { City of } \\
\text { September } 30\end{array}$ \\
\hline \multicolumn{7}{|l|}{ Electric Plant in Service } \\
\hline $\begin{array}{l}\text { Intangible Plant } \\
\text { Production Plant }\end{array}$ & 0 & 0 & 0 & 230 & 0 & 2,036 \\
\hline Steam & 0 & 0 & 0 & 429,164 & 0 & $\mathbf{0}$ \\
\hline 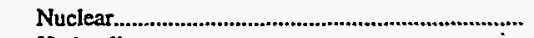 & 0 & 0 & 0 & $2,196,105$ & 0 & 0 \\
\hline 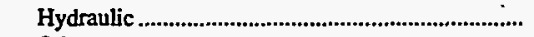 & 0 & 0 & 0 & $\mathbf{0}$ & 0 & 93,303 \\
\hline Other & 0 & 0 & 0 & 2,125 & 0 & 0 \\
\hline Total Production Plant & $\mathbf{0}$ & $\mathbf{0}$ & 0 & $2,627,394$ & 0 & 93,303 \\
\hline 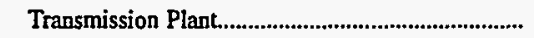 & 0 & 0 & 0 & 214,667 & 0 & 6,742 \\
\hline Distribution Plant & 13,245 & 45,129 & 6,864 & 111,100 & 16,177 & 26,111 \\
\hline 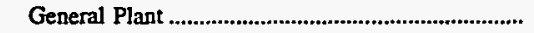 & 0 & 0 & 0 & 11,416 & 2,602 & 4,482 \\
\hline Total Electric Plant in Service .......................... & 13,245 & 45,129 & 6,864 & $2,964,807$ & 18,779 & 132,674 \\
\hline Electric Plant Leased to Others.................................. & 0 & 0 & 0 & 0 & 0 & 0 \\
\hline Electric Plant Held for Future Use ........................... & 0 & 0 & 0 & 484 & 0 & 0 \\
\hline Electric Plant Misc & 0 & 0 & 0 & 108,412 & 0 & 0 \\
\hline Total Electric Utility Plant............................... & 13,245 & 45,129 & 6,864 & $3,073,703$ & 18,779 & 132,674 \\
\hline $\begin{array}{l}\text { Construction Work in Progress - Electric............... } \\
\text { Accumulated Provision for Depreciation }\end{array}$ & 0 & 0 & 0 & 27,710 & 4 & 1,516 \\
\hline and Amortization & 4,103 & 19,942 & 4,146 & $1,031,797$ & 5,960 & 41,504 \\
\hline Net Electric Utility Plant..................................... & 9,142 & 25,187 & 2,718 & $2,069,616$ & 12,823 & 92,686 \\
\hline
\end{tabular}

\begin{tabular}{|c|c|c|c|c|c|c|}
\hline Item & $\begin{array}{l}\text { Illinois } \\
\text { Batavia } \\
\text { City of } \\
\text { December } 31\end{array}$ & $\begin{array}{l}\text { Illinois } \\
\text { Geneva } \\
\text { City of } \\
\text { April } 30\end{array}$ & $\begin{array}{c}\text { Illinois } \\
\text { Illinois } \\
\text { Municipal } \\
\text { Elec Agency } \\
\text { April } 30\end{array}$ & $\begin{array}{l}\text { Illinois } \\
\begin{array}{c}\text { Naperville } \\
\text { City of }\end{array} \\
\text { April } 30\end{array}$ & $\begin{array}{l}\text { Illinois } \\
\text { Rochelle } \\
\text { Municipal } \\
\text { Utilities } \\
\text { April } 30\end{array}$ & $\begin{array}{l}\text { Illinois } \\
\text { Springfield } \\
\text { City of } \\
\text { February } 28\end{array}$ \\
\hline \multicolumn{7}{|l|}{ Electric Plant in Service } \\
\hline $\begin{array}{l}\text { Intangible Plant } \\
\text { Production Plant }\end{array}$ & 0 & 0 & 0 & 0 & 0 & 0 \\
\hline 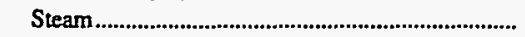 & 0 & 0 & 94,711 & 0 & 22,413 & 183,293 \\
\hline 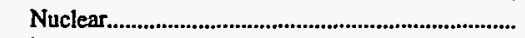 & 0 & 0 & 0 & 0 & 0 & 0 \\
\hline 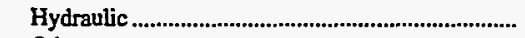 & 0 & 0 & 0 & 0 & 0 & 0 \\
\hline Other & 0 & 0 & 0 & 0 & 11,654 & 6,825 \\
\hline 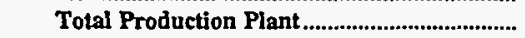 & $\mathbf{0}$ & 0 & 94,711 & 0 & 34,067 & 190,119 \\
\hline 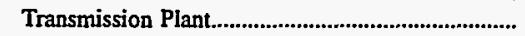 & 0 & 0 & 0 & 3,135 & 0 & 38,364 \\
\hline 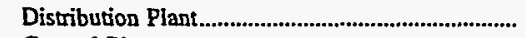 & 16,313 & 24,194 & 0 & 106,653 & 25,749 & 126,265 \\
\hline 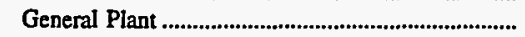 & 2,759 & 2,672 & 2,838 & 10,832 & 3,466 & 25,244 \\
\hline 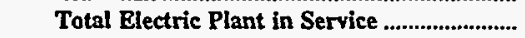 & 19,073 & 26,866 & 97,549 & 120,620 & 63,282 & 379,991 \\
\hline 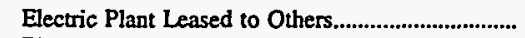 & 0 & 0 & 0 & 0 & 0 & 0 \\
\hline Electric Plant Held for Fuare Use .......................... & 0 & 0 & 0 & 0 & 0 & 4,987 \\
\hline 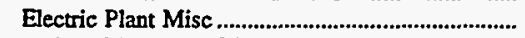 & 0 & 0 & 0 & 1,999 & 0 & 1,830 \\
\hline 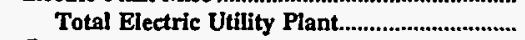 & 19,073 & 26,866 & 97,549 & 122,618 & 63,282 & 386,808 \\
\hline $\begin{array}{l}\text { Construction Work in Progress - Electric............... } \\
\text { Accumulated Provision for Depreciation }\end{array}$ & 0 & 0 & 900 & 14,360 & 1,133 & 34,511 \\
\hline and Amortization. & 8,347 & 10,989 & 15,667 & 28,912 & 49,742 & 198,495 \\
\hline 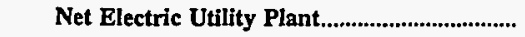 & 10,726 & 15,877 & 82,782 & 108,066 & 14,673 & 222,824 \\
\hline
\end{tabular}

Note: Totals may not equal sum of components because of independent rounding.

Source: Energy Information Administration, Form EIA-412, "Annual Report of Public Electric Utilities." 
Table 24. Electric Utility Plant by Major U.S. Publicly Owned Electric Utility Within State at End of Period, 1996 (Continued)

(Thousand Dollars)

\begin{tabular}{|c|c|c|c|c|c|c|}
\hline Item & $\begin{array}{l}\text { Illinois } \\
\text { St Charles } \\
\text { City of } \\
\text { April } 30\end{array}$ & $\begin{array}{l}\text { Indiana } \\
\text { Anderson } \\
\text { City of } \\
\text { December } 31\end{array}$ & $\begin{array}{l}\text { Indiana } \\
\text { Auburn } \\
\text { City of } \\
\text { December } 31\end{array}$ & $\begin{array}{l}\text { Indiana } \\
\text { Bluffton } \\
\text { City of } \\
\text { December } 31\end{array}$ & $\begin{array}{c}\text { Indiana } \\
\text { Crawfordsville } \\
\text { Elec } \\
\text { Lgt\&Pwr Co } \\
\text { December } 31\end{array}$ & $\begin{array}{l}\text { Indiana } \\
\text { Frankfort } \\
\text { City of } \\
\text { December } 31\end{array}$ \\
\hline 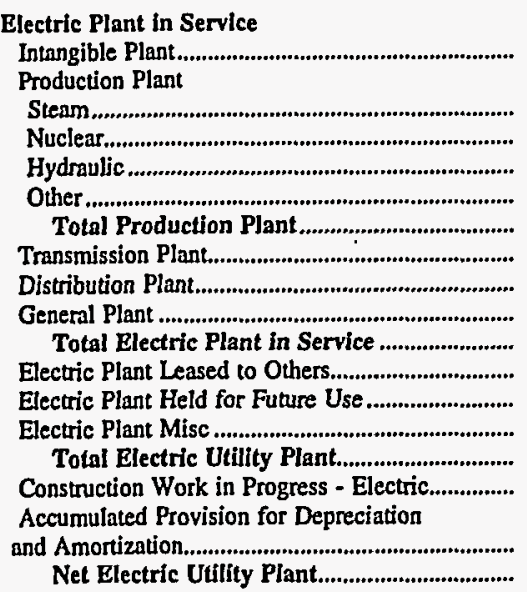 & $\begin{array}{r}0 \\
0 \\
0 \\
0 \\
0 \\
0 \\
30,607 \\
67 \\
30,674 \\
0 \\
0 \\
0 \\
30,674 \\
0\end{array}$ & $\begin{array}{r}0 \\
0 \\
0 \\
0 \\
0 \\
0 \\
1,179 \\
50,523 \\
7,954 \\
59,656 \\
0 \\
0 \\
0 \\
59,656 \\
1,020\end{array}$ & $\begin{array}{r}0 \\
0 \\
0 \\
0 \\
0 \\
42 \\
42 \\
275 \\
14,124 \\
2,508 \\
16,949 \\
0 \\
0 \\
0 \\
16,949 \\
3,243\end{array}$ & $\begin{array}{r}0 \\
0 \\
0 \\
1,238 \\
1,238 \\
268 \\
6,679 \\
1,101 \\
9,286 \\
0 \\
0 \\
0 \\
9,286 \\
0\end{array}$ & $\begin{array}{r}184 \\
12,952 \\
0 \\
0 \\
0 \\
12,952 \\
1,243 \\
15,061 \\
3,518 \\
32,958 \\
0 \\
140 \\
235 \\
33,333 \\
126\end{array}$ & $\begin{array}{r}0 \\
0 \\
0 \\
0 \\
0 \\
16,653 \\
2,752 \\
0 \\
19,405 \\
0 \\
0 \\
0 \\
19,405 \\
801\end{array}$ \\
\hline
\end{tabular}

\begin{tabular}{|c|c|c|c|c|c|c|}
\hline Item & $\begin{array}{l}\text { Indiana } \\
\text { Greenfield } \\
\text { City of } \\
\text { December } 31\end{array}$ & $\begin{array}{c}\text { Indiana } \\
\text { Indiana } \\
\text { Municipal } \\
\text { Power Agency } \\
\text { December } 31\end{array}$ & $\begin{array}{c}\text { Indiana } \\
\text { Jasper } \\
\text { City of } \\
\text { December } 31\end{array}$ & $\begin{array}{l}\text { Indiana } \\
\text { Lebanon } \\
\text { City of } \\
\text { December } 31\end{array}$ & $\begin{array}{c}\text { Indiana } \\
\text { Logansport } \\
\text { City of } \\
\text { December } 31\end{array}$ & $\begin{array}{l}\text { Indiana } \\
\text { Mishawaka } \\
\text { City of } \\
\text { December } 31\end{array}$ \\
\hline \multicolumn{7}{|l|}{ Electric Plant in Service } \\
\hline $\begin{array}{l}\text { Intangible Plant } \\
\text { Production Plant }\end{array}$ & 7 & 0 & 9,853 & 26 & 0 & $\mathbf{0}$ \\
\hline Steam & 0 & 194,066 & 0 & 0 & 21,946 & 0 \\
\hline 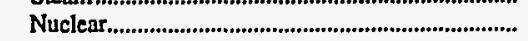 & 0 & 0 & 0 & 0 & 0 & 0 \\
\hline 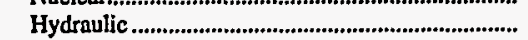 & 0 & 0 & 0 & 0 & 0 & 0 \\
\hline Other & 0 & 66,794 & 0 & 0 & 0 & 0 \\
\hline 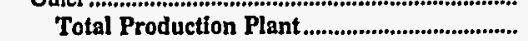 & $\mathbf{0}$ & 260,860 & $\mathbf{0}$ & 0 & 21,946 & 0 \\
\hline 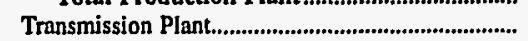 & 0 & 43,901 & 8 & 2,011 & 5,498 & 0 \\
\hline 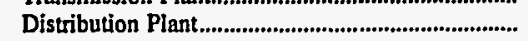 & 8,620 & 7,122 & 10,338 & 5,644 & 28,475 & 32,415 \\
\hline 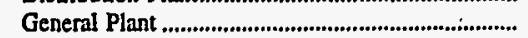 & 1,470 & 2,936 & 1,529 & 2,004 & 5,888 & 3,312 \\
\hline 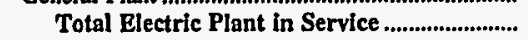 & 10,097 & 314,819 & 21,727 & 9,685 & 61,807 & 35,727 \\
\hline 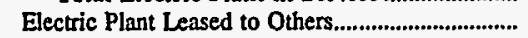 & 0 & 0 & 0 & 0 & 0 & 0 \\
\hline Electric Plant Held for Future Use ......................... & 0 & 0 & 0 & 0 & 0 & $\mathbf{0}$ \\
\hline 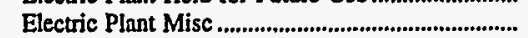 & 0 & 0 & 0 & 0 & $\mathbf{0}$ & 0 \\
\hline 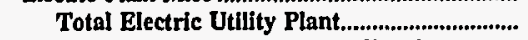 & 10,097 & 314,819 & 21,727 & 9,685 & 61,807 & 35,727 \\
\hline $\begin{array}{l}\text { Construction Work in Progress - Electric............... } \\
\text { Accumulated Provision for Depreciation }\end{array}$ & 0 & 3,082 & 301 & 0 & 151 & 279 \\
\hline 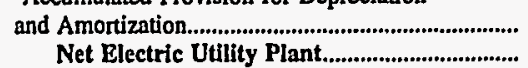 & $\begin{array}{l}2,733 \\
7,364\end{array}$ & $\begin{array}{r}82,790 \\
235,111\end{array}$ & $\begin{array}{r}7,535 \\
14,494\end{array}$ & $\begin{array}{l}5,189 \\
4,496\end{array}$ & $\begin{array}{l}30,190 \\
31,768\end{array}$ & $\begin{array}{l}17,852 \\
18,154\end{array}$ \\
\hline
\end{tabular}

Note: Totals may not equal sum of components because of independent rounding.

Source: Energy Information Administration, Form EIA-412, "Annual Report of Public Electric Utilities." 
Table 24. Electric Utility Plant by Major U.S. Publicly Owned Electric Utility Within State at End of Period, 1996 (Continued)

(Thousand Dollars)

\begin{tabular}{|c|c|c|c|c|c|c|}
\hline Item & $\begin{array}{c}\text { Indiana } \\
\text { Peru } \\
\text { City of } \\
\text { December } 31\end{array}$ & $\begin{array}{l}\text { Indiana } \\
\text { Richmond } \\
\text { City of } \\
\text { December } 31\end{array}$ & $\begin{array}{l}\text { Indiana } \\
\text { Scottsburg } \\
\text { City of } \\
\text { December } 31\end{array}$ & $\begin{array}{l}\text { Indiana } \\
\text { Washington } \\
\text { City of } \\
\text { December } 31\end{array}$ & $\begin{array}{l}\text { Iowa } \\
\text { Ames } \\
\text { City of } \\
\text { June } 30\end{array}$ & $\begin{array}{c}\text { Iowa } \\
\text { Cedar } \\
\text { Falls } \\
\text { City of } \\
\text { December } 31\end{array}$ \\
\hline 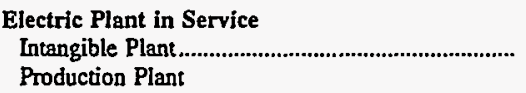 & 0 & 0 & 0 & 0 & 0 & 0 \\
\hline Steam & 10,798 & 29,975 & 0 & 0 & 103,795 & 39,598 \\
\hline 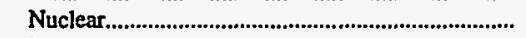 & 0 & 0 & 0 & 0 & 0 & 0 \\
\hline 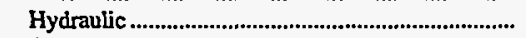 & 0 & 0 & 0 & 0 & 0 & 0 \\
\hline 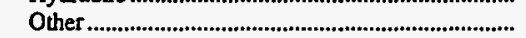 & 0 & 0 & 0 & 0 & 0 & 2,733 \\
\hline Total Production Plant & 10,798 & 29,975 & $\mathbf{0}$ & 0 & 103,795 & 42,331 \\
\hline 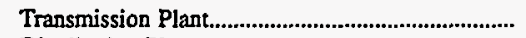 & 2,888 & 9,595 & 0 & 500 & 0 & 5,281 \\
\hline 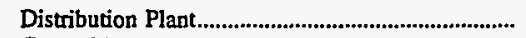 & 15,215 & 44,723 & 0 & 9,779 & 0 & 19,202 \\
\hline General Plant & 2,230 & 13,887 & 8,191 & 956 & 0 & 6,832 \\
\hline Total Electric Plant in Service ......................... & 31,132 & 98,180 & 8,191 & 11,235 & 103,795 & 73,646 \\
\hline 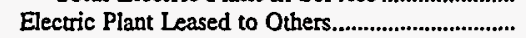 & 0 & 0 & 0 & 0 & 0 & 0 \\
\hline 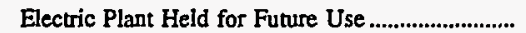 & 0 & 476 & 0 & 0 & 0 & 0 \\
\hline 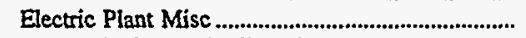 & 0 & 81 & 0 & 0 & 0 & 943 \\
\hline 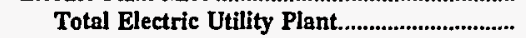 & 31,132 & 98,737 & 8,191 & 11,235 & 103,795 & 74,589 \\
\hline $\begin{array}{l}\text { Construction Work in Progress - Electric............... } \\
\text { Accumulated Provision for Depreciation }\end{array}$ & 20 & 3,568 & 66 & 39 & 0 & 77 \\
\hline 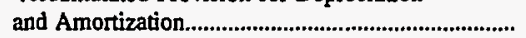 & 18,226 & 46,552 & 0 & 4,942 & 61,715 & 39,920 \\
\hline 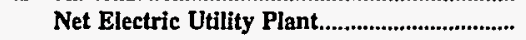 & 12,925 & 55,754 & 8,257 & 6,332 & 42,079 & 34,746 \\
\hline
\end{tabular}

\begin{tabular}{|c|c|c|c|c|c|c|}
\hline Item & $\begin{array}{c}\text { Iowa } \\
\text { Muscatine } \\
\text { City of } \\
\text { December } 31\end{array}$ & $\begin{array}{c}\text { Iowa } \\
\text { Pella } \\
\text { City of } \\
\text { December } 31\end{array}$ & $\begin{array}{l}\text { Kansas } \\
\text { Chanute } \\
\text { City of } \\
\text { December } 31\end{array}$ & $\begin{array}{c}\text { Kansas } \\
\text { Coffeyville } \\
\text { City of } \\
\text { December } 31\end{array}$ & $\begin{array}{c}\text { Kansas } \\
\text { Garden } \\
\text { City City of } \\
\text { December } 31\end{array}$ & $\begin{array}{c}\text { Kansas } \\
\text { Kansas } \\
\text { City City of } \\
\text { December } 31\end{array}$ \\
\hline 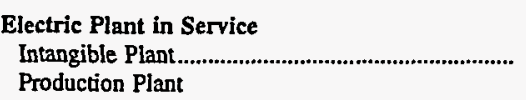 & 0 & 0 & 0 & 0 & 0 & 0 \\
\hline Steam & 248,804 & 0 & 0 & 24,790 & 0 & 355,959 \\
\hline 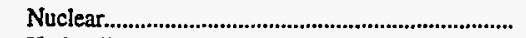 & 0 & 0 & 0 & 0 & 0 & 0 \\
\hline 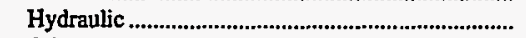 & 0 & 0 & 0 & 0 & 0 & 0 \\
\hline Other & 0 & 0 & 25,989 & 0 & 0 & 0 \\
\hline Total Production Plant & 248,804 & $\mathbf{0}$ & 25,989 & 24,790 & $\mathbf{0}$ & 355,959 \\
\hline 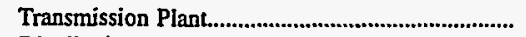 & 8,633 & 0 & 2,227 & 262 & 0 & 37,713 \\
\hline 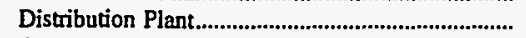 & 26,720 & 0 & 824 & 16,121 & 16,736 & 163,688 \\
\hline 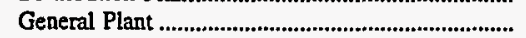 & 12,935 & 0 & 106 & 992 & 0 & 61,860 \\
\hline Total Electric Plant in Service ........................... & 297,093 & $\mathbf{0}$ & 29,146 & 42,164 & 16,736 & 619,220 \\
\hline Electric Plant Leased to Others.................................. & 0 & 0 & 0 & 0 & 0 & 0 \\
\hline 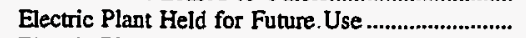 & 0 & 0 & 0 & $\mathbf{0}$ & 0 & 0 \\
\hline 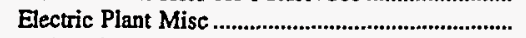 & 0 & 0 & 0 & 0 & 0 & 389 \\
\hline 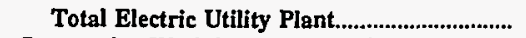 & 297,093 & 0 & 29,146 & 42,164 & 16,736 & 619,609 \\
\hline $\begin{array}{l}\text { Construction Work in Progress - Electric................ } \\
\text { Accumulated Provision for Depreciation }\end{array}$ & 640 & 0 & 0 & 0 & 0 & 37,484 \\
\hline 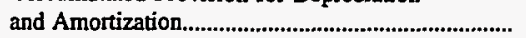 & 137,460 & 0 & 11,615 & 26,632 & 9,332 & 269,425 \\
\hline Net Electric Utility Plant...................................... & 160,272 & 0 & $\mathbf{1 7 , 5 3 1}$ & 15,532 & 7,404 & 387,668 \\
\hline
\end{tabular}

Note: Totals may not equal sum of components because of independent rounding.

Source: Energy Information Administration, Form ElA-412, "Annual Report of Public Electric Utilities." 
Table 24. Electric Utility Plant by Major U.S. Publicly Owned Electric Utility Within State at End of Period, 1996 (Continued)

(Thousand Dollars)

\begin{tabular}{|c|c|c|c|c|c|c|}
\hline Item & $\begin{array}{l}\text { Kansas } \\
\text { Kansas } \\
\text { Municipal } \\
\text { Energy } \\
\text { Agency } \\
\text { December } 31\end{array}$ & $\begin{array}{c}\text { Kansas } \\
\text { McPherson } \\
\text { City of } \\
\text { December } 31\end{array}$ & $\begin{array}{l}\text { Kansas } \\
\text { Winfield } \\
\text { City of } \\
\text { December } 31\end{array}$ & $\begin{array}{c}\text { Kentucky } \\
\text { Bardstown } \\
\text { City of } \\
\text { December } 31\end{array}$ & $\begin{array}{l}\text { Kentucky } \\
\text { Bowling } \\
\text { Green } \\
\text { City of } \\
\text { June } 30\end{array}$ & $\begin{array}{l}\text { Kentucky } \\
\text { Frankfort } \\
\text { City of } \\
\text { June } 30\end{array}$ \\
\hline 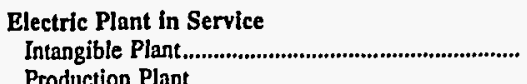 & 0 & 264 & 0 & 0 & 0 & 0 \\
\hline Steam & 0 & 5,692 & 10,915 & 0 & 0 & 0 \\
\hline 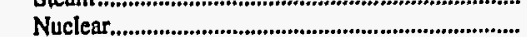 & 0 & 0 & 0 & 0 & 0 & 0 \\
\hline 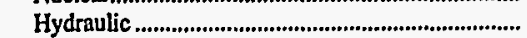 & 0 & 0 & 0 & 0 & 0 & 0 \\
\hline Other ..., & 0 & 19,774 & 0 & 0 & 0 & 0 \\
\hline Total Production Plant ...................................... & 0 & 25,466 & 10,915 & 0 & 0 & 0 \\
\hline 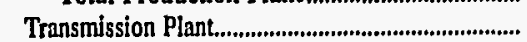 & 1,321 & 12,377 & 8,075 & 0 & 1,320 & 8,038 \\
\hline 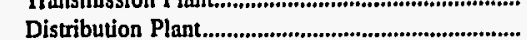 & 0 & 11,453 & 14,420 & 4,468 & 35,688 & 16,635 \\
\hline 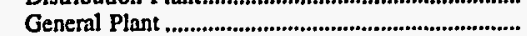 & 202 & 2,259 & 69 & 0 & 5,827 & 0 \\
\hline Total Electric Plant in Service & $1, \mathbf{5 2 3}$ & $\mathbf{5 1 , 8 1 9}$ & 33,479 & 4,468 & $\mathbf{4 2 , 8 3 5}$ & 24,673 \\
\hline 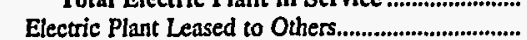 & 0 & 0 & 0 & 0 & 0 & 0 \\
\hline Electric Plant Held for Future Use & 0 & 0 & 0 & 0 & 488 & 0 \\
\hline Electric Plant Misc & 0 & 0 & 0 & 0 & 0 & 0 \\
\hline 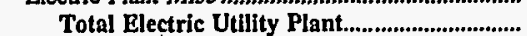 & 1,523 & 51,819 & 33,479 & 4,468 & 43,323 & 24,673 \\
\hline $\begin{array}{l}\text { Construction Work in Progress - Electric................... } \\
\text { Accumulated Provision for Depreciation }\end{array}$ & 0 & 5,563 & 204 & 0 & 3,920 & 0 \\
\hline 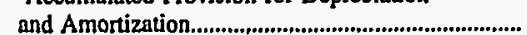 & 680 & 30,379 & 16,960 & 992 & 14,775 & 13,580 \\
\hline 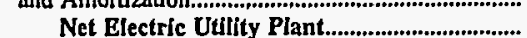 & 843 & 27,003 & 16,723 & 3,476 & 32,469 & 11,093 \\
\hline
\end{tabular}

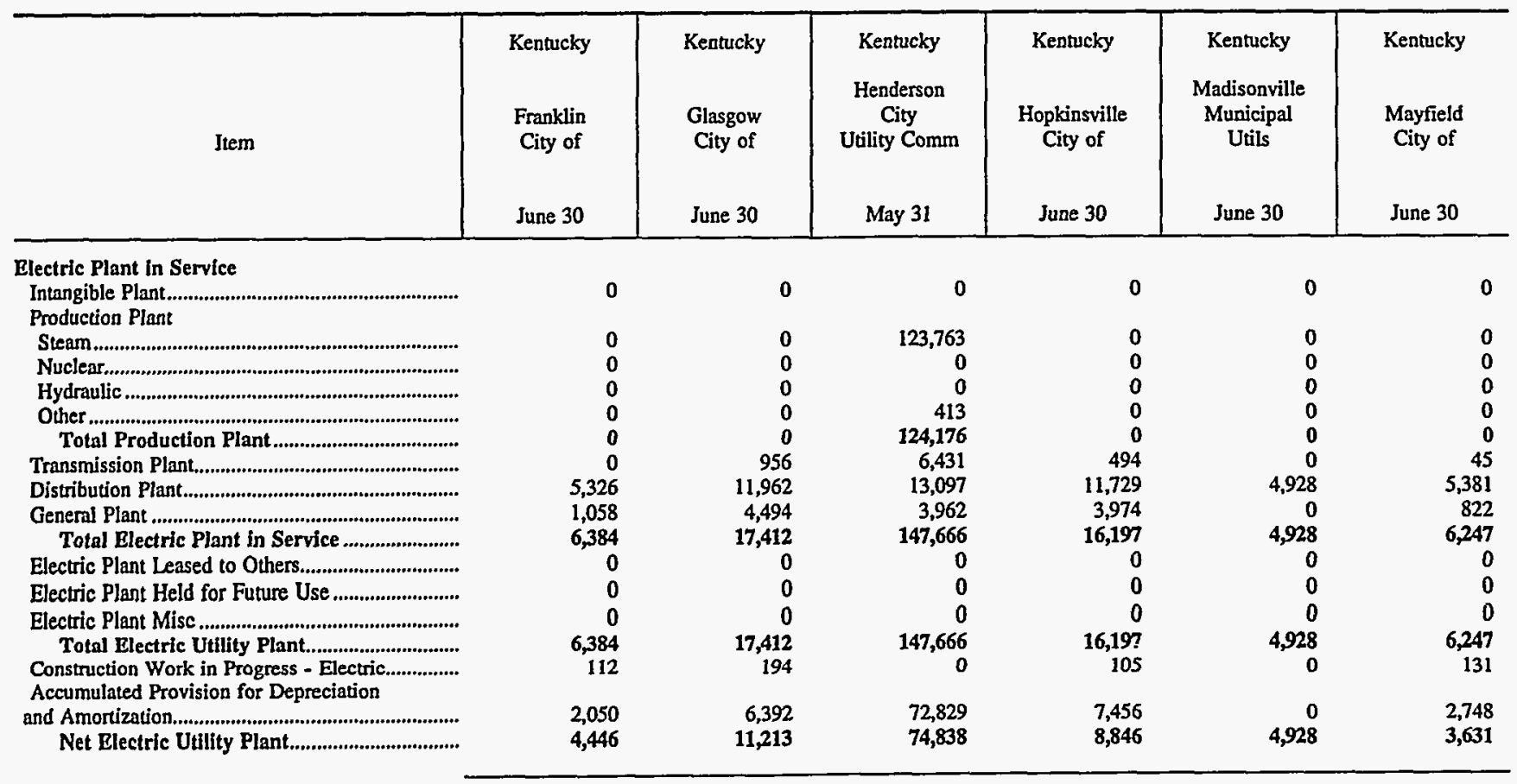

Note: Totals may not equal sum of components because of independent rounding.

Source: Energy Information Administration, Form EIA-412, "Annual Report of Public Electric Utilities." 
Table 24. Electric Utility Plant by Major U.S. Publicly Owned Electric Utility Within State at End of Period, 1996 (Continued)

(Thousand Dollars)

\begin{tabular}{|c|c|c|c|c|c|c|}
\hline Item & $\begin{array}{l}\text { Kentucky } \\
\text { Murray } \\
\text { City of } \\
\text { June } 30\end{array}$ & $\begin{array}{c}\text { Kentucky } \\
\begin{array}{c}\text { Owensboro } \\
\text { City of }\end{array} \\
\text { May } 31\end{array}$ & $\begin{array}{l}\text { Kentucky } \\
\text { Paducah } \\
\text { City of } \\
\text { June } 30\end{array}$ & $\begin{array}{c}\text { Kennucky } \\
\begin{array}{c}\text { Russellville } \\
\text { City of }\end{array} \\
\text { June } 30\end{array}$ & $\begin{array}{l}\text { Louisiana } \\
\text { Alexandria } \\
\text { City of } \\
\text { April } 30\end{array}$ & $\begin{array}{l}\text { Louisiana } \\
\text { Lafayette } \\
\text { City of } \\
\text { October } 31\end{array}$ \\
\hline 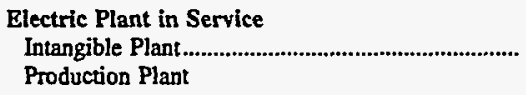 & 0 & 0 & 0 & 0 & 0 & 31 \\
\hline Steam & 0 & 221,310 & 0 & 0 & 15,375 & 51,769 \\
\hline 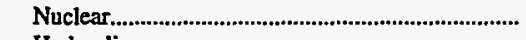 & 0 & 0 & 0 & 0 & 0 & 0 \\
\hline Hydraulic & 0 & 0 & 0 & $\mathbf{0}$ & 0 & $\mathbf{0}$ \\
\hline Other & $\mathbf{0}$ & 0 & 0 & 0 & 0 & 263 \\
\hline Total Production Plant & $\mathbf{0}$ & 221,310 & $\mathbf{0}$ & $\mathbf{0}$ & 15,375 & 52,031 \\
\hline 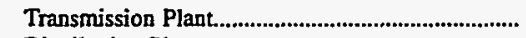 & 475 & 19,443 & 2,325 & 0 & 0 & 6,905 \\
\hline Distribution Plant & 8,571 & 35,974 & 37,179 & 3,228 & 33,552 & 97,478 \\
\hline 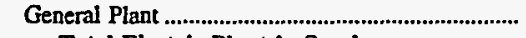 & 1,030 & 7,515 & 7,911 & 739 & 0 & 22,642 \\
\hline Total Electric Plant in Service & 10,076 & 284,242 & 47,414 & 3,967 & 48,927 & 179,087 \\
\hline 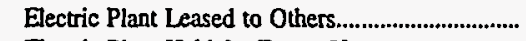 & 0 & 0 & 0 & 0 & 0 & 0 \\
\hline 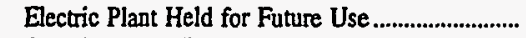 & 0 & 0 & 0 & 0 & 0 & 0 \\
\hline 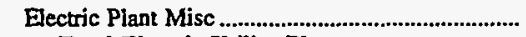 & 0 & 0 & 0 & 0 & 103,792 & 58,049 \\
\hline 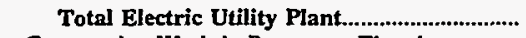 & 10,076 & 284,242 & 47,414 & 3,967 & 152,719 & 237,136 \\
\hline $\begin{array}{l}\text { Construction Work in Progress - Electric................ } \\
\text { Accumulated Provision for Depreciation }\end{array}$ & 117 & 3,018 & 745 & 39 & 2,935 & 177 \\
\hline 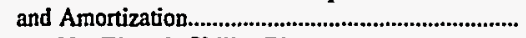 & 5,108 & 82,711 & 15,452 & 1,647 & 68,743 & 104,595 \\
\hline Net Electric Utility Plant...................................... & 5,085 & 204,550 & 32,707 & 2,359 & 86,910 & 132,718 \\
\hline
\end{tabular}

\begin{tabular}{|c|c|c|c|c|c|c|}
\hline Item & $\begin{array}{l}\text { Louisiana } \\
\text { Lafayette } \\
\text { Public } \\
\text { Power Auth } \\
\text { October } 31\end{array}$ & $\begin{array}{l}\text { Louisiana } \\
\text { Louisiana } \\
\text { Energy } \\
\text { \& } \\
\text { Power Auth } \\
\text { December } 31\end{array}$ & $\begin{array}{l}\text { Louisiana } \\
\text { Morgan } \\
\text { City City of } \\
\text { December } 31\end{array}$ & $\begin{array}{l}\text { Louisiana } \\
\text { Natchitoches } \\
\text { City of } \\
\text { May } 31\end{array}$ & $\begin{array}{l}\text { Louisiana } \\
\text { Ruston } \\
\text { City of } \\
\text { September } 30\end{array}$ & $\begin{array}{l}\text { Louisiana } \\
\text { Terrebonne } \\
\text { Parish } \\
\text { Consol Govt } \\
\\
\text { December } 31\end{array}$ \\
\hline \multicolumn{7}{|l|}{ Electric Plant in Service } \\
\hline $\begin{array}{l}\text { Intangible Plant } \\
\text { Production Plant }\end{array}$ & 0 & 8,575 & 11 & 0 & 0 & 0 \\
\hline Steam & 128,256 & 58,452 & 18,917 & 0 & 13,037 & 28,775 \\
\hline 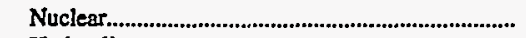 & 0 & 0 & 0 & 0 & 0 & 0 \\
\hline 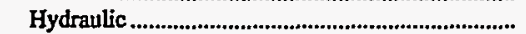 & 0 & 0 & 0 & 0 & 0 & 0 \\
\hline Other & 0 & 0 & 0 & 0 & 3,190 & 0 \\
\hline Total Production Plant & 128,256 & 58,452 & 18,917 & $\mathbf{0}$ & 16,227 & 28,775 \\
\hline Transmission Plant & 0 & 410 & 8,864 & 0 & 0 & 0 \\
\hline 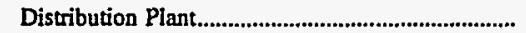 & 0 & 16 & 0 & 59,823 & 14,911 & 25,844 \\
\hline 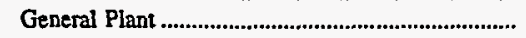 & 24,086 & 4,684 & 0 & 0 & 549 & 0 \\
\hline Total Electric Plant in Service......................... & 152,341 & 72,137 & 27,792 & 59,823 & 31,687 & 54,619 \\
\hline 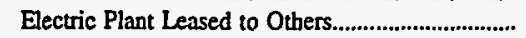 & 0 & 0 & 0 & 0 & 0 & 0 \\
\hline Electric Plant Held for Future Use .......................... & 0 & 0 & 0 & 0 & 0 & 0 \\
\hline Electric Plant Misc & 0 & 15,722 & 1,199 & 0 & 0 & 0 \\
\hline 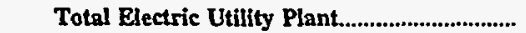 & 152,341 & 87,859 & 28,991 & 59,823 & 31,687 & 54,619 \\
\hline $\begin{array}{l}\text { Construction Work in Progress - Electric............... } \\
\text { Accumulated Provision for Depreciation }\end{array}$ & 583 & 273 & 0 & 0 & 172 & 4,570 \\
\hline 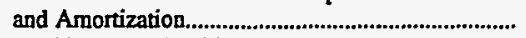 & 67,445 & 25,237 & 20,559 & 19,099 & 20,646 & 37,891 \\
\hline 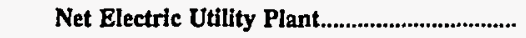 & 85,479 & 62,895 & 8,432 & 40,724 & 11,213 & 21,299 \\
\hline
\end{tabular}

Note: Totals may not equal sum of components because of independent rounding.

Source: Energy Information Administration, Form ElA-412, "Annual Report of Public Electric Utilities." 
Table 24. Electric Utility Plant by Major U.S. Publicly Owned Electric Utility

Within State at End of Period, 1996

(Thousand Dollars)

\begin{tabular}{|c|c|c|c|c|c|c|}
\hline Item & $\begin{array}{l}\text { Maryland } \\
\text { Easton } \\
\text { Utilities } \\
\text { Comm } \\
\text { June } 30\end{array}$ & $\begin{array}{l}\text { Maryland } \\
\text { Hagerstown } \\
\text { City of } \\
\text { June } 30\end{array}$ & $\begin{array}{l}\text { Massachusetts } \\
\text { Braintree } \\
\text { Town of } \\
\text { December } 31\end{array}$ & $\begin{array}{l}\text { Massachusetts } \\
\text { Chicopee } \\
\text { City of } \\
\text { December } 31\end{array}$ & $\begin{array}{l}\text { Massachusetts } \\
\text { Concord } \\
\text { Town of } \\
\text { December } 31\end{array}$ & $\begin{array}{c}\text { Massachusetts } \\
\text { Danvers } \\
\text { Town of } \\
\text { December } 31\end{array}$ \\
\hline $\begin{array}{l}\text { Electric Plant in Service } \\
\text { Intangible Plant.............................................................. } \\
\text { Production Plant }\end{array}$ & 0 & 0 & $\mathbf{0}$ & $\mathbf{0}$ & 2,086 & $\mathbf{0}$ \\
\hline 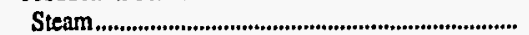 & 0 & 0 & 28,542 & $\mathbf{0}$ & 0 & $\mathbf{0}$ \\
\hline 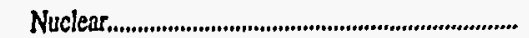 & 0 & 0 & 0 & 38,560 & 0 & $\mathbf{0}$ \\
\hline Hydraulic .................................................................................. & 0 & 0 & 0 & 0 & 0 & 0 \\
\hline Other & 22,728 & $\mathbf{0}$ & 755 & 1,730 & 0 & 0 \\
\hline Total Production Plant............................................... & 22,728 & 0 & 29,297 & 40,290 & 0 & $\mathbf{0}$ \\
\hline Transmission Plant............................................................... & 5,326 & 0 & 13,465 & 204 & 13,291 & $\mathbf{0}$ \\
\hline Distribution Plant............................................................... & 12,805 & 24,434 & 25,549 & 24,481 & 14,089 & 10,908 \\
\hline 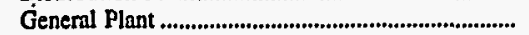 & 2,644 & 1,597 & 4,500 & 5,861 & 2,779 & 2,980 \\
\hline 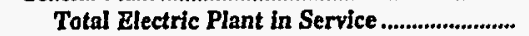 & 43,502 & 26,031 & 72,811 & 70,836 & 32,245 & 13,888 \\
\hline Electric Plant Leased to Others.................................... & 0 & 0 & 0 & $\mathbf{0}$ & $\mathbf{0}$ & 0 \\
\hline Electric Plant Held for Future Use ................................ & 0 & 0 & o & $\mathbf{0}$ & 0 & $\mathbf{0}$ \\
\hline Electric Plant Misc ............................................................ & 0 & 0 & 0 & 772 & 0 & o \\
\hline 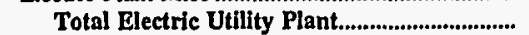 & 43,502 & 26,031 & 72,811 & 71,608 & 32,245 & 13,888 \\
\hline $\begin{array}{l}\text { Construction Work in Progress - Electric................ } \\
\text { Accumulated Provision for Depreciation }\end{array}$ & 2,142 & 1,825 & 0 & 245 & 273 & 0 \\
\hline 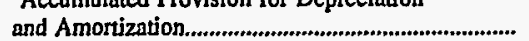 & 18,930 & 11,645 & 34,430 & 29,966 & 9,477 & \\
\hline Net Electric Utility Plant............................................ & 26,714 & 16,211 & 38,381 & 41,886 & 23,042 & 13,888 \\
\hline
\end{tabular}

\begin{tabular}{|c|c|c|c|c|c|c|}
\hline Item & $\begin{array}{l}\text { Massachusetts } \\
\text { Hingham } \\
\text { City of } \\
\text { December } 31\end{array}$ & $\begin{array}{l}\text { Massachusetts } \\
\text { Holyoke } \\
\text { City of } \\
\text { December } 31\end{array}$ & $\begin{array}{l}\text { Massachusetts } \\
\text { Hudson } \\
\text { Town of } \\
\text { December } 31\end{array}$ & $\begin{array}{l}\text { Massachusetts } \\
\text { Littleton } \\
\text { Town of } \\
\text { December } 31\end{array}$ & $\begin{array}{l}\text { Massachusetts } \\
\text { Mansfield } \\
\text { Town of } \\
\text { December } 31\end{array}$ & $\begin{array}{c}\text { Massachusetts } \\
\text { Massachusetts } \\
\text { Mun } \\
\text { Whls } \\
\text { Elec Co } \\
\text { December } 31\end{array}$ \\
\hline $\begin{array}{l}\text { Electric Plant in Service } \\
\text { Intangible Plant............................................................ } \\
\text { Production Plant }\end{array}$ & 0 & 0 & 4 & $\mathbf{0}$ & $\mathbf{0}$ & 1,168 \\
\hline Steam & 0 & 17,914 & 0 & 346 & 0 & 7,266 \\
\hline 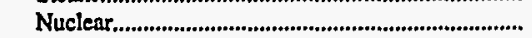 & $\mathbf{0}$ & 0 & 2,713 & 0 & 0 & 992,117 \\
\hline 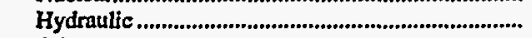 & 0 & 2,259 & 0 & 0 & 0 & 0 \\
\hline Other & $\mathbf{0}$ & 2,016 & 4,272 & 0 & 0 & 184,837 \\
\hline 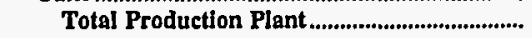 & o & 22,190 & 6,985 & 346 & $\mathbf{0}$ & $1,184,220$ \\
\hline Transmission Plant............................................................... & 1,448 & 6,185 & 1,644 & 15 & 0 & 30,715 \\
\hline Distribution Plant............................................................... & 19,601 & 24,522 & 9,485 & 11,839 & 9,864 & 0 \\
\hline General Plant ............................................................ & 2,126 & 4,252 & 1,847 & 4,851 & 1,654 & 18,098 \\
\hline Total Electric Plant in Service .......................... & 23,175 & 57,149 & 19,964 & 17,050 & 11,519 & $1,234,201$ \\
\hline 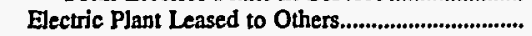 & 0 & 0 & 0 & 0 & 0 & 0 \\
\hline Electric Plant Held for Future Use............................. & 0 & 0 & 0 & 0 & 0 & 0 \\
\hline 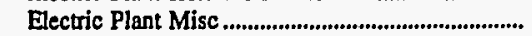 & 0 & 0 & 0 & $\mathbf{0}$ & $\mathbf{0}$ & 0 \\
\hline Total Electric Utlility Plant................................... & 23,175 & 57,149 & 19,964 & 17,050 & 11,519 & $1,234,201$ \\
\hline $\begin{array}{l}\text { Construction Work in Progress - Electric................. } \\
\text { Accumulated Provision for Depreciation }\end{array}$ & 0 & 2,325 & 0 & 206 & 0 & 3,104 \\
\hline 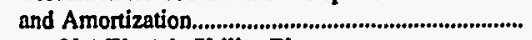 & 7,440 & 33,731 & 14,108 & 6,885 & 6,690 & 371,762 \\
\hline Net Blectric Utility Plant............................................... & 15,734 & 25,744 & $\mathbf{5 , 8 5 6}$ & 10,372 & 4,829 & 865,544 \\
\hline
\end{tabular}

Note: Totals may not equal sum of components because of independent rounding.

Source: Energy Information Administration, Form EIA-412, "Annual Report of Public Electric Utilities." 
Table 24. Electric Utility Plant by Major U.S. Publicly Owned Electric Utility Within State at End of Period, 1996 (Continued)

(Thousand Dollars)

\begin{tabular}{|c|c|c|c|c|c|c|}
\hline Item & $\begin{array}{l}\text { Massachusetts } \\
\text { Middleborough } \\
\text { Town of } \\
\text { December } 31\end{array}$ & $\begin{array}{l}\text { Massachusetts } \\
\text { North } \\
\text { Attleborough } \\
\text { Town of } \\
\text { December } 31\end{array}$ & $\begin{array}{c}\text { Massachusetts } \\
\text { Norwood } \\
\text { City of } \\
\text { June } 30\end{array}$ & $\begin{array}{l}\text { Massachusetts } \\
\text { Peabody } \\
\text { City of } \\
\text { December } 31\end{array}$ & $\begin{array}{l}\text { Massachusetts } \\
\text { Reading } \\
\text { Town of } \\
\text { December } 31\end{array}$ & $\begin{array}{l}\text { Massachusetts } \\
\text { Shrewsbury } \\
\text { Town of } \\
\text { December } 31\end{array}$ \\
\hline \multicolumn{7}{|l|}{ Electric Plant in Service } \\
\hline $\begin{array}{l}\text { Intangible Plant } \\
\text { Production Plant }\end{array}$ & 0 & 0 & 0 & 0 & 0 & 0 \\
\hline Steam & 0 & 673 & 0 & 0 & 0 & 0 \\
\hline 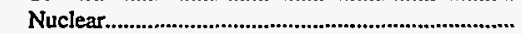 & 0 & 0 & $\mathbf{0}$ & 0 & 0 & 0 \\
\hline 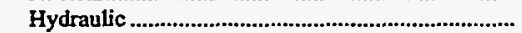 & 0 & 0 & 0 & 0 & 0 & 0 \\
\hline Other & 0 & 0 & 0 & 22,185 & 0 & 3,075 \\
\hline 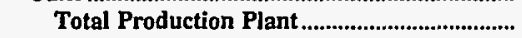 & 0 & 673 & 0 & 22,185 & 0 & 3,075 \\
\hline 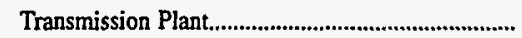 & 2,794 & 1,774 & 1,011 & 7,584 & 2,265 & 2,250 \\
\hline 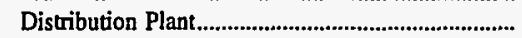 & 11,059 & 14,080 & 20,501 & 26,203 & 39,009 & 17,290 \\
\hline 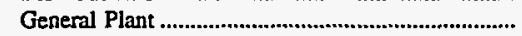 & 2,628 & 4,944 & 2,065 & 9,499 & 12,861 & 4,318 \\
\hline 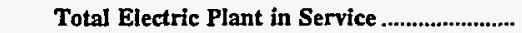 & 16,481 & 21,469 & 23,577 & 65,472 & 54,135 & 26,934 \\
\hline 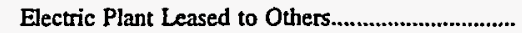 & 0 & 0 & 0 & 0 & 0 & 0 \\
\hline 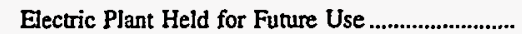 & 0 & 0 & 0 & 0 & 0 & 0 \\
\hline Electric Plant Misc & 0 & 0 & 0 & 0 & 0 & 0 \\
\hline 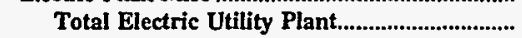 & 16,481 & 21,469 & 23,577 & 65,472 & 54,135 & 26,934 \\
\hline $\begin{array}{l}\text { Construction Work in Progress - Electric.............. } \\
\text { Accumulated Provision for Depreciation }\end{array}$ & 0 & 3,039 & 0 & 0 & 0 & 1,500 \\
\hline 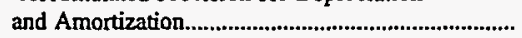 & 7,591 & 7,981 & 17,024 & 26,901 & 24,082 & 12,919 \\
\hline 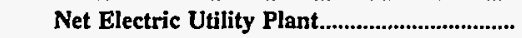 & $\mathbf{8 , 8 9 0}$ & 16,528 & 6,553 & 38,570 & 30,053 & 15,514 \\
\hline
\end{tabular}

\begin{tabular}{|c|c|c|c|c|c|c|}
\hline Item & $\begin{array}{l}\text { Massachusetts } \\
\text { Taunton } \\
\text { City of } \\
\text { December } 31\end{array}$ & $\begin{array}{l}\text { Massachusetts } \\
\text { Wakefield } \\
\text { Town of } \\
\text { December } 31\end{array}$ & $\begin{array}{l}\text { Massachusetts } \\
\text { Wellesley } \\
\text { Town of } \\
\text { December } 31\end{array}$ & $\begin{array}{l}\text { Massachusetts } \\
\text { Westfield } \\
\text { City of } \\
\text { December } 31\end{array}$ & $\begin{array}{c}\text { Michigan } \\
\text { Bay } \\
\text { City City of } \\
\text { June } 30\end{array}$ & $\begin{array}{l}\text { Michigan } \\
\text { Coldwater } \\
\text { Board } \\
\text { of } \\
\text { Public Util } \\
\text { June } 30\end{array}$ \\
\hline \multicolumn{7}{|l|}{ Electric Plant in Service } \\
\hline $\begin{array}{l}\text { Intangible Plant } \\
\text { Production Plant }\end{array}$ & 0 & 0 & 0 & 0 & 0 & 0 \\
\hline Steam & 57,947 & 0 & 0 & 0 & 0 & 7,132 \\
\hline 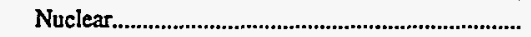 & 3,988 & 0 & 0 & 0 & 0 & 0 \\
\hline 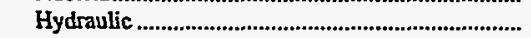 & 0 & 0 & 0 & 0 & 0 & 0 \\
\hline Other & 1,123 & 0 & 0 & 0 & 7,927 & 0 \\
\hline 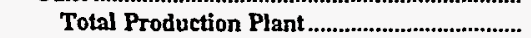 & 63,058 & 0 & $\mathbf{0}$ & 0 & 7,927 & 7,132 \\
\hline 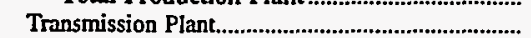 & 7,107 & 0 & 6,597 & 0 & 0 & 0 \\
\hline 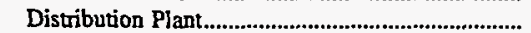 & 34,603 & 14,281 & 21,362 & 20,449 & 38,421 & 6,467 \\
\hline 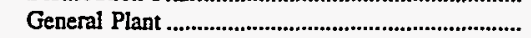 & 6,628 & 602 & 1,763 & 8,925 & 868 & 3,052 \\
\hline 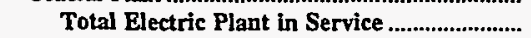 & 111,396 & 14,883 & 29,722 & 29,374 & 47,216 & 16,652 \\
\hline 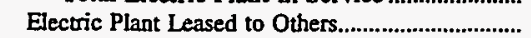 & 0 & 0 & 0 & 0 & 0 & 0 \\
\hline 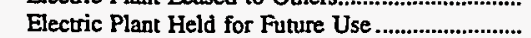 & 0 & 0 & 0 & 0 & 0 & 7,457 \\
\hline 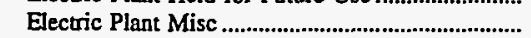 & 0 & 0 & 0 & 0 & 0 & 0 \\
\hline Total Electric Utility Plant & 111,396 & 14,883 & 29,722 & 29,374 & 47,216 & 24,109 \\
\hline $\begin{array}{l}\text { Construction Work in Progress - Electric................ } \\
\text { Accumulated Provision for Depreciation }\end{array}$ & 1,197 & 0 & 1,370 & 33 & 0 & 0 \\
\hline 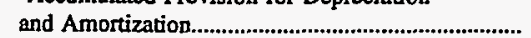 & 64,944 & 12,620 & 13,368 & 1,783 & 16,995 & 8,967 \\
\hline Net Electric Utility Plant................................... & 47,649 & 2,263 & 17,724 & 27,625 & 30,221 & 15,142 \\
\hline
\end{tabular}

Note: Totals may not equal sum of components because of independent rounding.

Source: Energy Information Administration, Form EIA-412, "Annual Report of Public Electric Utilities." 
Table 24. Electric Utility Plant by Major U.S. Publicly Owned Electric Utility Within State at End of Period, 1996 (Continued)

(Thousand Dollars)

\begin{tabular}{|c|c|c|c|c|c|c|}
\hline Item & $\begin{array}{l}\text { Michigan } \\
\text { Detroit } \\
\text { City of } \\
\text { June } 30\end{array}$ & $\begin{array}{l}\text { Michigan } \\
\text { Grand Haven } \\
\text { City of } \\
\text { June } 30\end{array}$ & $\begin{array}{l}\text { Michigan } \\
\text { Hillsdale } \\
\text { Board } \\
\text { of } \\
\text { Public Wks } \\
\text { June } 30\end{array}$ & $\begin{array}{l}\text { Michigan } \\
\text { Holland } \\
\text { City of } \\
\text { June } 30\end{array}$ & $\begin{array}{l}\text { Michigan } \\
\text { Lansing } \\
\text { City of } \\
\text { June } 30\end{array}$ & $\begin{array}{l}\text { Michigan } \\
\text { Marquette } \\
\text { City of } \\
\text { June } 30\end{array}$ \\
\hline \multicolumn{7}{|l|}{ Electric Plant In Service } \\
\hline 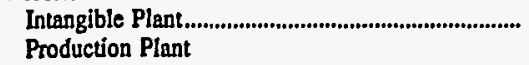 & 0 & $\mathbf{0}$ & 0 & 0 & 718 & 0 \\
\hline Steam & 96,656 & 81,758 & 0 & 37,990 & 193,387 & 66,385 \\
\hline 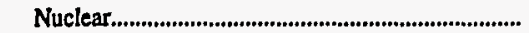 & $\mathbf{0}$ & $\mathbf{0}$ & 0 & 0 & 0 & 0 \\
\hline 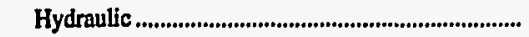 & 0 & 0 & 0 & $\mathbf{0}$ & 5,547 & 5,174 \\
\hline 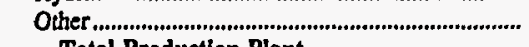 & 2,508 & 4,478 & 5,572 & 33,239 & 0 & 4,552 \\
\hline Total Production Plant & 99,164 & 86,236 & 5,572 & 71,229 & 198,934 & 76,110 \\
\hline Transmission Plant......................................................... & 23,454 & 0 & 25 & 0 & 39,738 & 1,324 \\
\hline Distribution Plant & 153,984 & 18,689 & 4,986 & 31,417 & 139,871 & 18,090 \\
\hline 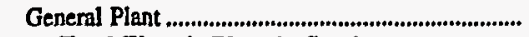 & 14,050 & 1,467 & 938 & 4,590 & 33,153 & 4,228 \\
\hline Total Electric Plant in Service ......................... & 290,653 & 106,391 & 11,520 & 107,235 & 412,415 & 99,751 \\
\hline Electric Plant Leased to Others................................. & 0 & 0 & 0 & 0 & 0 & 0 \\
\hline Electric Plant Held for Future Use ........................... & 0 & 0 & 17 & 0 & 0 & 0 \\
\hline Electric Plant Misc ........................................................ & 0 & 0 & 0 & 0 & 0 & 0 \\
\hline Total Electric Utillty Plant............................... & 290,653 & 106,391 & 11,538 & 107,235 & 412,415 & 99,751 \\
\hline $\begin{array}{l}\text { Construction Work in Progress - Electric............... } \\
\text { Accumulated Provision for Depreciation }\end{array}$ & 15,787 & 293 & 685 & 4,112 & 21,725 & 17 \\
\hline 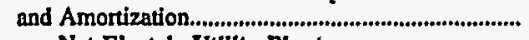 & 130,673 & 49,408 & 8,036 & 50,990 & 240,643 & 48,241 \\
\hline Net Electric Utility Plant..................................... & 175,766 & 57,276 & 4,187 & 60,357 & 193,497 & 51,527 \\
\hline
\end{tabular}

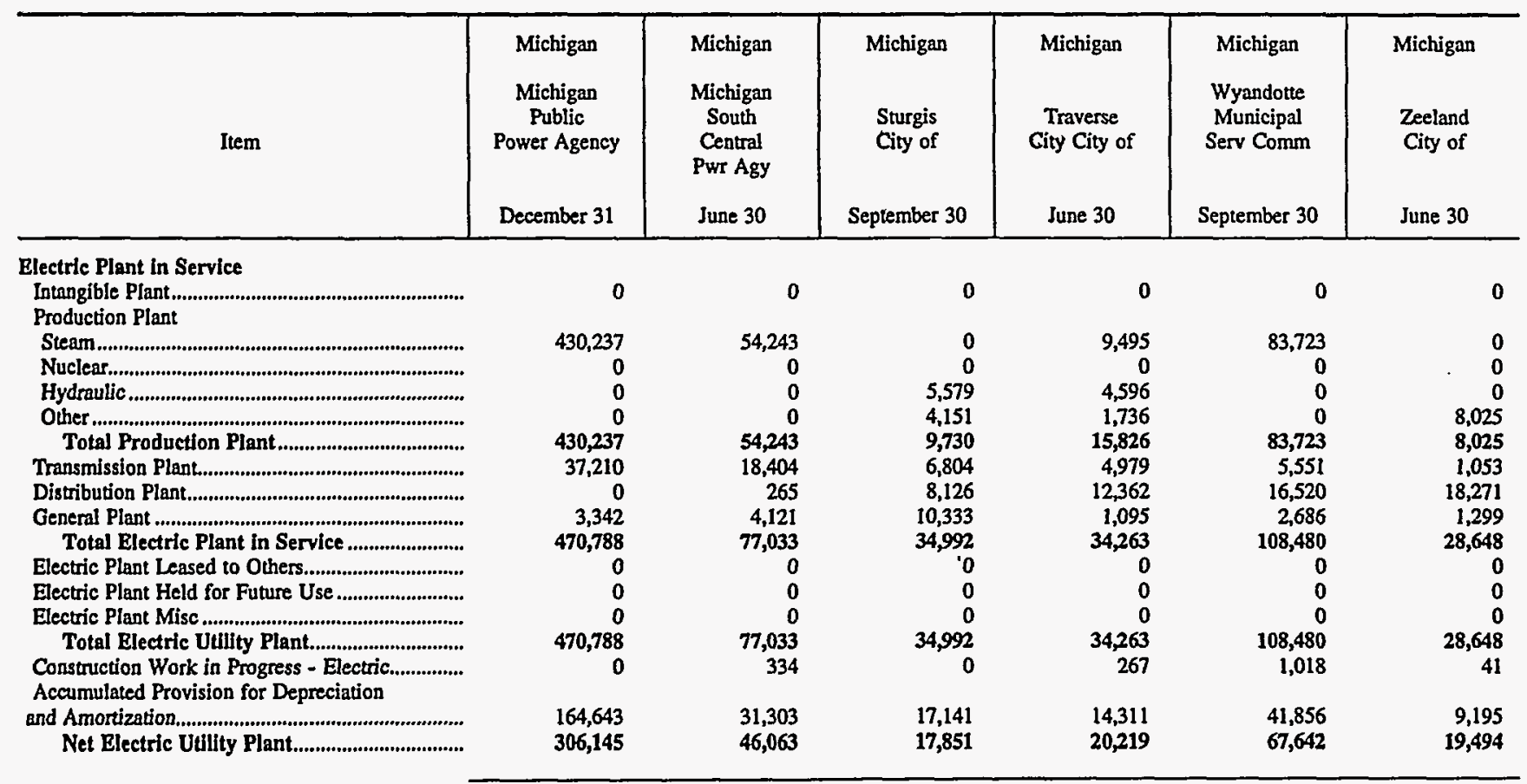

Note: Totals may not equal sum of components because of independent rounding.

Source: Energy Information Administration, Form EIA-412, "Annual Report of Public Electric Utilities." 
Table 24. Electric Utility Plant by Major U.S. Publicly Owned Electric Utility Within State at End of Period, 1996 (Continued)

(Thousand Dollars)

\begin{tabular}{|c|c|c|c|c|c|c|}
\hline Item & $\begin{array}{l}\text { Minnesota } \\
\text { Alexandria } \\
\text { City of } \\
\text { December } 31\end{array}$ & $\begin{array}{c}\text { Minnesota } \\
\text { Anoka } \\
\text { City of } \\
\text { December } 31\end{array}$ & $\begin{array}{c}\text { Minnesota } \\
\text { Austin } \\
\text { City of } \\
\text { December } 31\end{array}$ & $\begin{array}{l}\text { Minnesota } \\
\text { Brainerd } \\
\text { Public } \\
\text { Utilities } \\
\text { December } 31\end{array}$ & $\begin{array}{l}\text { Minnesota } \\
\text { Chaska } \\
\text { City of } \\
\text { December } 31\end{array}$ & $\begin{array}{l}\text { Minnesota } \\
\text { Fairmont } \\
\text { Public } \\
\text { Utilities } \\
\text { Comm } \\
\text { December } 31\end{array}$ \\
\hline \multicolumn{7}{|l|}{ Electric Plant in Service } \\
\hline $\begin{array}{l}\text { Intangible Plant } \\
\text { Production Plant }\end{array}$ & 0 & 0 & 0 & 0 & 0 & 390 \\
\hline 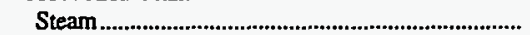 & 494 & 0 & 16,057 & 0 & 0 & 5,061 \\
\hline 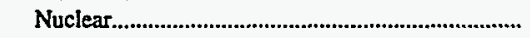 & 0 & 0 & 0 & 0 & 0 & 0 \\
\hline 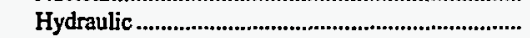 & 0 & 0 & 0 & 0 & 0 & 0 \\
\hline 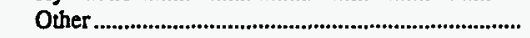 & 2,079 & 0 & 0 & 0 & 0 & 2,398 \\
\hline Total Production Plant & 2,573 & $\mathbf{0}$ & 16,057 & 0 & $\mathbf{0}$ & 7,459 \\
\hline 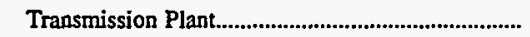 & 901 & 518 & 982 & 0 & 0 & 2,756 \\
\hline 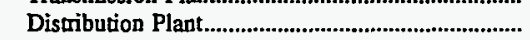 & 11,194 & 14,962 & 16,168 & 7,803 & 9,085 & 5,653 \\
\hline 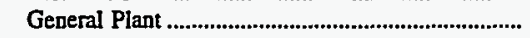 & 1,948 & 1,450 & 2,112 & 0 & 813 & 3,261 \\
\hline Total Electric Plant in Service .......................... & 16,616 & 16,931 & 35,319 & 7,803 & 9,898 & 19,519 \\
\hline 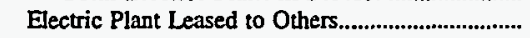 & 0 & 0 & 0 & 0 & 0 & 0 \\
\hline Electric Plant Held for Future Use ......................... & 0 & 0 & 0 & 0 & 0 & 0 \\
\hline 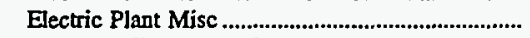 & 0 & 0 & 0 & 0 & 0 & 0 \\
\hline 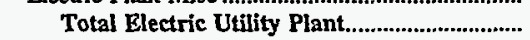 & 16,616 & 16,931 & 35,319 & $\mathbf{7 , 8 0 3}$ & 9,898 & 19,519 \\
\hline $\begin{array}{l}\text { Construction Work in Progress - Electric............... } \\
\text { Accumulated Provision for Depreciation }\end{array}$ & 2,074 & 0 & 211 & 3,017 & 0 & 0 \\
\hline and Amortization & 9,621 & 7,407 & 21,887 & 3,846 & 4,311 & 12,300 \\
\hline Net Electric Utility Plant...................................... & 9,069 & 9,524 & 13,643 & 6,974 & 5,587 & 7,219 \\
\hline
\end{tabular}

\begin{tabular}{|c|c|c|c|c|c|c|}
\hline Item & $\begin{array}{l}\text { Minnesota } \\
\text { Hutchinson } \\
\text { Utilities } \\
\text { Comm } \\
\text { December } 31\end{array}$ & $\begin{array}{c}\text { Minnesota } \\
\text { Marshall } \\
\text { City of } \\
\text { December } 31\end{array}$ & $\begin{array}{l}\text { Minnesota } \\
\text { Moorhead } \\
\text { City of } \\
\text { December } 31\end{array}$ & $\begin{array}{l}\text { Minnesota } \\
\text { New Ulm } \\
\text { Public } \\
\text { Utilities } \\
\text { Comm } \\
\text { December } 31\end{array}$ & $\begin{array}{c}\text { Minnesota } \\
\text { Northern } \\
\text { Municipal } \\
\text { Power Agny } \\
\text { December } 31\end{array}$ & $\begin{array}{c}\text { Minnesota } \\
\text { Owatonna } \\
\text { City of } \\
\text { December } 31\end{array}$ \\
\hline \multicolumn{7}{|l|}{ Electric Plant in Service } \\
\hline 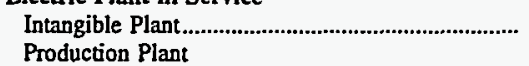 & 0 & 0 & 255 & 0 & 0 & 0 \\
\hline 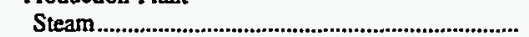 & 0 & 0 & 3,060 & 13,802 & 292,427 & 6,743 \\
\hline 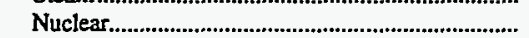 & 0 & 0 & 0 & 0 & 0 & 0 \\
\hline 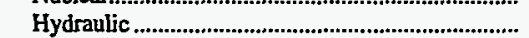 & 0 & 0 & 0 & 0 & 0 & 0 \\
\hline 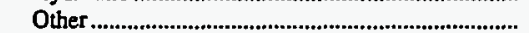 & 33,500 & 2,104 & 0 & 0 & 0 & 1,936 \\
\hline 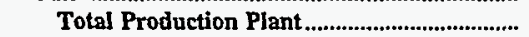 & 33,500 & 2,104 & 3,060 & 13,802 & 292,427 & 8,679 \\
\hline 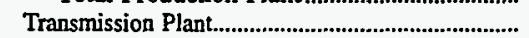 & 5,967 & 3,051 & 3,437 & 4,936 & 30,261 & 2,532 \\
\hline 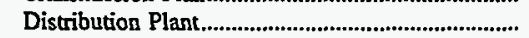 & 8,952 & 14,876 & 14,446 & 9,767 & 0 & 13,968 \\
\hline 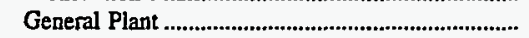 & 1,581 & 3,081 & 1,356 & 0 & 0 & 3,774 \\
\hline Total Electric Plant in Service ...................... & 50,000 & 23,111 & 22,554 & 28,505 & 322,689 & 28,953 \\
\hline Electric Plant Leased to Others............................. & 0 & 0 & 0 & 0 & 0 & 0 \\
\hline 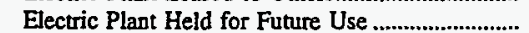 & 0 & 0 & 9,090 & 0 & 0 & 0 \\
\hline 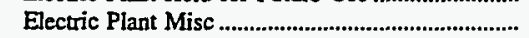 & 0 & 0 & 0 & 0 & 0 & 0 \\
\hline 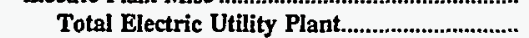 & 50,000 & 23,111 & 31,644 & 28,505 & 322,689 & 28,953 \\
\hline $\begin{array}{l}\text { Construction Work in Progress - Electric............... } \\
\text { Accumulated Provision for Depreciation }\end{array}$ & 0 & 136 & 639 & 0 & 0 & 123 \\
\hline 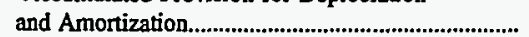 & 17,288 & 8,239 & 16,551 & 15,386 & 34,180 & 14,923 \\
\hline Net Electric Utility Plant.................................... & 32,712 & 15,008 & 15,732 & 13,118 & 288,509 & 14,153 \\
\hline
\end{tabular}

Note: Totals may not equal sum of components because of independent rounding.

Source: Energy Information Adrinistration, Form EIA-412, "Annual Report of Public Electric Utilities." 
Table 24. Electric Utility Plant by Major U.S. Publicly Owned Electric Utility Within State at End of Period, 1996 (Continued)

(Thousand Dollars)

\begin{tabular}{|c|c|c|c|c|c|c|}
\hline Item & $\begin{array}{l}\text { Minnesota } \\
\text { Rochester } \\
\text { Public } \\
\text { Utilities } \\
\text { December } 31\end{array}$ & $\begin{array}{c}\text { Minnesota } \\
\text { Shakopee } \\
\text { Public } \\
\text { Utilities } \\
\text { Comm } \\
\text { December } 31\end{array}$ & $\begin{array}{l}\text { Minnesota } \\
\text { Southem } \\
\text { Minnesota } \\
\text { Mun P } \\
\text { Agny } \\
\text { December } 31\end{array}$ & $\begin{array}{c}\text { Minnesota } \\
\text { Western } \\
\text { Minnesota } \\
\text { Mun } \\
\text { Pwr Agny } \\
\text { December } 31\end{array}$ & $\begin{array}{c}\text { Minnesota } \\
\text { Willmar } \\
\text { Municipal } \\
\text { Utils Comm } \\
\text { December } 31\end{array}$ & $\begin{array}{c}\text { Minnesota } \\
\text { Worthington } \\
\text { City of } \\
\text { December } 31\end{array}$ \\
\hline $\begin{array}{l}\text { Electric Plant in Service } \\
\text { Intangible Plant...................................................... } \\
\text { Production Plant }\end{array}$ & 2,290 & 0 & 30,543 & 0 & 0 & 0 \\
\hline Steam & 26,322 & 0 & 442,205 & 187,516 & 7,889 & 0 \\
\hline 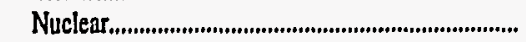 & 0 & 0 & 0 & 0 & 0 & 0 \\
\hline 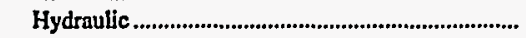 & 2,467 & 0 & 0 & 0 & 0 & 0 \\
\hline Other & 2,554 & 0 & 0 & 0 & 0 & 0 \\
\hline 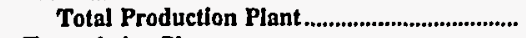 & 31,343 & 0 & 442,205 & 187,516 & 7,889 & 0 \\
\hline 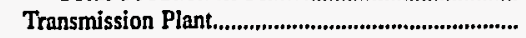 & 10,444 & 0 & 63,821 & 56,841 & 6,240 & 0 \\
\hline 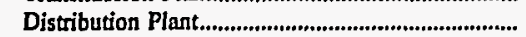 & 51,858 & 7,179 & 0 & 0 & 13,784 & 12,716 \\
\hline 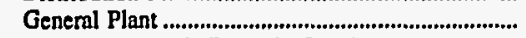 & 17,665 & 740 & 4,725 & 0 & 2,866 & 984 \\
\hline Total Electric Plant in Service ........................ & 113,599 & 7,919 & 541,295 & 244,357 & $\mathbf{3 0 , 7 8 0}$ & 13,700 \\
\hline Electric Plant Leased to Others................................ & 0 & 0 & 0 & 0 & 0 & 0 \\
\hline Electric Plant Held for Future Use ............................. & 0 & 0 & 0 & 0 & 0 & 0 \\
\hline 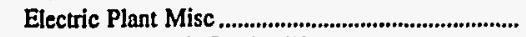 & 0 & 0 & 168 & 0 & 0 & 0 \\
\hline 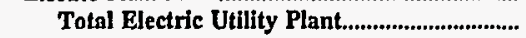 & 113,599 & 7,919 & 541,463 & 244,357 & 30,780 & 13,700 \\
\hline $\begin{array}{l}\text { Construction Work in Progress - Electric................ } \\
\text { Accumulated Provision for Depreciation }\end{array}$ & 3,422 & 1,482 & 7,877 & 343 & 1,979 & 0 \\
\hline 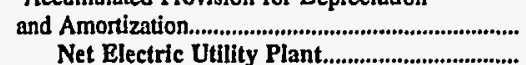 & $\begin{array}{l}57,260 \\
59,761\end{array}$ & $\begin{array}{l}2,667 \\
6,734\end{array}$ & $\begin{array}{l}144,106 \\
405,234\end{array}$ & $\begin{array}{r}57,946 \\
186,754\end{array}$ & $\begin{array}{l}17,538 \\
15,221\end{array}$ & $\begin{array}{l}5,668 \\
8,033\end{array}$ \\
\hline
\end{tabular}

\begin{tabular}{|c|c|c|c|c|c|c|}
\hline Item & $\begin{array}{l}\text { Mississippi } \\
\text { Aberdeen } \\
\text { City of } \\
\text { June } 30\end{array}$ & $\begin{array}{l}\text { Mississippi } \\
\text { Amory } \\
\text { City of } \\
\text { June } 30\end{array}$ & $\begin{array}{l}\text { Mississippi } \\
\text { Clarksdale } \\
\text { City of } \\
\text { September } 30\end{array}$ & $\begin{array}{l}\text { Mississippi } \\
\text { Columbus } \\
\text { City of } \\
\text { June } 30\end{array}$ & $\begin{array}{l}\text { Mississippi } \\
\text { Greenwood } \\
\text { Utilities } \\
\text { Comm } \\
\text { September } 30\end{array}$ & $\begin{array}{l}\text { Mississippi } \\
\text { Holly } \\
\text { Springs } \\
\text { City of } \\
\\
\text { June } 30\end{array}$ \\
\hline \multicolumn{7}{|l|}{ Electric Plant in Service } \\
\hline 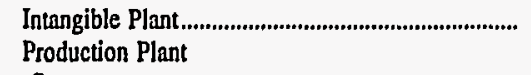 & 0 & 0 & 0 & 0 & 0 & 0 \\
\hline Steam & 0 & 0 & 15,218 & 0 & 13,823 & 0 \\
\hline 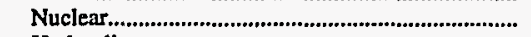 & $\mathbf{0}$ & 0 & 0 & 0 & 0 & 0 \\
\hline 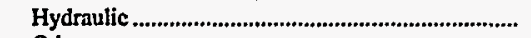 & 0 & 0 & 0 & $\mathbf{0}$ & 0 & 0 \\
\hline Other & 0 & 0 & 0 & 0 & 1,163 & 0 \\
\hline 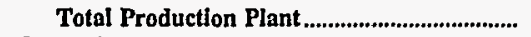 & 0 & 0 & 15,218 & $\mathbf{0}$ & 14,986 & $\mathbf{0}$ \\
\hline 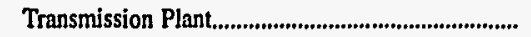 & 0 & 235 & 3,793 & 10 & 731 & 0 \\
\hline 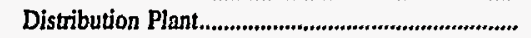 & 3,981 & 6,600 & 7,261 & 15,070 & 9,189 & 12,378 \\
\hline General Plant & 935 & 794 & 1,552 & 2,101 & 2,501 & 2,388 \\
\hline Total Electric Plant in Service & 4,916 & 7,628 & 27,823 & 17,181 & 27,407 & 14,767 \\
\hline 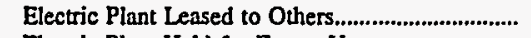 & 0 & 0 & 0 & 0 & 0 & 0 \\
\hline Electric Plant Held for Future Use .............................. & 0 & 0 & 0 & 0 & 0 & 0 \\
\hline 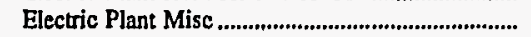 & 0 & 0 & 0 & 10,628 & 0 & $\mathbf{0}$ \\
\hline 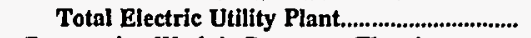 & 4,916 & 7,628 & 27,823 & $\mathbf{2 7 , 8 1 0}$ & 27,407 & 14,767 \\
\hline $\begin{array}{l}\text { Construction Work in Progress - Electric................ } \\
\text { Accumulated Provision for Depreciation }\end{array}$ & 225 & 109 & 1,424 & 31 & 5,764 & 1,347 \\
\hline 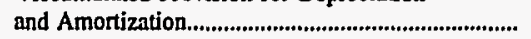 & 2,388 & 3,442 & 20,261 & 9,596 & 16,412 & 5,948 \\
\hline 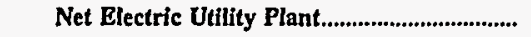 & 2,754 & 4,295 & 8,986 & 18,245 & 16,759 & 10,166 \\
\hline
\end{tabular}

Note: Totals may not equal sum of components because of independent rounding

Source: Energy Information Administration, Form EIA-412, "Annual Report of Public Electric Utilities." 
Table 24. Electric Utility Plant by Major U.S. Publicly Owned Electric Utility Within State at End of Period, 1996

(Thousand Dollars)

\begin{tabular}{|c|c|c|c|c|c|c|}
\hline Item & $\begin{array}{l}\text { Mississippi } \\
\text { Louisville } \\
\text { Electric } \\
\text { System } \\
\\
\text { June } 30\end{array}$ & $\begin{array}{l}\text { Mississippi } \\
\text { Municipal } \\
\text { Energy } \\
\text { Agency } \\
\text { of MS } \\
\text { September } 30\end{array}$ & $\begin{array}{l}\text { Mississippi } \\
\text { New Albany } \\
\text { City of } \\
\text { June } 30\end{array}$ & $\begin{array}{l}\text { Mississippi } \\
\text { Oxford } \\
\text { City of } \\
\text { June } 30\end{array}$ & $\begin{array}{c}\text { Mississippi } \\
\text { Philadelphia } \\
\text { City of } \\
\text { June } 30\end{array}$ & $\begin{array}{l}\text { Mississippi } \\
\text { Starkville } \\
\text { City of } \\
\text { June } 30\end{array}$ \\
\hline \multicolumn{7}{|l|}{ Electric Plant in Service } \\
\hline 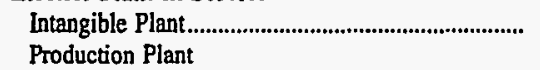 & 0 & 173 & 0 & 0 & 0 & 0 \\
\hline Steam & 0 & 0 & 0 & $\mathbf{0}$ & 0 & $\mathbf{0}$ \\
\hline 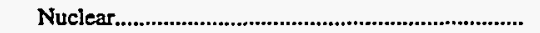 & 0 & 0 & 0 & 0 & 0 & 0 \\
\hline 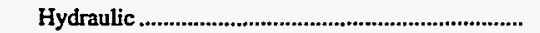 & 0 & 0 & 0 & $\mathbf{0}$ & 0 & 0 \\
\hline Other & 0 & 292 & 0 & 0 & 0 & 0 \\
\hline 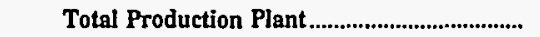 & 0 & 292 & 0 & 0 & 0 & $\mathbf{0}$ \\
\hline 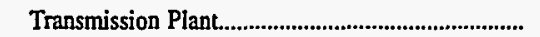 & 202 & 0 & 0 & 0 & 0 & 316 \\
\hline 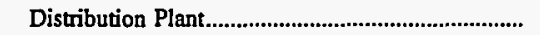 & 8,045 & 0 & 12,567 & 7,183 & 5,291 & 11,096 \\
\hline General Plant & 1,270 & 267 & 1,228 & 990 & 836 & 1,929 \\
\hline 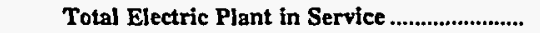 & 9,517 & 731 & 13,794 & 8,173 & 6,128 & 13,341 \\
\hline 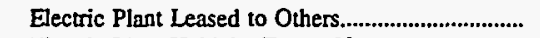 & 0 & 0 & 0 & 0 & 0 & $\mathbf{0}$ \\
\hline 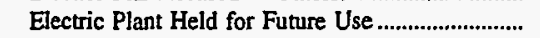 & 0 & 0 & 0 & 0 & 0 & 0 \\
\hline Electric Plant Misc & 0 & 0 & 0 & 0 & 0 & 10 \\
\hline 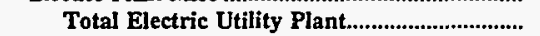 & 9,517 & 731 & 13,794 & 8,173 & 6,128 & 13,351 \\
\hline $\begin{array}{l}\text { Construction Work in Progress - Electric............... } \\
\text { Accumulated Provision for Depreciation }\end{array}$ & 149 & 10,765 & 629 & 504 & 68 & 4,716 \\
\hline 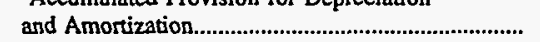 & 3,375 & 216 & 5,527 & 2,494 & 2,255 & 4,456 \\
\hline Net Electric Utility Plant....................................... & 6,290 & 11,281 & 8,896 & 6,183 & 3,940 & 13,612 \\
\hline
\end{tabular}

\begin{tabular}{|c|c|c|c|c|c|c|}
\hline Item & $\begin{array}{l}\text { Mississippi } \\
\text { Tupelo } \\
\text { City of } \\
\text { June } 30\end{array}$ & $\begin{array}{l}\text { Mississippi } \\
\text { West } \\
\text { Point } \\
\text { City of } \\
\text { June } 30\end{array}$ & $\begin{array}{l}\text { Missouri } \\
\text { Carthage } \\
\text { City of } \\
\text { June } 30\end{array}$ & $\begin{array}{l}\text { Missouri } \\
\text { Columbia } \\
\text { City of } \\
\text { September } 30\end{array}$ & $\begin{array}{c}\text { Missouri } \\
\text { Hannibal } \\
\text { City of } \\
\text { June } 30\end{array}$ & $\begin{array}{c}\text { Missouri } \\
\text { Independence } \\
\text { City of } \\
\text { June } 30\end{array}$ \\
\hline \multicolumn{7}{|l|}{ Electric Plant in Service } \\
\hline $\begin{array}{l}\text { Intangible Plant } \\
\text { Production Plant }\end{array}$ & 0 & 0 & 0 & 0 & 0 & 0 \\
\hline Steam & 0 & 0 & $\mathbf{0}$ & 19,255 & 0 & 78,226 \\
\hline 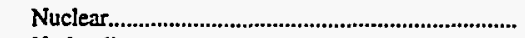 & 0 & 0 & 0 & 0 & 0 & 0 \\
\hline 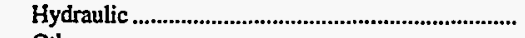 & 0 & 0 & 0 & 0 & 0 & 0 \\
\hline Other & 0 & 0 & 8,170 & 2,837 & 0 & 21,391 \\
\hline 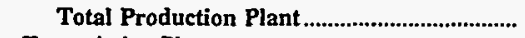 & 0 & 0 & 8,170 & 22,092 & 0 & 99,617 \\
\hline 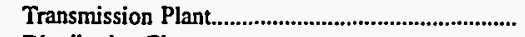 & 876 & 76 & 3,189 & 15,152 & 2,000 & 21,805 \\
\hline 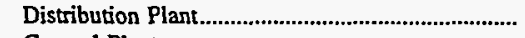 & 23,367 & 6,500 & 8,806 & 45,965 & 7,494 & 52,351 \\
\hline General Plant & 2,210 & 911 & 1,640 & 5,698 & 1,865 & 13,405 \\
\hline 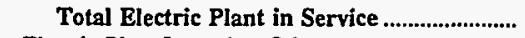 & 26,453 & 7,487 & 21,805 & 88,907 & 11,359 & 187,178 \\
\hline 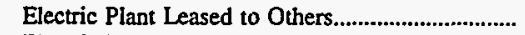 & 0 & 0 & 0 & 0 & 0 & 0 \\
\hline 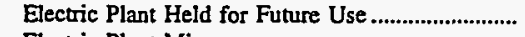 & 0 & 0 & $\mathbf{0}$ & 0 & $\mathbf{0}$ & 0 \\
\hline 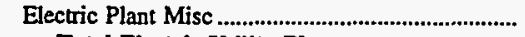 & 0 & 0 & 0 & 0 & 0 & 2,756 \\
\hline 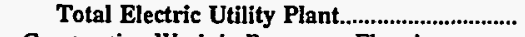 & 26,453 & 7,487 & 21,805 & 88,907 & 11,359 & 189,933 \\
\hline $\begin{array}{l}\text { Construction Work in Progress - Electric................ } \\
\text { Accumulated Provision for Depreciation }\end{array}$ & 20 & 261 & 221 & 4,544 & 125 & 5,148 \\
\hline 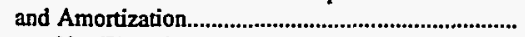 & 8,767 & 2,901 & 14,683 & 38,614 & 7,732 & 99,503 \\
\hline 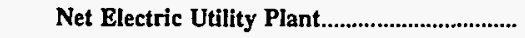 & 17,707 & 4,847 & 7,343 & 54,837 & 3,752 & 95,579 \\
\hline
\end{tabular}

Note: Totals may not equal sum of components because of independent rounding.

Source: Energy Information Administration, Form EIA-412, "Annual Report of Public Electric Utilities." 
Table 24. Electric Utility Plant by Major U.S. Publicly Owned Electric Utility Within State at End of Period, 1996 (Continued)

(Thousand Dollars)

\begin{tabular}{|c|c|c|c|c|c|c|}
\hline Item & $\begin{array}{l}\text { Missouri } \\
\text { Kennett } \\
\text { City of } \\
\text { June } 30\end{array}$ & $\begin{array}{l}\text { Missouri } \\
\text { Kirkwood } \\
\text { City of } \\
\text { March } 31\end{array}$ & $\begin{array}{l}\text { Missouri } \\
\text { Lebanon } \\
\text { City of } \\
\text { October } 31\end{array}$ & $\begin{array}{l}\text { Missouri } \\
\text { Marshall } \\
\text { City of } \\
\text { September } 30\end{array}$ & $\begin{array}{l}\text { Missouri } \\
\text { Monett } \\
\text { City of } \\
\text { March } 31\end{array}$ & $\begin{array}{c}\text { Missouri } \\
\text { Poplar } \\
\text { Bluff } \\
\text { City of } \\
\text { December } 31\end{array}$ \\
\hline $\begin{array}{l}\text { Electric Plant in Service } \\
\text { Intangible Plant....................................................... } \\
\text { Production Plant }\end{array}$ & 0 & 0 & 0 & 0 & 0 & 0 \\
\hline 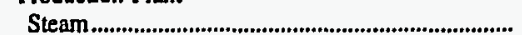 & 0 & $\mathbf{0}$ & 0 & 25,563 & 0 & 0 \\
\hline 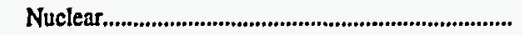 & 0 & 0 & 0 & 0 & 0 & 0 \\
\hline Hydraulic ............................................................................... & 0 & 0 & 0 & 0 & 0 & $\mathbf{0}$ \\
\hline 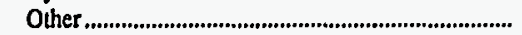 & 8,254 & 0 & 0 & 135 & 0 & 3,591 \\
\hline Total Production Plant ......................................... & 8,254 & 0 & 0 & 25,698 & 0 & 3,591 \\
\hline Transmission Plant.............................................................. & 790 & 0 & 0 & 8,784 & 0 & 0 \\
\hline Distribution Plant.............................................................. & 5,548 & 5,651 & 0 & 4,824 & 5,158 & 18,697 \\
\hline 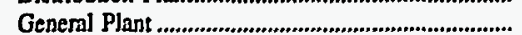 & 0 & 0 & 0 & 2,219 & 0 & 3,065 \\
\hline Total Electric Plant in Service ...................... & 14,592 & 5,651 & 0 & 41,525 & 5,158 & 25,353 \\
\hline Electric Plant Leased to Others...................................... & 0 & 0 & 0 & 0 & 0 & 0 \\
\hline Electric Plant Held for Future Use ................................. & 0 & 0 & 0 & 0 & 0 & 0 \\
\hline 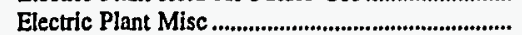 & 0 & 0 & 0 & 0 & 0 & 0 \\
\hline Total Electric Utility Plant................................. & 14,592 & 5,651 & 0 & 41,525 & 5,158 & 25,353 \\
\hline Construction Work in Progress - Electric................. & 0 & 0 & 0 & 44 & 0 & 0 \\
\hline 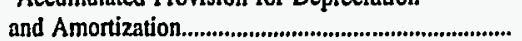 & 11,843 & 2,905 & 0 & 20,215 & 3,547 & 10,400 \\
\hline 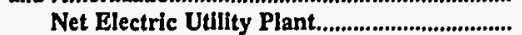 & 2,749 & $\mathbf{2 , 7 4 7}$ & 0 & 21,354 & 1,611 & 14,953 \\
\hline
\end{tabular}

\begin{tabular}{|c|c|c|c|c|c|c|}
\hline Item & $\begin{array}{c}\text { Missouri } \\
\text { Rolla } \\
\text { City of } \\
\text { September } 30\end{array}$ & $\begin{array}{l}\text { Missouri } \\
\text { Sikeston } \\
\text { City of } \\
\text { May } 31\end{array}$ & $\begin{array}{l}\text { Missouri } \\
\begin{array}{c}\text { Springfield } \\
\text { City of }\end{array} \\
\text { September } 30\end{array}$ & $\begin{array}{c}\text { Missouri } \\
\text { West } \\
\text { Plains } \\
\text { City of } \\
\text { December } 31\end{array}$ & $\begin{array}{l}\text { Nebraska } \\
\text { Beatrice } \\
\text { City of } \\
\text { July } 31\end{array}$ & $\begin{array}{c}\text { Nebraska } \\
\text { Central } \\
\text { Nebraska } \\
\text { Pub } \\
\text { P\&I Dist } \\
\text { December } 31\end{array}$ \\
\hline $\begin{array}{l}\text { Electric Plant in Service } \\
\text { Intangible Plant.......................................................... } \\
\text { Production Plant }\end{array}$ & 0 & 0 & 0 & 0 & 14,349 & 16,971 \\
\hline 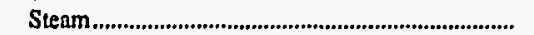 & 0 & 202,741 & 178,318 & 0 & 0 & 0 \\
\hline 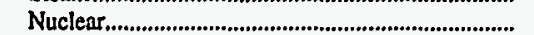 & 0 & 0 & 0 & 0 & 0 & 0 \\
\hline 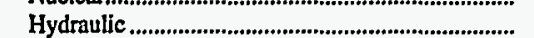 & 0 & 0 & 0 & 0 & 0 & 96,321 \\
\hline 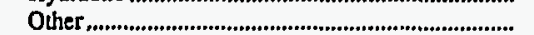 & 0 & 0 & 51,604 & 0 & 0 & 0 \\
\hline Total Production Plant......................................... & 0 & 202,741 & 229,922 & 0 & $\mathbf{0}$ & 96,321 \\
\hline 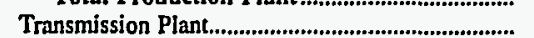 & 149 & 4,594 & 57,178 & 0 & 0 & 1,873 \\
\hline Distribution Plant.................................................... & 8,131 & 14,990 & 155,377 & 5,812 & 0 & 0 \\
\hline 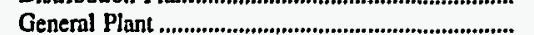 & 2,375 & 3,706 & 10,402 & 0 & 0 & 4,648 \\
\hline Total Electric Plant in Service & 10,656 & 226,032 & 452,879 & 5,812 & 14,349 & 119,812 \\
\hline 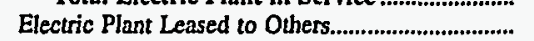 & 0 & 0 & 0 & 0 & 0 & 0 \\
\hline Electric Plant Held for Future Use ............................... & 0 & 0 & 0 & 0 & 0 & 0 \\
\hline 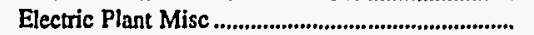 & 0 & $\mathbf{0}$ & 0 & 0 & 0 & 0 \\
\hline Total Electric Utillity Plant..................................... & 10,656 & 226,032 & 452,879 & 5,812 & 14,349 & 119,812 \\
\hline $\begin{array}{l}\text { Construction Work in Progress - Electric..................... } \\
\text { Accummlated Provision for Deprecjation }\end{array}$ & 0 & 952 & 6,036 & 0 & 743 & 155 \\
\hline 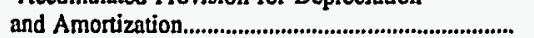 & 7,123 & 73,036 & 125,786 & $\mathbf{0}$ & 8,206 & 41,913 \\
\hline 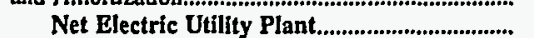 & $\mathbf{3 , 5 3 3}$ & 153,948 & 333,129 & 5,812 & 6,886 & 78,053 \\
\hline
\end{tabular}

Note: Totals may not equal sum of components because of independent rounding.

Source: Energy Information Administration, Form EIA-412, "Annual Report of Public Electric Utilities." 
Table 24. Electric Utility Plant by Major U.S. Publicly Owned Electric Utility Within State at End of Period, 1996 (Continued)

(Thousand Dollars)

\begin{tabular}{|c|c|c|c|c|c|c|}
\hline Item & $\begin{array}{c}\text { Nebraska } \\
\text { Cornhusker } \\
\text { Public } \\
\text { Power Dist } \\
\text { December } 31\end{array}$ & $\begin{array}{c}\text { Nebraska } \\
\text { Dawson } \\
\text { County } \\
\text { Public } \\
\text { Pwr Dist } \\
\text { December } 31\end{array}$ & $\begin{array}{l}\text { Nebraska } \\
\text { Fremont } \\
\text { City of } \\
\text { July } 31\end{array}$ & $\begin{array}{c}\text { Nebraska } \\
\begin{array}{c}\text { Grand Island } \\
\text { City of }\end{array} \\
\text { July } 31\end{array}$ & $\begin{array}{c}\text { Nebraska } \\
\text { Hastings } \\
\text { City of } \\
\text { December } 31\end{array}$ & $\begin{array}{l}\text { Nebraska } \\
\text { Lincoln } \\
\text { Electric } \\
\text { System } \\
\text { December } 31\end{array}$ \\
\hline 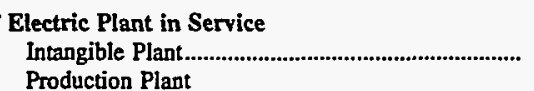 & 1 & 3 & 0 & 3,116 & 0 & 13,688 \\
\hline 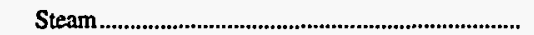 & 0 & 0 & 49,878 & 122,022 & 75,874 & 140,131 \\
\hline 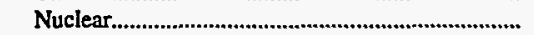 & 0 & $\mathbf{0}$ & 0 & 0 & 0 & 0 \\
\hline 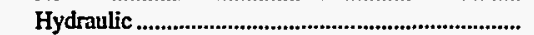 & 0 & 0 & 0 & 0 & 0 & 0 \\
\hline Other ................................................................... & 0 & 0 & 0 & 0 & 2,628 & 13,887 \\
\hline Total Production Plant............................................ & $\mathbf{0}$ & $\mathbf{0}$ & 49,878 & 122,022 & 78,503 & 154,018 \\
\hline Transmission Plant...................................................... & 3,235 & 5,227 & 289 & 10,766 & 9,742 & 90,619 \\
\hline 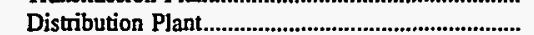 & 28,645 & 40,592 & 13,592 & 29,558 & 17,953 & 181,307 \\
\hline General Plant ........................................................... & 3,694 & 4,866 & 4,188 & 3,245 & 2,484 & 30,268 \\
\hline Total Electric Plant in Service ..................... & 35,575 & 50,687 & 67,947 & 168,709 & 108,681 & 469,900 \\
\hline 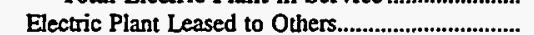 & 0 & 4 & 0 & 0 & 0 & 0 \\
\hline Electric Plant Held for Future Use ............................. & 0 & 1 & 0 & 0 & 0 & 0 \\
\hline 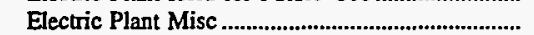 & 0 & 0 & 0 & 2,167 & 0 & 4,829 \\
\hline Total Electric Utility Plant............................. & 35,575 & 50,692 & 67,947 & 170,875 & 108,681 & 474,729 \\
\hline $\begin{array}{l}\text { Construction Work in Progress - Electric................ } \\
\text { Accumulated Provision for Depreciation }\end{array}$ & 306 & 171 & 2,643 & 2,472 & 302 & 54,005 \\
\hline 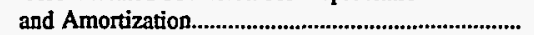 & 11,588 & 20,415 & 52,301 & 77,882 & 42,296 & 161,891 \\
\hline Net Electric Utility Plant....................................... & 24,293 & 30,449 & 18,289 & 95,466 & 66,688 & 366,843 \\
\hline
\end{tabular}

\begin{tabular}{|c|c|c|c|c|c|c|}
\hline Item & $\begin{array}{c}\text { Nebraska } \\
\text { Loup } \\
\text { River } \\
\text { Public } \\
\text { Power Dist } \\
\text { December } 31\end{array}$ & $\begin{array}{c}\text { Nebraska } \\
\text { Municipal } \\
\text { Energy } \\
\text { Agency } \\
\text { of NE } \\
\text { March } 31\end{array}$ & $\begin{array}{c}\text { Nebraska } \\
\text { Nebraska } \\
\text { Public } \\
\text { Power } \\
\text { District } \\
\text { December } 31\end{array}$ & $\begin{array}{c}\text { Nebraska } \\
\text { Norris } \\
\text { Public } \\
\text { Power } \\
\text { District } \\
\text { December } 31\end{array}$ & $\begin{array}{c}\text { Nebraska } \\
\text { North } \\
\text { Platte } \\
\text { City of } \\
\text { July } 31\end{array}$ & $\begin{array}{c}\text { Nebraska } \\
\text { Omaha Public } \\
\text { Power } \\
\text { District } \\
\text { December } 31\end{array}$ \\
\hline 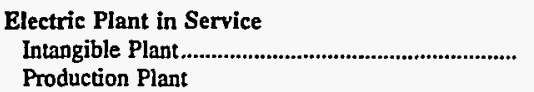 & 0 & 28,305 & 3,374 & 2 & 0 & 0 \\
\hline 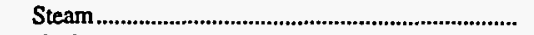 & 0 & 0 & 784,443 & 0 & 0 & 654,360 \\
\hline 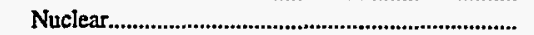 & 0 & 0 & 352,126 & 0 & 0 & 424,774 \\
\hline 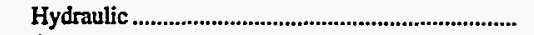 & 10,605 & $\mathbf{0}$ & 22,335 & 0 & 0 & 0 \\
\hline 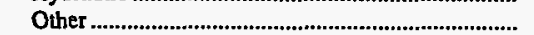 & 0 & 0 & 16,006 & 0 & 0 & 65,120 \\
\hline Total Production Plant ............................................... & 10,605 & 0 & $1,174,911$ & 0 & 0 & $1,144,253$ \\
\hline 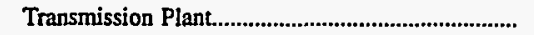 & 15,258 & 0 & 456,765 & 7,781 & 615 & 173,718 \\
\hline 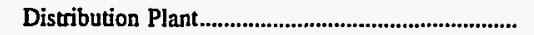 & 26,578 & 0 & 126,529 & 49,482 & 11,176 & 652,284 \\
\hline General Plant .................................................................... & 9,278 & 0 & 145,159 & 8,298 & 3,109 & 184,257 \\
\hline Total Electric Plant in Service ................................ & 61,720 & 28,305 & $1,906,738$ & 65,564 & 14,901 & $2,154,512$ \\
\hline Electric Plant Leased to Others..................................... & 0 & 0 & 0 & 0 & 0 & 0 \\
\hline Electric Plant Held for Future Use ................................. & 0 & 0 & 0 & 0 & 0 & 0 \\
\hline 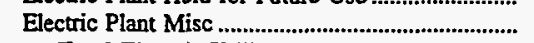 & 407 & 5,658 & 0 & 459 & 0 & 7,998 \\
\hline Total Electric Utility Plant..................................... & 62,127 & 33,963 & $1,906,738$ & 66,023 & 14,901 & $2,162,510$ \\
\hline $\begin{array}{l}\text { Construction Work in Progress - Electric................ } \\
\text { Accumulated Provision for Depreciation }\end{array}$ & 2,119 & 0 & 261,269 & 777 & 564 & 84,645 \\
\hline 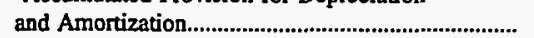 & 27,054 & 4,082 & 916,404 & 21,527 & 9,059 & 834,916 \\
\hline 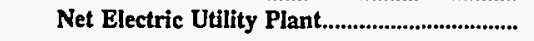 & 37,191 & 29,881 & $1,251,604$ & 45,273 & 6,406 & $1,412,239$ \\
\hline
\end{tabular}

Note: Totals may not equal sum of components because of independent rounding.

Source: Energy Information Administration, Form EIA-412, "Annual Report of Public Electric Uilities." 
Table 24. Electric Utility Plant by Major U.S. Publicly Owned Electric Utility Within State at End of Period, 1996 (Continued)

(Thousand Dollars)

\begin{tabular}{|c|c|c|c|c|c|c|}
\hline Item & $\begin{array}{c}\text { Nebraska } \\
\text { Southern } \\
\text { Nebraska Rural } \\
\text { P P D } \\
\text { December } 31\end{array}$ & $\begin{array}{c}\text { Nevada } \\
\text { Colorado } \\
\text { River } \\
\text { Comm } \\
\text { of Nevada } \\
\text { June } 30\end{array}$ & $\begin{array}{c}\text { Nevada } \\
\text { Overton } \\
\text { Power } \\
\text { District } \\
\text { No } 5 \\
\text { December } 31\end{array}$ & $\begin{array}{c}\text { New Jersey } \\
\text { Madison } \\
\text { Borough } \\
\text { December } 31\end{array}$ & $\begin{array}{l}\text { New Jersey } \\
\text { Vineland } \\
\text { City of } \\
\text { June } 30\end{array}$ & $\begin{array}{l}\text { New Mexico } \\
\text { Farmington } \\
\text { City of } \\
\text { June } 30\end{array}$ \\
\hline \multicolumn{7}{|l|}{ Electric Plant in Service } \\
\hline $\begin{array}{l}\text { Intangible Plant .............................................................. } \\
\text { Production Plant }\end{array}$ & 0 & 0 & 2 & 0 & 0 & 5,784 \\
\hline Steam & 0 & 0 & 0 & 0 & 39,316 & 74,329 \\
\hline Nuclear......., & 0 & 0 & 0 & 0 & 0 & 0 \\
\hline 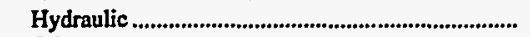 & $\mathbf{0}$ & 0 & 0 & $\mathbf{0}$ & 0 & 16,862 \\
\hline Other & 0 & 0 & 0 & $\mathbf{0}$ & 4,266 & 17,709 \\
\hline 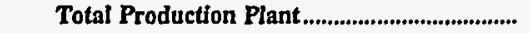 & 0 & 0 & $\mathbf{0}$ & $\mathbf{0}$ & 43,582 & 108,900 \\
\hline 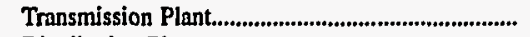 & 3,451 & 0 & 13,056 & 0 & 1,519 & 17,621 \\
\hline 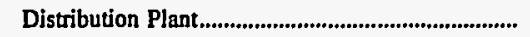 & 68,404 & 0 & 17,555 & 9,146 & 25,826 & 59,126 \\
\hline 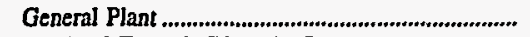 & 8,281 & 0 & 3,848 & 0 & 3,557 & 8,342 \\
\hline Total Electric Plant in Service .............................. & 80,135 & 0 & 34,461 & 9,146 & 74,484 & 199,773 \\
\hline 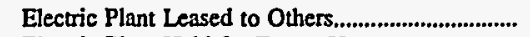 & 0 & $\mathbf{0}$ & 0 & 0 & 0 & 0 \\
\hline Electric Plant Held for Future Use ........................... & 0 & 0 & 0 & $\mathbf{0}$ & 0 & 0 \\
\hline 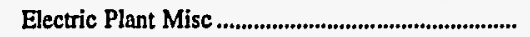 & 0 & 0 & 0 & 0 & 0 & $\mathbf{0}$ \\
\hline 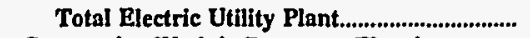 & 80,135 & $\mathbf{0}$ & 34,461 & 9,146 & 74,484 & 199,773 \\
\hline $\begin{array}{l}\text { Construction Work in Progress - Electric................ } \\
\text { Accumulated Provision for Depreciation }\end{array}$ & 513 & 0 & 764 & 2,447 & 7,474 & 4,762 \\
\hline 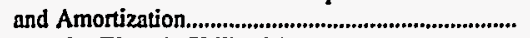 & 36,376 & 0 & 6,899 & 0 & 38,811 & 64,795 \\
\hline 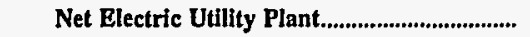 & 44,272 & 0 & 28,325 & 11,593 & 43,147 & 139,740 \\
\hline
\end{tabular}

\begin{tabular}{|c|c|c|c|c|c|c|}
\hline Item & $\begin{array}{l}\text { New Mexico } \\
\text { Gallup } \\
\text { City of } \\
\text { June } 30\end{array}$ & $\begin{array}{l}\text { New Mexico } \\
\text { Los Alamos } \\
\text { County } \\
\text { June } 30\end{array}$ & $\begin{array}{l}\text { New York } \\
\text { Fairport } \\
\text { Village of } \\
\text { May } 31\end{array}$ & $\begin{array}{c}\text { New York } \\
\text { Freeport } \\
\text { Village of } \\
\text { Ine }\end{array}$ & $\begin{array}{l}\text { New York } \\
\text { Jamestown } \\
\text { City of } \\
\text { December } 31\end{array}$ & $\begin{array}{c}\text { New York } \\
\text { Lake Placid } \\
\text { Village Inc } \\
\text { July } 31\end{array}$ \\
\hline \multicolumn{7}{|l|}{ Electric Plant in Service } \\
\hline 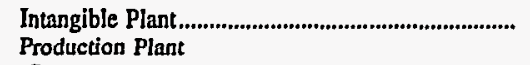 & 0 & 24 & 0 & 0 & 0 & 1 \\
\hline Steam & 0 & 41,942 & $\mathbf{0}$ & 0 & 48,960 & 0 \\
\hline 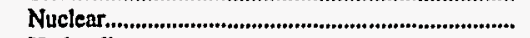 & 0 & 0 & 0 & 0 & 0 & 0 \\
\hline 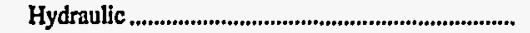 & 0 & 50,542 & $\mathbf{0}$ & 0 & 0 & 0 \\
\hline Other & 0 & 0 & $\mathbf{0}$ & 14,346 & 0 & $\mathbf{0}$ \\
\hline Total Production Plant ....................................... & 0 & 92,484 & 0 & 14,346 & 48,960 & 0 \\
\hline 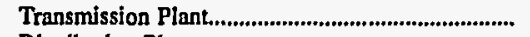 & 0 & 353 & 3,856 & 1,760 & 7,801 & 0 \\
\hline 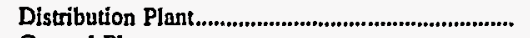 & 11,027 & 8,602 & 12,115 & 13,895 & 24,279 & 11,781 \\
\hline General Plant & 1,395 & 2,308 & 1,704 & 1,896 & 4,519 & 858 \\
\hline Total Electric Plant in Service ........................... & 12,422 & 103,771 & 17,675 & 31,896 & 85,559 & 12,640 \\
\hline 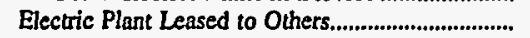 & 0 & 0 & 0 & 0 & 0 & 0 \\
\hline Electric Plant Held for Future Use ............................ & 0 & 0 & 0 & 13 & $\mathbf{0}$ & 0 \\
\hline 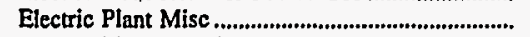 & 0 & 8,949 & 0 & 0 & 0 & 0 \\
\hline 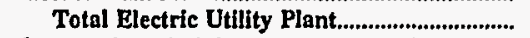 & 12,422 & 112,720 & 17,675 & 31,909 & 85,559 & 12,640 \\
\hline $\begin{array}{l}\text { Construction Work in Progress - Electric............... } \\
\text { Accumulated Provision for Depreciation }\end{array}$ & 0 & 636 & 17 & 15,277 & 1,715 & 28 \\
\hline 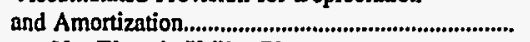 & 6,961 & 29,534 & 8,819 & 20,920 & 30,895 & 3,430 \\
\hline 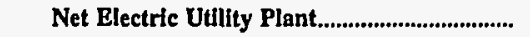 & 5,461 & 83,822 & 8,873 & 26,266 & 56,379 & 9,237 \\
\hline
\end{tabular}

Note: Totals may not equal sum of components because of independent rounding.

Source: Energy Information Administration, Form EIA-412, "Annual Report of Public Electric Utilities." 
Table 24. Electric Utility Plant by Major U.S. Publicly Owned Electric Utility Within State at End of Period, 1996 (Continued)

(Thousand Dollars)

\begin{tabular}{|c|c|c|c|c|c|c|}
\hline Item & $\begin{array}{c}\text { New York } \\
\text { Massena } \\
\text { Town of } \\
\text { December } 31\end{array}$ & $\begin{array}{l}\text { New York } \\
\text { Plattsburgh } \\
\text { City of } \\
\text { December } 31\end{array}$ & $\begin{array}{c}\text { New York } \\
\text { Power } \\
\text { Authority } \\
\text { of State of NY } \\
\text { December } 31\end{array}$ & $\begin{array}{c}\text { New York } \\
\text { Rockville } \\
\text { Centre } \\
\text { Village of } \\
\text { May } 31\end{array}$ & $\begin{array}{c}\text { New York } \\
\text { Solvay } \\
\text { Village of } \\
\text { May } 31\end{array}$ & $\begin{array}{l}\text { North Carolina } \\
\begin{array}{c}\text { Albemarle } \\
\text { City of }\end{array} \\
\text { June } 30\end{array}$ \\
\hline 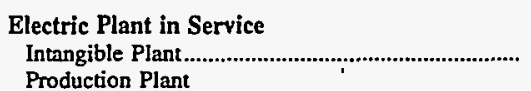 & 2,163 & 4 & 0 & 0 & 0 & 0 \\
\hline Steam & 0 & 0 & 441,908 & 0 & 0 & 0 \\
\hline 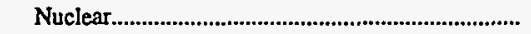 & 0 & 0 & $1,580,855$ & 0 & 0 & 0 \\
\hline 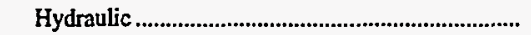 & 0 & 0 & $1,304,097$ & 0 & 0 & 0 \\
\hline 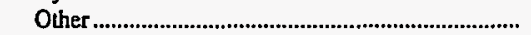 & 0 & 0 & 133,332 & 16,481 & 0 & 0 \\
\hline Total Production Plant ............................................ & 0 & $\mathbf{0}$ & $3,460,192$ & 16,481 & 0 & 0 \\
\hline 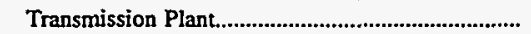 & 4,785 & 8,016 & $1,501,136$ & 5,528 & 0 & 0 \\
\hline 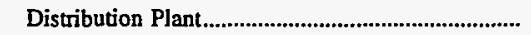 & 10,559 & 17,594 & 0 & 14,007 & 10,888 & 17,862 \\
\hline 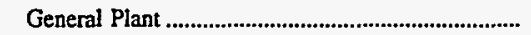 & 1,546 & 4,279 & 261,066 & 1,149 & 0 & 1,014 \\
\hline 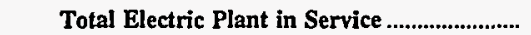 & 19,054 & 29,894 & $5,222,394$ & 37,165 & 10,888 & 18,877 \\
\hline Electric Plant Leased to Others.................................... & 0 & 0 & 0 & 0 & 0 & 0 \\
\hline 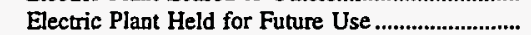 & $\mathbf{0}$ & $\mathbf{0}$ & 0 & $\mathbf{0}$ & 0 & 0 \\
\hline 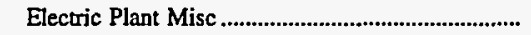 & 4,448 & 0 & 0 & 0 & 0 & 0 \\
\hline Total Electric Utility Plant................................... & 23,502 & 29,894 & $5,222,394$ & 37,165 & 10,888 & 18,877 \\
\hline $\begin{array}{l}\text { Construction Work in Progress - Electric................. } \\
\text { Accumulated Provision for Depreciation }\end{array}$ & 74 & 2,222 & 101,499 & 349 & 188 & 0 \\
\hline 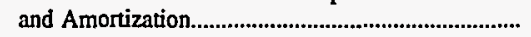 & 9,046 & 13,054 & $1,997,121$ & 15,340 & 4,578 & 11,564 \\
\hline 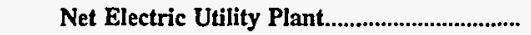 & 14,530 & 19,061 & $3,326,772$ & 22,173 & 6,498 & 7,313 \\
\hline
\end{tabular}

\begin{tabular}{|c|c|c|c|c|c|c|}
\hline Item & $\begin{array}{l}\text { North Carolina } \\
\text { Concord } \\
\text { City of } \\
\text { June } 30\end{array}$ & $\begin{array}{l}\text { North Carolina } \\
\text { Elizabeth } \\
\text { City City of } \\
\text { June } 30\end{array}$ & $\begin{array}{l}\text { North Carolina } \\
\text { Fayetteville } \\
\text { Public } \\
\text { Works Comm } \\
\text { June } 30\end{array}$ & $\begin{array}{l}\text { North Carolina } \\
\text { Forest City } \\
\text { Town of } \\
\text { June } 30\end{array}$ & $\begin{array}{l}\text { North Carolina } \\
\text { Gastonia } \\
\text { City of } \\
\text { June } 30\end{array}$ & $\begin{array}{l}\text { North Carolina } \\
\text { Greenville } \\
\text { Utilities } \\
\text { Comm } \\
\text { June } 30\end{array}$ \\
\hline $\begin{array}{l}\text { Electric Plant in Service } \\
\text { Intangible Plant.................................................... } \\
\text { Production Plant }\end{array}$ & 0 & 0 & 1,841 & 0 & 0 & 0 \\
\hline 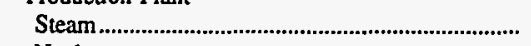 & 0 & 0 & 58,846 & 0 & 0 & 0 \\
\hline 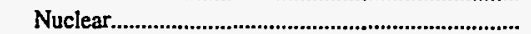 & 0 & 0 & 0 & 0 & 0 & $\mathbf{0}$ \\
\hline 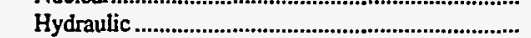 & 0 & 0 & 0 & 0 & 0 & 0 \\
\hline 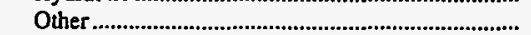 & 0 & 0 & 40,689 & 0 & 0 & 0 \\
\hline Total Production Plant ..................................... & 0 & 0 & 99,536 & 0 & 0 & 0 \\
\hline Transmission Plant..................................................... & 0 & 0 & 21,465 & 0 & 45,326 & 12,650 \\
\hline Distribution Plant & 0 & 19,801 & 96,433 & 5,011 & 0 & 72,780 \\
\hline 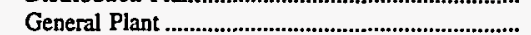 & 41,966 & 5,506 & 16,215 & 326 & 0 & 10,993 \\
\hline Total Electric Plant in Service & 41,966 & 25,307 & 235,489 & 5,337 & 45,326 & 96,423 \\
\hline 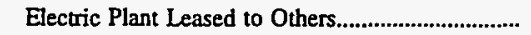 & 0 & 0 & 0 & 0 & 0 & 0 \\
\hline 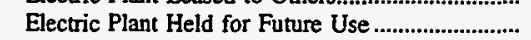 & 0 & 0 & 0 & 0 & 0 & 0 \\
\hline Electric Plant Misc ................................................... & 0 & 0 & 0 & 0 & 0 & 0 \\
\hline Total Electric Utility Plant.................................... & 41,966 & 25,307 & 235,489 & 5,337 & 45,326 & 96,423 \\
\hline $\begin{array}{l}\text { Construction Work in Progress - Electric...................... } \\
\text { Accumulated Provision for Depreciation }\end{array}$ & 0 & 0 & 18,376 & 0 & 0 & 8,504 \\
\hline and Amortization.............................................. & 22,313 & 9,862 & 81,449 & 2,726 & 23,655 & 50,932 \\
\hline Net Electric Utility Plant............................... & 19,652 & 15,445 & 172,416 & $\mathbf{2 , 6 1 1}$ & 21,671 & $\mathbf{5 3 , 9 9 5}$ \\
\hline
\end{tabular}

Note: Totals may not equal sum of components because of independent rounding.

Source: Energy Information Administration, Form EIA-412, "Annual Report of Public Electric Utilities." 
Table 24. Electric Utility Plant by Major U.S. Publicly Owned Electric Utility Within State at End of Period, 1996

(Thousand Dollars)

\begin{tabular}{|c|c|c|c|c|c|c|}
\hline Item & $\begin{array}{l}\text { North Carolina } \\
\text { High } \\
\text { Point } \\
\text { Town } \\
\text { of } \\
\text { June } 30\end{array}$ & $\begin{array}{l}\text { North Carolina } \\
\text { Kinston } \\
\text { City of } \\
\text { June } 30\end{array}$ & $\begin{array}{l}\text { North Carolina } \\
\text { Lexington } \\
\text { City of } \\
\text { June } 30\end{array}$ & $\begin{array}{l}\text { North Carolina } \\
\text { Lumberton } \\
\text { City of } \\
\text { June } 30\end{array}$ & $\begin{array}{l}\text { North Carolina } \\
\text { Monroe } \\
\text { City of } \\
\text { June } 30\end{array}$ & $\begin{array}{l}\text { North Carolina } \\
\text { Morganton } \\
\text { City of } \\
\text { June } 30\end{array}$ \\
\hline \multicolumn{7}{|l|}{ Blectric Plant in Service } \\
\hline $\begin{array}{l}\text { Intangible Plant } \\
\text { Production Plant }\end{array}$ & 0 & 0 & 0 & 0 & 0 & 0 \\
\hline 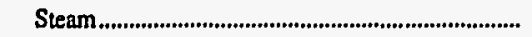 & 0 & 0 & 0 & $\mathbf{0}$ & 0 & 0 \\
\hline Nuclear,..........., & $\mathbf{0}$ & 0 & 0 & 0 & 0 & 0 \\
\hline 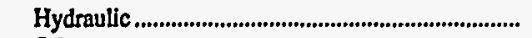 & $\mathbf{0}$ & 0 & 0 & 0 & 0 & 0 \\
\hline 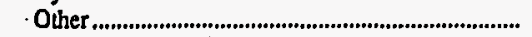 & $\mathbf{0}$ & 0 & 0 & 0 & 0 & 0 \\
\hline 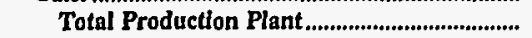 & 0 & 0 & 0 & 0 & $\mathbf{0}$ & $\mathbf{0}$ \\
\hline 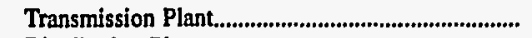 & 0 & 0 & 4,078 & 0 & 0 & 0 \\
\hline 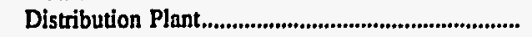 & $\mathbf{0}$ & 15,119 & 23,529 & 9,628 & 26,752 & 13,623 \\
\hline 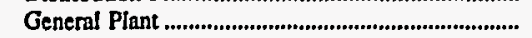 & 66,387 & 5,645 & 3,765 & 3,094 & 0 & 0 \\
\hline Total Electric Plant in Service ............................ & 66,387 & 20,764 & 31,372 & 12,721 & 26,752 & 13,623 \\
\hline Electric Plant Leased to Others.................................. & $\mathbf{0}$ & 0 & 0 & 0 & 0 & 0 \\
\hline Electric Plant Held for Future Use ......................... & 0 & 0 & 0 & 0 & 0 & 0 \\
\hline 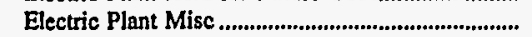 & 0 & 0 & 0 & 0 & $\mathbf{0}$ & 0 \\
\hline 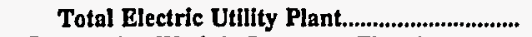 & 66,387 & 20,764 & 31,372 & 12,721 & 26,752 & 13,623 \\
\hline $\begin{array}{l}\text { Construction Work in Progress - Electric............... } \\
\text { Accumulated Provision for Depreciation }\end{array}$ & 0 & 3,940 & 3,024 & 130 & 8,496 & 61 \\
\hline and Amortization, & $\begin{array}{l}27,154 \\
39,233\end{array}$ & $\begin{array}{r}9,120 \\
15,584\end{array}$ & $\begin{array}{l}10,665 \\
23,731\end{array}$ & $\begin{array}{l}7,177 \\
5,674\end{array}$ & $\begin{array}{r}9,161 \\
26,087\end{array}$ & $\begin{array}{l}5,750 \\
7,934\end{array}$ \\
\hline
\end{tabular}

\begin{tabular}{|c|c|c|c|c|c|c|}
\hline Item & $\begin{array}{l}\text { North Carolina } \\
\text { Murphy } \\
\text { City of } \\
\text { June } 30\end{array}$ & $\begin{array}{l}\text { North Carolina } \\
\text { New Bern } \\
\text { City of } \\
\text { June } 30\end{array}$ & $\begin{array}{c}\text { North Carolina } \\
\text { New River } \\
\text { Light } \\
\& \\
\text { Power Co } \\
\text { December } 31\end{array}$ & $\begin{array}{c}\text { North Carolina } \\
\text { North } \\
\text { Carolina } \\
\text { Eastern M P A } \\
\text { December } 31\end{array}$ & $\begin{array}{c}\text { North Carolina } \\
\text { North } \\
\text { Carolina } \\
\text { Mun } \\
\text { Power Agny } \\
\text { December } 31\end{array}$ & $\begin{array}{l}\text { North Carolina } \\
\text { Rocky Mount } \\
\text { City of } \\
\text { June } 30\end{array}$ \\
\hline 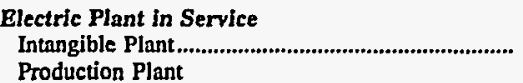 & $\mathbf{0}$ & 0 & 0 & 0 & $\mathbf{0}$ & $\mathbf{0}$ \\
\hline Steam & 0 & 0 & 0 & 133,540 & 0 & $\mathbf{0}$ \\
\hline 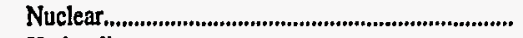 & 0 & 0 & 0 & $1,180,429$ & $1,416,520$ & 0 \\
\hline 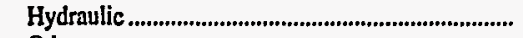 & 0 & 0 & 0 & 0 & 0 & 0 \\
\hline Other & 0 & 0 & 0 & 0 & $\mathbf{0}$ & 0 \\
\hline 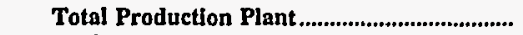 & $\mathbf{0}$ & $\mathbf{0}$ & $\mathbf{0}$ & $1,313,969$ & $1, \mathbf{4 1 6 , 5 2 0}$ & $\mathbf{0}$ \\
\hline 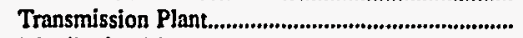 & 0 & 0 & 0 & 0 & 10,959 & 0 \\
\hline 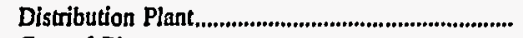 & 6,678 & 0 & 10,348 & 0 & 0 & 42,836 \\
\hline General Plant & 1,564 & 27,167 & 2,551 & 134,338 & 0 & 0 \\
\hline Total Electric Plant in Service ........................... & 8,243 & 27,167 & 12,899 & $1,448,307$ & $1,427,479$ & 42,836 \\
\hline 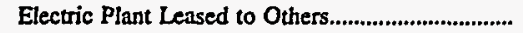 & 0 & 0 & 0 & 0 & 0 & 0 \\
\hline Electric Plant Held for Future Use ............................ & 0 & 0 & $\mathbf{0}$ & 0 & 0 & 0 \\
\hline 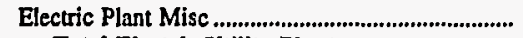 & 0 & 0 & 0 & 0 & $\mathbf{0}$ & 0 \\
\hline 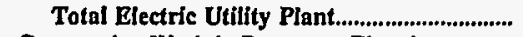 & 8,243 & 27,167 & 12,899 & $1,448,307$ & $1,427,479$ & 42,836 \\
\hline $\begin{array}{l}\text { Construction Work in Progress - Electric................ } \\
\text { Accumulated Provision for Depreciation }\end{array}$ & 309 & 134 & 86 & 4,342 & 12,875 & 0 \\
\hline 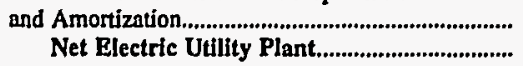 & $\begin{array}{l}2,691 \\
5,861\end{array}$ & $\begin{array}{l}11,398 \\
15,903\end{array}$ & $\begin{array}{l}3,551 \\
9,434\end{array}$ & $\begin{array}{l}489,293 \\
963,356\end{array}$ & $\begin{array}{r}387,581 \\
1,052,773\end{array}$ & $\begin{array}{l}17,253 \\
25,582\end{array}$ \\
\hline
\end{tabular}

Note: Totals may not equal sum of components because of independent rounding.

Source: Energy Information Administration, Form EIA-412, "Annual Report of Public Electric Utilities." 
Table 24. Electric Utility Plant by Major U.S. Publicly Owned Electric Utility Within State at End of Period, 1996 (Continued)

(Thousand Dollars)

\begin{tabular}{|c|c|c|c|c|c|c|}
\hline Item & $\begin{array}{l}\text { North Carolina } \\
\text { Shelby } \\
\text { City of } \\
\text { June } 30\end{array}$ & $\begin{array}{l}\text { North Carolina } \\
\text { Statesville } \\
\text { City of } \\
\text { June } 30\end{array}$ & $\begin{array}{c}\text { North Carolina } \\
\text { Tarboro } \\
\text { Town of } \\
\text { June } 30\end{array}$ & $\begin{array}{l}\text { North Carolina } \\
\text { Washington } \\
\text { City of } \\
\text { June } 30\end{array}$ & $\begin{array}{l}\text { North Carolina } \\
\text { Wilson } \\
\text { City of } \\
\text { June } 30\end{array}$ & $\begin{array}{c}\text { Ohio } \\
\text { American } \\
\text { Mun } \\
\text { Power } \\
\text { Ohio Inc } \\
\text { December } 31\end{array}$ \\
\hline 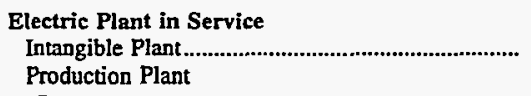 & 0 & 0 & 225 & 0 & 0 & 7,718 \\
\hline Steam & 0 & 0 & 0 & 0 & 0 & 61,251 \\
\hline 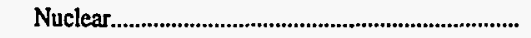 & 0 & 0 & 0 & 0 & 0 & 0 \\
\hline 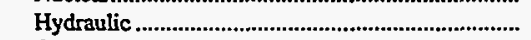 & 0 & 0 & 0 & 0 & 0 & 0 \\
\hline Other & 0 & 0 & 0 & 0 & 0 & 0 \\
\hline Total Production Plant & 0 & 0 & 0 & 0 & 0 & 61,251 \\
\hline 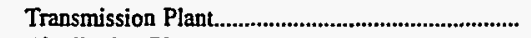 & 0 & 0 & 0 & 24,625 & 0 & 2,774 \\
\hline 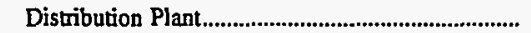 & 9,338 & 17,567 & 22,366 & 0 & 49,044 & 0 \\
\hline General Plant & 0 & 0 & 0 & 6,010 & 7,293 & 890 \\
\hline 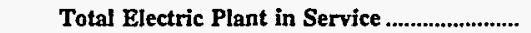 & 9,338 & 17,567 & 22,591 & 30,636 & 56,337 & $\mathbf{7 2 , 6 3 2}$ \\
\hline 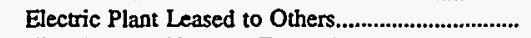 & 0 & 0 & 0 & 0 & 0 & 0 \\
\hline 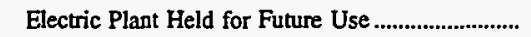 & 0 & 0 & 0 & 0 & 0 & 0 \\
\hline 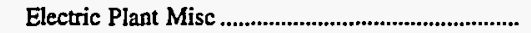 & 0 & 0 & 0 & 0 & 0 & 0 \\
\hline 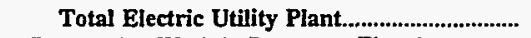 & 9,338 & 17,567 & 22,591 & 30,636 & 56,337 & 72,632 \\
\hline $\begin{array}{l}\text { Construction Work in Progress - Electric................ } \\
\text { Accumulated Provision for Depreciation }\end{array}$ & 0 & 577 & 0 & 158 & 3,389 & 0 \\
\hline 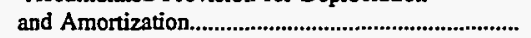 & 5,164 & 7,423 & 7,161 & 13,780 & 29,570 & 26,744 \\
\hline 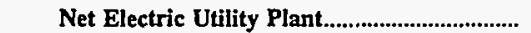 & 4,174 & 10,721 & 15,431 & 17,014 & 30,157 & 45,888 \\
\hline
\end{tabular}

\begin{tabular}{|c|c|c|c|c|c|c|}
\hline Item & $\begin{array}{c}\text { Ohio } \\
\text { Bowling } \\
\text { Green } \\
\text { City of } \\
\text { December } 31\end{array}$ & $\begin{array}{l}\text { Ohio } \\
\text { Bryan } \\
\text { City of } \\
\text { December } 31\end{array}$ & $\begin{array}{l}\text { Ohio } \\
\text { Celina } \\
\text { City of } \\
\text { December } 31\end{array}$ & $\begin{array}{c}\text { Ohio } \\
\text { Cleveland } \\
\text { City of } \\
\text { December } 31\end{array}$ & $\begin{array}{l}\text { Ohio } \\
\text { Clyde } \\
\text { City of } \\
\text { December } 31\end{array}$ & $\begin{array}{c}\text { Ohio } \\
\text { Columbus } \\
\text { City of } \\
\text { Decernber } 31\end{array}$ \\
\hline \multicolumn{7}{|l|}{ Electric Plant in Service } \\
\hline $\begin{array}{l}\text { Intangible Plant } \\
\text { Production Plant }\end{array}$ & 0 & 0 & 0 & 0 & 0 & 0 \\
\hline Steam & 0 & 0 & 5,898 & 37,037 & 0 & 3,933 \\
\hline 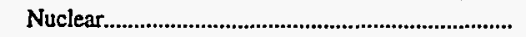 & 0 & 0 & 0 & 0 & 0 & 0 \\
\hline 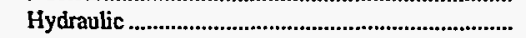 & 0 & 1,115 & 0 & 0 & $\mathbf{0}$ & 0 \\
\hline Other & 0 & 0 & 0 & 6,528 & 0 & 0 \\
\hline Total Production Plant & 0 & 1,115 & 5,898 & 43,565 & 0 & 3,933 \\
\hline 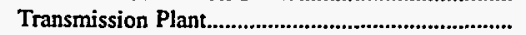 & 588 & 0 & 0 & 77,482 & 0 & 50,025 \\
\hline Distribution Plant & 14,271 & 0 & 14,624 & 142,261 & 10,765 & 10,580 \\
\hline 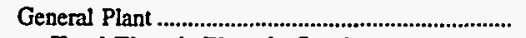 & 4,074 & 15,220 & 596 & 17,610 & 0 & 30,213 \\
\hline Total Electric Plant in Service ........................... & 18,933 & 16,335 & 21,118 & 280,919 & 10,765 & 94,751 \\
\hline Electric Plant Leased to Others................................... & 0 & 0 & 0 & 0 & 0 & 0 \\
\hline Electric Plant Held for Future Use ............................ & 0 & 0 & 0 & 0 & 0 & 0 \\
\hline Electric Plant Misc & 0 & 0 & 0 & 0 & $\mathbf{0}$ & 0 \\
\hline 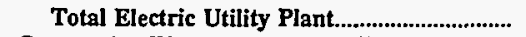 & 18,933 & 16,335 & 21,118 & 280,919 & 10,765 & 94,751 \\
\hline $\begin{array}{l}\text { Construction Work in Progress - Electric................ } \\
\text { Accumulated Provision for Depreciation }\end{array}$ & 1,770 & 0 & 0 & 76,304 & 0 & 0 \\
\hline 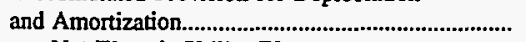 & 9,815 & 11,858 & 0 & 109,010 & 0 & 37,315 \\
\hline Net Electric Utility Plant....................................... & 10,888 & 4,477 & 21,118 & 248,213 & 10,765 & 57,436 \\
\hline
\end{tabular}

Note: Totals may not equal sum of components because of independent rounding.

Source: Energy Information Administration, Form EIA-412, "Annual Report of Public Electric Utilities." 
Table 24. Electric Utility Plant by Major U.S. Publicly Owned Electric Utility Within State at End of Period, 1996 (Continued)

(Thousand Dollars)

\begin{tabular}{|c|c|c|c|c|c|c|}
\hline Item & $\begin{array}{c}\text { Ohio } \\
\text { Cuyahoga } \\
\text { Falls } \\
\text { City of } \\
\text { December } 31\end{array}$ & $\begin{array}{l}\text { Ohio } \\
\text { Dover } \\
\text { City of } \\
\text { December } 31\end{array}$ & $\begin{array}{c}\text { Ohio } \\
\text { Hamilton } \\
\text { City of } \\
\text { December } 31\end{array}$ & $\begin{array}{c}\text { Ohio } \\
\text { Napoleon } \\
\text { City of } \\
\text { December } 31\end{array}$ & $\begin{array}{c}\text { Ohio } \\
\text { Niles } \\
\text { City of } \\
\text { December } 31\end{array}$ & $\begin{array}{l}\text { Ohio } \\
\text { Orville } \\
\text { City of } \\
\text { December } 31\end{array}$ \\
\hline \multicolumn{7}{|l|}{ Blectric Plant in Service } \\
\hline 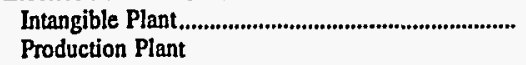 & 0 & 0 & 0 & 0 & 0 & 0 \\
\hline Steam & 0 & 0 & 42,142 & 0 & 0 & 41,315 \\
\hline 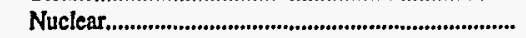 & 0 & 0 & 0 & 0 & 0 & 0 \\
\hline 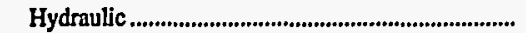 & 0 & 0 & 136,711 & 0 & 0 & $\mathbf{0}$ \\
\hline Other & 0 & 0 & 6,294 & 0 & 0 & 0 \\
\hline 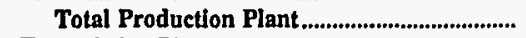 & 0 & 0 & 185,147 & 0 & 0 & 41,315 \\
\hline 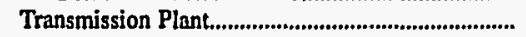 & 711 & 0 & 27,802 & 0 & 0 & 2,129 \\
\hline 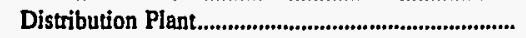 & 19,817 & 10,678 & 23,135 & 2,461 & 0 & 11,938 \\
\hline 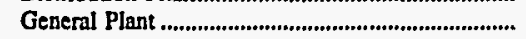 & 2,277 & 0 & 8,216 & 0 & 12,013 & 762 \\
\hline Total Electric Plant in Service .......................... & 22,805 & 10,678 & 244,300 & 2,461 & 12,013 & 56,145 \\
\hline Electric Plant Leased to Others.................................. & 0 & 0 & 0 & 0 & 0 & 0 \\
\hline Electric Plant Held for Future Use ........................... & 0 & 0 & $\mathbf{0}$ & $\mathbf{0}$ & 0 & 0 \\
\hline 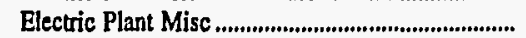 & 0 & 0 & 0 & 0 & 0 & 0 \\
\hline Total Electric Utility Plant............................... & 22,805 & 10,678 & 244,300 & 2,461 & 12,013 & 56,145 \\
\hline $\begin{array}{l}\text { Construction Work in Progress - Electric................ } \\
\text { Accumulated Provision for Depreciation }\end{array}$ & 0 & 0 & 7,332 & 0 & 0 & 17 \\
\hline 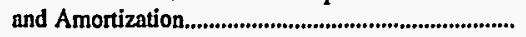 & 12,079 & 0 & 83,301 & 0 & 7,315 & 30,599 \\
\hline Net Electric Utility Plant................................... & 10,727 & 10,678 & 168,331 & 2,461 & 4,698 & 25,563 \\
\hline
\end{tabular}

\begin{tabular}{|c|c|c|c|c|c|c|}
\hline Item & $\begin{array}{c}\text { Ohio } \\
\text { Painesville } \\
\text { City of } \\
\text { December } 31\end{array}$ & $\begin{array}{c}\text { Ohio } \\
\text { Piqua } \\
\text { City of } \\
\text { December } 31\end{array}$ & $\begin{array}{c}\text { Ohio } \\
\text { St Marys } \\
\text { City of } \\
\text { December } 31\end{array}$ & $\begin{array}{c}\text { Ohio } \\
\text { Wadsworth } \\
\text { City of } \\
\text { December } 31\end{array}$ & $\begin{array}{c}\text { Ohio } \\
\text { Wapakoneta } \\
\text { City of } \\
\text { December } 31\end{array}$ & $\begin{array}{c}\text { Ohio } \\
\text { Westerville } \\
\text { City of } \\
\text { December } 31\end{array}$ \\
\hline $\begin{array}{l}\text { Electric Plant in Service } \\
\text { Intangible Plant.......................................................... } \\
\text { Production Plant }\end{array}$ & 0 & 761 & 0 & 0 & 0 & 0 \\
\hline 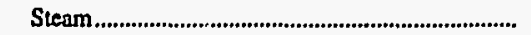 & 26,136 & 20,276 & 0 & $\mathbf{0}$ & 0 & 0 \\
\hline 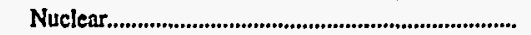 & $\mathbf{0}$ & 0 & 0 & 0 & 0 & 0 \\
\hline 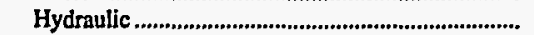 & 0 & 0 & 0 & 0 & 0 & 0 \\
\hline 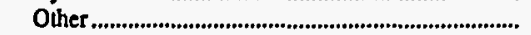 & 0 & 131 & 0 & $\mathbf{0}$ & 0 & 0 \\
\hline Total Production Plant......................................... & 26,136 & 20,407 & 0 & $\mathbf{0}$ & $\mathbf{0}$ & 0 \\
\hline Transmission Plant............................................................. & 0 & 2,572 & 0 & 0 & 0 & 1,497 \\
\hline Distribution Plant................................................................ & 9,642 & 20,756 & 0 & 14,352 & 0 & 19,561 \\
\hline 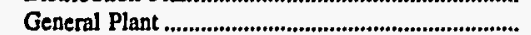 & 0 & 2,564 & 15,234 & 350 & 0 & 6,172 \\
\hline Total Electric Plant in Service ......................... & 35,778 & 47,059 & 15,234 & 14,702 & $\mathbf{0}$ & 27,229 \\
\hline 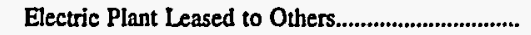 & 0 & 0 & 0 & $\mathbf{0}$ & 0 & 0 \\
\hline Electric Plant Held for Future Use .................................. & 0 & 0 & 0 & 0 & 0 & 0 \\
\hline 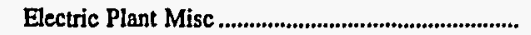 & 0 & 0 & $\mathbf{0}$ & $\mathbf{0}$ & 0 & 0 \\
\hline 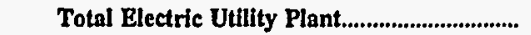 & 35,778 & 47,059 & 15,234 & 14,702 & 0 & 27,229 \\
\hline $\begin{array}{l}\text { Construction Work in Progress - Electric................. } \\
\text { Accumulated Provision for Depreciation }\end{array}$ & 0 & 694 & 15 & 0 & 0 & 0 \\
\hline 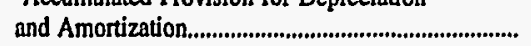 & 21,016 & 22,094 & 9,722 & 5,115 & 0 & 11,142 \\
\hline 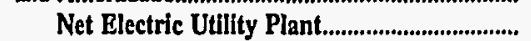 & 14,762 & 25,659 & 5,526 & 9,588 & 0 & 16,087 \\
\hline
\end{tabular}

Note: Totals may not equal sum of components because of independent rounding

Source: Energy Information Administration, Form EIA-412, "Annual Report of Public Electric Utilities." 
Table 24. Electric Utility Plant by Major U.S. Publicly Owned Electric Utility Within State at End of Period, 1996 (Continued)

(Thousand Dollars)

\begin{tabular}{|c|c|c|c|c|c|c|}
\hline Item & $\begin{array}{l}\text { Oklahoma } \\
\text { Altus } \\
\text { City of } \\
\text { June } 30\end{array}$ & $\begin{array}{l}\text { Oklahoma } \\
\text { Claremore } \\
\text { City of } \\
\text { June } 30\end{array}$ & $\begin{array}{l}\text { Oklahoma } \\
\text { Duncan } \\
\text { City of } \\
\text { June } 30\end{array}$ & $\begin{array}{l}\text { Oklahoma } \\
\text { Edmond } \\
\text { City of } \\
\text { June } 30\end{array}$ & $\begin{array}{l}\text { Oklahoma } \\
\text { Grand River } \\
\text { Dam } \\
\text { Authority } \\
\text { December } 31\end{array}$ & $\begin{array}{l}\text { Oklahoma } \\
\text { Miami } \\
\text { City of } \\
\text { June } 30\end{array}$ \\
\hline 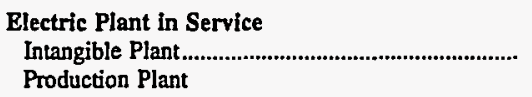 & 0 & 0 & 0 & 0 & $\mathbf{0}$ & 0 \\
\hline 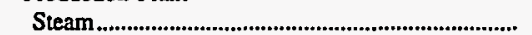 & 0 & 0 & 0 & 0 & 624,588 & 0 \\
\hline 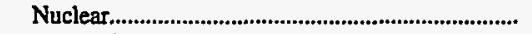 & 0 & 0 & 0 & 0 & 0 & 0 \\
\hline 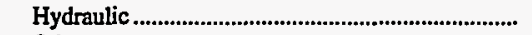 & 0 & 0 & $\mathbf{0}$ & 0 & 71,617 & 0 \\
\hline 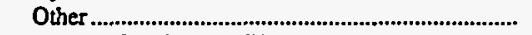 & 0 & 0 & 0 & 0 & 0 & 0 \\
\hline Total Production Plant ............................................... & $\mathbf{0}$ & $\mathbf{0}$ & $\mathbf{0}$ & $\mathbf{0}$ & 696,205 & 0 \\
\hline 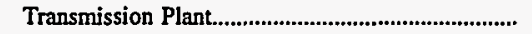 & 9,203 & 0 & 0 & 0 & 148,778 & 0 \\
\hline 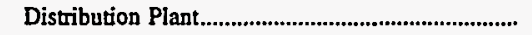 & 0 & 1,032 & 20,284 & 41,679 & 0 & 1,530 \\
\hline 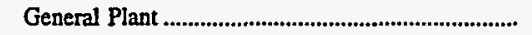 & 0 & 0 & 0 & 0 & 25,853 & 1,476 \\
\hline Total Electric Plant in Service .............................. & 9,203 & 1,032 & 20,284 & 41,679 & 870,836 & 3,006 \\
\hline 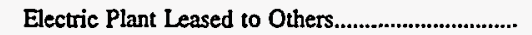 & 0 & 0 & 0 & 0 & 0 & 0 \\
\hline Electric Plant Held for Future Use .................................. & 0 & 0 & 0 & 0 & 14 & 0 \\
\hline 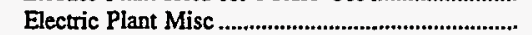 & 0 & 0 & 0 & 0 & 11,039 & 0 \\
\hline 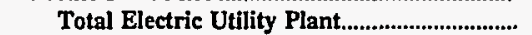 & 9,203 & 1,032 & 20,284 & 41,679 & 881,890 & 3,006 \\
\hline $\begin{array}{l}\text { Construction Work in Progress - Electric.............. } \\
\text { Accumulated Provision for Depreciation }\end{array}$ & 0 & 0 & 0 & 44 & 11,421 & 0 \\
\hline 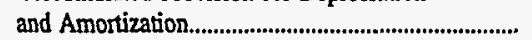 & 6,138 & 0 & 11,044 & 19,180 & 348,934 & 2,337 \\
\hline 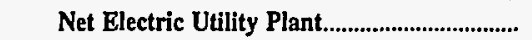 & 3,064 & 1,032 & 9,241 & 22,544 & 544,377 & 669 \\
\hline
\end{tabular}

\begin{tabular}{|c|c|c|c|c|c|c|}
\hline Item & $\begin{array}{c}\text { Oklahoma } \\
\text { OkJahoma } \\
\text { Municipal } \\
\text { Power Auth } \\
\text { December } 31\end{array}$ & $\begin{array}{c}\text { Oklahoma } \\
\text { Ponca } \\
\text { City City of } \\
\text { June } 30\end{array}$ & $\begin{array}{l}\text { Oklahoma } \\
\text { Stillwater } \\
\text { Utilities } \\
\text { Authority } \\
\text { June } 30\end{array}$ & $\begin{array}{l}\text { Oregon } \\
\text { Ashland } \\
\text { City of } \\
\text { June } 30\end{array}$ & $\begin{array}{c}\text { Oregon } \\
\text { Central } \\
\text { Lincoln } \\
\text { Peoples } \\
\text { Utl Dt } \\
\text { December } 31\end{array}$ & $\begin{array}{l}\text { Oregon } \\
\text { Clatskanie } \\
\text { Peoples } \\
\text { Util Dist } \\
\text { December 31 }\end{array}$ \\
\hline \multicolumn{7}{|l|}{ Electric Plant in Service } \\
\hline 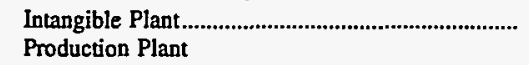 & 0 & 0 & 0 & 0 & 148 & 7 \\
\hline Steam & 114,813 & 16,538 & 15,172 & 0 & 0 & 0 \\
\hline 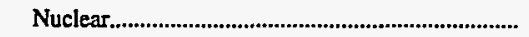 & 0 & 0 & 0 & 0 & 0 & 0 \\
\hline 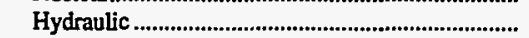 & 35,835 & 0 & 0 & 940 & 0 & 0 \\
\hline Other & 39,707 & 6,270 & $\mathbf{0}$ & 0 & $\mathbf{0}$ & 0 \\
\hline 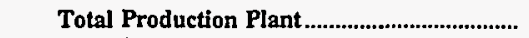 & 190,355 & 22,808 & 15,172 & 940 & 0 & 0 \\
\hline 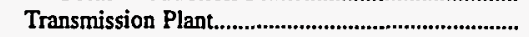 & 3,950 & 1,888 & 962 & 0 & 0 & 0 \\
\hline 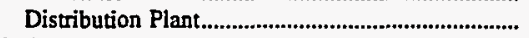 & 1,440 & 11,510 & 22,072 & 12,456 & 66,367 & 5,776 \\
\hline General Plant & 3,067 & 350 & 3,554 & 0 & 21,511 & 1,992 \\
\hline 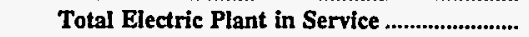 & 198,813 & 36,556 & 41,759 & 13,396 & 88,026 & 7,776 \\
\hline 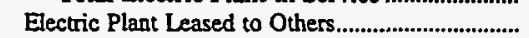 & 0 & 0 & 0 & 0 & 0 & 0 \\
\hline 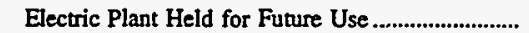 & 2,739 & 0 & 0 & 0 & 0 & 0 \\
\hline 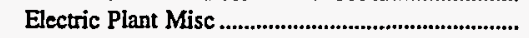 & 0 & 0 & 0 & 0 & 0 & 0 \\
\hline Total Electric Utility Plant................................... & 201,551 & 36,556 & 41,759 & 13,396 & 88,026 & 7,776 \\
\hline $\begin{array}{l}\text { Construction Work in Progress - Electric............... } \\
\text { Accumulated Provision for Depreciation }\end{array}$ & 74 & 0 & 715 & 0 & 19,995 & 246 \\
\hline 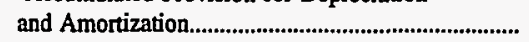 & 44,100 & 17,903 & 16,902 & 0 & 42,744 & 4,056 \\
\hline Net Electric Utility Plant................................... & 157,526 & 18,653 & 25,573 & 13,396 & 65,277 & 3,967 \\
\hline
\end{tabular}

Note: Totals may not equal sum of components because of independent rounding.

Source: Energy Information Administration, Form EIA-412, "Annual Report of Public Electric Utilities." 
Table 24. Electric Utility Plant by Major U.S. Publicly Owned Electric Utility Within State at End of Period, 1996 (Continued)

(Thousand Dollars)

\begin{tabular}{|c|c|c|c|c|c|c|}
\hline Item & $\begin{array}{c}\text { Oregon } \\
\text { Columbia } \\
\text { River } \\
\text { Peoples } \\
\text { Ut Dist } \\
\text { December } 31\end{array}$ & $\begin{array}{c}\text { Oregon } \\
\text { Emerald } \\
\text { Peoples } \\
\text { Utility Dist } \\
\text { December } 31\end{array}$ & $\begin{array}{l}\text { Oregon } \\
\text { Eugene } \\
\text { City of } \\
\text { December } 31\end{array}$ & $\begin{array}{l}\text { Oregon } \\
\begin{array}{l}\text { Forest Grove } \\
\text { City of }\end{array} \\
\text { June } 30\end{array}$ & $\begin{array}{c}\text { Oregon } \\
\text { McMinnville } \\
\text { City of } \\
\text { June } 30\end{array}$ & $\begin{array}{c}\text { Oregon } \\
\text { Northern } \\
\text { Wasco } \\
\text { County PUD } \\
\text { December } 31\end{array}$ \\
\hline \multicolumn{7}{|l|}{ Electric Plant in Service } \\
\hline \multicolumn{6}{|l|}{ Production Plant } & 71 \\
\hline 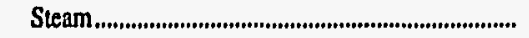 & 0 & 0 & 16,091 & 0 & 0 & 0 \\
\hline 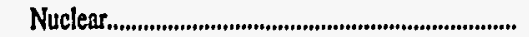 & 0 & 0 & 0 & 0 & 0 & 0 \\
\hline 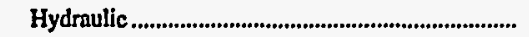 & 0 & 0 & 91,745 & 0 & 0 & 14,560 \\
\hline Other & 0 & 2,799 & 0 & 0 & 0 & 0 \\
\hline Total Production Plant........................................ & $\mathbf{0}$ & 2,799 & 107,836 & o & 0 & 14,560 \\
\hline 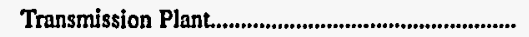 & 812 & 1,028 & 36,843 & 22 & 1,630 & 1,881 \\
\hline 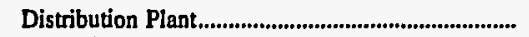 & 12,947 & 46,788 & 123,959 & 10,494 & 18,505 & 15,042 \\
\hline 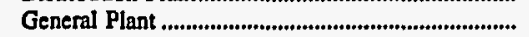 & 4,193 & 9,207 & 45,878 & 1,801 & 3,585 & 2,741 \\
\hline Total Blectric Plant in Service ............................ & 17,953 & 59,953 & 314,517 & 12,317 & $\mathbf{2 3 , 7 2 0}$ & 34,296 \\
\hline Electric Plant Leased to Others............................... & $\mathbf{0}$ & 0 & 0 & 0 & 0 & 0 \\
\hline Electric Plant Held for Future Use .......................... & $\mathbf{0}$ & 0 & 165 & 0 & $\mathbf{0}$ & 0 \\
\hline 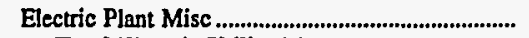 & 7,874 & 17,670 & 7,584 & 0 & 0 & 1,390 \\
\hline 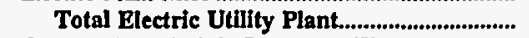 & 25,826 & 77,623 & 322,265 & 12,317 & $\mathbf{2 3 , 7 2 0}$ & 35,686 \\
\hline $\begin{array}{l}\text { Construction Work in Progress - Electric............... } \\
\text { Accumulated Provision for Depreciation }\end{array}$ & 139 & 280 & 12,627 & 391 & 277 & 5,888 \\
\hline \multirow{3}{*}{ 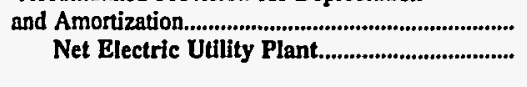 } & 5,438 & 31,186 & 145,660 & 4,381 & 6,870 & 11,427 \\
\hline & 20,527 & 46,717 & 189,233 & 8,326 & 17,127 & 30,147 \\
\hline & & & & & & \\
\hline
\end{tabular}

\begin{tabular}{|c|c|c|c|c|c|c|}
\hline Item & $\begin{array}{c}\text { Oregon } \\
\text { Springfield } \\
\text { City of } \\
\text { December } 31\end{array}$ & $\begin{array}{l}\text { Oregon } \\
\text { Tillamook } \\
\text { Peoples } \\
\text { Utility Dist } \\
\text { December } 31\end{array}$ & $\begin{array}{c}\text { Pennsylvania } \\
\text { Chambersburg } \\
\text { Borough of } \\
\text { December } 31\end{array}$ & $\begin{array}{c}\text { Pennsylvania } \\
\text { Ephrata } \\
\text { Borough of } \\
\text { December } 31\end{array}$ & $\begin{array}{c}\text { Pennsylvania } \\
\text { Lansdale } \\
\text { Borough of } \\
\text { December } 31\end{array}$ & $\begin{array}{l}\text { South Carolina } \\
\text { Camden } \\
\text { City of } \\
\text { June } 30\end{array}$ \\
\hline \multicolumn{7}{|l|}{ Blectric Plant In Service } \\
\hline $\begin{array}{l}\text { Intangible Plant............................................................. } \\
\text { Production Plant }\end{array}$ & $\mathbf{0}$ & 1 & 5 & $\mathbf{0}$ & 0 & 0 \\
\hline 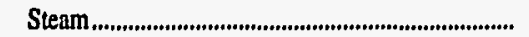 & 0 & 0 & 4,692 & 0 & 0 & 0 \\
\hline 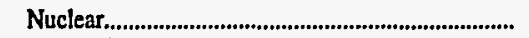 & $\mathbf{0}$ & 0 & 0 & 0 & 0 & 0 \\
\hline 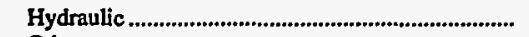 & $\mathbf{0}$ & $\mathbf{0}$ & 0 & 0 & 0 & 0 \\
\hline Other & 0 & 0 & 1,787 & $\mathbf{0}$ & 0 & $\mathbf{0}$ \\
\hline Total Production Plant ...................................... & 0 & 0 & 6,479 & $\mathbf{0}$ & 0 & 0 \\
\hline 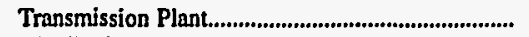 & 2,126 & 1,469 & 4,137 & $\mathbf{0}$ & 2,942 & 0 \\
\hline 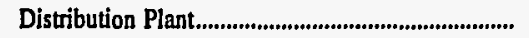 & 30,974 & 31,296 & 16,927 & 0 & 6,146 & 0 \\
\hline 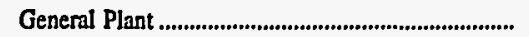 & 5,232 & 6,743 & 936 & 0 & 1,357 & 11,868 \\
\hline Total Electric Plant in Service ............................ & 38,333 & 39,509 & 28,484 & 0 & 10,445 & 11,868 \\
\hline Electric Plant Leased to Others.................................. & 0 & 0 & 0 & $\mathbf{0}$ & 0 & 0 \\
\hline Electric Plant Held for Future Use .............................. & 627 & 0 & 0 & $\mathbf{0}$ & 0 & $\mathbf{0}$ \\
\hline 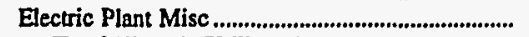 & 9,109 & 1,603 & $\mathbf{0}$ & $\mathbf{0}$ & $\mathbf{0}$ & 0 \\
\hline 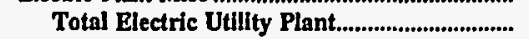 & 48,069 & 41,112 & 28,484 & $\mathbf{0}$ & 10,445 & 11,868 \\
\hline $\begin{array}{l}\text { Construction Work in Progress - Electric................ } \\
\text { Accumulated Provision for Depreciation }\end{array}$ & 1,747 & 800 & 529 & 0 & 0 & 1,027 \\
\hline and Amortization & $\begin{array}{l}15,411 \\
34,405\end{array}$ & $\begin{array}{l}11,014 \\
30,899\end{array}$ & $\begin{array}{l}15,503 \\
13,509\end{array}$ & $\begin{array}{l}\mathbf{0} \\
\mathbf{0}\end{array}$ & $\begin{array}{l}4,865 \\
5,580\end{array}$ & $\begin{array}{l}5,944 \\
6,951\end{array}$ \\
\hline
\end{tabular}

Note: Totals may not equal sum of components because of independent rounding.

Source: Energy Information Administration, Form EIA-412, "Annual Report of Public Electric Utilities." 
Table 24. Electric Utility Plant by Major U.S. Publicly Owned Electric Utility Within State at End of Period, 1996

(Thousand Dollars)

\begin{tabular}{|c|c|c|c|c|c|c|}
\hline Item & $\begin{array}{c}\text { South Carolina } \\
\text { Easley } \\
\text { Combined } \\
\text { Utility } \\
\text { System } \\
\text { March } 31\end{array}$ & $\begin{array}{l}\text { South Carolina } \\
\text { Gaffney } \\
\text { City of } \\
\text { March } 31\end{array}$ & $\begin{array}{l}\text { South Carolina } \\
\text { Greenwood } \\
\text { Commissioners } \\
\text { Pub Wk } \\
\text { December } 31\end{array}$ & $\begin{array}{c}\text { South Carolina } \\
\text { Greer } \\
\text { Comm } \\
\text { of } \\
\text { Public Works } \\
\text { December } 31\end{array}$ & $\begin{array}{l}\text { South Carolina } \\
\text { Newberry } \\
\text { City of } \\
\text { June } 30\end{array}$ & $\begin{array}{c}\text { South Carolina } \\
\text { Orangeburg } \\
\text { City of } \\
\text { September } 30\end{array}$ \\
\hline \multicolumn{7}{|l|}{ Electric Plant in Service } \\
\hline $\begin{array}{l}\text { Intangible Plant } \\
\text { Production Plant }\end{array}$ & 0 & 0 & 0 & 0 & 0 & 0 \\
\hline 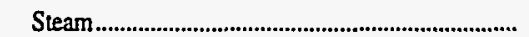 & 0 & 0 & 0 & 0 & 0 & 0 \\
\hline 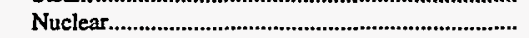 & 0 & 0 & 0 & 0 & 0 & 0 \\
\hline 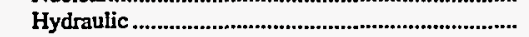 & 0 & 0 & 0 & 0 & 0 & 0 \\
\hline Other & 0 & 516 & 0 & 0 & 0 & 11,536 \\
\hline Total Production Plant & 0 & 516 & 0 & 0 & 0 & 11,536 \\
\hline 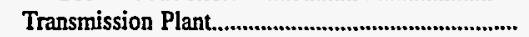 & 0 & 0 & 0 & 14,454 & 0 & 46,899 \\
\hline Distribution Plant & 20,045 & 1,722 & 10,502 & 0 & 0 & 0 \\
\hline 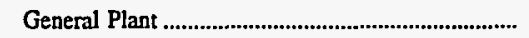 & 0 & 0 & 0 & 83,314 & 8,387 & 0 \\
\hline Total Electric Plant in Service ......................... & 20,045 & 2,238 & 10,502 & 97,768 & 8,387 & 58,435 \\
\hline 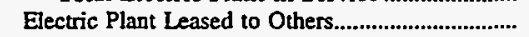 & 0 & 0 & 0 & 0 & 0 & 0 \\
\hline 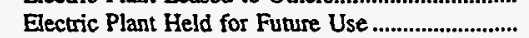 & 0 & 0 & 0 & 0 & 0 & 0 \\
\hline 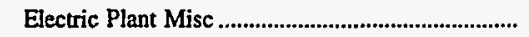 & 0 & 0 & o & 0 & 0 & 0 \\
\hline 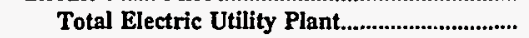 & 20,045 & 2,238 & 10,502 & 97,768 & 8,387 & 58,435 \\
\hline $\begin{array}{l}\text { Construction Work in Progress - Electric................ } \\
\text { Accumulated Provision for Depreciation }\end{array}$ & 0 & 0 & 0 & 3,918 & 0 & 667 \\
\hline 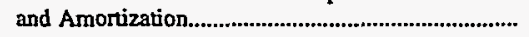 & 6,895 & 1,007 & 4,519 & 15,678 & 4,827 & 15,453 \\
\hline 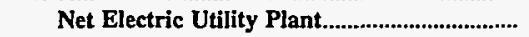 & 13,150 & 1,232 & 5,984 & 86,008 & 3,561 & 43,649 \\
\hline
\end{tabular}

\begin{tabular}{|c|c|c|c|c|c|c|}
\hline Item & $\begin{array}{c}\text { South Carolina } \\
\text { Piedmont } \\
\text { Municipal } \\
\text { Power Agny } \\
\text { December } 31\end{array}$ & $\begin{array}{l}\text { South Carolina } \\
\text { Rock Hill } \\
\text { City of } \\
\text { December } 31\end{array}$ & $\begin{array}{l}\text { South Carolina } \\
\text { Seneca } \\
\text { City of } \\
\text { June } 30\end{array}$ & $\begin{array}{l}\text { South Carolina } \\
\text { South } \\
\text { Carolina } \\
\text { Pub } \\
\text { Serv Auth } \\
\text { December } 31\end{array}$ & $\begin{array}{l}\text { South Dakota } \\
\text { Brookings } \\
\text { City of } \\
\text { December } 31\end{array}$ & $\begin{array}{l}\text { South Dakota } \\
\text { Heartland } \\
\text { Consumers } \\
\text { Power Dist } \\
\text { December } 31\end{array}$ \\
\hline \multicolumn{7}{|l|}{ Electric Plant in Service } \\
\hline 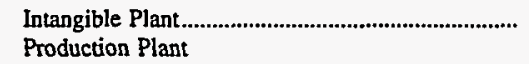 & 0 & 0 & 0 & 11,607 & 0 & 2,084 \\
\hline Steam & 0 & 0 & 0 & 976,692 & 0 & 39,660 \\
\hline 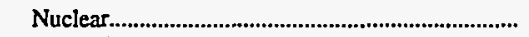 & 542,460 & 0 & 0 & 451,852 & 0 & 0 \\
\hline 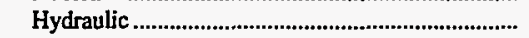 & 0 & 0 & 0 & 71,472 & 0 & 0 \\
\hline Other & 0 & 0 & 0 & 25,162 & 0 & 0 \\
\hline Total Production Plant & 542,460 & 0 & 0 & $1,525,178$ & $\mathbf{0}$ & 39,660 \\
\hline 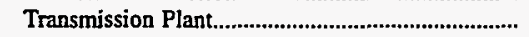 & 0 & 0 & 0 & 524,397 & 3,835 & 14,899 \\
\hline 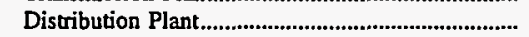 & 518 & 35,383 & 29,331 & 287,029 & 12,759 & 0 \\
\hline General Plant & 1,278 & 0 & 0 & 132,293 & 3,810 & 1,482 \\
\hline 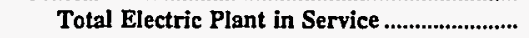 & 544,256 & 35,383 & 29,331 & $2,480,504$ & 20,404 & 58,125 \\
\hline 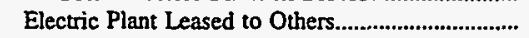 & 0 & 0 & 0 & 0 & 0 & 0 \\
\hline 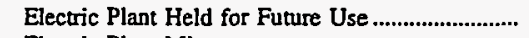 & 0 & 0 & 0 & 12,351 & 0 & 0 \\
\hline 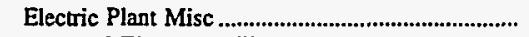 & 0 & 0 & 0 & 738,961 & 0 & 0 \\
\hline 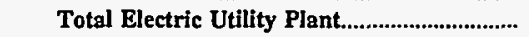 & 544,256 & 35,383 & 29,331 & $3,231,816$ & 20,404 & 58,125 \\
\hline $\begin{array}{l}\text { Construction Work in Progress - Electric............... } \\
\text { Accumulated Provision for Depreciation }\end{array}$ & 17,945 & 4,930 & 50 & 68,031 & 232 & 63 \\
\hline 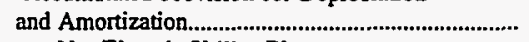 & 185,904 & 13,901 & 12,511 & $1,044,121$ & 6,608 & 10,807 \\
\hline 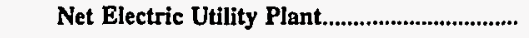 & 376,297 & 26,411 & 16,870 & $2,255,726$ & 14,027 & 47,380 \\
\hline
\end{tabular}

Note: Totals may not equal sum of components because of independent rounding.

Source: Energy Information Administration, Form EIA-412, "Annual Report of Public Electric Utilities." 
Table 24. Electric Utility Plant by Major U.S. Publicly Owned Electric Utility Within State at End of Period, 1996 (Continued)

(Thousand Dollars)

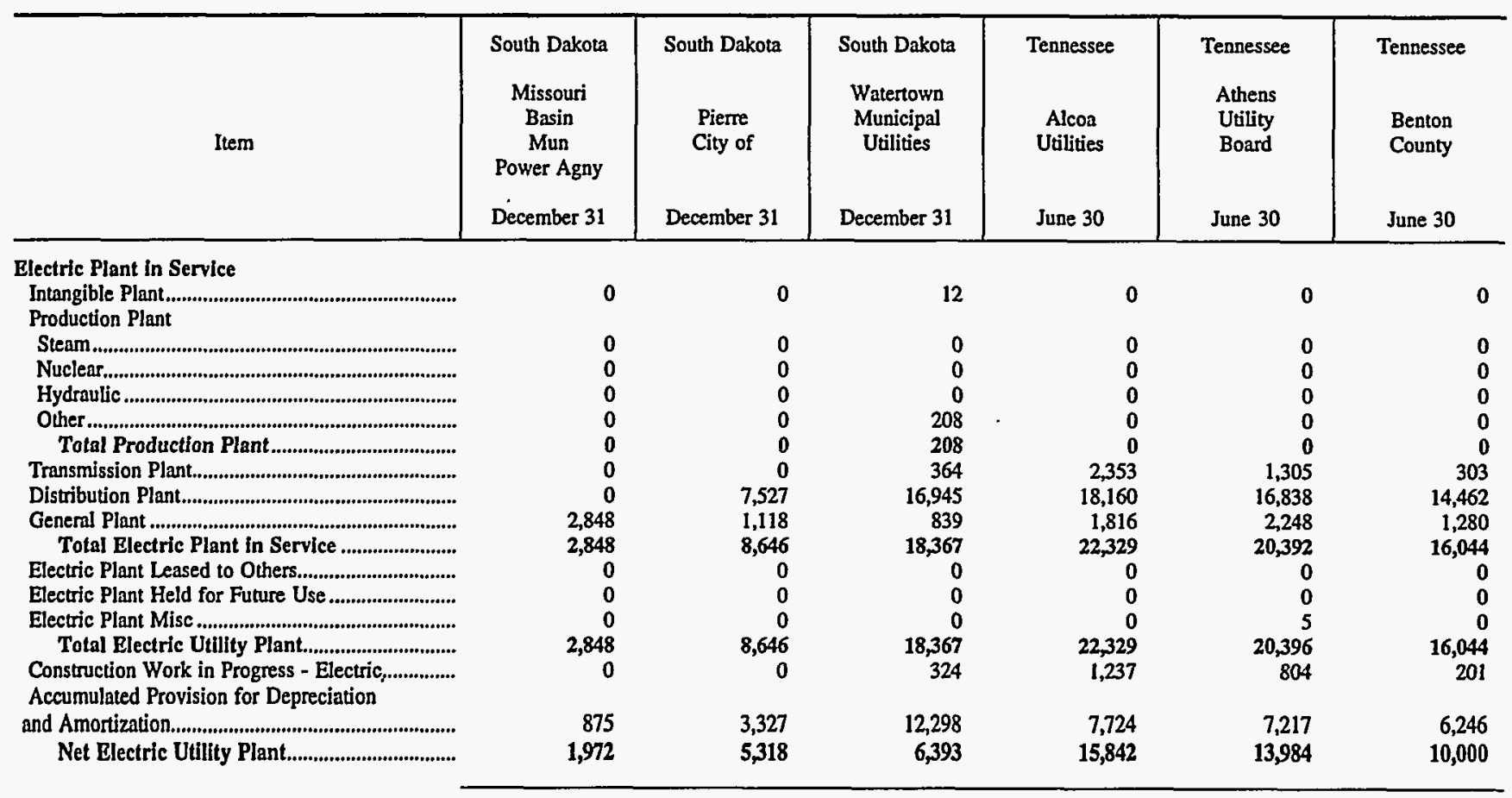

\begin{tabular}{|c|c|c|c|c|c|c|}
\hline Item & $\begin{array}{l}\text { Tennessee } \\
\text { Bolivar } \\
\text { City of } \\
\text { June } 30\end{array}$ & $\begin{array}{l}\text { Tennessee } \\
\text { Bristol } \\
\text { City of } \\
\text { June } 30\end{array}$ & $\begin{array}{c}\text { Tennessee } \\
\begin{array}{c}\text { Brownsville } \\
\text { City of }\end{array} \\
\text { June } 30\end{array}$ & $\begin{array}{l}\text { Tennessee } \\
\text { Carroll } \\
\text { County } \\
\text { June } 30\end{array}$ & $\begin{array}{c}\text { Tennessee } \\
\text { Chattanooga } \\
\text { City of } \\
\text { June } 30\end{array}$ & $\begin{array}{c}\text { Tennessee } \\
\begin{array}{c}\text { Clarksville } \\
\text { City of }\end{array} \\
\text { June } 30\end{array}$ \\
\hline \multicolumn{7}{|l|}{ Electric Plant in Service } \\
\hline $\begin{array}{l}\text { Intangible Plant............................................................ } \\
\text { Production Plant }\end{array}$ & 0 & 0 & 0 & 0 & 0 & $\mathbf{0}$ \\
\hline Steam & 0 & 0 & 0 & 0 & $\mathbf{0}$ & 0 \\
\hline 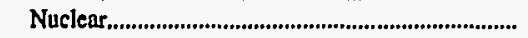 & 0 & 0 & 0 & 0 & 0 & 0 \\
\hline 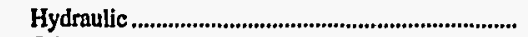 & 0 & 0 & 0 & 0 & 0 & 0 \\
\hline Other & 0 & 0 & 0 & 0 & 0 & 0 \\
\hline 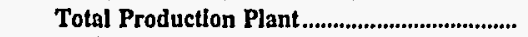 & $\mathbf{0}$ & 0 & 0 & $\mathbf{0}$ & $\mathbf{0}$ & $\mathbf{0}$ \\
\hline 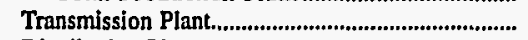 & 663 & 11,872 & 290 & 678 & 33,403 & 2,050 \\
\hline 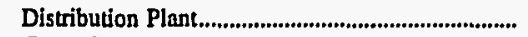 & 14,399 & 30,477 & 5,628 & 19,373 & 212,593 & 36,383 \\
\hline 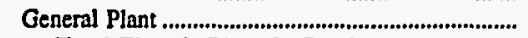 & 1,641 & 2,999 & 1,511 & 1,511 & 31,045 & 5,010 \\
\hline 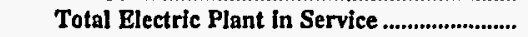 & 16,703 & 45,348 & 7,429 & 21,562 & 277,041 & 43,443 \\
\hline 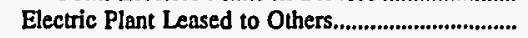 & 0 & 0 & 0 & 0 & 0 & 0 \\
\hline Electric Plant Held for Future Use ........................... & 0 & 0 & 0 & 0 & 0 & 0 \\
\hline 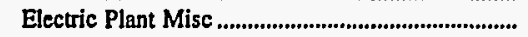 & 0 & 0 & 0 & 0 & $\mathbf{0}$ & 6,695 \\
\hline 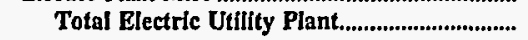 & 16,703 & 45,348 & 7,429 & 21,562 & 277,041 & 50,138 \\
\hline $\begin{array}{l}\text { Construction Work in Progress - Electric............... } \\
\text { Accumulated Provision for Depreciation }\end{array}$ & 747 & 4,663 & 1,037 & 423 & 7,814 & 385 \\
\hline 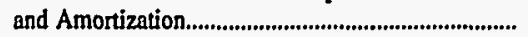 & 6,019 & 24,498 & 2,954 & 8,713 & 111,892 & 13,358 \\
\hline 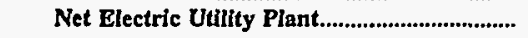 & 11,431 & 25,514 & 5,511 & 13,271 & 172,964 & 37,165 \\
\hline
\end{tabular}

Note: Totals may not equal sum of components because of independent rounding.

Source: Energy Information Administration, Form EIA-412, "Annual Report of Public Electric Utilities." 
Table 24. Electric Utility Plant by Major U.S. Publicly Owned Electric Utility Within State at End of Period, 1996 (Continued)

(Thousand Dollars)

\begin{tabular}{|c|c|c|c|c|c|c|}
\hline Item & $\begin{array}{c}\text { Tennessee } \\
\text { Cleveland } \\
\text { City of } \\
\text { June } 30\end{array}$ & $\begin{array}{l}\text { Tennessee } \\
\text { Clinton } \\
\text { City of } \\
\text { June } 30\end{array}$ & $\begin{array}{c}\text { Tennessee } \\
\text { Columbia } \\
\text { City of } \\
\text { June } 30\end{array}$ & $\begin{array}{c}\text { Tennessee } \\
\text { Cookeville } \\
\text { City of } \\
\text { June } 30\end{array}$ & $\begin{array}{l}\text { Tennessee } \\
\text { Covington } \\
\text { City of } \\
\text { June } 30\end{array}$ & $\begin{array}{l}\text { Tennessee } \\
\text { Dayton } \\
\text { City of } \\
\text { June } 30\end{array}$ \\
\hline \multicolumn{7}{|l|}{ Electric Plant in Service } \\
\hline $\begin{array}{l}\text { Intangible Plant } \\
\text { Production Plant }\end{array}$ & 0 & 0 & $\mathbf{0}$ & 0 & 0 & 0 \\
\hline 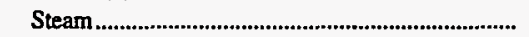 & $\mathbf{0}$ & 0 & 0 & $\mathbf{0}$ & 0 & 0 \\
\hline 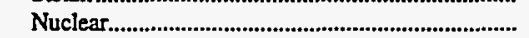 & 0 & 0 & 0 & 0 & 0 & 0 \\
\hline 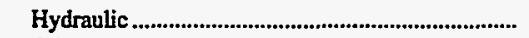 & 0 & 0 & 0 & $\mathbf{0}$ & 0 & 0 \\
\hline 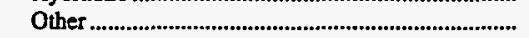 & 0 & 0 & 0 & 0 & 0 & 0 \\
\hline Total Production Piant & 0 & $\mathbf{0}$ & 0 & 0 & 0 & 0 \\
\hline Transmission Plant & 4,319 & 7,320 & 4,615 & 337 & 1,306 & $\mathbf{0}$ \\
\hline 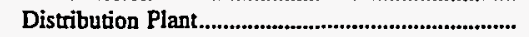 & 43,186 & 29,933 & 23,349 & 16,875 & 5,542 & 10,967 \\
\hline 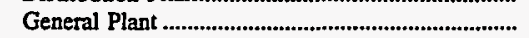 & 5,328 & 4,004 & 3,031 & 3,257 & 901 & 1,394 \\
\hline 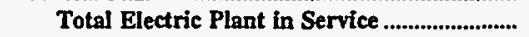 & 52,833 & 41,258 & 30,994 & 20,469 & $\mathbf{7 , 7 4 9}$ & 12,361 \\
\hline Electric Plant Leased to Others................................. & 0 & 0 & 0 & 0 & 0 & 0 \\
\hline 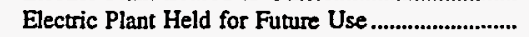 & 0 & 0 & 0 & 0 & 0 & 0 \\
\hline 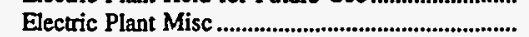 & 2,411 & $\mathbf{0}$ & 0 & 515 & 877 & 0 \\
\hline 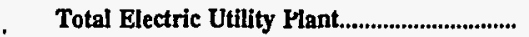 & 55,244 & 41,258 & 30,994 & 20,983 & 8,626 & 12,361 \\
\hline $\begin{array}{l}\text { Construction Work in Progress - Electric............... } \\
\text { Accumulated Provision for Depreciation }\end{array}$ & 836 & 1,462 & 365 & 324 & 47 & 100 \\
\hline 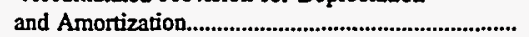 & 18,850 & 14,619 & 11,215 & 5,560 & 2,905 & 4,034 \\
\hline 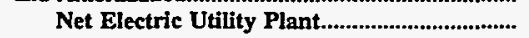 & 37,230 & 28,102 & 20,144 & 15,748 & 5,768 & 8,428 \\
\hline
\end{tabular}

\begin{tabular}{|c|c|c|c|c|c|c|}
\hline Item & $\begin{array}{l}\text { Tennessee } \\
\text { Dickson } \\
\text { City of } \\
\text { June } 30\end{array}$ & $\begin{array}{c}\text { Tennessee } \\
\text { Dyersburg } \\
\text { City of } \\
\text { June } 30\end{array}$ & $\begin{array}{l}\text { Tennessee } \\
\text { Elizabethton } \\
\text { City of } \\
\text { June } 30\end{array}$ & $\begin{array}{l}\text { Tennessee } \\
\text { Erwin } \\
\text { Town of } \\
\text { June } 30\end{array}$ & $\begin{array}{l}\text { Tennessee } \\
\text { Etowah } \\
\text { City of } \\
\text { June } 30\end{array}$ & $\begin{array}{c}\text { Tennessee } \\
\text { Fayetteville } \\
\text { City of } \\
\text { June } 30\end{array}$ \\
\hline \multicolumn{7}{|l|}{ Electric Plant in Service } \\
\hline $\begin{array}{l}\text { Intangible Plant ........................................................ } \\
\text { Production Plant }\end{array}$ & $\mathbf{0}$ & 0 & 0 & 0 & 0 & 0 \\
\hline Steam & 0 & 0 & 0 & 0 & 0 & 0 \\
\hline 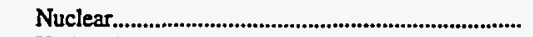 & $\mathbf{0}$ & 0 & 0 & 0 & 0 & 0 \\
\hline 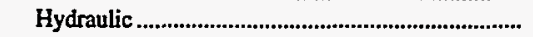 & $\mathbf{0}$ & 0 & 0 & 0 & 0 & 0 \\
\hline Other & 0 & 0 & 0 & 0 & 0 & $\mathbf{0}$ \\
\hline 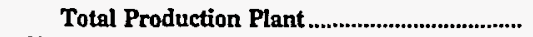 & 0 & 0 & 0 & 0 & 0 & $\mathbf{0}$ \\
\hline 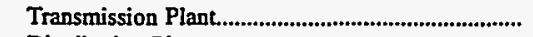 & $\mathbf{0}$ & 2,430 & 4,804 & 0 & 0 & 862 \\
\hline 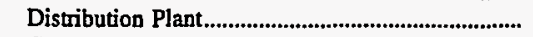 & 40,954 & 21,973 & 23,881 & 8,327 & 5,795 & 27,004 \\
\hline General Plant & 4,986 & 5,117 & 4,122 & 1,498 & 506 & 5,163 \\
\hline 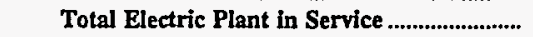 & 45,940 & 29,520 & 32,806 & 9,825 & 6,301 & 33,030 \\
\hline 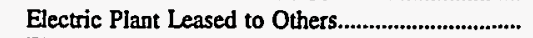 & 0 & 0 & 0 & 0 & 0 & 0 \\
\hline Electric Plant Held for Future Use ............................ & 0 & $\mathbf{0}$ & 0 & 0 & 0 & $\mathbf{0}$ \\
\hline 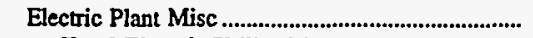 & $\mathbf{0}$ & $\mathbf{0}$ & 0 & 0 & 0 & $\mathbf{0}$ \\
\hline 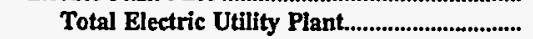 & 45,940 & 29,520 & 32,806 & 9,825 & 6,301 & 33,030 \\
\hline $\begin{array}{l}\text { Construction Work in Progress - Electric............... } \\
\text { Accumulated Provision for Depreciation }\end{array}$ & 2,790 & 1,910 & 829 & 791 & 134 & 1,516 \\
\hline and Amortization & 14,527 & 9,571 & 12,348 & 3,821 & 2,705 & 10,922 \\
\hline 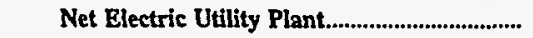 & 34,203 & 21,859 & 21,288 & 6,796 & 3,730 & 23,624 \\
\hline
\end{tabular}

Note: Totals may not equal sum of components because of independent rounding.

Source: Energy Information Administration, Form EIA-412, "Annual Report of Public Electric Utilities." 
Table 24. Electric Utility Plant by Major U.S. Publicly Owned Electric Utility Within State at End of Period, 1996 (Continued)

(Thousand Dollars)

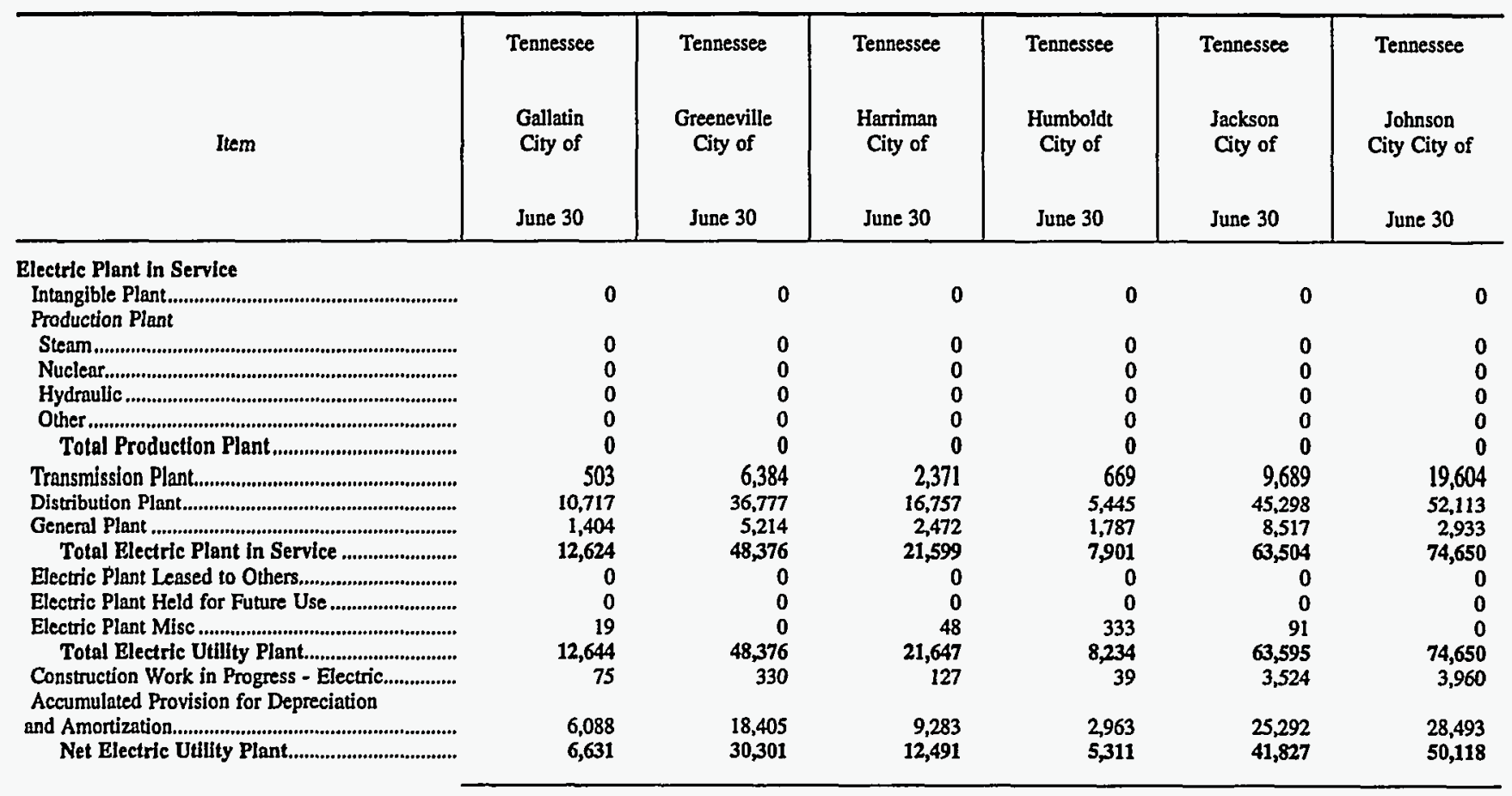

\begin{tabular}{|c|c|c|c|c|c|c|}
\hline Item & $\begin{array}{c}\text { Tennessee } \\
\text { Knoxville } \\
\text { Utilitics } \\
\text { Board } \\
\\
\text { June } 30\end{array}$ & $\begin{array}{c}\text { Tennessee } \\
\text { Lawrenceburg } \\
\text { City of } \\
\text { June } 30\end{array}$ & $\begin{array}{c}\text { Tennessee } \\
\text { LaFollette } \\
\text { City of } \\
\text { June } 30\end{array}$ & $\begin{array}{l}\text { Tennessee } \\
\text { Lebanon } \\
\text { City of } \\
\text { June } 30\end{array}$ & $\begin{array}{c}\text { Tennessee } \\
\text { Lenoir } \\
\text { City City of } \\
\text { June } 30\end{array}$ & $\begin{array}{c}\text { Tennessee } \\
\text { Lewisburg } \\
\text { City of } \\
\text { June } 30\end{array}$ \\
\hline \multicolumn{7}{|l|}{ Electric Plant in Service } \\
\hline 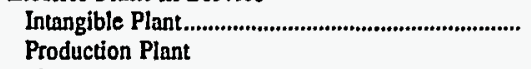 & 0 & 0 & 0 & 0 & $\mathbf{0}$ & 0 \\
\hline 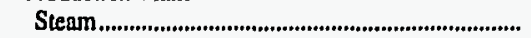 & 0 & 0 & 0 & 0 & 0 & 0 \\
\hline 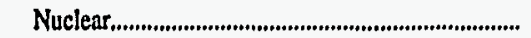 & 0 & 0 & 0 & 0 & 0 & 0 \\
\hline 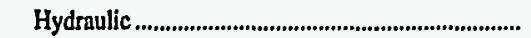 & 0 & 0 & 0 & 0 & 0 & 0 \\
\hline 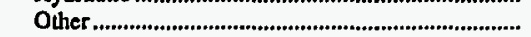 & 0 & 0 & 0 & $\mathbf{0}$ & 0 & $\mathbf{0}$ \\
\hline 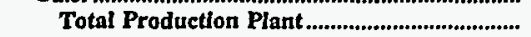 & 0 & 0 & $\mathbf{0}$ & 0 & 0 & 0 \\
\hline 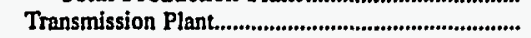 & 0 & 4,141 & 500 & 0 & $\mathbf{0}$ & $\mathbf{0}$ \\
\hline 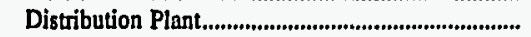 & 291,030 & 20,157 & 28,675 & 12,871 & 68,209 & 9,361 \\
\hline 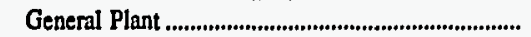 & 25,003 & 2,351 & 2,824 & 1,589 & 4,347 & 1,944 \\
\hline Total Electric Plant in Service......................... & 316,032 & 26,649 & 31,998 & 14,460 & 72,556 & 11,304 \\
\hline Electric Plant Leased to Others............................... & 0 & 0 & 0 & 0 & 0 & 0 \\
\hline Electric Plant Held for Funre Use .......................... & 0 & 0 & 0 & 0 & 0 & $\mathbf{0}$ \\
\hline 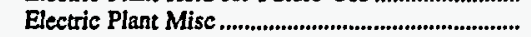 & 0 & 0 & $\mathbf{0}$ & 32 & 0 & 145 \\
\hline 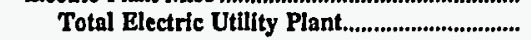 & 316,032 & 26,649 & 31,998 & 14,492 & 72,556 & 11,450 \\
\hline $\begin{array}{l}\text { Construction Work in Progress - Electric................ } \\
\text { Accumulated Provision for Depreciation }\end{array}$ & 8,157 & 953 & 3,281 & 428 & 776 & 122 \\
\hline 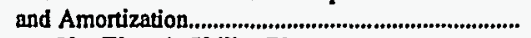 & 147,308 & 10,518 & 10,736 & 4,993 & 16,710 & 3,869 \\
\hline Net Electric Utility Plant.................................... & 176,881 & 17,085 & 24,544 & 9,927 & 56,621 & $\mathbf{7 , 7 0 3}$ \\
\hline
\end{tabular}

Note: Totals may not equal sum of components because of independent rounding.

Source: Energy Information Administration, Form EIA-412, "Annual Report of Public Electric Utilities." 
Table 24. Electric Utility Plant by Major U.S. Publicly Owned Electric Utility Within State at End of Period, 1996 (Continued)

(Thousand Dollars)

\begin{tabular}{|c|c|c|c|c|c|c|}
\hline Item & $\begin{array}{c}\text { Tennessee } \\
\text { Lexington } \\
\text { City of } \\
\text { June } 30\end{array}$ & $\begin{array}{c}\text { Tennessee } \\
\text { Loudon } \\
\text { Utilities } \\
\text { Board } \\
\\
\text { June } 30\end{array}$ & $\begin{array}{c}\text { Tennessee } \\
\text { Maryville } \\
\text { Utilities } \\
\text { June } 30\end{array}$ & $\begin{array}{c}\text { Tennessee } \\
\text { McMinnville } \\
\text { Electric } \\
\text { System } \\
\\
\text { June } 30\end{array}$ & $\begin{array}{c}\text { Tennessee } \\
\text { Memphis } \\
\text { City of } \\
\text { June } 30\end{array}$ & $\begin{array}{l}\text { Tennessee } \\
\text { Milan } \\
\text { City of } \\
\text { June } 30\end{array}$ \\
\hline \multicolumn{7}{|l|}{ Electric Plant in Service } \\
\hline 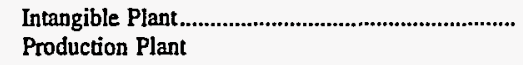 & 0 & 0 & 0 & 0 & 0 & 0 \\
\hline Steam & 0 & 0 & 0 & 0 & 0 & 0 \\
\hline 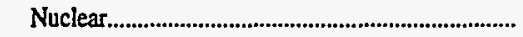 & 0 & 0 & 0 & 0 & 0 & 0 \\
\hline 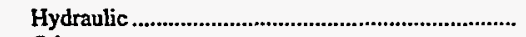 & 0 & 0 & 0 & 0 & 0 & 0 \\
\hline Other & 0 & $\mathbf{0}$ & $\mathbf{0}$ & 0 & 0 & $\mathbf{0}$ \\
\hline 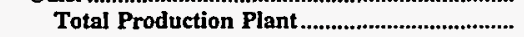 & $\mathbf{0}$ & $\mathbf{0}$ & 0 & o & $\mathbf{0}$ & $\mathbf{0}$ \\
\hline Transmission Plant & 0 & 5,560 & 3,444 & 0 & 145,101 & 2,162 \\
\hline 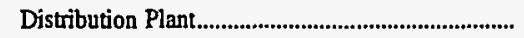 & 21,761 & 14,523 & 20,150 & 11,368 & 588,507 & 8,669 \\
\hline 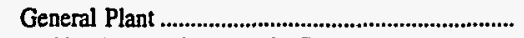 & 3,143 & 704 & 4,769 & 1,745 & 64,761 & 1,052 \\
\hline 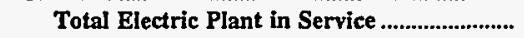 & 24,904 & 20,787 & 28,362 & 13,113 & 798,369 & 11,884 \\
\hline 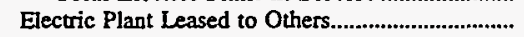 & 0 & 0 & 0 & 0 & 0 & 0 \\
\hline 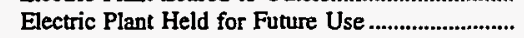 & 0 & 0 & 0 & 0 & 0 & 10 \\
\hline 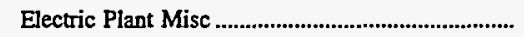 & 0 & 0 & 10 & 576 & 0 & 0 \\
\hline Total Electric Utility Plant.................................. & 24,904 & 20,787 & 28,373 & 13,690 & 798,369 & 11,894 \\
\hline $\begin{array}{l}\text { Construction Work in Progress - Electric............... } \\
\text { Accumulated Provision for Depreciation }\end{array}$ & 1,988 & 2,839 & 380 & 55 & 18,950 & 561 \\
\hline $\begin{array}{l}\text { and Amortization. } \\
\text { Net Electric Utility Plant }\end{array}$ & $\begin{array}{r}9,157 \\
17,735\end{array}$ & $\begin{array}{r}4,796 \\
18,829\end{array}$ & $\begin{array}{r}9,357 \\
19,396\end{array}$ & $\begin{array}{l}5,813 \\
7,931\end{array}$ & $\begin{array}{l}274,114 \\
543,205\end{array}$ & $\begin{array}{l}5,548 \\
6,907\end{array}$ \\
\hline
\end{tabular}

\begin{tabular}{|c|c|c|c|c|c|c|}
\hline Item & $\begin{array}{l}\text { Tennessee } \\
\text { Morristown } \\
\text { City of } \\
\text { June } 30\end{array}$ & $\begin{array}{c}\text { Tennessee } \\
\begin{array}{c}\text { Murfreesboro } \\
\text { City of }\end{array} \\
\text { June } 30\end{array}$ & $\begin{array}{l}\text { Tennessee } \\
\text { Nashville } \\
\text { Electric } \\
\text { Service } \\
\\
\text { June } 30\end{array}$ & $\begin{array}{l}\text { Tennessee } \\
\text { Newport } \\
\text { City of } \\
\text { June } 30\end{array}$ & $\begin{array}{l}\text { Tennessee } \\
\text { Oak Ridge } \\
\text { City of } \\
\text { June } 30\end{array}$ & $\begin{array}{c}\text { Tennessee } \\
\text { Paris } \\
\text { City of } \\
\text { June } 30\end{array}$ \\
\hline \multicolumn{7}{|l|}{ Electric Plant in Service } \\
\hline 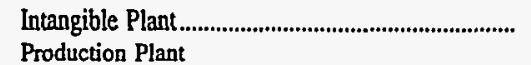 & 0 & 0 & 0 & 0 & 0 & 0 \\
\hline Steam & 0 & $\mathbf{0}$ & 0 & 0 & 0 & 0 \\
\hline 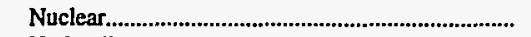 & 0 & 0 & 0 & 0 & 0 & $\mathbf{0}$ \\
\hline 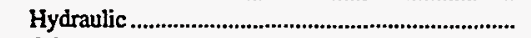 & 0 & 0 & 0 & 0 & 0 & 0 \\
\hline Other & $\mathbf{0}$ & 0 & 0 & 0 & 0 & 0 \\
\hline 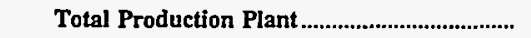 & 0 & 0 & 0 & 0 & 0 & $\mathbf{0}$ \\
\hline 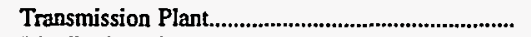 & 4,842 & 0 & 0 & 6,381 & 1,419 & 1,979 \\
\hline 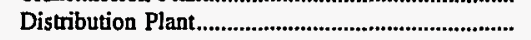 & 20,306 & 39,276 & 534,953 & 24,618 & 25,662 & 25,623 \\
\hline General Plant & 5,137 & 4,648 & 65,462 & 4,285 & 1,439 & 1,945 \\
\hline Total Electric Plant in Service & 30,284 & 43,924 & 600,415 & 35,284 & 28,520 & 29,547 \\
\hline 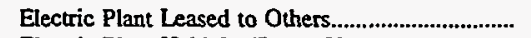 & 0 & 0 & 0 & 0 & 0 & 0 \\
\hline 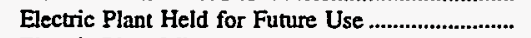 & 0 & 0 & 0 & 0 & 0 & 0 \\
\hline Electric Plant Misc & 1,888 & 464 & 0 & 0 & 89 & $\mathbf{0}$ \\
\hline 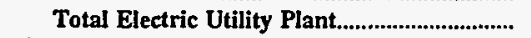 & 32,172 & 44,388 & 600,415 & 35,284 & 28,608 & 29,547 \\
\hline $\begin{array}{l}\text { Construction Work in Progress - Electric............... } \\
\text { Accumulated Provision for Depreciation }\end{array}$ & 1,521 & 883 & 24,972 & 28 & 19,432 & 350 \\
\hline 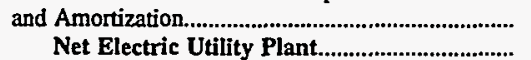 & $\begin{array}{l}11,413 \\
22,281\end{array}$ & $\begin{array}{l}12,730 \\
32,541\end{array}$ & $\begin{array}{l}227,272 \\
398,114\end{array}$ & $\begin{array}{l}13,128 \\
22,184\end{array}$ & $\begin{array}{l}11,266 \\
36,775\end{array}$ & $\begin{array}{l}13,206 \\
16,691\end{array}$ \\
\hline
\end{tabular}

Note: Totals may not equal sum of components because of independent rounding.

Source: Energy Information Administration, Form EIA-412, "Annual Report of Public Electric Utilities." 
, Table 24. Electric Utility Plant by Major U.S. Publicly Owned Electric Utility Within State at End of Period, 1996

(Thousand Dollars)

\begin{tabular}{|c|c|c|c|c|c|c|}
\hline Item & $\begin{array}{l}\text { Tennessee } \\
\text { Pulaski } \\
\text { City of } \\
\text { June } 30\end{array}$ & $\begin{array}{l}\text { Tennessee } \\
\text { Ripley } \\
\text { City of } \\
\text { June } 30\end{array}$ & $\begin{array}{c}\text { Tennessee } \\
\text { Sevier } \\
\text { County } \\
\text { Electric } \\
\text { System } \\
\text { June } 30\end{array}$ & $\begin{array}{l}\text { Tennessee } \\
\text { Rockwood } \\
\text { City of } \\
\text { June } 30\end{array}$ & $\begin{array}{c}\text { Tennessee } \\
\text { Shelbyville } \\
\text { City of } \\
\text { June } 30\end{array}$ & $\begin{array}{c}\text { Tennessee } \\
\text { Springfield } \\
\text { City of } \\
\text { June } 30\end{array}$ \\
\hline \multicolumn{7}{|l|}{ Electric Plant in Service } \\
\hline 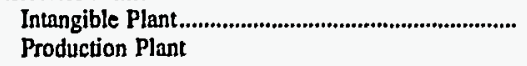 & 0 & 0 & 0 & 0 & 0 & 0 \\
\hline 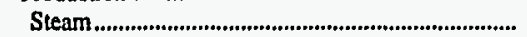 & 0 & 0 & 0 & 0 & 0 & 0 \\
\hline 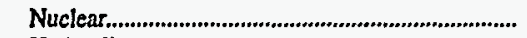 & 0 & 0 & 0 & 0 & 0 & $\mathbf{0}$ \\
\hline 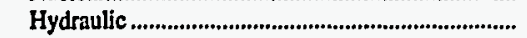 & 0 & 0 & 0 & 0 & 0 & 0 \\
\hline 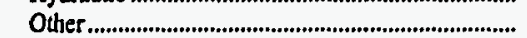 & 0 & 0 & 0 & 0 & 0 & 0 \\
\hline Total Production Plant ....................................... & 0 & $\mathbf{0}$ & $\mathbf{0}$ & $\mathbf{0}$ & 0 & $\mathbf{0}$ \\
\hline 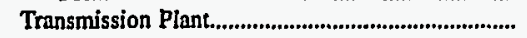 & 0 & 592 & 13,337 & 0 & 0 & 0 \\
\hline 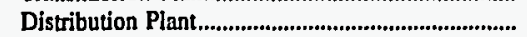 & 23,970 & 5,983 & 53,228 & 18,789 & 10,986 & 9,934 \\
\hline 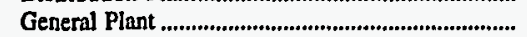 & 3,199 & 1,777 & 5,893 & 1,233 & 1,640 & 1,467 \\
\hline Total Electric Plant in Service ............................ & 27,169 & 8,352 & 72,459 & 20,022 & 12,626 & 11,401 \\
\hline Electric Plant Leased to Others................................... & 0 & 0 & 0 & 0 & 0 & 0 \\
\hline Electric Plant Held for Future Use ......................... & 0 & $\mathbf{0}$ & 0 & 0 & 0 & 828 \\
\hline Electric Plant Misc .......................................................... & $\begin{array}{r}0 \\
27169\end{array}$ & 855 & $\begin{array}{r}714 \\
73173\end{array}$ & 190 & 196 & $\begin{array}{r}0 \\
0 \\
1220\end{array}$ \\
\hline $\begin{array}{l}\text { Construction Work in Progress - Electric............... } \\
\text { Accumulated Provision for Depreciation }\end{array}$ & $\begin{array}{r}27,109 \\
1,666\end{array}$ & $\begin{array}{r}9,207 \\
149\end{array}$ & $\begin{array}{r}73,173 \\
1,284\end{array}$ & $\begin{array}{r}20,212 \\
438\end{array}$ & $\begin{array}{r}12,822 \\
1,893\end{array}$ & $\begin{array}{r}12,229 \\
188\end{array}$ \\
\hline 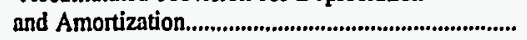 & 10,330 & 2,833 & 20,842 & 6,298 & 5,349 & 4,496 \\
\hline Net Electric Uttlity Plant..................................... & 18,505 & 6,523 & 53,615 & 14,352 & 9,366 & 7,921 \\
\hline
\end{tabular}

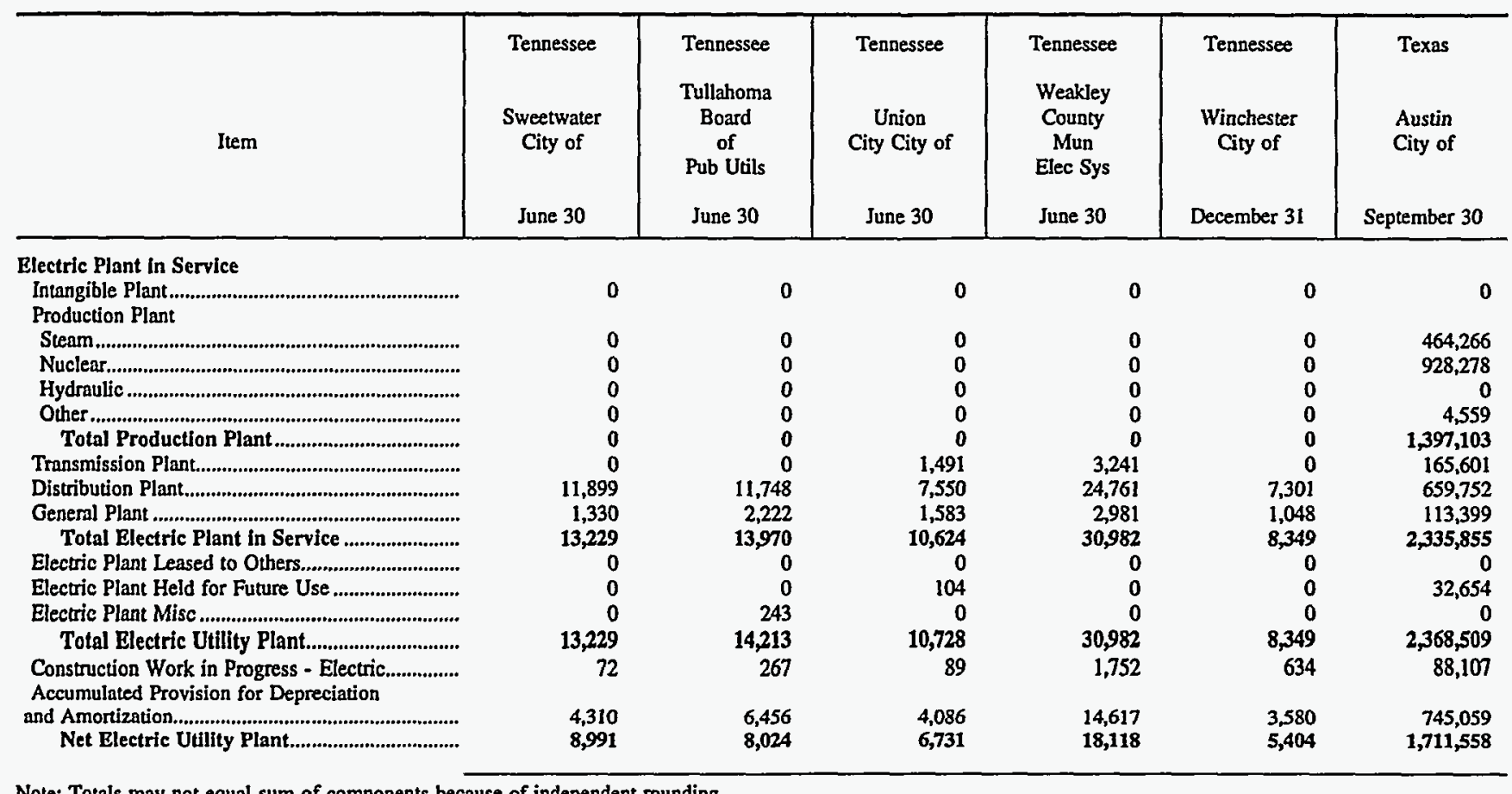

Note: Totals may not equal sum of components because of independent rounding.

Source: Energy Information Administration, Form EIA-412, "Annual Report of Public Electric Utilities." 
Table 24. Electric Utility Plant by Major U.S. Publicly Owned Electric Utility Within State at End of Period, 1996 (Continued) (Thousand Dollars)

\begin{tabular}{|c|c|c|c|c|c|c|}
\hline Item & $\begin{array}{c}\text { Texas } \\
\text { Brenham } \\
\text { City of } \\
\text { September } 30\end{array}$ & $\begin{array}{c}\text { Texas } \\
\text { Brownsville } \\
\text { Public } \\
\text { Utils Board } \\
\text { September } 30\end{array}$ & $\begin{array}{c}\text { Texas } \\
\text { Bryan } \\
\text { City of } \\
\text { September } 30\end{array}$ & $\begin{array}{l}\text { Texas } \\
\text { College } \\
\text { Station } \\
\text { City of } \\
\text { September } 30\end{array}$ & $\begin{array}{l}\text { Texas } \\
\text { Denton } \\
\text { City of } \\
\text { September } 30\end{array}$ & $\begin{array}{c}\text { Texas } \\
\text { Floresville } \\
\text { City of } \\
\text { December } 31\end{array}$ \\
\hline \multicolumn{7}{|l|}{ Electric Plant in Service } \\
\hline 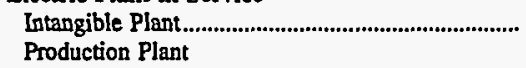 & 0 & 18,430 & 0 & 0 & 0 & $\mathbf{0}$ \\
\hline Steam & 0 & 0 & 52,602 & 0 & 31,155 & 0 \\
\hline 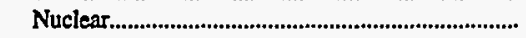 & 0 & 0 & 0 & 0 & 0 & 0 \\
\hline 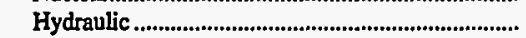 & 0 & $\mathbf{0}$ & 0 & 0 & 8,734 & 0 \\
\hline Other & 0 & 277 & 4,386 & 0 & 751 & 0 \\
\hline 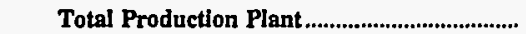 & 0 & 277 & 56,988 & 0 & 40,640 & $\mathbf{0}$ \\
\hline 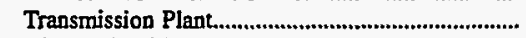 & 0 & 66,200 & 19,496 & 9,147 & 4,994 & 1,497 \\
\hline 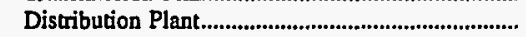 & 9,441 & 53,678 & 57,710 & 17,880 & 53,239 & 24,684 \\
\hline 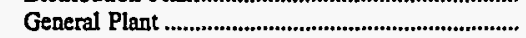 & 0 & 137,345 & 7,478 & 3,864 & 5,089 & 3,101 \\
\hline Total Electric Plant in Service .......................... & 9,441 & $\mathbf{2 7 5 , 9 3 0}$ & 141,672 & 30,891 & 103,961 & 29,282 \\
\hline 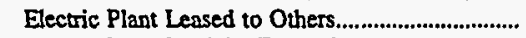 & 0 & 0 & 0 & 0 & 0 & 0 \\
\hline Electric Plant Held for Future Use ........................... & 0 & 0 & 0 & 0 & 0 & 0 \\
\hline 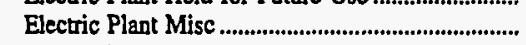 & 0 & 0 & 0 & 230 & 0 & 0 \\
\hline Total Electric Utillty Plant............................... & 9,441 & 275,930 & 141,672 & 31,121 & 103,961 & 29,282 \\
\hline $\begin{array}{l}\text { Construction Work in Progress - Electric............... } \\
\text { Accumulated Provision for Depreciation }\end{array}$ & 0 & 73,415 & 111 & 8,154 & 1,140 & 0 \\
\hline 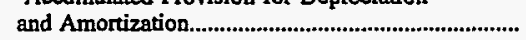 & 3,657 & 93,487 & 63,192 & 10,882 & 62,650 & 11,213 \\
\hline 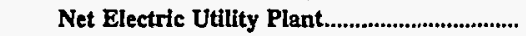 & 5,784 & 255,858 & $\mathbf{7 8 , 5 9 1}$ & 28,393 & 42,451 & 18,069 \\
\hline
\end{tabular}

\begin{tabular}{|c|c|c|c|c|c|c|}
\hline Item & $\begin{array}{l}\text { Texas } \\
\text { Garland } \\
\text { City of } \\
\text { September } 30\end{array}$ & $\begin{array}{c}\text { Texas } \\
\text { Georgetown } \\
\text { City of } \\
\text { September } 30\end{array}$ & $\begin{array}{c}\text { Texas } \\
\text { Greenville } \\
\text { Electric } \\
\text { Util Sys } \\
\text { September } 30\end{array}$ & $\begin{array}{c}\text { Texas } \\
\text { Jasper } \\
\text { City of } \\
\text { September } 30\end{array}$ & $\begin{array}{c}\text { Texas } \\
\text { Kerrille } \\
\text { Public } \\
\text { Utility } \\
\text { Board } \\
\text { September } 30\end{array}$ & $\begin{array}{l}\text { Texas } \\
\text { Lower } \\
\text { Colorado } \\
\text { River } \\
\text { Authority } \\
\text { June } 30\end{array}$ \\
\hline \multicolumn{7}{|l|}{ Electric Plant in Service } \\
\hline 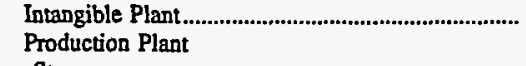 & 0 & 0 & 0 & 0 & 190 & 366 \\
\hline Steam & 77,452 & 0 & 18,573 & 0 & 0 & 899,683 \\
\hline 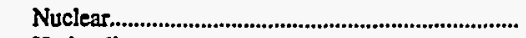 & 0 & 0 & 0 & 0 & 0 & 0 \\
\hline 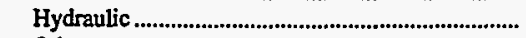 & 0 & 0 & 0 & 0 & 0 & 84,946 \\
\hline Other & 0 & 0 & 4,973 & 0 & 0 & 0 \\
\hline 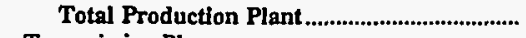 & 77,452 & $\mathbf{0}$ & 23,546 & $\mathbf{0}$ & 0 & 984,629 \\
\hline 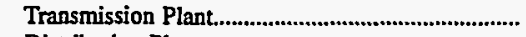 & 19,730 & 0 & 1,660 & 0 & $\mathbf{0}$ & 288,218 \\
\hline 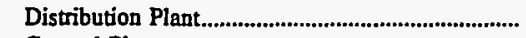 & 97,404 & 0 & 24,430 & 0 & 26,726 & 4,453 \\
\hline General Plant & 23,152 & 9,056 & 4,866 & 0 & 5,351 & 158,877 \\
\hline 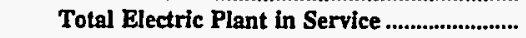 & 217,738 & 9,056 & 54,502 & $\mathbf{0}$ & 32,267 & $1,436,545$ \\
\hline 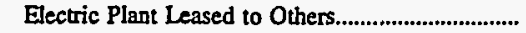 & 0 & 0 & 0 & 0 & 0 & 1 \\
\hline Electric Plant Held for Future Use .............................. & 0 & 0 & 0 & 0 & 0 & 0 \\
\hline 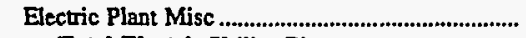 & 0 & 0 & 0 & 0 & -582 & 127,245 \\
\hline 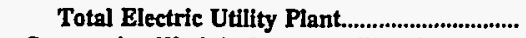 & 217,738 & 9,056 & 54,502 & 0 & 31,685 & $1,563,791$ \\
\hline $\begin{array}{l}\text { Construction Work in Progress - Electric............... } \\
\text { Accumulated Provision for Depreciation }\end{array}$ & 4,939 & 612 & 0 & 0 & 427 & 60,262 \\
\hline 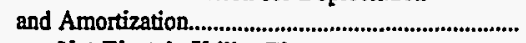 & 104,892 & 2,840 & 32,903 & 0 & 10,208 & 505,958 \\
\hline 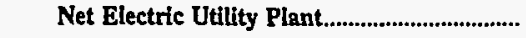 & 117,786 & 6,829 & 21,599 & $\mathbf{0}$ & 21,904 & $1,118,095$ \\
\hline
\end{tabular}

Note: Totals may not equal sum of components because of independent rounding.

Source: Energy Information Administration, Form EIA-412, "Annual Report of Public Electric Utilities," 
Table 24. Electric Utility Plant by Major U.S. Publicly Owned Electric Utility Within State at End of Period, 1996 (Continued)

(Thousand'Dollars)

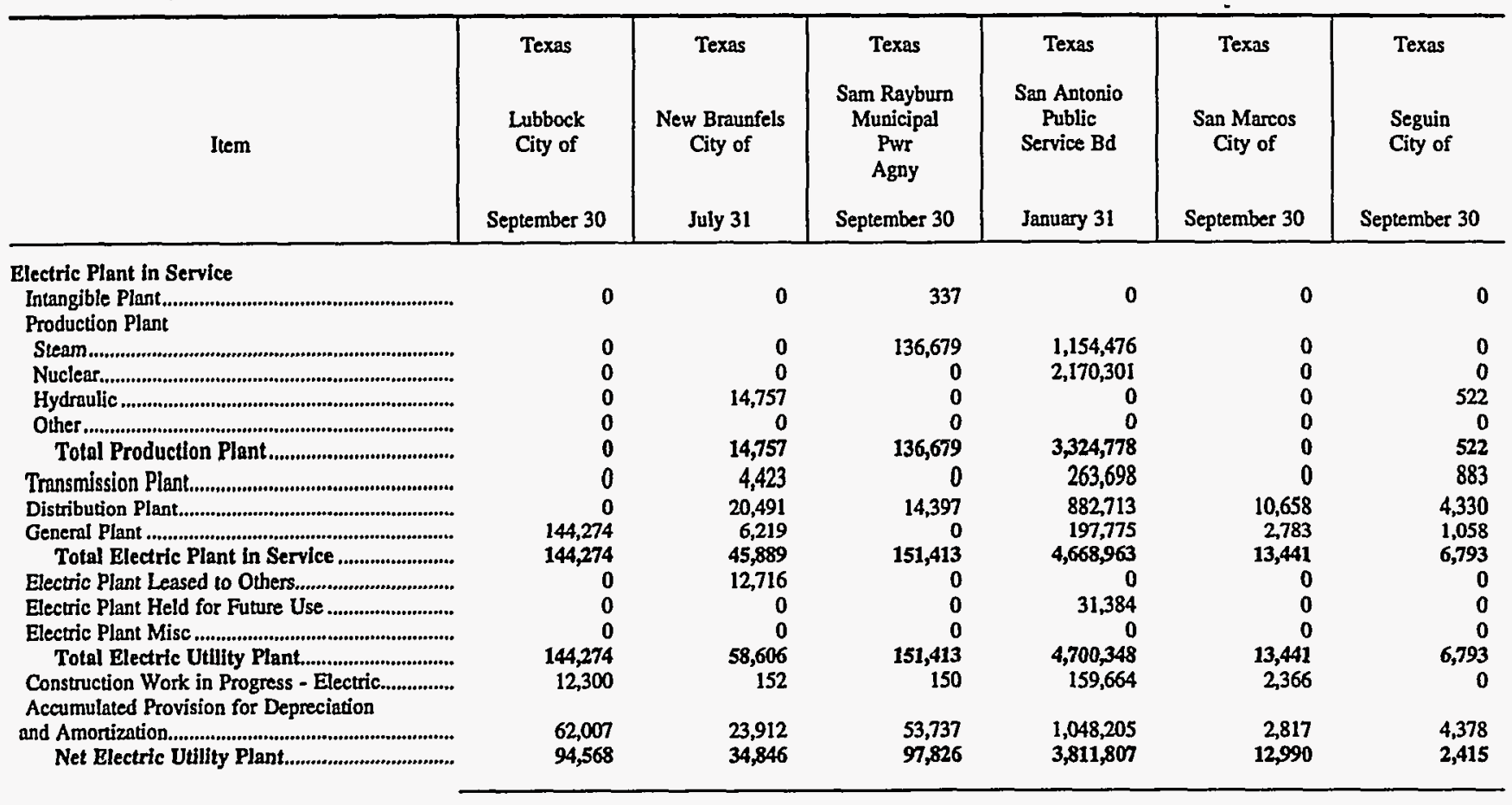

\begin{tabular}{|c|c|c|c|c|c|c|}
\hline Item & $\begin{array}{c}\text { Texas } \\
\text { Texas } \\
\text { Municipal } \\
\text { Power Agency } \\
\text { September } 30\end{array}$ & $\begin{array}{c}\text { Texas } \\
\text { Toledo Bend } \\
\text { Project } \\
\text { Joint } \\
\text { Oper } \\
\text { August } 30\end{array}$ & $\begin{array}{c}\text { Texas } \\
\text { Weatherford } \\
\text { Mun } \\
\text { Utility } \\
\text { System } \\
\text { September } 30\end{array}$ & $\begin{array}{c}\text { Utah } \\
\text { Bountiful } \\
\text { City City of } \\
\text { June } 30\end{array}$ & $\begin{array}{c}\text { Intermountain } \\
\text { Power Agency } \\
\text { June } 30\end{array}$ & $\begin{array}{l}\text { Utah } \\
\text { Logan } \\
\text { City of } \\
\text { June } 30\end{array}$ \\
\hline \multicolumn{7}{|l|}{ Electric Plant in Service } \\
\hline $\begin{array}{l}\text { Intangible Plant................................................................ } \\
\text { Production Plant }\end{array}$ & 78,649 & 0 & 0 & 0 & 43,938 & 0 \\
\hline Steam & 591,953 & 0 & $\mathbf{0}$ & $\mathbf{0}$ & $2,632,949$ & 0 \\
\hline 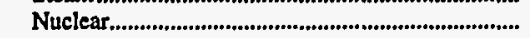 & 0 & 0 & 0 & 0 & 0 & 0 \\
\hline 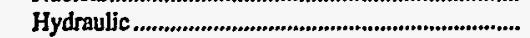 & 0 & 71,230 & $\mathbf{0}$ & 8,534 & 0 & 12,756 \\
\hline Other & $\mathbf{0}$ & 0 & 1,079 & 5,823 & 0 & 0 \\
\hline Total Production Plant...................................... & 591,953 & 71,230 & 1,079 & 14,357 & $2,632,949$ & 12,756 \\
\hline 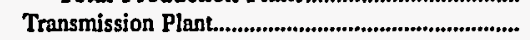 & 138,778 & 0 & 0 & 226 & 53,278 & 1,438 \\
\hline 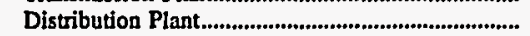 & 0 & $\mathbf{0}$ & 11,417 & 11,830 & 0 & 12,238 \\
\hline General Plant .................................................................. & $\begin{array}{r}11,095 \\
820,475\end{array}$ & $\begin{array}{r}1,664 \\
72,893\end{array}$ & $\begin{array}{r}2,025 \\
14,521\end{array}$ & $\begin{array}{r}9,951 \\
36,364\end{array}$ & $\begin{array}{r}41,270 \\
2,771,435\end{array}$ & $\begin{array}{r}2,487 \\
28,920\end{array}$ \\
\hline 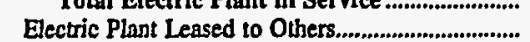 & $\begin{array}{r}0<0,410 \\
0\end{array}$ & 0 & 0 & 0 & 0 & 0 \\
\hline Electric Plant Held for Future Use .......................... & 9,515 & 0 & 0 & 0 & 0 & .0 \\
\hline 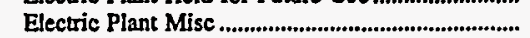 & 538 & $\mathbf{0}$ & 0 & $\mathbf{0}$ & $\mathbf{0}$ & 0 \\
\hline 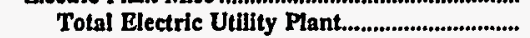 & 830,528 & 72,893 & 14,521 & 36,364 & $2,771,435$ & 28,920 \\
\hline $\begin{array}{l}\text { Construction Work in Progress - Electric............... } \\
\text { Accumulated Provision for Depreciation }\end{array}$ & 10,586 & 0 & 2,529 & 672 & 0 & 0 \\
\hline 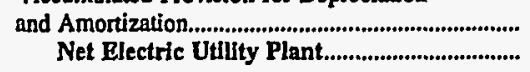 & $\begin{array}{l}357,237 \\
483,877\end{array}$ & $\begin{array}{r}0 \\
72,893\end{array}$ & $\begin{array}{l}7,920 \\
9,130\end{array}$ & $\begin{array}{l}14,272 \\
22,764\end{array}$ & $\begin{array}{r}716,847 \\
2,054,588\end{array}$ & $\begin{array}{l}11,380 \\
17,540\end{array}$ \\
\hline
\end{tabular}

Note: Totals may not equal sum of components because of independent rounding.

Source: Energy Information Administration, Form EIA-412, "Annual Report of Public Electric Utilities." 
Table 24. Electric Utility Plant by Major U.S. Publicly Owned Electric Utility Within State at End of Period, 1996 (Continued)

(Thousand Dollars)

\begin{tabular}{|c|c|c|c|c|c|c|}
\hline Item & $\begin{array}{l}\text { Utah } \\
\text { Murray } \\
\text { City of } \\
\text { June } 30\end{array}$ & $\begin{array}{l}\text { Utah } \\
\text { Provo } \\
\text { City Corp } \\
\text { June } 30\end{array}$ & $\begin{array}{c}\text { Utah } \\
\text { St George } \\
\text { City of } \\
\text { June } 30\end{array}$ & $\begin{array}{c}\text { Utah } \\
\text { Utah } \\
\text { Associated } \\
\text { Mun } \\
\text { Power Sys } \\
\text { March } 31\end{array}$ & $\begin{array}{c}\text { Utah } \\
\text { Utah } \\
\text { Municipal } \\
\text { Power Agency } \\
\text { June } 30\end{array}$ & $\begin{array}{l}\text { Vermont } \\
\text { Burlington } \\
\text { City of } \\
\text { June } 30\end{array}$ \\
\hline \multicolumn{7}{|l|}{ Electric Plant in Service } \\
\hline $\begin{array}{l}\text { Intangible Plant ....................................................... } \\
\text { Production Plant }\end{array}$ & 0 & 0 & 0 & 0 & 0 & 589 \\
\hline Steam & 0 & 45,186 & 0 & 89,028 & 26,448 & 39,923 \\
\hline 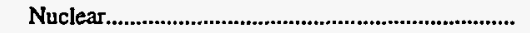 & 0 & 0 & 0 & 0 & 0 & 0 \\
\hline 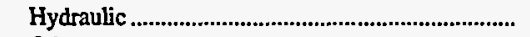 & 8,520 & 0 & 1,262 & 0 & 0 & 0 \\
\hline Other & 1,840 & 8,137 & 6,583 & 0 & 3,044 & 3,647 \\
\hline Total Production Plant & 10,359 & 53,323 & 7,845 & 89,028 & 29,492 & 43,570 \\
\hline 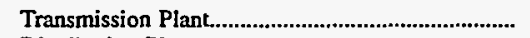 & 4,317 & 10,523 & 10,537 & 40,800 & 8,166 & 3,678 \\
\hline 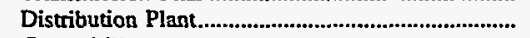 & 21,871 & 26,116 & 14,169 & 0 & 0 & 23,678 \\
\hline General Plant & 7,303 & 4,372 & 2,945 & 895 & 856 & 6,170 \\
\hline Total Electric Plant in Service & 43,851 & 94,334 & 35,496 & 130,723 & 38,515 & 77,685 \\
\hline 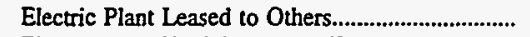 & 0 & 0 & 0 & 0 & 0 & 0 \\
\hline Electric Plant Held for Future Use ........................... & 0 & 0 & 0 & 0 & 0 & 89 \\
\hline Electric Plant Misc & 0 & 0 & 0 & 0 & 0 & 0 \\
\hline 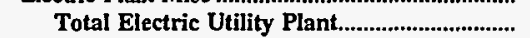 & 43,851 & 94,334 & 35,496 & 130,723 & 38,515 & 77,774 \\
\hline $\begin{array}{l}\text { Construction Work in Progress - Electric............... } \\
\text { Accumulated Provision for Depreciation }\end{array}$ & 2,309 & 0 & 0 & 0 & 0 & 245 \\
\hline 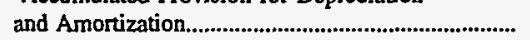 & 24,194 & 45,617 & 11,970 & 28,523 & 9,161 & 31,273 \\
\hline 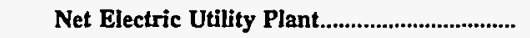 & 21,965 & 48,717 & 23,527 & 102,200 & 29,353 & 46,745 \\
\hline
\end{tabular}

\begin{tabular}{|c|c|c|c|c|c|c|}
\hline Item & $\begin{array}{l}\text { Vermont } \\
\text { Vermont } \\
\text { Public } \\
\text { Pwr } \\
\text { Supply Auth } \\
\text { December } 31\end{array}$ & $\begin{array}{l}\text { Virginia } \\
\text { Bedford } \\
\text { City of } \\
\text { June } 30\end{array}$ & $\begin{array}{l}\text { Virginia } \\
\text { Bristol } \\
\text { Utilities } \\
\text { Board } \\
\\
\text { June } 30\end{array}$ & $\begin{array}{l}\text { Virginia } \\
\text { Danville } \\
\text { City of } \\
\text { June } 30\end{array}$ & $\begin{array}{c}\text { Virginia } \\
\begin{array}{c}\text { Harrisonburg } \\
\text { City of }\end{array} \\
\text { June } 30\end{array}$ & $\begin{array}{c}\text { Virginia } \\
\text { Manassas } \\
\text { City of } \\
\text { June } 30\end{array}$ \\
\hline \multicolumn{7}{|l|}{ Electric Plant in Service } \\
\hline 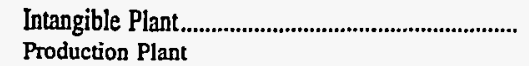 & 0 & 184 & 0 & 908 & 0 & 0 \\
\hline Steam & 16,997 & 0 & 0 & 0 & 286 & 0 \\
\hline 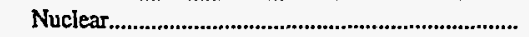 & 0 & 0 & 0 & 0 & 0 & 0 \\
\hline 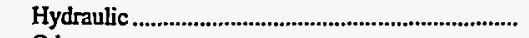 & 0 & 11,146 & 0 & 6,291 & 0 & 0 \\
\hline Other & 0 & 0 & 0 & 0 & 3,309 & $\mathbf{0}$ \\
\hline Total Production Plant......................................... & 16,997 & 11,146 & 0 & 6,291 & 3,595 & $\mathbf{0}$ \\
\hline Transmission Plant & 2,957 & 2,196 & 0 & 2,126 & 7,178 & 15 \\
\hline 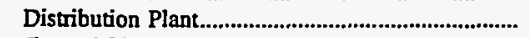 & 0 & 6,347 & 21,046 & 53,733 & 30,546 & 42,272 \\
\hline 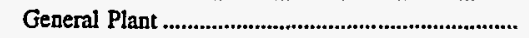 & 1,019 & 886 & 3,914 & 3,388 & 3,766 & 0 \\
\hline Total Electric Plant in Service ............................ & 20,973 & 20,758 & 24,960 & 66,446 & 45,086 & 42,287 \\
\hline 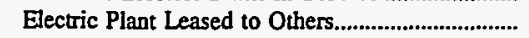 & 0 & 0 & 0 & 0 & 0 & 0 \\
\hline 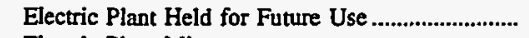 & 0 & 0 & 0 & 0 & 0 & 0 \\
\hline 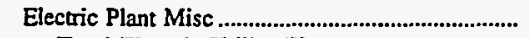 & $\mathbf{0}$ & 0 & 0 & 0 & 3,921 & 0 \\
\hline 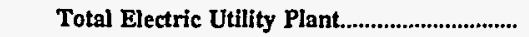 & 20,973 & 20,758 & 24,960 & 66,446 & 49,007 & 42,287 \\
\hline $\begin{array}{l}\text { Construction Work in Progress - Electric............... } \\
\text { Accumulated Provision for Depreciation }\end{array}$ & 0 & 0 & 501 & 3,469 & 2,559 & 348 \\
\hline and Amortization. & $\begin{array}{r}9,987 \\
10,986\end{array}$ & $\begin{array}{r}6,579 \\
14,179\end{array}$ & $\begin{array}{l}11,376 \\
14,086\end{array}$ & $\begin{array}{l}26,952 \\
42,963\end{array}$ & $\begin{array}{l}17,696 \\
33,871\end{array}$ & $\begin{array}{l}15,245 \\
27,391\end{array}$ \\
\hline
\end{tabular}

Note: Totals may not equal sum of components because of independent rounding.

Source: Energy Information Administration, Form EIA-412, "Annual Report of Public Electric Utilities." 
Table 24. Electric Utility Plant by Major U.S. Publicly Owned Electric Utility Within State at End of Period, 1996 (Continued)

(Thousand Dollars)

\begin{tabular}{|c|c|c|c|c|c|c|}
\hline Item & $\begin{array}{c}\text { Virginia } \\
\text { Martinsville } \\
\text { City of } \\
\text { June } 30\end{array}$ & $\begin{array}{l}\text { Virginia } \\
\text { Radford } \\
\text { City of } \\
\text { June } 30\end{array}$ & $\begin{array}{l}\text { Virginia } \\
\text { Salem } \\
\text { City of } \\
\text { June } 30\end{array}$ & $\begin{array}{l}\text { Virginia } \\
\text { Virginia } \\
\text { Tech } \\
\text { Electric } \\
\text { Service } \\
\text { June } 30\end{array}$ & $\begin{array}{l}\text { Washington } \\
\text { Centralia } \\
\text { City of } \\
\text { December } 31\end{array}$ & $\begin{array}{l}\text { Washington } \\
\text { Ellensburg } \\
\text { City of } \\
\text { December } 31\end{array}$ \\
\hline \multicolumn{7}{|l|}{ Electric Plant in Service } \\
\hline 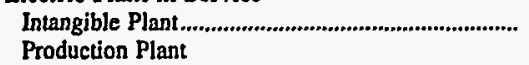 & 0 & 0 & 0 & $\mathbf{0}$ & 3,078 & 0 \\
\hline 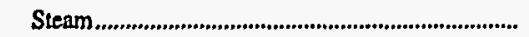 & 0 & 0 & 0 & $\mathbf{0}$ & 0 & 0 \\
\hline 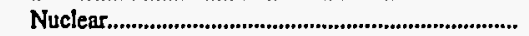 & 0 & 0 & 0 & $\mathbf{0}$ & 0 & 0 \\
\hline 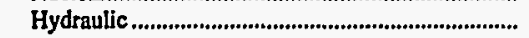 & 280 & 455 & 0 & 0 & 9,134 & 0 \\
\hline Other & 0 & 0 & 0 & 0 & 0 & $\mathbf{0}$ \\
\hline 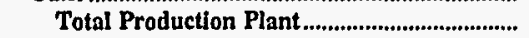 & 280 & 455 & 0 & 0 & 9,134 & $\mathbf{0}$ \\
\hline 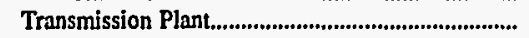 & 0 & 3,895 & 0 & 0 & 1,019 & 0 \\
\hline 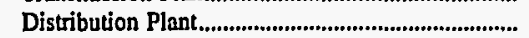 & 16,524 & 10,948 & 0 & 0 & 7,812 & 13,992 \\
\hline 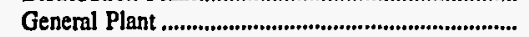 & 1,569 & 0 & 21,463 & 0 & 930 & 462 \\
\hline 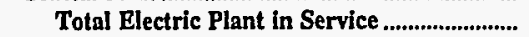 & 18,373 & 15,298 & 21,463 & $\mathbf{0}$ & 21,972 & 14,454 \\
\hline 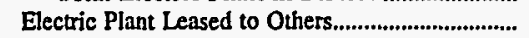 & 0 & 0 & 0 & 0 & 0 & 0 \\
\hline Electric Plant Held for Future Use........................... & $\mathbf{0}$ & 0 & 0 & 0 & 0 & $\mathbf{0}$ \\
\hline Electric Plant Misc & 0 & 0 & 0 & $\mathbf{0}$ & 0 & 137 \\
\hline 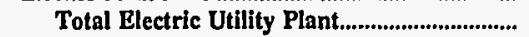 & 18,373 & 15,298 & 21,463 & 0 & 21,972 & 14,591 \\
\hline $\begin{array}{l}\text { Construction Work in Progress - Electric................ } \\
\text { Accumulated Provision for Depreciation }\end{array}$ & 0 & 0 & 0 & 0 & 0 & 0 \\
\hline 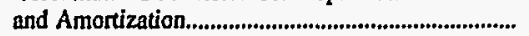 & 8,508 & 9,406 & 11,566 & 0 & 8,592 & 6,693 \\
\hline 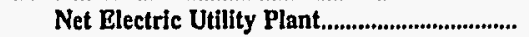 & 9,865 & 5,892 & 9,897 & 0 & 13,381 & $\mathbf{7 , 8 9 9}$ \\
\hline
\end{tabular}

\begin{tabular}{|c|c|c|c|c|c|c|}
\hline Item & $\begin{array}{c}\text { Washington } \\
\text { Port Angeles } \\
\text { City of }\end{array}$ & $\begin{array}{l}\text { Washington } \\
\text { PUD No } 1 \\
\text { of } \\
\text { Benton } \\
\text { County } \\
\text { December } 31\end{array}$ & $\begin{array}{c}\text { Washington } \\
\text { PUD No } 1 \\
\text { of } \\
\text { Chelan } \\
\text { County } \\
\text { December } 31\end{array}$ & $\begin{array}{l}\text { Washington } \\
\text { PUD No } 1 \text { of } \\
\text { Clallam } \\
\text { County } \\
\text { December } 31\end{array}$ & $\begin{array}{l}\text { Washington } \\
\text { PUD No } 1 \\
\text { of } \\
\text { Clark } \\
\text { County } \\
\text { Deçember } 31\end{array}$ & $\begin{array}{l}\text { Washington } \\
\text { PUD No } 1 \text { of } \\
\text { Cowlitz } \\
\text { County } \\
\text { December } 31\end{array}$ \\
\hline \multicolumn{7}{|l|}{ Electric Plant in Service } \\
\hline 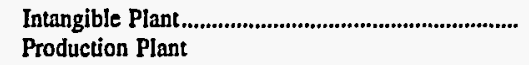 & 1 & 58 & 1,641 & 17 & 397 & 157 \\
\hline Steam & $\mathbf{0}$ & 0 & 0 & 0 & 0 & 0 \\
\hline 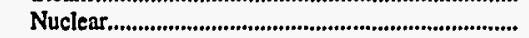 & 0 & 0 & 0 & 0 & 0 & 0 \\
\hline 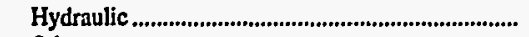 & 1,650 & 0 & 747,073 & 0 & 0 & 19,813 \\
\hline Other & 0 & 0 & 0 & 0 & 0 & 0 \\
\hline 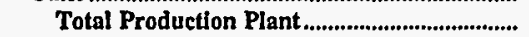 & 1,650 & $\mathbf{0}$ & 747,073 & 0 & $\mathbf{0}$ & 19,813 \\
\hline 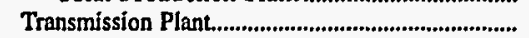 & 631 & 3,273 & 56,851 & 5,892 & 7,991 & 10,635 \\
\hline 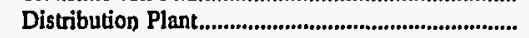 & 18,679 & 85,335 & 110,530 & 52,338 & 239,783 & 85,297 \\
\hline 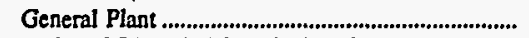 & 581 & 14,367 & 39,816 & 8,871 & 23,590 & 13,485 \\
\hline Total Electric Plant in Service ........................ & 21,542 & 103,033 & 955,911 & 67,117 & 271,760 & 129,387 \\
\hline Electric Plant Loased to Others................................ & 0 & 0 & 0 & 0 & 1,456 & 0 \\
\hline Electric Plant Held for Future Use ......................... & 0 & 472 & 0 & 0 & 90 & 0 \\
\hline 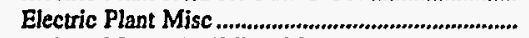 & 0 & 0 & 0 & 0 & $\mathbf{0}$ & 0 \\
\hline Total Electric Utility Plant................................. & 21,542 & 103,505 & 955,911 & 67,117 & 273,306 & 129,387 \\
\hline $\begin{array}{l}\text { Constnuction Work in Progress - Electric................ } \\
\text { Accumulated Provision for Depreciation }\end{array}$ & 1,608 & 1,791 & 15,592 & 3,387 & 5,027 & 704 \\
\hline 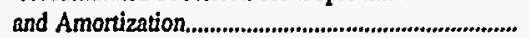 & 8,443 & 41,896 & 190,709 & 37,279 & 107,215 & 57,617 \\
\hline 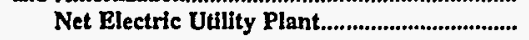 & 14,707 & 63,400 & 780,794 & 33,225 & 171,118 & 72,473 \\
\hline
\end{tabular}

Note: Totals may not equal sum of components because of independent rounding.

Source: Energy Information Administration, Form EIA-412, "Annual Report of Public Electric Utilities." 
Table 24. Electric Utility Plant by Major U.S. Publicly Owned Electric Utility Within State at End of Period, 1996

(Thousand Dollars)

\begin{tabular}{|c|c|c|c|c|c|c|}
\hline Item & $\begin{array}{l}\text { Washington } \\
\text { PUD No } 1 \text { of } \\
\text { Douglas } \\
\text { County } \\
\text { December } 31\end{array}$ & $\begin{array}{l}\text { Washington } \\
\text { PUD No } 1 \text { of } \\
\text { Franklin } \\
\text { County } \\
\text { December } 31\end{array}$ & $\begin{array}{c}\text { Washington } \\
\text { PUD No } 1 \\
\text { of } \\
\text { Grays } \\
\text { Harbor Cnty } \\
\text { December } 31\end{array}$ & $\begin{array}{c}\text { Washington } \\
\text { PUD No } 1 \\
\text { of } \\
\text { Klickitat } \\
\text { County } \\
\text { December } 31\end{array}$ & $\begin{array}{c}\text { Washington } \\
\text { PUD No } 1 \\
\text { of } \\
\text { Lewis } \\
\text { County } \\
\text { December } 31\end{array}$ & $\begin{array}{l}\text { Washington } \\
\text { PUD No } 1 \text { of } \\
\text { Okanogan } \\
\text { County } \\
\text { December } 31\end{array}$ \\
\hline \multicolumn{7}{|l|}{ Electric Plant in Service } \\
\hline 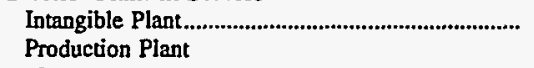 & 160 & 251 & 188 & 211 & 121 & 92 \\
\hline Steam & 0 & 0 & 14,731 & 0 & 0 & 0 \\
\hline 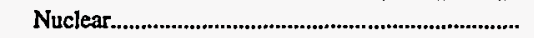 & 0 & 0 & 0 & 0 & 0 & 0 \\
\hline 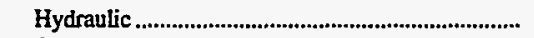 & 191,175 & 0 & 132 & 0 & 1,421 & 588 \\
\hline 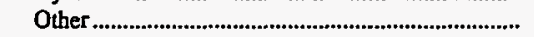 & 0 & 0 & 0 & 0 & 0 & 0 \\
\hline 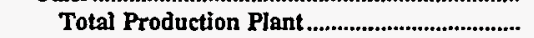 & 191,175 & $\mathbf{0}$ & 14,863 & 0 & 1,421 & 588 \\
\hline 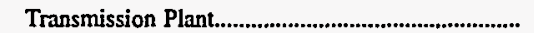 & 21,413 & 3,330 & 13,126 & 3,322 & 16,294 & 2,441 \\
\hline 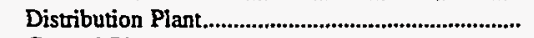 & 67,698 & 41,843 & 64,611 & 33,345 & 47,124 & 45,087 \\
\hline General Plant & 13,692 & 6,167 & 17,822 & 4,388 & 5,190 & 6,903 \\
\hline Total Electric Plant in Service ........................ & 294,137 & 51,591 & 110,609 & 41,267 & 70,150 & 55,111 \\
\hline Electric Plant Leased to Others................................. & 0 & 0 & 0 & 0 & 0 & 0 \\
\hline Electric Plant Held for Future Use .......................... & $\mathbf{0}$ & 0 & 0 & 0 & 0 & 0 \\
\hline 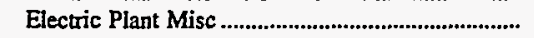 & 862 & 0 & 0 & 503 & 0 & 633 \\
\hline 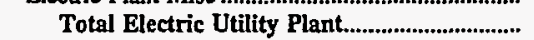 & 294,999 & 51,591 & 110,609 & 41,769 & 70,150 & 55,743 \\
\hline $\begin{array}{l}\text { Construction Work in Progress - Electric............... } \\
\text { Accumulated Ptovision for Depreciation }\end{array}$ & 1,142 & 1,410 & 8,497 & 4,892 & 9,461 & 2,214 \\
\hline $\begin{array}{l}\text { and Amortization. } \\
\text { Net Electric Utility Plant }\end{array}$ & $\begin{array}{r}60,562 \\
235,579\end{array}$ & $\begin{array}{l}19,304 \\
33,697\end{array}$ & $\begin{array}{l}40,280 \\
78,826\end{array}$ & $\begin{array}{l}15,503 \\
31,158\end{array}$ & $\begin{array}{l}17,638 \\
61,973\end{array}$ & $\begin{array}{l}29,207 \\
28,751\end{array}$ \\
\hline
\end{tabular}

\begin{tabular}{|c|c|c|c|c|c|c|}
\hline Item & $\begin{array}{l}\text { Washington } \\
\text { PUD No } 1 \text { of } \\
\text { Pend Oreille } \\
\text { Cnty } \\
\text { December } 31\end{array}$ & $\begin{array}{l}\text { Washington } \\
\text { PUD No } 1 \text { of } \\
\text { Snohomish } \\
\text { County } \\
\text { December } 31\end{array}$ & $\begin{array}{l}\text { Washington } \\
\text { PUD No } 1 \text { of } \\
\text { Whatcom } \\
\text { County } \\
\text { December } 31\end{array}$ & $\begin{array}{c}\text { Washington } \\
\text { PUD No } 2 \\
\text { of } \\
\text { Grant } \\
\text { County } \\
\text { December } 31\end{array}$ & $\begin{array}{l}\text { Washington } \\
\text { PUD No } 2 \text { of } \\
\text { Pacific } \\
\text { County } \\
\text { December } 31\end{array}$ & $\begin{array}{c}\text { Washington } \\
\text { PUD No } 3 \\
\text { of } \\
\text { Mason } \\
\text { County } \\
\text { December } 31\end{array}$ \\
\hline \multicolumn{7}{|l|}{ Blectric Plant in Service } \\
\hline $\begin{array}{l}\text { Intangible Plant ............................................................... } \\
\text { Production Plant }\end{array}$ & 204 & 13,302 & 0 & 33,070 & 0 & 12 \\
\hline 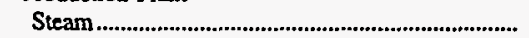 & 0 & 155,629 & 0 & 0 & 0 & 0 \\
\hline 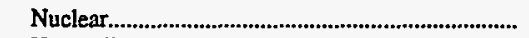 & 0 & 0 & 0 & 0 & 0 & 0 \\
\hline 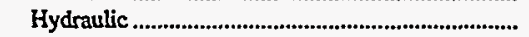 & 26,332 & 209,445 & 0 & 389,292 & 0 & 0 \\
\hline Other & 0 & 0 & 0 & 0 & 0 & 0 \\
\hline 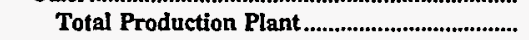 & 26,332 & 365,073 & 0 & 389,292 & $\mathbf{0}$ & 0 \\
\hline 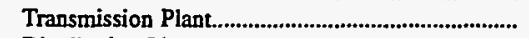 & 825 & 53,468 & 2,648 & 52,953 & 1,584 & 1,942 \\
\hline 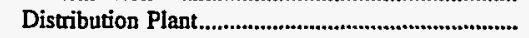 & 17,992 & 448,759 & 0 & 175,013 & 25,109 & 69,510 \\
\hline General Plant & 3,761 & 122,770 & 0 & 60,468 & 3,787 & 6,623 \\
\hline Total Electric Plant in Service ............................ & 49,114 & $1,003,372$ & 2,648 & 710,795 & 30,480 & 78,087 \\
\hline Electric Plant Leased to Others.................................. & 0 & 0 & 0 & 0 & 0 & $\mathbf{0}$ \\
\hline Electric Plant Held for Future Use ........................... & 500 & $\mathbf{0}$ & 0 & 0 & $\mathbf{0}$ & 0 \\
\hline 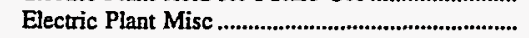 & 0 & 0 & 0 & 208 & 0 & 0 \\
\hline 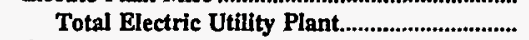 & 49,615 & $1,003,372$ & 2,648 & 711,004 & 30,480 & 78,087 \\
\hline $\begin{array}{l}\text { Construction Work in Progress - Electric............... } \\
\text { Accumulated Provision for Depreciation }\end{array}$ & 22,071 & 30,303 & 35 & 35,925 & 9,075 & 5,107 \\
\hline 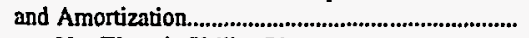 & 17,983 & 237,940 & 732 & 249,908 & 17,254 & 21,685 \\
\hline Net Electric Utility Plant..................................... & 53,703 & 795,734 & 1,950 & 497,021 & 22,301 & 61,509 \\
\hline
\end{tabular}

Note: Totals may not equal sum of components because of independent rounding.

Source: Energy Information Administration, Form EIA-412, "Annual Report of Public Electric Utilities." 
Table 24. Electric Utility Plant by Major U.S. Publicly Owned Electric Utility Within State at End of Period, 1996 (Continued)

(Thousand Dollars)

\begin{tabular}{|c|c|c|c|c|c|c|}
\hline Item & $\begin{array}{l}\text { Washingtoń } \\
\text { Richland } \\
\text { City of } \\
\text { December } 31\end{array}$ & $\begin{array}{l}\text { Washington } \\
\text { Seattle } \\
\text { City of } \\
\text { December } 31\end{array}$ & $\begin{array}{l}\text { Washington } \\
\text { Tacoma } \\
\text { City of } \\
\text { December } 31\end{array}$ & $\begin{array}{c}\text { Washington } \\
\text { Vera } \\
\text { Irrigation } \\
\text { District \# } 15 \\
\text { December } 31\end{array}$ & $\begin{array}{l}\text { Washington } \\
\text { Washington } \\
\text { Pub } \\
\text { Pwr } \\
\text { Supply Sys } \\
\text { June } 30\end{array}$ & $\begin{array}{l}\text { Wisconsin } \\
\text { Badger Power } \\
\text { Marketing } \\
\text { Auth } \\
\text { December } 31\end{array}$ \\
\hline $\begin{array}{l}\text { Electric Plant in Service } \\
\text { Intangible Plant........................................................... }\end{array}$ & $\mathbf{0}$ & 34,069 & 13,284 & 0 & $\mathbf{0}$ & 11 \\
\hline Production PJant & 0 & 27,012 & 86,362 & 0 & 0 & $\mathbf{0}$ \\
\hline 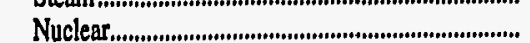 & 0 & 0 & 0 & 0 & $3,264,872$ & 0 \\
\hline 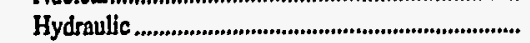 & 0 & 467,272 & 311,082 & 0 & 12,093 & 0 \\
\hline Other & 0 & 0 & 0 & 0 & 0 & 0 \\
\hline 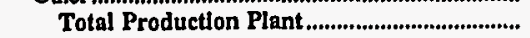 & 0 & 494,284 & 397,444 & 0 & $3,276,964$ & 0 \\
\hline Transmission Plant....................................................... & 659 & 87,495 & 78,106 & $\mathbf{0}$ & 5,202 & 5,271 \\
\hline 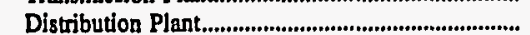 & 48,123 & 650,312 & 200,888 & 12,646 & 0 & 0 \\
\hline General Plant ........................................................... & 2,138 & 157,414 & 41,926 & 2,919 & 176,444 & 133 \\
\hline Total Electric Plant in Service ....................... & 50,920 & $1,423,573$ & 731,648 & 15,564 & $3,458,611$ & 5,415 \\
\hline Electric Plant Leased to Others................................... & 0 & 0 & 0 & 0 & 0 & 0 \\
\hline Electric Plant Held for Future Use .............................. & $\mathbf{0}$ & 1,456 & 275 & 0 & 0 & 0 \\
\hline 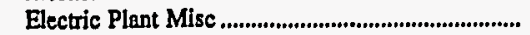 & 0 & $\mathbf{0}$ & 910 & 0 & 0 & 569 \\
\hline Total Electric Utility Plant...................................... & 50,920 & $1,425,029$ & 732,833 & 15,564 & $3,458,611$ & 5,984 \\
\hline $\begin{array}{l}\text { Construction Work in Progress - Electric................ } \\
\text { Accumulated Provision for Depreciation }\end{array}$ & 5,201 & 60,530 & 39,707 & 373 & 15,434 & 0 \\
\hline and Amortization. & 19,164 & 598,453 & 280,204 & 5,314 & $1,225,848$ & 1,634 \\
\hline 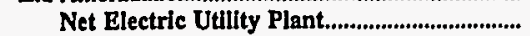 & 36,956 & 887,106 & 492,336 & 10,624 & $2,248,197$ & 4,350 \\
\hline
\end{tabular}

\begin{tabular}{|c|c|c|c|c|c|c|}
\hline Item & $\begin{array}{c}\text { Wisconsin } \\
\text { Jefferson } \\
\text { City of } \\
\text { December } 31\end{array}$ & $\begin{array}{l}\text { Wisconsin } \\
\text { Kaukauna } \\
\text { City of } \\
\text { December } 31\end{array}$ & $\begin{array}{l}\text { Wisconsin } \\
\text { Manitowoc } \\
\text { Public } \\
\text { Utilities } \\
\text { December } 31\end{array}$ & $\begin{array}{c}\text { Wisconsin } \\
\begin{array}{c}\text { Marshfield } \\
\text { City of }\end{array} \\
\text { December } 31\end{array}$ & $\begin{array}{c}\text { Wisconsin } \\
\begin{array}{c}\text { Menasha } \\
\text { City of }\end{array} \\
\text { December } 31\end{array}$ & $\begin{array}{c}\text { Wisconsin } \\
\text { New London } \\
\text { Electric\&Water } \\
\text { Util } \\
\text { December } 31\end{array}$ \\
\hline $\begin{array}{l}\text { Electric Plant in Service } \\
\text { Intangible Plant........................................................... } \\
\text { Production Plant }\end{array}$ & 0 & 0 & 0 & 0 & $\mathbf{0}$ & $\mathbf{0}$ \\
\hline Steam & 0 & 0 & 40,123 & 547 & 6,486 & 0 \\
\hline Nuclear, & 0 & 0 & 0 & 0 & 0 & 0 \\
\hline 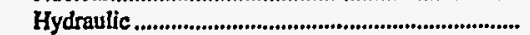 & 0 & 16,594 & 0 & 0 & $\mathbf{0}$ & 0 \\
\hline 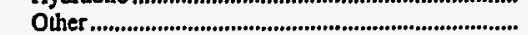 & $\mathbf{0}$ & $2 ; 699$ & 6,110 & 8,031 & 31 & 0 \\
\hline Total Production Plant....................................... & $\mathbf{0}$ & 19,293 & 46,233 & 8,578 & 6,516 & o \\
\hline 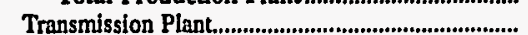 & 0 & 3,187 & 2,879 & 9,194 & 4,037 & 372 \\
\hline 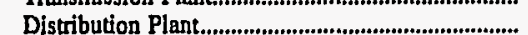 & 7,885 & 17,355 & $\overrightarrow{15,631}$ & 11,611 & 9,504 & 7,113 \\
\hline 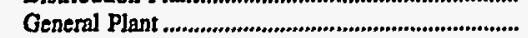 & 691 & 3,387 & 2,931 & 2,067 & 3,252 & 1,308 \\
\hline Total Electric Plant in Service ................................... & 8,576 & 43,222 & 67,675 & 31,450 & 23,309 & 8,793 \\
\hline 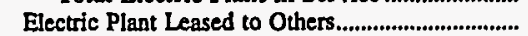 & 0 & 0 & 0 & 0 & 0 & 0 \\
\hline 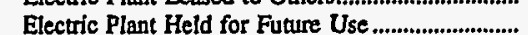 & 0 & 0 & 0 & 0 & 0 & 0 \\
\hline Electric Plant Misc .................................................... & 0 & 0 & 0 & 0 & 0 & 0 \\
\hline Total Electric Utillty Plant................................ & 8,576 & 43,222 & 67,675 & 31,450 & 23,309 & 8,793 \\
\hline $\begin{array}{l}\text { Construction Work in Progress - Electric................ } \\
\text { Accumulated Provision for Depreciation }\end{array}$ & 117 & 590 & 842 & 466 & 338 & 0 \\
\hline and Amortization............................................................ & 2,679 & 17,910 & 24,156 & 7,950 & 11,861 & 2,771 \\
\hline 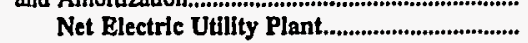 & 6,013 & 25,902 & 44,361 & 23,967 & 11,785 & 6,022 \\
\hline
\end{tabular}

Note: Totals may not equal sum of components because of independent rounding.

Source: Energy Information Administration, Form EIA-412, "Annual Report of Public Electric Utilities." 
Table 24. Electric Utility Plant by Major U.S. Publicly Owned Electric Utility Within State at End of Period, 1996 (Continued)

(Thousand Dollars)

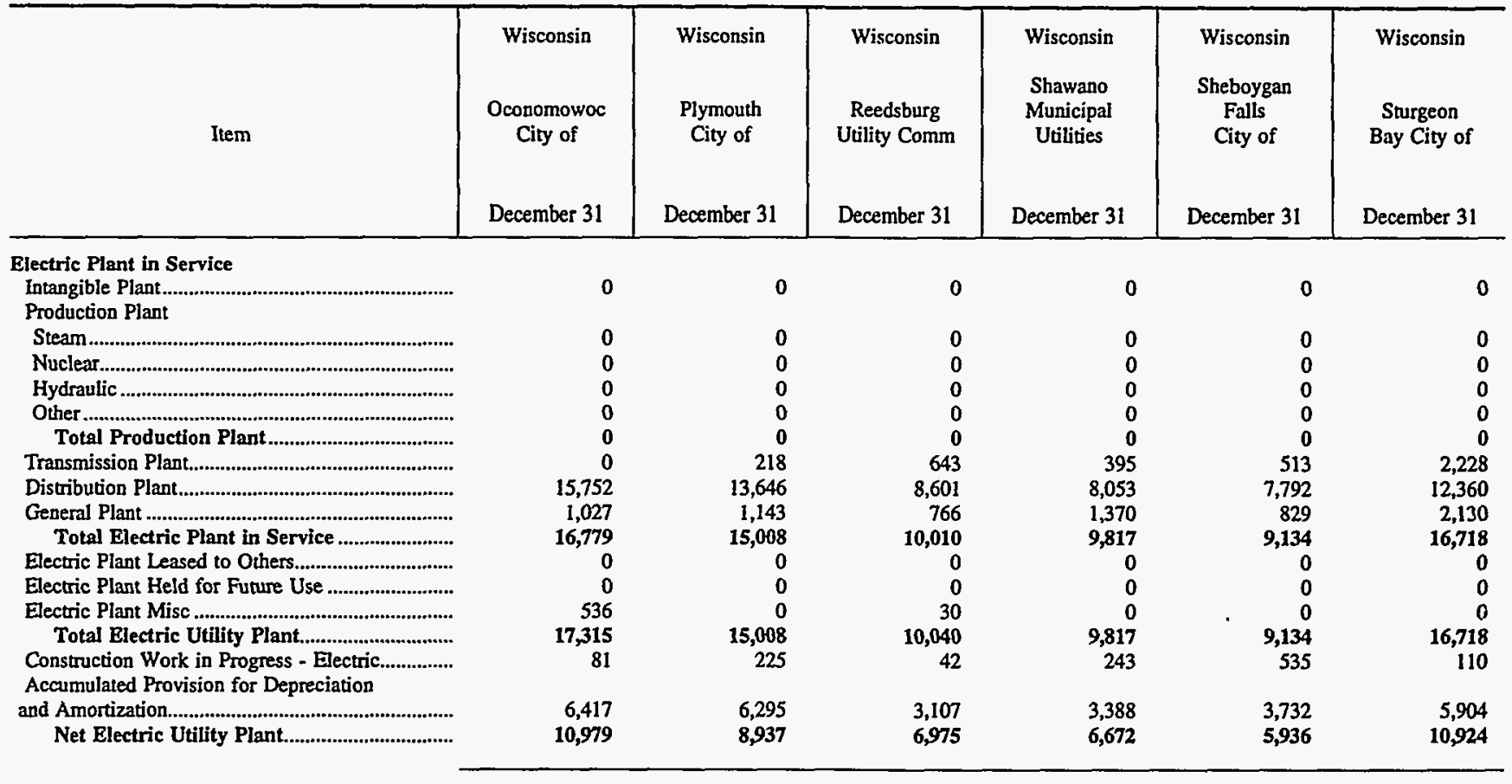

\begin{tabular}{|c|c|c|c|c|c|}
\hline Item & $\begin{array}{l}\text { Wisconsin } \\
\text { Sun Prairie } \\
\text { Water \& Light } \\
\text { Comm } \\
\text { December } 31\end{array}$ & $\begin{array}{l}\text { Wisconsin } \\
\text { Wisconsin } \\
\text { Public } \\
\text { Power } \\
\text { Inc Sys , } \\
\text { December } 31\end{array}$ & $\begin{array}{l}\text { Wisconsin } \\
\text { Wisconsin } \\
\text { Rapids W W } \\
\text { \& L } \\
\text { Comm } \\
\text { December } 31\end{array}$ & $\begin{array}{l}\text { Wyoming } \\
\text { Gillette } \\
\text { City of } \\
\text { June } 30\end{array}$ & $\begin{array}{l}\text { Wyoming } \\
\text { Wyoming } \\
\text { Municipal } \\
\text { Power Agency } \\
\text { December } 31\end{array}$ \\
\hline \multicolumn{6}{|l|}{ Electric Plant in Service } \\
\hline $\begin{array}{l}\text { Intangible Plant } \\
\text { Production Plant }\end{array}$ & 0 & 15,985 & 0 & 0 & 907 \\
\hline Steam & 0 & 74,870 & $\mathbf{0}$ & 0 & 15,726 \\
\hline 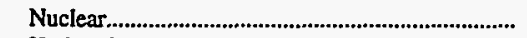 & 0 & 0 & 0 & 0 & 0 \\
\hline 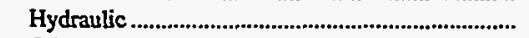 & 0 & 0 & 0 & 0 & 0 \\
\hline Other & 0 & 64,805 & $\mathbf{0}$ & 0 & 0 \\
\hline Total Production Plant & $\mathbf{0}$ & 139,675 & 0 & $\mathbf{0}$ & 15,726 \\
\hline 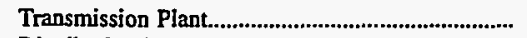 & 3,313 & 2,366 & 0 & 1,155 & 5,227 \\
\hline 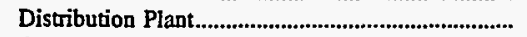 & 10,210 & 216 & 17,834 & 18,755 & 0 \\
\hline General Plant & 1,645 & 5,433 & 1,779 & 329 & 883 \\
\hline 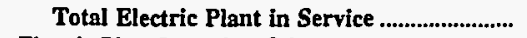 & 15,168 & 163,674 & 19,613 & 20,239 & 22,743 \\
\hline Electric Plant Leased to Others.................................. & 0 & 0 & 0 & 0 & 0 \\
\hline Electric Plant Held for Future Use ............................ & 17 & 0 & 1 & 0 & 0 \\
\hline 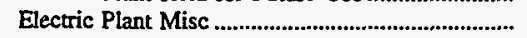 & 0 & 15,499 & 17,452 & 0 & 0 \\
\hline 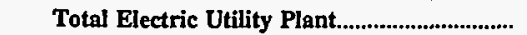 & 15,185 & 179,173 & 37,065 & 20,239 & 22,743 \\
\hline $\begin{array}{l}\text { Construction Work in Progress - Electric................ } \\
\text { Accumulated Provision for Depreciation }\end{array}$ & 120 & 19 & 357 & 0 & 1 \\
\hline 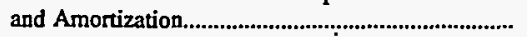 & 4,277 & 41,389 & 11,880 & 10,543 & 8,656 \\
\hline 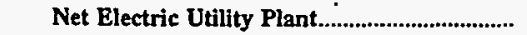 & 11,028 & 137,803 & 25,542 & 9,696 & 14,088 \\
\hline
\end{tabular}

Note: Totals may not equal sum of components because of independent rounding.

Source: Energy Information Administration, Form EIA-412, "Annual Report of Public Electric Utilities." 
Table 25. Number of Consumers, Sales, and Operating Revenue by Major U.S.

Publicly Owned Electric Utility Within State, 1996

\begin{tabular}{|c|c|c|c|c|c|c|}
\hline Item & $\begin{array}{l}\text { Alabama } \\
\text { Alabama } \\
\text { Municipal } \\
\text { Elec Auth } \\
\text { September } 30\end{array}$ & $\begin{array}{l}\text { Alabama } \\
\text { Albertville } \\
\text { Municipal } \\
\text { Utils Bd } \\
\text { June } 30\end{array}$ & $\begin{array}{l}\text { Alabama } \\
\text { Andalusia } \\
\text { City of } \\
\text { September } 30\end{array}$ & $\begin{array}{l}\text { Alabama } \\
\text { Athens } \\
\text { City of } \\
\text { December } 31\end{array}$ & $\begin{array}{l}\text { Alabama } \\
\text { Bessemer } \\
\text { City of } \\
\text { June } 30\end{array}$ & $\begin{array}{c}\text { Alabama } \\
\text { Cullman } \\
\text { Power Board } \\
\text { June } 30\end{array}$ \\
\hline \multicolumn{7}{|l|}{ Number of Consumers } \\
\hline 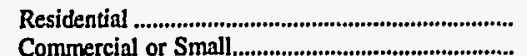 & $\begin{array}{l}0 \\
0\end{array}$ & $\begin{array}{l}6,932 \\
1,457\end{array}$ & $\begin{array}{r}3,720 \\
703\end{array}$ & $\begin{array}{r}24,861 \\
3,898\end{array}$ & $\begin{array}{r}10,850 \\
1,333\end{array}$ & $\begin{array}{l}6,067 \\
1,517\end{array}$ \\
\hline Industrial or Large & 0 & 171 & 49 & 366 & 249 & 223 \\
\hline 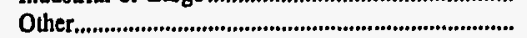 & 0 & 6 & 4 & 109 & 20 & 37 \\
\hline Total Ultimate Consumers.......................................... & $\mathbf{0}$ & 8,566 & 4,476 & 29,234 & 12,452 & 7,844 \\
\hline \multicolumn{7}{|l|}{ Sales for the Year (megawatthours) } \\
\hline 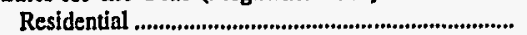 & 0 & 111,020 & 45,324 & 450,210 & 126,318 & 96,066 \\
\hline 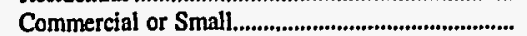 & 0 & 25,334 & 24,513 & 56,261 & 32,110 & 32,354 \\
\hline Industrial or Large........................................................... & 0 & 331,276 & 258,632 & 219,346 & 129,682 & 196,382 \\
\hline 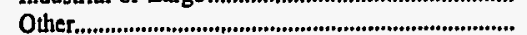 & o & 4,165 & 1,414 & 8,804 & 6,358 & 6,187 \\
\hline Total to UItimate Consumers............................. & 0 & 471,795 & 329,883 & 734,621 & 294,468 & 330,989 \\
\hline Sales for Resale .............................................. & $2,634,724$ & 0 & 0 & 0 & 0 & 0 \\
\hline 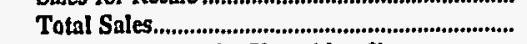 & $2,634,724$ & 471,795 & 329,883 & 734,621 & 294,468 & 330,989 \\
\hline \multicolumn{7}{|l|}{ Oper Revenues for the Year (thou\$) } \\
\hline 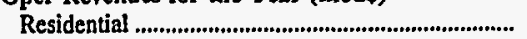 & 0 & 6,162 & 3,137 & 26,434 & 7,875 & 5,472 \\
\hline 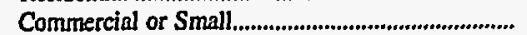 & 0 & 1,608 & 2,050 & 3,850 & 2,132 & 2,127 \\
\hline Industrial or Large ........................................................ & 0 & 13,365 & 9,298 & 12,029 & 7,482 & 10,005 \\
\hline Other & 0 & 317 & 127 & 817 & 537 & 382 \\
\hline 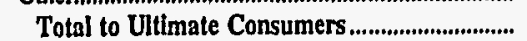 & 0 & 21,452 & 14,612 & 43,130 & 18,026 & 17,986 \\
\hline 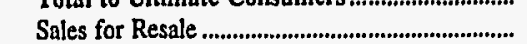 & 102,755 & 0 & 0 & 0 & 0 & \\
\hline Total Revenues From Sales of Elec.................... & 102,755 & 21,452 & 14,612 & 43,130 & 18,026 & 17,986 \\
\hline
\end{tabular}

\begin{tabular}{|c|c|c|c|c|c|c|}
\hline Item & $\begin{array}{l}\text { Alabama } \\
\text { Decatur } \\
\text { City of } \\
\text { June } 30\end{array}$ & $\begin{array}{l}\text { Alabama } \\
\text { Dothan } \\
\text { City of } \\
\text { September } 30\end{array}$ & $\begin{array}{l}\text { Alabama } \\
\begin{array}{l}\text { Florence } \\
\text { City of }\end{array} \\
\text { June } 30\end{array}$ & $\begin{array}{c}\text { Alabama } \\
\text { Foley } \\
\text { City of } \\
\text { (Riviera Utils) } \\
\text { December } 31\end{array}$ & $\begin{array}{l}\text { Alabama } \\
\text { For Payne } \\
\begin{array}{c}\text { Improvement } \\
\text { Auth }\end{array} \\
\text { June } 30\end{array}$ & $\begin{array}{l}\text { Alabama } \\
\text { Guntersville } \\
\text { Electric } \\
\text { Board } \\
\text { June } 30\end{array}$ \\
\hline \multicolumn{7}{|l|}{ Number of Consumers } \\
\hline Residential ........................ & 21,643 & 22,725 & 35,681 & 20,873 & 5,777 & 4,554 \\
\hline 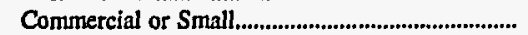 & 2,621 & 3,577 & 5,789 & 4,325 & 1,409 & 1,176 \\
\hline Industrial or Large...................................................... & 544 & 255 & 597 & 4 & 236 & 143 \\
\hline 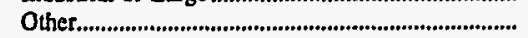 & 67 & 476 & 381 & 177 & 3 & 29 \\
\hline 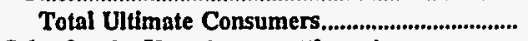 & 24,875 & 27,033 & 42,448 & 25,379 & $\mathbf{7 , 4 2 5}$ & 5,902 \\
\hline \multicolumn{7}{|l|}{ Sales for the Year (megawatthours) } \\
\hline Residential ..................................................... & 382,328 & 395,494 & 609,916 & 339,318 & 94,136 & 69,562 \\
\hline Commercial or Small.............................................. & 64,474 & 130,547 & 90,298 & 189,768 & 25,248 & 20,098 \\
\hline 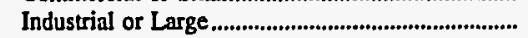 & $1,065,747$ & 436,218 & 387,652 & 46,146 & 212,132 & 146,418 \\
\hline 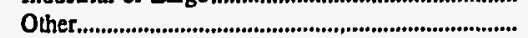 & 7,314 & 90,352 & 9,806 & 11,020 & 5,505 & 4,255 \\
\hline 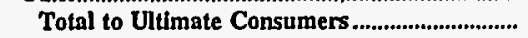 & $1,519,863$ & $1,052,611$ & $1,097,672$ & 586,252 & 337,021 & 240,333 \\
\hline Sales for Resale ...................................................... & & 0 & 0 & 0 & 0 & c \\
\hline Total Sales............................................................ & $1,519,863$ & $1,052,611$ & 1,$097 ; 672$ & 586,252 & 337,021 & 240,333 \\
\hline \multicolumn{7}{|l|}{ Oper Revenues for the Year (thou\$) } \\
\hline 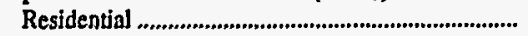 & 19,266 & 23,379 & 36,714 & 22,317 & 5,502 & 4,107 \\
\hline Commercial or Small.................................................... & 3,758 & 9,715 & 6,276 & 13,556 & 1,736 & 1,348 \\
\hline 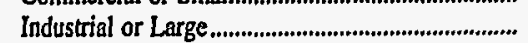 & 40,007 & 20,719 & 22,312 & 2,599 & 11,336 & 7,166 \\
\hline 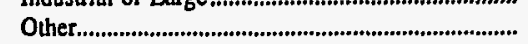 & 673 & 4,258 & 1,080 & 1,061 & 368 & 280 \\
\hline Total to Uitimate Consumers. & 63,704 & 58,071 & 66,382 & 39,533 & 18,942 & 12,901 \\
\hline Sales for Resale .......................................................... & & & 0 & 0 & 0 & \\
\hline Total Revenues From Sales of Elec.................. & 63,704 & 58,071 & 66,382 & 39,533 & 18,942 & 12,901 \\
\hline
\end{tabular}

Note: Totals may not equal sum of components because of independent rounding.

Source: Energy Information Administration, Form EIA-861, "Annual Electric Utility Report" Data are submitted on a calendar year. 
Table 25. Number of Consumers, Sales, and Operating Revenue by Major U.S. Publicly Owned Electric Utility Within State, 1996 (Continued)

\begin{tabular}{|c|c|c|c|c|c|c|}
\hline Item & $\begin{array}{l}\text { Alabama } \\
\text { Hartselle } \\
\text { City of } \\
\text { June } 30\end{array}$ & $\begin{array}{l}\text { Alabama } \\
\text { Huntsville } \\
\text { City of } \\
\text { September } 30\end{array}$ & $\begin{array}{l}\text { Alabama } \\
\text { Muscle } \\
\text { Shoals } \\
\text { City of } \\
\text { June } 30\end{array}$ & $\begin{array}{l}\text { Alabama } \\
\text { Opelika } \\
\text { City of } \\
\text { September } 30\end{array}$ & $\begin{array}{l}\text { Alabama } \\
\text { Scottsboro } \\
\text { City of } \\
\text { • } \\
\text { June } 30\end{array}$ & $\begin{array}{l}\text { Alabama } \\
\text { Sheffield } \\
\text { Utilities } \\
\text { June } 30\end{array}$ \\
\hline \multicolumn{7}{|l|}{ Number of Consumers } \\
\hline 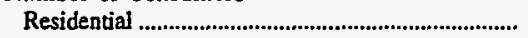 & 3,639 & 105,347 & 4,713 & 8,794 & 6,164 & 14,705 \\
\hline 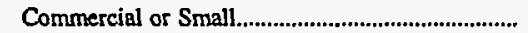 & 836 & 12,904 & 1,013 & 1,300 & 1,275 & 2,411 \\
\hline Industrial or Large & 85 & 2,250 & 180 & 6 & 170 & 254 \\
\hline 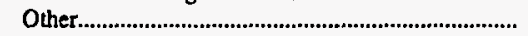 & 21 & 80 & 40 & 81 & 6 & $2 A 1$ \\
\hline 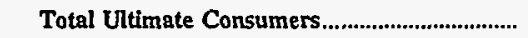 & 4,581 & 120,581 & 5,946 & 10,181 & 7,615 & 17,611 \\
\hline \multicolumn{7}{|l|}{ Sales for the Year (megawatthours) } \\
\hline 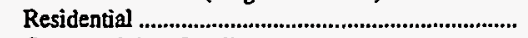 & 60,734 & $1,925,016$ & 79,894 & 105,244 & 102,030 & 235,306 \\
\hline 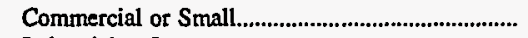 & 14,526 & 262,511 & 22,775 & 130,866 & 22,845 & 38,047 \\
\hline 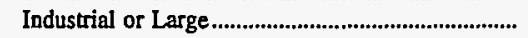 & 61,698 & $1,894,375$ & 105,205 & 93,984 & 246,983 & 144,822 \\
\hline 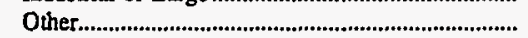 & 2,411 & 25,392 & 3,657 & 6,789 & 4,047 & 5,561 \\
\hline 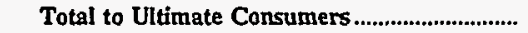 & 139,369 & $4,107,294$ & 211,531 & 336,883 & 375,905 & 423,736 \\
\hline 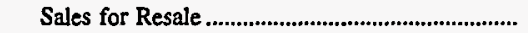 & 0 & 0 & 0 & 0 & 0 & 0 \\
\hline 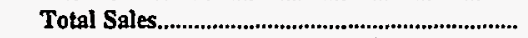 & 139,369 & $4,107,294$ & 211,531 & 336,883 & 375,905 & 423,736 \\
\hline \multicolumn{7}{|l|}{ Oper Revenues for the Year (thou\$) } \\
\hline Residential & 3,392 & 103,641 & 4,750 & 6,329 & 6,009 & 14,538 \\
\hline 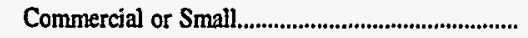 & 942 & 15,549 & 1,565 & 7,816 & 1,563 & 2,713 \\
\hline Industrial or Large & 3,389 & 88,082 & 5,915 & 4,573 & 10,863 & 8,235 \\
\hline 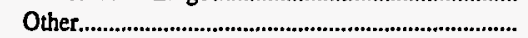 & 176 & 2,331 & 321 & 463 & 359 & 471 \\
\hline Total to Ultimate Consumers & 7,899 & 209,603 & 12,551 & 19,181 & 18,794 & 25,957 \\
\hline 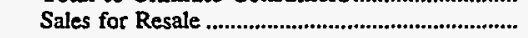 & 0 & 0 & 0 & 0 & 0 & 0 \\
\hline Total Revenues From Sales of Elec..................... & 7,899 & 209,603 & 12,551 & 19,181 & 18,794 & 25,957 \\
\hline
\end{tabular}

\begin{tabular}{|c|c|c|c|c|c|c|}
\hline Item & $\begin{array}{l}\text { Alabama } \\
\text { Sylacauga } \\
\text { Utilities } \\
\text { Board } \\
\text { September } 30\end{array}$ & $\begin{array}{c}\text { Alabama } \\
\text { Troy } \\
\text { City of } \\
\text { September } 30\end{array}$ & $\begin{array}{l}\text { Alabama } \\
\text { Tuskegee } \\
\text { City of } \\
\text { September } 30\end{array}$ & $\begin{array}{l}\text { Alaska } \\
\text { Alaska } \\
\text { Energy } \\
\text { Authority } \\
\\
\text { June } 30\end{array}$ & $\begin{array}{c}\text { Alaska } \\
\text { Anchorage } \\
\text { City of } \\
\text { December } 31\end{array}$ & $\begin{array}{c}\text { Alaska } \\
\text { Fairbanks } \\
\text { City of } \\
\text { December } 31\end{array}$ \\
\hline \multicolumn{7}{|l|}{ Number of Consumers } \\
\hline Residential & 5,082 & 5,307 & 6,576 & 0 & 23,418 & 4,580 \\
\hline 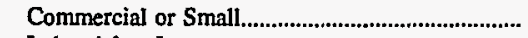 & 782 & 993 & 558 & 0 & 5,748 & 1,593 \\
\hline Industrial or Large & 16 & 107 & 78 & 0 & $\mathbf{0}$ & 0 \\
\hline 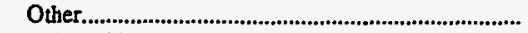 & 1 & 64 & 0 & 0 & 279 & 1 \\
\hline $\begin{array}{l}\text { Total Ultimate Consumers........................ } \\
\text { Sales for the Year (megawatthours) }\end{array}$ & 5,881 & 6,471 & 7,212 & 0 & 29,445 & 6,174 \\
\hline 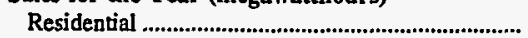 & 65,202 & 77,582 & 56,266 & 0 & 148,023 & 28,624 \\
\hline 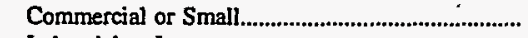 & 54,957 & 22,264 & 14,427 & 0 & 676,835 & 121,382 \\
\hline Industrial or Large & 56,871 & 142,604 & 73,578 & 0 & 0 & 0 \\
\hline 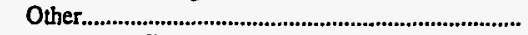 & 3,509 & 7,616 & 0 & $\mathbf{0}$ & 11,596 & 2,427 \\
\hline 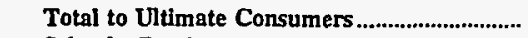 & 180,539 & 250,066 & 144,271 & 0 & 836,454 & 152,433 \\
\hline Sales for Resale & 0 & 0 & 0 & 659,812 & 40,571 & 0 \\
\hline 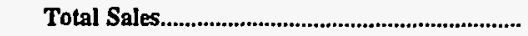 & 180,539 & 250,066 & 144,271 & 659,812 & 877,025 & 152,433 \\
\hline \multicolumn{7}{|l|}{ Oper Revenues for the Year (thou\$) } \\
\hline 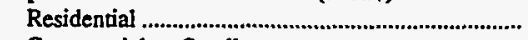 & 4,346 & 4,405 & 4,310 & 0 & 14,332 & 2,857 \\
\hline 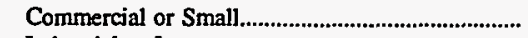 & 4,204 & 1,462 & 1,077 & 0 & 52,063 & 13,074 \\
\hline 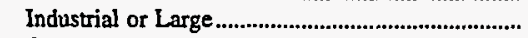 & 3,057 & 8,157 & 3,591 & 0 & 0 & 0 \\
\hline 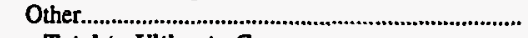 & 211 & 428 & 0 & 0 & 1,462 & 270 \\
\hline 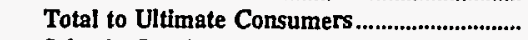 & 11,818 & 14,452 & 8,978 & 0 & 67,857 & 16,201 \\
\hline 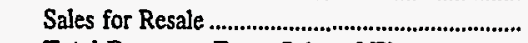 & 0 & 0 & 0 & 15,133 & 977 & 0 \\
\hline Total Revenues From Sales of Elec................... & 11,818 & 14,452 & 8,978 & 15,133 & 68,834 & 16,201 \\
\hline
\end{tabular}

Note: Totals may not equal sum of components because of independent rounding.

Sounce: Energy Information Administration, Form EIA-861, "Annual Electric Utility Report." Data are submitted on a calendar year. 
Table 25. Number of Consumers, Sales, and Operating Revenue by Major U.S. Publicly Owned Electric Utility Within State, 1996 (Continued)

\begin{tabular}{|c|c|c|c|c|c|c|}
\hline Item & $\begin{array}{c}\text { Alaska } \\
\text { Ketchikan } \\
\text { City of } \\
\text { December } 31\end{array}$ & $\begin{array}{l}\text { Arizona } \\
\text { Arizona } \\
\text { Power } \\
\text { Authority } \\
\text { June } 30\end{array}$ & $\begin{array}{l}\text { Arizona } \\
\text { Electrical } \\
\text { Dist } \\
\text { No2 } \\
\text { Pinal Cnty } \\
\text { December } 31\end{array}$ & $\begin{array}{c}\text { Arizona } \\
\text { Mesa } \\
\text { - City of } \\
\text { June } 30\end{array}$ & $\begin{array}{l}\text { Arizona } \\
\text { Navajo } \\
\text { Tribal } \\
\text { Utility } \\
\text { Auth } \\
\text { December } 31\end{array}$ & $\begin{array}{l}\text { Arizona } \\
\text { Salt River } \\
\text { Proj Ag } \\
\text { I \& P Dist } \\
\text { April } 30\end{array}$ \\
\hline \multicolumn{7}{|l|}{ Number of Consumers } \\
\hline 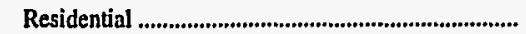 & 6,006 & $\mathbf{0}$ & 2,126 & 13,114 & 25,497 & 570,176 \\
\hline 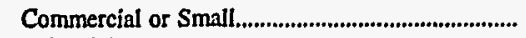 & 970 & 0 & 279 & 2,275 & 2,991 & 48,552 \\
\hline 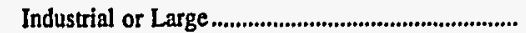 & 12 & 0 & 18 & 0 & 4 & 42 \\
\hline 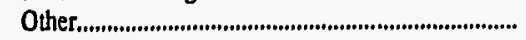 & 57 & 0 & 388 & 136 & 10,787 & 9,407 \\
\hline Total Ultimate Consumers................................. & 7,045 & 0 & 2,811 & 15,525 & 39,279 & 628,177 \\
\hline \multicolumn{7}{|l|}{ Sales for the Year (megawatthours) } \\
\hline 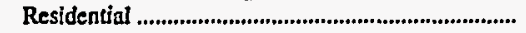 & 59,262 & $\mathbf{0}$ & 26,480 & 136,042 & 110,638 & $7,910,009$ \\
\hline 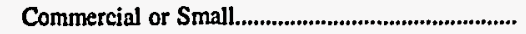 & 62,251 & 0 & 11,480 & 164,923 & 166,557 & $6,322,376$ \\
\hline Industrial or Large & 14,206 & 0 & 36,170 & 0 & 236,620 & $3,725,453$ \\
\hline 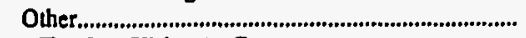 & 15,081 & 0 & 103,620 & 36,620 & 21,446 & 677,110 \\
\hline Total to Ultimate Consumers.............................. & 150,800 & 0 & 177,750 & $\mathbf{3 3 7 , 5 8 5}$ & 535,261 & $18,634,948$ \\
\hline 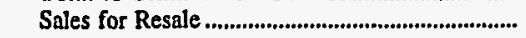 & 0 & $1,181,512$ & 0 & 3,325 & 0 & $5,589,734$ \\
\hline 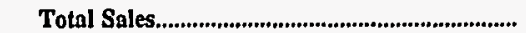 & 150,800 & $1,181,512$ & 177,750 & 340,910 & 535,261 & $24,224,682$ \\
\hline \multicolumn{7}{|l|}{ Oper Revenues for the Year (thou\$) } \\
\hline 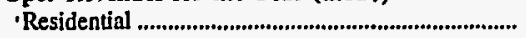 & 5.722 & 0 & 2,272 & 12,290 & 8,345 & 646,126 \\
\hline 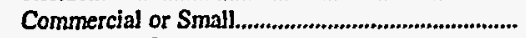 & 5,422 & 0 & 1,091 & 13,331 & 13,403 & 433,868 \\
\hline 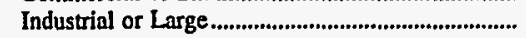 & 1,516 & 0 & 2,357 & 0 & 14,602 & 164,898 \\
\hline 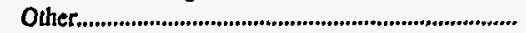 & 154 & 0 & 3,138 & 2,011 & 2,315 & 48,799 \\
\hline 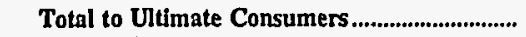 & 12,814 & 0 & 8,858 & 27,632 & 38,665 & $1,293,691$ \\
\hline 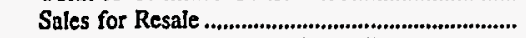 & 0 & 22,597 & 0 & 132 & 0 & 125,402 \\
\hline Total Revenues From Sales of Elec................... & 12,814 & 22,597 & 8,858 & 27,764 & 38,665 & $1,419,093$ \\
\hline
\end{tabular}

\begin{tabular}{|c|c|c|c|c|c|c|}
\hline Item & $\begin{array}{c}\text { Arizona } \\
\text { Tohono } \\
\text { OOdham } \\
\text { Utility Auth } \\
\text { December } 31\end{array}$ & $\begin{array}{l}\text { Arkansas } \\
\text { Benton } \\
\text { City of } \\
\text { December } 31\end{array}$ & $\begin{array}{c}\text { Arkansas } \\
\text { Bentonville } \\
\text { City of } \\
\text { December } 31\end{array}$ & $\begin{array}{l}\text { Arkansas } \\
\text { Clarksville } \\
\text { Light } \\
\& \\
\text { Water Co } \\
\text { September } 30\end{array}$ & $\begin{array}{l}\text { Arkansas } \\
\text { Conway } \\
\text { Corp } \\
\text { December } 31\end{array}$ & $\begin{array}{c}\text { Arkansas } \\
\text { Hope } \\
\text { City of } \\
\text { December 3] }\end{array}$ \\
\hline \multicolumn{7}{|l|}{ Number of Consumers } \\
\hline 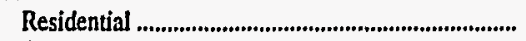 & 2,520 & 8,120 & 6,531 & 2,980 & 14,384 & 5,772 \\
\hline 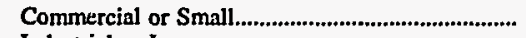 & 396 & 1,119 & 864 & 546 & 1,814 & 1,051 \\
\hline 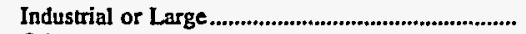 & 1 & 19 & 180 & 73 & 77 & 2 \\
\hline 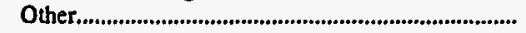 & 20 & 0 & $\mathbf{0}$ & 0 & 3 & 1,712 \\
\hline \multicolumn{7}{|l|}{ Sales for the Year (megawatthours) } \\
\hline 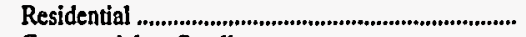 & 16,783 & 78,066 & 63,439 & 29,781 & 162,790 & 62,000 \\
\hline 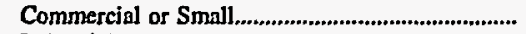 & 18,387 & 58,840 & 18,154 & 15,384 & 79,012 & 111,000 \\
\hline Industrial or Large & 62,402 & 39,487 & 176,900 & 157,749 & 358,754 & 86,000 \\
\hline 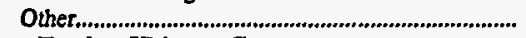 & 4,988 & 0 & 0 & 0 & 10,814 & 3,000 \\
\hline Total to Ultimate Consumers.............................. & 102,560 & 176,393 & 258,493 & 202,914 & 611,370 & 262,000 \\
\hline 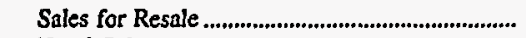 & $\mathbf{0}$ & 0 & 0 & 0 & 0 & 0 \\
\hline 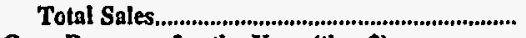 & 102,560 & 176,393 & 258,493 & 202,914 & 611,370 & 262,000 \\
\hline \multicolumn{7}{|l|}{ Oper Revenues for the Year (thous) } \\
\hline 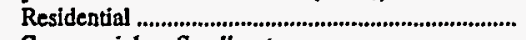 & 1,401 & 8,058 & 3,586 & 1,649 & 9,454 & 3,828 \\
\hline 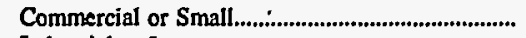 & 1,395 & 5,237 & 746 & 1,209 & 5,155 & 6,279 \\
\hline 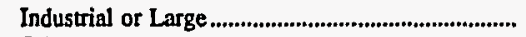 & 3,058 & 2,429 & 6,675 & 7,345 & 16,001 & 3,261 \\
\hline Other & 357 & 0 & 0 & 0 & 673 & 189 \\
\hline Total to Ultimate Consumers.............................. & 6,211 & 15,724 & 11,007 & 10,203 & 31,283 & 13,557 \\
\hline 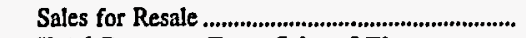 & 0 & 0 & 0 & 0 & 0 & \\
\hline Total Revenues From Sales of Elec.................... & 6,211 & 15,724 & 11,007 & 10,203 & 31,283 & 13,557 \\
\hline
\end{tabular}

Note: Totals may not equal sum of components because of independent rounding.

Source: Energy Information Administration, Form ElA-861, "Annual Electric Utility Report." Data are submitted on a calendar year. 
Table 25. Number of Consumers, Sales, and Operating Revenue by Major U.S. Publicly Owned Electric Utility Within State, 1996 (Continued)

\begin{tabular}{|c|c|c|c|c|c|c|}
\hline Item & $\begin{array}{l}\text { Arkansas } \\
\text { Jonesboro } \\
\text { City of } \\
\text { December } 31\end{array}$ & $\begin{array}{c}\text { Arkansas } \\
\text { North } \\
\text { Little } \\
\text { Rock } \\
\text { City of } \\
\text { December } 31\end{array}$ & $\begin{array}{l}\text { Arkansas } \\
\text { Osceola } \\
\text { City of } \\
\text { December } 31\end{array}$ & $\begin{array}{c}\text { Arkansas } \\
\text { Paragould } \\
\text { Light } \\
\& \\
\text { Water Comm } \\
\text { December } 31\end{array}$ & $\begin{array}{c}\text { Arkansas } \\
\text { Siloam } \\
\text { Springs } \\
\text { City of } \\
\text { December } 31\end{array}$ & $\begin{array}{l}\text { Arkansas } \\
\text { West } \\
\text { Memphis } \\
\text { City of } \\
\text { December } 31\end{array}$ \\
\hline \multicolumn{7}{|l|}{ Number of Consumers } \\
\hline 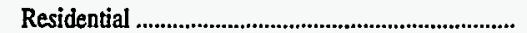 & 21,553 & 31,594 & 3,152 & 8,637 & 4,001 & 10,027 \\
\hline 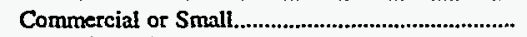 & 3,613 & 4,139 & 512 & 1,401 & 612 & 1,354 \\
\hline 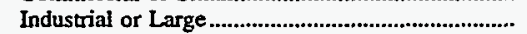 & 173 & 177 & 23 & 48 & 82 & 0 \\
\hline Other & 1 & 34 & 0 & 2,397 & 0 & 48 \\
\hline Total Ultimate Consumers..................................... & 25,340 & 35,944 . & 3,687 & 12,483 & 4,695 & 11,429 \\
\hline \multicolumn{7}{|l|}{ Sales for the Year (megawatthours) } \\
\hline 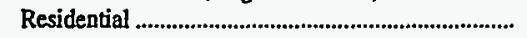 & 284,902 & 328,966 & 47,188 & 142,053 & 35,908 & 135,999 \\
\hline 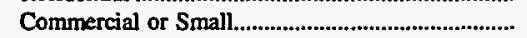 & 117,868 & 191,152 & 21,641 & 55,233 & 14,438 & 193,537 \\
\hline 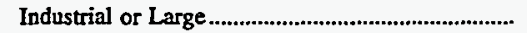 & 464,672 & 335,052 & 140,436 & 207,545 & 144,364 & 0 \\
\hline 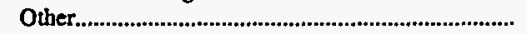 & 16,580 & 14,637 & 0 & 4,442 & 0 & 5,031 \\
\hline 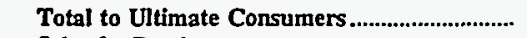 & 884,022 & 869,807 & 209,265 & 409,273 & 194,710 & 334,567 \\
\hline 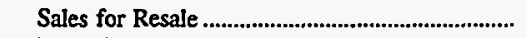 & 795,380 & 0 & 0 & 18,319 & 0 & 0 \\
\hline 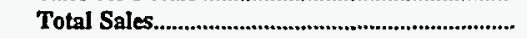 & $1,679,402$ & 869,807 & 209,265 & 427,592 & 194,710 & 334,567 \\
\hline \multicolumn{7}{|l|}{ Oper Revenues for the Year (thou\$) } \\
\hline 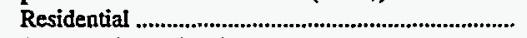 & 14,084 & 27,886 & 2,695 & 5,912 & 2,663 & 8,207 \\
\hline 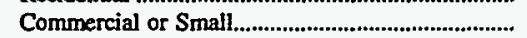 & 6,670 & 14,069 & 1,318 & 2,443 & 1,096 & 11,346 \\
\hline Industrial or Large & 16,505 & 21,743 & 5,617 & 7,025 & 4,423 & 0 \\
\hline 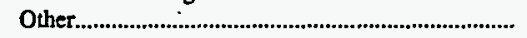 & 458 & 902 & 0 & 314 & 0 & 317 \\
\hline 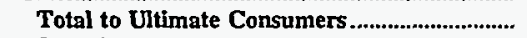 & 37,717 & 64,600 & 9,630 & 15,694 & 8,182 & 19,870 \\
\hline Sales for Resale & 15,428 & 0 & 0 & 285 & 0 & 0 \\
\hline Total Revenues From Sales of Elec................ & 53,145 & 64,600 & 9,630 & 15,979 & 8,182 & 19,870 \\
\hline
\end{tabular}

\begin{tabular}{|c|c|c|c|c|c|c|}
\hline Item & $\begin{array}{l}\text { California } \\
\text { Alameda } \\
\text { City of } \\
\text { June } 30\end{array}$ & $\begin{array}{l}\text { California } \\
\text { Anaheim } \\
\text { City of } \\
\text { June } 30\end{array}$ & $\begin{array}{l}\text { Califomia } \\
\text { Azusa } \\
\text { City of } \\
\text { June } 30\end{array}$ & $\begin{array}{l}\text { California } \\
\text { Burbank } \\
\text { City of } \\
\text { June } 30\end{array}$ & $\begin{array}{l}\text { California } \\
\text { California } \\
\text { Dept } \\
\text { Wtr } \\
\text { Resources } \\
\text { June } 30\end{array}$ & $\begin{array}{l}\text { Califomia } \\
\text { Colton } \\
\text { City of } \\
\text { June } 30\end{array}$ \\
\hline \multicolumn{7}{|l|}{ Number of Consumers } \\
\hline 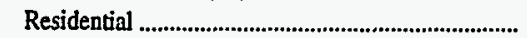 & 28,253 & 88,998 & 12,969 & 44,035 & 0 & 14,130 \\
\hline 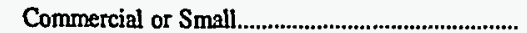 & 3,175 & 15,108 & 1,315 & 6,243 & 0 & 1,634 \\
\hline Industrial or Large & 3 & 579 & 33 & 215 & 0 & 25 \\
\hline 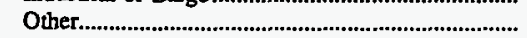 & 273 & 678 & 175 & 42 & 0 & 143 \\
\hline 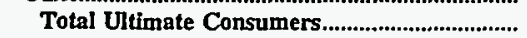 & 31,704 & 105,363 & 14,492 & 50,535 & 0 & 15,932 \\
\hline \multicolumn{7}{|l|}{ Sales for the Year (megawatthours) } \\
\hline 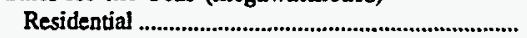 & 128,018 & 528,961 & 64,621 & 239,496 & 0 & 90,886 \\
\hline 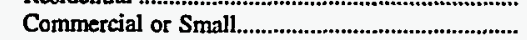 & 174,066 & 532,179 & 65,696 & 236,551 & 0 & 72,972 \\
\hline Industrial or Large & 89,827 & $1,133,500$ & 68,688 & 475,157 & 0 & 50,205 \\
\hline 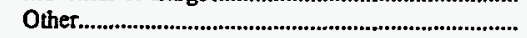 & 13,364 & 91,292 & 6,913 & 33,715 & 0 & 10,466 \\
\hline 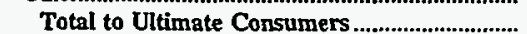 & 405,275 & $2,285,932$ & 205,918 & 984,919 & 0 & 224,529 \\
\hline Sales for Resale & 0 & 510,927 & 199,018 & 8,729 & $4,313,258$ & 155,562 \\
\hline 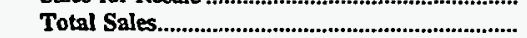 & 405,275 & $2,796,859$ & 404,936 & 993,648 & $4,313,258$ & 380,091 \\
\hline \multicolumn{7}{|l|}{ Oper Revenues for the Year (thouS) } \\
\hline 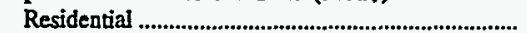 & 14,749 & 51,985 & 5,896 & 22,978 & 0 & 8,682 \\
\hline 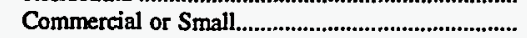 & 17,442 & 56,268 & 6,314 & 23,545 & 0 & 7,663 \\
\hline 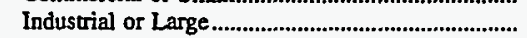 & 8,055 & 95,661 & 5,744 & 45,302 & 0 & 4,674 \\
\hline 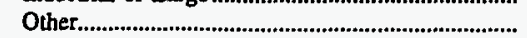 & 1,441 & 8,084 & 549 & 3,188 & 0 & 842 \\
\hline Total to Ultimate Consumers & 41,687 & 211,998 & 18,503 & 95,013 & 0 & 21,861 \\
\hline Sales for Resale & 0 & 6,564 & 4,190 & 129 & 117,958 & $\begin{array}{r}21,001 \\
2,975\end{array}$ \\
\hline Total Revenues From Sales of Elec................ & 41,687 & 218,562 & 22,693 & 95,142 & 117,958 & 24,836 \\
\hline
\end{tabular}

Note: Totals may not equal sum of components because of independent rounding.

Source: Energy Information Administration, Form ElA-861, "Annual Electric Utility Report." Data are submitted on a calendar year. 
Table 25. Number of Consumers, Sales, and Operating Revenue by Major U.S. Publicly Owned Electric Utility Within State, 1996 (Continued)

\begin{tabular}{|c|c|c|c|c|c|c|}
\hline Item & $\begin{array}{l}\text { Califormia } \\
\text { Glendale } \\
\text { City of } \\
\text { June } 30\end{array}$ & $\begin{array}{l}\text { California } \\
\text { Imperial } \\
\text { Irrigation } \\
\text { District } \\
\text { December } 31\end{array}$ & $\begin{array}{c}\text { California } \\
\text { Kings River } \\
\begin{array}{c}\text { Conservation } \\
\text { Dist }\end{array} \\
\text { June } 30\end{array}$ & $\begin{array}{l}\text { California } \\
\text { Lassen } \\
\text { Municipal } \\
\text { Utility Dist } \\
\text { June } 30\end{array}$ & $\begin{array}{l}\text { California } \\
\text { Lodi } \\
\text { City of } \\
\text { June } 30\end{array}$ & $\begin{array}{l}\text { California } \\
\text { Los Angeles } \\
\text { City of } \\
\text { June } 30\end{array}$ \\
\hline \multicolumn{7}{|l|}{ Number of Consumers } \\
\hline 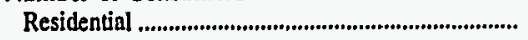 & 70,249 & 72,227 & 0 & 8,467 & 19,314 & $1,157,647$ \\
\hline Commercial or Small, & 12,164 & 12,891 & 0 & 1,241 & 2,993 & 170,812 \\
\hline Industrial or Large & 217 & 0 & 0 & 5 & 26 & 16,292 \\
\hline 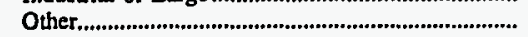 & 4 & 1,567 & $\mathbf{0}$ & 84 & 253 & 2,806 \\
\hline $\begin{array}{l}\text { Total Ultimate Consumers...................................... } \\
\text { Sales for the Year (megawatthours) }\end{array}$ & 82,634 & 86,685 & 0 & 9,797 & 22,586 & $1,347,557$ \\
\hline 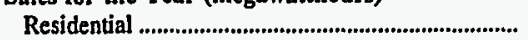 & 346,244 & 942,019 & 0 & 66,739 & 133,508 & $6,054,142$ \\
\hline 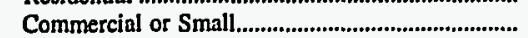 & 323,552 & $1,371,940$ & 0 & 41,891 & 132,766 & $12,215,599$ \\
\hline 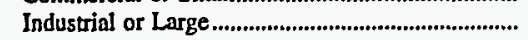 & 358,974 & 0 & 0 & 19,717 & 87,083 & $2,539,641$ \\
\hline 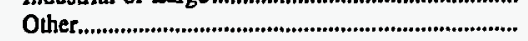 & 9,141 & 68,487 & 0 & 3,404 & 10,705 & 532,571 \\
\hline 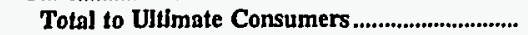 & $1,037,911$ & $2,382,446$ & $\mathbf{0}$ & 131,751 & 364,062 & $21,341,953$ \\
\hline 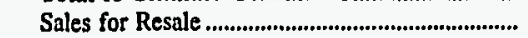 & 112,990 & 135,846 & 784,873 & 0 & $\mathbf{0}$ & 896,926 \\
\hline 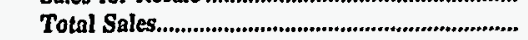 & $1,150,901$ & $2,518,292$ & 784,873 & 131,751 & 364,062 & $22,238,879$ \\
\hline \multicolumn{7}{|l|}{ Oper Revenues for the Year (thou\$) } \\
\hline 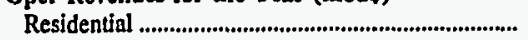 & 34,142 & 76,310 & 0 & 6,208 & 14,275 & 590,409 \\
\hline 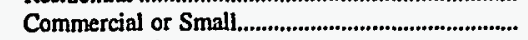 & 33,027 & 107,368 & 0 & 4,451 & 13,655 & $1,095,512$ \\
\hline 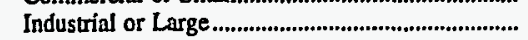 & 29,787 & 0 & 0 & 2,689 & 6,719 & 205,018 \\
\hline 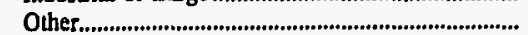 & 923 & 5,548 & 0 & 399 & 934 & 44,507 \\
\hline Total to Ultimate Consumers.............................. & 97,879 & 189,226 & 0 & 13,747 & 35,583 & $1,935,446$ \\
\hline 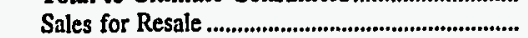 & 2,459 & 1,028 & 5,965 & 0 & 0 & 14,020 \\
\hline 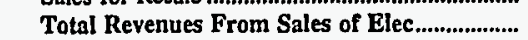 & 100,338 & 190,254 & 5,965 & 13,747 & $\mathbf{3 5 , 5 8 3}$ & $1,949,466$ \\
\hline
\end{tabular}

\begin{tabular}{|c|c|c|c|c|c|c|}
\hline Item & $\begin{array}{l}\text { California } \\
\text { Merced } \\
\text { Irrigation } \\
\text { District } \\
\text { December } 31\end{array}$ & $\begin{array}{c}\text { California } \\
\text { Metropolitan } \\
\text { Water } \\
\text { District } \\
\text { June } 30\end{array}$ & $\begin{array}{l}\text { California } \\
\text { Modesto } \\
\text { Irrigation } \\
\text { District } \\
\text { December } 31\end{array}$ & $\begin{array}{c}\text { California } \\
\text { MSR } \\
\text { Public } \\
\text { Power } \\
\text { Agency } \\
\text { December } 31\end{array}$ & $\begin{array}{l}\text { California } \\
\text { Northern } \\
\text { California } \\
\text { Power Agny } \\
\text { June } 30\end{array}$ & $\begin{array}{c}\text { California } \\
\text { Oakdale \& } \\
\text { South } \\
\text { San Joaquin } \\
\\
\text { December } 31\end{array}$ \\
\hline \multicolumn{7}{|l|}{ Number of Consumers } \\
\hline 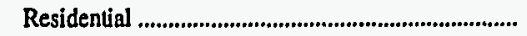 & 0 & 0 & 77,774 & 0 & 0 & 0 \\
\hline 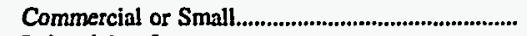 & 0 & 0 & 10,424 & 0 & 0 & 0 \\
\hline Industrial or Large & 1 & 0 & 44 & 0 & 0 & 0 \\
\hline Other, & 0 & 0 & 1,692 & 0 & $\mathbf{0}$ & 0 \\
\hline \multicolumn{7}{|l|}{ Sales for the Year (megawatthours) } \\
\hline 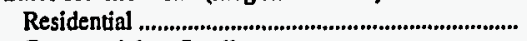 & 0 & 0 & 712,089 & 0 & 0 & 0 \\
\hline 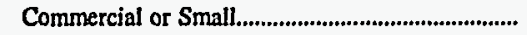 & 0 & 0 & 604,422 & 0 & 0 & 0 \\
\hline 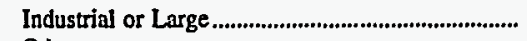 & 33,398 & 0 & 564,151 & 0 & 0 & 0 \\
\hline 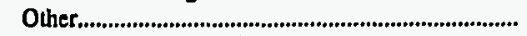 & 0 & 0 & 56,943 & $\mathbf{0}$ & 0 & $\mathbf{0}$ \\
\hline 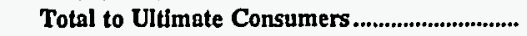 & 33,398 & 0 & $1,937,605$ & $\mathbf{0}$ & 0 & $\mathbf{0}$ \\
\hline Sales for Resale & 489,861 & 318,669 & 478,097 & $2,075,014$ & $2,961,505$ & 601,534 \\
\hline 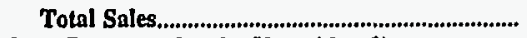 & 523,259 & 318,669 & $2,415,702$ & $2,075,014$ & $2,961,505$ & 601,534 \\
\hline \multicolumn{7}{|l|}{ Oper Revenues for the Year (thou\$) } \\
\hline 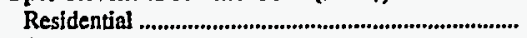 & 0 & 0 & 54,910 & $\mathbf{0}$ & 0 & 0 \\
\hline 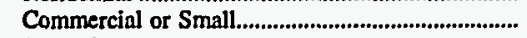 & 0 & $\mathbf{0}$ & 45,269 & 0 & 0 & $\mathbf{0}$ \\
\hline 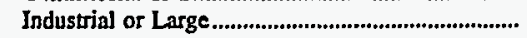 & 1,047 & 0 & 25,889 & $\mathbf{0}$ & 0 & 0 \\
\hline 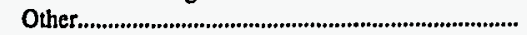 & $\mathbf{0}$ & $\mathbf{0}$ & 4,420 & 0 & 0 & $\mathbf{0}$ \\
\hline Total to Ultimate Consumers .......................... & 1,047 & $\mathbf{0}$ & 130,488 & $\mathbf{0}$ & o & $\mathbf{0}$ \\
\hline 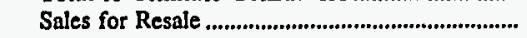 & 4,143 & 13,159 & 6,861 & 102,774 & 184,055 & 6,376 \\
\hline Total Revenues From Sales of Elec................... & 5,190 & 13,159 & 137,349 & 102,774 & 184,055 & 6,376 \\
\hline
\end{tabular}

Note: Totals may not equal sum of components because of independentrounding.

Source: Energy Information Administration, Form EIA-861, "Annual Electric Utility Report." Data are submitted on a calendar year. 
Table 25. Number of Consumers, Sales, and Operating Revenue by Major U.S.

Publicly Owned Electric Utility Within State, 1996 (Continued)

\begin{tabular}{|c|c|c|c|c|c|c|}
\hline Item & $\begin{array}{c}\text { California } \\
\text { Oroville } \\
\text { Wyandotte } \\
\text { Irrig Dist } \\
\text { December } 31\end{array}$ & $\begin{array}{l}\text { California } \\
\text { Palo Alto } \\
\text { City of } \\
\text { June } 30\end{array}$ & $\begin{array}{l}\text { Califomia } \\
\text { Pasadena } \\
\text { City of } \\
\text { June } 30\end{array}$ & $\begin{array}{c}\text { California } \\
\text { Placer } \\
\text { County } \\
\text { Water } \\
\text { Agency } \\
\text { December } 31\end{array}$ & $\begin{array}{l}\text { California } \\
\text { Redding } \\
\text { City of } \\
\text { June } 30\end{array}$ & $\begin{array}{l}\text { California } \\
\text { Riverside } \\
\text { City of } \\
\text { June } 30\end{array}$ \\
\hline \multicolumn{7}{|l|}{ Number of Consumers } \\
\hline 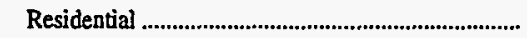 & 0 & 24,743 & 49,433 & 0 & 30,932 & 80,729 \\
\hline 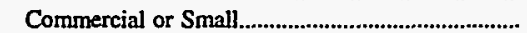 & 0 & 2,390 & 7,443 & 0 & 5,081 & 8,535 \\
\hline Industrial or Large & 0 & 197 & 923 & 0 & 520 & 197 \\
\hline 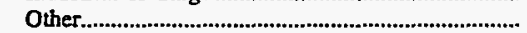 & 0 & 197 & 176 & 0 & 449 & 127 \\
\hline 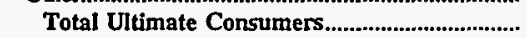 & $\mathbf{0}$ & 27,527 & 57,975 & 0 & 36,982 & 89,588 \\
\hline \multicolumn{7}{|l|}{ Sales for the Year (megawatthours) } \\
\hline 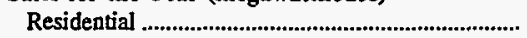 & 0 & 167,953 & 278,275 & 0 & 346,454 & 562,325 \\
\hline 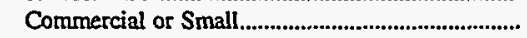 & 0 & 372,819 & 144,300 & 0 & 310,144 & 408,975 \\
\hline 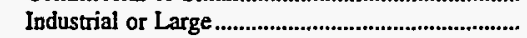 & 0 & 458,563 & 635,203 & 0 & 26,405 & 618,377 \\
\hline 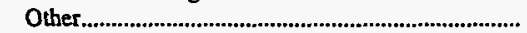 & 0 & 66,790 & 45,598 & 0 & 30,448 & 47,479 \\
\hline 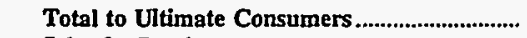 & $\mathbf{0}$ & $1,066,125$ & $1,103,376$ & 0 & 713,451 & $1,637,156$ \\
\hline 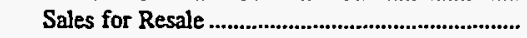 & 597,980 & 0 & 52,909 & $1,449,203$ & 696,228 & 20,740 \\
\hline 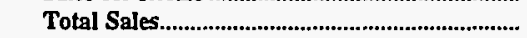 & 597,980 & $1,066,125$ & $1,156,285$ & $1,449,203$ & $1,409,679$ & $1,657,896$ \\
\hline \multicolumn{7}{|l|}{ Oper Revenues for the Year (thouS) } \\
\hline 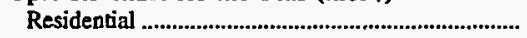 & 0 & 8,709 & 25,891 & 0 & 25,560 & 60,535 \\
\hline 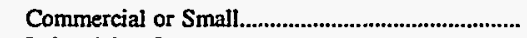 & 0 & 23,214 & 13,843 & 0 & 24,910 & 43,621 \\
\hline 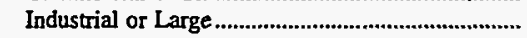 & 0 & 23,649 & 56,263 & 0 & 2,083 & 52,159 \\
\hline 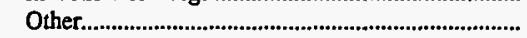 & 0 & 4,941 & 3,629 & 0 & 3,316 & 5,334 \\
\hline 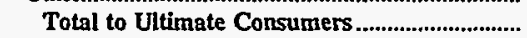 & 0 & 60,513 & 99,626 & 0 & 55,869 & 161,649 \\
\hline Sales for Resale & 9,623 & 0 & 4,320 & 8,169 & 30,720 & 563 \\
\hline Total Revenues From Sales of Elec..................... & 9,623 & 60,513 & 103,946 & 8,169 & 86,589 & 162,212 \\
\hline
\end{tabular}

\begin{tabular}{|c|c|c|c|c|c|c|}
\hline Item & $\begin{array}{c}\text { California } \\
\text { Roseville } \\
\text { City of } \\
\text { June } 30\end{array}$ & $\begin{array}{l}\text { Califomia } \\
\text { Sacramento } \\
\text { Municipal } \\
\text { Util Dist } \\
\text { December } 31\end{array}$ & $\begin{array}{l}\text { California } \\
\text { San Francisco } \\
\text { City } \\
\& \\
\text { County of } \\
\text { June } 30\end{array}$ & $\begin{array}{l}\text { Califomia } \\
\text { Santa } \\
\text { Clara } \\
\text { City of } \\
\text { June } 30\end{array}$ & $\begin{array}{l}\text { California } \\
\text { Southern } \\
\text { California } \\
\text { P P } \\
\text { A } \\
\text { June } 30\end{array}$ & $\begin{array}{l}\text { Califomia } \\
\text { Turlock } \\
\text { Irrigation } \\
\text { District } \\
\text { December } 31\end{array}$ \\
\hline \multicolumn{7}{|l|}{ Number of Consumers } \\
\hline 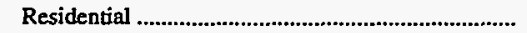 & 26,193 & 428,803 & 0 & 38,437 & 0 & 52,908 \\
\hline Commercial or Small. & 3,509 & 45,210 & 6 & 5,187 & 0 & 5,968 \\
\hline Industrial or Large & 31 & 7,753 & 0 & 1,676 & 0 & 1,294 \\
\hline Other & 122 & 1,895 & 2 & 403 & 0 & 4,373 \\
\hline 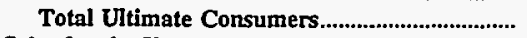 & 29,855 & 483,661 & 8 & 45,703 & 0 & 64,543 \\
\hline \multicolumn{7}{|l|}{ Sales for the Year (megawatthours) } \\
\hline Residential & 220,864 & $3,851,605$ & 0 & 207,300 & 0 & 498,919 \\
\hline 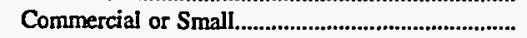 & 206,400 & 752,792 & 440 & 88,245 & 0 & 110,327 \\
\hline Industrial or Large & 230,710 & $4,208,926$ & 0 & $2,023,430$ & 0 & 563,845 \\
\hline Other & 35,494 & 75,938 & 642,260 & 21,310 & 0 & 137,752 \\
\hline 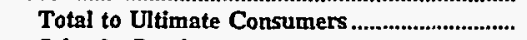 & 693,468 & $8,889,261$ & 642,700 & $2,340,285$ & 0 & $1,310,843$ \\
\hline 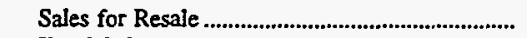 & 0 & 332,306 & $1,515,877$ & 226,312 & $2,147,802$ & 173,226 \\
\hline 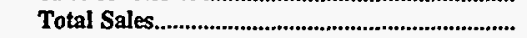 & 693,468 & $9,221,567$ & $2,158,577$ & $2,566,597$ & $2,147,802$ & $1,484,069$ \\
\hline \multicolumn{7}{|l|}{ Oper Revenues for the Year (thou\$) } \\
\hline 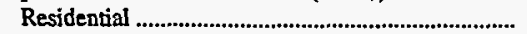 & 17,535 & 319,604 & 0 & 15,016 & 0 & 44,586 \\
\hline 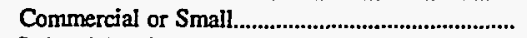 & 15,488 & 62,104 & 19 & 9,378 & 0 & 11,484 \\
\hline 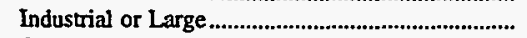 & 14,628 & 298,834 & 0 & 154,283 & 0 & 37,622 \\
\hline Other & 2,870 & 4,850 & 34,298 & 1,408 & 0 & 9,036 \\
\hline 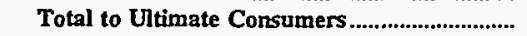 & 50,521 & 685,392 & 34,317 & 180,085 & 0 & 102,728 \\
\hline 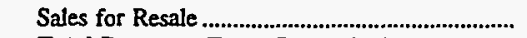 & 0 & 1,525 & 37,911 & 5,901 & 185,581 & 2,386 \\
\hline Total Revenues From Sales of Elec................... & 50,521 & 686,917 & 72,228 & 185,986 & 185,581 & 105,114 \\
\hline
\end{tabular}

Note: Totals may not equal sum of components because of independent rounding.

Source: Energy Information Administration, Form EIA-861, "Annual Electric Utility Report." Data are submitted on a calendar year. 
Table 25. Number of Consumers, Sales, and Operating Revenue by Major U.S. Publicly Owned Electric Utility Within State, 1996 (Continued)

\begin{tabular}{|c|c|c|c|c|c|c|}
\hline Item & $\begin{array}{l}\text { California } \\
\text { Vernon } \\
\text { City of } \\
\text { June } 30\end{array}$ & $\begin{array}{l}\text { California } \\
\text { Yuba } \\
\text { County } \\
\text { Water } \\
\text { Agency } \\
\text { June } 30\end{array}$ & $\begin{array}{c}\text { Colorado } \\
\text { Arkansas } \\
\text { River } \\
\text { Power } \\
\text { Authority } \\
\text { December } 31\end{array}$ & $\begin{array}{l}\text { Colorado } \\
\text { Colorado } \\
\text { Springs } \\
\text { City of } \\
\\
\text { December } 31\end{array}$ & $\begin{array}{l}\text { Colorado } \\
\text { Fort Collins } \\
\text { City of } \\
\text { December } 31\end{array}$ & $\begin{array}{l}\text { Colorado } \\
\text { Fort Morgan } \\
\text { City of } \\
\text { December } 31\end{array}$ \\
\hline \multicolumn{7}{|l|}{ Number of Consumers } \\
\hline 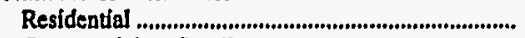 & 27 & 0 & 0 & 140,631 & 38,638 & 4,773 \\
\hline 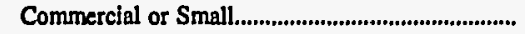 & 1,055 & 0 & 0 & 18,350 & 5,786 & 942 \\
\hline 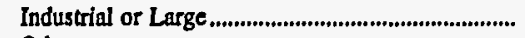 & 848 & 0 & 0 & 371 & 11 & 1 \\
\hline 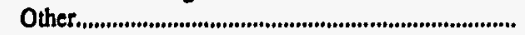 & 106 & 0 & 0 & 950 & 1 & 76 \\
\hline $\begin{array}{l}\text { Total Ultimate Consumers.................................... } \\
\text { Sales for the Year (megawatthours) }\end{array}$ & 2,036 & 0 & $\mathbf{0}$ & 160,302 & 44,436 & 5,792 \\
\hline 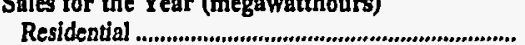 & 144 & 0 & 0 & 1.041 .207 & & Sales for the Year (megawatthours) \\
\hline 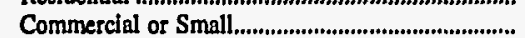 & 247,499 & 0 & 0 & $\begin{array}{r}1,041,201 \\
901,795\end{array}$ & $\begin{array}{l}311,748 \\
367,232\end{array}$ & $\begin{array}{l}40,450 \\
73,155\end{array}$ \\
\hline 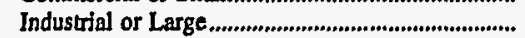 & 795,869 & 0 & 0 & $1,388,047$ & 327,895 & 58,535 \\
\hline 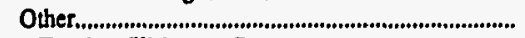 & 9,288 & 0 & 0 & 134,074 & 2,193 & 4,234 \\
\hline Total to Ultimate Consumers.............................. & $1,052,800$ & $\mathbf{0}$ & 0 & $3,465,123$ & $1,009,068$ & 182,374 \\
\hline 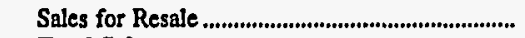 & 0 & $2,083,645$ & 286,209 & 176,954 & 0 & 0 \\
\hline 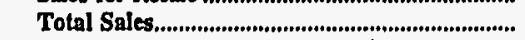 & $1,052,800$ & $2,083,645$ & 286,209 & $3,642,077$ & $1,009,068$ & 182,374 \\
\hline \multicolumn{7}{|l|}{ Oper Revenues for the Year (thou\$) } \\
\hline 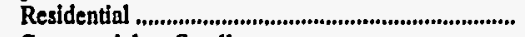 & 3 & $\mathbf{0}$ & 0 & 65,947 & 18,589 & 2,197 \\
\hline 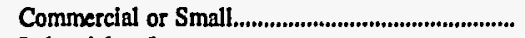 & 13,215 & 0 & 0 & 49,189 & 20,099 & 3,089 \\
\hline 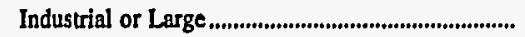 & 34,502 & 0 & 0 & 58,123 & 12,812 & 2,232 \\
\hline 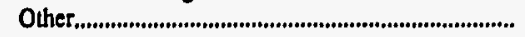 & 736 & 0 & 0 & 8,112 & 94 & 185 \\
\hline Total to Ultimate Consumers.............................. & 48,456 & 0 & $\mathbf{0}$ & 181,371 & 51,594 & 7,703 \\
\hline 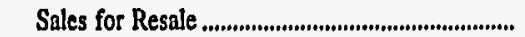 & 0 & 12,760 & 9,775 & 5,571 & 0 & \\
\hline Total Revenues From Sales of Elec.................... & 48,456 & 12,760 & 9,775 & 186,942 & 51,594 & 7,703 \\
\hline
\end{tabular}

\begin{tabular}{|c|c|c|c|c|c|c|}
\hline Item & $\begin{array}{l}\text { Colorado } \\
\text { Longmont } \\
\text { City of } \\
\text { December } 31\end{array}$ & $\begin{array}{l}\text { Colorado } \\
\text { Loveland } \\
\text { City of } \\
\text { December } 31\end{array}$ & $\begin{array}{l}\text { Colorado } \\
\text { Platte River } \\
\text { Power } \\
\text { Authority } \\
\text { December } 31\end{array}$ & $\begin{array}{l}\text { Connecticut } \\
\text { Connecticut } \\
\text { Mun } \\
\text { Elec } \\
\text { Engy Coop } \\
\text { December } 31\end{array}$ & $\begin{array}{l}\text { Connecticut } \\
\text { Groton } \\
\text { City of } \\
\text { June } 30\end{array}$ & $\begin{array}{l}\text { Connecticut } \\
\text { Norwich } \\
\text { City of } \\
\text { June } 30\end{array}$ \\
\hline \multicolumn{7}{|l|}{ Number of Consumers } \\
\hline 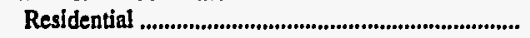 & 22,791 & 18,068 & 0 & 0 & 9,792 & 18,584 \\
\hline 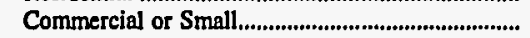 & 2,853 & 2,259 & 0 & 0 & 1,425 & 2,103 \\
\hline 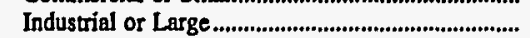 & 9 & 232 & 0 & 0 & 4 & 35 \\
\hline 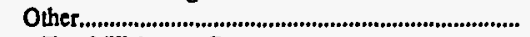 & 0 & 117 & 0 & 0 & 321 & 228 \\
\hline $\begin{array}{l}\text { Total Ultimate Consumers........................................ } \\
\text { Sales for the Year (megawatthours) }\end{array}$ & 25,653 & 20,676 & $\mathbf{0}$ & $\mathbf{0}$ & 11,542 & 20,950 \\
\hline 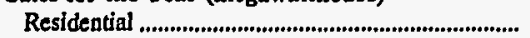 & 174,999 & 129,149 & 0 & 0 & 105,936 & 107,212 \\
\hline 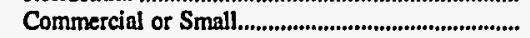 & 244,617 & 47,302 & 0 & 0 & 120,643 & 100,991 \\
\hline 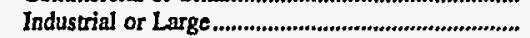 & 94,663 & 258,686 & 0 & 0 & 397,821 & 72,820 \\
\hline 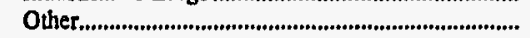 & 0 & 98 & 0 & 0 & 8,315 & 21,940 \\
\hline Total to Ultimate Consumers ............................. & 514,279 & 435,235 & 0 & 0 & 632,715 & 302,963 \\
\hline 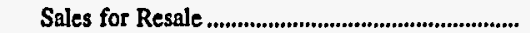 & 0 & 0 & $3,913,734$ & $2,142,530$ & 5,664 & 0 \\
\hline 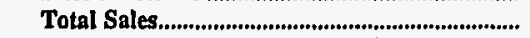 & 514,279 & 435,235 & $3,913,734$ & $2,142,530$ & 638,379 & 302,963 \\
\hline \multicolumn{7}{|l|}{ Oper Revenues for the Year (thou\$) } \\
\hline 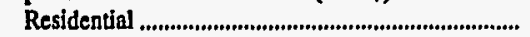 & 10,528 & 8,126 & 0 & 0 & 9,650 & 11,279 \\
\hline 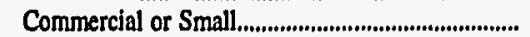 & 11,142 & 2,694 & 0 & 0 & 9,443 & 9,382 \\
\hline Industrial or Large..................................................... & 3,665 & 10,916 & 0 & 0 & 24,391 & 5,516 \\
\hline 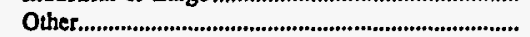 & 0 & 9 & 0 & 0 & 876 & 2,016 \\
\hline Total to Ultimate Consumers .............................. & 25,335 & 21,745 & $\mathbf{0}$ & $\mathbf{0}$ & 44,360 & 28,193 \\
\hline Sales for Resale & 0 & 0 & 135,957 & 107,127 & 387 & 0 \\
\hline Total Revenues From Sales of Elec.................... & 25,335 & 21,745 & 135,957 & 107,127 & 44,747 & 28,193 \\
\hline
\end{tabular}

Note: Totals may not equal sum of components because of independent rounding.

Source: Energy Information Administration, Form EIA-861, "Annual Electric Utility Report." Data are submitted on a calendar year. 
Table 25. Number of Consumers, Sales, and Operating Revenue by Major U.S.

Publicly Owned Electric Utility Within State, 1996 (Continued)

\begin{tabular}{|c|c|c|c|c|c|c|}
\hline Item & $\begin{array}{l}\text { Connecticut } \\
\text { Wallingford } \\
\text { Town of } \\
\text { June } 30\end{array}$ & $\begin{array}{l}\text { Delaware } \\
\text { Dover } \\
\text { City of } \\
\text { June } 30\end{array}$ & $\begin{array}{l}\text { Delaware } \\
\text { Milford } \\
\text { City of } \\
\text { September } 30\end{array}$ & $\begin{array}{l}\text { Delaware } \\
\text { Newark } \\
\text { City of } \\
\text { December } 31\end{array}$ & $\begin{array}{l}\text { Florida } \\
\text { Bartow } \\
\text { City of } \\
\text { September } 30\end{array}$ & $\begin{array}{c}\text { Florida } \\
\text { Florida } \\
\text { Municipal } \\
\text { Power Agency } \\
\text { September } 30\end{array}$ \\
\hline \multicolumn{7}{|l|}{ Number of Consumers } \\
\hline Residential .... & 19,174 & 17,351 & 3,923 & 8,653 & 8,525 & 0 \\
\hline 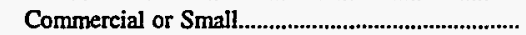 & 2,796 & 2,547 & 708 & 1,069 & 1,183 & \\
\hline Industrial or Large & 28 & 32 & 19 & 33 & 298 & 0 \\
\hline 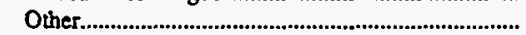 & 172 & 3 & 185 & 0 & 0 & 0 \\
\hline Total Ultimate Consumers........................................ & 22,170 & 19,933 & 4,835 & $\mathbf{9 , 7 5 5}$ & 10,006 & 0 \\
\hline \multicolumn{7}{|l|}{ Sales for the Year (megawatthours) } \\
\hline 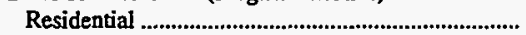 & 173,732 & 153,861 & 40,290 & 76,934 & 125,076 & 0 \\
\hline 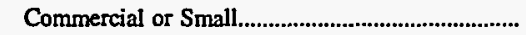 & 171,630 & 174,608 & 36,075 & 56,733 & 20,853 & 0 \\
\hline 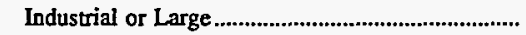 & 211,312 & 253,525 & 63,748 & 175,968 & 118,802 & 0 \\
\hline 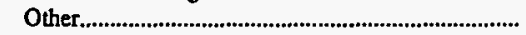 & 19,363 & 10,650 & 2,476 & 0 & 0 & 0 \\
\hline Total to Uitimate Consumers ................................... & 576,037 & 592,644 & 142,589 & 309,635 & 264,731 & o \\
\hline 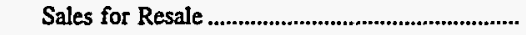 & 0 & 31,227 & 0 & 0 & 0 & $3,891,277$ \\
\hline Total Sales......................................... & 576,037 & 623,871 & 142,589 & 309,635 & 264,731 & $3,891,277$ \\
\hline \multicolumn{7}{|l|}{ Oper Revenues for the Year (thou\$) } \\
\hline 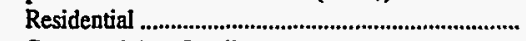 & 13,947 & 13,914 & 4,140 & 6,224 & 10,316 & 0 \\
\hline 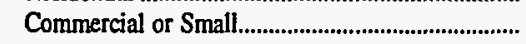 & 12,560 & 14,296 & 3,236 & 4,822 & 2,172 & 0 \\
\hline Industrial or Large & 12,231 & 14,020 & 3,945 & 9,685 & 10,348 & 0 \\
\hline 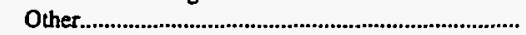 & 1,435 & 1,001 & 300 & & & 0 \\
\hline Total to Ultimate Consumers.................................. & 40,173 & 43,231 & 11,621 & 20,731 & 22,836 & 0 \\
\hline 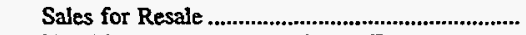 & & 32 & 0 & 0 & 0 & 205,549 \\
\hline Total Revenues From Sales of Elec................... & 40,173 & 43,263 & 11,621 & 20,731 & 22,836 & 205,549 \\
\hline
\end{tabular}

\begin{tabular}{|c|c|c|c|c|c|c|}
\hline Item & $\begin{array}{c}\text { Florida } \\
\text { Fort Pierce } \\
\text {. Udilities } \\
\text { Auth } \\
\text { September } 30\end{array}$ & $\begin{array}{c}\text { Florida } \\
\text { Gainesville } \\
\text { Regional } \\
\text { Utilities } \\
\text { September } 30\end{array}$ & $\begin{array}{c}\text { Florida } \\
\begin{array}{c}\text { Homestead } \\
\text { City of }\end{array} \\
\text { September } 30\end{array}$ & $\begin{array}{c}\text { Florida } \\
\text { Jacksonville } \\
\text { Beach } \\
\text { City of } \\
\text { September } 30\end{array}$ & $\begin{array}{c}\text { Florida } \\
\text { Jacksonville } \\
\text { Electric } \\
\text { Auth } \\
\text { September } 30\end{array}$ & $\begin{array}{c}\text { Florida } \\
\text { Key West } \\
\text { City of } \\
\text { September } 30\end{array}$ \\
\hline \multicolumn{7}{|l|}{ Number of Consumers } \\
\hline 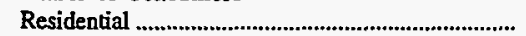 & 20,137 & 63,427 & 12,059 & 23,193 & 294,362 & 21,816 \\
\hline Commercial or Small........... & 3,960 & 7,539 & 1,490 & 4,084 & 32,999 & 2,512 \\
\hline 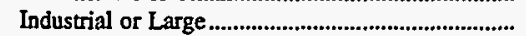 & 0 & 15 & 320 & 0 & 201 & 639 \\
\hline 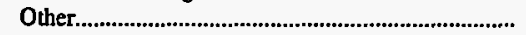 & 2 & 2,292 & 52 & 540 & 2,593 & 2 \\
\hline 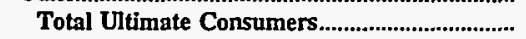 & 24,099 & 73,273 & 13,921 & 27,817 & 330,155 & 24,969 \\
\hline \multicolumn{7}{|l|}{ Sales for the Year (megawatthours) } \\
\hline Residential .... & 222,330 & 717,546 & 134,398 & 378,008 & $4,342,760$ & 256,236 \\
\hline Commercial or Small................. & 296,915 & 594,173 & 27,431 & 205,327 & $2,822,288$ & 54,528 \\
\hline Industrial or Large .............................................................. & 0 & 148,396 & 93,743 & 0 & $2,412,199$ & 195,408 \\
\hline 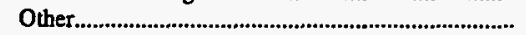 & 9,457 & 19,243 & 12,670 & 4,683 & 69,869 & 82,235 \\
\hline Total to Ultimate Consumers................................... & 528,702 & $1,479,358$ & 268,242 & 588,018 & $9,647,116$ & 588,407 \\
\hline Sales for Resale ......................................................... & 1,509 & 376,217 & 2,046 & 0 & $3,558,350$ & \\
\hline Total Sales.. & 530,211 & $1,855,575$ & 270,288 & 588,018 & $13,205,466$ & 588,407 \\
\hline \multicolumn{7}{|l|}{ Oper Revenues for the Year (thous) } \\
\hline Residential ....... & 19,220 & 55,584 & 11,929 & 28,783 & 302,491 & 17,006 \\
\hline 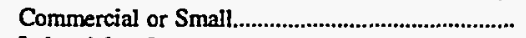 & 23,810 & 43,408 & 2,644 & 18,408 & 172,250 & 4,891 \\
\hline 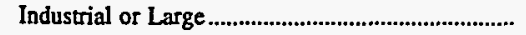 & 0 & 8,367 & 8,232 & 0 & 117,762 & 14,291 \\
\hline 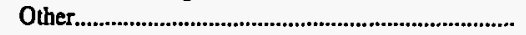 & 920 & 2,637 & 1,089 & 492 & 7,017 & 5,642 \\
\hline Total to Ultimate Consumers................................... & 43,950 & 109,996 & 23,894 & 47,683 & 599,520 & 41,830 \\
\hline 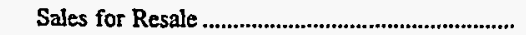 & 105 & 14,558 & 187 & 0 & 148,154 & 0 \\
\hline Total Revenues From Sales of Elec................... & 44,055 & 124,554 & 24,081 & 47,683 & 747,674 & 41,830 \\
\hline
\end{tabular}

Note: Totals may not equal sum of components because of independent rounding.

Source: Energy Information Administration, Form ElA-861, “Annual Electric Utility Report." Data are submitted on a calendar year. 
Table 25. Number of Consumers, Sales, and Operating Revenue by Major U.S. Publicly Owned Electric Utility Within State, 1996 (Continued)

\begin{tabular}{|c|c|c|c|c|c|c|}
\hline Item & $\begin{array}{c}\text { Florida } \\
\text { Kissimmee } \\
\text { Utility } \\
\text { Authority } \\
\text { September } 30\end{array}$ & $\begin{array}{l}\text { Florida } \\
\text { Lake Worth } \\
\text { City of } \\
\text { September } 30\end{array}$ & $\begin{array}{l}\text { Florida } \\
\text { Lakeland } \\
\text { City of } \\
\text { September } 30\end{array}$ & $\begin{array}{l}\text { Florida } \\
\text { Leesburg } \\
\text { City of } \\
\text { September } 30\end{array}$ & $\begin{array}{c}\text { Florida } \\
\text { New Smyma } \\
\text { Beach } \\
\text { Utils Comm } \\
\text { September } 30\end{array}$ & $\begin{array}{l}\text { Florida } \\
\text { Ocala } \\
\text { City of } \\
\text { September } 30\end{array}$ \\
\hline \multicolumn{7}{|l|}{ Number of Consumers } \\
\hline 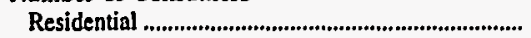 & 33,589 & 20,877 & 84,089 & 14,631 & 17,856 & 33,438 \\
\hline 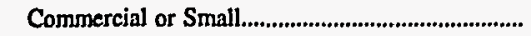 & 7,984 & 3,053 & 9,695 & 2,640 & 1,715 & 5,562 \\
\hline 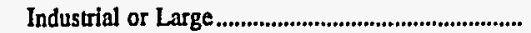 & 30 & 0 & 58 & $\mathbf{0}$ & 0 & 904 \\
\hline 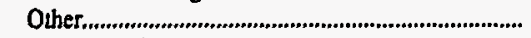 & 1,560 & 866 & 9,630 & 166 & 765 & 2,217 \\
\hline Total Ultimate Consumers................................... & 43,163 & 24,796 & 103,472 & $17, \mathbf{4 3 7}$ & 20,336 & 42,121 \\
\hline \multicolumn{7}{|l|}{ Sales for the Year (megawalthours) } \\
\hline 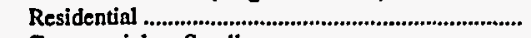 & 453,513 & 205,953 & $1,201,243$ & 180,599 & 203,253 & 433,903 \\
\hline 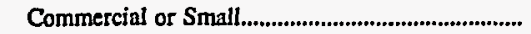 & 352,703 & 143,257 & 588,658 & 205,963 & 107,750 & 115,670 \\
\hline 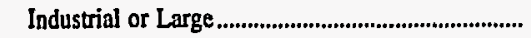 & 84,760 & 0 & 435,611 & 0 & 0 & 494,557 \\
\hline 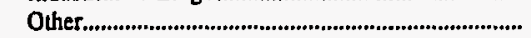 & 6,645 & 4,505 & 93,340 & 11,235 & 2,881 & 28,449 \\
\hline 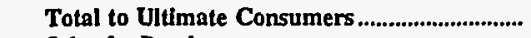 & 897,621 & 353,715 & $2,318,852$ & 397,797 & 313,884 & $1,072,579$ \\
\hline 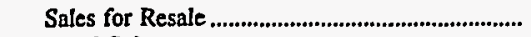 & 0 & 41 & 24,462 & 0 & 0 & 0 \\
\hline 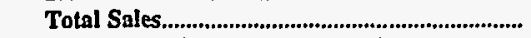 & 897,621 & 353,756 & $2,343,314$ & 397,797 & 313,884 & $1,072,579$ \\
\hline \multicolumn{7}{|l|}{ Oper Revenues for the Year (thou\$) } \\
\hline 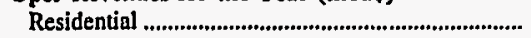 & 36,000 & 18,429 & 88,458 & 13,871 & 16,829 & 32,552 \\
\hline 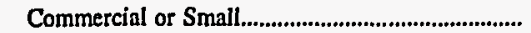 & 26,044 & 13,277 & 38,894 & 16,005 & 9,537 & 8,354 \\
\hline 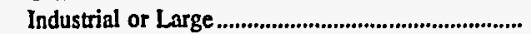 & 5,049 & 0 & 21,577 & 0 & $\mathbf{0}$ & 29,452 \\
\hline 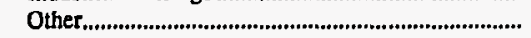 & 872 & 653 & 8,203 & 750 & 368 & 2,232 \\
\hline 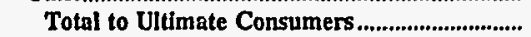 & 67,965 & 32,359 & 157,132 & 30,626 & 26,734 & 72,590 \\
\hline Sales for Resale & 0 & 1,019 & 1,207 & 0 & 0 & 0 \\
\hline Total Revenues From Sales of Elec.................. & 67,965 & 33,378 & 158,339 & 30,626 & 26,734 & 72,590 \\
\hline
\end{tabular}

\begin{tabular}{|c|c|c|c|c|c|c|}
\hline Item & $\begin{array}{l}\text { Florida } \\
\text { Orlando } \\
\text { Utilities } \\
\text { Comm } \\
\text { September } 30\end{array}$ & $\begin{array}{c}\text { Florida } \\
\text { Quincy } \\
\text { City of } \\
\text { September } 30\end{array}$ & $\begin{array}{c}\text { Florida } \\
\text { Reedy Creek } \\
\text { Improvement } \\
\text { Dist } \\
\text { September } 30\end{array}$ & $\begin{array}{l}\text { Florida } \\
\text { St Cloud } \\
\text { City of } \\
\text { September } 30\end{array}$ & $\begin{array}{c}\text { Florida } \\
\text { Tallahassee } \\
\text { City of } \\
\text { September } 30\end{array}$ & $\begin{array}{c}\text { Florida } \\
\text { Vero } \\
\text { Beach } \\
\text { City of } \\
\text { September } 30\end{array}$ \\
\hline \multicolumn{7}{|l|}{ Number of Consumers } \\
\hline 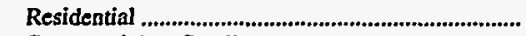 & 110,949 & 3,753 & 9 & 14,158 & 72,998 & 22,742 \\
\hline 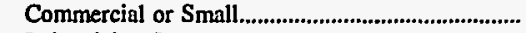 & 17,974 & 673 & 1,129 & 1,311 & 10,553 & 4,253 \\
\hline 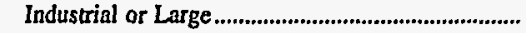 & 0 & 26 & 0 & 138 & 0 & 1 \\
\hline 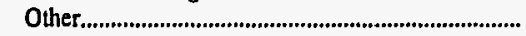 & 3 & 75 & 112 & 0 & 4,591 & 0 \\
\hline $\begin{array}{l}\text { Total Ultimate Consumers............................................ } \\
\text { Sales for the Year (megawatthours) }\end{array}$ & 128,926 & 4,527 & 1,250 & 15,607 & 88,142 & 26,996 \\
\hline 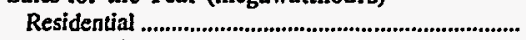 & $1,419,028$ & 44,048 & 140 & 190,163 & 892,846 & 301,359 \\
\hline 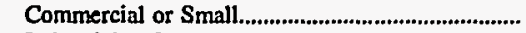 & $2,529,204$ & 32,614 & 773,153 & 18,361 & $1,241,222$ & 252,919 \\
\hline 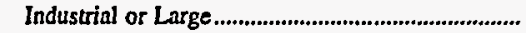 & 0 & 58,006 & 0 & 61,700 & 0 & 11,881 \\
\hline 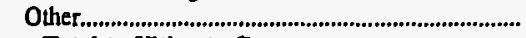 & 81,247 & 4,102 & 169,817 & 0 & 86,795 & 2,492 \\
\hline Total to Ultimate Consumers............................... & $4,029,479$ & 138,770 & 943,110 & 270,224 & $2,220,863$ & 568,651 \\
\hline 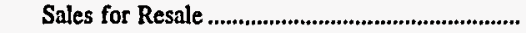 & $2,557,852$ & 0 & 5,703 & 111 & 146,873 & 92,880 \\
\hline $\begin{array}{l}\text { Total Sales. } \\
\text { Oper Revenues for the Year (thou\$) }\end{array}$ & $6,587,331$ & 138,770 & 948,813 & 270,335 & $2,367,736$ & 661,531 \\
\hline 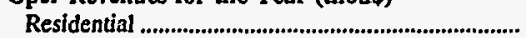 & 112,228 & 3,756 & 11 & 16,715 & 77,604 & 26,802 \\
\hline 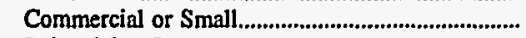 & 151,114 & 2,873 & 53,519 & 1,777 & 82,287 & 20,330 \\
\hline 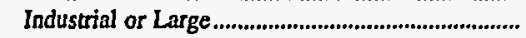 & 0 & 3,758 & 0 & 5,175 & 0 & 939 \\
\hline 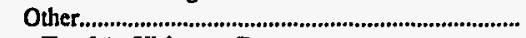 & 6,545 & 230 & 12,481 & 0 & 6,172 & 275 \\
\hline 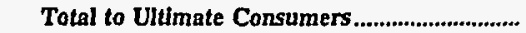 & 269,887 & 10,617 & 66,011 & 23,667 & 166,063 & 48,346 \\
\hline Sales for Resale & 86,025 & 0 & 184 & 0 & 13,367 & 1,964 \\
\hline Total Revenues From Sales of Elec...... & 355,912 & 10,617 & 66,195 & 23,667 & 179,430 & 50,310 \\
\hline
\end{tabular}

Note: Totals may not equal sum of components because of independent rounding.

Source: Energy Information Administration, Form EIA-861, "Annual Electric Utility Report." Data are submitted on a calendar year. 
Table 25. Number of Consumers, Sales, and Operating Revenue by Major U.S. Publicly Owned Electric Utility Within State, 1996 (Continued)

\begin{tabular}{|c|c|c|c|c|c|c|}
\hline Item & $\begin{array}{l}\text { Georgia } \\
\text { Albany Water } \\
\text { Gas \& Light } \\
\text { Comm } \\
\text { June } 30\end{array}$ & $\begin{array}{l}\text { Georgia } \\
\text { Calhoun } \\
\text { City of } \\
\text { June } 30\end{array}$ & $\begin{array}{l}\text { Georgia } \\
\text { Cartersville } \\
\text { City of } \\
\text { June } 30\end{array}$ & $\begin{array}{c}\text { Georgia } \\
\text { College } \\
\text { Park City of } \\
\text { June } 30\end{array}$ & $\begin{array}{c}\text { Georgia } \\
\text { Covington } \\
\text { City of } \\
\text { December } 31\end{array}$ & $\begin{array}{c}\text { Georgia } \\
\text { Crisp } \\
\text { County } \\
\text { Power } \\
\text { Comm } \\
\text { December } 31\end{array}$ \\
\hline \multicolumn{7}{|l|}{ Number of Consumers } \\
\hline Residential ........................ & 30,800 & 2,949 & 4,451 & 9,179 & 6,556 & 8,681 \\
\hline Commercial or Small... & 5,000 & 821 & 1,085 & 796 & 1,190 & 1,962 \\
\hline 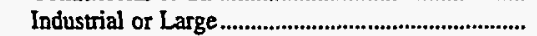 & 40 & 51 & 26 & 0 & 9 & 72 \\
\hline 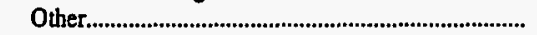 & 3,605 & 0 & 56 & 0 & 0 & 125 \\
\hline 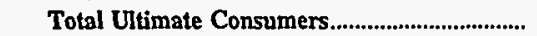 & 39,445 & 3,821 & 5,618 & 9,975 & $\mathbf{7 , 7 5 5}$ & 10,840 \\
\hline \multicolumn{7}{|l|}{ Sales for the Year (megawatthours) } \\
\hline 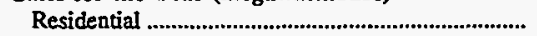 & 399,837 & 28,630 & 52,562 & 92,547 & 81,257 & 135,575 \\
\hline 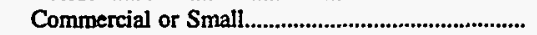 & 496,349 & 80,801 & 87,216 & 159,362 & 84,011 & 84,472 \\
\hline 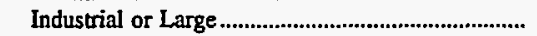 & 11,627 & 222,107 & 338,824 & 0 & 61,149 & 100,720 \\
\hline 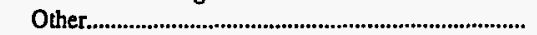 & 18,408 & 0 & 18,886 & 0 & 0 & 23,759 \\
\hline Total to Ultimate Consumers.................................. & 926,221 & $\mathbf{3 3 1 , 5 3 8}$ & 497,488 & 251,909 & 226,417 & 344,526 \\
\hline 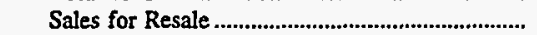 & 0 & 0 & 0 & 0 & 0 & 0 \\
\hline 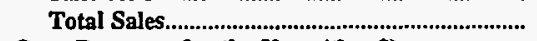 & 926,221 & 331,538 & 497,488 & 251,909 & 226,417 & 344,526 \\
\hline \multicolumn{7}{|l|}{ Oper Revenues for the Year (thou\$) } \\
\hline Residential & 28,384 & 2,200 & 3,611 & 7,035 & 6,866 & 7,382 \\
\hline 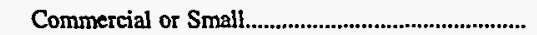 & 27,562 & 6,136 & 6,757 & 10,630 & 7,276 & 5,283 \\
\hline 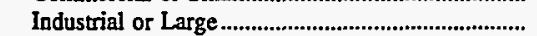 & 690 & 12,417 & 15,883 & 0 & 2,660 & 4,447 \\
\hline 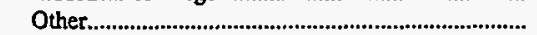 & 1,555 & o & 1,270 & 0 & 0 & 1,377 \\
\hline 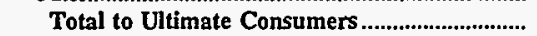 & 58,191 & 20,753 & 27,521 & 17,665 & 16,802 & 18,489 \\
\hline 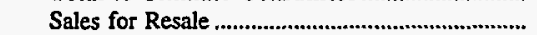 & & 0 & 0 & 0 & 0 & 0 \\
\hline Total Revenues From Sales of Elec...................... & 58,191 & 20,753 & 27,521 & 17,665 & 16,802 & 18,489 \\
\hline
\end{tabular}

\begin{tabular}{|c|c|c|c|c|c|c|}
\hline Item & $\begin{array}{l}\text { Georgia } \\
\text { Dalton } \\
\text { City of } \\
\text { November } 30\end{array}$ & $\begin{array}{l}\text { Georgia } \\
\text { Douglas } \\
\text { City of } \\
\text { June } 30\end{array}$ & $\begin{array}{l}\text { Georgia } \\
\text { East } \\
\text { Point } \\
\text { City of } \\
\text { June } 30\end{array}$ & $\begin{array}{c}\text { Georgia } \\
\text { Fitzgerald } \\
\text { Wtr Lgt } \\
\text { \& Bond Comm } \\
\text { December } 31\end{array}$ & $\begin{array}{l}\text { Georgia } \\
\text { Griffin } \\
\text { City of } \\
\text { June } 30\end{array}$ & $\begin{array}{l}\text { Georgia } \\
\text { La Grange } \\
\text { City of } \\
\text { June } 30\end{array}$ \\
\hline \multicolumn{7}{|l|}{ Number of Consumers } \\
\hline Residential ......................... & 9,355 & 3,824 & 14,329 & 5,211 & 12,062 & 10,071 \\
\hline 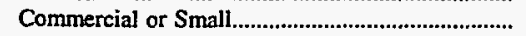 & 2,714 & 1,138 & 1,987 & 657 & 1,880 & 1,583 \\
\hline Industrial or Large ..................................................... & 87 & 11 & 55 & 40 & 12 & 36 \\
\hline 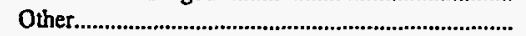 & 580 & 2 & 2 & 0 & $\eta 7$ & 0 \\
\hline Total Ultimate Consumers........................................... & 12,736 & $4,97 \overline{5}$ & 16,373 & 5,908 & 14,031 & 11,690 \\
\hline \multicolumn{7}{|l|}{ Sales for the Year (megawatthours) } \\
\hline 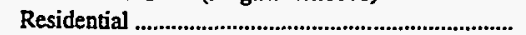 & 149,576 & 54,840 & 114,829 & 75,428 & 116,587 & 103,474 \\
\hline Commercial or Small................................................... & 388,897 & 35,851 & 103,911 & 36,842 & 134,009 & 113,407 \\
\hline Industrial or Large ......................................................... & 708,237 & 152,508 & 69,274 & 86,411 & 50,122 & 249,339 \\
\hline 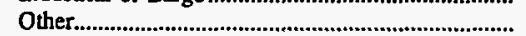 & 1,418 & 4,359 & 13,494 & 0 & 12,102 & 0 \\
\hline Total to Ultimate Consumers.................................... & $1,248,128$ & 247,558 & 301,508 & 198,681 & 312,820 & 466,220 \\
\hline 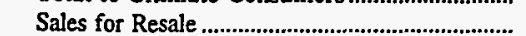 & 36,935 & 0 & 0 & 0 & 0 & 0 \\
\hline 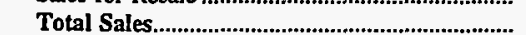 & $1,285,063$ & 247,558 & 301,508 & 198,681 & 312,820 & 466,220 \\
\hline \multicolumn{7}{|l|}{ Oper Revenues for the Year (thou\$) } \\
\hline 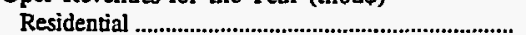 & 4,074 & 4,250 & 9,914 & 5,454 & 7,105 & 7,493 \\
\hline Commercial or Small....................................................... & 16,167 & 2,977 & 6,681 & 3,012 & 9,771 & 9,306 \\
\hline 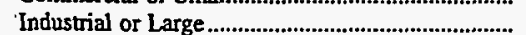 & 21,335 & 8,502 & 4,311 & 4,724 & 2,508 & 11,170 \\
\hline 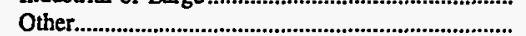 & 230 & 301 & 647 & 0 & 6,766 & \\
\hline Total to Ulitimate Consumers.................................. & 41,806 & 16,030 & 21,553 & 13,190 & 26,150 & 27,969 \\
\hline 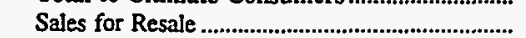 & 339 & 0 & 0 & 0 & 0 & 0 \\
\hline Total Revenues From Sales of Elec............... & 42,145 & 16,030 & 21,553 & 13,190 & 26,150 & 27,969 \\
\hline
\end{tabular}

Note: Totals may not equal sum of components because of independentrounding.

Source: Energy Information Administration, Form EIA-861, "Annual Electric Utility Report." Data are submitted on a calendar year. 
Table 25. Number of Consumers, Sales, and Operating Revenue by Major U.S. Publicly Owned Electric Utility Within State, 1996 (Continued)

\begin{tabular}{|c|c|c|c|c|c|c|}
\hline Item & $\begin{array}{l}\text { Georgia } \\
\text { Lawrenceville } \\
\text { City of } \\
\text { August } 30\end{array}$ & $\begin{array}{l}\text { Georgia } \\
\text { Marietta } \\
\text { City of } \\
\text { June } 30\end{array}$ & $\begin{array}{l}\text { Georgia } \\
\text { Moultrie } \\
\text { City of } \\
\text { September } 30\end{array}$ & $\begin{array}{l}\text { Georgia } \\
\text { Municipal } \\
\text { Electric } \\
\text { Authority } \\
\text { December } 31\end{array}$ & $\begin{array}{c}\text { Georgia } \\
\text { Thomasville } \\
\text { City of } \\
\text { December } 31\end{array}$ & $\begin{array}{l}\text { Idaho } \\
\text { Idaho } \\
\text { Falls } \\
\text { City of } \\
\text { September } 30\end{array}$ \\
\hline \multicolumn{7}{|l|}{ Number of Consumers } \\
\hline 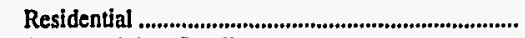 & 6,948 & 32,681 & 5,811 & $\mathbf{0}$ & 11,280 & 18,767 \\
\hline 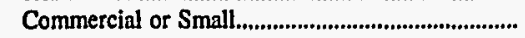 & 1,146 & 5,332 & 914 & 0 & 2,171 & 2,740 \\
\hline Industrial or Large & 0 & 0 & 122 & $\mathbf{0}$ & 0 & 7 \\
\hline 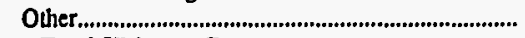 & 0 & 3,993 & 0 & 0 & 3,258 & 15 \\
\hline 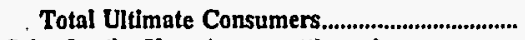 & 8,094 & 42,006 & 6,847 & 0 & 16,709 & 21,529 \\
\hline \multicolumn{7}{|l|}{ Sales for the Year (megawatthours) } \\
\hline 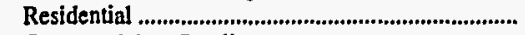 & 77,782 & 323,298 & 75,492 & 0 & 167,576 & 281,662 \\
\hline 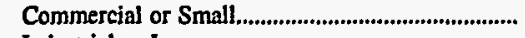 & 149,403 & 591,667 & 25,693 & 0 & 294,386 & 238,308 \\
\hline Industrial or Large & $\mathbf{0}$ & 0 & 60,745 & 0 & 0 & 42,780 \\
\hline 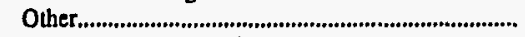 & 0 & 20,677 & 0 & 0 & 4,566 & 41,887 \\
\hline 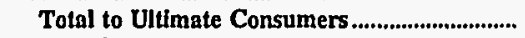 & 227,185 & 935,642 & 161,930 & 0 & 466,528 & 604,637 \\
\hline 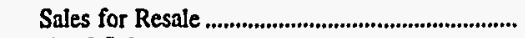 & 0 & 0 & 0 & $10,264,912$ & 0 & 0 \\
\hline 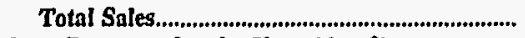 & 227,185 & 935,642 & 161,930 & $10,264,912$ & 466,528 & 604,637 \\
\hline \multicolumn{7}{|l|}{ Oper Revenues for the Year (thou\$) } \\
\hline 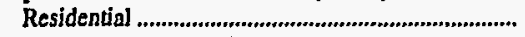 & 5,950 & 29,464 & 5,878 & 0 & 11,410 & 12,546 \\
\hline 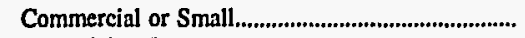 & 10,527 & 48,384 & 2,599 & 0 & 17,630 & 12,061 \\
\hline 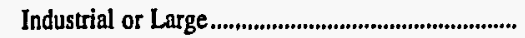 & 0 & 0 & 4,583 & 0 & 0 & 1,629 \\
\hline 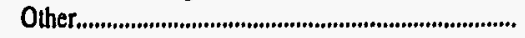 & 0 & 2,083 & 0 & 0 & 547 & 1,739 \\
\hline Total to Ultimate Consumers............................ & 16,477 & 79,931 & 13,060 & $\mathbf{0}$ & 29,587 & 27,975 \\
\hline Sales for Resale & 0 & 0 & & 497,316 & 0 & 8,104 \\
\hline Total Revenues From Sales of Rlec................... & 16,477 & 79,931 & 13,060 & 497,316 & 29,587 & 36,079 \\
\hline
\end{tabular}

\begin{tabular}{|c|c|c|c|c|c|c|}
\hline Item & $\begin{array}{l}\text { Illinois } \\
\text { Batavia } \\
\text { City of } \\
\text { December } 31\end{array}$ & $\begin{array}{l}\text { Illinois } \\
\text { Geneva } \\
\text { City of } \\
\text { April } 30\end{array}$ & $\begin{array}{c}\text { Illinois } \\
\text { Illinois } \\
\text { Municipal } \\
\text { Elec Agency } \\
\text { April } 30\end{array}$ & $\begin{array}{c}\text { Illinois } \\
\begin{array}{c}\text { Naperville } \\
\text { City of }\end{array} \\
\text { April } 30\end{array}$ & $\begin{array}{l}\text { Illinois } \\
\text { Rochelle } \\
\text { Municipal } \\
\text { Utilities } \\
\text { April } 30\end{array}$ & $\begin{array}{l}\text { Illinois } \\
\text { Springfield } \\
\text { City of } \\
\text { February } 28\end{array}$ \\
\hline \multicolumn{7}{|l|}{ Number of Consumers } \\
\hline 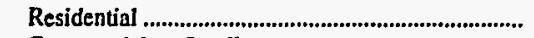 & 7,992 & 6,500 & 0 & 39,306 & 5,443 & 55,658 \\
\hline 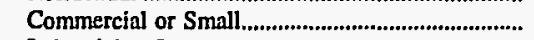 & 546 & 1,149 & 0 & 2,801 & 747 & 6,916 \\
\hline 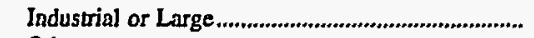 & 326 & 0 & 0 & 18 & 21 & 1 \\
\hline 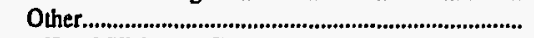 & 0 & 51 & 0 & 211 & 4 & 2,863 \\
\hline \multicolumn{7}{|l|}{ Sales for the Year (megawatthours) } \\
\hline 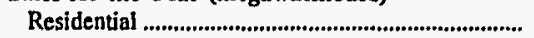 & 67,211 & 64,876 & 0 & 389,022 & 42,023 & 608,996 \\
\hline 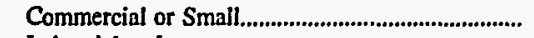 & 8,310 & 151,354 & 0 & 307,547 & 36,936 & 980,264 \\
\hline 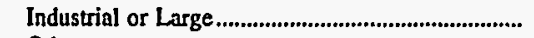 & 175,157 & 0 & 0 & 88,516 & 85,925 & 20,160 \\
\hline 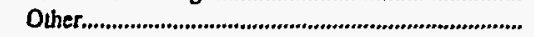 & 0 & 7,703 & 0 & 58,963 & 1,882 & 6,525 \\
\hline 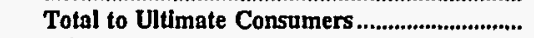 & 250,678 & 223,933 & 0 & 844,048 & 166,766 & $1,615,945$ \\
\hline 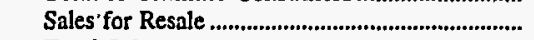 & 0 & 0 & $1,552,021$ & 0 & 0 & 265,319 \\
\hline 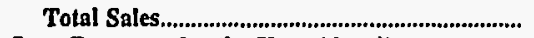 & 250,678 & 223,933 & $1,552,021$ & 844,048 & 166,766 & $1,881,264$ \\
\hline \multicolumn{7}{|l|}{ Oper Revenues for the Year (thou\$) } \\
\hline 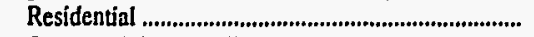 & 4,334 & 2,721 & 0 & 29,867 & 3,567 & 32,050 \\
\hline Commercial or Small & 597 & 6,348 & 10 & 20,558 & 2,977 & 60,491 \\
\hline 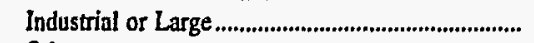 & 10,226 & 0 & 0 & 2,565 & 5,019 & 888 \\
\hline 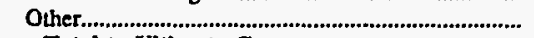 & 0 & 323 & 0 & 3,925 & 180 & 401 \\
\hline 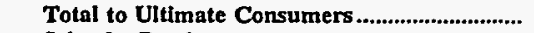 & 15,157 & 9,392 & $\mathbf{0}$ & 56,915 & 11,743 & 93,830 \\
\hline 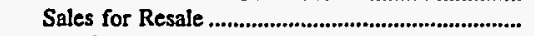 & 0 & 0 & 70,584 & 0 & 0 & 5,120 \\
\hline Total Revenues From Sales of Elec................... & 15,157 & 9,392 & 70,584 & 56,915 & 11,743 & 98,950 \\
\hline
\end{tabular}

Note: Totals may not equal sum of components because of independent rounding.

Source: Energy Information Administration, Form EIA-861, "Annual Electric Utility Report." Data are submitted on a calendar year. 
Table 25. Number of Consumers, Sales, and Operating Revenue by Major U.S. Publicly Owned Electric Utility Within State, 1996 (Continued)

\begin{tabular}{|c|c|c|c|c|c|c|}
\hline Item & $\begin{array}{l}\text { Illinois } \\
\text { St Charles } \\
\text { City of } \\
\text { April } 30\end{array}$ & $\begin{array}{l}\text { Indiana } \\
\text { Anderson } \\
\text { City of } \\
\text { December } 31\end{array}$ & $\begin{array}{l}\text { Indiana } \\
\text { Auburn } \\
\text { City of } \\
\text { December } 31\end{array}$ & $\begin{array}{l}\text { Indiana } \\
\text { Bluffton } \\
\text { City of } \\
\text { December } 31\end{array}$ & $\begin{array}{c}\text { Indiana } \\
\text { Crawfordsville } \\
\text { Elec } \\
\text { Lgt\&Pwr Co } \\
\\
\text { December } 31\end{array}$ & $\begin{array}{l}\text { Indiana } \\
\text { Frankfort } \\
\text { City of } \\
\text { December } 31\end{array}$ \\
\hline \multicolumn{7}{|l|}{ Number of Consumers } \\
\hline 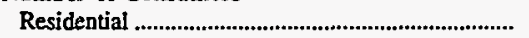 & 9,768 & 30,851 & 4,845 & 4,407 & 7,608 & 7,649 \\
\hline 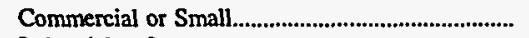 & 1,514 & 3,542 & 755 & 591 & 1,250 & 1,073 \\
\hline Industrial or Large & 0 & 38 & 83 & 33 & 94 & 103 \\
\hline 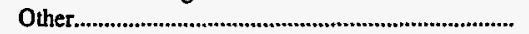 & 31 & 2 & 2 & 79 & 44 & 2 \\
\hline Total Ultimate Consumers..................................... & 11,313 & 34,433 & 5,685 & 5,110 & 8,996 & 8,827 \\
\hline \multicolumn{7}{|l|}{ Sales for the Year (megawatthours) } \\
\hline 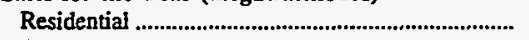 & 81,291 & 302,504 & 45,240 & 41,174 & 71,373 & 67,375 \\
\hline 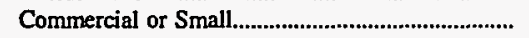 & 323,603 & 301,071 & 22,122 & 25,657 & 34,717 & 23,812 \\
\hline Industrial or Large & 0 & 75,357 & 399,361 & 105,654 & 270,435 & 244,137 \\
\hline 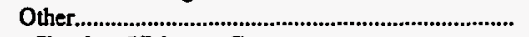 & 2,440 & 4,900 & 1,342 & 4,441 & 3,340 & 2,641 \\
\hline 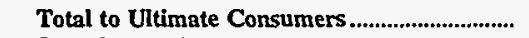 & 407,334 & 683,832 & 468,065 & 176,926 & 379,865 & 337,965 \\
\hline 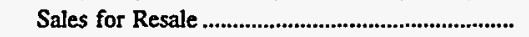 & 0 & 0 & 0 & 0 & 11,090 & 0 \\
\hline 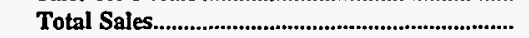 & 407,334 & 683,832 & 468,065 & 176,926 & 390,955 & 337,965 \\
\hline \multicolumn{7}{|l|}{ Oper Revenues for the Year (thou\$) } \\
\hline 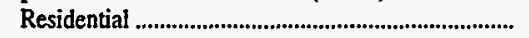 & 5,507 & 17,703 & 2,042 & 2,245 & 4,613 & 3,990 \\
\hline 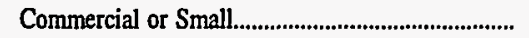 & 17,842 & 15,454 & 1,111 & 1,537 & 2,144 & 1,460 \\
\hline 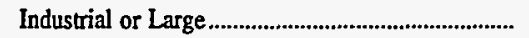 & 0 & 3,366 & 17,360 & 4,669 & 11,577 & 9,803 \\
\hline 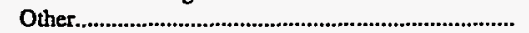 & 122 & 304 & 115 & 258 & 271 & 220 \\
\hline 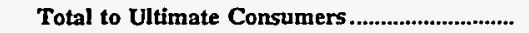 & 23,471 & 36,827 & 20,628 & 8,709 & 18,605 & 15,473 \\
\hline 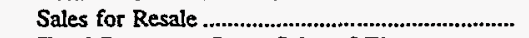 & 0 & 0 & 0 & 0 & 2,091 & \\
\hline Total Revenues From Sales of Elec..................... & 23,471 & 36,827 & 20,628 & 8,709 & 20,696 & 15,473 \\
\hline
\end{tabular}

\begin{tabular}{|c|c|c|c|c|c|c|}
\hline Item & $\begin{array}{l}\text { Indiana } \\
\text { Greenfield } \\
\text { City of } \\
\text { December } 31\end{array}$ & $\begin{array}{c}\text { Indiana } \\
\text { Indiana } \\
\text { Municipal } \\
\text { Power Agency } \\
\text { December 31 }\end{array}$ & $\begin{array}{l}\text { Indiana } \\
\text { Jasper } \\
\text { City of } \\
\text { December } 31\end{array}$ & $\begin{array}{l}\text { Indiana } \\
\text { Lebanon } \\
\text { City of } \\
\text { December } 31\end{array}$ & $\begin{array}{c}\text { Indiana } \\
\text { Logansport } \\
\text { City of } \\
\text { December } 31\end{array}$ & $\begin{array}{c}\text { Indiana } \\
\text { Mishawaka } \\
\text { City of } \\
\text { December } 31\end{array}$ \\
\hline \multicolumn{7}{|l|}{ Number of Consumers } \\
\hline 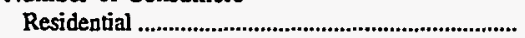 & 5,484 & 0 & 4,969 & 5,658 & 10,486 & 20,564 \\
\hline 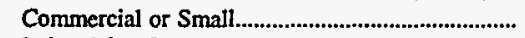 & 655 & 0 & 784 & 969 & 2,016 & 2,901 \\
\hline 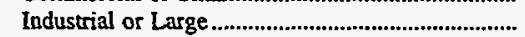 & 17 & 0 & 203 & 67 & 63 & 0 \\
\hline 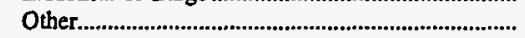 & 61 & 0 & 14 & 41 & 5 & 178 \\
\hline Total Ultimate Consumers.................................... & 6,217 & 0 & 5,970 & 6,735 & 12,570 & 23,643 \\
\hline Residential & 47,172 & 0 & 61.058 & 55.071 & 88.078 & 158.911 \\
\hline Commercial or Small. & 64,362 & 0 & 26,846 & 25,958 & 71,676 & 319,322 \\
\hline 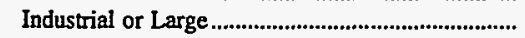 & 75,728 & 0 & 185,173 & 59,483 & 165,045 & 0 \\
\hline 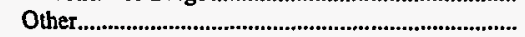 & 4,317 & 0 & 9,928 & 2,570 & 2,638 & 21,101 \\
\hline 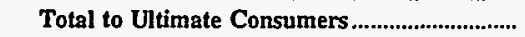 & 191,579 & 0 & 283,005 & 143,082 & 327,437 & 499,334 \\
\hline Sales for Resale & 0 & $4,385,743$ & 0 & 0 & 0 & 0 \\
\hline 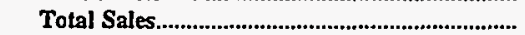 & 191,579 & $4,385,743$ & 283,005 & 143,082 & 327,437 & 499,334 \\
\hline \multicolumn{7}{|l|}{ Oper Revenues for the Year (thou\$) } \\
\hline 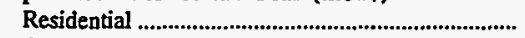 & 2,676 & 0 & 3,695 & 3,255 & 6,039 & 9,999 \\
\hline 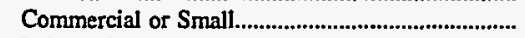 & 3,069 & 0 & 1,650 & 1,531 & 4,523 & 17,894 \\
\hline Industrial or Large & 3,115 & 0 & 9,861 & 2,913 & 8,356 & 0 \\
\hline 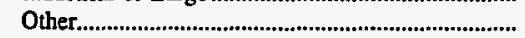 & 235 & 0 & 401 & 165 & 134 & 1,493 \\
\hline 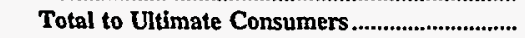 & 9,095 & 0 & 15,607 & 7,864 & 19,052 & 29,386 \\
\hline Sales for Resale & 0 & 154,905 & 0 & 0 & 0 & 0 \\
\hline Total Revenues From Sales of Elec.................... & 9,095 & 154,905 & 15,607 & 7,864 & 19,052 & 29,386 \\
\hline
\end{tabular}

Note: Totals may not equal sum of components because of independent rounding.

Source: Energy Information Administration, Form EIA-861, "Annual Electric Utility Report." Data are submitted on a calendar year. 
Table 25. Number of Consumers, Sales, and Operating Revenue by Major U.S. Publicly Owned Electric Utility Within State, 1996 (Continued)

\begin{tabular}{|c|c|c|c|c|c|c|}
\hline Item & $\begin{array}{c}\text { Indiana } \\
\text { Peru } \\
\text { City of } \\
\text { December } 31\end{array}$ & $\begin{array}{l}\text { Indiana } \\
\text { Richmond } \\
\text { City of } \\
\text { December } 31\end{array}$ & $\begin{array}{c}\text { Indiana } \\
\text { Scottsburg } \\
\text { City of } \\
\text { December } 31\end{array}$ & $\begin{array}{c}\text { Indiana } \\
\text { Washington } \\
\text { City of } \\
\text { December } 31\end{array}$ & $\begin{array}{l}\text { lowa } \\
\text { Ames } \\
\text { City of } \\
\text { June } 30\end{array}$ & $\begin{array}{c}\text { Iowa } \\
\text { Cedar } \\
\text { Falls } \\
\text { City of } \\
\text { December } 31\end{array}$ \\
\hline \multicolumn{7}{|l|}{ Number of Consumers } \\
\hline 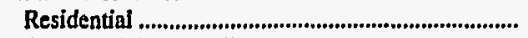 & 9,355 & 18,522 & 2,245 & 6,170 & 15,947 & 13,247 \\
\hline 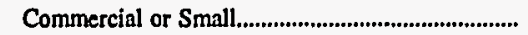 & 331 & 2,592 & 580 & 895 & 1,814 & 1,682 \\
\hline 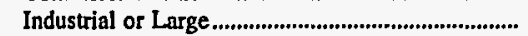 & 824 & 178 & 375 & 2 & 271 & 49 \\
\hline 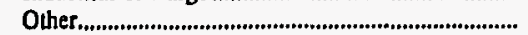 & 123 & 71 & 0 & 44. & 171 & 304 \\
\hline \multicolumn{7}{|l|}{ Sales for the Year (megawatthours) } \\
\hline Residential ....................................................................... & 84,672 & 190,404 & 28,550 & 64,026 & 111,428 & 129,608 \\
\hline 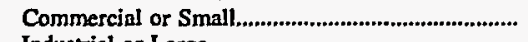 & 6,315 & 107,443 & 17,770 & 58,212 & 44,174 & 90,062 \\
\hline 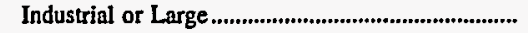 & 115,437 & 562,139 & 135,433 & 30,473 & 165,192 & 54,377 \\
\hline 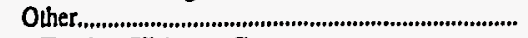 & 5,341 & 10,937 & 0 & 9,166 & 91,685 & 56,099 \\
\hline Total to Ultimate Consumers............................. & 211,765 & 870,923 & 181,753 & 161,877 & 412,479 & 330,146 \\
\hline 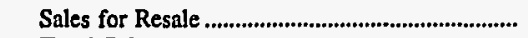 & 0 & 0 & 0 & 0 & 0 & 4,055 \\
\hline 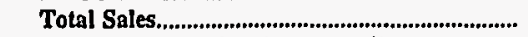 & 211,765 & 870,923 & 181,753 & 161,877 & 412,479 & 334,201 \\
\hline \multicolumn{7}{|l|}{ Oper Revenues for the Year (thouS) } \\
\hline 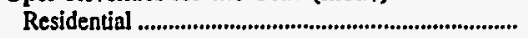 & 4,810 & 11,374 & 1,607 & 3,574 & 8,050 & 6,061 \\
\hline 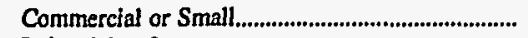 & 340 & 6,662 & 936 & 2,896 & 2,907 & 3,851 \\
\hline Industrial or Large & 5,078 & 25,122 & 5,701 & 1,134 & 8,397 & 2,022 \\
\hline 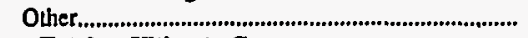 & 248 & 997 & 0 & 367 & 3,273 & 1,822 \\
\hline 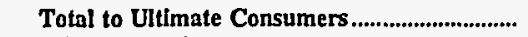 & 10,476 & 44,155 & 8,244 & 7,971 & 22,627 & 13,756 \\
\hline 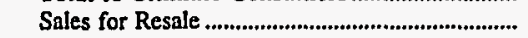 & 0 & 0 & 0 & 0 & 0 & 76 \\
\hline Total Revenues From Sales of Elec................... & 10,476 & 44,155 & 8,244 & 7,971 & 22,627 & 13,832 \\
\hline
\end{tabular}

\begin{tabular}{|c|c|c|c|c|c|c|}
\hline Item & $\begin{array}{c}\text { Iowa } \\
\text { Muscatine } \\
\text { City of } \\
\text { December } 31\end{array}$ & $\begin{array}{c}\text { Iowa } \\
\text { Peila } \\
\text { City of } \\
\text { December } 31\end{array}$ & $\begin{array}{l}\text { Kansas } \\
\text { Chanute } \\
\text { City of } \\
\text { December } 31\end{array}$ & $\begin{array}{c}\text { Kansas } \\
\text { Coffeyville } \\
\text { City of } \\
\text { December } 31\end{array}$ & $\begin{array}{c}\text { Kansas } \\
\text { Garden } \\
\text { City City of } \\
\text { December } 31\end{array}$ & $\begin{array}{c}\text { Kansas } \\
\text { Kansas } \\
\text { City City of } \\
\text { December } 31\end{array}$ \\
\hline \multicolumn{7}{|l|}{ Number of Consumers } \\
\hline Residential ......................... & 9,048 & 3,644 & 4,628 & 6,929 & 9,051 & 58,269 \\
\hline Commercial or Small.................... & 1,449 & 483 & 863 & 981 & 1,181 & 6,759 \\
\hline 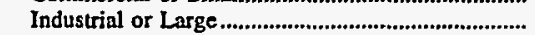 & 11 & 32 & 90 & 0 & 0 & 113 \\
\hline 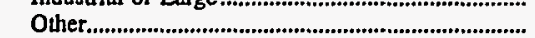 & 33 & 57 & 2 & 0 & 0 & 274 \\
\hline $\begin{array}{l}\text { Total Ultimate Consumers........................................... } \\
\text { Sales for the Year (megawatthours) }\end{array}$ & 10,541 & 4,216 & 5,583 & 7,910 & 10,232 & 65,415 \\
\hline $\begin{array}{l}\text { Sales for the Year (megawatthours) } \\
\text { Residential }\end{array}$ & 88,432 & \multicolumn{3}{|c|}{ Sales for the Year (megawatthours) } & & 408538 \\
\hline 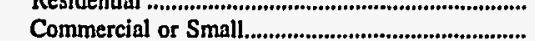 & $\begin{array}{r}00,432 \\
147,791\end{array}$ & 19,775 & $\begin{array}{l}41,299 \\
36,807\end{array}$ & $\begin{aligned} 23,350 \\
123,565\end{aligned}$ & $\begin{array}{l}03,431 \\
98,840\end{array}$ & $\begin{array}{l}490,300 \\
775,978\end{array}$ \\
\hline 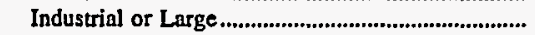 & 586,062 & 97,718 & 83,869 & 0 & 0 & 776,176 \\
\hline Othet......................, & 18,711 & 5,515 & 1,255 & 0 & 0 & 70,189 \\
\hline 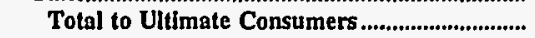 & 840,996 & 153,915 & 163,230 & 178,901 & 164,277 & $2,120,881$ \\
\hline 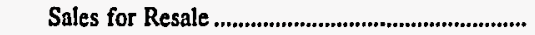 & 524,836 & 0 & 0 & 0 & $\mathbf{0}$ & 413,962 \\
\hline Total Sales.................................................................... & $1,365,832$ & 153,915 & 163,230 & 178,901 & 164,277 & $2,534,843$ \\
\hline \multicolumn{7}{|l|}{ Oper Revenues for the Year (thou\$) } \\
\hline 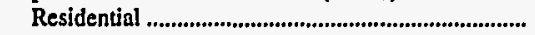 & 5,841 & 2,799 & 2,842 & 4,022 & 5,156 & 33,271 \\
\hline 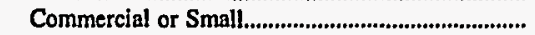 & 8,314 & 1,934 & 2,359 & 7,797 & 7,973 & 46,019 \\
\hline 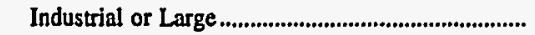 & 23,467 & 5,282 & 3,956 & 0 & 0 & 31,650 \\
\hline Other................................ & 762 & 462 & 69 & 0 & 0 & 4,137 \\
\hline Total to Ultimate Consumers................................... & 38,384 & 10,477 & 9,226 & 11,819 & 13,129 & 115,077 \\
\hline 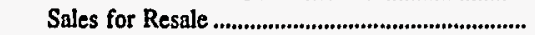 & 9,017 & 0 & 0 & 0 & 0 & 11,937 \\
\hline Total Revenues From Sales of Elec.................... & 47,401 & 10,477 & 9,226 & 11,819 & 13,129 & 127,014 \\
\hline
\end{tabular}

Note: Totals may not equal sum of components because of independent rounding.

Source; Energy Information Administration, Form EIA-861, "Annual Electric Utility Report" Data are submitted on a calendar year. 
Table 25. Number of Consumers, Sales, and Operating Revenue by Major U.S. Publicly Owned Electric Utility Within State, 1996 (Continued)

\begin{tabular}{|c|c|c|c|c|c|c|}
\hline Item & $\begin{array}{c}\text { Kansas } \\
\text { Kansas } \\
\text { Municipal } \\
\text { Energy } \\
\text { Agency } \\
\text { December } 31\end{array}$ & $\begin{array}{c}\text { Kansas } \\
\text { McPherson } \\
\text { City of } \\
\text { December 3I }\end{array}$ & $\begin{array}{l}\text { Winfield } \\
\text { City of } \\
\text { December } 31\end{array}$ & $\begin{array}{c}\text { Kentucky } \\
\text { Bardstown } \\
\text { City of } \\
\text { December } 31\end{array}$ & $\begin{array}{l}\text { Kentucky } \\
\text { Bowling } \\
\text { Green } \\
\text { City of } \\
\text { June } 30\end{array}$ & $\begin{array}{l}\text { Kentucky } \\
\text { Frankfort } \\
\text { City of } \\
\text { June } 30\end{array}$ \\
\hline \multicolumn{7}{|l|}{ Number of Consumers } \\
\hline 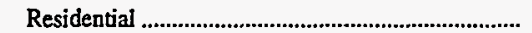 & 0 & 6,700 & 5,665 & 2,718 & 18,455 & 15,351 \\
\hline 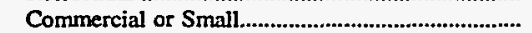 & 0 & 1,087 & 1,258 & 853 & 2,922 & 2,425 \\
\hline 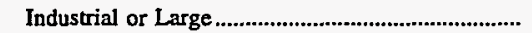 & 0 & 10 & 97 & 10 & 541 & 286 \\
\hline Other & 0 & 1 & 75 & 424 & 138 & 538 \\
\hline 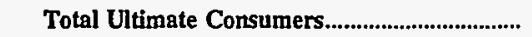 & $\mathbf{0}$ & 7,798 & 7,095 & 4,005 & 22,056 & 18,600 \\
\hline \multicolumn{7}{|l|}{ Sales for the Year (megawatthours) } \\
\hline Residential & 0 & 72,332 & 53,618 & 36,589 & 207,650 & 186,986 \\
\hline 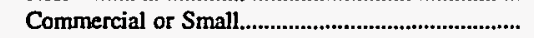 & 0 & 89,588 & 20,086 & 52,446 & 67,448 & 60,788 \\
\hline 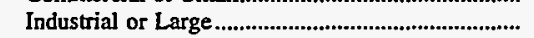 & 0 & 372,997 & 159,119 & 66,962 & 442,446 & 380,024 \\
\hline Other & 0 & 4,069 & 6,265 & 381 & 8,076 & 30,657 \\
\hline 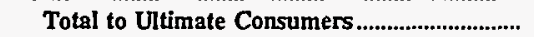 & 0 & 538,986 & 239,088 & 156,378 & 725,620 & 658,455 \\
\hline Sales for Resale & 293,506 & 36,034 & 5,178 & 0 & 0 & 0 \\
\hline 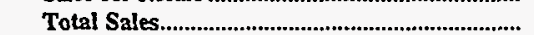 & 293,506 & 575,020 & 244,266 & 156,378 & 725,620 & 658,455 \\
\hline \multicolumn{7}{|l|}{ Oper Revenues for the Year (thou\$) } \\
\hline 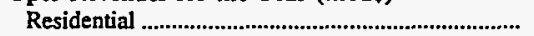 & 0 & 3,208 & 3,991 & 1,826 & 13,066 & 7,989 \\
\hline 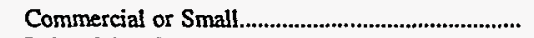 & 0 & 3,983 & 1,455 & 2,598 & 4,607 & 2,779 \\
\hline 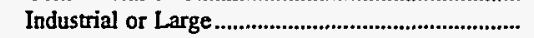 & 0 & 10,755 & 7,574 & 2,640 & 23,804 & 13,529 \\
\hline 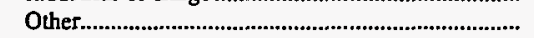 & 0 & 153 & 408 & 33 & 637 & 1,324 \\
\hline Total to Ultimate Consumers & 0 & 18,099 & 13,428 & 7,097 & 42,114 & 25,621 \\
\hline Sales for Resale & 8,797 & 2,967 & 445 & 0 & 0 & 0 \\
\hline Total Revenues From Sales of Elec..................... & 8,797 & 21,066 & 13,873 & 7,097 & 42,114 & 25,621 \\
\hline
\end{tabular}

\begin{tabular}{|c|c|c|c|c|c|c|}
\hline Item & $\begin{array}{l}\text { Kentucky } \\
\begin{array}{l}\text { Franklin } \\
\text { City of }\end{array} \\
\text { June } 30\end{array}$ & $\begin{array}{l}\text { Kentucky } \\
\text { Glasgow } \\
\text { City of } \\
\text { June } 30\end{array}$ & $\begin{array}{c}\text { Kentucky } \\
\text { Henderson } \\
\text { City } \\
\text { Utility Comm } \\
\text { May } 31\end{array}$ & $\begin{array}{l}\text { Kentucky } \\
\begin{array}{l}\text { Hopkinsville } \\
\text { City of }\end{array} \\
\text { June } 30\end{array}$ & $\begin{array}{c}\text { Kentucky } \\
\text { Madisonville } \\
\begin{array}{c}\text { Municipal } \\
\text { Utils }\end{array} \\
\text { June } 30\end{array}$ & $\begin{array}{l}\text { Kentucky } \\
\text { Mayfield } \\
\text { City of } \\
\text { June } 30\end{array}$ \\
\hline \multicolumn{7}{|l|}{ Number of Consumers } \\
\hline Residential .................. & 3,740 & 4,956 & 9,497 & 11,446 & 7,083 & 4,930 \\
\hline 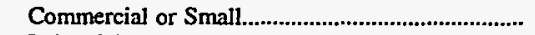 & 604 & 1,218 & 1,613 & 1,685 & 1,338 & 745 \\
\hline 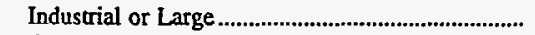 & 74 & 173 & 13 & 254 & 0 & 126 \\
\hline Other & 29 & 48 & 1,505 & 21 & 0 & 47 \\
\hline \multirow{2}{*}{\multicolumn{7}{|c|}{ Sales for the Year (megawatthours) }} \\
\hline & & & & & & \\
\hline 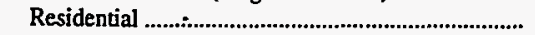 & 46,787 & 60,086 & 120,316 & 139,729 & 70,800 & 56,500 \\
\hline 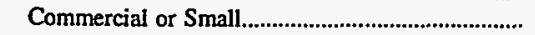 & 11,098 & 21,560 & 169,142 & 37,118 & 207,079 & 14,723 \\
\hline Industrial or Large & 144,832 & 239,529 & 177,898 & 252,924 & 0 & 76,786 \\
\hline 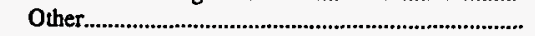 & 1,960 & 3,233 & 11,545 & 5,930 & 0 & 2,329 \\
\hline Total to Ultimate Consumers........................................ & 204,677 & 324,408 & 478,901 & 435,701 & 277,879 & 150,338 \\
\hline 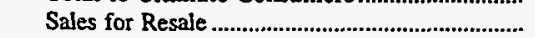 & 0 & & $1,525,698$ & 0 & 0 & \\
\hline Total Sales....... & 204,677 & 324,408 & $2,004,599$ & 435,701 & 277,879 & 150,338 \\
\hline \multicolumn{7}{|l|}{ Oper Revenues for the Year (thouS) } \\
\hline 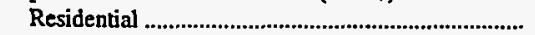 & 2,756 & 3,581 & 4,528 & 7,941 & 3,794 & 3,587 \\
\hline 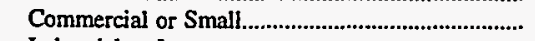 & 727 & 1,481 & 5,831 & 2,370 & 8,600 & 1,024 \\
\hline 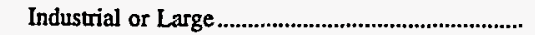 & 6,018 & 11,421 & 5,179 & 10,966 & 0 & 4,544 \\
\hline Other & 138 & 277 & 470 & 478 & 0 & 152 \\
\hline Total to Ultimate Consumers.................................. & 9,639 & 16,760 & 16,008 & 21,755 & 12,394 & 9,307 \\
\hline 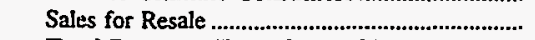 & & & 15,482 & 0 & 0 & \\
\hline Total Revenues From Sales of Elec................... & 9,639 & 16,760 & 31,490 & 21,755 & 12,394 & 9,307 \\
\hline
\end{tabular}

Note: Totals may not equal sum of components because of independent rounding.

Source: Energy Information Administration, Form EIA-861, "Annual Electric Utility Reporr." Data are submitted on a calendar year. 
Table 25. Number of Consumers, Sales, and Operating Revenue by Major U.S.

Publicly Owned Electric Utility Within State, 1996 (Continued)

\begin{tabular}{|c|c|c|c|c|c|c|}
\hline Item & $\begin{array}{l}\text { Kentucky } \\
\text { Murray } \\
\text { City of } \\
\text { June } 30\end{array}$ & $\begin{array}{c}\text { Kentucky } \\
\text { Owensboro } \\
\text { City of } \\
\text { May } 31\end{array}$ & $\begin{array}{l}\text { Kentucky } \\
\text { Paducah } \\
\text { City of } \\
\text { June } 30\end{array}$ & $\begin{array}{l}\text { Kentucky } \\
\begin{array}{c}\text { Russellville } \\
\text { City of }\end{array} \\
\text { June } 30\end{array}$ & $\begin{array}{l}\text { Louisiana } \\
\text { Alexandria } \\
\text { City of } \\
\text { April } 30\end{array}$ & $\begin{array}{l}\text { Louisiana } \\
\text { Lafayette } \\
\text { City of } \\
\text { October } 31\end{array}$ \\
\hline \multicolumn{7}{|l|}{ Number of Consumers } \\
\hline Residential ....................... & 5,412 & 22,077 & 18,528 & 3,348 & 19,993 & 43,791 \\
\hline 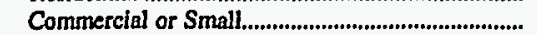 & 957 & 2,459 & 2,821 & 615 & 3,355 & 6,361 \\
\hline 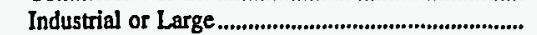 & 139 & 513 & 506 & 81 & 0 & 0 \\
\hline 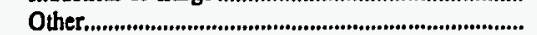 & 13 & 3 & 379 & 44 & 268 & 2,330 \\
\hline 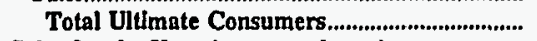 & 6,521 & 25,052 & 22,234 & 4,088 & 23,616 & 52,482 \\
\hline \multicolumn{7}{|l|}{ Sales for the Year (megawatthours) } \\
\hline Residential .............................................. & 75,813 & 215,098 & 229,302 & 38,538 & 257,863 & 655,419 \\
\hline 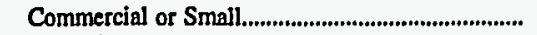 & 21,384 & $42,4 ? 4$ & 57,827 & 11,502 & 337,514 & 797,843 \\
\hline 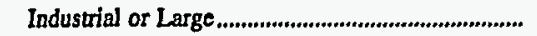 & 143,103 & 473,956 & 264,478 & 82,391 & 0 & 0 \\
\hline 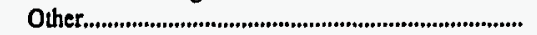 & 2,265 & 54,289 & 9,419 & 1,955 & 15,608 & 81,912 \\
\hline 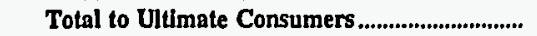 & 242,565 & $\mathbf{7 8 5 , 8 1 7}$ & 561,026 & 134,386 & 610,985 & $1,535,174$ \\
\hline 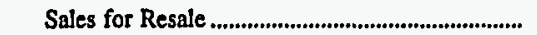 & 0 & $1,495,353$ & & 0 & 0 & 362,478 \\
\hline 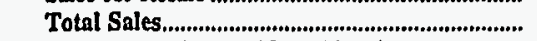 & 242,565 & $2,281,170$ & 561,026 & 134,386 & 610,985 & $1,897,652$ \\
\hline \multicolumn{7}{|l|}{ Oper Revenues for the Year (thouS) } \\
\hline 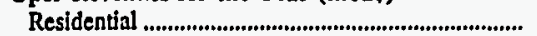 & 4,432 & 10,654 & 14,121 & 2,449 & 18,856 & 39,489 \\
\hline Commercial or Small & 1,378 & 2,162 & 4,016 & 823 & 23,588 & 46,075 \\
\hline 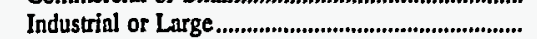 & 7,455 & 15,738 & 14,936 & 4,418 & 0 & 0 \\
\hline 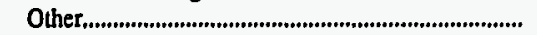 & 176 & 1,392 & 834 & 135 & 1,166 & 4,595 \\
\hline Total to Ultimate Consumers..................................... & 13,441 & 29,946 & 33,907 & 7,825 & 43,610 & 90,159 \\
\hline 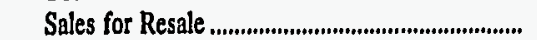 & 0 & 33,983 & 0 & 0 & 0 & 14,028 \\
\hline Total Revenues From Sales of Elec.................... & 13,441 & 63,929 & 33,907 & 7,825 & 43,610 & 104,187 \\
\hline
\end{tabular}

\begin{tabular}{|c|c|c|c|c|c|c|}
\hline Item & $\begin{array}{l}\text { Louisiana } \\
\text { Lafayette } \\
\text { Public } \\
\text { Power Auth } \\
\text { October } 31\end{array}$ & $\begin{array}{c}\text { Louisiana } \\
\text { Louisiana } \\
\text { Energy } \\
\& \\
\text { Power Auth } \\
\text { December } 31\end{array}$ & $\begin{array}{l}\text { Louisiana } \\
\text { Morgan } \\
\text { City City of } \\
\text { December } 31\end{array}$ & $\begin{array}{l}\text { Louisiana } \\
\text { Natchitoches } \\
\text { City of } \\
\text { May } 31\end{array}$ & $\begin{array}{l}\text { Louisiana } \\
\text { Ruston } \\
\text { City of } \\
\text { September } 30\end{array}$ & $\begin{array}{c}\text { Louisiana } \\
\text { Temrebonne } \\
\text { Parish } \\
\text { Consol Govt } \\
\text { December } 31\end{array}$ \\
\hline \multicolumn{7}{|l|}{ Number of Consumers } \\
\hline 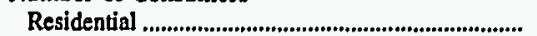 & 0 & $\mathbf{0}$ & 5,048 & 6,503 & 7,432 & 8,133 \\
\hline 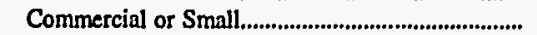 & 0 & 0 & 1,254 & 902 & 1,062 & 1,459 \\
\hline 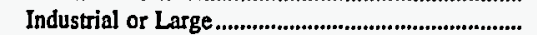 & 0 & 0 & 0 & 10 & 56 & 0 \\
\hline 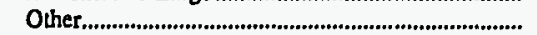 & $\mathbf{0}$ & 0 & 0 & 1 & 229 & 0 \\
\hline 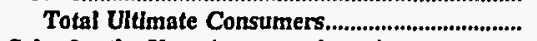 & 0 & D & 6,302 & 7,416 & 8,779 & 9,592 \\
\hline \multicolumn{7}{|l|}{ Sales for the Year (megawatthours) } \\
\hline Residential ...................................................................... & 0 & 0 & 71,858 & 66,667 & 80,077 & 124,445 \\
\hline 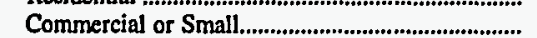 & 0 & 0 & 93,088 & 54,754 & 53,374 & 116,162 \\
\hline 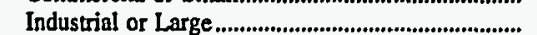 & 0 & 0 & 0 & 79,637 & 50,991 & 0 \\
\hline 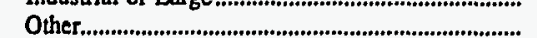 & 0 & 0 & 0 & 5,791 & 49,918 & 0 \\
\hline Total to Ulitimate Consumers......................... & $\mathbf{0}$ & 0 & 164,946 & 206,849 & 234,360 & 240,607 \\
\hline 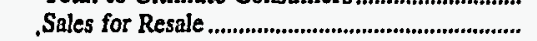 & $1,362,019$ & $1,349,805$ & 0 & 0 & 0 & 721 \\
\hline Total Sales..........................., & $1,362,019$ & $1,349,805$ & 164,946 & 206,849 & 234,360 & 241,328 \\
\hline \multicolumn{7}{|l|}{ Oper Revenues for the Year (thou\$) } \\
\hline 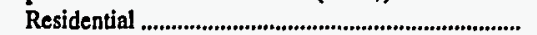 & 0 & 0 & 5,580 & 4,540 & 4,548 & 9,590 \\
\hline 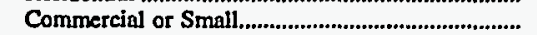 & 0 & 0 & 5,270 & 4,068 & 3,554 & 8,811 \\
\hline 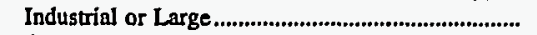 & 0 & $\mathbf{0}$ & 0 & 4,529 & 2,381 & 0 \\
\hline 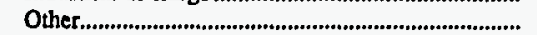 & 0 & 0 & 0 & 425 & 2,635 & 0 \\
\hline 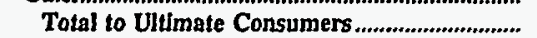 & 0 & $\mathbf{0}$ & 10,850 & 13,562 & 13,118 & 18,401 \\
\hline Sales for Resale ......................................................... & 43,222 & 54,126 & $\mathbf{0}$ & 0 & & 563 \\
\hline Total Revenues From Sales of Elec...................... & 43,222 & 54,126 & 10,850 & 13,562 & 13,118 & 18,964 \\
\hline
\end{tabular}

Note: Totals may not equal sum of components because of independentrounding.

Source: Energy Information Administration, Form EIA-861, "Annual Electric Utility Report" Data are submitted on a calendar year. 
Table 25. Number of Consumers, Sales, and Operating Revenue by Major U.S. Publicly Owned Electric Utility Within State, 1996 (Continued)

\begin{tabular}{|c|c|c|c|c|c|c|}
\hline Item & $\begin{array}{l}\text { Maryland } \\
\text { Easton } \\
\text { Utilities } \\
\text { Comm } \\
\text { June } 30\end{array}$ & $\begin{array}{l}\text { Maryland } \\
\text { Hagerstown } \\
\text { City of } \\
\text { June } 30\end{array}$ & $\begin{array}{l}\text { Massachusetts } \\
\text { Braintree } \\
\text { Town of } \\
\text { December } 31\end{array}$ & $\begin{array}{l}\text { Massachusetts } \\
\text { Chicopee } \\
\text { City of } \\
\text { December } 31\end{array}$ & $\begin{array}{l}\text { Massachusetts } \\
\text { Concord } \\
\text { Town of } \\
\text { December } 31\end{array}$ & $\begin{array}{l}\text { Massachusetts } \\
\text { Danvers } \\
\text { Town of } \\
\text { December } 31\end{array}$ \\
\hline \multirow{2}{*}{\multicolumn{7}{|c|}{ Number of Consumers }} \\
\hline & & & & & & 9,661 \\
\hline Commercial or Snall.... & $\cdot 1,669$ & 2,019 & 1,877 & 2,190 & 1,091 & 1,316 \\
\hline 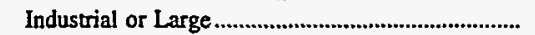 & 0 & 134 & 11 & 26 & 18 & 296 \\
\hline 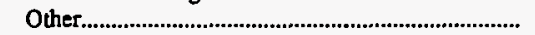 & 120 & 64 & 305 & 220 & 56 & 252 \\
\hline Total Ultimate Consumers....................................... & 8,059 & 17,493 & 13,954 & 25,296 & 7,219 & 11,525 \\
\hline \multicolumn{7}{|l|}{ Sales for the Year (megawatthours) } \\
\hline Residential .............................................. & 81,271 & 128,932 & 94,700 & 159,984 & 57,333 & 73,452 \\
\hline 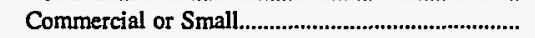 & 140,195 & 64,699 & 205,338 & 107,876 & 41,458 & 29,218 \\
\hline 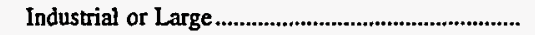 & 0 & 152,488 & 35,178 & 71,456 & 53,258 & 185,134 \\
\hline Other & 10,733 & 8,639 & 14,077 & 44,989 & 7,568 & 13,971 \\
\hline 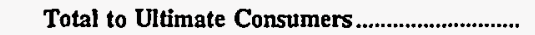 & 232,199 & 354,758 & 349,293 & 384,305 & 159,617 & 301,775 \\
\hline 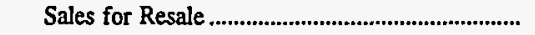 & 0 & 0 & 55,021 & 262 & 0 & 872 \\
\hline 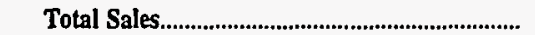 & 232,199 & 354,758 & 404,314 & 384,567 & 159,617 & 302,647 \\
\hline \multicolumn{7}{|l|}{ Oper Revenues for the Year (thou\$) } \\
\hline Residential ............................................ & 5,362 & 8,360 & 7,183 & 12,857 & 4,820 & 7,900 \\
\hline 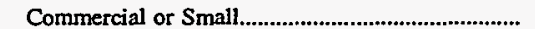 & 8,939 & 3,974 & 17,243 & 9,315 & 4.417 & 3,376 \\
\hline 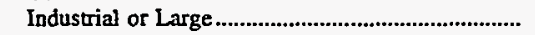 & 0 & 7,249 & 2,608 & 5,412 & 3,311 & 16,935 \\
\hline Other & 754 & 561 & 1,165 & 3,525 & 1,128 & 1,385 \\
\hline Total to Ultimate Consumers...................................... & 15,055 & 20,144 & 28,199 & 31,109 & 13,676 & 29,596 \\
\hline Sales for Resale ............................................................. & 0 & 0 & 3,531 & 12 & & 28 \\
\hline Total Revenues From Sales of Elec........................ & 15,055 & 20,144 & 31,730 & 31,121 & 13,676 & 29,624 \\
\hline
\end{tabular}

\begin{tabular}{|c|c|c|c|c|c|c|}
\hline Item & $\begin{array}{l}\text { Massachusetts } \\
\text { Hingham } \\
\text { City of } \\
\text { December } 31\end{array}$ & $\begin{array}{l}\text { Massachusetts } \\
\text { Holyoke } \\
\text { City of } \\
\text { December } 31\end{array}$ & $\begin{array}{c}\text { Massachusetts } \\
\text { Hudson } \\
\text { Town of } \\
\text { December } 31\end{array}$ & $\begin{array}{c}\text { Massachusetts } \\
\text { Litteton } \\
\text { Town of } \\
\text { December } 31\end{array}$ & $\begin{array}{l}\text { Massachusetts } \\
\text { Mansfield } \\
\text { Town of } \\
\text { December } 31\end{array}$ & $\begin{array}{l}\text { Massachusetts } \\
\text { Massachusetts } \\
\text { Mun } \\
\text { Whls } \\
\text { Elec Co } \\
\text { December } 31\end{array}$ \\
\hline \multicolumn{7}{|l|}{ Number of Consumers } \\
\hline Residential ..... & 7,854 & 15,010 & 9,052 & 5,131 & 7,620 & 0 \\
\hline 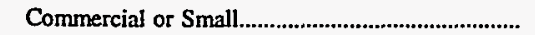 & 878 & 2,088 & 995 & 429 & 518 & 0 \\
\hline 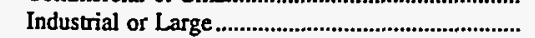 & 56 & 79 & 172 & 60 & 245 & 0 \\
\hline 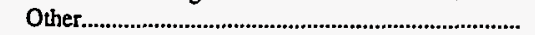 & 55 & 527 & 277 & 49 & 73 & 0 \\
\hline 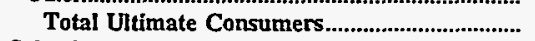 & 8,843 & 17,704 & 10,496 & 5,669 & 8,456 & 0 \\
\hline \multicolumn{7}{|l|}{ Sales for the Year (megawatthours) } \\
\hline 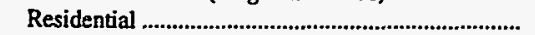 & 67,129 & 93,256 & 72,356 & 47,851 & 55,888 & 0 \\
\hline 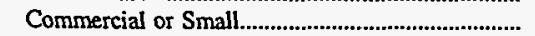 & 23,772 & 138,505 & 13,185 & 9,820 & 5,125 & 0 \\
\hline 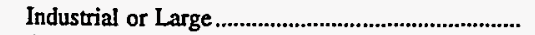 & 46,705 & 22,448 & 230,279 & 104,172 & 113,697 & 0 \\
\hline 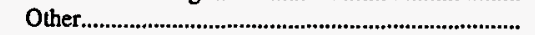 & 5,804 & 23,666 & 14,037 & 5,055 & 6,950 & 0 \\
\hline Total to Ultimate Consumers...................................... & 143,410 & 277,875 & 329,857 & 166,898 & 181,660 & o \\
\hline 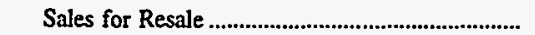 & 172 & 6,672 & 0 & 396 & 396 & $2,567,666$ \\
\hline Total Sales... & 143,582 & 284,547 & 329,857 & 167,294 & 182,056 & $2,567,666$ \\
\hline \multicolumn{7}{|l|}{ Oper Revenues for the Year (thou\$) } \\
\hline 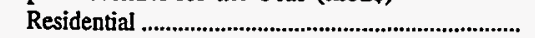 & 6,179 & 9,333 & 7,452 & 3,946 & 5,583 & 0 \\
\hline 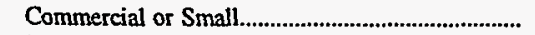 & 2,856 & 14,158 & 1,526 & 911 & 599 & 0 \\
\hline 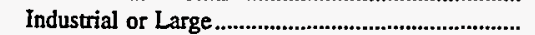 & 4,149 & 1,572 & 16,980 & 9,393 & 9,418 & 0 \\
\hline 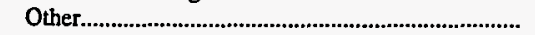 & 640 & 2,341 & 1,260 & 441 & 700 & 0 \\
\hline Total to Ultimate Consumers.................................. & 13,824 & 27,404 & 27,218 & 14,691 & 16,300 & 0 \\
\hline Sales for Resale .......................................................... & 22 & 168 & 0 & 9 & 41 & 211,216 \\
\hline Total Revenues From Sales of Elec...................... & 13,846 & 27,572 & 27,218 & 14,700 & 16,341 & 211,216 \\
\hline
\end{tabular}

Note: Totals may not equal sum of components because of independent rounding.

Source: Energy Information Administration, Form EIA-861, "Annual Electric Uülity Report." Data are submitted on a calendar year. 
Table 25. Number of Consumers, Sales, and Operating Revenue by Major U.S. Publicly Owned Electric Utility Within State, 1996 (Continued)

\begin{tabular}{|c|c|c|c|c|c|c|}
\hline Item & $\begin{array}{l}\text { Massachusetts } \\
\text { Middleborough } \\
\text { Town of } \\
\text { December } 31\end{array}$ & $\begin{array}{l}\text { Massachusetts } \\
\text { North } \\
\text { Attleborough } \\
\text { Town of } \\
\text { December } 31\end{array}$ & $\begin{array}{l}\text { Massachusetts } \\
\text { Norwood } \\
\text { City of } \\
\text { June } 30\end{array}$ & $\begin{array}{l}\text { Massachusetts } \\
\text { Peabody } \\
\text { City of } \\
\text { December } 31\end{array}$ & $\begin{array}{l}\text { Massachusetts } \\
\text { Reading } \\
\text { Town of } \\
\text { December } 31\end{array}$ & $\begin{array}{l}\text { Massachusetts } \\
\text { Shrewsbury } \\
\text { Town of } \\
\text { December } 31\end{array}$ \\
\hline \multicolumn{7}{|l|}{ Number of Consumers } \\
\hline Residential ... & 9,877 & 9,839 & 12,536 & 19,234 & 22,611 & 12,202 \\
\hline 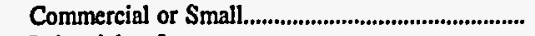 & 1,307 & 819 & 2,060 & 1,864 & 0 & 773 \\
\hline 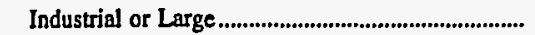 & 24 & 112 & 70 & 1,227 & 2,359 & 49 \\
\hline 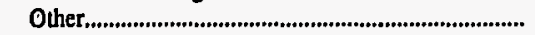 & 541 & 635 & 8 & 118 & 409 & 72 \\
\hline \multicolumn{7}{|l|}{ Sales for the Year (megawatthours) } \\
\hline 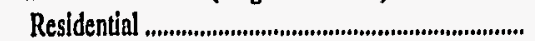 & 74,516 & 82,954 & 70,861 & 148,832 & 184,370 & 99,015 \\
\hline 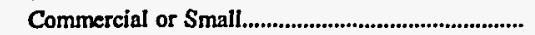 & 57,445 & 17,230 & 88,876 & 20,217 & 0 & 32,911 \\
\hline 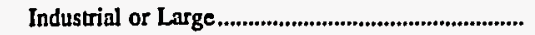 & 39,929 & 87,810 & 136,870 & 223,717 & 388,577 & 125,043 \\
\hline Other......, & 6,677 & 12,023 & 7,462 & 20,977 & 23,310 & 12,232 \\
\hline 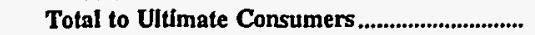 & 178,567 & 200,017 & 304,069 & 413,743 & 596,257 & 269,201 \\
\hline ............................................. & & 66 & 0 & 0 & 693 & \\
\hline 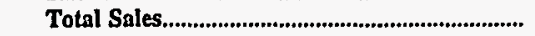 & 178,567 & 200,083 & 304,069 & 413,743 & 596,950 & 269,201 \\
\hline \multicolumn{7}{|l|}{ Oper Revenues for the Year (thou\$) } \\
\hline 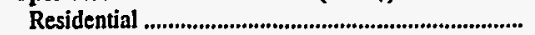 & 7,003 & 7,850 & 5,797 & 12,834 & 18,861 & 8,329 \\
\hline 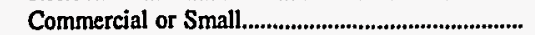 & 5,745 & 1,926 & 10,238 & 2,205 & 0 & 3,297 \\
\hline 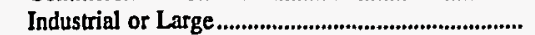 & 3,335 & 7,921 & 10,698 & 21,066 & 32,189 & 9,391 \\
\hline 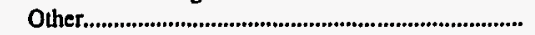 & 661 & 1,013 & 444 & 2,056 & 2,278 & 1,027 \\
\hline 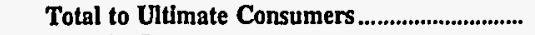 & 16,744 & 18,710 & 27,177 & 38,161 & 53,328 & 22,044 \\
\hline 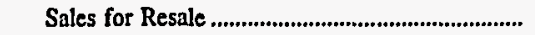 & & & & & & \\
\hline Total Revenues From Sales of Elec..................... & 16,744 & 18,710 & 27,177 & 38,161 & 53,395 & 22,044 \\
\hline
\end{tabular}

\begin{tabular}{|c|c|c|c|c|c|c|}
\hline Item & $\begin{array}{l}\text { Massachusetts } \\
\text { Taunton } \\
\text { City of } \\
\text { December } 31\end{array}$ & $\begin{array}{l}\text { Massachusetts } \\
\text { Wakefield } \\
\text { Town of } \\
\text { December } 31\end{array}$ & $\begin{array}{l}\text { Massachusetts } \\
\text { Wellesley } \\
\text { Town of } \\
\text { December } 31\end{array}$ & $\begin{array}{c}\text { Massachusetts } \\
\text { Westrield } \\
\text { City of } \\
\text { December } 31\end{array}$ & $\begin{array}{c}\text { Michigan } \\
\text { Bay } \\
\text { City City of } \\
\text { June } 30\end{array}$ & $\begin{array}{l}\text { Michigan } \\
\text { Coldwater } \\
\text { Board } \\
\text { of } \\
\text { Public Util } \\
\text { June } 30\end{array}$ \\
\hline \multicolumn{7}{|l|}{ Number of Consumers } \\
\hline 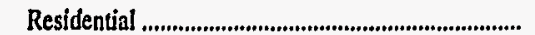 & 27,513 & 9,513 & 8,554 & 14,511 & 17,463 & 4,975 \\
\hline 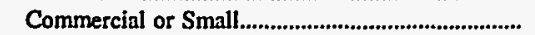 & 3,317 & 1,324 & 985 & 1,567 & 2,408 & 846 \\
\hline 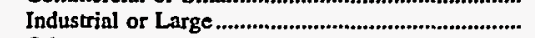 & 64 & 157 & 0 & 146 & 52 & 174 \\
\hline 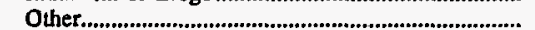 & 135 & 2 & 74 & 102 & 173 & 153 \\
\hline $\begin{array}{l}\text { Total Ultimate Consumers.................................... } \\
\text { Sales for the Year (megawatthours) }\end{array}$ & 31,029 & 10,996 & 9,613 & 16,326 & 20,096 & 6,148 \\
\hline 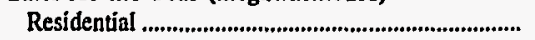 & 199,863 & 61,933 & 77,480 & 107,094 & 117,991 & 31,144 \\
\hline 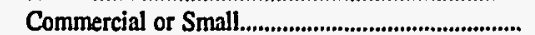 & 159,422 & 22,748 & 100,107 & 87,829 & 110,889 & 17,584 \\
\hline 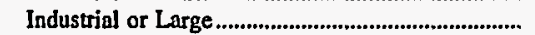 & 144,333 & 65,112 & $\mathbf{0}$ & 74,904 & 57,294 & 128,815 \\
\hline 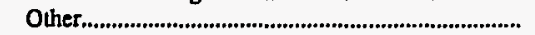 & 23,281 & 7,457 & 8,911 & 12,930 & 28,861 & 369 \\
\hline 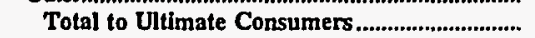 & 526,899 & 157,250 & 186,498 & 282,757 & 315,035 & 177,912 \\
\hline 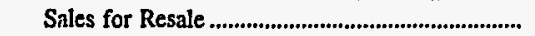 & 23,615 & 0 & $\mathbf{0}$ & 15,012 & $\mathbf{0}$ & 0 \\
\hline \multirow{2}{*}{\multicolumn{7}{|c|}{ Oper Revenues for the Year (thou\$) }} \\
\hline & & & & & & \\
\hline 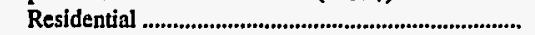 & 16,619 & 6,451 & 6,986 & 11,242 & 8,114 & 2,818 \\
\hline 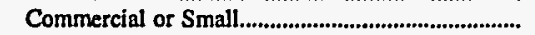 & 14,583 & 2,652 & 9,262 & 7,635 & 7,862 & 1,833 \\
\hline 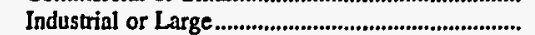 & 9,891 & 6,640 & 0 & 11,194 & 2,896 & 7,865 \\
\hline 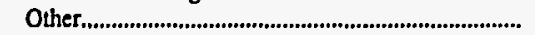 & 2,028 & 632 & 801 & 1,906 & 1,920 & 42 \\
\hline Total to Ultimate Consumers.................................. & 43,121 & 16,375 & 17,049 & 31,977 & 20,792 & 12,558 \\
\hline Sales for Resale .............................................................. & 2,843 & & 0 & 554 & 0 & \\
\hline Total Revenues From Sales of Elec.................. & 45,964 & 16,375 & 17,049 & 32,531 & 20,792 & 12,558 \\
\hline
\end{tabular}

Note: Totals may not equal sum of components because of independent rounding.

Source: Energy Information Administration, Form EIA-861, "Annual Electric Utility Report." Data are submitted on a calendar year. 
Table 25. Number of Consumers, Sales, and Operating Revenue by Major U.S. Publicly Owned Electric Utility Within State, 1996 (Continued)

\begin{tabular}{|c|c|c|c|c|c|c|}
\hline Item & $\begin{array}{l}\text { Michigan } \\
\text { Detroit } \\
\text { City of } \\
\text { June } 30\end{array}$ & $\begin{array}{l}\text { Michigan } \\
\text { Grand Haven } \\
\text { City of } \\
\text { June } 30\end{array}$ & $\begin{array}{l}\text { Michigan } \\
\text { Hillsdale } \\
\text { Board } \\
\text { of } \\
\text { Public Wks } \\
\text { June } 30\end{array}$ & $\begin{array}{l}\text { Michigan } \\
\text { Holland } \\
\text { City of } \\
\text { June } 30\end{array}$ & $\begin{array}{l}\text { Michigan } \\
\text { Lansing } \\
\text { City of } \\
\text { June } 30\end{array}$ & $\begin{array}{l}\text { Michigan } \\
\text { Marquette } \\
\text { City of } \\
\text { June } 30\end{array}$ \\
\hline \multicolumn{7}{|l|}{ Number of Consumers } \\
\hline 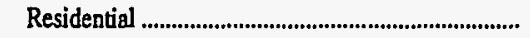 & 0 & 10,147 & 4,653 & 18,419 & 79,677 & 12,814 \\
\hline 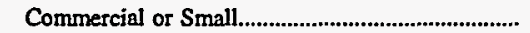 & 1,470 & 1,200 & 816 & 3,294 & 12,688 & 1,488 \\
\hline Industrial or Large. & 8 & 150 & 20 & 101 & 317 & \\
\hline 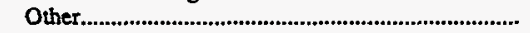 & 0 & 243 & 9 & 26 & 2 & 325 \\
\hline 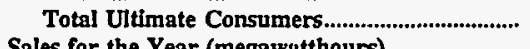 & 1,478 & 11,740 & 5,498 & 21,840 & 92,684 & 14,627 \\
\hline \multicolumn{7}{|l|}{ Sales for the Year (megawatthours) } \\
\hline Residential & 0 & 63,875 & 33,322 & 130,288 & 560,504 & 86,111 \\
\hline 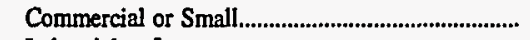 & 505,429 & 70,240 & 42,949 & 89,378 & $1,031,213$ & 119,359 \\
\hline 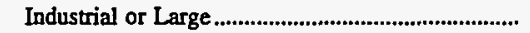 & 8,101 & 145,902 & 68,921 & 606,882 & 708,248 & $\mathbf{0}$ \\
\hline 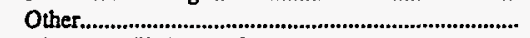 & 0 & 5,265 & 495 & 2,978 & 36,898 & 47,781 \\
\hline 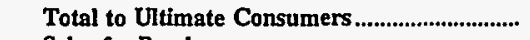 & 513,530 & 285,282 & 145,687 & 829,526 & $2,336,863$ & 253,251 \\
\hline 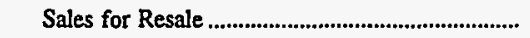 & 0 & 72,607 & 0 & 0 & 271,884 & 14,079 \\
\hline 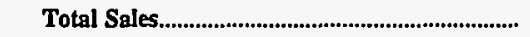 & 513,530 & 357,889 & 145,687 & 829,526 & $2,608,747$ & 267,330 \\
\hline \multicolumn{7}{|l|}{ Oper Revenues for the Year (thouS) } \\
\hline 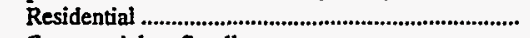 & $\mathbf{0}$ & 4,878 & 2,492 & 8,299 & 34,169 & 6,100 \\
\hline 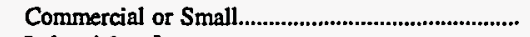 & 45,409 & 4,878 & 3,116 & 6,687 & 58,342 & 7,042 \\
\hline Industrial or Large & 1,104 & 8,478 & 4,096 & 31,267 & 34,901 & 0 \\
\hline Other & 0 & 532 & 26 & 377 & 4,541 & 2,884 \\
\hline Total to Ultimate Consumers.................................. & 46,513 & 18,766 & 9,730 & 46,630 & 131,953 & 16,026 \\
\hline 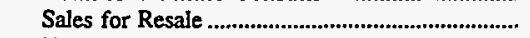 & 0 & 1,871 & 0 & 0 & 9,575 & 649 \\
\hline Total Revenues From Sales of Elec........................ & 46,513 & 20,637 & 9,730 & 46,630 & 141,528 & 16,675 \\
\hline
\end{tabular}

\begin{tabular}{|c|c|c|c|c|c|c|}
\hline Item & $\begin{array}{c}\text { Michigan } \\
\text { Michigan } \\
\text { Public } \\
\text { Power Agency } \\
\\
\text { December } 31\end{array}$ & $\begin{array}{l}\text { Michigan } \\
\text { Michigan } \\
\text { South } \\
\text { Central } \\
\text { Pwr Agy } \\
\text { June } 30\end{array}$ & $\begin{array}{l}\text { Michigan } \\
\text { Sturgis } \\
\text { City of } \\
\text { September } 30\end{array}$ & $\begin{array}{l}\text { Michigan } \\
\text { Traverse } \\
\text { City City of } \\
\text { June } 30\end{array}$ & $\begin{array}{l}\text { Michigan } \\
\text { Wyandotte } \\
\text { Municipal } \\
\text { Serv Comm } \\
\text { September } 30\end{array}$ & $\begin{array}{l}\text { Michigan } \\
\text { Zecland } \\
\text { City of } \\
\text { June } 30\end{array}$ \\
\hline \multicolumn{7}{|l|}{ Number of Consumers } \\
\hline 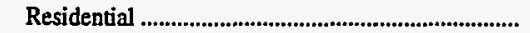 & 0 & 0 & 5,736 & 6,882 & 12,040 & 3,272 \\
\hline 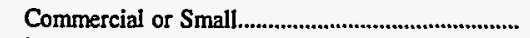 & 0 & 0 & 814 & 1,975 & 1,189 & 375 \\
\hline 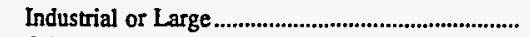 & 0 & 0 & 81 & 22 & 136 & 85 \\
\hline 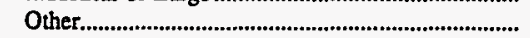 & 0 & 0 & 0 & 1 & 1 & 23 \\
\hline $\begin{array}{l}\text { Total Ultimate Consumers........................................... } \\
\text { Sales for the Year (megawatthonrs) }\end{array}$ & 0 & 0 & 6,631 & 8,880 & 13,366 & 3,755 \\
\hline \multicolumn{7}{|l|}{ Sales for the Year (megawatthours) } \\
\hline 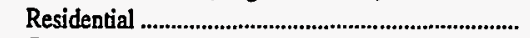 & 0 & 0 & 45,345 & 41,605 & 70,361 & 21,709 \\
\hline Commercial or Small & $\mathbf{0}$ & 0 & 54,052 & 111,681 & 21,983 & 22,291 \\
\hline 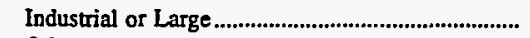 & 0 & 0 & 124,910 & 73,284 & 140,762 & 176,011 \\
\hline 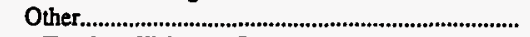 & 0 & 0 & 0 & 873 & 4,127 & 589 \\
\hline 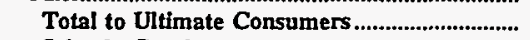 & 0 & $\mathbf{0}$ & 224,307 & 227,443 & 237,233 & 220,600 \\
\hline 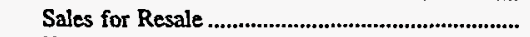 & $3,229,827$ & 495,524 & 0 & 0 & 0 & 0 \\
\hline 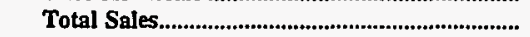 & $3,229,827$ & 495,524 & 224,307 & 227,443 & 237,233 & 220,600 \\
\hline \multicolumn{7}{|l|}{ Oper Revenues for the Year (thou\$) } \\
\hline 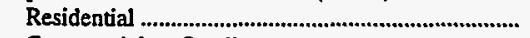 & 0 & 0 & 2,887 & 2,766 & 6,394 & 1,400 \\
\hline 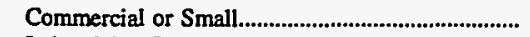 & 0 & 0 & 4,003 & 7,908 & 2,330 & 1,650 \\
\hline 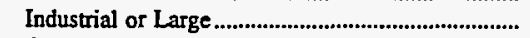 & 0 & 0 & 7,068 & 3,710 & 10,286 & 8,961 \\
\hline 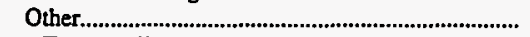 & 0 & 0 & 0 & 154 & 430 & 55 \\
\hline 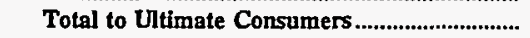 & 0 & 0 & 13,958 & 14,538 & 19,440 & 12,066 \\
\hline Sales for Resale & 106,415 & 25,571 & 0 & 0 & 0 & \\
\hline 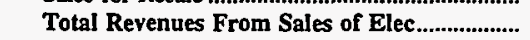 & 106,415 & 25,571 & 13,958 & 14,538 & 19,440 & 12,066 \\
\hline
\end{tabular}

Note: Totals may not equal sum of components because of independent rounding.

Source: Energy Information Administration, Form ElA-861, "Annual Electric Utility Report." Data are submitted on a calendar year. 
Table 25. Number of Consumers, Sales, and Operating Revenue by Major U.S. Publicly Owned Electric Utility Within State, 1996 (Continued)

\begin{tabular}{|c|c|c|c|c|c|c|}
\hline Item & $\begin{array}{l}\text { Minnesota } \\
\text { Alexandria } \\
\text { City of } \\
\text { December } 31\end{array}$ & $\begin{array}{c}\text { Minnesota } \\
\text { Anoka } \\
\text { City of } \\
\text { December } 31\end{array}$ & $\begin{array}{c}\text { Minnesota } \\
\text { Austin } \\
\text { City of } \\
\text { December } 31\end{array}$ & $\begin{array}{l}\text { Minnesota } \\
\text { Brainerd } \\
\text { Public } \\
\text { Utilities } \\
\text { December } 31\end{array}$ & $\begin{array}{c}\text { Minnesota } \\
\text { Caska } \\
\text { City of } \\
\text { December } 31\end{array}$ & $\begin{array}{l}\text { Minnesota } \\
\text { Fairmont } \\
\text { Public } \\
\text { Utilities } \\
\text { Comm } \\
\text { December } 31\end{array}$ \\
\hline \multicolumn{7}{|l|}{ Number of Consumers } \\
\hline 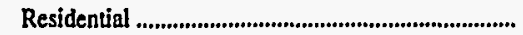 & 6,218 & 9,670 & 9,964 & 5,858 & 4,912 & 5,082 \\
\hline 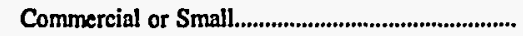 & 1,224 & 1,090 & 1,129 & 1,295 & 293 & 827 \\
\hline 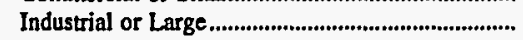 & 47 & 15 & 1 & 22 & 230 & 16 \\
\hline 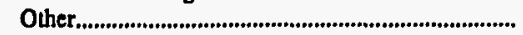 & 106 & 0 & 338 & 58 & 67 & 8 \\
\hline $\begin{array}{l}\text { Total Ultimate Consumers...................................... } \\
\text { Sales for the Year (megawatthours) }\end{array}$ & 7,595 & 10,775 & 11,432 & 7,233 & 5,502 & 5,933 \\
\hline 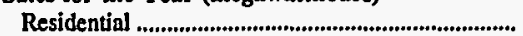 & 57,755 & 65,432 & 68,624 & 40,097 & 40,095 & 36,476 \\
\hline 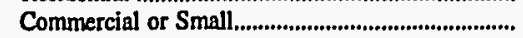 & 50,462 & 69,639 & 109,533 & 59,031 & 3,449 & 38,994 \\
\hline 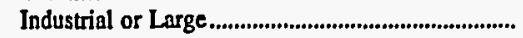 & 88,143 & 93,411 & 83,016 & 42,347 & 142,746 & 63,071 \\
\hline Other. & 2,765 & 0 & 1,903 & 5,038 & 6,305 & 4,145 \\
\hline Total to Ultimate Consumers............................... & 199,125 & 228,482 & 263,076 & 146,513 & 192,595 & 142,686 \\
\hline 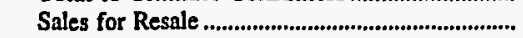 & 0 & 0 & 136,404 & 0 & 0 & 1,018 \\
\hline 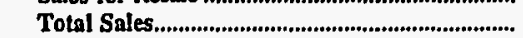 & 199,125 & 228,482 & 399,480 & 146,513 & 192,595 & 143,704 \\
\hline \multicolumn{7}{|l|}{ Oper Revenues for the Year (thou\$) } \\
\hline 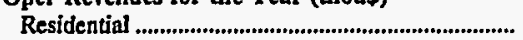 & 2,764 & 4,674 & 5,373 & 2,271 & 2,670 & 2,781 \\
\hline 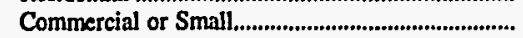 & 2,445 & 4,062 & 7,613 & 3,156 & 247 & 2,701 \\
\hline 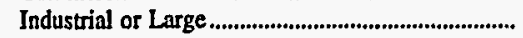 & 4,004 & 4,063 & 4,151 & 2,054 & 7,267 & 3,165 \\
\hline 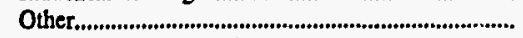 & 105 & 0 & 179 & 266 & 265 & 186 \\
\hline 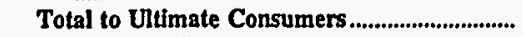 & 9,318 & 12,799 & 17,316 & $\mathbf{7 , 7 4 7}$ & 10,449 & 8,833 \\
\hline 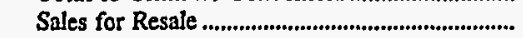 & 0 & 0 & 3,559 & 0 & 0 & 36 \\
\hline Total Revenues From Sales of Elec................... & 9,318 & 12,799 & 20,875 & 7,747 & 10,449 & 8,869 \\
\hline
\end{tabular}

\begin{tabular}{|c|c|c|c|c|c|c|}
\hline Item & $\begin{array}{l}\text { Minnesota } \\
\text { Hutchinson } \\
\text { Utilities } \\
\text { Comm } \\
\text { December } 31\end{array}$ & $\begin{array}{l}\text { Minnesota } \\
\text { Marshall } \\
\text { City of } \\
\text { December } 31\end{array}$ & $\begin{array}{l}\text { Minnesota } \\
\text { Moorhead } \\
\text { City of } \\
\text { December } 31\end{array}$ & $\begin{array}{l}\text { Minnesota } \\
\text { New Ulm } \\
\text { Public } \\
\text { Utilities } \\
\text { Comm } \\
\text { December } 31\end{array}$ & $\begin{array}{c}\text { Minnesota } \\
\text { Northem } \\
\text { Municipal } \\
\text { Power Agny } \\
\text { December } 31\end{array}$ & $\begin{array}{l}\text { Minnesota } \\
\text { Owatonna } \\
\text { City of } \\
\text { December } 31\end{array}$ \\
\hline \multicolumn{7}{|l|}{ Number of Consumers } \\
\hline Residential & 5,023 & 5,156 & 11,502 & 5,773 & 0 & 8,302 \\
\hline 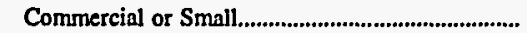 & 797 & 788 & 1,587 & 859 & 0 & 720 \\
\hline 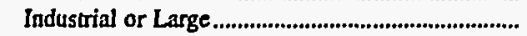 & 2 & 93 & 170 & 5 & 0 & 72 \\
\hline 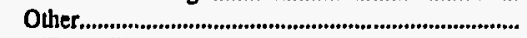 & 1 & 1 & 3 & 2 & 0 & 22 \\
\hline $\begin{array}{l}\text { Total Ultimate Consumers........................................... } \\
\text { Sales for the Year (megawatthours) }\end{array}$ & \multicolumn{5}{|c|}{ Sales for the Year (megawatthours) } & 9,116 \\
\hline 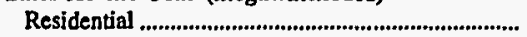 & 41,259 & 51,095 & 136,631 & 41,776 & 0 & 59,532 \\
\hline 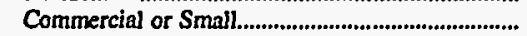 & 72,068 & 28,828 & 29,637 & 58,409 & 0 & 32,052 \\
\hline 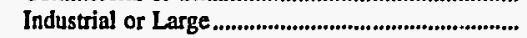 & 147,410 & 285,435 & 176,174 & 70,113 & 0 & 194,584 \\
\hline 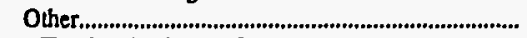 & 1,179 & 843 & 9,369 & 10,125 & 0 & 4,444 \\
\hline 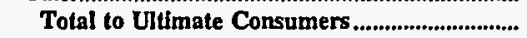 & 261,916 & 366,201 & 351,811 & 180,423 & 0 & 290,612 \\
\hline 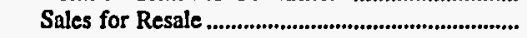 & 17,718 & 0 & 0 & 0 & 809,682 & 0 \\
\hline 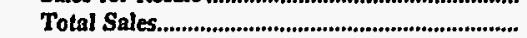 & 279,634 & 366,201 & 351,811 & 180,423 & 809,682 & 290,612 \\
\hline \multicolumn{7}{|l|}{ Oper Revenues for the Year (thous) } \\
\hline 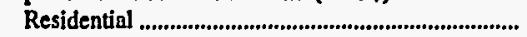 & 2,134 & 2,470 & 6,166 & 2,961 & $\mathbf{0}$ & 4,935 \\
\hline 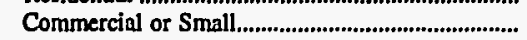 & 3,595 & 1,403 & 1,607 & 2,950 & 0 & 2,216 \\
\hline 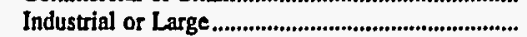 & 5,354 & 10,441 & 6,872 & 3,310 & 0 & 9,261 \\
\hline Other & 50 & 162 & 341 & 907 & $\mathbf{0}$ & 171 \\
\hline Total to Ultimate Consumers............................ & 11,133 & 14,476 & 14,986 & 10,128 & 0 & 16,583 \\
\hline 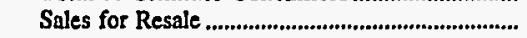 & 346 & 0 & 0 & 0 & 38,785 & 0 \\
\hline Total Revenues From Sales of Elec.................... & 11,479 & 14,476 & 14,986 & 10,128 & 38,785 & 16,583 \\
\hline
\end{tabular}

Note: Totals may not equal sum of components because of independent rounding.

Source: Energy Information Administration, Form EIA-861, “Annual Electric Utility Report." Data are submitted on a calendar year. 
Table 25. Number of Consumers, Sales, and Operating Revenue by Major U.S. Publicly Owned Electric Utility Within State, 1996 (Continued)

\begin{tabular}{|c|c|c|c|c|c|c|}
\hline Item & $\begin{array}{c}\text { Minnesota } \\
\text { Rochester } \\
\text { Public } \\
\text { Utilities } \\
\text { December } 31\end{array}$ & $\begin{array}{l}\text { Minnesota } \\
\text { Shakopee } \\
\text { Public } \\
\text { Utilities } \\
\text { Comm } \\
\text { December } 31\end{array}$ & $\begin{array}{c}\text { Minnesota } \\
\text { Southern } \\
\text { Minnesota } \\
\text { Mun P } \\
\text { Agny } \\
\text { December } 31\end{array}$ & $\begin{array}{l}\text { Minnesota } \\
\text { Western } \\
\text { Minnesota } \\
\text { Mun } \\
\text { Pwr Agny } \\
\text { December } 31\end{array}$ & $\begin{array}{c}\text { Minnesota } \\
\text { Wilimar } \\
\text { Municipal } \\
\text { Utils Comm } \\
\text { December } 31\end{array}$ & $\begin{array}{c}\text { Minnesota } \\
\begin{array}{c}\text { Worthington } \\
\text { City of }\end{array} \\
\text { December } 31\end{array}$ \\
\hline \multicolumn{7}{|l|}{ Number of Consumers } \\
\hline 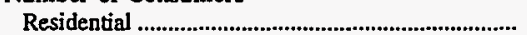 & 31,925 & 6,255 & 0 & 0 & 7,200 & 4,376 \\
\hline Commercial or Small. & 3,359 & 745 & 0 & 0 & 1,023 & 671 \\
\hline Industrial or Large & 19 & 0 & 0 & 0 & 32 & 5 \\
\hline 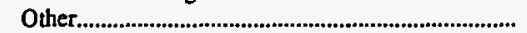 & 4 & 1 & 0 & $\mathbf{0}$ & 0 & 67 \\
\hline 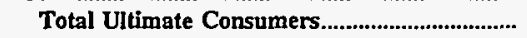 & 35,307 & 7,001 & $\mathbf{0}$ & 0 & 8,255 & 5,119 \\
\hline \multicolumn{7}{|l|}{ Sales for the Year (megawatthours) } \\
\hline 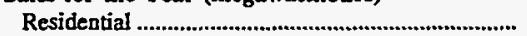 & 230,182 & 48,785 & 0 & 0 & 57,690 & 30,825 \\
\hline 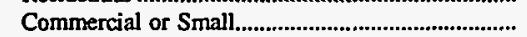 & 308,930 & 105,033 & 0 & $\mathbf{0}$ & 92,009 & 54,226 \\
\hline 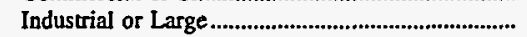 & 347,254 & 0 & 0 & 0 & 70,463 & 76,338 \\
\hline 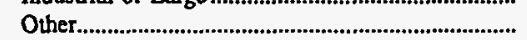 & 14,286 & 1,754 & c & 0 & 0 & 2,937 \\
\hline Total to Ultimate Consumers & 900,652 & 155,572 & $\mathbf{0}$ & $\mathbf{0}$ & 220,162 & 164,326 \\
\hline 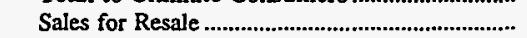 & 191,783 & 0 & $2,508,216$ & $1,997,174$ & 0 & 3,333 \\
\hline 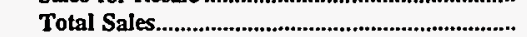 & $1,092,435$ & 155,572 & $2,508,216$ & $1,997,174$ & 220,162 & 167,659 \\
\hline \multicolumn{7}{|l|}{ Oper Revenues for the Year (thou\$) } \\
\hline 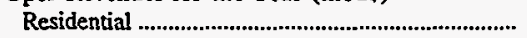 & 18,753 & 3,347 & 0 & 0 & 3,608 & 1,843 \\
\hline 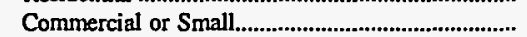 & 22,334 & 5,374 & 0 & 0 & 5,463 & 3,329 \\
\hline Industrial or Large & 21,343 & 0 & 0 & 0 & 3,493 & 3,426 \\
\hline Other & 1,409 & 54 & 0 & 0 & 0 & 250 \\
\hline Total to Ultimate Consumers & 63,839 & 8,775 & $\mathbf{0}$ & o & 12,564 & 8,848 \\
\hline Sales for Resale & 8,922 & 0 & 115,209 & 44,273 & 0 & 141 \\
\hline 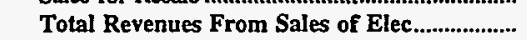 & 72,761 & 8,775 & 115,209 & 44,273 & 12,564 & 8,989 \\
\hline
\end{tabular}

\begin{tabular}{|c|c|c|c|c|c|c|}
\hline Item & $\begin{array}{l}\text { Mississippi } \\
\text { Aberdeen } \\
\text { City of } \\
\text { June } 30\end{array}$ & $\begin{array}{l}\text { Mississippi } \\
\text { Amory } \\
\text { City of } \\
\text { June } 30\end{array}$ & $\begin{array}{l}\text { Mississippi } \\
\text { Clarksdale } \\
\text { City of } \\
\text { September } 30\end{array}$ & $\begin{array}{l}\text { Mississippi } \\
\text { Columbus } \\
\text { City of } \\
\text { June } 30\end{array}$ & $\begin{array}{l}\text { Mississippi } \\
\text { Greenwood } \\
\text { Utilities } \\
\text { Comm } \\
\text { September } 30\end{array}$ & $\begin{array}{c}\text { Mississippi } \\
\text { Holly } \\
\text { Springs } \\
\text { City of } \\
\text { June } 30\end{array}$ \\
\hline \multicolumn{7}{|l|}{ Number of Consumers } \\
\hline 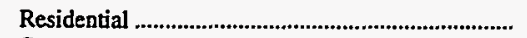 & 2,920 & 3,172 & 6,149 & 9,090 & 8,581 & 8,073 \\
\hline 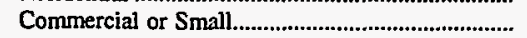 & 563 & 712 & 1,580 & 2,163 & 1,387 & 1,595 \\
\hline 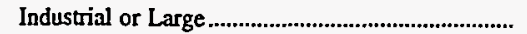 & 79 & 92 & 21 & 322 & 4 & 114 \\
\hline Other & 20 & 11 & 86 & 21 & 148 & 16 \\
\hline 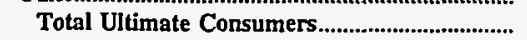 & 3,582 & 3,987 & 7,836 & 11,596 & 10,120 & 9,798 \\
\hline \multicolumn{7}{|l|}{ Sales for the Year (megawatthours) } \\
\hline 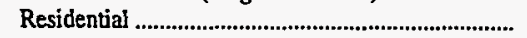 & 40,465 & 40,503 & 75,429 & 125,150 & 99,709 & 121,850 \\
\hline 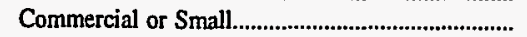 & 9,881 & 12,196 & 62,976 & 44,206 & 126,036 & 20,237 \\
\hline 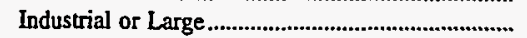 & 131,749 & 73,402 & 34,730 & 300,189 & 49,969 & 61,502 \\
\hline 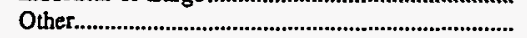 & 3,303 & 2,633 & 8,303 & 4,875 & 11,355 & 5,213 \\
\hline 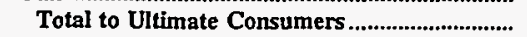 & 185,398 & 128,734 & 181,438 & 474,420 & 287,069 & 208,802 \\
\hline 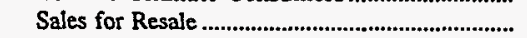 & 0 & 0 & 47,013 & 0 & 0 & 0 \\
\hline 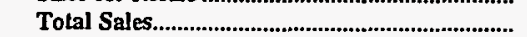 & 185,398 & 128,734 & 228,451 & 474,420 & 287,069 & 208,802 \\
\hline \multicolumn{7}{|l|}{ Oper Revenues for the Year (thou\$) } \\
\hline 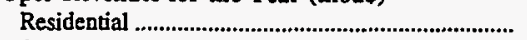 & 2,341 & 2,445 & 4,572 & 7,033 & 5,346 & 7,247 \\
\hline 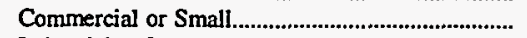 & 640 & 847 & 3,704 & 2,805 & 6,917 & 1,432 \\
\hline 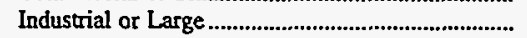 & 5,447 & 3,750 & 1,656 & 14,915 & 2,295 & 3,618 \\
\hline 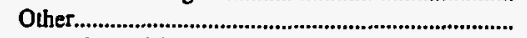 & 244 & 179 & 525 & 431 & 798 & 484 \\
\hline 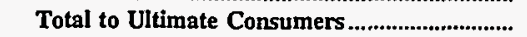 & 8,672 & 7,221 & 10,457 & 25,184 & 15,356 & 12,781 \\
\hline Sales for Resale & 0 & 0 & 2,267 & 0 & 0 & 0 \\
\hline 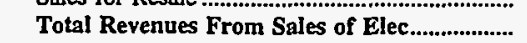 & 8,672 & 7,221 & 12,724 & 25,184 & 15,356 & 12,781 \\
\hline
\end{tabular}

Note: Totals may not equal sum of components because of independentrounding.

Source: Energy Information Administration, Form EIA-861, "Annual Electric Utility Report." Data are submitted on a calendar year. 
Table 25. Number of Consumers, Sales, and Operating Revenue by Major U.S.

Publicly Owned Electric Utility Within State, 1996 (Continued)

\begin{tabular}{|c|c|c|c|c|c|c|}
\hline Item & $\begin{array}{l}\text { Mississippi } \\
\text { Louisville } \\
\text { Electric } \\
\text { System } \\
\text { June } 30\end{array}$ & $\begin{array}{c}\text { Mississippi } \\
\text { Municipal } \\
\text { Energy } \\
\text { Agency } \\
\text { of MS } \\
\text { September } 30\end{array}$ & $\begin{array}{l}\text { Mississippi } \\
\text { New Albany } \\
\text { City of } \\
\text { June } 30\end{array}$ & $\begin{array}{l}\text { Mississippi } \\
\text { Oxford } \\
\text { City of } \\
\text { June } 30\end{array}$ & $\begin{array}{l}\text { Mississippi } \\
\text { Philadelphia } \\
\text { City of } \\
\text { June } 30\end{array}$ & $\begin{array}{l}\text { Mississippi } \\
\text { Starkville } \\
\text { City of } \\
\text { June } 30\end{array}$ \\
\hline \multicolumn{7}{|l|}{ Number of Consumers } \\
\hline Residential ......................... & 2,756 & $\mathbf{0}$ & 7,551 & 4,999 & 3,018 & 8,053 \\
\hline 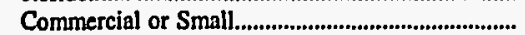 & 709 & 0 & 1,562 & 804 & 654 & 1,084 \\
\hline 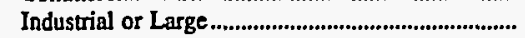 & 87 & 0 & 143 & 130 & 90 & 176 \\
\hline 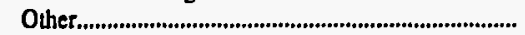 & 23 & $\mathbf{0}$ & 22 & 24 & 6 & 47 \\
\hline \multicolumn{7}{|l|}{ Sales for the Year (megawatthours) } \\
\hline 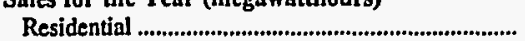 & 33,340 & 0 & 107,512 & 67,817 & 40,501 & 98,168 \\
\hline 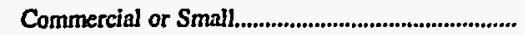 & 11,237 & 0 & 21,796 & 22,725 & 12,658 & 21,219 \\
\hline Industrial or Large ..................................................... & 123,684 & 0 & 107,256 & 68,365 & 80,711 & 224,802 \\
\hline 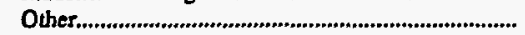 & 2,315 & 0 & 4,139 & 3,361 & 2,215 & 3,078 \\
\hline 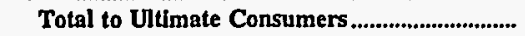 & 170,576 & $\mathbf{0}$ & 240,703 & 162,268 & 136,085 & 347,267 \\
\hline 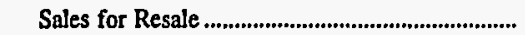 & 0 & 872,502 & 0 & 0 & 0 & 0 \\
\hline 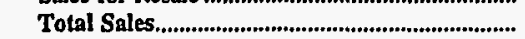 & 170,576 & 872,502 & 240,703 & 162,268 & 136,085 & 347,267 \\
\hline \multicolumn{7}{|l|}{ Oper Revenues for the Year (thou\$) } \\
\hline 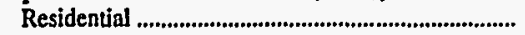 & 2,006 & $\mathbf{0}$ & 6,375 & 3,946 & 2,385 & 6,081 \\
\hline 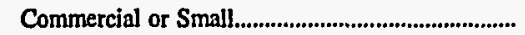 & 764 & $\mathbf{0}$ & 1,500 & 1,431 & 833 & 1,440 \\
\hline 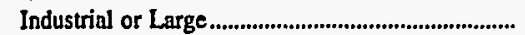 & 6,146 & 0 & 6,031 & 3,568 & 4,083 & 11,171 \\
\hline 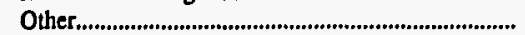 & 194 & 0 & 306 & 278 & 159 & 249 \\
\hline 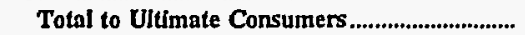 & 9,110 & 0 & 14,212 & 9,223 & 7,460 & 18,941 \\
\hline 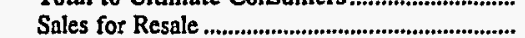 & & 27,567 & & 0 & 0 & 0 \\
\hline Total Revenues From Sales of Elec.................... & 9,110 & 27,567 & 14,212 & 9,223 & 7,460 & 18,941 \\
\hline
\end{tabular}

\begin{tabular}{|c|c|c|c|c|c|c|}
\hline Item & $\begin{array}{l}\text { Mississippi } \\
\text { Tupelo } \\
\text { City of } \\
\text { June } 30\end{array}$ & $\begin{array}{c}\text { Mississippi } \\
\text { West } \\
\text { Point } \\
\text { City of } \\
\text { June } 30\end{array}$ & $\begin{array}{l}\text { Missouri } \\
\text { Carthage } \\
\text { City of } \\
\text { June } 30\end{array}$ & $\begin{array}{l}\text { Missouri } \\
\text { Columbia } \\
\text { City of } \\
\text { September } 30\end{array}$ & $\begin{array}{l}\text { Missouri } \\
\text { Hannibal } \\
\text { City of } \\
\text { June } 30\end{array}$ & $\begin{array}{l}\text { Missouri } \\
\text { Independence } \\
\text { City of } \\
\text { June } 30\end{array}$ \\
\hline \multicolumn{7}{|l|}{ Number of Consumers } \\
\hline Residential ...................... & 11,019 & 3,421 & 5,676 & 27,694 & 7,461 & 45,762 \\
\hline 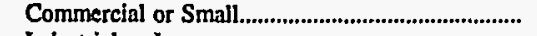 & 3,353 & 534 & 931 & 4,404 & 990 & 4,523 \\
\hline 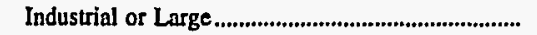 & 502 & 94 & 22 & 17 & 124 & 11 \\
\hline 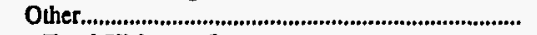 & 15 & 7 & 2 & 1 & 20 & 56 \\
\hline Total Ultimate Consumers....................................... & 14,889 & 4,056 & 6,631 & 32,116 & 8,595 & 50,352 \\
\hline \multicolumn{7}{|l|}{ Sales for the Year (megawatthours) } \\
\hline 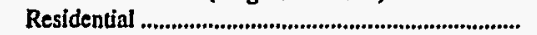 & 159,495 & 38,157 & 52,019 & 281,625 & 69,813 & 412,329 \\
\hline 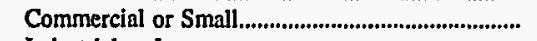 & 72,262 & 10,999 & 46,528 & 362,851 & 22,718 & 399,109 \\
\hline 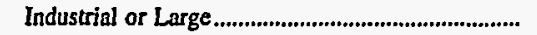 & 414,823 & 147,337 & 104,571 & 196,921 & 107,385 & 50,599 \\
\hline 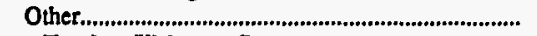 & 11,087 & 3,427 & 10,762 & 6,286 & 7,123 & 9,124 \\
\hline 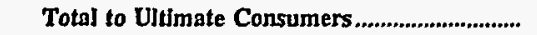 & 657,667 & 199,920 & 213,880 & 847,683 & 207,039 & 871,161 \\
\hline 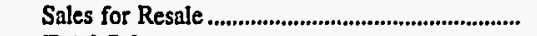 & 0 & $\mathbf{0}$ & 1,546 & 2,111 & 0 & 23,094 \\
\hline 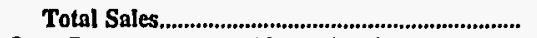 & 657,667 & 199,920 & 215,426 & 849,794 & 207,039 & 894,255 \\
\hline \multicolumn{7}{|l|}{ Oper Revenues for the Year (thou\$) } \\
\hline 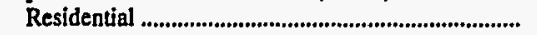 & 8,683 & 2,342 & 3,223 & 19,551 & 4,220 & 29,921 \\
\hline 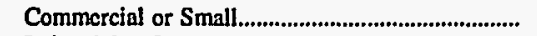 & 4,492 & 750 & 2,497 & 23,238 & 1,498 & 24,463 \\
\hline 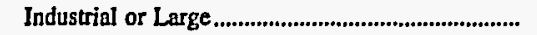 & 20,674 & 7,253 & 4,383 & 10,529 & 5,380 & 2,095 \\
\hline 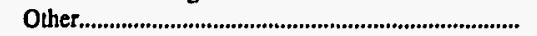 & 1,066 & 255 & 385 & 517 & 296 & 658 \\
\hline 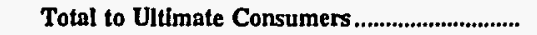 & 34,915 & 10,600 & 10,488 & 53,835 & 11,394 & 57,137 \\
\hline 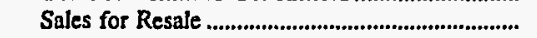 & 0 & 0 & 53 & 83 & 0 & 1,400 \\
\hline Total Revenues From Sales of Elec........................ & 34,915 & 10,600 & 10,541 & 53,918 & 11,394 & 58,537 \\
\hline
\end{tabular}

Note: Totals may not equal sum of components because of independent rounding.

Source: Energy Information Administration, Form ElA-861, "Annual Electric Utility Report." Data are submitted on a calendar year. 
Table 25. Number of Consumers, Sales, and Operating Revenue by Major U.S. Publicly Owned Electric Utility Within State, 1996 (Continued)

\begin{tabular}{|c|c|c|c|c|c|c|}
\hline Item & $\begin{array}{l}\text { Missouri } \\
\text { Kennett } \\
\text { City of } \\
\text { June } 30\end{array}$ & $\begin{array}{l}\text { Missouri } \\
\text { Kirkwood } \\
\text { City of } \\
\text { March } 31\end{array}$ & $\begin{array}{l}\text { Missouri } \\
\text { Lebanon } \\
\text { City of } \\
\text { October } 31\end{array}$ & $\begin{array}{c}\text { Missouri } \\
\text { Marshall } \\
\text { City of } \\
\text { September } 30\end{array}$ & $\begin{array}{l}\text { Missouri } \\
\text { Monett } \\
\text { City of } \\
\text { March } 31\end{array}$ & $\begin{array}{c}\text { Missouri } \\
\text { Poplar } \\
\text { Bluff } \\
\text { City of } \\
\text { December } 31\end{array}$ \\
\hline \multicolumn{7}{|l|}{ Number of Consumers } \\
\hline 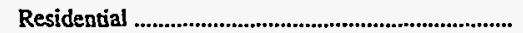 & 4,755 & 8,318 & 4,150 & 4,826 & 3,078 & 7,853 \\
\hline 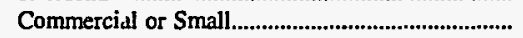 & 816 & 1,050 & 1,001 & 870 & 580 & 1,446 \\
\hline 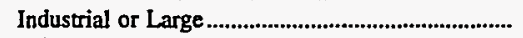 & 222 & 47 & 49 & 5 & 17 & 18 \\
\hline 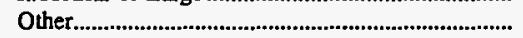 & 1 & 181 & 0 & 1 & 2 & 1 \\
\hline $\begin{array}{l}\text { Total Ultimate Consumers..................................... } \\
\text { Sales for the Year (megawatthours) }\end{array}$ & 5,794 & 9,596 & 5,200 & 5,702 & 3,677 & 9,318 \\
\hline 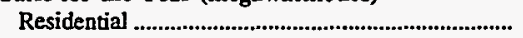 & 65,502 & 85,246 & 56,074 & 41,850 & 29,403 & 106,155 \\
\hline 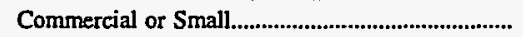 & 13,726 & 32,279 & 36,013 & 58,050 & 31,805 & 118,641 \\
\hline 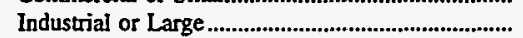 & 76,615 & 68,740 & 80,040 & 60,562 & 102,934 & 54,973 \\
\hline 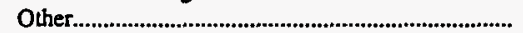 & 2,250 & 290 & 0 & 1,686 & 3,763 & 498 \\
\hline 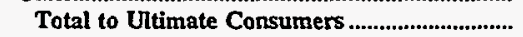 & 158,093 & 186,555 & 172,127 & 162,148 & 167,905 & 280,267 \\
\hline 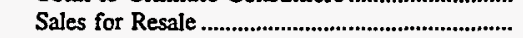 & 0 & 0 & 0 & 0 & 0 & 5,890 \\
\hline 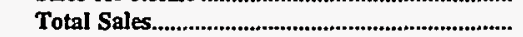 & 158,093 & 186,555 & 172,127 & 162,148 & 167,905 & 286,157 \\
\hline \multicolumn{7}{|l|}{ Oper Revenues for the Year (thou\$) } \\
\hline Residential & 2,509 & 6,306 & 3,305 & 3,078 & 1,730 & 4,421 \\
\hline 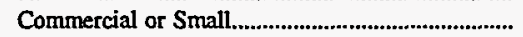 & 715 & 2,125 & 2,282 & 3,856 & 1,652 & 5,362 \\
\hline 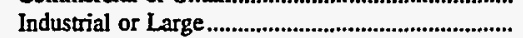 & 2,450 & 3,404 & 3,854 & 3,228 & 5,382 & 2,008 \\
\hline 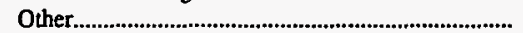 & 117 & 55 & 0 & 122 & 164 & 21 \\
\hline 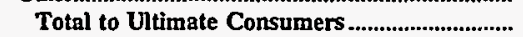 & 5,791 & 11,890 & 9,441 & 10,284 & 8,928 & 11,812 \\
\hline Sales for Resale & 0 & 0 & 0 & 0 & 0 & 118 \\
\hline 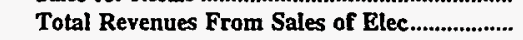 & 5,791 & 11,890 & 9,441 & 10,284 & 8,928 & 11,930 \\
\hline
\end{tabular}

\begin{tabular}{|c|c|c|c|c|c|c|}
\hline Item & $\begin{array}{c}\text { Missouri } \\
\text { Rolla } \\
\text { City of } \\
\text { September } 30\end{array}$ & $\begin{array}{l}\text { Missouri } \\
\text { Sikeston } \\
\text { City of } \\
\text { May 31 }\end{array}$ & $\begin{array}{c}\text { Missouri } \\
\begin{array}{c}\text { Springfield } \\
\text { City of }\end{array} \\
\text { September } 30\end{array}$ & $\begin{array}{c}\text { Missouri } \\
\text { West } \\
\text { Plains } \\
\text { City of } \\
\text { December } 31\end{array}$ & $\begin{array}{l}\text { Nebraska } \\
\text { Beatrice } \\
\text { City of } \\
\text { July } 31\end{array}$ & $\begin{array}{c}\text { Nebraska } \\
\text { Central } \\
\text { Nebraska } \\
\text { Pub } \\
\text { P\&I Dist } \\
\text { December } 31\end{array}$ \\
\hline \multicolumn{7}{|l|}{ Number of Consumers } \\
\hline Residential .... & 5,876 & 7,182 & $\mathbf{7 3 , 4 6 5}$ & 4,278 & 5,636 & 0 \\
\hline 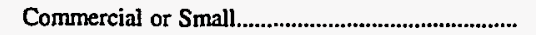 & 1,229 & 1,544 & 11,629 & 682 & 769 & 0 \\
\hline 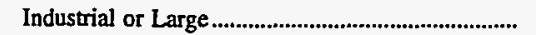 & 130 & 18 & 158 & 276 & 138 & 0 \\
\hline Other & 0 & 1 & 0 & 0 & 363 & 0 \\
\hline Total Ultimate Consumers......................................... & 7,235 & 8,745 & 85,252 & 5,236 & 6,906 & 0 \\
\hline \multicolumn{7}{|l|}{ Sales for the Year (megawatthours) } \\
\hline 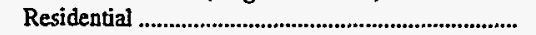 & 78,141 & 105,511 & 745,706 & 63,775 & 59,462 & $\mathbf{0}$ \\
\hline 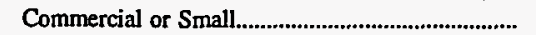 & 34,083 & 104,427 & $1,222,163$ & 17,007 & 17,932 & 0 \\
\hline Industrial or Large & 133,686 & 51,795 & 407,882 & 60,940 & 68,969 & 0 \\
\hline 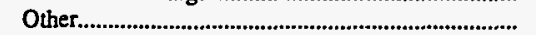 & 0 & 1,255 & 0 & 0 & 766 & 0 \\
\hline 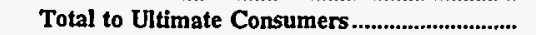 & 245,910 & 262,988 & $2,375,751$ & 141,722 & 147,129 & $\mathbf{0}$ \\
\hline Sales for Resale ...................................................... & 0 & $1,431,943$ & 224,756 & 0 & 0 & 440,025 \\
\hline Total Sales................... & 245,910 & $1,694,931$ & $2,600,507$ & 141,722 & 147,129 & 440,025 \\
\hline \multicolumn{7}{|l|}{ Oper Revenues for the Year (thous) } \\
\hline Residential ....................... & 4,224 & 5,101 & 40,575 & 3,120 & 3,569 & 0 \\
\hline 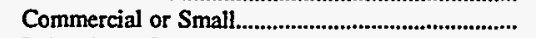 & 1,804 & 5,170 & 48,888 & 1,361 & 1,062 & 0 \\
\hline 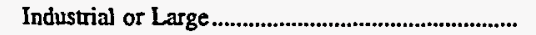 & 6,777 & 1,955 & 14,850 & 4,701 & 3,190 & 0 \\
\hline Other & 0 & 104 & 0 & 0 & 49 & 0 \\
\hline 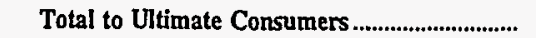 & 12,805 & 12,330 & 104,313 & 9,182 & 7,870 & 0 \\
\hline 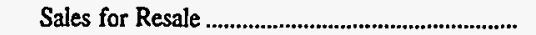 & & 42,732 & 5,753 & 0 & 0 & 11,379 \\
\hline 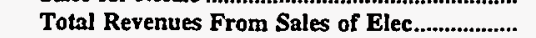 & 12,805 & 55,062 & 110,066 & 9,182 & $\mathbf{7 , 8 7 0}$ & 11,379 \\
\hline
\end{tabular}

Note: Totals may not equal sum of components because of independent rounding.

Source: Energy Information Administration, Form EIA-861, "Annual Electric Utility Report." Data are submitted on a calendar year. 
Table 25. Number of Consumers, Sales, and Operating Revenue by Major U.S.

Publicly Owned Electric Utility Within State, 1996 (Continued)

\begin{tabular}{|c|c|c|c|c|c|c|}
\hline Item & $\begin{array}{c}\text { Nebraska } \\
\text { Cormhusker } \\
\text { Public } \\
\text { Power Dist } \\
\\
\text { December } 31\end{array}$ & $\begin{array}{l}\text { Nebraska } \\
\text { Dawson } \\
\text { County } \\
\text { Public } \\
\text { Pwr Dist } \\
\text { December } 31\end{array}$ & $\begin{array}{l}\text { Nebraska } \\
\text { Fremont } \\
\text { City of } \\
\text { July } 31\end{array}$ & $\begin{array}{l}\text { Nebraska } \\
\begin{array}{c}\text { Grand Island } \\
\text { City of }\end{array} \\
\text { July } 31\end{array}$ & $\begin{array}{l}\text { Nebraska } \\
\text { Hastings } \\
\text { City of } \\
\text { December } 31\end{array}$ & $\begin{array}{l}\text { Nebraska } \\
\text { Lincoln } \\
\text { Electric } \\
\text { System } \\
\text { December } 31\end{array}$ \\
\hline \multicolumn{7}{|l|}{ Number of Consumers } \\
\hline 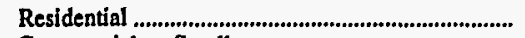 & 5,166 & 11,763 & 12,749 & 17,758 & 10,061 & 89,277 \\
\hline 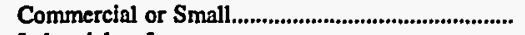 & 237 & 793 & 1,643 & 3,128 & 1,794 & 11,628 \\
\hline 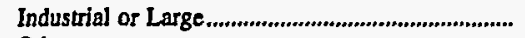 & 7 & 3 & 527 & 66 & 82 & 238 \\
\hline Other & 2,522 & 4,233 & 523 & 138 & 109 & 1,335 \\
\hline Total Ultimate Consumers................................. & 7,932 & 16,792 & 15,442 & 21,090 & 12,046 & 102,478 \\
\hline Sales for the Year (megawatthours) & & & & & 87416 & \\
\hline 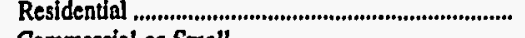 & $\begin{array}{r}121,504 \\
25,040\end{array}$ & 163,658 & 128,921 & 157,759 & 87,416 & 834,825 \\
\hline 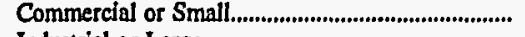 & 25,049 & 39,140 & 44,287 & 126,953 & 77,098 & 843,058 \\
\hline Industrial or Large & 47,772 & 9,389 & 197,858 & 244,347 & 164,811 & 488,687 \\
\hline Other & 17,082 & 46,949 & 8,801 & 8,437 & 14,394 & 271,503 \\
\hline Total to Ultimate Consumers.................................. & 211,407 & 259,136 & 379,867 & 537,496 & 343,719 & $2,438,073$ \\
\hline 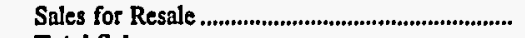 & 3,598 & 5,609 & 10,845 & 58,539 & 145,765 & 715,881 \\
\hline 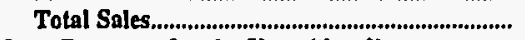 & 215,005 & 264,745 & 390,712 & 596,035 & 489,484 & $3,153,954$ \\
\hline \multicolumn{7}{|l|}{ Oper Revenues for the Year (thous) } \\
\hline 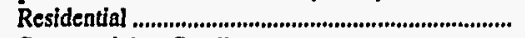 & 6,652 & 9,064 & 6,440 & 8,994 & 5,139 & 51,610 \\
\hline 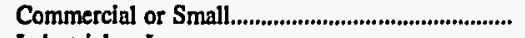 & 1,252 & 2,178 & 2,389 & 6,999 & 4,039 & 38,009 \\
\hline 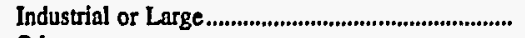 & 1,809 & 403 & 8,474 & 9,047 & 5,672 & 18,950 \\
\hline Other, & 1,616 & 5,016 & 458 & 439 & 582 & 11,898 \\
\hline Total to Ultimate Consumers................................... & 11,329 & 16,661 & 17,761 & 25,479 & 15,432 & 120,467 \\
\hline 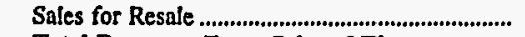 & 48 & 223 & 217 & 780 & 1,383 & 10,946 \\
\hline Total Revenues From Sales of Elec.................... & 11,377 & 16,884 & 17,978 & 26,259 & 16,815 & 131,413 \\
\hline
\end{tabular}

\begin{tabular}{|c|c|c|c|c|c|c|}
\hline Item & $\begin{array}{c}\text { Nebraska } \\
\text { Loup } \\
\text { River } \\
\text { Public } \\
\text { Power Dist } \\
\text { December } 31\end{array}$ & $\begin{array}{c}\text { Nebraska } \\
\text { Municipal } \\
\text { Energy } \\
\text { Agency } \\
\text { of NE } \\
\text { March } 31\end{array}$ & $\begin{array}{c}\text { Nebraska } \\
\text { Nebraska } \\
\text { Public } \\
\text { Power } \\
\text { District } \\
\text { December } 31\end{array}$ & $\begin{array}{c}\text { Nebraska } \\
\text { Norris } \\
\text { Public } \\
\text { Power } \\
\text { District } \\
\text { December } 31\end{array}$ & $\begin{array}{l}\text { Nebraska } \\
\text { North } \\
\text { Platte } \\
\text { City of } \\
\text { July } 31\end{array}$ & $\begin{array}{c}\text { Nebraska } \\
\text { Omaha Public } \\
\text { Power } \\
\text { District } \\
\text { December } 31\end{array}$ \\
\hline \multicolumn{7}{|l|}{ Number of Consumers } \\
\hline 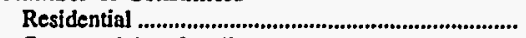 & 13,586 & 0 & 87,037 & 10,246 & 11,763 & 237.584 \\
\hline Commercial or Small.......................................................... & 2,740 & 0 & 19,751 & 2,845 & 1,982 & 33,993 \\
\hline 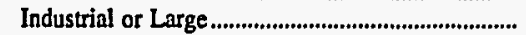 & 40 & 0 & 66 & 65 & 0 & 99 \\
\hline 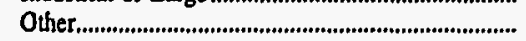 & 752 & 0 & 4,188 & 69 & 2 & 555 \\
\hline 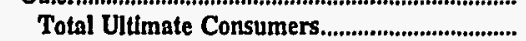 & 17,118 & 0 & 111,042 & 13,225 & 13,747 & 272,231 \\
\hline \multicolumn{7}{|l|}{ Sales for the Year (megawatthours) } \\
\hline 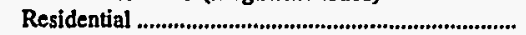 & 205,380 & 0 & 959,471 & 185,460 & 89,341 & $2,573,792$ \\
\hline 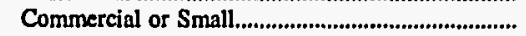 & 129,608 & 0 & 827,171 & 34,904 & 116,410 & $2,792,184$ \\
\hline 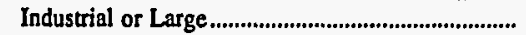 & 410,403 & 0 & 942,668 & 216,338 & 0 & $2,311,804$ \\
\hline 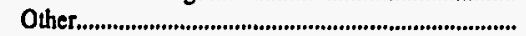 & 33,176 & 0 & 199,553 & 778 & 22,963 & 78,710 \\
\hline Total to Ultimate Consumers.................................. & 778,567 & 0 & $2,928,863$ & 437,480 & 228,714 & $\mathbf{7 , 7 5 6 , 4 9 0}$ \\
\hline 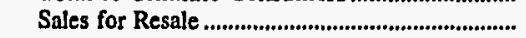 & 463,284 & $1,104,565$ & $13,523,505$ & 15,943 & 0 & 173,595 \\
\hline 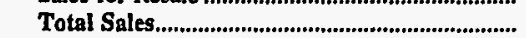 & $1,241,851$ & $1,104,565$ & $16,452,368$ & 453,423 & 228,714 & $7,930,085$ \\
\hline \multicolumn{7}{|l|}{ Oper Revenues for the Year (thou\$) } \\
\hline 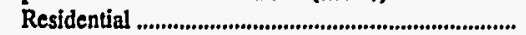 & 9,684 & 0 & 68,400 & 11,852 & 5,063 & 169,751 \\
\hline 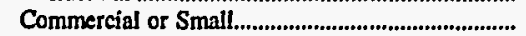 & 6,238 & 0 & 49,598 & 3,115 & 5,757 & 150,467 \\
\hline 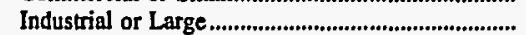 & 12,911 & 0 & 32,057 & 8,283 & 0 & 75,043 \\
\hline 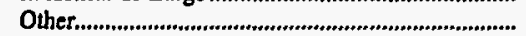 & 1,926 & 0 & 12,028 & 78 & 624 & 10,938 \\
\hline Total to Ultimate Consumers.............................. & 30,759 & 0 & 162,083 & 23,328 & 11,444 & 406,199 \\
\hline 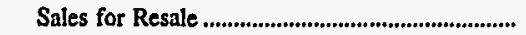 & 15,292 & 32,472 & 385,850 & 577 & 0 & 6,476 \\
\hline Total Revenues From Sales of Elec................... & 46,051 & 32,472 & 547,933 & 23,905 & 11,444 & 412,675 \\
\hline
\end{tabular}

Note: Totals may not equal sum of components becautse of independent rounding.

Source: Energy Information Administration, Form EIA-861, "Annual Electric Utility Report." Data are submitted on a calendar year. 
Table 25. Number of Consumers, Sales, and Operating Revenue by Major U.S.

Publicly Owned Electric Utility Within State, 1996 (Continued)

\begin{tabular}{|c|c|c|c|c|c|c|}
\hline Item & $\begin{array}{c}\text { Nebraska } \\
\text { Southern } \\
\text { Nebraska Rural } \\
\text { P P D } \\
\text { December } 31\end{array}$ & $\begin{array}{c}\text { Nevada } \\
\text { Colorado } \\
\text { River } \\
\text { Comm } \\
\text { of Nevada } \\
\text { June } 30\end{array}$ & $\begin{array}{c}\text { Nevada } \\
\text { Overton } \\
\text { Power } \\
\text { District } \\
\text { No } 5 \\
\text { December } 31\end{array}$ & $\begin{array}{l}\text { New Jersey } \\
\text { Madison } \\
\text { Borough } \\
\text { December } 31\end{array}$ & $\begin{array}{l}\text { New Jersey } \\
\text { Vineland } \\
\text { City of } \\
\text { June } 30\end{array}$ & $\begin{array}{c}\text { New Mexico } \\
\text { Farmington } \\
\text { City of } \\
\text { June } 30\end{array}$ \\
\hline \multicolumn{7}{|l|}{ Number of Consumers } \\
\hline Residential & 10,819 & 0 & 5,388 & 5,510 & 15,211 & 26,131 \\
\hline 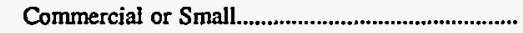 & 969 & 0 & 842 & 729 & 2,414 & 5,664 \\
\hline Industrial or Large & 141 & 4 & 0 & 0 & 65 & 4 \\
\hline Other & 7,208 & 0 & 131 & 1 & 3 & 2,106 \\
\hline Total Ultimate Consumers.................................. & 19,137 & 4 & 6,361 & 6,240 & 17,693 & 33,905 \\
\hline \multicolumn{7}{|l|}{ Sales for the Year (megawatthours) } \\
\hline Residential & 178,000 & 0 & 90,865 & 43,125 & 128,338 & 170,518 \\
\hline 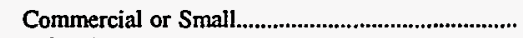 & 15,000 & 0 & 146,096 & 77,069 & 102,319 & 285,613 \\
\hline Industrial or Large & 170,000 & 762,030 & 0 & 0 & 197,693 & 153,145 \\
\hline 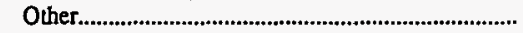 & 67,000 & 0 & 1,563 & 1,065 & 4,074 & 8,463 \\
\hline 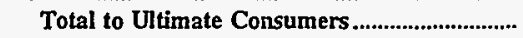 & 430,000 & 762,030 & 238,524 & 121,259 & 432,424 & 617,739 \\
\hline Sales for Resale & 0 & $1,142,235$ & 13,685 & 0 & 0 & 28,135 \\
\hline 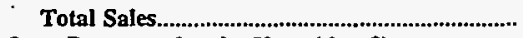 & 430,000 & $1,904,265$ & 252,209 & 121,259 & 432,424 & 645,874 \\
\hline \multicolumn{7}{|l|}{ Oper Revenues for the Year (thou\$) } \\
\hline 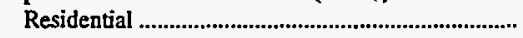 & 9,589 & 0 & 3,677 & 4,025 & 13,118 & 14,422 \\
\hline 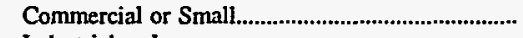 & 916 & 0 & 7,349 & 7,064 & 10,237 & 22,976 \\
\hline 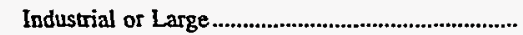 & 6,297 & 12,423 & 0 & 0 & 15,224 & 7,545 \\
\hline 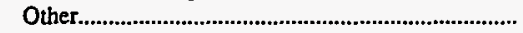 & 6,604 & 0 & 110 & 132 & 818 & 1,466 \\
\hline 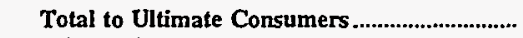 & 23,406 & 12,423 & 11,136 & 11,221 & 39,397 & 46,409 \\
\hline Sales for Resale & 0 & 12,630 & 455 & 0 & 0 & 1,280 \\
\hline Total Revenues From Sales of Elec...................... & 23,406 & 25,053 & 11,591 & 11,221 & 39,397 & 47,689 \\
\hline
\end{tabular}

\begin{tabular}{|c|c|c|c|c|c|c|}
\hline Item & $\begin{array}{l}\text { New Mexico } \\
\text { Gallup } \\
\text { City of } \\
\text { June } 30\end{array}$ & $\begin{array}{l}\text { New Mexico } \\
\text { Los Alamos } \\
\text { County } \\
\text { June } 30\end{array}$ & $\begin{array}{l}\text { New York } \\
\text { Fairport } \\
\text { Village of } \\
\text { May } 31\end{array}$ & $\begin{array}{c}\text { New York } \\
\text { Freeport } \\
\text { Village of } \\
\text { Inc }\end{array}$ & $\begin{array}{l}\text { New York } \\
\text { Jamestown } \\
\text { City of } \\
\text { December } 31\end{array}$ & $\begin{array}{c}\text { New York } \\
\text { Lake Placid } \\
\text { Village Inc } \\
\text { July } 31\end{array}$ \\
\hline \multicolumn{7}{|l|}{ Number of Consumers } \\
\hline 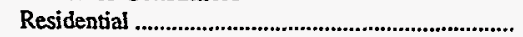 & 7,023 & 7,412 & 13,507 & 13,014 & 16,933 & 3,721 \\
\hline 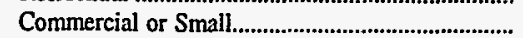 & 1,528 & 619 & 1,195 & 1,771 & 2,534 & 745 \\
\hline 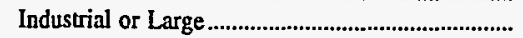 & 0 & 0 & 8 & 0 & 122 & 0 \\
\hline 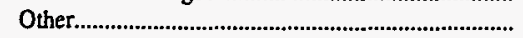 & 270 & 4 & 58 & 126 & 219 & 230 \\
\hline 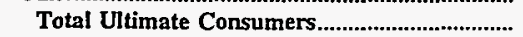 & 8,821 & 8,035 & 14,768 & 14,911 & 19,808 & 4,696 \\
\hline \multicolumn{7}{|l|}{ Sales for the Year (megawatthours) } \\
\hline 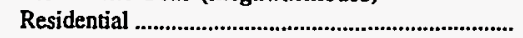 & 41,619 & 45,265 & 226,727 & 101,133 & 143,370 & 60,451 \\
\hline Commercial or Small & 114,002 & 34,405 & 104,911 & 126,807 & 139,856 & 50,131 \\
\hline 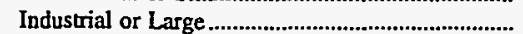 & 0 & 0 & 39,208 & 0 & 182,237 & 0 \\
\hline 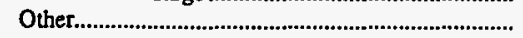 & 21,350 & 378,459 & 3,002 & 15,124 & 37,120 & 25,590 \\
\hline 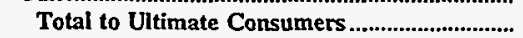 & 176,971 & 458,129 & 373,848 & 243,064 & 502,583 & 136,172 \\
\hline Sales for Resale & 0 & 12,687 & 0 & 282 & 57,445 & 0 \\
\hline 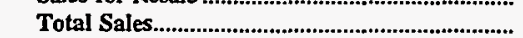 & 176,971 & 470,816 & 373,848 & 243,346 & 560,028 & 136,172 \\
\hline \multicolumn{7}{|l|}{ Oper Revenues for the Year (thou\$) } \\
\hline 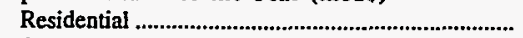 & 3,267 & 3,975 & 7,670 & 6,985 & 6,802 & 2,071 \\
\hline 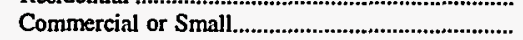 & 8,784 & 3,057 & 3,960 & 7,995 & 6,897 & 1,445 \\
\hline Industrial or Large & 0 & 0 & 925 & 0 & 7,697 & 0 \\
\hline 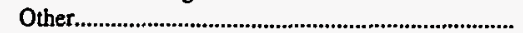 & 1,570 & 20,234 & 226 & 1,513 & 1,739 & 729 \\
\hline 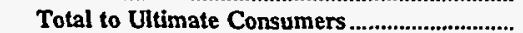 & 13,621 & 27,266 & 12,781 & 16,493 & 23,135 & 4,245 \\
\hline Sales for Resale & 0 & 185 & 0 & 25 & 1,173 & 0 \\
\hline 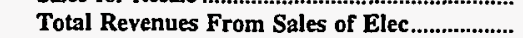 & 13,621 & 27,451 & 12,781 & 16,518 & 24,308 & 4,245 \\
\hline
\end{tabular}

Note: Totals may not equal sum of components because of independent rounding.

Source: Energy Information Administration, Form ElA-861, "Annual Electric Utility Report." Data are submitted on a calendar year. 
Table 25. Number of Consumers, Sales, and Operating Revenue by Major U.S.

Publicly Owned Electric Utility Within State, 1996 (Continued)

\begin{tabular}{|c|c|c|c|c|c|c|}
\hline Item & $\begin{array}{l}\text { New York } \\
\text { Massena } \\
\text { Town of } \\
\text { December } 31\end{array}$ & $\begin{array}{l}\text { New York } \\
\text { Plattsburgh } \\
\text { City of } \\
\text { December } 31\end{array}$ & $\begin{array}{c}\text { New York } \\
\text { Power } \\
\text { Authority } \\
\text { of State of NY } \\
\text { December } 31\end{array}$ & $\begin{array}{l}\text { New York } \\
\text { Rockville } \\
\text { Centre } \\
\text { Village of } \\
\text { May } 31\end{array}$ & $\begin{array}{c}\text { New York } \\
\text { Solvay } \\
\text { Village of } \\
\text { May } 31\end{array}$ & $\begin{array}{l}\text { North Carolina } \\
\text { Albemarle } \\
\text { City of } \\
\text { June } 30\end{array}$ \\
\hline \multicolumn{7}{|l|}{ Number of Consumers } \\
\hline 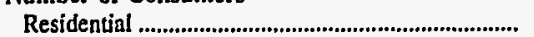 & 7,957 & 7,527 & 0 & 8,908 & 4,530 & 9,096 \\
\hline 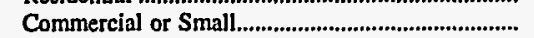 & 806 & 1,306 & 4 & 1,207 & 370 & 1,856 \\
\hline Industrial or Large & 177 & 6 & 28 & $\mathbf{0}$ & 17 & 22 \\
\hline 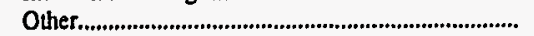 & 268 & 198 & 115 & 45 & 4 & 1 \\
\hline Total Ultimate Consumers................................. & 9,208 & 9,037 & 147 & 10,160 & 4,921 & 10,975 \\
\hline \multicolumn{7}{|l|}{ Sales for the Year (megawatthours) } \\
\hline 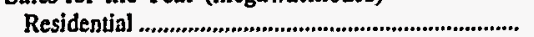 & 82,066 & 158,245 & 0 & 78,585 & 54,472 & 110,884 \\
\hline 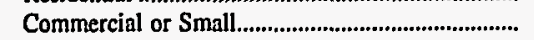 & 12,586 & 126,509 & 97,486 & 94,723 & 27,196 & 95,002 \\
\hline 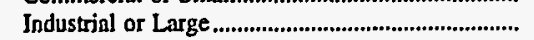 & 60,764 & 234,378 & $4,350,946$ & 0 & 146,080 & 50,310 \\
\hline 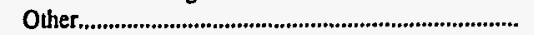 & 4,713 & 4,985 & $8,569,098$ & 5,738 & 2,135 & 7,280 \\
\hline 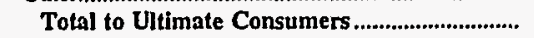 & 160,129 & 524,117 & $13,017,530$ & 179,046 & 229,883 & 263,476 \\
\hline 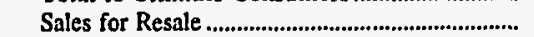 & 0 & 0 & $27,555,179$ & 0 & 0 & 0 \\
\hline 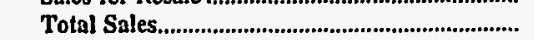 & 160,129 & 524,117 & $40,572,709$ & 179,046 & 229,883 & 263,476 \\
\hline \multicolumn{7}{|l|}{ Oper Revenues for the Year (thou\$) } \\
\hline 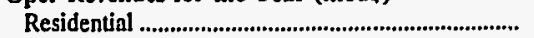 & 3,452 & 4,253 & 0 & 5,640 & 1,676 & 9,719 \\
\hline 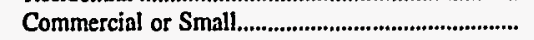 & 609 & 3,105 & 6,015 & 6,506 & 729 & 7,528 \\
\hline 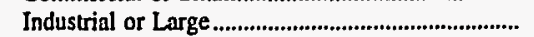 & 2,050 & 3,654 & 92,140 & 0 & 2,652 & 2,974 \\
\hline 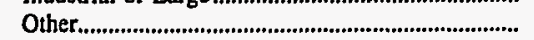 & 316 & 311 & 698,628 & 402 & 132 & 430 \\
\hline Total to Ultimate Consumers .............................. & 6,427 & 11,323 & 796,783 & 12,548 & 5,189 & 20,651 \\
\hline 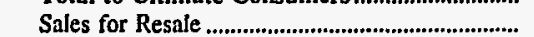 & 0 & 0 & 573,090 & 0 & 0 & \\
\hline Total Revenues From Sales of Elec.................... & 6,427 & 11,323 & $1,369,873$ & 12,548 & 5,189 & 20,651 \\
\hline
\end{tabular}

\begin{tabular}{|c|c|c|c|c|c|c|}
\hline Item & $\begin{array}{l}\text { North Carolina } \\
\text { Concord } \\
\text { City of } \\
\text { June } 30\end{array}$ & $\begin{array}{l}\text { North Carolina } \\
\text { Elizabeth } \\
\text { City City of } \\
\text { June } 30\end{array}$ & $\begin{array}{c}\text { North Carolina } \\
\text { Fayetteville } \\
\text { Public } \\
\text { Works Comm } \\
\text { June } 30\end{array}$ & $\begin{array}{l}\text { North Carolina } \\
\text { Forest City } \\
\text { Town of } \\
\text { June } 30\end{array}$ & $\begin{array}{l}\text { North Carolina } \\
\text { Gastonia } \\
\text { City of } \\
\text { June } 30\end{array}$ & $\begin{array}{c}\text { North Carolina } \\
\text { Greenville } \\
\text { Utilities } \\
\text { Comm } \\
\text { June } 30\end{array}$ \\
\hline \multicolumn{7}{|l|}{ Number of Consumers } \\
\hline 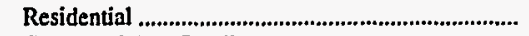 & 16,051 & 8,680 & 57,837 & 3,746 & 20,995 & 39,207 \\
\hline 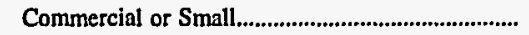 & 2,281 & 1,473 & 6,620 & 906 & 2,928 & 5,054 \\
\hline Industrial or Large & 0 & 0 & 22 & 0 & 76 & 23 \\
\hline 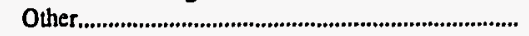 & 1 & 72 & 4,114 & 0 & 98 & 11 \\
\hline $\begin{array}{l}\text { Total Ultimate Consumers...................................... } \\
\text { Sales for the Year (megawatthours) }\end{array}$ & 18,333 & 10,225 & 68,593 & 4,652 & 24,097 & 44,295 \\
\hline 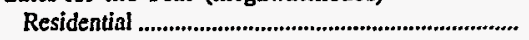 & 202,944 & 110,884 & 811,001 & 45,959 & 207,918 & 495,401 \\
\hline 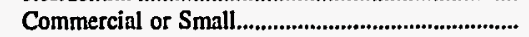 & 228,352 & 127,365 & 542,249 & 99,219 & 270,622 & 340,584 \\
\hline 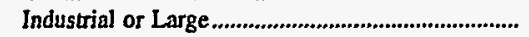 & 0 & 0 & 465,145 & 0 & 105,509 & 393,598 \\
\hline 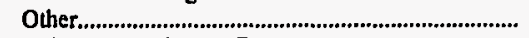 & 1,034 & 9,268 & 68,217 & 0 & 904 & 9,654 \\
\hline 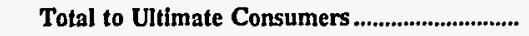 & 432,330 & 247,517 & $1,886,612$ & 145,178 & 584,953 & $1,239,237$ \\
\hline Sales for Resale & 0 & 0 & 0 & 0 & 0 & 37,956 \\
\hline 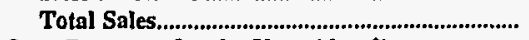 & 432,330 & 247,517 & $1,886,612$ & 145,178 & 584,953 & $1,277,193$ \\
\hline \multicolumn{7}{|l|}{ Oper Revenues for the Year (thou\$) } \\
\hline 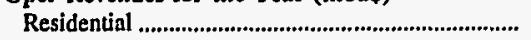 & 15,467 & 11,268 & 61,139 & 3,041 & 19,258 & 45,516 \\
\hline 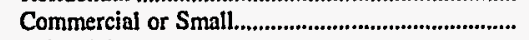 & 14,161 & 10,839 & 36,279 & 5,517 & 21,312 & 28,908 \\
\hline 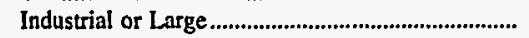 & 0 & 0 & 22,884 & 0 & 6,742 & 24,926 \\
\hline 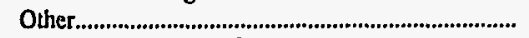 & 68 & 726 & 4,719 & 0 & 112 & 1,437 \\
\hline Total to Ultimate Consumers .............................. & 29,696 & 22,833 & 125,021 & 8,558 & $\mathbf{4 7 , 4 2 4}$ & 100,787 \\
\hline 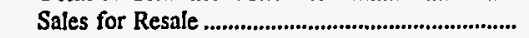 & 0 & 0 & 0 & 0 & 0 & 2,872 \\
\hline Total Revenues From Sales of Elec..................... & 29,696 & 22,833 & 125,021 & 8,558 & 47,424 & 103,659 \\
\hline
\end{tabular}

Note: Totals may not equal sum of components because of independentrounding.

Source: Energy Information Administration, Form ELA-861, “Annual Electric Utility Report." Data are submitted on a calendar year. 
Table 25. Number of Consumers, Sales, and Operating Revenue by Major U.S. Publicly Owned Electric Utility Within State, 1996 (Continued)

\begin{tabular}{|c|c|c|c|c|c|c|}
\hline Item & $\begin{array}{c}\text { North Carolina } \\
\text { High } \\
\text { Point } \\
\text { Town } \\
\text { of } \\
\text { June } 30\end{array}$ & $\begin{array}{l}\text { North Carolina } \\
\text { Kinston } \\
\text { City of } \\
\text { June } 30\end{array}$ & $\begin{array}{l}\text { North Carolina } \\
\text { Lexington } \\
\text { City of } \\
\text { June } 30\end{array}$ & $\begin{array}{l}\text { North Carolina } \\
\text { Lumberton } \\
\text { City of } \\
\text { June } 30\end{array}$ & $\begin{array}{l}\text { North Carolina } \\
\text { Monroe } \\
\text { City of } \\
\text { June } 30\end{array}$ & $\begin{array}{c}\text { North Carolina } \\
\begin{array}{c}\text { Morganton } \\
\text { City of }\end{array} \\
\text { June } 30\end{array}$ \\
\hline \multicolumn{7}{|l|}{ Number of Consumers } \\
\hline Residential & 26,790 & 10,849 & 14,850 & 7,891 & 6,559 & 6,268 \\
\hline 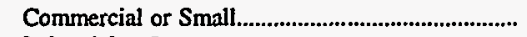 & 4,525 & 1,994 & 2,287 & 1,730 & 1,164 & 1,207 \\
\hline 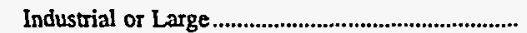 & 336 & 11 & 65 & 0 & 506 & 55 \\
\hline Other. & 2 & 1 & 74 & 1 & 1,215 & 72 \\
\hline 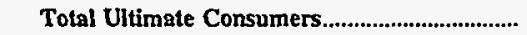 & 31,653 & 12,855 & 17,276 & 9,622 & 9,444 & 7,602 \\
\hline \multicolumn{7}{|l|}{ Sales for the Year (megawatthours) } \\
\hline 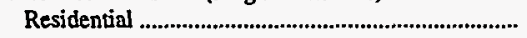 & 301,823 & 138,824 & 191,852 & 86,723 & 78,867 & 68,604 \\
\hline 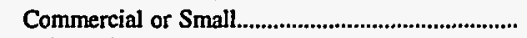 & 415,030 & 166,657 & 134,886 & 169,512 & 21,688 & 53,222 \\
\hline 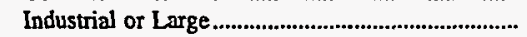 & 121,594 & 142,966 & 116,358 & 0 & 354,853 & 156,257 \\
\hline 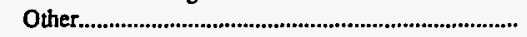 & 14,152 & 6,399 & 3,422 & 2,527 & 2,320 & 18,386 \\
\hline Total to Ultimate Consumers ............................ & 852,599 & 454,846 & 446,518 & 258,762 & 457,728 & 296,469 \\
\hline 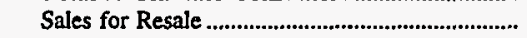 & 0 & 0 & 0 & 0 & 0 & 0 \\
\hline 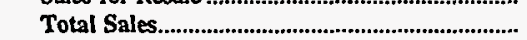 & 852,599 & 454,846 & 446,518 & 258,762 & $\mathbf{4 5 7 , 7 2 8}$ & 296,469 \\
\hline \multicolumn{7}{|l|}{ Oper Revenues for the Year (thouS) } \\
\hline 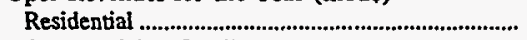 & 28,746 & 13,644 & 17,338 & 7,831 & 7,108 & 5,964 \\
\hline 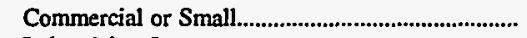 & 28,918 & 14,174 & 10,451 & 13,999 & 2,189 & 4,697 \\
\hline 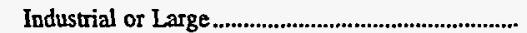 & 7,696 & 8,412 & 6,297 & 0 & 21,074 & 9,364 \\
\hline 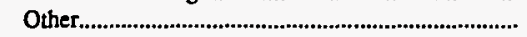 & 4,473 & 667 & 220 & 355 & 302 & 1,143 \\
\hline Total to Ultimate Consumers ............................... & 69,833 & 36,897 & 34,306 & 22,185 & 30,673 & 21,168 \\
\hline 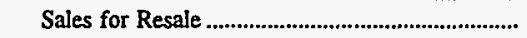 & 0 & 0 & 0 & 0 & 0 & 0 \\
\hline 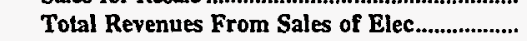 & 69,833 & 36,897 & 34,306 & 22,185 & 30,673 & 21,168 \\
\hline
\end{tabular}

\begin{tabular}{|c|c|c|c|c|c|c|}
\hline Item & $\begin{array}{l}\text { North Carolina } \\
\text { Murphy } \\
\text { City of } \\
\text { June } 30\end{array}$ & $\begin{array}{l}\text { North Carolina } \\
\text { New Bern } \\
\text { City of } \\
\text { June } 30\end{array}$ & $\begin{array}{c}\text { North Carolina } \\
\text { New River } \\
\text { Light } \\
\& \\
\text { Power Co } \\
\text { December } 31\end{array}$ & $\begin{array}{c}\text { North Carolina } \\
\text { North } \\
\text { Carolina } \\
\text { Eastern M P A } \\
\text { December } 31\end{array}$ & $\begin{array}{c}\text { North Carolina } \\
\text { North } \\
\text { Carolina } \\
\text { Mun } \\
\text { Power Agny } \\
\text { December } 31\end{array}$ & $\begin{array}{l}\text { North Carolina } \\
\text { Rocky Mount } \\
\text { City of } \\
\text { June } 30\end{array}$ \\
\hline \multicolumn{7}{|l|}{ Number of Consumers } \\
\hline 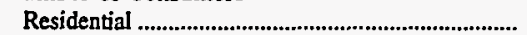 & 2,488 & 13,054 & 5,028 & 0 & 0 & 23,327 \\
\hline 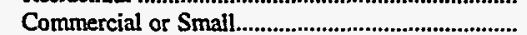 & 1,032 & 2,322 & 1,351 & 0 & 0 & 3,569 \\
\hline Industrial or Large ...................................................... & 83 & 7 & 3 & 0 & 0 & 9 \\
\hline 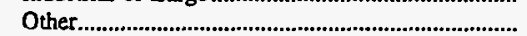 & 4 & $i$ & 233 & 0 & 0 & 119 \\
\hline Total Ultimate Consumers......................................... & 3,607 & 15,384 & 6,615 & 0 & 0 & 27,024 \\
\hline \multicolumn{7}{|l|}{ Sales for the Year (megawatthours) } \\
\hline 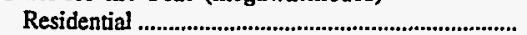 & 34,311 & 185,025 & 45,796 & 0 & 0 & 297,274 \\
\hline Commercial or Small.............................................................. & 15,748 & 168,851 & 80,164 & 0 & 0 & 312,623 \\
\hline Industrial or Large.................................................. & 76,771 & 39,720 & 8,092 & 0 & 0 & 111,313 \\
\hline 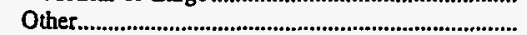 & 1,254 & 3,866 & 44,649 & 0 & 0 & 10,909 \\
\hline Total to Ultimate Consumers.......................... & 128,084 & 397,462 & 178,701 & 0 & $\mathbf{0}$ & 732,119 \\
\hline 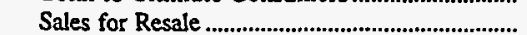 & 0 & 141 & 0 & $6,709,020$ & $6,556,548$ & 20,087 \\
\hline 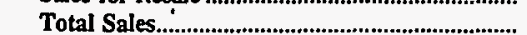 & 128,084 & 397,603 & 178,701 & $6,709,020$ & $6,556,548$ & $\mathbf{7 5 2 , 2 0 6}$ \\
\hline \multicolumn{7}{|l|}{ Oper Revenues for the Year (thous) } \\
\hline 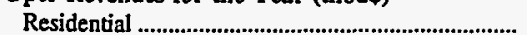 & 2,064 & 18,961 & 3,580 & 0 & 0 & 27,452 \\
\hline Commercial or Small..................................................... & 1,167 & 13,936 & 5,151 & 0 & 0 & 25,964 \\
\hline 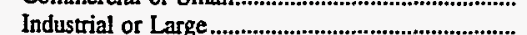 & 3,740 & 3,279 & 500 & 0 & 0 & 7,912 \\
\hline 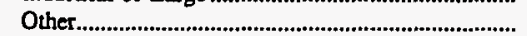 & 125 & 372 & 3,075 & 0 & 0 & 1,234 \\
\hline 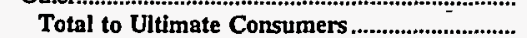 & 7,096 & 36,548 & 12,306 & 0 & $\mathbf{0}$ & 62,562 \\
\hline 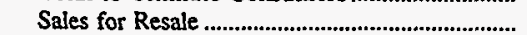 & 0 & 14 & 0 & 460,674 & 375,577 & 1,316 \\
\hline Total Revenues From Sales of Elec................. & 7,096 & 36,562 & 12,306 & 460,674 & 375,577 & 63,878 \\
\hline
\end{tabular}

Note: Totals may not equal sum of components because of independent rounding.

Source: Energy Information Administration, Form EIA-861, "Annual Electric Utility Report" Data are submitted on a calendar year. 
Table 25. Number of Consumers, Sales, and Operating Revenue by Major U.S.

Publicly Owned Electric Utility Within State, 1996 (Continued)

\begin{tabular}{|c|c|c|c|c|c|c|}
\hline Item & $\begin{array}{l}\text { North Carolina } \\
\text { Shelby } \\
\text { City of } \\
\text { June } 30\end{array}$ & $\begin{array}{c}\text { North Carolina } \\
\text { Statesville } \\
\text { City of } \\
\text { June } 30\end{array}$ & $\begin{array}{c}\text { North Carolina } \\
\text { Tarboro } \\
\text { Town of } \\
\text { June } 30\end{array}$ & $\begin{array}{l}\text { North Carolina } \\
\text { Washington } \\
\text { City of } \\
\text { June } 30\end{array}$ & $\begin{array}{l}\text { North Carolina } \\
\text { Wilson } \\
\text { City of } \\
\text { June } 30\end{array}$ & $\begin{array}{c}\text { Ohio } \\
\text { American } \\
\text { Mun } \\
\text { Power } \\
\text { Ohio Inc } \\
\text { December } 31\end{array}$ \\
\hline \multicolumn{7}{|l|}{ Number of Consumers } \\
\hline 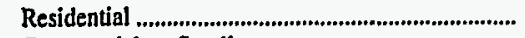 & 6,382 & 9,828 & 5,002 & 9,523 & 28,944 & 0 \\
\hline 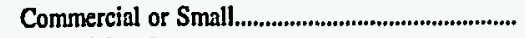 & 1,283 & 2,067 & 689 & 1,835 & 3,720 & 0 \\
\hline Industrial or Large & 11 & 30 & 34 & 35 & 16 & 1 \\
\hline 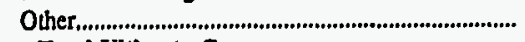 & 1 & 96 & 2 & 0 & 0 & 0 \\
\hline $\begin{array}{l}\text { Total Ultimate Consumers............................. } \\
\text { Sales for the Year (megawatthours) }\end{array}$ & 7,677 & 12,021 & 5,727 & 11,393 & 32,680 & 1 \\
\hline 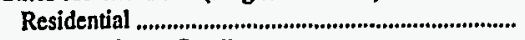 & 73,376 & 85,114 & 55,023 & 109,268 & 336,178 & 0 \\
\hline 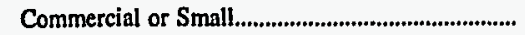 & 96,140 & 173,589 & 42,006 & 55,267 & 270,204 & 0 \\
\hline 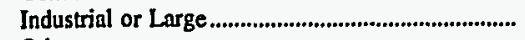 & 3,432 & 102,439 & 147,347 & 79,373 & 434,227 & 797,973 \\
\hline 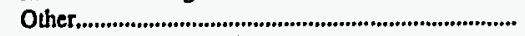 & 378 & 18,495 & 7,091 & 3,115 & 0 & $\mathbf{0}$ \\
\hline 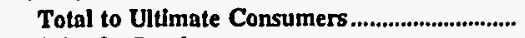 & 173,326 & 379,637 & 251,467 & 247,023 & $1,040,609$ & 797,973 \\
\hline 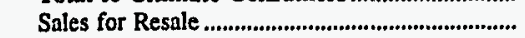 & 0 & $\mathbf{0}$ & 0 & 0 & 63,434 & $4,901,688$ \\
\hline 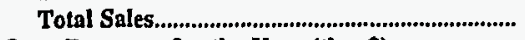 & 173,326 & 379,637 & 251,467 & 247,023 & $1,104,043$ & $5,699,661$ \\
\hline \multicolumn{7}{|l|}{ Oper Revenues for the Year (thou\$) } \\
\hline 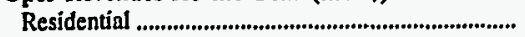 & 6,135 & 6,972 & 6,140 & 11,433 & 32,033 & 0 \\
\hline 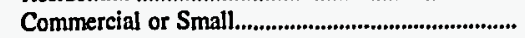 & 6,912 & 11,858 & 4,060 & 5,488 & 23,709 & 0 \\
\hline 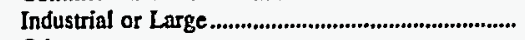 & 259 & 5,816 & 10,635 & 5,984 & 27,050 & 10,546 \\
\hline Other, & 203 & 1,163 & 700 & 365 & 0 & 0 \\
\hline 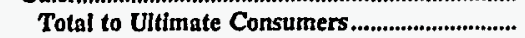 & 13,509 & 25,809 & 21,535 & 23,270 & 82,792 & 10,546 \\
\hline Sales for Resale & & 0 & 0 & $\mathbf{0}$ & 5,112 & 152,941 \\
\hline Total Revenues From Sales of Elec................... & 13,509 & 25,809 & 21,535 & 23,270 & 87,904 & 163,487 \\
\hline
\end{tabular}

\begin{tabular}{|c|c|c|c|c|c|c|}
\hline Item & $\begin{array}{c}\text { Ohio } \\
\text { Bowling } \\
\text { Green } \\
\text { City of } \\
\\
\text { December } 31\end{array}$ & $\begin{array}{c}\text { Ohio } \\
\text { Bryan } \\
\text { City of } \\
\text { December } 31\end{array}$ & $\begin{array}{c}\text { Ohio } \\
\text { Celina } \\
\text { City of } \\
\text { December } 31\end{array}$ & $\begin{array}{c}\text { Ohio } \\
\text { Cleveland } \\
\text { City of } \\
\text { December } 31\end{array}$ & $\begin{array}{l}\text { Ohio } \\
\text { Clyde } \\
\text { City of } \\
\text { December } 31\end{array}$ & $\begin{array}{l}\text { Ohio } \\
\text { Columbus } \\
\text { City of } \\
\text { December } 31\end{array}$ \\
\hline \multicolumn{7}{|l|}{ Number of Consumers } \\
\hline 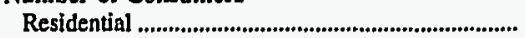 & 9,970 & 4,527 & 6,092 & 62,998 & 2,043 & 8,759 \\
\hline 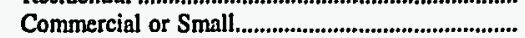 & 1,406 & 546 & 792 & 5,701 & 247 & 2,621 \\
\hline Industrial or Large & 69 & 126 & 16 & 19 & 6 & 385 \\
\hline 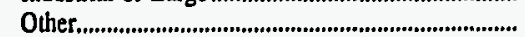 & 25 & 0 & 1 & 1,192 & 0 & 305 \\
\hline Total Ultimate Consumers................................... & 11,470 & 5,199 & 6,901 & 69,910 & 2,296 & 12,070 \\
\hline \multicolumn{7}{|l|}{ Sales for the Year (megawatthours) } \\
\hline 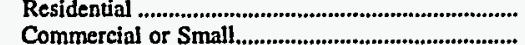 & 47,543 & $\begin{array}{l}43,915 \\
13,928\end{array}$ & $\begin{array}{l}67,521 \\
38,947\end{array}$ & $\begin{array}{l}355,000 \\
411,000\end{array}$ & $\begin{array}{l}16,675 \\
11,040\end{array}$ & $\begin{array}{l}52,776 \\
79,944\end{array}$ \\
\hline 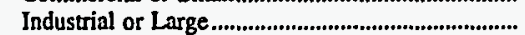 & 196,981 & 191,566 & 56,491 & 411,000 & 113,312 & 504,876 \\
\hline Other. & 2,107 & 0 & 1,179 & 68,000 & 0 & 28,285 \\
\hline Total to Ultimate Consumers ................................ & 320,591 & 249,469 & 164,138 & $1,245,000$ & 141,027 & 665,881 \\
\hline 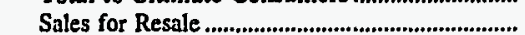 & 2,907 & 1,264 & 0 & 0 & 0 & 86 \\
\hline 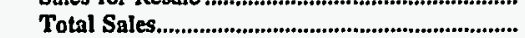 & 323,498 & 250,733 & 164,138 & $1,245,000$ & 141,027 & 665,967 \\
\hline \multicolumn{7}{|l|}{ Oper Revenues for the Year (thous) } \\
\hline 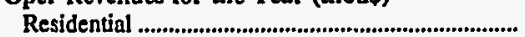 & 5,361 & 2,372 & 3,270 & 32,752 & 1,374 & 4,118 \\
\hline 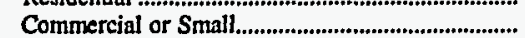 & 2,786 & 950 & 2,080 & 34,440 & 1,078 & 6,525 \\
\hline Industrial or Large & 10,951 & 9,055 & 2,336 & 23,272 & 1,868 & 26,783 \\
\hline Other, & 90 & 0 & 49 & 7,718 & 0 & 2,289 \\
\hline Total to Ultimate Consumers & 19,188 & 12,377 & $\mathbf{7 , 7 3 5}$ & 98,182 & 4,320 & 39,715 \\
\hline 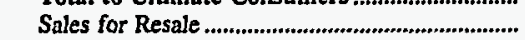 & 150 & 30 & 0 & 0 & 0 & 12 \\
\hline Total Revenues From Sales of Elec................... & 19,338 & 12,407 & 7,735 & 98,182 & 4,320 & 39,727 \\
\hline
\end{tabular}

Note: Totals may not equal sum of components because of independent rounding.

Source: Energy Information Administration, Form EIA-861, "Annual Electric Utility Report" Data are submitted on a calendar year. 
Table 25. Number of Consumers, Sales, and Operating Revenue by Major U.S. Publicly Owned Electric Utility Within State, 1996 (Continued)

\begin{tabular}{|c|c|c|c|c|c|c|}
\hline Item & $\begin{array}{c}\text { Ohio } \\
\text { Cuyahoga } \\
\text { Falls } \\
\text { City of } \\
\text { December } 31\end{array}$ & $\begin{array}{c}\text { Ohio } \\
\text { Dover } \\
\text { City of } \\
\text { December } 31\end{array}$ & $\begin{array}{c}\text { Ohio } \\
\text { Hamilton } \\
\text { City of } \\
\text { December } 31\end{array}$ & $\begin{array}{c}\text { Ohio } \\
\text { Napoleon } \\
\text { City of } \\
\text { December } 31\end{array}$ & $\begin{array}{c}\text { Ohio } \\
\text { Niles } \\
\text { City of } \\
\text { December } 31\end{array}$ & $\begin{array}{l}\text { Ohio } \\
\text { Orrville } \\
\text { City of } \\
\text { December } 31\end{array}$ \\
\hline \multicolumn{7}{|l|}{ Number of Consumers } \\
\hline Residential & 19,733 & 5,321 & 23,979 & 5,962 & 10,461 & 5,428 \\
\hline 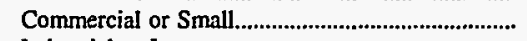 & 1,504 & 773 & 2,799 & 634 & 1,043 & 603 \\
\hline Industrial or Large & 141 & 88 & 49 & 52 & 91 & 18 \\
\hline 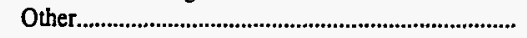 & 200 & 0 & 0 & 48 & 489 & 22 \\
\hline 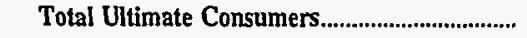 & 21,578 & 6,182 & 26,827 & 6,696 & 12,084 & 6,071 \\
\hline \multicolumn{7}{|l|}{ Sales for the Year (megawatthours) } \\
\hline 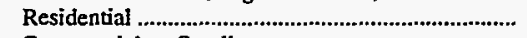 & 137,890 & 48,975 & 215,096 & 42,464 & 80,814 & 67,091 \\
\hline 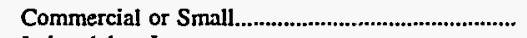 & 43,918 & 23,227 & 191,716 & 19,924 & 87,813 & 54,996 \\
\hline Industrial or Large & 132,667 & 106,859 & 177,688 & 85,271 & 91,686 & 157,683 \\
\hline 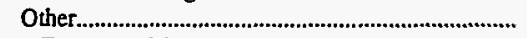 & 9,018 & 0 & 0 & 2,204 & 1,175 & 9,792 \\
\hline 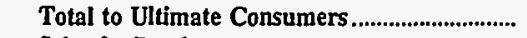 & 323,493 & 179,061 & 584,500 & 149,863 & 261,488 & 289,562 \\
\hline Sales for Resale & 0 & 0 & 165,563 & 0 & 0 & 2,456 \\
\hline 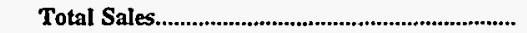 & 323,493 & 179,061 & 750,063 & 149,863 & 261,488 & 292,018 \\
\hline \multicolumn{7}{|l|}{ Oper Revenues for the Year (thou\$) } \\
\hline Residential & 10,188 & 3,343 & 16,027 & 2,880 & 6,548 & 3,919 \\
\hline 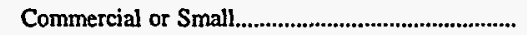 & 3,354 & 1,725 & 14,890 & 1,471 & 5,956 & 3,444 \\
\hline 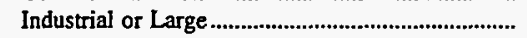 & 7,970 & 5,715 & 8,857 & 4,812 & 5,152 & 7,315 \\
\hline 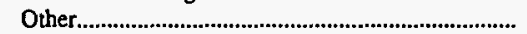 & 758 & 0 & 0 & 66 & 129 & 529 \\
\hline 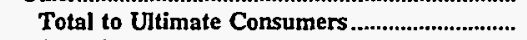 & 22,270 & 10,783 & 39,774 & 9,229 & 17,785 & 15,207 \\
\hline Sales for Resale & 0 & 0 & 3,904 & 0 & 0 & 997 \\
\hline Total Revenues From Sales of Elec..................... & 22,270 & 10,783 & 43,678 & 9,229 & 17,785 & 16,204 \\
\hline
\end{tabular}

\begin{tabular}{|c|c|c|c|c|c|c|}
\hline Item & $\begin{array}{c}\text { Ohio } \\
\text { Painesville } \\
\text { City of } \\
\text { December } 31\end{array}$ & $\begin{array}{c}\text { Ohio } \\
\text { Piqua } \\
\text { City of } \\
\text { December } 31\end{array}$ & $\begin{array}{c}\text { Ohio } \\
\text { St Marys } \\
\text { City of } \\
\text { December } 31\end{array}$ & $\begin{array}{c}\text { Ohio } \\
\text { Wadsworth } \\
\text { City of }\end{array}$ & $\begin{array}{c}\text { Ohio } \\
\text { Wapakoneta } \\
\text { City of } \\
\text { December } 31\end{array}$ & $\begin{array}{c}\text { Ohio } \\
\text { Westerville } \\
\text { City of } \\
\text { December } 31\end{array}$ \\
\hline \multicolumn{7}{|l|}{ Number of Consumers } \\
\hline 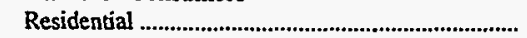 & 8,678 & 8,841 & 3,396 & 8,496 & 4,229 & 11,861 \\
\hline 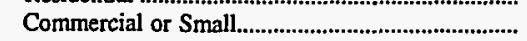 & 1,726 & 1,063 & 481 & 1,090 & 549 & 1,402 \\
\hline 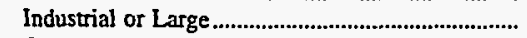 & 1 & 18 & 16 & 137 & 11 & 14 \\
\hline 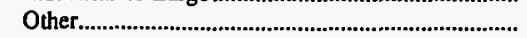 & 0 & 0 & 14 & 0 & 0 & 0 \\
\hline $\begin{array}{l}\text { Total Ultimate Consumers.............................. } \\
\text { Sales for the Year (megat }\end{array}$ & 10,405 & 9,922 & 3,907 & 9,723 & 4,789 & 13,277 \\
\hline 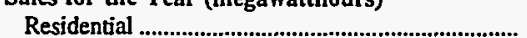 & 64,056 & 76,993 & 31,578 & 79,830 & 43,637 & 163,713 \\
\hline Commercial or Small. & 97,478 & 100,370 & 37,931 & 58,329 & $\begin{array}{l}43,031 \\
65,339\end{array}$ & 143,962 \\
\hline Industrial or Large & 29,902 & 91,909 & 89,696 & 96,214 & 49,942 & 67,317 \\
\hline Other & 0 & 0 & 1,890 & 0 & 0 & 267 \\
\hline 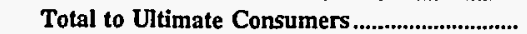 & 191,436 & 269,272 & 161,095 & 234,373 & 158,918 & 375,259 \\
\hline Sales for Resale & 0 & 38 & 8,917 & 0 & 0 & 0 \\
\hline 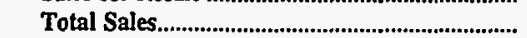 & 191,436 & 269,310 & 170,012 & 234,373 & 158,918 & 375,259 \\
\hline \multicolumn{7}{|l|}{ Oper Revenues for the Year (thou\$) } \\
\hline 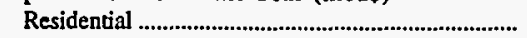 & 5,267 & 4,927 & 1,876 & 5,375 & 2,155 & 9,228 \\
\hline 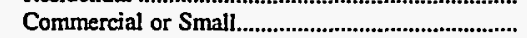 & 7,588 & 5,913 & 1,494 & 3,270 & 3,177 & 7,573 \\
\hline Industrial or Large & 1,413 & 4,602 & 3,420 & 4,283 & 1,958 & 2,645 \\
\hline Other & 0 & 0 & 58 & 0 & 0 & 27 \\
\hline Total to UItimate Consumers & 14,268 & 15,442 & 6,848 & 12,928 & 7,290 & 19,473 \\
\hline 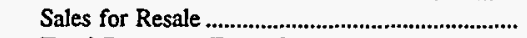 & 0 & 3 & 237 & 0 & 0 & 0 \\
\hline 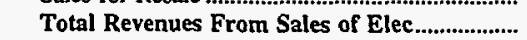 & 14,268 & 15,445 & 7,085 & 12,928 & 7,290 & 19,473 \\
\hline
\end{tabular}

Note: Totals may not equal sum of components because of independent rounding.

Source: Energy Information Administration, Form EIA-861, "Annual Electric Utility Report." Data are submitted on a calendar year. 
Table 25. Number of Consumers, Sales, and Operating Revenue by Major U.S.

Publicly Owned Electric Utility Within State, 1996 (Continued)

\begin{tabular}{|c|c|c|c|c|c|c|}
\hline Item & $\begin{array}{l}\text { Oklahoma } \\
\text { Altus } \\
\text { City of } \\
\text { June } 30\end{array}$ & $\begin{array}{l}\text { Oklahoma } \\
\text { Claremore } \\
\text { City of } \\
\text { June } 30\end{array}$ & $\begin{array}{l}\text { Oklahoma } \\
\text { Duncan } \\
\text { City of } \\
\text { June } 30\end{array}$ & $\begin{array}{l}\text { Oklahoma } \\
\text { Edmord } \\
\text { City of } \\
\text { June } 30\end{array}$ & $\begin{array}{l}\text { Oklahoma } \\
\text { Grand River } \\
\text { Dam } \\
\text { Authority } \\
\text { December } 31\end{array}$ & $\begin{array}{l}\text { OkJahoma } \\
\text { Miami } \\
\text { City of } \\
\text { June } 30\end{array}$ \\
\hline \multicolumn{7}{|l|}{ Number of Consumers } \\
\hline Residential.. & 7,934 & 7,653 & 6,957 & 23,468 & $\mathbf{0}$ & 5,737 \\
\hline 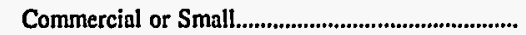 & 1,179 & 987 & 1,138 & 2,158 & 48 & 808 \\
\hline Industrial or Large ............................................................... & 5 & 106 & 46 & 163 & 18 & 165 \\
\hline 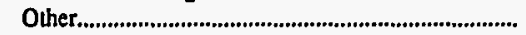 & 1 & 0 & 1 & 119 & 0 & 2 \\
\hline 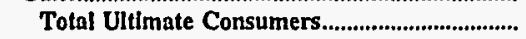 & 9,119 & 8,746 & 8,142 & 25,908 & 66 & 6,712 \\
\hline \multicolumn{7}{|l|}{ Sales for the Year (megawalthours) } \\
\hline 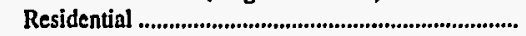 & 75,031 & 84,605 & 75,214 & 300,795 & 0 & 56,019 \\
\hline 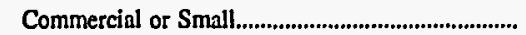 & 70,071 & 22,258 & 44,441 & 57,518 & 32,198 & 12,805 \\
\hline 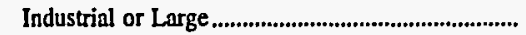 & 12,946 & 105,690 & 34,351 & 100,859 & 669,941 & 71,253 \\
\hline 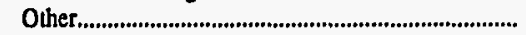 & 1,449 & 0 & 866 & 48,099 & 0 & 9,715 \\
\hline 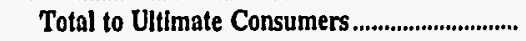 & 159,497 & 212,553 & 154,872 & 507,271 & 702,139 & 149,792 \\
\hline 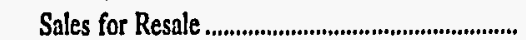 & 0 & 0 & 0 & 0 & $4,610,810$ & 0 \\
\hline Total Sales............................................................................ & 159,497 & 212,553 & 154,872 & 507,271 & $5,312,949$ & 149,792 \\
\hline \multicolumn{7}{|l|}{ Oper Revenues for the Year (thou\$) } \\
\hline 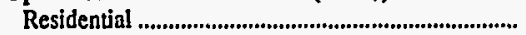 & 5,565 & 6,339 & 4,628 & 19,311 & 0 & 3,281 \\
\hline 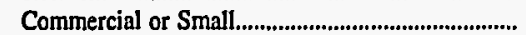 & 4,488 & 1,788 & 2,294 & 3,733 & 1,304 & 742 \\
\hline 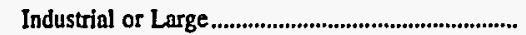 & 635 & 6,099 & 1,121 & 5,497 & 19,733 & 3,594 \\
\hline 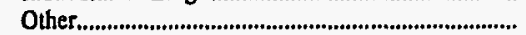 & 81 & 0 & 31 & 3,921 & 0 & 484 \\
\hline 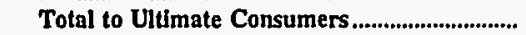 & 10,769 & 14,226 & 8,074 & 32,462 & 21,037 & 8,101 \\
\hline Sales for Resale .................................................... & & & 0 & 0 & 151,728 & \\
\hline Total Revenues From Sales of Elec..................... & 10,769 & 14,226 & 8,074 & 32,462 & 172,765 & 8,101 \\
\hline
\end{tabular}

\begin{tabular}{|c|c|c|c|c|c|c|}
\hline Item & $\begin{array}{c}\text { Oklahoma } \\
\text { Oklahoma } \\
\text { Municipal } \\
\text { Power Auth } \\
\text { December } 31\end{array}$ & $\begin{array}{l}\text { Oklahoma } \\
\text { Ponca } \\
\text { City City of } \\
\text { June } 30\end{array}$ & $\begin{array}{l}\text { Oklahoma } \\
\text { Stillwater } \\
\text { Utilities } \\
\text { Authority } \\
\text { June } 30\end{array}$ & $\begin{array}{l}\text { Oregon } \\
\begin{array}{l}\text { Ashland } \\
\text { City of }\end{array} \\
\text { June } 30\end{array}$ & $\begin{array}{c}\text { Oregon } \\
\text { Central } \\
\text { Lincoln } \\
\text { Peoples } \\
\text { Utl Dt } \\
\text { December } 31\end{array}$ & $\begin{array}{c}\text { Oregon } \\
\text { Clatskanie } \\
\text { Peoples } \\
\text { Util Dist } \\
\text { December } 31\end{array}$ \\
\hline \multicolumn{7}{|l|}{ Number of Consumers } \\
\hline Residential ....................... & 0 & 13,748 & 14,138 & 7,632 & 27,661 & 2,931 \\
\hline 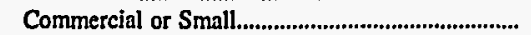 & 0 & 1,714 & 1,498 & 1,133 & 4,447 & 386 \\
\hline 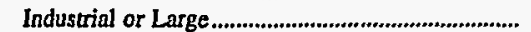 & 0 & 5 & 6 & $\mathbf{0}$ & 122 & 2 \\
\hline 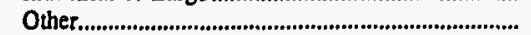 & 0 & 122 & 0 & 77 & 25 & i \\
\hline 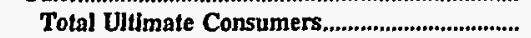 & 0 & 15,589 & 15,642 & 8,842 & 32,255 & 3,320 \\
\hline \multicolumn{7}{|l|}{ Sales for the Year (megawatthours) } \\
\hline 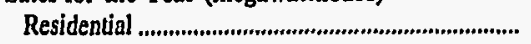 & 0 & 133,404 & 145,273 & 77,627 & 383,032 & 56,112 \\
\hline 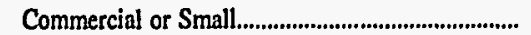 & 0 & 130,777 & 125,934 & 67,560 & 199,452 & 23,081 \\
\hline 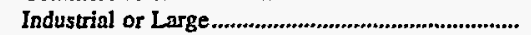 & 0 & 40,062 & 143,106 & 0 & 668,617 & 796,402 \\
\hline 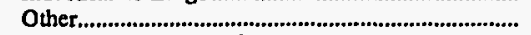 & 0 & 17,360 & & 3,555 & 3,597 & 141 \\
\hline Total to Ultimate Consumers ........................................ & o & 321,603 & 414,313 & 148,742 & $1,254,698$ & 875,736 \\
\hline 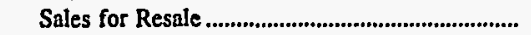 & $1,916,150$ & 0 & 0 & 0 & 0 & 0 \\
\hline 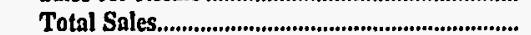 & $1,916,150$ & 321,603 & 414,313 & 148,742 & $1,254,698$ & 875,736 \\
\hline \multicolumn{7}{|l|}{ Oper Revenues for the Year (thous) } \\
\hline 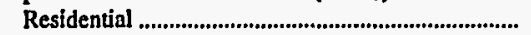 & 0 & 10,092 & 10,087 & 3,720 & 20,528 & 2,142 \\
\hline 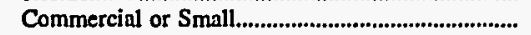 & $\mathbf{0}$ & 8,326 & 7,746 & 3,428 & 9,856 & 1,105 \\
\hline 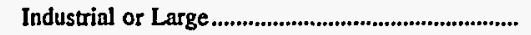 & 0 & 1,809 & 6,249 & 0 & 22,831 & 23,312 \\
\hline 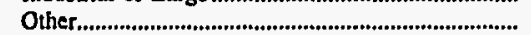 & $\mathbf{0}$ & 919 & 0 & 205 & 638 & \\
\hline 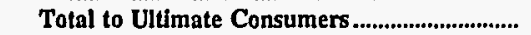 & $\mathbf{0}$ & 21,146 & 24,082 & 7,353 & 53,853 & 26,562 \\
\hline Sales for Resale .............................................................. & 76,990 & 0 & 0 & 0 & 0 & 0 \\
\hline Total Revenues From Sales of Elec................... & $\mathbf{7 6 , 9 9 0}$ & 21,146 & 24,082 & 7,353 & 53,853 & 26,562 \\
\hline
\end{tabular}

Note: Totals may not equal sum of components because of independent rounding.

Source: Energy Information Administration, Form EIA-861, "Annual Electric Utility Report." Data are submitted on a calendar year. 
Table 25. Number of Consumers, Sales, and Operating Revenue by Major U.S.

Publicly Owned Electric Utility Within State, 1996 (Continued)

\begin{tabular}{|c|c|c|c|c|c|c|}
\hline Item & $\begin{array}{l}\text { Oregon } \\
\text { Columbia } \\
\text { River } \\
\text { Peoples } \\
\text { Ut Dist } \\
\text { December } 31\end{array}$ & $\begin{array}{l}\text { Oregon } \\
\text { Emerald } \\
\text { Peoples } \\
\text { Utility Dist } \\
\text { December } 31\end{array}$ & $\begin{array}{l}\text { Oregon } \\
\text { Eugene } \\
\text { City of } \\
\text { December } 31\end{array}$ & $\begin{array}{c}\text { Oregon } \\
\text { Forest Grove } \\
\text { City of } \\
\text { June } 30\end{array}$ & $\begin{array}{c}\text { Oregon } \\
\begin{array}{c}\text { McMinnville } \\
\text { City of }\end{array} \\
\text { June } 30\end{array}$ & $\begin{array}{c}\text { Oregon } \\
\text { Northern } \\
\text { Wasco } \\
\text { County PUD } \\
\text { December } 31\end{array}$ \\
\hline \multicolumn{7}{|l|}{ Number of Consumers } \\
\hline Residential ....................... & 7,280 & 14,067 & 64,725 & 6,249 & 9,959 & 7,493 \\
\hline 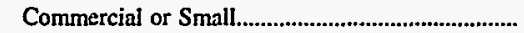 & 673 & 1,487 & 8,076 & 755 & 2,595 & 1,187 \\
\hline 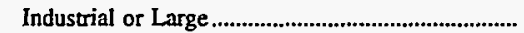 & 8 & 8 & 1 & 104 & 2 & 150 \\
\hline 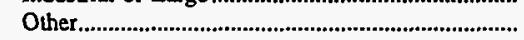 & 489 & 634 & 11 & 355 & 1 & 38 \\
\hline 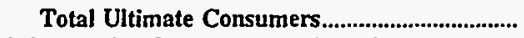 & 8,450 & 16,196 & $\mathbf{7 2 , 8 1 3}$ & 7,463 & 12,557 & 8,868 \\
\hline \multicolumn{7}{|l|}{ Sales for the Year (megawatthours) } \\
\hline 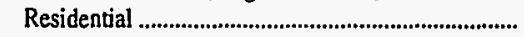 & 110,702 & 226,144 & 993,949 & 101,390 & 171,516 & 120,209 \\
\hline 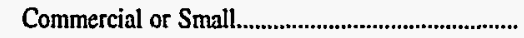 & 27,111 & 78,714 & $1,007,304$ & 41,961 & 153,002 & 29,132 \\
\hline 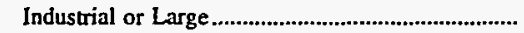 & 147,287 & 90,658 & 445,923 & 79,946 & 348,429 & 106,896 \\
\hline Other & 1,347 & 6,800 & 21,668 & 1,539 & 1,424 & 1,680 \\
\hline Total to Ultimate Consumers ................................. & 286,447 & 402,316 & $2,468,844$ & 224,836 & 674,371 & 257,917 \\
\hline 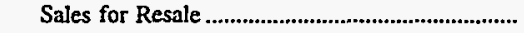 & 0 & 0 & 174,023 & 0 & 0 & 40,787 \\
\hline 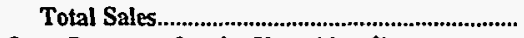 & 286,447 & 402,316 & $2,642,867$ & 224,836 & 674,371 & 298,704 \\
\hline \multicolumn{7}{|l|}{ Oper Revenues for the Year (thou\$) } \\
\hline 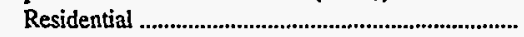 & 5,644 & 11,469 & 43,995 & 4,126 & 5,979 & 5,653 \\
\hline 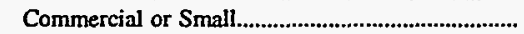 & 1,541 & 4,534 & 39,347 & 1,547 & 6,480 & 1,485 \\
\hline 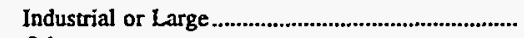 & 5,892 & 4,104 & 12,874 & 2,582 & 10,829 & 4,032 \\
\hline Other & 127 & 2,743 & 794 & 102 & 48 & 253 \\
\hline 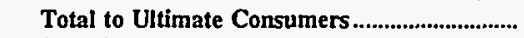 & 13,204 & 22,850 & 97,010 & 8,357 & 23,336 & 11,423 \\
\hline 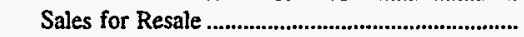 & 0 & 0 & 3,912 & 0 & 0 & 1,925 \\
\hline 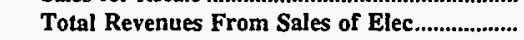 & 13,204 & 22,850 & 100,922 & 8,357 & 23,336 & 13,348 \\
\hline
\end{tabular}

\begin{tabular}{|c|c|c|c|c|c|c|}
\hline Item & $\begin{array}{l}\text { Oregon } \\
\text { Springfield } \\
\text { City of } \\
\text { December } 31\end{array}$ & $\begin{array}{c}\text { Oregon } \\
\text { Tillamook } \\
\text { Peoples } \\
\text { Utility Dist } \\
\text { December } 31\end{array}$ & $\begin{array}{l}\text { Pennsylvania } \\
\text { Chambersburg } \\
\text { Borough of } \\
\text { December } 31\end{array}$ & $\begin{array}{l}\text { Pennsylvania } \\
\text { Ephrata } \\
\text { Borough of } \\
\text { December } 31\end{array}$ & $\begin{array}{l}\text { Pennsylvania } \\
\text { Lansdale } \\
\text { Borough of } \\
\text { December } 31\end{array}$ & $\begin{array}{l}\text { South Carolina } \\
\text { Camden } \\
\text { City of } \\
\text { June } 30\end{array}$ \\
\hline \multicolumn{7}{|l|}{ Number of Consumers } \\
\hline 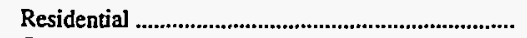 & 23,506 & 14,725 & 8,557 & 5,552 & 6,508 & 9,825 \\
\hline 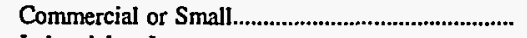 & 1,926 & 1,791 & 1,590 & 731 & 1,281 & 3,358 \\
\hline 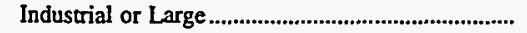 & 148 & 3 & 17 & 17 & 30 & 0 \\
\hline 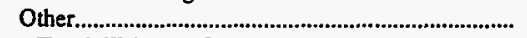 & 240 & 61 & 67 & 0 & 1 & 0 \\
\hline \multicolumn{7}{|l|}{ Sales for the Year (megawatthours) } \\
\hline 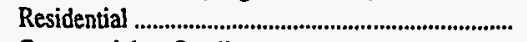 & 356,279 & 198,998 & 69,088 & 60,932 & 38,001 & 94,080 \\
\hline 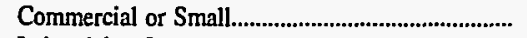 & 147,625 & 114,498 & 86,198 & 53,417 & 31,391 & 62,700 \\
\hline Industrial or Large & 329,176 & 89,545 & 93,214 & 13,259 & 54,893 & 0 \\
\hline 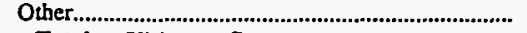 & 27,649 & 3,874 & 2,198 & 0 & 2,160 & 0 \\
\hline Total to Ultimate Consumers................................. & 860,729 & 406,915 & 250,698 & 127,608 & 126,445 & 156,780 \\
\hline Sales for Resale & 0 & 0 & 0 & 0 & 0 & 0 \\
\hline 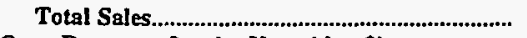 & 860,729 & 406,915 & 250,698 & 127,608 & 126,445 & 156,780 \\
\hline \multicolumn{7}{|l|}{ Oper Revenues for the Year (thous) } \\
\hline 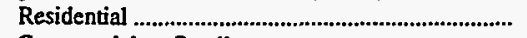 & 15,506 & 10,982 & 4,800 & 4,271 & 3,242 & 8,300 \\
\hline Commercial or Small & 5,853 & 5,137 & 5,509 & 3,535 & 3,139 & 2,800 \\
\hline 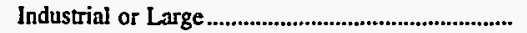 & 9,530 & 2,471 & 4,414 & 793 & 3,623 & $\mathbf{0}$ \\
\hline 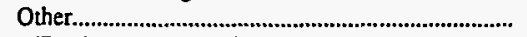 & 1,203 & 259 & 156 & 0 & 84 & 0 \\
\hline 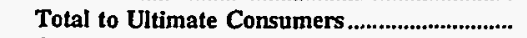 & 32,092 & 18,849 & 14,879 & 8,599 & 10,088 & 11,100 \\
\hline Sales for Resale & 0 & 0 & 0 & 0 & 0 & 0 \\
\hline 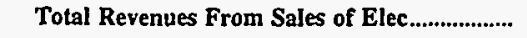 & 32,092 & 18,849 & 14,879 & 8,599 & 10,088 & 11,100 \\
\hline
\end{tabular}

Note: Totals may not equal sum of components because of independentrounding.

Source: Energy Information Administration, Form EIA-861, “Annual Electric Utility Report.” Data are submitted on a calendar year. 
Table 25. Number of Consumers, Sales, and Operating Revenue by Major U.S. Publicly Owned Electric Utility Within State, 1996 (Continued)

\begin{tabular}{|c|c|c|c|c|c|c|}
\hline Item & $\begin{array}{l}\text { South Carolina } \\
\text { Easley } \\
\text { Combined } \\
\text { Utility } \\
\text { System } \\
\text { March } 31\end{array}$ & $\begin{array}{l}\text { South Carolina } \\
\text { Gaffney } \\
\text { City of } \\
\text { March } 31\end{array}$ & $\begin{array}{l}\text { South Carolina } \\
\text { Greenwood } \\
\text { Commissioners } \\
\text { Pub Wk } \\
\text { December } 31\end{array}$ & $\begin{array}{c}\text { South Carolina } \\
\text { Greer } \\
\text { Comm } \\
\text { of } \\
\text { Public Works } \\
\text { December } 31\end{array}$ & $\begin{array}{l}\text { South Carolina } \\
\text { Newberry } \\
\text { City of } \\
\text { June } 30\end{array}$ & $\begin{array}{l}\text { South Carolina } \\
\text { Orangeburg } \\
\text { City of } \\
\text { September } 30\end{array}$ \\
\hline \multicolumn{7}{|l|}{ Number of Consumers } \\
\hline 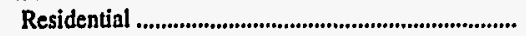 & 9,367 & 6,100 & 10,241 & 7,644 & 3,883 & 18,926 \\
\hline 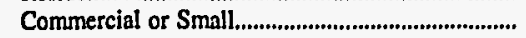 & 1,402 & 955 & 1,640 & 1,230 & 808 & 2,935 \\
\hline Industrial or Large .............................................................. & 0 & 23 & 231 & 0 & 13 & 112 \\
\hline 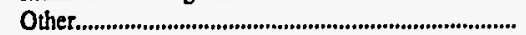 & 0 & 3,910 & 3 & 1 & 0 & 1 \\
\hline \multirow{2}{*}{\multicolumn{7}{|c|}{ Sales for the Year (megawatthours) }} \\
\hline & & & & & & \\
\hline 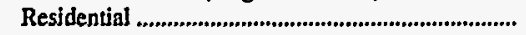 & 132,438 & 69,674 & 101,434 & 96,728 & 42,914 & 274,939 \\
\hline 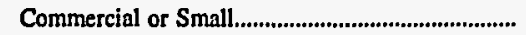 & 89,561 & 72,725 & 25,052 & 80,565 & 52,343 & 136,270 \\
\hline 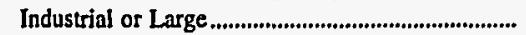 & 0 & 37,113 & 116,267 & 0 & 46,995 & 364,467 \\
\hline 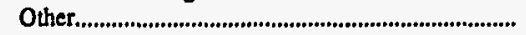 & 0 & 3,266 & 3,785 & 1,613 & $\mathbf{0}$ & 1,896 \\
\hline 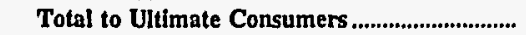 & 221,999 & 182,778 & 246,538 & 178,906 & 142,252 & $\mathbf{7 7 7 , 5 7 2}$ \\
\hline 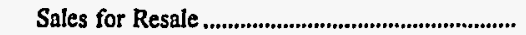 & & 0 & & 0 & 0 & \\
\hline Total Sales..................................................................... & 221,999 & 182,778 & 246,538 & 178,906 & 142,252 & 777,572 \\
\hline \multicolumn{7}{|l|}{ Oper Revenues for the Year (thou\$) } \\
\hline 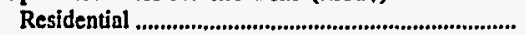 & 10,445 & 5,415 & 6,690 & 7,431 & 3,578 & 16,822 \\
\hline 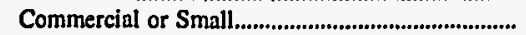 & 6,148 & 5,653 & 1,852 & 4,906 & 3,944 & 8,887 \\
\hline 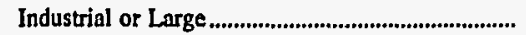 & 0 & 2,327 & 6,373 & 0 & 2,849 & 15,886 \\
\hline 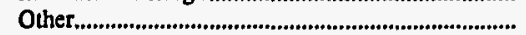 & 0 & 420 & 244 & 100 & 0 & 157 \\
\hline 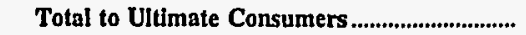 & 16,593 & 13,815 & 15,159 & 12,437 & 10,371 & 41,752 \\
\hline 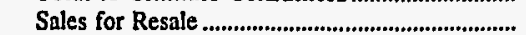 & 0 & 0 & 0 & 0 & 0 & 0 \\
\hline Total Revenues From Sales of Elec.................. & 16,593 & 13,815 & 15,159 & 12,437 & 10,371 & 41,752 \\
\hline
\end{tabular}

\begin{tabular}{|c|c|c|c|c|c|c|}
\hline Item & $\begin{array}{c}\text { South Carolina } \\
\text { Piedmont } \\
\text { Municipal } \\
\text { Power Agny } \\
\text { December } 31\end{array}$ & $\begin{array}{l}\text { South Carolina } \\
\text { Rock Hill } \\
\text { City of } \\
\text { December } 31\end{array}$ & $\begin{array}{l}\text { South Carolina } \\
\text { Seneca } \\
\text { City of } \\
\text { June } 30\end{array}$ & $\begin{array}{l}\text { South Carolina } \\
\text { South } \\
\text { Carolina } \\
\text { Pub } \\
\text { Serv Auth } \\
\text { December } 31\end{array}$ & $\begin{array}{l}\text { South Dakota } \\
\text { Brookings } \\
\text { City of } \\
\text { December } 31\end{array}$ & $\begin{array}{l}\text { South Dakota } \\
\text { Hearland } \\
\text { Consumers } \\
\text { Power Dist } \\
\text { December } 31\end{array}$ \\
\hline \multicolumn{7}{|l|}{ Number of Consumers } \\
\hline Residential. & 0 & 19,700 & 4,488 & 88,202 & 6,569 & 0 \\
\hline Commercial or Small.... & 0 & 2,726 & 816 & 17,711 & 919 & 0 \\
\hline 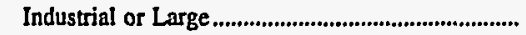 & 0 & 8 & 3 & 35 & 36 & 0 \\
\hline 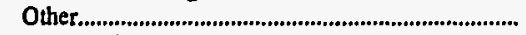 & 0 & 0 & 1 & 519 & 89 & 0 \\
\hline \multirow{2}{*}{\multicolumn{7}{|c|}{ Sales for the Year (megawatthours) }} \\
\hline & & & & & & \\
\hline 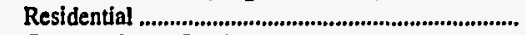 & 0 & 228,658 & 52,505 & $1,193,126$ & 66,457 & 0 \\
\hline Commercial or Smalj.. & 0 & 276,126 & 48,859 & $1,367,414$ & 38,499 & 0 \\
\hline 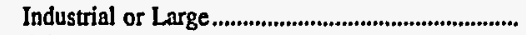 & 0 & 41,758 & 36,098 & $5,590,119$ & 74,337 & $\mathbf{0}$ \\
\hline 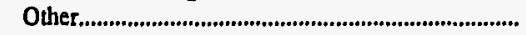 & 0 & $\mathbf{0}$ & 1,326 & 53,409 & 12,818 & 0 \\
\hline Total to Ultimate Consumers................................... & $\mathbf{0}$ & 546,542 & 138,788 & $8,204,068$ & 192,111 & o \\
\hline 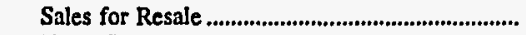 & $2,481,570$ & 0 & $\mathbf{0}$ & $9,339,589$ & $\mathbf{0}$ & 484,945 \\
\hline Total Sales... & $2,481,570$ & 546,542 & 138,788 & $17,543,657$ & 192,111 & 484,945 \\
\hline \multicolumn{7}{|l|}{ Oper Revenues for the Year (thou\$) } \\
\hline Residential ............ & 0 & 18,955 & 3,614 & 76,995 & 2,861 & 0 \\
\hline 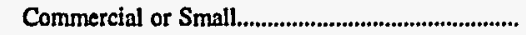 & 0 & 21,869 & 3,873 & 77,515 & $1,96 !$ & 0 \\
\hline 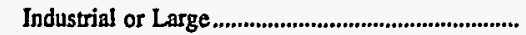 & 0 & 2,524 & 1,662 & 177,583 & 3,009 & 0 \\
\hline 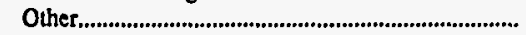 & 0 & 0 & 97 & 2,974 & 693 & 0 \\
\hline 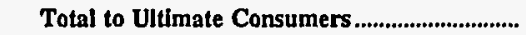 & $\mathbf{0}$ & 43,348 & 9,246 & 335,067 & 8,524 & o \\
\hline 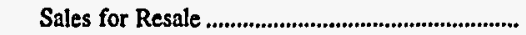 & 140,908 & 0 & 0 & 355,227 & & 12,562 \\
\hline Total Revenues From Sales of Elec..................... & 140,908 & 43,348 & 9,246 & 690,294 & 8,524 & 12,562 \\
\hline
\end{tabular}

Note: Totals may not equal sum of components because of independent rounding.

Source: Energy Information Administration, Form EIA-861, “Annual Electric Utility Report" Data are submitted on a calendar year. 
Table 25. Number of Consumers, Sales, and Operating Revenue by Major U.S. Publicly Owned Electric Utility Within State, 1996 (Continued)

\begin{tabular}{|c|c|c|c|c|c|c|}
\hline Item & $\begin{array}{l}\text { South Dakota } \\
\text { Missouri } \\
\text { Basin } \\
\text { Mun } \\
\text { Power Agny } \\
\text { December 31 }\end{array}$ & $\begin{array}{c}\text { South Dakota } \\
\text { Pierre } \\
\text { City of } \\
\text { December } 31\end{array}$ & $\begin{array}{l}\text { South Dakota } \\
\text { Watertown } \\
\text { Municipal } \\
\text { Utilities } \\
\text { December } 31\end{array}$ & $\begin{array}{c}\text { Tennessee } \\
\text { Alcoa } \\
\text { Utilities } \\
\text { June } 30\end{array}$ & $\begin{array}{l}\text { Tennessee } \\
\text { Athens } \\
\text { Utility } \\
\text { Board } \\
\\
\text { June } 30\end{array}$ & $\begin{array}{l}\text { Tennessee } \\
\text { Benton } \\
\text { County } \\
\text { June } 30\end{array}$ \\
\hline \multicolumn{7}{|l|}{ Number of Consumers } \\
\hline 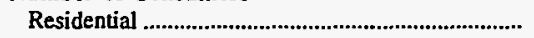 & 0 & 5,883 & 8,686 & 18,624 & 9,657 & 7,788 \\
\hline 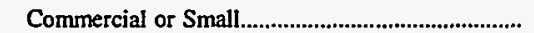 & 0 & 672 & 1,388 & 2,649 & 1,799 & 1,390 \\
\hline Industrial or Large & 0 & 87 & 268 & 222 & 229 & 91 \\
\hline 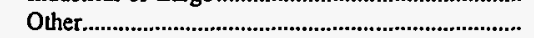 & 0 & 83 & 919 & 38 & 112 & 124 \\
\hline 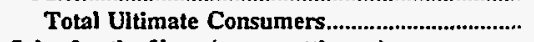 & 0 & 6,725 & 11,261 & 21,533 & 11,797 & 9,393 \\
\hline \multicolumn{7}{|l|}{ Sales for the Year (megawatthours) } \\
\hline 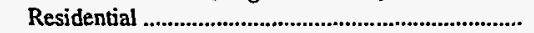 & 0 & 80,135 & 92,945 & 301,676 & 146,530 & 109,255 \\
\hline 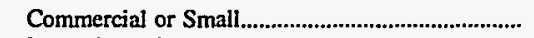 & 0 & 20,437 & 26,664 & 37,897 & 30,458 & 17,776 \\
\hline 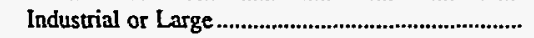 & 0 & 39,989 & 125,764 & 126,973 & 383,791 & 88,691 \\
\hline 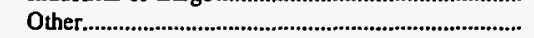 & 0 & 10,150 & 3,109 & 6,842 & 6,141 & 4,380 \\
\hline 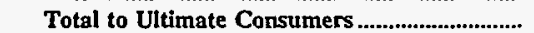 & 0 & 150,711 & 248,482 & 473,388 & 566,920 & 220,102 \\
\hline Sales for Resale & $1,978,368$ & 14,923 & 0 & 0 & 0 & 0 \\
\hline 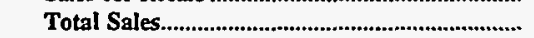 & $1,978,368$ & 165,634 & 248,482 & 473,388 & 566,920 & 220,102 \\
\hline \multicolumn{7}{|l|}{ Oper Revenues for the Year (thou\$) } \\
\hline 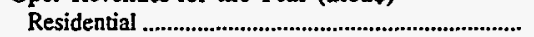 & 0 & 3,376 & 3,596 & 17,308 & 8,459 & 6,652 \\
\hline 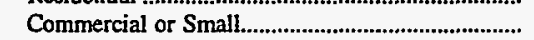 & 0 & 949 & 1,434 & 2,542 & 2,030 & 1,267 \\
\hline 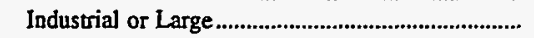 & 0 & 1,972 & 4,821 & 6,858 & 16,080 & 4,468 \\
\hline 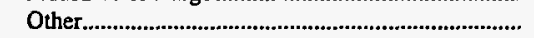 & 0 & 426 & 251 & 562 & 548 & 386 \\
\hline 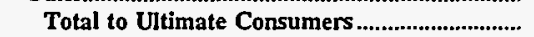 & 0 & 6,723 & 10,102 & 27,270 & 27,117 & 12,773 \\
\hline Sales for Resale & 61,786 & 314 & 0 & 0 & 0 & 0 \\
\hline Total Revenues From Sales of Elec..................... & 61,786 & 7,037 & 10,102 & 27,270 & 27,117 & 12,773 \\
\hline
\end{tabular}

\begin{tabular}{|c|c|c|c|c|c|c|}
\hline Item & $\begin{array}{l}\text { Tennessee } \\
\text { Bolivar } \\
\text { City of } \\
\text { June } 30\end{array}$ & $\begin{array}{l}\text { Tennessee } \\
\text { Bristol } \\
\text { City of } \\
\text { June } 30\end{array}$ & $\begin{array}{c}\text { Tennessee } \\
\begin{array}{c}\text { Brownsville } \\
\text { City of }\end{array} \\
\text { June } 30\end{array}$ & $\begin{array}{l}\text { Tennessee } \\
\text { Carroll } \\
\text { County } \\
\text { June } 30\end{array}$ & $\begin{array}{c}\text { Tennessee } \\
\text { Chattanooga } \\
\text { City of } \\
\text { June } 30\end{array}$ & $\begin{array}{l}\text { Tennessee } \\
\text { Clarksville } \\
\text { City of } \\
\text { June } 30\end{array}$ \\
\hline \multicolumn{7}{|l|}{ Number of Consumers } \\
\hline 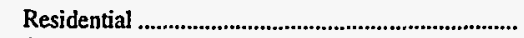 & 8,659 & 25,383 & 4,176 & 12,003 & 130,974 & 32,805 \\
\hline Commercial or Small & 1,709 & 3,048 & 753 & 2,437 & 15,693 & 3,849 \\
\hline Industrial or Large & 100 & 500 & 90 & 203 & 2,784 & 527 \\
\hline 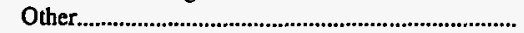 & 22 & 180 & 31 & 122 & 148 & 345 \\
\hline 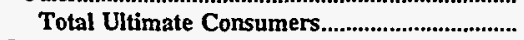 & 10,490 & 29,111 & 5,050 & 14,765 & 149,599 & 37,526 \\
\hline \multicolumn{7}{|l|}{ Sales for the Year (megawatthours) } \\
\hline 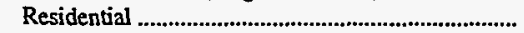 & 131,533 & 441,725 & 59,266 & 189,445 & $2,201,393$ & 521,628 \\
\hline 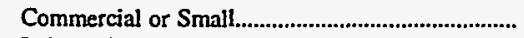 & 20,665 & 51,811 & 12,518 & 27,974 & 336,789 & 84,759 \\
\hline 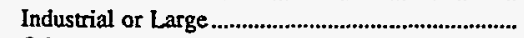 & 70,543 & 366,151 & 122,160 & 176,070 & $3,134,070$ & 354,158 \\
\hline Other. & 4,008 & 8,427 & 2,194 & 7,574 & 56,945 & 12,292 \\
\hline Total to Ultimate Consumers ................................. & 226,749 & 868,114 & 196,138 & 401,063 & $5,729,197$ & 972,837 \\
\hline 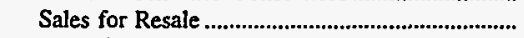 & 0 & 0 & 0 & 0 & 0 & 0 \\
\hline 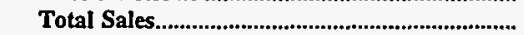 & 226,749 & 868,114 & 196,138 & 401,063 & $5,729,197$ & 972,837 \\
\hline \multicolumn{7}{|l|}{ Oper Revenues for the Year (thou\$) } \\
\hline 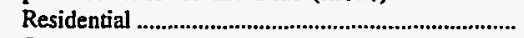 & 7,934 & 23,882 & 3,290 & 11,113 & 129,022 & 30,029 \\
\hline 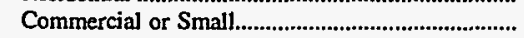 & 1,485 & 3,198 & 778 & 2,014 & 21,974 & 5,446 \\
\hline 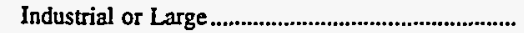 & 3,922 & 16,565 & 5,689 & 8,981 & 148,446 & 18,475 \\
\hline 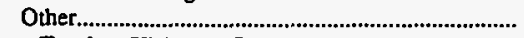 & 417 & 731 & 165 & 552 & 4,236 & 776 \\
\hline 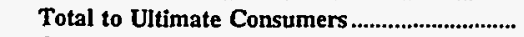 & 13,758 & 44,376 & 9,922 & 22,660 & 303,678 & 54,726 \\
\hline Sales for Resale & 0 & 0 & 0 & 0 & 0 & 0 \\
\hline Total Revenues From Sales of Elec................... & 13,758 & 44,376 & 9,922 & 22,660 & 303,678 & 54,726 \\
\hline
\end{tabular}

Note: Totals may not equal sum of components because of independent rounding.

Source: Energy Information Administration, Form EIA-861, "Annual Electric Utility Report." Data are submitted on a calendar year. 
Table 25. Number of Consumers, Sales, and Operating Revenue by Major U.S. Publicly Owned Electric Utility Within State, 1996 (Continued)

\begin{tabular}{|c|c|c|c|c|c|c|}
\hline Item & $\begin{array}{l}\text { Tennessee } \\
\text { Cleveland } \\
\text { City of } \\
\text { June } 30\end{array}$ & $\begin{array}{l}\text { Tennessee } \\
\text { Clinton } \\
\text { City of } \\
\text { June } 30\end{array}$ & $\begin{array}{c}\text { Tennessee } \\
\text { Columbia } \\
\text { City of } \\
\text { June } 30\end{array}$ & $\begin{array}{c}\text { Tennessee } \\
\text { Cookeville } \\
\text { City of } \\
\text { June } 30\end{array}$ & $\begin{array}{l}\text { Tennessee } \\
\text { Covington } \\
\text { City of } \\
\text { June } 30\end{array}$ & $\begin{array}{l}\text { Tennessee } \\
\text { Dayton } \\
\text { City of } \\
\text { June } 30\end{array}$ \\
\hline \multicolumn{7}{|l|}{ Number of Consumers } \\
\hline 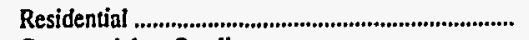 & 21,382 & 23,083 & 17,401 & 9,764 & 3,146 & 6,538 \\
\hline 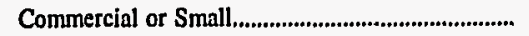 & 2,853 & 2,270 & 2,717 & 2,393 & 841 & 1,424 \\
\hline 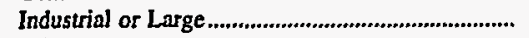 & 519 & 268 & 319 & 370 & 110 & 105 \\
\hline 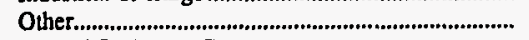 & 69 & 150 & 29 & 70 & 43 & 19 \\
\hline $\begin{array}{l}\text { Total Ultimate Consumers......................................... } \\
\text { Sales for the Year (megawatthours) }\end{array}$ & \multicolumn{5}{|c|}{ Sales for the Year (megawatthours) } & 8,086 \\
\hline 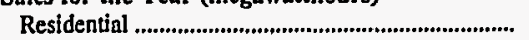 & 358,654 & 383,021 & 271,832 & 140,527 & 44,164 & 86,324 \\
\hline 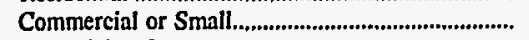 & 59,655 & 37,132 & 53,655 & 50,586 & 14,863 & 17,975 \\
\hline 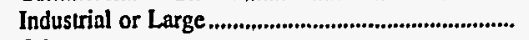 & 526,117 & 262,618 & 193,800 & 305,225 & 170,213 & 95,974 \\
\hline 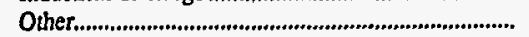 & 7,982 & 7,805 & 7,628 & 7,820 & 2,418 & 2,724 \\
\hline 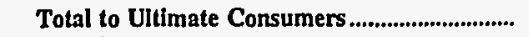 & 952,408 & 690,576 & 526,915 & 504,158 & 231,658 & 202,997 \\
\hline 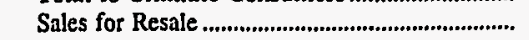 & 0 & 0 & 0 & 0 & 0 & 0 \\
\hline 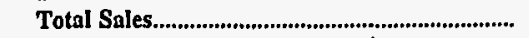 & 952,408 & 690,576 & 526,915 & 504,158 & 231,658 & 202,997 \\
\hline \multicolumn{7}{|l|}{ Oper Revenues for the Year (thou\$) } \\
\hline 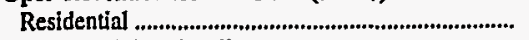 & 20,461 & 22,322 & 15,482 & 8,397 & 2,591 & 5,080 \\
\hline 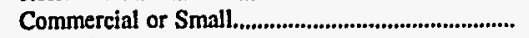 & 3,872 & 2,528 & 3,633 & 3,353 & 1,000 & 1,228 \\
\hline 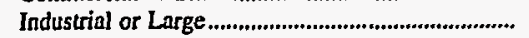 & 24,886 & 13,071 & 10,147 & 16,040 & 8,407 & 5,019 \\
\hline 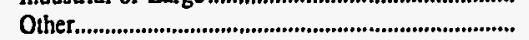 & 630 & 708 & 526 & 490 & 189 & 212 \\
\hline 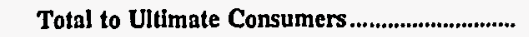 & 49,849 & 38,629 & 29,788 & 28,280 & 12,187 & 11,539 \\
\hline 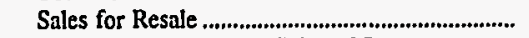 & 0 & 0 & 0 & 0 & 0 & \\
\hline Total Revenues From Sales of Elec................... & 49,849 & 38,629 & 29,788 & 28,280 & 12,187 & 11,539 \\
\hline
\end{tabular}

\begin{tabular}{|c|c|c|c|c|c|c|}
\hline Item & $\begin{array}{l}\text { Tennessee } \\
\text { Dickson } \\
\text { City of } \\
\text { June } 30\end{array}$ & $\begin{array}{l}\text { Tennessee } \\
\text { Dyersburg } \\
\text { City of } \\
\text { June } 30\end{array}$ & $\begin{array}{l}\text { Tennessee } \\
\text { Elizabethton } \\
\text { City of } \\
\text { June } 30\end{array}$ & $\begin{array}{l}\text { Tennessee } \\
\text { Enwin } \\
\text { Town of } \\
\text { June } 30\end{array}$ & $\begin{array}{l}\text { Tennessee } \\
\begin{array}{l}\text { Etowah } \\
\text { City of }\end{array} \\
\text { June } 30\end{array}$ & 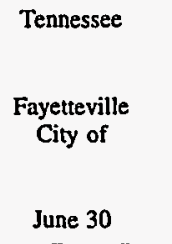 \\
\hline \multicolumn{7}{|l|}{ Number of Consumers } \\
\hline 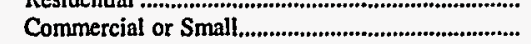 & $\begin{array}{r}21,333 \\
3,193\end{array}$ & 1,736 & 2,699 & $\begin{array}{r}r, 027 \\
910\end{array}$ & $\begin{array}{r}4,123 \\
524\end{array}$ & 2,141 \\
\hline 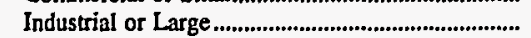 & 286 & 213 & 240 & 87 & 44 & 155 \\
\hline 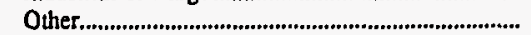 & 62 & 62 & 104 & 20 & 23 & 33 \\
\hline 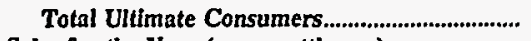 & 24,896 & 11,527 & 23,168 & 8,044 & 4,716 & 15,337 \\
\hline \multicolumn{7}{|l|}{ Sales for the Year (megawatthours) } \\
\hline 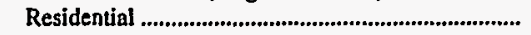 & 353,439 & 132,994 & 315,960 & 97,242 & 60,403 & 198,571 \\
\hline 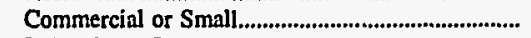 & 44,345 & 34,736 & 36,380 & 12,801 & 7,791 & 31,834 \\
\hline 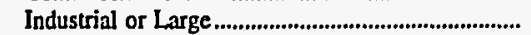 & 261,432 & 462,220 & 166,246 & 111,007 & 81,360 & 143,810 \\
\hline 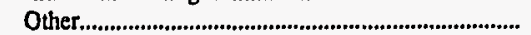 & 7,255 & 5,415 & 7,139 & 2,002 & 1,996 & 3,635 \\
\hline Total to Ultimate Consumers ................................. & 666,471 & 635,365 & 525,725 & 223,052 & 151,550 & 377,850 \\
\hline 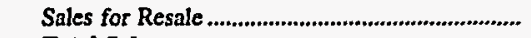 & & 0 & 0 & 0 & 0 & \\
\hline 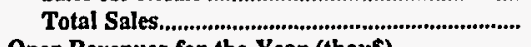 & 666,471 & 635,365 & 525,725 & 223,052 & 151,550 & 377,850 \\
\hline \multicolumn{7}{|l|}{ Oper Revenues for the Year (thou\$) } \\
\hline Residential ................. & 21,169 & 7,864 & 18,565 & 5,593 & 3,481 & 12,639 \\
\hline 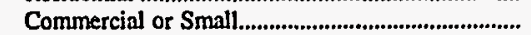 & 3,140 & 2,317 & 2,542 & 849 & 521 & 2,466 \\
\hline Industrial or Large .................................................... & 13,112 & 19,840 & 9,097 & 4,850 & 3,238 & 8,223 \\
\hline 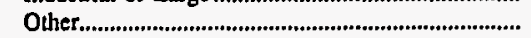 & 427 & 505 & 580 & 193 & 194 & 354 \\
\hline Total to Ultimate Consumers.............................. & 37,848 & 30,526 & $\mathbf{3 0 , 7 8 4}$ & 11,485 & $\mathbf{7 , 4 3 4}$ & 23,682 \\
\hline 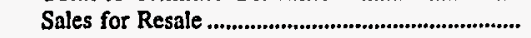 & & & & & 0 & \\
\hline Total Revenues From Sales of Elec..................... & $\mathbf{3 7 , 8 4 8}$ & 30,526 & 30,784 & 11,485 & $\mathbf{7 , 4 3 4}$ & 23,682 \\
\hline
\end{tabular}

Note: Totals may not equal sum of components because of independent rounding.

Source: Energy Information Administration, Form EIA-861, "Annual Electric Utility Report." Data are submitred on a calendar year. 
Table 25. Number of Consumers, Sales, and Operating Revenue by Major U.S. Publicly Owned Electric Utility Within State, 1996 (Continued)

\begin{tabular}{|c|c|c|c|c|c|c|}
\hline Item & $\begin{array}{l}\text { Tennessee } \\
\text { Gallatin } \\
\text { City of } \\
\text { June } 30\end{array}$ & $\begin{array}{c}\text { Tennessee } \\
\text { Greeneville } \\
\text { City of } \\
\text { June } 30\end{array}$ & $\begin{array}{c}\text { Tennessee } \\
\text { Harriman } \\
\text { City of } \\
\text { June } 30\end{array}$ & $\begin{array}{c}\text { Tennessee } \\
\text { Humboldt } \\
\text { City of } \\
\text { June } 30\end{array}$ & $\begin{array}{l}\text { Tennessee } \\
\text { Jackson } \\
\text { City of } \\
\text { June } 30\end{array}$ & $\begin{array}{c}\text { Tennessee } \\
\text { Johnson } \\
\text { City City of } \\
\text { June } 30\end{array}$ \\
\hline \multicolumn{7}{|l|}{ Number of Consumers } \\
\hline 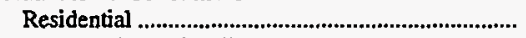 & 8,304 & 25,742 & 9,261 & 3,908 & 23,100 & 50,536 \\
\hline 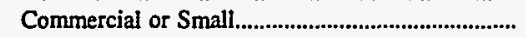 & 1,259 & 4,691 & 1,114 & 690 & 3,762 & 6,566 \\
\hline 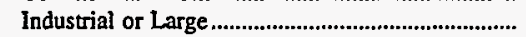 & 214 & 366 & 112 & 100 & 803 & 750 \\
\hline 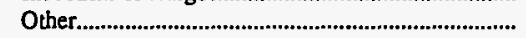 & 39 & 82 & 107 & 11 & 227 & 483 \\
\hline 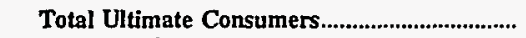 & 9,816 & 30,881 & 10,594 & 4,709 & 27,892 & 58,335 \\
\hline \multicolumn{7}{|l|}{ Sales for the Year (megawatthours) } \\
\hline 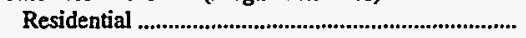 & 138,580 & 432,247 & 137,448 & 54,758 & 321,800 & 841.619 \\
\hline 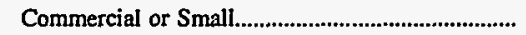 & 28,822 & 61,180 & 16,839 & 12,462 & 84,515 & 125,300 \\
\hline 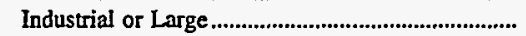 & 339,262 & 484,830 & 109,457 & 167,466 & 908,556 & 729,934 \\
\hline 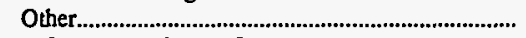 & 4,990 & 9,482 & 4,237 & 3,246 & 14,565 & 16,355 \\
\hline Total to Ultimate Consumers ............................... & 511,654 & 987,739 & 267,981 & 237,932 & $1,329,436$ & $1,713,208$ \\
\hline Sales for Resale & 0 & 0 & 0 & 0 & 0 & 0 \\
\hline 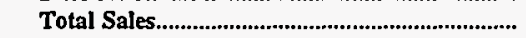 & 511,654 & 987,739 & 267,981 & 237,932 & $1,329,436$ & $1,713,208$ \\
\hline \multicolumn{7}{|l|}{ Oper Revenues for the Year (thou\$) } \\
\hline 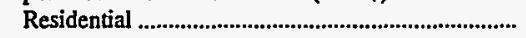 & 7,405 & 24,081 & 8,849 & 2,980 & 19,071 & 46,229 \\
\hline 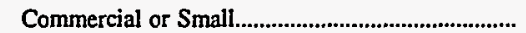 & 1,719 & 3,990 & 1,258 & 762 & 5,594 & 7,791 \\
\hline 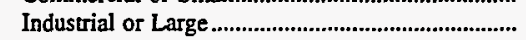 & 14,394 & 21,152 & 4,723 & 7,963 & 42,853 & 36,140 \\
\hline 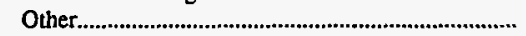 & 357 & 922 & 352 & 239 & 1,483 & 1,509 \\
\hline 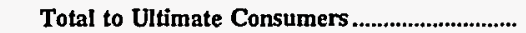 & 23,875 & 50,145 & 15,182 & 11,944 & 69,001 & 91,669 \\
\hline Sales for Resale & 0 & 0 & 0 & 0 & 0 & 0 \\
\hline Total Revenues From Sales of Elec................... & 23,875 & 50,145 & 15,182 & 11,944 & 69,001 & 91,669 \\
\hline
\end{tabular}

\begin{tabular}{|c|c|c|c|c|c|c|}
\hline Item & $\begin{array}{l}\text { Tennessee } \\
\text { Knoxville } \\
\text { Utilities } \\
\text { Board } \\
\text { June } 30\end{array}$ & $\begin{array}{c}\text { Tennessee } \\
\text { Lawrenceburg } \\
\text { City of } \\
\text { June } 30\end{array}$ & $\begin{array}{l}\text { Tennessee } \\
\text { LaFollette } \\
\text { City of } \\
\text { June } 30\end{array}$ & $\begin{array}{l}\text { Tennessee } \\
\text { Lebanon } \\
\text { City of } \\
\text { June } 30\end{array}$ & $\begin{array}{l}\text { Tennessee } \\
\text { Lenoir } \\
\text { City City of } \\
\text { June } 30\end{array}$ & $\begin{array}{c}\text { Tennessee } \\
\text { Lewisburg } \\
\text { City of } \\
\text { June } 30\end{array}$ \\
\hline \multicolumn{7}{|l|}{ Number of Consumers } \\
\hline Residential & 142,491 & 15,153 & 15,883 & 6,586 & 34,056 & 4,002 \\
\hline 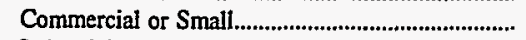 & 15.955 & 2,282 & 2,035 & 1,385 & 5,888 & 982 \\
\hline 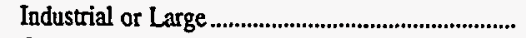 & 2,489 & 236 & 249 & 258 & 620 & 142 \\
\hline 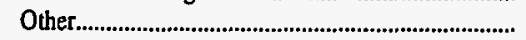 & 1,223 & 77 & 66 & 24 & 71 & 52 \\
\hline 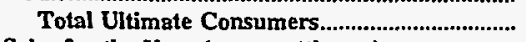 & 162,158 & 17,748 & 18,233 & 8,253 & 40,635 & 5,178 \\
\hline \multicolumn{7}{|l|}{ Sales for the Year (megawatthours) } \\
\hline 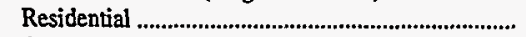 & $2,386,627$ & 232,270 & 228,648 & 104,519 & 643,641 & 59,243 \\
\hline 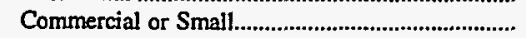 & 348,445 & 35,210 & 26,806 & 33,529 & 97,152 & 17,789 \\
\hline 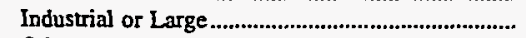 & $2,394,291$ & 214,867 & 110,698 & 234,260 & 412,017 & 211,388 \\
\hline 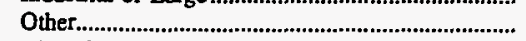 & 54,928 & 5,831 & 4,782 & 6,438 & 9,524 & 3,730 \\
\hline Total to Ultimate Consumers & $5,184,291$ & 488,178 & $\mathbf{3 7 0 , 9 3 4}$ & 378,746 & $1,162,334$ & 292,150 \\
\hline 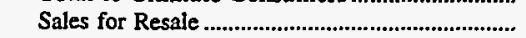 & 0 & 0 & 0 & 0 & 0 & 0 \\
\hline 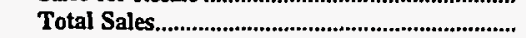 & $5,184,291$ & 488,178 & 370,934 & 378,746 & $1,162,334$ & 292,150 \\
\hline \multicolumn{7}{|l|}{ Oper Revenues for the Year (thou\$) } \\
\hline 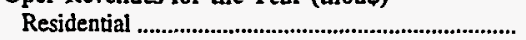 & 139,636 & 13,311 & 14,090 & 6,008 & 37,407 & 3,441 \\
\hline 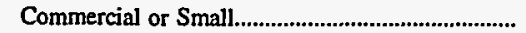 & 23,284 & 2,342 & 1,933 & 2,121 & 6,621 & 1,188 \\
\hline Industrial or Large & 115,839 & 9,903 & 6,832 & 11,719 & 22,525 & 10,343 \\
\hline 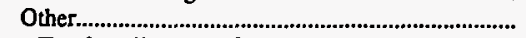 & 4,760 & 441 & 406 & 443 & 753 & 302 \\
\hline 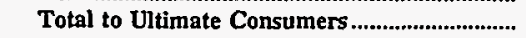 & 283,519 & 25,997 & 23,261 & 20,291 & 67,306 & 15,274 \\
\hline 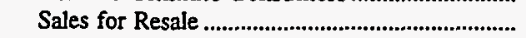 & 0 & 0 & 0 & 0 & 0 & \\
\hline Total Revenues From Sales of Elec...................... & 283,519 & 25,997 & 23,261 & 20,291 & 67,306 & 15,274 \\
\hline
\end{tabular}

Note: Totals may not equal sum of components because of independent rounding.

Source: Energy Information Administration, Form EIA-861, "Annual Electric Utility Report." Data are subminted on a calendar year. 
Table 25. Number of Consumers, Sales, and Operating Revenue by Major U.S. Publicly Owned Electric Utility Within State, 1996 (Continued)

\begin{tabular}{|c|c|c|c|c|c|c|}
\hline Item & $\begin{array}{l}\text { Tennessee } \\
\text { Lexington } \\
\text { City of } \\
\text { June } 30\end{array}$ & $\begin{array}{l}\text { Tennessee } \\
\text { Loudon } \\
\text { Utilities } \\
\text { Board } \\
\text { June } 30\end{array}$ & $\begin{array}{c}\text { Tennessee } \\
\text { Maryville } \\
\text { Utilities } \\
\text { June } 30\end{array}$ & $\begin{array}{l}\text { Tennessee } \\
\text { McMinnville } \\
\text { Electric } \\
\text { System } \\
\text { June } 30\end{array}$ & $\begin{array}{l}\text { Tennessee } \\
\text { Memphis } \\
\text { City of } \\
\text { June } 30\end{array}$ & $\begin{array}{l}\text { Tennessee } \\
\text { Milan } \\
\text { City of } \\
\text { June } 30\end{array}$ \\
\hline \multicolumn{7}{|l|}{ Number of Consumers } \\
\hline 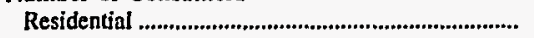 & 15,441 & 6,001 & 14,945 & 5,485 & 327,752 & 6,137 \\
\hline 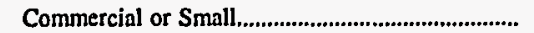 & 2,867 & 852 & 1,953 & 1,368 & 31,964 & 1,280 \\
\hline 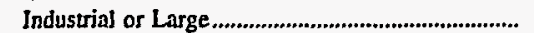 & 207 & 93 & 260 & 172 & 6,771 & 95 \\
\hline 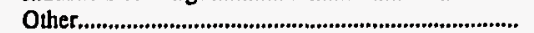 & 85 & 20 & 82 & 70 & 172 & 27 \\
\hline Total Ultimate Consumers.................................... & 18,600 & 6,966 & 17,240 & 7,095 & 366,659 & 7,539 \\
\hline \multicolumn{7}{|l|}{ Sales for the Year (megawatthours) } \\
\hline 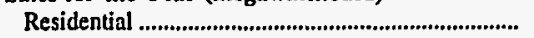 & 202,784 & 94,811 & 218,375 & 78,917 & $4,943,219$ & 102,751 \\
\hline 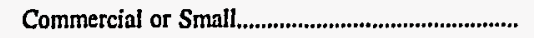 & 32,269 & 12,339 & 39,149 & 26,785 & 766,441 & 15,880 \\
\hline 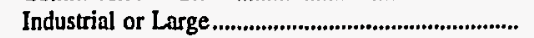 & 165,313 & 202,111 & 326,545 & 133,611 & $6,751,259$ & 116,685 \\
\hline 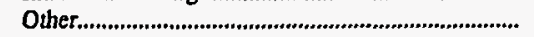 & 8,219 & 2,267 & 6,562 & 3,982 & 116,383 & 2,897 \\
\hline Total to Ultimate Consumers .............................. & 408,585 & 311,528 & 590,631 & 243,295 & $12,577,302$ & 238,213 \\
\hline 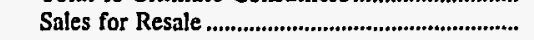 & 0 & 0 & 0 & 0 & 0 & 0 \\
\hline 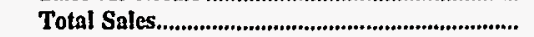 & 408,585 & 311,528 & 590,631 & 243,295 & $12,577,302$ & 238,213 \\
\hline \multicolumn{7}{|l|}{ Oper Revenues for the Year (thou\$) } \\
\hline 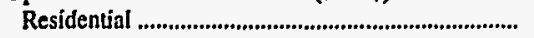 & 12,131 & 5,901 & 12,179 & 4,449 & 300,274 & 5,759 \\
\hline 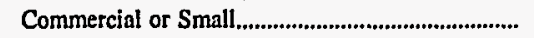 & 2,292 & 875 & 2,450 & 1,758 & 52,228 & 1,036 \\
\hline Industrial or Large & 9,203 & 9,809 & 14,596 & 6,873 & 342,237 & 6,110 \\
\hline 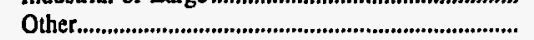 & 688 & 193 & 632 & 312 & 10,288 & 259 \\
\hline 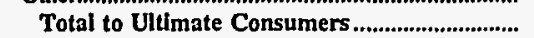 & 24,314 & 16,778 & 29,857 & 13,392 & 705,027 & 13,164 \\
\hline 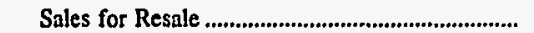 & 0 & 0 & 0 & 0 & 0 & \\
\hline Total Revenues From Sales of Elec.................... & 24,314 & 16,778 & 29,857 & 13,392 & 705,027 & 13,164 \\
\hline
\end{tabular}

\begin{tabular}{|c|c|c|c|c|c|c|}
\hline Item & $\begin{array}{c}\text { Tennessee } \\
\begin{array}{c}\text { Morristown } \\
\text { City of }\end{array} \\
\text { June } 30\end{array}$ & $\begin{array}{l}\text { Tennessee } \\
\begin{array}{l}\text { Murfreesboro } \\
\text { City of }\end{array} \\
\text { June } 30\end{array}$ & $\begin{array}{l}\text { Tennessee } \\
\text { Nashville } \\
\text { Electric } \\
\text { Service } \\
\text { June } 30\end{array}$ & $\begin{array}{l}\text { Tennessee } \\
\text { Newport } \\
\text { City of } \\
\text { June } 30\end{array}$ & $\begin{array}{l}\text { Tennessee } \\
\text { Oak Ridge } \\
\text { City of } \\
\text { June } 30\end{array}$ & $\begin{array}{l}\text { Tennessee } \\
\text { Paris } \\
\text { City of } \\
\text { June } 30\end{array}$ \\
\hline \multicolumn{7}{|l|}{ Number of Consumers } \\
\hline 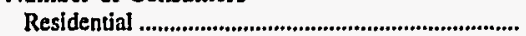 & 10,689 & 22,594 & 259,153 & 14,465 & 12,817 & 14,411 \\
\hline 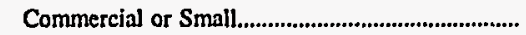 & 1,828 & 2,679 & 28,199 & 2,755 & 1,391 & 3,250 \\
\hline Industrial or Large....................................................... & 376 & 544 & 5,838 & 194 & 331 & 226 \\
\hline 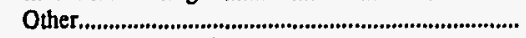 & 58 & 94 & 1,946 & 164 & 58 & 56 \\
\hline 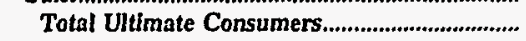 & 12,951 & 25,911 & 295,136 & 17,578 & 14,597 & 17,943 \\
\hline \multicolumn{7}{|l|}{ Sales for the Year (megawatthours) } \\
\hline 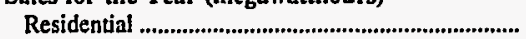 & 154,875 & 343,532 & $4,348,196$ & 207,996 & 185,457 & 227,526 \\
\hline 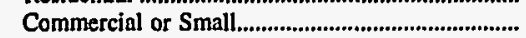 & 42,452 & 69,944 & 727,741 & 32,794 & 36,921 & 39,601 \\
\hline Industrial or Large...................................................... & 515,257 & 550,979 & $6,077,019$ & 196,805 & 272,249 & 179,569 \\
\hline 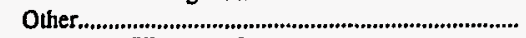 & 8,593 & 10,383 & 109,601 & 5,960 & 6,108 & 7,951 \\
\hline Total to Ultimate Consumers ................................. & 721,177 & $\mathbf{9 7 4 , 8 3 8}$ & $11,262,557$ & 443,555 & 500,735 & 454,647 \\
\hline 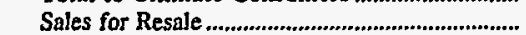 & 0 & 0 & 0 & 0 & 0 & 0 \\
\hline Total Sales............................................................... & 721,177 & $\mathbf{9 7 4 , 8 3 8}$ & $11,262,557$ & 443,555 & 500,735 & 454,647 \\
\hline \multicolumn{7}{|l|}{ Oper Revenues for the Year (thou\$) } \\
\hline 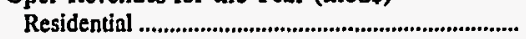 & 8,863 & 19,266 & 253,279 & 12,699 & 10,871 & 12,703 \\
\hline 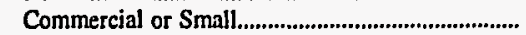 & 2,737 & 4,285 & 47,307 & 2,409 & 2,396 & 2,575 \\
\hline Industrial or Large........................................................... & 24,629 & 27,180 & 290,840 & 9,369 & 14,224 & 8,897 \\
\hline 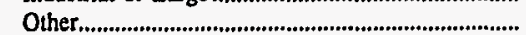 & 613 & 798 & 9,662 & 498 & 705 & 691 \\
\hline Total to Ultimate Consumers............................. & 36,842 & 51,529 & 601,088 & 24,975 & 28,196 & 24,866 \\
\hline 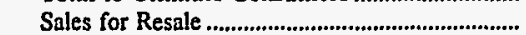 & & 0 & 0 & 0 & 0 & \\
\hline Total Revenues From Sales of Elec...................... & 36,842 & 51,529 & 601,088 & 24,975 & 28,196 & 24,866 \\
\hline
\end{tabular}

Note: Totals may not equal sum of components because of independentrounding.

Source: Energy Information Administration, Form ElA-861, “Annual Electric Uility Report." Data are submitted on a calendar year. 
Table 25. Number of Consumers, Sales, and Operating Revenue by Major U.S. Publicly Owned Electric Utility Within State, 1996 (Continued)

\begin{tabular}{|c|c|c|c|c|c|c|}
\hline Item & $\begin{array}{l}\text { Tennessee } \\
\text { Pulaski } \\
\text { City of } \\
\text { June } 30\end{array}$ & $\begin{array}{l}\text { Tennessee } \\
\text { Ripley } \\
\text { City of } \\
\text { June } 30\end{array}$ & $\begin{array}{c}\text { Tennessee } \\
\text { Sevier } \\
\text { County } \\
\text { Electric } \\
\text { System } \\
\text { June } 30\end{array}$ & $\begin{array}{l}\text { Tennessee } \\
\text { Rockwood } \\
\text { City of } \\
\text { June } 30\end{array}$ & $\begin{array}{c}\text { Tennessee } \\
\text { Shelbyville } \\
\text { City of } \\
\text { June } 30\end{array}$ & $\begin{array}{l}\text { Tennessee } \\
\begin{array}{c}\text { Springfield } \\
\text { City of }\end{array} \\
\text { June } 30\end{array}$ \\
\hline \multicolumn{7}{|l|}{ Number of Consumers } \\
\hline Residential. & 10,504 & 5,398 & 26,817 & 10,254 & 6.445 & 5,196 \\
\hline Commercial or Small............................................................ & 1,922 & 1,106 & 5,943 & 1,664 & 948 & 809 \\
\hline 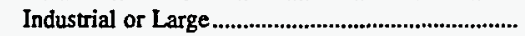 & 180 & 117 & 874 & 133 & 186 & 155 \\
\hline 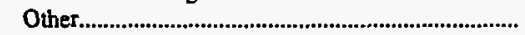 & 67 & 81 & 322 & 35 & 28 & 15 \\
\hline 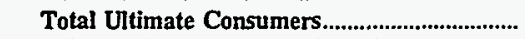 & 12,673 & 6,702 & 33,956 & 12,086 & $\mathbf{7 , 6 0 7}$ & 6,175 \\
\hline \multicolumn{7}{|l|}{ Sales for the Year (megawatthours) } \\
\hline 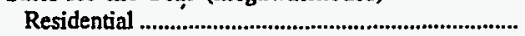 & 165,881 & 72,930 & 439,385 & 167,204 & 88,575 & 76,671 \\
\hline Commercial or Small..................................................... & 26,583 & 17,185 & 119,797 & 23,810 & 23,187 & 19,065 \\
\hline 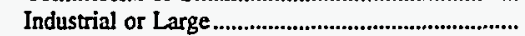 & 235,633 & 154,430 & 464,300 & 114,336 & 224,700 & 130,652 \\
\hline 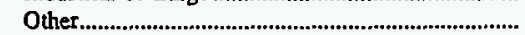 & 5,411 & 4,405 & 10,101 & 4,246 & 3,462 & 4,922 \\
\hline 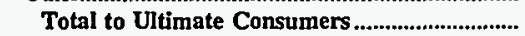 & 433,508 & 248,950 & $1,033,583$ & 309,596 & 339,924 & 231,310 \\
\hline Sales for Resale & 0 & 0 & 0 & 0 & 0 & 0 \\
\hline 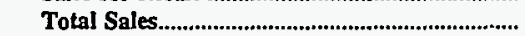 & 433,508 & 248,950 & $1,033,583$ & 309,596 & 339,924 & 231,310 \\
\hline \multicolumn{7}{|l|}{ Oper Revenues for the Year (thous) } \\
\hline Residential & 9,913 & 4,009 & 25,765 & 10,297 & 5,186 & 4,655 \\
\hline 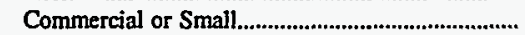 & 1,867 & 1,072 & 8,053 & 1,708 & 1,488 & 1,311 \\
\hline 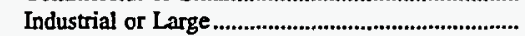 & 11,261 & 8,053 & 25,287 & 5,738 & 11,332 & 6,959 \\
\hline 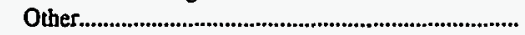 & 412 & 326 & 670 & 368 & 285 & 369 \\
\hline 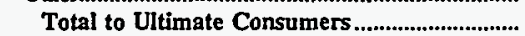 & 23,453 & 13,460 & 59,775 & 18,111 & 18,291 & 13,294 \\
\hline Sales for Resale & 0 & 0 & 0 & 0 & 0 & \\
\hline 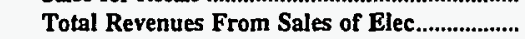 & 23,453 & 13,460 & 59,775 & 18,111 & 18,291 & 13,294 \\
\hline
\end{tabular}

\begin{tabular}{|c|c|c|c|c|c|c|}
\hline Item & $\begin{array}{l}\text { Tennessee } \\
\text { Sweetwater } \\
\text { City of } \\
\text { June } 30\end{array}$ & $\begin{array}{c}\text { Tennessee } \\
\text { Tullahoma } \\
\text { Board } \\
\text { of } \\
\text { Pub Utils } \\
\text { June } 30\end{array}$ & $\begin{array}{c}\text { Tennessee } \\
\text { Union } \\
\text { City City of } \\
\text { June } 30\end{array}$ & $\begin{array}{c}\text { Tennessee } \\
\text { Weakley } \\
\text { County } \\
\text { Mun } \\
\text { Elec Sys } \\
\text { June } 30\end{array}$ & $\begin{array}{c}\text { Tennessee } \\
\text { Winchester } \\
\text { City of } \\
\text { December } 31\end{array}$ & $\begin{array}{l}\text { Texas } \\
\text { Austin } \\
\text { City of } \\
\text { September } 30\end{array}$ \\
\hline \multicolumn{7}{|l|}{ Number of Consumers } \\
\hline Residential ........... & 5,542 & 7,763 & 4,994 & 15,438 & 3,705 & 276,349 \\
\hline 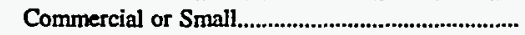 & 1,282 & 1,284 & 827 & 2,880 & 743 & 32,518 \\
\hline Industral or Large ............................................................ & 107 & 198 & 147 & 277 & 93 & 13 \\
\hline 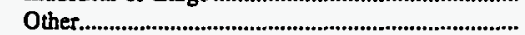 & 21 & 37 & 12 & 100 & 12 & 702 \\
\hline 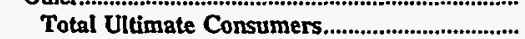 & 6,952 & 9,282 & 5,980 & 18,695 & 4,553 & 309,582 \\
\hline \multicolumn{7}{|l|}{ Sales for the Year (megawatthours) } \\
\hline 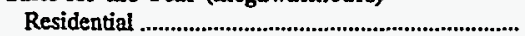 & 88,826 & 120,928 & 64,689 & 265,986 & 59,443 & $3,062,985$ \\
\hline 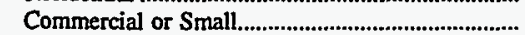 & 17,334 & 26,937 & 19,007 & 35,861 & 13,381 & $3,823,861$ \\
\hline 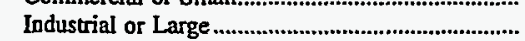 & 89,953 & 129,005 & 283,380 & 174,298 & 73,688 & $1,075,423$ \\
\hline 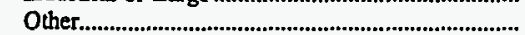 & 4,369 & 4,577 & 3,191 & 7,567 & 2,204 & 297,186 \\
\hline 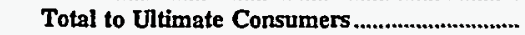 & 200,482 & 281,447 & 370,267 & 483,712 & 148,716 & $8,259,455$ \\
\hline 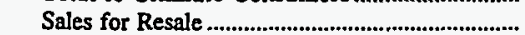 & 0 & 0 & 0 & 0 & 0 & $1,324,356$ \\
\hline 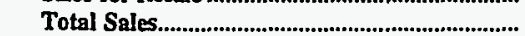 & 200,482 & 281,447 & 370,267 & 483,712 & 148,716 & $9,583,811$ \\
\hline \multicolumn{7}{|l|}{ Oper Revenues for the Year (thou\$) } \\
\hline 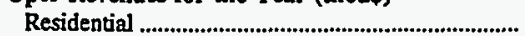 & 5,082 & 6,796 & 3,451 & 15,081 & 3,474 & 230,404 \\
\hline Commercial or Small............................................... & 1,148 & 1,692 & 1,101 & 2,385 & 889 & 255,148 \\
\hline 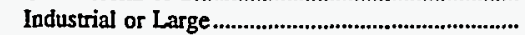 & 4,855 & 6,736 & 11,194 & 9,402 & 3,983 & 48,806 \\
\hline Other. & 328 & 418 & 265 & 568 & 148 & 20,491 \\
\hline Total to Ultimate Consumers.................................. & 11,413 & 15,642 & 16,011 & 27,436 & 8,494 & 554,849 \\
\hline 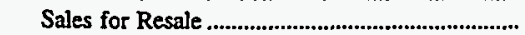 & & 0 & 0 & 0 & 0 & 36,576 \\
\hline Total Revenues From Sales of Elec....................... & 11,413 & 15,642 & 16,011 & 27,436 & 8,494 & 591,425 \\
\hline
\end{tabular}

Note: Totals may not equal sum of components because of independent rounding.

Source: Energy Information Administration, Form EIA-861, "Annual Electric Utility Report." Data are submitted on a calendar year. 
Table 25. Number of Consumers, Sales, and Operating Revenue by Major U.S.

Publicly Owned Electric Utility Within State, 1996 (Continued)

\begin{tabular}{|c|c|c|c|c|c|c|}
\hline Item & $\begin{array}{c}\text { Texas } \\
\text { Brenham } \\
\text { City of } \\
\text { September } 30\end{array}$ & $\begin{array}{c}\text { Texas } \\
\text { Brownsville } \\
\text { Public } \\
\text { Utils Board } \\
\text { September } 30\end{array}$ & $\begin{array}{l}\text { Texas } \\
\text { Bryan } \\
\text { City of } \\
\text { September } 30\end{array}$ & $\begin{array}{l}\text { Texas } \\
\text { College } \\
\text { Station } \\
\text { City of } \\
\text { September } 30\end{array}$ & $\begin{array}{l}\text { Texas } \\
\text { Denton } \\
\text { City of } \\
\text { September } 30\end{array}$ & $\begin{array}{c}\text { Texas } \\
\text { Floresville } \\
\text { Ciry of } \\
\text { December } 31\end{array}$ \\
\hline \multicolumn{7}{|l|}{ Number of Consumers } \\
\hline 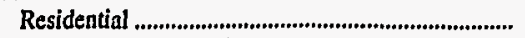 & 4,583 & 27,825 & 31,099 & 20,649 & 26,873 & 7,903 \\
\hline 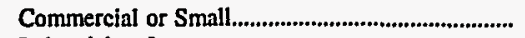 & 1,123 & 2,521 & 4,504 & 2,080 & 3,385 & 1,890 \\
\hline 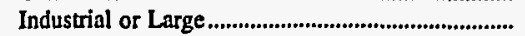 & 35 & 1,651 & 66 & 0 & 0 & 0 \\
\hline 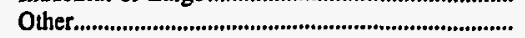 & 1 & 0 & 294 & 1 & 1,328 & 1,826 \\
\hline $\begin{array}{l}\text { Total Ultimate Consumers................................................ } \\
\text { Sales for the Year (megawatthours) }\end{array}$ & 5,742 & 31,997 & 35,963 & 22,730 & 31,586 & 11,619 \\
\hline 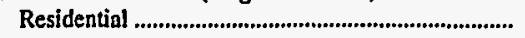 & 68,118 & 323,189 & 419,679 & 245,570 & 320,462 & 118,737 \\
\hline 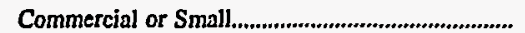 & 60,261 & 29,096 & 205,877 & 265,414 & 553,898 & 55,738 \\
\hline 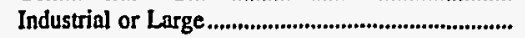 & 148,027 & 403,058 & 164,972 & 0 & 0 & 0 \\
\hline 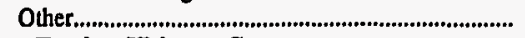 & 1,482 & $\mathbf{0}$ & 50,864 & 270 & 34,385 & 1,436 \\
\hline 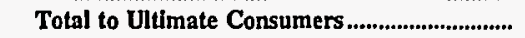 & 277,888 & 755,343 & 841,392 & 511,254 & 908,745 & 175,911 \\
\hline 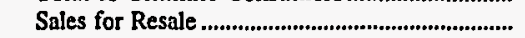 & 0 & 35,797 & 513,529 & 0 & 88,071 & 0 \\
\hline Total Sales.............................................................. & 277,888 & 791,140 & $1,354,921$ & 511,254 & 996,816 & 175,911 \\
\hline $\begin{array}{l}\text { Oper Revenues for the Year (thous) } \\
\text { Residential }\end{array}$ & 4,265 & 23,277 & 31,073 & 17,539 & 24,495 & 8,226 \\
\hline 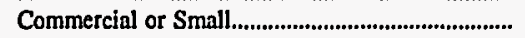 & 3,229 & 2,793 & 16,187 & 13,214 & 33,792 & 3,930 \\
\hline 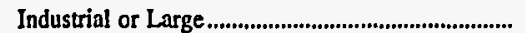 & 6,043 & 26,104 & 9,346 & 0 & 0 & 0 \\
\hline 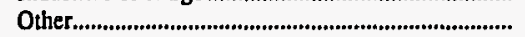 & 93 & 0 & 3,459 & 56 & 2,831 & 293 \\
\hline 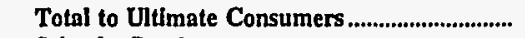 & 13,630 & 52,174 & 60,065 & 30,809 & 61,118 & 12,449 \\
\hline 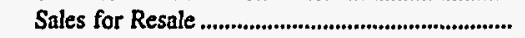 & 0 & 584 & 24,256 & 0 & 3,233 & 0 \\
\hline Total Revenues From Sales of Elec.................... & 13,630 & 52,758 & 84,321 & 30,809 & 64,351 & 12,449 \\
\hline
\end{tabular}

\begin{tabular}{|c|c|c|c|c|c|c|}
\hline Item & $\begin{array}{l}\text { Texas } \\
\text { Garland } \\
\text { City of } \\
\text { September } 30\end{array}$ & $\begin{array}{c}\text { Texas } \\
\text { Georgetown } \\
\text { City of } \\
\text { September } 30\end{array}$ & $\begin{array}{c}\text { Texas } \\
\text { Greenville } \\
\text { Electric } \\
\text { Util Sys } \\
\text { September } 30\end{array}$ & $\begin{array}{c}\text { Texas } \\
\text { Jasper } \\
\text { City of } \\
\text { September } 30\end{array}$ & $\begin{array}{c}\text { Texas } \\
\text { Kerrville } \\
\text { Public } \\
\text { Utility } \\
\text { Board } \\
\text { September } 30\end{array}$ & $\begin{array}{l}\text { Texas } \\
\text { Lower } \\
\text { Colorado } \\
\text { River } \\
\text { Authority } \\
\text { June } 30\end{array}$ \\
\hline \multicolumn{7}{|l|}{ Number of Consumers } \\
\hline 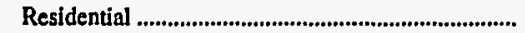 & 57,596 & 8,195 & 9,940 & 3,627 & 14,660 & 0 \\
\hline Commercial or Small & 3,936 & 1,139 & 1,827 & 924 & 2,896 & 14 \\
\hline 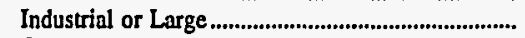 & 1,130 & 52 & 0 & 44 & 0 & 7 \\
\hline 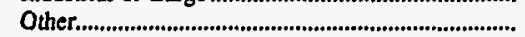 & 460 & 84 & 530 & 0 & 149 & 0 \\
\hline $\begin{array}{l}\text { Total Ultimate Consumers.................................... } \\
\text { Sales for the Year (megawatthours) }\end{array}$ & 63,122 & 9,470 & 12,297 & 4,595 & 17,705 & 21 \\
\hline 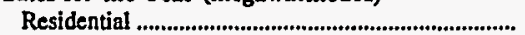 & 912,703 & 108,809 & 112,368 & 45,776 & 214,430 & 0 \\
\hline 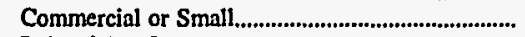 & 74,273 & 34,948 & 312,011 & 26,754 & 177,981 & 981 \\
\hline 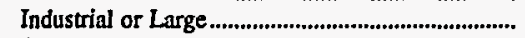 & 760,473 & 37,814 & 0 & 54,885 & 0 & 152,363 \\
\hline 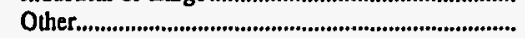 & 116,396 & 24,524 & 2,025 & 0 & 6,928 & 0 \\
\hline 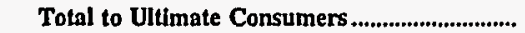 & $1,863,845$ & 206,095 & 426,404 & 127,415 & 399,339 & 153,344 \\
\hline 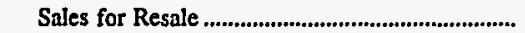 & 120,368 & 0 & 19,882 & 0 & 0 & $10,645,538$ \\
\hline 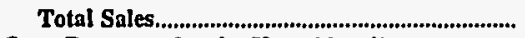 & $1,984,213$ & 206,095 & 446,286 & 127,415 & 399,339 & $10,798,882$ \\
\hline \multicolumn{7}{|l|}{ Oper Revenues for the Year (thou\$) } \\
\hline 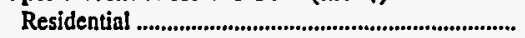 & 72,659 & 7,769 & 9,224 & 4,645 & 14,097 & 0 \\
\hline 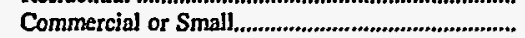 & 6,308 & 2,445 & 19,056 & 2,767 & 10,902 & 57 \\
\hline Industrial or Large & 45,802 & 1,930 & 0 & 4,642 & 0 & 5,667 \\
\hline 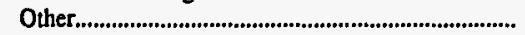 & 5,478 & 1,867 & 264 & 0 & 358 & 0 \\
\hline 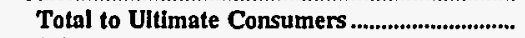 & 130,247 & 14,011 & 28,544 & 12,054 & 25,357 & 5,724 \\
\hline Sales for Resale & 20,215 & 0 & 1,756 & 0 & 0 & 417,677 \\
\hline Total Revenues From Sales of Elec................. & 150,462 & 14,011 & 30,300 & 12,054 & 25,357 & 423,401 \\
\hline
\end{tabular}

Note: Totols may not equal sum of components because of independent rounding.

Source: Energy Information Administration, Form EIA-861, "Annual Electric Utility Report." Data are submitted on a calendar year. 
Table 25. Number of Consumers, Sales, and Operating Revenue by Major U.S. Publicly Owned Electric Utility Within State, 1996 (Continued)

\begin{tabular}{|c|c|c|c|c|c|c|}
\hline Item & $\begin{array}{l}\text { Texas } \\
\text { Lubbock } \\
\text { City of } \\
\text { September } 30\end{array}$ & $\begin{array}{c}\text { Texas } \\
\text { New Braunfels } \\
\text { City of } \\
\text { July } 31\end{array}$ & $\begin{array}{c}\text { Texas } \\
\text { Sam Rayburn } \\
\text { Municipal } \\
\text { Pwr } \\
\text { Agny } \\
\text { September } 30\end{array}$ & $\begin{array}{c}\text { Texas } \\
\text { San Antonio } \\
\text { Public } \\
\text { Service Bd } \\
\\
\text { January } 31\end{array}$ & $\begin{array}{c}\text { Texas } \\
\text { San Marcos } \\
\text { City of } \\
\text { September } 30\end{array}$ & $\begin{array}{c}\text { Texas } \\
\text { Seguin } \\
\text { City of } \\
\text { September } 30\end{array}$ \\
\hline \multicolumn{7}{|l|}{ Number of Consumers } \\
\hline Residential ....................... & 44,822 & 16,000 & 0 & 467,166 & 11,487 & 7,146 \\
\hline 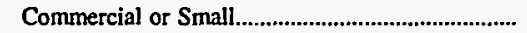 & 5,582 & 2,460 & 0 & 51,981 & 2,206 & 1,133 \\
\hline Industrial or Large & 83 & 12 & 0 & 1,551 & 9 & 8 \\
\hline 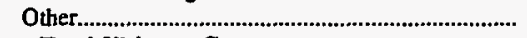 & 904 & 199 & 0 & 4,682 & 107 & 53 \\
\hline $\begin{array}{l}\text { Total UItimate Consumers............................................ } \\
\text { Sales for the Year (megayatthours) }\end{array}$ & 51,391 & 18,671 & $\mathbf{0}$ & 525,380 & 13,809 & 8,340 \\
\hline \multicolumn{7}{|l|}{ Sales for the Year (megawatthours) } \\
\hline 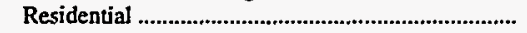 & 422,588 & 248,008 & 0 & $6,147,657$ & 137,966 & 75,326 \\
\hline 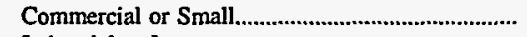 & 232,299 & 177,959 & 0 & $2,357,261$ & 136,571 & 71,925 \\
\hline Industrial or Large & 254,914 & 385,120 & 0 & $4,062,752$ & 77,303 & 63,328 \\
\hline 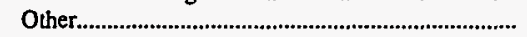 & 132,952 & 30,777 & 0 & $2,028,240$ & 8,913 & 7,425 \\
\hline 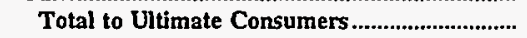 & $1,042,753$ & 841,864 & 0 & $14,595,910$ & 360,753 & 218,004 \\
\hline 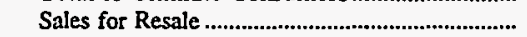 & 0 & 0 & 553,030 & 671,596 & 0 & 0 \\
\hline 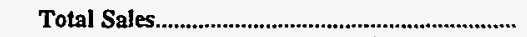 & $1,042,753$ & 841,864 & 553,030 & $15,267,506$ & 360,753 & 218,004 \\
\hline \multicolumn{7}{|l|}{ Oper Revenues for the Year (thou\$) } \\
\hline 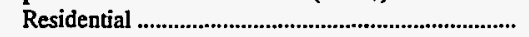 & 26,186 & 14,609 & 0 & 398,841 & 9,126 & 5,379 \\
\hline 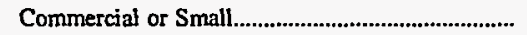 & 12,979 & 10,851 & 0 & 142,984 & 8,204 & 4,743 \\
\hline Industrial or Large & 11,171 & 15,790 & 0 & 180,796 & 3,767 & 3,372 \\
\hline 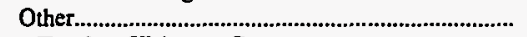 & 6,790 & 1,845 & 0 & 94,597 & 561 & 442 \\
\hline 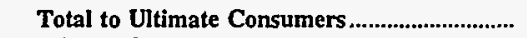 & 57,126 & 43,095 & $\mathbf{0}$ & 817,218 & 21,658 & 13,936 \\
\hline Sales for Resale & 0 & 0 & 31,350 & 11,268 & 0 & 0 \\
\hline Total Revenues From Sales of Elec.................... & 57,126 & 43,095 & 31,350 & 828,486 & 21,658 & 13,936 \\
\hline
\end{tabular}

\begin{tabular}{|c|c|c|c|c|c|c|}
\hline Item & $\begin{array}{c}\text { Texas } \\
\text { Texas } \\
\text { Municipal } \\
\text { Power Agency } \\
\text { September } 30\end{array}$ & $\begin{array}{l}\text { Texas } \\
\text { Toledo Bend } \\
\text { Project } \\
\text { Joint } \\
\text { Oper } \\
\text { August } 30\end{array}$ & $\begin{array}{c}\text { Texas } \\
\text { Weatherford } \\
\text { Mun } \\
\text { Utility } \\
\text { System } \\
\text { September } 30\end{array}$ & $\begin{array}{c}\text { Utah } \\
\text { Bountiful } \\
\text { City City of } \\
\text { June } 30\end{array}$ & $\begin{array}{c}\text { Utah } \\
\text { Intermountain } \\
\text { Power Agency } \\
\text { June } 30\end{array}$ & $\begin{array}{l}\text { Utah } \\
\text { Logan } \\
\text { City of } \\
\text { June } 30\end{array}$ \\
\hline \multicolumn{7}{|l|}{ Number of Consumers } \\
\hline Residential ....................... & 0 & 0 & 7,307 & 12,351 & 0 & 12,237 \\
\hline 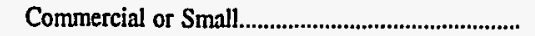 & 0 & 0 & 1,049 & 1,056 & 0 & 1,573 \\
\hline Industrial or Large & 0 & 0 & 23 & 1 & 0 & 1 \\
\hline 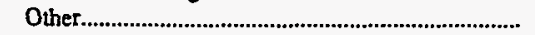 & 0 & 0 & 208 & 276 & 0 & I \\
\hline \multirow{2}{*}{\multicolumn{7}{|c|}{ Sales for the Year (megawatthours) }} \\
\hline & & & & & & \\
\hline 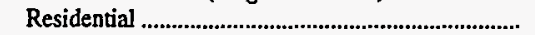 & 0 & 0 & 99,906 & 115,181 & 0 & 74,985 \\
\hline 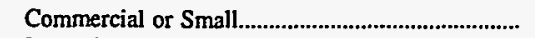 & 0 & 0 & 52,894 & 53,192 & 0 & 188,210 \\
\hline Industrial or Large & 0 & 0 & 62,207 & 52,823 & 0 & 52,450 \\
\hline 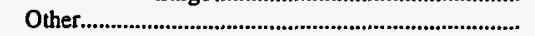 & 0 & 0 & 21,955 & 35,499 & 0 & 2,408 \\
\hline 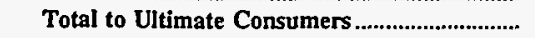 & 0 & 0 & 236,962 & 256,695 & o & 318,053 \\
\hline Sales for Resale ........................................................ & $2,587,905$ & 16,720 & 0 & 0 & $9,760,982$ & 0 \\
\hline 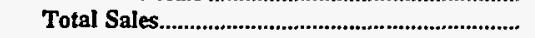 & $2,587,905$ & 16,720 & 236,962 & 256,695 & $9,760,982$ & 318,053 \\
\hline \multicolumn{7}{|l|}{ Oper Revenues for the Year (thous) } \\
\hline 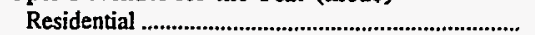 & 0 & 0 & 6,877 & 6,499 & 0 & 5,151 \\
\hline 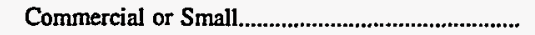 & 0 & 0 & 3,883 & 2,801 & 0 & 9,908 \\
\hline 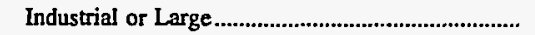 & 0 & 0 & 3,632 & 1,620 & 0 & 2,230 \\
\hline 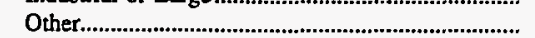 & 0 & 0 & 1,541 & 2,012 & 0 & 297 \\
\hline Total to Ultimate Consumers....................................... & 0 & o & 15,933 & 12,932 & $\mathbf{0}$ & 17,586 \\
\hline 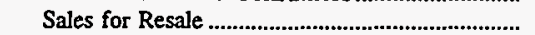 & 135,824 & 346 & 0 & 0 & 610,479 & \\
\hline Total Revenues From Sales of Elec..................... & 135,824 & 346 & 15,933 & 12,932 & 610,479 & 17,586 \\
\hline
\end{tabular}

Note: Totals may not equal sum of components because of independent rounding.

Source: Energy Information Administration, Form EIA-861, "Annual Electric Utility Report." Data are submitted on a calendar year. 
Table 25. Number of Consumers, Sales, and Operating Revenue by Major U.S.

Publicly Owned Electric Utility Within State, 1996 (Continued)

\begin{tabular}{|c|c|c|c|c|c|c|}
\hline Item & $\begin{array}{l}\text { Utah } \\
\text { Murray } \\
\text { City of } \\
\text { June } 30\end{array}$ & $\begin{array}{l}\text { Utah } \\
\text { Provo } \\
\text { City Corp } \\
\text { June } 30\end{array}$ & $\begin{array}{c}\text { Utah } \\
\text { St George } \\
\text { City of } \\
\text { June } 30\end{array}$ & $\begin{array}{l}\text { Utah } \\
\text { Utah } \\
\text { Associated } \\
\text { Mun } \\
\text { Power Sys } \\
\text { March } 31\end{array}$ & $\begin{array}{c}\text { Utah } \\
\text { Utah } \\
\text { Municipal } \\
\text { Power Agency } \\
\text { June } 30\end{array}$ & $\begin{array}{l}\text { Vermont } \\
\text { Burlington } \\
\text { City of } \\
\text { June } 30\end{array}$ \\
\hline \multicolumn{7}{|l|}{ Number of Consumers } \\
\hline 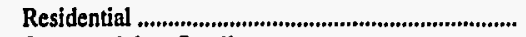 & 12,539 & 25,729 & 13,825 & 0 & 0 & 15,342 \\
\hline Commercial or Small................................................... & 2,418 & 3,377 & 2,508 & 0 & 0 & 2,837 \\
\hline 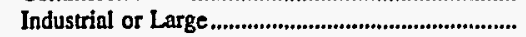 & 0 & 1 & 0 & 0 & 0 & 717 \\
\hline 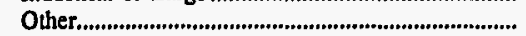 & 273 & 0 & 1 & 0 & 0 & 1 \\
\hline $\begin{array}{l}\text { Total Ultimate Consumers............................................. } \\
\text { Sales for the Year (megawatthours) }\end{array}$ & 15,230 & 29,107 & 16,334 & 0 & 0 & 18,897 \\
\hline 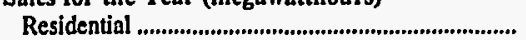 & 95,728 & 167,037 & 179,836 & 0 & $\mathbf{0}$ & 88,191 \\
\hline 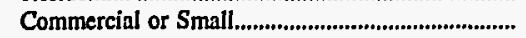 & 213,738 & 288,323 & 179,457 & 0 & 0 & 20,575 \\
\hline 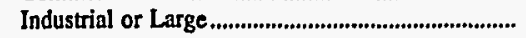 & 0 & 114,557 & 0 & 0 & 0 & 213,394 \\
\hline 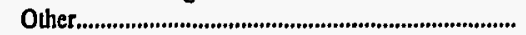 & 7,862 & 0 & 16,141 & 0 & 0 & 3,481 \\
\hline 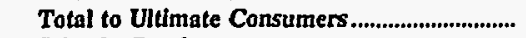 & 317,328 & 569,917 & 375,434 & 0 & 0 & 325,641 \\
\hline 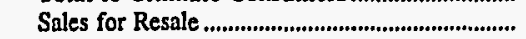 & 0 & 0 & 0 & $2,265,893$ & 835,377 & 128,983 \\
\hline 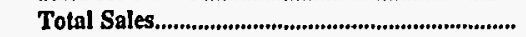 & 317,328 & 569,917 & 375,434 & $2,265,893$ & 835,377 & 454,624 \\
\hline \multicolumn{7}{|l|}{ Oper Revenues for the Year (thou\$) } \\
\hline 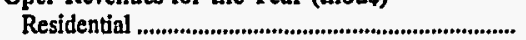 & 6,144 & 13,286 & 8,810 & 0 & 0 & 7,931 \\
\hline 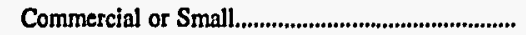 & 12,850 & 19,922 & 10,197 & 0 & 0 & 2,691 \\
\hline 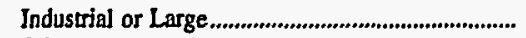 & 0 & 5,691 & 0 & 0 & 0 & 21,780 \\
\hline 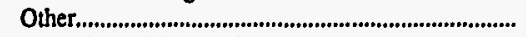 & 363 & 0 & 785 & 0 & $\mathbf{0}$ & 432 \\
\hline Total to Ultimate Consumers .............................. & 19,357 & 38,899 & 19,792 & 0 & 0 & 32,834 \\
\hline 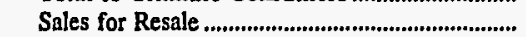 & 0 & 0 & 0 & 62,473 & 32,655 & 6,264 \\
\hline Total Revenues From Sales of Elec................... & 19,357 & 38,899 & 19,792 & 62,473 & 32,655 & 39,098 \\
\hline
\end{tabular}

\begin{tabular}{|c|c|c|c|c|c|c|}
\hline Item & $\begin{array}{l}\text { Vermont } \\
\text { Vermont } \\
\text { Public } \\
\text { Pwr } \\
\text { Supply Auth } \\
\text { December } 31\end{array}$ & $\begin{array}{l}\text { Virginia } \\
\text { Bedford } \\
\text { City of } \\
\text { June } 30\end{array}$ & $\begin{array}{l}\text { Virginia } \\
\text { Bristol } \\
\text { Utilities } \\
\text { Board } \\
\text { June } 30\end{array}$ & $\begin{array}{c}\text { Virginia } \\
\text { Danville } \\
\text { City of } \\
\text { June } 30\end{array}$ & $\begin{array}{l}\text { Virginin } \\
\text { Harrisonburg } \\
\text { City of } \\
\text { June } 30\end{array}$ & $\begin{array}{l}\text { Virginia } \\
\text { Manassas } \\
\text { City of } \\
\text { June } 30\end{array}$ \\
\hline \multicolumn{7}{|l|}{ Number of Consumers } \\
\hline 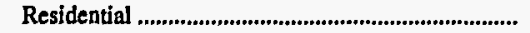 & 0 & 5,829 & 12,795 & 36,215 & 12,095 & 11,913 \\
\hline 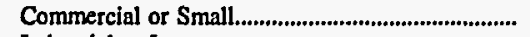 & 0 & 801 & 1,776 & 4,172 & 2,177 & 1,793 \\
\hline 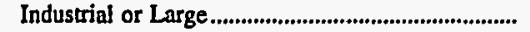 & 0 & 29 & 291 & 72 & 11 & 73 \\
\hline 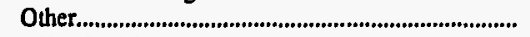 & 0 & 0 & 26 & 6,614 & 145 & 1 \\
\hline \multicolumn{7}{|l|}{ Sales for the Year (megawatthours) } \\
\hline 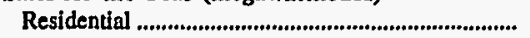 & 0 & 72,200 & 205,374 & 451,983 & 134,812 & 168,322 \\
\hline 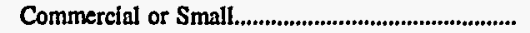 & $\mathbf{0}$ & 31,959 & 32,976 & 244,644 & 228,383 & 62,150 \\
\hline 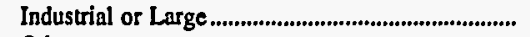 & 0 & 104,908 & 322,681 & 125,626 & 146,075 & 73,481 \\
\hline 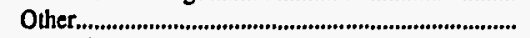 & 0 & 0 & 6,739 & 51,560 & 69,098 & 1,422 \\
\hline 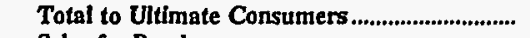 & 0 & 209,067 & 567,770 & 873,813 & 578,368 & 305,375 \\
\hline Sales for Resale & 103,611 & 0 & $\mathbf{0}$ & 0 & 0 & 0 \\
\hline 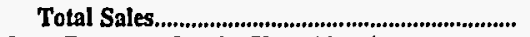 & 103,611 & 209,067 & 567,770 & 873,813 & 578,368 & 305,375 \\
\hline \multicolumn{7}{|l|}{ Oper Revenues for the Year (thou\$) } \\
\hline 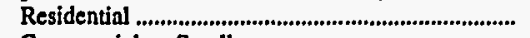 & $\mathbf{0}$ & 4,858 & 11,563 & 25,634 & 8,623 & 10,587 \\
\hline 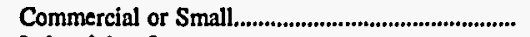 & 0 & 2,207 & 2,090 & 13,038 & 14,098 & 4,067 \\
\hline 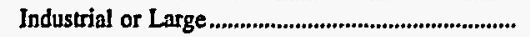 & 0 & 5,210 & 13,316 & 5,207 & 7,433 & 4,162 \\
\hline Other. & 0 & 0 & 583 & 2,787 & 4,359 & 90 \\
\hline Total to Ultimate Consumers .................................. & 0 & 12,275 & 27,552 & 46,666 & 34,513 & 18,906 \\
\hline 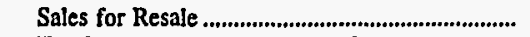 & 9,218 & 0 & 0 & 0 & 0 & 0 \\
\hline Total Revenues From Sales of Elec................... & 9,218 & 12,275 & 27,552 & 46,666 & 34,513 & 18,906 \\
\hline
\end{tabular}

Note: Totals may not equal sum of components because of independent rounding.

Source: Energy Information Administration, Form ElA-861, "Annual Electric Utility Report." Data are submitted on a calendar year. 
Table 25. Number of Consumers, Sales, and Operating Revenue by Major U.S. Publicly Owned Electric Utility Within State, 1996 (Continued)

\begin{tabular}{|c|c|c|c|c|c|c|}
\hline Item & $\begin{array}{c}\text { Virginia } \\
\begin{array}{c}\text { Martinsville } \\
\text { City of }\end{array} \\
\text { June } 30\end{array}$ & $\begin{array}{l}\text { Virginia } \\
\text { Radford } \\
\text { City of } \\
\text { June } 30\end{array}$ & $\begin{array}{l}\text { Virginia } \\
\text { Salem } \\
\text { City of } \\
\text { June } 30\end{array}$ & $\begin{array}{l}\text { Virginia } \\
\text { Virginia } \\
\text { Tech } \\
\text { Electric } \\
\text { Service } \\
\text { June } 30\end{array}$ & $\begin{array}{l}\text { Washington } \\
\text { Centralia } \\
\text { City of } \\
\text { December } 31\end{array}$ & $\begin{array}{l}\text { Washington } \\
\text { Ellensburg } \\
\text { City of } \\
\text { December } 31\end{array}$ \\
\hline \multicolumn{7}{|l|}{ Number of Consumers } \\
\hline 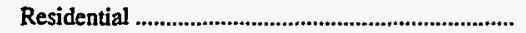 & 7,853 & 6,146 & 9,947 & 4,633 & 7,246 & 5,452 \\
\hline 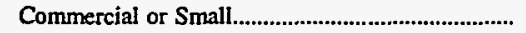 & 224 & 705 & 1,908 & 539 & 1,195 & 984 \\
\hline Industrial or Large & 7 & 22 & 103 & 2 & 40 & 1 \\
\hline 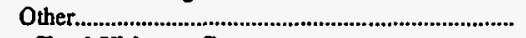 & 145 & 11 & 2 & 329 & 1 & 52 \\
\hline 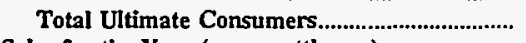 & 8,229 & 6,884 & 11,960 & 5,503 & 8,482 & 6,489 \\
\hline \multicolumn{7}{|l|}{ Sales for the Year (megawatthours) } \\
\hline 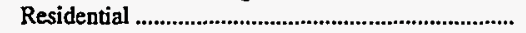 & 93,861 & 70,824 & 119,457 & 52,045 & 117,077 & 58,622 \\
\hline 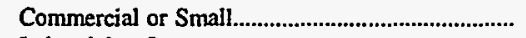 & 73,660 & 25,270 & 65,566 & 36,948 & 79,822 & 57,920 \\
\hline 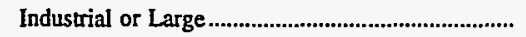 & 15,528 & 263,398 & 146,989 & 10,437 & 29,281 & 17,076 \\
\hline 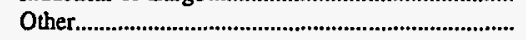 & 12,317 & 6,493 & 19,100 & 139,777 & 1,122 & 47,038 \\
\hline 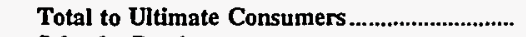 & 195,366 & 365,985 & 351,112 & 239,207 & 227,302 & 180,656 \\
\hline Sales for Resale & 0 & 0 & 0 & 0 & 0 & 0 \\
\hline 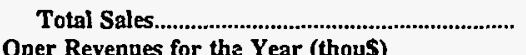 & 195,366 & 365,985 & 351,112 & 239,207 & 227,302 & 180,656 \\
\hline \multicolumn{7}{|l|}{ Oper Revenues for the Year (thou\$) } \\
\hline 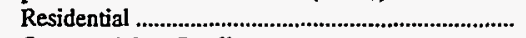 & 5,692 & 4,282 & 7,075 & 3,011 & 5,081 & 3,052 \\
\hline 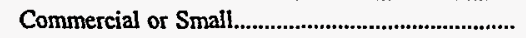 & 3,541 & 1,586 & 3,702 & 2,227 & 3,132 & 2,765 \\
\hline 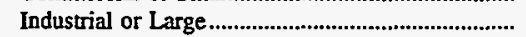 & 680 & 10,450 & 5,700 & 396 & 1,163 & 705 \\
\hline 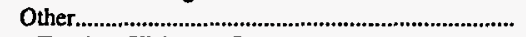 & 676 & 453 & 1,156 & 6,871 & 29 & 1,822 \\
\hline 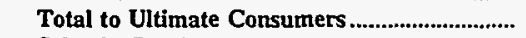 & 10,589 & 16,771 & 17,633 & 12,505 & 9,405 & 8,344 \\
\hline 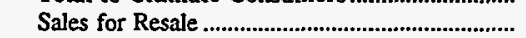 & 0 & 0 & 0 & 0 & 0 & 0 \\
\hline Total Revenues From Sales of Elec.................... & 10,589 & 16,771 & 17,633 & 12,505 & 9,405 & 8,344 \\
\hline
\end{tabular}

\begin{tabular}{|c|c|c|c|c|c|c|}
\hline Item & $\begin{array}{l}\text { Washington } \\
\text { Port Angeles } \\
\text { City of } \\
\text { December } 31\end{array}$ & $\begin{array}{l}\text { Washington } \\
\text { PUD No } 1 \\
\text { of } \\
\text { Benton } \\
\text { County } \\
\text { December } 31\end{array}$ & $\begin{array}{c}\text { Washington } \\
\text { PUD No } 1 \\
\text { of } \\
\text { Chelan } \\
\text { County } \\
\text { December } 31\end{array}$ & $\begin{array}{l}\text { Washington } \\
\text { PUD No } 1 \text { of } \\
\text { Clallam } \\
\text { County } \\
\text { December 3I }\end{array}$ & $\begin{array}{l}\text { Washington } \\
\text { PUD No } 1 \\
\text { of } \\
\text { Clark } \\
\text { County } \\
\text { December } 31\end{array}$ & $\begin{array}{l}\text { Washington } \\
\text { PUD No } 1 \text { of } \\
\text { Cowlitz } \\
\text { County } \\
\text { December } 31\end{array}$ \\
\hline \multicolumn{7}{|l|}{ Number of Consumers } \\
\hline 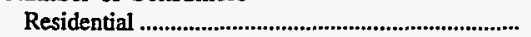 & 8,004 & 32,179 & 28,610 & 22,810 & 119,170 & 36,938 \\
\hline 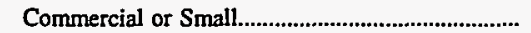 & 1,356 & 4,762 & 4,416 & 3,042 & 9,158 & 4,859 \\
\hline 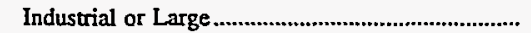 & 6 & 2 & 21 & 198 & 16 & 71 \\
\hline 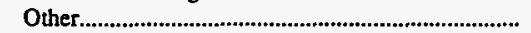 & 200 & 6 & 3,192 & 786 & 1,410 & 42 \\
\hline 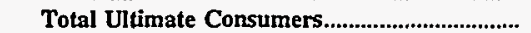 & 9,566 & 36,949 & 36,239 & 26,836 & 129,754 & 41,910 \\
\hline \multicolumn{7}{|l|}{ Sales for the Year (megawatthours) } \\
\hline 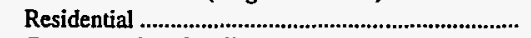 & 140,066 & 635,123 & 612,483 & 361,479 & $2,069,593$ & 731,873 \\
\hline 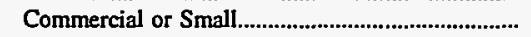 & 98,747 & 768,465 & 450,481 & 56,294 & $1,156,019$ & 349,212 \\
\hline 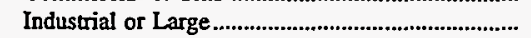 & 406,330 & 207,464 & 183,743 & 90,607 & 482,416 & $2,940,148$ \\
\hline 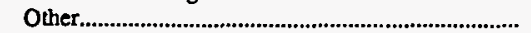 & 1,547 & 2,747 & 68,588 & 13,339 & 42,455 & 11,827 \\
\hline 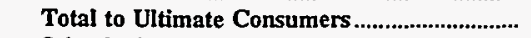 & 646,690 & $1,613,799$ & $1,315,295$ & 521,719 & $3,750,483$ & $4,033,060$ \\
\hline 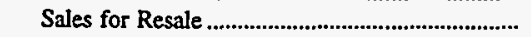 & 0 & 12,210 & $10,845,639$ & 0 & 0 & 30,160 \\
\hline 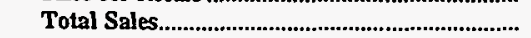 & 646,690 & $1,626,009$ & $12,160,934$ & 521,719 & $3,750,483$ & $4,063,220$ \\
\hline \multicolumn{7}{|l|}{ Oper Revenues for the Year (thouS) } \\
\hline 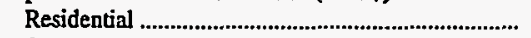 & 6,900 & 33,404 & 16,878 & 20,312 & 95,561 & 21,307 \\
\hline Commercial or Small. & 4,359 & 28,007 & 12,825 & 3,153 & 40,180 & 13,519 \\
\hline 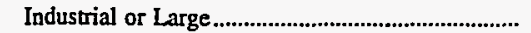 & 11,261 & 5,920 & 3,456 & 3,860 & 13,577 & 71,152 \\
\hline 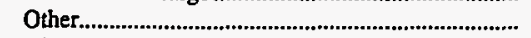 & 23 & 391 & 2,309 & 663 & 2,528 & 446 \\
\hline 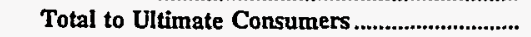 & 22,543 & 67,722 & 35,468 & 27,988 & 151,846 & 106,424 \\
\hline Sales for Resale & 0 & 209 & 125,422 & 0 & 0 & 654 \\
\hline Total Revenues From Sales of Elec................... & 22,543 & 67,931 & 160,890 & 27,988 & 151,846 & 107,078 \\
\hline
\end{tabular}

Note: Totals may not equal sum of components because of independentrounding.

Source: Energy Information Administration, Form EIA-861, “Annual Electric Utility Report." Data are submitted on a calendar year. 
Table 25. Number of Consumers, Sales, and Operating Revenue by Major U.S.

Publicly Owned Electric Utility Within State, 1996 (Continued)

\begin{tabular}{|c|c|c|c|c|c|c|}
\hline Item & $\begin{array}{l}\text { Washington } \\
\text { PUD No I of } \\
\text { Douglas } \\
\text { County } \\
\text { December } 31\end{array}$ & $\begin{array}{l}\text { Washington } \\
\text { PUD No } 1 \text { of } \\
\text { Franklin } \\
\text { County } \\
\text { December } 31\end{array}$ & $\begin{array}{c}\text { Washington } \\
\text { PUD No } 1 \\
\text { of } \\
\text { Grays } \\
\text { Harbor Cnty } \\
\text { December } 31\end{array}$ & $\begin{array}{l}\text { Washington } \\
\text { PUD No } 1 \\
\text { of } \\
\text { Klickitat } \\
\text { County } \\
\text { December } 31\end{array}$ & $\begin{array}{c}\text { Washington } \\
\text { PUD No } 1 \\
\text { of } \\
\text { Lewis } \\
\text { County } \\
\text { December } 31\end{array}$ & $\begin{array}{l}\text { Washington } \\
\text { PUD No } 1 \text { of } \\
\text { Okanogan } \\
\text { County } \\
\text { December } 31\end{array}$ \\
\hline \multicolumn{7}{|l|}{ Number of Consumers } \\
\hline Residential .... & 12,021 & 13,007 & 32,960 & 7,696 & 21,746 & 14,980 \\
\hline 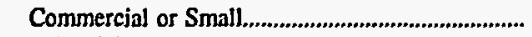 & 959 & 2,580 & 4,545 & 1,265 & 3,579 & 2,205 \\
\hline 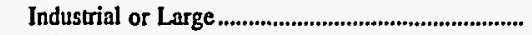 & 1 & 0 & 37 & 189 & 87 & \\
\hline 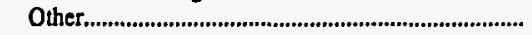 & 766 & 1,415 & 584 & 235 & 656 & 1,994 \\
\hline Total Ultimate Consumers..................................... & 13,747 & 17,002 & 38,126 & 9,385 & 26,068 & 19,184 \\
\hline \multicolumn{7}{|l|}{ Sales for the Year (megawatthours) } \\
\hline 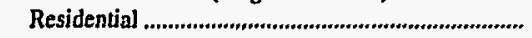 & 310,620 & 234,193 & 511,970 & 115,329 & 376,098 & 296,045 \\
\hline 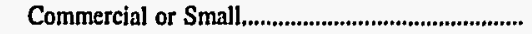 & 114,319 & 323,032 & 231,503 & 26,415 & 127,629 & 195,875 \\
\hline 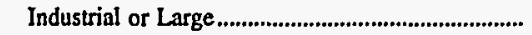 & 237,875 & 0 & 259,712 & 119,605 & 164,481 & 42,887 \\
\hline 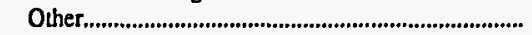 & 63,293 & 112,990 & 3,350 & 23,602 & 57,747 & 62,686 \\
\hline Total to Ultimate Consumers................................. & 726,107 & 670,215 & $1,006,535$ & 284,951 & 725,955 & 597,493 \\
\hline 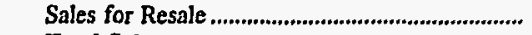 & $4,517,480$ & 0 & 14,775 & 0 & 0 & \\
\hline $\begin{array}{l}\text { Total Sales....................................................... } \\
\text { Oper Revenues for tear (theu }\end{array}$ & \multicolumn{2}{|c|}{ Oper Revenues for the Year (thou\$) } & $1,021,310$ & 284,951 & 725,955 & 597,493 \\
\hline 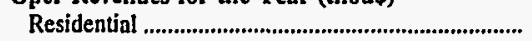 & 6,472 & 12,089 & 24,809 & 6,414 & 15,987 & 8,645 \\
\hline Commercial or Small & 2,516 & 12,923 & 11,625 & 1,489 & 5,365 & 6,494 \\
\hline 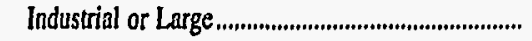 & 4,252 & 0 & 9,139 & 4,186 & 6,018 & 1,218 \\
\hline Other & 1,217 & 3,830 & 489 & 896 & 2,354 & 1,367 \\
\hline Total to Ultimate Consumers................................. & 14,457 & 28,842 & 46,062 & 12,985 & 29,724 & $\mathbf{1 7 , 7 2 4}$ \\
\hline Sales for Resale .............................................................. & 26,389 & 0 & 141 & & 0 & \\
\hline Total Revenues From Sales of Elec.................... & 40,846 & 28,842 & 46,203 & 12,985 & 29,724 & 17,724 \\
\hline
\end{tabular}

\begin{tabular}{|c|c|c|c|c|c|c|}
\hline Item & $\begin{array}{l}\text { Washington } \\
\text { PUD No } 1 \text { of } \\
\text { Pend Oreille } \\
\text { Cnty } \\
\text { December } 31\end{array}$ & $\begin{array}{l}\text { Washington } \\
\text { PUD No } 1 \text { of } \\
\text { Snohomish } \\
\text { County } \\
\text { December } 31\end{array}$ & $\begin{array}{l}\text { Washington } \\
\text { PUD No } 1 \text { of } \\
\text { Whatcom } \\
\text { County } \\
\text { December } 31\end{array}$ & $\begin{array}{c}\text { Washington } \\
\text { PUD No } 2 \\
\text { of } \\
\text { Grant } \\
\text { County } \\
\text { December 3I }\end{array}$ & $\begin{array}{l}\text { Washington } \\
\text { PUD No } 2 \text { of } \\
\text { Pacific } \\
\text { County } \\
\text { December } 31\end{array}$ & $\begin{array}{c}\text { Washington } \\
\text { PUD No } 3 \\
\text { of } \\
\text { Mason } \\
\text { County } \\
\text { December 31 }\end{array}$ \\
\hline \multicolumn{7}{|l|}{ Number of Consumers } \\
\hline Residential ..... & 6,419 & 214,637 & 0 & 27,911 & 13,226 & 24,080 \\
\hline 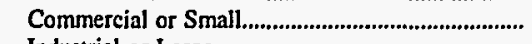 & 643 & 20,799 & 1 & 4,866 & 1,543 & 1,682 \\
\hline 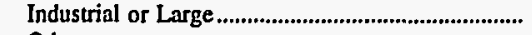 & 9 & 86 & 0 & 4,348 & 2 & 1 \\
\hline 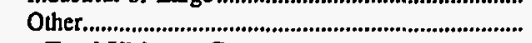 & 31 & 1,035 & 0 & 114 & 520 & 76 \\
\hline Total Uitimate Consumers....................................... & 7,102 & 236,557 & 1 & 37,239 & 15,291 & 25,839 \\
\hline \multicolumn{7}{|l|}{ Sales for the Year (megawatthours) } \\
\hline 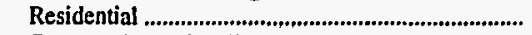 & 116,838 & $3,189,021$ & 0 & 664,193 & 165,033 & 332,321 \\
\hline 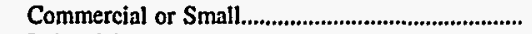 & 42,482 & $1,850,409$ & 177,465 & 356,462 & 61,075 & 142,868 \\
\hline 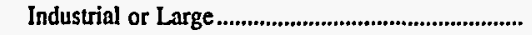 & 724,926 & 988,084 & 0 & $1,761,956$ & 26,562 & 65,827 \\
\hline Other.......... & 3,644 & 20,297 & 0 & 4,868 & 24,977 & 1,886 \\
\hline Total to Ultimate Consumers ........................................ & 887,890 & $6,047,811$ & 177,465 & $2,787,479$ & 277,647 & 542,902 \\
\hline 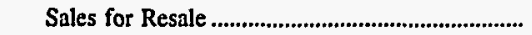 & 110,784 & $1,290,566$ & 0 & $8,482,068$ & 0 & 3,579 \\
\hline 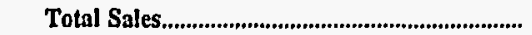 & 998,674 & $7,338,377$ & 177,465 & $11,269,547$ & 277,647 & 546,481 \\
\hline \multicolumn{7}{|l|}{ Oper Revenues for the Year (thou\$) } \\
\hline 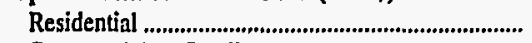 & 3,336 & 162,951 & 0 & 18,952 & 8,643 & 18,414 \\
\hline 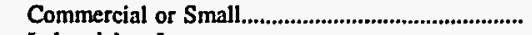 & 1,031 & 81,287 & 4,624 & 8,955 & 3,444 & 7,252 \\
\hline 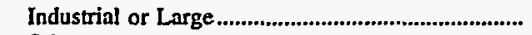 & 14,473 & 31,729 & 0 & 29,086 & 973 & 2,340 \\
\hline 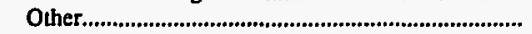 & 110 & 1,472 & 0 & 553 & 1,495 & 115 \\
\hline 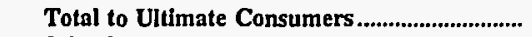 & 18,950 & 277,439 & 4,624 & 57,546 & 14,555 & 28,121 \\
\hline Sales for Resale ............................................................... & 879 & 20,521 & 0 & 46,752 & 0 & 106 \\
\hline Total Revenues From Sales of Elec.................... & 19,829 & 297,960 & 4,624 & 104,298 & 14,555 & 28,227 \\
\hline
\end{tabular}

Note: Totals may not equal sum of components because of independent rounding.

Source: Energy Information Administration, Form EIA-861, "Annual Electric Utility Report." Data are submitted on a calendar year. 
Table 25. Number of Consumers, Sales, and Operating Revenue by Major U.S. Publicly Owned Electric Utility Within State, 1996 (Continued)

\begin{tabular}{|c|c|c|c|c|c|c|}
\hline Item & $\begin{array}{l}\text { Washington } \\
\text { Richland } \\
\text { City of } \\
\text { December } 31\end{array}$ & $\begin{array}{c}\text { Washington } \\
\text { Seattle } \\
\text { City of } \\
\text { December } 31\end{array}$ & $\begin{array}{l}\text { Washington } \\
\text { Tacoma } \\
\text { City of } \\
\text { December } 31\end{array}$ & $\begin{array}{c}\text { Washington } \\
\text { Vera } \\
\text { Irrigation } \\
\text { District \# } 15 \\
\text { December } 31\end{array}$ & $\begin{array}{l}\text { Washington } \\
\text { Washington } \\
\text { Pub } \\
\text { Pwr } \\
\text { Supply Sys } \\
\text { June } 30\end{array}$ & $\begin{array}{l}\text { Wisconsin } \\
\text { Badger Power } \\
\text { Marketing } \\
\text { Auth } \\
\text { December } 31\end{array}$ \\
\hline \multicolumn{7}{|l|}{ Number of Consumers } \\
\hline 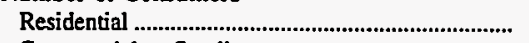 & 15,052 & 304,402 & 131,367 & 6,718 & $\mathbf{0}$ & \\
\hline 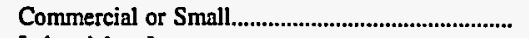 & 1,099 & 30,004 & 10,341 & 646 & 0 & \\
\hline 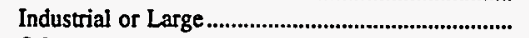 & 236 & 294 & 1,729 & 0 & 0 & \\
\hline Other & 417 & 1,944 & 329 & 38 & 0 & \\
\hline 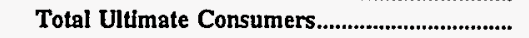 & 16,804 & 336,644 & 143,766 & 7,402 & 0 & \\
\hline \multicolumn{7}{|l|}{ Sales for the Year (megawatthours) } \\
\hline 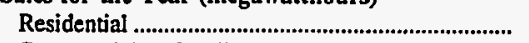 & 299,142 & $3,267,794$ & $1,829,151$ & 127,032 & 0 & \\
\hline 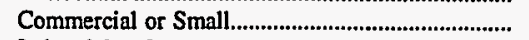 & 56,594 & $3,506,608$ & 321,503 & 54,583 & 0 & \\
\hline 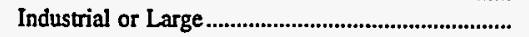 & 289,297 & $1,412,509$ & $2,755,154$ & 0 & 0 & \\
\hline 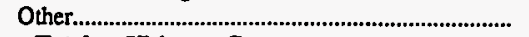 & 4,699 & $1,001,089$ & 565,288 & 6,560 & 0 & \\
\hline 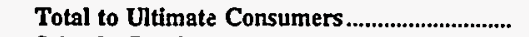 & 649,732 & $\mathbf{9 , 1 8 8 , 0 0 0}$ & $5,471,096$ & 188,175 & 0 & \\
\hline 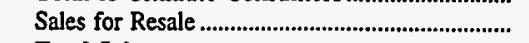 & 0 & 0 & 543,219 & 0 & $7,038,142$ & 282,054 \\
\hline 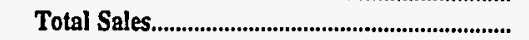 & 649,732 & $9,188,000$ & $6,014,315$ & 188,175 & $\mathbf{7 , 0 3 8 , 1 4 2}$ & 282,054 \\
\hline \multicolumn{7}{|l|}{ Oper Revenues for the Year (thou\$) } \\
\hline 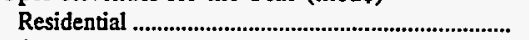 & 13,769 & 132,506 & 80,933 & 5,447 & 0 & \\
\hline 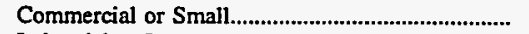 & 2,368 & 132,806 & 14,503 & 2,399 & 0 & \\
\hline 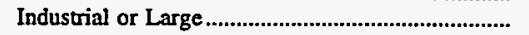 & 9,783 & 49,771 & 78,760 & 0 & 0 & 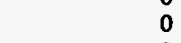 \\
\hline Other & 263 & 41,587 & 16,825 & 275 & 0 & \\
\hline Total to Ultimate Consumers.................................. & 26,183 & 356,670 & 191,021 & 8,121 & 0 & $\mathbf{0}$ \\
\hline 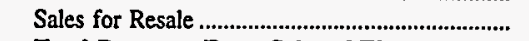 & 0 & 0 & 19,252 & 0 & 427,513 & 10,267 \\
\hline Total Revenues From Sales of Elec.................... & 26,183 & 356,670 & 210,273 & 8,121 & 427,513 & 10,267 \\
\hline
\end{tabular}

\begin{tabular}{|c|c|c|c|c|c|c|}
\hline Item & $\begin{array}{l}\text { Wisconsin } \\
\text { Jefferson } \\
\text { City of } \\
\text { December } 31\end{array}$ & $\begin{array}{c}\text { Wisconsin } \\
\text { Kaukauna } \\
\text { City of } \\
\text { December } 31\end{array}$ & $\begin{array}{c}\text { Wisconsin } \\
\text { Manitowoc } \\
\text { Public } \\
\text { Utilities } \\
\text { December } 31\end{array}$ & $\begin{array}{l}\text { Wisconsin } \\
\begin{array}{c}\text { Marshfield } \\
\text { City of }\end{array} \\
\text { December } 31\end{array}$ & $\begin{array}{l}\text { Wisconsin } \\
\text { Menasha } \\
\text { City of } \\
\text { December } 31\end{array}$ & $\begin{array}{c}\text { Wisconsin } \\
\text { New London } \\
\text { Electric\&Water } \\
\text { Util } \\
\text { December } 31\end{array}$ \\
\hline \multicolumn{7}{|l|}{ Number of Consumers } \\
\hline Residential ..... & 2,946 & 9,520 & 14,272 & 10,081 & 5,926 & 3,018 \\
\hline 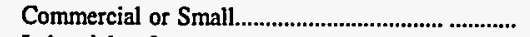 & 432 & 988 & 1,756 & 1,422 & 533 & 411 \\
\hline 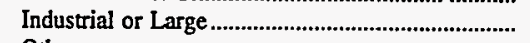 & 35 & 29 & 110 & 35 & 24 & 23 \\
\hline (1) & 1 & 32 & 1 & 26 & 110 & 13 \\
\hline $\begin{array}{l}\text { Total Ultimate Consumers................................. } \\
\text { Sales for the Year (megawytthours) }\end{array}$ & 3,414 & 10,569 & 16,139 & 11,564 & 6,593 & 3,465 \\
\hline 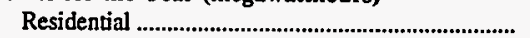 & 25,878 & 104,245 & $92,88 \mathrm{I}$ & 90,659 & 43,155 & 24,626 \\
\hline 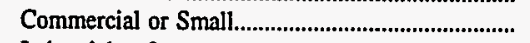 & 12,402 & 49,711 & 87,615 & 72,121 & $\begin{array}{l}43,130 \\
19,956\end{array}$ & $\begin{array}{l}24,020 \\
14,067\end{array}$ \\
\hline Industrial or Large & 111,435 & 585,328 & 316,196 & 153,831 & 495,328 & 127,363 \\
\hline 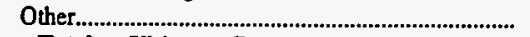 & 484 & 3,854 & 4,081 & 3,879 & 3,114 & 1,942 \\
\hline Total to Ultimate Consumers.................................... & 150,199 & 743,138 & 500,773 & 320,490 & 561,553 & 167,998 \\
\hline Sales for Resale .................................................................. & 0 & 0 & 98 & 0 & 0 & \\
\hline $\begin{array}{l}\text { Total Sales... } \\
\text { Oper Revenues for the Year (thous) }\end{array}$ & 150,199 & 743,138 & 500,871 & 320,490 & 561,553 & 167,998 \\
\hline 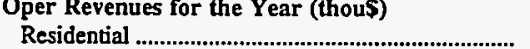 & \multicolumn{6}{|c|}{ Oper Revenues for the Year (thou\$) } \\
\hline 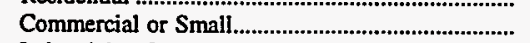 & $\begin{array}{r}1,484 \\
801\end{array}$ & $\begin{array}{l}4,175 \\
2,137\end{array}$ & $\begin{array}{l}6,062 \\
4,965\end{array}$ & $\begin{array}{l}4,028 \\
3,235\end{array}$ & $\begin{array}{l}2,859 \\
1,150\end{array}$ & $\begin{array}{r}1,509 \\
906\end{array}$ \\
\hline Industrial or Large.... & 4,285 & 17,646 & 13,336 & 5,296 & 16,327 & 4,912 \\
\hline Other & 49 & 256 & 417 & 205 & 1,495 & 142 \\
\hline Total to Ultimate Consumers..................................... & 6,619 & 24,214 & 24,780 & 12,764 & 21,831 & 7,469 \\
\hline 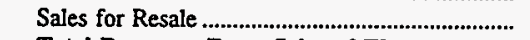 & & 0 & 4 & 0 & 0 & \\
\hline Total Revenues From Sales of Elec..................... & 6,619 & 24,214 & 24,784 & 12,764 & 21,831 & 7,469 \\
\hline
\end{tabular}

Note: Totals may not equal sum of components because of independent rounding.

Source: Energy Information Administration, Form EIA-861, "Annual Electric Utility Report." Data are submitted on a calendar year. 
Table 25. Number of Consumers, Sales, and Operating Revenue by Major U.S. Publicly Owned Electric Utility Within State, 1996 (Continued)

\begin{tabular}{|c|c|c|c|c|c|c|}
\hline Item & $\begin{array}{l}\text { Wisconsin } \\
\begin{array}{c}\text { Oconomowoc } \\
\text { City of }\end{array} \\
\text { December } 31\end{array}$ & $\begin{array}{l}\text { Wisconsin } \\
\text { Plymouth } \\
\text { City of } \\
\text { December } 31\end{array}$ & $\begin{array}{c}\text { Wisconsin } \\
\text { Reedsburg } \\
\text { Utility Comm } \\
\text { December } 31\end{array}$ & $\begin{array}{c}\text { Wisconsin } \\
\text { Shawano } \\
\text { Municipal } \\
\text { Utilities } \\
\text { December } 31\end{array}$ & $\begin{array}{c}\text { Wisconsin } \\
\text { Sheboygan } \\
\text { Falls } \\
\text { City of } \\
\text { December } 31\end{array}$ & $\begin{array}{c}\text { Wisconsin } \\
\text { Sturgeon } \\
\text { Bay City of } \\
\text { December } 31\end{array}$ \\
\hline \multicolumn{7}{|l|}{ Number of Consumers } \\
\hline 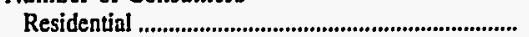 & 5,706 & 5,635 & 3,176 & 3,734 & 2,835 & 5,998 \\
\hline 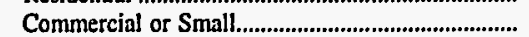 & 922 & 650 & 512 & 920 & 350 & 1,213 \\
\hline Industrial or Large & 31 & 71 & 86 & 108 & 43 & 19 \\
\hline 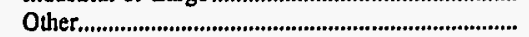 & 73 & 5 & 53 & 25 & 199 & 322 \\
\hline 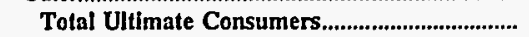 & 6,732 & 6,361 & 3,827 & 4,787 & 3,427 & $\mathbf{7 , 5 5 2}$ \\
\hline \multicolumn{7}{|l|}{ Sales for the Year (megawatthours) } \\
\hline 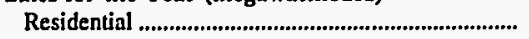 & 49,351 & 57,165 & 28,328 & 29,859 & 21,881 & 48,595 \\
\hline 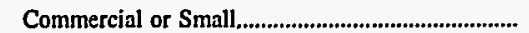 & 38,990 & 19,106 & 14,161 & 15,689 & 9,069 & 45,234 \\
\hline 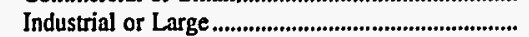 & 81,915 & 89,641 & 144,493 & 152,544 & 158,680 & 34,261 \\
\hline 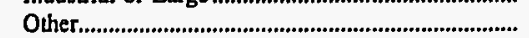 & 1,344 & 723 & 820 & 1,848 & 3,076 & 1,301 \\
\hline Total to Ultimate Consumers................................ & 171,600 & 166,635 & 187,802 & 199,940 & 192,706 & 129,391 \\
\hline Sales for Resale & 0 & 0 & 0 & $\mathbf{0}$ & 0 & 0 \\
\hline 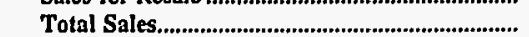 & 171,600 & 166,635 & 187,802 & 199,940 & 192,706 & 129,391 \\
\hline \multicolumn{7}{|l|}{ Oper Revenues for the Year (thou\$) } \\
\hline 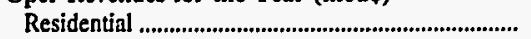 & 2,866 & 3,277 & 1,364 & 1,758 & 942 & 2,939 \\
\hline 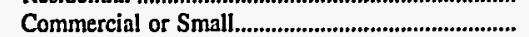 & 2,122 & 1,136 & 796 & 1,030 & 403 & 2,507 \\
\hline 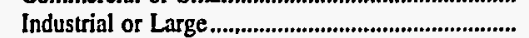 & 3,236 & 3,563 & 5,513 & 6,181 & 6,120 & 1,487 \\
\hline 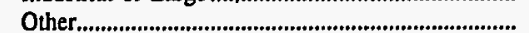 & 161 & 105 & 70 & 154 & 180 & 153 \\
\hline 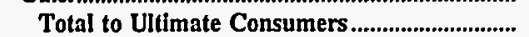 & 8,385 & 8,081 & 7,743 & 9,123 & 7,645 & 7,086 \\
\hline Sales for Resale & 0 & 0 & 0 & 0 & 0 & \\
\hline Total Revenues From Sales of Elec.................... & 8,385 & 8,081 & 7,743 & 9,123 & 7,645 & 7,086 \\
\hline
\end{tabular}

\begin{tabular}{|c|c|c|c|c|c|}
\hline Item & $\begin{array}{l}\text { Wisconsin } \\
\text { Sun Prairie } \\
\text { Water \& Light } \\
\text { Comm } \\
\text { December } 31\end{array}$ & $\begin{array}{l}\text { Wisconsin } \\
\text { Wisconsin } \\
\text { Public } \\
\text { Power } \\
\text { Inc Sys } \\
\text { December } 31\end{array}$ & $\begin{array}{l}\text { Wisconsin } \\
\text { Wisconsin } \\
\text { Rapids W W } \\
\text { \& L } \\
\text { Comm } \\
\text { December } 31\end{array}$ & $\begin{array}{l}\text { Wyoming } \\
\text { Gillette } \\
\text { City of } \\
\text { June } 30\end{array}$ & $\begin{array}{c}\text { Wyoming } \\
\text { Wyoming } \\
\text { Municipal } \\
\text { Power Agency } \\
\text { December } 31\end{array}$ \\
\hline \multicolumn{6}{|l|}{ Number of Consumers } \\
\hline 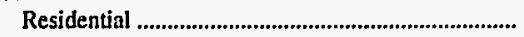 & 6,651 & 0 & 10,328 & 6,863 & 0 \\
\hline 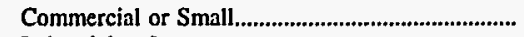 & 971 & 0 & 1,401 & 1,431 & $\mathbf{0}$ \\
\hline Industrial or Large & 30 & 0 & 31 & 0 & 0 \\
\hline 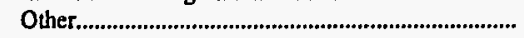 & 1 & 0 & 12 & 1 & 0 \\
\hline 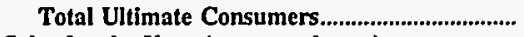 & 7,653 & $\mathbf{0}$ & $\mathbf{1 1 , 7 7 2}$ & 8,295 & $\mathbf{0}$ \\
\hline \multicolumn{6}{|l|}{ Sales for the Year (megawatthours) } \\
\hline Residential & 58,357 & 0 & 84,568 & 73,195 & 0 \\
\hline 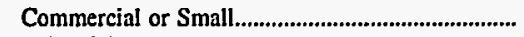 & 40,995 & 0 & 58,644 & 108,145 & 0 \\
\hline 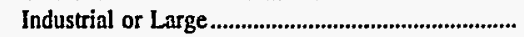 & 63,979 & 0 & 60,517 & 0 & 0 \\
\hline 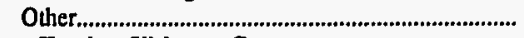 & 1,161 & 0 & 4,668 & 1,600 & 0 \\
\hline Tofal to Ultimate Consumers............................. & 164,492 & 0 & 208,397 & 182,940 & 0 \\
\hline 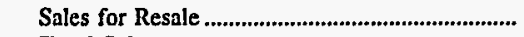 & 0 & $3,366,507$ & $\mathbf{0}$ & $\mathbf{0}$ & 206,847 \\
\hline 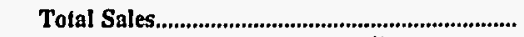 & 164,492 & $3,366,507$ & 208,397 & 182,940 & 206,847 \\
\hline \multicolumn{6}{|l|}{ Oper Revenues for the Year (thou\$) } \\
\hline Residential & 3,141 & 0 & 4,106 & 5,078 & 0 \\
\hline 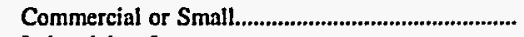 & 1,969 & 0 & 3,066 & 6,137 & 0 \\
\hline 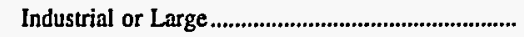 & 2,386 & 0 & 2,361 & 0 & 0 \\
\hline 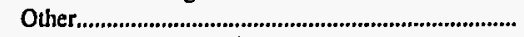 & 122 & 0 & 377 & 96 & 0 \\
\hline 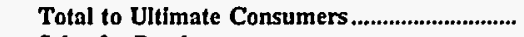 & 7,618 & $\mathbf{0}$ & 9,910 & 11,311 & $\mathbf{0}$ \\
\hline 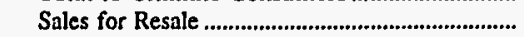 & 0 & 111,614 & 0 & 0 & 5,599 \\
\hline Total Revenues From Sales of Elec.................. & 7,618 & 111,614 & 9,910 & 11,311 & 5,599 \\
\hline
\end{tabular}

Note: Totals may not equal sum of components because of independentrounding.

Source: Energy Information Administration, Form EIA-861, "Annual Electric Utility Report." Data are submitted on a calendar year. 
Table 26. Electric Energy Account by Major U.S. Publicly Owned Electric Utility Within State, 1996

(Megawatthours)

\begin{tabular}{|c|c|c|c|c|c|c|}
\hline Item & $\begin{array}{l}\text { Alabama } \\
\text { Alabama } \\
\text { Municipal } \\
\text { Elec Auth } \\
\text { September } 30\end{array}$ & $\begin{array}{l}\text { Alabama } \\
\text { Albertville } \\
\text { Municipal } \\
\text { Utils Bd } \\
\text { June } 30\end{array}$ & $\begin{array}{l}\text { Alabama } \\
\text { Andalusia } \\
\text { City of } \\
\text { September } 30\end{array}$ & $\begin{array}{l}\text { Alabama } \\
\text { Athens } \\
\text { City of } \\
\text { December } 31\end{array}$ & $\begin{array}{l}\text { Alabama } \\
\text { Bessemer } \\
\text { City of } \\
\text { June } 30\end{array}$ & $\begin{array}{l}\text { Alabama } \\
\text { Cullman } \\
\text { Power Board } \\
\text { June } 30\end{array}$ \\
\hline \multicolumn{7}{|l|}{ Sources of Energy } \\
\hline 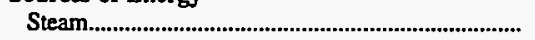 & 0 & 0 & $\mathbf{0}$ & $\mathbf{0}$ & 0 & $\mathbf{0}$ \\
\hline 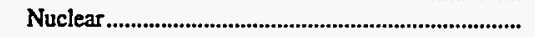 & 0 & 0 & 0 & 0 & 0 & 0 \\
\hline 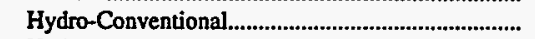 & 0 & 0 & 0 & 0 & 0 & 0 \\
\hline 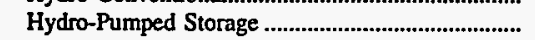 & 0 & 0 & $\mathbf{0}$ & 0 & 0 & 0 \\
\hline Other & 0 & 0 & 0 & 0 & 0 & 0 \\
\hline 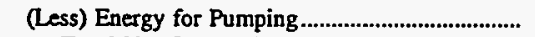 & 0 & 0 & 0 & 0 & 0 & 0 \\
\hline 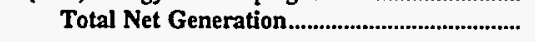 & $\mathbf{0}$ & 0 & $\mathbf{0}$ & o & $\mathbf{0}$ & $\mathbf{0}$ \\
\hline 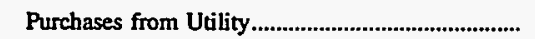 & $2,634,724$ & 485,045 & 337,831 & 798,708 & 320,104 & 343,100 \\
\hline $\begin{array}{l}\text { Purchases from Nonutility........................................ } \\
\text { Power Exchanges }\end{array}$ & 0 & 0 & 0 & 0 & 0 & 0 \\
\hline 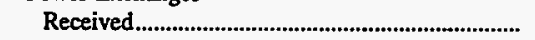 & 0 & 0 & 0 & 0 & 0 & 0 \\
\hline 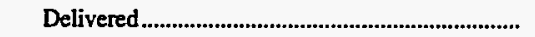 & 0 & 0 & 0 & 0 & 0 & 0 \\
\hline 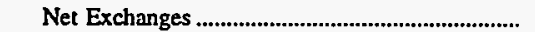 & 0 & 0 & 0 & 0 & 0 & 0 \\
\hline \multicolumn{7}{|l|}{ Transmission for Others (Wheeling) } \\
\hline 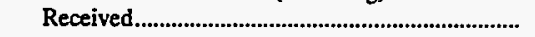 & $\mathbf{0}$ & 0 & 0 & 0 & 0 & 0 \\
\hline 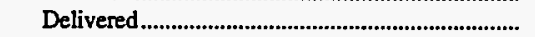 & 0 & 0 & 0 & 0 & 0 & 0 \\
\hline 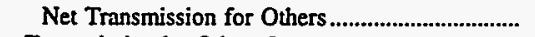 & 0 & 0 & 0 & 0 & 0 & 0 \\
\hline $\begin{array}{l}\text { Transmission by Others Losses...................................... } \\
\text { Total Net Energy }\end{array}$ & 0 & 0 & 0 & 0 & 0 & 0 \\
\hline 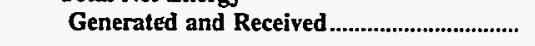 & $2,634,724$ & 485,045 & 337,831 & 798,708 & 320,104 & 343,100 \\
\hline \multicolumn{7}{|l|}{ Disposition of Energy } \\
\hline 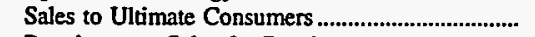 & 0 & 471,795 & 329,883 & 734,622 & 294,467 & 330,989 \\
\hline 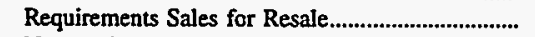 & $2,634,724$ & 0 & 0 & 0 & 0 & 0 \\
\hline 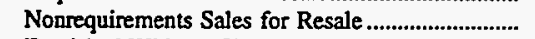 & 0 & 0 & 0 & 0 & 0 & 0 \\
\hline 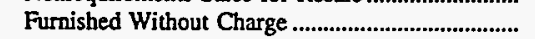 & 0 & 0 & 0 & 0 & 0 & 0 \\
\hline Used by Utility (excluding station use).................... & 0 & 0 & 0 & 0 & 480 & 60 \\
\hline 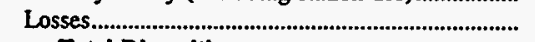 & 0 & 13,250 & 7,948 & 64,086 & 25,157 & 12,051 \\
\hline Total Disposition & $2,634,724$ & 485,045 & 337,831 & 798,708 & 320,104 & 343,100 \\
\hline
\end{tabular}

Note: Totals may not equal sum of components because of independent rounding. Double counting occurs in components of both sources and disposition of energy and thus neither provides a true total. Purchases from utilities, net interchanges, and net wheeling (except for imports) are included in net generation.

Source: Energy Information Administration, Form EIA-412, “Annual Report of Public Electric Utilities." 
Table 26. Electric Energy Account by Major U.S. Publicly Owned Electric Utility Within State, 1996 (Continued)

(Megawatthours)

\begin{tabular}{|c|c|c|c|c|c|c|}
\hline Item & $\begin{array}{l}\text { Alabama } \\
\text { Decatur } \\
\text { City of } \\
\text { June } 30\end{array}$ & $\begin{array}{l}\text { Alabama } \\
\text { Dothan } \\
\text { City of } \\
\text { September } 30\end{array}$ & $\begin{array}{l}\text { Alabama } \\
\begin{array}{c}\text { Florence } \\
\text { City of }\end{array} \\
\text { June } 30\end{array}$ & $\begin{array}{c}\text { Alabama } \\
\text { Foley } \\
\text { City of } \\
\text { (Riviera Utils) } \\
\text { December } 31\end{array}$ & $\begin{array}{l}\text { Alabama } \\
\text { Fort Payne } \\
\begin{array}{c}\text { Improvement } \\
\text { Auth }\end{array} \\
\text { June } 30\end{array}$ & $\begin{array}{l}\text { Alabama } \\
\text { Guntersville } \\
\text { Electric } \\
\text { Board } \\
\text { June } 30\end{array}$ \\
\hline \multicolumn{7}{|l|}{ Sources of Energy } \\
\hline Steam & 0 & 0 & 0 & 0 & 0 & 0 \\
\hline Nuclear.................................................................................. & 0 & 0 & 0 & 0 & 0 & 0 \\
\hline 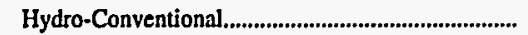 & 0 & 0 & 0 & 0 & 0 & 0 \\
\hline 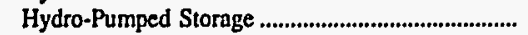 & 0 & $\mathbf{0}$ & $\mathbf{0}$ & 0 & $\mathbf{0}$ & $\mathbf{0}$ \\
\hline 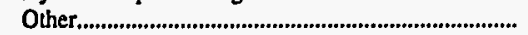 & 0 & $\mathbf{0}$ & $\mathbf{0}$ & 0 & $\mathbf{0}$ & 0 \\
\hline 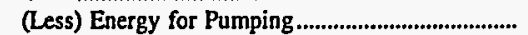 & 0 & $\mathbf{0}$ & 0 & 0 & 0 & 0 \\
\hline 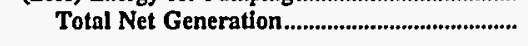 & D & 0 & $\mathbf{0}$ & $\mathbf{0}$ & 0 & 0 \\
\hline 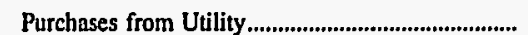 & $1,568,525$ & $1,089,916$ & $1,183,380$ & 618,361 & 356,684 & 251,916 \\
\hline \multicolumn{7}{|l|}{ Power Exchanges } \\
\hline 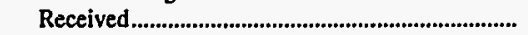 & 0 & 0 & 0 & 0 & 0 & $\mathbf{0}$ \\
\hline 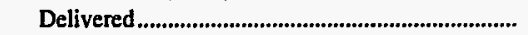 & 0 & 0 & 0 & 0 & 0 & $\mathbf{0}$ \\
\hline 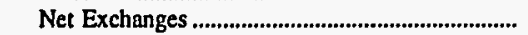 & 0 & $\mathbf{0}$ & $\mathbf{0}$ & 0 & 0 & $\mathbf{0}$ \\
\hline \multicolumn{7}{|l|}{ Transmission for Others (Wheeling) } \\
\hline 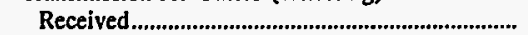 & 0 & 0 & 0 & 0 & 0 & $\mathbf{0}$ \\
\hline Delivered ............................................................... & 0 & 0 & 0 & 0 & 0 & $\mathbf{0}$ \\
\hline 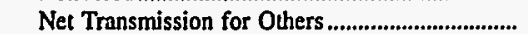 & 0 & 0 & 0 & 0 & 0 & $\mathbf{0}$ \\
\hline 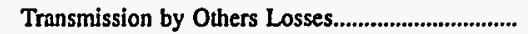 & 0 & $\mathbf{0}$ & 0 & 0 & 0 & $\mathbf{0}$ \\
\hline \multicolumn{7}{|l|}{ Total Net Energy } \\
\hline 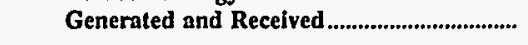 & $1,568,525$ & $1,090,678$ & $1,183,380$ & 618,361 & 356,684 & 251,916 \\
\hline \multicolumn{7}{|l|}{ Disposition of Energy } \\
\hline 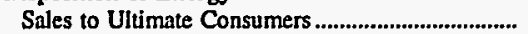 & $1,519,863$ & $1,062,611$ & $1,097,671$ & 586,252 & 337,020 & 240,332 \\
\hline Requirements Sales for Resale....................................... & 0 & 0 & 0 & 0 & 0 & 0 \\
\hline Nonrequirements Sales for Resale ............................... & 0 & 0 & 0 & 0 & 0 & 0 \\
\hline Furnished Without Charge ........................................... & 0 & 0 & 0 & 0 & 0 & 0 \\
\hline Used by Utility (excluding station use)....................... & 0 & $\mathbf{0}$ & 342 & 0 & 197 & 255 \\
\hline 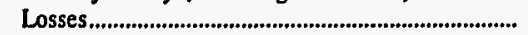 & 48,663 & 28,067 & 85,367 & 32,109 & 19,467 & 11,328 \\
\hline Total Disposition & $1,568,525$ & $1,090,678$ & $1,183,380$ & 618,361 & 356,684 & 251,916 \\
\hline
\end{tabular}

Note: Totals may not equal sum of components because of independent rounding. Double counting occurs in components of both sources and disposition of energy and thus neither provides a true total. Purchases from utilities, net interchanges, and net wheeling (except for imports) are included in net generation.

Source: Energy Information Administration, Form EIA-412, “Annual Report of Public Electric Utilities." 
Table 26. Electric Energy Account by Major U.S. Publicly Owned Electric Utility Within State, 1996 (Continued)

(Megawatthours)

\begin{tabular}{|c|c|c|c|c|c|c|}
\hline Item & $\begin{array}{l}\text { Alabama } \\
\text { Hartselle } \\
\text { City of } \\
\text { June } 30\end{array}$ & $\begin{array}{l}\text { Alabama } \\
\text { Huntsville } \\
\text { City of } \\
\text { September } 30\end{array}$ & $\begin{array}{l}\text { Alabama } \\
\text { Muscle } \\
\text { Shoals } \\
\text { City of } \\
\text { June } 30\end{array}$ & $\begin{array}{l}\text { Alabama } \\
\text { Opelika } \\
\text { City of } \\
\text { September } 30\end{array}$ & $\begin{array}{l}\text { Alabama } \\
\text { Scottsboro } \\
\text { City of } \\
\text { June } 30\end{array}$ & $\begin{array}{l}\text { Alabama } \\
\text { Sheffield } \\
\text { Utilities } \\
\text { June } 30\end{array}$ \\
\hline \multicolumn{7}{|l|}{ Sources of Energy } \\
\hline Steam & 0 & 0 & 0 & 0 & 0 & 0 \\
\hline Nuclear & 0 & 0 & 0 & 0 & 0 & 0 \\
\hline 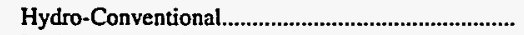 & 0 & 0 & 0 & 0 & 0 & 0 \\
\hline 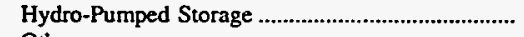 & 0 & 0 & $\mathbf{0}$ & 0 & $\mathbf{0}$ & 0 \\
\hline 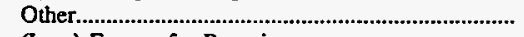 & 0 & 0 & 0 & 0 & 0 & 0 \\
\hline 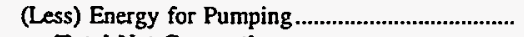 & 0 & 0 & 0 & 0 & 0 & 0 \\
\hline Total Net Generation ........................................ & $\mathbf{0}$ & $\mathbf{0}$ & 0 & 0 & $\mathbf{0}$ & $\mathbf{0}$ \\
\hline Purchases from Utility & 148,624 & $4,295,381$ & 224,340 & 345,761 & 395,731 & 458,495 \\
\hline $\begin{array}{l}\text { Purchases from Nonutility........................................... } \\
\text { Power Exchanges }\end{array}$ & 0 & 0 & 0 & 0 & $\mathbf{0}$ & 0 \\
\hline Received & 0 & 0 & 0 & 0 & $\mathbf{0}$ & 0 \\
\hline 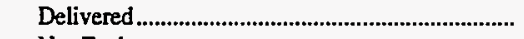 & 0 & 0 & 0 & 0 & $\mathbf{0}$ & 0 \\
\hline 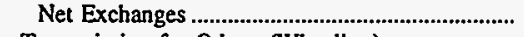 & 0 & 0 & 0 & 0 & 0 & 0 \\
\hline \multicolumn{7}{|l|}{ Transmission for Others (Wheeling) } \\
\hline Received & 0 & 0 & 0 & 0 & 0 & 0 \\
\hline Delivered & 0 & 0 & 0 & 0 & 0 & 0 \\
\hline Net Transmission for Others & 0 & 0 & 0 & 0 & 0 & 0 \\
\hline $\begin{array}{l}\text { Transmission by Others Losses................................... } \\
\text { Total Net Energy }\end{array}$ & 0 & 0 & 0 & 0 & 0 & 0 \\
\hline 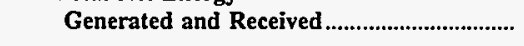 & 148,624 & $4,295,381$ & 224,340 & 345,761 & 395,731 & 458,495 \\
\hline \multicolumn{7}{|l|}{ Disposition of Energy } \\
\hline 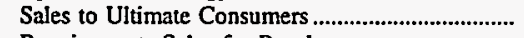 & 139,369 & $4,107,294$ & 211,531 & 338,384 & 375,906 & 423,736 \\
\hline Requirements Sales for Resale & $\mathbf{0}$ & 0 & 0 & $\mathbf{0}$ & 0 & 0 \\
\hline Nonrequirements Sales for Resale ............................. & 0 & 0 & 0 & 0 & 0 & 0 \\
\hline 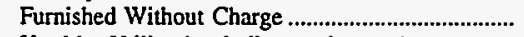 & 0 & 0 & 0 & 0 & $\mathbf{0}$ & 0 \\
\hline Used by Utility (excluding station use).................. & 0 & 584 & 286 & 0 & 310 & 0 \\
\hline 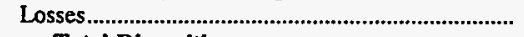 & 9,256 & 187,503 & 12,523 & 7,377 & 19,515 & 34,759 \\
\hline Total Disposition & 148,624 & $4,295,381$ & 224,340 & 345,761 & 395,731 & 458,495 \\
\hline
\end{tabular}

Note: Totals may not equal sum of components because of independent rounding. Double counting occurs in components of both sources and disposition of energy and thus neither provides a true total. Purchases from utilities, net interchanges, and net wheeling (except for imports) are included in net generation.

Source: Energy Information Administration, Form EIA-412, "Annual Report of Public Electric Utilities." 
Table 26. Electric Energy Account by Major U.S. Publicly Owned Electric Utility Within State, 1996 (Continued)

(Megawatthours)

\begin{tabular}{|c|c|c|c|c|c|c|}
\hline Item & $\begin{array}{l}\text { Alabama } \\
\text { Sylacauga } \\
\text { Utilities } \\
\text { Board } \\
\text { September } 30\end{array}$ & $\begin{array}{c}\text { Alabama } \\
\text { Troy } \\
\text { City of } \\
\text { September } 30\end{array}$ & $\begin{array}{l}\text { Alabama } \\
\text { Tuskegee } \\
\text { City of } \\
\text { September } 30\end{array}$ & $\begin{array}{l}\text { Alaska } \\
\text { Alaska } \\
\text { Energy } \\
\text { Authority } \\
\text { June } 30\end{array}$ & $\begin{array}{c}\text { Alaska } \\
\text { Anchorage } \\
\text { City of } \\
\text { December } 31\end{array}$ & $\begin{array}{l}\text { Alaska } \\
\text { Fairbanks } \\
\text { City of } \\
\text { December } 31\end{array}$ \\
\hline \multicolumn{7}{|l|}{ Sources of Energy } \\
\hline 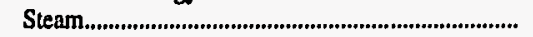 & 0 & 0 & 0 & 0 & 151,553 & 107,663 \\
\hline 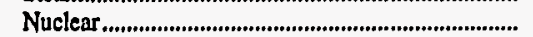 & 0 & 0 & 0 & 0 & 0 & 0 \\
\hline Hydro-Conventional.................................................... & 0 & 0 & 0 & 659,333 & 0 & 0 \\
\hline Hydro-Pumped Storage .................................................. & 0 & 0 & 0 & 0 & 0 & 0 \\
\hline Other, & 0 & 0 & $\mathbf{0}$ & 0 & 597,608 & 0 \\
\hline (Less) Energy for Pumping........................................ & 0 & 0 & 0 & 0 & 0 & 0 \\
\hline 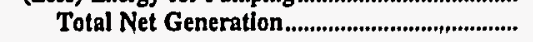 & 0 & $\mathbf{0}$ & 0 & 659,333 & 749,161 & 107,663 \\
\hline Purchases from Utility................................................... & 188,644 & 277,416 & 168,485 & 0 & 166,912 & 51,484 \\
\hline Purchases from Nonutility........................................... & 0 & 0 & 0 & 0 & 0 & 0 \\
\hline 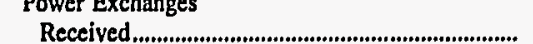 & 0 & 0 & 0 & 0 & 0 & 0 \\
\hline Delivered & 0 & $\mathbf{0}$ & 0 & 0 & 0 & 0 \\
\hline 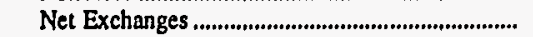 & 0 & 0 & 0 & 0 & 0 & 0 \\
\hline \multicolumn{7}{|l|}{ Transmission for Others (Wheeling) } \\
\hline 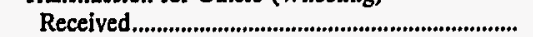 & 0 & 0 & 0 & 333,665 & 0 & 0 \\
\hline Delivered & 0 & 0 & 0 & 333,665 & 0 & 0 \\
\hline 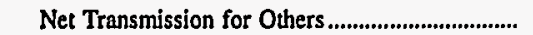 & 0 & 0 & 0 & 0 & 0 & 0 \\
\hline $\begin{array}{l}\text { Transmission by Others Losses................................. } \\
\text { Total Net Energy }\end{array}$ & 0 & 0 & 0 & 0 & 0 & 0 \\
\hline 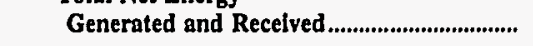 & 188,644 & 277,416 & 168,485 & 659,333 & 916,073 & 159,147 \\
\hline \multicolumn{7}{|l|}{ Disposition of Energy } \\
\hline 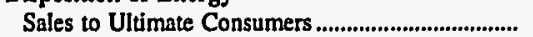 & 180,539 & 256,256 & 144,271 & $\mathbf{0}$ & 836,454 & 152,433 \\
\hline Requirements Sales for Resale................................... & 0 & 0 & 0 & 659,240 & 40,571 & 0 \\
\hline Nonrequirements Sales for Resale ........................... & 0 & 0 & 0 & 93 & 0 & 0 \\
\hline Furnished Without Charge ......................................... & 0 & 9,487 & 4,540 & 0 & $\mathbf{0}$ & 0 \\
\hline Used by Utility (excluding station use).................... & 0 & 6,322 & 0 & 0 & 0 & 0 \\
\hline 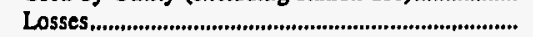 & 8,105 & 5,351 & 19,674 & $\mathbf{0}$ & 39,048 & 6,714 \\
\hline 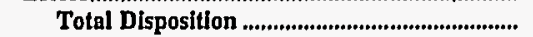 & 188,644 & 277,416 & 168,485 & 659,333 & 916,073 & 159,147 \\
\hline
\end{tabular}

Note: Totals may not equal sum of components because of independent rounding. Double counting occurs in components of both sources and disposition of energy and thus neither provides a true total. Purchases from utilities, net interchanges, and net wheeling (except for imports) are included in net generation.

Source: Energy Information Administration, Form EIA-412, “Annual Report of Public Electric Utilities." 
Table 26. Electric Energy Account by Major U.S. Publicly Owned Electric Utility Within State, 1996 (Continued)

(Megawatthours)

\begin{tabular}{|c|c|c|c|c|c|c|}
\hline Item & $\begin{array}{l}\text { Alaska } \\
\text { Ketchikan } \\
\text { City of } \\
\text { December } 31\end{array}$ & $\begin{array}{l}\text { Arizona } \\
\text { Arizona } \\
\text { Power } \\
\text { Authority } \\
\text { June } 30\end{array}$ & $\begin{array}{l}\text { Arizona } \\
\text { Electrical } \\
\text { Dist } \\
\text { No2 } \\
\text { Pinal Cnty } \\
\text { December } 31\end{array}$ & $\begin{array}{l}\text { Arizona } \\
\text { Mesa } \\
\text { City of } \\
\text { June } 30\end{array}$ & $\begin{array}{l}\text { Arizona } \\
\text { Navajo } \\
\text { Tribal } \\
\text { Utility } \\
\text { Auth } \\
\text { December } 31\end{array}$ & $\begin{array}{l}\text { Arizona } \\
\text { Salt River } \\
\text { Proj Ag } \\
\text { I \& P Dist } \\
\text { April } 30\end{array}$ \\
\hline \multicolumn{7}{|l|}{ Sources of Energy } \\
\hline 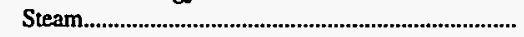 & 0 & 0 & 0 & 0 & 0 & $12,032,376$ \\
\hline 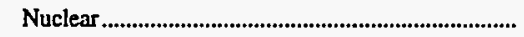 & $\mathbf{0}$ & 0 & 0 & 0 & 0 & $4,824,757$ \\
\hline 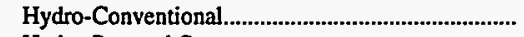 & 66,521 & 0 & 0 & 0 & 0 & 348,674 \\
\hline Hydro-Pumped Storage & 0 & $\mathbf{0}$ & 0 & 0 & 0 & 23,530 \\
\hline 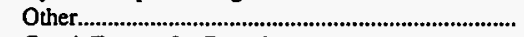 & 25,982 & 0 & 0 & 0 & 0 & 145,837 \\
\hline 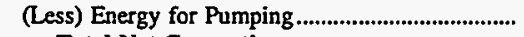 & 0 & $\mathbf{0}$ & 0 & 0 & $\mathbf{0}$ & 33,614 \\
\hline Total Net Generation & 92,503 & $\mathbf{0}$ & $\mathbf{0}$ & $\mathbf{0}$ & $\mathbf{0}$ & $17,341,560$ \\
\hline 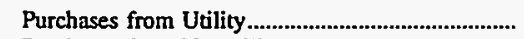 & 62,607 & $1,224,775$ & 191,530 & 355,977 & 576,871 & $5,565,103$ \\
\hline $\begin{array}{l}\text { Purchases from Nonutility...................................... } \\
\text { Power Exchanges }\end{array}$ & \multicolumn{2}{|c|}{ Power Exchanges } & 0 & 0 & 0 & 126 \\
\hline 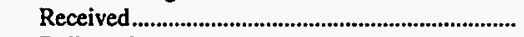 & 0 & 0 & 0 & 0 & 0 & 278,568 \\
\hline Delivered & 0 & $\mathbf{0}$ & 0 & 0 & 0 & 235,419 \\
\hline 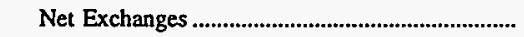 & 0 & 0 & 0 & 0 & 0 & 43.149 \\
\hline \multicolumn{7}{|l|}{ Transmission for Others (Wheeling) } \\
\hline 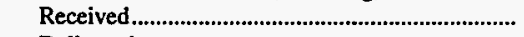 & 0 & 0 & 0 & 0 & 0 & 148,891 \\
\hline 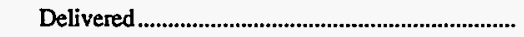 & 0 & 0 & 0 & 0 & 0 & 144,113 \\
\hline 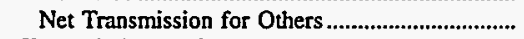 & 0 & 0 & 0 & 0 & 0 & 4,778 \\
\hline $\begin{array}{l}\text { Transmission by Others Losses................................... } \\
\text { Total Net Energy }\end{array}$ & 0 & $\mathbf{0}$ & 0 & 0 & 0 & 0 \\
\hline 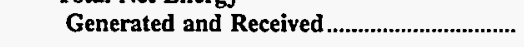 & 156,456 & $1,224,775$ & 191,530 & 355,977 & 576,871 & $22,954,716$ \\
\hline \multicolumn{7}{|l|}{ Disposition of Energy } \\
\hline 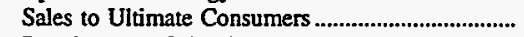 & 152,426 & 0 & 177,750 & 333,677 & 528,897 & $17,634,028$ \\
\hline 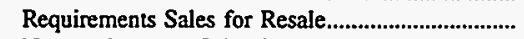 & 0 & $1,181,512$ & 0 & 0 & 0 & $4,202,520$ \\
\hline Nonrequirements Sales for Resale ............................... & 0 & 0 & 0 & 53 & 0 & 0 \\
\hline 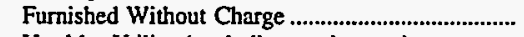 & 1,111 & 0 & 0 & 0 & 0 & 0 \\
\hline Used by Utility (excluding station use)................... & 2,919 & 0 & 0 & 0 & 0 & 0 \\
\hline Losses & 0 & 43,263 & 13,780 & 22,247 & 47,974 & $1,118,168$ \\
\hline Total Disposition & 156,456 & $1,224,775$ & 191,530 & 355,977 & $\mathbf{5 7 6 , 8 7 1}$ & $22,954,716$ \\
\hline
\end{tabular}

Note: Totals may not equal sum of components because of independent rounding. Double counting occurs in components of both sources and disposition of energy and thus neither provides a true total. Purchases from utilities, net interchanges, and net wheeling (except for imports) are included in net generation.

Source: Energy Information Administration, Form EIA-412, “Annual Report of Public Electric Utilities." 
Table 26. Electric Energy Account by Major U.S. Publicly Owned Electric Utility Within State, 1996 (Continued)

(Megawatthours)

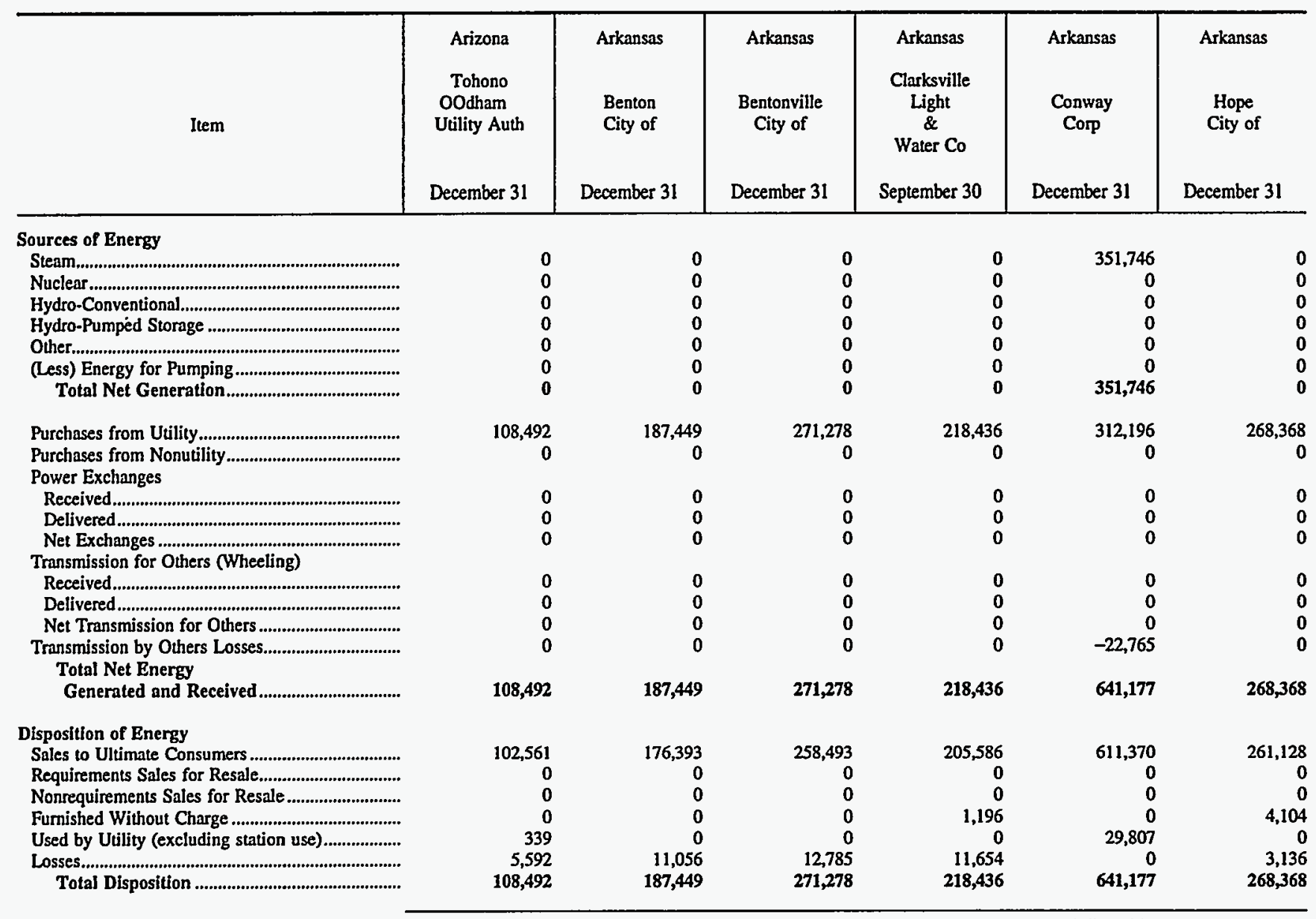

Note: Totals may not equal sum of components because of independent rounding. Double counting occurs in components of both sources and disposition of energy and thus neither provides a true total. Purchases from utilities, net interchanges, and net wheeling (except for imports) are included in net generation.

Source: Energy Information Administration, Form EIA-412, "Annual Report of Public Electric Utilities." 
Table 26. Electric Energy Account by Major U.S. Publicly Owned Electric - Utility Within State, 1996 (Continued)

(Megawatthours)

\begin{tabular}{|c|c|c|c|c|c|c|}
\hline Item & $\begin{array}{l}\text { Arkansas } \\
\text { Jonesboro } \\
\text { City of } \\
\text { December } 31\end{array}$ & $\begin{array}{c}\text { Arkansas } \\
\text { North } \\
\text { Little } \\
\text { Rock } \\
\text { City of } \\
\text { December } 31\end{array}$ & $\begin{array}{c}\text { Arkansas } \\
\text { Osceola } \\
\text { City of } \\
\text { December } 31\end{array}$ & $\begin{array}{l}\text { Arkansas } \\
\text { Paragould } \\
\text { Light } \\
\& \\
\text { Water Comm } \\
\text { December } 31\end{array}$ & $\begin{array}{l}\text { Arkansas } \\
\text { Siloam } \\
\text { Springs } \\
\text { City of } \\
\text { December } 31\end{array}$ & $\begin{array}{l}\text { Arkansas } \\
\text { West } \\
\text { Memphis } \\
\text { City of } \\
\text { December } 31\end{array}$ \\
\hline \multicolumn{7}{|l|}{ Sources of Energy } \\
\hline 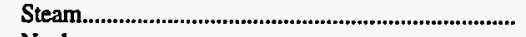 & $1,007,095$ & 0 & 0 & 0 & 0 & 175,873 \\
\hline 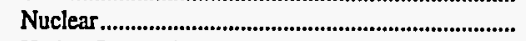 & 0 & 0 & 0 & 0 & 0 & 0 \\
\hline 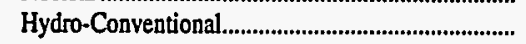 & 0 & 178,745 & 0 & 0 & 0 & 0 \\
\hline 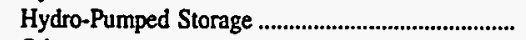 & 0 & 0 & 0 & 0 & 0 & 0 \\
\hline 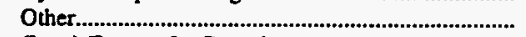 & 0 & 0 & 540 & 205 & 0 & 0 \\
\hline 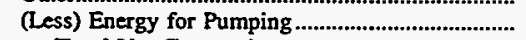 & 0 & 0 & 0 & 0 & 0 & 0 \\
\hline Total Net Generation & $1,007,095$ & 178,745 & 540 & 205 & 0 & 175,873 \\
\hline 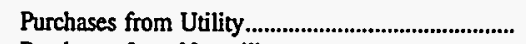 & 850,654 & 731,568 & 218,870 & 456,794 & 213,724 & 192,369 \\
\hline 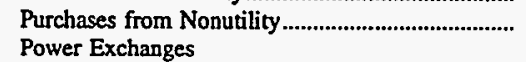 & 0 & 0 & 0 & 0 & 0 & 0 \\
\hline 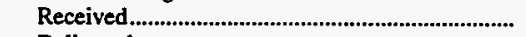 & 0 & 0 & 0 & 0 & 0 & 0 \\
\hline 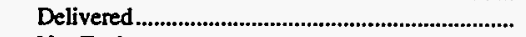 & 142,516 & 0 & 0 & 0 & 0 & 0 \\
\hline 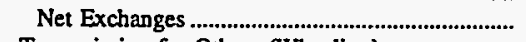 & $-142,516$ & 0 & 0 & 0 & 0 & 0 \\
\hline \multicolumn{7}{|l|}{ Transmission for Others (Wheeling) } \\
\hline 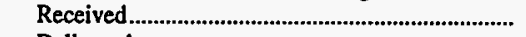 & 0 & 0 & 0 & 0 & 0 & 0 \\
\hline 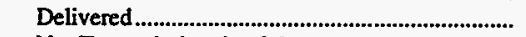 & 0 & 0 & 0 & 0 & 0 & $\mathbf{0}$ \\
\hline 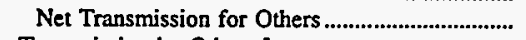 & 0 & 0 & 0 & 0 & 0 & 0 \\
\hline $\begin{array}{l}\text { Transmission by Others Losses................................. } \\
\text { Total Net Energy }\end{array}$ & 0 & 0 & 0 & 0 & 0 & 0 \\
\hline Generated and Received................................... & $1,715,233$ & 910,313 & 219,410 & 456,999 & 213,724 & 368,242 \\
\hline \multicolumn{7}{|l|}{ Disposition of Energy } \\
\hline 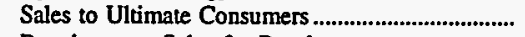 & 884,021 & 869,807 & 209,265 & 409,274 & 194,710 & 334,567 \\
\hline 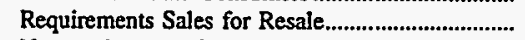 & 66,837 & 0 & 0 & 0 & 0 & 0 \\
\hline 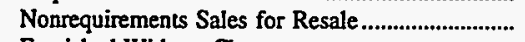 & 728,543 & 0 & 0 & 18,319 & 0 & 0 \\
\hline 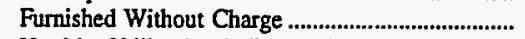 & 7,861 & 0 & 2,866 & 0 & 0 & 1,920 \\
\hline Used by Utility (excluding station use).................. & 0 & 0 & 713 & 0 & 0 & 5,744 \\
\hline 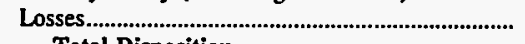 & 27,971 & 40,506 & 6,566 & 29,406 & 19,014 & 26,011 \\
\hline Total Disposition & $1,715,233$ & 910,313 & 219,410 & 456,999 & 213,724 & 368,242 \\
\hline
\end{tabular}

Note: Totals may not equal sum of components because of independent rounding. Double counting occurs in components of both sources and disposition of energy and thus neither provides a true total. Purchases from utilities, net interchanges, and net wheeling (except for imports) are included in net generation.

Source: Energy Information Administration, Form ELA-412, "Annual Report of Public Electric Utilities." 
Table 26. Electric Energy Account by Major U.S. Publicly Owned Electric Utility Within State, 1996 (Continued)

(Megawatthours)

\begin{tabular}{|c|c|c|c|c|c|c|}
\hline Item & $\begin{array}{l}\text { California } \\
\text { Alameda } \\
\text { City of } \\
\text { June } 30\end{array}$ & $\begin{array}{l}\text { California } \\
\text { Anaheim } \\
\text { City of } \\
\text { June } 30\end{array}$ & $\begin{array}{l}\text { Califomia } \\
\text { Azusa } \\
\text { City of } \\
\text { June } 30\end{array}$ & $\begin{array}{l}\text { California } \\
\text { Burbank } \\
\text { City of } \\
\text { June } 30\end{array}$ & $\begin{array}{c}\text { California } \\
\text { California } \\
\text { Dept } \\
\text { Wtr } \\
\text { Resources } \\
\text { June } 30\end{array}$ & $\begin{array}{l}\text { California } \\
\text { Colton } \\
\text { City of } \\
\text { June } 30\end{array}$ \\
\hline \multicolumn{7}{|l|}{ Sources of Energy } \\
\hline 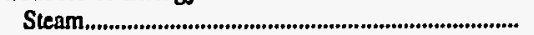 & $\mathbf{0}$ & 337,299 & 0 & 99,477 & 636,939 & 0 \\
\hline 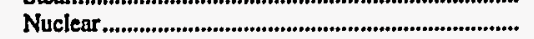 & 0 & 539,558 & 0 & 0 & 0 & 16,732 \\
\hline 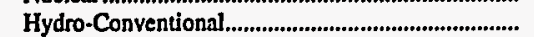 & $\mathbf{0}$ & 0 & 0 & $\mathbf{0}$ & $2,899,983$ & 4,237 \\
\hline 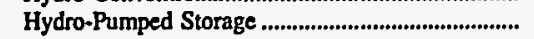 & $\mathbf{0}$ & 0 & 0 & 0 & $1,997,348$ & 0 \\
\hline 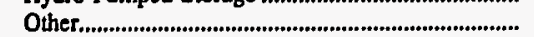 & 0 & 3,858 & $\mathbf{0}$ & 0 & 0 & 195,272 \\
\hline (Less) Energy for Pumping........................................ & 0 & 0 & $\mathbf{0}$ & 0 & 0 & 0 \\
\hline 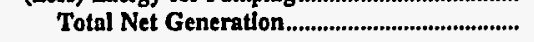 & 0 & 880,715 & 0 & 99,477 & $5,534,270$ & 216,241 \\
\hline 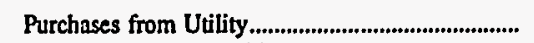 & 447,970 & $1,973,110$ & 409,415 & 978,169 & $1,561,511$ & 170,620 \\
\hline $\begin{array}{l}\text { Purchases from Nonutility......................................... } \\
\text { Power Exchanges }\end{array}$ & 0 & 0 & 0 & 0 & 0 & 0 \\
\hline 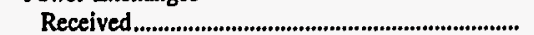 & 0 & 389 & $\mathbf{0}$ & $\mathbf{0}$ & $5,267,738$ & 0 \\
\hline Delivered & 0 & 30,048 & 0 & 0 & $2,713,496$ & 0 \\
\hline Net Exchanges & 0 & $-29,659$ & 0 & 0 & $2,554,242$ & $\mathbf{0}$ \\
\hline \multicolumn{7}{|l|}{ Transmission for Others (Wheeling) } \\
\hline 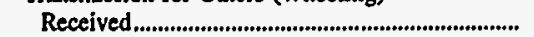 & 0 & 0 & 0 & $\mathbf{0}$ & 0 & $\mathbf{0}$ \\
\hline Delivered & 0 & 0 & 0 & 0 & 0 & $\mathbf{0}$ \\
\hline Net Transmission for Others ................................. & $\mathbf{0}$ & 0 & 0 & $\mathbf{0}$ & 0 & $\mathbf{0}$ \\
\hline Transmission by Others Losses.................................. & 0 & $-40,937$ & 0 & $-47,028$ & 0 & 0 \\
\hline Total Net Energy & & & & & & \\
\hline Generated and Received ................................ & 447,970 & $2,783,229$ & 409,415 & $1,030,618$ & $9,650,023$ & 386,861 \\
\hline \multicolumn{7}{|l|}{ Dispositlon of Energy } \\
\hline 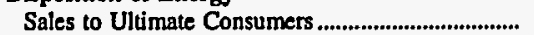 & 432,489 & $2,278,677$ & 205,919 & 972,508 & 0 & 224,530 \\
\hline Requirements Sales for Resale................................... & 0 & 354,351 & 178,151 & $\mathbf{0}$ & $4,313,258$ & 116,311 \\
\hline Nonrequirements Sales for Resale........................... & 0 & 0 & 0 & 3,361 & 0 & 42,045 \\
\hline Furnished Without Charge ....................................... & $\mathbf{0}$ & 0 & 0 & $\mathbf{0}$ & 0 & $\mathbf{0}$ \\
\hline Used by Utility (excluding station use)................... & $\mathbf{0}$ & 0 & 0 & o & $5,058,912$ & $\mathbf{0}$ \\
\hline 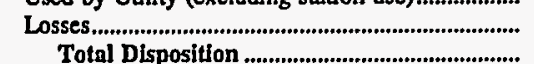 & $\begin{array}{r}15,481 \\
447,970\end{array}$ & $\begin{array}{r}150,201 \\
2,783,229\end{array}$ & $\begin{array}{r}25,345 \\
409,415\end{array}$ & $\begin{array}{r}54,749 \\
1,030,618\end{array}$ & $\begin{array}{r}277,853 \\
9,650,023\end{array}$ & $\begin{array}{r}3,975 \\
386,861\end{array}$ \\
\hline
\end{tabular}

Note: Totals may not equal sum of components because of independent rounding. Double counting occurs in components of both sources and disposition of energy and thus neither provides a true total. Purchases from utilities, net interchanges, and net wheeling (except for imports) are included in net generation.

Source: Energy Information Administration, Form EIA-412, “Annual Report of Public Electric Utilities." 
Table 26. Electric Energy Account by Major U.S. Publicly Owned Electric Utility Within State, 1996 (Continued)

(Megawatthours)

\begin{tabular}{|c|c|c|c|c|c|c|}
\hline Item & $\begin{array}{l}\text { California } \\
\text { Glendale } \\
\text { City of } \\
\text { June } 30\end{array}$ & $\begin{array}{l}\text { California } \\
\text { Imperial } \\
\text { Irrigation } \\
\text { District } \\
\text { December } 31\end{array}$ & $\begin{array}{c}\text { California } \\
\text { Kings River } \\
\begin{array}{c}\text { Conservation } \\
\text { Dist }\end{array} \\
\text { June } 30\end{array}$ & $\begin{array}{c}\text { Califomia } \\
\text { Lassen } \\
\text { Municipal } \\
\text { Utility Dist } \\
\text { June } 30\end{array}$ & $\begin{array}{l}\text { California } \\
\text { Lodi } \\
\text { City of } \\
\text { June } 30\end{array}$ & $\begin{array}{l}\text { California } \\
\begin{array}{l}\text { Los Angeles } \\
\text { City of }\end{array} \\
\text { June } 30\end{array}$ \\
\hline \multicolumn{7}{|l|}{ Sources of Energy } \\
\hline 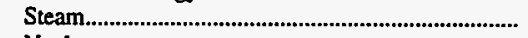 & 141,110 & 491,004 & 0 & 0 & 0 & $2,949,068$ \\
\hline 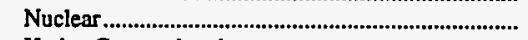 & 0 & 0 & 0 & 0 & 0 & $1,614,266$ \\
\hline 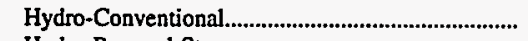 & 0 & 308,612 & 784,873 & 0 & 0 & $1,082,573$ \\
\hline 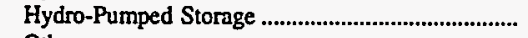 & 0 & 0 & 0 & 0 & $\mathbf{0}$ & 700,089 \\
\hline 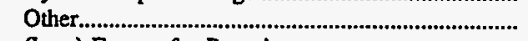 & 17,009 & 6,452 & 0 & 0 & 0 & -474 \\
\hline 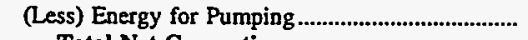 & 0 & 0 & $\mathbf{0}$ & 0 & 0 & 861,757 \\
\hline 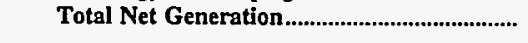 & 158,119 & 806,068 & 784,873 & 0 & $\mathbf{0}$ & $5,483,765$ \\
\hline 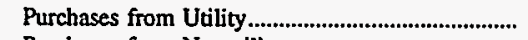 & 969,116 & $1,570,054$ & 0 & 165,856 & 352,103 & $12,588,177$ \\
\hline $\begin{array}{l}\text { Purchases from Nonutility } \\
\text { Power.......................................... }\end{array}$ & 0 & 0 & 0 & 0 & 0 & 490,957 \\
\hline 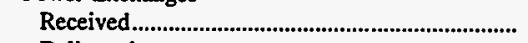 & 0 & 0 & 0 & 0 & 8,419 & 8 \\
\hline 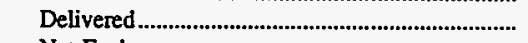 & 0 & 0 & 0 & 0 & 0 & $2,381,587$ \\
\hline Net Exchanges & 0 & 0 & 0 & 0 & 8,419 & $-2,381,587$ \\
\hline \multicolumn{7}{|l|}{ Transmission for Others (Wheeling) } \\
\hline 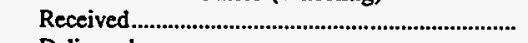 & 0 & $4,051,313$ & 0 & 172,814 & 0 & $21,315,941$ \\
\hline 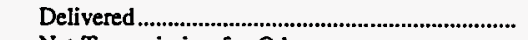 & 0 & $3,968,240$ & 0 & 172,814 & 0 & $14,146,592$ \\
\hline 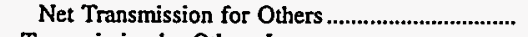 & 0 & 83,073 & 0 & 0 & 0 & $7,169,349$ \\
\hline 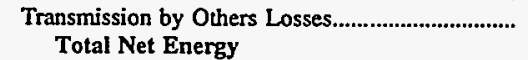 & 0 & 0 & 0 & 0 & 0 & 0 \\
\hline 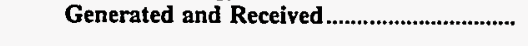 & $1,127,235$ & $2,459,195$ & $\mathbf{7 8 4 , 8 7 3}$ & 165,856 & 360,522 & $23,350,661$ \\
\hline \multicolumn{7}{|l|}{ Disposition of Energy } \\
\hline Sales to Ultimate Consumers & $1,011,925$ & $2,044,612$ & 0 & 153,401 & 347,633 & $21,233,474$ \\
\hline 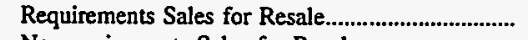 & 9,663 & 135,846 & 0 & 0 & 0 & 553,628 \\
\hline 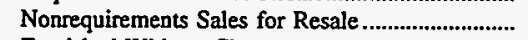 & 0 & 0 & 784,873 & 0 & 0 & 790,204 \\
\hline Furnished Without Charge & 11,229 & 0 & 0 & 0 & 0 & 0 \\
\hline Used by Utility (excluding station use).................... & 0 & 0 & 0 & 12,455 & 170 & 90,000 \\
\hline 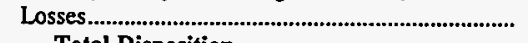 & 94,418 & 278,737 & 0 & 0 & 12,719 & 683,355 \\
\hline Total Disposition & $1,127,235$ & $2,459,195$ & 784,873 & 165,856 & 360,522 & $23,350,661$ \\
\hline
\end{tabular}

Note: Totals may not equal sum of components because of independent rounding. Double counting occurs in components of both sources and disposition of energy and thus neither provides a true total. Purchases from utilities, net interchanges, and net wheeling (except for imports) are included in net generation.

Source: Energy Information Administration, Form EIA-412, “Annual Report of Public Electric Utilities.” 
Table 26. Electric Energy Account by Major U.S. Publicly Owned Electric Utility Within State, 1996 (Continued)

(Megawatthours)

\begin{tabular}{|c|c|c|c|c|c|c|}
\hline Item & $\begin{array}{l}\text { Califomia } \\
\text { Merced } \\
\text { Irrigation } \\
\text { District } \\
\text { December } 31\end{array}$ & $\begin{array}{c}\text { California } \\
\text { Metropolitan } \\
\text { Water } \\
\text { District } \\
\text { June } 30\end{array}$ & $\begin{array}{l}\text { California } \\
\text { Modesto } \\
\text { Irrigation } \\
\text { District } \\
\text { December } 31\end{array}$ & $\begin{array}{c}\text { California } \\
\text { MSR } \\
\text { Public } \\
\text { Power } \\
\text { Agency } \\
\text { December } 31\end{array}$ & $\begin{array}{l}\text { California } \\
\text { Northern } \\
\text { California } \\
\text { Power Agny } \\
\text { June } 30\end{array}$ & $\begin{array}{c}\text { California } \\
\text { Oakdale \& } \\
\text { South } \\
\text { San Joaquin } \\
\text { December } 31\end{array}$ \\
\hline \multicolumn{7}{|l|}{ Sources of Energy } \\
\hline 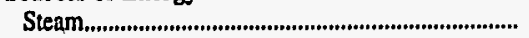 & 0 & 0 & 0 & $1,062,789$ & $1,302,975$ & 0 \\
\hline Nuclear & 0 & 0 & 0 & 0 & 0 & 0 \\
\hline 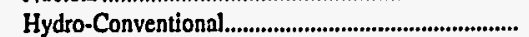 & 479,016 & 0 & 325,521 & 0 & 841,003 & 601,533 \\
\hline 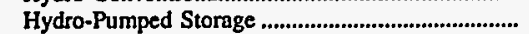 & 0 & 239,169 & 0 & 0 & 0 & 0 \\
\hline 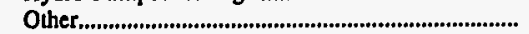 & 13,551 & 0 & 53,748 & 0 & 45,143 & $\mathbf{0}$ \\
\hline 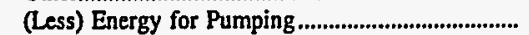 & $\mathbf{0}$ & 0 & 0 & 0 & 0 & $\mathbf{0}$ \\
\hline 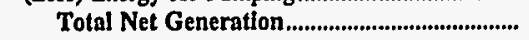 & 492,567 & 239,169 & 379,269 & $1,062,789$ & $2,189,121$ & 601,533 \\
\hline 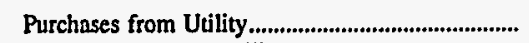 & 34,889 & $\mathbf{0}$ & $2,187,231$ & $1,012,225$ & 875,789 & 0 \\
\hline Purchases from Nonutility................................................ & 0 & 0 & 0 & 0 & 2,734 & 0 \\
\hline \multicolumn{7}{|l|}{ Power Exchanges } \\
\hline Received.................. & 0 & $\mathbf{0}$ & 15,510 & $\mathbf{0}$ & 86,941 & $\mathbf{0}$ \\
\hline Delivered ............................................................................ & 0 & 0 & 42,178 & 0 & 41,104 & 0 \\
\hline Net Exchanges ............................................................. & $\mathbf{0}$ & 0 & $-26,668$ & 0 & 45,837 & 0 \\
\hline \multicolumn{7}{|l|}{ Transmission for Others (Wheeling) } \\
\hline 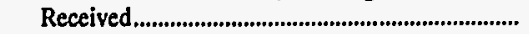 & 0 & 0 & 0 & $\mathbf{0}$ & 0 & $\mathbf{0}$ \\
\hline 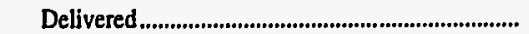 & $\mathbf{0}$ & 0 & 0 & $\mathbf{0}$ & 0 & $\mathbf{0}$ \\
\hline Net Transmission for Others .................................... & 0 & 0 & 0 & 0 & 0 & $\mathbf{0}$ \\
\hline 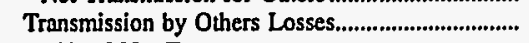 & 0 & 0 & 0 & 0 & 0 & 0 \\
\hline \multicolumn{7}{|l|}{ Total Net Energy } \\
\hline 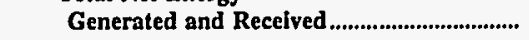 & 527,456 & 239,169 & $2,539,832$ & $2,075,014$ & $3,113,481$ & 601,533 \\
\hline \multicolumn{7}{|l|}{ Disposition of Energy } \\
\hline 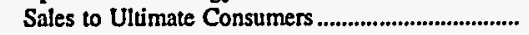 & 33,398 & 0 & $1,937,605$ & $\mathbf{0}$ & 0 & 0 \\
\hline 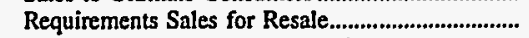 & 489,862 & 239,169 & 433,454 & $2,075,014$ & $2,961,505$ & 601,533 \\
\hline Nonrequirements Sales for Resale............................... & 0 & 0 & 44,643 & $\mathbf{0}$ & 151,976 & 0 \\
\hline Furnished Without Charge ........................................... & 0 & 0 & 0 & $\mathbf{0}$ & 0 & 0 \\
\hline Used by Utility (excluding station use).................... & 0 & 0 & 4,630 & 0 & 0 & 0 \\
\hline 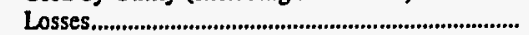 & 4,196 & 0 & 119,500 & 0 & 0 & 0 \\
\hline 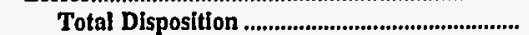 & 527,456 & 239,169 & $2,539,832$ & $2,075,014$ & $3,113,481$ & 601,533 \\
\hline
\end{tabular}

Note: Totals may not equal sum of components because of independent rounding. Double counting occurs in components of both sources and disposition of energy and thus neither provides a true total. Purchases from utilities, net interchanges, and net wheeling (except for imports) are included in net generation. Sales for resale is included in sales to ultimate consumers.

Source: Energy Information Administration, Form EIA-412, "Annual Report of Public Electric Utilities." 
Table 26. Electric Energy Account by Major U.S. Publicly Owned Electric Utility Within State, 1996 (Continued)

(Megawatthours)

\begin{tabular}{|c|c|c|c|c|c|c|}
\hline Item & $\begin{array}{l}\text { California } \\
\text { Oroville } \\
\text { Wyandorte } \\
\text { Irrig Dist } \\
\text { December } 31\end{array}$ & $\begin{array}{l}\text { California } \\
\text { Palo Alto } \\
\text { City of } \\
\text { June } 30\end{array}$ & $\begin{array}{l}\text { Califomia } \\
\text { Pasadena } \\
\text { City of } \\
\text { June } 30\end{array}$ & $\begin{array}{c}\text { California } \\
\text { Placer } \\
\text { County } \\
\text { Water } \\
\text { Agency } \\
\text { December } 31\end{array}$ & $\begin{array}{l}\text { California } \\
\text { Redding } \\
\text { City of } \\
\text { June } 30\end{array}$ & $\begin{array}{l}\text { California } \\
\text { Riverside } \\
\text { City of } \\
\text { June } 30\end{array}$ \\
\hline \multicolumn{7}{|l|}{ Sources of Energy } \\
\hline Steam & 0 & 0 & 177,209 & 0 & 26,245 & \\
\hline 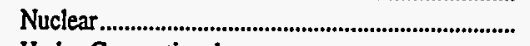 & 0 & 0 & 0 & 0 & 0 & 305,652 \\
\hline 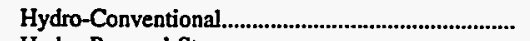 & 597,980 & 0 & 7,876 & $1,456,656$ & 16,863 & 0 \\
\hline 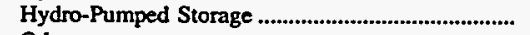 & 0 & 0 & 0 & 0 & 0 & \\
\hline Other & 0 & $\mathbf{0}$ & 0 & o & 3,400 & \\
\hline 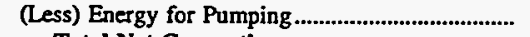 & 0 & $\mathbf{0}$ & 0 & 0 & $\mathbf{0}$ & 0 \\
\hline 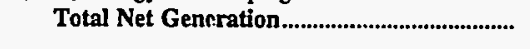 & 597,980 & $\mathbf{0}$ & 185,085 & $1,456,656$ & 46,508 & 305,652 \\
\hline 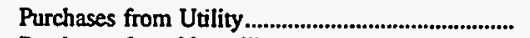 & 0 & $1,101,807$ & $1,069,627$ & 0 & $1,316,838$ & $1,491,016$ \\
\hline 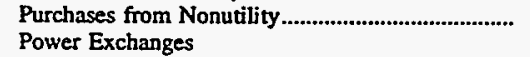 & 0 & 0 & 0 & 0 & 0 & $1,7,0$ \\
\hline 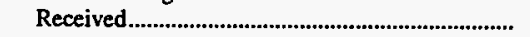 & 0 & 0 & 0 & 0 & 0 & 36,636 \\
\hline 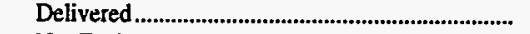 & 0 & 0 & 0 & 0 & 0 & 33,825 \\
\hline 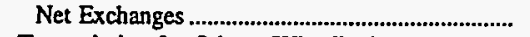 & 0 & 0 & $\mathbf{0}$ & 0 & 0 & 2,811 \\
\hline \multicolumn{7}{|l|}{ Transmission for Others (Wheeling) } \\
\hline 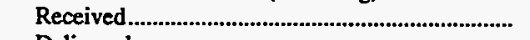 & 0 & 0 & $\mathbf{0}$ & 0 & 0 & 0 \\
\hline Delivered & 0 & 0 & 0 & 0 & 0 & 0 \\
\hline Net Transmission for Others..................................... & 0 & 0 & $\mathbf{0}$ & 0 & 0 & $\mathbf{0}$ \\
\hline 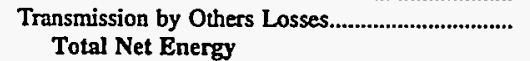 & 0 & 0 & $\mathbf{0}$ & $\mathbf{0}$ & 0 & 0 \\
\hline 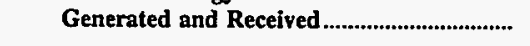 & 597,980 & $1,101,807$ & $1,254,712$ & $1,456,656$ & $1,363,346$ & $1,799,479$ \\
\hline \multicolumn{7}{|l|}{ Disposition of Energy } \\
\hline 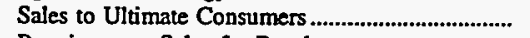 & 0 & $1,056,114$ & $1,166,811$ & 0 & 689,278 & $1,632,366$ \\
\hline Requirements Sales for Resale & 0 & 0 & 44,017 & 0 & 651,401 & 37,330 \\
\hline 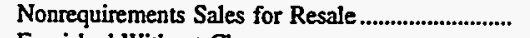 & 597,980 & 0 & 0 & $1,449,203$ & 0 & 0 \\
\hline 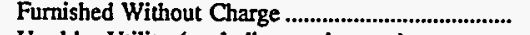 & 0 & 0 & 0 & 0 & 0 & $\mathbf{0}$ \\
\hline Used by Utility (excluding station use).................... & 0 & 0 & $\mathbf{0}$ & 0 & 0 & 0 \\
\hline Losses & 0 & 45,693 & 43,884 & 7,453 & 22,667 & 129,783 \\
\hline 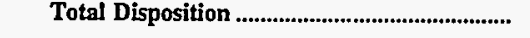 & 597,980 & $1,101,807$ & $1,254,712$ & $1,456,656$ & $1,363,346$ & $1,799,479$ \\
\hline
\end{tabular}

Note: Totals may not equal sum of components because of independent rounding. Double counting occurs in components of both sources and disposition of energy and thus neither provides a true total. Purchases from utilities, net interchanges, and net wheeling (except for imports) are included in net generation.

Source: Energy Information Administration, Form EIA-412, “Annual Report of Public Electric Utilities." 
Table 26. Electric Energy Account by Major U.S. Publicly Owned Electric Utility Within State, 1996 (Continued)

(Megawatthours)

\begin{tabular}{|c|c|c|c|c|c|c|}
\hline Item & $\begin{array}{l}\text { California } \\
\text { Roseville } \\
\text { City of } \\
\text { June } 30\end{array}$ & $\begin{array}{l}\text { California } \\
\text { Sacramento } \\
\text { Municipal } \\
\text { Util Dist } \\
\text { December } 31\end{array}$ & $\begin{array}{l}\text { Califomia } \\
\text { San Francisco } \\
\text { City } \\
\& \\
\text { County of } \\
\text { June } 30\end{array}$ & $\begin{array}{l}\text { Califomia } \\
\text { Santa } \\
\text { Clara } \\
\text { City of } \\
\text { June } 30\end{array}$ & $\begin{array}{l}\text { California } \\
\text { Southem } \\
\text { California } \\
\text { P P } \\
\text { A } \\
\text { June } 30\end{array}$ & $\begin{array}{c}\text { California } \\
\text { Turlock } \\
\text { Irrigation } \\
\text { District } \\
\text { December } 31\end{array}$ \\
\hline \multicolumn{7}{|l|}{ Sources of Energy } \\
\hline Steam.............., & 0 & 464,756 & 0 & $\mathbf{0}$ & 364,529 & $\mathbf{0}$ \\
\hline 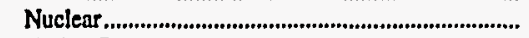 & 0 & $\mathbf{0}$ & 0 & 0 & $1,673,273$ & 0 \\
\hline 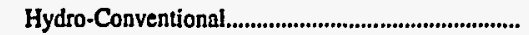 & 0 & $2,557,145$ & $2,060,421$ & 88,641 & 0 & 700,671 \\
\hline 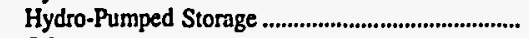 & 0 & 0 & 0 & 0 & 0 & 0 \\
\hline Other, & 0 & 342,258 & 0 & 46,592 & 0 & 69,243 \\
\hline 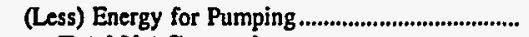 & 0 & 0 & 0 & 0 & 0 & 0 \\
\hline Total Net Generation........................................ & 0 & $3,364,159$ & $2,060,421$ & 135,233 & $2,037,802$ & 769,914 \\
\hline Purchases from Utility................................................. & 682,600 & $6,494,143$ & 264,005 & $2,564,185$ & 110,000 & 828,989 \\
\hline $\begin{array}{l}\text { Purchases from Nonutility............................................ } \\
\text { Power Exchanges }\end{array}$ & 0 & 0 & 0 & 0 & 0 & 0 \\
\hline 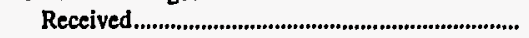 & 0 & 130,824 & 214,231 & 0 & 0 & 3,927 \\
\hline 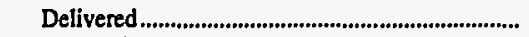 & 0 & 131,024 & 136,325 & 0 & 0 & 941 \\
\hline 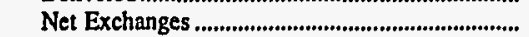 & 0 & -200 & 77,906 & 0 & 0 & 2,987 \\
\hline \multicolumn{7}{|l|}{ Transmission for Others (Wheeling) } \\
\hline Received & 0 & 0 & 0 & 156,158 & 0 & 13,822 \\
\hline 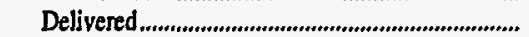 & 0 & 0 & 0 & 153,096 & 0 & 1,979 \\
\hline Net Transmission for Others.................................. & 0 & 0 & 0 & 3,062 & 0 & 11,843 \\
\hline $\begin{array}{l}\text { Transmission by Others Losses................................. } \\
\text { Total Net Energy }\end{array}$ & 0 & $-127,423$ & 0 & 0 & 0 & $-14,830$ \\
\hline 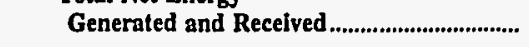 & 682,600 & $9,730,679$ & $2,402,332$ & $2,702,480$ & $2,147,802$ & $1,598,903$ \\
\hline \multicolumn{7}{|l|}{ Dlsposition of Energy } \\
\hline 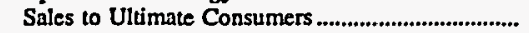 & 654,744 & $8,889,261$ & 617,333 & $2,296,835$ & 0 & $1,310,843$ \\
\hline 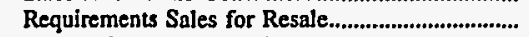 & 0 & 0 & 937,298 & 297,529 & $2,147,802$ & 54,736 \\
\hline Nonrequirements Sales for Resale ........................... & 0 & 332,306 & 736,796 & 19,607 & 0 & 118,490 \\
\hline 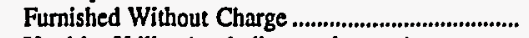 & 0 & 0 & 44 & 8,762 & 0 & 0 \\
\hline Used by Utility (excluding station use).................. & 0 & 23,941 & 2,408 & 0 & 0 & $\mathbf{0}$ \\
\hline 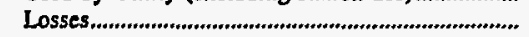 & 27,856 & 485,171 & 108,454 & 79,747 & 0 & 114,834 \\
\hline Total Disposition & 682,600 & $9,730,679$ & $2,402,332$ & $2,702,480$ & $2,147,802$ & $1,598,903$ \\
\hline
\end{tabular}

Note: Totals may not equal sum of components because of independent rounding. Double counting occurs in components of both sources and disposition of energy and thus neither provides a true total. Purchases from utilities, net interchanges, and net wheeling (except for imports) are included in net generation.

Source: Energy Information Administration, Form EIA-412, "Annual Report of Public Electric Utilities." 
Table 26. Electric Energy Account by Major U.S. Publicly Owned Electric Utility Within State, 1996 (Continued)

(Megawatthours)

\begin{tabular}{|c|c|c|c|c|c|c|}
\hline Item & $\begin{array}{l}\text { California } \\
\text { Vernon } \\
\text { City of } \\
\text { June } 30\end{array}$ & $\begin{array}{l}\text { California } \\
\text { Yuba } \\
\text { County } \\
\text { Water } \\
\text { Agency } \\
\text { June } 30\end{array}$ & $\begin{array}{l}\text { Colorado } \\
\text { Arkansas } \\
\text { River } \\
\text { Power } \\
\text { Authority } \\
\text { December 31 }\end{array}$ & $\begin{array}{l}\text { Colorado } \\
\text { Colorado } \\
\text { Springs } \\
\text { City of } \\
\text { December } 31\end{array}$ & $\begin{array}{l}\text { Colorado } \\
\text { Fort Collins } \\
\text { City of } \\
\text { December } 31\end{array}$ & $\begin{array}{c}\text { Colorado } \\
\text { Fort Morgan } \\
\text { City of } \\
\text { December } 31\end{array}$ \\
\hline \multicolumn{7}{|l|}{ Sources of Energy } \\
\hline Steam & 0 & 0 & 0 & $2,763,805$ & 0 & 0 \\
\hline Nuclear & 0 & 0 & $\mathbf{0}$ & 0 & 0 & 0 \\
\hline 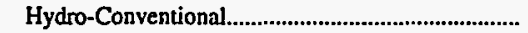 & 0 & $2,077,215$ & 0 & 24,845 & 0 & 0 \\
\hline 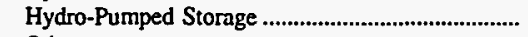 & 0 & 0 & 0 & 0 & 0 & 0 \\
\hline 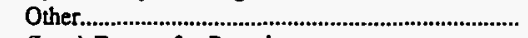 & 682 & 0 & $\mathbf{0}$ & 0 & 0 & 0 \\
\hline 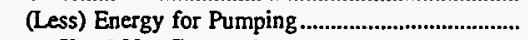 & 0 & 0 & 0 & 0 & $\mathbf{0}$ & 0 \\
\hline 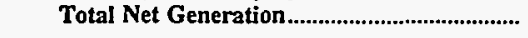 & 682 & $2,077,215$ & 0 & $2,788,650$ & 0 & $\mathbf{0}$ \\
\hline Purchases from Utility & 992,550 & 0 & 309,351 & $1,032,768$ & $1,042,109$ & 192,109 \\
\hline $\begin{array}{l}\text { Purchases from Nonutility.................................................... } \\
\text { Power Exchanges }\end{array}$ & \multicolumn{5}{|c|}{ Power Exchanges } & 0 \\
\hline 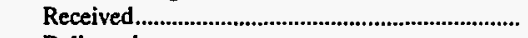 & 0 & 0 & $\mathbf{0}$ & 1,985 & 0 & 0 \\
\hline 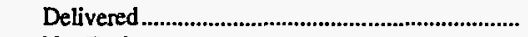 & 0 & 0 & 0 & 1,229 & 0 & 0 \\
\hline 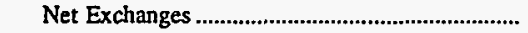 & 0 & 0 & 0 & 756 & 0 & 0 \\
\hline \multicolumn{7}{|l|}{ Transmission for Others (Wheeling) } \\
\hline Received & 0 & 0 & 0 & 47,650 & $\mathbf{0}$ & 0 \\
\hline 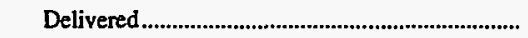 & 0 & 0 & 0 & 47,650 & 0 & 0 \\
\hline 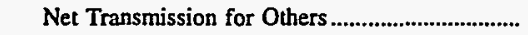 & 0 & 0 & 0 & 0 & 0 & 0 \\
\hline 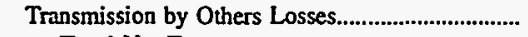 & 0 & 0 & 0 & -434 & $\mathbf{0}$ & 0 \\
\hline \multicolumn{7}{|l|}{ Total Net Energy } \\
\hline 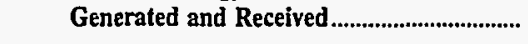 & $1,074,849$ & $2,077,215$ & 309,351 & $3,821,739$ & $1,042,109$ & 192,109 \\
\hline \multicolumn{7}{|l|}{ Disposition of Energy } \\
\hline Sales to Ultimate Consumers & $1,052,800$ & 0 & 0 & $3,465,123$ & $1,009,068$ & 182,374 \\
\hline 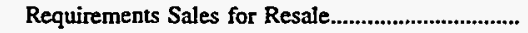 & $\mathbf{0}$ & $2,077,215$ & 286,209 & 150,600 & 0 & 0 \\
\hline Nonrequirements Sales for Resale .............................. & 0 & 0 & 0 & 26,354 & 0 & 0 \\
\hline Fumished Without Charge ..................................... & 0 & 0 & 0 & 0 & 6,774 & 0 \\
\hline 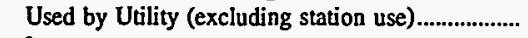 & 0 & 0 & 0 & 0 & 0 & 0 \\
\hline 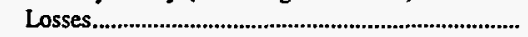 & 22,049 & 0 & 23,142 & 179,662 & 26,267 & 9,735 \\
\hline Total Disposition & $1,074,849$ & $2,077,215$ & 309,351 & $3,821,739$ & $1,042,109$ & 192,109 \\
\hline
\end{tabular}

Note: Totals may not equal sum of components because of independent rounding. Double counting occurs in components of both sources and disposition of energy and thus neither provides a true total. Purchases from utilities, net interchanges, and net wheeling (except for imports) are included in net generation.

Source: Energy Information Administration, Form EIA-412, “Annual Report of Public Electric Utilities." 
Table 26. Electric Energy Account by Major U.S. Publicly Owned Electric - Utility Within State, 1996 (Continued) (Megawatthours)

\begin{tabular}{|c|c|c|c|c|c|c|}
\hline Item & $\begin{array}{l}\text { Colorado } \\
\text { Longmont } \\
\text { City of } \\
\text { December } 31\end{array}$ & $\begin{array}{l}\text { Colorado } \\
\text { Loveland } \\
\text { City of } \\
\text { December } 31\end{array}$ & $\begin{array}{c}\text { Colorado } \\
\text { Platte River } \\
\text { Power } \\
\text { Authority } \\
\text { December } 31\end{array}$ & $\begin{array}{l}\text { Connecticut } \\
\text { Connecticut } \\
\text { Mun } \\
\text { Elec } \\
\text { Engy Coop } \\
\text { December } 31\end{array}$ & $\begin{array}{l}\text { Connecticut } \\
\text { Groton } \\
\text { City of } \\
\text { June } 30\end{array}$ & $\begin{array}{l}\text { Connecticut } \\
\text { Norwich } \\
\text { City of } \\
\text { June } 30\end{array}$ \\
\hline \multicolumn{7}{|l|}{ Sources of Energy } \\
\hline Steam, & 0 & 0 & $3,086,112$ & 0 & 0 & 3,172 \\
\hline Nuclear & 0 & 0 & 0 & 26,932 & 0 & 0 \\
\hline 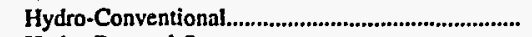 & 3,360 & 3,108 & $\mathbf{0}$ & 0 & $\mathbf{0}$ & 0 \\
\hline 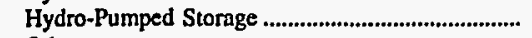 & 0 & 0 & 0 & 0 & 0 & 0 \\
\hline Other & 0 & 0 & 0 & 0 & 0 & 0 \\
\hline 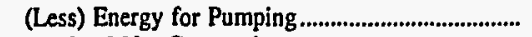 & 0 & 0 & 0 & 0 & $\mathbf{0}$ & 0 \\
\hline 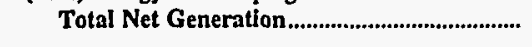 & 3,360 & 3,108 & $3,086,112$ & 26,932 & $\mathbf{0}$ & 3,172 \\
\hline 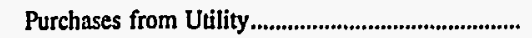 & 535,939 & 450,971 & 892,405 & $2,033,202$ & 646,759 & 320,099 \\
\hline 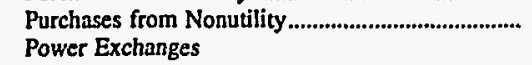 & 0 & 0 & 0 & 0 & 0 & 0 \\
\hline 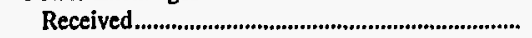 & 0 & 0 & 23,004 & 123,140 & 0 & 0 \\
\hline 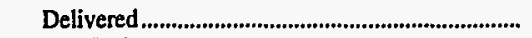 & 0 & 0 & 11,128 & 0 & 0 & 0 \\
\hline 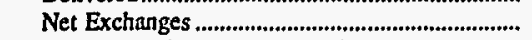 & 0 & 0 & 11,876 & 123,140 & $\mathbf{0}$ & 0 \\
\hline \multicolumn{7}{|l|}{ Transmission for Others (Wheeling) } \\
\hline 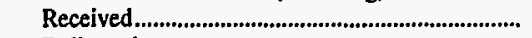 & 8,176 & 0 & 0 & 0 & $\mathbf{0}$ & 0 \\
\hline 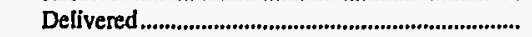 & 8,165 & 0 & 0 & 0 & 0 & 0 \\
\hline 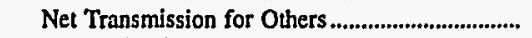 & 11 & 0 & 0 & 0 & 0 & 0 \\
\hline Transmission by Others Losses................................... & 0 & 0 & 0 & 0 & 0 & 0 \\
\hline $\begin{array}{l}\text { Total Net Energy } \\
\text { Generated and Received .................................. }\end{array}$ & 539,310 & 454,079 & $3,990,393$ & $2,183,274$ & 646,759 & 323,271 \\
\hline \multicolumn{7}{|l|}{ Disposition of Energy } \\
\hline 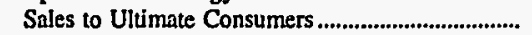 & 514,279 & 435,235 & 0 & 0 & 636,307 & 302,963 \\
\hline Requirements Sales for Resale................................... & 0 & 0 & $3,079,968$ & $2,142,530$ & 5,728 & 0 \\
\hline 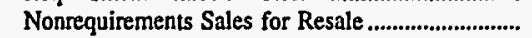 & 0 & 0 & 833,766 & 0 & 0 & 0 \\
\hline 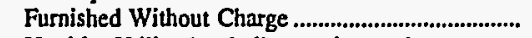 & 6,345 & 4,935 & $\mathbf{0}$ & 0 & 428 & $\mathbf{0}$ \\
\hline Used by Utility (excluding station use)................... & 0 & 0 & 0 & 0 & 1,077 & 0 \\
\hline 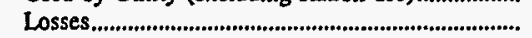 & 18,686 & 13,909 & 76,659 & 40,744 & 3,219 & 20,308 \\
\hline 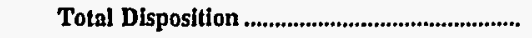 & 539,310 & 454,079 & $3,990,393$ & $2,183,274$ & 646,759 & 323,271 \\
\hline
\end{tabular}

Note: Totals may not equal sum of components because of independent rounding. Double counting occurs in components of both sources and disposition of energy and thus neither provides a true total. Purchases from utilities, net interchanges, and net wheeling (except for imports) are included in net generation.

Source: Energy Information Administration, Form ELA-412, "Annual Report of Public Electric Utilities." 
Table 26. Electric Energy Account by Major U.S. Publicly Owned Electric Utility Within State, 1996 (Continued)

(Megawatthours)

\begin{tabular}{|c|c|c|c|c|c|c|}
\hline Item & $\begin{array}{l}\text { Connecticut } \\
\text { Wallingford } \\
\text { Town of } \\
\text { June } 30\end{array}$ & $\begin{array}{l}\text { Delaware } \\
\text { Dover } \\
\text { City of } \\
\text { June } 30\end{array}$ & $\begin{array}{l}\text { Delaware } \\
\text { Milford } \\
\text { City of } \\
\text { September } 30\end{array}$ & $\begin{array}{l}\text { Delaware } \\
\text { Newark } \\
\text { City of } \\
\text { December } 31\end{array}$ & $\begin{array}{l}\text { Florida } \\
\text { Bartow } \\
\text { City of } \\
\text { September } 30\end{array}$ & $\begin{array}{c}\text { Florida } \\
\text { Florida } \\
\text { Municipal } \\
\text { Power Agency } \\
\text {. September } 30\end{array}$ \\
\hline \multicolumn{7}{|l|}{ Sources of Energy } \\
\hline Steam & 1,374 & 308,851 & $\mathbf{0}$ & 0 & 0 & 582,572 \\
\hline 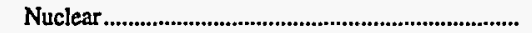 & 0 & $\mathbf{0}$ & 0 & 0 & 0 & 613,016 \\
\hline 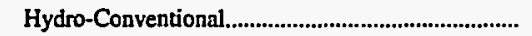 & 0 & 0 & 0 & 0 & 0 & 0 \\
\hline 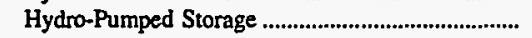 & 0 & 0 & 0 & 0 & 0 & 0 \\
\hline Other & 0 & 7,604 & 0 & 0 & 0 & 193,190 \\
\hline 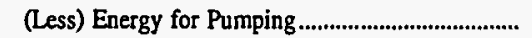 & 0 & 0 & 0 & 0 & 0 & 0 \\
\hline 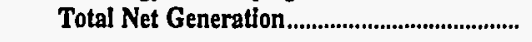 & 1,374 & 316,455 & 0 & 0 & 0 & $1,388,778$ \\
\hline 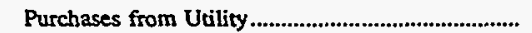 & 595,947 & 244,472 & 161,204 & 344,137 & 282,506 & $2,139,952$ \\
\hline $\begin{array}{l}\text { Purchases from Nonutility................................................. } \\
\text { Power Exchanges }\end{array}$ & 0 & 65,717 & 0 & 0 & 0 & 0 \\
\hline 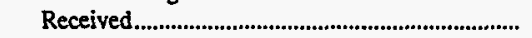 & 0 & 0 & 0 & 0 & 0 & 0 \\
\hline 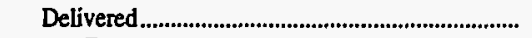 & 0 & 0 & 0 & 0 & 0 & 0 \\
\hline 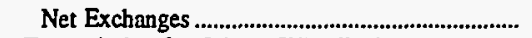 & 0 & 0 & 0 & 0 & 0 & 0 \\
\hline \multicolumn{7}{|l|}{ Transmission for Others (Wheeling) } \\
\hline 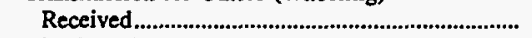 & 0 & 0 & 0 & 0 & 0 & 0 \\
\hline 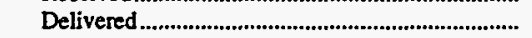 & 0 & 0 & 0 & 0 & 0 & 0 \\
\hline 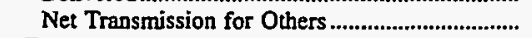 & 0 & 0 & 0 & 0 & 0 & 0 \\
\hline $\begin{array}{l}\text { Transmission by Others Losses................................. } \\
\text { Total Net Energy }\end{array}$ & 0 & 0 & 0 & 0 & 0 & 0 \\
\hline 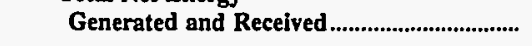 & 597,321 & 626,644 & 161,204 & 344,137 & 282,506 & $3,528,730$ \\
\hline \multicolumn{7}{|l|}{ Disposition of Energy } \\
\hline 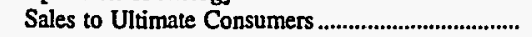 & 576,037 & 587,004 & 152,107 & 309,635 & 264,732 & 0 \\
\hline 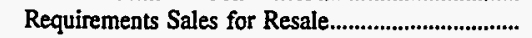 & 0 & 33,758 & 0 & 0 & 0 & $3,278,237$ \\
\hline 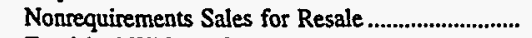 & 0 & 0 & 0 & 0 & $\mathbf{0}$ & 0 \\
\hline Furnished Without Charge ............................................. & 0 & 0 & 0 & 8,149 & 0 & 0 \\
\hline Used by Utility (excluding station use)...................... & 0 & 0 & 0 & 0 & 0 & 0 \\
\hline 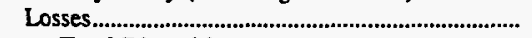 & 21,284 & 5,882 & 9,097 & 26,353 & 17,774 & 250,493 \\
\hline 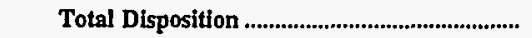 & 597,321 & 626,644 & 161,204 & 344,137 & 282,506 & $\mathbf{3 , 5 2 8 , 7 3 0}$ \\
\hline
\end{tabular}

Note: Totals may not equal sum of components because of independent rounding. Double counting occurs in components of both sources and disposition of energy and thus neither provides a true total. Purchases from utilities, net interchanges, and net wheeling (except for imports) are included in net generation.

Source: Energy Information Administration, Form EIA-412, “Annual Report of Public Electric Utilities.” 
Table 26. Electric Energy Account by Major U.S. Publicly Owned Electric Utility Within State, 1996 (Continued)

(Megawatthours)

\begin{tabular}{|c|c|c|c|c|c|c|}
\hline Item & $\begin{array}{l}\text { Florida } \\
\text { Fort Pierce } \\
\text { Utilities } \\
\text { Auth } \\
\text { September } 30\end{array}$ & $\begin{array}{l}\text { Florida } \\
\text { Gainesville } \\
\text { Regional } \\
\text { Utilities } \\
\text { September } 30\end{array}$ & $\begin{array}{l}\text { Florida } \\
\text { Homestead } \\
\text { City of } \\
\text { September } 30\end{array}$ & $\begin{array}{c}\text { Forida } \\
\text { Jacksonville } \\
\text { Beach } \\
\text { City of } \\
\text { September } 30\end{array}$ & $\begin{array}{l}\text { Florida } \\
\text { Jacksonville } \\
\text { Electric } \\
\text { Auth } \\
\text { September } 30\end{array}$ & $\begin{array}{l}\text { Florida } \\
\text { Key West } \\
\text { City of } \\
\text { September } 30\end{array}$ \\
\hline \multicolumn{7}{|l|}{ Sources of Energy } \\
\hline 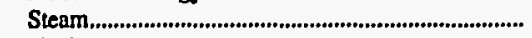 & 182,323 & $1,706,844$ & 0 & 0 & $11,149,717$ & 0 \\
\hline 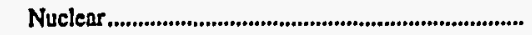 & $\mathbf{0}$ & 54,872 & 0 & $\mathbf{0}$ & 0 & $\mathbf{0}$ \\
\hline 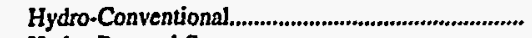 & $\mathbf{0}$ & $\mathbf{0}$ & 0 & $\mathbf{0}$ & 0 & $\mathbf{0}$ \\
\hline 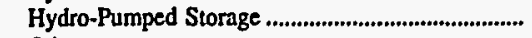 & 0 & 0 & 0 & $\mathbf{0}$ & $\mathbf{0}$ & $\mathbf{0}$ \\
\hline 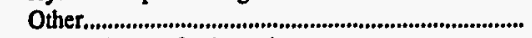 & 331 & 0 & 40,969 & $\mathbf{0}$ & 2,658 & 16,802 \\
\hline 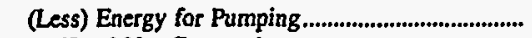 & $\mathbf{0}$ & $\mathbf{0}$ & 5,628 & 0 & 0 & 3,908 \\
\hline Total Net Generation & 182,654 & $1,761,716$ & 35,341 & $\mathbf{0}$ & $11,152,375$ & 12,894 \\
\hline 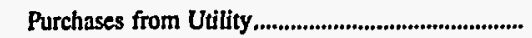 & 373,396 & 98,473 & 256,723 & 630,000 & $2,656,811$ & 621,227 \\
\hline 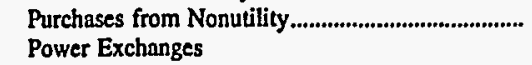 & 0 & 108,304 & 0 & 0 & 12,393 & 0 \\
\hline Received & $\mathbf{0}$ & 0 & 0 & $\mathbf{0}$ & 0 & 0 \\
\hline 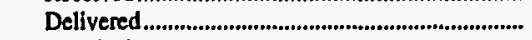 & 0 & 0 & 0 & $\mathbf{0}$ & 0 & $\mathbf{0}$ \\
\hline 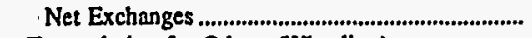 & $\mathbf{0}$ & 0 & 0 & 0 & $\mathbf{0}$ & 0 \\
\hline \multicolumn{7}{|l|}{ Transmission for Others (Wheeling) } \\
\hline 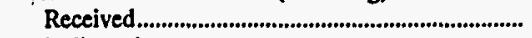 & $\mathbf{0}$ & 0 & 0 & 0 & 857,978 & 0 \\
\hline 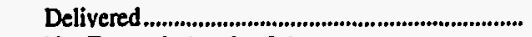 & 0 & 0 & 0 & $\mathbf{0}$ & 857,978 & $\mathbf{0}$ \\
\hline 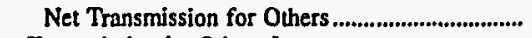 & 0 & 0 & $\mathbf{0}$ & 0 & 0 & 0 \\
\hline $\begin{array}{l}\text { Transmission by Others Losses...................................... } \\
\text { Total Net Energy }\end{array}$ & -470 & 0 & 0 & 0 & 0 & 0 \\
\hline Generated and Recelved.................................. & 555,580 & $1,968,493$ & 292,064 & 630,000 & $13,821,579$ & 634,121 \\
\hline \multicolumn{7}{|l|}{ Disposition of Energy } \\
\hline 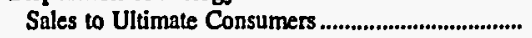 & 535,160 & $1,480,125$ & 265,571 & 630,000 & $9,753,452$ & 588,956 \\
\hline 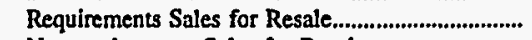 & $\mathbf{0}$ & 101,341 & 576 & 0 & $3,322,589$ & 262 \\
\hline Nonrequirements Sales for Resale ............................ & 1,598 & 284,031 & 1,109 & 0 & 255,224 & $\mathbf{0}$ \\
\hline 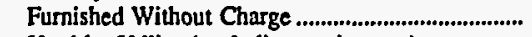 & 0 & $\mathbf{0}$ & $\mathbf{0}$ & 0 & $\mathbf{0}$ & 0 \\
\hline Used by Utility (excluding station use)................... & 1,068 & 0 & 0 & 0 & 19,669 & 954 \\
\hline 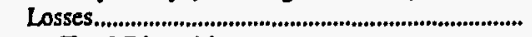 & 17,754 & 102,996 & 24,808 & $\mathbf{0}$ & 470,645 & 43,949 \\
\hline 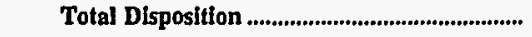 & 555,580 & $1,968,493$ & 292,064 & 630,000 & $13,821,579$ & 634,121 \\
\hline
\end{tabular}

Note: Totals may not equal sum of components because of independent rounding. Double counting occurs in components of both sources and disposition of energy and thus neither provides a true total. Purchases from utilities, net interchanges, and net wheeling (except for imports) are included in net generation.

Source: Energy Information Administration, Form EIA-412, “Annual Report of Public Electric Utilities.” 
Table 26. Electric Energy Account by Major U.S. Publicly Owned Electric Utility Within State, 1996 (Continued)

(Megawatthours)

\begin{tabular}{|c|c|c|c|c|c|c|}
\hline Item & $\begin{array}{c}\text { Florida } \\
\text { Kissimmee } \\
\text { Utility } \\
\text { Authority } \\
\text { September } 30\end{array}$ & $\begin{array}{l}\text { Florida } \\
\text { Lake Worth } \\
\text { City of } \\
\text { September } 30\end{array}$ & $\begin{array}{l}\text { Forida } \\
\text { Lakeland } \\
\text { City of } \\
\text { September } 30\end{array}$ & $\begin{array}{l}\text { Florida } \\
\text { Leesburg } \\
\text { City of } \\
\text { September } 30\end{array}$ & $\begin{array}{c}\text { Florida } \\
\text { New Smyrna } \\
\text { Beach } \\
\text { Utils Comm } \\
\text { September } 30\end{array}$ & $\begin{array}{l}\text { Florida } \\
\text { Ocala } \\
\text { City of } \\
\text { September } 30\end{array}$ \\
\hline \multicolumn{7}{|l|}{ Sources of Energy } \\
\hline Steam & 382,170 & 152,005 & $1,572,484$ & 0 & 0 & 0 \\
\hline Nuclear & 27,900 & 0 & 0 & 44,884 & 23,153 & 56,019 \\
\hline 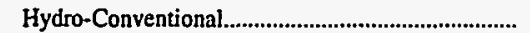 & 0 & 0 & 0 & 0 & 0 & 0 \\
\hline 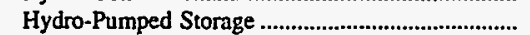 & 0 & 0 & 0 & 0 & 0 & 0 \\
\hline 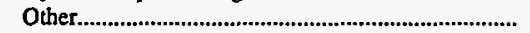 & 33,132 & 0 & 435,582 & 0 & 282 & 0 \\
\hline 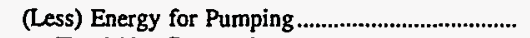 & 0 & 0 & 0 & 0 & 0 & 0 \\
\hline 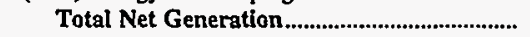 & 443,202 & 152,005 & $2,008,066$ & 44,884 & 23,435 & 56,019 \\
\hline 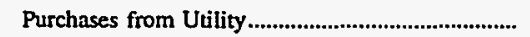 & 500,300 & 240,804 & 468,062 & 379,380 & 306,191 & $1,071,766$ \\
\hline 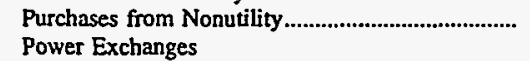 & 0 & 0 & 0 & 0 & 5,127 & 0 \\
\hline 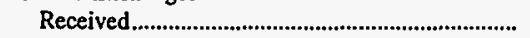 & 0 & 0 & 0 & 0 & 0 & 0 \\
\hline 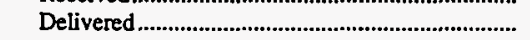 & 0 & 0 & 0 & 0 & 685 & 0 \\
\hline 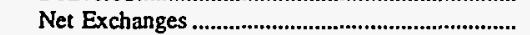 & 0 & 0 & 0 & 0 & -685 & 0 \\
\hline \multicolumn{7}{|l|}{ Transmission for Others (Wheeling) } \\
\hline 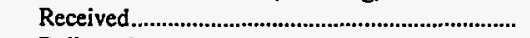 & 0 & 0 & 196,692 & 0 & 0 & 48,477 \\
\hline Delivered & $-2,002$ & 0 & 196,009 & 0 & 0 & 48,477 \\
\hline 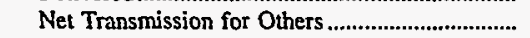 & 2,002 & 0 & 683 & 0 & 0 & 0 \\
\hline $\begin{array}{l}\text { Transmission by Others Losses.................................. } \\
\text { Total Net Energy }\end{array}$ & 0 & $-3,752$ & 0 & 0 & $-2,786$ & 0 \\
\hline Generated and Received & 945,504 & 389,057 & $2,476,811$ & 424,264 & 331,282 & $1,127,785$ \\
\hline \multicolumn{7}{|l|}{ Disposition of Energy } \\
\hline 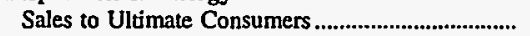 & 893,764 & 358,776 & $2,321,956$ & 400,438 & 313,884 & $1,075,365$ \\
\hline 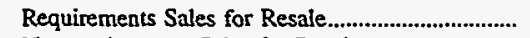 & 0 & 608 & 0 & 0 & 685 & 0 \\
\hline 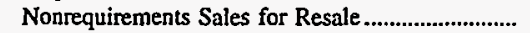 & 0 & 8,151 & 30,684 & 0 & 0 & $\mathbf{0}$ \\
\hline 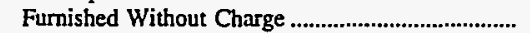 & $\mathbf{0}$ & 0 & 0 & 0 & 0 & 0 \\
\hline 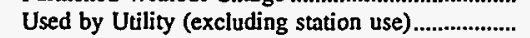 & 0 & 0 & 0 & 0 & 0 & 0 \\
\hline 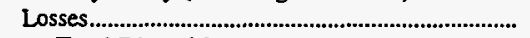 & 51,740 & 21,522 & 124,171 & 23,826 & 16,713 & 52,420 \\
\hline Total Disposition & 945,504 & 389,057 & $2,476,811$ & 424,264 & 331,282 & $1,127,785$ \\
\hline
\end{tabular}

Note: Totals may not equal sum of components because of independent rounding. Double counting occurs in components of both sources and disposition of energy and thus neither provides a true total. Purchases from utilities, net interchanges, and net wheeling (except for imports) are included in net generation.

Source: Energy Information Administration, Form EIA-412, "Annual Report of Public Electric Utilities." 
Table 26. Electric Energy Account by Major U.S. Publicly Owned Electric Utility Within State, 1996 (Continued)

(Megawatthours)

\begin{tabular}{|c|c|c|c|c|c|c|}
\hline Item & $\begin{array}{l}\text { Florida } \\
\text { Oriando } \\
\text { Utilities } \\
\text { Comm } \\
\text { September } 30\end{array}$ & $\begin{array}{l}\text { Florida } \\
\text { Quincy } \\
\text { City of } \\
\text { September } 30\end{array}$ & $\begin{array}{c}\text { Florida } \\
\text { Reedy Creek } \\
\text { Improvement } \\
\text { Dist } \\
\text { September } 30\end{array}$ & $\begin{array}{l}\text { Florida } \\
\text { St Cloud } \\
\text { City of } \\
\text { September } 30\end{array}$ & $\begin{array}{c}\text { Florida } \\
\text { Tallahassee } \\
\text { City of } \\
\text { September } 30\end{array}$ & $\begin{array}{c}\text { Florida } \\
\text { Vero } \\
\text { Beach } \\
\text { City of } \\
\text { September } 30\end{array}$ \\
\hline \multicolumn{7}{|l|}{ Sources of Energy } \\
\hline Steam & $5,213,375$ & 0 & 22,058 & 0 & $1,234,978$ & 394,019 \\
\hline 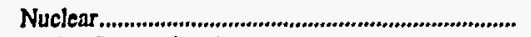 & 367,666 & 0 & 0 & 0 & 57,174 & 0 \\
\hline 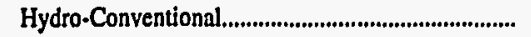 & 0 & 0 & 0 & 0 & 20,586 & 0 \\
\hline Hydro-Pumped Storage ............................................ & 0 & 0 & 0 & 0 & 0 & 0 \\
\hline 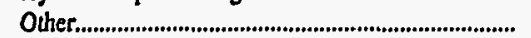 & 59,326 & 0 & 127,654 & 154 & 7,449 & 0 \\
\hline 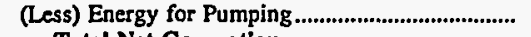 & 0 & 0 & 0 & 0 & 0 & 0 \\
\hline Total Net Generation & $5,640,367$ & $\mathbf{0}$ & 149,712 & 154 & $1,320,187$ & 394,019 \\
\hline 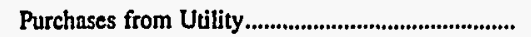 & 679,005 & 158,001 & 844,221 & 286,692 & 964,850 & 292,287 \\
\hline 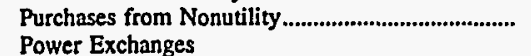 & 0 & 0 & 0 & 0 & 205,466 & 0 \\
\hline 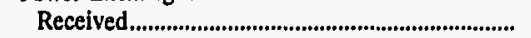 & 0 & 0 & 0 & 0 & 0 & 0 \\
\hline 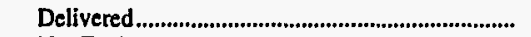 & $\mathbf{0}$ & 0 & 0 & 0 & 0 & 0 \\
\hline 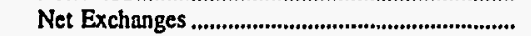 & $\mathbf{0}$ & 0 & 0 & $\mathbf{0}$ & 0 & 0 \\
\hline \multicolumn{7}{|l|}{ Transmission for Others (Wheeling) } \\
\hline 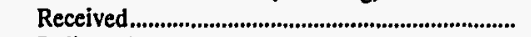 & 18,204 & 0 & 0 & 0 & 0 & 0 \\
\hline 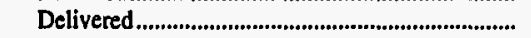 & 17,792 & 0 & 0 & 0 & 0 & 0 \\
\hline 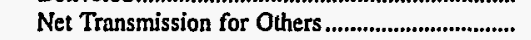 & 412 & 0 & 0 & 0 & 0 & 0 \\
\hline 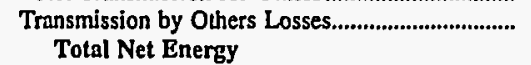 & $-1,249$ & 0 & 0 & 0 & 0 & $-4,689$ \\
\hline 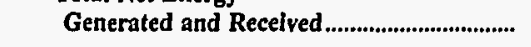 & $6,318,535$ & 158,001 & 993,933 & 286,846 & $2,490,503$ & 681,617 \\
\hline \multicolumn{7}{|l|}{ Disposition of Energy } \\
\hline 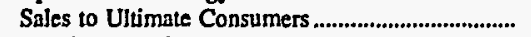 & $4,031,190$ & 106,540 & $\mathbf{0}$ & 269,238 & $2,239,404$ & 568,651 \\
\hline 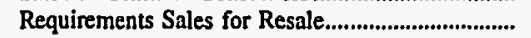 & 773,968 & 0 & 935,404 & 0 & 0 & 0 \\
\hline Nonrequirements Sales for Resale........................... & $1,429,967$ & 44,809 & 0 & $\mathbf{0}$ & 126,627 & 92,880 \\
\hline 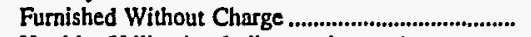 & 0 & 0 & 3,098 & 0 & 0 & 0 \\
\hline Used by Utility (excluding station use)................... & 0 & 0 & 0 & 0 & 0 & 0 \\
\hline 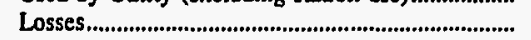 & 83,410 & 6,652 & 55,431 & 17,608 & 124,472 & 20,086 \\
\hline Total Dlsposition & $6,318,535$ & 158,001 & 993,933 & 286,846 & $2,490,503$ & 681,617 \\
\hline
\end{tabular}

Note: Totals may not equal sum of components because of independent rounding. Double counting occurs in components of both sources and disposition of energy and thus neither provides a true total. Purchases from utilities, net interchanges, and net wheeling (except for imports) are included in net generation.

Source: Energy Information Administration, Form ElA-412, “Annual Report of Public Electric Utilities." 
Table 26. Electric Energy Account by Major U.S. Publicly Owned Electric Utility Within State, 1996 (Continued)

(Megawatthours)

\begin{tabular}{|c|c|c|c|c|c|c|}
\hline Item & $\begin{array}{l}\text { Georgia } \\
\text { Albany Water } \\
\text { Gas \& Light } \\
\text { Comm } \\
\text { June } 30\end{array}$ & $\begin{array}{l}\text { Georgia } \\
\text { Calhoun } \\
\text { City of } \\
\text { June } 30\end{array}$ & $\begin{array}{c}\text { Georgia } \\
\text { Cartersville } \\
\text { City of } \\
\text { June } 30\end{array}$ & $\begin{array}{c}\text { Georgia } \\
\text { College } \\
\text { Park City of } \\
\text { June } 30\end{array}$ & $\begin{array}{c}\text { Georgia } \\
\text { Covington } \\
\text { City of } \\
\text { December } 31\end{array}$ & $\begin{array}{c}\text { Georgia } \\
\text { Crisp } \\
\text { County } \\
\text { Power } \\
\text { Comm } \\
\text { December 31 }\end{array}$ \\
\hline \multicolumn{7}{|l|}{ Sources of Energy } \\
\hline Steam...................... & $\mathbf{0}$ & 0 & $\mathbf{0}$ & 0 & 0 & 3,209 \\
\hline Nuclear & $\mathbf{0}$ & 0 & 0 & 0 & 0 & 0 \\
\hline 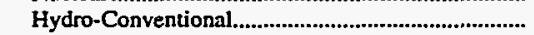 & $\mathbf{0}$ & 0 & 0 & 0 & 0 & 49,361 \\
\hline 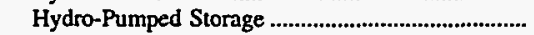 & 0 & 0 & 0 & 0 & $\mathbf{0}$ & $\mathbf{0}$ \\
\hline 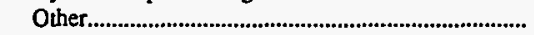 & 0 & 0 & 0 & 0 & 0 & 249 \\
\hline 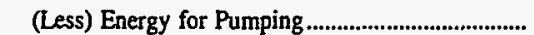 & 0 & 0 & 0 & 0 & 0 & 0 \\
\hline 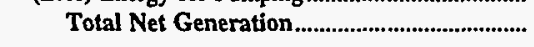 & 0 & 0 & 0 & $\mathbf{0}$ & 0 & 52,819 \\
\hline 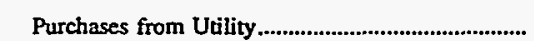 & 977,935 & 344,131 & 510,785 & 289,019 & 240,178 & 305,790 \\
\hline 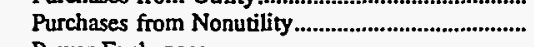 & 0 & 0 & 0 & 0 & 0 & 0 \\
\hline \multicolumn{7}{|l|}{ Power Exchanges } \\
\hline 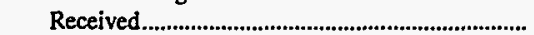 & 0 & 0 & 0 & 0 & 0 & 0 \\
\hline 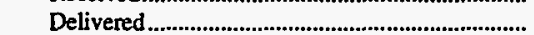 & 0 & 0 & 0 & 0 & 0 & 0 \\
\hline 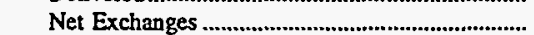 & 0 & 0 & 0 & 0 & 0 & 0 \\
\hline \multicolumn{7}{|l|}{ Transmission for Others (Wheeling) } \\
\hline 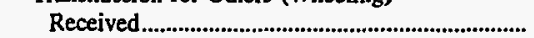 & 0 & 0 & 0 & 0 & 0 & 0 \\
\hline 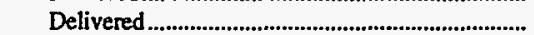 & $\mathbf{0}$ & 0 & 0 & 0 & 0 & 0 \\
\hline Net Transmission for Others & 0 & 0 & 0 & 0 & 0 & 0 \\
\hline 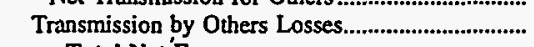 & 0 & 0 & 0 & 0 & 0 & 0 \\
\hline Total Net Energy & & & & & & \\
\hline 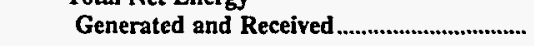 & 977,935 & 344,131 & 510,785 & 289,019 & 240,178 & 358,609 \\
\hline \multicolumn{7}{|l|}{ Disposition of Energy } \\
\hline Sales to Ultimate Consumers.................................... & 926,221 & 331,538 & 480,785 & 285,478 & 226,417 & 344,526 \\
\hline Requirements Sales for Resale..................................... & 0 & 0 & 0 & 0 & 0 & 0 \\
\hline Nonrequirements Sales for Resale................................ & $\mathbf{0}$ & 0 & 0 & 0 & 0 & $\mathbf{0}$ \\
\hline 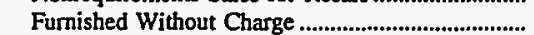 & 0 & 0 & 0 & 554 & 0 & 0 \\
\hline Used by Utility (excluding station use)....................... & 0 & 0 & 0 & 0 & 0 & 601 \\
\hline 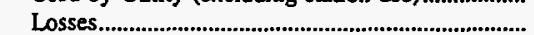 & 51,714 & 12,593 & 30,000 & 2,987 & 13,761 & 13,482 \\
\hline Total Disposition ........................................... & 977,935 & $\mathbf{3 4 4 , 1 3 1}$ & 510,785 & 289,019 & 240,178 & 358,609 \\
\hline
\end{tabular}

Note: Totals may not equal sum of components because of independent rounding. Double counting occurs in components of both sources and disposition of energy and thus neither provides a true total. Purchases from utilities, net interchanges, and net wheeling (except for imports) are included in net generation.

Source: Energy Information Administration, Form EIA-412, "Annual Report of Public Electric Utilities." 
Table 26. Electric Energy Account by Major U.S. Publicly Owned Electric Utility Within State, 1996 (Continued)

(Megawatthours)

\begin{tabular}{|c|c|c|c|c|c|c|}
\hline Item & $\begin{array}{c}\text { Georgia } \\
\text { Dalton } \\
\text { City of } \\
\text { November } 30\end{array}$ & $\begin{array}{l}\text { Georgia } \\
\text { Douglas } \\
\text { City of } \\
\text { June } 30\end{array}$ & $\begin{array}{l}\text { Georgia } \\
\text { East } \\
\text { Point } \\
\text { City of } \\
\\
\text { June } 30\end{array}$ & $\begin{array}{c}\text { Georgia } \\
\text { Fitzgerald } \\
\text { Wtr Lgt } \\
\text { \& Bond Comm } \\
\text { December } 31\end{array}$ & $\begin{array}{l}\text { Georgia } \\
\text { Griffin } \\
\text { City of } \\
\text { June } 30\end{array}$ & $\begin{array}{l}\text { Georgia } \\
\text { La Grange } \\
\text { City of } \\
\text { June } 30\end{array}$ \\
\hline \multicolumn{7}{|l|}{ Sources of Energy } \\
\hline Stcam & 215,509 & $\mathbf{0}$ & $\mathbf{0}$ & $\mathbf{0}$ & $\mathbf{0}$ & 0 \\
\hline 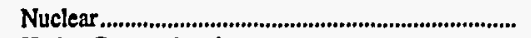 & 527,256 & 0 & 0 & 0 & 0 & 0 \\
\hline 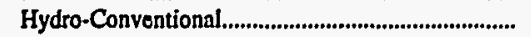 & 0 & 0 & 0 & 0 & 0 & 0 \\
\hline 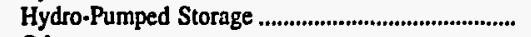 & 0 & 0 & 0 & 0 & 0 & 0 \\
\hline Other & 0 & 0 & 0 & 0 & 0 & 0 \\
\hline 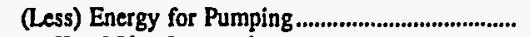 & 0 & 0 & 0 & 0 & 0 & 0 \\
\hline 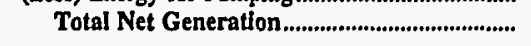 & 742,765 & 0 & 0 & 0 & $\mathbf{0}$ & 0 \\
\hline 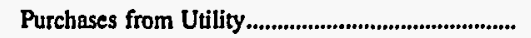 & 612,276 & 253,126 & 313,518 & 213,312 & 325,380 & 496,111 \\
\hline 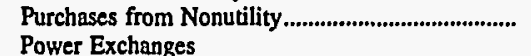 & $\mathbf{0}$ & 0 & 0 & 0 & 0 & 0 \\
\hline 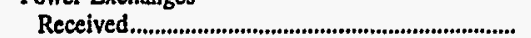 & 0 & 0 & 0 & 0 & 0 & 0 \\
\hline 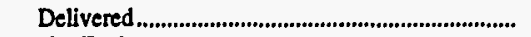 & $\mathbf{0}$ & 0 & 0 & 0 & 0 & 0 \\
\hline 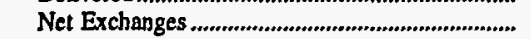 & 0 & 0 & 0 & 0 & 0 & 0 \\
\hline \multicolumn{7}{|l|}{ Transmission for Others (Wheeling) } \\
\hline 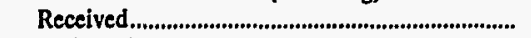 & 0 & 0 & 0 & 0 & $\mathbf{0}$ & $\mathbf{0}$ \\
\hline 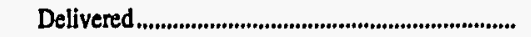 & 0 & 0 & 0 & 0 & 0 & 0 \\
\hline 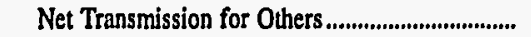 & 0 & 0 & 0 & 0 & 0 & 0 \\
\hline Transmission by Others Losses................................. & 0 & 0 & 0 & 0 & 0 & 0 \\
\hline \multicolumn{7}{|l|}{ Total Net Energy } \\
\hline 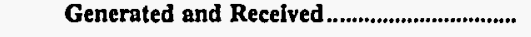 & $1,355,041$ & 253,126 & 313,518 & 213,312 & 325,380 & 496,111 \\
\hline \multicolumn{7}{|l|}{ Disposition of Energy } \\
\hline Sales to Ultimate Consumers ...................................... & $1,236,961$ & 247,558 & 299,967 & 198,681 & 325,380 & 466,471 \\
\hline 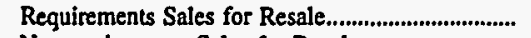 & 31,408 & 0 & 0 & $\mathbf{0}$ & 0 & $\mathbf{0}$ \\
\hline Nonrequirements Sales for Resale ................................ & $\mathbf{0}$ & $\mathbf{0}$ & 0 & 0 & 0 & 0 \\
\hline Furnished Without Charge .......................................... & 0 & 0 & 8,896 & 6,660 & 0 & 0 \\
\hline Used by Utility (excluding station use)................... & 0 & 0 & 4,381 & 0 & 0 & $\mathbf{0}$ \\
\hline 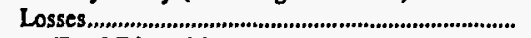 & 86,672 & 5,568 & 274 & 7,971 & 0 & 29,640 \\
\hline 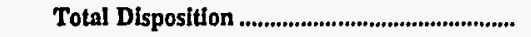 & $1,355,041$ & 253,126 & 313,518 & 213,312 & 325,380 & 496,111 \\
\hline
\end{tabular}

Note: Totals may not equal sum of components because of independent rounding. Double counting occurs in components of both sources and disposition of energy and thus neither provides a true total. Purchases from utilities, net interchanges, and net wheeling (except for imports) are included in net generation. Sales for resale is included in sales to ultimate consumers.

Source: Energy Information Administration, Form ELA-412, "Annual Report of Public Electric Utilities." 
Table 26. Electric Energy Account by Major U.S. Publicly Owned Electric - Utility Within State, 1996 (Continued)

(Megawatthours)

\begin{tabular}{|c|c|c|c|c|c|c|}
\hline Item & $\begin{array}{c}\text { Georgia } \\
\text { Lawrenceville } \\
\text { City of } \\
\text { August } 30\end{array}$ & $\begin{array}{l}\text { Georgia } \\
\text { Marietta } \\
\text { City of } \\
\text { June } 30\end{array}$ & $\begin{array}{l}\text { Georgia } \\
\text { Moultrie } \\
\text { City of } \\
\text { September } 30\end{array}$ & $\begin{array}{l}\text { Georgia } \\
\text { Municipal } \\
\text { Electric } \\
\text { Authority } \\
\text { December } 31\end{array}$ & $\begin{array}{c}\text { Georgia } \\
\text { Thomasville } \\
\text { City of }\end{array}$ & $\begin{array}{l}\text { Idaho } \\
\text { Idaho } \\
\text { Falls } \\
\text { City of } \\
\text { September } 30\end{array}$ \\
\hline \multicolumn{7}{|l|}{ Sources of Energy } \\
\hline 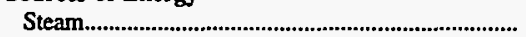 & 0 & 0 & 0 & $3,587,785$ & 0 & 0 \\
\hline 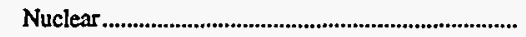 & 0 & 0 & 0 & $6,169,056$ & 0 & 0 \\
\hline 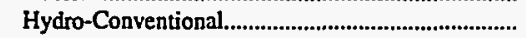 & 0 & 0 & 0 & 0 & 0 & 311,593 \\
\hline 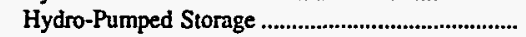 & 0 & 0 & 0 & 0 & 0 & 0 \\
\hline 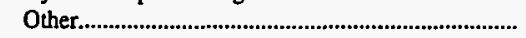 & 0 & 0 & 0 & 0 & 0 & 0 \\
\hline 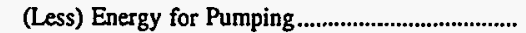 & 0 & 0 & 0 & 0 & 0 & 0 \\
\hline 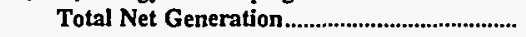 & 0 & 0 & $\mathbf{0}$ & $9,756,841$ & 0 & 311,593 \\
\hline 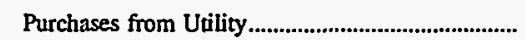 & 239,875 & 948,256 & 182,773 & $1,097,533$ & 487,304 & 320,670 \\
\hline 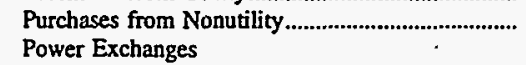 & 0 & 0 & 0 & 9,037 & 0 & 0 \\
\hline 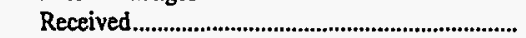 & 0 & 0 & 0 & 0 & 0 & 0 \\
\hline 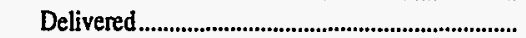 & 0 & 0 & 0 & 0 & 0 & 0 \\
\hline 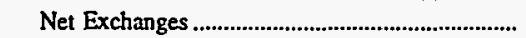 & 0 & 0 & 0 & 0 & 0 & $\mathbf{0}$ \\
\hline \multicolumn{7}{|l|}{ Transmission for Others (Wheeling) } \\
\hline Received & 0 & 0 & 0 & 790,799 & 0 & $\mathbf{0}$ \\
\hline 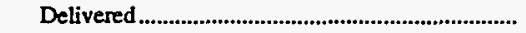 & $\mathbf{0}$ & 0 & 0 & 747,305 & 0 & $\mathbf{0}$ \\
\hline 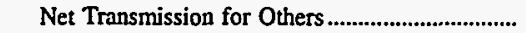 & 0 & 0 & 0 & 43,494 & 0 & $\mathbf{0}$ \\
\hline $\begin{array}{l}\text { Transmission by Others Losses................................... } \\
\text { Total Net Energy }\end{array}$ & 0 & 0 & 0 & 0 & 0 & 0 \\
\hline 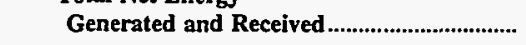 & 239,875 & 948,256 & 182,773 & $10,906,905$ & 487,304 & 632,263 \\
\hline \multicolumn{7}{|l|}{ Disposition of Energy } \\
\hline 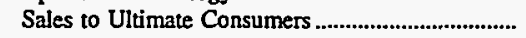 & 224,782 & 932,783 & 161,931 & 0 & 465,385 & 600,838 \\
\hline 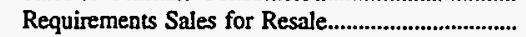 & 0 & 0 & 0 & $9,223,848$ & 0 & 0 \\
\hline Nonrequirements Sales for Resale ............................ & 0 & 0 & 0 & $1,041,064$ & 0 & $\mathbf{0}$ \\
\hline 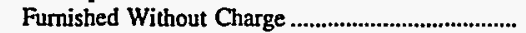 & 2,495 & 0 & 20,842 & 0 & 2,638 & 0 \\
\hline Used by Utility (excluding station use).................. & 12,598 & 0 & 0 & 1,456 & 1,143 & 0 \\
\hline 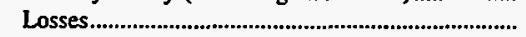 & 0 & 15,473 & 0 & 640,537 & 18,138 & 31,425 \\
\hline 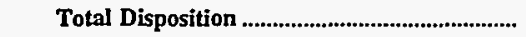 & 239,875 & 948,256 & 182,773 & $10,906,905$ & 487,304 & 632,263 \\
\hline
\end{tabular}

Note: Totals may not equal sum of components because of independent rounding. Double counting occurs in components of both sources and disposition of energy and thus neither provides a true total. Purchases from utilities, net interchanges, and net wheeling (except for imports) are included in net generation.

Source: Energy Information Administration, Form EIA-412, "Annual Report of Public Electric Utilities." 
Table 26. Electric Energy Account by Major U.S. Publicly Owned Electric Utility Within State, 1996 (Continued)

(Megawatthours)

\begin{tabular}{|c|c|c|c|c|c|c|}
\hline Item & $\begin{array}{l}\text { Illinois } \\
\text { Batavia } \\
\text { City of } \\
\text { December } 31\end{array}$ & $\begin{array}{l}\text { Illinois } \\
\text { Geneva } \\
\text { City of } \\
\text { April } 30\end{array}$ & $\begin{array}{c}\text { Illinois } \\
\text { Illinois } \\
\text { Municipal } \\
\text { Elec Agency } \\
\text { April } 30\end{array}$ & $\begin{array}{c}\text { Illinois } \\
\begin{array}{c}\text { Naperville } \\
\text { City of }\end{array} \\
\text { April } 30\end{array}$ & $\begin{array}{l}\text { Illinois } \\
\text { Roche!le } \\
\text { Municipal } \\
\text { Utilities } \\
\text { April } 30\end{array}$ & $\begin{array}{c}\text { Illinois } \\
\begin{array}{c}\text { Springfield } \\
\text { Ciry of }\end{array} \\
\text { February } 28\end{array}$ \\
\hline \multicolumn{7}{|l|}{ Sources of Energy } \\
\hline 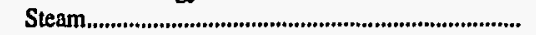 & $\mathbf{0}$ & 0 & 426,474 & 0 & $-1,768$ & $1,965,568$ \\
\hline 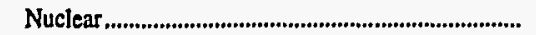 & 0 & 0 & 0 & 0 & 0 & \\
\hline 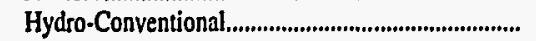 & 0 & 0 & 0 & 0 & 0 & 0 \\
\hline 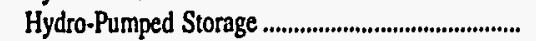 & 0 & 0 & 0 & 0 & 0 & 0 \\
\hline 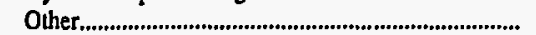 & $\mathbf{0}$ & 0 & 0 & 0 & 961 & 0 \\
\hline 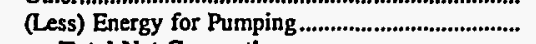 & 0 & 0 & 0 & 0 & 0 & \\
\hline 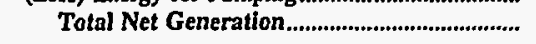 & 0 & $\mathbf{0}$ & 426,474 & o & -807 & $1,965,568$ \\
\hline 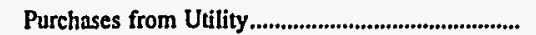 & 265,718 & 201,449 & $1,189,883$ & 830,989 & 180,862 & 35,050 \\
\hline 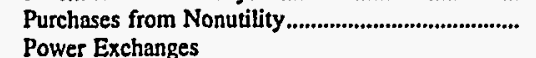 & 0 & 22,484 & 0 & 16,376 & 0 & 160 \\
\hline 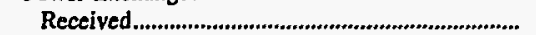 & $\mathbf{0}$ & 0 & 0 & 0 & 0 & \\
\hline 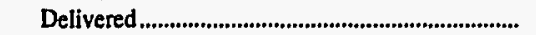 & 0 & 0 & 0 & 0 & 0 & 0 \\
\hline Net Exchanges ............................................................... & 0 & 0 & 0 & 0 & 0 & 0 \\
\hline \multicolumn{7}{|l|}{ Transmission for Others (Wheeling) } \\
\hline (.......................................................... & 0 & 0 & 0 & $\mathbf{0}$ & 0 & $\mathbf{0}$ \\
\hline 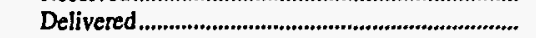 & 0 & 0 & 0 & 0 & 0 & 0 \\
\hline 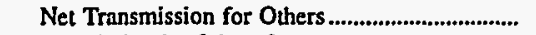 & $\mathbf{0}$ & $\mathbf{0}$ & 0 & 0 & 0 & 0 \\
\hline 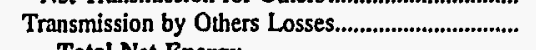 & 0 & 0 & 0 & $\mathbf{0}$ & 0 & 0 \\
\hline Total Net Energy & 765718 & 223033 & 1616357 & 847365 & 100055 & 2000778 \\
\hline & 200,110 & | & $1,010,301$ & & & \\
\hline \multicolumn{7}{|l|}{ Disposition of Energy } \\
\hline 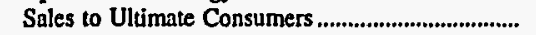 & 250,678 & 223,933 & 0 & 844,048 & 167,138 & $1,615,945$ \\
\hline Requirements Sales for Resale........................................ & 0 & 0 & $1,559,563$ & 0 & 0 & 265,319 \\
\hline 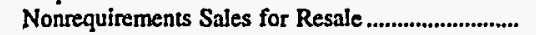 & $\mathbf{0}$ & 0 & 0 & 0 & 0 & 0 \\
\hline 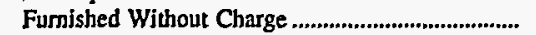 & 0 & 0 & 0 & 0 & 0 & 27,536 \\
\hline Used by Uiblity (excluding station use)......................... & 0 & 0 & 0 & 0 & 0 & 3,981 \\
\hline 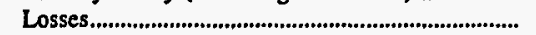 & 15,040 & 0 & 56,794 & 3,317 & 12,917 & 87,997 \\
\hline 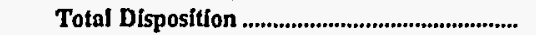 & 265,718 & 223,933 & $1,616,357$ & 847,365 & 180,055 & $2,000,778$ \\
\hline
\end{tabular}

Note: Totals may not equal sum of components because of independent rounding. Double counting occurs in components of both sources and disposition of energy and thus neither provides a true total. Purchases from utilities, net interchanges, and net wheeling (except for imports) are included in net generation.

Source: Energy Information Administration, Form EIA-412, "Annual Report of Public Electric Utilities." 
Table 26. Electric Energy Account by Major U.S. Publicly Owned Electric Utility Within State, 1996 (Continued)

(Megawatthours)

\begin{tabular}{|c|c|c|c|c|c|c|}
\hline Item & $\begin{array}{l}\text { Illinois } \\
\text { St Charles } \\
\text { City of } \\
\text { April } 30\end{array}$ & $\begin{array}{l}\text { Indiana } \\
\text { Anderson } \\
\text { City of } \\
\text { December } 31\end{array}$ & $\begin{array}{l}\text { Indiana } \\
\text { Auburn } \\
\text { City of } \\
\text { December } 31\end{array}$ & $\begin{array}{l}\text { Indiana } \\
\text { Bluffton } \\
\text { City of } \\
\text { December } 31\end{array}$ & $\begin{array}{c}\text { Indiana } \\
\text { Crawfordsville } \\
\text { Elec } \\
\text { Lgt\&\&wr Co } \\
\text { December } 31\end{array}$ & $\begin{array}{l}\text { Indiana } \\
\text { Frankfort } \\
\text { City of } \\
\text { December } 31\end{array}$ \\
\hline \multicolumn{7}{|l|}{ Sources of Energy } \\
\hline Steam. & 0 & 0 & 0 & 0 & 11,086 & 0 \\
\hline 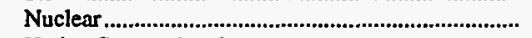 & 0 & 0 & 0 & 0 & 0 & 0 \\
\hline 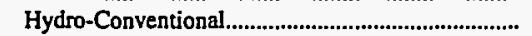 & 0 & 0 & 0 & 0 & 0 & 0 \\
\hline 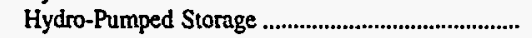 & 0 & 0 & 0 & 0 & 0 & 0 \\
\hline 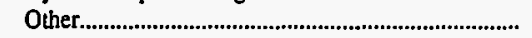 & 0 & 0 & 0 & 2,353 & 4 & 0 \\
\hline 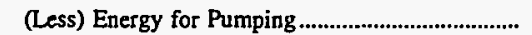 & 0 & 0 & 0 & 0 & 0 & 0 \\
\hline 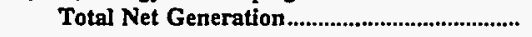 & $\mathbf{0}$ & $\mathbf{0}$ & $\mathbf{0}$ & 2,353 & 11,090 & $\mathbf{0}$ \\
\hline 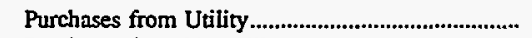 & 422,735 & 706,623 & 483,840 & 181,898 & 388,226 & 341,190 \\
\hline 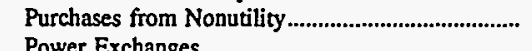 & 0 & 0 & 0 & 0 & 0 & 0 \\
\hline 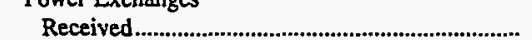 & 0 & 0 & 0 & 0 & 0 & 0 \\
\hline 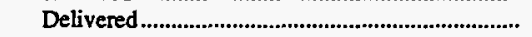 & 0 & 0 & 0 & 0 & 0 & 0 \\
\hline 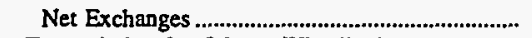 & 0 & 0 & 0 & 0 & 0 & 0 \\
\hline \multicolumn{7}{|l|}{ Transmission for Others (Wheeling) } \\
\hline 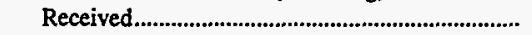 & 0 & 0 & 0 & 0 & 0 & 0 \\
\hline Delivered & 0 & 0 & 0 & 0 & 0 & 0 \\
\hline 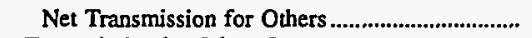 & 0 & 0 & 0 & 0 & 0 & 0 \\
\hline 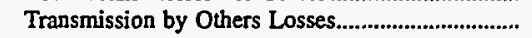 & 0 & 0 & 0 & 0 & 0 & 0 \\
\hline Total Net Energy & & & & & - & \\
\hline 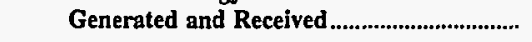 & 422,735 & 706,623 & 483,840 & 184,251 & 399,316 & 341,190 \\
\hline \multicolumn{7}{|l|}{ Disposition of Energy } \\
\hline 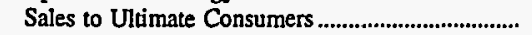 & 406,486 & 683,832 & 468,065 & 176,926 & 379,865 & 337,965 \\
\hline 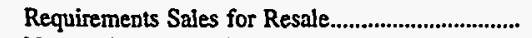 & 0 & 0 & 0 & 0 & 0 & 0 \\
\hline Nonrequirements Sales for Resale........................... & 0 & 0 & 0 & 0 & 11,090 & 0 \\
\hline 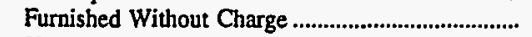 & 0 & 0 & 0 & 0 & 0 & 0 \\
\hline Used by Utility (excluding station use).................. & 0 & 0 & 243 & 0 & 2,016 & 465 \\
\hline 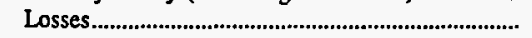 & 16,249 & 22,791 & 15,532 & 7,325 & 6,345 & 2,760 \\
\hline 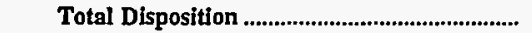 & 422,735 & 706,623 & 483,840 & 184,251 & 399,316 & 341,190 \\
\hline
\end{tabular}

Note: Totals may not equal sum of components because of independent rounding. Double counting occurs in components of both sources and disposition of energy and thus neither provides a true total. Purchases from utilities, net interchanges, and net wheeling (except for imports) are included in net generation.

Source: Energy Information Administration, Form EIA-412, “Annual Report of Public Electric Utilities." 
Table 26. Electric Energy Account by Major U.S. Publicly Owned Electric Utility Within State, 1996 (Continued)

(Megawatthours)

\begin{tabular}{|c|c|c|c|c|c|c|}
\hline Item & $\begin{array}{l}\text { Indiana } \\
\text { Greenfield } \\
\text { City of } \\
\text { December } 31\end{array}$ & $\begin{array}{c}\text { Indiana } \\
\text { Indiana } \\
\text { Municipal } \\
\text { Power Agency } \\
\text { December } 31\end{array}$ & $\begin{array}{l}\text { Indiana } \\
\text { Jasper } \\
\text { City of } \\
\text { December } 31\end{array}$ & $\begin{array}{l}\text { Indiana } \\
\text { Lebanon } \\
\text { City of } \\
\text { December } 31\end{array}$ & $\begin{array}{c}\text { Indiana } \\
\text { Logansport } \\
\text { City of } \\
\text { December } 31\end{array}$ & $\begin{array}{c}\text { Indiana } \\
\text { Mishawaka } \\
\text { City of } \\
\text { December } 31\end{array}$ \\
\hline \multicolumn{7}{|l|}{ Sources of Energy } \\
\hline Steam & 0 & $1,356,017$ & 59,112 & 0 & 156,645 & 0 \\
\hline 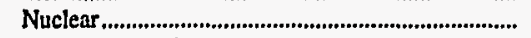 & 0 & 0 & 0 & 0 & 0 & 0 \\
\hline 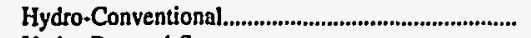 & 0 & 0 & 0 & 0 & 0 & 0 \\
\hline 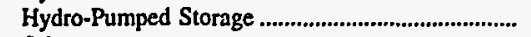 & 0 & 0 & 0 & 0 & 0 & 0 \\
\hline Other & 0 & 4,132 & 0 & 0 & 160 & 0 \\
\hline 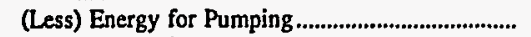 & 0 & 0 & 0 & 0 & 0 & 0 \\
\hline 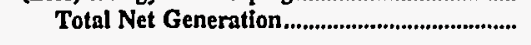 & $\mathbf{0}$ & $1,360,149$ & 59,112 & 0 & 156,805 & 0 \\
\hline 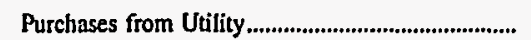 & 197,388 & $3,140,037$ & 237,444 & 143,082 & 193,890 & $\$ 22,156$ \\
\hline 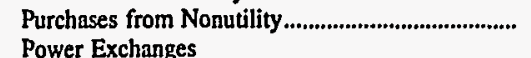 & 0 & 0 & 0 & 0 & 0 & 0 \\
\hline 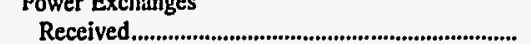 & 0 & 0 & 0 & \multicolumn{2}{|c|}{ Power Exchanges } & 0 \\
\hline 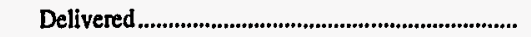 & 0 & 0 & 0 & 0 & 0 & 0 \\
\hline 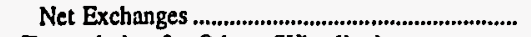 & 0 & 0 & 0 & 0 & 0 & 0 \\
\hline \multicolumn{7}{|l|}{ Transmission for Others (Wheeling) } \\
\hline 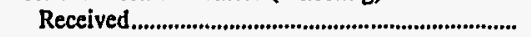 & 0 & 312,138 & 0 & 0 & 0 & 0 \\
\hline 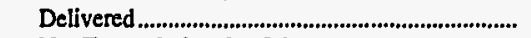 & $\mathbf{0}$ & 312,138 & 0 & 0 & 0 & 0 \\
\hline 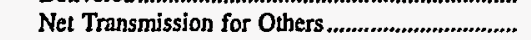 & $\mathbf{0}$ & 0 & 0 & 0 & 0 & 0 \\
\hline $\begin{array}{l}\text { Transmission by Others Losses.................................. } \\
\text { Total Net Energy }\end{array}$ & 0 & 0 & 0 & 0 & 0 & 0 \\
\hline Generated and Received................................... & 197,388 & $4,500,186$ & 296,556 & 143,082 & 350,695 & 522,156 \\
\hline \multicolumn{7}{|l|}{ Disposition of Energy } \\
\hline 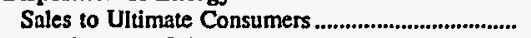 & 191,579 & 0 & 283,005 & 138,132 & 327,437 & 499,334 \\
\hline Requirements Sales for Resale.................................. & 0 & $4,165,247$ & 0 & 0 & 0 & 0 \\
\hline Nonrequirements Sales for Resale ........................... & 0 & 220,496 & 0 & 0 & 0 & 0 \\
\hline Furnished Without Charge ........................................... & 0 & 0 & 4 & 0 & 0 & 0 \\
\hline Used by Utility (excluding station use)................... & 0 & 2,584 & 834 & 0 & 0 & 0 \\
\hline 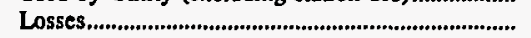 & 5,809 & 111,859 & 12,713 & 4,950 & 23,258 & 22,822 \\
\hline 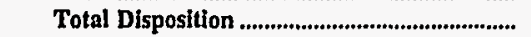 & 197,388 & $4,500,186$ & 296,556 & 143,082 & 350,695 & 522,156 \\
\hline
\end{tabular}

Note: Totals may not equal sum of components because of independent rounding. Double counting occurs in components of both sources and disposition of energy and thus neither provides a true total. Purchases from utilities, net interchanges, and net wheeling (except for imports) are included in net generation.

Source: Energy Information Administration, Form EIA-412, "Annual Report of Public Electric Utilities." 
Table 26. Electric Energy Account by Major U.S. Publicly Owned Electric Utility Within State, 1996 (Continued)

(Megawatthours)

\begin{tabular}{|c|c|c|c|c|c|c|}
\hline Item & $\begin{array}{c}\text { Indiana } \\
\text { Peru } \\
\text { City of } \\
\text { December } 31\end{array}$ & $\begin{array}{l}\text { Indiana } \\
\text { Richmond } \\
\text { City of } \\
\text { December } 31\end{array}$ & $\begin{array}{c}\text { Indiana } \\
\text { Scottsburg } \\
\text { City of } \\
\text { December } 31\end{array}$ & $\begin{array}{c}\text { Indiana } \\
\text { Washington } \\
\text { City of } \\
\text { December } 31\end{array}$ & $\begin{array}{l}\text { Iowa } \\
\text { Ames } \\
\text { City of } \\
\text { June } 30\end{array}$ & $\begin{array}{l}\text { Iowa } \\
\text { Cedar } \\
\text { Falls } \\
\text { City of } \\
\text { December } 31\end{array}$ \\
\hline \multicolumn{7}{|l|}{ Sources of Energy } \\
\hline Steam.......................... & 2,014 & 543,096 & 0 & 0 & 311,844 & 246,645 \\
\hline 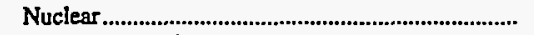 & 0 & $\mathbf{0}$ & $\mathbf{0}$ & 0 & 0 & 0 \\
\hline 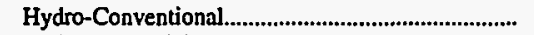 & 0 & 0 & 0 & 0 & $\mathbf{0}$ & 0 \\
\hline 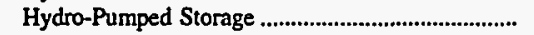 & 0 & 0 & 0 & 0 & 0 & 0 \\
\hline 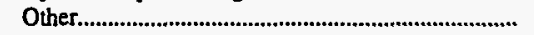 & 0 & 0 & 0 & 0 & 0 & 745 \\
\hline 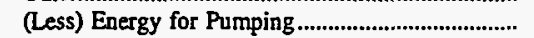 & 0 & 0 & 0 & 0 & 0 & 0 \\
\hline 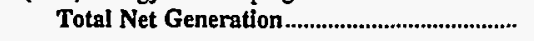 & 2,014 & 543,096 & 0 & $\mathbf{0}$ & 311,844 & 247,390 \\
\hline 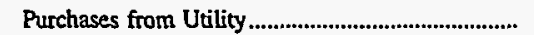 & 219,678 & 354,758 & 184,320 & 169,931 & 123,070 & 113,510 \\
\hline 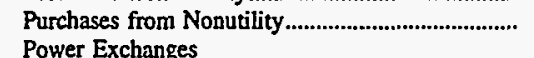 & 0 & 0 & 0 & 0 & 0 & \\
\hline 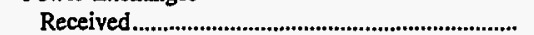 & 0 & 0 & 0 & 0 & 154 & 0 \\
\hline Delivered................................................................ & 0 & 0 & 0 & 0 & 227 & 0 \\
\hline 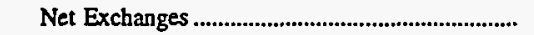 & 0 & 0 & 0 & 0 & -73 & 0 \\
\hline \multicolumn{7}{|l|}{ Transmission for Others (Wheeling) } \\
\hline 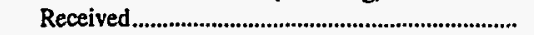 & 0 & 0 & 0 & 0 & 0 & 0 \\
\hline 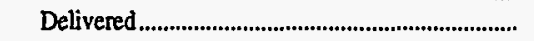 & 0 & 0 & 0 & 0 & 0 & 0 \\
\hline 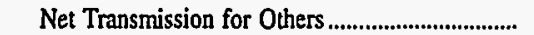 & 0 & 0 & 0 & 0 & 0 & 0 \\
\hline 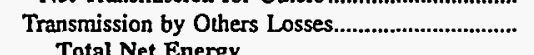 & 0 & 0 & 0 & 0 & 0 & 0 \\
\hline $\begin{array}{l}\text { Total Net Energy } \\
\text { Generated and Received .................................... }\end{array}$ & 221,692 & 897,854 & 184,320 & 169,931 & 434,841 & 360,901 \\
\hline \multicolumn{7}{|l|}{ Disposition of Energy } \\
\hline 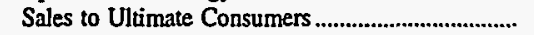 & 211,765 & 870,923 & 181,753 & 161,877 & 412,479 & 330,146 \\
\hline 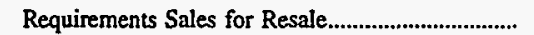 & 0 & 0 & 0 & 0 & 0 & 0 \\
\hline Nourequirements Sales for Resale .................................... & 0 & 0 & 0 & $\mathbf{0}$ & 0 & 4,055 \\
\hline Furnished Without Charge ............................................ & 0 & 4 & 0 & 0 & 0 & 0 \\
\hline Used by Utility (excluding station use)....................... & 0 & 2,248 & 0 & 0 & 510 & 2,733 \\
\hline 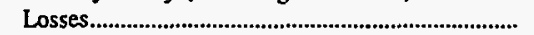 & 9,927 & 24,679 & 2,567 & 8,054 & 21,852 & 23,967 \\
\hline 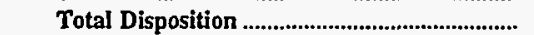 & 221,692 & 897,854 & 184,320 & 169,931 & 434,841 & 360,901 \\
\hline
\end{tabular}

Note: Totals may not equal sum of components because of independent rounding. Double counting occurs in components of both sources and disposition of energy and thus neither provides a true total. Purchases from utilities, net interchanges, and net wheeling (except for imports) are included in net generation.

Source: Energy Information Administration, Form EIA-412, "Annual Report of Public Electric Utilities." 
Table 26. Electric Energy Account by Major U.S. Publicly Owned Electric Utility Within State, 1996 (Continued)

(Megawatthours)

\begin{tabular}{|c|c|c|c|c|c|c|}
\hline Item & $\begin{array}{c}\text { Iowa } \\
\text { Muscatine } \\
\text { City of } \\
\text { December 31 }\end{array}$ & $\begin{array}{c}\text { Iowa } \\
\text { Pella } \\
\text { City of } \\
\text { December } 31\end{array}$ & $\begin{array}{l}\text { Kansas } \\
\text { Chanute } \\
\text { City of } \\
\text { December } 31\end{array}$ & $\begin{array}{c}\text { Kansas } \\
\begin{array}{c}\text { Coffeyville } \\
\text { City of }\end{array} \\
\text { December } 31\end{array}$ & $\begin{array}{c}\text { Kansas } \\
\text { Garden } \\
\text { City City of } \\
\text { December } 31\end{array}$ & $\begin{array}{c}\text { Kansas } \\
\text { Kansas } \\
\text { City City of } \\
\text { December } 31\end{array}$ \\
\hline \multicolumn{7}{|l|}{ Sources of Energy } \\
\hline 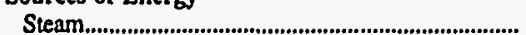 & $1,341,396$ & 71,070 & 0 & 57,210 & 0 & $2,366,353$ \\
\hline 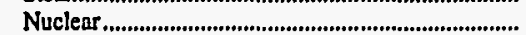 & 0 & 0 & 0 & 0 & 0 & \\
\hline 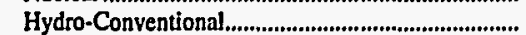 & 0 & 0 & 0 & 0 & 0 & 0 \\
\hline Hydro-Pumped Storage ........................................... & 0 & 0 & 0 & 0 & 0 & 0 \\
\hline Other, & 0 & 0 & 6,322 & 0 & 0 & 0 \\
\hline 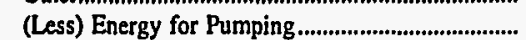 & 0 & 0 & 0 & 0 & 0 & \\
\hline 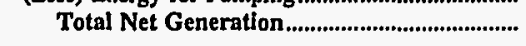 & $1,341,396$ & 71,070 & 6,322 & 57,210 & 0 & $2,366,353$ \\
\hline Purchases from Utility... & 49,214 & 91,885 & 105,830 & 136,857 & 184,821 & 384,941 \\
\hline Purchases from Nonutility......................................... & 0 & 0 & 0 & 0 & 0 & 0 \\
\hline 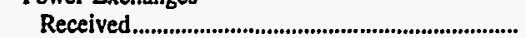 & 0 & 5,666 & 0 & 136,648 & 0 & 0 \\
\hline Delivered & 0 & 6,759 & 0 & 136,857 & 0 & 13,893 \\
\hline 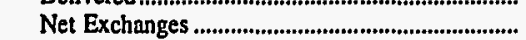 & 0 & $-1,093$ & 0 & -209 & 0 & $-13,893$ \\
\hline \multicolumn{7}{|l|}{ Transmission for Others (Wheeling) } \\
\hline 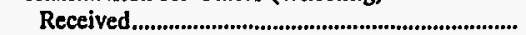 & 9,608 & 0 & 0 & 0 & 0 & \\
\hline Delivered & 1,136 & 0 & 0 & 0 & 0 & $\mathbf{0}$ \\
\hline Net Transmission for Others..................................... & 8,472 & 0 & 0 & 0 & 0 & 0 \\
\hline 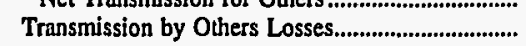 & $\begin{array}{r}0,472 \\
0\end{array}$ & 0 & 0 & 0 & $-8,371$ & 0 \\
\hline Total Net Energy & & & & & & \\
\hline 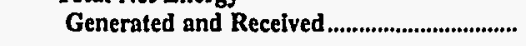 & $1,399,082$ & 161,862 & 113,152 & 193,858 & 176,450 & $2,737,401$ \\
\hline \multicolumn{7}{|l|}{ Disposition of Energy } \\
\hline Sales to Ultimate Consume & 840,996 & 153,915 & 113,152 & 178,901 & 164,277 & $2,120,881$ \\
\hline 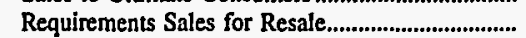 & 0 & 0 & 0 & 0 & 0 & 413,962 \\
\hline Nonrequirements Sales for Resale ............................... & 524,836 & 0 & 0 & 0 & 0 & 0 \\
\hline 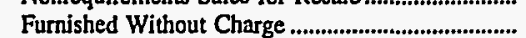 & 4,920 & 0 & 0 & 4,692 & 1,795 & 109,165 \\
\hline 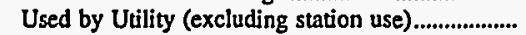 & 2,742 & 0 & 0 & 1,210 & 3,776 & 0 \\
\hline 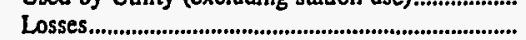 & 25,588 & 7,947 & 0 & 9,055 & 6,602 & 93,393 \\
\hline 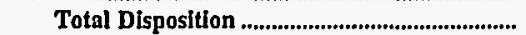 & $1,399,082$ & 161,862 & 113,152 & 193,858 & 176,450 & $2,737,401$ \\
\hline
\end{tabular}

Note: Totals may not equal sum of components because of independent rounding. Double counting occurs in components of both sources and disposition of energy and thus neither provides a true total. Purchases from utilities, net interchanges, and net wheeling (except for imports) are included in net generation.

Source: Energy Information Administration, Form ElA-412, “Annual Report of Public Electric Utilities." 
Table 26. Electric Energy Account by Major U.S. Publicly Owned Electric Utility Within State, 1996 (Continued)

(Megawatthours)

\begin{tabular}{|c|c|c|c|c|c|c|}
\hline Item & $\begin{array}{c}\text { Kansas } \\
\text { Kansas } \\
\text { Municipal } \\
\text { Energy } \\
\text { Agency } \\
\text { December } 31\end{array}$ & $\begin{array}{c}\text { Kansas } \\
\text { McPherson } \\
\text { City of } \\
\text { December } 31\end{array}$ & $\begin{array}{c}\text { Kansas } \\
\text { Winfield } \\
\text { City of } \\
\text { December } 31\end{array}$ & $\begin{array}{l}\text { Kentucky } \\
\text { Bardstown } \\
\text { City of } \\
\text { December } 31\end{array}$ & $\begin{array}{l}\text { Kentucky } \\
\text { Bowling } \\
\text { Green } \\
\text { City of } \\
\text { June } 30\end{array}$ & $\begin{array}{l}\text { Kentucky } \\
\text { Frankfort } \\
\text { City of } \\
\text { June } 30\end{array}$ \\
\hline \multicolumn{7}{|l|}{ Sources of Energy } \\
\hline Steam & 0 & 5,428 & 15,445 & 0 & 0 & \\
\hline 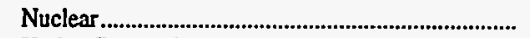 & 0 & 0 & 0 & 0 & 0 & \\
\hline 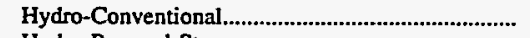 & 0 & 0 & 0 & 0 & 0 & \\
\hline Hydro-Pumped Storage .......................................................... & 0 & 0 & 0 & 0 & 0 & \\
\hline 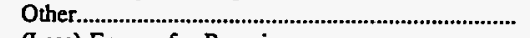 & 0 & 6,496 & 515 & 0 & 0 & \\
\hline 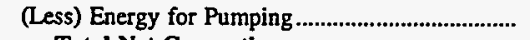 & 0 & 0 & $\mathbf{0}$ & 0 & 0 & 0 \\
\hline 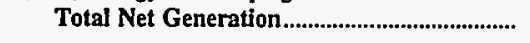 & 0 & 11,924 & 15,960 & 0 & 0 & \\
\hline 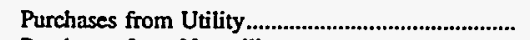 & 293,506 & 581,864 & 252,014 & 167,136 & 751,316 & 686,952 \\
\hline 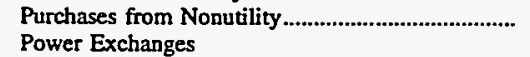 & 0 & 0 & 0 & 0 & 0 & 0 \\
\hline 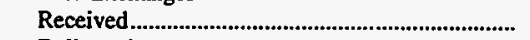 & 0 & 0 & 0 & 0 & 0 & \\
\hline 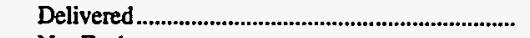 & 0 & 0 & 0 & 0 & 0 & 0 \\
\hline 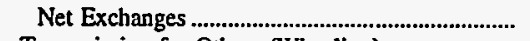 & 0 & 0 & 0 & 0 & 0 & 0 \\
\hline \multicolumn{7}{|l|}{ Transmission for Others (Wheeling) } \\
\hline 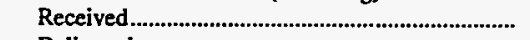 & 0 & 0 & 0 & 0 & 0 & 0 \\
\hline 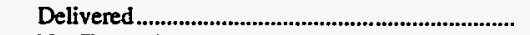 & 0 & 0 & 0 & 0 & 0 & 0 \\
\hline 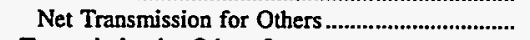 & 0 & 0 & 0 & 0 & 0 & 0 \\
\hline 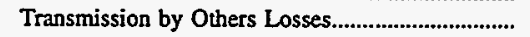 & 0 & 0 & 0 & 0 & 0 & 0 \\
\hline Total Net Energy & & & & & & \\
\hline 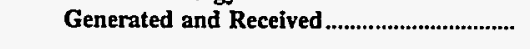 & 293,506 & 593,788 & 267,974 & 167,136 & 751,316 & 686,952 \\
\hline \multicolumn{7}{|l|}{ Disposition of Energy } \\
\hline 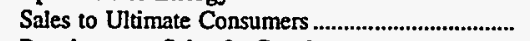 & 0 & 538,986 & 234,415 & 155,482 & 725,620 & 652,584 \\
\hline Requirements Sales for Resale............................................ & 293,506 & 36,034 & 9,851 & 0 & 0 & 0 \\
\hline Nonrequirements Sales for Resale ................................. & 0 & 0 & 0 & 0 & 0 & 0 \\
\hline 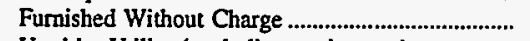 & 0 & 152 & 0 & 7,203 & $\mathbf{0}$ & 0 \\
\hline Used by Utility (excluding station use)........................ & 0 & 0 & 4,397 & 0 & 866 & 8,006 \\
\hline Losses & 0 & 18,616 & 19,311 & 4,451 & 24,829 & 26,362 \\
\hline Total Disposition ............................................................... & 293,506 & 593,788 & 267,974 & 167,136 & 751,316 & 686,952 \\
\hline
\end{tabular}

Note: Totals may not equal sum of components because of independent rounding. Double counting occurs in components of both sources and disposition of energy and thus neither provides a true total. Purchases from utilities, net interchanges, and net wheeling (except for imports) are included in net generation.

Source: Energy Information Administration, Form EIA-412, "Annual Report of Public Electric Utilities." 
Table 26. Electric Energy Account by Major U.S. Publicly Owned Electric Utility Within State, 1996 (Continued)

(Megawatthours)

\begin{tabular}{|c|c|c|c|c|c|c|}
\hline Item & $\begin{array}{l}\text { Kentucky } \\
\text { Franklin } \\
\text { City of } \\
\text { June } 30\end{array}$ & $\begin{array}{l}\text { Kentucky } \\
\text { Glasgow } \\
\text { City of } \\
\text { June } 30\end{array}$ & $\begin{array}{l}\text { Kentucky } \\
\text { Henderson } \\
\text { City } \\
\text { Utility Comm } \\
\text { May } 31\end{array}$ & $\begin{array}{l}\text { Kentucky } \\
\text { Hopkinsville } \\
\text { City of } \\
\text { June } 30\end{array}$ & $\begin{array}{l}\text { Kentucky } \\
\text { Madisonville } \\
\begin{array}{c}\text { Municipal } \\
\text { Utils }\end{array} \\
\text { June } 30\end{array}$ & $\begin{array}{l}\text { Kentucky } \\
\text { Mayfield } \\
\text { City of } \\
\text { June } 30\end{array}$ \\
\hline \multicolumn{7}{|l|}{ Sources of Energy } \\
\hline 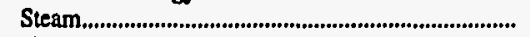 & 0 & $\mathbf{0}$ & $2,031,372$ & 0 & 0 & 0 \\
\hline 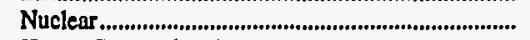 & $\mathbf{0}$ & $\mathbf{0}$ & 0 & 0 & 0 & 0 \\
\hline 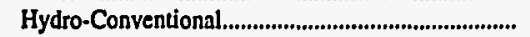 & 0 & 0 & 0 & 0 & 0 & 0 \\
\hline Hydro-Pumped Storage & 0 & 0 & 0 & 0 & 0 & 0 \\
\hline 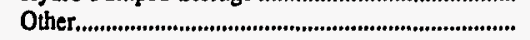 & $\mathbf{0}$ & 0 & 0 & 0 & 0 & 0 \\
\hline 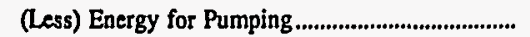 & $\mathbf{0}$ & 0 & 0 & 0 & 0 & 0 \\
\hline 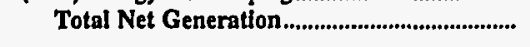 & 0 & $\mathbf{0}$ & $2,031,372$ & 0 & 0 & 0 \\
\hline 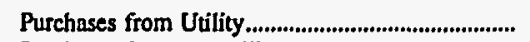 & 210,942 & 342,954 & 28,496 & 453,275 & 288,121 & 156,232 \\
\hline 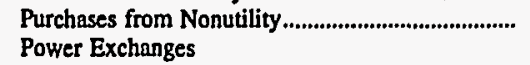 & $\mathbf{0}$ & 0 & 0 & 0 & 0 & 0 \\
\hline 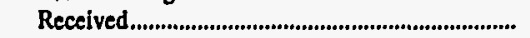 & 0 & 0 & 0 & 0 & 0 & 0 \\
\hline 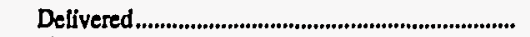 & 0 & 0 & 0 & 0 & 0 & 0 \\
\hline \multicolumn{7}{|l|}{ Transmission for Others (Wheeling) } \\
\hline 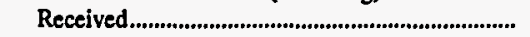 & 0 & 0 & $\mathbf{0}$ & 0 & 0 & 0 \\
\hline 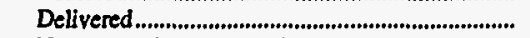 & $\mathbf{0}$ & 0 & 0 & 0 & 0 & 0 \\
\hline 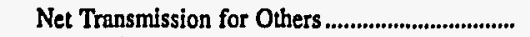 & 0 & 0 & 0 & 0 & 0 & 0 \\
\hline $\begin{array}{l}\text { Transmission by Others Losses..................................... } \\
\text { Total Net Energy }\end{array}$ & 0 & 0 & 0 & 0 & 0 & 0 \\
\hline Generated and Recelved ..................................... & 210,942 & 342,954 & $2,059,868$ & 453,275 & 288,121 & 156,232 \\
\hline \multicolumn{7}{|l|}{ Dispositton of Energy } \\
\hline 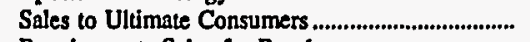 & 204,676 & 324,594 & 478,901 & 435,701 & 278,158 & 150,337 \\
\hline Requirements Sales for Resale................................. & 0 & $\mathbf{0}$ & $1,525,698$ & 0 & 0 & 0 \\
\hline 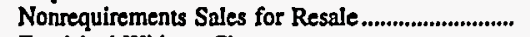 & 0 & $\mathbf{0}$ & 0 & 0 & 0 & 0 \\
\hline Furnished Without Charge .......................................... & 0 & 0 & 5,976 & 0 & 0 & 0 \\
\hline Used by Utility (excluding station use).................. & 210 & 841 & 9,809 & 471 & 0 & 213 \\
\hline Losses................................................................... & $\begin{array}{r}6,056 \\
61009\end{array}$ & 17,519 & 39,484 & 17,103 & 9,963 & 5,681 \\
\hline Total Disposition & 210,942 & 342,954 & $2,059,868$ & 453,275 & 288,121 & 156,232 \\
\hline
\end{tabular}

Note: Totals may not equal sum of components because of independent rounding. Double counting occurs in components of both sources and disposition of energy and thus neither provides a true total. Purchases from utilities, net interchanges, and net wheeling (except for imports) are included in net generation.

Source: Energy Information Administration, Form EIA-412, "Annual Report of Public Electric Utilities." 
Table 26. Electric Energy Account by Major U.S. Publicly Owned Electric Utility Within State, 1996 (Continued)

(Megawatthours)

\begin{tabular}{|c|c|c|c|c|c|c|}
\hline Item & $\begin{array}{l}\text { Kentucky } \\
\text { Murray } \\
\text { City of } \\
\text { June } 30\end{array}$ & $\begin{array}{c}\text { Kentucky } \\
\text { Owensboro } \\
\text { City of } \\
\text { May } 31\end{array}$ & $\begin{array}{l}\text { Kentucky } \\
\text { Paducah } \\
\text { City of } \\
\text { June } 30\end{array}$ & $\begin{array}{c}\text { Kentucky } \\
\begin{array}{c}\text { Russellville } \\
\text { City of }\end{array} \\
\text { June } 30\end{array}$ & $\begin{array}{l}\text { Louisiana } \\
\text { Alexandria } \\
\text { City of } \\
\text { April } 30\end{array}$ & $\begin{array}{l}\text { Louisiana } \\
\text { Lafayette } \\
\text { City of } \\
\text { October } 31\end{array}$ \\
\hline \multicolumn{7}{|l|}{ Sources of Energy } \\
\hline Steam & 0 & $2,239,214$ & 0 & $\mathbf{0}$ & 56,612 & 356,152 \\
\hline 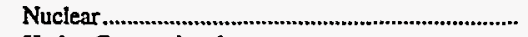 & 0 & 0 & 0 & 0 & 0 & 0 \\
\hline 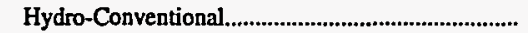 & 0 & 0 & 0 & 0 & 0 & 0 \\
\hline Hydro-Pumped Storage & 0 & 0 & $\mathbf{0}$ & 0 & 0 & 0 \\
\hline 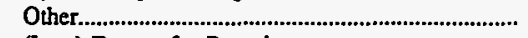 & 0 & 0 & $\mathbf{0}$ & 0 & 0 & 0 \\
\hline 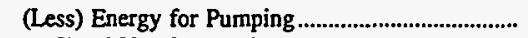 & 0 & 0 & 0 & 0 & 0 & 0 \\
\hline 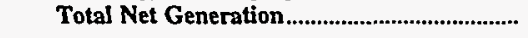 & 0 & $2,239,214$ & 0 & o & 56,612 & 356,152 \\
\hline 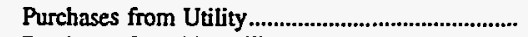 & 252,447 & 33,349 & 585,889 & 129,125 & 715,424 & $1,667,895$ \\
\hline $\begin{array}{l}\text { Purchases from Nonutility....................................... } \\
\text { Power Exchanges }\end{array}$ & 0 & 0 & 0 & 0 & 0 & 0 \\
\hline 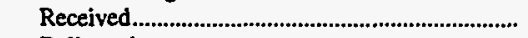 & 0 & 0 & 0 & 0 & 0 & 60 \\
\hline 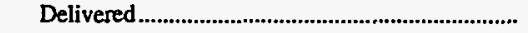 & 0 & 0 & 0 & 0 & 0 & 0 \\
\hline 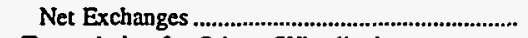 & 0 & 0 & 0 & 0 & 0 & 60 \\
\hline \multicolumn{7}{|l|}{ Transmission for Others (Wheeling) } \\
\hline 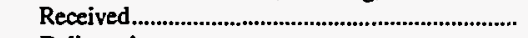 & 0 & 0 & 0 & 0 & 0 & 0 \\
\hline Delivered & 0 & 0 & $\mathbf{0}$ & 0 & 0 & 0 \\
\hline 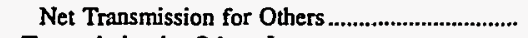 & 0 & 0 & 0 & 0 & 0 & 0 \\
\hline $\begin{array}{l}\text { Transmission by Others Losses.................................. } \\
\text { Total Net Energy }\end{array}$ & 0 & 0 & 0 & 0 & $\mathbf{0}$ & 0 \\
\hline 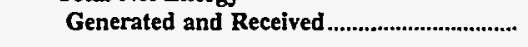 & 252,447 & $2,272,563$ & 585,889 & 129,125 & 772,036 & $2,024,107$ \\
\hline \multicolumn{7}{|l|}{ Disposition of Energy } \\
\hline 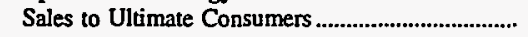 & 242,566 & 810,124 & 561,027 & 125,506 & 616,410 & $1,527,913$ \\
\hline Requirements Sales for Resale.................................... & 0 & 0 & 0 & 0 & 0 & 374,052 \\
\hline 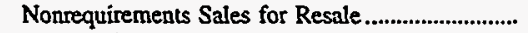 & 0 & $1,431,089$ & 0 & $\mathbf{0}$ & 53,203 & 0 \\
\hline Furnished Without Charge ................................... & 0 & $\mathbf{0}$ & 0 & 0 & 37,300 & 0 \\
\hline Used by Utility (excluding station use).................. & 180 & 2,445 & 1,471 & 102 & 23,025 & 122,142 \\
\hline 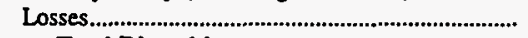 & 9,700 & 28,905 & 23,391 & 3,517 & 42,098 & 0 \\
\hline Total Disposition & 252,447 & $2,272,563$ & 585,889 & 129,125 & 772,036 & $2,024,107$ \\
\hline
\end{tabular}

Note: Totals may not equal sum of components because of independent rounding. Double counting occurs in components of both sources and disposition of energy and thus neither provides a true total. Purchases from utilities, net interchanges, and net wheeling (except for imports) are included in net generation.

Source: Energy Information Administration, Form EIA-412, "Annual Report of Public Electric Utilities." 
Table 26. Electric Energy Account by Major U.S. Publicly Owned Electric Utility Within State, 1996 (Continued)

(Megawatthours)

\begin{tabular}{|c|c|c|c|c|c|c|}
\hline Item & $\begin{array}{l}\text { Louisiana } \\
\text { Lafayette } \\
\text { Public } \\
\text { Power Auth } \\
\text { October } 31\end{array}$ & $\begin{array}{l}\text { Louisiana } \\
\text { Louisiana } \\
\text { Energy } \\
\& \\
\text { Power Auth } \\
\text { December } 31\end{array}$ & $\begin{array}{l}\text { Louisiana } \\
\text { Morgan } \\
\text { City City of } \\
\text { December } 31\end{array}$ & $\begin{array}{l}\text { Louisiana } \\
\text { Natchitoches } \\
\text { City of } \\
\text { May } 31\end{array}$ & $\begin{array}{l}\text { Louisiana } \\
\text { Ruston } \\
\text { City of } \\
\text { September } 30\end{array}$ & $\begin{array}{c}\text { Louisiana } \\
\text { Terrebonne } \\
\text { Parish } \\
\text { Consol Govt } \\
\\
\text { December } 31\end{array}$ \\
\hline \multicolumn{7}{|l|}{ Sources of Energy } \\
\hline 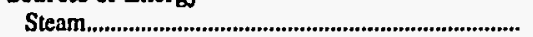 & $1,359,281$ & 825,059 & 0 & 0 & 153,565 & 87,533 \\
\hline 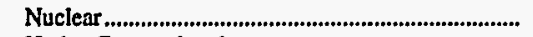 & 0 & 0 & $\mathbf{0}$ & 0 & 0 & 0 \\
\hline 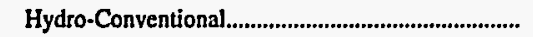 & 0 & 0 & 0 & 0 & 0 & 0 \\
\hline Hydro-Pumped Storage & 0 & 0 & 0 & 0 & 0 & $\mathbf{0}$ \\
\hline 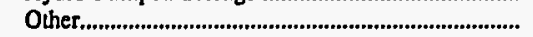 & 0 & $\mathbf{0}$ & 0 & 0 & 0 & 0 \\
\hline 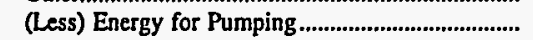 & 0 & 0 & 0 & 0 & 0 & $\mathbf{0}$ \\
\hline Total Net Generation.......................................... & $1,359,281$ & 825,059 & $\mathbf{0}$ & $\mathbf{0}$ & 153,565 & 87,533 \\
\hline 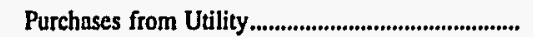 & 0 & 549,813 & 174,456 & 229,256 & 103,607 & 175,405 \\
\hline $\begin{array}{l}\text { Purchases from Nonutility................................................ } \\
\text { Power Exchanges }\end{array}$ & 0 & 0 & $\mathbf{0}$ & 0 & 0 & 0 \\
\hline Received & 0 & $\mathbf{0}$ & 0 & 0 & 0 & 0 \\
\hline 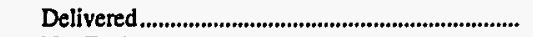 & 0 & 0 & $\mathbf{0}$ & 0 & 0 & 0 \\
\hline 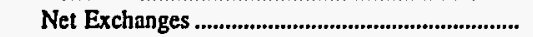 & 0 & 0 & 0 & 0 & 0 & 0 \\
\hline \multicolumn{7}{|l|}{ Transmission for Others (Wheeling) } \\
\hline 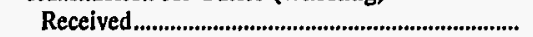 & 0 & 0 & 0 & 0 & 0 & 0 \\
\hline 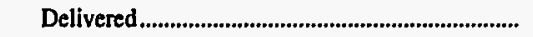 & 0 & 0 & $\mathbf{0}$ & 0 & 0 & $\mathbf{0}$ \\
\hline 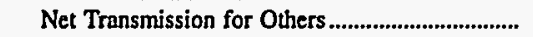 & 0 & 0 & $\mathbf{0}$ & 0 & 0 & 0 \\
\hline $\begin{array}{l}\text { Transmission by Others Losses.................................... } \\
\text { Total Net Energy }\end{array}$ & 0 & 0 & $\mathbf{0}$ & $-5,731$ & $\mathbf{0}$ & 0 \\
\hline Generated and Received....................................... & $1,359,281$ & $1,374,872$ & 174,456 & 223,525 & 257,172 & 262,938 \\
\hline \multicolumn{7}{|l|}{ Disposition of Energy } \\
\hline 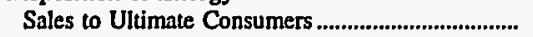 & 0 & 0 & 164,946 & 208,375 & 234,360 & 241,953 \\
\hline Requirements Sales for Resale.................................... & $1,359,281$ & $1,349,463$ & 0 & 0 & 0 & 7,233 \\
\hline Nonrequirements Sales for Resale ........................... & 0 & 342 & $\mathbf{0}$ & 0 & 0 & 0 \\
\hline Fumished Without Charge ........................................ & 0 & 0 & 0 & 0 & 0 & 0 \\
\hline Used by Utility (excluding station use)................... & 0 & 0 & 0 & 0 & 0 & 0 \\
\hline 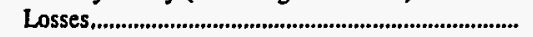 & $\mathbf{0}$ & 25,067 & 9,510 & 15,150 & 22,812 & 13,752 \\
\hline Total Disposition .................................................. & $1,359,281$ & $1,374,872$ & 174,456 & 223,525 & 257,172 & 262,938 \\
\hline
\end{tabular}

Note: Totals may not equal sum of components because of independent rounding. Double counting occurs in components of both sources and disposition of energy and thus neither provides a true total. Purchases from utilities, net interchanges, and net wheeling (except for imports) are included in net generation. Sales for resale is included in sales to ultimate consumers.

Source: Energy Information Administration, Form EIA-412, "Annual Report of Public Electric Utilities." 
Table 26. Electric Energy Account by Major U.S. Publicly Owned Electric Utility Within State, 1996 (Continued)

(Megawatthours)

\begin{tabular}{|c|c|c|c|c|c|c|}
\hline Item & $\begin{array}{l}\text { Maryland } \\
\text { Easton } \\
\text { Utilities } \\
\text { Comm } \\
\text { June } 30\end{array}$ & $\begin{array}{l}\text { Maryland } \\
\text { Hagerstown } \\
\text { City of } \\
\text { June } 30\end{array}$ & $\begin{array}{l}\text { Massachusetts } \\
\text { Braintree } \\
\text { Town of } \\
\text { December } 31\end{array}$ & $\begin{array}{c}\text { Massachusetts } \\
\text { Chicopee } \\
\text { City of } \\
\text { December } 31\end{array}$ & $\begin{array}{l}\text { Massachusetts } \\
\text { Concord } \\
\text { Town of } \\
\text { December } 31\end{array}$ & $\begin{array}{l}\text { Massachusetts } \\
\text { Danvers } \\
\text { Town of } \\
\text { December } 31\end{array}$ \\
\hline \multicolumn{7}{|l|}{ Sources of Energy } \\
\hline 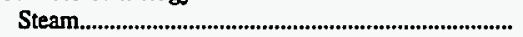 & 0 & 0 & 100,517 & 0 & 0 & 0 \\
\hline 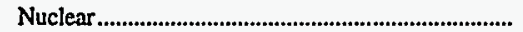 & $\mathbf{0}$ & 0 & 0 & 33,450 & 0 & $\mathbf{0}$ \\
\hline 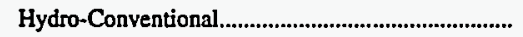 & 0 & 0 & 0 & 0 & 0 & $\mathbf{0}$ \\
\hline 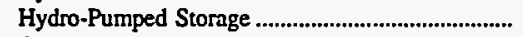 & 0 & 0 & 0 & 0 & 0 & 0 \\
\hline 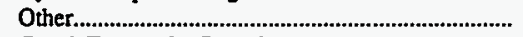 & 24,321 & 0 & 63 & 320 & 0 & $\mathbf{0}$ \\
\hline 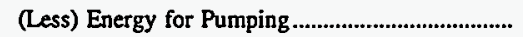 & 0 & 0 & 0 & 0 & 0 & 0 \\
\hline Total Net Generation & 24,321 & 0 & 100,580 & 33,770 & 0 & 0 \\
\hline 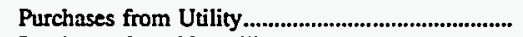 & 33,924 & 366,113 & 252,883 & 366,278 & 165,440 & 266,868 \\
\hline $\begin{array}{l}\text { Purchases from Nonutility....................................... } \\
\text { Power Exchanges }\end{array}$ & 0 & 0 & 0 & 0 & $\mathbf{0}$ & \\
\hline 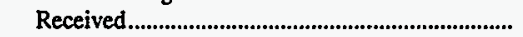 & 185,967 & 0 & 107,485 & 1,325 & 0 & 87,995 \\
\hline 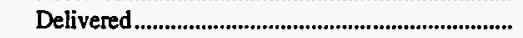 & 1,914 & 0 & 42,918 & -967 & 0 & 38,910 \\
\hline 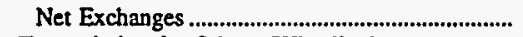 & 184,053 & 0 & 64,567 & 2,292 & 0 & 49,085 \\
\hline \multicolumn{7}{|l|}{ Transmission for Others (Wheeling) } \\
\hline 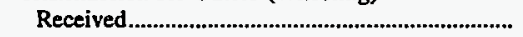 & 0 & 0 & 0 & 0 & 0 & $\mathbf{0}$ \\
\hline 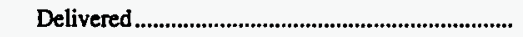 & 0 & 0 & 0 & 0 & 0 & 0 \\
\hline 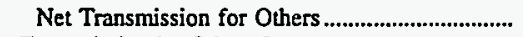 & 0 & 0 & 0 & 0 & 0 & $\mathbf{0}$ \\
\hline Transmission by Others Losses................................. & $\mathbf{0}$ & 0 & 0 & 0 & 0 & $\mathbf{0}$ \\
\hline 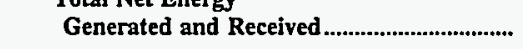 & 242,298 & 366,113 & 418,030 & 402,340 & 165,440 & 315,953 \\
\hline \multicolumn{7}{|l|}{ Disposition of Energy } \\
\hline 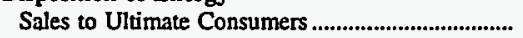 & 232,199 & 354,757 & 349,293 & 384,305 & 159,617 & 301,775 \\
\hline 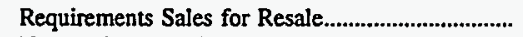 & 0 & 0 & 55,021 & 262 & 0 & 872 \\
\hline Nonrequirements Sales for Resale ......................... & 0 & 0 & 0 & 0 & 0 & 0 \\
\hline 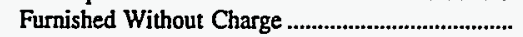 & 9 & 0 & 0 & 0 & 0 & 188 \\
\hline Used by Utility (excluding station use).................. & 239 & 380 & 4,882 & 1,460 & 538 & 676 \\
\hline 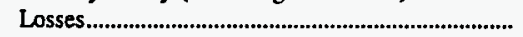 & 9,851 & 10,976 & 8,834 & 16,313 & 5,285 & 12,442 \\
\hline 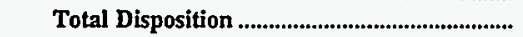 & 242,298 & 366,113 & 418,030 & 402,340 & 165,440 & 315,953 \\
\hline
\end{tabular}

Note: Totals may not equal sum of components because of independent rounding. Double counting occurs in components of both sources and disposition of energy and thus neither provides a true total. Purchases from utilities, net interchanges, and net wheeling (except for imports) are included in net generation.

Source: Energy Information Administration, Form EIA-412, "Annual Report of Public Electric Utilities." 
Table 26. Electric Energy Account by Major U.S. Publicly Owned Electric Utility Within State, 1996 (Continued)

(Megawatthours)

\begin{tabular}{|c|c|c|c|c|c|c|}
\hline Item & $\begin{array}{l}\text { Massachusetts } \\
\text { Hingham } \\
\text { City of } \\
\text { December } 31\end{array}$ & $\begin{array}{c}\text { Massachusetts } \\
\text { Holyoke } \\
\text { City of } \\
\text { December } 31\end{array}$ & $\begin{array}{l}\text { Massachusetts } \\
\text { Hudson } \\
\text { Town of } \\
\text { December } 31\end{array}$ & $\begin{array}{l}\text { Massachusetts } \\
\text { Littleton } \\
\text { Town of } \\
\text { December } 31\end{array}$ & $\begin{array}{l}\text { Massachusetts } \\
\text { Mansfield } \\
\text { Town of } \\
\text { December } 31\end{array}$ & $\begin{array}{l}\text { Massachusetts } \\
\text { Massachusetts } \\
\text { Mun } \\
\text { Whls } \\
\text { Elec Co } \\
\text { December } 31\end{array}$ \\
\hline \multicolumn{7}{|l|}{ Sources of Energy } \\
\hline Steam & $\mathbf{0}$ & $-3,609$ & 0 & 4,078 & 0 & 379,346 \\
\hline 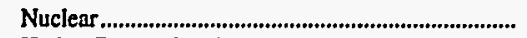 & 0 & 0 & 7,616 & $\mathbf{0}$ & 0 & $1,260,191$ \\
\hline 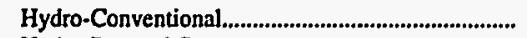 & 0 & 11,705 & 0 & 0 & 0 & 0 \\
\hline Hydro-Pumped Storage .......................................................... & 0 & 0 & 0 & 0 & 0 & $\mathbf{0}$ \\
\hline 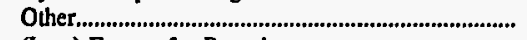 & 0 & 0 & 1,438 & 0 & 0 & 0 \\
\hline 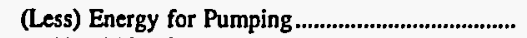 & 0 & 0 & 0 & 0 & 0 & 0 \\
\hline 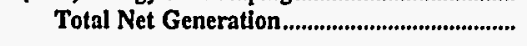 & 0 & 8,096 & 9,054 & 4,078 & $\mathbf{0}$ & $1,639,537$ \\
\hline 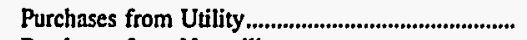 & 106,596 & 281,987 & 317,620 & 164,929 & 169,611 & 305,276 \\
\hline 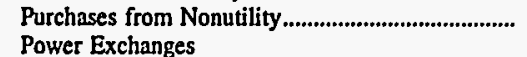 & 0 & 0 & 0 & 0 & 0 & 137,427 \\
\hline 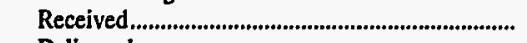 & 69,080 & 23,011 & 35,888 & 17,462 & 54,347 & 795,491 \\
\hline 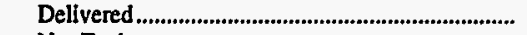 & 21,981 & 23,826 & 14,908 & 11,761 & 23,264 & 310,060 \\
\hline 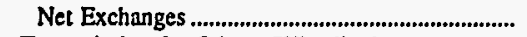 & 47,099 & -815 & 20,980 & 5,701 & 31,083 & 485,431 \\
\hline \multicolumn{7}{|l|}{ Transmission for Others (Wheeling) } \\
\hline 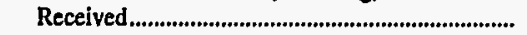 & 0 & 2,788 & 0 & 0 & $\mathbf{0}$ & 0 \\
\hline 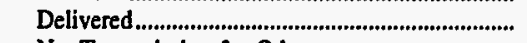 & 0 & 0 & 0 & 0 & 0 & 0 \\
\hline 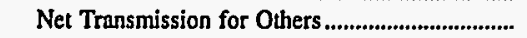 & 0 & 2,788 & 0 & 0 & 0 & 0 \\
\hline Transmission by Others Losses.................................... & 0 & 0 & $-5,888$ & $\mathbf{0}$ & 0 & 0 \\
\hline Total Net Energy & & & & & & \\
\hline Generated and Received ......................................... & 153,695 & 292,056 & 341,766 & 174,708 & 200,694 & $2,567,671$ \\
\hline \multicolumn{7}{|l|}{ Disposition of Energy } \\
\hline 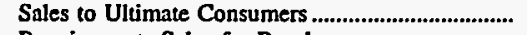 & 143,411 & 277,875 & 329,857 & 166,898 & 181,660 & 0 \\
\hline 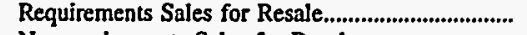 & 172 & 6,672 & 0 & 395 & 396 & $2,567,671$ \\
\hline Nonrequirements Sales for Resale .............................. & $\mathbf{0}$ & 0 & 0 & 0 & 0 & 0 \\
\hline Furnished Without Charge .............................................. & $\mathbf{0}$ & 0 & $\mathbf{0}$ & 0 & 0 & 0 \\
\hline Used by Utility (excluding station use)..................... & 288 & 608 & 268 & 211 & 30 & 0 \\
\hline 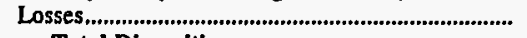 & 9,824 & 6,901 & 11,641 & 7,204 & 18,608 & 0 \\
\hline Total Disposition ................................................... & 153,695 & 292,056 & 341,766 & 174,708 & 200,694 & $2,567,671$ \\
\hline
\end{tabular}

Note: Totals may not equal sum of components because of independent rounding. Double counting occurs in components of both sources and disposition of energy and thus neither provides a true total. Purchases from utilities, net interchanges, and net wheeling (except for imports) are included in net generation.

Source: Energy Information Administration, Form EIA-412, “Annual Report of Public Electric Utilities." 
Table 26. Electric Energy Account by Major U.S. Publicly Owned Electric Utility Within State, 1996 (Continued)

(Megawatthours)

\begin{tabular}{|c|c|c|c|c|c|c|}
\hline Item & $\begin{array}{l}\text { Massachusetts } \\
\text { Middleborough } \\
\text { Town of } \\
\text { December } 31\end{array}$ & $\begin{array}{l}\text { Massachusetts } \\
\text { North } \\
\text { Attleborough } \\
\text { Town of } \\
\text { December } 31\end{array}$ & $\begin{array}{c}\text { Massachusetts } \\
\text { Norwood } \\
\text { City of } \\
\text { June } 30\end{array}$ & $\begin{array}{c}\text { Massachusetts } \\
\text { Peabody } \\
\text { City of } \\
\text { December } 31\end{array}$ & $\begin{array}{c}\text { Massachusetts } \\
\text { Reading } \\
\text { Town of } \\
\text { December } 31\end{array}$ & $\begin{array}{l}\text { Massachusetts } \\
\text { Shrewsbury } \\
\text { Town of } \\
\text { December } 31\end{array}$ \\
\hline \multicolumn{7}{|l|}{ Sources of Energy } \\
\hline Steam & 0 & 7,360 & 0 & 0 & 0 & 0 \\
\hline Nuclear & 0 & 0 & 0 & 0 & 0 & 0 \\
\hline 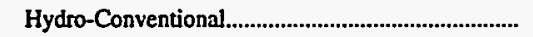 & 0 & 0 & 0 & 0 & 0 & 0 \\
\hline Hydro-Pumped Storage & 0 & $\mathbf{0}$ & 0 & 0 & 0 & 0 \\
\hline Other & 0 & 0 & 0 & 2,584 & 0 & 179 \\
\hline 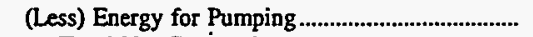 & 0 & 0 & 0 & 0 & 0 & 0 \\
\hline 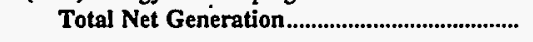 & $\mathbf{0}$ & 7,360 & 0 & 2,584 & $\mathbf{0}$ & 179 \\
\hline 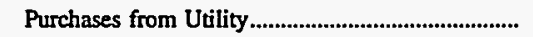 & 167,988 & 135,597 & 318,930 & 265,616 & 539,335 & 258,925 \\
\hline $\begin{array}{l}\text { Purchases from Nonutility...................................... } \\
\text { Power Exchanges }\end{array}$ & 0 & 0 & 0 & 0 & 0 & 0 \\
\hline 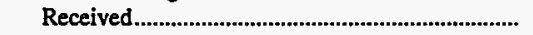 & 18,115 & 90,376 & 0 & 223,304 & 160,645 & 49,194 \\
\hline 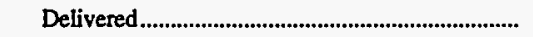 & 0 & 22,667 & 0 & 62,459 & 72,142 & 20,877 \\
\hline \multicolumn{7}{|l|}{ Transmission for Others (Wheeling) } \\
\hline 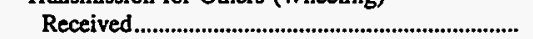 & 0 & 0 & 0 & 0 & 0 & 0 \\
\hline 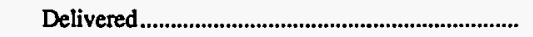 & 0 & 0 & 0 & 0 & 0 & 0 \\
\hline 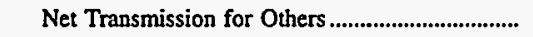 & 0 & 0 & 0 & 0 & 0 & 0 \\
\hline $\begin{array}{l}\text { Transmission by Others Losses............................... } \\
\text { Total Net Energy }\end{array}$ & 0 & 0 & 0 & 0 & 0 & 0 \\
\hline Generated and Received.................................. & 186,103 & 210,666 & 318,930 & 429,044 & 627,838 & 287,421 \\
\hline \multicolumn{7}{|l|}{ Disposition of Energy } \\
\hline 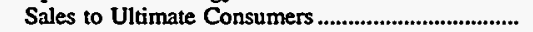 & 178,568 & 200,017 & 303,150 & 413,743 & 595,681 & 269,201 \\
\hline Requirements Sales for Resale.................................. & 0 & 0 & 0 & 0 & 693 & 0 \\
\hline Nonrequirements Sales for Resale & 0 & 66 & 0 & $\mathbf{0}$ & $\mathbf{0}$ & $\mathbf{0}$ \\
\hline 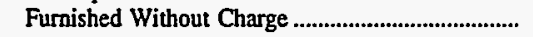 & 0 & 0 & 0 & 21 & 0 & 0 \\
\hline Used by Utility (excluding station use)................... & 0 & 391 & 0 & 1,619 & 576 & 1,241 \\
\hline Losses & 7,535 & 10,192 & 15,780 & 13,661 & 30,888 & 16,979 \\
\hline Total Disposition & 186,103 & 210,666 & 318,930 & 429,044 & 627,838 & 287,421 \\
\hline
\end{tabular}

Note: Totals may not equal sum of components because of independent rounding. Double counting occurs in components of both sources and disposition of energy and thus neither provides a true total. Purchases from utilities, net interchanges, and net wheeling (except for imports) are included in net generation.

Source: Energy Information Administration, Form EIA-412, “Annual Report of Public Electric Utilities." 
Table 26. Electric Energy Account by Major U.S. Publicly Owned Electric Utility Within State, 1996 (Continued)

(Megawatthours)

\begin{tabular}{|c|c|c|c|c|c|c|}
\hline Item & $\begin{array}{c}\text { Massachusetts } \\
\text { Taunton } \\
\text { City of } \\
\text { December } 31\end{array}$ & $\begin{array}{l}\text { Massachusetts } \\
\text { Wakefield } \\
\text { Town of } \\
\text { December } 31\end{array}$ & $\begin{array}{l}\text { Massachusetts } \\
\text { Wellesley } \\
\text { Town of } \\
\text { December } 31\end{array}$ & $\begin{array}{l}\text { Massachusetts } \\
\text { Westfield } \\
\text { City of } \\
\text { December } 31\end{array}$ & $\begin{array}{l}\text { Michigan } \\
\text { Bay } \\
\text { City City of } \\
\text { June } 30\end{array}$ & 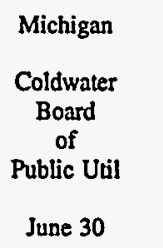 \\
\hline \multicolumn{7}{|l|}{ Sources of Energy } \\
\hline 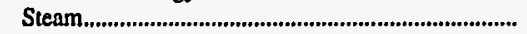 & 54,895 & 0 & 0 & 0 & 0 & $\mathbf{0}$ \\
\hline Nuclear & 0 & 0 & 0 & 0 & 0 & 0 \\
\hline 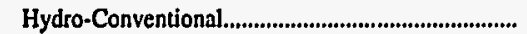 & 0 & 0 & 0 & 0 & 0 & 0 \\
\hline Hydro-Pumped Storage ....................................................... & 0 & 0 & 0 & 0 & 0 & 0 \\
\hline Other.............................................................................. & 13,103 & 0 & 0 & 0 & 3,681 & 3,653 \\
\hline 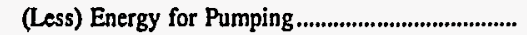 & 0 & 0 & 0 & 0 & 0 & 0 \\
\hline 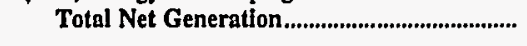 & 67,998 & 0 & $\mathbf{0}$ & $\mathbf{0}$ & 3,681 & 3,653 \\
\hline 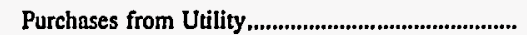 & 242,811 & 169,778 & 198,066 & 250,850 & 315,655 & 185,289 \\
\hline 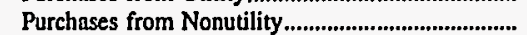 & 0 & 0 & 0 & 0 & 0 & 0 \\
\hline \multicolumn{7}{|l|}{ Power Exchanges } \\
\hline 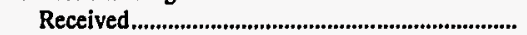 & 271,664 & 0 & 0 & 101,736 & 0 & 0 \\
\hline Delivered ......................................................................... & 12,054 & 0 & $\mathbf{0}$ & 38,518 & 0 & 0 \\
\hline 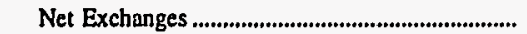 & 259,610 & $\mathbf{0}$ & 0 & 63,218 & $\mathbf{0}$ & o \\
\hline \multicolumn{7}{|l|}{ Transmission for Others (Wheeling) } \\
\hline 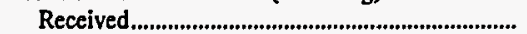 & 0 & $\mathbf{0}$ & 0 & 0 & 0 & 0 \\
\hline 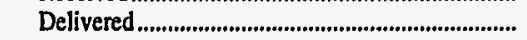 & 0 & 0 & 0 & 0 & 0 & 0 \\
\hline 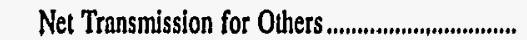 & 0 & 0 & 0 & 0 & 0 & 0 \\
\hline Transmission by Others Losses................................. & 0 & 0 & $-1,344$ & 0 & 0 & o \\
\hline 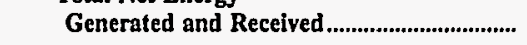 & 570,419 & 169,778 & 196,722 & 314,068 & 319,336 & 188,942 \\
\hline \multicolumn{7}{|l|}{ Disposition of Energy } \\
\hline 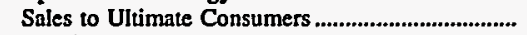 & 526,898 & 157,250 & 186,497 & 282,757 & 315,035 & 176,349 \\
\hline 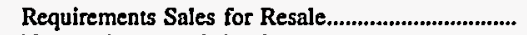 & 23,615 & $\mathbf{0}$ & $\mathbf{0}$ & 9,193 & $\mathbf{0}$ & o \\
\hline 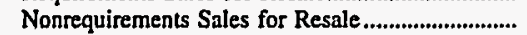 & 0 & 0 & 0 & 5,819 & 0 & 0 \\
\hline Furnished Without Charge ......................................... & 0 & 0 & 148 & 0 & 0 & 0 \\
\hline Used by Utility (excluding station use).................... & 6,850 & 327 & 390 & 1,272 & 0 & 211 \\
\hline 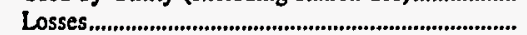 & 13,056 & 12,201 & 9,687 & 15,027 & 4,301 & 12,382 \\
\hline Total Disposition ........................................... & $\mathbf{5 7 0 , 4 1 9}$ & 169,778 & 196,722 & 314,068 & 319,336 & 188,942 \\
\hline
\end{tabular}

Note: Totals may not equal sum of components because of independent rounding. Double counting occurs in components of both sources and disposition of energy and thus neither provides a true total. Purchases from utilities, net interchanges, and net wheeling (except for imports) are included in net generation.

Source: Energy Information Administration, Form EIA-412, "Annual Report of Public Electric Utilities." 
Table 26. Electric Energy Account by Major U.S. Publicly Owned Electric . Utility Within State, 1996 (Continued)

(Megawatthours)

\begin{tabular}{|c|c|c|c|c|c|c|}
\hline Item & $\begin{array}{l}\text { Michigan } \\
\text { Detroit } \\
\text { City of } \\
\text { June } 30\end{array}$ & $\begin{array}{l}\text { Michigan } \\
\text { Grand Haven } \\
\text { City of } \\
\text { June } 30\end{array}$ & $\begin{array}{c}\text { Michigan } \\
\text { Hillsdale } \\
\text { Board } \\
\text { of } \\
\text { Public Wks } \\
\text { June } 30\end{array}$ & $\begin{array}{l}\text { Michigan } \\
\text { Holland } \\
\text { City of } \\
\text { June } 30\end{array}$ & $\begin{array}{l}\text { Michigan } \\
\text { Lansing } \\
\text { City of } \\
\text { June } 30\end{array}$ & $\begin{array}{l}\text { Michigan } \\
\text { Marquette } \\
\text { City of } \\
\text { June } 30\end{array}$ \\
\hline \multicolumn{7}{|l|}{ Sources of Energy } \\
\hline 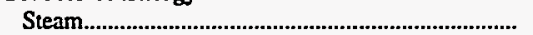 & 291,423 & 317,848 & 0 & 278,397 & $1,517,696$ & 217,555 \\
\hline 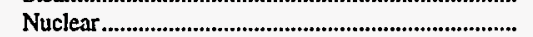 & 0 & 0 & 0 & 0 & 0 & 0 \\
\hline 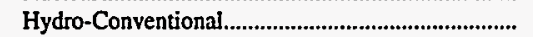 & 0 & 0 & 0 & 0 & 0 & 19,130 \\
\hline 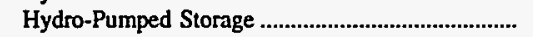 & 0 & 0 & 0 & 0 & 0 & 0 \\
\hline Other & 0 & 0 & 3,977 & 4,052 & 0 & 113 \\
\hline 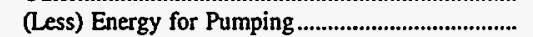 & 0 & 0 & 0 & 0 & 0 & 0 \\
\hline 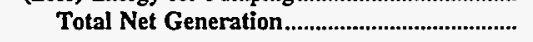 & 291,423 & 317,848 & 3,977 & 282,449 & $1,517,696$ & 236,798 \\
\hline 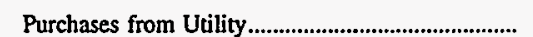 & 385,066 & 55,937 & 155,356 & 576,017 & $1,174,874$ & 42,478 \\
\hline Purchases from Nonutility......................................... & 0 & 0 & 0 & 0 & 0 & 0 \\
\hline 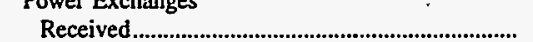 & 0 & 0 & 0 & 10,472 & 2,855 & 0 \\
\hline Delivered & 0 & 0 & 0 & 7,176 & 3,340 & 0 \\
\hline 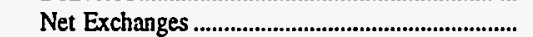 & 0 & 0 & 0 & 3,296 & -485 & 0 \\
\hline \multicolumn{7}{|l|}{ Transmission for Others (Wheeling) } \\
\hline 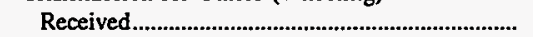 & 0 & 0 & 0 & 0 & 0 & 0 \\
\hline 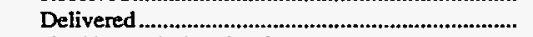 & 0 & 0 & 0 & 0 & 0 & 0 \\
\hline 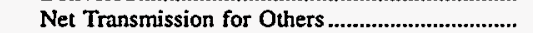 & $\mathbf{0}$ & 0 & 0 & 0 & $\mathbf{0}$ & 0 \\
\hline 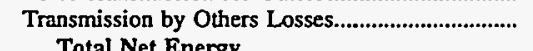 & 0 & 0 & 0 & 0 & 0 & $\mathbf{0}$ \\
\hline 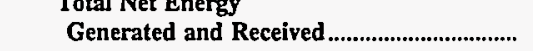 & 676,489 & 373,785 & 159,333 & 861,762 & $2,692,085$ & 279,276 \\
\hline \multicolumn{7}{|l|}{ Disposition of Energy } \\
\hline 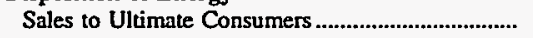 & 513,530 & 286,442 & 149,664 & 813,696 & $2,336,893$ & 253,251 \\
\hline Requirements Sales for Resale................................. & 0 & 82,892 & 0 & 0 & 271,884 & 12,289 \\
\hline Nonrequirements Sales for Resale ........................... & 0 & 0 & 0 & 0 & 0 & 1,790 \\
\hline Furnished Without Charge ......................................... & 127,195 & 0 & 0 & 0 & 0 & 0 \\
\hline Used by Utility (excluding station use)...................... & 2,911 & 0 & 0 & 0 & 0 & 595 \\
\hline 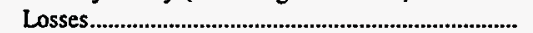 & 32,853 & 4,451 & 9,669 & 48,066 & 83,308 & 11,351 \\
\hline 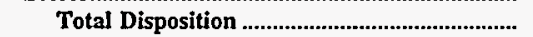 & 676,489 & 373,785 & 159,333 & 861,762 & $2,692,085$ & 279,276 \\
\hline
\end{tabular}

Note: Totals may not equal sum of components because of independent rounding. Double counting occurs in components of both sources and disposition of energy and thus neither provides a true total. Purchases from utilities, net interchanges, and net wheeling (except for imports) are included in net generation.

Source: Energy Information Administration, Form EIA-412, "Annual Report of Public Electric Utilities." 
Table 26. Electric Energy Account by Major U.S. Publicly Owned Electric Utility Within State, 1996 (Continued)

(Megawatthours)

\begin{tabular}{|c|c|c|c|c|c|c|}
\hline Item & $\begin{array}{c}\text { Michigan } \\
\text { Michigan } \\
\text { Public } \\
\text { Power Agency } \\
\text { December } 31\end{array}$ & $\begin{array}{l}\text { Michigan } \\
\text { Michigan } \\
\text { South } \\
\text { Central } \\
\text { Pwr Agy } \\
\text { June } 30\end{array}$ & $\begin{array}{l}\text { Michigan } \\
\text { Sturgis } \\
\text { City of } \\
\text { September } 30\end{array}$ & $\begin{array}{c}\text { Michigan } \\
\text { Traverse } \\
\text { City City of } \\
\text { June } 30\end{array}$ & $\begin{array}{c}\text { Michigan } \\
\text { Wyandotte } \\
\text { Municipal } \\
\text { Serv Comm } \\
\text { September } 30\end{array}$ & $\begin{array}{l}\text { Michigan } \\
\text { Zeeland } \\
\text { City of } \\
\text { June } 30\end{array}$ \\
\hline \multicolumn{7}{|l|}{ Sources of Energy } \\
\hline 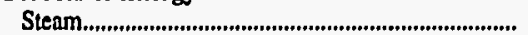 & $1,481,709$ & 106,587 & $\mathbf{0}$ & 1,711 & 175,436 & 0 \\
\hline 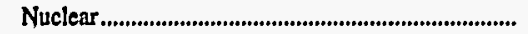 & 0 & $\mathbf{0}$ & $\mathbf{0}$ & 0 & 0 & $\mathbf{0}$ \\
\hline 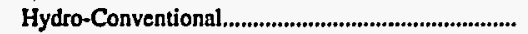 & 0 & $\mathbf{0}$ & 9,031 & 12,977 & 0 & 0 \\
\hline 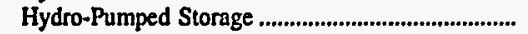 & 0 & $\mathbf{0}$ & 0 & 0 & 0 & 0 \\
\hline 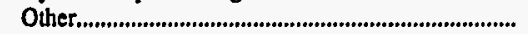 & 0 & 0 & 8,555 & 0 & 0 & 19,709 \\
\hline 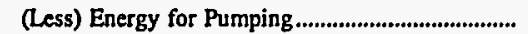 & 0 & 0 & 0 & 0 & 0 & 0 \\
\hline 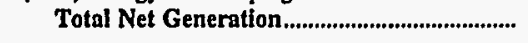 & $1,481,709$ & 106,587 & 17,586 & 14,688 & 175,436 & 19,709 \\
\hline 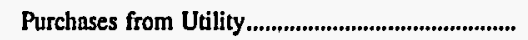 & $1,573,036$ & 379,884 & 212,144 & 228,353 . & 77,802 & 200,718 \\
\hline Purchases from Nonutility.............................................. & 391,975 & 0 & 3,149 & 0 & 0 & 0 \\
\hline \multicolumn{7}{|l|}{ Power Exchanges } \\
\hline 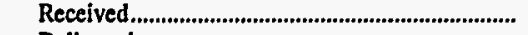 & 0 & $\mathbf{0}$ & 0 & 0 & 0 & 0 \\
\hline 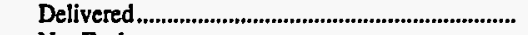 & 0 & $\mathbf{0}$ & $\mathbf{0}$ & 0 & $\mathbf{0}$ & 0 \\
\hline 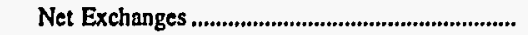 & 0 & 0 & 0 & 0 & 0 & 0 \\
\hline \multicolumn{7}{|l|}{ Transmission for Others (Wheeling) } \\
\hline 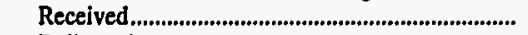 & 0 & $\mathbf{0}$ & 0 & $\mathbf{0}$ & 0 & 0 \\
\hline 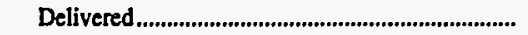 & 0 & 0 & 0 & 0 & 0 & 0 \\
\hline 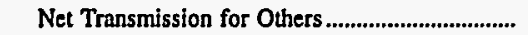 & 0 & $\mathbf{0}$ & 0 & 0 & 0 & 0 \\
\hline 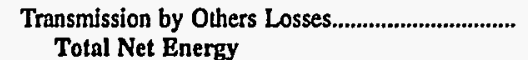 & 0 & $\mathbf{0}$ & 0 & 0 & 0 & 0 \\
\hline Generated and Received ..................................... & $3,446,720$ & 486,471 & 232,879 & 243,041 & 253,238 & 220,427 \\
\hline \multicolumn{7}{|l|}{ Disposition of Energy } \\
\hline 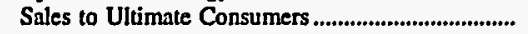 & 0 & $\mathbf{0}$ & 224,307 & 227,443 & 227,001 & 215,887 \\
\hline Requirements Sales for Resale...................................... & $2,103,482$ & 479,945 & $\mathbf{0}$ & $\mathbf{0}$ & $\mathbf{0}$ & 0 \\
\hline Nonrequirements Sales for Resale ................................. & $1,126,344$ & 0 & $\mathbf{0}$ & 3,628 & 0 & 0 \\
\hline 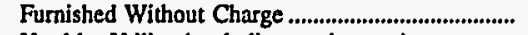 & $\mathbf{0}$ & 0 & $\mathbf{0}$ & 0 & 0 & 0 \\
\hline Used by Utility (excluding station use)................... & $\mathbf{0}$ & $\mathbf{0}$ & $\mathbf{0}$ & $\mathbf{0}$ & $\mathbf{0}$ & 0 \\
\hline 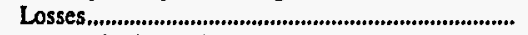 & 216,894 & 6,526 & 8,572 & 11,970 & 26,237 & 4,540 \\
\hline Total Disposition ......................................................... & $3,446,720$ & 486,471 & 232,879 & 243,041 & 253,238 & 220,427 \\
\hline
\end{tabular}

Note: Totals may not equal sum of components because of independent rounding. Double counting occurs in components of both sources and disposition of energy and thus neither provides a true total. Purchases from utilities, net interchanges, and net wheeling (except for imports) are included in net generation.

Source: Energy Information Administration, Form EIA-412, "Annual Report of Public Electric Utilities." 
Table 26. Electric Energy Account by Major U.S. Publicly Owned Electric Utility Within State, 1996 (Continued)

(Megawatthours)

\begin{tabular}{|c|c|c|c|c|c|c|}
\hline Item & $\begin{array}{l}\text { Minnesota } \\
\text { Alexandria } \\
\text { City of } \\
\text { December } 31\end{array}$ & $\begin{array}{c}\text { Minnesota } \\
\text { Anoka } \\
\text { City of } \\
\text { December } 31\end{array}$ & $\begin{array}{c}\text { Minnesota } \\
\text { Austin } \\
\text { City of } \\
\text { December } 31\end{array}$ & $\begin{array}{l}\text { Minnesota } \\
\text { Brainerd } \\
\text { Public } \\
\text { Utilities } \\
\text { December } 31\end{array}$ & $\begin{array}{l}\text { Minnesota } \\
\text { Chaska } \\
\text { City of } \\
\text { December } 31\end{array}$ & $\begin{array}{l}\text { Minnesota } \\
\text { Fairmont } \\
\text { Public } \\
\text { Utilities } \\
\text { Comm } \\
\text { December } 31\end{array}$ \\
\hline \multicolumn{7}{|l|}{ Sources of Energy } \\
\hline Steam & 0 & 0 & 146,871 & 0 & 0 & 1,018 \\
\hline 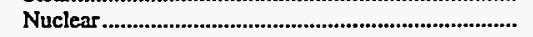 & 0 & 0 & 0 & $\mathbf{0}$ & 0 & $\mathbf{0}$ \\
\hline 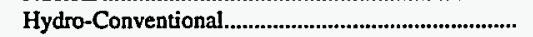 & 0 & 0 & 0 & 0 & 0 & 0 \\
\hline 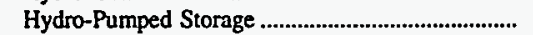 & 0 & 0 & 0 & 0 & 0 & $\mathbf{0}$ \\
\hline 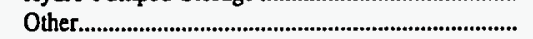 & 238 & 0 & 0 & 0 & 0 & 0 \\
\hline 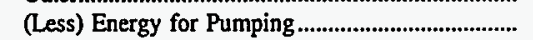 & 406 & 0 & 0 & 0 & 0 & 0 \\
\hline Total Net Generation & -168 & $\mathbf{0}$ & 146,871 & $\mathbf{0}$ & 0 & 1,018 \\
\hline 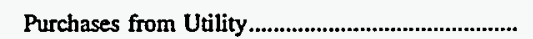 & 214,674 & 239,917 & 276,272 & 160,337 & 200,210 & 147,137 \\
\hline Purchases from Nonutility...................................... & 0 & 9 & 0 & 0 & 0 & 0 \\
\hline \multicolumn{7}{|l|}{ Power Exchanges } \\
\hline Received & 0 & 0 & 0 & 0 & 0 & 0 \\
\hline 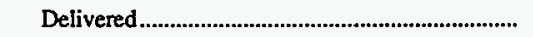 & 0 & 0 & 0 & 0 & 0 & 0 \\
\hline 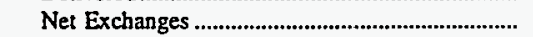 & 0 & 0 & 0 & 0 & 0 & 0 \\
\hline \multicolumn{7}{|l|}{ Transmission for Others (Wheeling) } \\
\hline 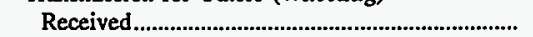 & 0 & 0 & 0 & 0 & 0 & 0 \\
\hline 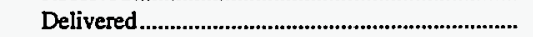 & 0 & 0 & 0 & 0 & 0 & 0 \\
\hline 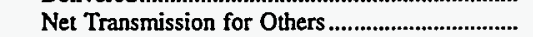 & 0 & 0 & 0 & 0 & $\mathbf{0}$ & 0 \\
\hline 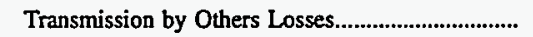 & 0 & 0 & 0 & 0 & $\mathbf{0}$ & 0 \\
\hline \multicolumn{7}{|l|}{ Total Net Energy } \\
\hline 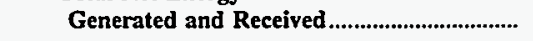 & 214,506 & 239,926 & 423,143 & 160,337 & 200,210 & 148,155 \\
\hline \multicolumn{7}{|l|}{ Disposition of Energy } \\
\hline 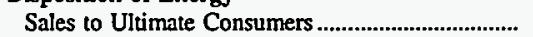 & 199,127 & 228,482 & 263,076 & 146,513 & 192,594 & 142,686 \\
\hline 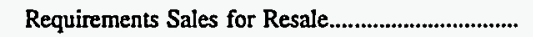 & 0 & 0 & 146,871 & 0 & $\mathbf{0}$ & 1,018 \\
\hline 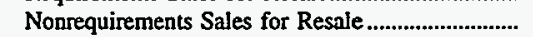 & 0 & 0 & 0 & 0 & 0 & 0 \\
\hline Furnished Without Charge ....................................... & 0 & 0 & 0 & 0 & $\mathbf{0}$ & 0 \\
\hline 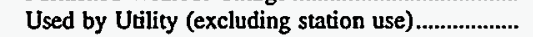 & 0 & 0 & 379 & 1,568 & 0 & 0 \\
\hline 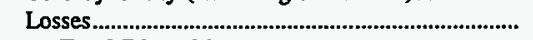 & 15,379 & 11,444 & 12,817 & 12,256 & 7,616 & 4,451 \\
\hline 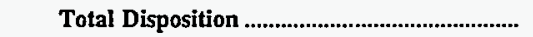 & 214,506 & 239,926 & 423,143 & 160,337 & 200,210 & 148,155 \\
\hline
\end{tabular}

Note: Totals may not equal sum of components because of independent rounding. Double counting occurs in components of both sources and disposition of energy and thus neither provides a true total. Purchases from utilities, net interchanges, and net wheeling (except for imports) are included in net generation.

Source: Energy Information Administration, Form EIA-412, “Annual Report of Public Electric Utilities." 
Table 26. Electric Energy Account by Major U.S. Publicly Owned Electric Utility Within State, 1996 (Continued)

(Megawatthours)

\begin{tabular}{|c|c|c|c|c|c|c|}
\hline Item & $\begin{array}{c}\text { Minnesota } \\
\text { Hutchinson } \\
\text { Utilities } \\
\text { Comm } \\
\text { December } 31\end{array}$ & $\begin{array}{c}\text { Minnesota } \\
\text { Marshall } \\
\text { City of } \\
\text { December } 31\end{array}$ & $\begin{array}{c}\text { Minnesota } \\
\text { Moorhead } \\
\text { City of } \\
\text { December } 31\end{array}$ & $\begin{array}{c}\text { Minnesota } \\
\text { New Ulm } \\
\text { Public } \\
\text { Utilities } \\
\text { Comm } \\
\text { December } 31\end{array}$ & $\begin{array}{c}\text { Minnesota } \\
\text { Northern } \\
\text { Municipal } \\
\text { Power Agny } \\
\text { December } 31\end{array}$ & $\begin{array}{l}\text { Minnesota } \\
\text { Owatonna } \\
\text { City of } \\
\text { December } 31\end{array}$ \\
\hline \multicolumn{7}{|l|}{ Sources of Energy } \\
\hline 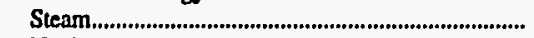 & $\mathbf{0}$ & $\mathbf{0}$ & 0 & 26,752 & 809,682 & \\
\hline Nuclear & $\mathbf{0}$ & 0 & 0 & 0 & 0 & \\
\hline 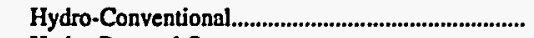 & $\mathbf{0}$ & 0 & 0 & 0 & $\mathbf{0}$ & \\
\hline 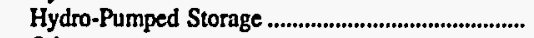 & $\mathbf{0}$ & 0 & 0 & 0 & 0 & \\
\hline 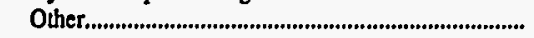 & 136,607 & 61 & 0 & 1,168 & 0 & \\
\hline 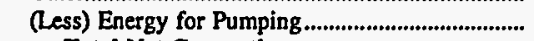 & 0 & 0 & 0 & 0 & 0 & 0 \\
\hline 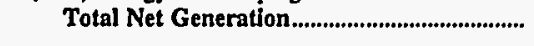 & 136,607 & 61 & 0 & 27,920 & 809,682 & 0 \\
\hline 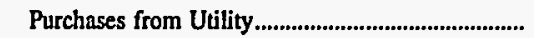 & 154,753 & 375,804 & 384,804 & 165,506 & 0 & 306,970 \\
\hline 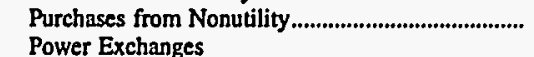 & 0 & 412 & 0 & 0 & 0 & \\
\hline 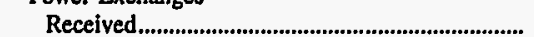 & 156 & 0 & 0 & 0 & 0 & \\
\hline 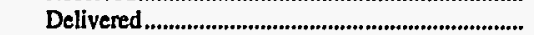 & 263 & 0 & 0 & 0 & 0 & \\
\hline 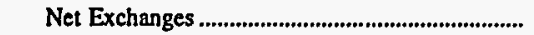 & -107 & $\mathbf{0}$ & 0 & 0 & 0 & \\
\hline \multicolumn{7}{|l|}{ Transmission for Others (Wheeling) } \\
\hline 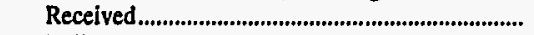 & 0 & 0 & 0 & 0 & $\mathbf{0}$ & \\
\hline 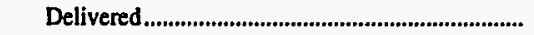 & $\mathbf{0}$ & $\mathbf{0}$ & 0 & 0 & 0 & 0 \\
\hline 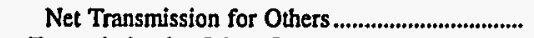 & 0 & 0 & $\mathbf{0}$ & 0 & 0 & 0 \\
\hline Transmission by Others Losses........................................... & 0 & 0 & 0 & $\mathbf{0}$ & $\mathbf{0}$ & 0 \\
\hline Total Net Energy & & & & & & \\
\hline 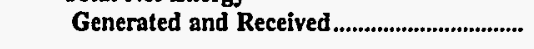 & 291,253 & 376,277 & 384,804 & 193,426 & 809,682 & 306,970 \\
\hline \multicolumn{7}{|l|}{ Disposition of Energy } \\
\hline 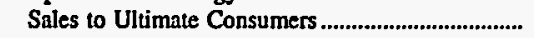 & 261,916 & 366,201 & 351,811 & 180,423 & 0 & 290,612 \\
\hline 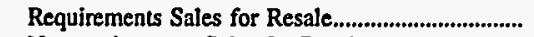 & 17,718 & $\mathbf{0}$ & $\mathbf{0}$ & 0 & 809,682 & \\
\hline Nonrequirements Sales for Resale................................. & 0 & 0 & $\mathbf{0}$ & 0 & $\mathbf{0}$ & $\mathbf{0}$ \\
\hline Furnished Without Charge ................................................. & 0 & 0 & 0 & 0 & 0 & 7,513 \\
\hline 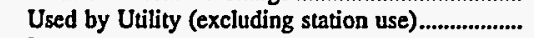 & 7,401 & 0 & 1,610 & 5,833 & $\mathbf{0}$ & \\
\hline 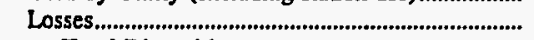 & 4,218 & 10,076 & 31,383 & 7,170 & 0 & 8,845 \\
\hline Total Disposition ............................................................. & 291,253 & 376,277 & 384,804 & 193,426 & 809,682 & 306,970 \\
\hline
\end{tabular}

Note: Totals may not equal sum of components because of independent rounding. Double counting occurs in components of both sources and disposition of energy and thus neither provides a true total. Purchases from utilities, net interchanges, and net wheeling (except for imports) are included in net generation.

Source: Energy Information Administration, Form EIA-412, “Annual Report of Public Electric Utilities." 
Table 26. Electric Energy Account by Major U.S. Publicly Owned Electric Utility Within State, 1996 (Continued)

(Megawatthours)

\begin{tabular}{|c|c|c|c|c|c|c|}
\hline Item & $\begin{array}{l}\text { Minnesota } \\
\text { Rochester } \\
\text { Public } \\
\text { Utilities } \\
\text { December } 31\end{array}$ & $\begin{array}{l}\text { Minnesota } \\
\text { Shakopee } \\
\text { Public } \\
\text { Utilities } \\
\text { Comm } \\
\text { December } 31\end{array}$ & $\begin{array}{c}\text { Minnesota } \\
\text { Southem } \\
\text { Minnesota } \\
\text { Mun P } \\
\text { Agny } \\
\text { December } 31\end{array}$ & $\begin{array}{c}\text { Minnesota } \\
\text { Western } \\
\text { Minnesota } \\
\text { Mun } \\
\text { Pwr Agny } \\
\text { December } 31\end{array}$ & $\begin{array}{c}\text { Minnesota } \\
\text { Willmar } \\
\text { Municipal } \\
\text { Utils Comm } \\
\text { December } 31\end{array}$ & $\begin{array}{c}\text { Minnesota } \\
\text { Worthington } \\
\text { City of } \\
\text { December } 31\end{array}$ \\
\hline \multicolumn{7}{|l|}{ Sources of Energy } \\
\hline 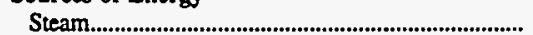 & 184,356 & 0 & $2,027,094$ & $1,997,174$ & 35,494 & $\mathbf{0}$ \\
\hline 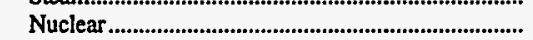 & 0 & 0 & 0 & 0 & 0 & $\mathbf{0}$ \\
\hline 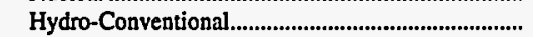 & 11,075 & 0 & 0 & 0 & 0 & $\mathbf{0}$ \\
\hline 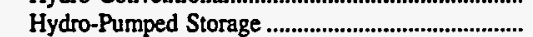 & 0 & 0 & 0 & 0 & 0 & 0 \\
\hline 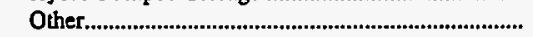 & 425 & 0 & 0 & 0 & 0 & $\mathbf{0}$ \\
\hline 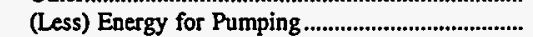 & 0 & 0 & 0 & 0 & 0 & $\mathbf{0}$ \\
\hline 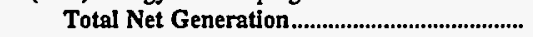 & 195,856 & $\mathbf{0}$ & $2,027,094$ & $1,997,174$ & 35,494 & 0 \\
\hline 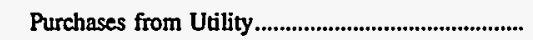 & 926,405 & 166,211 & 543,508 & 0 & 200,111 & 187,959 \\
\hline 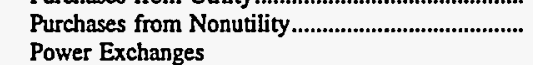 & 0 & 0 & 11,273 & 0 & 0 & 0 \\
\hline 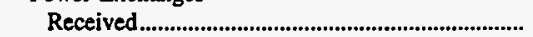 & 0 & 0 & 0 & 0 & 0 & $\mathbf{0}$ \\
\hline 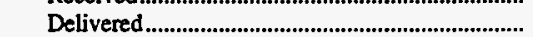 & 0 & 0 & 0 & 0 & 0 & $\mathbf{0}$ \\
\hline 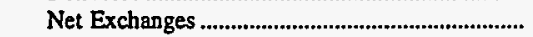 & 0 & 0 & 0 & 0 & 0 & $\mathbf{0}$ \\
\hline \multicolumn{7}{|l|}{ Transmission for Others (Wheeling) } \\
\hline 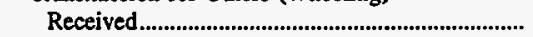 & 0 & 0 & 0 & 0 & 0 & 0 \\
\hline 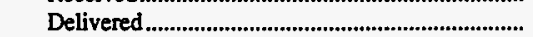 & 0 & 0 & 0 & $\mathbf{0}$ & 0 & 0 \\
\hline 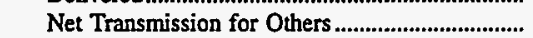 & 0 & 0 & 0 & 0 & 0 & 0 \\
\hline Transmission by Others Losses............................... & 0 & 0 & 0 & $\mathbf{0}$ & 0 & $-7,646$ \\
\hline \multicolumn{7}{|l|}{ Total Net.Energy } \\
\hline 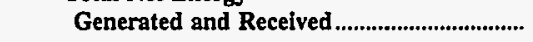 & $1,122,261$ & 166,211 & $2,581,875$ & $1,997,174$ & 235,605 & 180,313 \\
\hline \multicolumn{7}{|l|}{ Disposition of Energy } \\
\hline Sales to Ultimate Consumers ................................... & 900,652 & 155,571 & 0 & $\mathbf{0}$ & 220,162 & 164,326 \\
\hline 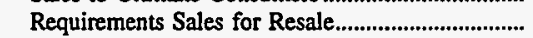 & 104,722 & 0 & $2,508,216$ & $1,997,174$ & 0 & 3,333 \\
\hline Nonrequirements Sales for Resale ............................. & 87,061 & 0 & 0 & 0 & 0 & 0 \\
\hline Furnished Without Charge .......................................... & 0 & 733 & 0 & 0 & 2,423 & 0 \\
\hline Used by Utility (excluding station use).................... & 0 & 187 & 0 & 0 & 3,017 & 75 \\
\hline 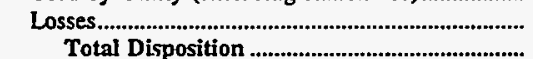 & $\begin{array}{r}29,826 \\
1,122,261\end{array}$ & $\begin{array}{r}9,720 \\
166,211\end{array}$ & $\begin{array}{r}73,659 \\
2,581,875\end{array}$ & $\begin{array}{r}0 \\
1,997,174\end{array}$ & $\begin{array}{r}10,003 \\
235,605\end{array}$ & $\begin{array}{r}12,579 \\
180,313\end{array}$ \\
\hline
\end{tabular}

Note: Totals may not equal sum of components because of independent rounding. Double counting occurs in components of both sources and disposition of energy and thus neither provides a true total. Purchases from utilities, net interchanges, and net wheeling (except for imports) are included in net generation.

Source: Energy Information Administration, Form EIA-412, "Annual Report of Public Electric Utilities." 
Table 26. Electric Energy Account by Major U.S. Publicly Owned Electric Utility Within State, 1996 (Continued)

(Megawatthours)

\begin{tabular}{|c|c|c|c|c|c|c|}
\hline Item & $\begin{array}{l}\text { Mississippi } \\
\text { Aberdeen } \\
\text { City of } \\
\text { June } 30\end{array}$ & $\begin{array}{l}\text { Mississippi } \\
\text { Amory } \\
\text { City of } \\
\text { June } 30\end{array}$ & $\begin{array}{l}\text { Mississippi } \\
\text { Clarksdale } \\
\text { City of } \\
\text { September } 30\end{array}$ & $\begin{array}{l}\text { Mississippi } \\
\text { Columbus } \\
\text { City of } \\
\text { June } 30\end{array}$ & $\begin{array}{l}\text { Mississippi } \\
\text { Greenwood } \\
\text { Utilities } \\
\text { Comm } \\
\text { September } 30\end{array}$ & $\begin{array}{l}\text { Mississippi } \\
\text { Holly } \\
\text { Springs } \\
\text { City of } \\
\\
\text { June } 30\end{array}$ \\
\hline \multicolumn{7}{|l|}{ Sources of Energy } \\
\hline Steam & $\mathbf{0}$ & 0 & 35.727 & 0 & 28,945 & 0 \\
\hline 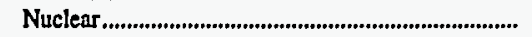 & $\mathbf{0}$ & 0 & 0 & 0 & 0 & 0 \\
\hline 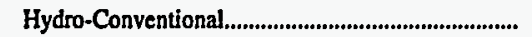 & $\mathbf{0}$ & 0 & 0 & $\mathbf{0}$ & $\mathbf{0}$ & 0 \\
\hline 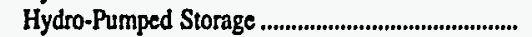 & 0 & 0 & 0 & 0 & 0 & 0 \\
\hline 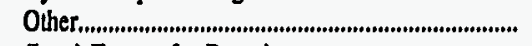 & 0 & 0 & 10,995 & 0 & 0 & 0 \\
\hline 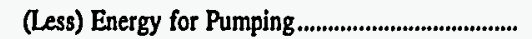 & 0 & 0 & 0 & 0 & 0 & 0 \\
\hline Total Net Generation & $\mathbf{0}$ & $\mathbf{0}$ & 46,722 & $\mathbf{0}$ & 28,945 & $\mathbf{0}$ \\
\hline Purchases from Utility................................................ & 192,617 & 130,891 & 197,487 & 501,365 & 280,158 & 225,588 \\
\hline 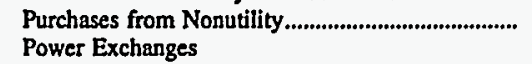 & 0 & 0 & 0 & 0 & 0 & $\mathbf{0}$ \\
\hline 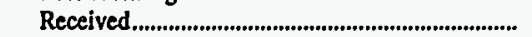 & 0 & $\mathbf{0}$ & 0 & 0 & 0 & $\mathbf{0}$ \\
\hline 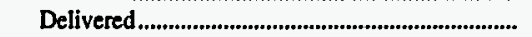 & 0 & $\mathbf{0}$ & 0 & 0 & 0 & 0 \\
\hline Net Exchanges ..................................................... & $\mathbf{0}$ & 0 & 0 & $\mathbf{0}$ & 0 & 0 \\
\hline 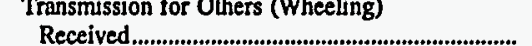 & 0 & 0 & 0 & \multicolumn{3}{|c|}{ Transmission for Others (Wheeling) } \\
\hline 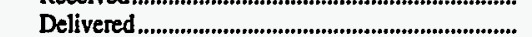 & $\mathbf{0}$ & 0 & 0 & 0 & $\begin{array}{l}0 \\
0\end{array}$ & $\begin{array}{l}0 \\
0\end{array}$ \\
\hline Net Transmission for Others.................................... & 0 & $\mathbf{0}$ & 0 & 0 & 0 & 0 \\
\hline $\begin{array}{l}\text { Transmission by Others Losses.................................. } \\
\text { Total Net Energy }\end{array}$ & 0 & $\mathbf{0}$ & $\mathbf{0}$ & 0 & 0 & $\mathbf{0}$ \\
\hline 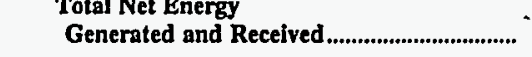 & 192,617 & 130,891 & 244,209 & 501,365 & 309,103 & 225,588 \\
\hline \multicolumn{7}{|l|}{ Disposition of Energy } \\
\hline 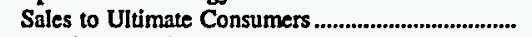 & 185,398 & 124,747 & 181,402 & 474,419 & 289,932 & 208,801 \\
\hline 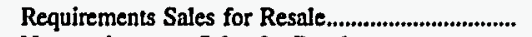 & $\mathbf{0}$ & 0 & 46,722 & 0 & 0 & 0 \\
\hline 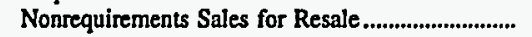 & 0 & 0 & 0 & 0 & 0 & $\mathbf{0}$ \\
\hline 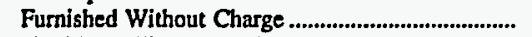 & 0 & 0 & $\mathbf{0}$ & 0 & 0 & 0 \\
\hline Used by Utility (excluding station use)................... & 89 & 0 & $\mathbf{0}$ & 204 & 0 & 266 \\
\hline 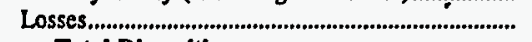 & 7,129 & 6,144 & 16,085 & 26,742 & 19,171 & 16,521 \\
\hline 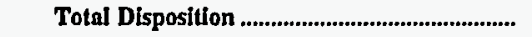 & 192,617 & 130,891 & 244,209 & 501,365 & 309,103 & 225,588 \\
\hline
\end{tabular}

Note: Totals may not equal sum of components because of independent rounding. Double counting occurs in components of both sources and disposition of energy and thus neither provides a true total. Purchases from utilities, net interchanges, and net wheeling (except for imports) are included in net generation. Sales for resale is included in sales to ultimate consumers.

Source: Energy Information Administration, Form ElA-412, "Annual Report of Public Electric Utilities." 
Table 26. Electric Energy Account by Major U.S. Publicly Owned Electric Utility Within State, 1996 (Continued)

(Megawatthours)

\begin{tabular}{|c|c|c|c|c|c|c|}
\hline Item & $\begin{array}{l}\text { Mississippi } \\
\text { Louisville } \\
\text { Electric } \\
\text { System } \\
\text { June } 30\end{array}$ & $\begin{array}{l}\text { Mississippi } \\
\text { Municipal } \\
\text { Energy } \\
\text { Agency } \\
\text { of MS } \\
\text { September } 30\end{array}$ & $\begin{array}{l}\text { Mississippi } \\
\text { New Albany } \\
\text { City of } \\
\text { June } 30\end{array}$ & $\begin{array}{l}\text { Mississippi } \\
\text { Oxford } \\
\text { City of } \\
\text { June } 30\end{array}$ & $\begin{array}{l}\text { Mississippi } \\
\text { Philadelphia } \\
\text { City of } \\
\text { June } 30\end{array}$ & $\begin{array}{l}\text { Mississippi } \\
\text { Starkville } \\
\text { City of } \\
\text { June } 30\end{array}$ \\
\hline \multicolumn{7}{|l|}{ Sources of Energy } \\
\hline Steam & 0 & 0 & 0 & 0 & 0 & 0 \\
\hline 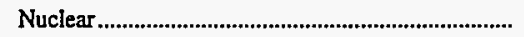 & 0 & 0 & 0 & 0 & 0 & 0 \\
\hline 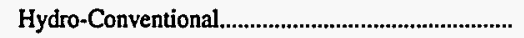 & 0 & 0 & 0 & 0 & 0 & 0 \\
\hline 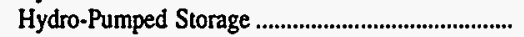 & 0 & 0 & 0 & 0 & 0 & 0 \\
\hline 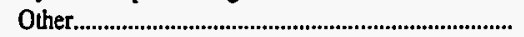 & 0 & 0 & 0 & 0 & 0 & 0 \\
\hline 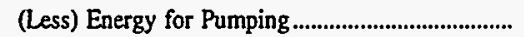 & 0 & 0 & 0 & 0 & 0 & 0 \\
\hline 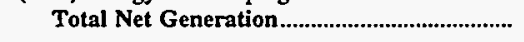 & $\mathbf{0}$ & $\mathbf{0}$ & $\mathbf{0}$ & 0 & 0 & $\mathbf{0}$ \\
\hline 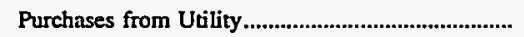 & 177,081 & 872,502 & 258,644 & 170,899 & 134,352 & 367,251 \\
\hline $\begin{array}{l}\text { Purchases from Nonutility........................................ } \\
\text { Power Exchanges }\end{array}$ & 0 & 0 & 0 & 0 & 0 & 0 \\
\hline Received & 0 & 0 & 0 & 0 & 0 & 0 \\
\hline 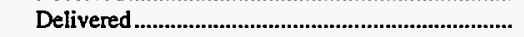 & 0 & 0 & 0 & 0 & 0 & 0 \\
\hline 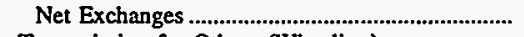 & 0 & 0 & 0 & 0 & 0 & 0 \\
\hline \multicolumn{7}{|l|}{ Transmission for Others (Wheeling) } \\
\hline 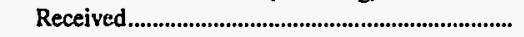 & 0 & 0 & 0 & 0 & 0 & 0 \\
\hline 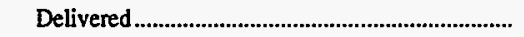 & 0 & 0 & 0 & 0 & 0 & 0 \\
\hline 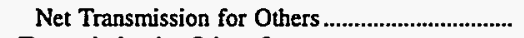 & 0 & 0 & 0 & 0 & 0 & 0 \\
\hline Transmission by Others Losses............................... & 0 & 0 & 0 & $\mathbf{0}$ & 0 & 0 \\
\hline \multicolumn{7}{|l|}{ Total Net Energy } \\
\hline Generated and Received ................................... & 177,081 & 872,502 & 258,644 & 170,899 & 134,352 & 367,251 \\
\hline \multicolumn{7}{|l|}{ Disposition of Energy } \\
\hline 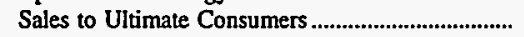 & 170,576 & 872,502 & 240,703 & 162,269 & 130,087 & 347,266 \\
\hline 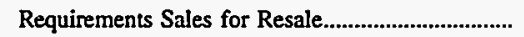 & 0 & 0 & 0 & 0 & 0 & 0 \\
\hline Nonrequirements Sales for Resale. .......................... & 0 & 0 & 0 & 0 & $\mathbf{0}$ & 0 \\
\hline 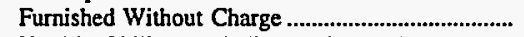 & 0 & 0 & 0 & 0 & 0 & 0 \\
\hline Used by Utility (excluding station use).................... & 122 & 0 & 219 & 79 & 110 & 222 \\
\hline 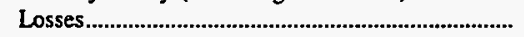 & 6,383 & 0 & 17,722 & 8,552 & 4,155 & 19,763 \\
\hline 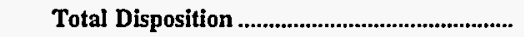 & 177,081 & 872,502 & 258,644 & 170,899 & 134,352 & 367,251 \\
\hline
\end{tabular}

Note: Totals may not equal sum of components because of independent rounding. Double counting occurs in components of both sources and disposition of energy and thus neither provides a true total. Purchases from utilities, net interchanges, and net wheeling (except for imports) are included in net generation.

Source: Energy Information Administration, Form EIA-412, "Annual Report of Public Electric Utilities." 
Table 26. Electric Energy Account by Major U.S. Publicly Owned Electric Utility Within State, 1996 (Continued)

(Megawatthours)

\begin{tabular}{|c|c|c|c|c|c|c|}
\hline Item & $\begin{array}{l}\text { Mississippi } \\
\text { Tupelo } \\
\text { City of } \\
\text { June } 30\end{array}$ & $\begin{array}{c}\text { Mississippi } \\
\text { West } \\
\text { Point } \\
\text { City of } \\
\text { June } 30\end{array}$ & $\begin{array}{l}\text { Missouri } \\
\text { Carthage } \\
\text { City of } \\
\text { June } 30\end{array}$ & $\begin{array}{l}\text { Missouri } \\
\text { Columbia } \\
\text { City of } \\
\text { September } 30\end{array}$ & $\begin{array}{l}\text { Missouri } \\
\text { Hannibal } \\
\text { City of } \\
\text { June } 30\end{array}$ & $\begin{array}{c}\text { Missouri } \\
\text { Independence } \\
\text { City of } \\
\text { June } 30\end{array}$ \\
\hline \multicolumn{7}{|l|}{ Sources of Energy } \\
\hline Steam, & 0 & 0 & 0 & 76,526 & 0 & 97,039 \\
\hline 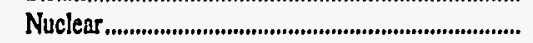 & 0 & 0 & 0 & 0 & 0 & 0 \\
\hline 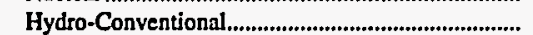 & 0 & 0 & 0 & 0 & $\mathbf{0}$ & $\mathbf{0}$ \\
\hline Hydro-Pumped Storage .................................................. & 0 & $\mathbf{0}$ & 0 & 0 & 0 & 0 \\
\hline 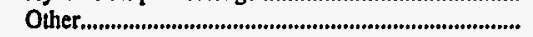 & 0 & 0 & 1,238 & 0 & 0 & 14,917 \\
\hline 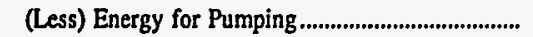 & 0 & 0 & 951 & 0 & 0 & 0 \\
\hline 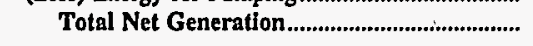 & 0 & $\mathbf{0}$ & 287 & 76,526 & $\mathbf{0}$ & 111,956 \\
\hline 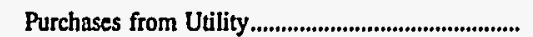 & 688,691 & 206,046 & 239,287 & 802,229 & 221,328 & 864,703 \\
\hline 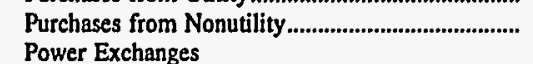 & 0 & 0 & 0 & 0 & 0 & 0 \\
\hline 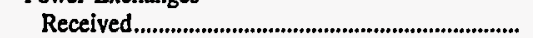 & 0 & 0 & $\mathbf{0}$ & 0 & 0 & 1,695 \\
\hline 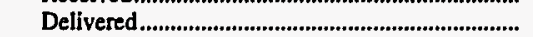 & 0 & 0 & 0 & 0 & 0 & 2,078 \\
\hline 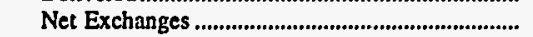 & 0 & 0 & 0 & 0 & 0 & -383 \\
\hline \multicolumn{7}{|l|}{ Transmission for Others (Wheeling) } \\
\hline 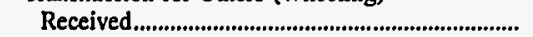 & 0 & 0 & 0 & 185,383 & 0 & 0 \\
\hline 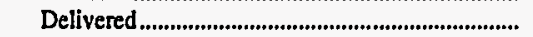 & 0 & 0 & 0 & 183,499 & 0 & 0 \\
\hline 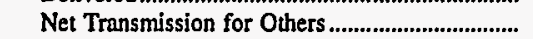 & 0 & 0 & 0 & 1,884 & $\mathbf{0}$ & 0 \\
\hline $\begin{array}{l}\text { Transmission by Others Losses..................................... } \\
\text { Total Net Energy }\end{array}$ & 0 & 0 & $-12,129$ & 0 & $\mathbf{0}$ & 0 \\
\hline 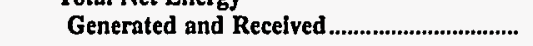 & 688,691 & 206,046 & 227,445 & 880,639 & 221,328 & 976,276 \\
\hline \multicolumn{7}{|l|}{ Disposition of Energy } \\
\hline 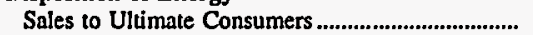 & 657,668 & 199,919 & 212,334 & 836,010 & 207,040 & 882,994 \\
\hline Requirements Sales for Resale................................... & 0 & 0 & 0 & 0 & 0 & 2,987 \\
\hline Nonrequirements Sales for Resale............................ & 0 & 0 & 1,546 & 1,939 & 0 & 25,961 \\
\hline Furnished Without Charge ........................................... & 0 & 0 & 0 & 0 & 3,266 & 0 \\
\hline Used by Utility (excluding station use)...................... & 435 & 0 & 0 & 0 & 0 & 1,986 \\
\hline Losses & 30,588 & 6,126 & 13,565 & 42,690 & 11,022 & 62,348 \\
\hline Total Disposition & 688,691 & 206,046 & 227,445 & 880,639 & 221,328 & 976,276 \\
\hline
\end{tabular}

Note: Totals may not equal sum of components because of independent rounding. Double counting occurs in components of both sources and disposition of energy and thus neither provides a true total. Purchases from utilities, net interchanges, and net wheeling (except for imports) are included in net generation.

Source: Energy Information Administration, Form EIA-412, "Annual Report of Public Electric Utilities." 
Table 26. Electric Energy Account by Major U.S. Publicly Owned Electric Utility Within State, 1996 (Continued)

(Megawatthours)

\begin{tabular}{|c|c|c|c|c|c|c|}
\hline Item & $\begin{array}{l}\text { Missouri } \\
\text { Kennett } \\
\text { City of } \\
\text { June } 30\end{array}$ & $\begin{array}{l}\text { Missouri } \\
\text { Kirkwood } \\
\text { City of } \\
\text { March } 31\end{array}$ & $\begin{array}{l}\text { Missouri } \\
\text { Lebanon } \\
\text { City of } \\
\text { October } 31\end{array}$ & $\begin{array}{c}\text { Missouri } \\
\text { Marshall } \\
\text { City of } \\
\text { September } 30\end{array}$ & $\begin{array}{l}\text { Missouri } \\
\text { Monett } \\
\text { City of } \\
\text { March } 31\end{array}$ & $\begin{array}{c}\text { Missouri } \\
\text { Poplar } \\
\text { Bluff } \\
\text { City of } \\
\text { December } 31\end{array}$ \\
\hline \multicolumn{7}{|l|}{ Sources of Energy } \\
\hline 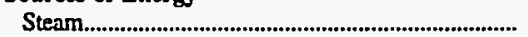 & 0 & 0 & 0 & 58,453 & 0 & $\mathbf{0}$ \\
\hline Nuclear & 0 & 0 & $\mathbf{0}$ & 0 & 0 & 0 \\
\hline 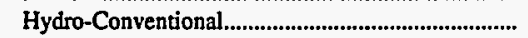 & 0 & 0 & 0 & 0 & 0 & 0 \\
\hline 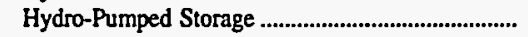 & 0 & 0 & 0 & 0 & 0 & 0 \\
\hline 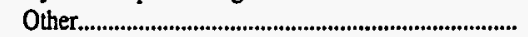 & 473 & 0 & 0 & 0 & 0 & 465 \\
\hline (Less) Energy for Pumping......................................... & 0 & 0 & 0 & 0 & 0 & 0 \\
\hline Total Net Generation & 473 & 0 & $\mathbf{0}$ & 58,453 & $\mathbf{0}$ & 465 \\
\hline 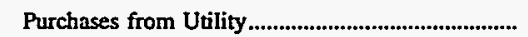 & 168,655 & 193,946 & 214,809 & 108,142 & 170,016 & 315,208 \\
\hline 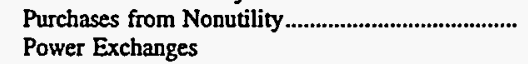 & 0 & 0 & 0 & 0 & 0 & 0 \\
\hline 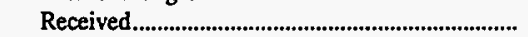 & 0 & 0 & 0 & 0 & 0 & 0 \\
\hline 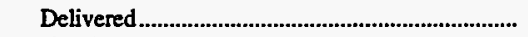 & 0 & 0 & 0 & 0 & $\mathbf{0}$ & 0 \\
\hline 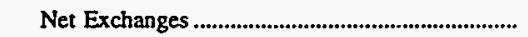 & 0 & 0 & 0 & 0 & 0 & 0 \\
\hline \multicolumn{7}{|l|}{ Transmission for Others (Wheeling) } \\
\hline 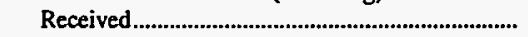 & 0 & 0 & 0 & 0 & 0 & 0 \\
\hline 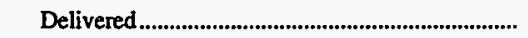 & 0 & 0 & 0 & 0 & $\mathbf{0}$ & 0 \\
\hline 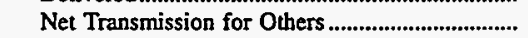 & 0 & 0 & 0 & 0 & $\mathbf{0}$ & 0 \\
\hline $\begin{array}{l}\text { Transmission by Others Losses................................. } \\
\text { Total Net Energy }\end{array}$ & 0 & 0 & 0 & 0 & 0 & 0 \\
\hline 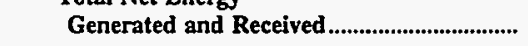 & 169,128 & 193,946 & 214,809 & 166,595 & 170,016 & 315,673 \\
\hline \multicolumn{7}{|l|}{ Disposition of Energy } \\
\hline 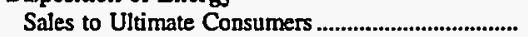 & 158,093 & 181,144 & 178,291 & 160,665 & 161,312 & 280,267 \\
\hline 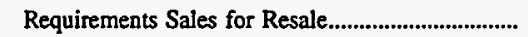 & 0 & $\mathbf{0}$ & 0 & 0 & 0 & 0 \\
\hline Nonrequirements Sales for Resale .............................. & 0 & 0 & 0 & 0 & 0 & 5,890 \\
\hline Furnished Without Charge ......................................... & 0 & 0 & 12,889 & 0 & 0 & 5,378 \\
\hline Used by Utility (excluding station use)................... & 318 & 0 & 0 & 0 & 4,458 & 3 \\
\hline 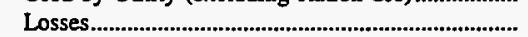 & 10,717 & 12,802 & 23,629 & 5,930 & 4,246 & 24,135 \\
\hline Total Disposition & 169,128 & 193,946 & 214,809 & 166,595 & 170,016 & 315,673 \\
\hline
\end{tabular}

Note: Totals may not equal sum of components because of independent rounding. Double counting occurs in components of both sources and disposition of energy and thus neither provides a true total. Purchases from utilities, net interchanges, and net wheeling (except for imports) are included in net generation.

Source: Energy Information Administration, Form EIA-412, “Annual Report of Public Electric Utilities." 
Table 26. Electric Energy Account by Major U.S. Publicly Owned Electric Utility Within State, 1996 (Continued)

(Megawatthours)

\begin{tabular}{|c|c|c|c|c|c|c|}
\hline Item & $\begin{array}{l}\text { Missouri } \\
\text { Rolla } \\
\text { City of } \\
\text { September } 30\end{array}$ & $\begin{array}{l}\text { Missouri } \\
\text { Sikeston } \\
\text { City of } \\
\text { May } 31\end{array}$ & $\begin{array}{c}\text { Missouri } \\
\begin{array}{c}\text { Springfield } \\
\text { City of }\end{array} \\
\text { September } 30\end{array}$ & $\begin{array}{c}\text { Missouri } \\
\text { West } \\
\text { Plains } \\
\text { City of } \\
\text { December } 31\end{array}$ & $\begin{array}{l}\text { Nebraska } \\
\text { Beatrice } \\
\text { City of } \\
\text { July } 31\end{array}$ & $\begin{array}{c}\text { Nebraska } \\
\text { Central } \\
\text { Nebraska } \\
\text { Pub } \\
\text { P\&I Dist } \\
\text { December } 31\end{array}$ \\
\hline \multicolumn{7}{|l|}{ Sources of Energy } \\
\hline 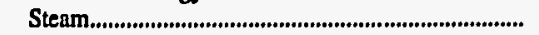 & $\mathbf{0}$ & $1,663,611$ & $2,167,830$ & 0 & $\mathbf{0}$ & \\
\hline 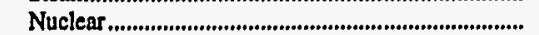 & 0 & 0 & 0 & 0 & 0 & \\
\hline 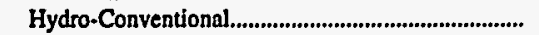 & 0 & $\mathbf{0}$ & 0 & 0 & 0 & 440,025 \\
\hline 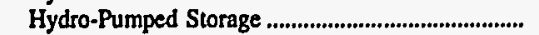 & 0 & 0 & 0 & 0 & 0 & 0 \\
\hline 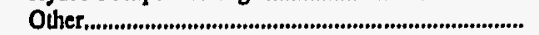 & 0 & $\mathbf{0}$ & 46,345 & 0 & .0 & 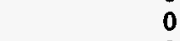 \\
\hline 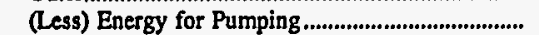 & 0 & 0 & 0 & 0 & 0 & \\
\hline 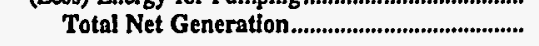 & $\mathbf{0}$ & $1,663,611$ & $2,214,175$ & o & o & 440,025 \\
\hline 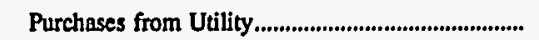 & 263,592 & 107,887 & 537,519 & 167,496 & 181,868 & \\
\hline Purchases from Nonutility............................................. & 0 & 0 & 0 & 0 & 0 & \\
\hline \multicolumn{7}{|l|}{ Power Exchanges } \\
\hline 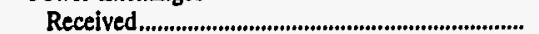 & 0 & 0 & 142,826 & $\mathbf{0}$ & 0 & \\
\hline 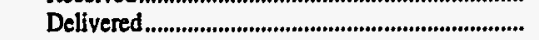 & 0 & 58,834 & 159,062 & 0 & 0 & \\
\hline Net Exchanges ......................................................... & 0 & $-58,834$ & $-16,236$ & 0 & 0 & \\
\hline \multicolumn{7}{|l|}{ Transmission for Others (Wheeling) } \\
\hline 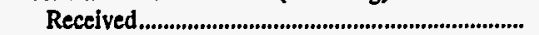 & $\mathbf{0}$ & 0 & 0 & 0 & 0 & \\
\hline 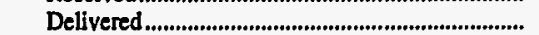 & $\mathbf{0}$ & 0 & 0 & 0 & 0 & c \\
\hline Net Transmission for Others ......................................... & 0 & 0 & $\mathbf{0}$ & 0 & 0 & \\
\hline Transmission by Others Losses................................... & 0 & 0 & $-4,616$ & 0 & 0 & \\
\hline Total Net Energy & & & & & & \\
\hline 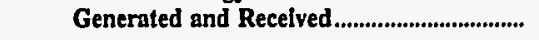 & 263,592 & $1,712,664$ & $2,730,842$ & 167,496 & 181,868 & 440,025 \\
\hline \multicolumn{7}{|l|}{ Disposition of Energy } \\
\hline 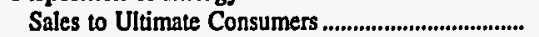 & 245,910 & 260,660 & $2,354,929$ & 141,722 & 170,757 & \\
\hline Requirements Sales for Resale........................................ & 0 & $1,431,943$ & 125,551 & 0 & 0 & \\
\hline Nonrequirements Sales for Resale................................. & 0 & 0 & 67,287 & 0 & 0 & 440,025 \\
\hline Furnished Without Charge ............................................. & 4,682 & 3,602 & 69,162 & 4,000 & 2,917 & \\
\hline Used by Utility (excluding station use)......................... & 305 & 0 & 1,854 & 0 & 915 & \\
\hline 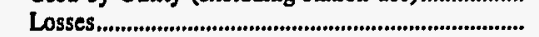 & 12,695 & 16,459 & 112,059 & 21,774 & 7,279 & \\
\hline Total Disposition ................................................... & 263,592 & $1,712,664$ & $2,730,842$ & 167,496 & 181,868 & 440,025 \\
\hline
\end{tabular}

Note: Totals may not equal sum of components because of independent rounding. Double counting occurs in components of both sources and disposition of energy and thus neither provides a true total. Purchases from utilities, net interchanges, and net whecling (except for imports) are included in net generation.

Source: Energy Information Administration, Form EIA-412, “Annual Report of Public Electric Utilities.” 
Table 26. Electric Energy Account by Major U.S. Publicly Owned Electric Utility Within State, 1996 (Continued)

(Megawatthours)

\begin{tabular}{|c|c|c|c|c|c|c|}
\hline Item & $\begin{array}{l}\text { Nebraska } \\
\text { Cornhusker } \\
\text { Public } \\
\text { Power Dist } \\
\text { December } 31\end{array}$ & $\begin{array}{l}\text { Nebraska } \\
\text { Dawson } \\
\text { County } \\
\text { Public } \\
\text { Pwr Dist } \\
\text { December } 31\end{array}$ & $\begin{array}{l}\text { Nebraska } \\
\text { Fremont } \\
\text { City of } \\
\text { July } 31\end{array}$ & $\begin{array}{l}\text { Nebraska } \\
\text { Grand Island } \\
\text { City of } \\
\text { July } 31\end{array}$ & $\begin{array}{c}\text { Nebraska } \\
\text { Hastings } \\
\text { City of } \\
\text { December } 31\end{array}$ & $\begin{array}{l}\text { Nebraska } \\
\text { Lincoln } \\
\text { Electric } \\
\text { System } \\
\text { December } 31\end{array}$ \\
\hline \multicolumn{7}{|l|}{ Sources of Energy } \\
\hline Steam & 0 & 0 & 345,135 & 568,209 & 432,311 & $1,335,920$ \\
\hline 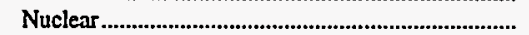 & 0 & 0 & 0 & 0 & 0 & 0 \\
\hline 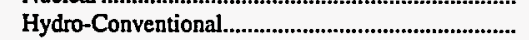 & 0 & 0 & 0 & 0 & 0 & 0 \\
\hline Hydro-Pumped Storage & 0 & 0 & 0 & 0 & 0 & 0 \\
\hline 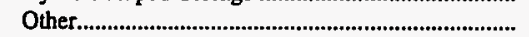 & 0 & 0 & 0 & 0 & 2,238 & 2,649 \\
\hline 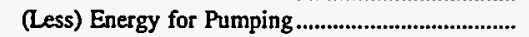 & 0 & 0 & 0 & 0 & 0 & 0 \\
\hline Total Net Generation & 0 & $\mathbf{0}$ & 345,135 & 568,209 & 434,549 & $1,338,569$ \\
\hline 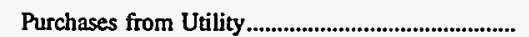 & 232,669 & 293,948 & 73,563 & 132,141 & 70,882 & $2,033,182$ \\
\hline 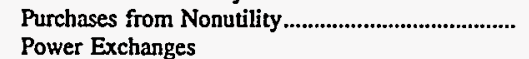 & 0 & 0 & 30,471 & 0 & 0 & 0 \\
\hline 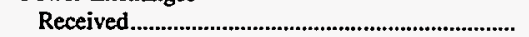 & 0 & 0 & 0 & 197 & 0 & 15,253 \\
\hline 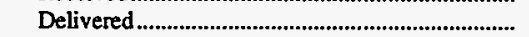 & 0 & 0 & 0 & 250 & 0 & 16,735 \\
\hline 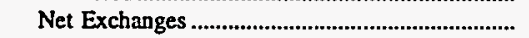 & 0 & 0 & 0 & -53 & 0 & $-1,482$ \\
\hline \multicolumn{7}{|l|}{ Transmission for Others (Wheeling) } \\
\hline 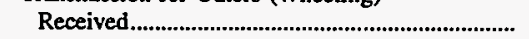 & 3,598 & 0 & 0 & 0 & 5,538 & 109,070 \\
\hline Delivered & 3,598 & 0 & $\mathbf{0}$ & 0 & 5,538 & 109,070 \\
\hline 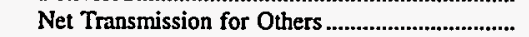 & 0 & 0 & 0 & 0 & 0 & 0 \\
\hline $\begin{array}{l}\text { Transmission by Others Losses.................................. } \\
\text { Total Net Energy }\end{array}$ & 0 & 0 & 0 & 0 & 0 & 0 \\
\hline 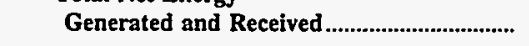 & 232,669 & 293,948 & 449,169 & 700,297 & 505,431 & $3,370,269$ \\
\hline \multicolumn{7}{|l|}{ Disposition of Energy } \\
\hline 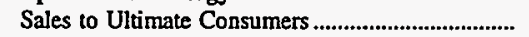 & 211,407 & 264,745 & 410,143 & 644,005 & 343,719 & $2,438,073$ \\
\hline 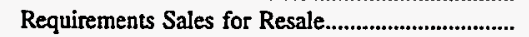 & 3,598 & 6,163 & 0 & 0 & 145,765 & 68,555 \\
\hline Nonrequirements Sales for Resale ............................ & 0 & 0 & 10,844 & 39,404 & 0 & 647,326 \\
\hline 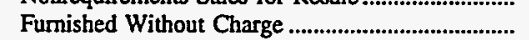 & 0 & 0 & 6,667 & 0 & 0 & 0 \\
\hline 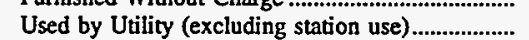 & 619 & 224 & 11,931 & 0 & 0 & 4,771 \\
\hline 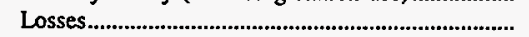 & 17,045 & 22,816 & 9,584 & 16,888 & 15,947 & 211,544 \\
\hline 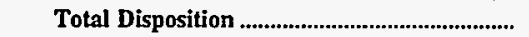 & 232,669 & 293,948 & 449,169 & 700,297 & 505,431 & $3,370,269$ \\
\hline
\end{tabular}

Note: Totals may not equal sum of components because of independent rounding. Double counting occurs in components of both sources and disposition of energy and thus neither provides a true totai. Purchases from utilities, net interchanges, and net wheeling (except for imports) are included in net generation.

Source: Energy Information Administration, Form EIA-412, “Annual Report of Public Electric Utilities.” 
Table 26. Electric Energy Account by Major U.S. Publicly Owned Electric Utility Within State, 1996 (Continued)

(Megawatthours)

\begin{tabular}{|c|c|c|c|c|c|c|}
\hline Item & $\begin{array}{c}\text { Nebraska } \\
\text { Loup } \\
\text { River } \\
\text { Public } \\
\text { Power Dist } \\
\text { December 31 }\end{array}$ & $\begin{array}{l}\text { Nebraska } \\
\text { Municipal } \\
\text { Energy } \\
\text { Agency } \\
\text { of NE } \\
\text { March } 31\end{array}$ & $\begin{array}{l}\text { Nebraska } \\
\text { Nebraska } \\
\text { Public } \\
\text { Power } \\
\text { District } \\
\text { December } 31\end{array}$ & $\begin{array}{c}\text { Nebraska } \\
\text { Norris } \\
\text { Public } \\
\text { Power } \\
\text { District } \\
\text { December } 31\end{array}$ & $\begin{array}{l}\text { Nebraska } \\
\text { North } \\
\text { Platte } \\
\text { City of } \\
\text { July } 31\end{array}$ & $\begin{array}{c}\text { Nebraska } \\
\text { Omaha Public } \\
\text { Power } \\
\text { District } \\
\text { December } 31\end{array}$ \\
\hline \multicolumn{7}{|l|}{ Sources of Energy } \\
\hline Steam & 0 & 197,564 & $8,792,850$ & 0 & 0 & $6,094,565$ \\
\hline 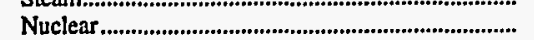 & 0 & 0 & $6,338,898$ & 0 & $\mathbf{0}$ & $3,117,919$ \\
\hline 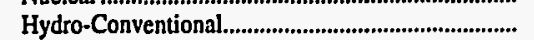 & 136,906 & 0 & 169,283 & 0 & $\mathbf{0}$ & 0 \\
\hline 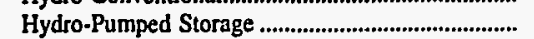 & 0 & 0 & 0 & 0 & 0 & 0 \\
\hline 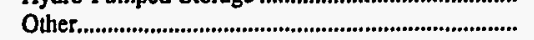 & 0 & 0 & 8,592 & 0 & 0 & 48,439 \\
\hline 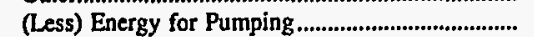 & 0 & 0 & 0 & 0 & 0 & 0 \\
\hline Total Net Generation & 136,906 & 197,564 & $15,309,623$ & 0 & $\mathbf{0}$ & $9,260,923$ \\
\hline 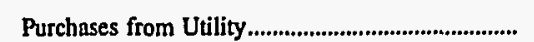 & $1,136,487$ & 939,357 & $12,555,576$ & 479,215 & 285,004 & 409,974 \\
\hline $\begin{array}{l}\text { Purchases from Nonutility........................................ } \\
\text { Power Exchanges }\end{array}$ & 0 & 0 & 0 & 0 & 0 & 0 \\
\hline 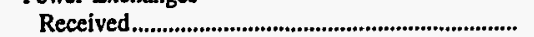 & $\mathbf{0}$ & $\mathbf{0}$ & 56,923 & 0 & 0 & 982,426 \\
\hline Delivered & 0 & 0 & 67,395 & 0 & 0 & $2,318,790$ \\
\hline 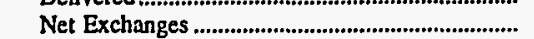 & 0 & 0 & $-10,472$ & 0 & 0 & $-1,336,364$ \\
\hline \multicolumn{7}{|l|}{ Transmission for Others (Wheeling) } \\
\hline 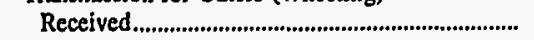 & 0 & 0 & 0 & 0 & 0 & 133,600 \\
\hline Delivered & 0 & 0 & 0 & 0 & 0 & 130,610 \\
\hline 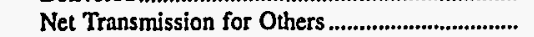 & 0 & 0 & 0 & 0 & 0 & 2,990 \\
\hline Transmission by Others Losses................................ & 0 & 0 & 0 & 0 & 0 & $\mathbf{0}$ \\
\hline Total Net Energy & & & & & & \\
\hline 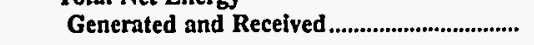 & $1,273,393$ & $1,136,921$ & $27,854,727$ & 479,215 & 285,004 & $8,337,523$ \\
\hline \multicolumn{7}{|l|}{ Disposition of Energy } \\
\hline 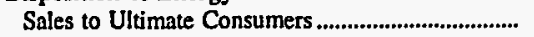 & 778,567 & 0 & $2,928,863$ & 437,479 & 278,366 & $7,756,491$ \\
\hline Requirements Sales for Resale.................................... & 463,284 & 893,619 & $5,726,470$ & 15,943 & 0 & 173,595 \\
\hline Nonrequirements Sales for Resale............................ & 0 & 180,412 & $18,508,709$ & 0 & 0 & 0 \\
\hline 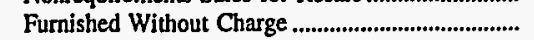 & 0 & 0 & 0 & 0 & 3,574 & $\mathbf{0}$ \\
\hline Used by Utility (excluding station use)................... & 1,682 & 0 & 9,956 & 0 & 598 & 0 \\
\hline 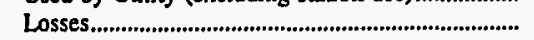 & 29,860 & 62,890 & 680,729 & 25,793 & 2,466 & 407,437 \\
\hline 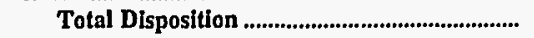 & $1,273,393$ & $1,136,921$ & $27,854,727$ & 479,215 & 285,004 & $8,337,523$ \\
\hline
\end{tabular}

Note: Totals may not equal sum of components because of independent rounding. Double counting occurs in components of both sources and disposition of energy and thus neither provides a true total. Purchases from utilities, net interchanges, and net wheeling (except for imports) are included in net

Source: Energy Information Administration, Form EIA-412, “Annual Report of Public Electric Utilities." 
Table 26. Electric Energy Account by Major U.S. Publicly Owned Electric Utility Within State, 1996 (Continued)

(Megawatthours)

\begin{tabular}{|c|c|c|c|c|c|c|}
\hline Item & $\begin{array}{c}\text { Nebraska } \\
\text { Southem } \\
\text { Nebraska Rural } \\
\text { P P D } \\
\text { December } 31\end{array}$ & $\begin{array}{l}\text { Nevada } \\
\text { Colorado } \\
\text { River } \\
\text { Comm } \\
\text { of Nevada } \\
\text { June } 30\end{array}$ & $\begin{array}{c}\text { Nevada } \\
\text { Overton } \\
\text { Power } \\
\text { District } \\
\text { No } 5 \\
\text { December } 31\end{array}$ & $\begin{array}{c}\text { New Jersey } \\
\text { Madison } \\
\text { Borough } \\
\text { December } 31\end{array}$ & $\begin{array}{l}\text { New Jersey } \\
\text { Vineland } \\
\text { City of } \\
\text { June } 30\end{array}$ & $\begin{array}{l}\text { New Mexico } \\
\text { Farmington } \\
\text { City of } \\
\text { June } 30\end{array}$ \\
\hline \multicolumn{7}{|l|}{ Sources of Energy } \\
\hline Steam & 0 & 0 & 0 & 0 & 71,818 & 403,523 \\
\hline 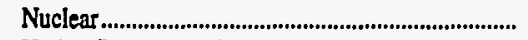 & 0 & 0 & 0 & 0 & 0 & 0 \\
\hline 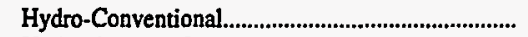 & 0 & 0 & 116,241 & 0 & 0 & 127,878 \\
\hline 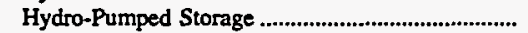 & 0 & 0 & 0 & 0 & 0 & 0 \\
\hline 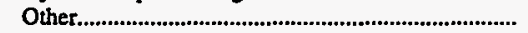 & $\mathbf{0}$ & $\mathbf{0}$ & 0 & 0 & $\mathbf{0}$ & 0 \\
\hline 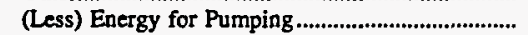 & 0 & 0 & 0 & 0 & 0 & 0 \\
\hline Total Net Generation & 0 & $\mathbf{0}$ & 116,241 & $\mathbf{0}$ & 71,818 & 531,401 \\
\hline 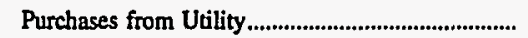 & 485,203 & $1,904,265$ & 132,480 & 126,672 & 17,618 & 140,128 \\
\hline 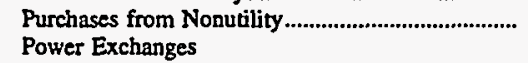 & 0 & 0 & 11,160 & 0 & 100,863 & 0 \\
\hline 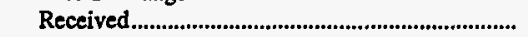 & 0 & $\mathbf{0}$ & 0 & 0 & 288,039 & 8,846 \\
\hline 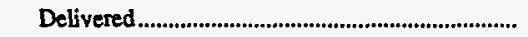 & 0 & 0 & 0 & 0 & 19,950 & 12,893 \\
\hline 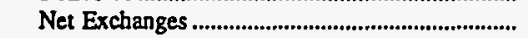 & 0 & 0 & 0 & 0 & 268,089 & $-4,047$ \\
\hline \multicolumn{7}{|l|}{ Transmission for Others (Wheeling) } \\
\hline 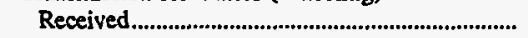 & 0 & $\mathbf{0}$ & 0 & 0 & 0 & 9,921 \\
\hline 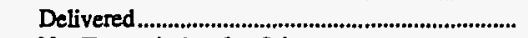 & 0 & 0 & 0 & 0 & 0 & 9,921 \\
\hline 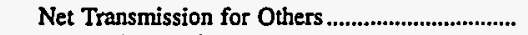 & 0 & 0 & 0 & 0 & 0 & 0 \\
\hline $\begin{array}{l}\text { Transmission by Others Losses................................. } \\
\text { Total Net Energy }\end{array}$ & 0 & 0 & 0 & $\mathbf{0}$ & 0 & 0 \\
\hline 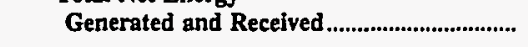 & 485,203 & $1,904,265$ & 259,881 & 126,672 & 458,388 & 667,482 \\
\hline \multicolumn{7}{|l|}{ Disposition of Energy } \\
\hline 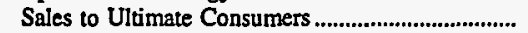 & 430,253 & 762,030 & 238,524 & 121,259 & 432,424 & 627,925 \\
\hline Requirements Sales for Resale................................ & 0 & $1,142,235$ & 13,684 & 0 & 0 & 21,110 \\
\hline Nonrequirements Sales for Resale ......................... & $\mathbf{0}$ & 0 & 0 & 0 & 0 & 5,328 \\
\hline Furnished Without Charge .......................................... & 0 & 0 & 0 & 0 & 102 & 0 \\
\hline 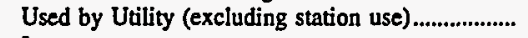 & 336 & 0 & 354 & 0 & 1,194 & 0 \\
\hline 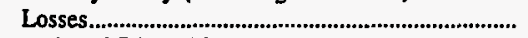 & 54,614 & 0 & 7,319 & 5,413 & 24,668 & 13,119 \\
\hline 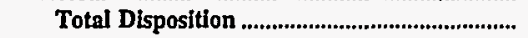 & 485,203 & $1,904,265$ & 259,881 & 126,672 & 458,388 & 667,482 \\
\hline
\end{tabular}

Note: Totals may not equal sum of components because of independent rounding. Double counting occurs in components of both sources and disposition of energy and thus neither provides a true total. Purchases from utilities, net interchanges, and net wheeling (except for imports) are included in net generation.

Source: Energy Information Administration, Form EIA-412, "Annual Report of Public Electric Utilities." 
Table 26. Electric Energy Account by Major U.S. Publicly Owned Electric Utility Within State, 1996 (Continued)

(Megawatthours)

\begin{tabular}{|c|c|c|c|c|c|c|}
\hline Item & $\begin{array}{l}\text { New Mexico } \\
\text { Gallup } \\
\text { City of } \\
\text { June } 30\end{array}$ & $\begin{array}{l}\text { New Mexico } \\
\text { Los Alamos } \\
\text { County } \\
\text { June } 30\end{array}$ & $\begin{array}{c}\text { New York } \\
\text { Faiport } \\
\text { Village of } \\
\text { May } 31\end{array}$ & $\begin{array}{c}\text { New York } \\
\text { Freeport } \\
\text { Village of } \\
\text { Inc } \\
\text { February } 28\end{array}$ & $\begin{array}{c}\text { New York } \\
\text { Jamestown } \\
\text { City of } \\
\text { December } 31\end{array}$ & $\begin{array}{l}\text { New York } \\
\text { Lake Placid } \\
\text { Village Inc } \\
\text { July } 31\end{array}$ \\
\hline \multicolumn{7}{|l|}{ Sources of Energy } \\
\hline Steam........................ & $\mathbf{0}$ & 198,827 & 0 & $\mathbf{0}$ & 156,134 & \\
\hline 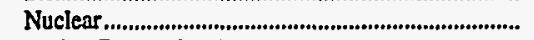 & 0 & 0 & 0 & 0 & 0 & \\
\hline 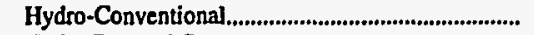 & 0 & 85,122 & $\mathbf{0}$ & 0 & 0 & 0 \\
\hline 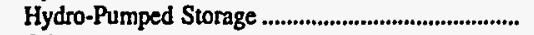 & $\mathbf{0}$ & 0 & $\mathbf{0}$ & $\mathbf{0}$ & $\mathbf{0}$ & $\mathbf{0}$ \\
\hline 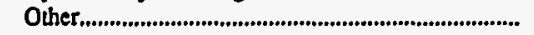 & $\mathbf{0}$ & 0 & 0 & 13,743 & $\mathbf{0}$ & o \\
\hline 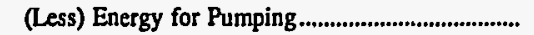 & 0 & $\mathbf{0}$ & $\mathbf{0}$ & $\mathbf{0}$ & $\mathbf{0}$ & 0 \\
\hline 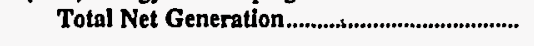 & $\mathbf{0}$ & 283,949 & 0 & 13,743 & 156,134 & 0 \\
\hline 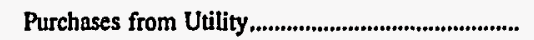 & 191,012 & 215,592 & 397,573 & 239,400 & 448,158 & 142,492 \\
\hline $\begin{array}{l}\text { Purchases from Nonucility............................................. } \\
\text { Power Exchanges }\end{array}$ & 0 & 0 & 0 & 0 & 0 & \\
\hline 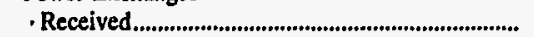 & 0 & 27,658 & 0 & $\mathbf{0}$ & 0 & 0 \\
\hline 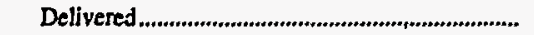 & $\mathbf{0}$ & 29,086 & $\mathbf{0}$ & $\mathbf{0}$ & 0 & 0 \\
\hline 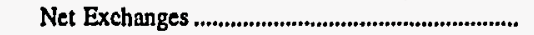 & $\mathbf{0}$ & $-1,425$ & 0 & $\mathbf{0}$ & 0 & 0 \\
\hline \multicolumn{7}{|l|}{ Transmission for Others (Wheeling) } \\
\hline ............................................. & $\mathbf{0}$ & 0 & 0 & 0 & 0 & \\
\hline 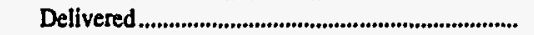 & $\mathbf{0}$ & $\mathbf{0}$ & 0 & 0 & 0 & 0 \\
\hline Net Transmission for Others.......................................... & $\mathbf{0}$ & 0 & 0 & 0 & 0 & 0 \\
\hline 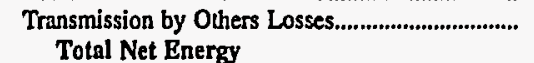 & 0 & 0 & 0 & 0 & $-26,664$ & 0 \\
\hline 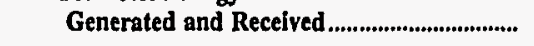 & 191,012 & 498,116 & 397,573 & 253,143 & 577,628 & 142,492 \\
\hline \multicolumn{7}{|l|}{ Disposition of Bnergy } \\
\hline 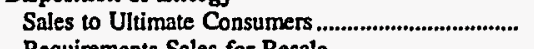 & 175,840 & 466,656 & 373,848 & 243,064 & $\begin{array}{r}502,583 \\
57\end{array}$ & 137,575 \\
\hline 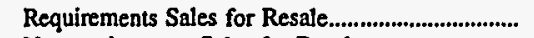 & $\mathbf{0}$ & & $\mathbf{0}$ & $\mathbf{0}$ & 57,445 & \\
\hline Nonrequirements Sales for Resale................................. & $\mathbf{0}$ & 9,706 & 0 & 282 & 0 & 0 \\
\hline Furnished Without Charge ............................................... & 0 & 0 & 0 & $\mathbf{0}$ & 0 & $\mathbf{0}$ \\
\hline Used by Utility (excluding station use)......................... & 0 & $\mathbf{0}$ & 432 & 0 & 1,016 & 283 \\
\hline 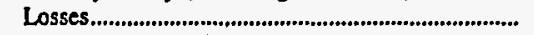 & 15,172 & 21,754 & 23,293 & 9,797 & 16,584 & 4,634 \\
\hline Total Disposition ........................................................... & 191,012 & 498,116 & 397,573 & 253,143 & 577,628 & 142,492 \\
\hline
\end{tabular}

Note: Totals may not equal sum of components because of independent rounding. Double counting occurs in components of both sources and disposition of energy and thus neither provides a true total. Purchases from utilities, net interchanges, and net wheeling (except for imports) are included in net generation.

Source: Energy Information Administration, Form EIA-412, "Annual Report of Public Electric Utilities." 
Table 26. Electric Energy Account by Major U.S. Publicly Owned Electric Utility Within State, 1996 (Continued)

(Megawatthours)

\begin{tabular}{|c|c|c|c|c|c|c|}
\hline Item & $\begin{array}{c}\text { New York } \\
\text { Massena } \\
\text { Town of } \\
\text { December } 31\end{array}$ & $\begin{array}{l}\text { New York } \\
\text { Plattsburgh } \\
\text { City of } \\
\text { December } 31\end{array}$ & $\begin{array}{c}\text { New York } \\
\text { Power } \\
\text { Authority } \\
\text { of State of NY } \\
\text { December } 31\end{array}$ & $\begin{array}{l}\text { New York } \\
\text { Rockville } \\
\text { Centre } \\
\text { Village of } \\
\text { May } 31\end{array}$ & $\begin{array}{c}\text { New York } \\
\text { Solvay } \\
\text { Village of } \\
\text { May } 31\end{array}$ & $\begin{array}{l}\text { North Carolina } \\
\text { Albemarle } \\
\text { City of } \\
\text { June } 30\end{array}$ \\
\hline \multicolumn{7}{|l|}{ Sources of Energy } \\
\hline 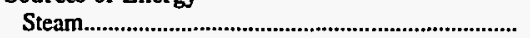 & 0 & 0 & $2,233,346$ & 0 & 0 & 0 \\
\hline 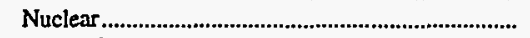 & 0 & 0 & $11,162,870$ & 0 & 0 & 0 \\
\hline 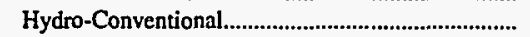 & 0 & 0 & $22,851,941$ & 0 & 0 & 0 \\
\hline Hydro-Pumped Storage & 0 & 0 & $2,149,399$ & 0 & 0 & 0 \\
\hline 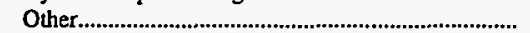 & 0 & 0 & 0 & 15,942 & 0 & 0 \\
\hline 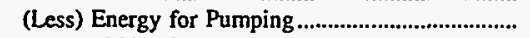 & 0 & 0 & $3,295,388$ & 0 & 0 & 0 \\
\hline 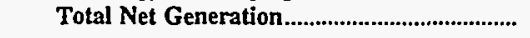 & $\mathbf{0}$ & 0 & $35,102,168$ & 15,942 & $\mathbf{0}$ & $\mathbf{0}$ \\
\hline 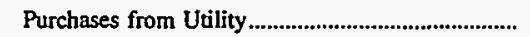 & 170,151 & 542,572 & $5,918,369$ & 165,880 & 254,878 & 284,535 \\
\hline $\begin{array}{l}\text { Purchases from Nonutility......................................... } \\
\text { Power Exchanges }\end{array}$ & 0 & 0 & 0 & 0 & 0 & 0 \\
\hline 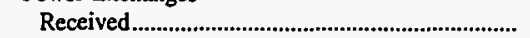 & 0 & 0 & 275,026 & 0 & 0 & 0 \\
\hline 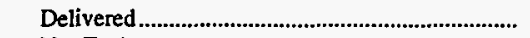 & 0 & 0 & 407,467 & 0 & 0 & 0 \\
\hline 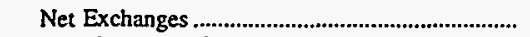 & 0 & 0 & $-132,441$ & 0 & 0 & 0 \\
\hline \multicolumn{7}{|l|}{ Transmission for Others (Wheeling) } \\
\hline 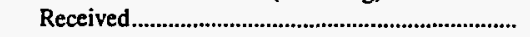 & 0 & 0 & $3,196,948$ & 0 & 0 & 0 \\
\hline 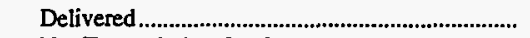 & 0 & 0 & $3,137,278$ & 0 & 0 & 0 \\
\hline 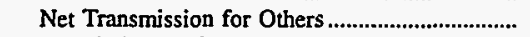 & 0 & 0 & 59,670 & 0 & 0 & 0 \\
\hline $\begin{array}{l}\text { Transmission by Others Losses................................. } \\
\text { Total Net Energy }\end{array}$ & 0 & 0 & 0 & 0 & 0 & 0 \\
\hline 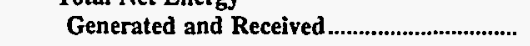 & 170,151 & 542,572 & $40,947,766$ & 181,822 & 254,878 & 284,535 \\
\hline \multicolumn{7}{|l|}{ Disposition of Energy } \\
\hline 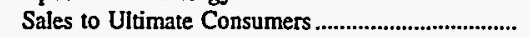 & 160,129 & 524,117 & $13,017,530$ & 178,905 & 230,866 & 263,283 \\
\hline 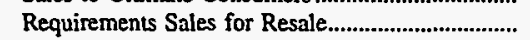 & 0 & 0 & $4,484,501$ & 0 & 0 & 0 \\
\hline 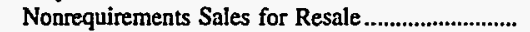 & 0 & 0 & $23,070,678$ & 140 & 0 & 0 \\
\hline 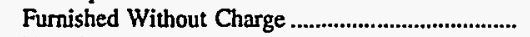 & 0 & 0 & 9,540 & 0 & 0 & 3,745 \\
\hline Used by Utility (excluding station use)..................... & 391 & 1,095 & 14,613 & 0 & 0 & 125 \\
\hline 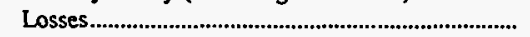 & 9,631 & 17,360 & 350,904 & 2,777 & 24,012 & 17,382 \\
\hline 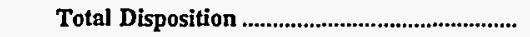 & 170,151 & 542,572 & $40,947,766$ & 181,822 & 254,878 & 284,535 \\
\hline
\end{tabular}

Note: Totals may not equal sum of components because of independent rounding. Double counting occurs in components of both sources and disposition of energy and thus neither provides a true total. Purchases from utilities, net interchanges, and net wheeling (except for imports) are included in net generation.

Source: Energy Information Administration, Form EIA-412, "Annual Report of Public Electric Utilities." 
Table 26. Electric Energy Account by Major U.S. Publicly Owned Electric Utility Within State, 1996 (Continued)

(Megawatthours)

\begin{tabular}{|c|c|c|c|c|c|c|}
\hline Item & $\begin{array}{l}\text { North Carolina } \\
\text { Concord } \\
\text { City of } \\
\text { June } 30\end{array}$ & $\begin{array}{l}\text { North Carolina } \\
\text { Elizabeth } \\
\text { City City of } \\
\text { June } 30\end{array}$ & $\begin{array}{c}\text { North Carolina } \\
\text { Fayetteville } \\
\text { Public } \\
\text { Works Comm } \\
\\
\text { June } 30\end{array}$ & $\begin{array}{c}\text { North Carolina } \\
\text { Forest City } \\
\text { Town of } \\
\text { June } 30\end{array}$ & $\begin{array}{c}\text { North Carolina } \\
\text { Gastonia } \\
\text { City of } \\
\text { June } 30\end{array}$ & $\begin{array}{c}\text { North Carolina } \\
\text { Greenville } \\
\text { Utilities } \\
\text { Comm } \\
\\
\text { June } 30\end{array}$ \\
\hline \multicolumn{7}{|l|}{ Sources of Energy } \\
\hline 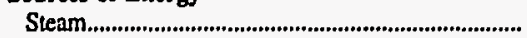 & 0 & 0 & $\mathbf{0}$ & 0 & 0 & 0 \\
\hline 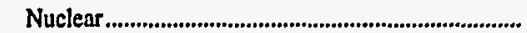 & 0 & 0 & 0 & 0 & 0 & 0 \\
\hline 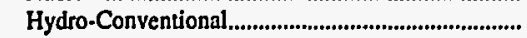 & 0 & 0 & $\mathbf{0}$ & 0 & 0 & 0 \\
\hline Hydro-Pumped Storage .............................................. & 0 & 0 & 0 & 0 & 0 & 0 \\
\hline 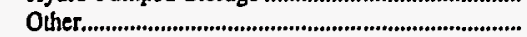 & 4,706 & 1,027 & 127,067 & 0 & 0 & 0 \\
\hline (Less) Energy for Pumping...................................... & 0 & 0 & 0 & 0 & 0 & 0 \\
\hline 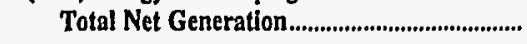 & 4,706 & 1,027 & 127,067 & 0 & 0 & 0 \\
\hline 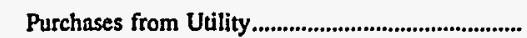 & 467,947 & 270,582 & $1,342,756$ & 150,600 & 659,903 & $1,329,000$ \\
\hline $\begin{array}{l}\text { Purchases from Nonutility............................................ } \\
\text { Power Exchanges }\end{array}$ & 0 & 0 & 0 & 0 & 0 & 0 \\
\hline 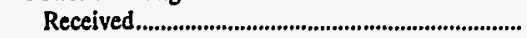 & 0 & 0 & 618,404 & 0 & 0 & 0 \\
\hline 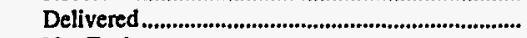 & 0 & 0 & 31,595 & 0 & 0 & 0 \\
\hline 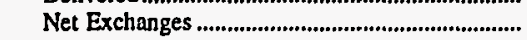 & 0 & 0 & 586,809 & $\mathbf{0}$ & 0 & 0 \\
\hline \multicolumn{7}{|l|}{ Transmission for Others (Wheeling) } \\
\hline 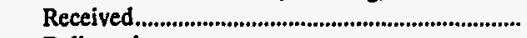 & $\mathbf{0}$ & 0 & 0 & 0 & 0 & 0 \\
\hline 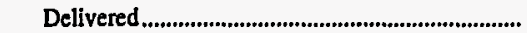 & 0 & 0 & 0 & 0 & 0 & 0 \\
\hline Net Transmission for Others ................................... & 0 & 0 & 0 & $\mathbf{0}$ & 0 & 0 \\
\hline $\begin{array}{l}\text { Transmission by Others Losses.................................... } \\
\text { Total Net Energy }\end{array}$ & 0 & $\mathbf{0}$ & 0 & 0 & 0 & 0 \\
\hline Generated and Received.................................. & 472,653 & 271,609 & $2,056,632$ & 150,600 & 659,903 & $1,329,000$ \\
\hline \multicolumn{7}{|l|}{ Dispositton of Energy } \\
\hline 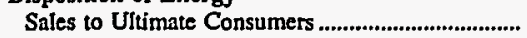 & 432,330 & 251,408 & $2,003,129$ & 145,178 & 586,858 & $1,227,000$ \\
\hline 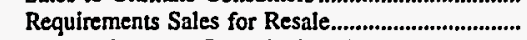 & 0 & 0 & 0 & 0 & 0 & 37,000 \\
\hline Nonrequirements Sales for Resale .......................... & 0 & 0 & 31,595 & 0 & 0 & 0 \\
\hline 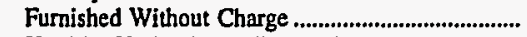 & 0 & 0 & 0 & 0 & 21,377 & 0 \\
\hline Used by Utility (excluding station use)................... & 2,342 & $\mathbf{0}$ & 0 & 0 & 9,448 & 0 \\
\hline 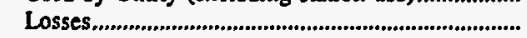 & 37,981 & 20,201 & 21,908 & 5,422 & 42,220 & 65,000 \\
\hline 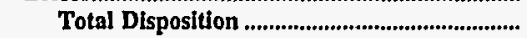 & 472,653 & 271,609 & $2,056,632$ & 150,600 & 659,903 & $1,329,000$ \\
\hline
\end{tabular}

Note: Totals may not equal sum of components because of independent rounding. Double counting occurs in components of both sources and disposition of energy and thus neither provides a true total. Purchases from utilities, net interchanges, and net wheeling (except for imports) are included in net generation. Sales for resale is included in sales to ultimate consumers.

Source: Energy Information Administration, Form EIA-412, "Annual Report of Public Electric Utilities." 
Table 26. Electric Energy Account by Major U.S. Publicly Owned Electric Utility Within State, 1996 (Continued)

(Megawatthours)

\begin{tabular}{|c|c|c|c|c|c|c|}
\hline Item & $\begin{array}{c}\text { North Carolina } \\
\text { High } \\
\text { Point } \\
\text { Town } \\
\text { of } \\
\text { June } 30\end{array}$ & $\begin{array}{l}\text { North Carolina } \\
\text { Kinston } \\
\text { City of } \\
\text { June } 30\end{array}$ & $\begin{array}{l}\text { North Carolina } \\
\text { Lexington } \\
\text { City of } \\
\text { June } 30\end{array}$ & $\begin{array}{l}\text { North Carolina } \\
\text { Lumberton } \\
\text { City of } \\
\text { June } 30\end{array}$ & $\begin{array}{l}\text { North Carolina } \\
\text { Monroe } \\
\text { City of } \\
\text { June } 30\end{array}$ & $\begin{array}{l}\text { North Carolina } \\
\text { Morganton } \\
\text { City of } \\
\text { June } 30\end{array}$ \\
\hline \multicolumn{7}{|l|}{ Sources of Energy } \\
\hline 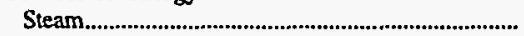 & 0 & 0 & 0 & 0 & 0 & \\
\hline Nuclear & 0 & 0 & $\mathbf{0}$ & 0 & 0 & 0 \\
\hline 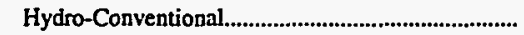 & 0 & $\mathbf{0}$ & 0 & 0 & 0 & 0 \\
\hline 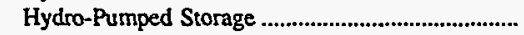 & 0 & $\mathbf{0}$ & $\mathbf{0}$ & 0 & $\mathbf{0}$ & 0 \\
\hline 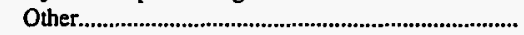 & 0 & 0 & 0 & 0 & 0 & 0 \\
\hline 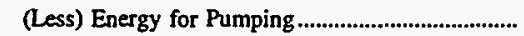 & 0 & $\mathbf{0}$ & 0 & 0 & 0 & 0 \\
\hline Total Net Generation & $\mathbf{0}$ & 0 & 0 & $\mathbf{0}$ & o & 0 \\
\hline Purchases from Utility................. & 914,222 & 462,655 & 482,171 & 279,920 & 484,110 & 313,816 \\
\hline 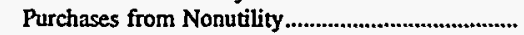 & $\mathbf{0}$ & 0 & 0 & 0 & 0 & \\
\hline \multicolumn{7}{|l|}{ Power Exchanges } \\
\hline Received & 0 & 0 & 0 & 0 & 0 & 0 \\
\hline 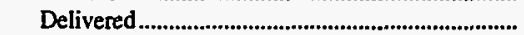 & 0 & 0 & 0 & 0 & 0 & 0 \\
\hline Net Exchanges.................................................................... & 0 & 0 & 0 & 0 & 0 & 0 \\
\hline \multicolumn{7}{|l|}{ Transmission for Others (Wheeling) } \\
\hline Received & 0 & 0 & $\mathbf{0}$ & 0 & 0 & 0 \\
\hline 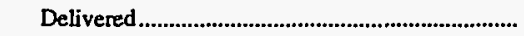 & 0 & 0 & $\mathbf{0}$ & 0 & $\mathbf{0}$ & 0 \\
\hline Net Transmission for Others ..................................... & 0 & $\mathbf{0}$ & o & 0 & 0 & 0 \\
\hline $\begin{array}{l}\text { Transmission by Others Losses................................... } \\
\text { Total Net Energy }\end{array}$ & 0 & 0 & 0 & 0 & 0 & 0 \\
\hline 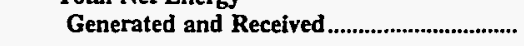 & 914,222 & 462,655 & 482,171 & 279,920 & 484,110 & 313,816 \\
\hline \multicolumn{7}{|l|}{ Disposition of Energy } \\
\hline Sales to Ultimate Consumers & 835,212 & 441,347 & 482,171 & 258,226 & 459,134 & 288,384 \\
\hline 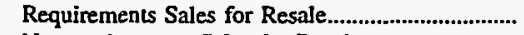 & 0 & 0 & 0 & 0 & 0 & 0 \\
\hline Nonrequirements Sales for Resale ................................ & 0 & 0 & $\mathbf{0}$ & 0 & 0 & 0 \\
\hline 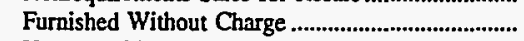 & 0 & 0 & 0 & 0 & 0 & 1.541 \\
\hline 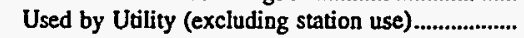 & 0 & 0 & $\mathbf{0}$ & 11,179 & 0 & 0 \\
\hline 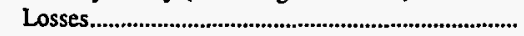 & 79,010 & 21,308 & 0 & 10,515 & 24,976 & 23,891 \\
\hline 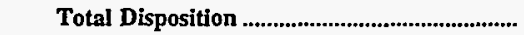 & 914,222 & 462,655 & 482,171 & 279,920 & 484,110 & 313,816 \\
\hline
\end{tabular}

Note: Totals may not equal sum of components because of independent rounding. Double counting occurs in components of both sources and disposition of energy and thus neither provides a true total. Purchases from utilities, net interchanges, and net wheeling (except for imports) are included in net generation.

Source: Energy Information Administration, Form EIA-412, "Annual Report of Public Electric Utilities." 
Table 26. Electric Energy Account by Major U.S. Publicly Owned Electric Utility Within State, 1996 (Continued)

(Megawatthours)

\begin{tabular}{|c|c|c|c|c|c|c|}
\hline Item & $\begin{array}{l}\text { North Carolina } \\
\text { Murphy } \\
\text { City of } \\
\text { June } 30\end{array}$ & $\begin{array}{l}\text { North Carolina } \\
\text { New Bern } \\
\text { City of } \\
\text { June } 30\end{array}$ & $\begin{array}{l}\text { North Carolina } \\
\text { New River } \\
\text { Light } \\
\text { \& } \\
\text { Power Co } \\
\text { December } 31\end{array}$ & $\begin{array}{c}\text { North Carolina } \\
\text { North } \\
\text { Carolina } \\
\text { Eastern M P A } \\
\text { December } 31\end{array}$ & $\begin{array}{l}\text { North Carolina } \\
\text { North } \\
\text { Carolina } \\
\text { Mun } \\
\text { Power Agny } \\
\text { December } 31\end{array}$ & $\begin{array}{l}\text { North Carolina } \\
\text { Rocky Mount } \\
\text { City of } \\
\text { June } 30\end{array}$ \\
\hline \multicolumn{7}{|l|}{ Sources of Energy } \\
\hline Steam & 0 & 0 & 0 & 979,297 & 0 & 0 \\
\hline 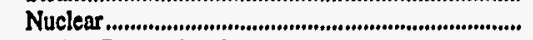 & 0 & 0 & 0 & $3,147,610$ & $5,832,618$ & 0 \\
\hline 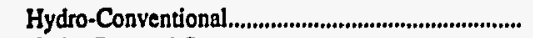 & 0 & 0 & 0 & 0 & 0 & 0 \\
\hline 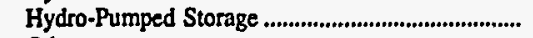 & 0 & 0 & 0 & 0 & 0 & 0 \\
\hline 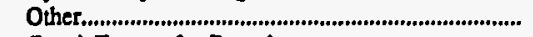 & 0 & 0 & 0 & 448,819 & 0 & 0 \\
\hline 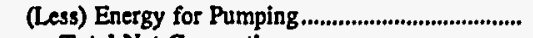 & 0 & 0 & 0 & 0 & $\mathbf{0}$ & 0 \\
\hline Total Net Generation & 0 & 0 & $\mathbf{0}$ & $4,575,726$ & $5,832,618$ & 0 \\
\hline 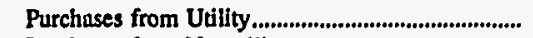 & 135,214 & 411,179 & 185,530 & $2,259,244$ & 820,959 & 828,273 \\
\hline $\begin{array}{l}\text { Purchases from Nonutility.......................................... } \\
\text { Power Exchanges }\end{array}$ & 0 & 0 & 0 & 0 & 0 & 0 \\
\hline Received & 0 & 0 & 0 & 0 & 0 & 0 \\
\hline 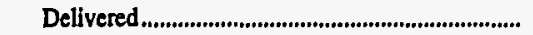 & 0 & 0 & 0 & 0 & 0 & 0 \\
\hline 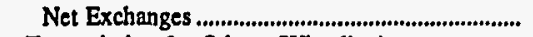 & 0 & 0 & 0 & 0 & 0 & 0 \\
\hline \multicolumn{7}{|l|}{ Transmission for Others (Wheeling) } \\
\hline Received & 0 & 0 & 0 & 0 & 0 & 0 \\
\hline 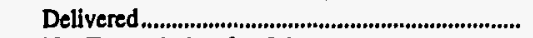 & 0 & 0 & 0 & 0 & 0 & 0 \\
\hline 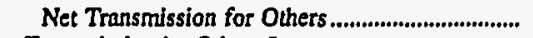 & 0 & 0 & $\mathbf{0}$ & 0 & 0 & 0 \\
\hline $\begin{array}{l}\text { Transmission by Others Losses....................................... } \\
\text { Total Net Energy }\end{array}$ & 0 & 0 & 0 & 0 & 0 & 0 \\
\hline 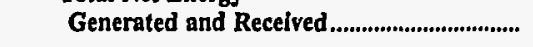 & 135,214 & 411,179 & 185,530 & $6,834,970$ & $6,653,577$ & 828,273 \\
\hline \multicolumn{7}{|l|}{ Disposition of Energy } \\
\hline 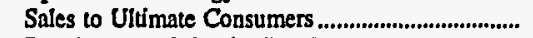 & 128,084 & 395,777 & 178,701 & 0 & $\mathbf{0}$ & 732,119 \\
\hline 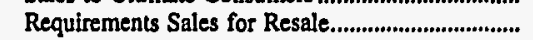 & 0 & 0 & 0 & $6,709,020$ & $6,556,548$ & 20,087 \\
\hline Nonrequirements Sales for Resale .......................... & 0 & 0 & 0 & 0 & 0 & 0 \\
\hline Furnished Without Charge .......................................... & 0 & 0 & 0 & 0 & 0 & 0 \\
\hline 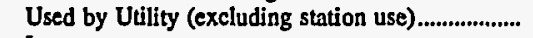 & 272 & 264 & 316 & 0 & 0 & $\mathbf{0}$ \\
\hline 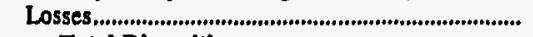 & 6,858 & 15,138 & 6,513 & 125,950 & 97,029 & 76,067 \\
\hline 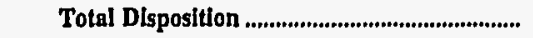 & 135,214 & 411,179 & 185,530 & $6,834,970$ & $6,653,577$ & 828,273 \\
\hline
\end{tabular}

Note: Totals may not equal sum of components because of independent rounding. Double counting occurs in components of both sources and disposition of energy and thus neither provides a true total. Purchases from utilities, net interchanges, and net wheeling (except for imports) are included in net generation.

Source: Energy Information Administration, Form ElA-412, "Annual Report of Public Electric Utilities." 
Table 26. Electric Energy Account by Major U.S. Publicly Owned Electric Utility Within State, 1996 (Continued)

(Megawatthours)

\begin{tabular}{|c|c|c|c|c|c|c|}
\hline Item & $\begin{array}{c}\text { North Carolina } \\
\text { Shelby } \\
\text { City of } \\
\text { June } 30\end{array}$ & $\begin{array}{c}\text { North Carolina } \\
\text { Statesville } \\
\text { City of } \\
\text { June } 30\end{array}$ & $\begin{array}{c}\text { North Carolina } \\
\text { Tarboro } \\
\text { Town of } \\
\text { June } 30\end{array}$ & $\begin{array}{c}\text { North Carolina } \\
\text { Washington } \\
\text { City of } \\
\text { June } 30\end{array}$ & $\begin{array}{l}\text { North Carolina } \\
\text { Wilson } \\
\text { City of } \\
\text { June } 30\end{array}$ & $\begin{array}{l}\text { Ohio } \\
\text { American } \\
\text { Mun } \\
\text { Power } \\
\text { Ohio Inc } \\
\text { December } 31\end{array}$ \\
\hline \multicolumn{7}{|l|}{ Sources of Energy } \\
\hline 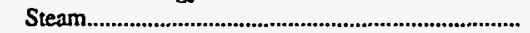 & 0 & 0 & $\mathbf{0}$ & 0 & 0 & $1,350,343$ \\
\hline Nuclear & 0 & 0 & 0 & 0 & 0 & 0 \\
\hline 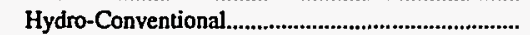 & 0 & 0 & 0 & 0 & $\mathbf{0}$ & 0 \\
\hline 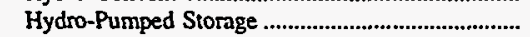 & 0 & 0 & 0 & 0 & 0 & 0 \\
\hline Other & 0 & $\mathbf{0}$ & $\mathbf{0}$ & 0 & 0 & 0 \\
\hline 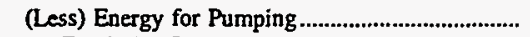 & 0 & 0 & 0 & 0 & 0 & $\mathbf{0}$ \\
\hline Total Net Generation & 0 & 0 & 0 & 0 & 0 & $1,350,343$ \\
\hline 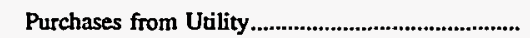 & 185,021 & 408,354 & 258,566 & 266,860 & $1,143,527$ & $4,461,725$ \\
\hline \multicolumn{7}{|l|}{ Power Exchanges } \\
\hline 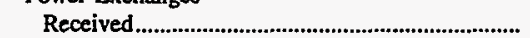 & 0 & 0 & 0 & 0 & 0 & 0 \\
\hline 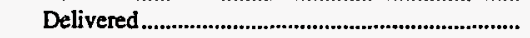 & 0 & 0 & 0 & 0 & 0 & 0 \\
\hline 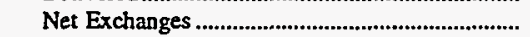 & 0 & 0 & 0 & 0 & 0 & 0 \\
\hline \multicolumn{7}{|l|}{ Transmission for Others (Wheeling) } \\
\hline 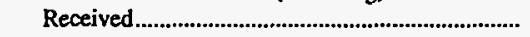 & 0 & 0 & 0 & 0 & 0 & 0 \\
\hline 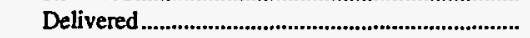 & 0 & 0 & $\mathbf{0}$ & 0 & 0 & 0 \\
\hline 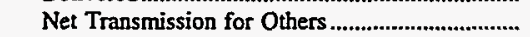 & 0 & 0 & 0 & 0 & 0 & 0 \\
\hline 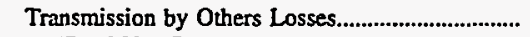 & 0 & 0 & 0 & 0 & 0 & 0 \\
\hline Total Net Energy & & & & & . & \\
\hline 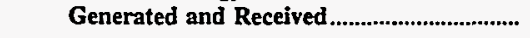 & 185,021 & 408,354 & 258,566 & 266,860 & $1,143,527$ & $5,812,068$ \\
\hline \multicolumn{7}{|l|}{ Disposition of Energy } \\
\hline 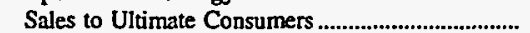 & 177,198 & 379,637 & 254,746 & 249,439 & $1,015,539$ & 797,973 \\
\hline 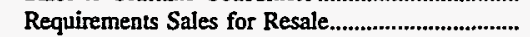 & 0 & 0 & 0 & 0 & 64,858 & $4,984,129$ \\
\hline Nonrequirements Sales for Resale ............................. & 0 & 0 & 0 & 0 & 0 & 0 \\
\hline 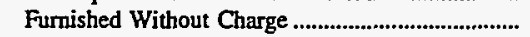 & 0 & 0 & 0 & 0 & 0 & 0 \\
\hline Used by Utility (excluding station use)...................... & 0 & 0 & 0 & 0 & 10,368 & 0 \\
\hline 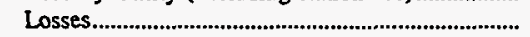 & 7,823 & 28,717 & 3,820 & 17,421 & 52,762 & 29,966 \\
\hline Total Disposition & 185,021 & 408,354 & 258,566 & 266,860 & $1,143,527$ & $5,812,068$ \\
\hline
\end{tabular}

Note: Totals may not equal sum of components because of independent rounding. Double counting occurs in components of both sources and disposition of energy and thus neither provides a true total. Purchases from utilities, net interchanges, and net wheeling (except for imports) are included in net generation.

Source: Energy Information Administration, Form EIA-412, "Annual Report of Public Electric Utilities." 
Table 26. Electric Energy Account by Major U.S. Publicly Owned Electric Utility Within State, 1996 (Continued)

(Megawatthours)

\begin{tabular}{|c|c|c|c|c|c|c|}
\hline Item & $\begin{array}{c}\text { Ohio } \\
\text { Bowling } \\
\text { Green } \\
\text { City of } \\
\text { December } 31\end{array}$ & $\begin{array}{l}\text { Ohio } \\
\text { Bryan } \\
\text { City of } \\
\text { December } 31\end{array}$ & $\begin{array}{l}\text { Ohio } \\
\text { Celina } \\
\text { City of } \\
\text { December } 31\end{array}$ & $\begin{array}{l}\text { Ohio } \\
\text { Cleveland } \\
\text { City of } \\
\text { December } 31\end{array}$ & $\begin{array}{l}\text { Ohio } \\
\text { Clyde } \\
\text { City of } \\
\text { December } 31\end{array}$ & $\begin{array}{l}\text { Ohio } \\
\text { Columbus } \\
\text { City of } \\
\text { December } 31\end{array}$ \\
\hline \multicolumn{7}{|l|}{ Sources of Energy } \\
\hline Steam,........................... & 0 & 0 & $\mathbf{0}$ & 0 & $\mathbf{0}$ & 0 \\
\hline 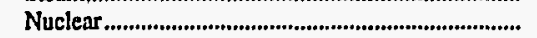 & 0 & 0 & $\mathbf{0}$ & 0 & 0 & 0 \\
\hline 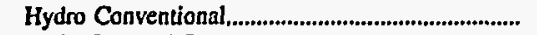 & 0 & 1,264 & 0 & 0 & $\mathbf{0}$ & 2,437 \\
\hline Hydro-Pumped Storage & $\mathbf{0}$ & 0 & $\mathbf{0}$ & $\mathbf{0}$ & $\mathbf{0}$ & 0 \\
\hline 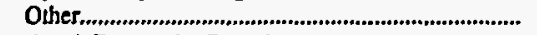 & $\mathbf{0}$ & 3,225 & 0 & 3,821 & $\mathbf{0}$ & 0 \\
\hline 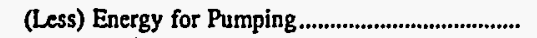 & 0 & 0 & $\mathbf{0}$ & 0 & 0 & 0 \\
\hline 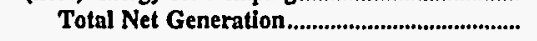 & 0 & 4,489 & 0 & 3,821 & 0 & 2,437 \\
\hline 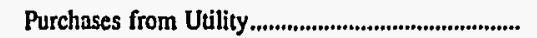 & 340,425 & 256,669 & 170,220 & $1,483,475$ & 140,301 & 738,055 \\
\hline 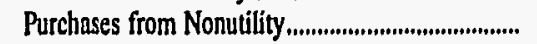 & 0 & 0 & 0 & 0 & 0 & 0 \\
\hline \multicolumn{7}{|l|}{ Power Exchanges } \\
\hline Received .................. & 0 & 0 & $\mathbf{0}$ & o & D & 0 \\
\hline 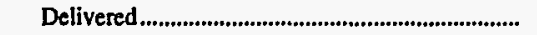 & $\mathbf{0}$ & 0 & 0 & 63,527 & 0 & 0 \\
\hline 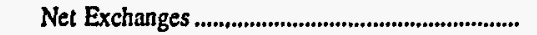 & $\mathbf{0}$ & 0 & 0 & $-63,527$ & o & 0 \\
\hline \multicolumn{7}{|l|}{ Transmission for Others (Wheeling) } \\
\hline Received ..............., & 0 & 0 & $\mathbf{0}$ & 0 & $\mathbf{0}$ & $\mathbf{0}$ \\
\hline 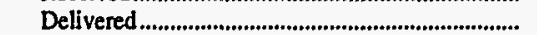 & 0 & 0 & 0 & 0 & 0 & 0 \\
\hline 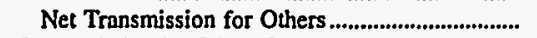 & 0 & $\mathbf{0}$ & 0 & 0 & 0 & 0 \\
\hline 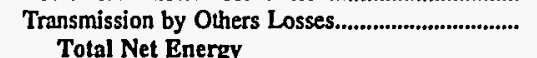 & 0 & 0 & 0 & $-53,295$ & 0 & 0 \\
\hline 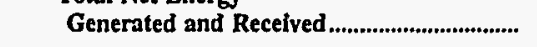 & 340,425 & 261,158 & 170,220 & $1,370,474$ & 140,301 & 740,492 \\
\hline \multicolumn{7}{|l|}{ Disposition of Energy } \\
\hline Sales to Ultimate Consumers........... & 320,591 & 249,469 & 164,138 & $1,370,474$ & 140,301 & 665,881 \\
\hline 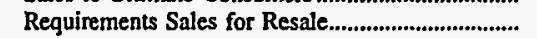 & 2,907 & & 0 & 0 & 0 & 86 \\
\hline 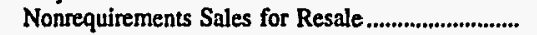 & 0 & 1,264 & 0 & 0 & 0 & $\mathbf{0}$ \\
\hline 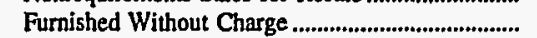 & 2,091 & 3,342 & 2,411 & 0 & 0 & 29,874 \\
\hline Used by Utility (excluding station use).................... & 346 & 1,513 & 352 & D & 0 & 687 \\
\hline 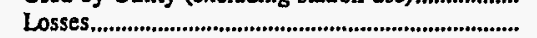 & 14,490 & 5,570 & 3,319 & 0 & 0 & 43,964 \\
\hline 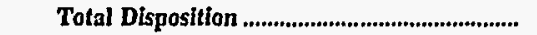 & 340,425 & 261,158 & 170,220 & $1,370,474$ & 140,301 & 740,492 \\
\hline
\end{tabular}

Note: Totals may not equal sum of components because of independent rounding. Double counting occurs in components of both sources and disposition of energy and thus neither provides a true total. Purchases from utilities, net interchanges, and net wheeling (except for imports) are included in net generation.

Source: Energy Information Administration, Form EIA-412, “Annual Report of Public Electric Utilities." 
Table 26. Electric Energy Account by Major U.S. Publicly Owned Electric Utility Within State, 1996 (Continued)

(Megawatthours)

\begin{tabular}{|c|c|c|c|c|c|c|}
\hline Item & $\begin{array}{l}\text { Ohio } \\
\text { Cuyahoga } \\
\text { Falls } \\
\text { City of } \\
\text { December } 31\end{array}$ & $\begin{array}{l}\text { Ohio } \\
\text { Dover } \\
\text { City of } \\
\text { December } 31\end{array}$ & $\begin{array}{c}\text { Ohio } \\
\text { Hamilton } \\
\text { City of } \\
\text { December } 31\end{array}$ & $\begin{array}{c}\text { Ohio } \\
\text { Napoleon } \\
\text { City of } \\
\text { December } 31\end{array}$ & $\begin{array}{c}\text { Ohio } \\
\text { Niles } \\
\text { City of } \\
\text { December } 31\end{array}$ & $\begin{array}{l}\text { Ohio } \\
\text { Orrville } \\
\text { City of } \\
\text { December } 31\end{array}$ \\
\hline \multicolumn{7}{|l|}{ Sources of Energy } \\
\hline 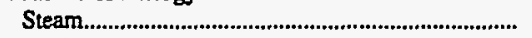 & 0 & 0 & 500,978 & 0 & 0 & 287,007 \\
\hline 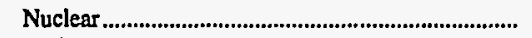 & 0 & 0 & 0 & 0 & 0 & 0 \\
\hline 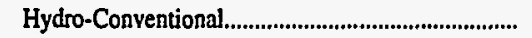 & 0 & 0 & 0 & 0 & 0 & 0 \\
\hline 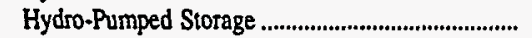 & 0 & 0 & 0 & 0 & 0 & 0 \\
\hline 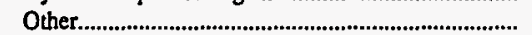 & 0 & 0 & 0 & 0 & 0 & 0 \\
\hline 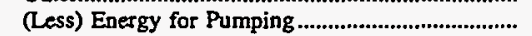 & 0 & 0 & 0 & 0 & 0 & 0 \\
\hline 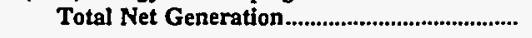 & $\mathbf{0}$ & $\mathbf{0}$ & 500,978 & $\mathbf{0}$ & $\mathbf{0}$ & 287,007 \\
\hline 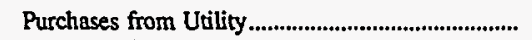 & 358,004 & 125,031 & 298,681 & 159,069 & 291,867 & 33,058 \\
\hline 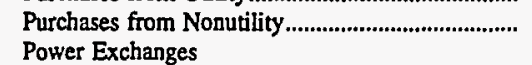 & 0 & 0 & 0 & 0 & 0 & 0 \\
\hline 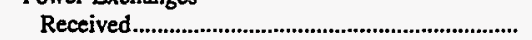 & 0 & 0 & 18,066 & 0 & 0 & 1,016 \\
\hline 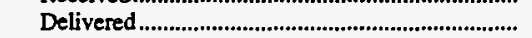 & 0 & 0 & 4,185 & 0 & 0 & 864 \\
\hline 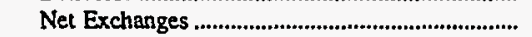 & 0 & 0 & 13,881 & 0 & 0 & 152 \\
\hline \multicolumn{7}{|l|}{ Transmission for Others (Wheeling) } \\
\hline 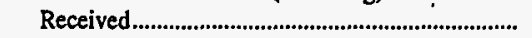 & 0 & 0 & 0 & 0 & 0 & 0 \\
\hline 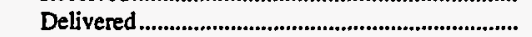 & 0 & 0 & 0 & 0 & 0 & 0 \\
\hline 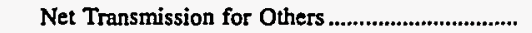 & 0 & 0 & 0 & 0 & 0 & 0 \\
\hline $\begin{array}{l}\text { Transmission by Others Losses.................................... } \\
\text { Total Net Energy }\end{array}$ & 0 & 0 & 0 & 0 & 0 & 0 \\
\hline 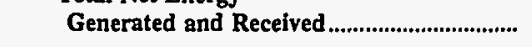 & 358,004 & 125,031 & 813,540 & 159,069 & 291,867 & 320,217 \\
\hline \multicolumn{7}{|l|}{ Disposition of Energy } \\
\hline 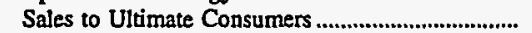 & 323,493 & 125,031 & 570,349 & 149,863 & 261,488 & 289,562 \\
\hline 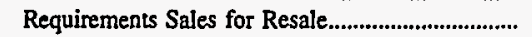 & 0 & 0 & 165,563 & 0 & 0 & 39,095 \\
\hline 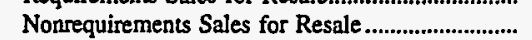 & 0 & 0 & 0 & 0 & 0 & 152 \\
\hline Furnished Without Charge & 12,234 & 0 & 0 & 584 & 11,676 & 2,305 \\
\hline 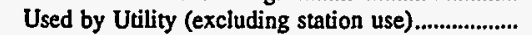 & 797 & 0 & 11,036 & 0 & 45 & 345 \\
\hline 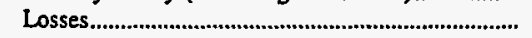 & 21,480 & 0 & 66,591 & 8,622 & 18,658 & $-11,242$ \\
\hline 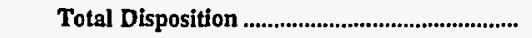 & 358,004 & 125,031 & 813,540 & 159,069 & 291,867 & 320,217 \\
\hline
\end{tabular}

Note: Totals may not equal sum of components because of independent rounding. Double counting occurs in components of both sources and disposition of energy and thus neither provides a true total. Purchases from utilities, net interchanges, and net wheeling (except for imports) are included in net generation.

Source: Energy Information Administration, Form EIA-412, "Annual Report of Public Electric Utilities." 
Table 26. Electric Energy Account by Major U.S. Publicly Owned Electric Utility Within State, 1996 (Continued)

(Megawatthours)

\begin{tabular}{|c|c|c|c|c|c|c|}
\hline Item & $\begin{array}{c}\text { Ohio } \\
\text { Painesville } \\
\text { City of } \\
\text { December } 31\end{array}$ & $\begin{array}{c}\text { Ohio } \\
\text { Piqua } \\
\text { City of } \\
\text { December } 31\end{array}$ & $\begin{array}{c}\text { Ohio } \\
\text { St Marys } \\
\text { City of } \\
\text { December } 31\end{array}$ & $\begin{array}{c}\text { Ohio } \\
\text { Wadsworth } \\
\text { City of } \\
\text { December } 31\end{array}$ & $\begin{array}{c}\text { Ohio } \\
\text { Wapakoneta } \\
\text { City of } \\
\text { December } 31\end{array}$ & $\begin{array}{c}\text { Ohio } \\
\text { Westerville } \\
\text { City of } \\
\text { December } 31\end{array}$ \\
\hline \multicolumn{7}{|l|}{ Sources of Energy } \\
\hline 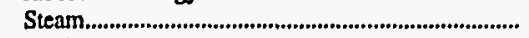 & 143,829 & 24,302 & 39,796 & 0 & 0 & 0 \\
\hline 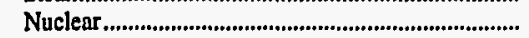 & 0 & 0 & 0 & 0 & 0 & 0 \\
\hline 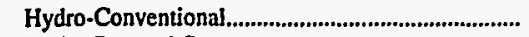 & $\mathbf{0}$ & 0 & 0 & 0 & 0 & 0 \\
\hline Hydro-Pumped Storage .............................................. & 0 & 0 & 0 & 0 & 0 & 0 \\
\hline 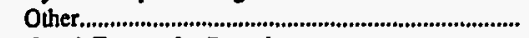 & 0 & 338 & $\mathbf{0}$ & 0 & 0 & 0 \\
\hline 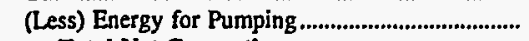 & 0 & 0 & $\mathbf{0}$ & 0 & 0 & 0 \\
\hline 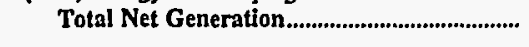 & 143,829 & 24,640 & 39,796 & 0 & 0 & $\mathbf{0}$ \\
\hline 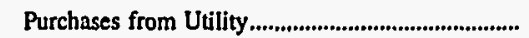 & 67,712 & 261,762 & 143,913 & 247,061 & 168,350 & 392,667 \\
\hline $\begin{array}{l}\text { Purchases from Nonutility........................................... } \\
\text { Power Exchanges }\end{array}$ & $\mathbf{0}$ & 0 & 2,257 & $\mathbf{0}$ & 0 & 0 \\
\hline Received & 3,988 & 1 & 947 & $\mathbf{0}$ & $\mathbf{0}$ & 0 \\
\hline 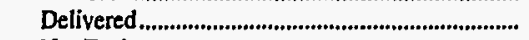 & 2,158 & 0 & 3,661 & 0 & 0 & 0 \\
\hline 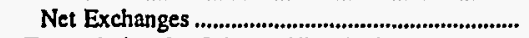 & 1,830 & 0 & $-2,714$ & $\mathbf{0}$ & 0 & 0 \\
\hline \multicolumn{7}{|l|}{ Transmission for Others (Wheeling) } \\
\hline Received & $\mathbf{0}$ & 1 & 0 & 0 & 0 & $\mathbf{0}$ \\
\hline Delivered & 0 & 0 & 0 & $\mathbf{0}$ & 0 & 0 \\
\hline 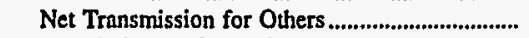 & 0 & 0 & 0 & 0 & 0 & 0 \\
\hline $\begin{array}{l}\text { Transmission by Others Losses................................ } \\
\text { Total Net Energy }\end{array}$ & $\mathbf{0}$ & 0 & 0 & $\mathbf{0}$ & 0 & -395 \\
\hline Generated and Received.................................... & 213,371 & 286,403 & 183,252 & 247,061 & 168,350 & 392,272 \\
\hline \multicolumn{7}{|l|}{ Disposition of Energy } \\
\hline 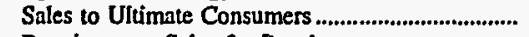 & 191,436 & 269,272 & 161,095 & 234,373 & 158,918 & 375,259 \\
\hline 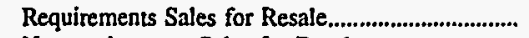 & $\mathbf{0}$ & 38 & 8,917 & 0 & 0 & 0 \\
\hline Nonrequirements Sales for Resale ........................... & $\mathbf{0}$ & 0 & 0 & $\mathbf{0}$ & 0 & 0 \\
\hline 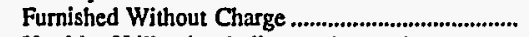 & 9,133 & 3,166 & 2,156 & 6,919 & 9,432 & 1,472 \\
\hline Used by Utility (excluding station use)..................... & 0 & 0 & 0 & 57 & 0 & 0 \\
\hline 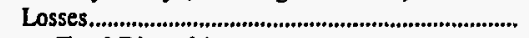 & 12,802 & 13,927 & 11,084 & 5,712 & 0 & 15,541 \\
\hline 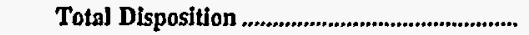 & 213,371 & 286,403 & 183,252 & 247,061 & 168,350 & 392,272 \\
\hline
\end{tabular}

Note: Totals may not equal sum of components because of independent rounding. Double counting occurs in components of both sources and disposition of energy and thus neither provides a true total. Purchases from utilities, net interchanges, and net wheeling (except for imports) are included in net generation.

Source: Energy Information Administration, Form EIA-412, "Annual Report of Public Electric Utilities." 
Table 26. Electric Energy Account by Major U.S. Publicly Owned Electric Utility Within State, 1996 (Continued)

(Megawatthours)

\begin{tabular}{|c|c|c|c|c|c|c|}
\hline Item & $\begin{array}{l}\text { Oklahoma } \\
\text { Altus } \\
\text { City of } \\
\text { June } 30\end{array}$ & $\begin{array}{l}\text { Oklahoma } \\
\text { Claremore } \\
\text { City of } \\
\text { June } 30\end{array}$ & $\begin{array}{l}\text { Oklahoma } \\
\text { Duncan } \\
\text { City of } \\
\text { June } 30\end{array}$ & $\begin{array}{l}\text { Oklahoma } \\
\text { Edmond } \\
\text { City of } \\
\text { June } 30\end{array}$ & $\begin{array}{l}\text { Oklahoma } \\
\text { Grand River } \\
\text { Dam } \\
\text { Authority } \\
\text { December } 31\end{array}$ & $\begin{array}{l}\text { Oklahoma } \\
\text { Miami } \\
\text { City of } \\
\text { June } 30\end{array}$ \\
\hline \multicolumn{7}{|l|}{ Sources of Energy } \\
\hline 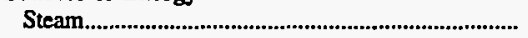 & 0 & 0 & 0 & 0 & $4,417,699$ & 0 \\
\hline Nuclear & 0 & $\mathbf{0}$ & 0 & 0 & 0 & 0 \\
\hline 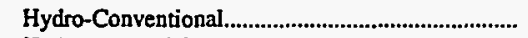 & 0 & 0 & 0 & 0 & 455,459 & 0 \\
\hline 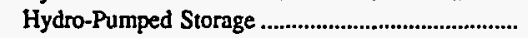 & 0 & 0 & 0 & 0 & 116,128 & 0 \\
\hline 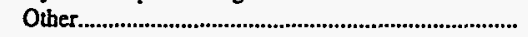 & 0 & 0 & 0 & 0 & 0 & 0 \\
\hline 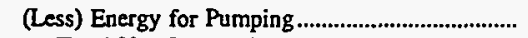 & 0 & 0 & 0 & 0 & 195,999 & 0 \\
\hline Total Net Generation & o & 0 & $\mathbf{0}$ & 0 & $4,793,287$ & 0 \\
\hline 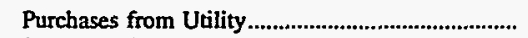 & 179,278 & 240,420 & 165,371 & 562,002 & 673,266 & 156,561 \\
\hline \multicolumn{7}{|l|}{ Power Exchanges } \\
\hline 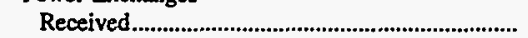 & 0 & 0 & 0 & 0 & 109,026 & 0 \\
\hline 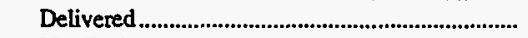 & 0 & 0 & 0 & 0 & 21,197 & 0 \\
\hline 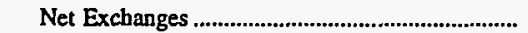 & 0 & 0 & 0 & 0 & 87,829 & 0 \\
\hline \multicolumn{7}{|l|}{ Transmission for Others (Wheeling) } \\
\hline 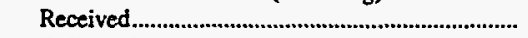 & 0 & 0 & 0 & 0 & 11,745 & 0 \\
\hline 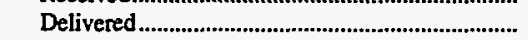 & 0 & 0 & 0 & 0 & 11,745 & 0 \\
\hline 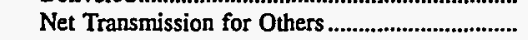 & 0 & 0 & 0 & 0 & 0 & 0 \\
\hline $\begin{array}{l}\text { Transmission by Others Losses............................. } \\
\text { Total Net Energy }\end{array}$ & 0 & 0 & 0 & 0 & 0 & 0 \\
\hline 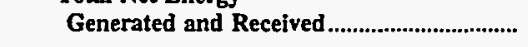 & 179,278 & 240,420 & 165,371 & 562,002 & $5,554,382$ & 156,561 \\
\hline \multicolumn{7}{|l|}{ Disposition of Energy } \\
\hline 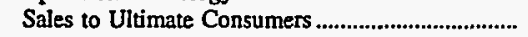 & 167,602 & 211,251 & 155,110 & 562,002 & 702,139 & 145,508 \\
\hline 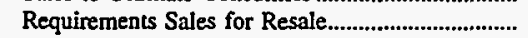 & 0 & 0 & 0 & 0 & $4,289,447$ & 0 \\
\hline Nonrequirements Sales for Resale ............................. & 0 & 0 & 0 & 0 & 321,363 & 0 \\
\hline 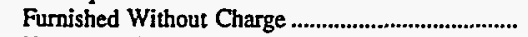 & 0 & 3,681 & 0 & 0 & 0 & 0 \\
\hline 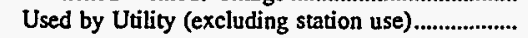 & 0 & 0 & 85 & 0 & 0 & 4,284 \\
\hline 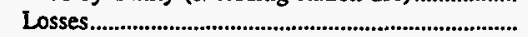 & 11,676 & 25,488 & 10,176 & 0 & 241,433 & 6,769 \\
\hline Total Disposition & 179,278 & 240,420 & 165,371 & 562,002 & $5,554,382$ & 156,561 \\
\hline
\end{tabular}

Note: Totals may not equal sum of components because of independent rounding. Double counting occurs in components of both sources and disposition of energy and thus neither provides a true total. Purchases from utilities, net interchanges, and net wheeling (except for imports) are included in net generation.

Source: Energy Information Administration, Form EIA-412, "Annual Report of Public Electric Utilities." 
Table 26. Electric Energy Account by Major U.S. Publicly Owned Electric Utility Within State, 1996 (Continued)

(Megawatthours)

\begin{tabular}{|c|c|c|c|c|c|c|}
\hline Item & $\begin{array}{l}\text { Oklahoma } \\
\text { Oklahoma } \\
\text { Municipal } \\
\text { Power Auth } \\
\text { December } 31\end{array}$ & $\begin{array}{l}\text { Oklahoma } \\
\text { Ponca } \\
\text { City City of } \\
\text { June } 30\end{array}$ & $\begin{array}{l}\text { Oklahoma } \\
\text { Stillwater } \\
\text { Utilities } \\
\text { Authority } \\
\text { June } 30\end{array}$ & $\begin{array}{l}\text { Oregon } \\
\text { Ashland } \\
\text { City of } \\
\text { June } 30\end{array}$ & $\begin{array}{l}\text { Oregon } \\
\text { Central } \\
\text { Lincoln } \\
\text { Peoples } \\
\text { Utl Dt } \\
\text { December } 31\end{array}$ & $\begin{array}{c}\text { Oregon } \\
\text { Clatskanie } \\
\text { Peoples } \\
\text { Util Dist } \\
\text { December } 31\end{array}$ \\
\hline \multicolumn{7}{|l|}{ Sources of Energy } \\
\hline 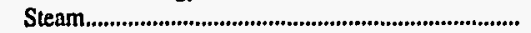 & 747,679 & 8,230 & 38,055 & 0 & $\mathbf{0}$ & $\mathbf{0}$ \\
\hline 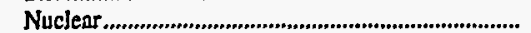 & 0 & $\mathbf{0}$ & 0 & 0 & 0 & $\mathbf{0}$ \\
\hline 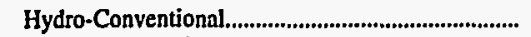 & 86,503 & $\mathbf{0}$ & 0 & 1,826 & 0 & 0 \\
\hline 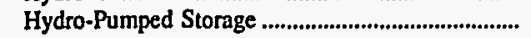 & 0 & 0 & 0 & 0 & 0 & 0 \\
\hline 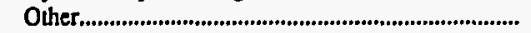 & 61,540 & 0 & 0 & 0 & $\mathbf{0}$ & $\mathbf{0}$ \\
\hline 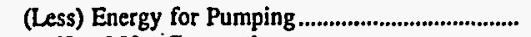 & 0 & $\mathbf{0}$ & 1,775 & 0 & 0 & 0 \\
\hline 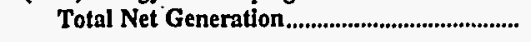 & 895,722 & 8,230 & 36,280 & 1,826 & $\mathbf{0}$ & 0 \\
\hline 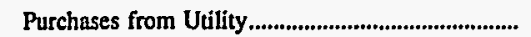 & $1,067,242$ & 328,218 & 398,180 & 153,057 & $1,303,275$ & 26,508 \\
\hline 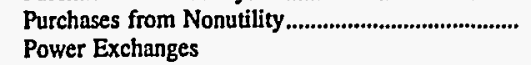 & 0 & 0 & 0 & 0 & 0 & 853,532 \\
\hline 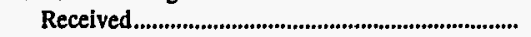 & 0 & 0 & 0 & $\mathbf{0}$ & 0 & 0 \\
\hline 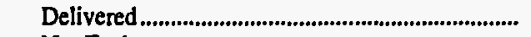 & 0 & 0 & 0 & 0 & 0 & 0 \\
\hline 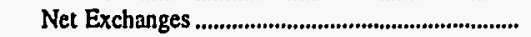 & 0 & 0 & 0 & $\mathbf{0}$ & 0 & $\mathbf{0}$ \\
\hline \multicolumn{7}{|l|}{ Transmission for Others (Wheeling) } \\
\hline 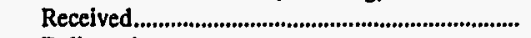 & 0 & $\mathbf{0}$ & 0 & 0 & $\mathbf{0}$ & 0 \\
\hline 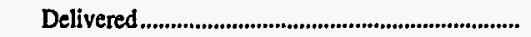 & 0 & 0 & 0 & 0 & 0 & 0 \\
\hline 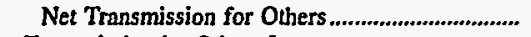 & 0 & 0 & 0 & 0 & 0 & 0 \\
\hline Transmission by Others Losses.................................. & 0 & $\mathbf{0}$ & 0 & 0 & 0 & 0 \\
\hline \multicolumn{7}{|l|}{ Total Net Energy } \\
\hline 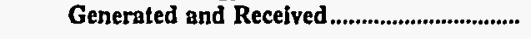 & $1,962,964$ & 336,448 & 434,460 & 154,883 & $1,303,275$ & 880,040 \\
\hline \multicolumn{7}{|l|}{ Disposition of Energy } \\
\hline 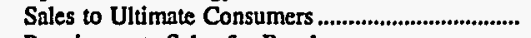 & 0 & 309,426 & 400,702 & 144,288 & $1,254,698$ & 875,736 \\
\hline Requirements Sales for Resale....................................... & $1,916,150$ & 0 & 0 & 0 & 0 & 0 \\
\hline Nonrequirements Sales for Resale ............................ & 0 & 0 & 0 & 0 & 0 & 0 \\
\hline Furnished Without Charge .......................................... & 0 & $\mathbf{0}$ & 12,160 & 0 & 0 & 0 \\
\hline Used by Utility (excluding station use)................... & 0 & 0 & 401 & 4,453 & 6,426 & 198 \\
\hline 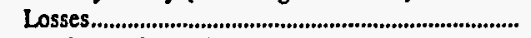 & 46,814 & 27,022 & 21,197 & 6,142 & 42,151 & 4,106 \\
\hline 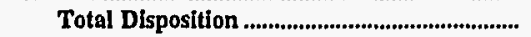 & $1,962,964$ & 336,448 & 434,460 & 154,883 & $1,303,275$ & 880,040 \\
\hline
\end{tabular}

Note: Totals may not equal sum of components because of independent rounding. Double counting occurs in components of both sources and disposition of energy and thus neither provides a true total. Purchases from utilities, net interchanges, and net wheeling (except for imports) are included in net generation.

Source: Energy Information Administration, Form EIA-412, "Annual Report of Public Electric Utilities." 
Table 26. Electric Energy Account by Major U.S. Publicly Owned Electric Utility Within State, 1996 (Continued)

(Megawatthours)

\begin{tabular}{|c|c|c|c|c|c|c|}
\hline Item & $\begin{array}{l}\text { Oregon } \\
\text { Columbia } \\
\text { River } \\
\text { Peoples } \\
\text { Ut Dist } \\
\text { December } 31\end{array}$ & $\begin{array}{l}\text { Oregon } \\
\text { Emerald } \\
\text { Peoples } \\
\text { Utility Dist } \\
\text { December } 31\end{array}$ & $\begin{array}{l}\text { Oregon } \\
\text { Eugene } \\
\text { City of } \\
\text { December } 31\end{array}$ & $\begin{array}{l}\text { Oregon } \\
\text { Forest Grove } \\
\text { City of } \\
\text { June } 30\end{array}$ & $\begin{array}{c}\text { Oregon } \\
\begin{array}{c}\text { McMinnville } \\
\text { City of }\end{array} \\
\text { June } 30\end{array}$ & $\begin{array}{c}\text { Oregon } \\
\text { Northern } \\
\text { Wasco } \\
\text { County PUD } \\
\\
\text { December } 31\end{array}$ \\
\hline \multicolumn{7}{|l|}{ Sources of Energy } \\
\hline 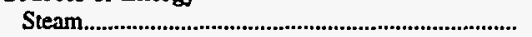 & 0 & 0 & 103,904 & 0 & 0 & 0 \\
\hline 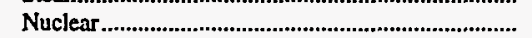 & 0 & 0 & 0 & 0 & 0 & 0 \\
\hline 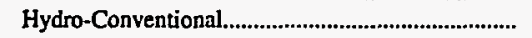 & 0 & 0 & 654,710 & 0 & 0 & 41,431 \\
\hline 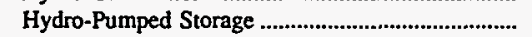 & 0 & 0 & 0 & 0 & 0 & 0 \\
\hline Other. & 0 & 17,333 & 0 & 0 & 0 & 0 \\
\hline (Less) Energy for Pumping........................................ & 0 & 0 & 0 & 0 & 0 & 0 \\
\hline Total Net Generation & $\mathbf{0}$ & 17,333 & 758,614 & 0 & $\mathbf{0}$ & 41,431 \\
\hline 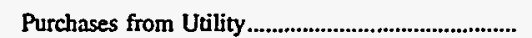 & 296,272 & 406,817 & $1,981,738$ & 230,576 & 685,807 & 266,227 \\
\hline $\begin{array}{l}\text { Purchases from Nonutility ........................................ } \\
\text { Power Exchanges }\end{array}$ & 0 & 0 & 0 & 0 & 0 & 0 \\
\hline 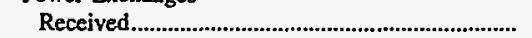 & $\mathbf{0}$ & 0 & 13,450 & 0 & 0 & 0 \\
\hline 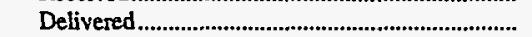 & 0 & 0 & 0 & 0 & 0 & 0 \\
\hline 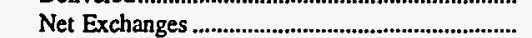 & 0 & 0 & 13,450 & 0 & 0 & 0 \\
\hline \multicolumn{7}{|l|}{ Transmission for Others (Wheeling) } \\
\hline 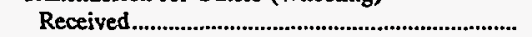 & 0 & 0 & 0 & 0 & 0 & 0 \\
\hline 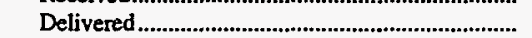 & 0 & 0 & 0 & $\mathbf{0}$ & 0 & 0 \\
\hline Net Transmission for Others ................................. & 0 & 0 & 0 & 0 & $\mathbf{0}$ & 0 \\
\hline 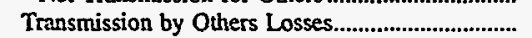 & 0 & 0 & 0 & 0 & 0 & 0 \\
\hline \multicolumn{7}{|l|}{ Total Net Energy } \\
\hline 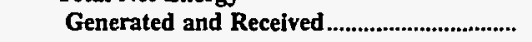 & 296,272 & 424,150 & $2,753,802$ & 230,576 & 685,807 & 307,658 \\
\hline \multicolumn{7}{|l|}{ Disposition of Energy } \\
\hline 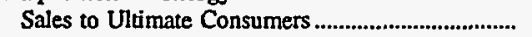 & 286,447 & 402,316 & $2,468,849$ & 224,199 & 674,371 & 257,917 \\
\hline Requirements Sales for Resale.................................... & 0 & 0 & 174,023 & 0 & 0 & 0 \\
\hline Nonrequirements Sales for Resale .............................. & 0 & 0 & 0 & 0 & 0 & 41,431 \\
\hline 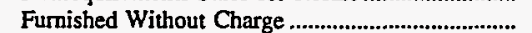 & 0 & 0 & 0 & 0 & 0 & 0 \\
\hline Used by Utility (excluding station use)................... & 468 & 0 & 0 & 0 & 689 & 193 \\
\hline 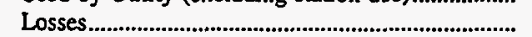 & 9,357 & 21,834 & 110,930 & 6,377 & 10,747 & 8,117 \\
\hline Total Disposition & 296,272 & 424,150 & $2,753,802$ & 230,576 & 685,807 & 307,658 \\
\hline
\end{tabular}

Note: Totals may not equal sum of components because of independent rounding. Double counting occurs in components of both sources and disposition of energy and thus neither provides a true total. Purchases from utilities, net interchanges, and net wheeling (except for imports) are included in net generation.

Source: Energy Information Administration, Form EIA-412, “Annual Report of Public Electric Utilities." 
Table 26. Electric Energy Account by Major U.S. Publicly Owned Electric

Utility Within State, 1996 (Continued)

(Megawatthours)

\begin{tabular}{|c|c|c|c|c|c|c|}
\hline Item & $\begin{array}{c}\text { Oregon } \\
\begin{array}{c}\text { Springfield } \\
\text { City of }\end{array} \\
\text { December } 31\end{array}$ & $\begin{array}{l}\text { Oregon } \\
\text { Tillamook } \\
\text { Peoples } \\
\text { Utility Dist } \\
\text { December } 31\end{array}$ & $\begin{array}{l}\text { Pennsylvania } \\
\text { Chambersburg } \\
\text { Borough of } \\
\text { December } 31\end{array}$ & $\begin{array}{c}\text { Pennsylvania } \\
\text { Ephrata } \\
\text { Borough of } \\
\text { December } 31\end{array}$ & $\begin{array}{l}\text { Pennsylvania } \\
\text { Lansdale } \\
\text { Borough of } \\
\text { December } 31\end{array}$ & $\begin{array}{l}\text { South Carolina } \\
\text { Camden } \\
\text { City of } \\
\text { June } 30\end{array}$ \\
\hline \multicolumn{7}{|l|}{ Sources of Energy } \\
\hline Steam & 0 & 0 & 0 & 0 & 0 & \\
\hline 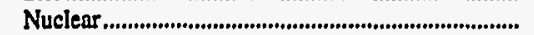 & 0 & 0 & 0 & 0 & 0 & 0 \\
\hline 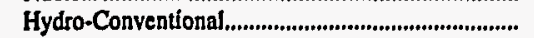 & 0 & 0 & 0 & 0 & 0 & 0 \\
\hline 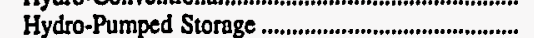 & 0 & 0 & 0 & 0 & 0 & 0 \\
\hline 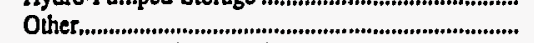 & 0 & 0 & 1,061 & 0 & 0 & 0 \\
\hline 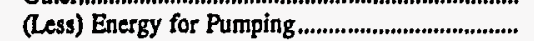 & 0 & 0 & 0 & 0 & 0 & 0 \\
\hline Total Net Generation & $\mathbf{0}$ & o & 1,061 & 0 & 0 & 0 \\
\hline 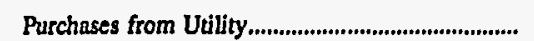 & 0 & 438,443 & 260,092 & 135,359 & 136,225 & 175,311 \\
\hline 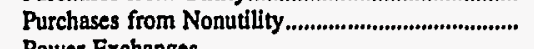 & 894,954 & 0 & 0 & 0 & 0 & 0 \\
\hline \multicolumn{7}{|l|}{ Power Exchanges } \\
\hline 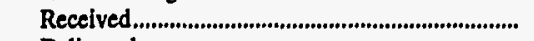 & $\mathbf{0}$ & 0 & 0 & 0 & 0 & 0 \\
\hline 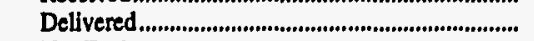 & 0 & 0 & 0 & 0 & 0 & 0 \\
\hline Net Exchanges ...................................................................... & 0 & $\mathbf{0}$ & 0 & 0 & 0 & 0 \\
\hline \multicolumn{7}{|l|}{ Transmission for Others (Wheeling) } \\
\hline 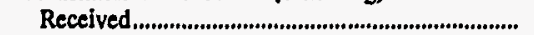 & $\mathbf{0}$ & 0 & 0 & 0 & 0 & 0 \\
\hline Delivered........................................................................... & 0 & 0 & 0 & 0 & 0 & 0 \\
\hline Net Transmission for Others ............................... & 0 & 0 & 0 & 0 & 0 & 0 \\
\hline Transmission by Others Losses.................................... & 0 & 0 & 0 & 0 & 0 & 0 \\
\hline 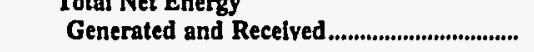 & 894,954 & 438,443 & 261,153 & 135,359 & 136,225 & 175,311 \\
\hline \multicolumn{7}{|l|}{ Disposition of Energy } \\
\hline 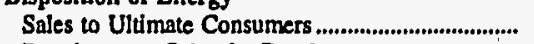 & 845,575 & 406,915 & 250,698 & 127,735 & 125,607 & 160,791 \\
\hline 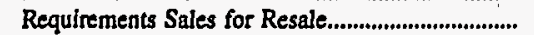 & 0 & 0 & 0 & 0 & 0 & \\
\hline 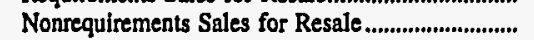 & 0 & 0 & 0 & o & 0 & 0 \\
\hline Furnished Without Charge .......................................... & 0 & 0 & 0 & 1,633 & 2,446 & 6,900 \\
\hline Used by Utility (excluding station use).................... & 17,754 & 926 & 0 & 1,267 & 1,230 & 0 \\
\hline Losses................................................................................. & 31,625 & 30,602 & 10,455 & 4,724 & 6,942 & 7,620 \\
\hline 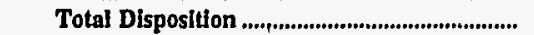 & 894,954 & 438,443 & 261,153 & 135,359 & 136,225 & $.175,311$ \\
\hline
\end{tabular}

Note: Totals may not equal sum of components because of independent rounding. Double counting occurs in components of both sources and disposition of energy and thus neither provides a true total. Purchases from utilities, net interchanges, and net wheeling (except for inmorts) are included in net generation. Sales for resale is included in sales to ultimate consumers.

Source: Energy Information Administration, Form ElA-412, "Annual Report of Public Electric Utilities." 
Table 26. Electric Energy Account by Major U.S. Publicly Owned Electric Utility Within State, 1996 (Continued)

(Megawatthours)

\begin{tabular}{|c|c|c|c|c|c|c|}
\hline Item & $\begin{array}{c}\text { South Carolina } \\
\text { Easley } \\
\text { Combined } \\
\text { Utility } \\
\text { System } \\
\text { March } 31\end{array}$ & $\begin{array}{l}\text { South Carolina } \\
\text { Gaffney } \\
\text { City of } \\
\text { March } 31\end{array}$ & $\begin{array}{l}\text { South Carolina } \\
\text { Greenwood } \\
\text { Commissioners } \\
\text { Pub Wk } \\
\text { December } 31\end{array}$ & $\begin{array}{c}\text { South Carolina } \\
\text { Greer } \\
\text { Comm } \\
\text { of } \\
\text { Public Works } \\
\text { December } 31\end{array}$ & $\begin{array}{l}\text { South Carolina } \\
\text { Newberry } \\
\text { City of } \\
\text { June } 30\end{array}$ & $\begin{array}{l}\text { South Carolina } \\
\text { Orangeburg } \\
\text { City of } \\
\text { September } 30\end{array}$ \\
\hline \multicolumn{7}{|l|}{ Sources of Energy } \\
\hline (n) & 0 & 0 & 0 & 0 & $\mathbf{0}$ & \\
\hline Nuclear & 0 & 0 & 0 & 0 & $\mathbf{0}$ & 0 \\
\hline 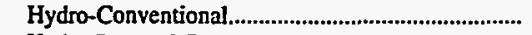 & $\mathbf{0}$ & 0 & 0 & 0 & 0 & 0 \\
\hline Hydro-Pumped Storage .......................................................... & $\mathbf{0}$ & $\mathbf{0}$ & 0 & 0 & $\mathbf{0}$ & 0 \\
\hline 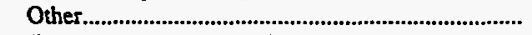 & 415 & 462 & 0 & $\mathbf{0}$ & $\mathbf{0}$ & 12,344 \\
\hline 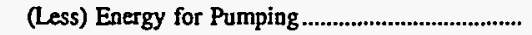 & 0 & 0 & 0 & 0 & $\mathbf{0}$ & \\
\hline 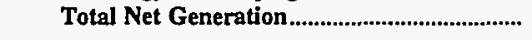 & 415 & 462 & 0 & $\mathbf{0}$ & 0 & 12,344 \\
\hline Purchases from Utility............. & 234,479 & 195,618 & 259,992 & 189,484 & 151,631 & 784,639 \\
\hline 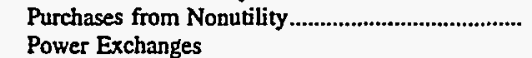 & 0 & 0 & 0 & 0 & 0 & 25,631 \\
\hline 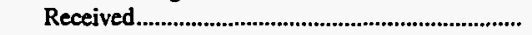 & 0 & 0 & 0 & 0 & $\mathbf{0}$ & 0 \\
\hline 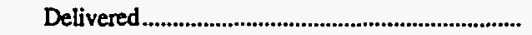 & 0 & 0 & 0 & 0 & 0 & 0 \\
\hline 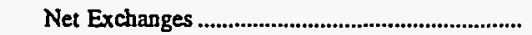 & 0 & 0 & 0 & 0 & 0 & 0 \\
\hline \multicolumn{7}{|l|}{ Transmission for Others (Wheeling) } \\
\hline 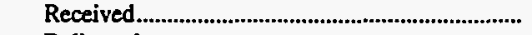 & 0 & 0 & 0 & 0 & $\mathbf{0}$ & 0 \\
\hline Delivered & 0 & 0 & 0 & 0 & 0 & 0 \\
\hline 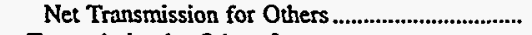 & 0 & 0 & $\mathbf{0}$ & 0 & $\mathbf{0}$ & 0 \\
\hline 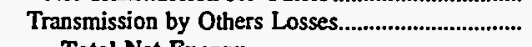 & 0 & 0 & 0 & 0 & 0 & 0 \\
\hline Total Net Energy & & & & & & \\
\hline 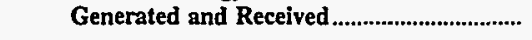 & 234,894 & 196,080 & 259,992 & 189,484 & 151,631 & 822,614 \\
\hline \multicolumn{7}{|l|}{ Disposition of Energy } \\
\hline 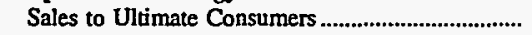 & 207,317 & 169,861 & 246,538 & 178,906 & 142,972 & 777,572 \\
\hline 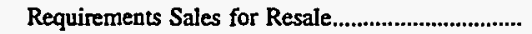 & 0 & 0 & 0 & 0 & 0 & \\
\hline Nonrequirements Sales for Resale ................................ & $\mathbf{0}$ & 0 & $\mathbf{0}$ & $\mathbf{0}$ & 0 & 0 \\
\hline 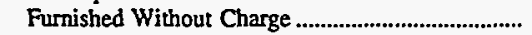 & 2,720 & 2,282 & 0 & 0 & 1,464 & 0 \\
\hline 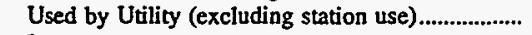 & 8,827 & 10,805 & $\mathbf{0}$ & 2,632 & 158 & 0 \\
\hline 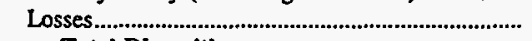 & 16,030 & 13,132 & 13,454 & 7,946 & 7,037 & 45,042 \\
\hline 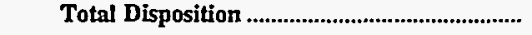 & 234,894 & 196,080 & 259,992 & 189,484 & 151,631 & 822,614 \\
\hline
\end{tabular}

Note: Totals may not equal sum of components because of independent rounding. Double counting occurs in components of both sources and disposition of energy and thus neither provides a true total. Purchases from utilities, net interchanges, and net wheeling (except for imports) are included in net generation.

Source: Energy Information Administration, Form EIA-412, "Annual Report of Public Electric Utilities." 
Table 26. Electric Energy Account by Major U.S. Publicly Owned Electric Utility Within State, 1996 (Continued)

(Megawatthours)

\begin{tabular}{|c|c|c|c|c|c|c|}
\hline Item & $\begin{array}{c}\text { South Carolina } \\
\text { Piedmont } \\
\text { Municipal } \\
\text { Power Agny } \\
\text { December } 31\end{array}$ & $\begin{array}{l}\text { South Carolina } \\
\text { Rock Hill } \\
\text { City of } \\
\text { December } 31\end{array}$ & $\begin{array}{l}\text { South Carolina } \\
\text { Seneca } \\
\text { City of } \\
\text { June } 30\end{array}$ & $\begin{array}{l}\text { South Carolina } \\
\text { South } \\
\text { Carolina } \\
\text { Pub } \\
\text { Serv Auth } \\
\text { December } 31\end{array}$ & $\begin{array}{l}\text { South Dakota } \\
\text { Brookings } \\
\text { City of } \\
\text { December } 31\end{array}$ & $\begin{array}{c}\text { South Dakota } \\
\text { Heartland } \\
\text { Consumers } \\
\text { Power Dist } \\
\text { December } 31\end{array}$ \\
\hline \multicolumn{7}{|l|}{ Sources of Energy } \\
\hline Steam & 0 & 0 & $\mathbf{0}$ & $14,501,760$ & $\mathbf{0}$ & 395,435 \\
\hline 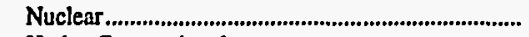 & $1,952,065$ & 0 & 0 & $2,375,096$ & $\mathbf{0}$ & $\mathbf{0}$ \\
\hline 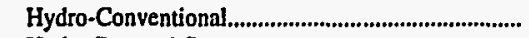 & 0 & 0 & 0 & 522,760 & 0 & 0 \\
\hline 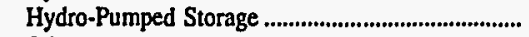 & $\mathbf{0}$ & $\mathbf{0}$ & 0 & 0 & 0 & 0 \\
\hline 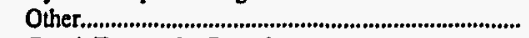 & 0 & 0 & 0 & 2,579 & 0 & 0 \\
\hline 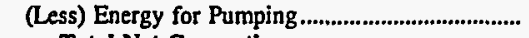 & 0 & 0 & $\mathbf{0}$ & 0 & $\mathbf{0}$ & 0 \\
\hline 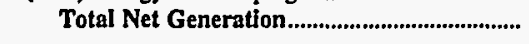 & $1,952,065$ & $\mathbf{0}$ & 0 & $17,402,195$ & $\mathbf{0}$ & 395,435 \\
\hline 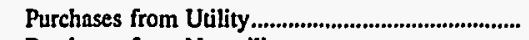 & 564,312 & 556,217 & 146,251 & 685,481 & 203,460 & 114,959 \\
\hline $\begin{array}{l}\text { Purchases from Nonutility....................................... } \\
\text { Power Exchanges }\end{array}$ & $\quad \mathbf{0}$ & 0 & 3,594 & 2,926 & $\mathbf{0}$ & 0 \\
\hline 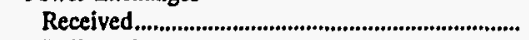 & 614,652 & 0 & 0 & 38,184 & 0 & 24 \\
\hline 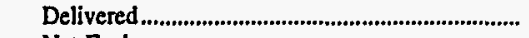 & 622,028 & 0 & $\mathbf{0}$ & 45,798 & 0 & $\mathbf{0}$ \\
\hline 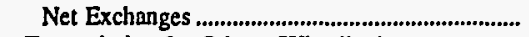 & $-7,376$ & 0 & 0 & $-7,614$ & $\mathbf{0}$ & 24 \\
\hline \multicolumn{7}{|l|}{ Transmission for Others (Wheeling) } \\
\hline 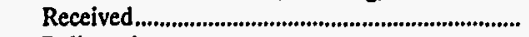 & 0 & 0 & 0 & 439,088 & $\mathbf{0}$ & 0 \\
\hline 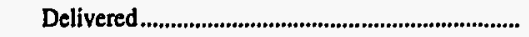 & 0 & 0 & $\mathbf{0}$ & 496,367 & 0 & 0 \\
\hline 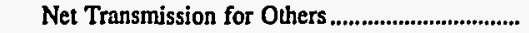 & 0 & 0 & 0 & $-57,279$ & $\mathbf{0}$ & 0 \\
\hline $\begin{array}{l}\text { Transmission by Others Losses.............................. } \\
\text { Total Net Energy }\end{array}$ & $\mathbf{0}$ & 0 & 0 & 0 & $\mathbf{0}$ & 0 \\
\hline Generated and Received................................. & $2,509,001$ & 556,217 & 149,845 & $18,025,709$ & 203,460 & $\mathbf{5 1 0 , 4 1 8}$ \\
\hline \multicolumn{7}{|l|}{ Disposition of Energy } \\
\hline 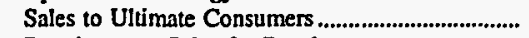 & 0 & 546,542 & 137,464 & $8,209,218$ & 192,111 & 0 \\
\hline Requirements Sales for Resale & $2,481,570$ & 0 & 0 & $9,339,589$ & 0 & 323,892 \\
\hline Nonrequirements Sales for Resale & $\mathbf{0}$ & 0 & 0 & 0 & $\mathbf{0}$ & 161,053 \\
\hline 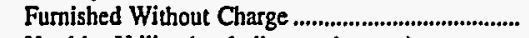 & 0 & 0 & 0 & 0 & $\mathbf{0}$ & 0 \\
\hline Used by Utility (excluding station use)................... & 0 & 0 & 4,399 & 16,527 & $\mathbf{0}$ & 0 \\
\hline Losses, & 27,431 & 9,675 & 7,982 & 460,375 & 11,349 & 25,473 \\
\hline Total Disposition & $2,509,001$ & 556,217 & 149,845 & $18,025,709$ & 203,460 & 510,418 \\
\hline
\end{tabular}

Note: Totals may not equal sum of components because of independent rounding. Double counting occurs in components of both sources and disposition of energy and thus neither provides a true total. Purchases from utilities, net interchanges, and net wheeling (except for imports) are included in net generstion.

Source: Energy Information Administration, Form EIA-412, “Annual Report of Public Electric Utilities." 
Table 26. Electric Energy Account by Major U.S. Publicly Owned Electric Utility Within State, 1996 (Continued)

(Megawatthours)

\begin{tabular}{|c|c|c|c|c|c|c|}
\hline Item & $\begin{array}{l}\text { South Dakota } \\
\text { Missouri } \\
\text { Basin } \\
\text { Mun } \\
\text { Power Agny } \\
\text { December 31 }\end{array}$ & $\begin{array}{c}\text { South Dakota } \\
\text { Pierre } \\
\text { City of } \\
\text { December } 31\end{array}$ & $\begin{array}{l}\text { South Dakota } \\
\text { Watertown } \\
\text { Municipal } \\
\text { Utilities } \\
\text { December } 31\end{array}$ & $\begin{array}{l}\text { Tennessee } \\
\text { Alcoa } \\
\text { Utilities } \\
\text { June } 30\end{array}$ & $\begin{array}{l}\text { Tennessee } \\
\text { Athens } \\
\text { Utility } \\
\text { Board } \\
\text { June } 30\end{array}$ & $\begin{array}{l}\text { Tennessee } \\
\text { Benton } \\
\text { County } \\
\text { June } 30\end{array}$ \\
\hline \multicolumn{7}{|l|}{ Sources of Energy } \\
\hline Steam. & 0 & 0 & 0 & 0 & 0 & \\
\hline 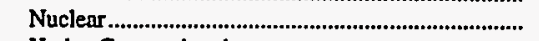 & 0 & 0 & 0 & 0 & $\mathbf{0}$ & \\
\hline 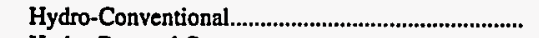 & $\mathbf{0}$ & 0 & $\mathbf{0}$ & 0 & 0 & \\
\hline 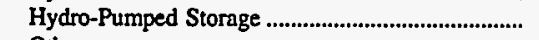 & 0 & 0 & 0 & 0 & 0 & \\
\hline 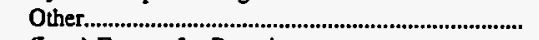 & 0 & 0 & 0 & 0 & 0 & \\
\hline 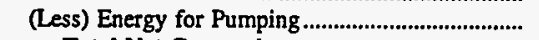 & 0 & 0 & 0 & 0 & 0 & \\
\hline 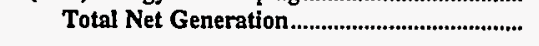 & 0 & 0 & 0 & o & $\mathbf{0}$ & \\
\hline 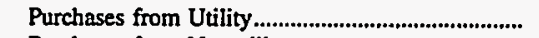 & $2,089,872$ & 176,923 & 261,539 & 510,266 & 591,868 & 239,459 \\
\hline 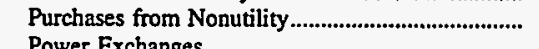 & 0 & 0 & 0 & 0 & 0 & \\
\hline 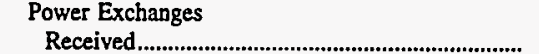 & & & & & & \\
\hline & $\begin{array}{r}18 \\
1,434\end{array}$ & 0 & 0 & 0 & 0 & \\
\hline 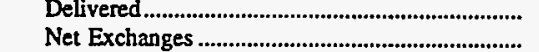 & $\begin{array}{r}1,434 \\
-1,416\end{array}$ & $\begin{array}{l}0 \\
0\end{array}$ & $\begin{array}{l}0 \\
0\end{array}$ & $\begin{array}{l}0 \\
0\end{array}$ & $\begin{array}{l}0 \\
0\end{array}$ & \\
\hline \multicolumn{7}{|l|}{ Transmission for Others (Wheeling) } \\
\hline 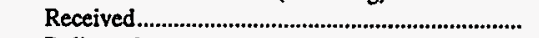 & 0 & 0 & 0 & 0 & 0 & \\
\hline 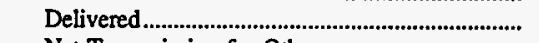 & 0 & 0 & 0 & 0 & 0 & \\
\hline 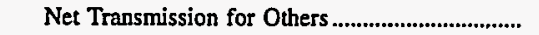 & 0 & 0 & 0 & $\mathbf{0}$ & 0 & \\
\hline $\begin{array}{l}\text { Transmission by Others Losses.................................... } \\
\text { Total Net Energy }\end{array}$ & 0 & 0 & 0 & 0 & 0 & \\
\hline 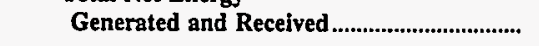 & $2,088,456$ & 176,923 & 261,539 & 510,266 & 591,868 & 239,459 \\
\hline \multicolumn{7}{|l|}{ Disposition of Energy } \\
\hline 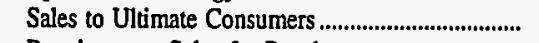 & 0 & 149,576 & 248,482 & 473,388 & 566,920 & 220,102 \\
\hline 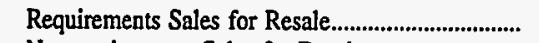 & $1,175,551$ & 14,923 & 0 & 0 & 0 & \\
\hline Nonrequirements Sales for Resale............................. & 802,817 & 0 & $\mathbf{0}$ & 0 & 0 & \\
\hline Furnished Without Charge & 0 & 0 & 0 & $\mathbf{0}$ & 0 & 0 \\
\hline Used by Utility (excluding station use).................... & 0 & 2,000 & 0 & 252 & 651 & 228 \\
\hline 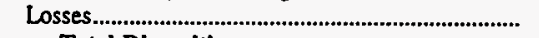 & 110,088 & 10,424 & 13,057 & 36,627 & 24,297 & 19,129 \\
\hline Total Disposition ..................................................... & $2,088,456$ & 176,923 & 261,539 & 510,266 & 591,868 & 239,459 \\
\hline
\end{tabular}

Note: Totals may not equal sum of components because of independent rounding. Double counting occurs in components of both sources and disposition of energy and thus neither provides a true total. Purchases from utilities, net interchanges, and net wheeling (except for imports) are included in net generation.

Source: Energy Information Administration, Form EIA-412, "Annual Report of Public Electric Utilities." 
Table 26. Electric Energy Account by Major U.S. Publicly Owned Electric Utility Within State, 1996 (Continued)

(Megawatthours)

\begin{tabular}{|c|c|c|c|c|c|c|}
\hline Item & $\begin{array}{l}\text { Tennessee } \\
\text { Bolivar } \\
\text { City of } \\
\text { June } 30\end{array}$ & $\begin{array}{l}\text { Tennessee } \\
\text { Bristol } \\
\text { City of } \\
\text { June } 30\end{array}$ & $\begin{array}{c}\text { Tennessee } \\
\text { Brownsville } \\
\text { City of } \\
\text { June } 30\end{array}$ & $\begin{array}{l}\text { Tennessee } \\
\text { Carroll } \\
\text { County } \\
\text { June } 30\end{array}$ & $\begin{array}{c}\text { Tennessee } \\
\text { Chattanooga } \\
\text { City of } \\
\text { June } 30\end{array}$ & $\begin{array}{c}\text { Tennessee } \\
\begin{array}{c}\text { Clarksville } \\
\text { City of }\end{array} \\
\text { June } 30\end{array}$ \\
\hline \multicolumn{7}{|l|}{ Sources of Energy } \\
\hline Steam & 0 & 0 & 0 & 0 & 0 & 0 \\
\hline 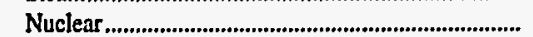 & 0 & 0 & 0 & 0 & 0 & 0 \\
\hline 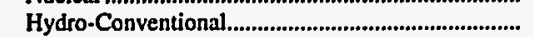 & $\mathbf{0}$ & 0 & 0 & 0 & 0 & 0 \\
\hline 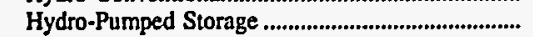 & 0 & 0 & 0 & $\mathbf{0}$ & 0 & 0 \\
\hline 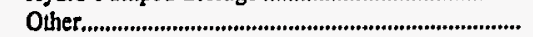 & 0 & 0 & 0 & 0 & $\mathbf{0}$ & 0 \\
\hline 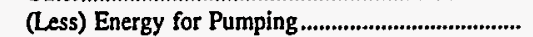 & 0 & 0 & 0 & $\mathbf{0}$ & $\mathbf{0}$ & 0 \\
\hline 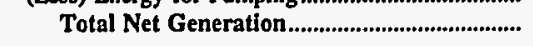 & $\mathbf{0}$ & $\mathbf{0}$ & 0 & 0 & $\mathbf{0}$ & $\mathbf{0}$ \\
\hline Purchases from Utility............................................... & 244,041 & 914,989 & 202,729 & 421,687 & $5,973,701$ & $1,019,076$ \\
\hline $\begin{array}{l}\text { Purchases from Nonutility......................................... } \\
\text { Power Exchanges }\end{array}$ & 0 & 0 & $\mathbf{0}$ & 0 & 0 & 0 \\
\hline 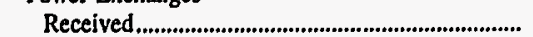 & 0 & 0 & 0 & 0 & 0 & 0 \\
\hline 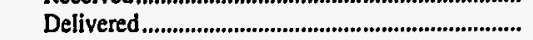 & 0 & 0 & 0 & 0 & 0 & 0 \\
\hline 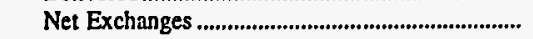 & 0 & 0 & $\mathbf{0}$ & 0 & 0 & 0 \\
\hline \multicolumn{7}{|l|}{ Transmission for Others (Wheeling) } \\
\hline 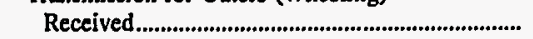 & 0 & 0 & $\mathbf{0}$ & 0 & 0 & 0 \\
\hline Delivered & 0 & 0 & 0 & $\mathbf{0}$ & $\mathbf{0}$ & 0 \\
\hline Net Transmission for Others ................................. & 0 & 0 & 0 & 0 & 0 & 0 \\
\hline 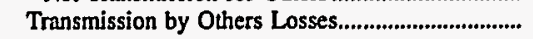 & $\mathbf{0}$ & 0 & $\mathbf{0}$ & $\mathbf{0}$ & $\mathbf{0}$ & 0 \\
\hline \multicolumn{7}{|l|}{ Total Net Energy } \\
\hline Generated and Received................................. & 244,041 & 914,989 & 202,729 & 421,687 & $5,973,701$ & $1,019,076$ \\
\hline \multicolumn{7}{|l|}{ Disposition of Energy } \\
\hline 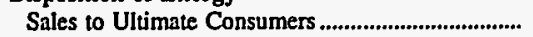 & 226,749 & 868,415 & 196,139 & 401,063 & $5,764,479$ & 972,837 \\
\hline Requirements Sales for Resale.................................. & 0 & 0 & 0 & 0 & $\mathbf{0}$ & 0 \\
\hline 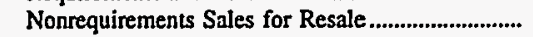 & 0 & 0 & 0 & 0 & 0 & 0 \\
\hline Furnished Without Charge ....................................... & 0 & 0 & $\mathbf{0}$ & 0 & 0 & 0 \\
\hline Used by Utility (excluding station use)................... & 313 & 952 & 118 & 211 & 9,205 & 1,156 \\
\hline 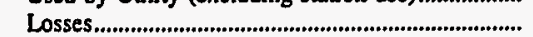 & 16,979 & 45,623 & 6,472 & 20,414 & 200,017 & 45,083 \\
\hline Total Disposition & 244,041 & 914,989 & 202,729 & 421,687 & $5,973,701$ & $1,019,076$ \\
\hline
\end{tabular}

Note: Totals may not equal sum of components because of independent rounding. Double counting occurs in components of both sources and disposition of energy and thus neither provides a true total. Purchases from utilities, net interchanges, and net wheeling (except for imports) are included in net generation.

Source: Energy Information Administration, Form EIA-412, "Annual Report of Public Electric Utilities." 
Table 26. Electric Energy Account by Major U.S. Publicly Owned Electric Utility Within State, 1996 (Continued)

(Megawatthours)

\begin{tabular}{|c|c|c|c|c|c|c|}
\hline Item & $\begin{array}{l}\text { Tennessee } \\
\text { Cleveland } \\
\text { City of } \\
\text { June } 30\end{array}$ & $\begin{array}{l}\text { Tennessee } \\
\text { Clinton } \\
\text { City of } \\
\text { June } 30\end{array}$ & $\begin{array}{l}\text { Tennessee } \\
\text { Columbia } \\
\text { City of } \\
\text { June } 30\end{array}$ & $\begin{array}{l}\text { Tennessee } \\
\text { Cookeville } \\
\text { City of } \\
\text { June } 30\end{array}$ & $\begin{array}{l}\text { Tennessee } \\
\begin{array}{c}\text { Covington } \\
\text { City of }\end{array} \\
\text { June } 30\end{array}$ & $\begin{array}{l}\text { Tennessee } \\
\text { Dayton } \\
\text { City of } \\
\text { June } 30\end{array}$ \\
\hline \multicolumn{7}{|l|}{ Sources of Energy } \\
\hline 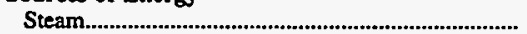 & $\mathbf{0}$ & $\mathbf{0}$ & 0 & $\mathbf{0}$ & 0 & 0 \\
\hline 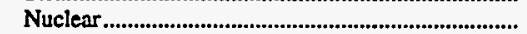 & 0 & 0 & 0 & 0 & 0 & 0 \\
\hline 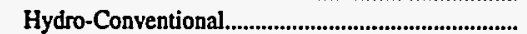 & 0 & 0 & 0 & 0 & 0 & 0 \\
\hline 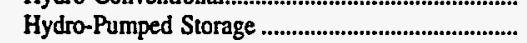 & 0 & 0 & 0 & 0 & 0 & 0 \\
\hline 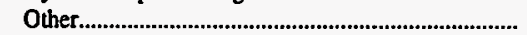 & 0 & $\mathbf{0}$ & 0 & 0 & 0 & 0 \\
\hline 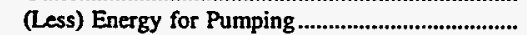 & 0 & 0 & 0 & 0 & 0 & 0 \\
\hline Total Net Generation & $\mathbf{0}$ & 0 & o & $\mathbf{0}$ & o & 0 \\
\hline 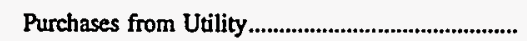 & 993,123 & 721,889 & 551,220 & 520,989 & 239,006 & 216,323 \\
\hline 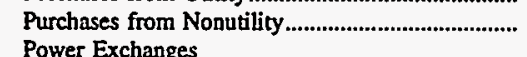 & 0 & 0 & 0 & 0 & 0 & 0 \\
\hline 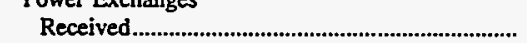 & $\mathbf{0}$ & 0 & 0 & 0 & 0 & 0 \\
\hline 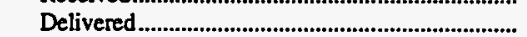 & 0 & 0 & 0 & 0 & 0 & 0 \\
\hline 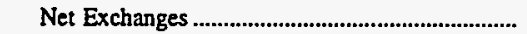 & 0 & 0 & 0 & 0 & 0 & 0 \\
\hline \multicolumn{7}{|l|}{ Transmission for Others (Wheeling) } \\
\hline 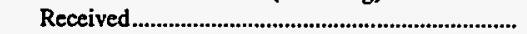 & 0 & 0 & $\mathbf{0}$ & 0 & 0 & 0 \\
\hline 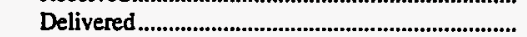 & 0 & 0 & 0 & 0 & 0 & 0 \\
\hline 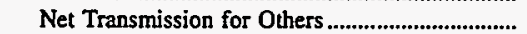 & 0 & 0 & 0 & 0 & 0 & 0 \\
\hline 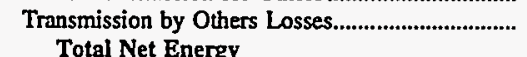 & 0 & 0 & 0 & 0 & $\mathbf{0}$ & 0 \\
\hline 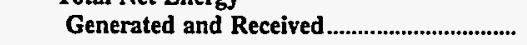 & 993,123 & 721,889 & 551,220 & 520,989 & 239,006 & 216,323 \\
\hline \multicolumn{7}{|l|}{ Disposition of Energy } \\
\hline Sales to Ultimate Consumers .......................................... & 952,409 & 690,576 & 526,915 & 504,157 & 231,658 & 202,998 \\
\hline 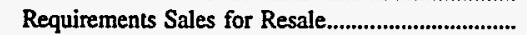 & 0 & 0 & 0 & 0 & 0 & 0 \\
\hline Nonrequirements Sales for Resale .............................. & 0 & 0 & 0 & 0 & 0 & 0 \\
\hline Furnished Without Charge ......................................... & 0 & 0 & 0 & 0 & 0 & 0 \\
\hline 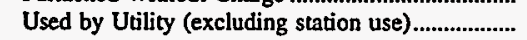 & 1,326 & 0 & 1,065 & 322 & 175 & 0 \\
\hline 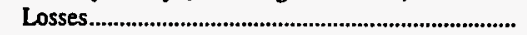 & 39,388 & 31,313 & 23,240 & 16,510 & 7,173 & 13,325 \\
\hline 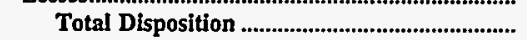 & 993,123 & $\mathbf{7 2 1 , 8 8 9}$ & $\mathbf{5 5 1 , 2 2 0}$ & 520,989 & 239,006 & 216,323 \\
\hline
\end{tabular}

Note: Totals may not equal sum of components because of independent rounding. Double counting occurs in components of both sources and disposition of energy and thus neither provides a true total. Purchases from utilities, net interchanges, and net wheeling (except for imports) are included in net generation.

Source: Energy Information Administration, Form EIA-412, “Annual Report of Public Electric Utilities." 
Table 26. Electric Energy Account by Major U.S. Publicly Owned Electric Utility Within State, 1996 (Continued)

(Megawatthours)

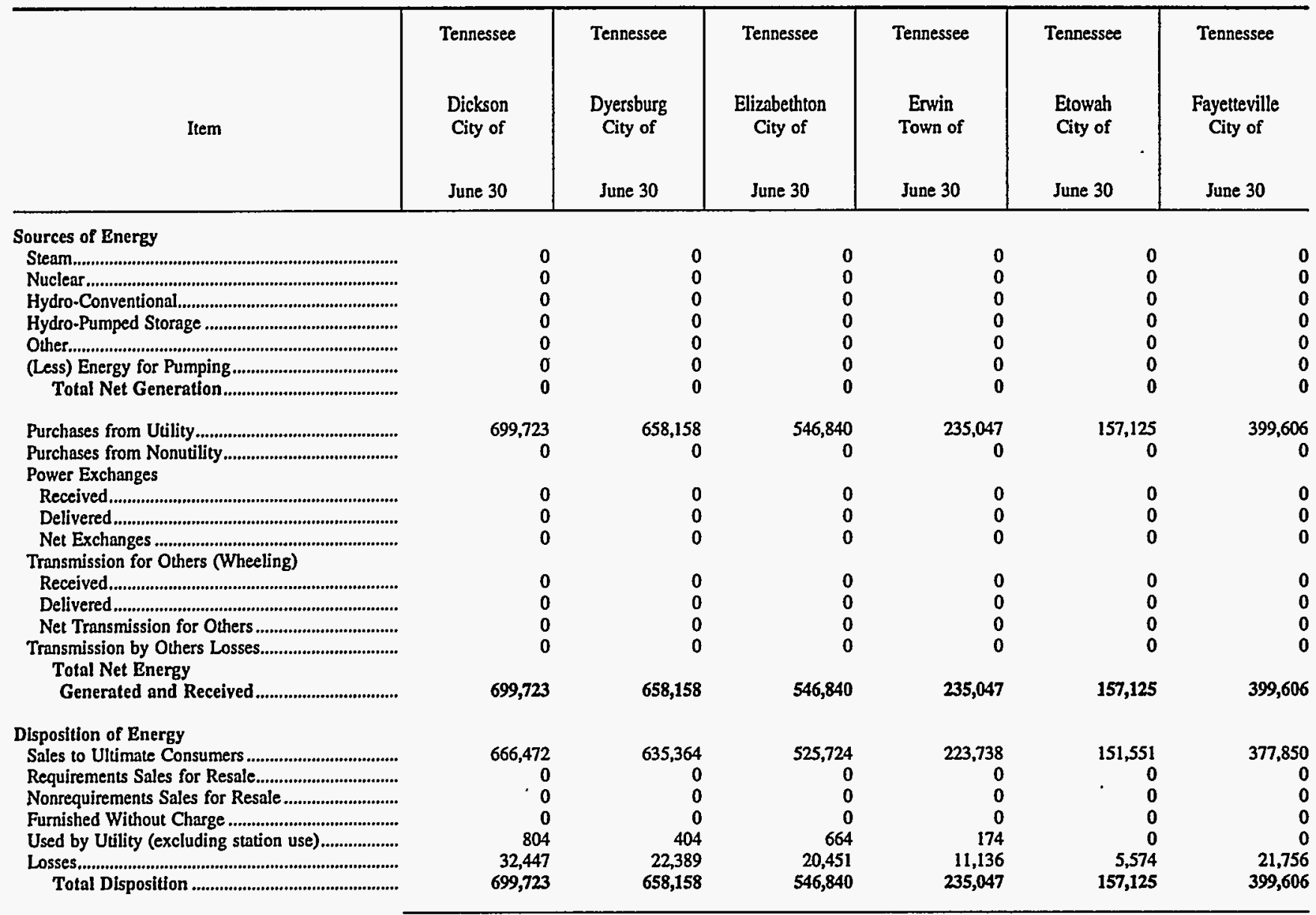

Note: Totals may not equal sum of components because of independent rounding. Double counting occurs in components of both sources and disposition of energy and thus reither provides a true total. Purchases from utilities, net interchanges, and net wheeling (except for imports) are included in net generation.

Source: Energy Information Administration, Form EIA-412, "Annual Report of Public Electric Utilities." 
Table 26. Electric Energy Account by Major U.S. Publicly Owned Electric Utility Within State, 1996 (Continued)

(Megawatthours)

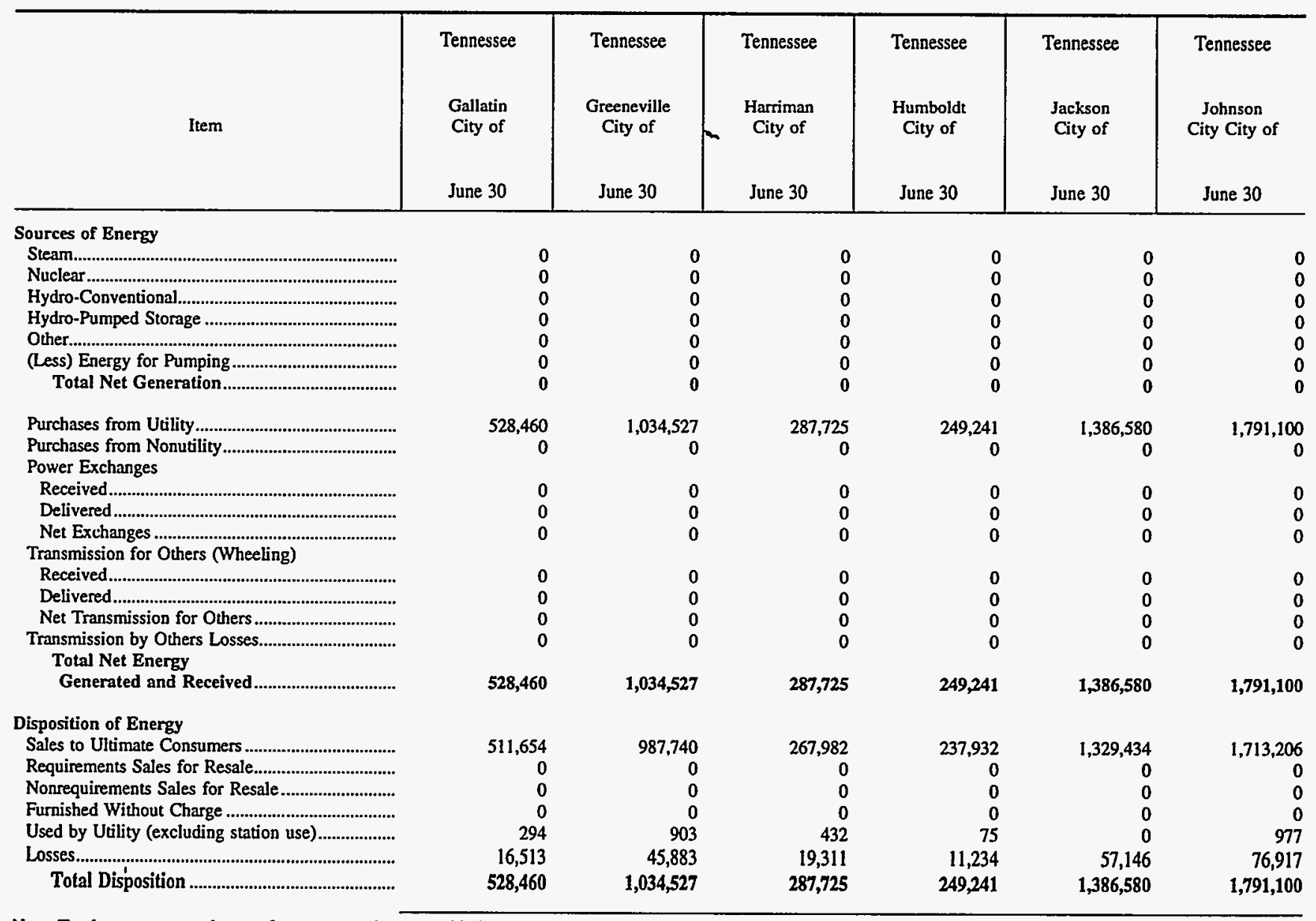

Note: Totals may not equal sum of components because of independent rounding. Double counting occurs in components of both sources and disposition of energy and thus neither provides a true total. Purchases from utilities, net interchanges, and net wheeling (except for imports) are included in net generation.

Source: Energy Information Administration, Form EIA-412, “Annual Report of Public Electric Utilities." 
Table 26. Electric Energy Account by Major U.S. Publicly Owned Electric Utility Within State, 1996 (Continued)

(Megawatthours)

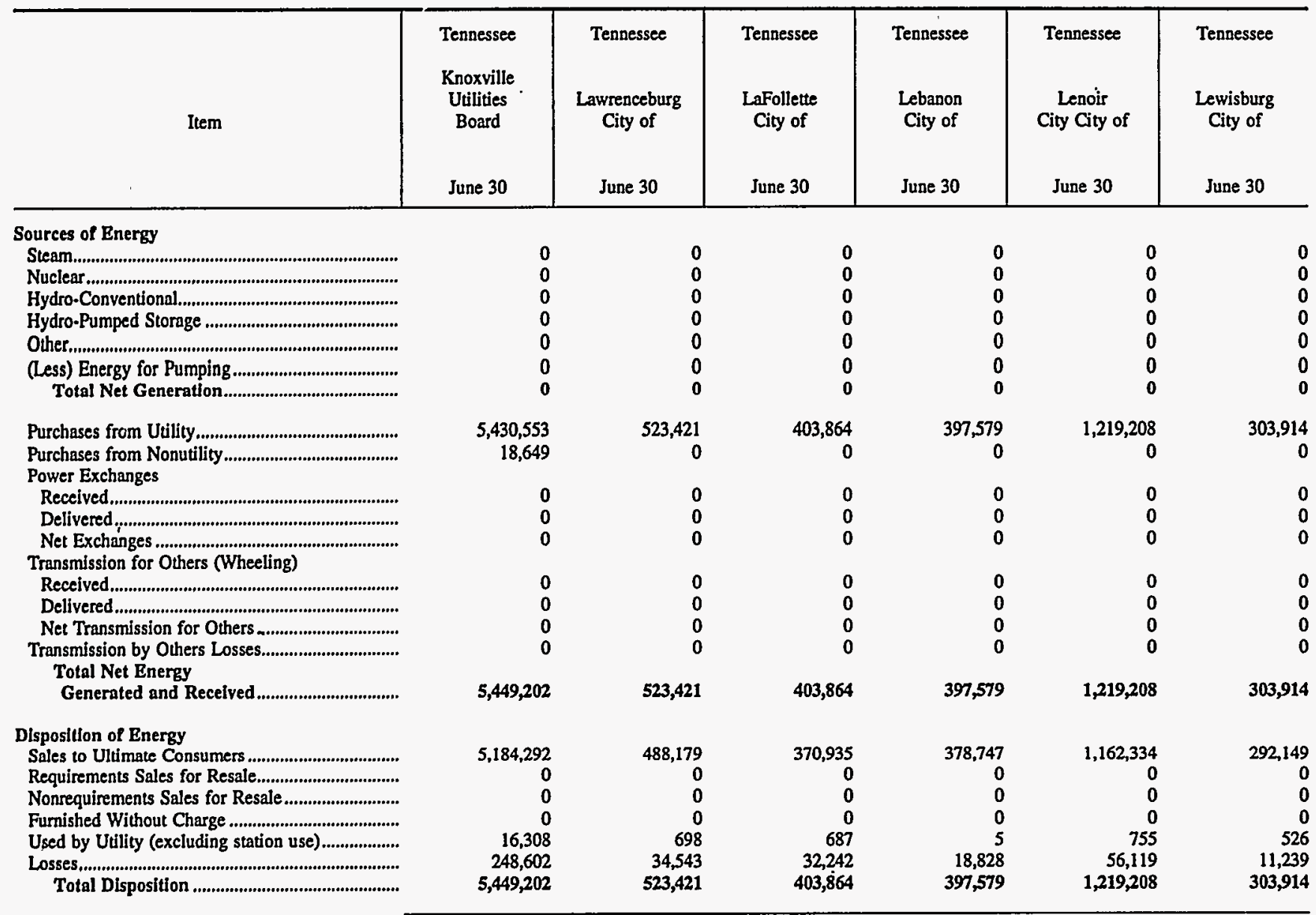

Note: Totals may not equal sum of components because of independent rounding. Double counting occurs in components of both sources and disposition of energy and thus neither provides a true total. Purchases from utilities, net interchanges, and net wheeling (except for imports) are included in net generation.

Source: Energy Information Administration, Form EIA-412, "Annual Report of Public Electric Utilities." 
Table 26. Electric Energy Account by Major U.S. Publicly Owned Electric Utility Within State, 1996 (Continued)

(Megawatthours)

\begin{tabular}{|c|c|c|c|c|c|c|}
\hline Item & $\begin{array}{l}\text { Tennessee } \\
\text { Lexington } \\
\text { City of } \\
\text { June } 30\end{array}$ & $\begin{array}{l}\text { Tennessee } \\
\text { Loudon } \\
\text { Utilities } \\
\text { Board } \\
\\
\text { June } 30\end{array}$ & $\begin{array}{c}\text { Tennessee } \\
\text { Maryville } \\
\text { Utilities } \\
\text { June } 30\end{array}$ & $\begin{array}{l}\text { Tennessee } \\
\text { McMinnville } \\
\text { Electric } \\
\text { System } \\
\\
\text { June } 30\end{array}$ & $\begin{array}{c}\text { Tennessee } \\
\text { Memphis } \\
\text { City of } \\
\text { June } 30\end{array}$ & $\begin{array}{l}\text { Tennessee } \\
\text { Milan } \\
\text { City of } \\
\text { June } 30\end{array}$ \\
\hline \multicolumn{7}{|l|}{ Sources of Energy } \\
\hline Steam & 0 & $\mathbf{0}$ & 0 & 0 & 0 & 0 \\
\hline 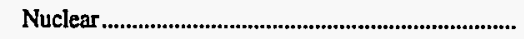 & 0 & 0 & 0 & 0 & 0 & 0 \\
\hline 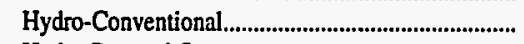 & 0 & 0 & 0 & 0 & 0 & 0 \\
\hline 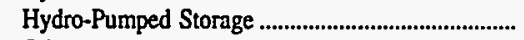 & 0 & 0 & 0 & 0 & 0 & 0 \\
\hline Other. & 0 & 0 & 0 & 0 & 0 & $\mathbf{0}$ \\
\hline 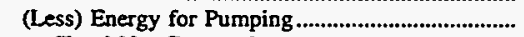 & 0 & 0 & 0 & 0 & 0 & $\mathbf{0}$ \\
\hline 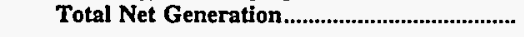 & $\mathbf{0}$ & $\mathbf{0}$ & o & $\mathbf{0}$ & $\mathbf{0}$ & 0 \\
\hline 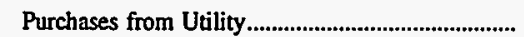 & 437,822 & 328,023 & 617,923 & 248,364 & $13,193,562$ & 253,333 \\
\hline \multicolumn{6}{|l|}{ Power Exchanges } & 0 \\
\hline 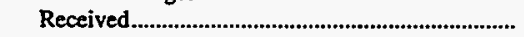 & 0 & 0 & $\mathbf{0}$ & 0 & 0 & $\mathbf{0}$ \\
\hline 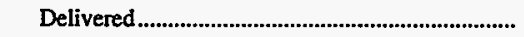 & 0 & 0 & 0 & 0 & 0 & $\mathbf{0}$ \\
\hline 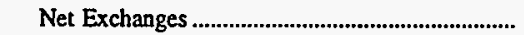 & 0 & 0 & 0 & 0 & $\mathbf{0}$ & 0 \\
\hline \multicolumn{7}{|l|}{ Transmission for Others (Wheeling) } \\
\hline Received & 0 & 0 & 0 & 0 & 0 & 0 \\
\hline 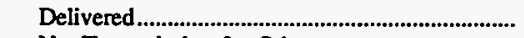 & 0 & 0 & 0 & 0 & 0 & 0 \\
\hline 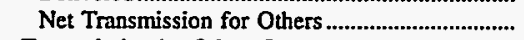 & 0 & 0 & 0 & 0 & 0 & $\mathbf{0}$ \\
\hline Transmission by Others Losses................................ & 0 & 0 & 0 & 0 & 0 & 0 \\
\hline Generated and Received................................. & 437,822 & 328,023 & 617,923 & 248,364 & $13,193,562$ & 253,333 \\
\hline \multicolumn{7}{|l|}{ Disposition of Energy } \\
\hline 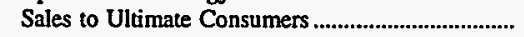 & 408,585 & 311,528 & 590,631 & 243,296 & $12,577,300$ & 238,214 \\
\hline 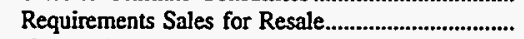 & 0 & 0 & 0 & 0 & 0 & 0 \\
\hline 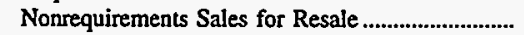 & 0 & 0 & 0 & 0 & 0 & 0 \\
\hline Furnished Without Charge ......................................... & 0 & 0 & $\mathbf{0}$ & 0 & 0 & 0 \\
\hline Used by Utility (excluding station use)................... & 632 & 0 & 0 & 352 & 7,308 & 0 \\
\hline 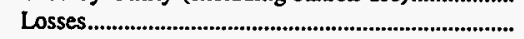 & 28,605 & 16,495 & 27,292 & 4,716 & 608,954 & 15,120 \\
\hline Total Disposition & 437,822 & 328,023 & 617,923 & 248,364 & $13,193,562$ & 253,333 \\
\hline
\end{tabular}

Note: Totals may not equal sum of components because of independent rounding. Double counting occurs in components of both sources and disposition of energy and thus neither provides a true total. Purchases from utilities, net interchanges, and net wheeling (except for imports) are included in net generation.

Source: Energy Information Administration, Form EIA-412, “Annual Report of Public Electric Utilities." 
Table 26. Electric Energy Account by Major U.S. Publicly Owned Electric Utility Within State, 1996 (Continued)

(Megawatthours)

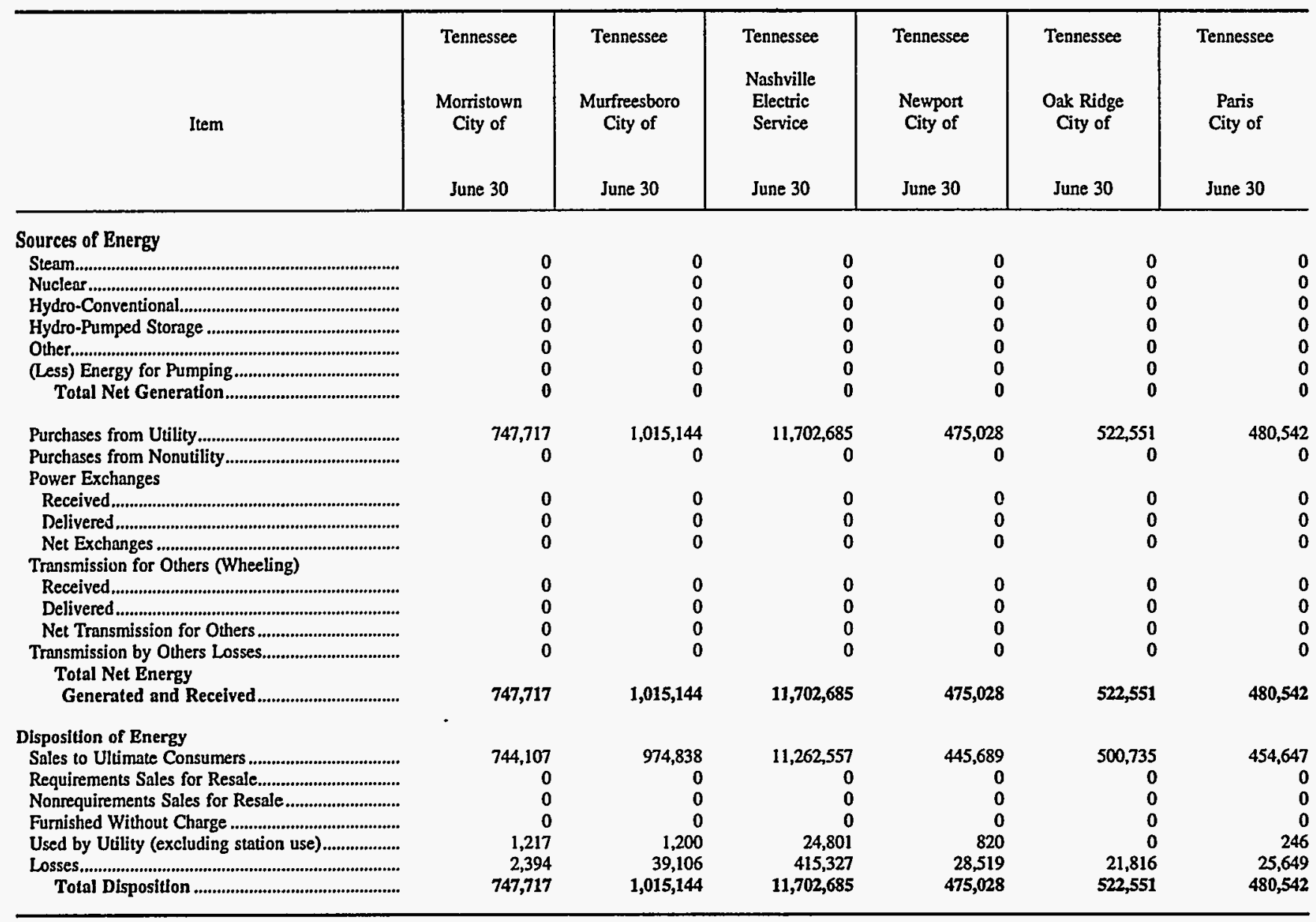

Note: Totals may not equal sum of components because of independent rounding. Double counting occurs in components of both sources and disposition of energy and thus neither provides a true total. Purchases from utilities, net interchanges, and net wheeling (except for imports) are included in net generation. Sales for resale is included in sales to ultimate consumers.

Source: Energy Information Administration, Form EIA-412, "Annual Report of Public Electric Utilities." 
Table 26. Electric Energy Account by Major U.S. Publicly Owned Electric Utility Within State, 1996 (Continued)

(Megawatthours)

\begin{tabular}{|c|c|c|c|c|c|c|}
\hline Item & $\begin{array}{l}\text { Tennessee } \\
\text { Pulaski } \\
\text { City of } \\
\text { June } 30\end{array}$ & $\begin{array}{l}\text { Tennessee } \\
\text { Ripley } \\
\text { City of } \\
\text { June } 30\end{array}$ & $\begin{array}{c}\text { Tennessee } \\
\text { Sevier } \\
\text { County } \\
\text { Electric } \\
\text { System } \\
\text { June } 30\end{array}$ & $\begin{array}{l}\text { Tennessee } \\
\begin{array}{c}\text { Rockwood } \\
\text { City of }\end{array} \\
\text { June } 30\end{array}$ & $\begin{array}{c}\text { Tennessee } \\
\begin{array}{c}\text { Shelbyville } \\
\text { City of }\end{array} \\
\text { June } 30\end{array}$ & $\begin{array}{l}\text { Tennessee } \\
\begin{array}{c}\text { Springfield } \\
\text { City of }\end{array} \\
\text { June } 30\end{array}$ \\
\hline \multicolumn{7}{|l|}{ Sources of Energy } \\
\hline 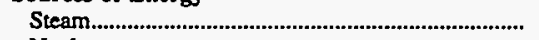 & 0 & 0 & 0 & 0 & 0 & \\
\hline Nuclear......................................................................... & 0 & $\mathbf{0}$ & 0 & 0 & 0 & \\
\hline 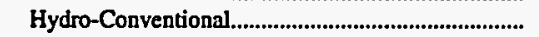 & 0 & 0 & 0 & 0 & 0 & 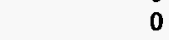 \\
\hline 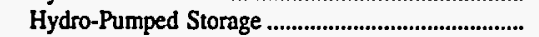 & 0 & 0 & 0 & 0 & 0 & 0 \\
\hline Other & 0 & 0 & 0 & 0 & 0 & 0 \\
\hline 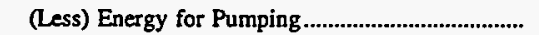 & 0 & 0 & $\mathbf{0}$ & 0 & $\mathbf{0}$ & 0 \\
\hline Total Net Generation & 0 & 0 & 0 & 0 & 0 & \\
\hline 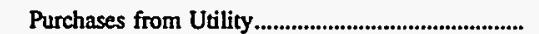 & 464,469 & 258,217 & $1,090,110$ & 332,030 & 352,838 & 241,188 \\
\hline 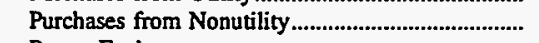 & 0 & 0 & 0 & 0 & $\begin{array}{r}0 \\
0\end{array}$ & 0 \\
\hline \multicolumn{7}{|l|}{ Power Exchanges } \\
\hline 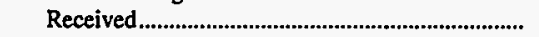 & 0 & 0 & $\mathbf{0}$ & $\mathbf{0}$ & 0 & 0 \\
\hline 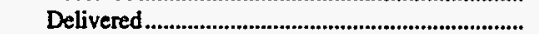 & 0 & 0 & 0 & 0 & 0 & 0 \\
\hline 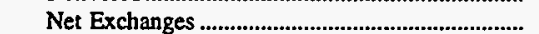 & 0 & 0 & 0 & 0 & 0 & 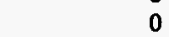 \\
\hline \multicolumn{7}{|l|}{ Transmission for Others (Wheeling) } \\
\hline 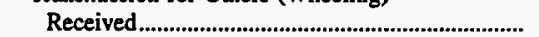 & 0 & 0 & 0 & 0 & 0 & $\mathbf{0}$ \\
\hline 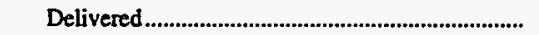 & 0 & $\mathbf{0}$ & 0 & 0 & 0 & 0 \\
\hline Net Transmission for Others......................................... & 0 & 0 & 0 & $\mathbf{0}$ & 0 & 0 \\
\hline 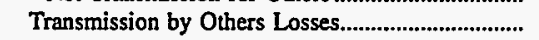 & 0 & 0 & $\mathbf{0}$ & 0 & 0 & 0 \\
\hline Total Net Energy & & & & & & \\
\hline 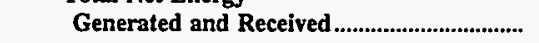 & 464,469 & 258,217 & $1,090,110$ & 332,030 & 352,838 & 241,188 \\
\hline \multicolumn{7}{|l|}{ Disposition of Energy } \\
\hline 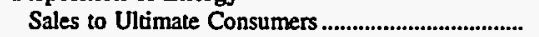 & 435,068 & 248,950 & $1,034,521$ & 312,177 & 339,925 & 231,310 \\
\hline Requirements Sales for Resale.................................... & 0 & 0 & 0 & 0 & 0 & \\
\hline Nonrequirements Sales for Resale .................................. & 0 & $\mathbf{0}$ & 0 & $\mathbf{0}$ & 0 & $\mathbf{0}$ \\
\hline Funnished Without Charge .......................................... & 0 & $\mathbf{0}$ & 0 & 0 & 0 & 0 \\
\hline 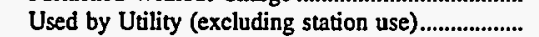 & 923 & 218 & 482 & 263 & 274 & 0 \\
\hline 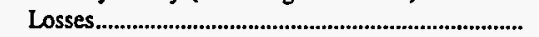 & 28,478 & 9,048 & 55,106 & 19,590 & 12,639 & 9,878 \\
\hline 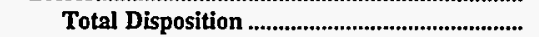 & 464,469 & 258,217 & $1,090,110$ & 332,030 & 352,838 & 241,188 \\
\hline
\end{tabular}

Note: Totals may not equal sum of components because of independent rounding. Double counting occurs in components of both sources and disposition of energy and thus neither provides a true total. Purchases from utilities, net interchanges, and net wheeling (except for imports) are included in net generation.

Source: Energy Information Administration, Form EIA-412, "Annual Report of Public Electric Utilities." 
Table 26. Electric Energy Account by Major U.S. Publicly Owned Electric Utility Within State, 1996 (Continued)

(Megawatthours)

\begin{tabular}{|c|c|c|c|c|c|c|}
\hline Item & $\begin{array}{c}\text { Tennessee } \\
\text { Sweetwater } \\
\text { City of } \\
\text { June } 30\end{array}$ & $\begin{array}{l}\text { Tennessee } \\
\text { Tullahoma } \\
\text { Board } \\
\text { of } \\
\text { Pub Utils } \\
\text { June } 30\end{array}$ & $\begin{array}{l}\text { Tennessee } \\
\text { Union } \\
\text { City City of } \\
\text { June } 30\end{array}$ & $\begin{array}{l}\text { Tennessee } \\
\text { Weakley } \\
\text { County } \\
\text { Mun } \\
\text { Elec Sys } \\
\text { June } 30\end{array}$ & $\begin{array}{c}\text { Tennessee } \\
\text { Winchester } \\
\text { Ciry of } \\
\text { December } 31\end{array}$ & $\begin{array}{l}\text { Texas } \\
\text { Austin } \\
\text { City of } \\
\text { September } 30\end{array}$ \\
\hline \multicolumn{7}{|l|}{ Sources of Energy } \\
\hline Steam & 0 & 0 & 0 & 0 & 0 & $6,507,003$ \\
\hline 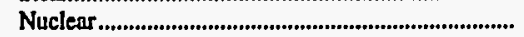 & 0 & 0 & 0 & $\mathbf{0}$ & $\mathbf{0}$ & $3,105,165$ \\
\hline 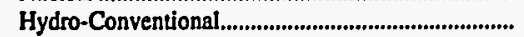 & 0 & 0 & 0 & $\mathbf{0}$ & $\mathbf{0}$ & 0 \\
\hline 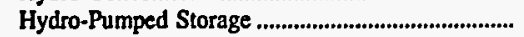 & $\mathbf{0}$ & 0 & $\mathbf{0}$ & $\mathbf{0}$ & $\mathbf{0}$ & 0 \\
\hline 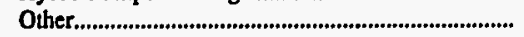 & 0 & $\mathbf{0}$ & 0 & 0 & 0 & 40,362 \\
\hline (Less) Energy for Pumping ........................................ & 0 & $\mathbf{0}$ & 0 & 0 & $\mathbf{0}$ & 0 \\
\hline 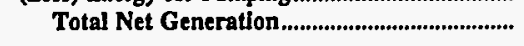 & $\mathbf{0}$ & o & $\mathbf{0}$ & $\mathbf{0}$ & $\mathbf{0}$ & $9,652,530$ \\
\hline 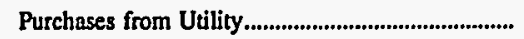 & 208,836 & 296,162 & 380,057 & 519,581 & 155,997 & 374,020 \\
\hline 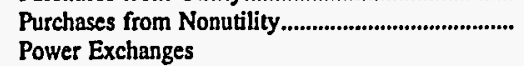 & 0 & $\mathbf{0}$ & 0 & 0 & 0 & 1,947 \\
\hline 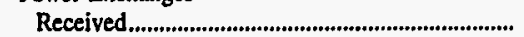 & 0 & $\mathbf{0}$ & $\mathbf{0}$ & $\mathbf{0}$ & $\mathbf{0}$ & 25,497 \\
\hline 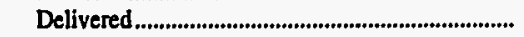 & $\mathbf{0}$ & $\mathbf{0}$ & 0 & $\mathbf{0}$ & 0 & 25,038 \\
\hline 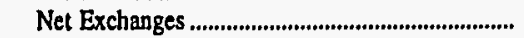 & 0 & 0 & 0 & 0 & 0 & 459 \\
\hline \multicolumn{7}{|l|}{ Transmission for Others (Wheeling) } \\
\hline 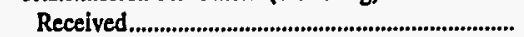 & 0 & 0 & 0 & 0 & 0 & 20,083 \\
\hline 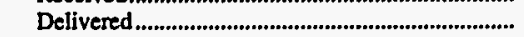 & 0 & 0 & $\mathbf{0}$ & $\mathbf{0}$ & $\mathbf{0}$ & 15,800 \\
\hline 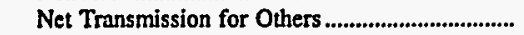 & 0 & $\mathbf{0}$ & $\mathbf{0}$ & $\mathbf{0}$ & $\mathbf{0}$ & 4,283 \\
\hline $\begin{array}{l}\text { Transmission by Others Losses.................................. } \\
\text { Total Net Energy }\end{array}$ & 0 & 0 & $\mathbf{0}$ & 0 & 0 & 0 \\
\hline 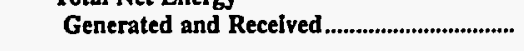 & 208,836 & 296,162 & 380,057 & 519,581 & 155,997 & $10,033,239$ \\
\hline \multicolumn{7}{|l|}{ Disposition of Energy } \\
\hline 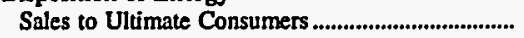 & 200,482 & 281,446 & 370,268 & 483,712 & 148,715 & $8,138,417$ \\
\hline Requirements Sales for Resale................................. & 0 & 0 & 0 & 0 & 0 & 203,565 \\
\hline 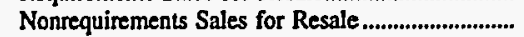 & $\mathbf{0}$ & 0 & 0 & $\mathbf{0}$ & 0 & $1,108,708$ \\
\hline 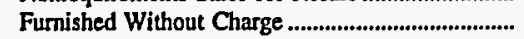 & $\mathbf{0}$ & 0 & 0 & $\mathbf{0}$ & 0 & 0 \\
\hline Used by Utility (excluding station use)................... & $\mathbf{0}$ & 939 & 242 & 463 & 119 & 11,082 \\
\hline 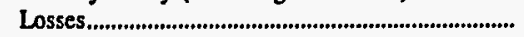 & 8,354 & 13,777 & 9,547 & 35,406 & 7,164 & 571,467 \\
\hline 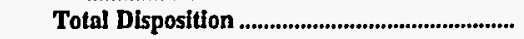 & 208,836 & 296,162 & 380,057 & 519,581 & 155,997 & $10,033,239$ \\
\hline
\end{tabular}

Note: Totals may not equal sum of components because of independent rounding. Double counting occurs in components of both sources and disposition of energy and thus neither provides a true totai. Purchases from utilities, net interchanges, and net wheeling (except for imports) are included in net generation.

Source: Energy Information Administration, Form EIA-412, “Annual Report of Public Electric Utilities." 
Table 26. Electric Energy Account by Major U.S. Publicly Owned Electric Utility Within State, 1996 (Continued)

(Megawatthours)

\begin{tabular}{|c|c|c|c|c|c|c|}
\hline Item & $\begin{array}{c}\text { Texas } \\
\text { Brenham } \\
\text { City of } \\
\text { September } 30\end{array}$ & $\begin{array}{c}\text { Texas } \\
\text { Brownsville } \\
\text { Public } \\
\text { Utils Board } \\
\text { September } 30\end{array}$ & $\begin{array}{c}\text { Texas } \\
\text { Bryan } \\
\text { City of } \\
\text { September } 30\end{array}$ & $\begin{array}{c}\text { Texas } \\
\text { College } \\
\text { Station } \\
\text { City of } \\
\text { September } 30\end{array}$ & $\begin{array}{l}\text { Texas } \\
\text { Denton } \\
\text { City of } \\
\text { September } 30\end{array}$ & $\begin{array}{c}\text { Texas } \\
\text { Floresville } \\
\text { City of } \\
\text { December } 31\end{array}$ \\
\hline \multicolumn{7}{|l|}{ Sources of Energy } \\
\hline 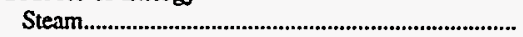 & 0 & 856,092 & 507,826 & 0 & 238,522 & 0 \\
\hline 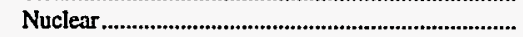 & 0 & 0 & 0 & 0 & 0 & 0 \\
\hline 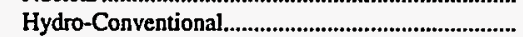 & 0 & 0 & 0 & 0 & 7,806 & 0 \\
\hline 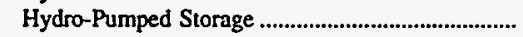 & 0 & 0 & 0 & 0 & 0 & 0 \\
\hline 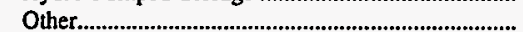 & 0 & 0 & 1,943 & 0 & 0 & 0 \\
\hline 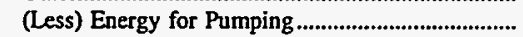 & 0 & 0 & 0 & 0 & 0 & 0 \\
\hline 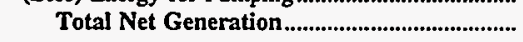 & $\mathbf{0}$ & 856,092 & 509,769 & 0 & 246,328 & 0 \\
\hline 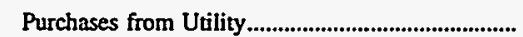 & 286,284 & 0 & 897,387 & 525,798 & 754,538 & 195,364 \\
\hline $\begin{array}{l}\text { Purchases from Nonutility...................................... } \\
\text { Power Exchanges }\end{array}$ & 0 & 0 & 0 & 0 & 0 & 0 \\
\hline 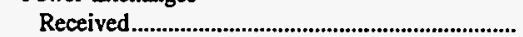 & 0 & 0 & 167,352 & 0 & 0 & 0 \\
\hline 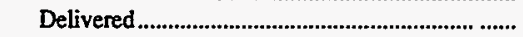 & 0 & 0 & 161,865 & 0 & 0 & 0 \\
\hline 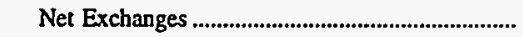 & 0 & 0 & 5,487 & 0 & 0 & 0 \\
\hline \multicolumn{7}{|l|}{ Transmission for Others (Wheeling) } \\
\hline 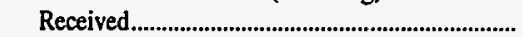 & 0 & 0 & 0 & 0 & 0 & 0 \\
\hline 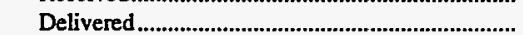 & 0 & 0 & 0 & 0 & 0 & 0 \\
\hline Net Transmission for Others & 0 & 0 & 0 & $\mathbf{0}$ & 0 & 0 \\
\hline 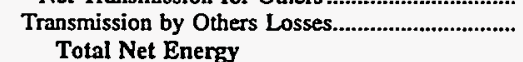 & 0 & 0 & 0 & 0 & 0 & $\mathbf{0}$ \\
\hline 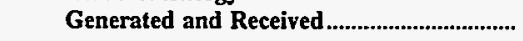 & 286,284 & 856,092 & $1,412,643$ & 525,798 & $1,000,866$ & 195,364 \\
\hline \multicolumn{7}{|l|}{ Disposition of Energy } \\
\hline 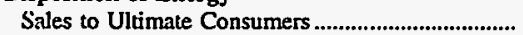 & 277,888 & 755,343 & 844,145 & 525,798 & 903,498 & 175,983 \\
\hline Requirements Sales for Resale................................. & 0 & 35,747 & 516,585 & 0 & 0 & 0 \\
\hline Nonrequirements Sales for Resale .......................... & 0 & 0 & 10,974 & 0 & 97,368 & 0 \\
\hline 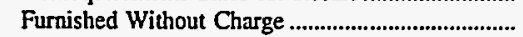 & 0 & 23,584 & 0 & 0 & 0 & 72 \\
\hline Used by Utility (excluding station use).................... & 0 & 27,976 & 0 & 0 & 0 & 320 \\
\hline 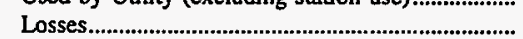 & 8,396 & 13,442 & 40,939 & $\mathbf{0}$ & 0 & 18,989 \\
\hline Total Disposition & 286,284 & 856,092 & $1,412,643$ & 525,798 & $1,000,866$ & 195,364 \\
\hline
\end{tabular}

Note: Totals may not equal sum of components because of independent rounding. Double counting occurs in components of both sources and disposition of energy and thus neither provides a true total. Purchases from utilities, net interchanges, and net wheeling (except for imports) are included in net generation.

Source: Energy Information Administration, Form EIA-412, “Annual Report of Public Electric Utilities.” 
Table 26. Electric Energy Account by Major U.S. Publicly Owned Electric Utility Within State, 1996 (Continued)

(Megawatthours)

\begin{tabular}{|c|c|c|c|c|c|c|}
\hline Item & $\begin{array}{c}\text { Texas } \\
\text { Garland } \\
\text { City of } \\
\text { September } 30\end{array}$ & $\begin{array}{c}\text { Texas } \\
\text { Georgetown } \\
\text { City of } \\
\text { September } 30\end{array}$ & $\begin{array}{l}\text { Texas } \\
\text { Greenville } \\
\text { Electric } \\
\text { Util Sys } \\
\text { September } 30\end{array}$ & $\begin{array}{c}\text { Texas } \\
\text { Jasper } \\
\text { City of } \\
\text { September } 30\end{array}$ & $\begin{array}{c}\text { Texas } \\
\text { Kerrville } \\
\text { Public } \\
\text { Utility } \\
\text { Board } \\
\text { September } 30\end{array}$ & $\begin{array}{l}\text { Texas } \\
\text { Lower } \\
\text { Colorado } \\
\text { River } \\
\text { Authority } \\
\text { June } 30\end{array}$ \\
\hline \multicolumn{7}{|l|}{ Sources of Energy } \\
\hline 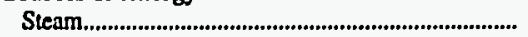 & $1,330,051$ & 0 & 36,295 & 0 & 0 & $10,312,605$ \\
\hline 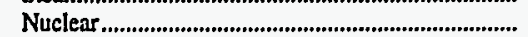 & 0 & 0 & 0 & 0 & 0 & 0 \\
\hline 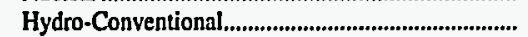 & 0 & 0 & 0 & 0 & 0 & 237,146 \\
\hline Hydro-Pumped Storage ............................................ & 0 & 0 & 0 & 0 & 0 & 0 \\
\hline 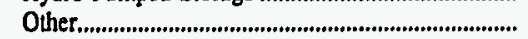 & 0 & 0 & 0 & 0 & 0 & 0 \\
\hline 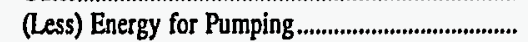 & 0 & 0 & 0 & 0 & 0 & 0 \\
\hline 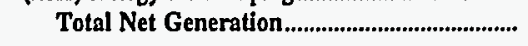 & $1,330,051$ & 0 & 36,295 & $\mathbf{0}$ & 0 & $10,549,751$ \\
\hline 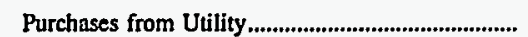 & 701,243 & 218,536 & 423,141 & 141,744 & 408,990 & 661,943 \\
\hline 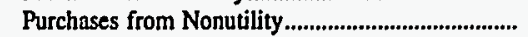 & 0 & 0 & 0 & 0 & 0 & 0 \\
\hline Power Exchanges & & & & & & \\
\hline 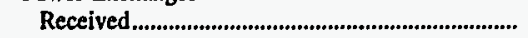 & 0 & 0 & 0 & 0 & 0 & 0 \\
\hline 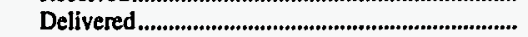 & 0 & 0 & 0 & 0 & 0 & 0 \\
\hline 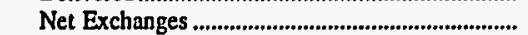 & 0 & 0 & 0 & 0 & 0 & 0 \\
\hline \multicolumn{7}{|l|}{ Transmission for Others (Wheeling) } \\
\hline 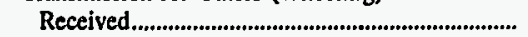 & 0 & 0 & 0 & 0 & 0 & 0 \\
\hline Delivered & 0 & 0 & 0 & 0 & 0 & 0 \\
\hline 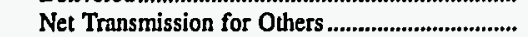 & $\mathbf{0}$ & 0 & 0 & 0 & 0 & 0 \\
\hline $\begin{array}{l}\text { Transmission by Others Losses..................................... } \\
\text { Total Net Energy }\end{array}$ & 0 & 0 & 0 & 0 & 0 & 0 \\
\hline 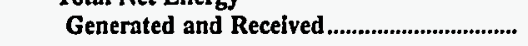 & $2,031,294$ & 218,536 & 459,436 & 141,744 & 408,990 & $11,211,694$ \\
\hline \multicolumn{7}{|l|}{ Disposition of Energy } \\
\hline 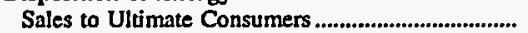 & $1,863,845$ & 204,095 & 426,404 & 128,886 & 393,125 & 153,344 \\
\hline 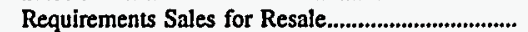 & 120,368 & 0 & 19,882 & 0 & 0 & $9,495,870$ \\
\hline 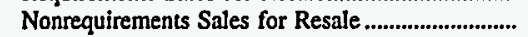 & 0 & $\mathbf{0}$ & 0 & 0 & 0 & $1,149,668$ \\
\hline Furnished Without Charge ...................................... & 0 & 0 & 0 & 1,583 & 0 & 0 \\
\hline Used by Utility (excluding station use).................. & 0 & 0 & 0 & 0 & 0 & 0 \\
\hline 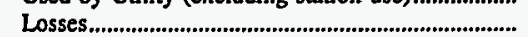 & 47,081 & 14,441 & 13,150 & 11,275 & 15,865 & 412,812 \\
\hline 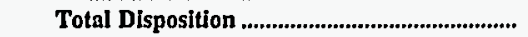 & $2,031,294$ & 218,536 & 459,436 & 141,744 & 408,990 & $11,211,694$ \\
\hline
\end{tabular}

Note: Totals may not equal sum of components because of independent rounding. Double counting occurs in components of both sources and disposition of energy and thus neither provides a true total. Purchases from utilities, net interchanges, and net wheeling (except for imports) are included in net generation.

Source: Energy Information Administration, Form EIA-412, "Annual Report of Public Electric Utilities." 
Table 26. Electric Energy Account by Major U.S. Publicly Owned Electric Utility Within State, 1996 (Continued)

(Megawatthours)

\begin{tabular}{|c|c|c|c|c|c|c|}
\hline Item & $\begin{array}{c}\text { Texas } \\
\text { Lubbock } \\
\text { City of } \\
\text { September } 30\end{array}$ & $\begin{array}{c}\text { Texas } \\
\text { New Braunfels } \\
\text { City of } \\
\text { July } 31\end{array}$ & $\begin{array}{c}\text { Texas } \\
\text { Sam Rayburn } \\
\text { Municipal } \\
\text { Pwr } \\
\text { Agny } \\
\text { September } 30\end{array}$ & $\begin{array}{c}\text { Texas } \\
\text { San Antonio } \\
\text { Public } \\
\text { Service Bd } \\
\text { January } 31\end{array}$ & $\begin{array}{c}\text { Texas } \\
\text { San Marcos } \\
\text { City of } \\
\text { September } 30\end{array}$ & $\begin{array}{c}\text { Texas } \\
\text { Seguin } \\
\text { City of } \\
\text { September } 30\end{array}$ \\
\hline \multicolumn{7}{|l|}{ Sources of Energy } \\
\hline 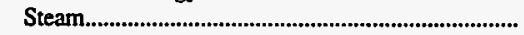 & 609,124 & 0 & 514,294 & $9,793,930$ & 0 & 0 \\
\hline 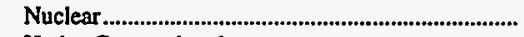 & 0 & 0 & 0 & $5,865,391$ & 0 & 0 \\
\hline 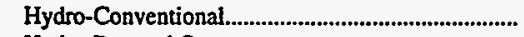 & 0 & 0 & 0 & 0 & 0 & 0 \\
\hline 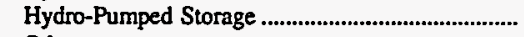 & 0 & 0 & 0 & 0 & $\mathbf{0}$ & 0 \\
\hline 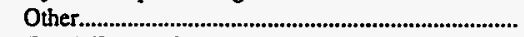 & 0 & 0 & $\mathbf{0}$ & 0 & 0 & 0 \\
\hline (Less) Energy for Pumping & 0 & 0 & 0 & $\mathbf{0}$ & 0 & 0 \\
\hline Total Net Generation & 609,124 & 0 & 514,294 & $15,659,321$ & 0 & 0 \\
\hline 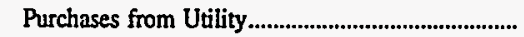 & 505,645 & 867,670 & 44,469 & 418,057 & 371,132 & 230,417 \\
\hline $\begin{array}{l}\text { Purchases from Nonutility.......................................... } \\
\text { Power Exchanges }\end{array}$ & 0 & 0 & 0 & 20,050 & $\mathbf{0}$ & 0 \\
\hline 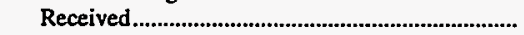 & 0 & 0 & 0 & 120,869 & 0 & 0 \\
\hline Delivered & $\mathbf{0}$ & 0 & 0 & 76,618 & 0 & 0 \\
\hline Net Exchanges & 0 & 0 & 0 & 44,251 & 0 & 0 \\
\hline \multicolumn{7}{|l|}{ Transmission for Others (Wheeling) } \\
\hline 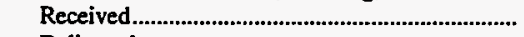 & 0 & 0 & 0 & 0 & 0 & 0 \\
\hline 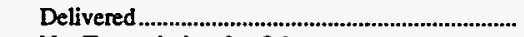 & 0 & 0 & 0 & 0 & 0 & 0 \\
\hline 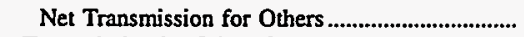 & 0 & 0 & 0 & $\mathbf{0}$ & 0 & 0 \\
\hline Transmission by Others Losses................................... & 0 & 0 & 0 & 0 & 0 & 0 \\
\hline \multicolumn{7}{|l|}{ Total Net Energy } \\
\hline 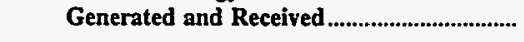 & $1,114,769$ & 867,670 & 558,763 & $16,141,679$ & 371,132 & 230,417 \\
\hline \multicolumn{7}{|l|}{ Disposition of Energy } \\
\hline 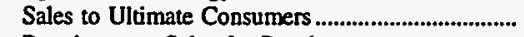 & $1,042,753$ & 839,434 & 0 & $14,595,910$ & 342,112 & 216,363 \\
\hline 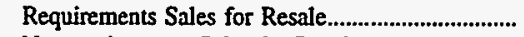 & 0 & 0 & 348,793 & 290,265 & 0 & 0 \\
\hline Nonrequirements Sales for Resale............................. & 0 & 0 & 204,237 & 381,331 & 0 & 0 \\
\hline 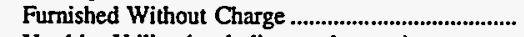 & 0 & 2,045 & 0 & 0 & 0 & 14,054 \\
\hline Used by Utility (excluding station use) .................. & 0 & 0 & 0 & 59,400 & 0 & 0 \\
\hline 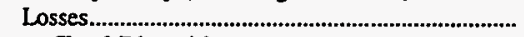 & 72,016 & 26,191 & 5,733 & 814,773 & 29,020 & 0 \\
\hline 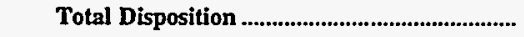 & $1,114,769$ & 867,670 & 558,763 & $16,141,679$ & 371,132 & 230,417 \\
\hline
\end{tabular}

Note: Totals may not equal sum of components because of independent rounding. Double counting occurs in components of both sources and disposition of energy and thus neither provides a ture total. Purchases from titities, net interchanges, and net wheeling (except for imports) are included in net generation.

Source: Energy Information Administration, Form EIA-412, “Annual Report of Public Electric Utilities.” 
Table 26. Electric Energy Account by Major U.S. Publicly Owned Electric Utility Within State, 1996 (Continued)

(Megawatthours)

\begin{tabular}{|c|c|c|c|c|c|c|}
\hline Item & $\begin{array}{c}\text { Texas } \\
\text { Texas } \\
\text { Municipal } \\
\text { Power Agency } \\
\text { September } 30\end{array}$ & $\begin{array}{c}\text { Texas } \\
\text { Toledo Bend } \\
\text { Project } \\
\text { Joint } \\
\text { Oper } \\
\text { August } 30\end{array}$ & $\begin{array}{c}\text { Texas } \\
\text { Weatherford } \\
\text { Mun } \\
\text { Utility } \\
\text { System } \\
\text { September } 30\end{array}$ & $\begin{array}{c}\text { Utah } \\
\text { Bountiful } \\
\text { City City of } \\
\text { June } 30\end{array}$ & $\begin{array}{c}\text { Utah } \\
\text { Intermountain } \\
\text { Power Agency } \\
\text { June } 30\end{array}$ & $\begin{array}{l}\text { Utah } \\
\text { Logan } \\
\text { City of } \\
\text { June } 30\end{array}$ \\
\hline \multicolumn{7}{|l|}{ Sources of Energy } \\
\hline 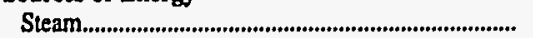 & $2,571,360$ & 0 & 0 & 0 & $9,760,982$ & 0 \\
\hline 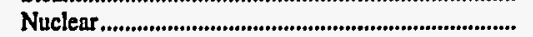 & 0 & 0 & 0 & 0 & 0 & 0 \\
\hline 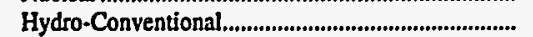 & $\mathbf{0}$ & 33,343 & 0 & 25,874 & 0 & 32,064 \\
\hline Hydro-Pumped Storage .............................................. & 0 & 0 & 0 & 0 & 0 & 0 \\
\hline 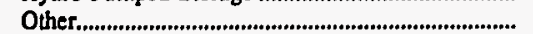 & $\mathbf{0}$ & $\mathbf{0}$ & 528 & 4,304 & 0 & 0 \\
\hline 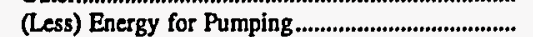 & 0 & 0 & 0 & 0 & 0 & 0 \\
\hline 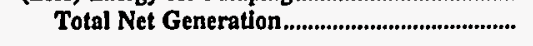 & $2,571,360$ & 33,343 & 528 & 30,178 & $9,760,982$ & 32,064 \\
\hline Purchases from Utility.............................................. & 101,690 & $\mathbf{0}$ & 252,951 & 235,085 & 0 & 289,074 \\
\hline $\begin{array}{l}\text { Purchases from Nonutility........................................ } \\
\text { Power Exchanges }\end{array}$ & 0 & 0 & 0 & 0 & 0 & 0 \\
\hline 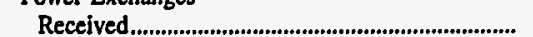 & $\mathbf{0}$ & 0 & 0 & 0 & 0 & 0 \\
\hline 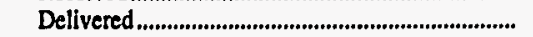 & $\mathbf{0}$ & 0 & 0 & 0 & 0 & 0 \\
\hline 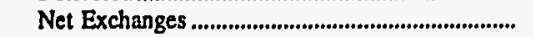 & $\mathbf{0}$ & 0 & 0 & $\mathbf{0}$ & $\mathbf{0}$ & $\mathbf{0}$ \\
\hline \multicolumn{7}{|l|}{ Transmission for Others (Wheeling) } \\
\hline 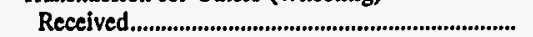 & $\mathbf{0}$ & 0 & 0 & 0 & 0 & 0 \\
\hline 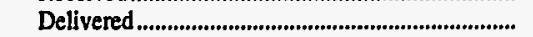 & $\mathbf{0}$ & 0 & 0 & 0 & 0 & 0 \\
\hline Net Transmission for Others .................................. & 0 & 0 & 0 & $\mathbf{0}$ & 0 & 0 \\
\hline $\begin{array}{l}\text { Transmission by Others Losses.................................... } \\
\text { Total Net Energy }\end{array}$ & $\mathbf{0}$ & $\mathbf{0}$ & 0 & $\mathbf{0}$ & 0 & $\mathbf{0}$ \\
\hline 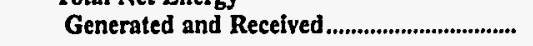 & $2,673,050$ & 33,343 & 253,479 & 265,263 & $9,760,982$ & 321,138 \\
\hline \multicolumn{7}{|l|}{ Disposition of Energy } \\
\hline 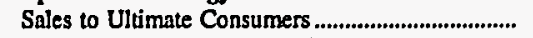 & 0 & 0 & 236,962 & 255,682 & 0 & 306,064 \\
\hline Requirements Sales for Resale................................... & $2,587,905$ & $\mathbf{0}$ & 0 & 0 & $9,760,982$ & $\mathbf{0}$ \\
\hline Nonsequirements Sales for Resale .............................. & 0 & 31,717 & $\mathbf{0}$ & 0 & 0 & $\mathbf{0}$ \\
\hline Furnished Without Charge ............................................. & $\mathbf{0}$ & 0 & $\mathbf{0}$ & $\mathbf{0}$ & $\mathbf{0}$ & 0 \\
\hline Used by Utility (excluding station use)...................... & 85,145 & 820 & 0 & 2,207 & 0 & 623 \\
\hline 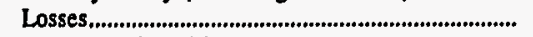 & 0 & 806 & 16,517 & 7,374 & $\mathbf{0}$ & 14,451 \\
\hline Total Disposition ................................................ & $2,673,050$ & 33,343 & 253,479 & 265,263 & $9,760,982$ & 321,138 \\
\hline
\end{tabular}

Note: Totals may not equal sum of components because of independent rounding. Double counting occurs in components of both sources and disposition of energy and thus neither provides a true total. Purchases from utilities, net interchanges, and net wheeling (except for imports) are included in net generation.

Source: Energy Information Administration, Form ELA-412, "Annual Report of Public Electric Utilities." 
Table 26. Electric Energy Account by Major U.S. Publicly Owned Electric Utility Within State, 1996 (Continued)

(Megawatthours)

\begin{tabular}{|c|c|c|c|c|c|c|}
\hline Item & $\begin{array}{l}\text { Utah } \\
\text { Murray } \\
\text { City of } \\
\text { June } 30\end{array}$ & $\begin{array}{l}\text { Utah } \\
\text { Provo } \\
\text { City Corp } \\
\text { June } 30\end{array}$ & $\begin{array}{c}\text { Utah } \\
\text { St George } \\
\text { City of } \\
\text { June } 30\end{array}$ & $\begin{array}{c}\text { Utah } \\
\text { Utah } \\
\text { Associated } \\
\text { Mun } \\
\text { Power Sys } \\
\text { March } 31\end{array}$ & $\begin{array}{c}\text { Utah } \\
\text { Utah } \\
\text { Municipal } \\
\text { Power Agency } \\
\text { June } 30\end{array}$ & $\begin{array}{l}\text { Vermont } \\
\text { Burlington } \\
\text { City of } \\
\text { June } 30\end{array}$ \\
\hline \multicolumn{7}{|l|}{ Sources of Energy } \\
\hline 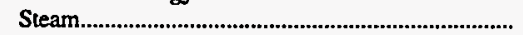 & 0 & 0 & $\mathbf{0}$ & 609,588 & 325,274 & 60,274 \\
\hline 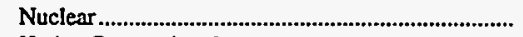 & 0 & 0 & 0 & 0 & 0 & 0 \\
\hline 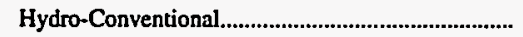 & 19,026 & 0 & 0 & 0 & 12,095 & 0 \\
\hline 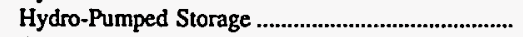 & 0 & 0 & 0 & 0 & 0 & 0 \\
\hline 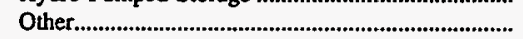 & 215 & 0 & 3,140 & 0 & 24,086 & 1,590 \\
\hline 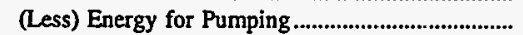 & 0 & 0 & 0 & 0 & 0 & 0 \\
\hline 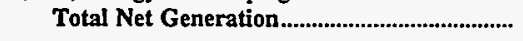 & 19,241 & $\mathbf{0}$ & 3,140 & 609,588 & 361,455 & 61,864 \\
\hline 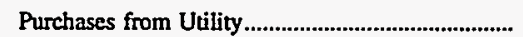 & 319,848 & 612,071 & 388,895 & $1,031,197$ & 491,785 & 396,649 \\
\hline $\begin{array}{l}\text { Purchases from Nonutility.......................................... } \\
\text { Power Exchanges }\end{array}$ & 0 & 0 & 0 & 0 & 0 & 4,182 \\
\hline 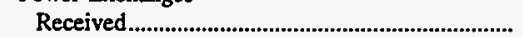 & 0 & $\mathbf{0}$ & 0 & 8,362 & 0 & 314 \\
\hline 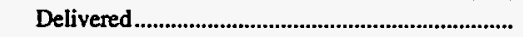 & 0 & 0 & 0 & 9,823 & 0 & 314 \\
\hline 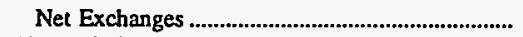 & 0 & 0 & 0 & $-1,461$ & 0 & 0 \\
\hline \multicolumn{7}{|l|}{ Transmission for Others (Wheeling) } \\
\hline 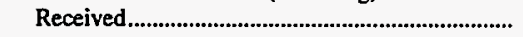 & 0 & 0 & $\mathbf{0}$ & 0 & 0 & 0 \\
\hline Delivered & 0 & 0 & 0 & 0 & 0 & 0 \\
\hline 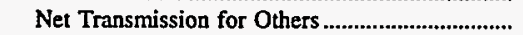 & 0 & 0 & 0 & 0 & 0 & 0 \\
\hline 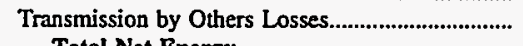 & 0 & 0 & 0 & 0 & 0 & 0 \\
\hline 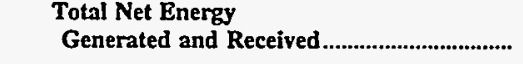 & 339,089 & 612,071 & 392,035 & $1,639,324$ & 853,240 & 462,695 \\
\hline \multicolumn{7}{|l|}{ Disposition of Energy } \\
\hline 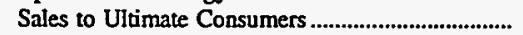 & 317,328 & 569,917 & 375,434 & 0 & $\mathbf{0}$ & 326,180 \\
\hline Requirements Sales for Resale & 0 & 0 & 0 & $1,639,324$ & 791,109 & 0 \\
\hline 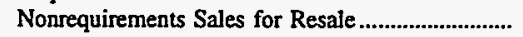 & 0 & 0 & 0 & 0 & 44,268 & 108,199 \\
\hline Furnished Without Charge ....................................... & 1,499 & 5,808 & 15,000 & 0 & 0 & 0 \\
\hline Used by Utility (excluding station use)................... & 0 & 1,856 & 0 & 0 & $\mathbf{0}$ & 1,301 \\
\hline 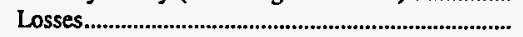 & 20,262 & 34,490 & 1,601 & 0 & 17,863 & 27,015 \\
\hline Total Disposition & 339,089 & 612,071 & 392,035 & $1,639,324$ & 853,240 & 462,695 \\
\hline
\end{tabular}

Note: Totals may not equal sum of components because of independent rounding. Double counting occurs in components of both sources and disposition of energy and thus neither provides a true total. Purchases from utilities, net interchanges, and net wheeling (except for imports) are included in net generation.

Source: Energy Information Administration, Form EIA-412, “Annual Report of Public Electric Utilities." 
Table 26. Electric Energy Account by Major U.S. Publicly Owned Electric Utility Within State, 1996 (Continued)

(Megawatthours)

\begin{tabular}{|c|c|c|c|c|c|c|}
\hline Item & $\begin{array}{c}\text { Vermont } \\
\text { Vermont } \\
\text { Public } \\
\text { Pwr } \\
\text { Supply Auth } \\
\text { December } 31\end{array}$ & $\begin{array}{l}\text { Virginia } \\
\text { Bedford } \\
\text { City of } \\
\text { June } 30\end{array}$ & $\begin{array}{l}\text { Virginia } \\
\text { Bristol } \\
\text { Utilities } \\
\text { Board } \\
\\
\text { June } 30\end{array}$ & $\begin{array}{l}\text { Virginia } \\
\text { Danville } \\
\text { City of } \\
\text { June } 30\end{array}$ & $\begin{array}{l}\text { Virginia } \\
\begin{array}{l}\text { Harrisonburg } \\
\text { City of }\end{array} \\
\text { June } 30\end{array}$ & $\begin{array}{l}\text { Virginia } \\
\text { Manassas } \\
\text { City of } \\
\text { June } 30\end{array}$ \\
\hline \multicolumn{7}{|l|}{ Sources of Rnergy } \\
\hline 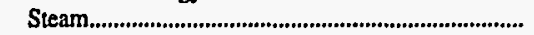 & 26,030 & 0 & 0 & $\mathbf{0}$ & 0 & \\
\hline Nuclear............................................................................ & 0 & 0 & 0 & 0 & 0 & 0 \\
\hline 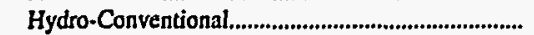 & 0 & 15,707 & 0 & 26,768 & $\mathbf{0}$ & 1,853 \\
\hline 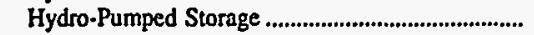 & 0 & 0 & $\mathbf{0}$ & 0 & 0 & 0 \\
\hline 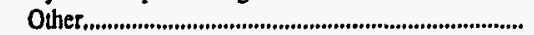 & 0 & 0 & 0 & 0 & 0 & 1,914 \\
\hline 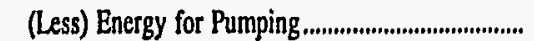 & 0 & 0 & 0 & 0 & 0 & 0 \\
\hline 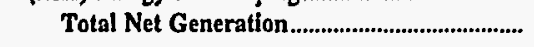 & 26,030 & 15,707 & 0 & 26,768 & 0 & 3,767 \\
\hline Purchases from Utility................................................. & 77,581 & 201,005 & 593,012 & 915,894 & 589,228 & 315,417 \\
\hline 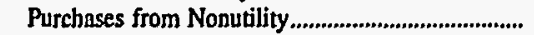 & 0 & 0 & 0 & 0 & $\mathbf{0}$ & 0 \\
\hline \multicolumn{7}{|l|}{ Power Exchanges } \\
\hline Received................... & 0 & 0 & 0 & $\mathbf{0}$ & 0 & 0 \\
\hline 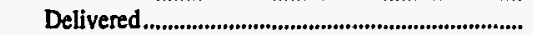 & 0 & 0 & 0 & $\mathbf{0}$ & 0 & 0 \\
\hline Net Exchanges ................................................................. & $\mathbf{0}$ & 0 & $\mathbf{0}$ & $\mathbf{0}$ & 0 & 0 \\
\hline \multicolumn{7}{|l|}{ Transmission for Others (Wheeling) } \\
\hline 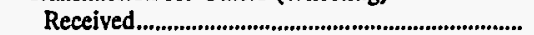 & 0 & 0 & 0 & 0 & 0 & $\mathbf{0}$ \\
\hline 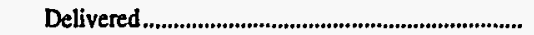 & 0 & 0 & 0 & 0 & 0 & 0 \\
\hline 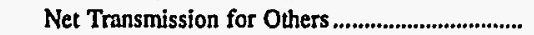 & $\mathbf{0}$ & 0 & 0 & o & o & 0 \\
\hline Transmission by Others Losses.................................... & 0 & 0 & 0 & 0 & 0 & 0 \\
\hline $\begin{array}{l}\text { Total Net Energy } \\
\text { Generated and Received........................................ }\end{array}$ & & & & & & \\
\hline Generated and Received .......................................... & 103,611 & 216,712 & 593,012 & 942,662 & 589,228 & 319,184 \\
\hline \multicolumn{7}{|l|}{ Disposition of Energy } \\
\hline 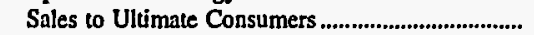 & $\mathbf{0}$ & 209,067 & 567,771 & 865,263 & 577,203 & 304,136 \\
\hline Requirements Sales for Resale..................................... & 0 & 0 & 0 & $\mathbf{0}$ & 0 & 0 \\
\hline Nonrequirements Sales for Resale ................................. & 103,611 & 0 & 0 & 0 & 0 & 0 \\
\hline Furnished Without Charge ............................................. & $\mathbf{0}$ & 0 & 0 & 0 & 0 & 0 \\
\hline Used by Utility (excluding station use)........................ & 0 & 0 & 0 & 0 & 0 & 0 \\
\hline 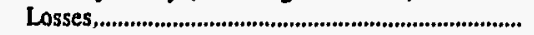 & $\mathbf{0}$ & 7,645 & 25,241 & 77,399 & 12,025 & 15,048 \\
\hline Total Disposition ....................................................... & 103,611 & 216,712 & 593,012 & 942,662 & 589,228 & 319,184 \\
\hline
\end{tabular}

Note: Totals may not equal sum of components because of independent rounding. Double counting occurs in components of both sources and disposition of energy and thus neither provides a true total. Purchases from utilities, net interchanges, and net wheeling (except for imports) are included in net generation.

Source: Energy Information Administration, Form EIA-412, “Annual Report of Public Electric Utilities.” 
Table 26. Electric Energy Account by Major U.S. Publicly Owned Electric Utility Within State, 1996 (Continued)

(Megawatthours)

\begin{tabular}{|c|c|c|c|c|c|c|}
\hline Item & $\begin{array}{c}\text { Virginia } \\
\begin{array}{c}\text { Martinsville } \\
\text { City of }\end{array} \\
\text { June } 30\end{array}$ & $\begin{array}{l}\text { Virginia } \\
\text { Radford } \\
\text { City of } \\
\text { June } 30\end{array}$ & $\begin{array}{l}\text { Virginia } \\
\text { Salem } \\
\text { City of } \\
\text { June } 30\end{array}$ & $\begin{array}{l}\text { Virginia } \\
\text { Virginia } \\
\text { Tech } \\
\text { Electric } \\
\text { Service } \\
\text { June } 30\end{array}$ & $\begin{array}{l}\text { Washington } \\
\text { Centralia } \\
\text { City of } \\
\text { December } 31\end{array}$ & $\begin{array}{l}\text { Washington } \\
\text { Ellensburg } \\
\text { City of } \\
\text { December } 31\end{array}$ \\
\hline \multicolumn{7}{|l|}{ Sources of Energy } \\
\hline Steam & 0 & 0 & $\mathbf{0}$ & 19,851 & 0 & 0 \\
\hline 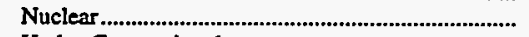 & 0 & 0 & $\mathbf{0}$ & 0 & 0 & 0 \\
\hline 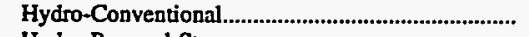 & 5,402 & 0 & $\mathbf{0}$ & 0 & 33,278 & $\mathbf{0}$ \\
\hline Hydro-Pumped Storage & 0 & 5,569 & 0 & 0 & 0 & 0 \\
\hline Other & 0 & 0 & 0 & 0 & 0 & 0 \\
\hline 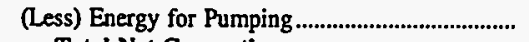 & 0 & 0 & 0 & 0 & 0 & 0 \\
\hline 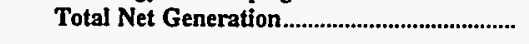 & 5,402 & 5,569 & 0 & 19,851 & 33,278 & $\mathbf{0}$ \\
\hline 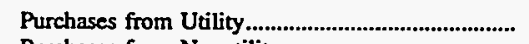 & 203,507 & 366,396 & 372,036 & 229,514 & 201,974 & 184,274 \\
\hline $\begin{array}{l}\text { Purchases from Nonutility....................................... } \\
\text { Power Exchanges }\end{array}$ & 0 & 0 & 0 & 0 & 0 & 0 \\
\hline 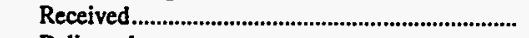 & 0 & 0 & 0 & 0 & 0 & 0 \\
\hline 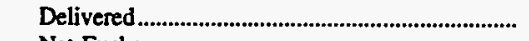 & 0 & 0 & 0 & 0 & 0 & 0 \\
\hline 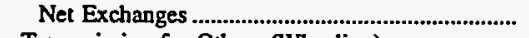 & 0 & 0 & 0 & 0 & 0 & 0 \\
\hline \multicolumn{7}{|l|}{ Transmission for Others (Wheeling) } \\
\hline 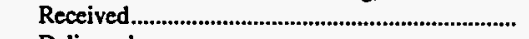 & 0 & 0 & 0 & 0 & 0 & 0 \\
\hline Delivered & 0 & 0 & 0 & 0 & 0 & 0 \\
\hline 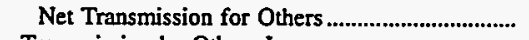 & 0 & 0 & $\mathbf{0}$ & 0 & 0 & 0 \\
\hline $\begin{array}{l}\text { Transmission by Others Losses.................................. } \\
\text { Total Net Energy }\end{array}$ & 0 & 0 & 0 & 0 & 0 & 0 \\
\hline Generated and Received................................... & 208,909 & 371,965 & 372,036 & 249,365 & 235,252 & 184,274 \\
\hline \multicolumn{7}{|l|}{ Disposition of Energy } \\
\hline 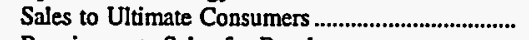 & 197,234 & 362,335 & 379,229 & 242,249 & 227,302 & 180,656 \\
\hline 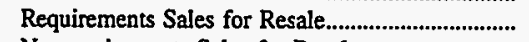 & 0 & 0 & 0 & 0 & 0 & 0 \\
\hline 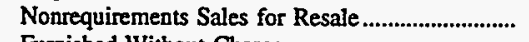 & 0 & 0 & 0 & 0 & 0 & 0 \\
\hline Furnished Without Charge & 1,362 & 9 & 0 & 0 & 0 & 0 \\
\hline Used by Utility (excluding station use).................. & 180 & 14 & 0 & 0 & 337 & 0 \\
\hline 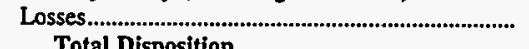 & 10,133 & 9,607 & $-7,193$ & 7,116 & 7,613 & 3,618 \\
\hline 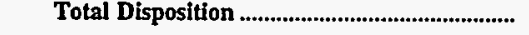 & 208,909 & 371,965 & 372,036 & 249,365 & 235,252 & 184,274 \\
\hline
\end{tabular}

Note: Totals may not equal sum of components because of independent rounding. Double counting occurs in components of both sources and disposition of energy and thus neither provides a true total. Purchases from utilities, net interchanges, and net wheeling (except for imports) are included in net generation.

Source: Energy Information Administration, Form EIA-412, “Annual Report of Public Electric Utilities." 
Table 26. Electric Energy Account by Major U.S. Publicly Owned Electric Utility Within State, 1996 (Continued)

(Megawatthours)

\begin{tabular}{|c|c|c|c|c|c|c|}
\hline Item & $\begin{array}{c}\text { Washington } \\
\text { Port Angeles } \\
\text { City of } \\
\text { December } 31\end{array}$ & $\begin{array}{l}\text { Washington } \\
\text { PUD No } 1 \\
\text { of } \\
\text { Benton } \\
\text { County } \\
\text { December } 31\end{array}$ & $\begin{array}{c}\text { Washington } \\
\text { PUD No } 1 \\
\text { of } \\
\text { Chelan } \\
\text { County } \\
\text { December } 31\end{array}$ & $\begin{array}{l}\text { Washington } \\
\text { PUD No I of } \\
\text { Clallam } \\
\text { County } \\
\text { December } 31\end{array}$ & $\begin{array}{c}\text { Washington } \\
\text { PUD No } 1 \\
\text { of } \\
\text { Clark } \\
\text { County } \\
\text { December } 31\end{array}$ & $\begin{array}{l}\text { Washington } \\
\text { PUD No } 1 \text { of } \\
\text { Cowlitz } \\
\text { County } \\
\text { December } 31\end{array}$ \\
\hline \multicolumn{7}{|l|}{ Sources of Energy } \\
\hline Steam & 0 & 0 & 0 & 0 & 0 & 0 \\
\hline Nuclear & 0 & $\mathbf{0}$ & 0 & 0 & 0 & 0 \\
\hline Hydro-Conventional.................................................. & 2,578 & 0 & $10,826,678$ & 0 & $\mathbf{0}$ & 284,402 \\
\hline 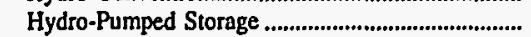 & 0 & 0 & 0 & 0 & 0 & 0 \\
\hline 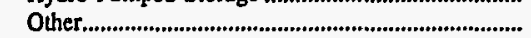 & 0 & 0 & 0 & 0 & 0 & 0 \\
\hline 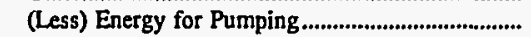 & 0 & 0 & 0 & 0 & 0 & 0 \\
\hline 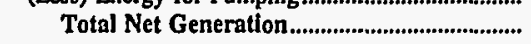 & 2,578 & $\mathbf{0}$ & $10,826,678$ & 0 & $\mathbf{0}$ & 284,402 \\
\hline 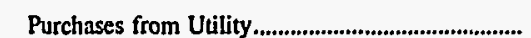 & 647,641 & $1,661,754$ & 652,920 & 560,572 & $3,871,522$ & $3,583,465$ \\
\hline $\begin{array}{l}\text { Purchases from Nonutility............................................ } \\
\text { Power Exchanges }\end{array}$ & 0 & 64,316 & 0 & 72 & 0 & 0 \\
\hline 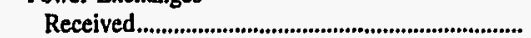 & 0 & $\mathbf{0}$ & $1,102,468$ & 0 & 213 & 267,412 \\
\hline 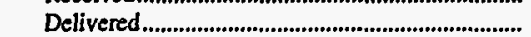 & 0 & $\mathbf{0}$ & 321,957 & 0 & 0 & 9,879 \\
\hline \multicolumn{6}{|l|}{ Transmission for Others (Wheeling) } & 257,533 \\
\hline 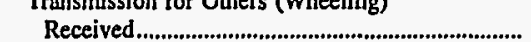 & 0 & 0 & 66,099 & 0 & 0 & 0 \\
\hline 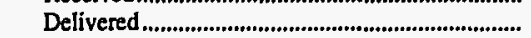 & 0 & 0 & 51,534 & 0 & 0 & 0 \\
\hline 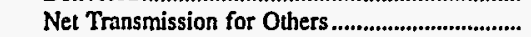 & 0 & 0 & 14,565 & 0 & 0 & 0 \\
\hline $\begin{array}{l}\text { Transmission by Others Losses................................... } \\
\text { Total Net Energy }\end{array}$ & 0 & 0 & -632 & 0 & 0 & 0 \\
\hline 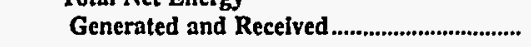 & 650,219 & $1,726,070$ & $12,274,042$ & 560,644 & $3,871,735$ & $4,125,400$ \\
\hline \multicolumn{7}{|l|}{ Disposition of Energy } \\
\hline 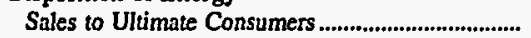 & 646,690 & $1,613,799$ & $1,315,295$ & 521,719 & $3,687,150$ & $4,033,060$ \\
\hline 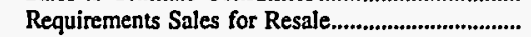 & 0 & 0 & $8,029,274$ & 0 & 0 & 30,160 \\
\hline 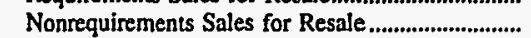 & 0 & 12,210 & $2,816,365$ & 0 & 0 & 0 \\
\hline Fumished Without Charge ....................................... & 1,540 & 0 & 21 & 0 & 0 & 0 \\
\hline Used by Utility (excluding station use)................... & 560 & 3,220 & 402 & 1,155 & 8,173 & 2,779 \\
\hline 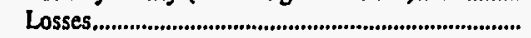 & 1,429 & 96,841 & 112,685 & 37,770 & 176,412 & 59,401 \\
\hline Total Disposition ................................................ & 650,219 & $1,726,070$ & $12,274,042$ & 560,644 & $3,871,735$ & $4,125,400$ \\
\hline
\end{tabular}

Note: Totals may not equal sum of components because of independent rounding. Double counting occurs in components of both sources and disposition of energy and thus neither provides a true total. Purchases from utilities, net interchanges, and net wheeling (except for imports) are included in net generation. Sales for resale is included in sales to ultimate consumers.

Source: Energy Information Administration, Form EIA-412, "Annual Report of Public Electric Utilities." 
Table 26. Electric Energy Account by Major U.S. Publicly Owned Electric Utility Within State, 1996 (Continued)

(Megawatthours)

\begin{tabular}{|c|c|c|c|c|c|c|}
\hline Item & $\begin{array}{l}\text { Washington } \\
\text { PUD No } 1 \text { of } \\
\text { Douglas } \\
\text { County } \\
\text { December } 31\end{array}$ & $\begin{array}{l}\text { Washington } \\
\text { PUD No } 1 \text { of } \\
\text { Franklin } \\
\text { County } \\
\text { December } 31\end{array}$ & $\begin{array}{c}\text { Washington } \\
\text { PUD No } 1 \\
\text { of } \\
\text { Grays } \\
\text { Harbor Cnty } \\
\text { December } 31\end{array}$ & $\begin{array}{l}\text { Washington } \\
\text { PUD No } 1 \\
\text { of } \\
\text { Klickitat } \\
\text { County } \\
\text { December } 31\end{array}$ & $\begin{array}{l}\text { Washington } \\
\text { PUD No 1 } \\
\text { of } \\
\text { Lewis } \\
\text { County } \\
\text { December } 31\end{array}$ & $\begin{array}{l}\text { Washington } \\
\text { PUD No } 1 \text { of } \\
\text { Okanogan } \\
\text { County } \\
\text { December } 31\end{array}$ \\
\hline \multicolumn{7}{|l|}{ Sources of Energy } \\
\hline Steam & 0 & $\mathbf{0}$ & 330,027 & 0 & 0 & $\mathbf{0}$ \\
\hline 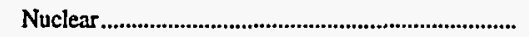 & 0 & 0 & 0 & 0 & 0 & 0 \\
\hline 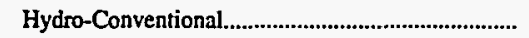 & $5,368,013$ & 0 & 0 & 0 & 0 & $\mathbf{0}$ \\
\hline 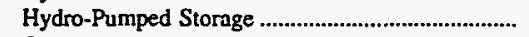 & 0 & 0 & 0 & 0 & 1,493 & $\mathbf{0}$ \\
\hline Other. & 0 & 0 & 0 & 0 & 0 & 0 \\
\hline 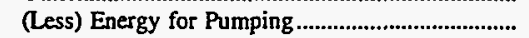 & 0 & 0 & 0 & 0 & 0 & 0 \\
\hline 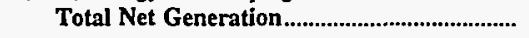 & $5,368,013$ & 0 & 330,027 & 0 & 1,493 & 0 \\
\hline 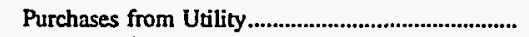 & 217,128 & 691,389 & 757,109 & 305 & 777,370 & 641,267 \\
\hline Purchases from Nonutility........................................ & 0 & 15,432 & 0 & 0 & 0 & 24,371 \\
\hline \multicolumn{7}{|l|}{ Power Exchanges } \\
\hline Received & 0 & 0 & 35,178 & 0 & 0 & 0 \\
\hline 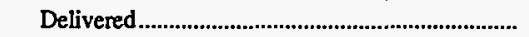 & $-46,328$ & 0 & 35,178 & 0 & 0 & 0 \\
\hline 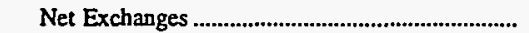 & 46,328 & 0 & 0 & 0 & 0 & 0 \\
\hline \multicolumn{7}{|l|}{ Transmission for Others (Wheeling) } \\
\hline Received & 0 & 0 & 0 & 0 & 0 & 0 \\
\hline 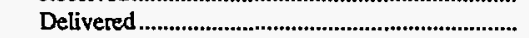 & 0 & 0 & 0 & 0 & 0 & 0 \\
\hline 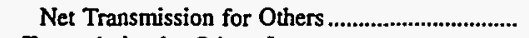 & 0 & 0 & 0 & 0 & 0 & 0 \\
\hline $\begin{array}{l}\text { Transmission by Others Losses...................................... } \\
\text { Total Net Energy }\end{array}$ & 0 & 0 & 0 & 0 & $\mathbf{0}$ & 0 \\
\hline 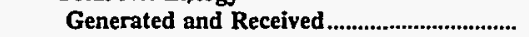 & $5,631,469$ & 706,821 & $1,087,136$ & 305 & 778,863 & 665,638 \\
\hline \multicolumn{7}{|l|}{ Disposition of Energy } \\
\hline 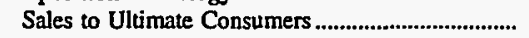 & 726,107 & 670,216 & $1,006,535$ & 285 & 725,955 & 597,493 \\
\hline 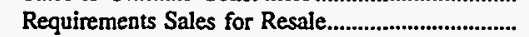 & $3,735,214$ & 0 & 0 & 0 & 0 & 0 \\
\hline Nonrequirements Sales for Resale ............................. & 782,266 & 0 & 11,996 & 0 & 0 & 0 \\
\hline Furnished Without Charge ......................................... & 258,270 & 0 & 0 & 0 & 0 & 0 \\
\hline Used by Utility (excluding station use)................... & 2,617 & 1,302 & 3,452 & 1 & 629 & 1,622 \\
\hline 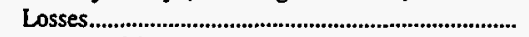 & 126,995 & 35,303 & 65,153 & 19 & 52,279 & 66,523 \\
\hline Total Disposition & $5,631,469$ & 706,821 & $1,087,136$ & 305 & 778,863 & 665,638 \\
\hline
\end{tabular}

Note: Totals may not equal sum of components because of independent rounding. Double counting occurs in components of both sources and disposition of energy and thus neither provides a true total. Purchases from utilities, net interchanges, and net wheeling (except for imports) are included in net generation.

Source: Energy Information Administration, Form EIA-412, “Annual Report of Public Electric Utilities." 
Table 26. Electric Energy Account by Major U.S. Publicly Owned Electric Utility Within State, 1996 (Continued)

(Megawatthours)

\begin{tabular}{|c|c|c|c|c|c|c|}
\hline Item & $\begin{array}{l}\text { Washington } \\
\text { PUD No I of } \\
\text { Pend Oreille } \\
\text { Cnty } \\
\text { December } 31\end{array}$ & $\begin{array}{l}\text { Washington } \\
\text { PUD No } 1 \text { of } \\
\text { Snohomish } \\
\text { County } \\
\text { December } 31\end{array}$ & $\begin{array}{l}\text { Washington } \\
\text { PUD No } 1 \text { of } \\
\text { Whatcom } \\
\text { County } \\
\text { December } 31\end{array}$ & $\begin{array}{c}\text { Washington } \\
\text { PUD No } 2 \\
\text { of } \\
\text { Grant } \\
\text { County } \\
\text { December } 31\end{array}$ & $\begin{array}{l}\text { Washington } \\
\text { PUD No } 2 \text { of } \\
\text { Pacific } \\
\text { County } \\
\text { December } 31\end{array}$ & $\begin{array}{c}\text { Washington } \\
\text { PUD No } 3 \\
\text { of } \\
\text { Mason } \\
\text { County } \\
\text { December } 31\end{array}$ \\
\hline \multicolumn{7}{|l|}{ Sources of Energy } \\
\hline Steam & 0 & $1,110,221$ & 0 & 0 & 0 & 0 \\
\hline 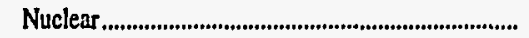 & 0 & 0 & 0 & 0 & 0 & 0 \\
\hline 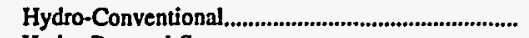 & 459,332 & 0 & $\mathbf{0}$ & $11,754,684$ & 0 & 0 \\
\hline 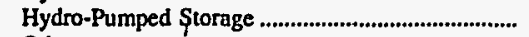 & 0 & 0 & 0 & 0 & 0 & 0 \\
\hline 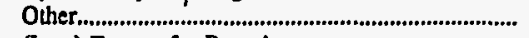 & $\mathbf{0}$ & 0 & 0 & $\mathbf{0}$ & $\mathbf{0}$ & $\mathbf{0}$ \\
\hline 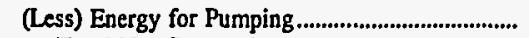 & 0 & 0 & 0 & 0 & 0 & 0 \\
\hline 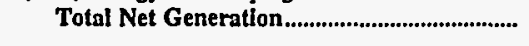 & 459,332 & $1,110,221$ & $\mathbf{0}$ & $11,754,684$ & $\mathbf{0}$ & 0 \\
\hline 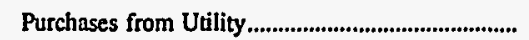 & 563,563 & $7,669,358$ & 177,465 & 533,512 & 283,048 & 603,375 \\
\hline $\begin{array}{l}\text { Purchases from Nonutility........................................ } \\
\text { Power Exchanges }\end{array}$ & 0 & 0 & $\mathbf{0}$ & 0 & 0 & 0 \\
\hline 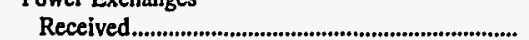 & 416 & 38,800 & \multicolumn{4}{|c|}{ Power Exchanges } \\
\hline 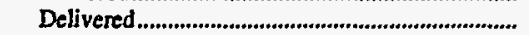 & 6,105 & 33,235 & 0 & 187,692 & 0 & 0 \\
\hline 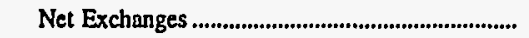 & $-5,689$ & 5,565 & 0 & 9,727 & 0 & 0 \\
\hline \multicolumn{7}{|l|}{ Transmission for Others (Wheeling) } \\
\hline 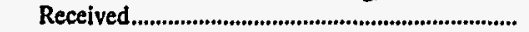 & $-1,443$ & 0 & 0 & 0 & 0 & 0 \\
\hline Delivered & 0 & 0 & 0 & 0 & 0 & 0 \\
\hline 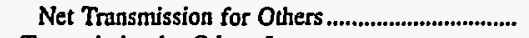 & $-1,443$ & 0 & 0 & $\mathbf{0}$ & 0 & 0 \\
\hline $\begin{array}{l}\text { Transmission by Others Losses..................................... } \\
\text { Total Net Energy }\end{array}$ & 0 & 0 & 0 & 0 & 0 & $\mathbf{0}$ \\
\hline 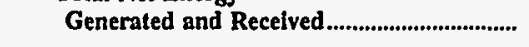 & $1,015,763$ & $8,785,144$ & 177,465 & $12,297,923$ & 283,048 & 603,375 \\
\hline \multicolumn{7}{|l|}{ Disposition of Energy } \\
\hline 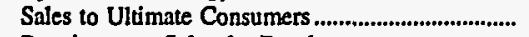 & 887,890 & $7,158,031$ & 177,465 & $2,787,479$ & 277,617 & 542,902 \\
\hline 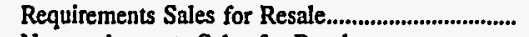 & 107,499 & $1,290,566$ & 0 & $7,028,040$ & 0 & 3,579 \\
\hline 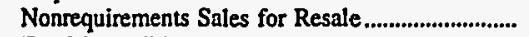 & 3,285 & 0 & 0 & $1,454,028$ & 0 & 0 \\
\hline 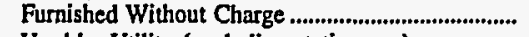 & 0 & 0 & 0 & 812,965 & 1,030 & $\mathbf{0}$ \\
\hline Used by Utility (excluding station use)................... & 737 & 13,557 & 0 & 8,494 & 672 & 791 \\
\hline 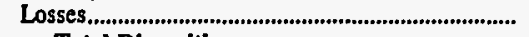 & 16,352 & 322,990 & 0 & 206,917 & 3,729 & 56,103 \\
\hline Total Disposition & $1,015,763$ & $8,785,144$ & 177,465 & $12,297,923$ & 283,048 & 603,375 \\
\hline
\end{tabular}

Note: Totals may not equal sum of components because of independent rounding. Double counting occurs in components of both sources and disposition of energy and thus neither provides a true total. Purchases from utilities, net interchanges, and net wheeling (except for imports) are included in net generation.

Source: Energy Information Administration, Form EIA-412, "Annual Report of Public Electric Utilities." 
Table 26. Electric Energy Account by Major U.S. Publicly Owned Electric Utility Within State, 1996 (Continued)

(Megawatthours)

\begin{tabular}{|c|c|c|c|c|c|c|}
\hline Item & $\begin{array}{l}\text { Washington } \\
\text { Richland } \\
\text { City of } \\
\text { December } 31\end{array}$ & $\begin{array}{c}\text { Washington } \\
\text { Seattle } \\
\text { City of } \\
\text { December } 31\end{array}$ & $\begin{array}{c}\text { Washington } \\
\text { Tacoma } \\
\text { City of } \\
\text { December } 31\end{array}$ & $\begin{array}{c}\text { Washington } \\
\text { Vern } \\
\text { Irigation } \\
\text { District \# } 15 \\
\text { December } 31\end{array}$ & $\begin{array}{l}\text { Washington } \\
\text { Washington } \\
\text { Pub } \\
\text { Pwr } \\
\text { Supply Sys } \\
\text { June } 30\end{array}$ & $\begin{array}{l}\text { Wisconsin } \\
\text { Badger Power } \\
\text { Marketing } \\
\text { Auth } \\
\text { December } 31\end{array}$ \\
\hline \multicolumn{7}{|l|}{ Sources of Energy } \\
\hline Steam............................. & 0 & 602,360 & 647,464 & 0 & 0 & \\
\hline 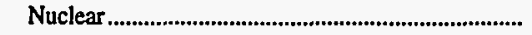 & 0 & 0 & 0 & 0 & $7,703,577$ & $\mathbf{0}$ \\
\hline 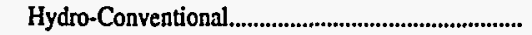 & 0 & $7,921,980$ & $2,769,256$ & 0 & 125,410 & 0 \\
\hline 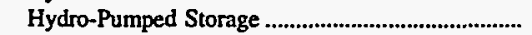 & 0 & 0 & 0 & 0 & 0 & 0 \\
\hline 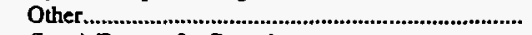 & 0 & $-11,928$ & $\mathbf{0}$ & 0 & 0 & 0 \\
\hline 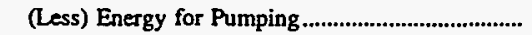 & 0 & & $\mathbf{0}$ & 0 & 0 & \\
\hline 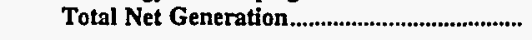 & $\mathbf{0}$ & $8,512,412$ & $3,416,720$ & $\mathbf{0}$ & $7,828,987$ & 0 \\
\hline Purchases from Utility... & 700,971 & $2,340,973$ & $2,305,821$ & 198,326 & 0 & 283,771 \\
\hline $\begin{array}{l}\text { Purchases from Nonutility......................................... } \\
\text { Power Exchanges }\end{array}$ & 0 & 8,828 & 503,943 & 0 & 0 & \\
\hline 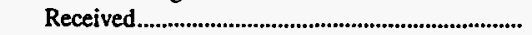 & 0 & $8,004,558$ & 100,206 & 0 & 0 & 0 \\
\hline 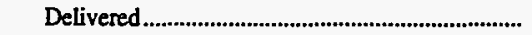 & $\mathbf{0}$ & $9,098,307$ & 15,949 & 0 & 0 & 0 \\
\hline 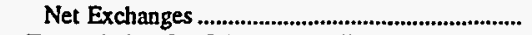 & 0 & $-1,093,749$ & 84,257 & 0 & $\mathbf{0}$ & 0 \\
\hline \multicolumn{7}{|l|}{ Transmission for Others (Wheeling) } \\
\hline 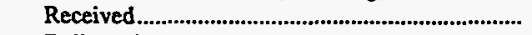 & 0 & 43,462 & $1,394,880$ & 0 & $\mathbf{0}$ & 0 \\
\hline 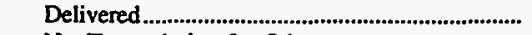 & $\mathbf{0}$ & 43,462 & $1,394,880$ & 0 & 0 & 0 \\
\hline 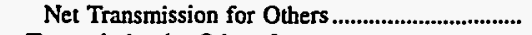 & 0 & 0 & $\mathbf{0}$ & $\mathbf{0}$ & $\mathbf{0}$ & 0 \\
\hline Transmission by Others Losses.................................... & 0 & 0 & 0 & 0 & 0 & 0 \\
\hline Total Net Energy & & & & & & \\
\hline 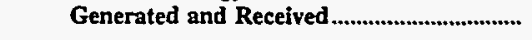 & 700,971 & $9,768,464$ & $6,310,741$ & 198,326 & $7,828,987$ & 283,771 \\
\hline \multicolumn{7}{|l|}{ Disposition of Energy } \\
\hline Sales to Ultimate Consumer & 649,732 & $9,188,000$ & $5,471,096$ & 188,175 & 0 & 0 \\
\hline 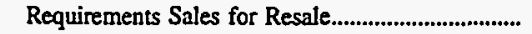 & 0 & 0 & 349,191 & $\mathbf{0}$ & $7,780,202$ & 282,054 \\
\hline 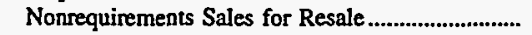 & $\mathbf{0}$ & 0 & 194,028 & 0 & 0 & $\mathbf{0}$ \\
\hline 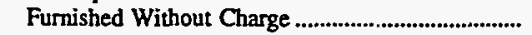 & 0 & 0 & 0 & 0 & 0 & 0 \\
\hline Used by Utility (excluding station use)................... & 0 & 25,273 & 9,110 & 0 & 0 & 0 \\
\hline Losses & 51,239 & 555,191 & 287,316 & 10,151 & 48,785 & 1,717 \\
\hline 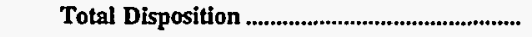 & 700,971 & $9,768,464$ & $6,310,741$ & 198,326 & $7,828,987$ & 283,771 \\
\hline
\end{tabular}

Note: Totals may not equal sum of components because of independent rounding. Double counting occurs in components of both sources and disposition of energy and thus neither provides a true total. Purchases from utilities, net interchanges, and net wheeling (except for imports) are included in net generation.

Source: Energy Information Administration, Form EIA-412, "Annual Report of Public Electric Utilities." 
Table 26. Electric Energy Account by Major U.S. Publicly Owned Electric Utility Within State, 1996 (Continued)

(Megawatthours)

\begin{tabular}{|c|c|c|c|c|c|c|}
\hline Item & $\begin{array}{c}\text { Wisconsin } \\
\text { Jefferson } \\
\text { City of } \\
\text { December } 31\end{array}$ & $\begin{array}{l}\text { Wisconsin } \\
\text { Kaukauna } \\
\text { City of } \\
\text { December } 31\end{array}$ & $\begin{array}{c}\text { Wisconsin } \\
\text { Manitowoc } \\
\text { Public } \\
\text { Utilities } \\
\\
\text { December } 31\end{array}$ & $\begin{array}{l}\text { Wisconsin } \\
\text { Marshfield } \\
\text { City of } \\
\text { December } 31\end{array}$ & $\begin{array}{l}\text { Wisconsin } \\
\text { Menasha } \\
\text { City of } \\
\text { December } 31\end{array}$ & $\begin{array}{c}\text { Wisconsin } \\
\text { New London } \\
\text { Electric\&Water } \\
\text { Util } \\
\text { December } 31\end{array}$ \\
\hline \multicolumn{7}{|l|}{ Sources of Energy } \\
\hline 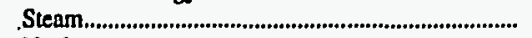 & $\mathbf{0}$ & 0 & 198,397 & 0 & 685,000 & \\
\hline 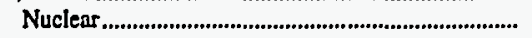 & 0 & $\mathbf{0}$ & $\mathbf{0}$ & 0 & 0 & 0 \\
\hline 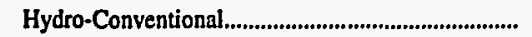 & 0 & 162,265 & 0 & 0 & $\mathbf{0}$ & $\mathbf{0}$ \\
\hline 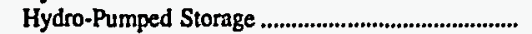 & 0 & $\mathbf{0}$ & 0 & 0 & 0 & 0 \\
\hline 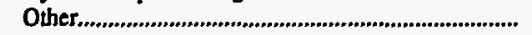 & 0 & $\mathbf{0}$ & 1,569 & 0 & 0 & \\
\hline 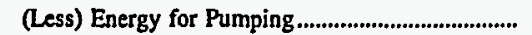 & 0 & $\mathbf{0}$ & $\mathbf{0}$ & 0 & 0 & 0 \\
\hline Total Net Generation & 0 & 162,265 & 199,966 & o & 685,000 & 0 \\
\hline 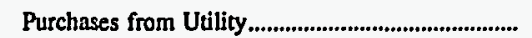 & 154,175 & 596,690 & 321,664 & 338,031 & 569,337 & 172,253 \\
\hline 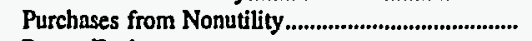 & 0 & $\mathbf{0}$ & 0 & 0 & 0 & 0 \\
\hline \multicolumn{7}{|l|}{ Power Exchanges } \\
\hline 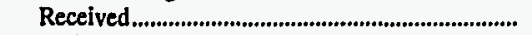 & 0 & $\mathbf{0}$ & $\mathbf{0}$ & 0 & 0 & 0 \\
\hline 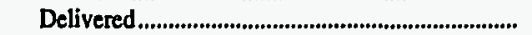 & 0 & 0 & 0 & 0 & 685,000 & 0 \\
\hline 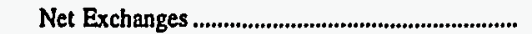 & 0 & $\mathbf{0}$ & 0 & 0 & $-685,000$ & 0 \\
\hline \multicolumn{7}{|l|}{ Transmission for Others (Wheeling) } \\
\hline 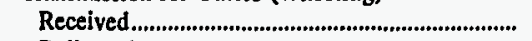 & 0 & 0 & $\mathbf{0}$ & $\mathbf{0}$ & 0 & 0 \\
\hline 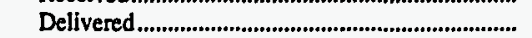 & 0 & 0 & 0 & 0 & 0 & 0 \\
\hline Net Transmission for Others ....................................... & 0 & 0 & 0 & 0 & $\mathbf{0}$ & 0 \\
\hline 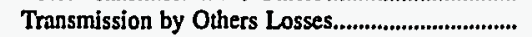 & 0 & 0 & 0 & 0 & $\mathbf{0}$ & 0 \\
\hline \multicolumn{7}{|l|}{ Total Net Energy } \\
\hline 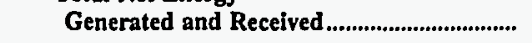 & 154,175 & 758,955 & 521,630 & 338,031 & 569,337 & 172,253 \\
\hline Disposition of Energy & & & & & & . \\
\hline (.................................. & 150,199 & 743,138 & 500,773 & 320,490 & 561,553 & 167,998 \\
\hline Requirements Sales for Resale.............................................. & 0 & 0 & 98 & 0 & 0 & \\
\hline 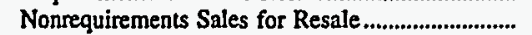 & 0 & 0 & 0 & $\mathbf{0}$ & 0 & \\
\hline 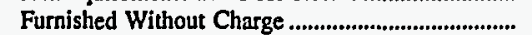 & $\mathbf{0}$ & 0 & 0 & 0 & 0 & 0 \\
\hline Used by Utility (excluding station use).................... & 0 & 710 & 476 & 1,356 & 0 & 1,373 \\
\hline 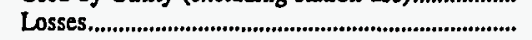 & 3,976 & 15,107 & 20,283 & 16,185 & 7,784 & 2,882 \\
\hline 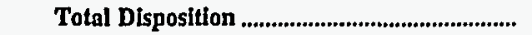 & 154,175 & 758,955 & 521,630 & 338,031 & 569,337 & 172,253 \\
\hline
\end{tabular}

Note: Totals may not equal sum of components because of independent rounding. Double counting occurs in components of both sources and disposition of energy and thus neither provides a true total. Purchases from utilities, net interchanges, and net wheeling (except for imports) are included in net generation.

Source: Energy Information Administration, Form ELA-412, "Annual Report of Public Electric Utilities." 
Table 26. Electric Energy Account by Major U.S. Publicly Owned Electric Utility Within State, 1996 (Continued)

(Megawatthours)

\begin{tabular}{|c|c|c|c|c|c|c|}
\hline Item & $\begin{array}{l}\text { Wisconsin } \\
\begin{array}{c}\text { Oconomowoc } \\
\text { City of }\end{array} \\
\text { December } 31\end{array}$ & $\begin{array}{l}\text { Wisconsin } \\
\text { Plymouth } \\
\text { City of } \\
\text { December } 31\end{array}$ & $\begin{array}{l}\text { Wisconsin } \\
\text { Reedsburg } \\
\text { Utility Comm } \\
\text { December } 31\end{array}$ & $\begin{array}{c}\text { Wisconsin } \\
\text { Shawano } \\
\text { Municipal } \\
\text { Utilities } \\
\text { December } 31\end{array}$ & $\begin{array}{l}\text { Wisconsin } \\
\text { Sheboygan } \\
\text { Falls } \\
\text { City of } \\
\\
\text { December } 31\end{array}$ & $\begin{array}{c}\text { Wisconsin } \\
\text { Sturgeon } \\
\text { Bay City of } \\
\text { December } 31\end{array}$ \\
\hline \multicolumn{7}{|l|}{ Sources of Energy } \\
\hline Steam & 0 & $\mathbf{0}$ & 0 & $\mathbf{0}$ & 0 & 0 \\
\hline 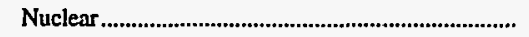 & 0 & 0 & 0 & 0 & 0 & 0 \\
\hline 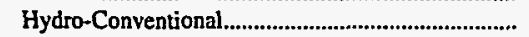 & 0 & 0 & 0 & 0 & 0 & 0 \\
\hline Hydro-Pumped Storage & 0 & 0 & 0 & 0 & 0 & 0 \\
\hline 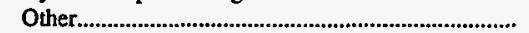 & 0 & 0 & 0 & $\mathbf{0}$ & $\mathbf{0}$ & $\mathbf{0}$ \\
\hline 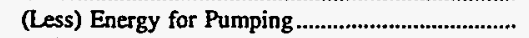 & 0 & 0 & 0 & 0 & 0 & 0 \\
\hline 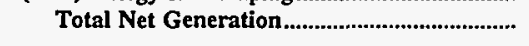 & $\mathbf{0}$ & $\mathbf{0}$ & $\mathbf{0}$ & $\mathbf{0}$ & $\mathbf{0}$ & $\mathbf{0}$ \\
\hline 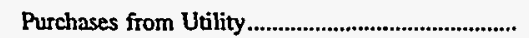 & 178,403 & 171,744 & 191,150 & 204,912 & 213,254 & 134,468 \\
\hline 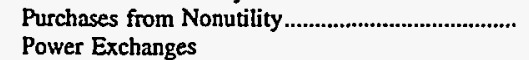 & 0 & 0 & 0 & 0 & 0 & 0 \\
\hline 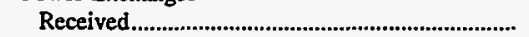 & $\mathbf{0}$ & 0 & 0 & 0 & 0 & 0 \\
\hline 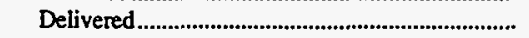 & 0 & 0 & 0 & 0 & 0 & 0 \\
\hline 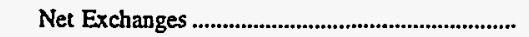 & 0 & 0 & 0 & 0 & 0 & 0 \\
\hline \multicolumn{7}{|l|}{ Transmission for Others (Wheeling) } \\
\hline 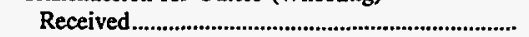 & 0 & 0 & 0 & 0 & 0 & 0 \\
\hline Delivered & 0 & 0 & 0 & 0 & 0 & 0 \\
\hline 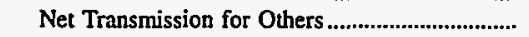 & 0 & 0 & 0 & 0 & 0 & 0 \\
\hline 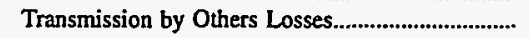 & 0 & 0 & 0 & 0 & 0 & 0 \\
\hline \multicolumn{7}{|l|}{ Total Net Energy } \\
\hline 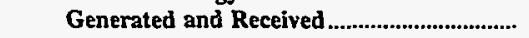 & $\mathbf{1 7 8 , 4 0 3}$ & 171,744 & 191,150 & 204,912 & 213,254 & 134,468 \\
\hline \multicolumn{7}{|l|}{ Disposition of Energy } \\
\hline Sales to Ultimate Consumers & 171,600 & 161,108 & 187,802 & 199,940 & 192,701 & 129,391 \\
\hline 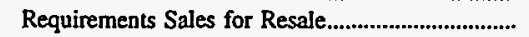 & 0 & 0 & 0 & 0 & 0 & 0 \\
\hline Nonrequiremenis Sales for Resale........................... & 0 & 0 & 0 & 0 & 0 & 0 \\
\hline 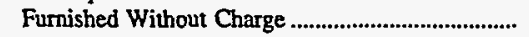 & 0 & 0 & 0 & 0 & 0 & 0 \\
\hline Used by Utility (excluding station use)...................... & 0 & 118 & 0 & 0 & 0 & 0 \\
\hline Losses & 6,803 & 10,518 & 3,348 & 4,972 & 20,553 & 5,077 \\
\hline 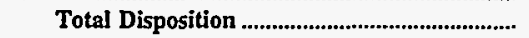 & 178,403 & 171,744 & 191,150 & 204,912 & 213,254 & 134,468 \\
\hline
\end{tabular}

Note: Totals may not equal sum of components because of independent rounding. Double counting occurs in components of both sources and disposition of energy and thus neither provides a true total. Purchases from utilities, net interchanges, and net wheeling (except for imports) are included in net generation.

Source: Energy Information Administration, Form EIA-412, “Annual Report of Public Electric Utilities." 
Table 26. Electric Energy Account by Major U.S. Publicly Owned Electric Utility Within State, 1996 (Continued)

(Megawatthours)

\begin{tabular}{|c|c|c|c|c|c|}
\hline Item & $\begin{array}{l}\text { Wisconsin } \\
\text { Sun Prairie } \\
\text { Water \& Light } \\
\text { Comm } \\
\text { December } 31\end{array}$ & $\begin{array}{l}\text { Wisconsin } \\
\text { Wisconsin } \\
\text { Public } \\
\text { Power } \\
\text { Inc Sys } \\
\text { December } 31\end{array}$ & $\begin{array}{l}\text { Wisconsin } \\
\text { Wisconsin } \\
\text { Rapids W W } \\
\text { \& L } \\
\text { Comm } \\
\text { December } 31\end{array}$ & $\begin{array}{l}\text { Wyoming } \\
\text { Gillette } \\
\text { City of } \\
\text { June } 30\end{array}$ & $\begin{array}{l}\text { Wyoming } \\
\text { Wyoming } \\
\text { Municipal } \\
\text { Power Agency } \\
\text { December } 31\end{array}$ \\
\hline \multicolumn{6}{|l|}{ Sources of Energy } \\
\hline 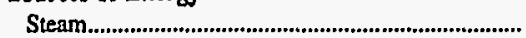 & 0 & 782,251 & 0 & 0 & 156,701 \\
\hline 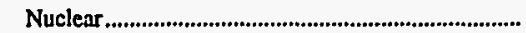 & 0 & 0 & 0 & 0 & 0 \\
\hline 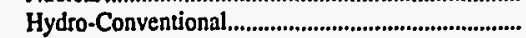 & $\mathbf{0}$ & 0 & 0 & 0 & 0 \\
\hline Hydro-Pumped Storage ............................................ & 0 & 0 & 0 & 0 & 0 \\
\hline 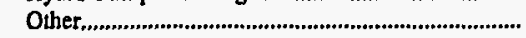 & 0 & 12,229 & 0 & 0 & 0 \\
\hline 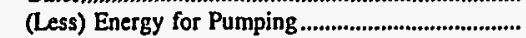 & 0 & 0 & 0 & 0 & 0 \\
\hline 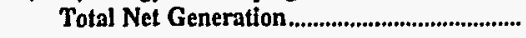 & 0 & 794,480 & 0 & $\mathbf{0}$ & 156,701 \\
\hline 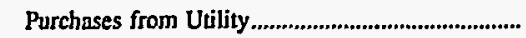 & 170,959 & $2,654,891$ & 220,623 & 190,270 & 56,991 \\
\hline $\begin{array}{l}\text { Purchases from Nonutility........................................ } \\
\text { Power Exchanges }\end{array}$ & 0 & 0 & 0 & 0 & 0 \\
\hline 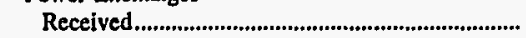 & 0 & 0 & 0 & 0 & 2,192 \\
\hline Delivered .......................................................................... & 0 & 0 & 0 & 0 & 3,873 \\
\hline 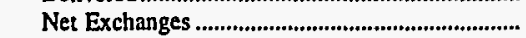 & 0 & 0 & 0 & 0 & $-1,681$ \\
\hline \multicolumn{6}{|l|}{ Transmission for Others (Wheeling) } \\
\hline 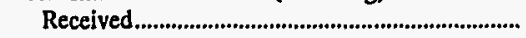 & 0 & 0 & 0 & 0 & 0 \\
\hline 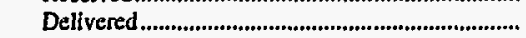 & 0 & 0 & 0 & 0 & 0 \\
\hline 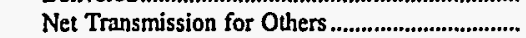 & 0 & 0 & 0 & 0 & 0 \\
\hline $\begin{array}{l}\text { Transmission by Others Losses.................................... } \\
\text { Total Net Energy }\end{array}$ & 0 & 0 & 0 & 0 & 0 \\
\hline 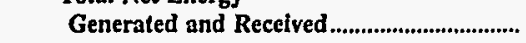 & 170,959 & $3,449,371$ & 220,623 & 190,270 & 212,011 \\
\hline \multicolumn{6}{|l|}{ Disposition of Energy } \\
\hline 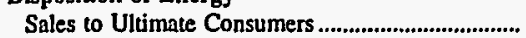 & 164,244 & 0 & 208,397 & 182,874 & 0 \\
\hline Requirements Sales for Resale................................ & 0 & $3,301,682$ & 0 & 0 & 206,847 \\
\hline Nonrequirements Sales for Resale .......................... & 0 & 64,825 & 0 & 0 & 0 \\
\hline 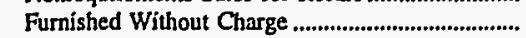 & 0 & 0 & 0 & 0 & 0 \\
\hline 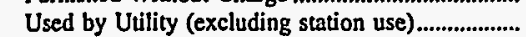 & 248 & 0 & 207 & 0 & 0 \\
\hline 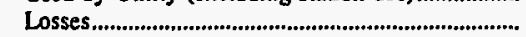 & 6,467 & 82,864 & 12,019 & 7,396 & 5,164 \\
\hline 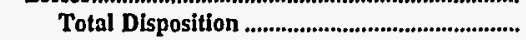 & 170,959 & $3,449,371$ & 220,623 & 190,270 & 212,011 \\
\hline
\end{tabular}

Note: Totals may not equal sum of components because of independent rounding. Double counting occurs in components of both sources and disposition of energy and thus neither provides a true total. Purchases from utilities, net interchanges, and net wheeling (except for imports) are included in net generation. Sales for resale is included in sales to ultimate consumers.

Source: Energy Information Administration, Form EIA-412, "Annual Report of Public Electric Utilities." 
Summary Statistics of U.S. Federal Electric Utilities 
Financial Performance

\section{Background}

There are 10 Federal electric utilities in the United States. They are the Department of Defense's U.S. Army Corps of Engineers; the Department of Energy's five power marketing administrations, Alaska, Bonneville, Southeastern, Southwestern, and Western Area Power Administrations; the Department of Interior's U.S. Bureau of Indian Affairs and the U.S. Bureau of Reclamation; the Department of State's International Water and Boundary Commission; and, the Tennessee Valley Authority.

The Federal electric utilities are primarily generators and wholesalers of electricity rather than distributors to ultimate consumers. Federal electric utilities operate over 150 power plants and produce approximately 8 percent of the electricity generated in the United States. Most of the power plants are Federal hydroelectric projects initially designed for flood control and irrigation purposes. Federal power is sold at cost. This cost includes production expenses and the repayment of the federally provided financing. Most Federal generation is sold for resale to municipals, cooperative electric utilities, and other nonprofit preference customers, as required by law.

There are three major producers of electricity: the Tennessee Valley Authority (TVA), the largest Federal producer; the U.S. Army Corps of Engineers (USCE); and the U.S. Bureau of Reclamation (USBR). The TVA markets its own power while generation by the USCE, except for the North Central Division (Saint Mary's Falls at Sault St. Marie, Michigan), and the USBR is marketed by four of the Federal power marketing administrations - Bonneville, Southeastern, Southwestern, and Western Area. These four power marketing administrations also purchase energy for resale from other electric utilities in the United States and Canada. Alaska, the fifth power marketing administration, operates its own power plants and distributes power to ultimate consumers.

\section{Income Statement}

As of the end of the fiscal year (September 31, 1996), operating revenues for the federal electric utilities totaled $\$ 9,098.6$ million. Total electric utility operating expenses were $\$ 6,431.8$ million in 1996. A major portion of these total electric utility operating expenses include production expenses that totaled $\$ 4,152.0$ million. Production expenses for the Federal electric utilities were 64.6 percent of total electric utility operating expenses. Total electric operation and maintenance expenses were $\$ 4,988.2$ million, 77.6 percent of total electric utility operating expenses for the Federal electric utilities.

Total electric utility income for the Federal electric utilities was $\$ 2,575.6$ million. Income deductions totaled $\$ 2,408.1$ million. Of the income deductions, $\$ 2,042.7$ million came from interest on long-term debt, which represented 84.8 percent of total income deductions. Net income for the Federal electric utilities as of the end of September 1996 was $\$ 434.5$ million a 40.5 percent increase from the 309.6 million in 1995.

\section{Balance Sheet}

As of September 30, 1996, net investment in electric utility plant for the Federal electric utilities was $\$ 36,723.1$ million, including construction work in progress, which decreased to $\$ 7,692.0$ million, compared with $\$ 16,461.2$ million in 1995 .

Total proprietary capital was $\$ 8,741.7$ million in 1996 , a 12.9 percent decrease from $\$ 10,038.0$ million in 1995, 17.3 percent of total liabilities and other credits. The amount of long-term debt and current and accrued liabilities was $\$ 32,978.3$ million, 65.2 percent of total liabilities and other credits of the Federal electric utilities.

\section{Sales of Electric Power}

In 1996, the Federal electric utilities had sales of electric energy to ultimate consumers of 47.5 million megawatthours and electricity sold for resale of 245.7 million megawatthours. Total disposition of energy was 304.8 million megawatthours of which the Federal electric utilities had a net generation of 300.5 million megawatthours (Table 32). 
Table 27. Statement of Income by U.S. Federal Electric Utility, 1996

(Thousand Dollars)

\begin{tabular}{|c|c|c|c|c|c|}
\hline Item & $\begin{array}{c}\text { Alaska } \\
\text { Power } \\
\text { Admin }^{* *}\end{array}$ & $\begin{array}{l}\text { Bonneville } \\
\text { Power } \\
\text { Admin } \\
\text { September } 30\end{array}$ & $\begin{array}{l}\text { Southeastern } \\
\text { Power } \\
\text { Admin } \\
\text { September } 30\end{array}$ & $\begin{array}{l}\text { Soutbwestern } \\
\text { Power } \\
\text { Admin } \\
\text { September } 30\end{array}$ & $\begin{array}{c}\text { Western Area } \\
\text { Power } \\
\text { Admin } \\
\text { September } 30\end{array}$ \\
\hline Electric Utility Operating Revenues & 10,760 & $2,418,321$ & 164,456 & 103,062 & 676,927 \\
\hline 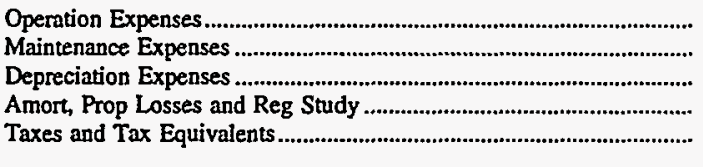 & $\begin{array}{r}3,344 \\
618 \\
3,016 \\
80,934 \\
0\end{array}$ & $\begin{array}{r}1,771,393 \\
87,709 \\
128,746 \\
67,299 \\
0\end{array}$ & $\begin{array}{r}32,326 \\
45 \\
91 \\
0 \\
69\end{array}$ & $\begin{array}{r}17,298 \\
17,299 \\
2,868 \\
190 \\
0\end{array}$ & $\begin{array}{r}504,500 \\
0 \\
0 \\
0 \\
0\end{array}$ \\
\hline 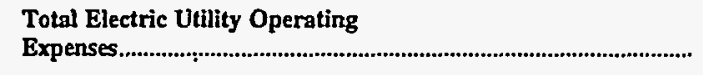 & 87,913 & $2,055,147$ & 32,531 & 37,655 & 504,500 \\
\hline 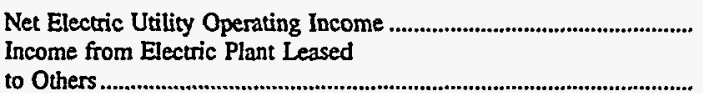 & $-77,153$ & 363,174 & $\begin{array}{r}131,924 \\
0\end{array}$ & $\begin{array}{r}65,407 \\
-51,865\end{array}$ & $\begin{array}{r}172,427 \\
0\end{array}$ \\
\hline 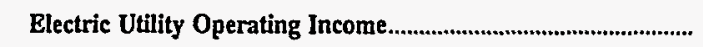 & $-77,153$ & 364,392 & 131,924 & 13,542 & 172,427 \\
\hline Other Electric Income & 0 & 4,070 & 13 & 0 & 122,836 \\
\hline 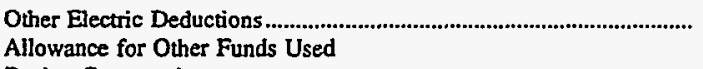 & $\mathbf{0}$ & 1,545 & 0 & 0 & 0 \\
\hline 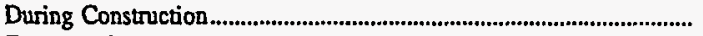 & 0 & 0 & 0 & 0 & 17,677 \\
\hline 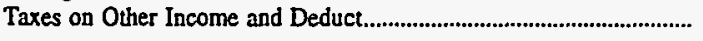 & 0 & 0 & $\mathbf{0}$ & 0 & 0 \\
\hline Electric Utility Income & $-77,153$ & 366,917 & 131,938 & 13,542 & 312,940 \\
\hline 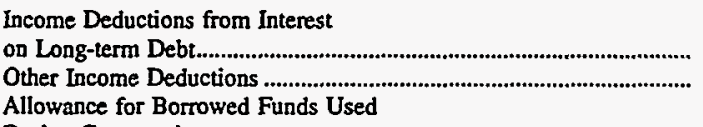 & $\begin{array}{r}4,876 \\
0\end{array}$ & $\begin{array}{r}218,453 \\
10,319\end{array}$ & $\begin{array}{r}28 \\
131,910\end{array}$ & $\begin{array}{r}346 \\
0\end{array}$ & $\begin{array}{r}211,350 \\
87,485\end{array}$ \\
\hline During Construction ....................................... & 0 & $-16,039$ & 0 & 0 & $\mathbf{0}$ \\
\hline 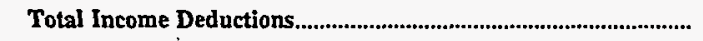 & 4,876 & 212,733 & 131,938 & 346 & 298,835 \\
\hline Income Before Extraondinary Items & $-82,029$ & 154,184 & 0 & 13,197 & 14,105 \\
\hline Extraordinary Income & 0 & 0 & 0 & 0 & 288,421 \\
\hline Extraordinary Deductions............................... & 0 & 0 & 0 & 0 & 0 \\
\hline Net Income & $-82,029$ & 154,184 & $\mathbf{0}$ & 13,197 & 302,526 \\
\hline
\end{tabular}

See endnotes at end of this table. 
Table 27. Statement of Income by U.S. Federal Electric Utility, 1996 (Continued) (Thousand Dollars)

\begin{tabular}{|c|c|c|c|c|c|}
\hline \multirow[b]{2}{*}{ Item } & \multirow[b]{2}{*}{$\begin{array}{l}\text { Tennessee } \\
\text { Valley } \\
\text { Authority } \\
\text { September } 30\end{array}$} & \multicolumn{2}{|c|}{ U.S. Bureau of Indian Affairs } & \multirow[b]{2}{*}{$\begin{array}{l}\text { USCE- } \\
\text { North Central } \\
\text { Division } 1 \\
\text { September } 30\end{array}$} & \multirow[b]{2}{*}{$\begin{array}{c}\text { Total } \\
\text { September } 30\end{array}$} \\
\hline & & $\begin{array}{l}\text { Mission } \\
\text { Valley Power } \\
\text { September } 30\end{array}$ & $\begin{array}{l}\text { San Carlos } \\
\text { September } 30\end{array}$ & & \\
\hline 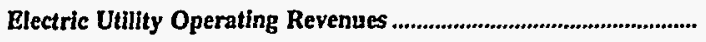 & $5,692,647$ & 15,797 & - & 67 & $9,082,037$ \\
\hline 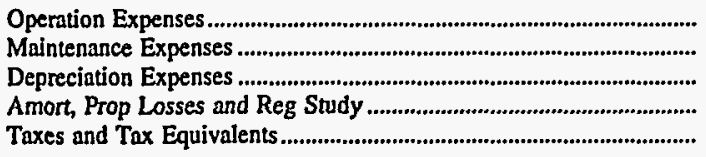 & $\begin{array}{r}2,172,160 \\
324,094 \\
904,191 \\
0 \\
255,678\end{array}$ & $\begin{array}{r}11,903 \\
686 \\
645 \\
11 \\
0\end{array}$ & $\begin{array}{l}- \\
- \\
- \\
-\end{array}$ & $\begin{array}{r}903 \\
1,758 \\
-88 \\
0 \\
0\end{array}$ & $\begin{array}{r}4,513,826 \\
432,210 \\
1,039,470 \\
148,434 \\
255,747\end{array}$ \\
\hline 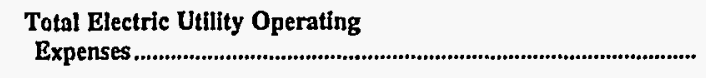 & $3,656,123$ & 13,244 & - & 2,572 & $6,389,686$ \\
\hline $\begin{array}{l}\text { Net Electric Utility Operating Income } \\
\text { Income from Electric Plant Leased }\end{array}$ & $2,036,524$ & 2,553 & - & $-2,506$ & $2,692,351$ \\
\hline 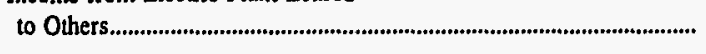 & 0 & 0 & - & 0 & $-50,647$ \\
\hline Electric Utility Operating Income & $2,036,524$ & 2,553 & - & $-2,506$ & $2,641,704$ \\
\hline 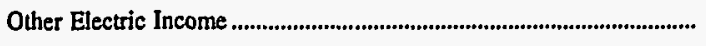 & 59,459 & 148 & - & 0 & 186,527 \\
\hline $\begin{array}{l}\text { Other Electric Deductions } \\
\text { Allowance for Other Funds Used }\end{array}$ & 60,643 & 0 & - & 190 & 62,378 \\
\hline 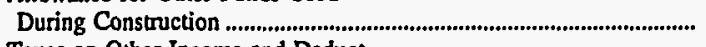 & 0 & 0 & - & 0 & 17,677 \\
\hline 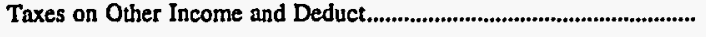 & 0 & 0 & - & 0 & 0 \\
\hline 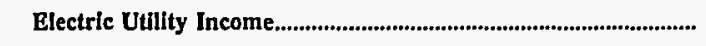 & $2,035,340$ & 2,701 & - & $-2,695$ & $2,783,530$ \\
\hline 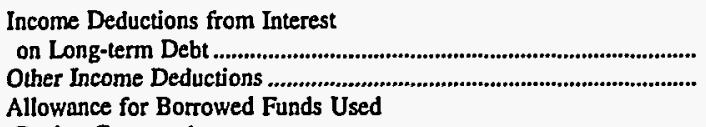 & $\begin{array}{r}1,818,988 \\
272,397\end{array}$ & $\begin{array}{l}0 \\
0\end{array}$ & - & $\begin{array}{l}0 \\
0\end{array}$ & $\begin{array}{r}2,254,041 \\
502,110\end{array}$ \\
\hline 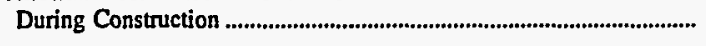 & $-116,747$ & 0 & - & 0 & $-132,786$ \\
\hline 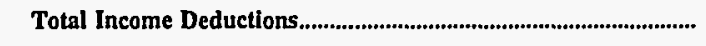 & $1,974,638$ & $\mathbf{0}$ & - & 0 & $2,623,365$ \\
\hline 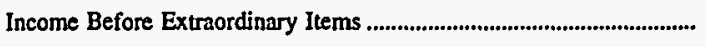 & 60,702 & 2,701 & - & $-2,695$ & 160,165 \\
\hline 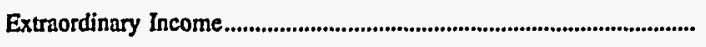 & 0 & 0 & - & $\mathbf{0}$ & 288,421 \\
\hline 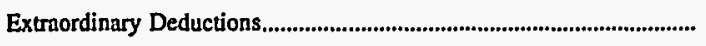 & 0 & 0 & - & 0 & 0 \\
\hline Net Income & 60,702 & 2,701 & - & $-2,695$ & 448,586 \\
\hline
\end{tabular}

- Fiscal year 1996 financial data not available.

** Fiscal year 1995 data reported.

I Includes data only for Saint Mary's Falls at Sault St. Marie, Michigan. The rest of the generation produced by the U.S. Army Corps of Engineers (USCE) is sold by the Department of Energy-Bonneville, Southeastern, Southwestern, and Western Area Power Administrations.

Note: Totals may not equal sum of components because of independent rounding.

Source: Energy Information Administration, Form EIA-412, "Annual Report of Public Electric Utilities." 
Table 28. Balance Sheet by U.S. Federal Electric Utility on September 30, 1996

(Thousand Dollars)

\begin{tabular}{|c|c|c|c|c|c|}
\hline Item & $\begin{array}{c}\text { Alaska } \\
\text { Power } \\
\text { Admin }\end{array}$ & $\begin{array}{l}\text { Bonneville } \\
\text { Power } \\
\text { Admin } \\
\text { September } 30\end{array}$ & $\begin{array}{l}\text { Southeastern } \\
\text { Power } \\
\text { Admin } \\
\text { September } 30\end{array}$ & $\begin{array}{l}\text { Southwestern } \\
\text { Power } \\
\text { Admin } \\
\text { September } 30\end{array}$ & $\begin{array}{c}\text { Western Area } \\
\text { Power } \\
\text { Admin } \\
\text { September } 30\end{array}$ \\
\hline \multicolumn{6}{|l|}{ Electric Uẗlity Plant } \\
\hline Electric Utility Plant \& Adjust.... & 187,057 & $4,554,101$ & 816 & 142,133 & $5,045.569$ \\
\hline Const Work in Progress.................... & 0 & 250,506 & 0 & 36,779 & 301,231 \\
\hline 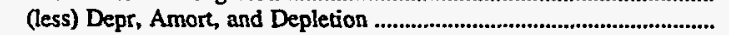 & 100,057 & $1,539,576$ & 455 & 31,765 & $1,662,435$ \\
\hline 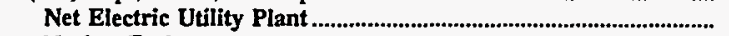 & 87,000 & $3,265,031$ & 361 & 147,147 & $3,684,365$ \\
\hline 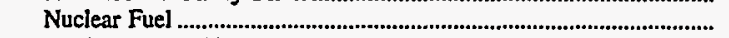 & 0 & 0 & 0 & 0 & 0 \\
\hline 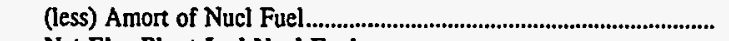 & 0 & 0 & 0 & 0 & 0 \\
\hline 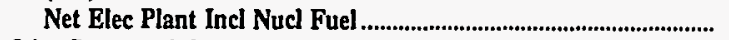 & 87,000 & $3,265,031$ & 361 & 147,147 & $3,684,365$ \\
\hline \multicolumn{6}{|l|}{ Other Psoperty \& Investments } \\
\hline 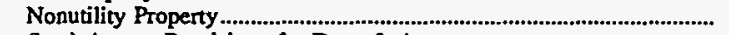 & 0 & $\mathbf{0}$ & 0 & 0 & $\mathbf{0}$ \\
\hline 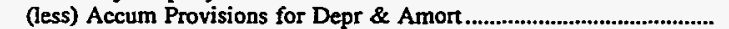 & 0 & 0 & 0 & 0 & 0 \\
\hline 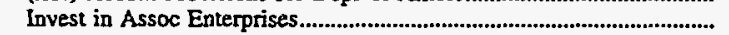 & 0 & 0 & 0 & 0 & 0 \\
\hline Invest \& Special Funds & 0 & 0 & 0 & 0 & 0 \\
\hline Total Other Property \& Investments & 0 & 0 & 0 & 0 & 0 \\
\hline \multicolumn{6}{|l|}{ Current and Accrued Assets } \\
\hline 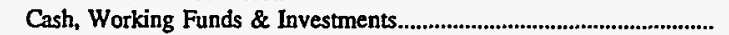 & 4,301 & 198,143 & 16,321 & 19,594 & 312,578 \\
\hline 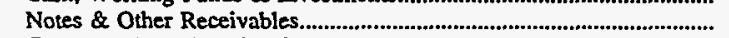 & 7 & 0 & I & 0 & 0 \\
\hline 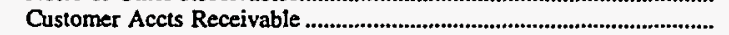 & 1,058 & 64,413 & 1,427 & 17,858 & 116,294 \\
\hline 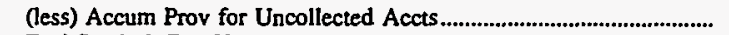 & & & 0 & 0 & 0 \\
\hline 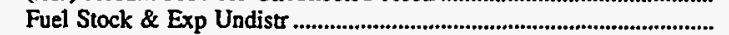 & 0 & 0 & 0 & 0 & 0 \\
\hline 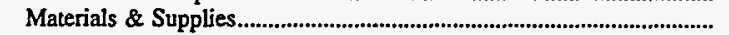 & 0 & 61,450 & 0 & 6,713 & 0 \\
\hline 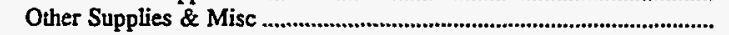 & 0 & 0 & 0 & 0 & 0 \\
\hline 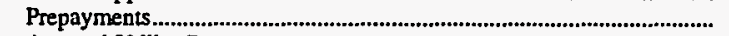 & 0 & 149,624 & 0 & 0 & 0 \\
\hline 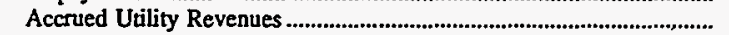 & o & 133,970 & 9,817 & 8,055 & 0 \\
\hline 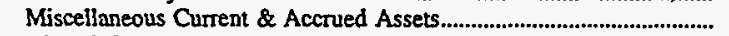 & $\mathbf{0}$ & 0 & 0 & 21 & 105,371 \\
\hline 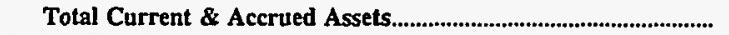 & 5,366 & 607,600 & 27,566 & 52,241 & 534,243 \\
\hline \multicolumn{6}{|l|}{ Deferred Debits } \\
\hline Unamortized Debt Expenses... & 0 & 0 & 0 & 0 & 0 \\
\hline 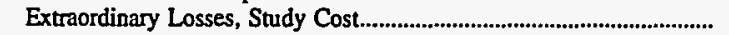 & 0 & 0 & 0 & 0 & 0 \\
\hline 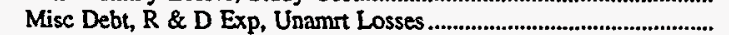 & 0 & $8,067,375$ & 0 & 0 & 0 \\
\hline 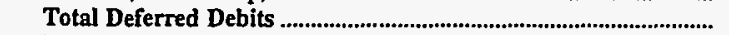 & 0 & $8,067,375$ & 0 & 0 & o \\
\hline 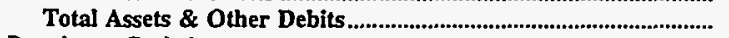 & 92,366 & $11,940,006$ & 27,927 & 199,388 & $4,218,608$ \\
\hline \multicolumn{6}{|l|}{ Proprietary Capital } \\
\hline Investment of Municipality...... & 170,759 & 0 & 0 & 66,532 & $11,918,437$ \\
\hline Misc Capital...1.1. & 0 & 0 & 25,897 & 0 & $-8,292,681$ \\
\hline 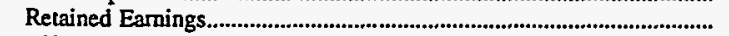 & $-78,798$ & 450,629 & 0 & 96,857 & 302,526 \\
\hline 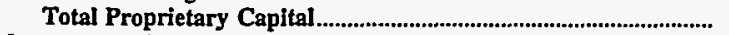 & 91,962 & 450,629 & 25,897 & 163,389 & $3,928,282$ \\
\hline \multicolumn{6}{|l|}{ Long-term Debt } \\
\hline 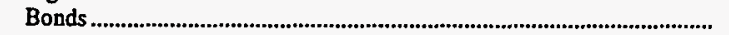 & 0 & $2,456,100$ & 0 & 0 & 0 \\
\hline 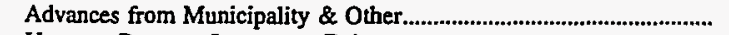 & 0 & $1,390,469$ & 0 & 0 & 0 \\
\hline 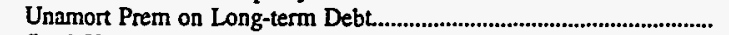 & 0 & 0 & 0 & 0 & 0 \\
\hline 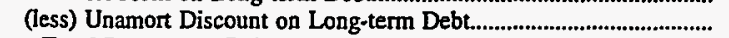 & 0 & 0 & 0 & 0 & 0 \\
\hline 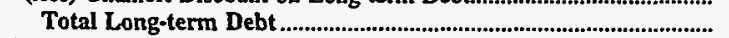 & 0 & $3,846,569$ & 0 & $\mathbf{0}$ & 0 \\
\hline \multicolumn{6}{|l|}{ Other Noncurrent Liabilities } \\
\hline Accum Operating Provisions ... & 0 & 0 & 0 & 0 & 0 \\
\hline 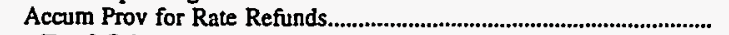 & 0 & 0 & 0 & 0 & o \\
\hline 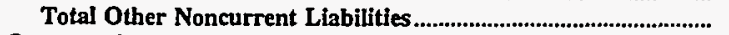 & 0 & 0 & 0 & 0 & 0 \\
\hline \multicolumn{6}{|l|}{ Current and Accrued Liabilities } \\
\hline 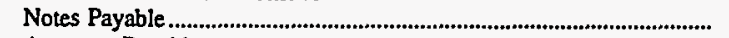 & 0 & 0 & 0 & 0 & 0 \\
\hline Accounts Payable & 0 & 194,515 & 1,708 & 11,706 & 73,039 \\
\hline 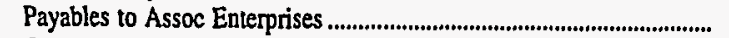 & 0 & 0 & 131 & 0 & 0 \\
\hline 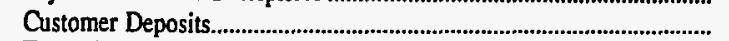 & 0 & 0 & 0 & 0 & 0 \\
\hline 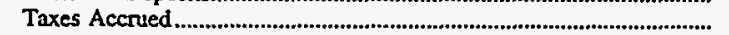 & 0 & 0 & 0 & 0 & 0 \\
\hline 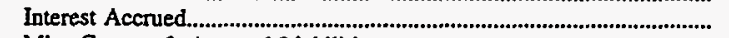 & 0 & 0 & 0 & 0 & 0 \\
\hline 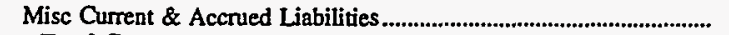 & 0 & 194,914 & 191 & 32 & 217,287 \\
\hline 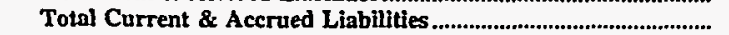 & 0 & 389,429 & 2,030 & 11,738 & 290,326 \\
\hline \multicolumn{6}{|l|}{ Deferred Credits } \\
\hline 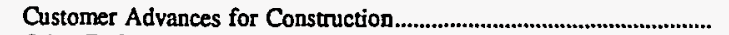 & 0 & 0 & 0 & 0 & $\mathbf{0}$ \\
\hline 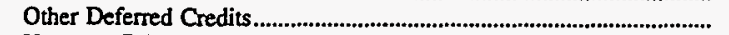 & 0 & $7,253,379$ & 0 & 24,261 & 0 \\
\hline 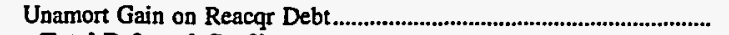 & 404 & 0 & 0 & 0 & 0 \\
\hline 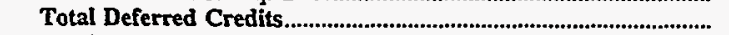 & 404 & $7,253,379$ & 0 & 24,261 & 0 \\
\hline 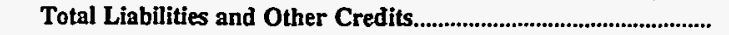 & 92,366 & $11,940,006$ & 27,927 & 199,388 & $4,218,608$ \\
\hline
\end{tabular}

See endnotes at end of this table. 
Table 28. Balance Sheet by U.S. Federal Electric Utility on September 30, 1996 (Continued) (Thousand Dollars)

\begin{tabular}{|c|c|c|c|c|c|}
\hline \multirow[b]{2}{*}{ Item } & \multirow[b]{2}{*}{$\begin{array}{c}\text { Tennessee } \\
\text { Valley } \\
\text { Authority } \\
\text { September } 30\end{array}$} & \multicolumn{2}{|c|}{ U.S. Bureau of Indian Affairs } & \multirow[b]{2}{*}{$\begin{array}{l}\text { USCE- } \\
\text { North Central } \\
\text { Division } 1 \\
\text { September } 30\end{array}$} & \multirow[b]{2}{*}{$\begin{array}{c}\text { Total } \\
\text { September } 30\end{array}$} \\
\hline & & $\begin{array}{c}\text { Mission } \\
\text { Valley Power } \\
\text { September } 30\end{array}$ & San Carlos * & & \\
\hline \multicolumn{6}{|l|}{ Electric Utility Plant } \\
\hline Electric Utility Plant \& Adjust & $28,156,997$ & 31,233 & - & 12,343 & $38,130,249$ \\
\hline 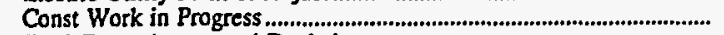 & $7,037,225$ & 5,019 & - & 0 & $7,630,760$ \\
\hline 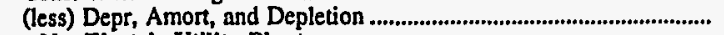 & $6,550,553$ & 8,128 & - & 3,524 & $9,896,494$ \\
\hline 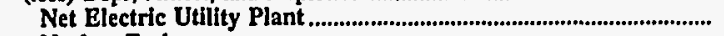 & $28,643,668$ & 28,123 & - & 8,819 & $35,864,514$ \\
\hline Nuclear Fuel & $2,648,592$ & 0 & - & 0 & $2,648,592$ \\
\hline 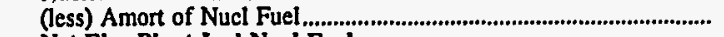 & $1,771,910$ & $\mathbf{0}$ & - & 0 & $1,771,910$ \\
\hline Net Elec Plant Incl Nucl Fuel & $29,520,350$ & 28,123 & $\rightarrow$ & 8,819 & $36,741,197$ \\
\hline \multicolumn{6}{|l|}{ Other Property \& Investments } \\
\hline 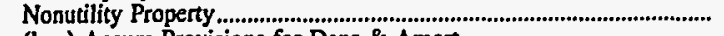 & 3,900 & $\mathbf{0}$ & - & $\mathbf{0}$ & 3,900 \\
\hline 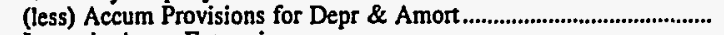 & 2,824 & 0 & $\rightarrow$ & 0 & 2,824 \\
\hline 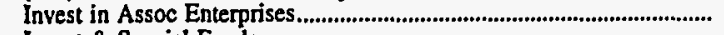 & 0 & 0 & - & 0 & 0 \\
\hline Invest \& Special Funds & 439,772 & 0 & - & 0 & 439,772 \\
\hline 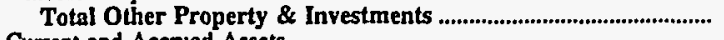 & 440,848 & 0 & - & $\mathbf{0}$ & 440,848 \\
\hline \multicolumn{6}{|l|}{ Current and Accrued Assets } \\
\hline 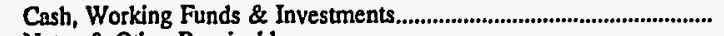 & 22,959 & 2,956 & - & 1 & 576,853 \\
\hline 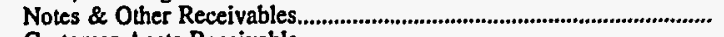 & 245,495 & -26 & - & 0 & 245,477 \\
\hline Customer Accts Receivable & 653,400 & 1,264 & - & 0 & 855,714 \\
\hline 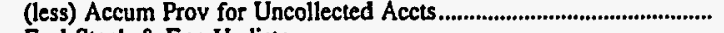 & 4,301 & -127 & - & 0 & 4,174 \\
\hline 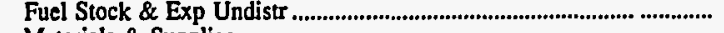 & 110,288 & 0 & - & 0 & 110,288 \\
\hline 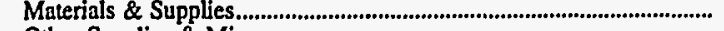 & 264,751 & 737 & - & 0 & 333,651 \\
\hline Other Supplies \& Misc & 4,175 & 37 & - & 0 & 4,212 \\
\hline Prepayments..., & 9,060 & 48 & - & 0 & 158,732 \\
\hline 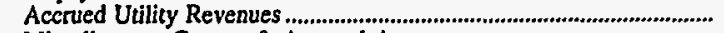 & 0 & 0 & - & 0 & 151,842 \\
\hline 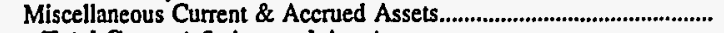 & 0 & 148 & $\rightarrow$ & 0 & 105,541 \\
\hline 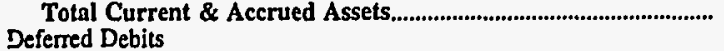 & $1,305,827$ & 5,291 & - & 1 & $2,538,136$ \\
\hline 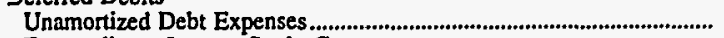 & $1,162,496$ & 0 & - & 0 & $1,162,496$ \\
\hline 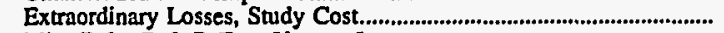 & $1,122,525$ & 0 & - & 0 & $1,122,525$ \\
\hline 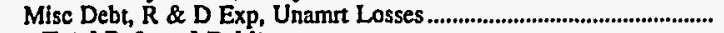 & 476,903 & 0 & - & 0 & $8,544,278$ \\
\hline 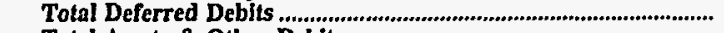 & $2,761,924$ & 0 & - & 0 & $10,829,299$ \\
\hline 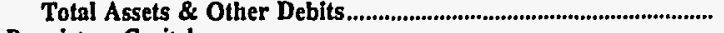 & $34,028,949$ & 33,415 & - & 8,820 & $50,549,479$ \\
\hline \multicolumn{6}{|l|}{ Proprietary Capital } \\
\hline 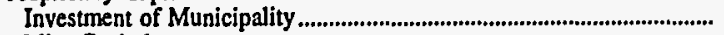 & 608,315 & 0 & - & 8,820 & $12,772,863$ \\
\hline 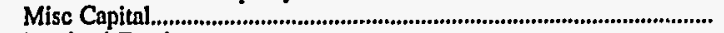 & & 0 & - & 0 & $-8,266,784$ \\
\hline 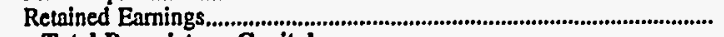 & $3,419,719$ & 27,053 & - & 0 & $4,217,986$ \\
\hline 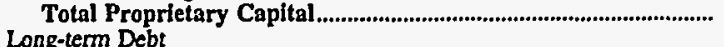 & $4,028,034$ & 27,053 & - & 8,820 & $8,724,066$ \\
\hline \multicolumn{6}{|l|}{ Long-term Debt } \\
\hline 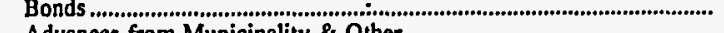 & $23,702,975$ & 0 & - & 0 & $26,159,075$ \\
\hline 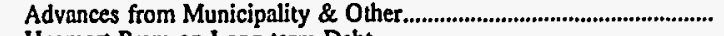 & & 4,575 & - & 0 & $1,395,044$ \\
\hline 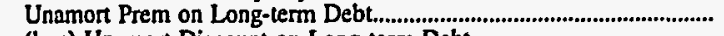 & 22,308 & 0 & - & 0 & 22,308 \\
\hline 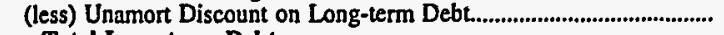 & 405,244 & 0 & - & 0 & 405,244 \\
\hline Total Long-term Debt & $23,320,039$ & 4,575 & - & 0 & $27,171,183$ \\
\hline \multicolumn{6}{|l|}{ Other Noncurrent Liabilities } \\
\hline Accum Operating Provisjons & 304,802 & 0 & - & 0 & 304,802 \\
\hline 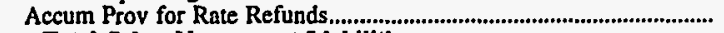 & & 0 & - & 0 & \\
\hline Total Other Noncurrent Liabilities & 304,802 & 0 & - & 0 & 304,802 \\
\hline \multicolumn{6}{|l|}{ Current and Accrued Liabilities } \\
\hline Notes Payable & $1,774,503$ & 0 & - & 0 & $1,774,503$ \\
\hline 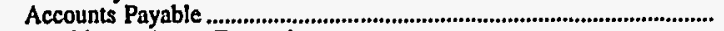 & 570,760 & 700 & - & 0 & 852,428 \\
\hline 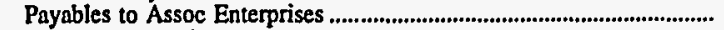 & 2,645 & 0 & - & 0 & 2,776 \\
\hline 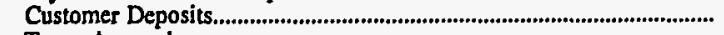 & 0 & 274 & - & 0 & 274 \\
\hline 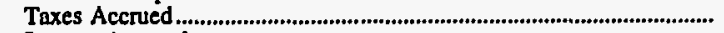 & & 2 & - & 0 & 2 \\
\hline 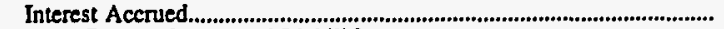 & 497,866 & 0 & - & $\mathbf{0}$ & 497,866 \\
\hline 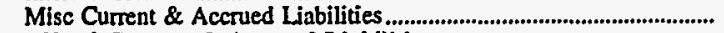 & $2,255,000$ & 245 & - & 0 & $2,667,669$ \\
\hline 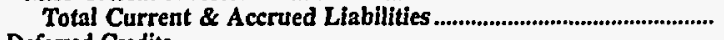 & $5,100,774$ & 1,220 & - & $\mathbf{0}$ & $5,795,517$ \\
\hline Deferred Credits & & & & & \\
\hline 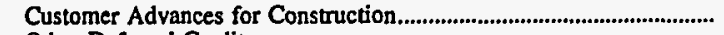 & & 566 & - & 0 & 566 \\
\hline 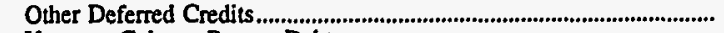 & $1,275,300$ & 0 & - & 0 & $8,552,941$ \\
\hline 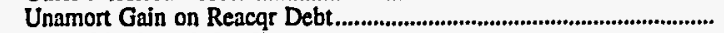 & & 0 & - & 0 & 404 \\
\hline 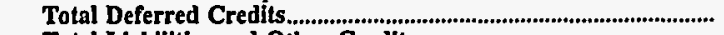 & $1,275,300$ & 566 & - & 0 & $8,553,911$ \\
\hline 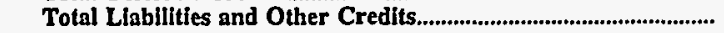 & $34,028,949$ & 33,415 & - & $\mathbf{8 , 8 2 0}$ & $50,549,479$ \\
\hline
\end{tabular}

- Fiscal year 1996 financial data not available.

* Fiscal year 1995 data reported.
1 Includes data only for Saint Mary's Falls at Sault St. Marie, Michigan. The rest of the generation produced by the U.S. Army Corps of Engineers (USCE) is sold by the Department of Energy-Bonneville, Southeastern, Southwestern, and Western Area Power Administrations.

Note: Totals may not equal sum of components because of independent rounding.

Source: Energy Information Administration, Form EIA-412, "Annual Report of Public Electric Utilities." 
Table 29. Electric Operation and Maintenance Expenses by U.S. Federal Electric Utility, 1996

(Thousand Dollars)

\begin{tabular}{|c|c|c|c|c|c|}
\hline Item & $\begin{array}{c}\text { Alaska } \\
\text { Power } \\
\text { Admin }\end{array}$ & $\begin{array}{c}\text { Bonneville } \\
\text { Power } \\
\text { Admin } \\
\text { September } 30\end{array}$ & $\begin{array}{c}\text { Southeastern } \\
\text { Power } \\
\text { Admin } \\
\text { September } 30\end{array}$ & $\begin{array}{c}\text { Southwestern } \\
\text { Power } \\
\text { Admin } \\
\text { September } 30\end{array}$ & $\begin{array}{c}\text { Western Area } \\
\text { Power } \\
\text { Admin } \\
\text { September } 30\end{array}$ \\
\hline \multicolumn{6}{|l|}{ Production Expenses } \\
\hline Steam Power Generation & 0 & 0 & 0 & 0 & 0 \\
\hline 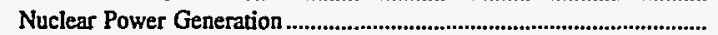 & 0 & 0 & 0 & 0 & 0 \\
\hline 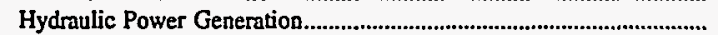 & 853 & 1,144 & 800 & 0 & 204,753 \\
\hline 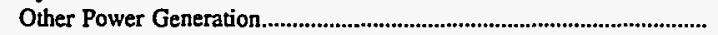 & 0 & 0 & 0 & 0 & 0 \\
\hline 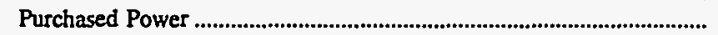 & 0 & 951,765 & 3,151 & 13,502 & 129,136 \\
\hline 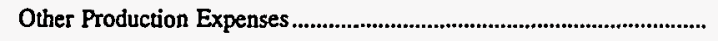 & 0 & 666,025 & 0 & 3,795 & 95,437 \\
\hline 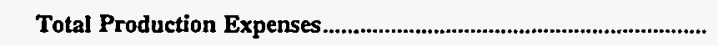 & 853 & $1,618,934$ & 3,951 & 17,298 & 429,326 \\
\hline Transmission Expenses & 1,002 & 186,633 & 25,888 & 17,299 & 29,929 \\
\hline 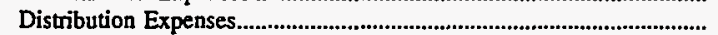 & 0 & 0 & 45 & 0 & 0 \\
\hline 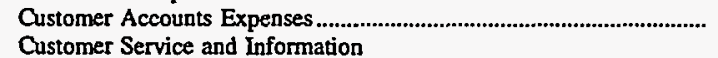 & 0 & 1,090 & 51 & 0 & o \\
\hline 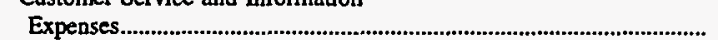 & 0 & 0 & 0 & 0 & 0 \\
\hline 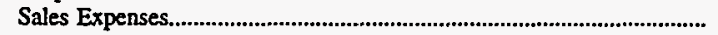 & $\mathbf{0}$ & 0 & 0 & 0 & 0 \\
\hline Administrative and General & & & & & \\
\hline 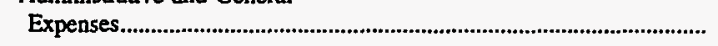 & 2,107 & 52,445 & 2,436 & 0 & 45,245 \\
\hline $\begin{array}{l}\text { Total Electric Operation and } \\
\text { Maintenance Expenses................... }\end{array}$ & 3,962 & $1,859,102$ & 32,371 & 34,597 & 504,500 \\
\hline \multicolumn{6}{|l|}{ Number of Elec Dept Employees } \\
\hline Regular Full-time & 11 & $3,830,000$ & 40 & 185 & 1,256 \\
\hline Part-time \& Temporary & 0 & 124,000 & 2 & 0 & 58 \\
\hline 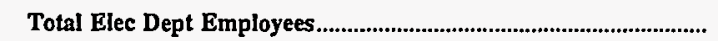 & 11 & $3,954,000$ & 42 & 185 & 1,314 \\
\hline
\end{tabular}

See endnotes at end of this table. 
Table 29. Electric Operation and Maintenance Expenses

by U.S. Federal Electric Utility, 1996 (Continued)

(Thousand Dollars)

\begin{tabular}{|c|c|c|c|c|c|}
\hline \multirow[b]{2}{*}{ Item } & \multirow[b]{2}{*}{$\begin{array}{c}\text { Tennessee } \\
\text { Valley } \\
\text { Authority } \\
\text { September } 30\end{array}$} & \multicolumn{2}{|c|}{ U.S. Bureau of Indian Affairs } & \multirow[b]{2}{*}{$\begin{array}{c}\text { USCE- } \\
\text { North Central } \\
\text { Division } 1 \\
\text { September } 30\end{array}$} & \multirow[b]{2}{*}{$\begin{array}{c}\text { Total } \\
\text { September } 30\end{array}$} \\
\hline & & $\begin{array}{c}\text { Mission } \\
\text { Valley Power } \\
\text { September } 30\end{array}$ & $\begin{array}{l}\text { San Carlos } \\
\text { September } 30\end{array}$ & & \\
\hline \multicolumn{6}{|l|}{ Production Expenses } \\
\hline 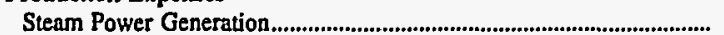 & $1,540,106$ & 0 & _ & $\mathbf{0}$ & $1,540,106$ \\
\hline 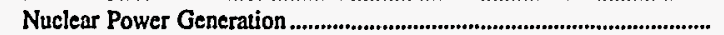 & 534,591 & 0 & - & 0 & 534,591 \\
\hline 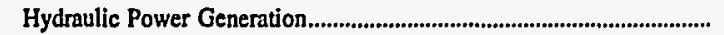 & 39,889 & 1 & - & 2,660 & 250,100 \\
\hline 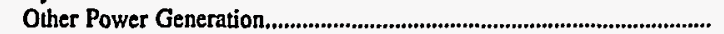 & 15,535 & $\mathbf{0}$ & - & 0 & 15,535 \\
\hline 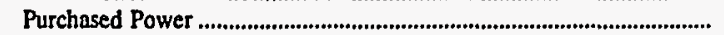 & $-116,695$ & 8,127 & _ & 0 & 988,986 \\
\hline 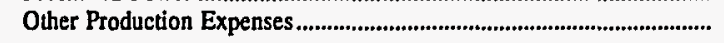 & 14,842 & $\mathbf{0}$ & - & $\mathbf{0}$ & 780,099 \\
\hline 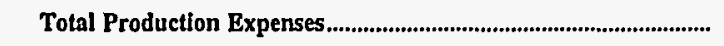 & $2,028,267$ & 8,128 & - & 2,660 & $4,109,417$ \\
\hline Transmission Expenses & 67,169 & 202 & - & o & 328,122 \\
\hline 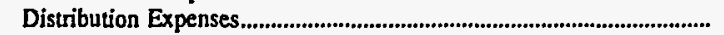 & 0 & 989 & - & 0 & 1,035 \\
\hline 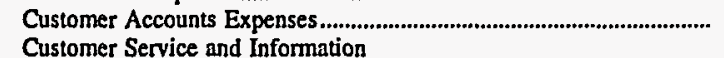 & 1,178 & 482 & - & 0 & 2,801 \\
\hline 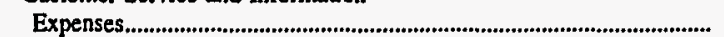 & 46,236 & 159 & - & 0 & 46,395 \\
\hline 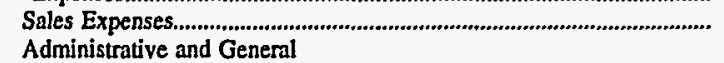 & 7,081 & 0 & - & $\mathbf{0}$ & 7,081 \\
\hline 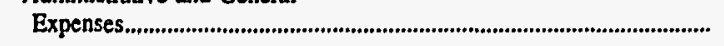 & 346,323 & 2,629 & - & 0 & 451,185 \\
\hline 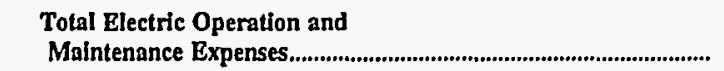 & $2,496,254$ & 12,589 & - & 2,660 & $4,946,036$ \\
\hline \multicolumn{6}{|l|}{ Number of Elec Dept Employees } \\
\hline 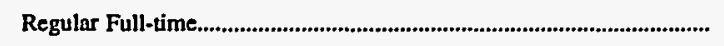 & 16,021 & 81 & - & 8 & $3,847,602$ \\
\hline 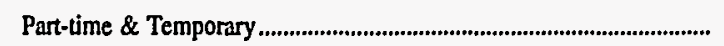 & 0 & 0 & - & 1 & 124,061 \\
\hline 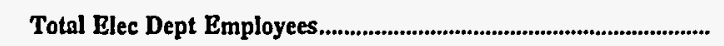 & 16,021 & 81 & - & 9 & $3,971,663$ \\
\hline
\end{tabular}

- Fiscal year 1996 financial data not available.

* Fiscal year 1995 data reported.

1 Includes data only for Saint Mary's Falls at Sault St. Marie, Michigan. The rest of the generation produced by the U.S. Army Corps of Engineers

(USCE) is sold by the Department of Energy-Bonneville, Southeastern, Southwestern, and Western Area Power Administrations.

Note: Totals may not equal sum of components because of independent rounding.

Source: Energy Information Administration, Form EIA-412, "Annual Report of Public Electric Utilities." 
Table 30. Electric Utility Plant by U.S. Federal Electric Utility

on September 30, 1996

(Thousand Dollars)

\begin{tabular}{|c|c|c|c|c|c|}
\hline Item & $\begin{array}{c}\text { Alaska } \\
\text { Power } \\
\text { Admin }\end{array}$ & $\begin{array}{c}\text { Bonneville } \\
\text { Power } \\
\text { Admin } \\
\text { September } 30\end{array}$ & $\begin{array}{c}\text { Southeastern } \\
\text { Power } \\
\text { Admin } \\
\text { September } 30\end{array}$ & $\begin{array}{c}\text { Southwestern } \\
\text { Power } \\
\text { Admin } \\
\text { September } 30\end{array}$ & $\begin{array}{c}\text { Westem Aren } \\
\text { Power } \\
\text { Admin }\end{array}$ \\
\hline 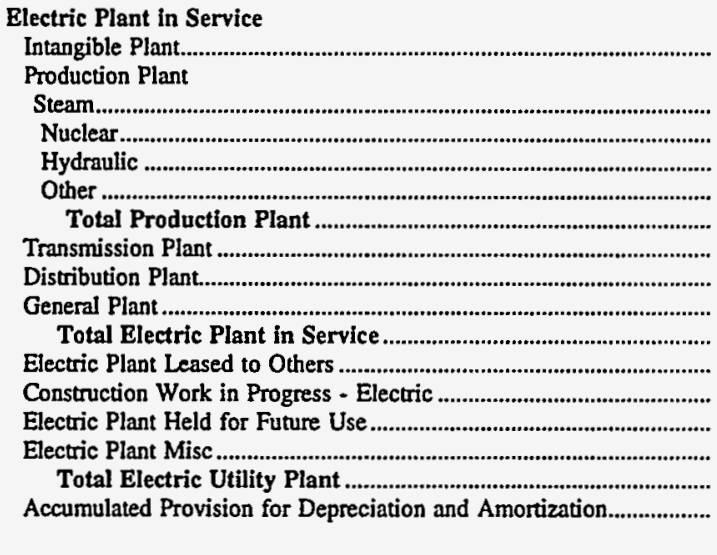 & $\begin{array}{r}331 \\
0 \\
0 \\
148,617 \\
0 \\
148,617 \\
32,431 \\
0 \\
5,678 \\
187,057 \\
0 \\
0 \\
0 \\
0 \\
187,057 \\
100,057 \\
87,000\end{array}$ & $\begin{array}{r}0 \\
0 \\
0 \\
0 \\
0 \\
0 \\
0 \\
3,968,006 \\
0 \\
584,202 \\
4,552,208 \\
188 \\
250,506 \\
1,705 \\
0 \\
4,804,607 \\
1,539,576 \\
3,265,031\end{array}$ & $\begin{array}{r}0 \\
0 \\
0 \\
0 \\
0 \\
0 \\
0 \\
816 \\
816 \\
0 \\
0 \\
0 \\
0 \\
816 \\
455 \\
361\end{array}$ & $\begin{array}{r}0 \\
0 \\
0 \\
0 \\
0 \\
109,889 \\
0 \\
32,243 \\
142,133 \\
0 \\
36,779 \\
0 \\
0 \\
178,912 \\
31,765 \\
147,147\end{array}$ & $\begin{array}{r}0 \\
0 \\
2,834,917 \\
0 \\
2,834,917 \\
2,210,652 \\
0 \\
0 \\
5,045,569 \\
0 \\
301,231 \\
0 \\
0 \\
5,346,800 \\
1,662,435 \\
3,684,365\end{array}$ \\
\hline
\end{tabular}

\begin{tabular}{|c|c|c|c|c|c|}
\hline \multirow[b]{2}{*}{ Item } & \multirow[b]{2}{*}{$\begin{array}{c}\text { Tennessee } \\
\text { Valley } \\
\text { Authority } \\
\text { September } 30\end{array}$} & \multicolumn{2}{|c|}{ U.S. Bureau of Indian Affairs } & \multirow[b]{2}{*}{$\begin{array}{l}\text { USCE- } \\
\text { North Central } \\
\text { Division }{ }^{*} 1 \\
\text { September } 30\end{array}$} & \multirow[b]{2}{*}{$\begin{array}{c}\text { Total } \\
\text { September } 30\end{array}$} \\
\hline & & $\begin{array}{c}\text { Mission } \\
\text { Valley Power } \\
\text { September } 30\end{array}$ & $\begin{array}{l}\text { San Carios } \\
\text { September } 30\end{array}$ & & \\
\hline \multicolumn{6}{|l|}{ Electric Plant in Service } \\
\hline \multicolumn{5}{|l|}{ Production Plant } & 348 \\
\hline Steam & $7,320,186$ & 0 & - & 0 & $7,320,186$ \\
\hline 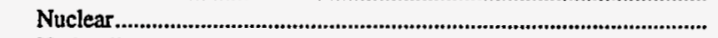 & $14,369,641$ & 0 & - & 0 & $14,369,641$ \\
\hline 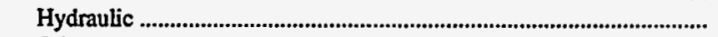 & $1,272,987$ & 69 & - & 12,343 & $4,268,933$ \\
\hline Other & 426,300 & 0 & - & 0 & 426,300 \\
\hline Total Production Plant & $23,389,113$ & 69 & - & 12,343 & $26,385,060$ \\
\hline 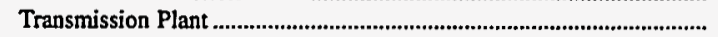 & $2,911,199$ & $\mathbf{3 , 3 7 0}$ & - & 0 & $9,235,547$ \\
\hline 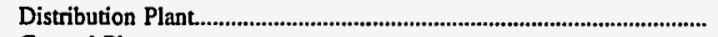 & 0 & 23,844 & - & 0 & 23,844 \\
\hline General Plant & $1,372,415$ & 3,932 & - & 0 & $1,999,287$ \\
\hline 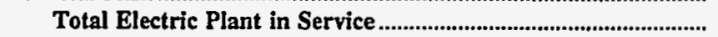 & $27,672,727$ & 31,233 & - & 12,343 & $37,644,086$ \\
\hline Electric Plant Leased to Others & 53,029 & 0 & - & 0 & 53,217 \\
\hline 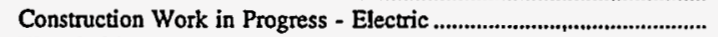 & $7,037,225$ & 5,019 & - & 0 & $7,630,760$ \\
\hline 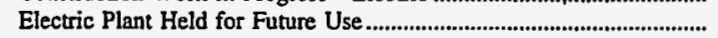 & 431,240 & 0 & - & 0 & 432,945 \\
\hline Electric Plant Misc & $\mathbf{0}$ & $\mathbf{0}$ & - & $\mathbf{0}$ & $\mathbf{0}$ \\
\hline 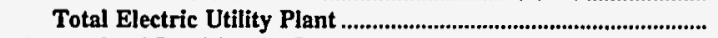 & $35,194,222$ & 36,252 & - & 12,343 & $45,761,008$ \\
\hline \multirow[t]{2}{*}{ Accumulated Provision for Depreciation and Amortization................... } & $6,550,553$ & 8,128 & - & 3,524 & $9,896,494$ \\
\hline & $28,643,668$ & 28,123 & - & 8,819 & $35,864,514$ \\
\hline
\end{tabular}

* Fiscal year 1996 financial data not available.

** Fiscal year 1995 data reported.

1 Includes data only for Saint Mary's Falls at Sault St. Marie, Michigan. The rest of the generation produced by the U.S. Army Corps of Engineers (USCE) is sold by the Department of Energy-Bonneville, Southeastern, Southwestern, and Western Area Power Administrations.

Note: Totals may not equal sum of components because of independent rounding.

Sousce: Energy Information Administration, Form EIA-412, "Annual Report of Public Electric Utilities." 
Table 31. Number of Consumers, Sales, and Operating Revenue by U.S. Federal Electric Utility, 1996

\begin{tabular}{|c|c|c|c|c|c|}
\hline Item & $\begin{array}{c}\text { Alaska } \\
\text { Power } \\
\text { Admin } \\
\\
\text { September } 30\end{array}$ & $\begin{array}{c}\begin{array}{c}\text { Bonneville } \\
\text { Power } \\
\text { Admin }\end{array} \\
\text { September } 30\end{array}$ & $\begin{array}{l}\text { Southeastern } \\
\text { Power } \\
\text { Admin } \\
\text { September } 30\end{array}$ & $\begin{array}{c}\text { Southwestern } \\
\text { Power } \\
\text { Admin } \\
\text { September } 30\end{array}$ & $\begin{array}{c}\text { Western Area } \\
\text { Power } \\
\text { Admin } \\
\text { September } 30\end{array}$ \\
\hline \multicolumn{6}{|l|}{ Number of Consumers } \\
\hline (1) & 0 & 0 & 0 & 0 & \\
\hline 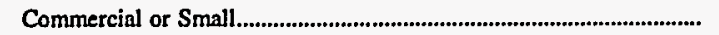 & 0 & $\mathbf{0}$ & 0 & 0 & \\
\hline 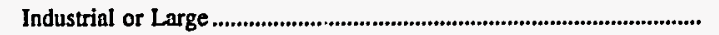 & $\mathbf{0}$ & 17 & $\mathbf{0}$ & $\mathbf{0}$ & \\
\hline 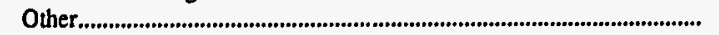 & 2 & 7 & 0 & $\mathbf{0}$ & 146 \\
\hline 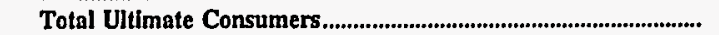 & 2 & 24 & $\mathbf{0}$ & $\mathbf{0}$ & 146 \\
\hline \multicolumn{6}{|l|}{ Sales for the Year (megawatthours) } \\
\hline 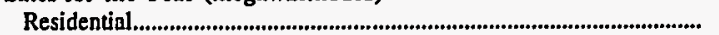 & 0 & $\mathbf{0}$ & $\mathbf{0}$ & $\mathbf{0}$ & \\
\hline 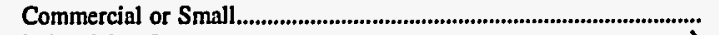 & 0 & $\mathbf{0}$ & $\mathbf{0}$ & $\mathbf{0}$ & \\
\hline Industrial or Large & 0 & $16,339,852$ & 0 & 0 & \\
\hline Other...., & 5,030 & 831,370 & $\mathbf{0}$ & $\mathbf{0}$ & $3,044,874$ \\
\hline 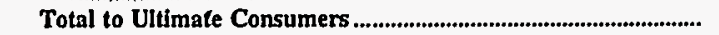 & $\mathbf{5 , 0 3 0}$ & $17,171,222$ & $\mathbf{0}$ & $\mathbf{0}$ & $3,044,874$ \\
\hline 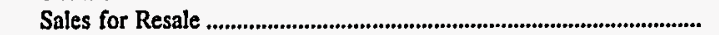 & 441,370 & $78,823,857$ & $8,757,525$ & $5,442,847$ & $38,802,666$ \\
\hline 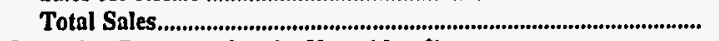 & 446,400 & $95,995,079$ & $8,757,525$ & $5,442,847$ & $41,847,540$ \\
\hline \multicolumn{6}{|l|}{ Operating Revenues for the Year (thou\$) } \\
\hline 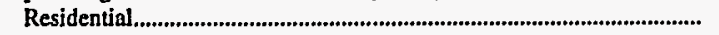 & 0 & $\mathbf{0}$ & $\mathbf{0}$ & $\mathbf{0}$ & \\
\hline 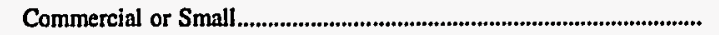 & $\mathbf{0}$ & $\mathbf{0}$ & 0 & $\mathbf{0}$ & \\
\hline 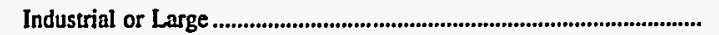 & $\mathbf{0}$ & 380,895 & 0 & $\mathbf{0}$ & \\
\hline Other, & 110 & 22,372 & 0 & 0 & 60,904 \\
\hline 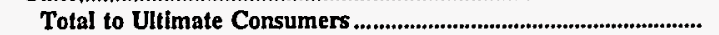 & 110 & 403,267 & o & $\mathbf{0}$ & 60,904 \\
\hline 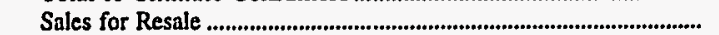 & 12,173 & $1,569,933$ & 164,455 & 92,628 & 616,022 \\
\hline 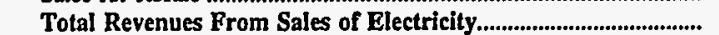 & 12,283 & $1,973,200$ & 164,455 & 92,628 & 676,926 \\
\hline
\end{tabular}

\begin{tabular}{|c|c|c|c|c|c|}
\hline \multirow[b]{2}{*}{ Item } & \multirow[b]{2}{*}{$\begin{array}{c}\text { Tennessee } \\
\text { Valley } \\
\text { Authority } \\
\text { September } 30\end{array}$} & \multicolumn{2}{|c|}{ U.S. Bureau of Indian Affairs } & \multirow[b]{2}{*}{$\begin{array}{c}\text { USCE- } \\
\text { Noth Central } \\
\text { Divisionl } \\
\text { September } 30\end{array}$} & \multirow[b]{2}{*}{$\begin{array}{c}\text { Total } \\
\text { September } 30\end{array}$} \\
\hline & & $\begin{array}{c}\begin{array}{c}\text { Mission } \\
\text { Valley Power }\end{array} \\
\text { September } 30\end{array}$ & September 30 & & \\
\hline \multicolumn{6}{|l|}{ Number of Consumers } \\
\hline Residential ........................ & 0 & 11,470 & 10,522 & $\mathbf{0}$ & 21,992 \\
\hline 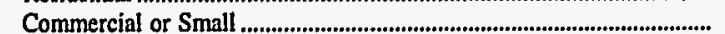 & 0 & 2,323 & 1,197 & $\mathbf{0}$ & 3,520 \\
\hline 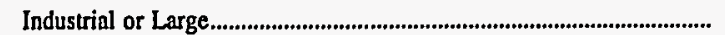 & 66 & 1 & 72 & 0 & 156 \\
\hline Other & 32 & 1,087 & 618 & 0 & 1,892 \\
\hline 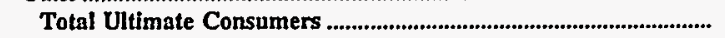 & 98 & 14,881 & 12,409 & $\mathbf{0}$ & 27,560 \\
\hline \multicolumn{6}{|l|}{ Sales for the Year (megawatthours) } \\
\hline 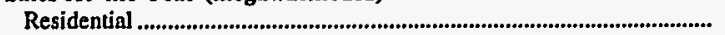 & $\mathbf{0}$ & 169,823 & 94,387 & $\mathbf{0}$ & 264,210 \\
\hline 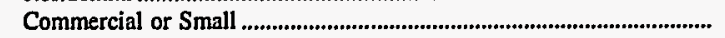 & $\mathbf{0}$ & 81,697 & 65,368 & 0 & 147,065 \\
\hline 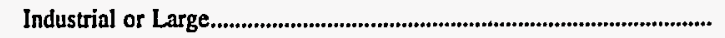 & $24,580,727$ & 20,530 & 99,141 & $\mathbf{0}$ & $41,040,250$ \\
\hline 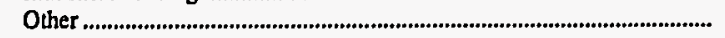 & 175,025 & 19,045 & 31,890 & 0 & $4,107,234$ \\
\hline 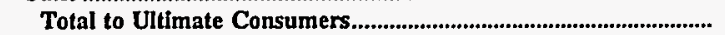 & $24,755,752$ & 291,095 & 290,786 & $\mathbf{0}$ & $45,558,759$ \\
\hline Sales for Resale & $116,809,185$ & 0 & & 130,475 & $249,207,925$ \\
\hline 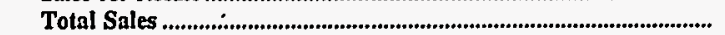 & $141,564,937$ & 291,095 & 290,786 & 130,475 & $294,766,684$ \\
\hline \multicolumn{6}{|l|}{ Operating Revenues for the Year (thou\$) } \\
\hline 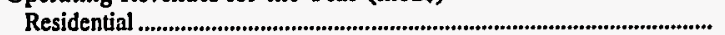 & $\mathbf{0}$ & 8,927 & 7,995 & $\mathbf{0}$ & 16,922 \\
\hline 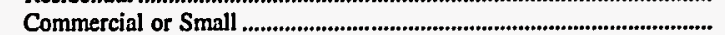 & 0 & 4,978 & 4,999 & 0 & 9,977 \\
\hline 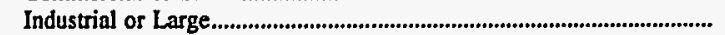 & 638,375 & 942 & 6,436 & $\mathbf{0}$ & $1,026,648$ \\
\hline Other & 7,569 & 1,186 & 1,328 & 0 & 93,469 \\
\hline 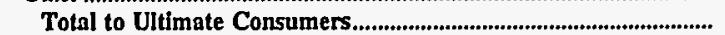 & 645,944 & 16,033 & 20,758 & $\mathbf{0}$ & $1,147,016$ \\
\hline Sales for Resale & $4,957,673$ & 0 & $\mathbf{0}$ & 67 & $7,412,951$ \\
\hline Total Revenues From Sales of Electricity ............................................. & $5,603,617$ & 16,033 & 20,758 & 67 & $8,559,967$ \\
\hline
\end{tabular}

I Includes data only for Saint Mary's Falls at Sault St. Marie, Michigan. The rest of the generation produced by the U.S. Army Corps of Engineers (USCE) is sold by the Department of Energy-Bonneville, Southeastern, Southwestern, and Western Area Power Administrations.

Note: Totals may not equal sum of components because of independent rounding. Data are submitted on a calendar year.

Source: Energy Information Administration, Form EIA-861, "Annual Electric Utility Report." Data are submitted on a calendar year. 
Table 32. Electric Energy Account by U.S. Federal Electric Utility, 1996 (Megawatthours)

\begin{tabular}{|c|c|c|c|c|c|}
\hline Item & $\begin{array}{c}\text { Alaska } \\
\text { Power } \\
\text { Admin } \\
\text { September } 30\end{array}$ & $\begin{array}{c}\text { Bonneville } \\
\text { Power } \\
\text { Admin } \\
\text { September } 30\end{array}$ & $\begin{array}{c}\text { Southeastern } \\
\text { Power } \\
\text { Admin } \\
\text { September } 30\end{array}$ & $\begin{array}{c}\text { Southwestern } \\
\text { Power } \\
\text { Admin } \\
\text { September } 30\end{array}$ & $\begin{array}{c}\text { Westem Area } \\
\text { Power } \\
\text { Admin } \\
\text { September } 30\end{array}$ \\
\hline \multicolumn{6}{|l|}{ Sources of Energy } \\
\hline Total Net Generation & 416,325 & $106,203,392$ & $8,988,860$ & $3,187,956$ & $39,818,000$ \\
\hline 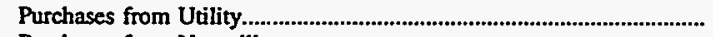 & 0 & $1,512,056$ & 191,751 & 100,219 & $6,088,000$ \\
\hline 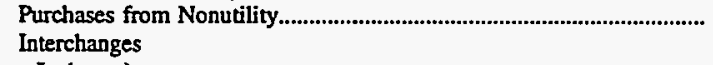 & $\mathbf{0}$ & $1,057,390$ & 0 & 0 & 9,000 \\
\hline In (gross) & $\mathbf{0}$ & $10,623,845$ & 719 & 941,515 & $\mathbf{5 0 7 , 0 0 0}$ \\
\hline Out (gross) & $\mathbf{0}$ & $16,477,780$ & 0 & 279,579 & $1,096,000$ \\
\hline 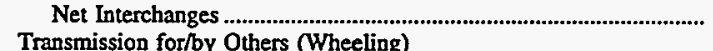 & $\mathbf{0}$ & $-5,853,935$ & 719 & 661,936 & $-589,000$ \\
\hline 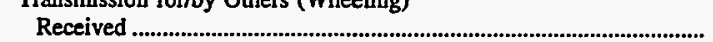 & \multicolumn{5}{|c|}{ Transmission for/by Others (Wheeling) } \\
\hline 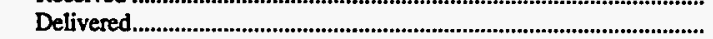 & 338,422 & $52,770,610$ & 515,208 & 0 & $\begin{array}{l}5,706,138 \\
5,706,138\end{array}$ \\
\hline 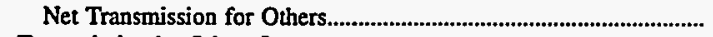 & 0 & $1,576,653$ & 0 & 0 & 0 \\
\hline 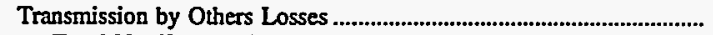 & 0 & 0 & 0 & 0 & 0 \\
\hline 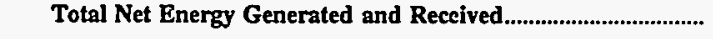 & 416,325 & $104,495,556$ & $9,181,330$ & $3,950,111$ & $45,326,000$ \\
\hline \multicolumn{6}{|l|}{ Disposition of Energy } \\
\hline 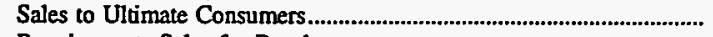 & 3,739 & $19,008,206$ & $\mathbf{0}$ & $\mathbf{0}$ & $3,045,000$ \\
\hline 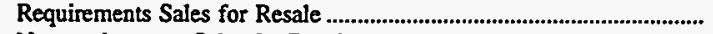 & 407,779 & $76,470,143$ & $8,602,216$ & $4,031,434$ & $29,437,000$ \\
\hline Nonrequirements Sales for Resale & 0 & $5,069,254$ & 155,309 & 0 & $9,365,000$ \\
\hline 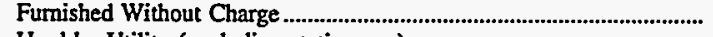 & 0 & 0 & 180,000 & 0 & 7,000 \\
\hline 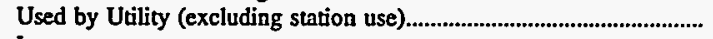 & 0 & 71,900 & 5,718 & $-114,178$ & $1,280,000$ \\
\hline Losses. & 4,807 & $3,876,053$ & 238,087 & 32,855 & $2,192,000$ \\
\hline Total Disposition & 416,325 & $104,495,556$ & $9,181,330$ & $3,950,111$ & $45,326,000$ \\
\hline
\end{tabular}

See endnotes at end of this table. 
Table 32. Electric Energy Account by U.S. Federal Electric Utility, 1996 (Continued) (Megawatthours)

\begin{tabular}{|c|c|c|c|c|c|}
\hline \multirow[b]{2}{*}{ Item } & \multirow[b]{2}{*}{$\begin{array}{c}\text { Tennessee } \\
\text { Valley } \\
\text { Authority } \\
\text { September } 30\end{array}$} & \multicolumn{2}{|c|}{ U.S. Bureau of Indian Affairs } & \multirow[b]{2}{*}{$\begin{array}{l}\text { USCE- } \\
\text { North Central } \\
\text { Division } 1 \\
\text { September } 30\end{array}$} & \multirow[b]{2}{*}{$\begin{array}{c}\text { Total } \\
\text { September } 30\end{array}$} \\
\hline & & $\begin{array}{c}\text { Mission } \\
\text { Valley Power } \\
\text { September } 30\end{array}$ & $\begin{array}{l}\text { San Carlos } \\
\text { September } 30\end{array}$ & & \\
\hline \multicolumn{6}{|l|}{ Sources of Energy } \\
\hline Total Net Generation & $148,796,115$ & 2,260 & - & 141,870 & $307,554,778$ \\
\hline 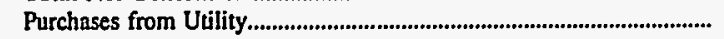 & $3,078,225$ & 351,314 & - & 0 & $11,321,565$ \\
\hline 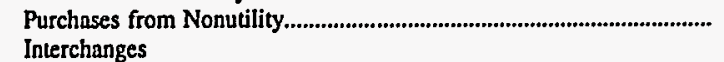 & $1,851,172$ & 1,565 & - & $\mathbf{0}$ & $2,919,127$ \\
\hline In (gross) & $22,416,396$ & 0 & - & $\mathbf{0}$ & $34,489,475$ \\
\hline Out (gross) & $30,352,919$ & 0 & - & 0 & $48,206,278$ \\
\hline 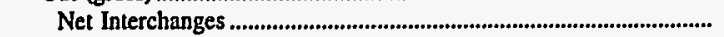 & $-7,936,523$ & 0 & - & 0 & $-13,716,803$ \\
\hline \multicolumn{6}{|l|}{ Transmission for/by Others (Wheeling) } \\
\hline 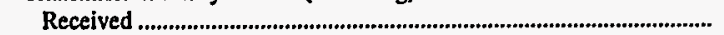 & $3,122,222$ & $\mathbf{0}$ & - & $\mathbf{0}$ & $64,029,253$ \\
\hline 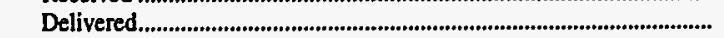 & $3,037,397$ & 0 & - & 0 & $62,367,775$ \\
\hline 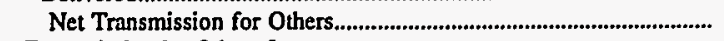 & 84,825 & 0 & - & 0 & $1,661,478$ \\
\hline 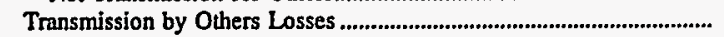 & 0 & 0 & - & $\mathbf{0}$ & $\mathbf{0}$ \\
\hline 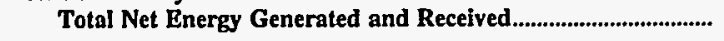 & $145,873,814$ & 355,139 & - & 141,870 & $309,740,145$ \\
\hline \multicolumn{6}{|l|}{ Disposition of Energy } \\
\hline 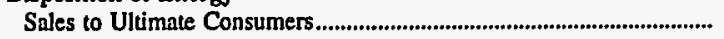 & $25,025,570$ & 291,095 & - & $\mathbf{0}$ & $47,373,610$ \\
\hline 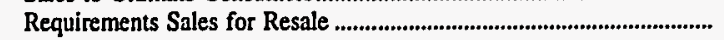 & $117,035,266$ & 0 & - & 133,668 & $236,117,506$ \\
\hline 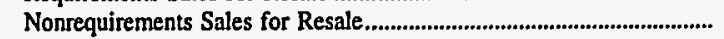 & 0 & $\mathbf{0}$ & - & 0 & $14,589,563$ \\
\hline Fumished Without Charge & 207,199 & 0 & - & 713 & 394,912 \\
\hline 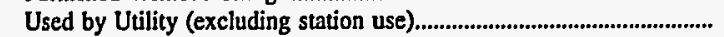 & 10,716 & 738 & - & 5,765 & $1,260,659$ \\
\hline 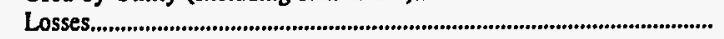 & $3,595,063$ & 63,306 & - & 1,724 & $10,003,895$ \\
\hline 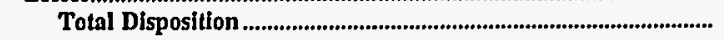 & $145,873,814$ & 355,139 & - & 141,870 & $309,740,145$ \\
\hline
\end{tabular}

- Fiscal year 1996 financial data not available.

* Fiscal year 1995 data reported.

1 Includes data only for Saint Mary's Falls at Sault St. Marie, Michigan. The rest of the generation produced by the U.S. Army Corps of Engineers (USCE) is sold by the Department of Energy-Bonneville, Southeastern, Southwester , and Western Aren Power Administrations.

Note: Totals may not equal sum of components because of independent rounding.

Source: Energy Information Administration, Form EIA-412, "Annual Report of Public Electric Utilities." 



\section{Appendix A}

\section{Summary}

Statistics of

U.S. Rural

Electric

Cooperative Borrowers 


\section{Appendix A}

\section{Summary Statistics of U.S. Rural Electric Cooperative Borrowers.}

\section{Background}

The Rural Utilities Service (RUS), U.S. Department of Agriculture, previously The Rural Electrification Administration (REA), was established under the Rural Electrification Act of 1936. The purpose was to extend electric service to small rural communities (usually under 1,500 customers) and farms where it was more expensive to provide service. Through the REA, electric cooperatives (customer-owned, nonprofit entities) were formed and provided with low interest rate, government-guaranteed loans to allow them to build power lines to transmit and distribute wholesale electricity purchased from other electric utilities. By the early 1960's, the REA began to make large loans to cooperatives for the construction of generating plants and transmission facilities to "protect the security and effectiveness of REA-financed systems."

The latest statistics taken from the 1996 Statistical Report, Rural Electric Borrowers ${ }^{3}$ publication show that 782 of 832 cooperative borrowers were distribution borrowers. The remaining 50 were power supply borrowers. By the end of 1996, the RUS-financed electric utilities were serving more than 11 million consumers in 46 States. When the REA was formed, less than 10 percent of rural areas in the United States had electric service. Today, about 99 percent of U.S. farmers have electric power.

\section{Composite Income Account}

Operating revenues for cooperative borrowers were $\$ 24.4$ billion in 1996 , compared with $\$ 24.6$ billion in 1995 , and $\$ 23.8$ billion in 1994 .

Total electric utility operating expenses for the cooperative borrowers were $\$ 23.1$ billion in 1996 . Operation and maintenance expenses represented $\$ 20.7$ billion or 89.6 percent of the total operating expenses.
Purchased power, a major portion of operation and maintenance expenses, was $\$ 12.9$ billion. Taxes were $\$ 0.6$ billion or 2.7 percent of total electric operating expenses.

Utility operating income for cooperative borrowers was $\$ 2.9$ billion in 1996 . Utility operating income, as a proportion of net utility plant, was 6.9 percent. Net income was $\$ 1.3$ billion.

Interest expense on long-term debt was $\$ 2.1$ billion in 1996 , a decrease from $\$ 2.2$ billion in 1995. Interest expenses as a percentage of long-term debt was 6.1 percent in 1996, the same as 1995.

\section{Balance Sheet}

The net investment in electric utility plant for cooperative borrowers was $\$ 41.7$ billion at the end of 1996 , which includes $\$ 1.4$ billion for construction work in progress (CWIP). The CWIP was also $\$ 1.4$ billion at the end of 1995. Accumulated Provisions for Depreciation and Amortization increased $\$ 0.6$ billion (3.4 percent) at the end of 1996 . The investment and funds accounts were $\$ 5.8$ billion and long-term debt was $\$ 33.9$ billion at the end of 1996 .

\section{Electric Utility Operating Revenues}

The number of residential consumers served by cooperative borrowers was 10.0 million in 1996, down slightly from 10.4 million in 1995. Revenues from residential consumers were $\$ 9.7$ billion or 65.9 percent of total revenues from all ultimate consumers. In 1996, consumption of electricity by each residential customer averaged 12.9 megawathours at an average annual cost of $\$ 965.47$, an increase from 1995 when each residential customer averaged 12.4 megawatthours at an average annual cost of $\$ 955.88$. 
Table A1. Composite Statement of Income for the U.S.

Cooperative Borrowers, 1992-1996

(Thousand Dollars)

\begin{tabular}{|c|c|c|c|c|c|}
\hline Item & 1996 & $1995^{\mathrm{R}}$ & 1994 & 1993 & 1992 \\
\hline $\begin{array}{l}\text { Electric Utility Operating Revenues............................. } \\
\text { Utility Operating Expenses }\end{array}$ & $24,423,637$ & $24,609,188$ & $23,776,646$ & $24,872,684$ & $23,325,191$ \\
\hline 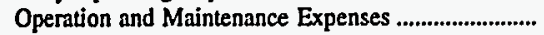 & $20,748,250$ & $19,333,521$ & $18,649,528$ & $19,291,776$ & $18,038,115$ \\
\hline 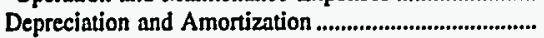 & $1,786,955$ & $1,777,568$ & $1,741,836$ & $1,767,525$ & $1,709,293$ \\
\hline 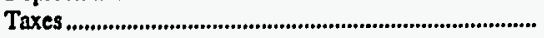 & 613,961 & 628,072 & 601,259 & 615,890 & 605,275 \\
\hline 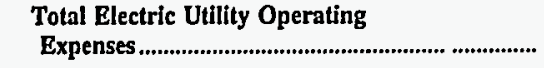 & $23,149,166$ & $21,741,161$ & $20,992,623$ & $21,675,191$ & $20,352,683$ \\
\hline 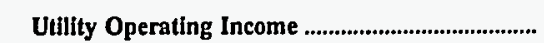 & $2,871,769$ & $2,868,026$ & $2,784,023$ & $3,197,493$ & $2,972,507$ \\
\hline 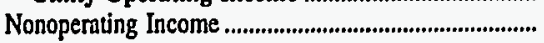 & 377,582 & 388,966 & 293,164 & 399,378 & 433,518 \\
\hline Capital Credits and Patronage Capital............................ & 300,426 & 285,748 & 279,622 & 323,345 & 248,996 \\
\hline Allowance for Funds Used During Construction . & 8,923 & 34,004 & 48,008 & 50,906 & 55,440 \\
\hline Gross Income & $3,558,700$ & $3,576,744$ & $3,404,817$ & $3,971,122$ & $3,710,461$ \\
\hline \multicolumn{6}{|l|}{ Income Deductions from } \\
\hline Interest on Long-term Debt.................................................. & $2,061,699$ & $2,205,174$ & $2,418,973$ & $2,718,249$ & $2,833,653$ \\
\hline 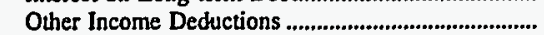 & 170,562 & 135,520 & 164,995 & 218,024 & 165,921 \\
\hline 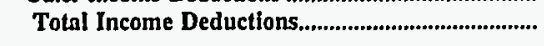 & $2,232,261$ & $2,340,694$ & $2,583,968$ & $2,936,273$ & $2,999,574$ \\
\hline 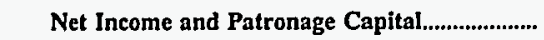 & $1,326,440$ & $1,236,050$ & 820,849 & $1,034,849$ & 710,887 \\
\hline
\end{tabular}

$\mathrm{R}=$ Revised data.

Notes: Totals may not equal sum of components because of independent rounding. Data for 1996 represent 782 Distribution Borrowers and 50 Power Supply Borrowers; data for 1995 represent 805 Distribution Borrowers and 51 Power Supply Borrowers; data for 1994 represent 808 Distribution Borrowers and 47 Power Supply Borrowers; data for 1993 represent 855 Distribution Borrowers and 54 Power Supply Borrowers; data for 1992 represent 862 Distribution Borrowers and 54 Power Supply Borrowers.

Source: U.S. Department of Agriculture, Rural Utilities Service (prior Rural Electrification Administration), Statistical Report, Rural Electric Borrowers publications for the years 1992, 1993, 1994, 1995, and 1996.

Table A2. Composite Balance Sheet for the U.S. Cooperative Borrowers on December 31, 1992-1996

(Thousand Dollars)

\begin{tabular}{|c|c|c|c|c|c|}
\hline Item & 1996 & $1995^{\mathrm{R}}$ & 1994 & 1993 & 1992 \\
\hline \multicolumn{6}{|l|}{ Assets and Other Debits } \\
\hline 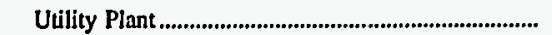 & $59,953,062$ & $60,431,984$ & $59,512,615$ & $60,946,122$ & $59,043,411$ \\
\hline $\begin{array}{l}\text { Construction Work in Progress .................................... } \\
\text { (Less) Accumulated Provisions for }\end{array}$ & $1,441,940$ & $1,435,854$ & $1,760,475$ & $1,708,168$ & $1,626,552$ \\
\hline Depreciation and Amortization ............................... & $19,712,785$ & $19,069,186$ & $18,266,323$ & $17,907.939$ & $16,594,358$ \\
\hline 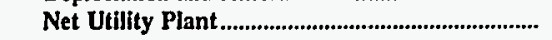 & $41,682,218$ & $42,798,652$ & $43,006,767$ & $44,746,351$ & $44,075,606$ \\
\hline 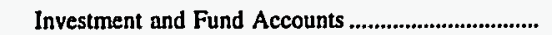 & $5,804,724$ & $5,747,458$ & $5,607,909$ & $5,379,236$ & $5,379,400$ \\
\hline 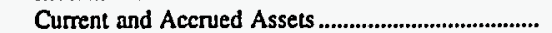 & $7,207,279$ & $7,683,116$ & $7,108,589$ & $7,986,359$ & $7,810,050$ \\
\hline 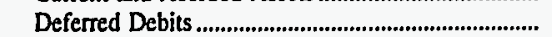 & $3,803,818$ & $4,046,858$ & $3,911,037$ & $3,970,658$ & $2,287,018$ \\
\hline Total Assets and Other Debits................................ & $58,498,039$ & $60,276,084$ & $59,634,347$ & $62,430,395$ & $59,552,073$ \\
\hline \multicolumn{6}{|l|}{ Liabilities and Other Credits } \\
\hline 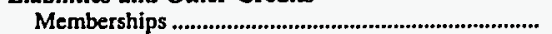 & 86,825 & 116,501 & 104,652 & 97,081 & 96,146 \\
\hline Patronage Capital and Other Equities ........................ & $15,609,514$ & $15,265,631$ & $12,277,054$ & $12,230,419$ & $11,372,465$ \\
\hline 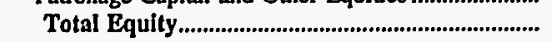 & $15,696,339$ & $15,382,132$ & $12,381,706$ & $12,327,500$ & $11,468,611$ \\
\hline 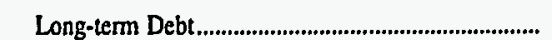 & $33,896,328$ & $36,061,751$ & $40,129,573$ & $42,719,188$ & $42,691,944$ \\
\hline 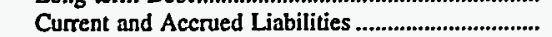 & $3,992,319$ & $3,870,455$ & $3,660,865$ & $3,852,903$ & $3,381,957$ \\
\hline 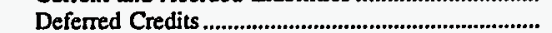 & $1,720,170$ & $1,735,838$ & $1,581,853$ & $1,555,059$ & $1,469,722$ \\
\hline Operating Reserves & $3,192,972$ & $3,225,911$ & $1,881,552$ & $1,975,745$ & 539,839 \\
\hline Total Liabilities and Other Credits.................... & $58,498,039$ & $60,276,084$ & $59,634,347$ & $62,430,395$ & $59,552,073$ \\
\hline
\end{tabular}

$\mathbf{R}=$ Revised data.

Notes: Totals may not equal sum of components because of independent rounding. Data for 1996 represent 782 Distribution Borrowers and 50 Power Supply Borrowers; data for 1995 represent 805 Distribution Borrowers and 51 Power Supply Borrowers; data for 1994 represent 808 Distribution Borrowers and 47 Power Supply Borrowers; data for 1993 represent 855 Distribution Borrowers and 54 Power Supply Borrowers; data for 1992 represent 862 Distribution Borrowers and 54 Power Supply Borrowers.

Source: U.S. Department of Agriculture, Rural Utilities Service (prior Rural Electrification Administration), Statistical Report, Rural Electric Borrowers publications for the years 1992, 1993, 1994, 1995 and 1996. 
Table A3. Electric Operation and Maintenance Expenses for the U.S. Cooperative Borrowers, 1992-1996

(Thousand Dollars)

\begin{tabular}{|c|c|c|c|c|c|}
\hline Item & 1996 & 1995 & 1994 & 1993 & 1992 \\
\hline \multicolumn{6}{|l|}{ Production Expenses } \\
\hline 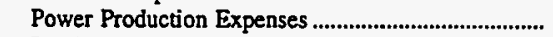 & $2,900,794$ & $3,093,246$ & $2,972,356$ & $3,083,578$ & $2,998,260$ \\
\hline 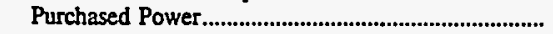 & $12,923,996$ & $13,065,741$ & $12,498,458$ & $13,017,485$ & $12,061,066$ \\
\hline Total Production Expenses............................................ & $15,824,790$ & $16,158,987$ & $15,470,814$ & $16,101,063$ & $15,059,326$ \\
\hline 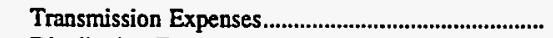 & 371,595 & 365,972 & 321,636 & 336,401 & 323,527 \\
\hline 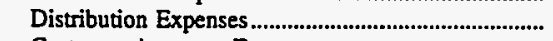 & $1,132,665$ & $1,126,924$ & $1,052,738$ & $1,044,359$ & 980,017 \\
\hline 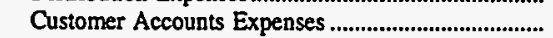 & 375,142 & 383,154 & 374,126 & 386,310 & 368,563 \\
\hline \multicolumn{6}{|l|}{ Customer Service and Informational } \\
\hline 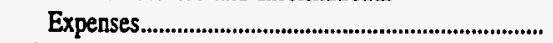 & 117,529 & 111,930 & 104,508 & 100,991 & 94,907 \\
\hline 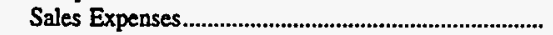 & 72,216 & 71,620 & 60,584 & 57,438 & 52,235 \\
\hline 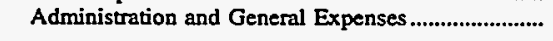 & $1,257,015$ & $1,366,960$ & $1,265,122$ & $1,265,214$ & $1,159,540$ \\
\hline \multicolumn{6}{|l|}{ Total Electric Operation and } \\
\hline Maintenance Expenses.......... & $19,150,952$ & $19,585,547$ & $18,649,528$ & $19,291,776$ & $18,038,115$ \\
\hline
\end{tabular}

Notes: Totals may not equal sum of components because of independent rounding. Data for 1996 represent 782 Distribution Borrowers and 50 Power Supply Borrowers; Data for 1995 represent 805 Distribution Borrowers and 51 Power Supply Borrowers; Data for 1994 represent 808 Distribution Borrowers and 47 Power Supply Borrowers; data for 1993 represent 855 Distribution Borrowers and 54 Power Supply Borrowers; data for 1992 represent 862 Distribution Borrowers and 54 Power Supply Borrowers.

Source: U.S. Department of Agriculture, Rural Utilities Service (prior Rural Electrification Administration), Statistical Report, Rural Electric Borrowers publications for the years 1992, 1993, 1994, 1995 and 1996. 
Table A4. Number of Consumers, Sales, and Operating Revenue for the

U.S. Cooperative Distributor Borrowers, 1992-1996

\begin{tabular}{|c|c|c|c|c|c|}
\hline Item & 1996 & $1995^{R}$ & 1994 & 1993 & 1992 \\
\hline \multicolumn{6}{|l|}{ Number of Consumers on December 31} \\
\hline Residential (farm and nonfarm) ..................... & $10,040,510$ & $10,393,104$ & $10,184,867$ & $10,533,502$ & $10,320,348$ \\
\hline \multicolumn{6}{|l|}{ Commercial and Industrial } \\
\hline Small (or commercial) .................., & 984,186 & $1,005,741$ & 970,786 & $1,007,028$ & 987,261 \\
\hline 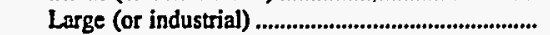 & 7,040 & 7,046 & 7,944 & 6,922 & 6,499 \\
\hline Other Sales to Ultimate Consumers.................................. & 168,039 & 175,910 & 182,387 & 176,307 & 172,995 \\
\hline 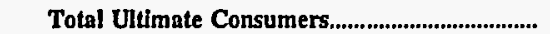 & $11,199,775$ & $11,581,801$ & $11,345,984$ & $11,723,759$ & $11,487,103$ \\
\hline Sales for Resale ............................................................... & 249 & 265 & 516 & 274 & \\
\hline Total Number of Consumers..................................... & $11,200,024$ & $11,582,066$ & $11,346,500$ & $11,723,973$ & $11,487,354$ \\
\hline \multicolumn{6}{|l|}{ Sales for the Year (Megawatthours) } \\
\hline Residential (farm and nonfarm) ............................... & $129,024,190$ & $129,138,195$ & $122,877,875$ & $129,030,270$ & $118,692,082$ \\
\hline \multicolumn{6}{|l|}{ Commercial and Industrial } \\
\hline Small (or commercial) & $38,521,425$ & $39,504,104$ & $37,833,413$ & $38,747,491$ & $37,109,870$ \\
\hline 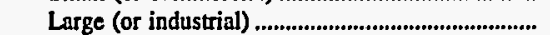 & $43,821,044$ & $41,616,526$ & $39,237,790$ & $39,237,790$ & $36,852,497$ \\
\hline Other Sales to Ultimate Consumers............................... & $5,850,289$ & $5,899,793$ & $6,717,253$ & $5,581,171$ & $5,633,095$ \\
\hline Total Sales to Ultimate Consumers......................... & $217,216,948$ & $216,158,618$ & $207,226,809$ & $212,596,722$ & $198,287,544$ \\
\hline 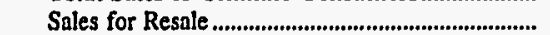 & $2,079,144$ & $2,110,446$ & $2,375,599$ & $2,645,738$ & $2,741,863$ \\
\hline 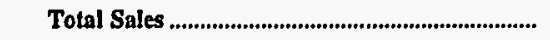 & $219,296,092$ & $218,269,064$ & $209,602,408$ & $215,242,460$ & $201,029,407$ \\
\hline \multicolumn{6}{|l|}{$\begin{array}{l}\text { Operating Revenues for the Year (thousand } \\
\text { dollars) }\end{array}$} \\
\hline \multirow{2}{*}{\multicolumn{6}{|c|}{ Commercial and Industrial }} \\
\hline & & & & & \\
\hline 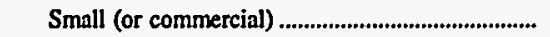 & $2,735,515$ & $2,848,613$ & $2,735,018$ & $2,823,106$ & $2,719,053$ \\
\hline 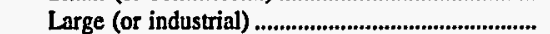 & $1,788,079$ & $1,745,063$ & $1,740,572$ & $1,717,394$ & $1,617,928$ \\
\hline Other Sales to Ultimate Consumers.............................. & 401,337 & 414,604 & 445,806 & 384,628 & 371,405 \\
\hline Total Sales to Ultimate Consumers.......................... & $14,618,776$ & $14,942,865$ & $14,430,135$ & $14,894,239$ & $13,880,744$ \\
\hline 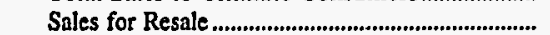 & 92,342 & 97,508 & 85,781 & 95,737 & 94,602 \\
\hline \multicolumn{6}{|l|}{ Total Revenues from Sales of } \\
\hline Electricity....................................... & $14,711,118$ & $15,040,373$ & $14,515,916$ & $14,989,976$ & $13,975,346$ \\
\hline 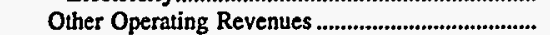 & 223,106 & 216,359 & 210,772 & 210,831 & 214,504 \\
\hline 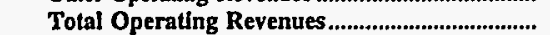 & $14,934,224$ & $15,256,732$ & $14,726,688$ & $15,200,807$ & $14,189,850$ \\
\hline
\end{tabular}

$R=$ Revised data.

Notes: Totals may not equal sum of components because of independent rounding. This table does not include in 1996 the 50 Power Supply Borrowers, in 1995 the 51 Power Supply Borrowers, in 1994 the 47 Power Supply Borrowers, in 1993 the 54 Power Supply Borrowers, and in 1992 the 54 Power Supply Borrowers included in Tables A1, A2, and A3. Data for 1996 represent 782 Distribution Borrowers; data for 1995 represent 805 Distribution Borrowers; data for 1994 represent 808 Distribution Borrowers; data for 1993 represent 855 Distribution Borrowers; and data for 1992 represent 862 Distribution Borrowers.

Source: U.S. Department of Agriculture, Rural Utilities Service (prior Rural Electrification Administration), Statistical Report, Rural Electric Borrowers publications for the years 1992, 1993, 1994, 1995, and 1996. 



\title{
Appendix 3
}

\author{
Major U.S. \\ Publicly \\ Owned \\ Electric Utility \\ Respondents
}




\section{Appendix B}

\section{Major U.S. Publicly Owned Electric Utility Respondents}

Table B1. Publicly Owned Electric Utilities Added to and Deleted from the Form EIA-412, 1992-1996

\begin{tabular}{|c|c|c|c|c|c|}
\hline \multirow{2}{*}{ Year } & \multicolumn{2}{|r|}{ Added } & \multicolumn{2}{|r|}{ Deleted } & \multirow{2}{*}{$\begin{array}{c}\text { Total Number } \\
\text { Availablel }\end{array}$} \\
\hline & No. & Name & No. & Name & \\
\hline $1992 \ldots \ldots . . .$. & 14 & $\begin{array}{l}\text { Badger Power Marketing Auth (Wisconsin) } \\
\text { Brainerd City of (Minnesota) } \\
\text { Chanute City of (Kansas) } \\
\text { Duncan City of (Okiahoma) } \\
\text { Electrical Dist No2 Pinal Cnty (Arizona) } \\
\text { Floresville City of (Texas) } \\
\text { Greenfield City of (Indiana) } \\
\text { Lafayette Public Power Auth (Louisiana) } \\
\text { Massena Town of (New York) } \\
\text { Milford City of (Delaware) } \\
\text { Pella City of (lowa) } \\
\text { Reedy Creek Improvement Dist (Florida) } \\
\text { Sebring Utilities Commission (Florida) } \\
\text { Tohono O dham Utility Auth (Arizona) }\end{array}$ & 01 & Milan City of (Tennessee) & 483 \\
\hline $1993 \ldots \ldots . . . .$. & 13 & $\begin{array}{l}\text { Chaska City of (Minnesota) } \\
\text { Clarksville Light \& Water Co (Arkansas) } \\
\text { Forest City Town of (North Carolina) } \\
\text { Fort Morgan City of (Colorado) } \\
\text { Lansdale Borough of (Pennyslvannia) } \\
\text { Lassen Municipal Utility Dist (California) } \\
\text { Merced Irigation Dist (California) } \\
\text { Miami City of (Okłahoma) } \\
\text { Napoleon City of (Ohio) } \\
\text { Seneca City of (South Carolina) } \\
\text { Shakopee Public Utilities Comm (Minnesota) } \\
\text { Sun Prairie Water \& Light Comm (Wisconsin) } \\
\text { Zeeland City of (Michigan) }\end{array}$ & 01 & Sebring Utilities Commission (Florida) & 495 \\
\hline $1994 \ldots \ldots . . . . .$. & 08 & $\begin{array}{l}\text { Beatrice City of (Nebraska) } \\
\text { Clyde Light \& Power (Ohio) } \\
\text { Hartselle City of (Alabama) } \\
\text { Kings River Conversation (California) } \\
\text { Lake Placid Village Inc (New York) } \\
\text { Milan City of (Tennessee) } \\
\text { Solvay Village of (New York) } \\
\text { Worthington Public Utility (Minnesota) }\end{array}$ & - & & 503 \\
\hline $1995 \ldots \ldots . . . .$. & 09 & $\begin{array}{l}\text { Bardstown City of (Kentucky) } \\
\text { Ephrata Borough of (Pennsylvania) } \\
\text { Lebanon City of (Indiana) } \\
\text { Jasper City of (Texas) } \\
\text { Madison City of (New Jersey) } \\
\text { Overton City of (Nevada) } \\
\text { Scottsburg City of (Indiana) } \\
\text { West Plains City of (Montana) } \\
\text { Winchester City of (Tennessee) }\end{array}$ & - & & 512 \\
\hline $1996 \ldots . . . . . . .$. & 03 & $\begin{array}{l}\text { Amory City of (Mississippi) } \\
\text { Philadelphia City of (Mississippi) } \\
\text { Russellville City of (Kentucky) }\end{array}$ & - & & 515 \\
\hline
\end{tabular}

1 Excluded are the Federal electric utilities. Source: Energy Information Administration, Form ELA-412, "Annual Report of Public Electric Utilities." 
Table B2. Major U.S. Publicly Owned Electric Utilities by Fiscal Year and Generator/Nongenerator Status from the Form EIA-412, 1996

\begin{tabular}{|c|c|c|c|}
\hline Fiscal Year & All Respondents & Generator Respondents & Nongenerator Respondents \\
\hline June $30, \ldots$ & 201 & 61 & 140 \\
\hline 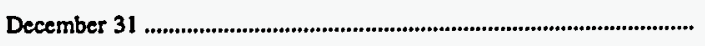 & 208 & 111 & 97 \\
\hline Other & 106 & 59 & 47 \\
\hline 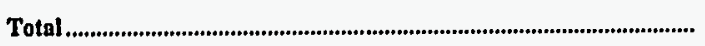 & 515 & 231 & 284 \\
\hline
\end{tabular}

Source: Energy Information Administration, Form ELA-412, "Annual Report of Public Electric Utilities." 
Table B3. Major U.S. Publicly Owned Electric Utilities by State and Generator/Nongenerator Status, 1996

\begin{tabular}{|c|c|c|c|}
\hline State & $\begin{array}{c}\text { All } \\
\text { Respondents }\end{array}$ & $\begin{array}{c}\text { Generator } \\
\text { Respondents }\end{array}$ & $\begin{array}{l}\text { Nongenerator } \\
\text { Respondents }\end{array}$ \\
\hline Alabama & 21 & 0 & 21 \\
\hline Alaska & 4 & 4 & 0 \\
\hline Arizona & 6 & 1 & 5 \\
\hline Arkansas & 11 & 6 & 5 \\
\hline California & 32 & 26 & 6 \\
\hline Colorado & 7 & 4 & 3 \\
\hline 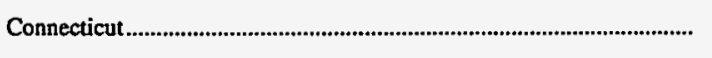 & 4 & 3 & 1 \\
\hline Delaware & 3 & 1 & 2 \\
\hline Florida & 20 & 17 & 3 \\
\hline Georgia & 17 & 3 & 14 \\
\hline 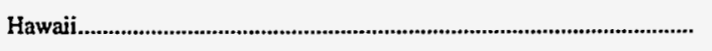 & 0 & 0 & 0 \\
\hline Idaho & 1 & 1 & 0 \\
\hline Illinois & 7 & 3 & 4 \\
\hline Indiana ............... & 15 & 7 & 8 \\
\hline lowa & 4 & 4 & 0 \\
\hline 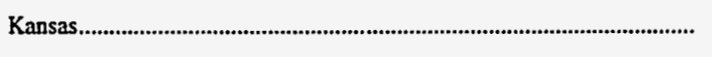 & 7 & 5 & 2 \\
\hline Kentucky & 13 & 2 & 11 \\
\hline Louisiana & 8 & 6 & 2 \\
\hline 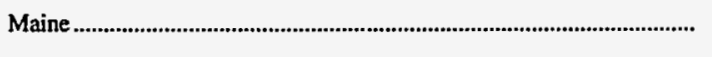 & 0 & 0 & 0 \\
\hline 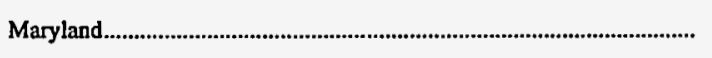 & 2 & 1 & 1 \\
\hline 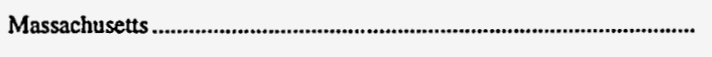 & 20 & 10 & 10 \\
\hline 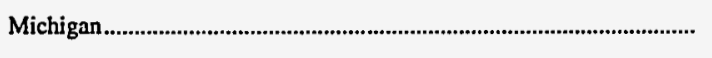 & 14 & 14 & 0 \\
\hline Minnesota & 18 & 11 & 7 \\
\hline 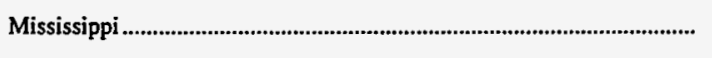 & 14 & 2 & 12 \\
\hline 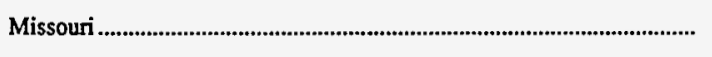 & 14 & 8 & 6 \\
\hline 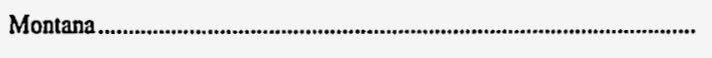 & 0 & 0 & 0 \\
\hline 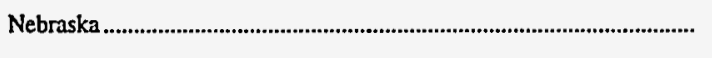 & 15 & 9 & 6 \\
\hline 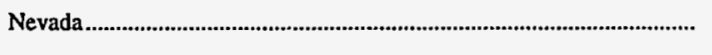 & 2 & 1 & 1 \\
\hline New Hampshire & 0 & 0 & 0 \\
\hline 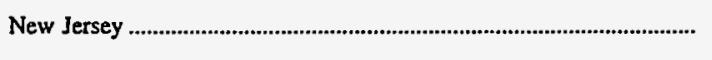 & 2 & 1 & 1 \\
\hline 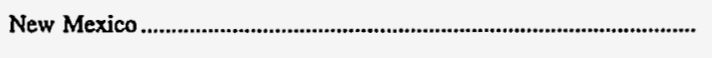 & 3 & 2 & 1 \\
\hline New York & 9 & 4 & 5 \\
\hline 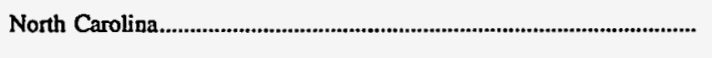 & 24 & 5 & 19 \\
\hline 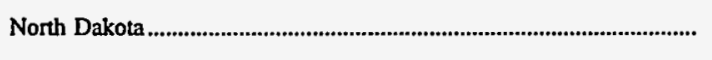 & 0 & 0 & 0 \\
\hline 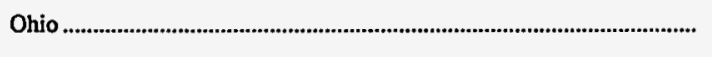 & 19 & 9 & 10 \\
\hline 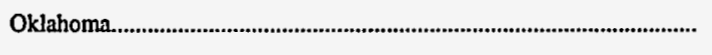 & 9 & 4 & 5 \\
\hline 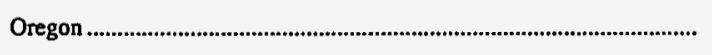 & 11 & 4 & 7 \\
\hline
\end{tabular}

See endnotes at end of this table. 
Table B3. Major U.S. Publicly Owned Electric Utilities by State and Generator/Nongenerator Status, 1996 Continued

\begin{tabular}{|c|c|c|c|}
\hline State & $\begin{array}{c}\text { All } \\
\text { Respondents }\end{array}$ & $\begin{array}{l}\text { Generator } \\
\text { Respondents }\end{array}$ & $\begin{array}{l}\text { Nongenerator } \\
\text { Respondents }\end{array}$ \\
\hline 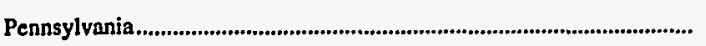 & 3 & 1 & 2 \\
\hline 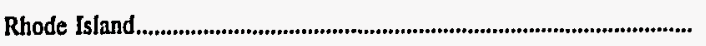 & $\mathbf{0}$ & $\mathbf{0}$ & $\mathbf{0}$ \\
\hline South Carolina & 11 & 5 & 6 \\
\hline South Dakota & 5 & 1 & 4 \\
\hline Tennessee & 56 & 0 & 56 \\
\hline 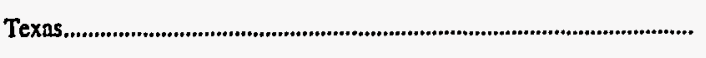 & 22 & 13 & 9 \\
\hline Utah & 8 & 7 & 1 \\
\hline 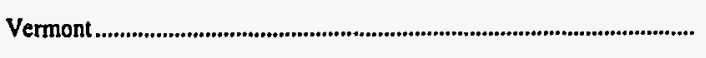 & 2 & 2 & 0 \\
\hline 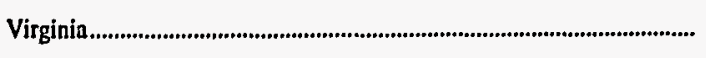 & 9 & 6 & 3 \\
\hline 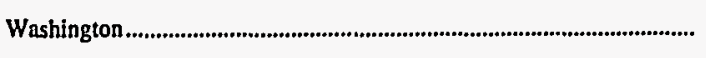 & 25 & 13 & 12 \\
\hline 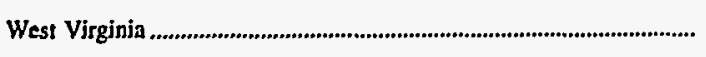 & 0 & $\mathbf{0}$ & 0 \\
\hline 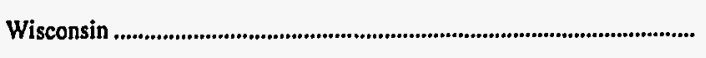 & 16 & 4 & 12 \\
\hline 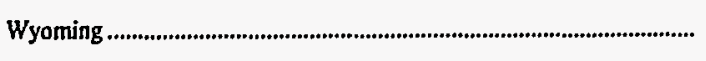 & 2 & 1 & 1 \\
\hline 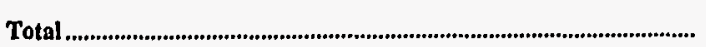 & 515 & 231 & 284 \\
\hline
\end{tabular}

Source: Energy Information Administration, Form EIA-412, “Annual Report of Public Electric Utilities.” 
Table B4. Publicly Owned Electric Utilities That Submitted the Form EIA-412, 1996

\begin{tabular}{|c|c|c|c|}
\hline Publicly Owned Electric Utilities & State & Reporting Date & Generating Status \\
\hline 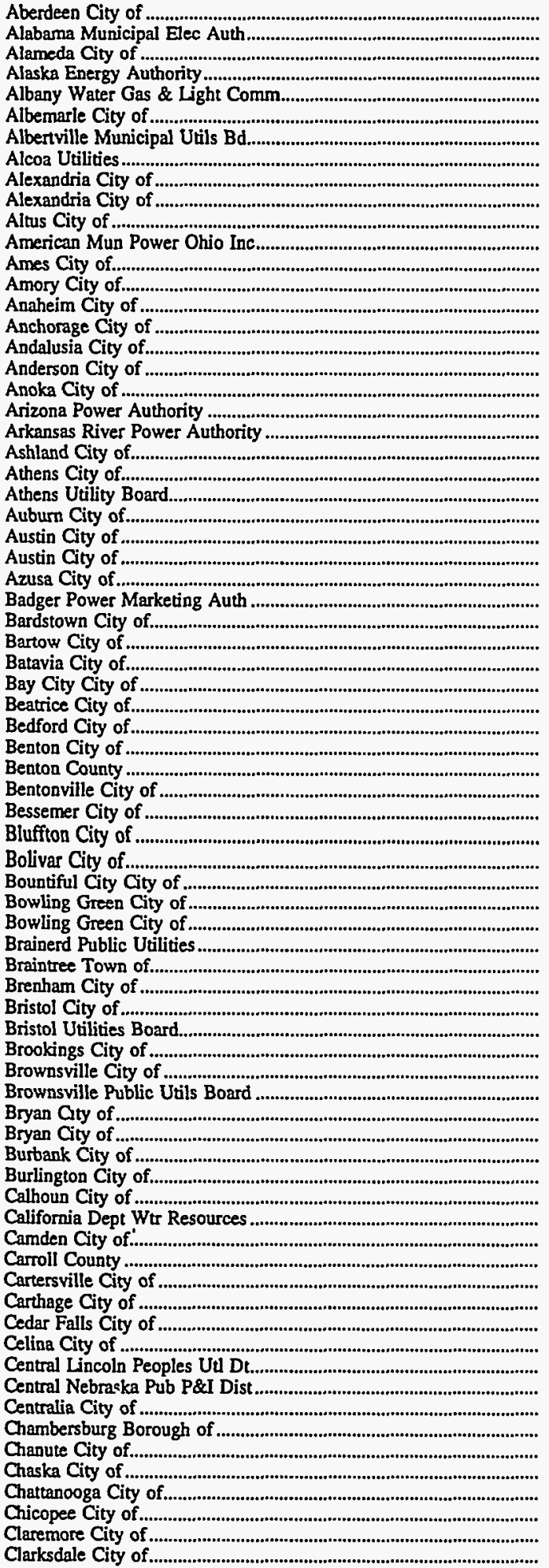 & 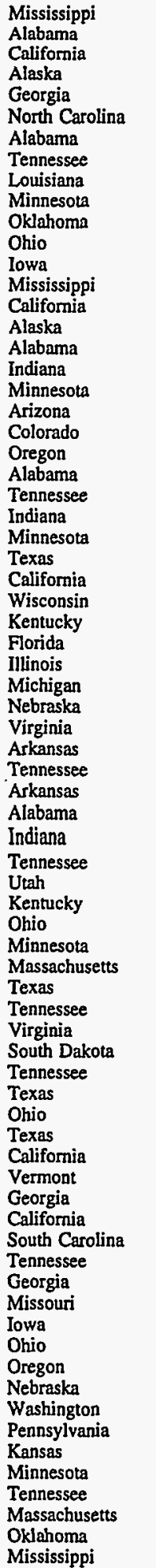 & 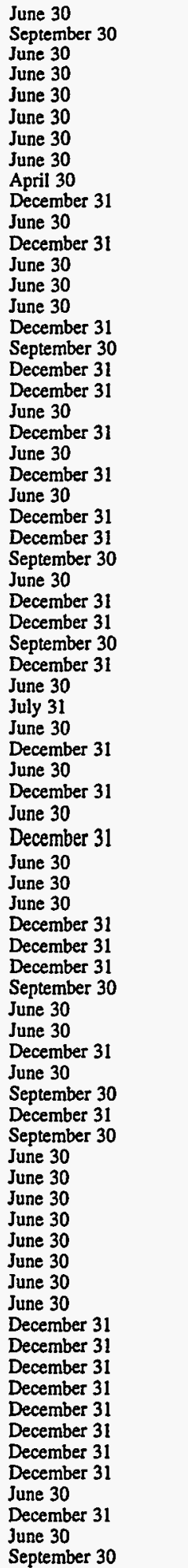 & 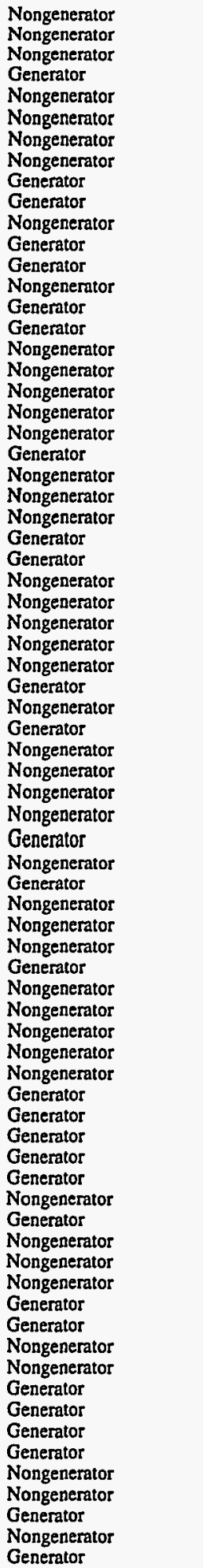 \\
\hline
\end{tabular}

See endnotes at end of this table. 


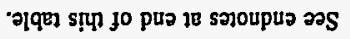

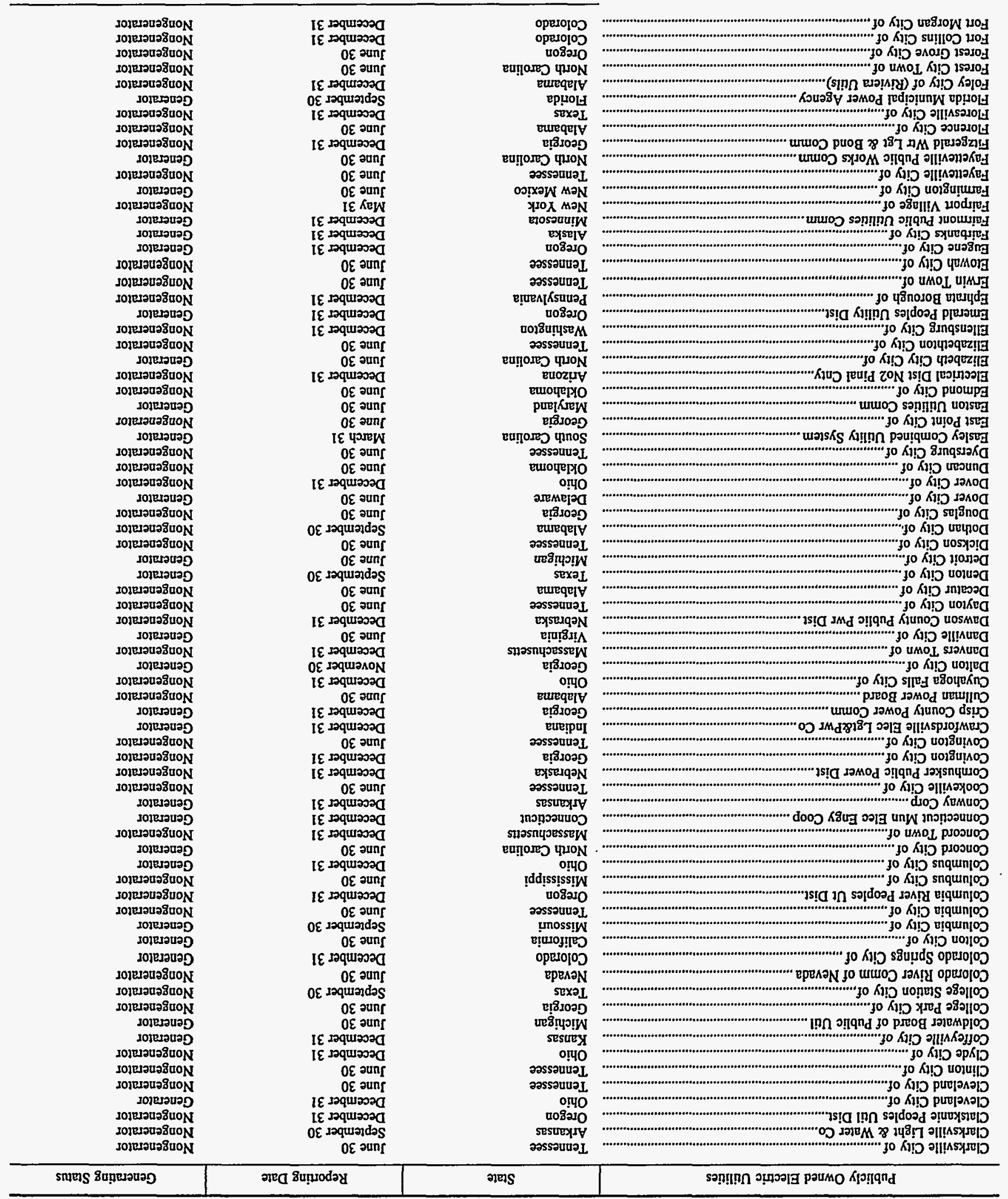


Table B4. Publicly Owned Electric Utilities That Submitted the Form EIA-412, 1996 (Continued)

\begin{tabular}{|c|c|c|c|}
\hline Publicly Owned Electric Utilities & State & Reporting Date & Generating Status \\
\hline 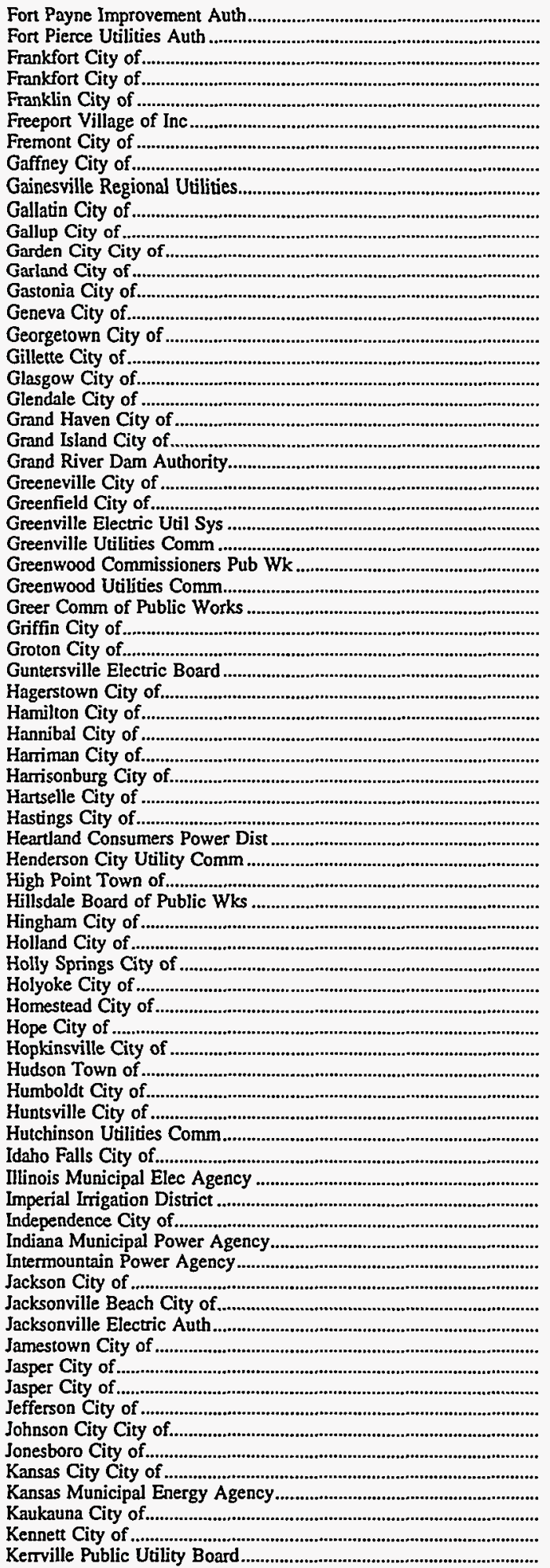 & 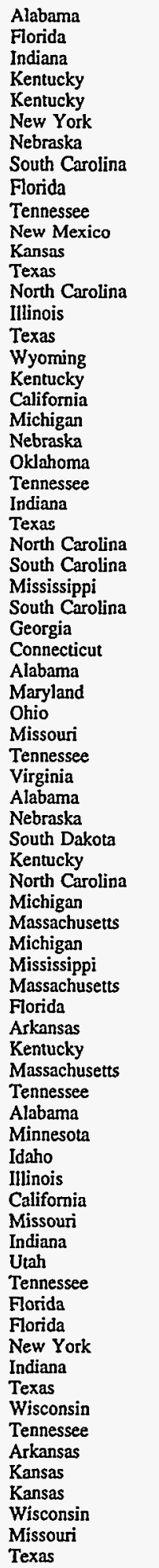 & 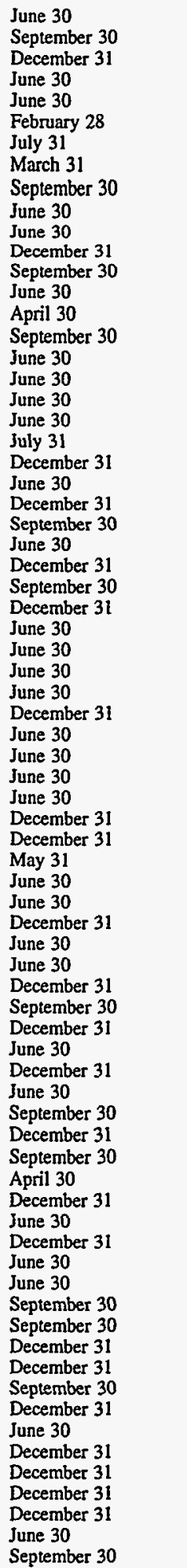 & 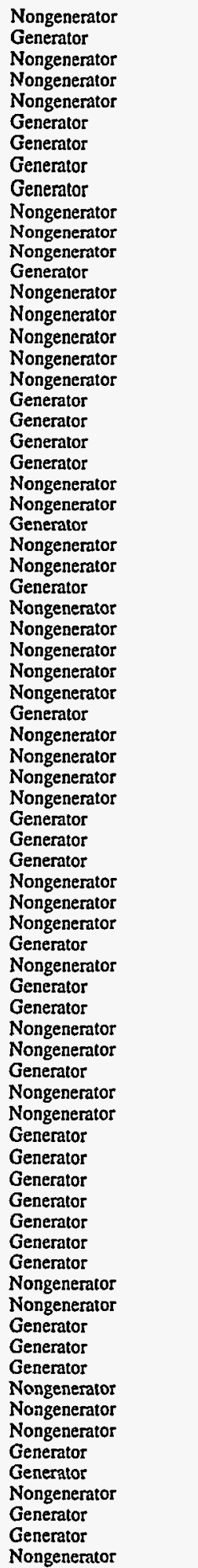 \\
\hline
\end{tabular}

See endnotes at end of this table. 
Table B4. Publicly Owned Electric Utilities That Submitted the Form EIA-412, 1996 (Continued)

\begin{tabular}{|c|c|c|c|}
\hline Publicly Owned Electric Utilities & State & Reporting Date & Generating Status \\
\hline 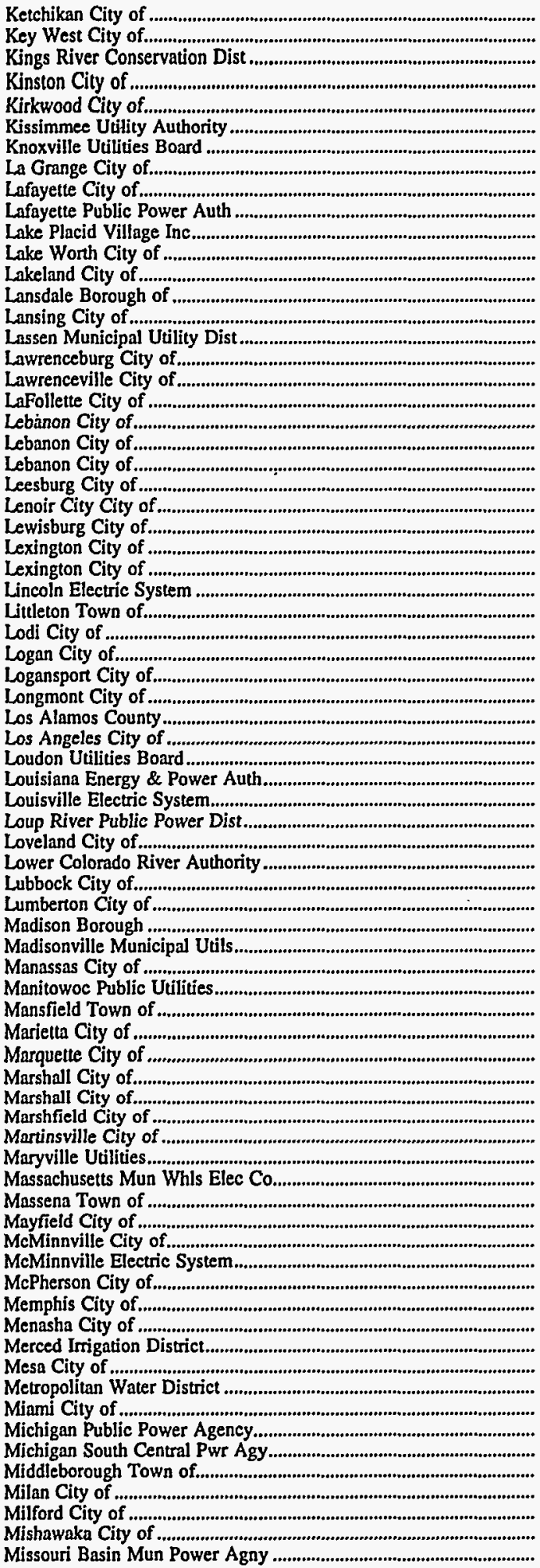 & 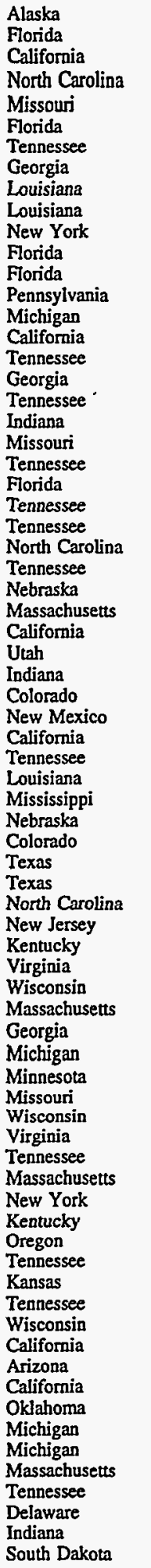 & 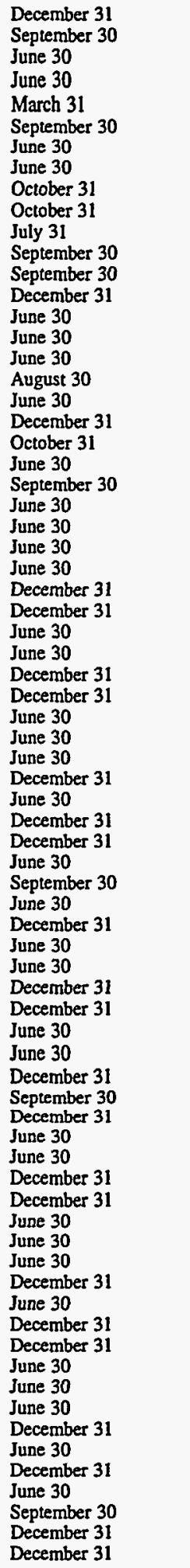 & 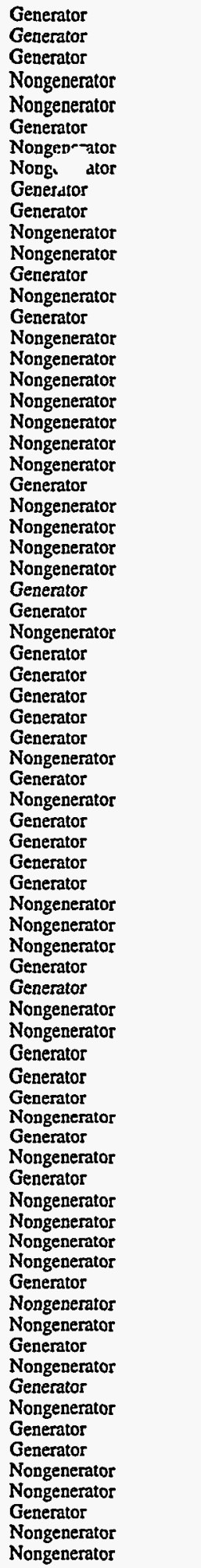 \\
\hline
\end{tabular}

See endnotes at end of this table. 
Table B4. Publicly Owned Electric Utilities That Submitted the Form EIA-412, 1996 (Continued)

\begin{tabular}{|c|c|c|c|}
\hline Publicly Owned Electric Utilities & State & Reporting Date & Generating Status \\
\hline 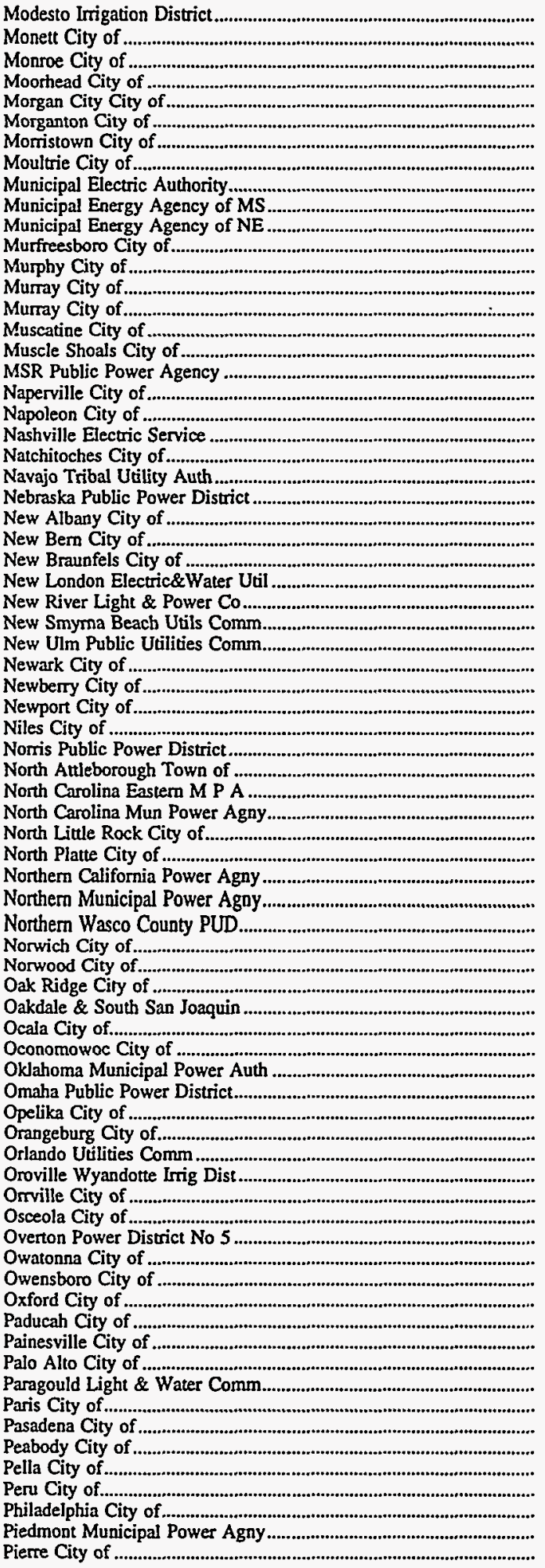 & 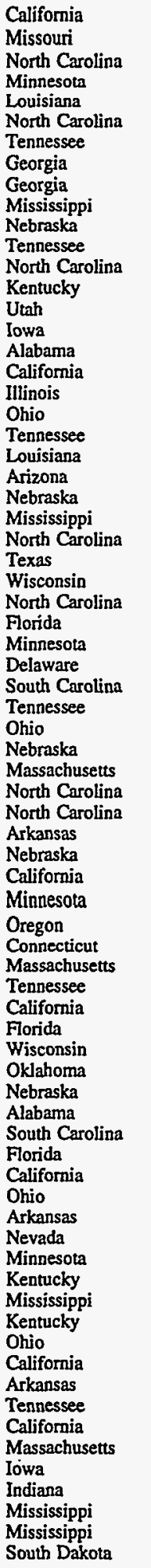 & 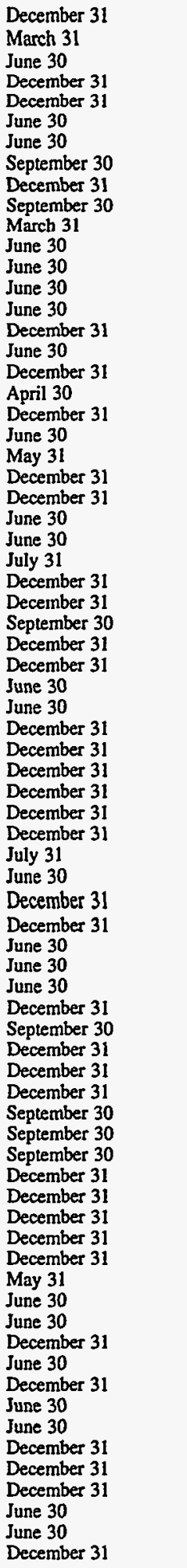 & 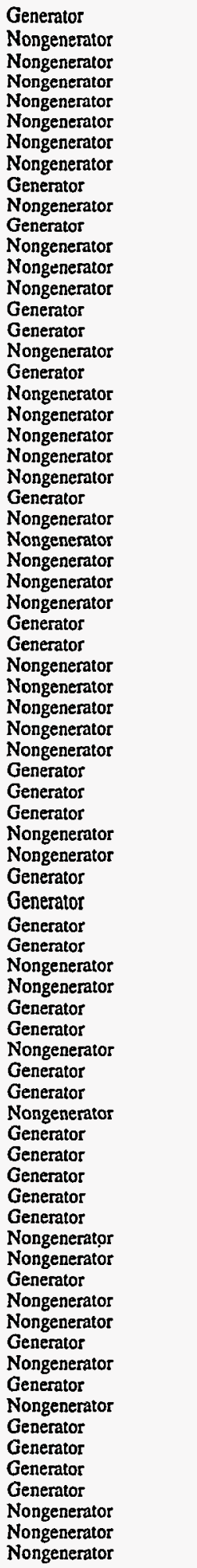 \\
\hline
\end{tabular}

See endnotes at end of this table. 
Table B4. Publicly Owned Electric Utilities That Submitted the Form EIA-412, 1996 (Continued)

\begin{tabular}{|c|c|c|c|}
\hline Publicly Owned Electric Utilities & State & Reporting Date & Generating Status \\
\hline 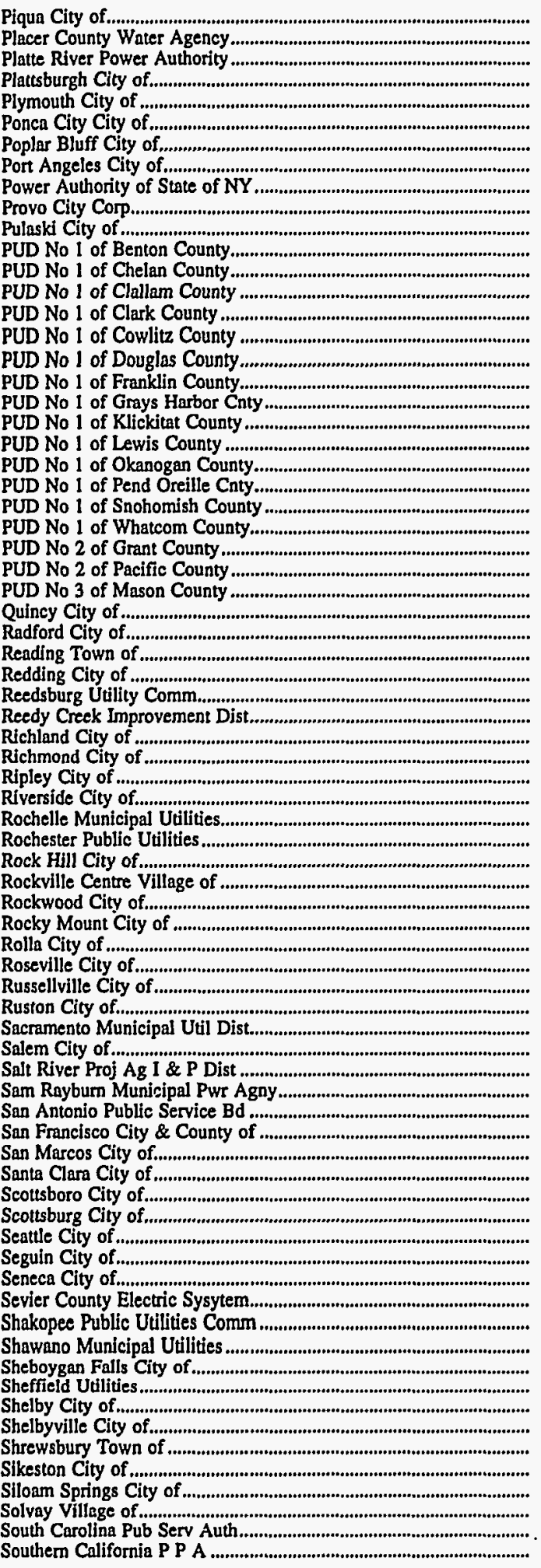 & 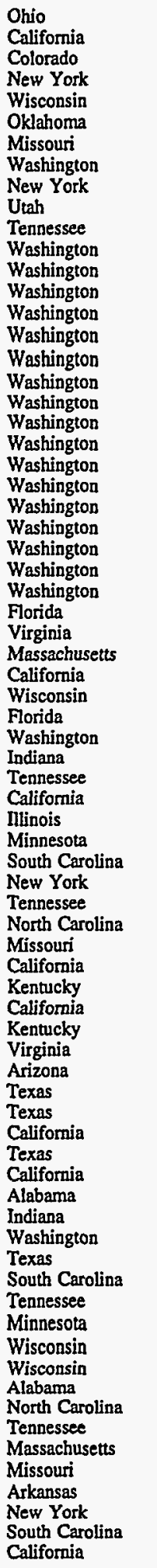 & 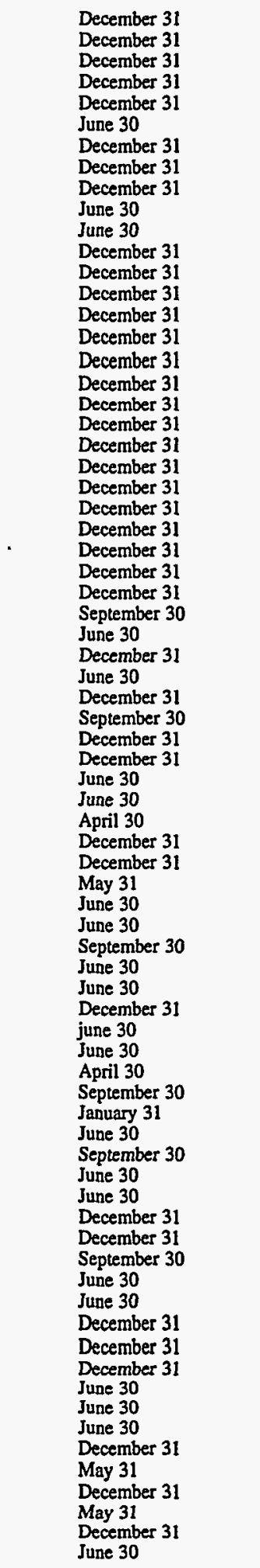 & 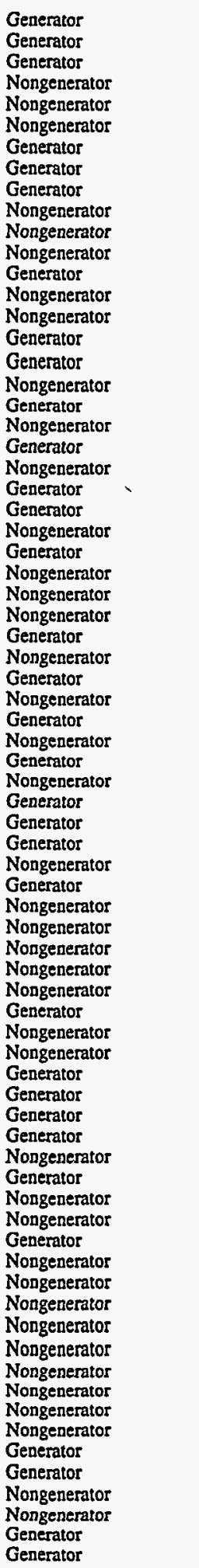 \\
\hline
\end{tabular}

Sec endnotes at end of this table. 
Table B4. Publicly Owned Electric Utilities That Submitted the Form EIA-412, 1996 (Continued)

\begin{tabular}{|c|c|c|c|}
\hline Publicly Owned Electric Utilities & State & Reporting Date & Generating Status \\
\hline 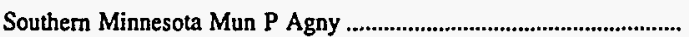 & Minnesota & December 31 & Generator \\
\hline Southern Nebraska Rural P P D & Nebraska & December 31 & Nongenerator \\
\hline Springfield City of & Illinois & February 28 & Generator \\
\hline Springfield City of & Missouri & September 30 & Generator \\
\hline Springfield City of & Oregon & December 31 & Nongenerator \\
\hline 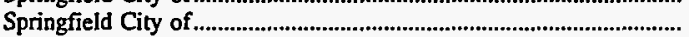 & Tennessec & June 30 & Nongenerator \\
\hline St Charles City of & Illinois & April 30 & Nongenerator \\
\hline 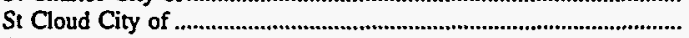 & Florida & September 30 & Generator \\
\hline 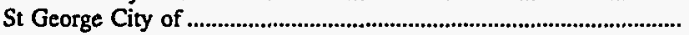 & Utah & June 30 & Generator \\
\hline St Marys City of & Ohio & December 31 & Generator \\
\hline Starkville City of & Mississippi & June 30 & Nongenerator \\
\hline Statesville City of & North Carolina & June 30 & Nongenerator \\
\hline 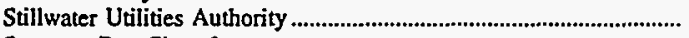 & Oklahoma & June 30 & Generator \\
\hline 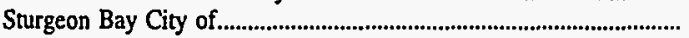 & Wisconsin & December 31 & Nongenerator \\
\hline Sturgis City of & Michigan & September 30 & Generator \\
\hline 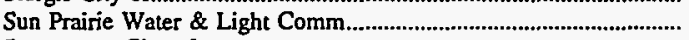 & Wisconsin & December 31 & Nongenerator \\
\hline Sweetwater City of & Tennessee & June 30 & Nongenerator \\
\hline 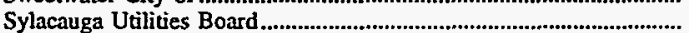 & Alabama & September 30 & Nongenerator \\
\hline Tacoma City of & Washington & December 31 & Generator \\
\hline Tallahassee City of & Florida & September 30 & Generator \\
\hline Taboro Town of & North Carolina & June 30 & Nongenerator \\
\hline 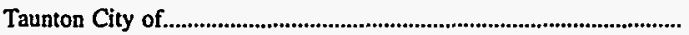 & Massachusetts & December 31 & Generator \\
\hline 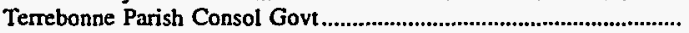 & Louisiana & December 31 & Generator \\
\hline Texas Municipal Power Agency & Texas & September 30 & Generator \\
\hline 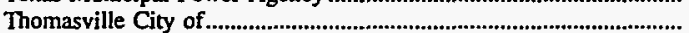 & Georgia & December 31 & Nongenerator \\
\hline 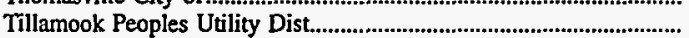 & Oregon & December 31 & Nongenerator \\
\hline 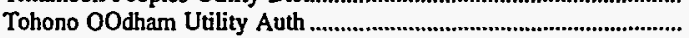 & Arizona & December 31 & Nongenerator \\
\hline Toledo Bend Project Joint Oper......... & Texas & August 30 & Generator \\
\hline Traverse City City of & Michigan & June 30 & Generator \\
\hline Troy City of & Alabama & September 30 & Nongenerator \\
\hline Tullahoma Board of Pub Utils & Tennessee & June 30 & Nongenerator \\
\hline Tupelo City of & Mississippi & June 30 & Nongenerator \\
\hline Turlock Irigation District & Califomia & December 31 & Generator \\
\hline 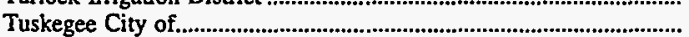 & Alabama & September 30 & Nongenerator \\
\hline 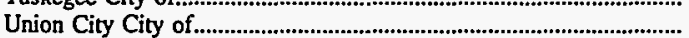 & Tennessee & June 30 & Nongenerator \\
\hline Utah Associated Mun Power Sys....... & Utah & March 31 & Generator \\
\hline 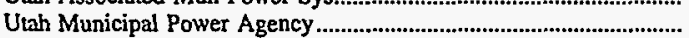 & Utah & June 30 & Generator \\
\hline Vera Irrigation District \# 15 & Washington & December 31 & Nongenerator \\
\hline 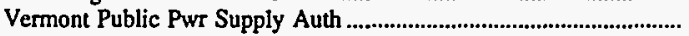 & Vermont & December 31 & Generator \\
\hline Vemon City of & California & June 30 & Generator \\
\hline Vero Beach City of & Florida & September 30 & Generator \\
\hline 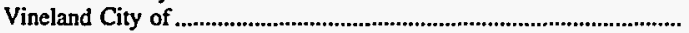 & New Jersey & June 30 & Generator \\
\hline Virginia Tech Electric Service & Virginia & June 30 & Generator \\
\hline Wadsworth City of & Ohio & December 31 & Nongenerator \\
\hline Wakefield Town of & Massachusetts & December 31 & Nongenerator \\
\hline 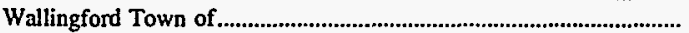 & Connecticut & June 30 & Generator \\
\hline 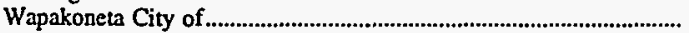 & Ohio & December 31 & Nongenerator \\
\hline 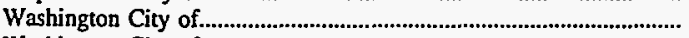 & Indiana & December 31 & Nongenerator \\
\hline Washington City of & North Carolina & June 30 & Nongenerator \\
\hline 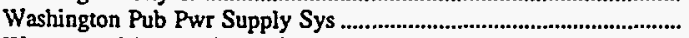 & Washington & June 30 & Generator \\
\hline 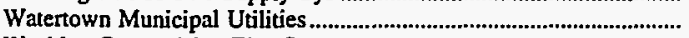 & South Dakota & December 31 & Nongenerator \\
\hline 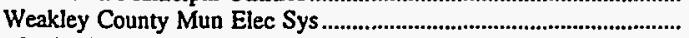 & Tennessee & June 30 & Nongenerator \\
\hline 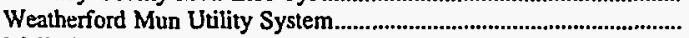 & Texas & September 30 & Generator \\
\hline Wellesley Town of & Massachusetts & December 31 & Nongenerator \\
\hline West Memphis City of & Arkansas & December 31 & Generator \\
\hline 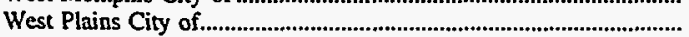 & Missouri & December 31 & Nongenerator \\
\hline West Point City of & Mississippi & June 30 & Nongenerator \\
\hline Western Minnesota Mun Pwr Agny & Minnesota & December 31 & Generator \\
\hline Westerville City of & Ohio & December 31 & Nongenerator \\
\hline Westfield City of & Massachusetts & December 31 & Nongenerator \\
\hline Willmar Municipal Utils Comm & Minnesota & December 31 & Generator \\
\hline Wilson City of & North Carolina & June 30 & Nongenerator \\
\hline Winchester City of & Tennessee & June 30 & Nongenerator \\
\hline Winfield City of & Kansas & December 31 & Generator \\
\hline Wisconsin Public Power Inc Sys & Wisconsin & December 31 & Generator \\
\hline 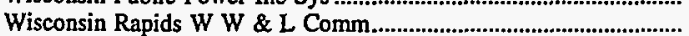 & Wisconsin & December 31 & Nongenerator \\
\hline Worthington City of & Minnesota & December 31 & Nongenerator \\
\hline Wyandotte Municipal Serv Comm & Michigan & September 30 & Generator \\
\hline 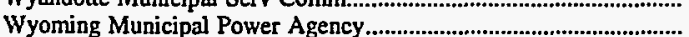 & Wyoming & December 31 & Generator \\
\hline 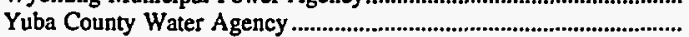 & Califomia & June 30 & Generator \\
\hline Zeeland City of & Michigan & June 30 & Generator \\
\hline
\end{tabular}

Source: Energy Information Administration, Form EIA-412, "Annual Report of Public Electric Utilities." 
Figure B1. Principal Business Office of the Major U.S. Publicly Owned Electric Utilities, 1996

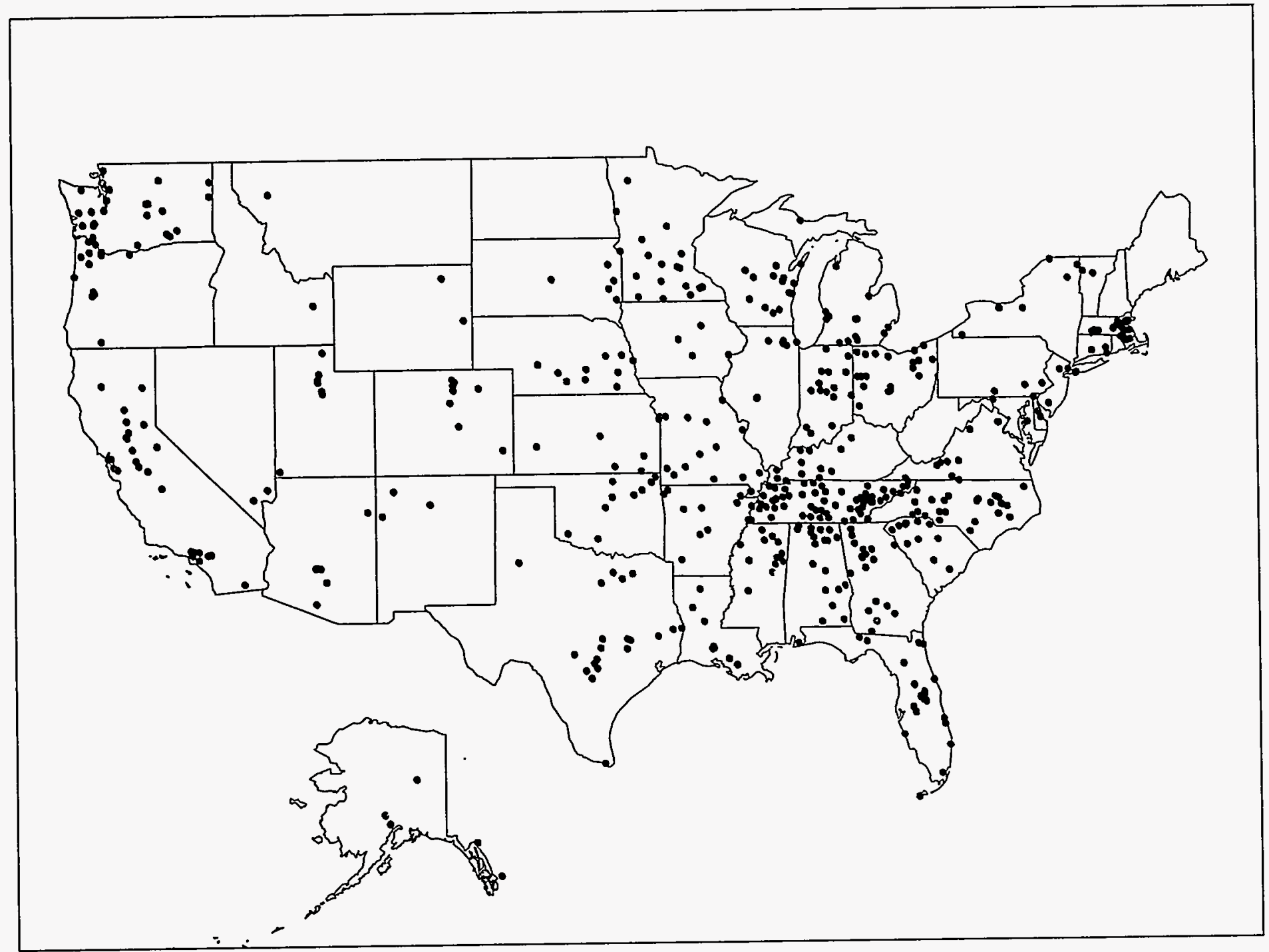

Source: Energy Information Administration, Form EIA-412, “Annual Report of Public Electric Utilities.” 



\section{Appendix C}

Major U.S. Generator/

Nongenerator

Respondents

by June 30

and December

31 Fiscal

Years and by

All

Respondents,

1992-1996 


\section{Appendix C}

\section{Major U.S. Generator/Nongenerator Respondents by June 30 and December 31 Fiscal Years and by All Respondents, 1992-1996}


Table C1. Ten Largest U.S. Publicly Owned Generator Electric Utilities Ranked by Megawatthour Sales to Ultimate Consumers with Financial Year Ending on June 30, 1996

\begin{tabular}{|c|c|c|c|}
\hline Publicly Owned Electric Utilities & State & Amount & Percent \\
\hline 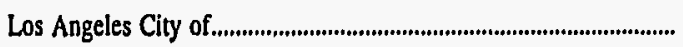 & Califomia & $21,233,474$ & 41.79 \\
\hline Lansing City of & Michigan & $2,336,893$ & 4.60 \\
\hline 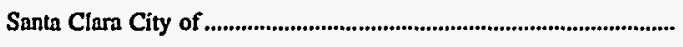 & California & $2,296,835$ & 4.52 \\
\hline Anaheim City of & California & $2,278,677$ & 4.48 \\
\hline Fayetteville Public Works Comm & North Carolina & $2,003,129$ & 3.94 \\
\hline Riverside City of & California & $1,632,366$ & 3.21 \\
\hline Pasadena City of ............................................................................................ & California & $1,166,811$ & 2.30 \\
\hline Vernon City of & California & $1,052,800$ & 2.07 \\
\hline 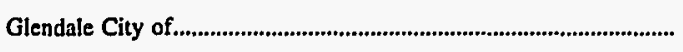 & Califomia & $1,011,925$ & 1.99 \\
\hline 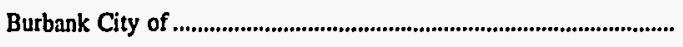 & California & 972,508 & 1.91 \\
\hline Subtotal & & $35,985,418$ & 70.82 \\
\hline
\end{tabular}

Source: Energy Information Administration, Form ELA-412, "Annual Report of Public Electric Utilities."

Table C2. Ten Largest U.S. Publicly Owned Generator Electric Utilities Ranked by Megawatthour Sales for Resale with Financial Year Ending on June 30, 1996

\begin{tabular}{|c|c|c|c|}
\hline Publicly Owned Electric Utilities & State & Amount & Percent \\
\hline 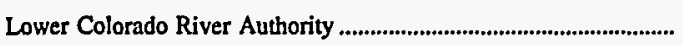 & Texas & $10,645,538$ & 22.27 \\
\hline 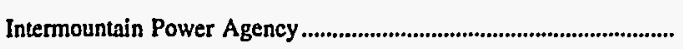 & Utah & $9,760,982$ & 20.42 \\
\hline 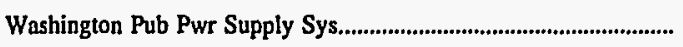 & Washington & $7,780,202$ & 16.28 \\
\hline 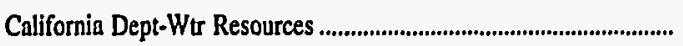 & California & $4,313,258$ & 9.02 \\
\hline 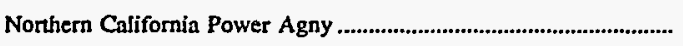 & California & $3,113,481$ & 6.51 \\
\hline Southern California P P A & Califormia & $2,147,802$ & 4.49 \\
\hline 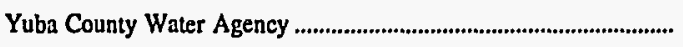 & California & $2,077,215$ & 4.35 \\
\hline 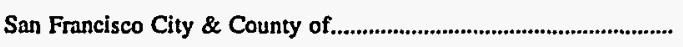 & California & $1,674,094$ & 3.50 \\
\hline 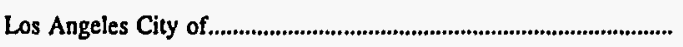 & Califomia & $1,343,832$ & 2.81 \\
\hline Utah Municipal Power Agency & Utah & 835,377 & 1.75 \\
\hline Subtotal........................................................................................................ & & $43,691,781$ & 91.40 \\
\hline
\end{tabular}

Source: Energy Information Administration, Form EIA-412, "Annual Report of Public Electric Utilities." 
Table C3. Composite Statement of Income for Major U.S. Publicly Owned

Generator Electric Utilities with Financial Year Ending on

June 30, 1992-1996

(Thousand Dollars)

\begin{tabular}{|c|c|c|c|c|c|}
\hline Item & 1996 & 1995 & 1994 & 1993 & 1992 \\
\hline 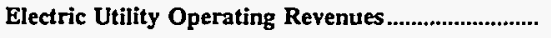 & $5,797,226$ & $6,189,104$ & $6,322,194$ & $6,056,616$ & $5,873,621$ \\
\hline 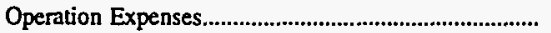 & $3,444,212$ & $3,604,623$ & $3,750,469$ & $3,607,659$ & $3,525,928$ \\
\hline Maintenance Expenses & 416,027 & 378,487 & 400,442 & 376,031 & 368,959 \\
\hline 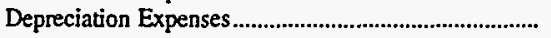 & 700,186 & 771,714 & 733,717 & 665.941 & 627,770 \\
\hline 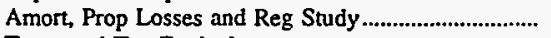 & 2,600 & 4,015 & 4,988 & 46,572 & 36,028 \\
\hline 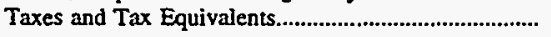 & 102,190 & 127,377 & 125,721 & 126,376 & 109,783 \\
\hline \multicolumn{6}{|l|}{ Total Electric Utility Operating } \\
\hline 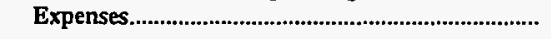 & $4,665,215$ & $4,886,217$ & $5,015,337$ & $4,822,580$ & $4,668,469$ \\
\hline $\begin{array}{l}\text { Net Electric Utility Operating Income } \\
\text { Income from Electric Plant Leased }\end{array}$ & $1,132,011$ & $1,302,887$ & $1,306,856$ & $1,234,036$ & $1,205,152$ \\
\hline to Others & 1,023 & 964 & 725 & 791 & 2,474 \\
\hline Electric IJtility Operating Income & $1,133,034$ & $1,303,851$ & $1,307,582$ & $1,234,827$ & $1,207,627$ \\
\hline 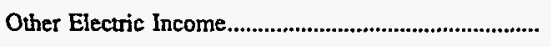 & 288,952 & 312,350 & 326,137 & 336,677 & 391,113 \\
\hline $\begin{array}{l}\text { Other Electric Deductions.......................................... } \\
\text { Allowance for Other Funds Used }\end{array}$ & 96,177 & 82,340 & 91,770 & 109,123 & 122,334 \\
\hline 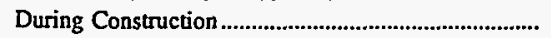 & - & - & - & - & - \\
\hline 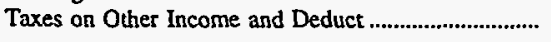 & 944 & - & 12,676 & 64 & 885 \\
\hline Electric Utility Income & $1,324,864$ & $1,533,860$ & $1,529,273$ & $1,462,317$ & $1, \mathbf{4 7 5}, \mathbf{5 2 1}$ \\
\hline Income Deductions from Interest & & & & & \\
\hline on Long-term Debt & 914,613 & $1,260,071$ & $1,266,410$ & $1,219,759$ & $1,298,247$ \\
\hline Other Income Deductions & 34,497 & 49,288 & 151 & $-73,744$ & $-12,878$ \\
\hline 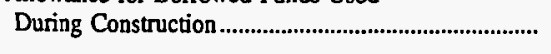 & $-5,120$ & $-3,712$ & $-7,380$ & $-15,152$ & $-10,592$ \\
\hline 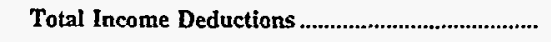 & 943,990 & $1,305,647$ & $1,259,181$ & $1,130,863$ & $1,274,778$ \\
\hline 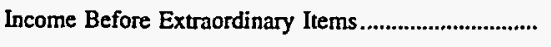 & 380,874 & 228,214 & 270,091 & 331,453 & 200,744 \\
\hline 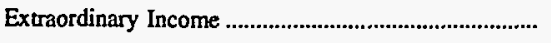 & 14,606 & 16,146 & 5,975 & 7,174 & 6,593 \\
\hline 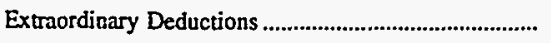 & 69,321 & 39,960 & 171,428 & 112,481 & 73,027 \\
\hline Net Income & 326,159 & 204,399 & 104,638 & 226,146 & 134,310 \\
\hline
\end{tabular}

- Data not available.

Note: Totals may not equal sum of components because of independent rounding. The number of generating publicly owned electric utilities for end of period is 61 for June 30, 1996; 59 for June 30, 1995; 57 for June 30, 1994; 56 for June 30, 1993; and 56 for June 30, 1992. The Calaifornia Deparment of Water Resources (CA) changed fiscal year from December 31 to June 30 in 1992 ; the Wisconsin Power Inc Sys (WI) changed fiscal year from June 30 to December 31 in 1993; and the City of Pella (IA) changed fiscal year from June 30 to December 31 in 1994, and the City of Burlingotn (VT) changed fiscal year from December 31 to June 30 in 1994. The City of Gaffiney (SC), City of Osceola (AR), and City of Redding (CA) were nongenerators for 1991 through 1993, but became generators in 1994. The City of Kennett (MO) and City of Miorgan City (LA) were generators for 1991 through 1993, but became nongenerators in 1994. Emerald Peopies Utility District (OR), City of Bryan (OH), and Northern Wasco County PUD (OR) were nongenerators for 1991, but became generators in 1992.

Source: Energy Information Administration, Form EIA-412, "Annual Report of Public Electric Utilities." 
Table C4. Composite Balance Sheet for Major U.S. Publicly Owned Generator Electric Utilities with Financial Year Ending on June 30 at End of Period, 1992-1996 (Thousand Dollars)

\begin{tabular}{|c|c|c|c|c|c|}
\hline Item & 1996 & 1995 & 1994 & 1993 & 1992 \\
\hline \multicolumn{6}{|l|}{ Electric Utility Plant } \\
\hline Electric Utility Plant \& Adjust......................................... & $24,560,756$ & $23,813,519$ & $23,649,149$ & $22,458,024$ & $21,821,753$ \\
\hline Const Work in Progress & 542,158 & 948,126 & 843,150 & 879,753 & $1,007,230$ \\
\hline (less) Depr, Amort, and Depletion................................. & $10,187,384$ & $7,802,514$ & $7,247,501$ & $6,525,704$ & $6,047,224$ \\
\hline 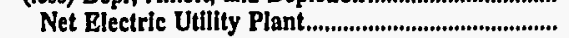 & $14,915,530$ & $16,959,131$ & $17,244,798$ & $16,812,072$ & $16,781,759$ \\
\hline 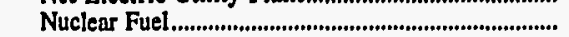 & 467,160 & 396,089 & 354,050 & 363,138 & 307,982 \\
\hline 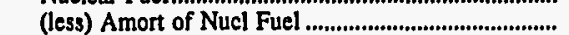 & 292,123 & 209,501 & 201,855 & 197,885 & 138,151 \\
\hline Net Elec Plant Incl Nucl Fuel.................................... & $15,090,567$ & $17,145,720$ & $17,396,994$ & $16,977,326$ & $16,951,590$ \\
\hline \multicolumn{6}{|l|}{ Other Property \& Investments } \\
\hline 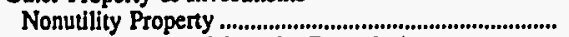 & $6,325,055$ & $5,810,617$ & $5,282,581$ & $4,783,966$ & $4,390,194$ \\
\hline (less) Accum Provisions for Depr \& Amort................ & $1,881,263$ & $1,765,771$ & $1,643,704$ & $1,532,462$ & $1,426,040$ \\
\hline 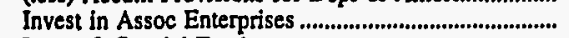 & 20,496 & 12,265 & 34,364 & 30,539 & 38,999 \\
\hline 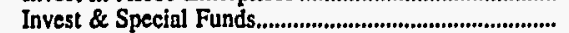 & $3,337,226$ & $5,848,427$ & $5,976,191$ & $5,470,789$ & $3,958,741$ \\
\hline Total Other Property \& Investments..................... & $\mathbf{7 , 8 0 1 , 5 1 4}$ & $9,905,538$ & $9,649,433$ & $8,752,832$ & $6,961,895$ \\
\hline \multicolumn{6}{|l|}{ Current and Accrued Assets } \\
\hline Cash, Working Funds \& Investments ........................... & $3,628,735$ & $3,370,548$ & $3,637,073$ & $3,842,190$ & $3,167,797$ \\
\hline 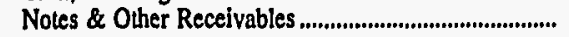 & 255,659 & 260,772 & 263,092 & 251,043 & 274,818 \\
\hline 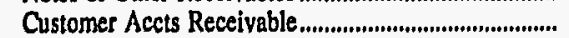 & 600,763 & 508,885 & 600,752 & 553,561 & 521,135 \\
\hline (less) Accum Prov for Uncollected Accts .................. & 22,416 & 22,517 & 19,483 & 18,891 & 14,961 \\
\hline 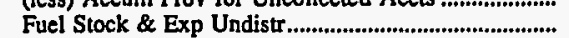 & 107,033 & 170,403 & 211,474 & 219,279 & 230,592 \\
\hline 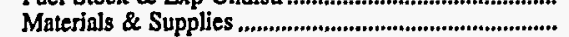 & 267,099 & 293,025 & 318,585 & 308,887 & 306,329 \\
\hline 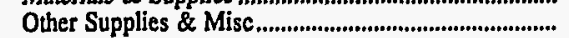 & 13,576 & 19,133 & - & 73,367 & 74,489 \\
\hline Prepayments & 167,562 & 105,653 & 84,928 & - & - \\
\hline 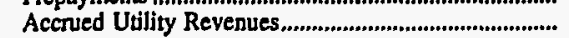 & 138,010 & 137,929 & 134,879 & 130,552 & 118,743 \\
\hline Miscellaneous Cument \& Accrued Assets .................... & 524,534 & 480,926 & 476,221 & 317,320 & 267,360 \\
\hline Total Current \& Accrued Assets & $5,680,554$ & $5,324,757$ & $5,707,521$ & $5,677,308$ & $4,946,301$ \\
\hline \multicolumn{6}{|l|}{ Deferred Debits } \\
\hline 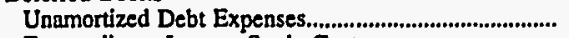 & 527,448 & $1,441,454$ & $1,515,843$ & $1,115,871$ & 920,381 \\
\hline 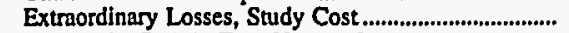 & 17,790 & 29,921 & 22,426 & 395,404 & 12,920 \\
\hline 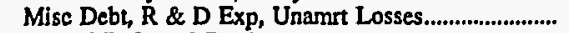 & $1,218,802$ & $2,293,374$ & $2,469,450$ & $2,379,389$ & $2,598,210$ \\
\hline 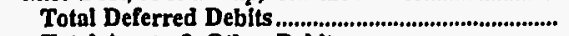 & $1,764,040$ & $3,764,750$ & $4,007,720$ & $3,890,664$ & $3,531,511$ \\
\hline Total Assets \& Other Debits........................................ & $30,336,675$ & $36,140,764$ & $36,761,667$ & $35,298,129$ & $32,391,297$ \\
\hline \multicolumn{6}{|l|}{ Proprietary Capital } \\
\hline 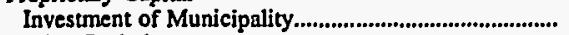 & $1,019,785$ & $1,253,767$ & $1,010,703$ & 980,695 & $1,020,857$ \\
\hline 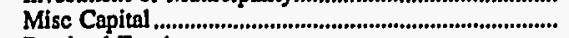 & 183,212 & 86,913 & 118,973 & 97,246 & $-14,376$ \\
\hline 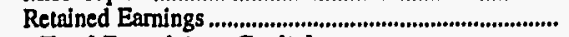 & $8,498,008$ & $7,481,164$ & $7,489,894$ & $7,165,700$ & $6,911,454$ \\
\hline 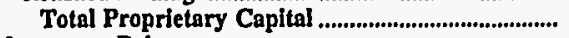 & $9,701,005$ & $8,821,844$ & $8,619,570$ & $8,243,641$ & $7,917,934$ \\
\hline \multicolumn{6}{|l|}{ Long-term Debt } \\
\hline 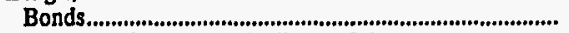 & $17,188,817$ & $22,390,678$ & $22,970,895$ & $22,602,706$ & $20,377,974$ \\
\hline Advances from Municipality \& Other ............................ & $1,518,557$ & $1,551,506$ & $1,577,910$ & 465,384 & 553,413 \\
\hline 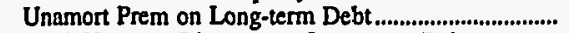 & 15,381 & 8,991 & 9,674 & 530,377 & 3,743 \\
\hline (less) Unamort Discount on Long-term Debt................ & 654,278 & 883,366 & 943,800 & $1,049,664$ & $1,072,415$ \\
\hline 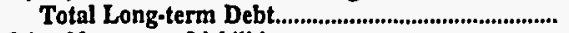 & $18,068,475$ & $23,067,809$ & $23,614,679$ & $22,548,802$ & $19,862,716$ \\
\hline \multicolumn{6}{|l|}{ Other Noncurrent Liabilities } \\
\hline 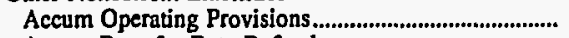 & 52,018 & 55,232 & 119,569 & 69,777 & 69,277 \\
\hline Accum Prov for Rate Refunds...................................... & 37,177 & 55,786 & - & - & - \\
\hline Total Other Noncurrent Liabilities.......................... & 89,195 & 111,018 & 119,569 & 69,777 & 69,277 \\
\hline \multicolumn{6}{|l|}{ Current and Accrued Liabilities } \\
\hline 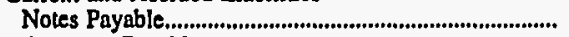 & 245,933 & 108,184 & 112,848 & 115,216 & 124,960 \\
\hline 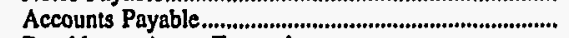 & 913,726 & 858,722 & 914,732 & 838,032 & 836,494 \\
\hline 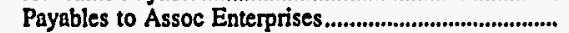 & 123,486 & 136,545 & 135,708 & 150,227 & 145,023 \\
\hline 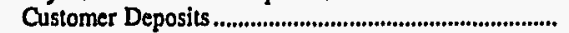 & 173,069 & 118,380 & 100,781 & 79,307 & 93,187 \\
\hline 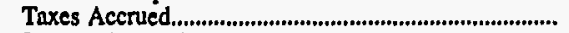 & 14,017 & 13,622 & 14,141 & 16,668 & 21,663 \\
\hline 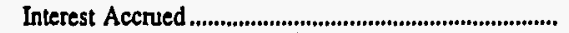 & 335,806 & 494,970 & 443,461 & 432,509 & 382,500 \\
\hline 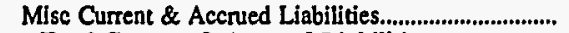 & 258,623 & $1,909,881$ & $1,968,441$ & $1,912,747$ & $1,940,659$ \\
\hline Total Current \& Accrued Liabilities......................... & $2,064,660$ & $3,640,302$ & $3,690,113$ & $3,544,706$ & $3,544,487$ \\
\hline \multirow{6}{*}{ 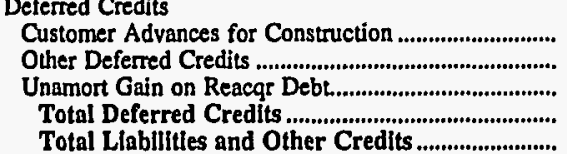 } & & & & & \\
\hline & 25,508 & 50,791 & 45,136 & 43,288 & $\begin{array}{r}42,340 \\
811,073\end{array}$ \\
\hline & 570,990 & 626,741 & 651,166 & 742,733 & 811,973 \\
\hline & $-183,158$ & $-177,740$ & 21,434 & 105,182 & 142,572 \\
\hline & 413,340 & 499,791 & 717,736 & 891,203 & 996,885 \\
\hline & $30,336,675$ & $36,140,764$ & $36,761,667$ & $35,298,129$ & $32,391,297$ \\
\hline
\end{tabular}

Note: Totals may not equal sum of components because of independent rounding. The number of generating publicly owned electric utilities for end of period is 61 for June 30, 1996; 59 for June 30, 1995; 57 for June 30, 1994; 56 for June 30, 1993; and 56 for June 30, 1992. The Californin Department of Water Resources (CA) changed fiscal year from December 31 to June 30 in 1992; the Wisconsin Public Power Inc Sys (WD changed fiscal year from December 31 to June 30 in 1993; and the City of Pella (IA) changed fiscal year from June 30 to December 31 in 1994, and the City of Burlington (VT) changed fiscal year from December 31 to June 30 in 1994. The City of Gaffney (SC), City of Osceola (AR), and City of Redding (CA) were nongenerators for 1991 through 1993; but became generators in 1994. The City of Kennett (MO) and City of Morgan City (LA) were generators for 1991 through 1993; but became nongenerators in 1994. Emerald Peoples Utility District (OR), City of Bryan (OH), and Northern Wasco County PUD (OR) were nongenerators for 1991, but became generators in 1992. The Utah Associated Municipal Power System (UT) changed fiscal year from June 30 to March 31 in 1991.

Source: Energy Information Administration, Form EIA-412, "Annual Report of Public Electric Utilities." 
Table C5. Composite Financial Indicators for Major U.S. Publicly Owned Generator Electric Utilities with Financial Year Ending on June 30, 1992-1996

\begin{tabular}{|c|c|c|c|c|c|}
\hline Item & 1996 & 1995 & 1994 & 1993 & 1992 \\
\hline Total Electric Utility Plant per Dollar of Revenue & 4.4 & 4.1 & 3.9 & 3.9 & 3.9 \\
\hline Current Assets to Current Liabilities .............................. & 2.8 & 1.5 & 1.5 & 1.6 & 1.4 \\
\hline $\begin{array}{l}\text { Total Electric Utility Plant as a Percent of Total } \\
\text { Assets .... }\end{array}$ & 84.3 & 69.6 & 67.6 & 67.1 & 71.4 \\
\hline $\begin{array}{l}\text { Net Electric Utility Plant as a Percent of Total } \\
\text { Assets }\end{array}$ & 49.7 & 47.4 & 47.3 & 48.1 & 52.3 \\
\hline 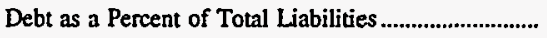 & 66.4 & 73.9 & 74.3 & 73.9 & 72.3 \\
\hline $\begin{array}{l}\text { Depreciation, Amortization and Depletion } \\
\text { as a Percent of Total Electric Utility Plant ................... }\end{array}$ & 41.0 & 31.8 & 30.0 & 28.4 & 26.7 \\
\hline 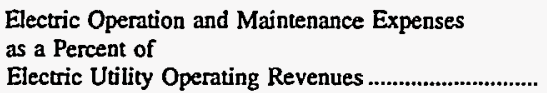 & 66.6 & 64.4 & 65.7 & 65.8 & 66.3 \\
\hline $\begin{array}{l}\text { Electric Depreciation and Amortization } \\
\text { as a Percent of } \\
\text { Electric Utility Operating Revenues }\end{array}$ & 12.1 & 12.5 & 11.6 & 11.0 & 10.7 \\
\hline $\begin{array}{l}\text { Taxes and Tax Equivalents } \\
\text { as a Percent of } \\
\text { Electric Utility Operating Revenues }\end{array}$ & 1.8 & 2.1 & 2.0 & 2.1 & 1.9 \\
\hline 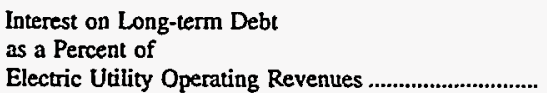 & 15.8 & 20.4 & 20.0 & 20.1 & 22.1 \\
\hline $\begin{array}{l}\text { Net Income as a Percent of Electric } \\
\text { Utility Operating Revenues............................................ }\end{array}$ & 5.6 & 3.3 & 1.7 & 3.7 & 2.3 \\
\hline Purchased Power Cents Per Kilowatthour..................... & 4.2 & 4.3 & 4.5 & 4.3 & 4.3 \\
\hline 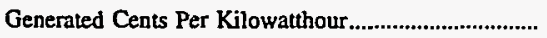 & 1.9 & 2.1 & 2.3 & 2.3 & 2.3 \\
\hline $\begin{array}{l}\text { Total Power Supply Per } \\
\text { Kilowatthour Sold............. }\end{array}$ & 3.0 & 3.2 & 3.4 & 3.4 & 3.5 \\
\hline
\end{tabular}

Note: Totals may not equal sum of components because of independent rounding. The number of generating publicly owned electric utilities for end of period is 61 for June 30, 1996; 59 for June 30, 1995; 57 for June 30, 1994; 56 for June 30, 1993 ; and 56 for June 30, 1996. The Califomia Department of Water Resources (CA) changed fiscal year from December 31 to June 30 in 1992 ; the Wisconsin Public Power Inc Sys (WI) changed fiscal year from December 31 to June 30 in 1993; and the City of Pella (IA) changed fiscal year from June 30 to December 31 in 1994, and the City of Burlington (VT) changed fiscal year from December 31 to June 30 in 1994. The City of Gaffney (SC). City of Osceola (AR), and City of Redding (CA) were nongenerators for 1991 through 1993; but became generators in 1994. The City of Kennett (MO) and City of Morgan City (LA) were generators for 1991 through 1993; but became nongenerators in 1994. Emerald Peoples Utility District (OR), City of Bryan (OH), and Northern Wasco County PUD (OR) were nongenerators for 1991, but became generators in 1992. The Utah Associated Municipal Power System (UT) changed fiscal year from June 30 to March 31 in 1991.

Source: Energy Information Administration, Form EIA-412, "Annual Report of Public Electric Utilities." 
Table C6. Electric Operation and Maintenance Expenses for Major U.S.

Publicly Owned Generator Electric Utilities with Financial

Year Ending on June 30, 1992-1996

(Thousand Dollars)

\begin{tabular}{|c|c|c|c|c|c|}
\hline Item & 1996 & 1995 & 1994 & 1993 & 1992 \\
\hline \multicolumn{6}{|l|}{ Production Expenses } \\
\hline 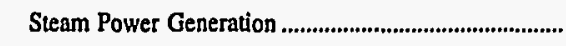 & 710,826 & 970,882 & $1,080,342$ & $1,078,045$ & 952,188 \\
\hline 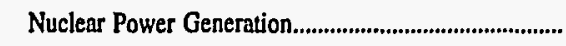 & 208,864 & 218,444 & 234,047 & 211,994 & 195,820 \\
\hline Hydraulic Power Generation & 56,934 & 54,523 & 48,678 & 51,177 & 51,216 \\
\hline 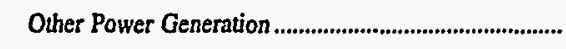 & 81,720 & 62,988 & 46,086 & 41,629 & 38,213 \\
\hline 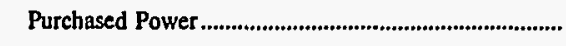 & $1,836,280$ & $1,619,076$ & $1,723,456$ & $1,618,260$ & $1,696,102$ \\
\hline 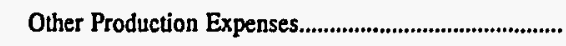 & 24,129 & 35,910 & 20,082 & 15,753 & 25,393 \\
\hline 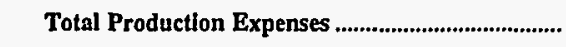 & 2,918,752 & $2,961,823$ & $3,152,691$ & $3,016,859$ & $2,958,932$ \\
\hline 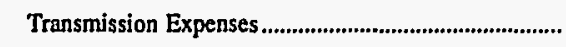 & 151,362 & 149,263 & 141,292 & 128,866 & 122,955 \\
\hline 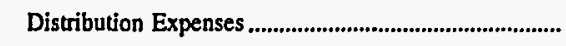 & 330,309 & 239,748 & 250,442 & 267,820 & 249,276 \\
\hline 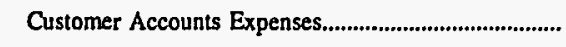 & 117,227 & 91,609 & 84,175 & 92,470 & 85,956 \\
\hline Customer Service and Information Expenses................... & 30,053 & 29,759 & 31,735 & 29,378 & 23,888 \\
\hline Sales Expenses & 1,379 & 906 & 812 & 813 & 1,507 \\
\hline 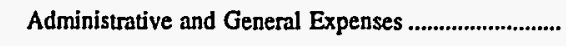 & 311,157 & 510,000 & 489,764 & 447,484 & 452,373 \\
\hline 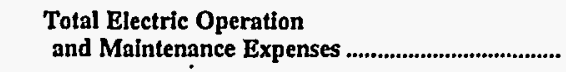 & $3,860,239$ & $3,983,110$ & $4,150,911$ & $3,983,691$ & $3,894,887$ \\
\hline \multicolumn{6}{|l|}{ Fuel Expenses in Operation } \\
\hline Steam Power Generation & 439,266 & 627,974 & 812,127 & 799,613 & 702,909 \\
\hline 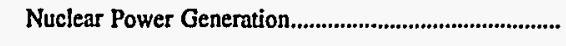 & 50,665 & 39,804 & 59,630 & 54,438 & 38,524 \\
\hline Other Power Generation & 8,226 & 10,478 & 21,917 & 19,689 & 17,832 \\
\hline \multicolumn{6}{|l|}{ Number of Elec Dept Employees } \\
\hline 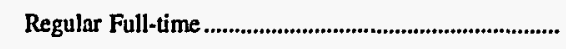 & 14,164 & 14,949 & 15,653 & 15,442 & 16,894 \\
\hline Part-time \& Temporary & 389 & 597 & 815 & 967 & 1,217 \\
\hline 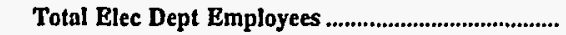 & 14,553 & 15,546 & 16,468 & 16,409 & 18,111 \\
\hline
\end{tabular}

Note: Totals may not equal sum of components because of independent rounding. The number of generating publicly owned electric utilities for end of period is 61 for June 30, 1996; 59 for June 30, 1995; 57 for June 30, 1994; 56 for June 30, 1993; and 56 for June 30, 1992. The California Department of Water Resources (CA) changed fiscal year from December 31 to June 30 in 1992; the Wisconsin Public Power Inc Sys (WI) changed fiscal year from December 31 to June 30 in 1993; and the City of Pella (IA) changed fiscal year from June 30 to December 31 in 1994, and the City of Burlington (VT) changed fiscal year from December 31 to June 30 in 1994. The City of Gaffney (SC), City of Osceola (AR), and City of Redding (CA) were nongenerators for 1991 through 1993; but became generators in 1994. The City of Kennett (MO) and City of Morgan City (LA) were generators for 1991 through 1993; but became nongenerators in 1994. Emerald Peoples Utility District (OR), City of Bryan (OH), and Northern Wasco County PUD (OR) were nongenerators for 1991, but became generators in 1992. The Utah Associated Municipal Power System (UT) changed fiscal year from June 30 to March 31 in 1991.

Source: Energy Information Administration, Form EIA-412, "Annual Report of Public Electric Utilities." 
Table C7. Electric Utility Plant for Major U.S. Publicly Owned Generator

Electric Utilities with Financial Year Ending

on June 30 at End of Period, 1992-1996

(Thousand Dollars)

\begin{tabular}{|c|c|c|c|c|c|}
\hline Item & 1996 & 1995 & 1994 & 1993 & 1992 \\
\hline \multicolumn{6}{|l|}{ Electric Plant in Service } \\
\hline Intangible Plant & 47,254 & 89,558 & 88,908 & 88,231 & 103,370 \\
\hline \multicolumn{6}{|l|}{ Production Plant } \\
\hline Steam & $3,938,686$ & $6,470,103$ & $6,264,976$ & $6,381,047$ & $6,074,387$ \\
\hline 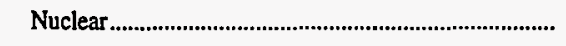 & $4,698,823$ & $4,646,849$ & $4,586,603$ & $4,580,460$ & $4,584,312$ \\
\hline 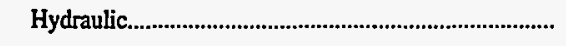 & $2,862,008$ & $2,692,206$ & $2,785,014$ & $2,627,882$ & $2,618,895$ \\
\hline Other & $1,074,757$ & 907,358 & 981,621 & 435,135 & 590,691 \\
\hline 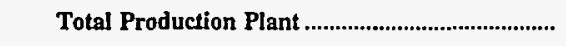 & $12,574,273$ & $14,716,515$ & $14,618,215$ & $14,024,524$ & $13,868,285$ \\
\hline Transmission Plant........ & $2,743,015$ & $2,523,452$ & $2,488,678$ & $2,443,364$ & $2,372,536$ \\
\hline 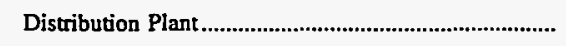 & $4,812,246$ & $4,583,704$ & $4,433,062$ & $4,237,454$ & $4,056,844$ \\
\hline General Plant & $1,744,750$ & $1,592,593$ & $1,701,054$ & $1,373,699$ & $1,189,667$ \\
\hline Total Electric Plant in Service................................... & $21,921,537$ & $23,505,822$ & $23,329,917$ & $22,167,272$ & $21,590,702$ \\
\hline 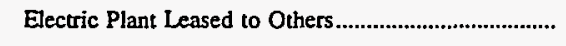 & 1 & 1 & 1 & 1 & 1 \\
\hline Construction Work in Progress - Electric....................... & 542,158 & 948,126 & 843,150 & 879,753 & $1,007,230$ \\
\hline 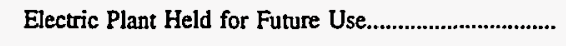 & 7,563 & 2,227 & 12,216 & 9,487 & 17 \\
\hline 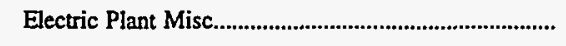 & $2,631,655$ & 305,470 & 307,016 & 281,264 & 231,033 \\
\hline 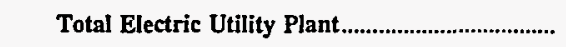 & $25,102,914$ & $24,761,645$ & $24,492,299$ & $23,337,776$ & $22,828,983$ \\
\hline $\begin{array}{l}\text { Accumulated Provision for } \\
\text { Depreciation and Amortization...................................... }\end{array}$ & $10,187,384$ & $7,802,514$ & $7,247,501$ & $6,525,704$ & $6,047,224$ \\
\hline 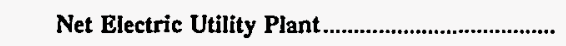 & $14,915,530$ & $16,959,131$ & $17,244,798$ & $16,812,072$ & $15,973,226$ \\
\hline
\end{tabular}

Note: Totals may not equal sum of components because of independent rounding. The number of generating publicly owned electric utilities for end of period is 61 for June 30, 1996; 59 for June 30, 1995; 57 for June 30, 1994; 56 for June 30, 1993; and 56 for June 30, 1992. The Califomia Department of Water Resources (CA) changed fiscal year from December 31 to June 30 in 1992 ; the Wisconsin Public Power Inc Sys (WI) changed fiscal year from December 31 to June 30 in 1993; and the City of Pella (IA) changed fiscal year from June 30 to December 31 in 1994, and the City of Burlington (VT) changed fiscal year from December 31 to June 30 in 1994. The City of Gaffney (SC), City of Osceola (AR), and City of Redding (CA) were nongenerators for 1991 through 1993; but became generators in 1994. The City of Kennett (MO) and City of Morgan City (LA) were generators for 1991 through 1993; but became nongenerators in 1994. Emerald Peoples Utility District (OR), City of Bryan (OH), and Northern Wasco County PUD (OR) were nongenemators for 1991, but became generators in 1992. The Utah Associated Municipal Power System (UT) changed fiscal year from June 30 to March 31 in 1991.

Source: Energy Information Administration, Form ElA-412, "Annual Report of Public Electric Utilities." 
Table C.8. Number of Consumers, Sales, and Operating Revenue for Major

U.S. Publicly Owned Generator Electric Utilities with Financial

Year Ending on June 30, 1992-1996

\begin{tabular}{|c|c|c|c|c|c|c|}
\hline Item & 1996 & & 1995 & 1994 & 1993 & 1992 \\
\hline \multicolumn{7}{|l|}{ Number of Consumers } \\
\hline 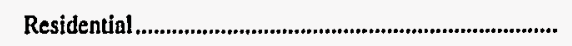 & $2,172,161$ & $\mathbf{R}$ & $2,093,040$ & $2,093,440$ & $2,068,364$ & $2,051,709$ \\
\hline Commercial or Small & 319,083 & & R 307,291 & 306,525 & 299,862 & 298,130 \\
\hline 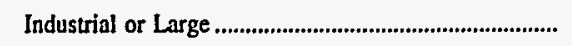 & 24,075 & & 22,468 & 24,124 & 23,482 & 23,782 \\
\hline Other & 20,795 & & 18,141 & 18,286 & 16,039 & 19,858 \\
\hline 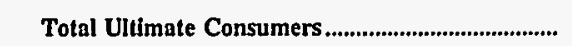 & $2,536,114$ & $\mathbf{R}$ & $2,440,940$ & $2,442,375$ & $2,407,747$ & $2,393,479$ \\
\hline \multicolumn{7}{|l|}{ Sales for the Year (megawatthours) } \\
\hline 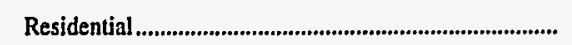 & $14,186,540$ & $\mathbf{R}$ & $13,361,232$ & $13,186,592$ & $12,646,336$ & $12,802,964$ \\
\hline 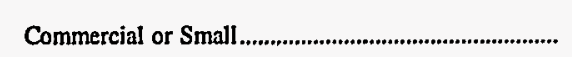 & $20,567,788$ & $\mathbf{R}$ & $19,756,093$ & $15,495,316$ & $19,091,042$ & $18,772,290$ \\
\hline 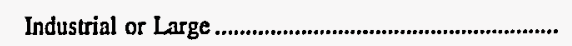 & $13,628,412$ & & $11,242,614$ & $16,261,239$ & $12,437,301$ & $12,741,755$ \\
\hline Other & $2,541,574$ & $\mathbf{R}$ & $2,584,785$ & $2,334,719$ & $2,180,702$ & $2,628,594$ \\
\hline Total Sales to Ultimate Consumers ............................. & $50,924,314$ & $\mathbf{R}$ & $46,944,724$ & $47,277,866$ & $46,355,381$ & $46,945,603$ \\
\hline 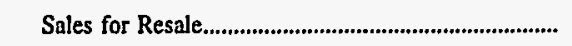 & $46,826,569$ & & $48,994,945$ & $44,154,103$ & $44,312,299$ & $39,068,959$ \\
\hline 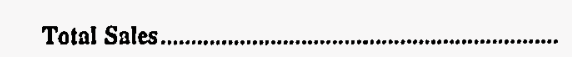 & $97,750,883$ & $\mathbf{R}$ & $95,939,669$ & $91,431,969$ & $90,667,680$ & $86,014,562$ \\
\hline \multicolumn{7}{|l|}{$\begin{array}{l}\text { Operating Revenues for the Year } \\
\text { (thousand dollars) }\end{array}$} \\
\hline Residential & $1,226,329$ & $\mathbf{R}$ & $1,172,083$ & $1,160,463$ & $1,109,153$ & $1,073,325$ \\
\hline 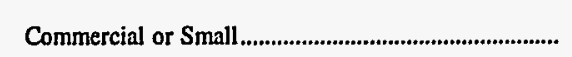 & $1,723,706$ & $\mathbf{R}$ & $1,670,638$ & $1,342,630$ & $1,618,563$ & $1,535,038$ \\
\hline 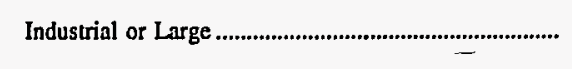 & 943,215 & & ${ }^{R} 784,173$ & $1,193,294$ & 905,778 & 881,541 \\
\hline 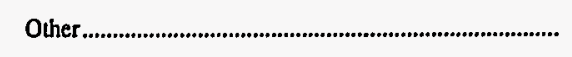 & 170,356 & & 158,697 & 159,079 & 143,731 & 177,005 \\
\hline $\begin{array}{l}\text { Total Revenues from Sales to } \\
\text { Ultimate Consumers................................................ }\end{array}$ & $4,063,606$ & $\mathbf{R}$ & $3,785,591$ & $3,855,466$ & $3,777,225$ & $3,666,909$ \\
\hline Sales for Resale & $2,175,377$ & & $2,216,554$ & $2,272,651$ & $2,131,533$ & $2,065,351$ \\
\hline 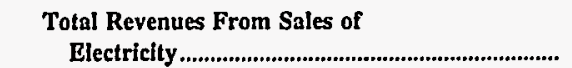 & $6,238,983$ & $\mathbf{R}$ & $6,002,145$ & $6,128,117$ & $5,908,758$ & $5,732,260$ \\
\hline
\end{tabular}

$\mathbf{R}=$ Revised data.

Note: Totals may not equal sum of components because of independent rounding. The number of generating publicly owned electric utilities for end of period is 61 for June 30, 1996; 59 for June 30, 1995; 57 for June 30, 1994; 56 for June 30, 1993 ; and 56 for June 30, 1992. The California Department of Water Resources (CA) changed fiscal year from December 31 to June 30 in 1992; the Wisconsin Public Power Inc Sys (WI) changed fiscal year from December 31 to June 30 in 1993; and the City of Pella (IA) changed fiscal year from June 30 to December 31 in 1994, and the City of Burlington (VT) changed fiscal year from December 31 to June 30 in 1994. The City of Gaffney (SC), City of Osceoln (AR), and City of Redding (CA) were nongenerators for 1991 through 1993; but became generators in 1994. The City of Kennett (MO) and City of Morgan City (LA) were generators for 1991 through 1993; but became nongenerators in 1994. Emerald Peoples Utility District (OR), City of Bryan (OH), and Northem Wasco County PUD (OR) were nongenerators for 1991, but became generators in 1992. The Utah Associated Municipal Power System (UT) changed fiscal year from June 30 to March 31 in 1991. sions.

Source: Energy Information Administration, Form EIA-861, "Annual Electric Utility Report." Data are based on calendar year submis- 
Table C9. Electric Energy Account for Major U.S. Publicly Owned

Generator Electric Utilities with Financial Year Ending

on June 30, 1992-1996

(Megawatthours)

\begin{tabular}{|c|c|c|c|c|c|}
\hline Item & 1996 & 1995 & 1994 & 1993 & 1992 \\
\hline \multicolumn{6}{|l|}{ Sources of Energy } \\
\hline Steam & $30,711,233$ & $40,044,844$ & $42,721,159$ & $39,909,551$ & $38,133,584$ \\
\hline 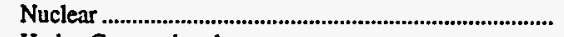 & $11,853,058$ & $10,779,961$ & $10,528,784$ & $10,074,201$ & $7,253,503$ \\
\hline 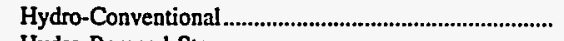 & $11,271,296$ & $9,681,575$ & $7,392,578$ & $8,244,651$ & $7,347,109$ \\
\hline 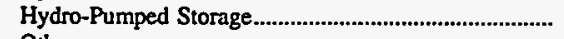 & $2,942,175$ & $3,234,118$ & $1,819,704$ & $2,247,668$ & $2,414,851$ \\
\hline Other & 563,269 & 251,296 & 603,785 & 496,659 & 580,196 \\
\hline 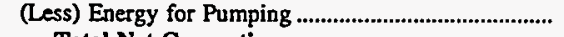 & 864,483 & 451,498 & 951,103 & 937,070 & $1,161,213$ \\
\hline 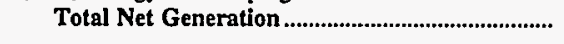 & $56,476,548$ & $63,540,296$ & $62,114,906$ & $60,035,659$ & $54,568,030$ \\
\hline 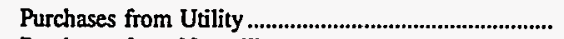 & $41,081,042$ & $34,860,785$ & $36,657,410$ & $35,417,196$ & $37,654,330$ \\
\hline $\begin{array}{l}\text { Purchases from Nonutility ................................................... } \\
\text { Power Exchanges }\end{array}$ & $1,043,222$ & 907,444 & 569,610 & 630,280 & 153,015 \\
\hline 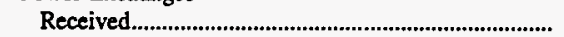 & $6,750,347$ & $6,051,872$ & $4,954,839$ & $5,475,410$ & $5,699,468$ \\
\hline Delivered & $5,446,504$ & $4,400,176$ & $3,791,556$ & $3,780,680$ & $3,637,592$ \\
\hline 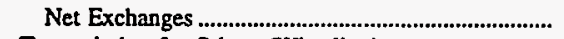 & $1,303,838$ & $1,651,696$ & $1,163,283$ & $1,694,730$ & $2,061,876$ \\
\hline \multicolumn{6}{|l|}{ Transmission for Others (Wheeling) } \\
\hline Received & $21,815,685$ & $14,428,382$ & $14,581,581$ & $16,078,009$ & $14,009,909$ \\
\hline Delivered & $14,643,274$ & $14,396,551$ & $14,528,824$ & $16,021,994$ & $13,959,201$ \\
\hline 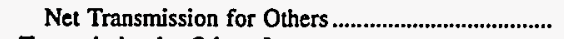 & $7,172,411$ & 31,831 & 52,758 & 56,015 & 50,708 \\
\hline 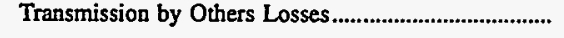 & $-18,801$ & $-166,523$ & $-214,516$ & $-174,994$ & $-141,770$ \\
\hline \multicolumn{6}{|l|}{ Total Net Energy Generated and } \\
\hline 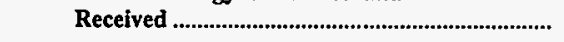 & $107,058,260$ & $100,825,529$ & $100,343,451$ & $97,658,887$ & $94,346,189$ \\
\hline \multicolumn{6}{|l|}{ Disposition of Energy } \\
\hline 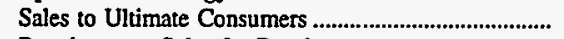 & $51,033,409$ & $46,076,430$ & $47,153,236$ & $47,089,512$ & $46,312,232$ \\
\hline Requirements Sales for Resale & $43,893,576$ & $45,580,165$ & $42,479,566$ & $40,980,045$ & $36,745,586$ \\
\hline 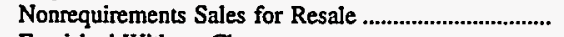 & $3,909,098$ & $2,304,988$ & $1,886,792$ & 947,898 & 453,567 \\
\hline 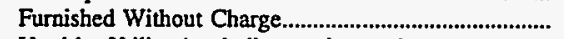 & 167,804 & 186,650 & 194,995 & 235,866 & 200,424 \\
\hline 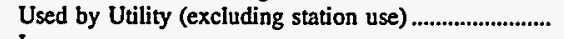 & $5,179,828$ & $3,593,552$ & $4,727,042$ & $4,631,889$ & $6,179,980$ \\
\hline Losses & $2,874,546$ & $3,083,744$ & $3,901,820$ & $3,773,677$ & $4,454,398$ \\
\hline Total Disposition & $107,058,261$ & $100,825,529$ & $100,343,451$ & $97,658,887$ & $94,346,189$ \\
\hline
\end{tabular}

Note: Totals may not equal sum of components because of independent rounding. The number of generating publicly owned electric utilities for end of period is 61 for June 30, 1996; 59 for June 30, 1995; 57 for June 30, 1994; 56 for June 30, 1993; and 56 for June 30, 1992. The Califomia Department of Water Resources (CA) changed fiscal year from December 31 to June 30 in 1992; the Wisconsin Public Power Inc Sys (WI) changed fiscal year from December 31 to June 30 in 1993; and the City of Pella (IA) changed fiscal year from June 30 to December 31 in 1994, and the City of Burlington (VT) changed fiscal year from December 31 to June 30 in 1994. The City of Gaffney (SC), City of Osceola (AR), and City of Redding (CA) were nongenerators for 1991 through 1993; but became generators in 1994. The City of Kennett (MO) and City of Morgan City (LA) were generators for 1991 through 1993; but became nongenerators in 1994. Emerald Peoples Utility District (OR), City of Bryan (OH), and Northern Wasco County PUD (OR) were nongenerators for 1991, but became generators in 1992. The Utah Associated Municipal Power System (UT) changed fiscal year from June 30 to March 31 in 1991.

Source: Energy Information Administration, Form EIA-412, "Annual Report of Public Electric Utilities." 
Table C10. Ten Largest U.S. Publicly Owned Generator Electric Utilities

Ranked by Megawatthour Sales to Ultimate Consumers with

Financial Year Ending on December 31, 1996

\begin{tabular}{|c|c|c|c|}
\hline Publicly Owned Electric Utilities & State & Amount & Percent \\
\hline Power Authority of State of NY & New York & $13,017,530$ & 11.15 \\
\hline Seattle City of & Washington & $9,188,000$ & 7.87 \\
\hline 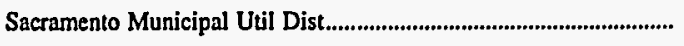 & California & $8,889,261$ & 7.61 \\
\hline 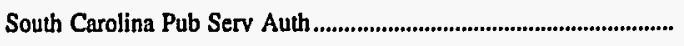 & South Carolina & $8,209,218$ & 7.03 \\
\hline 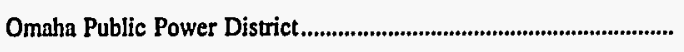 & Nebraska & $7,756,491$ & 6.64 \\
\hline 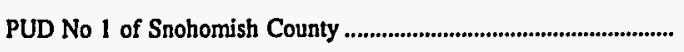 & Washington & $7,158,031$ & 6.13 \\
\hline Tacoma City of & Washington & $5,471,096$ & 4.69 \\
\hline 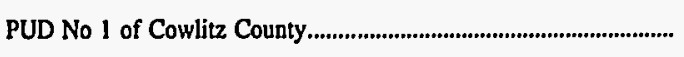 & Washington & $4,033,060$ & 3.45 \\
\hline 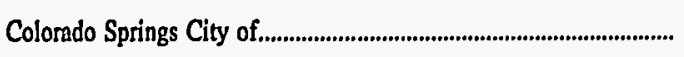 & Colorado & $3,465,123$ & 2.97 \\
\hline 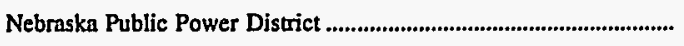 & Nebraska & $2,928,863$ & 2.51 \\
\hline 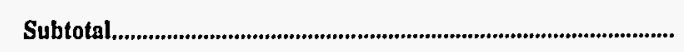 & & $70,116,673$ & 60.05 \\
\hline
\end{tabular}

Source: Energy Information Administration, Form EIA-412, "Annual Report of Public Electric Utilities."

Table C11. Ten Largest U.S. Publicly Owned Generator Electric Utilities Ranked by Megawatthour Sales for Resale with Financial Year Ending on December 31, 1996

\begin{tabular}{|c|c|c|c|}
\hline Publicly Owned Electric Utilities & State & Amount & Percent \\
\hline Power Authority of State of NY & New York & $27,555,179$ & 16.93 \\
\hline 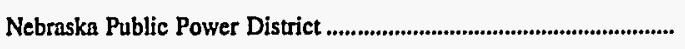 & Nebraska & $24,235,179$ & 14.89 \\
\hline 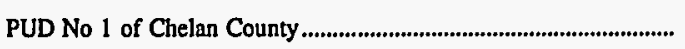 & Washington & $10,845,639$ & 6.66 \\
\hline 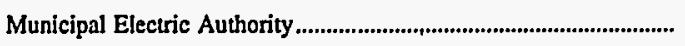 & Georgia & $10,264,912$ & 6.31 \\
\hline 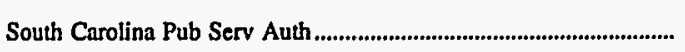 & South Carolina & $9,339,589$ & 5.74 \\
\hline 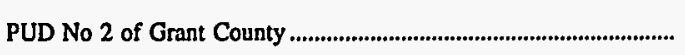 & Washington & $8,482,068$ & 5.21 \\
\hline 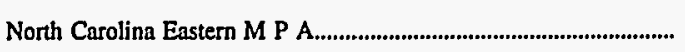 & North Carolina & $6,709,020$ & 4.12 \\
\hline North Carolina Mun Power Agny.......................................................... & North Carolina & $6,556,548$ & 4.03 \\
\hline 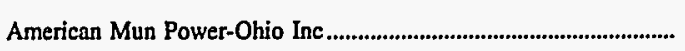 & Ohio & $4,984,129$ & 3.06 \\
\hline 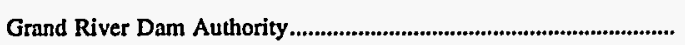 & Oklahoma & $4,610,810$ & 2.83 \\
\hline 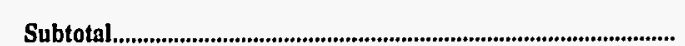 & & $113,583,073$ & 69.77 \\
\hline
\end{tabular}

Source: Energy Information Administration, Form ELA-412, “Annual Report of Public Electric Utilities." 
Table C12. Composite Statement of Income for Major U.S. Publicly Owned Generator Electric Utilities with Financial Year Ending on

December 31, 1992-1996

(Thousand Dollars)

\begin{tabular}{|c|c|c|c|c|c|}
\hline Item & 1996 & 1995 & 1994 & 1993 & 1992 \\
\hline Electric Utility Operating Revenues............................ & $11,182,251$ & $10,681,781$ & $10,636,841$ & $10,265,144$ & $9,978,727$ \\
\hline 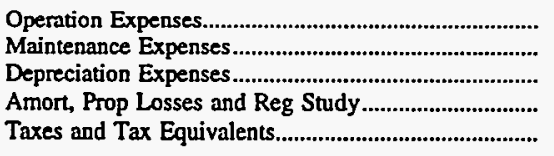 & $\begin{array}{r}6,254,977 \\
748,425 \\
1,704,801 \\
129,049 \\
293,836\end{array}$ & $\begin{array}{r}6,581,774 \\
749,959 \\
1,236,692 \\
116,100 \\
269,795\end{array}$ & $\begin{array}{r}6,449,328 \\
735,879 \\
1,159,118 \\
112,749 \\
260,857\end{array}$ & $\begin{array}{r}6,271,036 \\
726,808 \\
1,082,958 \\
99,467 \\
261,135\end{array}$ & $\begin{array}{r}5,929,885 \\
785,806 \\
1,042,213 \\
93,501 \\
236,234\end{array}$ \\
\hline 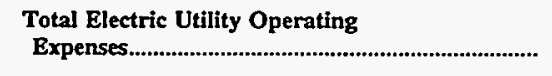 & $9,131,088$ & $8,954,320$ & $8,717,931$ & $8,441,404$ & $8,087,639$ \\
\hline 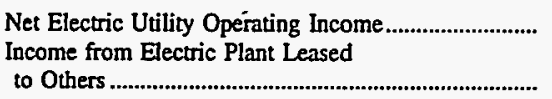 & $\begin{array}{r}2,051,163 \\
7,987\end{array}$ & $\begin{array}{r}1,727,461 \\
6,556\end{array}$ & $\begin{array}{r}1,918,910 \\
19,756\end{array}$ & $\begin{array}{r}1,823,740 \\
10,131\end{array}$ & $\begin{array}{r}1,891,088 \\
1,865\end{array}$ \\
\hline Electric Utility Operating Income .......................... & $2,059,151$ & $1,734,017$ & $1,938,665$ & $1,833,871$ & $1,892,953$ \\
\hline 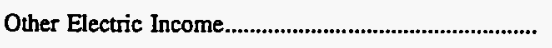 & 725,349 & 704,513 & 521,486 & 720,647 & $1,021,872$ \\
\hline $\begin{array}{l}\text { Other Electric Deductions..................................................... } \\
\text { Allowance for Other Funds Used }\end{array}$ & 20,023 & 76,439 & $-1,286$ & 34,484 & 31,702 \\
\hline $\begin{array}{l}\text { During Construction } \\
\text { Taxes on Other Income and Deduct }\end{array}$ & $\begin{array}{r}6,139 \\
220\end{array}$ & $\begin{array}{l}8,197 \\
5,132\end{array}$ & $\begin{array}{l}5,888 \\
3,059\end{array}$ & $\begin{array}{l}5,721 \\
2,952\end{array}$ & $\begin{array}{l}6,151 \\
2,755\end{array}$ \\
\hline Electric Utility Income ............................................... & $2,770,395$ & $2,365,155$ & $2,464,266$ & $2,522,803$ & $2,886,519$ \\
\hline 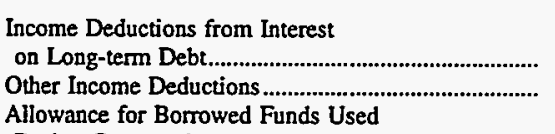 & $\begin{array}{r}1,943,912 \\
241,987\end{array}$ & $\begin{array}{r}1,963,770 \\
218,562\end{array}$ & $\begin{array}{r}2,020,118 \\
178,527\end{array}$ & $\begin{array}{r}2,088,036 \\
173,302\end{array}$ & $\begin{array}{r}2,258,140 \\
136,087\end{array}$ \\
\hline 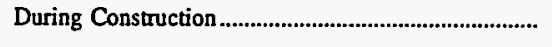 & $-11,870$ & $-20,977$ & $-12,812$ & $-10,057$ & $-10,843$ \\
\hline 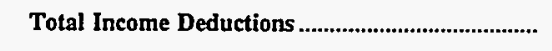 & $2,174,029$ & $2,161,355$ & $2,185,833$ & $2,251,282$ & $2,383,383$ \\
\hline 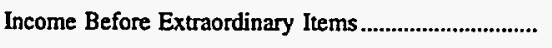 & 596,366 & 203,800 & 278,433 & 271,521 & 503,136 \\
\hline Extraordinary Income & 18,840 & 53,778 & 67,950 & 54,810 & 72,686 \\
\hline 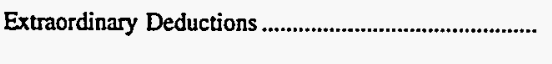 & 12,679 & 15,603 & 18,296 & 137,312 & 126,373 \\
\hline Net Income & 602,526 & 241,975 & 328,086 & 189,020 & 449,449 \\
\hline
\end{tabular}

Note: Totals may not equal sum of components because of independent rounding. The number of generating publicly owned electric utilities for end of period is 111 for December 31, 1996; 108 for December 31, 1995; 112 for December 31, 1994; 113 for December 31, 1993; and 111 for December 31, 1992. The California Department of Water Resources (CA) changed fiscal year from December 31 to June 30 in 1992; the Wisconsin Public Power Inc Sys (WI) changed fiscal year from December 31 to June 30 in 1993; and the City of Pella changed fiscal year from June 30 to Decemebr 31, and the City of Burlington (VT) changed fiscal year from December 31 to June 30 in 1994. The City of Gaffney (SC), City of Osceola (AR), and City of Redding (CA) were nongenerators for 1991 through 1993, but became generators in 1994. The City of Kennett (MO) and City of Morgan City (LA) were generators for 1991 through 1993, but became nongenerators in 1994. Emerald Peoples Utility District (OR), City of Bryan (OH), and Northern Wasco County PUD (OR) were nongenerators for 1991, but became generators in 1992. The Utah Associated Municipal Power System (UT) changed fiscal year from June 30 to March 31 in 1991.

Source: Energy Information Administration, Form EIA-412, “Annual Report of Public Electric Utilities." 
Table C13. Composite Balance Sheet for Major U.S. Publicly Owned Generator Electric Utilities with Financial Year Ending on December 31 at End of Period, 1992-1996 (Thousand Dollars)

\begin{tabular}{|c|c|c|c|c|c|}
\hline Item & 1996 & 1995 & 1994 & 1993 & 1992 \\
\hline 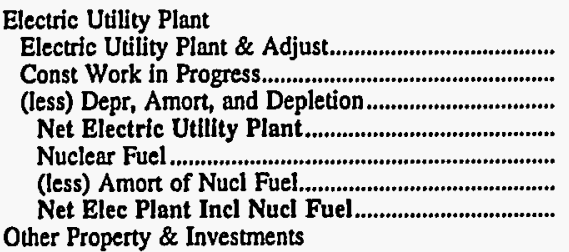 & $\begin{array}{r}41,444,043 \\
1,578,567 \\
14,596,097 \\
28,426,513 \\
1,660,261 \\
1,179,525 \\
28,907,250\end{array}$ & $\begin{array}{r}38,223,333 \\
1,906,103 \\
13,122,194 \\
27,007,243 \\
1,642,191 \\
1,148,674 \\
27,500,760\end{array}$ & $\begin{array}{r}37,327,308 \\
2,065,590 \\
12,251,762 \\
27,141,136 \\
1,665,312 \\
1,131,769 \\
27,674,679\end{array}$ & $\begin{array}{r}36,270,042 \\
1,950,440 \\
11,345,511 \\
26,874,970 \\
1,705,807 \\
1,150,437 \\
27,430,340\end{array}$ & $\begin{array}{r}35,222,457 \\
1,523,008 \\
10,493,142 \\
26,252,323 \\
1,653,317 \\
1,042,691 \\
26,862,950\end{array}$ \\
\hline 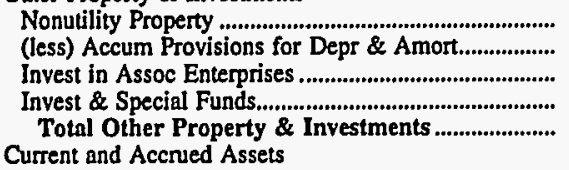 & $\begin{array}{r}324,215 \\
69,367 \\
16,417 \\
6,699,043 \\
6,970,309\end{array}$ & $\begin{array}{r}304,358 \\
64,712 \\
-3,662 \\
6,915,284 \\
7,151,268\end{array}$ & $\begin{array}{r}431,540 \\
195,510 \\
195,315 \\
6,930,525 \\
7,361,870\end{array}$ & $\begin{array}{r}430,836 \\
182,708 \\
295,967 \\
7,101,773 \\
7,645,868\end{array}$ & $\begin{array}{r}370,608 \\
172,216 \\
205,979 \\
6,994,760 \\
7,399,131\end{array}$ \\
\hline 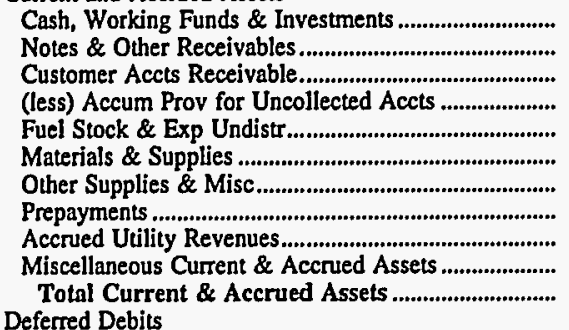 & $\begin{array}{r}4,392,594 \\
484,827 \\
987,012 \\
28,439 \\
254,581 \\
456,955 \\
10,603 \\
150,95 . " \\
112,248 \\
698,666 \\
7,520,004\end{array}$ & $\begin{array}{r}3,968,919 \\
432,039 \\
897,922 \\
25,139 \\
171,240 \\
447,204 \\
15,798 \\
100,454 \\
176,662 \\
708,129 \\
6,893,228\end{array}$ & $\begin{array}{r}4,469,068 \\
339,165 \\
902,986 \\
21,816 \\
163,651 \\
470,433 \\
- \\
154,265 \\
99,997 \\
760,070 \\
7,337,819\end{array}$ & $\begin{array}{r}4,303,347 \\
375,331 \\
872,478 \\
20,667 \\
122,831 \\
457,540 \\
151,661 \\
- \\
97,627 \\
614,489 \\
6,974,638\end{array}$ & $\begin{array}{r}4,546,678 \\
281,987 \\
770,319 \\
20,575 \\
183,952 \\
436,404 \\
148,608 \\
- \\
88,636 \\
640,721 \\
7,076,731\end{array}$ \\
\hline 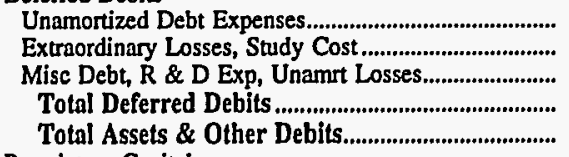 & $\begin{array}{r}1,006,001 \\
1,063,096 \\
5,881,570 \\
\mathbf{7 , 9 5 0 , 6 6 7} \\
\mathbf{5 1 , 3 4 8 , 2 3 0}\end{array}$ & $\begin{array}{r}997,680 \\
1,204,623 \\
5,701,868 \\
7,904,171 \\
49,449,426\end{array}$ & $\begin{array}{r}1,038,464 \\
425,374 \\
5,982,141 \\
7,445,979 \\
49,820,347\end{array}$ & $\begin{array}{r}1,083,853 \\
443,321 \\
6,112,902 \\
7,640,077 \\
49,690,923\end{array}$ & $\begin{array}{r}942,727 \\
384,193 \\
5,228,559 \\
6,555,478 \\
47,894,290\end{array}$ \\
\hline 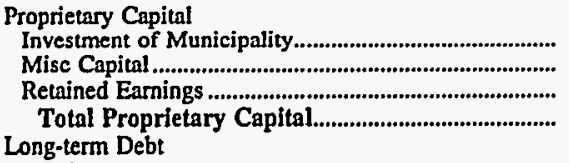 & $\begin{array}{r}383,351 \\
107,781 \\
8,898,661 \\
9,389,793\end{array}$ & $\begin{array}{r}398,679 \\
58,378 \\
8,109,618 \\
8,566,675\end{array}$ & $\begin{array}{r}385,076 \\
40,945 \\
7,866,971 \\
8,292,993\end{array}$ & $\begin{array}{r}382,728 \\
54,912 \\
7,607,441 \\
8,045,082\end{array}$ & $\begin{array}{r}394,516 \\
50,262 \\
7,443,810 \\
7,888,588\end{array}$ \\
\hline 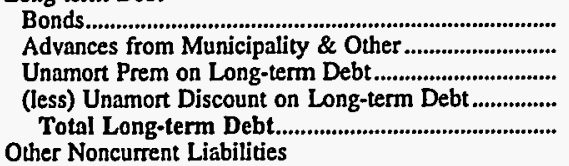 & $\begin{array}{r}33,638,422 \\
2,206,821 \\
122,697 \\
1,256,367 \\
34,711,572\end{array}$ & $\begin{array}{r}33,450,397 \\
1,973,168 \\
25,427 \\
1,265,868 \\
34,183,124\end{array}$ & $\begin{array}{r}34,488,676 \\
2,268,730 \\
27,659 \\
1,460,972 \\
35,324,094\end{array}$ & $\begin{array}{r}34,703,101 \\
1,762,850 \\
68,644 \\
916,321 \\
35,618,275\end{array}$ & $\begin{array}{r}34,287,344 \\
1,223,179 \\
35,176 \\
1,012,260 \\
34,533,438\end{array}$ \\
\hline 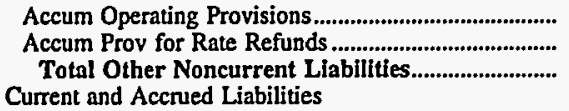 & $\begin{array}{r}187,009 \\
97,822 \\
284,830\end{array}$ & $\begin{array}{l}158,108 \\
101,520 \\
259,628\end{array}$ & $\begin{array}{l}133,156 \\
103,878 \\
237,035\end{array}$ & $\begin{array}{l}109,206 \\
109,290 \\
218,495\end{array}$ & $\begin{array}{r}409,800 \\
4,277 \\
414,077\end{array}$ \\
\hline 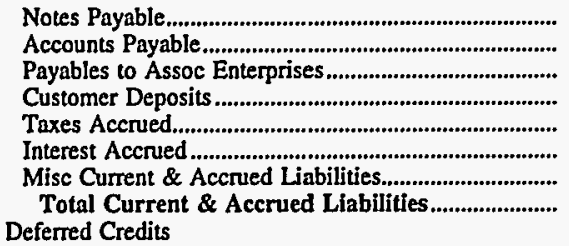 & $\begin{array}{r}1,165,254 \\
864,921 \\
72,290 \\
52,073 \\
111,424 \\
668,366 \\
952,913 \\
3,887,241\end{array}$ & $\begin{array}{r}1,127,030 \\
786,417 \\
81,547 \\
46,511 \\
111,101 \\
678,512 \\
929,816 \\
3,760,934\end{array}$ & $\begin{array}{r}1,053,159 \\
768,765 \\
62,883 \\
45,455 \\
111,791 \\
709,566 \\
907,434 \\
3,659,055\end{array}$ & $\begin{array}{r}1,089,125 \\
733,766 \\
55,730 \\
44,848 \\
108,973 \\
700,474 \\
826,121 \\
3,559,037\end{array}$ & $\begin{array}{r}861,989 \\
690,877 \\
38,023 \\
44,205 \\
89,751 \\
716,138 \\
550,077 \\
2,991,060\end{array}$ \\
\hline 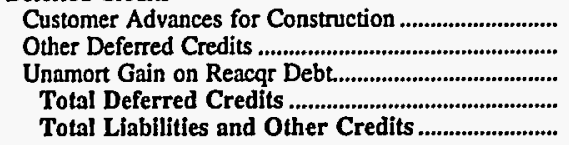 & $\begin{array}{r}71,580 \\
2,557,180 \\
446,033 \\
3,074,793 \\
51,348,230\end{array}$ & $\begin{array}{r}42,227 \\
2,433,084 \\
203,753 \\
2,679,065 \\
49,449,426\end{array}$ & $\begin{array}{r}40,752 \\
2,067,330 \\
199,089 \\
2,307,171 \\
49,820,347\end{array}$ & $\begin{array}{r}37,909 \\
2,021,905 \\
190,221 \\
2,250,035 \\
49,690,923\end{array}$ & $\begin{array}{r}37,120 \\
1,813,190 \\
216,817 \\
2,067,127 \\
47,894,290\end{array}$ \\
\hline
\end{tabular}

- Data not available.

Note: Totals may not equal sum of components because of independent rounding. The number of generating publicly owned electric utilities for end of period is 111 for December 31, 1996; 108 for December 31, 1995; 112 for December 31, $1994 ; 113$ for December 31, 1993; and 111 for December 31, 1992. The California Department of Water Resources (CA) changed fiscal year from December 31 to June 30 in 1992; the Wisconsin Public Power Inc Sys (WI) changed fiscal year from December 31 to June 30 in 1993; and the City of Pella changed fiscal year from June 30 to Decemebr 31, and the City of Burlington (VT) changed fiscal year from December 31 to June 30 in 1994. The City of Gaffney (SC), City of Osceola (AR), and City of Redding (CA) were nongenerators for 1991 through 1993, but became generators in 1994. The City of Kennett (MO) and City of Morgan City (LA) were generators for 1991 through 1993, but became nongenerators in 1994. Emerald Peoples Utility District (OR), City of Bryan (OH), and Northern Wasco County PUD (OR) were nongenerators for 1991, but became generators in 1992. The Utah Associated Municipal Power System (UT) changed fiscal year from June 30 to March 31 in 1991.

Source: Energy Information Administration, Form EIA-412, “Annual Report of Public Electric Utilities." 
Table C14. Composite Financial Indicators for Major U.S. Publicly Owned

Generator Electric Utilities with Financial Year Ending on

December 31, 1992-1996

\begin{tabular}{|c|c|c|c|c|c|}
\hline Item & 1996 & 1995 & 1994 & 1993 & 1992 \\
\hline Total Electric Utility Plant per Dollar of Revenue & 4.0 & 3.9 & 3.9 & 3.9 & 3.8 \\
\hline 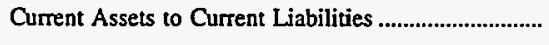 & 1.9 & 1.8 & 2.0 & 2.0 & 2.4 \\
\hline $\begin{array}{l}\text { Total Electric Utility Plant as a Percent of Total } \\
\text { Assets }\end{array}$ & 87.0 & 84.5 & 82.4 & 80.3 & 80.2 \\
\hline $\begin{array}{l}\text { Net Electric Utility Plant as a Percent of Total } \\
\text { Assets }\end{array}$ & 56.3 & 55.6 & 55.5 & 55.2 & 56.1 \\
\hline 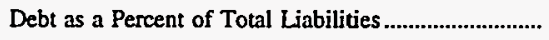 & 75.2 & 76.7 & 78.2 & 78.8 & 78.3 \\
\hline $\begin{array}{l}\text { Depreciation, Amortization and Depletion } \\
\text { as a Percent of Total Electric Utility Plant ................... }\end{array}$ & 35.3 & 34.2 & 32.6 & 31.3 & 30.0 \\
\hline 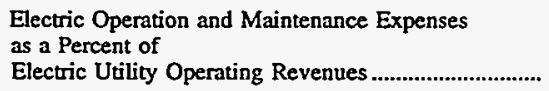 & 62.6 & 68.6 & 67.6 & 68.2 & 67.3 \\
\hline 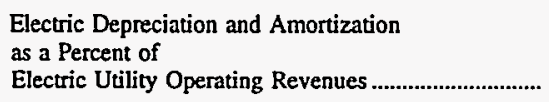 & 15.2 & 11.6 & 10.9 & 10.5 & 10.4 \\
\hline $\begin{array}{l}\text { Taxes and Tax Equivalents } \\
\text { as a Percent of } \\
\text { Electric Utility Operating Revenues............................. }\end{array}$ & 2.6 & 2.5 & 2.5 & 2.5 & 2.4 \\
\hline 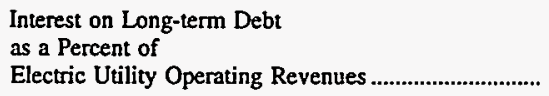 & 17.4 & 18.4 & 19.0 & 20.3 & 22.6 \\
\hline $\begin{array}{l}\text { Net Income as a Percent of Electric } \\
\text { Electric Operating Revenues }\end{array}$ & 5.4 & 2.3 & 3.1 & 1.8 & 4.5 \\
\hline Purchased Power Cents Per Kilowatthour ...................... & 3.5 & 3.5 & 3.2 & 3.2 & 3.4 \\
\hline 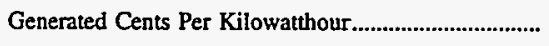 & 1.1 & 1.4 & 1.5 & 1.5 & 1.6 \\
\hline $\begin{array}{l}\text { Total Power Supply Per } \\
\text { Kilowatthour Sold.............. }\end{array}$ & 2.0 & 2.2 & 2.2 & 2.2 & 2.3 \\
\hline
\end{tabular}

Note: Totals may not equal sum of components because of independent rounding. The number of generating publicly owned electric uilities for end of period is 111 for December 31, 1996; 108 for December 31, 1995; 112 for December 31, 1994; 113 for December 31, 1993; and 111 for December 31, 1992. The California Department of Water Resources (CA) changed fiscal year from December 31 to June 30 in 1992; the Wisconsin Public Power Inc Sys (WI) changed fiscal year from December 31 to June 30 in 1993; and the City of Pella changed fiscal year from June 30 to Decemebr 31, and the City of Burlington (VT) changed fiscal year from December 31 to June 30 in 1994. The City of Gaffney (SC), City of Osceola (AR), and City of Redding (CA) were nongenerators for 1991 through 1993, but became generators in 1994. The City of Kennett (MO) and City of Morgan City (LA) were generators for 1991 through 1993, but became nongenerators in 1994. Emerald Peoples Utility District (OR), City of Bryan (OH), and Northem Wasco County PUD (OR) were nongenerators for 1991, but became generators in 1992. The Utah Associated Municipal Power System (UT) changed fiscal year from June 30 to March 31 in 1991.

Source: Energy Information Administration, Form EIA-412, "Annual Report of Public Electric Utilities." 
Table C15. Electric Operation and Maintenance Expenses for Major U.S.

Publicly Owned Generator Electric Utilities with Financial

Year Ending on December 31, 1992-1996

(Thousand Dollars)

\begin{tabular}{|c|c|c|c|c|c|}
\hline Item & 1996 & 1995 & 1994 & 1993 & 1992 \\
\hline \multicolumn{6}{|l|}{ Production Expenses } \\
\hline 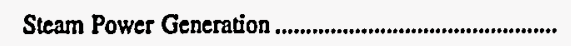 & $1,267,709$ & $1,337,834$ & $1,350,805$ & $1,338,540$ & $1,282,834$ \\
\hline 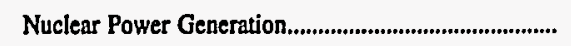 & 528,924 & 798,873 & 803,743 & 833,951 & 874,038 \\
\hline Hydraulic Power Generation ............................................... & 135,774 & 185,529 & 183,959 & 176,149 & 179,079 \\
\hline 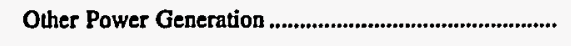 & 80,555 & 76,132 & 59,723 & 56,429 & 73,927 \\
\hline 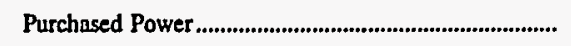 & $3,472,719$ & $2,985,912$ & $2,935,592$ & $2,794,807$ & $2,659,016$ \\
\hline 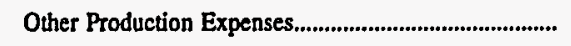 & 61,670 & 110,486 & 91,726 & 94,807 & 31,459 \\
\hline Total Production Expenses & $5,547,351$ & $5,494,766$ & $5,425,548$ & $5,294,683$ & $5,100,351$ \\
\hline 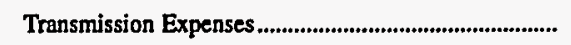 & 183,986 & 512,799 & 493,491 & 482,984 & 439,935 \\
\hline 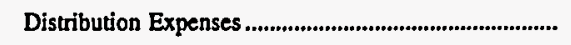 & 482,383 & 338,581 & 344,322 & 330,158 & 308,399 \\
\hline 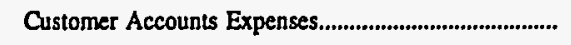 & 126,165 & 123,586 & 127,227 & 124,537 & 116,469 \\
\hline Customer Service and Information Expenses................. & 37,518 & 40,304 & 42,526 & 38,145 & 40,755 \\
\hline Sales Expenses ............................................................................ & 6,017 & 13,012 & 10,597 & 7,990 & 8,274 \\
\hline Administrative and General Expenses .............................. & 620,759 & 808,684 & 742,985 & 719,348 & 701,509 \\
\hline $\begin{array}{l}\text { Total Electric Operation } \\
\text { and Maintenance Expenses }\end{array}$ & $7,004,179$ & $\mathbf{7 , 3 3 1 , 7 3 3}$ & $7,186,697$ & $6,997,844$ & $6,715,691$ \\
\hline \multicolumn{6}{|l|}{ Fuel Expenses in Operation } \\
\hline 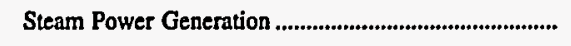 & 698,974 & 575,620 & 949,985 & 951,608 & 728,151 \\
\hline Nuclear Power Generation........................................................ & 132,361 & 133,784 & 192,535 & 205,222 & 170,926 \\
\hline 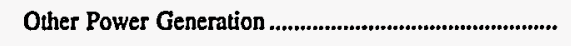 & 45,688 & 48,007 & 37,290 & 32,663 & 32,729 \\
\hline \multicolumn{6}{|l|}{ Number of Elec Dept Employees } \\
\hline 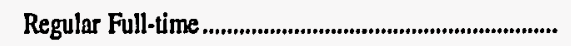 & 161,376 & 24,798 & 25,928 & 26,313 & 26,379 \\
\hline 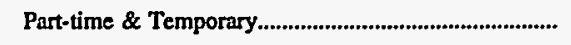 & 848 & 962 & 1,191 & 973 & 1,127 \\
\hline 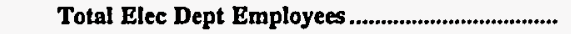 & 162,224 & 25,760 & 27,119 & 27,286 & 27,506 \\
\hline
\end{tabular}

Note: Totals may not equal sum of components because of independent rounding. The number of generating publicly owned electric utilities for end of period is 111 for December 31, 1996; 108 for December 31, 1995; 112 for December 31, 1994; 113 for December 31, 1993; and 111 for December 31, 1992. The California Department of Water Resources (CA) changed fiscal year from December 31 to June 30 in 1992; the Wisconsin Public Power Inc Sys (WI) changed fiscal year from December 31 to June 30 in 1993; and the City of Pella changed fiscal year from June 30 to Decemebr 31, and the City of Burlington (VT) changed fiscal year from December 31 to June 30 in 1994. The City of Gaffney (SC), City of Osceola (AR), and City of Redding (CA) were nongenerators for 1991 through 1993, but became generators in 1994. The City of Kennett (MO) and City of Morgan City (LA) were generators for 1991 through 1993, but became nongenerators in 1994. Emerald Peoples Utility District (OR), City of Bryan (OH), and Northerm Wasco County PUD (OR) were nongenerators for 1991, but became generators in 1992. The Utah Associated Municipal Power System (UT) changed fiscal year from June 30 to March 31 in 1991.

Source: Energy Information Administration, Form EIA-412, "Annual Report of Public Electric Utilities." 
Table C16. Electric Utility Plant for Major U.S. Publicly Owned Generator Electric Utilities with Financial Year Ending on December 31 at End of Period, 1992-1996

(Thousand Dollars)

\begin{tabular}{|c|c|c|c|c|c|}
\hline Item & 1996 & 1995 & 1994 & 1993 & 1992 \\
\hline \multicolumn{6}{|l|}{ Electric Plant In Service } \\
\hline 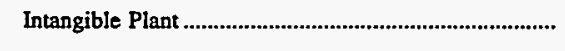 & 281,778 & 322,727 & 281,796 & 187,454 & 147,119 \\
\hline \multicolumn{6}{|l|}{ Production Plant } \\
\hline 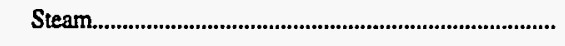 & $9,351,708$ & $8,888,446$ & $9,037,839$ & $8,922,654$ & $8,631,927$ \\
\hline 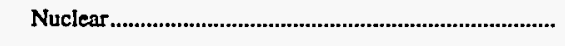 & $9,233,190$ & $9,079,196$ & $9,106,436$ & $9,156,237$ & $9,134,357$ \\
\hline 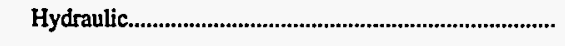 & $5,102,181$ & $4,891,907$ & $4,774,883$ & $4,742,634$ & $4,615,920$ \\
\hline Other & $1,147,883$ & 933,799 & 878,763 & 744,582 & 653,883 \\
\hline 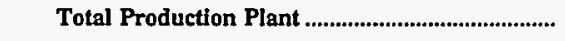 & $24,834,963$ & $23,793,348$ & $23,797,922$ & $23,566,107$ & $23,036,088$ \\
\hline 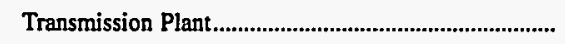 & $4,925,816$ & $4,617,421$ & $4,545,568$ & $4,415,887$ & $4,391,256$ \\
\hline 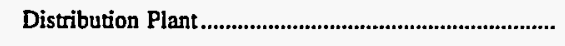 & $7,742,717$ & $6,175,369$ & $5,873,794$ & $5,391,646$ & $5,099,992$ \\
\hline 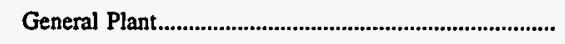 & $2,418,061$ & $2,271,154$ & $2,098,518$ & $1,885,786$ & $1,761,568$ \\
\hline Total Electric Plant in Service............................... & $40,203,334$ & $37,180,018$ & $36,597,599$ & $35,446,880$ & $34,436,024$ \\
\hline 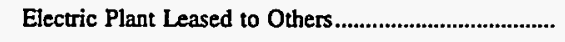 & 25,508 & 35,606 & 15,141 & 16,297 & 17,376 \\
\hline Construction Work in Progress - Electric...................... & $1,578,567$ & $1,906,103$ & $2,065,590$ & $1,950,440$ & $1,523,008$ \\
\hline Electric Plant Held for Future Use.................................. & 19,465 & 20,658 & 21,559 & 34,897 & 35,048 \\
\hline 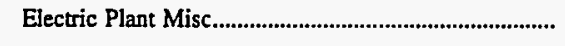 & $1,195,736$ & 987,051 & 693,008 & 771,967 & 734,009 \\
\hline Total Electric Utility Plant...................................... & $43,022,610$ & $40,129,437$ & $39,392,898$ & $38,220,481$ & $36,745,465$ \\
\hline $\begin{array}{l}\text { Accumulated Provision for } \\
\text { Depreciation and Amortization }\end{array}$ & $14,596,097$ & $13,122,194$ & $12,251,762$ & $11,345,511$ & $10,493,142$ \\
\hline 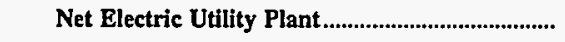 & $28,426,513$ & $27,007,243$ & $27,141,136$ & $26,874,970$ & $27,404,148$ \\
\hline
\end{tabular}

Note: Totals may not equal sum of components because of independent rounding. The number of generating publicly owned electric utilities for end of period is 111 for December 31, 1996; 108 for December 31, 1995; 112 for December 31, $1994 ; 113$ for December 31, 1993; and 111 for December 31, 1992. The California Department of Water Resources (CA) changed fiscal year from December 31 to June 30 in 1992; the Wisconsin Public Power Inc Sys (WI) changed fiscal year from December 31 to June 30 in 1993 ; and the City of Pella changed fiscal year from June 30 to Decemebr 31, and the City of Burlington (VT) changed fiscal year from December 31 to June 30 in 1994. The City of Gaffney (SC), City of Osceola (AR), and City of Redding (CA) were nongenerators for 1991 through 1993, but became generators in 1994. The City of Kennett (MO) and City of Morgan City (LA) were generators for 1991 through 1993, but became nongenerators in 1994. Emerald Peoples Utility District (OR), City of Bryan (OH), and Northern Wasco County PUD (OR) were nongenerators for 1991, but became generators in 1992. The Utah Associated Municipal Power System (UT) changed fiscal year from June 30 to March 31 in 1991.

Source: Energy Information Administration, Form EIA-412, "Annual Report of Public Electric Utilities." 
Table C17. Number of Consumers, Sales, and Operating Revenue for Major

U.S. Publicly Owned Generator Electric Utilities with

Financial Year Ending on December 31, 1992-1996

\begin{tabular}{|c|c|c|c|c|c|c|}
\hline Item & 1996 & & 1995 & 1994 & 1993 & 1992 \\
\hline \multicolumn{7}{|l|}{ Number of Consumers } \\
\hline 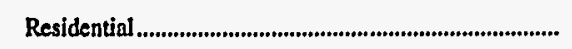 & $2,959,747$ & & $2,876,943$ & $2,877,171$ & $2,849,810$ & $2,814,249$ \\
\hline 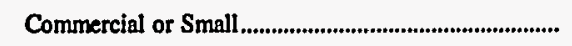 & 379,372 & & 369,673 & 367,325 & 375,533 & 374,138 \\
\hline Industrial or Large & 22,545 & & 19,566 & 20,128 & 19,037 & 17,308 \\
\hline 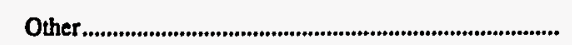 & 36,532 & & 34,749 & 34,191 & 32,448 & 31,715 \\
\hline Total Ultimate Consumers............................................ & $3,398,196$ & & $3,300,931$ & $3,298,815$ & $3,276,828$ & $3,237,410$ \\
\hline \multicolumn{7}{|l|}{ Sales for the Year (megawatthours) } \\
\hline Residential & $32,565,266$ & & $30,706,097$ & $30,425,166$ & $30,738,423$ & $28,973,686$ \\
\hline 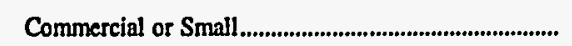 & $25,092,667$ & & $24,179,421$ & $23,875,138$ & $23,277,718$ & $22,588,007$ \\
\hline 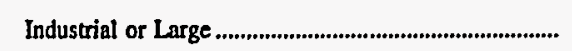 & $46,083,267$ & & $44,132,758$ & $44,343,337$ & $43,249,135$ & $43,005,294$ \\
\hline Other & $12,193,453$ & & $12,086,822$ & $12,289,490$ & $11,832,364$ & $11,573,845$ \\
\hline 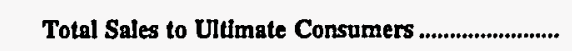 & $115,934,653$ & & $111,105,098$ & $110,933,131$ & $109,097,640$ & $106,140,832$ \\
\hline 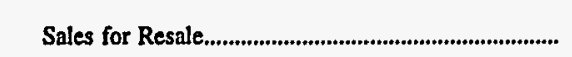 & $151,948,188$ & $\mathbf{R}$ & $138,115,005$ & $130,489,161$ & $128,758,878$ & $119,936,732$ \\
\hline 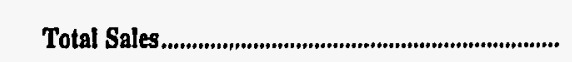 & $267,882,841$ & $\mathbf{R}$ & $249,220,103$ & $241,422,292$ & $237,856,518$ & $226,077,564$ \\
\hline \multicolumn{7}{|l|}{$\begin{array}{l}\text { Operating Revenues for the Year } \\
\text { (thousand dollars) }\end{array}$} \\
\hline 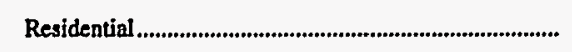 & $1,949,375$ & & $1,813,724$ & $1,810,153$ & $1,731,902$ & $1,643,062$ \\
\hline 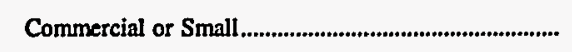 & $1,392,878$ & & $1,335,020$ & $1,327,964$ & $1,266,181$ & $1,207,356$ \\
\hline 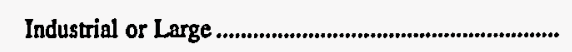 & $1,719,864$ & & $1,653,302$ & $1,684,922$ & $1,635,752$ & $1,606,898$ \\
\hline 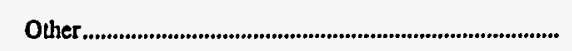 & 890,734 & & 878,301 & 944,538 & 829,771 & 829,977 \\
\hline $\begin{array}{l}\text { Total Revenues from Sales to } \\
\text { Ultimate Consumers.............. }\end{array}$ & $5,952,851$ & & $5,680,347$ & $5,767,577$ & $5,525,606$ & $5,287,293$ \\
\hline 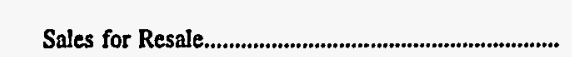 & $4,786,776^{\circ}$ & R & $4,580,285$ & $4,670,772$ & $4,554,309$ & $4,266,138$ \\
\hline 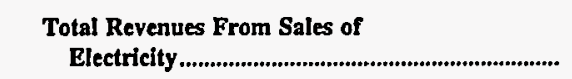 & $10,739,627$ & $\mathbf{R}$ & $10,260,632$ & $10,438,349$ & $10,079,915$ & $9.553,431$ \\
\hline
\end{tabular}

$\mathrm{R}=$ Revised data

Note: Totals may not equal sum of components because of independent rounding. The number of generating publicly owned electric utilities for end of period is 111 for December 31, 1996; 108 for December 31, 1995; 112 for December 31, 1994; 113 for December 31, 1993; and 111 for December 31, 1992. The California Department of Water Resources (CA) changed fiscal year from December 31 to June 30 in 1992; the Wisconsin Public Power Inc Sys (WD) changed fiscal year from December 31 to June 30 in 1993; and the City of Pella changed fiscal year from June 30 to Decemebr 31, and the City of Burlington (VT) changed fiscal year from December 31 to June 30 in 1994. The City of Gaffney (SC), City of Osceola (AR), and City of Redding (CA) were nongenerators for 1991 through 1993, but became generators in 1994. The City of Kennett (MO) and City of Morgan City (LA) were generators for 1991 through 1993, but became nongenerators in 1994. Emerald Peoples Utility District (OR), City of Bryan (OH), and Northern Wasco County PUD (OR) were nongenerators for 1991, but became generators in 1992. The Utah Associated Municipal Power System (UT) changed fiscal year from June 30 to March 31 in 1991. sions.

Source: Energy Information Administration, Form EIA-861, "Annual Electric Utility Report." Data are based on calendar year submis- 
Table C18. Electric Energy Account for Major U.S. Publicly Owned

Generator Electric Utilities with Financial Year

Ending on December 31, 1992-1996

(Megawatthours)

\begin{tabular}{|c|c|c|c|c|c|}
\hline Item & 1996 & 1995 & 1994 & 1993 & 1992 \\
\hline \multicolumn{6}{|l|}{ Sources of Energy } \\
\hline 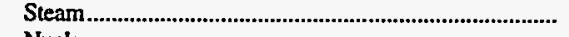 & $74,752,774$ & $65,710,430$ & $70,059,538$ & $68,884,126$ & $65,609,210$ \\
\hline 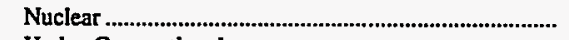 & $41,397,389$ & $35,728,897$ & $31,690,091$ & $31,537,345$ & $31,849,000$ \\
\hline 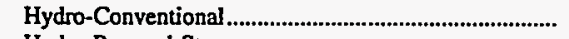 & $72,321,039$ & $67,443,317$ & $56,393,285$ & $61,442,436$ & $57,178,818$ \\
\hline Hydro-Pumped Storage & $2,267,020$ & $2,141,893$ & $2,185,137$ & $2,100,289$ & $2,170,285$ \\
\hline 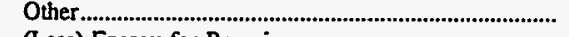 & $1,889,718$ & $1,853,400$ & $1,373,792$ & 933,116 & $1,203,274$ \\
\hline 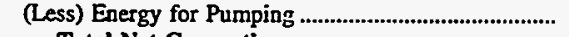 & $3,491,793$ & $3,403,958$ & $3,433,444$ & $3,309,882$ & $2,897,644$ \\
\hline 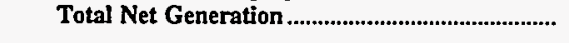 & $189,136,147$ & $169,473,979$ & $158,268,402$ & $161,587,430$ & $155,112,932$ \\
\hline Purchases from Utility & $98,137,682$ & $81,206,442$ & $91,292,304$ & $87,548,082$ & $79,898,277$ \\
\hline $\begin{array}{l}\text { Purchases from Nonutility } \\
\text { Power Exchanges }\end{array}$ & $3,039,939$ & $5,473,283$ & 674,308 & 704,617 & 711,796 \\
\hline \multicolumn{6}{|l|}{ Power Exchanges } \\
\hline 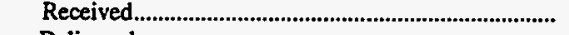 & $13,933,691$ & $12,596,439$ & $11,407,000$ & $12,472,066$ & $11,060,566$ \\
\hline 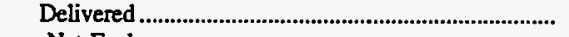 & $14,932,003$ & $12,765,492$ & $11,143,025$ & $14,404,251$ & $12,420,396$ \\
\hline Net Exchanges & $-998,313$ & $-169,064$ & 263,975 & $-1,932,178$ & $-1,359,823$ \\
\hline \multicolumn{6}{|l|}{ Transmission for Others (Wheeling) } \\
\hline 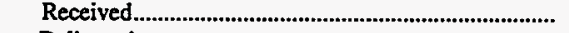 & $10,635,282$ & $10,023,671$ & $14,263,247$ & $10,300,909$ & $7,563,741$ \\
\hline 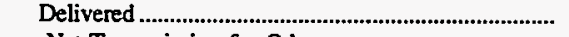 & $10,467,097$ & $9,860,411$ & $14,031,759$ & $10,105,033$ & $7,426,968$ \\
\hline Net Transmission for Others & 168,184 & 163,260 & 231,488 & 195,876 & 136,773 \\
\hline 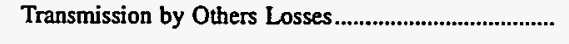 & $-251,931$ & $-71,096$ & $-102,774$ & $-50,570$ & $-42,446$ \\
\hline \multicolumn{6}{|l|}{ Total Net Energy Generated and } \\
\hline 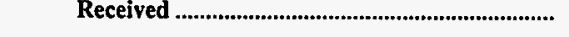 & $289,231,708$ & $256,076,818$ & $250,627,705$ & $248,053,261$ & $234,457,495$ \\
\hline \multicolumn{6}{|l|}{ Disposition of Energy } \\
\hline 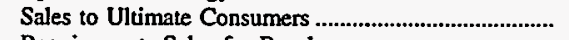 & $116,771,740$ & $111,075,139$ & $110,979,294$ & $109,361,116$ & $106,146,840$ \\
\hline 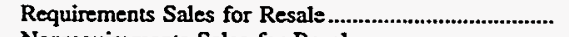 & $107,005,361$ & $90,140,469$ & $97,099,485$ & $96,509,633$ & $92,606,439$ \\
\hline Nonrequirements Sales for Resale & $55,793,253$ & $45,768,673$ & $33,340,798$ & $32,199,27 !$ & $27,422,443$ \\
\hline 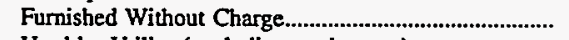 & $1,284,109$ & $1,315,378$ & $1,306,975$ & $1,306,097$ & $1,250,309$ \\
\hline 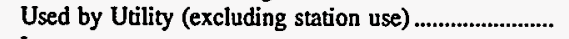 & 254,210 & 218,840 & 227,473 & 254,107 & 258,375 \\
\hline Losses & $8,123,034$ & $7,558,320$ & $7,673,666$ & $8,423,045$ & $6,773,090$ \\
\hline 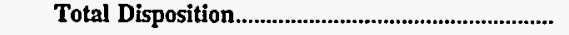 & $289,231,708$ & $256,076,818$ & $250,627,705$ & $248,053,261$ & $234,457,495$ \\
\hline
\end{tabular}

Note: Totals may not equal sum of components because of independent rounding. The number of generating publicly owned electric utilities for end of period is 111 for December 31, 1996; 108 for December 31, 1995; 112 for December 31, 1994; 113 for December 31, 1993; and 111 for December 31, 1992. The California Department of Water Resources (CA) changed fiscal year from December 31 to June 30 in 1992; the Wisconsin Public Power Inc Sys (WI) changed fiscal year from December 31 to June 30 in 1993; and the City of Pella changed fiscal year from June 30 to Decemebr 31, and the City of Burlington (VT) changed fiscal year from December 31 to June 30 in 1994. The City of Gaffney (SC), City of Osceola (AR), and City of Redding (CA) were nongenerators for 1991 through 1993, but became generators in 1994. The City of Kennett (MO) and City of Morgan City (LA) were generators for 1991 through 1993, but became nongenerators in 1994. Emerald Peoples Utility District (OR), City of Bryan (OH), and Northern Wasco County PUD (OR) were nongenerators for 1991, but became generators in 1992. The Utah Associated Municipal Power System (UT) changed fiscal year from June 30 to March 31 in 1991 .

Source: Energy Information Administration, Form EIA-412, "Annual Report of Public Electric Utilities." 
Table C19. Ten Largest U.S. Publicly Owned Nongenerator Electric Utilities .

Ranked by Megawatthour Sales to Ultimate Consumers with

Financial Year Ending on June 30, 1996

\begin{tabular}{|c|c|c|c|}
\hline Publicly Owned Electric Utilities & State & Amount & Percent \\
\hline 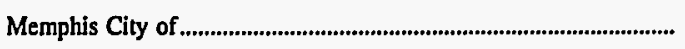 & Tennessee & $12,577,300$ & 13.15 \\
\hline 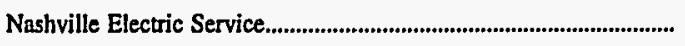 & Tennessee & $11,262,557$ & 11.78 \\
\hline 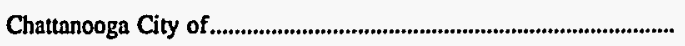 & Tennessee & $5,764,479$ & 6.03 \\
\hline 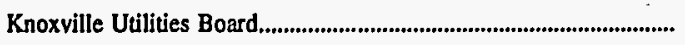 & Tennessee & $5,184,292$ & 5.42 \\
\hline 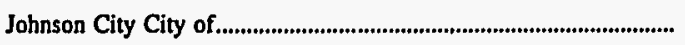 & Tennessee & $1,713,206$ & 1.79 \\
\hline Decatur City of & Alabama & $1,519,863$ & 1.59 \\
\hline 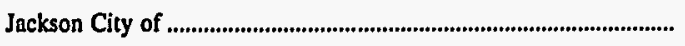 & Tennessee & $1,329,434$ & 1.39 \\
\hline Greenville Utilities Comm........................................................................... & North Carolina & $1,227,000$ & $1.28^{\circ}$ \\
\hline 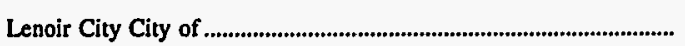 & Tennessee & $1,162,334$ & 1.22 \\
\hline Florence City of & Alabama & $1,097,671$ & 1.15 \\
\hline 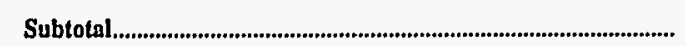 & & $42,838,136$ & 44.80 \\
\hline
\end{tabular}

Source: Energy Information Administration, Form ELA-412, "Annual Report of Public Electric Utilities."

Table C20. U.S. Publicly Owned Nongenerator Electric Utilities Ranked by Megawatthour Sales for Resale with Financial Year Ending on June 30, 1996

\begin{tabular}{|c|c|c|c|}
\hline Publicly Owned Electric Utilities & State & Amount & Percent \\
\hline 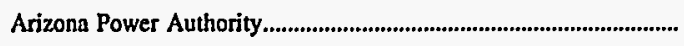 & Arizona & $1,181,512$ & 44.93 \\
\hline Colondo River Comm of Nevada & Nevada & $1,142,235$ & 43.44 \\
\hline Azusa City of & California & 178,151 & 6.77 \\
\hline 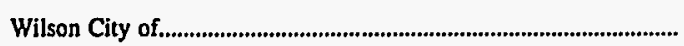 & North Carolina & 64,858 & 2.47 \\
\hline 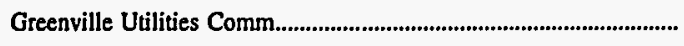 & North Carolina & 37,000 & 1.41 \\
\hline Rocky Mount City of & North Carolina & 20,087 & .76 \\
\hline 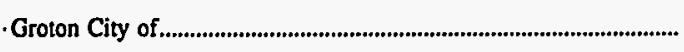 & Connecticut & 5,728 & .22 \\
\hline 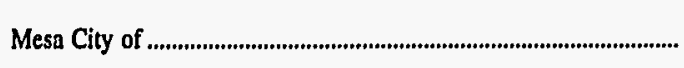 & Arizona & 53 & .00 \\
\hline 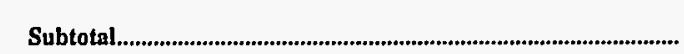 & & $2,629,624$ & 100.00 \\
\hline
\end{tabular}

Source: Energy Information Administration, Form EIA-412, "Annual Report of Public Electric Utilities." 
Table C21. Composite Statement of Income for Major U.S. Publicly Owned Nongenerator Electric Utilities with Financial Year Ending on June 30, 1992-1996

(Thousand Dollars)

\begin{tabular}{|c|c|c|c|c|c|}
\hline Item & 1996 & 1995 & 1994 & 1993 & 1992 \\
\hline 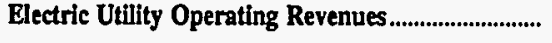 & $5,618,935$ & $5,417,247$ & $5,348,931$ & $5,046,608$ & $4,265,830$ \\
\hline 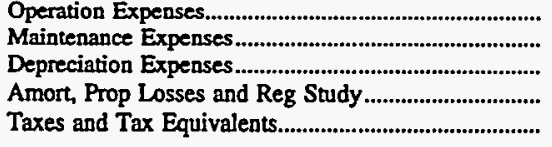 & $\begin{array}{r}4,926,760 \\
163,364 \\
178,329 \\
6,735 \\
120,285\end{array}$ & $\begin{array}{r}4,716,815 \\
168,604 \\
175,842 \\
1,300 \\
137,150\end{array}$ & $\begin{array}{r}4,682,620 \\
165,878 \\
158,525 \\
1,689 \\
124,898\end{array}$ & $\begin{array}{r}4,390,415 \\
143,949 \\
153,256 \\
1,492 \\
108,434\end{array}$ & $\begin{array}{r}3,735,743 \\
109,346 \\
126,288 \\
476 \\
85,310\end{array}$ \\
\hline 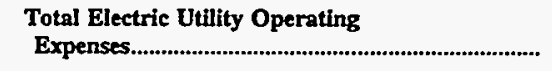 & $5,395,474$ & $5,199,710$ & $5,133,611$ & $4,797,546$ & $4,057,164$ \\
\hline 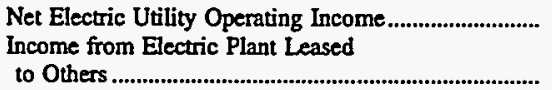 & 223,461 & $\begin{array}{r}217,537 \\
-\end{array}$ & $\begin{array}{r}215,320 \\
230\end{array}$ & 249,062 & $\begin{array}{r}208,666 \\
81\end{array}$ \\
\hline Electric Utility Operating Income ........................... & 223,461 & 217,537 & 215,550 & 249,062 & 208,748 \\
\hline Other Electric Income & 139,055 & 140,467 & 124,914 & 117,290 & 80,578 \\
\hline $\begin{array}{l}\text { Other Electric Deductions......................................... } \\
\text { Allowance for Other Funds Used }\end{array}$ & 26,704 & 42,245 & 43,956 & 44,866 & 44,944 \\
\hline $\begin{array}{l}\text { During Construction } \\
\text { Taxes on Other Income and Deduct }\end{array}$ & $\overline{76}$ & $21 \overline{2}$ & $26 \overline{5}$ & - & $\overline{53}$ \\
\hline Electric Utility Income & 335,737 & 315,547 & 296,243 & 321,486 & 244,329 \\
\hline 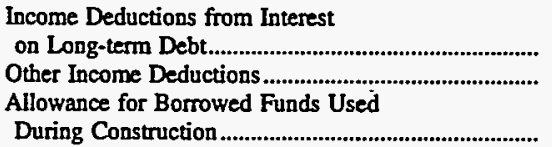 & $\begin{array}{l}47,889 \\
29,628\end{array}$ & $\begin{array}{l}61,620 \\
25,752\end{array}$ & $\begin{array}{l}53,397 \\
28,461\end{array}$ & $\begin{array}{l}60,302 \\
32,697\end{array}$ & $\begin{array}{l}42,612 \\
18,618\end{array}$ \\
\hline 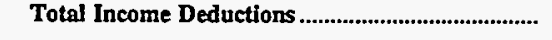 & 78,467 & 87,569 & 81,858 & 92,999 & 61,230 \\
\hline 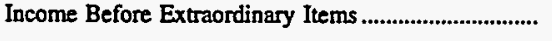 & 257,270 & 227,978 & 214,385 & 228,486 & 183,099 \\
\hline 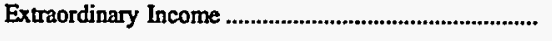 & 10,899 & 11,616 & 12,548 & 16,698 & 18,338 \\
\hline 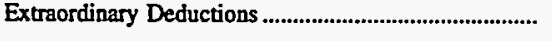 & 14,144 & 14,803 & 31,430 & 29,130 & 11,979 \\
\hline 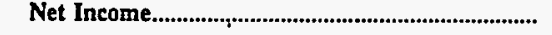 & 254,025 & 224,792 & 195,504 & 216,054 & 189,459 \\
\hline
\end{tabular}

- Data not available.

Note: Totals may not equal sum of components because of independent rounding. The number of nongenerating publicly owned electric utilities for end of period is 140 for June 30, 1996; 144 for June 30, 1995; 144 for June 30, 1994; 142 for June 30, 1993; 137 for June 30, 1992. The City of Pella (IA) changed fiscal year from June 30 to December 31 in 1994; and the City of Burlington (VT) changed fiscal year from June 30 to December 31 in 1994; the City of Hagerstown (MD) changed fiscal year from December 31 to June 30 in 1993; and the City of Memphis (TN) and the City of LaFollette (TN) changed fiscal years from December 31 to June 30 in 1992. The City of Gaffney (SC). City of Osceola (AR), and City of Redding (CA) generators for 1991 through 1993, but became generators in 1994. The City of Kennett (MO) and City of Morgan City (LA) were generators for 1991 through 1993, but became nongenerators in 1994. Emerald Peoples Utility District (OR), City of Bryan (OH), and Northern Wasco County PUD (OR) were nongenerators for ,but became generators in 1992 Source: Energy Information Administration, Form EIA-412, "Annual Report of Public Electric Utilities." 
Table C22. Composite Balance Sheet for Major U.S. Publicly Owned Nongenerator Electric Utilities with Financial Year Ending on June 30 at End of Period, 1992-1996 (Thousand Dollars)

\begin{tabular}{|c|c|c|c|c|c|}
\hline Item & 1996 & 1995 & 1994 & 1993 & 1992 \\
\hline \multicolumn{6}{|l|}{ Electric Utility Plant } \\
\hline 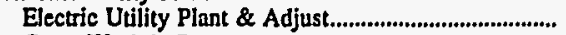 & $5,600,235$ & $5,577,820$ & $5,097,032$ & $4,931,174$ & $3,876,053$ \\
\hline 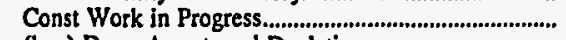 & 223,196 & 182,996 & 137,145 & 151,064 & 131,760 \\
\hline 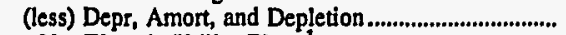 & $2,157,793$ & $2,130,817$ & $1,968,516$ & $1,866,469$ & $1,457,939$ \\
\hline 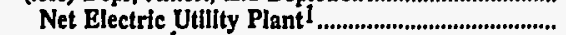 & $3,665,638$ & $3,629,999$ & $3,265,662$ & $3,215,769$ & $2,549,875$ \\
\hline 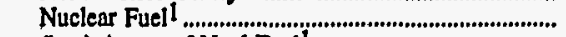 & & & & - & - \\
\hline 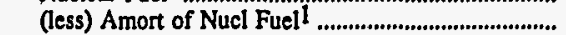 & - & - & - & - & - \\
\hline 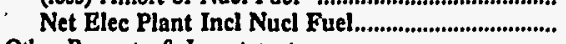 & $3,665,638$ & $3,629,999$ & $3,265,662$ & $3,215,769$ & $2,549,875$ \\
\hline \multicolumn{6}{|l|}{ Other Property \& Investments } \\
\hline 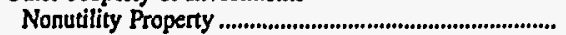 & 966,911 & $1,205,657$ & $1,155,762$ & $1,119,736$ & $1,081,940$ \\
\hline (less) Accum Provisions for Depr \& Amort................... & 252,649 & 316,772 & 286,802 & 277,219 & 246,838 \\
\hline 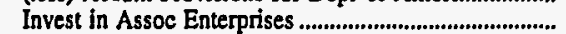 & 10,036 & 44,355 & 9,960 & 11,010 & 8,808 \\
\hline Invest \& Special Funds...................................................... & 472,494 & 518,091 & 402,807 & 467,481 & 373,447 \\
\hline Total Other Property \& Investments ........................... & $1,196,792$ & $1,451,331$ & $1,281,726$ & $1,321,008$ & $1,217,357$ \\
\hline \multicolumn{6}{|l|}{ Current and Accrued Assets } \\
\hline 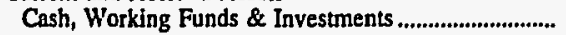 & 693,765 & 880,379 & 713,076 & 759,413 & 645,610 \\
\hline Notes \& Other Receivables ............................................ & 374,141 & 354,234 & 344,874 & 330,984 & 220,262 \\
\hline 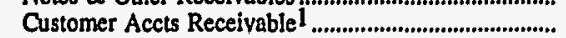 & 156,135 & 165,164 & 152,084 & 145,997 & 173,544 \\
\hline (less) Accum Prov for Uncollected Accts ........................ & 7,861 & 8,294 & 8,536 & 8,418 & 10,382 \\
\hline Fuel Stock \& Exp Undistr 1 ........................................... & & & 108 & & 680 \\
\hline Materials \& Supplies ........................................................... & 98,714 & 97,135 & 95,061 & 95,307 & 81,063 \\
\hline Other Supplies \& Misc.......................................................... & 4,230 & 2,043 & & & \\
\hline 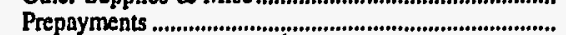 & 18,792 & 23,800 & 23,969 & 23,649 & 21,100 \\
\hline Accrued Udility Revenues 1 .................................................. & 24,700 & 12,904 & 16,966 & 14,928 & 14,061 \\
\hline Miscellaneous Current \& Accrued Assets ..................... & 72,681 & 73,516 & $\mathbf{7 0 , 7 7 2}$ & 63,745 & 42,405 \\
\hline 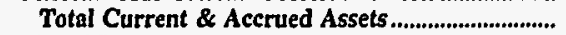 & $1,435,297$ & $1,600,883$ & $1,408,372$ & $1,425,605$ & $1,188,343$ \\
\hline \multicolumn{6}{|l|}{ Deferred Debits } \\
\hline Unamortized Debt Expenses.................................................. & 63,364 & 70,652 & 64,746 & 67,342 & 54,266 \\
\hline Extraordinary Losses, Sudy Cost......................................... & 159 & 1,232 & 73 & 283 & .380 \\
\hline 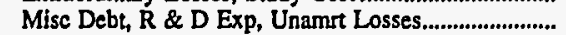 & 227,691 & 218,807 & 221,074 & 231,823 & 207,957 \\
\hline Total Deferred Debits & 291,214 & 290,690 & 285,893 & 299,449 & 262,602 \\
\hline 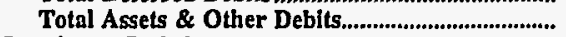 & $6,588,942$ & $6,972,904$ & $6,241,654$ & $6,261,830$ & $5,218,177$ \\
\hline \multicolumn{6}{|l|}{ Proprietary Capital } \\
\hline 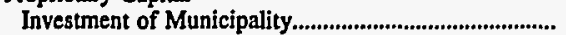 & 163,235 & 148,223 & 146,341 & 140,533 & 130,155 \\
\hline Misc Capital ........................................................ & 342,051 & 327,056 & 332,346 & 322,812 & 321,883 \\
\hline Retained Earnings ................................................................ & $3,706,856$ & $3,669,131$ & $3,288,956$ & $3,182,217$ & $2,655,556$ \\
\hline Total Proprietary Capital ............................................ & $4,212,142$ & $4,144,410$ & $3,767,643$ & $3,645,562$ & $3,107,593$ \\
\hline \multicolumn{6}{|l|}{ Long-term Debt } \\
\hline 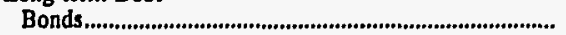 & $1,217,414$ & $1,636,727$ & $1,320,555$ & $1,499,796$ & $1,121,996$ \\
\hline Advances from Municipality \& Other ............................. & 187,086 & 359,698 & 355,209 & 367,687 & 350,771 \\
\hline Unamort Prem on Long-term Debt............................... & 76,727 & $-2,397$ & 1,780 & $-1,857$ & 6,144 \\
\hline (less) Unamort Discount on Long-term Debt................. & 2,404 & 7,842 & 2,327 & 7,964 & 8,254 \\
\hline Total Long-term Debt.................................................... & $1,478,822$ & $1,986,186$ & $1,675,218$ & $1,857,662$ & $1,470,657$ \\
\hline \multicolumn{6}{|l|}{ Other Noncurrent Liabilities } \\
\hline Accum Operating Provisions... & 1,753 & 2,024 & 1,976 & 1,694 & 3,437 \\
\hline Accum Prov for Rate Refunds 1 ........................................ & & & & & 206 \\
\hline Total Other Noncurrent Llabilities........................... & 1,753 & 2,024 & 1,976 & 1,694 & 3,643 \\
\hline \multicolumn{6}{|l|}{ Current and Accrued Liabilities } \\
\hline 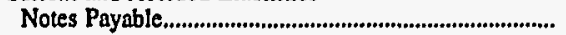 & 78,351 & 76,747 & 30,728 & 22,173 & 24,735 \\
\hline Accounts Payable .............................................................. & 469,374 & 471,756 & 465,214 & 450,921 & 353,395 \\
\hline Payables to Assoc Enterprises.................................. & 90,148 & 5,127 & 4,833 & 5,786 & 10,252 \\
\hline 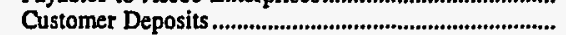 & 82,239 & 99,396 & 100,135 & 95,561 & 87,252 \\
\hline 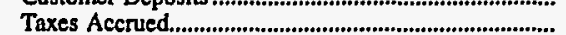 & 5,138 & 11,188 & 12,199 & 10,564 & 9,891 \\
\hline 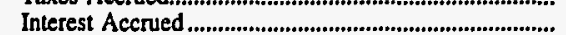 & 25,501 & 24,176 & 24,530 & 24,215 & 46,566 \\
\hline Misc Current \& Accrued Liabilities................................ & 58,790 & 72,872 & 67,888 & 62,787 & 50,848 \\
\hline 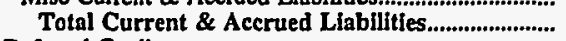 & 809,541 & 761,262 & 705,526 & 672,006 & 582,938 \\
\hline \multicolumn{6}{|l|}{ Deferred Credits } \\
\hline 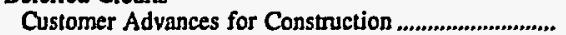 & 23,179 & 6,497 & 5,746 & 5,712 & 3,614 \\
\hline 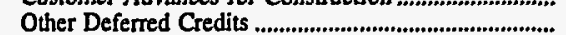 & 63,505 & 72,525 & 85,544 & 79,194 & 49,733 \\
\hline Unamort Gain on Reacgr Debt............................................... & & & & - & \\
\hline Total Deferred Credits ................................................. & 86,684 & 79,022 & 91,290 & 84,906 & 53,346 \\
\hline Total Llabillties and Other Credits ............................. & $6,588,942$ & $6,972,904$ & $6,241,654$ & $6,261,830$ & $5,218,177$ \\
\hline
\end{tabular}

1 Continuity break.

Note: Totals may not equal sum of components because of independent rounding. The number of nongenerating publicly owned electric utilities for end of period is 140 for June 30, 1996; 144 for June 30, 1995; 144 for June 30, 1994; 142 for June 30, 1993; 137 for June 30, 1992. The City of Pella (IA) changed fiscal year from June 30 to December 31 in 1994; and the City of Burlington (VT) changed fiscal year from June 30 to December 31 in 1994; the City of Hagerstown (MD) changed fiscal year from December 31 to June 30 in 1993; and the City of Memphis (TN) and the City of LaFollette (TN) changed fiscal years from December 31 to June 30 in 1992. The City of Gaffney (SC), City of Osceola (AR), and City of Redding (CA) generators for 1991 through 1993, but became generators in 1994. The City of Kennett (MO) and City of Morgan City (LA) were generators for 1991 through 1993, but became nongenerators in 1994. Emerald Peoples Utility District (OR), City of Bryan (OH), and Northern Wasco County PUD (OR) were nongenerators for ,but became generators in 1992.

Source: Energy Information Administration, Form EIA-412, "Annual Report of Public Electric Utilities." 
Table C23. Composite Financial Indicators for Major U.S. Publicly Owned Nongenerator Electric Utilities with Financial Year Ending on

June 30, 1992-1996

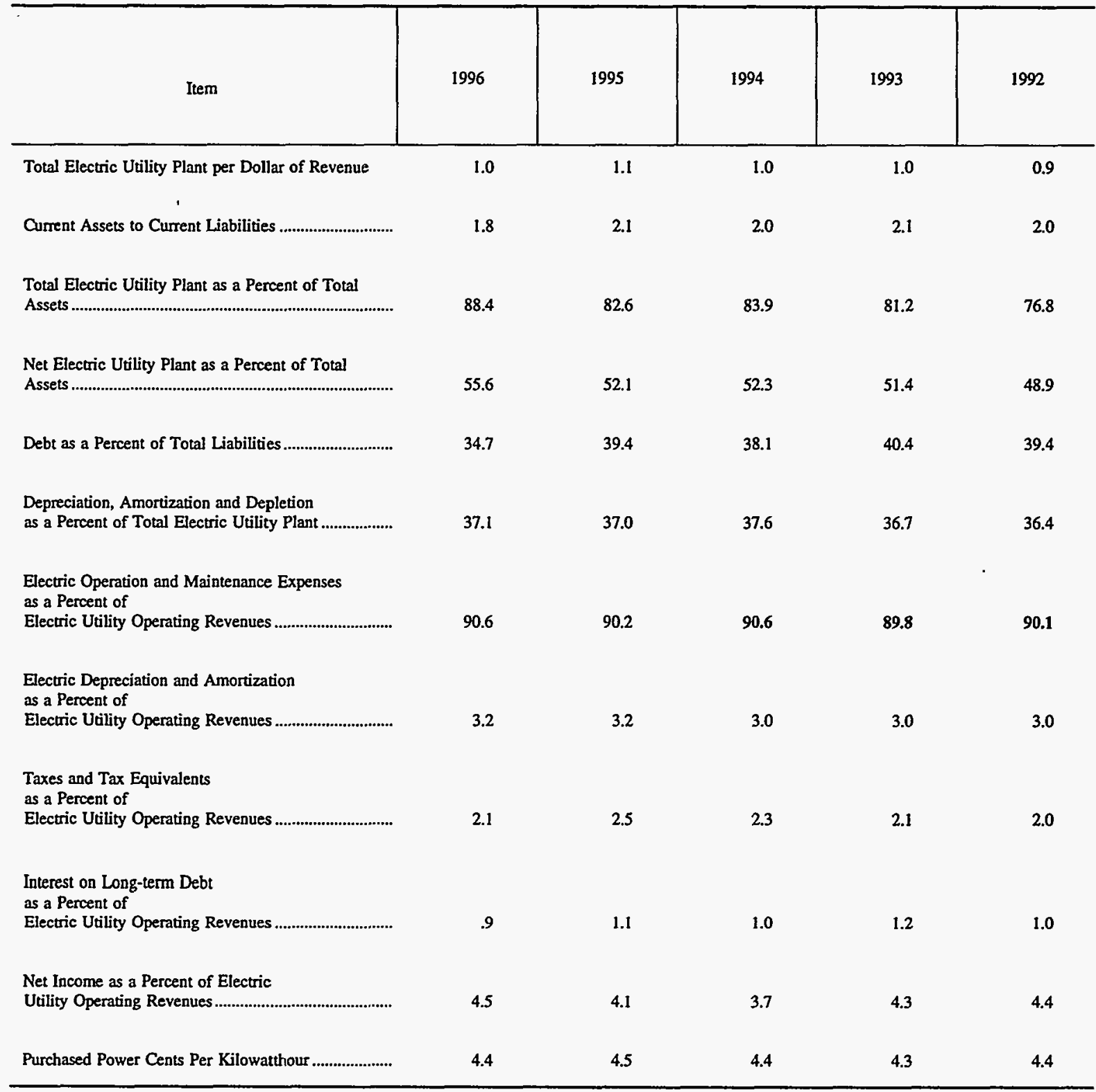

Note: Totals may not equal sum of components because of independent rounding. The number of nongenerating publicly owned electric utilities for end of period is 140 for June 30,1996; 144 for June 30, 1995; 144 for June 30, 1994; 142 for June 30, 1993 ; 137 for June 30, 1992. The City of Pella (IA) changed fiscal year from June 30 to December 31 in 1994; and the City of Burlington (VT) changed fiscal year from June 30 to December 31 in 1994; the City of Hagerstown (MD) changed fiscal year from December 31 to June 30 in 1993; and the City of Memphis (TN) and the City of LaFollette (TN) changed fiscal years from December 31 to June 30 in 1992 . The City of Gaffney (SC), City of Osceola (AR), and City of Redding (CA) generators for 1991 through 1993, but became generators in 1994. The City of Kennett (MO) and City of Morgan City (LA) were generators for 1991 through 1993, but became nongenerators in 1994. Emerald Peoples Utility District (OR), City of Bryan (OH), and Northern Wasco County PUD (OR) were nongenerators for ,but became generators in 1992.

Source: Energy Information Administration, Form EIA-412, "Annual Report of Public Electric Utilities." 
Table C24. Electric Operation and Maintenance Expenses for Major U.S.

Publicly Owned Nongenerator Electric Utilities with Financial

Year Ending on June 30, 1992-1996

(Thousand Dollars)

\begin{tabular}{|c|c|c|c|c|c|}
\hline Item & 1996 & 1995 & 1994 & 1993 & 1992 \\
\hline \multicolumn{6}{|l|}{ Production Expenses } \\
\hline 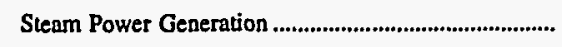 & 3 & 810 & - & - & - \\
\hline 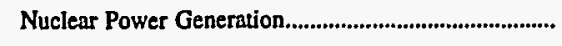 & - & - & - & - & - \\
\hline 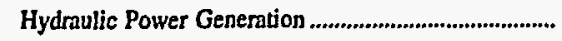 & - & 55 & - & - & - \\
\hline 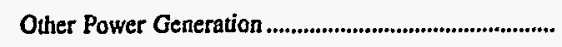 & - & 8,579 & 437 & - & - \\
\hline Purchased Power ......................................................................... & $4,480,402$ & $4,259,417$ & $4,271,419$ & $3,981,725$ & $3,410,265$ \\
\hline 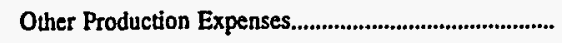 & 2,093 & 6,471 & 5,853 & 2,789 & 2,565 \\
\hline 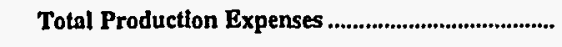 & $4,482,498$ & $4,275,332$ & $4,277,709$ & $3,984,514$ & $3,412,829$ \\
\hline 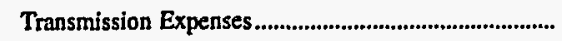 & 26,482 & 20,368 & 18,929 & 18,336 & 17,158 \\
\hline 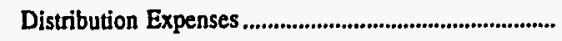 & 291,775 & 277,980 & 276,734 & 253,320 & 194,782 \\
\hline 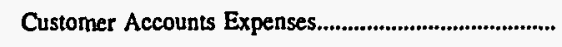 & 82,451 & 80,592 & 76,473 & 77,485 & 64,164 \\
\hline Customer Service and Information Expenses................. & 9,161 & 9,191 & 9,417 & 9,559 & 7,703 \\
\hline 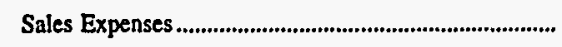 & 5,147 & 6,613 & 7,121 & 6,386 & 8,597 \\
\hline 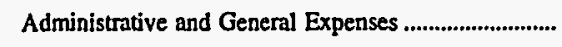 & 192,611 & 215,343 & 182,115 & 184,764 & 139,857 \\
\hline $\begin{array}{l}\text { Total Electric Operation } \\
\text { and Maintenance Expenses }\end{array}$ & $5,090,124$ & $4,885,419$ & $4,848,498$ & $4,534,363$ & $3,845,089$ \\
\hline \multicolumn{6}{|l|}{ Fuel Expenses in Operation } \\
\hline Steam Power Generation & - & - & - & - & - \\
\hline 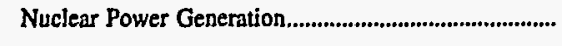 & - & - & - & - & - \\
\hline Other Power Generation & - & 124 & 13 & - & - \\
\hline \multicolumn{6}{|l|}{ Number of Elec Dept Ėmployees } \\
\hline Regular Full-time & 9,382 & 9,233 & 9,716 & 9,749 & 7,772 \\
\hline 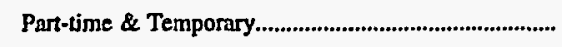 & 70 & 70 & 67 & 101 & 165 \\
\hline 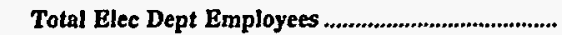 & 9,452 & 9,303 & $\mathbf{9 , 7 8 3}$ & 9,850 & $\mathbf{7 , 9 3 7}$ \\
\hline
\end{tabular}

Note: Totals may not equal sum of components because of independent rounding. The number of nongenerating publicly owned electric utilities for end of period is 140 for June 30, 1996; 144 for June 30, 1995; 144 for June 30, 1994; 142 for June 30, 1993; 137 for June 30, 1992. The City of Pella (IA) changed fiscal year from June 30 to December 31 in 1994; and the City of Burlington (VT) changed fiscal year from June 30 to December 31 in 1994; the City of Hagerstown (MD) changed fiscal year from December 31 to June 30 in 1993; and the City of Memphis (TN) and the City of LaFollette (TN) changed fiscal years from December 31 to June 30 in 1992. The City of Gaffney (SC), City of Osceola (AR), and City of Redding (CA) generators for 1991 through 1993, but became generators in 1994. The City of Kennetu (MO) and City of Morgan City (LA) were generators for 1991 through 1993, but became nongenerators in 1994. Emerald Peoples Utility District (OR), City of Bryan (OH), and Northern Wasco County PUD (OR) were nongenerators for ,but became generators in 1992.

Source: Energy Information Administration, Form ELA-412, "Annual Report of Public Electric Utilities." 
Table C25. Electric Utility Plant for Major U.S. Publicly Owned Nongenerator

Electric Utilities with Financial Year Ending on

June 30 at End of Period, 1992-1996

(Thousand Dollars)

\begin{tabular}{|c|c|c|c|c|c|}
\hline Item & 1996 & 1995 & 1994 & 1993 & 1992 \\
\hline \multicolumn{6}{|l|}{ Electric Plant in Service } \\
\hline 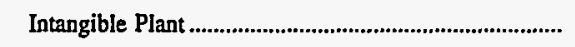 & 225 & - & 102 & 102 & 102 \\
\hline \multicolumn{6}{|l|}{ Production Plant } \\
\hline Steam & 45,472 & 61,798 & 44,786 & 53,463 & 41,649 \\
\hline 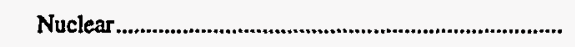 & - & - & - & - & - \\
\hline 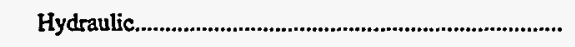 & - & 136,573 & - & - & - \\
\hline (n) & 11,446 & 42,807 & 19,549 & 13,151 & 12,615 \\
\hline 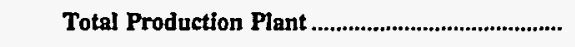 & 56,918 & 241,179 & 64,336 & 66,613 & 54,264 \\
\hline 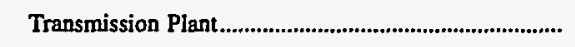 & 511,780 & 476,193 & 445,363 & 409,023 & 264,009 \\
\hline 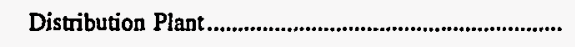 & $4,300,011$ & $4,079,094$ & $3,828,961$ & $3,595,158$ & $2,793,942$ \\
\hline 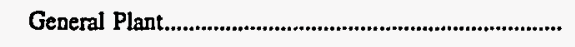 & 692,595 & 750,455 & 726,406 & 813,520 & 719,782 \\
\hline 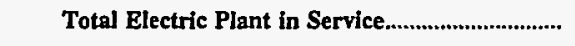 & $5,561,530$ & $5,546,921$ & $5,065,167$ & $4,884,416$ & $3,832,099$ \\
\hline 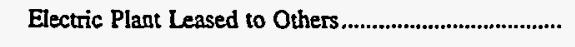 & 110 & 18,871 & - & 0 & - \\
\hline Construction Work in Progress - Electric.......................... & 223,196 & 182,996 & 137,145 & 151,064 & 131,760 \\
\hline Electric Plant Held for Future Use....................................... & 2,013 & 2,017 & 1,198 & 14,976 & 14,765 \\
\hline 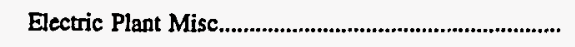 & 36,582 & 10,012 & 30,667 & 31,782 & 29,189 \\
\hline 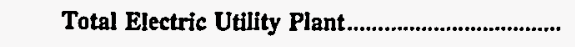 & $5,823,431$ & $5,760,816$ & $\mathbf{5}, 234,178$ & $5,082,237$ & $4,007,814$ \\
\hline $\begin{array}{l}\text { Accumulated Provision for } \\
\text { Depreciation and Amortization }\end{array}$ & $2,157,793$ & $2,130,817$ & $1,968,516$ & $1,866,469$ & $1,457,939$ \\
\hline Net Electric Utility Plant & $3,665,638$ & $3,629,999$ & $3,265,662$ & $3,215,769$ & $2,549,875$ \\
\hline
\end{tabular}

Note: Totals may not equal sum of components because of independent rounding. The number of nongenerating publicly owned electric utilities for end of period is 140 for June 30, 1996; 144 for June 30, 1995; 144 for June 30, 1994; 142 for June 30, 1993; 137 for June 30, 1992. The City of Pella (IA) changed fiscal year from June 30 to December 31 in 1994; and the City of Burlington (VT) changed fiscal year from June 30 to December 31 in 1994; the City of Hagerstown (MD) changed fiscal year from December 31 to June 30 in 1993; and the City of Memphis (TN) and the City of LaFollette (TN) changed fiscal years from December 31 to June 30 in 1992. The City of Gaffney (SC), City of Osceola (AR), and City of Redding (CA) generators for 1991 through 1993, but became generators in 1994. The City of Kennet (MO) and City of Morgan City (LA) were generators for 1991 through 1993, but became nongenerators in 1994. Emerald Peoples Utility District (OR), City of Bryan (OH), and Northern Wasco County PUD (OR) were nongenerators for ,but became generators in 1992.

Source: Energy Information Administration, Form EIA-412, "Annual Report of Public Electric Utilities." 
Table C26. Number of Consumers, Sales, and Operating Revenue for Major U.S. Publicly Owned Nongenerator Electric Utilities with

Financial Year Ending on June 30, 1992-1996

\begin{tabular}{|c|c|c|c|c|c|}
\hline Item & 1996 & 1995 & 1994 & 1993 & 1992 \\
\hline \multicolumn{6}{|l|}{ Number of Consumers } \\
\hline 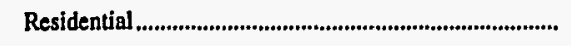 & $2,526,178$ & $2,557,864$ & $2,516,576$ & $2,483,259$ & $2,076,553$ \\
\hline 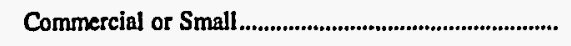 & 360,588 & 359,897 & 357,545 & 344,439 & 302,966 \\
\hline 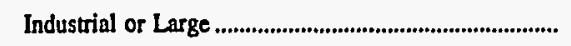 & 41,074 & 41,387 & 39,825 & 36,716 & 28,125 \\
\hline Other & 22,087 & 26,607 & 28,486 & 28,713 & 29,744 \\
\hline 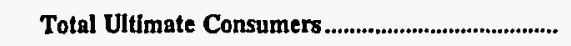 & $2,949,927$ & $2,985,755$ & $2,942,432$ & $2,893,127$ & $2,437,388$ \\
\hline \multicolumn{6}{|l|}{ Sales for the Year (mẹgawatthours) } \\
\hline Residential.................................................................................... & $35,897,291$ & $32,536,450$ & $34,215,665$ & $32,114,016$ & $26,477,707$ \\
\hline 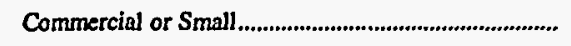 & $12,765,500$ & $12,661,614$ & $12,773,866$ & $12,317,727$ & $11,831,242$ \\
\hline 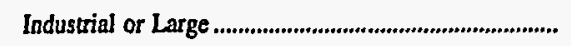 & $45,567,489$ & $46,176,156$ & $42,836,730$ & $40,115,218$ & $31,979,721$ \\
\hline 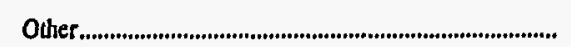 & $1,401,032$ & $1,440,092$ & $1,386,109$ & $1,501,485$ & $1,304,399$ \\
\hline 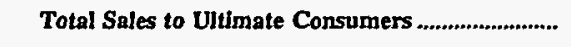 & $95,631,312$ & $92,814,312$ & $91,212,370$ & $86,048,446$ & $71,593,069$ \\
\hline 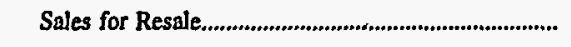 & $2,653,372$ & $2,274,495$ & $1,929,669$ & $1,611,743$ & $1,601,017$ \\
\hline 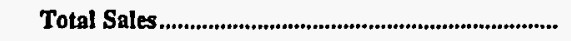 & $98,284,684$ & $95,088,807$ & $93,142,039$ & $87,660,189$ & $73,194,086$ \\
\hline \multicolumn{6}{|l|}{$\begin{array}{l}\text { Operating Revenues for the Year } \\
\text { (thousand dollars) }\end{array}$} \\
\hline 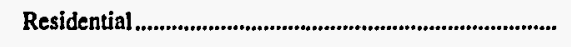 & $2,263,671$ & $2,066,393$ & $2,153,567$ & $1,995,684$ & $1,638,723$ \\
\hline 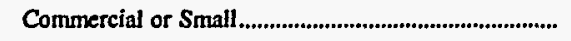 & 903,424 & 891,817 & 903,477 & 878,922 & 830,365 \\
\hline 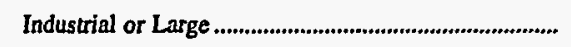 & $2,242,429$ & $2,313,456$ & $2,110,190$ & $2,027,104$ & $1,634,958$ \\
\hline 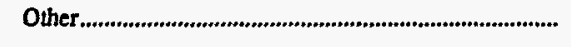 & 120,956 & 117,260 & 106,227 & 113,894 & 98,564 \\
\hline $\begin{array}{l}\text { Total Revenues from Sales to } \\
\text { Ultimnte Consumers................. }\end{array}$ & $5,530,480$ & $5,388,926$ & $5,273,461$ & $5,015,604$ & $4,202,610$ \\
\hline 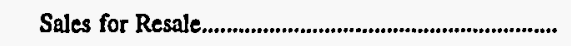 & 49,250 & 50,953 & 44,215 & 43,755 & 37,832 \\
\hline 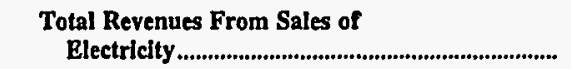 & $5,579,730$ & $5,439,879$ & $5,317,676$ & $5,059,359$ & $4,240,442$ \\
\hline
\end{tabular}

Note: Totals may not equal sum of components because of independent rounding. The number of nongenerating publicly owned electric utilities for end of period is 140 for June 30, 1996; 144 for June 30, 1995; 144 for June 30, 1994; 142 for June 30, 1993; 137 for June 30, 1992. The City of Pella (IA) changed fiscal year from June 30 to December 31 in 1994; and the City of Burlington (VT) changed fiscal year from June 30 to December 31 in 1994; the City of Hagerstown (MD) changed fiscal year from December 31 to June 30 in 1993; and the City of Memphis (TN) and the City of LaFollette (TN) changed fiscal years from December 31 to June 30 in 1992. The City of Gaffney (SC), City of Osceola (AR), and City of Redding (CA) generators for 1991 through 1993, but became generators in 1994. The City of Kennett (MO) and City of Morgan City (LA) were generators for 1991 through 1993, but became nongenerators in 1994, Emerald Peoples Utility District (OR), City of Bryan (OH), and Northern Wasco County PUD (OR) were nongenerators for ,but became generators in 1992. sions.

Source: Energy Information Administration, Form EIA-861, "Annual Electric Utility Report." Data are based on calendar year submis- 
Table C27. Electric Energy Account for Major U.S. Publicly Owned Nongenerator

Electric Utilities with Financial Year Ending on

June 30, 1992-1996

(Megawatthours)

\begin{tabular}{|c|c|c|c|c|c|c|}
\hline Item & 1996 & & 1995 & 1994 & 1993 & 1992 \\
\hline \multicolumn{7}{|l|}{ Sources of Energy } \\
\hline Steam & - & & - & - & - & - \\
\hline Nuclear & - & & - & - & - & - \\
\hline 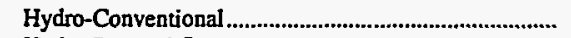 & - & & - & - & - & - \\
\hline 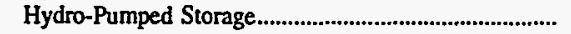 & - & & - & - & - & - \\
\hline Other & - & & - & - & - & - \\
\hline 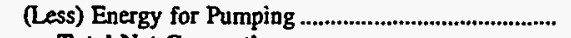 & - & & - & - & - & - \\
\hline Total Net Generation & - & & - & - & - & - \\
\hline 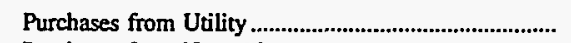 & $102,775,030$ & $\mathbf{R}$ & $93,232,430$ & $97,458,889$ & $91,646,505$ & $76,788,784$ \\
\hline $\begin{array}{l}\text { Purchases from Nonutility } \\
\text { Power Exchanges }\end{array}$ & 22,243 & & 482,969 & 16,213 & 2 & 2 \\
\hline 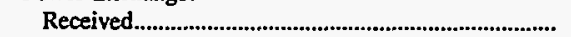 & 8,419 & & 8,433 & - & 3,314 & - \\
\hline Delivered & - & & - & - & 11,649 & - \\
\hline 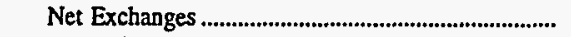 & 8,419 & & 8,433 & - & $-8,335$ & - \\
\hline \multicolumn{7}{|l|}{ Transmission for Others (Wheeling) } \\
\hline Received & 172,814 & & 583,703 & 351,967 & 304,378 & - \\
\hline 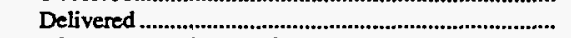 & 172,814 & & 243,121 & 351,967 & 300,448 & - \\
\hline 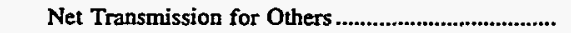 & - & & 340,582 & - & 3,930 & - \\
\hline 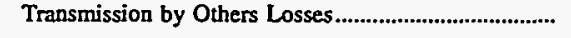 & - & & - & - & $-3,930$ & - \\
\hline \multicolumn{7}{|l|}{ Total Net Energy Generated and } \\
\hline 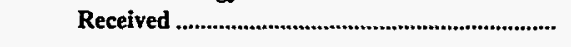 & $102,805,692$ & $\mathbf{R}$ & $94,064,414$ & $97,475,102$ & $91,638,172$ & $76,788,786$ \\
\hline \multicolumn{7}{|l|}{ Disposition of Energy } \\
\hline 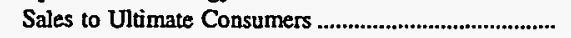 & $95,616,073$ & R & $88,485,509$ & $91,130,426$ & $85,534,702$ & $71,571,297$ \\
\hline 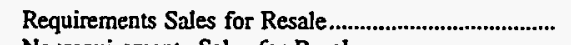 & $2,629,571$ & $\mathbf{R}$ & $1,736,491$ & $1,955,584$ & $1,517,540$ & $1,668,178$ \\
\hline Nonrequirements Sales for Resale & 53 & & - & - & - & 6,542 \\
\hline 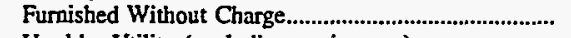 & 57,660 & & 86,864 & 110,975 & 78,854 & 51,491 \\
\hline 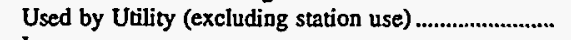 & 157,324 & & 176,605 & 100,833 & 126,866 & 112,766 \\
\hline 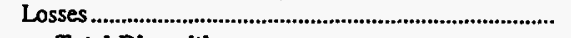 & $4,345,011$ & & $3,578,945$ & $4,177,289$ & $4,380,140$ & $3,378,453$ \\
\hline Total Disposition & $102,805,692$ & $\mathbf{R}$ & $94,064,414$ & $97,475,102$ & $91,638,172$ & $76,788,786$ \\
\hline
\end{tabular}

$R=$ Revised data

Note: Totals may not equal sum of components because of independent rounding. The number of nongenerating publicly owned electric utilities for end of period is 140 for June 30, 1996; 144 for June 30, 1995; 144 for June 30, 1994; 142 for June 30, 1993; 137 for June 30, 1992. The City of Pella (IA) changed fiscal year from June 30 to December 31 in 1994; and the City of Burlington (VT) changed fiscal year from June 30 to December 31 in 1994; the City of Hagerstown (MD) changed fiscal year from December 31 to June 30 in 1993; and the City of Memphis (TN) and the City of LaFollette (TN) changed fiscal years from December 31 to June 30 in 1992. The City of Gaffney (SC), City of Osceola (AR), and City of Redding (CA) generators for 1991 through 1993, but became generators in 1994. The City of Kennet (MO) and City of Morgan City (LA) were generators for 1991 through 1993, but became nongenerators in 1994. Emerald Peoples Utility District (OR), City of Bryan (OH), and Northern Wasco County PUD (OR) were nongenerators for ,but became generators in 1992. Source: Energy Information Administration, Form EIA-412, "Annual Report of Public Electric Utilities." 
Table C28. Ten Largest U.S. Publicly Owned Nongenerator Electric Utilities

Ranked by Megawatthour Sales to Ultimate Consumers with

Financial Year Ending on December 31, 1996

\begin{tabular}{|c|c|c|c|}
\hline Publicly Owned Electric Utilities & State & Amount & Percent \\
\hline 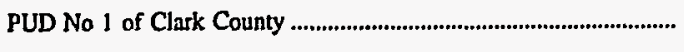 & Washington & $3,687,150$ & 11.10 \\
\hline 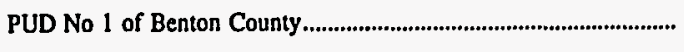 & Washington & $1,613,799$ & 4.86 \\
\hline 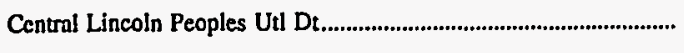 & Oregon & $1,254,698$ & 3.78 \\
\hline 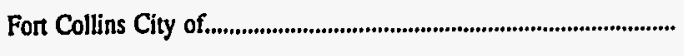 & Colorado & $1,009,068$ & 3.04 \\
\hline 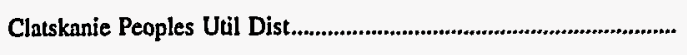 & Oregon & 875,736 & 2.64 \\
\hline 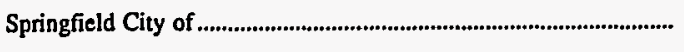 & Oregon & 845,575 & 2.55 \\
\hline 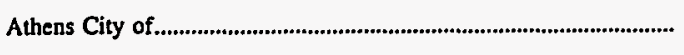 & Alabama & 734,622 & 2.21 \\
\hline 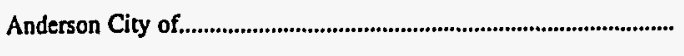 & Indiana & 683,832 & 2.06 \\
\hline 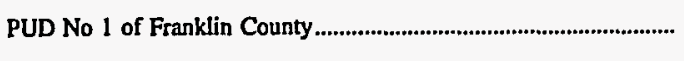 & Washington & 670,216 & 2.02 \\
\hline Richland City of & Washington & 649,732 & 1.96 \\
\hline 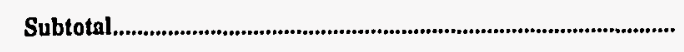 & & $12,024,428$ & 36.21 \\
\hline
\end{tabular}

Source: Energy Information Administration, Form EIA-412, "Annual Report of Public Electric Utilities."

Table C29. Ten Largest U.S. Publicly Owned Nongenerator Electric Utilities Ranked by Megawatthour Sales for Resale with Financial Year Ending on December 31, 1996

\begin{tabular}{|c|c|c|c|}
\hline Publicly Owned Electric Utilities & State & Amount & Percent \\
\hline 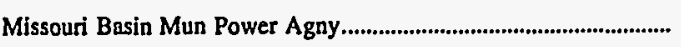 & South Dakota & $1,978,368$ & 67.75 \\
\hline 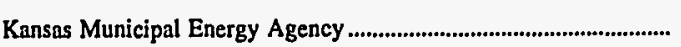 & Kansas & 293,506 & 10.05 \\
\hline 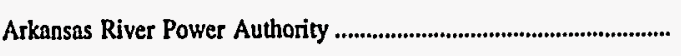 & Colorado & 286,209 & 9.80 \\
\hline 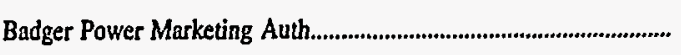 & Wisconsin & 282,054 & 9.66 \\
\hline Norris Public Power District .................... & Nebraska & 15,943 & .55 \\
\hline 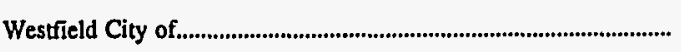 & Massachusetts & 15,012 & .51 \\
\hline 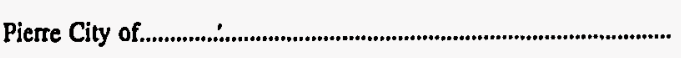 & South Dakota & 14,923 & .51 \\
\hline 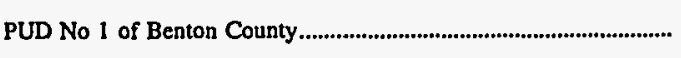 & Washington & 12,210 & .42 \\
\hline 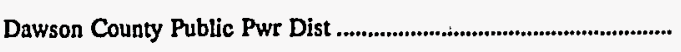 & Nebraska & 6,163 & .21 \\
\hline Cornhusker Public Power Dist ...................................................................... & Nebraska & 3,598 & .12 \\
\hline 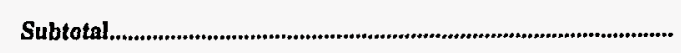 & & $2,907,986$ & 99.59 \\
\hline
\end{tabular}

Source: Energy Information Administration, Form EIA-412, "Annual Report of Public Electric Utilities." 
Table C30. Composite Statement of Income for Major U.S. Publicly Owned Nongenerator Electric Utilities with Financial Year Ending on December 31, 1992-1996

(Thousand Dollars)

\begin{tabular}{|c|c|c|c|c|c|}
\hline Item & 1996 & 1995 & 1994 & 1993 & 1992 \\
\hline 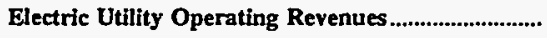 & $1,879,478$ & $1,977,474$ & $1,735,983$ & $1,629,821$ & $2,158,597$ \\
\hline 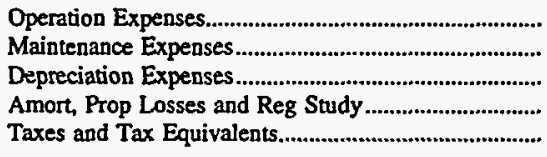 & $\begin{array}{r}1,544,451 \\
56,423 \\
91,235 \\
1,197 \\
64,683\end{array}$ & $\begin{array}{r}1,610,840 \\
55,945 \\
97,869 \\
1,367 \\
79,001\end{array}$ & $\begin{array}{r}1,428,431 \\
48,814 \\
82,297 \\
3,097 \\
52,911\end{array}$ & $\begin{array}{r}1,343,821 \\
46,241 \\
74,479 \\
2,168 \\
48,592\end{array}$ & $\begin{array}{r}1,833,153 \\
68,719 \\
87,335 \\
2,340 \\
56,344\end{array}$ \\
\hline 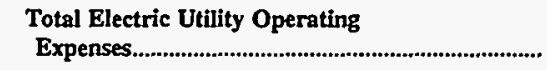 & $1,757,990$ & $1,845,022$ & $1,615,551$ & $1,515,301$ & $2,047,891$ \\
\hline 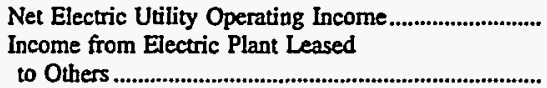 & $\begin{array}{r}121,489 \\
2,462\end{array}$ & $\begin{array}{r}132,452 \\
3,299\end{array}$ & $\begin{array}{r}120,432 \\
941\end{array}$ & $\begin{array}{r}114,520 \\
1,440\end{array}$ & $\begin{array}{r}110,707 \\
750\end{array}$ \\
\hline 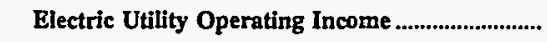 & 123,950 & 135,751 & 121,373 & 115,960 & 111,456 \\
\hline 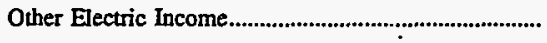 & 45,671 & 46,695 & 32,199 & 34,556 & 65,687 \\
\hline $\begin{array}{l}\text { Other Electric Deductions................................................. } \\
\text { Allowance for Other Funds Used }\end{array}$ & 11,952 & 10,205 & 14,718 & 8,155 & 23,319 \\
\hline 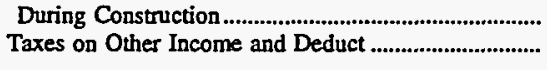 & $\begin{array}{r}21 \\
2,468\end{array}$ & $\begin{array}{r}9 \\
3,033\end{array}$ & $\begin{array}{r}32 \\
2,616\end{array}$ & $\begin{array}{r}87 \\
1,838\end{array}$ & $\begin{array}{r}21 \\
1,374\end{array}$ \\
\hline 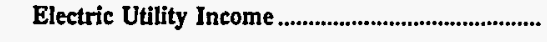 & 155,222 & 169,217 & 136,269 & 140,610 & 152,471 \\
\hline 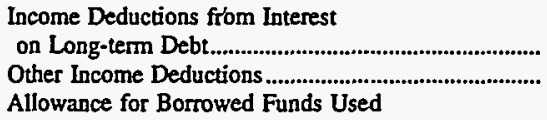 & $\begin{array}{r}25,561 \\
3,937\end{array}$ & $\begin{array}{r}40,547 \\
8,121\end{array}$ & $\begin{array}{r}30,434 \\
6,394\end{array}$ & $\begin{array}{l}30,060 \\
14,211\end{array}$ & $\begin{array}{r}46,371 \\
4,172\end{array}$ \\
\hline During Construction & -177 & -149 & -175 & -270 & -78 \\
\hline 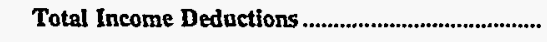 & 29,321 & 48,518 & 36,653 & 44,002 & 50,465 \\
\hline 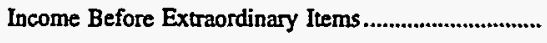 & 125,901 & 120,698 & 99,616 & 96,609 & 102,006 \\
\hline 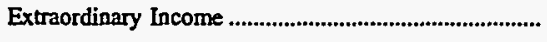 & 3,297 & 4,042 & 18,254 & 1,284 & 13,557 \\
\hline Extraordinary Deductions & 3,422 & 1,254 & 436 & 1,900 & 14,209 \\
\hline 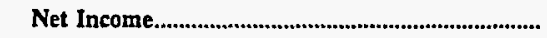 & 125,776 & 123,487 & 117,435 & 95,993 & 101,354 \\
\hline
\end{tabular}

Note: Totals may not equal sum of components because of independent rounding. The number of nongenerating publicly owned electric utilities for end of period is 97 for December 31, 1996; 106 for December 31, 1995; 95 for December 31, 1994; 95 for December 31, 1993; and 88 for December 31, 1992. The City of Pella (IA) changed fiscal year from June 30 to December 31 in 1994, and the City of Burlington (VT) changed fiscal year from December 31 to June 30 in 1994; the City of Hagerstown (MD) changed fiscal year from December 31 to June 30 in 1993; and the City of Memphis (TN) and the City of LaFollette (IN) changed fiscal years from December 31 to June 30 in 1992. The City of Gaffney (SC), City of Osceola (AR), and City of Redding (CA) were nongenerators for 1991 through 1993, but became generators in 1994. The City of Kennett (MO) and City of Morgan City (LA) were generators for 1991 through 1993, but became nongenerators in 1994. Emerald Peoples Utility District (OR), City of Bryan (OH), and Northern Wasco County PUD (OR) were nongenerators for 1991, but became generators in 1992.

Source: Energy Information Administration, Form EIA-412, "Annual Report of Public Electric Utilities." 
Table C31. Composite Balance Sheet for Major U.S. Publicly Owned Nongenerator Electric Utilities with Financial Year Ending on December 31 at End of Period, 1992-1996 (Thousand Dollars)

\begin{tabular}{|c|c|c|c|c|c|}
\hline Item & 1996 & 1995 & 1994 & 1993 & 1992 \\
\hline \multicolumn{6}{|l|}{ Electric Utility Plant } \\
\hline 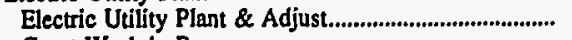 & $2,936,576$ & $2,984,283$ & $2,551,527$ & $2,354,689$ & $2,882,052$ \\
\hline 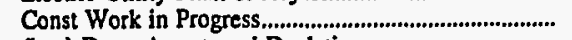 & 104,625 & 91,787 & 86,019 & 85,520 & 115,017 \\
\hline 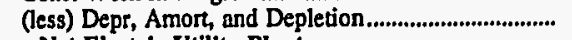 & $1,138,541$ & $1,149,397$ & 986,935 & 907,475 & $1,096,972$ \\
\hline 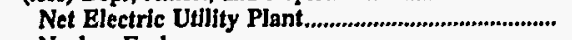 & $1,902,661$ & $1,926,673$ & $1,650,611$ & $1,532,734$ & $1,900,097$ \\
\hline 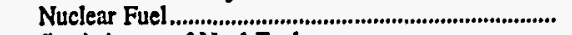 & - & 787 & - & - & - \\
\hline 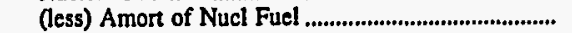 & - & - & - & - & - \\
\hline Net Elec Plant Incl Nucl Fuel ..................................... & $1,902,661$ & $1,927,460$ & $1,650,611$ & $1,532,734$ & $1,900,097$ \\
\hline \multicolumn{6}{|l|}{ Other Property \& Investments } \\
\hline Nonutility Property & 244,824 & 240,731 & 225,807 & 227,813 & 203,618 \\
\hline (less) Accum Provisions for Depr \& Amort.................. & 65,327 & 57,327 & 49,099 & 54,766 & 48,346 \\
\hline 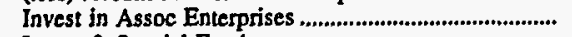 & 17,218 & 22,104 & 10,140 & 9,550 & 7,762 \\
\hline 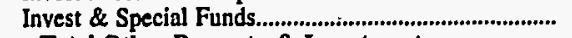 & 239,893 & 278,806 & 201,944 & 207,033 & 304,054 \\
\hline Total Other Property \& Investments ..................... & 436,609 & 484,314 & 388,793 & 389,631 & 467,088 \\
\hline \multicolumn{6}{|l|}{ Current and Accrued Assets } \\
\hline Cash, Working Funds \& Investments ............................. & 457,246 & 447,635 & 379,980 & 357,472 & 339,322 \\
\hline 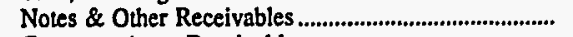 & 42,600 & 63,238 & 42,893 & 26,934 & 71,293 \\
\hline Customer Accts Receivable................................................ & 187,312 & 196,112 & 161,292 & 162,190 & 147,247 \\
\hline (less) Accum Prov for Uncollected Accts ................... & 8,563 & 8,058 & 7,068 & 7,801 & 8,016 \\
\hline 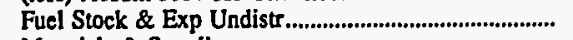 & 164 & 168 & 1,518 & 264 & 500 \\
\hline 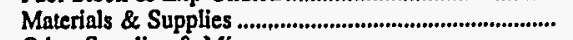 & 66,898 & 62,358 & 61,447 & 61,358 & 69,972 \\
\hline 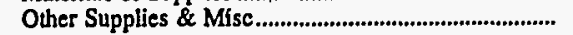 & 2,335 & 5,179 & - & - & - \\
\hline 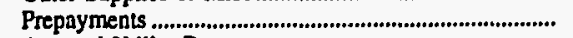 & 25,859 & 24,290 & 21,326 & 23,490 & 21,237 \\
\hline 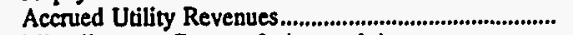 & 20,117 & 26,332 & 12,861 & 12,311 & 11,517 \\
\hline Miscellancous Current \& Accrued Assets .................... & 15,567 & 19,297 & 8,803 & 9,526 & 15,415 \\
\hline 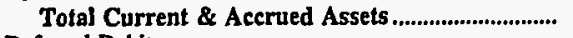 & 809,535 & 836,551 & 683,052 & 645,745 & 668,487 \\
\hline \multicolumn{6}{|l|}{ Deferred Debits } \\
\hline 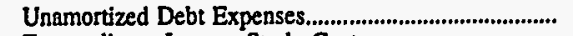 & 19,169 & 57,615 & 22,207 & 22,259 & 18,917 \\
\hline 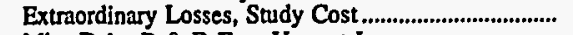 & 11,672 & 7,448 & 5,086 & 6,434 & 3,980 \\
\hline Misc Debt, $\dot{R} \&$ D Exp, Unamrt Losses............................ & 27,838 & 74,828 & 24,352 & 24,497 & 39,228 \\
\hline 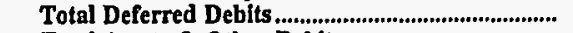 & 58,679 & 139,891 & 51,645 & $\mathbf{5 3 , 1 9 0}$ & 62,125 \\
\hline 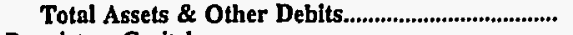 & $3,207,483$ & $3,388,217$ & $2,774,101$ & $2,621,300$ & $3,097,797$ \\
\hline \multicolumn{6}{|l|}{ Proprietary Capital } \\
\hline 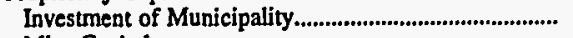 & 187,907 & 173,256 & 145,798 & 135,447 & 91,968 \\
\hline Misc Capital & 151,101 & 184,379 & 116,911 & 81,107 & 88,736 \\
\hline 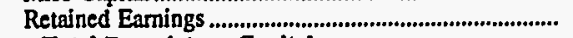 & $1,744,615$ & $1,610,246$ & $1,542,416$ & $1,471,780$ & $1,702,946$ \\
\hline 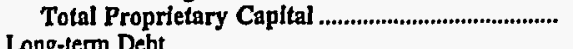 & $2,083,623$ & $1,967,881$ & $1,805,126$ & $1,688,335$ & $1,883,650$ \\
\hline \multicolumn{6}{|l|}{ Long-term Debt } \\
\hline 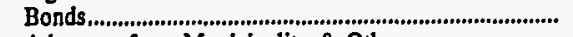 & 579,512 & 834,302 & 544,692 & 547,884 & 759,756 \\
\hline 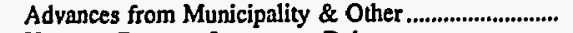 & 113,070 & 141,678 & 71,133 & 55,206 & 70,241 \\
\hline Unamort Prem on Long-term Debt .................................. & 4,639 & 2,295 & 2,681 & 2,398 & 2,791 \\
\hline (less) Unamort Discount on Long-term Debt............... & 7,137 & 2,563 & 2,783 & 2,151 & 1,481 \\
\hline 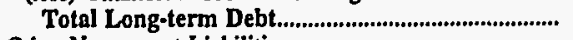 & 690,084 & 975,713 & 615,724 & 603,337 & 831,307 \\
\hline \multicolumn{6}{|l|}{ Other Noncurrent Liabilities } \\
\hline 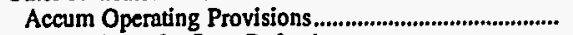 & 9,775 & 7,651 & 9,268 & 8,712 & 6,035 \\
\hline 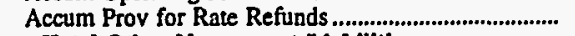 & - & 376 & 34 & 224 & - \\
\hline Total Other Noncurrent Liabllities........................... & 9,775 & 8,027 & 9,302 & 8,936 & 6,035 \\
\hline \multicolumn{6}{|l|}{ Current and Accrued Liabilities } \\
\hline 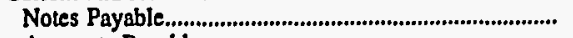 & 36,305 & 40,986 & 30,220 & 29,567 & 22,041 \\
\hline Accounts Payable & 156,858 & 166,823 & 153,115 & 149,460 & 190,881 \\
\hline 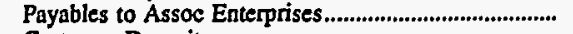 & 9,785 & 11,359 & 2,696 & 2,700 & 2,998 \\
\hline 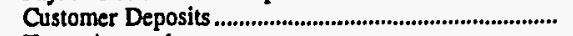 & 21,269 & 20,119 & 19,155 & 17,498 & 16,811 \\
\hline 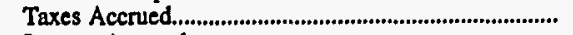 & 14,847 & 14,953 & 14,293 & 12,960 & 11,124 \\
\hline 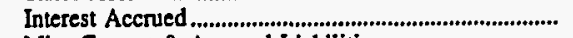 & 11,214 & 13,472 & 8,872 & 7,859 & 8,666 \\
\hline Misc Current \& Accrued Liabilities................................. & 43,493 & 46,823 & 38,341 & 35,012 & 40,286 \\
\hline Total Current \& Accrued Liabilities....................... & 293,769 & 314,535 & 266,693 & 255,055 & 292,806 \\
\hline \multicolumn{6}{|l|}{ Deferred Credits } \\
\hline Customer Advances for Construction ............................. & 73,634 & 43,191 & 44,785 & 43,169 & 35,813 \\
\hline Other Deferred Credits & 51,981 & 60,244 & 27,572 & 20,959 & 43,212 \\
\hline 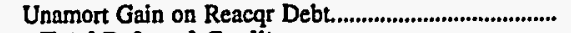 & 4,617 & 18,626 & 4,900 & 1,508 & 4,973 \\
\hline 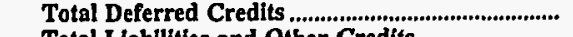 & 130,232 & 122,060 & 77,257 & 65,637 & 83,998 \\
\hline Total Llabilities and Other Credits.... & $3,207,483$ & $3,388,217$ & $2,774,101$ & $2,621,300$ & $3,097,797$ \\
\hline
\end{tabular}

Note: Totals may not equal sum of components because of independent rounding. The number of nongenerating publicly owned electric utilities for end of period is 97 for December 31, 1996; 106 for December 31, 1995; 95 for December 31, 1994; 95 for December 31, 1993; and 88 for December 31, 1992. The City of Pella (IA) changed fiscal year from June 30 to December 31 in 1994, and the City of Burlington (VT) changed fiscal year from December 31 to June 30 in 1994; the City of Hagerstown (MD) changed fiscal year from December 31 to June 30 in 1993; and the City of Memphis (TN) and the City of LaFollette (TN) changed fiscal years from December 31 to June 30 in 1992. The City of Gaffney (SC), City of Osceola (AR), and City of Redding (CA) were nongenerators for 1991 through 1993, but became generntors in 1994. The City of Kennett (MO) and City of Morgan City (LA) were generators for 1991 through 1993, but became nongenerators in 1994. Emerald Peoples Utility District (OR), City of Bryan (OH), and Northerm Wasco County PUD (OR) were nongenerators for 1991, but became generators in 1992

Source: Energy Information Administration, Form EIA-412, “Annual Report of Public Electric Utilities." 
Table C32. Composite Financial Indicators for Major U.S. Publicly Owned Nongenerator Electric Utilities with Financial Year Ending on

December 31, 1992-1996

\begin{tabular}{|c|c|c|c|c|c|}
\hline Item & 1996 & 1995 & 1994 & 1993 & 1992 \\
\hline Total Electric Utility Plant per Dollar of Revenue & 1.6 & 1.6 & 1.5 & 1.5 & 1.4 \\
\hline 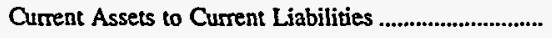 & 2.8 & 2.7 & 2.6 & 2.5 & 2.3 \\
\hline 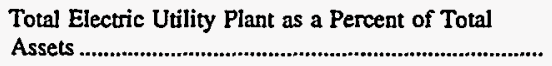 & 94.8 & 90.8 & 95.1 & 93.1 & 96.7 \\
\hline Net Electric Utility Plant as a Percent of Total & & & & & \\
\hline Assets & 59.3 & 56.9 & 59.5 & 58.5 & 61.3 \\
\hline 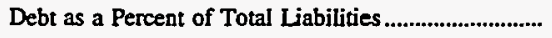 & 30.7 & 38.1 & 31.8 & 32.7 & 36.3 \\
\hline $\begin{array}{l}\text { Depreciation, Amortization and Depletion } \\
\text { as a Percent of Total Electric Utility Plant ................... }\end{array}$ & 37.4 & 37.4 & 37.4 & 37.2 & 36.6 \\
\hline 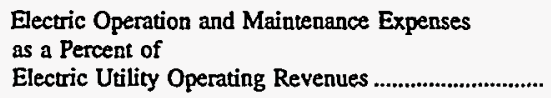 & 85.2 & 84.3 & 85.1 & 85.3 & 88.1 \\
\hline 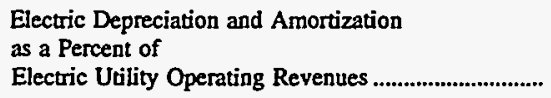 & 4.9 & 4.9 & 4.7 & 4.6 & 4.0 \\
\hline $\begin{array}{l}\text { Taxes and Tax Equivalents } \\
\text { as a Percent of } \\
\text { Electric Utility Operating Revenues }\end{array}$ & 3.4 & 4.0 & 3.0 & 3.0 & 2.6 \\
\hline $\begin{array}{l}\text { Interest on Long-term Debt } \\
\text { as a Percent of } \\
\text { Electric Utility Operating Revenues.............................. }\end{array}$ & 1.4 & 2.1 & 1.8 & 1.8 & 2.1 \\
\hline 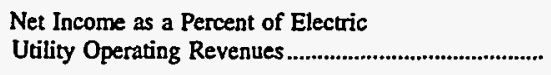 & 6.7 & 6.2 & 6.8 & 5.9 & 4.7 \\
\hline Purchased Power Cents Per Kilowatthour ...................... & 3.3 & 3.6 & 3.5 & 3.3 & 3.6 \\
\hline
\end{tabular}

Note: Totals may not equal sum of components because of independent rounding. The number of nongenerating publicly owned electric utilities for end of period is 97 for December 31, 1996; 106 for December 31, 1995; 95 for December 31, 1994; 95 for December 31, 1993; and 88 for December 31, 1992. The City of Pella (IA) changed fiscal year from June 30 to December 31 in 1994, and the City of Burlington (VT) changed fiscal year from December 31 to June 30 in 1994; the City of Hagerstown (MD) changed fiscal year from December 31 to June 30 in 1993; and the City of Memphis (TN) and the City of LaFollette (IN) changed fiscal years from December 31 to June 30 in 1992. The City of Gaffney (SC), City of Osceola (AR), and City of Redding (CA) were nongenerators for 1991 through 1993, but became generators in 1994. The City of Kennett (MO) and City of Morgan City (LA) were generators for 1991 through 1993, but became nongenerators in 1994. Emerald Peoples Utility District (OR), City of Bryan (OH), and Northern Wasco County PUD (OR) were nongenerators for 1991, but became generators in 1992.

Source: Energy Information Administration, Form EIA-412, "Annual Report of Public Electric Utilities." 
Table C33. Electric Operation and Maintenance Expenses for Major U.S.

Publicly Owned Nongenerator Electric Utilities with

Financial Year Ending on December 31, 1992-1996

(Thousand Dollars)

\begin{tabular}{|c|c|c|c|c|c|}
\hline Item & 1996 & 1995 & 1994 & 1993 & 1992 \\
\hline \multicolumn{6}{|l|}{ Production Expenses } \\
\hline 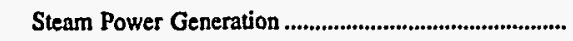 & 78 & 967 & 284 & 362 & 416 \\
\hline 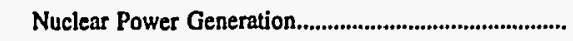 & - & - & - & - & - \\
\hline 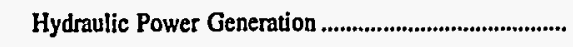 & 13 & 19 & 11 & 9 & 1 \\
\hline 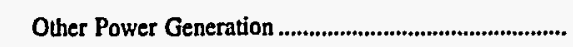 & 15,062 & 8,996 & 1,063 & 1,249 & 622 \\
\hline 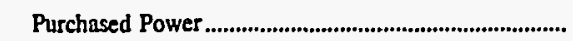 & $1,247,764$ & $1,359,541$ & $1,222,573$ & $1,140,781$ & $1,579,889$ \\
\hline 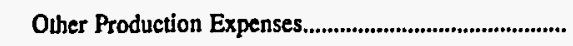 & 55,897 & 17,112 & 6,605 & 8,113 & 4,576 \\
\hline 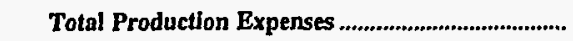 & $1,318,813$ & $1,386,635$ & $1,230,536$ & $1,150,514$ & $1,585,505$ \\
\hline Transmission Expenses......................................................... & 25,447 & 19,761 & 21,067 & 19,145 & 22,387 \\
\hline 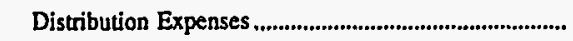 & 111,826 & 114,258 & 95,362 & 97,151 & 134,814 \\
\hline 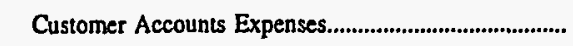 & 37,138 & 35,612 & 33,948 & 33,441 & 38,622 \\
\hline Customer Service and Information Expenses................ & 7,021 & 6,726 & 5,699 & 5,753 & 6,113 \\
\hline 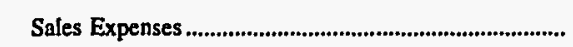 & 6,293 & 2,765 & 2,649 & 2,167 & 2,495 \\
\hline 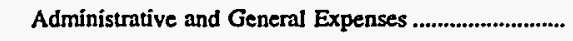 & 94,336 & 101,029 & 87,985 & 81,871 & 111,937 \\
\hline $\begin{array}{l}\text { Total Electric Operation } \\
\text { and Maintenance Expenses ........................................ }\end{array}$ & $1,600,874$ & $1,666,785$ & $1,477,246$ & $1,390,042$ & $1,901,872$ \\
\hline \multicolumn{6}{|l|}{ Fuel Expenses in Operation } \\
\hline 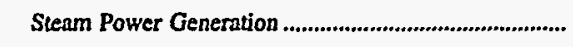 & - & 124 & - & 2 & 13 \\
\hline 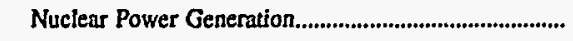 & - & - & - & - & - \\
\hline 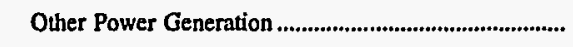 & - & -2 & - & 13 & 5 \\
\hline \multicolumn{6}{|l|}{ Number of Elec Dept Employees } \\
\hline 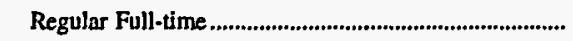 & 3,774 & 3,787 & 3,764 & 3,714 & 5,493 \\
\hline 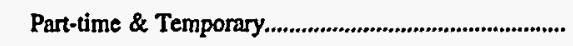 & 244 & 224 & 269 & 911 & 870 \\
\hline 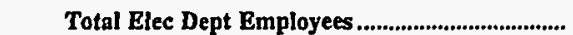 & 4,018 & 4,011 & 4,033 & 4,625 & 6,363 \\
\hline
\end{tabular}

Note: Totals may not equal sum of components because of independent rounding. The number of nongenerating publicly owned electric utilities for end of period is 97 for December 31, 1996; 106 for December 31, 1995; 95 for December 31, 1994; 95 for December 31, 1993; and 88 for December 31, 1992. The City of Pella (IA) changed fiscal year from June 30 to December 31 in 1994, and the City of Burlington (VT) changed fiscal year from December 31 to June 30 in 1994; the City of Hagerstown (MD) changed fiscal year from December 31 to June 30 in 1993; and the City of Memphis (TN) and the City of LaFollette (TN) changed fiscal years from December 31 to June 30 in 1992. The City of Gaffney (SC), City of Osceola (AR), and City of Redding (CA) were nongenerators for 1991 through 1993, but became generators in 1994. The City of Kennett (MO) and City of Morgan City (LA) were generators for 1991 through 1993, but became nongenerators in 1994. Emerald Peoples Utility District (OR), City of Bryan (OH), and Northern Wasco County PUD (OR) were nongenerators for 1991, but became generators in 1992.

Source: Energy Information Administration, Form EIA-412, "Annual Report of Public Electric Uuilities." 
Table C34. Electric Utility Plant for Major U.S. Publicly Owned Nongenerator

Electric Utilities with Financial Year Ending on

December 31 at End of Period, 1992-1996

(Thousand Dollars)

\begin{tabular}{|c|c|c|c|c|c|}
\hline Item & 1996 & 1995 & 1994 & 1993 & 1992 \\
\hline \multicolumn{6}{|l|}{ Electric Plant in Service } \\
\hline 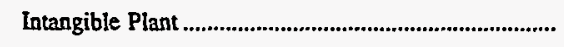 & 5,957 & 6,871 & 5,929 & 10,181 & 10,091 \\
\hline \multicolumn{6}{|l|}{ Production Plant } \\
\hline Steam & 35,165 & 43,051 & 34,995 & 16,298 & 28,078 \\
\hline 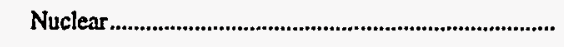 & - & - & - & - & - \\
\hline 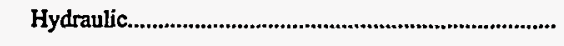 & 588 & 112,386 & 588 & 582 & 582 \\
\hline Other & 19,578 & 19,353 & 15,701 & 13,931 & 6,369 \\
\hline 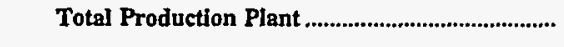 & 55,331 & 174,790 & 51,283 & 30,811 & 35,029 \\
\hline Transmission Plant............ & 217,605 & 273,202 & 184,372 & 157,091 & 287,707 \\
\hline 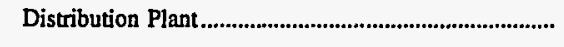 & $2,129,110$ & $1,967,739$ & $1,848,637$ & $1,752,874$ & $2,129,995$ \\
\hline General Plant & 465,393 & 513,423 & 416,677 & 359,138 & 376,397 \\
\hline 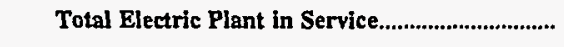 & $2,873,396$ & $2,936,023$ & $2,506,898$ & $2,310,095$ & $2,839,219$ \\
\hline 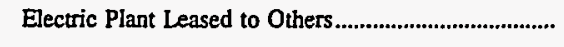 & 1,460 & 755 & 745 & 704 & 615 \\
\hline Construction Work in Progress - Electric........................ & 104,625 & 91,787 & 86,019 & 85,520 & 115,017 \\
\hline Electric Plant Held for Future Use...................................... & 10,297 & 10,426 & 9,871 & 1,292 & 1,309 \\
\hline 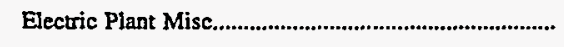 & 51,422 & 37,079 & 34,013 & 42,599 & 40,909 \\
\hline 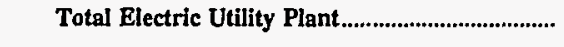 & $3,041,201$ & $3,076,070$ & $2,637,546$ & $2,440,209$ & $2,997,069$ \\
\hline $\begin{array}{l}\text { Accumulated Provision for } \\
\text { Depreciation and Amortization ..................................... }\end{array}$ & $1,138,541$ & $1,149,397$ & 986,935 & 907,475 & $1,096,972$ \\
\hline 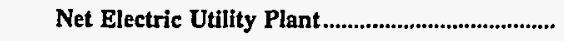 & $1,902,661$ & $1,926,673$ & $1,650,611$ & $1,532,734$ & $1,900,097$ \\
\hline
\end{tabular}

Note: Totals may not equal sum of components because of independent rounding. The number of nongenerating publicly owned electric utilities for end of period is 97 for December 31, 1996; 106 for December 31, 1995; 95 for December 31, 1994; 95 for December 31,

1993; and 88 for December 31, 1992. The City of Pella (IA) changed fiscal year from June 30 to December 31 in 1994, and the City of Burlington (VT) changed fiscal year from December 31 to June 30 in 1994; the City of Hagerstown (MD) changed fiscal year from December 31 to June 30 in 1993; and the City of Memphis (TN) and the City of LaFollette (TN) changed fiscal years from December 31 to June 30 in 1992. The City of Gaffney (SC), City of Osceola (AR), and City of Redding (CA) were nongenerators for 1991 through 1993, but became generators in 1994. The City of Kennett (M0) and City of Morgan City (LA) were generators for 1991 through 1993, but became nongenerators in 1994. Emerald Peoples Utility District (OR), City of Bryan (OH), and Northern Wasco County PUD (OR) were nongenerators for 1991, but became generators in 1992.

Source: Energy Information Administration, Form ELA-412, "Annual Report of Public Electric Utilities." 
Table C35. Number of Consumers, Sales, and Operating Revenue for Major

U.S. Publicly Owned Nongenerator Electric Utilities with

Financial Year Ending on December 31, 1992-1996

\begin{tabular}{|c|c|c|c|c|c|}
\hline Item & 1996 & 1995 & 1994 & 1993 & 1992 \\
\hline \multicolumn{6}{|l|}{ Number of Consumers } \\
\hline 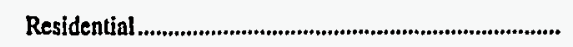 & $1,050,200$ & $1,068,368$ & 991,878 & 959,670 & $1,252,787$ \\
\hline 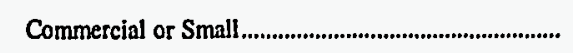 & 133,148 & 132,839 & 127,666 & 118,845 & 143,672 \\
\hline 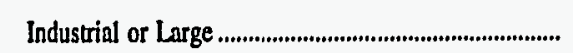 & 8,347 & 8,639 & 8,525 & 8,683 & 14,306 \\
\hline Other & 45,551 & 43,298 & 33,200 & 35,169 & 49,680 \\
\hline 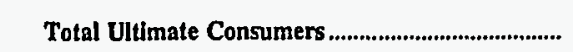 & $1,237,246$ & $1,253,144$ & $1,161,269$ & $1,122,367$ & $1,460,445$ \\
\hline \multicolumn{6}{|l|}{ Sales for the Year (megawatthours) } \\
\hline 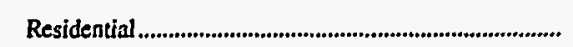 & $12,882,562$ & $12,620,247$ & $11,779,639$ & $11,728,301$ & $15,090,546$ \\
\hline 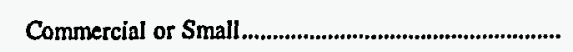 & $8,638,786$ & $8,114,055$ & $7,443,714$ & $6,937,032$ & $7,259,565$ \\
\hline 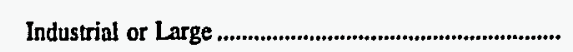 & $11,144,601$ & $11,779,846$ & $10,610,208$ & $10,315,963$ & $15,685,347$ \\
\hline Other & 971,343 & $1,028,996$ & 938,474 & 783,628 & $1,250,985$ \\
\hline 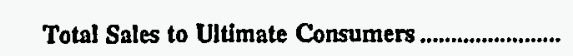 & $33,637,292$ & $33,543,144$ & $30,772,035$ & $29,764,924$ & $39,286,443$ \\
\hline 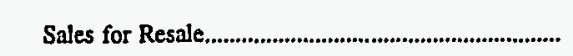 & $2,919,384$ & $4,168,582$ & $2,785,813$ & $2,725,475$ & $2,881,020$ \\
\hline Total Sales................................................................. & $36,556,676$ & $37,711,726$ & $33,557,848$ & $32,490,399$ & $42,167,463$ \\
\hline \multicolumn{6}{|l|}{$\begin{array}{l}\text { Operating Revenues for the Year } \\
\text { (thousand dollars) }\end{array}$} \\
\hline 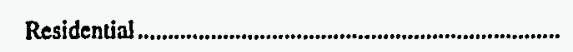 & 748,017 & 746,501 & 686,077 & 651,990 & 851,333 \\
\hline 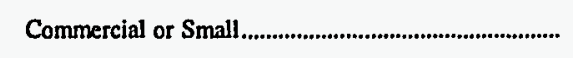 & 460,688 & 451,333 & 416,137 & 376,440 & 399,907 \\
\hline 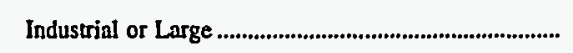 & 494,655 & 523,081 & 469,267 & 450,122 & 726,419 \\
\hline 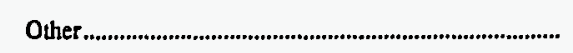 & 60,899 & 64,824 & 56,992 & 49,644 & 71,459 \\
\hline $\begin{array}{l}\text { Total Revenues from Sales to } \\
\text { Ultimate Consumers................. }\end{array}$ & $1,764,259$ & $1,785,739$ & $1,628,473$ & $1,528,196$ & $2,049,118$ \\
\hline 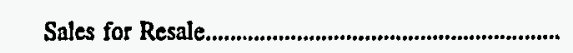 & 93,105 & 175,171 & 90,366 & 84,259 & 79,291 \\
\hline 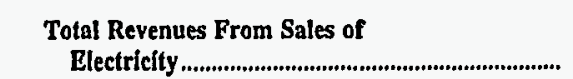 & $1,857,364$ & $1,960,910$ & $1,718,839$ & $1,612,455$ & $2,128,409$ \\
\hline
\end{tabular}

Note: Totals may not equal sum of components because of independent rounding. The number of nongenerating publicly owned electric utilities for end of period is 97 for December 31, 1996; 106 for December 31, 1995; 95 for December 31, 1994; 95 for December 31, 1993; and 88 for December 31, 1992. The City of Pella (IA) changed fiscal year from June 30 to December 31 in 1994, and the City of Burlington (VT) changed fiscal year from December 31 to June 30 in 1994; the City of Hagerstown (MD) changed fiscal year from December 31 to June 30 in 1993; and the City of Memphis (TN) and the City of LaFollette (TN) changed fiscal years from December 31 to June 30 in 1992. The City of Gaffney (SC), City of Osceola (AR), and City of Redding (CA) were nongenerators for 1991 through 1993, but became generators in 1994. The City of Kennet (MO) and City of Morgan City (LA) were generators for 1991 through 1993, but became nongenerators in 1994. Emerald Peoples Utility District (OR), City of Bryan (OH), and Northern Wasco County PUD (OR) were nongenerators for 1991, but became generators in 1992.

Source: Energy Information Administration, Form EIA-861. “Annual Electric Utility Report." Data are based on calendar year submisșions. 
Table C36. Electric Energy Account for Major U.S. Publicly Owned

Nongenerator Electric Utilities with Financial Year

Ending on December 31, 1992-1996

(Megawatthours)

\begin{tabular}{|c|c|c|c|c|c|}
\hline Item & 1996 & 1995 & 1994 & 1993 & 1992 \\
\hline \multicolumn{6}{|l|}{ Sources of Energy } \\
\hline Steam & - & - & - & - & - \\
\hline 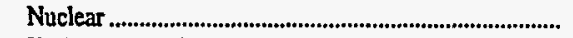 & - & - & - & - & - \\
\hline 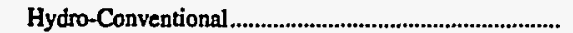 & - & - & - & - & - \\
\hline 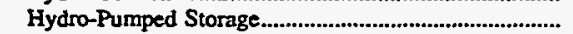 & - & - & - & - & - \\
\hline Other & - & - & - & - & - \\
\hline 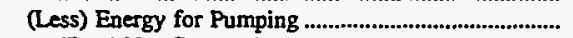 & - & - & - & - & - \\
\hline Total Net Generation & - & - & - & - & - \\
\hline 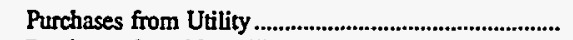 & $36,010,499$ & $36,909,610$ & $34,770,562$ & $33,801,100$ & $43,971,877$ \\
\hline $\begin{array}{l}\text { Purchases from Nonutility.................................................... } \\
\text { Power Exchanges }\end{array}$ & $1,852,686$ & 413,271 & 176,000 & 156,083 & 160,421 \\
\hline 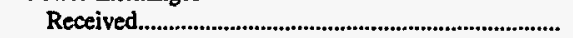 & 492,149 & 639,820 & 505,977 & 325,173 & 363,092 \\
\hline Delivered & 196,249 & 126,371 & 163,845 & 116,248 & 158,997 \\
\hline 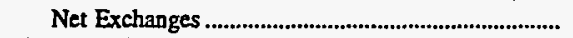 & 295,900 & 513,449 & 342,132 & 208,926 & 204,095 \\
\hline \multicolumn{6}{|l|}{ Transmission for Others (Wheeling) } \\
\hline 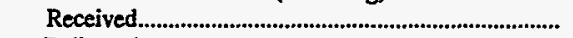 & 3,598 & 2,601 & - & 7,476 & 1,986 \\
\hline 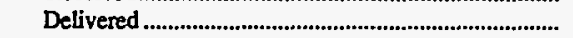 & 3,598 & 2,601 & - & 7,476 & 1,986 \\
\hline 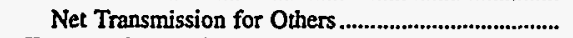 & - & - & - & - & - \\
\hline 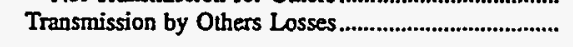 & $-17,756$ & $-31,053$ & $-2,416$ & - & -220 \\
\hline \multicolumn{6}{|l|}{ Total Net Energy Generated and } \\
\hline Received & $38,141,329$ & $37,805,277$ & $35,286,279$ & $34,166,108$ & $44,336,172$ \\
\hline \multicolumn{6}{|l|}{ Disposition of Energy } \\
\hline Sales to Ultimate Consumers & $33,204,356$ & $32,004,172$ & $30,772,100$ & $29,773,216$ & $39,282,927$ \\
\hline 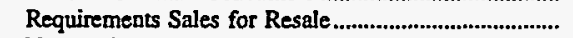 & $2,099,092$ & $3,408,526$ & $1,645,780$ & $1,806,499$ & $1,459,980$ \\
\hline 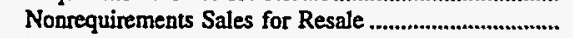 & 820,846 & 756,760 & 857,994 & 918,823 & $1,420,967$ \\
\hline 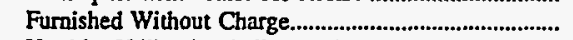 & 89,069 & 91,052 & 87,554 & 106,278 & 77,698 \\
\hline 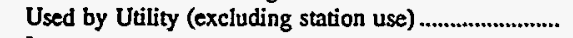 & 70,273 & 62,467 & 52,972 & 58,697 & 57,199 \\
\hline Losses & $1,857,693$ & $1,482,300$ & $1,587,845$ & $1,502,590$ & $2,037,395$ \\
\hline 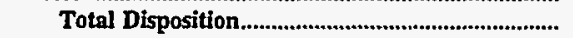 & $38,141,329$ & $37,805,277$ & $35,286,279$ & $34,166,108$ & $44,336,172$ \\
\hline
\end{tabular}

- Data not available.

Note: Totals may not equal sum of components because of independent rounding. The number of nongenerating publicly owned electric utilities for end of period is 97 for December 31, 1996; 106 for December 31, 1995; 95 for December 31, 1994; 95 for December 31, 1993; and 88 for December 31, 1992. The City of Pella (LA) changed fiscal year from June 30 to December 31 in 1994, and the City of Burlington (VT) changed fiscal year from December 31 to June 30 in 1994; the City of Hagerstown (MD) changed fiscal year from December 31 to June 30 in 1993; and the City of Memphis (TN) and the City of LaFollette (TN) changed fiscal years from December 31 to June 30 in 1992. The City of Gaffney (SC), City of Osceola (AR), and City of Redding (CA) were nongenerators for 1991 through 1993, but became generators in 1994. The City of Kennett (MO) and City of Morgan City (LA) were generators for 1991 through 1993, but became nongenerators in 1994. Emerald Peoples Utility District (OR), City of Bryan (OH), and Northern Wasco County PUD (OR) were nongenerators for 1991, but became generators in 1992.

Source: Energy Information Administration, Form EIA-412, "Annual Report of Public Electric Utilities." 
Table C37. Twenty Largest U.S. Publicly Owned Electric Utilities Ranked by Megawatthour Sales to Ultimate Consumers

for All Respondents, 1996

\begin{tabular}{|c|c|c|c|}
\hline Publicly Owned Electric Utilities & State & Amount & Reporting Date \\
\hline 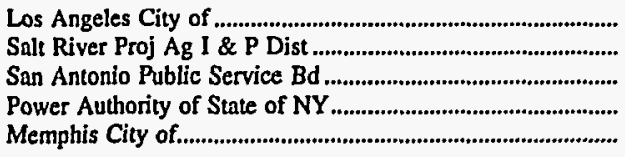 & $\begin{array}{l}\text { California } \\
\text { Arizona } \\
\text { Texas } \\
\text { New York } \\
\text { Tennessee }\end{array}$ & $\begin{array}{l}21,233,474 \\
17,634,028 \\
14,595,910 \\
13,017,530 \\
12,577,300\end{array}$ & $\begin{array}{l}\text { June } 30 \\
\text { April } 30 \\
\text { January } 31 \\
\text { December } 31 \\
\text { June } 30\end{array}$ \\
\hline 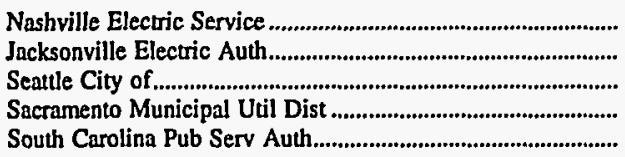 & $\begin{array}{l}\text { Tennessee } \\
\text { Florida } \\
\text { Washington } \\
\text { California } \\
\text { South Carolina }\end{array}$ & $\begin{array}{r}11,262,557 \\
9,753,452 \\
9,188,000 \\
8,889,261 \\
8,209,218\end{array}$ & $\begin{array}{l}\text { June } 30 \\
\text { September } 30 \\
\text { December } 31 \\
\text { December } 31 \\
\text { December } 31\end{array}$ \\
\hline 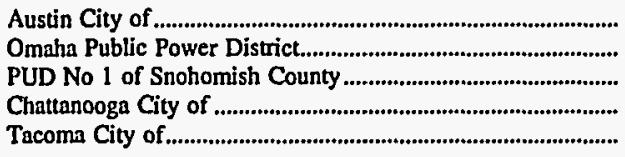 & $\begin{array}{l}\text { Texas } \\
\text { Nebraska } \\
\text { Washington } \\
\text { Teanessee } \\
\text { Washington }\end{array}$ & $\begin{array}{l}8,138,417 \\
7,756,491 \\
7,158,031 \\
5,764,479 \\
5,471,096\end{array}$ & $\begin{array}{l}\text { September } 30 \\
\text { December } 31 \\
\text { December } 31 \\
\text { June } 30 \\
\text { December } 31\end{array}$ \\
\hline 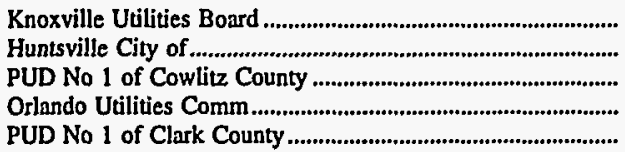 & $\begin{array}{l}\text { Tennessee } \\
\text { Alabama } \\
\text { Washington } \\
\text { Florida } \\
\text { Washington }\end{array}$ & $\begin{array}{l}5,184,292 \\
4,107,294 \\
4,033,060 \\
4,031,190 \\
3,687,150\end{array}$ & $\begin{array}{l}\text { June } 30 \\
\text { September } 30 \\
\text { December } 31 \\
\text { September } 30 \\
\text { December } 31\end{array}$ \\
\hline
\end{tabular}

Source: Energy Information Administration, Form EIA-412, “Annual Report of Public Electric Utilities.” Individual electric utilities report fiscal year data. Appendix $B$ shows the fiscal year for each electric utility.

Table C38. Twenty Largest U.S. Publicly Owned Electric Utilities Ranked by Megawatthour Sales for Resale for All Respondents, 1996

\begin{tabular}{|c|c|c|c|}
\hline Publicly Owned Electric Utilities & State & Amount & Reporting Date \\
\hline 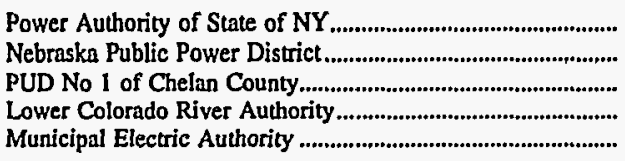 & $\begin{array}{l}\text { New York } \\
\text { Nebraska } \\
\text { Washington } \\
\text { Texas } \\
\text { Georgia }\end{array}$ & $\begin{array}{l}27,555,179 \\
24,235,179 \\
10,845,639 \\
10,645,538 \\
10,264,912\end{array}$ & $\begin{array}{l}\text { December } 31 \\
\text { December } 31 \\
\text { December } 31 \\
\text { June } 30 \\
\text { December } 31\end{array}$ \\
\hline 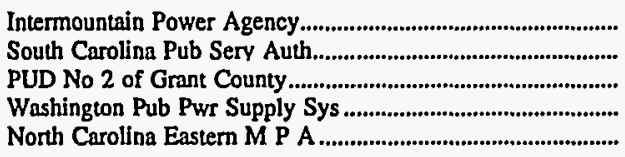 & $\begin{array}{l}\text { Utah } \\
\text { South Carolina } \\
\text { Washington } \\
\text { Washington } \\
\text { North Carolina }\end{array}$ & $\begin{array}{l}9,760,982 \\
9,339,589 \\
8,482,068 \\
7,780,202 \\
6,709,020\end{array}$ & $\begin{array}{l}\text { June } 30 \\
\text { December } 31 \\
\text { December } 31 \\
\text { June } 30 \\
\text { December } 31\end{array}$ \\
\hline 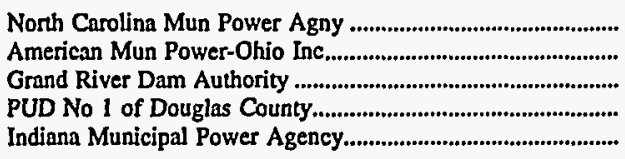 & $\begin{array}{l}\text { North Carolina } \\
\text { Ohio } \\
\text { Oklahoma } \\
\text { Washington } \\
\text { Indiana }\end{array}$ & $\begin{array}{l}6,556,548 \\
4,984,129 \\
4,610,810 \\
4,517,480 \\
4,385,743\end{array}$ & $\begin{array}{l}\text { December } 31 \\
\text { December } 31 \\
\text { December } 31 \\
\text { December } 31 \\
\text { December } 31\end{array}$ \\
\hline 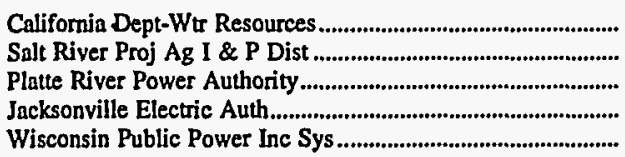 & $\begin{array}{l}\text { California } \\
\text { Arizona } \\
\text { Colorado } \\
\text { Florida } \\
\text { Wisconsin }\end{array}$ & $\begin{array}{l}4,313,258 \\
4,202,520 \\
3,913,734 \\
3,577,813 \\
3,366,507\end{array}$ & $\begin{array}{l}\text { June } 30 \\
\text { April } 30 \\
\text { December } 31 \\
\text { September } 30 \\
\text { December } 31\end{array}$ \\
\hline
\end{tabular}

Source: Energy Information Administration, Form EIA-412, "Annual Report of Public Electric Utilities." Individual electric utilities report fiscal year data. Appendix B shows the fiscal year for each electric utility. 
Table C39. Twenty Largest U.S. Publicly Owned Electric Utilities Ranked by Electric Utility Revenues for All Respondents, 1996

(Thousand Dollars)

\begin{tabular}{|c|c|c|c|}
\hline Publicly Owned Electric Utilities & State & Amount & Reporting Date \\
\hline 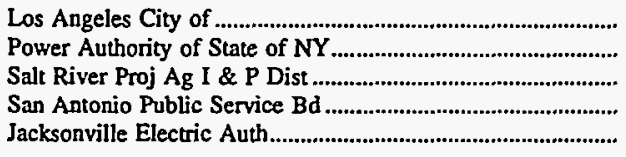 & $\begin{array}{l}\text { California } \\
\text { New York } \\
\text { Arizona } \\
\text { Texas } \\
\text { Florida }\end{array}$ & $\begin{array}{r}1,946,851 \\
1,430,150 \\
1,347,496 \\
840,177 \\
785,111\end{array}$ & $\begin{array}{l}\text { June } 30 \\
\text { December } 31 \\
\text { April } 30 \\
\text { January } 31 \\
\text { September } 30\end{array}$ \\
\hline 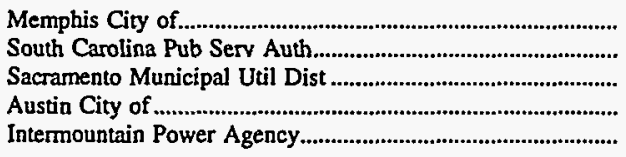 & $\begin{array}{l}\text { Tennessee } \\
\text { South Carolina } \\
\text { California } \\
\text { Texas } \\
\text { Utah }\end{array}$ & $\begin{array}{l}711,356 \\
696,026 \\
670,284 \\
613,648 \\
611,861\end{array}$ & $\begin{array}{l}\text { June } 30 \\
\text { December } 31 \\
\text { December } 31 \\
\text { September } 30 \\
\text { June } 30\end{array}$ \\
\hline 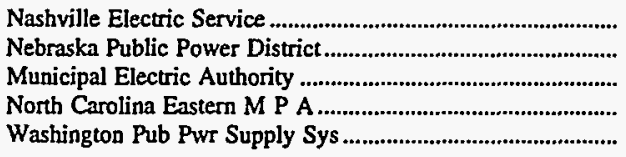 & $\begin{array}{l}\text { Tennessee } \\
\text { Nebraska } \\
\text { Georgia } \\
\text { North Carolina } \\
\text { Washington }\end{array}$ & $\begin{array}{l}604,910 \\
535,740 \\
500,805 \\
460,674 \\
447,049\end{array}$ & $\begin{array}{l}\text { June } 30 \\
\text { December } 31 \\
\text { December } 31 \\
\text { December } 31 \\
\text { June } 30\end{array}$ \\
\hline 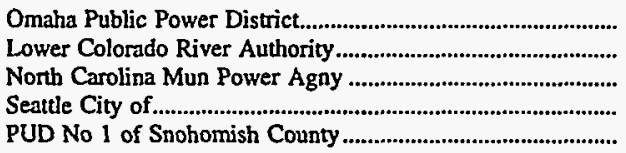 & $\begin{array}{l}\text { Nebraska } \\
\text { Texas } \\
\text { North Carolina } \\
\text { Washington } \\
\text { Washington }\end{array}$ & $\begin{array}{l}420,090 \\
414,657 \\
375,577 \\
356,671 \\
354,551\end{array}$ & $\begin{array}{l}\text { December } 31 \\
\text { June } 30 \\
\text { December } 31 \\
\text { December. } 31 \\
\text { December } 31\end{array}$ \\
\hline
\end{tabular}

Source: Energy Information Administration, Form EIA-412, "Annual Report of Public Electric Utilities." Individual electric utilities report fiscal year data. Appendix B shows the fiscal year for each electric utility.

Table C40. Twenty Largest U.S. Publicly Owned Electric Utilities Ranked by Purchase Power Expenses for All Respondents, 1996 (Thousand Dollars)

\begin{tabular}{|c|c|c|c|}
\hline Publicly Owned Electric Utilities & State & Amount & Reporting Date \\
\hline 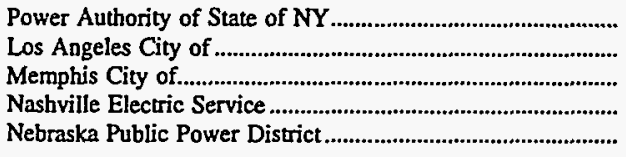 & $\begin{array}{l}\text { New York } \\
\text { California } \\
\text { Tennessee } \\
\text { Tennessee } \\
\text { Nebraska }\end{array}$ & $\begin{array}{l}884,440 \\
707,938 \\
574,568 \\
499,317 \\
302,587\end{array}$ & $\begin{array}{l}\text { December } 31 \\
\text { June } 30 \\
\text { June } 30 \\
\text { June } 30 \\
\text { December } 31\end{array}$ \\
\hline 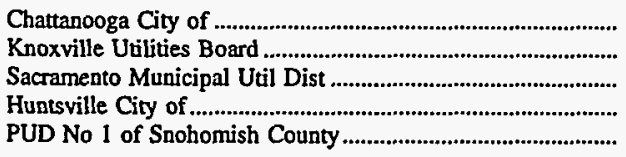 & $\begin{array}{l}\text { Tennessee } \\
\text { Tennessee } \\
\text { California } \\
\text { Alabama } \\
\text { Washington }\end{array}$ & $\begin{array}{l}251,684 \\
230,769 \\
220,056 \\
186,878 \\
183,095\end{array}$ & $\begin{array}{l}\text { June } 30 \\
\text { June } 30 \\
\text { December } 31 \\
\text { September } 30 \\
\text { December } 31\end{array}$ \\
\hline 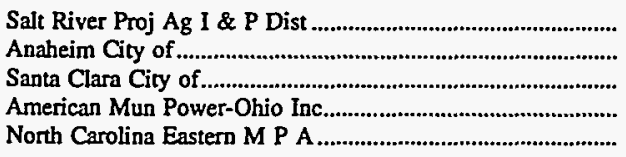 & $\begin{array}{l}\text { Arizona } \\
\text { California } \\
\text { California } \\
\text { Ohio } \\
\text { North Carolina }\end{array}$ & $\begin{array}{l}159,082 \\
127,839 \\
127,270 \\
122,270 \\
115,028\end{array}$ & $\begin{array}{l}\text { April } 30 \\
\text { June } 30 \\
\text { June } 30 \\
\text { December } 31 \\
\text { December } 31\end{array}$ \\
\hline 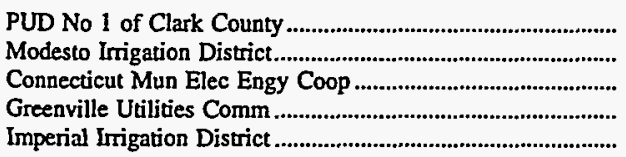 & $\begin{array}{l}\text { Washington } \\
\text { California } \\
\text { Connecticut } \\
\text { North Carolina } \\
\text { California }\end{array}$ & $\begin{array}{r}109,552 \\
92,826 \\
92,449 \\
91,565 \\
88,709\end{array}$ & $\begin{array}{l}\text { December } 31 \\
\text { December } 31 \\
\text { December } 31 \\
\text { June } 30 \\
\text { December } 31\end{array}$ \\
\hline
\end{tabular}

Source: Ènergy Information Administration, Form ELA-412, “Annual Report of Public Electric Utilities." Individual electric utilities report fiscal year data. Appendix B shows the fiscal year for each electric utility. 
Table C41. Twenty Largest U.S. Publicly Owned Electric Utilities Ranked by Electric Utility Plant for All Respondents, 1996

(Thousand Dollars)

\begin{tabular}{|c|c|c|c|}
\hline Publicly Owned Electric Utiltties & State & Amount & Reporting Date \\
\hline 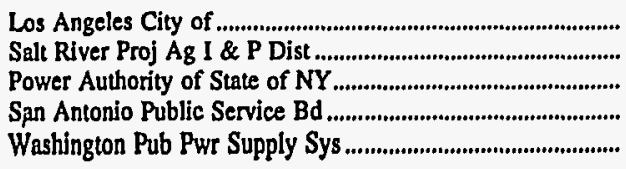 & $\begin{array}{l}\text { California } \\
\text { Arizona } \\
\text { New York } \\
\text { Texas } \\
\text { Washington }\end{array}$ & $\begin{array}{l}6,815,947 \\
5,923,650 \\
5,222,394 \\
4,700,348 \\
3,458,611\end{array}$ & $\begin{array}{l}\text { June } 30 \\
\text { April } 30 \\
\text { December } 31 \\
\text { January } 31 \\
\text { June } 30\end{array}$ \\
\hline 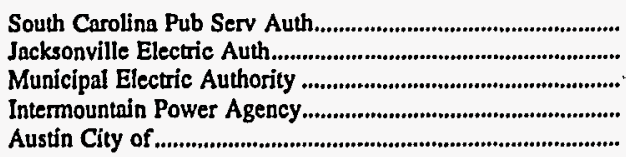 & $\begin{array}{l}\text { South Carolina } \\
\text { Forida } \\
\text { Georgia } \\
\text { Utah } \\
\text { Texas }\end{array}$ & $\begin{array}{l}3,231,816 \\
3,085,809 \\
3,073,703 \\
2,771,435 \\
2,368,509\end{array}$ & $\begin{array}{l}\text { December } 31 \\
\text { September } 30 \\
\text { December } 31 \\
\text { June } 30 \\
\text { September } 30\end{array}$ \\
\hline 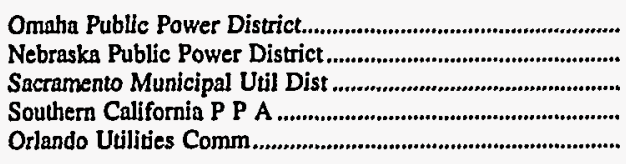 & $\begin{array}{l}\text { Nebraska } \\
\text { Nebraska } \\
\text { California } \\
\text { California } \\
\text { Florida }\end{array}$ & $\begin{array}{l}2,162,510 \\
1,906,738 \\
1,806,812 \\
1,737,254 \\
1,646,908\end{array}$ & $\begin{array}{l}\text { December } 31 \\
\text { December } 31 \\
\text { December } 31 \\
\text { June } 30 \\
\text { September } 30\end{array}$ \\
\hline 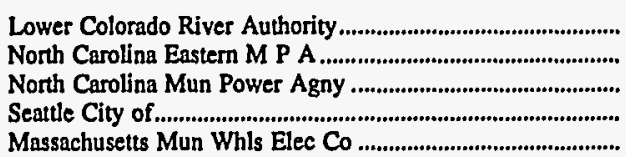 & $\begin{array}{l}\text { Texas } \\
\text { North Carolina } \\
\text { North Carolina } \\
\text { Washington } \\
\text { Massachusetts }\end{array}$ & $\begin{array}{l}1,563,791 \\
1,448,307 \\
1,427,479 \\
1,425,029 \\
1,234,201\end{array}$ & $\begin{array}{l}\text { June } 30 \\
\text { December } 31 \\
\text { December } 31 \\
\text { December } 31 \\
\text { December } 31\end{array}$ \\
\hline
\end{tabular}

Source: Energy Information Administration, Form EIA-412, "Annual Report of Public Electric Utilities." Individual electric utilities report fiscal year data. Appendix $B$ shows the fiscal year for each electric utility.

Table C42. Twenty Largest U.S. Publicly Owned Electric Utilities Ranked by Construction Work in Progress for All Respondents, 1996 (Thousand Dollars)

\begin{tabular}{|c|c|c|c|}
\hline Publicly Owned Electric Utilities & State & Amount & Reporting Date \\
\hline 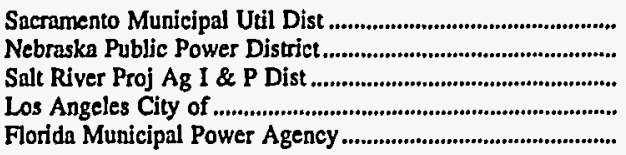 & $\begin{array}{l}\text { California } \\
\text { Nebraska } \\
\text { Arizona } \\
\text { California } \\
\text { Florida }\end{array}$ & $\begin{array}{l}387,345 \\
261,269 \\
212,552 \\
203,705 \\
176,178\end{array}$ & $\begin{array}{l}\text { December } 31 \\
\text { December } 31 \\
\text { April } 30 \\
\text { June } 30 \\
\text { September } 30\end{array}$ \\
\hline 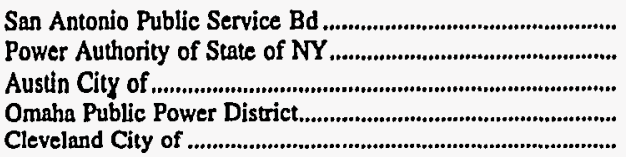 & $\begin{array}{l}\text { Texas } \\
\text { New York } \\
\text { Texas } \\
\text { Nebraska } \\
\text { Ohio }\end{array}$ & $\begin{array}{r}159,664 \\
101,499 \\
88,107 \\
84,645 \\
76,304\end{array}$ & $\begin{array}{l}\text { January } 31 \\
\text { December } 31 \\
\text { September } 30 \\
\text { December } 31 \\
\text { December } 31\end{array}$ \\
\hline 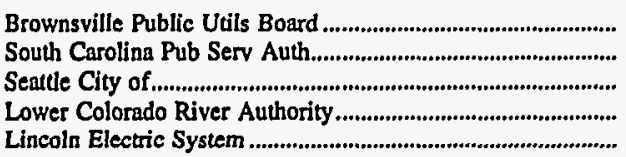 & $\begin{array}{l}\text { Texas } \\
\text { South Carolina } \\
\text { Washington } \\
\text { Texas } \\
\text { Nebraska }\end{array}$ & $\begin{array}{l}73,415 \\
68,031 \\
60,530 \\
60,262 \\
54,005\end{array}$ & $\begin{array}{l}\text { September } 30 \\
\text { December } 31 \\
\text { December } 31 \\
\text { June } 30 \\
\text { December } 31\end{array}$ \\
\hline 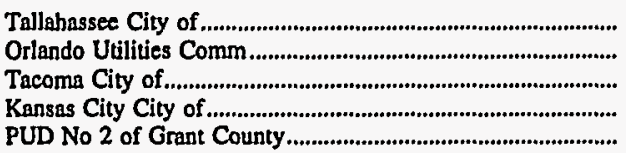 & $\begin{array}{l}\text { Florida } \\
\text { Florida } \\
\text { Washington } \\
\text { Kansas } \\
\text { Washington }\end{array}$ & $\begin{array}{l}52,924 \\
45,098 \\
39,707 \\
37,484 \\
35,925\end{array}$ & $\begin{array}{l}\text { September } 30 \\
\text { September } 30 \\
\text { December } 31 \\
\text { December } 31 \\
\text { December } 31\end{array}$ \\
\hline
\end{tabular}

Source: Energy Information Administration, Form EIA-412, “Annual Report of Public Electric Utilities." Individual electric utilities report fiscal year data. Appendix B shows the fiscal year for each electric utility. 
Table C43. Composite Statement of Income for Major U.S. Publicly Owned Electric Utilities for All Respondents, 1992-1996 (Thousand Dollars)

\begin{tabular}{|c|c|c|c|c|c|}
\hline Item & 1996 & 1995 & 1994 & 1993 & 1992 \\
\hline Electric Utility Operating Revenues........................... & $32,780,306$ & $31,908,333$ & $31,262,318$ & $30,045,300$ & $28,933,756$ \\
\hline 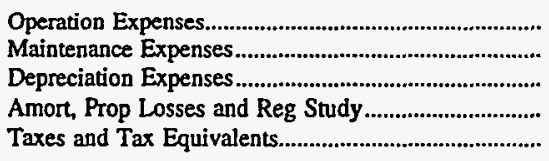 & $\begin{array}{r}21,119,055 \\
1,881,797 \\
3,176,821 \\
152,322 \\
868,594\end{array}$ & $\begin{array}{r}20,825,743 \\
1,824,788 \\
3,112,365 \\
133,953 \\
1,040,837\end{array}$ & $\begin{array}{r}20,435,585 \\
1,818,411 \\
2,860,213 \\
134,117 \\
967,106\end{array}$ & $\begin{array}{r}19,666,365 \\
1,772,339 \\
2,694,777 \\
158,059 \\
933,886\end{array}$ & $\begin{array}{r}18,772,266 \\
1,757,427 \\
2,533,847 \\
134,511 \\
836,134\end{array}$ \\
\hline 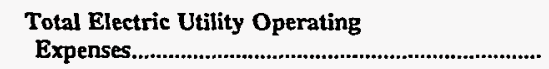 & $27,198,590$ & $26,937,686$ & $26,215,432$ & $25,225,425$ & $24,034,185$ \\
\hline 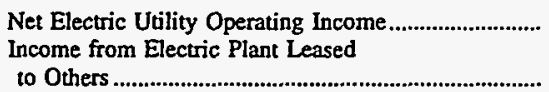 & $\begin{array}{r}5,581,716 \\
38,483\end{array}$ & $\begin{array}{r}4,970,646 \\
20,710\end{array}$ & $\begin{array}{r}5,046,885 \\
32,426\end{array}$ & $\begin{array}{r}4,819,876 \\
25,981\end{array}$ & $\begin{array}{r}4,899,571 \\
16,902\end{array}$ \\
\hline 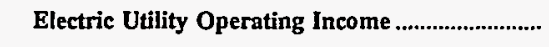 & $5,620,199$ & $4,991,356$ & $5,079,312$ & $4,845,856$ & $4,916,473$ \\
\hline Other Electric Income & $1,648,155$ & $1,587,180$ & $1,415,582$ & $1,628,552$ & $2,012,422$ \\
\hline $\begin{array}{l}\text { Other Electric Deductions............................................ } \\
\text { Allowance for Other Funds Used }\end{array}$ & 293,982 & 272,663 & 216,181 & 336,659 & 324,310 \\
\hline 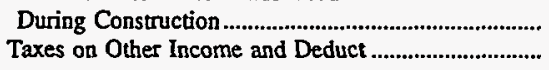 & $\begin{array}{l}6,730 \\
8,503\end{array}$ & $\begin{array}{r}9,186 \\
27,883\end{array}$ & $\begin{array}{r}7,923 \\
43,164\end{array}$ & $\begin{array}{l}28,582 \\
27,925\end{array}$ & $\begin{array}{l}24,222 \\
25,807\end{array}$ \\
\hline Electric Utility Income & $6,972,599$ & $6,287,175$ & $6,243,471$ & $6,138,407$ & $6,603,001$ \\
\hline 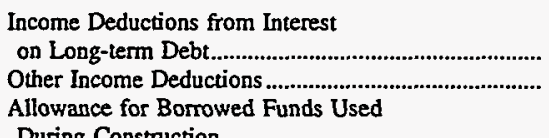 & $\begin{array}{r}4,255,559 \\
563,057\end{array}$ & $\begin{array}{r}4,333,306 \\
611,883\end{array}$ & $\begin{array}{r}4,440,943 \\
435,458\end{array}$ & $\begin{array}{r}4,547,594 \\
350,500\end{array}$ & $\begin{array}{r}4,866,961 \\
345,454 \\
45,707\end{array}$ \\
\hline 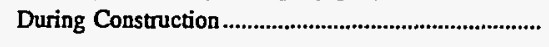 & $-35,970$ & $-48,495$ & $-38,827$ & $-43,279$ & $-45,797$ \\
\hline 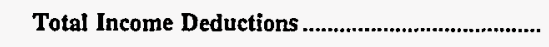 & $4,782,646$ & $4,896,694$ & $4,837,574$ & $4,854,815$ & $5,166,618$ \\
\hline 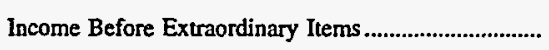 & $2,189,953$ & $1,390,481$ & $1,405,898$ & $1,283,592$ & $1,436,382$ \\
\hline Extraordinary Income & 248,781 & 323,098 & 113,547 & 87,738 & 146,747 \\
\hline Extraordinary Deductions & 255,195 & 78,840 & 241,579 & 327,565 & 264,178 \\
\hline 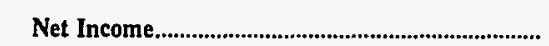 & $2,183,540$ & $1,634,740$ & $1,277,865$ & $1,043,766$ & $1,318,951$ \\
\hline
\end{tabular}

Note: Totals may not equal sum of components because of independent rounding. The number of publicly owned electric utilities for end of period is 515 for 1996, 512 for 1995, 503 for 1994, 495 for 1993, and 483 for 1992.

Source: Energy Information Administration, Form EIA-412, "Annual Report of Public Electric Utilities." Individual electric utilities report

fiscal year data. Appendix B shows the fiscal year for each electric utility. 
Table C44. Composite Balance Sheet for Major U.S. Publicly Owned Electric Utilities for All Respondents at End of Period, 1992-1996 (Thousand Dollars)

\begin{tabular}{|c|c|c|c|c|c|}
\hline Item & 1996 & 1995 & 1994 & 1993 & 1992 \\
\hline \multicolumn{6}{|l|}{ Electric Utility Plant } \\
\hline 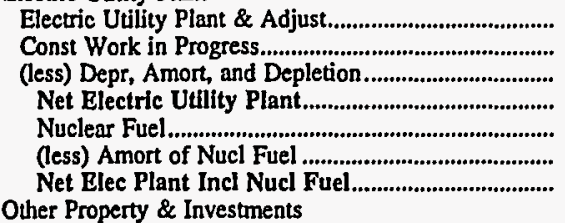 & $\begin{array}{r}101,106,576 \\
3,509,164 \\
35,000,702 \\
69,615,038 \\
2,734,959 \\
1,934,162 \\
70,415,835\end{array}$ & $\begin{array}{r}96,514,499 \\
4,592,439 \\
32,264,546 \\
68,842,392 \\
2,601,232 \\
1,763,678 \\
69,679,946\end{array}$ & $\begin{array}{r}93,757,308 \\
4,482,626 \\
30,043,282 \\
68,196,652 \\
2,564,002 \\
1,688,491 \\
69,072,163\end{array}$ & $\begin{array}{r}90,051,059 \\
4,038,613 \\
27,273,454 \\
66,816,218 \\
2,580,570 \\
1,650,975 \\
67,745,814\end{array}$ & $\begin{array}{r}87,030,170 \\
3,790,826 \\
25,153,126 \\
65,667,870 \\
2,271,919 \\
1,348,032 \\
66,591,756\end{array}$ \\
\hline 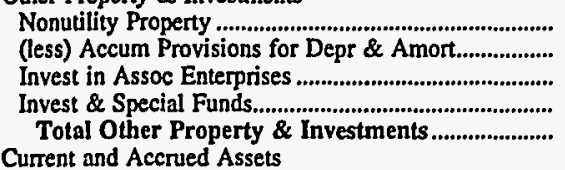 & $\begin{array}{r}8,423,947 \\
2,404,295 \\
98,154 \\
15,440,223 \\
21,558,029\end{array}$ & $\begin{array}{r}8,069,208 \\
2,330,245 \\
108,000 \\
17,346,848 \\
23,193,812\end{array}$ & $\begin{array}{r}7,541,303 \\
2,281,902 \\
282,296 \\
17,336,494 \\
22,878,191\end{array}$ & $\begin{array}{r}6,957,760 \\
2,138,049 \\
371,792 \\
17,207,623 \\
22,399,126\end{array}$ & $\begin{array}{r}6,407,886 \\
1,977,104 \\
272,261 \\
15,416,345 \\
20,119,388\end{array}$ \\
\hline 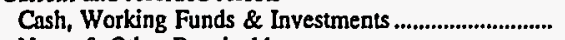 & $11,189,365$ & $10,362,961$ & $10,864,021$ & $10,890,858$ & $10,521,181$ \\
\hline 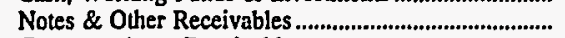 & $1,339,235$ & $1,248,745$ & $1,099,320$ & $1,102,841$ & $1,047,920$ \\
\hline Customer Accts Receivable & $2,596,415$ & $2,396,525$ & $2,384,190$ & $2,374,004$ & $2,141,086$ \\
\hline 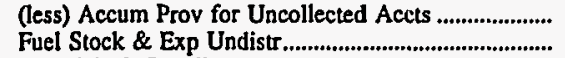 & $\begin{array}{l}100,387 \\
613,660\end{array}$ & $\begin{array}{r}93,127 \\
540,206\end{array}$ & $\begin{array}{r}86,436 \\
545,130\end{array}$ & $\begin{array}{l}125,658 \\
496,413\end{array}$ & $\begin{array}{l}121,384 \\
545,311\end{array}$ \\
\hline 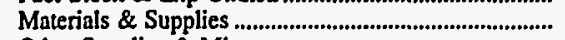 & $1,257,905$ & $1,263,123$ & $1,306,958$ & $1,283,844$ & $1,331,630$ \\
\hline 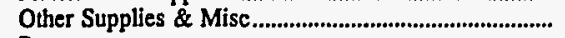 & 42,999 & 56,839 & - & 393,267 & 405,601 \\
\hline 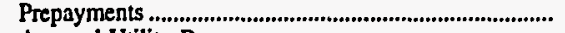 & 454,520 & 360,396 & 395,189 & - & - \\
\hline 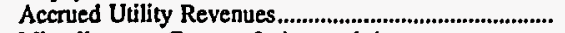 & 408,309 & 440,845 & 347,559 & 334,841 & 287,479 \\
\hline Miscellaneous Current \& Accrued Assets ..................... & $1,419,484$ & $1,394,017$ & $1,424,177$ & $1,102,461$ & $1,058,968$ \\
\hline $\begin{array}{l}\text { Total Current \& Accrued Assets ................................... } \\
\text { Deferred Debits }\end{array}$ & $19,221,504$ & $17,970,530$ & $18,280,108$ & $17,852,872$ & $17,217,791$ \\
\hline 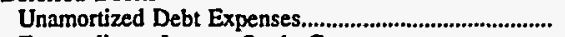 & $1,802,459$ & $2,726,265$ & $2,889,438$ & $2,536,132$ & $2,291,314$ \\
\hline 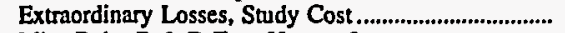 & $1,175,711$ & $1,642,157$ & 522,396 & 918,432 & 469,651 \\
\hline 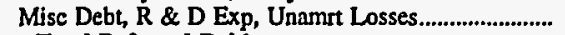 & $10,950,409$ & $10,366,946$ & $10,902,367$ & $10,956,667$ & $9,642,339$ \\
\hline 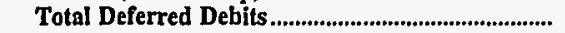 & $13,928,580$ & $14,735,368$ & $14,314,201$ & $14,411,230$ & $12,403,304$ \\
\hline 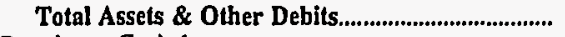 & $125,123,948$ & $125,579,656$ & $124,544,663$ & $122,409,042$ & $116,332,239$ \\
\hline \multicolumn{6}{|l|}{ Proprietary Capital } \\
\hline 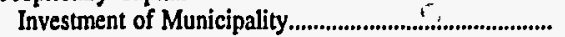 & $2,000,477$ & $2,246,446$ & $1,897,267$ & $1,891,224$ & $1,865,553$ \\
\hline 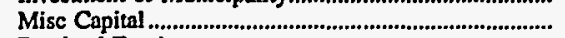 & 964,755 & 836,320 & 772,032 & 656,589 & 522,116 \\
\hline $\begin{array}{l}\text { Retained Eamings } \\
\text { Total Proprietary Capital }\end{array}$ & $\begin{array}{l}31,652,710 \\
34,617,943\end{array}$ & $\begin{array}{l}29,303,365 \\
32,386,130\end{array}$ & $\begin{array}{l}28,131,199 \\
30,800,498\end{array}$ & $\begin{array}{l}26,963,161 \\
29,510,973\end{array}$ & $\begin{array}{l}25,957,799 \\
28,345,468\end{array}$ \\
\hline Long-term Débt & & & & & \\
\hline 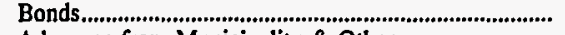 & $75,257,901$ & $76,256,520$ & $77,480,231$ & $77,624,677$ & $74,650,183$ \\
\hline 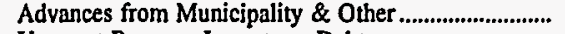 & $4,764,964$ & $4,945,640$ & $5,378,929$ & $3,667,150$ & $2,972,620$ \\
\hline Unamort Prem on Long-term Debt ................................ & 492,098 & 347,940 & 60,952 & 619,822 & 70,350 \\
\hline 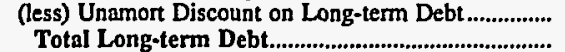 & $\begin{array}{r}3,973,222 \\
76,541,741\end{array}$ & $\begin{array}{r}3,126,187 \\
78,423,914\end{array}$ & $\begin{array}{r}3,381,297 \\
79,538,816\end{array}$ & $\begin{array}{r}2,844,050 \\
79,067,600\end{array}$ & $\begin{array}{r}2,975,041 \\
74,718,112\end{array}$ \\
\hline \multicolumn{6}{|l|}{ Other Noncurrent Liabilities } \\
\hline 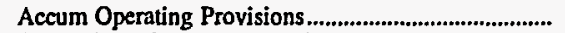 & 646,300 & 569,350 & 608,278 & 486,149 & 704,151 \\
\hline 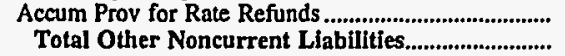 & $\begin{array}{l}137,783 \\
784,083\end{array}$ & $\begin{array}{l}161,183 \\
730,533\end{array}$ & $\begin{array}{l}104,542 \\
712,820\end{array}$ & $\begin{array}{l}115,389 \\
601,538\end{array}$ & $\begin{array}{r}4,483 \\
708,635\end{array}$ \\
\hline \multicolumn{6}{|l|}{ Current and Accrued Liabilities } \\
\hline 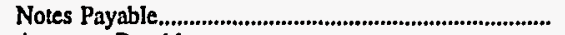 & $1,872,925$ & $1,471,926$ & $1,314,967$ & $1,364,779$ & $1,167,670$ \\
\hline 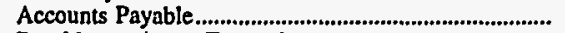 & $3,065,802$ & $2,862,965$ & $2,839,333$ & $2,723,943$ & $2,627,626$ \\
\hline 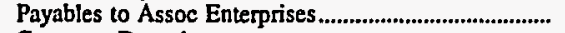 & 446,674 & 374,750 & 325,697 & 314,445 & 300,678 \\
\hline 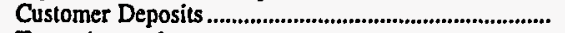 & 511,192 & 467,452 & 455,925 & 422,191 & 423,866 \\
\hline 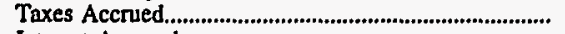 & 241,395 & 242,160 & 246,280 & 226,289 & 213,220 \\
\hline Interest Accrued & $1,650,069$ & $1,580,370$ & $1,545,141$ & $1,508,730$ & $1,524,242$ \\
\hline Misc Current \& Accrued Liabilities.................................... & $1,642,374$ & $3,317,862$ & $3,284,753$ & $3,073,542$ & $2,807,340$ \\
\hline $\begin{array}{l}\text { Total Current \& Accrued Liabilities........................ } \\
\text { Deferred Credits }\end{array}$ & \multicolumn{2}{|c|}{ Deferred Credits } & $10,012,095$ & $9,633,919$ & $9,064,642$ \\
\hline 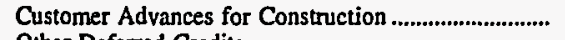 & 278,207 & 260,047 & 231,478 & 228,397 & 216,947 \\
\hline 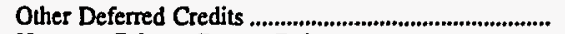 & $3,453,606$ & $3,406,465$ & $3,010,570$ & $3,055,314$ & $2,888,796$ \\
\hline 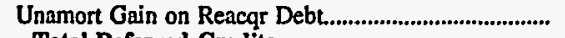 & 17,937 & 55,081 & 238,386 & 311,302 & 389,640 \\
\hline 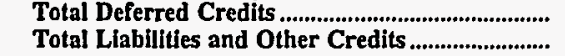 & $\begin{array}{r}3,749,750 \\
125,123,948\end{array}$ & $\begin{array}{r}3,721,593 \\
125,579,656\end{array}$ & $\begin{array}{r}3,480,434 \\
124,544,663\end{array}$ & $\begin{array}{r}3,595,012 \\
122,409,042\end{array}$ & $\begin{array}{r}3,495,383 \\
116,332,239\end{array}$ \\
\hline
\end{tabular}

Note: Totals may not equal sum of components because of independent rounding. The number of publicly owned electric utilities for end of period is 515 for 1996, 512 for 1995, 503 for 1994, 495 for 1993, and 483 for 1992 .

Source: Energy Information Administration, Form EIA-412, "Annual Report of Public Electric Utilities." Individual electric utilities report fiscal year data. Appendix B shows the fiscal year for each electric utility. 
Table C45. Composite Financial Indicators for Major U.S. Publicly Owned Electric Utilities for All Respondents, 1992-1996

\begin{tabular}{|c|c|c|c|c|c|}
\hline Item & 1996 & 1995 & 1994 & 1993 & 1992 \\
\hline Total Electric Utility Plant per Dollar of Revenue & 3.3 & 3.3 & 3.2 & 3.2 & 3.2 \\
\hline 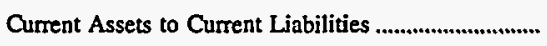 & 2.0 & 1.7 & 1.8 & 1.9 & 1.9 \\
\hline $\begin{array}{l}\text { Total Electric Utility Plant as a Percent of Total } \\
\text { Assets }\end{array}$ & 85.8 & 82.6 & 80.9 & 79.0 & 80.0 \\
\hline $\begin{array}{l}\text { Net Electric Uuility Plant as a Percent of Total } \\
\text { Assets }\end{array}$ & 56.3 & 55.5 & 55.5 & 55.3 & 57.2 \\
\hline 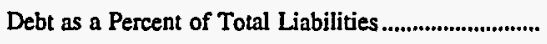 & 68.7 & 70.7 & 71.9 & 72.5 & 72.0 \\
\hline $\begin{array}{l}\text { Depreciation, Amortization and Depletion } \\
\text { as a Percent of Total Electric Utility Plant ................... }\end{array}$ & 34.4 & 32.8 & 31.5 & 29.9 & 28.5 \\
\hline 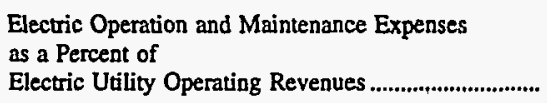 & 70,2 & 71.0 & 71.2 & 71.4 & 71.0 \\
\hline $\begin{array}{l}\text { Electric Depreciation and Amortization } \\
\text { as a Percent of } \\
\text { Electric Utility Operating Revenues ................................ }\end{array}$ & 9.7 & 9.8 & 9.1 & 9.0 & 8.8 \\
\hline $\begin{array}{l}\text { Taxes and Tax Equivalents } \\
\text { as a Percent of } \\
\text { Electric Utility Operating Revenues ................................ }\end{array}$ & 2.6 & 3.3 & 3.1 & 3.1 & 2.9 \\
\hline $\begin{array}{l}\text { Interest on Long-term Debt } \\
\text { as a Percent of } \\
\text { Electric Utility Operating Revenues }\end{array}$ & 13.0 & 13.6 & 14.2 & 15.1 & 16.8 \\
\hline 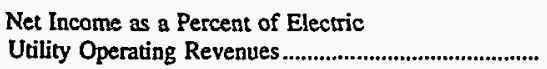 & 6.7 & 5.1 & 4.1 & 3.5 & 4.6 \\
\hline Purchased Power Cents Per Kilowathour ........................ & 3.9 & 3.9 & 3.8 & 3.8 & 3.9 \\
\hline 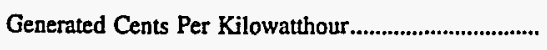 & 1.5 & 1.8 & 1.9 & 1.9 & 1.9 \\
\hline $\begin{array}{l}\text { Total Power Supply Per } \\
\text { Kilowatthour Sold............... }\end{array}$ & 2.9 & 3.0 & 3.0 & 3.0 & 3.1 \\
\hline
\end{tabular}

Note: Totals may not equal sum of components because of independent rounding. The number of publicly owned electric utilities for end of period is 515 for 1996, 512 for 1995, 503 for 1994, 495 for 1993, and 483 for 1992.

Source: Energy Information Administration, Form EIA-412, "Annual Report of Public Electric Utilities.". Individual electric utilities report fiscal year data. Appendix $B$ shows the fiscal year for each electric utility. 
Table C46. Electric Operation and Maintenance Expenses for Major U.S.

Publicly Owned Electric Utilities for All Respondents, 1992-1996

(Thousand Dollars)

\begin{tabular}{|c|c|c|c|c|c|}
\hline Item & 1996 & 1995 & 1994 & 1993 & 1992 \\
\hline \multicolumn{6}{|l|}{ Production Expenses } \\
\hline 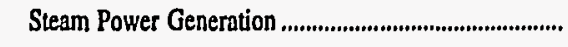 & $3,773,659$ & $3,894,795$ & $4,037,846$ & $4,105,022$ & $3,762,399$ \\
\hline 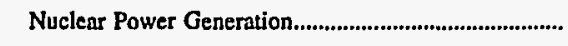 & 915,094 & $1,276,994$ & $1,291,932$ & $1,304,604$ & $1,318,443$ \\
\hline Hydraulic Power Generation & 220,104 & 260,920 & 243,817 & 241,549 & 244,158 \\
\hline Other Power Generation & 266,310 & 230,873 & 178,922 & 179,738 & 175,873 \\
\hline 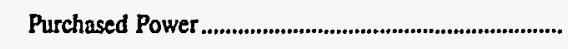 & $13,245,482$ & $11,988,014$ & $11,808,880$ & $11,097,082$ & $10,834,814$ \\
\hline 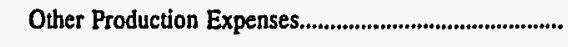 & 188,484 & 211,509 & 154,833 & 140,863 & 80,582 \\
\hline 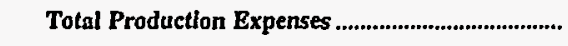 & $18,609,131$ & $17,863,105$ & $17,716,230$ & $17,068,858$ & $16,416,269$ \\
\hline 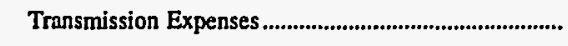 & 656,198 & 788,473 & 755,019 & 729,745 & 677,711 \\
\hline 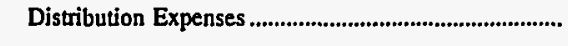 & $1,394,826$ & $1,273,878$ & $1,240,104$ & $1,199,411$ & $1,125,391$ \\
\hline 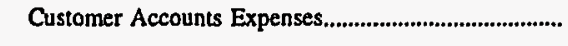 & 506,455 & 448,265 & 435,813 & 432,345 & 408,405 \\
\hline Customer Service and Information Expenses................. & 121,628 & 119,994 & 121,042 & 111,255 & 98,360 \\
\hline 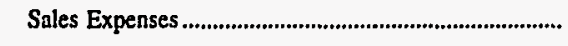 & 29,143 & 29,152 & 32,281 & 25,914 & 29,191 \\
\hline 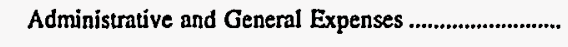 & $1,684,247$ & $2,127,664$ & $1,954,998$ & $1,871,156$ & $1,774,365$ \\
\hline 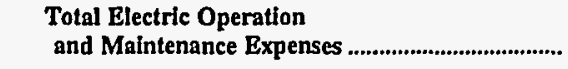 & $23,001,629$ & $22,650,531$ & $22,255,486$ & $21,438,683^{\circ}$ & $20,529,693$ \\
\hline \multicolumn{6}{|l|}{ Fuel Expenses in Operation } \\
\hline 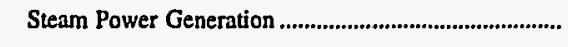 & $2,177,924$ & $2,163,327$ & $2,970,626$ & $3,036,077$ & $2,562,527$ \\
\hline 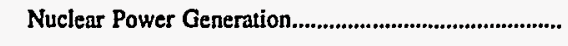 & 229,664 & 221,948 & 313,803 & 299,445 & 290,674 \\
\hline Other Power Generation & 89,627 & 100,742 & 101,302 & 102,414 & 82,758 \\
\hline \multicolumn{6}{|l|}{ Number of Elec Dept Employees } \\
\hline 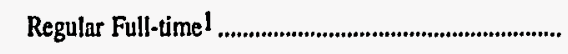 & 69,690 & 70,688 & 73,923 & 73,315 & 74,893 \\
\hline 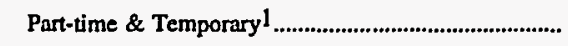 & 2,222 & 2,484 & 2,934 & 3,641 & 3,866 \\
\hline Total Elec Dept Employees ........................................ & 71,912 & 73,172 & 76,857 & 76,956 & 78,759 \\
\hline
\end{tabular}

1 Data reporting initiated in 1992.

Note: Totals may not equal sum of components because of independent rounding. The number of publicly owned electric utilities for end of period is 515 for 1996, 512 for 1995, 503 for 1994, 495 for 1993, and 483 for 1992.

Source: Energy Information Administration, Form EIA-412, "Annual Report of Public Electric Utilities." Individual electric utilities report fiscal year data. Appendix B shows the fiscal year for each electric utility. 
Table C47. Electric Utility Plant for Major U.S. Publicly Owned Electric

Utilities for All Respondents at End of Period, 1992-1996

(Thousand Dollars)

\begin{tabular}{|c|c|c|c|c|c|}
\hline Item & 1996 & 1995 & 1994 & 1993 & 1992 \\
\hline \multicolumn{6}{|l|}{ Electric Plant in Service } \\
\hline 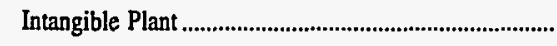 & 622,974 & 642,085 & 527,021 & 351,952 & 294,715 \\
\hline \multicolumn{6}{|l|}{ Production Plant } \\
\hline Steam.................. & $25,705,131$ & $24,669,840$ & $24,334,206$ & $24,239,169$ & $23,415,826$ \\
\hline Nuclear & $18,903,044$ & $18,663,445$ & $18,786,140$ & $18,814,910$ & $18,743,463$ \\
\hline 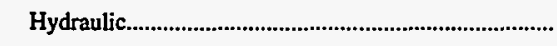 & $8,265,937$ & $8,124,665$ & $7,839,107$ & $7,648,279$ & $7,506,785$ \\
\hline Other & $2,939,165$ & $2,540,910$ & $2,471,596$ & $1,843,331$ & $1,887,069$ \\
\hline 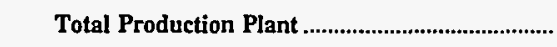 & $55,813,277$ & $53,998,860$ & $53,431,049$ & $52,545,689$ & $51,553,142$ \\
\hline 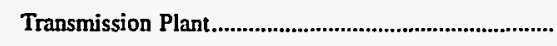 & $11,098,954$ & $10,320,798$ & $9,920,599$ & $9,548,867$ & $9,345,935$ \\
\hline 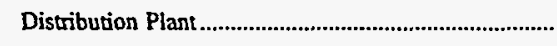 & $24,247,730$ & $22,859,351$ & $21,598,897$ & $20,145,751$ & $18,846,975$ \\
\hline 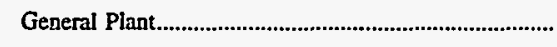 & $7,234,070$ & $6,841,840$ & $6,768,554$ & $5,860,450$ & $5,455,979$ \\
\hline 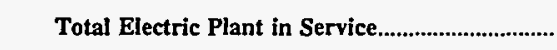 & $99,017,005$ & $94,662,935$ & $92,246,120$ & $88,452,709$ & $85,496,746$ \\
\hline 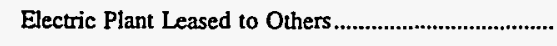 & 39,795 & 55,635 & 16,290 & 17,404 & 68,195 \\
\hline 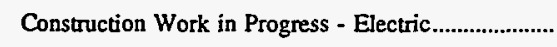 & $3,509,164$ & $4,592,439$ & $4,482,626$ & $4,038,613$ & $3,790,826$ \\
\hline 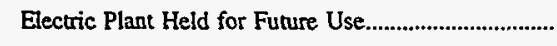 & 157,777 & 306,095 & 313,636 & 337,975 & 321,639 \\
\hline 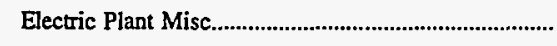 & $1,891,999$ & $1,489,834$ & $1,181,262$ & $1,242,970$ & $1,143,590$ \\
\hline Total Electric Utility Plant & $104,615,740$ & $101,106,938$ & $98,239,934$ & $94,089,672$ & $90,820,996$ \\
\hline $\begin{array}{l}\text { Accumulated Provision for } \\
\text { Depreciation and Amortization }\end{array}$ & $35,000,702$ & $32,264,546$ & $30,043,282$ & $27,273,454$ & $25,153,126$ \\
\hline Net Electric Utility Plant & $69,615,038$ & $68,842,392$ & $68,196,652$ & $66,816,218$ & $65,667,870$ \\
\hline
\end{tabular}

Note: Totals may not equal sum of components because of independent rounding. The number of publicly owned electric utilities for end of period is 515 for 1996, 512 for 1995, 503 for 1994, 495 for 1993, and 483 for 1992.

Source: Energy Information Administration, Form EIA-412, "Annual Report of Public Electric Utilities." Individual electric utilities report fiscal year data. Appendix B shows the fiscal year for each electric utility. 
Table C48. Number of Consumers, Sales, and Operating Revenue

for Major U.S. Publicly Owned Electric Utilities

for All Respondents, 1992-1996

\begin{tabular}{|c|c|c|c|c|c|}
\hline Item & 1996 & 1995 & 1994 & 1993 & 1992 \\
\hline \multicolumn{6}{|l|}{ Number of Consumers } \\
\hline 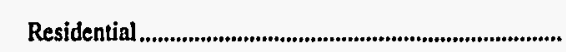 & $11,951,748$ & R $11,755,365$ & $11,528,503$ & $11,319,426$ & $11,105,178$ \\
\hline 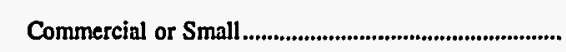 & $1,593,547$ & $\mathrm{R}_{1,561,508}$ & $1,534,098$ & $1,502,701$ & $1,477,033$ \\
\hline 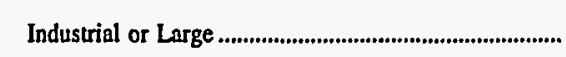 & 109,705 & R $_{106,842}$ & 106,152 & 100,641 & 96,002 \\
\hline 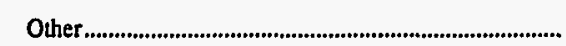 & 184,972 & $R_{178,451}$ & 164,096 & 160,934 & 245,135 \\
\hline 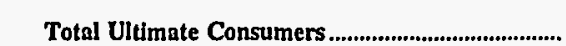 & $13,839,972$ & $\mathrm{R}_{13,602,166}$ & $13,332,849$ & $13,083,702$ & $12,923,348$ \\
\hline
\end{tabular}

Sales for the Year (megawatthours)

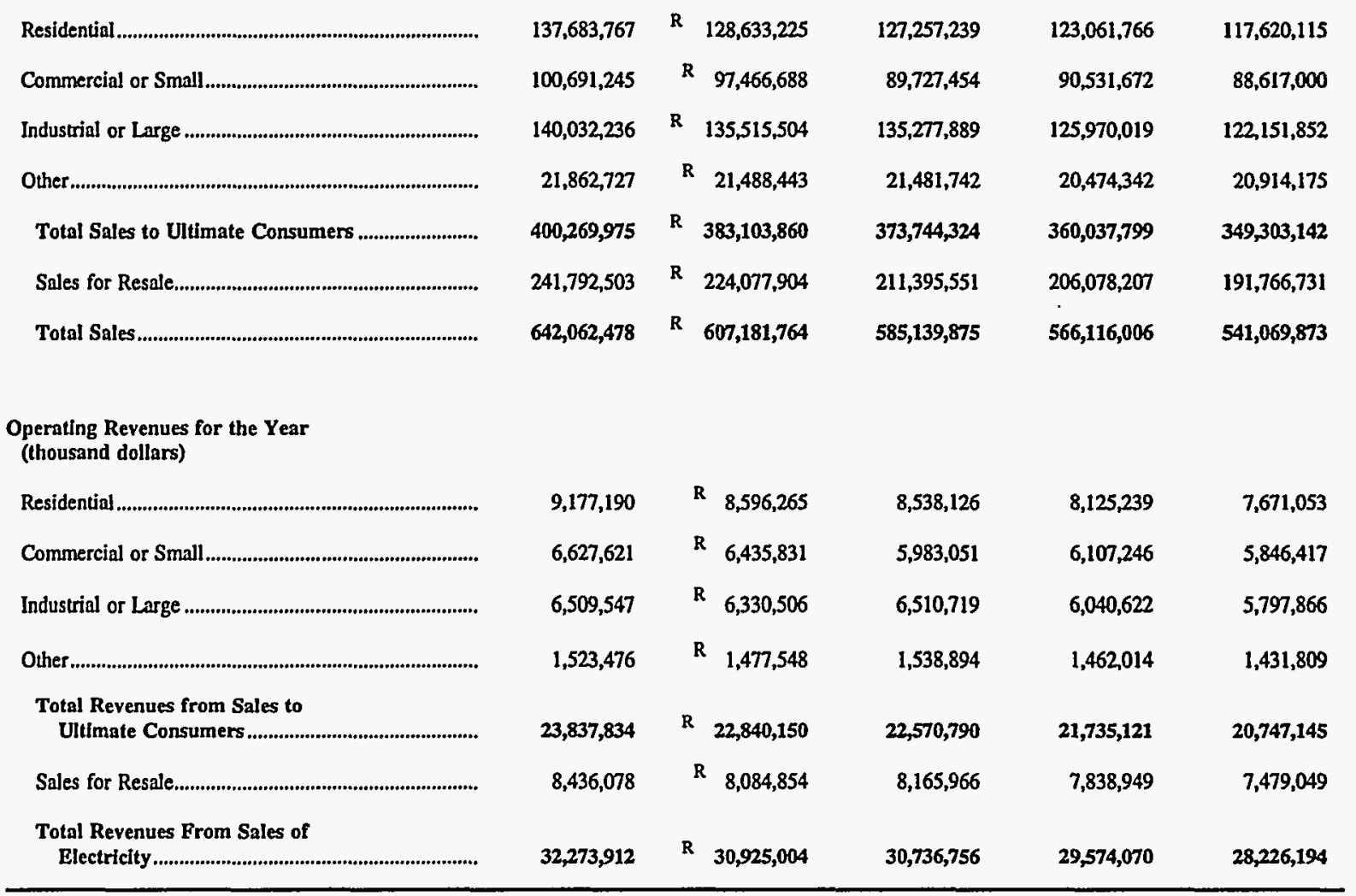

$\mathrm{R}=$ Revised data.

Note: Totals may not equal sum of components because of independent rounding. The number of publicly owned electric utilities for end of period is 515 for 1996, 512 for 1995, 503 for 1994, 495 for 1993, and 483 for 1992.

Source: Energy Information Administration, Form EIA-861, "Annual Electric Utility Report." Data are based on calender year submissions. 
Table C49. Electric Energy Account for Major U.S. Publicly Owned Electric Utilities for All Respondents, 1992-1996

(Megawatthours)

\begin{tabular}{|c|c|c|c|c|c|}
\hline Item & 1996 & 1995 & 1994 & 1993 & 1992 \\
\hline \multicolumn{6}{|l|}{ Sources of Energy } \\
\hline 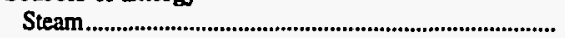 & $177,758,982$ & $170,232,784$ & $181,935,951$ & $179,616,592$ & $169,087,041$ \\
\hline 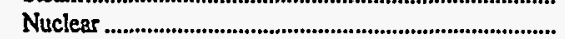 & $68,817,700$ & $61,425,458$ & $53,082,028$ & $48,580,405$ & $52,565,245$ \\
\hline 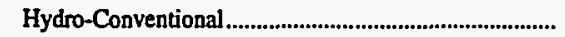 & $84,439,609$ & $78,246,578$ & $64,584,646$ & $71,114,954$ & $65,807,396$ \\
\hline 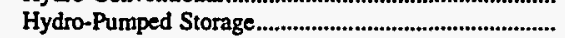 & $5,232,725$ & $5,488,354$ & $4,161,991$ & $4,423,179$ & $4,722,771$ \\
\hline Other & $3,668,948$ & $3,741,342$ & $3,288,915$ & $3,053,440$ & $2,940,656$ \\
\hline 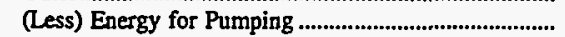 & $4,399,426$ & $4,025,506$ & $4,609,045$ & $4,354,233$ & $4,255,476$ \\
\hline Total Net Generation & $335,518,538$ & $315,109,010$ & $302,444,488$ & $302,434,335$ & $290,867,622$ \\
\hline 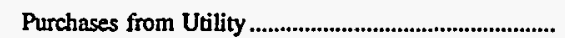 & $334,199,883$ & $292,413,856$ & $305,007,688$ & $289,691,688$ & $276,321,959$ \\
\hline 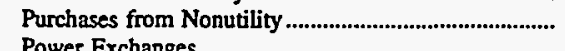 & $4,154,030$ & $8,075,028$ & $1,640,476$ & $1,543,815$ & $1,085,377$ \\
\hline 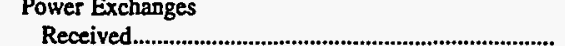 & 21.928337 & $28,532,264$ & 19.042 .914 & $21.477,360$ & \\
\hline 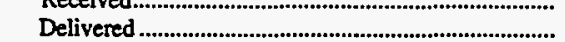 & $\begin{array}{l}21,920,331 \\
21,300,804\end{array}$ & $\begin{array}{l}28,392,204 \\
21,973,488\end{array}$ & $\begin{array}{l}19,042,914 \\
16,912,965\end{array}$ & $\begin{array}{l}21,4 / 1,300 \\
21,164,186\end{array}$ & $\begin{array}{l}18,593,247 \\
18,641,568\end{array}$ \\
\hline 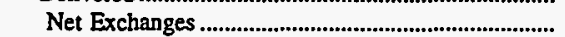 & 627,527 & $6,558,765$ & $2,129,952$ & 313,183 & 351,686 \\
\hline \multicolumn{6}{|l|}{ Transmission for Others (Wheeling) } \\
\hline 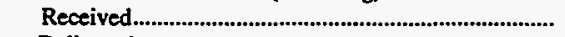 & $34,103,087$ & $26,002,200$ & $30,085,871$ & $27,233,740$ & $22,142,579$ \\
\hline 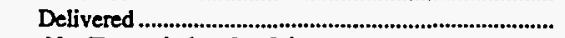 & $26,748,449$ & $25,455,190$ & $29.787,957$ & $26,962,627$ & $21,938,318$ \\
\hline 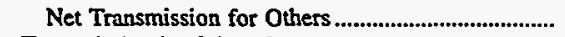 & $7,354,637$ & 547,010 & 297,915 & 271,113 & 204,261 \\
\hline 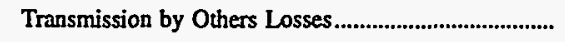 & $-393,074$ & $-161,056$ & $-357,929$ & $-286,279$ & $-243,202$ \\
\hline \multicolumn{6}{|l|}{ Total Net Energy Generated and } \\
\hline 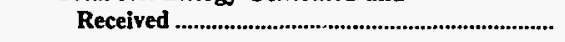 & $681,461,541$ & $622,542,622$ & $611,162,593$ & $593,967,859$ & $568,587,689$ \\
\hline \multicolumn{6}{|l|}{ Disposition of Energy } \\
\hline 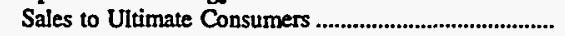 & $399,626,743$ & $374,821,005$ & $372,306,680$ & $359,971,921$ & $347,801,781$ \\
\hline 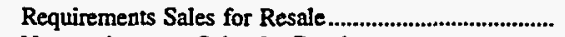 & $184,506,957$ & $164,826,112$ & $165,817,872$ & $161,161,514$ & $152,099,605$ \\
\hline Nonrequirements Sales for Resale ................................ & $66,418,811$ & $55,174,544$ & $43,051,318$ & $41,942,525$ & $37,818,022$ \\
\hline Furnished Without Charge & $1,883,276$ & $3,027,202$ & $1,996,571$ & $2,008,578$ & $1,851,080$ \\
\hline 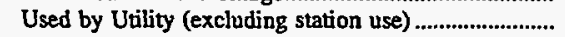 & $6,081,978$ & $4,434,146$ & $5,442,205$ & $5,333,241$ & $6,877,310$ \\
\hline 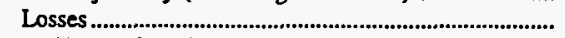 & $22,943,775$ & $20,259,625$ & $22,547,945$ & $23,550,023$ & $22,139,822$ \\
\hline 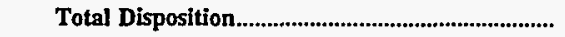 & $681,461,541$ & $622,542,622$ & $611,162,593$ & $593,967,859$ & $568,587,689$ \\
\hline
\end{tabular}

Note: Totals may not equal sum of components because of independent rounding. The number of publicly owned electric utilities for end of period is 515 for 1996,512 for 1995, 503 for 1994, 495 for 1993, and 483 for 1992. Double counting occurs in components of both sources and disposition of energy and thus neither provides a true total. Purchases from utilities, net exchanges, and net wheeling (except for imports) are included in net generation. Sales for resale is inciuded in sales to ultimate coniumers.

Source: Energy Information Administration, Form ElA-412, "Annual Report of Public Eiectric Utilities." Individual electric utilities report fiscal year data. Appendix B shows the fiscal year for each electric utility. 
Table C50. Comparison of the Energy Account for Major U.S. Publicly Owned Electric Utilities for All Respondents, 1992-1996

\begin{tabular}{|c|c|c|c|c|c|}
\hline Item & $\begin{array}{c}1996 \\
\text { (million } \\
\text { megawatthours) }\end{array}$ & $\begin{array}{c}1995 \\
\text { (million } \\
\text { megawatthours) }\end{array}$ & $\begin{array}{c}1994 \\
\text { (million } \\
\text { megawatthours) }\end{array}$ & $\begin{array}{c}1993 \\
\text { (million } \\
\text { megawatthours) }\end{array}$ & $\begin{array}{c}1992 \\
\text { (million } \\
\text { megawatthours) }\end{array}$ \\
\hline \multicolumn{6}{|l|}{ Sources of Energy } \\
\hline Steam & 177.8 & 170.2 & 181.9 & 179.6 & 169.1 \\
\hline 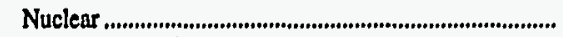 & 68.8 & 61.4 & 53.1 & 48.6 & 52.6 \\
\hline 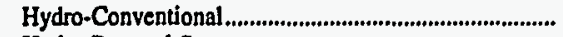 & 84.4 & 78.2 & 64.6 & 71.1 & 65.8 \\
\hline Hydro-Pumped Storage ......................................................... & 5.2 & 5.5 & 4.2 & 4.4 & 4.7 \\
\hline Other & 3.7 & 3.7 & 3.3 & 3.1 & 2.9 \\
\hline 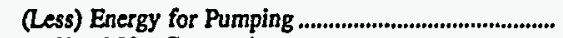 & 4.4 & 4.0 & 4.6 & 4.4 & 4.3 \\
\hline 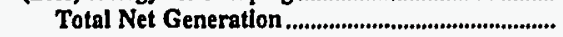 & 335.5 & 315.1 & 302.4 & 302.4 & 290.9 \\
\hline 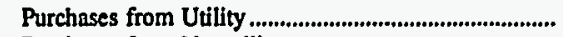 & 334.2 & 292.4 & 305.0 & 289.7 & 276.3 \\
\hline 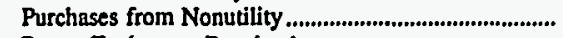 & 4.2 & 8.1 & 1.6 & 1.5 & 1.1 \\
\hline 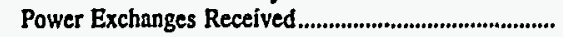 & 21.9 & 28.5 & 19.0 & 21.5 & 19.0 \\
\hline 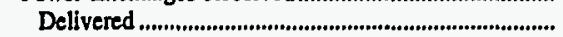 & 21.3 & 22.0 & 16.9 & 21.2 & 18.6 \\
\hline 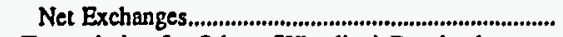 & .6 & 6.6 & 2.1 & .3 & .4 \\
\hline Transmission for Others (Wheeling) Received............. & 34.1 & 26.0 & 30.1 & 27.2 & 22.1 \\
\hline 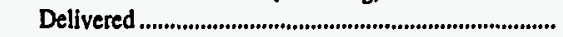 & 26.7 & 25.5 & 29.8 & 27.0 & 21.9 \\
\hline 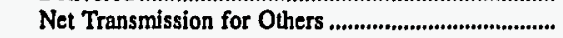 & 7.4 & .5 & .3 & .3 & .2 \\
\hline $\begin{array}{l}\text { Transmission by Others Losses..................................... } \\
\text { Total Net Energy Generated and }\end{array}$ & -.4 & -.2 & -.4 & -.3 & -.2 \\
\hline 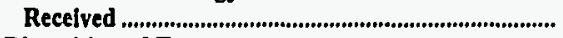 & 681.5 & 622.5 & 611.2 & 594.0 & 568.6 \\
\hline \multicolumn{6}{|l|}{ Disposition of Energy } \\
\hline 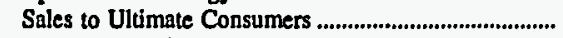 & 399.6 & 374.8 & 372.3 & 360.0 & 347.8 \\
\hline Requirements Sales for Resale......................................... & 184.5 & 164.8 & 165.8 & 161.2 & 152.1 \\
\hline 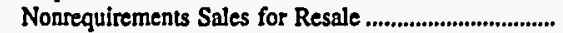 & 66.4 & 55.2 & 43.1 & 41.9 & 37.8 \\
\hline Furnished Without Charge............................................. & 1.9 & 3.0 & 2.0 & 2.0 & 1.9 \\
\hline Used by Utility(excluding station use)........................... & 6.1 & 4.4 & 5.4 & 5.3 & 6.9 \\
\hline Losses & 22.9 & 20.3 & 22.5 & 23.6 & 22.1 \\
\hline 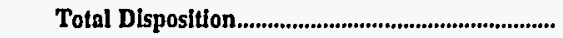 & 681.5 & 622.5 & 611.2 & 594.0 & 568.6 \\
\hline
\end{tabular}

\begin{tabular}{|c|c|c|c|c|}
\hline Item & $\begin{array}{c}\text { Percent } \\
\text { Change } \\
1995-96\end{array}$ & $\begin{array}{l}\text { Percent } \\
\text { Change } \\
199495\end{array}$ & $\begin{array}{l}\text { Percent } \\
\text { Change } \\
1993-94\end{array}$ & $\begin{array}{l}\text { Percent } \\
\text { Change } \\
\text { 1992-93 }\end{array}$ \\
\hline \multicolumn{5}{|l|}{ Sources of Energy } \\
\hline Steam & 4.5 & -6.4 & 1.3 & 6.2 \\
\hline 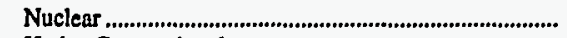 & 12.1 & 15.6 & 9.3 & -7.6 \\
\hline 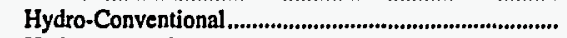 & 7.9 & 20.9 & -9.1 & 8.1 \\
\hline 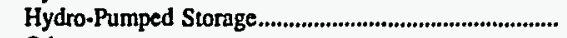 & -5.5 & 31.1 & -4.5 & -6.4 \\
\hline Other & .0 & 12.1 & 6.5 & 6.9 \\
\hline (Less) Energy for Pumping .............................................. & 10.0 & -13.0 & 4.5 & 2.3 \\
\hline 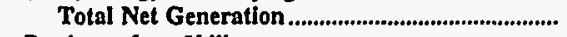 & 6.5 & 4.2 & .0 & 4.0 \\
\hline 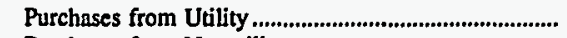 & 14.3 & -4.1 & 5.3 & 4.8 \\
\hline Purchases from Nonutility............................................ & -48.1 & 392.2 & 6.7 & 36.4 \\
\hline 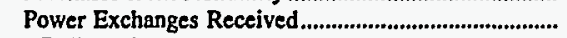 & -23.2 & 50.0 & -11.6 & 13.2 \\
\hline 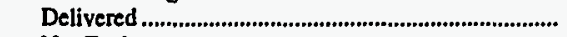 & -3.2 & 30.2 & -20.3 & 14.0 \\
\hline 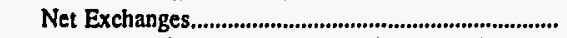 & -90.9 & 214.3 & 600 & -25.0 \\
\hline Transmission for Others (Wheeling) Received............ & 31.2 & -13.6 & 10.7 & 23.1 \\
\hline 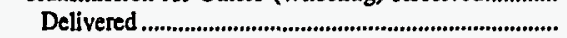 & 4.7 & -14.4 & 10.4 & 23.3 \\
\hline 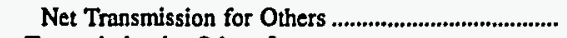 & 1244.5 & 83.6 & 9.9 & 32.7 \\
\hline $\begin{array}{l}\text { Transmission by Others Losses................................... } \\
\text { Total Net Energy Generated and }\end{array}$ & -144.0 & 55.0 & -25.0 & -17.7 \\
\hline Recelved & 9.5 & 1.8 & 2.9 & 4.5 \\
\hline \multicolumn{5}{|l|}{ Disposition of Energy } \\
\hline 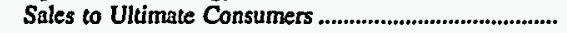 & 6.6 & .7 & 3.4 & 3.5 \\
\hline 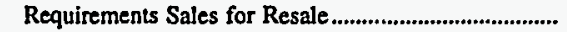 & 12.0 & -.6 & 2.9 & 6.0 \\
\hline 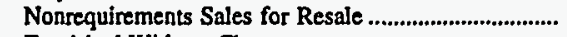 & 20.3 & 28.1 & 2.9 & 10.8 \\
\hline 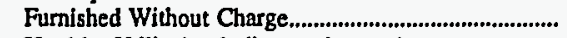 & -36.7 & 50.0 & .0 & 5.3 \\
\hline Used by Utility(excluding station use)......................... & 38.6 & -18.5 & 1.9 & -23.2 \\
\hline Losses & 12.8 & -9.8 & -4.7 & 6.8 \\
\hline 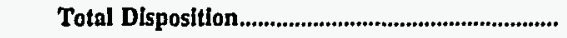 & 9.5 & 1.8 & 2.9 & 4.5 \\
\hline
\end{tabular}

Note: Totals may not equal sum of components because of independent rounding. The number of publicly owned electric utilities for end of period is 515 for 1996, 512 for 1995, 503 for 1994, 495 for 1993, and 483 for 1992. Double counting occurs in components of both sources and disposition of energy and thus neither provides a true total. Purchases from utilities, net exchanges, and net wheeling (except for imports) are included in net generation. Sales for resale is included in sales to ultimate consumers.

Source: Energy Information Administration, Form EIA-412, “Annual Report of Public Electric Utilities." Individual electric utilities report fiscal year data. Appendix B shows the fiscal year for each electric utility. 


\title{
Appendix D
}

\author{
Regulation of \\ U.S. Publicly \\ Owned \\ Electric \\ Utilities
}




\section{Regulation of U.S. Publicly Owned Electric Utilities}

Table D1. State Agency Authority to Regulate Rates of Public Owned Electric Utilities, 1996

\begin{tabular}{|c|c|c|c|c|c|c|}
\hline \multirow[b]{2}{*}{ State } & \multirow[b]{2}{*}{ State Agency Authority } & \multirow{2}{*}{$\begin{array}{l}\text { Authority } \\
\text { To Regulate } \\
\text { Rates }\end{array}$} & \multirow[b]{2}{*}{ Boundaries } & \multicolumn{3}{|c|}{ Sales Regulated } \\
\hline & & & & $\begin{array}{l}\text { Ultimate } \\
\text { Consumer }\end{array}$ & $\begin{array}{l}\text { Public } \\
\text { Authority }\end{array}$ & $\begin{array}{l}\text { Sales for } \\
\text { Resale }\end{array}$ \\
\hline AL & Alabama Public Service Commission & No & & & & \\
\hline AK & Alaska Public Utilities Commission & YES & inside \& outside & $x$ & 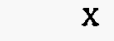 & $\mathrm{x}$ \\
\hline $\mathrm{AZ}$ & Arizona Corporation Commission & No & & & & \\
\hline AR & Arkansas Public Service Commission & No & & & & \\
\hline $\mathrm{CA}$ & Califomia Public Utilities Commission & No & & & & \\
\hline $\mathrm{CO}$ & Colorado Public Utilities Commission & LTD & outside & & & \\
\hline CT & Connecticut Department of Public Utility Control & LTD & & & & $\mathrm{x}$ \\
\hline $\mathrm{DE}$ & Delaware Public Service Commission & No & & & & \\
\hline F & Florida Public Service Commision & LTD & inside \& outsidel & $\mathrm{X}$ & $X$ & \\
\hline GA & Georgia Public Service Commission & No & outside home cty & & & \\
\hline HI & Hawaii Public Utilities Commission & No & & & & \\
\hline ID & Idaho Public Utilities Commission & No & & & & \\
\hline IL.... & Illinois Commerce Commission & No & inside \& outside & & & \\
\hline $\mathbb{N}$ & Indiana Utility Regulatory Commision & LTD & inside \& outside ${ }^{2}$ & $x$ & $\mathbf{x}$ & $\mathbf{x}$ \\
\hline IA & Iowa Utilities Board & No & inside \& outside & $x$ & $\mathbf{x}$ & \\
\hline KS & Kansas State Corporation Commission & YES & outside & $x$ & $\mathbf{x}$ & $\mathbf{x}$ \\
\hline KY & Kentucky Public Service Commission & No & & & & \\
\hline LA & Lousiana Public Service Commission & No & & & & \\
\hline ME & Maine Public Utilities Commission & YES & outside & $x$ & $\mathbf{x}$ & \\
\hline MD & Maryland Public Service Commission & YES & inside \& outside & $x$ & $\mathrm{x}$ & \\
\hline MA & Massachusetts Department of Public Utilities & YES & inside \& outside & $\mathrm{x}$ & $\mathbf{x}$ & $\mathbf{x}$ \\
\hline MI & Michigan Public Service Commission & No & & & & \\
\hline$M N$ & Minnesota Public Service Commission & No & & & & \\
\hline MS & Mississippi Public Service Commission & LTD & safety inside,full outside & $x$ & $\mathbf{x}$ & \\
\hline MO & Missouri Public Service Commission & No & & & & \\
\hline MT & Montana Public Service Commission & No & inside \& outside 3 & & & \\
\hline
\end{tabular}

See footnotes at end of table. 
Table D1. State Agency Authority to Regulate Rates of Public Owned Electric Utilities, 1996 (Continued)

\begin{tabular}{|c|c|c|c|c|c|c|}
\hline \multirow[b]{2}{*}{ State } & \multirow[b]{2}{*}{ State Agency Authority } & \multirow{2}{*}{$\begin{array}{c}\text { Authority } \\
\text { To Regulate } \\
\text { Rates }\end{array}$} & \multirow[b]{2}{*}{ Boundaries } & \multicolumn{3}{|c|}{ Sales Regulated } \\
\hline & & & & $\begin{array}{l}\text { Ultimate } \\
\text { Consumer }\end{array}$ & $\begin{array}{l}\text { Public } \\
\text { Authority }\end{array}$ & $\begin{array}{c}\text { Sales for } \\
\text { Resale }\end{array}$ \\
\hline NE & Nebraska Public Service Commission & NO & inside \& outside & & & \\
\hline NV & Nevada Public Service Commission & NO & & & & \\
\hline NH & New Hampshire Public Utilities Commission & YES & outside & $\mathbf{x}$ & $\mathbf{X}$ & $\mathbf{x}$ \\
\hline NJ & New Jersey Board of Public Utilities & YES & outside & $\mathbf{X}$ & & \\
\hline NM & New Mexico Public Service Commission & NO & & & & \\
\hline NY & New York Public Service Commission & YES & inside \& outside & $\mathbf{X}$ & $\mathbf{X}$ & $X$ \\
\hline NC & North Carolina Utilities Commission & NO & & & & \\
\hline ND & North Dakota Public Service Commission & No & & & & \\
\hline $\mathrm{OH}$ & Ohio Public Utilities Commission & NO & & & & \\
\hline OK & Oklahoma Corporation Commission & No & & & & \\
\hline OR & Oregon Public Utility Commission & NO & & & & \\
\hline PA & PennsysIvania Public Utility Commission & YES & outside & $\mathbf{X}$ & & \\
\hline RI & Rhode Island Public Utilities Commission & YES & inside \& outside & $\mathbf{x}$ & $\mathbf{X}$ & \\
\hline SC & South Carolina Public Service Commission & LTD & inside $\&$ outside & & & \\
\hline SD & South Dakota Public Utilities Commission & LTD & outside & & & \\
\hline TN & Tennessee Public Service Commission & No & outside & & & \\
\hline $\mathrm{TX}$ & Texas Public Utility Commission & YES & outside & $\mathbf{X}$ & $\mathbf{X}$ & $\mathbf{X}$ \\
\hline UT & Utah Public Service Commission & No & & & & \\
\hline VT & Vermont Public Service Board & YES & inside \& outside & $\mathbf{X}$ & $\mathbf{x}$ & $\mathrm{x}$ \\
\hline VA & Virginia State Corporation Commission & No & & & & \\
\hline WA & Washington Utilities \& Transportation Commission & NO & inside \& outside & & & \\
\hline WV & West Virginia Public Service Commission & LTD & & & & · \\
\hline WI & Wisconsin Public Service Commission & YES & inside \& outside & $\mathbf{x}$ & $\mathbf{x}$ & $\mathrm{X}$ \\
\hline WY & Wyoming Public Service Commission & YES & outside & $\mathbf{x}$ & & \\
\hline
\end{tabular}

\footnotetext{
1 Rate Schedule.

2 Rates Only.

3 Annual revenue increase greater than 12 percent.

Note: There are no publicly owned electric utilities in the District of Columbia. The District of Columbia Public Service Commission does regulate invester-owned electric utilities.

Source: National Association of Regulatory Utility Commissioners, Utility Regulatory Policy in the United States and Canada Compilation 1994-1995, publication.
} 



\section{Appendix E}

Technical

Notes 


\section{Appendix E}

\section{Technical Notes}




\section{Sources of Data}

The Financial Statistics of Major U.S. Publicly Owned Electric Utilities (FSMPO) publication is prepared by the Electric Power Division; Office of Coal, Nuclear, Electric and Alternate Fuels; Energy Information Administration (EIA); U.S. Department of Energy (DOE). Detailed financial data published in this publication are from the Form EIA-412, "Annual Report of Public Electric Utilities. "Other summary data are provided from the Form EIA-861, "Annual Electric Utility Report," and the Rural Utilities Service statistics taken from the Statistical Report, Rural Electric Borrowers publication for the years 1991 through 1996. A brief summary of surveys used in this publication is presented below.

\section{Form EIA-412}

The Form EIA-412 is used annually to collect accounting, financial, and operating data from major publicly owned electric utilities in the United States. For the fiscal or calendar year that ended December 31,1996 , the criteria used to select the respondents for this survey resulted in submissions by 512 publicly owned and 8 Federal electric utilities. Those publicly owned electric utilities engaged in the generation, transmission, or distribution of electricity which had 120,000 megawatthours of sales to ultimate consumers and/or 120,000 megawatthours of sales for resale for the 2 previous years, as reported on the Form EIA-861, "Annual Electric Utility Report," must submit the Form EIA-412. Summary data are also published in the Electric Power Annual, Volume II.

Federally owned electric utilities are required to file the Form EIA-412. The financial data for the U.S. Army Corps of Engineers (except for Saint Mary's Falls at Sault St. Marie, Michigan), the U.S. International Boundary and Water Commission, and the U.S. Department of Interior Bureau of Reclamation were collected on the Form EIA-412 from the Federal power marketing administrations.

Instrument and Design History. The FPC created the Form $1 \mathrm{M}$ in 1961 as a mandatory survey. It became the responsibility of the EIA in October 1977 when the FPC was merged with DOE. Since 1979, the FPC Form $1 \mathrm{M}$ has been superseded by the Economic Regulatory Administration (ERA) Form ERA-412, and in January 1980 by the Form EIA-412.

Data Processing. The processing of data reported on this survey is the responsibility of the Electric Power Division; Office of Coal, Nuclear, Electric and Alternate Fuels. The completed surveys are due on April 30 or before the last day of the third month following the close of the fiscal year. Nonresponse follow-up procedures are used to attain 100 percent response. Automated systems are used to edit data from the surveys using deterministic and statistical checks. When all data have passed the edit process, the data are aggregated into a master file used as input to the publication.
Form EIA-861

The Form EIA-861 is a mandatory census of electric utilities in the United States, its territories, and Puerto Rico. The survey is used to collect information on power production and sales data from approximately 3,200 electric utilities in the United States and its territories. These data collected are used to maintain and update the electric utility frame data base for the EIA. This data base supports queries from the Executive Branch, Congress, other public agencies, and the general public. Summary data from the Form EIA-861 are also contained in Electric Power Monthly , Electric Power Annual, Electric Sales and Revenue, Annual Outlook for U.S. Electric Power, Financial Statistics of Major U.S. Investor-Owned Electric Utilities and Financial Statistics of Major U.S. Publicly Owned Electric Utilities. These reports present aggregate totals for electric utilities on the national and State level by and by ownership type.

Instrument and Design History. The Form EIA-861 was implemented in January 1985 to collect data as of year-end 1984. The Federal Administration Act of 1974 (Public Law 93-275) defines the legislative authority to collect these data.

Data Processing. The Form EIA-861 is mailed to the respondents at year end to collect data for the calendar year. The completed surveys are due to the EIA by April 30. These data are manually edited before being entered into an interactive on-line system. Internal edit checks are performed to verify that current data total across and between schedules and are comparable to data reported the previous year. Edit checks are also performed to compare data reported on the Form EIA-861 with similar data reported on the Form EIA-826, "Monthly Electric Utility Sales and Revenue Report with State Distributions," the FERC Form 1, "Annual Report of Major Electric Utilities, Licensees and Others," and the Form EIA-412, "Annual Report of Public Electric Utilities." These are utility-level checks. Respondents are called to clarify reported data and to obtain missing data.

\section{Rural Utiltities Service}

The Rural Utilities Service (RUS), prior the The Rural Electrification Administration (REA), in the U.S. Department of Agriculture is authorized to provide long-term financing and guarantee long-term loans for utilities supplying power to rural America. Borrowing electric utilities file the RUS Form 7, "Financial and Statistical Report" and the RUS Form 12a through $12 i$, "Electric Power Supply Borrowers" or the RUS Form 12c through 12g, "Electric Distribution Borrowers with Generating Facilities." Data are provided on a yearly basis. Other revenue and expense statistics show the year's financial operations. For 1996, borrowers' operations data are based on the financial and operating statements of 832 active borrowers, of which 782 were distribution borrowers and 50 were power supply borrowers. Operations of cooperative borrowers systems are based on reports submitted by borrowers. The reports are subject to possible 
revisions from audits and adjustments. No attempt has been made to consolidate (in the technical accounting sense) the borrowers' accounts in the summary state- ment appearing in this publication. The combined totals represent the sum of all accounts as reported by the individual borrowers. 


\section{Quality of Data}

The Office of Coal, Nuclear, Electric and Alternate Fuels (CNEAF) is responsible for routine data improvement and quality assurance. All operations at CNEAF are done in accordance with formal standards established by EIA. Data improvement efforts include verification of data-keyed input by computerized methods, editing by subject matter specialists, and follow-up on nonrespondents. CNEAF reviews the structure of information requirements and proposed designs for new and revised data collection surveys and systems. Once started, the performance of working data collection systems is also validated. Computerized respondent data files are checked to identify those respondents which fail to respond to the survey. EIA tries to obtain required information by encouraging the cooperation of nonrespondents. By law, nonrespondents may be fined or penalized for not filing a mandatory EIA data survey.

CNEAF screens submitted surveys for completeness and keys the data onto computer tapes for storage. These data are transferred to random access databases for computer processing. The information coded on the computer tapes is manually spot-checked against the surveys to certify accuracy of the tapes. To ensure EIA quality standards, formulas using the past history of data values in the data base have been designed and implemented to automatically check data input for errors. Data values falling outside the ranges prescribed in the formulas are verified by telephoning respondents to resolve any discrepancies.

Conceptual problems affecting the quality of data are discussed in the report, An Assessment of the Quality of Selected EIA Data Series : Electric Power Data. This report is published by the Office of Statistical Standards in EIA.

\section{Data Entry System}

Manual editing of the reported data is completed prior to data entry. Additional edit checks of the data are performed through computer programs. The program edits include both deterministic checks, in which records are checked for the presence of data in required fields, and statistical checks, in which data are checked against a range of values based on historical data values and for logical or mathematical consistency with data elements reported in the survey. Discrepancies found in the data, as a result of these checks, are resolved either by the processing office or by further information obtained from a telephone call to the respondent.

\section{Confidentiality of the Data}

Data collected on the surveys for this publication arz not confidential.

\section{Rounding Rules for Data}

Given a number with $r$ digits to the left of the decimal and $d+t$ digits in the fraction part, with $d$ being the place to which the number is to be rounded and $t$ being the remaining digits which will be truncated. This number is then rounded to $r+d$ digits by adding five to the $(r+d+1)$ th digit when the number is positive or by subtracting five when the number is negative. The $t$ digits are then truncated at the $(r+d+1)$ th digit. The symbol for a rounded number truncated to zero is $\left(^{*}\right)$.

\section{Data Correction and Revision Procedures}

The CNEAF has adopted the following policy with respect to the revision and correction of recurrent data in energy publications :

- Annual survey data collected by this office are published either as preliminary or final when first appearing in a data report. Data initially released as preliminary will be so noted in the report. These data will be revised, if necessary, and declared final in the next publication of the data.

- All monthly and quarterly survey data collected by this office are published as preliminary. These data are revised only after the completion of the 12-month cycle of the data. No revisions are made to the published data before this.

- The magnitudes of changes due to revisions experienced in the past will be included in the data reports, so that the reader can assess the accuracy of the data.

- After data are published as final, corrections will be made only in the event of a greater than one percent difference at the national level. Corrections for differences that are less than the before-mentioned threshold are left to the discretion of the Office Director.

\section{Formulas and Calculations}




\section{Composite Financial Indicators for Selected Publicly Owned Electric Utilities}

Total Electric Utility Plant per Dollar of Revenue =

$$
\frac{\sum_{i}\left(T E U P_{i}\right)}{\sum_{i}\left(E U O R_{i}\right)},
$$

where TEUP is the Total Electric Utility Plant for the $i^{\text {th }}$ public utility; and, EUOR is the Electric Utility Operating Revenue for the $i^{\text {th }}$ public utility.

Current Assets to Current Liabilities =

$$
\frac{\sum_{i}\left(C A_{i}\right)}{\sum_{i}\left(C L_{i}\right)},
$$

where $C A_{i}$ are the Current and Accrued Assets for the $i^{\text {th }}$ public utility; and, $C L_{i}$ are the Current and Accrued Liabilities for the $i^{\text {th }}$ public utility.

Total Electric Utility Plant as a Percent of Total Assets =

$$
\frac{\sum_{i}\left(T E U P_{i}\right)}{\sum_{i}\left(T A_{i}\right)} \times 100
$$

where TEUP $i$ is the Total Electric Utility Plant for the $i^{t h}$ public utility; and, $T A_{i}$ are the Total Assets for the $i^{\text {th }}$ public utility.

\section{Net Electric Utility Plant as a Percent of} Total Assets =

$$
\frac{\sum_{i}\left(N E U P_{i}\right)}{\sum_{i}\left(T A_{i}\right)} \times 100
$$

where $N E U P_{i}$ is the Net Electric Utility Plant for the $i^{\text {th }}$ public utility; and, $T A_{i}$ is the Total Assets for the $i^{\text {th }}$ public utility.

\section{Debt as a percent of Total Liabilities $=$}

$$
\frac{\sum_{i}\left(D_{i}\right)}{\sum_{i}\left(T L_{i}\right)} \times 100,
$$

where $D_{i}$ is the Debt for the $i^{\text {ih }}$ public utility; and, $T L_{i}$ is the Total Liabilities for the $i^{\text {th }}$ public utility.

Depreciation, Amortization and Depletion as a Percent of Total Electric Utility Plant =

$$
\frac{\sum_{i}\left(D A D_{i}\right)}{\sum_{i}\left(T E U P_{i}\right)} \times 100
$$

where $D A D_{i}$ is the Depreciation, Amortization and Depletion for the $i^{\text {th }}$ public utility; and, TEUP is the Total Electric Plant for the $i^{\text {ih }}$ public utility.

Electric Operation and Maintenance Expenses as a Percent of Electric Utility Operating Revenues =

$$
\frac{\sum_{i}\left(E^{\prime}{ }_{i} E_{i}\right)}{\sum_{i}\left(E^{\prime} R_{i}\right)} \times 100
$$

where $E O M E_{i}$ is the Electric Operation and Maintenance Expenses for the $i^{\text {th }}$ public utility; and, EUOR is the Electric Utility Operating Revenues for the $i^{\text {th }}$ public utility.

Electric Depreciation and Amortization as a Percent of Electric Utility Operating Revenues =

$$
\frac{\sum_{i}\left(E D A_{i}\right)}{\sum_{i}\left(E U O R_{i}\right)} \times 100
$$

where $E D A_{i}$ is Electric Depreciation and Amortization for the $i^{i \text { th }}$ public utility; and, EUOR is the Electric Utility Operating Revenues for the $i^{\text {th }}$ public utility.

Taxes and Tax Equivalents as a Percent of Electric Utility Operating Revenues =

$$
\frac{\sum_{i}\left(T T E_{i}\right)}{\sum_{i}\left(E U O R_{i}\right)} \times 100
$$

where $T T E_{i}$ are the Taxes and Tax Equivalents for the $i^{\text {th }}$ public utility; and, EUOR $R_{i}$ is the Electric Utility Operating Revenues for the $i^{\text {th }}$ public utility.

Interest on Long-term Debt as a Percent of Electric Utility Operating Revenues =

$$
\frac{\sum_{i}\left(I L T D_{i}\right)}{\sum_{i}\left(E U O R_{i}\right)} \times 100,
$$


where $I L T D_{i}$ is the Interest on Long-term Debt for the $i^{\text {th }}$ public utility; and, EUOR is the Electric Utility Operating Revenues for the $i^{\text {th }}$ public utility.

Net Income as a Percent of Electric Utility Operating Revenues $=$

$$
\frac{\sum_{i}\left(N I_{i}\right)}{\sum_{i}\left(E U O R_{i}\right)} \times 100
$$

where $N I_{l}$ is the Net Income for the $i^{\text {ih }}$ public utility; and, EUOR is the Electric Utility Operating Revenues for the $i^{\text {th }}$ public utility.

Purchase Power Cents Per Kilowatthour $=$

$$
\frac{\sum_{i}\left(P P C_{i}\right)}{\sum_{i}\left(P P K_{i}\right)} \times 10
$$

where $P P C_{i}$ is the Purchase Power Costs (in cents) for the $i^{\text {th }}$ public utility; and, $P P K_{i}$ is the Purchased Power Kilowatthours for the $i^{\text {th }}$ public utility.

\section{Generated Cents Per Kilowatthour =}

$$
\frac{\sum_{i}\left(T G C_{i}\right)}{\sum_{i}\left(T G K_{i}\right)} \times 10
$$

where $T G C_{l}$ is the Total Generation Costs (in cents) for the $i^{\text {th }}$ public utility; and, $T G K_{i}$ is the Total Generated Kilowatthours for the $i^{\text {th }}$ public utility.

Total Power Supply Per Kilowatthour Sold =

$$
\frac{\sum_{i}\left(T P C_{i}\right)}{\sum_{i}\left(T P K_{i}\right)} \times 10
$$

where $T P C_{i}$ is the Total Generation and Purchase Power Cost for the $i^{\text {th }}$ public utility; and, $T P K_{i}$ is the Total Generated and Purchased Power Kilowatthours Sold for the $i^{\text {th }}$ public utility.

\section{General Information}

\section{Use of the Glossary}

The terms in the glossary have been defined for general use. Restrictions on the definitions, as used in these data collection systems, are included in each definition when necessary to define the terms as they are used in this report.

\section{Obtaining Copies of Data}

Upon EIA approval of the Financial Statistics of Major U.S. Publicly Owned Electric Utilities, these data are available for public use.

Computer listings are obtained by submitting a written request to :

Energy Information Administration

Electric Power Division, EI-53

U. S. Department of Energy

1000 Independence Avenue, S.W.

Washington, DC 20585

(202) 426-1160

FAX (202) 426-1311

Magnetic tapes may be purchased by using Visa, Master Card, or American Express cards, as well as money orders or checks payable to the National Technical Information Service (NTIS). Purchasers may also use NTIS and Government Printing Office deposit accounts. To place an order, contact :

National Technical Information Service (NTIS)

Office of Data Base Services

U.S. Department of Commerce

5285 Port Royal Road

Springfield, Virginia 22161

(703) $487-4650$

FAX (703) $321-8547$

Personal computer diskettes ( $31 / 2^{\prime \prime}$ or $\left.51 / 4^{\prime \prime}\right)$ may be purchased by using Visa or Master Card, as well as money orders or checks payable to the Superintendent of Documents. Purchasers may also use Government Printing Office deposit accounts. To place an order, contact :

Superintendent of Documents

U.S. Government Printing Office

Attn : Electronic Products Sales Coordinator

P.O. Box 37080

Washington, DC 20013-7082

(202) $512-1530$

FAX (202) 512-1262 


\section{Glossary}

Accounting System: A method of recording accounting data for a utility or company or a method of supplying accounting information for controlling, evaluating, planning and decisionmaking.

Administrative and General Expenses: Expenses of an electric utility relating to the overall directions of its corporate offices and administrative affairs, as contrasted with expenses incurred for specialized functions. Examples include office salaries, office supplies, advertising, and other general expenses.

Allowance for Funds Used During Construction (AFUDC): A noncash item representing the estimated composite interest costs of debt and a return on equity funds used to finance construction. The allowance is capitalized in the property accounts and included in income.

Amortization: The gradual write-off of an amount in an account by distributing such amount over a fixed period, over the life of the asset or liability to which it applies, or over the period during which it is anticipated the benefit will be realized.

Asset: An economic resource, tangible or intangible, which is expected to provide benefits to a business.

Average Stream Flow: The rate, usually expressed in cubic feet per second, at which water passes a given point in a stream over a set period of time.

Capacity: The amount of electric power delivered or required for which a generator, turbine, transformer, transmission circuit, station, or system is rated by the manufacturer.

Capacity (Purchased): The amount of energy and capacity available for purchase from outside the system.

Capital: The equity interest of the owners consisting of common stock, preferred stock, and retained earnings in the entity, that is the difference between assets and liabilities.

Capital (Financial): The line items on the right side of a balance sheet, that include debt, preferred stock, and common equity. A net increase in assets must be financed by an increase in one or more forms of capital.

Capital Intensive: A condition in which investment in plant and equipment is relatively large compared to labor and to operation and maintenance expenses.

Capitalization: The long-term sources of funds comprising an entity's total capitalization; that is, the long-term debt, preferred stock, and common equity. The short-term sources of capital are not included.
Capitalization Ratio: The percentage of debt, or preferred stock, or common stock, or other equity to the total capital structure of an entity.

Circuit: A conductor or a system of conductors through which electric current flows.

Circuit-Mile: The total length in miles of separate circuits regardless of the number of conductors used per circuit.

Classes of Service: Consumers grouped by similar characteristics in order to be identified for the purpose of setting a common rate for electric service. Usually classified into groups identified as residential, commercial, industrial and other.

Commercial: The commercial sector is generally defined as nonmanufacturing business establishments, including hotels, motels, restaurants, wholesale businesses, retail stores, and health, social, and educational institutions. The utility may classify commercial service as all consumers whose demand or annual use exceeds some specified limit. The limit may be set by the utility based on the rate schedule of the utility.

Commercial and Industrial: Classes of service supplied to a similar grouping of consumers. These customer groupings are usually subdivided into smaller segments by classifying such consumers as commercial or industrial using the Federal Government's Office Of Management and Budget's Standard Industrial Classification Guide and/or a scale of energy usage as yardsticks; other consumers are reclassified as commercial or industrial when their demands or annual use exceeds some specified limit. These limits are generally based on a utility's rate schedules, except for those consumers who are supplied under special contracts or agreements calling for particular services.

Common Equity (Book Value): The retained earnings and common stock earnings plus the balances in common equity reserves and all other common stock accounts. This also includes the capital surplus, the paid-in surplus, the premium on common stocks, except those balances specifically related to preferred or preference stocks; less any common stocks held in the treasury.

Condenser Cooling Water: A source of water external to a boiler's feed system is passed through the steam leaving the turbine in order to cool and condense the steam. This reduces the steam's exit pressure and recaptures its heat, which is then used to preheat fluid entering the boiler, thereby increasing the plant's thermodynamic efficiency. 
Conditionally Effective Rates: An electric rate schedule that has been put into effect by the FERC subject to refund pending final disposition or refiling.

\section{Construction Costs (of the electric power industry): All direct and indirect costs incurred in acquiring and constructing electric utility plant and equipment and proportionate shares of common utility plant. Included are the cost of land and improvements, nuclear fuel and spare parts, allowance for funds used during construction, general overheads capitalized, less the cost of acquiring plant and equipment previ- ously operated in utility service.}

Construction Expenditures (of the electric power industry): The gross expenditures for construction costs, including the cost of replacing worn-out plants, and electric construction costs and land held for future use.

Construction Work In Progress (CWIP): The balance shown on a utility's balance sheet for construction work not yet completed but in process. This balance line item may or may not be included in the rate base.

Conventional Hydroelectric Plant: A plant in which all of the power is produced from natural streamflow as regulated by available storage.

Cooperative EIectric Utility: An electric utility legally established to be owned by and operated for the benefit of those using its service. The utility company will generate, transmit, and/or distribute supplies of electric energy to a specified area not being serviced by another utility. Such ventures are generally exempt from Federal income tax laws. Most electric cooperatives have been initially financed by the Rural Electrification Administration, U.S. Department of Agriculture.

Cost: The amount paid to acquire resources, such as plant and equipment, fuel, or labor services.

Cost of Capital: The rate of return a utility must offer to obtain additional funds. The cost of capital varies with the leverage ratio, the effective income tax rate, conditions in the bond and stock markets, growth rate of the utility, its dividend strategy, stability of net income, the amount of new capital required, and other factors dealing with business and financial risks. It is a composite of the cost for debt interest, preferred stock dividends, and common stockholders' earnings that provide the facilities used in supplying utility service.

Cost of Debt: The interest rate paid on new increments of debt capital multiplied by 1 minus the tax rate.

Cost of Preferred Stock: The preferred dividend divided by the net price of preferred stock.

Cost of Retained Earnings: The residual of a utility's earnings over expenditures, including taxes and dividends, that are reinvested in its business. The cost of these funds is always lower than the cost of new equity capital, due to taxes and transactions costs. Therefore, the cost of retained earnings is the yield that retained earnings accrue upon reinvestment.

Cost of Service: A ratemaking concept used for the design and development of rate schedules to ensure that the filed rate schedules recover only the cost of providing the electric service at issue. These costs include operating and maintenance expenses, depreciation and amortization expenses, and income and other taxes found just and reasonable by the regulatory agency for ratemaking purposes plus, in the case of privately owned electric utilities, an allowance for a return on capital (usually computed by applying a rate of return to the rate base). This concept attempts to equate the cost incurred by the utility to the revenue received for the service provided to each of the consumer classes.

Current Assets: Cash and other assets that are expected to be turned into cash, sold, or exchanged within the normal operating cycle of the utility, usually one year. Current assets include cash, marketable securities, receivables, inventory and current prepayments.

Current Liabilities: A debt or other obligation that must be discharged within one year or the normal operating cycle of the utility by expending a current asset or the incurrence of another short-term obligation. Current liabilities included account payable, short-term notes payable, and accrued expenses payable such as taxes and salaries payable.

Current Ratio: The ratio of current assets divided by current liabilities that shows the ability of a utility to pay its current obligations from its current assets. A measure of liquidity, the higher the current ratio, the more assurance that current liabilities can be paid.

Debt: Money or services owed through a legal obligation to an outside party. Debt may be classified short-term which is one year or less or long-term which is more than one year.

Deferred Cost: An expenditure not recognized as a cost of operation of the period in which incurred, but carried forward to be written off in future periods.

Deferred Fuel Costs: An expenditure for fuel that is not recognized for bookkeeping practices as a cost in the operating period incurred, but carried forward to be written off in future periods.

Deferred Income Tax (Liability): A liability in the balance sheet representing the additional Federal income taxes that would have been due if a utility had not been allowed to compute tax expenses differently for income tax reporting purposes than for ratemaking purposes.

Depreciation: Charges made against income for distributing the cost of a tangible asset, so as to allocate it systematically across the period in which the asset is used. 
Design Head: The achieved river, pondage, or reservoir surface height (forebay elevation) that provides the water level to produce the full flow at the gate of the turbine in order to attain the manufacturer's installed nameplate rating for generation capacity.

Diesel-Electric Plant: A generating station that uses diesel engines to drive its electric generators.

Distribution System: The portion of an electric system that is dedicated to delivering electric energy to an end user.

Docket: A formal record of a Federal Energy Regulatory Commission proceeding. These records are available for inspection and copying by the public. Each individual case proceeding is identified by an assigned number.

Economy of Scale: The principle that larger production facilities have lower unit costs than smaller facilities.

Electric Expenses: The cost of labor, material, and expenses incurred in operating a facility's prime movers, generators, auxiliary apparatus, switching gear, and other electric equipment for each of the points where electricity enters the transmission or distribution grid.

Electric Operating Expenses: Summation of electric operation-related expenses, such as operation expenses, maintenance expenses, depreciation expenses, amortization, taxes other than income taxes, Federal income taxes, other income taxes, provision for deferred income taxes, provision for deferred income-credit, and investment tax credit adjustment.

Electric Plant (Financial): Assets comprising land, building, and equipment permanently employed.

Electric Power Industry: The privately, publicly, federally and cooperatively owned electric utilities of the United States taken as a whole. This includes all electric systems serving the public: regulated investor-owned electric utility companies; Federal power projects; State, municipal, and other government-owned systems, including electric public utility districts; electric cooperatives, including generation and transmission entities. Excluded from this definition are the special purpose electric facilities or systems that do not offer service to the public.

Electric Power System: An individual electric power entity -- a company, an electric cooperative, a public electric supply corporation as the Tennessee Valley Authority, a similar Federal department or agency as the Bonneville Power Administration, the Bureau of Reclamation or the Corps of Engineers, a municipally owned, electric department offering service to the public, or an electric public utility district (a "PUD"); also a jointly owned electric supply project such as the Keystone.

Electric Rate Schedule: A statement of the electric rate and the terms and conditions governing its application, including attendant contract terms and condi- tions that have been accepted by a regulatory body with appropriate oversite authority.

Electric Utility: A corporation, person, agency, authority, or other legal entity or instrumentality that owns and/or operates facilities within the United States, its territories, or Puerto Rico for the generation, transmission, distribution, or sale of electric energy primarily for use by the public and files forms listed in the Code of Federal Regulations, Title 18, Part 141. Facilities that qualify as cogenerators or small power producers under the Public Utility Regulatory Policies Act (PURPA) are not considered electric utilities.

Electrical System Energy Losses: The amount of energy lost during generation, transmission, and distribution of electricity, including plant and unaccounted for use.

End User: The final consumer of electricity.

Energy: The capacity for doing work as measured by the capability of doing work (potential energy) or the conversion of this capability to motion (kinetic energy). Energy has several forms, some of which are easily convertible and can be changed to another form useful for work. Most of the world's convertible energy comes from fossil fuels that are burned to produce heat that is then used as a transfer medium to mechanical or other means in order to accomplish tasks. Electrical energy is usually measured in kilowatthours, while heat energy is usually measured in British thermal units.

Energy Deliveries: Energy generated by one electric utility system and delivered to another system through one or more transmission lines.

Energy Information Administration (EIA): An independent agency within the U.S. Department of Energy that develops surveys, collects energy data, and does analytical and modeling analyses of energy issues. The Agency must satisfy the requests of Congress, other elements within the Department of Energy, Federal Energy Regulatory Commission, the Executive Branch, its own independent needs, and assist the general public, or other interest groups, without taking a policy position.

Energy Loss: The difference between energy input and output as a result of transfer of energy between two points.

Energy Receipts: Energy generated by one electric utility system and received by another system through one or more transmission lines.

Equity (Financial): Ownership of shareholders in a corporation represented by stock.

Equity Capital: The sum of capital from retained earnings and the issuance of stocks.

Exchange Energy: Exchange energy refers to specific electricity transactions between electric utilities where electricity received is returned in kind at a later 
time or accumulated as energy balances until the end of the stated period, after which settlement may be by monetary payment.

Expenditure: The incurrence of a liability to obtain an asset or service.

Federal Flectric Utility: A utility that is either owned or financed by the Federal Government.

Federal Energy Regulatory Commission (FERC): A quasi-independent regulatory agency within the Department of Energy having jurisdiction over interstate electricity sales, wholesale electric rates, hydroelectric licensing, natural gas pricing, oil pipeline rates, and gas pipeline certification.

Federal Power Act: Enacted in 1920, and amended in 1935, the Act consists of three parts. The first part incorporated the Federal Water Power Act administered by the former Federal Power Commission, whose activities were confined almost entirely to licensing non-Federal hydroelectric projects. Parts II and III were added with the passage of the Public Utility Act. These parts extended the Act's jurisdiction to include regulating the interstate transmission of electrical energy and rates for its sale as wholesale in interstate commerce. The Federal Energy Regulatory Commission is now charged with the administration of this law.

Federal Power Commission: The predecessor agency of the Federal Energy Regulatory Commission. The Federal Power Commission (FPC) was created by an Act of Congress under the Federal Water Power Act on June 10, 1920. It was charged originally with regulating the electric power and natural gas industries. The FPC was abolished on September 20,1977, when the Department of Energy was created. The functions of the FPC were divided between the Department of Energy and the Federal Energy Regulatory Commission.

FERC: The Federal Energy Regulatory Commission.

FERC Guidelines: A compilation of the Federal Energy Regulatory Commission's enabling statutes, procedural and program regulations, and orders, opinions and decisions.

Financial Accounting Standards Board (FASB): An independent board responsible, since 1973, for establishing generally accepted accounting principles. Its official pronouncement are called "Statements of Financial Accounting Standards" and "Interpretations of Financial Accounting Standards."

Fiscal Year: A financial year based on a predetermined starting date. The Federal Government's financial year runs from October 1 through September 30.

Fixed Asset Turnover: A ratio of revenue to fixed assets which is a measure of the productivity and efficiency of property, plant, and equipment in generating revenue. A higher turnover reflects positively on the entity's ability to utilize properly its fixed assets in business operations.

Fixed Assets: Tangible property used in the operations of an entity, but not expected to be consumed or converted into cash in the ordinary course of events. With a life in excess of one year, not intended for resale to customers, and subject to depreciation (with the exception of land), they are usually referred to as property, plant, and equipment.

Fixed Charge Coverage: The ratio of earnings available to pay so-called fixed charges to such fixed charges. Fixed charges include interest on funded debt, including leases, plus the related amortization of debt discount, premium and expense. Earnings available for fixed charges may be computed before or after deducting income taxes. Occasionally credits for the. "allowance for fund used during construction" are excluded from the earnings figures. The precise procedures followed in calculating fixed charge or interest coverages vary widely.

Fixed Cost (expense): An expenditure or expense that does not vary with volume level of activity.

Fixed Operating Costs: Costs other than those associated with capital investment that do not vary with the operation, such as maintenance and payroll.

Fossil Fuel: Any naturally occurring organic fuel, such as petroleum, coal, and natural gas.

Fossil-Fuel Plant: A plant using coal, petroleum, or gas as its source of energy.

Fuel Expenses: These costs include the fuel used in the production of steam or driving another prime mover for the generation of electricity. Other associated expenses include unloading the shipped fuel and all handling of the fuel up to the point where it enters the first bunker, hopper, bucket, tank, or holder in the boiler-house structure.

Gas Turbine Plant: A plant in which the prime mover is a gas turbine. A gas turbine consists typically of an axial-flow air compressor, one or more combustion chambers, where liquid or gaseous fuel is burned and the hot gases are passed to the turbine and where the hot gases expand to drive the generator and are then used to run the compressor.

Generally Accepted Accounting Principles (GAAP): Defined by the FASB as the conventions, rules, and procedures necessary to define accepted accounting practice at a particular time; includes both broad guidelines and relatively detailed practices and procedures.

Generating Unit: Any combination of physically connected generator(s), reactor(s), boiler(s), combustion turbine(s), or other prime mover(s) operated together to produce electric power.

Generator Nameplate Capacity: The full-load continuous rating of a generator, prime mover, or other electric power production equipment under specific 
conditions as designated by the manufacturer. Installed generator nameplate rating is usually indicated on a nameplate physically attached to the generator.

Geothermal Plant: A plant in which the prime mover is a steam turbine. The turbine is driven either by steam produced from hot water or by natural steam that derives its energy from heat found in rocks or fluids at various depths beneath the surface of the earth. The energy is extracted by drilling and/or pumping.

Grid: The layout of an electrical distribution system.

Gross Generation: The total amount of electric energy produced by a generating facility, as measured at the generator terminals.

Head: The product of the water's weight and a usable difference in elevation gives a measurement of the potential energy possessed by water.

Historical Plant Cost of Equipment: The charges for equipment assigned to power production include: the net purchased price thereof; sales taxes; investigation and inspection expenses necessary for such purchases, any expenses of transportation when borne by the utility; labor employed charges; materials and supplies consumed; and expenses incurred by the utility in unloading and placing the equipment in readiness to operate.

Historical Plant Cost of Land and Land Rights: The cost of land purchased or the fees paid by the utility for rights, interests, and privileges to be held by the utility in land owned by others. The types of rights acquired include leaseholds, easements, water and water power rights, rights-of-way, and other like interests.

Historical Plant Cost of Structures and Improvements (Expenses): The cost of all buildings and facilities to house, support, or safeguard property or persons, including all fixtures permanently attached to and made a part of building. Also includes the cost incurred in connection with the first clearing and grading of land and rights-of-ways.

Holding Company: A company that confines its activities to owning stock in, and supervising management of, other companies. The Securities and Exchange Commission, as administrator of the Public Utility Holding Company Act of 1935, defines a holding company as "a company which directly or indirectly owns, controls or holds 10 percent or more of the outstanding voting securities of a holding company" (15 USC 79b, par. a (7)).

Hydroelectric Energy: The production of electricity from kinetic energy in flowing water.

Hydroelectric Plant: A plant in which the turbine generators are driven by falling water.

Hydroelectric Plant Capacity: This capacity figure is a function of fluid flow losses, hydraulic turbines, head, and water flow. The minimum net head limits the firm capacity of the plant.

Hydroelectric Power: The harnessing of flowing water to produce mechanical or electrical energy.

Independent Power Producer: A corporation, person, agency, authority, or other legal entity or instrumentality that owns electric generating capacity and is a wholesale electric producer without a designated franchised service area. The entity is not a qualifying facility as defined in the Public Utility Regulatory Policies Act of 1978.

Industrial: The industrial sector is generally defined as manufacturing, construction, mining, agriculture, fishing and forestry establishments Standard Industrial Classification (SIC) codes 01-39. The utility may classify industrial service using the SIC codes, or based on demand or annual usage exceeding some specified limit. The limit may be set by the utility based on the rate schedule of the utility.

Instantaneous Peak Demand: The maximum demand at the instant of greatest load.

Interchange Energy: Kilowatthours delivered to or received by one electric utility or pooling system from another. Settlement may be by payment, returned in kind at a later time or accumulated as energy balances until the end of the stated period.

Interconnection: Two or more electric systems having a common transmission line that permits a flow of energy between them. The physical connection of the electric power transmission facilities allows for the sale or exchange of energy.

Interdepartmental Service (Electric): Interdepartmental service includes amounts charged by the electric department at tariff or other specified rates for electricity supplied by it to other utility departments.

Interest Coverage Ratio: The number of times that fixed interest charges were earned. It indicates the margin of safety of interest on fixed debt. The timesinterest-earned ratio is calculated using net income before and after income taxes; and the credits of interest charged to construction being treated as other income. The interest charges include interest on longterm debt, interest on debt of associated companies, and other interest expense.

Interlocking Directorates: The holding of a significant position in management or a position on the corporate board of a utility, while simultaneously holding a comparable position with another utility, or with a firm doing business with the utility.

Internal Combustion Plant: A plant in which the prime mover is an internal combustion engine. An internal combustion engine has one or more cylinders in which the process of combustion takes place, converting energy released from the rapid burning of a fuel-air mixture into mechanical energy. Diesel or gas-fired engines are the principal types used in elec- 
tric plants. The plant is usually operated during periods of high demand for electricity.

Investor-Owned Electric Utility: A class of utility that is investor owned and organized as a tax paying business, usually financed by the sales of securities in the capital market.

Kilowatt (kW): One thousand watts.

Kilowatthour (kWh): One thousand watthours.

Leverage Ratio: A measure that indicates the financial ability to meet debt service requirements and increase the value of the investment to the stockholders. (i.e. the ratio of total debt to total assets).

Liability: An amount payable in dollars or by future services to be rendered.

Licensees: Entity that has been granted permission to engage in an activity otherwise unlawful (i.e. hydropower project).

Line Loss: Energy (in kilowatthours) lost in transmission and distribution lines.

Load (Electric): The amount of electric power delivered or required at any specific point or points on a system. The requirement originates at the energyconsuming equipment of the consumers.

Long-term Debt: Debt securities or borrowings having a maturity of more than one year.

Maintenance Expenses: That portion of operating expenses consisting of labor, materials, and other direct and indirect expenses incurred for preserving the operating efficiency and/or physical condition of utility plants used for power production, transmission, and distribution of energy.

Maximum Demand: The greatest of all demands of the load that has occurred within a specified period of time.

Mcf: One thousand cubic feet.

Megawatt (MW): One million watts.

Megawatthour (MWh): One million watthours.

Mill: A monetary cost and billing unit used by utilities; it is equal to $1 / 1000$ of the U.S. dollar (equivalent to $1 / 10$ of 1 cent).

Multiple Purpose Reservoir: Stored water and its usage governed by advanced water resource conservation practices to achieve more than one water control objective. Some of the objectives include flood control, hydro- electric power development, irrigation, recreation usage, and wilderness protection.

Municipality: (As defined in section 3, paragraph (7) of the Federal Power Act, P.L. 66-280 as amended) A city, county, irrigation district, drainage district, or other political subdivision or agency of a State competent under the laws thereof to carry on the business of developing, transmitting, utilizing, or distributing power (41 Stat. $1064 ; 49$ Stat. 838; 16 U.S.C. 796(7)).

Net Generation: Gross generation minus plant use from all electric utility owned plants. The energy required for pumping at a pumped-storage plant is regarded as plant use and must be deducted from the gross generation.

Net Income: The excess of all revenues and gains for a period over all expenses and losses of the period.

Nonutility Power Producer: A corporation, person, agency, authority, or other legal entity or instrumentality that owns electric generating capacity and is not an electric utility. Nonutility power producers include qualifying cogenerators, qualifying small power producers, and other nonutility generators (including independent power producers) without a designated franchised service area, and which do not file forms listed in the Code of Federal Regulations, Title 18, Part 141.

Nuclear Fuel: Fissionable materials that have been enriched to such a composition that, when placed in a nuclear reactor, will support a self-sustaining fission chain reaction, producing heat in a controlled manner for process use.

Nuclear Power Plant: A facility in which heat produced in a reactor by the fissioning of nuclear fuel is used to drive a steam turbine.

Nuclear Reactor: An apparatus in which the nuclear fission chain can be initiated, maintained, and controlled so that energy is released at a specific rate. The reactor includes fissionable material (fuel), such as uranium or plutonium; fertile material; moderating material (unless it is a fast reactor); a heavy-walled pressure vessel; shielding to protect personnel; provision for heat removal; and control elements and instrumentation.

Ohm: The unit of measurement of electrical resistance. The resistance of a circuit in which a potential difference of 1 volt produces a current of 1 ampere.

Operating Expenses: Expenses related to utility operations, which include operation and maintenance expenses, provisions for depreciation and amortization, taxes other than income taxes, income taxes, provision for deferred income taxes, income taxes deferred in prior years-- credit and investment tax credit adjustments--net.

Operating Income: Operating revenues less operating expenses.

Operation Expenses: The components of power production expenses that incur cost for operations that are directly related to producing electricity. The major item is almost always fuel that has to be burned to generate the electricity. 
Operation Supervision and Engineering (Expenses): These expenses include the cost of labor and expenses incurred in the general supervision and direction of the operation of power generation stations. The supervision and engineering costs consist of the pay and expenses of staff and consultants engaged in supervising and directing the operation of each utility function. Direct supervision and engineering of activities, such as fuel handling, boiler room operations, and generator operations, are charged to the appropriate accounts.

Original Cost: The initial amount of money spent to acquire an asset. It is equal to the price paid, or present value of the liability incurred, or fair value of stock issued, plus normal incidental costs necessary to put the asset into its initial use.

Other Generation: Electricity originating from these sources: biomass, fuel cells, geothermal heat, solar power, waste, wind, and wood.

Owner's Equity: Interest of the owners in the assets of the business represented by capital contributions and retained earnings.

Parent Company: Company owning more than 50 percent of the voting shares of another company, called the subsidiary.

Plant: A facility at which are located prime movers, electric generators, and auxiliary equipment for converting mechanical, chemical, and/or nuclear energy into electric energy. A plant may contain more than one type of prime mover. Electric utility plants exclude facilities that satisfy the definition of a qualifying facility under the Public Utility Regulatory Policies Act of 1978.

Plant-Use Electricity: The electric energy used in the operation of a plant. This energy total is subtracted from the gross energy production of the plant; for reporting purposes the plant energy production is then reported as a net figure. The energy required for pumping at pumped-storage plants is, by definition, subtracted, and the energy production for these plants is then reported as a net figure.

Pole-Mile: A unit of measuring the simple length of a transmission line carrying electric conductors, without regard to the number of conductors carried.

Power: The rate at which energy is transferred. Electrical energy is usually measured in watts. Also used for a measurement of capacity.

Power (Electrical): An electric measurement unit of power called a voltampere is equal to the product of 1 volt and 1 ampere. This is equivalent to 1 Watt for a direct current system and a unit of apparent power is separated into real and reactive power. Real power is the work-producing part of apparent power that measures the rate of supply of energy and is denoted as Kilowatts (KW). Reactive power is the portion of apparent power that does no work and is referred to as kilovars; this type of power must be supplied to most types of magnetic equipment, such as motors, and is supplied by generator or by electrostatic equipment. Voltamperes are usually divided by 1,000 and called kilovoltamperes (kVA). Energy is denoted by the product of real power and the length of time utilized; this product is expressed as kilowatthours.

Power Production Plant: All the land and land rights, structures and improvements, boiler or reactor vessel equipment, engines and engine-driven generator, turbogenerator units, accessory electric equipment, and miscellaneous power plant equipment are grouped together for each individual facility.

Preferred Stock: Ownership interests in a corporation which have been granted a preference, usually in the distribution of dividends before payment of dividends to common stockholders and assets in dissolution. It is usually nonvoting.

Price: The amount of money or consideration-inkind for which a service is bought, sold, or offered for sale.

Prime Mover: The motive force that drives an electric generator (e.g., steam engine, turbine, or water wheel).

Production (Electric): Act or process of producing electric energy from other forms of energy; also, the amount of electric energy expressed in watthours (Wh).

Production Expenses: Costs incurred in the production of electric power that conform to the accounting requirements of the Operation and Maintenance Expense Accounts of the FERC Uniform System of Accounts.

Profit: The income remaining after all business expenses are paid.

Public Authority Service to Public Authorities: Public authority service includes electricity supplied and services rendered to municipalities or divisions or agencies of State or Federal governments, under special contracts or agreements or service classifications applicable only to public authorities.

Public Street and Highway Lighting: Public street and highway lighting includes electricity supplied and services rendered for the purposes of lighting streets, highways, parks, and other public places; or for traffic or other signal system service, for municipalities, or other divisions or agencies of State or Federal governments.

Public Utility: Enterprise providing essential public services as electric, gas, telephone, water, and sewer, under legally established monopoly conditions.

Public Utility District: Municipal corporations organized to provide electric service to both incorporated cities and towns and unincorporated rural areas. Public utility districts, sometimes called "People's Utility Districts" or "Public Power Districts," operate in six States. 
Publicly Owned Electric Utility: A class of ownership found in the electric power industry. This group includes those utilities operated by municipalities, and State and Federal power agencies.

Pumped-Storage Hydroelectric Plant: A plant that usually generates electric energy during peak-load periods by using water previously pumped into an elevated storage reservoir during off-peak periods when excess generating capacity is available to do so. When additional generating capacity is needed, the water can be released from the reservoir through a conduit to turbine generators located in a power plant at a lower level.

Purchased Power: Power purchased or available for purchase from a source outside the system.

Railroad and Railway Services: Railroad and railway services include electricity supplied and services rendered to railroads and interurban and street railways, for general railroad use, including the propulsion of cars or locomotives, where such electricity is supplied under separate and distinct rate schedules.

Rate Base: The value of property upon which a utility is permitted to earn a specified rate of return as established by a regulatory authority. The rate base generally represents the value of property used by the utility in providing service and may be calculated by any one or a combination of the following accounting methods: fair value, prudent investment, reproduction cost, or original cost. Depending on which method is used, the rate base includes cash, working capital, materials and supplies, and deductions for'accumulated provisions for depreciation, contributions in aid of construction, customer advances for construction, accumulated deferred income taxes, and accumulated deferred investment tax credits.

Ratemaking Authority: A utility commission's legal authority to fix, modify, approve, or disapprove rates, as determined by the powers given the commission by a State or Federal legislature.

Rate of Return: The ratio of net operating income earned by a utility is calculated as a percentage of its rate base.

Rate of Return on Rate Base: The ratio of net operating income earned by a utility calculated as a percentage of its rate base.

Refunding: Retirement of one security issue with proceeds received from selling another. Refunding provides for retiring maturing debt by taking advantage of favorable money market conditions.

Regulation: The governmental function of controlling or directing economic entities through the process of rulemaking and adjudication.

Resale (Wholesale) Sales: Resale or wholesale sales are electrciity sold (except under exchange agreements) to other electric utilities or to the public authorities for resale distribution.
Residential: The residential sector is defined as private household establishments which consume energy primarily for space heating, water heating, air conditioning, lighting, refrigeration, cooking and clothes drying. The classification of an individual consumer's account, where the use is both residential and commercial, is based on principal use. For the residential class, do not duplicate consumer accounts due to multiple metering for special services (water, heating, etc.). Apartment houses are also included.

Retail: Sales covering electrical energy supplied for residential, commercial, and industrial end-use purposes. Other small classes, such as agriculture and street lighting, also are included in this category.

Retail Wheeling: An arrangement in which a utility transmits electricity from outside its service territory to a retail customer within its customer service territory.

Retained Earnings: The balance, either debit or credit, of appropriated or unappropriated earnings of an entity that are retained in the business.

Return on Common Equity: The net income less preferred stock dividends divided by the average common stock equity.

Return on Common Stock Equity: An entity's earnings available for common stockholders calculated as a percentage of its common equity capital.

Revenue: The total amount of money received by a firm from sales of its products and/or services, gains from the sales or exchange of assets, interest and dividends earned on investments, and other increases in the owner's equity except those arising from capital adjustments.

Revenue Requirement: The total revenue that the utility is authorized an opportunity to recover, which includes operating expenses and a reasonable return on rate base.

Rural Electrification Administration (REA): A lending agency of the U.S. Department of Agriculture, the REA makes self-liquidation loans to qualified borrowers to finance electric and telephone service to rural areas. The REA also finances the construction and operation of generating plants, electric transmission and distribution lines, or systems for the furnishing of initial and continued adequate electric services to persons in rural areas not receiving central station service.

Sales: The amount of kilowatthours sold in a given period of time; usually grouped by classes of service, such as residential, commercial, industrial, and other. Other sales include public street and highway lighting, other sales to public authorities and railways, and interdepartmental sales.

Sales for Resale: Energy supplied to other electric utilities, cooperatives, municipalities, and Federal and State electric agencies for resale to ultimate consumers. 
Short-term Debt or Borrowings: Debt securities or borrowings having a maturity of less than one year.

Solar Energy: Energy produced from the sun's radiation.

Steam-Electric Plant (Conventional): A plant in which the prime mover is a steam turbine. The steam used to drive the turbine is produced in a boiler where fossil fuels are burned.

Steam Expenses: The cost of labor, materials, fuel, and other expenses incurred in production of steam for electric generation.

Steam from other Sources: Steam purchased, transferred from another department of the utility, or acquired from others under a joint-facility operating agreement.

Steam Transferred-Credit: The expenses of producing steam charged to others or to other utility departments under a joint operating arrangement.

Stranded Commitments: The potential monetary losses in the electric power industry that may be incurred because of the change due to restructuring. Stranded commitments include assets, primarily in expensive power plants and excess capacity; liabilities such as power-purchase and fuel supply contracts; and regulatory assets (whose value is based on regulatory decisions rather than on market prices), including the phase-in of new power plants and deferred expenses for demand-side management programs that regulators allow utilities to place on their balance sheets.

Substation: Facility equipment that switches, changes, or regulates electric voltage.

Switching Station: Facility equipment used to tie together two or more electric circuits through switches. The switches are selectively arranged to permit a circuit to be disconnected, or to change the electric connection between the circuits.

System (Electric): Physically connected generation, transmission, and distribution facilities operated as an integrated unit under one central management, or operating supervision.
Transformer: An electrical device for changing the voltage of alternating current.

Transmission: The movement or transfer of electric energy over an interconnected group of lines and associated equipment between points of supply and points at which it is transformed for delivery to consumers, or is delivered to other electric systems. Transmission is considered to end when the energy is transformed for distribution to the consumer.

Transmission System (Electric): An interconnected group of electric transmission lines and associated equipment for moving or transferring electric energy in bulk between points of supply and points at which it is transformed for delivery over the distribution system lines to consumers, or is delivered to other electric systems.

Turbine: A machine for generating rotary mechanical power from the energy of a stream of fluid (such as water, steam, or hot gas). Turbines convert the kinetic energy of fluids to mechanical energy through the principles of impulse and reaction, or a mixture of the two.

Ultimate Consumer: A consumer that purchases electricity for its own use and not for resale.

Uniform System of Accounts: Prescribed financial rules and regulations established by the Federal Energy Regulatory Commission for utilities subject to its jurisdiction under the authority granted by the Federal Power Act.

Utility Generation: Generation by electric systems engaged in selling electric energy to the public.

Watt: The electrical unit of power. The rate of energy transfer equivalent to 1 ampere flowing under a pressure of 1 volt at unity power factor.

Watthour (Wh): An electrical energy unit of measure equal to 1 watt of power supplied to, or taken from, an electric circuit steadily for 1 hour.

Wheeling Service: The movement of electricity from one system to another over transmission facilities of intervening systems. Wheeling service contracts can be established between two or more systems. 